Florida International University FIU Digital Commons

FIU Electronic Theses and Dissertations

University Graduate School

7-1-2014

\title{
Reanalysis of the 1954-1963 Atlantic Hurricane Seasons
}

Sandy Delgado

Florida International University, sdelg010@fiu.edu

DOI: $10.25148 /$ etd.FI14071185

Follow this and additional works at: https://digitalcommons.fiu.edu/etd

\section{Recommended Citation}

Delgado, Sandy, "Reanalysis of the 1954-1963 Atlantic Hurricane Seasons" (2014). FIU Electronic Theses and Dissertations. 1511. https://digitalcommons.fiu.edu/etd/1511

This work is brought to you for free and open access by the University Graduate School at FIU Digital Commons. It has been accepted for inclusion in FIU Electronic Theses and Dissertations by an authorized administrator of FIU Digital Commons. For more information, please contact dcc@fiu.edu. 


\section{FLORIDA INTERNATIONAL UNIVERSITY}

Miami, FL

REANALYSIS OF THE 1954-1963 ATLANTIC HURRICANE SEASONS

A thesis submitted in partial fulfillment of the

requirements for the degree of

MASTER OF SCIENCE

in

GEOCIENCES

by

Sandy Delgado

2014 
To: Interim Dean Michael R. Heithaus

College of Arts and Sciences

This thesis, written by Sandy Delgado, and entitled Reanalysis of the 1954-1963 Atlantic Hurricane Seasons, having been approved in respect to style and intellectual content, is referred to you for judgment.

We have read this thesis and recommend that it be approved.

Christopher W. Landsea

$\begin{array}{r}\hline \text { Ping Zhu } \\ \hline \text { Haiyan Jiang } \\ \hline \text { Hugh E. Willoughby, Major Professor }\end{array}$

Date of Defense: July 1, 2014

The thesis of Sandy Delgado is approved.

Interim Dean, Michael R. Heithaus

College of Arts and Sciences

Dean Lakshmi N. Reddi University Graduate School

Florida International University, 2014 
(C) Copyright 2014 by Sandy Delgado

All rights reserved. 


\section{DEDICATION}

I dedicate this thesis to my family. Their love, understanding and support have been pivotal to the fruition of this research. 


\section{ACKNOWLEDGMENTS}

The completion of these nine years of reanalysis was not a sole effort. I was fortunate to have the support, encouragement and help from several people. I was very lucky to have started working on the reanalysis about four years ago before I had finished my bachelors' degree. I will always be grateful to Dr. Hugh Willoughby, professor and advisor at FIU, for noticing my love and enthusiasm for hurricanes and understanding that working on past hurricanes would be a perfect place for me. Almost four years ago, Dr. Chris Landsea, advisor and mentor, provided the setting for me to use my love and understanding of hurricanes to travel back in time and improve on the work done by great scientists in the 1950s and 1960s with the advancements in the understanding of hurricanes and technology we have today. Dr. Landsea and I worked countless hours to make sure that my assessments on the tracks and intensities of all the tropical cyclones analyzed and added were as accurate as possible. I also had an instrumental person in this

effort, Astryd Rodriguez spent countless of hours helping me with the plotting of many of the storms that were reanalyzed. Without her help, this reanalysis would have taken many more months. We also had a great partnership and it was a pleasure working together. I would also like to thank the NHC for allowing me to use the library where I spent most of my time working on the reanalysis. I would also like to thank all the hurricane specialists at the NHC for their encouragement and help, it has been a real pleasure all these years to be able to talk to everyone and gain some of their knowledge and experience. Special thanks to Dr. Lixion Avila for allowing me to borrow the United States Weather Bureau tropical cyclone advisories from 1954-1963. Thanks to Gloria Aversano, Librarian at the 
NHC, for allowing me to use her library and always being helpful. Likewise, I would like to thank all the employers of the NHC for the support, many I consider my friends.

I would like to acknowledge Dr. Jack Beven, Hurricane Specialist at the NHC, David Roth, Meteorologist at the Weather Prediction Center, and Ryan Truchelut, graduate student in meteorology at FSU, for their research on missing tropical cyclones in the Atlantic and composing lists of potential suspects. Their work was influential in our effort to improve the completeness of HURDAT. Thanks to Bob Stearns for coming down to the NHC and providing an insight into the workings of the hurricane hunters in the early 1960s. Also very rewarding was the cooperation by Ramón Pérez and Maritza Ballester of the Cuban Meteorological Institute. Thanks to Andrew Hagen for his support, training on the reanalysis process and eagerness to always lend a helping hand. Thanks to Karina Castillo for her work on the NHC Storm Wallets and friendship. I would also like to acknowledge Joan David for creating all the maps for the reanalysis between 1954 and 1959. Thanks Joni for your time, dedication and positive influence.

Support for this research is from the NOAA Climate Program Office through a funded proposal entitled "Re-analysis of the Atlantic Basin Tropical Cyclone Database in the Modern Era." 


\section{ABSTRACT OF THE THESIS \\ REANALYSIS OF THE 1954-1963 ATLANTIC HURRICANE SEASONS \\ by}

Sandy Delgado

Florida International University, 2014

Miami, Florida

Professor Hugh E. Willoughby, Major Professor

HURDAT is the main historical archive of all tropical storms and hurricanes in the North Atlantic Basin, which includes the Caribbean Sea and Gulf of Mexico, from 1851 to the present. HURDAT is maintained and updated annually by the National Hurricane Center at Miami, Florida. Today, HURDAT is widely used by research scientists, operational hurricane forecasters, insurance companies, emergency managers and others. HURDAT contains both systematic biases and random errors. Thus, the reanalysis of HURDAT is vital. For this thesis, HURDAT is reanalyzed for the period of 1954-1963. The track and intensity of each existing tropical cyclone in HURDAT is assessed in the light of $21^{\text {st }}$ century understanding and previously unrecognized tropical cyclones are detected and analyzed. The resulting changes will be recommended to the National Hurricane Center Best Track Change Committee for inclusion in HURDAT. 


\section{TABLE OF CONTENTS}

CHAPTER

PAGE

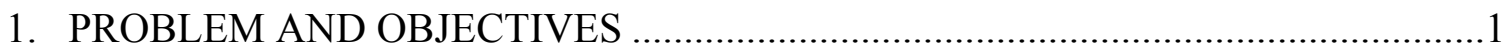

2. BACKGROUND INFORMATION .................................................................4

a. Pressure-Wind Relationship.......................................................... 4

b. Saffir-Simpson Hurricane Wind Scale................................................. 7

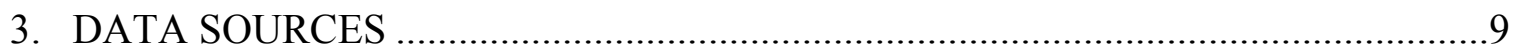

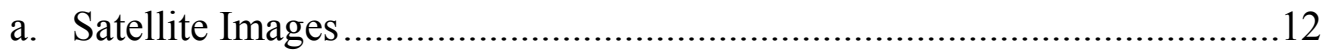

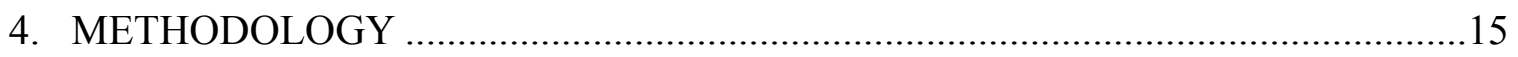

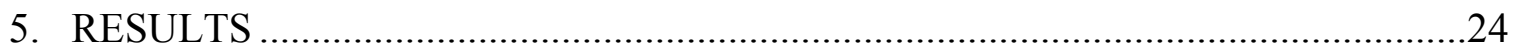

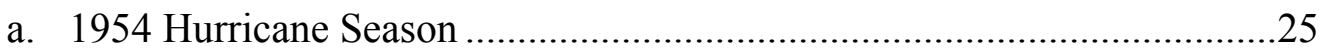

b. 1955 Hurricane Season ......................................................................29

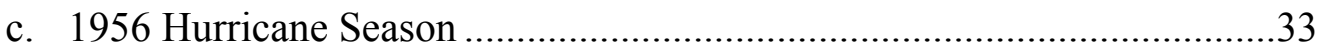

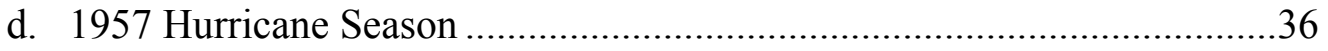

e. 1958 Hurricane Season ........................................................................40

f. 1959 Hurricane Season ......................................................................43

g. 1960 Hurricane Season ............................................................................46

h. 1961 Hurricane Season ........................................................................49

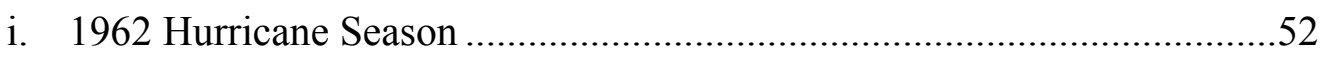

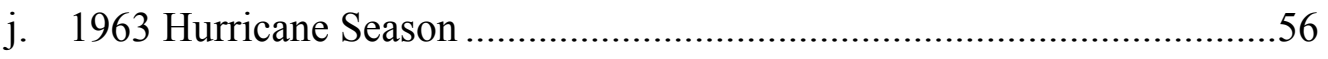

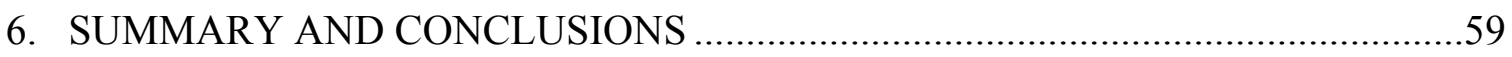

a. Changes to US Landfalling Hurricanes .............................................62

b. Changes to US Landfalling Tropical Storms ........................................64

c. Changes to Non-US Landfalling Tropical Cyclones ..............................67

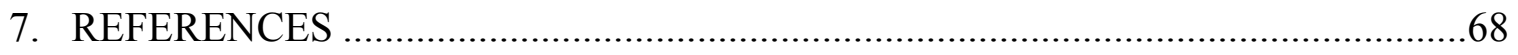

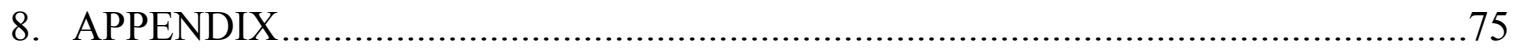




\section{LIST OF FIGURES}

FIGURES

PAGE

1. This graphic was obtained from McAdie et al. (2009) and shows the advancements in technology between 1850 and early 2000. The blue shaded strip includes the years covered in this reanalysis, 1954-1963

2. Historical Weather Map for September 27, 1958, zoomed-in, showing Hurricane Helene close to the eastern coast of the United States as a frontal boundary approaches from the northwest

3. Microfilm image on September 27, 1958, at 15Z showing Hurricane Helene impacting parts of the Carolinas

4. Satellite images captured by TIROS in 1961 and 1962 showing several tropical

systems at different stages of development

5. Part of the original track in HURDAT of Hurricane Esther, 1961, with the plotted reconnaissance aircraft data

6. 1954 original track map

7. 1954 revised track map

8. Top image is the microfilm on September $23^{\text {rd }}, 1955$ at $18 \mathrm{Z}$ showing a tropical disturbance listed as Katie and the bottom image is the microfilm on September $23^{\text {rd }}, 1955$ at $12 \mathrm{Z}$ showing another disturbance listed as Linda...........30

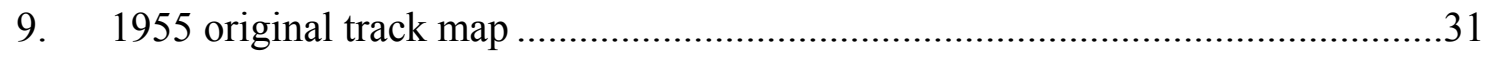

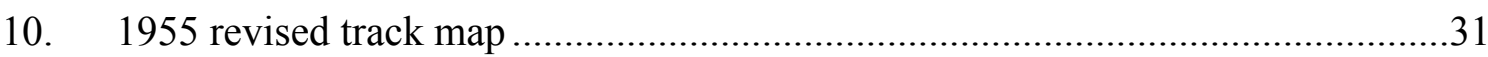

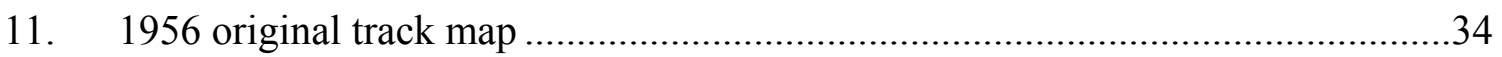

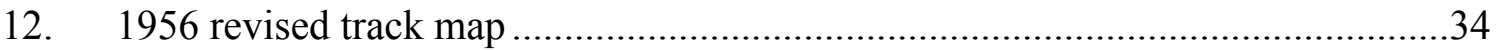

13. Microfilm image of the new tropical storm off the Louisiana coast on May $1^{\text {st }}$, 1957 at $12 Z$

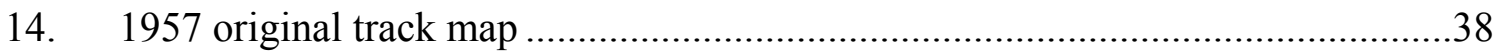

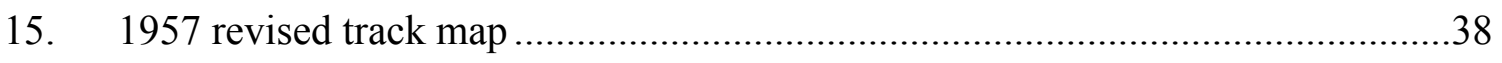

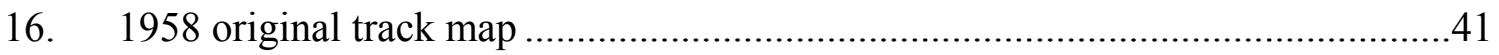




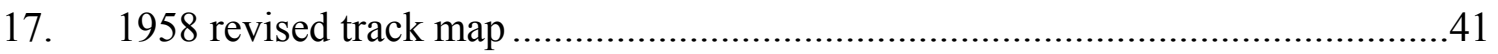

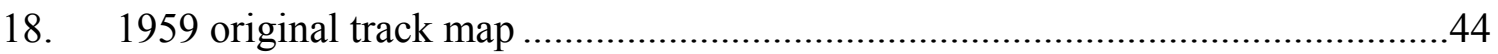

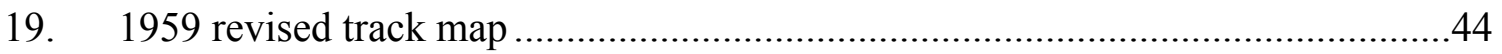

20. 1960 original track map ..............................................................................

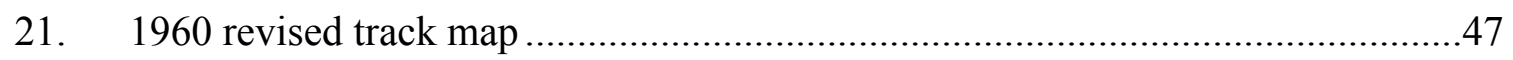

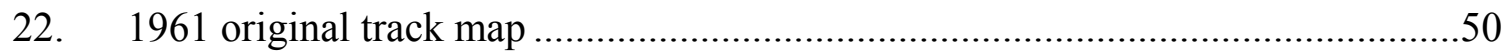

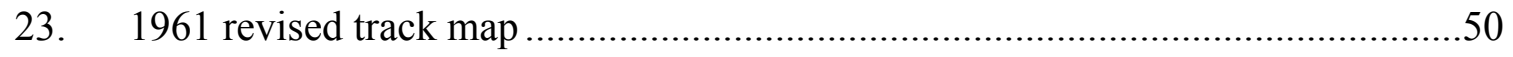

24. Microfilm image of the Unnamed Hurricane \#7 on December $2^{\text {nd }}$ at $12 Z$ off the

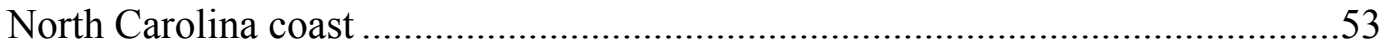

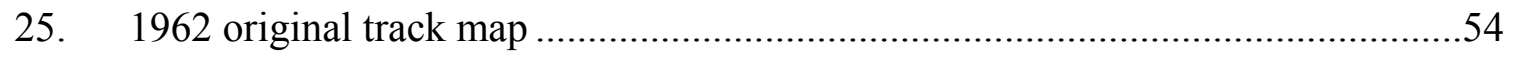

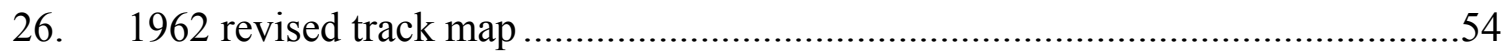

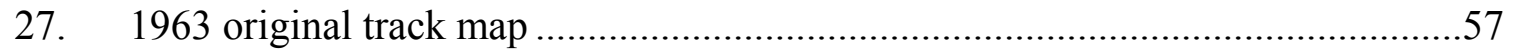

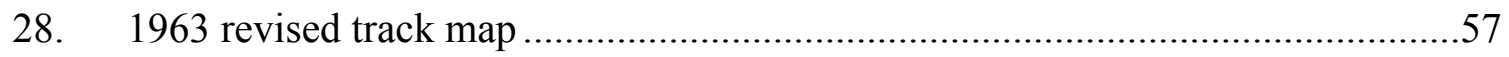

29. Microfilm map showing Hurricane Greta on November $4^{\text {th }}, 1956$, at $12 Z$...........61 


\section{LIST OF TABLES}

TABLE

PAGE

1. Saffir-Simpson Hurricane Wind Scale..................................................................

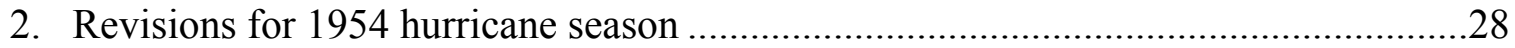

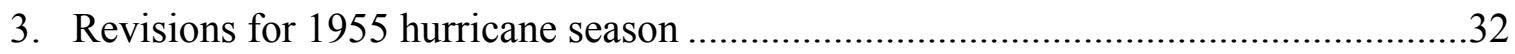

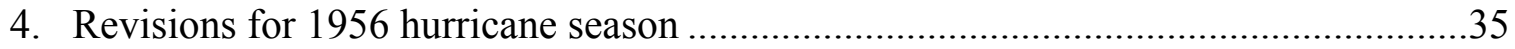

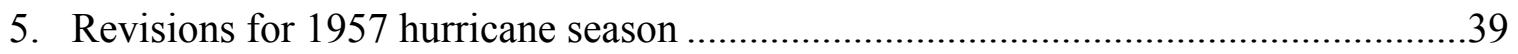

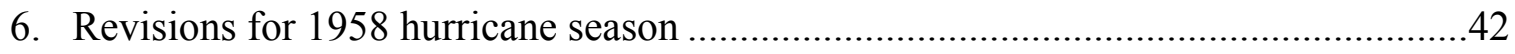

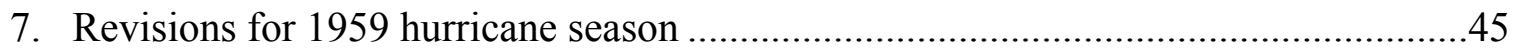

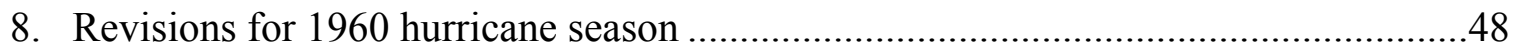

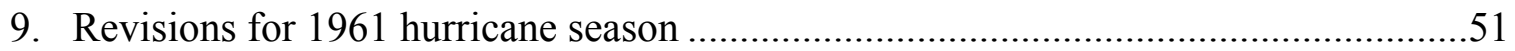

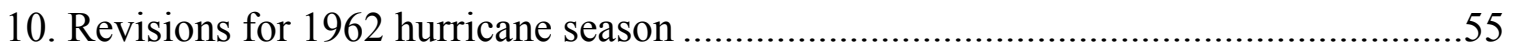

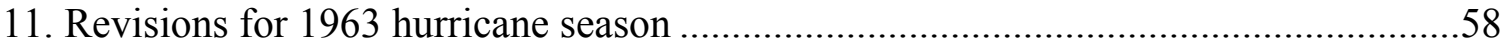

12. Changes to US Landfalling Hurricanes (1954-1963) ..............................................62

13. Changes to US Landfalling Tropical Storms (1954-1963) ..........................................64

14. Changes to Non-US Landfalling Tropical Cyclones (1954-1963) ..............................67 


\section{ABBREVIATIONS AND ACRONYMS}

Atlantic Hurricane Reanalysis Project

AHRP

Atlantic Multidecadal Oscillation

AMO

Atlantic Tropical Storm Report

ATSR

Automated Tropical Cyclone Forecast

ATCF

Central Texas

BTX

Comprehensive Ocean-Atmosphere Dataset

COADS

East

E

East-northeast

ENE

El Niño Southern Oscillation

ENSO

East-southeast

ESE

Extratropical

ET

Hour

$\mathrm{hr}$

Hurricane Database

HURDAT

Hurricane Weather Maps

HWM

Knot

$\mathrm{kt}$

Latitude

Lat

Longitude

Lon

Louisiana

LA

Maine

ME

Mariners Weather Logs

MWL

Maryland

MD

Massachusetts

MA 
Miles per hour

Millibar

Mississippi

National Aeronautics and Space Administration

National Climatic Data Center

National Hurricane Center Best Track Change Committee

National Hurricane Research Project

Nautical mile

New Hampshire

New York

NHC Microfilm Maps

NHC Storm Wallets

North Carolina

North Texas

North

Northeast Florida

Northeast

North-northeast

North-northwest

Northwest Florida

Northwest

Radius of Maximum Winds

Rhode Island mph

$\mathrm{mb}$

MS

NASA

NCDC

NHCBTCC

NHRP

$\mathrm{nm}$

$\mathrm{NH}$

NY

MICRO

WALLETS

NC

CTX

$\mathrm{N}$

DFL

NE

NNE

NNW

AFL

NW

RMW

RI 
Saffir-Simpson Hurricane Wind Scale

SSHWS

South Carolina

$\mathrm{SC}$

South Texas

ATX

South

S

Southeast Florida

CFL

Southeast

SE

South-southeast

SSE

South-southwest

WSW

Southwest Florida

BFL

Southwest

SW

Television Infrared Observation Satellite TIROS

Tropical Storm

TS

Virginia

VA

West

W

West-northwest

WNW

West-southwest

SSW

Zulu time

Z 


\section{CHAPTER 1}

\section{PROBLEM AND OBJECTIVES}

The objective here is the reanalysis of the North Atlantic hurricane database for the period of 1954-1963. Since the database was initially developed in the 1960s, HURDAT has been utilized for such purposes as "setting appropriate building codes for coastal zones, risk assessment for emergency managers, analysis of potential losses for insurance and business interests, intensity forecasting techniques, verification of official and model projections of track and intensity, seasonal forecasting, and climatic change studies" (Landsea et al. 2008a,b). The challenge is that HURDAT was not developed with these purposes in mind. Therefore, the focus of the Atlantic Hurricane Reanalysis Project is to improve the accuracy and completeness of HURDAT through the correction of random errors and biases. Some of the random errors include errors to the tracks and positions that are the consequence of a lack of sufficient observations near the storm. Sparse observations also introduce biases in estimated intensity. For example, the intensity may have been underestimated until a ship passed close or through the center of a storm or a reconnaissance airplane reached the tropical cyclone. Also, in the early 1960s, the first satellite images produced by TIROS showed cloud masses that the forecasters were able to identify as tropical cyclones. But without a technique to estimate intensity, the forecasters had to still wait for the reconnaissance aircraft or ship to investigate the storm intensity.

New data sources have become available that were not available in real-time when the tropical cyclone was active. Another objective is correction of US hurricanes landfall characteristics, because many landfall intensities are inaccurate. Moreover, some 
tropical cyclones that existed were not included in the original HURDAT possibly because of the lack of data over the open Atlantic or because they were considered to have been extratropical. Also, advancements in understanding of tropical cyclones and better analysis techniques support a more accurate archive.

Systematic biases in the original HURDAT database are typically easier to detect and quantify than are random errors. For example, when the original HURDAT was developed, the position and intensity of the tropical cyclones was estimated only once daily and then interpolated to 6-hourly intervals (Landsea et al. 2008). This caused many errors, including artificial apparent weakening before landfall. Another problem was that many tropical cyclones showed unrealistic accelerations or decelerations at the beginnings and/or the ends of their tracks. In other cases, the analysis did not follow storms until dissipation or extratropical transition. Many intensities obtained by the reconnaissance aircraft were overestimates (Stearns, personal communication). In the 1950s and 1960s, reconnaissance aircraft were not able to measure surface winds directly. The onboard aerologists made estimates of the surface winds visually based upon sea state. They were able to measure the minimum sea-surface pressure by extrapolation or dropsonde, and often estimated the size of the eye from radar. Modern pressure-wind relationships allow us to improve estimates of the actual maximum surface winds. Sometimes the central pressures yield maximum wind speeds of 20 to even $50 \mathrm{kt} \mathrm{less}$ (according to the Brown et al. 2006 pressure-wind relationships) than the estimated maximum wind speed provided by the flight aerologist. This happens because modern pressure-wind relationships take into account factors, such as size, latitude and 
translational velocity, that affect the direct relationship between central pressure and maximum wind.

A thorough search of the records reveals tropical cyclones that existed but were not originally listed in HURDAT. A tropical cyclone is defined by the National Hurricane Center as a "warm-core non-frontal synoptic-scale cyclone, originating over tropical or subtropical waters, with organized deep convection and a closed surface wind circulation about a well-defined center" (Glossary of NHC Terms). For inclusion in HURDAT, these tropical cyclones must have produced winds of gale-force (34 kt) or greater. Normally a dozen or more potential cyclones (called "suspects") are found for each historical year. The search extends beyond the boundaries of the official Atlantic hurricane season, which lasts from June to November. Usually most of the suspects were tropical waves/troughs or occluded baroclinic cyclones but never became tropical cyclones. But we find a few previously unknown systems that qualify as tropical cyclones each year. Their tracks, positions and intensities are catalogued every 6 hours and presented to the NHCBTCC for potential inclusion to HURDAT. For the suspects in the early 1960s, the first satellite images are very helpful in our search and in the understanding of the structure of potential tropical cyclones. 


\section{CHAPTER 2}

\section{BACKGROUND INFORMATION}

Prior to the reanalysis of the 1954-1963 Atlantic hurricane seasons, the AHRP had been completed and approved by the NHCBTCC for the years 1851-1950 and the new changes were made available to the community (Landsea et al. 2004a, 2008a, 2008b, 2012, 2013). The NHCBTCC is currently reviewing the hurricane seasons of 1951-1953. It should be noted that the reanalysis of the hurricanes Carol, Edna and Hazel of 1954 was conducted by Donna Strahan prior to the present study (Landsea et al. 2008b). Also the reanalysis of Hurricanes Donna (1960) and Carla (1961) was conducted by Chris Landsea, Jason Dunion and Cristina Carrasco, but not yet published. These hurricanes impacted the United States severely, and for this reason the reanalysis was done in advance. For completeness, the metadata from these studies have been included in the appendix. The tables in the results section include the information from these cyclones. The results of the present study will be submitted to the NHCBTCC together with the five hurricanes reanalyzed by others.

\section{Pressure-Wind Relationship}

The relationship between lower pressure and the increase in the winds around the center of tropical cyclones was well known during the decade of the 1950s and early 1960s, but the process was poorly understood. The first paper to tackle the problem was Fletcher (1955) using data collected from 10 significant hurricanes that affected the southern United States between 1909 and 1949. Fletcher (1955) provides a simple equation, $\mathrm{vm}=16(p n-p o)^{\frac{1}{2}}$ that can be used to estimate the intensity of the 
hurricane. In the equation, $\mathrm{v}$ is the maximum surface wind in knots, $p_{n}$ is the barometric pressure of the outermost closed isobar and $p_{o}$ is the central pressure of the hurricane. Fletcher (1955) even indicates that when the outermost closed isobar is unknown; using $1010 \mathrm{mb}$ would likely provide a reliable result. He acknowledges that if the tropical cyclone is embedded within usually low or high environmental pressures, using $1010 \mathrm{mb}$ would result on estimated winds that are too high or too low. Nevertheless, the simple formula was step in the right direction. Later, Kraft (1961) published a paper that presented data from 13 Atlantic hurricanes and one Northwest Pacific typhoon. These systems made landfall around the time of their greatest intensity and relatively reliable measurements were made of the maximum winds and central pressures. Kraft (1961) provides a formula to estimate maximum surface winds is similar to Fletcher (1955), $\mathrm{V} \max =14(1013-\text { Pcenter })^{\frac{1}{2}}$.

The pressure-wind relationship used for the present reanalysis (Brown et al. 2006), which was derived using a large sample of reconnaissance aircraft data between 1998 and 2005. Aside from the difference in the number of observations, Brown et al. (2006) differs from Fletcher (1955) and Kraft (1961) in that it takes into account the latitude of the tropical cyclone and adjusts as the system moves poleward. The formulas provided by Fletcher (1955) and Kraft (1961) would indicate the same intensity for a hurricane located at $10 \mathrm{~N}$ or $30 \mathrm{~N}$ for the same given pressure. But today we know that the shape of the profiles of hurricanes in the lower latitudes $(10-25 \mathrm{~N})$ is smaller than for storms in the higher latitudes or in a weakening state (Willoughby and Rahn, 2004). Thus, for example, a hurricane with a central pressure of $970 \mathrm{mb}$ tends to have stronger maximum winds in the lower latitudes than when it approaches the mid latitudes (25- 
$45 \mathrm{~N})$. Brown et al. (2006) also takes into account whether the system is intensifying, weakening or steady-state, providing a slightly different intensity for these situations at the same central pressure values. The reanalysis does not use the exact value provided by Brown et al. (2006), it also takes into consideration forward speed, the RMW, as well as environmental pressures and then rounds the value to the nearest $5 \mathrm{kt}$. Since Brown et al. (2006) was published, more recent physically-based pressure-wind relationships have become available. Knaff and Zehr (2007) and Courtney and Knaff (2009) incorporate many aspects of the hurricanes which may possibly translate into a better assessment of the intensity. Nonetheless, Brown et al. (2006) has been used since the reanalysis effort began more than a decade ago, and more than 100 years have been reanalyzed using this method. Furthermore, some of the factors included in the Knaff and Zehr (2007) and Courtney and Knaff (2009) are unavailable for many of the historical tropical cyclones.

Finally, the original six-hourly assessment of the intensity in HURDAT are changed only if evidence is sufficient to justify the change. During the nine years of reanalysis it was evident that in the mid-1950s, the intensities in HURDAT had a high degree of correlation with the estimated surface or flight level winds from the reconnaissance aircraft no matter what central pressure was reported. This slowly shifted in the late 1950s and early 1960s as the forecasters had a better grasp on the pressurewind relationship. For an example of how the reanalysis used the pressure-wind information, if a central pressure of $970 \mathrm{mb}$ south of $25 \mathrm{~N}$ would suggest maximum surface winds of $90 \mathrm{kt}$ from the Brown et al. (2006) pressure-wind relationship at steady state, and the original intensity in HURDAT was $85 \mathrm{kt}$, the original intensity would likely be retained, as making a $5 \mathrm{kt}$ change may not be justifiable given the somewhat crude 
methodology employed. But if the hurricane were moving with a faster than typical forward speed and/or the RMW were smaller than the climatological value, then the intensity may be increased to $95 \mathrm{kt}$.

\section{Saffir-Simpson Hurricane Wind Scale}

The Saffir-Simpson Hurricane Wind Scale (Saffir and Simpson, 1974) is a 1 to 5 rating system that uses the maximum hurricane surface winds. Hurricanes in categories 1 and 2 will cause between minor to extensive damage, especially to trees and roofs. Hurricanes in categories 3, 4 and 5 are considered major hurricanes and the damage potential ranges from devastating to catastrophic. The hurricane scale was devised in 1974 by Herbert Saffir, an engineer, and Robert Simpson, a meteorologist. Originally it also included the storm surge for at each category but this aspect was removed in 2010 since the direct correlation between the maximum wind and storm surge is weak. In addition, a minor adjustment was made in 2012 to correct the boundaries between category 3 and 4 , and 4 and 5 . The inconsistency arose from the conversion between knots and miles per hour. For example, $115 \mathrm{kt}$ is equivalent to $132.3 \mathrm{mph}$, which to the nearest $5 \mathrm{mph}$ is $130 \mathrm{mph}$. In the old version, $130 \mathrm{mph}$ was category 3 but $115 \mathrm{kt}$ was category 4 . The new version solves this problem. 


\begin{tabular}{|c|c|}
\hline SSHWS Category & Winds (kt) \\
\hline 1 & $64-82$ \\
\hline 2 & $83-95$ \\
\hline 3 & $96-113$ \\
\hline 4 & $114-135$ \\
\hline 5 & $>136$ \\
\hline
\end{tabular}

Table 1. Saffir-Simpson Hurricane Wind Scale. (Source: http://www.nhc. noaa.gov/sshws.shtml) 


\section{CHAPTER 3}

\section{DATA SOURCES}

A gamut of data sources supports the reanalysis. As shown in Landsea (2007) and McAdie et al. (2009) (Figure 1), technological advances have allowed us to re-examine past tropical cyclones and make their histories more accurate and detailed.

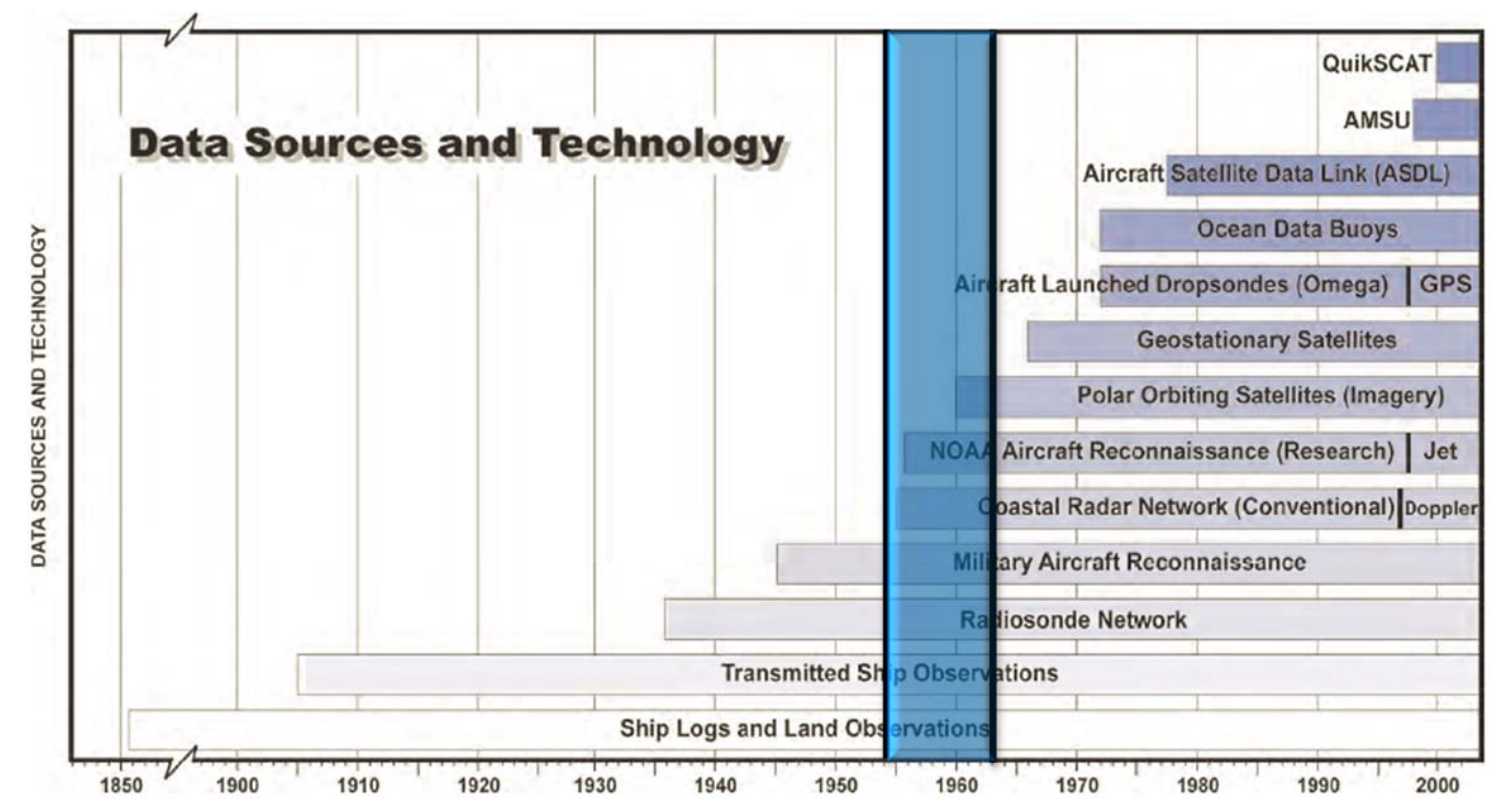

Figure 1. This graphic was obtained from McAdie et al. (2009) and shows the advancements in technology between 1850 and early 2000 . The blue shaded strip includes the years covered in this reanalysis, 1954-1963.

Two different types of synoptic maps are keys to the process, the NHC microfilms of synoptic weather maps and the Historical Weather Maps (HWM) series. The Historical Weather Maps (Figure 2) provides surface analyses of the entire northern hemisphere once daily at $12 \mathrm{Z}$ and once daily $500 \mathrm{mb}$ maps. The microfilm maps (Figure 3) are available every six hours for the entire Atlantic basin, except during the months of November and December. Microfilm maps of hurricanes making landfall in the United 
States are available every hour for most storms. The HWM and microfilm show the observations from ships and land stations,

including the direction and strength of winds, sea level pressure, temperature, and dewpoint observed at the time of the measurement. The temperature and dewpoint are key in determining when a tropical cyclone has acquired non-tropical characteristics, or in the case of suspects, when a non-tropical cyclone has acquired tropical characteristics. The Comprehensive Ocean-Atmospheric Dataset (COADS), first introduced by Woodruff (1987), is a global database containing millions of ship observations. Many, but not all, of the ships in COADS are already plotted in the microfilm. Once all the

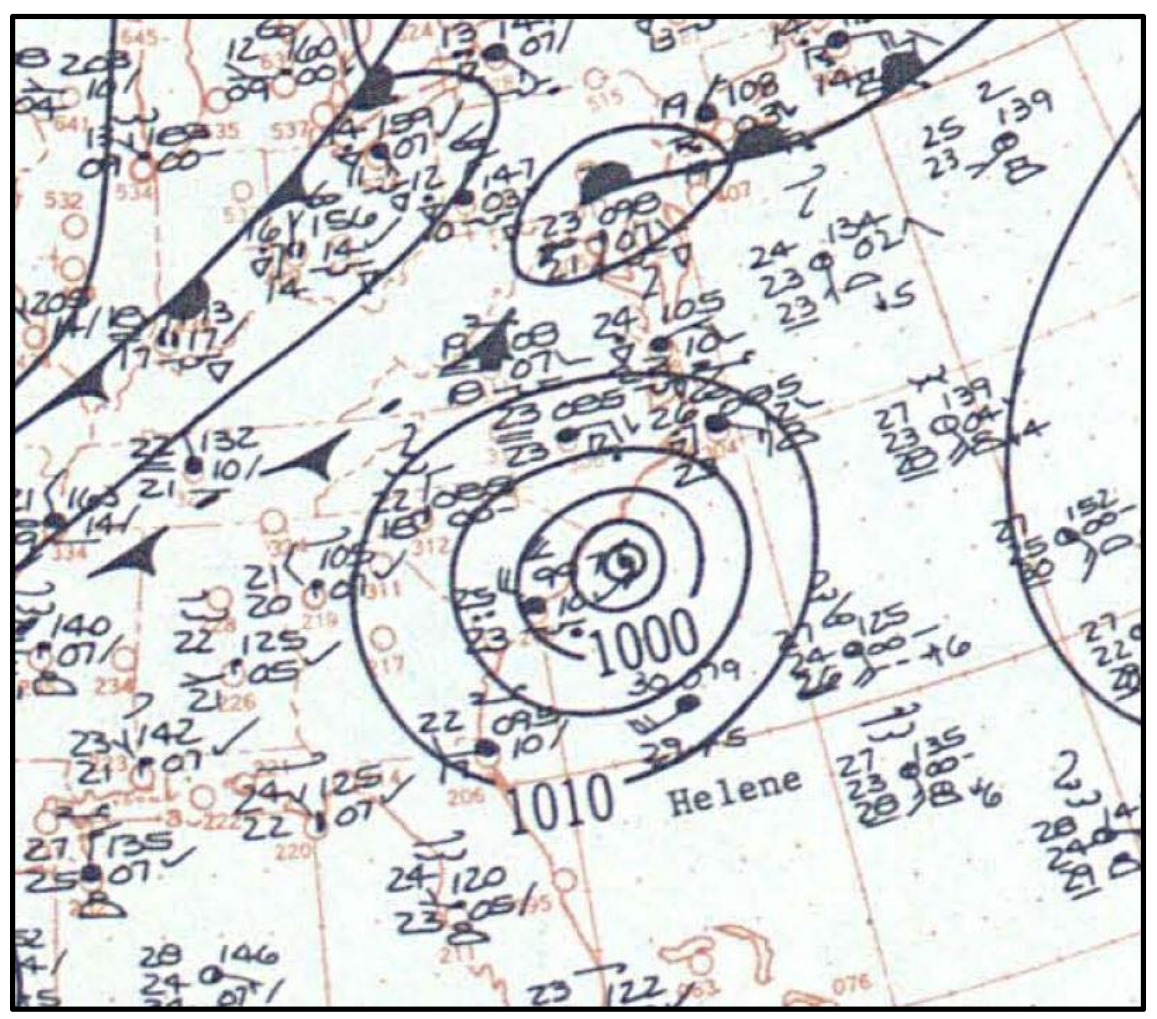

Figure 2. Historical Weather Map for September 27, 1958, zoomed-in, showing Hurricane Helene close to the eastern coast of the United States as a frontal boundary approaches from the northwest. 
synoptic data is plotted in a single map, it usually provides for a better assessment of tropical cyclone intensity and position. Another source for ship data is the Mariners Weather Log (MWL), available starting in 1957. Data in the MWL sometimes reveal important observations that were not available from other sources. The Monthly Weather Review (MWR) contains monthly charts of cyclone tracks and annual post-season hurricane summaries and track maps. Monthly summaries in MWR also provide detailed information on significant hurricane that affected the United States. Other sources include the Local and State Monthly Climatologically Data Summaries from the National

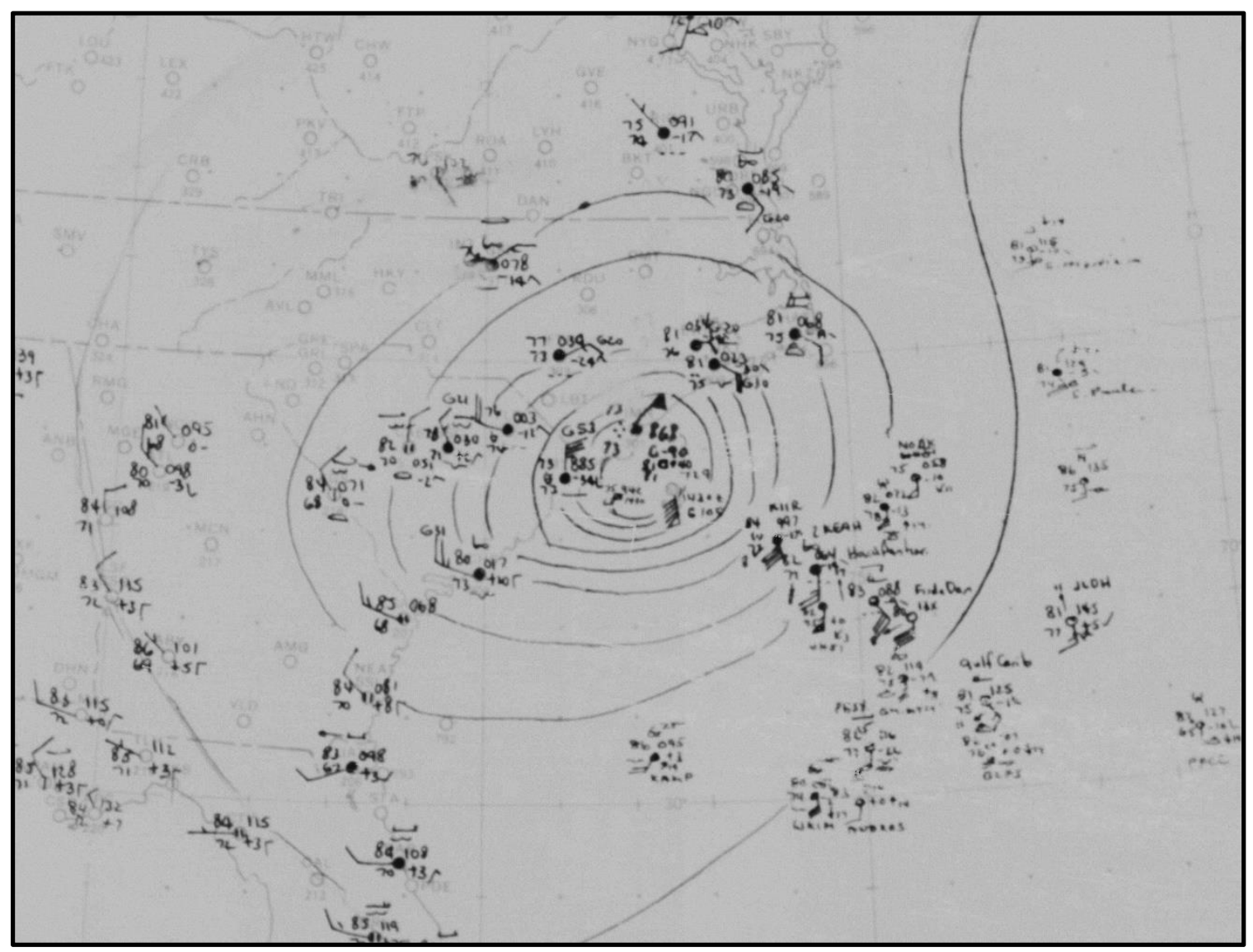

Figure 3. Microfilm image on September 27, 1958, at 15Z showing Hurricane Helene impacting parts of the Carolinas. 
Climatic Data Center. These data are essential for tropical cyclones that make landfall or pass close to the United States.

The Annual Tropical Storm Report provides reconnaissance center fixes, including latitude, longitude, and the Storm Report provides reconnaissance center fixes, including latitude, longitude, and intensity. Furthermore, it includes a summary of the tropical cyclone's lifetime and observations from every mission. These data are crucial for the current project because they come directly from the centers of the tropical cyclones, even when the tropical cyclone misses ships and major population centers. The NHC Storm Wallets, an online site of all NHC archives for a particular system available starting in 1958, were very helpful they because they contain most of the available data on the tropical cyclones in one place. They provide the Weather Bureau advisories, radar center fixes, reconnaissance aircraft center fixes, tracks, storm summaries, and more. The current analysis also incorporates meteorological observations obtained from the meteorological offices of Caribbean countries and Mexico. We also use raw U.S. station data and previous analysis by Ho et al. (1987) and Jarrell et al. (1992)

\section{Satellite Images}

The time interval analyzed here encompasses the first use of satellite data to track tropical cyclones. The TIROS Program was engineered by NASA to understand the possibility of satellites' usefulness to study the Earth. Since the satellite technology was new in the late 1950s, TIROS was used to test designs and instruments. The first weather satellite, TIROS I, was launched on April 1, 1960. It lasted 78 days in orbit. The satellite sent thousands of pictures of cloud-covered areas and proved that satellites could provide 
useful weather information from space. The TIROS cameras captured tropical cyclones (Figure 4) in various stages of development, from tropical waves to hurricanes, and at different stages of organization, from well-organized to poorly-organized systems.

Nonetheless, satellite images were not available for all tropical cyclones and for most systems, only a single satellite image is available. Moreover, the quality of most

photographs do not allow use of the Dvorak technique (Velden et al. 2006) provide an estimate of the storm intensity. Still, it is a tool with potential to enhance the completeness of HURDAT. 

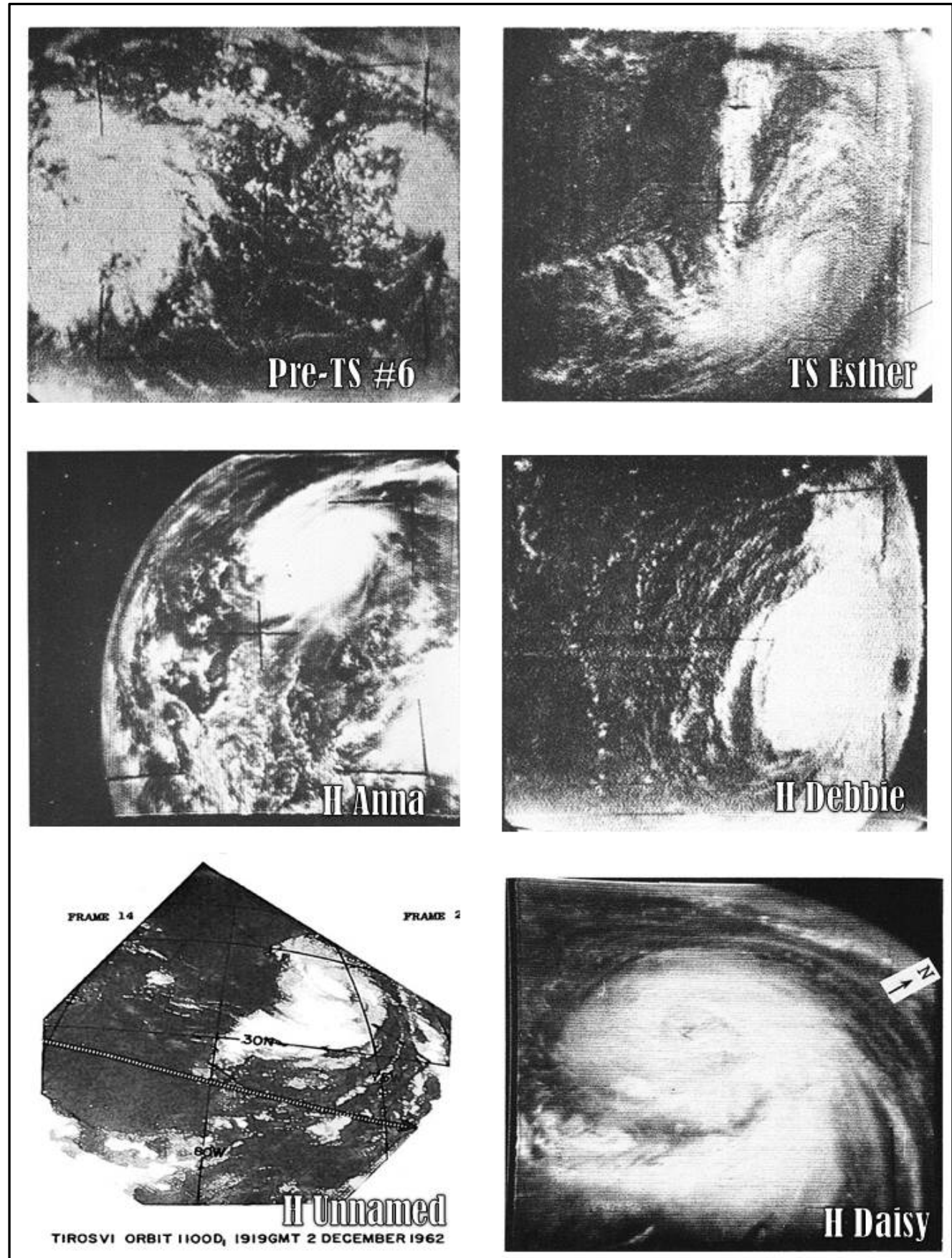

Figure 4. Satellite images captured by TIROS in 1961 and 1962 showing several tropical systems at different stages of development. 


\section{CHAPTER 4}

\section{METHODOLOGY}

The reanalysis entails several steps. The first is to obtain all the meteorological data available from all sources and compile them into a single database for each cyclone. The microfilm maps are scanned using a scanner in NHC Library. The HWM is available online and the desired area is blown up and used for the reanalysis. The images are later printed to plot all the observations from all the sources onto synoptic maps for every 6-hr interval. Key pieces of information that are important for the track and intensity of a hurricane are the data collected by the reconnaissance aircraft. The center fixes positions, pressures, estimated surface or flight level winds and estimates of the eye diameter are recorded in an excel file containing all information about each tropical cyclone. Later, after obtaining a map of the original track in HURDAT from the ATCF, the reconnaissance aircraft data are plotted and compared to the original track (Figure 5). After all the data have been plotted, a daily metadata paragraph is written for each tropical cyclone. The metadata includes a summary of the synoptic analysis shown on the HWM and microfilm maps, the center positions and intensities at $12 \mathrm{Z}$ according to HURDAT, highlighted observations of gale-force winds (35 kts or more), low pressures (usually $1005 \mathrm{mb}$ or lower), and the center fixes from the reconnaissance aircraft. When available, the center fixes from the satellites images are included. Important observations or accounts of visual observations, storm damage, etc. contribute to the daily metadata paragraph. For example, below is the daily summary of Hurricane Helene, 1958, on September 27: 


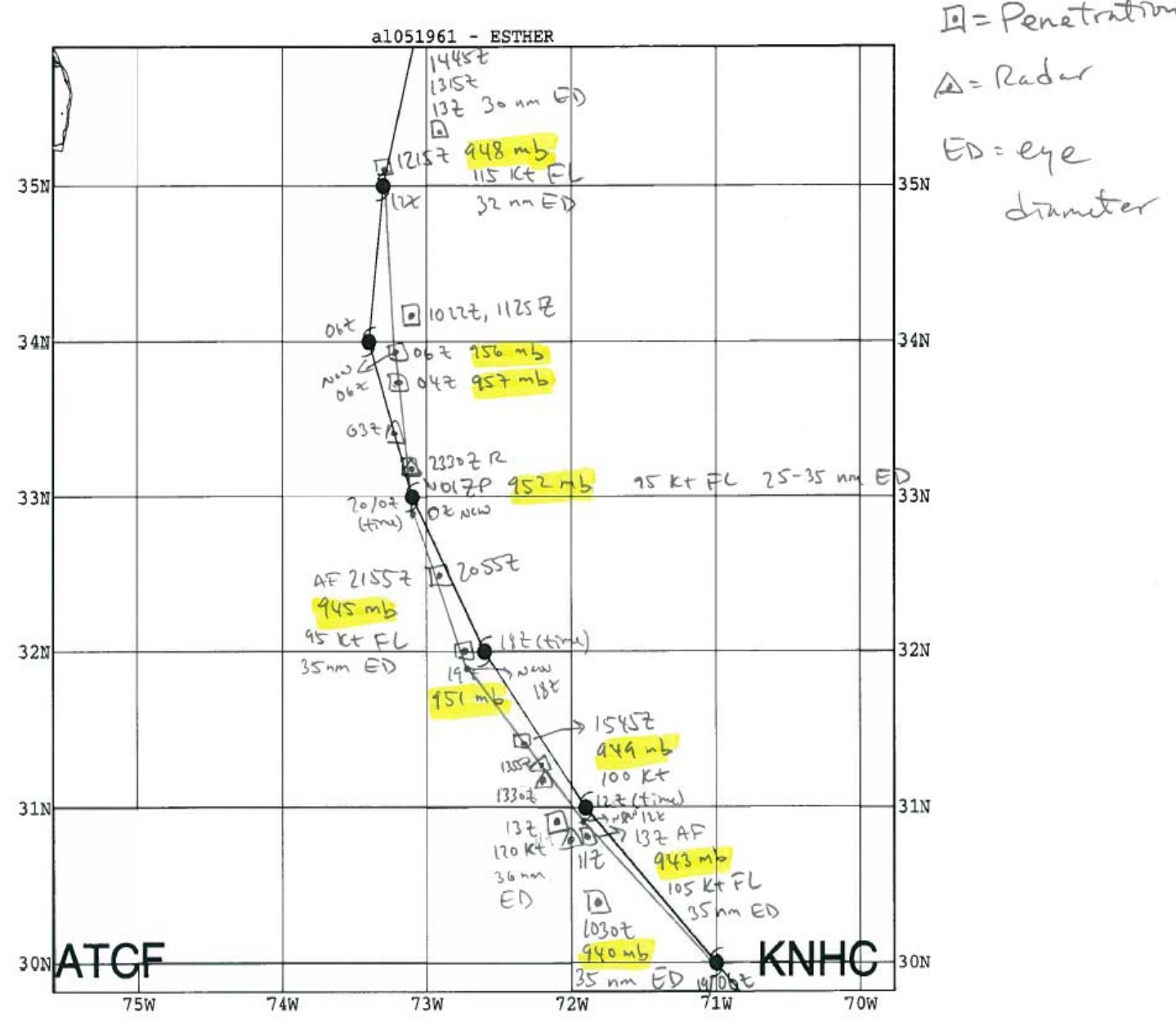

Figure 5. Part of the original track in HURDAT of Hurricane Esther, 1961, with the plotted reconnaissance aircraft data. 
HWM analyzes a hurricane of at most $990 \mathrm{mb}$ at 33.4N, 78.0W and a frontal boundary to the northwest at 12Z. HURDAT lists a 115 knot hurricane at 33.1N, 78.2W at 12Z.

Microfilm shows a closed low pressure of at most $993 \mathrm{mb}$ at 33.5N, 78.5W with a frontal boundary to the northwest at 12Z. Ship highlights: $50 \mathrm{kt} \mathrm{W}$ and $1006 \mathrm{mb}$ at 29.3N, 78.6W at 00Z (COADS). $40 \mathrm{kt} \mathrm{SE}$ and $1011 \mathrm{mb}$ at 33.7N, 74.7W at 03Z (micro). $35 \mathrm{kt} \mathrm{SW}$ and $1006 \mathrm{mb}$ at 30.8N, 77.3W at 06Z (COADS). $40 \mathrm{kt} \mathrm{SE}$ and $1006 \mathrm{mb}$ at 32.0N, 75.5W at $12 \mathrm{Z}$ (micro). $55 \mathrm{kt} \mathrm{S}$ at 32.1N, 75.6W at 15Z (micro). $55 \mathrm{kt} \mathrm{SSW}$ and $996 \mathrm{mb}$ at 36.6N, 76.5W at 18Z (COADS). $65 \mathrm{kt}$ S and $994 \mathrm{mb}$ at 34.1N, 74.9W at 20Z (MWL). $70 \mathrm{kt} \mathrm{SSW}$ and $1000 \mathrm{mb}$ at 32.4N, 75.7W at 21Z (MWL). Land highlights: $40 \mathrm{kt} \mathrm{E}$ and $1004 \mathrm{mb}$ at Frying Pan, NC at 06Z (micro). 994 mb at Sullivan's Islands, SC at 0920Z (WALLET). $60 \mathrm{kt} E$ and $992 \mathrm{mb}$ at Frying Pan, NC at 12Z (micro). $90 \mathrm{kt} \mathrm{S}$ (gusts to $105 \mathrm{kt}$ ) and 973 $\mathrm{mb}$ at Frying Pan, NC at 1430Z (micro). $50 \mathrm{kt} \mathrm{NNE} \mathrm{(gusts} \mathrm{to} 90 \mathrm{kt}$ ) and $987 \mathrm{mb}$ at Wilmington, $N C$ at $15 Z$ (micro). $74 \mathrm{kt} \mathrm{N}$ (gusts to $117 \mathrm{kt}$ ) and $977 \mathrm{mb}$ at Wilmington, $\mathrm{NC}$ at 18Z (micro). $60 \mathrm{kt} \mathrm{NW}$ (gusts to $108 \mathrm{kt}$ ) and $983 \mathrm{mb}$ at Wilmington, NC at 20Z (SWO). Gusts estimated to 125 kt, $948 \mathrm{mb}$ at Cape Lookout, NC at 2230Z (WALLET). $971 \mathrm{mb}$ at Oriental, NC at 2330Z (WALLET). 56 kt NNW (gusts to $84 \mathrm{kt}$ ) and $983 \mathrm{mb}$ at Cherry Point, NC at 2359Z (SWO). Aircraft highlights: Penetration center fix estimated surface winds of $100 \mathrm{kt}$ and an eye diameter of $25 \mathrm{~nm}$ at 31.5N, 78.3W at 0130Z (ATSR). Penetration center fix measured a central pressure of $943 \mathrm{mb}$ at 31.7N, 78.5W at 0230Z (ATSR). Penetration center fix measured a central pressure of $933 \mathrm{mb}$ and an eye diameter of $25 \mathrm{~nm}$ at 32.4N, 78.6W at 0630Z (ATSR). Penetration center fix measured a central pressure of $932 \mathrm{mb}$, estimated surface winds of $100 \mathrm{kt}$ and an eye diameter of 25 $\mathrm{nm}$ at 32.7N, 78.7W at 08Z (ATSR). Penetration center fix measured a central pressure of $938 \mathrm{mb}$, estimated surface winds of $75 \mathrm{kt}$ and an eye diameter of $25 \mathrm{~nm}$ at $33.1 \mathrm{~N}$, 78.5W at $11 \mathrm{Z}$ (ATSR). Radar center fix measured a peripheral pressure of $940 \mathrm{mb}$ at $1730 \mathrm{Z}$ (ATSR). Penetration center fix measured a central pressure of $938 \mathrm{mb}$ and estimated surface winds of $75 \mathrm{kt}$ at 34.4N, 76.3W at 2230Z (ATSR).

MWR: "Helene moved on a northwestward course at 8 to 10 mph during the 26th as it continued to deepen, finally attaining a minimum pressure of $933 \mathrm{mb}$ around midnight (local time) at a position some 80 miles east of Charleston, S.C. Hurricane-force winds, accompanied by high tides and torrential rains, pounded the coastal areas from Cape Fear to Cape Lookout. The Weather Bureau at Wilmington, N.C. recorded a maximum wind (one mile) of $88 \mathrm{mph}$ and a peak gust of $135 \mathrm{mph}$. Both of these speeds greatly exceeded all previous records there. Total rainfall at Wilmington during the hurricane was 8.29 inches. At Cape Fear, winds were estimated at 125 mph with gusts to 150 to 160 mph. According to Sumner, the wind speeds and wind damage associated with Helene indicate a more intense hurricane than Hazel of 1954, but the fact that the center of Helene passed about 20 miles off the coast prevented the extremely high tides and wave damage associated with the 1954 hurricane. Reconnaissance and other types of observational data from hurricane Helene provided a wealth of material for research and some interesting experimental work was accomplished. Two balloon-borne radio tracking beacons were dropped into the eye of Helene by aircraft of the National Hurricane Research Project and remained in the eye for a significant period. A Navy plane also dropped a metallicized inflated plastic ball on the ocean surface in the eye for radar tracking. It was observed on radar for 12 hours or more.” 
Later, the reanalyzed positions and intensities for each storm at six hour intervals are prepared. Changes are made to HURDAT only when the available data suggest that a change is needed. In general, tiny ( 0.1 degrees latitude/longitude for position and $5 \mathrm{kt}$ for intensity) alterations are not made to the HURDAT database given the sizable uncertainties inherent in the observations. On the basis of available data, the status of a tropical cyclone may be changed from the original HURDAT. Genesis can be indicated to have occurred earlier or later than originally shown, same with the transition to an extratropical cyclone or dissipation. Furthermore, a couple of the tropical cyclones reanalyzed weakened below tropical depression intensity and later regenerated, and a tropical wave stage is now shown.

After the positions, intensities and statuses are determined, opening and closing paragraphs are added to each tropical cyclone. The opening paragraph begins by describing minor, major or no proposed changes to HURDAT. Track changes larger than two degrees latitude/longitude are considered major changes, and intensity changes of 20 knots or greater (approximately one Saffir-Simpson category) are considered major intensity changes. The opening paragraph of the metadata also lists all sources. Below is an example of the opening paragraph from Hurricane Helene, 1958:

Major changes to the track and intensity shown in McAdie et al. (2009). Evidence for these alterations comes from the NHC microfilm maps, the Historical Weather Maps series, the COADS ship database, Monthly Weather Review, Surface Weather Observations, Navy reconnaissance book, Mariners Weather Log and NHC Storm Wallets. 
The closing paragraphs of the metadata for each storm contain a summary

highlighting the changes and explain the reasoning behind them. Below is an example of

the closing paragraphs from Hurricane Helene, 1958:

Hurricane Helene developed from a tropical wave that left the African coast around midSeptember. Microfilm indicates that the wave showed little signs of development as it tracked westward across the eastern and central Atlantic, although the ship data over this area of the basin are sparse. Minor track changes are analyzed during the lifetime of Helene as a tropical cyclone; major track changes were analyzed at $12 \mathrm{Z}$ and $18 \mathrm{Z}$ on October $2^{\text {nd }}$ when the system was an extratropical cyclone. The first position is at $06 \mathrm{Z}$ on September $21^{\text {st }}$ as a 25 kt tropical depression, same as the original HURDAT. The actual genesis of this tropical cyclone is highly uncertain due to the low ship traffic east of the Lesser Antilles, but the data available suggests that the center was about $90 \mathrm{~nm}$ south than originally shown in HURDAT. It is also possible that the tropical cyclone did not develop a well-defined low-level circulation until September $22^{\text {nd }}$ based on aircraft reconnaissance reports and ship observations. A ship reported 40 kt SE on September $21^{\text {st }}$ at $18 \mathrm{Z}$ but this was about $300 \mathrm{~nm}$ east of the center and appears to have a high wind bias. The first reconnaissance aircraft penetration center fix measured a central pressure of $1013 \mathrm{mb}$ and estimated surface winds of $20 \mathrm{kt}$ at $1930 \mathrm{Z}$ on September $22^{\text {nd }}$. (Central pressures values for each 6 hour period were present in the original HURDAT between September $22^{\text {nd }}$ at $12 \mathrm{Z}$ and September $30^{\text {th }}$ at 00Z. Some of these were obviously analyses that were added in, not based upon actual observations. Thus, based on actual observations, some were retained and others removed. Detailed information on these changes can be found in the table at the end.) Intensification to a tropical storm is analyzed at $00 \mathrm{Z}$ on September $23^{\text {rd }}$, same as the original HURDAT. The next reconnaissance aircraft reached Helene at $1330 \mathrm{Z}$ and measured a central pressure of $1003 \mathrm{mb}$ and estimated surface winds of $45 \mathrm{kt}$. A central pressure of $1003 \mathrm{mb}$ suggests maximum sustained winds of $41 \mathrm{kt}$ intensifying south of $25 \mathrm{~N}$ from the Brown et al. pressure-wind relationship. An intensity of $40 \mathrm{kt}$ is selected for $12 \mathrm{Z}$ on the $23^{\text {rd }}$, $5 \mathrm{kt}$ less than originally shown in HURDAT, a minor intensity change. A few ships late on September $23^{\text {rd }}$ reported low-end tropical storm force winds near the tropical cyclone.

On September $24^{\text {th }}$, Helene continued to intensify while moving to the northwest. A reconnaissance aircraft reached the tropical cyclone at $1330 \mathrm{Z}$ and measured a central pressure of $997 \mathrm{mb}$, estimated surface winds of $55 \mathrm{kt}$ and an eye diameter of $9 \mathrm{~nm}$. A central pressure of $997 \mathrm{mb}$ suggests maximum surface winds of $51 \mathrm{kt}$ north of $25 \mathrm{~N}$ from the pressure-wind relationship. An eye diameter of $9 \mathrm{~nm}$ suggests an RMW of about $7 \mathrm{~nm}$ and the climatological value is $20 \mathrm{~nm}$. Based on an RMW smaller than the climatology value and a forward speed of about $14 \mathrm{kt}$, an intensity of $60 \mathrm{kt}$ is selected at $12 \mathrm{Z}$ on the 
$24^{\text {th }}$, down from 65 kt originally in HURDAT, a minor intensity change. Intensification to a hurricane is analyzed at $18 \mathrm{Z}$ on the $24^{\text {th }}$, six hours later than originally shown in HURDAT. A ship reported $65 \mathrm{kt} S$ at $09 \mathrm{Z}$ on the $24^{\text {th }}$, but it was located about $150 \mathrm{~nm}$ southeast of the center and it is likely to have a high wind bias, compared to other ships nearby. Late on September $25^{\text {th }}$, the Navy and NHRP were investigating Helene and measured a central pressure of $982 \mathrm{mb}$ around 18Z. The Navy aircraft also estimated surface winds of $75 \mathrm{kt}$ and an eye diameter of $30 \mathrm{~nm}$, while the NHRP aircraft estimated surface winds of $76 \mathrm{kt}$ and an $R M W$ of $28 \mathrm{~nm}$. A central pressure of $982 \mathrm{mb}$ suggests maximum sustained winds of $73 \mathrm{kt}$ north of $25 \mathrm{~N}$ intensifying. Since the forward speed of the hurricane had decreased to about $5 \mathrm{kt}$ and the RMW is somewhat larger than climatology (28 nm vs $22 \mathrm{~nm}$ ), an intensity of $70 \mathrm{kt}$ is selected for $18 \mathrm{Z}$ on the $25^{\text {th }}$, down from $80 \mathrm{kt}$ originally in HURDAT, a minor intensity change. Another penetration center fix at $0230 \mathrm{Z}$ on September $26^{\text {th }}$ measured a central pressure of $986 \mathrm{mb}$, indicating that Helene may have temporarily weakened. A central pressure of $986 \mathrm{mb}$ suggests maximum sustained winds of $65 \mathrm{kt}$ north of $25 \mathrm{~N}$ from the pressure-wind relationship. An intensity of $65 \mathrm{kt}$ is selected for $00 \mathrm{Z}$ on the $26^{\text {th }}$, down from $85 \mathrm{kt}$ originally in HURDAT, a major intensity change. It is possible that Helene may have weakened to a high-end tropical storm early on the $26^{\text {th }}$. Soon thereafter, Helene started to rapidly intensify. A reconnaissance aircraft measured a central pressure of $974 \mathrm{mb}$, estimated surface winds of $50 \mathrm{kt}$ and an eye diameter of $20 \mathrm{~nm}$ at $08 \mathrm{Z}$ on the $26^{\text {th }}$. A central pressure of $974 \mathrm{mb}$ suggests maximum surface winds of $83 \mathrm{kt}$ north of $25 \mathrm{~N}$ intensifying from the pressure wind-relationship. An eye diameter of $20 \mathrm{~nm}$ suggests an RMW of about $15 \mathrm{~nm}$ and the climatological value is $23 \mathrm{~nm}$. Based on the RMW being smaller than the climatological value and a forward speed of about $8 \mathrm{kt}$, an intensity of $80 \mathrm{kt}$ is selected for $06 \mathrm{Z}$ on the $26^{\text {th }}$, down from 85 kt originally in HURDAT, a minor intensity change. Another reconnaissance aircraft measured a central pressure of $963 \mathrm{mb}$, estimated surface winds of $55 \mathrm{kt}$ and an eye diameter of $32 \mathrm{~nm}$ at $14 \mathrm{Z}$ on the $26^{\text {th }}$. A central pressure of $963 \mathrm{mb}$ suggests maximum surface winds of $96 \mathrm{kt}$ north of $25 \mathrm{~N}$ intensifying from the pressure wind-relationship. An eye diameter of $32 \mathrm{~nm}$ suggests an $R M W$ of about $24 \mathrm{~nm}$ and the climatological value is $22 \mathrm{~nm}$. Because the RMW is similar to climatology and the forward speed was about $10 \mathrm{kt}$, an intensity of $95 \mathrm{kt}$ is selected for $12 \mathrm{Z}$ on the $26^{\text {th }}$, up from 90 kt originally in HURDAT, a minor intensity change. Finally, a NHRP reconnaissance aircraft measured a central pressure of $948 \mathrm{mb}$, estimated surface winds of $99 \mathrm{kt}$ and an RMW of $25 \mathrm{~nm}$ around $1830 \mathrm{Z}$ on the $26^{\text {th }}$. Later at 20Z, a Navy aircraft measured a central pressure of $948 \mathrm{mb}$, estimated surface winds of $110 \mathrm{kt}$ and an eye diameter of $32 \mathrm{~nm}$. A central pressure of $948 \mathrm{mb}$ suggests maximum surface winds of 112 $k t$ north of $25 N$ intensifying from the pressure wind-relationship. Based on an RMW slightly larger than climatology ( $25 \mathrm{~nm}$ versus $20 \mathrm{~nm}$ ) and a forward speed of about 13 $\mathrm{kt}$, an intensity of $110 \mathrm{kt}$ is selected for $18 \mathrm{Z}$ on the $26^{\text {th }}$, up from $105 \mathrm{kt}$ originally in 
HURDAT, a minor intensity change. Intensification to a major hurricane is analyzed at $18 \mathrm{Z}$ on the $26^{\text {th }}$, same as shown in the original HURDAT.

On September $27^{\text {th }}$, Helene continued to intensify as it approached the United States and started to turn to the north and later to the northeast. A reconnaissance aircraft measured a central pressure of $943 \mathrm{mb}$ at $0230 \mathrm{Z}$ on the $27^{\text {th }}$. A central pressure of 943 $\mathrm{mb}$ suggests maximum surface winds of $117 \mathrm{kt}$ north of $25 \mathrm{~N}$ intensifying from the pressure wind-relationship. An eye diameter of $25 \mathrm{~nm}$ measured at $0630 \mathrm{Z}$ at the $27^{\text {th }}$ suggests an RMW of about $19 \mathrm{~nm}$ and the climatological value is $21 \mathrm{~nm}$. Since the RMW is close to the climatological value and the forward speed was about $10 \mathrm{kt}$, an intensity of $115 \mathrm{kt}$ is selected for 00Z on the $27^{\text {th }}$, up from $110 \mathrm{kt}$ originally in HURDAT, a minor intensity change. Another reconnaissance aircraft measured a central pressure of $933 \mathrm{mb}$ at $06 \mathrm{Z}$ on the $27^{\text {th }}$. The aircraft also estimated surface winds of $100 \mathrm{kt}$ and an eye diameter of $25 \mathrm{~nm}$ at 08Z. A central pressure of $933 \mathrm{mb}$ suggests maximum surface winds of $127 \mathrm{kt}$ north of $25 \mathrm{~N}$ intensifying from the pressure wind-relationship. An eye diameter of $25 \mathrm{~nm}$ suggests an RMW of about $19 \mathrm{~nm}$ and the climatological value is $21 \mathrm{~nm}$. An intensity of $125 \mathrm{kt}$ is selected for $06 \mathrm{Z}$ on the $27^{\text {th }}$, up from $110 \mathrm{kt}$ originally in HURDAT, a minor intensity change. The next reconnaissance aircraft measured a central pressure of $938 \mathrm{mb}$, estimated surface winds of $75 \mathrm{kt}$ and an eye diameter of $25 \mathrm{~nm}$ at $11 \mathrm{Z}$ on the $27^{\text {th }}$. A central pressure of $938 \mathrm{mb}$ suggests maximum surface winds of $116 \mathrm{kt}$ north of $25 \mathrm{~N}$ and $111 \mathrm{kt}$ north of $25 \mathrm{~N}$ weakening from the pressure wind-relationship. An eye diameter of $25 \mathrm{~nm}$ suggests an RMW of about $19 \mathrm{~nm}$ and the climatological value is 23 $\mathrm{nm}$. An intensity of $120 \mathrm{kt}$ is selected for $12 \mathrm{Z}$ on the $27^{\text {th }}$, up from $115 \mathrm{kt}$ originally in HURDAT, a minor intensity change. Late on the $27^{\text {th }}$, the eye of Helene passed very close to North Carolina, about $10 \mathrm{~nm}$ south of Cape Fear and Cape Lookout. The strongest winds likely affected southeast North Carolina. The strongest winds reported in North Carolina were $74 \mathrm{kt}$ at Wilmington and $110 \mathrm{kt}$ estimated at Cape Fear. The Schwerdt et al. parametric hurricane wind model suggests that the highest sustained winds that impacted North Carolina reached 110 kt. The same wind model suggests that South Carolina was impacted by $92 \mathrm{kt}$ winds, but since the winds that affected the state were coming from the north and northeast moving over land, a 15\% wind reduction was implemented, suggesting maximum winds of $80 \mathrm{kt}$. Therefore, Helene is analyzed as a category 3 hurricane impact for North Carolina and category 1 hurricane impact for South Carolina. The strongest winds likely affected eastern South Carolina. The strongest winds reported in South Carolina were $35 \mathrm{kt}$ at Myrtle Beach on the $27^{\text {th }}$ at $15 \mathrm{Z}$.

Moreover, tropical storm force winds impacted southern Virginia and both, the hurricane wind model and surface observations at Norfolk and Langley, indicate that the highest winds were around $40 \mathrm{kt}$. Early on September $28^{\text {th }}$, Helene started to move away from the United States ahead of a frontal boundary. A reconnaissance aircraft measured a central pressure of $938 \mathrm{mb}$ and estimated surface winds of $75 \mathrm{kt}$ at $2230 \mathrm{Z}$ on the $27^{\text {th }}$. A central 
pressure of $938 \mathrm{mb}$ suggests maximum surface winds of $116 \mathrm{kt}$ north of $25 \mathrm{~N}$ from the Brown et al. pressure wind-relationship and 104 kt north of $35 \mathrm{~N}$ from the Landsea et al. pressure-wind relationship. Based on a forward speed of about $10 \mathrm{kt}$, an intensity of 115 $k$ is selected for $00 \mathrm{Z}$ on the $28^{\text {th }}$, up from $110 \mathrm{kt}$ originally in HURDAT, a minor intensity change. Two more penetration center fixes reported a central pressure of $945 \mathrm{mb}$ at $03 \mathrm{Z}$ and $955 \mathrm{mb}$ at $08 \mathrm{Z}$ on the $28^{\text {th }}$. A blend of these two measurements suggests a central pressure of about $950 \mathrm{mb}$ around $06 \mathrm{Z}$ on the $27^{\text {th }}$, same as the original HURDAT. The aircraft also reported an eye diameter of $24 \mathrm{~nm}$ at $08 \mathrm{Z}$ on the $28^{\text {th }}$. A central pressure of $950 \mathrm{mb}$ suggests sustained maximum winds of $101 \mathrm{kt}$ north of $25 \mathrm{~N}$ weakening and $97 \mathrm{kt}$ north of 35kt, according to the corresponding pressure-wind relationships. An eye diameter of $24 \mathrm{~nm}$ suggests an RMW of about $18 \mathrm{~nm}$ and the climatological value is 25 $\mathrm{nm}$. At this time, Helene was increasing in forward speed as it moved northeastward. Based on a forward speed of about $25 \mathrm{kt}$ and an RMW smaller than climatology, an intensity of $110 \mathrm{kt}$ is selected at $06 \mathrm{Z}$ on the $28^{\text {th }}$, same as originally shown in HURDAT.

On the $28^{\text {th }}$, Helene started to interact with a frontal boundary off the Mid-Atlantic of the United States and began to acquire extratropical characteristics. A reconnaissance aircraft at 14Z estimated surface winds of $90 \mathrm{kt}$ and measured a pressure of $966 \mathrm{mb}$. Based on central pressure reports earlier and later on the day, it is likely that this pressure report was not a central pressure and has not been added to HURDAT. The last reconnaissance aircraft to reach Helene measured a central pressure of $943 \mathrm{mb}$ and estimated surface winds of $105 \mathrm{kt}$ at $2130 \mathrm{Z}$ and $951 \mathrm{mb}$ at $2230 \mathrm{Z}$ on the $28^{\text {th }}$. A central pressure of $943 \mathrm{mb}$ suggests maximum surface winds of $101 \mathrm{kt}$ north of $35 \mathrm{~N}$ from the pressure-wind relationship. Since the hurricane was becoming extratropical and also moving very rapidly ( $\sim 39 \mathrm{kt}$ ) towards the east-northeast, an intensity of $100 \mathrm{kt}$ is selected at $18 \mathrm{Z}$ on the $28^{\text {th }}$, up from 90 kt originally in HURDAT, a minor intensity change. Early on September $29^{\text {th }}$, coastal and ship observations indicate that Helene had become an extratropical cyclone. A temperature gradient had developed $E-W$ across the circulation, along with frontal features. Extratropical transition is analyzed eighteen hours earlier than originally shown in HURDAT. Later on the $29^{\text {th }}$, Helene moved over the Atlantic provinces of Canada before moving northeast into the North Atlantic. It is analyzed that Helene reached Canada as a powerful extratropical cyclone and not as a hurricane as originally shown in HURDAT. Weakening below hurricane force occurred at $06 \mathrm{Z}$ on September $30^{\text {th }}$, six hours later than originally shown in HURDAT. Late on October $1^{\text {st }}$, ship observations indicate that the extratropical cyclone regained winds of hurricane force, but the strengthening was short-lived as the system started to weaken again on October $2^{\text {nd }}$. Major intensity changes are analyzed at $18 \mathrm{Z}$ on the $1^{\text {st }}$, and $00 \mathrm{Z}$ and $06 \mathrm{Z}$ on the $2^{\text {nd }}$. The analyzed intensity for these times is $70 \mathrm{kt}, 70 \mathrm{kt}$ and $65 \mathrm{kt}$, and HURDAT originally showed $50 \mathrm{kt}, 50 \mathrm{kt}$ and $45 \mathrm{kt}$, respectively. Late on the $2^{\text {nd }}$, the extratropical cyclone weakened again below hurricane force and kept a general eastward track. Early 
on October $4^{\text {th }}$, the weakened extratropical cyclone merged with another extratropical cyclone to the north. The last position is analyzed at $00 \mathrm{Z}$ on the $4^{\text {th }}$, same as originally shown in HURDAT. 


\section{CHAPTER 5}

\section{RESULTS}

The decade reanalyzed here contained several devastating events for many countries that border the Atlantic Ocean, Caribbean Sea and Gulf of Mexico. In 1954, three hurricanes impacted the eastern coast of the United States and three more the next year. In 1955, category 5 Hurricane Janet caused catastrophic damage in Swan Island and parts of the Yucatan Peninsula and a reconnaissance aircraft was lost flying into the powerful tropical cyclone. In 1956, Hurricane Betsy struck Puerto Rico, and Hurricane Greta became one of the largest tropical cyclones ever observed in the Atlantic, with a radius of tropical storm force winds comparable to Hurricane Sandy. In 1957, Hurricane Audrey surprised many in the northern Gulf Coast by evolving into a potent hurricane in late June and driving a deadly storm surge as it made landfall near the Texas and Louisiana border. In 1958, Hurricane Helene did not make landfall but passed only a few miles off the North Carolina coast as a high end category 4 hurricane while it recurved toward the Atlantic. Still, it was able to produce winds of major hurricane intensity over parts of the coastline. In 1959, Hurricane Gracie made landfall in South Carolina as a powerful category 4 hurricane. In 1960, Hurricane Donna affected the entire eastern seaboard after making landfall in South Florida and turning to the northeast. In 1961, Hurricane Carla hit Texas as a category 4 hurricane causing devastating damage. In 1962, the Atlantic experienced a quiet year with no hurricane landfalls. In 1963, two tropical storms affected the United States and Hurricane Flora caused over 8,000 deaths in Cuba and Haiti, making it one of the deadliest hurricane in the history of the Atlantic. 
The reanalysis process is a time-consuming endeavor. Each season took a few months to complete because each day of each tropical cyclone to be reanalyzed as well as searching for new systems. The metadata files containing the detailed changes to HURDAT are included in Appendix (URL for supplementary data). The Appendix illustrates most of the work of this thesis, but this Results Section will summarize the most important changes to the original HURDAT.

\section{Hurricane Season}

The 1954 hurricane season was very active for the United States with the landfalls of hurricanes Carol, Edna and Hazel. These hurricanes were reanalyzed by Donna Strahan. La Niña was active in the equatorial waters of the Pacific Ocean. The original HURDAT lists 11 tropical cyclones that reached tropical storm intensity, 8 reached hurricane intensity, and 2 became major hurricanes. The reanalysis adds three new tropical cyclones to the season, and none of the original systems were removed, increasing the season total to 14 tropical cyclones. The number of hurricanes decreased to 7 but the number of major hurricanes increased to 3. Hurricane Carol is shown in the original HURDAT with a peak intensity of $85 \mathrm{kt}$ but as a major hurricane (Category 3 on the SSHWS) at landfall in New York and New England. This is an example of the original errors in HURDAT for many hurricanes that made U.S. landfall. This hurricane season also contained hurricane Alice that formed in late December and lasted into 1955. It was analyzed operationally as a tropical storm in early January of 1955, took the first name of the 1955 hurricane season, moved across the Leeward Islands, and dissipated over the eastern Caribbean Sea. Alice was the first known tropical cyclone to exist in two 
calendar years. Of the new tropical cyclones, two occurred early in the season and moved northeastward, parallel to the eastern seaboard, while the third new system formed over the north Atlantic and was not a threat to land. Overall, there were minor changes to the intensities and tracks of the tropical cyclones originally in HURDAT. Figure 6 shows the original tracks and Figure 7 illustrates the revised tracks. The changes to the season are shown in Table 2. 


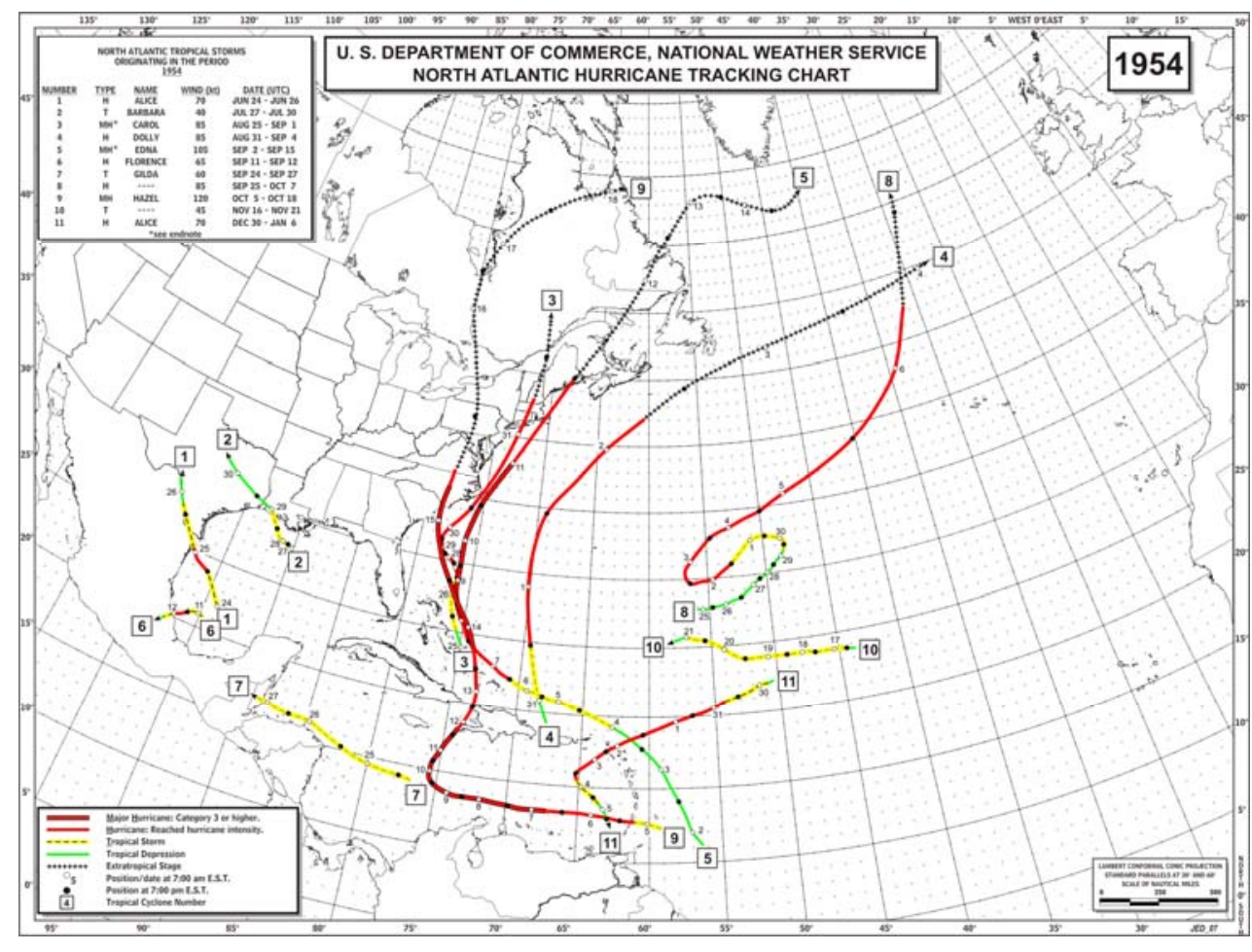

Figure 6. 1954 original track map.

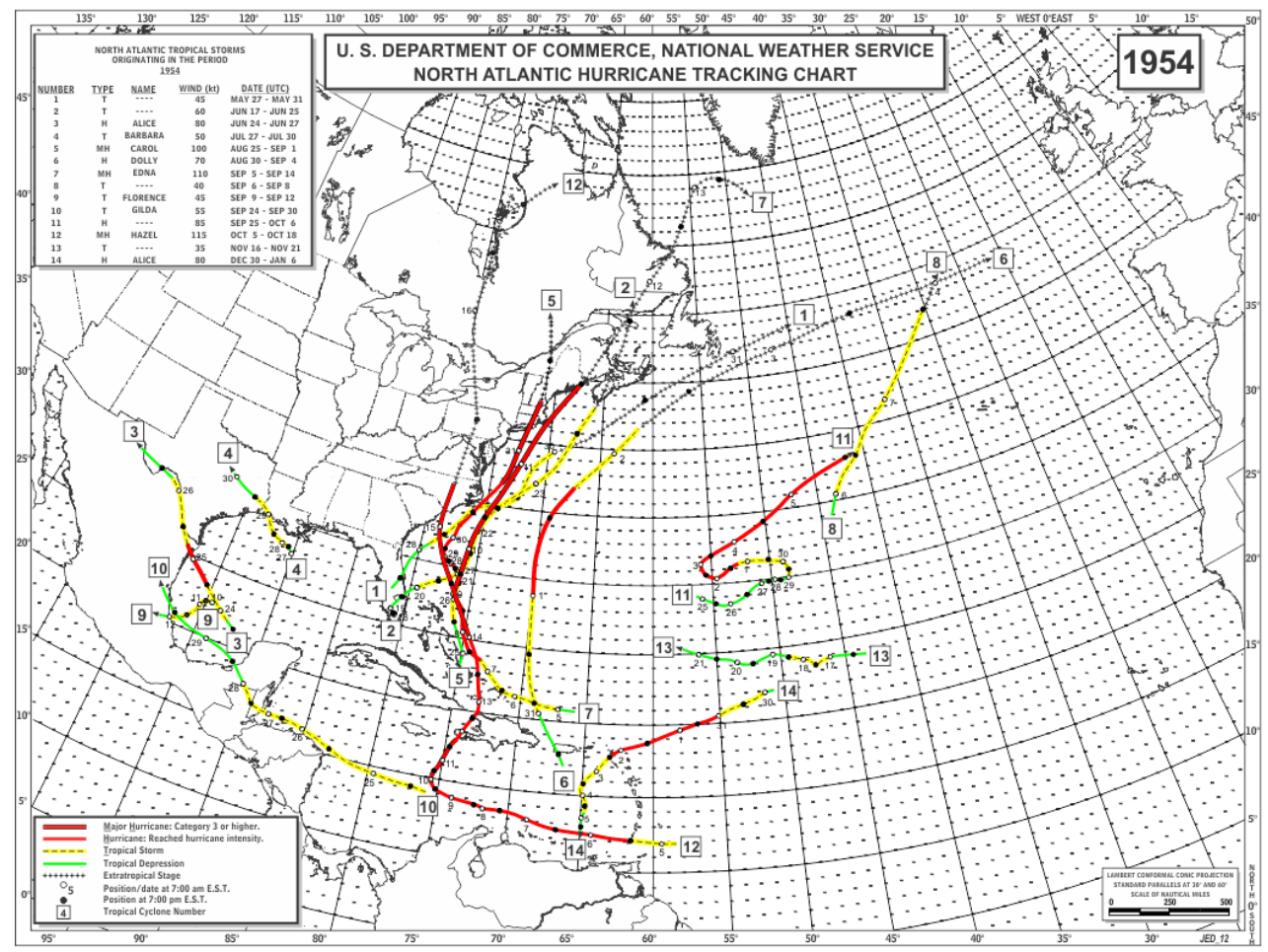

Figure 7.1954 revised track map. 


\section{Revision for the 1954 Atlantic Hurricane Season}

\begin{tabular}{|c|c|c|c|c|c|c|}
\hline Name & Date & $\begin{array}{l}\text { Original } \\
\text { Peak } \\
\text { Intensity } \\
(\mathrm{kt})\end{array}$ & $\begin{array}{l}\text { Revised } \\
\text { Peak } \\
\text { Intensity } \\
(\mathrm{kt})\end{array}$ & $\begin{array}{c}\text { Track } \\
\text { Change }\end{array}$ & $\begin{array}{c}\text { Intensity } \\
\text { Change }\end{array}$ & $\begin{array}{l}\text { Genesis/ } \\
\text { Decay } \\
\text { Change }\end{array}$ \\
\hline Unnamed & $\begin{array}{c}05 / 27- \\
05 / 31\end{array}$ & - & 45 & - & - & - \\
\hline Unnamed & $\begin{array}{c}06 / 17- \\
06 / 25\end{array}$ & - & 60 & - & - & - \\
\hline Alice & $\begin{array}{c}06 / 24- \\
06 / 27\end{array}$ & 70 & 80 & Minor & Minor & $\begin{array}{c}\text { Genesis } 12 \\
\text { hr earlier, } \\
\text { Decay } 12 \mathrm{hr} \\
\text { later }\end{array}$ \\
\hline Barbara & $\begin{array}{c}07 / 27- \\
07 / 30\end{array}$ & 40 & 50 & Minor & Major & $\begin{array}{c}\text { Genesis } 6 \mathrm{hr} \\
\text { later, } \\
\text { Decay } 6 \mathrm{hr} \\
\text { earlier }\end{array}$ \\
\hline Carol & $\begin{array}{c}08 / 25- \\
09 / 01\end{array}$ & 85 & 100 & Minor & Minor & $\begin{array}{c}\text { Genesis } 6 \text { hr } \\
\text { earlier }\end{array}$ \\
\hline Dolly & $\begin{array}{c}08 / 31- \\
09 / 04\end{array}$ & 85 & 70 & Minor & Major & $\begin{array}{c}\text { Genesis } 6 \mathrm{hr} \\
\text { earlier, } \\
\text { Decay } 6 \mathrm{hr} \\
\text { later }\end{array}$ \\
\hline Edna & $\begin{array}{c}09 / 05- \\
09 / 14\end{array}$ & 105 & 110 & Major & Major & $\begin{array}{c}\text { Genesis } 60 \\
\text { hr later, } \\
\text { Decay } 24 \mathrm{hr} \\
\text { earlier }\end{array}$ \\
\hline Unnamed & $\begin{array}{c}09 / 06- \\
09 / 08\end{array}$ & - & 40 & - & - & - \\
\hline Florence & $\begin{array}{c}09 / 10- \\
09 / 12\end{array}$ & 65 & 45 & Minor & Major & $\begin{array}{c}\text { Genesis } 12 \\
\text { hr earlier }\end{array}$ \\
\hline Gilda & $\begin{array}{c}09 / 24- \\
09 / 30\end{array}$ & 60 & 55 & Major & Minor & $\begin{array}{c}\text { Decay } 60 \mathrm{hr} \\
\text { later }\end{array}$ \\
\hline Unnamed & $\begin{array}{c}09 / 25- \\
10 / 07\end{array}$ & 85 & 85 & Minor & Minor & $\begin{array}{c}\text { Decay } 24 \mathrm{hr} \\
\text { earlier }\end{array}$ \\
\hline Hazel & $\begin{array}{c}10 / 05- \\
10 / 18\end{array}$ & 120 & 115 & Minor & Major & $\begin{array}{c}\text { Decay } 6 \text { hr } \\
\text { earlier }\end{array}$ \\
\hline Unnamed & $\begin{array}{c}11 / 16- \\
11 / 21\end{array}$ & 45 & 35 & Minor & Minor & No change \\
\hline Alice & $\begin{array}{l}12 / 30- \\
01 / 06\end{array}$ & 70 & 80 & Major & Major & $\begin{array}{l}\text { Decay } 6 \mathrm{hr} \\
\text { later }\end{array}$ \\
\hline
\end{tabular}

Table 2. 1954 revisions. 


\section{Hurricane Season}

The 1955 hurricane season was also very active for the United States with the landfalls by hurricanes Connie, Diane and Ione. La Niña was present in the equatorial waters of the Pacific. The original HURDAT lists 12 tropical cyclones that reached tropical storm intensity, 9 reached hurricane intensity and 6 became major hurricanes. The reanalysis adds two new tropical cyclones to the season and none of the original systems were removed, increasing the total to 14 tropical cyclones. The number of hurricanes is decreased to 7 and the number of major hurricanes is decreased to 4 . Hurricane Janet was the strongest hurricane in the season, reaching a peak intensity of $150 \mathrm{kt}$ before passing over the Yucatan peninsula. Both of the newly added tropical storms developed over the eastern Atlantic and originally the names "Katie" and "Linda" were associated with these systems, as it appears in the microfilm images (Figure 8), but in 1955 neither was upgraded officially and the name "Katie" was used later in the season. This reanalysis suggests that the name "Linda" be used for the other proposed tropical storm. Overall, there were major changes to the intensities and minor alterations to the tracks of the tropical cyclones originally in HURDAT. Figure 9 shows the original tracks and Figure 10 illustrates the revised tracks. The changes to the season are shown in Table 3. 

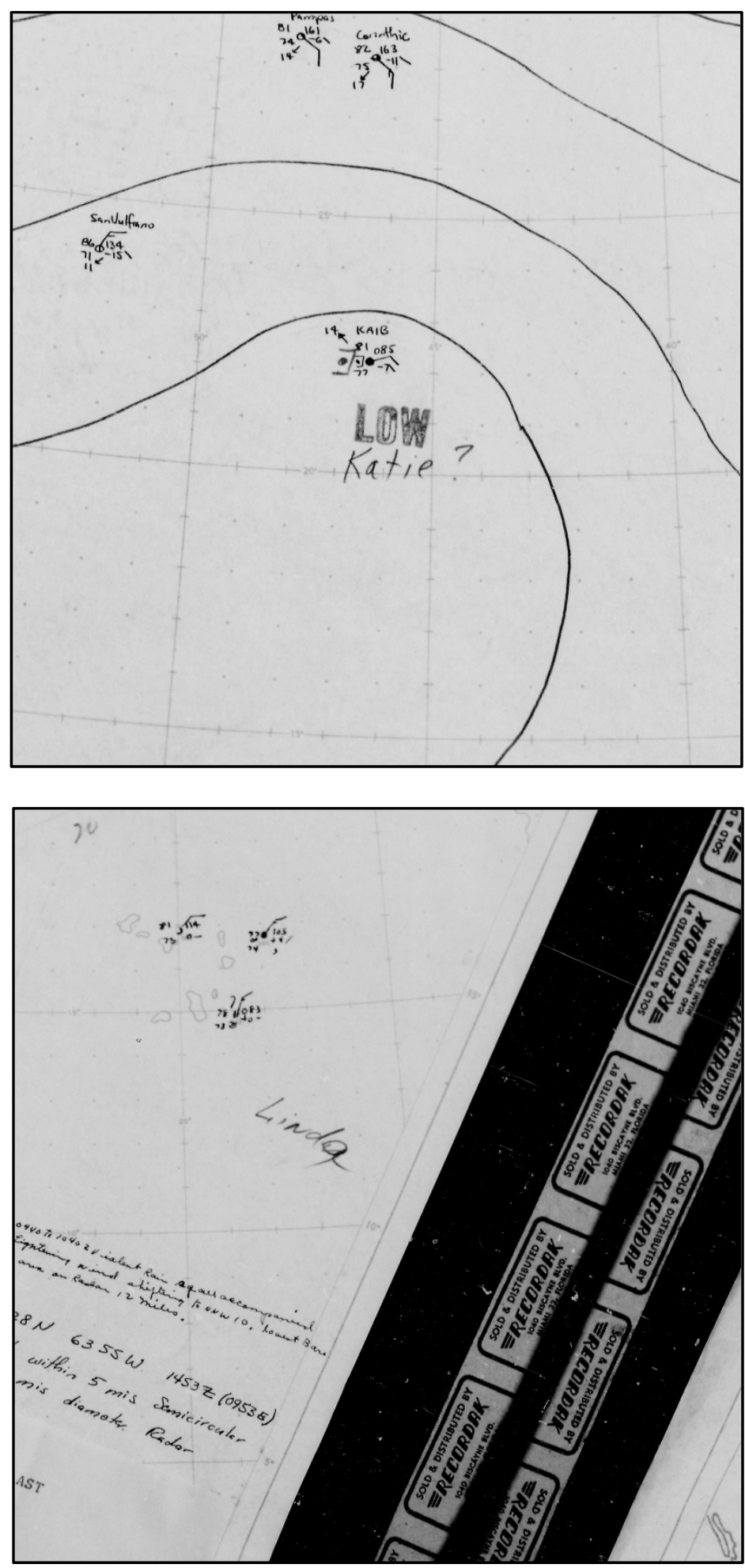

Figure 8. Top image is the microfilm on September $23^{\text {rd }}, 1955$ at $18 \mathrm{Z}$ showing a tropical disturbance listed as "Katie" and the bottom image is the microfilm on September 23 , 1955 at $12 Z$ showing another disturbance listed as "Linda". 


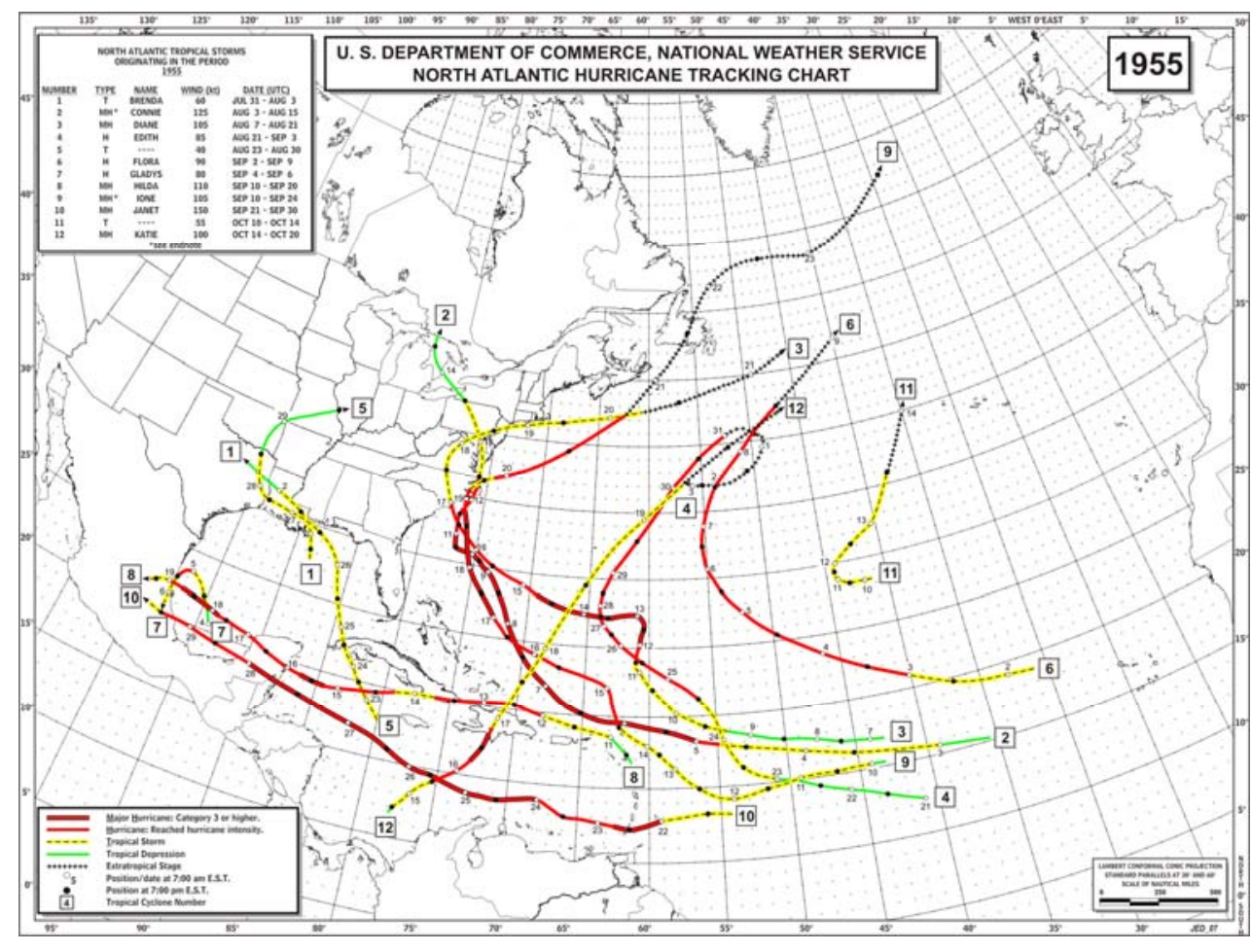

Figure 9. 1955 original track map.

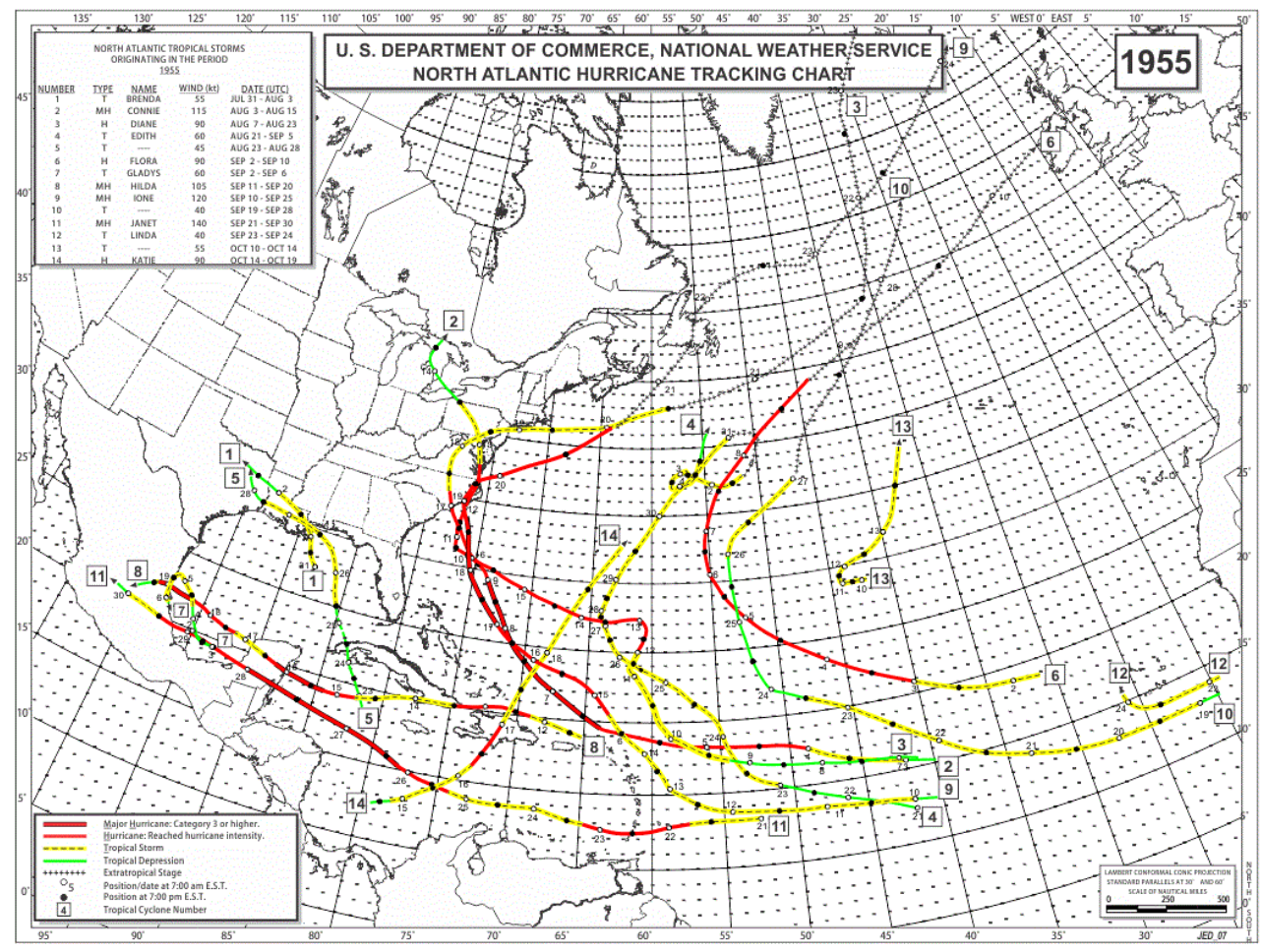

Figure 10. 1955 revised track map. 


\section{Revision for the 1955 Atlantic Hurricane Season}

\begin{tabular}{|c|c|c|c|c|c|c|}
\hline Name & Date & $\begin{array}{l}\text { Original } \\
\text { Peak } \\
\text { Intensity } \\
(\mathrm{kt})\end{array}$ & $\begin{array}{l}\text { Revised } \\
\text { Peak } \\
\text { Intensity } \\
\text { (kt) }\end{array}$ & $\begin{array}{c}\text { Track } \\
\text { Change }\end{array}$ & $\begin{array}{l}\text { Intensity } \\
\text { Change }\end{array}$ & $\begin{array}{c}\text { Genesis/Decay } \\
\text { Change }\end{array}$ \\
\hline Brenda & $\begin{array}{c}07 / 31- \\
08 / 03\end{array}$ & 60 & 55 & Minor & Minor & $\begin{array}{c}\text { Genesis } 6 \mathrm{hr} \\
\text { earlier }\end{array}$ \\
\hline Connie & $\begin{array}{c}08 / 03- \\
08 / 15\end{array}$ & 125 & 115 & Major & Major & $\begin{array}{c}\text { Decay } 6 \mathrm{hr} \\
\text { earlier }\end{array}$ \\
\hline Diane & $\begin{array}{c}08 / 07- \\
08 / 22\end{array}$ & 105 & 90 & Major & Major & $\begin{array}{c}\text { Decay } 48 \mathrm{hr} \\
\text { later }\end{array}$ \\
\hline Edith & $\begin{array}{l}08 / 21- \\
09 / 05\end{array}$ & 80 & 60 & Major & Major & $\begin{array}{c}\text { Decay } 36 \mathrm{hr} \\
\text { later }\end{array}$ \\
\hline Unnamed & $\begin{array}{c}08 / 23- \\
08 / 28\end{array}$ & 40 & 45 & Minor & Minor & $\begin{array}{l}\text { Decay } 30 \mathrm{hr} \\
\text { earlier }\end{array}$ \\
\hline Flora & $\begin{array}{c}09 / 02- \\
09 / 10\end{array}$ & 90 & 90 & Minor & Major & $\begin{array}{c}\text { Decay } 24 \mathrm{hr} \\
\text { later }\end{array}$ \\
\hline Gladys & $\begin{array}{c}09 / 02- \\
09 / 06\end{array}$ & 80 & 60 & Minor & Major & $\begin{array}{c}\text { Genesis } 48 \mathrm{hr} \\
\text { earlier }\end{array}$ \\
\hline Ione & $\begin{array}{l}09 / 10- \\
09 / 25\end{array}$ & 110 & 120 & Major & Major & $\begin{array}{c}\text { Decay } 42 \mathrm{hr} \\
\text { later }\end{array}$ \\
\hline Hilda & $\begin{array}{c}09 / 11- \\
09 / 20\end{array}$ & 110 & 105 & Major & Major & $\begin{array}{c}\text { Genesis } 18 \mathrm{hr} \\
\text { later }\end{array}$ \\
\hline Unnamed & $\begin{array}{c}09 / 19- \\
09 / 28\end{array}$ & - & 40 & - & - & - \\
\hline Janet & $\begin{array}{c}09 / 21- \\
09 / 30\end{array}$ & 150 & 150 & Minor & Major & $\begin{array}{c}\text { Genesis } 6 \mathrm{hr} \\
\text { earlier, Decay } \\
6 \mathrm{hr} \text { later }\end{array}$ \\
\hline "Linda" & $\begin{array}{c}09 / 23- \\
09 / 24\end{array}$ & - & 40 & - & - & - \\
\hline Unnamed & $\begin{array}{l}10 / 10- \\
10 / 14\end{array}$ & 50 & 50 & Minor & Major & - \\
\hline Katie & $\begin{array}{l}10 / 14- \\
10 / 19\end{array}$ & 100 & 90 & Minor & Major & $\begin{array}{l}\text { Decay } 24 \mathrm{hr} \\
\text { earlier }\end{array}$ \\
\hline
\end{tabular}

Table 3. 1955 revisions. 


\section{Hurricane Season}

The 1956 hurricane season was relatively quiet for the Atlantic in terms of landfalls. La Niña was present in the equatorial waters of the Pacific, but was weaker than in 1954 or 1955 . The original HURDAT lists 8 tropical cyclones that reached tropical storm intensity, 4 reached hurricane intensity and 2 became major hurricanes. The reanalysis adds four new tropical cyclones to the season and none of the original systems were removed, increasing the total to 12 tropical cyclones. The number of hurricanes is retained at 4 and the number of major hurricanes is decreased to 1 . Hurricane Betsy was the only major hurricane this season. Betsy marked a milestone in the communication of hurricane warnings in Puerto Rico, because hurricane warnings were issued on television for the first time. It was also the first hurricane observed by the San Juan Weather Radar (Pérez, 1971). Betsy later passed closed to the Bahamas producing hurricane conditions. Hurricane Flossy was the only hurricane to strike the United States. It affected the northern and northeastern Gulf of Mexico. Hurricane Greta was a large tropical cyclone late in the season. It's intensity was decreased from $120 \mathrm{kt}$ to $85 \mathrm{kt}$, a major intensity change. Overall, there were major changes to the intensities and minor alterations to the tracks of the tropical cyclones originally in HURDAT. Figure 11 shows the original tracks and Figure 12 illustrates the revised tracks. The changes to the season are shown in Table 4. 


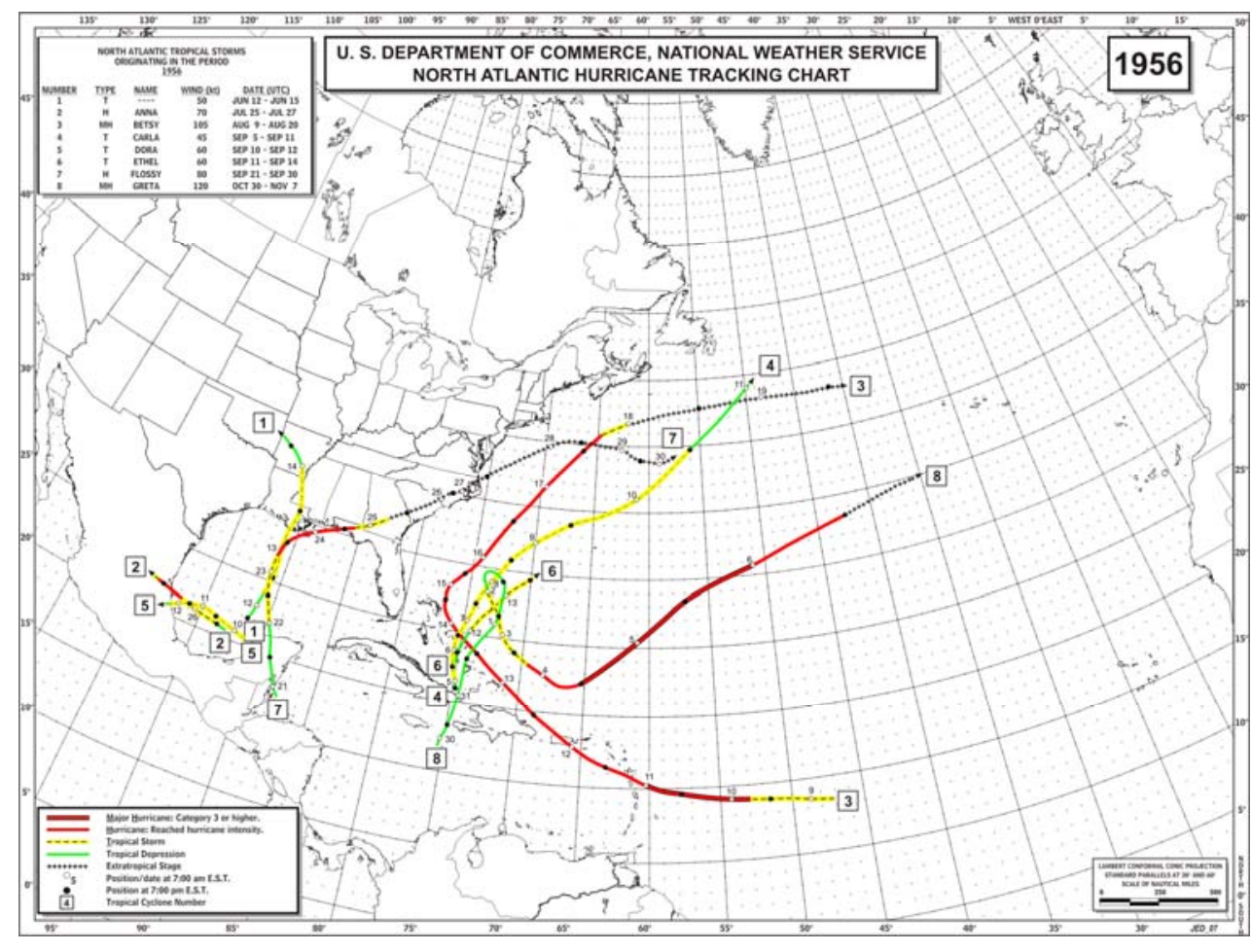

Figure 11. 1956 original track map.

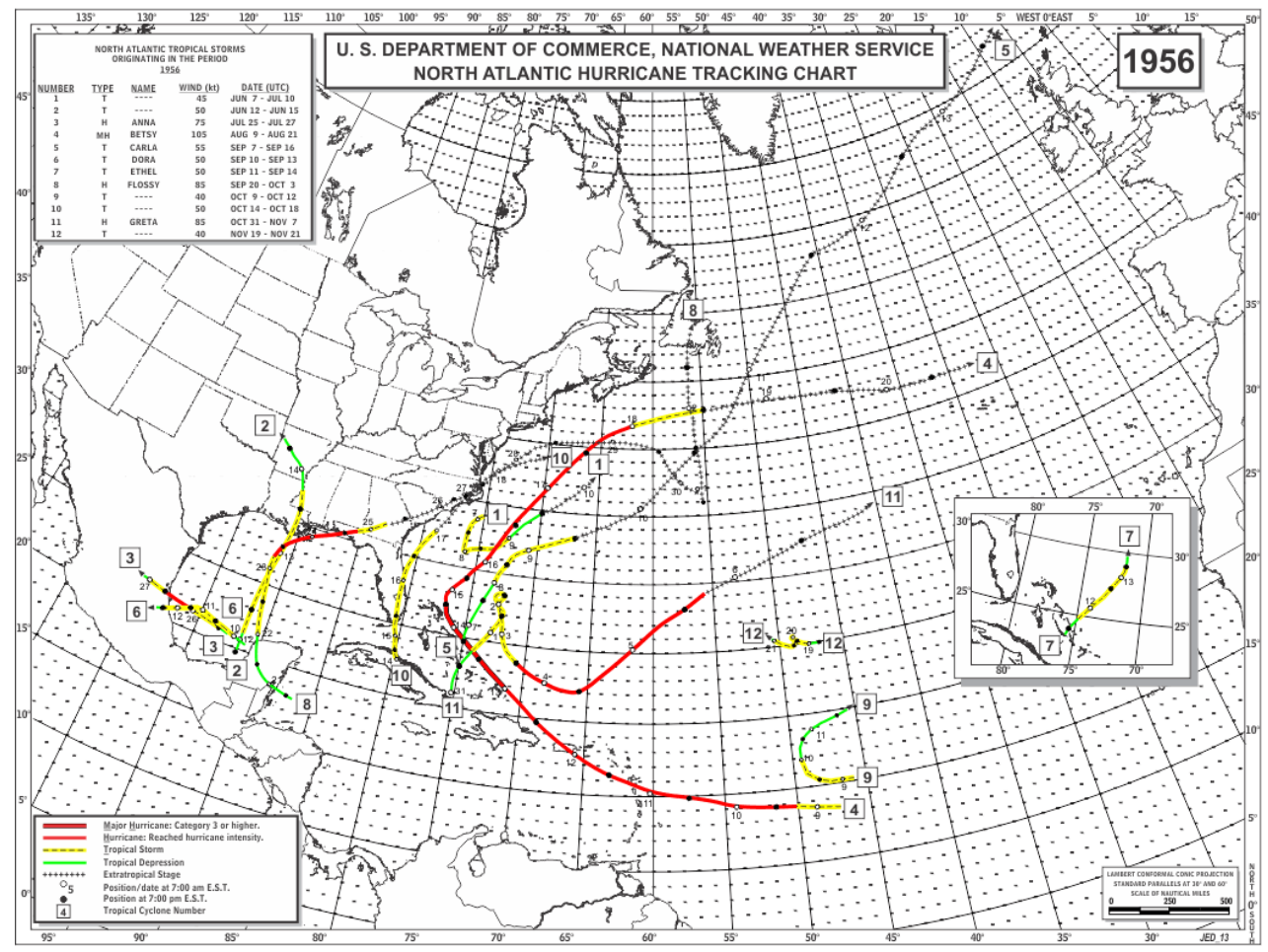

Figure 12. 1956 revised track map. 


\section{Revision for the 1956 Atlantic Hurricane Season}

\begin{tabular}{|c|c|c|c|c|c|c|}
\hline Name & Date & $\begin{array}{l}\text { Original } \\
\text { Peak } \\
\text { Intensity } \\
\quad(\mathrm{kt})\end{array}$ & $\begin{array}{l}\text { Revised } \\
\text { Peak } \\
\text { Intensity } \\
\quad(\mathrm{kt})\end{array}$ & $\begin{array}{c}\text { Track } \\
\text { Change }\end{array}$ & $\begin{array}{l}\text { Intensity } \\
\text { Change }\end{array}$ & $\begin{array}{l}\text { Genesis/Decay } \\
\text { Change }\end{array}$ \\
\hline Unnamed & $\begin{array}{c}06 / 07- \\
06 / 10\end{array}$ & - & 45 & - & - & - \\
\hline Unnamed & $\begin{array}{l}06 / 12- \\
06 / 15\end{array}$ & 50 & 50 & Major & Minor & No change \\
\hline Anna & $\begin{array}{c}07 / 25- \\
07 / 27\end{array}$ & 70 & 75 & Minor & Major & Decay $6 \mathrm{hr}$ later \\
\hline Betsy & $\begin{array}{c}08 / 09- \\
08 / 21\end{array}$ & 105 & 105 & Minor & Major & Decay $30 \mathrm{hr}$ later \\
\hline Carla & $\begin{array}{c}09 / 05- \\
09 / 16\end{array}$ & 45 & 55 & Minor & Major & $\begin{array}{l}\text { Genesis } 42 \text { hr later, } \\
\text { Decay } 114 \text { hr later }\end{array}$ \\
\hline Dora & $\begin{array}{l}09 / 10- \\
09 / 13\end{array}$ & 60 & 50 & Minor & Major & Decay 6 hr later \\
\hline Ethel & $\begin{array}{c}09 / 11- \\
09 / 14\end{array}$ & 60 & 50 & Minor & Minor & Decay 6 hr later \\
\hline Flossy & $\begin{array}{c}09 / 20- \\
10 / 03\end{array}$ & 80 & 85 & Major & Major & $\begin{array}{c}\text { Genesis } 6 \mathrm{hr} \text { earlier, } \\
\text { Decay } 60 \mathrm{hr} \text { later }\end{array}$ \\
\hline Unnamed & $\begin{array}{l}10 / 09- \\
10 / 12\end{array}$ & - & 40 & - & - & - \\
\hline Unnamed & $\begin{array}{c}10 / 14- \\
10 / 18\end{array}$ & - & 50 & - & - & - \\
\hline Greta & $\begin{array}{c}10 / 31- \\
11 / 07\end{array}$ & 120 & 85 & - & - & Genesis 30 hr later \\
\hline
\end{tabular}

Table 4. 1956 revisions. 


\section{Hurricane Season}

The 1957 hurricane season experienced near normal levels of tropical cyclone activity and El Niño was active in the equatorial waters of the Pacific Ocean. The original HURDAT lists 8 tropical cyclones that reached tropical storm intensity, 3 that reached hurricane intensity and 2 that became major hurricanes. The reanalysis adds two new tropical cyclones to the season and none of the original systems were removed, increasing the total to 10 tropical cyclones. The number of hurricanes is retained at 3 and the number of major hurricanes is also retained to 2. Hurricane Audrey made landfall in the United States causing significant damage and hundreds of deaths in Cameron Parrish, Louisiana. The peak intensity, that at landfall was decreased from $125 \mathrm{kt}$ originally, to $105 \mathrm{kt}$, a major intensity change. Hurricane Carrie was a long-lived tropical cyclone, that initially formed near the western coast of Africa and dissipated near the United Kingdom. The system lasted about 24 days. Two near tropical cyclones were added to the season, including a tropical storm forming in late April in the northern Gulf of Mexico (Figure 13). Overall, there were minor changes to the intensities and tracks original in HURDAT. The changes to the season are shown in Table 5. Figure 14 shows the original tracks and Figure 15 illustrates the revised tracks. 


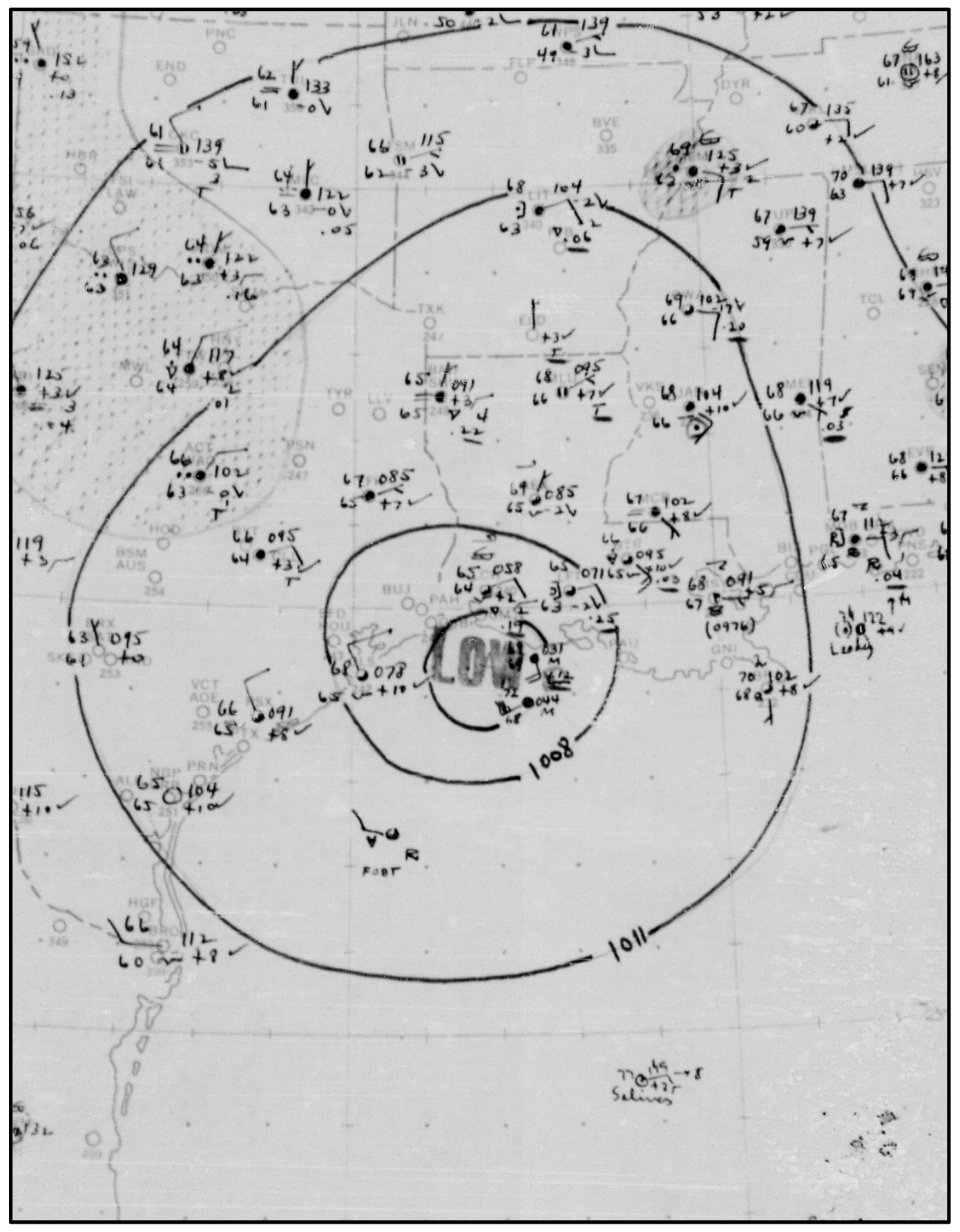

Figure 13. Microfilm image of the new tropical storm off the Louisiana coast on May $1^{\text {st }}$, 1957 at $12 Z$. 


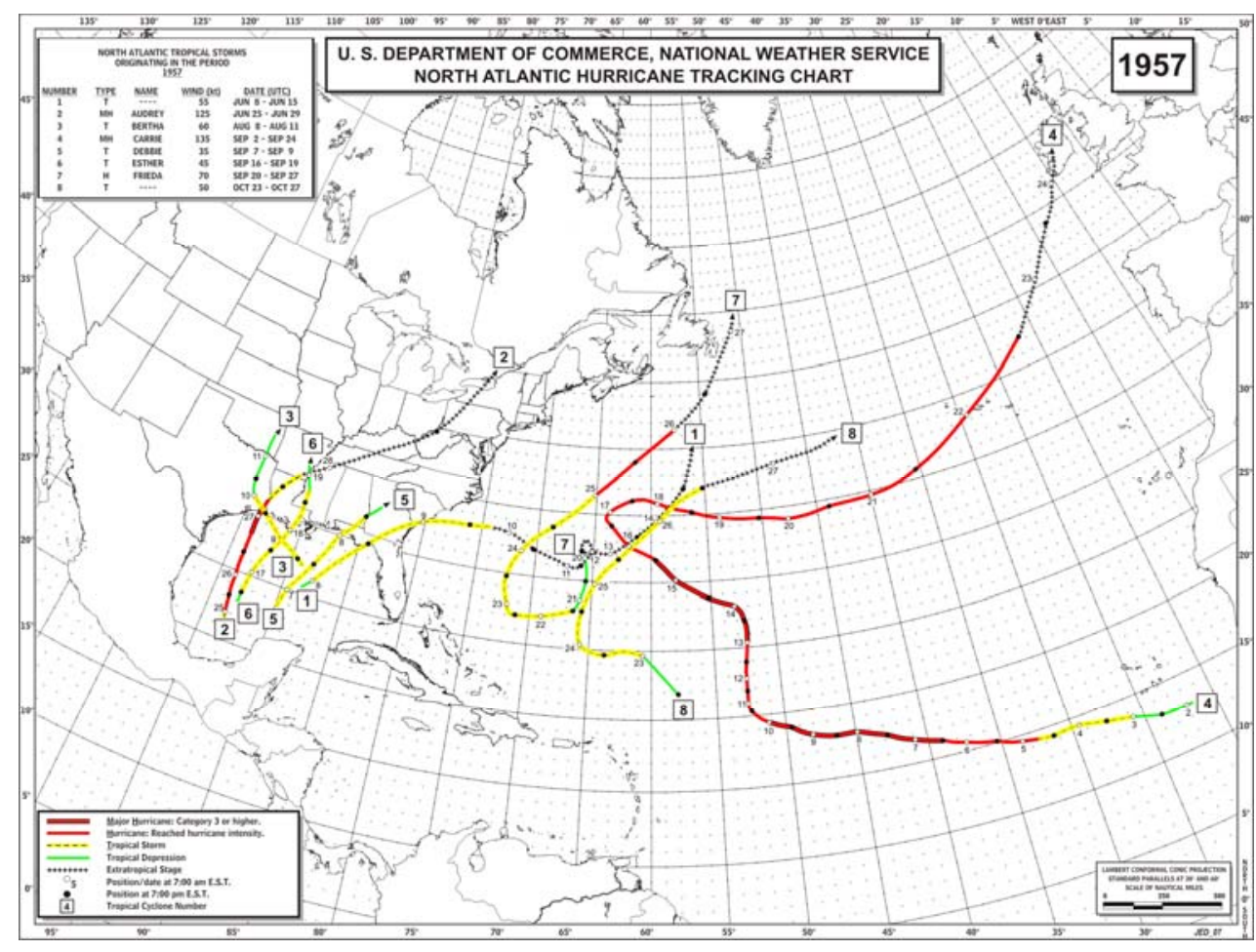

Figure 14. 1957 original track map.

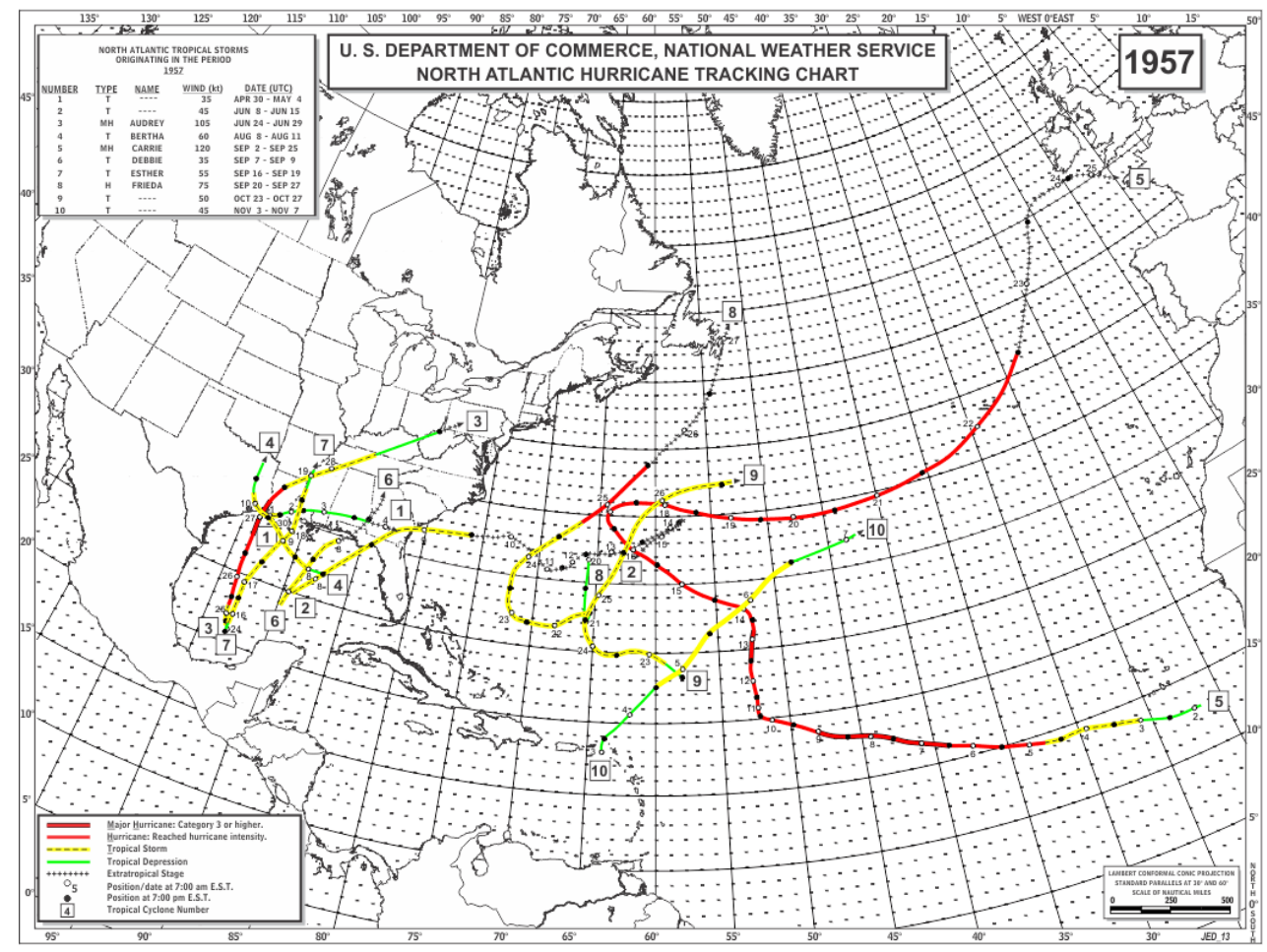

Figure 15. 1957 revised track map. 
Revision for the 1957 Atlantic Hurricane Season

\begin{tabular}{|c|c|c|c|c|c|c|}
\hline Name & Date & $\begin{array}{c}\text { Original } \\
\text { Peak } \\
\text { Intensity } \\
(\mathrm{kt})\end{array}$ & $\begin{array}{l}\text { Revised } \\
\text { Peak } \\
\text { Intensity } \\
(\mathrm{kt})\end{array}$ & $\begin{array}{c}\text { Track } \\
\text { Change }\end{array}$ & $\begin{array}{l}\text { Intensity } \\
\text { Change }\end{array}$ & $\begin{array}{c}\text { Genesis/Decay } \\
\text { Change }\end{array}$ \\
\hline Unnamed & $\begin{array}{c}04 / 30- \\
05 / 04\end{array}$ & - & 35 & - & - & - \\
\hline Unnamed & $\begin{array}{c}06 / 08- \\
06 / 15\end{array}$ & 55 & 45 & Minor & Minor & $\begin{array}{c}\text { Decay } 12 \mathrm{hr} \\
\text { later }\end{array}$ \\
\hline Audrey & $\begin{array}{c}06 / 24- \\
06 / 29\end{array}$ & 125 & 105 & Minor & Major & $\begin{array}{l}\text { Genesis } 12 \mathrm{hr} \\
\text { earlier, } \\
\text { Decay } 6 \mathrm{hr} \\
\text { earlier }\end{array}$ \\
\hline Bertha & $\begin{array}{c}08 / 08- \\
08 / 11\end{array}$ & 60 & 60 & Minor & Minor & $\begin{array}{l}\text { Genesis } 12 \mathrm{hr} \\
\text { earlier, } \\
\text { Decay } 12 \mathrm{hr} \\
\text { earlier }\end{array}$ \\
\hline Carrie & $\begin{array}{c}09 / 02- \\
09 / 25\end{array}$ & 135 & 120 & Major & Major & $\begin{array}{c}\text { Decay } 24 \mathrm{hr} \\
\text { later }\end{array}$ \\
\hline Debbie & $\begin{array}{c}09 / 07- \\
09 / 09\end{array}$ & 35 & 35 & Minor & Minor & No change \\
\hline Esther & $\begin{array}{c}09 / 16- \\
09 / 19\end{array}$ & 45 & 55 & Minor & Minor & $\begin{array}{c}\text { Genesis } 18 \mathrm{hr} \\
\text { earlier }\end{array}$ \\
\hline Frieda & $\begin{array}{c}09 / 20- \\
09 / 27\end{array}$ & 70 & 75 & Minor & Minor & No change \\
\hline Unnamed & $\begin{array}{c}10 / 23- \\
10 / 27\end{array}$ & 50 & 50 & Major & Minor & $\begin{array}{l}\text { Decay } 18 \mathrm{hr} \\
\text { earlier }\end{array}$ \\
\hline Unnamed & $\begin{array}{c}11 / 03- \\
11 / 07\end{array}$ & - & 45 & - & - & - \\
\hline
\end{tabular}

Table 5. 1957 revisions. 


\section{Hurricane Season}

The 1958 hurricane season was active with several long-lived tropical cyclones, that stayed away from land for the most part and neither El Niño nor La Niña was present in the equatorial waters of the Pacific. The original HURDAT lists 10 tropical cyclones that reached tropical storm intensity, 7 reached hurricane intensity and 5 became major hurricanes. The reanalysis adds one new tropical cyclone and none of the original systems were removed, increasing the total to 11 tropical cyclones. The number of hurricanes decreased to 6 and the number of major hurricanes remains the same. No hurricanes made landfall in the United States but Hurricane Helene passed a couple of miles off the North Carolina coastline producing damaging winds. Hurricane Ella struck Haiti and Cuba and continued west-northwest into the Gulf of Mexico. Fortunately, it was not able to regain its former intensity and made landfall in Texas as a tropical storm. The new tropical storm formed in late May over the central Caribbean Sea. It moved into the southeast Gulf of Mexico, then parallel to the east coast of the United States where it intensified into a tropical cyclone. Overall, there were major changes to the intensities and tracks originally in HURDAT. The changes to the season are shown in Table 6. Figure 16 shows the original tracks and Figure 17 illustrates the revised tracks. 


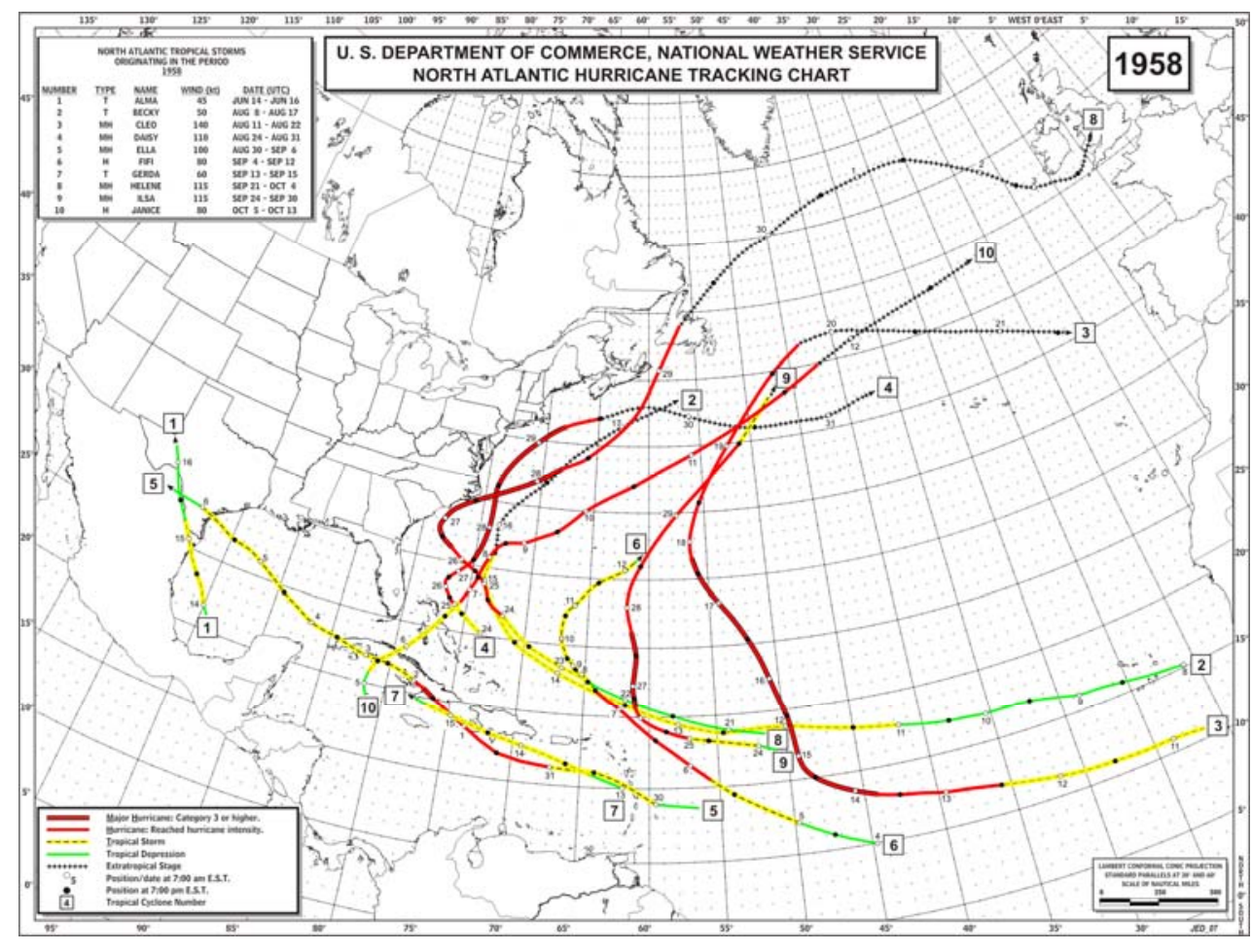

Figure 16. 1958 original track map.

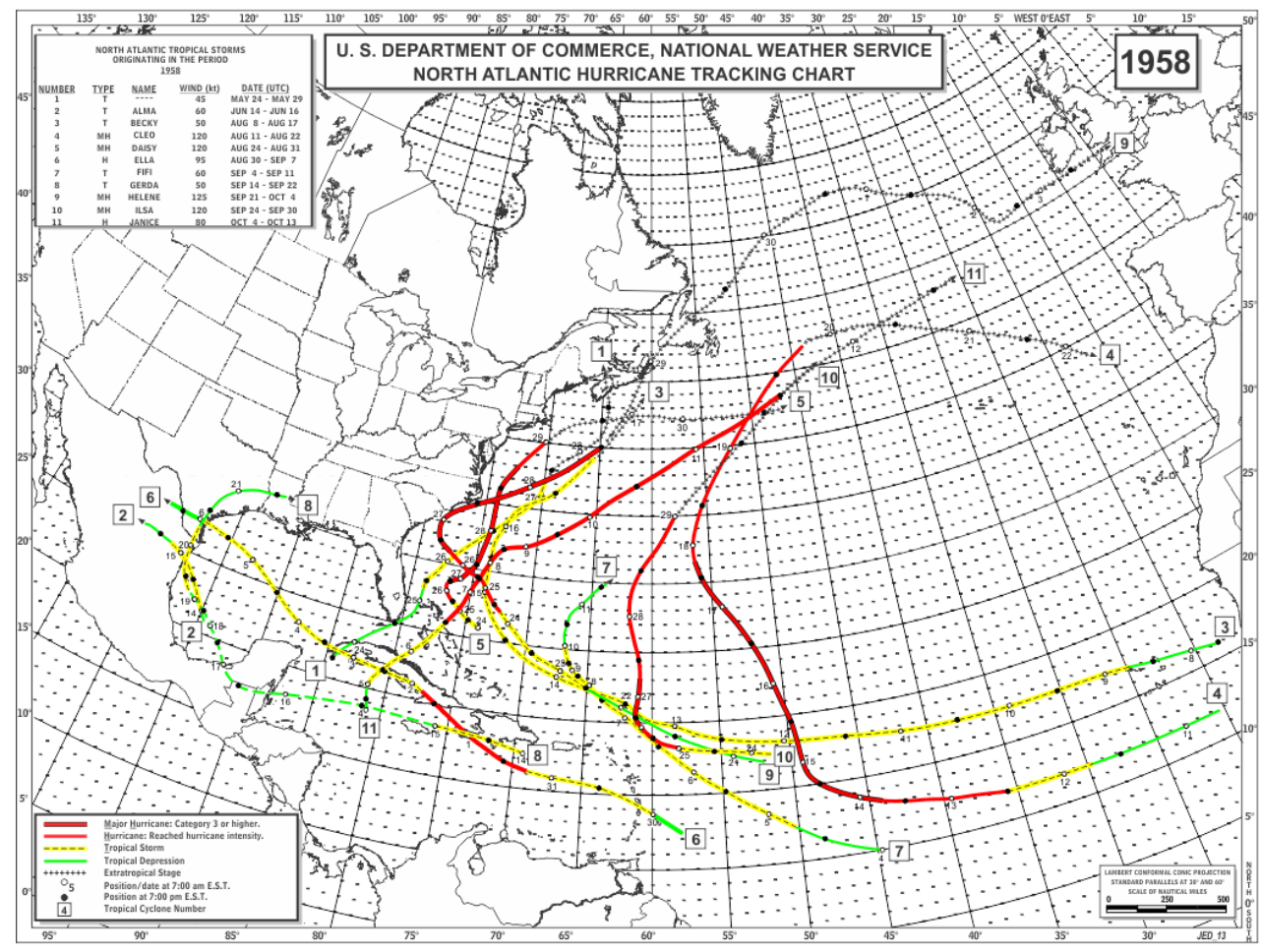

Figure 17. 1958 revised track map. 


\section{Revision for the 1958 Atlantic Hurricane Season}

\begin{tabular}{|c|c|c|c|c|c|c|}
\hline Name & Date & $\begin{array}{l}\text { Original } \\
\text { Peak } \\
\text { Intensity } \\
(\mathrm{kt})\end{array}$ & $\begin{array}{l}\text { Revised } \\
\text { Peak } \\
\text { Intensity } \\
(\mathrm{kt})\end{array}$ & $\begin{array}{c}\text { Track } \\
\text { Change }\end{array}$ & $\begin{array}{l}\text { Intensity } \\
\text { Change }\end{array}$ & $\begin{array}{c}\text { Genesis/Decay } \\
\text { Change }\end{array}$ \\
\hline Unnamed & $\begin{array}{c}05 / 24- \\
05 / 29\end{array}$ & - & 50 & - & - & - \\
\hline Alma & $\begin{array}{c}06 / 14- \\
06 / 16\end{array}$ & 45 & 60 & Major & Major & $\begin{array}{l}\text { Decay } 12 \mathrm{hr} \\
\text { earlier }\end{array}$ \\
\hline Becky & $\begin{array}{c}08 / 08- \\
08 / 17\end{array}$ & 50 & 50 & Major & Major & $\begin{array}{c}\text { Genesis } 12 \mathrm{hr} \\
\text { earlier, } \\
\text { Decay } 6 \mathrm{hr} \\
\text { earlier }\end{array}$ \\
\hline Cleo & $\begin{array}{c}08 / 11- \\
08 / 22\end{array}$ & 140 & 120 & Major & Major & Decay 18 hr later \\
\hline Daisy & $\begin{array}{c}08 / 24- \\
08 / 31\end{array}$ & 110 & 120 & Minor & Major & $\begin{array}{l}\text { Decay } 18 \mathrm{hr} \\
\text { earlier }\end{array}$ \\
\hline Ella & $\begin{array}{c}08 / 30- \\
09 / 07\end{array}$ & 110 & 120 & Major & Minor & Decay 6 hr later \\
\hline Fifi & $\begin{array}{c}09 / 04- \\
09 / 11\end{array}$ & 80 & 60 & Major & Major & $\begin{array}{l}\text { Decay } 24 \mathrm{hr} \\
\text { earlier }\end{array}$ \\
\hline Gerda & $\begin{array}{c}09 / 14- \\
09 / 12\end{array}$ & 60 & 50 & Minor & Minor & $\begin{array}{l}\text { Genesis } 24 \mathrm{hr} \\
\text { earlier, } \\
\text { Decay } 150 \mathrm{hr} \\
\text { later }\end{array}$ \\
\hline Helene & $\begin{array}{c}09 / 21- \\
10 / 04\end{array}$ & 115 & 125 & Major & Major & No change \\
\hline Ilsa & $\begin{array}{c}09 / 24- \\
09 / 30\end{array}$ & 115 & 120 & Minor & Major & No change \\
\hline Janice & $\begin{array}{c}10 / 04- \\
10 / 13\end{array}$ & 80 & 80 & Minor & Minor & $\begin{array}{c}\text { Genesis } 18 \mathrm{hr} \\
\text { earlier, } \\
\text { Decay } 6 \mathrm{hr} \\
\text { earlier }\end{array}$ \\
\hline
\end{tabular}

Table 6. 1958 revisions. 


\section{Hurricane Season}

The 1959 hurricane season was active for the basin with many tropical cyclones developing over the western Atlantic while ENSO was neutral. The original HURDAT lists 11 tropical cyclones that reached tropical storm intensity, 7 reached hurricane intensity and 2 became major hurricanes. The reanalysis adds three new tropical cyclones and none of the original systems were removed, increasing the total to 14 tropical cyclones. The number of hurricanes is decreased to 5 and the number of major hurricanes remains 2. Two hurricanes, Debra and Gracie, made landfall in the United States, in Texas and South Carolina, respectively. Both were small hurricanes, but Gracie reached major hurricane intensity and made landfall at peak intensity of $115 \mathrm{kt}$. A third system Cindy - was initially indicated to have reached hurricane intensity and no stroke to the South Carolina as a Category 1 hurricane. The reanalysis, instead, indicates the cyclone only reached high end tropical storm status at both its peak and U.S. landfall. Unnamed tropical cyclone \#3 was found to have been extratropical at the time it reached hurricane intensity, thus it peaked below hurricane intensity as a tropical cyclone. The three new tropical cyclones formed in the mid-latitudes from initially baroclinic systems and were threats only to marine interests. Overall, there were minor changes to original HURDAT. Figure 18 shows the original tracks and Figure 19 illustrates the revised tracks. The changes to the season are shown in Table 7. 


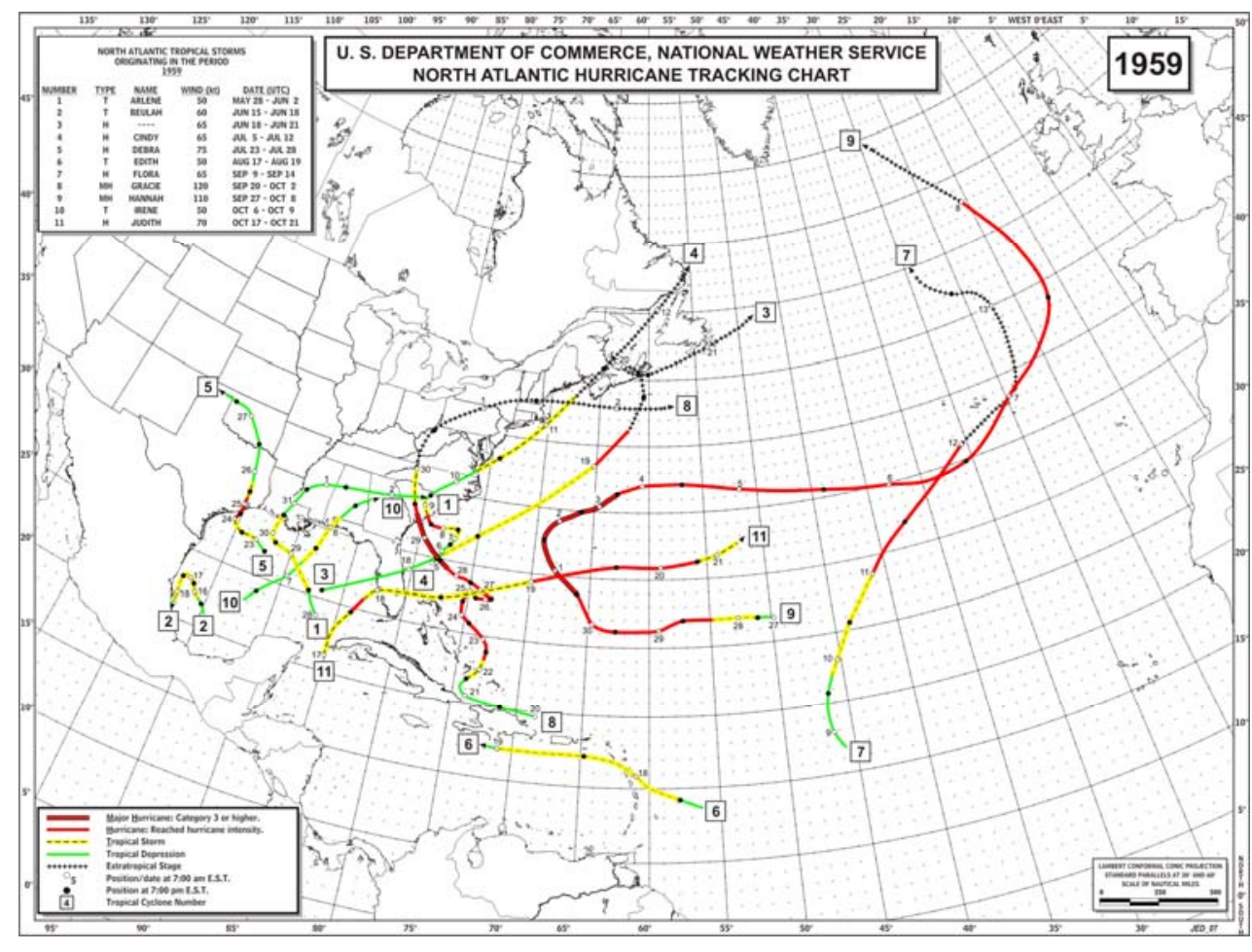

Figure 18. 1959 original track map.

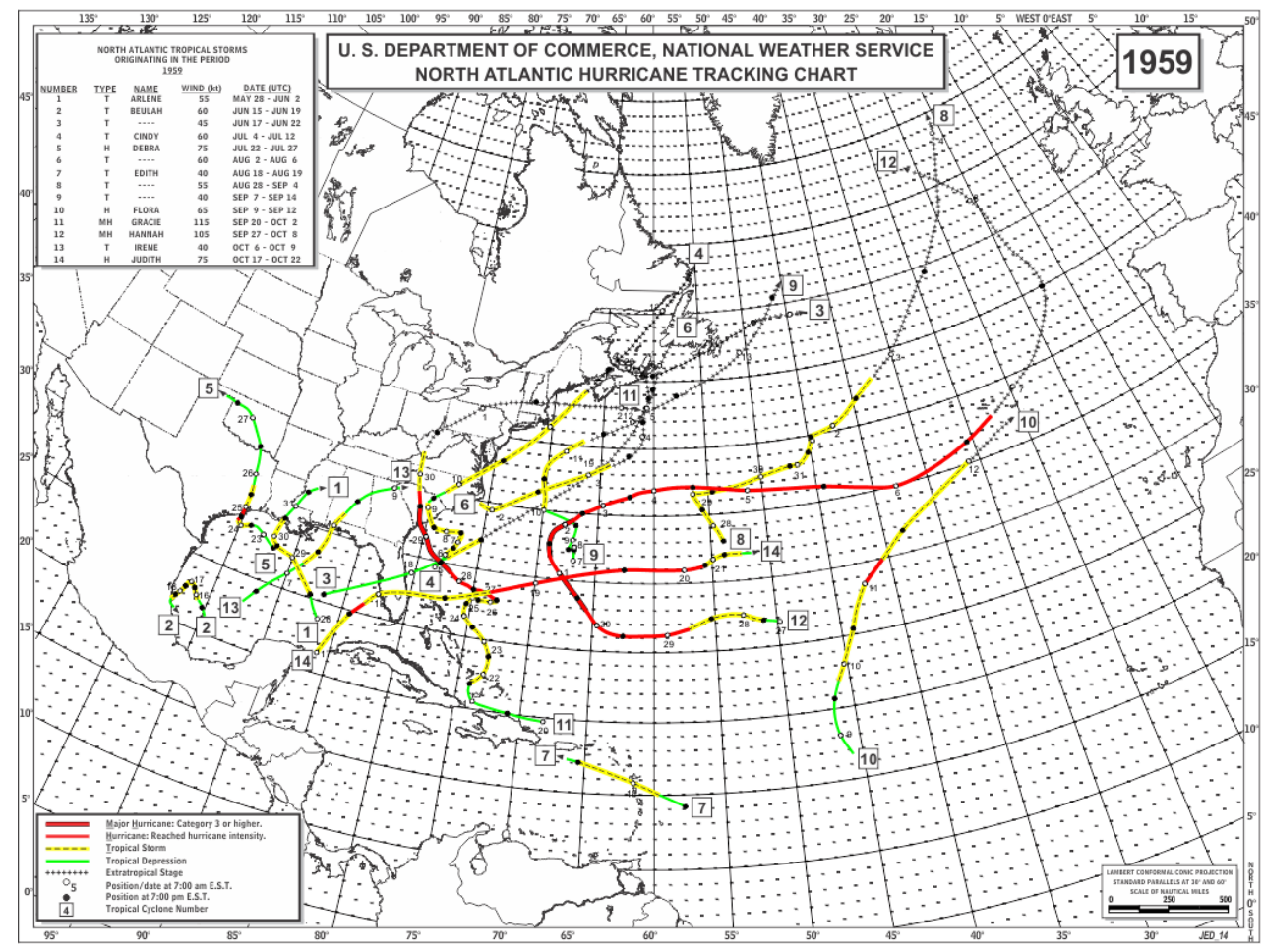

Figure 19. 1959 revised track map. 


\section{Revision for the 1959 Atlantic Hurricane Season}

\begin{tabular}{|c|c|c|c|c|c|c|}
\hline Name & Date & $\begin{array}{l}\text { Original } \\
\text { Peak } \\
\text { Intensity } \\
\text { (kt) }\end{array}$ & $\begin{array}{l}\text { Revised } \\
\text { Peak } \\
\text { Intensity } \\
\text { (kt) }\end{array}$ & $\begin{array}{c}\text { Track } \\
\text { Change }\end{array}$ & $\begin{array}{l}\text { Intensity } \\
\text { Change }\end{array}$ & $\begin{array}{c}\text { Genesis/Decay } \\
\text { Change }\end{array}$ \\
\hline Arlene & $\begin{array}{c}05 / 28- \\
06 / 02\end{array}$ & 50 & 55 & Minor & Major & $\begin{array}{l}\text { Decay } 42 \mathrm{hr} \\
\text { earlier }\end{array}$ \\
\hline Beulah & $\begin{array}{c}06 / 15- \\
06 / 19\end{array}$ & 60 & 60 & Minor & Minor & $\begin{array}{l}\text { Decay } 12 \mathrm{hr} \\
\text { later }\end{array}$ \\
\hline Unnamed & $\begin{array}{c}06 / 17- \\
06 / 22\end{array}$ & 65 & 45 & Minor & Minor & $\begin{array}{c}\text { Genesis } 6 \mathrm{hr} \\
\text { earlier, Decay } \\
18 \mathrm{hr} \text { later }\end{array}$ \\
\hline Cindy & $\begin{array}{c}07 / 04- \\
07 / 12\end{array}$ & 65 & 60 & Minor & Minor & $\begin{array}{c}\text { Genesis } 24 \mathrm{hr} \\
\text { earlier }\end{array}$ \\
\hline Debra & $\begin{array}{c}07 / 22- \\
07 / 27\end{array}$ & 75 & 75 & Minor & Minor & $\begin{array}{c}\text { Genesis } 6 \mathrm{hr} \\
\text { earlier, Decay } \\
12 \mathrm{hr} \text { earlier }\end{array}$ \\
\hline Unnamed & $\begin{array}{c}08 / 02- \\
08 / 06\end{array}$ & - & 60 & - & - & - \\
\hline Edith & $\begin{array}{c}08 / 18- \\
08 / 19\end{array}$ & 50 & 40 & Minor & Minor & $\begin{array}{l}\text { Genesis } 6 \mathrm{hr} \\
\text { later, Decay } \\
12 \mathrm{hr} \text { earlier }\end{array}$ \\
\hline Unnamed & $\begin{array}{c}09 / 07- \\
09 / 14\end{array}$ & - & 40 & - & - & - \\
\hline Flora & $\begin{array}{c}09 / 09- \\
09 / 12\end{array}$ & 65 & 65 & Minor & Minor & $\begin{array}{l}\text { Decay } 12 \mathrm{hr} \\
\text { earlier }\end{array}$ \\
\hline Gracie & $\begin{array}{c}09 / 20- \\
10 / 02\end{array}$ & 120 & 115 & Minor & Major & $\begin{array}{c}\text { Decay } 6 \mathrm{hr} \\
\text { earlier }\end{array}$ \\
\hline Hannah & $\begin{array}{c}09 / 27- \\
10 / 08\end{array}$ & 110 & 105 & Minor & Major & No change \\
\hline Irene & $\begin{array}{c}10 / 06- \\
10 / 09\end{array}$ & 50 & 40 & Minor & Minor & $\begin{array}{c}\text { Decay } 6 \mathrm{hr} \\
\text { later }\end{array}$ \\
\hline Judith & $\begin{array}{c}10 / 17- \\
10 / 22\end{array}$ & 70 & 75 & Major & Minor & $\begin{array}{c}\text { Decay } 12 \mathrm{hr} \\
\text { later }\end{array}$ \\
\hline
\end{tabular}

Table 7. 1959 revisions. 


\section{Hurricane Season}

The 1960 hurricane season was quiet in terms of the number of tropical cyclones that formed in the basin while the ENSO was neutral. The original HURDAT lists 7 tropical cyclones that reached tropical storm intensity, 4 reached hurricane intensity and 2 became major hurricanes. The reanalysis did not find any missing tropical cyclones and none of the original systems were removed. The number of hurricanes remained 4 and the number of major hurricanes remained 2. Two hurricanes made landfall in the United States. Hurricane Donna was the more significant hurricane, affecting the US East Coast from the Florida Keys to Maine. Donna was reanalyzed by Chris Landsea, Cristina Carrasco and Jason Dunion (unpublished work). Hurricane Ethel struck Louisiana and Mississippi and rapidly weakened as it moved inland. The peak intensity of both Donna and Ethel was $140 \mathrm{kt}$, category 5, in the original HURDAT. The reanalysis suggests a peak intensity of $125 \mathrm{kt}$, category 4, for Donna and only $100 \mathrm{kt}$, category 3, for Ethel. Overall, there were major changes to the intensities and minor alterations to the tracks of the tropical cyclones in the original HURDAT. Figure 20 shows the original tracks and Figure 21 illustrates the revised tracks. The changes to the season are shown in Table 8 . 


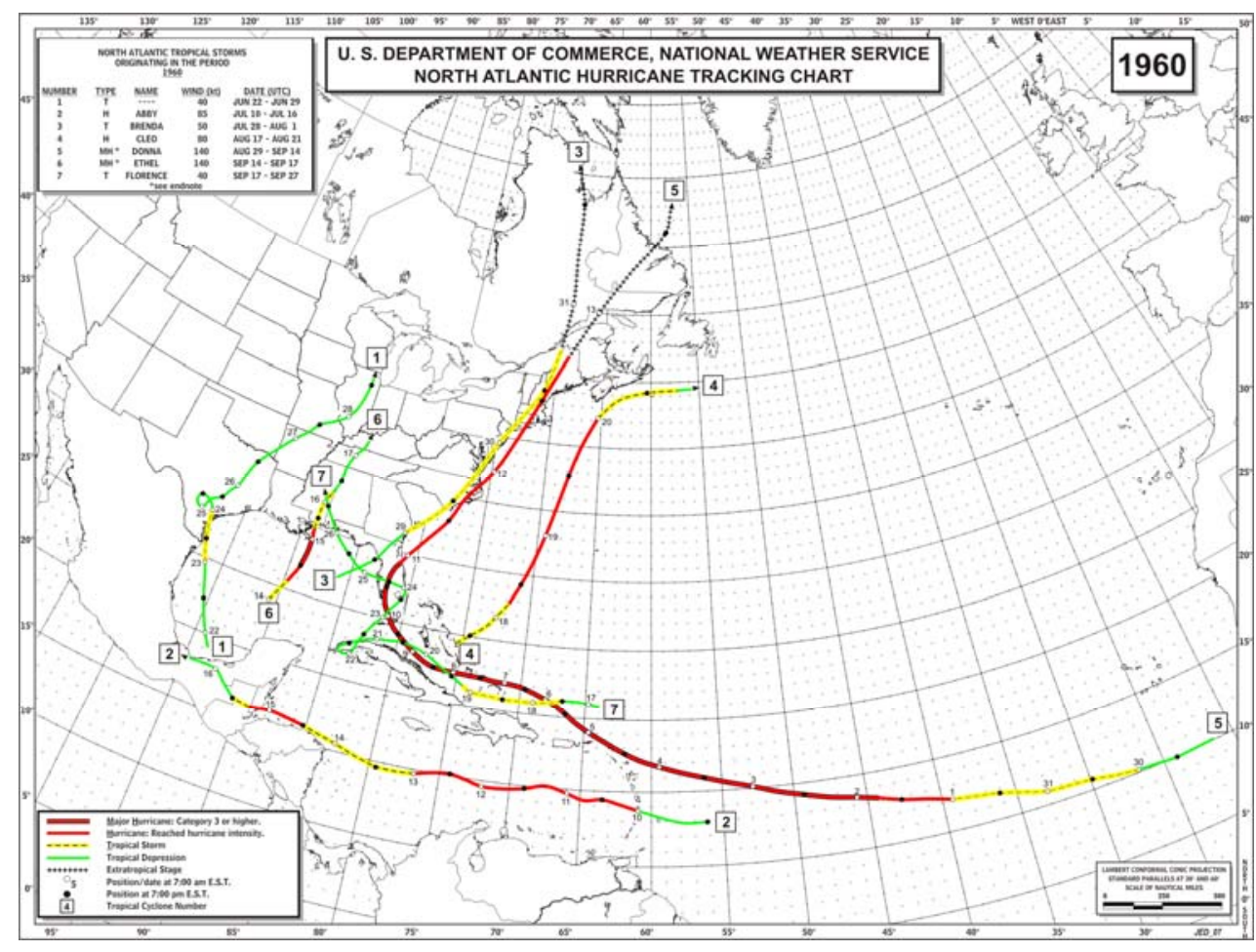

Figure 20. 1960 original track map.

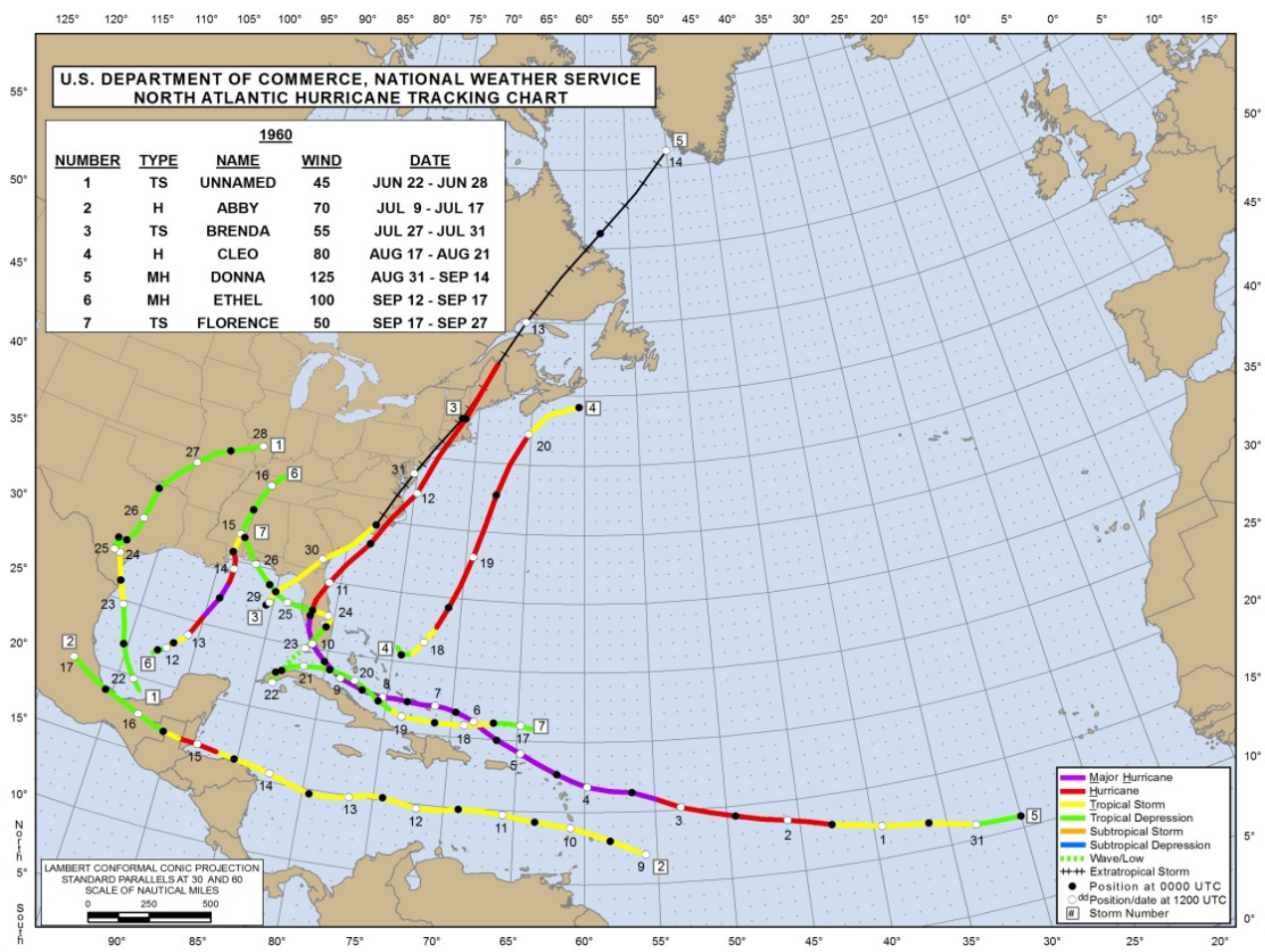

Figure 21. 1960 revised track map. 


\section{Revision for the 1960 Atlantic Hurricane Season}

\begin{tabular}{|c|c|c|c|c|c|c|}
\hline Name & Date & $\begin{array}{l}\text { Original } \\
\text { Peak } \\
\text { Intensity } \\
(\mathrm{kt})\end{array}$ & $\begin{array}{l}\text { Revised } \\
\text { Peak } \\
\text { Intensity } \\
(\mathrm{kt})\end{array}$ & $\begin{array}{c}\text { Track } \\
\text { Change }\end{array}$ & $\begin{array}{l}\text { Intensity } \\
\text { Change }\end{array}$ & $\begin{array}{c}\text { Genesis/Decay } \\
\text { Change }\end{array}$ \\
\hline Unnamed & $\begin{array}{c}06 / 22- \\
06 / 28\end{array}$ & 40 & 45 & Minor & Minor & $\begin{array}{c}\text { Decay } 12 \mathrm{hr} \\
\text { earlier }\end{array}$ \\
\hline Abby & $\begin{array}{l}07 / 09- \\
07 / 16\end{array}$ & 70 & 70 & Major & Major & $\begin{array}{c}\text { Genesis } 12 \mathrm{hr} \\
\text { earlier, Decay } \\
18 \mathrm{hr} \text { later }\end{array}$ \\
\hline Brenda & $\begin{array}{c}07 / 27- \\
07 / 31\end{array}$ & 50 & 55 & Minor & Minor & $\begin{array}{c}\text { Genesis } 24 \mathrm{hr} \\
\text { earlier, Decay } \\
18 \mathrm{hr} \text { earlier }\end{array}$ \\
\hline Cleo & $\begin{array}{c}08 / 17- \\
08 / 21\end{array}$ & 80 & 80 & Minor & Minor & $\begin{array}{c}\text { Decay } 6 \mathrm{hr} \\
\text { earlier }\end{array}$ \\
\hline Donna & $\begin{array}{l}08 / 31- \\
09 / 14\end{array}$ & 140 & 125 & Major & Major & $\begin{array}{c}\text { Genesis } 30 \mathrm{hr} \\
\text { later, Decay } \\
12 \mathrm{hr} \text { later }\end{array}$ \\
\hline Ethel & $\begin{array}{l}09 / 12- \\
09 / 17\end{array}$ & 140 & 100 & Minor & Major & $\begin{array}{c}\text { Genesis } 18 \mathrm{hr} \\
\text { earlier }\end{array}$ \\
\hline Florence & $\begin{array}{c}09 / 17 \text { - } \\
09 / 27\end{array}$ & 40 & 50 & Minor & Major & $\begin{array}{c}\text { Decay } 6 \mathrm{hr} \\
\text { earlier }\end{array}$ \\
\hline
\end{tabular}

Table 8. 1960 revisions. 


\section{Hurricane Season}

The 1961 hurricane season was very active with two devastating hurricanes while the ENSO was neutral. The original HURDAT listed 11 tropical cyclones that reached tropical storm intensity, 8 reached hurricane intensity and 7 became major hurricanes. The reanalysis adds one new tropical cyclone and none of the original systems were removed, increasing the season total to 12 . The number of hurricanes is retained at 8 and the number of major hurricanes is decreased to 5 . It is interesting to note that 11 of the 12 tropical cyclones formed between September and November. Hurricane Carla was the only hurricane to make landfall in the United States, striking Texas as a powerful category 4. Carla was reanalyzed by Chris Landsea and Cristina Carrasco (unpublished work). Hurricane Hattie formed late in the season in the Caribbean Sea and devastated Belize, also at category 4 . The peak intensity of Hattie was $140 \mathrm{kt}$ originally in HURDAT, making it a category 5 hurricane. The reanalysis suggests a peak intensity of $135 \mathrm{kt}$, high-end category 4 . The new tropical storm formed from a disturbed area associated with a tropical wave over the eastern Caribbean Sea. The system gradually moved northeastward becoming better organized. It was not a threat to land as a tropical cyclone. Overall, there were major changes to the intensities and minor alterations to the tracks of the tropical cyclones originally in HURDAT. Figure 22 shows the original tracks and Figure 23 illustrates the revised tracks. The changes to the season are shown in Table 9. 


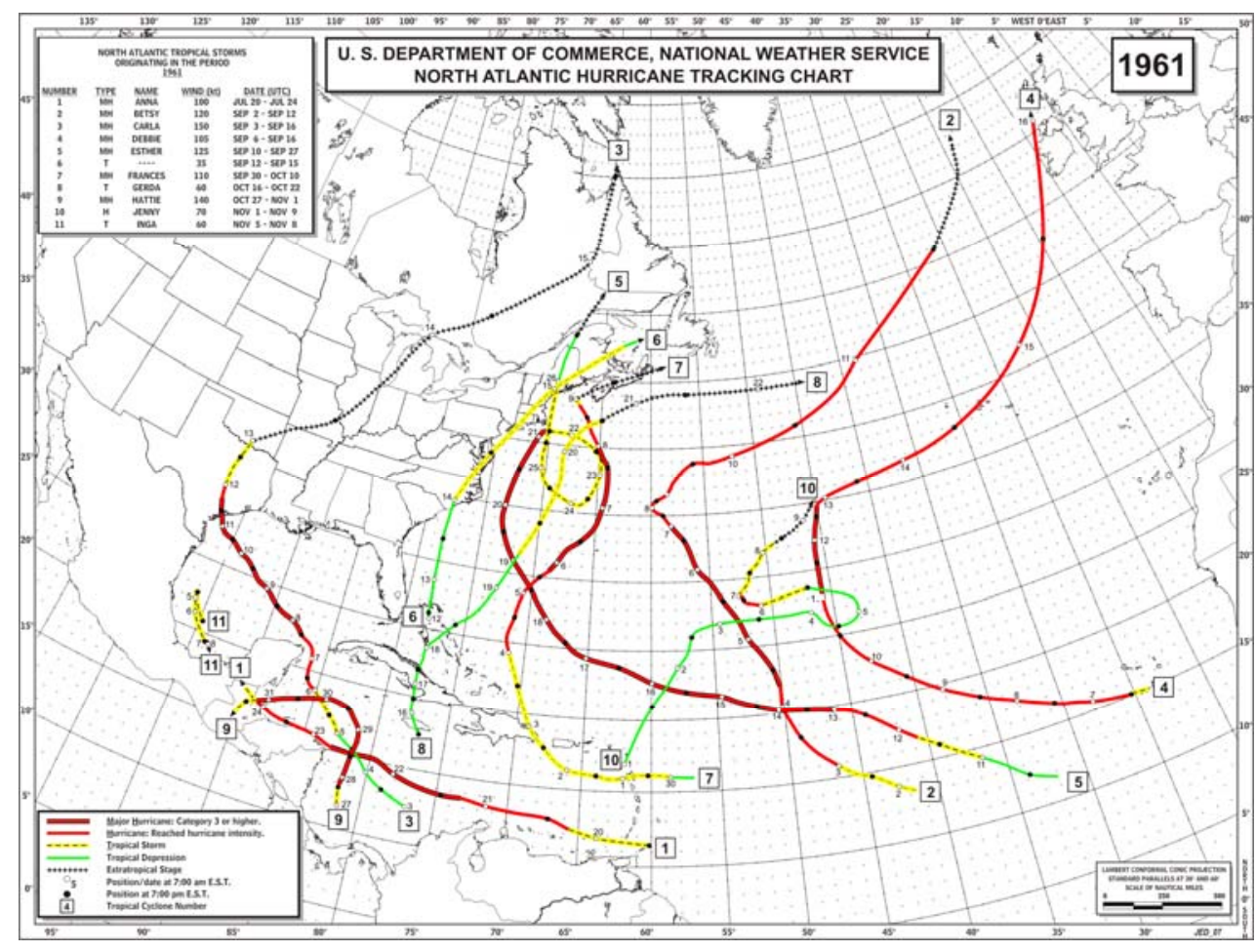

Figure 22. 1961 original track map.

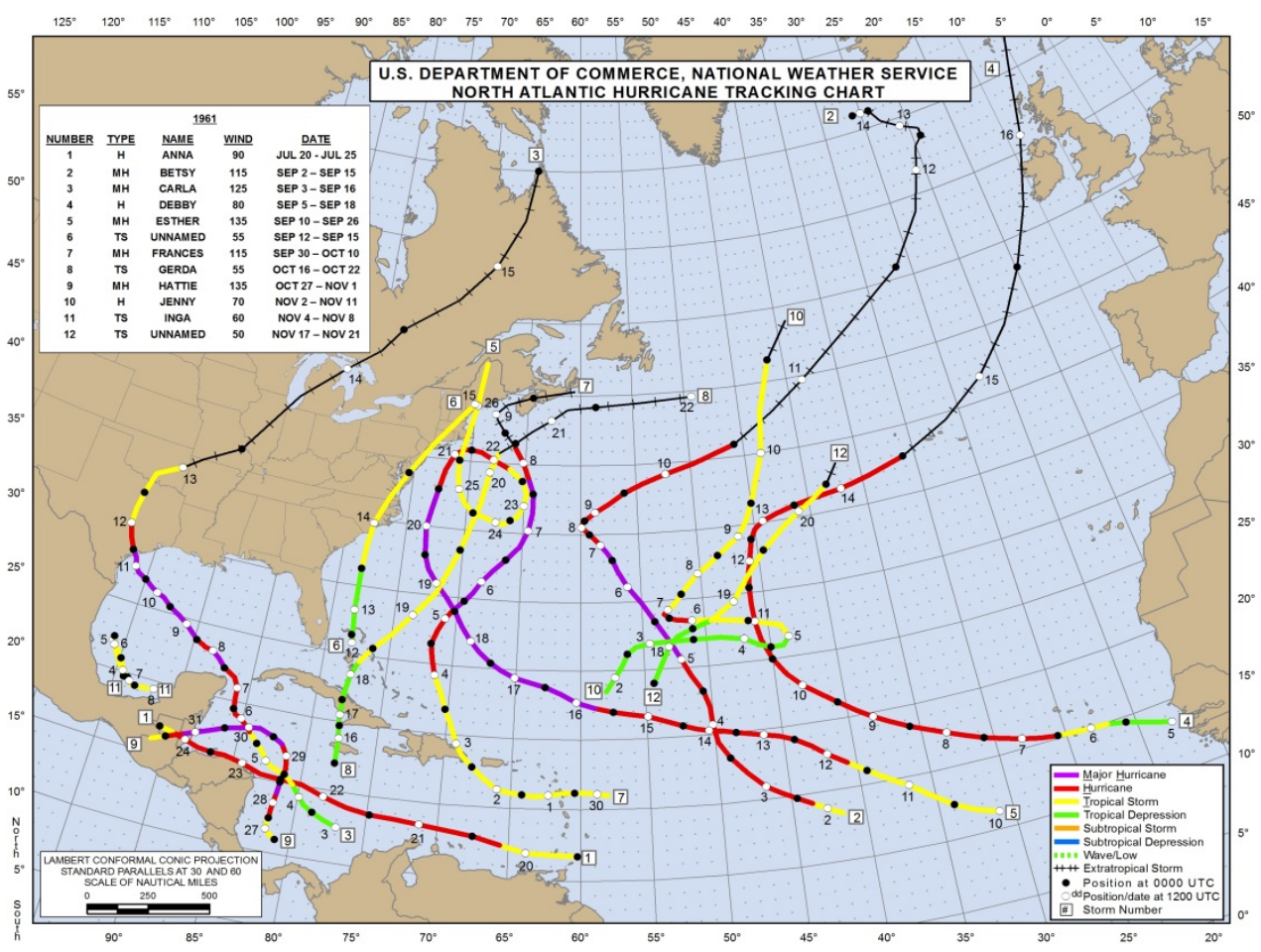

Figure 23. 1961 revised track map. 


\section{Revision for the 1961 Atlantic Hurricane Season}

\begin{tabular}{|c|c|c|c|c|c|c|}
\hline Name & Date & $\begin{array}{c}\text { Original } \\
\text { Peak } \\
\text { Intensity } \\
(\mathrm{kt})\end{array}$ & $\begin{array}{c}\text { Revised } \\
\text { Peak } \\
\text { Intensity } \\
(\mathrm{kt})\end{array}$ & $\begin{array}{c}\text { Track } \\
\text { Change }\end{array}$ & $\begin{array}{c}\text { Intensity } \\
\text { Change }\end{array}$ & $\begin{array}{c}\text { Genesis/Decay } \\
\text { Change }\end{array}$ \\
\hline Anna & $\begin{array}{c}07 / 20- \\
07 / 24\end{array}$ & 100 & 90 & Minor & Major & $\begin{array}{c}\text { Decay } 6 \mathrm{hr} \\
\text { later }\end{array}$ \\
\hline Betsy & $\begin{array}{c}09 / 02- \\
09 / 12\end{array}$ & 120 & 115 & Minor & Major & $\begin{array}{c}\text { Decay } 66 \mathrm{hr} \\
\text { later }\end{array}$ \\
\hline Carla & $\begin{array}{c}09 / 03- \\
09 / 16\end{array}$ & 150 & 125 & Minor & Minor & No changes \\
\hline Debbie & $\begin{array}{c}09 / 05- \\
09 / 18\end{array}$ & 105 & 75 & Minor & Major & $\begin{array}{c}\text { Genesis } 30 \mathrm{hr} \\
\text { earlier, Decay } \\
54 \mathrm{hr} \text { later }\end{array}$ \\
\hline Esther & $\begin{array}{c}09 / 10- \\
09 / 26\end{array}$ & 125 & 135 & Minor & Major & $\begin{array}{c}\text { Decay } 12 \mathrm{hr} \\
\text { earlier }\end{array}$ \\
\hline Unnamed & $\begin{array}{c}09 / 12- \\
09 / 15\end{array}$ & 35 & 55 & Minor & Major & $\begin{array}{c}\text { Decay } 6 \mathrm{hr} \\
\text { earlier }\end{array}$ \\
\hline Frances & $\begin{array}{c}09 / 30- \\
10 / 10\end{array}$ & 110 & 115 & Minor & Minor & $\begin{array}{c}\text { Decay } 6 \mathrm{hr} \\
\text { earlier }\end{array}$ \\
\hline Gerda & $\begin{array}{c}10 / 16- \\
10 / 22\end{array}$ & 60 & 55 & Major & Major & $\begin{array}{c}\text { Decay } 6 \mathrm{hr} \\
\text { earlier }\end{array}$ \\
\hline Hattie & $\begin{array}{c}10 / 27- \\
11 / 01\end{array}$ & 140 & 135 & Minor & Minor & $\begin{array}{c}\text { Genesis } 12 \mathrm{hr} \\
\text { earlier }\end{array}$ \\
\hline Inga & $\begin{array}{c}11 / 04- \\
11 / 08\end{array}$ & 60 & 60 & Minor & Minor & $\begin{array}{c}\text { Genesis } 24 \mathrm{hr} \\
\text { earlier }\end{array}$ \\
\hline Jenny & $\begin{array}{c}11 / 02- \\
11 / 10\end{array}$ & 70 & 70 & Minor & Major & $\begin{array}{c}\text { Genesis } 18 \mathrm{hr} \\
\text { earlier, Decay } \\
24 \mathrm{hr} \text { later }\end{array}$ \\
\hline Unnamed & $\begin{array}{c}11 / 17- \\
11 / 21\end{array}$ & - & 50 & - & - & - \\
\hline
\end{tabular}

Table 9. 1961 revisions. 


\section{Hurricane Season}

The 1962 hurricane season was relatively quiet in the Atlantic while ENSO was neutral. The original HURDAT listed 5 tropical cyclones that reached tropical storm intensity, 3 reached hurricane intensity and 1 became a major hurricane. The reanalysis adds three new tropical cyclones and none of the original systems were removed, increasing the season total to 8 . The number of hurricanes is increased to 4 and the intensity of Hurricane Ella is decreased from $100 \mathrm{kt}$ originally in HURDAT to $90 \mathrm{kt}$, thus the analysis shows no major hurricanes. It is interesting to note that no tropical cyclones formed in the Gulf of Mexico and Caribbean Sea. The previous occurrence was in 1914 when only one tropical cyclone was recorded in the entire basin. Most of the tropical cyclone activity was concentrated over the western Atlantic but no hurricane made landfall in the United States. All of the new tropical cyclones formed in the mid-latitudes from initially baroclinic origins. The last tropical cyclone (Figure 24) of the season was a long-lived, late-season system with an erratic track over the waters off the southeast coast of the United States. Overall, there were major changes to the intensities and minor alterations to the tracks of the tropical cyclones originally in HURDAT. Figure 25 shows the original tracks and Figure 26 illustrates the revised tracks. The changes to the season appear in Table 10. 


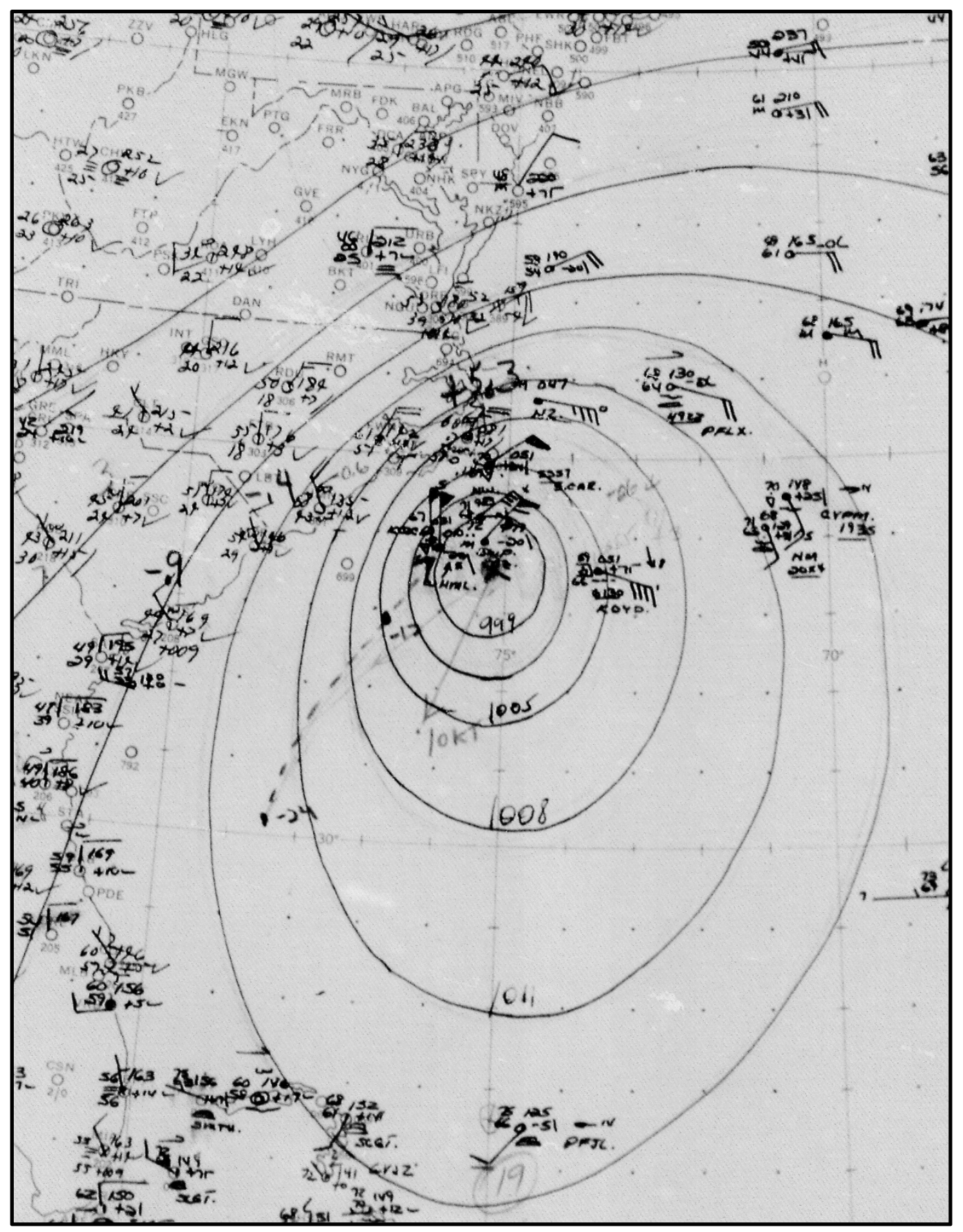

Figure 24. Microfilm image of the Unnamed Hurricane \#7 on December $2^{\text {nd }}$ at $12 \mathrm{Z}$ off the North Carolina coast. 


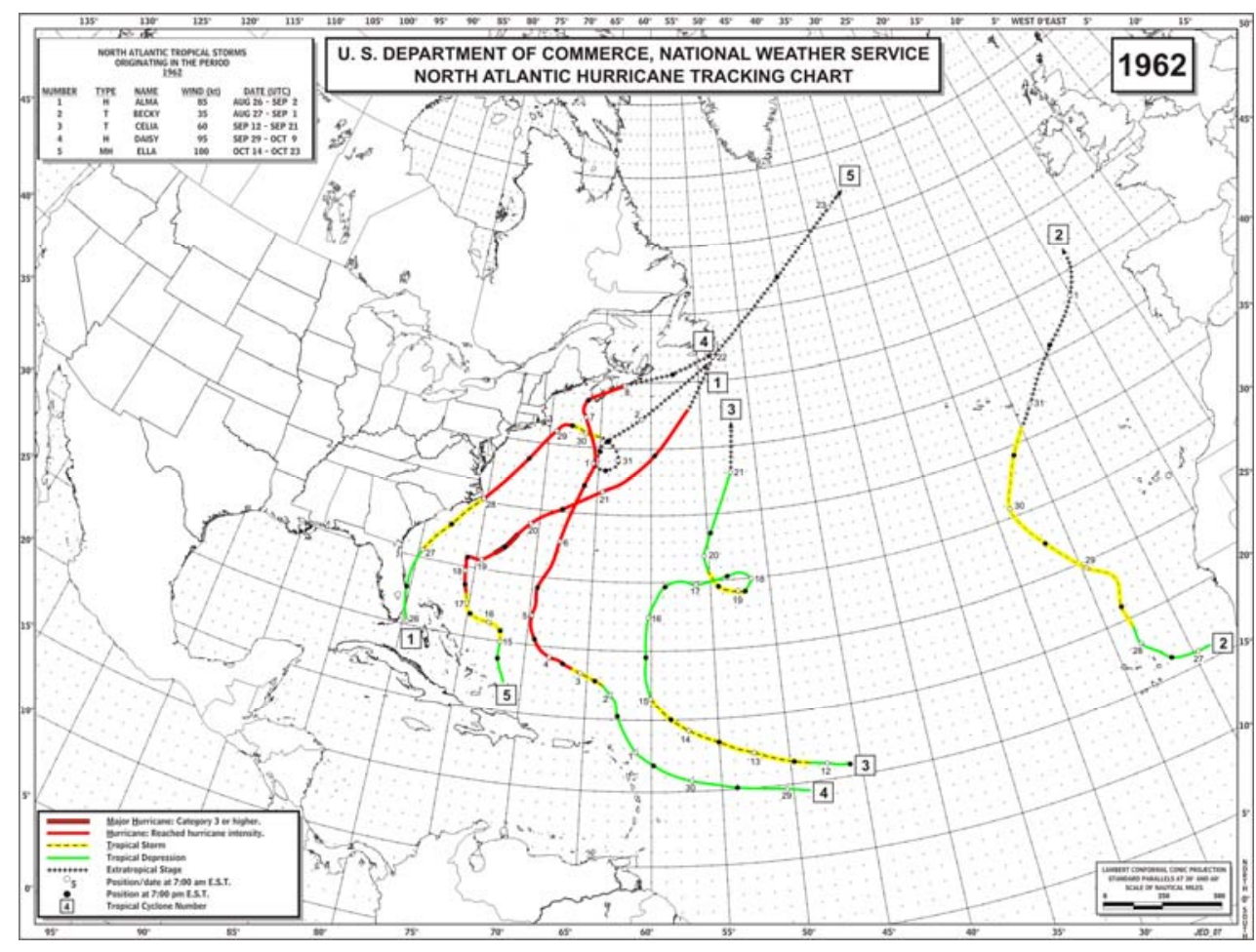

Figure 25. 1962 original track map.

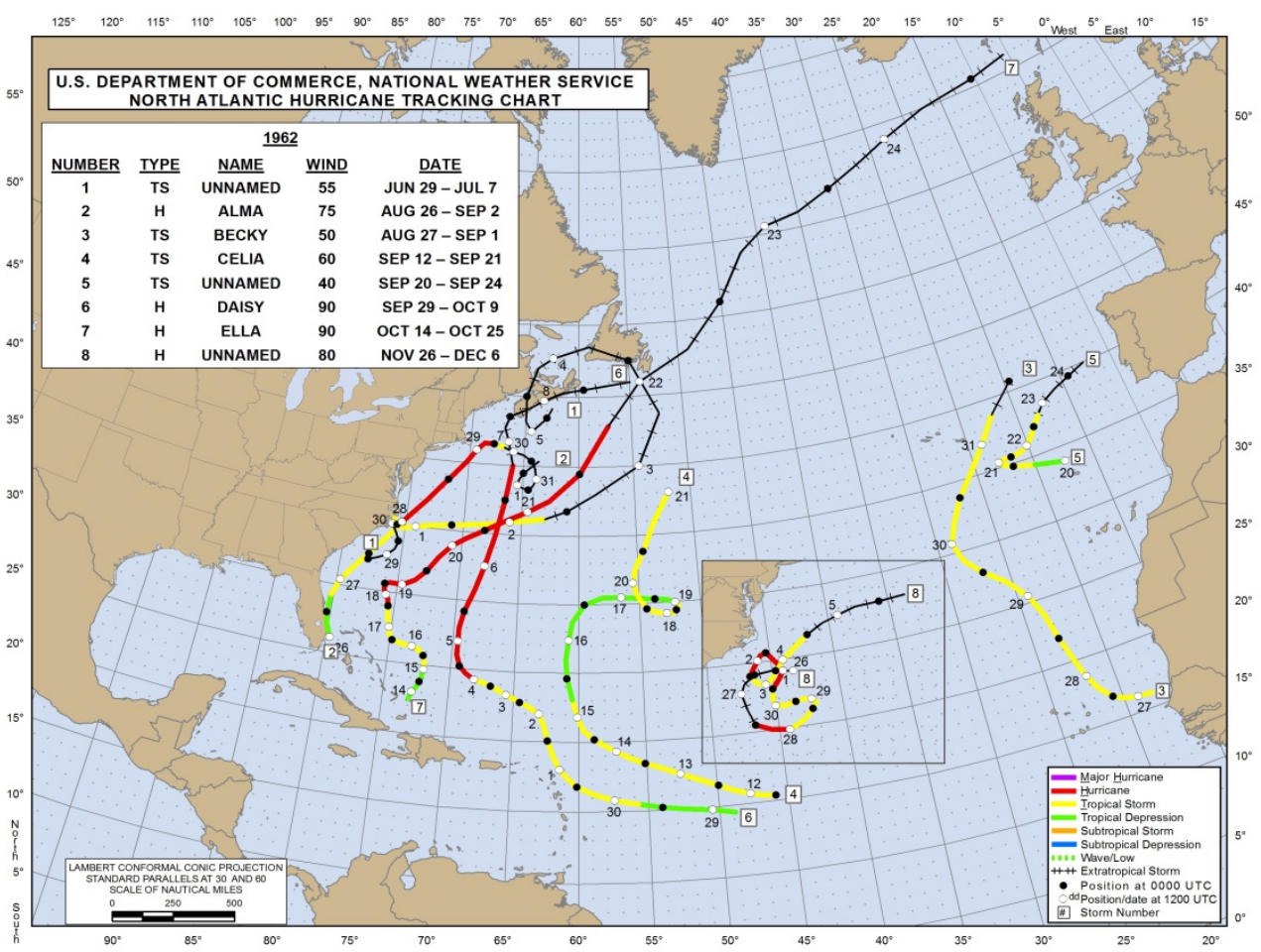

Figure 26. 1962 revised track map. 


\section{Revision for the 1962 Atlantic Hurricane Season}

\begin{tabular}{|c|c|c|c|c|c|c|}
\hline Name & Date & $\begin{array}{l}\text { Original } \\
\text { Peak } \\
\text { Intensity } \\
\quad(\mathrm{kt})\end{array}$ & $\begin{array}{l}\text { Revised } \\
\text { Peak } \\
\text { Intensity } \\
\quad(\mathrm{kt})\end{array}$ & $\begin{array}{c}\text { Track } \\
\text { Change }\end{array}$ & $\begin{array}{l}\text { Intensity } \\
\text { Change }\end{array}$ & $\begin{array}{c}\text { Genesis/ } \\
\text { Decay } \\
\text { Change }\end{array}$ \\
\hline Unnamed & $\begin{array}{c}06 / 29- \\
07 / 06\end{array}$ & - & 55 & - & - & - \\
\hline Alma & $\begin{array}{c}08 / 26- \\
09 / 02\end{array}$ & 85 & 75 & Minor & Minor & $\begin{array}{l}\text { Decay } 12 \\
\text { hr earlier }\end{array}$ \\
\hline Becky & $\begin{array}{c}08 / 27- \\
09 / 01\end{array}$ & 35 & 50 & Minor & Major & $\begin{array}{l}\text { Decay } 18 \\
\text { hr earlier }\end{array}$ \\
\hline Celia & $\begin{array}{c}09 / 12 \text { - } \\
09 / 21\end{array}$ & 60 & 60 & Minor & Major & $\begin{array}{l}\text { Decay } 6 \\
\text { hr earlier }\end{array}$ \\
\hline Unnamed & $\begin{array}{c}09 / 20- \\
09 / 24\end{array}$ & - & 40 & - & - & - \\
\hline Daisy & $\begin{array}{c}09 / 29- \\
10 / 09\end{array}$ & 95 & 90 & Minor & Minor & $\begin{array}{c}\text { No } \\
\text { changes }\end{array}$ \\
\hline Ella & $\begin{array}{c}10 / 14- \\
10 / 23\end{array}$ & 100 & 90 & Minor & Major & $\begin{array}{l}\text { Decay } 6 \\
\text { hr earlier }\end{array}$ \\
\hline Unnamed & $\begin{array}{c}11 / 26- \\
12 / 06\end{array}$ & - & 70 & - & - & - \\
\hline
\end{tabular}

Table 10. 1962 revisions. 


\section{Hurricane Season}

The 1963 hurricane season was an active season for the Atlantic while ENSO was neutral. The original HURDAT listed 9 tropical cyclones that reached tropical storm intensity, 7 reached hurricane intensity and 2 became a major hurricane. The reanalysis adds 1 new tropical cyclone and none of the original systems were removed, increasing the season total to 10 . The number of hurricanes is decreased to 6 and the number of major hurricanes is increased to 3. Most of the tropical cyclone activity was located over the western Atlantic. Hurricanes Edith and Flora affected the Lesser and Greater Antilles causing significant damages. Flora produced over 100 inches of rain over eastern Cuba. The new tropical storm began as a disturbance over the Caribbean Sea and moved northward becoming a tropical storm off the Southeast coast of the United States and later impacting North Carolina. Overall, there were minor changes to the intensities and tracks of the tropical cyclones originally in HURDAT. Figure 27 shows the original tracks and Figure 28 illustrates the revised tracks. The changes to the season appear in Table 11. 


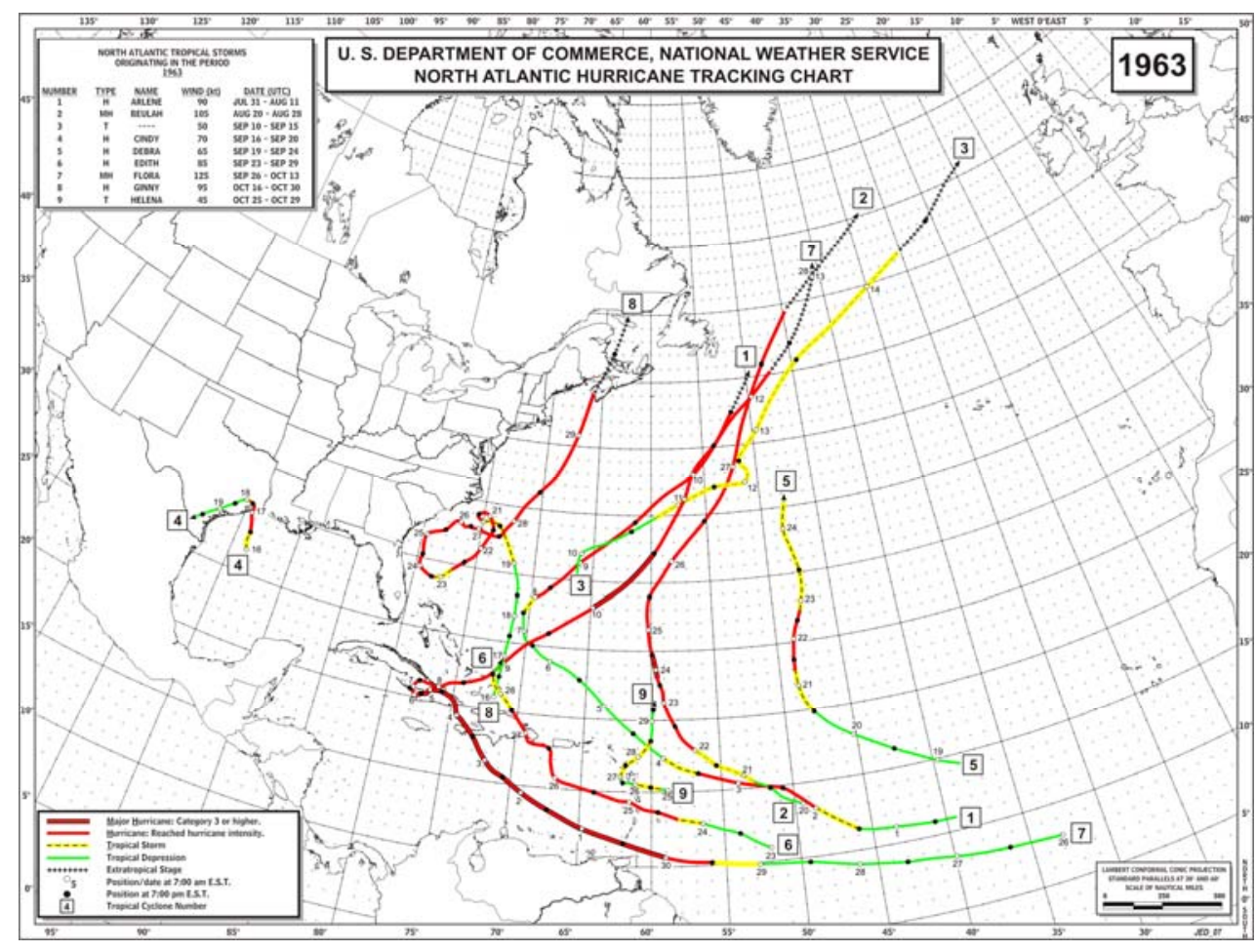

Figure 27. 1963 original track map.

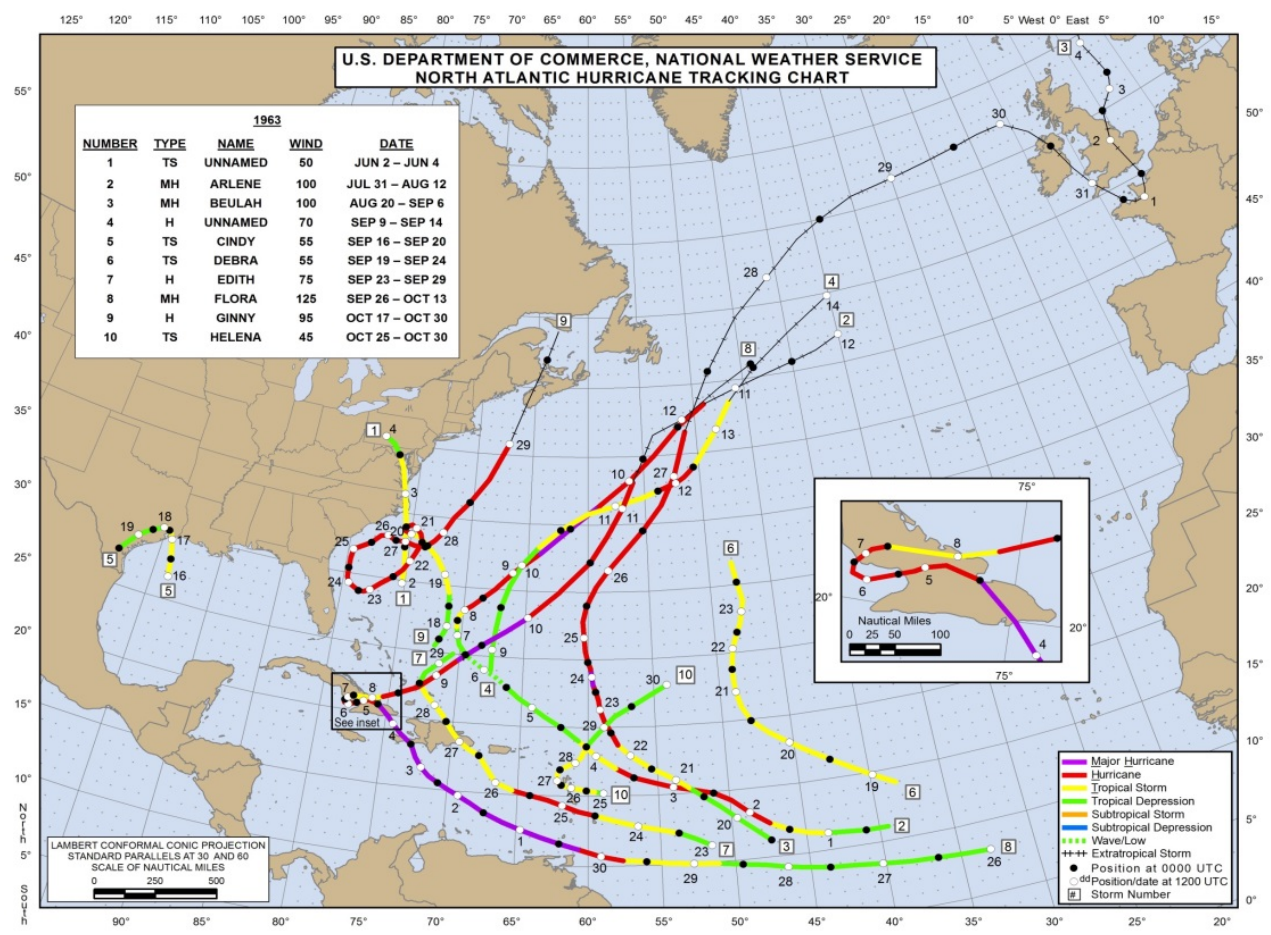

Figure 28. 1963 revised track map. 


\section{Revision for the 1963 Atlantic Hurricane Season}

\begin{tabular}{|c|c|c|c|c|c|c|}
\hline Name & Date & $\begin{array}{l}\text { Original } \\
\text { Peak } \\
\text { Intensity } \\
(\mathrm{kt})\end{array}$ & $\begin{array}{l}\text { Revised } \\
\text { Peak } \\
\text { Intensity } \\
(\mathrm{kt})\end{array}$ & $\begin{array}{c}\text { Track } \\
\text { Change }\end{array}$ & $\begin{array}{l}\text { Intensity } \\
\text { Change }\end{array}$ & $\begin{array}{c}\text { Genesis/ } \\
\text { Decay } \\
\text { Change }\end{array}$ \\
\hline Unnamed & $\begin{array}{c}06 / 02- \\
06 / 04\end{array}$ & - & 50 & - & - & - \\
\hline Arlene & $\begin{array}{c}07 / 31- \\
08 / 12\end{array}$ & 90 & 100 & Minor & Minor & $\begin{array}{c}\text { Decay } 30 \\
\text { hr later } \\
\text { Genesis } 12\end{array}$ \\
\hline Beulah & $\begin{array}{c}08 / 20- \\
09 / 06\end{array}$ & 105 & 100 & Minor & Minor & $\begin{array}{c}\text { hr earlier, } \\
\text { Decay } 9 \\
\text { days later }\end{array}$ \\
\hline Unnamed & $\begin{array}{c}09 / 09- \\
09 / 14\end{array}$ & 50 & 70 & Minor & Major & $\begin{array}{c}\text { Genesis } 24 \\
\text { hr earlier, } \\
\text { Decay } 18 \\
\text { hr earlier }\end{array}$ \\
\hline Cindy & $\begin{array}{c}09 / 16- \\
09 / 20\end{array}$ & 70 & 55 & Minor & Major & None \\
\hline Debra & $\begin{array}{c}09 / 19- \\
09 / 24\end{array}$ & 65 & 55 & Minor & Major & $\begin{array}{l}\text { Decay } 12 \\
\text { hr earlier }\end{array}$ \\
\hline Edith & $\begin{array}{c}09 / 23- \\
09 / 29\end{array}$ & 85 & 75 & Minor & Minor & $\begin{array}{c}\text { Decay } 12 \\
\text { hr later }\end{array}$ \\
\hline Flora & $\begin{array}{c}09 / 26- \\
10 / 13\end{array}$ & 125 & 125 & Minor & Major & $\begin{array}{l}\text { Decay } 12 \\
\text { hr earlier }\end{array}$ \\
\hline Ginny & $\begin{array}{c}10 / 17- \\
10 / 30\end{array}$ & 95 & 95 & Minor & Minor & $\begin{array}{c}\text { Genesis } 30 \\
\text { hr later }\end{array}$ \\
\hline Helena & $\begin{array}{c}10 / 25- \\
10 / 30\end{array}$ & 45 & 45 & Minor & Minor & $\begin{array}{c}\text { Decay } 18 \\
\text { hr later }\end{array}$ \\
\hline
\end{tabular}

Table 11. 1963 revisions. 


\section{CHAPTER 6}

\section{SUMMARY AND CONCLUSIONS}

The years reanalyzed were generally active in the North Atlantic, especially so for the United States and the countries of the Caribbean (Tables 12, 13 and 14). A total of 14 hurricanes either made landfall in the United States or produced hurricane-force winds. Of these 8 were major hurricanes at landfall (Table 12). Originally in HURDAT, the average number of tropical cyclones per season in the Atlantic between 1954 and 1963 (inclusive) was 9.2 tropical storms, 6.0 hurricanes and 3.1 major hurricanes. The reanalysis added 20 new tropical storms, preliminarily increasing the total in HURDAT to 102 . The number of hurricanes decreased from 60 to 55 and the number of major hurricanes also declined from 31 to 27 . None of the tropical cyclones originally in HURDAT for these seasons were removed, though occasionally there have been cyclones taken out of HURDAT in earlier seasons. The new average is 11.2 tropical storms, 5.5 hurricanes and 2.7 major hurricanes. There were six category 5 hurricanes in the original HURDAT and five were downgraded; only Hurricane Janet in 1955 remained. The most noteworthy change for the United States was the decrease in intensity of Hurricane Audrey of 1957 from $125 \mathrm{kt}$ originally in HURDAT to $105 \mathrm{kt}$. The most substantial change in the Atlantic was Hurricane Greta of 1956. The original peak intensity in HURDAT was $120 \mathrm{kt}$, and the reanalyzed intensity was $85 \mathrm{kt}$. Greta (Figure 29) was a large and slow-moving hurricane, with the radius of the outermost closed isobar extending to about $500 \mathrm{~nm}$, similar to Hurricane Sandy of 2012.

The most significant changes in this reanalysis were related to the overestimation of the intensity of tropical cyclones. The estimated surface winds reported by the 
reconnaissance aircrafts normally exhibited a high bias, leading to overestimation of the intensity overall. This bias was originally identified by Landsea (1993). Even though this pattern was recognized between 1954 and 1963, the Weather Bureau forecasters realized that this was occurring in the late 1950s and adjusted the estimated winds more reasonable values, likely using the formulas by Fletcher (1955) and Kraft (1961). Generally, there were minor alterations to the tracks. The most significant changes were generally extending the tracks of cyclones that had become extratropical into the North Atlantic and Western Europe.

The goals of this thesis were to document and reanalyze of all the original tropical cyclones in HURDAT for the years 1954 through 1963, inclusive, and to add the tropical cyclones that were not originally included in HURDAT for a range of reasons. The goal was to improve the completeness and accuracy of HURDAT, since it remains the prime source for the studies of climate change, risk assessment, insurance underwriting, planning, building code revision and the verification of model projections. An array of sources was used for the reanalysis included satellite images for the first time. Still, the most important source of data was the reconnaissance aircraft as they provided numerous central pressure measurements and eyewall diameter estimates. El Niño conditions prevailed during the 1957 season, while La Niña was present from 1954 through 1956 and neutral conditions were registered from 1958 through 1963. During all ten years, the AMO (Atlantic Multidecadal Oscillation) was in its warm phase. 


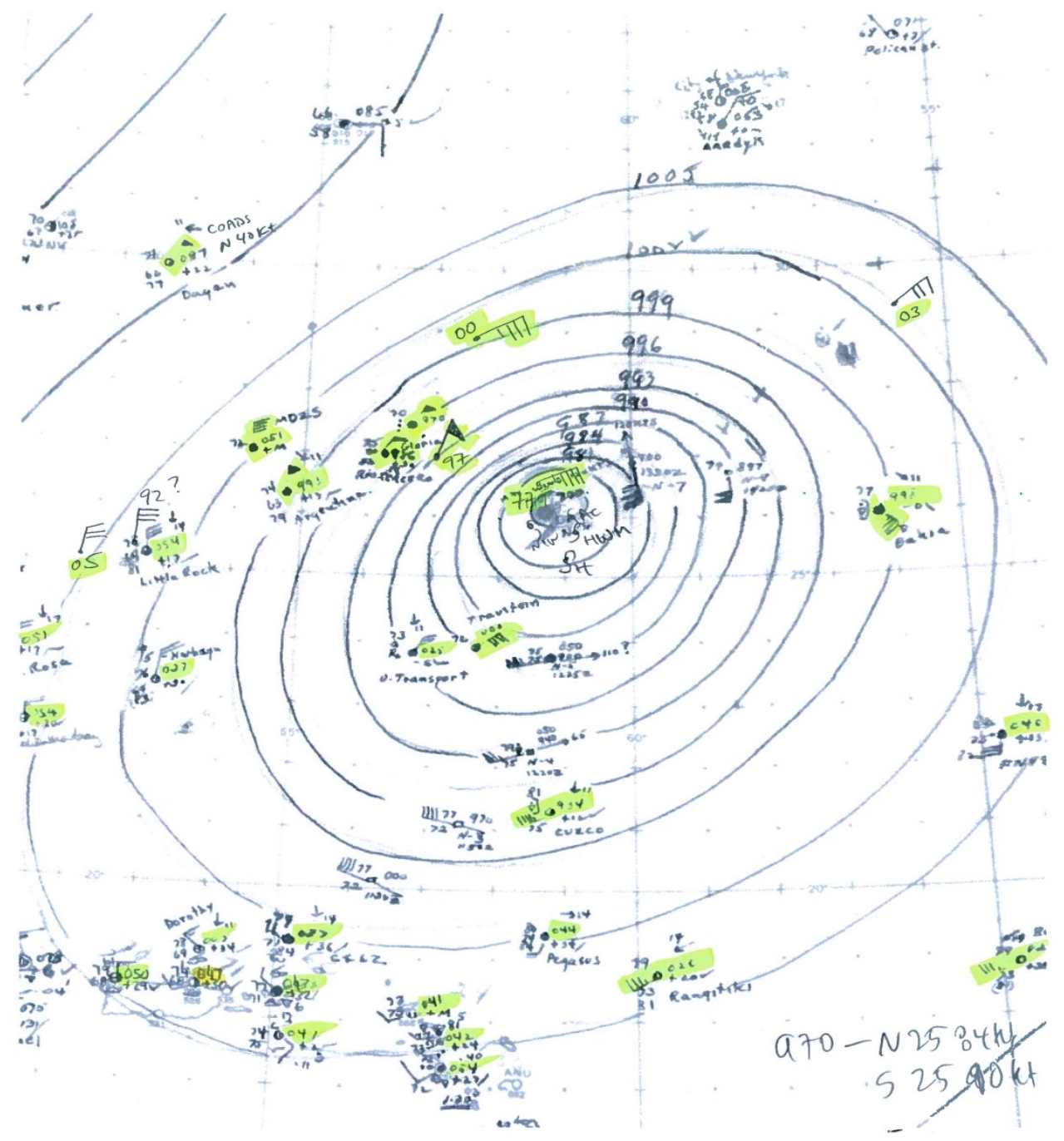

Figure 29. Microfilm map showing Hurricane Greta on November $4^{\text {th }}, 1956$, at $12 Z$. 


\begin{tabular}{|c|c|c|c|c|c|}
\hline Year & Name & $\begin{array}{l}\text { Original } \\
\text { Intensity }\end{array}$ & $\begin{array}{l}\text { Revised } \\
\text { Intensity }\end{array}$ & $\begin{array}{c}\text { Original SSHWS } \\
\text { at landfall }\end{array}$ & $\begin{array}{c}\text { Revised SSHWS } \\
\text { at landfall }\end{array}$ \\
\hline 1954 & Carol & $\begin{array}{l}85 \mathrm{kt} \\
85 \mathrm{kt} \\
85 \mathrm{kt}\end{array}$ & $\begin{array}{l}95 \mathrm{kt} \\
100 \mathrm{kt} \\
100 \mathrm{kt}\end{array}$ & $\begin{array}{l}\text { None } \\
\text { NY3 } \\
\text { RI3 }\end{array}$ & $\begin{array}{c}\mathrm{NC}^{*}{ }^{*} \\
\mathrm{NY} 3 \\
\mathrm{CT} 2, \mathrm{RI} 3, \mathrm{MA} 2\end{array}$ \\
\hline 1954 & Edna & $\begin{array}{l}105 \mathrm{kt} \\
90 \mathrm{kt} \\
90 \mathrm{kt} \\
70 \mathrm{kt}\end{array}$ & $\begin{array}{l}110 \mathrm{kt} \\
105 \mathrm{kt} \\
100 \mathrm{kt} \\
75 \mathrm{kt}\end{array}$ & $\begin{array}{l}\text { None } \\
\text { None } \\
\text { MA3 } \\
\text { ME1 }\end{array}$ & $\begin{array}{c}\mathrm{NC} 1 * \\
\mathrm{NY} 1 * \\
\text { RI1*, MA3 } \\
\text { Removed - ET }\end{array}$ \\
\hline 1954 & Hazel & $110 \mathrm{kt}$ & $120 \mathrm{kt}$ & $\mathrm{SC} 4, \mathrm{NC} 4, \mathrm{MD} 2$ & $\mathrm{SC} 3, \mathrm{NC} 4$ \\
\hline 1955 & Connie & $70 \mathrm{kt}$ & $85 \mathrm{kt}$ & NC3, VA1 & $\mathrm{NC} 2, \mathrm{VA} 1$ \\
\hline 1955 & Diane & $75 \mathrm{kt}$ & $65 \mathrm{kt}$ & $\mathrm{NC1}$ & $\mathrm{NC1}$ \\
\hline 1955 & Ione & $90 \mathrm{kt}$ & $90 \mathrm{kt}$ & $\mathrm{NC} 3$ & $\mathrm{NC} 2$ \\
\hline 1956 & Flossy & $\begin{array}{l}80 \mathrm{kt} \\
65 \mathrm{kt}\end{array}$ & $\begin{array}{l}80 \mathrm{kt} \\
85 \mathrm{kt}\end{array}$ & $\begin{array}{l}\text { LA2 } \\
\text { AFL1 }\end{array}$ & $\begin{array}{l}\text { LA1 } \\
\text { AFL2 }\end{array}$ \\
\hline 1957 & Audrey & $125 \mathrm{kt}$ & $105 \mathrm{kt}$ & CTX4, LA4 & CTX2, LA3 \\
\hline 1958 & Helene & & $\begin{array}{l}80 \mathrm{kt} \\
110 \mathrm{kt}\end{array}$ & $\begin{array}{l}\text { None } \\
\text { NC3 }\end{array}$ & $\begin{array}{l}\mathrm{SC}^{*} \\
\mathrm{NC} 3 *\end{array}$ \\
\hline 1959 & Cindy & $65 \mathrm{kt}$ & $60 \mathrm{kt}$ & $\mathrm{SC} 1$ & Removed - TS \\
\hline 1959 & Debra & $75 \mathrm{kt}$ & $75 \mathrm{kt}$ & CTX1 & CTX1 \\
\hline 1959 & Gracie & $120 \mathrm{kt}$ & $115 \mathrm{kt}$ & $\mathrm{SC} 3$ & SC4, GA1 \\
\hline 1960 & Donna & $\begin{array}{l}115 \mathrm{kt} \\
100 \mathrm{kt} \\
95 \mathrm{kt} \\
90 \mathrm{kt} \\
90 \mathrm{kt}\end{array}$ & $\begin{array}{l}115 \mathrm{kt} \\
100 \mathrm{kt} \\
95 \mathrm{kt} \\
85 \mathrm{kt} \\
80 \mathrm{kt}\end{array}$ & $\begin{array}{c}\text { None } \\
\text { DFL2 } \\
\text { NC3 } \\
\text { NY3 } \\
\text { RI1, MA1, NH1, } \\
\text { ME1 }\end{array}$ & $\begin{array}{c}\text { BFL4, CFL2 } \\
\text { DFL1 } \\
\text { NC2, VA1* } \\
\text { NY2 } \\
\text { CT1, RI1, MA1 }\end{array}$ \\
\hline 1960 & Ethel & $80 \mathrm{kt}$ & $70 \mathrm{kt}$ & MS1 & LA $1 *$, MS1 \\
\hline 1961 & Carla & $125 \mathrm{kt}$ & $120 \mathrm{kt}$ & HRBTX4 & $\begin{array}{c}\text { TX4, CTX3, } \\
\text { ATX1 }\end{array}$ \\
\hline
\end{tabular}

\footnotetext{
* = Hurricane did not make landfall but produced hurricane-force winds
}

Table 12. Changes to US Landfalling Hurricanes (1954-1963) 


\begin{tabular}{|c|c|c|c|c|c|}
\hline Date & Name & $\begin{array}{l}\text { Landfall } \\
\text { time }\end{array}$ & Location & $\begin{array}{l}\text { Original } \\
\text { Intensity }\end{array}$ & $\begin{array}{l}\text { Revised } \\
\text { Intensity }\end{array}$ \\
\hline $07 / 29 / 1954$ & Barbara & $10 Z$ & Louisiana & $35 \mathrm{kt}$ & $50 \mathrm{kt}$ \\
\hline $08 / 01 / 1955$ & Brenda & $17 Z$ & Louisiana & $60 \mathrm{kt}$ & $55 \mathrm{kt}$ \\
\hline $08 / 27 / 1955$ & Unnamed & $04 Z$ & Louisiana & $40 \mathrm{kt}$ & $45 \mathrm{kt}$ \\
\hline $06 / 13 / 1956$ & Unnamed & $17 Z$ & Louisiana & $50 \mathrm{kt}$ & $50 \mathrm{kt}$ \\
\hline $10 / 15 / 1956$ & Unnamed & $21 Z$ & Florida & - & $50 \mathrm{kt}$ \\
\hline $05 / 01 / 1957$ & Unnamed & $14 Z$ & Louisiana & - & $40 \mathrm{kt}$ \\
\hline $06 / 09 / 1957$ & Unnamed & $0030 Z$ & Florida & $35 \mathrm{kt}$ & $45 \mathrm{kt}$ \\
\hline $08 / 10 / 1957$ & Bertha & $06 Z$ & Texas & $45 \mathrm{kt}$ & $60 \mathrm{kt}$ \\
\hline $09 / 08 / 1957$ & Debbie & & Florida & $35 \mathrm{kt}$ & $\begin{array}{c}\text { Removed - } \\
\text { ET }\end{array}$ \\
\hline $09 / 18 / 1957$ & Esther & $12 Z$ & Louisiana & $45 \mathrm{kt}$ & $55 \mathrm{kt}$ \\
\hline $09 / 06 / 1958$ & Ella & $08 Z$ & Texas & $40 \mathrm{kt}$ & $50 \mathrm{kt}$ \\
\hline $05 / 30 / 1959$ & Arlene & $\begin{array}{l}21 Z \\
23 Z\end{array}$ & Louisiana & $\begin{array}{l}40 \mathrm{kt} \\
40 \mathrm{kt}\end{array}$ & $\begin{array}{l}55 \mathrm{kt} \\
55 \mathrm{kt}\end{array}$ \\
\hline $06 / 18 / 1959$ & Unnamed & $08 Z$ & Florida & $30 \mathrm{kt}$ & $40 \mathrm{kt}$ \\
\hline $\begin{array}{l}07 / 09 / 1959 \\
07 / 11 / 1959 \\
07 / 11 / 1959\end{array}$ & Cindy & $\begin{array}{l}03 Z \\
12 Z \\
13 Z\end{array}$ & $\begin{array}{c}\text { South } \\
\text { Carolina } \\
\text { Massachusetts } \\
\text { Massachusetts }\end{array}$ & $\begin{array}{l}65 \mathrm{kt} \\
50 \mathrm{kt} \\
50 \mathrm{kt}\end{array}$ & $\begin{array}{l}60 \mathrm{kt} \\
50 \mathrm{kt} \\
50 \mathrm{kt}\end{array}$ \\
\hline $10 / 08 / 1959$ & Irene & $10 Z$ & Alabama & $45 \mathrm{kt}$ & $40 \mathrm{kt}$ \\
\hline $10 / 18 / 1959$ & Judith & $14 Z$ & Florida & $45 \mathrm{kt}$ & $55 \mathrm{kt}$ \\
\hline $06 / 24 / 1960$ & Unnamed & $04 Z$ & Texas & $40 \mathrm{kt}$ & $45 \mathrm{kt}$ \\
\hline $\begin{array}{l}07 / 29 / 1960 \\
07 / 29 / 1960\end{array}$ & Brenda & $\begin{array}{l}06 Z \\
21 Z\end{array}$ & $\begin{array}{c}\text { Florida } \\
\text { North } \\
\text { Carolina }\end{array}$ & $\begin{array}{l}30 \mathrm{kt} \\
45 \mathrm{kt}\end{array}$ & $\begin{array}{l}35 \mathrm{kt} \\
55 \mathrm{kt}\end{array}$ \\
\hline 09/14/1961 & Unnamed & 09Z & $\begin{array}{c}\text { North } \\
\text { Carolina }\end{array}$ & $30 \mathrm{kt}$ & $35 \mathrm{kt}$ \\
\hline $09 / 26 / 1961$ & & $05 Z$ & Massachusetts & $40 \mathrm{kt}$ & $50 \mathrm{kt}$ \\
\hline $09 / 26 / 1961$ & Esther & $06 Z$ & Massachusetts & $35 \mathrm{kt}$ & $50 \mathrm{kt}$ \\
\hline $09 / 26 / 1961$ & & $11 Z$ & Maine & $35 \mathrm{kt}$ & $35 \mathrm{kt}$ \\
\hline $06 / 30 / 1962$ & Unnamed & $21 Z$ & North & - & $55 \mathrm{kt}$ \\
\hline
\end{tabular}




\begin{tabular}{|c|c|c|c|c|c|}
\hline & & & Carolina & & \\
\hline $06 / 03 / 1963$ & Unnamed & $08 \mathrm{Z}$ & $\begin{array}{c}\text { North } \\
\text { Carolina }\end{array}$ & - & $50 \mathrm{kt}$ \\
\hline $09 / 17 / 1963$ & Cindy & $14 \mathrm{Z}$ & Texas & $65 \mathrm{kt}$ & $55 \mathrm{kt}$ \\
\hline
\end{tabular}

Table 13. Changes to US Landfalling Tropical Storms (1954-1963) 


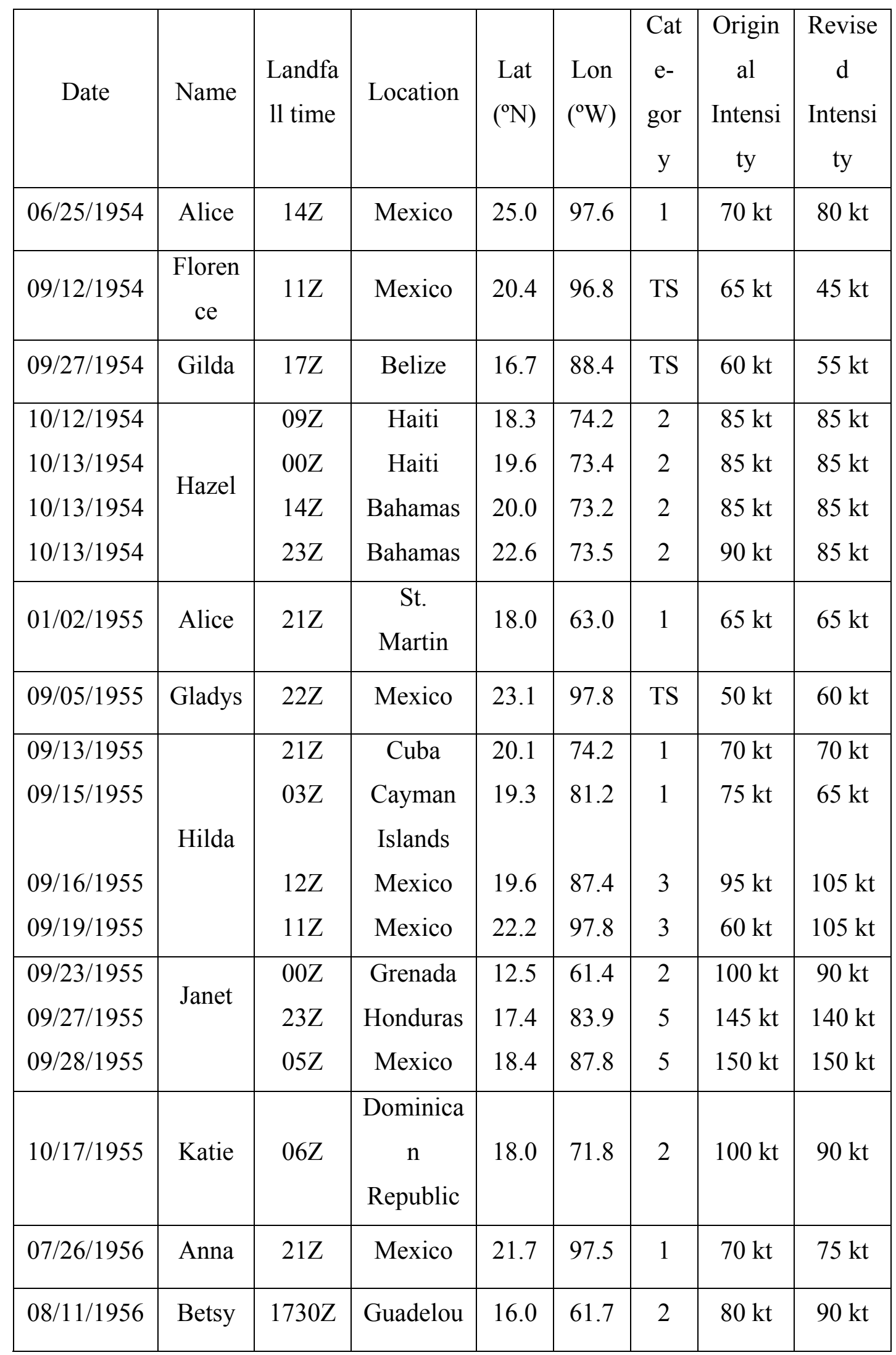




\begin{tabular}{|c|c|c|c|c|c|c|c|c|}
\hline $08 / 12 / 1956$ & & $1230 Z$ & $\begin{array}{c}\text { pe } \\
\text { Puerto } \\
\text { Rico }\end{array}$ & 18.0 & 66.0 & 2 & $80 \mathrm{kt}$ & $85 \mathrm{kt}$ \\
\hline $09 / 12 / 1956$ & Dora & $18 Z$ & Mexico & 20.9 & 97.3 & $\mathrm{TS}$ & $50 \mathrm{kt}$ & $50 \mathrm{kt}$ \\
\hline 09/22/1957 & Carrie & $16 Z$ & Azores & 38.7 & 27.3 & 1 & $70 \mathrm{kt}$ & $75 \mathrm{kt}$ \\
\hline $06 / 15 / 1958$ & Alma & 09Z & Mexico & 24.4 & 97.7 & $\mathrm{TS}$ & $35 \mathrm{kt}$ & $60 \mathrm{kt}$ \\
\hline 09/01/1958 & \multirow{4}{*}{ Ella } & $12 Z$ & Haiti & 18.2 & 73.4 & 2 & $95 \mathrm{kt}$ & $95 \mathrm{kt}$ \\
\hline 09/02/1958 & & $00 \mathrm{Z}$ & Cuba & 20.0 & 76.2 & 1 & $100 \mathrm{kt}$ & $75 \mathrm{kt}$ \\
\hline 09/03/1958 & & $11 Z$ & Cuba & 21.8 & 82.7 & $\mathrm{TS}$ & $55 \mathrm{kt}$ & $55 \mathrm{kt}$ \\
\hline 09/03/1958 & & $17 Z$ & Cuba & 22.1 & 84.0 & $\mathrm{TS}$ & $60 \mathrm{kt}$ & $60 \mathrm{kt}$ \\
\hline 09/14/1958 & & $21 Z$ & $\begin{array}{c}\text { Dominica } \\
n\end{array}$ & 18.0 & 71.2 & $\mathrm{TS}$ & $60 \mathrm{kt}$ & $50 \mathrm{kt}$ \\
\hline $09 / 14 / 1958$ & Uciua & $08 Z$ & $\begin{array}{c}\text { Republic } \\
\text { Mexico }\end{array}$ & 24.5 & 97.7 & TS & - & $40 \mathrm{kt}$ \\
\hline $10 / 06 / 1958$ & \multirow{4}{*}{ Janice } & $03 Z$ & Cuba & 22.0 & 80.3 & TS & $45 \mathrm{kt}$ & $50 \mathrm{kt}$ \\
\hline $10 / 06 / 1958$ & & $16 Z$ & Bahamas & 24.2 & 78.0 & TS & $55 \mathrm{kt}$ & $55 \mathrm{kt}$ \\
\hline $10 / 06 / 1958$ & & $21 Z$ & Bahamas & 25.1 & 77.1 & $\mathrm{TS}$ & $60 \mathrm{kt}$ & $60 \mathrm{kt}$ \\
\hline $10 / 06 / 1958$ & & $23 Z$ & Bahamas & 25.5 & 76.8 & 1 & $60 \mathrm{kt}$ & $65 \mathrm{kt}$ \\
\hline 06/19/1959 & Beulah & $02 Z$ & Mexico & 21.7 & 97.5 & $\mathrm{TS}$ & - & $35 \mathrm{kt}$ \\
\hline 08/18/1959 & Edith & $12 Z$ & $\begin{array}{c}\text { Guadelou } \\
\text { pe }\end{array}$ & 15.9 & 61.5 & TS & $50 \mathrm{kt}$ & $40 \mathrm{kt}$ \\
\hline $07 / 10 / 1960$ & \multirow{3}{*}{ Abby } & $11 Z$ & St. Lucia & 13.9 & 60.9 & $\mathrm{TS}$ & $65 \mathrm{kt}$ & $55 \mathrm{kt}$ \\
\hline $07 / 15 / 1960$ & & $06 Z$ & Honduras & 16.3 & 86.6 & 1 & $70 \mathrm{kt}$ & $70 \mathrm{kt}$ \\
\hline $07 / 15 / 1960$ & & $14 Z$ & Belize & 16.5 & 88.4 & 1 & $65 \mathrm{kt}$ & $70 \mathrm{kt}$ \\
\hline $09 / 08 / 1960$ & \multirow{2}{*}{ Donna } & $05 Z$ & Bahamas & 22.3 & 74.1 & 3 & $130 \mathrm{kt}$ & $105 \mathrm{kt}$ \\
\hline $09 / 08 / 1960$ & & $16 Z$ & Bahamas & 22.4 & 75.8 & 3 & $130 \mathrm{kt}$ & $105 \mathrm{kt}$ \\
\hline $07 / 23 / 1961$ & \multirow{2}{*}{ Anna } & $12 Z$ & Honduras & 15.8 & 84.3 & 1 & $90 \mathrm{kt}$ & $70 \mathrm{kt}$ \\
\hline 07/24/1961 & & $01 Z$ & Honduras & 16.1 & 86.9 & 1 & $85 \mathrm{kt}$ & $75 \mathrm{kt}$ \\
\hline
\end{tabular}




\begin{tabular}{|c|c|c|c|c|c|c|c|c|}
\hline $07 / 24 / 1961$ & & $10 Z$ & Belize & 16.4 & 88.5 & 1 & $80 \mathrm{kt}$ & $75 \mathrm{kt}$ \\
\hline 09/05/1961 & $\begin{array}{c}\text { Debbi } \\
\mathrm{e}\end{array}$ & $13 Z$ & $\begin{array}{l}\text { Cape } \\
\text { Verde } \\
\text { Islands }\end{array}$ & 15.0 & 23.4 & TS & - & $40 \mathrm{kt}$ \\
\hline $\begin{array}{l}10 / 01 / 1961 \\
10 / 03 / 1961\end{array}$ & $\begin{array}{c}\text { France } \\
\mathrm{s}\end{array}$ & $\begin{array}{l}08 \mathrm{Z} \\
05 \mathrm{Z}\end{array}$ & $\begin{array}{c}\text { Guadelou } \\
\text { pe } \\
\text { Dominica } \\
\mathrm{n} \\
\text { Republic }\end{array}$ & $\begin{array}{l}16.1 \\
18.3\end{array}$ & $\begin{array}{l}61.6 \\
68.5\end{array}$ & $\begin{array}{l}\text { TS } \\
\text { TS }\end{array}$ & $\begin{array}{l}40 \mathrm{kt} \\
50 \mathrm{kt}\end{array}$ & $\begin{array}{l}50 \mathrm{kt} \\
45 \mathrm{kt}\end{array}$ \\
\hline 10/31/1961 & Hattie & $13 Z$ & Belize & 17.1 & 88.3 & 4 & $120 \mathrm{kt}$ & $135 \mathrm{kt}$ \\
\hline $08 / 09 / 1963$ & Arlene & $1530 Z$ & Bermuda & 32.3 & 64.8 & 2 & $75 \mathrm{kt}$ & $95 \mathrm{kt}$ \\
\hline $\begin{array}{l}09 / 25 / 1963 \\
09 / 27 / 1963 \\
09 / 28 / 1963\end{array}$ & Edith & $\begin{array}{l}07 \mathrm{Z} \\
10 \mathrm{Z} \\
\\
18 \mathrm{Z}\end{array}$ & $\begin{array}{c}\text { St. Lucia } \\
\text { Dominica } \\
\mathrm{n} \\
\text { Republic } \\
\text { Turks } \\
\text { and } \\
\text { Caicos }\end{array}$ & $\begin{array}{r}14.0 \\
18.4 \\
\\
21.8\end{array}$ & $\begin{array}{r}60.9 \\
69.1 \\
\\
72.2\end{array}$ & $\begin{array}{c}1 \\
\text { TS } \\
\text { TS }\end{array}$ & $\begin{array}{l}75 \mathrm{kt} \\
65 \mathrm{kt} \\
35 \mathrm{kt}\end{array}$ & $\begin{array}{l}75 \mathrm{kt} \\
60 \mathrm{kt} \\
35 \mathrm{kt}\end{array}$ \\
\hline $09 / 30 / 1963$ & & $18 \mathrm{Z}$ & Tobago & 11.2 & 60.7 & 3 & $105 \mathrm{kt}$ & $100 \mathrm{kt}$ \\
\hline $10 / 04 / 1963$ & & $01 Z$ & Haiti & 18.2 & 73.0 & 4 & $125 \mathrm{kt}$ & $125 \mathrm{kt}$ \\
\hline $10 / 04 / 1963$ & Flora & $18 \mathrm{Z}$ & Cuba & 20.0 & 74.9 & 3 & $105 \mathrm{kt}$ & $105 \mathrm{kt}$ \\
\hline $10 / 07 / 1963$ & & $06 Z$ & Cuba & 20.8 & 78.1 & 2 & $80 \mathrm{kt}$ & $85 \mathrm{kt}$ \\
\hline $10 / 09 / 1963$ & & $06 Z$ & Bahamas & 22.3 & 72.8 & 2 & $75 \mathrm{kt}$ & $85 \mathrm{kt}$ \\
\hline $10 / 28 / 1963$ & Helena & $02 Z$ & Antigua & 17.0 & 61.8 & TS & $35 \mathrm{kt}$ & $35 \mathrm{kt}$ \\
\hline
\end{tabular}

Table 14. Changes to Non-US Landfalling Tropical Cyclones (1954-1963) 


\section{REFERENCES}

1. $" 50^{\text {th }}$ Anniversary of Hurricane Gracie" (PDF). National Weather Service Charleston, South Carolina (National Oceanic and Atmospheric Administration). http://www.erh.noaa.gov/chs/events/HurricaneGracie.pdf. Web. 30 Apr. 2014.

2. Andrews, James F. "The Weather and Circulation of May 1958." Monthly Weather Review 86.5 (1958): 177-85. Print.

3. Annual Tropical Storm Report. Miami, FL: U.S. Fleet Weather Facility, 1954-1963. Print.

4. Brown, D. P., J. L. Franklin, and C. W. Landsea, 2006: A fresh look at tropical cyclone pressure-wind relationships using recent reconnaissance-based "best track" data (1998-2005). Preprints, 27th Conf. on Hurricanes and Tropical Meteorology, Monterey, CA, Amer. Meteor. Soc., 3B.5.

5. "Canadian Tropical Cyclone Season Summaries for 1954-1959." Government of Canada, Environment Canada. http://www.ec.gc.ca/ouraganshurricanes/default.asp?lang=En\&n=3B0118E1-1, n.d. Web. 30 Apr. 2014.

6. "Canadian Tropical Cyclone Season Summaries for 1960-1969." Government of Canada, Environment Canada. http:/www.ec.gc.ca/ouraganshurricanes/default.asp?lang=En\&n=D295D67A-1, n.d. Web. 30 Apr. 2014.

7. Caribbean Station Observations. 20 May 2013. NOAA National Hurricane Center Library, Miami, FL.

8. C.E. Rhodes. Tropical Storms of the North Atlantic, September 1955. United States Weather Bureau. p. 326-328.

9. Chapman, William T., and Young T. Sloan. "The Paths of Hurricanes Connie and Diane." Monthly Weather Review 83.8 (1955): 171-80. Print.

10. Clark, John R., and William O. French. "Some Interesting Aspects of A Subtropical Depression May 18-28, 1958." Monthly Weather Review 86.5 (1958): 186-96. Print.

11. "Climatological Data publications.” National Climatic Data Center. http://www.ncdc.noaa.gov/IPS/cd/cd.html. Web. 30 Apr. 2014.

12. Colón, José A. "Meteorological Conditions over Puerto Rico During Hurricane Betsy, 1956." Monthly Weather Review 87.2 (1959): 69-80. Print. 
13. Colón, José A. "On The Formation Of Hurricane Alice, 1955." Monthly Weather Review 84.1 (1956): 1-14. Print.

14. Connor, W. C., 1956: Preliminary Summary of Gulf of Mexico Hurricane Data. New Orleans Forecast Office Rep., 178 pp

15. Courtney, J., and J. A. Knaff, 2009: Adapting the Knaff and Zehr wind-pressure relationship for operational use in tropical cyclone warning centres. Austr. Meteor. Oceanogr. J., 58, 167-179.

16. Davis, Walter R. "Hurricanes of 1954." Monthly Weather Review 82.12 (1954): 37073. Print.

17. Donovan Landreneau and Sam Shamburger. "Hurricane Audrey". National Weather Service Office in Lake Charles, Louisiana. National Oceanic and Atmospheric Administration. http://www.srh.noaa.gov/lch/?n=audrey. Web. 30 Apr. 2014.

18. Dunn, Carlos R. "The Weather and Circulation of July 1959." Monthly Weather Review 87.7 (1959): 275-82. Print.

19. Dunn, Gordon E. "The Hurricane Season of 1959." Monthly Weather Review 87.12 (1959): 441-50. Print.

20. Dunn, Gordon E. "The Hurricane Season of 1960." Monthly Weather Review 89.3 (1961): 99-108. Print.

21. Dunn, Gordon E. "The Hurricane Season of 1961." Monthly Weather Review 90.3 (1962): 107-19. Print.

22. Dunn, Gordon E., and Staff. "The Hurricane Season of 1962." Monthly Weather Review 91.4 (1963): 199-207. Print.

23. Dunn, Gordon E., and Staff. "The Hurricane Season Of 1963." Monthly Weather Review 92.3 (1964): 128-38. Print.

24. Dunn, Gordon E., Walter R. Davis, and Paul L. Moore. "Hurricanes of 1955." Monthly Weather Review 83.12 (1955): 315-26. Print.

25. Dunn, Gordon E., Walter R. Davis, and Paul L. Moore. "Hurricane Season of 1956." Monthly Weather Review 84.12 (1956): 436-43. Print.

26. "El Nino - Previous El Nino Events." El Nino - Previous El Nino Events. Web. 21 May 2014. 
27. Erickson, C. O. "An Incipient Hurricane near The West African Coast." Monthly Weather Review 91.2 (1963): 61-68. Print.

28. "Exceptional Weather Events - "Hurricane Debbie"'" (PDF). Met Éireann. 2012. http://www.met.ie/climate-ireland/weather-events/Sep1961_hurricane-Debbie.pdf. Web. 30 Apr. 2014.

29. "EV2." https://www.ncdc.noaa.gov/EdadsV2/libraries. Web. 30 Apr. 2014.

30. Fay, Richard. "Northbound Tropical Cyclone." Monthly Weather Review 90.8 (1962): 351-61. Print.

31. Fritz, Sigmund. "Satellite Pictures and The Origin Of Hurricane Anna." Monthly Weather Review 90.12 (1962): 507-13. Print.

32. Fletcher, R.D., 1955: Computation of Maximum Winds in Hurricanes. Bulletin of the American Meteorological Society, 36, 6, 346-350.

33. Gelhard, Robert H. "The Weather and Circulation of October 1959." Monthly Weather Review 87.10 (1959): 388-94. Print.

34. "Glossary of NHC Terms." Glossary of NHC Terms. Web. 22 May 2014.

35. Hagen, A.B., 2010. A Reanalysis of the 1944-1953 Atlantic Hurricane Seasons - The First Decade of Aircraft Reconnaissance. Master's of Science Thesis, University of Miami, Miami, FL,851 pp.

36. Hagen, A.B., D. Strahan-Sakoskie, and C. Luckett, 2012. A reanalysis of the 1944-53 Atlantic Hurricane seasons -The first decade of aircraft reconnaissance. Journal of Climate, 25, 4441-4460 pp.

37. Historical Weather Maps. 20 May 2013. NOAA National Hurricane Center Library, Miami, FL. http://docs.lib.noaa.gov/rescue/swm/

38. Ho, Francis P. Hurricane Climatology for the Atlantic and Gulf Coasts of the United States. Silver Spring, MD: U.S. Dept. of Commerce, National Oceanic and Atmospheric Administration, National Weather Service, 1987. Print.

39. Hoover, Eugene W. "Comments on "Some Interesting Aspects of a Subtropical Depression, May 18-28, 1958". Monthly Weather Review 86.9 (1958): 333-34. Print.

40. Jarrell, J. D., P. J. Hebert, and M. Mayfield, 1992: Hurricane experience levels of coastal county populations from Texas to Maine. NOAA Tech. Memo. NWS NHC$46,152 \mathrm{pp}$. 
41. Jarvinen, Brian R. "Storm Tides in Twelve Tropical Cyclones (including Four Intense New England Hurricanes)." http://www.aoml.noaa.gov/hrd/Landsea/12Tides.pdf. Web. 30 Apr. 2014.

42. Jordan, Harold M., and David J. Stowell. "Some Small-Scale Features of the Track of Hurricane Ione." Monthly Weather Review 83.9 (1955): 210-15. Print.

43. Kaplan, J., and M. DeMaria, 1995: A Simple Empirical Model for Predicting the Decay of Tropical Cyclone Winds After Landfall. J. Appl. Meteor., 34, 2 499-2512.

44. Knaff, J. A., and R. M. Zehr, 2007: Reexamination of Tropical Cyclone PressureWind Relationships. Weather and Forecasting, 22, 71-88.

45. Keith A. Forbes (2009-10-19). Bermuda Climate and Weather (Report). Bermudaonline.org. Web. 30 Apr. 2014.

46. Kieran R. Hickey and Christina Connolly-Johnston (2012). The Impact of Hurricane Debbie (1961) and Hurricane Charley (1986) on Ireland, Advances in Hurricane Research - Modelling, Meteorology, Preparedness and Impacts, Dr. Kieran Hickey (Ed.), ISBN: 978-953-51-0867-2, InTech, DOI: 10.5772/54039. Available from: http://www.intechopen.com/books/advances-in-hurricane-research-modellingmeteorology-preparedness-and-impacts/the-impact-of-hurricane-debbie-1961-andhurricane-charley-1986-on-ireland

47. Klein, William H. "The Weather and Circulation Of June 1957." Monthly Weather Review 85.6 (1957): 208-20. Print.

48. Kraft, R. H., 1961: The Hurricane's Central Pressure and Highest Wind. Mar. Wea. Log, 5, 157

49. Landsea, C.W., 1993: A climatology of intense (or major) Atlantic hurricanes. Mon. Wea. Rev., 121, pp. 1703-1713.

50. Landsea, Christopher W. "HURDAT 1851 - 2010." Re-Analysis Project. Web. 30 Apr. 2014.

51. Landsea, C. W., and J. L. Franklin, 2013: How 'good' are the best tracks? - Estimating uncertainty in the Atlantic Hurricane Database. Mon. Wea. Rev., (in press)

52. Landsea, C.W., A. Hagen, W. Bredemeyer, C. Carrasco, D. A. Glenn, A. Santiago, D. Strahan-Sakoskie, and M. Dickinson, 2013: A reanalysis of the 1931 to 1943 Atlantic hurricane database. 
53. Landsea, C. W., C. Anderson, N. Charles, G. Clark, J. Dunion, J. Fernandez-Partagas, P. Hungerford, C. Neumann, and M. Zimmer, 2004: The Atlantic hurricane database re-analysis project: Documentation for the 1851-1910 alterations and additions to the HURDAT database. _Hurricanes and Typhoons: Past, Present and Future_, R. J. Murname and K.-B. Liu, Eds., Columbia University Press, 177-221.

54. Landsea, C.W., M. Dickinson, and D. Strahan, 2008b. Reanalysis of Ten U.S. Landfalling Hurricanes. Final report submitted to the Risk Prediction Initiative, 120 pp. http://www.aoml.noaa.gov/hrd/hurdat/10_US_hurricanes.pdf

55. Landsea, C.W., R.A. Pielke Jr., A.M. Mestas-Nuñez, and J.A. Knaff, Atlantic basin hurricanes: Indices of climatic changes, Climatic Changes 42, 89-129 (1999).

56. Landsea, C.W., David A. Glenn, William Bredemeyer, Michael Chenoweth, Ryan Ellis, John Gamache, Lyle Hufstetler, Cary Mock, Ramon Perez, Ricardo Prieto, Jorge Sánchez-Sesma, Donna Thomas, and Lenworth Woolcock. "A Reanalysis of the 1911-20 Atlantic Hurricane Database." Journal of Climate 21.10 (2008a): 2138. Print.

57. Landsea, C. W., 2007: Counting Atlantic Tropical Cyclones Back to 1900. EOS, 88, $197 \& 2002$.

58. Landsea, C. W., Steve Feuer, Andrew Hagen, David A. Glenn, Jamese Sims, Ramon Perez, Michael Chenoweth, and Nicholas Anderson. "A Reanalysis of the 1921-30 Atlantic Hurricane Database*." Journal of Climate 25.3 (2012): 865-85. Print.

59. McAdie, C. J., C. W. Landsea, C. J. Neumann, J. E. David, E. Blake, G. R. Hamner, 2009: Tropical Cyclones of the North Atlantic Ocean, 1851-2006. Historical Climatology Series 6-2, Prepared by the National Climatic Data Center, Ashville, NC in cooperation with the National Hurricane Center, Miami, FL, 238 pp.

60. "Mexico Climatological Data - NOAA Central Library." Mexico Climatological Data - NOAA Central Library. Web. 05 May 2013

61. "Missions - TIROS - NASA Science." Missions - TIROS - NASA Science. NASA. Web. 14 May 2014.

62. Moore, Paul L. "The Hurricane Season of 1957." Monthly Weather Review 85.12 (1957): 401-08. Print.

63. Namias, Jerome, and Carlos R. Dunn. "The Weather and Circulation of August 1955." Monthly Weather Review 83.8 (1955): 163-70. Print. 
64. National Hurricane Center - Microfilm of synoptic weather maps. 20 May 2013. NOAA National Hurricane Center Library, Miami, FL.

65. National Hurricane Center - Weather Bureau Advisories 1954-1963. 30 Apr. 2014. NOAA National Hurricane Center Library, Miami, FL.

66. "NOAA's National Weather Service (NWS) Collection." NOAA Photo Library. Web. 30 Apr. 2014.

67. Pérez, Orlando. "Notes on the Tropical Cyclones of Puerto Rico, 1508-1970" (PDF). p. 30-31. http://www.aoml.noaa.gov/hrd/data_sub/perez_21_34.pdf

68. Pérez Suarez, R., R. Vega y M. Limia, 2000: Cronología de los Ciclones Tropicales de Cuba. El Informe Final del Proyecto "Los Ciclones Tropicales de Cuba, su Variabilidad y su Posible Vinculación con los Cambios Globales". Instituto de Meteorología, La Habana, Cuba, 100 pp.

69. Preliminary Report of Hurricane Diane and Floods in Northeast - August 1955 (Report). United States Weather Bureau. 1955-08-25

70. Ross, Robert B., and Maurice D. Blum. "Hurricane Audrey, 1957." Monthly Weather Review 85.6 (1957): 221-27. Print.

71. Rhodes, C.E. Tropical Storms of the North Atlantic, September 1955. United States Weather Bureau. pp. 326-328.

72. Richter, D. A., and E. A. Diloreto. "The Transformation of Hurricane Flossy Into An Extratropical Cyclone, September 25-29, 1956." Monthly Weather Review 84.9 (1956): 343-52. Print.

73. Sadowski, Alexander. "Atlantic Coastal Radar Tracking of 1958 Hurricanes." Journal of Geophysical Research 64.9 (1959): 1277-282. Print.

74. Saffir, Herbert and Simpson R.H., 1974: Hurricane disaster potential scale. Weatherwise, 27(4) $169 \& 170$.

75. Smith, John S. "The Hurricane-Tornado." Monthly Weather Review 93.7 (1965): 45359. Print.

76. "SP-168 EXPLORING SPACE WITH A CAMERA." http://history.nasa.gov/SP168/section1.htm. Web. 30 Apr. 2014.

77. Staff. "The Hurricane Season of 1958." Monthly Weather Review 86.12 (1958): 47785. Print. 
78. Storm Wallets. "http://www.nhc.noaa.gov/archive/storm_wallets/atlantic" Web. 30 Apr. 2014.

79. Tucker, Terry. Beware the Hurricane!: The Story of the Cyclonic Tropical Storms That Have Struck Bermuda and the Islanders' Folk-lore regarding Them. Hamilton?: Island, 1972. Print.

80. The Mariner's Weather Log. Washington. 1957-1963. Print.

81. Tracy, Jack D. "Correction to the Article "The Hurricane Season of 1958"." Monthly Weather Review 94.5 (1966): 327. Print.

82. United States Weather Bureau Operational Advisories Maps. 20 May 2013. NOAA National Hurricane Center Library, Miami, FL.

83. United States Weather Bureau (PDF). Bulletins and Advisories Issued by Weather Bureau Airport Station, San Juan, Puerto Rico, Weather Bureau Office, Miami, Florida, and Weather Bureau Office, New Orleans, Louisiana on Hurricane "Janet" (Preliminary Report). United States Department of Commerce. pp. 1-14

84. Velden, Christopher, Bruce Harper, Frank Wells, John L. Beven, Ray Zehr, Timothy Olander, Max Mayfield, Charles “Chip" Guard, Mark Lander, Roger Edson, Lixion Avila, Andrew Burton, Mike Turk, Akihiro Kikuchi, Adam Christian, Philippe Caroff, and Paul Mccrone. "The Dvorak Tropical Cyclone Intensity Estimation Technique: A Satellite-Based Method That Has Endured for over 30 Years." Bulletin of the American Meteorological Society 87.9 (2006): 1195-210. Web.

85. "Weather Notes: Betsy's Roving Eye." Monthly Weather Review 84.8 (1956): 311-12. Print.

86. Wiegman, Eldon J., Rex G. Hadfield, and Sidney M. Serebreny. Atlas of Cloud Vortex Patterns Observed in Satellite Photographs. Menlo Park, CA: SRI, 1964. Print.

87. Willoughby, H. E., and M. E. Rahn. "Parametric Representation of the Primary Hurricane Vortex. Part I: Observations and Evaluation of the Holland (1980) Model." Monthly Weather Review 132.12 (2004): 3033-048. Web.

88. Woodruff, S. D., R. J. Slutz, R. L. Jenne, and P. M. Steurer, 1987: A comprehensive ocean-atmosphere dataset (COADS). Bull. Amer. Meteor. Soc., 68, 1239-1250. 


\section{APPENDIX}

\section{REANALYSIS MEDATA}

\section{4 hurricane season}

New Tropical Storm [May 27-31, 1954]

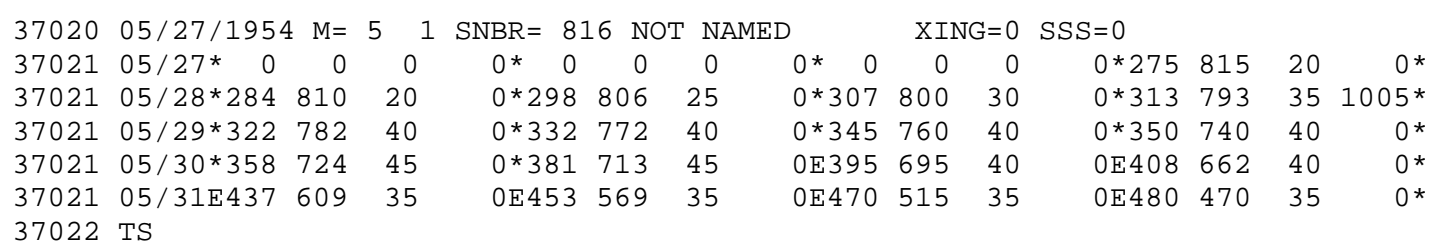

This new tropical storm was not previously documented in HURDAT. Evidence for the existence of this system was extracted from the Cooperative Ocean-Atmosphere Data Set (COA), the Historical Weather Maps (HWM) series, the Climatological Data publication (NCDC), the Local Climatological Data forms (NCDC), the Monthly Weather Review Tracks of Centers of Cyclones (May 1954), and the United States Weather Bureau microfilm data.

May 26: HWM indicates a stalled surface front near 24N, 78W. The MWR Tracks of Centers of Cyclones does not list the system on this date. No gales or low pressures were observed.

May 27: HWM indicates a frontal wave over east-central Florida near 27N, 80W. The MWR Tracks of Centers of Cyclones does not list the system on this date. No gales or low pressures were observed.

May 28: HWM indicates a closed surface low of at most $1010 \mathrm{mb}$ near $30.5 \mathrm{~N}, 80 \mathrm{~W}$. The MWR Tracks of Centers of Cyclones lists the system with a pressure of $1011 \mathrm{mb}$ at 31.1N, 81.6W (a.m.). Available observations suggest that the center of the tropical depression, located east of HWM's position, was situated at $31.0 \mathrm{~N}, 80.5 \mathrm{~W}$. Ship highlights: $30 \mathrm{kt} \mathrm{SE}$ and $1008 \mathrm{mb}$ at $31.6 \mathrm{~N}, 78.6 \mathrm{~W}$ at $18 \mathrm{UTC}$ (COA). No gales or low pressures were observed.

May 29: HWM indicates a closed surface low of at most $1010 \mathrm{mb}$ near $33.7 \mathrm{~N}, 71.1 \mathrm{~W}$. The MWR Tracks of Centers of Cyclones lists the system with a pressure of $1009 \mathrm{mb}$ at $35.3 \mathrm{~N}, 75.5 \mathrm{~W}$ (a.m.). Available observations suggest that the center of the tropical storm was situated at $34.5 \mathrm{~N}, 76.0 \mathrm{~W}$. Ship highlights: $35 \mathrm{kt} \mathrm{S}$ and $1010 \mathrm{mb}$ at $31.3 \mathrm{~N}, 76.6 \mathrm{~W}$ at $00 \mathrm{UTC}$ (COA); $30 \mathrm{kt} \mathrm{SW}$ and $1009 \mathrm{mb}$ at 32.5N, 75.7W at $12 \mathrm{UTC}$ (COA); $30 \mathrm{kt} \mathrm{SSW}$ 
and $1008 \mathrm{mb}$ at $34.5 \mathrm{~N}, 74.4 \mathrm{~W}$ at $18 \mathrm{UTC}(\mathrm{COA}) ; 35 \mathrm{kt} \mathrm{S}$ and $1005 \mathrm{mb}$ at $34.7 \mathrm{~N}, 73.3 \mathrm{~W}$ at 18 UTC (COA). No other gales or low pressures were observed. North Carolina conditions: "Finally, on the 27 th, southerly winds began to add moisture as well as heat to the atmosphere, and showers became increasingly prevalent. Rain never became general, however, and the sun and winds brought temperatures up to several degrees above normal for the first time since the 3rd. On the final two afternoons the temperatures climbed to the upper 80's and low 90's in all sections of the State" (Climatological Data).

May 30: HWM indicates a baroclinic surface low, associated with a surface cold front, of at most $1010 \mathrm{mb}$ near 40N, 68W. The MWR Tracks of Centers of Cyclones lists the system with a pressure of $1010 \mathrm{mb}$ at $39.8 \mathrm{~N}, 70.8 \mathrm{~W}$ (a.m.). Available observations suggest that the center of the extratropical cyclone was situated at $39.5 \mathrm{~N}, 69.5 \mathrm{~W}$. Ship highlights: $40 \mathrm{kt} \mathrm{S}$ and $997 \mathrm{mb}$ (with SST of 22C) at 38.1N, 70.5W at 06 UTC (COA); 40 kt SSE and $1004 \mathrm{mb}$ at 37.8N, 70.0W at $06 \mathrm{UTC}$ (COA); $35 \mathrm{kt} \mathrm{SSW}$ and $1012 \mathrm{mb}$ at $36.7 \mathrm{~N}, 69.6 \mathrm{~W}$ at $06 \mathrm{UTC}(\mathrm{COA}) ; 35 \mathrm{kt} \mathrm{W}$ and $1006 \mathrm{mb}$ at $40.0 \mathrm{~N}, 66.8 \mathrm{~W}$ at $18 \mathrm{UTC}$ (HWM). Several additional gales and low pressures were observed in association with the baroclinic system.

May 31: The MWR Tracks of Centers of Cyclones lists the system with a pressure of 997 $\mathrm{mb}$ at $47.6 \mathrm{~N}, 51.4 \mathrm{~W}$ (a.m.). Ship highlights: $10 \mathrm{kt} \mathrm{SE}$ and $1003 \mathrm{mb}$ at $43.8 \mathrm{~N}, 60.1 \mathrm{~W}$ at 00 UTC (USWB); $35 \mathrm{kt} \mathrm{WSW}$ and $1009 \mathrm{mb}$ at $43 \mathrm{~N}, 51.7 \mathrm{~W}$ at $12 \mathrm{Z}$ (HWM); $35 \mathrm{kt} \mathrm{WSW}$ and $1003 \mathrm{mb}$ at $45 \mathrm{~N}, 46.8 \mathrm{~W}$ at $18 \mathrm{Z}$ (COA); $35 \mathrm{kt} \mathrm{SW}$ and $998 \mathrm{mb}$ at $46.7 \mathrm{~N}, 46.6 \mathrm{~W}$ at $18 \mathrm{Z}$ (COA). Land highlights: $10 \mathrm{kt} \mathrm{NNW}$ and $999 \mathrm{mb}$ at Cape Race, Newfoundland, at 12Z (USWB).

The genesis of this new tropical storm began on May 27. Early on May 26, a broad surface trough developed over the southeastern Gulf of Mexico. On this date, there were no indications of a developing circulation along the trough axis, based on available land and ship observations. Early on the 27th, signs of a developing circulation were evident, including a westerly ship wind near Key West and increasing turning of the winds over the southern Florida peninsula and adjacent Atlantic Ocean. As the area of vorticity moved north-northeast over Florida, available observations suggest that the circulation became quite defined, and it is estimated that a closed circulation was present by the afternoon. This conclusion is supported by good land data coverage from several Florida stations, including Everglades City (WSW wind), Fort Myers (WSW wind), Moore Haven (SSW wind), Melbourne (SE wind), and Tampa (E wind). Thus, it is estimated that a tropical depression developed by 18 UTC on the date. A few land stations observed $15 \mathrm{kt}$ winds at the time, and the lowest observed pressures were 1013-1014 mb. The initial intensity is placed at $20 \mathrm{kt}$ at $18 \mathrm{UTC}$. (It is also noted that the United States Weather Bureau microfilm data listed the system as a tropical cyclone on the 27 th.) Early 
on May 28, the depression maintained a closed circulation and moved north-northeast and entered the western Atlantic Ocean. At this time, the surface pressure gradient briefly weakened and the circulation became less defined around 00 UTC on the 28th. However, the system quickly organized as it moved offshore. Several ships reported 25-30 kt winds between 12 and 18 UTC. One of the ships recorded a peripheral pressure of $1008 \mathrm{mb}$ and winds of $30 \mathrm{kt}$ at $18 \mathrm{UTC}$. This pressure would support a plausible central pressure near $1005 \mathrm{mb}$. A central pressure of $1005 \mathrm{mb}$ would substantiate a wind speed of $34 \mathrm{kt}$ from the Brown et al. (2006) pressure-wind relationship for systems north of $25 \mathrm{~N}-35 \mathrm{kt}$ is chosen for $18 \mathrm{UTC}$ on the 28th. This estimate is also supported by the relatively small size of the system at the time. Based on available ship and land data, the system continued to intensify on May 29 as it bypassed the Carolinas. The first gale force ship wind (35 kt) was reported at 00 UTC on the 29 th and was accompanied by a peripheral pressure of $1010 \mathrm{mb}-40 \mathrm{kt}$ is chosen for 00 UTC. Several 20-30 kt ship observations were reported between 12 and 18 UTC on the 29th. At 18 UTC, another gale force wind $(35 \mathrm{kt})$ was recorded in association with a peripheral pressure of $1005 \mathrm{mb}$. Based on a comparison with surrounding ship observations, this pressure may have been slightly too low, but it is believed to have been reasonably accurate. Based on the wind report, the peripheral pressure of $1005 \mathrm{mb}$ would support a central pressure near $1001 \mathrm{mb}$. A central pressure of $1001 \mathrm{mb}$ would support a wind speed of $46 \mathrm{kt}$ from the Neumann et al. (1999) pressure-wind relationship for systems between $25-35 \mathrm{~N}$. For systems north of $35 \mathrm{~N}$, a wind speed of $47 \mathrm{kt}$ would be supported. However, ship coverage was relatively good at this time, and the highest reported wind speed near the center was $35 \mathrm{kt}$. Furthermore, since the system was enlarging and was close to the boundary between the pressure-wind relationships, $40 \mathrm{kt}$ is maintained at $18 \mathrm{UTC}$ on the 29th. This intensity is also justified by subsequent data on May 30. Early on the 30th, the system accelerated and turned northnortheast ahead of an approaching mid-level trough. This movement occurred after a brief east-northeast movement on the 29th. Two ships reported $40 \mathrm{kt}$ winds and peripheral pressures of $997 \mathrm{mb}$ and $1004 \mathrm{mb}$ at 06 UTC on the 30th, respectively. The $997 \mathrm{mb}$ report would support a wind speed value of at least $53 \mathrm{kt}$ from the Neumann et al. (1999) pressure-wind relationship for systems north of 35N. However, the forward speed was slower than climatology for this latitude. Thus, $45 \mathrm{kt}$ is chosen for 00 and 06 UTC on this date. This wind speed is estimated to have been the peak intensity of the cyclone. Subsequently, available observations suggest that the system became an extratropical cyclone by 12 UTC. This conclusion is supported by the existence of a strong east to west surface temperature gradient in the vicinity of the system. Ships reported temperatures in the 70 s on the south edge of this gradient, while adjacent reports indicated surface temperatures in the low 60s on the north side. Based on the data, a warm front was likely extending eastward from the extratropical low at this time. At this time, an approaching surface cold front was still located northwest of the system. Subsequently, observations 
indicate that the strong surface cold front reformed farther east in association with the extratropical cyclone. As the extratropical low moved northeast, it gradually filled and weakened. After 18 UTC on May 31, the extratropical system was absorbed by another non-tropical low, which was situated farther northwest.

The reasons as to why this system was not originally included in HURDAT are unknown. Indeed, no known publications have explicitly mentioned this system or its nature. (However, the MWR Tracks of Centers of Cyclones did list the system during a portion of its life.) The circulation was concentric throughout the system's life as a tropical storm. The surrounding low level air mass was clearly barotropic, as evidenced by uniform temperatures in the 70 s and low $80 \mathrm{~s}$. The system was not associated with an extensive or noticeable mid-level trough during its life. Additionally, the system remained over the Gulf Stream throughout its life prior to extratropical transition. As late as the 30th, ship reports indicated that surrounding SSTs were at least 22C. The confirmation of several gale force ship reports and corroborating low pressures justify the implementation of this new system in HURDAT.

New Tropical Storm [June 17-25, 1954]

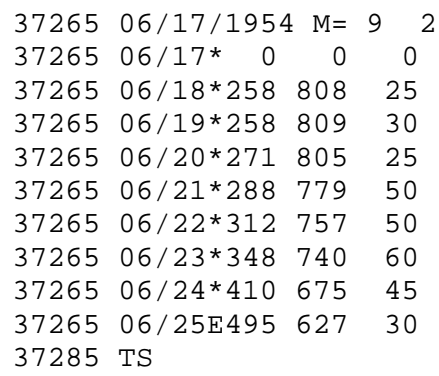

\begin{tabular}{|c|c|c|c|c|c|}
\hline$N B R=82$ & $20 \mathrm{~N}$ & & & & XIN \\
\hline$\Theta^{*}$ & $\odot$ & $\odot$ & $0^{*}$ & & 0 \\
\hline ๑*257 & 808 & 25 & $0 * 25$ & & 808 \\
\hline ๑*259 & 811 & 30 & $0 * 261$ & & 812 \\
\hline ๑*276 & 801 & 25 & $0 * 28 C$ & & 795 \\
\hline ๑*292 & 770 & 50 & $0 * 297$ & & 763 \\
\hline 0*321 & 756 & 50 & $0 * 325$ & & 754 \\
\hline ๑*359 & 726 & 55 & $0 * 37$ & & 709 \\
\hline OE430 & 659 & 40 & OE45 & & 645 \\
\hline$\Theta^{*} \quad \odot$ & $\odot$ & $\odot$ & $0^{*}$ & ? & $\odot$ \\
\hline
\end{tabular}

$X I N G=\odot \quad S S S=\odot$

\begin{tabular}{|c|c|c|c|}
\hline ๑*260 & 808 & 25 & $0^{*}$ \\
\hline $0 * 258$ & 808 & 30 & 0 * \\
\hline $0 * 266$ & 809 & 30 & ๑* \\
\hline $0 * 284$ & 788 & 45 & ○* \\
\hline $0 * 304$ & 759 & 50 & $\Theta^{*}$ \\
\hline $0 * 338$ & 749 & 60 & ○* \\
\hline $0 * 384$ & 692 & 50 & ०* \\
\hline OE475 & 635 & 30 & $\Theta$ * \\
\hline $0^{*} \quad \odot$ & $\odot$ & $\odot$ & $\odot^{*}$ \\
\hline
\end{tabular}

A new tropical storm has been added to HURDAT, not previously shown in McAdie et al. (2009). Evidence for its existence comes from the Historical Weather Map series, the microfilm maps at NHC (including Air Force reconnaissance observations), Climatological Data National Summary, the COADS ship database, and Monthly Weather Review.

June 17:

HWM does not analyze an organized system. HURDAT does not list a tropical cyclone. Microfilm shows a trough or tropical wave near $25 \mathrm{~N}$ and along $80 \mathrm{~W}$ at $12 \mathrm{Z}$. MWR shows a low pressure of at most $1012 \mathrm{mb}$ near $26.4 \mathrm{~N}, 79.5 \mathrm{~W}$ at $12 \mathrm{Z}$. No gales or low pressures.

June 18: 
HWM analyzes a low pressure of at most $1011 \mathrm{mb}$ centered near $24.5 \mathrm{~N}, 79.2 \mathrm{~W}$ at 12Z. Microfilm shows a low pressure of at most $1008 \mathrm{mb}$ centered near $25.6 \mathrm{~N}, 81.2 \mathrm{~W}$ at 12Z. MWR lists a low pressure of at most $1012 \mathrm{mb}$ near 25.5N, 80.5W. Ship highlights: $35 \mathrm{kt} \mathrm{E}$ and $1012 \mathrm{mb}$ near 24.8N, 80.6W at 18Z. Report from Microfilm.

June 19:

HWM analyzes a cold front stretching from the eastern Gulf of Mexico, across central Florida, and into the western Atlantic at 12Z. Microfilm shows a low pressure of at most $1008 \mathrm{mb}$ centered near $26.0 \mathrm{~N}, 81.5 \mathrm{~W}$ at $12 \mathrm{Z}$. MWR lists a low pressure of at most 1008 mb near $26.5 \mathrm{~N}, 80.5 \mathrm{~W}$. Ship highlights: No gales or low pressures.

June 20:

HWM shows a closed low pressure of at most $1010 \mathrm{mb}$ at $28.0 \mathrm{~N}, 79.5 \mathrm{~W}$ at $12 \mathrm{Z}$. Microfilm analyzes a low pressure of at most $1008 \mathrm{mb}$ near $28.0 \mathrm{~N}, 79.5 \mathrm{~W}$ at $12 \mathrm{Z}$. MWR lists a low pressure of at most $1008 \mathrm{mb}$ near $28.0 \mathrm{~N}, 79.8 \mathrm{~W}$. Ship highlights: $40 \mathrm{kt} \mathrm{ENE}$ and $1007 \mathrm{mb}$ near $29.2 \mathrm{~N}, 78.2 \mathrm{~W}$ at $18 \mathrm{Z} .50 \mathrm{kt} \mathrm{NE}$ and $1008 \mathrm{mb}$ near $30.0 \mathrm{~N}, 78.5 \mathrm{~W}$ at 18Z. All reports from Microfilm.

June 21:

HWM shows a closed low pressure of at most $1010 \mathrm{mb}$ at $30.0 \mathrm{~N}, 77.0 \mathrm{~W}$ at $12 \mathrm{Z}$. Microfilm shows a low pressure of at most $1008 \mathrm{mb}$ centered near $29.5 \mathrm{~N}, 75.7 \mathrm{~W}$ at $12 \mathrm{Z}$. MWR lists a low pressure of at most $1006 \mathrm{mb}$ near 29.0N, 76.2W. Ship highlights: $45 \mathrm{kt}$ ENE and $1011 \mathrm{mb}$ near 30.3N, 77.6W at 00Z. Report from Microfilm.

June 22:

HWM shows a closed low pressure of at most $1005 \mathrm{mb}$ at $33.2 \mathrm{~N}, 75.0 \mathrm{~W}$ at $12 \mathrm{Z}$. Microfilm shows a low pressure of at most $1005 \mathrm{mb}$ centered near $33.6 \mathrm{~N}, 75.7 \mathrm{~W}$ at $12 \mathrm{Z}$. MWR lists a low pressure of at most $1009 \mathrm{mb}$ near 33.2N, 75.9W. Ship highlights: $40 \mathrm{kt}$ NNW and $1010 \mathrm{mb}$ near 33.3N, 76.6W at 12Z. $35 \mathrm{kt} \mathrm{NNW}$ and $1008 \mathrm{mb}$ near $33.7 \mathrm{~N}$, $76.1 \mathrm{~W}$ at $15 \mathrm{Z} .40 \mathrm{kt} \mathrm{NNE}$ and $1014 \mathrm{mb}$ near $34.3 \mathrm{~N}, 76.4 \mathrm{~W}$ at $18 \mathrm{Z} .35 \mathrm{kt} \mathrm{S}$ and $1013 \mathrm{mb}$ near $32.9 \mathrm{~N}, 73.4 \mathrm{~W}$ at 18Z. All reports from COADS. Aircraft highlights: Air Force center fix at $1530 \mathrm{Z}$ at $33.2 \mathrm{~N}, 75.3 \mathrm{~W}$; center fix at $1749 \mathrm{Z}$ at $33.7 \mathrm{~N}, 75.9 \mathrm{~W}, 998 \mathrm{mb}$ and 70 kt winds; and center fix at 2000Z at 33.9N, 74.5W. All reports from Microfilm.

June 23:

HWM shows a closed low pressure of at most $1005 \mathrm{mb}$ at $36.7 \mathrm{~N}, 77.2 \mathrm{~W}$ at $12 \mathrm{Z}$. Microfilm shows a low pressure of at most $1002 \mathrm{mb}$ centered near $37.3 \mathrm{~N}, 76.3 \mathrm{~W}$ at $12 \mathrm{Z}$. MWR lists a low pressure of at most $1000 \mathrm{mb}$ near 37.2N, 76.0W. Ship highlights: $40 \mathrm{kt}$ 
$\mathrm{S}$ and $1002 \mathrm{mb}$ near $34.0 \mathrm{~N}, 72.8 \mathrm{~W}$ at $0 \mathrm{Z} .40 \mathrm{kt} \mathrm{SW}$ and $1005 \mathrm{mb}$ near $36.7 \mathrm{~N}, 69.6 \mathrm{~W}$ at 15Z. $35 \mathrm{kt} \mathrm{NNE}$ and $1014 \mathrm{mb}$ near $35.5 \mathrm{~N}, 73.7 \mathrm{~W}$ at 18Z. $35 \mathrm{kt} \mathrm{SW}$ and $1008 \mathrm{mb}$ near $36.7 \mathrm{~N}, 69.6 \mathrm{~W}$ at $18 \mathrm{Z}$. All reports from COADS.

June 24:

HWM shows a closed low pressure of at most $1005 \mathrm{mb}$ at $45.0 \mathrm{~N}, 64.5 \mathrm{~W}$ at $12 \mathrm{Z}$. Microfilm shows a low pressure of at most $1002 \mathrm{mb}$ centered near $45.5 \mathrm{~N}, 64.5 \mathrm{~W}$ at $12 \mathrm{Z}$. MWR lists a low pressure of at most $998 \mathrm{mb}$ near 44.5N, 64.8W. Ship highlights: $40 \mathrm{kt}$ $\mathrm{SE}$ and $1005 \mathrm{mb}$ near $41.2 \mathrm{~N}, 64.8 \mathrm{~W}$ at $03 \mathrm{Z} .35 \mathrm{kt} \mathrm{SSE}$ and $1013 \mathrm{mb}$ near $40.4 \mathrm{~N}, 61.1 \mathrm{~W}$ at $06 \mathrm{Z}$. All reports from COADS.

This new tropical storm originated from a surface trough over southern Florida on the 17 th of June. By $18 \mathrm{Z}$ on the 17th, a closed center had formed and - despite remaining over the Florida peninsula near the Everglades - a tropical depression is analyzed to begin at that point. The cyclone moved very little from the 17th through the 19th, remaining over land. At $18 \mathrm{Z}$ on the $18 \mathrm{th}$, a ship well northeast of the center reported $35 \mathrm{kt} \mathrm{ENE.}$ However, due to other nearby observations indicating substantially less than that, the intensity is kept at $30 \mathrm{kt}$, just below tropical storm strength. At $12 \mathrm{Z}$ on the 19 th, two observations of $35 \mathrm{kt} \mathrm{S}$ winds were reported from Carysfort Reef and Alligator Reef lighthouses. As these anemometers are elevated (30 m and $45 \mathrm{~m}$, respectively), these winds reduce down to 32 and $30 \mathrm{kt}$, respectively, at $10 \mathrm{~m}$. Intensity is kept at $30 \mathrm{kt}$ at that time, though it is possible that the system was a minimal tropical storm, even though the center was still over land in southern Florida. As the cyclone's center began moving slowly northeastward late on the 19th and early on the 20th away from the Everglades, it appears that the system weakened slightly and an intensity of $25 \mathrm{kt}$ is analyzed for $00 \mathrm{Z}$ and $06 \mathrm{Z}$ on the 20th. The system moved back over water around $06 \mathrm{Z}$ on the 20th. From that point, a rather pronounced intensification occurred. At $18 \mathrm{Z}$ on the 20th, two ships reported $40 \mathrm{kt} \mathrm{ENE}$ and $50 \mathrm{kt} \mathrm{NE}$, respectively. It is analyzed that it became a tropical storm by $12 \mathrm{Z}$ on the 20 th with $35 \mathrm{kt}$ winds, $45 \mathrm{kt}$ at $18 \mathrm{Z}$, and $50 \mathrm{kt}$ at $00 \mathrm{Z}$ on the $21 \mathrm{st}$. It is noted that both the Historical Weather Map series and the NHC microfilm suggest a frontal boundary existed from the center of the system and extending eastward on the 19th and 20th for HWM and on the 20th and 21st for the microfilm. However, despite the cyclone showing a somewhat asymmetric structure both in the wind field and in the pressure field on these dates, it does not appear that a front actually existed. It could be, though, that on the 19th through the 21 st that the system was a subtropical cyclone. (However, this designation is not utilized in HURDAT until 1968, with the advent of routine satellite imagery.) Little inner core observations were available on the 21 st, so the intensity is held steady at $50 \mathrm{kt}$. Late on this date, the cyclone turned toward the north-northeast. There was one Air Force reconnaissance mission into the cyclone on the 
22nd, as the system was becoming more symmetric and intensifying. This mission did not penetrate the center, but instead boxed the cyclone to provide three position fixes. However, it did obtain three observations helpful with the intensity. They were $70 \mathrm{kt} \mathrm{SW}$ surface winds (visually estimated) and $998 \mathrm{mb}$ pressure (adjusted from flight level pressure) at 1745Z, $75 \mathrm{kt} \mathrm{SW}$ and $998 \mathrm{mb}$ at 2050Z, and $20 \mathrm{kt} \mathrm{SSW}$ and $996 \mathrm{mb}$ at unknown time (but later) all on the 22nd. The $996 \mathrm{mb}$ peripheral pressure suggests winds of at least $50 \mathrm{kt}$ (or at least $52 \mathrm{kt}$ for intensifying tropical cyclones) from the Brown et al. north of $25 \mathrm{~N}$ pressure-wind relationship. It is possible that the $996 \mathrm{mb}$ and $20 \mathrm{kt}$ observation suggests a $994 \mathrm{mb}$ central pressure. However, it is not clear whether these two measurements were really simultaneous both in time and space. The intensity is analyzed to be $60 \mathrm{kt}$ late on the 22nd and early on the 23rd, though it is possible that the system was a minimal hurricane. This is also the peak intensity for the cyclone. Late on the 22nd, the cyclone turned toward the northeast and began accelerating. Early on the 23rd, Wilmington, North Carolina experienced its peak fastest mile winds of the month $29 \mathrm{kt} \mathrm{NW}$ - in association with this cyclone. (Cape Hatteras had its peak winds of the month of $28 \mathrm{kt}$ on the 18th, not in association with this system.) It is likely that a portion of the North Carolina coast between Wilmington and Cape Hatteras experienced $35 \mathrm{kt}$ tropical storm force winds. The cyclone gradually weakened on the 23rd. Peak observed winds were $40 \mathrm{kt}$ at $15 \mathrm{Z}$ and the intensity is brought down to $50 \mathrm{kt}$ at 12 and $18 \mathrm{Z}$. On the 24th, the cyclone underwent extratropical transition as a cold front approached from the west and reached the center of the system around 06Z. After 06Z on the 24th, the extratropical cyclone made landfall in Nova Scotia, Canada. The system gradually weakened on this date and dropped below tropical storm strength by $18 \mathrm{Z}$. The system continued diminishing and it is analyzed that it dissipated after $00 \mathrm{Z}$ on the 25th.

"The storm center was first located at $1530 \mathrm{Z}$ at three three two north seven five three west. At first entry the center was ill formed with a ring cloud to twenty five thousand feet in an arc from two seven zero degrees through one two zero degrees. By departure time $2100 \mathrm{Z}$ the ring cloud has risen above $35000 \mathrm{ft}$ and covered the arc from three zero zero degrees through zero five zero degrees. The strata cumulus clouds gradually formed a perfect circle at $1830 \mathrm{Z}$ and by $1900 \mathrm{Z}$ took on the shape of the synoptic hurricane symbol of a six nine superimposed. The lowest sea level pressure was nine nine eight millibars and maximum surface wind was two three zero degrees at seven five knots in southeast quadrant. The weakest quadrant was north with no winds over three five knots the weather in the southeast quadrant was banded in twenty mile widths. With the exception of the cirro stratus and the wall of cumulonimbus no clouds were over ten thousand feet. Depressions at 500 and 700 millibars were superimposed over the surface center. The storm was boxed at 1500 feet and had a closed low cell wind pattern with a wind shear across the center of approximately eighty miles which later became about fifty miles. 
Hurricane Alice [June 24-26, 1954]

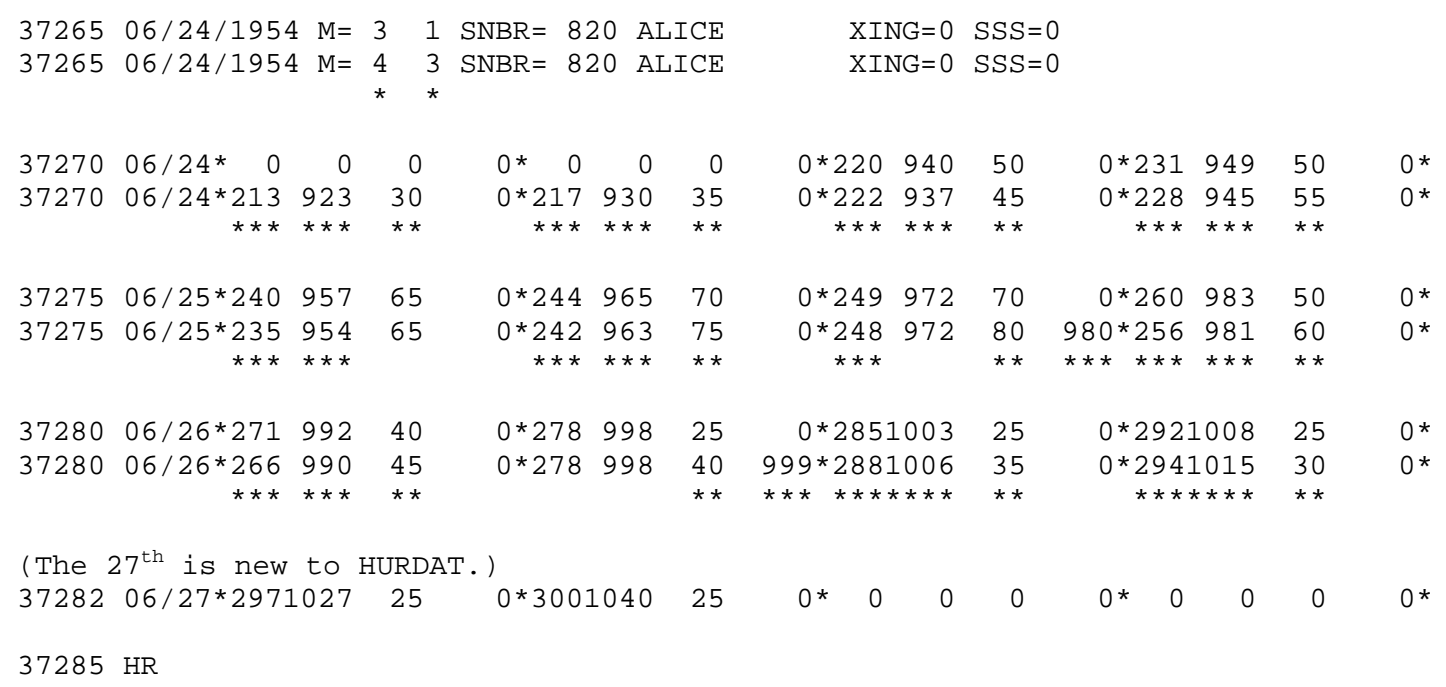

Minor alterations are introduced to the track and to the intensity shown in McAdie et al. (2009). Evidence for these alterations comes from the Historical Weather Map series, the microfilm maps at NHC, the Navy aircraft reconnaissance book, Climatological Data, the COADS ship database, and Monthly Weather Review, and Connor (1956).

June 23:

HWM analyzes a low pressure of at most $1010 \mathrm{mb}$ centered near $20.0 \mathrm{~N}, 93.3 \mathrm{~W}$. HURDAT and microfilm did not previously list this system. No gales or equivalent in pressure were observed.

June 24:

HWM analyzes a tropical storm of at most $1005 \mathrm{mb}$ centered near $22.0 \mathrm{~N}, 94.5 \mathrm{~W}$. HURDAT lists this as a 50 knot tropical storm at $22.0 \mathrm{~N}, 94.0 \mathrm{~W}$. Microfilm analyzes a closed low pressure of at most $1008 \mathrm{mb}$ centered near $22.3 \mathrm{~N}, 94.8 \mathrm{~W}$, at $18 \mathrm{Z}$. Ship highlights: $50 \mathrm{kt} \mathrm{E}$ and $999 \mathrm{mb}$ at $18 \mathrm{Z}$ near $23.1 \mathrm{~N}, 94.5 \mathrm{~W} .30 \mathrm{kt} \mathrm{SE}$ and $1011 \mathrm{mb}$ at $23 \mathrm{Z}$ near $23.2 \mathrm{~N}, 94.2 \mathrm{~W}$. All ship reports come from the microfilm. "A tropical storm developed rapidly in the west Gulf of Mexico on the $24^{\text {th }}$ of June" (MWR).

June 25:

HWM analyzes a tropical storm of at most $1005 \mathrm{mb}$ centered near $24.7 \mathrm{~N}, 97.5 \mathrm{~W}$. HURDAT lists this as a 70 knot hurricane at $24.9 \mathrm{~N}, 97.2 \mathrm{~W}$. MWR shows this system as a hurricane near $24.9 \mathrm{~N}, 97.5 \mathrm{~W}$ at $12 \mathrm{Z}$. In the microfilm at $12 \mathrm{Z}$, the storm is analyzed as a hurricane of $990 \mathrm{mb}$ centered near 25.1N, 97.3W. Ship highlights: $45 \mathrm{kt}$ ESE and $997 \mathrm{mb}$ 
at $06 \mathrm{Z}$ near $24.0 \mathrm{~N}, 97.0 \mathrm{~W} ; 75 \mathrm{kt} \mathrm{N}$ at $0817 \mathrm{Z}$ near $24.6 \mathrm{~N}, 97.2 \mathrm{~W}$. All ship reports come from the microfilm. Aircraft highlights: NAVY center fix at $0650 \mathrm{Z}$ at $23.8 \mathrm{~N}, 96.0 \mathrm{~W}$; center fix at $0726 \mathrm{Z}$ at $23.9 \mathrm{~N}, 96.1 \mathrm{~W}$; center fix at $0907 \mathrm{Z}$ at $24.4 \mathrm{~N}, 96.8 \mathrm{~W}$; center fix at $0932 \mathrm{Z}$ at $24.6 \mathrm{~N}, 96.8 \mathrm{~W}$, center fix at $1530 \mathrm{Z}$ at $25.0 \mathrm{~N}, 98.0 \mathrm{~W}$ and flight level winds of 60 kt . Land highlight: $37 \mathrm{kt} \mathrm{ESE}$ and $1007 \mathrm{mb}$ at 12Z at Brownsville (climo); $45 \mathrm{kt} \mathrm{E}$ (maximum 1-minute wind) at Brownsville sometime between 12Z-18Z (climo). $43 \mathrm{kt} \mathrm{SE}$ at $13-15 \mathrm{Z}$ and $1009 \mathrm{mb}$ at 22Z at Port Isabel (Connor); $43 \mathrm{kt}$ at $19 \mathrm{Z}$ and $1008 \mathrm{mb}$ at $18 \mathrm{Z}$ at Harlingen (Connor); $55 \mathrm{kt} \mathrm{SW}$ and $1003 \mathrm{mb}$ at 19Z at Mercedes (Connor); $45 \mathrm{kt} \mathrm{SE} \mathrm{at}$ $15 \mathrm{Z}$ at Raymondville (Connor); $35 \mathrm{kt} \mathrm{E}$ at 20-21Z and $1006 \mathrm{mb}$ at $21 \mathrm{Z}$ at Sarita (Connor); $35 \mathrm{kt} \mathrm{SE}$ at $0850 \mathrm{Z}$ and $1011 \mathrm{mb}$ at $2130 \mathrm{Z}$ at Corpus Christi (Connor). All cities are in Texas. "By early on the $25^{\text {th }}$ [Alice] was of hurricane force. It moved inland south of Brownsville, Tex., early on the morning of the $25^{\text {th }}$. A fishing camp along the Mexican coast, about 100 miles south of Brownsville, estimated a maximum wind of 70 to 80 mph." (MWR) An Aircraft report at 15Z indicated that the center was moving inland, "closed elliptical shape circulation over beach." (Hurricane Reconnaissance)

June 26:

HWM shows a closed low pressure of at most $1010 \mathrm{mb}$ at $28.7 \mathrm{~N}, 100.6 \mathrm{~W}$. HURDAT lists this as a 25 knot tropical depression at $28.5 \mathrm{~N}, 100.3 \mathrm{~W}$. Microfilm analyzes a low pressure near 28.4N, 101.5W at 12Z. Land highlight: $37 \mathrm{kt} \mathrm{NE}$ and 999 $\mathrm{mb}$ at $0430 \mathrm{Z}$ at Laredo (Connor). $28 \mathrm{kt} \mathrm{SE}$ at Del Rio (NCDC/NHC Library). All cities are in Texas.

June 27:

HWM and HURDAT did not analyze previously this system. Microfilm lists a low pressure near $27.5 \mathrm{~N}, 103.0 \mathrm{~W}$ at $12 \mathrm{Z}$. Land highlights: $10 \mathrm{kt} \mathrm{W}$ and $1008 \mathrm{mb}$ at $06 \mathrm{Z}$ at Presidio, TX (microfilm).

"The storm of June 25-28 produced the maximum flood of record on the middle Rio Grande and lower Pecos Rivers ... The river [Pecos] rose to approximately 70 feet above the stream bed on the night of June 26, at which time the trusses of the bridge were washed away. On the night of June 27, the river again rose to $85 \mathrm{feet}$, at which time the center pies of the bridge was completely washed away. Both of these floods were the direct result of the atmospheric circulation of the dying hurricane "Alice" remaining over the Lower Pecos Watershed for about 3 days" (NCDC/NHC Library).

Genesis originally begun unrealistically as $50 \mathrm{kt}$ tropical storm at $12 \mathrm{Z}$ on the 24 th. Data are quite sparse in the southwestern Gulf of Mexico on the $23^{\text {rd }}$ and early on the $24^{\text {th }}$, making conclusive statement about genesis time and location problematic. A $50 \mathrm{kt}$ E/999 mb ship report at $18 \mathrm{Z}$ suggested that the system was already well-developed by that time. 
$999 \mathrm{mb}$ peripheral pressure suggests maximum winds of at least $49 \mathrm{kt}$ from the Brown et al. south of $25 \mathrm{~N}$ pressure-wind relationship. Intensity selected to be $55 \mathrm{kt}$ at $12 \mathrm{Z}$ on the $24^{\text {th }}$, up from $50 \mathrm{kt}$ originally. Decision was made to backtrack from that point to obtain positions earlier on the $24^{\text {th }}$ and assume a rather rapid intensification rate of $10 \mathrm{kt}$ per six hours to begin the system at $00 \mathrm{Z}$ on the $24^{\text {th }}$ as a tropical depression. Genesis is thus indicated to have begun 12 hours earlier than shown originally. Minor track changes were introduced for the duration of the tropical cyclone. A ship reported $75 \mathrm{kt} \mathrm{N}$ at $0817 \mathrm{Z}$ on the $25^{\text {th }}$. On the $25^{\text {th }}$, aircraft reconnaissance was monitoring the cyclone, but only provided radar-based center fixes and no central pressures and no measurements of the peak wind.

The cyclone made landfall around $14 \mathrm{Z}$ on the $25^{\text {th }}$ near $25.0 \mathrm{~N} 97.6 \mathrm{~W}$, about $50 \mathrm{~nm}$ s of the Texas-Mexico border. No 1-min winds of hurricane force were recorded, with peak observed winds of $56 \mathrm{kt}$ from Mercedes, Texas about 3 hours after landfall. Category 1 hurricane-force winds were estimated south of the center along the Mexican coast. About 15 hours after landfall, a $999 \mathrm{mb}$ pressure (likely a central pressure reading) was recorded at Laredo, Texas. Using the Ho et al. pressure-decay model, this suggests a central pressure of $979 \mathrm{mb}$ at landfall. Using a rounded value of $980 \mathrm{mb}$ gives $80 \mathrm{kt}$ from the south of $25 \mathrm{~N}$ Brown et al. pressure-wind relationship for intensifying cyclones and $78 \mathrm{kt}$ from the north of $25 \mathrm{~N}$ relationship. $80 \mathrm{kt}$ are chosen at the time of landfall and were likely the peak intensity of the hurricane. This also is consistent with the $75 \mathrm{kt}$ ship report early on the $25^{\text {th }} .80 \mathrm{kt}$ at landfall and at $12 \mathrm{Z}$ on the $25^{\text {th }}$ is $10 \mathrm{kt}$ higher than that indicated in HURDAT originally. This system was certainly at least a tropical storm impact for Texas and it is possible that it produced 1-min hurricane force winds inland in Texas. The reanalysis indicates $60 \mathrm{kt}$ peak winds for Texas.

After landfall, the highest winds within 2 hours of synoptic time were $56 \mathrm{kt}$ near $18 \mathrm{Z}$ on the $25^{\text {th }}$, no tropical storm force winds near $00 \mathrm{Z}$ on the $26^{\text {th }}$, and $36 \mathrm{kt}$ near $06 \mathrm{Z}$ on the $26^{\text {th }}$. Runs of the Kaplan-DeMaria inland wind-decay model suggest intensity of $58 \mathrm{kt}$ at $18 \mathrm{Z}$ on the $25^{\text {th }}, 43 \mathrm{kt}$ at $00 \mathrm{Z}$ on the $26^{\text {th }}$, and $32 \mathrm{kt}$ at $06 \mathrm{Z}$. Intensities are selected to be $60 \mathrm{kt}$ at $18 \mathrm{Z}$ (up from $50 \mathrm{kt}$ originally), $45 \mathrm{kt}$ at $00 \mathrm{Z}$ (up from $40 \mathrm{kt}$ originally), and $40 \mathrm{kt}$ at $06 \mathrm{Z}$ (up from $25 \mathrm{kt}$ originally). For the $06 \mathrm{Z}$ slot a $999 \mathrm{mb}$ central pressure is added. This pressure would suggest $45 \mathrm{kt}$ from the north of $25 \mathrm{~N}$ pressure-wind relationship. Assuming 15\% less because of overland exposure, this would be $37 \mathrm{kt}$ - consistent with the increase of intensity at that time. The cyclone originally was dissipated after $18 \mathrm{Z}$ on the $26^{\text {th }}$. However, observations from west Texas indicate that a closed low was still present until $06 \mathrm{Z}$ on the $27^{\text {th }}$. HURDAT modified to keep system until that time with weakening to a depression at $18 \mathrm{Z}$ on the $26^{\text {th }}, 12$ hours later than originally indicated. 
Tropical Storm Barbara [July 27-30, 1954]

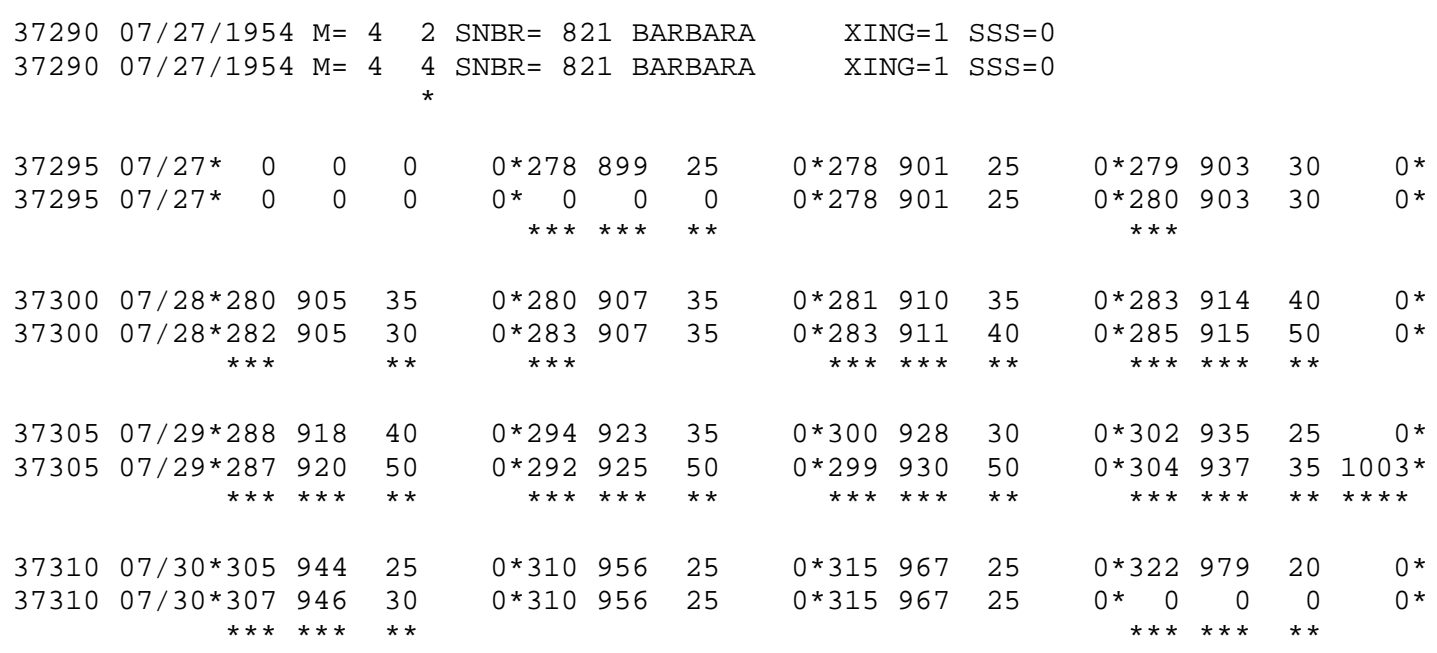

37315 TS

U.S. Tropical Storm Landfall

07/29 10Z 29.7N 92.8W 50 kt LA

Minor changes to the track, but major alterations to the intensity shown in McAdie et al. (2009). Evidence for these alterations comes from the NHC microfilm maps, the Historical Weather Maps series, the COADS ship database, Monthly Weather Review, the Climatological Data, Connor (1956) and the Navy aircraft reconnaissance book.

July 26:

HWM analyzes a low pressure located near 28.3N, 88.7W. HURDAT and MWR do not list this system. Microfilm analyzes a closed low of at most $1011 \mathrm{mb}$ at $29.3 \mathrm{~N}$, $88.2 \mathrm{~W}$ at $12 \mathrm{Z}$. No gales.

July 27:

HWM analyzes a tropical storm located near 27.9N, 90.6W. HURDAT lists this as a $25 \mathrm{kt}$ tropical depression at $27.8 \mathrm{~N}, 90.1 \mathrm{~W}$. MWR shows this system centered near $26.6 \mathrm{~N}, 92.0 \mathrm{~W}$ with a central pressure of $1007 \mathrm{mb}$ at $12 \mathrm{Z}$. Microfilm analyzes a closed low of at most $1008 \mathrm{mb}$ at $27.8 \mathrm{~N}, 89.0 \mathrm{~W}$ at $12 \mathrm{Z}$. No gales.

July 28: 
HWM analyzes a tropical storm of at most $1005 \mathrm{mb}$ located near 28.0N, 92.3W. HURDAT lists this as a $35 \mathrm{kt}$ tropical storm at $28.1 \mathrm{~N}, 91.0 \mathrm{~W}$. MWR shows this system centered near $28.5 \mathrm{~N}, 91.8 \mathrm{~W}$ with a central pressure of $1004 \mathrm{mb}$ at $12 \mathrm{Z}$. Microfilm analyzes a closed low of at most $1005 \mathrm{mb}$ at $28.3 \mathrm{~N}, 92.5 \mathrm{~W}$ at $12 \mathrm{Z}$. Ship highlights: $35 \mathrm{kt}$ ESE and $1012 \mathrm{mb}$ at $12 \mathrm{Z}$, near $28.6 \mathrm{~N}, 89.2 \mathrm{~W} .40 \mathrm{kt} \mathrm{S}$ and $1005 \mathrm{mb}$ at $18 \mathrm{Z}$ near $28.2 \mathrm{~N}$, 91.5W. $50 \mathrm{kt} \mathrm{S}$ and $1006 \mathrm{mb}$ at $18 \mathrm{Z}$ near $28.4 \mathrm{~N}, 90.7 \mathrm{~W} .45 \mathrm{kt} \mathrm{SE}$ and $1009 \mathrm{mb}$ at $18 \mathrm{Z}$ near 29.4N, 89.9W. $45 \mathrm{kt} \mathrm{S}$ and $1004 \mathrm{mb}$ at $21 \mathrm{Z}$ near $28.5 \mathrm{~N}, 91.0 \mathrm{~W} .40 \mathrm{kt} \mathrm{SE}$ and 1005 $\mathrm{mb}$ at $21 \mathrm{Z}$ near $28.2 \mathrm{~N}, 90.7 \mathrm{~W}$. All observations are from microfilm. Aircraft highlights: center fix at $2038 \mathrm{Z}$ at $28.2 \mathrm{~N}, 93.0 \mathrm{~W}$, the measured central pressure was $1006 \mathrm{mb}$ and 30 kt winds. "Elongated very poorly defined center ... radar coverage not feasible as center defined by wind shifts and pressures only" (NAVY).

July 29:

HWM analyzes a tropical storm of at most $1005 \mathrm{mb}$ located near $30.0 \mathrm{~N}, 92.5 \mathrm{~W}$. HURDAT lists this as a $30 \mathrm{kt}$ tropical depression at 30.0N, 92.8W. MWR shows this system centered near $31.0 \mathrm{~N}, 93.0 \mathrm{~W}$ with a central pressure of $1004 \mathrm{mb}$ at $12 \mathrm{Z}$. Microfilm analyzes a closed low of at most $1005 \mathrm{mb}$ at $30.0 \mathrm{~N}, 92.8 \mathrm{~W}$ at $12 \mathrm{Z}$. Ship highlights: $35 \mathrm{kt}$ $\mathrm{SE}$ and $1008 \mathrm{mb}$ at $0 \mathrm{Z}$, near 28.0N, 90.3W (micro). $40 \mathrm{kt} \mathrm{S}$ and $1013 \mathrm{mb}$ at $06 \mathrm{Z}$ near $27.1 \mathrm{~N}, 90.6 \mathrm{~W}$ (COA). $35 \mathrm{kt} \mathrm{SSW}$ and $1008 \mathrm{mb}$ at $12 \mathrm{Z}$ near $28.0 \mathrm{~N}, 92.7 \mathrm{~W}$ (COA). $50 \mathrm{kt}$ SSW and $1008 \mathrm{mb}$ at 12Z near 28.6N, 92.3W (COA). $47 \mathrm{kt}$ at Ship Shoal Lighthouse (CONNOR). Land highlight: Lake Charles recorded a probable central pressure of 1003 $\mathrm{mb}$ at $12 \mathrm{Z}$ (climo). $41 \mathrm{kt} \mathrm{SE}$ and $1003 \mathrm{mb}$ at 10Z at Grand Isle (CONNOR), $1004 \mathrm{mb}$ at $04 \mathrm{Z}$ at Morgan City (CONNOR), $40 \mathrm{kt} \mathrm{SE}$ at Jeanerette at 1230Z (CONNOR), $35 \mathrm{kt} \mathrm{NE}$ at $08 \mathrm{Z}$ at Lake Arthur (CONNOR). All cities in Louisiana.

July 30:

HWM analyzes a closed low of at most $1010 \mathrm{mb}$ located near 31.1N, 96.0W. HURDAT lists this as a $25 \mathrm{kt}$ tropical depression at $31.5 \mathrm{~N}, 96.7 \mathrm{~W}$. MWR shows this system centered near $32.0 \mathrm{~N}, 96.0 \mathrm{~W}$ with a central pressure of $1008 \mathrm{mb}$ at $12 \mathrm{Z}$. Microfilm doesn't analyze a closed low at $12 \mathrm{Z}$. No gales.

"This storm formed in the north Gulf of Mexico off the Louisiana coast on July 28 and moved inland in the Vermilion Bay area early on the morning of the 29th. Highest wind reported was $60 \mathrm{mph}$ by the Henry M. Dawes on the afternoon of the 28th. Some damage to crops, such as rice and corn, was reported from the heavy rains, but the general opinion was that the rains associated with the storm were far more beneficial than damaging" (MWR). 
Genesis is delayed by six hours, as observations at $06 \mathrm{Z}$ on the 27 th indicate that the system did not yet have a closed circulation. Minor track changes were introduced on all four days of this system's existence. Onset of tropical storm intensity was delayed by six hours to $06 \mathrm{Z}$ on the 28th through the evidence of numerous ship observations near the system's center. HURDAT originally had a peak of $40 \mathrm{kt}$ intensity from $18 \mathrm{Z} 28$ th to $00 \mathrm{Z}$ 29 th with landfall in Louisiana after $06 \mathrm{Z}$ as a $35 \mathrm{kt}$ tropical storm. However, a few ship observations as well as some station reports from Louisiana indicate that the system peaked at $50 \mathrm{kt}$ from $18 \mathrm{Z}$ on the 28th until landfall around $10 \mathrm{Z}$ on the 29th. Highest observations from ships were $50 \mathrm{kt} \mathrm{S}$ and $1006 \mathrm{mb}$ at $18 \mathrm{Z}$ on the 28th and $50 \mathrm{kt} \mathrm{SSW}$ and $1008 \mathrm{mb}$ at $12 \mathrm{Z}$ on the 29th (just after landfall). Highest observations from land were 52 kt from Ship Shoal Lighthouse, which after adjusting from $38 \mathrm{~m}$ anemometer height to 10 $\mathrm{m}$ suggest winds of $47 \mathrm{kt}$. After landfall, the cyclone went directly over Lake Charles, which observed a $1003 \mathrm{mb}$ central pressure which occurred between 12 and $18 \mathrm{Z}$ on the 29th. $1003 \mathrm{mb}$ central pressure suggests winds of $38 \mathrm{kt}$ from the Brown et al. north of $25 \mathrm{~N}$ pressure-wind relationship. Assuming reduced $1 \mathrm{~min}$ winds because of the overland exposure (a factor of 0.85 ), this would suggest $32 \mathrm{kt}$. Given that $50 \mathrm{kt}$ was last observed just six hours earlier, intensity is analyzed to be $35 \mathrm{kt}$ at $18 \mathrm{Z}$, up from $30 \mathrm{kt}$ originally. Weakening to a tropical depression is delayed by twelve hours to $00 \mathrm{Z}$ on the 30th. The cyclone dissipated after $12 \mathrm{Z}$ on the 30th, based upon numerous observations over the south Central United States. This dissipation is six hours earlier than that in HURDAT originally.

Hurricane Carol [August 25 - September 1, 1954]

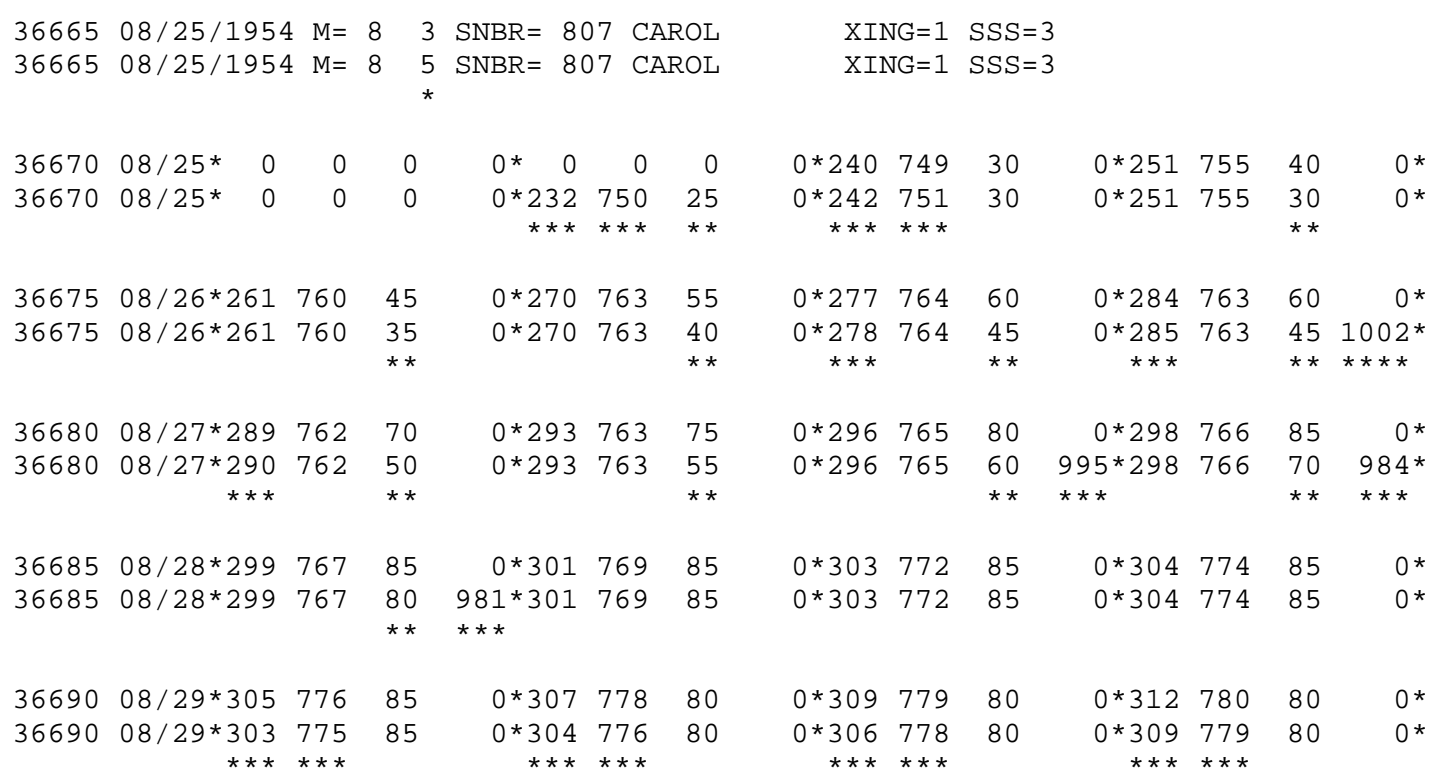




\begin{tabular}{|c|c|c|c|c|c|c|c|c|c|c|c|c|c|}
\hline 36695 & $08 / 30 * 315$ & 781 & 80 & $0 * 319$ & 780 & 85 & $0 * 325$ & 776 & 85 & $0 * 331$ & 770 & 85 & ○* \\
\hline 36695 & $\begin{array}{r}08 / 30 * 312 \\
* * *\end{array}$ & $\begin{array}{l}779 \\
* * *\end{array}$ & 80 & $\begin{array}{r}0 * 316 \\
* * *\end{array}$ & $\begin{array}{l}777 \\
* * *\end{array}$ & 85 & $\begin{array}{r}0 * 321 \\
* \star \star\end{array}$ & $\begin{array}{l}774 \\
\star \star \star\end{array}$ & $\begin{array}{l}90 \\
* *\end{array}$ & $\begin{array}{r}0 * 330 \\
* \star *\end{array}$ & 770 & $\begin{array}{l}95 \\
* *\end{array}$ & ०* \\
\hline 36700 & $08 / 31 * 342$ & 761 & 85 & $0 * 373$ & 742 & 85 & $0 * 402$ & 729 & 85 & OE431 & 718 & 75 & 976 * \\
\hline 36700 & $08 / 31 * 342$ & 761 & $\begin{array}{l}95 \\
\star *\end{array}$ & $\begin{array}{l}960 * 366 \\
\star \star \star \star \star \star *\end{array}$ & $\begin{array}{l}739 \\
* * *\end{array}$ & $\begin{array}{l}100 \\
* * *\end{array}$ & $\begin{array}{r}0 * 393 \\
\star \star \star\end{array}$ & 729 & $\begin{array}{l}100 \\
\star \star \star\end{array}$ & $\begin{array}{l}955 \mathrm{E} 431 \\
\star \star \star\end{array}$ & $\begin{array}{l}714 \\
\star \star *\end{array}$ & 75 & $\begin{array}{l}973^{*} \\
* * *\end{array}$ \\
\hline 36705 & ๑9/01E462 & 711 & 60 & 987E489 & 712 & 50 & $992 *$ & $\odot$ & 0 & ○* & $\odot$ & $\odot$ & ○* \\
\hline 36705 & ๑9/01E462 & 711 & $\begin{array}{l}50 \\
* *\end{array}$ & 987E489 & 712 & $\begin{array}{l}40 \\
\star *\end{array}$ & $992 *$ & $\odot$ & $\odot$ & ०* & $\odot$ & $\odot$ & ○* \\
\hline
\end{tabular}

36710 HR NY3 CT3 RI3 NC2

36710 HR NY3 CT2 RI3 MA2 NC1

Landfall:

8/31 0230Z Closest approach to NC (offshore Cape Hatteras)

$95 \mathrm{kt} / 960 \mathrm{mb}$, RMW $23 \mathrm{~nm}$, NC1 impact

8/31/1430Z 40.9N 72.2W landfall in NY

$100 \mathrm{kt} / 955 \mathrm{mb}$, RMW $22 \mathrm{~nm}, \mathrm{NY3}$ impact

8/31/1515Z 41.3N 72.0W landfall in CT

$100 \mathrm{kt} / 957 \mathrm{mb}$, RMW $22 \mathrm{~nm}, \mathrm{CT} 2$, RI3, MA2 impacts

Minor changes to the track, but major alterations to the intensity shown in Neumann et al. (1999). Evidence for these alterations comes from the Historical Weather Map series, Monthly Weather Review, daily Surface Weather Observations from NCDC, U.S.

Weather Bureau six hourly maps available via microfilm at NHC, aircraft observations available from the Storm Wallets at NHC, the COADS ship database, McGuire (1954), Rhodes (1954), Dunn and Miller (1960), Harris (1963), Schwerdt et al. (1979), Ho et al. (1987), Jarrell et al. (1992), Boose et al. (2001), and Jarvinen (2006).

August 25: HWM does not analyze a closed low on this day. HURDAT listed the storm as a $30 \mathrm{kt}$ tropical depression at $24.0 \mathrm{~N}, 74.9 \mathrm{~W}$. Available observations suggest that the $30 \mathrm{kt}$ tropical depression was centered at 24.2N, 75.1W. Ship highlights: No gales or low pressures present on this day.

August 26: HWM analyzes a closed low of at most $1010 \mathrm{mb}$ centered near $28.0 \mathrm{~N}, 76.6 \mathrm{~W}$. HURDAT listed the storm as a $60 \mathrm{kt}$ tropical storm at $27.7 \mathrm{~N}, 76.4 \mathrm{~W}$. The MWR Tracks of Lows for August 1954 (Chart IX) places the center at 29.9N, 76.8 W with a central pressure of $1011 \mathrm{mb}$. Available observations suggest that the $45 \mathrm{kt}$ tropical storm was centered at $27.8 \mathrm{~N}, 76.4 \mathrm{~W}$. Ship highlights: No gales or low pressures present on this day. The intensity on this day, as recorded by aircraft reconnaissance at 2050 UTC was 1002 $\mathrm{mb}$ at $28.8 \mathrm{~N}, 76.2 \mathrm{~W}$. At 1:30 AM (630 UTC) on the $26 \mathrm{th}$, it was centered near latitude 
$27 \mathrm{~N}$, longitude 76W, or 300 miles east-northeast of Miami (Climatological Data National Summary August 1954).

August 27: HWM analyzes a closed low of at most $1005 \mathrm{mb}$ centered near 29.9N, 76.4W. HURDAT listed the storm as an 85 kt category 2 hurricane centered at $29.6 \mathrm{~N}, 76.5 \mathrm{~W}$. The MWR Tracks of Lows for August 1954 (Chart IX) places the center at 29.9N, 76.8W with a central pressure of $995 \mathrm{mb}$. Available observations suggest that the $65 \mathrm{kt}$ category 1 hurricane was centered at $29.6 \mathrm{~N}, 76.5 \mathrm{~W}$. Ship highlights: $35 \mathrm{kt}$ NNE at $12 \mathrm{UTC}$ at $30.1 \mathrm{~N}, 76.9 \mathrm{~W}$ (COA ship \# 9332). Aircraft reconnaissance recorded center fixes at 1400 UTC at 29.8N, 76.4W with $995 \mathrm{mb}$, at $2013 \mathrm{UTC}$ at 29.9N, 76.6W with $984 \mathrm{mb}$, and at $2130 \mathrm{UTC}$ at $29.9 \mathrm{~N}, 76.5 \mathrm{~W}$ with $981 \mathrm{mb}$.

August 28: HWM analyzes a closed low of at most $995 \mathrm{mb}$ centered near $30.6 \mathrm{~N}, 77.0 \mathrm{~W}$. HURDAT listed the storm as an $85 \mathrm{kt}$ category 2 hurricane centered at $30.3 \mathrm{~N}, 77.2 \mathrm{~W}$. The MWR Track of Lows for August 1954 (Chart IX) places the center at 31.0N, $76.9 \mathrm{~W}$ with a central pressure of $975 \mathrm{mb}$. Available observations suggest that the $85 \mathrm{kt}$ category 1 hurricane was centered at $30.3 \mathrm{~N}, 77.2 \mathrm{~W}$. Ship observations: $35 \mathrm{kt} \mathrm{NE}$ at $18 \mathrm{UTC}$ at 32.2N, 791.W (COA ship \# 7622).

August 29: HWM analyzes a closed low of at most $995 \mathrm{mb}$ centered near $31.0 \mathrm{~N}, 78.2 \mathrm{~W}$. HURDAT listed the storm as an $80 \mathrm{kt}$ category 1 hurricane centered at $30.9 \mathrm{~N}, 77.9 \mathrm{~W}$. The MWR Tracks of Lows for August 1954 (Chart IX) places the center at 31.1N, 77.5W with a central pressure of $995 \mathrm{mb}$. Available observations suggest the $80 \mathrm{kt}$ category 1 hurricane was centered at 30.6N, 77.8W. Ship observations: $1005 \mathrm{mb}$ and $40 \mathrm{kt} \mathrm{NE}$ at 12 UTC at 32.0N, 78.5W (HWM); $1005 \mathrm{mb}$ and $45 \mathrm{NE}$ at12 UTC at kt 31.8, 78.3W (COA 8152). At 1:30 AM (0630 UTC) of the 29th (the storm) had traveled less than 300 miles to a central location near latitude $30 \mathrm{~N}$, longitude $77 \mathrm{~W}$, some 200 miles off the extreme northeastern coast of Florida. On the 29th, still moving sluggishly, Carol changed direction to northwestward. This change, at first, posing a threat to the South Carolina shore, developed within twenty-four hours into a return to a northerly heading.

August 30: HWM analyzes a closed low of at most $985 \mathrm{mb}$ centered near $32.0 \mathrm{~N}, 77.1 \mathrm{~W}$. HURDAT listed the storm as an $85 \mathrm{kt}$ category 2 hurricane centered at $32.5 \mathrm{~N}, 77.6 \mathrm{~W}$. The MWR Tracks of Lows for August 1954 (Chart IX) places the center at 32.4N, 77.3W with a central pressure of $966 \mathrm{mb}$. Available observations suggest the $90 \mathrm{kt}$ category 2 hurricane was centered at $32.1 \mathrm{~N}, 77.4 \mathrm{~W}$. Ship observations: $65 \mathrm{kt} \mathrm{NNW}$ at $12 \mathrm{UTC}$ at $32.2 \mathrm{~N}, 72.0 \mathrm{~W} ; 986 \mathrm{mb}$ and $65 \mathrm{kt} \mathrm{N}$ at $18 \mathrm{UTC}$ at $33.5 \mathrm{n}, 77.3 \mathrm{~W} ; 991 \mathrm{mb}$ and $65 \mathrm{kt} \mathrm{NNE}$ at 0 UTC at $31.5 \mathrm{~N}, 78.5 \mathrm{~W}$. Land observations: $991 \mathrm{mb}$ and $61 \mathrm{kt} \mathrm{E}$ at $1130 \mathrm{UTC}$ at $33.8 \mathrm{~N}$, 78.0W (SWO Frying Pan Lightship, NC); $983 \mathrm{mb}$ and $70 \mathrm{kt} \mathrm{W}$ at $1730 \mathrm{UTC}$ at $33.8 \mathrm{~N}$, 78.0W (SWO Frying Pan Lightship, NC); $990 \mathrm{mb}$ at $2330 \mathrm{UTC}$ at 35.2N, 75.0W (SWO Diamond Shoals Lightship, NC). At 5 AM (10 UTC), the hurricane was centered near 
latitude $32 \mathrm{~N}$, longitude $78 \mathrm{~W}$, or about 150 miles east-southeast of Charleston, SC; it was moving at about $5 \mathrm{mph}$ toward the north. By noon (17 UTC), heading slightly east of north at the same slow speed, the center had reached latitude $33 \mathrm{~N}$, longitude $73 \mathrm{~W}$, or about 100 miles south-southeast of Wilmington, NC. Carol now grew into a large storm, was entered upon the second or mature stage of its career. An official bulletin issued at 1 PM (18 UTC) on the 30th stated that it was still moving very slowly north-northwestward but increasing in intensity. Winds near the center were reported to be over $100 \mathrm{mph}$, while winds of hurricane force extended over 100 miles to the east of the center and 5060 miles to the west. Gales ranged further outwards, 200 miles to the east and about half that distance to the west. Elizabeth City, NC: lowest pressure reading was 29.25 inches at 2325E (0425 UTC). Norfolk Airport, VA: The tide reached a height of 5.6 feet above mean low water at midnight and began falling. The time of normal high tide would have been at 10:34 PM but due to strong NE winds the tide kept building until midnight. The tower reported observing gusts to $60 \mathrm{mph}$ at 8:55 PM but the highest observed on the W.B. dial was $54 \mathrm{mph}$ about 9:15 PM.

August 31: HWM analyzes a closed low of at most $975 \mathrm{mb}$ centered near $40.0 \mathrm{~N}, 72.5 \mathrm{~W}$. HURDAT listed the storm as an $85 \mathrm{kt}$ category 2 hurricane centered at $40.2 \mathrm{~N}, 72.9 \mathrm{~W}$. The MWR Tracks of Lows for August 1954 places the center of the storm at $40.2 \mathrm{~N}$, $72.8 \mathrm{~W}$ with a central pressure of $960 \mathrm{mb}$. Available observations suggest the $100 \mathrm{kt}$ category 3 hurricane was centered at $39.3 \mathrm{~N}, 73.0 \mathrm{~W}$. Ship observations: $975 \mathrm{mb}$ at 9 UTC at $37.5 \mathrm{~N}, 74.0 \mathrm{~W} ; 976 \mathrm{mb}$ and $65 \mathrm{kt} \mathrm{NNE}$ at $12 \mathrm{UTC}$ at $38.4 \mathrm{~N}, 74.2 \mathrm{~W}$ (COA ship \# 77811); $984 \mathrm{mb}$ and $55 \mathrm{kt} \mathrm{N}$ at $12 \mathrm{UTC}$ at 39.8N, 73.9W (COA ship \# 1791). Land observations: $957 \mathrm{mb}$ and calm at $15 \mathrm{UTC}$ at $41.3 \mathrm{~N}, 72.1 \mathrm{~W}$ (Jarvinen - Croton, CT); 960 $\mathrm{mb}$ at $40.8 \mathrm{~N}, 72.6 \mathrm{~W}$ at $14 \mathrm{UTC}$ at $40.8 \mathrm{~N}, 72.6 \mathrm{~W}$ (SWO Suffolk County Air Force Base); $87 \mathrm{kt}$ at $1505 \mathrm{UTC}$ at $41.2 \mathrm{~N}, 71.6 \mathrm{~W}$ (SWO Block Island, RI). $78 \mathrm{kt} \mathrm{ESE}$ at $1530 \mathrm{UTC}$ at $41.8 \mathrm{~N}, 71.4 \mathrm{~W}$ (SWO Providence, RI); $972 \mathrm{mb}$ at $0223 \mathrm{UTC}$ and $68 \mathrm{kt} \mathrm{N}$ at $35.3 \mathrm{~N}, 75.6 \mathrm{~W}$ (SWO Hatteras, NC). The intensity on this day, as recorded by aircraft reconnaissance at 1337 UTC was $964 \mathrm{mb}$ at $40.2 \mathrm{~N}, 72.6 \mathrm{~W}$. The western side of Carol lashed the shore from Wilmington northward to Cape Hatteras (NC). Damage amounted to an estimated $\$ 227,500$. Strong winds tore down power and telephone lines, and the Trent and Neuse Rivers, their levels raised by the high water accompanying the storm, flooded the waterfront section of New Bern (NC). A peak gust of $78 \mathrm{mph}$ was observed at the Hatteras station of the Weather Bureau. Late on the 30th (31 in UTC time), the hurricanes center passed a few miles east of Cape Hatteras. At 11 PM (4 UTC on 31st) Carol was centered near latitude $36 \mathrm{~N}$, longitude $75 \mathrm{~W}$, or about 100 miles south-southeast of Norfolk, VA. Its size and the strength of its winds remained about the same, but a rapid and sharp increase occurred in the rate of forward motion as it passed northnortheastward along the Middle Atlantic coast during the early morning of the 31 st. The forward speed accelerated to $40 \mathrm{mph}$, brought the center over extreme eastern Long 
Island by 9 AM (14 UTC). The effects of the hurricanes passage from the Virginia shore area to Long Island were comparatively slight. The track of the center was 75-100 miles east of the mainland, so that dangerous winds did not reach westward to the coast...The amount of damage in New Jersey was estimated at $\$ 250,000$. No monetary estimates of damage in Virginia, Maryland and Delaware were received but it is known to have been minor. The impact of the storm on Long Island and New England was far more serious. The center crossed the south shore of Long Island slightly east of West Hampton about 8:30 AM (1330 UTC). An hour later it passed into Long Island Sound off Cutchogue. By 10:30 AM (1530 UTC) it was over the southeast shore of Connecticut near the mouth of the Connecticut River. Curving slightly on a northward course, the center passed 5-10 miles west of Worcester, MA, about noon (17 UTC) and penetrated into south-central New Hampshire about 1:30 PM (1830 UTC). In mid-afternoon, Carol passed into the third and final stage of its history. The strength of its winds and its speed of forward progress diminished as the center traveled northward over the rugged terrain of New Hampshire. Norfolk Airport, VA: Hurricane Carol passed 110 miles east of Norfolk at 2 AM (7 UTC) at a heading of 35o. Portland, ME: Hurricane Carol caused one death in Portland, one at Port Clyde and at Columbia Falls. Many hundreds of trees fell. Eye of storm passed west of Portland, moving from Concord, NH to near Bethel, Maine. These were highest winds ever recorded in August. East Boston, MA: Hurricane Carol moved north-northeastward from the Cape Hatteras area, entering southern New England on the morning of the 31st and thence sweeping northward into the St. Lawrence Valley early on Sept 1st. The course of the center of the storm extended across Rhode Island, eastern Massachusetts, and northward along the Maine-New Hampshire border; areas traversed suffered damage comparable to the Sept. 1938 Hurricane, but loss of life was much less. South Weymouth, MA: Lowest pressure observed as Hurricane Carol passed station was 28.677 inches at $1050 \mathrm{AM}$ (1550 UTC), and maximum gust of 81 knots at $1028 \mathrm{AM}$ (1528 UTC). Concord, NH: Winds extremely gusty, resulted in considerable local damage. Some trees and wires, as well as TV antennas blown down. Damage around Concord while important was not near so bad as in some other southern and central NH communities. The local rainfall was one of the heaviest on record. Driving on the roads was very hazardous due to the combined strong winds and reduced visibility from the extremely heavy rainfall.

Genesis of Carol is begun six hours earlier than in HURDAT originally from observations of a closed low at 06 UTC on the 25th. Only small alterations were introduced into the track of Carol on all days except for the 28th and 1st when no changes were made. Aircraft reconnaissance center fix observations were available for Carol for much of its lifetime. However, as is typical for hurricanes of the 1950s, most of these were from radar fixes rather than an aircraft penetration of the cyclone. Thus while there are several dozen radar fixes, there only are six central pressure measurements. For the 
few actual penetrations, winds provided were visually estimated and not reliable (e.g., $125 \mathrm{kt}$ winds for a central pressure of $984 \mathrm{mb}$ ). At $2050 \mathrm{UTC}$ on the 26th, aircraft measured a central pressure of $1002 \mathrm{mb}$ and a circular eye of $20 \mathrm{~nm}$ diameter. $1002 \mathrm{mb}$ pressure suggests maximum winds of $40 \mathrm{kt}$ from the north of $25 \mathrm{~N}$ Brown et al. pressurewind relationship. Given the small size of the reported eye, maximum winds are boosted to $45 \mathrm{kt}$ in HURDAT, which is a reduction from the $60 \mathrm{kt}$ originally at $18 \mathrm{UTC}$. Three reconnaissance central pressures were reported on the 27th: $995 \mathrm{mb}$ with an $8 \mathrm{~nm}$ eye at 1400 UTC, $984 \mathrm{mb}$ with a $13 \mathrm{~nm}$ eye at $2013 \mathrm{UTC}$, and $981 \mathrm{mb}$ at $2130 \mathrm{UTC}$. The last observation suggests winds of $71 \mathrm{kt}$ from the subtropical pressure-wind relationship. Given the small size, $80 \mathrm{kt}$ at 0000 UTC on the 28th (down from $85 \mathrm{kt}$ originally) was analyzed as the intensity. Carol likely became a hurricane around 18 UTC on the 27th, which is about 18 hours later than originally analyzed. No observations were available to determine the inner core intensity of Carol for all of the 28th and 29th and no changes were made to the HURDAT winds. Hurricane force winds and peripheral pressures as low as $983 \mathrm{mb}$ were reported by ships, the Frying Pan Lightship, and Diamond Shoals Lightship on the 30th as Carol approached the Carolinas. An aircraft reconnaissance did measure a $960 \mathrm{mb}$ central pressure late on the 30th southeast of North Carolina. This pressure suggests maximum winds of $95 \mathrm{kt}$ from the Brown et al. north of $25 \mathrm{~N}$ and $90 \mathrm{kt}$ from the Landsea et al. north of $35 \mathrm{~N}$ pressure-wind relationships, respectively. Ho et al. estimated a $23 \mathrm{~nm}$ RMW, which is slightly smaller $(27 \mathrm{~nm})$ than climatology for this latitude and central pressure. Thus $95 \mathrm{kt}$ is chosen for HURDAT at $18 \mathrm{UTC}$ on the 30th and $00 \mathrm{UTC}$ on the $31 \mathrm{st}$. This is an increase from the $85 \mathrm{kt}$ originally indicated in HURDAT. Carol made its closest approach to North Carolina between 02 and 03 UTC on the $31 \mathrm{st}$, as a pressure of $972 \mathrm{mb}$ was observed in Cape Hatteras with $38 \mathrm{kt}$ NNE winds at $0230 \mathrm{UTC}$ followed by a $978 \mathrm{mb}$ and $58 \mathrm{kt} \mathrm{WNW}$ wind at $0326 \mathrm{UTC}$. (A lower pressure value may have occurred at Cape Hatteras between these observations.) Thus it appears that the center of the eye stayed just offshore of North Carolina, but it is estimated that Category 1 conditions impacted a portion of the extreme eastern North Carolina coast (which is a downgrade from the Category 2 impact originally recorded). Carol accelerated north-northeastward after making a close by-pass of North Carolina and made landfall in New England about 12 hours later. A final aircraft reconnaissance mission reported a central pressure of $964 \mathrm{mb}$ at 1337 UTC on the 31st just south of Long Island, New York.

Carol made a first landfall in Long Island around 1430 UTC on the $31^{\text {st }}$ and a second landfall in Connecticut around 1515 UTC on the 31 st. Ho et al. estimated a central pressure at landfall in New York of $961 \mathrm{mb}$. Jarrell et al. indicated a minimum central pressure at landfall in the United States as $960 \mathrm{mb}$, though it is ambiguous as to whether this was for North Carolina or New York. Jarvinen analyzed Carol as making an initial landfall with $955 \mathrm{mb}$ central pressure in New York and $957 \mathrm{mb}$ central pressure in 
Connecticut, based upon an eye reading of $957 \mathrm{mb}$ at Groton, Connecticut on the coast. This value is somewhat lower than the aircraft reconnaissance measurement, but given the uncertainties of the aircraft observational technologies at the time, their $964 \mathrm{mb}$ value could have been biased high. Both Ho et al. and Jarvinen agree that Carol had about a 22 $\mathrm{nm}$ RMW at landfall in New England. $955 \mathrm{mb}$ and $957 \mathrm{mb}$ give $93 \mathrm{kt}$ and $92 \mathrm{kt}$ from the north of $35 \mathrm{~N}$ pressure-wind relationship, respectively. Carol's RMW of $22 \mathrm{~nm}$ is slightly smaller than climatology for this pressure and latitude (26 nm - Vickery et al. 2000) and the hurricane was moving at about $40 \mathrm{kt}$ at landfall. Both of these factors indicated a stronger wind at landfall than suggested by the pressure-wind relationship. Both at landfall in New York and in Connecticut the maximum sustained surface winds are estimated to be $100 \mathrm{kt}$. This is in agreement with Schwerdt et al., but is lower than the $113 \mathrm{kt}$ and $110 \mathrm{kt}$ values from the SLOSH runs at the New York and Connecticut coasts, respectively, provided by Jarvinen. (However, it is to be noted that the SLOSH runs do not take into account the cold water and stable conditions that occur around New England, which would reduce the SLOSH winds.) Based upon the landfall location and the RMW, the $100 \mathrm{kt}$ maximum winds likely only occurred along easternmost New York and the Rhode Island coast, retaining New York and Rhode Island as Category 3 impacts. Both Connecticut and Massachusetts likely received a peak of Category 2 sustained winds, which is a downgrade from Category 3 originally for Connecticut but an upgrade (from no hurricane impact) for Massachusetts. Peak observed 1 minute winds were $87 \mathrm{kt}$ at Block Island, R.I., but as usual the RMW intersected the coast at an area lacking in wind observations.

After landfall, the highest observed winds within two hours of the synoptic times were: at 18 UTC - $78 \mathrm{kt}$ (Block Island at 1600 UTC), at 00 UTC on the 1st - 44 kt (Pollock Rip Lightship at 2345 UTC). Application of the Kaplan and DeMaria (2001) New England inland wind decay model suggests winds of $65 \mathrm{kt}$ at $18 \mathrm{UTC}$ and $43 \mathrm{kt}$ at $00 \mathrm{UTC}$. Winds in HURDAT are retained at $75 \mathrm{kt}$ at $18 \mathrm{UTC}$ and lowered from 60 down to $50 \mathrm{kt}$ at 00 UTC. Carol's transition to an extratropical storm at $18 \mathrm{UTC}$ on the 31 st is unaltered.

\section{Hurricane Dolly [August 30 - September 4, 1954]}

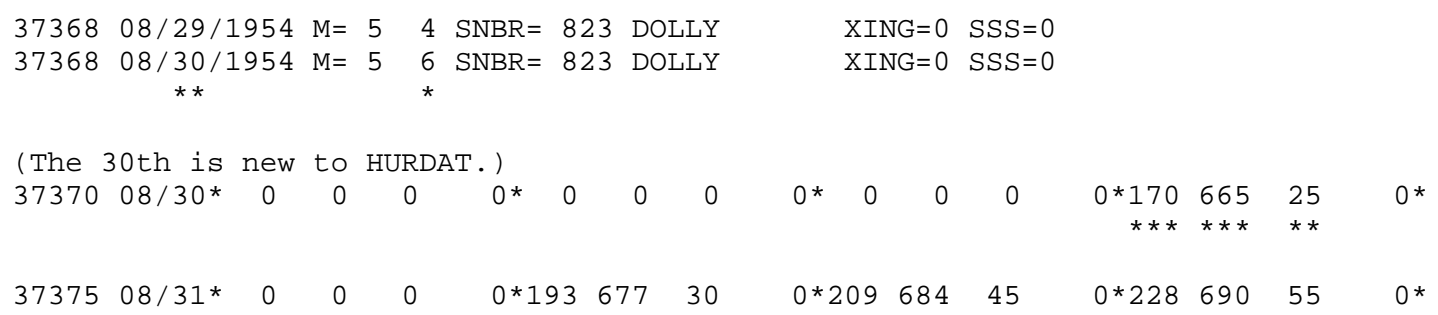




\begin{tabular}{|c|c|c|c|c|c|c|c|c|c|c|c|c|c|}
\hline 37375 & $\begin{array}{r}08 / 31 * 178 \\
* * *\end{array}$ & $\begin{array}{l}669 \\
* * *\end{array}$ & $\begin{array}{l}25 \\
* *\end{array}$ & $\begin{array}{l}0 * 19 \odot \\
* * *\end{array}$ & 677 & 30 & $\begin{array}{r}0 * 205 \\
* * *\end{array}$ & $\begin{array}{l}686 \\
* * *\end{array}$ & $\begin{array}{l}35 \\
* *\end{array}$ & $\begin{array}{r}0 * 223 \\
* * *\end{array}$ & $\begin{array}{l}694 \\
* * *\end{array}$ & $\begin{array}{l}35 \\
* *\end{array}$ & ${ }_{* \star * *}^{1011^{*}}$ \\
\hline $\begin{array}{l}37380 \\
37380\end{array}$ & $\begin{array}{r}09 / 01 * 248 \\
09 / 01 * 246 \\
\star \star *\end{array}$ & $\begin{array}{l}695 \\
698 \\
\star * *\end{array}$ & $\begin{array}{l}65 \\
45 \\
\star *\end{array}$ & $\begin{array}{l}\Theta^{*} 268 \\
\Theta^{*} 266 \\
* \star \star\end{array}$ & $\begin{array}{l}699 \\
699\end{array}$ & $\begin{array}{l}75 \\
55 \\
* *\end{array}$ & $\begin{array}{r}\Theta^{*} 290 \\
\Theta^{*} 288 \\
* \star *\end{array}$ & $\begin{array}{l}702 \\
700 \\
\star * *\end{array}$ & $\begin{array}{l}85 \\
65 \\
\star *\end{array}$ & $\begin{array}{l}0^{*} 317 \\
0^{*} 317\end{array}$ & $\begin{array}{l}701 \\
701\end{array}$ & $\begin{array}{l}85 \\
70 \\
* *\end{array}$ & $\begin{array}{l}\Theta^{*} \\
\Theta^{*}\end{array}$ \\
\hline $\begin{array}{l}37385 \\
37385\end{array}$ & $\begin{array}{l}09 / 02 * 346 \\
09 / 02 * 346\end{array}$ & $\begin{array}{l}693 \\
693\end{array}$ & $\begin{array}{l}75 \\
65 \\
\star *\end{array}$ & $\begin{array}{r}\odot * 372 \\
994 * 370 \\
* * * * * *\end{array}$ & $\begin{array}{l}669 \\
673 \\
* * *\end{array}$ & $\begin{array}{l}70 \\
60 \\
* *\end{array}$ & $\begin{array}{l}\odot * 397 \\
\odot * 397\end{array}$ & $\begin{array}{l}642 \\
638 \\
\star * *\end{array}$ & $\begin{array}{l}7 \odot \\
6 \odot \\
* *\end{array}$ & $\begin{array}{r}\text { OE421 } \\
\text { OE416 } \\
* * *\end{array}$ & $\begin{array}{l}605 \\
615 \\
* * *\end{array}$ & $\begin{array}{l}70 \\
6 \odot \\
* *\end{array}$ & $\begin{array}{l}\Theta^{*} \\
\Theta^{*}\end{array}$ \\
\hline $\begin{array}{l}37390 \\
37390\end{array}$ & $\begin{array}{l}09 / 03 E 443 \\
09 / 03 E 443\end{array}$ & $\begin{array}{l}564 \\
564\end{array}$ & $\begin{array}{l}65 \\
60 \\
* *\end{array}$ & $\begin{array}{l}\text { OE458 } \\
\text { OE458 }\end{array}$ & $\begin{array}{l}519 \\
519\end{array}$ & $\begin{array}{l}55 \\
55\end{array}$ & $\begin{array}{l}\text { OE468 } \\
\text { OE468 }\end{array}$ & $\begin{array}{l}474 \\
474\end{array}$ & $\begin{array}{l}50 \\
50\end{array}$ & $\begin{array}{l}\text { OE476 } \\
\text { OE476 }\end{array}$ & $\begin{array}{l}429 \\
429\end{array}$ & $\begin{array}{l}45 \\
45\end{array}$ & $\begin{array}{l}\odot^{*} \\
\odot^{*}\end{array}$ \\
\hline $\begin{array}{l}37395 \\
37395\end{array}$ & $\begin{array}{l}\text { ๑9/०4E483 } \\
09 / 04 \mathrm{E} 483\end{array}$ & $\begin{array}{l}383 \\
383\end{array}$ & $\begin{array}{l}40 \\
45 \\
\star *\end{array}$ & $\begin{array}{r}\text { OE49๑ } \\
\text { OE485 } \\
\star \star \star\end{array}$ & $\begin{array}{l}335 \\
335\end{array}$ & $\begin{array}{l}40 \\
45 \\
\star *\end{array}$ & $\begin{array}{r}\text { OE497 } \\
\text { OE485 } \\
* \star *\end{array}$ & $\begin{array}{l}288 \\
285 \\
\star \star \star\end{array}$ & $\begin{array}{l}35 \\
45 \\
\star *\end{array}$ & $\begin{array}{l}\Theta^{*} \quad \odot \\
0 E 485 \\
* * * *\end{array}$ & $\begin{array}{r}0 \\
235 \\
* * *\end{array}$ & $\begin{array}{r}\odot \\
4 \odot \\
* *\end{array}$ & $\begin{array}{l}\Theta^{*} \\
\Theta^{*}\end{array}$ \\
\hline
\end{tabular}

Minor changes to the track, but major alterations to the intensity shown in McAdie et al. (2009). Evidence for these alterations comes from the NHC microfilm maps, the Historical Weather Maps series, the COADS ship database, the Navy aircraft reconnaissance book, and Monthly Weather Review.

August 28:

HWM analyzes a possible tropical wave or disturbance located near longitude $53 \mathrm{~W}$. HURDAT does not list this system and it is located outside the area of coverage of Microfilm and MWR.

August 29:

HWM analyzes a tropical wave located near longitude $60 \mathrm{~W}$, over the Lesser Antilles. HURDAT does not list this system. It is located outside the area of coverage of MWR.

August 30:

HWM analyzes a tropical storm of at most $1010 \mathrm{mb}$ located near $16.8 \mathrm{~N}, 64.2 \mathrm{~W}$. HURDAT and MWR do not list this system. Microfilm analyzes a closed low of at most $1008 \mathrm{mb}$ at $19.4 \mathrm{~N}, 64.0 \mathrm{~W}$ at $12 \mathrm{Z}$. Ship highlights: $15 \mathrm{SE}$ and $1008 \mathrm{mb}$ at $18 \mathrm{Z}$ near $17.0 \mathrm{~N}$ and 64.8W. $20 \mathrm{kt} \mathrm{SW}$ and $1009 \mathrm{mb}$ at $18 \mathrm{Z}$ near $14.2 \mathrm{~N}, 66.1 \mathrm{~W}$. All observations from COADS. Aircraft highlights: "Large diffuse low pressure center on axis centered near Saint Croix with lowest observed pressure $1008 \mathrm{mb}$, no definite weather patterns on radar. Entire area of flight enclosed by $1010 \mathrm{mb}$ isobar with weak cyclonic circulation, strongest winds observed 30 knots northeast of Virgin Islands." (NAVY) 
August 31:

HWM analyzes a tropical storm of at most $1010 \mathrm{mb}$ located near $20.8 \mathrm{~N}, 68.8 \mathrm{~W}$. HURDAT lists this as a $45 \mathrm{kt}$ tropical storm at $20.9 \mathrm{~N}, 68.4 \mathrm{~W}$ at $12 \mathrm{Z}$. MWR shows this system centered near $21.5 \mathrm{~N}, 67.0 \mathrm{~W}$ with a central pressure of $1008 \mathrm{mb}$ at $12 \mathrm{Z}$. Microfilm analyzes a closed low of at most $1011 \mathrm{mb}$ at $21.0 \mathrm{~N}, 68.9 \mathrm{~W}$ at $12 \mathrm{Z}$. Ship highlights: $35 \mathrm{kt}$ $\mathrm{E}$ and $1011 \mathrm{mb}$ at $12 \mathrm{Z}$, near 22.4N, 67.8W (COADS). $30 \mathrm{kt} \mathrm{ESE}$ and $1019 \mathrm{mb}$ at $12 \mathrm{Z}$ near $22.5 \mathrm{~N}, 61.4 \mathrm{~W}$ (COADS). $35 \mathrm{kt} \mathrm{W}$ and $1015 \mathrm{mb}$ at $12 \mathrm{Z}$ near $18.9 \mathrm{~N}, 67.5 \mathrm{~W}$ (micro). $30 \mathrm{kt} \mathrm{SSE}$ and $1013 \mathrm{mb}$ at $18 \mathrm{Z}$ near 21.1N, 67.2W (COADS). $30 \mathrm{kt} \mathrm{SE}$ and $1012 \mathrm{mb}$ at $18 \mathrm{Z}$ near $22.1 \mathrm{~N}, 67.2 \mathrm{~W}$ (COADS). $30 \mathrm{kt} \mathrm{SSE}$ and $1013 \mathrm{mb}$ at $18 \mathrm{Z}$ near $20.6 \mathrm{~N}, 66.9 \mathrm{~W}$ (COADS). Aircraft highlights: center fix at $2108 \mathrm{Z}$ at $22.9 \mathrm{~N}, 70.0 \mathrm{~W}$, the measured central pressure was $1011 \mathrm{mb}$ and peak flight level winds of $30 \mathrm{kt}$ winds. (NAVY)

September 1:

HWM analyzes a hurricane of at most $1005 \mathrm{mb}$ located near 29.0N, 69.9W. HURDAT lists this as a $85 \mathrm{kt}$ hurricane at $29.0 \mathrm{~N}, 70.2 \mathrm{~W}$ at $12 \mathrm{Z}$. MWR doesn't show this system. MWR shows this system centered near $28.9 \mathrm{~N}, 69.2 \mathrm{~W}$ with a central pressure of $998 \mathrm{mb}$ at $12 \mathrm{Z}$. Microfilm analyzes a closed low of at most $1005 \mathrm{mb}$ at $28.5 \mathrm{~N}, 70.0 \mathrm{~W}$ at 12Z. Ship highlights: $35 \mathrm{kt} \mathrm{SSE}$ and $1012 \mathrm{mb}$ at 03Z, near 25.4N, 60.5W (micro). $50 \mathrm{kt}$ $\mathrm{SE}$ and $1001 \mathrm{mb}$ at $03 \mathrm{Z}$, near $25.8 \mathrm{~N}, 68.8 \mathrm{~W}$ (micro). $40 \mathrm{kt} \mathrm{E}$ and $1015 \mathrm{mb}$ at $08 \mathrm{Z}$ near $30.0 \mathrm{~N}, 69.0 \mathrm{~W}$ (micro). $40 \mathrm{kt} \mathrm{SSE}$ at $08 \mathrm{Z}$ near $25.0 \mathrm{~N}, 66.3 \mathrm{~W}$ (micro). $50 \mathrm{kt} \mathrm{SSE}$ and 1011 $\mathrm{mb}$ at $08 \mathrm{Z}$ near $24.8 \mathrm{~N}, 66.5 \mathrm{~W}$ (micro). $35 \mathrm{kt} \mathrm{S}$ and $1021 \mathrm{mb}$ at $09 \mathrm{Z}$ near $24.8 \mathrm{~N}, 68.7 \mathrm{~W}$ (micro). $40 \mathrm{kt} \mathrm{SSE}$ and $1016 \mathrm{mb}$ at $12 \mathrm{Z}$ near $27.8 \mathrm{~N}, 68.0 \mathrm{~W}$ (micro). $50 \mathrm{kt} \mathrm{SSE}$ and 1019 $\mathrm{mb}$ at $12 \mathrm{Z}$ near $29.2 \mathrm{~N}, 68.7 \mathrm{~W}$ (micro). $40 \mathrm{kt} \mathrm{ENE}$ and $1009 \mathrm{mb}$ at $12 \mathrm{Z}$ near $29.2 \mathrm{~N}$, 70.0W (micro). $45 \mathrm{kt} \mathrm{N}$ and $1000 \mathrm{mb}$ at $13 \mathrm{Z}$ near $29.5 \mathrm{~N}, 70.0 \mathrm{~W}$ (micro). $40 \mathrm{kt} \mathrm{SE}$ and $1016 \mathrm{mb}$ at $14 \mathrm{Z}$ near $30.4 \mathrm{~N}, 67.3 \mathrm{~W}$ (micro). $35 \mathrm{kt} \mathrm{SE}$ and $1017 \mathrm{mb}$ at $14 \mathrm{Z}$ near $30.0 \mathrm{~N}$, 67.0W (COADS). $40 \mathrm{kt} \mathrm{SE}$ and $1016 \mathrm{mb}$ at $15 \mathrm{Z}$ near $30.5 \mathrm{~N}, 67.9 \mathrm{~W}$ (micro). $50 \mathrm{kt} \mathrm{ESE}$ and $996 \mathrm{mb}$ at $15 \mathrm{Z}$ near $30.7 \mathrm{~N}, 69.6 \mathrm{~W}$ (micro). $60 \mathrm{kt} \mathrm{S}$ and $1022 \mathrm{mb}$ at $15 \mathrm{Z}$ near $29.4 \mathrm{~N}$, 68.8W (micro). $35 \mathrm{kt} \mathrm{SSE}$ and $1018 \mathrm{mb}$ at $18 \mathrm{Z}$ near 30.0N, 66.0W (COADS). $50 \mathrm{kt} \mathrm{S}$ and $1022 \mathrm{mb}$ at $18 \mathrm{Z}$ near $29.4 \mathrm{~N}, 68.8 \mathrm{~W}$ (micro). $50 \mathrm{kt} \mathrm{SE}$ and $1016 \mathrm{mb}$ at $18 \mathrm{Z}$ near $30.5 \mathrm{~N}$, 68.0W (micro). $45 \mathrm{kt} \mathrm{SE}$ and $1017 \mathrm{mb}$ at $18 \mathrm{Z}$ near $30.6 \mathrm{~N}, 67.0 \mathrm{~W}$ (micro). $40 \mathrm{kt} \mathrm{SE}$ and $1016 \mathrm{mb}$ at $18 \mathrm{Z}$ near $33.0 \mathrm{~N}, 68.2 \mathrm{~W}$ (micro). $40 \mathrm{kt} \mathrm{S}$ and $1018 \mathrm{mb}$ at $21 \mathrm{Z}$ near $30.3 \mathrm{~N}$, $67.8 \mathrm{~W}$ (micro). $35 \mathrm{kt} \mathrm{S}$ and $1023 \mathrm{mb}$ at $21 \mathrm{Z}$ near $29.2 \mathrm{~N}, 69.8 \mathrm{~W}$ (micro). "Strongest winds estimated by aircraft were around $100-115 \mathrm{mph}$ on the afternoon of the $1 \mathrm{st}$. This hurricane remained at sea and no damage was reported" (MWR). Aircraft highlights: center fix at $2103 \mathrm{Z}$ at $33.0 \mathrm{~N}, 69.5 \mathrm{~W}$, the measured central pressure was $994 \mathrm{mb}$ and estimated surface winds of $100 \mathrm{kt}$ winds. "The storm is poorly defined for visual recognition but radar returns show a well-defined eye. The area is completely covered with stratus layers with breaks in the low layer in the eye, however, radar shows strongest 
quadrants to be the northwest, northeast, and east with weaker returns to southeast and southwest. There is no calm area in the center with minimum winds in the eye estimated to 35 to 40 knots. Visual reconnaissance around the parameter of the wall indicates winds to 100 knots in the southwest and southeast and 80 knots in the northwest quadrant." (AF)

September 2:

HWM analyzes a closed low of at most $1005 \mathrm{mb}$ located near 40.0N, 64.0W. HURDAT lists this as a $70 \mathrm{kt}$ hurricane at $39.7 \mathrm{~N}, 64.2 \mathrm{~W}$ at $12 \mathrm{Z}$. MWR shows this system centered near $39.2 \mathrm{~N}, 64.4 \mathrm{~W}$ with a central pressure of $996 \mathrm{mb}$ at 12Z. Microfilm analyzes a closed low of at most $1002 \mathrm{mb}$ at $39.7 \mathrm{~N}, 63.8 \mathrm{~W}$ at $12 \mathrm{Z}$. Ship highlights: $30 \mathrm{kt}$ $\mathrm{SE}$ and $1020 \mathrm{mb}$ at $00 \mathrm{Z}$ near $30.0 \mathrm{~N}, 67.7 \mathrm{~W}$ (micro). $30 \mathrm{kt} \mathrm{NE}$ and $1014 \mathrm{mb}$ at $06 \mathrm{Z}$ near $36.6 \mathrm{~N}, 72.0 \mathrm{~W}$ (COADS). $30 \mathrm{kt} \mathrm{SW}$ and $1015 \mathrm{mb}$ at $06 \mathrm{Z}$ near 34.3N, 66.7W (COADS). $30 \mathrm{kt} \mathrm{NE}$ and $1003 \mathrm{mb}$ at $18 \mathrm{Z}$ near $42.2 \mathrm{~N}, 61.2 \mathrm{~W}$ (COADS). $30 \mathrm{kt} \mathrm{SSE}$ and $1017 \mathrm{mb}$ at $18 \mathrm{Z}$ near $40.1 \mathrm{~N}, 59.7 \mathrm{~W}$ (COADS). $50 \mathrm{kt} \mathrm{S}$ and $1016 \mathrm{mb}$ at $18 \mathrm{Z}$ near $38.6 \mathrm{~N}, 61.2 \mathrm{~W}$ (COADS). $40 \mathrm{kt} \mathrm{SW}$ and $1015 \mathrm{mb}$ at $18 \mathrm{Z}$ near $38.6 \mathrm{~N}, 61.2 \mathrm{~W}$ (COADS). $35 \mathrm{kt} \mathrm{S}$ and $1016 \mathrm{mb}$ at $18 \mathrm{Z}$ near $39.5 \mathrm{~N}, 59.4 \mathrm{~W}$ (COADS). Aircraft highlight: center fix at $0530 \mathrm{Z}$ at $36.9 \mathrm{~N}, 67.5 \mathrm{~W}, 50 \mathrm{kt}$ winds surface winds. (NAVY)

September 3:

HWM analyzes a closed low of at most $1005 \mathrm{mb}$ located near 47.0N, 48.8W. HURDAT lists this as a $50 \mathrm{kt}$ extratropical storm at $46.8 \mathrm{~N}, 47.4 \mathrm{~W}$ at $12 \mathrm{Z}$. MWR shows this system centered near $47.0 \mathrm{~N}, 47.2 \mathrm{~W}$ with a central pressure of $1000 \mathrm{mb}$ at $12 \mathrm{Z}$. Microfilm analyzes a closed low of at most $1014 \mathrm{mb}$ at $46.5 \mathrm{~N}, 51.7 \mathrm{~W}$ at $12 \mathrm{Z}$. Ship highlights: $30 \mathrm{kt}$ SW and $1022 \mathrm{mb}$ at $0 \mathrm{Z}$ near $44.0 \mathrm{~N}, 41.0 \mathrm{~W} .30 \mathrm{kt} \mathrm{SW}$ and 1021 at $03 \mathrm{Z}$ near $44.0 \mathrm{~N}$, $41.0 \mathrm{~W} .30 \mathrm{kt} \mathrm{SW}$ and $1018 \mathrm{mb}$ at $06 \mathrm{Z}$ near $41.0 \mathrm{~N}, 54.4 \mathrm{~W} .30 \mathrm{kt} \mathrm{SW}$ and $2021 \mathrm{mb}$ at $06 \mathrm{Z}$ near $44.0 \mathrm{~N}, 41.0 \mathrm{~W} .30 \mathrm{kt} \mathrm{SW}$ and $1021 \mathrm{mb}$ at $09 \mathrm{Z}$ near $44.0 \mathrm{~N}, 41.0 \mathrm{~W} .30 \mathrm{kt} \mathrm{SW}$ and $1022 \mathrm{mb}$ at $12 \mathrm{Z}$ near $44.0 \mathrm{~N}, 41.0 \mathrm{~W}$. $30 \mathrm{kt} \mathrm{SSW}$ and $1016 \mathrm{mb}$ at $16 \mathrm{Z}$ near $45.0 \mathrm{~N}, 45.0 \mathrm{~W}$. $30 \mathrm{kt} \mathrm{SW}$ and $1020 \mathrm{mb}$ at $18 \mathrm{Z}$ near $44.0 \mathrm{~N}, 41.0 \mathrm{~W} .45 \mathrm{kt} \mathrm{SW}$ and $1017 \mathrm{mb}$ at $20 \mathrm{Z}$ near $44.0 \mathrm{~N}, 44.0 \mathrm{~W} .30 \mathrm{kt} \mathrm{SW}$ and $1019 \mathrm{mb}$ at $21 \mathrm{Z}$ near $44.0 \mathrm{~N}, 41.0 \mathrm{~W}$. All observations come from COADS.

September 4:

HWM analyzes a closed low of at most $1000 \mathrm{mb}$ located near 48.0N, 29.0W. HURDAT lists this as a $35 \mathrm{kt}$ extratropical storm at $49.7 \mathrm{~N}, 28.8 \mathrm{~W}$ at $12 \mathrm{Z}$. MWR shows this system centered near $50.2 \mathrm{~N}, 29.5 \mathrm{~W}$ with a central pressure of $995 \mathrm{mb}$ at 12Z. Ship highlights: 35 $\mathrm{kt} \mathrm{SW}$ and $1011 \mathrm{mb}$ at $06 \mathrm{Z}$ near $44.8 \mathrm{~N}, 34.2 \mathrm{~W}$. $25 \mathrm{kt} \mathrm{SSW}$ and $1003 \mathrm{mb}$ at $06 \mathrm{Z}$ near $48.8 \mathrm{~N}, 31.6 \mathrm{~W} .35 \mathrm{kt} \mathrm{NW}$ and $1015 \mathrm{mb}$ at $12 \mathrm{Z}$ near $44.9 \mathrm{~N}, 35.1 \mathrm{~W} .45 \mathrm{kt} \mathrm{NW}$ and 1008 $\mathrm{mb}$ at $12 \mathrm{Z}$ near $46.5 \mathrm{~N}, 32.6 \mathrm{~W} .30 \mathrm{kt} \mathrm{N}$ and $1016 \mathrm{mb}$ at $12 \mathrm{Z}$ near $48.2 \mathrm{~N}, 32.8 \mathrm{~W} .30 \mathrm{kt} \mathrm{N}$ 
and $1004 \mathrm{mb}$ at $12 \mathrm{Z}$ near $48.5 \mathrm{~N}, 31.5 \mathrm{~W} .15 \mathrm{kt} \mathrm{SE}$ and $1000 \mathrm{mb}$ at $12 \mathrm{Z}$ near $48.7 \mathrm{~N}$, $27.3 \mathrm{~W} .35 \mathrm{kt} \mathrm{NW}$ and $1011 \mathrm{mb}$ at $12 \mathrm{Z}$ near $52.8 \mathrm{~N}, 35.5 \mathrm{~W} .35 \mathrm{kt} \mathrm{NNW}$ and $1001 \mathrm{mb}$ at $18 \mathrm{Z}$ near $45.5 \mathrm{~N}, 28.2 \mathrm{~W} .40 \mathrm{kt} \mathrm{NNW}$ and $1013 \mathrm{mb}$ at $18 \mathrm{Z}$ near $46.8 \mathrm{~N}, 31.0 \mathrm{~W} .40 \mathrm{kt} \mathrm{NW}$ and $1002 \mathrm{mb}$ at $18 \mathrm{Z}$ near 46.5N, 27.3W. All observations come from COADS.

Genesis for Dolly is begun as a tropical depression twelve hours earlier than shown in HURDAT originally, due to ship and coastal station observations late on the 30th that showed a circulation center had developed south of Puerto Rico. Two aircraft reconnaissance missions were flown on that date: one early in the day in the eastern Caribbean (before formation of the tropical cyclone) and one late in the day north of Puerto Rico, which thus did not sample near the center of the system. The revised track has only minor modifications for the lifetime of this system, except for no changes on the 3rd. The upgrade to tropical storm remains at $12 \mathrm{Z}$ on the $31 \mathrm{st}$, due to $35 \mathrm{kt}$ ship observations at that time. An aircraft reconnaissance mission at $2108 \mathrm{Z}$ on the $31 \mathrm{st}$ obtained a central pressure of $1011 \mathrm{mb}$. This along with peak ship observations as earlier are the reason for a $35 \mathrm{kt}$ intensity at $18 \mathrm{Z}$ on the $31 \mathrm{st}$, which is a large reduction from the $55 \mathrm{kt}$ in HURDAT originally. From that point, the cyclone began rapidly intensifying. A ship measured $1001 \mathrm{mb}$ peripheral pressure along with simultaneous $50 \mathrm{kt} \mathrm{SE}$ winds at $03 \mathrm{Z}$ on the 1 st. This pressure suggests winds of at least $45 \mathrm{kt}$ from the south of $25 \mathrm{~N}$ Brown et al. pressure-wind relationship and $42 \mathrm{kt}$ from the north of $25 \mathrm{~N}$ pressure-wind relationship. Also at $08 \mathrm{Z}$ on this day a separate ship had $50 \mathrm{kt} \mathrm{SSE}$. The intensity is analyzed to be $45 \mathrm{kt}$ at $00 \mathrm{Z}$ and $55 \mathrm{kt}$ at $06 \mathrm{Z}$, a major change from $65 \mathrm{kt}$ and $75 \mathrm{kt}$, respectively. Later on the 1st, a ship measured $50 \mathrm{kt} \mathrm{ESE} \mathrm{with} 996 \mathrm{mb}$ and a separate ship observed $60 \mathrm{kt} \mathrm{S}$ both at 15Z. $996 \mathrm{mb}$ suggests winds of at least $50 \mathrm{kt}$ from the north of $25 \mathrm{~N}$ pressure-wind relationship. An aircraft reconnaissance measured a central pressure of $994 \mathrm{mb}$ at $2103 \mathrm{Z}$ on the 1st along with an eye diameter of $25 \mathrm{~nm}$, but also visually estimated surface winds of $100 \mathrm{kt}$. These extremely high winds are very unlikely to be accurate and are discounted. $994 \mathrm{mb}$ central pressure suggests maximum winds of $53 \mathrm{kt}$, though given its small RMW ( 15-20 nm versus climatology of $26 \mathrm{~nm}$ for its latitude and central pressure) and its fast forward speed, intensities of $65 \mathrm{kt}$ and $70 \mathrm{kt}$ are selected at 12 and 18Z, respectively. These are large reductions from $85 \mathrm{kt}$ in HURDAT originally for these two times. After late on the 1st, it appears that Dolly started weakening as it began extratropical transition. Aircraft reconnaissance into Dolly on the 2nd did not report a central pressure, but did provide an $850 \mathrm{mb}$ minimum height value of 4700 ' at $0530 \mathrm{Z}$ which corresponds to a reasonable range of central pressures between 995 and $1005 \mathrm{mb}$. These possible pressures suggest maximum winds between 40 and 56 $\mathrm{kt}$ from the Landsea et al. north of $35 \mathrm{~N}$ pressure-wind relationship. Again, some boost over these values is reasonable given the quite rapid forward speed, thus $60 \mathrm{kt}$ is selected at $06 \mathrm{Z}$ on the $2 \mathrm{nd}$ (down from $70 \mathrm{kt}$ originally). Thus the duration that Dolly spent as a hurricane was only about 18 hours, compared with 42 hours originally. Transition to 
extratropical is kept at $18 \mathrm{Z}$ on the $2 \mathrm{nd}$ as it was passing south of Canada. Gradually weakening of the system continued for the next couple of days until absorption of the system by a large extratropical low. Dissipation is delayed by six hours after that shown in HURDAT due to existence of a closed circulation through $18 \mathrm{Z}$ on the 4 th.

\section{Hurricane Edna [September 5-14, 1954]}

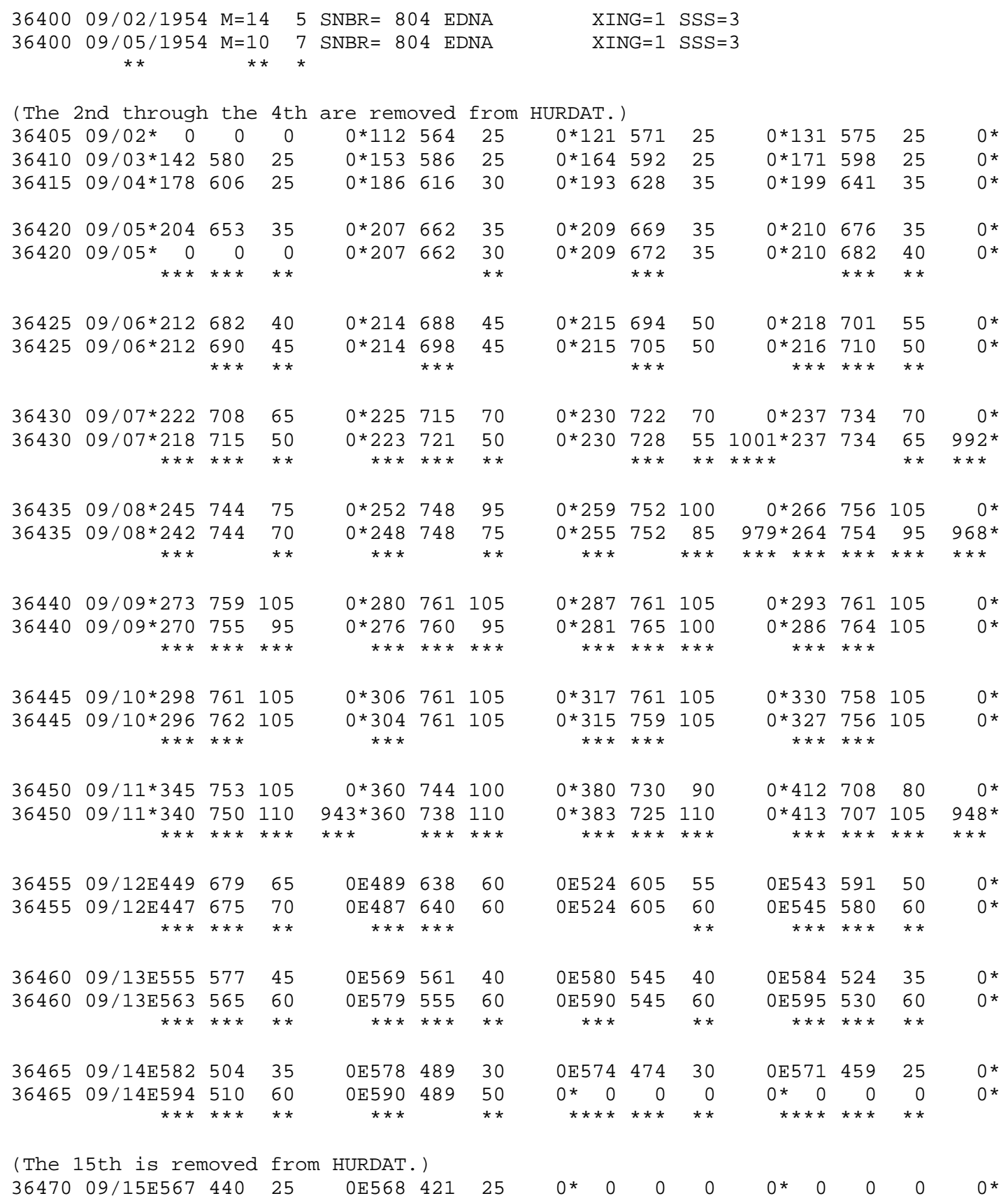


36475 HR MA3 ME1

36475 HR NC1 MA3 NY1 RI1

Landfalls:

$11 \mathrm{th} / 03 \mathrm{Z}-35.0 \mathrm{~N} 74.5 \mathrm{~W}$ (closest point of approach) $-943 \mathrm{mb} / 110 \mathrm{kt}$ -

$15 \mathrm{~nm}$ RMW - $65 \mathrm{kt}$ at NC coast

$11 \mathrm{th} / 18 \mathrm{Z}-41.3 \mathrm{~N} 70.7 \mathrm{~W}-948 \mathrm{mb} / 105 \mathrm{kt}-20 \mathrm{~nm} \mathrm{RMW}$

$11 \mathrm{th} / 19 \mathrm{Z}-41.6 \mathrm{~N} 70.5 \mathrm{~W}-950 \mathrm{mb} / 100 \mathrm{kt}-20 \mathrm{~nm}$ RMW

$11 \mathrm{th} / 2330 \mathrm{Z}-44.6 \mathrm{~N} 67.7 \mathrm{~W}$ - Already extratropical - Winds at landfall $75 \mathrm{kt}$

Major changes to both the track and the intensity shown in McAdie et al. (2009). The system previously identified as Edna has been reanalyzed to instead be two separate tropical cyclones: a previously unrecognized tropical depression from September 1st to the $3 \mathrm{rd}$ and the main cyclone which instead formed on the 5th and became the hurricane that struck the United States. Evidence for these alterations comes from the Historical Weather Map series, Monthly Weather Review, daily Surface Weather Observations from NCDC, U.S. Weather Bureau six hourly maps available via microfilm at NHC, aircraft observations available from the Storm Wallets at NHC, the COADS ship database, Rhodes (1954), Dunn and Miller (1960), Schwerdt et al. (1979), Ho et al. (1987), Jarrell et al. (1992), and Boose et al. (2001).

September 1: HWM does not analyze a closed low in association with the system at 12 UTC on this day. Available observations indicate the formation of a $25 \mathrm{kt}$ tropical depression (not pre-Edna) with a center located at $11.2 \mathrm{~N}, 54.0 \mathrm{~W}$ at $18 \mathrm{UTC}$ on this day. HURDAT does not list a tropical depression in this area. Ship observations: no gales or low pressures reported on this day.

September 2: HWM does not analyze a closed low on this day. However, it does show a tropical wave along $51 \mathrm{~W}$ from 15 to $25 \mathrm{~N}$. HURDAT listed a tropical depression with 25 kt winds with a center at $12.1 \mathrm{~N}, 57.1 \mathrm{~W}$. Available observations suggest the tropical depression maintained its $25 \mathrm{kt}$ wind speed as analyzed at on September 1 and is now located at $11.2 \mathrm{~N}, 56.4 \mathrm{~W}$. Ship observations: no gales or low pressures reported on this day.

September 3: HWM analyzes a closed low associated with the new tropical depression with a pressure of at most $1010 \mathrm{mb}$ and a center at $10.0 \mathrm{~N}, 62.5 \mathrm{~W}$. HWM also shows a tropical wave along $57 \mathrm{~W}$ from $17 \mathrm{~N}$ to $27 \mathrm{~N}$. HURDAT listed a $25 \mathrm{kt}$ tropical depression with a center at $16.4 \mathrm{~N}, 59.2 \mathrm{~W}$.

Available observations indicate a single $25 \mathrm{kt}$ tropical depression (not pre-Edna) with a center at $11.2 \mathrm{~N}, 62.5 \mathrm{~W}$. No closed circulation is in the vicinity of the supposed 
HURDAT pre-Edna depression location. Ship observations: no gales or low pressures reported on this day.

September 4: HWM analyzes a weak low near $13.5 \mathrm{~N}, 68 \mathrm{~W}$. HWM also shows a tropical wave along $65 \mathrm{~W}$ from $17 \mathrm{~N}$ to $26 \mathrm{~W}$. HURDAT listed a $35 \mathrm{kt}$ tropical storm (Edna) with a center at $19.3 \mathrm{~N}, 62.8 \mathrm{~W}$. Available observations suggest the system tracked in HURDAT is not a closed low, but is an open wave. It is also analyzed that the (new) tropical depression dissipated around $06-12$ UTC on the 4th in the vicinity of $11 \mathrm{~N}, 65 \mathrm{~W}$. Ship observations: no gales or low pressures reported on this day.

September 5: HWM analyzes a closed low of at most $1010 \mathrm{mb}$ at 13.5N, 72W and a tropical wave along $68 \mathrm{~W}$ from $15 \mathrm{~N}$ to $26 \mathrm{~W}$ including a show a tropical storm symbol with a center at $19.2 \mathrm{~N}, 68.5 \mathrm{~W}$. HURDAT listed this as a $35 \mathrm{kt}$ tropical storm with a center at $20.9 \mathrm{~N}, 66.9 \mathrm{~W}$. Available observations do suggest development of a $35 \mathrm{kt}$ tropical storm with a center at $20.9 \mathrm{~N}, 67.2 \mathrm{~W}$ at $12 \mathrm{UTC}$ on this day. Ship observations: $45 \mathrm{kt}$ at $2100 \mathrm{UTC}$ at $22.5 \mathrm{~N}, 67.7 \mathrm{~W}$ (MWR). September 1954 MWR:

"The first indication of an apparently closed circulation that subsequently became Edna was noted the night of September 5, in the extreme southwestern Atlantic between Puerto Rico and the Bahama Islands. Some forewarning of the possible formation of a tropical storm was given by a 2100 GMT, September 5 ship report from a position near $22.5 \mathrm{~N}$, $67.7 \mathrm{~W}$. This report from the Bulk Oil stated that she was encountering very heavy squalls, winds to $50 \mathrm{mph}$, with gusts to $70 \mathrm{mph}$, and rapidly falling barometer (MWR)"

September 6: HWM analyzes a closed low and a tropical storm of at most $1000 \mathrm{mb}$ with a center at $21.8 \mathrm{~N}, 69.5 \mathrm{~W}$. HURDAT listed this as a $50 \mathrm{kt}$ tropical storm centered at $21.5 \mathrm{~N}, 69.4 \mathrm{~W}$. The MWR Tracks of Centers of Cyclones (Chart X) places the center at $21.3 \mathrm{~N}, 68.3 \mathrm{~W}$ at $0 \mathrm{UTC}$ on this day. The MWR Tracks of Centers of Cyclones (Chart X) places the center at $21.3 \mathrm{~N}, 69.1 \mathrm{~W}$ with a central pressure of $1006 \mathrm{mb}$ at $12 \mathrm{UTC}$ on this day. Figure 1 from the September 1954 issue of the Monthly Weather Review also places the center of the circulation at $22.0 \mathrm{~N}, 69.3 \mathrm{~W}$ at $12 \mathrm{UTC}$ on this day. Available observations suggest a $50 \mathrm{kt}$ tropical storm is present on this day with a center at $21.5 \mathrm{~N}$, $70.5 \mathrm{~W}$ at $12 \mathrm{UTC}$ on this day. Ship observations: $45 \mathrm{kt} \mathrm{S}$ at $18 \mathrm{UTC}$ at $22.0 \mathrm{~N}, 69.3 \mathrm{~W}$ (COA ship \# 77942); a few other gales of 35 and 40 kt reported throughout the day; no low pressures reported on this day. "Hurricane Edna formed in an easterly wave on the afternoon of September 6 near 22N, 70W, and increased to hurricane intensity during the night (MWR)"

September 7: HWM analyzes a closed low of at most $1005 \mathrm{mb}$ centered near 23.3N, $72.3 \mathrm{~W}$. HURDAT listed this as a $70 \mathrm{kt}$ category 1 hurricane at $23.0 \mathrm{~N}, 72.2 \mathrm{~W}$. The MWR Tracks of Centers of Cyclones places the center at $22.0 \mathrm{~N}, 70.7 \mathrm{~W}$ at 0 UTC on this 
day. The MWR Tracks of Centers of Cyclones (Chart X) places the center at 22.5N, $72.6 \mathrm{~W}$ with a central pressure of $1002 \mathrm{mb}$ at $12 \mathrm{UTC}$ on this day. Figure 1 from the September 1954 issue of the Monthly Weather Review places a center of circulation at $23.5 \mathrm{~N}, 72.8 \mathrm{~W}$ at $12 \mathrm{UTC}$ on this day. Available observations suggest a $55 \mathrm{kt}$ tropical storm is present on this day with a center located at $23.0 \mathrm{~N}, 70.5 \mathrm{~W}$ at $12 \mathrm{UTC}$ on this day. Aircraft Reconnaissance: $23.2 \mathrm{~N}, 73.3 \mathrm{~W}$ at 1443 UTC with $1001 \mathrm{mb}$ central pressure and 85 kt estimated winds; $23.8 \mathrm{~N}, 73.8 \mathrm{~W}$ at $2000 \mathrm{UTC}$ with $992 \mathrm{mb}$ central pressure and 100 kt estimate winds; $23.8 \mathrm{~N}, 73.8 \mathrm{~W}$ at $2030 \mathrm{UTC}$ with $990 \mathrm{mb}$ central pressure and $100 \mathrm{kt}$ estimated winds (NHC). Ship observations: $1002 \mathrm{mb}$ and $65 \mathrm{kt} \mathrm{NE}$ at $18 \mathrm{UTC}$ at 24.2N, 74.2W (COA ship \# 00473); $45 \mathrm{kt} \mathrm{ESE} \mathrm{at} 0$ UTC at 22.9N, 68.9W (COA ship \# 03981); $1004 \mathrm{mb}$ at $12 \mathrm{UTC}$ at $20.1 \mathrm{~N}, 75.2 \mathrm{~W}$ (HWM); a few other gales of 35 and $40 \mathrm{kt}$ reported throughout the day. December 1954 MWR: "During the 7th and 8th it swept the outer Bahama Islands as it moved on a broad curving path northward. The center very close to San Salvador Island, Bahamas, late on the 7th where winds were up to hurricane force in gusts, but no appreciable wind damage resulted."

September 8: HWM analyzes a closed low of at most $1000 \mathrm{mb}$ centered near $25.5 \mathrm{~N}$, $75.5 \mathrm{~W}$. HURDAT listed this as a $100 \mathrm{kt}$ category 3 hurricanes at $25.9 \mathrm{~N}, 75.2 \mathrm{~W}$. The MWR Tracks of Centers of Cyclones (Chart X) places the center at $24.0 \mathrm{~N}, 74.0 \mathrm{~W}$ at 0 UTC on this day. The MWR Tracks of Centers of Cyclones (Chart X) places the center at $25.3 \mathrm{~N}, 75.1 \mathrm{~W}$ with a central pressure of $991 \mathrm{mb}$ at $12 \mathrm{UTC}$ on this day. Figure 1 from the September 1954 issue of the Monthly Weather Review places a center of circulation at $25.7 \mathrm{~N}, 75.3 \mathrm{~W}$ at $12 \mathrm{UTC}$ on this day. Available observations suggest an $85 \mathrm{kt}$ category 2 hurricane centered at $23.3 \mathrm{~N}, 75.2 \mathrm{~W}$ at $12 \mathrm{UTC}$ on this day. Aircraft Reconnaissance: Several radar fixes early on the 8th. $25.9 \mathrm{~N}, 75.4 \mathrm{~W}$ at $1413 \mathrm{UTC}$ with $979 \mathrm{mb}$ central pressure and $70 \mathrm{kt}$ estimated wind; $26.4 \mathrm{~N}, 75.4 \mathrm{~W}$ at $1934 \mathrm{UTC}$ with 968 $\mathrm{mb}$ central pressure and $75 \mathrm{kt}$ estimated wind (NHC). Ship observations: $975 \mathrm{mb} \mathrm{mb}$ and $120 \mathrm{kt}$ at $16 \mathrm{UTC}$ at $26.5 \mathrm{~N} 75.5 \mathrm{~W}$ (Rhodes); $997 \mathrm{mb}$ and $70 \mathrm{kt} \mathrm{NE}$ at $12 \mathrm{UTC}$ at $26.2 \mathrm{~N}$, $76.0 \mathrm{~W} ; 992 \mathrm{mb}$ and $65 \mathrm{kt}$ at $18 \mathrm{UTC}$ at $25.9 \mathrm{~N}, 75.7 \mathrm{~W}$ (COADS); a few other gales of 35 and $40 \mathrm{kt}$ reported throughout the day.

September 9: HWM analyzes a closed low of at most $995 \mathrm{mb}$ centered near $28.7 \mathrm{~N}$, $76.2 \mathrm{~W}$. HURDAT listed this as a $105 \mathrm{kt}$ category 3 hurricane at $28.7 \mathrm{~N}, 76.1 \mathrm{~W}$. The MWR Tracks of Centers of Cyclones (Chart X) places the center at $26.9 \mathrm{~N}, 75.7 \mathrm{~W}$ at 0 UTC on this day. The MWR Tracks of Centers of Cyclones (Chart X) places the center at $28.2 \mathrm{~N}, 76.5 \mathrm{~W}$ with a central pressure of $978 \mathrm{mb}$ at $12 \mathrm{UTC}$ on this day. Figure 1 from the September 1954 issue of the Monthly Weather Review places a center of circulation at $28.8 \mathrm{~N}, 76.9 \mathrm{~W}$ at $12 \mathrm{UTC}$ on this day. Available observations suggest a $100 \mathrm{kt}$ Category 3 hurricane with a center at $28.5 \mathrm{~N}, 76.8 \mathrm{~W}$ at $12 \mathrm{UTC}$ on this day. Ship observations: $50 \mathrm{kt} \mathrm{N}$ at $18 \mathrm{UTC}$ at $28.3 \mathrm{~N}, 79.8 \mathrm{~W}$ (COA ship \# 57111); a few gales of 35 
kt reported throughout the day. Land observations: $999 \mathrm{mb}$ at $2330 \mathrm{UTC}$ at $36.1 \mathrm{~N}$, 76.6W (SWO Edenton, NC). December 1954 MWR: "During the 9th and 10th the storm moved northward very near the 76th meridian and gradually turned to the north-northeast closely paralleling Carols path 11 days earlier. It passed just east of Cape Hatteras early in the night of the 10th and winds of about $75 \mathrm{mph}$ were felt on the North Carolina Capes from Cape Lookout to Manteo."

September 10: HWM analyzes a closed low of at most $990 \mathrm{mb}$ centered near $31.1 \mathrm{~N}$, $75.8 \mathrm{~W}$. HURDAT listed this as a $105 \mathrm{kt}$ category 3 hurricane at $31.7 \mathrm{~N}, 76.1 \mathrm{~W}$. The MWR Tracks of Centers of Cyclones (Chart X) places the center at $29.5 \mathrm{~N}, 76.1 \mathrm{~W}$ at 0 UTC on this day. The MWR Tracks of Centers of Cyclones (Chart X) places the center at $31.2 \mathrm{~N}, 75.9 \mathrm{~W}$ with a central pressure of $980 \mathrm{mb}$ at $12 \mathrm{UTC}$ on this day. Figure 1 from the September 1954 issue of the Monthly Weather Review places a center of circulation at $31.3 \mathrm{~N}, 76.0 \mathrm{~W}$ at $12 \mathrm{UTC}$ on this day. Available observations suggest a $105 \mathrm{kt}$ Category 3 hurricane with a center at $31.5 \mathrm{~N}, 75.9 \mathrm{~W}$ at $12 \mathrm{UTC}$ on this day. Ship observations: $60 \mathrm{kt} \mathrm{SSE}$ at 6 UTC at 28.2N, 72.7W (COA ship \# 63001); $992 \mathrm{mb}$ and 65 kt SE at $18 \mathrm{UTC}$ at $33.0 \mathrm{~N}, 73.5 \mathrm{~W}$ (COA ship \# 62061); a few other gales of 35 and $40 \mathrm{kt}$ reported throughout the day. Land observations: $991 \mathrm{mb}$ at $2224 \mathrm{UTC}$ at $35.3 \mathrm{~N}, 75.6 \mathrm{~W}$ (SWO Hatteras, NC); $987 \mathrm{mb}$ at 2230 UTC at 34.3N, 77.9W (SWO - Wilmington, NC). September 1954 Climatological Data National Summary (coastal North Carolina area): Storm center offshore; damage minor, but widespread. TV aerials, roofs, and piers damaged along most of coastline. Section of Outer Banks Highway washed out. Corn crop damaged 2 or 3 percent over large area.

September 11: HWM analyzes a closed low of at most $970 \mathrm{mb}$ centered near $38.5 \mathrm{~N}$, $72.5 \mathrm{~W}$. HURDAT listed this as a $90 \mathrm{kt}$ category 2 hurricane at $38.0 \mathrm{~N}, 73.0 \mathrm{~W}$. The MWR Tracks of Centers of Cyclones (Chart X) places the center at 34.0N, 75.0W at 0 UTC on this day. The MWR Tracks of Centers of Cyclones (Chart X) places the center at $38.1 \mathrm{~N}, 72.1 \mathrm{~W}$ with a central pressure of $978 \mathrm{mb}$ at $12 \mathrm{UTC}$ on this day. Figure 1 from the September 1954 issue of the Monthly Weather Review places a center of circulation at $38.5 \mathrm{~N}, 72.3 \mathrm{~W}$ at $12 \mathrm{UTC}$ on this day. Available observations suggest a $110 \mathrm{kt}$ Category 3 hurricane with a center at $38.3 \mathrm{~N}, 72.5 \mathrm{~W}$ at $12 \mathrm{UTC}$ on this day. Aircraft reconnaissance: $943 \mathrm{mb}$ at $34.0 \mathrm{~N}, 75.6 \mathrm{~W}$ around $00 \mathrm{UTC} ; 947 \mathrm{mb}$ at $39.7 \mathrm{~N}, 71.3 \mathrm{~W}$ around 15 UTC (Ho). Ship observations: $80 \mathrm{kt} \mathrm{NW}$ at 0 UTC at 30.4N, 76.5W (COA ship \# 08342); $90 \mathrm{kt} \mathrm{NNW}$ at $6 \mathrm{UTC}$ at $36.5 \mathrm{~N}, 75.3 \mathrm{~W}$ (COA ship \# 1775); $982 \mathrm{mb}$ and $70 \mathrm{kt}$ $\mathrm{S}$ at $0 \mathrm{UTC}$ at $32.3 \mathrm{~N}, 74.5 \mathrm{~W}$ (COA ship \# 62061); $979 \mathrm{mb}$ and $52 \mathrm{kt} \mathrm{SE}$ at $12 \mathrm{UTC}$ at $38.5 \mathrm{~N}, 71.1 \mathrm{~W}$ (HWM). Land observations: $65 \mathrm{kt}$ at Manteo, NC (Rhodes); $65 \mathrm{kt}$ at Cape Lookout, NC (Rhodes); $983 \mathrm{mb}$ at 0324 UTC and $49 \mathrm{kt} \mathrm{NW}$ at $0335 \mathrm{UTC}$ at $35.3 \mathrm{~N}$, 75.6W (SWO Hatteras, NC); 83 kt at Brookhaven National Laboratory, Long Island, NY (MWR); $76 \mathrm{kt}$ at $1930 \mathrm{UTC}$ and $969 \mathrm{mb}$ at $18 \mathrm{UTC}$ at Block Island, RI (SWO); $954 \mathrm{mb}$ 
and $52 \mathrm{kt} \mathrm{SSE}$ at 1826 UTC at 41.3N, 70.1W (SWO Nantucket). December 1954 MWR: "It moved rapidly northeastward and passed over Cape Cod on the 11th." September 1954 Climatological Data National Summary (New Jersey shore and adjacent areas): "Some damage extending from Cape May County in South to Raritan Bay In north. Losses mostly minor, but totaling considerable sum. Estimate of damage includes estimated amount of damage by flooding of $\$ 15,000$ in Newark and Elizabeth suburbs from heavy rains. Gale winds and heavy rains (some were 5 inches) a hurricane moved northeasterly, approximately 125 miles off New Jersey shore. Deaths due to traffic accidents, in which storm believed to have been contributing factor." September 1954 Climatological Data National Summary (New England southeaster and coastal sections): "Hurricane struck New England a glancing blow. Its center crossed Martha's Vineyard and Cape Cod shortly after 1 p.m. From then until it passed south and east of Eastport, Me., its course was northeastward, offshore and fairly parallel to New England east coast. Thus nearly all of New England (except Cape Cod and Islands to south). Being on west or north side of center was spared worst of storm with respect to wind force; highest speeds there came with Edna's" backlash, in gusts up to 93 m.p.h. In southern Rhode Island and up to 92 m.p.h. over central Maine coast. Gust speeds above 100 m.p.h. recorded at Martha's Vineyard and over outer Cape Cod. Attendant rainfall was of nearrecord intensity, measuring 4 to 8 Inches over coastal areas and southeast. Widespread floods and washouts produced by these excessive rains caused more damage then that produced by winds. Radar reports in afternoon of 11 th indicated that hurricane had 2 'eyes' about 60 miles apart." September 1954 Climatological Data National Summary (Long Island, New York): "Hurricane winds which attained velocity of 95 m.p.h at Brookhaven National Laboratory swept Long Island where trees were blown down, numerous buildings. Many Small craft sunk, particularly on North Shore Highways and railroads washed out in places by high seas while benches seriously eroded. In Suffolk County, heavy rain washed potato tubers from soil so they were damaged by exposure to sun while other vegetable crops sustained substantial injuries."

September 12: HWM analyzes a closed extratropical low of at most $980 \mathrm{mb}$ centered near $52.0 \mathrm{~N}, 59.9 \mathrm{~W}$. HURDAT listed this as a $55 \mathrm{kt}$ extratropical storm at $52.4 \mathrm{~N}, 60.5 \mathrm{~W}$. The MWR Tracks of Centers of Cyclones (Chart X) places the center at $44.5 \mathrm{~N}, 68.9 \mathrm{~W}$ at 0 UTC on this day. The MWR Tracks of Centers of Cyclones (Chart X) places the center at $52.5 \mathrm{~N}, 60.1 \mathrm{~W}$ with a central pressure of $978 \mathrm{mb}$ at $12 \mathrm{UTC}$ on this day. Figure 1 from the September 1954 issue of the Monthly Weather Review places a center of circulation at $52.5 \mathrm{~N}, 60.8 \mathrm{~W}$ at $12 \mathrm{UTC}$ on this day. Available observations suggest a $60 \mathrm{kt}$ extratropical storm with a center at $52.4 \mathrm{~N}, 60.5 \mathrm{~W}$ at $12 \mathrm{UTC}$ on this day. Land observations: $987 \mathrm{mb}$ at $0 \mathrm{UTC}$ at $45.5 \mathrm{~N}, 69.6 \mathrm{~W}$ (SWO Greenville, ME); $975 \mathrm{mb}$ and 50 kt NNW at 0028 UTC at 44.8N, 66.8W (SWO Dow AFB, ME); $976 \mathrm{mb}$ at 0228 UTC at 46.1N, 67.8W (SWO Houlton, ME). Ship observations: $992 \mathrm{mb}$ at $21 \mathrm{UTC}$ at $56.5 \mathrm{~N}$, 
51.0W (COA ship \# 07024); $997 \mathrm{mb}$ and $45 \mathrm{kt}$ at $0 \mathrm{UTC}$ at 40.8N, 68.8W (COA ship \# 309 7740).

September 13: HWM analyzes a closed extratropical low of at most $985 \mathrm{mb}$ centered near $59.5 \mathrm{~N}, 53.5 \mathrm{~W}$. HURDAT listed this as a $40 \mathrm{kt}$ extratropical storm at $58.0 \mathrm{~N}, 54.5 \mathrm{~W}$. The MWR Tracks of Centers of Cyclones (Chart X) places the center at 56.2N, 57.0W at 0 UTC on this day. The MWR Tracks of Centers of Cyclones (Chart X) places the center at $58.1 \mathrm{~N}, 52.8 \mathrm{~W}$ with a central pressure of $980 \mathrm{mb}$ at $12 \mathrm{UTC}$ on this day. Figure 1 from the September 1954 issue of the Monthly Weather Review places a center of circulation at $59.1 \mathrm{~N}, 54.1 \mathrm{~W}$ at $12 \mathrm{UTC}$ on this day. Available observations suggest a $60 \mathrm{kt}$ extratropical storm with a center at $59.0 \mathrm{~N}, 54.5 \mathrm{~W}$ at $12 \mathrm{UTC}$ on this day. Ship observations: $988 \mathrm{mb}$ at $0 \mathrm{UTC}$ at $56.5 \mathrm{~N}, 51.0 \mathrm{~W} ; 990 \mathrm{mb}$ at $12 \mathrm{UTC}$ at $62.0 \mathrm{~N}, 49.0 \mathrm{~W}$ (COA ship \# 07024); $995 \mathrm{mb}$ and $60 \mathrm{kt}$ at $21 \mathrm{UTC}$ at 56.5N, 51.0W (COA ship \# 07024).

September 14: HWM analyzes a closed extratropical low of at most $995 \mathrm{mb}$ centered near $57.3 \mathrm{~N}, 47.9 \mathrm{~W}$. HURDAT listed this as a $30 \mathrm{kt}$ extratropical storm at $57.4 \mathrm{~N}, 47.4 \mathrm{~W}$. The MWR Tracks of Centers of Cyclones (Chart X) places the center at 59.2N, $50.1 \mathrm{~W}$ at 0 UTC on this day. The MWR Tracks of Centers of Cyclones (Chart X) places the center at $56.8 \mathrm{~N}, 46.5 \mathrm{~W}$ with a central pressure of $989 \mathrm{mb}$ at $12 \mathrm{UTC}$ on this day. Available observations suggest a $50 \mathrm{kt}$ extratropical storm with a center at $59.0 \mathrm{~N}, 58.9 \mathrm{~W}$ at $06 \mathrm{UTC}$ on this day. Available observations also suggest that the extratropical storm is no longer closed at 12 UTC on this day. Ship observations: $993 \mathrm{mb}$ and $60 \mathrm{kt} \mathrm{WSW}$ at $3 \mathrm{UTC}$ at $57.5 \mathrm{~N}, 51.5 \mathrm{~W}$ (COA ship \# 07024); $995 \mathrm{mb}$ and $50 \mathrm{kt} \mathrm{WSW}$ at $0 \mathrm{UTC}$ at $57.5 \mathrm{~N}, 51.5 \mathrm{~W}$ (COA ship \# 07024).

September 15: The MWR Tracks of Centers of Cyclones (Chart X) places the center at $56.7 \mathrm{~N}, 43.2 \mathrm{~W}$ at $12 \mathrm{UTC}$ on this day. Available observations do not suggest the presence of a closed low in this vicinity on this day. Ship observations: $988 \mathrm{mb}$ at 0 UTC at $62.0 \mathrm{~N}, 33.1 \mathrm{~W}$ (COA ship \# 014); $983 \mathrm{mb}$ at 0 UTC at 55.0N, 30.0W (COA ship \# 307 7858); $985 \mathrm{mb}$ at $6 \mathrm{UTC}$ at $59.5 \mathrm{~N}, 33.9 \mathrm{~W}$ (COA ship \# 309 7858).

Observations clearly indicate that the system currently in HURDAT for Edna was instead two separate tropical cyclones. The first system formed around 18 UTC on the 1st, moved westward, passed close to the coasts of Trinidad and Venezuela on the 3rd, and dissipated around 06-12 UTC on the 4th. The system that became Edna is first seen as a tropical wave along $51 \mathrm{~W}$ on the $2 \mathrm{nd}$. It continued moving westward with little change until the 5th. By late on the 5th, the system became a tropical storm.

This major change from HURDAT is supported by rather abundant surface observations, the Historical Weather Map analysis, and the Monthly Weather Review's summary. The remaining track changes for this hurricane are minor. The intensity is slightly increased 
late on the 5th and early on the 6th to account for observations from the Bulk Oil ship. The first aircraft reconnaissance to investigate the cyclone found $1001 \mathrm{mb}$ central pressure, $28 \mathrm{~nm}$ eye, and $85 \mathrm{kt}$ winds at $1433 \mathrm{UTC}$ on the $7 \mathrm{th}$. However, because of the crude instrumentation of the era for the Navy reconnaissance aircraft, these winds are likely not reliable. At $20 \mathrm{UTC}$ on the 7th the pressure dropped to $992 \mathrm{mb}$ and further down to $990 \mathrm{mb}$ at 2030 UTC. These pressures suggest intensity of 45, 61 and $64 \mathrm{kt}$, respectively, from the Brown et al. south of $25 \mathrm{~N}$ pressure-wind relationship. Additionally, a ship reported $65 \mathrm{kt}$ winds at $18 \mathrm{UTC}$ on the 7 th. Thus intensities in HURDAT reduced down from $70 \mathrm{kt}$ to $55 \mathrm{kt}$ at $12 \mathrm{UTC}, 70 \mathrm{kt}$ to $65 \mathrm{kt}$ at $18 \mathrm{UTC}$, and 75 $\mathrm{kt}$ to $70 \mathrm{kt}$ at $00 \mathrm{UTC}$ on the $8 \mathrm{th}$. The next aircraft reconnaissance to provide a central pressure was $979 \mathrm{mb}$ at 1413 UTC on the 8th with a $15 \mathrm{~nm}$ eye. This suggests maximum winds of $79 \mathrm{kt}$ from the south of $25 \mathrm{~N}$ and $74 \mathrm{kt}$ from the north of $25 \mathrm{~N}$ Brown et al. pressure-wind relationships (and 80 and $78 \mathrm{kt}$ from the subset of intensifying cyclones, respectively). $85 \mathrm{kt}$ chosen for HURDAT at $12 \mathrm{UTC}$ (down from $100 \mathrm{kt}$ originally) because of the small eye size. At 1934 UTC on the 8th aircraft reconnaissance measured $968 \mathrm{mb}$ central pressure with a circular $12 \mathrm{~nm}$ eye. $968 \mathrm{mb}$ suggests maximum winds of $87 \mathrm{kt}$ from the north of $25 \mathrm{~N}$ pressure-wind relationship (91 kt for the subset of intensifying cyclones). $95 \mathrm{kt}$ (down from $105 \mathrm{kt}$ originally) chosen for HURDAT at 18 UTC because of the small eye size. These two aircraft-measured central pressures were corroborated by a ship that measured $975 \mathrm{mb}$ at $16 \mathrm{UTC}$, in between the 979 and $968 \mathrm{mb}$ values. As was typical of the $1950 \mathrm{~s}$, there were only two additional hurricane penetrations from aircraft reconnaissance even though it remained off of the U.S. Atlantic coast for three more days. No ship or coastal stations reported hurricane force winds (or equivalent in pressure) from late on the 8th to late on the 10th. Thus it is relatively unknown how intense Edna was on these dates. Aircraft reconnaissance did measure 943 mb central pressure and a $15 \mathrm{~nm}$ eye around $00 \mathrm{UTC}$ on the $11 \mathrm{th}$. This pressure suggests maximum wind of $112 \mathrm{kt}$ from the Brown et al. north of $25 \mathrm{~N}$ and $101 \mathrm{kt}$ from the Landsea et al. north of $35 \mathrm{~N}$ pressure-wind relationships. $110 \mathrm{kt}$ chosen at 00 UTC on the 11 th (up slightly from $105 \mathrm{kt}$ ) because of the small eye size. Winds on the 9th and 10th are interpolated between the 1934 UTC September 8th and 00 UTC September 11th reconnaissance-based estimates, which made for slight reductions on the 9th and no changes on the 10th. Two locations in North Carolina - Mateo and Cape Lookout observed minimal 1-min hurricane force winds. Thus Edna is revised to be considered Category 1 impact in North Carolina, as it bypassed the coast by about 60-75 nm. After passing North Carolina, the hurricane accelerated while moving north-northeast. A final reconnaissance penetration occurred around 15 UTC on the 11th and gave a $947 \mathrm{mb}$ central pressure. 
The hurricane made landfall first on Martha's Vineyard, MA around 18 UTC on the 11th and a second landfall around 19 UTC just west of Hyannis, MA. Lowest observed sea level pressure from a land station was $954 \mathrm{mb}$ at Nantucket at 1826 UTC while the wind was blowing $52 \mathrm{kt} \mathrm{SSE}$. Thus it is estimated that the first landfall was with a central pressure of $948 \mathrm{mb}$ (just slightly higher than measured by reconn three hours earlier) and $950 \mathrm{mb}$ at the second landfall. These pressures suggest intensities of 98 and $97 \mathrm{kt}$ from the north of $35 \mathrm{~N}$ pressure-wind relationship. Given the small RMW of $20 \mathrm{~nm}$ and translational velocity of about $35 \mathrm{kt}$ at landfall, maximum 1 min surface winds are estimated at 105 and $100 \mathrm{kt}$ at the first and second landfall. Massachusetts is retained as Category 3 impact and New York and Rhode Island are added as Category 1 impact based upon observed hurricane force sustained winds in both states. After landfall in Massachusetts, Edna moved back over the Atlantic Ocean for about 5 hours before making a final landfall in Maine at 2330 UTC on the 11th. Based upon available observations, Edna had transformed into a strong extratropical cyclone by 00 UTC on the 12th (as well as at landfall a half an hour earlier). Thus Maine is removed as having a Category 1 hurricane impact, though maximum 1 min winds at Maine landfall were about $75 \mathrm{kt}$. Winds during the 12 th to the $14^{\text {th }}$ were increased in its extratropical phase from observed ship observations. Edna's final position is now given as 06 UTC on the 14th, as observations and HWM analyses suggest that it had dissipated by 12 UTC on the $14^{\text {th }}$. Thus positions through 06 UTC on the 15 th are removed.

Tropical Storm Florence [September 10-12, 1954]

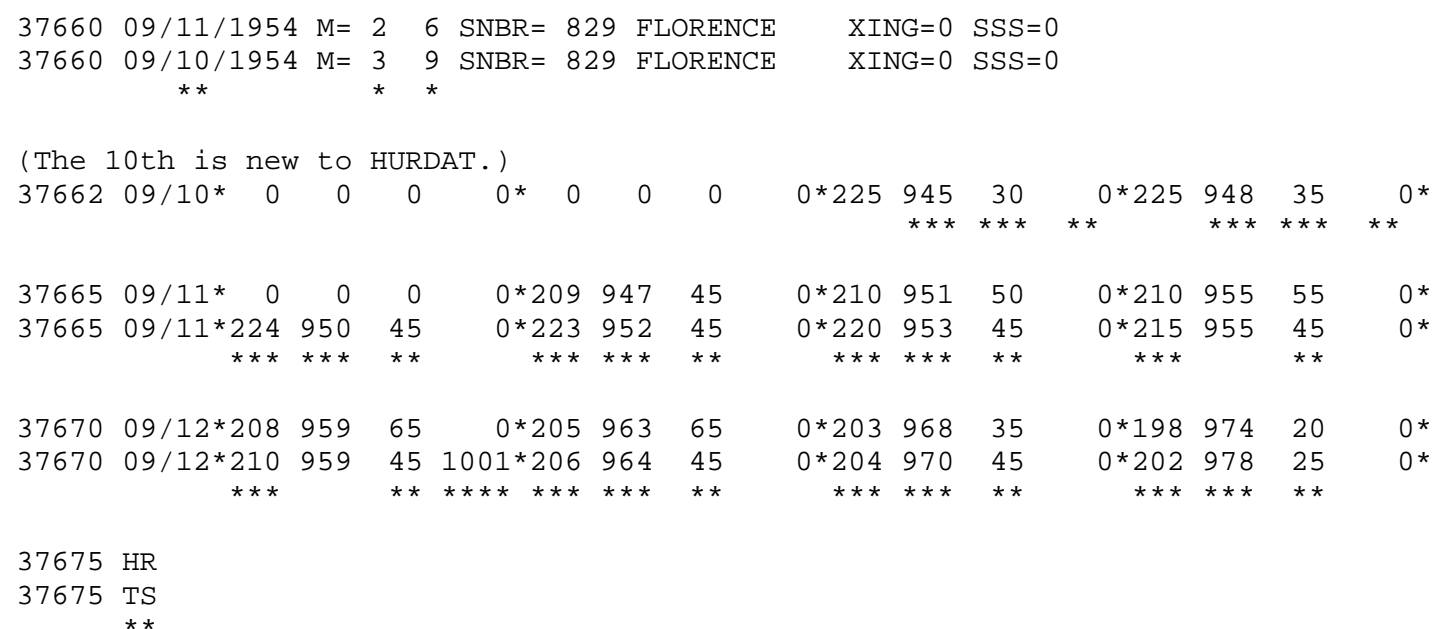

Minor changes to the track, but major alterations to the intensity shown in McAdie et al. (2009). Evidence for these alterations comes from the NHC microfilm maps, the 
Historical Weather Maps series, the COADS ship database, the Navy aircraft reconnaissance book, and Monthly Weather Review.

September 10:

HWM and HURDAT do not analyze a tropical system. Microfilm shows a possible low pressure near 22.5N, 94.0W at 12Z. Ship highlights: $30 \mathrm{kt} \mathrm{E}$ and $1012 \mathrm{mb}$ at $6 \mathrm{Z}$ near 24.0N, 90.0W (COADS). Aircraft highlights: "No wind circulation found, max wind in squall $60^{\circ} 25 \mathrm{kt}$, heavy rain band located $23 \mathrm{~N}$, between $91.3 \mathrm{~W}$ and $94.4 \mathrm{~W}, 60$ miles wide. Scattered cumulus along track, much high cirrus, overcast sky most of track west of 85W." (NAVY)

September 11:

HWM analyzes a tropical storm located near 22.5N, 95.2W. HURDAT lists this as a $50 \mathrm{kt}$ tropical storm at $21.0 \mathrm{~N}, 95.1 \mathrm{~W}$ at $12 \mathrm{Z}$. Microfilm shows this system centered near $22.0 \mathrm{~N}, 94.2 \mathrm{~W}$ at 12Z. Ship highlights: $35 \mathrm{kt} \mathrm{NE}$ and $1009 \mathrm{mb}$ at $0 \mathrm{Z}$ near $23.0 \mathrm{~N}$, 95.3W (COADS). $45 \mathrm{kt} \mathrm{ESE}$ and $1012 \mathrm{mb}$ at $01 \mathrm{Z}$ near 22.8N, 89.7W (micro), possible error and the longitude was likely $94.7 \mathrm{~W}$. Aircraft highlights: center fix at $2155 \mathrm{Z}$ at 21.2N, 95.8W, the measured central pressure was $1001 \mathrm{mb}$ and $60 \mathrm{kt}$ winds in the southwest quadrant, eye diameter was 50 miles. "Poorly defined ... turbulence moderate to heavy, seas high to very high close to eye. "(NAVY)

September 12:

HWM analyzes a tropical storm of at most $1005 \mathrm{mb}$ located near $20.5 \mathrm{~N}, 96.5 \mathrm{~W}$. HURDAT lists this as a $35 \mathrm{kt}$ tropical storm at 20.3N, 96.8W AT 12Z. Microfilm analyzes a closed low of at most $1005 \mathrm{mb}$ at $20.4 \mathrm{~N}, 96.8 \mathrm{~W}$ at $12 \mathrm{Z}$. No gale winds.

"This storm formed in the southwestern Gulf of Mexico and moved into Mexico between Tuxpan and Nautla on the morning of September 12. The highest wind reported by reconnaissance aircraft was about $65 \mathrm{mph}$. The press reported 5 dead and more than $\$ 1,500,000$ damage around the oil center of Poza Rica, mostly to the banana crop. The storm was possibly of hurricane force as it hit the coast."

Genesis for Florence is begun as a tropical depression at $12 \mathrm{Z}$ on the 10th, 18 hours earlier than shown in HURDAT originally. The reason for the earlier genesis is due to indications that a closed low existed by $12 \mathrm{Z}$ on the 10 th, as well as the system being very well developed with two gale force ship winds around $00 \mathrm{z}$ on the $11 \mathrm{th}$. One aircraft reconnaissance mission was flown on the 10th but remained northwest of the tropical cyclone and did not sample near the center. The revised track has only minor 
modifications for the lifetime of this system. The upgrade to tropical storm occurred at $18 \mathrm{Z}$ on the 10th, six hours earlier than shown in HURDAT due to a $35 \mathrm{kt} \mathrm{NE}$ ship at $00 \mathrm{Z}$ and a $45 \mathrm{kt}$ ESE ship at $01 \mathrm{Z}$ on the 11th. An aircraft reconnaissance mission was flown on the 11 th measuring $1001 \mathrm{mb}$ central pressure at $2155 \mathrm{Z}$. This central pressure is added to HURDAT at $00 \mathrm{Z}$ on the 12th. This pressure suggests maximum winds of $45 \mathrm{kt}$ from the south of $25 \mathrm{~N}$ Brown et al. pressure-wind relationship. The aircraft also measured a RMW of 35-40 nmi, which is larger than climatology of $18 \mathrm{~nm}$ for this latitude and central pressure. Given this information, the intensity is kept at $45 \mathrm{kt}$ until landfall on the 12th. This is a large reduction from $65 \mathrm{kt}$ in HURDAT originally at $00 \mathrm{Z}$ and $06 \mathrm{Z}$ on the 12th. This reduction also means that Florence is downgraded from a hurricane to a tropical storm for peak intensity. Aircraft reconnaissance on the 12th arrived in the vicinity of the cyclone around $14 \mathrm{Z}$ and indicated that Florence had either moved inland and/or degenerated into an area of squally weather. After making landfall in Veracruz, Mexico on the 12 th at $11 \mathrm{Z}$ near $20.4 \mathrm{~N} 96.8 \mathrm{~W}$, the system quickly dissipated over the mountainous terrain. Dissipation after $18 \mathrm{Z}$ on the 12 th is unchanged.

Tropical Storm Gilda [September 24-30, 1954]

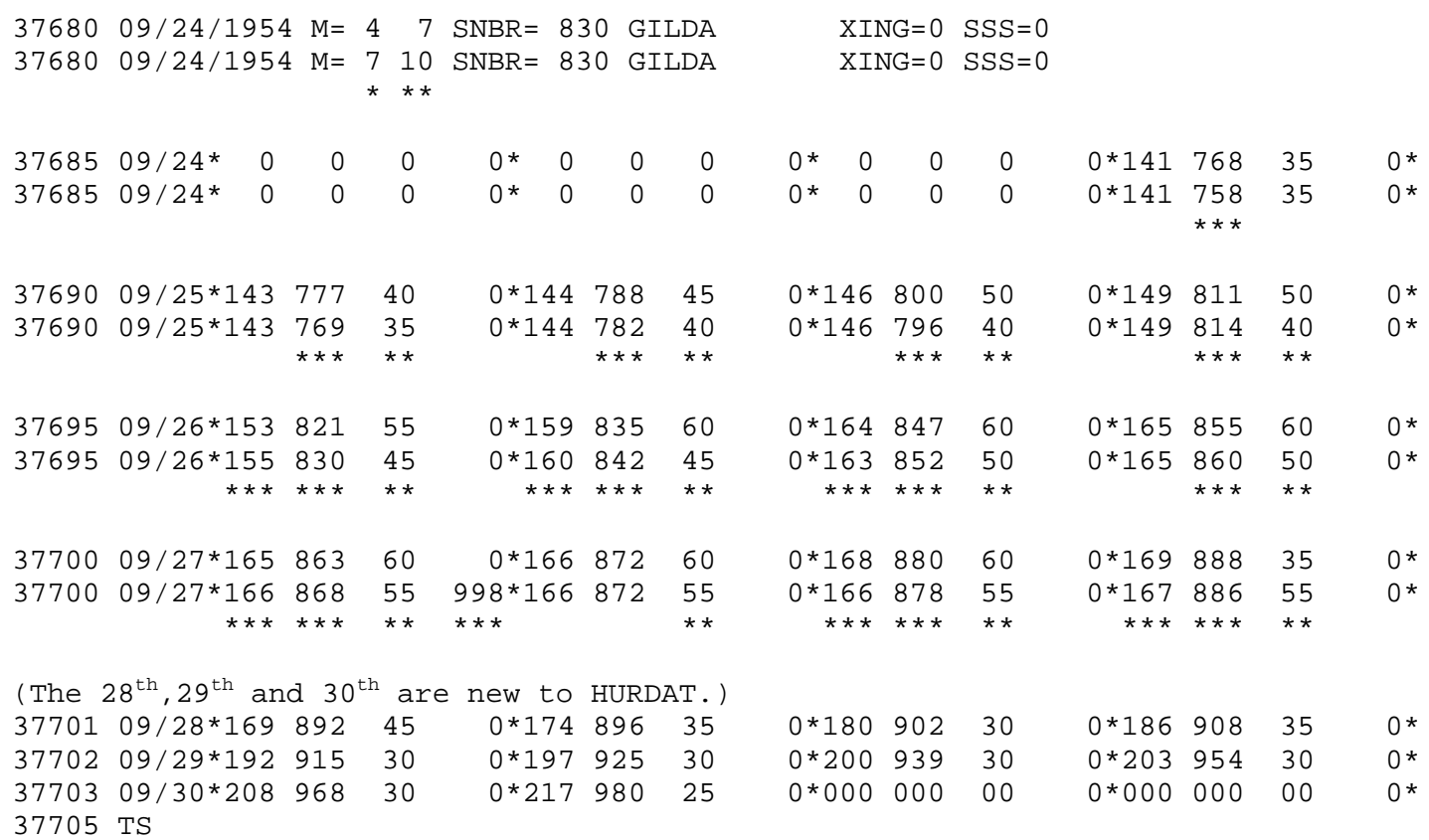

Minor changes to the track, but major alterations to the intensity shown in McAdie et al. (2009). Three additional days are added to the end of this cyclone. Evidence for these alterations comes from the NHC microfilm maps, the Historical Weather Maps series, the COADS ship database, the Navy aircraft reconnaissance book, and Monthly Weather Review. 
September 23:

HWM analyzes a low pressure of at most $1010 \mathrm{mb}$ located near $15.8 \mathrm{~N}$, 83.5W.HURDAT and microfilm does not analyze a tropical system. No gales or low pressures.

September 24:

HWM analyzes a low pressure of at most $1010 \mathrm{mb}$ located near $15.5 \mathrm{~N}, 82.5 \mathrm{~W}$. HURDAT lists this as a $35 \mathrm{kt}$ tropical storm at $14.1 \mathrm{~N}, 76.8 \mathrm{~W}$ at $18 \mathrm{Z}$. Microfilm shows this system centered near 13.0N, 79.6W at 18Z. Ship highlights: $30 \mathrm{kt} \mathrm{ESE} \mathrm{and} 1010 \mathrm{mb}$ at $18 \mathrm{Z}$ near $15.3 \mathrm{~N}, 73.6 \mathrm{~W}$. All observations from COADS.

September 25:

HWM analyzes a low pressure located near $14.7 \mathrm{~N}, 79.5 \mathrm{~W}$. HURDAT lists this as a $45 \mathrm{kt}$ tropical storm at $14.6 \mathrm{~N}, 80.0 \mathrm{~W}$ AT $12 \mathrm{Z}$. Microfilm analyzes a low pressure at $13.6 \mathrm{~N}, 81.7 \mathrm{~W}$ at $12 \mathrm{Z}$. Ship highlights: $30 \mathrm{kt}$ ESE and $1010 \mathrm{mb}$ at $0 \mathrm{Z}$ near $14.6 \mathrm{~N}, 72.5 \mathrm{~W}$. $30 \mathrm{kt}$ ENE and $1011 \mathrm{mb}$ at $18 \mathrm{Z}$ near $19.1 \mathrm{~N}, 78.4 \mathrm{~W}$. All observations from COADS. "Small tropical storm Gilda formed in the Caribbean Sea east of Cape Gracias, Nicaragua on September 25" (MWR).

September 26:

HWM analyzes a tropical storm of at most $1005 \mathrm{mb}$ located near $16.0 \mathrm{~N}, 85.3 \mathrm{~W}$. HURDAT lists this as a $60 \mathrm{kt}$ tropical storm at $16.4 \mathrm{~N}, 84.7 \mathrm{~W}$ AT $12 \mathrm{Z}$. Microfilm analyzes a closed low pressure of at most $1002 \mathrm{mb}$ at $16.2 \mathrm{~N}, 84.7 \mathrm{~W}$ at $12 \mathrm{Z}$. Ship highlights: $25 \mathrm{kt} \mathrm{E}$ and $1008 \mathrm{mb}$ at $12 \mathrm{Z}$ near 17.3N, 84.0W (MICRO). $35 \mathrm{kt} \mathrm{E}$ and 1012 $\mathrm{mb}$ at $18 \mathrm{Z}$ near $19.6 \mathrm{~N}, 86.2 \mathrm{~W}$ (COADS). $30 \mathrm{kt} \mathrm{SE}$ and $1010 \mathrm{mb}$ at $18 \mathrm{Z}$ near $18.4 \mathrm{~N}$, 83.0W (COADS). $40 \mathrm{kt} \mathrm{SE}$ and $1009 \mathrm{mb}$ at $21 \mathrm{Z}$ near 20.0N, 85.8W (MICRO). $35 \mathrm{kt} \mathrm{E}$ and $1012 \mathrm{mb}$ at $23 \mathrm{Z}$ near $19.5 \mathrm{~N}, 86.1 \mathrm{~W}$ (MICRO). Ship highlights: $5 \mathrm{kt} \mathrm{WNW}$ and 1003 $\mathrm{mb}$ at $00 \mathrm{Z}$ in Cabo Gracias a Dios, Honduras. $50 \mathrm{kt} \mathrm{E}$ at $15 \mathrm{Z}$ in Guanaja, Honduras. Aircraft highlights: center fix at $2240 \mathrm{Z}$ at $16.7 \mathrm{~N}, 86.6 \mathrm{~W}$, the measured central pressure was $998 \mathrm{mb}, 45 \mathrm{kt}$ winds and an eye diameter of 20 miles. (NAVY)

September 27:

HWM analyzes a tropical storm of at most $1005 \mathrm{mb}$ located near $16.8 \mathrm{~N}, 87.2 \mathrm{~W}$. HURDAT lists this as a $60 \mathrm{kt}$ tropical storm of at most $1002 \mathrm{mb}$ at $16.8 \mathrm{~N}, 88.0 \mathrm{~W}$ AT $12 \mathrm{Z}$. Microfilm analyzes a tropical storm at $16.4 \mathrm{~N}, 87.9 \mathrm{~W}$ at $12 \mathrm{Z}$. Ship highlights: $30 \mathrm{kt}$ SE and $1007 \mathrm{mb}$ at $18 \mathrm{Z}$ near 17.6N, 86.1W (COADS). Land highlight: $5 \mathrm{kt} \mathrm{SW}$ and 1004 $\mathrm{mb}$ at $00 \mathrm{Z}$ in Tela, Honduras. $10 \mathrm{kt} \mathrm{NNE}$ and $1006 \mathrm{mb}$ at $0 \mathrm{Z}$ in Belize City, Belize. $10 \mathrm{kt}$ $\mathrm{N}$ and $1006 \mathrm{mb}$ at $06 \mathrm{Z}$ in Belize City, Belize. $30 \mathrm{kt} \mathrm{S}$ and $1005 \mathrm{mb}$ at $12 \mathrm{Z}$ in Tela, 
Honduras. $20 \mathrm{kt} \mathrm{NE}$ and $1005 \mathrm{mb}$ at $12 \mathrm{Z}$ in Dandriga, Belize. $10 \mathrm{kt} \mathrm{NE}$ and $1006 \mathrm{mb}$ at $12 \mathrm{Z}$ in Belize City, Belize. $25 \mathrm{kt} \mathrm{NE}$ and $1002 \mathrm{mb}$ at $18 \mathrm{Z}$ in Dandriga, Belize. All observations from the Microfilm. "...moved westward along the north coast of Honduras and into British Honduras near Stann Creek, about 60 miles south of Belize, around 1530 EST of the 27th. The storm was less than hurricane force throughout its life, with highest winds of 60 to $70 \mathrm{mph}$ in squalls. Damage was slight to buildings and no casualties resulted from the storm. Rainfall was very heavy in northern Honduras, resulting in disastrous floods, especially around San Pedro Sula, La Lima, and the adjacent valley areas. Press reports indicated 29 dead and thousands homeless and marooned in the flooded areas, and extensive damage to property and crops.” (MWR)

September 28:

HWM analyzes a low pressure of at most $1005 \mathrm{mb}$ located near $16.5 \mathrm{~N}, 90.0 \mathrm{~W}$. HURDAT does not list this system. Microfilm analyzes a low pressure of at most 1005 mb located near $16.8 \mathrm{~N}, 89.8 \mathrm{~W}$ at $12 \mathrm{Z}$. Ship highlights: $30 \mathrm{kt} \mathrm{SE}$ and $1009 \mathrm{mb}$ at $06 \mathrm{Z}$ near 18.2N, 86.3W (COADS). Land highlight: $25 \mathrm{kt} \mathrm{S}$ and $1007 \mathrm{mb}$ at $12 \mathrm{Z}$ in Dandriga, Belize. $30 \mathrm{kt} \mathrm{S}$ and $1008 \mathrm{mb}$ at $18 \mathrm{Z}$ in Dandriga, Belize. All observations from the Microfilm.

September 29:

HWM and microfilm does not analyze a low pressure. HURDAT does not list this system. Ship highlights: $10 \mathrm{kt}$ ENE and $1003 \mathrm{mb}$ at $00 \mathrm{Z}$ near 19.5N, 91.5W. Land highlight: $10 \mathrm{kt} \mathrm{E}$ and $1003 \mathrm{mb}$ at $00 \mathrm{Z}$ in Campeche, Mexico. $10 \mathrm{kt} \mathrm{NW}$ and $1004 \mathrm{mb}$ at $00 \mathrm{Z}$ in Isla del Carmen, Mexico. All observations from the Microfilm.

September 30:

HWM does not analyze a low pressure. Microfilm analyses a low pressure near $22.2 \mathrm{~N}, 95.9 \mathrm{~W}$ at $00 \mathrm{Z}$. HURDAT does not list this system. Land highlight: $10 \mathrm{kt} \mathrm{N}$ and $1003 \mathrm{mb}$ at $00 \mathrm{Z}$ in Tuxpan, Mexico. $10 \mathrm{kt} \mathrm{SE}$ and $1004 \mathrm{mb}$ at $00 \mathrm{Z}$ in Veracruz, Mexico. 5 $\mathrm{kt} \mathrm{S}$ and $1005 \mathrm{mb}$ at $06 \mathrm{Z}$ in Tampico, Mexico. All observations from the Microfilm.

No changes are made to the genesis time for this tropical cyclone, which is retained as starting as a $35 \mathrm{kt}$ tropical storm at $18 \mathrm{Z}$ on the 24th of September, as a $30 \mathrm{kt}$ ESE ship was observed at that time. Minor track alterations were made for all four of the existing days of this cyclone. Intensity is reduced by $5-10 \mathrm{kt}$ on the 25 th, due to numerous ship and coastal stations indicating a somewhat weaker system on those dates. At $00 \mathrm{Z}$ on the 26th, a $1003 \mathrm{mb}$ peripheral pressure with $5 \mathrm{kt} \mathrm{WNW}$ winds was measured at Cabo Gracias, Honduras. This suggests maximum winds of at least $41 \mathrm{kt}$ from the south of $25 \mathrm{~N}$ Brown et al. pressure-wind relationship. $45 \mathrm{kt}$ is selected at that time for the 
intensity, down from $55 \mathrm{kt}$ previously. The cyclone continued westward just north of the Honduras coastline and $50 \mathrm{kt} \mathrm{E}$ winds were reported from Isla Guanaja around 16Z on the 26th. A single aircraft reconnaissance mission into this storm measured $998 \mathrm{mb}$ central pressure and an RMW of about $15 \mathrm{~nm}$ at $2240 \mathrm{Z}$ on the 26th, which suggests maximum winds of $51 \mathrm{kt}$. Given the small size of the cyclone, intensity is analyzed to be $55 \mathrm{kt}$ at $00 \mathrm{Z}$ on the $27 \mathrm{th}$. This intensity is also the peak for the tropical storm, which previously was $60 \mathrm{kt}$. No further inner core observations were available until after landfall later that day in Belize. Landfall is analyzed to have occurred around $17 \mathrm{Z}$ on the 27 th near $16.7 \mathrm{~N} 88.4 \mathrm{~W}$, south of Belize City with an intensity of $55 \mathrm{kt}$ (previously indicated in HURDAT to be $60 \mathrm{kt}$ in the last synoptic time before landfall).

Previously in HURDAT, the cyclone was analyzed to have dissipated after $18 \mathrm{Z}$ on the 27 th. However, numerous ship and land-based observations indicate that the system continued for three more days, albeit as a weak tropical cyclone. While inner core observations are sparse on the 28th after landfall, a reasonable weakening down to $45 \mathrm{k}$ at $00 \mathrm{Z}$ on the 28th, $35 \mathrm{kt}$ at $06 \mathrm{Z}, 30 \mathrm{kt}$ at $12 \mathrm{Z}$, and $30 \mathrm{kt}$ at $18 \mathrm{Z}$ is assumed, which is in agreement with the $30 \mathrm{kt} \mathrm{S}$ wind observed at Belize City at 18Z. The cyclone moved toward the northwest on the 28th, across southeastern Mexico. By 00Z on the 29th, the system reached the Gulf of Mexico. Two observations - one ship and one land station of $1003 \mathrm{mb}$ both with $10 \mathrm{kt}$ suggest maximum winds of at least $41 \mathrm{kt}$ from the Brown et al. south of $25 \mathrm{~N}$ pressure-wind relationship. Given the slow motion, low environmental pressures, and that the cyclone's circulation was still primarily overland, an intensity at that time of $30 \mathrm{kt}$ analyzed. Unfortunately, little to no ship data were available for the remainder of the 29th and early on the 30th. However, observations from Veracruz, Tuxpan, and Tampico, Mexico indicate that the system made a second landfall just south of Tampico, around $04 \mathrm{Z}$ near $21.3 \mathrm{~N} 97.6 \mathrm{~W}$. No tropical storm force winds were observed in the Gulf of Mexico or from the Mexican stations. However, Tuxpan measured $1003 \mathrm{mb}$ with N $10 \mathrm{kt}$ wind at 00Z, which suggests maximum wind from that pressure of at least $41 \mathrm{kt}$. Again because of the low environmental pressure, the intensity at $00 \mathrm{Z}$ and at landfall a few hours later is estimated to be $30 \mathrm{kt}$. However, it is quite possible that the system regained tropical storm intensity before the second landfall. After landfall, it is analyzed that the cyclone continued northwestward over Mexico and dissipated after $06 \mathrm{Z}$ on the 30th. The addition of three more days for the existence of this system is a major change. 
Unnamed Hurricane 8 [September 25 - October 6, 1954]

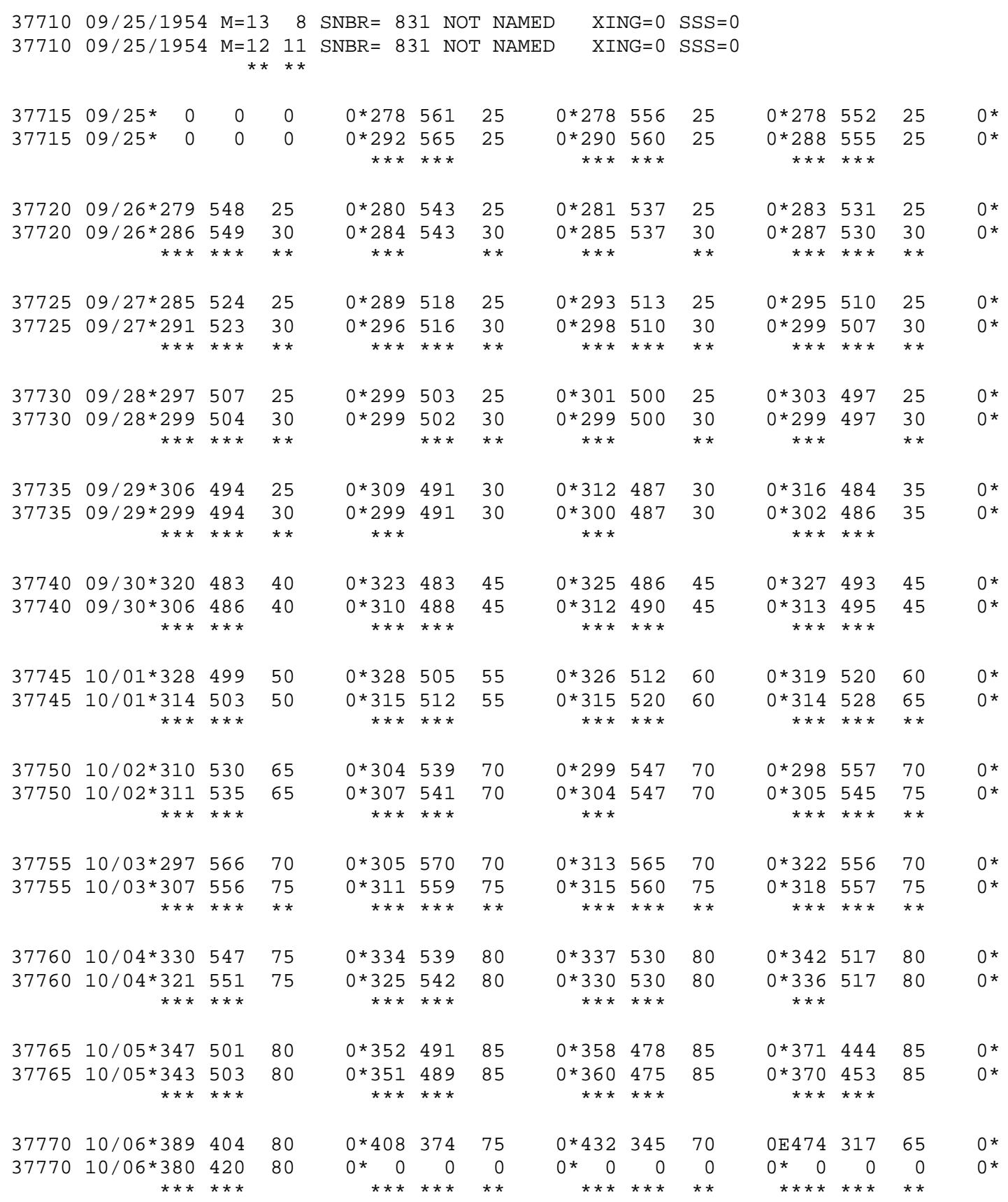

(The $7^{\text {th }}$ is removed from HURDAT.)

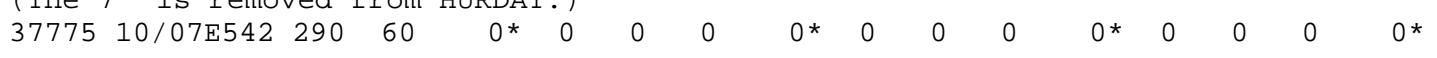

$37780 \mathrm{HR}$

Minor changes to the track and intensity shown in McAdie et al. (2009). One major change to this system is to indicate dissipation 24 hours earlier than shown in HURDAT. 
Evidence for these alterations comes from the NHC microfilm maps, the Historical Weather Maps series, the COADS ship database, and Monthly Weather Review.

September 24:

HWM analyzes a trough of low pressure extending from latitude $20 \mathrm{~N}$ to $35 \mathrm{~N}$ near longitude 54W. HURDAT does not list this system. Microfilm shows a low pressure near $32.0 \mathrm{~N}, 64.5 \mathrm{~W}$ at $18 \mathrm{Z}$. Ship highlights: No gales or low pressures.

September 25:

HWM analyzes a low pressure of at most $1015 \mathrm{mb}$ centered near $28.8 \mathrm{~N}, 56.2 \mathrm{~W}$ with a trough extending as well as a dissipating cold front to the system's northwest. HURDAT lists this as a $25 \mathrm{kt}$ tropical depression at $27.8 \mathrm{~N}, 55.6 \mathrm{~W}$ at $12 \mathrm{Z}$. Microfilm does not show an organized system. Ship highlights: No gales or low pressures.

September 26:

HWM analyzes a low pressure of at most $1015 \mathrm{mb}$ centered near $28.5 \mathrm{~N}, 53.0 \mathrm{~W}$. HURDAT lists this as a $25 \mathrm{kt}$ tropical depression at $28.1 \mathrm{~N}, 53.7 \mathrm{~W}$ at $12 \mathrm{Z}$. Microfilm shows a low pressure near 23.3N, 56.8. Ship highlights: $25 \mathrm{kt} \mathrm{S}$ and $1017 \mathrm{mb}$ at $0 \mathrm{Z}$ near $27.9 \mathrm{~N}, 51.3 \mathrm{~W} .15 \mathrm{kt} \mathrm{SSW}$ and $1015 \mathrm{mb}$ at $06 \mathrm{Z}$ near $27.4 \mathrm{~N}, 52.8 \mathrm{~W} .25 \mathrm{kt} \mathrm{SW}$ and 1017 $\mathrm{mb}$ at $06 \mathrm{Z}$ near $28.1 \mathrm{~N}, 50.0 \mathrm{~W}$. All observations from COADS.

September 27:

HWM analyzes a low pressure of at most $1015 \mathrm{mb}$ centered near $30.0 \mathrm{~N}, 50.5 \mathrm{~W}$. HURDAT lists this as a $25 \mathrm{kt}$ tropical depression at $29.3 \mathrm{~N}, 51.3 \mathrm{~W}$ at $12 \mathrm{Z}$. Microfilm does not show an organized system. Ship highlights: $30 \mathrm{kt} \mathrm{SE}$ and $1014 \mathrm{mb}$ at $12 \mathrm{Z}$ near $30.8 \mathrm{~N}, 49.3 \mathrm{~W} .15 \mathrm{kt} \mathrm{NW}$ and $1014 \mathrm{mb}$ at $12 \mathrm{Z}$ near $29.1 \mathrm{~N}, 52.4 \mathrm{~W}$. All observations from COADS.

September 28:

HWM analyzes a low pressure centered near $29.8 \mathrm{~N}, 51.5 \mathrm{~W}$. HURDAT lists this as a $25 \mathrm{kt}$ tropical depression at $30.1 \mathrm{~N}, 50.0 \mathrm{~W}$ at $12 \mathrm{Z}$. Microfilm does not show an organized system. Ship highlights: $25 \mathrm{kt}$ ESE and $1014 \mathrm{mb}$ at $0 \mathrm{Z}$ near $31.0 \mathrm{~N}, 49.7 \mathrm{~W} .20$ $\mathrm{kt} \mathrm{S}$ and $1009 \mathrm{mb}$ at $06 \mathrm{Z}$ near $29.5 \mathrm{~N}, 49.5 \mathrm{~W} .20 \mathrm{kt} \mathrm{NW}$ and $1013 \mathrm{mb}$ at $12 \mathrm{Z}$ near $28.8 \mathrm{~N}$, $50.9 \mathrm{~W}$. All observations from COADS.

September 29:

HWM analyzes a low pressure centered near 30.5N, 50.6W. HURDAT lists this as a $30 \mathrm{kt}$ tropical depression at $31.2 \mathrm{~N}, 48.7 \mathrm{~W}$ at $12 \mathrm{Z}$. Microfilm does not show an 
organized system. Ship highlights: $30 \mathrm{kt} \mathrm{SE}$ and $1009 \mathrm{mb}$ at $06 \mathrm{Z}$ near $29.0 \mathrm{~N}, 47.0 \mathrm{~W} .30$ kt NW and $1010 \mathrm{mb}$ at $12 \mathrm{Z}$ near $29.0 \mathrm{~N}, 48.0 \mathrm{~W} .20 \mathrm{kt} \mathrm{W}$ and $1013 \mathrm{mb}$ at $18 \mathrm{Z}$ near $28.0 \mathrm{~N}$, 48.0W. All observations from COADS.

September 30:

HWM analyzes a low pressure of at most $1010 \mathrm{mb}$ centered near $31.4 \mathrm{~N}, 49.2 \mathrm{~W}$. HURDAT lists this as a $45 \mathrm{kt}$ tropical storm at $32.5 \mathrm{~N}, 48.6 \mathrm{~W}$ at $12 \mathrm{Z}$. Microfilm shows a low pressure of at most $1017 \mathrm{mb}$ near $32.5 \mathrm{~N}, 47.5 \mathrm{~W}$. Ship highlights: $25 \mathrm{kt} \mathrm{NE}$ and 1016 $\mathrm{mb}$ at $12 \mathrm{Z}$ near $33.6 \mathrm{~N}, 49.7 \mathrm{~W} .5 \mathrm{kt} \mathrm{W}$ and $1011 \mathrm{mb}$ at $18 \mathrm{Z}$ near $29.9 \mathrm{~N}, 49.5$. All observations from COADS.

October 1:

HWM analyzes a low pressure of at most $1005 \mathrm{mb}$ centered near $32.5 \mathrm{~N}, 52.0 \mathrm{~W}$. HURDAT lists this as a $60 \mathrm{kt}$ tropical storm at $32.6 \mathrm{~N}, 51.2 \mathrm{~W}$ at $12 \mathrm{Z}$. Microfilm shows a low pressure of at most $996 \mathrm{mb}$ near $32.3 \mathrm{~N}, 51.6 \mathrm{~W}$. MWR analyzes a low pressure near 32.8N, 52.0W. Ship highlights: $35 \mathrm{kt} \mathrm{E}$ and $1005 \mathrm{mb}$ at $06 \mathrm{Z}$ near $32.3 \mathrm{~N}, 50.1 \mathrm{~W}$ (COADS). $40 \mathrm{kt} \mathrm{NW}$ and $999 \mathrm{mb}$ at $12 \mathrm{Z}$ near 31.5N, 53.0W (MICRO). $30 \mathrm{SE} \mathrm{kt}$ and $1002 \mathrm{mb}$ at $12 \mathrm{Z}$ near $31.7 \mathrm{~N}, 51.1 \mathrm{~W}$ (COADS). $35 \mathrm{kt} \mathrm{WSW}$ and $1013 \mathrm{mb}$ at $12 \mathrm{Z}$ near 29.7N, 51.4W (COADS). $40 \mathrm{kt}$ ESE and $996 \mathrm{mb}$ at $17 \mathrm{Z}$ near 31.0N, 51.5W (MICRO). 60 kt NW at $18 \mathrm{Z}$ near $31.6 \mathrm{~N}, 53.6 \mathrm{~W}$ (COADS). $35 \mathrm{kt} \mathrm{WSW}$ and $1005 \mathrm{mb}$ at $18 \mathrm{Z}$ near $30.4 \mathrm{~N}, 52.9 \mathrm{~W}$ (COADS). $50 \mathrm{kt} \mathrm{SE}$ and $992 \mathrm{mb}$ at $18 \mathrm{Z}$ near $31.1 \mathrm{~N}, 52.2 \mathrm{~W}$ (COADS).

October 2:

HWM analyzes a low pressure of at most $1000 \mathrm{mb}$ centered near $30.7 \mathrm{~N}, 54.9 \mathrm{~W}$. HURDAT lists this as a $70 \mathrm{kt}$ hurricane at $29.9 \mathrm{~N}, 54.7 \mathrm{~W}$ at $12 \mathrm{Z}$. Microfilm shows a low pressure of at most $999 \mathrm{mb}$ near 29.6N, 54.3W. MWR analyzes a low pressure near 28.8N, 54.2W. Ship highlights: $55 \mathrm{kt} \mathrm{ESE}$ and $990 \mathrm{mb}$ at $0 \mathrm{Z}$ near 31.7N, 53.2W. $45 \mathrm{kt} \mathrm{SE}$ and $998 \mathrm{mb}$ at $0 \mathrm{Z}$ near $30.5 \mathrm{~N}, 52.7 \mathrm{~W} .55 \mathrm{kt} \mathrm{WSW}$ and $1000 \mathrm{mb}$ at $06 \mathrm{Z}$ near $30.2 \mathrm{~N}$, 53.7W. $50 \mathrm{kt} \mathrm{SE}$ and $994 \mathrm{mb}$ at $06 \mathrm{Z}$ near $30.0 \mathrm{~N}, 53.1 \mathrm{~W} .30 \mathrm{kt} \mathrm{W}$ and $1001 \mathrm{mb}$ at $06 \mathrm{Z}$ near $29.5 \mathrm{~N}, 55.0 \mathrm{~W} .55 \mathrm{kt} \mathrm{SW}$ and $1001 \mathrm{mb}$ at $12 \mathrm{Z}$ near $30.0 \mathrm{~N}, 54.2 \mathrm{~W} .35 \mathrm{kt} \mathrm{SW}$ and $1008 \mathrm{mb}$ at $12 \mathrm{Z}$ near $29.4 \mathrm{~N}, 54.0 \mathrm{~W} .50 \mathrm{kt} \mathrm{SE}$ and $989 \mathrm{mb}$ at $12 \mathrm{Z}$ near $29.4 \mathrm{~N}, 53.8 \mathrm{~W} .40$ kt SW and $1006 \mathrm{mb}$ at $18 \mathrm{Z}$ near $29.0 \mathrm{~N}, 54.9 \mathrm{~W} .55 \mathrm{kt} \mathrm{S}$ and $986 \mathrm{mb}$ at $18 \mathrm{Z}$ near $29.2 \mathrm{~N}$, 54.3W. $35 \mathrm{kt} \mathrm{SW}$ and $1009 \mathrm{mb}$ at $18 \mathrm{Z}$ near $29.8 \mathrm{~N}, 52.9 \mathrm{~W}$. All observations from COADS.

October 3:

HWM analyzes a low pressure of at most $1000 \mathrm{mb}$ centered near $31.8 \mathrm{~N}, 55.7 \mathrm{~W}$. HURDAT lists this as a $70 \mathrm{kt}$ hurricane at $31.3 \mathrm{~N}, 56.5 \mathrm{~W}$ at $12 \mathrm{Z}$. Microfilm shows a low 
pressure of at most $1011 \mathrm{mb}$ near $33.8 \mathrm{~N}, 56.0 \mathrm{~W}$. MWR analyzes a low pressure near $30.5 \mathrm{~N}, 56.8 \mathrm{~W}$. Ship highlights: $35 \mathrm{kt} \mathrm{SW}$ and $1007 \mathrm{mb}$ at $0 \mathrm{Z}$ near $29.6 \mathrm{~N}, 56.3 \mathrm{~W} .55 \mathrm{kt} \mathrm{S}$ and $996 \mathrm{mb}$ at $0 \mathrm{Z}$ near $28.8 \mathrm{~N}, 54.1 \mathrm{~W} .30 \mathrm{kt} \mathrm{SE}$ and $1014 \mathrm{mb}$ at $0 \mathrm{Z}$ near $31.8 \mathrm{~N}, 53.9 \mathrm{~W}$. $40 \mathrm{kt} \mathrm{SSW}$ and $1003 \mathrm{mb}$ at $06 \mathrm{Z}$ near $28.5 \mathrm{~N}, 54.2 \mathrm{~W} .30 \mathrm{kt} \mathrm{WNW}$ and $1010 \mathrm{mb}$ at $12 \mathrm{Z}$ near $29.8 \mathrm{~N}, 57.2 \mathrm{~W} .30 \mathrm{kt} \mathrm{SW}$ and $1009 \mathrm{mb}$ at $12 \mathrm{Z}$ near $28.1 \mathrm{~N}, 54.7 \mathrm{~W} .45 \mathrm{kt} \mathrm{NE}$ and $1008 \mathrm{mb}$ at $12 \mathrm{Z}$ near $32.9 \mathrm{~N}, 56.9 \mathrm{~W}$. $30 \mathrm{kt} \mathrm{SW}$ and $1011 \mathrm{mb}$ at $18 \mathrm{Z}$ near $28.8 \mathrm{~N}, 55.5 \mathrm{~W}$. All observations from COADS.

October 4:

HWM analyzes a low pressure of at most $1000 \mathrm{mb}$ centered near $32.5 \mathrm{~N}, 53.7 \mathrm{~W}$. HURDAT lists this as a $80 \mathrm{kt}$ hurricane at $33.7 \mathrm{~N}, 53.0 \mathrm{~W}$ at $12 \mathrm{Z}$. Microfilm shows a low pressure of at most $996 \mathrm{mb}$ near $33.4 \mathrm{~N}, 53.7 \mathrm{~W}$. MWR analyzes a low pressure near $32.8 \mathrm{~N}, 53.7 \mathrm{~W}$. Ship highlights: $75 \mathrm{kt} \mathrm{S}$ and $998 \mathrm{mb}$ at $0 \mathrm{Z}$ near 32.0N, 54.0W (MICRO). $30 \mathrm{kt} \mathrm{S}$ and $1017 \mathrm{mb}$ at $06 \mathrm{Z}$ near $29.1 \mathrm{~N}, 50.2 \mathrm{~W}$ (COADS). $30 \mathrm{kt} \mathrm{S}$ and $1018 \mathrm{mb}$ at $06 \mathrm{Z}$ near 29.0N, 49.0W (COADS). $35 \mathrm{kt} \mathrm{E}$ and $1001 \mathrm{mb}$ at $06 \mathrm{Z}$ near 33.7N, $54.9 \mathrm{~W}$ (MICRO). $30 \mathrm{kt} \mathrm{SW}$ and $1016 \mathrm{mb}$ at $12 \mathrm{Z}$ near 28.5N, 54.4W (COADS). $30 \mathrm{kt} \mathrm{SW}$ and $1018 \mathrm{mb}$ at $12 \mathrm{Z}$ near $27.9 \mathrm{~N}, 51.2 \mathrm{~W}$ (COADS). $50 \mathrm{kt} \mathrm{S}$ and $999 \mathrm{mb}$ at $12 \mathrm{Z}$ near $32.8 \mathrm{~N}, 53.1 \mathrm{~W}$ (MICRO). $55 \mathrm{kt} \mathrm{SE}$ and $1006 \mathrm{mb}$ at $12 \mathrm{Z}$ near $34.2 \mathrm{~N}, 52.2 \mathrm{~W}$ (MICRO). $45 \mathrm{kt} \mathrm{SE}$ and $1010 \mathrm{mb}$ at $12 \mathrm{Z}$ near $34.6 \mathrm{~N}, 50.4 \mathrm{~W}$ (MICRO). $30 \mathrm{kt} \mathrm{N}$ and $1008 \mathrm{mb}$ at $12 \mathrm{Z}$ near $33.4 \mathrm{~N}$, $55.9 \mathrm{~W}$ (MICRO). $50 \mathrm{kt} \mathrm{WSW}$ and $1012 \mathrm{mb}$ at $15 \mathrm{Z}$ near $32.4 \mathrm{~N}, 53.2 \mathrm{~W}$ (MICRO). $75 \mathrm{kt}$ SSE and $979 \mathrm{mb}$ at $1515 \mathrm{Z}$ near $33.6 \mathrm{~N}, 51.5 \mathrm{~W}$ (MICRO). $30 \mathrm{kt} \mathrm{S}$ and $1014 \mathrm{mb}$ at $18 \mathrm{Z}$ near $31.3 \mathrm{~N}, 49.5 \mathrm{~W} .50 \mathrm{kt} \mathrm{S}$ and $1000 \mathrm{mb}$ at $18 \mathrm{Z}$ near $34.1 \mathrm{~N}, 48.7 \mathrm{~W}$ (MICRO). $50 \mathrm{kt} \mathrm{SW}$ and $1003 \mathrm{mb}$ at $18 \mathrm{Z}$ near $33.4 \mathrm{~N}, 50.0 \mathrm{~W}$ (MICRO).

October 5:

HWM analyzes a hurricane of at most $985 \mathrm{mb}$ centered near $38.1 \mathrm{~N}, 47.3 \mathrm{~W}$. HURDAT lists this as a $85 \mathrm{kt}$ hurricane at $35.8 \mathrm{~N}, 47.8 \mathrm{~W}$ at $12 \mathrm{Z}$. Microfilm shows a low pressure of at most $987 \mathrm{mb}$ near $35.4 \mathrm{~N}, 47.6 \mathrm{~W}$. MWR analyzes a low pressure near $36.2 \mathrm{~N}$, 46.6W. Ship highlights: $45 \mathrm{kt} \mathrm{S}$ and $1005 \mathrm{mb}$ at $0 \mathrm{Z}$ near 34.9N, 48.0W (COADS). $40 \mathrm{kt} \mathrm{S}$ and $1010 \mathrm{mb}$ at $0 \mathrm{Z}$ near $34.8 \mathrm{~N}, 47.3 \mathrm{~W}$ (COADS). $60 \mathrm{kt} \mathrm{S}$ and $990 \mathrm{mb}$ at $0 \mathrm{Z}$ near $34.3 \mathrm{~N}, 50.0 \mathrm{~W}$ (MICRO). $50 \mathrm{kt} \mathrm{S}$ and $1002 \mathrm{mb}$ at $0 \mathrm{Z}$ near $34.4 \mathrm{~N}, 48.5 \mathrm{~W}$ (MICRO). $65 \mathrm{kt}$ $\mathrm{S}$ and $997 \mathrm{mb}$ at $03 \mathrm{Z}$ near $34.8 \mathrm{~N}, 48.0 \mathrm{~W}$ (COADS). $75 \mathrm{kt} \mathrm{S}$ and $984 \mathrm{mb}$ at $06 \mathrm{Z}$ near $34.8 \mathrm{~N}, 48.0 \mathrm{~W}$ (COADS). $40 \mathrm{kt}$ SSE and $1002 \mathrm{mb}$ at $06 \mathrm{Z}$ near 35.1 N, 46.4W (COADS). $40 \mathrm{kt} \mathrm{S}$ and $1009 \mathrm{mb}$ at $06 \mathrm{Z}$ near 33.0N, $46.3 \mathrm{~W}$ (COADS). $30 \mathrm{kt} \mathrm{S}$ and $1015 \mathrm{mb}$ at $06 \mathrm{Z}$ near $29.6 \mathrm{~N}, 48.2 \mathrm{~W}$ (COADS). $80 \mathrm{kt} \mathrm{WSW}$ and $984 \mathrm{mb}$ at $09 \mathrm{Z}$ near $34.8 \mathrm{~N}, 48.0 \mathrm{~W}$ (COADS). $30 \mathrm{kt} \mathrm{SW}$ and $1012 \mathrm{mb}$ at $12 \mathrm{Z}$ near 32.5N, $48.8 \mathrm{~W}$ (COADS). $60 \mathrm{kt} \mathrm{W}$ and 999 $\mathrm{mb}$ at $12 \mathrm{Z}$ near $34.8 \mathrm{~N}, 48.0 \mathrm{~W}$ (COADS). $40 \mathrm{kt} \mathrm{SW}$ and $1011 \mathrm{mb}$ at $12 \mathrm{Z}$ near $32.4 \mathrm{~N}$, $45.7 \mathrm{~W}$ (COADS). $70 \mathrm{kt} \mathrm{SSW}$ and $990 \mathrm{mb}$ at $12 \mathrm{Z}$ near $35.3 \mathrm{~N}, 45.5 \mathrm{~W}$ (COADS). $30 \mathrm{kt}$ $\mathrm{SW}$ and $1012 \mathrm{mb}$ at $12 \mathrm{Z}$ near $32.5 \mathrm{~N}, 48.8 \mathrm{~W}$ (COADS). $45 \mathrm{kt} \mathrm{W}$ and 1006 at $15 \mathrm{Z}$ near 
$34.8 \mathrm{~N}, 48.0 \mathrm{~W}$ (COADS). $70 \mathrm{kt} \mathrm{SSW}$ and $985 \mathrm{mb}$ at $15 \mathrm{Z}$ near $36.0 \mathrm{~N}, 44.6 \mathrm{~W}$ (COADS). $35 \mathrm{kt} \mathrm{S}$ and $1000 \mathrm{mb}$ at $18 \mathrm{Z}$ near $36.8 \mathrm{~N}, 41.3 \mathrm{~W}$ (COADS). $35 \mathrm{kt} \mathrm{S}$ and $1008 \mathrm{mb}$ at $12 \mathrm{Z}$ near $36.1 \mathrm{~N}, 40.0 \mathrm{~W}$ (COADS). $75 \mathrm{kt} \mathrm{S}$ and $997 \mathrm{mb}$ at $18 \mathrm{Z}$ near $37.0 \mathrm{~N}, 44.0 \mathrm{~W}$ (MICRO). $30 \mathrm{kt} \mathrm{W}$ and $1010 \mathrm{mb}$ at $21 \mathrm{Z}$ near $34.5 \mathrm{~N}, 48.0 \mathrm{~W}$ (COADS). $60 \mathrm{kt} \mathrm{W}$ and $977 \mathrm{mb}$ at $21 \mathrm{Z}$ near $37.0 \mathrm{~N}, 44.0 \mathrm{~W}$ (COADS).

October 6:

HWM analyzes a hurricane of at most $980 \mathrm{mb}$ centered near $44.6 \mathrm{~N}, 35.0 \mathrm{~W}$. HURDAT lists this as a $70 \mathrm{kt}$ hurricane at $43.2 \mathrm{~N}, 34.5 \mathrm{~W}$ at $12 \mathrm{Z}$. MWR analyzes a low pressure near $42.7 \mathrm{~N}, 34.8 \mathrm{~W}$. Ship highlights: $60 \mathrm{kt} \mathrm{W}$ and $992 \mathrm{mb}$ at $0 \mathrm{Z}$ near $37.2 \mathrm{~N}$, $44.2 \mathrm{~W} .35 \mathrm{kt} \mathrm{S}$ and $983 \mathrm{mb}$ at $0 \mathrm{Z}$ near $36.6 \mathrm{~N}, 41.4 \mathrm{~W} .50 \mathrm{kt} \mathrm{S}$ and $1005 \mathrm{mb}$ at $06 \mathrm{Z}$ near $35.3 \mathrm{~N}, 39.7 \mathrm{~W} .35 \mathrm{kt} \mathrm{S}$ and $1013 \mathrm{mb}$ at $0 \mathrm{Z}$ near $39.0 \mathrm{~N}, 34.5 \mathrm{~W} .35 \mathrm{kt} \mathrm{SE}$ and $1016 \mathrm{mb}$ at $0 \mathrm{Z}$ near $39.3 \mathrm{~N}, 31.6 \mathrm{~W} .35 \mathrm{kt} \mathrm{SSE}$ and $998 \mathrm{mb}$ at $06 \mathrm{Z}$ near $40.4 \mathrm{~N}, 35.1 \mathrm{~W} .35 \mathrm{kt}$ SSE and $984 \mathrm{mb}$ at $12 \mathrm{Z}$ near $45.7 \mathrm{~N}, 33.4 \mathrm{~W} .40 \mathrm{kt} \mathrm{SW}$ and $1013 \mathrm{mb}$ at $12 \mathrm{Z}$ near $36.8 \mathrm{~N}, 35.3 \mathrm{~W} .35$ $\mathrm{kt} \mathrm{S}$ and $1011 \mathrm{mb}$ at $12 \mathrm{Z}$ near $36.8 \mathrm{~N}, 31.2 \mathrm{~W} .40 \mathrm{kt} \mathrm{S}$ and $1016 \mathrm{mb}$ at $12 \mathrm{Z}$ near $37.7 \mathrm{~N}$, 29.5W. $60 \mathrm{kt} \mathrm{SSE}$ and $998 \mathrm{mb}$ at $18 \mathrm{Z}$ near $49.0 \mathrm{~N}, 29.1 \mathrm{~W} .50 \mathrm{kt} \mathrm{SE}$ and $964 \mathrm{mb}$ at $18 \mathrm{Z}$ near $50.7 \mathrm{~N}, 30.7 \mathrm{~W}$. All observations from COADS.

\section{October 7:}

HWM does not analyze a system. HURDAT lists this as a $60 \mathrm{kt}$ extratropical cyclone at $54.2 \mathrm{~N}, 29.0 \mathrm{~W}$ at $0 \mathrm{Z}$. Ship highlights: $50 \mathrm{kt} \mathrm{SW}$ and $993 \mathrm{mb}$ at $0 \mathrm{Z}$ near $51.2 \mathrm{~N}, 27.0 \mathrm{~W} .50$ $\mathrm{kt} \mathrm{SW}$ and $994 \mathrm{mb}$ at $0 \mathrm{Z}$ near $51.5 \mathrm{~N}, 27.4 \mathrm{~W}$. All observations from COADS.

The genesis for this system is unchanged from that previously in HURDAT at $06 \mathrm{Z}$ on the 26th of September, though the first definitive evidence for a closed circulation was at $12 Z$ on the 25th. Minor track changes were introduced for all of the days of its existence. It should be noted that on the 1st and 2nd of October, in particular, there were several ship observations that provided contradictory information (more than usual), likely because of difficulty in the ships knowing their true location over the open Atlantic Ocean. While the intensity is increased slightly from 25 to $30 \mathrm{kt}$ on the 27 th through $00 \mathrm{Z}$ on the 29th, there is no evidence to introduce a change to the time of intensification to a tropical storm from the 18Z 29th originally shown in HURDAT. (This does keep in HURDAT the somewhat unlikely classification of a tropical depression for the first four and a half days of its existence. However, it is certainly possible that tropical storm intensity was reached earlier than shown here.) Several observations on the 1st of October indicated a well-developed tropical storm. At $18 \mathrm{Z}$ on the 1st, a ship reported $60 \mathrm{kt} \mathrm{NW}$ winds and a separate ship observed $50 \mathrm{kt} \mathrm{SE}$ winds with $992 \mathrm{mb}$ pressure. This pressure suggests maximum winds of at least $56 \mathrm{kt}$ from the Brown et al. north of $25 \mathrm{~N}$ pressure-wind relationship and at least $59 \mathrm{kt}$ from the intensifying subset. Given the high environmental 
pressure and the single observation of $60 \mathrm{kt}$, the maximum winds at that time are analyzed to be $65 \mathrm{kt}$ ( $5 \mathrm{kt}$ higher than HURDAT originally). Intensification to hurricane stage at that time is six hours earlier than in HURDAT originally. On the 2nd, a ship at $18 \mathrm{Z}$ reported $55 \mathrm{kt} \mathrm{S}$ and $986 \mathrm{mb}$ pressure. This peripheral pressure reading suggests winds of at least $65 \mathrm{kt}$ and at least $68 \mathrm{kt}$ from the same pressure-wind relationships. The intensity at that time is analyzed to be $75 \mathrm{kt}$ (70 kt originally), again in part because of the high environmental pressures. On the 4 th, a ship at $1515 \mathrm{Z}$ reported $75 \mathrm{kt} \mathrm{SSE}$ and 979 $\mathrm{mb}$. This pressure suggests at least $74 \mathrm{kt}$ and at least $77 \mathrm{kt}$ from the same pressure-wind relationships. $80 \mathrm{kt}$ is analyzed for the intensity at both 12 and 18Z, no change from HURDAT, as the environmental pressures had returned to near normal. At $21 \mathrm{Z}$ on the 5th, a ship reported $60 \mathrm{kt} \mathrm{W}$ winds and $977 \mathrm{mb}$ pressure. This pressure suggests maximum winds of $76 \mathrm{kt}$ from the Landsea et al. north of $35 \mathrm{~N}$ pressure-wind relationship. Because of the fast movement of the hurricane toward the northeast, the intensity is estimated to be $85 \mathrm{kt}$ at $18 \mathrm{Z}$ on the 5 th and $80 \mathrm{kt}$ at $00 \mathrm{Z}$ on the 6 th (no change to HURDAT). Late on the 5th and early on the 6th, the hurricane quickly was overtaken and absorbed by a very large and powerful extratropical cyclone. Numerous observations show at $06 \mathrm{Z}$ on the 6 th that the system no longer had a closed circulation. Thus the last best track position is indicated to be at $00 \mathrm{Z}$ on the 6 th, still as an $80 \mathrm{kt}$ cyclone. With the system becoming absorbed into the extratropical low, the last point at $00 \mathrm{Z}$ on the 6 th is shown as extratropical. Such a dissipation for a hurricane is somewhat rare with the last intensity at such a high value of $80 \mathrm{kt}$. It is worth noting that the extratropical low that absorbed the hurricane continued with extremely low pressures (into the 940s) and very strong winds for a few more days as it moved across the high latitudes of the North Atlantic.

Hurricane Hazel [October 5-18]

\begin{tabular}{|c|c|c|c|c|c|c|c|c|c|c|c|c|c|}
\hline 36605 & $10 / 05 / 195$ & $4 M=1$ & 9 & $\mathrm{SNBR}=8 \mathrm{C}$ & $8 \mathrm{HA}$ & AZEL & XII & $V G=1$ & $\mathrm{SSS}=$ & & & & \\
\hline $366 \odot 5$ & $10 / 05 / 195$ & $4 M=1$ & $4 \underset{* *}{12}$ & SNBR $=8 C$ & $8 \mathrm{HA}$ & AZEL & XII & $V G=1$ & $\mathrm{SSS}=$ & & & & \\
\hline 36610 & $10 / 05$ * & $\odot$ & $\odot$ & $\odot * 124$ & 592 & 60 & $\Theta * 127$ & 602 & 60 & $0 * 128$ & 611 & 70 & ๑* \\
\hline 36610 & $10 / 05$ * & $\odot$ & $\odot$ & $\begin{array}{r}0 * 120 \\
* * *\end{array}$ & $\begin{array}{l}585 \\
* * *\end{array}$ & $\begin{array}{l}40 \\
* *\end{array}$ & $\begin{array}{r}0 * 120 \\
* * *\end{array}$ & $\begin{array}{l}595 \\
* * *\end{array}$ & $\begin{array}{l}50 \\
* *\end{array}$ & $0_{* \star \star}^{*} 121$ & $\begin{array}{l}605 \\
* * *\end{array}$ & $\begin{array}{l}55 \\
* *\end{array}$ & $\underbrace{1002^{*}}_{\star \star * \star}$ \\
\hline $\begin{array}{l}36615 \\
36615\end{array}$ & $\begin{array}{r}10 / 06 * 129 \\
10 / 06 * 122 \\
* * *\end{array}$ & $\begin{array}{l}621 \\
616 \\
* * *\end{array}$ & $\begin{array}{l}75 \\
65 \\
* *\end{array}$ & $\begin{array}{l}\Theta * 131 \\
\Theta * 123 \\
* * *\end{array}$ & $\begin{array}{l}631 \\
629 \\
* * *\end{array}$ & $\begin{array}{l}80 \\
7 \odot \\
* *\end{array}$ & $\begin{array}{r}\Theta^{*} 132 \\
\Theta^{*} 125 \\
* * *\end{array}$ & $\begin{array}{l}641 \\
643 \\
* * *\end{array}$ & $\begin{array}{l}85 \\
70 \\
* *\end{array}$ & $\begin{array}{r}0^{*} 133 \\
998^{*} 126 \\
* * * * * *\end{array}$ & $\begin{array}{l}651 \\
656 \\
* * *\end{array}$ & $\begin{array}{l}85 \\
70 \\
* *\end{array}$ & $\begin{array}{l}\Theta^{*} \\
998^{*} \\
* * *\end{array}$ \\
\hline $\begin{array}{l}36620 \\
36620\end{array}$ & $\begin{array}{r}10 / 07 * 133 \\
10 / 07 * 127 \\
* * *\end{array}$ & $\begin{array}{l}661 \\
667 \\
\star * *\end{array}$ & $\begin{array}{l}9 \odot \\
7 \odot \\
* *\end{array}$ & $\begin{array}{r}\Theta * 133 \\
0 * 129 \\
* * *\end{array}$ & $\begin{array}{l}672 \\
677 \\
\star * *\end{array}$ & $\begin{array}{r}100 \\
70 \\
* * *\end{array}$ & $\begin{array}{r}0^{*} 133 \\
0^{*} 132 \\
* * *\end{array}$ & $\begin{array}{l}682 \\
687 \\
* * *\end{array}$ & $\begin{array}{r}105 \\
70 \\
* * *\end{array}$ & $\begin{array}{r}0^{*} 133 \\
997^{*} 135 \\
* * * * * *\end{array}$ & $\begin{array}{l}691 \\
697 \\
\star * *\end{array}$ & $\begin{array}{r}105 \\
70 \\
* * *\end{array}$ & $\begin{array}{l}\Theta^{*} \\
994^{*} \\
* * *\end{array}$ \\
\hline $\begin{array}{l}36625 \\
36625\end{array}$ & $\begin{array}{r}10 / 08 * 134 \\
10 / 08 * 136 \\
* * *\end{array}$ & $\begin{array}{l}699 \\
706 \\
* * *\end{array}$ & $\begin{array}{r}105 \\
75 \\
* * *\end{array}$ & $\begin{array}{r}0 * 135 \\
0 * 136 \\
* * *\end{array}$ & $\begin{array}{l}709 \\
713 \\
\star \star *\end{array}$ & $\begin{array}{r}110 \\
75 \\
\star * *\end{array}$ & $\begin{array}{l}0^{*} 136 \\
0^{*} 136\end{array}$ & $\begin{array}{l}719 \\
718 \\
\star * *\end{array}$ & $\begin{array}{r}110 \\
75 \\
\star * *\end{array}$ & $\begin{array}{r}0 * 136 \\
986 * 137 \\
\star * \star * * *\end{array}$ & $\begin{array}{l}725 \\
720 \\
\star * *\end{array}$ & $\begin{array}{r}110 \\
80 \\
\star * *\end{array}$ & $\begin{array}{l}\Theta^{*} \\
\Theta^{*}\end{array}$ \\
\hline
\end{tabular}




\begin{tabular}{|c|c|c|c|c|c|c|c|c|c|c|c|c|c|}
\hline 36630 & $10 / 09 * 136$ & 731 & 115 & $0 * 136$ & 737 & 115 & $0 * 137$ & 742 & 115 & $0 * 139$ & 748 & 115 & ○* \\
\hline 36630 & $10 / 09 * 138$ & 724 & 85 & $0 * 139$ & 732 & 90 & $0 * 140$ & 740 & 95 & $0 * 142$ & 747 & 100 & ○* \\
\hline & $* * *$ & $\star * *$ & $\star \star *$ & *** & $\star * *$ & $* * *$ & $\star \star *$ & $\star \star *$ & $* * *$ & $\star * *$ & $\star * *$ & $* * *$ & \\
\hline 36635 & $10 / 10 * 142$ & 753 & 115 & $0 * 146$ & 756 & 110 & $0 * 150$ & 756 & 105 & $0 * 154$ & 756 & 105 & 0* \\
\hline 36635 & $10 / 10 * 144$ & 752 & 105 & $0 * 147$ & 755 & 105 & $0 * 150$ & 756 & 105 & $0 * 153$ & 756 & 105 & $0^{*}$ \\
\hline & *** & $\star * *$ & $\star \star *$ & *** & $* * *$ & $\star \star *$ & & & & $* * *$ & & & \\
\hline 36640 & $10 / 11^{*} 157$ & 755 & 105 & $0 * 161$ & 753 & 105 & $0 * 165$ & 751 & 105 & $0 * 171$ & 748 & 105 & 0 * \\
\hline 36640 & $10 / 11^{*} 156$ & 755 & 105 & $0 * 159$ & 753 & 105 & $\begin{array}{c}0 * 164 \\
* * *\end{array}$ & 751 & 105 & $0 * 169$ & $\begin{array}{l}749 \\
* * *\end{array}$ & 105 & 0* \\
\hline 36645 & $10 / 12 * 177$ & 744 & 105 & $0 * 182$ & 741 & 85 & $0 * 187$ & 738 & 85 & $0 * 193$ & 735 & 85 & 0 * \\
\hline 36645 & $10 / 12 * 174$ & 747 & 105 & $0 * 180$ & 743 & 95 & $0 * 186$ & 740 & 85 & 0*191 & 737 & 85 & ०* \\
\hline & $* * *$ & $* * *$ & & *** & $* * *$ & ** & $* * *$ & $* * *$ & & *** & $\star \star *$ & & \\
\hline 36650 & $10 / 13 * 199$ & 733 & 85 & $0 * 205$ & 732 & 85 & $\odot * 210$ & 732 & 85 & $994 * 216$ & 733 & 85 & 0* \\
\hline 36650 & $10 / 13 * 196$ & 734 & 85 & $0 * 201$ & 731 & 85 & $\odot * 208$ & 731 & 85 & ๑*217 & 733 & 85 & $972^{*}$ \\
\hline & $* * *$ & $\star * *$ & & *** & $* * *$ & & $\star * *$ & $* * *$ & & $\star * \star * * *$ & & & $* \star *$ \\
\hline 36655 & $10 / 14 * 226$ & 735 & 90 & $\Theta * 24 \odot$ & 739 & 100 & $0 * 255$ & 746 & 105 & $\Theta * 270$ & 757 & 110 & 0 * \\
\hline 36655 & $10 / 14 * 227$ & 735 & 85 & $974 * 238$ & 738 & 90 & ○*252 & 746 & 100 & $\Theta * 270$ & 757 & 110 & ०* \\
\hline & $\star * *$ & & ** & $\star * * \quad * * *$ & $* * *$ & $* * *$ & $\star * *$ & & $* * *$ & & & & \\
\hline 36660 & $10 / 15^{*} 286$ & 768 & 115 & $0 * 302$ & 778 & 120 & $0 * 328$ & 787 & 110 & 937E368 & 782 & 80 & $970^{*}$ \\
\hline 36660 & $10 / 15^{*}{ }_{\star \star *} 288$ & 768 & 115 & $0 * 307$ & $\begin{array}{l}780 \\
\star * *\end{array}$ & 120 & $0 * 327$ & 787 & 120 & $938 \mathrm{E} 360$ & $\begin{array}{l}783 \\
\star \star *\end{array}$ & 80 & $970 *$ \\
\hline & & & & & & & & & & & & & \\
\hline 36665 & $10 / 16 \mathrm{E} 410$ & 774 & 70 & OE452 & 786 & 60 & OE488 & $80 \odot$ & 50 & OE5०7 & $80 \odot$ & 45 & $0^{*}$ \\
\hline 36665 & 10/16E410 & 774 & 70 & $\begin{array}{r}\mathrm{OE} 46 \odot \\
* * *\end{array}$ & $\begin{array}{l}793 \\
* * *\end{array}$ & 60 & ○E488 & 800 & 50 & $\begin{array}{l}982 \mathrm{E} 515 \\
\star * \star * * *\end{array}$ & $\begin{array}{l}795 \\
* * *\end{array}$ & 45 & $\begin{array}{l}988^{*} \\
* * *\end{array}$ \\
\hline 36670 & 10/17E517 & 799 & 45 & OE528 & 792 & 35 & OE54๑ & 782 & 35 & OE556 & 762 & 35 & 0 * \\
\hline 36670 & 10/17E532 & 795 & 45 & OE545 & 795 & 35 & ○E555 & 795 & 35 & ๑E563 & 788 & 35 & $\Theta^{*}$ \\
\hline & $\star \star \star *$ & $* * *$ & & *** & $* \star *$ & & *** & $* * *$ & & $* * *$ & $* * *$ & & \\
\hline 36675 & 10/18E570 & 730 & 30 & OE581 & 694 & 25 & OE588 & 651 & 25 & $\Theta^{*}$ & $\odot$ & $\odot$ & $\Theta^{*}$ \\
\hline 36675 & 10/18E570 & 770 & 30 & OE581 & 750 & 25 & ०* 0 & $\odot$ & $\odot$ & $0^{*}$ & $\odot$ & $\odot$ & ○* \\
\hline & & $\star \star \star *$ & & & $\star \star \star$ & & & $\star \star *$ & ** & & & & \\
\hline
\end{tabular}

36680 HR SC4 NC4 MD2

36680 HR SC3 NC4

Landfall:

10/15 1530Z 33.9N 78.5W, 12 nm RMW, 938 mb central pressure, $26 \mathrm{kt}$ speed, $120 \mathrm{kt}$ maximum sustained surface winds

Minor changes to the track, but major adjustments to the intensity shown in McAdie et al. (2009). Evidence for these alterations comes from the Historical Weather Map series, Monthly Weather Review, daily Surface Weather Observations from NCDC, U.S.

Weather Bureau six hourly maps available via microfilm at NHC, aircraft observations available from the Storm Wallets at NHC, the COADS ship database, Rhodes (1954), Dunn and Miller (1960), Schwerdt et al. (1979), Ho et al. (1987), Jarrell et al. (1992), and Perez et al. (2000). 
October 5: HWM indicates a closed low of at most 1010mb near 13N, 61 W. HURDAT lists this as a Tropical Storm with $60 \mathrm{kt}$ winds at $12.7 \mathrm{~N}, 60.2 \mathrm{~W}$ at 12 UTC. Station highlight: No gales or low pressures. Ship highlight: No gales or low pressures. Aircraft highlight: $85 \mathrm{kt}$ with pressure of $1002 \mathrm{mb}$ at $12.1 \mathrm{~N}, 61.0 \mathrm{~W}$ at 2037 UTC (Navy). "This hurricane developed in an easterly wave at latitude $12 \mathrm{~N}$, longitude $61.2 \mathrm{~W}$, on October 5 at which time highest winds were estimated about $100 \mathrm{mph}$. The hurricane passed near or slightly north of the island of Grenada in the Windward Islands and into the Caribbean Sea during the evening of the 5th" (MWR). "The center of the storm passed between the islands of Grenada and Carriacou during the evening of the 5th. All of the Grenadine Islands except Carriacou escaped with only minor damage and no loss of life. Total losses on this island were estimated at $\$ 35,000$ to property, $\$ 5,000$ to crops and $\$ 2,500$ to livestock" (Rhodes).

October 6: HWM indicates a storm with a pressure of most $1010 \mathrm{mb}$ near $13.5 \mathrm{~N}, 64 \mathrm{~W}$. HURDAT lists this as a Category 2 hurricane with $85 \mathrm{kt}$ winds at $13.2 \mathrm{~N}, 64.1 \mathrm{~W}$ at 12 UTC. Station highlight: No gales or low pressures. Ship highlight: $35 \mathrm{kt} \mathrm{NW}$ with pressure of $1002 \mathrm{mb}$ at $12.9 \mathrm{~N}, 62.8 \mathrm{~W}$ at $0625 \mathrm{UTC}$ (USWB). Aircraft highlight: 90kt with pressure of $998 \mathrm{mb}$ at $12.5 \mathrm{~N}, 64.3 \mathrm{~W}$ at $1200 \mathrm{UTC}$ (NAVY).

October 7: HWM indicates a storm with a pressure of at most $1005 \mathrm{mb}$ near $13 \mathrm{~N}, 64 \mathrm{~W}$. HURDAT lists this as a Category 3 hurricane with $105 \mathrm{kt}$ winds at $13.3 \mathrm{~N}, 68.2 \mathrm{~W}$ at 12 UTC. Station highlight: No gales or low pressures. Ship highlight: 35kt ENE with pressure of $1010 \mathrm{mb}$ at $15.4 \mathrm{~N}, 68.1 \mathrm{~W}$ at $1800 \mathrm{UTC}$ (COA). Aircraft highlight: 110kt with pressure of $997 \mathrm{mb}$ at $12.9 \mathrm{~N}, 68.7 \mathrm{~W}$ at 1153 UTC (NAVY). "Highest winds were $115 \mathrm{mph}$ on the 7 th ... as estimated by reconnaissance aircraft" (MWR).

October 8: HWM indicates a storm with a pressure of at most $1000 \mathrm{mb}$ near $13.8 \mathrm{~N}, 72 \mathrm{~W}$. HURDAT lists this as a Category 3 hurricane with $110 \mathrm{kt}$ winds at $13.6 \mathrm{~N}, 70.9 \mathrm{~W}$ at 12 UTC. Station highlight: No gales or low pressures. Ship highlight: No gales or low pressures. Aircraft highlight: $100 \mathrm{kt}$ with pressure of $986 \mathrm{mb}$ at $13.5 \mathrm{~N}, 71.9 \mathrm{~W}$ at 1200 UTC (NAVY). Highest winds estimated by reconnaissance aircraft were "125mph on the 8th" (MWR). Also on the 8th, "the Navy reconnaissance plane encountered severe turbulence and one member of the crew was severely injured, requiring hospitalization, and another sustained minor injuries" (MWR).

October 9: HWM indicates a storm with a pressure of at most $995 \mathrm{mb}$ near $14 \mathrm{~N}, 73.9 \mathrm{~W}$. HURDAT lists this as a Category 4 hurricane with $115 \mathrm{kt}$ winds at $13.6 \mathrm{~N}, 73.7 \mathrm{~W}$ at 12 UTC. Station highlight: No gales or low pressures. Ship highlight: 10kt E with pressure of $999 \mathrm{mb}$ at $12.8 \mathrm{~N}, 70.2 \mathrm{~W}$ at $1200 \mathrm{UTC}$ (COA). Aircraft highlight: No gales or low 
pressures. The MWR Tracks of Centers of Cyclones at Sea Level showed a center at 14N, 74W with 990mb (12 UTC). "[Hazel] continued on a west to west-northwest course until the night of the 9th-10th when it slowed down in forward speed and curved northward" (MWR).

October 10: HWM indicates a storm with a pressure of at most 990mb near $15.3 \mathrm{~N}, 76 \mathrm{~W}$. HURDAT lists this as a Category 3 hurricane with $105 \mathrm{kt}$ winds at $15.0 \mathrm{~N}, 75.6 \mathrm{~W}$ at 12 UTC. Station highlight: No gales or low pressures. Ship highlights: 55kt E with pressure of $1000 \mathrm{mb}$ at $15.4 \mathrm{~N}, 75.5 \mathrm{~W}$ at $1800 \mathrm{UTC}(\mathrm{COA}) ; 35 \mathrm{kt} \mathrm{SW}$ with pressure of $992 \mathrm{mb}$ at $14.6 \mathrm{~N}, 75.3 \mathrm{~W}$ at $1800 \mathrm{UTC}$ (COA). Aircraft highlight: $100 \mathrm{kt}$ at $15.2 \mathrm{~N}, 75.6 \mathrm{~W}$ at 1441 UTC (NAVY). The MWR Tracks of Centers of Cyclones at Sea Level showed a center at $14 \mathrm{~N}, 15 \mathrm{~W}$ (0 UTC) and at $14.8 \mathrm{~N}, 75.5 \mathrm{~W}$ with $990 \mathrm{mb}$ (12 UTC). "The hurricane moved on a north-northeast course from the night of the 10th-11th until it passed through the Windward Channel and into the southeast Bahamas on the morning of the 13th" (MWR).

October 11: HWM indicates a storm with a pressure of at most $990 \mathrm{mb}$ near $16.5 \mathrm{~N}, 75 \mathrm{~W}$. HURDAT lists this as a Category 3 hurricane with $105 \mathrm{kt}$ winds at $16.5 \mathrm{~N}, 75.1 \mathrm{~W}$ at 12 UTC. Station highlight: 44kt NNW with pressure of $1001 \mathrm{mb}$ at Morant Point (17.9N, $76.2 \mathrm{~W}$ ) at 1800 UTC (USWB). Ship highlights: 52kt NNE with pressure of $1001 \mathrm{mb}$ at $16.3 \mathrm{~N}, 75.9 \mathrm{~W}$ at $0700 \mathrm{UTC}$ (USWB); 30kt ESE with pressure of $995 \mathrm{mb}$ at $15.8 \mathrm{~N}, 74.6 \mathrm{~W}$ at 0000 UTC (COA). Aircraft highlight: $35 \mathrm{kt} \mathrm{ENE} \mathrm{at} 18.2 \mathrm{~N}, 75.6 \mathrm{~W}$ at $1330 \mathrm{UTC}$ (USWB). The MWR Tracks of Centers of Cyclones at Sea Level showed a center at $15.5 \mathrm{~N}, 75.5 \mathrm{~W}$ (0 UTC) and at 16.3N, 75.2W with $988 \mathrm{mb}$ (12 UTC).

October 12: HWM indicates a storm with a pressure of at most $990 \mathrm{mb}$ near $19 \mathrm{~N}, 74 \mathrm{~W}$. HURDAT lists this as a Category 2 hurricane with $85 \mathrm{kt}$ winds at $18.7 \mathrm{~N}, 73.8 \mathrm{~W}$ at 12 UTC. Station highlight: 30kt NE with pressure of 998 at Baracoa at 2130 UTC (USWB). Ship highlights: $50 \mathrm{kt} \mathrm{S}$ with pressure of $1005 \mathrm{mb}$ at $16.4 \mathrm{~N}, 72.4 \mathrm{~W}$ at $0000 \mathrm{UTC}$ (COA); $12 \mathrm{kt}$ ESE with pressure of $999 \mathrm{mb}$ at $19.3 \mathrm{~N}, 73.8 \mathrm{~W}$ at $0230 \mathrm{UTC}$ (USWB). Aircraft highlight: $61 \mathrm{kt} \mathrm{E}$ at $20.0 \mathrm{~N}, 74.0 \mathrm{~W}$ at 1815 UTC (USWB). The MWR Tracks of Centers of Cyclones at Sea Level showed a center at 17.4N, 74.9W (0 UTC) and at 18.9N, 74.2W with $988 \mathrm{mb}$ (12 UTC). "Considerable damage and loss of life resulted in Haiti, especially on the SW peninsula. This area is very mountainous, with peaks of $8,000 \mathrm{ft}$ in the western portion. High winds and seas and torrential rains resulting in floods and landslides accounted for the loss of life, estimated between 400 and 1,000 including 200 or more buried in landslides" (MWR). "The center passed over the western tip of the south peninsula of Haiti during the early morning of October 12, and crossed the northwest peninsula that evening. The western portions of both Haitian peninsula were devastated by the hurricane. Several towns were almost totally demolished, including Dame Marie, 
Anse d' Hainault, Mole St. Nicolas, and Jean Rabel. The larger cities of Jeremie, Les Cayes, and Port de Paix suffered severe damage from hurricane winds. High tides on the southern coast from Les Cayes westward added to the destruction. Torrential rains fell over most of Haiti, flooding rivers, washing out roads, and destroying property, livestock, and crops. A landslide caused by heavy rains a few days after the hurricane buried the mountain village of Berley...Estimates of total damage in Haiti are not available. The number of deaths were estimated between 400 and 1,000, including 200 or more buried in the landslide. Extreme winds of $125 \mathrm{mph}$ at several places in the western part of the southern peninsula were reported by the Coprs d'Aviation, Bowen Field, Port-au-Prince, Haiti" (Rhodes).

October 13: HWM indicates a storm with a pressure of at most $990 \mathrm{mb}$ near $20.6 \mathrm{~N}, 73 \mathrm{~W}$. HURDAT lists this as a Category 2 hurricane with $85 \mathrm{kt}$ winds at $21.0 \mathrm{~N}, 73.2 \mathrm{~W}$ at 12 UTC. Station highlight: $22 \mathrm{kt}$ ENE with pressure of $994 \mathrm{mb}$ at Great Inagua (20.9N, $73.6 \mathrm{~W})$ at $1200 \mathrm{UTC}(\mathrm{HWM}) ; 52 \mathrm{kt} \mathrm{SSW}$ at Mayaguana $(22.3 \mathrm{~N}, 72.9 \mathrm{~W})$ at $21.30 \mathrm{UTC}$ (USWB). Ship highlight: $35 \mathrm{kt} \mathrm{W}$ with pressure of $1005 \mathrm{mb}$ at $17.5 \mathrm{~N}, 73.8 \mathrm{~W}$ at $0000 \mathrm{UTC}$ (COA); 30kt NNW with pressure of $999 \mathrm{mb}$ at $20.2 \mathrm{~N}, 74.3 \mathrm{~W}$ at $0630 \mathrm{UTC}$ (USWB). Aircraft highlight: $100 \mathrm{kt}$ with pressure of $974 \mathrm{mb}$ at $22.2 \mathrm{~N}, 73.5 \mathrm{~W}$ at $2136 \mathrm{UTC}$ (NAVY); $80 \mathrm{kt}$ with pressure of $972 \mathrm{mb}$ at $21.6 \mathrm{~N}, 73.4 \mathrm{~W}$ at 1615 UTC (NAVY). The MWR Tracks of Centers of Cyclones at

Sea Level showed a center at 20N, 73.5W (0 UTC) and at 21N, 73W with $987 \mathrm{mb}(12$ UTC). "[Hazel] changed course to north then to north-northwest on the 13th, continuing on that course until it passed inland on the North Carolina coast about 0915 EST of the 15th" (MWR). "After passing through the Windward Channel the hurricane moved northward and passed directly over the Island of Great Inagua and between Mayaguana and Acklin Islands, and passed a short distance east of the remainder of the Bahamas. A minimum pressure of 29.34 inches and a maximum wind of only $40 \mathrm{mph}$ were reported at Great Inagua Island. The low wind speed was thought to be due to distortion of the hurricane in its passage through the mountainous terrain bordering the Windward Channel. Damage was minor in the Bahamas. Six lives were lost out of a total of 15 aboard a sailboat that capsized when it was trying to take shelter at Inagua" (Rhodes). "Hazel - October 12-13 - Category 1 impact in Cuba" (Perez).

October 14: HWM indicates a storm with a pressure of at most $990 \mathrm{mb}$ near $25.5 \mathrm{~N}$, 74.6W. HURDAT lists this as a Category 3 hurricane with $105 \mathrm{kt}$ winds at $25.5 \mathrm{~N}, 74.6 \mathrm{~W}$ at 12 UTC. Station highlight: $52 \mathrm{kt} \mathrm{SSW}$ at Mayuguana at 0030 UTC (USWB); 30kt ENE with pressure of $992 \mathrm{mb}$ at San Salvador at 0930 UTC (USWB). Ship highlight: 52kt NE with pressure of $988 \mathrm{mb}$ at $28.2 \mathrm{~N}, 77.5 \mathrm{~W}$ at $2130 \mathrm{UTC}$ (USWB); $26 \mathrm{kt} \mathrm{N}$ with pressure of $982 \mathrm{mb}$ at $33.2 \mathrm{~N}, 77.8 \mathrm{~W}$ at $2330 \mathrm{UTC}$ (USWB). Aircraft highlight: $52 \mathrm{kt} \mathrm{SE}$ at $27.8 \mathrm{~N}$, 
$72.5 \mathrm{~W}$ at $1354 \mathrm{UTC}$ (USWB); $100 \mathrm{kt}$ with pressure of $974 \mathrm{mb}$ at $22.5 \mathrm{~N}, 73.4 \mathrm{~W}$ at 0045 UTC (NAVY). The MWR Tracks of Centers of Cyclones at Sea Level showed a center at $23.1 \mathrm{~N}, 73 \mathrm{~W}$ (0 UTC) and at $25.5 \mathrm{~N}, 74 \mathrm{~W}$ with $987 \mathrm{mb}$ (12 UTC). "Storm warnings were hoisted at 1100 EST on the 14th from Charleston, S.C., northward on the Virginia Capes, and the remainder of the coast northward to New England was placed on the alert by Washington and Boston Weather Bureau offices" (MWR).

October 15: HWM indicates a closed low of at most $980 \mathrm{mb}$ near $33 \mathrm{~N}, 78.5 \mathrm{~W}$. HURDAT lists this as a Category 3 hurricane with $110 \mathrm{kt}$ winds at $32.8 \mathrm{~N}, 78.7 \mathrm{~W}$ at $12 \mathrm{UTC}$. Station highlight: 70kt SW at Kinston at 1845 UTC (SWO); $966 \mathrm{mb}$ at Spartanburg (34.9N, $81.9 \mathrm{~W}$ ) at $1750 \mathrm{UTC}$ (SWO). Ship highlight: $35 \mathrm{kt} \mathrm{N}$ with pressure of $972 \mathrm{mb}$ at $31.3 \mathrm{~N}$, $78.8 \mathrm{~W}$ at $0800 \mathrm{UTC}$ (USWB); $70 \mathrm{kt}$ ENE with pressure of $1006 \mathrm{mb}$ at $32.4 \mathrm{~N}, 77.8 \mathrm{~W}$ at 0000 UTC (COA). Aircraft highlight: No gales or low pressures. The MWR Tracks of Centers of Cyclones at Sea Level showed a center at 28.9N, 76.8W (0 UTC) and at $33.8 \mathrm{~N}, 78.5 \mathrm{~W}$ with $976 \mathrm{mb}$ (12 UTC). "During the 14th and 15th, and until the hurricane passed inland, the highest winds were estimated in all warning messages in excess of $100 \mathrm{mph}$. Wilmington, N.C., reported a top gust of $98 \mathrm{mph}$ and the fastest mile was $82 \mathrm{mph}$. Minimum pressure there was 28.68in. Myrtle Beach, S.C., reported top gusts of $106 \mathrm{mph}$ and lowest pressure reported of 28.47in. (This was the lowest pressure reported on land although 27.70in was reported by a fishing boat at Tilgham Point while in the eye of the storm at 10:30 a.m. EST.) Wind estimates from several points between Myrtle Beach and Cape Fear varied from 130 to $150 \mathrm{mph}$. The devastation along the North and South Carolina beaches was staggering. Every pier in a distance of 170 miles of coastline was demolished and whole lines of beach homes literally disappeared. In some places the tide was over $17 \mathrm{ft}$ higher than the mean low water" (MWR). "Total casualties in the Carolinas were 20, most of which were drownings. Damage to the Carolinas is estimated at around \$163 million with \$36 million from the N. Carolina beach area, \$25 million from the S. Carolina beach area, and the remainder from crop and property losses in the interior" (MWR). "More than one half of the total damage in the US occurred in N. Carolina" (Seamon). "Long Beach (NC) was completely destroyed with all of its 300 houses gone, as was Holden Beach with lost all of its 200 houses, and Ocean Isle where no houses remained" (Seamon). "Total losses for South Carolina totaled \$27,000,000 all occurring along the coast except $\$ 2,000,000$ in the interior" (Seamon). "Tropical Cyclones in the South Atlantic States - Carolinas and Georgia - 1954 - Oct. 15 (Hazel) Carolinas - Extreme [Category 4 or 5] - 20 killed, damage $\$ 163,000,000$. Tropical Cyclones in the Middle Atlantic States - 1954 - Oct. 15 (Hazel) - All Sections - Major [Category 2 or 3] - 74 killed, damage \$88,595,000" (Dunn and Miller). "1011 mb environmental pressure, $114 \mathrm{kt}$ maximum sustained winds at the coast" (Schwerdt et al.). "Hazel - Oct. 15 - $938 \mathrm{mb}$ central pressure at landfall - $25 \mathrm{nmi}$ RMW - $26 \mathrm{kt}$ forward 
speed - 33.9N, 78.5W landfall point" (Ho et al.) "1954 Oct SC, NC 4; MD, 2 - 938 mb central pressure - Hazel" (Jarrell et al.)

October 16: HWM indicates a closed low of at most $985 \mathrm{mb}$ near $51 \mathrm{~N}, 79.5 \mathrm{~W}$. HURDAT lists this as an Extratropical storm with $50 \mathrm{kt}$ winds at $48.8 \mathrm{~N}, 80.0 \mathrm{~W}$ at $12 \mathrm{UTC}$. Station highlight: 60kt SE at Binghampton (42.1N, 75.9W) at $0246 \mathrm{UTC}$ (SWO); $975 \mathrm{mb}$ at Sampson AFB (42.8N, 76.9W) at 0226 UTC (SWO); $984 \mathrm{mb}$ and $12 \mathrm{kt} \mathrm{N}$ at Kirkland Lake, Canada (47.7N, 79.8W) at 1130 UTC (USWB). $990 \mathrm{mb}$ and $12 \mathrm{kt} \mathrm{NW}$ at Moosonee, Canada (51.3N, 80.7W) at 1730 UTC (USWB). Ship highlight: 45kt SE with pressure of $998 \mathrm{mb}$ at $0000 \mathrm{UTC}$ at $40.1 \mathrm{~N}, 73.4 \mathrm{~W}$ (COA); $45 \mathrm{kt}$ SE with pressure of $998 \mathrm{mb}$ at $40.1 \mathrm{~N}, 73.4 \mathrm{~W}$ at $0000 \mathrm{UTC}$. Aircraft highlight: No gales or low pressures. The MWR Tracks of Centers of Cyclones at Sea Level showed a center at 42N, 78W (0 UTC) and at $48.8 \mathrm{~N}, 79.5 \mathrm{~W}$ with $981 \mathrm{mb}$ (12 UTC). "Twenty-one deaths were attributed to Hazel in New York and damage ran in the millions. Heavy rains in the extreme west flooded basements and washed out several bridges" (Seamon).

October 17: HWM indicates a closed low of at most 995mb near 56N, 77W. HURDAT lists this as an Extratropical storm with $35 \mathrm{kt}$ winds at $54.0 \mathrm{~N}, 78.2 \mathrm{~W}$ at $12 \mathrm{UTC}$. Station highlight: $43 \mathrm{kt}$ SE $993 \mathrm{mb}$ at $55.0 \mathrm{~N}, 780 . \mathrm{W}$ at 1200 UTC. No ship or Aircraft data. The MWR Tracks of Centers of Cyclones at Sea Level showed a center at 52N, 79W (0 UTC) and at $53.4 \mathrm{~N}, 77.5 \mathrm{~W}$ with $990 \mathrm{mb}$ (12 UTC).

October 18: HWM indicates a closed low of at most 990mb near 61N, 56W. HURDAT lists this as an Extratropical storm with $25 \mathrm{kt}$ winds at $58.8 \mathrm{~N}, 65.1 \mathrm{~W}$ at $12 \mathrm{UTC}$. The MWR Tracks of Centers of Cyclones at Sea Level showed a center at 57N, 72.5W (0 UTC). Station highlight: $993 \mathrm{mb}$ at $63.0 \mathrm{~N}, 49.0 \mathrm{~W}$ at $1200 \mathrm{UTC}$. No ship or aircraft data.

No change is made to the genesis of Hazel, though the first report in HURDAT is now begun with a $40 \mathrm{kt}$ intensity rather than $60 \mathrm{kt}$ originally. Track changes are introduced for the entire lifecycle of Hazel, but all are minor adjustments. A central pressure of $1002 \mathrm{mb}$ with a tiny eye diameter of $4 \mathrm{~nm}$ was measured by aircraft reconnaissance at 2037 UTC on the 5th along with estimated winds of $85 \mathrm{kt}$. (From here on in, the estimated winds will not be mentioned, as they are unreliable.) $1002 \mathrm{mb}$ central pressure suggests maximum winds of $43 \mathrm{kt}$ from the Brown et al. south of $25 \mathrm{~N}$ pressure-wind relationship. Given the extremely tiny size and slightly weighting the estimated winds, the intensities are chosen to be $55 \mathrm{kt}$ at $18 \mathrm{UTC}$ and $65 \mathrm{kt}$ at $00 \mathrm{UTC}$ on the 6th, down from 70 and $75 \mathrm{kt}$, respectively. A central pressure of $998 \mathrm{mb}$ was observed twice, once with an eye diameter of $10 \mathrm{~nm}$ and and once with $5 \mathrm{~nm}$ by aircraft at 12 UTC and 1920 UTC. $998 \mathrm{mb}$ central pressure suggests maximum winds of $51 \mathrm{kt}$ from the south of $25 \mathrm{~N}$ pressure-wind relationship. At 12 and $18 \mathrm{UTC}$, the intensities are analyzed to be $70 \mathrm{kt}$ due to the tiny size of Hazel - down from 85 kt originally. On the 7th, aircraft measured 
central pressure of $997 \mathrm{mb}$ with a $7 \mathrm{~nm}$ eye at $1153 \mathrm{UTC}$ and $994 \mathrm{mb}$ with a $10 \mathrm{~nm}$ eye at 1930 UTC. These pressures suggest maximum winds of 53 and $58 \mathrm{kt}$, respectively, from the south of $25 \mathrm{~N}$ pressure-wind relationship. Intensities are set at $70 \mathrm{kt}$ at 12 and $18 \mathrm{UTC}$ on the 7 th (down from $105 \mathrm{kt}$ originally) due to the small size of Hazel. At 12 UTC on the 8th, aircraft reconnaissance measured $986 \mathrm{mb}$ central pressure with an eye diameter of $25 \mathrm{~nm}$. This suggests maximum winds of $70 \mathrm{kt}$ from the south of $25 \mathrm{~N}$ pressure-wind relationship. Maximum winds chosen to be $75 \mathrm{kt}$ (down from $110 \mathrm{kt}$ originally) from a blend of the deepening the occurred between the $7^{\text {th }}$ and the $8^{\text {th }}$ but also accounting for the inner core size of the hurricane becoming larger. This was the last aircraft penetration for five days until the 13th. From the 9th until the 12th, Hazel moved over the central Caribbean Sea with no ships, aircraft, or land stations within the inner core of strongest winds and lowest pressure. Thus maximum winds are gradually ramped up from $75 \mathrm{kt}$ at the 12 UTC on the 8th to the $105 \mathrm{kt}$ originally shown in HURDAT by 12 UTC on the 10th. The resulting reduction in maximum winds on the $9^{\text {th }}$ (from $115 \mathrm{kt}$ down to $95 \mathrm{kt}$ at 12 UTC) is somewhat supported by the ragged and open eye reported from the radar aircraft reports on that date. By the 10th and 11th, the radar observations suggest a smaller and closed eye, suggesting the Category 3 conditions originally shown in HURDAT are reasonable.

Hazel's landfall in Haiti was disastrous for that country, and while no measured extreme observations were available, retaining Hazel as a $105 \mathrm{kt}$ hurricane at landfall appears to be prudent. After passing Haiti (with some weakening likely due to interaction with the mountainous island), Hazel moved slowly off to the north over the Atlantic. The $994 \mathrm{mb}$ central pressure in HURDAT originally at 12 UTC on the 13th is erroneous. This value was from Great Inagua, but they were not in the eye at the time, so the value is a peripheral measurement. Aircraft penetrations at 1615 UTC (13th), 2136 UTC (13th), and 0045 UTC (14th) measured $972 \mathrm{mb}, 974 \mathrm{mb}$ with an eye diameter of $17 \mathrm{~nm}$, and 974 $\mathrm{mb}$ with an eye diameter of $15 \mathrm{~nm}$, respectively. These central pressures suggest maximum winds of 88,85 , and $85 \mathrm{kt}$ from the southern pressure-wind relationship. $85 \mathrm{kt}$ at 18 UTC on the 13 th and at 00 UTC on the $14^{\text {th }}$ are chosen for HURDAT, the same as original at 18 UTC and down from $90 \mathrm{kt}$ originally at $00 \mathrm{UTC}$.

No further aircraft penetrations were available for the next 36 hours until landfall in the Carolinas. A ship at the Carolina's coast reported a central pressure in the eye of Hazel of $938 \mathrm{mb}$ at $1530 \mathrm{UTC}$ on the 15th. Aircraft radar suggested an eye diameter of $18 \mathrm{~nm}$, which is equivalent to roughly 13-14 nm RMW (Kimball and Mulekar 2004). Assuming that the $938 \mathrm{mb}$ is the central pressure at landfall (which agrees with Ho et al. and Jarrell et al.), this value suggests maximum winds of $116 \mathrm{kt}$ from the Brown et al. north of $25 \mathrm{~N}$ pressure-wind relationship. The RMW size being smaller than climatology for this pressure and latitude $(23 \mathrm{~nm})$ and fast moving ( $25 \mathrm{kt}$ at landfall) would argue for a 
slightly stronger wind for this pressure, while the roughly $1008 \mathrm{mb}$ outer closed isobar would suggest slightly less winds. Winds are thus estimated to be $120 \mathrm{kt}$ at landfall, keeping it a Category 4 hurricane. As Hazel made landfall right at the North Carolina/South Carolina border, it is estimated that South Carolina missed experiencing the peak (Category 4) winds and is thus assessed as a Category 3 impact. The winds in HURDAT are adjusted up slightly at 12 UTC on the 15 th from $110 \mathrm{kt}$ to $115 \mathrm{kt}$. After landfall, peak observed winds within 2 hours of the synoptic times were $70 \mathrm{kt}$ at Kinston, NC around 18 UTC on the 15th and $60 \mathrm{kt}$ at Philadelphia, PA around 00 UTC on the 16th. A run of the Kaplan/DeMaria inland decay model suggests winds of $68 \mathrm{kt}$ at 18 UTC on the 15 th, though the system was judged to be extratropical at that point (unchanged from originally in HURDAT), so the Kaplan/DeMaria model may not be very applicable by this time. $80 \mathrm{kt}$ are retained in HURDAT at $18 \mathrm{UTC}$ on the $15 \mathrm{th}$. Given the extratropical transition occurring around 18 UTC on the 15th while the system was over North Carolina, impacts farther north would not be considered as a tropical cyclone. It should be noted that observed $1 \mathrm{~min}$ hurricane force winds were also observed in Virginia and Washington D.C., and likely also occurred in Maryland, Pennsylvania, and New York as well. Thus the "MD2" (Maryland - Saffir-Simpson Hurricane Scale Category 2) originally in HURDAT is removed. A couple of analyzed central pressures of $982 \mathrm{mb}$ and $988 \mathrm{mb}$ were added for 12 and 18 UTC on the 16th based upon land-based observations. Post-tropical Hazel likely was absorbed by a larger extratropical low by 12 UTC on the 18th, thus this position is removed from HURDAT.

Unnamed Tropical Storm 10 [November 16-21, 1954]

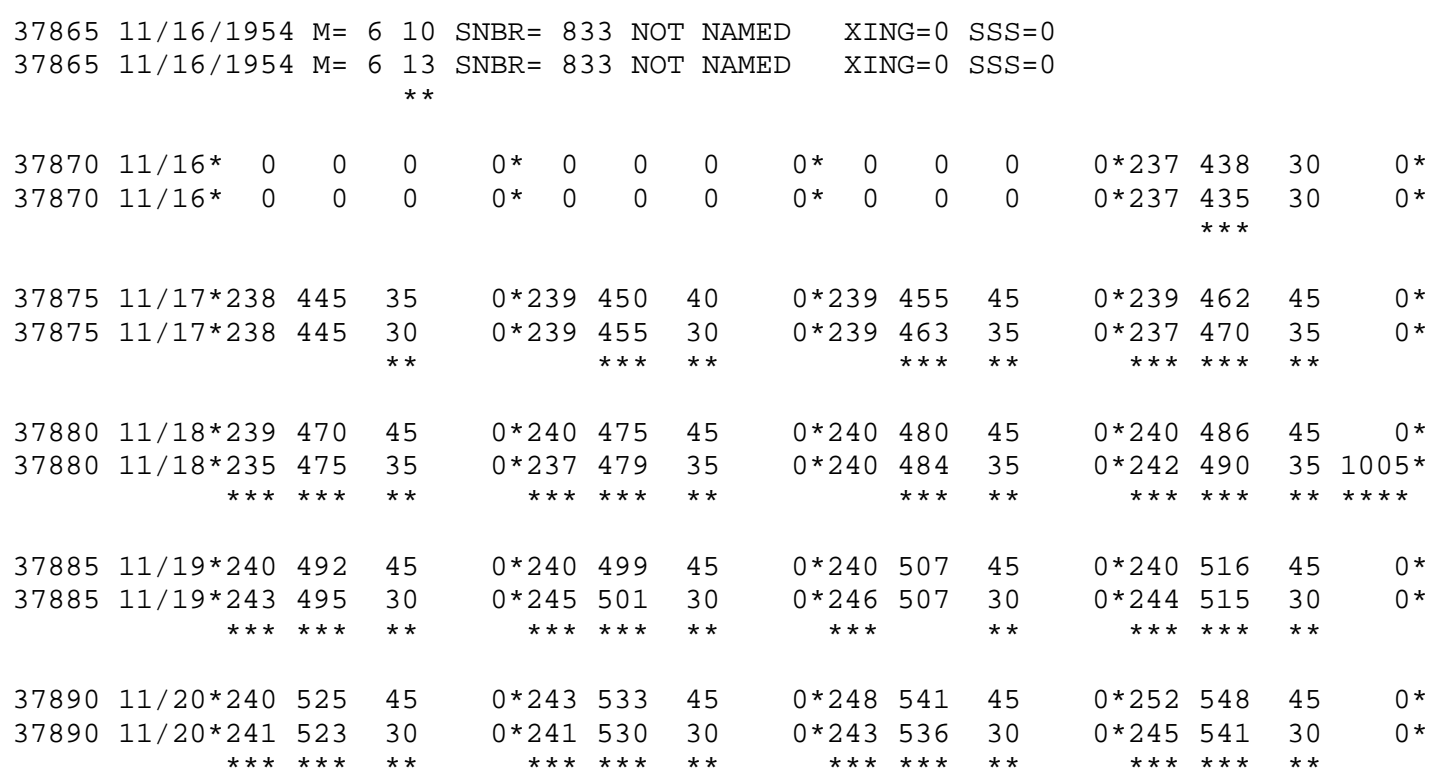


$3789511 / 21$ *255 55645

$3789511 / 21 * 246551$
$* * *$
$* * *$

0 *256 56340

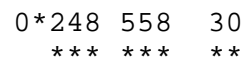

○*258 $571 \quad 30$

○*256 $57825 \quad 0$ *

37900 TS

Minor changes to the track and intensity shown in McAdie et al. (2009). Evidence for these alterations comes from the NHC microfilm maps, the Historical Weather Maps series, and the COADS ship database.

November 16:

HWM analyzes a warm front between $23 \mathrm{~N}$ and $35 \mathrm{~N}$ and near $43 \mathrm{~W}$. HURDAT lists this as a $30 \mathrm{kt}$ tropical depression at $23.9 \mathrm{~N}, 43.8 \mathrm{~W}$ at $18 \mathrm{Z}$. Ship highlights: $20 \mathrm{kt} \mathrm{SE}$ and $1009 \mathrm{mb}$ at $18 \mathrm{Z}$ near $23.9 \mathrm{~N}, 41.2 \mathrm{~W}$ (COADS).

November 17:

HWM analyzes a low pressure of at most $1010 \mathrm{mb}$ centered near $23.5 \mathrm{~N}, 46.5 \mathrm{~W}$. HURDAT lists this as a $45 \mathrm{kt}$ tropical storm at $23.9 \mathrm{~N}, 45.5 \mathrm{~W}$ at 12Z. Ship highlights: 15 $\mathrm{kt} \mathrm{N}$ and $1011 \mathrm{mb}$ at $0 \mathrm{Z}$ near $24.2 \mathrm{~N}, 46.2 \mathrm{~W}$ (COADS). $15 \mathrm{kt} \mathrm{SE}$ and $1013 \mathrm{mb}$ at $0 \mathrm{Z}$ near $22.0 \mathrm{~N}, 42.9 \mathrm{~W}$ (COADS). $25 \mathrm{kt} \mathrm{SE}$ and $1012 \mathrm{mb}$ at $0 \mathrm{Z}$ near $23.2 \mathrm{~N}, 39.9 \mathrm{~W}$ (COADS). 15 $\mathrm{kt} \mathrm{N}$ and $1010 \mathrm{mb}$ at $06 \mathrm{Z}$ near $23.5 \mathrm{~N}, 47.0 \mathrm{~W}$ (COADS). $25 \mathrm{kt} \mathrm{N}$ and $1011 \mathrm{mb}$ at $12 \mathrm{Z}$ near $23.9 \mathrm{~N}, 48.8 \mathrm{~W}$ (HWM). $30 \mathrm{kt} \mathrm{NE}$ and $1014 \mathrm{mb}$ at $12 \mathrm{Z}$ near $27.0 \mathrm{~N}, 47.0 \mathrm{~W}$ (COADS). $15 \mathrm{kt} \mathrm{NNW}$ and $1010 \mathrm{mb}$ at $18 \mathrm{Z}$ near $22.0 \mathrm{~N}, 48.7 \mathrm{~W}$ (COADS).

November 18:

HWM analyses a low pressure of at most $1010 \mathrm{mb}$ centered near $24.1 \mathrm{~N}, 47.9 \mathrm{~W}$. HURDAT lists this as a $45 \mathrm{kt}$ tropical storm at $24.0 \mathrm{~N}, 48.0 \mathrm{~W}$ at $12 \mathrm{Z}$. Ship highlights: 30 $\mathrm{kt}$ ENE and $1013 \mathrm{mb}$ at $0 \mathrm{Z}$ near $28.3 \mathrm{~N}, 49.4 \mathrm{~W} .10 \mathrm{kt} \mathrm{NW}$ and $1010 \mathrm{mb}$ at $0 \mathrm{Z}$ near $21.4 \mathrm{~N}$, $49.3 \mathrm{~W} .15 \mathrm{kt} \mathrm{WSW}$ and $1008 \mathrm{mb}$ at $06 \mathrm{Z}$ near $27.2 \mathrm{~N}, 46.2 \mathrm{~W} .10 \mathrm{kt}$ ENE and $1006 \mathrm{mb}$ at $18 \mathrm{Z}$ near $25.4 \mathrm{~N}, 49.1 \mathrm{~W} .15 \mathrm{kt} \mathrm{WSW}$ and $1007 \mathrm{mb}$ at $18 \mathrm{Z}$ near $23.9 \mathrm{~N}, 49.2 \mathrm{~W}$. All observations from COADS.

November 19:

HWM analyses a low pressure of at most $1010 \mathrm{mb}$ centered near $24.5 \mathrm{~N}, 49.8 \mathrm{~W}$. HURDAT lists this as a $45 \mathrm{kt}$ tropical storm at $24.0 \mathrm{~N}, 50.7 \mathrm{~W}$ at $12 \mathrm{Z}$. Ship highlights: 10 $\mathrm{kt}$ ENE and $1008 \mathrm{mb}$ at $0 \mathrm{Z}$ near $24.5 \mathrm{~N}, 50.6 \mathrm{~W} .10 \mathrm{kt} \mathrm{NW}$ and $1008 \mathrm{mb}$ at $06 \mathrm{Z}$ near 23.6N, 51.9W. $25 \mathrm{kt} \mathrm{NE}$ and $1012 \mathrm{mb}$ at $12 \mathrm{Z}$ near 26.5N, 53.4W. $10 \mathrm{kt} \mathrm{NNW}$ and 1011 $\mathrm{mb}$ at $12 \mathrm{Z}$ near $22.6 \mathrm{~N}, 53.3 \mathrm{~W}$. $20 \mathrm{kt} \mathrm{NE}$ and $1009 \mathrm{mb}$ at $18 \mathrm{Z}$ near $25.3 \mathrm{~N}, 52.9 \mathrm{~W}$. All observations from COADS.

November 20: 
HWM analyses a low pressure of at most $1010 \mathrm{mb}$ centered near 23.1N, 54.2W. HURDAT lists this as a $45 \mathrm{kt}$ tropical storm at $24.8 \mathrm{~N}, 54.1 \mathrm{~W}$ at $12 \mathrm{Z}$. Ship highlights: 15 $\mathrm{kt} \mathrm{NE}$ and $1012 \mathrm{mb}$ at $0 \mathrm{Z}$ near $24.5 \mathrm{~N}, 53.4 \mathrm{~W} .30 \mathrm{kt} \mathrm{ENE}$ and $1015 \mathrm{mb}$ at $06 \mathrm{Z}$ near 29.1N, 55.3W. $15 \mathrm{kt} \mathrm{NE}$ and $1012 \mathrm{mb}$ at $12 \mathrm{Z}$ near 24.6N, 57.9W. $15 \mathrm{kt} \mathrm{NE}$ and $1011 \mathrm{mb}$ at $18 \mathrm{Z}$ near $25.2 \mathrm{~N}, 56.6 \mathrm{~W}$. All observations from COADS.

November 21:

HWM analyses a low pressure of at most $1010 \mathrm{mb}$ centered near $22.7 \mathrm{~N}, 55.2 \mathrm{~W}$. HURDAT lists this as a $30 \mathrm{kt}$ tropical depression at $25.8 \mathrm{~N}, 57.1 \mathrm{~W}$ at $12 \mathrm{Z}$. Microfilm shows a low pressure of at most $1011 \mathrm{mb}$ at $12 \mathrm{Z}$ near $22.5 \mathrm{~N}, 60.5 \mathrm{~W}$. Ship highlights: 30 $\mathrm{kt} \mathrm{SE}$ and $1012 \mathrm{mb}$ at $0 \mathrm{Z}$ near $25.6 \mathrm{~N}, 51.7 \mathrm{~W} .15 \mathrm{kt} \mathrm{NE}$ and $1011 \mathrm{mb}$ at $0 \mathrm{Z}$ near $26.0 \mathrm{~N}$, $55.5 \mathrm{~W} .30 \mathrm{kt} \mathrm{S}$ and $1013 \mathrm{mb}$ at $12 \mathrm{Z}$ near $24.5 \mathrm{~N}, 53.8 \mathrm{~W} .30 \mathrm{kt} \mathrm{SE}$ and $1019 \mathrm{mb}$ at $18 \mathrm{Z}$ near 25.6N, 51.7W. All observations from COADS.

No changes are made to the genesis time of this late season tropical storm. Minor track changes are introduced for the six day duration of this system. Numerous observations from ships on the 17 th to the $21 \mathrm{st}$ indicate that the cyclone was weaker than the $45 \mathrm{kt}$ shown in HURDAT for those dates. Based upon a $30 \mathrm{kt} \mathrm{NE}$ ship observation at $12 \mathrm{Z}$ on the $17 \mathrm{th}$, an intensity of $35 \mathrm{kt}$ is estimated at that time. This time is now the new onset of tropical storm intensity, twelve hours later than originally shown. A few other $30 \mathrm{kt}$ ship reports were observed between that date and the $21 \mathrm{st}$, but no gales were reported during the lifetime of this system. A central pressure of $1005 \mathrm{mb}$ is analyzed at $18 \mathrm{Z}$ on the $18 \mathrm{th}$, from a ship with $1006 \mathrm{mb}$ and $10 \mathrm{kt}$ ENE and another ship close by with $1007 \mathrm{mb}$ and 15 kt WSW. $1005 \mathrm{mb}$ central pressure suggests maximum winds of $37 \mathrm{kt}$ from the Brown et al. south of $25 \mathrm{~N}$ pressure-wind relationship and $34 \mathrm{kt}$ from the north of $25 \mathrm{~N}$ relationship. Given the structure with strongest winds 100-250 $\mathrm{nm}$ from the center (resembling a subtropical cyclone), intensity at this time is analyzed to be $35 \mathrm{kt}$, which could be somewhat generous. Numerous observations of higher pressure and lower winds on the 19th and the 20th strongly suggest that the cyclone weakened and the intensity is analyzed to be $30 \mathrm{kt}$ for all of the times of those two dates, down from $45 \mathrm{kt}$ originally in HURDAT. Thus the new peak intensity of this system is $35 \mathrm{kt}$ from $12 \mathrm{Z}$ on the 17 th until $18 \mathrm{Z}$ on the $18 \mathrm{th}$, down from $45 \mathrm{kt}$ originally. It is to be noted that there were no explicit tropical storm force winds observed in the reanalysis effort and it is possible that this system never truly achieved tropical storm intensity. However, the ship observations are not complete and therefore it is not conclusive in removing the system from HURDAT. Further weakening occurred on the 21 st, as the cyclone opened up to a trough after 18Z. No change to the dissipation stage is indicated. 
Hurricane Alice [December 30 - January 6, 1954-1955]

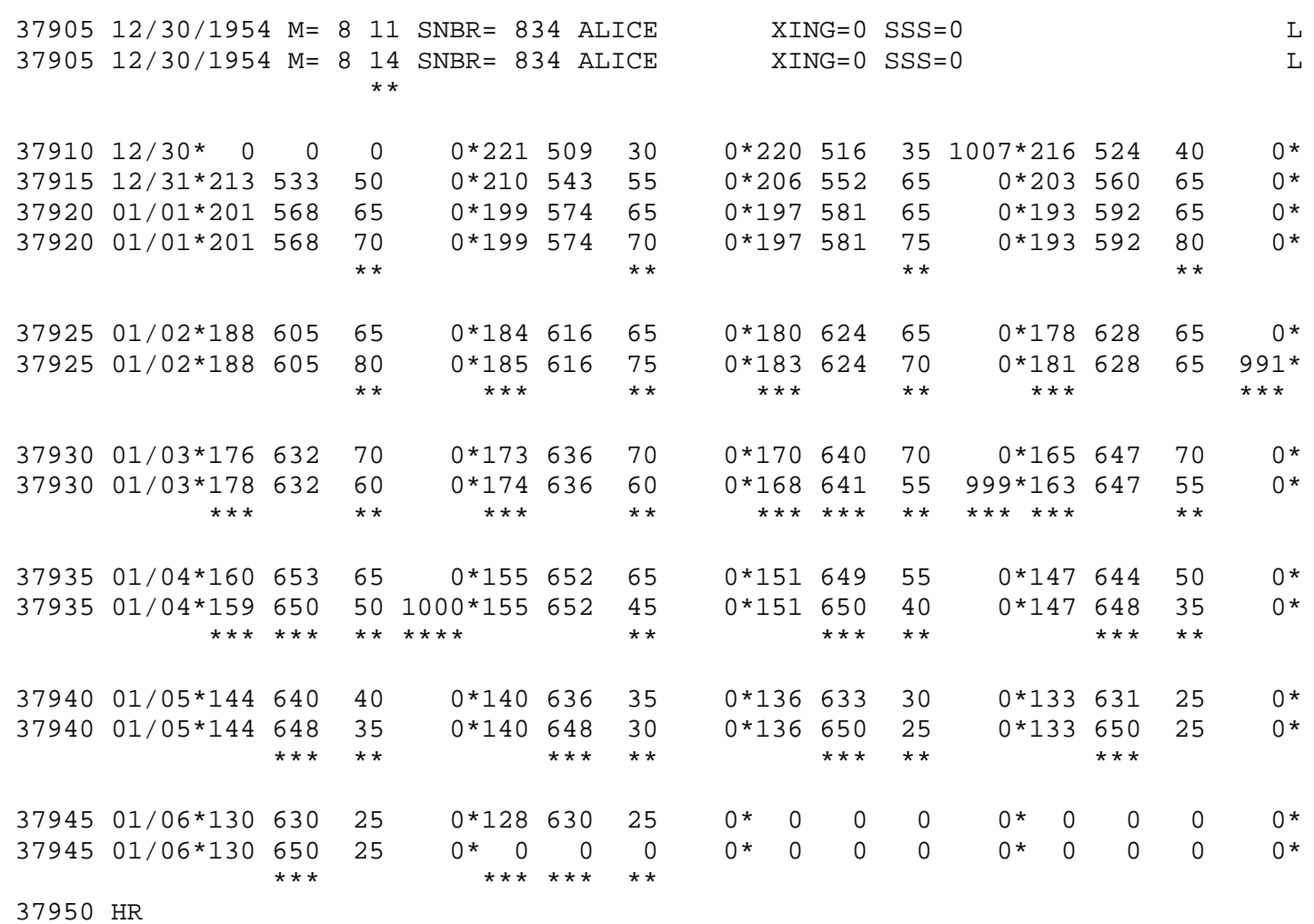

Major changes to both the track and intensity shown in McAdie et al. (2009). Evidence for these alterations comes from the NHC microfilm maps, the Historical Weather Maps series, the COADS ship database, the Navy aircraft reconnaissance book, and three Monthly Weather Review articles (the 1955 hurricane season summary, Colon (1956), and O'Neill and Jordan (1962)).

December 29:

HWM analyzes a low pressure of at most $1010 \mathrm{mb}$ centered near $19.5 \mathrm{~N}, 49.5 \mathrm{~W}$. HURDAT does not analyze this system. Ship highlights: $30 \mathrm{kt} \mathrm{E}$ and $1015 \mathrm{mb}$ at $00 \mathrm{Z}$ near $23.9 \mathrm{~N}, 45.1 \mathrm{~W} .30 \mathrm{kt}$ ENE and $1015 \mathrm{mb}$ at $12 \mathrm{Z}$ near $21.3 \mathrm{~N}, 53.8 \mathrm{~W} .35 \mathrm{kt} \mathrm{ENE}$ and $1013 \mathrm{mb}$ at $18 \mathrm{Z}$ near $22.1 \mathrm{~N}, 52.7 \mathrm{~W}$. All observations from COADS.

December 30:

HWM analyzes a low pressure of at most $1010 \mathrm{mb}$ centered near $22.0 \mathrm{~N}, 52.7 \mathrm{~W}$. HURDAT lists this as a $35 \mathrm{kt}$ tropical storm at $22.0 \mathrm{~N}, 51.6 \mathrm{~W}$ at 12Z. Ship highlights: 20 $\mathrm{kt} \mathrm{NE}$ and $1008 \mathrm{mb}$ at $06 \mathrm{Z}$ near $22.7 \mathrm{~N}, 51.7 \mathrm{~W} .30 \mathrm{kt} \mathrm{SE}$ and $1010 \mathrm{mb}$ at $12 \mathrm{Z}$ near $23.6 \mathrm{~N}$, $50.5 \mathrm{~W} .30 \mathrm{kt} \mathrm{S}$ and $1006 \mathrm{mb}$ at $12 \mathrm{Z}$ near $23.7 \mathrm{~N}, 50.9 \mathrm{~W} .40 \mathrm{kt} \mathrm{E}$ and $1011 \mathrm{mb}$ at $18 \mathrm{Z}$ near $23.9 \mathrm{~N}, 50.0 \mathrm{~W} .25 \mathrm{kt} \mathrm{S}$ and $1005 \mathrm{mb}$ at $18 \mathrm{Z}$ near $21.5 \mathrm{~N}, 53.6 \mathrm{~W}$. All observations from 
COADS. "A low pressure of extra-tropical or nature was noted some 600 miles northeast of the Leeward Islands on December 30 ..." (MWR) "The first tropical disturbance of the 1955 season was first detected as an easterly wave, labeled locally "December 1," on 30 December 1954 (Figure A-5).” (ATSR)

December 31:

HWM analyses a tropical storm of at most $1000 \mathrm{mb}$ centered near $21.5 \mathrm{~N}, 54.2 \mathrm{~W}$. HURDAT lists this as a $65 \mathrm{kt}$ hurricane at $20.6 \mathrm{~N}, 55.2 \mathrm{~W}$ at $12 \mathrm{Z}$. Microfilm shows a low pressure system located near $20.0 \mathrm{~N}, 55.5 \mathrm{~W}$ at 12Z. Ship highlights: $20 \mathrm{kt} \mathrm{SE}$ and 1007 $\mathrm{mb}$ at $00 \mathrm{Z}$ near $22.0 \mathrm{~N}, 53.0 \mathrm{~W} .30 \mathrm{kt} \mathrm{E}$ and $1014 \mathrm{mb}$ at $00 \mathrm{Z}$ near $24.8 \mathrm{~N}, 49.9 \mathrm{~W} .20 \mathrm{kt} \mathrm{SW}$ and $1006 \mathrm{mb}$ at $06 \mathrm{Z}$ near $20.1 \mathrm{~N}, 54.7 \mathrm{~W} .30 \mathrm{kt} \mathrm{N}$ and $1003 \mathrm{mb}$ at $12 \mathrm{Z}$ near $21.2 \mathrm{~N}, 55.7 \mathrm{~W}$. $30 \mathrm{kt}$ ENE and $1007 \mathrm{mb}$ at $18 \mathrm{Z}$ near 22.0N, 57.0W. All observations from COADS.

January 1:

HWM analyses a tropical storm of at most $1005 \mathrm{mb}$ centered near 19.6N, 58.0W. HURDAT lists this as a $65 \mathrm{kt}$ hurricane at $19.7 \mathrm{~N}, 58.1 \mathrm{~W}$ at $12 \mathrm{Z}$. Microfilm shows a low pressure system near $19.2 \mathrm{~N}, 57.6 \mathrm{~W}$ at $12 \mathrm{Z}$. Ship highlights: $30 \mathrm{kt}$ ENE and $1011 \mathrm{mb}$ at $00 \mathrm{Z}$ near $22.7 \mathrm{~N}, 58.1 \mathrm{~W}$ (COADS). $30 \mathrm{kt} \mathrm{NE}$ and $1012 \mathrm{mb}$ at $00 \mathrm{Z}$ near $21.3 \mathrm{~N}, 60.0 \mathrm{~W}$ (COADS). $25 \mathrm{kt} \mathrm{NNE}$ and $1008 \mathrm{mb}$ at $18 \mathrm{Z}$ near 19.6N, 61.6W (COADS). $30 \mathrm{kt} \mathrm{E}$ and $1009 \mathrm{mb}$ at $18 \mathrm{Z}$ near $21.8 \mathrm{~N}, 59.1 \mathrm{~W}$ (COADS). $70 \mathrm{kt} \mathrm{W}$ and $987 \mathrm{mb}$ at $1919 \mathrm{Z}$ near 19.2N, 59.2W; "west wind 12, barometer 987, temperature 66, visibility nil" (MWR). 47 $\mathrm{kt}$ and $998 \mathrm{mb}$ at $2330 \mathrm{Z}$ (MWR). “ “.. on January 1 it reached hurricane intensity with definite tropical characteristics." (MWR) "This very rare wintertime disturbance moved westward at about 12 knots until $1830 \mathrm{Z}$ on 1 January (Figure A-11), when it became apparent that a vortex, possibly of tropical storm intensity, had formed in the Atlantic Caribbean area for the 1st time of record." (ATSR)

January 2:

HWM analyses a hurricane of at most $1005 \mathrm{mb}$ centered near $18.5 \mathrm{~N}, 62.0 \mathrm{~W}$. HURDAT lists this as a $65 \mathrm{kt}$ hurricane at $18.0 \mathrm{~N}, 62.4 \mathrm{~W}$ at $12 \mathrm{Z}$. Microfilm shows a low pressure system near $18.5 \mathrm{~N}, 62.1 \mathrm{~W}$ at 12Z. Ship highlights: $35 \mathrm{kt}$ ESE and $1011 \mathrm{mb}$ at $00 \mathrm{Z}$ near $20.5 \mathrm{~N}, 60.2 \mathrm{~W}$ (COADS). $45 \mathrm{kt} \mathrm{WNW}$ and $1000 \mathrm{mb}$ at $00 \mathrm{Z}$ near $18.6 \mathrm{~N}, 60.5 \mathrm{~W}$ (COADS). $25 \mathrm{kt}$ ENE and $1006 \mathrm{mb}$ at $06 \mathrm{Z}$ near $19.7 \mathrm{~N}, 61.8 \mathrm{~W}$ (COADS). $30 \mathrm{kt} \mathrm{NE}$ and $1007 \mathrm{mb}$ at $06 \mathrm{Z}$ near $19.6 \mathrm{~N}, 61.7 \mathrm{~W}$ (COADS). $30 \mathrm{kt} \mathrm{NE}$ and $1009 \mathrm{mb}$ at $12 \mathrm{Z}$ near $18.7 \mathrm{~N}$, $63.1 \mathrm{~W}$ (COADS). $45 \mathrm{kt} \mathrm{E}$ and $1010 \mathrm{mb}$ at $15 \mathrm{Z}$ near 20.0N, 61.4W (MICRO). $35 \mathrm{kt}$ ENE and $1007 \mathrm{mb}$ at $15 \mathrm{Z}$ near $19.1 \mathrm{~N}, 63.2 \mathrm{~W}$ (MICRO). $35 \mathrm{kt} \mathrm{NNE}$ and $1006 \mathrm{mb}$ at $15 \mathrm{Z}$ near $18.4 \mathrm{~N}, 63.5 \mathrm{~W}$ (MICRO). $40 \mathrm{kt} \mathrm{NE}$ and $1003 \mathrm{mb}$ at $18 \mathrm{Z}$ near $18.4 \mathrm{~N}, 63.5 \mathrm{~W}$ (COADS). 30 $\mathrm{kt} \mathrm{N}$ and $1005 \mathrm{mb}$ at $18 \mathrm{Z}$ near $17.7 \mathrm{~N}, 64.2 \mathrm{~W}$ (COADS). $1002 \mathrm{mb}$ at $18 \mathrm{Z}$ near $17.2 \mathrm{~N}$, 64.1W (COADS). Land highlights: $991 \mathrm{mb}$ at Sint Maarten (MWR). $991 \mathrm{mb}$ at St. 
Barthelemy, maximum winds $35 \mathrm{kt} \mathrm{S}$ (MWR). 60-70 kt and $997 \mathrm{mb}$ at $12 \mathrm{Z}$ at St. Barthelemy (MICRO). $10 \mathrm{kt} \mathrm{W}$ and $1008 \mathrm{mb}$ at 12Z at St. Kitts (MICRO). $10 \mathrm{kt} \mathrm{S}$ and $1007 \mathrm{mb}$ at $12 \mathrm{Z}$ at Antigua (MICRO). $15 \mathrm{kt} \mathrm{SW}$ and $1004 \mathrm{mb}$ at $18 \mathrm{Z}$ at St. Kitts (MICRO). $25 \mathrm{kt} \mathrm{W}$ and $1004 \mathrm{mb}$ at $18 \mathrm{Z}$ at St. Eustatius (MICRO). St. Kitts reported 25$35 \mathrm{kt}, \mathrm{SW}$ winds and $1002.4 \mathrm{mb}$ (MWR). St. Eustatius reported $1001.4 \mathrm{mb}$ (MWR). "It moved on a west-southwestward course passing through the Leeward Islands on January 2. An estimated wind of $75 \mathrm{mph}$ was reported at St. Kitts and the last observation from St. Barthélemy indicated wind speeds ranging from 69 to $81 \mathrm{mph}$. Winds of hurricane intensity were observed at other points." (MWR) "Confirmation of "Tropical Storm Alice" came on 2 January via a delayed report from a US Naval Ship which reported maximum observed surface winds of 47 knots and an eye with a spiral weather band clearly defined on radar. Coordination was effected with the San Juan Weather Bureau Office and Warning Number One on "Tropical Storm Alice" was released as of 021900Z, locating the center near St. Barthelemy, Leeward Islands." (ATSR) " The maximum wind velocity reported from a land station was 38 knots at St. Barthelemy late on 2 January 1955." (ATSR)

January 3:

HWM analyses a hurricane of at most $1005 \mathrm{mb}$ centered near $16.3 \mathrm{~N}, 64.4 \mathrm{~W}$. HURDAT lists this as a $70 \mathrm{kt}$ hurricane at $17.0 \mathrm{~N}, 64.0 \mathrm{~W}$ at $12 \mathrm{Z}$. Microfilm shows a hurricane of at most $1002 \mathrm{mb}$ at $12 \mathrm{Z}$ near $16.7 \mathrm{~N}, 64.2 \mathrm{~W}$. Ship highlights: $40 \mathrm{kt} \mathrm{WNW}$ and $1001 \mathrm{mb}$ at $00 \mathrm{Z}$ near $17.1 \mathrm{~N}, 64.0 \mathrm{~W} .30 \mathrm{kt} \mathrm{NE}$ and $1012 \mathrm{mb}$ at $00 \mathrm{Z}$ near $19.8 \mathrm{~N}$, 69.5W. $30 \mathrm{kt} \mathrm{NE}$ and $1012 \mathrm{mb}$ at $06 \mathrm{Z}$ near $21.2 \mathrm{~N}, 67.3 \mathrm{~W} .25 \mathrm{kt} \mathrm{W}$ and $1006 \mathrm{mb}$ at $06 \mathrm{Z}$ near $16.0 \mathrm{~N}, 64.4 \mathrm{~W} .20 \mathrm{kt} \mathrm{NE}$ and $1001 \mathrm{mb}$ at $09 \mathrm{Z}$ near $19.9 \mathrm{~N}, 64.4 \mathrm{~W} .30 \mathrm{kt} \mathrm{NNW}$ and $1008 \mathrm{mb}$ at $12 \mathrm{Z}$ near $16.5 \mathrm{~N}, 65.0 \mathrm{~W} .25 \mathrm{kt} \mathrm{SE}$ and $1007 \mathrm{mb}$ at $18 \mathrm{Z}$ near $17.2 \mathrm{~N}, 64.5 \mathrm{~W}$. All observations from COADS. Land Highlights: $15 \mathrm{kt} \mathrm{SSE}$ and $1007 \mathrm{mb}$ at $00 \mathrm{Z}$ at St. Kitts. $20 \mathrm{kt} \mathrm{NE}$ and $1008 \mathrm{mb}$ at $06 \mathrm{Z}$ at St. Thomas. All observations from microfilm. Aircraft Highlights: Air Force center fix at $1355 \mathrm{Z}$ at $16.6 \mathrm{~N}, 64.2 \mathrm{~W}$ with $999 \mathrm{mb}$ central pressure and $55 \mathrm{kt}$ max winds (MICRO, ATSR). NAVY center fix at $2100 \mathrm{Z}$ at $16.1 \mathrm{~N}$, 65.2W with $1000 \mathrm{mb}$ central pressure and $50 \mathrm{kt}$ max winds (MICRO, ATSR). NAVY center fix at $2215 \mathrm{Z}$ at $16.1 \mathrm{~N}, 65.5 \mathrm{~W}$ (ATSR). "On January 3, aircraft reconnaissance reported maximum winds of $86 \mathrm{mph}$ and a dropsonde in the eye confirmed the warm-core system. After January 3, the hurricane diminished rapidly in intensity." (MWR) "On 3 January, weather reconnaissance aircraft found a poorly defined eye, visually and on radar, with maximum winds of about 55 knots." (ATSR)

January 4:

HWM analyses a tropical storm of at most $1010 \mathrm{mb}$ centered near $14.6 \mathrm{~N}, 64.9 \mathrm{~W}$. HURDAT lists this as a $55 \mathrm{kt}$ tropical storm at $15.1 \mathrm{~N}, 64.9 \mathrm{~W}$ at $12 \mathrm{Z}$. Microfilm shows a 
low pressure system of at most $1011 \mathrm{mb}$ at $12 \mathrm{Z}$ near $15.4 \mathrm{~N}, 64.9 \mathrm{~W}$. Ship highlights: $25 \mathrm{kt}$ $\mathrm{NE}$ and $1012 \mathrm{mb}$ at $00 \mathrm{Z}$ near $16.6 \mathrm{~N}, 68.7 \mathrm{~W} .30 \mathrm{kt} \mathrm{S}$ and $1007 \mathrm{mb}$ at $12 \mathrm{Z}$ near $15.2 \mathrm{~N}$, 63.9W. $30 \mathrm{kt} \mathrm{N}$ and $1008 \mathrm{mb}$ at $18 \mathrm{Z}$ near $15.2 \mathrm{~N}, 66.1 \mathrm{~W} .20 \mathrm{kt} \mathrm{W}$ and $1008 \mathrm{mb}$ at $18 \mathrm{Z}$ near 14.1N, 65.1W. All observations from COADS. Aircraft Highlights: NAVY center fix at $1346 \mathrm{Z}$ at $15.1 \mathrm{~N}, 64.8 \mathrm{~W}$ with $30-35 \mathrm{kt}$ (ATSR). "On 4 January, U.S. Navy reconnaissance aircraft reported only scattered showers with a weak wind circulation center near $15 \mathrm{~N}$ and $65 \mathrm{~W}$. Maximum winds were now only 30 to 35 knots in squalls some distance from the circulation center. The final warning on "Tropical Storm Alice" was issued on 041600Z." (ATSR)

January 5:

HURDAT lists this as a $30 \mathrm{kt}$ tropical depression at $13.6 \mathrm{~N}, 63.3 \mathrm{~W}$ at $12 \mathrm{Z}$. HWM and microfilm does not show an organized system. Ship highlights: $20 \mathrm{kt} \mathrm{NE}$ and 1009 $\mathrm{mb}$ at $00 \mathrm{Z}$ near $16.5 \mathrm{~N}, 65.0 \mathrm{~W} .15 \mathrm{kt} \mathrm{N}$ and $1009 \mathrm{mb}$ at $00 \mathrm{Z}$ near $14.5 \mathrm{~N}, 65.0 \mathrm{~W} .10 \mathrm{kt} \mathrm{N}$ and $1008 \mathrm{mb}$ at $06 \mathrm{Z}$ near $13.8 \mathrm{~N}, 65.9 \mathrm{~W} .15 \mathrm{kt} \mathrm{NE}$ and $1009 \mathrm{mb}$ at $06 \mathrm{Z}$ near $16.0 \mathrm{~N}$, 65.0W. $15 \mathrm{kt} \mathrm{W}$ and $1009 \mathrm{mb}$ at $18 \mathrm{Z}$ near $13.0 \mathrm{~N}, 64.9 \mathrm{~W}$. All observations from COADS.

January 6:

HURDAT lists this as a $25 \mathrm{kt}$ tropical depression at $12.8 \mathrm{~N}, 63.0 \mathrm{~W}$ at $06 \mathrm{Z}$. HWM and microfilm does not show an organized system. Ship highlights: $20 \mathrm{kt} \mathrm{NE}$ and 1014 $\mathrm{mb}$ at $00 \mathrm{Z}$ near $14.7 \mathrm{~N}, 66.6 \mathrm{~W} .15 \mathrm{kt} \mathrm{NNW}$ and $1010 \mathrm{mb}$ at $00 \mathrm{Z}$ near $12.9 \mathrm{~N}, 65.6 \mathrm{~W} .15 \mathrm{kt}$ $\mathrm{N}$ and $1011 \mathrm{mb}$ at $06 \mathrm{Z}$ near $12.7 \mathrm{~N}, 67.1 \mathrm{~W}$. All observations from COADS.

"The records do indicate, however, that a winter hurricane of somewhat similar origin passed through the Leeward Islands on March 8, 1908, with Basseterre, St. Kitts, reporting a minimum pressure of 29.28 inches. Columbus described several of the winter storms encountered by him on his journeys to the New World as "hurricanes." Brooks [4], however, has found they were probably normal winter storms. Occasional winter hurricanes do occur in the Pacific Ocean and tropical Lows are more rarely observed in the Atlantic, but it is most unusual for one of the latter to reach full hurricane intensity during the winter season. Possibly this may be another consequence of the general warming observed during the past several decades. There was no loss of life from Alice and damage is estimated at around $\$ 100,000$. The rainfall was beneficial in Puerto Rico where it alleviated a dry period which had persisted since the middle of the previous October.” (MWR)

"Alice" was believed to be of hurricane intensity but from post analysis it never appeared to have attained winds greater than 55 knots. From inception, "Alice" moved on a southwesterly course at speeds ranging from 5 to 10 knots. The flow at the $500 \mathrm{mb}$ level indicated a more west-southwest movement of "Alice" with possible movement more 
westerly as the storm moved across the Caribbean. The exact flow at the $200 \mathrm{mb}$ level over the Caribbean was doubtful, reports were sparse and at times, non-existent, therefore it can only be conjecture as to what really caused "Alice" to swing to the southwest and finally weaken and dissipate while moving slowly south to southeast. "Alice" was never a very large circulation. Further weakening was due to the southerly component of motion plus the lack of sufficient divergence aloft to maintain the circulation. As far as is known, no damage to shipping or shore installations resulted from "Alice."”

No change to the genesis of this rare out-of-season hurricane, which likely formed from an old frontal boundary that had pushed quite far equatorward. No track changes were introduced for the first three days of its lifecycle. Minor alterations were made on the 2nd to the 5th of January and a large change was introduced for the very last position kept in HURDAT due to additional ship observations not available to earlier analyses. Only one central pressure was in HURDAT originally for this system - $1007 \mathrm{mb}$ at $12 \mathrm{Z}$ on the 30th of December. While no such observation could be located to confirm it, this value appears to be in the right ballpark so it is retained. A believable $40 \mathrm{kt}$ ship with $1011 \mathrm{mb}$ pressure at $18 \mathrm{Z}$ on the 30 th was obtained. No change to the intensity of $40 \mathrm{kt}$ listed in HURDAT at that time and no change to the timing of upgrade to a tropical storm ( $12 \mathrm{Z}$ on the 30 th) were made. Little inner core data was available on the 31 st and the transition to hurricane intensity at $12 \mathrm{Z}$ on that date is retained. At $1919 \mathrm{Z}$ on the 1 st of January, the ship Arawak reported $70 \mathrm{kt} \mathrm{W}$ wind with $987 \mathrm{mb}$ pressure. This peripheral pressure suggests peak winds of at least $68 \mathrm{kt}$ from the Brown et al. south of $25 \mathrm{~N}$ pressure-wind relationship. Additionally, radar imagery from a separate ship - the USS Midway - depicted a complete eyewall of $25 \mathrm{~nm}$ diameter just a few hours later. This suggests an RMW of about 15-20 nm, which is nearly the same as climatology (16 nm Vickery et al. 2000) for its latitude and a central pressure $\sim 980 \mathrm{mb}$. The intensity is estimated to be $80 \mathrm{kt}$ at $18 \mathrm{Z}$ on the 1 st and $00 \mathrm{Z}$ on the $2 \mathrm{nd}$, which is the new peak for the cyclone's lifetime (previously the lifetime peak was $70 \mathrm{kt}$ on the $3 \mathrm{rd}$ ). On the $2 \mathrm{nd}$, the hurricane had begun weakening and passed over St. Martin and St. Barthelemy with 991 $\mathrm{mb}$ pressure and near calm winds reported. While the time of these observations was not given, it is likely that these were just after $18 \mathrm{Z}$ on the $2 \mathrm{nd}$ and $991 \mathrm{mb}$ is added to HURDAT as a central pressure. This central pressure suggests winds of $62 \mathrm{kt}$. Observations from the Leeward Islands were confused as various articles from the Monthly Weather Review are contradictory. For example, "estimated wind of 75 m.p.h. was reported at St. Kitts" in the seasonal summary published in December 1955, though Colon's table in the January 1956 article showed "force 6-8" (25-35 kt). Likewise, the seasonal summary had 69 to 81 m.p.h. (likely converted from 60-70 kt) at St.

Barthelemy, while Colon showed a maximum wind of only $35 \mathrm{kt}$ for the same location. Colon did report strongest wind of 75 m.p.h. estimated at Saba. An intensity of $65 \mathrm{kt}$ at $18 \mathrm{Z}$ is selected, which is the same as HURDAT previously. A landfall is indicated for St. 
Martin around $21 \mathrm{Z}$ on the $2 \mathrm{nd}$ near $18.0 \mathrm{~N} 63.0 \mathrm{~W}$ and Category 1 sustained hurricane force winds likely occurred in St. Martin, Anguilla, Saba, and St. Barthelemy. As the cyclone moved into the northeastern Caribbean Sea, it continued weakening. Two aircraft reconnaissance flights were undertaken on the $3 \mathrm{rd}$ and one on the 4th. At $1355 \mathrm{Z}$ on the 3rd, the Air Force reconnaissance reported $999 \mathrm{mb}$ central pressure, a poorly defined eye of $15 \mathrm{~nm}$ diameter (suggesting an RMW of $\sim 10-15 \mathrm{~nm}$ ), and estimated maximum flight level winds of $55 \mathrm{kt}$ as seen in the microfilm. (It is noted that the MWR summary article stated that winds of $86 \mathrm{~m} . \mathrm{p}$.h. were reported from reconnaissance. However, this is contradicted by all of the remaining reports.) $999 \mathrm{mb}$ central pressure suggests winds of $49 \mathrm{kt}$. $55 \mathrm{kt}$ is reanalyzed for the intensity at $12 \mathrm{Z}$ and $18 \mathrm{Z}$ on the $3 \mathrm{rd}$ (in part due to the small size) down originally from $70 \mathrm{kt}$. A $2110 \mathrm{Z}$ Navy center fix from the same day measured $1000 \mathrm{mb}$ central pressure and estimated maximum flight level winds of $50 \mathrm{kt}$. This central pressure suggests maximum winds of $47 \mathrm{kt}$. $50 \mathrm{kt}$ is analyzed for $00 \mathrm{Z}$ (again slightly boosted because of the small size), down from $65 \mathrm{kt}$ originally. The revised intensities are lowered to below hurricane force at $00 \mathrm{Z}$ on the 3rd, 36 hours earlier than in HURDAT originally. The last reconnaissance at $1346 Z$ on the 4th by the Navy gave no central pressure, but did indicate that the highest estimated flight-level winds were down 30 to $35 \mathrm{kt}$. The intensity is reduced to $40 \mathrm{kt}$ at $12 \mathrm{Z}$ on the 4th, down from $55 \mathrm{kt}$ originally. While the intensity was dropped by at least $15 \mathrm{kt}$ between $12 \mathrm{Z}$ on the $3 \mathrm{rd}$ to $18 \mathrm{Z}$ on the 4 th, only one synoptic time $-06 \mathrm{Z}$ on the 4 th - had a $20 \mathrm{kt}$ reduction, a major change. Observations on the 5th and 6th over the eastern Caribbean continued to indicate gradual weakening and the cyclone is analyzed to have degraded to a depression around $06 \mathrm{Z}$ on the 5th (six hours earlier than originally) and dissipated after $00 \mathrm{Z}$ on the 6 th (also six hours earlier than originally). The genesis and track of this rare December-January hurricane is analogous to Tropical Storm Zeta in 2005 and Tropical Storm Olga in 2007. It is also of note that in January 1951 yet another out-of-season cyclone developed, which has been reanalyzed to be a tropical storm.

\section{4 - Additional Notes}

1) Historical Weather Maps and Microfilm depict a low pressure system northeast of the Leeward Islands with gale-force winds that moved generally northeast before becoming absorbed by a cold front. On the 25th of January, the tail-end of a frontal boundary was located north of Puerto Rico and by the 26th, a $1015 \mathrm{mb}$ low pressure had developed north of the Leeward Islands on the tail of the frontal boundary. HWM also depicts on the 26 th a trough or wave extending from $20 \mathrm{~N}$ to $10 \mathrm{~N}$ along $57 \mathrm{~W}$. These systems interacted and on the 27th, HWM shows a $1010 \mathrm{mb}$ low pressure along the northern part of the trough near $23 \mathrm{~N} 57 \mathrm{~W}$. By this time, HWM indicates that the frontal boundary had 
dissipated. On the 28th, the system continued slowly moving north or northwest. The first gales associated with this disturbance appear at $18 \mathrm{Z}$ on the $28 \mathrm{th}$. COADS shows a $35 \mathrm{kt}$ ship near $27.1 \mathrm{~N} 52.5 \mathrm{~W}$ and another $35 \mathrm{kt}$ ship near $23.2 \mathrm{~N} 50.2 \mathrm{~W}$. Other available data at this time indicate that a low pressure may have been present but is not sufficient to close it. On the 29th, a strong cold front moved across the area and absorbed the system. Therefore, it is not added to HURDAT; but it might be considered as a possible hybrid or subtropical storm. This system is on David Roth's list of suspects.

\section{DAY LAT LON STATUS \\ Jan. 27 23N 57W Subtropical Depression \\ Jan. 28 25N 59W Subtropical Storm? \\ Jan. $2933 \mathrm{~N} 55 \mathrm{~W} \quad$ Extratropical}

2) Historical Weather Maps depicts an extratropical low pressure system meandering over the north Atlantic for almost two weeks during the 2nd and 3rd week of April. The system is first shown on the 13 th near $40 \mathrm{~N} 55 \mathrm{~W}$ associated with an eastward-moving cold front. Over the next few days, the strong extratropical cyclone drifts to the northeast and on the 16th, HWM shows a low pressure of at most $995 \mathrm{mb}$ near 44N 51W. Over the next 2 days it moves to the southeast and on the 18th it's located near $35 \mathrm{~N} 45 \mathrm{~W}$. At this time, HWM shows that the cold front associated with the disturbance has begun to dissipate as it evolves into a large occluded cyclone of at most $1005 \mathrm{mb}$. Over the next 3 days, the low pressure drift to the southeast and continues to show a large circulation associated with a non-tropical cyclone. On the $22 \mathrm{nd}$ it's located near $32 \mathrm{~N} 43 \mathrm{~W}$ as a cold front is approaching from the northwest. HWM shows an elongated low pressure system, likely as a response to the approaching cold front. The circulation remains broad and gale-force winds are depicted over 200 miles away from the center, indicating that the system is likely non-tropical. By the 23th, the system is gone from HWM, likely absorbed by the cold front. Therefore, it is not added to HURDAT; but it might be considered as a possible hybrid or subtropical storm. This system is on David Roth's list of suspects.

$\begin{array}{llll}\text { DAY } & \text { LAT LON } & \text { STATUS } \\ \text { Apr. 21 } & 32 \mathrm{~N} & 42 \mathrm{~W} & \text { Extratropical } \\ \text { Apr. 22 } & 32 \mathrm{~N} & 43 \mathrm{~W} & \text { Subtropical Storm? } \\ \text { Apr. 23 } & 41 \mathrm{~N} & 29 \mathrm{~W} & \text { Extratropical }\end{array}$

3) Historical Weather Maps depicts an extratropical cyclone embedded within a cold front near $47 \mathrm{~N} 30 \mathrm{~W}$. The non-tropical system moved south over the next 3 days and on the 19th of May it's located near 41N 31W. By this time, HWM shows that the frontal system has dissipated and the storm has developed into an occluded cyclone of at most 
$1010 \mathrm{mb}$. Over the next few days, the cyclone moves southwest and weakens until dissipation by the 26th over the central Atlantic. Gale-force winds are reported by a ship on the 20th but this ship is about 4 degrees of longitude to the west of the center of the cyclone, an indication that the strongest winds are away from the low pressure, which is normal in non-tropical cyclones. Therefore, it is not added to HURDAT; but it might be considered as a possible hybrid or subtropical storm. This system is on David Roth's list of suspects.

$\begin{array}{llll}\text { DAY } & \text { LAT } & \text { LON } & \text { STATUS } \\ \text { May 19 } & 41 \mathrm{~N} & 31 \mathrm{~W} & \text { Subtropical Depression } \\ \text { May 20 } & 39 \mathrm{~N} & 30 \mathrm{~W} & \text { Subtropical Storm? } \\ \text { May 21 } & 38 \mathrm{~N} & 30 \mathrm{~W} & \text { Subtropical Storm? } \\ \text { May 22 } & 35 \mathrm{~N} & 33 \mathrm{~W} & \text { Subtropical Depression } \\ \text { May 23 } & 33 \mathrm{~N} & 36 \mathrm{~W} & \text { Subtropical Depression } \\ \text { May 24 } & 30 \mathrm{~N} & 37 \mathrm{~W} & \text { Subtropical Depression } \\ \text { May 25 } & 27 \mathrm{~N} & 43 \mathrm{~W} & \text { Subtropical Depression }\end{array}$

4) Historical Weather Maps depicts a stationary cold front over the central Atlantic on the 21 st of June. The system slowly moves to the east and on the 23rd a low pressure of at most $1020 \mathrm{mb}$ is shown near $32 \mathrm{~N} 54 \mathrm{~W}$. On the 24th, HWM shows a trough of low pressure extending from $35 \mathrm{~N}$ to $25 \mathrm{~N}$ and along $54 \mathrm{~W}$. At $18 \mathrm{Z}$ on the 24 th, there is some indication that a small low pressure could have been located near 33N 53W. HWM shows a $30 \mathrm{kt}$ ship near $33.7 \mathrm{~N} 51.2 \mathrm{~W}$ but microfilm shows $40 \mathrm{kt}$ in relation to the same ship. Unfortunately, there is not enough data to close the low pressure. At $0 \mathrm{Z}$ on the 25 th the low pressure looks better defined based on the plotted COADS' data and could have been located near $34.5 \mathrm{~N} 53 \mathrm{~W}$. But at this time there are no gales or low pressures to indicate that it was a tropical storm. Later on the day, a cold front approaching from the west absorbs the small system. Therefore, it is not added to HURDAT; but it might be considered as a possible tropical storm.

$\begin{array}{llll}\text { DAY } & \text { LAT LON } & \text { STATUS } \\ \text { June 23 } & 32 \mathrm{~N} & 54 \mathrm{~W} & \text { Tropical Depression } \\ \text { June 24 } & 33 \mathrm{~N} & 53 \mathrm{~W} & \text { Tropical Storm? } \\ \text { June 25 } & 35 \mathrm{~N} & 32 \mathrm{~W} & \text { Absorbed }\end{array}$

5) Historical Weather Maps and Microfilm depict a cold front across the southeast of the United States on July 9. By July 10, a low pressure had developed near the Georgia coast and on July 11, the system had moved over the Atlantic Ocean and began to intensify. At this time, the low pressure was moving to the northeast over or near the Gulf Current. The first gale on COADS appears on July 11 at 18Z, $45 \mathrm{kt} \mathrm{S}$ and $1011 \mathrm{mb}$. On the 12th, the storm continued to move northeast and made its closest approach to North Carolina. At 0Z, a ship reported $35 \mathrm{kt} \mathrm{NE}$ and $1006 \mathrm{mb}$. At 6Z, the Flying Pan lighttower reported 
$35 \mathrm{kt}$ at a height of $56 \mathrm{ft}$ or 17 meters, which is $34 \mathrm{kt}$ at 10 meters. At 12Z, another ship reported $35 \mathrm{kt} \mathrm{SW}$ and $1010 \mathrm{mb}$. On the 13th, the system accelerates to the northeast and is rapidly absorbed by an approaching cold front. During the analyses it was decided that the system did not completely lose its non-tropical characteristics. The dew point values over land but near the coast were in the 40s and 50s late on the 12th and early on the 13th, indicating cold, dry air over the western portion of the system. But it's possible that it may have been a subtropical or tropical storm. Therefore, it's not added to HURDAT.

\begin{tabular}{llll} 
DAY & \multicolumn{2}{c}{ LAT LON } & \multicolumn{1}{c}{ STATUS } \\
July 10 & $31 \mathrm{~N}$ & $81 \mathrm{~W}$ & Extratropical \\
July 11 & $33 \mathrm{~N}$ & $78 \mathrm{~W}$ & Subtropical Storm? \\
July 12 & $34 \mathrm{~N}$ & $75 \mathrm{~W}$ & Tropical Storm? \\
July 13 & $38 \mathrm{~N}$ & $71 \mathrm{~W}$ & Tropical Depression
\end{tabular}

6) Historical Weather Maps and Microfilm depict a cold front between Bermuda and the SE United States on the last week of July. By the 28th, a low pressure had formed along the cold front or trough and it was moving to the southwest. By the 29th, the system turns to the west while ships in the area indicate that the surface pressures were rising. By July 31 , the weakened system was approaching the coast and appears to have dissipated by August 1st. No gales appear on COADS, HWM or Microfilm. Therefore, it is not added to HURDAT. This system is on David Roth's list of suspects.

\section{DAY LAT LON STATUS}

July $2835 \mathrm{~N} 71 \mathrm{~W} \quad$ Extratropical

July $2931 \mathrm{~N} 73 \mathrm{~W} \quad$ Subtropical Depression

July $3031 \mathrm{~N} 76 \mathrm{~W} \quad$ Subtropical Depression

July $3130 \mathrm{~N}$ 80W Subtropical Depression

7) Historical Weather Maps, the microfilm maps, COADS, and Monthly Weather Review observations indicate that a system that was indicated to be the early portion of Hurricane Edna on the $2^{\text {nd }}$ through the $4^{\text {th }}$ of September was instead a separate tropical depression. The cyclone formed east of the Lesser Antilles on the $1^{\text {st }}$ of September and moved due westward over the next three days before dissipating over South America late on the $4^{\text {th }}$. No gales or low pressures were observed from this system, but it is possible that it reached tropical storm intensity at some point during its lifetime.

DAY LAT LON STATUS

Sep 1 11N 54W Tropical Depression

Sep 2 11N 56W Tropical Depression

Sep 3 11N 62W Tropical Depression

Sep 4 11N 65W Tropical Depression 
8) Historical Weather Map, Microfilm and Monthly Weather Review depict a trough or low pressure system that moved across the Gulf of Mexico during the second week of September. On September 14 at 12Z, HWM indicates that a low pressure was present just north of the Yucatan peninsula. On the 15th at 12Z, HWM indicates a closed low pressure system of at most $1005 \mathrm{mb}$ near $25.5 \mathrm{~N}, 89.0 \mathrm{~W}$. MWR puts the system near $25 \mathrm{~N}$, $89 \mathrm{~W}$. A NAVY aircraft flew into the disturbance late on the 15 th and didn't find a closed circulation. Three gales, all from the ship named "Gulf Skipper," are on COADS and microfilm on the 15 th but other ship data indicates that these gales are likely too high. On the 16th at 12Z, HWM shows a closed system of at most 1005 mb near 27N, 93W. MWR places the center much further south at the same time, located near $23 \mathrm{~N}, 90 \mathrm{~W}$. The NAVY aircraft had 2 flights and in both cases found no closed circulation. On the second flight it did find $40-\mathrm{kt}$ winds at $20 \mathrm{Z}$ near $29 \mathrm{~N}, 88 \mathrm{~W}$, about 300 miles away from the apparent center. Two ships reported gale-force winds on the 16 th at $0 \mathrm{Z}$ and appear to be consistent with the winds reported by the nearby ships. Unfortunately, there is no information available to indicate that a closed low pressure was present. At 18Z, 2 more gales are present on the NE quadrant of the system and winds in the coast of Louisiana are up to $25 \mathrm{kt}$, which is possibly a result of the pressure gradient with the strong high pressure over the SE of the United States. On September 17 at 12Z, the low pressure system was near $26 \mathrm{~N}, 95 \mathrm{~W}$ according to HWM and near $25 \mathrm{~N}, 95 \mathrm{~W}$ according to MWR. No gales or low pressures were present on the 17th and based on the data, the system was inland over NE Mexico by 18Z. Dissipation occurred on September 18. Therefore, it is not added to HURDAT but it's possible it may have been a tropical storm. This system is on Jack Beven's list of suspects.

\section{DAY LAT LON STATUS}

September 14 24N 87W Disturbance

September 15 25N 89W Tropical Depression

September 16 27N 93W Tropical Storm?

September 17 26N 95W Tropical Storm?

September 18 26N 99W Dissipated

9) Historical Weather Map and Microfilm depict a trough or low pressure system over the Gulf of Mexico that moved generally to the west during the first week of October. Three flights made by the NAVY aircrafts indicate that the disturbance had a closed low-level circulation but no winds of gale force or low pressures were measured. No gales were observed on COADS and only one 35-kt ship appears on microfilm on October 3rd at 18Z. Due to the lack of evidence of tropical storm force winds, this system is not added to HURDAT but it may have been a weak tropical storm. This system is on Jack Beven's and David Roth's list of suspects. 


$\begin{array}{lll}\text { DAY } & \text { LAT LON } & \text { STATUS } \\ \text { October 2 } 23 \mathrm{~N} 85 \mathrm{~W} & \text { Tropical Depression } \\ \text { October 3 } & 24 \mathrm{~N} 93 \mathrm{~W} & \text { Tropical Depression } \\ \text { October 4 } & 27 \mathrm{~N} 97 \mathrm{~W} & \text { Tropical Depression } \\ \text { October 5 } & 28 \mathrm{~N} 101 \mathrm{~W} & \text { Dissipated }\end{array}$

10) Historical Weather Map depicts a cold front on the 26th in the Central Atlantic. A low pressure develops near $29 \mathrm{~N}, 57 \mathrm{~W}$ along the frontal boundary on the 27th. On the 28 th, the system is located near $31 \mathrm{~N}, 52 \mathrm{~W}$ and although the HWM shows it associated with a frontal feature; ships in the area indicate that the front may have already dissipated. On the 29 th at $0 \mathrm{Z}$, a stationary ship at $35 \mathrm{~N}, 48 \mathrm{~W}$ reported $35 \mathrm{kt}$ but it reports the lowest central pressure of $1011 \mathrm{mb}$ nine hours later and $25 \mathrm{kt}$. On the 29th at 12Z, the well-defined low pressure was located near $36 \mathrm{~N}, 46 \mathrm{~W}$ and a strong cold front was approaching from the northwest. By the 30th, the low pressure had become embedded with the cold front. It's possible that this system was a tropical storm but at the moment there's insufficient data and won't be added to HURDAT.

\section{DAY LAT LON STATUS}

October 27 24N 57W Low Pressure

October $2831 \mathrm{~N} 52 \mathrm{~W}$ Tropical Depression

October $2936 \mathrm{~N}$ 46W Tropical Storm?

October $3037 \mathrm{~N} 45 \mathrm{~W} \quad$ Extratropical

11) Historical Weather Maps, Monthly Weather Review and Microfilm depict a low pressure system in the Gulf of Mexico during the second week of November that moved generally north and became an extratropical cyclone before moving over the southeast. A cold front dropped into the Gulf of Mexico on the first week of November and a low pressure is depicted in the HWM on the $12^{\text {th }}$ near $22 \mathrm{~N}, 93 \mathrm{~W}$. MWR shows the system located near $24 \mathrm{~N}, 92 \mathrm{~W}$. Ship and land reports show a cold airmass over the western Gulf of Mexico. The cold air subsided over the next few days as the system moved north, but it remained too cold to allow for subtropical or tropical transition before frontogenesis took place on the $15^{\text {th }}$. Therefore, this system is not added to HURDAT. This system is on Jack Beven's list of suspects.

\section{DAY LAT LON STATUS}

November $1120 \mathrm{~N} 93 \mathrm{~W}$ Extratropical

November $1222 \mathrm{~N} 93 \mathrm{~W}$ Extratropical

November $1325 \mathrm{~N} 93 \mathrm{~W}$ Extratropical

November $1426 \mathrm{~N} 93 \mathrm{~W}$ Extratropical

November $1528 \mathrm{~N} 90 \mathrm{~W}$ Extratropical

12) Historical Weather Maps depict an extratropical low pressure on the third week of December over the north Atlantic. The system moves southeast and becomes occluded by 
the 20 th near $31 \mathrm{~N}, 45 \mathrm{~W}$. Gale-force winds were present but temperature reports from nearby ships indicate that the low pressure remained embedded within a cold airmass and the system never transitioned to a subtropical or tropical storm. Therefore, this system is not added to HURDAT. This system is on David Roth's list of suspects.

$\begin{array}{llll}\text { DAY } & \text { LAT } & \text { LON } & \text { STATUS } \\ \text { December 18 } & 40 \mathrm{~N} & 43 \mathrm{~W} & \text { Extratropical } \\ \text { December 19 } & 37 \mathrm{~N} & 41 \mathrm{~W} & \text { Extratropical } \\ \text { December 20 } & 36 \mathrm{~N} & 46 \mathrm{~W} & \text { Occluded } \\ \text { December 21 } & 27 \mathrm{~N} & 45 \mathrm{~W} & \text { Occluded } \\ \text { December 22 } & 24 \mathrm{~N} & 39 \mathrm{~W} & \text { Occluded } \\ \text { December 23 } & 22 \mathrm{~N} & 39 \mathrm{~W} & \text { Occluded } \\ \text { December 24 } & 22 \mathrm{~N} & 39 \mathrm{~W} & \begin{array}{l}\text { Occluded } \\ \text { Dissipated }\end{array} \\ \text { December 25 } & & & \end{array}$




\section{5 hurricane season}

Tropical Storm Brenda [July 31 - August 3, 1955]

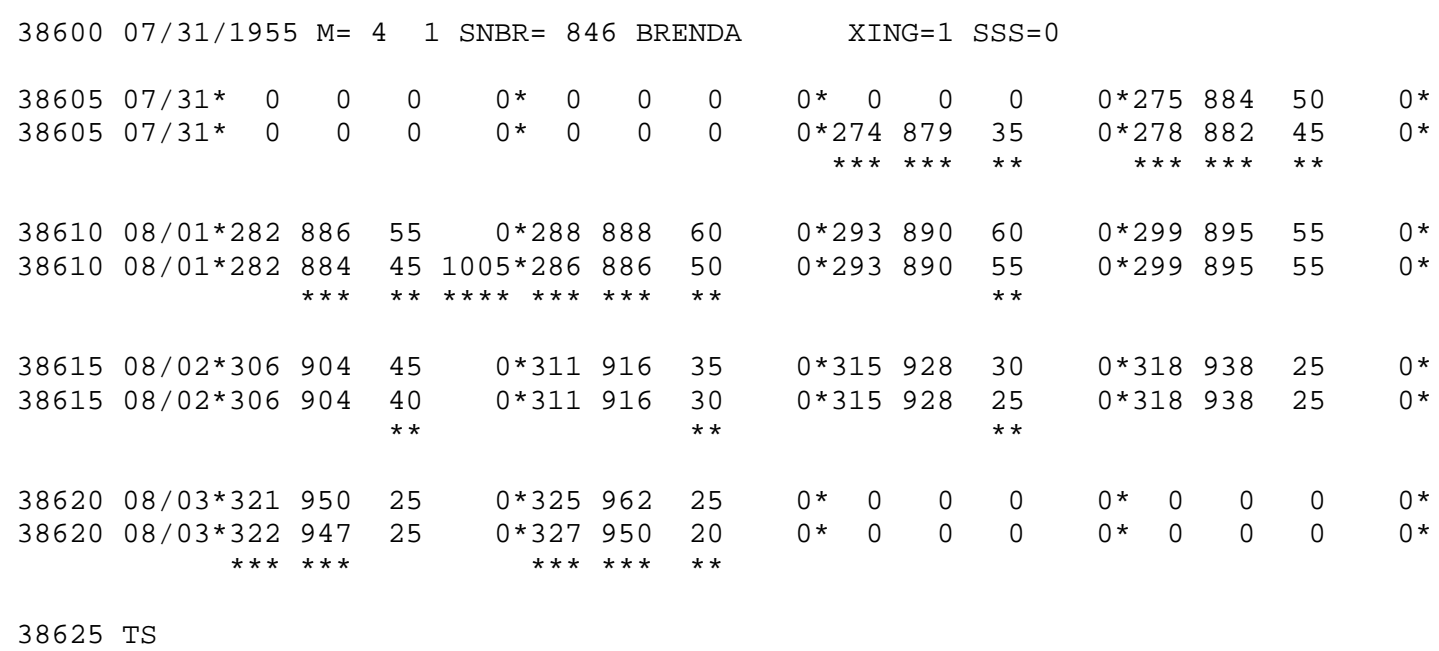

U.S. Tropical Storm Landfall

08/01 17Z 29.7N 89.4W 55 kt LA

Minor changes to the track and to the intensity shown in McAdie et al. (2009). Evidence for these alterations comes from the NHC microfilm maps, the Historical Weather Maps series, the COADS ship database, Monthly Weather Review, the Local Climatological Data, Connor (1956) and the Navy aircraft reconnaissance book.

July 30:

HWM and HURDAT does not analyze an organized system. Microfilm analyzes a low pressure centered near $27.5 \mathrm{~N}, 84.2 \mathrm{~W}$ at $12 \mathrm{Z}$. MWR shows a low pressure of 1010 mb located near $30.5 \mathrm{~N}, 87.2 \mathrm{~W}$ at 12Z. Ship highlights: No gales or low pressures.

July 31 :

HWM shows a closed low pressure of at most $1010 \mathrm{mb}$ centered near $28.0 \mathrm{~N}$, $88.2 \mathrm{~W}$ at $12 \mathrm{Z}$. HURDAT lists this as a 50 knot tropical storm at $27.5 \mathrm{~N}, 88.4 \mathrm{~W}$ at $18 \mathrm{Z}$. Microfilm analyzes a closed low pressure of at most $1011 \mathrm{mb}$ centered near $27.0 \mathrm{~N}$, 88.0W at 12Z. MWR shows a low pressure of $1007 \mathrm{mb}$ located near $27.3 \mathrm{~N}, 87.5 \mathrm{~W}$ at 12Z. Ship highlights: $35 \mathrm{kt} \mathrm{WNW}$ and $1014 \mathrm{mb}$ at $12 \mathrm{Z}$ near 26.6N, 87.8W (COADS). 45 $\mathrm{kt} \mathrm{SW}$ and $1014 \mathrm{mb}$ at $15 \mathrm{Z}$ near $26.9 \mathrm{~N}, 87.9 \mathrm{~W}$ (micro). $35 \mathrm{kt} \mathrm{W}$ and $1008 \mathrm{mb}$ at $18 \mathrm{Z}$ near $26.9 \mathrm{~N}, 88.9 \mathrm{~W}$ (COADS). $40 \mathrm{kt} \mathrm{WSW}$ and $1012 \mathrm{mb}$ at $18 \mathrm{Z}$ near $27.6 \mathrm{~N}, 88.3 \mathrm{~W}$ (COADS). $35 \mathrm{kt}$ and $1009 \mathrm{mb}$ at $18 \mathrm{Z}$ near $27.3 \mathrm{~N}, 88.0 \mathrm{~W}$ (COADS). Aircraft highlights: NAVY center fix at $2105 \mathrm{Z}$ at $27.6 \mathrm{~N}, 88.3 \mathrm{~W}$ (micro). 
August 1:

HWM shows a tropical storm of at most $1005 \mathrm{mb}$ centered near $29.5 \mathrm{~N}, 88.5 \mathrm{~W}$ at 12Z. HURDAT lists this as a $60 \mathrm{kt}$ tropical storm at $29.3 \mathrm{~N}, 89.0 \mathrm{~W}$ at $12 \mathrm{Z}$. Microfilm analyzes a closed low pressure of at most $1005 \mathrm{mb}$ centered near $29.2 \mathrm{~N}, 89.0 \mathrm{~W}$ at $12 \mathrm{Z}$. MWR shows a low pressure of $1003 \mathrm{mb}$ located near $29.5 \mathrm{~N}, 88.5 \mathrm{~W}$ at $12 \mathrm{Z}$. Ship highlights: $40 \mathrm{kt} \mathrm{SSW}$ and $1004 \mathrm{mb}$ at $00 \mathrm{Z}$ near $28.0 \mathrm{~N}, 87.6 \mathrm{~W}$ (micro). $35 \mathrm{kt} \mathrm{WSW}$ and $1010 \mathrm{mb}$ at $00 \mathrm{Z}$ near $26.5 \mathrm{~N}, 88.8 \mathrm{~W}$ (COADS). $45 \mathrm{kt} \mathrm{SW}$ and $1010 \mathrm{mb}$ at $00 \mathrm{Z}$ near $26.6 \mathrm{~N}, 88.0 \mathrm{~W}$ (COADS). $35 \mathrm{kt} \mathrm{W}$ and $1010 \mathrm{mb}$ at $06 \mathrm{Z}$ near $26.5 \mathrm{~N}, 89.7 \mathrm{~W}$ (COADS). Aircraft highlights: NAVY center fix at $0025 \mathrm{Z}$ at $28.1 \mathrm{~N}, 88.4 \mathrm{~W}$, max winds of $35 \mathrm{kt}$ and $1005 \mathrm{mb}$ (micro). NAVY center fix near $1630 \mathrm{Z}$ at $29.7 \mathrm{~N}, 89.1 \mathrm{~W}$, max winds of $60 \mathrm{kt}$ and $998 \mathrm{mb}$ (peripheral) (micro). Land highlights: $25 \mathrm{kt} \mathrm{SW}$ and $1000 \mathrm{mb}$ at Pilottown, LA at $13 \mathrm{Z}$ (micro). $40 \mathrm{kt} \mathrm{SSE}$ and $1008 \mathrm{mb}$ at Fort Morgan, AL at 15Z (micro/CONNOR). 35 kt SSE at Bay St. Louis, MS (CONNOR). $1003 \mathrm{mb}$ at New Orleans (CLIMA)

August 2:

HWM shows a closed low pressure of at most $1010 \mathrm{mb}$ centered near $31.3 \mathrm{~N}$, $92.5 \mathrm{~W}$ at $12 \mathrm{Z}$. HURDAT lists this as a $30 \mathrm{kt}$ tropical depression at $31.5 \mathrm{~N}, 92.8 \mathrm{~W}$ at $12 \mathrm{Z}$. Microfilm analyzes a closed low pressure of at most $1011 \mathrm{mb}$ centered near $32.5 \mathrm{~N}$, $93.5 \mathrm{~W}$ at $12 \mathrm{Z}$. MWR shows a low pressure of $1007 \mathrm{mb}$ located near $31.7 \mathrm{~N}, 93.0 \mathrm{~W}$ at 12Z. Land highlights: $39 \mathrm{kt}$ at Gulfport, MS, at 0340Z (CONNOR). $15 \mathrm{kt} \mathrm{NW}$ and 1004 mb at Baton Rouge, LA (CLIMA). 30 kt at Lake Charles, LA (MWR 1955).

August 3:

HWM shows a closed low pressure of at most $1010 \mathrm{mb}$ centered near $33.2 \mathrm{~N}$, 95.0W at 12Z. HURDAT lists this as a $25 \mathrm{kt}$ tropical depression at $32.5 \mathrm{~N}, 96.2 \mathrm{~W}$ at $06 \mathrm{Z}$ (last position). Microfilm does not analyze a tropical low pressure at 12Z. MWR shows a low pressure of $1007 \mathrm{mb}$ located near $33.7 \mathrm{~N}, 95.9 \mathrm{~W}$ at $12 \mathrm{Z}$.

ATSR: "Tropical Storm Brenda," the second storm of the 1955 season, formed and behaved quite the same as tropical storm "Barbara" of the 1954 season (see annual Tropical Storm Report - 1954). Both storms generated from a weak low pressure circulation associated with a quasi-stationary front extending westward from the Atlantic Seaboard into Georgia and Alabama. The first indication of the extratropical low was detected on 30 July at $0030 \mathrm{Z}$ and by $0300 \mathrm{Z}$ a closed low was also evident at the $700 \mathrm{mb}$ level. The surface low was watched carefully for tropical storm development since the surface low was moving slowly southward toward the warm waters of the Gulf of Mexico and was being subjected to divergent flow aloft at the 500 and $200 \mathrm{mb}$ levels. By $310300 \mathrm{Z}$, the surface and $700 \mathrm{mb}$ low had deepened and slightly intensified as it had moved southwesterly to the south of Burrwood, Louisiana. 
Aircraft weather reconnaissance was immediately ordered for the afternoon of 31 July. Shortly after arriving in the area, the weather reconnaissance aircraft reported maximum winds of 50 knots on the southern edge of a large calm area centered near $27.6 \mathrm{~N} 88.3 \mathrm{~W}$ at $312105 \mathrm{Z}$. This elongated, calm area was without tropical eye characteristics but was located by wind shift and minimum pressure. The first coordinated warning on "Tropical Storm Brenda" was issued at $312300 \mathrm{Z}$ on the basis at the aircraft reports and the $311830 \mathrm{Z}$ surface reports. At this time, "Brenda" was expected to intensify and move toward the west or west-northwest with the flow in which it was embedded. Instead, "Brenda's" center became larger and orientated north-south while drifting slowly some 120 miles to the north before changing course to the west. By 011830Z, "Brenda" appeared to have become more tropical in character. The pressure gradient had increased and it is probable that an eye had replaced the weak circulation center. It was fortunate that "Brenda" passed inland before being able to intensify into a destructive hurricane. "Brenda" moved inland between Gulfport, Mississippi, and New Orleans, Louisiana, about $012030 \mathrm{Z}$ without significant damage to the coast. The final warning was issued at 012200Z, August, placing the storm just north of Lake Pontchartrain, Louisiana, moving westward and weakening rapidly.

"Tropical Storm Brenda" and "Barbara" of the 1954 season were almost identical twins. Both formed from a low center associated with a frontal trough which moved south of the southern United States into the Gulf of Mexico. They were both unique in that they were "hybrid" storms, half tropical and half extra-tropical, Neither, as far as is known, attained an "eye" but "Brenda" most probably would have assumed complete tropical characteristics had it remained over the waters of the Gulf of Mexico for a slightly longer period of time.

MWR: July 31-August 2. A weak low-pressure area over the northern Gulf of Mexico on July 29 and 30 was designated Tropical Storm Brenda on July 31 when it was about 100 miles south-southeast of Burrwood, LA. Winds were estimated at 50 to $60 \mathrm{mph}$ near the center. The storm moved slowly for several hours, crossed the Louisiana coast during the afternoon at August 1 and was centered about 30 miles northeast of New Orleans. After moving inland the storm weakened rapidly and at $10 \mathrm{pm}$ had reached a position 20 miles northwest of Baton Rouge, LA, with the strongest winds near the center 20 to $25 \mathrm{mph}$. Two deaths occurred in automobile accidents directly attributable to the storm. Damage along the Mississippi, Louisiana, and Alabama coasts was limited to small piers, fishing and pleasure craft, and flooding of highways.

Genesis for Brenda is begun six hours earlier than originally shown in HURDAT, as observations at $12 \mathrm{Z}$ on July $31^{\text {st }}$ indicate that the system did have a closed circulation. The system is started as a tropical storm through the evidence of ship observations near 
the system's center. Observations early on the $31^{\text {st }}$ indicate that the circulation was still very elongated and broad, therefore, a depression stage is not shown. Minor track changes were introduced on all four days of this system's existence except for the $2^{\text {nd }}$ of August. The largest change ( $>$ deg) on the last position of the cyclone ( $06 \mathrm{Z}$ on the $3^{\text {rd }}$ ).

The Navy Aircraft Reconnaissance flew three missions to the cyclone making three fixes. On August $1^{\text {st }}$ at $0025 \mathrm{Z}$, it measured a central pressure of $1005 \mathrm{mb}$, which suggests winds of $34 \mathrm{kt}$ from the Brown et al. north of $25 \mathrm{~N}$ pressure-wind relationship and $36 \mathrm{kt}$ intensifying. An intensity of $45 \mathrm{kt}$ is selected for August $1^{\text {st }}$ at $0 \mathrm{Z}$ based on the Reconnaissance data and ship observations (down from $55 \mathrm{kt}$ originally). On August $1^{\text {st }}$ at 1906Z, the NAVY airplane measured a peripheral pressure of $998 \mathrm{mb}$, which suggests maximum winds of at least $47 \mathrm{kt}$ north of $25 \mathrm{~N}$ and $49 \mathrm{kt}$ intensifying. Based on the 1000 $\mathrm{mb}$ measured in Pilottown, LA at $13 \mathrm{Z}$ and $998 \mathrm{mb}$ measured by reconnaissance near $1630 \mathrm{Z}$, an intensity of $50 \mathrm{kt}$ is selected during $12 \mathrm{Z}$ to $18 \mathrm{Z} .55 \mathrm{kt}$ is the peak intensity for this cyclone (originally $60 \mathrm{kt}$ ). The tropical storm made landfall in SE Louisiana around $17 \mathrm{Z}$ on the $1^{\text {st }}$ near $29.7 \mathrm{~N}, 89.4 \mathrm{~W}$ with maximum winds around $55 \mathrm{kt}$. This is five knots lower than the last synoptic time before landfall in HURDAT originally. Highest observations from land were $25 \mathrm{kt} \mathrm{SW}$ and $1000 \mathrm{mb}$ at Pilottown, LA, at 13Z on August $1^{\text {st }}, 40 \mathrm{kt} \mathrm{SSE}$ at Fort Morgan, AL, at $15 \mathrm{Z}$ on the $1^{\text {st }}$ and $39 \mathrm{kt}$ at Gulfport, MS, at $0340 \mathrm{Z}$ on the $2^{\text {nd }}$. After landfall, the cyclone moved west-northwest across Louisiana entering eastern Texas late on the $2^{\text {nd }}$. New Orleans, LA measured $1003 \mathrm{mb}$ on August $1^{\text {st }}$ and $1004 \mathrm{mb}$ were recorded at Baton Rouge, LA on the $2^{\text {nd }}$. Gradual weakening took place after landfall and weakening to a tropical depression occurred at $06 \mathrm{Z}$ on August $2^{\text {nd }}$, six hours earlier than originally shown in HURDAT. The cyclone dissipated after 06Z on the $3^{\text {rd }}$, based upon numerous observations over the south Central United States.

Hurricane Connie [August 3-15, 1955]

\begin{tabular}{|c|c|c|c|c|c|c|c|c|c|c|c|c|c|}
\hline 38630 & ๑8/๑3/195 & $M=1$ & & SNBR $=84$ & $47 \mathrm{C}$ & NNIE & $X I$ & $N G=1$ & SSS $=$ & & & & \\
\hline 38630 & $08 / 03 / 195$ & $5=1$ & & SNBR $=84$ & $47 \mathrm{C}$ & NNIE & $X I$ & $N G=1$ & SSS $=$ & $=2$ & & & \\
\hline 38635 & $08 / 03^{*}$ & $\odot$ & $\odot$ & $\odot * 153$ & 356 & 30 & $0 * 157$ & 392 & 35 & $\odot * 161$ & 427 & $4 \odot$ & $\Theta^{*}$ \\
\hline 38635 & $08 / 03$ * & $\odot$ & $\odot$ & $0 * 153$ & $\begin{array}{l}400 \\
* * *\end{array}$ & 30 & $0 * 157$ & $\begin{array}{l}421 \\
\star * *\end{array}$ & 35 & $0 * 161$ & $\begin{array}{l}442 \\
* * *\end{array}$ & $4 \odot$ & $\begin{array}{l}10 \odot 4^{*} \\
* * * *\end{array}$ \\
\hline 38640 & $\odot 8 / \odot 4 * 164$ & 453 & 40 & $\odot * 167$ & 470 & 40 & $0 * 170$ & 487 & 45 & $1002 * 174$ & 509 & 50 & ○* \\
\hline 38640 & $\begin{array}{r}\odot 8 / \odot 4 * 165 \\
* * *\end{array}$ & $\begin{array}{l}460 \\
* * *\end{array}$ & $\begin{array}{l}50 \\
* *\end{array}$ & $\begin{array}{r}\Theta * 170 \\
* \star *\end{array}$ & $\begin{array}{l}475 \\
* * *\end{array}$ & $\begin{array}{l}60 \\
* *\end{array}$ & $\begin{array}{r}0 * 176 \\
* * *\end{array}$ & $\begin{array}{l}488 \\
\star * *\end{array}$ & $\begin{array}{l}70 \\
* *\end{array}$ & $\begin{array}{l}0 * 180 \\
* * * *\end{array}$ & $\begin{array}{l}505 \\
* * *\end{array}$ & $\begin{array}{l}70 \\
* *\end{array}$ & ○* \\
\hline 38645 & $08 / 05 * 177$ & 530 & 60 & $\odot * 180$ & 549 & 95 & $0 * 183$ & 566 & 110 & $985 * 187$ & 577 & 115 & ०* \\
\hline 38645 & $08 / 05 * 181$ & $\begin{array}{l}523 \\
* * *\end{array}$ & $\begin{array}{l}70 \\
* *\end{array}$ & $\Theta_{* * *}^{*} 182$ & $\begin{array}{l}542 \\
* * *\end{array}$ & $\begin{array}{l}70 \\
* *\end{array}$ & $\begin{array}{r}0 * 183 \\
* * *\end{array}$ & $\begin{array}{l}561 \\
* * *\end{array}$ & $\begin{array}{l}75 \\
* *\end{array}$ & $\begin{array}{l}0 * 184 \\
* \quad * * *\end{array}$ & $\begin{array}{l}579 \\
* * *\end{array}$ & $\begin{array}{l}75 \\
* *\end{array}$ & $\begin{array}{l}985^{*} \\
* * *\end{array}$ \\
\hline 38650 & $08 / 06 * 190$ & 588 & 120 & $0 * 193$ & 603 & 120 & $0 * 196$ & 619 & 125 & $982 * 197$ & 636 & 125 & 0 * \\
\hline 38650 & $08 / 06 * 187$ & $\begin{array}{l}595 \\
* * *\end{array}$ & $\begin{array}{l}80 \\
* *\end{array}$ & $\begin{array}{l}\odot * 190 \\
* * *\end{array}$ & $\begin{array}{l}609 \\
* * *\end{array}$ & $\begin{array}{l}85 \\
* *\end{array}$ & $\begin{array}{r}0^{*} 193 \\
* * *\end{array}$ & $\begin{array}{l}624 \\
* * *\end{array}$ & $\begin{array}{l}9 \odot \\
* *\end{array}$ & $\begin{array}{l}0 * 196 \\
* * * *\end{array}$ & $\begin{array}{l}639 \\
* * *\end{array}$ & $\begin{array}{l}100 \\
\star * *\end{array}$ & $\begin{array}{l}968 * \\
* * *\end{array}$ \\
\hline
\end{tabular}




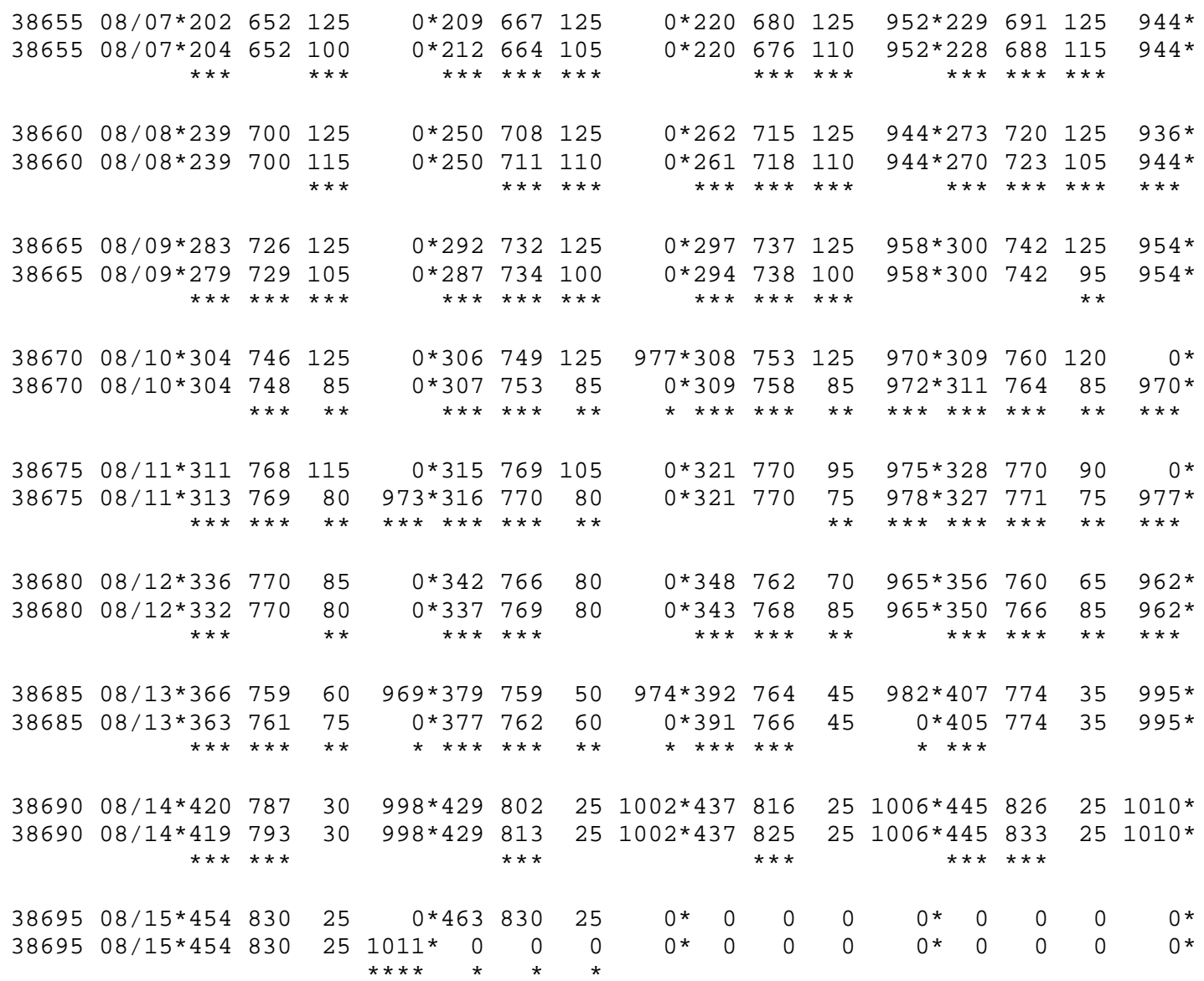

38700 HR NC3 VA1

38700 HR NC2 VA1

U.S. Hurricane:

Aug $12^{\text {th }}-15 \mathrm{Z}-34.7 \mathrm{~N} 76.7 \mathrm{~W}-85 \mathrm{kt}$ - Category $2-962 \mathrm{mb}-1011 \mathrm{mb}$ OCI $-425 \mathrm{~nm}$ ROCI

Major track and intensity changes are analyzed for this classic Cape Verde hurricane that made landfall in North Carolina. A major change is made to the time this cyclone first became a hurricane and a major hurricane. Evidence for these alterations comes from the Historical Weather Maps Series, the COADS ship database, Monthly Weather Review, USWB/NHC microfilm of synoptic weather maps, the Climatological Data, Schwerdt et al. (1979), Ho et al. (1987) and Jarrell et al. (1992).

August 2:

HWM shows a closed low pressure of at most $1010 \mathrm{mb}$ centered near $11.0 \mathrm{~N}$, 41.0W along the ITCZ at 12Z. HURDAT does not analyze an organized system on this date. Microfilm is not available. Ship highlights: No gales or low pressures. "The 
irregular Cape Verde reports provide no evidence of any unstable wave passing through the area in which Connie might later have developed" (MWR).

August 3:

HWM shows a closed low pressure of at most $1010 \mathrm{mb}$ centered near $12.0 \mathrm{~N}$, $44.0 \mathrm{~W}$ along the ITCZ at $12 \mathrm{Z}$. HURDAT lists this as a $35 \mathrm{knot}$ tropical storm at $15.7 \mathrm{~N}$, $39.2 \mathrm{~W}$ at $12 \mathrm{Z}$. Microfilm analyzes a closed low pressure of at most $1011 \mathrm{mb}$ centered near $16.5 \mathrm{~N}, 44.0 \mathrm{~W}$ at $18 \mathrm{Z}$ (first available). Ship highlights: $10 \mathrm{kt} \mathrm{NW}$ and $1005 \mathrm{mb}$ at $18 \mathrm{Z}$ near $15.8 \mathrm{~N}, 44.5 \mathrm{~W}$ (COADS/MICRO). "The first indications of hurricane Connie were noted on the morning of August 3 when the SS Mormacreed reported unusually strong westerly winds and showery, squally weather between Latitudes $5^{\circ}$ and $10^{\circ} \mathrm{N}$, and Longitudes $50^{\circ}$ and $55^{\circ} \mathrm{W}$. At the same time another ship, the African Sun, passed through a strong easterly wave in the vicinity of Latitude $16^{\circ} \mathrm{N}$ and Longitude $45^{\circ} \mathrm{W}$ " (MWR). "On the $2^{\text {nd }}$ and $3^{\text {rd }}$ of August, the tropical analysis to the east of the Lesser Antilles, from the scant number of reports, indicated a weak vortex, in the Intertropical Convergence Zone (ITC), moving along the $12^{\text {th }}$ parallel. In addition, an easterly wave, previously believed to be of weak to moderate intensity, indicated possible vortex development in the vicinity of $13 \mathrm{~N}$ and $46 \mathrm{~W}$ at $031230 \mathrm{Z}$. Later the combined ship reports from the BONAIRE and KFDE at $031230 \mathrm{Z}$ and $031830 \mathrm{Z}$ indicated the vortex had developed slightly further north in the vicinity of $15 \mathrm{~N} 46.5 \mathrm{~W}$ " (ATSR).

August 4:

HWM shows a closed low pressure of at most $1000 \mathrm{mb}$ centered near $17.7 \mathrm{~N}$, $48.8 \mathrm{~W}$ at $12 \mathrm{Z}$. HURDAT lists this as a 45 knot tropical storm at $17.0 \mathrm{~N}, 48.7 \mathrm{~W}$ at $12 \mathrm{Z}$. Microfilm analyzes a closed low pressure of at most $999 \mathrm{mb}$ centered near $18.1 \mathrm{~N}, 48.5 \mathrm{~W}$ at 18Z. Ship highlights: $40 \mathrm{kt} \mathrm{NW}$ and $996 \mathrm{mb}$ at $03 \mathrm{Z}$ near $17.0 \mathrm{~N}, 47.2 \mathrm{~W} .30-40 \mathrm{kt} \mathrm{NW}$ and $997 \mathrm{mb}$ at $17.8 \mathrm{~N}, 49.5 \mathrm{~W}$ at $1130 \mathrm{Z} .30 \mathrm{kt} \mathrm{S}$ and $1003 \mathrm{mb}$ at $17.0 \mathrm{~N}, 50.5 \mathrm{~W}$ at $15 \mathrm{Z}$. All observations from MICRO. "The SS Bonaire reported a pressure of $996.2 \mathrm{mb}(29.42$ inches) and a wind of east-northeast force 8 at $2200 \mathrm{EST}$ of the $3^{\text {rd }}$, providing the first indication that a strong vortex had formed in the northern end of the easterly wave. Earlier in the day, there were some indications of a vortex in the southern end but the principal cyclogenesis took place in the top end of the wave, as is usually the case, and hurricane Connie was born. Reconnaissance aircraft on the $4^{\text {th }}$ reported the eye at Latitude $15.8^{\circ} \mathrm{N}$ and Longitude $52.8^{\circ} \mathrm{W}$, with a false radar eye about 75 miles northeast of this position. Highest wind observed was 55 knots in the northeast quadrant. As it turned out, the false eye proved to be the real vortex which developed rapidly into hurricane Connie" (MWR). "A later report from the ship BONAIRE at 040300Z was the first definite indication that the disturbance was deepening rapidly. Their surface pressure had fallen from $1005 \mathrm{mbs}$ to $996.2 \mathrm{mbs}$ in three hours and the wind had veered from north to 
east-northeast 40 knots. This revealed the center to be very near the position of the BONAIRE at $040300 \mathrm{Z}$ and that the disturbance was of storm intensity. A good fix was obtained at $041130 Z$ on the center of "Storm Connie" when the ship LINDA ELRA, heading on a south-west course at a speed of advance of 15 knots, passed within an estimated 12 miles of the storm center. Hourly reports received from this ship showed the winds backing from northeast to northwest and increasing to 40 knots, and the pressure falling from $1002.4 \mathrm{mbs}$ to $996.6 \mathrm{mbs}$ in an hour and a half, as the ship neared the estimated position of the storm center. From this information, a speed check indicated the storm center to be moving west-northwest at 15 knots. Aircraft reconnaissance was first made into "Connie" by an Air Force flight from Bermuda on the $4^{\text {th }}$ of August. Flying at the $500 \mathrm{mb}$ level, the center fix reported by the reconnaissance flight was approximately 150 miles to the southwest of the expected storm track, therefore, it was believed unreliable in weight of other data, and was not used" (ATSR).

August 5:

HWM shows a hurricane of at most $1000 \mathrm{mb}$ centered near $18.3 \mathrm{~N}, 57.9 \mathrm{~W}$ at $12 \mathrm{Z}$. HURDAT lists this as a $110 \mathrm{kt}$ hurricane at $18.3 \mathrm{~N}, 56.6 \mathrm{~W}$ at $12 \mathrm{Z}$. Microfilm analyzes a closed low pressure of at most $993 \mathrm{mb}$ centered at $18.2 \mathrm{~N}, 57.0 \mathrm{~W}$ at 12Z. Ship highlights: $65 \mathrm{kt} \mathrm{N}$ and $1008 \mathrm{mb}$ at $18.1 \mathrm{~N}, 58.5 \mathrm{~W}$ at 21Z (MICRO). Aircraft highlights: Penetration center fix at $18.2 \mathrm{~N}, 56.7 \mathrm{~W}$ at $1110 \mathrm{Z}$ (ATSR); Penetration center fix, $75-90 \mathrm{kt}$ max surface winds, $985 \mathrm{mb}$ central pressure centered at $18.4 \mathrm{~N}, 57.9 \mathrm{~W}$ at $1805 \mathrm{Z}$ (MICRO). "The storm moved west to west-northwest at 14 to $16 \mathrm{mph}$, gradually increasing in size and intensity and by the morning of the $5^{\text {th }}$, maximum winds were estimated at $125 \mathrm{mph}$ with a central pressure of $985 \mathrm{mb}$ (29.09 inches)" (MWR). "The second reconnaissance flight was made by a Navy reconnaissance aircraft with a low level center penetration. This center fix obtained at $051110 \mathrm{Z}$ revealed that "Connie" had continued on a west to west-northwest course, as anticipated, at a speed of about 18 knots and had not dipped to the southwest as the first reconnaissance flight had indicated. Maximum winds reported had increased to 110 knots and the minimum central surface pressure had decreased to 985 mbs showing a considerable intensification during the past 24 hours" (ATSR).

August 6:

HWM shows a hurricane of at most $995 \mathrm{mb}$ centered near $20.3 \mathrm{~N}, 62.0 \mathrm{~W}$ at $12 \mathrm{Z}$. HURDAT lists this as a $125 \mathrm{kt}$ hurricane at $19.6 \mathrm{~N}, 61.9 \mathrm{~W}$ at $12 \mathrm{Z}$. MWR shows a low pressure of $992 \mathrm{mb}$ located near $20.0 \mathrm{~N}, 62.3 \mathrm{~W}$ at $12 \mathrm{Z}$. Microfilm analyzes a closed low pressure of at most $1002 \mathrm{mb}$ centered at $20.0 \mathrm{~N}, 62.0 \mathrm{~W}$ at 12Z. Ship highlights: $45 \mathrm{kt}$ ESE and $1005 \mathrm{mb}$ at $21.1 \mathrm{~N}, 60.5 \mathrm{~W}$ at $12 \mathrm{Z} .40 \mathrm{kt} \mathrm{E}$ and $1006 \mathrm{mb}$ at $22.5 \mathrm{~N}, 62.0 \mathrm{~W}$ at $12 \mathrm{Z} .65$ $\mathrm{kt} \mathrm{N}$ and $979 \mathrm{mb}$ at $19.8 \mathrm{~N}, 64.5 \mathrm{~W}$ at $18 \mathrm{Z} .50 \mathrm{kt} \mathrm{E}$ and $1008 \mathrm{mb}$ at $21.0 \mathrm{~N}, 60.7 \mathrm{~W}$ at $18 \mathrm{Z}$. $35 \mathrm{kt} \mathrm{S}$ and $977 \mathrm{mb}$ at $19.8 \mathrm{~N}, 64.6 \mathrm{~W}$ at 21Z. All observations from MICRO. Land 
highlights: $20 \mathrm{kt} \mathrm{W}$ and $1002 \mathrm{mb}$ at St. Kitts and Navis at 9Z. $45 \mathrm{kt} \mathrm{SW}$ and $1002 \mathrm{mb}$ at Anguilla at 15Z. $35 \mathrm{kt} \mathrm{S}$ and $1004 \mathrm{mb}$ at Anguilla at 21Z. All observations from MICRO. Aircraft highlights: Radar center fix at 19.1N, 60.9W at 0609Z (ATSR); Radar center fix at $19.9 \mathrm{~N}, 62.8 \mathrm{~W}$ at $1009 \mathrm{Z}$ (ATSR); Penetration center fix measured a central pressure of 978 at $19.5 \mathrm{~N}, 63.8 \mathrm{~W}$ at $1712 \mathrm{Z}$ (micro); Penetration center fix measured a central pressure of $968 \mathrm{mb}$ and max surface winds of $125 \mathrm{kt}$ centered at $19.6 \mathrm{~N}, 63.9 \mathrm{~W}$ at $18 \mathrm{Z}$ (micro); Penetration center fix at 20.3N, 64.6W at 2005Z (ATSR). "The hurricane center passed some 40 to 50 miles north of the northern Leeward Islands and Puerto Rico, attended by gale winds with peak gusts of 80 to $100 \mathrm{mph}$ and moderately heavy rains in the islands" (MWR).

August 7:

HWM shows a hurricane of at most $995 \mathrm{mb}$ centered near $22.5 \mathrm{~N}, 67.5 \mathrm{~W}$ at $12 \mathrm{Z}$. HURDAT lists this as a $125 \mathrm{kt}$ hurricane at $22.0 \mathrm{~N}, 68.0 \mathrm{~W}$ at $12 \mathrm{Z}$. MWR shows a low pressure of $980 \mathrm{mb}$ located near $22.5 \mathrm{~N}, 67.9 \mathrm{~W}$ at $12 \mathrm{Z}$. Microfilm analyzes a closed low pressure of at most $990 \mathrm{mb}$ centered at $22.3 \mathrm{~N}, 68.3 \mathrm{~W}$ at 12Z. Ship highlights: $45 \mathrm{kt}$ SSE and $998 \mathrm{mb}$ at $20.3 \mathrm{~N}, 64.7 \mathrm{~W}$ at $0 \mathrm{Z}$ (COADS/MICRO). $50 \mathrm{kt}$ SE and $1003 \mathrm{mb}$ at $20.8 \mathrm{~N}$, $64.9 \mathrm{~W}$ at $6 \mathrm{Z}$ (COADS). $55 \mathrm{kt} \mathrm{ENE}$ and $1003 \mathrm{mb}$ at $23.9 \mathrm{~N}, 68.0 \mathrm{~W}$ at $15 \mathrm{Z}$ (MICRO). $65 \mathrm{kt}$ $\mathrm{E}$ and $999 \mathrm{mb}$ at $23.7 \mathrm{~N}, 60.6 \mathrm{~W}$ at $18 \mathrm{Z}$ (COADS). $100 \mathrm{kt} \mathrm{WNW}$ and $995 \mathrm{mb}$ at $23.4 \mathrm{~N}$, 69.3W at 21Z (COADS). $100 \mathrm{kt} \mathrm{SE}$ and $998 \mathrm{mb}$ at $23.7 \mathrm{~N}, 67.5 \mathrm{~W}$ at $21 \mathrm{Z}$ (micro). Land highlights: $15 \mathrm{kt} \mathrm{SW}$ and $1004 \mathrm{mb}$ at San Juan, Puerto Rico at 0Z (MICRO). $20 \mathrm{kt} \mathrm{SW}$ and $1003 \mathrm{mb}$ at Punta Cana, Dominican Republic at 12Z. $25 \mathrm{kt} \mathrm{WNW}$ and $1002 \mathrm{mb}$ at Grand Turk at 21Z. Aircraft highlights: Radar center fix at 20.8N, $65.9 \mathrm{~W}$ at $0304 \mathrm{Z}$ (ATSR); Radar center fix at $21.7 \mathrm{~N} 66.8 \mathrm{~W}$ at $0634 \mathrm{Z}$ (ATSR); Radar center fix at $22.0 \mathrm{~N}$, $67.7 \mathrm{~W}$ at $1251 \mathrm{Z}$ (ATSR); Penetration center fix at $22.4 \mathrm{~N}, 68.3 \mathrm{~W}$ at $1355 \mathrm{Z}$ (ATSR); Penetration center fix at $22.4 \mathrm{~N}, 68.3 \mathrm{~W}$ at $1430 \mathrm{Z}$ (ATSR); Penetration center fix at $22.3 \mathrm{~N}$, $68.4 \mathrm{~W}$ at $1530 \mathrm{Z}$ (ATSR); Penetration center fix at $22.4 \mathrm{~N}, 68.4 \mathrm{~W}$ at $16 \mathrm{Z}$ (ATSR); Penetration center fix at $22.9 \mathrm{~N}, 68.6 \mathrm{~W}$ at $1730 \mathrm{Z}$ (ATSR); Penetration center fix measured max surface winds of $125 \mathrm{kt}$, central pressure of $944 \mathrm{mb}$ and a 38 mile diameter eye at $22.8 \mathrm{~N}, 68.8 \mathrm{~W}$ at $1800 \mathrm{Z}$ (micro). "On August 7 the eye was described by the observer as being shaped like an inverted cone, with the calm area less than 8 miles in diameter at the surface and 38 miles across at 18,000 feet. Maximum surface wind at this time was estimated at $145 \mathrm{mph}$ and lowest pressure was $952 \mathrm{mb}$ (28.11 inches) measured by dropsonde" (MWR). "Lowest pressure in the hurricane eye estimated 27.88 inches" (WBO).

August 8:

HWM shows a hurricane of at most $995 \mathrm{mb}$ centered near $26.7 \mathrm{~N}, 71.3 \mathrm{~W}$ at $12 \mathrm{Z}$. HURDAT lists this as a $125 \mathrm{kt}$ hurricane at $26.2 \mathrm{~N}, 71.5 \mathrm{~W}$ at $12 \mathrm{Z}$. MWR shows a low 
pressure of $960 \mathrm{mb}$ located near $26.8 \mathrm{~N}, 71.9 \mathrm{~W}$ at $12 \mathrm{Z}$. Microfilm analyzes a closed low pressure of at most $984 \mathrm{mb}$ centered at $26.0 \mathrm{~N}, 72.0 \mathrm{~W}$ at 12Z. Ship highlights: $55 \mathrm{kt} \mathrm{SE}$ and $1002 \mathrm{mb}$ at $24.3 \mathrm{~N}, 67.6 \mathrm{~W}$ at $0 \mathrm{Z}$ (COADS). $80 \mathrm{kt} \mathrm{SE}$ and $1004 \mathrm{mb}$ at $23.9 \mathrm{~N}, 67.5 \mathrm{~W}$ at $0 \mathrm{Z}$ (COADS). $55 \mathrm{kt} \mathrm{SE}$ and $1006 \mathrm{mb}$ at $25.5 \mathrm{~N}, 68.0 \mathrm{~W}$ at $6 \mathrm{Z}$ (COADS). $55 \mathrm{kt} \mathrm{SE}$ and $1004 \mathrm{mb}$ at $27.0 \mathrm{~N}, 72.0 \mathrm{~W}$ at $18 \mathrm{Z}$ (MICRO). Land highlights: $20 \mathrm{kt} \mathrm{SW}$ and $1003 \mathrm{mb}$ at Grand Turk at 0Z. $25 \mathrm{kt} \mathrm{NW}$ and $1002 \mathrm{mb}$ at San Salvador, Bahamas at 9Z. $25 \mathrm{kt} \mathrm{W}$ and $1005 \mathrm{mb}$ at San Salvador, Bahamas at 21Z. All observations from MICRO. Aircraft highlights: Radar center fix measured a 28 mi diameter eye at $24.3 \mathrm{~N}, 70.7 \mathrm{~W}$ at $02 \mathrm{Z}$ (ATSR/micro); Radar center fix measured a $35 \mathrm{mi}$ diameter eye at $25.0 \mathrm{~N}, 71.6 \mathrm{~W}$ at $06 \mathrm{Z}$ (ATSR/micro); Penetration center fix at $26.5 \mathrm{~N}, 71.9 \mathrm{~W}$ at $1350 \mathrm{Z}$ (ATSR); Penetration center fix measured max surface winds of $120 \mathrm{kt}$, a central pressure of $944 \mathrm{mb}$ and a 40 mile diameter eye at $27.0 \mathrm{~N}, 72.5 \mathrm{~W}$ at $1600 \mathrm{Z}$ (MICRO); Penetration center fix measured max surface winds of $110 \mathrm{kt}$, a central pressure of $944 \mathrm{mb}$ and a 40 mile diameter eye at $26.8 \mathrm{~N}, 72.2 \mathrm{~W}$ at $1704 \mathrm{Z}$ (MICRO). "On the next day, the central pressure had diminished to $944 \mathrm{mb}$ (27.88 inches) the lowest during the life of the hurricane, as it moved northwestward some 200 to 250 miles east of the Bahama Islands" (MWR). "The Navy Reconnaissance plane this morning found the eye 40 miles in diameter and the central pressure 27.88 inches" (WBO). "Air Force and Navy Reconnaissance planes late this forenoon found that the central pressure was remaining steady at 27.88 inches" (WBO). August 9:

HWM shows a hurricane of at most $990 \mathrm{mb}$ centered near $30.2 \mathrm{~N}, 73.3 \mathrm{~W}$ at $12 \mathrm{Z}$. HURDAT lists this as a $125 \mathrm{kt}$ hurricane at $29.7 \mathrm{~N}, 73.7 \mathrm{~W}$ at $12 \mathrm{Z}$. MWR shows a low pressure of $960 \mathrm{mb}$ located near $29.8 \mathrm{~N}, 74.0 \mathrm{~W}$ at $12 \mathrm{Z}$. Microfilm analyzes a closed low pressure of at most $987 \mathrm{mb}$ centered at $30.0 \mathrm{~N}, 74.0 \mathrm{~W}$ at $12 \mathrm{Z}$. Ship highlights: $50 \mathrm{kt} \mathrm{SE}$ and $1007 \mathrm{mb}$ at $31.3 \mathrm{~N}, 71.2 \mathrm{~W}$ at $10 \mathrm{Z}$ (MICRO). $50 \mathrm{kt} \mathrm{SE}$ and $1007 \mathrm{mb}$ at $31.2 \mathrm{~N}, 70.0 \mathrm{~W}$ at $15 \mathrm{Z}$ (MICRO). $50 \mathrm{kt} \mathrm{SE}$ and $1007 \mathrm{mb}$ at $31.5 \mathrm{~N}, 71.5 \mathrm{~W}$ at $18 \mathrm{Z}$ (COADS). $50 \mathrm{kt} \mathrm{N}$ and $1005 \mathrm{mb}$ at $31.5 \mathrm{~N}, 77.2 \mathrm{~W}$ at $18 \mathrm{Z}$ (MICRO). Aircraft highlights: Penetration center fix at $28.5 \mathrm{~N}, 73.0 \mathrm{~W}$ at $0245 \mathrm{Z}$ (ATSR); Penetration center fix at $28.5 \mathrm{~N}, 73.0 \mathrm{~W}$ at $0330 \mathrm{Z}$ (ATSR); Penetration center fix at $28.7 \mathrm{~N}, 74.1 \mathrm{~W}$ at $0630 \mathrm{Z}$ (ATSR); Penetration center fix at $29.1 \mathrm{~N}, 73.3 \mathrm{~W}$ at $0706 \mathrm{Z}$ (ATSR); Penetration center fix at $29.2 \mathrm{~N}, 73.5 \mathrm{~W}$ at $08 \mathrm{Z}$ (ATSR); Penetration center fix measured a central pressure of $959 \mathrm{mb}$ and a 35 mile diameter eye at $29.9 \mathrm{~N}, 74.1 \mathrm{~W}$ at $1440 \mathrm{Z}$ (ATSR); Penetration center fix measured a central pressure of $961 \mathrm{mb}$ and a 34 mile diameter eye at $30.1 \mathrm{~N}, 74.5 \mathrm{~W}$ at $20 \mathrm{Z}$ (MICRO); Penetration center fix measured max surface winds of $135 \mathrm{kt}$ at $30.2 \mathrm{~N}, 74.8 \mathrm{~W}$ at $2248 \mathrm{Z}$ (micro). "The hurricane slowed to 6 to $8 \mathrm{mph}$ in forward speed 400 to 500 miles off the northeastern coast of Florida and central pressure had filled to $954 \mathrm{mb}$ (28.17 inches) by the afternoon of the $9^{\text {th }}$ " (MWR). "From the time of the second aircraft reconnaissance flight until the time in which "Connie" encroached upon the mainland of the United 
States, almost constant aircraft surveillance was maintained. The center fixes by aircraft reconnaissance were so numerous from the $9^{\text {th }}$ of August until the $12^{\text {th }}$ of August that at times the reports were difficult to plot when the storm movement was slow and erratic. The aircraft center fixes during this period revealed erratic storm movement which is discussed in Section II (2) of the report on "Connie" (ATSR).

August 10:

HWM shows a hurricane of at most $990 \mathrm{mb}$ centered near $31.2 \mathrm{~N}, 75.6 \mathrm{~W}$ at $12 \mathrm{Z}$. HURDAT lists this as a $125 \mathrm{kt}$ hurricane at $30.8 \mathrm{~N}, 75.3 \mathrm{~W}$ at $12 \mathrm{Z}$. MWR shows a low pressure of $960 \mathrm{mb}$ located near 29.8N, 74.0 W at 12Z. Microfilm analyzes a closed low pressure of at most $993 \mathrm{mb}$ centered at $31.0 \mathrm{~N}, 76.0 \mathrm{~W}$ at $12 \mathrm{Z}$. Ship highlights: $50 \mathrm{kt} \mathrm{W}$ and $998 \mathrm{mb}$ at $28.9 \mathrm{~N}, 77.0 \mathrm{~W}$ at $6 \mathrm{Z}$ (COADS). $50 \mathrm{kt} \mathrm{NNW}$ and $1005 \mathrm{mb}$ at $31.5 \mathrm{~N}, 79.2 \mathrm{~W}$ at $12 \mathrm{Z}$ (COADS). $50 \mathrm{kt} \mathrm{NE}$ and $1006 \mathrm{mb}$ at $33.5 \mathrm{~N}, 77.5 \mathrm{~W}$ at $15 \mathrm{Z}$ (MICRO). $55 \mathrm{kt} \mathrm{NNW}$ and $1002 \mathrm{mb}$ at $31.3 \mathrm{~N}, 79.3 \mathrm{~W}$ at $18 \mathrm{Z}$ (COADS). Aircraft highlights: Penetration center fix measured a 35 mile diameter eye at $30.6 \mathrm{~N}, 75.5 \mathrm{~W}$ at $0410 \mathrm{Z}$ (micro); Penetration center fix measured a central pressure of $972 \mathrm{mb}$ at $31.0 \mathrm{~N}, 75.7 \mathrm{~W}$ at 1232Z; Penetration center fix measured a central pressure of $977 \mathrm{mb}$ and a 30 mile diameter eye at $31.0 \mathrm{~N}$, $75.3 \mathrm{~W}$ at 1432Z; Penetration center fix measured max surface winds of $120 \mathrm{kt}$, a central pressure of $970 \mathrm{mb}$ and a 35 mile diameter eye at $31.1 \mathrm{~N}, 76.7 \mathrm{~W}$ at $18 \mathrm{Z}$; Penetration center fix measured a central pressure of $980 \mathrm{mb}$ at $31.3 \mathrm{~N}, 76.6 \mathrm{~W}$ at 1916Z; Penetration center fix at $31.3 \mathrm{~N}, 76.5 \mathrm{~W}$ at 2004Z; Penetration center fix measured a central pressure of $973 \mathrm{mb}$ and a 50 mile diameter eye at $31.1 \mathrm{~N}, 76.9 \mathrm{~W}$ at $2229 \mathrm{Z}$. All observations from MICRO. “ . ..977 $\mathrm{mb}$ (28.85 inches) by the morning of the $10^{\text {th }}$. Penetration during the $10^{\text {th }}$ indicated the eye was becoming filled with clouds and poorly defined. Connie drifted slowly towards the west-northwest and west on the $9^{\text {th }}$ and $10^{\text {th }}$ and north-northeast on the $11^{\text {th" }}$ (MWR). "The central pressure in the hurricane has filled about nine tenths of an inch during the past 36 to 48 hours and is now 28.70 inches" (WBO).

August 11:

HWM shows a hurricane of at most $990 \mathrm{mb}$ centered near $32.8 \mathrm{~N}, 76.8 \mathrm{~W}$ at $12 \mathrm{Z}$. HURDAT lists this as a $95 \mathrm{kt}$ hurricane at $32.1 \mathrm{~N}, 77.0 \mathrm{~W}$ at $12 \mathrm{Z}$. MWR shows a low pressure of $972 \mathrm{mb}$ located near $32.5 \mathrm{~N}, 77.2 \mathrm{~W}$ at $12 \mathrm{Z}$. Microfilm analyzes a closed low pressure of at most $990 \mathrm{mb}$ centered at $32.2 \mathrm{~N}, 77.3 \mathrm{~W}$ at 12Z. Ship highlights: $70 \mathrm{kt}$ ENE and $999 \mathrm{mb}$ at $33.5 \mathrm{~N}, 77.5 \mathrm{~W}$ at $0 \mathrm{Z}$ (MICRO). $60 \mathrm{kt} \mathrm{N}$ and $1003 \mathrm{mb}$ at $31.1 \mathrm{~N}, 79.5 \mathrm{~W}$ at 0Z (COADS). $60 \mathrm{kt} \mathrm{SW}$ and $992 \mathrm{mb}$ at 31.5N, 76.4W at 15Z (MICRO). $60 \mathrm{kt} \mathrm{WSW}$ and $992 \mathrm{mb}$ at $31.1 \mathrm{~N}, 76.4 \mathrm{~W}$ at $18 \mathrm{Z}$ (COADS). Land highlights: $30 \mathrm{kt} \mathrm{NE}$ and $997 \mathrm{mb}$ at Wilmington, $\mathrm{NC}$ at $19 \mathrm{Z}$ (MICRO). Aircraft highlights: $978 \mathrm{mb}$ at $32.3 \mathrm{~N}, 77.5 \mathrm{~W}$ at $13 \mathrm{Z}$. $977 \mathrm{mb}$ at $32.0 \mathrm{~N}, 77.2 \mathrm{~W}$ at $1540 \mathrm{Z} .977 \mathrm{mb}$ at $32.4 \mathrm{~N}, 77.0 \mathrm{~W}$ at $1715 \mathrm{Z} .976 \mathrm{mb}$ at $32.8 \mathrm{~N}$, 
$77.3 \mathrm{~W}$ at $19 \mathrm{Z} .965 \mathrm{mb}$ at $32.8 \mathrm{~N}, 77.0 \mathrm{~W}$ at $20 \mathrm{Z} .976 \mathrm{mb}$ at $32.8 \mathrm{~N}, 77.3 \mathrm{~W}$ at $2050 \mathrm{Z} .976$ $\mathrm{mb}$ at $32.7 \mathrm{~N}, 77.2 \mathrm{~W}$ at $2130 \mathrm{Z}$. All observations from MICRO.

August 12:

HWM shows a hurricane of at most $985 \mathrm{mb}$ centered near $34.7 \mathrm{~N}, 75.8 \mathrm{~W}$ at $12 \mathrm{Z}$. HURDAT lists this as a $70 \mathrm{kt}$ hurricane at $34.8 \mathrm{~N}, 76.2 \mathrm{~W}$ at $12 \mathrm{Z}$. MWR shows a low pressure of $972 \mathrm{mb}$ located near $34.5 \mathrm{~N}, 76.5 \mathrm{~W}$ at $12 \mathrm{Z}$. Microfilm analyzes a closed low pressure of at most $981 \mathrm{mb}$ centered at $34.8 \mathrm{~N}, 76.4 \mathrm{~W}$ at 12Z. Ship highlights: $60 \mathrm{kt}$ WSW and $992 \mathrm{mb}$ at $31.2 \mathrm{~N}, 76.5 \mathrm{~W}$ at $0 \mathrm{Z}$ (COADS). $65 \mathrm{kt} \mathrm{SW}$ and $992 \mathrm{mb}$ at $32.3 \mathrm{~N}$, $77.1 \mathrm{~W}$ at $03 \mathrm{Z}$ (MICRO). $60 \mathrm{kt} \mathrm{SW}$ and $992 \mathrm{mb}$ at 32.3N, $75.8 \mathrm{~W}$ at $06 \mathrm{Z}$ (COADS). $67 \mathrm{kt}$ $\mathrm{N}$ and $981 \mathrm{mb}$ at Frying Pan Lighthouse at 8Z (MICRO). $65 \mathrm{kt} \mathrm{SE}$ and $996 \mathrm{mb}$ at Diamond Shoals Lighthouse at 8Z (MICRO). $60 \mathrm{kt} \mathrm{SE}$ and $989 \mathrm{mb}$ at 34.4N, $75.0 \mathrm{~W}$ at 15Z (MICRO). Land highlights: $63 \mathrm{kt}$ (gusts to $72 \mathrm{kt}$ ) at Wilmington, NC, no time given (MWR). $60 \mathrm{kt} \mathrm{NE}$ and $992 \mathrm{mb}$ at Newport, $\mathrm{NC}$ at 03Z (MICRO). $67 \mathrm{kt} \mathrm{SE}$ and $997 \mathrm{mb}$ at Frying Pan Lighthouse at 6Z (MICRO). $50 \mathrm{kt} \mathrm{NNE}$ and $969 \mathrm{mb}$ at Newport, NC at $15 \mathrm{Z}$ (MICRO). $30 \mathrm{kt} \mathrm{W}$ and $976 \mathrm{mb}$ at Newport, $\mathrm{NC}$ at 18Z (MICRO). $962 \mathrm{mb}$ at Fort Macon, NC, no time given (MWR). Aircraft highlights: Center fix at $33.3 \mathrm{~N}, 77.1 \mathrm{~W}$ at $01 \mathrm{Z}$ (ATSR); Center fix at 33.4N, $77.0 \mathrm{~W}$ at $06 \mathrm{Z}$ (ATSR); Center fix at $34.1 \mathrm{~N}, 76.5 \mathrm{~W}$ at $0956 \mathrm{Z}$ (ATSR) and center fix at $35.0 \mathrm{~N}, 76.8 \mathrm{~W}$ at $1715 \mathrm{Z}$ (ATSR). "It then turned northward again on the $12^{\text {th }}$ as it passed inland on the North Carolina coast near Morehead City. At Wilmington, NC, the fastest measured mile was $72 \mathrm{mph}$, and the peak gust was $83 \mathrm{mph}$ during the evening of the $11^{\text {th }}$ as the hurricane passed about 100 miles to the southeast and east of the station. Winds of $75 \mathrm{mph}$ with peak gusts of $100 \mathrm{mph}$ and lowest pressure of $962 \mathrm{mb}$ (28.40 inches) were reported at Fort Macon, NC, near the point where the hurricane crossed the coastline. However, it has not been established whether this was a measured or an estimated speed" (MWR). "After making numerous erratic changes in course and speed from the $9^{\text {th }}$ through the $12^{\text {th }}$ of August, the center moved inland over Morehead City, North Carolina. The partial blocking action of the high ridge to the north of the storm was being gradually eliminated as the trough over the Great Lakes region on the $10^{\text {th }}$ of August deepened as it moved eastward" (ATSR). " $34.7 \mathrm{~N}, 76.1 \mathrm{~W}-962 \mathrm{mb}$ at $34.7 \mathrm{~N}, 76.1 \mathrm{~W}-1011 \mathrm{mb}$ Penv - RMW $45 \mathrm{nmi}-$ speed $7 \mathrm{kt}$ - 71 kt est max sustained 10m, 10-min wind” (Schwardt et al. (1979)). “28.40” (961.7 $\mathrm{mb}$ ) central pressure measured by land barometer at Fort Macon, NC - RMW $38 \mathrm{nmi}-7$ kt forward speed - landfall pt 34.9N, 76.2W" (Ho et al. (1987). "Aug - NC3, VA1 - Cat 3 - $962 \mathrm{mb}$ " (Jarrell et al. (1992).

August 13:

HWM shows a hurricane of at most $990 \mathrm{mb}$ centered near $39.8 \mathrm{~N}, 75.5 \mathrm{~W}$ at $12 \mathrm{Z}$. HURDAT lists this as a $45 \mathrm{kt}$ tropical storm at $39.2 \mathrm{~N}, 76.4 \mathrm{~W}$ at $12 \mathrm{Z}$. MWR shows a low 
pressure of $983 \mathrm{mb}$ located near 39.5N, 76.5W at 12Z. Microfilm analyzes a closed low pressure of at most $987 \mathrm{mb}$ centered at $39.4 \mathrm{~N}, 76.5 \mathrm{~W}$ at $12 \mathrm{Z}$. Ship highlights: $50 \mathrm{kt} \mathrm{SSW}$ and $993 \mathrm{mb}$ at $35.2 \mathrm{~N}, 74.6 \mathrm{~W}$ at $0 \mathrm{Z}$ (COADS). $50 \mathrm{kt} \mathrm{SSE}$ and $997 \mathrm{mb}$ at $38.3 \mathrm{~N}, 72.9 \mathrm{~W}$ at $6 \mathrm{Z}$ (COADS). $40 \mathrm{kt} \mathrm{SSE}$ and $1002 \mathrm{mb}$ at $38.6 \mathrm{~N}, 73.0 \mathrm{~W}$ at $12 \mathrm{Z}$ (COADS). Land highlights: $20 \mathrm{kt} \mathrm{NW}$ and $978 \mathrm{mb}$ at Elizabeth City at $0 \mathrm{Z}$ (micro). $53 \mathrm{kt} \mathrm{E}$ at Philadelphia, PA, no time given (CLIMA). $39 \mathrm{kt} \mathrm{E}$ at Reading, PA, no time given (CLIMA). $49 \mathrm{kt} \mathrm{NE}$ at Rochester, NY, no time given (CLIMA). $38 \mathrm{kt} \mathrm{NE}$ at Buffalo, NY, no time given (CLIMA). $30 \mathrm{kt} \mathrm{NE}$ and $988 \mathrm{mb}$ at Washington, DC at 09Z (micro). "At the $200 \mathrm{mb}$ level the trough was shallow on the $11^{\text {th }}$ as it approached the Great Lakes, but deepened during the next 24 hours, and on the $13^{\text {th }}$ of August a low center had formed over Illinois. Thus, a natural path of least resistance was created to the north of the center which caused "Hurricane Connie" to move in that direction as a more rapid rate during the final day of her existence. "Hurricane Connie" had shown a rapid decrease in intensity on 11 August while she remained nearly stationary off the North Carolina coast and at the time in which the center moved inland, the maximum winds reported were 80 knots in a very small area near the center. Further decrease in intensity continued as the center moved over land becoming less than hurricane intensity at 131000Z" (ATSR).

August 14:

HWM shows a low pressure of at most $1010 \mathrm{mb}$ centered near $44.0 \mathrm{~N}, 81.0 \mathrm{~W}$ at 12Z. HURDAT lists this as a $25 \mathrm{kt}$ tropical depression at $43.7 \mathrm{~N}, 81.6 \mathrm{~W}$ at $12 \mathrm{Z}$. MWR shows a low pressure of $1006 \mathrm{mb}$ located near $43 \mathrm{~N}, 82 \mathrm{~W}$ at $12 \mathrm{Z}$. Microfilm analyzes a closed low pressure of at most $1008 \mathrm{mb}$ centered at $43.5 \mathrm{~N}, 82 \mathrm{~W}$ at $12 \mathrm{Z}$. Land highlights: $20 \mathrm{kt} \mathrm{NE}$ and $1002 \mathrm{mb}$ at Buffalo, NY at 00Z (MICRO) and $5 \mathrm{kt} \mathrm{SE}$ and $1003 \mathrm{mb}$ at London, Canada at $06 \mathrm{Z}$ (MICRO).

August 15:

HWM shows a spot low pressure centered near $46.0 \mathrm{~N}, 81.0 \mathrm{~W}$ at 12Z. HURDAT lists this as a $25 \mathrm{kt}$ tropical depression at $46.3 \mathrm{~N}, 83.0 \mathrm{~W}$ at $06 \mathrm{Z}$ (last position). Microfilm analyzes a closed low pressure of at most $1014 \mathrm{mb}$ centered at $49 \mathrm{~N}, 91 \mathrm{~W}$ with fronts to the east and southwest at $12 \mathrm{Z}$. A trough exist in microfilm along $83 \mathrm{~W}$ between $43 \mathrm{~N}$ and $47 \mathrm{~N}$.

"Tornadic activity was reported in the Carolinas during the afternoon and evening of August 10, while the hurricane was about due east of the Georgia coast, and before the winds had increased to strong along the Carolina coasts. One tornado occurred in North Carolina at Penderlea in northern Pender County and five others were reported in South Carolina from Georgetown northward. These tornadoes were reported as moving from east to west. Beach erosion on the North Carolina coast was considerable, as tides rose to 
as much as 7 feet above normal from Southport to Nags Head, and to 5 to 8 feet above normal in the sounds at the mouths of the rivers. Total damage in North Carolina was estimated at $\$ 40$ million, of which about $3 / 4$ was crop damage. The hurricane caused no deaths or serious injuries in North Carolina. The slow and somewhat meandering course of Connie and the loss of intensity while off the south Atlantic coast for a 48 to 72 hour period from late on the $8^{\text {th }}$ to early on the $11^{\text {th }}$ were the principal forecast problems during the life of the storm. Synoptically, on August 8, a strong (1027 mb) surface high pressure system was located over the eastern Atlantic with a ridge extending to the middle Atlantic coast. At the 500-mb level the picture was rather similar, with the ridge aloft along the Atlantic coast trending to move slowly northward with time. Several rather weak polar troughs moved eastward over northern latitudes with little effect in the latitude of and the area immediately to the north of the hurricane. The situation in the sub-Tropics was more complicated in the middle and upper troposphere. A cold Low extended down below the $500-\mathrm{mb}$ surface and at the 500-mb level moved from a position off the Georgia coast on the $6^{\text {th }}$ southwestward into the central Gulf of Mexico by the $8^{\text {th }}$. Heights of the $500-\mathrm{mb}$ surface continues to build to the northeast of the dying hurricane as it progressed into the Middle Atlantic States and eventually into Michigan where it filled. Apparently during the period of slow movement, the average gradients on all sides of Connie were well balanced but tended to become progressively a little stronger on the east side and no polar trough extended sufficiently far south to materially disturb this balance. Hurricane Diane was forming during this period and developing hurricane intensity. However, since Connie was larger and more intense, the "Fujiwara effect" on it was slight, but what there was would exert some equator-ward pull.” (MWR)

"No reports of property damages or personal injury were noted through the West Indies, since the path of the strong and damaging winds of "Connie" were too far from the land areas. As "Connie" moved ashore, the Carolina coastal regions were buffeted with damaging winds, but greater damage in this region was caused by the pounding of heavy seas which were built up while the storm center was lying, nearly stationary, off the Carolina coast. In North Carolina, approximately 14,000 personas were forced from their beach homes into emergency shelters as the hurricane moved inland. Piers, boats and beach buildings sustained extensive damage. "Connie's" final damaging blow was to cause heavy rains in the northeastern section of the United States resulting in flash floods, power failures and other related damages. New York City reported its heaviest downpour since 1926. The wake of the hurricane had left a death toll of 2 persons and property damage estimated to be at least $\$ 15,000,000$.” (ATSR)

Genesis for this system remains at $06 \mathrm{Z}$ on the $3^{\text {rd }}$ of August, unchanged from the original HURDAT. Unfortunately, there is little data available over the eastern and central Atlantic and a closed circulation cannot be corroborated to have been present at the time 
of genesis. A major change in the track is made on the $3^{\text {rd }}$ as the positions shown in HURDAT indicate a very fast motion of about $36 \mathrm{kt}$ in the first 12 hours of existence of the tropical cyclone that does not appear to be real. The intensity remains unchanged at $06 \mathrm{Z}$ and $12 \mathrm{Z}$ on August $3^{\text {rd }}, 30 \mathrm{kt}$ and $35 \mathrm{kt}$ respectively. No change is made to the time the cyclone became a tropical storm (six hours after genesis). The first definitive indication that a well-defined closed circulation is present is at $18 \mathrm{Z}$ on the $3^{\text {rd }}$ when the ship KFDE measured $10 \mathrm{kt} \mathrm{NW}$ and $1005 \mathrm{mb}$. A central pressure of $1004 \mathrm{mb}$ at has been added at $18 \mathrm{Z}$ on the $3^{\text {rd }}$. A central pressure of $1004 \mathrm{mb}$ yields $39 \mathrm{kt}$ according to the Brown et al. southern pressure-wind relationship. The original intensity analyzed by HURDAT of $40 \mathrm{kt}$ at $18 \mathrm{Z}$ is kept. Later at $03 \mathrm{Z}$ on the $4^{\text {th }}$ of August, the ship BONAIRE measured $40 \mathrm{kt} \mathrm{NE}$ and $996 \mathrm{mb}$. A peripheral pressure of $996 \mathrm{mb}$ yields maximum winds greater than $54 \mathrm{kt}$ according to the Brown et al. southern pressure-wind relationship. A pressure of $1002 \mathrm{mb}$ was originally in HURDAT at $12 \mathrm{Z}$ on the $4^{\text {th }}$ but this pressure has been removed because the ship Linda Elra reported a pressure of $997 \mathrm{mb}$ and winds of 40 $\mathrm{kt}$ at this time. The first reconnaissance aircraft to reach the cyclone occurred at $1820 \mathrm{Z}$ on the $4^{\text {th }}$ making a center fix at $15.8 \mathrm{~N}$ and $52.8 \mathrm{~W}$. Clearly it missed the storm and reported a "false" eye 75 miles to the NE of the fix, which was likely the true center of Connie. The intensity of Connie on the $4^{\text {th }}$ is reanalyzed to be $50 \mathrm{kt}$ at $0 \mathrm{Z}, 60 \mathrm{kt}$ at $06 \mathrm{Z}$, and $70 \mathrm{kt}$ at $12 \mathrm{Z}$ and 18Z. The original intensity on this date in HURDAT was $40 \mathrm{kt}, 40 \mathrm{kt}, 45 \mathrm{kt}$, and $50 \mathrm{kt}$, respectively. This suggests that Connie became a hurricane about 18 hours before originally shown. Two aircraft penetrations occurred on August $5^{\text {th }}$, one at $1110 \mathrm{Z}$ making a center fix at $18.2 \mathrm{~N}, 56.7 \mathrm{~W}$ and another one at $1805 \mathrm{Z}$ at $18.4 \mathrm{~N}, 57.9 \mathrm{~W}$. The second fix measured a pressure of $985 \mathrm{mb}$, which corresponds to $71 \mathrm{kt}$ in the pressurewind relationship south of $25 \mathrm{~N}$. The aircraft also reported an eye of a 20 mile diameter, indicating an RMW of $15 \mathrm{~nm}$, which is the same as suggested by climatology. An intensity of $75 \mathrm{kt}$ is selected for the $5^{\text {th }}$ at $18 \mathrm{Z}$, a major change from $115 \mathrm{kt}$ originally in HURDAT. Moreover, the $985 \mathrm{mb}$ central pressure was originally at $12 \mathrm{Z}$ in HURDAT, and it has been moved to $18 \mathrm{Z}$. Major changes to the intensity were also made at $06 \mathrm{Z}$ and $12 \mathrm{Z}$ on the $5^{\text {th }}$ and the intensity selected for those times is $70 \mathrm{kt}$, down from $95 \mathrm{kt}$ and 110 $\mathrm{kt}$, respectively. At 21Z, a ship at $18.1 \mathrm{~N}, 58.5 \mathrm{~W}$ reported $65 \mathrm{kt} \mathrm{N}$. On the $6^{\text {th }}$ of August, Connie made its closest approach to the northern Leeward Islands passing about $90 \mathrm{~nm}$ while on a west-northwest to northwest heading. The strongest winds in the islands shown in microfilm were $45 \mathrm{kt} \mathrm{SW}$ at $15 \mathrm{Z}$ at Anguilla. Later on the $6^{\text {th }}$, a ship named Pelican State passed very close, if not through the center of Connie. At 18Z, it reported $65 \mathrm{kt} \mathrm{N}$ and $979 \mathrm{mb}$ and at 21Z, $35 \mathrm{kt} \mathrm{S}$ and $977 \mathrm{mb}$. A central pressure of $982 \mathrm{mb}$ is originally shown in HURDAT at $12 \mathrm{Z}$ on the $6^{\text {th }}$ but it has been removed since observations do not support it. At 18Z, an aircraft penetration made a center fix measuring a central pressure of $968 \mathrm{mb}$ and a surface wind of $125 \mathrm{kt}$ is reported. A central pressure of $968 \mathrm{mb}$ yields $92 \mathrm{kt}$ in the pressure-wind relationship south of $25 \mathrm{~N}$ 
and $93 \mathrm{kt}$ south of $25 \mathrm{~N}$ intensifying. An intensity of $100 \mathrm{kt}$ is selected for $18 \mathrm{Z}$ on the $6^{\text {th }}$ making Connie a major hurricane, but down from $125 \mathrm{kt}$ originally in HURDAT. Major changes in intensity are also shown on the $6^{\text {th }}$ as HURDAT originally had $120 \mathrm{kt}$ at $0 \mathrm{Z}$ and $06 \mathrm{Z}$, and $125 \mathrm{kt}$ at $12 \mathrm{Z}$ and $18 \mathrm{Z}$. Eight center fixes were made by the aircrafts on the $6^{\text {th }}$ helping to identify the position of the hurricane and only minor track changes are added.

Connie continued to steadily intensity on the $7^{\text {th }}$ of August as it moved towards the northwest, east of the Bahamas. At 18Z, an aircraft center fix reported a central pressure of $944 \mathrm{mb}$, a diameter of 40 miles, and the report indicates that the eye was shaped like an inverted cone. The diameter information indicates that Connie had an RMW of $30 \mathrm{~nm}$ at $18 \mathrm{Z}$ and climatology suggests an RMW of $15 \mathrm{~nm}$. A central pressure of $944 \mathrm{mb}$ yields $117 \mathrm{kt}$ south of $25 \mathrm{~N}$ and $119 \mathrm{kt}$ south of $25 \mathrm{~N}$ intensifying. An intensity of $115 \mathrm{kt}$ is selected for $18 \mathrm{Z}$ on the $7^{\text {th }}$, down from $125 \mathrm{kt}$ originally in HURDAT. $115 \mathrm{kt}$ is also the peak intensity for the lifetime of hurricane Connie. Major changes in the intensity are indicated at $0 \mathrm{Z}, 06 \mathrm{Z}$ and $12 \mathrm{Z}$ on the $7^{\text {th }}$ as the intensities selected are $100 \mathrm{kt}, 105 \mathrm{kt}$ and $110 \mathrm{kt}$, respectively, down from $125 \mathrm{kt}$. At 21Z, a ship at $23.7 \mathrm{~N}, 67.5 \mathrm{~W}$ measured 100 $\mathrm{kt} \mathrm{SE}$ and $998 \mathrm{mb}$. Minor changes are introduced for the track on the $7^{\text {th }}$. At $18 \mathrm{Z}$ on the $8^{\text {th }}$, an aircraft reconnaissance measured a central pressure of $944 \mathrm{mb}$ and an eye diameter of 40 miles. A central pressure of $944 \mathrm{mb}$ yields $111 \mathrm{kt}$ north of $25 \mathrm{~N}$. The eye diameter information indicates an RMW of $30 \mathrm{~nm}$ and climatology suggest $17 \mathrm{~nm}$. Therefore, an intensity of $105 \mathrm{kt}$ is selected for $18 \mathrm{Z}$ on the $8^{\text {th }}$, down from $125 \mathrm{kt}$ originally in HURDAT. Thus on the $7^{\text {th }}$, Connie started to weaken. A central pressure of $936 \mathrm{mb}$ is originally shown in HURDAT at $18 \mathrm{Z}$ but the corresponding advisory shows that it was $944 \mathrm{mb}$ at this time. Starting on the $9^{\text {th }}$ of August, Connie began to move at a slower rate of speed. The intensity continued to decrease and the last position in which the cyclone was a major hurricane was at $12 \mathrm{Z}$ on the $9^{\text {th }}$. At $1440 \mathrm{Z}$ and $20 \mathrm{Z}$, aircraft center fixes reported central pressures of 959 and $961 \mathrm{mb}$, respectively. It is apparent that these central pressures were believed to be a bit high in 1955 because the MWR article on Connie indicates that the central pressure late on the $9^{\text {th }}$ was $954 \mathrm{mb}$. A central pressure of $954 \mathrm{mb}$ yields $101 \mathrm{kt}$ north of $25 \mathrm{~N}$ and $97 \mathrm{kt}$ weakening north of $25 \mathrm{~N}$ according to the pressure-wind relationship. At 1440Z, an eye diameter of 35 miles is reported. This indicates an RMW of about $25 \mathrm{~nm}$ and climatology suggests $21 \mathrm{~nm}$. The cyclone is also moving at about $8 \mathrm{kt}$. Thus, an intensity of $95 \mathrm{kt}$ is selected for $18 \mathrm{Z}$ on the $9^{\text {th }}$, down from $125 \mathrm{kt}$ originally in HURDAT, a major change.

The hurricane continued to fill on the $10^{\text {th }}$ while the track changed to a more westnorthwest heading, just to the southeast of the Carolinas. At $18 \mathrm{Z}$ on the $10^{\text {th }}$, a central pressure of $970 \mathrm{mb}$ was measured by the reconnaissance aircraft. A central pressure of 970 yields $84 \mathrm{kt}$ north of $25 \mathrm{~N}$ and $81 \mathrm{kt}$ north of $25 \mathrm{~N}$ weakening according to the 
pressure-wind relationship. The aircraft also reported an eye of a 35 mile diameter, which allows us to calculate a RMW of about $25 \mathrm{~nm}$. This is close to the suggested climatological RMW of $23 \mathrm{~nm}$. The aircraft as well reported a visual estimate of the wind of $120 \mathrm{kt}$, which is not given much weighting here. Hence, an intensity of $85 \mathrm{kt}$ is selected for $18 \mathrm{Z}$ on the $10^{\text {th }}$. The Air Force reconnaissance plane measured central pressures of $977 \mathrm{mb}$ at $1432 \mathrm{Z}$ and $980 \mathrm{mb}$ at $1916 \mathrm{Z}$, which are higher than the reports from the Navy, and discounted in the reanalysis. Ships in the area avoided getting close to Connie and the strongest winds reported on this day were $50 \mathrm{kt}$. At 2229Z, an aircraft reconnaissance measured a central pressure of $973 \mathrm{mb}$ and this is added to $0 \mathrm{Z}$ on the $11^{\text {th }}$. This pressure yields $81 \mathrm{kt}$ on the $\mathrm{N} 25 \mathrm{~N}$ according to the pressure-wind relationship. An intensity of $80 \mathrm{kt}$ is selected for this time. On August $11^{\text {th }}$, Connie turned to the north and continued to slowly move towards the East Coast of the United States. Other central pressures were reported at $13 \mathrm{Z}$ and 1715Z, $978 \mathrm{mb}$ and $977 \mathrm{mb}$, respectively. The last report indicated that the diameter of the eye had decreased to 20 miles, which gives a RMW of about $15 \mathrm{~nm}$. Climatology suggests a RMW of $25 \mathrm{~nm}$. These central pressures yield about $75 \mathrm{kt}$ on the $\mathrm{N} 25 \mathrm{~N}$ pressure-wind relationship. An intensity of $75 \mathrm{kt}$ is selected for $12 \mathrm{Z}$ and $18 \mathrm{Z}$ on the $11^{\text {th }}$.

Hurricane Connie began to move faster on the $12^{\text {th }}$ of August making landfall near Fort Macon, NC at 15Z. Fort Macon, NC measured a central pressure of $962 \mathrm{mb}$, which yields $93 \mathrm{kt}$ north of $25 \mathrm{~N}$ and $88 \mathrm{kt}$ north of $35 \mathrm{~N}$ according to the pressure-wind relationship. Ho et al. indicates that the RMW at landfall is $38 \mathrm{~nm}$ and climatology suggests $27 \mathrm{~nm}$. When Connie made landfall, it was moving at around $8 \mathrm{kt}$. An intensity of $85 \mathrm{kt}$ is selected for $12 \mathrm{Z}$ and $18 \mathrm{Z}$ on the $12^{\text {th }}$, which is an increase from $70 \mathrm{kt}$ and $65 \mathrm{kt}$ respectively, as originally shown in HURDAT. The last center fix was at $1715 \mathrm{Z}$ over eastern North Carolina. The radar in Cape Hatteras allowed for center fixes to be made from $1050 \mathrm{Z}$ to $1725 \mathrm{Z}$. Before making landfall, ships in the area measured winds up to 65 kt. Over land, Wilmington measured sustained winds of $63 \mathrm{kt}$ and Newport reported 60 kt. After landfall, Connie moved generally north-northeast over extreme eastern North Carolina possibly moving back briefly over the Atlantic Ocean around $0 \mathrm{Z}$ on the $13^{\text {th }}$ of August near the North Carolina/Virginia border. The Kaplan and DeMaria model was not run because the cyclone straddled the coast for a day. Interaction with land caused the hurricane to weaken, especially later on the $13^{\text {th }}$ when it moved toward the northnorthwest and into the Mid-Atlantic States. Connie weakened to a tropical storm at $06 \mathrm{Z}$ on the $13^{\text {th }}$. Washington DC reported $30 \mathrm{kt} \mathrm{NE}$ and $988 \mathrm{mb}$ at $09 \mathrm{Z}$ on August $13^{\text {th }}$, Philadelphia reported $53 \mathrm{kt} \mathrm{E} \mathrm{(no} \mathrm{time} \mathrm{given)} \mathrm{and} \mathrm{Buffalo,} \mathrm{NY} \mathrm{reported} 38 \mathrm{kt} \mathrm{NE}$ (no time given). Early on the day, ships reported top winds of $50 \mathrm{kt}$. The central pressures originally shown in HURDAT from $0 \mathrm{Z}$ to $12 \mathrm{Z}$ on the $13^{\text {th }}$ are likely to have been estimated a bit lower than the actual value. $969 \mathrm{mb}$ indicated at $0 \mathrm{Z}$ was likely around $972-975 \mathrm{mb}, 974 \mathrm{mb}$ at $06 \mathrm{Z}$ was likely around $981-985 \mathrm{mb}$ and $982 \mathrm{mb}$ at $12 \mathrm{Z}$ was likely 
around 988-992. The estimate of $995 \mathrm{mb}$ at $18 \mathrm{Z}$ appears to be correct. A gradual weakening is shown, $75 \mathrm{kt}$ at $0 \mathrm{Z}, 60 \mathrm{kt}$ at $06 \mathrm{Z}, 45 \mathrm{kt}$ at $12 \mathrm{Z}$ and $35 \mathrm{kt}$ at $18 \mathrm{Z}$ (up from 60 $\mathrm{kt}$ at $0 \mathrm{Z}, 50 \mathrm{kt}$ at $6 \mathrm{Z}$, same for $12 \mathrm{Z}$ and $18 \mathrm{Z}$, as originally shown in HURDAT). Late on the $13^{\text {th }}$, Connie turned to the northwest and moved over the Great Lakes early on the $14^{\text {th }}$. Transition to a tropical depression remains unchanged at $0 \mathrm{Z}$ on the $14^{\text {th }}$. The central pressures indicated on the synoptic times of the $14^{\text {th }}$ appear to be correct. Dissipation occurred after $00 \mathrm{Z}$ on the $15^{\text {th }}$ as an approaching cold front absorbed the weakened cyclone. A central pressure of $1011 \mathrm{mb}$ is added at this time. Dissipation is six hours earlier than originally shown in HURDAT.

Hurricane Daine [August 7-23, 1955]

\begin{tabular}{|c|c|c|c|c|c|c|c|c|c|c|c|c|c|}
\hline $\begin{array}{l}38705 \\
38705\end{array}$ & $\begin{array}{l}08 / 07 / 1955 \\
08 / 07 / 1955\end{array}$ & $\begin{array}{r}M=1 \\
M=1 \\
\text { * }\end{array}$ & $\begin{array}{l}5 \\
7 \\
*\end{array}$ & $\begin{array}{l}\text { SNBR }=84 \\
\text { SNBR }=84\end{array}$ & $\begin{array}{ll}48 & \mathrm{D} \\
48 & \mathrm{D}\end{array}$ & $\begin{array}{l}\text { ANE } \\
\text { ANE }\end{array}$ & $\begin{array}{l}\text { XII } \\
\text { XII }\end{array}$ & $\begin{array}{l}N G=1 \\
N G=1\end{array}$ & $\begin{array}{l}\text { SSS }=1 \\
\text { SSS }=1\end{array}$ & & & & \\
\hline 38710 & $\odot 8 / \odot 7^{*}$ & $\odot$ & $\odot$ & $\odot * 170$ & 430 & 25 & $0 * 171$ & 440 & 25 & ๑*172 & 451 & 25 & $\Theta^{*}$ \\
\hline 38710 & $08 / 07$ * & $\odot$ & $\odot$ & $\begin{array}{l}0 * 157 \\
* * *\end{array}$ & $\begin{array}{l}412 \\
* * *\end{array}$ & 25 & $\begin{array}{r}0 * 160 \\
* * *\end{array}$ & $\begin{array}{l}425 \\
* * *\end{array}$ & 25 & $\begin{array}{r}\Theta * 161 \\
* * *\end{array}$ & $\begin{array}{l}438 \\
\star * *\end{array}$ & 25 & ०* \\
\hline $\begin{array}{l}38715 \\
38715\end{array}$ & $\begin{array}{r}08 / 08 * 173 \\
08 / 08 * 162 \\
* * *\end{array}$ & $\begin{array}{l}461 \\
452 \\
* * *\end{array}$ & $\begin{array}{l}25 \\
25\end{array}$ & $\begin{array}{r}\odot * 175 \\
\odot * 163 \\
* * *\end{array}$ & $\begin{array}{l}469 \\
466 \\
\star \star *\end{array}$ & $\begin{array}{l}25 \\
25\end{array}$ & $\begin{array}{r}\odot * 177 \\
0 * 165 \\
* * *\end{array}$ & $\begin{array}{l}478 \\
480 \\
\star \star *\end{array}$ & $\begin{array}{l}25 \\
25\end{array}$ & $\begin{array}{r}0^{*} 179 \\
0 * 166 \\
* * *\end{array}$ & $\begin{array}{l}490 \\
497 \\
* * *\end{array}$ & $\begin{array}{l}25 \\
25\end{array}$ & $\begin{array}{l}\Theta^{*} \\
\Theta^{*}\end{array}$ \\
\hline $\begin{array}{l}38720 \\
38720\end{array}$ & $\begin{array}{r}08 / 09 * 180 \\
08 / 09 * 167 \\
* * *\end{array}$ & $\begin{array}{l}502 \\
507 \\
* * *\end{array}$ & $\begin{array}{l}25 \\
25\end{array}$ & $\begin{array}{l}\Theta * 182 \\
\Theta * 168 \\
* * *\end{array}$ & $\begin{array}{l}514 \\
519 \\
* * *\end{array}$ & $\begin{array}{l}30 \\
30\end{array}$ & $\begin{array}{l}\Theta^{*} 185 \\
\Theta^{*} 170 \\
* * *\end{array}$ & $\begin{array}{l}526 \\
531 \\
\star * *\end{array}$ & $\begin{array}{l}30 \\
30\end{array}$ & $\begin{array}{l}\Theta^{*} 189 \\
0 * 173 \\
* * *\end{array}$ & $\begin{array}{l}543 \\
545 \\
* * *\end{array}$ & $\begin{array}{l}35 \\
35\end{array}$ & $\begin{array}{l}\Theta^{*} \\
\Theta^{*}\end{array}$ \\
\hline $\begin{array}{l}38725 \\
38725\end{array}$ & $\begin{array}{r}08 / 10^{*} 193 \\
08 / 10^{*} 177 \\
* * *\end{array}$ & $\begin{array}{l}559 \\
560 \\
\star * *\end{array}$ & $\begin{array}{l}35 \\
35\end{array}$ & $\begin{array}{l}\odot * 198 \\
\odot * 182 \\
* * *\end{array}$ & $\begin{array}{l}570 \\
574 \\
* * *\end{array}$ & $\begin{array}{l}35 \\
35\end{array}$ & $\begin{array}{r}\theta^{*} 203 \\
\Theta^{*} 190 \\
* \star *\end{array}$ & $\begin{array}{l}580 \\
586 \\
\star * *\end{array}$ & $\begin{array}{l}35 \\
35\end{array}$ & $\begin{array}{l}\Theta^{*} 211 \\
\Theta^{*} 20 \Theta \\
* \star *\end{array}$ & $\begin{array}{l}589 \\
595 \\
\star * *\end{array}$ & $\begin{array}{l}4 \odot \\
4 \odot\end{array}$ & $\begin{array}{l}\Theta^{*} \\
\Theta^{*}\end{array}$ \\
\hline $\begin{array}{l}38730 \\
38730\end{array}$ & $\begin{array}{r}08 / 11^{*} 220 \\
08 / 11^{*} 212 \\
* * *\end{array}$ & $\begin{array}{l}598 \\
60 \odot \\
\star * *\end{array}$ & $\begin{array}{l}45 \\
45\end{array}$ & $\begin{array}{l}\Theta * 227 \\
\Theta * 223 \\
* * *\end{array}$ & $\begin{array}{l}604 \\
606 \\
\star * *\end{array}$ & $\begin{array}{l}50 \\
45 \\
* *\end{array}$ & $\begin{array}{l}\Theta^{*} 233 \\
\Theta^{*} 233\end{array}$ & $\begin{array}{l}608 \\
613 \\
\star \star *\end{array}$ & $\begin{array}{l}55 \\
45 \\
* *\end{array}$ & $\begin{array}{r}0 * 236 \\
\Theta^{*} 238 \\
* * *\end{array}$ & $\begin{array}{l}611 \\
618 \\
\star * *\end{array}$ & $\begin{array}{l}60 \\
45 \\
\star *\end{array}$ & $\begin{array}{r}0^{*} \\
1004^{*} \\
* * * *\end{array}$ \\
\hline $\begin{array}{l}38735 \\
38735\end{array}$ & $\begin{array}{r}08 / 12 * 24 \odot \\
08 / 12 * 242 \\
* * *\end{array}$ & $\begin{array}{l}611 \\
616 \\
\star * *\end{array}$ & $\begin{array}{l}65 \\
50 \\
* *\end{array}$ & $\begin{array}{l}\Theta * 247 \\
\Theta * 246 \\
* * *\end{array}$ & $\begin{array}{l}610 \\
614 \\
* * *\end{array}$ & $\begin{array}{l}9 \odot \\
6 \odot \\
* *\end{array}$ & $\begin{array}{r}\Theta^{*} 253 \\
\Theta^{*} 25 \odot \\
* \star *\end{array}$ & $\begin{array}{l}608 \\
612 \\
\star * *\end{array}$ & $\begin{array}{r}105 \\
70 \\
* *\end{array}$ & $\begin{array}{r}975 * 259 \\
0^{*} 255 \\
* * * *\end{array}$ & $\begin{array}{l}607 \\
610 \\
* * *\end{array}$ & $\begin{array}{r}105 \\
75 \\
* *\end{array}$ & $\begin{array}{r}\odot^{*} \\
975^{*} \\
* * *\end{array}$ \\
\hline $\begin{array}{l}38740 \\
38740\end{array}$ & $\begin{array}{r}08 / 13 * 264 \\
08 / 13 * 26 \odot \\
* * *\end{array}$ & $\begin{array}{l}605 \\
608 \\
\star * *\end{array}$ & $\begin{array}{r}105 \\
70 \\
\star *\end{array}$ & $\begin{array}{r}0^{*} 269 \\
980^{*} 267 \\
* * * * * *\end{array}$ & $\begin{array}{l}605 \\
614 \\
* * *\end{array}$ & $\begin{array}{r}105 \\
70 \\
* *\end{array}$ & $\begin{array}{r}969 * 274 \\
0 * 273 \\
* * * *\end{array}$ & $\begin{array}{l}610 \\
614 \\
\star \star *\end{array}$ & $\begin{array}{r}105 \\
80 \\
* *\end{array}$ & $\begin{array}{l}\odot * 274 \\
\odot * 274\end{array}$ & $\begin{array}{l}622 \\
626 \\
\star * *\end{array}$ & $\begin{array}{r}105 \\
90 \\
* *\end{array}$ & $\begin{array}{r}\odot^{*} \\
969^{*} \\
* * *\end{array}$ \\
\hline $\begin{array}{l}38745 \\
38745\end{array}$ & $\begin{array}{l}\odot 8 / 14 * 272 \\
\odot 8 / 14 * 272\end{array}$ & $\begin{array}{l}634 \\
638 \\
* * *\end{array}$ & $\begin{array}{r}105 \\
90 \\
* *\end{array}$ & $\begin{array}{l}\odot * 273 \\
\odot * 273\end{array}$ & $\begin{array}{l}644 \\
647 \\
* * *\end{array}$ & $\begin{array}{r}105 \\
80 \\
* *\end{array}$ & $\begin{array}{r}0 * 274 \\
976 * 275 \\
* * * * * *\end{array}$ & $\begin{array}{l}654 \\
657 \\
\star * *\end{array}$ & $\begin{array}{r}105 \\
75 \\
* *\end{array}$ & $\begin{array}{r}\theta^{*} 276 \\
980^{*} 278 \\
* * * * * *\end{array}$ & $\begin{array}{l}667 \\
668 \\
* * *\end{array}$ & $\begin{array}{r}105 \\
70 \\
* *\end{array}$ & $\begin{array}{l}\Theta^{*} \\
\Theta^{*}\end{array}$ \\
\hline $\begin{array}{l}38750 \\
38750\end{array}$ & $\begin{array}{r}08 / 15^{*} 280 \\
08 / 15^{*} 282 \\
* * *\end{array}$ & $\begin{array}{l}681 \\
681\end{array}$ & $\begin{array}{r}100 \\
75 \\
* *\end{array}$ & $\begin{array}{r}\odot * 285 \\
\Theta * 287 \\
* \star *\end{array}$ & $\begin{array}{l}694 \\
695 \\
* * *\end{array}$ & $\begin{array}{l}95 \\
80 \\
* *\end{array}$ & $\begin{array}{r}0 * 291 \\
973 * 292 \\
* * * * * *\end{array}$ & $\begin{array}{l}706 \\
709 \\
\star \star *\end{array}$ & $\begin{array}{l}95 \\
80 \\
* *\end{array}$ & $\begin{array}{r}\Theta^{*} 296 \\
0 * 297 \\
* * *\end{array}$ & $\begin{array}{l}720 \\
723 \\
* * *\end{array}$ & $\begin{array}{l}90 \\
80 \\
\star *\end{array}$ & $\begin{array}{l}\odot^{*} \\
973^{*} \\
* * *\end{array}$ \\
\hline $\begin{array}{l}38755 \\
38755\end{array}$ & $\begin{array}{r}08 / 16 * 302 \\
08 / 16 * 30 \odot \\
* * *\end{array}$ & $\begin{array}{l}734 \\
734\end{array}$ & $\begin{array}{l}85 \\
75 \\
\star *\end{array}$ & $\begin{array}{r}\Theta * 307 \\
\Theta * 304 \\
* * *\end{array}$ & $\begin{array}{l}743 \\
744 \\
\star * *\end{array}$ & $\begin{array}{l}85 \\
75 \\
\star *\end{array}$ & $\begin{array}{r}0 * 312 \\
0 * 309 \\
* * *\end{array}$ & $\begin{array}{l}750 \\
753 \\
* * *\end{array}$ & $\begin{array}{l}85 \\
75 \\
* *\end{array}$ & $\begin{array}{r}\theta^{*} 320 \\
982 * 317 \\
* * * * * *\end{array}$ & $\begin{array}{l}760 \\
762 \\
\star * *\end{array}$ & $\begin{array}{l}80 \\
75 \\
\star *\end{array}$ & $\begin{array}{r}\Theta^{*} \\
983^{*} \\
* * *\end{array}$ \\
\hline
\end{tabular}




\begin{tabular}{|c|c|c|c|c|c|c|c|c|c|c|c|c|c|}
\hline 38760 & $08 / 17 * 328$ & 769 & 75 & $0 * 335$ & 775 & 75 & $0 * 343$ & 780 & 60 & $986 * 354$ & 785 & 60 & $990^{*}$ \\
\hline 38760 & $08 / 17 * 326$ & 769 & 70 & $984 * 334$ & 774 & 65 & $0 * 342$ & 780 & 65 & $985 * 353$ & 785 & 55 & $990^{*}$ \\
\hline & *** & & ** & $* * * \quad * * *$ & $* * *$ & ** & *** & & ** & $\star \star \star \star \star * \star *$ & & ** & \\
\hline 38765 & $08 / 18 * 366$ & 790 & 60 & $993 * 377$ & 790 & 55 & $999 * 388$ & 781 & 50 & 1001 * 396 & 768 & 45 & 1004 * \\
\hline 38765 & $08 / 18 * 365$ & 788 & 50 & $993 * 378$ & 788 & 45 & $999 * 388$ & 781 & 40 & 1001 *396 & 769 & 35 & 1004 * \\
\hline & *** & $* * *$ & ** & $* * *$ & $* * *$ & ** & & & ** & & $\star \star *$ & ** & \\
\hline 38770 & $\odot 8 / 19 * 4 \odot 2$ & 753 & 40 & $10 \odot 3 * 407$ & 737 & 40 & $1002 * 410$ & 721 & 35 & $1000 * 413$ & $7 \odot 4$ & 35 & ○* \\
\hline 38770 & $\odot 8 / 19 * 4 \odot 2$ & 757 & 35 & $1003 * 405$ & 745 & $4 \odot$ & $1001 * 407$ & 730 & 40 & $998 * 409$ & 715 & 40 & $\Theta^{*}$ \\
\hline & & & $* *$ & $* * *$ & $\star \star *$ & & $\star \star \star \star \star \star * * *$ & $* * *$ & ** & $\star \star \star * \star * *$ & $\star * *$ & $\star \star$ & \\
\hline 38775 & $08 / 20 * 415$ & 686 & 35 & $0 * 418$ & 666 & 35 & $0 * 421$ & 640 & 35 & ๑E426 & 607 & 35 & $\Theta^{*}$ \\
\hline 38775 & $08 / 20 * 410$ & 699 & 40 & ๑*412 & 675 & 45 & ๑*415 & 645 & 45 & $0 * 423$ & 618 & 45 & ○* \\
\hline & $\star * *$ & $\star * *$ & ** & *** & $\star \star *$ & ** & *** & *** & * * & $\star \star \star *$ & $\star * *$ & $\star *$ & \\
\hline 38780 & $08 / 21 E 433$ & 570 & 35 & OE442 & 532 & 35 & OE45० & 493 & 35 & ๑E462 & 459 & 30 & ०* \\
\hline 38780 & ๑8/21E430 & 584 & 50 & OE438 & 535 & 50 & OE450 & 480 & 50 & OE470 & 420 & 50 & ○* \\
\hline & $\star * *$ & $* * *$ & ** & $\star \star *$ & $\star \star *$ & ** & & $\star * *$ & ** & $\star * *$ & $\star * *$ & ** & \\
\hline (Aus & $22^{\mathrm{nc}}$ & $23^{r d}$ & are & new & RDA & & & & & & & & \\
\hline 38781 & ๑8/22E49๑ & 360 & 55 & OE525 & 340 & 55 & OE560 & 330 & 55 & OE585 & 325 & 55 & $\Theta^{*}$ \\
\hline 38783 & ๑8/23E605 & 320 & 50 & OE620 & 320 & 45 & OE635 & 310 & 40 & OE650 & 290 & 35 & 0 * \\
\hline
\end{tabular}

38785 HR NC1

U.S. Hurricane:

Aug $17^{\text {th }}-11 \mathrm{Z}-34.0 \mathrm{~N} 78.0 \mathrm{~W}-65 \mathrm{kt}-$ Category $1-986 \mathrm{mb}-1011 \mathrm{mb}$ OCI $-400 \mathrm{~nm}$ ROCI

Major track and intensity changes are analyzed for this classic Cape Verde hurricane that made landfall in North Carolina and later affected the Mid-Atlantic and Northeast. A major alteration is to add two additional days at the end of the cyclone's lifetime. Evidence for these alterations comes from the Historical Weather Maps Series, the COADS ship database, Monthly Weather Review, USWB/NHC microfilm of synoptic weather maps, the Climatological Data, and Jarrell et al. (1992).

August 6:

HWM shows a spot low centered near $15.0 \mathrm{~N}, 38.5 \mathrm{~W}$ along the ITCZ at $12 \mathrm{Z}$. HURDAT does not analyze an organized system on this date. Microfilm and MWR are not available on this date. Ship highlights: No gales or low pressures.

August 7:

HWM shows a closed low of at most $1010 \mathrm{mb}$ centered near $16.0 \mathrm{~N}, 43.0 \mathrm{~W}$ along the ITCZ at $12 \mathrm{Z}$. HURDAT lists this as a 25 knot tropical depression at $17.1 \mathrm{~N}, 44.0 \mathrm{~W}$ at 12Z. Microfilm and MWR are not available on this date. Ship highlights: No gales or low pressures.

August 8: 
HWM shows a closed low of at most $1010 \mathrm{mb}$ centered near $17.0 \mathrm{~N}, 50.0 \mathrm{~W}$ along the ITCZ at $12 \mathrm{Z}$. HURDAT lists this as a 25 knot tropical depression at $17.7 \mathrm{~N}, 47.8 \mathrm{~W}$ at 12Z. Microfilm and MWR are not available on this date on this date. Ship highlights: No gales or low pressures.

August 9:

HWM shows a closed low of at most $1010 \mathrm{mb}$ centered near $18.0 \mathrm{~N}, 53.0 \mathrm{~W}$ along the ITCZ at $12 \mathrm{Z}$. HURDAT lists this as a 30 knot tropical depression at $18.5 \mathrm{~N}, 52.6 \mathrm{~W}$ at 12Z. Microfilm and MWR are not available on this date. Ship highlights: No gales or low pressures.

August 10:

HWM shows a closed low pressure of at most $1010 \mathrm{mb}$ centered near $19.5 \mathrm{~N}$, $59.0 \mathrm{~W}$ at $12 \mathrm{Z}$. HURDAT lists this as a 35 knot tropical storm at $20.3 \mathrm{~N}, 58.0 \mathrm{~W}$ at $12 \mathrm{Z}$. Microfilm does not analyze an organized system at 12Z. MWR is not available on this date. Ship highlights: No gales or low pressures. "There were some indications of a weak easterly wave earlier but the first conclusive evidence of the disturbance that was to become Diane was observed on August 10. Analysis that morning indicated a cyclonic circulation northeast of the Leeward Islands and at 1930 EST ships some 400 to 500 miles from the northernmost islands reported heavy showers and east to southeast winds of 35 to $45 \mathrm{mph}$ " (MWR). "On the $10^{\text {th }}$ of August, as "Hurricane Connie" progressed slowly and erratically northwestward toward the North Carolina coast, attention was called to the area about 300 miles northeast of the Lesser Antilles. An easterly wave, labeled locally as "August \#2" after being verified on the "time cross-section" as being of moderate intensity, had shown development of a weak vortex to the north of the Lesser Antilles at 101230Z. The lack of reports in the area, at this time, prohibited determination of the intensity of the vortex and a reasonably accurate position of the center. Belief was expressed but forecasters from both the Fleet Weather Center, Miami, and the Weather Bureau Office, Miami, that there was drought of any rapid and intense development following so close in the wake of "Hurricane Connie" but the area needed watching. Action taken to obtain more data for the area consisted of a request by the Weather Bureau Office at San Juan for special ship reports and the Air Force Hurricane Liaison Officer scheduled an early flight for the $11^{\text {th }}$ of August from Bermuda to the area" (ATSR).

August 11:

HWM shows a tropical storm of at most $1005 \mathrm{mb}$ centered near $23.5 \mathrm{~N}, 60.6 \mathrm{~W}$ at 12Z. HURDAT lists this as a $55 \mathrm{knot}$ tropical storm at $23.3 \mathrm{~N}, 60.8 \mathrm{~W}$ at $12 \mathrm{Z}$. Microfilm analyses a closed low pressure of at most $1011 \mathrm{mb}$ at $23 \mathrm{~N}, 62 \mathrm{~W}$ at $12 \mathrm{Z}$. MWR shows a 
low pressure of $1004 \mathrm{mb}$ located near 23N, 62W at 12Z. Ship highlights: $35 \mathrm{kt}$ ENE and $1006 \mathrm{mb}$ at $22.9 \mathrm{~N}, 59.3 \mathrm{~W}$ at $0 \mathrm{Z}$ (COADS); $45 \mathrm{kt} \mathrm{E}$ and $1009 \mathrm{mb}$ at $24.0 \mathrm{~N}, 60.0 \mathrm{~W}$ at $6 \mathrm{Z}$ (COADS); $40 \mathrm{kt}$ ENE and $1003 \mathrm{mb}$ at $19.2 \mathrm{~N}, 61.9 \mathrm{~W}$ at $15 \mathrm{Z}$ (micro), and $20 \mathrm{kt} \mathrm{NE}$ and $1005 \mathrm{mb}$ at $24.0 \mathrm{~N}, 62.0 \mathrm{~W}$ at $21 \mathrm{Z}$ (COADS). Aircraft highlights: Penetration center fix measured a central pressure of $1004 \mathrm{mb}$ at $23.9 \mathrm{~N}, 62.2 \mathrm{~W}$ at $1655 \mathrm{Z}$ (ATSR/micro). "On August 11 the first aircraft reconnaissance of Diane found the lowest pressure of $1004 \mathrm{mb}$ (29.65 inches) with maximum winds of $46 \mathrm{mph}$, representing little or no wind increase from that shown by the ship observations 24 hours earlier. Clouds and rain extended in all directions from the pressure center with no variation of weather in the various quadrants. This early stage of growth was typical in the poorly defined eye and lack of organization" (MWR). "Ship reports received in the area for $110030 \mathrm{Z}$ indicated the intensity near the center of the vortex to be about 40 knots and the center to be near $20 \mathrm{~N} 60 \mathrm{~W}$. Data compiled on the "Detection Sheet" revealed favorable conditions for tropical storm development and intensification. Thus, it appeared only a matter of time before it would be necessary to announce the birth of "Tropical Storm Diane" in the form of a numbered warning. Although the area was picked up and carried by the Fleet Weather Central, Washington, as a Gale Warning and it would have been desirable to await the reconnaissance flight information scheduled for early the next morning, it became advisable to coordinate a Warning Number One for "Tropical Storm Diane" which was issued at 111200Z. From the time of the first aircraft reconnaissance fix at $111655 \mathrm{Z}$ until "Diane" entered the coast, close surveillance was maintained by weather reconnaissance aircraft. During this time, no special eccentricities of the storm structure were noted, but there appeared to be a pattern of gradual increase in intensity, with slight variations in cloud formations, to the maximum intensity of an average hurricane, then a gradual decrease in intensity before entering the coast" (ATSR).

August 12:

HWM shows a hurricane of at most $995 \mathrm{mb}$ centered near $25.7 \mathrm{~N}, 61.2 \mathrm{~W}$ at $12 \mathrm{Z}$. HURDAT lists this as a 105 knot hurricane at $25.3 \mathrm{~N}, 60.8 \mathrm{~W}$ at $12 \mathrm{Z}$. Microfilm analyses a closed low pressure of at most $999 \mathrm{mb}$ at $25 \mathrm{~N}, 61 \mathrm{~W}$ at $12 \mathrm{Z}$. MWR shows a low pressure of $981 \mathrm{mb}$ located near $25.8 \mathrm{~N}, 61.8 \mathrm{~W}$ at $12 \mathrm{Z}$. Ship highlights: $40 \mathrm{kt} \mathrm{SE}$ and $1000 \mathrm{mb}$ at $24.5 \mathrm{~N}, 61.0 \mathrm{~W}$ at $0 \mathrm{Z}$ (micro); $45 \mathrm{kt} \mathrm{NNE}$ and $996 \mathrm{mb}$ at $25.0 \mathrm{~N}, 61.0 \mathrm{~W}$ at $9 \mathrm{Z}$ (micro); 40 kt ESE and $1009 \mathrm{mb}$ at $24.2 \mathrm{~N}, 60.0 \mathrm{~W}$ at $13 \mathrm{Z}$ (micro), and $35 \mathrm{kt} \mathrm{SW}$ and $1004 \mathrm{mb}$ at $24.0 \mathrm{~N}, 60.0 \mathrm{~W}$ at $18 \mathrm{Z}$ (COADS). Aircraft highlights: Penetration center fix at $25.6 \mathrm{~N}$, $60.1 \mathrm{~W}$ at $1210 \mathrm{Z}$ (ATSR); Penetration center fix at 25.1N, 61.2W at $1250 \mathrm{Z}$ (ATSR); Penetration center fix measured a central pressure of $975 \mathrm{mb}$ and an eye of a 50 mile diameter at $25.7 \mathrm{~N}, 61.0 \mathrm{~W}$ at $20 \mathrm{Z}$ (ATSR/micro). "During the night the storm curved abruptly from a northwest course and began moving toward the northeast, at the same time undergoing rapid intensification. The MS Coourg, just west of center on a parallel 
course to the northeast during part of the night, turned southward and eastward in evasive maneuvers early on the morning of the $12^{\text {th }}$. The intensification was so rapid that even though the ship was southeast of the center and the distance between it and the hurricane was increasing, the barometer continued to drop and the wind to increase, leading the crew to believe that the storm was looping back in their direction. The reconnaissance plane on the $12^{\text {th }}$ reported that winds had increased to $125 \mathrm{mph}$ and the central pressure was found to be $975 \mathrm{mb}$ (28.79 inches). The eye by this time was well-defined and 30 miles in diameter. It was described by the observer as resembling an inverted teacup. The weather distribution had become more typical with the northeast quadrant showing more activity than the others. An interesting feature of the reconnaissance was a secondary pressure minimum, at first thought to be the principal center, located 62 miles northeast of the primary eye. In view of the rapid growth, sudden change in direction and multiple eye structure, it is interesting to speculate as to what extent factors other than strictly steering currents were involved in the storm's course at this stage. Possibly a process in which more rapid deepening was favored to the northeast of the storm than in other quadrants was partially responsible for the movement. It is likely that the original easterly wave began deepening as it moved under a cold Low (with super-imposed warm air at still higher levels) and that this condition provided added instability for growth and imposed the cyclonic flow of the large scale cold Low on the movement of the smaller warm vortex" (MWR). "Tropical Storm Diane" became of hurricane intensity at $120000 \mathrm{Z}$ and remained hurricane intensity until 171800Z. The average maximum winds during hurricane intensity were 105 knots between $121200 \mathrm{Z}$ and $141200 \mathrm{Z}$ with a gradual decrease in intensity to 70 knots upon entering the coast" (ATSR).

August 13:

HWM shows a hurricane of at most $995 \mathrm{mb}$ centered near $27.2 \mathrm{~N}, 60.8 \mathrm{~W}$ at $12 \mathrm{Z}$. HURDAT lists this as a 105 knot hurricane at $27.4 \mathrm{~N}, 61.0 \mathrm{~W}$ at $12 \mathrm{Z}$. Microfilm analyses a closed low pressure of at most $999 \mathrm{mb}$ at 27N, 61.5W at 12Z. MWR shows a low pressure of $977 \mathrm{mb}$ located near $27.5 \mathrm{~N}, 61.2 \mathrm{~W}$ at $12 \mathrm{Z}$. Ship highlights: $35 \mathrm{kt} \mathrm{SW}$ and $1005 \mathrm{mb}$ at $24.0 \mathrm{~N}, 60.0 \mathrm{~W}$ at $0 \mathrm{Z}$ (COADS); $50 \mathrm{kt} \mathrm{E}$ and $1003 \mathrm{mb}$ at $27.8 \mathrm{~N}, 60.0 \mathrm{~W}$ at $6 \mathrm{Z}$ (COADS); $60 \mathrm{kt} \mathrm{E}$ and $999 \mathrm{mb}$ at 27.8N, 60.0W at 9Z (micro), $70 \mathrm{kt} \mathrm{ESE}$ and $1000 \mathrm{mb}$ at $27.6 \mathrm{~N}, 59.9 \mathrm{~W}$ at $12 \mathrm{Z}$ (COADS), and $65 \mathrm{kt} \mathrm{ESE}$ and $1005 \mathrm{mb}$ at $27.8 \mathrm{~N}, 60.0 \mathrm{~W}$ at $18 \mathrm{Z}$ (micro). Aircraft highlights: Penetration center fix measured a central pressure of $980 \mathrm{mb}$ at $26.4 \mathrm{~N}, 60.5 \mathrm{~W}$ at $2 \mathrm{Z}$ (ATSR); Radar center fix measured an eye of a 30 mile diameter at $26.6 \mathrm{~N}, 61.3 \mathrm{~W}$ at $0808 \mathrm{Z}$ (ATSR/micro); Penetration center fix at $27.4 \mathrm{~N}, 61.9 \mathrm{~W}$ at $1515 Z$ (ATSR); Penetration center fix at 27.4N, 62.0W at 1545Z (ATSR); Penetration center fix at $27.4 \mathrm{~N}, 63.0 \mathrm{~W}$ at $19 \mathrm{Z}$ (ATSR); and penetration center fix measured max surface winds of $80 \mathrm{kt}$ and a central pressure of $969 \mathrm{mb}$ at $27.1 \mathrm{~N}, 63.2 \mathrm{~W}$ at $20 \mathrm{Z}$ (ATSR/micro). "Diane followed this cyclonic path until August 13 when it became re- 
established on a more normal west-northwest-ward course. By this time the developing system had caused warming through the deep layer, resulting in a weakening of the cold Low and its influence on the hurricane's movement. The possibility of some influence from the "Fujiwhara effect", or tendency for cyclonic rotation of cyclone pairs about a point representing the center of mass, should also be considered here. Diane's erratic movement was at least in general agreement with this effect. A more normal path was resumed when Connie weakened and moved farther north. The lowest pressure measured in the storm was $969 \mathrm{mb}$ (28.62 inches) by dropsonde on August 13" (MWR).

August 14:

HWM shows a hurricane of at most $995 \mathrm{mb}$ centered near $27.5 \mathrm{~N}, 65.4 \mathrm{~W}$ at $12 \mathrm{Z}$. HURDAT lists this as a 105 knot hurricane at $27.4 \mathrm{~N}, 65.4 \mathrm{~W}$ at $12 \mathrm{Z}$. Microfilm analyses a closed low pressure of at most $1005 \mathrm{mb}$ at $27 \mathrm{~N}, 66 \mathrm{~W}$ at $12 \mathrm{Z}$. MWR shows a low pressure of $972 \mathrm{mb}$ located near 28N, 66W at 12Z. Ship highlights: $10 \mathrm{kt} \mathrm{NW}$ and $989 \mathrm{mb}$ at $26.9 \mathrm{~N}, 64.1 \mathrm{~W}$ at $0 \mathrm{Z}$ (micro); $45 \mathrm{kt} \mathrm{SE}$ and $1007 \mathrm{mb}$ at $28.1 \mathrm{~N}, 62.2 \mathrm{~W}$ at $12 \mathrm{Z}$ (COADS); $40 \mathrm{kt} \mathrm{E}$ and $1019 \mathrm{mb}$ at $32.8 \mathrm{~N}, 65.0 \mathrm{~W}$ at $18 \mathrm{Z}$ (COADS), and $30 \mathrm{kt} \mathrm{NW}$ and $1004 \mathrm{mb}$ at $25.5 \mathrm{~N}, 68.2 \mathrm{~W}$ at $20 \mathrm{Z}$ (micro). Aircraft highlights: Penetration center fix measured a central pressure of $984 \mathrm{mb}$ and an eye of a 30 mile diameter at $27.1 \mathrm{~N}, 64.4 \mathrm{~W}$ at $0240 \mathrm{Z}$ (ATSR/micro); Penetration center fix measured a central pressure of $976 \mathrm{mb}$ at $27.3 \mathrm{~N}$, $64.7 \mathrm{~W}$ at $0745 \mathrm{Z}$ (ATSR/micro); Penetration center fix measured a central pressure of 980 $\mathrm{mb}$ and an eye of a 30 mile diameter at $27.7 \mathrm{~N}, 66.2 \mathrm{~W}$ at $1440 \mathrm{Z}$ (ATSR/micro); and penetration center fix at $28.1 \mathrm{~N}, 67.4 \mathrm{~W}$ at $20 \mathrm{Z}$ (ATSR). "After the $13^{\text {th }}$ a tendency for slight filling began and, coincidental with this, there was a gradual cooling of the layer below about $750 \mathrm{mb}$ " (MWR).

August 15:

HWM shows a hurricane of at most $990 \mathrm{mb}$ centered near $29.5 \mathrm{~N}, 70.8 \mathrm{~W}$ at $12 \mathrm{Z}$. HURDAT lists this as a $95 \mathrm{knot}$ hurricane at $29.1 \mathrm{~N}, 70.6 \mathrm{~W}$ at $12 \mathrm{Z}$. Microfilm analyses a closed low pressure of at most $999 \mathrm{mb}$ at $29 \mathrm{~N}, 71 \mathrm{~W}$ at $12 \mathrm{Z}$. MWR shows a low pressure of $978 \mathrm{mb}$ located near $29.2 \mathrm{~N}, 71.3 \mathrm{~W}$ at 12Z. Ship highlights: $55 \mathrm{kt} \mathrm{SSE}$ and $1011 \mathrm{mb}$ at $30.8 \mathrm{~N}, 69.0 \mathrm{~W}$ at $0 \mathrm{Z}$ (micro); $40 \mathrm{kt} \mathrm{N}$ and $1006 \mathrm{mb}$ at $29.6 \mathrm{~N}, 72.0 \mathrm{~W}$ at $6 \mathrm{Z}$ (COADS); 50 $\mathrm{kt} \mathrm{NW}$ and $998 \mathrm{mb}$ at $28.7 \mathrm{~N}, 72.0 \mathrm{~W}$ at $12 \mathrm{Z}$ (COADS), and $60 \mathrm{kt} \mathrm{NE}$ and $1009 \mathrm{mb}$ at $32.5 \mathrm{~N}, 73.0 \mathrm{~W}$ at $15 \mathrm{Z}$ (micro). Aircraft highlights: Penetration center fix measured a central pressure of $975 \mathrm{mb}$ at $28.7 \mathrm{~N}, 68.8 \mathrm{~W}$ at $0340 \mathrm{Z}$ (ATSR/micro); Radar center fix measured a central pressure of $973 \mathrm{mb}$ at $28.8 \mathrm{~N}, 70.1 \mathrm{~W}$ at $08 \mathrm{Z}$ (ATSR/micro); Penetration center fix measured a central pressure of $973 \mathrm{mb}$ at $29.6 \mathrm{~N}, 72.1 \mathrm{~W}$ at $1715 \mathrm{Z}$ (ATSR), and penetration center fix measured a central pressure of $975 \mathrm{mb}$ at $29.9 \mathrm{~N}$, $72.6 \mathrm{~W}$ at $20 \mathrm{Z}$ (ATSR/micro). "On the $15^{\text {th }}$, the eye was reported as poorly defined and completely filled with clouds" (MWR). 
August 16:

HWM shows a hurricane of at most $995 \mathrm{mb}$ centered near $31.3 \mathrm{~N}, 75.5 \mathrm{~W}$ at $12 \mathrm{Z}$. HURDAT lists this as an 85 knot hurricane at $31.2 \mathrm{~N}, 75.0 \mathrm{~W}$ at $12 \mathrm{Z}$. Microfilm analyses a closed low pressure of at most $993 \mathrm{mb}$ at $31.3 \mathrm{~N}, 75.6 \mathrm{~W}$ at $12 \mathrm{Z}$. MWR shows a low pressure of $980 \mathrm{mb}$ located near $31.2 \mathrm{~N}, 75.4 \mathrm{~W}$ at 12Z. Ship highlights: $35 \mathrm{kt} \mathrm{SE}$ and $1013 \mathrm{mb}$ at $35.1 \mathrm{~N}, 72.8 \mathrm{~W}$ at $0 \mathrm{Z}$ (COADS); $55 \mathrm{kt} \mathrm{SSE}$ and $1013 \mathrm{mb}$ at $29.6 \mathrm{~N}, 68.6 \mathrm{~W}$ at $6 \mathrm{Z}$ (COADS); $35 \mathrm{kt} \mathrm{SE}$ and $1011 \mathrm{mb}$ at $30.2 \mathrm{~N}, 71.4 \mathrm{~W}$ at $12 \mathrm{Z}$ (COADS), and $20 \mathrm{kt} \mathrm{S}$ and $1000 \mathrm{mb}$ at 30.4N, 75.5W at 18Z (COADS). Land highlights: $45 \mathrm{kt} \mathrm{NE}$ and $1006 \mathrm{mb}$ at Frying Pan at 12Z; $30 \mathrm{kt} \mathrm{NE}$ and $1003 \mathrm{mb}$ at Frying Pan at 18Z, and $25 \mathrm{kt} \mathrm{NE}$ and 1005 $\mathrm{mb}$ at Wilmington at 20Z. All observations from micro. Aircraft highlights: Radar center fix measured an eye of a 8 mile diameter at $30.1 \mathrm{~N}, 74.1 \mathrm{~W}$ at $0230 \mathrm{Z}$ (ATSR/micro); Penetration center fix at $30.2 \mathrm{~N}, 74.2 \mathrm{~W}$ at $0459 \mathrm{Z}$ (ATSR); Radar center fix measured an eye of a 10 mile diameter $30.3 \mathrm{~N}, 74.3 \mathrm{~W}$ at $0630 \mathrm{Z}$ (ATSR/micro); Radar center fix measured a central pressure of $986 \mathrm{mb}$ at $30.4 \mathrm{~N}, 74.7 \mathrm{~W}$ at $0823 \mathrm{Z}$ (ATSR/micro); Penetration center fix measured a central pressure of $982 \mathrm{mb}$ and an eye of a 10 mile diameter at $31.1 \mathrm{~N}, 75.4 \mathrm{~W}$ at $13 \mathrm{Z}$ (ATSR/ micro); Penetration center fix at $31.1 \mathrm{~N}, 75.4 \mathrm{~W}$ at $1345 \mathrm{Z}$ (ATSR); Penetration center fix at $31.3 \mathrm{~N}, 75.8 \mathrm{~W}$ at $1448 \mathrm{Z}$ (ATSR); Penetration center fix measured a central pressure of $983 \mathrm{mb}$ and an eye of a 10 mile diameter at $31.6 \mathrm{~N}, 75.8 \mathrm{~W}$ at $1720 \mathrm{Z}$ (ATSR/micro); Penetration center fix at $31.9 \mathrm{~N}, 76.5 \mathrm{~W}$ at $20 \mathrm{Z}$ (ATSR); Penetration center fix at 31.7N, 76.4W at 2015Z (ATSR); Penetration center fix at $31.8 \mathrm{~N}, 76.6 \mathrm{~W}$ at $2115 \mathrm{Z}$ (ATSR); and penetration center fix measured max surface winds of $65 \mathrm{kt}$ and a central pressure of $984 \mathrm{mb}$ at $31.9 \mathrm{~N}, 76.5 \mathrm{~W}$ at $2230 \mathrm{Z}$ (ATSR/ micro). "Maximum winds were down to $86 \mathrm{mph}$ on the $16^{\text {th" }}$ (MWR). "On the $16^{\text {th }}$ of August at all levels from the surface to the $200 \mathrm{mb}$ level, a north-south trough extending from the Great Lakes to the Gulf of Mexico was in evidence. A small closed low, centered near St. Louis, Missouri, was also in evidence at all levels above the surface layer" (ATSR).

August 17:

HWM shows a hurricane of at most $995 \mathrm{mb}$ centered near $34.2 \mathrm{~N}, 77.9 \mathrm{~W}$ at $12 \mathrm{Z}$. HURDAT lists this as a 60 knot tropical storm at $34.3 \mathrm{~N}, 78.0 \mathrm{~W}$ at $12 \mathrm{Z}$. Microfilm analyses a closed low pressure of at most $990 \mathrm{mb}$ at $34.0 \mathrm{~N}, 78.0 \mathrm{~W}$ at $12 \mathrm{Z}$. MWR shows a low pressure of $986 \mathrm{mb}$ located near $34.2 \mathrm{~N}, 77.8 \mathrm{~W}$ at 12Z. Ship highlights: $50 \mathrm{kt} \mathrm{SSE}$ and $1008 \mathrm{mb}$ at $33.0 \mathrm{~N}, 73.9 \mathrm{~W}$ at $0 \mathrm{Z}$ (micro); $35 \mathrm{kt} \mathrm{SSE}$ and $1010 \mathrm{mb}$ at $32.2 \mathrm{~N}, 73.2 \mathrm{~W}$ at $6 \mathrm{Z}$ (COADS); $45 \mathrm{kt} \mathrm{SE}$ and $1013 \mathrm{mb}$ at $36.1 \mathrm{~N}, 73.4 \mathrm{~W}$ at $12 \mathrm{Z}$ (COADS), and $35 \mathrm{kt} \mathrm{E}$ and $1009 \mathrm{mb}$ at $37.5 \mathrm{~N}, 76.1 \mathrm{~W}$ at $18 \mathrm{Z}$ (COADS). Land highlights: $45 \mathrm{kt} \mathrm{NE}$ and $1001 \mathrm{mb}$ at Frying Pan at 0Z; $40 \mathrm{kt} \mathrm{N}$ and $989 \mathrm{mb}$ at Frying Pan at 6Z, $20 \mathrm{kt} \mathrm{E}$ and $988 \mathrm{mb}$ at Wilmington at 12Z, $40 \mathrm{kt} \mathrm{S}$ and $992 \mathrm{mb}$ at Frying Pan at 12Z, and $20 \mathrm{kt} \mathrm{E}$ and $994 \mathrm{mb}$ at 
Raleigh at 18Z. $45 \mathrm{kt}$ at Cape Hatteras (time not given) (MWR). All observations from micro. Aircraft highlights: Penetration center fix at 33.3N, 77.0W at 0445Z (ATSR); Penetration center fix at $33.6 \mathrm{~N}, 77.5 \mathrm{~W}$ at $0730 \mathrm{Z}$ (ATSR), and radar center fix measured an eye of a 45 mile diameter at $08 Z$ (ATSR/micro). "When the center passed very close to Wilmington on the morning of the $17^{\text {th }}$, the highest sustained winds reported from any weather station was $50 \mathrm{mph}$ at Hatteras, wind gusts of $74 \mathrm{mph}$ at Wilmington. It is estimated that winds of just about hurricane intensity were experienced at a few exposed points on the coast between Cape Hatteras and Cape Fear. While some damage resulted from the storm tide and wave action along the coast, it was not extensive" (MWR). "As "Diane" preceded on a northwest course from the $15^{\text {th }}$ to the $17^{\text {th }}$ of August, being steered by the Bermuda high, the trough over the Midwest states remained stationary and broadened slightly. The low aloft had moved southward down the trough to be centered over Mississippi late on the $17^{\text {th }}$ of August and the Bermuda high at all levels was pushing westward onto the coast. This resulted in moist southerly flow accompanying and following the movement of "Diane" inland which caused record rains and floods throughout the Northeastern United States" (ATSR). "Aug - NC1 - Cat 1 - 987 mb" (Jarrell et al. (1992).

August 18:

HWM shows a closed low pressure of at most $1005 \mathrm{mb}$ centered near $38.5 \mathrm{~N}$, $77.9 \mathrm{~W}$ at $12 \mathrm{Z}$. HURDAT lists this as a 50 knot tropical storm at $38.8 \mathrm{~N}, 78.1 \mathrm{~W}$ at $12 \mathrm{Z}$. Microfilm analyses a closed low pressure of at most $1008 \mathrm{mb}$ at $39.0 \mathrm{~N}, 78.5 \mathrm{~W}$ at $12 \mathrm{Z}$. MWR shows a low pressure of $1001 \mathrm{mb}$ located near $38.5 \mathrm{~N}, 78.0 \mathrm{~W}$ at $12 \mathrm{Z}$. Ship highlights: $45 \mathrm{kt} \mathrm{S}$ and $1014 \mathrm{mb}$ at $35.6 \mathrm{~N}, 73.2 \mathrm{~W}$ at $0 \mathrm{Z} ; 45 \mathrm{kt} \mathrm{SSE}$ and $1010 \mathrm{mb}$ at $36.0 \mathrm{~N}$, $74.9 \mathrm{~W}$ at $6 \mathrm{Z} ; 40 \mathrm{kt} \mathrm{S}$ and $1012 \mathrm{mb}$ at $35.2 \mathrm{~N}, 75.2 \mathrm{~W}$ at $12 \mathrm{Z}$, and $40 \mathrm{kt} \mathrm{SSW}$ and $1016 \mathrm{mb}$ at $34.3 \mathrm{~N}, 74.2 \mathrm{~W}$ at $12 \mathrm{Z}$. All observations from COADS. Land highlights: $15 \mathrm{kt} \mathrm{SW}$ and $997 \mathrm{mb}$ at Raleigh at 0Z; $10 \mathrm{kt} \mathrm{NW}$ and $1000 \mathrm{mb}$ at Lynchburg at 6Z, and $15 \mathrm{kt} \mathrm{SSW}$ and $1005 \mathrm{mb}$ at Quantico at 18Z. All observations from micro.

August 19:

HWM shows a closed low pressure of at most $1000 \mathrm{mb}$ centered near $41.0 \mathrm{~N}$, $73.0 \mathrm{~W}$ at $12 \mathrm{Z}$. HURDAT lists this as a 35 knot tropical storm at $41.0 \mathrm{~N}, 72.1 \mathrm{~W}$ at $12 \mathrm{Z}$. Microfilm analyses a closed low pressure of at most $1008 \mathrm{mb}$ at $41.2 \mathrm{~N}, 72.3 \mathrm{~W}$ at $12 \mathrm{Z}$. MWR shows a low pressure of $1003 \mathrm{mb}$ located near 41.0N, 73.0W at 12Z. Ship highlights: $15 \mathrm{kt} \mathrm{SW}$ and $1000 \mathrm{mb}$ at $40.1 \mathrm{~N}, 73.6 \mathrm{~W}$ at $12 \mathrm{Z} ; 5 \mathrm{kt} \mathrm{E}$ and $1001 \mathrm{mb}$ at $41.3 \mathrm{~N}$, $71.3 \mathrm{~W}$ at $18 \mathrm{Z}$, and $40 \mathrm{kt} \mathrm{NE}$ and $1013 \mathrm{mb}$ at $34.4 \mathrm{~N}, 76.2 \mathrm{~W}$ at $18 \mathrm{Z}$. All observations from COADS. Land highlights: $10 \mathrm{kt} \mathrm{W}$ and $1005 \mathrm{mb}$ at Harrisburg at 0Z; $15 \mathrm{kt} \mathrm{NW}$ and 1002 $\mathrm{mb}$ at Philadelphia at 6Z; $30 \mathrm{kt} \mathrm{NNW}$ and $1003 \mathrm{mb}$ at New York City at 12Z, and $20 \mathrm{kt}$ ESE and $1004 \mathrm{mb}$ at Nantucket at 18Z. All observations from micro. 
August 20:

HWM shows a closed low pressure of at most $1000 \mathrm{mb}$ centered near $43.0 \mathrm{~N}$, $65.0 \mathrm{~W}$ at $12 \mathrm{Z}$. HURDAT lists this as a 35 knot tropical storm at $42.1 \mathrm{~N}, 64.0 \mathrm{~W}$ at $12 \mathrm{Z}$ (last position as a tropical system). Microfilm analyses a closed low pressure of at most $1005 \mathrm{mb}$ at $43.0 \mathrm{~N}, 63.0 \mathrm{~W}$ at 12Z. MWR shows a low pressure of $1001 \mathrm{mb}$ located near 42.0N, 64.2W at 12Z. Ship highlights: $20 \mathrm{kt} \mathrm{SW}$ and $1001 \mathrm{mb}$ at $41.1 \mathrm{~N}, 69.2 \mathrm{~W}$ at 0Z; 20 $\mathrm{kt} \mathrm{W}$ and $996 \mathrm{mb}$ at $40.5 \mathrm{~N}, 68.4 \mathrm{~W}$ at $6 \mathrm{Z} ; 30 \mathrm{kt} \mathrm{W}$ and $995 \mathrm{mb}$ at $40.9 \mathrm{~N}, 65.3 \mathrm{~W}$ at $12 \mathrm{Z}$; $30 \mathrm{kt} \mathrm{W}$ and $995 \mathrm{mb}$ at $41.3 \mathrm{~N}, 62.2 \mathrm{~W}$ at $18 \mathrm{Z}$ and $50 \mathrm{kt} \mathrm{WSW}$ and $1009 \mathrm{mb}$ at $39.0 \mathrm{~N}$, 62.0W at 20Z. All observations from COADS. Land highlights: $15 \mathrm{kt} \mathrm{N}$ and $1000 \mathrm{mb}$ at Nantucket at 0Z; $20 \mathrm{kt}$ ENE and $1005 \mathrm{mb}$ at Yarmouth at 6Z; $10 \mathrm{kt} \mathrm{NE}$ and $1004 \mathrm{mb}$ at Halifax at 12Z, and $10 \mathrm{kt} \mathrm{NE}$ and $1001 \mathrm{mb}$ at Sable Island at 18Z. All observations from micro.

August 21:

HWM shows a closed low pressure of at most $990 \mathrm{mb}$ centered near $45.0 \mathrm{~N}$, $47.0 \mathrm{~W}$ at $12 \mathrm{Z}$. HURDAT lists this as a 35 knot extratropical cyclone at $45.0 \mathrm{~N}, 49.3 \mathrm{~W}$ at 12Z. Microfilm analyses a closed low pressure of at most $996 \mathrm{mb}$ at $47.5 \mathrm{~N}, 47.0 \mathrm{~W}$ at 12Z. MWR shows a low pressure of $993 \mathrm{mb}$ located near $45.2 \mathrm{~N}, 49.7 \mathrm{~W}$ at $12 \mathrm{Z}$. Ship highlights: $30 \mathrm{kt} \mathrm{W}$ and $995 \mathrm{mb}$ at $41.7 \mathrm{~N}, 59.1 \mathrm{~W}$ at $0 \mathrm{Z} ; 40 \mathrm{kt} \mathrm{SW}$ and $998 \mathrm{mb}$ at $41.6 \mathrm{~N}$, $54.0 \mathrm{~W}$ at $6 \mathrm{Z} ; 40 \mathrm{kt} \mathrm{S}$ and $994 \mathrm{mb}$ at $44.8 \mathrm{~N}, 45.5 \mathrm{~W}$ at $12 \mathrm{Z}$; and $45 \mathrm{kt} \mathrm{S}$ and $990 \mathrm{mb}$ at $46.6 \mathrm{~N}, 40.1 \mathrm{~W}$ at $18 \mathrm{Z}$. All observations from COADS. Land highlights: $15 \mathrm{kt} \mathrm{NE}$ and $1003 \mathrm{mb}$ at Sable Island at 0Z, and $35 \mathrm{kt} \mathrm{NNW}$ and $1008 \mathrm{mb}$ at Sable Island at 06Z. All observations from micro.

August 22:

HWM shows a closed low pressure of at most $980 \mathrm{mb}$ centered near $57.0 \mathrm{~N}$, $33.0 \mathrm{~W}$ at $12 \mathrm{Z}$. HURDAT does not list this system on this date. Microfilm analyses a low pressure at $56.2 \mathrm{~N}, 29.8 \mathrm{~W}$ at $6 \mathrm{Z}$. MWR shows a low pressure of $976 \mathrm{mb}$ located near 55.5N, 32.0W at 12Z. Ship highlights: $50 \mathrm{kt} \mathrm{NNE}$ and $981 \mathrm{mb}$ at $50.5 \mathrm{~N}, 38.0 \mathrm{~W}$ at $0 \mathrm{Z} ; 40$ kt SSE and $979 \mathrm{mb}$ at $52.8 \mathrm{~N}, 35.5 \mathrm{~W}$ at $3 \mathrm{Z} ; 40 \mathrm{kt} \mathrm{W}$ and $984 \mathrm{mb}$ at $53.7 \mathrm{~N}, 33.7 \mathrm{~W}$ at $12 \mathrm{Z}$; and $30 \mathrm{kt} \mathrm{SW}$ and $997 \mathrm{mb}$ at 54.6N, 27.3W at 18Z. All observations from COADS.

\section{August 23:}

HWM shows a closed low pressure of at most $985 \mathrm{mb}$ centered near $63.0 \mathrm{~N}$, 31.0W at 12Z. HURDAT does not list this system on this date. Microfilm is not available on this date. MWR shows a low pressure of $978 \mathrm{mb}$ located near $63.5 \mathrm{~N}, 30.5 \mathrm{~W}$ at $12 \mathrm{Z}$. Ship highlights: $25 \mathrm{kt} \mathrm{W}$ and $978 \mathrm{mb}$ at $61.9 \mathrm{~N}, 32.5 \mathrm{~W}$ at $0 \mathrm{Z} ; 5 \mathrm{kt} \mathrm{NW}$ and $974 \mathrm{mb}$ at 
$62.0 \mathrm{~N}, 32.5 \mathrm{~W}$ at $6 \mathrm{Z} ; 35 \mathrm{kt} \mathrm{WNW}$ and $984 \mathrm{mb}$ at $62.0 \mathrm{~N}, 32.9 \mathrm{~W}$ at $12 \mathrm{Z}$; and $30 \mathrm{kt} \mathrm{NW}$ and $996 \mathrm{mb}$ at $61.9 \mathrm{~N}, 32.7 \mathrm{~W}$ at $18 \mathrm{Z}$. All observations from COADS.

August 24:

HWM shows a closed low pressure of at most $995 \mathrm{mb}$ centered near $73.0 \mathrm{~N}$, $11.0 \mathrm{~W}$ at $12 \mathrm{Z}$. HURDAT does not list this system on this date. Microfilm and MWR are not available on this date. Land highlights: $10 \mathrm{kt} \mathrm{SSE}$ and $999 \mathrm{mb}$ at Jan Mayer Island at $12 \mathrm{Z}$ (HWM).

Genesis for this tropical cyclone remains at $06 \mathrm{Z}$ on the $7^{\text {th }}$ of August as a $25 \mathrm{kt}$ tropical depression, unchanged from the original HURDAT. The data available during the first few days of Diane's existence as a cyclone is very sparse but a ship report at $12 \mathrm{Z}$ on the $7^{\text {th }}$ indicates that the center needs to be repositioned to the southeast of the position originally shown in HURDAT. Due to this change, the track of Diane has been shifted about a degree and a half southeast than originally shown in HURDAT on August $7^{\text {th }}$ and $8^{\text {th }}$. Ship data on the $9^{\text {th }}$ continued to indicate that the center of this tropical cyclone was located farther south than originally shown in HURDAT. Intensification to a tropical storm remains at $18 \mathrm{Z}$ on the $9^{\text {th }}$, unchanged from the original HURDAT, though the sparse amount of observations makes the timing quite uncertain. No gales or low pressure were reported from August $7^{\text {th }}$ to the $10^{\text {th }}$. The first gale-force winds $(35 \mathrm{kt})$ were reported at $00 \mathrm{Z}$ on the $11^{\text {th }}$ by a ship located in the northeast quadrant of the tropical storm. The highest winds for the day were $45 \mathrm{kt}$ at $06 \mathrm{Z}$ by a ship located near $24 \mathrm{~N} 60 \mathrm{~W}$. The first aircraft reconnaissance mission to reach the storm occurred at $1655 \mathrm{Z}$ on the $11^{\text {th }}$ measuring a central pressure of $1004 \mathrm{mb}$. A central pressure of $1004 \mathrm{mb}$ yields $39 \mathrm{kt}$ according to the Brown et al. southern pressure-wind relationship. An intensity of $45 \mathrm{kt}$ has been analyzed for $18 \mathrm{Z}$ on August $11^{\text {th }}$, down from $60 \mathrm{kt}$ originally in HURDAT. Also, a central pressure of $1004 \mathrm{mb}$ has been added at $18 \mathrm{Z}$ on the $11^{\text {th }}$. Diane continued to intensify on the $12^{\text {th }}$ while located north of the Lesser Antilles. HURDAT originally has the system reaching hurricane intensity at $00 \mathrm{Z}$ on the $12^{\text {th }}$ and rapidly intensifying to a major hurricane 12 hours later. Fortunately, another reconnaissance aircraft reached Diane late on the $12 \mathrm{Z}$ measuring a central pressure of $975 \mathrm{mb}$ at $20 \mathrm{Z}$. A central pressure of $975 \mathrm{mb}$ yields $79 \mathrm{kt}$ north of $25 \mathrm{~N}$ ( $82 \mathrm{kt}$ for the intensifying subset) according to the Brown et al. pressure-wind relationship. The aircraft also reported an eye of a 50 mile diameter, which allows computing a 35-40 nm RMW, and climatology suggests a $19 \mathrm{~nm}$ RMW for this central pressure and latitude. Furthermore, the storm was moving very slowly, at about $5 \mathrm{kt}$ at this time. Thus, because of the large RMW and slow movement, an intensity of $75 \mathrm{kt}$ is analyzed for $18 \mathrm{Z}$ on the $12^{\text {th }}$, a major change from $105 \mathrm{kt}$ originally in HURDAT. A central pressure of $975 \mathrm{mb}$ has been added to $18 \mathrm{Z}$ on the $12^{\text {th }}$. Major intensity changes are also analyzed for $06 \mathrm{Z}$ and $12 \mathrm{Z}$ as the intensities chosen are 
$60 \mathrm{kt}$ and $70 \mathrm{kt}$, respectively, compared to $90 \mathrm{kt}$ and $105 \mathrm{kt}$, respectively, originally in HURDAT. A few gales were reported on the $12^{\text {th }}$, most significant being $45 \mathrm{kt}$ and 996 $\mathrm{mb}$ at $09 \mathrm{Z}$ by a ship located near $25 \mathrm{~N} 61 \mathrm{~W}$. An aircraft reconnaissance mission reached Diane at $02 \mathrm{Z}$ on the $13^{\text {th }}$ measuring a central pressure of $980 \mathrm{mb}$, indicating that the deepening had ended and a slight filling of the hurricane occurred. A central pressure of $980 \mathrm{mb}$ yields $73 \mathrm{kt}$ north of $25 \mathrm{~N}$ according to the pressure-wind relationship. An intensity of $70 \mathrm{kt}$ has been analyzed for $00 \mathrm{Z}$ on the $13^{\text {th }}$, a major change from $105 \mathrm{kt}$ originally in HURDAT. Also, a central pressure of $980 \mathrm{mb}$ has been added at $00 \mathrm{Z} \mathrm{n}$ the $13^{\text {th }}$. At $20 \mathrm{Z}$ on the $13^{\text {th }}$ of August, another reconnaissance aircraft reached Diane measuring a central pressure of $969 \mathrm{mb}$, an indication that the system had re-intensified. A central pressure of $969 \mathrm{mb}$ yields $86 \mathrm{kt}$ north of $25 \mathrm{~N}$ ( $89 \mathrm{kt}$ for the intensifying subset), according to the pressure-wind relationship. As the translational speed had increased to about $12 \mathrm{kt}$ (but the size was unknown), an intensity of $90 \mathrm{kt}$ is analyzed for $18 \mathrm{Z}$ on the $13^{\text {th }}$. $90 \mathrm{kt}$ is also the new peak for the lifetime of Diane - a category 2 hurricane - and not as a major hurricane (105 kt) as shown originally in HURDAT. Major changes are also shown at $06 \mathrm{Z}$ and $12 \mathrm{Z}$ as HURDAT originally showed $105 \mathrm{kt}$ and the intensity has been analyzed at $70 \mathrm{kt}$ and $80 \mathrm{kt}$, respectively. The central pressure of $969 \mathrm{mb}$ was originally in HURDAT incorrectly at $06 \mathrm{Z}$ and has been moved to $18 \mathrm{Z}$ on the $13^{\text {th }}$. Several reports of strong winds were observed on the $13^{\text {th }}$, including a report of $70 \mathrm{kt}$ and $1000 \mathrm{mb}$ by a ship located at $27.6 \mathrm{~N}, 59.9 \mathrm{~W}$. A center fix by the reconnaissance aircraft on the $14^{\text {th }}$ measured a central pressure of $976 \mathrm{mb}$ at $0745 \mathrm{Z}$. A central pressure of $976 \mathrm{mb}$ yields $77 \mathrm{kt}$ according to the north of $25 \mathrm{~N}$ pressure-wind relationship. An intensity of 80 kt was selected for $06 Z$, down from 105 kt originally in HURDAT, a major change. A central pressure of $976 \mathrm{mb}$ has been added to $06 \mathrm{Z}$ on the $14^{\text {th }}$. Another center fix measured a central pressure of $980 \mathrm{mb}$ at $1440 \mathrm{Z}$. A central pressure of $980 \mathrm{mb}$ yields 73 $\mathrm{kt}$ according to the north of $25 \mathrm{~N}$ pressure-wind relationship. The aircraft also reported an eye diameter of 30 miles, allowing the computation of about 20-25 nm RMW, and climatology suggests a $21 \mathrm{~nm}$ RMW. Therefore, with near climatological RMW and speed (11 kt), an intensity of $75 \mathrm{kt}$ was selected for 12Z, down from $105 \mathrm{kt}$ originally in HURDAT, a major change. A central pressure of $980 \mathrm{mb}$ has been added to $12 \mathrm{Z}$ on the $14^{\text {th }}$. Major changes to the intensity also occurred at $00 \mathrm{Z}$ as the intensity is analyzed as $90 \mathrm{kt}$, respectively, down from $105 \mathrm{kt}$ originally in HURDAT. A slight deepening occurred on the $15^{\text {th }}$ as the central pressure dropped to $973 \mathrm{mb}$ according to reconnaissance aircraft reports at $08 \mathrm{Z}$ and 20Z. A central pressure of $973 \mathrm{mb}$ yields $81 \mathrm{kt}$ according to the north of $25 \mathrm{~N}$ pressure-wind relationship. An intensity of $80 \mathrm{kt}$ was selected for 06Z, $12 \mathrm{Z}$ and 18Z, down from $95 \mathrm{kt}, 95 \mathrm{kt}$, and $90 \mathrm{kt}$, respectively, as originally shown in HURDAT. Central pressures of $973 \mathrm{mb}$ have been added to $06 \mathrm{Z}$ and $18 \mathrm{Z}$ on the $15^{\text {th }}$. Diane weakened again on August $16^{\text {th }}$ as an aircraft reconnaissance mission measured a central pressure of $982 \mathrm{mb}$ at 13Z. A central pressure of $982 \mathrm{mb}$ 
yields $70 \mathrm{kt}$ according to the north of $25 \mathrm{~N}$ pressure-wind relationship. The report also indicated a 10 mile eye diameter, yielding a small RMW of about 7-8 nm, and climatology suggests an RMW of about $24 \mathrm{~nm}$. A central pressure of $982 \mathrm{mb}$ has been added to $12 \mathrm{Z}$ on the $16^{\text {th }}$. Another reconnaissance mission reported a central pressure of $983 \mathrm{mb}$ at $1720 \mathrm{Z}$, suggesting maximum winds of $69 \mathrm{kt}$ according to the north of $25 \mathrm{~N}$ pressure-wind relationship. Due to the quite small size but somewhat slow moving $(8 \mathrm{kt})$ hurricane, an intensity of $75 \mathrm{kt}$ is analyzed for both $12 \mathrm{Z}$ and $18 \mathrm{Z}$ on the $16^{\text {th }}$. A central pressure of $983 \mathrm{mb}$ has been added to $18 \mathrm{Z}$ on the $16^{\text {th }}$.

On the $17^{\text {th }}$, Diane approached the North Carolina coastline making landfall very near Wilmington at 11Z. Just before landfall, the Frying Pan Shoals light reported $40 \mathrm{kt}$ and $989 \mathrm{mb}$ at $06 \mathrm{Z}$. At 12Z, Wilmington was reporting $20 \mathrm{kt}$ and $988 \mathrm{mb}$, and HURDAT originally had a $986 \mathrm{mb}$ central pressure at 12Z. The Frying Pan Shoals and Wilmington observations support a central pressure of $985 \mathrm{mb}$ at landfall and is also added to $12 \mathrm{Z}$. A central pressure of $985 \mathrm{mb}$ yields $66 \mathrm{kt}$ north of $25 \mathrm{~N}$ and $68 \mathrm{kt}$ from the Landsea et al. north of $35 \mathrm{~N}$ the pressure-wind relationships. The radar in Cape Hatteras estimated an eye diameter of 50 miles, allowing computing a 35-40 nm RMW while climatology (of central pressure and latitude) suggests an RMW of about $30 \mathrm{~nm}$. The hurricane was moving at about $9 \mathrm{kt}$. Thus, an intensity of $65 \mathrm{kt}$ is selected for 12Z, up from $60 \mathrm{kt}$ originally in HURDAT. This makes Diane a Category 1 hurricane landfall for North Carolina, which is the same as originally analyzed in HURDAT. The highest surface wind reports were $45 \mathrm{kt}$ from Cape Hatteras at an unknown time. Late on the $17^{\text {th }}$, Diane continued inland approaching Virginia early on the $18^{\text {th }}$. The Kaplan and DeMaria model was run for $18 \mathrm{Z}$ on the $17^{\text {th }}$ yielding $37 \mathrm{kt}$ and for $00 \mathrm{Z}$ on the $18^{\text {th }}$ yielding $32 \mathrm{kt}$. However, at $18 \mathrm{Z}$ on the $17^{\text {th }}$, the Diamond Shoals Lighthouse was reporting $50 \mathrm{kt}$ and an intensity of $55 \mathrm{kt}$ is analyzed. Diane is shown to have weakened to a tropical storm at $18 \mathrm{Z}$ on the $17^{\text {th }}, 6$ hours later than originally in HURDAT. At $00 \mathrm{Z}$ on the $18^{\text {th }}$, an intensity of $50 \mathrm{kt}$ is selected as $45 \mathrm{kt}$ winds are reported by a ship near the coast at $06 \mathrm{Z}$. Winds of tropical storm force likely affected portions of eastern South Carolina, Virginia and Maryland on the $17^{\text {th }}$ and early on the $18^{\text {th }}$. Minor changes were analyzed for the rest of the $18^{\text {th }}$ as the system began to turn to the northeast and continued to weaken. (It is of note that HURDAT had central pressures included every six hours from $12 \mathrm{Z}$ on the $17^{\text {th }}$ through $12 Z$ on the $19^{\text {th }}$. Undoubtedly, someone had included central pressure analyses that were not all based upon actual central pressure measurements. [Such comprehensive analyses have also been included in HURDAT for other very destructive hurricanes.] Most of these appeared to be reasonable, even if they could not be confirmed by explicit observations. Minor adjustments to these central pressures were made at $12 \mathrm{Z}$ on the $17^{\text {th }}$ and $06 \mathrm{Z}$ and $12 \mathrm{Z}$ on the $19^{\text {th }}$.) 
Early on the $19^{\text {th }}$, Diane returned to the Atlantic Ocean near New York City still as a tropical storm as various ships continued to report gale-force winds. The highest winds reported by ships on the $19^{\text {th }}$ were $40 \mathrm{kt}$ at $06 \mathrm{Z}$, and this is the intensity selected from $06 \mathrm{Z}$ to $18 \mathrm{Z}$, up from $35 \mathrm{kt}$ at $12 \mathrm{Z}$ and $18 \mathrm{Z}$ as originally shown in HURDAT. Transition to an extratropical cyclone is originally shown at $18 \mathrm{Z}$ on the $20^{\text {th }}$ but data at this time suggests that the frontal boundary was still to the north of the cyclone. Therefore, extratropical transition is delayed 6 hours until $00 \mathrm{Z}$ on the $21^{\text {st }}$. On the $21^{\text {st }}$, HURDAT originally showed that Diane weakened to $30 \mathrm{kt}$ at $18 \mathrm{Z}$ and this was the final point, likely indicating that the system had been absorbed by the frontal system. However, data suggests that the extratropical system did not weaken and dissipate, but instead strengthened reaching an intensity of $50 \mathrm{kt}$ on the $21^{\text {st }}$ according to ship reports close to storm. The Monthly Weather Review Track of Centers of Cyclones for the month of August also indicates that Diane continued into the north Atlantic and was not absorbed by the frontal system. On the $22^{\text {nd }}$, the intensity further increased to $55 \mathrm{kt}$ based on ship reports. Data suggests that the extratropical cyclone began to weaken on the $23^{\text {rd }}$, while located between Greenland and Iceland, and dissipated after 18Z. Adding two additional days to the dissipation phase of Diane is a major change.

Tropical Storm Edith [August 21 - September 5, 1955]

\begin{tabular}{|c|c|c|c|c|c|c|c|c|c|c|c|c|c|}
\hline $\begin{array}{l}38790 \\
38790\end{array}$ & $\begin{array}{l}08 / 21 / 1955 \\
08 / 21 / 1955\end{array}$ & $\begin{array}{r}M=1 \\
M=1 \\
\text { * }\end{array}$ & $\begin{array}{l}4 \\
4\end{array}$ & $\begin{array}{l}\text { SNBR }=8 \\
\text { SNBR }=8\end{array}$ & $\begin{array}{ll}49 & E D \\
49 & E D\end{array}$ & $\begin{array}{l}\text { ITH } \\
\text { ITH }\end{array}$ & $\begin{array}{l}\text { XII } \\
\text { XII }\end{array}$ & $\begin{array}{l}J G=\odot \\
J G=\odot\end{array}$ & $\begin{array}{l}\mathrm{SSS}=0 \\
\mathrm{SSS}=0\end{array}$ & & & & \\
\hline 38795 & $08 / 21$ * & $\odot$ & $\odot$ & $0^{*}$ & $\odot$ & $\odot$ & $\odot * 124$ & 410 & 25 & $0 * 128$ & 423 & 25 & 0 * \\
\hline 38795 & $08 / 21^{*}$ & $\odot$ & $\odot$ & 0* & $\odot$ & $\odot$ & $0 * 124$ & $\begin{array}{l}420 \\
* * *\end{array}$ & 25 & $0 * 128$ & $\begin{array}{l}431 \\
* * *\end{array}$ & 25 & $0^{*}$ \\
\hline $3880 \odot$ & $08 / 22 * 132$ & 435 & 25 & $\odot * 136$ & 447 & 25 & $\odot * 139$ & 459 & 25 & $0 * 142$ & 470 & 25 & $0^{*}$ \\
\hline 38800 & $08 / 22 * 132$ & $\begin{array}{l}442 \\
* * *\end{array}$ & 25 & $\odot * 136$ & $\begin{array}{l}453 \\
\star * *\end{array}$ & 25 & $\odot * 139$ & $\begin{array}{l}465 \\
\star * *\end{array}$ & 25 & $0 * 142$ & $\begin{array}{l}477 \\
* * *\end{array}$ & 25 & $0^{*}$ \\
\hline $\begin{array}{l}38805 \\
38805\end{array}$ & $\begin{array}{l}08 / 23 * 145 \\
08 / 23 * 145\end{array}$ & $\begin{array}{l}480 \\
488 \\
\star * *\end{array}$ & $\begin{array}{l}25 \\
25\end{array}$ & $\begin{array}{l}\odot * 150 \\
\odot * 15 \odot\end{array}$ & $\begin{array}{l}495 \\
499 \\
* * *\end{array}$ & $\begin{array}{l}30 \\
30\end{array}$ & $\begin{array}{l}\odot * 153 \\
\odot * 153\end{array}$ & $\begin{array}{l}510 \\
510\end{array}$ & $\begin{array}{l}45 \\
35 \\
\star *\end{array}$ & $\begin{array}{r}0 * 157 \\
0 * 158 \\
\star \star \star\end{array}$ & $\begin{array}{l}523 \\
521 \\
* * *\end{array}$ & $\begin{array}{l}45 \\
35 \\
\star *\end{array}$ & $\begin{array}{l}\Theta^{*} \\
\Theta^{*}\end{array}$ \\
\hline $\begin{array}{l}38810 \\
38810\end{array}$ & $\begin{array}{r}08 / 24 * 163 \\
08 / 24 * 166 \\
* * *\end{array}$ & $\begin{array}{l}533 \\
532 \\
* * *\end{array}$ & $\begin{array}{l}6 \odot \\
4 \odot \\
\star *\end{array}$ & $\begin{array}{r}\odot * 172 \\
\odot * 177 \\
* * *\end{array}$ & $\begin{array}{l}540 \\
541 \\
* * *\end{array}$ & $\begin{array}{l}60 \\
40 \\
* *\end{array}$ & $\begin{array}{r}\odot * 183 \\
\odot * 19 \odot \\
* * *\end{array}$ & $\begin{array}{l}546 \\
550 \\
* * *\end{array}$ & $\begin{array}{l}60 \\
45 \\
* *\end{array}$ & $\begin{array}{r}\Theta^{*} 199 \\
0 * 202 \\
* * *\end{array}$ & $\begin{array}{l}552 \\
559 \\
* * *\end{array}$ & $\begin{array}{l}60 \\
45 \\
* *\end{array}$ & $\begin{array}{l}\Theta^{*} \\
\Theta^{*}\end{array}$ \\
\hline $\begin{array}{l}38815 \\
38815\end{array}$ & $\begin{array}{l}\odot 8 / 25 * 213 \\
08 / 25 * 213\end{array}$ & $\begin{array}{l}563 \\
569 \\
* * *\end{array}$ & $\begin{array}{l}70 \\
50 \\
* *\end{array}$ & $\begin{array}{r}\Theta * 221 \\
\Theta * 223 \\
* * *\end{array}$ & $\begin{array}{l}574 \\
580 \\
\star * *\end{array}$ & $\begin{array}{l}70 \\
50 \\
* *\end{array}$ & $\begin{array}{r}0 * 228 \\
0 * 229 \\
\star \star \star\end{array}$ & $\begin{array}{l}586 \\
590 \\
* * *\end{array}$ & $\begin{array}{l}70 \\
50 \\
* *\end{array}$ & $\begin{array}{r}\Theta * 234 \\
\Theta * 234 \\
* * *\end{array}$ & $\begin{array}{l}596 \\
600 \\
* * *\end{array}$ & $\begin{array}{l}75 \\
50 \\
* *\end{array}$ & $\begin{array}{r}0^{*} \\
998^{*} \\
* * *\end{array}$ \\
\hline $\begin{array}{l}38820 \\
38820\end{array}$ & $\begin{array}{r}08 / 26 * 240 \\
08 / 26 * 238 \\
* \star *\end{array}$ & $\begin{array}{l}606 \\
609 \\
\star * \star\end{array}$ & $\begin{array}{l}75 \\
55 \\
* *\end{array}$ & $\begin{array}{r}\Theta * 246 \\
\Theta^{*} 242 \\
* * *\end{array}$ & $\begin{array}{l}615 \\
617 \\
\star * *\end{array}$ & $\begin{array}{l}75 \\
60 \\
\star *\end{array}$ & $\begin{array}{l}\Theta^{*} 252 \\
\Theta^{*} 247 \\
* * *\end{array}$ & $\begin{array}{l}623 \\
624 \\
\star \star *\end{array}$ & $\begin{array}{l}75 \\
60 \\
* *\end{array}$ & $\begin{array}{r}0 * 257 \\
0 * 253 \\
* \star *\end{array}$ & $\begin{array}{l}628 \\
631 \\
\star * *\end{array}$ & $\begin{array}{l}75 \\
6 \odot \\
\star *\end{array}$ & $\begin{array}{r}0^{*} \\
987^{*} \\
* * *\end{array}$ \\
\hline $\begin{array}{l}38825 \\
38825\end{array}$ & $\begin{array}{l}\odot 8 / 27 * 26 \odot \\
\odot 8 / 27 * 259\end{array}$ & $\begin{array}{l}631 \\
634\end{array}$ & $\begin{array}{l}80 \\
55\end{array}$ & $\begin{array}{l}\odot^{*} 263 \\
\odot^{*} 263\end{array}$ & $\begin{array}{l}634 \\
636\end{array}$ & $\begin{array}{l}80 \\
55\end{array}$ & $\begin{array}{l}\odot * 266 \\
\Theta^{*} 267\end{array}$ & $\begin{array}{l}637 \\
638\end{array}$ & $\begin{array}{l}80 \\
50\end{array}$ & $\begin{array}{r}0^{*} 269 \\
992^{*} 271\end{array}$ & $\begin{array}{l}639 \\
640\end{array}$ & $\begin{array}{l}80 \\
50\end{array}$ & $\begin{array}{r}0^{*} \\
993^{*}\end{array}$ \\
\hline
\end{tabular}




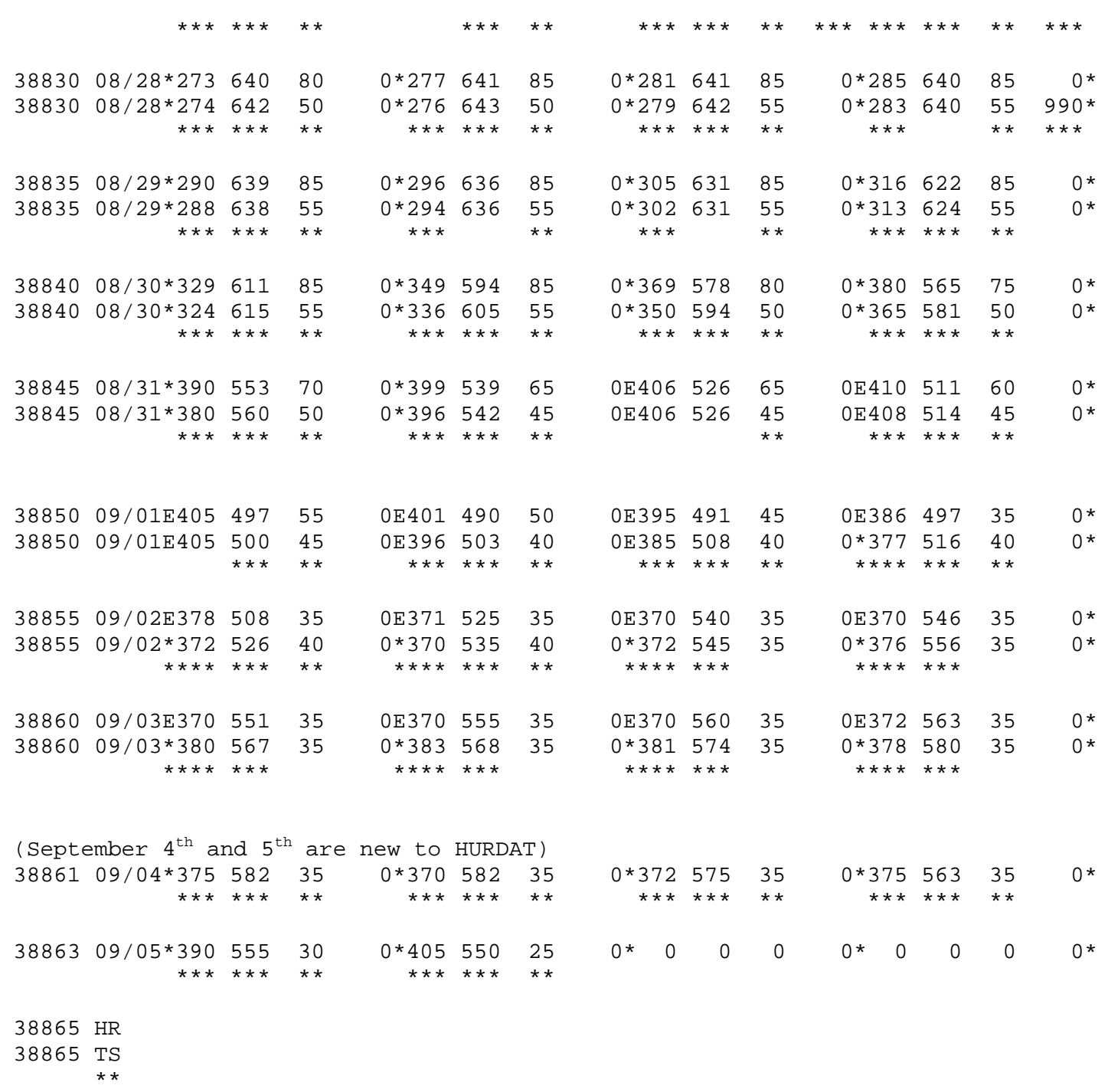

Major track and intensity changes are analyzed for this hurricane that remained over the open Atlantic. A major alteration is to add two additional days at the end of the cyclone's lifetime. Evidence for these alterations comes from the Historical Weather Maps Series, the COADS ship database, Monthly Weather Review, and USWB/NHC microfilm of synoptic weather maps.

August 20:

HWM shows a closed low pressure of at most $1010 \mathrm{mb}$ centered near $17.0 \mathrm{~N}$, 29.0W along the ITCZ at 12Z. HURDAT and microfilm do not analyze an organized system. MWR is not available. Ship highlights: No gales or low pressures.

August 21: 
HWM shows a closed low pressure of at most $1010 \mathrm{mb}$ centered near $11.0 \mathrm{~N}$, 43.0W along the ITCZ at 12Z. HURDAT lists this as a 25 knot tropical depression at $12.4 \mathrm{~N}, 41.0 \mathrm{~W}$ at $12 \mathrm{Z}$. Microfilm does not analyze an organized system. MWR is not available. Ship highlights: No gales or low pressures.

August 22:

HWM shows a closed low pressure of at most $1010 \mathrm{mb}$ centered near $12.0 \mathrm{~N}$, 45.0W along the ITCZ at 12Z. HURDAT lists this as a 25 knot tropical depression at $13.9 \mathrm{~N}, 45.9 \mathrm{~W}$ at $12 \mathrm{Z}$. Microfilm does not analyze an organized system. MWR is not available. Ship highlights: No gales or low pressures. "Hurricane Edith" was first detected as an easterly wave, labeled locally "August \#4," on 22 August. The wave was situated some 400 to 500 miles east of the Antilles in an area of sparse reports. From available surface indicates there appeared to be a wave of weak to moderate intensity" (ATSR).

August 23:

HWM shows a closed low pressure of at most $1010 \mathrm{mb}$ centered near $14.0 \mathrm{~N}$, 47.0W along the ITCZ at 12Z. HURDAT lists this as a 45 knot tropical storm at $15.3 \mathrm{~N}$, $51.0 \mathrm{~W}$ at $12 \mathrm{Z}$. Microfilm does not analyze an organized system. MWR is not available. Ship highlights: No gales or low pressures.

August 24:

HWM shows a tropical storm of at most $1005 \mathrm{mb}$ centered near $18.3 \mathrm{~N}, 54.8 \mathrm{~W}$ at $12 \mathrm{Z}$. HURDAT lists this as a 60 knot tropical storm at $18.3 \mathrm{~N}, 54.6 \mathrm{~W}$ at $12 \mathrm{Z}$. Microfilm does not analyze an organized system at 12Z. MWR is not available. Ship highlights: No gales or low pressures. "Late on 23 August "August \#4" passed into southern Antilles moving very slowly with an orientation NE to SW. By $240300 Z$ the wave was evident at the $700 \mathrm{mb}$ level. During the morning of the 24th the northern half of the wave progressed very slowly indicating a possible vortex development to the northeast" (ATSR).

August 25:

HWM shows a hurricane of at most $1000 \mathrm{mb}$ centered near $22.8 \mathrm{~N}, 58.5 \mathrm{~W}$ at $12 \mathrm{Z}$. HURDAT lists this as a 70 knot hurricane at $22.8 \mathrm{~N}, 58.6 \mathrm{~W}$ at $12 \mathrm{Z}$. Microfilm shows a closed low pressure of at most $1005 \mathrm{mb}$ centered near $23.2 \mathrm{~N}, 59.2 \mathrm{~W}$ at $12 \mathrm{Z}$. MWR is not available. Ship highlights: $35 \mathrm{kt} \mathrm{SW}$ and $1012 \mathrm{mb}$ at $19.9 \mathrm{~N}, 55.8 \mathrm{~W}$ at $0 \mathrm{Z}$ (micro); $45 \mathrm{kt}$ $\mathrm{SE}$ and $999 \mathrm{mb}$ (pressure likely $4 \mathrm{mb}$ too low) at 22.4N, 57.9W at 06Z (COADS); $45 \mathrm{kt}$ $\mathrm{SE}$ and $1013 \mathrm{mb}$ at $22.6 \mathrm{~N}, 56.9 \mathrm{~W}$ at $12 \mathrm{Z}$ (COADS), and $40 \mathrm{kt} \mathrm{SE}$ and $1017 \mathrm{mb}$ at $23.0 \mathrm{~N}$, 
57.1W at $15 \mathrm{Z}$ (micro). Aircraft highlights: Penetration center fix measured a max surface winds of $65 \mathrm{kt}$, a central pressure of $1002 \mathrm{mb}$ and an eye of a 100 mile diameter at $23.2 \mathrm{~N}$, $59.4 \mathrm{~W}$ at $15 \mathrm{Z}$ (micro); Penetration center fix measured central pressure of $998 \mathrm{mb}$ near $23.7 \mathrm{~N}, 60.5 \mathrm{~W}$ at $20 \mathrm{Z}$ (ATSR/micro). "The Air Force Gull Nectar flight was diverted to investigate this suspicious area and arrived in the area late on the 24th of August flying at the $500 \mathrm{mb}$ level. Continuous cloud layers prevented a location of an eye but maximum winds of $70 \mathrm{kt}$ were reported to the east of the circulation. "Edith" intensified very slowly during the next few days as it moved to the northwest along the southwest periphery of the 500 mb Bermuda high" (ATSR).

August 26:

HWM shows a hurricane of at most $1000 \mathrm{mb}$ centered near $25.5 \mathrm{~N}, 62.5 \mathrm{~W}$ at $12 \mathrm{Z}$. HURDAT lists this as a 75 knot hurricane at $25.2 \mathrm{~N}, 62.3 \mathrm{~W}$ at $12 \mathrm{Z}$. Microfilm shows a closed low pressure of at most $1005 \mathrm{mb}$ centered near $25.2 \mathrm{~N}, 63.0 \mathrm{~W}$ at $12 \mathrm{Z}$. MWR indicates a low pressure of $1004 \mathrm{mb}$ located near $25.8 \mathrm{~N}, 63.2 \mathrm{~W}$ at 12Z. Ship highlights: $35 \mathrm{kt} \mathrm{N}$ at $24.7 \mathrm{~N}, 62.9 \mathrm{~W}$ at $03 \mathrm{Z}$ (micro). $35 \mathrm{kt} \mathrm{SSE}$ and $1004 \mathrm{mb}$ at $25.8 \mathrm{~N}, 62.6 \mathrm{~W}$ at $21 \mathrm{Z}$ (micro). Aircraft highlights: Penetration center fix at 25.0N, $61.7 \mathrm{~W}$ at $0524 \mathrm{Z}$ (ATSR); Penetration center fix measured an eye of a 25 mile diameter at $25.4 \mathrm{~N}, 62.1 \mathrm{~W}$ at $08 \mathrm{Z}$ (ATSR/micro); Penetration center fix at $25.1 \mathrm{~N}, 63.3 \mathrm{~W}$ at $14 \mathrm{Z}$ (ATSR); Penetration center fix at $25.2 \mathrm{~N}, 63.2 \mathrm{~W}$ at $1415 \mathrm{Z}$ (ATSR); Penetration center fix at $25.3 \mathrm{~N}, 63.1 \mathrm{~W}$ at $1830 \mathrm{Z}$ (ATSR); Penetration center fix at 25.4N, 63.4W at 19Z (ATSR); Penetration center fix at 25.4N, 63.3W at 1930Z (ATSR), and penetration center fix measured a central pressure of $987 \mathrm{mb}$ and an eye of a 40 mile diameter at $25.7 \mathrm{~N}, 63.4 \mathrm{~W}$ at $20 \mathrm{Z}$ (ATSR/micro).

August 27:

HWM shows a hurricane of at most $1000 \mathrm{mb}$ centered near $26.8 \mathrm{~N}, 63.8 \mathrm{~W}$ at $12 \mathrm{Z}$. HURDAT lists this as an 80 knot hurricane at $26.6 \mathrm{~N}, 63.7 \mathrm{~W}$ at $12 \mathrm{Z}$. Microfilm shows a closed low pressure of at most $1005 \mathrm{mb}$ centered near $27.0 \mathrm{~N}, 64.0 \mathrm{~W}$ at $12 \mathrm{Z}$. MWR indicates a low pressure of $996 \mathrm{mb}$ located near $27.0 \mathrm{~N}, 64.2 \mathrm{~W}$ at 12Z. Ship highlights: 25 $\mathrm{kt} \mathrm{SSW}$ and $1003 \mathrm{mb}$ at $25.2 \mathrm{~N}, 62.9 \mathrm{~W}$ at $06 \mathrm{Z}$ (COADS); $35 \mathrm{kt} \mathrm{S}$ and $1011 \mathrm{mb}$ at $24.5 \mathrm{~N}$, $61.9 \mathrm{~W}$ at $18 \mathrm{Z}$ (COADS). Aircraft highlights: Penetration center fix at $27.0 \mathrm{~N}, 63.8 \mathrm{~W}$ at $1330 Z$ (ATSR); Penetration center fix measured max surface winds of $50 \mathrm{kt}$ and a central pressure of $992 \mathrm{mb}$ at $27.0 \mathrm{~N}, 64.0 \mathrm{~W}$ at $1456 \mathrm{Z}$ (ATSR), and a penetration center fix measured a central pressure of $993 \mathrm{mb}$ and an eye of a 60 mile diameter at $27.3 \mathrm{~N}, 64.0 \mathrm{~W}$ at $20 \mathrm{Z}$ (ATSR/micro). "Late on the 26th "Edith" began to recurved and slowed in forward movement to 5 knots. This deceleration and recurvature were the resultant of the weak gradient surrounding the storm at $500 \mathrm{mb}$ and the orientation of the $500 \mathrm{mb}$ steering high to the northeast of the storm center. The weak gradient continued through the 27th and 28th of August" (ATSR). 
August 28:

HWM shows a hurricane of at most $1000 \mathrm{mb}$ centered near $28.4 \mathrm{~N}, 64.2 \mathrm{~W}$ at $12 \mathrm{Z}$. HURDAT lists this as an 85 knot hurricane at $28.1 \mathrm{~N}, 64.1 \mathrm{~W}$ at $12 \mathrm{Z}$. Microfilm shows a closed low pressure of at most $996 \mathrm{mb}$ centered near $27.8 \mathrm{~N}, 64.2 \mathrm{~W}$ at $12 \mathrm{Z}$. MWR indicates a low pressure of $990 \mathrm{mb}$ located near 28.7N, 64.2W at 12Z. Ship highlights: No gales or low pressures. Aircraft highlights: Penetration center fix measured an eye of an 80 mile diameter at $27.3 \mathrm{~N}, 64.4 \mathrm{~W}$ at $0250 \mathrm{Z}$ (ATSR/micro); Penetration center fix measured an eye of an 80 mile diameter at $27.6 \mathrm{~N}, 64.8 \mathrm{~W}$ at $0730 \mathrm{Z}$ (ATSR/micro); Penetration center fix measured an eye of a 60 mile diameter at $28.0 \mathrm{~N}, 64.1 \mathrm{~W}$ at $1548 \mathrm{Z}$ (ATSR/micro); Penetration center fix measured an eye of a 75 mile diameter at $28.3 \mathrm{~N}$, 63.7W at $1855 \mathrm{Z}$ (ATSR/micro); and penetration center fix measured a central pressure of $990 \mathrm{mb}$ and an eye of a 60 mile diameter at $28.6 \mathrm{~N}, 63.7 \mathrm{~W}$ at $0730 \mathrm{Z}$ (ATSR/micro). "However, by $280300 \mathrm{Z}$, the slowly moving $500 \mathrm{mb}$ trough approaching the storm from the east coast of the United States pulled the hurricane to the north and through recurvature slowly" (ATSR).

August 29:

HWM shows a hurricane of at most $1000 \mathrm{mb}$ centered near $30.6 \mathrm{~N}, 63.1 \mathrm{~W}$ at $12 \mathrm{Z}$. HURDAT lists this as an 85 knot hurricane at $30.5 \mathrm{~N}, 63.1 \mathrm{~W}$ at $12 \mathrm{Z}$. Microfilm shows a closed low pressure of at most $996 \mathrm{mb}$ centered near $30.7 \mathrm{~N}, 63.3 \mathrm{~W}$ at $12 \mathrm{Z}$. MWR indicates a low pressure of $992 \mathrm{mb}$ located near 30.8N, 63.9W at 12Z. Ship highlights: 25 kt SW and $1005 \mathrm{mb}$ at $27.9 \mathrm{~N}, 62.5 \mathrm{~W}$ at $06 \mathrm{Z}$ (COADS); $35 \mathrm{kt} \mathrm{SSW}$ and $1015 \mathrm{mb}$ at $29.9 \mathrm{~N}, 57.6 \mathrm{~W}$ at $12 \mathrm{Z}$ (COADS), and $35 \mathrm{kt} \mathrm{SSW}$ and $1014 \mathrm{mb}$ at $29.7 \mathrm{~N}, 58.1 \mathrm{~W}$ at $18 \mathrm{Z}$ (COADS). Aircraft highlights: Penetration center fix measured an eye of a 60 mile diameter at 29.4N, 63.8W at $0415 \mathrm{Z}$ (ATSR/micro); Penetration center fix at $31.1 \mathrm{~N}$, $62.8 \mathrm{~W}$ at $1545 \mathrm{Z}$ (ATSR), and Penetration center fix at $31.2 \mathrm{~N}, 62.3 \mathrm{~W}$ at $1750 \mathrm{Z}$ (ATSR). "By 290300Z, "Edith" had completed recurvature and accelerated from 2.5 knots at $280300 Z$ to 6.5 knots" (ATSR).

August 30:

HWM shows a tropical storm of at most $1000 \mathrm{mb}$ centered near $37.2 \mathrm{~N}, 57.5 \mathrm{~W}$ at $12 \mathrm{Z}$. HURDAT lists this as an 80 knot hurricane at $36.9 \mathrm{~N}, 57.8 \mathrm{~W}$ at $12 \mathrm{Z}$. Microfilm shows a closed low pressure of at most $1002 \mathrm{mb}$ centered near $36.0 \mathrm{~N}, 59.0 \mathrm{~W}$ at $12 \mathrm{Z}$. MWR indicates a low pressure of $990 \mathrm{mb}$ located near $35.2 \mathrm{~N}, 60.0 \mathrm{~W}$ at $12 \mathrm{Z}$. Ship highlights: 50 $\mathrm{kt} \mathrm{SSE}$ and $1008 \mathrm{mb}$ at $32.5 \mathrm{~N}, 58.9 \mathrm{~W}$ at $0 \mathrm{Z}$ (COADS); $50 \mathrm{kt} \mathrm{SSW}$ and $1010 \mathrm{mb}$ at $32.5 \mathrm{~N}, 58.5 \mathrm{~W}$ at $06 \mathrm{Z}$ (COADS); $40 \mathrm{kt} \mathrm{E}$ and $999 \mathrm{mb}$ at $36.8 \mathrm{~N}, 59.5 \mathrm{~W}$ at $12 \mathrm{Z}$ (micro), and $45 \mathrm{kt} \mathrm{E}$ and $999 \mathrm{mb}$ at 36.5N, 59.4W at 18Z (COADS). Aircraft highlights: Penetration center fix measured an eye of a 40 mile diameter at $35.7 \mathrm{~N}, 59.0 \mathrm{~W}$ at $1449 \mathrm{Z}$ 
(ATSR/micro). "Edith" continued accelerating slowly and by $301600 \mathrm{Z}$ was moving toward the northeast at 20 knots. Between $290300 \mathrm{Z}$ and 300300Z, "Edith" $500 \mathrm{mb}$ cyclonic circulation was completely destroyed by the deep trough in the Westerlies. Thus, "Edith" entered post maturity with attendant decrease in maximum wind velocity and, in this case, frontogenesis" (ATSR).

\section{August 31:}

HWM shows a tropical storm of at most $1005 \mathrm{mb}$ with a warm front extending to the northeast and a cold front extending to the south, centered near $40.5 \mathrm{~N}, 52.3 \mathrm{~W}$ at $12 \mathrm{Z}$. HURDAT lists this as a 65 knot extratropical cyclone at $40.6 \mathrm{~N}, 52.6 \mathrm{~W}$ at $12 \mathrm{Z}$. Microfilm shows a closed low pressure of at most $1011 \mathrm{mb}$ centered near $41.0 \mathrm{~N}, 53.0 \mathrm{~W}$ at $12 \mathrm{Z}$. MWR indicates a low pressure of $996 \mathrm{mb}$ located near 41.0N, 53.0W at 12Z. Ship highlights: $40 \mathrm{kt} \mathrm{E}$ and $1013 \mathrm{mb}$ at $42.0 \mathrm{~N}, 53.5 \mathrm{~W}$ at $12 \mathrm{Z}$ (COADS), and $40 \mathrm{kt} \mathrm{NE}$ and $1014 \mathrm{mb}$ at $42.5 \mathrm{~N}, 51.3 \mathrm{~W}$ at $18 \mathrm{Z}$ (COADS).

\section{September 1:}

HWM shows a closed low pressure of at most $1010 \mathrm{mb}$ with a warm front extending to the northeast and a cold front extending to the south, centered near $38.5 \mathrm{~N}, 50.0 \mathrm{~W}$ at $12 \mathrm{Z}$. HURDAT lists this as a 45 knot extratropical cyclone at $39.5 \mathrm{~N}, 49.1 \mathrm{~W}$ at $12 \mathrm{Z}$. Microfilm shows a closed low pressure of at most $1014 \mathrm{mb}$ centered near $37.0 \mathrm{~N}, 51.0 \mathrm{~W}$ at $12 \mathrm{Z}$. MWR indicates a low pressure of $1012 \mathrm{mb}$ located near 39.5N, 48.7W at 12Z. Ship highlights: $40 \mathrm{kt} \mathrm{NNE}$ and $1014 \mathrm{mb}$ at $40.9 \mathrm{~N}, 53.0 \mathrm{~W}$ at $0 \mathrm{Z}$ (COADS), and $40 \mathrm{kt} \mathrm{NW}$ and $1019 \mathrm{mb}$ at $36.2 \mathrm{~N}, 54.5 \mathrm{~W}$ at $12 \mathrm{Z}$ (COADS).

September 2:

HWM shows a closed low pressure of at most $1010 \mathrm{mb}$ centered near $36.2 \mathrm{~N}, 54.3 \mathrm{~W}$ at 12Z. HURDAT lists this as a 35 knot extratropical cyclone at $37.0 \mathrm{~N}, 54.0 \mathrm{~W}$ at $12 \mathrm{Z}$. Microfilm shows a closed low pressure of at most $1014 \mathrm{mb}$ centered near $37.5 \mathrm{~N}, 56.5 \mathrm{~W}$ at 12Z. MWR indicates a low pressure of $1006 \mathrm{mb}$ located near 37.0N, 54.0W at $12 \mathrm{Z}$. Ship highlights: $35 \mathrm{kt} \mathrm{N}$ and $1007 \mathrm{mb}$ at 38.0N, 55.4W at 06Z (COADS).

\section{September 3:}

HWM shows a closed low pressure of at most $1010 \mathrm{mb}$ centered near $36.2 \mathrm{~N}, 56.2 \mathrm{~W}$ with a stationary front to the north at $12 \mathrm{Z}$. HURDAT lists this as a 35 knot extratropical cyclone at $37.0 \mathrm{~N}, 56.0 \mathrm{~W}$ at $12 \mathrm{Z}$. Microfilm shows a closed low pressure of at most 1008 $\mathrm{mb}$ centered near $38.0 \mathrm{~N}, 57.5 \mathrm{~W}$ at $12 \mathrm{Z}$. MWR indicates a low pressure of $1006 \mathrm{mb}$ located near $37.6 \mathrm{~N}, 57.8 \mathrm{~W}$ at $12 \mathrm{Z}$. Ship highlights: $20 \mathrm{kt} \mathrm{SE}$ and $1008 \mathrm{mb}$ at $38.0 \mathrm{~N}$, $57.1 \mathrm{~W}$ at $12 \mathrm{Z}$ (COADS). 


\section{September 4:}

HWM shows a spot low centered near $37.5 \mathrm{~N}, 47.5 \mathrm{~W}$ with a stationary front to the northwest at 12Z. HURDAT and MWR are not available for this date. Microfilm shows a closed low pressure of at most $1017 \mathrm{mb}$ centered near $38.0 \mathrm{~N}, 51.0 \mathrm{~W}$ at $12 \mathrm{Z}$. MWR is not available on this date at 12Z. Ship highlights: $30 \mathrm{kt} \mathrm{SW}$ and $1015 \mathrm{mb}$ at $36.1 \mathrm{~N}, 56.1 \mathrm{~W}$ at $18 \mathrm{Z}$ (COADS).

\section{September 5:}

HWM shows a stationary front associated with a $1015 \mathrm{mb}$ low pressure southeast of Nova Scotia at 12Z. HURDAT and MWR are not available for this date. Microfilm shows a closed low pressure of at most $1017 \mathrm{mb}$ centered near $41.0 \mathrm{~N}, 56.0 \mathrm{~W}$ at $06 \mathrm{Z}$. MWR is not available on this date. Ship highlights: No gales or low pressures.

MWR: "Hurricane Edith formed on August 24 in an easterly and moved on a smooth parabolic curve passing well to the east of Bermuda on the 29th. Highest winds reported by reconnaissance were $90 \mathrm{mph}$. The lowest pressure in the center was $991 \mathrm{mb}(29.26$ inches) measured by dropsondes in the eye on the same dates."

Genesis for this tropical cyclone remains at $12 \mathrm{Z}$ on the $21 \mathrm{st}$ of August as a $25 \mathrm{kt}$ tropical depression, unchanged from the original HURDAT. Data is very sparse between the $21 \mathrm{st}$ and 24 th, but a ship at $12 \mathrm{Z}$ on the 21 st located near $10 \mathrm{~N}, 41 \mathrm{~W}$ reported $15 \mathrm{kt} \mathrm{SW}$ and $1010 \mathrm{mb}$. This indicates that the center of the cyclone was located about a degree farther west than originally shown in HURDAT. Intensification to a tropical storm remains at $12 \mathrm{Z}$ on the $23 \mathrm{rd}$, unchanged from the original HURDAT. The original intensity in HURDAT at $06 \mathrm{Z}$ and $12 \mathrm{Z}$ is $30 \mathrm{kt}$ and $45 \mathrm{kt}$, respectively. The data on the 23rd is very sparse and does not justify such a large $15 \mathrm{kt}$ increase in intensity over six hours. Thus, an intensity of $30 \mathrm{kt}$ and $35 \mathrm{kt}$ has been selected for the aforementioned times. The first reconnaissance aircraft mission occurred late on the 24th of August, but it was unsuccessful in obtaining a center fix, although aircraft and ship observations suggest that the center was near $20 \mathrm{~N}, 55 \mathrm{~W}$ at $21 \mathrm{Z}$. A gradual intensification is shown on the 24th, including major changes at $00 \mathrm{Z}$ and $06 \mathrm{Z}$ as an intensity of $40 \mathrm{kt}$ is selected for those times, down from $60 \mathrm{kt}$ originally in HURDAT. The first winds of gale force were reported on the $25 \mathrm{th}$, including $45 \mathrm{kt}$ at 06Z, 09Z, and 12Z. An aircraft reconnaissance mission on the 25 th measured central pressures of $1002 \mathrm{mb}$ at $15 \mathrm{Z}$ and $998 \mathrm{mb}$ at 20Z. A central pressure of $998 \mathrm{mb}$ yields $51 \mathrm{kt}$ according to Brown et al. southern pressure-wind relationship. An intensity of $50 \mathrm{kt}$ is selected for $18 \mathrm{Z}$ on the $25 \mathrm{th}$, down from $75 \mathrm{kt}$ originally in HURDAT, a major change. A central pressure of $998 \mathrm{mb}$ was also added to $18 \mathrm{Z}$ on the 25 th. Major changes in intensity are thus indicated from $00 \mathrm{Z}$ to $12 \mathrm{Z}$ on the 25 th as an intensity of $50 \mathrm{kt}$ has been selected, down from $70 \mathrm{kt}$ originally in HURDAT. 
Edith continued to strengthen on the 26th while located southeast of Bermuda. Another aircraft mission reached the storm on the 26th at $20 \mathrm{Z}$ measuring a central pressure of 987 $\mathrm{mb}$. A central pressure of $987 \mathrm{mb}$ yields $68 \mathrm{kt}$ south of $25 \mathrm{~N}, 64 \mathrm{kt}$ north of $25 \mathrm{~N}$, and $66 \mathrm{kt}$ north of $25 \mathrm{~N}$ intensifying subset of the pressure-wind relationships. The aircraft also reported an eye diameter of 40 miles, which allows computing an RMW of about $30 \mathrm{~nm}$ and climatology suggests $20 \mathrm{~nm}$. Thus, an intensity of $60 \mathrm{kt}$ is selected for 18Z, down from $75 \mathrm{kt}$ originally in HURDAT. A central pressure of $987 \mathrm{mb}$ has been added to $18 \mathrm{Z}$ on the 26th. $60 \mathrm{kt}$ is also the new peak intensity for the lifetime of Edith. (The original peak intensity of Edith was $85 \mathrm{kt}$ from the 28th through the 30th. Thus the revision in peak intensity reduces Edith down from a Category 2 hurricane to a high end tropical storm.) A major change is shown at $00 \mathrm{Z}$ on the $26 \mathrm{th}$ as $55 \mathrm{kt}$ is selected as the intensity, down from 75 kt originally in HURDAT. Some weakening occurred on the 27th, as a central pressure of $992 \mathrm{mb}$ was measured by a reconnaissance aircraft at 1456Z. A central pressure of $992 \mathrm{mb}$ yields $56 \mathrm{kt}$ north of $25 \mathrm{~N}$ and $54 \mathrm{kt}$ north of $25 \mathrm{~N}$ weakening subset of the pressure-wind relationships. Another aircraft mission at $20 \mathrm{Z}$ measured a central pressure of $993 \mathrm{mb}$ and an eye diameter of 60 miles, which allows calculating an RMW of about $45 \mathrm{~nm}$ while climatology suggests an RMW of $23 \mathrm{~nm}$. Thus, an intensity of 50 $\mathrm{kt}$ has been selected for $12 \mathrm{Z}$ and 18Z, down from 80 kt originally in HURDAT, a major change. Central pressures of $992 \mathrm{mb}$ and $993 \mathrm{mb}$ have been added to $12 \mathrm{Z}$ and 18Z, respectively. Major changes are also indicated at $00 \mathrm{Z}$ and $06 \mathrm{Z}$ on the $27 \mathrm{th}$, as $55 \mathrm{kt}$ have been selected for those times, down from 80 kt originally in HURDAT. Slight deepening occurred on the 28th as a central pressure of $990 \mathrm{mb}$ was measured by a reconnaissance aircraft at 2012Z. A central pressure of $990 \mathrm{mb}$ yields $59 \mathrm{kt}$ north of $25 \mathrm{~N}$ according to the pressure-wind relationship. The aircraft also reported a large eye diameter of $60 \mathrm{~nm}$. Thus, an intensity of $55 \mathrm{kt}$ is selected for 18Z, down from $85 \mathrm{kt}$ originally in HURDAT. A central pressure of $990 \mathrm{mb}$ is added to $18 \mathrm{Z}$ on the 28th. Major changes in intensity are also shown from $0 \mathrm{Z}$ to $12 \mathrm{Z}$ on the 28th. HURDAT originally had $80 \mathrm{kt}$ at $0 \mathrm{Z}$, and $85 \mathrm{kt}$ at $06 \mathrm{Z}$ and 12Z. $50 \mathrm{kt}$ was selected for $00 \mathrm{Z}$ and 06Z, and $55 \mathrm{kt}$ for 12Z. On the 29th, Edith passed to the east of Bermuda and only a few ships reported gale-force winds on this day. An intensity of $55 \mathrm{kt}$ is analyzed from $00 \mathrm{Z}$ to $18 \mathrm{Z}$ - persisting with the reanalyzed intensity from the day before, down from $85 \mathrm{kt}$ originally in HURDAT, a major change.

On the 30th of August, the ship 12201 reported winds of $50 \mathrm{kt}$ at $00 \mathrm{Z}$ and $06 \mathrm{Z}$. An intensity of $55 \mathrm{kt}$ has been analyzed at those times, down from $85 \mathrm{kt}$ originally at HURDAT, a major change. At $12 \mathrm{Z}$ and 18Z, HURDAT originally showed $80 \mathrm{kt}$ and 75 $\mathrm{kt}$, respectively. An intensity of $50 \mathrm{kt}$ has been analyzed for those times, a major change. At 18Z, the position of the ship Mulberry Hills appears to be wrong although the data looks consistent with a nearby ship Coruth. Transition to an extratropical cyclone remains at $12 \mathrm{Z}$ on the $31 \mathrm{st}$, as originally shown in HURDAT. Major changes in intensity are indicated from $00 \mathrm{Z}$ to $12 \mathrm{Z}$. HURDAT originally showed $70 \mathrm{kt}$ at $00 \mathrm{Z}$, and $65 \mathrm{kt}$ at $06 \mathrm{Z}$ 
and 12Z. $50 \mathrm{kt}$ has been analyzed at 00Z, and $45 \mathrm{kt}$ at $06 \mathrm{Z}$ and 12Z. Late on September $1 \mathrm{st}$, data indicates that the temperature gradient that had been surrounding the storm for the past day was nearly non-existent, the circulation had become more circular and no frontal system was present near the center of circulation. Therefore, Edith is analyzed to have become a tropical cyclone again at $18 \mathrm{Z}$ on this date. (The original HURDAT did not indicate a tropical transition stage.) Edith remained a tropical cyclone for the remainder of its lifetime. Various ships reported gale-force winds on the 1st, including $40 \mathrm{kt}$ at $0 \mathrm{Z}$ and 12Z. The last gale-force winds were reported at $06 \mathrm{Z}$ on the $2 \mathrm{nd}$. Minor intensity and track changes are evaluated on the 2 nd and 3rd of September. The last position in HURDAT is at $18 \mathrm{Z}$ on the $3 \mathrm{rd}$, but data on the 4th suggests that a closed circulation was still present. An approaching cold front started to interact with Edith on the 4th and by $12 \mathrm{Z}$ on the 5 th, the circulation had dissipated. The last position is analyzed at $06 \mathrm{Z}$ on the 5 th as a $25 \mathrm{kt}$ tropical depression. Adding 36 hours to the lifetime of Edith is a major change to HURDAT.

Unnamed Tropical Storm 5 [August 23-28, 1955]

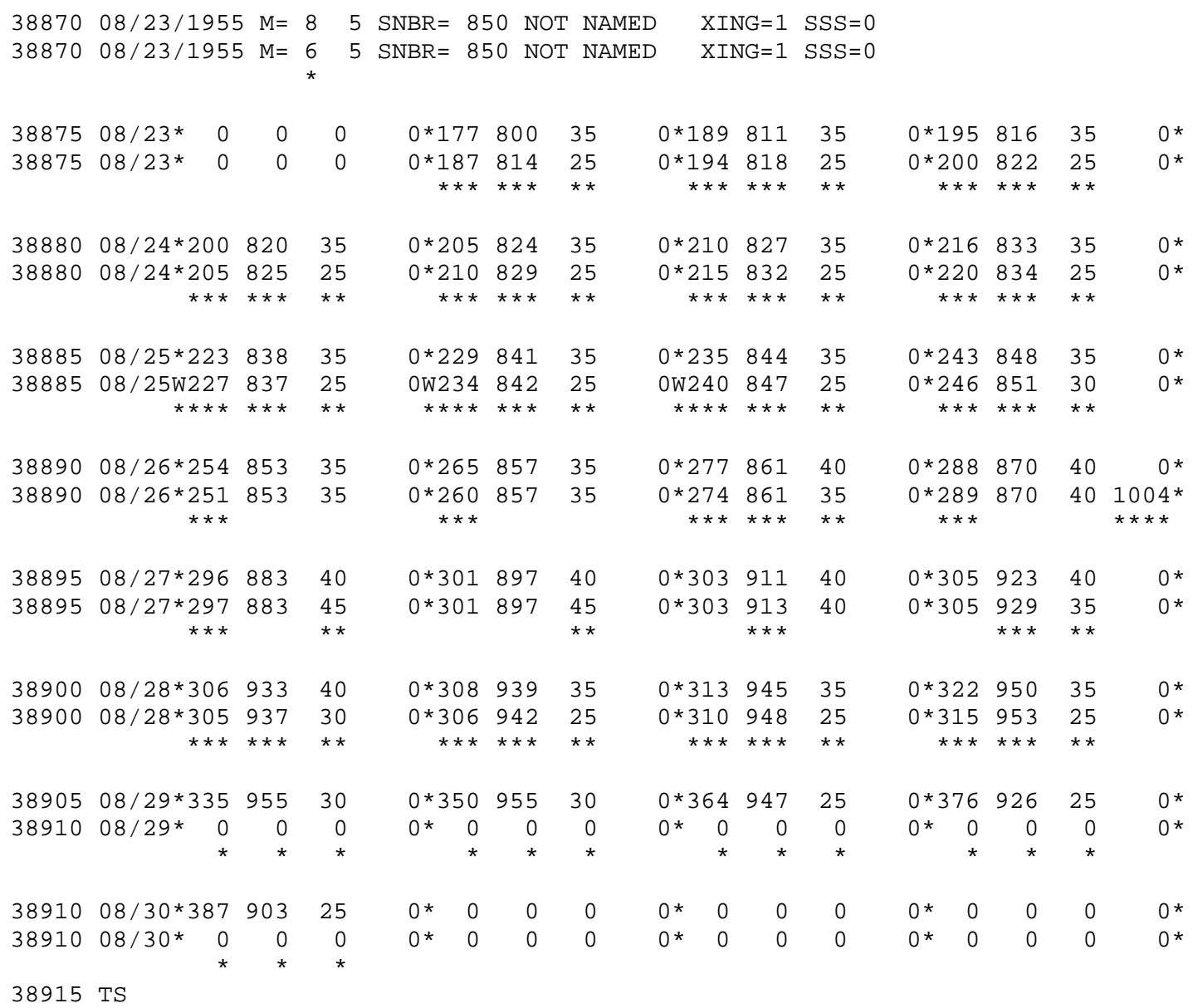




\section{U.S. Tropical Storm Landfall}

08/27 04Z 30.0N 89.2W $45 \mathrm{kt} \mathrm{LA}$

Minor changes to the track and to the intensity shown in McAdie et al. (2009). Two major alterations are to show a wave stage on the $25^{\text {th }}$ and to indicate dissipation 30 hours earlier than originally shown. Evidence for these alterations comes from the NHC microfilm maps, the Historical Weather Maps series, the COADS ship database, Monthly Weather Review, the Local Climatological Data, Connor (1956), Mexican weather maps, the Navy aircraft reconnaissance book, and Perez et al. (2000).

August 21:

HWM, HURDAT, Microfilm and MWR do not analyze an organized system on this date. Ship highlights: No gales or low pressures.

August 22:

HWM, HURDAT, and MWR do not analyze an organized system on this date. Microfilm shows a closed low pressure of at most $1011 \mathrm{mb}$ at 19.0N, 81.0W at 18Z. Ship highlights: No gales or low pressures.

August 23:

HWM shows a spot low centered near $17.3 \mathrm{~N}, 82.0 \mathrm{~W}$ at $12 \mathrm{Z}$. HURDAT lists this as a $35 \mathrm{knot}$ tropical storm at $18.9 \mathrm{~N}, 81.1 \mathrm{~W}$ at $12 \mathrm{Z}$. Microfilm analyzes a closed low pressure of at most $1008 \mathrm{mb}$ centered near $20.5 \mathrm{~N}, 81.0 \mathrm{~W}$ at $12 \mathrm{Z}$. MWR shows a low pressure of $1008 \mathrm{mb}$ located near $19.2 \mathrm{~N}, 82.0 \mathrm{~W}$ at 12Z. Ship highlights: No gales or low pressures. "A weak circulation was observed near Grand Cayman on August 23" (MWR).

August 24:

HWM shows a spot low centered near $20.5 \mathrm{~N}, 82.5 \mathrm{~W}$ at $12 \mathrm{Z}$. HURDAT lists this as a $35 \mathrm{knot}$ tropical storm at $21.0 \mathrm{~N}, 82.7 \mathrm{~W}$ at $12 \mathrm{Z}$. Microfilm analyzes a closed low pressure of at most $1008 \mathrm{mb}$ centered near $21.0 \mathrm{~N}, 82.0 \mathrm{~W}$ at $12 \mathrm{Z}$. MWR shows a low pressure of $1007 \mathrm{mb}$ located near $21.0 \mathrm{~N}, 83.8 \mathrm{~W}$ at 12Z. Ship highlights: No gales or low pressures. "Tropical Storm landfall in Cuba, August 24" (Perez et al.)

\section{August 25:}

HWM shows a spot low centered near $24.5 \mathrm{~N}, 88.0 \mathrm{~W}$ at $12 \mathrm{Z}$. HURDAT lists this as a $35 \mathrm{knot}$ tropical storm at $23.5 \mathrm{~N}, 84.4 \mathrm{~W}$ at $12 \mathrm{Z}$. Microfilm analyzes a closed low pressure of at most $1008 \mathrm{mb}$ centered near $25.0 \mathrm{~N}, 88.0 \mathrm{~W}$ at $12 \mathrm{Z}$. MWR shows a low 
pressure of $1009 \mathrm{mb}$ located near $22.5 \mathrm{~N}, 86.0 \mathrm{~W}$ and new center of $1009 \mathrm{mb}$ located near $28.2 \mathrm{~N}, 85.8 \mathrm{~W}$ at $12 \mathrm{Z}$. Ship highlights: No gales or low pressures.

August 26:

HWM shows a closed low pressure of at most $1010 \mathrm{mb}$ centered near $28.0 \mathrm{~N}$, 88.0W at $12 \mathrm{Z}$. HURDAT lists this as a 40 knot tropical storm at $27.7 \mathrm{~N}, 86.1 \mathrm{~W}$ at $12 \mathrm{Z}$. Microfilm analyzes a closed low pressure of at most $1008 \mathrm{mb}$ centered near $25.5 \mathrm{~N}$, 86.0W at 12Z. MWR shows a low pressure of $1009 \mathrm{mb}$ located near $27.4 \mathrm{~N}, 86.2 \mathrm{~W}$ at 12Z. Ship highlights: No gales or low pressures. Aircraft highlights: Navy reconnaissance measured a central pressure of $1004 \mathrm{mb}$ and surface winds of $40 \mathrm{kt}$ at $29.0 \mathrm{~N}, 89.0 \mathrm{~W}$ at $18 Z$ (micro).

August 27:

HWM shows a spot low centered near $29.2 \mathrm{~N}, 92.2 \mathrm{~W}$ at $12 \mathrm{Z}$. HURDAT lists this as a 40 knot tropical storm at $30.3 \mathrm{~N}, 91.1 \mathrm{~W}$ at $12 \mathrm{Z}$. Microfilm analyzes a closed low pressure of at most $1005 \mathrm{mb}$ centered near $30.5 \mathrm{~N}, 91.5 \mathrm{~W}$ at 12Z. MWR does not analyze an organized system on this date. Ship highlights: No gales or low pressures. Land highlights: Max surface winds of 35-45 kt and $1000 \mathrm{mb}$ at New Orleans at 29.8N, 90.0W (likely around 07Z)(MWR), and $1004 \mathrm{mb}$ at Baton Rouge at 12Z (CLIMO). "It moved on a northwestward course and gained intensity very slowly, passing between New Orleans Airport and the Naval Air Station about 0200 EST, August 27. The highest wind was 40 to $50 \mathrm{mph}$ with lowest pressure $1000.3 \mathrm{mb}$ (29.54 inches). Only very minor damage was reported" (MWR).

August 28:

HWM shows a spot low centered near $31.0 \mathrm{~N}, 94.8 \mathrm{~W}$ at $12 \mathrm{Z}$. HURDAT lists this as a 35 knot tropical storm at $31.3 \mathrm{~N}, 94.5 \mathrm{~W}$ at 12Z. Microfilm and MWR does not analyze an organized system on this date. Land highlights: $1005 \mathrm{mb}$ at Lake Charles (likely early on the $28^{\text {th }}$ ) (CLIMO).

August 29:

HWM shows a cold front across the central states of the United States at $12 Z$. HURDAT lists this as a 25 knot tropical depression at $36.4 \mathrm{~N}, 94.7 \mathrm{~W}$ at $12 \mathrm{Z}$. Microfilm and MWR does not analyze an organized system on this date.

August 30: 
HWM shows a cold front stretching from the Great Lakes to Texas at $12 \mathrm{Z}$. HURDAT lists this as a 25 knot tropical depression at $38.7 \mathrm{~N}, 90.3 \mathrm{~W}$ at $0 \mathrm{Z}$ (last position). Microfilm and MWR does not analyze an organized system on this date.

This unnamed tropical storm developed from a tropical wave over the western Caribbean Sea late on August. The genesis is unchanged from $06 \mathrm{Z}$ on the $23^{\text {rd }}$ although the system may not have had a well-defined low level circulation according to the land stations in the area. Winds on the $23^{\text {rd }}$ stayed below gale force winds and no surface pressures below $1008 \mathrm{mb}$ were reported. Therefore, the cyclone is started as a $25 \mathrm{kt}$ tropical depression and this intensity is kept from the $06 \mathrm{Z}$ to $18 \mathrm{Z}$ on the $23^{\text {rd }}$. This is a decrease from the $35 \mathrm{kt}$ originally shown in HURDAT from the $06 \mathrm{Z}$ to $18 \mathrm{Z}$ on the $23^{\text {rd }}$. On the $24^{\text {th }}$ the organization of the cyclone did not improve according to the observations from the western Caribbean and western Cuba. The depression moved slowly to the northwest and then to north-northwest making landfall in Pinar del Rio late on the $24^{\text {th }}$. HURDAT originally had $35 \mathrm{kt}$ throughout the day but the intensity is kept at $25 \mathrm{kt}$ since no gales or low pressures were observed on the $24^{\text {th }}$. Note that this assessment does not agree with Perez et al., as they had the system as a Cuban tropical storm impact.

Early on the $25^{\text {th }}$ of August, observations across the eastern Gulf of Mexico and western Caribbean indicate that the depression dissipated into a trough of low pressure and a new center formed farther to the northwest later in the day. The MWR Tracks of Lows for the month of August also agrees on this solution. The new low level circulation became better organized by $18 \mathrm{Z}$ on the $25^{\text {th }}$ and the cyclone redeveloped with winds of $30 \mathrm{kt}$. The highest winds for the $25^{\text {th }}$ were $30 \mathrm{kt}$ reported by a ship at $12 \mathrm{Z}$. The cyclone is analyzed to have reached tropical storm intensity at $0 \mathrm{Z}$ on the $26^{\text {th }}$. A reconnaissance aircraft reached the tropical cyclone at $18 \mathrm{Z}$ on the $26^{\text {th }}$ measuring a central pressure of $1004 \mathrm{mb}$ and surface winds of $40 \mathrm{kt}$. A central pressure of $1004 \mathrm{mb}$ suggests maximum winds of $36 \mathrm{kt}$ north of $25 \mathrm{~N}$ and $38 \mathrm{kt}$ north of $25 \mathrm{~N}$ intensifying from the Brown et al. pressurewind relationships. Given the visual estimate of the intensity and the fast-forward motion of the storm, the intensity is kept at $40 \mathrm{kt}$ at $18 \mathrm{Z}$ on the $26^{\text {th }}$. The cyclone turned to the northwest and west-northwest late on the $26^{\text {th }}$ and early on the $27^{\text {th }}$ making landfall at $04 \mathrm{Z}$ on the $27^{\text {th }}$ in southeast Louisiana. Three hours later, New Orleans, LA, measured a pressure of $1000 \mathrm{mb}$, which indicates maximum winds of at least $44 \mathrm{kt}$ according to the pressure-wind relationship. (It is unknown whether this was a central pressure.) Thus, a peak wind of $45 \mathrm{kt}$ is selected for $00 \mathrm{Z}$ and $06 \mathrm{Z}$ on the $27^{\text {th }}$, up from $40 \mathrm{kt}$ originally shown in HURDAT. $45 \mathrm{kt}$ is also the intensity at landfall. New Orleans reported winds of 35-45 kt, consistent with this analysis. The small tropical storm continued moving over southern Louisiana on August $27^{\text {th }}$ weakening to a tropical depression at $0 \mathrm{Z}$ on the $28^{\text {th }}$. Dissipation is shown over eastern Texas at $18 \mathrm{Z}$ on the $28^{\text {th }}$ based on surface observations. HURDAT originally kept the cyclone as a tropical storm until $18 \mathrm{Z}$ on the 
$28^{\text {th }}$, downgrading it to a tropical depression at $0 \mathrm{Z}$ on the $29^{\text {th }}$ and finally dissipating it at $0 \mathrm{Z}$ on August $30^{\text {th }}$. Thus, dissipation 30 hours earlier is a major change to HURDAT.

Hurricane Flora [September 2-10, 1955]

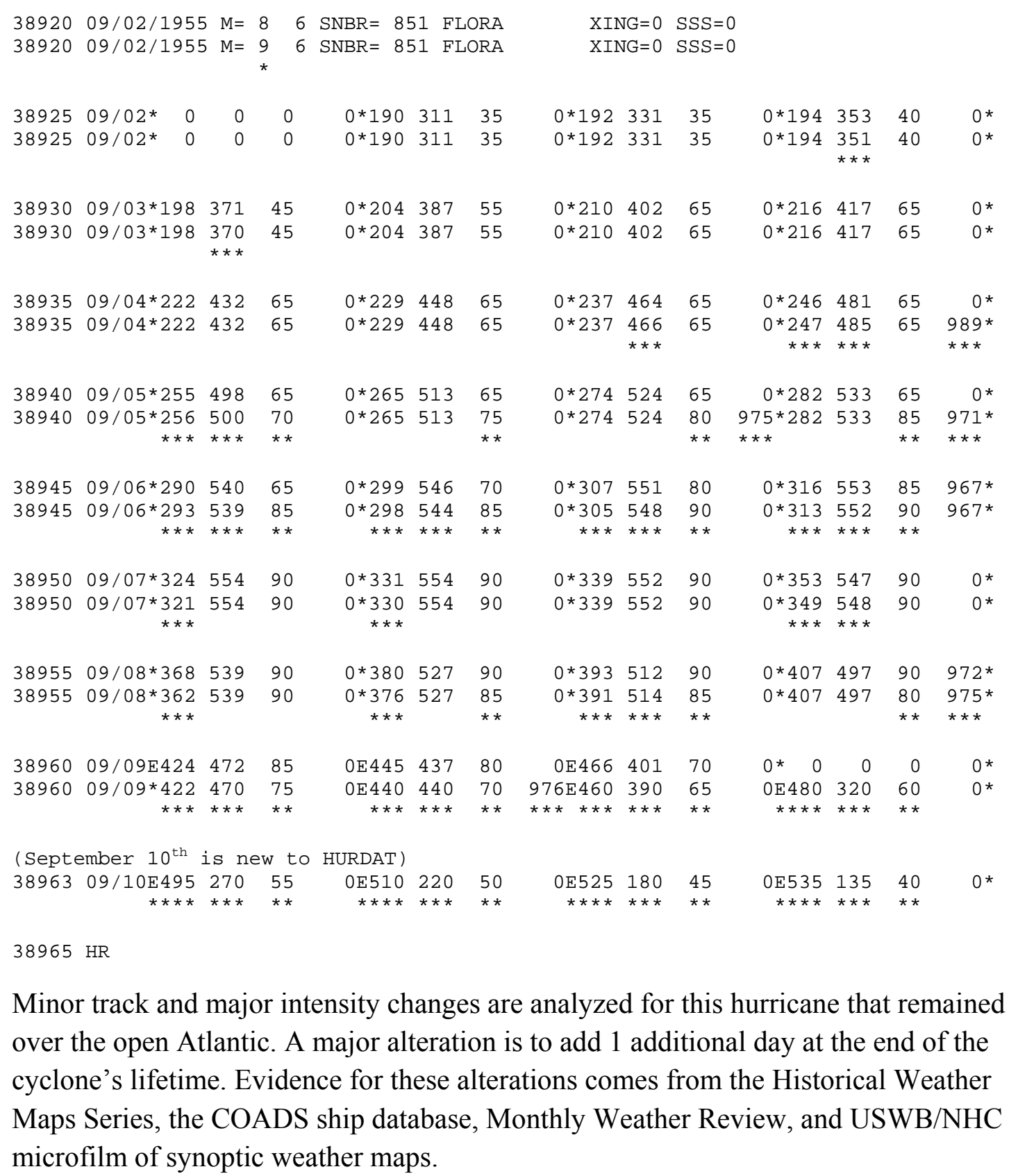

Minor track and major intensity changes are analyzed for this hurricane that remained over the open Atlantic. A major alteration is to add 1 additional day at the end of the cyclone's lifetime. Evidence for these alterations comes from the Historical Weather Maps Series, the COADS ship database, Monthly Weather Review, and USWB/NHC microfilm of synoptic weather maps.

August 30: 
HWM and HURDAT do not analyze an organized system on this date. Microfilm and MWR are not available on this date. Ship highlights: No gales or low pressures. August 31:

HWM and HURDAT do not analyze an organized system on this date. Microfilm and MWR are not available on this date. Ship highlights: No gales or low pressures. September 1:

HWM and HURDAT do not analyze an organized system on this date. Microfilm and MWR are not available on this date. Ship highlights: No gales or low pressures.

September 2:

HWM shows a spot low centered near $14.5 \mathrm{~N}$, $40 \mathrm{~W}$ at $12 \mathrm{Z}$. HURDAT lists this as a 35 knot tropical storm at $19.0 \mathrm{~N}, 31.1 \mathrm{~W}$ at $12 \mathrm{Z}$. Microfilm and MWR are not available on this date. Ship highlights: No gales or low pressures.

September 3:

HWM shows a tropical storm of at most $1010 \mathrm{mb}$ centered near $18.0 \mathrm{~N}, 42.0 \mathrm{~W}$ at 12Z. HURDAT lists this as a 65 knot hurricane at $21.0 \mathrm{~N}, 40.2 \mathrm{~W}$ at $12 \mathrm{Z}$. Microfilm shows a closed low pressure of at most $1008 \mathrm{mb}$ at $21.0 \mathrm{~N}, 40.2 \mathrm{~W}$ at $12 \mathrm{Z}$. MWR is not available on this date. Ship highlights: $55 \mathrm{kt} \mathrm{NE}$ and $1015 \mathrm{mb}$ at $21.9 \mathrm{~N}, 40.5 \mathrm{~W}$ at $12 \mathrm{Z}$, and $50 \mathrm{kt}$ $\mathrm{NE}$ and $1006 \mathrm{mb}$ at 22.3N, 42.0W at 18Z. All observations from micro. "On 31 August the surface reports from the Cape Verde Islands indicated the passage of an easterly wave with a possible vortex. The vortex was extrapolated westward at 12.5 knots on each succeeding surface chart but no reports were received in the vicinity of the disturbance until 3 September when the SS Belmare and the SS Almora reports indicated a small but intense tropical storm near 22N 42W late on 3 September" (ATSR).

September 4:

HWM shows a hurricane of at most $1010 \mathrm{mb}$ centered near $23.2 \mathrm{~N}, 45.1 \mathrm{~W}$ at $12 \mathrm{Z}$. HURDAT lists this as a 65 knot hurricane at $23.7 \mathrm{~N}, 46.4 \mathrm{~W}$ at $12 \mathrm{Z}$. Microfilm shows a closed low pressure of at most $1002 \mathrm{mb}$ at $24.0 \mathrm{~N}, 46.8 \mathrm{~W}$ at $12 \mathrm{Z}$. MWR is not available on this date. Ship highlights: $55 \mathrm{kt} \mathrm{NE}$ and $1008 \mathrm{mb}$ at $22.3 \mathrm{~N}, 42.0 \mathrm{~W}$ at $0 \mathrm{Z} ; 45 \mathrm{kt} \mathrm{S}$ and $1000 \mathrm{mb}$ at $24.7 \mathrm{~N}, 46.0 \mathrm{~W}$ at $12 \mathrm{Z}$, and $45 \mathrm{kt} \mathrm{NNW}$ and $1013 \mathrm{mb}$ at $24.0 \mathrm{~N}, 48.6 \mathrm{~W}$ at $15 \mathrm{Z}$. All observations from micro. Aircraft highlight: Penetration center fix measured a central pressure of $989 \mathrm{mb}$ and an eye of a 20 mile diameter at $24.7 \mathrm{~N}, 48.5 \mathrm{~W}$ at $1810 \mathrm{Z}$ (ATSR/micro). "Aircraft reconnaissance was ordered and Warning Number One on "Hurricane Flora" was issued at 040400Z. Between the $31^{\text {st }}$ of August and detection late 
on the $3^{\text {rd }}$ of September, "Flora" had moved on a course of about 295 degrees at 14 to 16 knots. This movement continued for the next 24 hours" (ATSR).

September 5:

HWM shows a hurricane of at most $1005 \mathrm{mb}$ centered near $27.5 \mathrm{~N}, 52.7 \mathrm{~W}$ at $12 \mathrm{Z}$. HURDAT lists this as a 65 knot hurricane at $27.4 \mathrm{~N}, 52.4 \mathrm{~W}$ at $12 \mathrm{Z}$. Microfilm shows a closed low pressure of at most $996 \mathrm{mb}$ at $27.5 \mathrm{~N}, 52.8 \mathrm{~W}$ at $12 \mathrm{Z}$. MWR is not available on this date. Ship highlights: $45 \mathrm{kt} \mathrm{N}$ and $1004 \mathrm{mb}$ at 29.1N, 54.5W at 21Z, and $35 \mathrm{kt} \mathrm{NNW}$ and $1013 \mathrm{mb}$ at $29.3 \mathrm{~N}, 55.5 \mathrm{~W}$ at $21 \mathrm{Z}$. All observations from micro. Aircraft highlight: Penetration center fix measured a central pressure of $975 \mathrm{mb}$ and an eye of a 40 mile diameter at $27.9 \mathrm{~N}, 53.0 \mathrm{~W}$ at $1430 \mathrm{Z}$ (ATSR/micro). Penetration center fix measured a central pressure of $971 \mathrm{mb}$ and an eye of a 40 mile diameter at $28.2 \mathrm{~N}, 54.2 \mathrm{~W}$ at $2010 \mathrm{Z}$ (ATSR/micro). "Beginning late on 4 September "Flora" began turning to the northwest and decelerating. By 050300Z, "Flora" was moving northwest at 13 knots with maximum winds barely of hurricane force" (ATSR).

September 6:

HWM shows a hurricane of at most $1005 \mathrm{mb}$ centered near $30.7 \mathrm{~N}, 55.5 \mathrm{~W}$ at $12 \mathrm{Z}$. HURDAT lists this as a 80 knot hurricane at $30.7 \mathrm{~N}, 55.1 \mathrm{~W}$ at $12 \mathrm{Z}$. Microfilm shows a closed low pressure of at most $999 \mathrm{mb}$ at $30.8 \mathrm{~N}, 55.0 \mathrm{~W}$ at $12 \mathrm{Z}$. MWR analyses a low pressure of at most $980 \mathrm{mb}$ at $30.5 \mathrm{~N}, 55.2 \mathrm{~W}$ at 12Z. Ship highlights: $50 \mathrm{kt} \mathrm{N}$ and $994 \mathrm{mb}$ at $29.5 \mathrm{~N}, 54.0 \mathrm{~W}$ at $0 \mathrm{Z} ; 60 \mathrm{kt} \mathrm{NNE}$ and $991 \mathrm{mb}$ at $30.0 \mathrm{~N}, 54.5 \mathrm{~W}$ at $0730 \mathrm{Z}$, and $40 \mathrm{kt} \mathrm{SE}$ and $1019 \mathrm{mb}$ at $30.0 \mathrm{~N}, 51.5 \mathrm{~W}$ at $12 \mathrm{Z}$. All observations from micro. Aircraft highlight: Penetration center fix measured a central pressure of $977 \mathrm{mb}$ and an eye of a 30 mile diameter at $29.2 \mathrm{~N}, 54.0 \mathrm{~W}$ at $02 \mathrm{Z}$ (ATSR/micro). Penetration center fix measured an eye of a 30 mile diameter at $28.2 \mathrm{~N}, 54.3 \mathrm{~W}$ at $0230 \mathrm{Z}$ (ATSR/micro). Penetration center fix measured an eye of a 40 mile diameter at $30.1 \mathrm{~N}, 54.9 \mathrm{~W}$ at $0730 \mathrm{Z}$ (ATSR/micro). Penetration center fix measured a central pressure of $967 \mathrm{mb}$ and an eye of a 30 mile diameter at $31.5 \mathrm{~N}, 54.2 \mathrm{~W}$ at $1947 \mathrm{Z}$ (ATSR/micro). "“Flora" remained a very small storm as far as size and maximum wind velocity were concerned. Not until late on the $6^{\text {th }}$ of September did "Flora's" course pass through north and speed decrease to the minimum. At approximately the same time, the maximum wind velocity began to increase as the pressure gradient increased on the eastern side of the hurricane" (ATSR).

September 7:

HWM shows a hurricane of at most $1000 \mathrm{mb}$ centered near $33.9 \mathrm{~N}, 55.2 \mathrm{~W}$ at $12 \mathrm{Z}$. HURDAT lists this as a 90 knot hurricane at $33.9 \mathrm{~N}, 55.2 \mathrm{~W}$ at $12 \mathrm{Z}$. Microfilm shows a closed low pressure of at most $1005 \mathrm{mb}$ at $33.9 \mathrm{~N}, 55.2 \mathrm{~W}$ at $12 \mathrm{Z}$. MWR analyses a low pressure of at most $980 \mathrm{mb}$ at 33.9N, 56.2W at 12Z. Ship highlights: $45 \mathrm{kt}$ SE and 1014 
$\mathrm{mb}$ at $32.0 \mathrm{~N}, 53.0 \mathrm{~W}$ at $12 \mathrm{Z}$, and $40 \mathrm{kt} \mathrm{SW}$ and $1014 \mathrm{mb}$ at $32.0 \mathrm{~N}, 53.8 \mathrm{~W}$ at $18 \mathrm{Z}$. All observations from COADS. Aircraft highlight: Penetration center fix at $33.9 \mathrm{~N}, 55.2 \mathrm{~W}$ at $1230 Z$ (ATSR). Penetration center fix measured an eye of a 40 mile diameter at $34.9 \mathrm{~N}$, 54.8W at $1830 \mathrm{Z}$ (ATSR/micro).

September 8:

HWM shows a hurricane of at most $1000 \mathrm{mb}$ centered near $38.8 \mathrm{~N}, 52.6 \mathrm{~W}$ at $12 \mathrm{Z}$. HURDAT lists this as a 90 knot hurricane at $39.3 \mathrm{~N}, 51.2 \mathrm{~W}$ at $12 \mathrm{Z}$. Microfilm shows a closed low pressure of at most $999 \mathrm{mb}$ at $39.0 \mathrm{~N}, 52.0 \mathrm{~W}$ at $12 \mathrm{Z}$. MWR analyses a low pressure of at most $984 \mathrm{mb}$ at $38.9 \mathrm{~N}, 52.5 \mathrm{~W}$ at 12Z. Ship highlights: $50 \mathrm{kt} \mathrm{S}$ and $993 \mathrm{mb}$ at $36.5 \mathrm{~N}, 51.0 \mathrm{~W}$ at $06 \mathrm{Z}$ (micro), $50 \mathrm{kt} \mathrm{SW}$ and $1001 \mathrm{mb}$ at $36.2 \mathrm{~N}, 51.3 \mathrm{~W}$ at $12 \mathrm{Z}$ (COADS), and $35 \mathrm{kt} \mathrm{S}$ and $1016 \mathrm{mb}$ at $38.7 \mathrm{~N}, 47.0 \mathrm{~W}$ at $18 \mathrm{Z}$ (COADS). Aircraft highlight: Penetration center fix at $40.5 \mathrm{~N}, 50.7 \mathrm{~W}$ at $1650 \mathrm{Z}$ (ATSR). Penetration center fix measured a central pressure of $975 \mathrm{mb}$ and an eye of a 38 mile diameter at $41.0 \mathrm{~N}$, 49.4W at $1930 \mathrm{Z}$ (ATSR/micro).

September 9:

HWM shows a closed low pressure of at most $1005 \mathrm{mb}$ with a cold front going through the cyclone centered near $47.0 \mathrm{~N}, 40.0 \mathrm{~W}$ at $12 \mathrm{Z}$. HURDAT lists this as a $70 \mathrm{knot}$ extratropical cyclone at $46.6 \mathrm{~N}, 40.1 \mathrm{~W}$ (last position) at $12 \mathrm{Z}$. Microfilm shows a closed low pressure of at most $1002 \mathrm{mb}$ at $46.5 \mathrm{~N}, 40.0 \mathrm{~W}$ at $12 \mathrm{Z}$. MWR analyses a low pressure of at most $992 \mathrm{mb}$ at $46.5 \mathrm{~N}, 41.0 \mathrm{~W}$ at 12Z. Ship highlights: $35 \mathrm{kt} \mathrm{SW}$ and $1022 \mathrm{mb}$ at $40.0 \mathrm{~N}, 42.4 \mathrm{~W}$ at $0 \mathrm{Z}$ (micro); $40 \mathrm{kt} \mathrm{S}$ and $1012 \mathrm{mb}$ at $43.6 \mathrm{~N}, 41.7 \mathrm{~W}$ at $06 \mathrm{Z}$ (micro); Queen Eleonor measured a central pressure of $976 \mathrm{mb}$ at $43.7 \mathrm{~N}, 42.5 \mathrm{~W}$ at $0826 \mathrm{Z}$ (micro); 45-55 kt WSW and $1008 \mathrm{mb}$ at 43.5N, 40.9W at 12Z (micro), and $45 \mathrm{kt} \mathrm{SSE}$ and 1002 $\mathrm{mb}$ at $48.2 \mathrm{~N}, 31.4 \mathrm{~W}$ at $18 \mathrm{Z}$ (COADS). "As "Flora" moved to the northeast and later eastnortheast it was overtaken by the cold front resulting in further degeneration and development of extratropical characteristics. "Flora" was completely absorbed by the cold front on the $9^{\text {th }}$ of September and rapidly lost its identity as an extratropical low. The last warning was issued at $091600 \mathrm{Z}$. The last identifiable position was near $48 \mathrm{~N}, 33 \mathrm{~W}$ at $092200 Z$.

September 10:

HWM shows a closed low pressure of at most $1005 \mathrm{mb}$ centered near $52.0 \mathrm{~N}$, $17.0 \mathrm{~W}$ with a warm front to the northeast and a cold front to the south at 12Z. HURDAT does not list an organized system on this date. Microfilm and MWR are not available on this date. Ship highlights: $35 \mathrm{kt} \mathrm{W}$ and $1012 \mathrm{mb}$ at $48.0 \mathrm{~N}, 30.0 \mathrm{~W}$ at $0 \mathrm{Z}$ (COADS); $45 \mathrm{kt}$ SW and $1007 \mathrm{mb}$ at 49.0N, 22.8W at 06Z (COADS), and $35 \mathrm{kt} \mathrm{SW}$ and $1009 \mathrm{mb}$ at $49.8 \mathrm{~N}, 16.4 \mathrm{~W}$ at $12 \mathrm{Z}$ (COADS). 
September 11:

HWM shows a closed low pressure of at most $980 \mathrm{mb}$ centered near $67.0 \mathrm{~N}, 6.0 \mathrm{~W}$ with a warm front to the northeast at 12Z. HURDAT does not list an organized system on this date. Microfilm and HWM are not available on this date. Ship highlights: No gales or low pressures.

MWR: "An unstable easterly wave passed through the Cape Verde Islands during August 30-31. A message was received on the $30^{\text {th }}$ from Panair du Brazil at Recife, Brazil:

Tropical storm evident. Cyclonic circulation aloft to 4000 meters. Center approximately $11^{\circ} \mathrm{N}, 21^{\circ} \mathrm{W}$. Displacement $18 \mathrm{mph}$ WNW. Storm associated with easterly wave along ITC [intertropical convergence zone]. This weak circulation was the genesis of Flora which reached hurricane intensity on September 3 at approximately Latitude $21^{\circ} \mathrm{N}$ and Longitude $40^{\circ} \mathrm{W}$. Hurricane Flora moved on a smooth parabolic path northward through the middle Atlantic, passing some $9^{\circ}$ east of Bermuda on the $6^{\text {th }}$ and early on the $7^{\text {th }}$. The highest wind reported was $104 \mathrm{mph}$ at $1230 \mathrm{EST}$ on the $8^{\text {th }}$ at Latitude $41.0^{\circ} \mathrm{N}$ and Longitude $49.4^{\circ} \mathrm{W}$, with central pressure of $972 \mathrm{mb}$ (28.70 inches). The lowest reported pressure during the storm's history was $967 \mathrm{mb}(28.55$ inches $)$ at $31.5^{\circ} \mathrm{N}$ and $55.3^{\circ} \mathrm{W}$ on the $6^{\text {th }}$."

Genesis for this tropical cyclone remains at $06 \mathrm{Z}$ on the $2^{\text {nd }}$ of September as a $35 \mathrm{kt}$ tropical storm, unchanged from the original HURDAT. Data over the eastern and central Atlantic are very sparse and the exact time of formation cannot be confirmed. The first ship to encounter Flora occurred at $12 \mathrm{Z}$ on the $3^{\text {rd }}$ when Belmare reported $55 \mathrm{kt}$ NE winds and $1015 \mathrm{mb}$. This is the time that Flora reaches hurricane intensity as originally shown in HURDAT and our reanalysis concurs with this assessment. The first airplane reconnaissance reached Flora at $1810 \mathrm{Z}$ on the $4^{\text {th }}$ measuring a central pressure of $989 \mathrm{mb}$ and an eye diameter of 20 miles. This allows computing an RMW of about $15 \mathrm{~nm}$ and climatology suggests an RMW of $20 \mathrm{~nm}$. A central pressure of $989 \mathrm{mb}$ yields $65 \mathrm{kt}$ according to Brown et al. southern pressure-wind relationship and $61 \mathrm{kt}$ in the northern. Thus, an intensity of $65 \mathrm{kt}$ is analyzed at 18Z, which agrees with HURDAT original assessment and the surface winds estimated by the reconnaissance mission. A central pressure of $989 \mathrm{mb}$ has been added at $18 \mathrm{Z}$ on the $4^{\text {th }}$. On the $5^{\text {th }}$, reconnaissance aircraft reported a central pressure of $975 \mathrm{mb}$ at $1430 \mathrm{Z}$ and $971 \mathrm{mb}$ at 2010Z. A central pressure of $975 \mathrm{mb}$ yields $79 \mathrm{kt}$ north of $25 \mathrm{~N}$ and $82 \mathrm{kt}$ north of $25 \mathrm{~N}$ in the intensifying subset of the pressure-wind relationships. An intensity of $80 \mathrm{kt}$ has been selected for $12 \mathrm{Z}$ on the $5^{\text {th }}$, up from $65 \mathrm{kt}$ originally in HURDAT. A central pressure of $975 \mathrm{mb}$ has been added to $12 \mathrm{Z}$ on the $5^{\text {th }}$. A central pressure of $971 \mathrm{mb}$ yields $83 \mathrm{kt}$ north of $25 \mathrm{~N}$ and $87 \mathrm{kt}$ north of $25 \mathrm{~N}$ in the intensifying subset of the pressure-wind relationships. This mission also measured an eye diameter of 40 miles, which allows computing an RMW of about 30 
$\mathrm{nm}$, somewhat larger than climatology at $22 \mathrm{~nm}$. The hurricane was also moving at about $16 \mathrm{kt}$, a fairly rapid rate. Therefore, an intensity of $85 \mathrm{kt}$ has been selected for $18 \mathrm{Z}$ on the $4^{\text {th }}$ and a central pressure of $971 \mathrm{mb}$ has been added to this time. Major changes are analyzed at $18 \mathrm{Z}$ on the $5^{\text {th }}$ and $00 \mathrm{Z}$ on the $6^{\text {th }}$ as HURDAT originally showed $65 \mathrm{kt}$, while $85 \mathrm{kt}$ have been selected for the aforementioned times. The highest maximum winds reported by ships on the $5^{\text {th }}$ were $45 \mathrm{kt}$ at $21 \mathrm{Z}$ and on the $6^{\text {th }}$ were $60 \mathrm{kt}$ at $0730 \mathrm{Z}$.

Another aircraft reconnaissance mission measured $977 \mathrm{mb}$ on the $6^{\text {th }}$ at $02 \mathrm{Z}$ but this information is believed to be unreliable as it is not supported by previous and subsequent drops. A cause for the anomaly could be that the drop was made at $500 \mathrm{mb}$, compared to the $700 \mathrm{mb}$ level for the other drops, with the dropsonde likely landing in the eyewall and not the eye. Therefore, this data was not used on the reanalysis. At $1947 \mathrm{Z}$ on the $6^{\text {th }}$, a central pressure of $967 \mathrm{mb}$ was measured by a reconnaissance aircraft. This report also indicated an eye diameter of 30 miles, which allows computing an RMW of about 20-25 $\mathrm{nm}$ versus a climatology of $25 \mathrm{~nm}$. A central pressure of $967 \mathrm{mb}$ yields $88 \mathrm{kt}$ north of $25 \mathrm{~N}$ and $92 \mathrm{kt}$ north of $25 \mathrm{~N}$ and intensifying, according to the pressure-wind relationships. Hence, an intensity of $90 \mathrm{kt}$ has been selected for $18 \mathrm{Z}$ on the $6^{\text {th }} .90 \mathrm{kt}$ is also the peak intensity for the lifetime of Flora, which is unchanged from that originally shown in HURDAT. No change in intensity is analyzed to have occurred between $12 \mathrm{Z}$ on the $6^{\text {th }}$ to $00 \mathrm{Z}$ on the $8^{\text {th }}$. The next reconnaissance aircraft to measure a central pressure was at $1930 \mathrm{Z}$ on the $8^{\text {th }}$ measuring $975 \mathrm{mb}$. A central pressure of $975 \mathrm{mb}$ yields $78 \mathrm{kt}$ north of $35 \mathrm{~N}$ according to the Landsea et al. pressure-wind relationship. The aircraft also reported an eye diameter of 38 miles, which allows computing an RMW of about $30 \mathrm{~nm}$ while climatology gives $34 \mathrm{~nm}$. Thus, an intensity of $80 \mathrm{kt}$ is selected for $18 \mathrm{Z}$ on the $8^{\text {th }}$, down from $90 \mathrm{kt}$ as originally shown in HURDAT. $85 \mathrm{kt}$ was selected for $06 \mathrm{Z}$ and 12Z on the $8^{\text {th }}$, down from $90 \mathrm{kt}$ originally in HURDAT. A few ships reported gale-force winds on the $8^{\text {th }}$, including $60 \mathrm{kt}$ measured at $12 \mathrm{Z}$. On the $9^{\text {th }}$, Flora started to rapidly accelerate to the northeast while losing its tropical characteristics. Extratropical transition was originally shown in HURDAT to have occurred at $00 \mathrm{Z}$ on the $9^{\text {th }}$ but the data suggests that the cold front was still to the northwest of the cyclone. By 06Z, Flora was already part of the frontal system and transition to an extratropical cyclone is analyzed to have occurred at this time, six hours later than shown in HURDAT. Early on the $9^{\text {th }}$, the ship Queen Eleanor passed through the center of Flora measuring a central pressure of $976 \mathrm{mb}$ at $0826 \mathrm{Z}$. A central pressure of $976 \mathrm{mb}$ has been added to $06 \mathrm{Z}$ on the $9^{\text {th }}$. The last position originally on HURDAT is at $12 \mathrm{Z}$ on the $9^{\text {th }}$ possibly indicating that Flora had been absorbed by a larger extratropical system. Nevertheless, data suggests that Flora continued moving northeast and later, east-northeast, towards the northeast Atlantic. The extratropical cyclone gradually weakened and dissipated after $18 \mathrm{Z}$ on the $10^{\text {th }}$. Adding 30 hours to the lifetime of Flora is a major change to HURDAT. 
Tropical Storm Gladys [September 2-6, 1955]

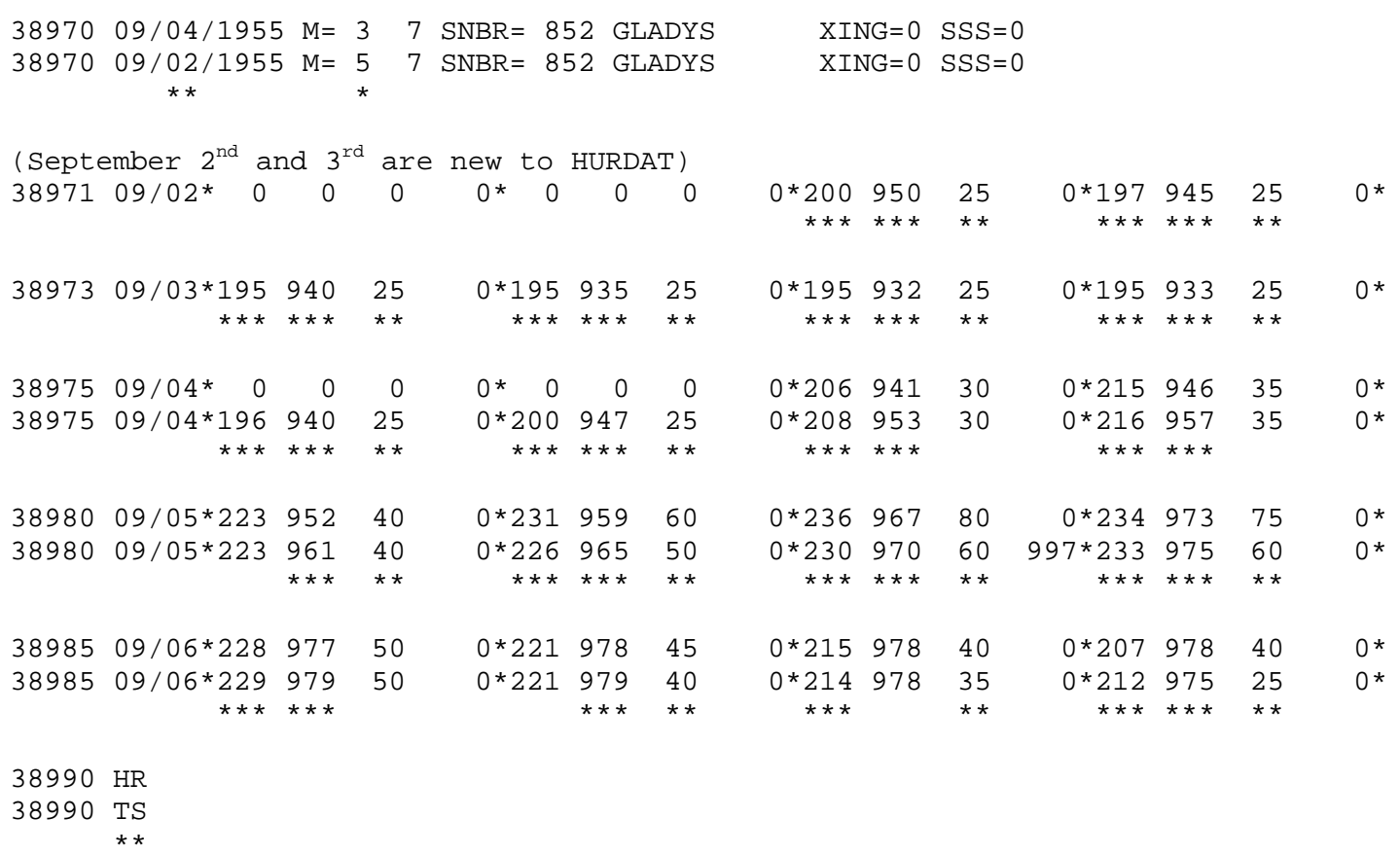

Minor alterations are introduced to the track and major changes to the intensity shown in McAdie et al. (2009). Additionally, two days have been added to the lifetime of this cyclone. Evidence for these alterations comes from the NHC microfilm maps, the Historical Weather Maps series, the COADS ship database, Monthly Weather Review, Mexican synoptic maps and the Navy aircraft reconnaissance book.

September 2:

HWM shows a closed low pressure of at most $1005 \mathrm{mb}$ centered near 20.0N, $96.0 \mathrm{~W}$ at 12Z. HURDAT does not list an organized system on this date. Microfilm shows a closed low pressure of at most $1005 \mathrm{mb}$ at $21.0 \mathrm{~N}, 94.0 \mathrm{~W}$ at $12 \mathrm{Z}$. MWR is not available on this date. Ship highlights: No low pressures or gales. "As early as 27 August a weak vortex with an associated easterly trough was detected while located just west of Balboa, Canal Zone. The vortex was tracked as it progressed slowly westward along with the associated upper trough at $700 \mathrm{mb}$ and $500 \mathrm{mb}$. By 1 September, the disturbance was still not unduly suspicious but was centered over the Gulf of Campeche whose warm waters are most productive of tropical storms. The upper trough was reflected on the surface and extended northeastward into a quasi-stationary frontal area. During the next three days it was not apparent that any appreciable intensification had taken place but it was evident that the vortex was slowly drifting northward" (ATSR). 
September 3:

HWM shows a closed low pressure of at most $1005 \mathrm{mb}$ centered near $20.5 \mathrm{~N}$, $92.5 \mathrm{~W}$ at $12 \mathrm{Z}$. HURDAT does not list an organized system on this date. Microfilm shows an elongated closed low pressure of at most $1008 \mathrm{mb}$ near $20.5 \mathrm{~N}, 93.5 \mathrm{~W}$ at $12 \mathrm{Z}$. MWR is not available on this date. Ship highlights: No low pressures or gales. Land highlights: 5 $\mathrm{kt} \mathrm{N}$ and $1005 \mathrm{mb}$ at Ciudad del Carmen at 0Z (micro), and $5 \mathrm{kt} \mathrm{NE}$ and $1005 \mathrm{mb}$ at Coatzacoalcos at $0 \mathrm{Z}$ (micro).

September 4:

HWM shows a closed low pressure of at most $1005 \mathrm{mb}$ centered near $22.1 \mathrm{~N}$, $95.5 \mathrm{~W}$ at $12 \mathrm{Z}$. HURDAT lists a $30 \mathrm{kt}$ tropical depression near $20.8 \mathrm{~N}, 95.3 \mathrm{~W}$ at $12 \mathrm{Z}$. Microfilm shows a closed low pressure of at most $1005 \mathrm{mb}$ near $22.0 \mathrm{~N}, 95.5 \mathrm{~W}$ at $12 \mathrm{Z}$. MWR shows a low pressure of $1004 \mathrm{mb}$ at $21.0 \mathrm{~N}, 95.0 \mathrm{~W}$ at 12Z. Ship highlights: $5 \mathrm{kt} \mathrm{W}$ and $1005 \mathrm{mb}$ at $19.0 \mathrm{~N}, 91.9 \mathrm{~W}$ at $0 \mathrm{Z}$ (micro), and $25 \mathrm{kt} \mathrm{NNW}$ and $1003 \mathrm{mb}$ at $23.1 \mathrm{~N}$, $97.5 \mathrm{~W}$ at $21 \mathrm{Z}$ (micro). Land highlights: $10 \mathrm{kt} \mathrm{N}$ and $1004 \mathrm{mb}$ at Veracruz at $0 \mathrm{Z}$ (micro). "Beginning on the $4^{\text {th }}$ of September, ships in the Western Gulf of Mexico began reporting squally weather with surface winds of 20 to 30 knots. These reports, as were the land station reports, were at some distance from the center of the tropical disturbance. It was decided to send an investigative flight into the Western Gulf to locate the center of the disturbance. In the meantime, an unnumbered tropical depression warning was issued at $042100 Z$ with an estimated position of the center" (ATSR).

September 5:

HWM shows a tropical storm of at most $1005 \mathrm{mb}$ centered near $23.5 \mathrm{~N}, 96.3 \mathrm{~W}$ at 12Z. HURDAT lists an $80 \mathrm{kt}$ hurricane near 23.6N, 96.7W at 12Z. Microfilm shows a closed low pressure of at most $1002 \mathrm{mb}$ near $23.5 \mathrm{~N}, 96.8 \mathrm{~W}$ at $12 \mathrm{Z}$. MWR shows a low pressure of $1006 \mathrm{mb}$ at $23.3 \mathrm{~N}, 96.8 \mathrm{~W}$ at 12Z. Ship highlights: $25 \mathrm{kt} \mathrm{N}$ and $1003 \mathrm{mb}$ at 23.3N, 97.2W at $0 \mathrm{Z}$ (micro), and $35 \mathrm{kt} \mathrm{N}$ and $1011 \mathrm{mb}$ at $25.2 \mathrm{~N}, 96.5 \mathrm{~W}$ at $06 \mathrm{Z}$ (micro). Aircraft highlights: Penetration center fix measured a central pressure of $997 \mathrm{mb}$ and an eye of a 20 mile diameter at $23.1 \mathrm{~N}, 97.1 \mathrm{~W}$ at $1403 \mathrm{Z}$ (ATSR/micro), and penetration center fix at $23.3 \mathrm{M}, 97.3 \mathrm{~W}$ at $1615 \mathrm{Z}$ (ATSR). "Navy reconnaissance aircraft on the $5^{\text {th }}$ found a poorly defined eye, visually and by radar. A center fix was made on the surface wind circulation. The maximum wind velocity was reported as 80 knots near the center and minimum central pressure of $996 \mathrm{mb}$. "Gladys" was thus typical of most of the storms forming in the Gulf which have poorly defined eyes, relatively high central pressures, yet at times have strong winds over a small area. The four aircraft fixes reported on the morning of the $5^{\text {th }}$ showed the hurricane to be on a west-northwest to 
northwest course moving at about 8 knots. The last reconnaissance fix placed the center at $23.5 \mathrm{~N}, 97.4 \mathrm{~W}$ only 20 miles off the coast of Mexico" (ATSR).

September 6:

HWM shows a tropical storm of at most $1005 \mathrm{mb}$ centered near $21.5 \mathrm{~N}, 97.5 \mathrm{~W}$ at 12Z. HURDAT lists an $40 \mathrm{kt}$ tropical storm near $21.5 \mathrm{~N}, 97.8 \mathrm{~W}$ at $12 \mathrm{Z}$. Microfilm shows a spot low near $24.5 \mathrm{~N}, 96.2 \mathrm{~W}$ at $12 \mathrm{Z}$. MWR shows a low pressure of $1006 \mathrm{mb}$ at $24.7 \mathrm{~N}$, 97.8W at 12Z. Ship highlights: No gales or low pressures. Land highlights: $42 \mathrm{kt} \mathrm{NW}$ at Tampico (no time given but likely early on the $6^{\text {th }}$ ) (MWR), and $20 \mathrm{kt} \mathrm{ENE}$ and $1001 \mathrm{mb}$ at Tampico at $06 \mathrm{Z}$ (micro). "On the $4^{\text {th }}$ and $5^{\text {th }}$, a trough in the westerlies, extending from the Great Lakes region into Northern Texas, was almost stationary. The trough in the easterlies associated with "Gladys" was moving slowly westward and also extended from the surface through $500 \mathrm{mb}$. Between 050300Z and 060300Z, the westward movement of "Gladys" trough was arrested by the westerly trough and it began an oscillation westward and eastward all the while oriented north-south along the Texas and Mexican Gulf Coast. The two troughs met and merged in northeastern Texas resulting in heavy rain and extremely squally weather along the trough axis. "Gladys" weakened rapidly and filled when the troughs merged. The filling took place near Tampico, Mexico, and by $061830 \mathrm{Z}$ all that remained of "Gladys" was a large flat low centered east of Tampico. The final regular numbered warning of "Hurricane Gladys" was issued at 061000Z. The storm had filled rapidly and lost force almost as suddenly as it had developed. Degeneration had come as a result of the westerly trough and passage over land" (ATSR).

September 7:

HWM, HURDAT and Microfilm does not show an organized system on this date. MWR shows a low pressure of $1010 \mathrm{mb}$ at 27.4N, 96.5W at 12Z. Ship highlights: No gales or low pressures.

MWR: "This tropical storm formed in the Gulf of Campeche and moved first northwestward and later southward entering the coast of Mexico north of Tampico. Highest wind reported from Tampico was $48 \mathrm{mph}$ from the northwest but higher winds may have occurred along the coast to the north of Tampico. The lowest pressure reported by reconnaissance was $997 \mathrm{mb}(29.44 \mathrm{mb})$. Winds of $81 \mathrm{mph}$ were reported by the reconnaissance plane on one occasion and also by a civilian plane on the same date, and therefore, Gladys has been classified as of hurricane intensity. There was a fairly report of 25 inches of rain in 3 days at Tampico beginning the sequence of hurricane-associated rains which culminated in the Tampico disaster. Meager reports indicate some deaths and damage along the Mexican coast. At the same time an area of heavy squalls developed off the middle Texas coast on September 5 and moved inland on the $6^{\text {th }}$. Highest winds 
reported were $45 \mathrm{mph}$ in the Corpus Christi-Port O'Connor area, and an oil rig 15 miles east of Port Aransas, Tex., reported gusts of 55 to $65 \mathrm{mph}$. The Naval Air Station at Corpus Christi received 12.23 inches of rain in 24 hours and a high tide of 4.5 feet was reported in the Bay. Damage was estimated at $\$ 500,000$ in the Corpus Christi area. It is reported that radar observations during this period indicated briefly the presence of a cyclonic circulation, consequently this may have been a separate tropical storm."

Genesis is originally begun at $12 \mathrm{Z}$ on September $4^{\text {th }}$ as a $30 \mathrm{kt}$ tropical depression. Observations from land stations and ships in the Bay of Campeche suggest that a welldefined low pressure center was present as early as the $2^{\text {nd }}$. Therefore, the cyclone is begun as a $25 \mathrm{kt}$ tropical depression at $12 \mathrm{Z}$ on September $2^{\text {nd }}$. This is a major change to HURDAT. In the next 24 hours, the depression slowly moved to the east, indicated by a drop in the barometric pressures in the land stations along the southeast Bay of Campeche. Late on the $3^{\text {rd }}$, the cyclone began to move to the west. The highest surface winds on September $2^{\text {nd }}$ and $3^{\text {rd }}$ were $25 \mathrm{kt}$ on from a ship located at $22.5 \mathrm{~N}, 93.2 \mathrm{~W}$ at $18 \mathrm{Z}$ on the $3^{\text {rd }}$. Based on this, the intensity is kept at $25 \mathrm{kt}$ from September $2^{\text {nd }}$ at $12 \mathrm{Z}$ to the $4^{\text {th }}$ at $6 \mathrm{Z}$. Although no gales were reported on this date by ships or land stations, the system was getting better organized structurally and a barometric pressure of $1003 \mathrm{mb}$ was reported by a ship at $21 \mathrm{Z}$ on the $4^{\text {th }} .1003 \mathrm{mb}$ peripheral pressure suggests maximum winds of at least $41 \mathrm{kt}$ from the Brown et al. pressure-wind relationship. Intensification to a tropical storm is thus retained at $18 \mathrm{Z}$ on the $4^{\text {th }}$ as shown in HURDAT. Gladys turned to the northwest on the $4^{\text {th }}$ and continued this general motion on the $5^{\text {th }}$. The first gale associated with the cyclone is reported at $6 \mathrm{Z}$ on the $5^{\text {th }}$ as a ship reported $35 \mathrm{kt} \mathrm{N}$ and $1011 \mathrm{mb}$ at $25.2 \mathrm{~N}, 96.5 \mathrm{~W}$. Later on the $5^{\text {th }}$, a single aircraft reconnaissance mission into this storm measured an RMW of about $15 \mathrm{~nm}$ and a $997 \mathrm{mb}$ central pressure at 1403Z, which suggests maximum winds of $53 \mathrm{kt}$ south of $25 \mathrm{~N}$ Brown et al. Given the small size of the cyclone and providing a small weighting on the visual estimate of $80 \mathrm{kt}$, intensity is analyzed to be $60 \mathrm{kt}$ at $12 \mathrm{Z}$ and $18 \mathrm{Z}$ on the $5^{\text {th }}$. This intensity is also the peak for the tropical storm, which previously was $80 \mathrm{kt}$, a major change to HURDAT. No further inner core observations were available until after landfall later that day in Tamaulipas, Mexico. Landfall is analyzed to have occurred around $22 \mathrm{Z}$ on the $5^{\text {th }}$ near $23.1 \mathrm{~N} 97.8 \mathrm{~W}$, north of Tampico with an intensity of $60 \mathrm{kt}$. HURDAT originally had Gladys making landfall around $05 \mathrm{Z}$ on the $6^{\text {th }}$ as a weakening tropical storm.

Late on the $5^{\text {th }}$, Gladys turned to the southwest causing the center to move inland. On the $6^{\text {th }}$, the system moved generally to the south passing close or over Tampico around $06 \mathrm{Z}$. Microfilm at this time shows a barometric pressure of $1001 \mathrm{mb}$ being reported by Tampico. MWR also reports that the city reported maximum winds of $42 \mathrm{kt}$ at an unknown time on September $6^{\text {th }}$, but it is likely that these winds occurred early in the day. HURDAT originally kept the system moving south inland and the last point at $18 \mathrm{Z}$ on the 
$6^{\text {th }}$ had an intensity of $40 \mathrm{kt}$. Weakening to a tropical depression is now shown at $18 \mathrm{Z}$ on the $6^{\text {th }}$ with dissipation shortly afterwards.

Hurricane Ione [September 10-25, 1955]

\begin{tabular}{|c|c|c|c|c|c|c|c|c|c|c|c|c|c|}
\hline \multirow{3}{*}{$\begin{array}{l}39060 \\
39060 \\
39065\end{array}$} & \multirow{2}{*}{$\begin{array}{l}09 / 10 / 1955 \\
09 / 10 / 1955\end{array}$} & \multirow{2}{*}{\multicolumn{2}{|c|}{$\begin{array}{r}M=15 \\
M=16 \\
* *\end{array}$}} & \multirow{2}{*}{\multicolumn{3}{|c|}{$\begin{array}{ll}\text { SNBR }=854 & \text { IONE } \\
\text { SNBR }=854 & \text { IONE }\end{array}$}} & \multicolumn{2}{|c|}{$X I N G=1$} & \multicolumn{5}{|c|}{$S S S=3$} \\
\hline & & & & & & & XII & $N G=1$ & SSS $=$ & & & & \\
\hline & $09 / 10 *$ & $\odot$ & 0 & ๑*154 & 432 & 25 & ๑*154 & 442 & 35 & 0*154 & 454 & 35 & ○* \\
\hline 39065 & $09 / 10 *$ & $\odot$ & $\odot$ & $0^{*} 128$ & $\begin{array}{l}405 \\
* * *\end{array}$ & 25 & $\begin{array}{r}0 * 130 \\
* * *\end{array}$ & $\begin{array}{l}420 \\
* * *\end{array}$ & 35 & $\begin{array}{r}0 * 132 \\
\star * *\end{array}$ & $\begin{array}{l}435 \\
* * *\end{array}$ & 35 & $\odot$ * \\
\hline 9070 & $09 / 11 * 153$ & 467 & 35 & ๑*153 & 480 & 35 & 0*152 & 493 & 35 & $0 * 149$ & 505 & 35 & $\odot^{*}$ \\
\hline $3907 \odot$ & $\begin{array}{r}09 / 11 * 133 \\
* * *\end{array}$ & $\begin{array}{l}450 \\
\star * *\end{array}$ & 35 & $\begin{array}{r}0 * 134 \\
\star * *\end{array}$ & $\begin{array}{l}465 \\
\star * *\end{array}$ & 35 & $\begin{array}{r}0 * 135 \\
* * *\end{array}$ & $\begin{array}{l}480 \\
* * *\end{array}$ & 35 & $\begin{array}{c}0 * 135 \\
* * *\end{array}$ & $\begin{array}{l}496 \\
* * *\end{array}$ & 35 & $\odot$ * \\
\hline 39075 & $09 / 12 * 147$ & 517 & 35 & $0 * 144$ & 529 & 35 & $0 * 142$ & 541 & 35 & $0 * 144$ & 553 & 40 & $1008^{*}$ \\
\hline 39075 & $\begin{array}{r}09 / 12 * 136 \\
* * *\end{array}$ & $\begin{array}{l}513 \\
* * *\end{array}$ & 35 & $\begin{array}{r}0 * 137 \\
\star * *\end{array}$ & $\begin{array}{l}530 \\
* * *\end{array}$ & 35 & $\begin{array}{r}0 * 138 \\
* * *\end{array}$ & $\begin{array}{l}545 \\
* * *\end{array}$ & 35 & $\begin{array}{c}0 * 140 \\
\star \star *\end{array}$ & $\begin{array}{l}558 \\
* * *\end{array}$ & $\begin{array}{l}35 \\
* *\end{array}$ & $\begin{array}{l}1007 * \\
* * * *\end{array}$ \\
\hline 39080 & $09 / 13 * 150$ & 565 & 40 & $0 * 157$ & 575 & 40 & $0 * 164$ & 582 & 45 & $0 * 169$ & 588 & 45 & $\Theta^{*}$ \\
\hline 39080 & $\begin{array}{r}09 / 13 * 144 \\
* * *\end{array}$ & $\begin{array}{l}569 \\
* * *\end{array}$ & $\begin{array}{l}35 \\
* *\end{array}$ & $\begin{array}{r}0 * 149 \\
\star * *\end{array}$ & $\begin{array}{l}580 \\
* * *\end{array}$ & $\begin{array}{l}35 \\
* *\end{array}$ & $\begin{array}{r}0 * 155 \\
* * *\end{array}$ & $\begin{array}{l}588 \\
* * *\end{array}$ & $\begin{array}{l}35 \\
* *\end{array}$ & $\begin{array}{r}0 * 161 \\
* * *\end{array}$ & $\begin{array}{l}593 \\
* * *\end{array}$ & $\begin{array}{l}40 \\
* *\end{array}$ & $\odot$ * \\
\hline 39085 & $09 / 14 * 174$ & 593 & 50 & $\odot * 177$ & 597 & 55 & $0 * 180$ & 602 & 60 & $0 * 185$ & 612 & 60 & $\odot$ * \\
\hline 39085 & $\begin{array}{r}09 / 14 * 167 \\
* * *\end{array}$ & $\begin{array}{l}597 \\
* * *\end{array}$ & $\begin{array}{l}45 \\
\star *\end{array}$ & $\begin{array}{r}0 * 173 \\
\star * *\end{array}$ & $\begin{array}{l}601 \\
* * *\end{array}$ & $\begin{array}{l}45 \\
\star *\end{array}$ & $\begin{array}{r}\odot * 179 \\
* * *\end{array}$ & $\begin{array}{l}606 \\
* * *\end{array}$ & $\begin{array}{l}50 \\
* *\end{array}$ & $\begin{array}{l}1001 * 185 \\
\star * * *\end{array}$ & $\begin{array}{l}614 \\
* * *\end{array}$ & $\begin{array}{l}55 \\
* *\end{array}$ & $\begin{array}{l}1000^{*} \\
* * * *\end{array}$ \\
\hline 39090 & $09 / 15 * 193$ & 623 & 65 & $0 * 207$ & 628 & 65 & $\Theta * 221$ & 633 & 70 & $990 * 229$ & 652 & 70 & ०* \\
\hline $39 \odot 9 \odot$ & $09 / 15 * 193$ & 623 & $\begin{array}{l}60 \\
\star *\end{array}$ & $\begin{array}{r}0 * 206 \\
\star \star \star\end{array}$ & $\begin{array}{l}633 \\
* * *\end{array}$ & 65 & $\begin{array}{r}\odot * 219 \\
* \star *\end{array}$ & $\begin{array}{l}644 \\
* * *\end{array}$ & 70 & $\begin{array}{r}990 * 228 \\
* \star *\end{array}$ & $\begin{array}{l}656 \\
* * *\end{array}$ & 70 & ○* \\
\hline 39095 & $09 / 16 * 234$ & 671 & 75 & $0 * 238$ & 681 & 75 & $\Theta * 242$ & 691 & 80 & $990 * 247$ & 704 & 85 & ०* \\
\hline 39095 & $\begin{array}{r}09 / 16 * 233 \\
* \star *\end{array}$ & $\begin{array}{l}670 \\
\star * *\end{array}$ & 75 & $\begin{array}{r}0 * 237 \\
* * *\end{array}$ & $\begin{array}{l}683 \\
* * *\end{array}$ & 75 & $\begin{array}{r}\Theta * 241 \\
* * *\end{array}$ & $\begin{array}{l}693 \\
* * *\end{array}$ & 80 & $\begin{array}{l}985 * 246 \\
\star * * * * *\end{array}$ & $\begin{array}{l}702 \\
\star * *\end{array}$ & 85 & ○* \\
\hline $3910 \odot$ & $09 / 17 * 252$ & 714 & $9 \odot$ & $\odot * 258$ & 720 & 95 & $\odot * 265$ & 727 & $10 \odot$ & $950 * 273$ & 733 & $10 \odot$ & $938^{*}$ \\
\hline $3910 \odot$ & $\begin{array}{r}09 / 17^{*} \underset{* \star *}{251} \\
\end{array}$ & $\begin{array}{l}711 \\
\star \star *\end{array}$ & $9 \odot$ & $\begin{array}{r}\Theta * 257 \\
\star \star *\end{array}$ & $\begin{array}{l}719 \\
\star * *\end{array}$ & $\begin{array}{l}90 \\
* *\end{array}$ & $\begin{array}{l}971 * 263 \\
\star \star \star * \star * *\end{array}$ & $\begin{array}{l}725 \\
* * *\end{array}$ & $\begin{array}{l}105 \\
\star * *\end{array}$ & $\begin{array}{r}950 * 270 \\
* \star *\end{array}$ & $\begin{array}{l}732 \\
\star * *\end{array}$ & $\begin{array}{l}120 \\
\star * *\end{array}$ & 938 * \\
\hline 39105 & $09 / 18$ *281 & 740 & $10 \odot$ & ๑*289 & 747 & 105 & ๑*298 & 753 & $10 \odot$ & $940 * 312$ & 758 & $10 \odot$ & $\odot^{*}$ \\
\hline 39105 & $\begin{array}{r}09 / 18 * 279 \\
\star \star *\end{array}$ & 740 & $\begin{array}{l}120 \\
\star * *\end{array}$ & $\begin{array}{r}\Theta * 288 \\
\star * *\end{array}$ & 747 & $\begin{array}{l}115 \\
* * *\end{array}$ & $\odot * 298$ & 753 & $\begin{array}{l}110 \\
\star * *\end{array}$ & $\begin{array}{l}943 * 312 \\
\star * *\end{array}$ & 758 & $\begin{array}{l}105 \\
* * *\end{array}$ & $\odot^{*}$ \\
\hline 39110 & $09 / 19 * 328$ & 762 & $10 \odot$ & ๑*339 & 766 & $9 \odot$ & $\odot * 348$ & 767 & 65 & $960 * 356$ & 765 & 60 & $\Theta^{*}$ \\
\hline 39110 & $\begin{array}{r}09 / 19 * 326 \\
* * *\end{array}$ & $\begin{array}{l}761 \\
* * *\end{array}$ & 100 & $\begin{array}{r}0 * 337 \\
* * *\end{array}$ & $\begin{array}{l}765 \\
* * *\end{array}$ & $\begin{array}{l}95 \\
* *\end{array}$ & $\odot * 348$ & $\begin{array}{l}770 \\
* * *\end{array}$ & $\begin{array}{l}90 \\
* *\end{array}$ & $\begin{array}{r}960 * 355 \\
* * *\end{array}$ & $\begin{array}{l}767 \\
* * *\end{array}$ & $\begin{array}{l}80 \\
* *\end{array}$ & ๑* \\
\hline 39115 & $09 / 20 * 364$ & 754 & 60 & ๑*367 & 745 & 65 & $\odot * 370$ & 734 & 90 & ๑*378 & 711 & 85 & $982 *$ \\
\hline 39115 & $\begin{array}{r}09 / 20 * 362 \\
\star \star \star *\end{array}$ & $\begin{array}{l}763 \\
\star * *\end{array}$ & $\begin{array}{l}70 \\
* *\end{array}$ & $\begin{array}{l}976 * 366 \\
\star * * * * *\end{array}$ & $\begin{array}{l}757 \\
* * *\end{array}$ & 65 & $\begin{array}{r}0 * 371 \\
* * *\end{array}$ & $\begin{array}{l}742 \\
* * *\end{array}$ & $\begin{array}{l}70 \\
* *\end{array}$ & $\begin{array}{r}\Theta * 380 \\
\star * \star\end{array}$ & $\begin{array}{l}720 \\
\star * *\end{array}$ & $\begin{array}{l}75 \\
* *\end{array}$ & $982 *$ \\
\hline 39120 & $09 / 21$ * 394 & 678 & 75 & OE423 & 625 & 60 & OE45० & 594 & 50 & OE467 & 574 & 45 & ○* \\
\hline 39120 & $\begin{array}{r}09 / 21 * 393 \\
\star \star \star *\end{array}$ & $\begin{array}{l}683 \\
\star * *\end{array}$ & $\begin{array}{l}80 \\
* *\end{array}$ & $\begin{array}{l}976 \mathrm{E} 415 \\
\star * \star * \star *\end{array}$ & $\begin{array}{l}640 \\
* * *\end{array}$ & $\begin{array}{l}80 \\
* *\end{array}$ & ๑E45० & 594 & $\begin{array}{l}75 \\
* *\end{array}$ & $\begin{array}{r}\mathrm{OE} 485 \\
\star * \star\end{array}$ & $\begin{array}{l}550 \\
\star * *\end{array}$ & $\begin{array}{l}75 \\
* *\end{array}$ & ○* \\
\hline 39125 & 09/22E484 & 558 & 45 & OE501 & 547 & 45 & OE518 & 530 & 45 & OE531 & 499 & 45 & ○* \\
\hline 39125 & $\begin{array}{r}09 / 22 \mathrm{E} 503 \\
* * *\end{array}$ & $\begin{array}{l}545 \\
* * *\end{array}$ & $\begin{array}{l}70 \\
* *\end{array}$ & $\begin{array}{r}0 \mathrm{E} 507 \\
* * *\end{array}$ & $\begin{array}{l}545 \\
\star * *\end{array}$ & $\begin{array}{l}70 \\
* *\end{array}$ & $\begin{array}{r}\text { OE510 } \\
* \star \star\end{array}$ & $\begin{array}{l}538 \\
* * *\end{array}$ & $\begin{array}{l}65 \\
* *\end{array}$ & $\begin{array}{r}\text { OE525 } \\
* * *\end{array}$ & $\begin{array}{l}510 \\
* * *\end{array}$ & $\begin{array}{l}65 \\
* *\end{array}$ & $0^{*}$ \\
\hline
\end{tabular}




\begin{tabular}{|c|c|c|c|c|c|c|c|c|c|c|c|c|c|}
\hline 39130 & ๑9/23E534 & 468 & 45 & OE533 & 437 & 45 & OE531 & 406 & 45 & OE546 & 350 & 45 & ○* \\
\hline 39130 & ๑9/23E534 & 468 & $\begin{array}{l}60 \\
\star *\end{array}$ & OE533 & 437 & $\begin{array}{l}55 \\
\star *\end{array}$ & OE531 & 406 & $\begin{array}{l}50 \\
* *\end{array}$ & ○E546 & 350 & 45 & $0^{*}$ \\
\hline 39135 & 09/24E572 & 293 & 45 & $0^{*}$ & $\odot$ & $\odot$ & ○* & $\odot$ & $\odot$ & ०* & $\odot$ & ○ & ०* \\
\hline 39135 & ๑9/24E572 & 293 & 45 & $\begin{array}{r}\text { OE } 600 \\
* * *\end{array}$ & $\begin{array}{l}220 \\
* * *\end{array}$ & $\begin{array}{l}45 \\
* *\end{array}$ & $\begin{array}{r}\text { OE625 } \\
* * *\end{array}$ & $\begin{array}{l}155 \\
* * *\end{array}$ & $\begin{array}{l}45 \\
* *\end{array}$ & $\begin{array}{r}\text { OE650 } \\
* * *\end{array}$ & $\begin{array}{l}140 \\
* * *\end{array}$ & $\begin{array}{l}40 \\
* *\end{array}$ & ०* \\
\hline sep & ber $25^{\text {th }} i$ & nev & in & RDAT & & & & & & & & & \\
\hline 39137 & $\begin{array}{r}09 / 25 E 675 \\
* \star *\end{array}$ & $\begin{array}{l}115 \\
* * *\end{array}$ & $\begin{array}{l}40 \\
* *\end{array}$ & $\begin{array}{r}\text { OE690 } \\
\star \star *\end{array}$ & $\begin{array}{l}095 \\
* * *\end{array}$ & $\begin{array}{l}35 \\
* *\end{array}$ & $\begin{array}{r}\odot \mathrm{E} 7 \odot \odot \\
* \star \star\end{array}$ & $\begin{array}{l}080 \\
\star * *\end{array}$ & $\begin{array}{l}35 \\
* *\end{array}$ & $\begin{array}{r}\text { OE710 } \\
* \star *\end{array}$ & $\begin{array}{l}\odot 70 \\
* * *\end{array}$ & $\begin{array}{l}30 \\
* *\end{array}$ & ०* \\
\hline
\end{tabular}

39140 HR NC3

$39140 \mathrm{HR}$ NC2

U.S. Hurricane:

Sep $19^{\text {th }}-11 \mathrm{Z}-34.9 \mathrm{~N} 76.7 \mathrm{~W}-90 \mathrm{kt}-$ Category $2-960 \mathrm{mb}-1013 \mathrm{mb}$ OCI $-375 \mathrm{~nm}$ ROCI

Major track and intensity changes are analyzed for this classic Cape Verde hurricane that made landfall in North Carolina before moving away into the North Atlantic. A major alteration is to add one additional day at the end of the cyclone's lifetime. Evidence for these alterations comes from the Historical Weather Maps Series, the COADS ship database, Monthly Weather Review, USWB/NHC microfilm of synoptic weather maps, the Climatological Data, the Navy aircraft reconnaissance book, Schwerdt et al. (1979), Ho et al. (1987) and Jarrell et al. (1992).

September 9:

HWM shows a spot low centered near $14.5 \mathrm{~N}, 34.0 \mathrm{~W}$ at $12 \mathrm{Z}$. HURDAT does not analyze an organized system on this date. Microfilm does not show an organized system on this date. MWR is not available on this date. Ship highlights: No gales or low pressures.

September 10:

HWM shows a closed low pressure of at most $1010 \mathrm{mb}$ centered near $11.5 \mathrm{~N}$, 41.0W at 12Z. HURDAT lists this as a 35 knot tropical storm at $15.4 \mathrm{~N}, 44.2 \mathrm{~W}$ at $12 \mathrm{Z}$. Microfilm does not show an organized system on this date. MWR is not available on this date. Ship highlights: No gales or low pressures.

September 11:

HWM shows a closed low pressure of at most $1010 \mathrm{mb}$ centered near $12.5 \mathrm{~N}$, $49.5 \mathrm{~W}$ at $12 \mathrm{Z}$. HURDAT lists this as a 35 knot tropical storm at $15.2 \mathrm{~N}, 49.3 \mathrm{~W}$ at $12 \mathrm{Z}$. Microfilm does not show an organized system on this date. MWR is not available on this date. Ship highlights: No gales or low pressures. Aircraft highlights: GULL aircraft 
reported an "eye" near $15.7 \mathrm{~N}, 45.5 \mathrm{~W}$ at $1545 \mathrm{Z}$ (micro). "The birth of "Hurricane Ione" followed close in the wake of "Hurricane Hilda." In the easterly flow in the tropical regions to the east of the Lesser Antilles, were embedded two easterly waves approximately 1000 miles apart. The firt of these waves developed a vortex which later became "Hurricane Hilda" and moved in almost a due west direction into Mexico. The second easterly wave, later labeled locally "September \#2," appeared the stronger of the two waves, while east of the islands, and subsequently developed into "Hurricane Ione. A weak vortex indicated on "September \#2" on the $11^{\text {th }}$ of September was showing slight intensification as it moved northwestward; therefore, an investigative flight was ordered to reconnoiter the area in the vicinity of $17 \mathrm{~N}$ and $55 \mathrm{~W}$ early on the $12^{\text {th }}$ of September" (ATSR).

September 12:

HWM shows a closed low pressure of at most $1005 \mathrm{mb}$ centered near $13.5 \mathrm{~N}$, $54.2 \mathrm{~W}$ at $12 \mathrm{Z}$. HURDAT lists this as a 35 knot tropical storm at $14.2 \mathrm{~N}, 54.1 \mathrm{~W}$ at $12 \mathrm{Z}$. Microfilm shows a closed low pressure of at most $1005 \mathrm{mb}$ centered near 14.0N, 57.0W at 18Z. MWR is not available on this date. Ship highlights: No gales or low pressures. "The collection of reports received from the reconnaissance flight showed the maximum winds in squalls to be 35 knots. No definite cyclonic circulation was revealed by the reports, however, a weak circulation with a minimum surface pressure of about $1008 \mathrm{mb}$ was estimated to be to the south of the reports in the vicinity of 14N 55W at 121600Z" (ATSR).

September 13:

HWM shows a tropical storm of at most $1005 \mathrm{mb}$ centered near $14.8 \mathrm{~N}, 55.8 \mathrm{~W}$ at 12Z. HURDAT lists this as a 45 knot tropical storm at $16.4 \mathrm{~N}, 58.2 \mathrm{~W}$ at $12 \mathrm{Z}$. Microfilm shows a closed low pressure of at most $1011 \mathrm{mb}$ centered near $14.5 \mathrm{~N}, 62.5 \mathrm{~W}$ at $12 \mathrm{Z}$. MWR is not available on this date. Ship highlights: $35 \mathrm{kt} \mathrm{E}$ and $1015 \mathrm{mb}$ at $21.1 \mathrm{~N}$, $58.9 \mathrm{~W}$ at $21 \mathrm{Z}$ (micro).

September 14:

HWM shows a tropical storm of at most $1005 \mathrm{mb}$ centered near $18.2 \mathrm{~N}, 60.3 \mathrm{~W}$ at 12Z. HURDAT lists this as a 60 knot tropical storm at $18.0 \mathrm{~N}, 60.2 \mathrm{~W}$ at $12 \mathrm{Z}$. Microfilm shows a closed low pressure of at most $1005 \mathrm{mb}$ centered near $18.0 \mathrm{~N}, 61.0 \mathrm{~W}$ at $12 \mathrm{Z}$. MWR is not available on this date. Ship highlights: $45 \mathrm{kt}$ ENE and $1013 \mathrm{mb}$ at $20.4 \mathrm{~N}$, $59.5 \mathrm{~W}$ at $0 \mathrm{Z}$ (micro); $40 \mathrm{kt}$ ENE and $1011 \mathrm{mb}$ at $19.7 \mathrm{~N}, 59.5 \mathrm{~W}$ at $0 \mathrm{Z}$ (micro); $35 \mathrm{kt} \mathrm{E}$ and $1007 \mathrm{mb}$ at $20.5 \mathrm{~N}, 61.2 \mathrm{~W}$ at $18 \mathrm{Z}$ (COADS), and $40 \mathrm{kt} \mathrm{N}$ and $1005 \mathrm{mb}$ at $18.1 \mathrm{~N}$, $63.5 \mathrm{~W}$ at $18 \mathrm{Z}$ (micro). Land highlights: $15 \mathrm{kt} \mathrm{SW}$ and $1005 \mathrm{mb}$ at St. Kitts and Navis at $12 \mathrm{Z}$ (micro), and $10 \mathrm{kt} \mathrm{NW}$ and $1005 \mathrm{mb}$ at Anguilla at 21Z (micro). Aircraft highlight: 
Penetration center fix measured a central pressure of $1001 \mathrm{mb}$ and surface winds of $60 \mathrm{kt}$ at $18.0 \mathrm{~N}, 60.5 \mathrm{~W}$ at $1145 \mathrm{Z}$ (micro); Penetration center fix measured a central pressure of $1000 \mathrm{mb}$ and an eye of a 30 mile diameter at $18.3 \mathrm{~N}, 61.5 \mathrm{~W}$ at $1830 \mathrm{Z}$ (ATSR/micro). "The next aircraft reconnaissance flight, on the $14^{\text {th }}$ of September, revealed that the vortex had intensified gradually to tropical storm intensity as it moved northwestward. Winds of 60 knots in a small area near the center and a minimum pressure of $1001 \mathrm{mbs}$ were reported by the aircraft. Coordination was thus completed for Warning Number One on "Tropical Storm Ione" centered at 19.1N 61.2W ar 141500Z" (ATSR).

September 15:

HWM shows a hurricane of at most $1000 \mathrm{mb}$ centered near $21.9 \mathrm{~N}, 63.2 \mathrm{~W}$ at $12 \mathrm{Z}$. HURDAT lists this as a 70 knot hurricane at $22.1 \mathrm{~N}, 63.3 \mathrm{~W}$ at $12 \mathrm{Z}$. Microfilm shows a closed low pressure of at most $1005 \mathrm{mb}$ centered near $21.7 \mathrm{~N}, 63.5 \mathrm{~W}$ at $12 \mathrm{Z}$. MWR shows a low pressure of $996 \mathrm{mb}$ at $21.1 \mathrm{~N}, 64.0 \mathrm{~W}$ at 12Z. Ship highlights: $35 \mathrm{kt} \mathrm{NE}$ and $1010 \mathrm{mb}$ at $19.8 \mathrm{~N}, 61.5 \mathrm{~W}$ at $0 \mathrm{Z}$ (COADS); $35 \mathrm{kt} \mathrm{E}$ and $1008 \mathrm{mb}$ at $22.0 \mathrm{~N}, 60.4 \mathrm{~W}$ at $06 \mathrm{Z}$ (micro), $70 \mathrm{kt} \mathrm{E}$ and $1007 \mathrm{mb}$ at $21.8 \mathrm{~N}, 63.0 \mathrm{~W}$ at 12Z (micro), and $40 \mathrm{kt} \mathrm{NNE}$ and 1008 $\mathrm{mb}$ at $24.1 \mathrm{~N}, 69.3 \mathrm{~W}$ at $21 \mathrm{Z}$ (micro). Aircraft highlight: Penetration center fix measured surface winds of $66 \mathrm{kt}$ at $21.7 \mathrm{~N}, 63.2 \mathrm{~W}$ at $1052 \mathrm{Z}$ (ATSR); Penetration center fix at $23.1 \mathrm{~N}, 65.4 \mathrm{~W}$ at $1725 \mathrm{Z}$ (ATSR); Penetration center fix at $22.7 \mathrm{~N}, 66.0 \mathrm{~W}$ at $18 \mathrm{Z}$ (ATSR), and penetration center fix at $23.2 \mathrm{~N}, 66.3 \mathrm{~W}$ at $2024 \mathrm{Z}$ (ATSR). "“'Ione" continued to increase gradually in intensity reaching hurricane force at 150000Z” (ATSR).

September 16:

HWM shows a hurricane of at most $1000 \mathrm{mb}$ centered near $24.7 \mathrm{~N}, 69.2 \mathrm{~W}$ at $12 \mathrm{Z}$. HURDAT lists this as an 80 knot hurricane at $24.2 \mathrm{~N}, 69.1 \mathrm{~W}$ at $12 \mathrm{Z}$. Microfilm shows a closed low pressure of at most $1002 \mathrm{mb}$ centered near $24.2 \mathrm{~N}, 69.8 \mathrm{~W}$ at $12 \mathrm{Z}$. MWR shows a low pressure of $988 \mathrm{mb}$ at $24.5 \mathrm{~N}, 69.8 \mathrm{~W}$ at 12Z. Ship highlights: $40 \mathrm{kt} \mathrm{NNE}$ and $1008 \mathrm{mb}$ at $24.2 \mathrm{~N}, 69.2 \mathrm{~W}$ at $0 \mathrm{Z}$ (micro); $30 \mathrm{kt} \mathrm{W}$ and $994 \mathrm{mb}$ at $23.7 \mathrm{~N}, 69.1 \mathrm{~W}$ at $09 \mathrm{Z}$ (micro), and $50 \mathrm{kt} \mathrm{W}$ and $1002 \mathrm{mb}$ at $28.2 \mathrm{~N}, 69.7 \mathrm{~W}$ at $18 \mathrm{Z}$ (micro). Aircraft highlight: Penetration center fix measured surface winds of $80 \mathrm{kt}$, a central pressure of $985 \mathrm{mb}$ and an eye of a 50 mile diameter at $24.3 \mathrm{~N}, 69.4 \mathrm{~W}$ at $1317 \mathrm{Z}$ (ATSR); Penetration center fix at $24.2 \mathrm{~N}, 69.6 \mathrm{~W}$ at $14 \mathrm{Z}$ (ATSR); and penetration center fix at $24.7 \mathrm{~N}, 70.4 \mathrm{~W}$ at $22 \mathrm{Z}$ (ATSR).

September 17:

HWM shows a hurricane of at most $995 \mathrm{mb}$ centered near $26.4 \mathrm{~N}, 72.7 \mathrm{~W}$ at $12 \mathrm{Z}$. HURDAT lists this as a 100 knot hurricane at $26.5 \mathrm{~N}, 72.7 \mathrm{~W}$ at $12 \mathrm{Z}$. Microfilm shows a closed low pressure of at most $1002 \mathrm{mb}$ centered near $26.5 \mathrm{~N}, 72.3 \mathrm{~W}$ at $12 \mathrm{Z}$. MWR shows a low pressure of $988 \mathrm{mb}$ at $26.2 \mathrm{~N}, 73.0 \mathrm{~W}$ at 12Z. Ship highlights: $45 \mathrm{kt} \mathrm{SE}$ and 
$1000 \mathrm{mb}$ at $25.4 \mathrm{~N}, 69.0 \mathrm{~W}$ at $0 \mathrm{Z}$ (micro); $50 \mathrm{kt} \mathrm{SE}$ and $999 \mathrm{mb}$ at $25.8 \mathrm{~N}, 71.1 \mathrm{~W}$ at $06 \mathrm{Z}$ (micro); $70 \mathrm{kt} \mathrm{SE}$ and $981 \mathrm{mb}$ at 25.6N, 72.0W at 12Z (micro), and $60 \mathrm{kt} \mathrm{SSE}$ and 1004 $\mathrm{mb}$ at $26.4 \mathrm{~N}, 71.9 \mathrm{~W}$ at $18 \mathrm{Z}$ (micro). Land highlights: $20 \mathrm{kt} \mathrm{NW}$ and $1005 \mathrm{mb}$ at Mayaguana, Bahamas at $06 \mathrm{Z}$ (micro). Aircraft highlights: Penetration center fix measure an eye of a 5 mile diameter at $25.4 \mathrm{~N}, 71.7 \mathrm{~W}$ at $02 \mathrm{Z}$ (ATSR/ micro); Penetration center fix at $25.7 \mathrm{~N}, 72.0 \mathrm{~W}$ at $07 \mathrm{Z}$ (ATSR); Penetration center fix measured surface winds of $100 \mathrm{kt}$, central pressure of $971 \mathrm{mb}$ and an eye of a 15 mile diameter at $25.7 \mathrm{~N}, 72.0 \mathrm{~W}$ at $0745 Z$ (ATSR/micro); Penetration center fix measure an eye of a 15 mile diameter at $26.4 \mathrm{~N}, 72.8 \mathrm{~W}$ at $14 \mathrm{Z}$ (ATSR); Penetration center fix at $26.7 \mathrm{~N}, 73.1 \mathrm{~W}$ at $1707 \mathrm{Z}$ (ATSR); Penetration center fix at 26.8N, $73.1 \mathrm{~W}$ at $1709 \mathrm{Z}$ (ATSR); Penetration center fix at 27.2N, $73.5 \mathrm{~W}$ at $1927 \mathrm{Z}$ (ATSR); and penetration center fix measured surface winds of $100 \mathrm{kt}$, central pressure of $938 \mathrm{mb}$ and an eye of a 15 mile diameter at $27.3 \mathrm{~N}, 73.6 \mathrm{~W}$ at $20 \mathrm{Z}$ (ATSR/micro). “... and 100 knots near the center on the $17^{\text {th }}$ of September" (ATSR).

September 18:

HWM shows a hurricane of at most $995 \mathrm{mb}$ centered near $29.8 \mathrm{~N}, 75.5 \mathrm{~W}$ at $12 \mathrm{Z}$. HURDAT lists this as a 100 knot hurricane at $29.8 \mathrm{~N}, 75.3 \mathrm{~W}$ at $12 \mathrm{Z}$. Microfilm shows a closed low pressure of at most $978 \mathrm{mb}$ centered near $30.2 \mathrm{~N}, 75.4 \mathrm{~W}$ at 12Z. MWR shows a low pressure of $988 \mathrm{mb}$ at $29.5 \mathrm{~N}, 75.3 \mathrm{~W}$ at 12Z. Ship highlights: $60 \mathrm{kt} \mathrm{NE}$ and $997 \mathrm{mb}$ at $29.0 \mathrm{~N}, 75.0 \mathrm{~W}$ at $03 \mathrm{Z}$ (micro); $40 \mathrm{kt}$ ESE and $1014 \mathrm{mb}$ at $31.7 \mathrm{~N}, 72.2 \mathrm{~W}$ at $12 \mathrm{Z}$ (COADS); $50 \mathrm{kt} \mathrm{NE}$ and $1008 \mathrm{mb}$ at 32.1N, $78.1 \mathrm{~W}$ at $15 \mathrm{Z}$ (micro); $50 \mathrm{kt} \mathrm{NE}$ and 1005 $\mathrm{mb}$ at $31.8 \mathrm{~N}, 78.8 \mathrm{~W}$ at $18 \mathrm{Z}$ (micro); and $55 \mathrm{kt} \mathrm{NNW}$ and $998 \mathrm{mb}$ at $31.2 \mathrm{~N}, 77.9 \mathrm{~W}$ at $21 \mathrm{Z}$ (micro). Aircraft highlight: Penetration center fix at $28.7 \mathrm{~N}, 74.7 \mathrm{~W}$ at $0525 \mathrm{Z}$ (ATSR); Penetration center fix at $29.1 \mathrm{~N}, 75.0 \mathrm{~W}$ at $08 \mathrm{Z}$ (ATSR); Penetration center fix measured surface winds of $95 \mathrm{kt}$ and a central pressure of $943 \mathrm{mb}$ at $30.1 \mathrm{~N}, 75.5 \mathrm{~W}$ at $1340 \mathrm{Z}$ (ATSR/micro); Penetration center fix at $30.3 \mathrm{~N}, 75.5 \mathrm{~W}$ at $14 \mathrm{Z}$ (ATSR); Penetration center fix at $31.3 \mathrm{~N}, 75.7 \mathrm{~W}$ at $1825 \mathrm{Z}$ (ATSR); and penetration center fix at $31.7 \mathrm{~N}, 75.9 \mathrm{~W}$ at $1930 \mathrm{Z}$ (ATSR). “...then reached her maximum intensity of about 110 knots on the $18^{\text {th }}$ of September” (ATSR).

September 19:

HWM shows a hurricane of at most $985 \mathrm{mb}$ centered near $35.0 \mathrm{~N}, 76.2 \mathrm{~W}$ at $12 \mathrm{Z}$. HURDAT lists this as a 65 knot hurricane at $34.8 \mathrm{~N}, 76.7 \mathrm{~W}$ at $12 \mathrm{Z}$. Microfilm shows a closed low pressure of at most $987 \mathrm{mb}$ centered near $35.0 \mathrm{~N}, 76.8 \mathrm{~W}$ at $12 \mathrm{Z}$. MWR shows a low pressure of $976 \mathrm{mb}$ at $35.0 \mathrm{~N}, 77.0 \mathrm{~W}$ at 12Z. Ship highlights: $50 \mathrm{kt} \mathrm{E}$ and $1009 \mathrm{mb}$ at $34.8 \mathrm{~N}, 74.2 \mathrm{~W}$ at $03 \mathrm{Z}$ (micro); $45 \mathrm{kt} \mathrm{SW}$ and $1004 \mathrm{mb}$ at $32.0 \mathrm{~N}, 72.5 \mathrm{~W}$ at $06 \mathrm{Z}$ (micro); $40 \mathrm{kt} \mathrm{S}$ and $1015 \mathrm{mb}$ at $315 \mathrm{~N}, 70.4 \mathrm{~W}$ at $12 \mathrm{Z}$ (micro)1; $55 \mathrm{kt} \mathrm{SSW}$ and $1010 \mathrm{mb}$ at $31.6 \mathrm{~N}$, $74.4 \mathrm{~W}$ at $18 \mathrm{Z}$ (COADS), and $20 \mathrm{kt} \mathrm{ESE}$ and $991 \mathrm{mb}$ at $36.5 \mathrm{~N}, 74.8 \mathrm{~W}$ at $18 \mathrm{Z}$ (micro). Land highlights: $987 \mathrm{mb}$ at Wilmington (no time given) (CLIMO); $960 \mathrm{mb}$ at Morehead 
City (no time given, but likely around 11Z) (MWR/Ho et al.); $67 \mathrm{kt}$ E at Diamond Shoals at $06 \mathrm{Z}$ (micro); $962 \mathrm{mb}$ at $1127 \mathrm{Z}$ at Cherry Point (MWR); $40 \mathrm{kt} \mathrm{E}$ and $965 \mathrm{mb}$ at Cherry Point at 12Z (micro); $40 \mathrm{kt} \mathrm{SW}$ and $987 \mathrm{mb}$ at Cape Hatteras at 18Z (micro); $25 \mathrm{kt} \mathrm{SE}$ and $986 \mathrm{mb}$ at Elizabeth City at $21 \mathrm{Z}$ (micro). Aircraft highlight: Penetration center fix at $32.7 \mathrm{~N}, 76.1 \mathrm{~W}$ at $0137 \mathrm{Z}$ (ATSR); Penetration center fix at $32.8 \mathrm{~N}, 76.3 \mathrm{~W}$ at $02 \mathrm{Z}$ (ATSR); Penetration center fix at $32.5 \mathrm{~N}, 76.5 \mathrm{~W}$ at $0220 \mathrm{Z}$ (ATSR), and penetration center fix at $34.2 \mathrm{~N}, 76.4 \mathrm{~W}$ at $0723 \mathrm{Z}$ (ATSR). "960 mb at 34.7N, 76.7W - $1016 \mathrm{mb}$ PenV - RMW 42 nmi - speed $9 \mathrm{kt}-78 \mathrm{kt}$ est max sustained 10m, 10-min wind, (Schwerdt et al.), "960 mb central pressure measured by land barometer at Morehead City, NC - RMW 22 nmi - 9 kt forward speed - landfall pt 34.7N, 76.7W, (Ho et al.)," "NC3-Cat 3-960 mb (Jarrell et al.). "Fortunately, a rapid decrease in intensity occurred on 19 September as "Ione" moved ashore" (ATSR).

September 20:

HWM shows a hurricane of at most $985 \mathrm{mb}$ centered near $37.5 \mathrm{~N}, 73.5 \mathrm{~W}$ with a cold front to the northwest at 12Z. HURDAT lists this as a 90 knot hurricane at $37.0 \mathrm{~N}$, $73.4 \mathrm{~W}$ at $12 \mathrm{Z}$. Microfilm shows a closed low pressure of at most $990 \mathrm{mb}$ centered near $37.5 \mathrm{~N}, 73.5 \mathrm{~W}$ at $12 \mathrm{Z}$. MWR shows a low pressure of $976 \mathrm{mb}$ at $37.5 \mathrm{~N}, 74.4 \mathrm{~W}$ at $12 \mathrm{Z}$. Ship highlights: $35 \mathrm{kt} \mathrm{NE}$ and $996 \mathrm{mb}$ at $37.6 \mathrm{~N}, 76.1 \mathrm{~W}$ at $0 \mathrm{Z}$ (COADS); $45 \mathrm{kt} \mathrm{S}$ and 991 $\mathrm{mb}$ at $36.8 \mathrm{~N}, 74.5 \mathrm{~W}$ at $06 \mathrm{Z}$ (COADS); $25 \mathrm{kt} \mathrm{SSE}$ and $989 \mathrm{mb}$ at $37.3 \mathrm{~N}, 73.3 \mathrm{~W}$ at $12 \mathrm{Z}$ (micro), and $50 \mathrm{kt} \mathrm{WSW}$ and $989 \mathrm{mb}$ at $37.0 \mathrm{~N}, 72.5 \mathrm{~W}$ at $18 \mathrm{Z}$ (COADS). Land highlights: $986 \mathrm{mb}$ at Norfolk (no time given) (CLIMO); $15 \mathrm{kt} \mathrm{SE}$ and $979 \mathrm{mb}$ at Elizabeth City at 03Z (micro); $25 \mathrm{kt} \mathrm{NE}$ and $987 \mathrm{mb}$ at Norfolk at 06Z (micro), and $25 \mathrm{kt} \mathrm{NW}$ and $996 \mathrm{mb}$ at Elizabeth City at $12 Z$ (micro). Aircraft highlights: Penetration center fix measured surface winds of $95 \mathrm{kt}$ and a central pressure of $982 \mathrm{mb}$ and an eye of a 30 mile diameter at $37.0 \mathrm{~N}, 73.0 \mathrm{~W}$ at $15 \mathrm{Z}$ (ATSR/micro); Penetration center fix at $37.7 \mathrm{~N}, 72.4 \mathrm{~W}$ at $16 \mathrm{Z}$ (ATSR); Penetration center fix at $38.7 \mathrm{~N}, 70.9 \mathrm{~W}$ at $20 \mathrm{Z}$ (ATSR); Penetration center fix at $38.7 \mathrm{~N}, 71.2 \mathrm{~W}$ at $2015 \mathrm{Z}$ (ATSR), and penetration center fix measured a central pressure of $976 \mathrm{mb}$ at $39.2 \mathrm{~N}, 69.6 \mathrm{~W}$ at $2245 \mathrm{Z}$ (ATSR/micro). "On the $20^{\text {th }}$ of September, movement out to sea was followed by regeneration with attendant increase in intensity" (ATSR).

September 21:

HWM shows a closed area of low pressure of at most $970 \mathrm{mb}$ centered near $45.5 \mathrm{~N}, 58.8 \mathrm{~W}$ with a warm front to the east and a cold front to the south at $12 \mathrm{Z}$. HURDAT lists this as a 50 knot extratropical cyclone at $45.0 \mathrm{~N}, 59.4 \mathrm{~W}$ at $12 \mathrm{Z}$. Microfilm shows a closed low pressure of at most $972 \mathrm{mb}$ centered near $45.0 \mathrm{~N}, 59.0 \mathrm{~W}$ with a cold front to the south at $12 \mathrm{Z}$. MWR shows a low pressure of $972 \mathrm{mb}$ at $45.9 \mathrm{~N}, 59.1 \mathrm{~W}$ at $12 \mathrm{Z}$. Ship highlights: $65 \mathrm{kt} \mathrm{W}$ and $987 \mathrm{mb}$ at 38.0N, 70.0W at $0 \mathrm{Z}$ (micro); $40 \mathrm{kt} \mathrm{S}$ and $972 \mathrm{mb}$ 
at $41.5 \mathrm{~N}, 68.9 \mathrm{~W}$ at $06 \mathrm{Z}$ (micro); $65 \mathrm{kt} \mathrm{S}$ and $982 \mathrm{mb}$ at $41.0 \mathrm{~N}, 62.0 \mathrm{~W}$ at $06 \mathrm{Z}$ (micro); 50 $\mathrm{kt} \mathrm{SW}$ and $973 \mathrm{mb}$ at $44.0 \mathrm{~N}, 58.0 \mathrm{~W}$ at $12 \mathrm{Z}$ (micro), and $50 \mathrm{kt} \mathrm{SW}$ and $979 \mathrm{mb}$ at $46.5 \mathrm{~N}$, $54.1 \mathrm{~W}$ at $18 \mathrm{Z}$ (micro). Land highlights: $10 \mathrm{kt} \mathrm{SE}$ and $992 \mathrm{mb}$ at Sable Island at $06 \mathrm{Z}$ (micro); $50 \mathrm{kt} \mathrm{NW}$ and $974 \mathrm{mb}$ at Sable Island at $12 \mathrm{Z}$ (micro), and $15 \mathrm{kt} \mathrm{SSW}$ and 957 mb Garner, Canada at $18 \mathrm{Z}$ (micro). Aircraft highlight: Radar center fix measured an eye of a 32 mile diameter at $39.3 \mathrm{~N}, 68.1 \mathrm{~W}$ at $0015 \mathrm{Z}$ (ATSR/micro); Radar center fix measured an eye of a 30 mile diameter at $39.3 \mathrm{~N}, 67.8 \mathrm{~W}$ at $0045 \mathrm{Z}$ (ATSR/micro), and radar center fix measured a central pressure of $976 \mathrm{mb}$ at $40.2 \mathrm{~N}, 66.2 \mathrm{~W}$ at $0245 \mathrm{Z}$ (ATSR/micro).

September 22:

HWM shows a closed area of low pressure of at most $970 \mathrm{mb}$ centered near $50.5 \mathrm{~N}, 52.5 \mathrm{~W}$ with a dissipating cold front to the northeast at 12Z. HURDAT lists this as a 45 knot extratropical cyclone at $51.8 \mathrm{~N}, 53.0 \mathrm{~W}$ at $12 \mathrm{Z}$. Microfilm shows a closed low pressure of at most $972 \mathrm{mb}$ centered near $50.5 \mathrm{~N}, 53.5 \mathrm{~W}$ at $12 \mathrm{Z}$. MWR shows a low pressure of $958 \mathrm{mb}$ at $45.9 \mathrm{~N}, 59.1 \mathrm{~W}$ at $12 \mathrm{Z}$. Ship highlights: $70 \mathrm{kt} \mathrm{E}$ and $966 \mathrm{mb}$ at $52.3 \mathrm{~N}, 53.0 \mathrm{~W}$ at $0 \mathrm{Z}$ (COADS); $50 \mathrm{kt} \mathrm{ENE}$ and $998 \mathrm{mb}$ at $56.5 \mathrm{~N}, 51.0 \mathrm{~W}$ at $06 \mathrm{Z}$ (COADS); $55 \mathrm{kt} \mathrm{SW}$ and $984 \mathrm{mb}$ at $47.1 \mathrm{~N}, 51.4 \mathrm{~W}$ at $12 \mathrm{Z}$ (COADS), and $60 \mathrm{kt} \mathrm{ENE}$ and $989 \mathrm{mb}$ at $55.8 \mathrm{~N}, 50.7 \mathrm{~W}$ at $18 \mathrm{Z}$ (COADS). Land highlights: $20 \mathrm{kt} \mathrm{SW}$ and $972 \mathrm{mb}$ at St. Johns at $0 \mathrm{Z}$ (micro); $30 \mathrm{kt} \mathrm{S}$ and $970 \mathrm{mb}$ at Garner at $49.0 \mathrm{~N}, 54.6 \mathrm{~W}$ at $06 \mathrm{Z}$ (micro); $40 \mathrm{kt}$ SW and $973 \mathrm{mb}$ at Garner at $12 \mathrm{Z}$ (micro), and $45 \mathrm{kt} \mathrm{SW}$ and $990 \mathrm{mb}$ at St. Johns at $18 \mathrm{Z}$ (micro).

September 23:

HWM shows a closed area of low pressure of at most $985 \mathrm{mb}$ centered near $53.5 \mathrm{~N}, 40.5 \mathrm{~W}$ at $12 \mathrm{Z}$. HURDAT lists this as a 45 knot extratropical cyclone at $53.1 \mathrm{~N}$, $40.6 \mathrm{~W}$ at 12Z. Microfilm shows a closed low pressure of at most $996 \mathrm{mb}$ centered near $54.0 \mathrm{~N}, 48.0 \mathrm{~W}$ at $06 \mathrm{Z}$ (last position available). MWR shows a low pressure of $960 \mathrm{mb}$ at $53.0 \mathrm{~N}, 41.0 \mathrm{~W}$ at 12Z. Ship highlights: $50 \mathrm{kt} \mathrm{E}$ and $987 \mathrm{mb}$ at $54.8 \mathrm{~N}, 50.0 \mathrm{~W}$ at $0 \mathrm{Z}$ (micro); $50 \mathrm{kt} \mathrm{W}$ and $987 \mathrm{mb}$ at $48.6 \mathrm{~N}, 43.6 \mathrm{~W}$ at $06 \mathrm{Z}$ (COADS/micro); $25 \mathrm{kt} \mathrm{SW}$ and $983 \mathrm{mb}$ at $52.8 \mathrm{~N}, 37.6 \mathrm{~W}$ at $12 \mathrm{Z}$ (COADS), and $45 \mathrm{kt} \mathrm{NE}$ and $998 \mathrm{mb}$ at $58.2 \mathrm{~N}, 43.2 \mathrm{~W}$ at $18 \mathrm{Z}$ (COADS).

September 24:

HWM shows a closed area of low pressure of at most $985 \mathrm{mb}$ centered near $62.5 \mathrm{~N}, 14.0 \mathrm{~W}$ with a stationary front to the east and southeast at 12Z. HURDAT lists this as a 45 knot extratropical cyclone at $57.2 \mathrm{~N}, 29.3 \mathrm{~W}$ at $0 \mathrm{Z}$ (last position). Microfilm and MWR are not available on this date. Ship highlights: $40 \mathrm{kt} \mathrm{WSW}$ and $1001 \mathrm{mb}$ at 51.4N, $29.2 \mathrm{~W}$ at $0 \mathrm{Z}$ (COADS); $35 \mathrm{kt} \mathrm{WSW}$ and $1000 \mathrm{mb}$ at $53.1 \mathrm{~N}, 21.6 \mathrm{~W}$ at $06 \mathrm{Z}$ (COADS); 25 
kt NE and $980 \mathrm{mb}$ at $63.0 \mathrm{~N}, 16.0 \mathrm{~W}$ at $12 \mathrm{Z}$ (COADS), $35 \mathrm{kt} \mathrm{WSW}$ and $1007 \mathrm{mb}$ at $55.2 \mathrm{~N}$, $17.0 \mathrm{~W}$ at $18 \mathrm{Z}$ (COADS), and $20 \mathrm{kt} \mathrm{W}$ and $979 \mathrm{mb}$ at $63.0 \mathrm{~N}, 16.0 \mathrm{~W}$ at $18 \mathrm{Z}$ (COADS).

September 25:

HWM shows a closed area of low pressure of at most $980 \mathrm{mb}$ centered near $70.0 \mathrm{~N}, 8.0 \mathrm{~W}$ with a stationary front to the northeast at $12 \mathrm{Z}$. HURDAT, microfilm and MWR are not available on this date. Ship highlights: $25 \mathrm{kt} \mathrm{S}$ and $993 \mathrm{mb}$ at $62.8 \mathrm{~N}, 2.0 \mathrm{~W}$ at $0 \mathrm{Z}$ (COADS); $35 \mathrm{kt} \mathrm{SSW}$ and $993 \mathrm{mb}$ at $63.7 \mathrm{~N}, 1.0 \mathrm{~W}$ at $06 \mathrm{Z}$ (COADS); $10 \mathrm{kt} \mathrm{SW}$ and $979 \mathrm{mb}$ at $68.7 \mathrm{~N}, 4.4 \mathrm{~W}$ at $12 \mathrm{Z}$ (COADS), and $30 \mathrm{kt} \mathrm{SW}$ and $985 \mathrm{mb}$ at $70.5 \mathrm{~N}, 1.7 \mathrm{~W}$ at $18 \mathrm{Z}$ (COADS). Land highlights: $10 \mathrm{kt} \mathrm{ESE} \mathrm{and} 980 \mathrm{mb}$ at Dan Mayen Island at $12 \mathrm{Z}$ (micro).

September 26:

HWM shows a closed area of low pressure of at most $990 \mathrm{mb}$ centered near $72.5 \mathrm{~N}, 7.0 \mathrm{~W}$ at 12Z. HURDAT, microfilm and MWR are not available on this date. Ship highlights: $25 \mathrm{kt} \mathrm{S}$ and $989 \mathrm{mb}$ at $68.3 \mathrm{~N}, 4.8 \mathrm{~W}$ at $03 \mathrm{Z}$ (COADS).

MWR: "Ione developed in an easterly wave which passed through the Cape Verdes on September 6 and the circulation was still quite weak on the $11^{\text {th }}$, but Ione began to develop on this date and reached hurricane intensity during the night of September 14-15 in about Latitude $19.5 \mathrm{~N}$ and Longitude $62.6 \mathrm{~W}$. Ione then pursued a general northwesterly course toward the North Carolina coast. It reached greatest intensity on the $17^{\text {th }}$ when a central pressure of $938 \mathrm{mb}$ (27.70 inches) was reported with maximum winds of 125 $\mathrm{mph}$. By the time the hurricane reached the North Carolina coastline on the $19^{\text {th }}$, the central pressure had filled to about 28.35 inches and the maximum winds had decreased slightly. Ione was the third hurricane to pass through eastern North Carolina within six weeks and the fourth within eleven months. Not within the known meteorological history of this section have so many hurricanes affected the area within so short a period. Total storm damage, mostly to crops in eastern North Carolina, is estimated at $\$ 88,035,000$. There were 7 fatalities directly or indirectly attributable to the hurricane. The lack of any deaths from Connie and Diane in North Carolina and only 7 in Ione and the comparatively small property damage, excluding crop damage, in this area, is a tribute to the effectiveness of the warnings and precautionary measures taken by governmental and private agencies such as the Red Cross."

NC CLIMO: "The center of Hurricane "Ione" entered the North Carolina coast near Salter Path, about 10 miles west of Morehead City, at about 0500E on September 19. Meandering slowly northward, the center passed west of Cherry Point, east of New Bern 
and Aurora, west of Belhaven, east of Plymouth and Elizabeth City, and thence off the coast of Currituck County. Ocean tides rose to seven to ten feet above normal at the beaches around Morehead City and three to five feet above normal elsewhere along the ocean front. The western portion of the inland sounds and their estuaries had tides from six to ten feet above normal. Water rose into forty city blocks of New Bern, while considerable areas of Washington, Belhaven, Aurora, Oriental and Arapahoe were flooded deep water to enter the first floor of buildings. Thousands of acres of low-lying farm land were also inundated."

The genesis of Ione is retained at $06 \mathrm{Z}$ on September 10 as a $25 \mathrm{kt}$ tropical depression as originally shown in HURDAT. Data on this day is sparse but if a closed low level circulation was present, it must have been located substantially farther southeast of the position originally in HURDAT. There are no other major changes to the track while the system was a tropical cyclone. However, major track alterations were introduced on the $21^{\text {st }}$ when the cyclone was extratropical. Intensification to a tropical storm is retained at $12 \mathrm{Z}$ on the $10^{\text {th }}$, but there is no data to support it. Ione moved generally westward to west-northwestward during the next following days. At $1545 \mathrm{Z}$ on the $11^{\text {th }}$, microfilm indicates that an Air Force (GULL) airplane reported an "eye" near 15.7N, 45.5W. No other information was available about this mission either on the Monthly Weather Review or the Navy reconnaissance book; therefore, it has been ignored for the reanalysis. Ship and Lesser Antilles stations data on the $12^{\text {th }}$ and $13^{\text {th }}$ suggests that the low level circulation of Ione was poorly-defined and it is possible that it may have not been closed. A reconnaissance mission arrived late on the $12^{\text {th }}$ to investigate the cyclone, but it did not go south enough to sample the center and only sampled the northern portion of the circulation. The mission measured $10 \mathrm{kt}$ and $1008 \mathrm{mb}$ at $1629 \mathrm{Z}$ on the $12^{\text {th }}$. This allows computing a central pressure of about $1007 \mathrm{mb}$, which has been added to HURDAT at $18 \mathrm{Z}$ on the $12^{\text {th }}$. A central pressure of $1007 \mathrm{mb}$ yields $32 \mathrm{kt}$ according to Brown et al. southern pressure-wind relationship. Thus, an intensity of $35 \mathrm{kt}$ is analyzed for $18 \mathrm{Z}$ on the $12^{\text {th }}$, down from $40 \mathrm{kt}$ originally in HURDAT. A ship named "Franca" passed close to the cyclone on the $12^{\text {th }}$ and early on the $13^{\text {th }}$. The wind direction and intensity reported by the ship appear to be correct, but the pressure reported was a few millibars below the actual value based upon intercomparing Franca's subsequent observations against other nearby ships. Another reconnaissance mission investigated the cyclone at around $1145 \mathrm{Z}$ on the $14^{\text {th }}$ measuring a central pressure of $1001 \mathrm{mb}$ and estimated surface winds of $60 \mathrm{kt}$. A central pressure of $1001 \mathrm{mb}$ yields $45 \mathrm{kt}$ from the south of $25 \mathrm{~N}$ pressure-wind relationship. An intensity of $50 \mathrm{kt}$ has been selected for $12 \mathrm{Z}$ on the 14th, down from $60 \mathrm{kt}$ originally in HURDAT. A central pressure of $1001 \mathrm{mb}$ has been added to $12 \mathrm{Z}$ on the $14^{\text {th }}$. The final reconnaissance mission of the day arrived at $1830 \mathrm{Z}$ measuring a central pressure of $1000 \mathrm{mb}$ and an eye of 30 mile diameter. An intensity of $55 \mathrm{kt}$ is selected for $18 \mathrm{Z}$ and a central pressure of $1000 \mathrm{mb}$ has been added. 
Late on the $14^{\text {th }}$, Ione made its closest approach to the Leeward Islands passing about 55 $\mathrm{nm}$ from Barbuda at 18Z. Tropical storm force winds are likely to have affected the northernmost of the Leeward Islands. The circulation of Ione continued to become better organized as it moved away from the Leeward Islands on the $15^{\text {th }}$ reaching hurricane intensity at 06Z, six hours later than originally shown in HURDAT. A central pressure of $990 \mathrm{mb}$ was in HURDAT at $12 \mathrm{Z}$ on the $15^{\text {th }}$ and although there is no data to directly support it, it is a reasonable value and is retained. A central pressure of $990 \mathrm{mb}$ yields 64 $\mathrm{kt}$ from the south of $25 \mathrm{~N}$ pressure-wind relationship. A ship named "BA CANADA" reported $70 \mathrm{kt} \mathrm{E}$ and $1007 \mathrm{mb}$ at $12 \mathrm{Z}$ on the $15^{\text {th }}$. This wind value appears reasonable but the ship continued to report the same wind value at $15 \mathrm{Z}$ and $18 \mathrm{Z}$ as the storm moved away, which begs into question the validity of the report. A reconnaissance airplane at $1052 \mathrm{Z}$ reported estimated maximum surface winds of $66 \mathrm{kt}$. Thus, an intensity of $70 \mathrm{kt}$ at $12 \mathrm{Z}$ is retained as originally shown in HURDAT.

Ione continued to gain strength on the $16^{\text {th }}$ reaching category 2 at $18 \mathrm{Z}$. A reconnaissance aircraft reached the hurricane at $1317 \mathrm{Z}$ reporting estimated surface winds of $80 \mathrm{kt}$ and at $14 Z$ reporting a 50 mile eye diameter. The Navy reconnaissance book indicates that a central pressure of $985 \mathrm{mb}$ was reported on this day, but does not specify the time. It is likely that this central pressure was measured on the aforementioned center fixes and a $985 \mathrm{mb}$ central pressure has been added to $12 \mathrm{Z}$ on the $16^{\text {th }}$. A central pressure of $985 \mathrm{mb}$ yields $71 \mathrm{kt}$ from the south of $25 \mathrm{~N}$ pressure-wind relationship. Thus, an intensity of $80 \mathrm{kt}$ is retained as originally shown in HURDAT. Intensification continued on the 17th and a central pressure of $971 \mathrm{mb}$ and an eye of a 15 mile diameter were measured by a reconnaissance aircraft at $0745 \mathrm{Z}$. This central pressure yields $89 \mathrm{kt}$ from the south of $25 \mathrm{~N}$ and $83 \mathrm{kt}$ from the north of $25 \mathrm{~N}$ ( $87 \mathrm{kt}$ from north $25 \mathrm{~N}$ and intensifying subset) pressurewind relationships. The 15 mile eye diameter allows computing an RMW of about $12 \mathrm{~nm}$ and climatology suggests an RMW of $18 \mathrm{~nm}$. Therefore, in part due to the small size an intensity of $90 \mathrm{kt}$ is selected for $06 \mathrm{Z}$ on the $17^{\text {th }}$, down from $95 \mathrm{kt}$ originally shown in HURDAT. A central pressure of $971 \mathrm{mb}$ has been added to HURDAT at $06 \mathrm{Z}$ on the 17th. A $950 \mathrm{mb}$ central pressure is present in the original HURDAT at $12 \mathrm{Z}$ and while there were no specific observations to corroborate it, this value is retained as it is reasonable based on the rapid intensification the hurricane was going through on this day. A central pressure of $950 \mathrm{mb}$ yields $105 \mathrm{kt}$ from the north of $25 \mathrm{~N}$ and $110 \mathrm{kt}$ from the north of $25 \mathrm{~N}$ intensifying subset of the pressure-wind relationships. An intensity of $105 \mathrm{mb}$ has been selected for 12Z, up from $100 \mathrm{kt}$ originally shown in HURDAT. Another reconnaissance aircraft made a center fix at $20 \mathrm{Z}$ measuring estimated surface winds of $100 \mathrm{kt}$, a central pressure of $938 \mathrm{mb}$ and an eye with a 15 mile diameter. A central pressure of $938 \mathrm{mb}$ yields $116 \mathrm{kt}$ north of $25 \mathrm{~N}$ and $122 \mathrm{kt}$ north of $25 \mathrm{~N}$ intensifying subset from the pressurewind relationships. An RMW of about $12 \mathrm{~nm}$ was computed from the available eye diameter information and climatology suggests $17 \mathrm{~nm}$. Therefore, an intensity of $120 \mathrm{kt}$ is 
selected for $18 \mathrm{Z}$ on the $17^{\text {th }}$ and $00 \mathrm{Z}$ on the $18^{\text {th }}$, up from $100 \mathrm{kt}$ originally shown in HURDAT, a major change. $120 \mathrm{kt}$ is also the revised peak intensity for this hurricane, up from $105 \mathrm{kt}$ originally in HURDAT. Ione remained a major hurricane on the $18^{\text {th }}$, but its intensity began to decrease as it moved toward the East Coast. Another reconnaissance mission reached the cyclone at $1340 \mathrm{Z}$ on the $18^{\text {th }}$ measuring estimated surface winds of $95 \mathrm{kt}$ and a central pressure of $943 \mathrm{mb}$. A central pressure of $943 \mathrm{mb}$ yields $112 \mathrm{kt}$ from the north of $25 \mathrm{~N}$ and $107 \mathrm{kt}$ from the north of $25 \mathrm{~N}$ weakening subset of the pressure-wind relationships. An intensity of $110 \mathrm{kt}$ has been selected for $12 \mathrm{Z}$ on the $17^{\text {th }}$, up from $100 \mathrm{kt}$ originally shown in HURDAT. A central pressure of $943 \mathrm{mb}$ has been added to $12 \mathrm{Z}$ on the $18^{\text {th }}$.

Ione reached the North Carolina coast around $11 \mathrm{Z}$ on the $19^{\text {th }}$ making landfall just west of Morehead City. The center of Ione passed about 5-10 nm from Morehead City where a minimum pressure of $960 \mathrm{mb}$ was reported. Given that Ho et al.'s RMW estimate of the RMW of 20-25 $\mathrm{nm}$ appears reasonable, $960 \mathrm{mb}$ can be considered a central pressure. This pressure yields $91 \mathrm{kt}$ north of $25 \mathrm{~N}$ weakening and $90 \mathrm{kt}$ north of $35 \mathrm{~N}$ according to the Brown et al. and Landsea et al. pressure-wind relationships. The estimated RMW of $20-25 \mathrm{~nm}$ is slightly smaller than the $27 \mathrm{~nm}$ from climatology. An intensity of $90 \mathrm{kt}$ is selected at landfall and 12Z, up from $65 \mathrm{kt}$ originally shown in HURDAT, a major change. This makes Ione a Category 2 impact in North Carolina, which is down from Category 3 originally assessed by Taylor and Hebert. The hurricane moved northward to northeast across eastern North Carolina reaching the Atlantic Ocean again around 06Z on the $20^{\text {th }}$. The only reports of sustained hurricane-force winds were on the Frying Pan and Diamond Shoals lighthouses. Cherry Point reported a $93 \mathrm{kt}$ gust. Ione remained a hurricane while moving across North Carolina weakening to $65 \mathrm{kt}$ as it made oceanfall. Elizabeth City reported $15 \mathrm{kt} \mathrm{SE}$ and $979 \mathrm{mb}$ at $03 \mathrm{Z}$ on the $20^{\text {th }}$, which allows computing a central pressure of about $976 \mathrm{mb}$. A central pressure of $976 \mathrm{mb}$ has been added to $00 \mathrm{Z}$ on the $20^{\text {th }}$. It is estimated that no hurricane-force winds affected Virginia, but tropical storm force winds impacted the southeast portion of the state.

Over the open Atlantic, Ione began to regain strength while accelerating to the northeast. A reconnaissance plane reached the hurricane on the $20^{\text {th }}$ at $15 \mathrm{Z}$ measuring estimated surface winds of $95 \mathrm{kt}$, a central pressure of $982 \mathrm{mb}$ and an eye of 30 mile diameter. A central pressure of $982 \mathrm{mb}$ yields $71 \mathrm{kt}$ from the north of $35 \mathrm{~N}$ pressure-wind relationship. The eye diameter information permits computing an RMW of about $20-25 \mathrm{~nm}$ and climatology suggests $30 \mathrm{~nm}$. An intensity of $75 \mathrm{kt}$ is selected for $18 \mathrm{Z}$ on the $20^{\text {th }}$ due to the small RMW, down from the $85 \mathrm{kt}$ intensity originally shown in HURDAT. At $0245 \mathrm{Z}$ on the $21^{\text {st }}$, a reconnaissance mission reported a central pressure of $976 \mathrm{mb}$. A central pressure of $976 \mathrm{mb}$ suggests $77 \mathrm{kt}$ from the north of $35 \mathrm{~N}$ pressure-wind relationship. An intensity of $80 \mathrm{kt}$ is selected for $00 \mathrm{Z}$ on the $21^{\text {st }}$, up from $75 \mathrm{kt}$ originally shown in 
HURDAT. A central pressure of $976 \mathrm{mb}$ has been added to $00 \mathrm{Z}$ on the $21^{\text {th }}$. Transition to a powerful extratropical cyclone is retained at $06 \mathrm{Z}$ on the $21^{\text {st }}$. Ione passed just west of Sable Island around $11 \mathrm{Z}$ on $21^{\text {st }}$ and made landfall in Newfoundland around 17Z. Reports from ships and land stations in Newfoundland indicate that Ione remained a very strong extratropical cyclone late on the $21^{\text {st }}$ and $22^{\text {nd }}$. The motion of the cyclone came to an almost standstill late on the $21^{\text {st }}$ into the $22^{\text {nd }}$ while located near the northern coast of Newfoundland. Late on the $22^{\text {nd }}$, Ione began to accelerate east-northeastward. Weakening below hurricane-force intensity occurred at $00 \mathrm{Z}$ on the $23^{\text {rd }}$. The system continued to weaken on the $24^{\text {th }}$ passing over eastern Iceland around $18 \mathrm{Z}$ and dissipating late on the next day near Jan Mayen Island. HURDAT originally dissipated the system after $00 \mathrm{Z}$ on the $24^{\text {th }}$, so an additional 42 hours is included now before dissipation after $18 \mathrm{Z}$ on the $25^{\text {th }}$.

Hurricane Hilda [September 11-20, 1955]

\begin{tabular}{|c|c|c|c|c|c|c|c|c|c|c|c|c|c|}
\hline $\begin{array}{l}38995 \\
38995\end{array}$ & $\begin{array}{c}09 / 10 / 1955 \\
09 / 11 / 1955 \\
* *\end{array}$ & $\begin{array}{l}M^{M}=1 \\
M=1\end{array}$ & $\begin{array}{l}1 \\
\text { * }\end{array}$ & $\begin{array}{l}\text { SNBR }=85 \\
\text { SNBR }=85\end{array}$ & $53 \mathrm{H}$ & $\begin{array}{l}\text { [LDA } \\
\text { [LDA }\end{array}$ & $\begin{array}{l}\text { XII } \\
\text { XII }\end{array}$ & $\begin{array}{l}N G=0 \\
N G=\odot\end{array}$ & $\begin{array}{l}\mathrm{SSS}= \\
\mathrm{SSS}=\end{array}$ & & & & \\
\hline $\begin{array}{l}390 \odot \odot \\
390 \odot \odot\end{array}$ & $\begin{array}{ll}09 / 10^{*} & \odot \\
09 / 10^{*} & \odot\end{array}$ & $\begin{array}{l}\odot \\
\odot\end{array}$ & $\begin{array}{l}\odot \\
\odot\end{array}$ & $\begin{array}{ll}\Theta^{*} & \odot \\
\Theta^{*} & \odot\end{array}$ & $\begin{array}{l}\odot \\
\odot\end{array}$ & $\begin{array}{l}\odot \\
\odot\end{array}$ & $\begin{array}{ll}\Theta^{*} & \odot \\
\Theta^{*} & \odot\end{array}$ & $\begin{array}{l}\odot \\
\odot\end{array}$ & $\begin{array}{l}0 \\
0\end{array}$ & $\begin{array}{l}\Theta^{*} 168 \\
\Theta^{*} \quad \odot \\
*\end{array}$ & $\begin{array}{r}613 \\
0 \\
*\end{array}$ & $\begin{array}{r}30 \\
0 \\
*\end{array}$ & $\begin{array}{l}\Theta^{*} \\
\Theta^{*}\end{array}$ \\
\hline $\begin{array}{l}39005 \\
39005\end{array}$ & $\begin{array}{l}09 / 11^{*} 174 \\
09 / 11^{*} \\
\end{array}$ & $\begin{array}{r}617 \\
0 \\
*\end{array}$ & $\begin{array}{r}30 \\
0 \\
*\end{array}$ & $\begin{array}{l}0 * 180 \\
0 * \quad 0 \\
0^{*}\end{array}$ & $\begin{array}{r}623 \\
0 \\
*\end{array}$ & $\begin{array}{r}30 \\
\odot \\
*\end{array}$ & $\begin{array}{r}\Theta^{*} 186 \\
\Theta^{*} \quad{ }^{*} \\
\\
*\end{array}$ & $\begin{array}{r}629 \\
0 \\
*\end{array}$ & $\begin{array}{r}35 \\
0 \\
*\end{array}$ & $\begin{array}{l}\odot * 189 \\
\odot * 189\end{array}$ & $\begin{array}{l}641 \\
652 \\
* * *\end{array}$ & $\begin{array}{l}40 \\
35 \\
* *\end{array}$ & $\begin{array}{l}\Theta^{*} \\
\Theta^{*}\end{array}$ \\
\hline $\begin{array}{l}39010 \\
39010\end{array}$ & $\begin{array}{l}09 / 12 * 192 \\
09 / 12 * 192\end{array}$ & $\begin{array}{l}656 \\
661 \\
\star \star *\end{array}$ & $\begin{array}{l}45 \\
40 \\
* *\end{array}$ & $\begin{array}{l}\text { ๑*195 } \\
\text { ๑*195 }\end{array}$ & $\begin{array}{l}668 \\
670 \\
* * *\end{array}$ & $\begin{array}{l}50 \\
45 \\
* *\end{array}$ & $\begin{array}{l}\odot * 198 \\
\text { ๑*198 }\end{array}$ & $\begin{array}{l}680 \\
680\end{array}$ & $\begin{array}{l}65 \\
55 \\
* *\end{array}$ & $\begin{array}{l}1007 \text { * } 201 \\
996 * 201 \\
* * *\end{array}$ & $\begin{array}{l}691 \\
691\end{array}$ & $\begin{array}{l}75 \\
65 \\
* *\end{array}$ & $\begin{array}{l}\Theta^{*} \\
\Theta^{*}\end{array}$ \\
\hline $\begin{array}{l}39015 \\
39015\end{array}$ & $\begin{array}{r}09 / 13^{*} 204 \\
09 / 13^{*} 203 \\
* * *\end{array}$ & $\begin{array}{l}702 \\
702\end{array}$ & $\begin{array}{l}80 \\
70 \\
* *\end{array}$ & $\begin{array}{r}\Theta * 204 \\
\Theta * 205 \\
* \star *\end{array}$ & $\begin{array}{l}713 \\
713\end{array}$ & $\begin{array}{l}85 \\
7 \odot \\
* *\end{array}$ & $\begin{array}{r}\Theta^{*} 203 \\
\Theta^{*} 204 \\
* \star *\end{array}$ & $\begin{array}{l}725 \\
725\end{array}$ & $\begin{array}{l}85 \\
70 \\
* *\end{array}$ & $\begin{array}{l}\odot * 2 \odot 2 \\
\odot * 2 \odot 2\end{array}$ & $\begin{array}{l}736 \\
736\end{array}$ & $\begin{array}{l}70 \\
70\end{array}$ & $\begin{array}{l}0^{*} \\
986^{*} \\
\star * *\end{array}$ \\
\hline $\begin{array}{l}39 \odot 20 \\
39 \odot 20\end{array}$ & $\begin{array}{l}09 / 14 * 201 \\
09 / 14 * 201\end{array}$ & $\begin{array}{l}747 \\
748 \\
\star * *\end{array}$ & $\begin{array}{l}65 \\
6 \odot \\
* *\end{array}$ & $\begin{array}{l}\odot * 201 \\
\odot * 201\end{array}$ & $\begin{array}{l}762 \\
762\end{array}$ & $\begin{array}{l}60 \\
55 \\
* *\end{array}$ & $\begin{array}{l}\odot^{*} 201 \\
\Theta^{*} 201\end{array}$ & $\begin{array}{l}777 \\
777\end{array}$ & $\begin{array}{l}60 \\
50 \\
* *\end{array}$ & $\begin{array}{l}\odot * 199 \\
\odot * 199\end{array}$ & $\begin{array}{l}792 \\
792\end{array}$ & $\begin{array}{l}65 \\
50 \\
* *\end{array}$ & $\begin{array}{l}\Theta^{*} \\
\Theta^{*}\end{array}$ \\
\hline $\begin{array}{l}39025 \\
39025\end{array}$ & $\begin{array}{r}09 / 15^{*} 196 \\
09 / 15 * 195 \\
* * *\end{array}$ & $\begin{array}{l}806 \\
806\end{array}$ & $\begin{array}{l}75 \\
6 \odot \\
* *\end{array}$ & $\begin{array}{r}0 * 194 \\
995 * 192 \\
* * * * * *\end{array}$ & $\begin{array}{l}821 \\
821\end{array}$ & $\begin{array}{l}85 \\
75 \\
* *\end{array}$ & $\begin{array}{r}\Theta^{*} 192 \\
\Theta^{*} 191 \\
* \star *\end{array}$ & $\begin{array}{l}834 \\
834\end{array}$ & $\begin{array}{l}9 \odot \\
9 \odot\end{array}$ & $\begin{array}{l}980^{*} 191 \\
980^{*} 191\end{array}$ & $\begin{array}{l}844 \\
844\end{array}$ & $\begin{array}{l}10 \odot \\
100\end{array}$ & $\begin{array}{l}\Theta^{*} \\
\Theta^{*}\end{array}$ \\
\hline $\begin{array}{l}39030 \\
39030\end{array}$ & $\begin{array}{l}09 / 16 * 192 \\
09 / 16 * 192\end{array}$ & $\begin{array}{l}854 \\
854\end{array}$ & $\begin{array}{l}100 \\
105 \\
* * *\end{array}$ & $\begin{array}{l}963 * 194 \\
963 * 194\end{array}$ & $\begin{array}{l}864 \\
864\end{array}$ & $\begin{array}{r}95 \\
105 \\
* * *\end{array}$ & $\begin{array}{l}\odot * 196 \\
\odot * 196\end{array}$ & $\begin{array}{l}874 \\
874\end{array}$ & $\begin{array}{r}95 \\
105 \\
* * *\end{array}$ & $\begin{array}{l}0 * 199 \\
0 * 199\end{array}$ & $\begin{array}{l}884 \\
884\end{array}$ & $\begin{array}{l}90 \\
75 \\
* *\end{array}$ & $\begin{array}{l}\Theta^{*} \\
\Theta^{*}\end{array}$ \\
\hline $\begin{array}{l}39035 \\
39035\end{array}$ & $\begin{array}{l}09 / 17 * 202 \\
09 / 17 * 202\end{array}$ & $\begin{array}{l}893 \\
893\end{array}$ & $\begin{array}{l}85 \\
55 \\
* *\end{array}$ & $\begin{array}{r}\theta^{*} 206 \\
0 * 205 \\
* \star *\end{array}$ & $\begin{array}{l}9 \odot 2 \\
9 \odot 2\end{array}$ & $\begin{array}{l}85 \\
50 \\
* *\end{array}$ & $\begin{array}{r}\Theta^{*} 209 \\
\Theta^{*} 208 \\
* \star \star\end{array}$ & $\begin{array}{l}910 \\
911 \\
* * *\end{array}$ & $\begin{array}{l}90 \\
55 \\
* *\end{array}$ & $\begin{array}{l}0 * 211 \\
0 * 210 \\
\star * *\end{array}$ & $\begin{array}{l}920 \\
920\end{array}$ & $\begin{array}{l}90 \\
65 \\
* *\end{array}$ & $\begin{array}{l}0^{*} \\
985^{*} \\
* * *\end{array}$ \\
\hline $\begin{array}{l}39040 \\
39040\end{array}$ & $\begin{array}{r}09 / 18 * 213 \\
09 / 18 * 211 \\
* * *\end{array}$ & $\begin{array}{l}929 \\
928 \\
* * *\end{array}$ & $\begin{array}{l}95 \\
75 \\
* *\end{array}$ & $\begin{array}{l}\Theta^{*} 214 \\
\Theta^{*} 213 \\
* * *\end{array}$ & $\begin{array}{l}936 \\
935 \\
* * *\end{array}$ & $\begin{array}{r}100 \\
80 \\
* *\end{array}$ & $\begin{array}{r}\Theta^{*} 216 \\
\Theta^{*} 215 \\
* * *\end{array}$ & $\begin{array}{l}942 \\
942\end{array}$ & $\begin{array}{r}105 \\
85 \\
* *\end{array}$ & $\begin{array}{l}\Theta^{*} 218 \\
970^{*} 218 \\
* * *\end{array}$ & $\begin{array}{l}950 \\
949 \\
* * *\end{array}$ & $\begin{array}{r}110 \\
95 \\
* *\end{array}$ & $\begin{array}{l}\Theta^{*} \\
\Theta^{*}\end{array}$ \\
\hline
\end{tabular}




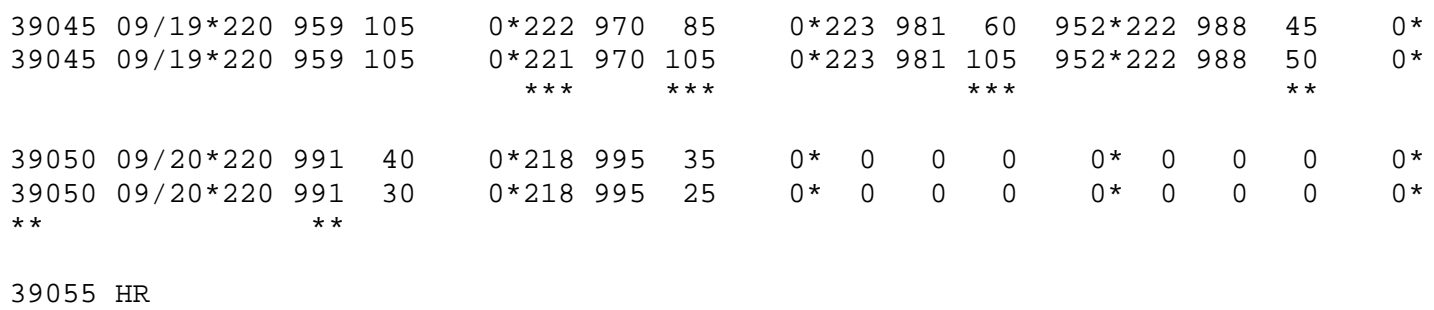

39055 HR

Evidence for these alterations comes from the NHC microfilm maps, the Historical Weather Maps series, the COADS ship database, Monthly Weather Review, Mexican synoptic maps, Perez et al., and the Navy aircraft reconnaissance book.

September 9:

HWM shows a spot low centered near $13.0 \mathrm{~N}, 64.0 \mathrm{~W}$ at $12 \mathrm{Z}$. HURDAT and Microfilm do not list an organized system on this date. MWR is not available on this date. Ship highlights: No gales or low pressures. "The synoptic analysis of the tropical regions to the east of the Lesser Antilles on the $9^{\text {th }}$ and $10^{\text {th }}$ of September indicated a moderately strong easterly flow in which were embedded two easterly waves approximately 1000 miles apart and believed to be of moderate intensity" (ATSR).

September 10:

HWM shows a spot low centered near $14.5 \mathrm{~N}, 64.0 \mathrm{~W}$ at 12Z. HURDAT lists a 30 kt tropical depression near $16.8 \mathrm{~N}, 61.3 \mathrm{~W}$ (first position) at 18Z. Microfilm does not show an organized system on this date. MWR is not available on this date. Ship highlights: No gales or low pressures.

September 11:

HWM shows a spot low centered near $16.0 \mathrm{~N}, 64.0 \mathrm{~W}$ at 12Z. HURDAT lists a 30 kt tropical depression near $18.6 \mathrm{~N}, 62.9 \mathrm{~W}$ at $12 \mathrm{Z}$. Microfilm shows a NE-SW extending tropical wave or trough across the Virgin Islands from $22 \mathrm{~N}, 61 \mathrm{~W}$ to $13 \mathrm{~N}, 67 \mathrm{~W}$ at $12 \mathrm{Z}$. MWR is not available on this date. Ship highlights: No gales or low pressures. "Easterly wave defined by shifting winds weather pattern and pressure pattern in vicinity of Saint Thomas oriented NNE-SSW, moderate rain with max wind $40 \mathrm{kt}$ " (micro). "The first of these waves was verified on the "time cross-section" as being of moderate intensity upon passing Guadaloupe Island at $110000 \mathrm{Z}$ and was labeled locally as "September \#1." As this wave moved westward, the development of a very weak vortex became evident at 110900Z. This vortex moved northward up in the wave increased in intensity slightly by $111830 Z$ was centered over Culebra Island" (ATSR).

September 12: 
HWM shows a tropical storm of at most $1005 \mathrm{mb}$ centered near $20.0 \mathrm{~N}, 67.4 \mathrm{~W}$ at 12Z. HURDAT lists a $65 \mathrm{kt}$ hurricane near $19.8 \mathrm{~N}, 68.0 \mathrm{~W}$ at $12 \mathrm{Z}$. Microfilm shows a closed low pressure of at most $1005 \mathrm{mb}$ near $20.0 \mathrm{~N}, 69.0 \mathrm{~W}$ at $12 \mathrm{Z}$. MWR shows a low pressure of $1000 \mathrm{mb}$ near $20.7 \mathrm{~N}, 67.9 \mathrm{~W}$ at 12Z. Ship highlights: $25 \mathrm{kt} \mathrm{S}$ and $1005 \mathrm{mb}$ at $19.7 \mathrm{~N}, 66.4 \mathrm{~W}$ at $06 \mathrm{Z}$ (COADS); $40 \mathrm{kt} \mathrm{ENE}$ at $20.3 \mathrm{~N}, 68.7 \mathrm{~W}$ at $1430 \mathrm{Z}$ (micro), and 996 mb near $20.3 \mathrm{~N}, 68.7 \mathrm{~W}$ at $1445 \mathrm{Z}$ (micro). Aircraft highlights: Penetration center fix measured a central pressure of $1007 \mathrm{mb}$ and an eye of a 50 mile diameter at $19.8 \mathrm{~N}$, 68.7W at 1345Z (ATSR/micro). "the Air Force reconnaissance flight on easterly wave "September \#1," at $121345 Z$ reported a "small" storm with an eye poorly defined centered at $19-48 \mathrm{~N} 68-42 \mathrm{~W}$ with maximum winds of 70 knots near the center and 40 knot winds extending 65 miles north of the center. The minimum pressure was $1007 \mathrm{mb}$ as determined by dropsonde" (ATSR).

September 13:

HWM shows a hurricane of at most $1010 \mathrm{mb}$ centered near $20.3 \mathrm{~N}, 72.1 \mathrm{~W}$ at $12 \mathrm{Z}$. HURDAT lists an $85 \mathrm{kt}$ hurricane near $20.3 \mathrm{~N}, 72.5 \mathrm{~W}$ at $12 \mathrm{Z}$. Microfilm shows a closed low pressure of at most $1011 \mathrm{mb}$ near $20.0 \mathrm{~N}, 73.0 \mathrm{~W}$ at $12 \mathrm{Z}$. MWR shows a low pressure of $996 \mathrm{mb}$ near $20.7 \mathrm{~N}, 72.5 \mathrm{~W}$ at 12Z. Ship highlights: $35 \mathrm{kt} \mathrm{E}$ and $1011 \mathrm{mb}$ at $21.0 \mathrm{~N}$, 68.2W at $0 \mathrm{Z}$ (micro). Land highlights: $40 \mathrm{kt} \mathrm{E}$ and $1014 \mathrm{mb}$ at Mayaguana, Bahamas at 12Z. Aircraft highlights: Penetration center fix measured a central pressure of $986 \mathrm{mb}$, maximum sustained winds of $85 \mathrm{kt}$, and an eye of a 20 mile diameter at $20.1 \mathrm{~N}, 73.7 \mathrm{~W}$ at $1737 \mathrm{Z}$ (ATSR/micro), and a penetration center fix at $20.0 \mathrm{~N}, 73.9 \mathrm{~W}$ at $1955 \mathrm{Z}$ (ATSR). “Sep 13-14, Category 1, 65 kt, landfall 9/13, deaths 4, damage \$2,000,000" (Perez et al.) "During the next 24 hours, "Hilda" moved west to west-northwest at 8 to 12 knots. The track paralleled Hispaniola at about 55 miles north of the eastern end of the island then dipped southwest to within 20 miles of the western end. The Navy low level penetration center fix at $131530 \mathrm{Z}$ reported a well-defined horseshoe shaped eye 20 miles in diameter. The minimum surface pressure had decreased to $986 \mathrm{mb}$ and the maximum winds were reported as 85 knots in a small area near the center. Severe turbulence and mountainous seas were reported near the center by the flight aerologist. Although the center of "Hilda" at this time was only approximately 25 miles from the western end of Hispaniola, little damage was reported because of the very small diameter of destructive winds of "Hurricane Hilda"” (ATSR).

September 14:

HWM shows a tropical storm of at most $1010 \mathrm{mb}$ centered near $20.8 \mathrm{~N}, 77.5 \mathrm{~W}$ at 12Z. HURDAT lists a $60 \mathrm{kt}$ tropical storm near $20.1 \mathrm{~N}, 77.7 \mathrm{~W}$ at $12 \mathrm{Z}$. Microfilm shows a closed low pressure of at most $1008 \mathrm{mb}$ near $19.7 \mathrm{~N}, 78.5 \mathrm{~W}$ at $12 \mathrm{Z}$. MWR shows a low pressure of $996 \mathrm{mb}$ near $20.4 \mathrm{~N}, 78.2 \mathrm{~W}$ at 12Z. Ship highlights: No gales or low 
pressures. Aircraft highlights: Radar center fix measured a central pressure of $1004 \mathrm{mb}$ and an eye of a 15 mile diameter at $20.1 \mathrm{~N}, 77.2 \mathrm{~W}$ at $1645 \mathrm{Z}$ (ATSR/micro). "The circulation aloft showed moderately strong easterly flow across the Bahamas Islands just north of the "small" circulation of "Hilda" at both the $700 \mathrm{mb}$ and $500 \mathrm{mb}$ level. The course of "Hilda" was, therefore, expected to continue nearly westward for the near future. In making a slight dip to the southwest, "Hilda" made transit through the Windward Passage and then encroached upon the eastern tip of Cuba passing approximately 15 miles north of Guantanamo Bay. In crossing southeastern Cuba at a speed of 14 knots, "Hilda" decreased in intensity to barely hurricane force in squalls, and also lost some of her characteristic cloud patterns. The small cyclonic circulation of "Hilda," being rather obscure in the strong easterly flow even caused considerable confusion to reconnaissance radar tracking crews as it moved west-southwest from Cape Cruz" (ATSR).

September 15:

HWM shows a hurricane of at most $1005 \mathrm{mb}$ centered near $19.5 \mathrm{~N}, 83.8 \mathrm{~W}$ at $12 \mathrm{Z}$. HURDAT lists a $90 \mathrm{kt}$ hurricane near 19.2N, 83.4W at 12Z. Microfilm shows a closed low pressure of at most $999 \mathrm{mb}$ near $19.0 \mathrm{~N}, 83.5 \mathrm{~W}$ at 12Z. MWR indicates the system was located near $19.0 \mathrm{~N}, 83.7 \mathrm{~W}$ at 12Z. Ship highlights: $20 \mathrm{kt} \mathrm{SSE}$ and $1004 \mathrm{mb}$ at $18.4 \mathrm{~N}$, $81.4 \mathrm{~W}$ at $12 \mathrm{Z}$ (micro), and $50 \mathrm{kt} \mathrm{N}$ and $1004 \mathrm{mb}$ at $19.5 \mathrm{~N}, 86.1 \mathrm{~W}$ at $21 \mathrm{Z}$ (micro). Land highlights: $48 \mathrm{kt} \mathrm{NNW}$ at Grand Cayman at 0230Z (micro), $5 \mathrm{kt} \mathrm{SSE}$ and $995 \mathrm{mb}$ at Grand Cayman after 0230Z (micro), $15 \mathrm{kt} \mathrm{W}$ and $1005 \mathrm{mb}$ at Swan Island at $12 \mathrm{Z}$ (micro), and $10 \mathrm{kt} \mathrm{S}$ and $1004 \mathrm{mb}$ at Swan Island at $21 \mathrm{Z}$ (micro). Aircraft highlights: Penetration center fix measured a central pressure of $980 \mathrm{mb}$ and an eye of a 8-10 mile diameter at $19.0 \mathrm{~N}, 83.5 \mathrm{~W}$ at $1130 \mathrm{Z}$ (ATSR/micro), penetration center fix at $19.1 \mathrm{~N}, 83.5 \mathrm{~W}$ at $12 \mathrm{Z}$ (ATSR), and penetration center fiz measured a central pressure of $963 \mathrm{mb}$ and an eye of a 9 mile diameter at $2230 \mathrm{Z}$ (ATSR/micro). "A slight increase in intensity was noted as "Hilda" moved over the open water of the Caribbean. The center passed directly over Grand Cayman Island at 050300Z, and a considerable increase in intensity was noted by the Navy reconnaissance flight establishing a center fix at 151200Z. The maximum winds had now reached 100 knots with the minimum surface pressure at $980 \mathrm{mb}$ " (ATSR).

September 16:

HWM shows a hurricane of at most $995 \mathrm{mb}$ centered near $20.0 \mathrm{~N}, 87.7 \mathrm{~W}$ at $12 \mathrm{Z}$. HURDAT lists a $95 \mathrm{kt}$ hurricane near 19.6N, 87.4W at 12Z. Microfilm shows a closed low pressure of at most $1002 \mathrm{mb}$ near $19.5 \mathrm{~N}, 87.5 \mathrm{~W}$ at $12 \mathrm{Z}$. MWR shows a low pressure of $988 \mathrm{mb}$ near $19.4 \mathrm{~N}, 87.5 \mathrm{~W}$ at 12Z. Ship highlights: $30 \mathrm{kt} \mathrm{E}$ and $993 \mathrm{mb}$ at $19.3 \mathrm{~N}$, $84.9 \mathrm{~W}$ at $00 \mathrm{Z}$ (micro); $10 \mathrm{kt} \mathrm{W}$ and $1005 \mathrm{mb}$ at $16.6 \mathrm{~N}, 86.9 \mathrm{~W}$ at $0 \mathrm{Z}$ (COADS), and $20 \mathrm{kt}$ SSW and $1004 \mathrm{mb}$ at 17.3N, 86.2W at 06Z (COADS). Land highlights: $5 \mathrm{kt} \mathrm{S}$ and 1004 
$\mathrm{mb}$ at Swan Island at $0 \mathrm{Z}$ (micro); $5 \mathrm{kt} \mathrm{SW}$ and $1005 \mathrm{mb}$ at Belize City at $12 \mathrm{Z}$ (micro), and $15 \mathrm{kt} \mathrm{SW}$ and $1003 \mathrm{mb}$ at Chetumal at $18 \mathrm{Z}$ (micro). "“Hilda" continued at the same intensity on westward at about 10 knots until entering the Yucatan Peninsula, then a slight decrease in intensity was observed while crossing the Yucatan Peninsula" (ATSR). September 17:

HWM shows a hurricane of at most $1000 \mathrm{mb}$ centered near $21.0 \mathrm{~N}, 91.1 \mathrm{~W}$ at $12 \mathrm{Z}$. HURDAT lists a $90 \mathrm{kt}$ hurricane near 20.9N, $91.0 \mathrm{~W}$ at 12Z. Microfilm shows a closed low pressure of at most $1002 \mathrm{mb}$ near $20.5 \mathrm{~N}, 91.5 \mathrm{~W}$ at $12 \mathrm{Z}$. MWR shows a low pressure of $992 \mathrm{mb}$ near $20.7 \mathrm{~N}, 91.1 \mathrm{~W}$ at 12Z. Ship highlights: $35 \mathrm{kt} \mathrm{E}$ and $1014 \mathrm{mb}$ at $23.5 \mathrm{~N}$, $91.5 \mathrm{~W}$ at $18 \mathrm{Z}$ (micro). Land highlights: $10 \mathrm{kt} \mathrm{SE}$ and $1000 \mathrm{mb}$ at Cozumel at $0 \mathrm{Z}$ (micro); $35 \mathrm{kt} \mathrm{NE}$ and $998 \mathrm{mb}$ at Merida at 03Z (micro); $25 \mathrm{kt} \mathrm{E}$ and $999 \mathrm{mb}$ at Merida at 06Z (micro); $40 \mathrm{kt} \mathrm{SSE}$ and $1001 \mathrm{mb}$ at Campeche at $12 \mathrm{Z}$ (micro), and $10 \mathrm{kt} \mathrm{S}$ and $1004 \mathrm{mb}$ at Ciudad del Carmen at 21Z (micro). Aircraft highlights: Penetration center fix measured a central pressure of $987 \mathrm{mb}$ and an eye of a 40 mile diameter at $21.0 \mathrm{~N}, 91.8 \mathrm{~W}$ at $1515 \mathrm{Z}$ (ATSR/micro), penetration center fix measured an eye of a 35 mile diameter at $21.0 \mathrm{~N}$, $92.0 \mathrm{~W}$ at $1630 \mathrm{Z}$ (ATSR/micro), penetration center fix at $21.0 \mathrm{~N}, 92.1 \mathrm{~W}$ at $1845 \mathrm{Z}$ (ATSR), and penetration center fix measured a central pressure of $982 \mathrm{mb}$ and an eye of a 30 mile diameter at $21.0 \mathrm{~N}, 89.6 \mathrm{~W}$ at $2045 \mathrm{Z}$ (ATSR/micro). "Upon moving out into the Gulf of Campeche on the $17^{\text {th }}$ of September, "Hilda" began increasing gradually to a maximum intensity of 100 knots in a small area near the center" (ATSR).

September 18:

HWM shows a hurricane of at most $990 \mathrm{mb}$ centered near $21.5 \mathrm{~N}, 94.5 \mathrm{~W}$ at $12 \mathrm{Z}$. HURDAT lists a $90 \mathrm{kt}$ hurricane near $21.6 \mathrm{~N}, 94.2 \mathrm{~W}$ at $12 \mathrm{Z}$. Microfilm shows a closed low pressure of at most $990 \mathrm{mb}$ near $21.5 \mathrm{~N}, 94.7 \mathrm{~W}$ at $12 \mathrm{Z}$. MWR shows a low pressure of $992 \mathrm{mb}$ near 21.5N, $94.8 \mathrm{~W}$ at 12Z. Ship highlights: No gales or low pressures. Aircraft highlights: Radar center fix at $20.8 \mathrm{~N}, 92.5 \mathrm{~W}$ at $0130 \mathrm{Z}$ (ATSR); radar center fix at $21.1 \mathrm{~N}$, $93.7 \mathrm{~W}$ at $0625 \mathrm{Z}$ (ATSR), and penetration center fix measured a central pressure of 970 $\mathrm{mb}$ and an eye of a 40 mile diameter at $21.6 \mathrm{~N}, 94.5 \mathrm{~W}$ at $1422 \mathrm{Z}$ (ATSR/micro).

September 19:

HWM shows a hurricane of at most $995 \mathrm{mb}$ centered near $22.0 \mathrm{~N}, 98.0 \mathrm{~W}$ at $12 \mathrm{Z}$. HURDAT lists a $60 \mathrm{kt}$ tropical storm near 22.3N, $98.1 \mathrm{~W}$ at 12Z. Microfilm shows a closed low pressure of at most $993 \mathrm{mb}$ near $22.3 \mathrm{~N}, 98.5 \mathrm{~W}$ at $12 \mathrm{Z}$. MWR shows a low pressure of $988 \mathrm{mb}$ near $22.5 \mathrm{~N}, 98.0 \mathrm{~W}$ at 12Z. Ship highlights: No gales or low pressures. Land highlights: $10 \mathrm{kt} \mathrm{NW}$ and $995 \mathrm{mb}$ at Tampico at 06Z (micro); calm and $952 \mathrm{mb}$ at Tampico (no time given but likely around 12Z) (MWR); $979 \mathrm{mb}$ at Ciudad Victoria at $1630 \mathrm{Z}$ (micro), and $15 \mathrm{kt} \mathrm{NE}$ and $998 \mathrm{mb}$ at Ciudad Victoria at $18 \mathrm{Z}$ (micro). 
"“Hilda" moved inland just north of Tampico and degenerated into an area of squalls in the Sierra Madre Oriental Mountains of Mexico" (ATSR).

September 20:

HWM shows a closed low pressure of at most $1005 \mathrm{mb}$ at $23.0 \mathrm{~N}, 102.0 \mathrm{~W}$ at $12 \mathrm{Z}$. HURDAT lists a $35 \mathrm{kt}$ tropical storm at $21.8 \mathrm{~N}, 99.8 \mathrm{~W}$ (last position) at 06Z. Microfilm shows a closed low pressure of at most $1008 \mathrm{mb}$ near $21.0 \mathrm{~N}, 99.0 \mathrm{~W}$ at $12 \mathrm{Z}$. MWR is not available on this date at $12 \mathrm{Z}$.

MWR: "Hilda formed in an easterly wave and reached hurricane intensity at Latitude $20.0 \mathrm{~N}$ and Longitude $69.1 \mathrm{~W}$ on the $12^{\text {th }}$. It remained very small with a very narrow ring of strong winds around the eye of several days. It passed over the southeastern tip of Cuba where 4 persons were killed and there was moderate damage. By 1730 EST on the $15^{\text {th }}$, in the northwestern Caribbean, the central pressure had dropped to $963 \mathrm{mb}(28.44$ inches). On the $16^{\text {th }}$, Hilda crossed the Yucatan peninsula midway between Chetumal and Cozumel, an area very sparsely populated. Hilda reached its greatest intensity in the Gulf of Campeche. The center moved inland early on the $19^{\text {th }}$ at Tampico which experienced calm for 45 minutes. The lowest pressure at Tampico was $952 \mathrm{mb}$ (28.11 inches). Highest wind recorded before anemometer blew away was $105 \mathrm{mph}$ and the maximum winds were estimated at $150 \mathrm{mph}$. Newspaper reports indicate 300 deaths and $\$ 120,000,000$ damage, largely from floods."

Genesis for this tropical cyclone has been delayed 24 hours to September $11^{\text {th }}$ at $18 \mathrm{Z}$ as a $35 \mathrm{kt}$ tropical storm. HURDAT originally had genesis at $18 \mathrm{Z}$ on the $10^{\text {th }}$ as a $30 \mathrm{kt}$ tropical depression. Delaying genesis is based on data from ships and land stations in and around the northeast Caribbean on the $10^{\text {th }}$ and $11^{\text {th }}$ of September that indicate that a closed low level circulation was not present until late on the $11^{\text {th }}$. Furthermore, a reconnaissance airplane late on the $11^{\text {th }}$ was unable to locate a closed low level circulation and found a tropical wave in the vicinity of longitude $65^{\circ} \mathrm{W}$. The basis to start the cyclone as a $35 \mathrm{kt}$ tropical storm is on a $40 \mathrm{kt}$ surface estimated report from the reconnaissance airplane at $19 \mathrm{Z}$ on the $11^{\text {th }}$ and a $30 \mathrm{kt}$ ship report at $18 \mathrm{Z}$. Hilda continued to intensify on the $12^{\text {th }}$ as it moved westward north of Puerto Rico and the Dominican Republic. A ship at $1430 \mathrm{Z}$ on the $12^{\text {th }}$ passed through the center of the storm measuring a central pressure of $996 \mathrm{mb}$ and 15 minutes later, measured sustained surface winds of force 9 or about $40 \mathrm{kt}$. A central pressure of $996 \mathrm{mb}$ yields $54 \mathrm{kt}$ according to Brown et al. southern pressure-wind relationship. Thus, an intensity of $55 \mathrm{kt}$ is analyzed for $12 \mathrm{Z}$ on the $12^{\text {th }}$, down from $65 \mathrm{kt}$ originally in HURDAT. A reconnaissance airplane reached Hilda at $1345 \mathrm{Z}$ measuring a central pressure reportedly of $1007 \mathrm{mb}$. It is likely that the dropsonde did not land in the center based on a couple ships around this time reporting lower pressures. Therefore, the central pressure of $1007 \mathrm{mb}$ originally in HURDAT at 
$12 \mathrm{Z}$ on the $12^{\text {th }}$ has been replaced by $996 \mathrm{mb}$ measured by the aforementioned ship. Hilda is analyzed to have reached hurricane intensity at $18 \mathrm{Z}$ on the $12^{\text {th }}, 6$ hours later than originally in HURDAT. At $1530 \mathrm{Z}$ on the $13^{\text {th }}$, a reconnaissance mission reported a central pressure of $986 \mathrm{mb}$ and an eye of a 20 mile diameter. A central pressure of 986 $\mathrm{mb}$ yields $70 \mathrm{kt}$ south of $25 \mathrm{~N}$, according to the pressure-wind relationship. A 20 mile diameter eye allows calculating roughly a $15 \mathrm{~nm}$ RMW and climatology suggests around $16 \mathrm{~nm}$. Thus, a $70 \mathrm{kt}$ intensity is analyzed at $18 \mathrm{Z}$ on the $13^{\text {th }}$, same as originally in HURDAT. A central pressure of $986 \mathrm{mb}$ has been added to 18Z. Hilda was a small cyclone and gale reports were sparse, but $40 \mathrm{kt}$ were measured in the SE Bahamas at $12 \mathrm{Z}$ on the $13^{\text {th }}$.

Hilda made its first landfall in eastern Cuba at $21 \mathrm{Z}$ on the $13^{\text {th }}$ near $20.2 \mathrm{~N}, 74.2 \mathrm{~W}$ with maximum sustained winds of $70 \mathrm{kt}$. This intensity is consistent with the Perez et al. assessment. The hurricane moved westward over the entire length of eastern Cuba, entering the waters of the Caribbean Sea around $11 \mathrm{Z}$ on the $14^{\text {th }}$. A reconnaissance aircraft on the $14^{\text {th }}$ had trouble locating the center of Hilda due to the mountainous terrain. The center locations from the reconnaissance aircraft are inconsistent with the reports from the land stations. The aircraft even reported a central pressure of $1004 \mathrm{mb}$ overland at $1645 \mathrm{Z}$ on the $14^{\text {th }}$ although the land station reports indicate that the storm was already over the Caribbean Sea. Because of the uncertainty, this information is not being used in the reanalysis. Hilda is analyzed to have weakened to a tropical storm at $0 \mathrm{Z}$ on the $14^{\text {th }}, 6$ hours before than originally in HURDAT. After moving over the Caribbean Sea, Hilda began to rapidly reorganize making landfall in the Cayman Islands $(19.3 \mathrm{~N}$, $81.2 \mathrm{~W})$ at $03 \mathrm{Z}$ on the $15^{\text {th }}$ as a $65 \mathrm{kt}$ hurricane. A central pressure of $995 \mathrm{mb}$ was measured in Grand Cayman. A central pressure of $995 \mathrm{mb}$ yields $56 \mathrm{kt} \mathrm{S} 25 \mathrm{~N}$ according to the pressure-wind relationship. A central pressure of $995 \mathrm{mb}$ has been added to $00 \mathrm{Z}$ on the $15^{\text {th }}$. A reconnaissance aircraft reached Hilda on the $15^{\text {th }}$ of September at $12 \mathrm{Z}$ measuring a central pressure of $980 \mathrm{mb}$, estimated surface winds of $90 \mathrm{kt}$, and an eye of an $8-10 \mathrm{~nm}$ diameter. A central pressure of $980 \mathrm{mb}$ yields $78 \mathrm{kt} \mathrm{S} 25 \mathrm{~N}$ according to the pressure-wind relationship. An 8-10 nm eye diameter allows calculating an RMW of about $7 \mathrm{~nm}$ and climatology suggests about $15 \mathrm{~nm}$. Thus, an intensity of $90 \mathrm{kt}$ has been selected for $12 \mathrm{Z}$ on the $15^{\text {th }}$, same as originally shown in HURDAT. An intensity of $60 \mathrm{kt}$ is selected at $00 \mathrm{Z}$, and $75 \mathrm{kt}$ at $06 \mathrm{Z}$. HURDAT originally showed $75 \mathrm{kt}$ at $00 \mathrm{Z}, 85 \mathrm{kt}$ at $06 \mathrm{Z}$, and $90 \mathrm{kt}$ at $12 \mathrm{Z}$. Another reconnaissance airplane reached Hilda on the $15^{\text {th }}$ at $2230 \mathrm{Z}$ measuring a central pressure of $963 \mathrm{mb}$ and an eye diameter of 9 miles. A central pressure of $963 \mathrm{mb}$ yields $98 \mathrm{kt} \mathrm{S} 25 \mathrm{~N}$, according to the pressure-wind relationship. A 9 mile eye diameter allows calculating an RMW of about $7 \mathrm{~nm}$ and climatology suggests about $14 \mathrm{~nm}$. Thus, an intensity of $105 \mathrm{kt}$ has been selected for $0 \mathrm{Z}$ on the $16^{\text {th }}$, up from $100 \mathrm{kt}$ originally in HURDAT. Hilda is analyzed to have reached major hurricane intensity at $18 \mathrm{Z}$ on the $15^{\text {th }}$, same as originally in HURDAT. Ships remained away from 
the hurricane and due to the small size of Hilda, no gales were reported on the $15^{\text {th }}$ and $16^{\text {th }}$ of September.

Over the northwest Caribbean, this cyclone moved west-northwest reaching the Yucatan eastern coast $(19.7 \mathrm{~N}, 87.7 \mathrm{~W})$ around $14 \mathrm{Z}$ with an intensity of $105 \mathrm{kt}$. HURDAT originally showed a decrease in intensity below major hurricane intensity before Hilda made landfall in Yucatan. There is no data to justify this weakening, and it is very likely that Hilda continued to intensify after the reconnaissance airplane left late on the $15^{\text {th }}$. The hurricane made landfall in a very sparsely populated area and no inner core data is available during its crossing of the Yucatan Peninsula. The Kaplan and DeMaria model was run for $18 \mathrm{Z}$ on the $16^{\text {th }}$, and $00 \mathrm{Z}$, and $06 \mathrm{Z}$ on the $17^{\text {th }}$ yielding $74 \mathrm{kt}, 51 \mathrm{kt}$ and $48 \mathrm{kt}$, respectively. An intensity of $75 \mathrm{kt}$ is selected for $18 \mathrm{Z}$ on the $16^{\text {th }}, 55 \mathrm{kt}$ at $00 \mathrm{Z}$ and $50 \mathrm{kt}$ at $06 \mathrm{Z}$ on the $17^{\text {th }}$ (down from $90 \mathrm{kt}, 65 \mathrm{kt}$ and $60 \mathrm{kt}$, respectively, originally in HURDAT), a major change at $00 \mathrm{Z}$ and $06 \mathrm{Z}$ on the $17^{\text {th }}$. Hilda entered the Gulf of Mexico around $08 \mathrm{Z}$ on the $17^{\text {th }}$ as a tropical storm. Two reconnaissance airplanes investigated the cyclone on the $17^{\text {th }}$, measuring a central pressure of $987 \mathrm{mb}$ at $1515 \mathrm{Z}$ and $982 \mathrm{mb}$ at 2045Z. Since the missions occurred at around three hours before and after 18Z, a central pressure of $985 \mathrm{mb}$ has been added to $18 \mathrm{Z}$ on the $17^{\text {th }}$. A central pressure of $985 \mathrm{mb}$ yields $71 \mathrm{kt}$ south of $25 \mathrm{~N}$ according to the pressure-wind relationship. The aircrafts also reported an eye diameter of $40 \mathrm{~nm}$ at $1515 \mathrm{Z}$ and $30 \mathrm{~nm}$ at 2045Z, which is larger than climatology suggests. Therefore, an intensity of $65 \mathrm{kt}$ is selected for $18 \mathrm{Z}$ on the $17^{\text {th }}$, bringing Hilda back to hurricane status for the $3^{\text {rd }}$ time. HURDAT originally showed 90 kt at $18 \mathrm{Z}$ on the $17^{\text {th }}$. Major downward changes were then made for all the intensities on the $17^{\text {th }}$.

Hilda continued to intensify on the $18^{\text {th }}$ while moving on a west-northwest heading over the southern Gulf of Mexico. At $1422 Z$ on September $18^{\text {th }}$, a reconnaissance aircraft reported a central pressure of $970 \mathrm{mb}$ and an eye of a 40 mile diameter. A central pressure of $970 \mathrm{mb}$ yields $90 \mathrm{kt}$ south of $25 \mathrm{~N}$ according to the pressure-wind relationship. A $40 \mathrm{~nm}$ diameter allows calculating an RMW of about $30 \mathrm{~nm}$ and climatology suggests near $15 \mathrm{~nm}$. Thus, an intensify of $85 \mathrm{kt}$ is selected for $12 \mathrm{Z}$ on the $18^{\text {th }}$, down from $105 \mathrm{kt}$ originally shown in HURDAT, a major change. A central pressure of $970 \mathrm{mb}$ has been added to $12 \mathrm{Z}$ on the $18^{\text {th }}$. Major downward changes are also introduced at $00 \mathrm{Z}$, and $06 \mathrm{Z}$. HURDAT originally showed $95 \mathrm{kt}$ and $100 \mathrm{kt}$, respectively, and our reanalysis shows 75 $\mathrm{kt}$ and $80 \mathrm{kt}$, respectively. Hilda made its $4^{\text {th }}$ and final landfall at $11 \mathrm{Z}$ on the $19^{\text {th }}$ near Tampico where a central pressure of $952 \mathrm{mb}$ was measured and MWR indicates that a calm was experienced for 45 minutes. A central pressure of $952 \mathrm{mb}$ yields $109 \mathrm{kt}$ south of $25 \mathrm{~N}$ and $111 \mathrm{kt}$ south of $25 \mathrm{~N}$ intensifying, according to the pressure-wind relationship. An intensity of $105 \mathrm{kt}$ is selected for $12 \mathrm{Z}$ on the $19^{\text {th }}$ due to the size of the hurricane. Major upward changes in intensity are analyzed at $06 Z$ and 12Z, as HURDAT originally 
showed $85 \mathrm{kt}$ and $60 \mathrm{kt}$, respectively. The cyclone is analyzed to have reached major hurricane intensity for a $2^{\text {nd }}$ time at $00 \mathrm{Z}$ on the $19^{\text {th }}, 18$ hours later than shown originally in HURDAT. There is no data to justify weakening Hilda before it makes landfall in Tamaulipas. After moving inland, Hilda weakened rapidly becoming a tropical depression at $0 \mathrm{Z}$ on the $20^{\text {th }}$ and dissipating after $06 \mathrm{Z}$. HURDAT originally kept Hilda as a $35 \mathrm{kt}$ tropical storm at the last position on September $20^{\text {th }}$ at $06 Z$.

New Tropical Storm [September 19-28, 1955]

\begin{tabular}{|c|c|c|c|c|c|c|}
\hline 265 & $09 / 19 / 19$ & $M=1 C$ & 10 & SNBR= & 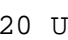 & ED \\
\hline 37265 & $09 / 19 *$ & $\odot$ & $\odot$ & $0 * 130$ & 200 & 30 \\
\hline 37265 & $09 / 20 * 130$ & 245 & 40 & $0 * 130$ & 260 & 40 \\
\hline 37265 & $09 / 21 * 133$ & 305 & 40 & $0 * 136$ & 320 & 40 \\
\hline 37265 & $09 / 22 * 149$ & 365 & 40 & ๑*156 & 380 & 40 \\
\hline 37265 & $09 / 23 * 183$ & 425 & 40 & ๑*192 & 440 & 40 \\
\hline 37265 & $09 / 24 * 211$ & 485 & 30 & $0 * 216$ & 503 & 30 \\
\hline 37265 & $09 / 25^{*} 241$ & 522 & 30 & ๑*256 & 526 & 30 \\
\hline 37265 & $09 / 26$ * 296 & 534 & 30 & $0 * 308$ & 535 & 30 \\
\hline 37265 & $09 / 27$ *342 & 515 & 40 & $0 * 354$ & 495 & 35 \\
\hline 3726 & $09 / 28 E 440$ & 410 & 45 & OE470 & 375 & 40 \\
\hline
\end{tabular}

\begin{tabular}{|c|c|c|c|c|c|c|}
\hline \multicolumn{7}{|c|}{$X I N G=0 \quad S S S=0$} \\
\hline ๑*130 & 215 & 35 & $0 * 130$ & 230 & 40 & ○* \\
\hline ๑*130 & 275 & 40 & $0 * 131$ & 290 & 40 & ○* \\
\hline ๑ *140 & 335 & 40 & $0 * 144$ & 350 & 40 & ○* \\
\hline ๑*165 & 395 & 40 & $0 * 174$ & 410 & 40 & ○* \\
\hline ๑* $20 \odot$ & 455 & 40 & ๑*206 & 470 & 35 & ○* \\
\hline ๑*220 & 510 & 30 & ๑*228 & 516 & 30 & ○* \\
\hline ๑*270 & 530 & 30 & ๑*283 & 532 & 30 & ○* \\
\hline ๑ *320 & 535 & 35 & $0 * 331$ & 530 & 40 & ○* \\
\hline ӘE370 & 470 & 35 & ○E4०5 & 455 & 45 & ○* \\
\hline E50० & 340 & 35 & ๑E535 & 300 & 30 & ๑* \\
\hline
\end{tabular}

A new tropical storm has been added to HURDAT, not previously shown in McAdie et al. (2009). Evidence for its existence comes from the Historical Weather Map series, Microfilm, Monthly Weather Reviews, COADS ship database, and Jack Beven's suspect list.

September 18:

HWM and microfilm do not analyze an organized system at 12Z. HURDAT and MWR do not list this system at 12Z. Ship highlights: No gale force winds or equivalent low pressures.

September 19:

HWM shows a closed low pressure of at most $1010 \mathrm{mb}$ at $14.0 \mathrm{~N}, 21.0 \mathrm{~W}$ at $12 \mathrm{Z}$. Microfilm does not analyze an organized system at 12Z. HURDAT and MWR do not list this system at 12Z. Ship highlights: $15 \mathrm{kt} \mathrm{NW}$ and $1004 \mathrm{mb}$ at $12.7 \mathrm{~N}, 24.0 \mathrm{~W}$ at $18 \mathrm{Z}$ (COADS).

September 20:

HWM shows a closed low pressure of at most $1010 \mathrm{mb}$ at $11.0 \mathrm{~N}, 25.0 \mathrm{~W}$ at $12 \mathrm{Z}$. Microfilm analyses a spot low pressure near $13.5 \mathrm{~N}, 28.5 \mathrm{~W}$ at 12Z. HURDAT and MWR do not list this system at $12 \mathrm{Z}$. Ship highlights: No gale force winds or equivalent low pressures. 
September 21:

HWM shows a closed low pressure of at most $1010 \mathrm{mb}$ at $12.0 \mathrm{~N}, 33.0 \mathrm{~W}$ at $12 \mathrm{Z}$. Microfilm does not analyze an organized system at 12Z. HURDAT and MWR do not list this system at 12Z. Ship highlights: No gale force winds or equivalent low pressures.

September 22:

HWM shows a closed low pressure of at most $1010 \mathrm{mb}$ at $14.5 \mathrm{~N}, 39.0 \mathrm{~W}$ at $12 \mathrm{Z}$. Microfilm does not analyze an organized system at 12Z. HURDAT and MWR do not list this system at 12Z. Ship highlights: No gale force winds or equivalent low pressures.

September 23:

HWM shows a closed low pressure of at most $1005 \mathrm{mb}$ at $19.5 \mathrm{~N}, 45.0 \mathrm{~W}$ at $12 \mathrm{Z}$. Microfilm analyses a closed low pressure of at most $1011 \mathrm{mb}$ at $20.0 \mathrm{~N}, 45.0 \mathrm{~W}$ at $12 \mathrm{Z}$. HURDAT and MWR do not list this system at 12Z. Ship highlights: No gale force winds or equivalent low pressures.

September 24:

HWM shows a closed low pressure of at most $1010 \mathrm{mb}$ at $21.5 \mathrm{~N}, 49.0 \mathrm{~W}$ at $12 \mathrm{Z}$. Microfilm does not analyze an organized system at 12Z. HURDAT and MWR do not list this system at 12Z. Ship highlights: No gale force winds or equivalent low pressures.

September 25:

HWM shows a spot low pressure near $26.0 \mathrm{~N}, 54.0 \mathrm{~W}$ with trough extending from 21-31N, 52-54W at 12Z. Microfilm analyses a closed low pressure of at most $1011 \mathrm{mb}$ at 29.0N, 54.0W at 18Z. HURDAT and MWR do not list this system at 12Z. Ship highlights: No gale force winds or equivalent low pressures.

September 26:

HWM shows a spot low pressure at $31.0 \mathrm{~N}, 53.0 \mathrm{~W}$ at $12 \mathrm{Z}$. Microfilm analyses a closed low pressure of at most $1014 \mathrm{mb}$ at $32.0 \mathrm{~N}, 54.0 \mathrm{~W}$ at $12 \mathrm{Z}$. HURDAT does not list this system at $12 \mathrm{Z}$. MWR analyses a low pressure of $1008 \mathrm{mb}$ at $31.8 \mathrm{~N}, 54.0 \mathrm{~W}$ at $12 \mathrm{Z}$. Ship highlights: $35 \mathrm{kt} \mathrm{SE}$ and $1015 \mathrm{mb}$ at $32.1 \mathrm{~N}, 52.0 \mathrm{~W}$ at $12 \mathrm{Z}$ (micro). $40 \mathrm{kt} \mathrm{SSE}$ and $1012 \mathrm{mb}$ at $33.0 \mathrm{~N}, 51.3 \mathrm{~W}$ at $18 \mathrm{Z}$ (micro).

September 27:

HWM shows a frontal boundary over the central north Atlantic extending from an extratropical cyclone near $60.0 \mathrm{~N}, 43.0 \mathrm{~W}$ at $12 \mathrm{Z}$. Microfilm analyses a closed low 
pressure of at most $1011 \mathrm{mb}$ at $38.0 \mathrm{~N}, 48.0 \mathrm{~W}$ and a frontal boundary extending through the system at $12 \mathrm{Z}$. HURDAT does not list this system at $12 \mathrm{Z}$. MWR analyses a low pressure of $1010 \mathrm{mb}$ at $37.5 \mathrm{~N}, 46.8 \mathrm{~W}$ at $12 \mathrm{Z}$. Ship highlights: $35 \mathrm{kt} \mathrm{SE}$ and $1016 \mathrm{mb}$ at $34.0 \mathrm{~N}, 49.6 \mathrm{~W}$ at $0 \mathrm{Z}$ (micro). $45 \mathrm{kt} \mathrm{NNW}$ and $1009 \mathrm{mb}$ at $40.3 \mathrm{~N}, 46.7 \mathrm{~W}$ at $18 \mathrm{Z}$ (micro).

September 28:

HWM shows a closed low pressure of at most $1010 \mathrm{mb}$ at $49.0 \mathrm{~N}, 36.0 \mathrm{~W}$ with a cold front extending through the system at $12 \mathrm{Z}$. Microfilm analyses a closed low pressure of at most $1011 \mathrm{mb}$ at $44.0 \mathrm{~N}, 37.0 \mathrm{~W}$ at $06 \mathrm{Z}$. HURDAT does not list this system at $12 \mathrm{Z}$. MWR analyses a low pressure of $1006 \mathrm{mb}$ at 50.7N, 33.8W at 12Z. Ship highlights: $35 \mathrm{kt}$ SW and $1008 \mathrm{mb}$ at $46.5 \mathrm{~N}, 36.5 \mathrm{~W}$ at $0 \mathrm{Z}$ (micro).

A tropical wave left the African coast on September 18 rapidly organizing into a tropical cyclone. Ship data at $18 \mathrm{Z}$ on the $19^{\text {th }}$ indicate that the cyclone had already reached tropical storm intensity. The ship 3098235 reported $15 \mathrm{kt} \mathrm{NW}$ and $1004 \mathrm{mb}$ at $12.7 \mathrm{~N}$, $24.0 \mathrm{~W}$. This is also a $5 \mathrm{mb}$ drop from 12Z. A peripheral pressure of $1004 \mathrm{mb}$ suggests maximum winds greater than $39 \mathrm{kt}$ south of $25 \mathrm{~N}$ from the Brown et al. pressure-wind relationship. An intensity of $40 \mathrm{kt}$ is selected for $18 \mathrm{Z}$ on the $19^{\text {th }}$. Genesis is begun on September $19^{\text {th }}$ at $06 \mathrm{Z}$ as a $30 \mathrm{kt}$ tropical depression. The cyclone is analyzed to have reached tropical storm intensity at $12 \mathrm{Z}$ on the $19^{\text {th }}$, six hours after genesis. Data becomes very sparse between September $20^{\text {th }}$ and $23^{\text {rd }}$. During this period, it is believed that the tropical storm moved on a general northwest course and the intensity is kept at $40 \mathrm{kt}$ based almost entirely upon persistence. The analyzed track agrees with the daily Historical Weather Maps, but the intensity is speculative and could in fact be much stronger or somewhat weaker.

Another ship passed close to the tropical cyclone on September $23^{\text {rd }}$ at $12 \mathrm{Z}$ reporting 30 $\mathrm{kt} \mathrm{ENE}$ and $1007 \mathrm{mb}$ at $21.2 \mathrm{~N}, 45.0 \mathrm{~W}$. Data on the $24^{\text {th }}$ indicate that the circulation was not well organized, and it is possible that the tropical cyclone had degenerated into a tropical wave. Therefore, the intensity is decreased to $30 \mathrm{kt}$ at $0 \mathrm{Z}$ on the $24^{\text {th }}$. At this time, a cold front was approaching and the system began to track toward the north. On the $25^{\text {th }}$, ship data shows that the system became better organized although no gale-force winds were reported, and the analyzed intensity is kept at $30 \mathrm{kt}$. On the $26^{\text {th }}$, the tropical depression turns to the northeast and begins to gain in forward speed. At $12 \mathrm{Z}$ on the $26^{\text {th }}$, the ship "Richelien" reported $35 \mathrm{kt} \mathrm{SE}$ and $1015 \mathrm{mb}$ at $32.1 \mathrm{~N}, 52.0 \mathrm{~W}$. At this time it is estimated that the tropical cyclone regained tropical storm intensity. The intensity is increased to $40 \mathrm{kt}$ at $18 \mathrm{Z}$ based on the report of the ship "GCTF" (40 kt SSE and 1012 $\mathrm{mb}) .40 \mathrm{kt}$ is also the estimated intensity at $0 \mathrm{Z}$ on the $27^{\text {th }}$ and it is the peak intensity for the lifetime of this tropical cyclone. Extratropical transition occurred around $12 \mathrm{Z}$ on the $27^{\text {th }}$ as the system continued to increase in forward speed over the north-central Atlantic. 
The system also strengthened as an extratropical cyclone reaching $45 \mathrm{kt}$ from $18 \mathrm{Z}$ on the $27^{\text {th }}$ to $06 \mathrm{Z}$ on the $28^{\text {th }}$. This is also the peak intensity as an extratropical storm.

Weakening occurred thereafter and the storm dissipated or was absorbed by a larger extratropical cyclone to the north late on the $28^{\text {th }}$ while located southeast of Iceland.

\section{Hurricane Janet [September 21-30, 1955]}

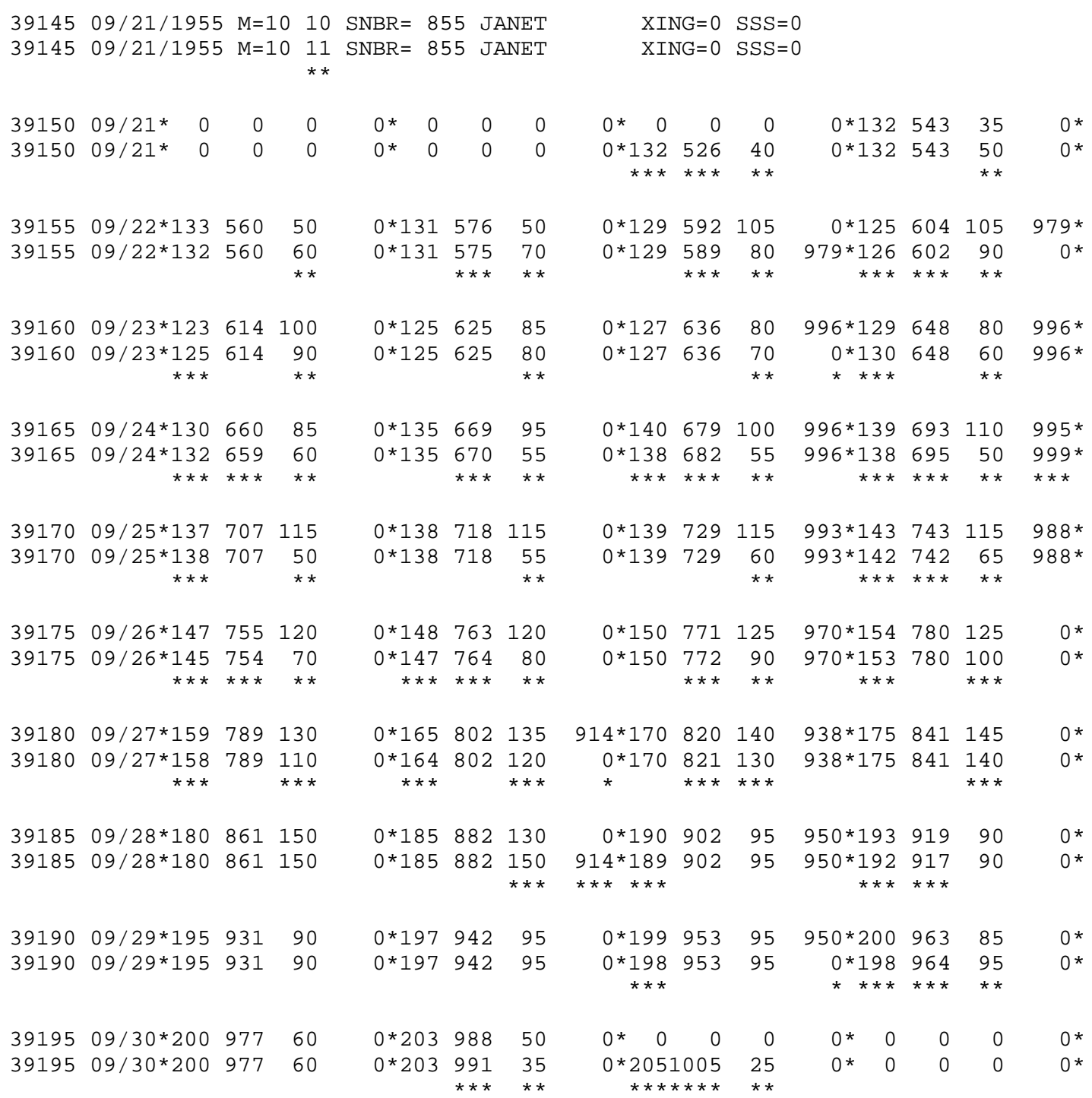

$39200 \mathrm{HR}$

Minor changes to the track and major changes to the intensity shown in McAdie et al. (2009). Evidence for these alterations comes from the NHC microfilm maps, the Historical Weather Maps series, the COADS ship database, Monthly Weather Review, Mexican synoptic maps and the Navy aircraft reconnaissance book. 
September 14:

HWM, microfilm and HURDAT does not show an organized system at $12 Z$. MWR is not available on this date. Ship highlights: No gales or low pressures.

September 15:

HWM analyzes a closed low pressure of at most $1010 \mathrm{mb}$ at $13.2 \mathrm{~N}, 22.3 \mathrm{~W}$ at 12Z. Microfilm and HURDAT does not show an organized system at $12 \mathrm{Z}$. MWR is not available on this date. Ship highlights: No gales or low pressures.

September 16:

HWM, microfilm and HURDAT does not show an organized system at $12 Z$. MWR is not available on this date. Ship highlights: No gales or low pressures.

September 17:

HWM, microfilm and HURDAT does not show an organized system at $12 Z$. MWR is not available on this date. Ship highlights: No gales or low pressures.

September 18:

HWM, microfilm and HURDAT does not show an organized system at $12 \mathrm{Z}$. MWR is not available on this date. Ship highlights: No gales or low pressures.

September 19:

HWM, microfilm and HURDAT does not show an organized system at $12 \mathrm{Z}$. MWR is not available on this date. Ship highlights: No gales or low pressures.

September 20:

HWM analyzes a closed low pressure of at most $1010 \mathrm{mb}$ centered near $12.0 \mathrm{~N}$, $51.5 \mathrm{~W}$ at $12 \mathrm{Z}$. Microfilm and HURDAT does not show an organized system. MWR is not available on this date. Ship highlights: No gales or low pressures.

September 21:

HWM shows a closed low pressure of at most $1010 \mathrm{mb}$ centered near $13.7 \mathrm{~N}$, $55.6 \mathrm{~W}$ at $12 \mathrm{Z}$. HURDAT lists this as a 35 knot tropical storm at $13.2 \mathrm{~N}, 54.3 \mathrm{~W}$ at $18 \mathrm{Z}$. Microfilm analyzes a closed low pressure of at most $1014 \mathrm{mb}$ centered near $15.5 \mathrm{~N}$, $55.3 \mathrm{~W}$ at 12Z. MWR is not available on this date. Ship highlights: $10 \mathrm{kt} \mathrm{W}$ and $1010 \mathrm{mb}$ at $11.9 \mathrm{~N}, 56.0 \mathrm{~W}$ at $12 \mathrm{Z} .10 \mathrm{kt}$ and $1009 \mathrm{mb}$ at $10.8 \mathrm{~N}, 54.5 \mathrm{~W}$ at $18 \mathrm{Z}$. All reports from COADS. MWR: "Early on the $21^{\text {st }}$, pilot reports from the airlines Air France and Iberia 
indicated the presence of a weak tropical disturbance at about latitude $13.5 \mathrm{~N}$ and longitude $53.0 \mathrm{~W} \ldots$ it is believed that Janet was just attaining hurricane intensity when encountered by the SS Mormacdale in latitude 13.6N and longitude 55.2W at 1900 EST on September 21 when it reported winds of 63 mph." ATSR: "Hurricane Janet," rightfully designated the "killer" hurricane of 1955, came into existence on September $22^{\text {nd }}$ about 200 miles east of the Lesser Antilles. Several days earlier, on the $18^{\text {th }}$, an easterly wave of weak to moderate intensity that was eventually to bear "Janet" passed over the ship ROBIN HOOD near 38W. During the next few days the easterly wave was tracked westward at 12.5 knots although hardly any reports were received to verify its existence or reveal its intensity. On the $21^{\text {st }}$, the ship SS DEL NORTE in the vicinity of $11 \mathrm{~N} 55 \mathrm{~W}$ reported a light west wind with surface pressures of $1010.2 \mathrm{mb}$ abd $1009.1 \mathrm{mb}$ at $1230 \mathrm{Z}$ and $1830 \mathrm{Z}$ respectively, thus verifying the easterly wave and revealing the development of a vortex, then estimated to be centered near 14N 55W."

September 22:

HWM shows a tropical storm of at most $1005 \mathrm{mb}$ centered near $14.1 \mathrm{~N}, 57.9 \mathrm{~W}$ at 12Z. HURDAT lists this as a $105 \mathrm{kt}$ hurricane at $12.9 \mathrm{~N}, 59.2 \mathrm{~W}$ at $12 \mathrm{Z}$. Microfilm analyzes a closed low pressure of at most $1005 \mathrm{mb}$ centered near $13.0 \mathrm{~N}, 59.0 \mathrm{~W}$ at $12 \mathrm{Z}$. MWR is not available on this date. Ship highlights: $55 \mathrm{kt} \mathrm{S}$ and $1003 \mathrm{mb}$ at $13.5 \mathrm{~N}, 55.3 \mathrm{~W}$ at $00 \mathrm{Z} .35 \mathrm{kt} \mathrm{W}$ and $998 \mathrm{mb}$ at $12.6 \mathrm{~N}, 56.1 \mathrm{~W}$ at $00 \mathrm{Z} .40 \mathrm{kt} \mathrm{W}$ and $1007 \mathrm{mb}$ at $11.5 \mathrm{~N}$, $62.0 \mathrm{~W}$ at 21Z. All reports from microfilm. Aircraft highlights: Penetration center fix measured a central pressure of $979 \mathrm{mb}$ at $12.8 \mathrm{~N}, 59.4 \mathrm{~W}$ at $1425 \mathrm{Z}$ (ATSR/MWR). Land highlights: $30 \mathrm{kt} \mathrm{N}$ (gusts to $50 \mathrm{kt}$ ) and $1003 \mathrm{mb}$ at Barbados at 15Z (micro). 85+ kt ESE (maybe estimated) and $989 \mathrm{mb}$ at Barbados around 1610Z (MWR). MWR: "The eye of hurricane Janet passed just south of the island of Barbados shortly after 1100 EST on the $22^{\text {nd }}$. It was an immature hurricane at this time with a very small ring of hurricane winds around the 20-mile eye. The reconnaissance plane reported the wall cloud around the eye only 5 miles wide but turbulence was very severe. Maximum winds were estimated by an observer on the south side of the island at 110 to $120 \mathrm{mph}$, dropping off very rapidly 20 miles out from the edge of the eye ... the hurricane was moving at $11 \mathrm{mph}$ at this time so it can be seen the ring of hurricane winds was very narrow. The lowest pressure reported by plane in the eye just to the south of the island was $979 \mathrm{mb}$. This was the first hurricane in Barbados in 57 years." ATSR: "Due to the lack of any other information, the vortex was believed to be only of moderate intensity, however, subsequent data from the ship SS MORMAC DALE at 220030Z, reporting south wind 50 to 55 knots and surface pressure of $1003.1 \mathrm{mb}$, confirmed the development of "Janet." Warning Number One was issued at $220200 \mathrm{Z}$ after coordination accomplished with the Weather Bureau Office at San Juan, Puerto Rico. Navy aircraft reconnoiter the storm area located a small but intense hurricane centered near Barbados islands. Surface winds were reported in excess of 100 
knots and the minimum surface pressure was reported as $979 \mathrm{mb}$. Further evidence of the severity of "Hurricane Janet" was exemplified by the wake of destruction left on Barbados Islands followed about 12 hours later with similar conditions wrought at Grenada Island.”

September 23:

HWM shows a hurricane of at most $1000 \mathrm{mb}$ centered near $12.8 \mathrm{~N}, 63.1 \mathrm{~W}$ at $12 \mathrm{Z}$. HURDAT lists this as an $80 \mathrm{kt}$ hurricane at $12.7 \mathrm{~N}, 63.6 \mathrm{~W}$ at $12 \mathrm{Z}$. Microfilm analyzes a closed low pressure of at most $996 \mathrm{mb}$ centered near $12.8 \mathrm{~N}, 64.5 \mathrm{~W}$ at $12 \mathrm{Z}$. MWR is not available on this date. Ship highlights: $30 \mathrm{kt} \mathrm{SW}$ and $1002 \mathrm{mb}$ at $12.5 \mathrm{~N}, 65.4 \mathrm{~W}$ at $18 \mathrm{Z}$ (micro). $20 \mathrm{kt} \mathrm{NW}$ and $1002 \mathrm{mb}$ at $13.5 \mathrm{~N}, 68.2 \mathrm{~W}$ at $20 \mathrm{Z}$ (micro). $25 \mathrm{kt} \mathrm{SW}$ and $1003 \mathrm{mb}$ at $12.2 \mathrm{~N}, 65.3 \mathrm{~W}$ at $21 \mathrm{Z}$ (micro). Aircraft highlights: Radar center fix measured an eye of a 25 mile diameter at $12.4 \mathrm{~N}, 62.1 \mathrm{~W}$ at $0454 \mathrm{Z}$ (ATSR/micro). Radar center fix measured an eye of a 45 mile diameter at $12.9 \mathrm{~N}, 63.1 \mathrm{~W}$ at $09 \mathrm{Z}$ (ATSR/micro). Radar center fix measured an eye of a 37 mile diameter near $12.5 \mathrm{~N}, 63.9 \mathrm{~W}$ at $1432 \mathrm{Z}$ (ATSR/micro). Penetration center fix measured a central pressure of $996 \mathrm{mb}$, maximum sustained winds of $80 \mathrm{kt}$ and an eye of a 40 mile diameter at $13.0 \mathrm{~N}, 64.7 \mathrm{~W}$ at $1815 \mathrm{Z}$ (ATSR/micro). Land highlights: $10 \mathrm{kt} \mathrm{NW}$ and $1004 \mathrm{mb}$ at $0 \mathrm{Z}$ at Grenada (micro). MWR: "During the next several days in the eastern Caribbean, Janet pursued a course generally toward the west with some actual decrease in intensity. The center was located at $3 \mathrm{pm}$ on September 23 at latitude $13.2 \mathrm{~N}$ and longitude $64.8 \mathrm{~W}$ with central pressure $996 \mathrm{mb}$ and wind $92 \mathrm{mph}$, radar eye 40 miles in diameter and wind eye 20 miles N-S, 27 E-W. Turbulence was moderate, sea high, no weather bands in northern semicircle but some in the southern semicircle." ATSR: "During "Janet's" transit across the Caribbean almost constant aircraft surveillance was maintained; therefore an accurate account was maintained of the movement and changing intensity of the storm. On a westward course describing a sinusoidal track, "Janet" moved at an average rate of speed of about 12 knots from Barbados Island to the $76^{\text {th }}$ Meridian."

September 24:

HWM shows a hurricane of at most $1000 \mathrm{mb}$ centered near $13.9 \mathrm{~N}, 68.4 \mathrm{~W}$ at $12 \mathrm{Z}$. HURDAT lists this as a $100 \mathrm{kt}$ hurricane at $14.0 \mathrm{~N}, 67.9 \mathrm{~W}$ at $12 \mathrm{Z}$. Microfilm analyzes a closed low pressure of at most $1005 \mathrm{mb}$ centered near $13.5 \mathrm{~N}, 69.1 \mathrm{~W}$ at $12 \mathrm{Z}$. MWR shows an area of low pressure of at most $996 \mathrm{mb}$ near $13.5 \mathrm{~N}, 68.7 \mathrm{~W}$ at $12 \mathrm{Z}$. Ship highlights: $15 \mathrm{kt} \mathrm{SW}$ and $1005 \mathrm{mb}$ at $11.5 \mathrm{~N}, 67.5 \mathrm{~W}$ at $06 \mathrm{Z}$ (micro). $35 \mathrm{kt} \mathrm{SE}$ and 1004 $\mathrm{mb}$ at $15.5 \mathrm{~N}, 69.2 \mathrm{~W}$ at $21 \mathrm{Z}$ (micro). Land highlights: Aircraft highlights: $30 \mathrm{kt} \mathrm{SW}$ and 1004 at Aruba at $18 \mathrm{Z}$ (micro). $15 \mathrm{kt} \mathrm{SW}$ and $1005 \mathrm{mb}$ at Curazao at $18 \mathrm{Z}$ (micro). $10 \mathrm{kt}$ SW and 1004 at Aruba at 21Z (micro). Penetration center fix measured a central pressure of $996 \mathrm{mb}$ and maximum sustained winds of $55 \mathrm{kt}$ at $14.0 \mathrm{~N}, 68.3 \mathrm{~W}$ at $1345 \mathrm{Z}$ (ATSR). 
Penetration center fix at $14.3 \mathrm{~N}, 68.6 \mathrm{~W}$ at $1454 \mathrm{Z}$ (ATSR). Penetration center fix measured a central pressure of $996 \mathrm{mb}$ and an eye of a 20 mile diameter at $14.1 \mathrm{~N}, 68.6 \mathrm{~W}$ at $1520 \mathrm{Z}$ (ATSR/micro). Penetration center fix measured a central pressure of $995 \mathrm{mb}$ and an eye of a 15-20 mile diameter at $14.3 \mathrm{~N}, 68.6 \mathrm{~W}$ at $1545 \mathrm{Z}$ (micro). Penetration center fix measured a central pressure of $999 \mathrm{mb}$ and maximum sustained winds of $100 \mathrm{kt}$ at $13.5 \mathrm{~N}$, $69.8 \mathrm{~W}$ at $1745 \mathrm{Z}$ (micro). Penetration center fix at $13.9 \mathrm{~N}, 68.7 \mathrm{~W}$ at $1645 \mathrm{Z}$ (ATSR). Penetration center fix at $13.8 \mathrm{~N}, 69.5 \mathrm{~W}$ at $1815 \mathrm{Z}$ (ATSR). Penetration center fix at $13.8 \mathrm{~N}$, $69.9 \mathrm{~W}$ at $2002 \mathrm{Z}$ (ATSR). MWR: "During the early hours on the $24^{\text {th }}$, according to the NAVY reconnaissance plane, Janet never presented good center definition and it is not certain the center was found. Weather targets consisted of large areas of diffuse targets with no spiral relationship. All center fixes were taken on strongest, most promising targets and the plane stated the fixes were of unknown accuracy. The radar bands were so disorganized, radar coverage was not considered feasible. Late in the afternoon, one very strong spiral weather band was found although the central pressure remained about the same. The reconnaissance plane reported: Eye centered Lat $13.8 \mathrm{~N}$ and Long $69.9 \mathrm{~W}$ at 3:02 pm EST circular eye with well defined cloud and wind eye approximately 20 miles in diameter. Minimum pressure $995 \mathrm{mb}$, maximum wind $127 \mathrm{mph}$... in weather band 40 miles from eye in southwest quadrant, wind shifted in weather band from 240 to 330 , band approximately 25 miles thick, section we went through showed up weakest on radar, maximum winds northwest through southwest $52 \mathrm{mph}$, turbulence light to none except in weather band where it was moderate to heavy, precipitation light to none, navigation good, radar coverage not considered feasible for eye positions, however, weather band to west presents good picture."

September 25:

HWM shows a hurricane of at most $1000 \mathrm{mb}$ centered near $13.9 \mathrm{~N}, 72.9 \mathrm{~W}$ at $12 \mathrm{Z}$. HURDAT lists this as a $115 \mathrm{kt}$ hurricane at $13.9 \mathrm{~N}, 72.9 \mathrm{~W}$ at $12 \mathrm{Z}$. Microfilm analyzes a closed low pressure of at most $996 \mathrm{mb}$ centered near 13.8N, 73.0W at 12Z. MWR shows an area of low pressure of at most $992 \mathrm{mb}$ near $13.9 \mathrm{~N}, 72.9 \mathrm{~W}$. Ship highlights: $30 \mathrm{kt} \mathrm{S}$ and $1005 \mathrm{mb}$ at $14.9 \mathrm{~N}, 69.5 \mathrm{~W}$ at $0 \mathrm{Z}$ (micro). $35 \mathrm{kt} \mathrm{ESE}$ and $1009 \mathrm{mb}$ at $14.5 \mathrm{~N}, 70.4 \mathrm{~W}$ at $18 \mathrm{Z}$ (ATSR). $25 \mathrm{kt} \mathrm{S}$ and $1005 \mathrm{mb}$ at $13.2 \mathrm{~N}, 74.0 \mathrm{~W}$ at $21 \mathrm{Z}$ (micro). Aircraft highlights: Penetration center fix at $13.9 \mathrm{~N}, 73.2 \mathrm{~W}$ at $1345 \mathrm{Z}$ (ATSR). Penetration center fix measured a central pressure of $988 \mathrm{mb}$, maximum sustained winds of $85 \mathrm{kt}$ and an eye of a 20 mile diameter at $14.3 \mathrm{~N}, 74.2 \mathrm{~W}$ at $19 \mathrm{Z}$ (ATSR/MWR/micro). MWR: "On the $25^{\text {th }}$ the eye was located at $1400 \mathrm{EST}$ at latitude $14.3 \mathrm{~N}$ and longitude $74.2 \mathrm{~W}$ with a maximum wind at 98 $\mathrm{mph}$, central pressure $987.7 \mathrm{mb}$. The eye was described as well defined but there was evidence it was very changeable - hoop-shaped on one occasion, a figure " 6 " on another. One obtains the impression of a slowly but definitely intensifying storm. The reconnaissance flight on the night of September 25-26 summarizes its observations as 
follows: Eye completely closed circle after 9:15 pm, average diameter 22 miles, storm presented symmetrical pattern of intense weather bands which extended 120 miles south, 140 east, 130 north and 170 west, high overcast throughout area, low scattered to broken stratocumulus with tops near 6000, thunderstorms generally oriental in spiral bands throughout area, frequent lighting. Rapid intensification was evident." "For the next 150 miles "Janet" moved at a slower speed of 9 knots,this was followed by gradual acceleration to 17 knots at the $80^{\text {th }}$ meridian and 20 knots at the $86^{\text {th }}$ meridian."

September 26:

HWM shows a hurricane of at most $995 \mathrm{mb}$ centered near $14.7 \mathrm{~N}, 76.5 \mathrm{~W}$ at $12 \mathrm{Z}$. HURDAT lists this as a $125 \mathrm{kt}$ hurricane at $15.0 \mathrm{~N}, 77.1 \mathrm{~W}$ at $12 \mathrm{Z}$. Microfilm analyzes a closed low pressure of at most $999 \mathrm{mb}$ centered near $14.6 \mathrm{~N}, 77.2 \mathrm{~W}$ at $12 \mathrm{Z}$. MWR is not available on this date. Ship highlights: $40 \mathrm{kt} \mathrm{SW}$ and $1004 \mathrm{mb}$ at $13.1 \mathrm{~N}, 78.1 \mathrm{~W}$ at $6 \mathrm{Z}$ (micro). $35 \mathrm{kt} \mathrm{ESE}$ and $1008 \mathrm{mb}$ at $17.6 \mathrm{~N}, 77.7 \mathrm{~W}$ at $18 \mathrm{Z}$ (micro). $40 \mathrm{kt}$ ESE and 1008 $\mathrm{mb}$ at $17.4 \mathrm{~N}, 77.5 \mathrm{~W}$ at $21 \mathrm{Z}$ (micro). Aircraft highlights: Radar center fix at $14.3 \mathrm{~N}$, $76.3 \mathrm{~W}$ at $0115 \mathrm{Z}$ (ATSR). Radar center fix measured an eye of a 25 mile diameter at $14.6 \mathrm{~N}, 76.6 \mathrm{~W}$ at $0615 \mathrm{Z}$ (ATSR/micro). Radar center fix measured an eye of a 22 mile diameter at $14.7 \mathrm{~N}, 76.3 \mathrm{~W}$ AT $09 \mathrm{Z}$ (ATSR/micro). Radar center fix at $14.8 \mathrm{~N}, 77.1 \mathrm{~W}$ at $12 \mathrm{Z}$ (ATSR). Radar center fix at 15.2N, 78.8W at 22Z (ATSR). MWR: "At 0830 EST of the $26^{\text {th }}$, Lt. Comdr. Windham with crew of 8 and 2 newspapermen reported in latitude $15.4 \mathrm{~N}$ and longitude $78.2 \mathrm{~W}$ that they were about to begin penetration of the main core of the storm. No further report was ever received from this plane. Janet had become a very severe hurricane."

September 27:

HWM shows a hurricane of at most $995 \mathrm{mb}$ centered near $16.5 \mathrm{~N}, 81.5 \mathrm{~W}$ at $12 \mathrm{Z}$. HURDAT lists this as a $140 \mathrm{kt}$ hurricane at $17.0 \mathrm{~N}, 82.0 \mathrm{~W}$ at $12 \mathrm{Z}$. Microfilm analyzes a closed low pressure of at most $996 \mathrm{mb}$ centered near $16.8 \mathrm{~N}, 82.5 \mathrm{~W}$ at $12 \mathrm{Z}$. MWR is not available on this date. Ship highlights: $40 \mathrm{kt} \mathrm{ESE}$ and $1008 \mathrm{mb}$ at $17.5 \mathrm{~N}, 77.3 \mathrm{~W}$ at $0 \mathrm{Z}$ (micro). $50 \mathrm{kt} \mathrm{NE}$ and $1001 \mathrm{mb}$ at $18.0 \mathrm{~N}, 81.0 \mathrm{~W}$ at $09 \mathrm{Z}$ (micro). $50 \mathrm{kt} \mathrm{S}$ at $16.6 \mathrm{~N}, 81.8 \mathrm{~W}$ at $12 \mathrm{Z}$ (micro). $50 \mathrm{kt} \mathrm{ENE}$ and $1001 \mathrm{mb}$ at $18.0 \mathrm{~N}, 80.8 \mathrm{~W}$ at $18 \mathrm{Z}$ (ATSR). Land highlight: $10 \mathrm{kt} \mathrm{SW}$ and $1003 \mathrm{mb}$ at Cabo Gracias a Dios at 12Z (micro). $30 \mathrm{kt} \mathrm{N}$ and $1000 \mathrm{mb}$ at Swan Island at $15 \mathrm{Z}$ (micro). $15 \mathrm{kt} \mathrm{SW}$ and $1004 \mathrm{mb}$ at Cabo Gracias a Dios at $18 \mathrm{Z}$ (micro). Aircraft highlight: Radar center fix at $15.6 \mathrm{~N}, 78.8 \mathrm{~W}$ at $01 \mathrm{Z}$ (ATSR). Radar center fix at $16.5 \mathrm{~N}, 80.2 \mathrm{~W}$ at $0630 \mathrm{Z}$ (ATSR). Radar center fix at $16.9 \mathrm{~N}, 82.8 \mathrm{~W}$ at $13 \mathrm{Z}$ (ATSR). Penetration center fix measured a central pressure of $938 \mathrm{mb}$ at $16.9 \mathrm{~N}, 82.7 \mathrm{~W}$ at $1540 \mathrm{Z}$ (ATSR/MWR). Penetration center fix at $17.0 \mathrm{~N}, 82.7 \mathrm{~W}$ at $1615 \mathrm{Z}$ (ATSR). MWR: "The NAVY reconnaissance plane at $1040 \mathrm{EST}$ on the $27^{\text {th }}$ reported the center at latitude $16.9 \mathrm{~N}$ and longitude $82.7 \mathrm{~W}$ with lowest pressure $938 \mathrm{mb}$, and maximum winds in excess 
of $115 \mathrm{mph}$ by a large and incalculable amount. Janet passed over Swan Island during midday with winds estimated at $200 \mathrm{mph} . "$

September 28:

HWM shows a hurricane of at most $990 \mathrm{mb}$ centered near $19.2 \mathrm{~N}, 89.6 \mathrm{~W}$ at $12 \mathrm{Z}$. HURDAT lists this as a $95 \mathrm{kt}$ hurricane at $19.0 \mathrm{~N}, 90.2 \mathrm{~W}$ at $12 \mathrm{Z}$. Microfilm analyzes a closed low pressure of at most $993 \mathrm{mb}$ centered near $19.4 \mathrm{~N}, 90.3 \mathrm{~W}$ at $12 \mathrm{Z}$. MWR is not available on this date. Ship highlights: $20 \mathrm{kt} \mathrm{WSW}$ and $1003 \mathrm{mb}$ at $16.5 \mathrm{~N}, 87.5 \mathrm{~W}$ at $0 \mathrm{Z}$ (micro). Land highlights: $25 \mathrm{kt} \mathrm{SW}$ and $1002 \mathrm{mb}$ at Belize City at 03Z (micro). $994 \mathrm{mb}$ at Corozal at 04Z (MWR). $50 \mathrm{kt} \mathrm{SW}$ and $994 \mathrm{mb}$ at Belize City at 6Z (micro). $152 \mathrm{kt}$ (before collapsing) and $914 \mathrm{mb}$ (southern edge of the eye) at Chetumal (no time given but likely around 06Z) (MWR). $918 \mathrm{mb}$ at $0610 \mathrm{Z}$ at Corozal (MWR). $55 \mathrm{kt} \mathrm{S}$ and $998 \mathrm{mb}$ at Belize City at $09 \mathrm{Z}$ (micro). $40 \mathrm{kt} \mathrm{N}$ (gusts to $70 \mathrm{kt}$ ) and $1009 \mathrm{mb}$ at Campeche, Mexico at 12Z (micro). $10 \mathrm{kt} \mathrm{WSW}$ and $990 \mathrm{mb}$ at Ciudad del Carmen at 18Z (micro). Aircraft highlights: Radar center fix measured an eye of a 10 mile diameter at $19.0 \mathrm{~N}, 91.9 \mathrm{~W}$ at 1945Z (ATSR/micro). MWR: "The hurricane center reached Corozal, British Honduras, and Chetumal, Mexico, about 1 am, local time, September 28. It was still a very concentrated storm with winds reaching hurricane force only about 2 hours before the arrival of the eye. In Corozal the barometer read 29.34 inches [994 mb] at 2300 EST and 27.10 inches [918 mb] at 0110 EST, falling 2.24 inches in 2 hours and 10 minutes with most of the fall occurring after 2330 EST. The official minimum barometer reading in Corozal was 27.10 inches [918 mb] (aneroid) and another aneroid in the house of a clergyman read 27.05 inches [916 mb]. In Chetumal the radio operator of the Mexican Aviation Company read $920.1 \mathrm{mb}$ (27.17 inches) on the mercurial barometer some minutes before the eye arrived. The original barograph trace (fig. 6) at Chetumal was furnisged vy Mr. S.B Lizama Frias, Flight Dispatch Superintendent, CIA, Mexicana de Aviation, S.A. The pen passed off the trace at 27.94 inches. A barometer reading of 27.00 inches $[914 \mathrm{mb}]$ in the eye at Chetumal was forwarded by Mr. D.N.A. Fairweather, the meteorological observer at Corozal. Corozal was in the southern edge of the eye and since the eye passed directly over Chetumal, it is believed the reading of 27.00 inches can be accepted. Therefore on the inset in figure 6 we have constructed a continuation of the trace below 28.00 inches based on this reading and the length of the period of calm at Chetumal. The anemometer at the airport terminal building at Chetumal registered 152 knots or $175 \mathrm{mph}$ before it collapsed. The wind continued to increase and the maximum is estimated in excess of $200 \mathrm{mph}$. In British Honduras 16 persons were killed and total damage is estimated at about $\$ 5,000,000$. In Chetumal, a town of about 2,500 people, only 4 badly battered buildings were left standing. Sea water reached a height of $6 \frac{1}{2}$ feet some 1,600 feet inland. The area is rather well protected from the Caribbean Sea by a sizable peninsula but there was one report of a hurricane wave south of Corozal. In 
Chetumal approximately 120 bodies were found in and about the ruins but the sea dragged away an unknown number. Altogether in the Mexican state of Quintana Roo, the death toll is estimated at about 500 with $\$ 40,000,000$ damage." "“Janet" maintained this fast rate of movement even in crossing the Yucatan Peninsula. This speed was a result of the intensification of the subtropical ridge over the Gulf of Mexico and southeastern United States."

September 29:

HWM shows a hurricane of at most $1000 \mathrm{mb}$ centered near $20.2 \mathrm{~N}, 95.5 \mathrm{~W}$ at $12 \mathrm{Z}$. HURDAT lists this as a $95 \mathrm{kt}$ hurricane at $19.9 \mathrm{~N}, 95.3 \mathrm{~W}$ at $12 \mathrm{Z}$. Microfilm analyzes a closed low pressure of at most $990 \mathrm{mb}$ centered near $20.0 \mathrm{~N}, 94.5 \mathrm{~W}$ at $12 \mathrm{Z}$. MWR is not available on this date. Ship highlights: $30 \mathrm{ENE}$ and $1007 \mathrm{mb}$ at $0 \mathrm{Z}$ near $23.8 \mathrm{~N}, 93.0 \mathrm{~W}$. Land highlights: $15 \mathrm{SSW}$ and $999 \mathrm{mb}$ at Coatzacoalcos, Mexico at 12Z (micro). Aircraft highlights: Radar center fix near 19.8N, 96.4W at 1745Z (ATSR). ATSR: "After "Janet" moved in to the Gulf of Campeche the circulation became distorted and partially disrupted by the surrounding land masses. This being an area of sparse upper air reports it is difficult to say why "Janet" decelerated to 14 knots and finally to 8 knots before entering the coast of Mexico."

September 30:

HWM and Microfilm does not show an organized system at 12Z. HURDAT lists this as a $50 \mathrm{kt}$ tropical storm at $20.3 \mathrm{~N}, 98.8 \mathrm{~W}$ at $6 \mathrm{Z}$ (last position). MWR is not available on this date. Land highlights: $10 \mathrm{kt} \mathrm{E}$ and $1002 \mathrm{mb}$ at Veracruz at $0 \mathrm{Z}$ (micro). $10 \mathrm{kt} \mathrm{SW}$ and $1004 \mathrm{mb}$ at Mexico City at $06 \mathrm{Z}$ (micro).

MWR: "Hurricane Janet passed into the Gulf of Campeche and moved inland between Veracruz and Nautla. The circulation aloft continued its westward movement across Mexico and a squally disturbed area developed off the west coast of Mexico under this circulation late on the first of October. Floods were already occurring in the Tampico area from the rains of Gladys and Hilda when the torrential rains of this hurricane were added. Little information is available on fatalities and damage which should be attributed to Janet in this area, but according to the Weather Bureau Office at New Orleans, the floods in the Tampico area from the tropical storms of 1955 were probably one of the greatest natural disasters ever to occur in that country."

Hurricane Janet developed from a tropical wave that left the African coast around midSeptember. The tropical wave traveled westward organizing into a tropical cyclone east of the Lesser Antilles. The time of genesis is uncertain as data east of $55 \mathrm{~W}$ is very sparse and by the time Janet was detected on September $21^{\text {st }}$, it was already a well-organized tropical storm. The data at $12 \mathrm{Z}$ on the $21^{\text {st }}$ does suggest that a well-defined center was 
present and this is the first entry into HURDAT (not genesis) of our analysis, six hours earlier than originally in HURDAT. At $0 \mathrm{Z}$ on the $22^{\text {nd }}$, two separate ships reported galeforce winds and pressures below $1005 \mathrm{mb}$. The ship Mormac Dale located at 13.5N, $55.3 \mathrm{~W}$ reported sustained winds of $55 \mathrm{kt} \mathrm{S}$ and $1003 \mathrm{mb}$, while another ship near $12.6 \mathrm{~N}$, $56.1 \mathrm{~W}$ reported $35 \mathrm{kt} \mathrm{W}$ and $998 \mathrm{mb}$. A peripheral pressure of $998 \mathrm{mb}$ suggests maximum sustained winds greater than $51 \mathrm{kt}$ from the south of $25 \mathrm{~N}$ Brown et al. pressure-wind relationship. An intensity of $60 \mathrm{kt}$ is selected for $0 \mathrm{Z}$ on September $22^{\text {nd }}$, a minor upward change from original HURDAT. Also, an intensity of $40 \mathrm{kt}$ is selected for $12 \mathrm{Z}$ and $50 \mathrm{kt}$ for $18 \mathrm{Z}$ on the $21^{\text {st }}$, the latter is a minor change as originally HURDAT had $35 \mathrm{kt}$. Janet approached Barbados late on the $22^{\text {nd }}$ passing just south of the island. Winds over $100 \mathrm{mph}$ (possibly an estimate) were reported by an observer on the island. An aircraft reconnaissance mission reached Janet at $1425 \mathrm{Z}$ measuring a central pressure of $979 \mathrm{mb}$. A central pressure of $979 \mathrm{mb}$ suggests maximum sustained winds of $79 \mathrm{kt}$ the south of pressure-wind relationship. At this point Janet was a small hurricane, with a RMW of about $8 \mathrm{nmi}$ and climatology suggests about $12 \mathrm{nmi}$. Therefore, an intensify of $80 \mathrm{kt}$ is selected for $12 \mathrm{Z}$ on the $22^{\text {nd }}$ and $90 \mathrm{kt}$ at $18 \mathrm{Z}$, down from $105 \mathrm{kt}$ at both times originally in HURDAT. Janet did not make landfall in Barbados but category 1 force winds, and possibly category 2 force winds, did impact the island causing significant damage to houses and other structures.

The hurricane continued on a west-southwest path toward the Lesser Antilles maintaining $90 \mathrm{kt}$ winds at $00 \mathrm{Z}$ on the $23^{\text {rd }}$. Around this time, the center of Janet moved over Grenada also causing significant damage to the Caribbean nation. Weakening began thereafter as Janet began to move west and west-northwest over the eastern Caribbean. A reconnaissance aircraft reached the cyclone at $1815 \mathrm{Z}$ on the $23^{\text {rd }}$ measuring a central pressure of $996 \mathrm{mb}$, estimated maximum surface winds of $80 \mathrm{kt}$, and an eye diameter of $40 \mathrm{~nm}$. A central pressure of $996 \mathrm{mb}$ yields maximum sustained winds of $54 \mathrm{kt}$ south of $25 \mathrm{~N}$ according to the south of $25 \mathrm{~N}$ pressure-wind relationship. The large eye diameter suggests an RMW of $\sim 30 \mathrm{~nm}$ compared with climatology of $\sim 13 \mathrm{~nm}$, which would usually indicate winds weaker than that from the pressure-wind relationship. Putting some weight on the visual estimate of the winds, an intensity of $60 \mathrm{kt}$ is selected for $18 \mathrm{Z}$ on the $23^{\text {rd }}$. This is a major change as originally HURDAT indicated $80 \mathrm{kt}$ at this time. A central pressure of $996 \mathrm{mb}$ was originally in HURDAT at $12 \mathrm{Z}$ on the $23^{\text {rd }}$ but it has been removed as there is no evidence that it was an actual measurement and that the cyclone substantially filling during the day, not steady state. The shipping presence was scarce over the southeast Caribbean as Janet moved across the area. Around mid-day on the $24^{\text {th }}$, the tropical storm passed about $80 \mathrm{nmi}$ north of the $\mathrm{ABC}$ islands. It is possible that tropical storm force winds on the southern portion of the circulation affected the islands. At 1345Z, a reconnaissance aircraft reached the cyclone measuring a central pressure of $996 \mathrm{mb}$ and estimated maximum surface winds of $55 \mathrm{kt}$. As stated before, a central 
pressure of $996 \mathrm{mb}$ yields $54 \mathrm{kt}$ according to the south of $25 \mathrm{~N}$ pressure-wind relationship. An intensity of $55 \mathrm{kt}$ is selected for $12 \mathrm{Z}$ on the $24^{\text {th }}$, a major change from $100 \mathrm{kt}$ originally in HURDAT. $60 \mathrm{kt}$ is selected for $00 \mathrm{Z}$ and $55 \mathrm{kt}$ for $06 \mathrm{Z}$ on the $24^{\text {th }}$, both major changes to HURDAT ( $85 \mathrm{kt}$ and $95 \mathrm{kt}$, respectively). Another reconnaissance mission reached the storm at $1520 \mathrm{Z}$ measuring a central pressure of $996 \mathrm{mb}$, estimated maximum surface of $45 \mathrm{kt}$ and an eye diameter of $20 \mathrm{~nm}$. At 1745Z, the last aircraft mission for the day reported a central pressure of $999 \mathrm{mb}$ and estimated maximum surface winds of $100 \mathrm{kt}$. A central pressure of $999 \mathrm{mb}$ suggests maximum sustained winds of $49 \mathrm{kt}$ according to the south of $25 \mathrm{~N}$ pressure-wind relationship. An intensity of $50 \mathrm{kt}$ is selected for $18 \mathrm{Z}$ on the $24^{\text {th }}$, a major change as originally HURDAT indicated $110 \mathrm{kt}$. A central pressure of $999 \mathrm{mb}$ is added to $18 \mathrm{Z}$ on the $24^{\text {th }}$, replacing the existing $995 \mathrm{mb}$.

On September $25^{\text {th }}$, Janet was moving westward entering the central Caribbean Sea and like many other cyclones before and since, the storm began to strengthen. A reconnaissance aircraft reached the cyclone at $19 \mathrm{Z}$ on the $25^{\text {th }}$ measuring a central pressure of $988 \mathrm{mb}$, estimated maximum surface winds of $85 \mathrm{kt}$ and an eye diameter of 20 miles. A central pressure of $988 \mathrm{mb}$ suggests maximum sustained winds of $67 \mathrm{kt}$ according to the south of $25 \mathrm{~N}$ pressure-wind relationship. The diameter data indicates a RWM of about $15 \mathrm{~nm}$ and climatology suggests $13 \mathrm{~nm}$. Therefore, an intensity of $65 \mathrm{kt}$ is selected for $18 \mathrm{Z}$ on the $25^{\text {th }}$, a major change in HURDAT as it indicates $115 \mathrm{kt}$ for this time. At $18 \mathrm{Z}$ on the $25^{\text {th }}$, Janet is analyzed to have regained hurricane intensity. A central pressure of $993 \mathrm{mb}$ was present in the original HURDAT at $12 \mathrm{Z}$ on the $25^{\text {th }}$, and although there is no data to verify it, it looks reasonable and it is retained. An intensity of $50 \mathrm{kt}$ is selected for $0 \mathrm{Z}$ on the $25^{\text {th }}, 55 \mathrm{kt}$ at $06 \mathrm{Z}$, and $60 \mathrm{kt}$ at $12 \mathrm{Z}$. Major changes to HURDAT as at these times it indicates $115 \mathrm{kt}$. No inner core pressure or wind data was received on the $26^{\text {th }}$ as this was the day of the fateful flight that never made it back. But Janet likely continued to intensify reaching major hurricane status at $18 \mathrm{Z}$ on the $26^{\text {th }}$. An intensity of $100 \mathrm{kt}$ is selected for $18 \mathrm{Z}$, a major change to HURDAT as it indicates $125 \mathrm{kt}$. A central pressure of $970 \mathrm{mb}$ is in the original HURDAT at $12 \mathrm{Z}$ and although this appears to be an interpretation and not a measurement, it looks reasonable and it is retained. An intensity of $70 \mathrm{kt}$ is selected for $0 \mathrm{Z}$ on the $26^{\text {th }}, 80 \mathrm{kt}$ at $06 \mathrm{Z}$ and $90 \mathrm{kt}$ at $12 \mathrm{Z}$. All of these are major downward changes to HURDAT as it shows $120 \mathrm{kt}$ at $00 \mathrm{Z}$ and $06 \mathrm{Z}$ and $125 \mathrm{kt}$ at $12 \mathrm{Z}$ on the $26^{\text {th }}$.

On September $27^{\text {th }}$, Janet continued to intensify while moving on a west-northwest course entering the western Caribbean Sea. Around 18Z, the system devastated Swan Island after making a direct landfall. No direct wind measurements were made at Swan Island, 
just estimates that placed the wind at over $200 \mathrm{mph}$. Certainly it is possible that wind gusts could have approached or reached that velocity but very likely not maximum sustained winds. Gale-force winds also affected Grand Cayman as Janet passed about 165 $\mathrm{nmi}$ to the southwest. A reconnaissance aircraft reached the hurricane at $1540 \mathrm{Z}$ measuring a central pressure of $938 \mathrm{mb}$. A central pressure of $938 \mathrm{mb}$ suggests maximum sustained winds of $123 \mathrm{kt}$ and $125 \mathrm{kt}$ intensifying, according to the south of $25 \mathrm{~N}$ pressure-wind relationships. An intensity of $130 \mathrm{kt}$ is selected for $12 \mathrm{Z}$ and $140 \mathrm{kt}$ for $18 \mathrm{Z}$, as the hurricane was traveling at about $20 \mathrm{kt}$. It is analyzed that at $18 \mathrm{Z}$ on the $27^{\text {th }}$, Janet reached category 5. Originally HURDAT had a central pressure of 914 at $06 \mathrm{Z}$ on the $27^{\text {th }}$, but this was measured at $06 \mathrm{Z}$ on the $28^{\text {th }}$, and therefore, it is moved to its correct time slot. Only 12 hours after devastating Swan Island, Janet was moving over the Yucatan Peninsula with an even stronger intensity. Janet moved over Chetumal, Mexico, where a central pressure of $914 \mathrm{mb}$ was measured around $06 \mathrm{Z}$ on the $28^{\text {th }}$. The nearby city of Corozal, Belize, measured a pressure of $916 \mathrm{mb}$ at 0610Z. A central pressure of $914 \mathrm{mb}$ suggests $144 \mathrm{kt}$ and $146 \mathrm{kt}$ intensifying, according to the south of $25 \mathrm{~N}$ pressure-wind relationships. An intensity of $150 \mathrm{kt}$ is selected at $06 \mathrm{Z}$ on the $28^{\text {th }}$, a major change to HURDAT as it originally had $130 \mathrm{kt} .150 \mathrm{kt}$ is also selected for $00 \mathrm{Z}$ on the $28^{\text {th }}$, matching original HURDAT. A central pressure of $950 \mathrm{mb}$ is in the original HURDAT at $12 \mathrm{Z}$ on the $28^{\text {th }}$ while the hurricane was still over land, appears to be an estimate but it is kept as it is reasonable. Weakening occurred over the Yucatan Peninsula although the data is very sparse. The Kaplan-DeMaria model was run for $12 \mathrm{Z}$ on the $28^{\text {th }}$ suggesting maximum sustained winds of $88 \mathrm{kt}$. Janet weakened below major hurricane status at $12 \mathrm{Z}$ as the intensity of $95 \mathrm{kt}$ is kept from original HURDAT. Around $15 \mathrm{Z}$ on the $28^{\text {th }}$, Janet reached the Bay of Campeche and a reconnaissance aircraft reached the hurricane at $1945 Z$ measuring an eye diameter of 10 miles but no information is provided on the central pressure or estimated maximum surface winds. Therefore, no changes are made to HURDAT's intensities late on the $28^{\text {th }}$ and $29^{\text {th }}$. At $12 \mathrm{Z}$ on the $29^{\text {th }}$, HURDAT shows a central pressure of $950 \mathrm{mb}$. This appears to be a (rather dubious) estimate and it is removed because of the lack of inner-core data on this day and the rest of the lifetime of Janet. The hurricane made its final landfall around $18 \mathrm{Z}$ on the $29^{\text {th }}$ on the Mexican state of Veracruz with maximum sustained winds of $95 \mathrm{kt}$. It is possible that Janet had regained major hurricane status by the time it made its final landfall but there is no data to show this. Weakening rapidly occurred over the mountainous terrain and it is analyzed that Janet was a depression by $12 \mathrm{Z}$ on the $30^{\text {th }}$ and dissipated shortly after. 
New Tropical Storm Linda [September 23-24, 1955]

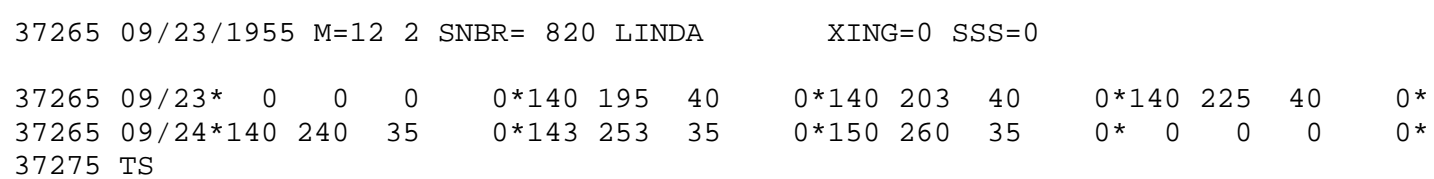

A new tropical storm has been added to HURDAT, not previously shown in McAdie et al. (2009). Evidence for its existence comes from the Historical Weather Map series, Microfilm, and COADS ship database.

September 22:

HWM shows a closed low pressure of at most $1010 \mathrm{mb}$ at $13.5 \mathrm{~N}, 18.8 \mathrm{~W}$ at $12 \mathrm{Z}$. Microfilm does not analyze an organized system at 12Z. HURDAT and MWR do not list this system at 12Z. Ship highlights: No gale force winds or equivalent low pressures.

September 23:

HWM shows a closed low pressure of at most $1010 \mathrm{mb}$ at $14.0 \mathrm{~N}, 20.0 \mathrm{~W}$ at $12 \mathrm{Z}$. Microfilm does not analyze an organized system at 12Z. HURDAT and MWR do not list this system at 12Z. Ship highlights: $40 \mathrm{kt} \mathrm{SE}$ and $1004 \mathrm{mb}$ (likely $1009 \mathrm{mb}$ ) at $14.3 \mathrm{~N}$, $18.0 \mathrm{~W}$ at $06 \mathrm{Z}$ (COADS). $15 \mathrm{kt} \mathrm{NE}$ and $1005 \mathrm{mb}$ at $15.6 \mathrm{~N}, 22.5 \mathrm{~W}$ at $18 \mathrm{Z}$ (COADS). Land highlights: $10 \mathrm{kt} \mathrm{N}$ and $1005 \mathrm{mb}$ at $14.9 \mathrm{~N}, 23.5 \mathrm{~W}$ at Praia, Cape Verde Islands at $18 \mathrm{Z}$ (micro).

September 24:

HWM shows a closed low pressure of at most $1010 \mathrm{mb}$ at $16.5 \mathrm{~N}, 24.7 \mathrm{~W}$ at $12 \mathrm{Z}$. Microfilm does not analyze an organized system at 12Z. HURDAT and MWR do not list this system at 12Z. Ship highlights: No gale force winds or equivalent low pressures.

September 25:

HWM shows a closed low pressure of at most $1010 \mathrm{mb}$ at $18.2 \mathrm{~N}, 31.8 \mathrm{~W}$ at $12 \mathrm{Z}$. Microfilm does not analyze an organized system at 12Z. HURDAT and MWR do not list this system at 12Z. Ship highlights: No gale force winds or equivalent low pressures.

September 26:

HWM shows a spot low at $18.2 \mathrm{~N}, 35.3 \mathrm{~W}$ at $12 \mathrm{Z}$. Microfilm does not analyze an organized system at 12Z. HURDAT and MWR do not list this system at 12Z. Ship highlights: No gale force winds or equivalent low pressures. 
September 27:

HWM shows a spot low at $18.0 \mathrm{~N}, 41.5 \mathrm{~W}$ at $12 \mathrm{Z}$. Microfilm does not analyze an organized system at 12Z. HURDAT and MWR do not list this system at 12Z. Ship highlights: No gale force winds or equivalent low pressures.

September 28:

HWM and microfilm do not analyze an organized system at 12Z. HURDAT and MWR do not list this system at 12Z. Ship highlights: No gale force winds or equivalent low pressures.

A tropical wave left the African coast on late on September $22^{\text {nd }}$ rapidly organizing into a tropical cyclone. Ship data at $06 \mathrm{Z}$ on the $23^{\text {rd }}$ indicate that the cyclone had already reached tropical storm intensity. A ship located at $14.3 \mathrm{~N}, 18.0 \mathrm{~W}$ reported $40 \mathrm{kt} \mathrm{SE}$ and $1004 \mathrm{mb}$ at $06 \mathrm{Z}$ on the $23^{\text {rd }}$. The pressure appears to have about a $5 \mathrm{mb}$ low bias. An intensity of $40 \mathrm{kt}$ is selected for $06 \mathrm{Z}$ on the $23^{\text {rd }}$. Genesis is begun on September $23^{\text {rd }}$ at $06 Z$ as a $40 \mathrm{kt}$ tropical storm. Tropical Storm Linda moved generally westward during the first 24 hours after formation. The pressure at Praia, Cape Verde Islands decreased from $1008.3 \mathrm{mb}$ at $12 \mathrm{Z}$ on the $23^{\text {rd }}$ to $1004.8 \mathrm{mb}$ at $18 \mathrm{Z}$ as Linda passed close to the station. A peripheral pressure of $1005 \mathrm{mb}$ suggests maximum sustained winds of at least $37 \mathrm{kt}$ south of $25 \mathrm{~N}$ from the Brown et al. pressure-wind relationship. The intensity is kept at $40 \mathrm{kt}$ at $18 \mathrm{Z} .40 \mathrm{kt}$ is also the peak intensity for this tropical cyclone, but this is highly speculative since no inner-core data was ever received from this system. Data on September $24^{\text {th }}$ becomes very sparse as Linda moves away from the African continent. Data from the Cape Verde Islands indicates that the track of the cyclone turned to the northwest on the $24^{\text {th }}$ and after $12 Z$, there is no data to locate Linda anymore. Therefore, it was decided to make $12 \mathrm{Z}$ on the $24^{\text {th }}$ the last position but it is very likely that the storm continued toward the central Atlantic dissipating on a later date. The low pressure associated with Linda is tracked by HWM until September $27^{\text {th }}$ but there is no data to indicate that it was a tropical cyclone on these days. The name "Linda" was given to the low pressure system in 1955 and appears on the microfilm data. The track of Linda is reminiscent to the track of Tropical Storm Melissa in 2007, a system that became a tropical cyclone close to the Cape Verde Islands only to dissipate as it entered the central Atlantic.

Unnamed Tropical Storm 11 [October 10-14, 1955]

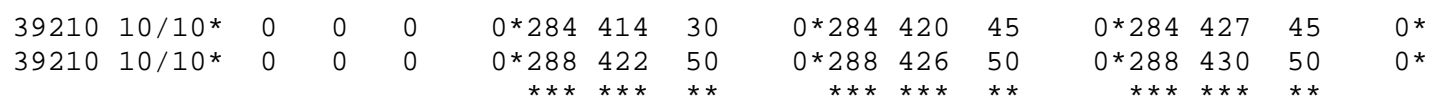




\begin{tabular}{|c|c|c|c|c|c|c|c|c|c|c|c|c|c|}
\hline 39215 & $10 / 11 * 284$ & 433 & 45 & $\Theta * 286$ & 438 & 55 & $\Theta * 288$ & 442 & 50 & $0 * 291$ & 444 & 50 & $\Theta^{*}$ \\
\hline 39215 & $10 / 11 * 288$ & $\begin{array}{l}434 \\
* * *\end{array}$ & $\begin{array}{l}50 \\
* *\end{array}$ & $\Theta^{*} 288$ & 438 & $\begin{array}{l}55 \\
\star *\end{array}$ & $0 * 288$ & 442 & $\begin{array}{l}55 \\
\star *\end{array}$ & $0 * 290$ & 444 & 50 & $\Theta^{*}$ \\
\hline 39220 & $10 / 12 * 294$ & 444 & 50 & ๑*297 & 444 & 50 & $0 * 300$ & 442 & 50 & $0 * 306$ & 435 & 50 & 0 * \\
\hline 39220 & $10 / 12 * 294$ & 444 & 50 & ๑*297 & $\begin{array}{l}442 \\
* * *\end{array}$ & 50 & $0 * 300$ & $\begin{array}{l}438 \\
* * *\end{array}$ & 50 & $\begin{array}{r}0 * 303 \\
* * *\end{array}$ & $\begin{array}{l}431 \\
* * *\end{array}$ & 50 & $0^{*}$ \\
\hline $\begin{array}{l}39225 \\
39225\end{array}$ & $\begin{array}{r}10 / 13^{*} 312 \\
10 / 13^{*} 306 \\
* * *\end{array}$ & $\begin{array}{l}426 \\
420 \\
\star * *\end{array}$ & $\begin{array}{l}50 \\
5 \odot\end{array}$ & $\begin{array}{r}\Theta^{*} 318 \\
\Theta^{*} 311 \\
\star \star \star \star\end{array}$ & $\begin{array}{l}416 \\
410 \\
\star * *\end{array}$ & $\begin{array}{l}50 \\
50\end{array}$ & $\begin{array}{r}\Theta^{*} 324 \\
0^{*} 319 \\
* * *\end{array}$ & $\begin{array}{l}405 \\
400 \\
\star * *\end{array}$ & $\begin{array}{l}5 \odot \\
5 \odot\end{array}$ & $\begin{array}{r}0 * 337 \\
0 * 329 \\
* \star *\end{array}$ & $\begin{array}{l}394 \\
390 \\
* * *\end{array}$ & $\begin{array}{l}50 \\
50\end{array}$ & $\begin{array}{l}\Theta^{*} \\
\Theta^{*}\end{array}$ \\
\hline $\begin{array}{l}39230 \\
39230\end{array}$ & $\begin{array}{r}10 / 14 \mathrm{E} 358 \\
10 / 14 * 350 \\
* * * *\end{array}$ & $\begin{array}{l}380 \\
380\end{array}$ & $\begin{array}{l}50 \\
50\end{array}$ & $\begin{array}{r}\text { OE378 } \\
\text { O*372 } \\
* * \star *\end{array}$ & $\begin{array}{l}366 \\
370 \\
\star * *\end{array}$ & $\begin{array}{l}45 \\
50 \\
\star *\end{array}$ & $\begin{array}{l}\Theta \mathrm{EE} 400 \\
\Theta^{*} \quad \odot \\
\\
*\end{array}$ & $\begin{array}{r}351 \\
0 \\
*\end{array}$ & $\begin{array}{r}40 \\
0 \\
*\end{array}$ & $\begin{array}{ll}\Theta^{*} & \odot \\
\Theta^{*} & \odot\end{array}$ & $\begin{array}{l}\odot \\
\odot\end{array}$ & 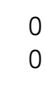 & $\begin{array}{l}\Theta^{*} \\
\Theta^{*}\end{array}$ \\
\hline
\end{tabular}

Minor changes to the track but major revision to the intensity shown in McAdie et al. (2009). Evidence for these alterations comes from the NHC microfilm maps, the Historical Weather Maps series, the COADS ship database, and Monthly Weather Review. Additionally, the reanalysis indicates that the cyclone did not undergo an extratropical transition.

October 9:

HWM shows a cold front over the northeast Atlantic extending to the southwest to $30 \mathrm{~N}, 40 \mathrm{~W}$ at $12 \mathrm{Z}$. HURDAT and Microfilm do not analyze an organized system on this date. MWR is not available in this date. Ship highlights: No gales or low pressures.

October 10:

HWM shows a weakening cold front over the northeast Atlantic extending to a spot low located at $25.5 \mathrm{~N}, 40.5 \mathrm{~W}$ at $12 \mathrm{Z}$. HURDAT lists this as a 45 knot tropical storm at $28.4 \mathrm{~N}, 42.0 \mathrm{~W}$ at $12 \mathrm{Z}$. Microfilm analyzes a closed low pressure of at most $1005 \mathrm{mb}$ centered at $28.5 \mathrm{~N}, 42 . \mathrm{W}$ at $18 \mathrm{Z}$. MWR is not available in this date. Ship highlights: $45 \mathrm{kt}$ $\mathrm{SW}$ and $1002 \mathrm{mb}$ at $28.7 \mathrm{~N}, 42.8 \mathrm{~W}$ at $16 \mathrm{Z}$ (micro). $45 \mathrm{kt} \mathrm{SW}$ and $1002 \mathrm{mb}$ at $28.6 \mathrm{~N}$, $42.8 \mathrm{~W}$ at $18 \mathrm{Z}$ (micro).

October 11:

HWM shows a closed low pressure of at most $1015 \mathrm{mb}$ located at $27.5 \mathrm{~N}, 44.5 \mathrm{~W}$ at $12 \mathrm{Z}$. HURDAT lists this as a 50 knot tropical storm at $28.8 \mathrm{~N}, 44.2 \mathrm{~W}$ at $12 \mathrm{Z}$. Microfilm analyzes a closed low pressure of at most $1008 \mathrm{mb}$ centered at $29.0 \mathrm{~N}, 45.0 \mathrm{~W}$ at 12Z. MWR is not available in this date. Ship highlights: $35 \mathrm{kt} \mathrm{SW}$ and $1007 \mathrm{mb}$ at $27.7 \mathrm{~N}, 44.5 \mathrm{~W}$ at $18 \mathrm{Z}$ (micro).

October 12: 
HWM shows a closed low pressure of at most $1005 \mathrm{mb}$ located at $30.0 \mathrm{~N}, 45.0 \mathrm{~W}$ at $12 \mathrm{Z}$. HURDAT lists this as a 50 knot tropical storm at $30.0 \mathrm{~N}, 44.2 \mathrm{~W}$ at $12 \mathrm{Z}$. Microfilm analyzes a closed low pressure of at most $1008 \mathrm{mb}$ centered at $30.0 \mathrm{~N}, 44.0 \mathrm{~W}$ at $12 \mathrm{Z}$. MWR is not available in this date. Ship highlights: $35 \mathrm{kt} \mathrm{SSW}$ and $1007 \mathrm{mb}$ at $29.3 \mathrm{~N}, 41.5 \mathrm{~W}$ at $18 \mathrm{Z}$ (micro).

October 13:

HWM shows a closed low pressure of at most 1005 mb located at 30.3N, 40.8W and an approaching cold front to the north near $40 \mathrm{~N}$ at $12 \mathrm{Z}$. HURDAT lists this as a 50 knot tropical storm at $32.4 \mathrm{~N}, 40.5 \mathrm{~W}$ at $12 \mathrm{Z}$. Microfilm analyzes a closed low pressure of at most $1008 \mathrm{mb}$ centered at $32.0 \mathrm{~N}, 40.0 \mathrm{~W}$ at $12 \mathrm{Z}$. MWR is not available in this date. Ship highlights: $35 \mathrm{kt} \mathrm{S}$ and $1006 \mathrm{mb}$ at $31.3 \mathrm{~N}, 38.7 \mathrm{~W}$ at 06Z (COADS). $25 \mathrm{kt} \mathrm{SSE}$ and $1003 \mathrm{mb}$ at $32.6 \mathrm{~N}, 38.0 \mathrm{~W}$ at $18 \mathrm{Z}$ (COADS).

October 14:

HWM shows a closed low pressure of at most $990 \mathrm{mb}$ located at $41.5 \mathrm{~N}, 37.0 \mathrm{~W}$ with a cold front extending to the southwest and a warm front to the northeast $12 \mathrm{Z}$. HURDAT lists this as a 40 knot extratropical cyclone at $40.4 \mathrm{~N}, 40.5 \mathrm{~W}$ (last position) at 12Z. Microfilm analyzes a closed low pressure of at most $996 \mathrm{mb}$ centered at $43.0 \mathrm{~N}$, $39.0 \mathrm{~W}$ at $12 \mathrm{Z}$. MWR is not available in this date. Ship highlights: $1000 \mathrm{mb}$ at $35.0 \mathrm{~N}$, $48.3 \mathrm{~W}$ at $0 \mathrm{Z}$ (micro). $50 \mathrm{kt} \mathrm{SW}$ and $1008 \mathrm{mb}$ at $34.0 \mathrm{~N}, 34.3 \mathrm{~W}$ at $06 \mathrm{Z}$ (micro).

MWR: "A small vortex apparently developed in an easterly wave which passed through the Cape Verde islands on October 4. It was first reported by two passing ships on October 10 at approximately Latitude $28.5^{\circ} \mathrm{N}$ and Longitude $42.8^{\circ} \mathrm{W}$. The storm recurved to the northeast on the $11^{\text {th }}$ and merged with an extra-tropical storm on the $14^{\text {th }}$. The combined storm was quite severe with one ship reporting $979 \mathrm{mb}$ (28.91 inches). The lowest reported pressure in the tropical storm was $1000 \mathrm{mb}$ (29.53 inches) and highest winds were about $55 \mathrm{mph."}$

This unnamed tropical storm developed from the remnants of a frontal boundary over the central Atlantic during the second week of October. The genesis remains unchanged from $06 \mathrm{Z}$ on the $10^{\text {th }}$ of October, although it is very probable that the system developed earlier. Very minor alterations were made to the positions of the cyclone for all five days of its existance. The first ship to encounter the tropical system was ELBJ reporting sustained winds of $45 \mathrm{kt} \mathrm{SW}$ and a barometric pressure of $1002 \mathrm{mb}$ at $16 \mathrm{Z}$ on the $10^{\text {th }}$. A peripheral pressure of $1002 \mathrm{mb}$ suggests maximum winds greater than $42 \mathrm{kt}$ from the north of $25 \mathrm{~N}$ Brown et al. pressure-wind relationship. An intensity of $50 \mathrm{kt}$ is selected for $06 \mathrm{Z}$ on the $10^{\text {th }}$, up from $30 \mathrm{kt}$ originally in HURDAT, as the system was already well-developed when it was first encountered. During the next 24 hours, the storm moved slowly 
westward while slightly intensifying to $55 \mathrm{kt}$. This intensification was present in the original HURDAT but there is no data to justify or change it. The intensity is decreased to $50 \mathrm{kt}$ at $18 \mathrm{Z}$ on the $11^{\text {th }}$ of October, as it is originally in HURDAT. On the $12^{\text {th }}$, the track changed to the northeast while accelerating as a cold front approached from the west. A reconnaissance aircraft reached the tropical storm late on the $12^{\text {th }}$ reporting a squall area between $30-32 \mathrm{~N}, 44-45 \mathrm{~W}$, and maximum sustained winds of only $20 \mathrm{kt}$. Based on the ship data at the time, it is analyzed that the reconnaissance aircraft visited the northwest portion of the circulation, never reaching the center of the cyclone. Late on the $13^{\text {th }}$, the tropical storm began to interact with the frontal boundary, and the large circulation began to become elongated N-S at 18Z. Another ship (S.S. Mateo) passed close to the center at $00 \mathrm{Z}$ on the $14^{\text {th }}$ measuring a peripheral pressure of $1000 \mathrm{mb}$. A pressure of $1000 \mathrm{mb}$ yields maximum sustained winds greater than $45 \mathrm{kt}$ north of $25 \mathrm{~N}$ and $49 \mathrm{kt}$ north of $35 \mathrm{~N}$ according to the Brown et al. and Landsea et al. pressure-wind relationships, respectively. The intensity is kept at $50 \mathrm{kt}$ at $00 \mathrm{Z}$, unchanged from original HURDAT. By $12 Z$ on the $14^{\text {th }}$, the tropical storm had been absorbed by a larger extratropical cyclone, making 06Z the last position. Originally in HURDAT, the tropical cyclone became extratropical at $00 \mathrm{Z}$ on the $14^{\text {th }}$ and the last position was at $12 \mathrm{Z}$. The reanalysis keeps the system tropical for 12 hours longer but ends the cyclone's lifetime six hours earlier than the original HURDAT. The extratropical cyclone moved northwest over the next few days toward Newfoundland, dissipating on the $17^{\text {th }}$.

Hurricane Katie [October 14-20, 1955]

\begin{tabular}{|c|c|c|c|c|c|c|c|c|c|c|c|c|c|}
\hline 39240 & $10 / 14 / 195$ & $M=$ & 712 & SNBR $=85$ & $57 \mathrm{KA}$ & IE & XIN & $G=\odot$ & $S S S=0$ & & & & L \\
\hline 39240 & $10 / 14 / 195$ & $M=$ & 614 & SNBR $=85$ & $57 \mathrm{KA}$ & IE & XII & $\mathrm{G}=\odot$ & $S S S=0$ & & & & L \\
\hline 39245 & $10 / 14^{*}$ & $\odot$ & $\odot$ & $\Theta^{*}$ & $\odot$ & $\odot$ & $\Theta^{*}$ & $\odot$ & $\odot$ & ๑*117 & 779 & 30 & ○* \\
\hline 39245 & $10 / 14$ * & $\odot$ & $\odot$ & $\Theta^{*}$ & $\odot$ & $\odot$ & $\Theta^{*}$ & $\odot$ & $\odot$ & $\Theta^{*}+\frac{125}{* * *}$ & $\begin{array}{l}793 \\
\star * *\end{array}$ & $\begin{array}{l}25 \\
* *\end{array}$ & ○* \\
\hline 39250 & $10 / 15 * 121$ & 777 & 35 & $0 * 126$ & 772 & 45 & $\odot * 132$ & 767 & 50 & ๑*138 & 761 & 60 & $\odot$ * \\
\hline 39250 & $\begin{array}{r}10 / 15 * 127 \\
* * *\end{array}$ & $\begin{array}{l}787 \\
* * *\end{array}$ & $\begin{array}{l}30 \\
* *\end{array}$ & $\begin{array}{r}0 * 129 \\
* * *\end{array}$ & $\begin{array}{l}780 \\
\star * *\end{array}$ & $\begin{array}{l}35 \\
* *\end{array}$ & $0 * 132$ & $\begin{array}{l}772 \\
* * *\end{array}$ & $\begin{array}{l}40 \\
* *\end{array}$ & $\begin{array}{r}0 * 137 \\
* * *\end{array}$ & $\begin{array}{l}764 \\
\star * *\end{array}$ & $\begin{array}{l}45 \\
* *\end{array}$ & ○* \\
\hline 39255 & $10 / 16 * 143$ & 753 & 70 & $0 * 148$ & 745 & 80 & ๑*153 & 737 & 90 & $0 * 161$ & 729 & 100 & $984^{*}$ \\
\hline 39255 & $10 / 16 * 143$ & 753 & $\begin{array}{l}50 \\
* *\end{array}$ & $0 * 148$ & 745 & $\begin{array}{l}55 \\
* *\end{array}$ & $\begin{array}{r}\odot * 154 \\
* * *\end{array}$ & 737 & $\begin{array}{l}60 \\
* *\end{array}$ & $\begin{array}{l}\theta^{*} 162 \\
* * *\end{array}$ & 729 & $\begin{array}{l}70 \\
* *\end{array}$ & 984 * \\
\hline 39260 & $10 / 17 * 171$ & 722 & 100 & ๑*181 & 718 & 55 & ๑*193 & 713 & 50 & $\Theta * 207$ & 705 & 60 & $\Theta^{*}$ \\
\hline 39260 & $10 / 17 * 171$ & $\begin{array}{l}723 \\
* * *\end{array}$ & $\begin{array}{l}80 \\
* *\end{array}$ & 0*181 & $\begin{array}{l}717 \\
* * *\end{array}$ & $\begin{array}{l}9 \odot \\
* *\end{array}$ & 0*193 & $\begin{array}{l}711 \\
* * *\end{array}$ & 50 & $\begin{array}{r}\Theta * 205 \\
* * *\end{array}$ & $\begin{array}{l}706 \\
* * *\end{array}$ & $\begin{array}{l}45 \\
* *\end{array}$ & ○* \\
\hline 39265 & $10 / 18 * 221$ & 698 & 60 & $0 * 233$ & 690 & 60 & $0 * 247$ & 683 & 60 & ๑*269 & 671 & 50 & $0^{*}$ \\
\hline 39265 & $\begin{array}{r}10 / 18 * 219 \\
* * *\end{array}$ & $\begin{array}{l}700 \\
\star * *\end{array}$ & $\begin{array}{l}50 \\
* *\end{array}$ & $\begin{array}{l}1000^{*} 233 \\
\star * * *\end{array}$ & $\begin{array}{l}692 \\
* * *\end{array}$ & $\begin{array}{l}50 \\
* *\end{array}$ & $0 * 247$ & 683 & $\begin{array}{l}50 \\
\star *\end{array}$ & $\Theta^{*} 269$ & 671 & 50 & $\begin{array}{l}999 * \\
\star * *\end{array}$ \\
\hline 39270 & $10 / 19 * 295$ & 654 & 40 & $\theta * 320$ & 633 & 40 & $\odot * 345$ & 605 & 35 & OE371 & 569 & 35 & $0^{*}$ \\
\hline 39270 & $10 / 19 * 295$ & 654 & 45 & $0 * 320$ & 633 & 40 & $0^{*} \quad \odot$ & $\odot$ & $\odot$ & $0^{*} \quad 0$ & $\odot$ & $\odot$ & $0^{*}$ \\
\hline
\end{tabular}


$3927510 / 20 E 397524 \quad 35$

OE419 $471 \quad 35$

$\Theta^{*}$

39280 HR

Minor changes to the track, but major alterations to the intensity shown in McAdie et al. (2009). Another major change is to show dissipation a day earlier than originally indicated. Evidence for these alterations comes from the NHC microfilm maps, the Historical Weather Maps series, the COADS ship database, and Monthly Weather Review. Additionally, the reanalysis indicates that the cyclone did not undergo an extratropical transition.

October 13:

HWM, HURDAT and Microfilm do not analyze an organized system on this date. MWR is not available in this date. Ship highlights: No gales or low pressures.

October 14:

HWM shows a spot low located at $12.0 \mathrm{~N}, 80.5 \mathrm{~W}$ at $12 \mathrm{Z}$. HURDAT lists this as a $30 \mathrm{kt}$ tropical depression at $11.7 \mathrm{~N}, 77.9 \mathrm{~W}$ at $18 \mathrm{Z}$. Microfilm does not analyze an organized system on this date. MWR is not available in this date. Ship highlights: No gales or low pressures.

October 15:

HWM shows a tropical storm of at most $1005 \mathrm{mb}$ located at $14.7 \mathrm{~N}, 77.1 \mathrm{~W}$ at $12 \mathrm{Z}$. HURDAT lists this as a $50 \mathrm{kt}$ tropical storm at $13.2 \mathrm{~N}, 76.7 \mathrm{~W}$ at $12 \mathrm{Z}$. Microfilm analyses a closed low pressure of at most $1005 \mathrm{mb}$ at $13.5 \mathrm{~N}, 76.8 \mathrm{~W}$ at $12 \mathrm{Z}$. MWR is not available in this date. Ship highlights: $20 \mathrm{kt} \mathrm{NNE}$ and $1005 \mathrm{mb}$ at $13.2 \mathrm{~N}, 77.7 \mathrm{~W}$ at $12 \mathrm{Z}$ (COADS).

October 16:

HWM shows a hurricane of at most $1000 \mathrm{mb}$ located at $15.5 \mathrm{~N}, 73.1 \mathrm{~W}$ at $12 \mathrm{Z}$. HURDAT lists this as a $90 \mathrm{kt}$ hurricane at $15.3 \mathrm{~N}, 73.7 \mathrm{~W}$ at $12 \mathrm{Z}$. Microfilm analyses a closed low pressure of at most $1005 \mathrm{mb}$ at $15.0 \mathrm{~N}, 74.0 \mathrm{~W}$ at $12 \mathrm{Z}$. MWR is not available in this date. Ship highlights: $50 \mathrm{kt} \mathrm{NW}$ and $1001 \mathrm{mb}$ at $14.9 \mathrm{~N}, 74.1 \mathrm{~W}$ at $12 \mathrm{Z}$ (COADS). Aircraft highlights: Penetration center fix at $16.4 \mathrm{~N}, 72.9 \mathrm{~W}$ at $2010 \mathrm{Z}$ (ATSR). Radar center fix measured a central pressure of $984 \mathrm{mb}$, an eye diameter of 20 miles and maximum surface winds of $100 \mathrm{kt}$ at $16.9 \mathrm{~N}, 72.3 \mathrm{~W}$ at $23 \mathrm{Z}$ (ATSR/micro).

October 17:

HWM shows a hurricane of at most $1005 \mathrm{mb}$ located at $19.1 \mathrm{~N}, 70.5 \mathrm{~W}$ at $12 \mathrm{Z}$. HURDAT lists this as a $50 \mathrm{kt}$ tropical storm at $19.3 \mathrm{~N}, 71.3 \mathrm{~W}$ at $12 \mathrm{Z}$. Microfilm analyses 
a closed low pressure of at most $1008 \mathrm{mb}$ at $18.5 \mathrm{~N}, 70.5 \mathrm{~W}$ at $12 \mathrm{Z}$. MWR is not available in this date. Ship highlights: $25 \mathrm{kt} \mathrm{E}$ and $1005 \mathrm{mb}$ at $20.0 \mathrm{~N}, 70.7 \mathrm{~W}$ at $12 \mathrm{Z}$ (COADS). Aircraft highlights: Radar center fix at $17.7 \mathrm{~N}, 72.0 \mathrm{~W}$ at $04 \mathrm{Z}$ (ATSR). Penetration center fix at $21.3 \mathrm{~N}, 70.4 \mathrm{~W}$ at $22 \mathrm{Z}$ (ATSR). Radar center fix measured a central pressure of 1000 $\mathrm{mb}$ and maximum surface winds of $65 \mathrm{kt}$ at $21.5 \mathrm{~N}, 70.3 \mathrm{~W}$ at $22 \mathrm{Z}$ (ATSR/micro).

October 18:

HWM shows a tropical storm of at most $1000 \mathrm{mb}$ located at $24.9 \mathrm{~N}, 68.8 \mathrm{~W}$ with an approaching cold front to the northwest at 12Z. HURDAT lists this as a $60 \mathrm{kt}$ tropical storm at $24.7 \mathrm{~N}, 68.3 \mathrm{~W}$ at $12 \mathrm{Z}$. Microfilm analyses a closed low pressure of at most 1008 $\mathrm{mb}$ at $24.5 \mathrm{~N}, 68.0 \mathrm{~W}$ at $12 \mathrm{Z}$. MWR is not available in this date. Ship highlights: $35 \mathrm{kt} \mathrm{SW}$ and $1004 \mathrm{mb}$ at $22.0 \mathrm{~N}, 69.0 \mathrm{~W}$ at $03 \mathrm{Z}$ (micro). $35 \mathrm{kt} \mathrm{SSE}$ and $1014 \mathrm{mb}$ at $24.5 \mathrm{~N}, 66.0 \mathrm{~W}$ at $12 \mathrm{Z}$ (micro). $45 \mathrm{kt} \mathrm{SSE}$ and $1009 \mathrm{mb}$ at $27.0 \mathrm{~N}, 66.9 \mathrm{~W}$ at $18 \mathrm{Z}$ (micro). Aircraft highlights: Penetration center fix measured a central pressure of $999 \mathrm{mb}$, an eye of a 40 mile diameter and maximum surface winds of $50 \mathrm{kt}$ at $25.8 \mathrm{~N}, 66.7 \mathrm{~W}$ at $1630 \mathrm{Z}$ (micro). Penetration center fix at $27.3 \mathrm{~N}, 67.3 \mathrm{~W}$ at $2010 \mathrm{Z}$ (micro).

October 19:

HWM shows an extratropical cyclone of at most $1000 \mathrm{mb}$ located at $40.0 \mathrm{~N}$, $67.0 \mathrm{~W}$, which may indicate that the tropical cyclone has been absorbed, at $12 \mathrm{Z}$. HURDAT lists this as a $35 \mathrm{kt}$ tropical storm at $34.5 \mathrm{~N}, 60.5 \mathrm{~W}$ at $12 \mathrm{Z}$. Microfilm analyses a closed low pressure of at most $1008 \mathrm{mb}$ at $34.5 \mathrm{~N}, 60.5 \mathrm{~W}$ at $12 \mathrm{Z}$. MWR is not available in this date. Ship highlights: No gales or low pressures.

October 20:

HWM shows an extratropical cyclone of at most $985 \mathrm{mb}$ located at $51.0 \mathrm{~N}, 50.0 \mathrm{~W}$ at $12 \mathrm{Z}$. HURDAT lists this as a $35 \mathrm{kt}$ extratropical cyclone at $41.9 \mathrm{~N}, 47.1 \mathrm{~W}$ at $06 \mathrm{Z}$. Microfilm analyses an extratropical cyclone of at most $993 \mathrm{mb}$ at $50.0 \mathrm{~N}, 52.0 \mathrm{~W}$ at $12 \mathrm{Z}$. MWR is not available in this date. Ship highlights: $30 \mathrm{kt} \mathrm{W}$ and $1003 \mathrm{mb}$ at $41.5 \mathrm{~N}$, $47.0 \mathrm{~W}$ at $06 \mathrm{Z}$ (micro).

ATSR: "Hurricane Katie," the final storm of the 1955 season, had a life span of a short duration before becoming extratropical after crossing the island of Hispaniola. "Katie" came into existence in the Caribbean south of Hispaniola from a weak vortex on the Intertropical Convergence Zone and developed to full hurricane intensity rapidly after being detected as a tropical storm. The first indication of the vortex as on the $15^{\text {th }}$ of October when a weak vortex could be drawn at 0030Z. There was no indication of intensification at $151230 \mathrm{Z}$, and as late as $160630 \mathrm{Z}$ there were no reports in the area to indicate intensification. A weak to moderate cold front was moving southeast into the 
Caribbean. The vortex was not considered potentially suspicious since the charts for the previous few days and current charts revealed an orderly procession of vortices moving westward along the Intertropical Convergence Zone which is normal in this area during the summer and early fall months. However, at $161200 \mathrm{Z}$ a report from the ship SS POSEIDON was received, giving a west wind of 50 knots and a low surface pressure of $1001.3 \mathrm{mb}$, confirming the development of "Katie" near 15N 74W. A Navy aircraft was ordered immediately from San Juan to reconnoiter the suspicious area and verify the report from the SS POSEIDON. A small intense hurricane with winds of 100 knots and minimum surface pressure of $984 \mathrm{mb}$ centered at $16-23 \mathrm{~N} 72-52 \mathrm{~W}$ at $162010 \mathrm{Z}$ was reported by the reconnaissance aircraft. Warning Number One for "Hurricane Katie" was coordinated with the Weather Bureau Office of San Juan and issued at 162200Z. As reported by the Navy Reconnaissance aircraft, rapid intensification of "Katie" was taking place. The eye, reported to be well defined both visually and by radar by the reconnaissance aircraft was 20 miles in diameter with spiral squall bands extending from the storm center. With the rapid intensification and the north-northeast movement the island of Hispaniola was in line for the full force of "Katie" in a matter of hours. In moving across the island of Hispaniola, "Katie" lost some of her intensity, but later regained hurricane intensity over the water north of the island for a few hours before becoming extratropical. On the $18^{\text {th }}$ of October the final aircraft reconnaissance into "Katie" reported maximum winds of 55 knots, no definite eye, flat pressure pattern and that the storm consisted of a line of isolated cumulonimbus oriented east-west. In view of this information, verifying the belief that "Katie" had become extratropical, the final warning was issued at 182200Z."

MWR: "Hurricane Katie probably developed from a wave on the intratropical convergence zone in the vicinity of Panama. The first definite evidence was a ship report from the Dutch motor vessel Poseidon on the morning of the 16th. A Navy reconnaissance plane the same afternoon located the center with a pressure of $984 \mathrm{mb}$ (29.06 inches) and winds up to $115 \mathrm{mph}$. The center crossed the coastline of Hispaniola near the border between Haiti and the Dominican Republic about midnight that night. This area is thinly populated but the small border towns of Anse-a-Pitre and Pedernales were badly damaged with highest winds estimated at $115 \mathrm{mph}$. On the basis of incomplete reports, total damage is estimated at between $\$ 200,000$ and $\$ 300,000$ with 7 deaths. Katie became almost completely disorganized in crossing the high mountains of Hispaniola but briefly intensified to near hurricane intensity after passing out into the Atlantic. However, it shortly reached an area containing the remains of an old cold front and again lost intensity. The vortex was probably last encountered by SS Amsterdam at $0130 \mathrm{EST}$ on the 20th in Latitude $37.3^{\circ} \mathrm{N}$ and Longitude $56.4^{\circ} \mathrm{W}$." 
Hurricane Katie developed in the central Caribbean Sea at $18 \mathrm{Z}$ on the $14^{\text {th }}$ of October, unchanged from HURDAT. It is analyzed at genesis as a $25 \mathrm{kt}$ tropical depression, down from $30 \mathrm{kt}$ in HURDAT. The time of genesis is somewhat uncertain as the data is sparse. Minor track changes were introduced on all days of this system except the $19^{\text {th }}$, with the most significant change made at genesis with a new position $100 \mathrm{~nm} \mathrm{WNW}$ of the original one. Intensification to a tropical storm occurred at $06 \mathrm{Z}$ on the $15^{\text {th }}, 6$ hours later than originally shown in HURDAT. Katie generally moved northeastward and the first report of tropical storm force winds occurred at $12 \mathrm{Z}$ on the $16^{\text {th }}$ when the ship Poseidon reported $50 \mathrm{kt} \mathrm{W}$ and $1001 \mathrm{mb}$, about $40 \mathrm{~nm}$ from the center of the system. Intensification to a hurricane occurred at $18 \mathrm{Z}$ on the $16^{\text {th }}, 18$ hours later than originally shown in HURDAT. A reconnaissance aircraft reached Katie at $2010 \mathrm{Z}$ on the $16^{\text {th }}$ measuring a central pressure of $984 \mathrm{mb}$ and an eye diameter of 20 miles. A central pressure of $984 \mathrm{mb}$ suggests maximum winds of $72 \mathrm{kt}$ south of $25 \mathrm{~N}$ from the Brown et al. pressure-wind relationship. The eye diameter information suggests an RMW of around $15 \mathrm{~nm}$, which is close to climatology. An intensity of $70 \mathrm{kt}$ is selected for $18 \mathrm{Z}$ on the $16^{\text {th }}$ and $80 \mathrm{kt}$ for $0 \mathrm{Z}$ on the $17^{\text {th }}$, down from $100 \mathrm{kt}$ at both times originally in HURDAT, a major change.

Katie was a small hurricane that continued to intensify until landfall occurred around $06 Z$ on the $17^{\text {th }}$ on the Dominican Republic, near the city of Pedernales (18.0N, 71.8W). Landfall intensity is estimated at $90 \mathrm{kt}$, a category 2 hurricane. It is possible that Katie was even stronger as the aircraft left the hurricane 8 hours before landfall as it was intensifying. But there is no data to suggest that Katie was a major hurricane. Weakening occurred after landfall and Katie reached the north coast of Hispaniola around $15 Z$ on the $17^{\text {th }}$. The intensity decreased to $45 \mathrm{kt}$ at $18 \mathrm{Z}$ and slight intensification ensued after. Another aircraft investigated Katie at $22 \mathrm{Z}$ on the $17^{\text {th }}$ measuring a central pressure of $1000 \mathrm{mb}$ and estimated maximum surface winds of $65 \mathrm{kt}$. A central pressure of $1000 \mathrm{mb}$ yields $47 \mathrm{kt}$ south of $25 \mathrm{~N}$ according to the pressure-wind relationship. An intensity of 50 $\mathrm{kt}$ is selected at $0 \mathrm{Z}$ on the $18^{\text {th }}$ (down from $60 \mathrm{kt}$ originally in HURDAT) as the system was starting to accelerating toward the north-northeast. A central pressure of $1000 \mathrm{mb}$ is added to $00 \mathrm{Z}$ on the $18^{\text {th }}$. A second reconnaissance mission reached Katie at $1630 \mathrm{Z}$ measuring a central pressure of $999 \mathrm{mb}$, estimated maximum sustained winds of $50 \mathrm{kt}$ and an eye diameter of 40 miles. A central pressure of $999 \mathrm{mb}$ yields $45 \mathrm{kt}$ north of $25 \mathrm{~N}$ according to the pressure-wind relationship. A central pressure of $999 \mathrm{mb}$ has been added to $18 \mathrm{Z}$ on the $18^{\text {th }}$. An intensity of $50 \mathrm{kt}$ is selected at $18 \mathrm{Z}$ on the $18^{\text {th }}$ due in part to the fast motion of the storm. Early on the $19^{\text {th }}$, Katie began to interact with an approaching frontal boundary and the storm became absorbed by $12 \mathrm{Z}$. This is supported by the synoptic maps of $12 \mathrm{Z}$ on the $19^{\text {th }}$ and $0 \mathrm{Z}$ on the $20^{\text {th }}$. The analyzed last position is $06 \mathrm{Z}$ on the $19^{\text {th }}, 24$ hours earlier than originally shown in HURDAT. The ship AMST at 06Z on the $20^{\text {th }}$ reported $30 \mathrm{kt} \mathrm{W}$ and $1003 \mathrm{mb}$ at $41.5 \mathrm{~N}, 47.0 \mathrm{~W}$ indicating an extratropical cyclone development along this frontal boundary at that time. Also, unlike HURDAT, the 
reanalysis does not show Katie becoming extratropical. The extratropical cyclone continued moving northeastward for several days, eventually passing east of Greenland on the $22^{\text {nd }}$ of October.

\section{5 - Additional Notes}

1) February 18-27: A low pressure developed along the tail-end of a frontal boundary over the western Atlantic on the 19th. It moved eastward reaching the central Atlantic on the 21st according to the Historical Weather Maps and Microfilm. The system became an occluded low pressure on the 22nd and gale-force winds were present on the 23rd but far to the north $(\sim 300 \mathrm{~nm})$ of the center. The low pressure remained over the area for a couple more days while producing gale-force winds. The system persisted as a large, occluded low until it was absorbed by a cold front on the 27th. Therefore, it is not added to HURDAT. This disturbance was in Beven's and Roth's List of Suspects.

$\begin{array}{llll}\text { Day } & \text { LAT } & \text { LONG } & \text { STATUS } \\ \text { February 18 } & 13-29 \mathrm{~N} & 75-79 \mathrm{~W} & \text { Trough } \\ \text { February 19 } & 27 \mathrm{~N} & 71 \mathrm{~W} & \text { Extratropical } \\ \text { February 20 } & 27 \mathrm{~N} & 68 \mathrm{~W} & \text { Extratropical } \\ \text { February 21 } & 28 \mathrm{~N} & 60 \mathrm{~W} & \text { Extratropical } \\ \text { February 22 } & 26 \mathrm{~N} & 52 \mathrm{~W} & \text { Occluded } \\ \text { February 23 } & 30 \mathrm{~N} & 51 \mathrm{~W} & \text { Occluded } \\ \text { February 24 } & 26 \mathrm{~N} & 52 \mathrm{~W} & \text { Occluded } \\ \text { February 25 } & 28 \mathrm{~N} & 53 \mathrm{~W} & \text { Occluded } \\ \text { February 26 } & 28 \mathrm{~N} & 50 \mathrm{~W} & \text { Occluded } \\ \text { February 27 } & & & \text { Absorbed by front }\end{array}$

2) April 21-26: A low pressure system formed over the central Atlantic on the 21 st of April according to the Historical Weather Maps. It moved generally northward for about five days before weakening to a trough and becoming absorbed by a cold front on April 26th over the north Atlantic. No gale-force winds were found in COADS or HWM associated with this disturbance. Therefore, it is not added to HURDAT.

\begin{tabular}{|c|c|c|c|}
\hline Day & LAT & LONG & STATUS \\
\hline April 21 & $23 \mathrm{~N}$ & $57 \mathrm{~W}$ & Tropical Depression? \\
\hline April 22 & $25 \mathrm{~N}$ & $47 \mathrm{~W}$ & Tropical Depression? \\
\hline April 23 & $28 \mathrm{~N}$ & $48 \mathrm{~W}$ & Tropical Depression? \\
\hline April 24 & $32 \mathrm{~N}$ & $49 \mathrm{~W}$ & Tropical Depression? \\
\hline April 25 & $42-34 \mathrm{~N}$ & $44 \mathrm{~W}$ & Trough \\
\hline April 26 & & & Absorbed by front \\
\hline
\end{tabular}


3) May 1-7: A weakening cold front over the western Atlantic spawned a non-tropical low pressure between the United States East Coast and Bermuda on May 1st according to the Historical Weather Maps and Microfilm. The system was producing gale-force winds to the west and northeast of its center on May 1st, 2nd and 3rd. The disturbance moved generally southwestward becoming an occluded low on the 2nd and degenerating into a trough of low pressure on the 5th. On May 7th, the system had dissipated. Because it only had gale force winds while it was occluded, it is not added to HURDAT. This disturbance was in Roth's List of Suspects.

$\begin{array}{llll}\text { Day } & \text { LAT } & \text { LONG } & \text { STATUS } \\ \text { May 1 } & 32 \mathrm{~N} & 69 \mathrm{~W} & \text { Extratropical } \\ \text { May 2 } & 30 \mathrm{~N} & 72 \mathrm{~W} & \text { Occluded } \\ \text { May 3 } & 28 \mathrm{~N} & 73 \mathrm{~W} & \text { Occluded } \\ \text { May 4 } & 28 \mathrm{~N} & 70 \mathrm{~W} & \text { Occluded } \\ \text { May 5 } & 20-30 \mathrm{~N} & 65-68 \mathrm{~W} & \text { Trough } \\ \text { May 6 } & 19-34 \mathrm{~N} & 62-66 \mathrm{~W} & \text { Trough } \\ \text { May 7 } & & & \text { Dissipated }\end{array}$

4) September 5-8: A trough of low pressure was present over the northwest Gulf of Mexico at the same time that Hurricane Gladys churned over the Bay of Campeche according to the Monthly Weather Review, Microfilm and Annual Tropical Storm Report. The disturbance produced tropical storm force conditions across southern Texas but it moved inland before developing a well-defined circulation. Therefore, it is not added to HURDAT. MWR: "At the same time an area of heavy squalls developed off the middle Texas coast on September 5 and moved inland on the 6th. Highest winds reported were $45 \mathrm{mph}$ in the Corpus Christi-Port O'Connor area, and an oil rig 15 miles east of Port Aransas, Tex., reported gusts of 55 to $65 \mathrm{mph}$. The Naval Air Station at Corpus Christi received 12.23 inches of rain in 24 hours and a high tide of 4.5 feet was reported in the Bay. Damage was estimated at $\$ 500,000$ in the Corpus Christi area. It is reported that radar observations during this period indicated briefly the presence of a cyclonic circulation, consequently this may have been a separate tropical storm." ATSR: "Between $050300 \mathrm{Z}$ and $06300 \mathrm{Z}$, the westward movement of "Gladys" trough was arrested by the westerly trough and it began an oscillation westward and eastward all the while oriented north-south along the Texas and Mexican Gulf Coast. The two troughs met and merged in northeastern Texas resulting in heavy rain and extremely squally weather along the trough axis. ... However, the stagnant trough along the Texas Gulf coast continued to give heavy rains to the Galveston-Brownsville area. By request two additional recoinnaissance aircraft flights were ordered into the Western Gulf to investigate the area along the Texas coast for possible tropical storm existence or development. None was expected and none was found." This disturbance was in Beven's List of Suspects. 


$\begin{array}{llll}\text { Day } & \text { LAT } & \text { LONG } & \text { STATUS } \\ \text { September 5 } & \text { 25-29N } 96 \mathrm{~W} & \text { Trough } \\ \text { September 6 } & \text { 25-28N 97W } & \text { Trough } \\ \text { September 7 } & \text { 25-28N 99W } & \text { Trough } \\ \text { September 8 } & & & \text { Dissipated }\end{array}$

5) October 25-28: A low pressure developed on October 25th over the central Atlantic along the tail-end of a weakening cold front according to the Historical Weather Maps and Microfilm. The disturbance became better organized on the 26th and a ship near $28.5 \mathrm{~N}, 57.5 \mathrm{~W}$ reported gale-force winds. The disturbance generally moved northeast and an approaching cold front absorbed the low pressure late on the 27th. It is possible the system may have been a short-lived tropical storm but the data is not enough to justify such an assestment with only one gale-force report. Therefore, it is not added to HURDAT.

\begin{tabular}{llll} 
Day & LAT & LONG & \multicolumn{1}{c}{ STATUS } \\
October 25 & 23N & $57 \mathrm{~W}$ & Tropical Depression? \\
October 26 & 28N & $56 \mathrm{~W}$ & Tropical Storm? \\
October 27 & $28 \mathrm{~N}$ & $53 \mathrm{~W}$ & Tropical Storm? \\
October 28 & & & Absorbed by front
\end{tabular}

6) November 2-5: A non-tropical low pressure developed on November 2nd to the southeast of Nova Scotia according to the Historical Weather Maps and Microfilm. The system moved eastward becoming a large, occluded cyclone on the 3rd with gale-force winds to the west and northeast of the its center. An approaching cold front absorbed the cyclone on the 5th. Because gale force winds were recorded only while the system was an occluded low, it is not added to HURDAT. This disturbance was in Roth's List of Suspects.

$\begin{array}{lccl}\text { Day } & \text { LAT } & \text { LONG } & \text { STATUS } \\ \text { November 2 } & 40 \mathrm{~N} & 60 \mathrm{~W} & \text { Extratropical } \\ \text { November 3 } & 38 \mathrm{~N} & 58 \mathrm{~W} & \text { Occluded } \\ \text { November 4 } & 40 \mathrm{~N} & 53 \mathrm{~W} & \text { Occluded } \\ \text { November 5 } & & & \text { Dissipated }\end{array}$

7) November 5-8: A trough of low pressure formed over the central Atlantic during the first week of November according to the Historical Weather Maps. A low pressure developed on the 6th as it moved generally on an eastward course. Dissipation occurred around the 9th over the eastern Atlantic. No gale-force winds were found in COADS or HWM associated with this disturbance. Therefore, it is not added to HURDAT. 
Day LAT LONG

November $5 \quad 20-30 \mathrm{~N}$ 48-58W

November $6 \quad 28 \mathrm{~N} \quad 42 \mathrm{~W}$

November $7 \quad 28 \mathrm{~N} \quad 31 \mathrm{~W}$

November $8 \quad 28 \mathrm{~N} \quad 24 \mathrm{~W}$

November 9
STATUS

Trough

Tropical Depression?

Tropical Depression?

Tropical Depression?

Dissipated 


\section{6 hurricane season}

New Tropical Storm [June 7-10, 1956]

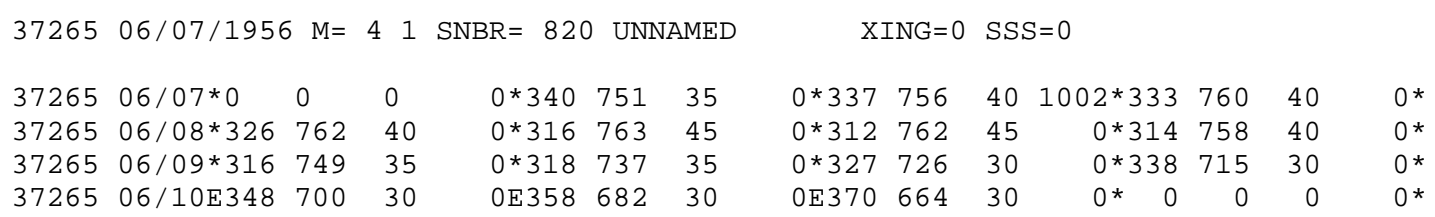
37285 TS

A new tropical storm has been added to HURDAT, not previously shown in McAdie et al. (2009). Evidence for its existence comes from the Historical Weather Map series, Microfilm, Monthly Weather Review, COADS ship database, and Jack Beven's and David Roth's suspect lists.

June 5:

HWM shows a stationary front over the eastern United States at 12Z. Microfilm analyses a frontal boundary east of the United States at 12Z. Ship highlights: No gale force winds or equivalent low pressures.

June 6:

HWM shows a closed low pressure of at most $1010 \mathrm{mb}$ at $28.0 \mathrm{~N}, 75.0 \mathrm{~W}$ at $12 \mathrm{Z}$. Microfilm analyses a closed low pressure of at most $1011 \mathrm{mb}$ at $29.0 \mathrm{~N}, 76.0 \mathrm{~W}$ and another closed low pressure of at most $1011 \mathrm{mb}$ at $23.5 \mathrm{~N}, 76.5 \mathrm{~W}$ at $12 \mathrm{Z}$. Neither analysis indicates a frontal boundary near the low(s). MWR shows a low pressure of $1011 \mathrm{mb}$ located near $26.9 \mathrm{~N}, 77.0 \mathrm{~W}$ at $12 \mathrm{Z}$. Ship highlights: No gale force winds or equivalent low pressures.

June 7:

HWM shows a closed low pressure of at most $1005 \mathrm{mb}$ at $34.0 \mathrm{~N}, 73.8 \mathrm{~W}$ with a weakening front to its northeast at $12 \mathrm{Z}$. Microfilm analyses a closed low pressure of at most $1008 \mathrm{mb}$ at $34.0 \mathrm{~N}, 74.0 \mathrm{~W}$ at 12Z. MWR shows a low pressure of $1002 \mathrm{mb}$ located near $34.8 \mathrm{~N}, 74.3 \mathrm{~W}$ at $12 \mathrm{Z}$. Ship highlights: $30 \mathrm{kt} \mathrm{N}$ and $1005 \mathrm{mb}$ at $33.8 \mathrm{~N}, 76.1 \mathrm{~W}$ at $12 \mathrm{Z}$ (COADS). $20 \mathrm{kt} \mathrm{SE}$ and $1004 \mathrm{mb}$ at 33.5N, 75.6W at 12Z (COADS). $35 \mathrm{kt} \mathrm{NE}$ and 1006 $\mathrm{mb}$ at $34.5 \mathrm{~N}, 75.6 \mathrm{~W}$ at $18 \mathrm{Z}$ (COADS).

June 8:

HWM shows a closed low pressure of at most $1005 \mathrm{mb}$ at $31.3 \mathrm{~N}, 75.0 \mathrm{~W}$ at $12 \mathrm{Z}$. Microfilm analyses a closed low pressure of at most $1008 \mathrm{mb}$ at $32.0 \mathrm{~N}, 76.0 \mathrm{~W}$ at $12 \mathrm{Z}$. MWR shows a low pressure of $1003 \mathrm{mb}$ located near 32.7N, 76.7W at 12Z. Ship 
highlights: $35 \mathrm{kt} \mathrm{NE}$ and $1007 \mathrm{mb}$ at $32.8 \mathrm{~N}, 77.0 \mathrm{~W}$ at $12 \mathrm{Z}$ (COADS). $30 \mathrm{kt} \mathrm{SSW}$ and $1001 \mathrm{mb}$ at $31.3 \mathrm{~N}, 76.2 \mathrm{~W}$ at $06 \mathrm{Z}$ (micro). $30 \mathrm{kt} \mathrm{SW}$ and $1004 \mathrm{mb}$ at $31.3 \mathrm{~N}, 76.9 \mathrm{~W}$ at $09 \mathrm{Z}$ (micro). $35 \mathrm{kt} \mathrm{WNW}$ and $1009 \mathrm{mb}$ at $30.9 \mathrm{~N}, 76.5 \mathrm{~W}$ at $18 \mathrm{Z}$ (micro).

June 9:

HWM shows a closed low pressure of at most $1010 \mathrm{mb}$ at $32.5 \mathrm{~N}, 72.5 \mathrm{~W}$ and a frontal boundary to the north at $12 \mathrm{Z}$. Microfilm analyses a closed low pressure of at most $1011 \mathrm{mb}$ at $32.5 \mathrm{~N}, 72.5 \mathrm{~W}$ and a frontal boundary to the north at $12 \mathrm{Z}$. MWR shows a low pressure of $1008 \mathrm{mb}$ located near $32.5 \mathrm{~N}, 72.0 \mathrm{~W}$ at 12Z. Ship highlights: No gale force winds or equivalent low pressures.

June 10:

HWM shows a closed low pressure of at most $1015 \mathrm{mb}$ at $37.0 \mathrm{~N}, 66.0 \mathrm{~W}$ with a frontal boundary going through the system at $12 \mathrm{Z}$. Microfilm analyses a closed low pressure of at most $1017 \mathrm{mb}$ at $37.0 \mathrm{~N}, 66.0 \mathrm{~W}$ with a frontal boundary going through the system at 12Z. MWR shows a low pressure of $1014 \mathrm{mb}$ located near $37.0 \mathrm{~N}, 66.0 \mathrm{~W}$ at 12Z. Ship highlights: No gale force winds or equivalent low pressures.

June 11:

HWM shows an extratropical cyclone of at most $1010 \mathrm{mb}$ at $41.0 \mathrm{~N}, 58.0 \mathrm{~W}$ at 12Z. Microfilm analyses an extratropical cyclone of at most $1008 \mathrm{mb}$ at $43.0 \mathrm{~N}, 61.0 \mathrm{~W}$ at 12Z. MWR shows a low pressure of $1008 \mathrm{mb}$ located near $42.5 \mathrm{~N}, 60.0 \mathrm{~W}$ at $12 \mathrm{Z}$. Ship highlights: No gale force winds or equivalent low pressures.

June 12:

HWM shows an extratropical cyclone of at most $1005 \mathrm{mb}$ at $43.5 \mathrm{~N}, 53.2 \mathrm{~W}$ at 12Z. Microfilm analyses an extratropical cyclone of at most $1008 \mathrm{mb}$ at $43.0 \mathrm{~N}, 61.0 \mathrm{~W}$ at 12Z. MWR shows a low pressure of $1005 \mathrm{mb}$ located near $53.5 \mathrm{~N}, 62.0 \mathrm{~W}$ and a frontal boundary south of Newfoundland, Canada at 12Z. Ship highlights: No gale force winds or equivalent low pressures.

A low pressure developed off the southeast coast of the United States from a weakening frontal boundary during the first week of June. Ship data indicates that a trough of low pressure was present north of the Bahamas along longitude $76 \mathrm{~W}$ on June $6^{\text {th }}$ and it was slowly moving northward. The frontal boundary dissipated by the $6^{\text {th }}$. By early June $7^{\text {th }}$, pressures had decreased about 3-5 mb near the disturbance compared to the previous day and a closed circulation is analyzed to have developed around 06Z on June $7^{\text {th }}$. Several ships reported $30 \mathrm{kt}$ early on the $7^{\text {th }}$ and the intensity of the first position is analyzed at $35 \mathrm{kt}$ on June $7^{\text {th }}$ at $06 \mathrm{Z}$. A ship close to the center at $12 \mathrm{Z}$ reported $20 \mathrm{kt}$ 
and $1004 \mathrm{mb}$, which suggests a central pressure of about $1002 \mathrm{mb}$ and has been added to HURDAT. A peripheral pressure of $1004 \mathrm{mb}$ suggests maximum sustained winds of at least $36 \mathrm{kt}$ north of $25 \mathrm{~N}$ from the Brown et al. pressure-wind relationship. An intensity of $40 \mathrm{kt}$ is selected for $12 \mathrm{Z}$ on June $7^{\text {th }}$. On June $7^{\text {th }}$ and early on the $8^{\text {th }}$, the tropical storm moved generally southward, near the warm waters of the Gulf Stream.

Gale force winds were also reported on June $8^{\text {th }}$ by a couple of ships near the tropical cyclone. At $06 \mathrm{Z}$ on the $8^{\text {th }}$, a ship reported $30 \mathrm{kt}$ and $1001 \mathrm{mb}$. A peripheral pressure of $1001 \mathrm{mb}$ suggests maximum sustained winds of at least $42 \mathrm{kt}$ north of the $25 \mathrm{~N}$ pressure-wind relationship. An intensity of $45 \mathrm{kt}$ is selected for $06 \mathrm{Z}$ and $12 \mathrm{Z}$ on the $8^{\text {th }} .45 \mathrm{kt}$ is the peak intensity for the lifetime of this tropical cyclone. Late on the $8^{\text {th }}$ and into the $9^{\text {th }}$, the forward speed increased to the northeast ahead of a deepening frontal boundary. Weakening is analyzed to have started late on the $8^{\text {th }}$ and by $12 \mathrm{Z}$ on the $9^{\text {th }}$; the cyclone had diminished to a tropical depression. Late on the $9^{\text {th }}$, ship data indicates that the circulation of the tropical depression began to interact with the frontal boundary. It is analyzed that by $00 \mathrm{Z}$ on June $10^{\text {th }}$, the tropical depression became an extratropical cyclone. Its duration as an extratropical cyclone was short-lived as the system continued to weaken, becoming a trough of low pressure between Bermuda and Nova Scotia after $12 \mathrm{Z}$ on the $10^{\text {th }}$.

\section{Unnamed Tropical Storm 1 [June 12-15, 1956]}

\begin{tabular}{|c|c|c|c|c|c|c|c|c|c|c|c|c|c|c|}
\hline 39285 & $06 / 12 / 1956$ & $M=$ & 4 & SNBR $=85$ & $58 \mathrm{NO}^{-}$ & T NAMED & & XIN & $J G=1$ & SSS $=$ & & & & \\
\hline 39285 & $06 / 12 / 1956$ & $M=$ & 4 & SNBR $=85$ & $58 \mathrm{NO}^{-}$ & T NAMED & & XIN & $J G=1$ & SSS $=$ & & & & \\
\hline 39290 & $06 / 12 * 220$ & 915 & 25 & $0 * 225$ & 913 & 30 & $0 * 23$ & & 912 & 30 & $1009 * 240$ & 910 & 35 & ○* \\
\hline 39290 & $06 / 12^{*} \underset{* \star *}{200}$ & 915 & 25 & $\begin{array}{l}0 * 203 \\
* * *\end{array}$ & $\begin{array}{l}915 \\
\star \star *\end{array}$ & $\begin{array}{l}25 \\
\star *\end{array}$ & $\theta^{*} 20$ & & $\begin{array}{l}915 \\
* \star *\end{array}$ & 30 & $\begin{array}{l}1007 * 212 \\
\star * * * * * *\end{array}$ & $\begin{array}{l}915 \\
\star * *\end{array}$ & 35 & $0^{*}$ \\
\hline $\begin{array}{l}39295 \\
39295\end{array}$ & $\begin{array}{r}06 / 13 * 253 \\
06 / 13 * 230 \\
* * *\end{array}$ & $\begin{array}{l}907 \\
915 \\
* * *\end{array}$ & $\begin{array}{l}4 \odot \\
4 \odot\end{array}$ & $\begin{array}{l}\Theta^{*} 264 \\
\Theta^{*} 251 \\
* \star \star\end{array}$ & $\begin{array}{l}907 \\
913 \\
* * *\end{array}$ & $\begin{array}{l}50 \\
45 \\
* *\end{array}$ & $\begin{array}{l}\odot * 27 \\
\odot * 27\end{array}$ & & $\begin{array}{l}909 \\
909\end{array}$ & $\begin{array}{l}50 \\
50\end{array}$ & $\begin{array}{r}1004 * 290 \\
1004 * 294 \\
* * *\end{array}$ & $\begin{array}{l}908 \\
906 \\
* * *\end{array}$ & $\begin{array}{l}45 \\
50 \\
\star *\end{array}$ & $\begin{array}{r}0^{*} \\
1002^{*} \\
* * * *\end{array}$ \\
\hline $\begin{array}{l}39300 \\
39300\end{array}$ & $\begin{array}{r}06 / 14 * 306 \\
06 / 14 * 310 \\
* * *\end{array}$ & $\begin{array}{l}905 \\
906 \\
\star * *\end{array}$ & $\begin{array}{l}40 \\
35 \\
* *\end{array}$ & $\begin{array}{r}\Theta * 322 \\
\Theta * 324 \\
* * *\end{array}$ & $\begin{array}{l}910 \\
910\end{array}$ & $\begin{array}{l}35 \\
30 \\
\star *\end{array}$ & & & $\begin{array}{l}917 \\
917\end{array}$ & $\begin{array}{l}25 \\
25\end{array}$ & $\begin{array}{r}1006 * 347 \\
1006 * 345 \\
* * *\end{array}$ & $\begin{array}{l}928 \\
928\end{array}$ & $\begin{array}{l}25 \\
25\end{array}$ & $\begin{array}{l}0^{*} \\
0^{*}\end{array}$ \\
\hline 39305 & $06 / 15 * 349$ & 933 & 25 & $0 * 352$ & 938 & 20 & $\Theta^{*}$ & $\odot$ & $\odot$ & $\odot$ & $\Theta^{*}$ & $\odot$ & $\odot$ & ○* \\
\hline
\end{tabular}

U.S. Tropical Storm Landfall

06/13 17Z 29.1N 90.7W $50 \mathrm{kt} \mathrm{LA}$ 
Major changes to the track and minor changes to the intensity shown in McAdie et al. (2009). Evidence for these alterations comes from the NHC microfilm maps, the Historical Weather Maps series, the COADS ship database, Monthly Weather Review, the Local Climatological Data, Surface Weather Observations, Connor (1956) and Mexican synoptic maps.

June 11:

HWM, HURDAT and MWR does not analyze an organized system at $12 \mathrm{Z}$. Microfilm shows a low pressure over eastern Mexico and a tropical wave/trough along $92 \mathrm{~W}$ at $12 \mathrm{Z}$. No gales or low pressures.

June 12:

HWM does not analyze an organized system over the Gulf of Mexico at $12 Z$. HURDAT lists this as a 30 knot tropical depression at $23.1 \mathrm{~N}, 91.2 \mathrm{~W}$ at $12 \mathrm{Z}$. Microfilm analyzes a low pressure of at most $1011 \mathrm{mb}$ centered near $20.2 \mathrm{~N}, 92.5 \mathrm{~W}$ at $12 \mathrm{Z}$. MWR shows a low pressure of $1009 \mathrm{mb}$ located near $20.3 \mathrm{~N}, 91.8 \mathrm{~W}$ at $12 \mathrm{Z}$. No gales or low pressures. "This was the second tropical storm to occur in June in 10 years. On June 9, a fracture occurred in the polar trough lying just off the Atlantic coast, and the southern section began moving westward across Florida into the Gulf of Mexico while the northern portion continued eastward over the western Atlantic. The westward moving southern section apparently induced an easterly wave which moved across the extreme western Caribbean, western Cuba, southern Florida, and the Yucatan Peninsula, and on the $12^{\text {th }}$ formed a depression in the Bay of Campeche under the mid-tropospheric trough." (MWR)

June 13:

HWM shows a closed low pressure of at most $1010 \mathrm{mb}$ centered near $28.3 \mathrm{~N}$, 91.5W at $12 \mathrm{Z}$. HURDAT lists this as a 50 knot tropical storm at $27.5 \mathrm{~N}, 90.9 \mathrm{~W}$ at $12 \mathrm{Z}$. Microfilm analyzes a closed low pressure of at most $1005 \mathrm{mb}$ centered near $28.2 \mathrm{~N}$, $90.9 \mathrm{~W}$ at $12 \mathrm{Z}$. MWR shows a low pressure of $1004 \mathrm{mb}$ located near $27.8 \mathrm{~N}, 91.2 \mathrm{~W}$ at 12Z. Ship highlights: $40 \mathrm{kt} \mathrm{SE}$ and $1013 \mathrm{mb}$ near $24.0 \mathrm{~N}, 87.4 \mathrm{~W}$ at $06 \mathrm{Z}$ (micro). $35 \mathrm{kt} \mathrm{SE}$ and $1008 \mathrm{mb}$ near $28.2 \mathrm{~N}, 90.1 \mathrm{~W}$ at $12 \mathrm{Z}$ (micro). $40 \mathrm{kt} \mathrm{SSE}$ and $1008 \mathrm{mb}$ near $28.7 \mathrm{~N}$, 89.3W at $18 \mathrm{Z}$ (COADS). Land highlights: $40 \mathrm{kt} \mathrm{SE}$ and $1011 \mathrm{mb}$ at SW Pass Lighthouse, LA at $12 \mathrm{Z}$ (micro). $48 \mathrm{kt} \mathrm{E}$ at Grand Isle, LA at $1315 \mathrm{Z}$ (MWR). $1004 \mathrm{mb}$ at New Orleans (no time given) (MWR). $40 \mathrm{kt}$ at Golden Meadow, LA (no time given) (CONNOR). "The disturbance moved northward, acquiring tropical storm intensity and the center crossed the Louisiana coast a short distance west of Grand Isle during the late afternoon of the $13^{\text {th }}$. According to the report from the hurricane forecast center at New Orleans, "The storm had both tropical and extratropical characteristics. Rainfall was tropical in nature 
but never formed in bands characteristics of tropical storm and there was never any definite center or eye. The temperature aloft over the surface Low remained as cold as or colder than the surrounding air." The situation in the high troposphere was also markedly different from that usually observed during hurricane formation." "The highest wind reported ashore was $55 \mathrm{mph}$ from the east at Grand Isle, at 0715 CST on the $13^{\text {th }}$. A boat 5 miles south of Pilottown, La, reported gusts to $60 \mathrm{mph}$ from the south-southeast. The lowest observed pressure was 29.66 inches at Moissant Airpor, New Orleans, and at McComb, Miss. The highest measured tide was 4.7 feet above mean sea level at Biloxi, Miss. The heaviest rainfall was within 100 miles of and to the east of the storm track and decreased from 6.13 inches at Grand Isle, La., to 5.60 inches at Monticello, Miss., 3.17 inches at Jackson, Miss., and 1.60 inches at Greenwood, Miss. The benefit to crops from these rains, which ended a drought at least temporarily, exceeded property loses from wind and water on the coast. Four persons were drowned, three of them when a tug sank off the Mississippi coast and the other, a truck driver, when his truck skidded on the bridge over Lake Pontchartrain and plunged into the lake. The bridge was damaged by the truck but more seriously by a loose barge. The total damage to the bridge was estimated at $\$ 12,000$. Tides generally ranged from 1 to 4 feet above normal along the Louisiana and Mississippi coasts. The Freeport Sulphur Co. suffered some damage to their sulphur mines near the coast south of Houma, La, where the tide was 4.5 feet above mean sea level. Minor damage to the beaches, small boats, and piers occurred along the Mississippi coast in places where tides were said to have reached as much as 5 feet above mean sea level. The total damage from this storm is estimated at $\$ 50,000$.” (MWR)

June 14:

HWM shows a closed low pressure of at most $1010 \mathrm{mb}$ centered near $34.0 \mathrm{~N}$, $92.5 \mathrm{~W}$ at $12 \mathrm{Z}$. HURDAT lists this as a 25 knot tropical depression at $33.8 \mathrm{~N}, 91.7 \mathrm{~W}$ at 12Z. Microfilm analyzes a closed low pressure of at most $1008 \mathrm{mb}$ centered near $34.0 \mathrm{~N}$, $92.0 \mathrm{~W}$ at $12 \mathrm{Z}$. MWR shows a low pressure of $1006 \mathrm{mb}$ located near $33.5 \mathrm{~N}, 91.5 \mathrm{~W}$ at 12Z. Land highlights: $1004 \mathrm{mb}$ at McComb, MS (no time given) (CONNOR). $5 \mathrm{kt} \mathrm{N}$ and $1005 \mathrm{mb}$ at Liberty, MS at $0 \mathrm{Z}$ (micro). "At $250 \mathrm{mb}$, at $0300 \mathrm{GMT}$ on the $12^{\text {th }}$, an intense cyclonic circulation was centered southwest of Fort Worth and at 0300 GMT on the $14^{\text {th }}$ this center had moved almost over the tropical storm in Louisiana." (MWR)

June 15:

HWM shows a low pressure system over SW Wyoming with a cold front to the south and a warm front to the east stretching over the north of the US. The tropical cyclone appears to have dissipated. HURDAT lists this as a $20 \mathrm{kt}$ tropical depression at $35.2 \mathrm{~N}, 93.8 \mathrm{~W}$ at $06 \mathrm{Z}$ (last position). Microfilm does not analyze an organized system at 12Z. No gales or low pressures. 
The first tropical cyclone of the 1956 hurricane season developed in the Bay of Campeche during the second week of June as a tropical wave moved into the region. Genesis of this tropical storm is kept at $00 \mathrm{Z}$ on the $12^{\text {th }}$ of June, but ship and land stations data on this day indicate that the center was located about $120 \mathrm{~nm}$ south than originally shown in HURDAT, a major change. Only minor changes to the track were subsequently introduced on the $13^{\text {th }}$, and $14^{\text {th }}$, with no alterations on the $15^{\text {th }}$. The cyclone is initialized as a $25 \mathrm{kt}$ tropical depression, as originally shown in HURDAT. The depression moved northward, initially slow but gaining forward speed later in the day. A central pressure of $1009 \mathrm{mb}$ was in original HURDAT at $12 \mathrm{Z}$ and appears to be an estimate, not an actual measurement. A ship within the RMW reported $20 \mathrm{kt} \mathrm{E}$ and $1009 \mathrm{mb}$, suggesting a possible central pressure of $1007 \mathrm{mb}$. Therefore, the $1009 \mathrm{mb}$ at $12 \mathrm{Z}$ has been replaced by $1007 \mathrm{mb}$. Intensification to a tropical storm occurred at $18 \mathrm{Z}$ on the $12^{\text {th }}$ in agreement with the original HURDAT. The first gales were observed early on the $13^{\text {th }}$ as various ships reported 35-40 kt about 150-300 nm away from the center. At this time the system was moving at about $22 \mathrm{kt}$ to the north with an elongated N-S structure and most of the rainbands and winds concentrated on the eastern quadrant. The structure, as mentioned by the Monthly Weather Review summary, exhibited subtropical characteristics and it is possible that during this time this system was a subtropical cyclone. Note, however, that formally designating systems as "subtropical" is not feasible until the advent of satellite imagery to assess the convective distribution. Nonetheless, intensification continued and by $12 \mathrm{Z}$ on the $13^{\text {th }}$ it had reached a peak intensity of $50 \mathrm{kt}$ as originally shown in HURDAT. At this time, the cyclone became more symmetric and the circulation became more concentrated although the winds remained stronger on the eastern quadrant. Another reason for the winds to be stronger on the eastern semi-circle was the presence of an intense high pressure system over the Ohio Valley causing a strong pressure gradient on that side of the storm.

Landfall occurred around $17 \mathrm{Z}$ on the $13^{\text {th }}$ on southeast Louisiana near $29.1 \mathrm{~N}$, $90.7 \mathrm{~W}$ with maximum winds of $50 \mathrm{kt}$, no changes from original HURDAT. The highest wind report over land was $48 \mathrm{kt}$ at Grand Isle, LA. A central pressure of $1004 \mathrm{mb}$ was on the original HURDAT at $12 \mathrm{Z}$ on the $13^{\text {th }}$ and appears to be an estimate, but it looks to be reasonable and is retained. The tropical storm passed at about 30 miles west of New Orleans where the pressure dropped to $1004 \mathrm{mb}$ at the airport (unknown time, but likely soon after 18Z) and the winds at the time were at about $10 \mathrm{kt}$ from the south. Therefore, this suggests that the central pressure of the system was around $1002 \mathrm{mb}$. A central pressure of $1002 \mathrm{mb}$ is selected for $18 \mathrm{Z}$ on the $13^{\text {th }}$ and added to HURDAT. Weakening began after landfall and the system is analyzed to have become a tropical depression at $06 \mathrm{Z}$ on June $14^{\text {th }}$, six hours earlier than originally shown in HURDAT. At this time the track of the cyclone changed to the northwest and its forward speed began to decrease. A central pressure of $1006 \mathrm{mb}$ was present on the original HURDAT at $12 \mathrm{Z}$ on the $14^{\text {th }}$ and 
although it appears to be an estimate, it looks to be reasonable and is retained. Dissipation occurred after $06 Z$ on June $15^{\text {th }}$ as originally shown in HURDAT.

Hurricane Anna [July 25-27, 1956]

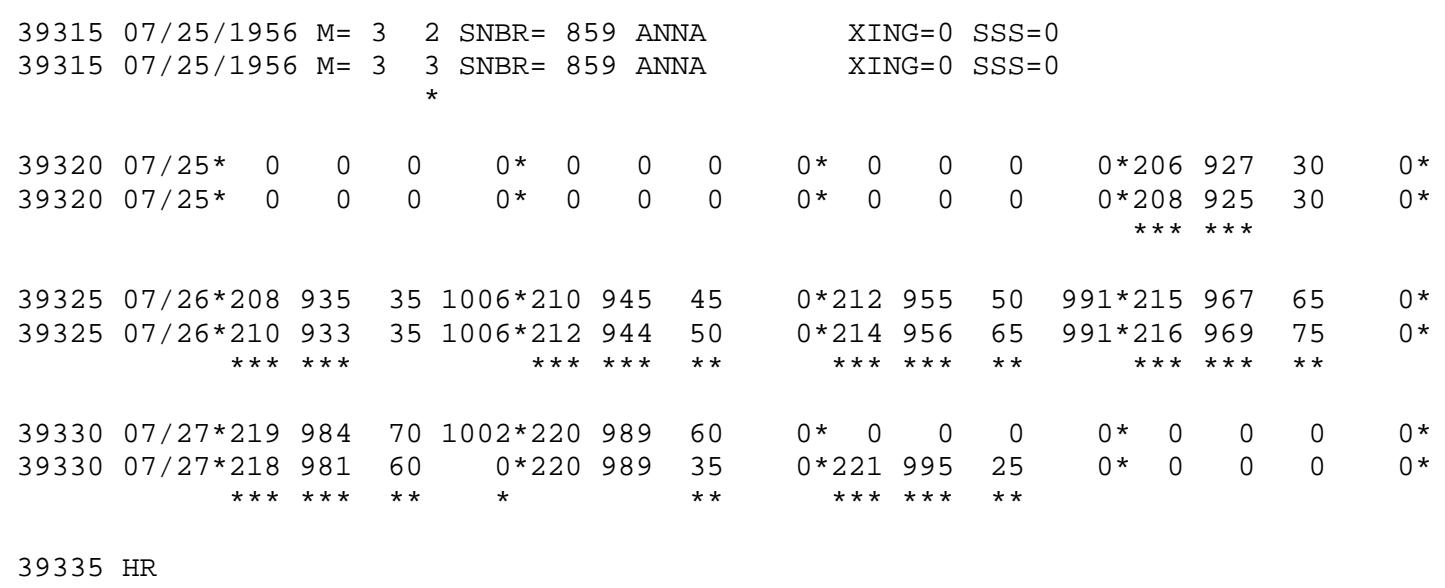

Minor changes to the track and major changes to the intensity shown in McAdie et al. (2009). Evidence for these alterations comes from the NHC microfilm maps, the Historical Weather Maps series, the COADS ship database, Monthly Weather Review, Connor (1956), Navy reconnaissance book and Mexican synoptic maps.

July 24:

HWR and microfilm do not analyze an organized system at 12Z. HURDAT does not list a tropical cyclone on this day. No gales or low pressures. "The easterly wave in which Anna developed passed through the Lesser Antilles on July 20 and continued westward through the Caribbean. Instability of the wave began to increase on the $23^{\text {rd }}$ as the wave, extending on the surface from central Cuba to Panama, passed under a very well developed anticyclone in the middle and upper troposphere. A weak circulation may have developed as it moved over the Yucatan Peninsula on the night of the $24^{\text {th }}$ but all surface winds were under $20 \mathrm{mph}$." (MWR) "“"Tropical Storm Anna formed from an easterly wave, locally numbered "July \#1," which moved into the Antilles from the Atlantic on 20 July. "July \#1" was a wave of moderate intensity while moving across the Caribbean but exhibited no signs of vortex development. The first indications of vortex development came late on the $24^{\text {th }}$ of July. Previously the easterly wave had not been capped with divergent flow at higher levels but, beginning on the $24^{\text {th }}$, the easterly moved under divergent flow of the $200 \mathrm{mb}$ level. The perturbation of the pressure pattern shortly became more accentuated and a weak vortex developed." (ATSR)

July 25: 
HWM shows a closed low pressure of at most $1010 \mathrm{mb}$ centered near $20.5 \mathrm{~N}$, $91.0 \mathrm{~W}$ at $12 \mathrm{Z}$. HURDAT lists this as a 30 knot tropical depression at $20.6 \mathrm{~N}, 92.7 \mathrm{~W}$ at 18Z. Microfilm analyzes a closed low pressure of at most $1008 \mathrm{mb}$ centered near $20.5 \mathrm{~N}$, $92.5 \mathrm{~W}$ at $12 \mathrm{Z}$. No gales or low pressures. Aircraft highlights: Penetration center fix measured a central pressure of $1006 \mathrm{mb}$ and maximum surface winds of $35 \mathrm{kt}$ at $20.9 \mathrm{~N}$, 93.0W at 2225Z (ATSR). "Intensification was steady after the center passed into the Bay of Campeche and the depression intensified to storm intensity on the afternoon of the $25^{\text {th }}$." (MWR) "Moving westward at about 10 knots, the vortex and associated wave moved over the warm waters of the Gulf of Campeche on the $25^{\text {th }}$ of July, meanwhile the intensity was slowly increasing. The first weather reconnaissance flight was ordered out of Jacksonville on the $25^{\text {th }}$. Late that afternoon the Navy flight reported a center of light wind circulation, minimum surface pressure of $1006 \mathrm{mb}$ and maximum winds of 35 knots at some distance from the center. Spiral bands, although evident, did not define the center. It was decided not to issue warnings on this vortex until the wind force and circulation increased." (ATSR)

July 26:

HWM shows a closed low pressure of at most $1005 \mathrm{mb}$ centered near $21.3 \mathrm{~N}$, $95.9 \mathrm{~W}$ at $12 \mathrm{Z}$. HURDAT lists this as a 50 knot tropical storm at $21.2 \mathrm{~N}, 95.5 \mathrm{~W}$ at $12 \mathrm{Z}$. Microfilm analyzes a closed low pressure of at most $1002 \mathrm{mb}$ centered near $20.6 \mathrm{~N}$, 91.0W at 12Z. Ship highlights: $20 \mathrm{kt} \mathrm{N}$ and $1005 \mathrm{mb}$ at 22.0N, 97.1W at 12Z (COADS). Land highlights: $70 \mathrm{kt}, 1002 \mathrm{mb}$ measured at Tampico (no time given) (MWR). Aircraft highlights: Penetration center fix measured a central pressure of $991 \mathrm{mb}$, maximum surface winds of $50 \mathrm{kt}$, and an eye diameter of 4 miles at $21.3 \mathrm{~N}, 96.3 \mathrm{~W}$ at $1442 \mathrm{Z}$ (ATSR). Penetration center fix at $21.6 \mathrm{~N}, 96.6 \mathrm{~W}$ at $1530 \mathrm{Z}$ (ATSR). "On the morning of the $26^{\text {th }}$, Navy reconnaissance located the center with lowest pressure $991 \mathrm{mb}$ (29.26 in.) and found maximum winds of 50 knots in the northern semicircle. Early that evening the center moved inland south of Tampico, Mexico where a maximum wind of 70 knots (81 $\mathrm{mph}$ ) was reported that winds of hurricane force existed only for about three hours as the center approached and crossed the coastline. Many houses in the poorer sections of Tampico were blown down and some roofs of the better homes were blown off. Although only 2.5 inches of rain were reported, downtown streets in Tampico were flooded. There were no reports of deaths and injuries. Damage has been estimated at around $\$ 50,000$." (MWR) "During the night of the $25^{\text {th }}$ and the morning of the $26^{\text {th }}$, the vortex and wave moved westward at 11 to 12 knots intensifying very slowly. Another reconnaissance flight was flown early on the $26^{\text {th }}$. This flight reported a very small center of wind circulation of $4 \mathrm{~nm}$ diameter, a minimum pressure of $991 \mathrm{mb}$ and maximum winds of 50 knots in the north quadrant. These facts prompted the issue of warning number ONE of Tropical Storm Anna at 261600Z. The past movement of Anna had been west to west- 
northwest at 11 to 12 knots. Anna had been moving along the south and southwest periphery of the $700 \mathrm{mb}$ and $500 \mathrm{mb}$ ridge. At the time Anna was expected to continue to move west-northwest at about 11 knots. Actually, Anna moved almost due west after 261600Z. The third and last reconnaissance flight was ordered into the storm area late on the $26^{\text {th }}$ on a radar tracking mission. The only fix placed the "eye" inland west of Cape Rojo and about half way between Tampico and Tuxpan. Thus "eye" fix, at 262235Z, was followed by a report at $262300 \mathrm{Z}$ indicating that the "eye" was no longer discernible, The final warning had been issued at $262200 \mathrm{Z}$ when it became apparent from land station reports that the center was moving overland. The maximum wind velocity report from aircraft and ship reports was 50 knots. Tampico reported a maximum wind of 42 knots with occasional gusts to 60 knots when Anna was passing south of the city. After passing overland Anna rapidly degenerated into an area of squalls. Except for some flooding damage, no reports of damage were received." (ATSR)

July 27:

HWM and Microfilm do not analyze an organized system at 12Z. HURDAT lists this as a $60 \mathrm{kt}$ tropical storm at $22.0 \mathrm{~N}, 98.9 \mathrm{~W}$ at $06 \mathrm{Z}$ (last position). Land highlights: 40 kt ESE and $1006 \mathrm{mb}$ at Tampico at 00Z (micro).

Hurricane Anna formed over the central Bay of Campeche from a tropical wave that likely entered the area late on July $24^{\text {th }}$. The pressure at Ciudad del Carmen, Mexico [18.6N, 91.8W] decreased from $1011.3 \mathrm{mb}$ on July 24 at $12 \mathrm{Z}$ to $1006.8 \mathrm{mb}$ on the $25^{\text {th }}$ at $12 \mathrm{Z}$, a drop of $4.5 \mathrm{mb}$ in 24 hours. The data on the Bay of Campeche is sparse but it indicates the possibility that this tropical cyclone developed earlier on the $25^{\text {th }}$ than shown. Very minor track changes were introduced for the duration of this system. Because of the lack of data, the genesis of this tropical cyclone is retained from original HURDAT at $18 \mathrm{Z}$ on the $25^{\text {th }}$ as a $30 \mathrm{kt}$ tropical depression. The first aircraft reconnaissance reached the system at $2225 \mathrm{Z}$ measuring estimated surface winds of $35 \mathrm{kt}$ and a central pressure of $1006 \mathrm{mb}$. A central pressure of $1006 \mathrm{mb}$ suggests maximum winds of $35 \mathrm{kt}$ south of $25 \mathrm{~N}$ from the Brown et al. pressure-wind relationship. Therefore, an intensity of $35 \mathrm{kt}$ is selected for $00 \mathrm{Z}$ on the $26^{\text {th }}$, which agrees with the original HURDAT. A central pressure of $1006 \mathrm{mb}$ was present in HURDAT at $00 \mathrm{Z}$ on the $26^{\text {th }}$ and it has been kept. At this time it is analyzed that the tropical depression had become a tropical storm. Anna moved generally on a west-northwest course and another aircraft mission at $1442 \mathrm{Z}$ on the $26^{\text {th }}$ found that the system had rapidly intensified. The plane measured a central pressure of $991 \mathrm{mb}$, estimated maximum surface winds of $50 \mathrm{kt}$ and an eye diameter of just $4 \mathrm{~nm}$. A central pressure of $991 \mathrm{mb}$ suggests maximum sustained winds of $62 \mathrm{kt}$ south of $25 \mathrm{~N}$ according to the pressure-wind relationship. The eye diameter $4 \mathrm{~nm}$ suggests an RMW of about $3 \mathrm{~nm}$, while climatology suggests an RMW of 
about $16 \mathrm{~nm}$. Due to the small size of Anna, an intensity of $65 \mathrm{kt}$ is selected for $12 \mathrm{Z}$ on the $26^{\text {th }}$, up from $50 \mathrm{kt}$ on HURDAT. At this time it is analyzed that Anna became a hurricane, six hours earlier than originally shown in HURDAT. A central pressure of 991 mb appears in HURDAT at $12 \mathrm{Z}$ on the $26^{\text {th }}$ and it has been kept.

Late on July 26, the hurricane continued to intensify making landfall around $21 \mathrm{Z}$ near $21.7 \mathrm{~N}, 97.5 \mathrm{~W}$ between Tampico and Tuxpan in the Mexican state of Veracruz. The intensity at landfall is estimated at $75 \mathrm{kt}$ but it is possible that Anna was stronger, possibly a category 2 hurricane when it crossed the coast as there is no data from the core between $15 \mathrm{Z}$ and $21 \mathrm{Z}$ on the $26^{\text {th }}$. The last aircraft reconnaissance mission reached Anna at $2235 \mathrm{Z}$ on the $26^{\text {th }}$ finding that the cyclone had already made landfall, and thus the plane only provided a radar fix position. MWR reports that Tampico experienced winds of $70 \mathrm{kt}$ causing damage to numerous houses, yet the reports from the Annual Tropical Storm Report on Anna contradicts this information indicating that the city only experienced maximum winds of $42 \mathrm{kt}$ and no damage was reported. Anna continued inland weakening to a tropical storm at $00 \mathrm{Z}$ on the $27^{\text {th }}$, six hours earlier than originally shown in HURDAT. Furthermore, a $1002 \mathrm{mb}$ central pressure was present in the original HURDAT at $00 \mathrm{Z}$ on the $27^{\text {th }}$ but this is very likely to be from the lowest pressure reported by Tampico. Since Anna passed about $60 \mathrm{~nm}$ south of the city, this is not a central pressure and has been removed. The mountainous terrain continued to take its toll on the cyclone and by $12 \mathrm{Z}$ on the $27^{\text {th }}$ it is analyzed to have weakened to a tropical depression. Dissipation occurred after 12Z, six hours later than originally shown in HURDAT which has the last position of Anna unrealistically listed as a $60 \mathrm{kt}$ tropical storm.

Hurricane Betsy [August 9-21, 1956]

\begin{tabular}{|c|c|c|c|c|c|c|c|c|c|c|c|c|c|}
\hline 39780 & $08 / 09 / 1956$ & $M=1$ & 2 & SNBR $=86$ & $66 \mathrm{BE}$ & ETSY & $X I$ & $N G=\odot$ & SSS $=c$ & & & & \\
\hline 39780 & $08 / 09 / 1956$ & $M=1$ & * & $\mathrm{SNBR}=86$ & $66 \mathrm{BE}$ & ETSY & $\mathrm{XI}$ & $N G=0$ & SSS $=0$ & & & & \\
\hline 39785 & $08 / 09$ * & $\odot$ & $\odot$ & $\odot * 135$ & 472 & $5 \odot$ & $0 * 137$ & 488 & 50 & $\odot * 139$ & 502 & 50 & 0 * \\
\hline 39785 & $08 / 09$ * & $\odot$ & $\odot$ & $0 * 135$ & $47 \overline{2}$ & 50 & $0 * 137$ & 488 & $\begin{array}{l}60 \\
* *\end{array}$ & $0 * 139$ & 502 & $\begin{array}{l}70 \\
* *\end{array}$ & ○* \\
\hline 39790 & $08 / 10 * 140$ & 516 & $6 \odot$ & $0 * 141$ & 530 & 105 & $0 * 142$ & 543 & 105 & $0 * 144$ & 560 & 105 & $979 *$ \\
\hline 39790 & $08 / 10 * 140$ & 516 & $\begin{array}{l}80 \\
* *\end{array}$ & $0 * 141$ & 530 & $\begin{array}{l}85 \\
* *\end{array}$ & $\begin{array}{r}0 * 143 \\
* * *\end{array}$ & $\begin{array}{l}545 \\
* * *\end{array}$ & $\begin{array}{l}90 \\
* *\end{array}$ & $\begin{array}{r}0 * 147 \\
* * *\end{array}$ & 560 & $\begin{array}{l}90 \\
* *\end{array}$ & $979 *$ \\
\hline 39795 & $08 / 11 * 147$ & 578 & 105 & $0 * 149$ & 591 & 100 & $0 * 153$ & 603 & 95 & $0 * 160$ & 618 & 80 & $991^{*}$ \\
\hline 39795 & $08 / 11^{*} 150$ & $\begin{array}{l}576 \\
* * *\end{array}$ & $\begin{array}{l}90 \\
* *\end{array}$ & $\begin{array}{c}0 * 152 \\
* * *\end{array}$ & 591 & $\begin{array}{l}90 \\
* *\end{array}$ & $\begin{array}{r}0 * 155 \\
* * *\end{array}$ & $\begin{array}{l}604 \\
* * *\end{array}$ & $\begin{array}{l}90 \\
* *\end{array}$ & $0 * 160$ & 618 & $\begin{array}{l}90 \\
* *\end{array}$ & $\begin{array}{l}979 * \\
* * *\end{array}$ \\
\hline 39800 & $08 / 12 * 165$ & 632 & 80 & $0 * 170$ & 644 & 80 & $0 * 178$ & 657 & 80 & $0 * 188$ & 672 & 80 & ○* \\
\hline 39800 & $08 / 12 * 165$ & 632 & $\begin{array}{l}85 \\
* *\end{array}$ & $\begin{array}{r}0 * 171 \\
* * *\end{array}$ & $\begin{array}{l}645 \\
* * *\end{array}$ & $\begin{array}{l}85 \\
* *\end{array}$ & $\begin{array}{r}0 * 179 \\
* * *\end{array}$ & $\begin{array}{l}659 \\
\star * *\end{array}$ & $\begin{array}{l}85 \\
* *\end{array}$ & ${ }_{* * *}^{981 * 188}$ & $\begin{array}{l}673 \\
* * *\end{array}$ & 80 & $0^{*}$ \\
\hline
\end{tabular}




\begin{tabular}{|c|c|c|c|c|c|c|c|c|c|c|c|c|c|}
\hline 39805 & $08 / 13 * 198$ & 687 & 85 & ๑*209 & 700 & 95 & $0 * 219$ & 713 & 95 & $974 * 228$ & 725 & 95 & $0^{*}$ \\
\hline 39805 & $08 / 13 * 198$ & 687 & 85 & ๑*209 & $70 \odot$ & 95 & $\begin{array}{r}\Theta * 220 \\
* * *\end{array}$ & $\begin{array}{l}714 \\
* * *\end{array}$ & $\begin{array}{l}100 \\
* * *\end{array}$ & $\begin{array}{l}972 * 230 \\
\star * \star * * *\end{array}$ & $\begin{array}{l}727 \\
* * *\end{array}$ & $\begin{array}{l}100 \\
* * *\end{array}$ & $0^{*}$ \\
\hline $\begin{array}{l}39810 \\
39810\end{array}$ & $\begin{array}{r}\odot 8 / 14^{*} 237 \\
\odot 8 / 14^{*} 24 \odot \\
* * *\end{array}$ & $\begin{array}{l}736 \\
739 \\
* * *\end{array}$ & $\begin{array}{r}95 \\
100 \\
* * *\end{array}$ & $\begin{array}{l}\Theta * 246 \\
\Theta * 249 \\
* \star *\end{array}$ & $\begin{array}{l}748 \\
750 \\
\star * *\end{array}$ & $\begin{array}{r}95 \\
105 \\
* * *\end{array}$ & $\begin{array}{l}0^{*} 256 \\
0 * 257 \\
* * *\end{array}$ & $\begin{array}{l}760 \\
760\end{array}$ & $\begin{array}{r}95 \\
105 \\
* * *\end{array}$ & $\begin{array}{r}\Theta^{*} 265 \\
960^{*} 265 \\
* * *\end{array}$ & $\begin{array}{l}767 \\
767\end{array}$ & $\begin{array}{r}95 \\
100 \\
* * *\end{array}$ & $\begin{array}{l}\Theta^{*} \\
\Theta^{*}\end{array}$ \\
\hline $\begin{array}{l}39815 \\
39815\end{array}$ & $\begin{array}{l}\odot 8 / 15 * 272 \\
08 / 15 * 272\end{array}$ & $\begin{array}{l}768 \\
769 \\
\star * *\end{array}$ & $\begin{array}{l}9 \odot \\
9 \odot\end{array}$ & $\begin{array}{l}968 * 278 \\
968 * 278\end{array}$ & $\begin{array}{l}768 \\
770 \\
* * *\end{array}$ & $\begin{array}{l}85 \\
9 \odot \\
* *\end{array}$ & $\begin{array}{l}\odot * 283 \\
\Theta^{*} 283\end{array}$ & $\begin{array}{l}766 \\
767 \\
* * *\end{array}$ & $\begin{array}{l}85 \\
95 \\
* *\end{array}$ & $\begin{array}{l}963 * 288 \\
963 * 288\end{array}$ & $\begin{array}{l}761 \\
762 \\
* * *\end{array}$ & $\begin{array}{l}85 \\
95 \\
* *\end{array}$ & $\begin{array}{l}\Theta^{*} \\
\Theta^{*}\end{array}$ \\
\hline $\begin{array}{l}39820 \\
39820\end{array}$ & $\begin{array}{l}08 / 16 * 293 \\
08 / 16 * 293\end{array}$ & $\begin{array}{l}756 \\
757 \\
\star * *\end{array}$ & $\begin{array}{l}85 \\
90 \\
\star *\end{array}$ & $\begin{array}{r}\text { ๑*298 } \\
\text { ○*299 } \\
\star \star \star *\end{array}$ & $\begin{array}{l}750 \\
752 \\
\star * *\end{array}$ & $\begin{array}{l}85 \\
80 \\
\star *\end{array}$ & $\begin{array}{r}0 * 307 \\
973 * 308 \\
* * * * * *\end{array}$ & $\begin{array}{l}743 \\
743\end{array}$ & $\begin{array}{l}85 \\
85\end{array}$ & $\begin{array}{l}0 * 322 \\
0 * 322\end{array}$ & $\begin{array}{l}733 \\
734 \\
* * *\end{array}$ & $\begin{array}{l}85 \\
95 \\
\star *\end{array}$ & $\begin{array}{l}0^{*} \\
0^{*}\end{array}$ \\
\hline $\begin{array}{l}39825 \\
39825\end{array}$ & $\begin{array}{l}08 / 17 \text { * } 337 \\
08 / 17 \text { *337 }\end{array}$ & $\begin{array}{l}722 \\
724 \\
* * *\end{array}$ & $\begin{array}{r}80 \\
100 \\
* * *\end{array}$ & $\begin{array}{l}954 * 351 \\
954 * 351\end{array}$ & $\begin{array}{l}709 \\
712 \\
\star * *\end{array}$ & $\begin{array}{l}75 \\
95 \\
* *\end{array}$ & $\begin{array}{l}\odot * 366 \\
\odot * 366\end{array}$ & $\begin{array}{l}696 \\
698 \\
* * *\end{array}$ & $\begin{array}{l}70 \\
85 \\
* *\end{array}$ & $\begin{array}{l}0^{*} 380 \\
0^{*} 380\end{array}$ & $\begin{array}{l}681 \\
684 \\
* * *\end{array}$ & $\begin{array}{l}70 \\
75\end{array}$ & $\begin{array}{l}\Theta^{*} \\
\Theta^{*}\end{array}$ \\
\hline $\begin{array}{l}39830 \\
39830\end{array}$ & $\begin{array}{l}08 / 18 * 395 \\
08 / 18 * 395\end{array}$ & $\begin{array}{l}664 \\
667 \\
* * *\end{array}$ & $\begin{array}{l}65 \\
70 \\
* *\end{array}$ & $\begin{array}{l}\odot * 4 \odot 8 \\
\odot * 4 \odot 8\end{array}$ & $\begin{array}{l}647 \\
647\end{array}$ & $\begin{array}{l}50 \\
65 \\
\star *\end{array}$ & $\begin{array}{l}\text { ○E417 } \\
\text { ๑*417 } \\
*\end{array}$ & $\begin{array}{l}621 \\
621\end{array}$ & $\begin{array}{l}50 \\
6 \odot \\
* *\end{array}$ & $\begin{array}{l}\Theta E 424 \\
0^{*} 424 \\
*\end{array}$ & $\begin{array}{l}586 \\
586\end{array}$ & $\begin{array}{l}50 \\
55 \\
\star *\end{array}$ & $\begin{array}{l}0^{*} \\
\Theta^{*}\end{array}$ \\
\hline $\begin{array}{l}39835 \\
39835\end{array}$ & $\begin{array}{l}08 / 19 E 428 \\
08 / 19 E 428\end{array}$ & $\begin{array}{l}550 \\
550\end{array}$ & $\begin{array}{l}50 \\
55 \\
\star *\end{array}$ & $\begin{array}{l}\text { OE431 } \\
\text { OE431 }\end{array}$ & $\begin{array}{l}517 \\
517\end{array}$ & $\begin{array}{l}45 \\
55 \\
\star *\end{array}$ & $\begin{array}{l}\text { OE432 } \\
\text { OE432 }\end{array}$ & $\begin{array}{l}486 \\
486\end{array}$ & $\begin{array}{l}45 \\
55 \\
\star *\end{array}$ & $\begin{array}{l}\text { OE431 } \\
\text { OE431 }\end{array}$ & $\begin{array}{l}451 \\
451\end{array}$ & $\begin{array}{l}45 \\
50 \\
\star *\end{array}$ & $\begin{array}{l}\Theta^{*} \\
0^{*}\end{array}$ \\
\hline $\begin{array}{l}39840 \\
39840\end{array}$ & $\begin{array}{r}\odot 8 / 20 \mathrm{E} 431 \\
08 / 20 \mathrm{E} 429 \\
* \star *\end{array}$ & $\begin{array}{l}416 \\
416\end{array}$ & $\begin{array}{l}40 \\
45 \\
\star *\end{array}$ & $\begin{array}{l}\Theta * \quad \odot \\
\text { OE425 } \\
\star * * *\end{array}$ & $\begin{array}{r}0 \\
385 \\
\star * *\end{array}$ & $\begin{array}{r}\odot \\
4 \odot \\
* *\end{array}$ & $\begin{array}{l}\Theta^{*} \quad \odot \\
\odot \mathrm{E} 421 \\
* * * *\end{array}$ & $\begin{array}{r}0 \\
365 \\
* * *\end{array}$ & $\begin{array}{r}0 \\
35 \\
* *\end{array}$ & $\begin{array}{l}\Theta^{*} \quad 0 \\
0 \mathrm{E} 42 \odot \\
* * * *\end{array}$ & $\begin{array}{r}0 \\
340 \\
* * *\end{array}$ & $\begin{array}{r}\odot \\
30 \\
* *\end{array}$ & $\begin{array}{l}\theta^{*} \\
0^{*}\end{array}$ \\
\hline $\begin{array}{l}\text { (Sept } \\
39843\end{array}$ & $\begin{array}{r}\text { ember 21st } \\
08 / 21 \mathrm{E} 420 \\
* \star \star *\end{array}$ & $\begin{array}{l}\text { is } r \\
320 \\
* * *\end{array}$ & $\begin{array}{l}\text { ew tc } \\
25 \\
* *\end{array}$ & $\begin{array}{c}\text { HURDAT) } \\
\text { OE420 } \\
\star \star \star *\end{array}$ & $\begin{array}{l}310 \\
* * *\end{array}$ & $\begin{array}{l}25 \\
\star *\end{array}$ & $\odot^{*} \odot$ & $\odot$ & $\odot$ & $\Theta^{*}$ & $\odot$ & $\odot$ & $0^{*}$ \\
\hline
\end{tabular}

Minor track changes and major intensity changes shown in McAdie et al. (2009). A major alteration is to add one additional day at the end of the cyclone's lifetime. Evidence for these alterations comes from the NHC microfilm maps, the Historical Weather Maps series, the COADS ship database, Navy reconnaissance book, Monthly Weather Review 1956 (MWR), MWR Weather Notes (MWR-WN), Monthly Weather Review 1959 (MWR-1959), Notes on the Tropical Cyclones of Puerto Rico (Perez), and Puerto Rico and Virgin Islands State Climatological Data (CLIMO).

August 8:

HWM analyzes a spot low near 10.6N, 50.8W at 12Z. Microfilm and HURDAT does not show an organized system on this date. Ship highlights: No gales or low pressures.

August 9: 
HWM analyzes a closed low pressure of at most $1015 \mathrm{mb}$ at $13.2 \mathrm{~N}, 54.5 \mathrm{~W}$ at 12Z. HURDAT lists this as a 50 knot tropical storm at $13.7 \mathrm{~N}, 48.8 \mathrm{~W}$ at $12 \mathrm{Z}$. Microfilm shows a closed low pressure of at most $1008 \mathrm{mb}$ at $13.5 \mathrm{~N}, 49.0 \mathrm{~W}$ at $12 \mathrm{Z}$. Ship highlights: $50 \mathrm{kt}$ and $1008 \mathrm{mb}$ at $14.1 \mathrm{~N}, 49.1 \mathrm{~W}$ at $1218 \mathrm{Z}$ (micro). $40 \mathrm{kt} \mathrm{NE}$ and $1011 \mathrm{mb}$ at $15.7 \mathrm{~N}$, $50.8 \mathrm{~W}$ at $18 \mathrm{Z}$ (micro).

MWR: "Around August 9, when the development of Betsy was first suspected, the anticyclone had reached maximum intensity and immediately began to subside and to return to its previous position south of its north track. Lack of reports in the eastern Atlantic makes it impossible to arrive at a detailed analysis for the period preceding the first indications of this storm but there was some evidence of an easterly wave near longitude $33 \mathrm{~W}$ on August 6. Extrapolation at a normal rate of movement would have brought it to the vicinity of $50 \mathrm{~W}$ on the $9^{\text {th }}$. On that date the following report was received from the M/T Marisa: "At 1218 GMT passed through trough of tropical storm in position $14.05 \mathrm{~N}, 55.25 \mathrm{~W}$. At $1200 \mathrm{GMT} 1008 \mathrm{mb}$, winds force 10, very high wild sea, heavy squalls." It was not possible to fit this report into any logical analysis and consequently efforts were made to verify the ship's position. At 1730 GMT a corrected position of $14.05 \mathrm{~N}, 49.05 \mathrm{~W}$ was obtained. This was only a short distance from the routine Gull Papa reconnaissance track but the developing storm was too small to alert the reconnaissance observer and there was no diversion from the scheduled track." CLIMO: "An easterly wave appeared on the surface chart at 1800Z on August 6 at the longitude of $33^{\circ} \mathrm{W}$. Its orientation was almost North and South while its amplitude at that time was slight. This easterly wave was followed across the Atlantic until on August 9 the SS Marisa radioed in a report that gave cause to suspect possible intensification in the easterly wave."

August 10:

HWM analyzes a hurricane of at most $1005 \mathrm{mb}$ at $14.0 \mathrm{~N}, 54.9 \mathrm{~W}$ at $12 \mathrm{Z}$. HURDAT lists this as a 105 knot hurricane at $14.2 \mathrm{~N}, 54.3 \mathrm{~W}$ at $12 \mathrm{Z}$. Microfilm shows a closed low pressure of at most $1008 \mathrm{mb}$ at $13.5 \mathrm{~N}, 54.5 \mathrm{~W}$ at $12 \mathrm{Z}$. Ship highlights: $30 \mathrm{kt}$ $\mathrm{NE}$ and $1004 \mathrm{mb}$ at $14.6 \mathrm{~N}, 54.2 \mathrm{~W}$ at $06 \mathrm{Z}$ (micro). 60-65 kt and $1005 \mathrm{mb}$ at $14.6 \mathrm{~N}, 54.2 \mathrm{~W}$ at $0930 \mathrm{Z}$ (micro). $35 \mathrm{kt} \mathrm{NE}$ and $1012 \mathrm{mb}$ at $15.7 \mathrm{~N}, 55.8 \mathrm{~W}$ at $12 \mathrm{Z}$ (COADS). $50 \mathrm{kt} \mathrm{NW}$ and $1004 \mathrm{mb}$ at $14.6 \mathrm{~N}, 56.6 \mathrm{~W}$ at $18 \mathrm{Z}$ (COADS). Aircraft highlights: Penetration center fix at $14.2 \mathrm{~N}, 54.5 \mathrm{~W}$ at $1455 \mathrm{Z}$ (ATSR). Penetration center fix estimated maximum surface winds of $100 \mathrm{kt}$, measured a central pressure of $979 \mathrm{mb}$ and an eye diameter of $10 \mathrm{~nm}$ at $1955 Z$ (ATSR).

MWR: "A special reconnaissance flight was made on August 10, but confirmation of storm development was received through surface ship reports before the plane reached the area. The M/S Sagaland at 1200 GMT reported: "Lat. $14.35 \mathrm{~N}$, Long. 54.10W, at 0400 
GMT, wind 035 GMT northeast force 5, barometer $1008 \mathrm{mb}$. At $0930 \mathrm{GMT}$, northeast force 11/12, barometer 1004, violent sea, heavy rain, no visibility. At 1200 GMT wind east force 6, barometer 1009, heavy seas, rain, decreasing sea." The 1200 GMT observations from the SS Mormac Lark and SS Willamstadt on the outskirts of the storm, were also helpful in the location of the storm and evaluation of its intensity. The first advisory was issued at 1100 EST, August 10, at which time a hurricane watch was issued for the Leeward and Windward Islands from Antigua to Barbados. When reconnaissance aircraft reached the storm later in the day, it was found to be a very small hurricane but with winds of $120 \mathrm{mph}$ near the center and central pressure $979 \mathrm{mb}$. The eye was defined by a very tightly closed pattern on the radar as only 10 miles in diameter." CLIMO: "During the $10^{\text {th }}$ further ship reports confirmed the presence of a tropical storm and at $1600 \mathrm{Z}$ on the $10^{\text {th }}$ the first advisory on tropical storm Betsy was issued. Hurricane intensity was reached later on the $10^{\text {th }}$."

August 11:

HWM analyzes a hurricane of at most $1005 \mathrm{mb}$ at $15.5 \mathrm{~N}, 59.9 \mathrm{~W}$ at $12 \mathrm{Z}$. HURDAT lists this as a 95 knot hurricane at $15.3 \mathrm{~N}, 60.3 \mathrm{~W}$ at $12 \mathrm{Z}$. Microfilm shows a closed low pressure of at most $1008 \mathrm{mb}$ at $15.5 \mathrm{~N}, 60.5 \mathrm{~W}$ at $12 \mathrm{Z}$. Ship highlights: $35 \mathrm{kt} \mathrm{E}$ and $1014 \mathrm{mb}$ at $17.3 \mathrm{~N}, 58.0 \mathrm{~W}$ at $06 \mathrm{Z}$ (COADS). $35 \mathrm{kt} \mathrm{E}$ and $1014 \mathrm{mb}$ at $18.3 \mathrm{~N}, 58.0 \mathrm{~W}$ at $12 \mathrm{Z}$ (COADS). $45 \mathrm{kt} \mathrm{NE}$ and $1011 \mathrm{mb}$ at $16.8 \mathrm{~N}, 60.5 \mathrm{~W}$ at $18 \mathrm{Z}$ (micro). $15 \mathrm{kt} \mathrm{NNE}$ and $989 \mathrm{mb}$ at $14.4 \mathrm{~N}, 62.9 \mathrm{~W}$ at $21 \mathrm{Z}$ (micro). Land highlights: $50 \mathrm{kt} \mathrm{NNW}$ and $1009 \mathrm{mb}$ at $1010 \mathrm{mb}$ at Dubuc, Dominica at $15 \mathrm{Z}$ (micro). $991 \mathrm{mb}$ at Point-au-Pitre, Guadaloupe at 18Z (MWR-1959). 85-105 kt (estimated) at Guadaloupe (no time given) (MWR). Aircraft highlights: Radar center fix at $15.1 \mathrm{~N}, 59.3 \mathrm{~W}$ at $07 \mathrm{Z}$ (ATSR). Radar center fix at $15.6 \mathrm{~N}, 60.4 \mathrm{~W}$ at $12 \mathrm{Z}$ (ATSR). Radar center fix at $16.3 \mathrm{~N}, 61.9 \mathrm{~W}$ at $19 \mathrm{Z}$ (ATSR).

MWR: "The hurricane moved on a west-northwest course at about $17 \mathrm{mph}$ during the next 24 hours and passed through the central Lesser Antilles about midday August 11. It crossed over the islands of Marie Galante and between Isle des Saintes and the extreme south portion of Basse Terre, Guadaloupe. Reports indicate 18 lives lost and severe damage. On Guadaloupe, 1000 dwellings were extensively damaged, all communications disrupted, and about 50 to 60 percent of the banana, breadfruit, coconut, and papaya trees destroyed, a serious blow to the economy of the island. The banana crop loss was estimated at $\$ 3.5$ million and preliminary estimates give $\$ 10$ million for the total damage figure. Winds were estimated at 100 to $120 \mathrm{mph}$ on Guadeloupe and the lowest pressure was 991 mb." CLIMO: "Betsy crossed through the Central Antilles between noon and 2 pm on August 11, passing over the south portion of the Island of Marie Galente and between Les Saintes and the extreme south portion of Basseterre, Guadaloupe. By 4 pm August 11 Betsy had entered the northeastern Caribbean Sea." 
August 12:

HWM analyzes a hurricane of at most $1000 \mathrm{mb}$ at $18.1 \mathrm{~N}, 65.2 \mathrm{~W}$ at $12 \mathrm{Z}$. HURDAT lists this as an 80 knot hurricane at $17.8 \mathrm{~N}, 65.7 \mathrm{~W}$ at $12 \mathrm{Z}$. Microfilm shows a closed low pressure of at most $1008 \mathrm{mb}$ at $18.0 \mathrm{~N}, 66.0 \mathrm{~W}$ at 12Z. Ship highlights: $35 \mathrm{kt}$ $\mathrm{ENE}$ and $1012 \mathrm{mb}$ at $19.4 \mathrm{~N}, 64.3 \mathrm{~W}$ at $00 \mathrm{Z}$ (COADS/micro). $35 \mathrm{kt} \mathrm{E}$ at $20.0 \mathrm{~N}, 63.0 \mathrm{~W}$ at 06Z (COADS). $45 \mathrm{kt} \mathrm{ENE}$ and $1017 \mathrm{mb}$ at $19.6 \mathrm{~N}, 65.3 \mathrm{~W}$ at $12 \mathrm{Z}$ (micro). $50 \mathrm{kt}$ ENE and $1013 \mathrm{mb}$ at $19.6 \mathrm{~N}, 65.2 \mathrm{~W}$ at $14 \mathrm{Z}$ (micro). Land highlights: $55 \mathrm{kt} \mathrm{SE}$, gusts to $75 \mathrm{kt}$ and $1004 \mathrm{mb}$ at St. Croix at 09Z (micro). $983 \mathrm{mb}$ at Guayama, PR at 1230Z (MWR-1959). 65 kt, gusts to $80 \mathrm{kt}$ at San Juan, PR at 1235Z(MWR-1959). $75 \mathrm{kt}$, gusts to $100 \mathrm{kt}$ at Ramsey Air Force Base, PR near 16Z (MWR-1959). $60 \mathrm{kt} \mathrm{WSW,} \mathrm{gusts} \mathrm{to} 85 \mathrm{kt}$ at Arecibo, PR at $17 Z$ (micro). Aircraft highlights: Radar center fix at $16.4 \mathrm{~N}, 63.2 \mathrm{~W}$ at $00 \mathrm{Z}$ (ATSR). Radar center fix at $17.1 \mathrm{~N}, 64.5 \mathrm{~W}$ at $06 \mathrm{Z}$ (ATSR). Radar center fix at $17.9 \mathrm{~N}, 65.9 \mathrm{~W}$ at $12 \mathrm{Z}$ (ATSR).

MWR: "After moving through the Leeward Islands, the hurricane began a more northwesterly course, passing about 30 miles south of St. Croix, Virgin Islands, and reaching the southeastern tip of Puerto Rico in the early morning of August 12. Prior to reaching Puerto Rico the storm displayed a small but apparently real oscillatory motion about the mean track with an amplitude of a little less than $1 / 2$ degree and a period on the order of one day. The oscillation was sufficiently definite that, some forecast use could be made of it, on an extrapolation basis. Following the turn to a more northwesterly direction, this oscillation was not present or was obscured. A hurricane watch had been ordered for Puerto Rico and the Virgin Islands on the evening of August 10. As the hurricane continued to move toward Puerto Rico, the watch was changed to hurricane warnings on the afternoon of August 11. The eye of the storm crossed Puerto Rico between 1200 and 1530 GMT, August 12, on an erratic coarse between northwest and west-northwest at about $17 \mathrm{mph}$, emerging on the north coast near Camuy with only slight and temporary weakening of its circulation. According to reports, all of Puerto Rico, except the south-western portion which was protected by the mountain backbone of the island, experienced winds of 75 m. p. h. or higher in gusts. Maximum sustained winds at San Juan were $73 \mathrm{mph}$, with gusts to $92 \mathrm{mph}$. Rainfall totaled 3.19 inches. Ramey Air Force Base, on the northeastern tip of the island, recorded wind gusts to $115 \mathrm{mph}$. Nine deaths were reported in Puerto Rico and the property damage totaled $\$ 25,500,000$ or more." CLIMO: "Betsy passed about 30 miles south of St. Croix, VI between 4 and 4:30 am Sunday morning with winds from ESE at $86 \mathrm{mph}$ in gusts and entered the SE coastal area of Puerto Rico in the vicinity of Maunabo between $1147 \mathrm{Z}$ and $12 \mathrm{Z}$ on August 12 on a WNW course at about $20 \mathrm{mph}$ and passed out to sea in the Atlantic near Camuy (west of Arecibo) at $1515 \mathrm{Z}$ on the same day. According to reports all of Puerto Rico except the 
southwestern portion experienced winds of $75 \mathrm{mph}$ or higher in extreme gusts. West Ponce to Mayagüez maximum velocities reached 45 to 50 knots."

August 13:

HWM analyzes a closed low pressure of at most $1010 \mathrm{mb}$ at $22.0 \mathrm{~N}, 71.3 \mathrm{~W}$ at 12Z. HURDAT lists this as a 95 knot hurricane at $21.9 \mathrm{~N}, 71.3 \mathrm{~W}$ at $12 \mathrm{Z}$. Microfilm shows a closed low pressure of at most $1008 \mathrm{mb}$ at $21.7 \mathrm{~N}, 71.6 \mathrm{~W}$ at 12Z. Ship highlights: No gales or low pressures. Land highlights: $30 \mathrm{kt} \mathrm{W}$ and $1011 \mathrm{mb}$ at Turks and Caicos at $18 \mathrm{Z}$ (micro). $35 \mathrm{kt} \mathrm{NE}$ and $1012 \mathrm{mb}$ at San Salvador, Bahamas at 24.1N, 74.5W at 23Z (micro). Aircraft highlights: Radar center fix at 20.8N, 69.9W at 06Z (ATSR). Radar center fix at $22.2 \mathrm{~N}, 71.5 \mathrm{~W}$ at $12 \mathrm{Z}$ (ATSR). Penetration center fix measured a central pressure of $972 \mathrm{mb}$ at $22.2 \mathrm{~N}, 71.8 \mathrm{~W}$ at $1350 \mathrm{Z}$ (ATSR/MWR). Penetration center fix at $23.3 \mathrm{~N}, 73.1 \mathrm{~W}$ at $1940 \mathrm{Z}$ (ATSR).

MWR: "Hurricane Betsy continued at a speed of about $17 \mathrm{mph}$ to near Turks Island early on August 13 and, with some acceleration, reached the vicinity of San Salvador in the Bahamas about 2000 EST on that date. Winds at San Salvador reached $132 \mathrm{mph}$. in gusts. Sustained winds were $100 \mathrm{mph}$ or more. Approximately 5 inches of rain fell in 5 hours. Several houses were demolished and most of the churches, which are generally better constructed, lost their roofs. Aircraft reconnaissance on August 13 had shown a slight increase in size of the storm but little change in central pressure or maximum winds. Gale winds were reported as extending 125 miles north and 60 miles south of the center. Lack of important increase in size or intensity was compatible with the fact that turbulence and rain in all quadrants were predominantly light with only intermittent bursts of heavy rain and moderate turbulence."

August 14:

HWM analyzes a hurricane of at most $1010 \mathrm{mb}$ at $26.0 \mathrm{~N}, 76.0 \mathrm{~W}$ at $12 \mathrm{Z}$. HURDAT lists this as a 95 knot hurricane at $25.6 \mathrm{~N}, 76.0 \mathrm{~W}$ at $12 \mathrm{Z}$. Microfilm shows a closed low pressure of at most $1011 \mathrm{mb}$ at $25.8 \mathrm{~N}, 76.1 \mathrm{~W}$ at 12Z. Ship highlights: $65 \mathrm{kt}$ $\mathrm{NE}$ and $1012 \mathrm{mb}$ at $24.6 \mathrm{~N}, 74.7 \mathrm{~W}$ at $00 \mathrm{Z}$ (COADS). $65 \mathrm{kt} \mathrm{E}$ and $1014 \mathrm{mb}$ at $25.2 \mathrm{~N}$, $74.8 \mathrm{~W}$ at $03 \mathrm{Z}$ (micro). $40 \mathrm{kt} \mathrm{S}$ and $1015 \mathrm{mb}$ at 24.1N, 74.0W at 06Z (COADS). $35 \mathrm{kt} \mathrm{SE}$ and $1017 \mathrm{mb}$ at $25.9 \mathrm{~N}, 74.0 \mathrm{~W}$ at $12 \mathrm{Z}$ (COADS). Land highlights: $85 \mathrm{kt}$, gusts to $115 \mathrm{kt}$ at San Salvador, Bahamas (no time given) (MWR). $80 \mathrm{kt} \mathrm{NW}$, gusts to $104 \mathrm{kt}$ and $985 \mathrm{mb}$ at San Salvador, Bahamas at 02Z (micro). $45 \mathrm{kt} \mathrm{SW}$ and $1011 \mathrm{mb}$ at San Salvador, Bahamas at 06Z (micro). $50 \mathrm{kt} \mathrm{NNW}$ and $1002 \mathrm{mb}$ at Hope Town, Bahamas at 26.5N, $77.0 \mathrm{~W}$ at $18 \mathrm{Z}$ (micro). Aircraft highlights: Radar center fix at $24.2 \mathrm{~N}, 74.6 \mathrm{~W}$ at $0234 \mathrm{Z}$ (ATSR). Radar center fix at 24.9N, 74.8W at 0604Z (ATSR). Penetration center fix at $26.2 \mathrm{~N}, 76.2 \mathrm{~W}$ at $14 \mathrm{Z}$ (ATSR). Penetration center fix at $26.2 \mathrm{~N}, 76.2 \mathrm{~W}$ at $1430 \mathrm{Z}$ (ATSR). 
Penetration center fix at $26.6 \mathrm{~N}, 76.6 \mathrm{~W}$ at $1930 \mathrm{Z}$ (ATSR). Penetration center fix at $26.7 \mathrm{~N}$, $76.6 \mathrm{~W}$ at $20 \mathrm{Z}$ (ATSR).

MWR: "On the 14th, central pressure was reported as $960 \mathrm{mb}$., the eye was 12 miles in diameter and well formed, and associated clouds extended 250 miles north and 200 miles to the east. On August 14 and 15, Betsy began recurvature with sharp deceleration in forward movement."

August 15:

HWM analyzes a hurricane of at most $995 \mathrm{mb}$ at $28.5 \mathrm{~N}, 76.9 \mathrm{~W}$ at $12 \mathrm{Z}$. HURDAT lists this as an 85 knot hurricane at $28.3 \mathrm{~N}, 76.6 \mathrm{~W}$ at $12 \mathrm{Z}$. Microfilm shows a closed low pressure of at most $1008 \mathrm{mb}$ at $28.2 \mathrm{~N}, 76.5 \mathrm{~W}$ at $12 \mathrm{Z}$. Ship highlights: $50 \mathrm{kt} \mathrm{SW}$ and 1003 $\mathrm{mb}$ at $27.5 \mathrm{~N}, 76.6 \mathrm{~W}$ at $12 \mathrm{Z}$ (COADS). $45 \mathrm{kt} \mathrm{NW}$ and $1004 \mathrm{mb}$ at $28.0 \mathrm{~N}, 78.0 \mathrm{~W}$ at $18 \mathrm{Z}$ (COADS). Aircraft highlights: Radar center fix at 27.0N, $76.8 \mathrm{~W}$ at $0130 \mathrm{Z}$ (ATSR). Radar center fix at $27.7 \mathrm{~N}, 77.0 \mathrm{~W}$ at $06 \mathrm{Z}$ (ATSR). Radar center fix at $28.1 \mathrm{~N}, 76.5 \mathrm{~W}$ at $1030 \mathrm{Z}$ (ATSR). Radar center fix at $28.6 \mathrm{~N}, 76.8 \mathrm{~W}$ at $18 \mathrm{Z}$ (ATSR). Penetration center fix at $28.7 \mathrm{~N}, 76.2 \mathrm{~W}$ at $1940 \mathrm{Z}$ (ATSR).

August 16:

HWM analyzes a hurricane of at most $995 \mathrm{mb}$ at $31.0 \mathrm{~N}, 73.6 \mathrm{~W}$ at $12 \mathrm{Z}$. HURDAT lists this as an 85 knot hurricane at $30.7 \mathrm{~N}, 74.3 \mathrm{~W}$ at $12 \mathrm{Z}$. Microfilm shows a closed low pressure of at most $996 \mathrm{mb}$ at $30.0 \mathrm{~N}, 74.7 \mathrm{~W}$ at $12 \mathrm{Z}$. Ship highlights: $45 \mathrm{kt} \mathrm{S}$ and $1009 \mathrm{mb}$ at $27.7 \mathrm{~N}, 74.5 \mathrm{~W}$ at $00 \mathrm{Z}$ (COADS). $35 \mathrm{kt} \mathrm{SW}$ and $1003 \mathrm{mb}$ at $28.7 \mathrm{~N}, 73.7 \mathrm{~W}$ at $06 \mathrm{Z}$ (micro). $40 \mathrm{kt} \mathrm{S}$ and $1016 \mathrm{mb}$ at $28.0 \mathrm{~N}, 71.2 \mathrm{~W}$ at $12 \mathrm{Z}$ (COADS). $40 \mathrm{kt} \mathrm{S}$ and $1014 \mathrm{mb}$ at $29.7 \mathrm{~N}, 71.0 \mathrm{~W}$ at $15 \mathrm{Z}$ (micro). Aircraft highlights: Radar center fix at $29.4 \mathrm{~N}, 75.4 \mathrm{~W}$ at $03 Z$ (ATSR). Radar center fix at $29.7 \mathrm{~N}, 75.3 \mathrm{~W}$ at $06 \mathrm{Z}$ (ATSR). Penetration center fix measured a central pressure of $973 \mathrm{mb}$ at $0735 \mathrm{Z}$ (ATSR). Radar center fix at $30.8 \mathrm{~N}$, $74.1 \mathrm{~W}$ at $12 \mathrm{Z}$ (ATSR). Penetration center fix at $31.1 \mathrm{~N}, 73.7 \mathrm{~W}$ at $14 \mathrm{Z}$ (ATSR). Penetration center fix at $33.7 \mathrm{~N}, 72.6 \mathrm{~W}$ at $2349 \mathrm{Z}$ (ATSR).

MWR: "Between the $13^{\text {th }}$ when the storm was near Turks Island, and the 16 th, when a dropsonde was released in the eye near $30 \mathrm{~N}$., $75 \mathrm{~W}$., temperatures in the eye between the surface and $700 \mathrm{mb}$. fell about $2 \mathrm{C}$. The normal sea-surface temperature difference between these areas is less than 1' and, while some anomaly may have existed, it' seems likely that the cooling was an indication of the beginning, even at this time, of some other factors interfering with the efficiency of the storm engine. By the 16th it was moving toward the northeast and had increased its forward speed to about $20 \mathrm{mph}$. Maximum winds began to decrease on the $16^{\text {th }}$."

August 17: 
HWM analyzes a hurricane of at most $1000 \mathrm{mb}$ at $37.0 \mathrm{~N}, 69.8 \mathrm{~W}$ at $12 \mathrm{Z}$. HURDAT lists this as a 70 knot hurricane at $36.6 \mathrm{~N}, 69.6 \mathrm{~W}$ at $12 \mathrm{Z}$. Microfilm shows a closed low pressure of at most $1005 \mathrm{mb}$ at $37.0 \mathrm{~N}, 70.0 \mathrm{~W}$ at 12Z. Ship highlights: $35 \mathrm{kt}$ $\mathrm{SW}$ and $1018 \mathrm{mb}$ at 31.3N, 71.1W at 00Z (micro). $45 \mathrm{kt} \mathrm{NE}$ and $1002 \mathrm{mb}$ at 35.2N, $72.6 \mathrm{~W}$ at $03 \mathrm{Z}$ (COADS). $35 \mathrm{kt} \mathrm{ENE}$ and $1009 \mathrm{mb}$ at $38.3 \mathrm{~N}, 71.0 \mathrm{~W}$ at $12 \mathrm{Z}$ (micro). $55 \mathrm{kt}$ SSE and $985 \mathrm{mb}$ at $38.0 \mathrm{~N}, 69.0 \mathrm{~W}$ at $15 \mathrm{Z}$ (micro). $50 \mathrm{kt} \mathrm{SE}$ and $1011 \mathrm{mb}$ at $38.2 \mathrm{~N}, 66.5 \mathrm{~W}$ at $18 \mathrm{Z}$ (micro). Aircraft highlights: Penetration center fix at $34.6 \mathrm{~N}, 71.6 \mathrm{~W}$ at $0230 \mathrm{Z}$ (ATSR). Penetration center fix at $37.3 \mathrm{~N}, 69.5 \mathrm{~W}$ at $14 \mathrm{Z}$ (ATSR). Penetration center fix at $38.8 \mathrm{~N}, 68.1 \mathrm{~W}$ at $20 \mathrm{Z}$ (ATSR).

MWR: "and by late August $17^{\text {th }}$ had dropped to $80 \mathrm{mph}$. Reconnaissance at this time reported the eye was becoming poorly defined as the hurricane moved northeastward at about 23 mph past the latitude of Nantucket."

August 18:

HWM analyzes a closed low pressure of at most $1000 \mathrm{mb}$ at $42.0 \mathrm{~N}, 62.0 \mathrm{~W}$ with a frontal boundary about $300 \mathrm{~nm}$ to the north at 12Z. HURDAT lists this as a $50 \mathrm{knot}$ extratropical cyclone at $41.7 \mathrm{~N}, 62.1 \mathrm{~W}$ at $12 \mathrm{Z}$. Microfilm shows a closed low pressure of at most $999 \mathrm{mb}$ at $42.5 \mathrm{~N}, 62.3 \mathrm{~W}$ with a frontal boundary just to the north at $12 \mathrm{Z}$. Ship highlights: $50 \mathrm{kt} \mathrm{S}$ and $1007 \mathrm{mb}$ at $38.0 \mathrm{~N}, 65.5 \mathrm{~W}$ at $00 \mathrm{Z}$ (micro). $65 \mathrm{kt} \mathrm{S}$ and $990 \mathrm{mb}$ at $40.1 \mathrm{~N}, 64.3 \mathrm{~W}$ at $06 \mathrm{Z}$ (COADS). $40 \mathrm{kt} \mathrm{W}$ and $999 \mathrm{mb}$ at $40.0 \mathrm{~N}, 65.0 \mathrm{~W}$ at $09 \mathrm{Z}$ (micro). 50 kt SW and $1013 \mathrm{mb}$ at $40.0 \mathrm{~N}, 56.0 \mathrm{~W}$ at 18Z (COADS). Aircraft highlights: Penetration center fix at $40.7 \mathrm{~N}, 65.3 \mathrm{~W}$ at $0422 \mathrm{Z}$ (ATSR). Penetration center fix at $41.3 \mathrm{~N}, 64.0 \mathrm{~W}$ at 08Z (ATSR).

MWR: "The last advisory was issued on the morning of August 18 as the storm assumed more extratropical characteristics."

August 19:

HWM analyzes a closed low pressure of at most $995 \mathrm{mb}$ at $43.0 \mathrm{~N}, 48.5 \mathrm{~W}$ with a dissipating warm front to the north and east at 12Z. HURDAT lists this as a $45 \mathrm{knot}$ extratropical cyclone at $43.2 \mathrm{~N}, 48.6 \mathrm{~W}$ at $12 \mathrm{Z}$. Microfilm shows a closed low pressure of at most $1002 \mathrm{mb}$ at $43.0 \mathrm{~N}, 48.0 \mathrm{~W}$ at 12Z. Ship highlights: $45 \mathrm{kt} \mathrm{SSW}$ and $998 \mathrm{mb}$ at $41.3 \mathrm{~N}, 54.7 \mathrm{~W}$ at $00 \mathrm{Z}$ (COADS). $45 \mathrm{kt} \mathrm{SW}$ and $999 \mathrm{mb}$ at $41.0 \mathrm{~N}, 50.8 \mathrm{~W}$ at $06 \mathrm{Z}$ (COADS). $55 \mathrm{kt} \mathrm{W}$ and $1004 \mathrm{mb}$ at 40.9N, 51.1W at 12Z (COADS). $35 \mathrm{kt}$ ESE and 990 $\mathrm{mb}$ at $43.7 \mathrm{~N}, 44.2 \mathrm{~W}$ at $18 \mathrm{Z}$ (COADS).

MWR: "It moved due east on the $19^{\text {th }}$ and $20^{\text {th }}$, gradually losing its identity." August 20: 
HWM analyzes a closed low pressure of at most $995 \mathrm{mb}$ at $41.5 \mathrm{~N}, 37.0 \mathrm{~W}$ at $12 \mathrm{Z}$. HURDAT lists this as a 40 knot extratropical cyclone at $43.1 \mathrm{~N}, 41.6 \mathrm{~W}$ at $0 \mathrm{Z}$ (last position). Microfilm shows a closed low pressure of at most $1005 \mathrm{mb}$ at $43.0 \mathrm{~N}, 39.0 \mathrm{~W}$ at 06Z. Ship highlights: $45 \mathrm{kt} \mathrm{E}$ and $999 \mathrm{mb}$ at 43.3N, 41.1W at 00Z (COADS). $30 \mathrm{kt} \mathrm{SSW}$ and $1001 \mathrm{mb}$ at $41.0 \mathrm{~N}, 36.5 \mathrm{~W}$ at $06 \mathrm{Z}$ (COADS). $25 \mathrm{kt} \mathrm{W}$ and $1000 \mathrm{mb}$ at $40.1 \mathrm{~N}, 38.0 \mathrm{~W}$ at $12 \mathrm{Z}(\mathrm{COADS})$.

August 21:

HWM analyzes a closed low pressure of at most $995 \mathrm{mb}$ at $48.8 \mathrm{~N}, 12.7 \mathrm{~W}$ with a trough extending to the south and southwest at 12Z. HURDAT is not available on this date. Microfilm shows a low pressure at $44.5 \mathrm{~N}, 31.0 \mathrm{~W}$ with a frontal boundary extending to the north, southwest and southeast at 0Z. Ship highlights: No gales or low pressures.

Hurricane Betsy developed from a tropical wave that left the west coast of Africa at the beginning of August. On August $9^{\text {th }}$ at $1218 \mathrm{Z}$, a ship located at $14.1 \mathrm{~N}, 49.1 \mathrm{~W}$ reported sustained winds of $50 \mathrm{kt}$ and $1008 \mathrm{mb}$. This was the first indication that a tropical cyclone had developed. The time of genesis is uncertain because ship data between Africa and the Lesser Antilles was very sparse. COADS were acquired for the previous days to see if it was possible to detect the exact time of formation but the lack of data gave no results. Therefore, the first entry into HURDAT (not genesis) remains unchanged on August $9^{\text {th }}$ at $06 \mathrm{Z}$ as a $50 \mathrm{kt}$ tropical storm. No changes are made to the track on the $9^{\text {th }}$ and $19^{\text {th }}$, and minor track changes are introduced on the other days. Betsy was a small and fast-moving tropical cyclone. Intensification to hurricane is analyzed at $18 \mathrm{Z}$ on the $9^{\text {th }}$ and an intensity of $70 \mathrm{kt}$ is selected, up from $50 \mathrm{kt}$ originally in HURDAT, a major change. Intensification to hurricane is analyzed 12 hours earlier than originally shown in HURDAT. HURDAT indicated an unrealistic increase in intensity from $60 \mathrm{kt}$ at $0 \mathrm{Z}$ on the $10^{\text {th }}$ to $105 \mathrm{kt}$ at $06 \mathrm{Z}$. Major intensity changes are also introduced on those times as our analysis suggests $80 \mathrm{kt}$ at $0 \mathrm{Z}$ and $85 \mathrm{kt}$ at $06 \mathrm{Z}$ on the $10^{\text {th }}$. Betsy is not assessed to have reached major hurricane status east of the Lesser Antilles. At $0930 \mathrm{Z}$ on the $10^{\text {th }}$, a ship reports winds of 60 to $65 \mathrm{kt}$ and $1005 \mathrm{mb}$. At $1955 \mathrm{Z}$ on the $10^{\text {th }}$, the first reconnaissance aircraft reached the hurricane estimating sustained surface winds of $100 \mathrm{kt}$, measuring a central pressure of $979 \mathrm{mb}$ and an eye diameter of $10 \mathrm{~nm}$. A central pressure of $979 \mathrm{mb}$ suggests maximum sustained winds of $79 \mathrm{kt}$ from the south of $25 \mathrm{~N}$ Brown et al. pressure-wind relationship. An eye diameter of $10 \mathrm{~nm}$ suggests an RMW of about $8 \mathrm{~nm}$ and climatology suggests about 13 $\mathrm{nm}$. An intensity of $90 \mathrm{kt}$ is selected at $18 \mathrm{Z}$ on the $10^{\text {th }}$ because Betsy was moving at about $15 \mathrm{kt}$ and its RMW was smaller than the climatological value. This is a minor intensity change to HURDAT. On August $11^{\text {th }}$, Betsy continued moving toward the Lesser Antilles while its intensity remained at $90 \mathrm{kt}$. Crossing the chain of islands occurred late in the day. The tropical cyclone made landfall in the southern end of the 
island of Guadeloupe near $16.0 \mathrm{~N}, 61.7 \mathrm{~W}$ around $1730 \mathrm{Z}$ with an intensity of $90 \mathrm{kt}$. HURDAT originally had a central pressure of $991 \mathrm{mb}$ at $18 \mathrm{Z}$ on the $11^{\text {th }}$ but this was not a central pressure as there was never a report of calm by the station. Furthermore, the report of José Colón in 1959 titled "Meteorological Conditions over Puerto Rico during Hurricane Betsy, 1956" indicates that the center of the hurricane passed about 12 miles from the station that reported $991 \mathrm{mb}$ and provides an estimate of $979 \mathrm{mb}$ for the real central pressure at the time of landfall. Therefore, a central pressure of $979 \mathrm{mb}$ is added to $18 \mathrm{Z}$ on the $11^{\text {th }}$. According to the MWR, the damage in Guadeloupe was very severe and winds in the island were estimated between 85 and $105 \mathrm{kt}$. A ship at $18 \mathrm{Z}$ located at $16.8 \mathrm{~N}, 60.5 \mathrm{~W}$ reported $45 \mathrm{kt} \mathrm{NE}$ and $1011 \mathrm{mb}$.

Hurricane Betsy entered the northeast Caribbean Sea late on the $11^{\text {th }}$ while its track turned to the northwest. Moving rapidly, the center of the cyclone passed south of St. Croix early on the $12 \mathrm{Z}$ producing gusts of hurricane intensity. Landfall in Puerto Rico occurred near the town of Arroyo at $18.0 \mathrm{~N}, 66.0 \mathrm{~W}$ around 1230Z. According to the report by José Colón, the town of Guayama recorded a minimum pressure of $983 \mathrm{mb}$ and it was located about 1-2 miles from the point of landfall. José Colón estimated that Betsy had a central pressure near $981 \mathrm{mb}$ at the time of landfall and this central pressure has been added to HURDAT at $12 \mathrm{Z}$ on the $12^{\text {th }}$. A central pressure of $981 \mathrm{mb}$ suggests winds of $76 \mathrm{kt}$ south of $25 \mathrm{~N}$ according to the pressure-wind relationship. Due to the small size of Betsy and that it was moving at about 21 miles, an intensity of $85 \mathrm{kt}$ is selected for $12 \mathrm{Z}$ on the $12^{\text {th }}$, up from $80 \mathrm{kt}$ in the original HURDAT, a minor change. Minor intensity changes are also introduced at $0 \mathrm{Z}$ and $06 \mathrm{Z}$ on the $12^{\text {th }}$. Sustained hurricane-force winds affected a great portion of Puerto Rico. San Juan, on the northeast side of the island, reported sustained winds of $65 \mathrm{kt}$ with gusts to $80 \mathrm{kt}$ at 1235Z. The Ramey Air Force Base, on the northwest side of the island, reported sustained winds of $75 \mathrm{kt}$ with gusts to $100 \mathrm{kt}$ around $16 \mathrm{Z}$ on the $12^{\text {th }}$. The hurricane warnings for Hurricane Betsy were the first to be televised in Puerto Rico. Betsy crossed Puerto Rico diagonally in about 2 and half hours. Late on the $12^{\text {th }}$, Betsy moved back to the Atlantic en route to the Bahamas. The hurricane passed north of Hispaniola early on the $13^{\text {th }}$ and just north of the Turks and Caicos late on the day. Hurricane Betsy remained under the surveillance of reconnaissance aircraft during its crossing of the northeast Caribbean but only radar fixes were made. At $1350 \mathrm{Z}$ on the $13^{\text {th }}$, a penetration fix measured a central pressure of 972 $\mathrm{mb}$, indicating that Betsy had intensified after leaving Puerto Rico. A central pressure of $972 \mathrm{mb}$ suggests maximum sustained winds of $88 \mathrm{kt}$ south of $25 \mathrm{~N}$ according to the pressure-wind relationship. Due to the small size of the hurricane, fast forward speed and relatively high environmental pressures, an intensity of $100 \mathrm{kt}$ is selected for $12 \mathrm{Z}$ on the $13^{\text {th }}$, which is a minor change from the original $95 \mathrm{kt}$ in HURDAT. At this time it is analyzed that Betsy reached major hurricane status. Originally HURDAT had a central pressure of $974 \mathrm{mb}$ at $12 \mathrm{Z}$ on the $13^{\text {th }}$, but the report of José Colón indicates that the 
central pressure was $972 \mathrm{mb}$. Therefore, a central pressure of $972 \mathrm{mb}$ is added at $12 \mathrm{Z}$ on the $13^{\text {th }}$. All ships remained away from Betsy on the $13^{\text {th }}$ and no gale-force winds or low pressures were reported on this date. On the $14^{\text {th }}$, Betsy began to slow down as it approached the western end of the ridge. A ship at $24.6 \mathrm{~N}, 74.7 \mathrm{~W}$ at $0 \mathrm{Z}$ on the $14^{\text {th }}$ reported $65 \mathrm{kt} \mathrm{NE}$ and $1012 \mathrm{mb}$. At 02Z, the island of San Salvador in the Bahamas reported sustained winds of $80 \mathrm{kt}$ with gusts to $104 \mathrm{kt}$ and $985 \mathrm{mb}$. MWR indicates that the island registered gusts up to $115 \mathrm{kt}$. MWR also indicates that a central pressure of 960 $\mathrm{mb}$ and an eye diameter of $12 \mathrm{~nm}$ were measured on August $14^{\text {th }}$. The Navy book shows that penetration fixes were made on this date at 14Z, 1430Z, 1930Z and 20Z. We don't know which of these fixes made the measurements but for this analysis it will be attributed to the fix at $14 \mathrm{Z}$ and a central pressure of $960 \mathrm{mb}$ is added to HURDAT at $12 \mathrm{Z}$. A central pressure of $960 \mathrm{mb}$ suggests maximum sustained winds of $101 \mathrm{kt}$ south of $25 \mathrm{~N}$ and $102 \mathrm{kt}$ south of $25 \mathrm{~N}$ intensifying, and $95 \mathrm{kt}$ north of $25 \mathrm{~N}$ and $100 \mathrm{kt}$ north of $25 \mathrm{~N}$ intensifying. An eye diameter of $12 \mathrm{~nm}$ suggests an RMW of about $10 \mathrm{~nm}$ and climatology indicates about $22 \mathrm{~nm}$. Due to the small size of Betsy, an intensity of $105 \mathrm{kt}$ is selected for $12 \mathrm{Z}$ on the $14^{\text {th }}$, up from $95 \mathrm{kt}$ in HURDAT, a minor change in intensity. $100 \mathrm{kt}$ are selected for $0 \mathrm{Z}$ and $18 \mathrm{Z}$, and $105 \mathrm{kt}$ for $06 \mathrm{Z}$, all up from $95 \mathrm{kt}$, a minor intensity change. $105 \mathrm{kt}$ is the peak intensity for the lifetime of this tropical cyclone.

A central pressure of $968 \mathrm{mb}$ is present in HURDAT at $00 \mathrm{Z}$ on the $15^{\text {th }}$ and although it was not in the MWR report or the Navy book, it appears to be accurate and it is retained. A central pressure of $968 \mathrm{mb}$ suggests maximum sustained winds of $87 \mathrm{kt}$ north of $25 \mathrm{~N}$ according to the pressure-wind relationship. HURDAT has $90 \mathrm{kt}$ at $0 \mathrm{Z}$ on the $15^{\text {th }}$ and this intensity is retained. At this time is analyzed that Betsy weakened below major hurricane intensity. On the $15^{\text {th }}$, the track of Betsy turned to the north and later to the northeast. Another central pressure of $963 \mathrm{mb}$ is present in HURDAT at $12 \mathrm{Z}$ on the $15^{\text {th }}$ and appears to be accurate, so it is retained. A central pressure of $963 \mathrm{mb}$ suggests maximum sustained winds of $92 \mathrm{kt}$ north of $25 \mathrm{~N}$ according to the pressure-wind relationship. An intensity of $95 \mathrm{kt}$ is selected for $12 \mathrm{Z}$ on the $15^{\text {th }}$, up from $85 \mathrm{kt}$ originally in HURDAT, a minor intensity change. Various ships got close to Betsy on this date reporting winds up to $50 \mathrm{kt}$. On the $16^{\text {th }}$, Betsy began to accelerate to the northeast. Another reconnaissance aircraft reached the storm at $0735 \mathrm{Z}$ measuring a central pressure of $973 \mathrm{mb}$. A central pressure of $973 \mathrm{mb}$ suggests maximum sustained winds of $81 \mathrm{kt}$ north of $25 \mathrm{~N}$ and $77 \mathrm{kt}$ north of $25 \mathrm{~N}$ weakening according to the pressure-wind relationship. An intensity of $80 \mathrm{kt}$ is selected for $06 \mathrm{Z}$ on the $16^{\text {th }}$, down from $85 \mathrm{kt}$ originally in HURDAT, a minor change. A central pressure of $973 \mathrm{mb}$ is added to $06 \mathrm{Z}$ on the $16^{\text {th }}$. Minor intensity changes are also introduced at $0 \mathrm{Z}$ and $18 \mathrm{Z}$ on this date. Ships remained away from the center of Betsy on the $16^{\text {th }}$. A central pressure of $954 \mathrm{mb}$ appears on HURDAT at $00 \mathrm{Z}$ on the $17^{\text {th }}$ and although there was a penetration fix late on the $16^{\text {th }}$ and early on the $17^{\text {th }}$, there is no report of a central pressure around $00 \mathrm{Z}$ on the $17^{\text {th }}$ in 
MWR or the Navy book. Nonetheless, it appears to be accurate and it is retained. A central pressure of $954 \mathrm{mb}$ suggests maximum sustained winds of $101 \mathrm{kt}$ south of $25 \mathrm{~N}$ according to the pressure-wind relationship. An intensity of $100 \mathrm{kt}$ is selected for $00 \mathrm{Z}$ on the $17^{\text {th }}$, making Betsy a major hurricane for the second time. This is also a major change as HURDAT originally had $80 \mathrm{kt}$ at this time. Betsy is analyzed to have weakened below major hurricane intensity at $06 \mathrm{Z}$. No other central pressures were reported and HURDAT suggests that Betsy weakened later on the $17^{\text {th }}$. The ship data on the $17^{\text {th }}$ suggests that although Betsy increased in size, it remained a small tropical cyclone passing about 250 $\mathrm{nm}$ east of North Carolina early on this day. A ship at $15 \mathrm{Z}$ passed close to the hurricane measuring $55 \mathrm{kt} \mathrm{SE}$. On the $18^{\text {th }}$, the track of Betsy turned to the east-northeast and is analyzed to have weakened below hurricane intensity at $12 \mathrm{Z}$. This is six hours later than originally shown in HURDAT. Furthermore, HURDAT has Betsy transitioning to extratropical at $12 \mathrm{Z}$ on the $18^{\text {th }}$ but the analysis of the ship data and the symmetry of the storm suggests that Betsy did not become extratropical until $0 \mathrm{Z}$ on the $19^{\text {th }}$, twelve hours later than shown in HURDAT. The last aircraft reconnaissance to reach Betsy occurred at $08 \mathrm{Z}$ on the $18^{\text {th }}$ when the hurricane was north of $40 \mathrm{~N}$. Betsy moved generally eastward on the $19^{\text {th }}$ and remained an intense and small extratropical cyclone with ships reporting winds up to $55 \mathrm{kt}$. At the same time, another extratropical cyclone was gaining strength north of Betsy. Betsy is analyzed to have weakened below gale force at $18 \mathrm{Z}$ on the $20^{\text {th }}$ and dissipated after $06 \mathrm{Z}$ on the $21^{\text {st }}$ becoming absorbed by the larger and intense extratropical cyclone to the northeast.

Tropical Storm Carla [September 7-16, 1956]

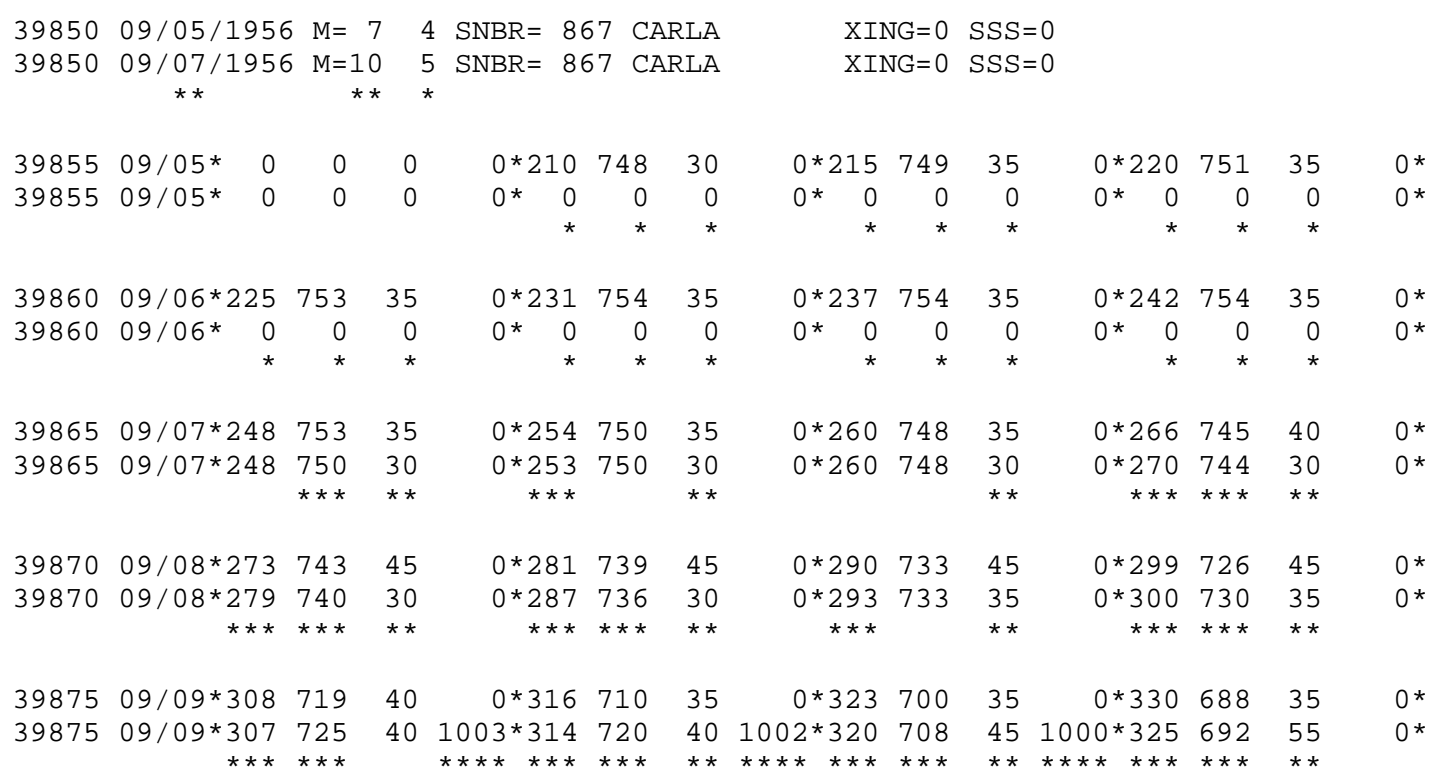




\begin{tabular}{|c|c|c|c|c|c|c|c|c|c|c|c|c|c|}
\hline 39880 & $09 / 10 * 338$ & 670 & 35 & $998 * 347$ & 642 & 35 & $0 * 360$ & 612 & 35 & $996 * 377$ & 587 & 35 & ०* \\
\hline 39880 & $\begin{array}{r}09 / 10 \mathrm{E} 332 \\
* \star *\end{array}$ & 670 & $\begin{array}{l}55 \\
* *\end{array}$ & $\begin{array}{r}998 \mathrm{E} 343 \\
* * \star *\end{array}$ & 642 & $\begin{array}{l}55 \\
* *\end{array}$ & $\underset{* * * *}{\text { OE356 }}$ & 612 & $\begin{array}{l}60 \\
* *\end{array}$ & $\begin{array}{l}\text { @E377 } \\
\star \star\end{array}$ & 587 & $\begin{array}{l}60 \\
* *\end{array}$ & ०* \\
\hline 39885 & $09 / 11$ * 397 & 561 & 30 & $0 * 418$ & 530 & 25 & $\odot * 440$ & 500 & 25 & $0^{*}$ & 0 & 0 & ०* \\
\hline 39885 & ๑9/11E397 & 561 & $\begin{array}{l}60 \\
* *\end{array}$ & $\underset{*}{\mathrm{OE} 418}$ & 530 & $\begin{array}{l}60 \\
* *\end{array}$ & $\begin{array}{r}\text { OE455 } \\
* * * *\end{array}$ & 500 & $\begin{array}{l}55 \\
* *\end{array}$ & $\begin{array}{r}\odot \mathrm{E} 50 \odot \\
* * *\end{array}$ & $\begin{array}{l}450 \\
* * *\end{array}$ & $\begin{array}{l}50 \\
* *\end{array}$ & $0 *$ \\
\hline \multicolumn{14}{|c|}{ (September 12th through 16th are new to HURDAT) } \\
\hline 39886 & $09 / 12 \mathrm{E} 530$ & 410 & 50 & OE535 & 380 & 50 & 0E545 & 340 & 50 & @E561 & 300 & 50 & 0* \\
\hline 39887 & 09/13E578 & 265 & 55 & OE59๑ & 230 & 60 & OE595 & 190 & 60 & OE605 & 145 & 60 & $0^{*}$ \\
\hline 39888 & ๑9/14E620 & 095 & 55 & OE640 & $04 \odot$ & 55 & OE6603 & 3585 & 55 & OE6753 & 3530 & 50 & $0^{*}$ \\
\hline 39889 & $09 / 15 E 6853$ & 3500 & 50 & OE6933 & 3470 & 50 & OE7023 & 3453 & 50 & OE7103 & 3443 & 45 & $0^{*}$ \\
\hline 39890 & $09 / 16 E 7203$ & 3440 & 40 & OE7303 & 3440 & 35 & $\Theta^{*} \quad 0$ & $\odot$ & 0 & $\Theta^{*} \quad 0$ & 0 & $\odot$ & ○* \\
\hline
\end{tabular}

39895 TS

Minor changes to the track and major changes to the intensity shown in McAdie et al. (2009). Two additional major changes are to remove the first two days of its existence and adding an extratropical stage seven days (with five of those being new to HURDAT). Evidence for these alterations comes from the NHC microfilm maps, the Historical Weather Maps series, the COADS ship database, Navy reconnaissance book and Monthly Weather Review.

September 4:

HWM analyzes a trough of low pressure at $75 \mathrm{~W}$ at $12 \mathrm{Z}$. Microfilm does not show an organized system at 12Z. HURDAT does not list a tropical cyclone on this day. No gales or low pressures. "A brief review of the history of Carla indicates that this storm was of tropical origin, but acquired gale and storm intensity. However, because of the rapid increase in intensity to storm force on the $9^{\text {th }}$, it was agreed upon by the members of the Joint Hurricane Warning Service to issue numbered warnings as Tropical Storm Carla, even though the true characteristics of the storm were debatable at this time. Only three numbered warnings were issued, the first at 092230Z and the final warning at 101000Z." (ATSR)

September 5:

HWM analyzes a trough of low pressure at $78 \mathrm{~W}$ at $12 \mathrm{Z}$. Microfilm does not show an organized system at $12 \mathrm{Z}$. HURDAT lists this as a $35 \mathrm{kt}$ tropical storm at $21.5 \mathrm{~N}, 74.9 \mathrm{~W}$ at $12 \mathrm{Z}$. No gales or low pressures. "The first indication of Carla appeared on September 5 when a weak circulation showed up in an easterly wave which was moving into the southeastern Bahamas." (MWR) 
September 6:

HWM does not analyze an organized system at 12Z. HURDAT lists this as a 35 knot tropical storm at $23.7 \mathrm{~N}, 75.4 \mathrm{~W}$ at $12 \mathrm{Z}$. Microfilm shows a closed low pressure of at most $1011 \mathrm{mb}$ centered near $24.5 \mathrm{~N}, 75.5 \mathrm{~W}$ at $12 \mathrm{Z}$. No gales or low pressures. "As early as the $6^{\text {th }}$ of September, it was noted that an incipient tropical depression was located over the Bahamas, with the formation taking place in semi-stationary weak low pressure trough extending aloft through the $200 \mathrm{mb}$ level." (ATSR)

September 7:

HWM analyzes a spot low centered near $25.7 \mathrm{~N}, 74.5 \mathrm{~W}$ at $12 \mathrm{Z}$. HURDAT lists this as a $35 \mathrm{kt}$ tropical storm at $26.0 \mathrm{~N}, 74.8 \mathrm{~W}$ at $12 \mathrm{Z}$. Microfilm shows a closed low pressure of at most $1008 \mathrm{mb}$ centered near $26.0 \mathrm{~N}, 76.0 \mathrm{~W}$ at $12 \mathrm{Z}$. No gales or low pressures. "During the next several days it moved on a parabolic course and on the $7^{\text {th }}$ recurved northeastward with some deepening and the area of strong winds expanded to cover an area 300 to 400 miles in diameter. A strong southeastward outbreak of polar air was taking place in the eastern and central United States and the accompanying cold front passed off the coast during the morning of the $7^{\text {th }}$." (MWR) "Early movement of the weak depression along an oscillatory northerly track at 7 to $10 \mathrm{kt}$ followed by a recurvature to the northeast after 071010Z. Continues northeast to east-northeast movement with a gradual acceleration to 25 to $30 \mathrm{kt}$ was observed iin the latter potion of the life cycle of Carla. This northeastward movement and accelerated speed was produced by the upper level trough in the westerlies moving eastward across the track of Carla. An important synoptic feature, which was later to affect the development of Carla into a storm was the cold front moving off the southeastern coast of the United States on the $7^{\text {th }}$ of September." (ATSR)

September 8:

HWM analyzes a closed low pressure of at most $1010 \mathrm{mb}$ centered near $31.0 \mathrm{~N}$, $73.0 \mathrm{~W}$ at $12 \mathrm{Z}$. HURDAT lists this as a $45 \mathrm{kt}$ tropical storm at $29.0 \mathrm{~N}, 73.3 \mathrm{~W}$ at $12 \mathrm{Z}$. Microfilm shows a closed low pressure of at most $1008 \mathrm{mb}$ centered near $29.0 \mathrm{~N}, 73.5 \mathrm{~W}$ at 12Z. Ship highlights: $35 \mathrm{kt} \mathrm{SE}$ and $1012 \mathrm{mb}$ at $31.2 \mathrm{~N}, 70.8 \mathrm{~W}$ at $12 \mathrm{Z}$ (COADS). $35 \mathrm{kt}$ $\mathrm{SE}$ and $1012 \mathrm{mb}$ at $30.6 \mathrm{~N}, 70.2 \mathrm{~W}$ at $18 \mathrm{Z}$ (micro). "On the $8^{\text {th }}$ interaction between the high with central pressure $1034 \mathrm{mb}$ over the Lakes Region and the tropical Low off the southeastern United States coast was causing strong northeast winds from the central Florida coast northward along and off Georgia and Carolina coasts." (MWR) "The exact time in which the front moved into Carla and changed her characteristics to extratropical is difficult to determine, but it is believed that it took place sometimes between late on 
the $8^{\text {th }}$ and early on the $9^{\text {th }}$ of September. This coincided with the increase in intensity to gale force." (ATSR)

September 9:

HWM analyzes a closed low pressure of at most $1000 \mathrm{mb}$ centered near $32.0 \mathrm{~N}$, $71.0 \mathrm{~W}$ at $12 \mathrm{Z}$. HURDAT lists this as a $35 \mathrm{kt}$ tropical storm at $32.3 \mathrm{~N}, 70.0 \mathrm{~W}$ at $12 \mathrm{Z}$. Microfilm shows a closed low pressure of at most $1005 \mathrm{mb}$ centered near $32.0 \mathrm{~N}, 70.0 \mathrm{~W}$ at 12Z. Ship highlights: $20 \mathrm{kt} \mathrm{NE}$ and $1005 \mathrm{mb}$ at $31.2 \mathrm{~N}, 72.6 \mathrm{~W}$ at $00 \mathrm{Z}$ (COADS). $10 \mathrm{kt}$ WSW and $1003 \mathrm{mb}$ at $31.0 \mathrm{~N}, 71.8 \mathrm{~W}$ at $06 \mathrm{Z}$ (COADS). $15 \mathrm{kt} \mathrm{S}$ and $1001 \mathrm{mb}$ at $31.9 \mathrm{~N}$, $70.5 \mathrm{~W}$ at $12 \mathrm{Z}$ (COADS). $40 \mathrm{kt} \mathrm{SSW}$ and $996 \mathrm{mb}$ at $32.3 \mathrm{~N}, 69.1 \mathrm{~W}$ at $16 \mathrm{Z}$ (micro). $50 \mathrm{kt}$ $\mathrm{N}$ and $1000 \mathrm{mb}$ at $32.3 \mathrm{~N}, 70.0 \mathrm{~W}$ at $18 \mathrm{Z}$ (micro). Aircraft highlights: Penetration fix measured $40 \mathrm{kt}$ at $32.1 \mathrm{~N}, 69.5 \mathrm{~W}$ at $1445 \mathrm{Z}$ (ATSR). Penetration fix at $33.1 \mathrm{~N}, 68.6 \mathrm{~W}$ at $20 Z$ (ATSR). "Gales spread to the New England coast as the Low moved to a position near Lat. $32.5^{\circ} \mathrm{N}$., Long. $70^{\circ} \mathrm{W}$. by the morning of the $9^{\text {th }}$. Reconnaissance aircraft on the morning of the $9^{\text {th }}$ located an ill-defined center but reported no eye existed and no spiral bands were in evidence. Highest surface winds near the center were estimated at 30 knots. However, 40 to $50 \mathrm{mph}$ winds were found extending 200 miles to the west and northwest and $40 \mathrm{mph}$ winds some distance to the east and south. During the period of greatest intensity, the storm was probably not a true tropical storm." (MWR) "Further intensification to storm force followed later on the $9^{\text {th }}$ as deepening took place. With respect to determining the true characteristics of Carla it is interesting to note the remarks of the Air Force weather reconnaissance reports on the $9^{\text {th }}$ and $10^{\text {th }}$ of September. The track of Carla was entirely over the open water of the Atlantic when storm intensity was reached and no damage was reported." (ATSR)

September 10:

HWM analyzes a tropical storm of at most $1000 \mathrm{mb}$ centered near $39.8 \mathrm{~N}, 58.2 \mathrm{~W}$ with a warm front extending to the northeast and another low pressure of at most 1000 $\mathrm{mb}$ centered at $35.0 \mathrm{~N}, 63.5 \mathrm{~W}$ with a cold front extending to the south at 12Z. HURDAT lists this as a $35 \mathrm{kt}$ tropical storm at $36.0 \mathrm{~N}, 61.2 \mathrm{~W}$ at $12 \mathrm{Z}$. Microfilm shows a closed low pressure of at most $993 \mathrm{mb}$ centered near $36.0 \mathrm{~N}, 62.0 \mathrm{~W}$ with a cold front extending to the southwest at 12Z. Ship highlights: $35 \mathrm{kt} \mathrm{NE}$ and $1004 \mathrm{mb}$ at $34.6 \mathrm{~N}, 67.0 \mathrm{~W}$ at $0 \mathrm{Z}$ (COADS). $20 \mathrm{kt} \mathrm{N}$ and $997 \mathrm{mb}$ at $33.3 \mathrm{~N}, 65.5 \mathrm{~W}$ at $6 \mathrm{Z}$ (COADS). $60 \mathrm{kt} \mathrm{SSW}$ and $992 \mathrm{mb}$ at $35.3 \mathrm{~N}, 61.1 \mathrm{~W}$ at $12 \mathrm{Z}$ (micro). $50 \mathrm{kt} \mathrm{NNE}$ and $1000 \mathrm{mb}$ at $40.0 \mathrm{~N}, 57.0 \mathrm{~W}$ at $18 \mathrm{Z}$ (micro). Aircraft highlights: Penetration fix at $35.3 \mathrm{~N}, 61.7 \mathrm{~W}$ at $1230 \mathrm{Z}$ (ATSR). Penetration fix at 36.4N, 61.5W at 1530Z (ATSR). "It has definitely taken on extratropical characteristics by the forenoon of the $10^{\text {th }}$ and only three advisories were issued." (MWR) 
September 11:

HWM analyzes an extratropical system of at most $990 \mathrm{mb}$ centered near $47.0 \mathrm{~N}$, $49.0 \mathrm{~W}$ with a warm front extending to the northeast and a cold front extending to the south at $12 \mathrm{Z}$. HURDAT lists this as a $25 \mathrm{kt}$ tropical depression at $44.0 \mathrm{~N}, 50.0 \mathrm{~W}$ at $12 \mathrm{Z}$ (last position). Microfilm shows a closed low pressure of at most $1002 \mathrm{mb}$ centered near $45.0 \mathrm{~N}, 50.0 \mathrm{~W}$ with a cold front extending to the southwest at 12Z. Ship highlights: $60 \mathrm{kt}$ $\mathrm{SE}$ at $39.9 \mathrm{~N}, 55.5 \mathrm{~W}$ at $0 \mathrm{Z}$ (micro). $60 \mathrm{kt} \mathrm{S}$ and $998 \mathrm{mb}$ at $39.5 \mathrm{~N}, 53.0 \mathrm{~W}$ at $06 \mathrm{Z}$ (micro). $40 \mathrm{kt} \mathrm{NNE}$ and $993 \mathrm{mb}$ at $47.4 \mathrm{~N}, 50.4 \mathrm{~W}$ at $12 \mathrm{Z}$ (COADS). $40 \mathrm{kt} \mathrm{N}$ and $997 \mathrm{mb}$ at $48.0 \mathrm{~N}$, $48.7 \mathrm{~W}$ at $18 \mathrm{Z}(\mathrm{COADS})$.

September 12:

HWM analyzes an extratropical system of at most $1000 \mathrm{mb}$ centered near $53.5 \mathrm{~N}$, $37.0 \mathrm{~W}$ with a warm front extending to the northeast and a cold front extending to the south at 12Z. Microfilm shows a closed low pressure of at most $1011 \mathrm{mb}$ centered near $54.5 \mathrm{~N}, 35.0 \mathrm{~W}$ with a cold front extending to the south at $12 \mathrm{Z}$. HURDAT does not list this system on this date. Ship highlights: $35 \mathrm{kt} \mathrm{NNW}$ and $1002 \mathrm{mb}$ at $48.5 \mathrm{~N}, 46.8 \mathrm{~W}$ at $00 \mathrm{Z}$ (COADS). $45 \mathrm{kt} \mathrm{SW}$ and $1015 \mathrm{mb}$ at $47.9 \mathrm{~N}, 33.3 \mathrm{~W}$ at $18 \mathrm{Z}$ (COADS).

September 13:

HWM analyzes an extratropical system of at most $985 \mathrm{mb}$ centered near $60.0 \mathrm{~N}$, $19.0 \mathrm{~W}$ with a warm front extending to the northeast and a cold front extending to the south at $12 Z$. HURDAT does not list this system on this date. Microfilm is not available on this date. Ship highlights: $20 \mathrm{kt} \mathrm{SSW}$ and $996 \mathrm{mb}$ at 59.0N, 19.7W at 0Z (COADS). $35 \mathrm{kt} \mathrm{SW}$ and $1013 \mathrm{mb}$ at 52.6N, 19.2W at 09Z (COADS). $10 \mathrm{kt} \mathrm{S}$ and $986 \mathrm{mb}$ at $59.1 \mathrm{~N}$, $19.7 \mathrm{~W}$ at $12 \mathrm{Z}$ (COADS). $60 \mathrm{kt} \mathrm{NW}$ and $992 \mathrm{mb}$ at $59.0 \mathrm{~N}, 19.5 \mathrm{~W}$ at $15 \mathrm{Z}$ (COADS). $50 \mathrm{kt}$ $\mathrm{W}$ and $1000 \mathrm{mb}$ at $57.6 \mathrm{~N}, 15.4 \mathrm{~W}$ at $18 \mathrm{Z}$ (COADS).

September 14:

HWM analyzes an extratropical system of at most $985 \mathrm{mb}$ centered near $65.0 \mathrm{~N}$, 2.0E with a warm front extending to the northeast and a cold front extending to the south at 12Z. HURDAT does not list this system on this date. Microfilm is not available on this date. Ship highlights: $35 \mathrm{kt}$ ESE and $995 \mathrm{mb}$ at $65.9 \mathrm{~N}, 2.1 \mathrm{E}$ at $03 \mathrm{Z}$ (COADS). $45 \mathrm{kt} \mathrm{W}$ and $1010 \mathrm{mb}$ at $58.0 \mathrm{~N}, 0.0 \mathrm{~W}$ at $07 \mathrm{Z}$ (COADS). $15 \mathrm{kt} \mathrm{SSE}$ and $982 \mathrm{mb}$ at $66.0 \mathrm{~N}, 2.3 \mathrm{E}$ at $12 \mathrm{Z}$ (COADS). $50 \mathrm{kt} \mathrm{NW}$ and $990 \mathrm{mb}$ at $66.0 \mathrm{~N}, 1.8 \mathrm{E}$ at $17 \mathrm{Z}$ (COADS). $50 \mathrm{kt} \mathrm{W}$ and $1005 \mathrm{mb}$ at $64.0 \mathrm{~N}, 6.0 \mathrm{E}$ at $21 \mathrm{Z}$ (COADS). Land highlights: $35 \mathrm{kt} \mathrm{SW}$ and $995 \mathrm{mb}$ at Hustad, Norway [63.0N, 7.1E] at 12Z (micro). $35 \mathrm{kt} \mathrm{NW}$ and $1013 \mathrm{mb}$ at Shetland Island, England [60.3N, 1.3W] at $12 \mathrm{Z}$ (micro). 
September 15:

HWM analyzes an extratropical system of at most $990 \mathrm{mb}$ centered near $70.0 \mathrm{~N}$, 13.0E with a dissipating front to the east and southeast at 12Z. HURDAT does not list this system on this date. Microfilm is not available on this date. Ship highlights: $50 \mathrm{kt}$ $\mathrm{NW}$ and $990 \mathrm{mb}$ at $65.0 \mathrm{~N}, 8.0 \mathrm{E}$ at $0 \mathrm{Z}$ (COADS). $10 \mathrm{kt} \mathrm{SE}$ and $988 \mathrm{mb}$ at $68.0 \mathrm{~N}, 13.0 \mathrm{E}$ at $06 Z$ (COADS). $50 \mathrm{kt} \mathrm{WNW}$ and $998 \mathrm{mb}$ at $67.0 \mathrm{~N}, 9.0 \mathrm{E}$ at $12 \mathrm{Z}$ (COADS). $35 \mathrm{kt} \mathrm{WW}$ and $1003 \mathrm{mb}$ at $67.0 \mathrm{~N}, 10.0 \mathrm{E}$ at $18 \mathrm{Z}$ (COADS). Land highlights: $10 \mathrm{kt} \mathrm{SW}$ and $993 \mathrm{mb}$ at Tromso, Norway [69.7N, 18.9E] at $12 \mathrm{Z}$ (micro). $35 \mathrm{kt} \mathrm{W}$ and $992 \mathrm{mb}$ at Rost, Norway $[67.5 \mathrm{~N}, 12.1 \mathrm{E}]$ at $12 \mathrm{Z}$ (micro).

September 16:

HWM analyzes a closed low pressure of at most $1000 \mathrm{mb}$ centered near $74.5 \mathrm{~N}$, $10.0 \mathrm{E}$ at $12 \mathrm{Z}$. HURDAT does not list this system on this date. Microfilm is not available on this date. Ship highlights: $15 \mathrm{kt} \mathrm{E}$ and $996 \mathrm{mb}$ at $73.0 \mathrm{~N}, 17.0 \mathrm{E}$ at $0 \mathrm{Z}$ (COADS). $10 \mathrm{kt}$ $\mathrm{SE}$ and $997 \mathrm{mb}$ at $74.0 \mathrm{~N}, 16.0 \mathrm{E}$ at 12Z (COADS). Land highlights: $10 \mathrm{kt} \mathrm{SE}$ and $998 \mathrm{mb}$ at Bear Island, Norway [74.5N, 19.0E] at $12 \mathrm{Z}$ (micro).

September 17:

HWM analyzes a closed low pressure of at most $1000 \mathrm{mb}$ centered near $78.0 \mathrm{~N}$, $20.0 \mathrm{E}$ at $12 \mathrm{Z}$. HURDAT does not list this system on this date. Microfilm is not available on this date. Ship highlights: $25 \mathrm{kt} \mathrm{W}$ and $1004 \mathrm{mb}$ at 74.1N, 15.9E at 08Z (COADS). Land highlights: $10 \mathrm{kt} \mathrm{WNW}$ and $998 \mathrm{mb}$ at Svalbard, Norway [78.0N, 16.0E] at 12Z (micro).

September 18:

HWM analyzes a closed low pressure of at most $990 \mathrm{mb}$ centered near $78.0 \mathrm{~N}$, $12.0 \mathrm{E}$ at $12 \mathrm{Z}$. HURDAT does not list this system on this date. Microfilm is not available on this date. Ship highlights: $35 \mathrm{kt} \mathrm{SW}$ and $1005 \mathrm{mb}$ at $71.0 \mathrm{~N}, 27.0 \mathrm{E}$ at 10Z (COADS). Land highlights: $10 \mathrm{kt} \mathrm{SE}$ and $990 \mathrm{mb}$ at Svalbard, Norway [78.0N, 16.0E] at $12 \mathrm{Z}$ (micro).

September 19:

HWM analyzes a closed low pressure of at most $995 \mathrm{mb}$ centered near $75.0 \mathrm{~N}$, $37.0 \mathrm{E}$ at $12 \mathrm{Z}$. HURDAT does not list this system on this date. Microfilm is not available on this date. Ship highlights: $35 \mathrm{kt} \mathrm{W}$ and $1005 \mathrm{mb}$ at 70.0N, 32.0E at 09Z (COADS). Land highlights: $10 \mathrm{kt} \mathrm{SE}$ and $998 \mathrm{mb}$ at Hopen, Norway [76.6N, 25.1E] at 12Z (micro). 
September 20:

HWM analyzes a closed low pressure of at most $995 \mathrm{mb}$ centered near $70.0 \mathrm{~N}$, $51.0 \mathrm{E}$ at $12 \mathrm{Z}$. HURDAT does not list this system on this date. Microfilm is not available on this date. Ship highlights: $30 \mathrm{kt} \mathrm{NW}$ and $994 \mathrm{mb}$ at $70.8 \mathrm{~N}, 45.0 \mathrm{E}$ at $12 \mathrm{Z}$ (COADS). Land highlights: $10 \mathrm{kt} \mathrm{SE}$ and $998 \mathrm{mb}$ at Hopen, Norway [76.6N, 25.1E] at 12Z (micro).

A tropical disturbance reached the Bahamas during the first days of September while moving slowly toward the northwest. A well-defined center slowly became better organized and a $30 \mathrm{kt}$ tropical depression developed at $00 \mathrm{Z}$ on September 7 th just north of the central Bahamas. This time of genesis is 42 hours later than originally shown in HURDAT. Data from the Bahamas and ships indicate that a well-defined center was not present on September $5^{\text {th }}$ and $6^{\text {th }}$. Furthermore, no low pressures or gales were reported on these days, but the environmental pressure did decrease about two mb in the 24 hours before genesis. Minor track changes were introduced for the duration of this system. The depression moved north-northeast after formation while becoming better organized.

Intensification to a tropical storm is analyzed at $12 \mathrm{Z}$ on September $8^{\text {th }}, 72$ hours later than originally shown in HURDAT. The first gale was reported at $12 \mathrm{Z}$ on the $8^{\text {th }}$, a ship located at $31.2 \mathrm{~N}, 70.8 \mathrm{~W}$ reported $35 \mathrm{kt}$. On September $9^{\text {th }}$, Carla began to feel the effects of an approaching frontal boundary from the west and its track turned to the northeast while gaining in forward speed. A ship located at $31.2 \mathrm{~N}, 72.6 \mathrm{~W}$ at $00 \mathrm{Z}$ on the $9^{\text {th }}$ reported $20 \mathrm{kt} \mathrm{NE}$ and $1005 \mathrm{mb}$. It is analyzed that this ship was inside the RMW of the tropical storm, resulting in an estimated central pressure of $1003 \mathrm{mb}$. A central pressure of $1003 \mathrm{mb}$ has been added to $00 \mathrm{Z}$ on September $9^{\text {th }}$. A central pressure of $1003 \mathrm{mb}$ suggests maximum sustained winds of $38 \mathrm{kt}$ north of $25 \mathrm{~N}$ from the Brown et al. pressurewind relationship. An intensity of $40 \mathrm{kt}$ is selected for $00 \mathrm{Z}$ on the $9^{\text {th }}$. Another ship located at $31.0 \mathrm{~N}, 71.8 \mathrm{~W}$ at $06 \mathrm{Z}$ on the $9^{\text {th }}$ reported $10 \mathrm{kt} \mathrm{WSW}$ and $1003 \mathrm{mb}$, resulting in an estimated central pressure of $1002 \mathrm{mb}$. A central pressure of $1002 \mathrm{mb}$ has been added to $06 \mathrm{Z}$ on September $9^{\text {th }}$. An intensity of $40 \mathrm{kt}$ has been selected for $06 \mathrm{Z}$ on the $9^{\text {th }}$. At $12 \mathrm{Z}$ on the $9^{\text {th }}$, a ship reported $15 \mathrm{kt} \mathrm{S}$ and $1001 \mathrm{mb}$ at $31.9 \mathrm{~N}, 70.5 \mathrm{~W}$, resulting in an estimated central pressure of $1000 \mathrm{mb}$. A central pressure of $1000 \mathrm{mb}$ has been added to $12 \mathrm{Z}$ on September $9^{\text {th }}$. A central pressure of $1000 \mathrm{mb}$ suggests maximum sustained winds of $44 \mathrm{kt}$ north of $25 \mathrm{~N}$ according to the pressure-wind relationship. An intensity of $45 \mathrm{kt}$ has been selected for $12 \mathrm{Z}$ on the $9^{\text {th }}$, up from $35 \mathrm{kt}$ originally in HURDAT. The first aircraft reconnaissance to reach Carla occurred on September $9^{\text {th }}$ at $1445 Z$ measuring estimated surface winds of $40 \mathrm{kt}$ and making a center fix at $32.1 \mathrm{~N}, 69.5 \mathrm{~W}$. At 18Z, a ship located at $32.3 \mathrm{~N}, 70.0 \mathrm{~W}$ reported $50 \mathrm{kt} \mathrm{N}$ and $1000 \mathrm{mb}$. An intensity of $55 \mathrm{kt}$ has been selected for $18 \mathrm{Z}$ on the $9^{\text {th }}$, up from $35 \mathrm{kt}$ originally in HURDAT, a major intensity change. This is also the peak intensity for Carla as a tropical cyclone, up from $45 \mathrm{kt}$ 
originally in HURDAT. (HURDAT indicated that the peak intensity of this tropical cyclone occurred between $00 \mathrm{Z}$ to $18 \mathrm{Z}$ on September $8^{\text {th }}$.)

HURDAT indicates that Carla remained a tropical cyclone for all of its lifetime, but ship data indicates that the Carla became an extratropical cyclone around $00 \mathrm{Z}$ on the $10^{\text {th }}$. At this time, the circulation became elongated NE-SW with a warm front to the northeast and a cold front to the southwest of the center. A prominent temperature gradient is noticeable on the ship data on the $10^{\text {th }}$ and the strongest winds are located about $250 \mathrm{~nm}$ from the center, mainly to the north and west. A central pressure of $998 \mathrm{mb}$ is present in HURDAT at $00 \mathrm{Z}$ on the $10^{\text {th }}$, and although there is no data to confirm it was an observation, it appears reasonable and it is retained. Two aircraft reconnaissance reported center fixes at $35.3 \mathrm{~N}, 61.7 \mathrm{~W}$ at $1230 \mathrm{Z}$ and $36.4 \mathrm{~N}, 61.5 \mathrm{~W}$ at $1530 \mathrm{Z}$ on the $10^{\text {th }}$. A central pressure of $996 \mathrm{mb}$ is present in HURDAT at $12 \mathrm{Z}$ on the $10^{\text {th }}$ and it has been removed because ship data indicates that the central pressure was lower at this time, likely in the $980 \mathrm{~s} \mathrm{mb}$ range. A ship reported $60 \mathrm{kt} \mathrm{SSW}$ and $992 \mathrm{mb}$ at $12 \mathrm{Z}$ on the $10^{\text {th }}$. An intensity of $60 \mathrm{kt}$ has been selected for $12 \mathrm{Z}$ on the $10^{\text {th }}$, up from $35 \mathrm{kt}$ in HURDAT, a major intensity change to HURDAT. Major changes in intensity are also analyzed at $06 \mathrm{Z}$ and $18 \mathrm{Z}$ on the $10^{\text {th }} .55 \mathrm{kt}$ and $60 \mathrm{kt}$, respectively are analyzed, while HURDAT has $35 \mathrm{kt}$ for both times. Around midday on the $11^{\text {th }}$, Carla passed about $200 \mathrm{~nm}$ east of Newfoundland while heading on a northeast course. HURDAT weakens Carla to a $30 \mathrm{kt}$ tropical depression at $00 \mathrm{Z}$ on the $11^{\text {th }}$ but ship data suggests that the system was a powerful extratropical cyclone at this time with winds around $60 \mathrm{kt}$. A major change in intensity to HURDAT. The last position in HURDAT is at $12 \mathrm{Z}$ on September $11^{\text {th }}$ as a $25 \mathrm{kt}$ tropical depression at $44 \mathrm{~N}, 50 \mathrm{~W}$. Ship data indicates that Carla was a $55 \mathrm{kt}$ extratropical cyclone at this time and this is a major change in intensity to HURDAT. Over the next five days, Carla continued toward the northeast passing southeast of Iceland on September $13^{\text {th }}$. On September $16^{\text {th }}$ at $06 \mathrm{Z}$, while located north of Norway near $73.0 \mathrm{~N}, 16.0 \mathrm{E}$, Carla dissipated as it merged with another extratropical low pressure system.

Tropical Storm Dora [September 10-13, 1956]

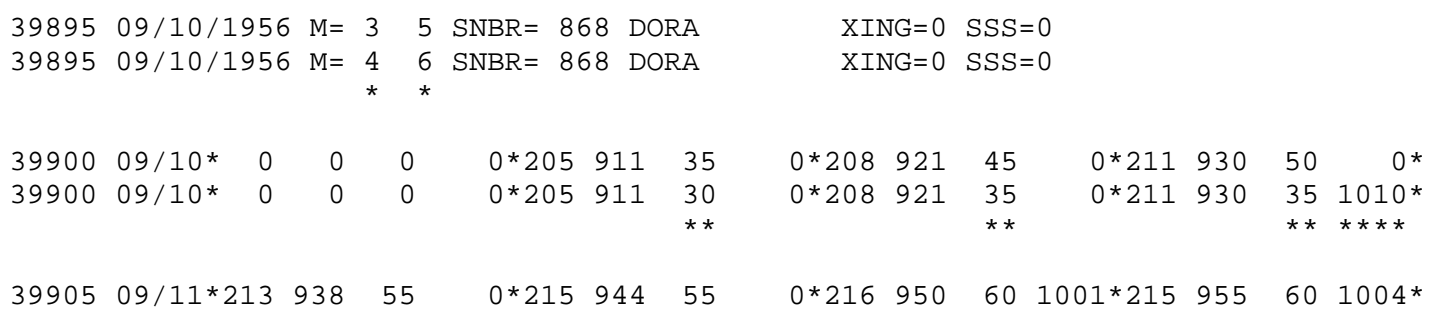




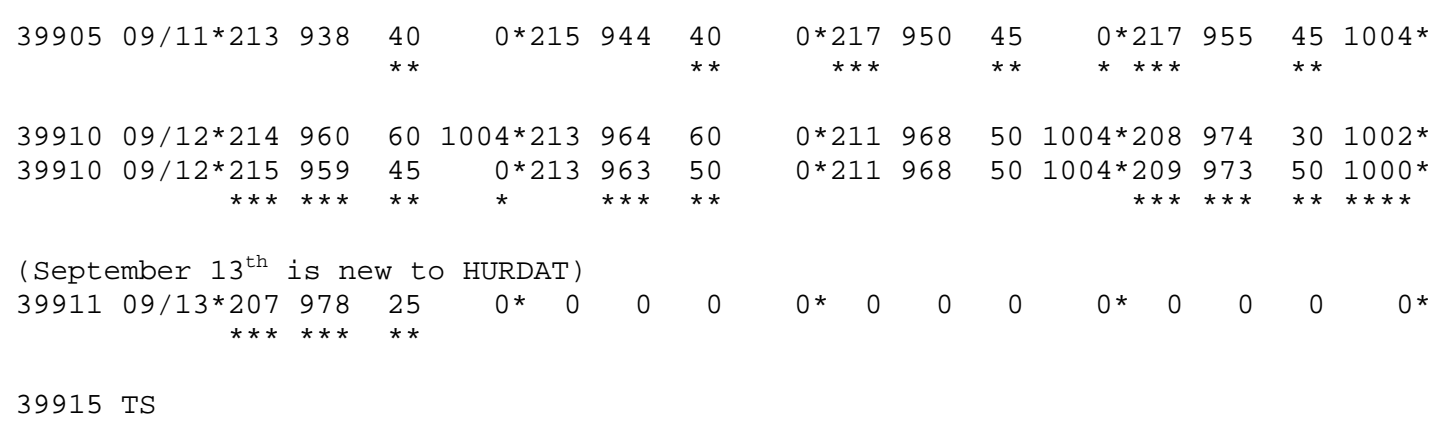

Minor changes to the track and major changes to the intensity shown in McAdie et al. (2009). Evidence for these alterations comes from the NHC microfilm maps, the Historical Weather Maps series, the COADS ship database, Monthly Weather Review, Connor (1956) and Mexican synoptic maps.

September 9:

HWM analyzes a closed low pressure of at most $1015 \mathrm{mb}$ at $18.5 \mathrm{~N}, 88.5 \mathrm{~W}$ at 12Z. HURDAT does not list an organized system on this date. Microfilm shows a closed low pressure of at most $1011 \mathrm{mb}$ at $18.5 \mathrm{~N}, 93.0 \mathrm{~W}$ at 12Z. Ship highlights: No gales or low pressures. "As early as $071230 \mathrm{Z}$ a weak vortex was detected over the Yucatan Peninsula. By 9 September the vortex, moving in a westerly direction, had moved off the west coast of the Yucatan Peninsula over the warm waters of the Gulf of Campeche. A low level investigative flight was ordered for the afternoon of the $9^{\text {th }}$ of September to investigate the Gulf of Campeche. The Navy post-flight summary from the 9 September flight showed minimum pressure of $1011 \mathrm{mb}$, maximum observed surface winds of seven knots, and evidence of a wind circulation but inability to determine the exact center due to the large calm central area. (ATSR)

September 10:

HWM analyzes a closed low pressure of at most $1010 \mathrm{mb}$ at $21.5 \mathrm{~N}, 96.5 \mathrm{~W}$ at 12Z. HURDAT lists this as a $45 \mathrm{knot}$ tropical storm at $20.8 \mathrm{~N}, 92.1 \mathrm{~W}$ at $12 \mathrm{Z}$. Microfilm shows a closed low pressure of at most $1011 \mathrm{mb}$ at $21.2 \mathrm{~N}, 94.1 \mathrm{~W}$ at $12 \mathrm{Z}$. Ship highlights: No gales or low pressures. "Navy reconnaissance during the previous afternoon [Sep 10] found a rather large area in the Bay of Campeche with scattered squalls. The lowest pressure was $1010 \mathrm{mb}$ and the maximum wind 35 knots." (MWR) "As is frequent in this area, few ship reports were received. A second low level flight was flown on 10 September. The reports showed a minimum surface pressure of $1010 \mathrm{mb}$, maximum surface winds of 35 knots in squalls and the area characterized by isolated squalls and low stratiform clouds. No "eye" was discernible at this time." (ATSR)

September 11: 
HWM analyzes a closed low pressure of at most $1010 \mathrm{mb}$ at $22.5 \mathrm{~N}, 95.5 \mathrm{~W}$ at 12Z. HURDAT lists this as a 60 knot tropical storm at $21.6 \mathrm{~N}, 95.0 \mathrm{~W}$ at $12 \mathrm{Z}$. Microfilm shows a closed low pressure of at most $1011 \mathrm{mb}$ at $22.0 \mathrm{~N}, 94.5 \mathrm{~W}$ at $12 \mathrm{Z}$. Ship highlights: No gales or low pressures. Aircraft highlights: Penetration fix at 22.1N, 95.4W at $1627 \mathrm{Z}$ (ATSR). Penetration fix estimated surface winds of $65 \mathrm{kt}$ and a central pressure of 1004 $\mathrm{mb}$ at $21.6 \mathrm{~N}, 95.8 \mathrm{~W}$ at $1950 \mathrm{Z}$ (ATSR/micro). "A tropical storm formed during the afternoon of September 11 in the southwest Gulf of Mexico in a depression that has been drifting westward. On the $11^{\text {th }}$, aircraft reconnaissance found the lowest pressure to be $1004 \mathrm{mb}$ and the maximum wind 65 knots. This storm has not been classified as a hurricane since the 65-knot wind was an estimate and not a measurement, and it is not believed that the required pressure gradient for this speed existed." (MWR) "Two flights were flown on the $11^{\text {th }}$ of September; one by the Navy and the other by an Air Force Research aircraft. At $111950 Z$ the Navy low level flight located the center of the wind circulation. The minimum surface winds were 60 knots in the northeast quadrant. The center of circulation could not be defined by the weather bands. The Air Force Research flight at higher levels located a wind circulation and again the radar bands showed a strong cyclonic curvature but did not define an "eye." From the wind reports it was decided to issue Warning Number ONE of Tropical Storm Dora at 112200Z." Dora, upon leaving the Yucatan Peninsula, had maintained a west to west-northwest course and accelerated until it reached its most northward position of $21.7 \mathrm{~N}$, maximum speed of 9 knots and maximum intensity of 60 knots at about 111900Z. Until this time, Dora had been under the influence of the anticyclonic circulation at the $200 \mathrm{mb}$ level but a trough at $200 \mathrm{mb}$ oriented northeast-southwest over Mexico and central United States moving eastward forced the high cell over Dora to move eastward. As the trough approached, Dora reached maximum intensity and moved more northwestward. With the passage of the trough, Dora was under the convergent and more northeastly flow, causing a decrease in intensity and a movement toward the southwest to west-southwest." (ATSR)

September 12:

HWM analyzes a tropical storm of at most $1005 \mathrm{mb}$ at $21.2 \mathrm{~N}, 96.5 \mathrm{~W}$ at $12 \mathrm{Z}$. HURDAT lists this as a 50 knot tropical storm at $21.1 \mathrm{~N}, 96.8 \mathrm{~W}$ at $12 \mathrm{Z}$. Microfilm shows a closed low pressure of at most $1002 \mathrm{mb}$ at $20.8 \mathrm{~N}, 97.0 \mathrm{~W}$ at 12Z. Ship highlights: $35 \mathrm{kt}$ $\mathrm{N}$ and $1010 \mathrm{mb}$ at $21.7 \mathrm{~N}, 97.1 \mathrm{~W}$ at $00 \mathrm{Z}$ (micro). $30 \mathrm{kt} \mathrm{NE}$ and $1003 \mathrm{mb}$ at $21.1 \mathrm{~N}, 96.5 \mathrm{~W}$ at $06 \mathrm{Z}$ (micro). $40 \mathrm{kt} \mathrm{SW}$ and $1005 \mathrm{mb}$ at $20.7 \mathrm{~N}, 96.2 \mathrm{~W}$ at $09 \mathrm{Z}$ (micro). Land highlights: $10 \mathrm{kt} \mathrm{W}$ and $1005 \mathrm{mb}$ at Tuxpan, Mexico [21.0N, 97.4W] at $12 \mathrm{Z}$ (micro). $10 \mathrm{kt} \mathrm{N}$ and $1002 \mathrm{mb}$ at Tuxpan, Mexico [21.0N, 97.4W] at 18Z (micro).Aircraft highlights:

Penetration fix estimated surface winds of $50 \mathrm{kt}$, central pressure of $1004 \mathrm{mb}$, and an eye diameter of $8 \mathrm{~nm}$ at $21.6 \mathrm{~N}, 95.8 \mathrm{~W}$ at $1235 \mathrm{Z}$ (ATSR/micro). "The next morning the minimum pressure was the same and maximum winds were 50 knots. The center moved 
inland around noon near Tuxpan, Mexico with lowest pressure $1002 \mathrm{mb}$ and highest wind 30 knots." (MWR) "A fifth flight was ordered 12 September before Dora entered the Mexican coast. The Navy flight at low level located and reported the center of the wind circulation 32 miles east-northeast of Tuxpan, Mexico, with a minimum surface pressure of $1004 \mathrm{mb}$ and maximum wind of 50 knots. Warning Number FOUR at $121600 \mathrm{Z}$ was the final warning issued. At 121700Z, Dora entered the Mexican coast just south of Tuxpan where maximum winds of 30 knots ans slight flooding was reported." (ATSR)

September 13:

HWM analyzes a spot low at $21.2 \mathrm{~N}, 102.0 \mathrm{~W}$ at $12 \mathrm{Z}$. HURDAT does not list an organized system on this date (last position at $18 \mathrm{Z}$ on the $12^{\text {th }}$ ). Microfilm shows a spot low at $19.5 \mathrm{~N}, 99.0 \mathrm{~W}$ at $12 \mathrm{Z}$. Ship highlights: No gales or low pressures.

Tropical Storm Dora formed over the eastern Bay of Campeche on the $10^{\text {th }}$ of September likely from a tropical wave. The genesis of this cyclone is unchanged from the original HURDAT at $06 \mathrm{Z}$ on the $10^{\text {th }}$ of September, but the intensity is decreased from 35 to 30 knots, a minor change. The reason for this is because the system started about $40 \mathrm{~nm}$ from the western Yucatan coast and the strongest winds would have been located on the eastern quadrant, which was partially over land and is consistent with the few available observations. Ship and land reports were sparse over the Bay of Campeche and the genesis time is bit uncertain. Intensification to tropical storm is delayed six hours from the original HURDAT to $12 \mathrm{Z}$ on the $10^{\text {th }}$. A reconnaissance aircraft reached Dora in the afternoon of the $11^{\text {th }}$ measuring a central pressure of $1010 \mathrm{mb}$ and estimated surface winds of 35 knots. No center position was reported but the data from the plane at $18 \mathrm{Z}$ on the $11^{\text {th }}$ on the microfilm map does suggest that a closed circulation was present. A 1010 $\mathrm{mb}$ central pressure has been added to $18 \mathrm{Z}$ on the $10^{\text {th }}$ based on the reconnaissance report. The intensity at $12 \mathrm{Z}$ and $18 \mathrm{Z}$ on the $10^{\text {th }}$ is analyzed at $35 \mathrm{kt}$, down from $45 \mathrm{kt}$ and $50 \mathrm{kt}$, respectively, originally in HURDAT. Both changes are minor. No track changes are introduced on the $10^{\text {th }}$ of September as Dora was moving on a west-northwest course and slowly decreasing in speed.

On September $11^{\text {th }}$, a reconnaissance aircraft reached Dora at $1627 \mathrm{Z}$ but only reported a fix position. The next fix at $1950 \mathrm{Z}$ on this day reported a central pressure of $1004 \mathrm{mb}$ and estimated surface winds of 65 knots. A central pressure of $1004 \mathrm{mb}$ suggests maximum winds of $39 \mathrm{kt}$ south of $25 \mathrm{~N}$ from the Brown et al. pressure-wind relationship. An intensity of $45 \mathrm{kt}$ was selected for $18 \mathrm{Z}$ on the $11^{\text {th }}$ because Dora was a small system with $30 \mathrm{kt}$ winds only extending about 50-60 $\mathrm{nm}$ away from the center according to the reconnaissance report. A central pressure of $1001 \mathrm{mb}$ was present at $12 \mathrm{Z}$ on the original HURDAT and has been removed since there is no evidence to suggest it was an actual observation and is not consistent with what was observed a few hours later. The intensity 
at $00 \mathrm{Z}, 06 \mathrm{Z}$ and $12 \mathrm{Z}$ on the $11^{\text {th }}$ is selected to be $40 \mathrm{kt}, 40 \mathrm{kt}$ and $45 \mathrm{kt}$, respectively (down from $55 \mathrm{kt}, 55 \mathrm{kt}$, and $60 \mathrm{kt}$, respectively, originally in HURDAT, a minor change). Minor track changes are introduced at $12 \mathrm{Z}$ and $18 \mathrm{Z}$ on the $11^{\text {th }}$ based on the center fixes made by the reconnaissance missions. The only ship to report tropical storm force winds was the S.S Atzacapotzalco early on the $12^{\text {th }}$ of September as it was moving away from the western coast of the Bay of Campeche. At $06 \mathrm{Z}$ on the $12^{\text {th }}$ it reported $30 \mathrm{kt}$ $\mathrm{NE}$ and $1003 \mathrm{mb}$. A peripheral pressure of $1003 \mathrm{mb}$ suggests winds greater than $41 \mathrm{kt}$ south of $25 \mathrm{~N}$ according to the pressure-wind relationship. If we assume that the ship was inside the RMW of Dora, this would suggest a central pressure of $1000 \mathrm{mb}$ (but not certain enough to add this value in to HURDAT). A central pressure of $1000 \mathrm{mb}$ yields maximum winds at or greater than $47 \mathrm{kt}$ south of $25 \mathrm{~N}$ according to the pressure-wind relationship. An intensity of $50 \mathrm{kt}$ is selected for $06 \mathrm{Z}$ on the $12^{\text {th }}$ based on this data and on the small size of the cyclone. HURDAT originally had $60 \mathrm{kt}$ at $06 \mathrm{Z}$, thus the reduction is a minor change. A central pressure of $1004 \mathrm{mb}$ is present at $00 \mathrm{Z}$ on the $12^{\text {th }}$ but there is no data to suggest that this is a measurement and it is not consistent with the ship measurements, so it has been removed. The intensity at $00 \mathrm{Z}$ on the $12^{\text {th }}$ is analyzed at 45 $\mathrm{kt}$, down from $60 \mathrm{kt}$ in the original HURDAT, a minor change. The final aircraft reconnaissance reached Dora at $1235 \mathrm{Z}$ on the $12^{\text {th }}$ measuring a central pressure of 1004 $\mathrm{mb}$, estimated surface winds of $50 \mathrm{kt}$, and reported a tiny eye diameter of $8 \mathrm{~nm}$. A central pressure of $1004 \mathrm{mb}$ suggests maximum sustained winds of $39 \mathrm{kt}$ south of $25 \mathrm{~N}$ according to the pressure-wind relationship. The eye diameter suggests an RMW of about $6 \mathrm{~nm}$ and climatology suggests about $16 \mathrm{~nm}$. Due to the small size of the storm, the intensity is kept at $50 \mathrm{kt}$ for $12 \mathrm{Z}$ on the $12^{\text {th }}$, down from $60 \mathrm{kt}$ originally in HURDAT. Dora moved generally west-southwest on the $12^{\text {th }}$ and the analyzed track on this day shows minor changes. Landfall occurred around $18 \mathrm{Z}$ on the $12^{\text {th }}$ around $5 \mathrm{~nm}$ south of Tuxpan, Mexico as a $50 \mathrm{kt}$ tropical storm, up from $30 \mathrm{kt}$ originally in HURDAT, a major change. A central pressure of $1002 \mathrm{mb}$ was in HURDAT at $18 \mathrm{Z}$ on the $12^{\text {th }}$ but Tuxpan at this time reported $10 \mathrm{kt} \mathrm{N}$ and $1002 \mathrm{mb}$, suggesting that the measurement was not in the center and that the central pressure of the cyclone was likely around $1000 \mathrm{mb}$. Therefore, a central pressure of $1000 \mathrm{mb}$ had been added at $18 \mathrm{Z}$ on the $12^{\text {th }}$ replacing the original $1002 \mathrm{mb}$ in HURDAT. Dora quickly lost organization over the mountainous terrain of Mexico but a circulation was still present at $00 \mathrm{Z}$ on the $13^{\text {th }}$ extending its lifetime six hours from original HURDAT. At this time it is analyzed that the system had weakened to a $25 \mathrm{kt}$ tropical depression. Dissipation occurred after $00 \mathrm{Z}$ on the $13^{\text {th }}$. 
Tropical Storm Ethel [September 11-14, 1956]

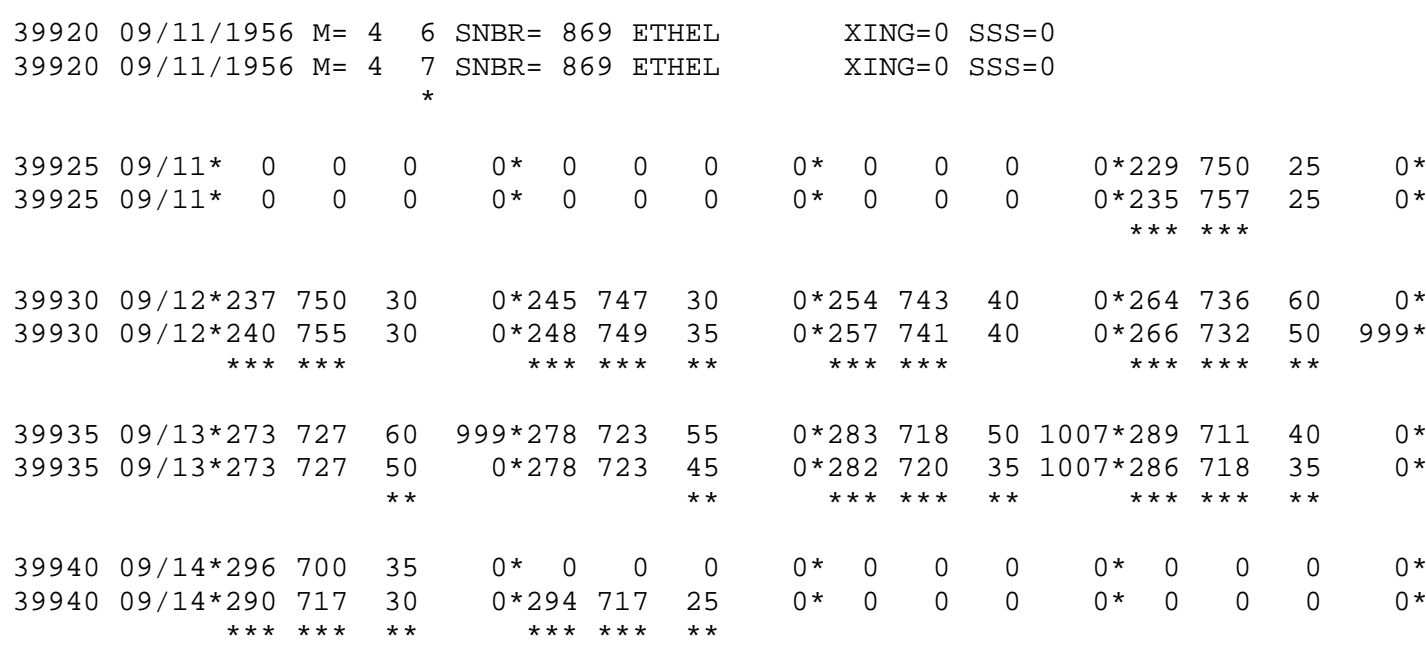

39945 TS

Minor track and intensity changes shown in McAdie et al. (2009). Evidence for these alterations comes from the NHC microfilm maps, the Historical Weather Maps series, the COADS ship database, Navy reconnaissance book and Monthly Weather Review.

September 10:

HWM analyzes a stationary cold front over the central Bahamas at $12 \mathrm{Z}$. HURDAT does not list an organized system on this date. Microfilm does not show an organized system on this date. Ship highlights: No gales or low pressures. "Tropical Storm Ethel is another storm pecular to the 1956 season in that its tropical characteristics were not clearly defined. In the frontal trough left in the wake of Carla, a very small and weak vortex or wave formation was noticed on the $10^{\text {th }}$ of September over the Bahamas. During the next two days the low moved northeasterly only slight to moderate intensification as indicated by the synoptic reports." (ATSR)

September 11:

HWM analyzes a weakening frontal boundary over the central Bahamas at $12 \mathrm{Z}$. HURDAT lists this as a 25 knot tropical depression at $22.9 \mathrm{~N}, 75.0 \mathrm{~W}$ at $18 \mathrm{Z}$ (first advisory). Microfilm shows a closed low pressure of at most $1011 \mathrm{mb}$ at $23.5 \mathrm{~N}, 77.0 \mathrm{~W}$ at 12Z. Ship highlights: No gales or low pressures. "At 1330 EST September 11, a weak circulation was noted over Great Exuma Island is the Bahamas, about 100 miles south of a quasi-stationary front." (MWR)

September 12: 
HWM analyzes a closed low pressure of at most $1010 \mathrm{mb}$ at $25.5 \mathrm{~N}, 74.0 \mathrm{~W}$ at 12Z. HURDAT lists this as a 40 knot tropical storm at $25.4 \mathrm{~N}, 74.3 \mathrm{~W}$ at $12 \mathrm{Z}$. Microfilm shows a closed low pressure of at most $1008 \mathrm{mb}$ at $25.5 \mathrm{~N}, 74.5 \mathrm{~W}$ at $12 \mathrm{Z}$. Ship highlights: $40 \mathrm{kt} \mathrm{NE}$ and $1001 \mathrm{mb}$ at $26.7 \mathrm{~N}, 73.3 \mathrm{~W}$ at $18 \mathrm{Z}$ (micro). Aircraft highlight: Penetration center fix estimated surface winds of $66 \mathrm{kt}$, central pressure of $999 \mathrm{mb}$, and an eye diameter of $20 \mathrm{~nm}$ at $27.2 \mathrm{~N}, 73.2 \mathrm{~W}$ at 2030Z (ATSR). "During the next 24 hours the tropical depression moved north-northeastward and gradually intensified. On the afternoon of the $12^{\text {th }}$, research aircraft reconnaissance entered the storm and found a welldeveloped eye about 20 miles in diameter and entirely surrounded by a typical wall could extending upward about 30,000 feet. A maximum wind of 66 knots was encountered while entering the eye over a distance of some 3 miles in the northeastern quadrant. Thirty-knot winds extended outward 30 to 100 miles in all directions but no hurricane winds were found in any other quadrant." (MWR) "Unlike Carla, Ethel was of extratropical origin but possibly gained and then lost her tropical characteristics on the $12^{\text {th }}$ of September. An Air Force Research reconnaissance aircraft departed West Palm Beach, Florida, on the $12^{\text {th }}$ of September to investigate the low which was then just north of the Bahamas. The aircraft reported locating an "eye" with a diameter of 20 miles, minimum surface pressure of $999 \mathrm{mb}$, and maximum winds of 66 knots in a squall band within three miles of the center (by post-analysis it is believed that this wind was measured at the flight level of the aircraft which was near $700 \mathrm{mb}$ ). The small and comparatively weak surface wind field reported by ship and island reports did not indicate that the storm had winds of much more than forty knots in squalls and no more than twenty-five knots of wind as a rule. The night reconnaissance reports received from the Navy reconnaissance aircraft indicated that Ethel was evidently rapidly filling and losing any possible tropical characteristics.” (ATSR)

September 13:

HWM analyzes a closed low pressure of at most $1010 \mathrm{mb}$ at $29.0 \mathrm{~N}, 70.0 \mathrm{~W}$ with a stationary cold front extending to the northeast at 12Z. HURDAT lists this as a $50 \mathrm{knot}$ tropical storm at $28.3 \mathrm{~N}, 71.8 \mathrm{~W}$ at $12 \mathrm{Z}$. Microfilm shows a closed low pressure of at most $1008 \mathrm{mb}$ at $28.2 \mathrm{~N}, 72.3 \mathrm{~W}$ at 12Z. Ship highlights: $35 \mathrm{kt} \mathrm{E}$ and $1008 \mathrm{mb}$ at $27.7 \mathrm{~N}, 73.4 \mathrm{~W}$ at $00 \mathrm{Z}$ (micro). $35 \mathrm{kt} \mathrm{NW}$ and $1007 \mathrm{mb}$ at $27.9 \mathrm{~N}, 72.4 \mathrm{~W}$ at $18 \mathrm{Z}$ (micro). Penetration center fix estimated surface winds of $40 \mathrm{kt}$, central pressure of $1007 \mathrm{mb}$, and an eye diameter of $30 \mathrm{~nm}$ at $28.5 \mathrm{~N}, 71.9 \mathrm{~W}$ at $1110 \mathrm{Z}$ (ATSR). Penetration center fix at $28.1 \mathrm{~N}$, $72.2 \mathrm{~W}$ at $1433 \mathrm{Z}$ (ATSR). "By late on the $13^{\text {th }}$, the storm had assumed extratropical characteristics and lost intensity. It is thought that the storm may have developed strongly for a short time as a new source of energy in the form of cold air entered the system. If the research plane had not flown into the storm on the $12^{\text {th }}$, no advisories would have been issued and it would not have been listed as a tropical storm." (MWR) "Based on the 
reports from the reconnaissance aircraft, Warning Number ONE was $130100 Z$ on Tropical Storm Ethel. After a $700 \mathrm{mb}$ level penetration of the center during the early morning of the $13^{\text {th }}$ of September, the Navy reconnaissance aircraft descended to 500 feet in the center and observed a minimum surface pressure of $1007 \mathrm{mb}$, a 30 mile diameter of the wind circulation and maximum surface winds of 40 knots. Warning Number THREE was the final warning issued on Ethel at 131000Z. All information available revealed that further weakening was taking place.” (ATSR)

September 14:

HWM analyzes a closed low pressure of at most $1015 \mathrm{mb}$ at $31.0 \mathrm{~N}, 70.0 \mathrm{~W}$ with a stationary cold front extending to the northeast at $12 \mathrm{Z}$. HURDAT lists this as a $35 \mathrm{knot}$ tropical storm at 29.6N, 70.0W at 00Z (last advisory). Microfilm shows a closed low pressure of at most $1014 \mathrm{mb}$ at $29.5 \mathrm{~N}, 72.0 \mathrm{~W}$ at $06 \mathrm{Z}$. Ship highlights: No gales or low pressures.

September 15:

HWM analyzes a trough over the northwest Bahamas extending northeast toward a weakening cold front, no organized system is depicted at 12Z. HURDAT do not list an organized system on this date. Microfilm shows a closed low pressure of $1014 \mathrm{mb}$ at $29.5 \mathrm{~N}, 72.8 \mathrm{~W}$ at $00 \mathrm{Z}$. Ship highlights: No gales or low pressures.

A frontal boundary moved off the eastern seaboard of the United States during the first week of September absorbing Tropical Storm Carla. The tail-end of the frontal system reached the Bahamas where a low pressure developed around September 11. A 25-kt tropical depression formed around $18 \mathrm{Z}$ on September 11, this is the time of genesis and in agreement with the original HURDAT. Minor track changes were introduced for the duration of this system with the most significant change made early on the 14th to westsouthwest near the end of the system's lifetime. The tropical depression started moving north-northeast to northeast while increasing in forward speed. Intensification to tropical storm is analyzed to have occurred at $06 \mathrm{Z}$ on the $12^{\text {th }}$, six hours earlier than originally shown in HURDAT. No gales were reported early on the $12^{\text {th }}$ but HURDAT shows an intensification from $30 \mathrm{kt}$ at $06 \mathrm{Z}$ to $40 \mathrm{kt}$ at $12 \mathrm{Z}$ on the $12^{\text {th }}$ and there is no data to support this rapid increase in intensity. Thus, the reanalysis shows a gradual increase in intensity. The first gale-force wind is reported at $18 \mathrm{Z}$ on the $12^{\text {th }} .40 \mathrm{kt}$ and $1001 \mathrm{mb}$ were reported by a ship located at $26.7 \mathrm{~N}, 73.3 \mathrm{~W}$. A peripheral central pressure of $1001 \mathrm{mb}$ suggests maximum sustained winds greater than $42 \mathrm{kt}$ south of $25 \mathrm{~N}$ from the Brown et al. pressure-wind relationship. Also, the first aircraft reconnaissance to reach the storm occurred at $2030 \mathrm{Z}$ on the $12^{\text {th }}$ measuring a central pressure of $999 \mathrm{mb}$, estimated surface winds of $66 \mathrm{kt}$ and a $20 \mathrm{~nm}$ eye diameter. A central pressure of $999 \mathrm{mb}$ suggests 
maximum sustained winds of $45 \mathrm{kt}$ south of $25 \mathrm{~N}$ according to the pressure-wind relationship. An eye diameter of $20 \mathrm{~nm}$ suggests an RMW of about $15 \mathrm{~nm}$ and climatology indicates $22 \mathrm{~nm}$. Due to the small size of Ethel and based on the data from the ship and reconnaissance aircraft, an intensity of $50 \mathrm{kt}$ is selected for $18 \mathrm{Z}$ on the $12^{\text {th }}$, down from $60 \mathrm{kt}$ originally in HURDAT. A central pressure of $999 \mathrm{mb}$ was present in HURDAT at $00 \mathrm{Z}$ on the $13^{\text {th }}$ and has been moved to $18 \mathrm{Z}$ on the $12^{\text {th }}$ in agreement with the reconnaissance report. An intensity of $50 \mathrm{kt}$ is also analyzed at $00 \mathrm{Z}$ on the $13^{\text {th }}$, down from $60 \mathrm{kt}$ originally in HURDAT. $50 \mathrm{kt}$ is analyzed as the peak intensity for the lifetime of Tropical Storm Ethel, down from $60 \mathrm{kt}$ originally in HURDAT.

On September $13^{\text {th }}$, Ethel began to weaken while moving at a slower speed. A reconnaissance aircraft reached the storm at $1110 \mathrm{Z}$ on the $13^{\text {th }}$ measuring a central pressure of only $1007 \mathrm{mb}$, estimated surface winds of $40 \mathrm{kt}$ and a $30 \mathrm{~nm}$ diameter of the wind circulation ( 15 nm RMW). A central pressure of $1007 \mathrm{mb}$ suggests $30 \mathrm{kt}$ north of $25 \mathrm{~N}$ according to the pressure-wind relationship. An intensity of $35 \mathrm{kt}$ is selected for $12 \mathrm{Z}$ on the $14^{\text {th }}$, down from $50 \mathrm{kt}$ originally in HURDAT. The last gale was reported at $18 \mathrm{Z}$ on the $14^{\text {th }}$. Ethel is analyzed to have weakened to a tropical depression at $00 \mathrm{Z}$ on the $14^{\text {th }}$. HURDAT originally does not show Ethel weakening to a tropical depression and the intensity is $35 \mathrm{kt}$ in the last position at $00 \mathrm{Z}$ on the $14^{\text {th }}$. The system continued to lose intensity on the $14^{\text {th }}$ and weakened to a trough of low pressure after 06Z. Dissipation is six hours later than originally shown in HURDAT. The trough of low pressure continued over the western Atlantic for another 48 hours, finally dissipating on September 16. HWM and microfilm depict a weakening frontal boundary on these days but there is no temperature gradient to suggest that a frontal system was present. Furthermore, there is no indication that the system redeveloped.

Hurricane Flossy [September 20 - October 3, 1956]

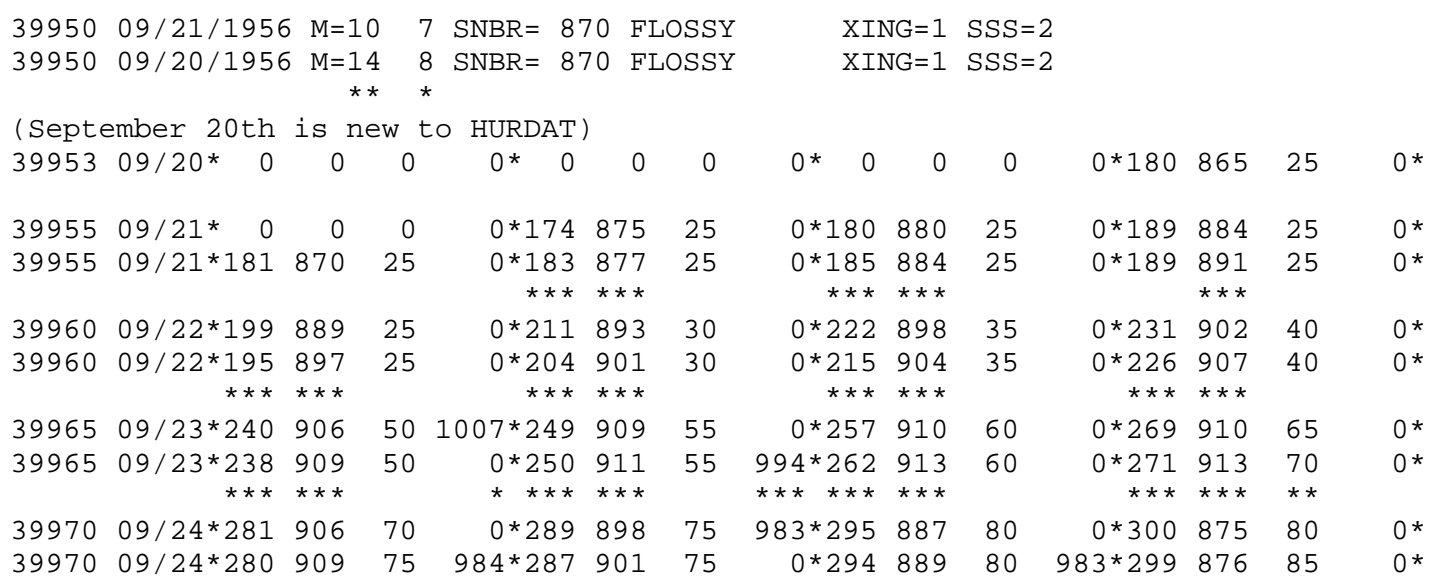




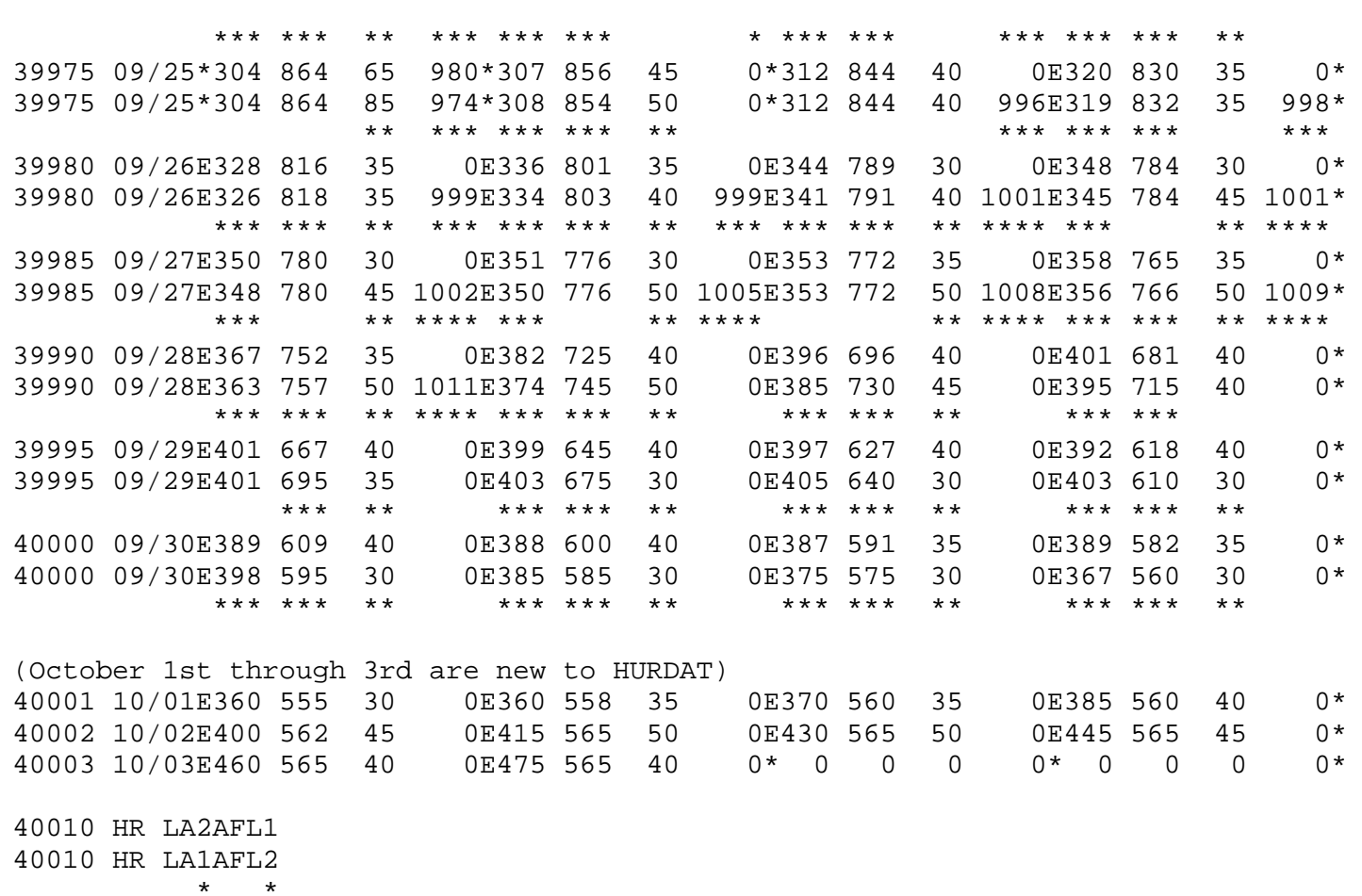

U.S. Hurricane:

Sep $24^{\text {th }}-10 \mathrm{Z}-29.1 \mathrm{~N} 89.4 \mathrm{~W}-80 \mathrm{kt}-$ Category $1-983 \mathrm{mb}-1010 \mathrm{mb}$ OCI $-300 \mathrm{~nm}$ ROCI

Sep $25^{\text {th }}-00 \mathrm{Z}-30.4 \mathrm{~N} 86.4 \mathrm{~W}-85 \mathrm{kt}-$ Category $2-974 \mathrm{mb}-1010 \mathrm{mb}$ OCI $-300 \mathrm{~nm}$ ROCI

Major track and intensity changes shown in McAdie et al. (2009). Also, a major alteration is to add four additional days to the cyclone's lifetime. Evidence for these alterations comes from the NHC microfilm maps, the Historical Weather Maps series, the COADS ship database, Navy reconnaissance book, Connor (1956), Surface Weather Observations, Monthly Weather Review, Mexican synoptic maps, Schwardt et al. (1979), Ho et al. (1987), and Jarrell et al. (1992).

September 20:

HWM analyzes a trough or tropical wave extending from South Florida to Swan Island along longitude $84 \mathrm{~W}$ to a spot low at $15.8 \mathrm{~N}, 84.8 \mathrm{~W}$ at $12 \mathrm{Z}$. HURDAT does not list an organized system on this date. Microfilm shows a closed low pressure of at most 1008 $\mathrm{mb}$ at $18.0 \mathrm{~N}, 86.0 \mathrm{~W}$ at $18 \mathrm{Z}$. Ship highlights: No gales or low pressures. MWR: "The origin of this hurricane - the only one to reach the coast of the United States in 1956 - is the rather obscure. Hurricane squalls were reported in the Pacific south of Guatemala on the $20^{\text {th }}$, and the initial impulse may have moved northward from there or from the 
Caribbean." ATSR: "During the period 18-20 September the ITC was oriented across the Yucatan Peninsula-Lower Mexico area with several small active vortices in evidence. By $1830 \mathrm{Z}$ on the $20^{\text {th }}$, a closed vortex began to break away from the ITC over the Yucatan Peninsula, which was the beginning of subsequent Hurricane Flossy."

September 21:

HWM analyzes a trough or tropical wave extending from Central Florida to the north of the Yucatan Peninsula to a spot low at 20.5N, 88.5W at 12Z. HURDAT lists this as a $25 \mathrm{knot}$ tropical depression at $18.0 \mathrm{~N}, 88.0 \mathrm{~W}$ at $12 \mathrm{Z}$. Microfilm shows a spot low pressure over the Yucatan Peninsula at 18.5N, 89.0W at 12Z. Ship highlights: No gales or low pressures. MWR: "The first well-developed circulation was noted over the Yucatan Peninsula at 1330 EST on the $21^{\text {st }}$, passing into the Gulf of Mexico near Merida."

September 22:

HWM analyzes a tropical storm of at most $1005 \mathrm{mb}$ at $23.0 \mathrm{~N}, 88.8 \mathrm{~W}$ at $12 \mathrm{Z}$. HURDAT lists this as a $35 \mathrm{knot}$ tropical storm at $22.2 \mathrm{~N}, 89.8 \mathrm{~W}$ at $12 \mathrm{Z}$. Microfilm shows a closed low pressure of at most $1005 \mathrm{mb}$ at $22.0 \mathrm{~N}, 90.0 \mathrm{~W}$ at 12Z. Ship highlights: $40 \mathrm{kt}$ ESE and $1009 \mathrm{mb}$ at $24.8 \mathrm{~N}, 89.5 \mathrm{~W}$ at $18 \mathrm{Z}$ (COADS). $45 \mathrm{kt}$ SE and $1011 \mathrm{mb}$ at $23.0 \mathrm{~N}$, $87.0 \mathrm{~W}$ at $21 \mathrm{Z}$ (COADS). Land highlights: $1004 \mathrm{mb}$ at Campeche, Mexico at 00Z (micro). MWR: "According to the report of the hurricane forecast center at New Orleans, the circulation intensified gradually while moving northward over the Gulf and reached storm intensity on the afternoon of the $22^{\text {nd }}$. After this time the size of the storm increased considerably but the pressure gradient around the center intensified only slowly." ATSR: "The vortex moved across the Yucatan Peninsula in a northwesterly direction at about 8 knots during the period from 1830z, 20 September, to 1000z, 22 September. During this time, winds from reporting stations on the peninsula were gradually increasing from 10 knots to 30 knots. A low-level reconnaissance flight was ordered for 22 September. The flight estimated the center of circulation at $23.8 \mathrm{~N} 90.9 \mathrm{~W}$ at $2300 \mathrm{Z}$ [table lists $0000 \mathrm{Z}$ on $23^{\text {rd }}$ ] on 22 September, with maximum winds of 45 knots in the northeast quadrant and a minimum observed surface pressure of 1007 mbs. Coordination was established with the Weather Bureau, New Orleans, and Warning Number ONE on Tropical Storm Flossy was issued at $2300 \mathrm{Z}$ on 22 September. After departing the land area near Merida at $0600 \mathrm{Z}$ on the $22^{\text {nd }}$, Flossy moved almost straight north at 12 knots for the next 24-hour period. Flossy was held on the northerly course during that time due to intensification of the subtropical high over the East Gulf of Mexico and Florida."

September 23:

HWM analyzes a tropical storm of at most $1000 \mathrm{mb}$ at $27.2 \mathrm{~N}, 91.0 \mathrm{~W}$ with a stationary cold front extending to the northeast at 12Z. HURDAT lists this as a 60 knot 
tropical storm at $25.7 \mathrm{~N}, 91.0 \mathrm{~W}$ at $12 \mathrm{Z}$. Microfilm shows a closed low pressure of at most $999 \mathrm{mb}$ at $27.2 \mathrm{~N}, 90.6 \mathrm{~W}$ at 12Z. Ship highlights: $45 \mathrm{kt} \mathrm{SE}$ and $1011 \mathrm{mb}$ at $23.0 \mathrm{~N}, 88.0 \mathrm{~W}$ at $00 \mathrm{Z}$ (COADS). $35 \mathrm{kt} \mathrm{ESE}$ and $1006 \mathrm{mb}$ at $26.0 \mathrm{~N}, 88.5 \mathrm{~W}$ at $06 \mathrm{Z}$ (COADS). $65 \mathrm{kt} \mathrm{SSW}$ and $1007 \mathrm{mb}$ at $25.9 \mathrm{~N}, 89.2 \mathrm{~W}$ at $12 \mathrm{Z}$ (micro). $65 \mathrm{kt} \mathrm{S}$ and $1006 \mathrm{mb}$ at $25.7 \mathrm{~N}, 89.0 \mathrm{~W}$ at $15 \mathrm{Z}$ (micro). $60 \mathrm{kt} \mathrm{SSW}$ and $1004 \mathrm{mb}$ at 28.4N, 91.2W at 18Z (COADS). Land highlights: $35 \mathrm{kt} \mathrm{SE}$ and $1011 \mathrm{mb}$ at Grand Isle, LA at 09Z (micro). Aircraft highlights: Penetration center fix estimated maximum surface winds of $45 \mathrm{kt}$ at $23.8 \mathrm{~N}, 90.9 \mathrm{~W}$ at $00 \mathrm{Z}$ (ATSR). Penetration center fix at 26.0N, 90.9W at 1830Z (ATSR). Penetration center fix measured a central pressure of $984 \mathrm{mb}$, maximum surface winds of $45 \mathrm{kt}$ and an eye diameter of $10 \mathrm{~nm}$ at $27.4 \mathrm{~N}, 91.2 \mathrm{~W}$ at $2105 \mathrm{Z}$ (ATSR). MWR: "The tropical storm reached hurricane force near or somewhat before noon on the $23^{\text {rd }}$ when the center was about 125 miles off the southeastern Louisiana coast." ATSR: "Flossy first attained winds of hurricane force during the $23^{\text {rd }}$."

September 24:

HWM analyzes a closed low pressure of at most $985 \mathrm{mb}$ at $28.5 \mathrm{~N}, 89.1 \mathrm{~W}$ at $12 \mathrm{Z}$. HURDAT lists this as an 80 knot hurricane at $29.5 \mathrm{~N}, 88.7 \mathrm{~W}$ at $12 \mathrm{Z}$. Microfilm shows a closed low pressure of at most $981 \mathrm{mb}$ at $29.0 \mathrm{~N}, 88.9 \mathrm{~W}$ at $12 \mathrm{Z}$. Ship highlights: $45 \mathrm{kt} \mathrm{S}$ and $1001 \mathrm{mb}$ at $27.6 \mathrm{~N}, 89.0 \mathrm{~W}$ at $00 \mathrm{Z}$ (COADS). $50 \mathrm{kt} \mathrm{N}$ and $1001 \mathrm{mb}$ at $28.6 \mathrm{~N}, 91.5 \mathrm{~W}$ at $06 \mathrm{Z}$ (micro). $65 \mathrm{kt} \mathrm{SSW}$ and $984 \mathrm{mb}$ at $28.1 \mathrm{~N}, 89.0 \mathrm{~W}$ at $12 \mathrm{Z}$ (COADS). $60 \mathrm{kt} \mathrm{SSE}$ and $982 \mathrm{mb}$ at $29.5 \mathrm{~N}, 87.2 \mathrm{~W}$ at $00 \mathrm{Z}$ (micro). Land highlights: $72 \mathrm{kt}$, gusts to $82 \mathrm{kt}$ at an Oil Rig at 29.1N, 90.5W at 0505Z (CONNOR/MWR). $80 \mathrm{kt} \mathrm{NW}$, gusts to $85 \mathrm{kt}, 989 \mathrm{mb}$ at Grande Isle, LA at 09Z-10Z (CONNOR). $983 \mathrm{mb}$ at Burrwood, LA at $1010 \mathrm{Z}$ (CONNOR). $983 \mathrm{mb}$ at Venice, LA (calm between 0950Z-1155Z) (CONNOR). $73 \mathrm{kt} \mathrm{N}$ or NW at Burrwood, LA at 1228Z (CONNOR). $980 \mathrm{mb}$ at Pensacola, FL at 2023Z (CONNOR). $50 \mathrm{kt} \mathrm{NE}$, gusts to $68 \mathrm{kt}$ at Pensacola, FL at 2235Z (CONNOR). Aircraft highlights: Penetration center fix at $30.2 \mathrm{~N}, 87.1 \mathrm{~W}$ at $2142 \mathrm{Z}$ (ATSR). Penetration center fix measured a central pressure of $974 \mathrm{mb}$, maximum surface winds of $80 \mathrm{kt}$ and an eye diameter of $30 \mathrm{~nm}$ at $30.3 \mathrm{~N}, 86.9 \mathrm{~W}$ at $2230 \mathrm{Z}$ (ATSR). Penetration center fix at $30.4 \mathrm{~N}$, 86.3W at 2330Z (ATSR). "29.2N, 89.6W - $974 \mathrm{mb}-1013 \mathrm{mb}$ Penv - RMW $22 \mathrm{nmi}-$ speed $10 \mathrm{kt}-70 \mathrm{kt}$ est max sustained 10m, 10-min wind" (Schwardt et al. (1979)).(973.9 $\mathrm{mb}$ ) central pressure measured by land barometer at Destin, FL and RECON - RMW 18 nmi - 10 kt forward speed - landfall pt 30.4N, 86.4W" (Ho et al. (1987). "Sep - LA2, FL1 - Cat 2 - 975 mb" (Jarrell et al. (1992). MWR: "During the afternoon the hurricane turned rather sharply toward the east-northeast, crossing the Mississippi delta a little north Burrwood near Pilottown early on the $24^{\text {th }}$. Here it seems to have reached maximum intensity with the highest wind at Burrwood 84 m.p.h and lowest pressure 29.03 inches. An oil rig a little west of Grande Isle reported a maximum wind of 83 m.p.h and gust to 95. The center passed a little south of Pensacola, Florida, during the afternoon 
and later about over Fort Walton. The storm became extra-tropical shortly after the center passed out of Florida but it moved northeastward inside the coastlines as an energetic storm until it passed out to sea near the Virginia Capes. As far as known, no hurricane winds were reported at any Florida point although winds were near hurricane force eastward along the coast to Panama City. The lowest pressure reported during the storm was 28.93 inches at the Pensacola Naval Air Station. The highest storm tide was 7.4 feet m.s.l at Laguna Beach, Florida. Some higher values were reported along the eastern side of the Mississippi delta but have not been verified. Tides flooded portions of Norfolk, Va., and water stood 2.5 feet deep in several of the principal street. Beach erosion occurred as far north as Delaware. The heaviest rainfall reported was 16.70 inches at Golden Meadow, La., and 16.30 inches at Gulf Shore, Ala. The rainfall intensity decreased gradually as the storm moved northeastward but 1 to 3 inches fell as far north as Virginia. Three tornados were reported in advance of the storm in northeastern Florida and another at Hilton Head Island near Savannah, Ga., but each caused only minor damage. Total damage in the States of Louisiana, Florida, Alabama, and Mississippi was $424,774,000$ of which 415,204,00 was to crops. Damage in other States such as Georgia, the Carolinas, and Virginia was $\$ 100,000$ or less and was greatly outweighed by the beneficial rains which relieved drought conditions. Deaths, mainly from plane and automobile accidents attributed to the storm, totaled 15. Warnings throughout the storm were timely and accurate." ATSR: "Flossy entered the Mississippi Delta 10 miles north of Burwood, Louisiana, at $1100 \mathrm{Z}$ on the $24^{\text {th }}$ and continued on the northeast course until passing into the Atlantic at Elizabeth City, North Carolina, on the $27^{\text {th }}$." "... and continued increasing to a maximum of 105 knots while passing south of Mobile, Alabama, on the $24^{\text {th }}$. No sustained winds greater than 40 knots existed after Flossy passed Dothan, Alabama."

September 25:

HWM analyzes a tropical storm of at most $1005 \mathrm{mb}$ at $31.5 \mathrm{~N}, 84.1 \mathrm{~W}$ at $12 \mathrm{Z}$. HURDAT lists this as a 40 knot tropical storm at $31.2 \mathrm{~N}, 84.4 \mathrm{~W}$ at $12 \mathrm{Z}$. Microfilm shows a closed low pressure of at most $999 \mathrm{mb}$ at $31.0 \mathrm{~N}, 84.5 \mathrm{~W}$ at 12Z. Ship highlights: $40 \mathrm{kt}$ SW and $1006 \mathrm{mb}$ at $27.9 \mathrm{~N}, 85.2 \mathrm{~W}$ at $00 \mathrm{Z}$ (micro). $35 \mathrm{kt} \mathrm{WSW}$ and $1006 \mathrm{mb}$ at $27.2 \mathrm{~N}$, $85.4 \mathrm{~W}$ at $06 \mathrm{Z}$ (COADS). $35 \mathrm{kt} \mathrm{W}$ and $1006 \mathrm{mb}$ at $27.9 \mathrm{~N}, 86.0 \mathrm{~W}$ at $12 \mathrm{Z}$ (COADS). $35 \mathrm{kt}$ $\mathrm{S}$ and $1000 \mathrm{mb}$ at $29.9 \mathrm{~N}, 80.7 \mathrm{~W}$ at $18 \mathrm{Z}$ (COADS). Land highlights: $50 \mathrm{kt} \mathrm{NNE}$ at Crestview, FL at 00Z (SWO). $15 \mathrm{kt} \mathrm{N}$ and $982 \mathrm{mb}$ at Fort Walton Beach, FL at 00Z (micro). $20 \mathrm{kt} \mathrm{SW}$ and $995 \mathrm{mb}$ at Marianna, FL at 06Z (micro). $30 \mathrm{kt} \mathrm{NE}$ and $1001 \mathrm{mb}$ at Montgomery, AL at 0728Z (SWO). $10 \mathrm{kt} \mathrm{SE}$ and $998 \mathrm{mb}$ at Albany, GA at 12Z (micro). $10 \mathrm{kt} \mathrm{NW}$ and $998 \mathrm{mb}$ at Albany, GA at 18Z (micro). ATSR: "Definite extra-tropical characteristics were evident by $1830 \mathrm{Z}$ on the $25^{\text {th }}$. Numbered warnings were continued 
only due to the Weather Bureau's request. Such advisories were requested because of expected torrential rains in the South Atlantic coastal states."

September 26:

HWM analyzes a tropical storm of at most $1005 \mathrm{mb}$ at $34.0 \mathrm{~N}, 79.3 \mathrm{~W}$ with a trough extending to the south and a warm front to the northeast at 12Z. HURDAT lists this as a 30 knot extratropical cyclone at $34.4 \mathrm{~N}, 78.9 \mathrm{~W}$ at $12 \mathrm{Z}$. Microfilm shows a closed low pressure of at most $1002 \mathrm{mb}$ at $34.1 \mathrm{~N}, 78.8 \mathrm{~W}$ with a warm front to the east and a cold front to the south at 12Z. Ship highlights: $35 \mathrm{kt} \mathrm{S}$ and $1003 \mathrm{mb}$ at $32.2 \mathrm{~N}, 79.1 \mathrm{~W}$ at $00 \mathrm{Z}$ (COADS). $40 \mathrm{kt} \mathrm{SE}$ and $1004 \mathrm{mb}$ at $34.2 \mathrm{~N}, 75.8 \mathrm{~W}$ at $06 \mathrm{Z}$ (COADS). $35 \mathrm{kt} \mathrm{SW}$ and $1004 \mathrm{mb}$ at $31.5 \mathrm{~N}, 79.3 \mathrm{~W}$ at $12 \mathrm{Z}$ (COADS). $45 \mathrm{kt} \mathrm{ENE}$ and $1010 \mathrm{mb}$ at $36.2 \mathrm{~N}, 72.3 \mathrm{~W}$ at $18 \mathrm{Z}$ (COADS). Land highlights: $10 \mathrm{kt} \mathrm{SW}$ and $1001 \mathrm{mb}$ at Savannah, GA at 00Z (micro). $10 \mathrm{kt} \mathrm{SSE}$ and $1001 \mathrm{mb}$ at Edisto Beach, SC at 06Z (micro). $40 \mathrm{kt} \mathrm{ENE}$ and $1011 \mathrm{mb}$ at Diamond Shoals, NC at $12 \mathrm{Z}$ (micro). $37 \mathrm{kt} \mathrm{E}$ at Atlantic City, NJ at 18Z (SWO). ATSR: "Commencing with Warning Number FIFTEEN at 0400Z on 26 September all warnings were issued at Storm Flossy, since no evidence of a tropical nature existed within the storm."

September 27:

HWM analyzes a closed low pressure of at most $1010 \mathrm{mb}$ at $35.5 \mathrm{~N}, 76.5 \mathrm{~W}$ with a cold front extending to the south and a warm front to the northeast at 12Z. HURDAT lists this as a 35 knot extratropical cyclone at $35.3 \mathrm{~N}, 77.2 \mathrm{~W}$ at $12 \mathrm{Z}$. Microfilm shows a closed low pressure of at most $1008 \mathrm{mb}$ at $36.0 \mathrm{~N}, 76.2 \mathrm{~W}$ with a warm front to the east and a cold front to the south at 12Z. Ship highlights: $35 \mathrm{kt} \mathrm{ENE}$ and $1007 \mathrm{mb}$ at $35.6 \mathrm{~N}, 74.9 \mathrm{~W}$ at $00 \mathrm{Z}$ (COADS). $50 \mathrm{kt} \mathrm{NE}$ and $1016 \mathrm{mb}$ at $37.9 \mathrm{~N}, 70.7 \mathrm{~W}$ at $06 \mathrm{Z}$ (COADS). $50 \mathrm{kt} \mathrm{NE}$ and $1016 \mathrm{mb}$ at $38.2 \mathrm{~N}, 70.3 \mathrm{~W}$ at $12 \mathrm{Z}$ (COADS). $45 \mathrm{kt} \mathrm{E}$ and $1016 \mathrm{mb}$ at $38.1 \mathrm{~N}, 69.9 \mathrm{~W}$ at $18 Z$ (COADS). Land highlights: $40 \mathrm{kt} \mathrm{NE}$ and $1017 \mathrm{mb}$ at Ocean City, NJ at 00Z (SWO). $45 \mathrm{kt} \mathrm{NE}$ and $1018 \mathrm{mb}$ at Ocean City, NJ at 00Z (SWO). $42 \mathrm{kt}$ E at Atlantic City, NJ at $12 \mathrm{Z}$ (SWO). $47 \mathrm{kt} \mathrm{E}$, gusts to $60 \mathrm{kt}$ at Atlantic City, NJ at 18Z (SWO). ATSR: "The final warning was issued at 1600Z, 27 September. Minor damage to small craft and coastal installations in the Mississippi Delta and Gulf Coast from New Orleans to Apalachicola was reported. Minor damage from heavy rains was also reported in the Carolinas and Georgia."

September 28:

HWM analyzes a closed low pressure of at most $1015 \mathrm{mb}$ at $38.5 \mathrm{~N}, 73.5 \mathrm{~W}$ with a cold front extending to the south and a warm front to the northeast at 12Z. HURDAT lists this as a 40 knot extratropical cyclone at $39.6 \mathrm{~N}, 69.6 \mathrm{~W}$ at $12 \mathrm{Z}$. Microfilm shows a closed low pressure of at most $1014 \mathrm{mb}$ at $40.0 \mathrm{~N}, 69.5 \mathrm{~W}$ with a warm front to the east and a 
cold front to the south at 12Z. Ship highlights: $45 \mathrm{kt} \mathrm{NE}$ and $1021 \mathrm{mb}$ at $40.5 \mathrm{~N}, 71.0 \mathrm{~W}$ at $00 \mathrm{Z}$ (COADS). $60 \mathrm{kt} \mathrm{E}$ and $1020 \mathrm{mb}$ at $40.2 \mathrm{~N}, 72.1 \mathrm{~W}$ at $06 \mathrm{Z}$ (COADS). Land highlights: $36 \mathrm{kt} \mathrm{E}$ at Atlantic City, NJ at 00Z (SWO).

September 29:

HWM analyzes a closed low pressure of at most $1015 \mathrm{mb}$ at $40.0 \mathrm{~N}, 60.0 \mathrm{~W}$ with a stationary front extending through the system and to the southeast and a cold front to the south at 12Z. HURDAT lists this as a 40 knot extratropical cyclone at $39.7 \mathrm{~N}, 62.7 \mathrm{~W}$ at 12Z. Microfilm shows a closed low pressure of at most $1014 \mathrm{mb}$ at $40.0 \mathrm{~N}, 63.0 \mathrm{~W}$ with a warm front to the east and a cold front to the southwest at 12Z. Ship highlights: No gales or low pressures.

September 30:

HWM analyzes a closed low pressure of at most $1015 \mathrm{mb}$ at $37.0 \mathrm{~N}, 58.0 \mathrm{~W}$ with a weakening cold front to the west and south, and a warm front to the southeast at $12 \mathrm{Z}$. HURDAT lists this as a $35 \mathrm{knot}$ extratropical cyclone at $38.7 \mathrm{~N}, 59.1 \mathrm{~W}$ at $12 \mathrm{Z}$. Microfilm shows a closed low pressure of at most $1014 \mathrm{mb}$ at $37.5 \mathrm{~N}, 58.8 \mathrm{~W}$ with a warm front to the east and a cold front to the southwest at 12Z. Ship highlights: No gales or low pressures.

October 1:

HWM analyzes a closed low pressure of at most $1005 \mathrm{mb}$ at $37.5 \mathrm{~N}, 55.5 \mathrm{~W}$ with a warm front to the northeast at 12Z. HURDAT does not list an organized cyclone on this date (last position at $18 \mathrm{Z}$ on the $30^{\text {th }}$ ). Microfilm shows a closed low pressure of at most $1008 \mathrm{mb}$ at $36.5 \mathrm{~N}, 57.5 \mathrm{~W}$ at $12 \mathrm{Z}$. Ship highlights: $35 \mathrm{kt}$ ENE and $1010 \mathrm{mb}$ at $40.0 \mathrm{~N}$, $55.0 \mathrm{~W}$ at $08 \mathrm{Z}$ (COADS). $35 \mathrm{kt} \mathrm{E}$ and $1010 \mathrm{mb}$ at $40.0 \mathrm{~N}, 54.0 \mathrm{~W}$ at $12 \mathrm{Z}$ (COADS). $35 \mathrm{kt}$ $\mathrm{E}$ and $1010 \mathrm{mb}$ at $40.0 \mathrm{~N}, 53.0 \mathrm{~W}$ at $16 \mathrm{Z}$ (COADS). $35 \mathrm{kt} \mathrm{E}$ and $1002 \mathrm{mb}$ at $39.5 \mathrm{~N}, 55.9 \mathrm{~W}$ at $18 \mathrm{Z}(\mathrm{COADS})$.

October 2:

HWM analyzes a closed low pressure of at most $1000 \mathrm{mb}$ at $43.0 \mathrm{~N}, 57.0 \mathrm{~W}$ with a warm front to the northeast and a cold front to the southeast at 12Z. HURDAT does not list an organized cyclone on this date. Microfilm shows a closed low pressure of at most $1002 \mathrm{mb}$ at $42.0 \mathrm{~N}, 56.2 \mathrm{~W}$ with a warm front to the southeast and a cold front to the south at 12Z. Ship highlights: $45 \mathrm{kt} \mathrm{SE}$ and $1007 \mathrm{mb}$ at $40.5 \mathrm{~N}, 52.8 \mathrm{~W}$ at $00 \mathrm{Z}$ (COADS). $45 \mathrm{kt}$ $\mathrm{SE}$ and $997 \mathrm{mb}$ at $42.2 \mathrm{~N}, 54.4 \mathrm{~W}$ at $06 \mathrm{Z}$ (COADS). $45 \mathrm{kt} \mathrm{E}$ and $1000 \mathrm{mb}$ at $44.7 \mathrm{~N}, 52.5 \mathrm{~W}$ at $12 \mathrm{Z}$ (COADS). $40 \mathrm{kt} \mathrm{E}$ and $997 \mathrm{mb}$ at $46.2 \mathrm{~N}, 56.6 \mathrm{~W}$ at $18 \mathrm{Z}$ (COADS). 
October 3:

HWM analyzes a closed low pressure of at most $1000 \mathrm{mb}$ at $49.0 \mathrm{~N}, 58.0 \mathrm{~W}$ with a stationary front to the east and southeast at 12Z. HURDAT does not list an organized cyclone on this date. Microfilm shows a closed low pressure of at most $999 \mathrm{mb}$ at $49.5 \mathrm{~N}$, $64.5 \mathrm{~W}$ with a cold front to the south at 12Z. Ship highlights: $20 \mathrm{kt} \mathrm{SSW}$ and $1001 \mathrm{mb}$ at $40.6 \mathrm{~N}, 57.6 \mathrm{~W}$ at $00 \mathrm{Z}$ (COADS). $15 \mathrm{kt} \mathrm{SW}$ and $1000 \mathrm{mb}$ at $41.5 \mathrm{~N}, 54.0 \mathrm{~W}$ at $06 \mathrm{Z}$ (COADS). $15 \mathrm{kt} \mathrm{S}$ and $1001 \mathrm{mb}$ at $44.5 \mathrm{~N}, 51.4 \mathrm{~W}$ at $12 \mathrm{Z}$ (COADS). $30 \mathrm{kt} \mathrm{SSE}$ and 1000 $\mathrm{mb}$ at $49.6 \mathrm{~N}, 47.2 \mathrm{~W}$ at $18 \mathrm{Z}$ (micro). Land highlights: $10 \mathrm{kt} \mathrm{SW}$ and $997 \mathrm{mb}$ at St. Pierre and Miquelon at 06Z (micro). $20 \mathrm{kt} \mathrm{SSW}$ and $994 \mathrm{mb}$ at CFB Gander, Canada at $18 \mathrm{Z}$ (micro).

October 4:

HWM analyzes a closed low pressure of at most $990 \mathrm{mb}$ at $55.5 \mathrm{~N}, 54.0 \mathrm{~W}$ with a stationary front to the east and southeast, and another closed low pressure of at most 990 $\mathrm{mb}$ at $50.0 \mathrm{~N}, 48.0 \mathrm{~W}$ with a stationary front to the south at $12 \mathrm{Z}$. HURDAT does not list an organized cyclone on this date. Microfilm shows a closed low pressure of at most $990 \mathrm{mb}$ at $56.5 \mathrm{~N}, 53.0 \mathrm{~W}$ with a warm front to the southeast and a cold front to the south at $12 \mathrm{Z}$. Ship highlights: $30 \mathrm{kt} \mathrm{SSE}$ and $1003 \mathrm{mb}$ at 53.3N, 43.7W at 00Z (COADS). $20 \mathrm{kt} \mathrm{SSW}$ and $1001 \mathrm{mb}$ at $40.6 \mathrm{~N}, 57.6 \mathrm{~W}$ at $00 \mathrm{Z}$ (COADS). $30 \mathrm{kt} \mathrm{SSW}$ and $993 \mathrm{mb}$ at $53.0 \mathrm{~N}, 47.0 \mathrm{~W}$ at $06 \mathrm{Z}$ (COADS). $10 \mathrm{kt} \mathrm{SW}$ and $989 \mathrm{mb}$ at $54.5 \mathrm{~N}, 55.0 \mathrm{~W}$ at $12 \mathrm{Z}$ (COADS). $15 \mathrm{kt} \mathrm{SW}$ and $991 \mathrm{mb}$ at $56.5 \mathrm{~N}, 51.0 \mathrm{~W}$ at $18 \mathrm{Z}$ (COADS).

October 5:

HWM analyzes a closed low pressure of at most $985 \mathrm{mb}$ at $57.0 \mathrm{~N}, 47.0 \mathrm{~W}$ with a stationary front to the southeast and a dissipating front to the north at $12 \mathrm{Z}$. HURDAT does not list an organized cyclone on this date. Microfilm shows a closed low pressure of at most $993 \mathrm{mb}$ at $57.5 \mathrm{~N}, 50.0 \mathrm{~W}$ with a cold front to the southeast at 06Z. Ship highlights: $35 \mathrm{kt} \mathrm{NW}$ and $998 \mathrm{mb}$ at $53.0 \mathrm{~N}, 51.1 \mathrm{~W}$ at $00 \mathrm{Z}$ (COADS). $15 \mathrm{kt} \mathrm{NNW}$ and $993 \mathrm{mb}$ at $56.5 \mathrm{~N}, 51.0 \mathrm{~W}$ at $06 \mathrm{Z}$ (COADS). $35 \mathrm{kt} \mathrm{W}$ and $998 \mathrm{mb}$ at $53.5 \mathrm{~N}, 48.6 \mathrm{~W}$ at $12 \mathrm{Z}$ (COADS). $40 \mathrm{kt} \mathrm{NNE}$ and $994 \mathrm{mb}$ at 59.5N, 43.2W at 18Z (micro). Land highlights: 45 kt $\mathrm{NE}$ and $1001 \mathrm{mb}$ at Aluk Island, Greenland at 12Z (micro).

October 6:

HWM analyzes a closed low pressure of at most $985 \mathrm{mb}$ at $71.5 \mathrm{~N}, 62.0 \mathrm{~W}$ at $12 \mathrm{Z}$. HURDAT does not list an organized cyclone on this date. Microfilm is not available on this date. Ship highlights: No gales or low pressures. 
The only hurricane to hit the United States during the 1956 Atlantic Hurricane Season started as a tropical wave that entered the Caribbean Sea during the third week of September. The disturbance became better organized over the western Caribbean Sea and a $25 \mathrm{kt}$ tropical depression is analyzed to have formed at $18 \mathrm{Z}$ on September $20^{\text {th }}$, twelve hours earlier than originally shown in HURDAT, based on data from ships and land stations. Minor track changes are introduced between September $20^{\text {th }}$ and $27^{\text {th }}$; and major track changes are introduced between September $28^{\text {th }}$ and $30^{\text {th }}$. Early on September $21^{\text {st }}$, while on a west-northwest course, the tropical depression moved over the Yucatan peninsula. On September $22^{\text {nd }}$, the tropical depression changed course and began moving to the north-northwest entering the Gulf of Mexico after 09Z. Various ships reported winds up to $45 \mathrm{kt}$ at $18 \mathrm{Z}$ and $21 \mathrm{Z}$ on the $22^{\text {nd }}$. Intensification to a tropical storm is analyzed at $12 Z$ on September $22^{\text {nd }}$, same as it appears in HURDAT. The first reconnaissance aircraft to reach Flossy occurred at $0 Z$ on September $23^{\text {nd }}$ and estimated maximum surface winds of $45 \mathrm{kt}$ and observed a minimum surface pressure of $1007 \mathrm{mb}$. A central pressure of $1007 \mathrm{mb}$ is present in HURDAT at $00 \mathrm{Z}$ on September $23^{\text {rd }}$ and it has been removed based on observation by various ships of lower pressures and also because the reconnaissance report does not indicate that the measurement was a central pressure. The tropical cyclone rapidly grew in strength on September $23^{\text {rd }}$ as it moved generally northward toward the Louisiana coast. At $0650 \mathrm{Z}$ on the $23^{\text {rd }}$, the ship "SS Tasculus" located at $26.3 \mathrm{~N}, 90.2 \mathrm{~W}$ reported a central pressure of $994 \mathrm{mb}$. The position of the ship appears to be wrong but the pressure looks to be correct and has been added to HURDAT at 06Z. A central pressure of $994 \mathrm{mb}$ suggests maximum winds of $58 \mathrm{kt}$ south of $25 \mathrm{~N}$ and $53 \mathrm{kt}$ north of $25 \mathrm{~N}$ from the Brown et al. pressure-wind relationship. An intensity of $55 \mathrm{kt}$ has been selected for $12 \mathrm{Z}$ on the $23^{\text {rd }}$, same as in HURDAT. The ship "Lima" reported $65 \mathrm{kt} \mathrm{S}$ and $1006 \mathrm{mb}$ at $15 \mathrm{Z}$ on the $23^{\text {rd }}$, while other ships reported winds of 55 and $60 \mathrm{kt}$ late on the day. Intensification to hurricane is retained at $18 \mathrm{Z}$ on September $23^{\text {rd }}$, but an intensity of $70 \mathrm{kt}$ is analyzed at this time, up from $65 \mathrm{kt}$ originally in HURDAT, a minor intensity change. Another reconnaissance aircraft reached Flossy at $2105 \mathrm{Z}$ measuring a central pressure of $984 \mathrm{mb}$, a $10 \mathrm{~nm}$ eye diameter and estimating surface winds of $45 \mathrm{kt}$. A central pressure of $984 \mathrm{mb}$ suggests maximum surface winds of $68 \mathrm{kt}$ north of $25 \mathrm{~N}$ according to the pressure-wind relationship. The $10 \mathrm{~nm}$ eye diameter suggests an RMW of about $8 \mathrm{~nm}$, which is smaller than the climatological value of about $20 \mathrm{~nm}$. An intensity of $75 \mathrm{kt}$ is analyzed at $00 \mathrm{Z}$ on September $24^{\text {th }}$, up from $70 \mathrm{kt}$ originally in HURDAT, a minor intensity change. A central pressure of $984 \mathrm{mb}$ has been added to HURDAT at $00 \mathrm{Z}$ on the $24^{\text {th }}$.

Early on September $24^{\text {th }}$, Hurricane Flossy turned to the northeast making landfall in the delta region of southeast Louisiana around $10 \mathrm{Z}$ with maximum sustained winds of $80 \mathrm{kt}$. Landfall occurred between the towns of Burrwood and Venice, with both registering a central pressure of $983 \mathrm{mb}$. Venice reported calm conditions between 0950Z and 1150Z. 
It is plausible that the central pressure of Flossy was slightly lower than measured by these towns. Nonetheless, a central pressure of $983 \mathrm{mb}$ was present in HURDAT at 06Z on the $24^{\text {th }}$ and has been moved to $12 \mathrm{Z}$. Grand Isle registered sustained winds of $80 \mathrm{kt}$ with gusts up to $85 \mathrm{kt}$. Flossy continued to deepen after leaving Lousiana and a reconnaissance airplane at $2230 \mathrm{Z}$ on the $24^{\text {th }}$ measured a central pressure of $974 \mathrm{mb}$, estimated maximum surface winds of $80 \mathrm{kt}$ and a $30 \mathrm{~nm}$ eye diameter. A central pressure of $974 \mathrm{mb}$ suggests maximum surface winds of $80 \mathrm{kt}$ north of $25 \mathrm{~N}$ and $83 \mathrm{kt}$ north of $25 \mathrm{~N}$ intensifying, according to the pressure-wind relationship. An intensity of $85 \mathrm{kt}$ is selected at $18 \mathrm{Z}$ on the $24^{\text {th }}$ and $00 \mathrm{Z}$ on the $25^{\text {th }}$. The original HURDAT shows $80 \mathrm{kt}$ and $65 \mathrm{kt}$, respectively, which is a minor and major intensity change, respectively. A central pressure of $974 \mathrm{mb}$ has been added to HURDAT at $00 \mathrm{Z}$ on the $25^{\text {th }}$, replacing the existing $980 \mathrm{mb}$, which was measured at Pensacola and the hurricane passed about $10 \mathrm{~nm}$ south of the city. Hurricane Flossy is analyzed to have made landfall in Florida around 00Z on September $25^{\text {th }}$ near $30.4 \mathrm{~N}, 86.4 \mathrm{~W}$, about $5 \mathrm{~nm}$ east of Destin, with an intensity of $85 \mathrm{kt}$. $85 \mathrm{kt}$ is also the peak intensity for the lifetime of Flossy, up from $80 \mathrm{kt}$ in HURDAT, a minor intensity change. Pensacola reported $56 \mathrm{kt} \mathrm{N}$ at $2058 \mathrm{Z}$ on the $24^{\text {th }}$ and gusts up to $72 \mathrm{kt}$. Crestview reported $50 \mathrm{kt}$ at $00 \mathrm{Z}$ on the $25^{\text {th }}$. Flossy rapidly weakened over land while moving to the northeast. The hurricane weakened to tropical storm intensity at $06 \mathrm{Z}$ on the $25^{\text {th }}$, same as in HURDAT. The Kaplan and DeMaria model was run for 06Z, $12 \mathrm{Z}$ and $18 \mathrm{Z}$ on the $25^{\text {th }}$, yielding $56 \mathrm{kt}, 41 \mathrm{kt}$ and $31 \mathrm{kt}$, respectively. The only gales during these times were from ships. An intensity of $50 \mathrm{kt}$ is selected for $06 \mathrm{Z}, 40 \mathrm{kt}$ at $12 \mathrm{Z}$ and 35 $\mathrm{kt}$ at $18 \mathrm{Z}$ on the $25^{\text {th }}$. Albany, GA reported $10 \mathrm{kt} \mathrm{SE}$ and $998 \mathrm{mb}$ at $12 \mathrm{Z}$ on the $25^{\text {th }}$, suggesting a central pressure of $996 \mathrm{mb}$, which has been added to HURDAT. Late on September $25^{\text {th }}$, the structure of Flossy became less symmetric and dry continental air entered the center causing the storm to become extratropical around 18Z, same as shown by HURDAT. Albany, GA reported $10 \mathrm{kt} \mathrm{NW}$ and $998 \mathrm{mb}$ at $18 \mathrm{Z}$ on the $25^{\text {th }}$, and a central pressure of $998 \mathrm{mb}$ has been added to HURDAT at this time.

Early on September $26^{\text {th }}$, Flossy crossed into South Carolina while continuing its course to the northeast. HURDAT shows that the storm weakens to an extratropical depression at $12 \mathrm{Z}$ on the $26^{\text {th }}$, but ship data indicates that the storm retained gale-force winds. An intensity of $35 \mathrm{kt}$ is selected for 00Z, $40 \mathrm{kt}$ for 06Z, 12Z and 18Z. HURDAT shows $35 \mathrm{kt}$ at $00 \mathrm{Z}$ and $06 \mathrm{Z}$ and $30 \mathrm{kt}$ for $12 \mathrm{Z}$ and $18 \mathrm{Z}$, minor intensity changes. Savannah measured $10 \mathrm{kt} \mathrm{SW}$ and $1001 \mathrm{mb}$ at $00 \mathrm{Z}$, suggesting a central pressure of $999 \mathrm{mb}$, which has been added to HURDAT. Edisto Beach, SC measured $10 \mathrm{kt} \mathrm{SSE}$ and $1001 \mathrm{mb}$ at 06Z, suggesting a central pressure of $999 \mathrm{mb}$, which has been added to HURDAT. Myrtle Beach, SC measured $10 \mathrm{kt} \mathrm{SW}$ and $1003 \mathrm{mb}$ at 12Z, suggesting a central pressure of 1001 mb, which has been added to HURDAT. New Bern, NC measured $10 \mathrm{kt} \mathrm{SW}$ and 1003 $\mathrm{mb}$ at 1931Z, suggesting a central pressure of $1001 \mathrm{mb}$, which has been added to HURDAT at 18Z. A strong pressure gradient between Flossy and a high pressure to the 
north produced strong winds along the Mid-Atlantic. Ocean City, MD reported $46 \mathrm{kt} \mathrm{NE}$ at $18 \mathrm{Z}$ on the $26^{\text {th }}$. Flossy entered North Carolina around $12 \mathrm{Z}$ on the $26^{\text {th }}$ and its forward speed slowed late on the day and into the $27^{\text {th }}$. At $06 Z$ on the $27^{\text {th }}$, an intensity of $50 \mathrm{kt}$ is analyzed, up from $30 \mathrm{kt}$ in HURDAT, a major intensity change. $50 \mathrm{kt}$ is also the peak intensity Flossy is analyzed to have reached as an extratropical cyclone. Cherry Point, $\mathrm{NC}$ measured $6 \mathrm{kt} \mathrm{E}$ and $1003 \mathrm{mb}$ at $2330 \mathrm{Z}$ on the $26^{\text {th }}$, suggesting a central pressure of $1002 \mathrm{mb}$, which has been added to HURDAT at $00 \mathrm{Z}$ on the $27^{\text {th }}$. New Bern, NC measured $6 \mathrm{kt}$ ESE and $1006 \mathrm{mb}$ at 0530Z, suggesting a central pressure of $1005 \mathrm{mb}$, which has been added to HURDAT at 06Z. New Bern, NC reported calm conditions and $1008 \mathrm{mb}$ at $1130 \mathrm{Z}$, suggesting a central pressure of $1008 \mathrm{mb}$, which has been added to HURDAT at 12Z. New Bern, NC measured $10 \mathrm{kt} \mathrm{SSW}$ and $1011 \mathrm{mb}$ at 18Z, suggesting a central pressure of $1009 \mathrm{mb}$, which has been added to HURDAT. Early on September $28^{\text {th }}$, Flossy moved back into the Atlantic Ocean but the organization of the system continued to degrade, potentially becoming a trough based on ship data. The intensity of the extratropical cyclone is analyzed to have decreased to $45 \mathrm{kt}$ at $12 \mathrm{Z}$ and $40 \mathrm{kt}$ at $18 \mathrm{Z}$ on the $28^{\text {th }}$. Elizabeth City, NC measured $7 \mathrm{kt} \mathrm{SSW}$ and $1012 \mathrm{mb}$ at $2332 \mathrm{Z}$ on the $27^{\text {th }}$, suggesting a central pressure of $1011 \mathrm{mb}$, which has been added to HURDAT at 00Z on the $28^{\text {th }}$. Flossy turned to the east on the $29^{\text {th }}$ weakening to a $30 \mathrm{kt}$ extratropical depression at 06Z, down from $40 \mathrm{kt}$ originally in HURDAT, a minor intensity change. On September $30^{\text {th }}$, the system moved to the southeast slowing its forward speed. A small clockwise loop was completed early on October $1^{\text {st }}$ and its forward speed increased to the north. Flossy regained gale-force winds around $06 \mathrm{Z}$ on October $1^{\text {st }}$ and continued to intensify until reaching $50 \mathrm{kt}$ on October $2^{\text {nd }}$ at $06 Z$. Early on October $3^{\text {rd }}$, Flossy began to interact with another extratropical cyclone to its west. It is analyzed that Flossy merged with the other cyclone after $06 \mathrm{Z}$ on October $3^{\text {rd }}$. October $3^{\text {rd }}$ at $06 \mathrm{Z}$ is the last position for Flossy. It is also analyzed that Flossy lasted 60 hours more than originally shown in HURDAT, a major change.

New Storm [October 9-12, 1956]

\begin{tabular}{|c|c|c|c|c|c|c|}
\hline 37265 & $10 / 09 / 195$ & $M=9$ & 4 & $R=820$ & UNN & MED \\
\hline 37265 & $10 / 09$ * & $\odot$ & $\odot$ & $\odot * 153$ & 460 & 40 \\
\hline 37265 & $10 / 10 * 155$ & 484 & 40 & $\odot * 160$ & 492 & 35 \\
\hline 37265 & $10 / 11 * 184$ & 492 & 30 & $\odot * 187$ & 489 & 30 \\
\hline 37265 & $10 / 12 * 197$ & 465 & 30 & 0 * & 0 & 0 \\
\hline
\end{tabular}

\begin{tabular}{|c|c|c|}
\hline \multicolumn{2}{|c|}{ XING $=\odot$} & \\
\hline *153 & 468 & \\
\hline * 17 & 4 & \\
\hline 196 & 485 & \\
\hline & & \\
\hline
\end{tabular}

$0 * 153 \quad 476 \quad 40$ $0 * 178 \quad 495 \quad 30$ $0 * 193478 \quad 30$ 37285 TS

A new tropical storm has been added to HURDAT, not previously shown in McAdie et al. (2009). Evidence for its existence comes from the Historical Weather Map series, Microfilm, COADS ship database, Mariners Weather Log and Jack Beven's suspect list. 
October 4:

HWM shows a spot low pressure at $12.0 \mathrm{~N}, 36.0 \mathrm{~W}$ at $12 \mathrm{Z}$. Microfilm does not analyze an organized system at $12 \mathrm{Z}$. Ship highlights: No gale force winds or equivalent low pressures.

October 5:

HWM shows a closed low pressure of at most $1010 \mathrm{mb}$ at $8.0 \mathrm{~N}, 39.5 \mathrm{~W}$ at $12 \mathrm{Z}$. Microfilm does not analyze an organized system at 12Z. Ship highlights: No gale force winds or equivalent low pressures.

October 6:

HWM shows a closed low pressure of at most $1010 \mathrm{mb}$ at $9.0 \mathrm{~N}, 40.5 \mathrm{~W}$ at $12 \mathrm{Z}$. Microfilm analyses a closed low pressure of at most $1011 \mathrm{mb}$ at $12.5 \mathrm{~N}, 43.0 \mathrm{~W}$ at $12 \mathrm{Z}$. Ship highlights: $35 \mathrm{kt} \mathrm{E}$ and $1011 \mathrm{mb}$ at $15.0 \mathrm{~N}, 41.1 \mathrm{~W}$ at $18 \mathrm{Z}$ (micro).

\section{October 7:}

HWM shows a closed low pressure of at most $1010 \mathrm{mb}$ at $12.0 \mathrm{~N}, 44.5 \mathrm{~W}$ at $12 \mathrm{Z}$. Microfilm analyses a closed low pressure of at most $1011 \mathrm{mb}$ at $12.0 \mathrm{~N}, 47.5 \mathrm{~W}$ at $12 \mathrm{Z}$. Ship highlights: $45 \mathrm{kt} \mathrm{NNE}$ and $1011 \mathrm{mb}$ at $14.1 \mathrm{~N}, 47.8 \mathrm{~W}$ at $00 \mathrm{Z}$ (micro).

October 8:

HWM shows a closed low pressure of at most $1010 \mathrm{mb}$ at $14.0 \mathrm{~N}, 46.0 \mathrm{~W}$ at $12 \mathrm{Z}$. Microfilm does not analyze an organized system at 12Z. Ship highlights: No gale force winds or equivalent low pressures.

October 9:

HWM shows a closed low pressure of at most $1010 \mathrm{mb}$ at $15.5 \mathrm{~N}, 46.0 \mathrm{~W}$ at $12 \mathrm{Z}$. Microfilm analyses a closed low pressure of at most $1011 \mathrm{mb}$ at $15.5 \mathrm{~N}, 46.5 \mathrm{~W}$ at $12 \mathrm{Z}$. Ship highlights: $40 \mathrm{kt}$ ENE and $1004 \mathrm{mb}$ at 16.4N, 46.4W at 09Z (MWL). MWR: "Some 1,300 miles east of Puerto Rico on this date, ships reported squalls of 40 to $45 \mathrm{mph}$ and there was evidence of at least a quasi-circulation. It was completely damped out within 24 hours."

October 10:

HWM shows a spot low pressure at $18.5 \mathrm{~N}, 46.5 \mathrm{~W}$ and another spot low pressure at $25.5 \mathrm{~N}, 49.5 \mathrm{~W}$ at $12 \mathrm{Z}$. Microfilm does not analyze an organized system at $12 \mathrm{Z}$. Ship highlights: No gale force winds or equivalent low pressures. 
October 11:

HWM shows a spot low pressure at $18.5 \mathrm{~N}, 46.5 \mathrm{~W}$ and another spot low pressure at $25.5 \mathrm{~N}, 49.5 \mathrm{~W}$ at $12 \mathrm{Z}$. Microfilm does not analyze an organized system at $12 \mathrm{Z}$. Ship highlights: No gale force winds or equivalent low pressures.

October 12:

HWM shows a spot low pressure at 20.0N, 50.0W at 12Z. Microfilm does not analyze an organized system at $12 \mathrm{Z}$. Ship highlights: No gale force winds or equivalent low pressures.

A strong tropical wave moved off the African coast in early October. The disturbance gained strength and by the $6^{\text {th }}$, a ship reported $35 \mathrm{kt} \mathrm{E}$ and $1011 \mathrm{mb}$ at $15.0 \mathrm{~N}, 41.1 \mathrm{~W}$. Unfortunately, the data in the southern quadrant was sparse and is not possible to determine whether a closed circulation was present. Early on the $7^{\text {th }}$, another ship reported gale force winds but once again, the ship data is too sparse to show a closed circulation was present. The system continued slowly westward and early on the $9^{\text {th }}$, the ship SS ANTONIA reported $11 \mathrm{kt} \mathrm{N}$ (not that microfilm had a comment that they were unclear whether "11" meant "kt" or "force 11" (60 kt)) and $989 \mathrm{mb}$. Data from nearby ships indicate that the pressure reported by the SS ANTONIA likely had a significant low bias or the cyclone was extremely small. At $09 \mathrm{Z}$ on October $9^{\text {th }}$, the ship DEL SOL reported $40 \mathrm{kt} E$ and $1004 \mathrm{mb}$. The pressure reported by the ship DEL SOL dropped 10 $\mathrm{mb}$ in 21 hours between $12 \mathrm{Z}$ on the $8^{\text {th }}$ and $09 \mathrm{Z}$ on the $9^{\text {th }}$. A peripheral pressure of 1004 $\mathrm{mb}$ suggests maximum sustained winds of at least $39 \mathrm{kt}$ south of $25 \mathrm{~N}$ from the Brown et al. pressure-wind relationship. Ship data on the $9^{\text {th }}$ indicates that a closed low level circulation was present. The first position is analyzed at $06 \mathrm{Z}$ on October $9^{\text {th }}$ as a $40 \mathrm{kt}$ tropical storm given the slow motion of the cyclone. This is not the genesis of the tropical cyclone as it likely formed a day to even a few days earlier. The tropical storm moved slowly westward and early on the $10^{\text {th }}$ turned to the north. Weakening to a tropical depression is analyzed at $12 \mathrm{Z}$ on the $10^{\text {th }}$. No other ships reported gales or equivalent pressures. Early on the $11^{\text {th }}$, the tropical depression turned to the northeast and it is analyzed that it dissipated after $00 \mathrm{Z}$ on the $12^{\text {th }}$.

New Tropical Storm [October 14-18, 1956]

\begin{tabular}{|c|c|c|c|c|c|c|}
\hline 37265 & $10 / 14 / 195$ & $M=10$ & 6 & SNBR $=82$ & \multicolumn{2}{|c|}{ UNNAMED } \\
\hline 37265 & $10 / 14$ * & $\odot$ & 0 & ๑* & $\odot$ & $\odot$ \\
\hline 37265 & $10 / 15^{*} 232$ & 801 & $4 \odot$ & $0 * 237$ & 802 & 40 \\
\hline 37265 & $10 / 16 * 256$ & 806 & 50 & $\odot * 269$ & 807 & 50 \\
\hline 37265 & $10 / 17 * 301$ & 803 & 50 & $997 * 311$ & 798 & 50 \\
\hline 37265 & 10/18E352 & 770 & 45 & OE364 & 759 & 45 \\
\hline
\end{tabular}

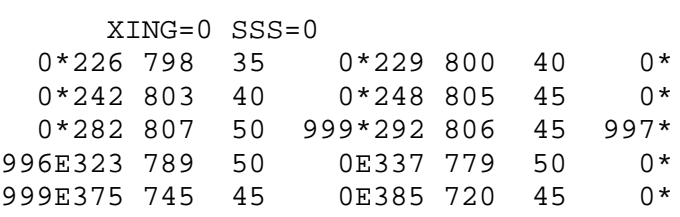




\section{U.S. Tropical Storm Landfall}

$10 / 1521 \mathrm{Z} 25.2 \mathrm{~N} 80.6 \mathrm{~W} 50 \mathrm{kt} \mathrm{FL}$

A new tropical storm has been added to HURDAT, not previously shown in McAdie et al. (2009). Evidence for its existence comes from the Historical Weather Map series, Microfilm, Monthly Weather Review, COADS ship database, and Jack Beven's and David Roth's suspect lists.

October 13:

HWM shows a stationary cold front over Cuba and eastern Bahamas at $12 \mathrm{Z}$. Microfilm analyses frontal boundary over the Bahamas, a closed low pressure of at most $1008 \mathrm{mb}$ at $21.5 \mathrm{~N}, 77.5 \mathrm{~W}$ and another closed low pressure of at most $1008 \mathrm{mb}$ at $14.5 \mathrm{~N}$, $81.5 \mathrm{~W}$ at $12 \mathrm{Z}$. Ship highlights: $35 \mathrm{kt} \mathrm{NE}$ and $1008 \mathrm{mb}$ at $22.9 \mathrm{~N}, 79.2 \mathrm{~W}$ at $18 \mathrm{Z}$ (COADS).

October 14:

HWM shows spot a low pressure at $20.5 \mathrm{~N}, 80.0 \mathrm{~W}$ and a warm front over the Bahamas to the northeast of the low at $12 \mathrm{Z}$. Microfilm analyses a closed low pressure of at most $1005 \mathrm{mb}$ at $23.3 \mathrm{~N}, 80.0 \mathrm{~W}$ at $12 \mathrm{Z}$. MWR shows a low pressure of $1006 \mathrm{mb}$ located near $21.5 \mathrm{~N}, 79.8 \mathrm{~W}$ at 12Z. Ship highlights: $35 \mathrm{kt} \mathrm{NE}$ and $1013 \mathrm{mb}$ at $24.6 \mathrm{~N}$, 83.0W at $12 \mathrm{Z}$ (micro). $40 \mathrm{kt} \mathrm{N}$ and $1011 \mathrm{mb}$ at $24.3 \mathrm{~N}, 82.5 \mathrm{~W}$ at $18 \mathrm{Z}$ (COADS). Land highlights: $20 \mathrm{kt} \mathrm{E}$ and $1004 \mathrm{mb}$ at Caibarien, Cuba at 00Z (micro). $35 \mathrm{kt} \mathrm{N}$ and $1003 \mathrm{mb}$ at Matanzas, Cuba at $18 \mathrm{Z}$ (micro).

October 15:

HWM shows a closed low pressure of at most $1005 \mathrm{mb}$ at $23.5 \mathrm{~N}, 79.5 \mathrm{~W}$ and a warm front extending from the low to the northeast at $12 \mathrm{Z}$. Microfilm analyses a closed low pressure of at most $1005 \mathrm{mb}$ at $24.0 \mathrm{~N}, 80.5 \mathrm{~W}$ with a frontal boundary to the north at 12Z. MWR shows a low pressure of $1004 \mathrm{mb}$ located near 24.5N, 80.1W at 12Z. Ship highlights: $40 \mathrm{kt} \mathrm{NNE}$ and $1006 \mathrm{mb}$ at $24.1 \mathrm{~N}, 79.8 \mathrm{~W}$ at $00 \mathrm{Z}$ (micro). $40 \mathrm{kt} \mathrm{NNE}$ and $1009 \mathrm{mb}$ at $23.6 \mathrm{~N}, 82.8 \mathrm{~W}$ at $06 \mathrm{Z}$ (micro). $35 \mathrm{kt} \mathrm{NNE}$ and $1009 \mathrm{mb}$ at $24.6 \mathrm{~N}, 83.7 \mathrm{~W}$ at $12 \mathrm{Z}$ (COADS). $35 \mathrm{kt} \mathrm{NE}$ and $1009 \mathrm{mb}$ at $27.5 \mathrm{~N}, 79.8 \mathrm{~W}$ at $12 \mathrm{Z}$ (COADS). Land highlights: $16 \mathrm{kt} \mathrm{NE}$ and $1004 \mathrm{mb}$ at Key West, FL at 0930Z (SWO). $12 \mathrm{kt} \mathrm{NE}$ and 1002 $\mathrm{mb}$ at Miami, FL at $2025 \mathrm{Z}$ (SWO). 
October 16:

HWM shows a closed low pressure of at most $1005 \mathrm{mb}$ at $28.0 \mathrm{~N}, 79.0 \mathrm{~W}$ and a warm front extends from the low to the northeast at $12 \mathrm{Z}$. Microfilm analyses a closed low pressure of at most $1002 \mathrm{mb}$ at $28.0 \mathrm{~N}, 80.0 \mathrm{~W}$ with a frontal boundary to the north of the low at 12Z. MWR shows a low pressure of $1002 \mathrm{mb}$ located near $28.5 \mathrm{~N}, 80.0 \mathrm{~W}$ at $12 \mathrm{Z}$. Ship highlights: $40 \mathrm{kt} \mathrm{NE}$ and $1008 \mathrm{mb}$ at $28.3 \mathrm{~N}, 79.7 \mathrm{~W}$ at $00 \mathrm{Z}$ (COADS). $40 \mathrm{kt} \mathrm{NE}$ and $1011 \mathrm{mb}$ at $31.2 \mathrm{~N}, 74.4 \mathrm{~W}$ at $06 \mathrm{Z}$ (COADS). $35 \mathrm{kt} \mathrm{S}$ and $1009 \mathrm{mb}$ at $25.3 \mathrm{~N}, 47.4 \mathrm{~W}$ at $12 \mathrm{Z}$ (COADS). $40 \mathrm{kt} \mathrm{S}$ and $1004 \mathrm{mb}$ at $28.5 \mathrm{~N}, 78.7 \mathrm{~W}$ at $18 \mathrm{Z}$ (COADS). $20 \mathrm{kt} \mathrm{SSE}$ and $999 \mathrm{mb}$ at $29.0 \mathrm{~N}, 79.8 \mathrm{~W}$ at $18 \mathrm{Z}$ (SWO). Land highlights: $10 \mathrm{kt} \mathrm{SSW}$ and $1002 \mathrm{mb}$ at West Palm Beach, FL at 0728Z (SWO). $11 \mathrm{kt} \mathrm{NE}$ and $1001 \mathrm{mb}$ at Patrick AFB, FL at 1028Z (SWO). $33 \mathrm{kt} \mathrm{SSW}$ and $998 \mathrm{mb}$ at Cape Canaveral, FL at 1938Z (SWO). $47 \mathrm{kt} \mathrm{N}$ and $1002 \mathrm{mb}$ at Mayport, FL at 23Z (SWO).

October 17:

HWM shows a closed low pressure of at most $1005 \mathrm{mb}$ at $31.5 \mathrm{~N}, 78.3 \mathrm{~W}$ and a warm front extending from the low to the northeast at $12 \mathrm{Z}$. Microfilm analyses a closed low pressure of at most $1002 \mathrm{mb}$ at $32.5 \mathrm{~N}, 78.5 \mathrm{~W}$ with a frontal boundary extending from the low to the northeast at 12Z. MWR shows a low pressure of $998 \mathrm{mb}$ located near $32.5 \mathrm{~N}, 78.9 \mathrm{~W}$ at $12 \mathrm{Z}$. Ship highlights: $10 \mathrm{kt} \mathrm{SE}$ and $998 \mathrm{mb}$ at $30.1 \mathrm{~N}, 80.3 \mathrm{~W}$ at $00 \mathrm{Z}$ (COADS). $40 \mathrm{kt} \mathrm{S}$ and $1003 \mathrm{mb}$ at $29.4 \mathrm{~N}, 78.0 \mathrm{~W}$ at $00 \mathrm{Z}$ (COADS). $50 \mathrm{kt} \mathrm{WSW}$ and $1001 \mathrm{mb}$ at $29.5 \mathrm{~N}, 79.7 \mathrm{~W}$ at $05 \mathrm{Z}$ (micro). $10 \mathrm{kt} \mathrm{WNW}$ and $999 \mathrm{mb}$ at $30.6 \mathrm{~N}, 80.1 \mathrm{~W}$ at 06Z (COADS). $30 \mathrm{kt} \mathrm{SW}$ and $997 \mathrm{mb}$ at 30.3N, 79.7W at 06Z (COADS). $45 \mathrm{kt} \mathrm{E}$ and $996 \mathrm{mb}$ at $32.4 \mathrm{~N}, 78.7 \mathrm{~W}$ at $12 \mathrm{Z}$ (COADS). $50 \mathrm{kt} \mathrm{S}$ and $996 \mathrm{mb}$ at $33.1 \mathrm{~N}, 78.3 \mathrm{~W}$ at $15 \mathrm{Z}$ (micro). $35 \mathrm{kt} \mathrm{SSE}$ and $1008 \mathrm{mb}$ at 34.0N, 74.9W at 18Z (COADS). Land highlights: 16 kt NNW and $1004 \mathrm{mb}$ at Brunswick, GA at 0428Z (SWO). $16 \mathrm{kt} \mathrm{N}$ and $1003 \mathrm{mb}$ at Hunter AFB, GA at 0728Z (SWO). $30 \mathrm{kt} \mathrm{S}$ and $999 \mathrm{mb}$ at Frying Pan Shoals, SC at $33.5 \mathrm{~N}, 77.6 \mathrm{~W}$ at $17 \mathrm{Z}$ (micro). $8 \mathrm{kt} \mathrm{E}$ and $998 \mathrm{mb}$ at New Bern, NC at 2234Z (SWO).

October 18:

HWM shows a closed low pressure of at most $1005 \mathrm{mb}$ at $38.0 \mathrm{~N}, 74.0 \mathrm{~W}$ and a weakening warm front extending to its northeast and a cold front extending to its north at 12Z. Microfilm analyses a closed low pressure of at most $1002 \mathrm{mb}$ at $37.5 \mathrm{~N}, 74.4 \mathrm{~W}$ with a frontal boundary extending to its northeast at 12Z. MWR shows a low pressure of 1000 mb located near $38.0 \mathrm{~N}, 80.1 \mathrm{~W}$ at $12 \mathrm{Z}$. Ship highlights: $40 \mathrm{kt} \mathrm{SSW}$ and $1009 \mathrm{mb}$ at $32.5 \mathrm{~N}$, 76.0W at $00 \mathrm{Z}$ (COADS). $35 \mathrm{kt} \mathrm{SSW}$ and $1010 \mathrm{mb}$ at $33.1 \mathrm{~N}, 75.1 \mathrm{~W}$ at $06 \mathrm{Z}$ (COADS). 35 kt SW and $1003 \mathrm{mb}$ at $36.3 \mathrm{~N}, 74.0 \mathrm{~W}$ at $12 \mathrm{Z}$ (COADS). $40 \mathrm{kt} \mathrm{N}$ and $1006 \mathrm{mb}$ at 37.9N, 74.6W at 18Z (COADS). Land highlights: $5 \mathrm{kt} \mathrm{SSW}$ and $1000 \mathrm{mb}$ at Elizabeth City, NC at $0730 \mathrm{Z}(\mathrm{SWO})$. 
October 19:

HWM shows a frontal boundary over the northwest Atlantic at 12Z. Microfilm analyses a closed low pressure of at most $1002 \mathrm{mb}$ at $40.0 \mathrm{~N}, 55.0 \mathrm{~W}$ along a frontal boundary at 12Z. MWR shows a low pressure of $998 \mathrm{mb}$ located near $39.2 \mathrm{~N}, 56.1 \mathrm{~W}$ at 12Z. Ship highlights: $40 \mathrm{kt} \mathrm{SW}$ and $1003 \mathrm{mb}$ at $37.5 \mathrm{~N}, 68.0 \mathrm{~W}$ at $00 \mathrm{Z}$ (micro). $50 \mathrm{kt} \mathrm{NE}$ and $1004 \mathrm{mb}$ at $39.2 \mathrm{~N}, 64.5 \mathrm{~W}$ at $06 \mathrm{Z}$ (COADS). $35 \mathrm{kt} \mathrm{S}$ and $1009 \mathrm{mb}$ at $25.3 \mathrm{~N}, 47.4 \mathrm{~W}$ at $12 \mathrm{Z}$ (COADS).

MWR: "This Low formed as a wave on a dissipating polar front north of Hispaniola on the 12th and moved west-northwestward to the extreme southeastern Florida coast south of Miami on the 15th, when it turned north and north-northeastward passing over the North Carolina Capes west of Cape Hatteras. Rainfall was excessive in portions of Florida ranging from 6 to 20 inches over a 50-mile wide belt from the northeastern corner of Lake Okeechobee to Jacksonville. This storm never became wholly tropical, and maximum winds and most of the precipitation occurred well in advance of the low pressure center. Highest winds reported were gusts of 60 to $65 \mathrm{mph}$ and probably some sustained winds of near $60 \mathrm{mph}$ at sea. Damage from flooding in Florida, particularly around Kissimmee, totaled about $\$ 3,000,000$. Two persons were drowned in the surf during the storm."

A broad area of low pressure was present over the western Caribbean Sea during the second week of October while a weakening cold front moved into the Bahamas. A well-defined low pressure developed on October $14^{\text {th }}$ and genesis is analyzed at $12 \mathrm{Z}$ on the $14^{\text {th }}$ as a $35 \mathrm{kt}$ tropical storm. A strong pressure gradient was present to the north of the tropical cyclone, generating gale-force winds over $300 \mathrm{~nm}$ from the center, which was not directly due to this system. Microfilm and Historical Weather Maps indicate that a frontal boundary was present to the northeast of the center while ship data showed a very moist environment around the storm. Data does suggests that this system may have been a subtropical storm but without satellite images to determine the convective structure of the cyclone, it is analyzed as a tropical cyclone. The tropical storm moved generally northward increasing in strength. An intensity of $40 \mathrm{kt}$ is analyzed at $18 \mathrm{Z}$ on the $14^{\text {th }}$ and increasing to $45 \mathrm{kt}$ at $18 \mathrm{Z}$ on the $15^{\text {th }}$. Early on the $15^{\text {th }}$, several ships reported gale-force winds within $120 \mathrm{~nm}$ of the center. A ship reported $55 \mathrm{kt} \mathrm{NNW}$ at $00 \mathrm{Z}$ on the $15^{\text {th }}$ but the measurement appears to be too high compared to nearby ship data. Ship data on October $15^{\text {th }}$ continued to indicate that a warm front may have been present to the northeast of the center although the temperature gradient across the cyclone was almost non-existent. The northward forward motion brought the storm to South Florida making landfall at $21 \mathrm{Z}$ on the $15^{\text {th }}$ near $25.2 \mathrm{~N}, 80.6 \mathrm{~W}$ over extreme southern Miami-Dade with an intensity of $50 \mathrm{kt}$. 
Early on October $16^{\text {th }}$, the strongest winds were reported about $350 \mathrm{~nm}$ away from the center. A ship reported $55 \mathrm{kt}$ at $00 \mathrm{Z}$ on the $16^{\text {th }}$ and the intensity is analyzed at $50 \mathrm{kt}$ at this time. $50 \mathrm{kt}$ is also the peak intensity for this tropical cyclone. The tropical storm moved back into the Atlantic Ocean around $15 \mathrm{Z}$ on October 16th and started moving on a northeast course. No change in intensity is analyzed for the $16^{\text {th }}$ and $17^{\text {th }}$. At $1027 \mathrm{Z}$ on the $16^{\text {th }}$, Patrick AFB, FL reported $11 \mathrm{NE}$ and $1001 \mathrm{mb}$, suggesting a central pressure of 999 $\mathrm{mb}$, which has been added to HURDAT at $12 \mathrm{Z}$. At $18 \mathrm{Z}$ on the $16^{\text {th }}$, a ship reported $20 \mathrm{kt}$ SSE and $999 \mathrm{mb}$ suggesting a central pressure of $997 \mathrm{mb}$, which has been added to HURDAT. $47 \mathrm{kt} \mathrm{N}$ were measured at Mayport, FL at $23 \mathrm{Z}$ on October $16^{\text {th }}$. Late on the $16^{\text {th }}$, the structure of the storm again became more symmetric with gale-force winds reported just $120 \mathrm{~nm}$ to the east and southeast of the center. Furthermore, dew points across the southeast United States and ship data continued to indicate that a moist environment was present around the tropical cyclone. At $00 \mathrm{Z}$ on October $17^{\text {th }}$, a ship reported $10 \mathrm{kt} \mathrm{SE}$ and $998 \mathrm{mb}$, suggesting a central pressure of $997 \mathrm{mb}$, which has been added to HURDAT. At $06 \mathrm{Z}$ on the $17^{\text {th }}$, a ship reported $10 \mathrm{kt} \mathrm{NW}$ and $999 \mathrm{mb}$ and another reported $30 \mathrm{kt} \mathrm{SW}$ and $997 \mathrm{mb}$, suggesting a central pressure of around $996 \mathrm{mb}$ (given the uncertainties in the accuracy of the two ships' barometers), which has been added to HURDAT. At $12 \mathrm{Z}$ on the $17^{\text {th }}$, several ships near the center reported winds up to $45 \mathrm{kt}$ while lighter winds were being reported in the periphery. Still, the system had become elongated NE-SW with a clear warm front present extending northeast from the center and continental dry air likely entraining into the circulation. It is analyzed that at $12 \mathrm{Z}$ on October $17^{\text {th }}$, the tropical cyclone became an extratropical cyclone. A ship near the center reported $50 \mathrm{kt} \mathrm{S}$ at $15 \mathrm{Z}$ on the $17^{\text {th }}$. The extratropical cyclone made landfall in North Carolina around $21 \mathrm{Z}$ on the $17^{\text {th }}$. Early on October $18^{\text {th }}$, the extratropical cyclone turned to the east-northeast ahead of a deepening frontal boundary. At $0730 \mathrm{Z}$ on the $18^{\text {th }}$, Elizabeth City, NC reported $5 \mathrm{kt} \mathrm{SSW}$ and $1000 \mathrm{mb}$, suggesting a central pressure of 999 $\mathrm{mb}$, which has been added to $06 \mathrm{Z}$ on the $18^{\text {th }}$ in HURDAT. Early on the $19^{\text {th }}$, ship data suggests that the extratropical cyclone became less organized and likely was absorbed by a frontal boundary. Therefore, the last position is at $18 \mathrm{Z}$ on October 18. The development and characteristics of this tropical cyclone bear similarities to Tropical Storm Leslie in 2000 and Tropical Storm Nicole in 2010.

Hurricane Greta [October 31 - November 7, 1956]

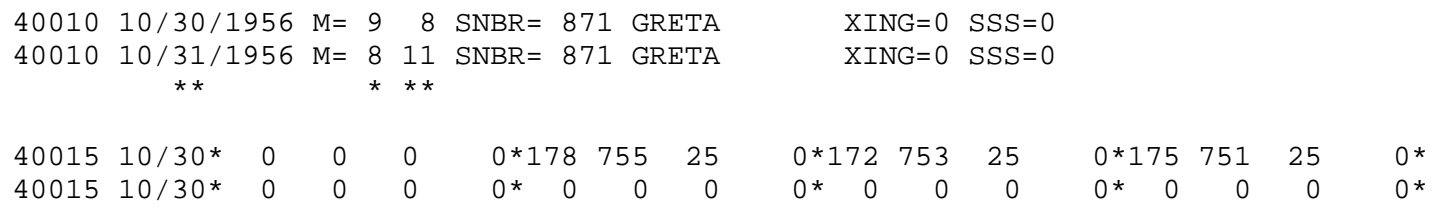

$X I N G=0 \quad S S S=0$ $X I N G=\odot \quad S S S=0$ 


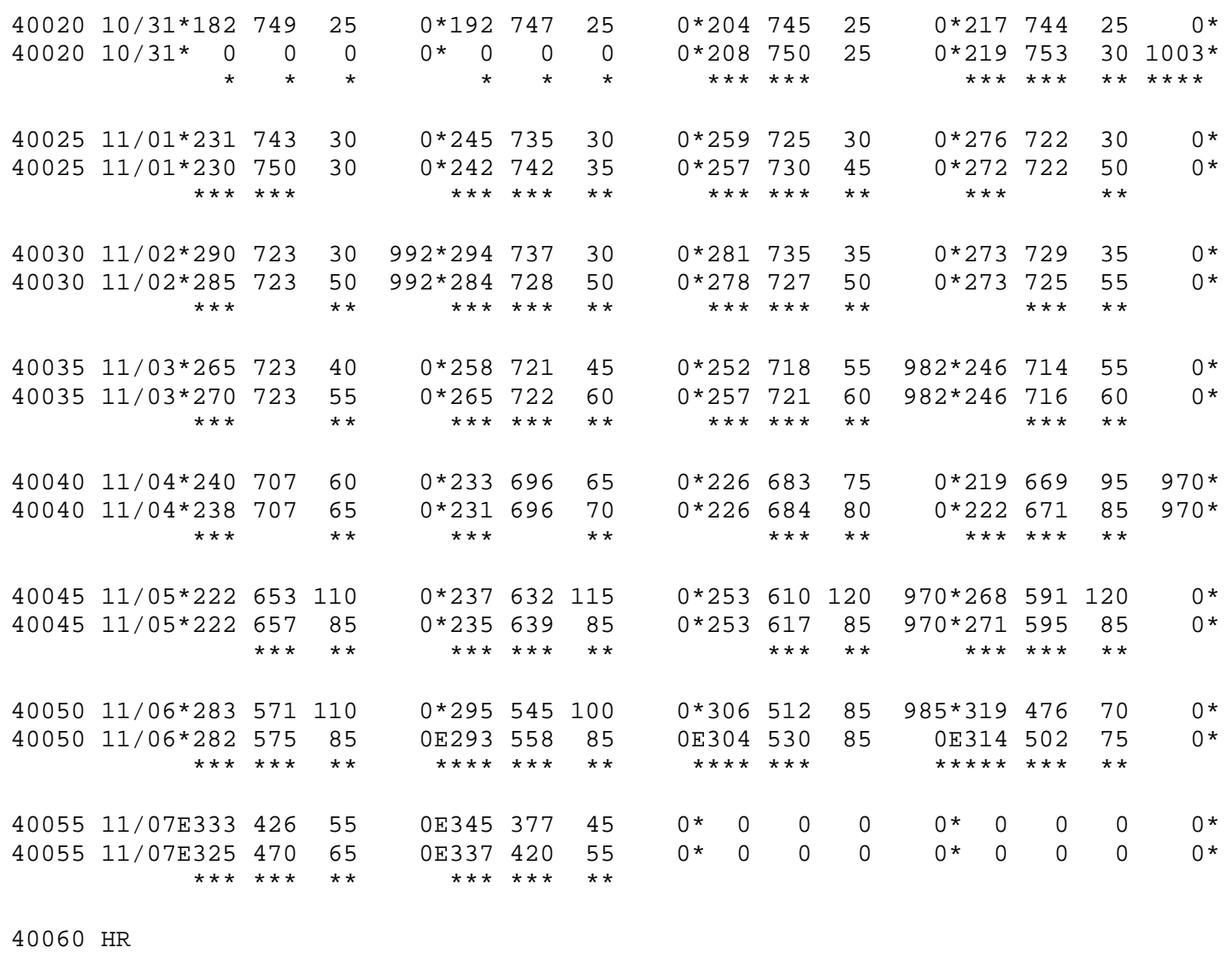

Major changes to the track and intensity shown in McAdie et al. (2009). Another major change is to indicate tropical storm intensity 30 hour earlier. Evidence for these alterations comes from the NHC microfilm maps, the Historical Weather Maps series, the COADS ship database, Monthly Weather Review, and Navy reconnaissance book.

October 28:

HWM analyzes a closed low pressure of at most $1010 \mathrm{mb}$ at $14 \mathrm{~N}, 76.5 \mathrm{~W}$ at $12 \mathrm{Z}$. HURDAT does not list an organized system on this date. Microfilm shows a closed low pressure of at most $1008 \mathrm{mb}$ at $11 \mathrm{~N}, 80.5 \mathrm{~W}$ at 18Z. Ship highlights: No gales or low pressures.

ATSR: "On 28 October a large low pressure area was observed in the western Caribbean between Cuba and Panama. This area, a large vortex of the ITC, remained static near 14N and 77W for the next few days." 
October 29:

HWM analyzes a closed low pressure of at most $1010 \mathrm{mb}$ at $14.5 \mathrm{~N}, 79.5 \mathrm{~W}$ at 12Z. HURDAT does not list an organized system on this date. Microfilm shows a closed low pressure of at most $1011 \mathrm{mb}$ at $14.0 \mathrm{~N}, 78.5 \mathrm{~W}$ at 12Z. Ship highlights: No gales or low pressures.

October 30:

HWM analyzes a closed low pressure of at most $1010 \mathrm{mb}$ at $17.0 \mathrm{~N}, 79.5 \mathrm{~W}$ at 12Z. HURDAT lists this as a 25 knot tropical depression at $17.2 \mathrm{~N}, 75.3 \mathrm{~W}$ at $12 \mathrm{Z}$. Microfilm shows a spot low pressure at $14.5 \mathrm{~N}, 76.8 \mathrm{~W}$ at $12 \mathrm{Z}$. Ship highlights: No gales or low pressures.

MWR: "A tropical depression, which is believed to have had its origin along the intertropical convergence zone over the southern Caribbean, was first noted southeast of Jamaica on October 30 when a Navy reconnaissance flight observed $35 \mathrm{mph}$ southeasterly winds. Numerous showers and a large area of relative calm near the location of lowest pressure were also observed." ATSR: "On the 30 October, a second center was observed forming near the eastern tip of Cuba within the large low pressure area. The circulation was evident as high as $500 \mathrm{mb}$ level and was under the southwesterly and divergent flow of a $200 \mathrm{mb}$ trough in the westerlies. A high pressure area moving off the northeast coast of the United States was tightening the gradient to the north of the low pressure center causing high winds over the broad area."

October 31:

HWM analyzes a closed low pressure of at most $1005 \mathrm{mb}$ at $21.2 \mathrm{~N}, 75.5 \mathrm{~W}$ at 12Z. HURDAT lists this as a 25 knot tropical depression at $20.4 \mathrm{~N}, 74.5 \mathrm{~W}$ at $12 \mathrm{Z}$. Microfilm shows a closed low pressure of at most $1005 \mathrm{mb}$ at $21.0 \mathrm{~N}, 76.0 \mathrm{~W}$ at $12 \mathrm{Z}$. Ship highlights: $5 \mathrm{kt} \mathrm{NW}$ and $1005 \mathrm{mb}$ at 19.6N, 75.0W at $12 \mathrm{Z}$ (micro). $20 \mathrm{kt} \mathrm{NW}$ and 1004 $\mathrm{mb}$ at $22.0 \mathrm{~N}, 77.3 \mathrm{~W}$ at $18 \mathrm{Z}$ (COADS). Land highlights: $10 \mathrm{kt} \mathrm{N}$ and $1005 \mathrm{kt}$ at Santiago de Cuba at $12 \mathrm{Z}$ (micro). $1003 \mathrm{mb}$ at Ragged Island, Bahamas at $18 \mathrm{Z}$ (micro).

MWR: "The Woods Hole Oceanographic Institution research vessel Crawford, on a weather mission in the Caribbean, was very near the circulation center during the afternoon and evening of the $30^{\text {th }}$ and encountered $25 \mathrm{mph}$ southeasterly winds and a minimum pressure near $1005 \mathrm{mb}$ (29.68 in). A radiosonde observation taken by the Crawford shortly after their winds shifted from the southeast to northwest indicated the Low was definitely cold-core as opposed to the warm core associated with hurricanes." 
November 1:

HWM analyzes a tropical storm of at most $1000 \mathrm{mb}$ at $25.0 \mathrm{~N}, 72.3 \mathrm{~W}$ at $12 \mathrm{Z}$. HURDAT lists this as a 30 knot tropical depression at $25.9 \mathrm{~N}, 72.5 \mathrm{~W}$ at $12 \mathrm{Z}$. Microfilm shows a closed low pressure of at most $1002 \mathrm{mb}$ at $27.0 \mathrm{~N}, 72.0 \mathrm{~W}$ at $12 \mathrm{Z}$. Ship highlights: $10 \mathrm{kt} \mathrm{WSW}$ and $1004 \mathrm{mb}$ at $22.4 \mathrm{~N}, 74.6 \mathrm{~W}$ at $00 \mathrm{Z}$ (micro). $35 \mathrm{kt} \mathrm{E}$ and $1010 \mathrm{mb}$ at $28.1 \mathrm{~N}$, $72.2 \mathrm{~W}$ at $06 \mathrm{Z}$ (micro). $40 \mathrm{kt} \mathrm{SE}$ and $1001 \mathrm{mb}$ at $27.2 \mathrm{~N}, 71.0 \mathrm{~W}$ at $12 \mathrm{Z}$ (micro). $45 \mathrm{kt} \mathrm{E}$ and $1002 \mathrm{mb}$ at $27.6 \mathrm{~N}, 71.3 \mathrm{~W}$ at $18 \mathrm{Z}$ (micro). Land highlights: $20 \mathrm{kt} \mathrm{WSW}$ and $1004 \mathrm{mb}$ at Mayaguana, Bahamas at 00Z (micro). $5 \mathrm{kt} \mathrm{WSW} \mathrm{and} 1003 \mathrm{mb}$ at San Salvador, Bahamas at 06Z (micro). $10 \mathrm{kt} \mathrm{N}$ and $1005 \mathrm{mb}$ at North Eleuthera at 12Z (micro). $5 \mathrm{kt}$ SW and 1003 mb at Ragged Island, Bahamas at 18Z (micro).

MWR: "The Low continued northward at about $15 \mathrm{mph}$ with a gradual intensification and by November 1 the lowest pressure had decreased to $998 \mathrm{mb}$ (29.47 in). Winds of 30 to $40 \mathrm{mph}$ were reported over a large area surrounding the center, but gentle variable winds and calm still covered an extensive area near the center. A large high pressure system, which had stagnated some distance off the middle Atlantic coast during the last few days of October, blocked further northwest movement so that during the night of November 1, the storm looped and took a southeastward course with a somewhat slower speed. It was during this period, as shown by data received from planes of the National Hurricane Research Project, that Greta assumed tropical storm characteristics with a minimum pressure of $992 \mathrm{mb}$ (29.29 in)." ATSR: "Between 1 and 2 November the new low pressure area increased greatly in area of circulation. The central pressure had decreased as expected under the divergent flow aloft. Future intensification was expected, not in the form of hurricane formation, but rather as a large North Atlantic extratropical storm. On 2 November the storm became nearly stationary within an area of a radius of 30 miles from $26.8 \mathrm{~N}$ and $72.3 \mathrm{~W}$. Southerly movement at about 11 knots then became apparent."

November 2:

HWM analyzes a tropical storm of at most $990 \mathrm{mb}$ at $27.5 \mathrm{~N}, 72.0 \mathrm{~W}$ at $12 \mathrm{Z}$. HURDAT lists this as a 35 knot tropical storm at $28.1 \mathrm{~N}, 73.5 \mathrm{~W}$ at $12 \mathrm{Z}$. Microfilm shows a closed low pressure of at most $996 \mathrm{mb}$ at $27.5 \mathrm{~N}, 72.0 \mathrm{~W}$ at $12 \mathrm{Z}$. Ship highlights: $40 \mathrm{kt} \mathrm{E}$ and $1002 \mathrm{mb}$ at $30.0 \mathrm{~N}, 71.9 \mathrm{~W}$ at $00 \mathrm{Z}$ (COADS). $40 \mathrm{kt} \mathrm{NE}$ and $1003 \mathrm{mb}$ at $30.3 \mathrm{~N}, 72.6 \mathrm{~W}$ at $06 \mathrm{Z}$ (COADS). $45 \mathrm{kt} \mathrm{E}$ and $1003 \mathrm{mb}$ at $30.2 \mathrm{~N}, 72.4 \mathrm{~W}$ at $12 \mathrm{Z}$ (COADS). $45 \mathrm{kt} \mathrm{E}$ and $1002 \mathrm{mb}$ at $30.5 \mathrm{~N}, 72.7 \mathrm{~W}$ at $18 \mathrm{Z}$ (COADS). $55 \mathrm{kt} \mathrm{NE}$ and $1001 \mathrm{mb}$ at $29.8 \mathrm{~N}, 74.1 \mathrm{~W}$ at $21 \mathrm{Z}$ (micro). Land highlights: $10 \mathrm{kt} \mathrm{WNW}$ and $1002 \mathrm{mb}$ at Cat Island, Bahamas at 00Z (micro). $20 \mathrm{kt} \mathrm{WNW} \mathrm{and} 1002 \mathrm{mb}$ at San Salvador, Bahamas at 06Z (micro). $25 \mathrm{kt} \mathrm{NNE}$ 
and $1001 \mathrm{mb}$ at Abaco Island at $12 \mathrm{Z}$ (micro). $30 \mathrm{kt} \mathrm{N}$ and $1000 \mathrm{mb}$ at Abaco Island at 18Z (micro). Aircraft highlight: $992 \mathrm{mb}$ central pressure around 0Z (MWR).

November 3:

HWM analyzes a tropical storm of at most $990 \mathrm{mb}$ at $25.3 \mathrm{~N}, 72.3 \mathrm{~W}$ at $12 \mathrm{Z}$. HURDAT lists this as a 55 knot tropical storm at $25.2 \mathrm{~N}, 71.8 \mathrm{~W}$ at $12 \mathrm{Z}$. Microfilm shows a closed low pressure of at most $990 \mathrm{mb}$ at $25.5 \mathrm{~N}, 71.5 \mathrm{~W}$ at 12Z. Ship highlights: $45 \mathrm{kt}$ ENE and $1004 \mathrm{mb}$ at $30.5 \mathrm{~N}, 72.7 \mathrm{~W}$ at $00 \mathrm{Z}$ (COADS). $45 \mathrm{kt} \mathrm{NE}$ and $1000 \mathrm{mb}$ at $28.3 \mathrm{~N}$, $71.4 \mathrm{~W}$ at $06 \mathrm{Z}$ (COADS). $35 \mathrm{kt} \mathrm{ENE}$ and $989 \mathrm{mb}$ at $26.8,71.8 \mathrm{~W}$ at $12 \mathrm{Z}$ (micro). $55 \mathrm{kt} \mathrm{NE}$ and $1005 \mathrm{mb}$ at $30.1 \mathrm{~N}, 72.0 \mathrm{~W}$ at $18 \mathrm{Z}$ (COADS). Land highlights: $30 \mathrm{kt} \mathrm{N}$ and $1000 \mathrm{mb}$ at Abaco Island at 00Z (micro). $25 \mathrm{kt} \mathrm{W}$ and $996 \mathrm{mb}$ at San Salvador at 06Z (micro). 15 kt NW and $991 \mathrm{mb}$ at Mayaguana, Bahamas at 12Z (micro). $35 \mathrm{kt} \mathrm{NNE}$ and $1002 \mathrm{mb}$ at Abaco Island, Bahamas at $18 \mathrm{Z}$ (micro). $40 \mathrm{kt} \mathrm{W}$ and $992 \mathrm{mb}$ at Grand Turk and Caicos at $21 \mathrm{Z}$ (micro).

MWR: "It is believed that Greta reached hurricane intensity on the afternoon of November 3 or early on the $4^{\text {th }}$." ATSR: "Air Force reconnaissance on 2 and 3 November reported intensification and the 3 November flight reports indicated the center of circulation had become a warm core circulation. The surface wind field still exhibited extratropical characteristics, therefore hurricane or tropical storm warnings were not issued since a warning of this type would indicate to the users of the information that the maximum winds were near the center and such was not the case at this time."

November 4:

HWM analyzes a hurricane of at most $985 \mathrm{mb}$ at $23.3 \mathrm{~N}, 69.7 \mathrm{~W}$ at $12 \mathrm{Z}$. HURDAT lists this as a $75 \mathrm{knot}$ hurricane at $22.6 \mathrm{~N}, 68.3 \mathrm{~W}$ at $12 \mathrm{Z}$. Microfilm shows a closed low pressure of at most $984 \mathrm{mb}$ at $22.5 \mathrm{~N}, 68.5 \mathrm{~W}$ at 12Z. Ship highlights: $40 \mathrm{kt} \mathrm{W}$ and $987 \mathrm{mb}$ at $23.2 \mathrm{~N}, 70.7 \mathrm{~W}$ at $00 \mathrm{Z}$ (COADS). $70 \mathrm{kt} \mathrm{E}$ and $1005 \mathrm{mb}$ at $26.7 \mathrm{~N}, 68.5 \mathrm{~W}$ at $03 \mathrm{Z}$ (micro). $50 \mathrm{kt} \mathrm{NE}$ and $994 \mathrm{mb}$ at $24.0 \mathrm{~N}, 71.0 \mathrm{~W}$ at $06 \mathrm{Z}$ (COADS). $40 \mathrm{kt} \mathrm{SE}$ and $982 \mathrm{mb}$ at $22.5 \mathrm{~N}$, $67.7 \mathrm{~W}$ at $12 \mathrm{Z}$ (micro). $80 \mathrm{kt} \mathrm{SSW}$ and $991 \mathrm{mb}$ at $22.7 \mathrm{~N}, 65.9 \mathrm{~W}$ at $15 \mathrm{Z}$ (micro). $25 \mathrm{kt} \mathrm{W}$ and $975 \mathrm{mb}$ at $22.0 \mathrm{~N}, 67.2 \mathrm{~W}$ at $18 \mathrm{Z}$ (micro). $70 \mathrm{kt} \mathrm{SSW}$ and $985 \mathrm{mb}$ at $21.9 \mathrm{~N}, 65.8 \mathrm{~W}$ at 21Z (micro). Land highlights: $35 \mathrm{kt} \mathrm{ENE}$ and $1006 \mathrm{mb}$ at Abaco Island at 00Z (micro). 15 kt SW and $994 \mathrm{mb}$ at Puerto Plata, Dominican Republic at 06Z (micro). $10 \mathrm{kt} \mathrm{N}$ and 998 $\mathrm{mb}$ at Grand Turk and Caicos at 12Z (micro). $20 \mathrm{kt} \mathrm{SW}$ and $996 \mathrm{mb}$ at Aguadilla, Puerto Rico at $18 Z$ (micro). Aircraft highlights: Penetration center fix estimated maximum surface winds of $60 \mathrm{kt}$ and an eye diameter of $40 \mathrm{~nm}$ at $22.6 \mathrm{~N}, 66.4 \mathrm{~W}$ at $1915 \mathrm{Z}$ (ATSR/climo). Penetration center fix at 22.6N, 66.2W at 2020Z (ATSR).

ATSR: "By 4 November the $200 \mathrm{mb}$ chart indicated a more east to northeasterly trend and continued intensification due to divergent flow aloft and the warm waters over which 
the storm was now passing. High level Air Force reconnaissance on 4 November reported an "eye" centered at $22.6 \mathrm{~N}$ and $66.4 \mathrm{~W}$ at $1915 \mathrm{Z}$ and maximum surface winds estimated at $60 \mathrm{kt}$. The wind field estimated from ship and reconnaissance reports now indicated intensification near the center. At 2200Z, 4 November, coordinated Warning Number One Hurricane Greta was issued."

November 5:

HWM analyzes a hurricane of at most $970 \mathrm{mb}$ at $25.8 \mathrm{~N}, 60.7 \mathrm{~W}$ with a warm front extending to the east at 12Z. HURDAT lists this as a 120 knot hurricane at $25.3 \mathrm{~N}, 61.0 \mathrm{~W}$ at $12 \mathrm{Z}$. Microfilm shows a closed low pressure of at most $975 \mathrm{mb}$ at $26.2 \mathrm{~N}, 61.2 \mathrm{~W}$ at 12Z. Ship highlights: $50 \mathrm{kt} \mathrm{N}$ and $978 \mathrm{mb}$ at 22.6N, 66.3W at $00 \mathrm{Z}$ (COADS). $55 \mathrm{kt} \mathrm{N}$ and $997 \mathrm{mb}$ at $22.5 \mathrm{~N}, 66.0 \mathrm{~W}$ at $03 \mathrm{Z}$ (micro). $45 \mathrm{kt} \mathrm{SSW}$ and $987 \mathrm{mb}$ at $22.4 \mathrm{~N}, 62.0 \mathrm{~W}$ at $06 \mathrm{Z}$ (COADS). $50 \mathrm{kt} \mathrm{NNE}$ and $997 \mathrm{mb}$ at 27.0N, 63.0W at 12Z (COADS). $35 \mathrm{kt} \mathrm{NE}$ and 969 $\mathrm{mb}$ at $28.5 \mathrm{~N}, 63.5 \mathrm{~W}$ (longitude appears too far west)(no time given but likely around 18Z). Land highlights: $30 \mathrm{kt} \mathrm{SW}$ and $1001 \mathrm{mb}$ at St. Martin at 00Z (micro). Aircraft highlights: Penetration center fix estimated maximum surface winds of $120 \mathrm{kt}$ and a central pressure of $970 \mathrm{mb}$ at $26.1 \mathrm{~N}, 61.1 \mathrm{~W}$ at $1320 \mathrm{Z}$ (ATSR). Penetration center fix estimated maximum surface winds of $70 \mathrm{kt}$ at $27.4 \mathrm{~N}, 58.5 \mathrm{~W}$ at $2220 \mathrm{Z}$ (ATSR).

MWR: "Continued to intensify until November 5 when winds in excess of $100 \mathrm{mph}$ and a minimum pressure of $970 \mathrm{mb}$ (28.64 in) were reported by reconnaissance aircraft. During this period the forward motion became east-northeast at 20-25 mph." ATSR: "On 5 November, Navy low level reconnaissance reported the "eye" centered by radar precipitation echoes and wind circulation at $26-03 \mathrm{~N}$ and $61-03 \mathrm{~W}$ at $1320 \mathrm{Z}$ with a minimum surface pressure of $970 \mathrm{mb}$, maximum surface winds of 120 knots to the north and east quadrants. At 2220Z, 5 November, Air Force reconnaissance penetrated after dark at the $500 \mathrm{mb}$ level and reported the center at $27-25 \mathrm{~N}$ and $58-27 \mathrm{~W}$ with maximum winds of 70 knots east and south of the storm at that level. It was also reported that much of the cloudiness surrounding the "eye" could be topped at 10,000 to 14,000 feet."

November 6:

HWM analyzes a hurricane of at most $980 \mathrm{mb}$ at $29.9 \mathrm{~N}, 53.5 \mathrm{~W}$ with a cold front about $120 \mathrm{~nm}$ miles to the northwest at 12Z. HURDAT lists this as an 85 knot hurricane at $30.6 \mathrm{~N}, 51.2 \mathrm{~W}$ at $12 \mathrm{Z}$. Microfilm shows a closed low pressure of at most $990 \mathrm{mb}$ at $30.5 \mathrm{~N}, 53.5 \mathrm{~W}$ at $12 \mathrm{Z}$. Ship highlights: $60 \mathrm{kt} \mathrm{N}$ and $1004 \mathrm{mb}$ at $28.7 \mathrm{~N}, 63.5 \mathrm{~W}$ at $00 \mathrm{Z}$ (micro). $60 \mathrm{kt} \mathrm{E}$ and $992 \mathrm{mb}$ at 31.2N, 53.8W at 06Z (COADS). $40 \mathrm{kt} \mathrm{SE}$ and $984 \mathrm{mb}$ at $31.0 \mathrm{~N}, 52.6 \mathrm{~W}$ at $12 \mathrm{Z}$ (COADS). $80 \mathrm{kt} \mathrm{NNE}$ and $999 \mathrm{mb}$ at $31.0 \mathrm{~N}, 53.0 \mathrm{~W}$ at $15 \mathrm{Z}$ (micro). $60 \mathrm{kt} \mathrm{SW}$ and $996 \mathrm{mb}$ at 30.2N, 50.6W at 18Z (COADS). Aircraft highlights: Penetration 
center fix at $28.3 \mathrm{~N}, 56.8 \mathrm{~W}$ at $0245 \mathrm{Z}$ (ATSR). Penetration center fix at $29.5 \mathrm{~N}, 55.5 \mathrm{~W}$ at 0720Z (ATSR).

MWR: "On November 6 and 7 the storm continued east-northeastward at an accelerated speed, gradually assuming extratropical characteristics due to much colder ocean temperatures and an influx of cold air." ATSR: "Hurricane Greta continued on a northeasterly course reaching a speed of 22 knots by 1000Z, 6 November. By this time, a combination of effects was beginning to limit Greta's life span. The increased forward speed and the course over cooler water had decreased the maximum surface winds from 120 knots to about 85 to 90 knots by 1000Z, 6 November. By 2200Z, 6 November, Hurricane Greta had become extratropical with maximum surface winds of 55 to 60 knots and the final warning was issued."

November 7:

HWM analyzes a closed low pressure of at most $1000 \mathrm{mb}$ at $35.0 \mathrm{~N}, 36.0 \mathrm{~W}$ with a cold front extending through the system northeast to southwest at 12Z. HURDAT lists this as a 45 knot extratropical cyclone at $34.5 \mathrm{~N}, 37.7 \mathrm{~W}$ at $06 \mathrm{Z}$ (last position). Microfilm shows a closed low pressure of at most $996 \mathrm{mb}$ at $33.5 \mathrm{~N}, 46.0 \mathrm{~W}$ at $00 \mathrm{Z}$. Ship highlights: $35 \mathrm{kt} \mathrm{NE}$ and $998 \mathrm{mb}$ at $33.5 \mathrm{~N}, 48.0 \mathrm{~W}$ at $00 \mathrm{Z}$ (micro). $40 \mathrm{kt} \mathrm{NW}$ and $1006 \mathrm{mb}$ at $32.5 \mathrm{~N}$, $47.2 \mathrm{~W}$ at $06 \mathrm{Z}$ (COADS). $40 \mathrm{kt} \mathrm{SW}$ and $1009 \mathrm{mb}$ at $32.6 \mathrm{~N}, 35.0 \mathrm{~W}$ at $12 \mathrm{Z}$ (COADS).

A broad area of low pressure was present over the central Caribbean Sea late in October, possibly associated with the eastern Pacific monsoon trough. The low pressure started to become better organized around October 30 south of Jamaica while slowly moving northward. A $25 \mathrm{kt}$ tropical depression is analyzed to have developed at $12 \mathrm{Z}$ on October $31^{\text {st }}$ just north of eastern Cuba. Genesis is delayed 30 hours compared to the original HURDAT, a major change. Ship and land observations indicate that a well-defined low level circulation was not present on October $30^{\text {th }}$ or early on the $31^{\text {st }}$. Minor track changes are analyzed from October $31^{\text {st }}$ to November $6^{\text {th }}$ at $12 \mathrm{Z}$, and major track changes are analyzed on November $6^{\text {th }}$ at $18 \mathrm{Z}$ and November $7^{\text {th }}$ at $00 \mathrm{Z}$ and $06 \mathrm{Z}$. The depression continued moving northward and later northeastward. At $18 \mathrm{Z}$ on the $31^{\text {st }}$, calm conditions and $1003 \mathrm{mb}$ were reported at Ragged Island, Bahamas. A central pressure of $1003 \mathrm{mb}$ is added to HURDAT at $18 \mathrm{Z}$ on the $31^{\text {st }}$. A central pressure of $1003 \mathrm{mb}$ suggests maximum sustained winds of $41 \mathrm{kt}$ from the south of $25 \mathrm{~N}$ Brown et al. pressure-wind relationship. Due to the large size of the cyclone, low environmental pressures and no reports of galeforce winds, an intensity of $30 \mathrm{kt}$ is selected at $18 \mathrm{Z}$ on the $31^{\text {st }}$. At $00 \mathrm{Z}$ on November $1^{\text {st }}$, the depression crossed Long Island, Bahamas, on its way to the Atlantic. Two ships reported $35 \mathrm{kt}$ at $06 \mathrm{Z}$ and it is analyzed that at this time, the depression reached tropical storm intensity. Intensification to a tropical storm is analyzed 30 hours earlier than originally shown in HURDAT, a major change. More gales were reported by ships on the 
$1^{\text {st }}$, reaching up to $45 \mathrm{kt}$ at $18 \mathrm{Z}$. At $18 \mathrm{Z}$, an intensity of $50 \mathrm{kt}$ is selected, up from $30 \mathrm{kt}$ in HURDAT, a major intensity change. Late on November $1^{\text {st }}$, the northward progression of Greta stopped and the storm turned to the west. Shortly after, Greta turned to the southeast completing a counter-clockwise loop early on the $3^{\text {rd }}$.

At $00 \mathrm{Z}$ on November $2^{\text {nd }}$, HURDAT shows a central pressure of $992 \mathrm{mb}$. According to the MWR, the National Hurricane Research Project made this measurement and the central pressure is retained. A central pressure of $992 \mathrm{mb}$ suggests maximum sustained winds of $56 \mathrm{kt}$ from the north of $25 \mathrm{~N}$ pressure-wind relationship and $59 \mathrm{kt} \mathrm{N} 25 \mathrm{~N}$ intensifying. Due to the large size of the tropical storm and slow forward speed, an intensity of $50 \mathrm{kt}$ is selected. Major intensity changes are introduced at $00 \mathrm{Z}, 06 \mathrm{Z}$ and $18 \mathrm{Z}$ on the $2^{\text {nd }}$. It is analyzed that Greta had an intensity of $50 \mathrm{kt}$ at $00 \mathrm{Z}$ and $06 \mathrm{Z}$ and $55 \mathrm{kt}$ at 18Z, while HURDAT indicates $30 \mathrm{kt}, 30 \mathrm{kt}$ and $35 \mathrm{kt}$, respectively. Numerous ships reported gale-force winds on the $2^{\text {nd }}$, including $55 \mathrm{kt}$ at $21 \mathrm{Z}$. On November $3^{\text {rd }}$, Greta started to gain forward speed while moving southeastward and passing over $100 \mathrm{~nm}$ northeast of the eastern Bahamas. The tropical cyclone slowly intensified on the $3^{\text {rd }}$ reaching $60 \mathrm{kt}$ at $06 \mathrm{Z}$ on the $3^{\text {rd }}$, up from $45 \mathrm{kt}$ in HURDAT, a minor intensity change. The cyclone continued to grow in size and on the $3^{\text {rd }}$ at $12 \mathrm{Z}$, the $34 \mathrm{kt}$ wind radii of Greta extended to about $500 \mathrm{~nm}$ to the northwest quadrant. A central pressure of $982 \mathrm{mb}$ is present in HURDAT at $12 \mathrm{Z}$ on the $3^{\text {rd }}$ and although it is not in the MWR or Navy book, reconnaissance aircraft was present around this time and it is retained. A central pressure of $982 \mathrm{mb}$ suggests maximum sustained winds of $70 \mathrm{kt}$ from the north of $25 \mathrm{~N}$ and $75 \mathrm{kt}$ south of $25 \mathrm{~N}$ pressure-wind relationship. Due to the large size of Greta and low environmental pressures, an intensity of $60 \mathrm{kt}$ is selected for $12 \mathrm{Z}$ on the $3^{\text {rd }}$, up from $55 \mathrm{kt}$ in HURDAT, a minor change. Gale-force winds continued to be reported by ships on the $3^{\text {rd }}$, reaching up to $45 \mathrm{kt}$. Gale-force winds were also reported by land stations late on the $3^{\text {rd }}$ over the eastern Bahamas. Tropical Storm Greta turned to the east late on the $4^{\text {th }}$ and then to the northeast on the $5^{\text {th }}$ while gaining in forward speed. Intensification to hurricane is analyzed at $00 \mathrm{Z}$ on the $4^{\text {th }}$, six hours earlier than HURDAT. A ship at $00 \mathrm{Z}$ on the $4^{\text {th }}$ reported $40 \mathrm{kt} \mathrm{W}$ and $986 \mathrm{mb}$. A pressure of 986 yields maximum sustained winds greater than $70 \mathrm{kt}$ south of $25 \mathrm{~N}$ according to the pressure-wind relationship. An intensity of $65 \mathrm{kt}$ is selected at $00 \mathrm{Z}$ on the $4^{\text {th }}$, bringing Greta to hurricane intensity. Winds of hurricane intensity were reported by ships on the $4^{\text {th }}$, including $80 \mathrm{kt}$ at $15 \mathrm{Z}$ and $70 \mathrm{kt}$ at $21 \mathrm{Z}$. The $34 \mathrm{kt}$ wind radii at $12 \mathrm{Z}$ on the $4^{\text {th }}$ is analyzed to have been about $550 \mathrm{~nm}$ to the northwest.

A reconnaissance aircraft estimated maximum surface winds of $60 \mathrm{kt}$ and an eye diameter of $40 \mathrm{~nm}$ at $1915 \mathrm{Z}$ on the $4^{\text {th }}$. At $18 \mathrm{Z}$, a central pressure of $970 \mathrm{mb}$ is present and it appears likely that it was from the same reconnaissance mission. A central pressure of $970 \mathrm{mb}$ suggests maximum sustained winds of $90 \mathrm{kt}$ from the south of $25 \mathrm{~N}$ pressure-wind 
relationship. An eye diameter of $40 \mathrm{~nm}$ suggests an RMW of about $30 \mathrm{~nm}$ and climatology for this central pressure and latitude $17 \mathrm{~nm}$. Due to the large size of Greta and forward speed of about $15 \mathrm{knots}$, an intensity of $85 \mathrm{kt}$ is selected at $18 \mathrm{Z}$ on the $4^{\text {th }}$, down from $95 \mathrm{kt}$ originally in HURDAT, a minor change. Hurricane Greta continued to move rapidly to the northeast on the $5^{\text {th }}$ while moving away from the northeastern Caribbean where the swells from the hurricane caused damage. A reconnaissance aircraft measured a central pressure of $970 \mathrm{mb}$ and estimated maximum surface winds of $120 \mathrm{kt}$ (which were used verbatim in HURDAT) at 1312Z. A central pressure of $970 \mathrm{mb}$ suggests maximum sustained winds of $84 \mathrm{kt}$ north of $25 \mathrm{~N}$ and $90 \mathrm{kt}$ south of $25 \mathrm{~N}$, according to the pressure-wind relationship. Greta was still a very large hurricane, the ROCI at $12 \mathrm{Z}$ is estimated at $500 \mathrm{~nm}$, but it was moving at a pace of about $25 \mathrm{kt}$, thus an intensity of $85 \mathrm{kt}$ is selected for $12 \mathrm{Z}$ on the $5^{\text {th }}$, down from $120 \mathrm{kt}$ originally in HURDAT, a major intensity change. Major intensity changes are also introduced at 00Z, 06Z, and 18Z. $85 \mathrm{kt}$ is selected for those times and HURDAT has $110 \mathrm{kt}, 115 \mathrm{kt}$ and $120 \mathrm{kt}$, respectively. $85 \mathrm{kt}$ is also the peak intensity for Greta, down from $120 \mathrm{kt}$ originally shown in HURDAT, a major intensity change. The reanalysis indicates that Greta never reached major hurricane status. Gale-force winds were reported by numerous ships on the $5^{\text {th }}$, including $50 \mathrm{kt}$ with $978 \mathrm{mb}$ at $00 \mathrm{Z}$. Transition to an extratropical cyclone is analyzed at $06 \mathrm{Z}$ on the $6^{\text {th }}, 18$ hours earlier than originally shown in HURDAT. Data analysis at $06 \mathrm{Z}$ on the $6^{\text {th }}$ indicates that a warm front had developed to the northeast of the center and a temperature gradient was clearly visible between the eastern and northern quadrants. Furthermore, the microfilm data suggests that the circulation was becoming elongated northeast-southwest. A central pressure of $985 \mathrm{mb}$ is present in HURDAT at 12Z on the $6^{\text {th }}$. It has been removed because a ship at $12 \mathrm{Z}$ located at $31.0 \mathrm{~N}, 52.0 \mathrm{~W}$ reported $40 \mathrm{kt} \mathrm{SE}$ and $984 \mathrm{mb}$. At $12 \mathrm{Z}$ on the $6^{\text {th }}$, a ship reported $80 \mathrm{kt}$ and the intensity has been kept at 85 kt. Late on the $6^{\text {th }}$ and early on the $7^{\text {th }}$, Greta continued northeastward becoming embedded within a frontal boundary. After $06 \mathrm{Z}$ on the $7^{\text {th }}$, the circulation had dissipated (unchanged from HURDAT). Microfilm data clearly indicates that major track changes are necessary at $18 \mathrm{Z}$ on the $6^{\text {th }}$ and $00 \mathrm{Z}$ and $06 \mathrm{Z}$ on the $7^{\text {th }}$ as the extratropical cyclone was not moving as fast as shown in HURDAT. The extratropical cyclone is analyzed to have weakened below hurricane intensity at $06 \mathrm{Z}$ on the $7^{\text {th }}$. The largest $34 \mathrm{kt}$ wind radii of Hurricane Sandy, analyzed at $00 Z$ on October 28, 2012, reached $480 \mathrm{~nm}$. The ROCI of Hurricane Sandy on October $28^{\text {th }}$ at $18 \mathrm{Z}$ was also estimated to be $500 \mathrm{~nm}$.

New Tropical Storm [November 19-21, 1956]

\begin{tabular}{|c|c|c|c|c|c|c|c|c|c|c|c|c|c|}
\hline 37265 & $11 / 19 / 1956$ & $M=12$ & 23 & $\mathrm{SNBR}=820$ & 0 UNN & AMED & & $I N G=c$ & $\mathrm{SSS}=0$ & & & & $\mathrm{~L}$ \\
\hline 37265 & $11 / 19 * 250$ & 470 & 25 & $0 * 250$ & 473 & 30 & $\odot * 25 \odot$ & 478 & 35 & $\Theta * 251$ & 483 & 40 & $0^{*}$ \\
\hline 37265 & $11 / 20 * 253$ & 487 & 40 & $0 * 255$ & 491 & 40 & $0 * 256$ & 490 & 40 & $0 * 253$ & 487 & 40 & ०* \\
\hline
\end{tabular}


A new tropical storm has been added to HURDAT, not previously shown in McAdie et al. (2009). Evidence for its existence comes from the Historical Weather Map series, COADS ship database, and Jack Beven's suspect list.

November 18:

HWM shows a spot low pressure at $23.5 \mathrm{~N}, 43.5 \mathrm{~W}$ at $12 \mathrm{Z}$. Ship highlights: No gale force winds or equivalent low pressures.

November 19:

HWM shows a closed low pressure of at most $1010 \mathrm{mb}$ at $25.0 \mathrm{~N}, 48.0 \mathrm{~W}$ at $12 \mathrm{Z}$. Ship highlights: No gale force winds or equivalent low pressures.

November 20:

HWM shows a closed low pressure of at most $1010 \mathrm{mb}$ at $25.5 \mathrm{~N}, 48.0 \mathrm{~W}$ and a stationary frontal boundary to the north at 12Z. Ship highlights: $30 \mathrm{kt} \mathrm{SSW}$ and $1002 \mathrm{mb}$ at $25.0 \mathrm{~N}, 48.7 \mathrm{~W}$ at $00 \mathrm{Z}$ (COADS). $30 \mathrm{kt} \mathrm{W}$ and $1005 \mathrm{mb}$ at $25.2 \mathrm{~N}, 49.5 \mathrm{~W}$ at $06 \mathrm{Z}$ (COADS). $35 \mathrm{kt} \mathrm{S}$ and $1009 \mathrm{mb}$ at $25.3 \mathrm{~N}, 47.4 \mathrm{~W}$ at $12 \mathrm{Z}$ (COADS).

November 21:

HWM shows a trough of low pressure along $22 \mathrm{~N}-30 \mathrm{~N}, 51 \mathrm{~W}$ at $12 \mathrm{Z}$. Ship highlights: No gale force winds or equivalent low pressures.

November 22:

HWM does not show an organized system at 12Z. Ship highlights: No gale force winds or equivalent low pressures.

A small area of low pressure developed as a frontal boundary weakened over the central Atlantic during the third week of November. Ship data indicates that it became better organized and a $25 \mathrm{kt}$ tropical depression is analyzed to have developed at $00 \mathrm{Z}$ on November $19^{\text {th }}$. It is certainly possible that the tropical cyclone developed late on the $18^{\text {th }}$ but the data is too scarce on this day. The tropical depression moved slowly to the west becoming a tropical storm at $12 \mathrm{Z}$ on November $19^{\text {th }}$. A ship reported $30 \mathrm{kt} \mathrm{SSW}$ and $1002 \mathrm{mb}$ at $06 \mathrm{Z}$ on November $20^{\text {th }}$. A peripheral pressure of $1002 \mathrm{mb}$ suggests maximum 
sustained winds of at least $43 \mathrm{kt}$ south of $25 \mathrm{~N}$ and $40 \mathrm{kt}$ north of the $25 \mathrm{~N}$ from the Brown et al. pressure-wind relationship. An intensity of $40 \mathrm{kt}$ is selected for $06 \mathrm{z}$ on November $20^{\text {th }}$ due to the slow forward motion of the storm. $40 \mathrm{kt}$ is the peak intensity of this tropical storm. At $12 \mathrm{Z}$ on the $20^{\text {th }}$, a ship reported $35 \mathrm{kt} \mathrm{S}$ and $1009 \mathrm{mb}$ and the ship mentioned previously was reporting $30 \mathrm{kt} \mathrm{W}$ and $1005 \mathrm{mb}$. The tropical cyclone began weakening early om November $21^{\text {st }}$, diminishing to a tropical depression at $12 \mathrm{Z}$ and degenerating later on the day into a trough of low pressure.

\section{6 - Additional Notes}

1) January 4-8: A low pressure developed along the tail-end of a frontal boundary over the central Atlantic on January 5th. The disturbance remained nearly stationary over the next few days according to the Historical Weather Map. A strong pressure gradient to the north resulted in gale-force winds $400 \mathrm{~nm}$ north of the center. On the 6th, numerous ships near the center reported low pressures (below $1000 \mathrm{mb}$ ) but no gale-force winds, which is likely an indication that the system was never a tropical cyclone or subtropical cyclone. The disturbance started weakening on the 7 th and was absorbed by a cold front on the 8th. Therefore, because it likely remained as an extratropical low, it is not added to HURDAT.

\begin{tabular}{|c|c|c|}
\hline Day & LONG & STATUS \\
\hline January 4 & Central Atlantic & Cold front \\
\hline January 5 & $25 \mathrm{~N}$ & Extratropical \\
\hline January 6 & $26 \mathrm{~N}$ & Extratropical \\
\hline January 7 & $45 \mathrm{~W}$ & Extratropical \\
\hline January 8 & $46 \mathrm{~W}$ & Absorbed by front \\
\hline
\end{tabular}

2) May 22-25: A trough of low pressure was located north of Hispaniola on May 22nd. The disturbance moved generally northeastward ahead of a frontal boundary, while becoming slighly better organized on the $23 \mathrm{rd}$ and 24 th. The system weakened back to a trough on the 25th over the central Atlantic and was absorbed by the cold front soon after. No gale-force winds were found in COADS or HWM associated with this disturbance. Therefore, it is not added to HURDAT. This disturbance was in Beven's and Roth's List of Suspects.

$\begin{array}{llll}\text { Day } & \text { LAT } & \text { LONG } & \text { STATUS } \\ \text { May 22 } & 20-25 \mathrm{~N} & 69 \mathrm{~W} & \text { Trough } \\ \text { May 23 } & 27 \mathrm{~N} & 64 \mathrm{~W} & \text { Tropical Depression? } \\ \text { May 24 } & 27 \mathrm{~N} & 60 \mathrm{~W} & \text { Tropical Depression? } \\ \text { May 25 } & 24-34 \mathrm{~N} & 53-60 \mathrm{~W} & \text { Trough }\end{array}$


3) June 18-20: A non-frontal low pressure developed east of the Bahamas on the 18th and moved northward. Two ships reported gale-force winds east of the disturbance on the 18 th. The disturbance was also monitored by a reconnaissance aircraft on the 18 th. The reconnaissance mission did not find a closed low-level circulation, just a minimum pressure of $1014 \mathrm{mb}$. The system continued northward on the 19th and by the 20th it was absorbed by a frontal boundary. Therefore, without a closed circulation when gale force winds were observed, it is not added to HURDAT. This disturbance was in Beven's and Roth's List of Suspects.

$\begin{array}{llll}\text { Day } & \text { LAT } & \text { LONG } & \text { STATUS } \\ \text { June 18 } & 25 \mathrm{~N} & 71 \mathrm{~W} & \text { Trough } \\ \text { June 19 } & 30 \mathrm{~N} & 69 \mathrm{~W} & \text { Trough } \\ \text { June 20 } & 33 \mathrm{~N} & 59 \mathrm{~W} & \text { Absorbed by front }\end{array}$

4) July 5-7: A low pressure developed over the northeast Gulf of Mexico on July 5th producing gusty conditions over the western Florida panhandle. Panama City reported a gust to $38 \mathrm{kt}$ on the 6th. No gales or equivalent low pressures were found in COADS, Microfilm, or Surface Weather Observations. By the 7th, the system had moved inland and dissipated soon thereafter. MWR: "A complete although very weak circulation was noted at 1930 EST on July 4, at Lat. 26.2N., Long. 86.2W., developing under a cold trough in the mid-troposphere. It moved north-northwestward and northwestward on the 6th causing gusts of 38 knots at Panama City and moved inland near Pensacola late on the 6th where the lowest barometer noted was $1011 \mathrm{mb}$. Whatley, Ala., reported 14.22 inches of rain during the storm and 10.85 inches in 24 hours. Property damage was estimated at $\$ 400,000$ from the heavy rains, plus $\$ 100,000$ crop and $\$ 3,000$ livestock damage. Many highway and railroad bridges were washed out and erosion of roads was extensive." Therefore, it is not added to HURDAT. Because this system did not have observed gale force sustained winds, disturbance was in Beven's List of Suspects.

\begin{tabular}{llll} 
Day & LAT & LONG & \multicolumn{1}{c}{ STATUS } \\
July 5 & $28 \mathrm{~N}$ & $85 \mathrm{~W}$ & Tropical Depression? \\
July 6 & $29 \mathrm{~N}$ & $87 \mathrm{~W}$ & Tropical Depression? \\
July 7 & $30 \mathrm{~N}$ & $88 \mathrm{~W}$ & Dissipated
\end{tabular}

5) August 14-17: A strong tropical wave followed Hurricane Betsy to the Caribbean Sea during the middle of August. The vigorous disturbance produced gale-force winds on the 15th as it approached the Lesser Antilles but a reconnaissance aircraft found that the circulation was poorly-organized with no west-winds on the southern quadrant. The disturbance continued westward and became less organized over the eastern Caribbean Sea as it interacted with the Greater Antilles. Therefore, because it did not have a closed circulation, it is not added to HURDAT. 


\begin{tabular}{|c|c|c|c|}
\hline Day & LAT & LONG & STATUS \\
\hline August 14 & $15 \mathrm{~N}$ & $53 \mathrm{~W}$ & Tropical Wave \\
\hline August 15 & $15 \mathrm{~N}$ & $56 \mathrm{~W}$ & Tropical Wave \\
\hline August 16 & $18 \mathrm{~N}$ & $64 \mathrm{~W}$ & Tropical Wave \\
\hline August 17 & $18 \mathrm{~N}$ & $66 \mathrm{~W}$ & Tropical Wa \\
\hline
\end{tabular}

6) August 29 - September 7: A strong tropical wave left the African coast on August 28. The system gradually moved westward and on August 31st, the pressure at Santa Maria in the Cape Verde Islands dropped to $1004 \mathrm{mb}$, a drop of six millibars from the previous day. The ship and land data is sparse to suggest a closed low level circulation was present. During the next few days, the strong disturbance moved away from the Cape Verde Islands into the central Atlantic where the ship data is even more sparse. By September 6th, ships northeast of the Lesser Antilles indicate that the tropical wave did not have a closed low level circulation. On the 7 th, the disturbance continued to lose organization as it moved toward the Lesser Antilles. MWR: "On August 28 an unusually strong wave on the intertropical convergence zone began approaching the Cape Verde Islands and soon developed considerable intensity. Station SAL in the Cape Verdes on the 31 st observed a barometer reading of $1004 \mathrm{mb}$. Several ships in the area reported winds of 35 to 40 knots. After leaving the Cape Verde area the storm apparently gradually decreased in intensity and finally dissipated northeast of the Leeward Islands on the 6th." Therefore, because it unknown whether the system had a closed low on the 31 st when the low pressure and gales were reported, it is not added to HURDAT. This disturbance was in Beven's List of Suspects.

\begin{tabular}{lrcl} 
Day & LAT & LONG & \multicolumn{1}{c}{ STATUS } \\
August 29 & $14 \mathrm{~N}$ & $19 \mathrm{~W}$ & Tropical Wave \\
August 30 & $14 \mathrm{~N}$ & $20 \mathrm{~W}$ & Tropical Depression? \\
August 31 & $15 \mathrm{~N}$ & $24 \mathrm{~W}$ & Tropical Storm? \\
September 1 & $14 \mathrm{~N}$ & $27 \mathrm{~W}$ & Tropical Storm? \\
September 2 & $15 \mathrm{~N}$ & $32 \mathrm{~W}$ & Tropical Storm? \\
September 3 & $15 \mathrm{~N}$ & $36 \mathrm{~W}$ & Tropical Storm? \\
September 4 & $15 \mathrm{~N}$ & $40 \mathrm{~W}$ & Tropical Storm? \\
September 5 & $18 \mathrm{~N}$ & $46 \mathrm{~W}$ & Tropical Depression? \\
September 6 & $17 \mathrm{~N}$ & $50 \mathrm{~W}$ & Tropical Wave \\
September 7 & $17 \mathrm{~N}$ & $55 \mathrm{~W}$ & Tropical Wave
\end{tabular}

7) September 11-13: A strong tropical wave left the African coast on September 10th. The disturbance moved westward passing by the Cape Verde Islands on the 12th. On this day, a ship just north of the islands reported a pressure of $1005 \mathrm{mb}$ but the data is very sparse to suggest a closed low level circulation was present. The tropical wave continued westward into the central Atlantic where the ship data is even sparser. No gales were 
found associated with this disturbance. MWR: "A vigorous depression passed through the Cape Verdes on the 13th, attended by squalls. Maximum winds are unknown. The depression was completely damped out before reaching the Antilles." Therefore, without any gale force winds or indications of a closed low, it is not added to HURDAT. This disturbance was in Beven's List of Suspects.

$\begin{array}{lccc}\text { Day } & \text { LAT } & \text { LONG } & \text { STATUS } \\ \text { September 11 } & 15 \mathrm{~N} & 20 \mathrm{~W} & \text { Tropical Wave } \\ \text { September 12 } & 13 \mathrm{~N} & 22 \mathrm{~W} & \text { Tropical Depression? } \\ \text { September 13 } & 12 \mathrm{~N} & 27 \mathrm{~W} & \text { Tropical Depression? }\end{array}$

8) September 29-30: A low pressure developed over the Gulf of Mexico on September 29 and moved to the northwest making landfall in Texas on the 30th. No gale-force winds were found in microfilm or HWM associated with this disturbance. Therefore, without any gale force winds, it is not added to HURDAT.

$\begin{array}{llll}\text { Day } & \text { LAT } & \text { LONG } & \text { STATUS } \\ \text { September 29 } & \text { 23N } & 92 \mathrm{~W} & \text { Tropical Depression? } \\ \text { September 30 } & \text { 26N } & 94 \mathrm{~W} & \text { Dissipated }\end{array}$

9) October 10-12: A low pressure developed over the central Atlantic on October 10th, possibly in the northern portion of a tropical wave. The disturbance drifted northward and was absorbed by a cold front on October 13. No gale-force winds were found in COADS or HWM associated with this disturbance. MWR: "Probably developing from the same easterly wave but farther to the north, a tropical depression formed on October 10 and moved in a general northerly direction for several days without further development. It was not the same depression noted on the 9th (new storm)." Therefore, without any gale force winds, it is not added to HURDAT. This disturbance was in Beven's List of Suspects.

$\begin{array}{llll}\text { Day } & \text { LAT } & \text { LONG } & \text { STATUS } \\ \text { October 10 } & 25 \mathrm{~N} & 50 \mathrm{~W} & \text { Tropical Depression? } \\ \text { October 11 } & 29 \mathrm{~N} & 52 \mathrm{~W} & \text { Tropical Depression? } \\ \text { October 12 } & 29 \mathrm{~N} & 54 \mathrm{~W} & \text { Tropical Depression? } \\ \text { October 13 } & & & \text { Absorbed by front }\end{array}$

10) October 22-26: A low pressure developed on the tail-end of a frontal boundary over the eastern Atlantic on October 22nd. The system moved southwestward on the 23rd and became an occluded low pressure. As another frontal boundary approached, the disturbance turned northward and by October 25th, gale-force winds were being reported about $150 \mathrm{~nm}$ north of the center. Nonetheless, data suggests that the disturbance never 
became a tropical or subtropical cyclone before being absorbed by the frontal boundary. Therefore, it is not added to HURDAT. This disturbance was in Roth's List of Suspects.

\begin{tabular}{llll} 
Day & LAT & LONG & \multicolumn{1}{c}{ STATUS } \\
October 22 & $32 \mathrm{~N}$ & $31 \mathrm{~W}$ & Extratropical \\
October 23 & $30 \mathrm{~N}$ & $35 \mathrm{~W}$ & Extratropical \\
October 24 & $34 \mathrm{~N}$ & $37 \mathrm{~W}$ & Extratropical \\
October 25 & $36 \mathrm{~N}$ & $41 \mathrm{~W}$ & Extratropical \\
October 26 & $45 \mathrm{~N}$ & $41 \mathrm{~W}$ & Absorbed by front
\end{tabular}

11) October 28-30: An extratropical cyclone was located east of North Carolina on October 28 and slowly moved southwestward becoming occluded the next day. Galeforce winds were reported about $200 \mathrm{~nm}$ from the center but data suggests it never acquired tropical characteristics. The disturbance made landfall on October 30th and dissipated a day later. Therefore, it is not added to HURDAT.

$\begin{array}{llll}\text { Day } & \text { LAT } & \text { LONG } & \text { STATUS } \\ \text { October 28 } & \text { 34N } & 73 \mathrm{~W} & \text { Extratropical } \\ \text { October 29 } & \text { 31N } & 76 \mathrm{~W} & \text { Extratropical } \\ \text { October 30 } & \text { 33N } & 78 \mathrm{~W} & \text { Extratropical } \\ \text { October 31 } & & & \text { Dissipated }\end{array}$

12) November 3-5: Microfilm shows that a non-frontal low pressure developed east of Hurricane Greta early on November 3rd. The disturbance moved rapidly to the northeast on the 4th with gale-force winds near the center and low pressures (below $1000 \mathrm{mb}$ ) according to ships in the area. At the same time, there was a powerful extratropical cyclone over the north Atlantic and ship data suggests that there may have been a trough connecting both systems as winds north of the non-frontal low pressure were responding to the larger extratropical cyclone. On November 5 th, the disturbance was absorbed by the extratropical cyclone. The environment around the disturbance was moist and temperatures were warm, suggesting the system was likely tropical or subtropical, but the data suggests that the low level circulation was probably not closed. Therefore, it is not added to HURDAT.

$\begin{array}{lccl}\text { Day } & \text { LAT } & \text { LONG } & \text { STATUS } \\ \text { November 3 } & 23 \mathrm{~N} & 57 \mathrm{~W} & \text { Trough } \\ \text { November 4 } & 29 \mathrm{~N} & 48 \mathrm{~W} & \text { Trough } \\ \text { November 5 } & & & \text { Absorbed by an extratropical cyclone }\end{array}$




\section{7 hurricane season}

New Tropical Storm [April 30-May 4, 1957]

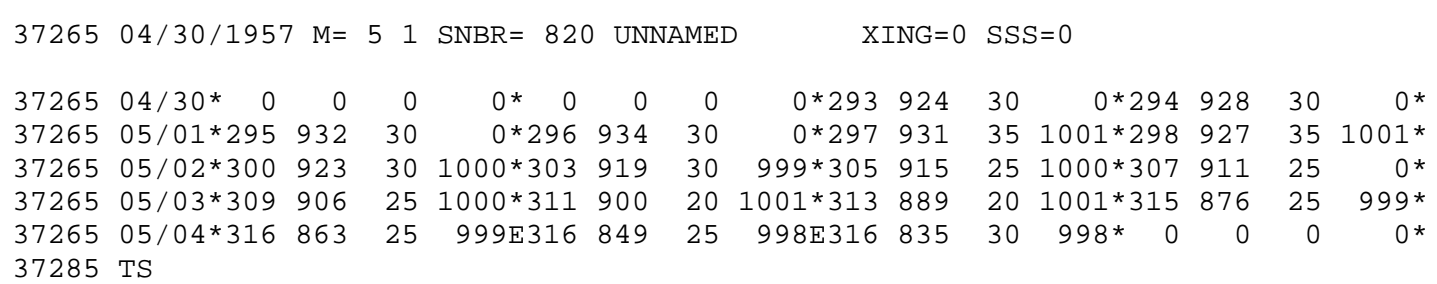

U.S. Tropical Storm Landfall

05/01 14Z 29.7N 93.0W 35 kt LA

A new tropical storm has been added to HURDAT, not previously shown in McAdie et al. (2009). Evidence for its existence comes from the Historical Weather Map series, Microfilm, COADS ship database and Surface Weather Observations.

April 29:

HWM analyzes a warm front over the central United States at 12Z. Microfilm shows a frontal boundary over the northwest Gulf of Mexico at 12Z. Ship highlights: No gale force winds or equivalent low pressures.

April 30:

HWM analyzes a closed low pressure of at most 1010 at $27.5 \mathrm{~N}, 91.5 \mathrm{~W}$ at $12 \mathrm{Z}$. Microfilm shows a closed low pressure of at most 1008 at $29.0 \mathrm{~N}, 92.0 \mathrm{~W}$ at $12 \mathrm{Z}$. Ship highlights: $30 \mathrm{kt}$ ENE and $1007 \mathrm{mb}$ at $29.5 \mathrm{~N}, 92.5 \mathrm{~W}$ at $12 \mathrm{Z}$ (micro).

May 1:

HWM analyzes a closed low pressure of at most 1010 at $29.0 \mathrm{~N}, 93.5 \mathrm{~W}$ at $12 \mathrm{Z}$. Microfilm shows a closed low pressure of at most 1005 at $29.5 \mathrm{~N}, 93.0 \mathrm{~W}$ at $12 \mathrm{Z}$. The MWR Track of Centers shows a low pressure of $1004 \mathrm{mb}$ at 29.5N, 93.2W at 12Z. Ship highlights: $30 \mathrm{kt} \mathrm{W}$ and $1003 \mathrm{mb}$ at $29.5 \mathrm{~N}, 92.5 \mathrm{~W}$ at $00 \mathrm{Z}$ (micro). $35 \mathrm{kt} \mathrm{WSW}$ and 1004 $\mathrm{mb}$ at $28.9 \mathrm{~N}, 92.6 \mathrm{~W}$ at $12 \mathrm{Z}$ (micro). $20 \mathrm{kt} \mathrm{SSE}$ and $1003 \mathrm{mb}$ at $29.5 \mathrm{~N}, 92.5 \mathrm{~W}$ at $12 \mathrm{Z}$ (micro). $30 \mathrm{kt} \mathrm{WSW}$ and $1005 \mathrm{mb}$ at $28.8 \mathrm{~N}, 92.7 \mathrm{~W}$ at $12 \mathrm{Z}$ (micro). Land highlights: 14 kt ESE and $1004 \mathrm{mb}$ at LaFayette, LA at $1828 \mathrm{Z}$ (SWO).

May 2:

HWM analyzes a closed low pressure of at most 1005 at $29.5 \mathrm{~N}, 91.5 \mathrm{~W}$ with a trough extending to another closed low pressure of at most $1005 \mathrm{mb}$ at $31.5 \mathrm{~N}, 78.5 \mathrm{~W}$ at 
12Z. Microfilm shows a closed low pressure of at most 1005 at $30.0 \mathrm{~N}, 91.5 \mathrm{~W}$ at $12 \mathrm{Z}$. The MWR Track of Centers shows a low pressure of $1002 \mathrm{mb}$ at $30.5 \mathrm{~N}, 91.5 \mathrm{~W}$ at $12 \mathrm{Z}$. Ship highlights: $20 \mathrm{kt} \mathrm{WNW}$ and $1004 \mathrm{mb}$ at $29.1 \mathrm{~N}, 92.4 \mathrm{~W}$ at $12 \mathrm{Z}$ (COADS). Land highlights: $14 \mathrm{kt} \mathrm{E}$ and $1003 \mathrm{mb}$ at LaFayette, LA at 0028Z (SWO). $15 \mathrm{kt} \mathrm{W}$ and 1002 $\mathrm{mb}$ at LaFayette, LA at 0628Z (SWO). $17 \mathrm{kt} \mathrm{SSE}$ and $1002 \mathrm{mb}$ at Baton Rouge, LA at $1128 \mathrm{Z}$ (SWO). $8 \mathrm{kt} \mathrm{WSW}$ and $1004 \mathrm{mb}$ at Baton Rouge, LA at 1828Z (SWO). $6 \mathrm{kt}$ ENE and $1001 \mathrm{mb}$ at McComb, MS at 2328Z (SWO.

May 3:

HWM analyzes a closed and E-W elongated low pressure of at most 1005 at $31.0 \mathrm{~N}, 90.0 \mathrm{~W}$ with a trough extending to another closed low pressure off the US east coast and a cold front to the north at 12Z. Microfilm shows a closed low pressure of at most 1005 at $32.0 \mathrm{~N}, 88.5 \mathrm{~W}$ with a frontal boundary to the north at $12 \mathrm{Z}$. The MWR Track of Centers shows a low pressure of $1003 \mathrm{mb}$ at $31.2 \mathrm{~N}, 88.5 \mathrm{~W}$ at 12Z. Ship highlights: 15 $\mathrm{kt} \mathrm{SW}$ and $1005 \mathrm{mb}$ at $28.8 \mathrm{~N}, 91.6 \mathrm{~W}$ at $00 \mathrm{Z}$ (COADS). Land highlights: $7 \mathrm{kt} \mathrm{NW}$ and $1004 \mathrm{mb}$ at Baton Rouge, LA at 0028Z (SWO). $8 \mathrm{kt} \mathrm{NW}$ and $1003 \mathrm{mb}$ at McComb, MS at $0528 \mathrm{Z}$ (SWO). $15 \mathrm{kt} \mathrm{W}$ and $1004 \mathrm{mb}$ at Mobile, AL at $12 \mathrm{Z}$ (micro). $15 \mathrm{kt} \mathrm{SW}$ and $1001 \mathrm{mb}$ at Evergreen, AL at $18 \mathrm{Z}$ (micro).

May 4:

HWM analyzes a frontal boundary from the northern Gulf of Mexico to the western Atlantic with an elongated area of low pressure near the SE United States at $12 \mathrm{Z}$. Microfilm shows a closed low pressure of at most 1002 at $32.0 \mathrm{~N}, 83.5 \mathrm{~W}$ with a frontal boundary extending to the east and south at $12 \mathrm{Z}$. The MWR Track of Centers shows a low pressure of $1000 \mathrm{mb}$ at $31.8 \mathrm{~N}, 83.0 \mathrm{~W}$ at 12Z. Ship highlights: $15 \mathrm{kt} \mathrm{SW}$ and 1005 $\mathrm{mb}$ at $27.9 \mathrm{~N}, 85.2 \mathrm{~W}$ at $00 \mathrm{Z}$ (COADS). $35 \mathrm{kt} \mathrm{NE}$ and $1005 \mathrm{mb}$ at $31.8 \mathrm{~N}, 80.5 \mathrm{~W}$ at $18 \mathrm{Z}$ (micro).Land highlights: $10 \mathrm{kt} \mathrm{S}$ and $1001 \mathrm{mb}$ at Dothan, AL at 00Z (micro). $10 \mathrm{kt} \mathrm{SSW}$ and $1000 \mathrm{mb}$ at Dothan, AL at 06Z (micro). $20 \mathrm{kt} \mathrm{SW}$ and $1002 \mathrm{mb}$ at Valdosta, GA at $12 \mathrm{Z}$ (micro).

May 5:

HWM analyzes a closed low pressure of at most $1005 \mathrm{mb}$ at $35.5 \mathrm{~N}, 68.0 \mathrm{~W}$ with a warm front to the east and a cold front to the southwest at 12Z. Microfilm shows a closed low pressure of at most $1005 \mathrm{mb}$ at $34.0 \mathrm{~N}, 70.0 \mathrm{~W}$ with a frontal boundary to the east and southwest at $12 \mathrm{Z}$. The MWR Track of Centers shows a low pressure at $31.7 \mathrm{~N}, 77.8 \mathrm{~W}$ at 00Z (last position).

The development of this off-season tropical storm appears to be associated with an upper level low that became cut-off over the southern United States and moved into the 
northern Gulf of Mexico late on April. A low pressure developed at the surface and a 30 $\mathrm{kt}$ tropical depression is analyzed to have formed at $12 \mathrm{Z}$ on April 30 just off the coast of Louisiana. At 12Z, a ship close to the center reported $30 \mathrm{kt} \mathrm{ENE}$ and $1007 \mathrm{mb}$. The environment around the tropical depression was very moist with dew points in the mid to high 60s. The surface analysis on Microfilm and Historical Weather Maps do not show any type of frontal boundary associated with the tropical cyclone and the strongest winds were close to the center. The $500 \mathrm{mb}$ analysis on the Historical Weather Maps shows an upper level low basically on top of the depression, thus it is likely that this cyclone was subtropical. But since we do not have satellite images to determine its structure, it is analyzed as a tropical cyclone. The system initially moved slowly to the west and later turned to the northeast on May $1^{\text {st }}$. Intensification to a tropical storm is analyzed at $12 \mathrm{Z}$ on the $1^{\text {st }}$. A ship at that time reported $35 \mathrm{kt} \mathrm{WSW}$ and $1004 \mathrm{mb}$. Another ship at that time reported $20 \mathrm{kt} \mathrm{SSE}$ and $1003 \mathrm{mb}$, which allows us to estimate a central pressure of $1001 \mathrm{mb}$. A central pressure of $1001 \mathrm{mb}$ suggests maximum sustained winds of $42 \mathrm{kt}$ north of $25 \mathrm{~N}$ from the Brown et al. pressure-wind relationship. Due to the slow forward speed of the cyclone, an intensity of $35 \mathrm{kt}$ is selected for $12 \mathrm{Z}$ on the $1^{\text {st }}$. A central pressure of $1001 \mathrm{mb}$ is added at $12 \mathrm{Z}$ on the $1^{\text {st }} .35 \mathrm{kt}$ is the peak intensity for this tropical cyclone. At $14 \mathrm{Z}$ on the $1^{\text {st }}$, the small tropical storm made landfall in southern Louisiana near $29.7 \mathrm{~N}, 93.0 \mathrm{~W}$ or about 20 miles southeast of Cameron, LA, with an intensity of 35 kt. At $1828 \mathrm{Z}$ on the $1^{\text {st }}$, LaFayette, LA reported $15 \mathrm{kt}$ ESE and $1004 \mathrm{mb}$, and due to land exposure, this suggests a central pressure of $1001 \mathrm{mb}$, which has been added to $18 \mathrm{Z}$. Weakening to a tropical depression is analyzed at $00 \mathrm{Z}$ on May $2^{\text {nd }}$ over southern Louisiana. A ship near the coast reported $30 \mathrm{kt} \mathrm{W}$ and $1003 \mathrm{mb}$ at this time. At $00 \mathrm{Z}$ on the $2^{\text {nd }}$, LaFayette, LA reported $15 \mathrm{kt} \mathrm{E}$ and $1003 \mathrm{mb}$, this suggests a central pressure of $1000 \mathrm{mb}$, which has been added. At $06 \mathrm{Z}$ on the $2^{\text {nd }}$, LaFayette, LA reported $15 \mathrm{kt} \mathrm{W}$ and $1002 \mathrm{mb}$, this suggests a central pressure of $999 \mathrm{mb}$, which has been added. At $12 \mathrm{Z}$ on the $2^{\text {nd }}$, Baton Rouge, LA reported $15 \mathrm{kt} \mathrm{SW}$ and $1003 \mathrm{mb}$, this suggests a central pressure of $1000 \mathrm{mb}$, which has been added. Reports from ships and land stations indicate the depression continued to weaken and the winds are decreased to $25 \mathrm{kt}$ at $12 \mathrm{Z}$ on the $2^{\text {nd }}$. Late on the $2^{\text {nd }}$, the depression crossed into southern Mississippi. At $2328 \mathrm{Z}$ on the $2^{\text {nd }}$, McComb, MS reported $5 \mathrm{kt} \mathrm{ENE}$ and $1001 \mathrm{mb}$, this suggests a central pressure of $1000 \mathrm{mb}$, which has been added at $00 \mathrm{Z}$ on the $3^{\text {rd }}$. Early on the $3^{\text {rd }}$, the depression starts to accelerate to the east-northeast and the structure broadens, becoming elongated $\mathrm{E}-\mathrm{W}$, with weak winds near it. The intensity at $06 \mathrm{Z}$ and $12 \mathrm{Z}$ on the $3^{\text {rd }}$ is decreased to $20 \mathrm{kt}$. At $0528 \mathrm{Z}$ on the $3^{\text {nd }}$, McComb, MS reported $10 \mathrm{kt} \mathrm{NW}$ and $1003 \mathrm{mb}$, this suggests a central pressure of $1001 \mathrm{mb}$, which has been added at $06 \mathrm{Z}$. At $12 \mathrm{Z}$ on the $3^{\text {nd }}$, Meridian, MS reported $10 \mathrm{kt} \mathrm{S}$ and $1003 \mathrm{mb}$, suggesting a central pressure of $1001 \mathrm{mb}$, which has been added. Late on the $3^{\text {rd }}$, the tropical depression crossed into southern Alabama. At $18 \mathrm{Z}$ on the $3^{\text {rd }}$, Evergreen, AL reported $15 \mathrm{kt} \mathrm{SW}$ and $1001 \mathrm{mb}$, suggesting a central pressure of 
$999 \mathrm{mb}$, which has been added. Winds up to $20 \mathrm{kt}$ were reported on the coast of Alabama and northwest Florida at $18 \mathrm{Z}$ on the $3^{\text {rd }}$, therefore the intensity is increased to $25 \mathrm{kt}$ at this time. At $00 \mathrm{Z}$ on May $4^{\text {th }}$, the microfilm analysis included a frontal boundary that reached the system's center and also depicts another frontal boundary to the north. The observations around the system show that it was still tropical, with dew points in the mid 60s. At $00 \mathrm{Z}$ on the $4^{\text {nd }}$, Dothan, AL reported $10 \mathrm{kt} \mathrm{S}$ and $1001 \mathrm{mb}$, this suggests a central pressure of $999 \mathrm{mb}$, which has been added. At $06 \mathrm{Z}$ on the $4^{\text {th }}$, observations indicate that the depression became an extratropical cyclone over southeast Alabama. At the same time, Dothan, AL reported $10 \mathrm{kt} \mathrm{SSW} \mathrm{and} 1000 \mathrm{mb}$, suggesting a central pressure of 998 $\mathrm{mb}$, which has been added. At $12 \mathrm{Z}$ on the $4^{\text {th }}$, Valdosta, GA reported $20 \mathrm{kt} \mathrm{SW}$ and 1002 $\mathrm{mb}$, this suggests a central pressure of $998 \mathrm{mb}$, which has been added. Later on the $4^{\text {th }}$, the extratropical cyclone becomes embedded with another extratropical cyclone off the US SE coast forming a large extratropical cyclone that moved into the north Atlantic over the next couple of days. The last position is analyzed at $12 \mathrm{Z}$ on the $4^{\text {th }}$.

\section{Unnamed Tropical Storm 1 [June 8-15, 1957]}

\begin{tabular}{|c|c|c|c|c|c|c|c|c|c|c|c|c|c|c|}
\hline 40065 & $06 / 08 / 195$ & $M=$ & 8 & $\mathrm{SNBR}=8$ & $72 \mathrm{NO}$ & $\mathrm{NA}$ & MED & XII & $\mathrm{JG}=1$ & SSS= & & & & \\
\hline 40065 & $06 / 08 / 195$ & $M=$ & 8 & SNBR $=87$ & $72 \mathrm{NO}$ & & MED & XII & $J G=1$ & SSS $=$ & & & & \\
\hline 40070 & $06 / 08$ * & $\odot$ & $\odot$ & $0 * 255$ & 885 & 20 & & * 262 & 878 & 35 & $0 * 282$ & 862 & 35 & $0^{*}$ \\
\hline 40070 & $06 / 08$ * & $\odot$ & $\odot$ & $0 * 250$ & 892 & 35 & & * 265 & 878 & 40 & $1002 * 282$ & 862 & 45 & 0 * \\
\hline 40075 & $06 / 09 * 30 \odot$ & 843 & 35 & $0 * 316$ & 823 & 35 & & *326 & 802 & 35 & $0 * 330$ & 782 & 45 & $0^{*}$ \\
\hline 40075 & $06 / 09 * 300$ & 843 & 45 & $1000 * 316$ & 823 & 35 & 1003 & $3 * 321$ & 802 & 35 & $0 * 323$ & 782 & 45 & ०* \\
\hline 40080 & $06 / 10 * 331$ & 761 & 55 & OE332 & 742 & 60 & & E330 & 726 & 60 & OE325 & 714 & 60 & ०* \\
\hline $4 \odot \odot 8 \odot$ & ๑6/10E324 & 761 & 55 & ๑E326 & 742 & 65 & & E328 & 726 & 65 & 996E324 & 716 & 65 & ०* \\
\hline 40085 & $06 / 11 E 320$ & 703 & 55 & OE315 & 687 & 55 & & E310 & 673 & 50 & OE3०9 & 666 & 45 & 0* \\
\hline $4 \odot \odot 85$ & ๑6/11E319 & 707 & 60 & ๑E314 & 699 & 55 & & E308 & 692 & $5 \odot$ & ๑ЕЗ०9 & 685 & 50 & $\Theta^{*}$ \\
\hline 40090 & 06/12E311 & 661 & 45 & OE317 & 656 & 40 & & E322 & 652 & 35 & ОЕЗ3० & 658 & 35 & $0^{*}$ \\
\hline $4 \odot \odot 9 \odot$ & ๑6/12E310 & 680 & 45 & ๑E311 & 675 & 40 & & E314 & 672 & $4 \odot$ & ๑E318 & 667 & 40 & $\Theta^{*}$ \\
\hline 40095 & 06/13E322 & 661 & 35 & OE321 & 649 & 35 & & E321 & 636 & 35 & ӨE327 & 624 & 35 & ०* \\
\hline 40095 & 06/13E322 & 661 & 40 & OE322 & 653 & 40 & & E323 & 639 & $4 \odot$ & ๑Е327 & 624 & 40 & ○* \\
\hline 40100 & $06 / 14$ E334 & 613 & 35 & ๑E34๑ & 604 & 35 & & E346 & 596 & 35 & ๑E356 & 584 & 35 & ०* \\
\hline $4010 \odot$ & ๑6/14E332 & 611 & 40 & ๑E337 & 598 & 40 & & E341 & 588 & $4 \odot$ & ๑E345 & 582 & 40 & ○* \\
\hline 40105 & ๑6/15E37๑ & 571 & 35 & ОE387 & 564 & 35 & & * & $\odot$ & $\odot$ & $\Theta^{*} \quad \odot$ & $\odot$ & $\odot$ & $0^{*}$ \\
\hline 40105 & 06/15E345 & 580 & 35 & OE34๑ & 585 & 35 & & E335 & 595 & 30 & ОЕ33० & 605 & 25 & $0^{*}$ \\
\hline
\end{tabular}

40110 TS

U.S. Tropical Storm Landfall

06/09 0030Z 30.1N 84.2W $45 \mathrm{kt} \mathrm{FL}$ 
Minor track and intensity changes shown in McAdie et al. (2009). Evidence for these alterations comes from the NHC microfilm maps, the Historical Weather Maps series, the COADS ship database, Mexican synoptic maps, Surface Weather Observations and Monthly Weather Review.

June 7:

HWM analyzes a spot low pressure at $23.5 \mathrm{~N}, 93.2 \mathrm{~W}$ at $12 \mathrm{Z}$. HURDAT and microfilm do not list an organized storm on this date. Microfilm does not show an organized system on this date. Ship highlights: No gales or low pressures.

MWR: "Pressures were abnormally low over the southwestern Gulf of Mexico and Yucatan area on June 7 but lack of upper-air wind observations from Mexico made the amount of circulation uncertain."

June 8:

HWM analyzes a closed low pressure of at most $1005 \mathrm{mb}$ at $27.5 \mathrm{~N}, 87.5 \mathrm{~W}$ at 12Z. HURDAT lists a $35 \mathrm{kt}$ tropical storm at $26.2 \mathrm{~N}, 87.8 \mathrm{~W}$ at $12 \mathrm{Z}$. Microfilm shows a closed low pressure of at most $1005 \mathrm{mb}$ at $27.0 \mathrm{~N}, 88.0 \mathrm{~W}$ at 12Z. Ship highlights: $40 \mathrm{kt} \mathrm{S}$ and $1006 \mathrm{mb}$ at $26.7 \mathrm{~N}, 86.8 \mathrm{~W}$ at $12 \mathrm{Z}$ (COADS). $15 \mathrm{kt} \mathrm{S}$ and $1004 \mathrm{mb}$ at $25.9 \mathrm{~N}, 87.4 \mathrm{~W}$ at $12 \mathrm{Z}$ (COADS). $45 \mathrm{kt} \mathrm{SSW}$ and $1011 \mathrm{mb}$ at $25.9 \mathrm{~N}, 85.4 \mathrm{~W}$ at $18 \mathrm{Z}$ (COADS). $45 \mathrm{kt} \mathrm{NNE}$ and $1003 \mathrm{mb}$ at $28.7 \mathrm{~N}, 88.5 \mathrm{~W}$ at $21 \mathrm{Z}$ (micro). Land highlights: $5 \mathrm{kt} \mathrm{NNE}$ and $1005 \mathrm{mb}$ at Panama City, FL at $21 \mathrm{Z}$ (micro).

MWR: "However, late on the 7th and early on the 8th it became evident that a tropical depression existed. It moved rather rapidly northeastward with some deepening but little organization and crossed the Florida coastline in Apalachee Bay during the early evening. Two ships, one about 150 to 200 miles southeast of the center and later another 100 to 150 miles west of the center, reported winds of 45 knots. However, over coastal areas all strong winds were on the east side of the storm. Exposed places along the coast from Sarasota to north of Cedar Keys, Fla., experienced winds of $40 \mathrm{~m}$. p. h. or more and tides 2 to 3 feet above normal with some damage."

June 9:

HWM analyzes a closed low pressure of at most $1005 \mathrm{mb}$ at $32.0 \mathrm{~N}, 80.5 \mathrm{~W}$ at 12Z. HURDAT lists a $35 \mathrm{kt}$ tropical storm at $32.6 \mathrm{~N}, 80.2 \mathrm{~W}$ and a frontal boundary just north at 12Z. Microfilm shows a closed low pressure of at most $1005 \mathrm{mb}$ at $32.0 \mathrm{~N}$, $80.0 \mathrm{~W}$ at $12 \mathrm{Z}$. Ship highlights: $35 \mathrm{kt} \mathrm{SSE}$ and $1010 \mathrm{mb}$ at $25.6 \mathrm{~N}, 84.7 \mathrm{~W}$ at $00 \mathrm{Z}$ (COADS). $35 \mathrm{kt} \mathrm{N}$ and $1002 \mathrm{mb}$ at $32.8 \mathrm{~N}, 79.3 \mathrm{~W}$ at $15 \mathrm{Z}$ (micro). $35 \mathrm{kt} \mathrm{W}$ and $1005 \mathrm{mb}$ at $31.7 \mathrm{~N}, 78.6 \mathrm{~W}$ at $18 \mathrm{Z}$ (COADS). $50 \mathrm{kt} \mathrm{SW}$ and $1003 \mathrm{mb}$ at $31.8 \mathrm{~N}, 76.1 \mathrm{~W}$ at $21 \mathrm{Z}$ 
(micro). Land highlights: $1005 \mathrm{mb}$ at Panama City, FL at 00Z (micro). $1001 \mathrm{mb}$ at Tallahassee, FL (likely after 01Z) (CLIMO). $30 \mathrm{kt} \mathrm{S}$ at Sarasota, Fl at 01Z (SWO). $5 \mathrm{kt}$ NNW and $1004 \mathrm{mb}$ at Alma, GA at 06Z (micro). $1002 \mathrm{mb}$ at Savannah, GA (likely around 10Z) (CLIMO). $1005 \mathrm{mb}$ at Charleston, SC (likely around 12Z) (CLIMO).

MWR: "The storm weakened as it moved inland but set off an active frontal wave after moving off the Georgia coast on the 9th."

June 10:

HWM analyzes a closed low pressure of at most $1000 \mathrm{mb}$ at $33.5 \mathrm{~N}, 72.5 \mathrm{~W}$ with a warm front to the east and a cold front to the southwest at 12Z. HURDAT lists a $60 \mathrm{kt}$ extratropical cyclone at $33.0 \mathrm{~N}, 72.6 \mathrm{~W}$ at $12 \mathrm{Z}$. Microfilm shows a closed low pressure of at most $1002 \mathrm{mb}$ at $33.0 \mathrm{~N}, 72.5 \mathrm{~W}$ with a frontal boundary to the southeast and southwest at 12Z. Ship highlights: $45 \mathrm{kt} \mathrm{SW}$ and $1002 \mathrm{mb}$ at $31.7 \mathrm{~N}, 76.2 \mathrm{~W}$ at $00 \mathrm{Z}$ (COADS). $65 \mathrm{kt}$ $\mathrm{NE}$ and $1004 \mathrm{mb}$ at 32.9N, $72.3 \mathrm{~W}$ at $03 \mathrm{Z}$ (COADS). $60 \mathrm{kt} \mathrm{NE}$ and $1003 \mathrm{mb}$ at 33.9N, $73.5 \mathrm{~W}$ at $12 \mathrm{Z}$ (COADS). $65 \mathrm{kt} \mathrm{ESE}$ and $1009 \mathrm{mb}$ at $33.8 \mathrm{~N}, 70.5 \mathrm{~W}$ at $18 \mathrm{Z}$ (COADS).

MWR: "Late on the 9th when the storm became extratropical off the Atlantic coast, ship reports indicated winds up to 65 knots."

June 11:

HWM analyzes a closed low pressure of at most $1000 \mathrm{mb}$ at $31.5 \mathrm{~N}, 69.5 \mathrm{~W}$ with a warm front to the northeast and a cold front to the east and south at 12Z. HURDAT lists a $50 \mathrm{kt}$ extratropical cyclone at $31.0 \mathrm{~N}, 67.3 \mathrm{~W}$ at $12 \mathrm{Z}$. Microfilm shows a closed low pressure of at most $1005 \mathrm{mb}$ at $31.0 \mathrm{~N}, 66.0 \mathrm{~W}$ with a frontal boundary to the eastsoutheast and southwest at 12Z. Ship highlights: $50 \mathrm{kt}$ ENE and $1004 \mathrm{mb}$ at $32.3 \mathrm{~N}$, $70.3 \mathrm{~W}$ at $00 \mathrm{Z}$ (COADS). $50 \mathrm{kt} \mathrm{NE}$ at $34.0 \mathrm{~N}, 71.3 \mathrm{~W}$ at $06 \mathrm{Z}$ (COADS). $45 \mathrm{kt} \mathrm{NE}$ and $1009 \mathrm{mb}$ at $32.6 \mathrm{~N}, 69.4 \mathrm{~W}$ at $12 \mathrm{Z}$ (COADS). $50 \mathrm{kt} \mathrm{NNE}$ and $1003 \mathrm{mb}$ at $31.7 \mathrm{~N}, 70.0 \mathrm{~W}$ at $18 \mathrm{Z}$ (COADS).

June 12:

HWM analyzes a closed low pressure of at most $1005 \mathrm{mb}$ at $30.0 \mathrm{~N}, 68.0 \mathrm{~W}$ with a warm front to the northeast and a weakening cold front to the east and south at $12 \mathrm{Z}$. HURDAT lists a $35 \mathrm{kt}$ extratropical cyclone at $32.2 \mathrm{~N}, 65.2 \mathrm{~W}$ at $12 \mathrm{Z}$. Microfilm shows a closed low pressure of at most $1008 \mathrm{mb}$ at $32.0 \mathrm{~N}, 65.5 \mathrm{~W}$ with a frontal boundary to the east and south at 12Z. Ship highlights: $20 \mathrm{kt} \mathrm{SE}$ and $1003 \mathrm{mb}$ at $31.0 \mathrm{~N}, 67.2 \mathrm{~W}$ at $00 \mathrm{Z}$ (COADS). $25 \mathrm{kt} \mathrm{NW}$ and $1004 \mathrm{mb}$ at $30.0 \mathrm{~N}, 68.5 \mathrm{~W}$ at $12 \mathrm{Z}$ (micro). 
June 13:

HWM analyzes a closed low pressure of at most $1010 \mathrm{mb}$ at $31.5 \mathrm{~N}, 64.5 \mathrm{~W}$ at 12Z. HURDAT lists a $35 \mathrm{kt}$ extratropical cyclone at $32.1 \mathrm{~N}, 63.6 \mathrm{~W}$ at $12 \mathrm{Z}$. Microfilm shows a closed low pressure of at most $1008 \mathrm{mb}$ at $32.0 \mathrm{~N}, 64.5 \mathrm{~W}$ at $12 \mathrm{Z}$. Ship highlights: $35 \mathrm{kt} \mathrm{SW}$ and $1012 \mathrm{mb}$ at $28.2 \mathrm{~N}, 64.3 \mathrm{~W}$ at $00 \mathrm{Z}$ (COADS). $40 \mathrm{kt} \mathrm{W}$ and $1010 \mathrm{mb}$ at $30.2 \mathrm{~N}, 65.3 \mathrm{~W}$ at $12 \mathrm{Z}(\mathrm{COADS})$.

June 14:

HWM analyzes a closed low pressure of at most $1010 \mathrm{mb}$ at $34.0 \mathrm{~N}, 59.0 \mathrm{~W}$ at 12Z. HURDAT lists a $35 \mathrm{kt}$ extratropical cyclone at $32.1 \mathrm{~N}, 63.6 \mathrm{~W}$ at $12 \mathrm{Z}$. Microfilm shows a closed low pressure of at most $1014 \mathrm{mb}$ at $38.0 \mathrm{~N}, 60.0 \mathrm{~W}$ at $12 \mathrm{Z}$. Ship highlights: $40 \mathrm{kt} \mathrm{SW}$ and $1012 \mathrm{mb}$ at $34.2 \mathrm{~N}, 56.6 \mathrm{~W}$ at $18 \mathrm{Z}$ (COADS).

June 15:

HWM analyzes a spot low pressure at $34.0 \mathrm{~N}, 59.0 \mathrm{~W}$ at $12 \mathrm{Z}$. HURDAT lists a $35 \mathrm{kt}$ extratropical cyclone at 38.7N, 56.4W at 06Z (last position). Microfilm does not show an organized storm on this date. Ship highlights: $35 \mathrm{kt} \mathrm{SSE}$ and $1008 \mathrm{mb}$ at $35.0 \mathrm{~N}$, $57.9 \mathrm{~W}$ at $06 \mathrm{Z}$ (COADS).

June 16:

HWM analyzes a spot low pressure at $31.0 \mathrm{~N}, 59.0 \mathrm{~W}$ at $12 \mathrm{Z}$. HURDAT does not show an organized system on this date. Microfilm does not show an organized storm on this date. Ship highlights: No gales or low pressures.

MWR: "Exceptionally heavy rain attended passage of this storm, particularly in Suwannee and all adjacent counties; 48-hour amounts of nearly 15 inches at official stations and some unofficial amounts as high as 19 inches. There was considerable damage to field and truck crops, particularly to tobacco and watermelons. Between 100 and 200 families were evacuated near Perry, Fla. According to the Meteorologist in Charge at Jacksonville, at least nine tornadoes or damaging wind storms were reported in northeastern Florida on the afternoon and evening of the 8th and another tornado over Jekyll Island in south-eastern Georgia. No deaths were reported from these tornadoes and the damage and injuries were small. One small craft capsized in the Gulf of Mexico and five of the seven persons aboard were apparently drowned. Damage in northwestern Florida from sea and rainfall flooding from the mouth of the Suwannee River to Port St. Joe was estimated at $\$ 30,000$ and damage from tidal action along the Florida west coast mas about $\$ 10,000$. Tornado damage is estimated at $\$ 12,000$. Therefore, total damage from this tropical storm was around \$52,000 and there were five deaths." 
The first tropical cyclone of the 1957 Atlantic hurricane season developed in the central Gulf of Mexico at the start of the second week of June. A decrease in the barometric pressure by about 3-5 $\mathrm{mb}$ around the Bay of Campeche was noticeable on June $7^{\text {th }}$ from the previous day indicating that disturbance was organizing. The system moved rapidly to the northeast and HURDAT indicates that genesis occurred at $06 \mathrm{Z}$ on June $8^{\text {th }}$. Data over the western and southwest Gulf of Mexico is very sparse and the time of genesis is uncertain. Therefore, the first position (not genesis) remains unchanged from the original HURDAT. A ship reported $40 \mathrm{kt}$ at $12 \mathrm{Z}$ and, on this basis, the tropical cyclone initiated as a $35 \mathrm{kt}$ tropical storm at $06 \mathrm{Z}$, which is $15 \mathrm{kt}$ higher than HURDAT, a minor intensity change. Also, tropical storm intensity is analyzed six hours earlier than originally shown in HURDAT. Minor track changes are introduced for the duration of this cyclone's lifetime, except for $12 \mathrm{Z}$ on June $12^{\text {th }}$ and $06 \mathrm{Z}$ on June $15^{\text {th }}$ during the extratropical phase. The storm gradually intensified as it moved toward the panhandle of Florida. A ship reported $15 \mathrm{kt}$ and $1004 \mathrm{mb}$ at $12 \mathrm{Z}$ and this suggests a central pressure of around 1002 $\mathrm{mb}$, which has been added to HURDAT. The intensity was gradually increased to $40 \mathrm{kt}$ at $12 \mathrm{Z}, 5 \mathrm{kt}$ higher than the original HURDAT, a minor intensity change. At $18 \mathrm{Z}$ and $21 \mathrm{Z}$ on the $8^{\text {th }}$, two ships reported $45 \mathrm{kt}$. An intensity of $45 \mathrm{kt}$ is selected for $18 \mathrm{Z}$ on the $8^{\text {th }}, 10$ knots higher than the original HURDAT, a minor intensity change.

Landfall occurred around $0030 \mathrm{Z}$ on June $9^{\text {th }}$ as a $45 \mathrm{kt}$ tropical storm in the panhandle of Florida, just south of Tallahassee. Most of the winds associated with this tropical cyclone were on the eastern quadrant and Monthly Weather Review indicates that tropical storm force winds were reported between Sarasota and Cedar Key, FL. $45 \mathrm{kt}$ is also the peak intensity for this storm as a tropical cyclone. This is $10 \mathrm{kt}$ lower than originally shown in HURDAT, a minor intensity change. The pressure decreased to $1001 \mathrm{mb}$ in Tallahassee, FL according to the Local Climatological Data and this likely happened soon after landfall. A landfall pressure of $1000 \mathrm{mb}$ is estimated and has been added to HURDAT at $0 \mathrm{Z}$ on the $9^{\text {th }}$. Early on the $9^{\text {th }}$, the tropical cyclone moved across southeastern Georgia weakening to a minimal tropical storm. Alma, GA reported $5 \mathrm{kt} \mathrm{NNW}$ and $1004 \mathrm{mb}$ at $06 \mathrm{Z}$ on the $9^{\text {th }}$, suggesting a central pressure around $1003 \mathrm{mb}$, which has been added to HURDAT. The storm moved over the Atlantic Ocean around $10 \mathrm{Z}$ on June $9^{\text {th }}$ and immediately began to intensify as a cold front approached from the north and started to interact with the tropical cyclone. A ship reported $50 \mathrm{kt}$ at $21 \mathrm{Z}$ on the $9^{\text {th }}$ and an intensity of $45 \mathrm{kt}$ is selected for $18 \mathrm{Z}$ on the $9^{\text {th }}$, same as HURDAT. Late on the $9^{\text {th }}$ and early on the $10^{\text {th }}$, the structure of the storm began to resemble an extratropical cyclone with the data suggesting the circulation becoming elongated NE-SW. It is analyzed that the tropical storm became an extratropical cyclone around $00 \mathrm{Z}$ on June $10^{\text {th }}$, six hours earlier than originally shown in HURDAT. The intensity at $00 \mathrm{Z}$ on the $10^{\text {th }}$ is analyzed at $55 \mathrm{kt}$, same as HURDAT. HURDAT originally indicated that at this time it was still a tropical cyclone and $55 \mathrm{kt}$ was the original peak intensity. The extratropical cyclone moved 
generally eastward and various ships reported winds of $65 \mathrm{kt}$ on June $10^{\text {th }}$. An intensity of $65 \mathrm{kt}$ is analyzed at $06 \mathrm{Z}, 12 \mathrm{Z}$ and $18 \mathrm{Z}$ on the $10^{\text {th }}, 5 \mathrm{kt}$ higher at each time than originally shown in HURDAT, a minor intensity change. A ship reported $20 \mathrm{kt} \mathrm{SSE}$ and $998 \mathrm{mb}$ at $12 \mathrm{Z}$ on the $10^{\text {th }}$, suggesting a central pressure of $996 \mathrm{mb}$, which has been added to HURDAT.

On June $11^{\text {th }}$, the forward speed of the extratropical cyclone decreased and its intensity started to diminish. Various ships reported winds of $50 \mathrm{kt}$ on the $11^{\text {th }}$. Minor intensity changes are introduced from June $11^{\text {th }}$ to the $15^{\text {th }}$. On June $13^{\text {th }}$, the extratropical cyclone passed just south of Bermuda while moving northeast as a frontal boundary exited the United States. Late on June $14^{\text {th }}$ and early on the $15^{\text {th }}$, the northeast motion came to a stop and the cyclone turned to the south and southwest while continuing to lose strength. It's analyzed that it weakened below gale force at $12 \mathrm{Z}$ on the $15^{\text {th }}$ and degenerated into a trough of low pressure after $18 \mathrm{Z}$. The positions at $12 \mathrm{Z}$ and $18 \mathrm{Z}$ on June $15^{\text {th }}$ are new to HURDAT.

Hurricane Audrey [June 24-29, 1957]

\begin{tabular}{|c|c|c|c|c|c|c|c|c|c|c|c|c|c|}
\hline 40115 & $06 / 25 / 1957$ & $M=$ & 5 & SNBR $=8$ & $73 \mathrm{Al}$ & DREY & $X I$ & $N G=1$ & SSS $=$ & & & & \\
\hline 40115 & $\underset{* \star}{06 / 24 / 1957}$ & $M=$ & $\begin{array}{l}6 \\
\star\end{array}$ & SNBR $=8$ & $73 \mathrm{Al}$ & DREY & $X I$ & $N G=1$ & SSS $=$ & & & & \\
\hline (June & 24th is ne & ew to & HUF & DAT) & & & & & & & & & \\
\hline 40117 & $06 / 24$ * & $\odot$ & $\odot$ & $0^{*}$ & $\odot$ & $\odot$ & $0 * 210$ & 930 & 30 & $0 * 212$ & 931 & 35 & 0* \\
\hline 40120 & $06 / 25$ * & $\odot$ & $\odot$ & $0 * 216$ & 933 & 60 & $0 * 220$ & 934 & 85 & $989 * 226$ & 935 & 75 & $979 *$ \\
\hline 40120 & $06 / 25 * 214$ & $\begin{array}{l}932 \\
* * *\end{array}$ & $\begin{array}{l}40 \\
\star *\end{array}$ & $0 * 216$ & 933 & $\begin{array}{l}45 \\
* *\end{array}$ & $0 * 220$ & 934 & $\begin{array}{l}55 \\
* *\end{array}$ & $\begin{array}{l}\Theta_{*}^{*} 226 \\
\end{array}$ & 935 & $\begin{array}{l}65 \\
* *\end{array}$ & $\begin{array}{l}989 * \\
* * *\end{array}$ \\
\hline 40125 & $06 / 26$ *232 & 936 & 75 & $979 * 239$ & 937 & 80 & $0 * 247$ & 937 & 80 & $973 * 255$ & 938 & 85 & $\Theta^{*}$ \\
\hline 40125 & $\begin{array}{r}06 / 26 * 231 \\
* * *\end{array}$ & $\begin{array}{l}935 \\
* * *\end{array}$ & 75 & $\begin{array}{r}979 * 238 \\
* * *\end{array}$ & $\begin{array}{l}936 \\
* * *\end{array}$ & 80 & $0 * 247$ & 937 & 80 & $\begin{array}{l}\Theta^{*} 256 \\
* \quad * * *\end{array}$ & 938 & $\begin{array}{l}80 \\
* *\end{array}$ & $\begin{array}{l}973^{*} \\
* * *\end{array}$ \\
\hline 40130 & $06 / 27 * 265$ & 938 & 95 & $\odot * 279$ & 938 & 115 & $0 * 293$ & 938 & 125 & $946 * 307$ & 935 & 60 & $0^{*}$ \\
\hline 40130 & $\begin{array}{r}06 / 27^{*} 266 \\
* * *\end{array}$ & 938 & $\begin{array}{l}9 \odot \\
\star *\end{array}$ & $0 * 279$ & 938 & $\begin{array}{l}100 \\
* * *\end{array}$ & $0 * 293$ & 938 & $\begin{array}{l}105 \\
* * *\end{array}$ & $\begin{array}{l}950 * 307 \\
* * *\end{array}$ & 935 & $\begin{array}{l}80 \\
* *\end{array}$ & ○* \\
\hline 40135 & $06 / 28 * 320$ & 928 & 45 & 972 EЗ33 & 916 & $4 \odot$ & OE345 & 895 & 35 & ๑E365 & 861 & 30 & $\Theta^{*}$ \\
\hline 40135 & $06 / 28 * 320$ & 928 & $\begin{array}{l}55 \\
* *\end{array}$ & $\begin{array}{l}0 * 333 \\
* *\end{array}$ & $\begin{array}{l}912 \\
* * *\end{array}$ & 40 & $\begin{array}{r}0 * 347 \\
* * * *\end{array}$ & $\begin{array}{l}890 \\
* * *\end{array}$ & 35 & $\begin{array}{l}\odot * 365 \\
*\end{array}$ & 861 & 30 & $\Theta^{*}$ \\
\hline 40140 & ๑6/29E394 & 809 & 40 & OE437 & 771 & 50 & $\Theta^{*}$ & $\odot$ & $\odot$ & $\Theta^{*}$ & $\odot$ & $\odot$ & $\Theta^{*}$ \\
\hline 40140 & 06/29E394 & 809 & $\begin{array}{l}30 \\
* *\end{array}$ & $\begin{array}{r}\Theta^{*} \\
\text { * }\end{array}$ & $\odot$ & $\begin{array}{l}\odot \\
*\end{array}$ & $0^{*}$ & $\odot$ & $\odot$ & $\Theta^{*} \quad \odot$ & $\odot$ & $\odot$ & ○* \\
\hline
\end{tabular}


U.S. Hurricane:

June $27^{\text {th }}-14 \mathrm{Z}-29.8 \mathrm{~N} 93.6 \mathrm{~W}-105 \mathrm{kt}-$ Category $3-950 \mathrm{mb}-1003 \mathrm{mb}$ OCI -200 nm ROCI - 25 nm RMW

Minor changes to the track and major changes to the intensity shown in McAdie et al. (2009). Evidence for these alterations comes from the NHC microfilm maps, the Historical Weather Maps series, the COADS ship database, Monthly Weather Review, the Local Climatological Data, Surface Weather Observations, Mexican synoptic maps, National Weather Office in Lake Charles, LA (NWSLC), Schwardt et al. (1979), Ho et al. (1987), Jarrell et al. (1992) and Jarvinen (2006).

June 21:

HWM analyzes a closed low pressure of at most $1010 \mathrm{mb}$ at $16.5 \mathrm{~N}, 85.5 \mathrm{~W}$ at 12Z. HURDAT and microfilm do not list an organized storm on this date. Ship highlights: No gales or low pressures.

June 22:

HWM analyzes a spot low pressure at $18.0 \mathrm{~N}, 89.0 \mathrm{~W}$ at $12 \mathrm{Z}$. HURDAT and microfilm do not list an organized storm on this date. Ship highlights: No gales or low pressures.

June 23:

HWM analyzes a spot low pressure at 20.0N, $94.0 \mathrm{~W}$ at $12 \mathrm{Z}$. HURDAT and microfilm do not list an organized storm on this date. Ship highlights: No gales or low pressures.

June 24:

HWM analyzes a tropical storm of at most $1005 \mathrm{mb}$ at $21.8 \mathrm{~N}, 93.8 \mathrm{~W}$ at $12 \mathrm{Z}$. HURDAT does not list an organized storm on this date. Microfilm shows a closed low pressure of at most $1011 \mathrm{mb}$ at $20.0 \mathrm{~N}, 93.0 \mathrm{~W}$ at 12Z. Ship highlights: $5 \mathrm{kt} \mathrm{SW}$ and 1007 $\mathrm{mb}$ at $21.5 \mathrm{~N}, 93.2 \mathrm{~W}$ at $06 \mathrm{Z}$ (COADS). $10 \mathrm{kt} \mathrm{WNW}$ and $1006 \mathrm{mb}$ at $20.7 \mathrm{~N}, 94.4 \mathrm{~W}$ at $12 \mathrm{Z}$ (COADS). $20 \mathrm{kt} \mathrm{WW}$ and $1007 \mathrm{mb}$ at $19.8 \mathrm{~N}, 95.5 \mathrm{~W}$ at $18 \mathrm{Z}$ (COADS).

MWR: "Huricane Audrey, which struck the Gulf coast near the Texas-Louisiana border on June 27 with devastating effect, first became well defined over the Bay of Campeche, in the southwestern Gulf of Mexico, on June 24. A weak easterly wave which moved into the area. a day or two earlier, as evidenced by changes in the wind field across the western Caribbean and Yucatan and by increased shower activity, was probably instrumental in initiating the disturbance. The mean sea-surface temperatures for the Gulf 
of Mexico for June were generally 2 to 3F. above normal. In addition, warming was evident preceding the development of Audrey with the highest temperatures $(85 \mathrm{~F})$ in the area where the hurricane formed." ATSR: "An easterly wave located near $40^{\circ} \mathrm{W}$ on 14 June moved westward until 24 June when it became stationary in the Gulf of Campeche, it was from this early wave that Audrey developed. The easterly wave was very weak throughout its life span and did not show any tendencies of tropical storm development."

June 25:

HWM analyzes a hurricane of at most $1000 \mathrm{mb}$ at $22.5 \mathrm{~N}, 93.2 \mathrm{~W}$ at $12 \mathrm{Z}$. HURDAT lists an $85 \mathrm{kt}$ hurricane at 22.0N, 93.4W at 12Z. Microfilm shows a closed low pressure of at most $1008 \mathrm{mb}$ at $23.0 \mathrm{~N}, 93.0 \mathrm{~W}$ at $12 \mathrm{Z}$. Ship highlights: $35-40 \mathrm{kt}$, gusts to $55 \mathrm{kt}$ and $1009 \mathrm{mb}$ at $22.5 \mathrm{~N}, 94.5 \mathrm{~W}$ at $0230 \mathrm{Z}$ (MWR). $45 \mathrm{kt} \mathrm{WNW}$ and $998 \mathrm{mb}$ at $22.3 \mathrm{~N}$, 93.6W at $18 \mathrm{Z}$ (micro). $50 \mathrm{kt} \mathrm{SE}$ and $996 \mathrm{mb}$ at $23.5 \mathrm{~N}, 92.8 \mathrm{~W}$ at $21 \mathrm{Z}$ (micro). Aircraft highlights: Penetration center fix measured a central pressure of $989 \mathrm{mb}$, estimated maximum surface winds of $85 \mathrm{kt}$ and an eye diameter of $20 \mathrm{~nm}$ at $22.5 \mathrm{~N}, 93.5 \mathrm{~W}$ at $17 \mathrm{Z}$ (ATSR). Penetration center fix measured a central pressure of $979 \mathrm{mb}$ and estimated maximum surface winds of $60 \mathrm{kt}$ at $23.1 \mathrm{~N}, 93.4 \mathrm{~W}$ at $2257 \mathrm{Z}$ (ATSR). Penetration center fix measured a central pressure of $979 \mathrm{mb}$ and estimated maximum surface winds of 75 $\mathrm{kt}$ at $23.1 \mathrm{~N}, 93.4 \mathrm{~W}$ at $2348 \mathrm{Z}$ (ATSR).

MWR: "Audrey deepened during the night of June 24 while remaining nearly stationary. Aircraft reconnaissance on the morning of the 25 th reported maximum winds of 85 knots and minimum pressure $989 \mathrm{mb}$. Late on the afternoon of the 25th a second flight reported that the maximum observed wind was 75 knots and the minimum pressure $979 \mathrm{mb}$." ATSR: "By 0000Z, 25 June, a definite low center had formed near 22N 93W and a Navy low level reconnaissance flight was ordered to depart Jacksonville at daylight to investigate the area. A report from a fishing boat near $22.5 \mathrm{~N} 94.5 \mathrm{~W}$ at $250230 \mathrm{Z}$, reporting winds of 35 to $40 \mathrm{kt}$, was the first positive indication of a tropical storm in that area. The reconnaissance flight from Jacksonville reported the following at 251700Z: center of storm $22.5 \mathrm{~N} 93.5 \mathrm{~W}$, maximum winds of 85 knots, minimum pressure $989 \mathrm{mb}$. After Audrey developed hurricane force she moved almost straight north and entered the Gulf Coast near Texas-Louisiana coast."

June 26:

HWM analyzes a hurricane of at most $990 \mathrm{mb}$ at $24.9 \mathrm{~N}, 93.7 \mathrm{~W}$ at $12 \mathrm{Z}$. HURDAT lists an $80 \mathrm{kt}$ hurricane at $24.7 \mathrm{~N}, 93.8 \mathrm{~W}$ at $12 \mathrm{Z}$. Microfilm shows a closed low pressure of at most $993 \mathrm{mb}$ at $25.3 \mathrm{~N}, 93.3 \mathrm{~W}$ at 12Z. Ship highlights: $45 \mathrm{kt} \mathrm{SE}$ and 1003 $\mathrm{mb}$ at $24.6 \mathrm{~N}, 91.7 \mathrm{~W}$ at $02 \mathrm{Z}$ (micro). $40 \mathrm{kt} \mathrm{SE}$ and $1009 \mathrm{mb}$ at $25.7 \mathrm{~N}, 90.2 \mathrm{~W}$ at $06 \mathrm{Z}$ (COADS). $35 \mathrm{kt} \mathrm{NW}$ and $1005 \mathrm{mb}$ at 26.4N, 91.3W at 12Z (micro). $35 \mathrm{kt} \mathrm{SSE}$ and 1005 
$\mathrm{mb}$ at $25.4 \mathrm{~N}, 89.8 \mathrm{~W}$ at $18 \mathrm{Z}$ (COADS). $35 \mathrm{kt} \mathrm{ENE}$ and $998 \mathrm{mb}$ at $27.6 \mathrm{~N}, 93.7 \mathrm{~W}$ at $21 \mathrm{Z}$ (micro). Aircraft highlights: Penetration center fix measured a central pressure of $973 \mathrm{mb}$, estimated maximum surface winds of $90 \mathrm{kt}$ and an eye diameter of $20 \mathrm{~nm}$ at $25.4 \mathrm{~N}$, 93.8W at $1620 \mathrm{Z}$ (ATSR).

MWR: "On June 26 both the size and intensity of the hurricane increased slightly. Reconnaissance showed maximum winds of 90 knots and a minimum pressure of 973 mb."

June 27:

HWM analyzes a hurricane of at most $985 \mathrm{mb}$ at $29.3 \mathrm{~N}, 94.0 \mathrm{~W}$ at $12 \mathrm{Z}$. HURDAT lists a $125 \mathrm{kt}$ hurricane at $29.3 \mathrm{~N}, 93.8 \mathrm{~W}$ at $12 \mathrm{Z}$. Microfilm shows a closed low pressure of at most $984 \mathrm{mb}$ at 29.2N, 93.8W at 12Z. Ship highlights: $45 \mathrm{kt} \mathrm{NE}$ and 995 $\mathrm{mb}$ at $28.5 \mathrm{~N}, 93.2 \mathrm{~W}$ at $00 \mathrm{Z}$ (micro). $45 \mathrm{kt} \mathrm{ESE}$ and $989 \mathrm{mb}$ at $28.3 \mathrm{~N}, 92.9 \mathrm{~W}$ at $06 \mathrm{Z}$ (COADS). $969 \mathrm{mb}$ at 28.7N, 94.0W at 0910-1025Z (MWR). $75 \mathrm{kt} \mathrm{W}$ and $981 \mathrm{mb}$ at $28.6 \mathrm{~N}, 94.0 \mathrm{~W}$ at $12 \mathrm{Z}$ (COADS). Land highlights: $55 \mathrm{kt} \mathrm{E}$ at Port Arthur, TX at 06Z (micro). $959 \mathrm{mb}$ at Cameron, LA at 1430Z (MWR). "Calm" at Orange, TX at 1530Z (MWR). $65 \mathrm{kt}$ and gusts to $84 \mathrm{kt}$ at Lake Charles, LA at 1630Z (NWSLC). $55 \mathrm{kt} \mathrm{SW}$ and $977 \mathrm{mb}$ at Lake Charles, LA at $18 Z$ (micro). Aircraft highlights: Radar center fix at 27.3N, 93.8W at 03Z (ATSR). Radar center fix at 28.3N, 94.1W at 07Z (ATSR). Radar center fix estimated maximum surface winds of $95 \mathrm{kt}$ at $29.2 \mathrm{~N}, 94.2 \mathrm{~W}$ at $12 \mathrm{Z}$ (ATSR). Radar center fix at 29.6N, 94.2W and indicates landfall at 1330Z (ATSR). Radar center fix at $31.2 \mathrm{~N}, 92.7 \mathrm{~W}$ at $21 \mathrm{Z}$ (ATSR). "29.8N, 93.6W - $946 \mathrm{mb}-1007 \mathrm{mb}$ Penv - RMW $19 \mathrm{nmi}$ - speed $14 \mathrm{kt}-87 \mathrm{kt}$ est max sustained 10m, 10-min wind" (Schwardt et al. (1979)) (946.5 mb, 958.4 measured at Hackberry, LA - RMW $20 \mathrm{nmi}$ - $14 \mathrm{kt}$ forward speed - landfall pt 29.8N, 93.6W" (Ho et al. (1987). "Jun - TX4, LA4 - Cat 4 - 945 mb" (Jarrell et al. (1992). "80 kt, 955 mb, 52 nm RMW” (Jarvinen, 2006)

MWR: "A radar tracking flight during the night of the 26th reported the precipitation field as considerably more intense than observed 24 hours previously. However, no central pressure measurement was obtained. The only additional observation of central pressure prior to the landfall of the storm was that by the Tanker Tillamook near latitude $28.7 \mathrm{~N}$, longitude $94.0 \mathrm{~W}$. from 0910 to $1025 \mathrm{GMT}$, June 27 . The minimum pressure observed was $969 \mathrm{mb}$. (The barometer was subsequently calibrated and the figure of 969 $\mathrm{mb}$. is the corrected value.) Indications are that the ship was in the western portion of the eye and that the pressure observed was not the absolute minimum in the center at that time. From June 26 until the center crossed the coast about 1430 GMT on the 27th, Audrey increased its forward speed from about $7 \mathrm{mph}$ to $15 \mathrm{mph}$. At the same time it intensified markedly. The central pressure when it struck the coast was some $30 \mathrm{mb}$. lower than that last reported by reconnaissance and there is no doubt that there was 
considerable deepening in the five hours between time of the observation of the Tillawmok and landfall. The exact minimum pressure as the center reached the coast has not been determined. The Calcasieu Coast Guard station, 20 miles east of the center, reported $960 \mathrm{mb}$. and at Port Arthur, Tex., about an equal distance west of the center, the lowest pressure was $966 \mathrm{mb}$. The lowest pressure observed was $958 \mathrm{mb}$. by the Fish and Wildlife Service at Hackberry, La." ATSR: "Although the official maximum winds and minimum pressures reported in Audrey during the forecasting periods were 95 knots and $960 \mathrm{mb}$, post-storm reports subsequently received via the Miami Weather Bureau City Office from ships and oil rigs near shore indicated winds of 125-155 knots and pressures as low as $924.5 \mathrm{mb}$. The highest winds reported by reconnaissance aircraft were 95 knots which was 110 miles from the center as Audrey was crossing the coastline."

June 28:

HWM analyzes a tropical storm of at most $995 \mathrm{mb}$ at $34.5 \mathrm{~N}, 89.0 \mathrm{~W}$ with an approaching frontal boundary to the northwest at 12Z. HURDAT lists a $35 \mathrm{kt}$ tropical storm at $34.5 \mathrm{~N}, 89.5 \mathrm{~W}$ at $12 \mathrm{Z}$. Microfilm shows a closed low pressure of at most $996 \mathrm{mb}$ at $35.0 \mathrm{~N}, 89.0 \mathrm{~W}$ at $12 \mathrm{Z}$. Ship highlights: $20 \mathrm{kt} \mathrm{SSW}$ and $1004 \mathrm{mb}$ at $26.8 \mathrm{~N}, 93.9 \mathrm{~W}$ at 00Z (COADS). $25 \mathrm{kt} \mathrm{S}$ and $1004 \mathrm{mb}$ at 29.6N, 94.7W at 06Z (COADS). Land highlights: $20 \mathrm{kt} \mathrm{S}$ and $982 \mathrm{mb}$ at Alexandria, LA at 00Z (micro). $984 \mathrm{mb}$ at Monroe, LA at 03Z (NWSLC). $15 \mathrm{kt} \mathrm{SE}$ and $996 \mathrm{mb}$ at Greenwood, MS at 06Z (micro). $10 \mathrm{kt} \mathrm{NNW}$ and 996 $\mathrm{mb}$ at Memphis, TN at 12Z (micro). $15 \mathrm{kt} \mathrm{SW}$ and $996 \mathrm{mb}$ at Nashville, TN at $18 \mathrm{Z}$ (micro).

June 29:

HWM analyzes a large extratropical cyclone of at most $975 \mathrm{mb}$ at $42.0 \mathrm{~N}$, $79.0 \mathrm{~W}$ with a warm front to the east and a cold front to the southeast at 12Z. HURDAT lists a $50 \mathrm{kt}$ extratropical cyclone at $43.7 \mathrm{~N}, 77.1 \mathrm{~W}$ at $06 \mathrm{Z}$ (last position). Microfilm shows a large closed low pressure of at most $978 \mathrm{mb}$ at $42.0 \mathrm{~N}, 79.0 \mathrm{~W}$ with a frontal boundary to the southeast at 12Z. Ship highlights: No gales or low pressures. Land highlights: $15 \mathrm{kt} \mathrm{SSE}$ and $994 \mathrm{mb}$ at Pittsburgh, PA at 00Z (micro). Aircraft highlights: Radar center fix at $32.9 \mathrm{~N}, 92.2 \mathrm{~W}$ at $02 \mathrm{Z}$ (ATSR).

MWR: "The exact number of deaths from Audrey will probably never be known. The list of known dead includes 371 in and near Cameron and 19 in other areas. To this list must be added a large number of others presumed dead from the 192 still listed as missing, although many of these may be among the 127 unidentified dead. The loss of life was the greatest in the United States since the New England hurricane of 1938 and about equal to the total for all other tropical storms in the United States in the past decade. Property damage in Audrey is estimated at $\$ 150,000,000$. In the Cameron to Grand Cheniere area, 
60 to 80 percent of the houses were destroyed or floated off their foundations. Inundation extended inland as much as 25 miles over the low-lying area. As the hurricane moved northeastward from Louisiana, it gradually weakened and began losing its tropical characteristics but was still attended by some damaging winds on the $28^{\text {th }}$. Reintensification occurred due to extratropical processes as the storm moved from the Ohio Valley through the eastern Great Lakes region and there was a large amount of flood damage in States south of the Great Lakes, particularly in Illinois and Indiana, and some damage from high winds and thundersqualls from western Pennsylvania through New York. Winds were reported as high as $65 \mathrm{mph}$ at Pittsburgh, Pa., and 95 to $100 \mathrm{mph}$ at Jamestown, NY."

A tropical wave entered the Bay of Campeche on June $22^{\text {nd }}$ causing the development of a low pressure that organized into a $30 \mathrm{kt}$ tropical depression on June 24 at $12 \mathrm{Z}$. This is 18 hours earlier than originally shown in HURDAT. The first position originally in HURDAT was of a $60 \mathrm{kt}$ tropical storm on June $25^{\text {th }}$ at $06 \mathrm{Z}$. A ship moving southwest across the Bay of Campeche on June $24^{\text {th }}$ reported $5 \mathrm{kt} \mathrm{SW}$ and $1007 \mathrm{mb}$ at $06 \mathrm{Z}$, and 10 kt NW and $1006 \mathrm{mb}$ at 12Z, and although the pressure appears to be dubious compared to the coastal observations, the direction of the winds does suggest that a closed low-level circulation was present by $12 \mathrm{Z}$ on the $24^{\text {th }}$. Minor track changes are introduced for the duration of this system. The tropical depression moved slowly to the north on the $24^{\text {th }}$ and the first gale-force winds were reported by a ship at $0230 \mathrm{Z}$ on June $25^{\text {th }}$ while located to the northwest of the tropical cyclone. Intensification to a tropical storm is analyzed at $18 \mathrm{Z}$ on the $24^{\text {th }}$, twelve hours earlier than originally in HURDAT. The first reconnaissance aircraft reached the tropical cyclone at $17 \mathrm{Z}$ on the $25^{\text {th }}$ measuring a central pressure of $989 \mathrm{mb}$, estimating surface winds of $85 \mathrm{kt}$ and an eye diameter of 20 $\mathrm{nm}$. A central pressure of $989 \mathrm{mb}$ suggests maximum sustained winds of $65 \mathrm{kt}$ south of $25 \mathrm{~N}$ from the Brown et al. pressure-wind relationship. The $20 \mathrm{~nm}$ eye diameter suggests an RMW of about $15 \mathrm{~nm}$ and climatology suggests about $18 \mathrm{~nm}$. An intensity of $65 \mathrm{kt}$ is selected for $18 \mathrm{Z}$ on the $25^{\text {th }}$, down from $75 \mathrm{kt}$ originally in HURDAT, a minor intensity change. A central pressure of $989 \mathrm{mb}$ appears in HURDAT at $12 \mathrm{Z}$ on the $25^{\text {th }}$ but it is in the wrong time slot and has been moved to $18 \mathrm{Z}$ on the same day. Intensification to a hurricane is analyzed at $18 Z$ on the $25^{\text {th }}$, six hours later than HURDAT. A major intensity change is analyzed at $12 \mathrm{Z}$ on the $25^{\text {th }}$. HURDAT originally had $85 \mathrm{kt}$ but it is analyzed that Audrey had winds of $55 \mathrm{kt}$ at this time. Another center fix was made at $2257 \mathrm{Z}$ on the $25^{\text {th }}$ measuring a central pressure of $979 \mathrm{mb}$ and estimating surface winds of $60 \mathrm{kt}$. A final center fix was made on the $25^{\text {th }}$ at $2348 \mathrm{Z}$ measuring a central pressure of $979 \mathrm{mb}$ and estimating surface winds of $75 \mathrm{kt}$. A central pressure of $979 \mathrm{mb}$ suggests maximum sustained winds of $79 \mathrm{kt}$ south of $25 \mathrm{~N}$ according to the pressure-wind relationship. Due to the slow motion (about $7 \mathrm{kt}$ ) of the hurricane and low environmental pressures (outer closed isobar of $1008 \mathrm{mb}$ ), an intensity of $75 \mathrm{kt}$ is selected for $00 \mathrm{Z}$ on June $26^{\text {th }}$. A central 
pressure of $979 \mathrm{mb}$ was present in HURDAT at $00 \mathrm{Z}$ on the $26^{\text {th }}$ and based on the reconnaissance observations, it has been retained. The rapid intensification observed on the $25^{\text {th }}$ became more gradual on the $26^{\text {th }}$ as indicated by a reconnaissance aircraft later on the day. At $1620 \mathrm{Z}$ on the $26^{\text {th }}$, the plane reported a central pressure of $973 \mathrm{mb}$, estimated surface winds of $90 \mathrm{kt}$ and an eye diameter of $20 \mathrm{~nm}$. A central pressure of $973 \mathrm{mb}$ suggests maximum sustained winds of $81 \mathrm{kt}$ north of $25 \mathrm{~N}$ intensifying and $85 \mathrm{kt}$ south of $25 \mathrm{~N}$ intensifying, according to the pressure-wind relationship. Due to the slow motion of the hurricane, low environmental pressures (outer closed isobar of $1007 \mathrm{mb}$ ), an intensity of $80 \mathrm{kt}$ is selected for $18 \mathrm{Z}$ on June $26^{\text {th }}$, down from $85 \mathrm{kt}$ originally in HURDAT, a minor intensity change. A central pressure of $973 \mathrm{mb}$ was present in HURDAT at $12 \mathrm{Z}$ on the $26^{\text {th }}$ and has been moved to $18 \mathrm{Z}$ based on the reconnaissance report. No more center penetrations were made by the reconnaissance aircrafts prior to landfall.

Hurricane Audrey increased in forward speed on June $27^{\text {th }}$ and another period of rapid intensification was noted. A reconnaissance mission made several radar center fixes early on the $27^{\text {th }}$. Hurricane Audrey made landfall around $14 \mathrm{Z}$ near $29.8 \mathrm{~N}, 93.6 \mathrm{~W}$, just east of the Louisiana-Texas border and about 20 miles east of Port Arthur, TX. There were no measurements of the central pressure at landfall and the lowest pressure of $958 \mathrm{mb}$ was recorded at Hackberry, LA at an unknown time but likely to be around $15 \mathrm{Z}$ on the $27^{\text {th }}$. Ho et al. analyzed that the RMW of Audrey at landfall was $20 \mathrm{~nm}$, but observations by the reconnaissance aircraft before landfall and the radar images indicate that the hurricane had a larger RMW. The radar images and aircraft reconnaissance showed an eye diameter of about $40 \mathrm{~nm}$, suggesting an RMW of about $30 \mathrm{~nm}$. A combination between these estimates and Ho et al. gives $25 \mathrm{~nm}$, which is the value selected. The center of Audrey passed about $12 \mathrm{~nm}$ to the west of Hackville, LA, and the environmental pressure was $1004 \mathrm{mb}$. The Schloemer equation was run three times using an RMW of $20 \mathrm{~nm}, 25 \mathrm{~nm}$ and $30 \mathrm{~nm}$. This gave a central pressure of $949 \mathrm{mb}, 951 \mathrm{mb}$ and $953 \mathrm{mb}$, accordingly. Since the $958 \mathrm{mb}$ measurement was made about one hour after landfall and a best estimate of an RMW of $25 \mathrm{~nm}$, a central pressure of $950 \mathrm{mb}$ is selected at landfall and added to $12 \mathrm{Z}$ on the $27^{\text {th }}$ replacing the existing $946 \mathrm{mb}$ estimate. A central pressure of $950 \mathrm{mb}$ suggests maximum sustained winds of $105 \mathrm{kt}$ north of $25 \mathrm{~N}$ and $110 \mathrm{kt}$ north of $25 \mathrm{~N}$ intensifying, according to the pressure-wind relationships. Due to the low environmental pressures and relatively large RMW (climatology suggests about $20 \mathrm{~nm}$ ), an intensity of $105 \mathrm{kt}$ is selected for $12 \mathrm{Z}$ and at landfall at $14 \mathrm{Z}$ on June $26^{\text {th }}$, down from $125 \mathrm{kt}$, a major intensity change to HURDAT. $105 \mathrm{kt}$ is the analyzed peak intensity for Hurricane Audrey, down from 125 kt originally in HURDAT, a major intensity change. The Schwerdt et al. parametric hurricane wind model suggests that the highest sustained winds that impacted Texas reached $92 \mathrm{kt}$. Therefore, Audrey is analyzed as a category 2 hurricane impact for Texas and category 3 hurricane impact for Louisiana. 
Audrey quickly weakened as it progressed inland. The Kaplan and DeMaria model was run for $18 \mathrm{Z}$ on the $27^{\text {th }}$, and $00 \mathrm{Z}$, and $06 \mathrm{Z}$ on the $28^{\text {th }}$ yielding $74 \mathrm{kt}, 48 \mathrm{kt}$ and $34 \mathrm{kt}$, respectively. The highest winds recorded at these times were $60 \mathrm{kt}, 45 \mathrm{kt}$ and $32 \mathrm{kt}$, respectively. An intensity of $80 \mathrm{kt}$ is selected for $18 \mathrm{Z}$ on the $27^{\text {th }}, 55 \mathrm{kt}$ at $00 \mathrm{Z}$ and $40 \mathrm{kt}$ at $06 \mathrm{Z}$ on the $28^{\text {th }}$ (up from $60 \mathrm{kt}$ at $18 \mathrm{Z}$ on the $27^{\text {th }}, 45 \mathrm{kt}$ at $00 \mathrm{Z}$ on the $28^{\text {th }}$ and no change at $06 \mathrm{Z}$, originally in HURDAT), a major intensity change was made at $18 \mathrm{Z}$ on the $27^{\text {th }}$. On June $28^{\text {th }}$, Audrey turned to the northeast and noticeably increased in forward speed ahead of a frontal boundary. A central pressure of $972 \mathrm{mb}$ was present originally at $00 \mathrm{Z}$ on the $28^{\text {th }}$. This value is not supported by observations, not is it reasonable given the system was overland 10 hours and is thus removed from HURDAT. HURDAT has Audrey transitioning to an extratropical cyclone at $06 \mathrm{Z}$ on the $28^{\text {th }}$ but surface observations indicate that the frontal boundary was still about $300 \mathrm{~nm}$ northwest of the storm at that time. Transition to an extratropical cyclone is delayed until $00 \mathrm{Z}$ on June $29^{\text {th }}, 18$ hours later than originally in HURDAT. By $18 \mathrm{Z}$ on the $28^{\text {th }}$, Audrey weakened to a tropical depression, it was absorbed by a large and intense extratropical cyclone over the Great Lakes after $06 \mathrm{Z}$ on the $29^{\text {th }}$. Dissipation is analyzed six hours earlier than originally in HURDAT.

Tropical Storm Bertha [August 8-11, 1957]

\begin{tabular}{|c|c|c|c|c|c|c|c|c|c|c|c|c|c|c|}
\hline 40150 & $08 / 08 / 195$ & $7 \mathrm{M}=$ & 4 & 3 SNBR= 8 & $4 \mathrm{BE}$ & RTHA & & XIN & $\mathrm{I}=1$ & SSS $=$ & & & & \\
\hline 40150 & $08 / 08 / 195$ & $7 \mathrm{M}=$ & 4 & 4 SNBR= 8 & $4 \mathrm{BE}$ & RTHA & & XII & $\mathrm{G}=1$ & SSS $=$ & & & & \\
\hline 40155 & ๑৪/०৪* & $\odot$ & $\odot$ & ○* & $\odot$ & $\odot$ & $0^{*}$ & $\odot$ & $\odot$ & $\odot$ & $0 * 270$ & 889 & 35 & ०* \\
\hline 40155 & $08 / 08 * 270$ & 874 & 25 & $0 * 270$ & 880 & 30 & $\odot * 2$ & 70 & 886 & 35 & $0 * 272$ & 892 & 45 & ०* \\
\hline 40160 & $08 / 09 * 274$ & 895 & 40 & $1000 * 279$ & 904 & 60 & $\odot * 2$ & 83 & 913 & 60 & $998 * 290$ & 923 & 60 & ०* \\
\hline 40160 & $\odot 8 / \odot 9 * 275$ & 899 & 55 & $1000 * 278$ & 906 & 55 & $\odot * 2$ & 83 & 913 & 50 & ๑*29๑ & 922 & 50 & 1005 * \\
\hline 40165 & $08 / 10 * 297$ & 933 & 60 & $0 * 302$ & 941 & 45 & $\Theta * 3$ & 06 & 948 & 30 & $0 * 311$ & 951 & 25 & ०* \\
\hline 40165 & $08 / 10 * 295$ & 931 & 55 & ๑*297 & 939 & 60 & $998 * 3$ & 01 & 946 & 40 & $0 * 308$ & 951 & 30 & 0* \\
\hline 40170 & $08 / 11$ *318 & 952 & 25 & $0 * 327$ & 952 & 25 & $0 * 3$ & 36 & 952 & 25 & $0 * 347$ & 952 & 25 & ○* \\
\hline 40170 & $08 / 11$ *317 & 952 & 25 & $\odot * 327$ & 952 & 25 & ๑* & 0 & 0 & 0 & $0^{*} \quad 0$ & $\odot$ & $\odot$ & ๑* \\
\hline
\end{tabular}

\section{U.S. Tropical Storm Landfall}

08/10 06Z 29.7N 93.9W $60 \mathrm{kt} \mathrm{TX}$

Minor changes to the track and intensity shown in McAdie et al. (2009). Evidence for these alterations comes from the NHC microfilm maps, Historical Weather Maps series, COADS ship database, Monthly Weather Review, the Local Climatological Data and Navy reconnaissance book. 
August 6:

HWM analyzes weakening frontal boundary over the northern Gulf of Mexico at 12Z. HURDAT does not list an organized storm on this date. Ship highlights: No gales or low pressures.

MWR: "A weak extra-tropical Low entered the northeastern Gulf of Mexico on August 6 and drifted slowly westward for the next 2 days."

August 7:

HWM analyzes a spot low pressure at $27.5 \mathrm{~N}, 89.8 \mathrm{~W}$ with a warm front to the east at 12Z. HURDAT does not list an organized storm on this date. Microfilm shows a frontal boundary over the northeast Gulf of Mexico with a trough extending from $29.0 \mathrm{~N} / 87.0 \mathrm{~W}$ to $24.0 \mathrm{~N} / 89.0 \mathrm{~W}$ at $12 \mathrm{Z}$. Ship highlights: No gales or low pressures.

ATSR: "Bertha resulted when a frontal system moved into the Gulf of Mexico early on 7 August and became stationary with a low center forming in its trough."

August 8:

HWM analyzes a tropical storm with a central pressure of $1000 \mathrm{mb}$ at $27.7 \mathrm{~N}$, $89.7 \mathrm{~W}$ with a weakening stationary front to the northeast at $12 \mathrm{Z}$. HURDAT lists a $35 \mathrm{kt}$ tropical storm at $27.0 \mathrm{~N}, 88.9 \mathrm{~W}$ at $18 \mathrm{Z}$ (first advisory). Microfilm shows a closed low pressure of at most $1011 \mathrm{mb}$ at $27.5 \mathrm{~N}, 89.0 \mathrm{~W}$ at 12Z. Ship highlights: $45 \mathrm{kt}$ SE and 1009 $\mathrm{mb}$ at $27.4 \mathrm{~N}, 88.6 \mathrm{~W}$ at $17 \mathrm{Z}$ (micro). $40 \mathrm{kt} \mathrm{SE}$ and $1009 \mathrm{mb}$ at $27.7 \mathrm{~N}, 88.9 \mathrm{~W}$ at $21 \mathrm{Z}$ (COADS). Aircraft highlights: Penetration center fix estimated maximum surface winds of 60 knots and measured a central pressure of $1000 \mathrm{mb}$ at $27.6 \mathrm{~N}, 89.2 \mathrm{~W}$ at $23 \mathrm{Z}$ (ATSR).

MWR: "It developed into a tropical storm about 100 miles south of the mouth of the Mississippi River on August 8." ATSR: "The first positive indication of Bertha was a report received from the ship SS TELDE at 1715Z, 8 August, reporting winds from the southeast, Force 9, seas 15 feet and pressure of $1008.8 \mathrm{mb}$, near 27N 89W. Earlier (6 hours previous) the maximum winds reported in that area was 25 knots in a squall. A Navy low-level reconnaissance flight was dispatched from $2250 \mathrm{Z}$ with maximum winds of 60 knots and minimum pressure of $1000 \mathrm{mb}$. Radar coverage was determined to be feasible and storm eye was described as open to the west. After Bertha developed into a tropical storm she was under an easterly flow at all upper levels, due to a large high pressure system located over the east central United States.” 
August 9:

HWM analyzes a tropical storm with a central pressure of $1007 \mathrm{mb}$ at $28.3 \mathrm{~N}$, $91.5 \mathrm{~W}$ at $12 \mathrm{Z}$. HURDAT lists a $60 \mathrm{kt}$ tropical storm at $28.3 \mathrm{~N}, 91.3 \mathrm{~W}$ at $12 \mathrm{Z}$. Microfilm shows a trough extending along Longitude $92.0 \mathrm{~W}$ over the north Gulf of Mexico at $12 \mathrm{Z}$. Ship highlights: $55 \mathrm{kt} \mathrm{E}$ and $1010 \mathrm{mb}$ at $28.0 \mathrm{~N}, 89.6 \mathrm{~W}$ at $00 \mathrm{Z}$ (COADS). $50 \mathrm{kt} \mathrm{NE}$ and $1012 \mathrm{mb}$ at $28.7 \mathrm{~N}, 91.3 \mathrm{~W}$ at $06 \mathrm{Z}$ (COADS). $45 \mathrm{kt} \mathrm{N}$ and $1008 \mathrm{mb}$ at $27.9 \mathrm{~N}, 91.5 \mathrm{~W}$ at 09Z (micro). $50 \mathrm{kt} \mathrm{W}$ and $1010 \mathrm{mb}$ at $28.4 \mathrm{~N}, 92.8 \mathrm{~W}$ at 19Z (COADS). Aircraft highlights: Radar center fix at $27.5 \mathrm{~N}, 89.8 \mathrm{~W}$ at $0330 \mathrm{Z}$ (ATSR). Radar center fix at $28.5 \mathrm{~N}, 91.5 \mathrm{~W}$ at $08 \mathrm{Z}$ (ATSR). Penetration center fix estimated maximum surface winds of 40 knots, measured a central pressure of $1007 \mathrm{mb}$ and an eye diameter of $8 \mathrm{~nm}$ at $28.9 \mathrm{~N}, 91.8 \mathrm{~W}$ at $1625 \mathrm{Z}$ (ATSR). Penetration center fix estimated maximum surface winds of 40 knots, measured a central pressure of $1005 \mathrm{mb}$ and an eye diameter of $8 \mathrm{~nm}$ at $29.1 \mathrm{~N}, 92.5 \mathrm{~W}$ at $1755 \mathrm{Z}$ (ATSR).

MWR: ".. then moved in a general northwesterly direction, crossing the coast near Cameron, La., late on August 9. Since it was moving toward the same portion of the coast devastated by hurricane Audrey 2 months earlier, Bertha was viewed with alarm by the population and full safety precautions and evacuations were evidently carried out promptly. Fortunately, Bertha did not develop to full hurricane intensity. Highest winds were estimated by ships and land stations at 50 to $70 \mathrm{~m}$. p. h. The fastest mile at Beaumont, Tex., was measured at $44 \mathrm{mph}$ with gusts to 52. Tides did not approach the disastrous proportions of those in Audrey, the highest reported being 4.7 feet at the west end of Vermilion Bay. The heaviest rainfall observed was 10.73 inches at Livingston, Tex." ATSR: "Bertha moved west-northwest just ahead of a retrograding trough at the $200 \mathrm{mb}$ level until 0000Z, 9 August, when the trough overtook the storm; at this point a low center formed at $200 \mathrm{mb}$ over Bertha, which is believed to have contributed to the decrease in, or failure of, Bertha's development. Of interest during the period when this low developed over the storm at $200 \mathrm{mb}$ is that a night Navy radar reconnaissance aircraft was in the storm area and reported strong radar echoes and a well-defined storm center during the first 3 hours of his flight but, by the end of the flight, some ten hours later, his report was of very weak echoes, patterns diffuse and that further radar coverage was not feasible. A low-level reconnaissance flight into Bertha at daylight on 9 August reported a maximum wind of 40 knots, minimum pressure of $1005 \mathrm{mb}$, and radar coverage not feasible. Bertha entered the coast near the Texas-Louisiana border very near the place her earlier and more destructive sister, Audrey, had entered some six weeks earlier. Damages from Bertha were minor." 
August 10:

HWM analyzes a closed low pressure of at most $1005 \mathrm{mb}$ at $31.0 \mathrm{~N}, 95.0 \mathrm{~W}$ at 12Z. HURDAT lists a $30 \mathrm{kt}$ tropical depression at $30.4 \mathrm{~N}, 94.8 \mathrm{~W}$ at $12 \mathrm{Z}$. Microfilm shows a closed low pressure of at most $1008 \mathrm{mb}$ at $31.0 \mathrm{~N}, 94.5 \mathrm{~W}$ at $12 \mathrm{Z}$. Ship highlights: $40 \mathrm{kt} \mathrm{NE}$ and $1012 \mathrm{mb}$ at 28.6N, 95.1W at 00Z (micro). Land highlights: $30 \mathrm{kt} \mathrm{NNE}$ and $1004 \mathrm{mb}$ at Port Arthur, TX at 03Z (micro). $38 \mathrm{kt}$, gusts to $45 \mathrm{kt}$ at Port Arthur, TX at 0344Z (CLIMO). $15 \mathrm{kt} \mathrm{NNE}$ and $1001 \mathrm{mb}$ at Port Arthur, TX at 06Z (micro). $1001 \mathrm{mb}$ at Port Arthur, TX at 0605Z (CLIMO).

August 11:

HWM analyzes a tropical storm of at most $1010 \mathrm{mb}$ at $33.5 \mathrm{~N}, 95.0 \mathrm{~W}$ at $12 \mathrm{Z}$. HURDAT lists a $25 \mathrm{kt}$ tropical depression at 33.6N, 95.2W at 12Z. Microfilm shows a closed low pressure of at most $1008 \mathrm{mb}$ at $34.0 \mathrm{~N}, 96.5 \mathrm{~W}$ at 06Z. Ship highlights: No gales or low pressures.

MWR: "The storm weakened and turned northward after moving inland, reaching southeastern Oklahoma on August 11. Although the storm was not identifiable as a surface circulation thereafter, it was apparent in the circulation aloft and in the accompanying heavy rains as it turned eastward across Arkansas. Two deaths resulting from Bertha were reported; property damage was slight, and the accompanying rain has been described by the Meteorologist in Charge at New Orleans Weather Bureau Office as over-all more beneficial than harmful."

August 12:

HWM, HURDAT and micro do not analyze an organized tropical cyclone on this date. No gales or low pressures.

A frontal boundary entered the northern Gulf of Mexico on August $6^{\text {th }}$ and a low pressure system developed soon thereafter. The disturbance became better organized on the $7^{\text {th }}$ based on ship reports while the frontal boundary dissipated. Genesis is analyzed at $00 \mathrm{Z}$ on the $8^{\text {th }}$ as a $25 \mathrm{kt}$ tropical depression, 18 hours earlier than the original HURDAT. Minor track changes are introduced for the duration of this system. The depression intensified on the $8^{\text {th }}$ reaching tropical storm status at $12 \mathrm{Z}$, six hours earlier than originally shown in HURDAT. Various ships reported gales late on the $8^{\text {th }}$, including 45 $\mathrm{kt}$ at $17 \mathrm{Z}$. An aircraft reconnaissance reached Bertha at $23 \mathrm{Z}$ on the $8^{\text {th }}$ estimating maximum surface winds of $60 \mathrm{kt}$ and a central pressure of $1000 \mathrm{mb}$. A central pressure of $1000 \mathrm{mb}$ is present in HURDAT at $00 \mathrm{Z}$ on the $9^{\text {th }}$ and it is retained. 
Tropical Storm Bertha moved generally westward on the $8^{\text {th }}$ but its course changed to the west-northwest on the $9^{\text {th }}$ while passing south of Louisiana. At 00 and $06 \mathrm{Z}$ on the $9^{\text {th }}$, Bertha is analyzed to have reached an intensity of $55 \mathrm{kt}$ based on various ships reporting winds of $50 \mathrm{kt}$ and $55 \mathrm{kt}$. A minor intensity change to the original HURDAT. Late on the $9^{\text {th }}$, another reconnaissance mission reached Bertha and found a disorganized system. The central pressure had risen to $1005 \mathrm{mb}$, while the estimated maximum surface winds had dropped to $40 \mathrm{kt}$, but the eye diameter was just $8 \mathrm{~nm}$. A central pressure of $1005 \mathrm{mb}$ is added to $18 \mathrm{Z}$ on the $9^{\text {th }}$. A central pressure of $1005 \mathrm{mb}$ suggests maximum winds of $34 \mathrm{kt}$ north of $25 \mathrm{~N}$ from the Brown et al. pressure-wind relationship. Based on the aircraft reports and ships reporting winds between $35-50 \mathrm{kt}$, the intensity of Bertha is reanalyzed at $50 \mathrm{kt}$ at $12 \mathrm{Z}$ and $18 \mathrm{Z}$, a minor intensity change to HURDAT. A central pressure of 998 $\mathrm{mb}$ is present in HURDAT at $12 \mathrm{Z}$ on the $9^{\text {th }}$ and based on the reconnaissance reports, it is likely to be inaccurate and has been removed.

The tropical cyclone approached landfall early on August $10^{\text {th }}$ and is analyzed to have crossed the coast near the Texas-Lousiana border, $29.7 \mathrm{~N}, 93.9 \mathrm{~W}$, at $06 \mathrm{Z}$. At this time, the barometric pressure at Port Arthur, TX, had decreased to $1001 \mathrm{mb}$ and winds were $15 \mathrm{kt}$ from the northeast. Based on this report, it is analyzed that Bertha made landfall with a central pressure of $998 \mathrm{mb}$, which has been added to HURDAT at $06 \mathrm{Z}$ on the $10^{\text {th }}$. A central pressure of $998 \mathrm{mb}$ suggests maximum winds of $47 \mathrm{kt}$ north of $25 \mathrm{~N}$ according to the pressure-wind relationship. Based on the small size of the storm, an intensity of $60 \mathrm{kt}$ is analyzed at $06 \mathrm{Z}$ on the $10^{\text {th }}$, a minor change to HURDAT. Nonetheless, HURDAT indicated an earlier landfall and an intensity of $60 \mathrm{kt}$. This is also the peak intensity of Bertha. Port Arthur, TX reported sustained winds of $38 \mathrm{kt}$ and gusts to $52 \mathrm{kt}$ early on the $10^{\text {th }}$. The small tropical storm weakened after landfall and became a tropical depression at $18 \mathrm{Z}$ on the $10^{\text {th }}$, six hours later than originally shown by HURDAT. Early on August $11^{\text {th }}$, Bertha turned to the north over eastern Texas dissipating after 06Z, 12 hours earlier than originally shown in HURDAT.

\section{Hurricane Carrie [September 2-25, 1957]}

\begin{tabular}{|c|c|c|c|c|c|c|c|c|c|c|c|c|c|}
\hline 40180 & $09 / 02 / 1957$ & $M=23$ & 4 & SNBR $=87$ & $75 \mathrm{Cr}$ & RRIE & XII & $N G=\odot$ & SSS $=0$ & & & & \\
\hline 40180 & $09 / 02 / 1957$ & $\begin{array}{r}M=24 \\
* *\end{array}$ & $\begin{array}{l}5 \\
\text { * }\end{array}$ & SNBR $=87$ & $75 \mathrm{Cr}$ & RIE & XII & $V G=\odot$ & $S S S=0$ & & & & \\
\hline 40185 & $09 / 02$ * & $\odot$ & $\odot$ & $0 * 130$ & 217 & 25 & $0 * 130$ & 222 & 25 & $0 * 130$ & 231 & 25 & $1001^{*}$ \\
\hline 40185 & $09 / 02$ * & $\odot$ & $\odot$ & $0 * 130$ & $\begin{array}{l}213 \\
* * *\end{array}$ & 25 & $0 * 130$ & 222 & 25 & $0 * 130$ & 231 & 25 & $\begin{array}{l}\Theta^{*} \\
\text { * }\end{array}$ \\
\hline 40190 & $09 / 03 * 131$ & 240 & 25 & $0 * 134$ & 250 & 30 & $0 * 137$ & 259 & 35 & $0 * 139$ & 268 & 35 & ○* \\
\hline 40195 & $09 / 04 * 141$ & 277 & $4 \odot$ & 0*143 & 286 & 45 & $0 * 145$ & 296 & 50 & $0 * 145$ & 306 & 55 & ○* \\
\hline 40200 & $09 / 05 * 144$ & 315 & 60 & ๑*145 & 326 & 65 & $\odot * 147$ & 337 & 70 & $0 * 149$ & 346 & 75 & $\Theta^{*}$ \\
\hline 40200 & $09 / 05 * 145$ & 316 & 60 & ๑*145 & 326 & 65 & $\odot * 147$ & 336 & 70 & $0 * 149$ & 346 & 75 & ○* \\
\hline
\end{tabular}




\begin{tabular}{|c|c|c|c|c|c|c|c|c|c|c|c|c|c|}
\hline & $* * *$ & & & & & & & ** & & & & & \\
\hline $\begin{array}{l}40205 \\
40205\end{array}$ & $\begin{array}{r}09 / 06 * 152 \\
09 / 06 * 151 \\
* * *\end{array}$ & $\begin{array}{l}354 \\
356 \\
\star * *\end{array}$ & $\begin{array}{l}80 \\
80\end{array}$ & $\begin{array}{l}\Theta^{*} 154 \\
0 * 154\end{array}$ & $\begin{array}{l}365 \\
366 \\
\star * *\end{array}$ & $\begin{array}{l}80 \\
80\end{array}$ & $\begin{array}{l}\odot * 157 \\
\Theta * 157\end{array}$ & $\begin{array}{l}375 \\
375\end{array}$ & $\begin{array}{l}85 \\
85\end{array}$ & $\begin{array}{l}\Theta * 159 \\
0 * 159\end{array}$ & $\begin{array}{l}383 \\
383\end{array}$ & $\begin{array}{l}95 \\
95\end{array}$ & $\begin{array}{l}\Theta^{*} \\
\Theta^{*}\end{array}$ \\
\hline $\begin{array}{l}40210 \\
40210\end{array}$ & $\begin{array}{l}09 / 07 * 162 \\
09 / 07 * 161\end{array}$ & $\begin{array}{l}391 \\
391\end{array}$ & $\begin{array}{l}100 \\
10 \odot\end{array}$ & $\begin{array}{l}\Theta^{*} 164 \\
\Theta^{*} 164\end{array}$ & $\begin{array}{l}40 \odot \\
40 \odot\end{array}$ & $\begin{array}{l}105 \\
105\end{array}$ & $\begin{array}{l}\odot^{*} 167 \\
\Theta^{*} 167\end{array}$ & $\begin{array}{l}410 \\
410\end{array}$ & $\begin{array}{l}110 \\
110\end{array}$ & $\begin{array}{l}945^{*} 170 \\
0^{*} 170\end{array}$ & $\begin{array}{l}420 \\
420\end{array}$ & $\begin{array}{l}115 \\
115\end{array}$ & $\begin{array}{l}\Theta^{*} \\
\Theta^{*}\end{array}$ \\
\hline $\begin{array}{l}40215 \\
40215\end{array}$ & $\begin{array}{l}09 / 08 * 174 \\
09 / 08 * 174\end{array}$ & $\begin{array}{l}429 \\
429\end{array}$ & $\begin{array}{l}120 \\
120\end{array}$ & $\begin{array}{r}\odot^{*} 177 \\
945 * 177 \\
* * *\end{array}$ & $\begin{array}{l}439 \\
437 \\
* * *\end{array}$ & $\begin{array}{l}125 \\
120 \\
* * *\end{array}$ & $\begin{array}{r}\Theta^{*} 180 \\
\Theta^{*} 179 \\
* * *\end{array}$ & $\begin{array}{l}450 \\
445 \\
* * *\end{array}$ & $\begin{array}{l}130 \\
120 \\
* * *\end{array}$ & $\begin{array}{l}945 * 180 \\
0^{*} 180 \\
*\end{array}$ & $\begin{array}{l}457 \\
452 \\
\star * *\end{array}$ & $\begin{array}{l}135 \\
120 \\
* * *\end{array}$ & $\begin{array}{l}\Theta^{*} \\
945^{*} \\
* * *\end{array}$ \\
\hline $\begin{array}{l}40220 \\
40220\end{array}$ & $\begin{array}{r}\odot 9 / 09 * 180 \\
09 / 09 * 181 \\
* * *\end{array}$ & $\begin{array}{l}465 \\
461 \\
\star * *\end{array}$ & $\begin{array}{l}135 \\
115 \\
* * *\end{array}$ & $\begin{array}{l}\theta^{*} 181 \\
0^{*} 183 \\
* * *\end{array}$ & $\begin{array}{l}473 \\
472 \\
\star * *\end{array}$ & $\begin{array}{l}135 \\
105 \\
\star * *\end{array}$ & $\begin{array}{r}\Theta^{*} 183 \\
\Theta^{*} 187 \\
* * *\end{array}$ & $\begin{array}{l}482 \\
482\end{array}$ & $\begin{array}{r}135 \\
95 \\
* *\end{array}$ & $\begin{array}{r}975^{*} 186 \\
0^{*} 191 \\
\star \star \star *\end{array}$ & $\begin{array}{l}490 \\
491 \\
\star * *\end{array}$ & $\begin{array}{r}130 \\
85 \\
* *\end{array}$ & $\begin{array}{l}\Theta^{*} \\
975^{*} \\
* * *\end{array}$ \\
\hline $\begin{array}{l}40225 \\
40225\end{array}$ & $\begin{array}{r}09 / 10 * 190 \\
09 / 10 * 194 \\
* * *\end{array}$ & $\begin{array}{l}497 \\
499 \\
\star * *\end{array}$ & $\begin{array}{r}125 \\
80 \\
* *\end{array}$ & $\begin{array}{r}0^{*} 192 \\
\Theta^{*} 197 \\
* * *\end{array}$ & $\begin{array}{l}505 \\
507 \\
* * *\end{array}$ & $\begin{array}{r}115 \\
75 \\
* *\end{array}$ & $\begin{array}{r}0 * 195 \\
977 * 199 \\
* * * * * *\end{array}$ & $\begin{array}{l}513 \\
514 \\
* * *\end{array}$ & $\begin{array}{l}95 \\
70 \\
\star *\end{array}$ & $\begin{array}{l}987 * 199 \\
985 * 201 \\
* * * * * *\end{array}$ & $\begin{array}{l}520 \\
520\end{array}$ & $\begin{array}{l}85 \\
65 \\
\star *\end{array}$ & $\begin{array}{l}\Theta^{*} \\
\Theta^{*}\end{array}$ \\
\hline $\begin{array}{l}40230 \\
40230\end{array}$ & $\begin{array}{r}09 / 11 * 204 \\
09 / 11 * 203 \\
* * *\end{array}$ & $\begin{array}{l}525 \\
523 \\
\star * *\end{array}$ & $\begin{array}{l}75 \\
65 \\
\star *\end{array}$ & $\begin{array}{l}0 * 207 \\
0 * 206 \\
* * *\end{array}$ & $\begin{array}{l}527 \\
524 \\
\star * *\end{array}$ & $\begin{array}{l}65 \\
65\end{array}$ & $\begin{array}{r}0 * 210 \\
985^{*} 209 \\
* * * * *\end{array}$ & $\begin{array}{l}527 \\
524 \\
* * *\end{array}$ & $\begin{array}{l}65 \\
65\end{array}$ & $\begin{array}{r}984 * 215 \\
984 * 212 \\
\star * *\end{array}$ & $\begin{array}{l}527 \\
524 \\
* * *\end{array}$ & $\begin{array}{l}70 \\
70\end{array}$ & $\begin{array}{l}0^{*} \\
978^{*} \\
* * *\end{array}$ \\
\hline $\begin{array}{l}40235 \\
40235\end{array}$ & $\begin{array}{r}09 / 12 * 219 \\
09 / 12 * 216 \\
* * *\end{array}$ & $\begin{array}{l}527 \\
524 \\
\star * *\end{array}$ & $\begin{array}{l}80 \\
80\end{array}$ & $\begin{array}{l}\theta^{*} 224 \\
\Theta^{*} 221 \\
* \star *\end{array}$ & $\begin{array}{l}527 \\
525 \\
\star * *\end{array}$ & $\begin{array}{l}85 \\
85\end{array}$ & $\begin{array}{l}\Theta^{*} 228 \\
\Theta^{*} 228\end{array}$ & $\begin{array}{l}527 \\
526 \\
* * *\end{array}$ & $\begin{array}{l}9 \odot \\
9 \odot \\
* *\end{array}$ & $\begin{array}{l}957^{*} 233 \\
960^{*} 236 \\
* * * * * *\end{array}$ & $\begin{array}{l}527 \\
527\end{array}$ & $\begin{array}{l}95 \\
95 \\
* *\end{array}$ & $\begin{array}{l}\Theta^{*} \\
957^{*} \\
* * *\end{array}$ \\
\hline $\begin{array}{l}40240 \\
40240\end{array}$ & $\begin{array}{r}09 / 13^{*} 24 \odot \\
09 / 13^{*} 243 \\
* * *\end{array}$ & $\begin{array}{l}526 \\
526\end{array}$ & $\begin{array}{r}95 \\
100 \\
* * *\end{array}$ & $\begin{array}{l}\Theta^{*} 247 \\
\Theta^{*} 25 \odot \\
* * *\end{array}$ & $\begin{array}{l}525 \\
525\end{array}$ & $\begin{array}{r}95 \\
105 \\
\star * *\end{array}$ & $\begin{array}{r}\theta^{*} 254 \\
951 * 257 \\
* * * * * *\end{array}$ & $\begin{array}{l}524 \\
524\end{array}$ & $\begin{array}{l}10 \odot \\
10 \odot\end{array}$ & $\begin{array}{l}963 * 262 \\
953^{*} 264 \\
* * * * * *\end{array}$ & $\begin{array}{l}524 \\
522 \\
* * *\end{array}$ & $\begin{array}{r}100 \\
90 \\
* *\end{array}$ & $\begin{array}{l}\Theta^{*} \\
963^{*} \\
* * *\end{array}$ \\
\hline $\begin{array}{l}40245 \\
40245\end{array}$ & $\begin{array}{r}09 / 14 * 27 \odot \\
09 / 14^{*} 271 \\
* * *\end{array}$ & $\begin{array}{l}525 \\
523 \\
* * *\end{array}$ & $\begin{array}{r}100 \\
90 \\
* *\end{array}$ & $\begin{array}{l}\Theta^{*} 276 \\
\Theta^{*} 277 \\
* \star *\end{array}$ & $\begin{array}{l}527 \\
525 \\
* * *\end{array}$ & $\begin{array}{r}105 \\
90 \\
* *\end{array}$ & $\begin{array}{l}\odot^{*} 281 \\
964^{*} 281 \\
* * *\end{array}$ & $\begin{array}{l}532 \\
530 \\
* * *\end{array}$ & $\begin{array}{r}110 \\
9 \odot \\
* *\end{array}$ & $\begin{array}{l}963^{*} 284 \\
964^{*} 284 \\
* * *\end{array}$ & $\begin{array}{l}541 \\
540 \\
* * *\end{array}$ & $\begin{array}{r}115 \\
9 \odot \\
* *\end{array}$ & $\begin{array}{r}0^{*} \\
963^{*} \\
* * *\end{array}$ \\
\hline $\begin{array}{l}40250 \\
40250\end{array}$ & $\begin{array}{l}09 / 15^{*} 288 \\
09 / 15^{*} 288\end{array}$ & $\begin{array}{l}553 \\
552 \\
\star * *\end{array}$ & $\begin{array}{r}120 \\
9 \odot \\
* *\end{array}$ & $\begin{array}{r}\theta^{*} 295 \\
\Theta^{*} 293 \\
* * *\end{array}$ & $\begin{array}{l}567 \\
565 \\
\star * *\end{array}$ & $\begin{array}{r}110 \\
85 \\
* *\end{array}$ & $\begin{array}{r}\odot * 302 \\
967 * 30 \odot \\
* * * * *\end{array}$ & $\begin{array}{l}580 \\
578 \\
* * *\end{array}$ & $\begin{array}{r}105 \\
85 \\
* *\end{array}$ & $\begin{array}{l}963 * 310 \\
965 * 308 \\
* * * * * *\end{array}$ & $\begin{array}{l}589 \\
589\end{array}$ & $\begin{array}{r}100 \\
90 \\
* *\end{array}$ & $\begin{array}{r}\Theta^{*} \\
961^{*} \\
* * *\end{array}$ \\
\hline $\begin{array}{l}40255 \\
40255\end{array}$ & $\begin{array}{r}09 / 16 * 317 \\
09 / 16 * 314 \\
* * *\end{array}$ & $\begin{array}{l}597 \\
599 \\
\star * *\end{array}$ & $\begin{array}{l}90 \\
85 \\
\star *\end{array}$ & $\begin{array}{r}0 * 322 \\
964 * 320 \\
* * * * * *\end{array}$ & $\begin{array}{l}608 \\
609 \\
* * *\end{array}$ & $\begin{array}{l}85 \\
85\end{array}$ & $\begin{array}{r}0 * 327 \\
966 * 325 \\
* * * * * *\end{array}$ & $\begin{array}{l}620 \\
620\end{array}$ & $\begin{array}{l}85 \\
80 \\
\star *\end{array}$ & $\begin{array}{l}964 * 335 \\
969 * 332 \\
* * * * * *\end{array}$ & $\begin{array}{l}629 \\
629\end{array}$ & $\begin{array}{l}85 \\
80 \\
\star *\end{array}$ & $\begin{array}{l}\Theta^{*} \\
\Theta^{*}\end{array}$ \\
\hline $\begin{array}{l}40260 \\
40260\end{array}$ & $\begin{array}{r}09 / 17 * 342 \\
09 / 17 * 339 \\
* * *\end{array}$ & $\begin{array}{l}636 \\
636\end{array}$ & $\begin{array}{l}80 \\
80\end{array}$ & $\begin{array}{r}0 * 347 \\
970 * 346 \\
* * * * * *\end{array}$ & $\begin{array}{l}641 \\
643 \\
* * *\end{array}$ & $\begin{array}{l}80 \\
75 \\
* *\end{array}$ & $\begin{array}{r}0 * 352 \\
974 * 353 \\
* * * * *\end{array}$ & $\begin{array}{l}638 \\
642 \\
\star * *\end{array}$ & $\begin{array}{l}80 \\
75 \\
* *\end{array}$ & $\begin{array}{l}972 * 357 \\
975 * 358 \\
* * * * *\end{array}$ & $\begin{array}{l}629 \\
633 \\
* * *\end{array}$ & $\begin{array}{l}80 \\
75 \\
* *\end{array}$ & $\begin{array}{l}0^{*} \\
978^{*} \\
* * *\end{array}$ \\
\hline $\begin{array}{l}40265 \\
40265\end{array}$ & $\begin{array}{r}09 / 18 * 361 \\
09 / 18 * 36 \odot \\
* * *\end{array}$ & $\begin{array}{l}618 \\
621 \\
\star * *\end{array}$ & $\begin{array}{l}80 \\
70 \\
\star *\end{array}$ & $\begin{array}{r}0 * 362 \\
0 * 360 \\
* * *\end{array}$ & $\begin{array}{l}607 \\
607\end{array}$ & $\begin{array}{l}75 \\
70 \\
\star *\end{array}$ & $\begin{array}{l}0 * 359 \\
978 * 359 \\
* * *\end{array}$ & $\begin{array}{l}595 \\
593 \\
* * *\end{array}$ & $\begin{array}{l}75 \\
70 \\
\star *\end{array}$ & $\begin{array}{l}978 * 355 \\
978 * 355\end{array}$ & $\begin{array}{l}580 \\
578 \\
* * *\end{array}$ & $\begin{array}{l}75 \\
70 \\
* *\end{array}$ & $\begin{array}{l}\Theta^{*} \\
\Theta^{*}\end{array}$ \\
\hline $\begin{array}{l}40270 \\
4 \odot 270\end{array}$ & $\begin{array}{l}09 / 19 * 352 \\
09 / 19 * 352\end{array}$ & $\begin{array}{l}564 \\
562 \\
\star * *\end{array}$ & $\begin{array}{l}75 \\
75\end{array}$ & $\begin{array}{l}0 * 349 \\
0 * 349\end{array}$ & $\begin{array}{l}552 \\
548 \\
\star * *\end{array}$ & $\begin{array}{l}70 \\
75 \\
* *\end{array}$ & $\begin{array}{l}\odot * 347 \\
\odot * 347\end{array}$ & $\begin{array}{l}539 \\
534 \\
* * *\end{array}$ & $\begin{array}{l}70 \\
80 \\
\star *\end{array}$ & $\begin{array}{l}970 * 345 \\
970 * 345\end{array}$ & $\begin{array}{l}522 \\
519 \\
* * *\end{array}$ & $\begin{array}{l}70 \\
80 \\
\star *\end{array}$ & $\begin{array}{l}\Theta^{*} \\
\Theta^{*}\end{array}$ \\
\hline $\begin{array}{l}40275 \\
40275\end{array}$ & $\begin{array}{l}09 / 20 * 344 \\
09 / 20 * 344\end{array}$ & $\begin{array}{l}504 \\
506 \\
* * *\end{array}$ & $\begin{array}{l}70 \\
80 \\
* *\end{array}$ & $\begin{array}{l}0 * 343 \\
0 * 343\end{array}$ & $\begin{array}{l}492 \\
492\end{array}$ & $\begin{array}{l}70 \\
80 \\
\star *\end{array}$ & $\begin{array}{r}\Theta * 341 \\
0 * 342 \\
* * *\end{array}$ & $\begin{array}{l}478 \\
477 \\
\star * *\end{array}$ & $\begin{array}{l}70 \\
80 \\
\star *\end{array}$ & $\begin{array}{l}\Theta * 342 \\
0 * 342\end{array}$ & $\begin{array}{l}459 \\
460 \\
\star * *\end{array}$ & $\begin{array}{l}70 \\
80 \\
* *\end{array}$ & $\begin{array}{l}\Theta^{*} \\
\Theta^{*}\end{array}$ \\
\hline $\begin{array}{l}40280 \\
40280\end{array}$ & $\begin{array}{r}09 / 21 * 345 \\
09 / 21 * 343 \\
* * *\end{array}$ & $\begin{array}{l}440 \\
440\end{array}$ & $\begin{array}{l}70 \\
80 \\
\star *\end{array}$ & $\begin{array}{r}0 * 346 \\
0 * 345 \\
* * *\end{array}$ & $\begin{array}{l}421 \\
420 \\
\star * *\end{array}$ & $\begin{array}{l}70 \\
80 \\
\star *\end{array}$ & $\begin{array}{l}\odot * 347 \\
\odot * 347\end{array}$ & $\begin{array}{l}401 \\
4 \odot \odot \\
\star * *\end{array}$ & $\begin{array}{l}70 \\
80 \\
\star *\end{array}$ & $\begin{array}{c}972 * 350 \\
* * 350 \\
*\end{array}$ & $\begin{array}{l}380 \\
380\end{array}$ & $\begin{array}{l}70 \\
80 \\
\star *\end{array}$ & $\begin{array}{l}\Theta^{*} \\
972^{*} \\
\star * *\end{array}$ \\
\hline
\end{tabular}




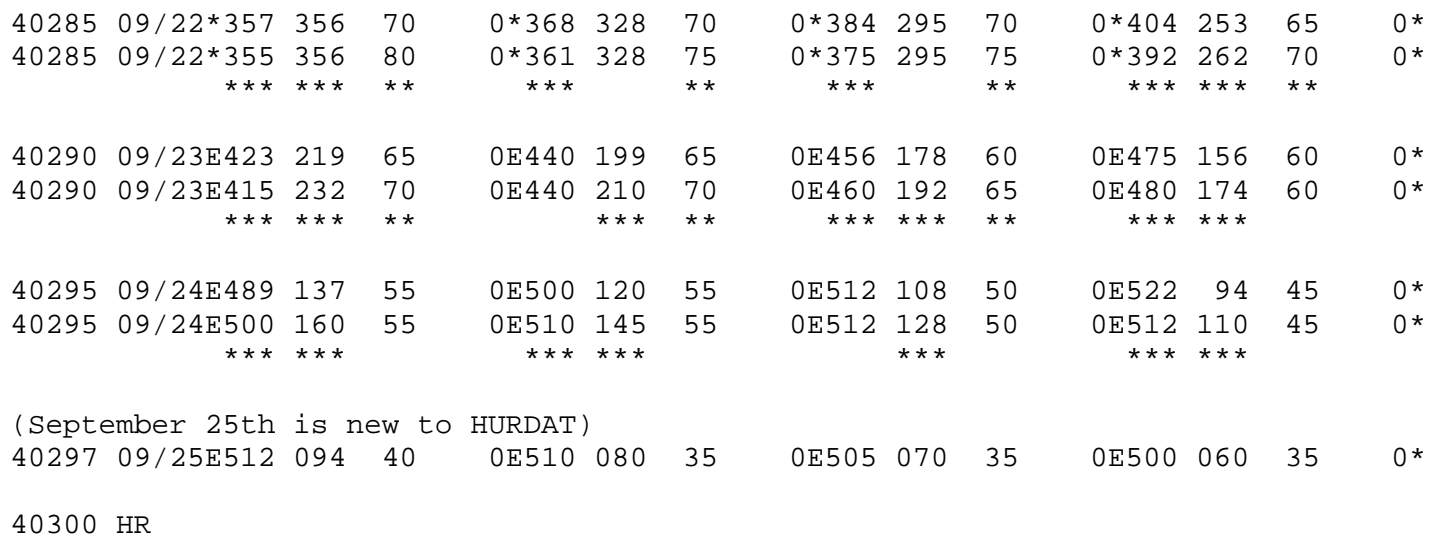

Major changes to the track and intensity shown in McAdie et al. (2009). Evidence for these alterations comes from the NHC microfilm maps, the Historical Weather Maps series, the COADS ship database, Monthly Weather Review, Reconnaissance aircraft missions and the National Hurricane Research Project (NHRP)(Shea and Gray, 1973). September 1:

HWM is not available on this date (system is south of $20^{\circ} \mathrm{N}$ ). HURDAT and microfilm do not list an organized storm on this date. Ship highlights: No gales or low pressures.

September 2:

HWM is not available on this date (system is south of $20^{\circ} \mathrm{N}$ ). HURDAT lists a 25 knot tropical depression at $13.0 \mathrm{~N}, 22.2 \mathrm{~W}$ at $12 \mathrm{Z}$. Microfilm does not show an organized storm on this date. Ship highlights: No gales or low pressures.

MWR: "Observations from the Cape Verdes on September 2 showed evidence of a vortex passing just to the south of the islands, and a message from Panair do Brasil reported a tropical storm developing near latitude $11 \mathrm{~N}$., longitude $25 \mathrm{~W}$." ATSR: "A report was received via the Recife, Brazil Office and is quoted as follows, 'Time $021741 \mathrm{Z}$ September. Tropical cyclonic development evident located approximately $11 \mathrm{~N} 25 \mathrm{~W}$.' This storm is believed to have been the beginning of hurricane CARRIE."

September 3:

HWM is not available on this date (system is south of $20^{\circ} \mathrm{N}$ ). HURDAT lists a 35 knot tropical storm at $13.7 \mathrm{~N}, 25.9 \mathrm{~W}$ at $12 \mathrm{Z}$. Microfilm does not show an organized storm on this date. Ship highlights: No gales or low pressures. 
September 4:

HWM is not available on this date (system is south of $20^{\circ} \mathrm{N}$ ). HURDAT lists a 50 knot tropical storm at $14.5 \mathrm{~N}, 29.6 \mathrm{~W}$ at $12 \mathrm{Z}$. Microfilm does not show an organized storm on this date. Ship highlights: No gales or low pressures.

September 5:

HWM is not available on this date (system is south of $20^{\circ} \mathrm{N}$ ). HURDAT lists a 70 knot hurricane at $14.7 \mathrm{~N}, 33.7 \mathrm{~W}$ at $12 \mathrm{Z}$. Microfilm does not show an organized storm on this date. Ship highlights: No gales or low pressures.

September 6:

HWM is not available on this date (system is south of $20^{\circ} \mathrm{N}$ ). HURDAT lists an 85 knot hurricane at $15.7 \mathrm{~N}, 37.5 \mathrm{~W}$ at $12 \mathrm{Z}$. Microfilm shows a closed low pressure of at most $1011 \mathrm{mb}$ at $14.0 \mathrm{~N}, 35.0 \mathrm{~W}$ at 12Z. Ship highlights: $35 \mathrm{kt} \mathrm{NNE}$ and $1011 \mathrm{mb}$ at $16.1 \mathrm{~N}, 38.5 \mathrm{~W}$ at $12 \mathrm{Z}$ (COADS). $80 \mathrm{kt} \mathrm{ENE}$ and $1001 \mathrm{mb}$ at $16.0 \mathrm{~N}, 38.5 \mathrm{~W}$ at $16 \mathrm{Z}$ (micro).

MWR: "On September 6 the SS African Star, about 700 miles west of the Cape Verde Islands, forwarded a succession of special reports showing falling pressure, increasing winds, and squalliness. The existence of hurricane Carrie was confirmed when the 1600 GMT report (somewhat delayed) showed an east-northeast wind of $92 \mathrm{mph}$ and a pressure of 1,001 mb. Later analyses indicate that the vortex noted on the $2 \mathrm{nd}$ was the genesis stage of Carrie and that it moved west-northwestward at about $12 \mathrm{mph}$ to the position at which it was encountered by the African Star." ATSR: "No reports were received to confirm a storm in that area until 0600Z, 6 September, when the ship KATTY near $17 \mathrm{~N} 40 \mathrm{~W}$ reported a win from NNE, 20 knots, and seas of 9.5 feet with a 8-second period. The AFRICAN STAR reported again at $1600 \mathrm{Z}$ with 80 knots of wind, high seas and pressure of $1001.0 \mathrm{mb}$. Warning number ONE on hurricane CARRIE was promulgated, as coordinated with the San Juan Weather Bureau, at 2230Z, 6 September.” September 7:

HWM is not available on this date (system is south of $20^{\circ} \mathrm{N}$ ). HURDAT lists a 110 knot hurricane at $16.7 \mathrm{~N}, 41.0 \mathrm{~W}$ at $12 \mathrm{Z}$. Microfilm shows a closed low pressure of at most $1005 \mathrm{mb}$ at $16.0 \mathrm{~N}, 45.5 \mathrm{~W}$ at 12Z. Ship highlights: No gales or low pressures. Aircraft highlights: Penetration center fix measured a central pressure of $945 \mathrm{mb}$, estimated maximum winds of $120 \mathrm{kt}$ at $700 \mathrm{mb}$, and an eye diameter of $20 \mathrm{~nm}$ at $17.2 \mathrm{~N}$, $42.5 \mathrm{~W}$ at $2148 \mathrm{Z}$ (micro). 
MWR: "On September 7, in an unusually long flight, the regular Air Force Gull reconnaissance plane from Bermuda was diverted to the storm area. The observer reported maximum winds of $138 \mathrm{mph}$ at the $700-\mathrm{mb}$. level with a well-defined eye 20 miles in diameter and a minimum surface pressure of $945 \mathrm{mb}$." ATSR: "No further reports were received until $072210 \mathrm{Z}$ when a $59^{\text {th }}$ Weather Reconnaissance Squadron aircraft, which had been diverted from its normal GULL PAPA track to its maximum range, reported CARRIE at $17.2 \mathrm{~N} 42.6 \mathrm{~W}$ with flight winds of 110 knots, and a $700 \mathrm{mb}$ height of 8740 feet."

September 8:

HWM is not available on this date (system is south of $20^{\circ} \mathrm{N}$ ). HURDAT lists a 130 knot hurricane at $18.0 \mathrm{~N}, 45.0 \mathrm{~W}$ at $12 \mathrm{Z}$. Microfilm shows a closed low pressure of at most $1008 \mathrm{mb}$ at $18.0 \mathrm{~N}, 45.0 \mathrm{~W}$ at 12Z. Ship highlights: $35 \mathrm{kt} \mathrm{NE}$ and $1013 \mathrm{mb}$ at $19.2 \mathrm{~N}$, $49.7 \mathrm{~W}$ at $15 \mathrm{Z}$ (micro). Aircraft highlights: Penetration center fix at $18.0 \mathrm{~N}, 45.1 \mathrm{~W}$ at 1930Z (ATSR).

September 9:

HWM is not available on this date (system is south of $20^{\circ} \mathrm{N}$ ). HURDAT lists a 135 knot hurricane at $18.3 \mathrm{~N}, 48.2 \mathrm{~W}$ at $12 \mathrm{Z}$. Microfilm shows a closed low pressure of at most $999 \mathrm{mb}$ at $18.5 \mathrm{~N}, 48.8 \mathrm{~W}$ at 12Z. Ship highlights: No gales or low pressures. Aircraft highlights: Penetration center fix at $19.5 \mathrm{~N}, 49.8 \mathrm{~W}$ at $2226 \mathrm{Z}$ (ATSR). Penetration center fix measured a central pressure of $975 \mathrm{mb}$, estimated maximum winds of $135 \mathrm{kt}$ at $700 \mathrm{mb}$ and an eye diameter of $10 \mathrm{~nm}$ at $19.4 \mathrm{~N}, 49.6 \mathrm{~W}$ at $2021 \mathrm{Z}$ (micro).

ATSR: "Due to the extreme range, only one aircraft fix per day was available on CARRIE."

September 10:

HWM is not available on this date (system is south of $20^{\circ} \mathrm{N}$ ). HURDAT lists a 95 knot hurricane at $19.5 \mathrm{~N}, 51.3 \mathrm{~W}$ at $12 \mathrm{Z}$. Microfilm shows a closed low pressure of at most $999 \mathrm{mb}$ at $18.5 \mathrm{~N}, 48.8 \mathrm{~W}$ at 12Z. Ship highlights: No gales or low pressures. Aircraft highlights: Penetration center fix measured a central pressure of $977 \mathrm{mb}$ and an eye diameter of $20 \mathrm{~nm}$ at $19.3 \mathrm{~N}, 50.8 \mathrm{~W}$ at $0815 \mathrm{Z}$ (micro). Penetration center fix measured a central pressure of $985 \mathrm{mb}$, estimated maximum surface winds of $75 \mathrm{kt}$, and an eye diameter of $20 \mathrm{~nm}$ at $19.3 \mathrm{~N}, 50.9 \mathrm{~W}$ at $0930 \mathrm{Z}$ (micro). Penetration center fix estimated maximum winds of $65 \mathrm{mb}$ at $700 \mathrm{mb}$, and an eye diameter of $20 \mathrm{~nm}$ at $20.7 \mathrm{~N}$, $52.1 \mathrm{~W}$ at $1930 \mathrm{Z}$ (micro).

ATSR: “... until 10 September when two or more fixes per day were available ...” 
September 11:

HWM analyzes a hurricane with a central pressure of $985 \mathrm{mb}$ at $21.0 \mathrm{~N}, 52.5 \mathrm{~W}$ at $12 \mathrm{Z}$. HURDAT lists a $65 \mathrm{knot}$ hurricane at $21.0 \mathrm{~N}, 52.7 \mathrm{~W}$ at $12 \mathrm{Z}$. Microfilm shows a closed low pressure of at most $1005 \mathrm{mb}$ at $20.5 \mathrm{~N}, 52.5 \mathrm{~W}$ at 12Z. Ship highlights: $35 \mathrm{kt}$ $\mathrm{SE}$ and $1009 \mathrm{mb}$ at $19.1 \mathrm{~N}, 49.9 \mathrm{~W}$ at $12 \mathrm{Z}$ (micro). $35 \mathrm{kt} \mathrm{SE}$ and $1010 \mathrm{mb}$ at $18.8 \mathrm{~N}, 51.7 \mathrm{~W}$ at $15 \mathrm{Z}$ (micro). $35 \mathrm{kt} \mathrm{SE}$ and $1005 \mathrm{mb}$ at $22.1 \mathrm{~N}, 51.1 \mathrm{~W}$ at $18 \mathrm{Z}$ (micro). Aircraft highlights: Penetration center fix measured a central pressure of $985 \mathrm{mb}$, estimated maximum surface winds of $50 \mathrm{kt}$, and an eye diameter of $20 \mathrm{~nm}$ at $20.5 \mathrm{~N}, 52.4 \mathrm{~W}$ at $09 \mathrm{Z}$ (ATSR). Penetration center fix measured a central pressure of $978 \mathrm{mb}$, estimated maximum winds of $60 \mathrm{mb}$ at $500 \mathrm{mb}$, and an eye diameter of $25 \mathrm{~nm}$ at $20.9 \mathrm{~N}, 52.2 \mathrm{~W}$ at $20 Z$ (micro).

MWR: "Reconnaissance on the next 4 days showed a gradual rise in central pressure and on the $11^{\text {th }}$, the minimum pressure was $984 \mathrm{mb}$ and the highest winds were reported as about $70 \mathrm{mph}$. The weakening of the hurricane was apparently due to decreasing pressure gradient to the north as a low pressure trough formed across the subtropical High to a deepening Low near Newfoundland. This Low moved southward, reaching its most southerly position on the $11^{\text {th }}$, after which it begun a slow retreat to the north."

September 12:

HWM analyzes a hurricane with a central pressure of 960 at $22.9 \mathrm{~N}, 52.7 \mathrm{~W}$ at 12Z. HURDAT lists a 90 knot hurricane at $22.8 \mathrm{~N}, 52.7 \mathrm{~W}$ at $12 \mathrm{Z}$. Microfilm shows a closed low pressure of at most $999 \mathrm{mb}$ at $22.5 \mathrm{~N}, 52.3 \mathrm{~W}$ at 12Z. Ship highlights: $40 \mathrm{kt} \mathrm{SE}$ and $1007 \mathrm{mb}$ at $22.0 \mathrm{~N}, 50.6 \mathrm{~W}$ at $00 \mathrm{Z}$ (COADS). $30 \mathrm{kt} \mathrm{N}$ and $1002 \mathrm{mb}$ at $22.6 \mathrm{~N}, 53.0 \mathrm{~W}$ at $06 \mathrm{Z}$ (micro). $50 \mathrm{kt} \mathrm{SE}$ and $1009 \mathrm{mb}$ at $23.8 \mathrm{~N}, 50.9 \mathrm{~W}$ at $21 \mathrm{Z}$ (COADS). Aircraft highlights: Penetration center fix measured a central pressure of $960 \mathrm{mb}$, estimated maximum surface winds of $90 \mathrm{kt}$, and an eye diameter of $25 \mathrm{~nm}$ at $23.5 \mathrm{~N}, 52.2 \mathrm{~W}$ at $1405 \mathrm{Z}$ (micro). Penetration center fix measured a central pressure of $957 \mathrm{mb}$, estimated maximum surface winds of $95 \mathrm{kt}$, and an eye diameter of $20 \mathrm{~nm}$ at $23.9 \mathrm{~N}, 53.0 \mathrm{~W}$ at $1930 Z$ (micro).

MWR: “... on the 12th reconnaissance aircraft found maximum winds of $108 \mathrm{mph}$ and minimum sea level pressure of $960 \mathrm{mb}$. There were heavy wall clouds in all quadrants except the southwest."

September 13:

HWM analyzes a hurricane with a central pressure of $951 \mathrm{mb}$ at $25.5 \mathrm{~N}, 52.1 \mathrm{~W}$ at $12 \mathrm{Z}$. HURDAT lists a 100 knot hurricane at $25.4 \mathrm{~N}, 52.4 \mathrm{~W}$ at $12 \mathrm{Z}$. Microfilm shows a closed low pressure of at most $1008 \mathrm{mb}$ at $25.5 \mathrm{~N}, 52.8 \mathrm{~W}$ at $12 \mathrm{Z}$. Ship highlights: $70 \mathrm{kt}$ 
ENE and $1009 \mathrm{mb}$ at $26.1 \mathrm{~N}, 54.5 \mathrm{~W}$ at $03 \mathrm{Z}$ (micro). $65 \mathrm{kt} \mathrm{NNE}$ and $1010 \mathrm{mb}$ at $26.1 \mathrm{~N}$, $55.2 \mathrm{~W}$ at $09 \mathrm{Z}$ (micro). Aircraft highlights: Penetration center fix measured a central pressure of $951 \mathrm{mb}$ at $26.0 \mathrm{~N}, 52.4 \mathrm{~W}$ at $0839 \mathrm{Z}$ (micro). Penetration center fix measured a central pressure of $953 \mathrm{mb}$ at $26.6 \mathrm{~N}, 52.0 \mathrm{~W}$ at $1430 \mathrm{Z}$ (micro). Penetration center fix measured a central pressure of $963 \mathrm{mb}$, estimated maximum surface winds of $90 \mathrm{kt}$, and an eye diameter of $20 \mathrm{~nm}$ at $26.5 \mathrm{~N}, 52.0 \mathrm{~W}$ at $1930 \mathrm{Z}$ (micro).

September 14:

HWM analyzes a hurricane with a central pressure of $968 \mathrm{mb}$ at $28.5 \mathrm{~N}, 53.0 \mathrm{~W}$ at $12 \mathrm{Z}$. HURDAT lists a $110 \mathrm{knot}$ hurricane at $28.1 \mathrm{~N}, 53.2 \mathrm{~W}$ at $12 \mathrm{Z}$. Microfilm shows a closed low pressure of at most $1005 \mathrm{mb}$ at $29.0 \mathrm{~N}, 53.0 \mathrm{~W}$ at 12Z. Ship highlights: $35 \mathrm{kt}$ $\mathrm{NNE}$ and $1010 \mathrm{mb}$ at $27.7 \mathrm{~N}, 55.0 \mathrm{~W}$ at $12 \mathrm{Z}$ (micro). $45 \mathrm{kt} \mathrm{SW}$ and $1011 \mathrm{mb}$ at $27.6 \mathrm{~N}$, $53.6 \mathrm{~W}$ at $18 \mathrm{Z}$ (micro). Aircraft highlight: Penetration center fix measured a central pressure of $964 \mathrm{mb}$ at $28.2 \mathrm{~N}, 52.4 \mathrm{~W}$ at $0735 \mathrm{Z}$ (micro). Penetration center fix measured a central pressure of $964 \mathrm{mb}$, estimated maximum surface winds of $75 \mathrm{kt}$, and an eye diameter of $25 \mathrm{~nm}$ at $28.1 \mathrm{~N}, 53.8 \mathrm{~W}$ at $1440 \mathrm{Z}$ (micro). Penetration center fix measured a central pressure of $963 \mathrm{mb}$, estimated maximum winds of $130 \mathrm{kt}$ at $500 \mathrm{mb}$, and an eye diameter of $35 \mathrm{~nm}$ at $28.3 \mathrm{~N}, 54.5 \mathrm{~W}$ at $20 \mathrm{Z}$ (micro).

MWR: "Carrie, having curved to a northerly course at this time, continued northward at 7 to $10 \mathrm{mph}$ until September 14 when rebuilding of the high pressure ridge over the north Atlantic forced it to change course toward the northwest."

September 15:

HWM analyzes a hurricane with a central pressure of $965 \mathrm{mb}$ at $30.0 \mathrm{~N}, 57.5 \mathrm{~W}$ at $12 \mathrm{Z}$. HURDAT lists a $105 \mathrm{knot}$ hurricane at $30.2 \mathrm{~N}, 58.0 \mathrm{~W}$ at $12 \mathrm{Z}$. Microfilm shows a closed low pressure of at most $1014 \mathrm{mb}$ at $30.5 \mathrm{~N}, 59.0 \mathrm{~W}$ at $12 \mathrm{Z}$. Ship highlights: $35 \mathrm{kt}$ $\mathrm{SW}$ and $1015 \mathrm{mb}$ at $28.2 \mathrm{~N}, 53.0 \mathrm{~W}$ at $00 \mathrm{Z}$ (micro). $50 \mathrm{kt} \mathrm{E}$ at $32.2 \mathrm{~N}, 58.0 \mathrm{~W}$ at $18 \mathrm{Z}$ (micro). Aircraft highlight: Penetration center fix measured a central pressure of $967 \mathrm{mb}$, estimated maximum surface winds of $80 \mathrm{kt}$, and an eye diameter of $40 \mathrm{~nm}$ at $29.7 \mathrm{~N}$, $56.8 \mathrm{~W}$ at $0740 \mathrm{Z}$ (micro). Penetration center fix measured a central pressure of $965 \mathrm{mb}$, estimated maximum surface winds of $72 \mathrm{kt}$, and an eye diameter of $40 \mathrm{~nm}$ at $30.3 \mathrm{~N}$, $58.2 \mathrm{~W}$ at $1350 \mathrm{Z}$ (micro). Penetration center fix measured a central pressure of $963 \mathrm{mb}$, estimated maximum surface winds of $84 \mathrm{kt}$, and a RMW of about $22 \mathrm{~nm}$ near $30.0 \mathrm{~N}$, 58.0W around 19Z (NHRP). Penetration center fix measured a central pressure of $961 \mathrm{mb}$ and an eye diameter of $40 \mathrm{~nm}$ at $31.1 \mathrm{~N}, 59.2 \mathrm{~W}$ at $1930 \mathrm{Z}$ (micro). Penetration center fix estimated maximum surface winds of $70 \mathrm{kt}$ and an eye diameter of $40 \mathrm{~nm}$ at $31.8 \mathrm{~N}$, $60.3 \mathrm{~W}$ at $2146 \mathrm{Z}$ (micro). Penetration center fix measured a central pressure of $963 \mathrm{mb}$, 
estimated maximum surface winds of $80 \mathrm{kt}$, and a RMW of about $22 \mathrm{~nm}$ near $30.0 \mathrm{~N}$, 58.0W around 22Z (NHRP).

September 16:

HWM analyzes a hurricane with a central pressure of $970 \mathrm{mb}$ at $33.0 \mathrm{~N}, 62.0 \mathrm{~W}$ at 12Z. HURDAT lists an 85 knot hurricane at $32.7 \mathrm{~N}, 62.0 \mathrm{~W}$ at $12 \mathrm{Z}$. Microfilm shows a closed low pressure of at most $1008 \mathrm{mb}$ at $32.0 \mathrm{~N}, 62.6 \mathrm{~W}$ at 12Z. Ship highlights: $35 \mathrm{kt}$ $\mathrm{NE}$ and $1021 \mathrm{mb}$ at $35.5 \mathrm{~N}, 57.8 \mathrm{~W}$ at $00 \mathrm{Z}$ (micro). Aircraft highlight: Penetration center fix measured a central pressure of $964 \mathrm{mb}$ and an eye diameter of $40 \mathrm{~nm}$ at $31.8 \mathrm{~N}, 60.3 \mathrm{~W}$ at $0146 \mathrm{Z}$ (micro). Penetration center fix measured a central pressure of $966 \mathrm{mb}$, estimated maximum surface winds of $90 \mathrm{kt}$, and an eye diameter of $60 \mathrm{~nm}$ at $32.1 \mathrm{~N}, 61.0 \mathrm{~W}$ at $0557 \mathrm{Z}$ (micro). Penetration center fix measured a central pressure of $967 \mathrm{mb}$, estimated maximum surface winds of $60 \mathrm{kt}$, and an eye diameter of $60 \mathrm{~nm}$ at $32.0 \mathrm{~N}, 61.2 \mathrm{~W}$ at $07 \mathrm{Z}$ (micro). Penetration center fix measured a central pressure of $970 \mathrm{mb}$, estimated maximum surface winds of $90 \mathrm{kt}$, and an eye diameter of $70 \mathrm{~nm}$ at $32.3 \mathrm{~N}, 61.7 \mathrm{~W}$ at 0955Z (micro). Penetration center fix measured a central pressure of $969 \mathrm{mb}$ and estimated maximum surface winds of $90 \mathrm{kt}$ at $32.7 \mathrm{~N}, 62.4 \mathrm{~W}$ at $1351 \mathrm{Z}$ (micro). Penetration center fix at $33.5 \mathrm{~N}, 62.2 \mathrm{~W}$ at $2127 \mathrm{Z}$ (ATSR). Penetration center fix at $33.9 \mathrm{~N}$, 63.6W at 2352Z (ATSR).

MWR: "A continued increase in intensity and in size culminated on the $16^{\text {th }}$ in what National Hurricane Research Project observers characterized as one of the most perfectly formed hurricanes they had seen. The winds of $138 \mathrm{mph}$ reported on this date were the maximum surface winds observed during the life of Carrie but it is likely that higher wind speeds occurred during the period of lowest central pressure on September 7 and 8 . When the hurricane passed to the northeast of Bermuda on the $16^{\text {th }}$, poor radar definition and an increase in the diameter of the eye to 40 to 70 miles indicated weakening. However, as it curved eastward in advance of a trough moving into the North Atlantic, it still maintained maximum winds of near $100 \mathrm{mph}$ for the next several days."

September 17:

HWM analyzes a hurricane of at most $1000 \mathrm{mb}$ at $35.5 \mathrm{~N}, 63.2 \mathrm{~W}$ at $12 \mathrm{Z}$. HURDAT lists an 80 knot hurricane at $35.2 \mathrm{~N}, 63.8 \mathrm{~W}$ at $12 \mathrm{Z}$. Microfilm shows a closed low pressure of at most $999 \mathrm{mb}$ at $35.5 \mathrm{~N}, 64.0 \mathrm{~W}$ at 12Z. Ship highlights: $35 \mathrm{kt} \mathrm{SE}$ and $1017 \mathrm{mb}$ at $36.3 \mathrm{~N}, 61.3 \mathrm{~W}$ at $03 \mathrm{Z}$ (micro). $40 \mathrm{kt} \mathrm{S}$ and $1018 \mathrm{mb}$ at $33.4 \mathrm{~N}, 60.9 \mathrm{~W}$ at $12 \mathrm{Z}$ (COADS). $50 \mathrm{kt} \mathrm{S}$ and $1001 \mathrm{mb}$ at 35.8N, 62.8W at 15Z (COADS). $80 \mathrm{kt} \mathrm{SE}$ and $977 \mathrm{mb}$ at $35.9 \mathrm{~N}, 63.2 \mathrm{~W}$ at $18 \mathrm{Z}$ (micro). Aircraft highlights: Penetration center fix measured a central pressure of $970 \mathrm{mb}$ and estimated maximum surface winds of $70 \mathrm{kt}$ at $34.1 \mathrm{~N}$, 63.7W at $0130 \mathrm{Z}$ (micro). Penetration center fix measured a central pressure of $974 \mathrm{mb}$ 
and estimated maximum surface winds of $75 \mathrm{kt}$ and an eye diameter of about $65 \mathrm{~nm}$ at $34.8 \mathrm{~N}, 64.8 \mathrm{~W}$ at $08 \mathrm{Z}$ (micro). Penetration center fix measured a central pressure of 975 $\mathrm{mb}$ and estimated maximum surface winds of $80 \mathrm{kt}$ at $35.4 \mathrm{~N}, 63.9 \mathrm{~W}$ at $1425 \mathrm{Z}$ (micro). Penetration center fix at $35.6 \mathrm{~N}, 63.5 \mathrm{~W}$ at $1736 \mathrm{Z}$ (ATSR). Penetration center fix measured a central pressure of $978 \mathrm{mb}$, estimated maximum surface winds of $84 \mathrm{kt}$, and a RMW of about $32 \mathrm{~nm}$ near 35.0N, 64.0W around 18Z (NHRP).

September 18:

HWM analyzes a hurricane with a central pressure of $975 \mathrm{mb}$ at $36.0 \mathrm{~N}, 59.9 \mathrm{~W}$ with a cold front to the north at 12Z. HURDAT lists a 75 knot hurricane at $35.9 \mathrm{~N}, 59.5 \mathrm{~W}$ at $12 \mathrm{Z}$. Microfilm shows a closed low pressure of at most $1005 \mathrm{mb}$ at $36.0 \mathrm{~N}, 59.0 \mathrm{~W}$ at 12Z. Ship highlights: $40 \mathrm{kt} \mathrm{SW}$ and $1014 \mathrm{mb}$ at 33.9N, 60.7W at 00Z (COADS). $65 \mathrm{kt} \mathrm{S}$ and $995 \mathrm{mb}$ at $36.0 \mathrm{~N}, 60.0 \mathrm{~W}$ at $06 \mathrm{Z}$ (COADS). $80 \mathrm{kt} \mathrm{SE}$ and $1002 \mathrm{mb}$ at $36.1 \mathrm{~N}, 53.2 \mathrm{~W}$ at $12 \mathrm{Z}$ (micro). $65 \mathrm{kt} \mathrm{E}$ and $1002 \mathrm{mb}$ at $36.7 \mathrm{~N}, 59.5 \mathrm{~W}$ at $18 \mathrm{Z}$ (micro). $50 \mathrm{kt} \mathrm{NNW}$ and $999 \mathrm{mb}$ at $35.2 \mathrm{~N}, 57.6 \mathrm{~W}$ at $2050 \mathrm{Z}$ (micro). Aircraft highlight: Penetration center fix measured a central pressure of $978 \mathrm{mb}$, estimated maximum surface winds of $80 \mathrm{kt}$, and an eye diameter of $80 \mathrm{~nm}$ at $35.9 \mathrm{~N}, 60.4 \mathrm{~W}$ at $07 \mathrm{Z}$ (micro). Penetration center fix at $36.1 \mathrm{~N}, 58.9 \mathrm{~W}$ at $1356 \mathrm{Z}$ (ATSR).

September 19:

HWM analyzes a hurricane with a central pressure of $985 \mathrm{mb}$ at $34.5 \mathrm{~N}, 54.0 \mathrm{~W}$ with a weakening cold front to the north at $12 \mathrm{Z}$. HURDAT lists a 70 knot hurricane at $34.7 \mathrm{~N}, 53.9 \mathrm{~W}$ at $12 \mathrm{Z}$. Microfilm shows a closed low pressure of at most $1005 \mathrm{mb}$ at $34.5 \mathrm{~N}, 53.5 \mathrm{~W}$ with a frontal boundary to the north at 12Z. Ship highlights: $65 \mathrm{kt} \mathrm{NW}$ and $985 \mathrm{mb}$ at $35.0 \mathrm{~N}, 56.2 \mathrm{~W}$ at $00 \mathrm{Z}$ (COADS). $45 \mathrm{kt} \mathrm{SSW}$ and $1004 \mathrm{mb}$ at $33.2 \mathrm{~N}, 53.2 \mathrm{~W}$ at $06 \mathrm{Z}$ (micro). $45 \mathrm{kt} \mathrm{NW}$ and $1007 \mathrm{mb}$ at $33.1 \mathrm{~N}, 54.5 \mathrm{~W}$ at $12 \mathrm{Z}$ (COADS). $40 \mathrm{kt} \mathrm{ENE}$ and $1006 \mathrm{mb}$ at $35.5 \mathrm{~N}, 49.0 \mathrm{~W}$ at $18 \mathrm{Z}$ (micro). $990 \mathrm{mb}$ at $34.2 \mathrm{~N}, 50.0 \mathrm{~W}$ at $21 \mathrm{Z}$ (micro). Aircraft highlights: Penetration center fix at $34.7 \mathrm{~N}, 52.9 \mathrm{~W}$ at $14 \mathrm{Z}$ (ATSR). Penetration center fix at $34.8 \mathrm{~N}, 52.1 \mathrm{~W}$ at $1448 \mathrm{Z}$ (ATSR). Penetration center fix at $34.4 \mathrm{~N}, 51.3 \mathrm{~W}$ at $19 Z$ (ATSR).

ATSR: "...until after 19 September when range again restricted fixes to one per day. CARRIE was the "greatest" hurricane of the 1957 season and set a modern report for life span, containing winds of knows hurricane force for sixteen days."

September 20:

HWM analyzes a hurricane with a central pressure of $978 \mathrm{mb}$ at $34.0 \mathrm{~N}, 47.8 \mathrm{~W}$ with a warm front to the northeast and a cold front to the west at 12Z. HURDAT lists a 70 knot hurricane at $34.1 \mathrm{~N}, 47.8 \mathrm{~W}$ at $12 \mathrm{Z}$. Microfilm shows a closed low pressure of at 
most $999 \mathrm{mb}$ at $34.0 \mathrm{~N}, 47.0 \mathrm{~W}$ with a frontal boundary to the east at 12Z. Ship highlights: $55 \mathrm{kt} \mathrm{NE}$ and $1006 \mathrm{mb}$ at $35.5 \mathrm{~N}, 50.0 \mathrm{~W}$ at $01 \mathrm{Z}$ (micro). $45 \mathrm{kt} \mathrm{ENE}$ and $1004 \mathrm{mb}$ at $35.8 \mathrm{~N}, 48.4 \mathrm{~W}$ at $03 \mathrm{Z}$ (COADS). $50 \mathrm{kt} \mathrm{ENE}$ and $1002 \mathrm{mb}$ at $35.8 \mathrm{~N}, 48.8 \mathrm{~W}$ at $06 \mathrm{Z}$ (COADS). $50 \mathrm{kt} \mathrm{SE}$ and $993 \mathrm{mb}$ at 34.3N, 45.8W at 12Z (COADS). $70 \mathrm{kt} \mathrm{NE}$ and 997 $\mathrm{mb}$ at $34.7 \mathrm{~N}, 46.2 \mathrm{~W}$ at $16 \mathrm{Z}$ (COADS). $70 \mathrm{kt}$ and $987 \mathrm{mb}$ at $34.8 \mathrm{~N}, 45.3 \mathrm{~W}$ at $18 \mathrm{Z}$ (COADS). Aircraft highlights: Penetration center fix at $34.4 \mathrm{~N}, 45.6 \mathrm{~W}$ at $20 \mathrm{Z}$ (ATSR).

September 21:

HWM analyzes a hurricane with a central pressure of $972 \mathrm{mb}$ at $34.5 \mathrm{~N}, 40.0 \mathrm{~W}$ with a weakening warm front to the northeast and a cold front to the south at $12 \mathrm{Z}$. HURDAT lists a 70 knot hurricane at $34.7 \mathrm{~N}, 40.1 \mathrm{~W}$ at 12Z. Microfilm shows a closed low pressure of at most $1002 \mathrm{mb}$ at $34.0 \mathrm{~N}, 41.0 \mathrm{~W}$ at $06 \mathrm{Z}$. Ship highlights: $45 \mathrm{kt} \mathrm{N}$ and $1007 \mathrm{mb}$ at $34.8 \mathrm{~N}, 46.1 \mathrm{~W}$ at $01 \mathrm{Z}$ (COADS). $45 \mathrm{kt} \mathrm{NNE}$ and $1005 \mathrm{mb}$ at $35.4 \mathrm{~N}, 46.4 \mathrm{~W}$ at 06Z (COADS). $45 \mathrm{kt} \mathrm{S}$ and $1002 \mathrm{mb}$ at $36.0 \mathrm{~N}, 34.5 \mathrm{~W}$ at $12 \mathrm{Z}$ (COADS). $90 \mathrm{kt} \mathrm{SSW}$ and $995 \mathrm{mb}$ at $34.5 \mathrm{~N}, 36.1 \mathrm{~W}$ at $18 \mathrm{Z}$ (micro). Aircraft highlights: Penetration center fix at $35.1 \mathrm{~N}, 36.9 \mathrm{~W}$ at $1930 \mathrm{Z}$ (ATSR).

MWR: "Sixty-two warnings were issued by the Joint Center in Miami and an additional eight warning were issued by the U.S. Fleet Weather Central, Fort Lyautey, after CARRIE had crossed the $35^{\text {th }}$ meridian. CARRIE remained at sea through her life cycle. Damages and loss of life were limited to the sinking of the German sailing vessel PAMIR on 21 September with subsequent loss of all but six of the eighty-six crew members. On the 21 st the German sailing ship Pamir encountered the storm southwest of the Azores and went down with the loss of 80 of her 86 crew members."

September 22:

HWM analyzes a hurricane of at most $985 \mathrm{mb}$ at $38.0 \mathrm{~N}, 29.8 \mathrm{~W}$ with a cold front to the south at $12 \mathrm{Z}$. HURDAT lists a 70 knot hurricane at $38.4 \mathrm{~N}, 29.5 \mathrm{~W}$ at $12 \mathrm{Z}$. Microfilm shows a closed low pressure of at most $990 \mathrm{mb}$ at $37.0 \mathrm{~N}, 29.0 \mathrm{~W}$ at $12 \mathrm{Z}$. Ship highlights: $70 \mathrm{kt} \mathrm{W}$ and $980 \mathrm{mb}$ at $34.5 \mathrm{~N}, 34.9 \mathrm{~W}$ at $00 \mathrm{Z}$ (micro). $60 \mathrm{kt} \mathrm{NW}$ and $1003 \mathrm{mb}$ at $34.9 \mathrm{~N}, 35.6 \mathrm{~W}$ at $06 \mathrm{Z}$ (COADS). $60 \mathrm{kt} \mathrm{S}$ and $985 \mathrm{mb}$ at $36.4 \mathrm{~N}, 27.9 \mathrm{~W}$ at $12 \mathrm{Z}$ (micro). $50 \mathrm{kt} \mathrm{S}$ and $993 \mathrm{mb}$ at 39.3N, 23.4W at 18Z (COADS). Land highlights: $20 \mathrm{kt} \mathrm{SE}$ and $983 \mathrm{mb}$ at Pico Island, Azores at 12Z (micro). $45 \mathrm{kt} \mathrm{SW}$ and 1000 at Sao Miguel Island, Azores at $18 \mathrm{Z}$ (micro).

MWR: "Insufficient reports were obtained to indicate the maximum wind and lowest pressures observed as it passed through the Azores the next day [22] but it is likely that winds of hurricane force persisted." 
September 23:

HWM analyzes a tropical storm of at most $985 \mathrm{mb}$ at $45.5 \mathrm{~N}, 18.7 \mathrm{~W}$ with a stationary front to the north and a weakening cold front to the south at 12Z. HURDAT lists a 60 knot extratropical cyclone at $45.6 \mathrm{~N}, 17.8 \mathrm{~W}$ at $12 \mathrm{Z}$. Microfilm is not available on this date. Ship highlights: $55 \mathrm{kt} \mathrm{SSE}$ and $1002 \mathrm{mb}$ at $41.6 \mathrm{~N}, 18.5 \mathrm{~W}$ at $00 \mathrm{Z}$ (COADS). $70 \mathrm{kt} \mathrm{WNW}$ and $977 \mathrm{mb}$ at $44.0 \mathrm{~N}, 21.4 \mathrm{~W}$ at $06 \mathrm{Z}$ (COADS). $65 \mathrm{kt} \mathrm{SW}$ and $987 \mathrm{mb}$ at $45.5 \mathrm{~N}, 17.2 \mathrm{~W}$ at $12 \mathrm{Z}(\mathrm{COADS}) .50 \mathrm{kt} \mathrm{SW}$ and $994 \mathrm{mb}$ at $47.5 \mathrm{~N}, 13.0 \mathrm{~W}$ at $18 \mathrm{Z}$ (COADS).

September 24:

HWM analyzes a closed low pressure of at most $995 \mathrm{mb}$ at $51.0 \mathrm{~N}, 13.0 \mathrm{~W}$ with a frontal boundary to the north and a dissipating cold front to the south at 12Z. HURDAT lists a 50 knot extratropical cyclone at $51.2 \mathrm{~N}, 10.8 \mathrm{~W}$ at $12 \mathrm{Z}$. Microfilm is not available on this date. Ship highlights: $45 \mathrm{kt} \mathrm{S}$ and $976 \mathrm{mb}$ at 50.0N, 15.6W at 00Z (COADS). 45 $\mathrm{kt} \mathrm{NE}$ and $1000 \mathrm{mb}$ at $50.0 \mathrm{~N}, 16.7 \mathrm{~W}$ at $06 \mathrm{Z}$ (COADS). $45 \mathrm{kt} \mathrm{S}$ and $996 \mathrm{mb}$ at $50.0 \mathrm{~N}$, $10.7 \mathrm{~W}$ at $12 \mathrm{Z}$ (COADS). $45 \mathrm{kt}$ ENE and $1015 \mathrm{mb}$ at $56.0 \mathrm{~N}, 12.1 \mathrm{~W}$ at $18 \mathrm{Z}$ (COADS). Land highlights: $25 \mathrm{kt} \mathrm{SE}$ and $997 \mathrm{mb}$ at Dingle, Ireland at 12Z (HWM).

MWR: "Carrie began to assume extratropical feature thereafter and accelerated to the northeast, lashing the British Isles with high winds on the 24th and 25th and causing tremendous waves on the coast and floods over parts of the Isles. Carrie was charted over one of the longest tracks, probably the longest track, of record-approximately 6,000 miles from its origin off the African coast to near Bermuda and back across the Atlantic to the British Isles. Formal advisories were issued from September 6 to 21 and additional advices were issued through the NSS bulletin (report from Navy Radio station at Annapolis) after it passed east of longitude $35^{\prime} \mathrm{W}$. on that date. Aircraft reconnaissance of Carrie was of unusual quality. The Air Force flights from Bermuda on the 7 th and $21 \mathrm{st}$ went farther east than any previous hurricane reconnaissance flight and the initial flight on the 7th covered approximately 3,700 miles with almost 17 hours in the air."

September 25:

HWM analyzes a closed low pressure of at most $1005 \mathrm{mb}$ at $51.0 \mathrm{~N}, 6.0 \mathrm{~W}$ with a warm front to the north and cold front extending through the system to the southwest at 12Z. HURDAT does not list an organized system on this date. Microfilm is not available on this date. Ship highlights: $35 \mathrm{kt} \mathrm{W}$ and $1015 \mathrm{mb}$ at $47.3 \mathrm{~N}, 7.8 \mathrm{~W}$ at $18 \mathrm{Z}$ (COADS). 35 kt NW and $1022 \mathrm{mb}$ at 48.3N, 5.3W at 23Z (COADS). Land highlights: $15 \mathrm{kt} \mathrm{SW}$ and $1004 \mathrm{mb}$ at Isles of Scilly, England at 12Z (HWM). 
September 26:

HWM analyzes a frontal boundary over Western Europe and no organized low pressure system at 12Z. HURDAT does not list an organized system on this date. Microfilm is not available on this date.

A tropical wave left the African coast during the last days of August and rapidly organized into a tropical cyclone southeast of the Cape Verde Islands. Data over the eastern Atlantic is sparse and it is difficult to determine the exact time of formation but it is consistent with the presence of a low pressure system on the $2^{\text {nd }}$. A $25 \mathrm{kt}$ tropical depression is analyzed to have formed at $06 \mathrm{Z}$ on September $2^{\text {nd }}$, no change from the original HURDAT. A central pressure of $1001 \mathrm{mb}$ is present in HURDAT at $18 \mathrm{Z}$ on the $2^{\text {nd }}$. This value, if real, would suggest a moderate tropical storm, which is not consistent with the remaining other observations. Thus, it has been removed from HURDAT. Minor changes were made to the track on September $2^{\text {nd }}$, and $5^{\text {th }}$ through the $23 \mathrm{rd}$, no track changes on the $3^{\text {rd }}$ and $4^{\text {th }}$ and major track changes on the $24^{\text {th }}$ between $00 \mathrm{Z}$ and $12 \mathrm{Z}$. On September $3^{\text {rd }}$, the tropical depression passed south of the Cape Verde Islands.

Intensification to a tropical storm is analyzed at $12 \mathrm{Z}$ on the $3^{\text {rd }}$. There is no data to corroborate the intensification, so we are keeping the original HURDAT. Similarly, intensification to a hurricane is analyzed at $12 \mathrm{Z}$ on September $5^{\text {th }}$ and there are no ships or coastal stations for hundreds of miles from the center of the cyclone, thus we are retaining the original HURDAT. The first gale was observed at $12 \mathrm{Z}$ on September $6^{\text {th }}$ when a ship northwest of the hurricane reported $35 \mathrm{kt} \mathrm{NNE}$. Later at 16Z, another ship, very close to the hurricane, reported $80 \mathrm{kt} \mathrm{ENE}$ and $1001 \mathrm{mb}$. These data are consistent with the $85 \mathrm{kt}$ at $12 \mathrm{Z}$ and $95 \mathrm{kt}$ at $18 \mathrm{Z}$ on the $6^{\text {th }}$ in HURDAT, so no changes are made. Intensification to a major hurricane is analyzed at $00 \mathrm{Z}$ on September $7^{\text {th }}$, same as the original HURDAT. The first reconnaissance aircraft to reach Carrie occurred at $2148 \mathrm{Z}$ on the $7^{\text {th }}$, measuring a central pressure of $945 \mathrm{mb}$, estimating flight level winds (700 mb) of $120 \mathrm{kt}$ and an eye diameter of $20 \mathrm{~nm}$. A central pressure of $945 \mathrm{mb}$ suggests maximum sustained winds of $116 \mathrm{kt}$ south of $25 \mathrm{~N}$ and $118 \mathrm{kt}$ south of $25 \mathrm{~N}$ intensifying from the Brown et al. pressure-wind relationship. The $20 \mathrm{~nm}$ eye diameter suggests an RMW of about $15 \mathrm{~nm}$ and climatology indicates $17 \mathrm{~nm}$. An intensity of $120 \mathrm{~nm}$ is analyzed at $00 \mathrm{Z}$ on September $8^{\text {th }}$, same as the original HURDAT. A central pressure of $945 \mathrm{mb}$ was present in HURDAT at $12 \mathrm{Z}$ on the $7^{\text {th }}$ and based on the reconnaissance report, it appears to be in the wrong time slot and has been moved to $00 \mathrm{Z}$ on the $8^{\text {th }}$.

Hurricane Carrie continued to move west-northwest on September $8^{\text {th }}$ over the central Atlantic as a category 4 hurricane. A central pressure of $945 \mathrm{mb}$ appears in HURDAT at $12 \mathrm{Z}$ on the $8^{\text {th }}$ and has been moved to $18 \mathrm{Z}$ on this day since the reconnaissance aircraft made a center fix at $1930 Z$ and there were no central pressure reports earlier in the day. 
This central pressure of the $8^{\text {th }}$ seems reasonable and it is retained but was not confirmed. $120 \mathrm{kt}$ is the peak intensity for this hurricane, down from $135 \mathrm{kt}$ originally in HURDAT, a major intensity change. The next reconnaissance aircraft reached Carrie at $2021 \mathrm{Z}$ on September $9^{\text {th }}$ measuring a central pressure of $975 \mathrm{mb}$, estimating flight level winds of $135 \mathrm{kt}$ at $700 \mathrm{mb}$ and an eye diameter of $10 \mathrm{~nm}$. A central pressure of $975 \mathrm{mb}$ suggests maximum sustained winds of $83 \mathrm{kt}$ south of $25 \mathrm{~N}$ weakening according to the pressurewind relationship. An intensity of $85 \mathrm{kt}$ is selected for $18 \mathrm{Z}$ on the $9^{\text {th }}$, a major intensity change from the original $130 \mathrm{kt}$ in HURDAT. Major intensity changes are also analyzed between $00 \mathrm{Z}$ and $12 \mathrm{Z}$ on the $9^{\text {th }}$. HURDAT originally had $135 \mathrm{kt}$ for these times and the analyzed intensities are $115 \mathrm{kt}, 105 \mathrm{kt}$ and $95 \mathrm{kt}$, respectively. It is analyzed that Carrie weakened below major hurricane intensity at $12 \mathrm{Z}$ on the $9^{\text {th }}, 24$ hours earlier than originally shown in HURDAT. A central pressure of $975 \mathrm{mb}$ was present in HURDAT at $12 \mathrm{Z}$ on the $9^{\text {th }}$ and based on the reconnaissance reports, it has been moved to $18 \mathrm{Z}$ on this day. Further confirmation of the rapid weakening of Carrie occurred on September $10^{\text {th }}$ when another reconnaissance mission reported a central pressure of $977 \mathrm{mb}$ and an eye diameter of $20 \mathrm{~nm}$ at $0815 \mathrm{Z}$. Later at 0930Z, another report indicated a central pressure of $985 \mathrm{mb}$, estimated surface winds of $75 \mathrm{kt}$ and an eye diameter of $20 \mathrm{~nm}$. A central pressure of $977 \mathrm{mb}$ suggests maximum sustained winds of $80 \mathrm{kt}$ south of $25 \mathrm{~N}$ weakening according to the pressure-wind relationship. Due to the slow motion of the hurricane, an intensity of $75 \mathrm{kt}$ is selected for $06 \mathrm{Z}$ on the $10^{\text {th }}$, down from $115 \mathrm{kt}$ originally in HURDAT, a major intensity change. $80 \mathrm{kt}$ is analyzed at $00 \mathrm{Z}$ on the $10^{\text {th }}$, a major intensity change from the $125 \mathrm{kt}$ originally in HURDAT. A central pressure of $985 \mathrm{mb}$ suggests maximum sustained winds of $71 \mathrm{kt}$ south of $25 \mathrm{~N}$ weakening according to the pressure-wind relationship. An intensity of $70 \mathrm{kt}$ is selected for $12 \mathrm{Z}$ on the $10^{\text {th }}$, a major change from the original $95 \mathrm{kt}$ in HURDAT. A central pressure of $985 \mathrm{mb}$ was present in HURDAT at $06 Z$ on the $10^{\text {th }}$ and based on the reconnaissance report at $0815 \mathrm{Z}$, has been replaced with $977 \mathrm{mb}$. At $12 \mathrm{Z}$ on the $10^{\text {th }}$, HURDAT has a central pressure of $987 \mathrm{mb}$ and has been replaced with $985 \mathrm{mb}$ based on the reconnaissance report at 0930Z. An intensity of $65 \mathrm{kt}$ is analyzed at $18 \mathrm{Z}$ on the $10^{\text {th }}$, a major intensity change from the $85 \mathrm{kt}$ originally in HURDAT.

On September $11^{\text {th }}$, Carrie stopped weakening and its track turned to the north at a very slow forward speed. The center fixes by the reconnaissance aircrafts between September $9^{\text {th }}$ and the $11^{\text {th }}$ show substantial inconsistencies, potentially because Carrie was far from land and moving slowly. An aircraft reconnaissance investigated the hurricane at $09 \mathrm{Z}$ measuring a central pressure of $985 \mathrm{mb}$, estimated surface winds of $50 \mathrm{kt}$ and an eye diameter of $20 \mathrm{~nm}$. A central pressure of $985 \mathrm{mb}$ suggests maximum sustained winds of $71 \mathrm{kt}$ south of $25 \mathrm{~N}$ according to the pressure-wind relationship. Due to the slow motion of Carrie, an intensity of $65 \mathrm{kt}$ is selected for $06 \mathrm{Z}$ on the $11^{\text {th }}$, same as the original HURDAT. A central pressure of $978 \mathrm{mb}$ is added to $06 \mathrm{Z}$ on the $11^{\text {th }}$. A central pressure 
of $984 \mathrm{mb}$ is present in HURDAT at $12 \mathrm{Z}$ on the 11th, which appears reasonable and has been retained. Late on the $11^{\text {th }}$, Carrie began to re-intensify as a reconnaissance aircraft reported a central pressure of $978 \mathrm{mb}$, estimated surface winds of $60 \mathrm{kt}$ and an eye diameter of $25 \mathrm{~nm}$ at 20Z. A central pressure of $985 \mathrm{mb}$ suggests maximum sustained winds of $80 \mathrm{kt}$ south of $25 \mathrm{~N}$ according to the pressure-wind relationship. Due to the slow motion of Carrie, an intensity of $70 \mathrm{kt}$ is selected for $18 \mathrm{Z}$ on the $11^{\text {th }}$, same as the original HURDAT. Intensification continued on September $12^{\text {th }}$ and a reconnaissance aircraft reported a central pressure of $960 \mathrm{mb}$, estimated surface winds of $90 \mathrm{kt}$ and an eye diameter of $25 \mathrm{~nm}$ at 1405Z. A central pressure of $960 \mathrm{mb}$ suggests maximum sustained winds of $101 \mathrm{kt}$ south of $25 \mathrm{~N}$ according to the pressure-wind relationship. Due to the slow motion of Carrie, an intensity of $90 \mathrm{kt}$ is selected for $12 \mathrm{Z}$ on the $12^{\text {th }}$, same as the original HURDAT. Another aircraft reported a central pressure of $957 \mathrm{mb}$ at 1930Z, along with estimated surface winds of $95 \mathrm{kt}$ and an eye diameter of $20 \mathrm{~nm}$. A central pressure of $957 \mathrm{mb}$ suggests maximum sustained winds of $104 \mathrm{kt}$ south of $25 \mathrm{~N}$ according to the pressure-wind relationship. Due to the slow forward speed of the hurricane, an intensity of $95 \mathrm{kt}$ is selected for $18 \mathrm{Z}$ on the $12^{\text {th }}$, same as the original HURDAT. A central pressure of $957 \mathrm{mb}$ is present in HURDAT at $12 \mathrm{Z}$ on the $12^{\text {th }}$ and has been moved to $18 \mathrm{Z}$ based on the reconnaissance report. A central pressure of $960 \mathrm{mb}$ has been added to $12 \mathrm{Z}$ on the $12^{\text {th }}$. On September $13^{\text {th }}$, a reconnaissance mission reported a central pressure of $951 \mathrm{mb}$ at $0839 \mathrm{Z}$. A central pressure of $951 \mathrm{mb}$ suggests maximum sustained winds of $112 \mathrm{kt}$ south of $25 \mathrm{~N}$ intensifying and $109 \mathrm{kt}$ north of $25 \mathrm{~N}$ intensifying, according to the pressure-wind relationship. Due to the slow motion of Carrie, an intensity of $105 \mathrm{kt}$ is selected for $06 \mathrm{Z}$ on the $13^{\text {th }}$, up from $95 \mathrm{kt}$ originally in HURDAT, a minor intensity change. It is analyzed that Carrie regained major hurricane status at $00 \mathrm{Z}$ on the $13^{\text {th }}$, twelve hours earlier than originally in HURDAT. A reconnaissance aircraft reported a central pressure of $953 \mathrm{mb}$ at $1430 \mathrm{Z}$ on the $13^{\text {th }}$. An intensity of $100 \mathrm{kt}$ is selected for $12 \mathrm{Z}$ on the $13^{\text {th }}$, same as originally in HURDAT. A central pressure of 963 $\mathrm{mb}$ was measured by a reconnaissance aircraft at $1930 \mathrm{Z}$ on the $13^{\text {th }}$, along with estimated surface winds of $90 \mathrm{kt}$ and an eye diameter of $20 \mathrm{~nm}$. A central pressure of $963 \mathrm{mb}$ suggests maximum sustained winds of $92 \mathrm{kt}$ north of $25 \mathrm{~N}$ and $88 \mathrm{kt}$ north of $25 \mathrm{~N}$ weakening, according to the pressure-wind relationship. An intensity of $90 \mathrm{kt}$ is selected for $18 \mathrm{Z}$ on the $13^{\text {th }}$, down from $100 \mathrm{kt}$ originally in HURDAT, a minor intensity change. Weakening from major hurricane status is analyzed 54 hours earlier than originally shown in HURDAT. A central pressure of $963 \mathrm{mb}$ is present in HURDAT at $12 \mathrm{Z}$ on the $13^{\text {th }}$ and based on the reconnaissance reports, has been moved to $18 \mathrm{Z}$ on this day. Central pressures of $951 \mathrm{mb}$ and $953 \mathrm{mb}$, have been added to $06 \mathrm{Z}$ and 12Z, respectively, on the $13^{\text {th }}$.

On September $14^{\text {th }}$, Carrie turned to the northwest and slightly increased in forward speed. A reconnaissance aircraft measured a central pressure of $964 \mathrm{mb}$ at $0735 \mathrm{Z}$. A 
central pressure of $964 \mathrm{mb}$ suggests maximum sustained winds of $91 \mathrm{kt}$ north of $25 \mathrm{~N}$ according to the pressure-wind relationship. An intensity of $90 \mathrm{kt}$ is selected for $06 \mathrm{Z}$ on the $14^{\text {th }}$, down from $105 \mathrm{kt}$ originally in HURDAT, a minor intensity change. A central pressure of $964 \mathrm{mb}$ has been added to HURDAT at $06 \mathrm{Z}$ on the $14^{\text {th }}$. Other center fixes measured $964 \mathrm{mb}$ at $1440 \mathrm{Z}$ and $963 \mathrm{mb}$ at 20Z. The intensity is kept at $90 \mathrm{kt}$ for $12 \mathrm{Z}$ and $18 \mathrm{Z}$ on the $14^{\text {th }}$, down from the original $110 \mathrm{kt}$ and $115 \mathrm{kt}$, respectively, in HURDAT, a major intensity change. On September $15^{\text {th }}$, the central pressure had minor variations from the previous day, but the eye diameter had increased to about $40 \mathrm{~nm}$. A central pressure report of $967 \mathrm{mb}$ was received from a reconnaissance aircraft at 0740Z and 965 $\mathrm{mb}$ at 1350Z. An eye diameter of $40 \mathrm{~nm}$ suggests an RMW of about $30 \mathrm{~nm}$ and climatology suggests about $23 \mathrm{~nm}$. Due to the larger RMW, an intensity of $85 \mathrm{kt}$ is selected for $06 \mathrm{Z}$ and $12 \mathrm{Z}$ on the $15^{\text {th }}$, down from $110 \mathrm{kt}$ and $105 \mathrm{kt}$, respectively, originally in HURDAT, a major intensity change at both times. A central pressure of 967 $\mathrm{mb}$ has been added to HURDAT at $06 \mathrm{Z}$ on the $15^{\text {th }}$. On this day, the National Hurricane Research Project investigated Carrie estimating surface winds of $84 \mathrm{kt}$, measuring a central pressure of $963 \mathrm{mb}$ and an RMW of about $22 \mathrm{~nm}$ around 19Z. Another reconnaissance mission at $1930 \mathrm{Z}$ reported a central pressure of $961 \mathrm{mb}$ and an eye diameter of $40 \mathrm{~nm}$. A central pressure of $961 \mathrm{mb}$ suggests maximum sustained winds of $94 \mathrm{kt}$ north of $25 \mathrm{~N}$ according to the pressure-wind relationship. An intensity of $90 \mathrm{kt}$ is selected for $18 \mathrm{Z}$ on the $15^{\text {th }}$, down from $100 \mathrm{kt}$ originally in HURDAT, a minor intensity change. A central pressure of $961 \mathrm{mb}$ is added to HURDAT at $18 \mathrm{Z}$ on the $15^{\text {th }}$. A central pressure of $963 \mathrm{mb}$ was present in HURDAT at $12 \mathrm{Z}$ and, based on the reconnaissance report at 1350Z, it has been replaced with $965 \mathrm{mb}$.

Hurricane Carrie continued moving to the northwest on September $16^{\text {th }}$, slowly losing strength. The first reconnaissance reports on the $16^{\text {th }}$ measured a central pressure of 964 $\mathrm{mb}$ at $0146 \mathrm{Z}, 966 \mathrm{mb}$ at $0557 \mathrm{Z}, 967 \mathrm{mb}$ at $07 \mathrm{Z}$ and $970 \mathrm{mb}$ at $0955 \mathrm{Z}$. An intensity of 85 $\mathrm{kt}$ is selected for $00 \mathrm{Z}$ and $06 \mathrm{Z}$ on the $16^{\text {th }}$. HURDAT originally had $90 \mathrm{kt}$ at $00 \mathrm{Z}$ and 85 $\mathrm{kt}$ at 06Z, minor and no intensity change, respectively. A central pressure of $964 \mathrm{mb}$ is added to HURDAT at $00 \mathrm{Z}$ on the $16^{\text {th }}$ and $966 \mathrm{mb}$ is added to $06 \mathrm{Z}$. A central pressure of $969 \mathrm{mb}$ and estimated surface winds of $90 \mathrm{kt}$ were reported by a reconnaissance aircraft at $1351 \mathrm{Z}$. A central pressure of $969 \mathrm{mb}$ suggests maximum sustained winds of $86 \mathrm{kt}$ north of $25 \mathrm{~N}$ according to the pressure-wind relationship. At 0955Z, the reconnaissance aircraft estimated an eye diameter of $70 \mathrm{~nm}$, suggesting an RMW of about $53 \mathrm{~nm}$ and climatology suggests about $25 \mathrm{~nm}$. Since the RMW is larger than suggested by climatology, an intensity of $80 \mathrm{kt}$ is selected at $12 \mathrm{Z}$ on the $16^{\text {th }}$, down from $85 \mathrm{kt}$ originally in HURDAT, a minor intensity change. Early on September $17^{\text {th }}$, Carrie passed about $110 \mathrm{~nm}$ northeast of Bermuda. No adverse effects were reported on the island as the strongest pressure gradient was located on the northeast quadrant of the hurricane. A reconnaissance mission reported a central pressure of $970 \mathrm{mb}$ and estimated surface 
winds of $70 \mathrm{kt}$ at $0130 \mathrm{Z}$. An intensity of $80 \mathrm{kt}$ is selected for $00 \mathrm{Z}$ on the $17^{\text {th }}$, same as originally in HURDAT. A central pressure of $970 \mathrm{mb}$ is added to HURDAT at $00 \mathrm{Z}$ on the $17^{\text {th }}$. Another center fix at $08 \mathrm{Z}$ reported a central pressure of $974 \mathrm{mb}$ and estimated surface winds of $75 \mathrm{kt}$ and an eye diameter of about $65 \mathrm{~nm}$. A central pressure of $974 \mathrm{mb}$ suggests maximum sustained winds of $80 \mathrm{kt}$ north of $25 \mathrm{~N}$ and $79 \mathrm{kt}$ north of $35 \mathrm{~N}$, according to the pressure-wind relationship. A diameter of $65 \mathrm{~nm}$ suggests an RMW of about $49 \mathrm{~nm}$ and climatology suggests about $29 \mathrm{~nm}$. Since the size of the hurricane was larger than normal and it was moving at about $8 \mathrm{kt}$, an intensity of $75 \mathrm{kt}$ is selected for $06 \mathrm{Z}$ on the $17^{\text {th }}$, down from $80 \mathrm{kt}$ originally in HURDAT, a minor intensity change. A central pressure of $974 \mathrm{mb}$ has been added to HURDAT at $06 \mathrm{Z}$ on the $17^{\text {th }}$. A central pressure of $975 \mathrm{mb}$ appears in microfilm associated with a reconnaissance report at 1425Z. A central pressure of $972 \mathrm{mb}$ is present in HURDAT at $12 \mathrm{Z}$ on the $17^{\text {th }}$ and based on the reconnaissance report, has been replaced with $975 \mathrm{mb}$. An intensity of $75 \mathrm{kt}$ is selected for $12 \mathrm{Z}$ on the $17^{\text {th }}$, down from the original $80 \mathrm{kt}$ in HURDAT, a minor intensity change. Around 18Z, the National Hurricane Research Project reported a central pressure of $978 \mathrm{mb}$, estimated surface winds of $84 \mathrm{kt}$ and an RMW of $32 \mathrm{~nm}$. A central pressure of $978 \mathrm{mb}$ suggests maximum sustained winds of $75 \mathrm{kt}$ north of $25 \mathrm{~N}$ and north of $35 \mathrm{~N}$, according to the pressure-wind relationship. An intensity of $75 \mathrm{kt}$ is selected for $18 \mathrm{Z}$ on the $17^{\text {th }}$, down from $80 \mathrm{kt}$ originally in HURDAT, a minor intensity change. A central pressure of $978 \mathrm{mb}$ is added to HURDAT at $18 \mathrm{Z}$ on the $17^{\text {th }}$. A ship reported $80 \mathrm{kt} \mathrm{SSE}$ at $18 \mathrm{Z}$ on the $17^{\text {th }}$ but based on the large size of the circulation and pressure reports by the reconnaissance aircraft, it appears to be biased slightly high. Late on the $17^{\text {th }}$, Carrie turned to the northeast and to the east on the $18^{\text {th }}$. A couple of ships reported hurricaneforce winds on September $18^{\text {th }}$. A reconnaissance aircraft measured a central pressure of $978 \mathrm{mb}$, estimated surface winds of $80 \mathrm{kt}$ and an eye diameter of $80 \mathrm{kt}$. An intensity of 70 kt is selected for $06 \mathrm{Z}$ on the $18^{\text {th }}$, down from 75 kt originally in HURDAT, a minor intensity change.

The structure of Hurricane Carrie began to be affected by an approaching frontal boundary on September $19^{\text {th }}$, causing the cyclone to become elongated E-W. A central pressure of $970 \mathrm{mb}$ is present in HURDAT at $12 \mathrm{Z}$ on the $19^{\text {th }}$ and although there is no confirmation that it was a measurement, there was a reconnaissance aircraft that made a center fix at 1356Z. Thus, it is retained. A central pressure of $970 \mathrm{mb}$ suggests maximum sustained winds of $90 \mathrm{kt}$ north of $25 \mathrm{~N}$ and $82 \mathrm{kt}$ north of $35 \mathrm{~N}$ according to the pressurewind relationship. An intensity of $80 \mathrm{kt}$ is selected for $12 \mathrm{Z}$ on the $18^{\text {th }}$, up from $70 \mathrm{kt}$ originally in HURDAT, a minor intensity change. On September $20^{\text {th }}$, Carrie continued eastward with no appreciable change in strength. Two ships reported hurricane-force winds at $18 \mathrm{Z}$ on the $20^{\text {th }}$ and the structure of the hurricane continued to be elongated. A central pressure of $972 \mathrm{mb}$ is present in HURDAT at $12 \mathrm{Z}$ on the $21^{\text {st }}$ but the only reconnaissance mission occurred at $1930 \mathrm{Z}$, thus it has been moved to $18 \mathrm{Z}$ on this day. 
Late on the $21^{\text {st }}$, a warm front started developing northeast of the circulation but the hurricane remained tropical. A central pressure of $972 \mathrm{mb}$ suggests maximum sustained winds of $88 \mathrm{kt}$ north of $25 \mathrm{~N}$ and $80 \mathrm{kt}$ north of $35 \mathrm{~N}$ according to the pressure-wind relationship. Due to the large RMW of Carrie during the last couple of days reported by the reconnaissance aircraft, an intensity of $80 \mathrm{kt}$ is selected for $18 \mathrm{Z}$ on the $21^{\text {th }}$, up from 70 kt originally in HURDAT, a minor intensity change. A ship at $18 \mathrm{Z}$ on the $21^{\text {st }}$ appears to be reporting $90 \mathrm{kt} \mathrm{SSW}$ on microfilm but do to the large RMW of the hurricane, the report may be biased slightly high. Carrie turned to the northeast and increased in forward speed on September $22^{\text {nd }}$ passing over the central Azores as a $75 \mathrm{kt}$ hurricane around 16Z. The highest winds on microfilm at the Azores were $45 \mathrm{kt}$ and lowest pressure was $983 \mathrm{mb}$. Transition to an extratropical cyclone is analyzed at $00 \mathrm{Z}$ on September $23^{\text {rd }}$ northeast of the Azores, as originally shown in HURDAT. Weakening below hurricane force is analyzed at $18 \mathrm{Z}$ on the $23^{\text {rd }}$, six hours later than originally in HURDAT. Further weakening occurred on September $24^{\text {th }}$ as Carrie turned eastward and slowed its forward speed. Late on the $24^{\text {th }}$ and $25^{\text {th }}$, Carrie affected the British Isles and continued to weaken. Dissipation is analyzed to have occurred after $18 \mathrm{Z}$ on the $25^{\text {th }}$. September $25^{\text {th }}$ is new to HURDAT. Hurricane Carrie is tied with Hurricane \#4, 1926 for the second longest duration of tropical cyclone to be re-analyzed, both lasting 23 days and 18 hours, only the San Siriaco Hurricane of 1899 lasted longer.

Tropical Storm Debbie [September 7-9, 1957]

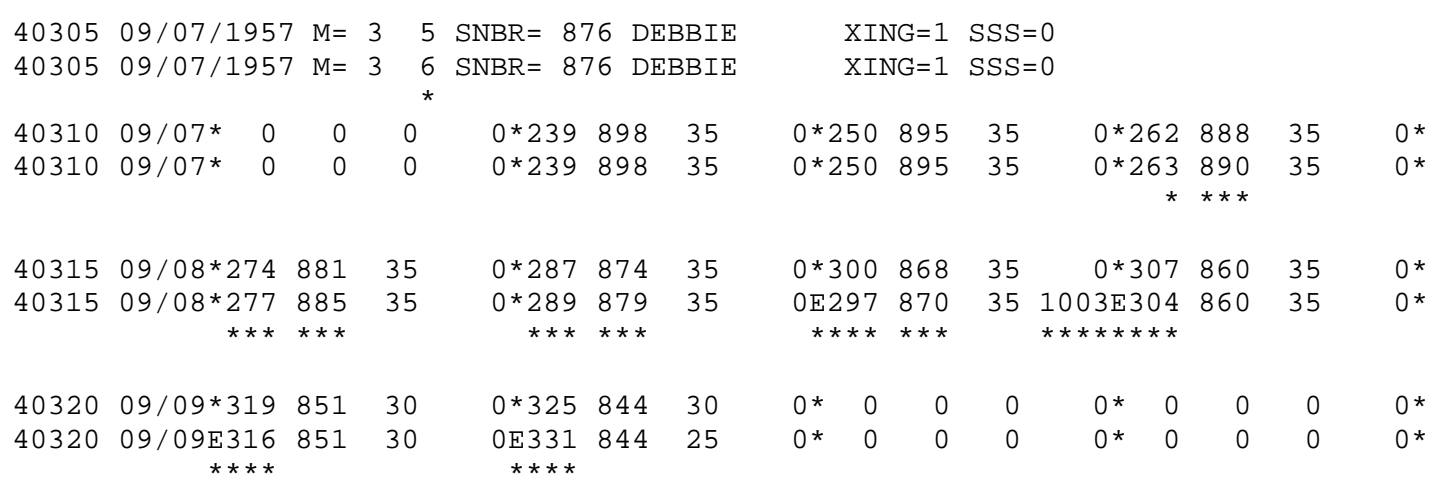

40325 TS

Minor changes to the track and intensity shown in McAdie et al. (2009). A major alteration is to change to extratropical the last 24 hours of this tropical cyclone's lifetime.Evidence for these alterations comes from the NHC microfilm maps, Historical Weather Maps series, COADS ship database, Monthly Weather Review, Local Climatological Data, Surface Weather Observations and Mexican synoptic maps. 
September 5:

HWM analyzes a spot low pressure at $24.2 \mathrm{~N}, 91.5 \mathrm{~W}$ at $12 \mathrm{Z}$. HURDAT does not list an organized storm on this date. Microfilm does not show an organized system on this date. Ship highlights: No gales or low pressures.

MWR: "On September 5 there was evidence of a weak easterly wave moving from the Caribbean into the Gulf of Mexico where a stagnant upper trough prevailed." ASTR:

"The position of an easterly wave (located near $46^{\circ} \mathrm{W}$ ) was forwarded to this office by Fleet Weather Central, Port Lyautey, on August 25."

September 6:

HWM analyzes a spot low pressure at $24.2 \mathrm{~N}, 90.5 \mathrm{~W}$ at $12 \mathrm{Z}$. HURDAT does not list an organized storm on this date. Microfilm shows a trough or tropical wave over the eastern central Gulf of Mexico at 12Z. Ship highlights: No gales or low pressures. September 7:

HWM analyzes a tropical storm of at most $1010 \mathrm{mb}$ at $25.0 \mathrm{~N}, 90.0 \mathrm{~W}$ at $12 \mathrm{Z}$. HURDAT lists a $35 \mathrm{kt}$ tropical storm at $25.0 \mathrm{~N}, 89.5 \mathrm{~W}$ at $12 \mathrm{Z}$. Microfilm does not show an organized system on this date. Ship highlights: $35 \mathrm{kt} \mathrm{SW}$ and $1015 \mathrm{mb}$ at $25.7 \mathrm{~N}$, 86.0W at $00 \mathrm{Z}$ (COADS).

MWR: "This wave was apparently the trigger which set off a weak circulation in the central Gulf on September 7." ATSR: "This wave, although of weak intensity, crossed the Antilles on 2 September and continued across the Yucatan Peninsula at 0000Z, 7 September, and stagnated near $93^{\circ} \mathrm{W}$. By 1200Z, 7 September, a weak cold front moved southward into the Gulf of Mexico causing a large area of unstable conditions and heavy showers over the eastern Gulf of Mexico."

September 8:

HWM analyzes a tropical storm of at most $1005 \mathrm{mb}$ at $29.9 \mathrm{~N}, 87.0 \mathrm{~W}$ with a warm front to the northwest at 12Z. HURDAT lists a $35 \mathrm{kt}$ tropical storm at $30.0 \mathrm{~N}$, $86.8 \mathrm{~W}$ at $12 \mathrm{Z}$. Microfilm shows a closed low pressure of at most $1005 \mathrm{mb}$ at $29.5 \mathrm{~N}$, $87.0 \mathrm{~W}$ with a frontal boundary extending north-south through the center at $12 \mathrm{Z}$. Ship highlights: $10 \mathrm{kt} \mathrm{NNE}$ and $1005 \mathrm{mb}$ at $29.6 \mathrm{~N}, 88.6 \mathrm{~W}$ at $09 \mathrm{Z}$ (micro). $20 \mathrm{kt} \mathrm{SE}$ and 1005 $\mathrm{mb}$ at $29.8 \mathrm{~N}, 86.6 \mathrm{~W}$ at $12 \mathrm{Z}$ (COADS). Land highlights: $20 \mathrm{kt} \mathrm{SE}$ and $1005 \mathrm{mb}$ at Pensacola, FL at 09Z (micro). $10 \mathrm{kt} \mathrm{E}$ and $1004 \mathrm{mb}$ at Milton, FL at 12Z (SWO). $9 \mathrm{kt} \mathrm{E}$ and $1005 \mathrm{mb}$ at Dothan, AL at $19 \mathrm{Z}$ (SWO). $35 \mathrm{kt}$ at St. Marks, FL (no time given, may be an estimate) (MWR). 
MWR: "This depression moved northeastward and only barely reached storm force before going inland near Fort Walton, Fla., about 40 miles east of Pensacola, on the morning of the 8th. Highest winds reported were around $40 \mathrm{mph}$ at St. Marks. Tampa had gusts to $52 \mathrm{mph}$ in a squall. The highest tide reported was some 150 miles east of the center on Apalachee Bay where it ranged from 2.5 to 4 feet. Some flooding occurred due to the tides and rains, which were locally heavy, with 9.10 inches at Crawfordsville, Fla. There were no fatalities as a direct result of the storm although it was indirectly responsible for four deaths. The failure of Debbie to intensify further may be attributable to two factors. The upper-air pattern never conformed to that found to favor intensification. In addition, there was evidence that cooler air entered the circulation as it moved near the coast." ATSR: "By 000Z, 8 September, a low which had "spun off" the easterly wave had drifted northeast and was now located on the weak frontal system with increased shower activity and winds of 30 to 40 knots, causing squalls throughout the north-eastern Gulf. Warning number ONE on Tropical Depression Debbie was issued at 0400Z, 8 September. Although Debbie was labeled as a tropical system she never attained true tropical characteristics. Throughout the span of Debbie's life there was never a definite center on surface charts and at all times, she was under the influence of a cold trough extending aloft to all observed levels. Debbie moved ashore near Pensacola during the afternoon of 8 September. Only 3 warnings were issued on Debbie by this activity. The only results observed at coastal installations were gusty winds to 45 knots and heavy rains over West Florida, South Georgia and Alabama which caused minor flooding. Had upper level conditions been more favorable Debbie probably would have developed into a more definite tropical system. No reconnaissance flights were flown into Tropical Storm Debbie."

September 9:

HWM and microfilm analyze a stationary front over the southeast of the United States, likely indicating that Debbie dissipated at 12Z. HURDAT lists a $30 \mathrm{kt}$ tropical depression at $32.5 \mathrm{~N}, 84.4 \mathrm{~W}$ at $06 \mathrm{Z}$ (last position). Ship highlights: No gales or low pressures.

A tropical wave developed into Tropical Storm Debbie in the central Gulf of Mexico during the first week of September. The data is sparse over the Gulf of Mexico south of $25^{\circ} \mathrm{N}$ and therefore, it is possible that Debbie might have developed a day earlier than it is shown in HURDAT. The first position, not genesis, is retained at $06 \mathrm{Z}$ on September $7^{\text {th }}$ as a $35 \mathrm{kt}$ tropical storm. $35 \mathrm{kt}$ is also the peak intensity for the lifetime of this tropical cyclone. Minor track changes are introduced for the duration of this system. Debbie moved slowly to the northeast on the $7^{\text {th }}$. The only gale ( $\left.35 \mathrm{kt}\right)$ reported by a ship during the lifetime of this cyclone occurred at $00 \mathrm{Z}$ on the $7^{\text {th }}$ and based on the winds reported by 
nearby ships, it appears to be 5-10 kt too high. Nonetheless, a couple of ships reported 30 kt on the $8^{\text {th }}$ and the $35 \mathrm{kt}$ intensity in HURDAT is retained for September $7^{\text {th }}$ and $8^{\text {th }}$. No aircraft reconnaissance missions investigated this tropical cyclone. On September $8^{\text {th }}$, the forward speed of the tropical cyclone increased as a frontal boundary approached from the northwest. Ship and land observations at $12 \mathrm{Z}$ on the $8^{\text {th }}$ show that Debbie had become extratropical as dry air entered the center of the cyclone, indicated by the dew point gradient across the storm. A major change to HURDAT is to indicate that Debbie was an extratropical cyclone during the last 24 hours of its lifetime. At $12 \mathrm{Z}$ on the $8^{\text {th }}$, a ship inside the RMW of Debbie reported $20 \mathrm{kt} \mathrm{SE}$ and $1005 \mathrm{mb}$, indicating a central pressure of about $1003 \mathrm{mb}$, which has been added to HURDAT. The extratropical cyclone made landfall in the Florida panhandle near $30.3 \mathrm{~N}, 86.1 \mathrm{~W}$, about 30 miles west of Panama City, FL, around $17 \mathrm{Z}$ on the $8^{\text {th }}$ with winds of $35 \mathrm{kt}$. The only gales reported on land were $35 \mathrm{kt}$ at St. Marks, FL, according to the Monthly Weather Review, but it is possible that this was an estimate. No station report from that location was found during the reanalysis. It is also possible that Debbie never reached tropical storm intensity while a tropical cyclone. The ship data over the northeast Gulf of Mexico is substantial and there was no reliable report of gales. After making landfall in Florida, the extratropical cyclone moved over southeast Alabama before dissipating over western Georgia after 06Z on September $9^{\text {th }}$. Its remnants became part of the frontal boundary over the Southeast of the United States. The development and characteristics of this tropical cyclone bear similarities to Tropical Storm Lee in 2011.

Tropical Storm Esther [September 16-19, 1957]

\begin{tabular}{|c|c|c|c|c|c|c|c|c|c|c|c|c|c|c|}
\hline 40330 & $09 / 16 / 1957$ & $M=$ & 4 & $6 \mathrm{SNBR}=87$ & $77 \mathrm{ES}$ & THEF & & XII & $\mathrm{JG}=1$ & SSS & & & & \\
\hline 40330 & $09 / 16 / 1957$ & $7 M=$ & 4 & 7 SNBR $=8$ & $77 \mathrm{ES}$ & THEF & & XII & $\mathrm{JG}=1$ & SSS & & & & \\
\hline 40335 & $09 / 16$ * & $\odot$ & $\odot$ & $\Theta^{*}$ & $\odot$ & $\odot$ & & ๑* & 0 & 0 & $0 * 23$ & 928 & 30 & $\Theta^{*}$ \\
\hline 40335 & $09 / 16 * 208$ & 930 & 30 & $0 * 214$ & 930 & 35 & & ○*220 & 930 & 40 & $0 * 22$ & 7930 & $4 \odot$ & ०* \\
\hline & *** & $* * *$ & ** & *** & $* * *$ & $\star *$ & & *** & *** & ** & ** & $\star \star \star \star *$ & ** & \\
\hline 40340 & $09 / 17 * 237$ & 928 & 35 & $1000 * 245$ & 927 & 45 & & ๑*253 & 926 & 45 & $1004 * 26$ & 3923 & 45 & 0 * \\
\hline 40340 & $09 / 17 * 234$ & 930 & 40 & $1000 * 241$ & 930 & 40 & & $0 * 245$ & 930 & 40 & $\odot * 25$ & 1928 & $4 \odot$ & 1004 * \\
\hline & *** & $* * *$ & ** & *** & $* * *$ & ** & & *** & $* *$ * & ** & * $\star *$ & $\star \star \star * *$ & * * & $\star * \star *$ \\
\hline 40345 & $09 / 18 * 273$ & 918 & 45 & $\Theta * 282$ & 913 & 45 & & ๑*292 & 909 & 45 & $1005 * 30$ & 4905 & 45 & 0 * \\
\hline 40345 & $09 / 18 * 264$ & 923 & 45 & ๑*279 & 916 & 50 & 1000 & 0*292 & 909 & 55 & $0 * 30$ & 4909 & 50 & 0 * \\
\hline & *** & $\star * *$ & & *** & $\star * *$ & ** & $* * * *$ & & & ** & * & $* * *$ & ** & \\
\hline 40350 & $09 / 19 * 315$ & 905 & 35 & $0 * 325$ & $9 \odot 5$ & 25 & & 0 0*335 & 910 & 25 & $\Theta^{*}$ & $\odot$ & 0 & 0 * \\
\hline 40350 & $09 / 19 * 315$ & 910 & 35 & $1002 * 325$ & $\begin{array}{l}910 \\
\star * *\end{array}$ & 25 & & ๑*335 & 910 & 25 & $\odot^{*}$ & $\odot$ & $\odot$ & ○* \\
\hline ๑ & $\mathrm{T}$ & & & & & & & & & & & & & \\
\hline
\end{tabular}




\section{U.S. Tropical Storm Landfall}

09/18 12Z 29.2N 90.9W 55 kt LA

Minor track and intensity changes shown in McAdie et al. (2009). Evidence for these alterations comes from the NHC microfilm maps, the Historical Weather Maps series, the COADS ship database, Monthly Weather Review, the Local Climatological Data, Surface Weather Observations, Navy reconnaissance book and Mexican synoptic maps. September 14:

HWM analyzes a closed low pressure of at most $1010 \mathrm{mb}$ at $22.7 \mathrm{~N}, 95.0 \mathrm{~W}$ at 12Z. HURDAT and microfilm do not list an organized storm on this date. Ship highlights: No gales or low pressures.

September 15:

HWM analyzes a closed low pressure of at most $1005 \mathrm{mb}$ at $23.5 \mathrm{~N}, 96.2 \mathrm{~W}$ at 12Z. HURDAT and microfilm do not list an organized storm on this date. Ship highlights: No gales or low pressures.

MWR: "Squalliness and abnormally low pressure in the southwestern Gulf of Mexico on September 15 indicated that a tropical depression might be forming. For about 2 days prior to this date a weak cyclonic circulation aloft had been drifting northwestward across Central America toward the Gulf of Mexico."

September 16:

HWM analyzes a closed low pressure of at most $1005 \mathrm{mb}$ at $23.0 \mathrm{~N}, 95.0 \mathrm{~W}$ at 12Z. HURDAT lists a $30 \mathrm{kt}$ tropical depression at $23.0 \mathrm{~N}, 92.8 \mathrm{~W}$ at $18 \mathrm{Z}$ (first advisory). Microfilm shows a closed low pressure of at most $1005 \mathrm{mb}$ at 21.0N, $94.0 \mathrm{~W}$ at 12Z. Ship highlights: $20 \mathrm{kt} \mathrm{E}$ and $1005 \mathrm{mb}$ at 21.0N, $92.9 \mathrm{~W}$ at $00 \mathrm{Z}$ (micro). $40 \mathrm{kt}$ ESE and $1006 \mathrm{mb}$ at $22.3 \mathrm{~N}, 90.5 \mathrm{~W}$ at $09 \mathrm{Z}$ (micro). $10 \mathrm{kt} \mathrm{SE}$ and $1005 \mathrm{mb}$ at $21.8 \mathrm{~N}, 92.8 \mathrm{~W}$ at $12 \mathrm{Z}$ (COADS). $15 \mathrm{kt} \mathrm{N}$ and $1005 \mathrm{mb}$ at 22.8N, $94.0 \mathrm{~W}$ at $18 \mathrm{Z}$ (micro). Aircraft highlights: Penetration center fix measured a central pressure of $1000 \mathrm{mb}$ and estimated maximum surface winds of $35 \mathrm{kt}$ at $23.0 \mathrm{~N}, 92.3 \mathrm{~W}$ at $23 \mathrm{Z}$ (ATSR).

MWR: "On the evening of the 15th the New Orleans Weather Bureau Office issued a bulletin announcing the development of a depression and forecasting intensification." ATSR: "On 12 September a low center on the UTC appeared at the surface and up to 700 $\mathrm{mb}$ over Nicaragua. This low persisted and drifted northwest on the ITC until early on 16 September when it broke away from the ITC and moved northward into the Gulf of Campeche near $92^{\circ} \mathrm{W}$. A Navy low-level reconnaissance flight was ordered to investigate 
the Campeche Area during the afternoon of 16 September; the post-flight summary from this flight reported a minimum pressure of $1000 \mathrm{mb}$ and a maximum wind of $35 \mathrm{knots}$ with circular bands of weather echoes on radar."

September 17:

HWM analyzes a tropical storm of at most $1000 \mathrm{mb}$ at $25.2 \mathrm{~N}, 93.2 \mathrm{~W}$ with a weakening frontal boundary to the west at $12 \mathrm{Z}$. HURDAT lists a $45 \mathrm{kt}$ tropical storm at $25.3 \mathrm{~N}, 92.6 \mathrm{~W}$ at $12 \mathrm{Z}$. Microfilm shows a closed low pressure of at most $1002 \mathrm{mb}$ at $25.5 \mathrm{~N}, 93.0 \mathrm{~W}$ at $12 \mathrm{Z}$. Ship highlights: $25 \mathrm{kt} \mathrm{NE}$ and $1003 \mathrm{mb}$ at $23.9 \mathrm{~N}, 93.1 \mathrm{~W}$ at $00 \mathrm{Z}$ (micro). $20 \mathrm{kt} \mathrm{ENE}$ and $1005 \mathrm{mb}$ at $25.2 \mathrm{~N}, 92.7 \mathrm{~W}$ at $06 \mathrm{Z}$ (COADS). $35 \mathrm{kt} \mathrm{SE}$ and 1011 $\mathrm{mb}$ at $28.6 \mathrm{~N}, 90.6 \mathrm{~W}$ at $12 \mathrm{Z}$ (COADS). $40 \mathrm{kt} \mathrm{ESE}$ and $1010 \mathrm{mb}$ at $28.6 \mathrm{~N}, 90.5 \mathrm{~W}$ at $18 \mathrm{Z}$ (micro). Aircraft highlights: Penetration center fix measured a central pressure of 1004 $\mathrm{mb}$, estimated maximum surface winds of $45 \mathrm{kt}$ and an eye diameter of $15 \mathrm{~nm}$ at $25.5 \mathrm{~N}$, 92.8W at 2000Z (ATSR).

MWR: "Esther grew to storm intensity by late on the 16th and began moving northward at about $10 \mathrm{mph}$. It never developed into a typical tropical storm with a small, welldefined eye but remained with a large area of relatively light winds roughly 100 miles across." ATSR: "Based on the recon flight and subsequent ship reports, Warning Number ONE, Tropical Storm Esther, was promulgated at 0400Z, 17 September. Although ESTHER never developed into a typically organized tropical storm, conditions at the upper levels were fairly favorable for further development. A second low-level recon flight was flown early on 17 September into ESTHER; this flight indicated that the storm was filling slightly (1004 mb) and that maximum winds were $45 \mathrm{kt}$. The strong winds were almost entirely on the east side of ESTHER and the center was poorly defined."

September 18:

HWM analyzes a tropical storm of at most $1000 \mathrm{mb}$ at $29.0 \mathrm{~N}, 90.9 \mathrm{~W}$ at $12 \mathrm{Z}$. HURDAT lists a $45 \mathrm{kt}$ tropical storm at $29.2 \mathrm{~N}, 90.9 \mathrm{~W}$ at $12 \mathrm{Z}$. Microfilm shows a closed low pressure of at most $1002 \mathrm{mb}$ at $29.8 \mathrm{~N}, 90.9 \mathrm{~W}$ at $12 \mathrm{Z}$. Ship highlights: $35 \mathrm{kt} \mathrm{SSW}$ and $1006 \mathrm{mb}$ at $25.0 \mathrm{~N}, 91.1 \mathrm{~W}$ at $00 \mathrm{Z}$ (micro). $40 \mathrm{kt} \mathrm{SE}$ and $1008 \mathrm{mb}$ at $27.7 \mathrm{~N}, 89.6 \mathrm{~W}$ at $02 \mathrm{Z}$ (micro). $40 \mathrm{kt} \mathrm{S}$ and $1008 \mathrm{mb}$ at 27.0N, 89.9W at 06Z (COADS). $50 \mathrm{kt} \mathrm{SSE}$ and $1009 \mathrm{mb}$ at $29.5 \mathrm{~N}, 88.8 \mathrm{~W}$ at $12 \mathrm{Z}$ (micro). Land highlights: $7 \mathrm{kt} \mathrm{S}$ and $1003 \mathrm{mb}$ at New Orleans, LA at $0955 \mathrm{Z}$ (SWO). $40 \mathrm{kt} \mathrm{SSW}$ and $1005 \mathrm{mb}$ at Burrwood, LA at 1010Z (SWO). $42 \mathrm{kt}$ $\mathrm{SE}$ and $1011 \mathrm{mb}$ at Mobile, AL at 1626Z (SWO). $45 \mathrm{kt} \mathrm{S}$, gusts to $65 \mathrm{kt}$ and $1012 \mathrm{mb}$ at Pensacola, FL at 1837Z (SWO). $43 \mathrm{kt} \mathrm{SSE}$ and $1010 \mathrm{mb}$ at Mobile, AL at 1848Z (SWO). $40 \mathrm{kt} \mathrm{SSE}$ and $1009 \mathrm{mb}$ at Mobile, AL at 2319Z (SWO). $6 \mathrm{kt} \mathrm{SE}$ and $1003 \mathrm{mb}$ at McComb, MS at $2158 Z$ (SWO). Aircraft highlights: Penetration center fix measured a central pressure of $1008 \mathrm{mb}$ and estimated maximum surface winds of $40 \mathrm{kt}$ at $28.0 \mathrm{~N}$, 
90.5W at $04 \mathrm{Z}$ (ATSR). Penetration center fix measured a central pressure of $1000 \mathrm{mb}$ at $28.4 \mathrm{~N}, 91.2 \mathrm{~W}$ at $0815 \mathrm{Z}$ (ATSR). Penetration center fix measured a central pressure of $1005 \mathrm{mb}$ and estimated maximum surface winds of $68 \mathrm{kt}$ at $28.8 \mathrm{~N}, 89.7 \mathrm{~W}$ at $1246 \mathrm{Z}$ (ATSR).

MWR: "This area passed inland on the southeastern Louisiana coast about day-break on September 18, subsequently moving up the Mississippi Valley and weakening. As in the case of the first storm of the season (unnamed) and Debbie, much of the squalliness and high wind was a considerable distance to the east of the center. The highest reported wind speed was $52 \mathrm{mph}$ at Pensacola airport, with gusts to $75 \mathrm{mph}$. The lowest pressure observed on land was $1003 \mathrm{mb}$ at New Orleans and McComb, La., with $1000 \mathrm{mb}$ reported by reconnaissance aircraft before the storm reached land. Squalls and heavy rains occurred in advance and to the east of the central area and continued along the Mississippi and Alabama coasts and near the mouth of the Mississippi River well after it passed. Five inches of rain fell at Buras, La., in 2.5 hours with a total of over 13 inches there. Amounts ranging upwards from 6 inches through southeastern Louisiana and near the Mississippi and Alabama coasts resulted in some flooding in those areas. The property damage chargeable to Esther was estimated at \$1,500,00." ATSR: "ESTHER continued on a NNE course at about 11 knots and moved inland on the southeast coast of Louisiana about daybreak 18 September. A third low-level flight was dispatched to the area south of New Orleans at daybreak, 18 September, to assure that ESTHER had not developed a second center during the night. Although this third flight could not locate a center, it did report winds in squall areas up to 68 knots. The maximum wind reported by land stations was 45 knots with gusts to 65 knots at Pensacola. Minimum pressure recorded at land stations was $1003 \mathrm{mb}$."

September 19:

HWM analyzes a warm front over the southeast of the United States and a cold front over the plains at 12Z. HURDAT lists a $25 \mathrm{kt}$ tropical depression at $33.5 \mathrm{~N}, 91.0 \mathrm{~W}$ at $12 \mathrm{Z}$ (last position). Microfilm shows a closed low pressure of at most $1008 \mathrm{mb}$ at 34.0N, 92.0W at 12Z. Ship highlights: $35 \mathrm{kt} \mathrm{SE}$ and $1008 \mathrm{mb}$ at $29.9 \mathrm{~N}, 88.2 \mathrm{~W}$ at $00 \mathrm{Z}$ (COADS). Land highlights: $10 \mathrm{kt} \mathrm{S}$ and $1004 \mathrm{mb}$ at Liberty, MS at 00Z (micro).

Tropical Storm Esther developed over the southern Gulf of Mexico during the third week of September. Land stations observations and ship data in the eastern Bay of Campeche indicate a decrease in pressures of about 4-6 mb between September $14^{\text {th }}$ and $16^{\text {th }}$. At $00 \mathrm{Z}$ on September $16^{\text {th }}$, ship data indicate that a well-defiled low level circulation had developed and a $30 \mathrm{kt}$ tropical depression is analyzed to have formed, 18 hours earlier than originally in HURDAT. Minor track changes are introduced for the duration of this system. The tropical cyclone moved slowly to the north on the $16^{\text {th }}$ and a ship at $09 \mathrm{Z}$ 
reported $40 \mathrm{kt} \mathrm{E}$ and $1006 \mathrm{mb}$. The tropical cyclone is analyzed to have become a tropical storm at $06 Z$ on the $16^{\text {th }}, 18$ hours earlier than originally shown in HURDAT. The first reconnaissance aircraft to investigate Esther reached the tropical storm at $23 \mathrm{Z}$ on the $16^{\text {th }}$ measuring a central pressure of $1000 \mathrm{mb}$ and estimating surface winds of $35 \mathrm{kt}$. A central pressure of $1000 \mathrm{mb}$ suggests maximum sustained winds of $47 \mathrm{kt}$ south of $25 \mathrm{~N}$ from the Brown et al. pressure-wind relationship. Due to the low environmental pressures and slow forward speed, an intensity of $40 \mathrm{kt}$ is selected for $00 \mathrm{Z}$ on the $17^{\text {th }}$, up from $35 \mathrm{kt}$ originally in HURDAT, a minor intensity change. A central pressure of $1000 \mathrm{mb}$ was present in HURDAT at $00 \mathrm{Z}$ on the $17^{\text {th }}$ and has been retained. A couple of gales up to 40 kt were reported on the $17^{\text {th }}$, all of them over the eastern quadrant where the pressure gradient was the strongest. Another reconnaissance aircraft mission reached Esther at $18 \mathrm{Z}$ on the $17^{\text {th }}$ measuring a central pressure of $1004 \mathrm{mb}$ and estimating surface winds of 45 kt. A central pressure of $1004 \mathrm{mb}$ suggests maximum surface winds of $36 \mathrm{kt}$ north of $25 \mathrm{~N}$ and $39 \mathrm{kt}$ south of $25 \mathrm{~N}$, according to the pressure-wind relationship. Based on the ship data, an intensity of $40 \mathrm{kt}$ is selected for $18 \mathrm{Z}$ on the $17^{\text {th }}$, down from $45 \mathrm{kt}$ originally in HURDAT, a minor intensity change. A central pressure of $1004 \mathrm{mb}$ is present in HURDAT at $12 \mathrm{Z}$ on the $17^{\text {th }}$ and has been moved to $18 \mathrm{Z}$ based on the aircraft reconnaissance data.

On September $18^{\text {th }}$, Esther turned to the north-northeast and gained in forward speed and strength. A reconnaissance mission at $0815 \mathrm{Z}$ on the $18^{\text {th }}$ measured a central pressure of $1000 \mathrm{mb}$. A central pressure of $1000 \mathrm{mb}$ suggests maximum sustained winds of $44 \mathrm{kt}$ north of $25 \mathrm{~N}$ according to the pressure-wind relationship. Based on the faster forward speed of the storm and now near-normal environmental pressures, the intensity is analyzed at $50 \mathrm{kt}$, up from $45 \mathrm{kt}$ in HURDAT, a minor intensity change. A central pressure of $1000 \mathrm{mb}$ is added to $06 \mathrm{Z}$ on September $18^{\text {th }}$. There were other center fixes during the morning of the $18^{\text {th }}$ but based on ship and land stations data, they likely missed the center, staying 60 to $120 \mathrm{~nm}$ east of the center. An aircraft reconnaissance mission at $1246 \mathrm{Z}$ reported a central pressure of $1005 \mathrm{mb}$, estimated surface winds of $68 \mathrm{kt}$, and indicated that the area of $50 \mathrm{kt}$ winds extended 150 miles from the center. Ship and land stations observations indicate that the center fix was about $80 \mathrm{~nm}$ to the east of the actual center and therefore, the $1005 \mathrm{mb}$ was likely not a central pressure, which has been removed from HURDAT at 12Z. Esther made landfall in southeast Louisiana around $12 \mathrm{Z}$ near 29.2N, $90.9 \mathrm{~W}$, about $60 \mathrm{~nm}$ southwest of New Orleans, with winds of $55 \mathrm{kt}$. This intensity is up from $45 \mathrm{kt}$ originally in HURDAT, a minor intensity change. $55 \mathrm{kt}$ is also the peak intensity for the lifetime of this tropical cyclone. The peak intensity is analyzed from a ship report of $50 \mathrm{kt}$ at $12 \mathrm{Z}$, also the large area of $50 \mathrm{kt}$ winds reported by the reconnaissance aircraft and a couple of land observations of winds between 40 and $45 \mathrm{kt}$, all on the eastern quadrant of the storm. After making landfall in Louisiana, Esther turned to the north and quickly weakened, becoming a tropical depression at $06 \mathrm{Z}$ on September 
$19^{\text {th }}$. At $00 \mathrm{Z}$ on the $19^{\text {th }}$, Liberty, MS reported $10 \mathrm{kt} \mathrm{S}$ and $1004 \mathrm{mb}$, indicating a central pressure of about $1002 \mathrm{mb}$, which has been added to HURDAT. Dissipation occurred after $12 \mathrm{Z}$ on the $19^{\text {th }}$.

Hurricane Frieda [September 20-27, 1957]

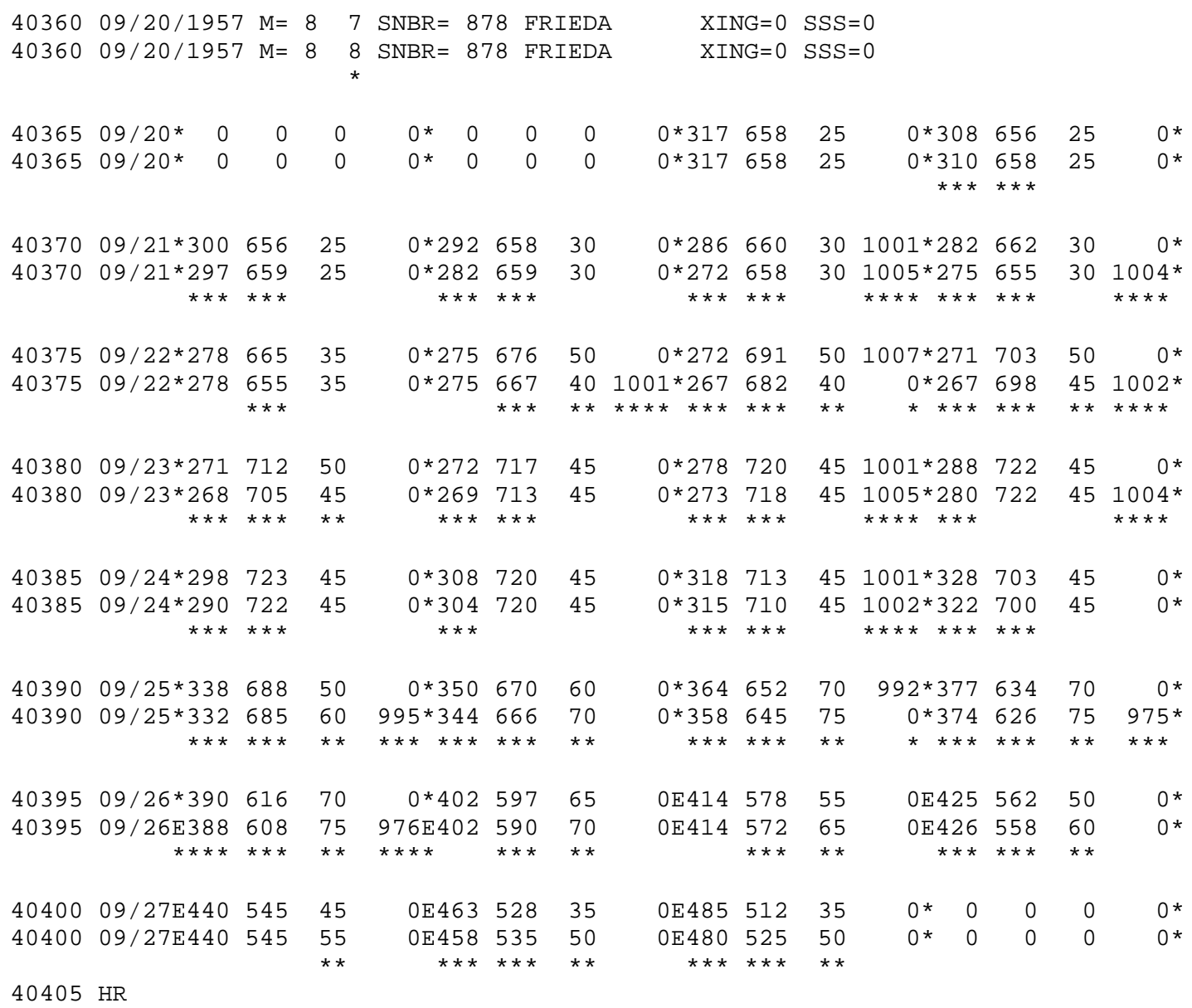

Minor changes the track and intensity shown in McAdie et al. (2009). Evidence for these alterations comes from the NHC microfilm maps, the Historical Weather Maps series, the COADS ship database, Reconnaissance aircraft and Monthly Weather Review.

September 18:

HWM analyzes a cold front off the United States east coast at 12Z. HURDAT does not list an organized storm on this date. Microfilm shows a closed low pressure of at 
most $1017 \mathrm{mb}$ with a frontal boundary going through the center at $37.0 \mathrm{~N}, 73.5 \mathrm{~W}$ at $12 \mathrm{Z}$. Ship highlights: No gales or low pressures.

September 19:

HWM analyzes a cold front off the United States east coast at 12Z. HURDAT does not list an organized storm on this date. Microfilm shows a frontal boundary off the United States east coast at 12Z. Ship highlights: No gales or low pressures.

ATSR: "When hurricane CARRIE moved eastward from Bermuda a weak cold front moved into the Atlantic between the southeast coast of the United States and Bermuda. On the 191200Z surface map a small closed low appeared on the cold front about 300 miles east-northeast of Cape Hatteras. During the next 48 hours this low drifted eastward then southeastward and became separated from the frontal system; meanwhile, it gradually assumed semitropical characteristics."

September 20:

HWM analyzes a closed low pressure of at most $1010 \mathrm{mb}$ at $30.1 \mathrm{~N}, 65.3 \mathrm{~W}$ with a weakening cold front to the north at 12Z. HURDAT lists a 25 knot tropical depression at $31.7 \mathrm{~N}, 65.8 \mathrm{~W}$ at $12 \mathrm{Z}$ (first position). Microfilm shows a closed low pressure of at most $1011 \mathrm{mb}$ at $32.5 \mathrm{~N}, 63.0 \mathrm{~W}$. Ship highlights: No gales or low pressures.

MWR: "Hurricane Frieda spent its life at sea and was of hurricane force for only a few hours. The circulation which developed into this storm began on September 20. A cold front pushing southward to the rear of Hurricane Carrie passed Bermuda and a low center of $1010 \mathrm{mb}$., appearing at first to be nothing more than an incipient frontal wave, rapidly developed. Elsewhere, significant features were a 1020-mb. surface anticyclone some 700 miles to the north, and northerly winds of near $55 \mathrm{mph}$ at $500 \mathrm{mb}$ and higher over the surface cyclone."

September 21:

HWM analyzes a tropical storm of at most $1005 \mathrm{mb}$ at $27.2 \mathrm{~N}, 66.9 \mathrm{~W}$ with a stationary front to the northeast at 12Z. HURDAT lists a $30 \mathrm{kt}$ tropical depression at $28.6 \mathrm{~N}, 66.0 \mathrm{~W}$ at $12 \mathrm{Z}$. Microfilm shows a closed low pressure of at most $1005 \mathrm{mb}$ at $27.0 \mathrm{~N}, 67.0 \mathrm{~W}$ with a frontal boundary to the north at $12 \mathrm{Z}$. Ship highlights: $5 \mathrm{kt} \mathrm{SE}$ and $1005 \mathrm{mb}$ at $27.5 \mathrm{~N}, 66.3 \mathrm{~W}$ at $12 \mathrm{Z}$ (COADS). $10 \mathrm{kt} \mathrm{NE}$ and $1005 \mathrm{mb}$ at $28.1 \mathrm{~N}, 65.4 \mathrm{~W}$ at $18 \mathrm{Z}$ (COADS).

MWR: "By early morning of the 21st, strong easterly winds of $63 \mathrm{mph}$ were observed at the gradient level at Bermuda. The LST Nurvik reported the central pressure in the developing storm, about 400 miles south-southwest of Bermuda, as $1005 \mathrm{mb}$. Several 
factors favored intensification at this time. The strong low-level easterly winds north of the area resulted in a strong cyclonic shear, the sea surface temperatures were very warm, raobs from the Narwik and from Bermuda indicated that the cold front had dissipated, and there were favorable high-level winds for evacuation."

September 22:

HWM analyzes a tropical storm of at most $1000 \mathrm{mb}$ at $26.7 \mathrm{~N}, 68.8 \mathrm{~W}$ with a warm front to the northeast at 12Z. HURDAT lists a $50 \mathrm{kt}$ tropical storm at $27.2 \mathrm{~N}, 69.1 \mathrm{~W}$ at $12 \mathrm{Z}$. Microfilm shows a closed low pressure of at most $1005 \mathrm{mb}$ at $26.5 \mathrm{~N}, 68.5 \mathrm{~W}$ at 12Z. Ship highlights: $35 \mathrm{kt} \mathrm{NE}$ and $1012 \mathrm{mb}$ at $28.9 \mathrm{~N}, 71.3 \mathrm{~W}$ at $00 \mathrm{Z}$ (COADS). $35 \mathrm{kt} \mathrm{NE}$ and $1005 \mathrm{mb}$ at $30.2 \mathrm{~N}, 71.7 \mathrm{~W}$ at $06 \mathrm{Z}$ (COADS). $35 \mathrm{kt} \mathrm{NNE}$ and $1011 \mathrm{mb}$ at $24.7 \mathrm{~N}$, $71.8 \mathrm{~W}$ at $12 \mathrm{Z}$ (micro). $35 \mathrm{kt} \mathrm{NE}$ and $1010 \mathrm{mb}$ at $29.1 \mathrm{~N}, 70.0 \mathrm{~W}$ at $18 \mathrm{Z}$ (micro). $20 \mathrm{kt} \mathrm{W}$ and $1004 \mathrm{mb}$ at $26.6 \mathrm{~N}, 70.0 \mathrm{~W}$ at $18 \mathrm{Z}$ (micro). Aircraft highlight: Penetration fix measured a central pressure of $1001 \mathrm{mb}$ at $27.4 \mathrm{~N}, 66.3 \mathrm{~W}$ at $03 \mathrm{Z}$ (micro). Penetration fix measured a minimum pressure of $1007 \mathrm{mb}$ and estimated surface maximum winds of 40 kt at $27.3 \mathrm{~N}, 70.3 \mathrm{~W}$ at $1750 \mathrm{Z}$ (micro). Radar fix at $27.1 \mathrm{~N}, 70.1 \mathrm{~W}$ at $2020 \mathrm{Z}$ (micro).

MWR: "By evening of the 21st, aircraft reconnaissance showed that central pressure had fallen to $1001 \mathrm{mb}$ and winds were up to $60 \mathrm{mph}$ in squalls east of the center. Frieda was a reality. The movement was rather slow to the southwest. Reconnaissance on the morning of September 22 found maximum winds of 50 to $60 \mathrm{mph}$ in gusts with sustained winds generally 30 to $40 \mathrm{mph}$. Shower activity was considerably less than normal and there was no extensive cloud shield. Meanwhile, upper winds at Bermuda were rapidly veering from northerly to southeasterly with decreasing speeds. This occurred as a high-level anticyclone northwest of the storm weakened and split in response to the approach of a short wave in the westerlies. This left the upper ridge with two cells, one over Florida and the other northeast of Bermuda." ATSR: "At 220400Z the low was named Tropical Storm Frieda and Warning Number ONE was issued."

September 23:

HWM analyzes a tropical storm of at most $1000 \mathrm{mb}$ at $27.8 \mathrm{~N}, 71.9 \mathrm{~W}$ at $12 \mathrm{Z}$. HURDAT lists a $45 \mathrm{kt}$ tropical storm at 27.8N, $72.0 \mathrm{~W}$ at 12Z. Microfilm shows a closed low pressure of at most $1005 \mathrm{mb}$ at $27.5 \mathrm{~N}, 72.0 \mathrm{~W}$ at $12 \mathrm{Z}$. Ship highlights: $40 \mathrm{kt} \mathrm{SE}$ at $27.6 \mathrm{~N}, 69.8 \mathrm{~W}$ at $02 \mathrm{Z}$ (micro). $40 \mathrm{kt} \mathrm{SSE}$ and $1006 \mathrm{mb}$ at $27.6 \mathrm{~N}, 69.0 \mathrm{~W}$ at $09 \mathrm{Z}$ (micro). $40 \mathrm{kt} \mathrm{SSE}$ and $1007 \mathrm{mb}$ at $27.7 \mathrm{~N}, 69.4 \mathrm{~W}$ at $12 \mathrm{Z}$ (COADS). $20 \mathrm{kt} \mathrm{E}$ and $1005 \mathrm{mb}$ at $27.9 \mathrm{~N}, 72.0 \mathrm{~W}$ at $15 \mathrm{Z}$ (COADS). $40 \mathrm{kt} \mathrm{S}$ and $1009 \mathrm{mb}$ at $27.3 \mathrm{~N}, 69.3 \mathrm{~W}$ at $18 \mathrm{Z}$ (COADS). Aircraft highlights: Penetration center fix measured a central pressure of $1005 \mathrm{mb}$, estimated maximum surface winds of $50 \mathrm{kt}$ and an eye diameter of $35 \mathrm{~nm}$ at $27.2 \mathrm{~N}$, 
$71.8 \mathrm{~W}$ at $12 \mathrm{Z}$ (ATSR). Penetration center fix measured a central pressure of $1004 \mathrm{mb}$ and estimated maximum surface winds of $45 \mathrm{kt}$ at $27.5 \mathrm{~N}, 71.5 \mathrm{~W}$ at $1945 \mathrm{Z}$ (micro).

MWR: "With a less favorable Circulation for intensification, Frieda showed little change through the $23^{\text {rd }}$. At the same time, recurvature was favored by the new circulation pattern around the storm and it began to move toward the northwest and north at about 10 mph during the night of the $23^{\text {rd }}$."

September 24:

HWM analyzes a tropical storm with a central pressure of $998 \mathrm{mb}$ at $31.8 \mathrm{~N}$, $71.9 \mathrm{~W}$ with a weakening front to the northwest at $12 \mathrm{Z}$. HURDAT lists a $45 \mathrm{kt}$ tropical storm at $31.8 \mathrm{~N}, 71.3 \mathrm{~W}$ at $12 \mathrm{Z}$. Microfilm shows a closed low pressure of at most 1002 $\mathrm{mb}$ at $30.5 \mathrm{~N}, 71.2 \mathrm{~W}$ with a frontal boundary to the northwest at 12Z. Ship highlights: 40 $\mathrm{kt} \mathrm{S}$ and $1008 \mathrm{mb}$ at $26.7 \mathrm{~N}, 70.7 \mathrm{~W}$ at $00 \mathrm{Z}$ (microfilm shows $45 \mathrm{kt}$ )(COADS). $40 \mathrm{kt} \mathrm{S}$ and $1008 \mathrm{mb}$ at $29.5 \mathrm{~N}, 69.8 \mathrm{~W}$ at $02 \mathrm{Z}$ (COADS). $45 \mathrm{kt} \mathrm{SE}$ and $1008 \mathrm{mb}$ at $29.6 \mathrm{~N}, 69.1 \mathrm{~W}$ at $06 \mathrm{Z}$ (COADS). $40 \mathrm{kt} \mathrm{S}$ and $1010 \mathrm{mb}$ at $29.1 \mathrm{~N}, 68.8 \mathrm{~W}$ at $12 \mathrm{Z}$ (micro). $40 \mathrm{kt} \mathrm{SSE}$ and $1005 \mathrm{mb}$ at $31.5 \mathrm{~N}, 67.7 \mathrm{~W}$ at $18 \mathrm{Z}$ (COADS). Aircraft highlights: Penetration center fix measured a central pressure of $1002 \mathrm{mb}$, estimated maximum surface winds of $50 \mathrm{kt}$ and an eye diameter of $40 \mathrm{~nm}$ at $32.2 \mathrm{~N}, 71.5 \mathrm{~W}$ at $1130 \mathrm{Z}$ (ATSR).

MWR: "Simultaneously, as the short wave in the westerlies progressed eastward, the upper trough weakened and, perhaps in response to a more favorable high-level evacuation mechanism, the cloud systems began to show more organization and radar coverage became feasible for the first time. Forward velocity increased to $20 \mathrm{mph}$. toward the north-northeast on the 24th and little change was observed in surface pressures." ATSR: "On 24 September reconnaissance aircraft could find only a large flat circulation center with no indications of a tropical storm cloud or precipitation center. FRIEDA never attained winds of hurricane force until after it became an extratropical low."

September 25:

HWM analyzes a hurricane of at most $990 \mathrm{mb}$ at $36.0 \mathrm{~N}, 65.4 \mathrm{~W}$ with a weakening stationary front to the west and a weakening cold front to the south at $12 Z$. HURDAT lists a $70 \mathrm{kt}$ hurricane at $36.4 \mathrm{~N}, 65.2 \mathrm{~W}$ at $12 \mathrm{Z}$. Microfilm shows a closed low pressure of at most $1002 \mathrm{mb}$ at $37.5 \mathrm{~N}, 64.7 \mathrm{~W}$ with a frontal boundary to the north and west at 12Z. Ship highlights: $25 \mathrm{kt} \mathrm{W}$ and $998 \mathrm{mb}$ at $32.4 \mathrm{~N}, 68.9 \mathrm{~W}$ at $00 \mathrm{Z}$ (micro). $40 \mathrm{kt}$ $\mathrm{S}$ and $986 \mathrm{mb}$ at $34.0 \mathrm{~N}, 66.3 \mathrm{~W}$ at $06 \mathrm{Z}$ (micro). $70 \mathrm{kt} \mathrm{S}$ and $992 \mathrm{mb}$ at $35.8 \mathrm{~N}, 64.7 \mathrm{~W}$ at $12 \mathrm{Z}$ (COADS/MWR). $60 \mathrm{kt} \mathrm{SSW}$ and $1000 \mathrm{mb}$ at $36.1 \mathrm{~N}, 62.0 \mathrm{~W}$ at $16 \mathrm{Z}$ (micro). $35 \mathrm{kt}$ $\mathrm{SW}$ and $978 \mathrm{mb}$ at $37.2 \mathrm{~N}, 67.3 \mathrm{~W}$ at $18 \mathrm{Z}$ (COADS/MWR). $50 \mathrm{kt} \mathrm{SE}$ and $994 \mathrm{mb}$ at $38.3 \mathrm{~N}, 60.3 \mathrm{~W}$ at $18 \mathrm{Z}$ (micro). 
MWR: "However, by morning of the 25th, the Canadian merchant ship Irvingbrook reported a barometer reading of $992 \mathrm{mb}$. and 80-mph winds. Frieda now was a hurricane but only for a few hours for the cold front associated with the short wave mentioned previously was dropping into her circulation. Some further decrease in central pressure occurred as shown by a report from the ship African Lightning, giving a pressure of 978 $\mathrm{mb}$. However, this was interpreted as the result of extratropical deepening since the storm was spreading out and there was no observed wind speed such as the $115 \mathrm{~m}$. p. h. that Fletcher's formula would indicate under true tropical conditions with such a pressure." ATSR: "FRIEDA never assumed truly tropical characteristics, but was reported throughout her life span as a large calm area near the center with the maximum winds being found several hundred miles away from the center in the east and north quadrants. FRIEDA drifted south, then west, and finally to a north to northeast direction and by 25 September was again under the influence of a polar trough.”

September 26:

HWM analyzes a hurricane of at most $985 \mathrm{mb}$ at $41.2 \mathrm{~N}, 58.0 \mathrm{~W}$ with a warm front to the north and a cold front to the south at 12Z. HURDAT lists a $55 \mathrm{kt}$ extratropical cyclone at $41.4 \mathrm{~N}, 57.8 \mathrm{~W}$ at $12 \mathrm{Z}$. Microfilm shows an extratropical low pressure of at most $993 \mathrm{mb}$ at $41.0 \mathrm{~N}, 57.5 \mathrm{~W}$ with a frontal boundary to the northeast and south at $12 \mathrm{Z}$. Ship highlights: $65 \mathrm{kt} \mathrm{NNE}$ and $991 \mathrm{mb}$ at $40.0 \mathrm{~N}, 63.0 \mathrm{~W}$ at $00 \mathrm{Z}$ (micro). $30 \mathrm{kt} \mathrm{SW}$ and $979 \mathrm{mb}$ at $38.7 \mathrm{~N}, 60.7 \mathrm{~W}$ at $00 \mathrm{Z}$ (micro). $60 \mathrm{kt} \mathrm{NE}$ and $989 \mathrm{mb}$ at $40.5 \mathrm{~N}, 59.9 \mathrm{~W}$ at $06 \mathrm{Z}$ (COADS). $55 \mathrm{kt} \mathrm{N}$ and $993 \mathrm{mb}$ at 40.6N, 58.5W at 12Z (COADS). $45 \mathrm{kt} \mathrm{NW}$ and 1002 $\mathrm{mb}$ at $40.6 \mathrm{~N}, 58.6 \mathrm{~W}$ at $15 \mathrm{Z}$ (COADS). $60 \mathrm{kt} \mathrm{SE}$ and $985 \mathrm{mb}$ at $42.3 \mathrm{~N}, 54.3 \mathrm{~W}$ at $18 \mathrm{Z}$ (COADS).

September 27:

HWM analyzes a tropical storm of at most $985 \mathrm{mb}$ at $49.0 \mathrm{~N}, 51.0 \mathrm{~W}$ with a warm front to the north and a cold front to the east and south at 12Z. HURDAT lists a 35 kt extratropical cyclone at $48.5 \mathrm{~N}, 51.2 \mathrm{~W}$ at $12 \mathrm{Z}$ (last position). Microfilm shows an extratropical low pressure of at most $993 \mathrm{mb}$ at $49.0 \mathrm{~N}, 52.0 \mathrm{~W}$ at 12Z. Ship highlights: 50 $\mathrm{kt} \mathrm{SE}$ and $991 \mathrm{mb}$ at $44.2 \mathrm{~N}, 53.2 \mathrm{~W}$ at $00 \mathrm{Z}$ (COADS). $50 \mathrm{kt} \mathrm{NNW}$ and $982 \mathrm{mb}$ at $44.2 \mathrm{~N}$, $55.2 \mathrm{~W}$ at $00 \mathrm{Z}$ (COADS). $10 \mathrm{kt} \mathrm{NE}$ and $988 \mathrm{mb}$ at $46.2 \mathrm{~N}, 53.5 \mathrm{~W}$ at $06 \mathrm{Z}$ (micro). $15 \mathrm{kt}$ $\mathrm{NW}$ and $986 \mathrm{mb}$ at $46.4 \mathrm{~N}, 52.3 \mathrm{~W}$ at $09 \mathrm{Z}$ (micro). $50 \mathrm{kt} \mathrm{SE}$ and $990 \mathrm{mb}$ at $48.2 \mathrm{~N}, 49.1 \mathrm{~W}$ at $12 \mathrm{Z}$ (COADS). $45 \mathrm{kt} \mathrm{SW}$ and $997 \mathrm{mb}$ at $47.7 \mathrm{~N}, 50.2 \mathrm{~W}$ at $18 \mathrm{Z}$ (COADS). Land highlights: $15 \mathrm{kt} \mathrm{W}$ and $993 \mathrm{mb}$ at St. John's, Newfoundland, Canada at 12Z (micro).

MWR: "After becoming extratropical, Frieda continued rapidly northeastward, with gradually decreasing intensity, and passed across Newfoundland on the night of the 26th. No deaths or property losses have been charged to this storm." 
September 28:

HWM analyzes an extratropical cyclone of at most $985 \mathrm{mb}$ at $55.0 \mathrm{~N}, 58.0 \mathrm{~W}$ with a stationary front to the south at $12 \mathrm{Z}$. HURDAT does not a list an organized system on this date. Microfilm shows an extratropical low pressure of at most $984 \mathrm{mb}$ at $55.0 \mathrm{~N}$, $58.0 \mathrm{~W}$ at $12 \mathrm{Z}$.

September 29:

HWM analyzes an extratropical cyclone of at most $995 \mathrm{mb}$ at $59.0 \mathrm{~N}, 54.0 \mathrm{~W}$ at 12Z. HURDAT does not a list an organized system on this date. Microfilm shows an extratropical of at most $993 \mathrm{mb}$ cyclone at $59.0 \mathrm{~N}, 52.0 \mathrm{~W}$ at $12 \mathrm{Z}$.

September 30:

HWM analyzes an extratropical cyclone of at most $995 \mathrm{mb}$ at $70.0 \mathrm{~N}, 69.0 \mathrm{~W}$ at 12Z. HURDAT does not a list an organized system on this date. Microfilm shows an extratropical of at most $990 \mathrm{mb}$ cyclone at $65.0 \mathrm{~N}, 70.0 \mathrm{~W}$ at $12 \mathrm{Z}$.

The final hurricane of the season developed from a frontal boundary that moved off the east coast of the United States into the western Atlantic on September $18^{\text {th }}$. An area of low pressure formed near Bermuda and at $12 \mathrm{Z}$ on September $20^{\text {th }}$, a $25 \mathrm{kt}$ tropical depression is analyzed to have developed, as originally indicated in HURDAT. It is possible that the tropical cyclone may have formed earlier in the day but the ship and land observations were sparse during that time. Also, the cyclone was elongated E-W and for most of its lifetime, it had a large circulation with the strongest winds away from the center, an indication that it may have started as a subtropical cyclone. Minor track changes are introduced for the duration of this system. The depression moved southward on the September $20^{\text {th }}$, making a small counter-clockwise loop on the $21^{\text {st }}$ before turning to the west. A ship passed close to the center at $12 \mathrm{Z}$ on the $21^{\text {st }}$ measuring $5 \mathrm{kt} \mathrm{SE}$ and $1005 \mathrm{mb}$, which suggests a central pressure near $1005 \mathrm{mb}$. A central pressure of $1005 \mathrm{mb}$ suggests maximum sustained winds of $34 \mathrm{kt}$ north of $25 \mathrm{~N}$ from the Brown et al. pressurewind relationship. Due to the slow movement of the depression and broad nature of the circulation, winds are analyzed at $30 \mathrm{kt}$ for $12 \mathrm{Z}$ on the $21^{\text {st }}$, same as originally in HURDAT. A central pressure of $1001 \mathrm{mb}$ was present in HURDAT at $12 \mathrm{Z}$ on the $21^{\text {st }}$ but appears to be incorrect since there was no aircraft reconnaissance on the $21^{\text {st }}$ or any ship report with a lower pressure measurement than $1005 \mathrm{mb}$. Thus, the $1001 \mathrm{mb}$ central pressure has been replaced with $1005 \mathrm{mb}$ at $12 \mathrm{Z}$ on the $21^{\text {st }}$. The same ship measured 10 $\mathrm{kt} \mathrm{NE}$ and $1005 \mathrm{mb}$ at $18 \mathrm{Z}$ on the $21^{\text {st }}$, suggesting a central pressure of $1004 \mathrm{mb}$, which has been added to HURDAT. The first reconnaissance aircraft into the tropical cyclone arrived early on September $22^{\text {nd }}$, measuring a central pressure of $1001 \mathrm{mb}$ at $03 \mathrm{Z}$. A central pressure of $1001 \mathrm{mb}$ suggests maximum sustained winds of $42 \mathrm{kt}$ north of $25 \mathrm{~N}$ 
according to the pressure-wind relationship. An intensity of $40 \mathrm{kt}$ is selected for $06 \mathrm{Z}$ on the $22^{\text {nd }}$, down from $50 \mathrm{kt}$ originally in HURDAT, a minor intensity change. Intensification to a tropical storm is analyzed at $00 \mathrm{Z}$ on the $22^{\text {nd }}$, as originally shown in HURDAT. A central pressure of $1001 \mathrm{mb}$ is added to $06 \mathrm{Z}$ on the $22^{\text {nd }}$. A central pressure of $1007 \mathrm{mb}$ appears in HURDAT at $12 \mathrm{Z}$ on the $22^{\text {nd }}$, but this measurement made at $1750 \mathrm{Z}$ on this day was a peripheral pressure from reconnaissance, not a central pressure. Therefore, it has been removed from HURDAT. A ship at $18 \mathrm{Z}$ on the $22^{\text {nd }}$ reported $20 \mathrm{kt}$ $\mathrm{W}$ and $1004 \mathrm{mb}$, suggesting a central pressure of $1002 \mathrm{mb}$, which has been added to HURDAT. Another ship at $18 \mathrm{Z}$ on the $22^{\text {nd }}$, located about $120 \mathrm{~nm}$ from the center, reported $55 \mathrm{kt}$ but observations from nearby ships indicate that it has a high bias. The intensity for Frieda at $12 \mathrm{Z}$ and $18 \mathrm{Z}$ on the $22^{\text {nd }}$ is analyzed at $45 \mathrm{kt}$, down from $50 \mathrm{kt}$ originally in HURDAT a minor intensity change.

On September $23^{\text {rd }}$, the track of Frieda turned to the north-northwest ahead of a frontal boundary approaching from the west. A ship reported $50 \mathrm{kt}$ about $180 \mathrm{~nm}$ north-northeast of the center and also appears to have a high bias compared to nearby ships. The intensity is kept at $45 \mathrm{kt}$ at $00 \mathrm{Z}$ on the $23^{\text {rd }}$, down from $50 \mathrm{kt}$ originally in HURDAT, a minor intensity change. A couple of ships reported $40 \mathrm{kt}$ winds at $02 \mathrm{Z}$ on the $23^{\text {rd }}$ on the eastern quadrant, which had the strongest pressure gradient. A reconnaissance aircraft reached Frieda on September $23^{\text {rd }}$ at $12 \mathrm{Z}$ measuring a central pressure of $1005 \mathrm{mb}$ and estimated surface winds of $50 \mathrm{kt}$. HURDAT originally had $1001 \mathrm{mb}$ at $12 \mathrm{Z}$ on the $24^{\text {th }}$, which seems to be an error and has been replaced with $1005 \mathrm{mb}$. A central pressure of $1005 \mathrm{mb}$ suggests maximum sustained winds of $34 \mathrm{kt}$ north of $25 \mathrm{~N}$ according to the pressure-wind relationship. The intensity is kept at $45 \mathrm{kt}$, same as originally in HURDAT, based on the numerous ship reports of $40 \mathrm{kt}$ and the $50 \mathrm{kt}$ surface wind estimate from the aircraft. Another center fix at $1945 \mathrm{Z}$ on the $23^{\text {rd }}$ measured a central pressure of $1004 \mathrm{mb}$, which has been added to HURDAT at $18 \mathrm{Z}$ on this day. On September $24^{\text {th }}$, Frieda turned to the north and later to the northeast ahead of the frontal boundary to the west. A reconnaissance mission arrived at $1130 \mathrm{Z}$ on the $24^{\text {th }}$ measuring a central pressure of 1002 $\mathrm{mb}$ and estimated surface winds of $50 \mathrm{kt}$. A central pressure of $1002 \mathrm{mb}$ suggests maximum sustained winds of $40 \mathrm{kt}$ north of $25 \mathrm{~N}$ according to the pressure-wind relationship. An intensity of $45 \mathrm{kt}$ (unchanged) is analyzed at $12 \mathrm{Z}$ based on the ship observations and the surface wind estimate from the aircraft. A central pressure of 1001 $\mathrm{mb}$ appears in HURDAT at $12 \mathrm{Z}$ on the $24^{\text {th }}$ and has been replaced with $1002 \mathrm{mb}$. It is interesting to note that the aircraft center fix at $1130 \mathrm{Z}$ on the $24^{\text {th }}$ was likely about $60 \mathrm{~nm}$ too far to the north based on ship observations at $12 \mathrm{Z}$ and $18 \mathrm{Z}$. On September $25^{\text {th }}$, Frieda gained in forward speed to the northeast and began to intensify, possibly due to the increase in baroclinicity. A ship reported $25 \mathrm{kt} \mathrm{W}$ and $998 \mathrm{mb}$ at $00 \mathrm{Z}$ on the $25^{\text {th }}$, suggesting a central pressure of $995 \mathrm{mb}$, which has been added to HURDAT. A central pressure of $995 \mathrm{mb}$ suggests maximum sustained winds of $52 \mathrm{kt}$ north of $25 \mathrm{~N}$ according 
to the pressure-wind relationship. Due to the increase in forward speed, an intensity of 60 $\mathrm{kt}$ is analyzed for $00 \mathrm{Z}$ on the $25^{\text {th }}$, up from $50 \mathrm{kt}$ in HURDAT, a minor intensity change. A ship close to the center of Frieda at $12 \mathrm{Z}$ on the $25^{\text {th }}$ reported $70 \mathrm{kt} \mathrm{S}$ and $992 \mathrm{mb}$, and an intensity of $75 \mathrm{kt}$ is analyzed at this time, up from $70 \mathrm{kt}$ in HURDAT, a minor intensity change. HURDAT originally had a central pressure of $992 \mathrm{mb}$ at $12 \mathrm{Z}$ on the $25^{\text {th }}$ but this is clearly from the ship report and not a central pressure, so it has been removed. Intensification to a hurricane is analyzed at $06 \mathrm{Z}$ on the $25^{\text {th }}$, six hours earlier than originally in HURDAT. $75 \mathrm{kt}$ is also the peak intensity for this tropical cyclone, up from 70 kt originally in HURDAT, a minor intensity change. At $18 \mathrm{Z}$ on the $25^{\text {th }}$, a ship very close to the center reported $35 \mathrm{kt} \mathrm{SW}$ and $978 \mathrm{mb}$, suggesting a central pressure of 975 $\mathrm{mb}$ which has been added to HURDAT. A central pressure of $975 \mathrm{mb}$ suggests maximum sustained winds of $78 \mathrm{kt}$ north of $35 \mathrm{~N}$ according to the pressure-wind relationship. An intensity of $75 \mathrm{kt}$ is analyzed at $18 \mathrm{Z}$ on the $25^{\text {th }}$ since Frieda was undergoing extratropical transition. Transition to an extratropical cyclone is analyzed at $00 \mathrm{Z}$ on September $26^{\text {th }}$ based coastal and ship observations clearly showing a temperature gradient across the storm and the development of frontal boundaries near the center. The extratropical transition is twelve hours earlier than originally shown in HURDAT. A ship near the center at $00 \mathrm{Z}$ on the $26^{\text {th }}$, reported $30 \mathrm{kt} \mathrm{SW}$ and $979 \mathrm{mb}$, suggesting a central pressure of $976 \mathrm{mb}$, which has been added to HURDAT. Frieda continued moving to the northeast as a powerful extratropical cyclone on the $26^{\text {th }}$. Early on September $27^{\text {th }}$, Frieda began to interact with another extratropical cyclone to the northwest and appears to have merged after $12 \mathrm{Z}$ on this day. The final position of Frieda at $12 \mathrm{Z}$ on the $27^{\text {th }}$ is unchanged from the original HURDAT. The resulting extratropical cyclone intensified over the Labrador Sea and moved northwestward over the next couple of days.

Unnamed Tropical Storm \#8 [October 23-27, 1957]

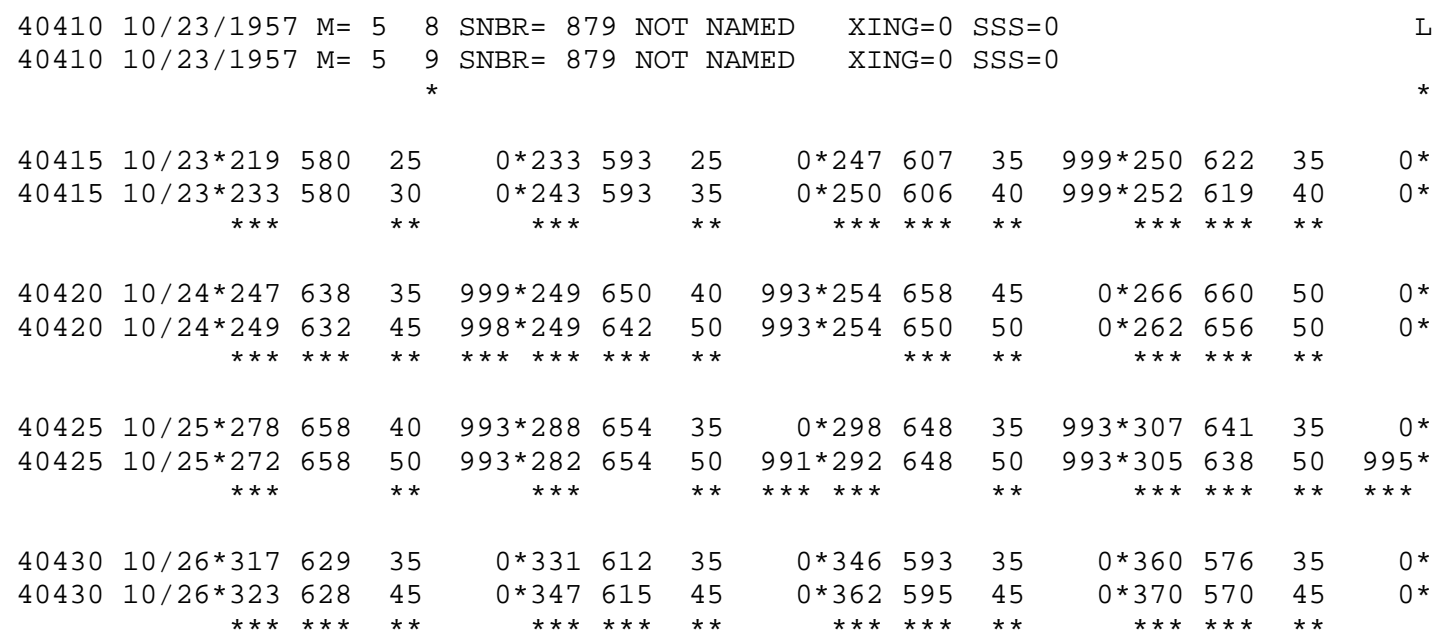


40435 10/27E370 $553 \quad 30$

$4043510 / 27 * 373 \quad 540 \quad 40$

OE376 $519 \quad 25$

OE383 $485 \quad 25$

$\begin{array}{llll}0^{*} & 0 & 0 & 0 \\ * & * & & \text { * }\end{array}$

$\begin{array}{llll}0 * & 0 & 0 & 0 \\ * & * & * & *\end{array}$

OE388 $446 \quad 25$

$\odot^{*} \odot \quad \odot \quad \odot \quad 0^{*}$

40440 TS

Major track changes and minor changes to the intensity shown in McAdie et al. (2009). Another major change is to indicate no extratropical transition for this cyclone. Evidence for these alterations comes from the NHC microfilm maps, the Historical Weather Maps series, the COADS ship database, Air Force aircraft reconnaissance, and Monthly Weather Review.

October 22:

HWM analyzes a closed low pressure of at most $1015 \mathrm{mb}$ at $23.0 \mathrm{~N}, 59.0 \mathrm{~W}$ with a stationary front to the north at $12 Z$. HURDAT does not list an organized storm on this date. Microfilm shows a frontal boundary north of the Leeward Islands at 12Z. Ship highlights: No gales or low pressures.

October 23:

HWM analyzes a tropical storm of at most $1005 \mathrm{mb}$ at $24.5 \mathrm{~N}, 60.5 \mathrm{~W}$ with a warm front about $100 \mathrm{~nm}$ to the north at $12 \mathrm{Z}$. HURDAT lists a $35 \mathrm{knot}$ tropical storm at $24.7 \mathrm{~N}, 60.7 \mathrm{~W}$ at $12 \mathrm{Z}$. Microfilm shows a closed low pressure of at most $1011 \mathrm{mb}$ at $24.0 \mathrm{~N}, 60.0 \mathrm{~W}$ with a frontal boundary to the north at $12 \mathrm{Z}$. Ship highlights: $15 \mathrm{kt} \mathrm{SW}$ and $1009 \mathrm{mb}$ at $21.9 \mathrm{~N}, 57.7 \mathrm{~W}$ at $00 \mathrm{Z}$ (micro). $35 \mathrm{kt} \mathrm{NE}$ and $1017 \mathrm{mb}$ at $29.2 \mathrm{~N}, 65.5 \mathrm{~W}$ at $18 \mathrm{Z}$ (COADS). $30 \mathrm{kt} \mathrm{NE}$ and $1002 \mathrm{mb}$ at 26.2N, 61.7W at 18Z (COADS).

MWR: "On October 22 and 23, shower activity increased and pressures began falling near and to the north of the Lesser Antilles. A strong upper trough extended from the vicinity of Bermuda to Puerto Rico and on October 23 a small cut-off Low developed in this trough. The surface circulation increased markedly on this date."

October 24:

HWM analyzes a tropical storm of at most $1000 \mathrm{mb}$ at $25.5 \mathrm{~N}, 65.3 \mathrm{~W}$ with a warm front $300 \mathrm{~nm}$ to the north at 12Z. HURDAT lists a $45 \mathrm{kt}$ tropical storm at $25.4 \mathrm{~N}$, $65.8 \mathrm{~W}$ at $12 \mathrm{Z}$. Microfilm shows a closed low pressure of at most $1002 \mathrm{mb}$ at $25.5 \mathrm{~N}$, 64.5W at 12Z. Ship highlights: $35 \mathrm{kt} \mathrm{NE}$ and $1018 \mathrm{mb}$ at $30.2 \mathrm{~N}, 65.6 \mathrm{~W}$ at $00 \mathrm{Z}$ (COADS). $10 \mathrm{kt} \mathrm{SE}$ and $999 \mathrm{mb}$ at $25.0 \mathrm{~N}, 63.0 \mathrm{~W}$ at $00 \mathrm{Z}$ (COADS). $35 \mathrm{kt} \mathrm{N}$ and $1003 \mathrm{mb}$ at $24.5 \mathrm{~N}$, $67.5 \mathrm{~W}$ at $06 \mathrm{Z}$ (COADS). $35 \mathrm{kt} \mathrm{NNW}$ and $1002 \mathrm{mb}$ at $24.5 \mathrm{~N}, 68.0 \mathrm{~W}$ at $12 \mathrm{Z}$ (COADS). 25 kt NNW and $1000 \mathrm{mb}$ at $25.1 \mathrm{~N}, 66.9 \mathrm{~W}$ at $18 \mathrm{Z}$ (COADS). Aircraft highlights: Penetration center fix estimated maximum surface winds of $30 \mathrm{kt}$ at $26.9 \mathrm{~N}, 65.7 \mathrm{~W}$ at $1130 \mathrm{Z}$ (micro). 
Penetration center fix measured a minimum pressure of $1002 \mathrm{mb}$ and a center diameter of $100 \mathrm{~nm}$ at $25.8 \mathrm{~N}, 63.7 \mathrm{~W}$ at $1430 \mathrm{Z}$ (micro).

MWR: "...in the evening a ship near the center of the circulation at about latitude $25 \mathrm{~N}$, longitude $63 \mathrm{~W}$, reported a barometer of $999 \mathrm{mb}$ and winds up to $35 \mathrm{mph}$. On the 24th reports showed that there had been further intensification with winds in squalls up to 50 to $60 \mathrm{mph}$ just north of the center and winds of 30 to $35 \mathrm{mph}$ prevailing 200 to 400 miles from the center. The storm gradually curved from a northwesterly to a northerly direction at 12 to $15 \mathrm{mph} . "$

October 25:

HWM analyzes a tropical storm of at most $995 \mathrm{mb}$ at $29.8 \mathrm{~N}, 64.8 \mathrm{~W}$ at $12 \mathrm{Z}$. HURDAT lists a $35 \mathrm{kt}$ tropical storm at $29.8 \mathrm{~N}, 64.8 \mathrm{~W}$ at $12 \mathrm{Z}$. Microfilm shows a closed low pressure of at most $1005 \mathrm{mb}$ at $30.0 \mathrm{~N}, 65.0 \mathrm{~W}$ at $12 \mathrm{Z}$. Ship highlights: $35 \mathrm{kt} \mathrm{E}$ and $997 \mathrm{mb}$ at $28.2 \mathrm{~N}, 63.9 \mathrm{~W}$ at $00 \mathrm{Z}$ (COADS). $20 \mathrm{kt} \mathrm{S}$ and $993 \mathrm{mb}$ at $27.8 \mathrm{~N}, 65.3 \mathrm{~W}$ at $06 \mathrm{Z}$ (micro). $40 \mathrm{kt} \mathrm{NE}$ and $1001 \mathrm{mb}$ at $30.3 \mathrm{~N}, 66.0 \mathrm{~W}$ at $06 \mathrm{Z}$ (micro). $50 \mathrm{kt} \mathrm{S}$ and $1002 \mathrm{mb}$ at $30.9 \mathrm{~N}, 61.4 \mathrm{~W}$ at $12 \mathrm{Z}$ (COADS). $35 \mathrm{kt} \mathrm{E}$ and $1003 \mathrm{mb}$ at $33.9 \mathrm{~N}, 62.7 \mathrm{~W}$ at $18 \mathrm{Z}$ (COADS). Land highlights: $10 \mathrm{kt} \mathrm{SE}$ and $1004 \mathrm{mb}$ at Bermuda at 06Z (micro). $15 \mathrm{kt} \mathrm{SE}$ and 1003 $\mathrm{mb}$ at Bermuda at $12 \mathrm{Z}$ (micro). $10 \mathrm{kt} \mathrm{NNE}$ and $1001 \mathrm{mb}$ at Bermuda at $18 \mathrm{Z}$ (micro).

MWR: "The lowest surface pressure reported was $993 \mathrm{mb}$. by a ship near $28 \mathrm{~N}, 65 \mathrm{~W}$ at 0600 GMT on the 25th."

October 26:

HWM analyzes a tropical storm of at most $1000 \mathrm{mb}$ at $35.3 \mathrm{~N}, 59.5 \mathrm{~W}$ with a weakening cold front to the east at 12Z. HURDAT lists a $35 \mathrm{kt}$ tropical storm at $34.6 \mathrm{~N}$, $59.3 \mathrm{~W}$ at $12 \mathrm{Z}$. Microfilm shows a closed low pressure of at most $1008 \mathrm{mb}$ at $35.5 \mathrm{~N}$, 60.0W at 12Z. Ship highlights: $35 \mathrm{kt} \mathrm{SSE}$ and $1006 \mathrm{mb}$ at $34.0 \mathrm{~N}, 61.5 \mathrm{~W}$ at $00 \mathrm{Z}$ (COADS). $20 \mathrm{kt} \mathrm{WSW}$ and $1000 \mathrm{mb}$ at $30.0 \mathrm{~N}, 62.4 \mathrm{~W}$ at $00 \mathrm{Z}$ (COADS). $35 \mathrm{kt} \mathrm{S}$ and $1006 \mathrm{mb}$ at $34.0 \mathrm{~N}, 60.4 \mathrm{~W}$ at $06 \mathrm{Z}$ (COADS). $1000 \mathrm{mb}$ at $35.4 \mathrm{~N}, 62.1 \mathrm{~W}$ at $06 \mathrm{Z}$ (micro). $40 \mathrm{kt} \mathrm{SSE}$ and $1003 \mathrm{mb}$ at $34.0 \mathrm{~N}, 58.7 \mathrm{~W}$ at $12 \mathrm{Z}$ (COADS). $45 \mathrm{kt} \mathrm{SW}$ and $1006 \mathrm{mb}$ at $35.0 \mathrm{~N}, 57.0 \mathrm{~W}$ at $18 \mathrm{Z}$ (micro). Land highlights: $10 \mathrm{kt} \mathrm{N}$ and $1004 \mathrm{mb}$ at Bermuda at $00 \mathrm{Z}$ (micro).

MWR: "When the storm passed just east of Bermuda on the evening of October 25, there were strong winds east of the center but only moderate winds to the west in the area of Bermuda, the pressure gradient there having been weakened by the approach of an extratropical system which gradually absorbed the remnants by the 27 th." 
October 27:

HWM analyzes a small closed low pressure of at most $1010 \mathrm{mb}$ at $39.0 \mathrm{~N}$, $49.0 \mathrm{~W}$ with a cold front to the north at $12 \mathrm{Z}$. HURDAT lists a $25 \mathrm{kt}$ extratropical cyclone at $38.3 \mathrm{~N}, 48.5 \mathrm{~W}$ at $12 \mathrm{Z}$. Microfilm shows a closed low pressure of at most $1011 \mathrm{mb}$ at $38.5 \mathrm{~N}, 48.0 \mathrm{~W}$ with a frontal boundary to the north at $12 \mathrm{Z}$. Ship highlights: $35 \mathrm{kt} \mathrm{W}$ and $1010 \mathrm{mb}$ at $36.1 \mathrm{~N}, 54.4 \mathrm{~W}$ at $00 \mathrm{Z}$ (COADS).

A frontal system moved into the western Atlantic during the third week of October. While north of the Leeward Islands, the weakening frontal boundary likely generated a surface low pressure that slowly became better organized. A tropical depression is analyzed to have formed at $00 \mathrm{Z}$ on October $23^{\text {rd }}$, same as in the original HURDAT. Minor track changes are introduced for the duration of this system. The tropical depression moved to the northwest on the $23^{\text {rd }}$ becoming a tropical storm at $06 \mathrm{Z}$, six hours earlier than originally shown in HURDAT. A central pressure of $999 \mathrm{mb}$ appears in HURDAT at $12 \mathrm{Z}$ on the $23^{\text {rd }}$ and although there was no reconnaissance aircraft investigating the tropical cyclone on this date or ship observations near the center, the estimate seems reasonable and is retained. A central pressure of $999 \mathrm{mb}$ suggests maximum sustained winds of $45 \mathrm{kt}$ north of $25 \mathrm{~N}$ and $49 \mathrm{kt}$ south of $25 \mathrm{~N}$ from the Brown et al. pressure-wind relationship. An intensity of $40 \mathrm{kt}$ is selected at $12 \mathrm{Z}$ on the $23^{\text {rd }}$ due to the broad circulation of this tropical cyclone. HURDAT originally had $35 \mathrm{kt}$ at $12 \mathrm{Z}$ on the $23^{\text {rd }}$, a minor change. On October $24^{\text {th }}$, the tropical storm turned to the westsouthwest, before turning northwestward later on the day. Ship reports on the $24^{\text {th }}$ indicate that this system was possibly a subtropical storm with weak winds near the center and the strongest winds found about $200 \mathrm{~nm}$ away from the center and a radius of closed isobar (ROCI) of about $350 \mathrm{~nm}$. A ship reported $10 \mathrm{kt}$ ESE and $999 \mathrm{mb}$, passing very close to the center. This suggests a central pressure of about $998 \mathrm{mb}$. HURDAT originally had $999 \mathrm{mb}$ at $00 \mathrm{Z}$ on the $24^{\text {th }}$ and this value has been replaced with $998 \mathrm{mb}$. A central pressure of $998 \mathrm{mb}$ suggests maximum sustained winds of $45 \mathrm{kt}$ north of $25 \mathrm{~N}$ and $51 \mathrm{kt}$ south of $25 \mathrm{~N}$ according to the pressure-wind relationship. An intensity of $45 \mathrm{kt}$ has been selected for $00 \mathrm{Z}$ on the $24^{\text {th }}$, up from $35 \mathrm{kt}$ originally in HURDAT, a minor change. Numerous ships reported gale force winds on the $24^{\text {th }}$, generally on the northern semicircle where the pressure gradient was the strongest. A central pressure of $993 \mathrm{mb}$ appears in HURDAT at $06 \mathrm{Z}$ on the $24^{\text {th }}$ and although there were no reconnaissance aircraft investigating the cyclone at this time or ship observations near the center, it seems reasonable and it is retained. A central pressure of $993 \mathrm{mb}$ suggests maximum sustained winds of $55 \mathrm{kt}$ north of $25 \mathrm{~N}$ and $59 \mathrm{kt}$ south of $25 \mathrm{~N}$ according to the pressurewind relationship. An intensity of $50 \mathrm{kt}$ has been selected for $06 \mathrm{Z}$ on the $24^{\text {th }}$, up from 40 
kt originally in HURDAT, a minor change. $50 \mathrm{kt}$ is also the peak intensity for this tropical cyclone, no change to HURDAT although the time at which it occurs is different. HURDAT originally indicated an intensity of $50 \mathrm{kt}$ at $18 \mathrm{Z}$ on the $24^{\text {th }}$, while the reanalysis suggests an intensity of $50 \mathrm{kt}$ between $06 \mathrm{Z}$ on the $24^{\text {th }}$ to $18 \mathrm{Z}$ on the $25^{\text {th }}$. A reconnaissance mission reached the tropical cyclone on the $24^{\text {th }}$, making a center fix at $26.9 \mathrm{~N}, 65.7 \mathrm{~W}$ at $1130 \mathrm{Z}$ and another center fix at $25.8 \mathrm{~N}, 63.7 \mathrm{~W}$ at $1422 \mathrm{Z}$. In the second center fix, the aircraft reported a minimum pressure of $1002 \mathrm{mb}$ and an eye diameter of about $100 \mathrm{~nm}$. This reported pressure is not believed to be a central pressure and thus, not added to HURDAT. Furthermore, the center fixes contradict with the forward motion of the storm and it is believed that they are erroneous, likely in part due to the size of the cyclone. On October $25^{\text {th }}$, the tropical storm turned to the northeast and numerous ships close to the center continue to show a structure that is characterized by weak winds near the center and the strongest winds located about $200 \mathrm{~nm}$ away, especially to the north and east. A central pressure of $993 \mathrm{mb}$ appears in HURDAT at $00 \mathrm{Z}$ on the $25^{\text {th }}$ and although it seems to be an estimate, it looks reasonable and it is retained. A ship reported $20 \mathrm{kt} \mathrm{S}$ and $993 \mathrm{mb}$ at $06 \mathrm{Z}$ on the $25^{\text {th }}$, which suggests a central pressure of about $991 \mathrm{mb}$ and has been added to HURDAT. A central pressure of $991 \mathrm{mb}$ suggests maximum sustained winds of $58 \mathrm{kt}$ north of $25 \mathrm{~N}$ according to the pressure-wind relationship. Due to the broad nature of the tropical cyclone, an intensity of $50 \mathrm{kt}$ has been selected for $06 \mathrm{Z}$ on the $25^{\text {th }}$, up from $35 \mathrm{kt}$ originally in HURDAT, a minor change. A central pressure of $993 \mathrm{mb}$ is present in HURDAT at $12 \mathrm{Z}$ on the $25^{\text {th }}$ and appears to be an estimate but looks reasonable and it is retained. As a frontal boundary approached the tropical cyclone from the west, the cyclone began to increase in forward speed. At $18 \mathrm{Z}$ on the $25^{\text {th }}$, a ship close to the center reported $20 \mathrm{kt} \mathrm{WSW}$ and $997 \mathrm{mb}$, suggesting a central pressure of $995 \mathrm{mb}$, which has been added to HURDAT. A central pressure of $995 \mathrm{mb}$ suggests maximum sustained winds of $52 \mathrm{kt}$ north of $25 \mathrm{~N}$ according to the pressure-wind relationship. An intensity of $50 \mathrm{kt}$ has been selected for $18 \mathrm{Z}$ on the $25^{\text {th }}$, up from $35 \mathrm{kt}$ originally in HURDAT, a minor change. Late on the $25^{\text {th }}$, the tropical cyclone made its closest approach to Bermuda, passing about $90 \mathrm{~nm}$ southeast of the island. At this time, the strongest winds continued to be located on the northern and eastern quadrants of the storm, leaving Bermuda on the weak side with no tropical storm force winds reported. On October $26^{\text {th }}$, the tropical cyclone continued to increase in forward speed to the northeast. Late on the $26^{\text {th }}$, the circulation of the tropical cyclone began to become less organized as the frontal boundary started to absorb it. This process was completed by $06 \mathrm{Z}$ on October $27^{\text {th }}$ based on ship reports and it is analyzed that the tropical cyclone had dissipated. This is 18 hours earlier than originally shown in HURDAT. Furthermore, it is analyzed that the tropical cyclone did not become extratropical at $00 \mathrm{Z}$ on the $27^{\text {th }}$ before being absorbed as originally shown in HURDAT, a major change. 
New Tropical Storm [November 3-7, 1957]

\begin{tabular}{|c|c|c|c|c|c|c|c|c|c|c|c|c|c|}
\hline 37265 & $11 / 03 / 195$ & $7 M=$ & 510 & $\mathrm{SNBR}=$ & $820 \mathrm{U}$ & NAME & & $X I N G=$ & $\theta$ SS & & & & L \\
\hline 37265 & $11 / 03$ * & $\odot$ & $\odot$ & ○* & $\odot$ & $\odot$ & $0 * 180$ & 640 & 25 & $0 * 185$ & 640 & 25 & 1004 * \\
\hline 37265 & $11 / 04 * 190$ & 638 & 30 & $0 * 19$ & 7630 & 30 & $1004 * 207$ & 620 & 30 & ๑*217 & 610 & 30 & 0 * \\
\hline 37265 & $11 / 05 * 227$ & 600 & 35 & $0 * 23$ & 3590 & 40 & $1001 * 239$ & 580 & 45 & $0 * 250$ & 570 & 45 & 0 * \\
\hline 37265 & $11 / 06 * 264$ & 558 & 40 & $\odot * 27$ & 4542 & 40 & $0 * 286$ & 523 & 35 & $0 * 301$ & 504 & 35 & 0 * \\
\hline 37265 & $11 / 07 * 310$ & 485 & 30 & $0 * 31$ & 5460 & 30 & $0 * 320$ & 435 & 25 & $0^{*}$ & $\odot$ & $\odot$ & ○* \\
\hline
\end{tabular}
37285 TS

A new tropical storm has been added to HURDAT, not previously shown in McAdie et al. (2009). Evidence for its existence comes from the Historical Weather Map series, Microfilm, COADS ship database, and David Roth's suspect list.

November 1:

HWM analyzes a closed low pressure of at most 1010 near $20.0 \mathrm{~N}, 64.0 \mathrm{~W}$ with a stationary front to the north at $12 \mathrm{Z}$. Microfilm shows a spot low pressure at $20.3 \mathrm{~N}$, $64.1 \mathrm{~W}$ at 12Z. Ship highlights: No gale force winds or equivalent low pressures.

November 2:

HWM analyzes a closed low pressure of at most 1010 near but south of $20.0 \mathrm{~N}$, $64.0 \mathrm{~W}$ with a weakening stationary front to the north at $12 \mathrm{Z}$. Microfilm shows a closed and broad low pressure of at most 1011 at $15.0 \mathrm{~N}, 65.0 \mathrm{~W}$ at 12Z. Ship highlights: No gale force winds or equivalent low pressures.

MICRO: Miami Weather Bureau 1423Z “Attn Dunn. CNDS over northern Leewards at $1200 \mathrm{Z}$ and $1500 \mathrm{Z}$ indicate definite circulation pattern. Radar indicates two bands oriented WNW/SSE with nearest band 20 miles from station 60 miles long and about 5 miles wide and farthest band 60 miles from station 100 miles long. Center of circulation seems to be located $18.0 \mathrm{~N} 63.7 \mathrm{~W}$ at $1500 \mathrm{Z}$. Request low level NAVY RECON soon as possible to scan area KNRR to $19 \mathrm{~N} 63 \mathrm{~W}$ thence to $16 \mathrm{~N} 62 \mathrm{~W}$ thence to KNRR."

November 3:

HWM analyzes a closed low pressure of at most 1010 near but south of $20.0 \mathrm{~N}$, $64.0 \mathrm{~W}$ with a weakening stationary front to the north at $12 \mathrm{Z}$. Microfilm shows a closed low pressure of at most 1008 at $18.0 \mathrm{~N}, 64.0 \mathrm{~W}$ at 12Z. Ship highlights: No gale force winds or equivalent low pressures. Land highlights: $5 \mathrm{kt} \mathrm{SSW}$ and $1005 \mathrm{mb}$ at Saint Martin at $18 \mathrm{Z}$ (micro).

MICRO: San Juan Weather Bureau Bulletin at 01Z "Little change has been noted in connection with the weak circulation located near the Leeward Islands earlier this 
afternoon. At 9 pm AST .. 0100Z ... it appears to be still centered near the island of Sint Maarten Netherlands Antilles or about 180 miles east-southeast of San Juan P.R. Its future movement remains uncertain but indications are for a slow northward drift during the next 12 hours. Highest winds are $25 \mathrm{mph}$ in rain showers about 180 miles to west and northwest of center. Some slight increase in intensity is expected during the next 12 hours but no dangerous conditions are expected tonight."

MICRO: San Juan Weather Bureau Bulletin at 10Z "The weak low pressure noted Saturday near the island of Sint Maarten Netherlands Antilles appears to have drifted slowly eastward during the night and at 6 AM AST ... 1000Z is located about 230 miles east-southeast of San Juan Puerto Rico. No dangerous winds have been reported.

Pressures are low throughout the eastern Caribbean and adjacent Atlantic areas. Little or no intensification has taken place during the night and the highest winds are about 20 to 25 miles per hour in heavy rain showers over the Virgin Islands and eastern Puerto Rico. Future movement is uncertain but indications are for a slow northward movement with little intensification during the next 12 hours. People in the Northern Leeward and Virgin Islands should be on the lookout for later bulletins."

MICRO: San Juan Weather Bureau Bulletin at 16Z "An area of low pressure continues over the Northern Leeward islands. At 12 noon ... 1600Z the center of this low pressure is poorly defined but appears to be located about 200 miles east-southeast of San Juan. It has remained almost stationary in the past 6 hours and there has been no intensification. NAVY reconnaissance aircraft in the area report highest winds of 20 to 30 miles per hour in showers to the northeast of the center. The aircraft are continuing to search the area for any signs of development. Movement during the next 12 hours is uncertain, however, indications are for a slow northward motion with little intensification."

MICRO: San Juan Weather Bureau Bulletin at 22Z "Pressures continue abnormally low over the northeastern Caribbean. The weak circulation noted yesterday is drifting slowly northward. At 600 AST $2200 \mathrm{Z}$ it is estimated to be centered a short distance northnorthwest of the island of Sint Maarten Netherlands Antilles or about 200 miles east of San Juan P.R. NAVY reconnaissance this morning into the area gave evidence that only slight intensification has taken place during the past 12 hours but no dangerous winds are reported. Highest winds are estimated to be 20 to $25 \mathrm{mph}$ in heavier rainshowers to the north and east of the center. Indications are for a continued northerly movement during the next 12 hours with little intensification during the period. People in the northern Leeward and Virgin Islands should however be in the lookout for later bulletins tonight." 
November 4:

HWM analyzes a closed low pressure of at most 1010 near $20.0 \mathrm{~N}, 63.0 \mathrm{~W}$ at $12 \mathrm{Z}$. Microfilm shows a closed low pressure of at most 1005 at $23.0 \mathrm{~N}, 62.0 \mathrm{~W}$ at $12 \mathrm{Z}$. Ship highlights: $30 \mathrm{kt} \mathrm{NE}$ and $1007 \mathrm{mb}$ at 20.7N, 65.5W at 00Z (COADS/micro). Land highlights: $5 \mathrm{kt} \mathrm{W}$ and $1005 \mathrm{mb}$ at Saint Martin at 06Z (micro).

MICRO: San Juan Weather Bureau Bulletin at 01Z "Although pressures still continue abnormally low in the eastern Caribbean there now appears to be a definite trend toward rising pressure. The weak circulation is now accelerating north-northwestward. At $10 \mathrm{pm}$ AST ... 0100Z ... It is estimated to be about 180 miles northeast of San Juan Puerto Rico moving north-northwestward. Indications are for a continued north-northwestward movement and some acceleration during the next 12 hours but with little intensification during the period. Highest winds are only 25 to 30 miles epr hour in the heavier showers to the north of the center. This is the last final bulletin to be issued by the San Juan Weather Bureau as the circulation no longer poses a threat to this area. Davis Weather Bureau."

November 5:

HWM analyzes a closed low pressure of at most 1010 near $22.2 \mathrm{~N}, 62.5 \mathrm{~W}$ with a cold front to the north at 12Z. Microfilm shows a closed low pressure of at most 1008 at 23.0N, 62.5W at 12Z. Ship highlights: $20 \mathrm{kt} \mathrm{SW}$ and $1003 \mathrm{mb}$ at $23.3 \mathrm{~N}, 59.0 \mathrm{~W}$ at $06 \mathrm{Z}$ (COADS). $45 \mathrm{kt} \mathrm{SW}$ and $1012 \mathrm{mb}$ at $21.8 \mathrm{~N}, 56.2 \mathrm{~W}$ at $12 \mathrm{Z}$ (micro). $20 \mathrm{kt} \mathrm{NE}$ and 1005 $\mathrm{mb}$ at $25.3 \mathrm{~N}, 56.7 \mathrm{~W}$ at $18 \mathrm{Z}$ (COADS)

November 6:

HWM analyzes a closed low pressure of at most 1010 near $27.0 \mathrm{~N}, 50.5 \mathrm{~W}$ with a weakening cold front to the west at $12 \mathrm{Z}$. Microfilm does not show an organized storm at 12Z. Ship highlights: No gale force winds or equivalent low pressures.

November 7:

HWM analyzes a closed low pressure of at most 1010 near $32.5 \mathrm{~N}, 44.0 \mathrm{~W}$ with a cold front approaching from the west at 12Z. Microfilm does not show an organized storm at 12Z. Ship highlights: $10 \mathrm{kt} \mathrm{NE}$ and $1005 \mathrm{mb}$ at 32.3N, 46.0W at 06Z (COADS).

November 8:

HWM shows a cold front over the north Atlantic associated with a strong extratropical cyclone, appears likely that the tropical cyclone or its remnants have been absorbed before 12Z. Microfilm is not available on this date. 
A tropical wave moved into the eastern Caribbean Sea during the last days of October causing the development of a broad area of low pressure. The broad disturbance moved very little during the first days of November. A well-defined low pressure developed at $12 \mathrm{Z}$ on November $3^{\text {rd }}$ near $18.0 \mathrm{~N} 64.0 \mathrm{~W}$ and a $25-\mathrm{kt}$ tropical depression is analyzed to have developed at this time. The tropical cyclone moved slowly to the north on the $3^{\text {rd }}$ and turned to the northeast on the $4^{\text {th }}$ while gaining in forward speed. Saint Martin reported $5 \mathrm{kt} \mathrm{SSW}$ and $1005 \mathrm{mb}$ at $18 \mathrm{Z}$ on the $3^{\text {rd }}$, suggesting a central pressure of $1004 \mathrm{mb}$, which has been added. A ship reported $30 \mathrm{kt}$ northeast of the center and the intensity is increased to $30 \mathrm{kt}$ at $00 \mathrm{Z}$ on November $4^{\text {th }}$. Saint Martin reported $5 \mathrm{kt} \mathrm{W}$ and $1005 \mathrm{mb}$ at $06 \mathrm{Z}$ on the $4^{\text {th }}$, suggesting a central pressure of $1004 \mathrm{mb}$, which has been added. Intensification to a $35 \mathrm{kt}$ tropical storm is analyzed at $00 \mathrm{Z}$ on November $5^{\text {th }}$, based primarily upon evidence later in the day. At $06 \mathrm{Z}$ on the $5^{\text {th }}$, a ship close to the center reported $20 \mathrm{kt} \mathrm{SW}$ and $1003 \mathrm{mb}$, suggesting a central pressure of $1001 \mathrm{mb}$, which has been added. A central pressure of $1001 \mathrm{mb}$ suggests maximum sustained winds of $45 \mathrm{kt}$ south of $25 \mathrm{~N}$ from the Brown et al. pressure-wind relationship. Due to the low environmental pressures, an intensity of $40 \mathrm{kt}$ is selected for $06 \mathrm{Z}$ on the $5^{\text {th }}$. A ship located on the southeast quadrant reported $45 \mathrm{kt} \mathrm{SW}$ at $12 \mathrm{Z}$ on the $5^{\text {th }}$ and the intensity is increased to $45 \mathrm{kt} .45 \mathrm{kt}$ is also the peak intensity for this tropical cyclone. Weakening started on November $6^{\text {th }}$ as a frontal boundary approached from the west. It is analyzed that weakening to a tropical depression occurred at $00 \mathrm{Z}$ on November $7^{\text {th }}$. Later on the $7^{\text {th }}$, ship observations indicate that the tropical depression became less organized and either dissipated over the north Atlantic or was absorbed by the approaching frontal boundary. The last position is analyzed at $12 \mathrm{Z}$ on the $7^{\text {th }}$ as a $25 \mathrm{kt}$ tropical depression. An analog to this tropical cyclone is Hurricane Klaus in 1984.

\section{7 - Additional Notes}

1) October 3-7: Historical Weather Maps and Microfilm indicate that an extratropical cyclone developed on October 4th along a frontal boundary over the western Atlantic, just off the southeast of the United States. The system rapidly intensified while moving to the north and later northwest into the Mid-Atlantic. Ships reported winds up to $60 \mathrm{kt}$. Nonetheless, the structure of the storm remained clearly non-tropical with a temperature gradient across the cyclone and low dew point values close to the center. Therefore, because the system was likely not tropical or subtropical, it is not added to HURDAT. This disturbance was in Jack Beven's List of Suspects.

Day LAT LONG STATUS

October 3 Off US SE Coast Cold front

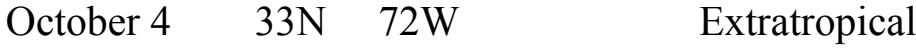




$\begin{array}{llll}\text { October } 5 & 33 \mathrm{~N} & 73 \mathrm{~W} & \text { Extratropical } \\ \text { October 6 } & 37 \mathrm{~N} & 75 \mathrm{~W} & \text { Extratropical } \\ \text { October } 7 & 40 \mathrm{~N} & 80 \mathrm{~W} & \text { Extratropical }\end{array}$

2) December 10-12: Historical Weather Maps indicate that a low pressure formed over the central Atlantic ahead of a frontal boundary. The disturbance moved rapidly to the north and only 1 gale was reported near the system during its lifetime (16Z on December 10th). Ship data on December 10th at $18 Z$ show that the low-level circulation may have been closed. Nonetheless, ship data on December 11 th indicate that the frontal boundary was absorbing the disturbance and the system was clearly gone by the 12 th. It is interesting to note that Microfilm does not show a disturbance in this general area on these days. Therefore, because there is only one piece of evidence and the low-level circulation data is inconclusive, it is not added to HURDAT. This disturbance was in David Roth's List of Suspects.

$\begin{array}{llll}\text { Day } & \text { LAT } & \text { LONG } & \text { STATUS } \\ \text { December 10 } & \text { 25N } & 55 \mathrm{~W} & \text { Tropical Depression? } \\ \text { December 11 } & 32 \mathrm{~N} & 57 \mathrm{~W} & \text { Tropical Depression? } \\ \text { December 12 } & & & \text { Absorbed }\end{array}$




\section{8 hurricane season}

New Tropical Storm [May 24-29, 1958]

\begin{tabular}{|c|c|c|c|c|c|c|c|c|c|c|c|c|c|}
\hline 5 & & & & & & & & & & & & & \\
\hline 37265 & $05 / 24 * 215$ & 845 & 25 & $1004 * 222$ & 840 & 25 & $0 * 230$ & 832 & 25 & $0 * 240$ & 820 & 25 & ๑* \\
\hline $3 / 265$ & $95 / 25 * 250$ & 805 & 25 & $1002 * 26 \odot$ & 793 & 25 & $1003 * 270$ & 790 & 30 & $10 \odot 4 * 279$ & 789 & 5 & 00 \\
\hline $5 / \angle 05$ & $26 \times 285$ & 788 & 35 & ○*292 & 782 & 35 & $\odot * 302$ & 774 & 35 & $1001 * 315$ & $\odot$ & 5 & $\theta$ \\
\hline & $/ 27 * 330$ & 740 & $4 \odot$ & $0 * 345$ & 720 & 45 & $0 * 358$ & 705 & 50 & ОЕ370 & 700 & ○ & \\
\hline & /28E380 & 695 & 50 & ОЕ388 & 685 & 55 & OE396 & 670 & 50 & OE410 & 650 & 45 & ๑* \\
\hline & /29E430 & 645 & 40 & OE450 & 50 & 35 & ○* & $\odot$ & $\odot$ & ๑* & 0 & $\odot$ & \\
\hline
\end{tabular}

37285 TS

A new tropical storm has been added to HURDAT, not previously shown in McAdie et al. (2009). Evidence for its existence comes from the Historical Weather Map series, Microfilm, Monthly Weather Review, COADS ship database, Surface Weather Observations, Mariners Weather Log and Jack Beven's and David Roth's suspect list.

May 21:

HWM is not available on this date (system south of $20^{\circ} \mathrm{N}$ ). Microfilm shows a closed low pressure of at most 1008 near $16.0 \mathrm{~N}, 82.0 \mathrm{~W}$ at 12Z. Ship highlights: No gale force winds or equivalent low pressures.

May 22:

HWM is not available on this date (system south of $20^{\circ} \mathrm{N}$ ). Microfilm shows a closed low pressure of at most 1008 near $16.0 \mathrm{~N}, 84.0 \mathrm{~W}$ at 12Z. Ship highlights: No gale force winds or equivalent low pressures.

May 23:

HWM analyzes a closed low pressure of at most 1010 near but south of $20.0 \mathrm{~N}$, 84.0W at 12Z. Microfilm shows a closed low pressure of at most 1008 near $19.0 \mathrm{~N}$, 84.0W at 12Z. Ship highlights: No gale force winds or equivalent low pressures.

May 24:

HWM analyzes a closed low pressure of at most 1010 near $22.0 \mathrm{~N}, 84.0 \mathrm{~W}$ at $12 \mathrm{Z}$. Microfilm shows a closed low pressure of at most 1008 at $23.0 \mathrm{~N}, 84.0 \mathrm{~W}$ at $12 \mathrm{Z}$. Ship highlights: No gale force winds or equivalent low pressures. Land highlights: $10 \mathrm{kt} \mathrm{NE}$ and $1005 \mathrm{mb}$ at Cabo San Antonio, Cuba at 00Z (micro).

May 25:

HWM analyzes a closed low pressure of at most 1010 near $27.5 \mathrm{~N}, 79.0 \mathrm{~W}$ with a dissipating warm front to the north at $12 \mathrm{Z}$. Microfilm shows a closed low pressure of at 
most 1005 at $27.5 \mathrm{~N}, 79.0 \mathrm{~W}$ at $12 \mathrm{Z}$. Ship highlights: $5 \mathrm{kt} \mathrm{NE}$ and $1005 \mathrm{mb}$ at $24.8 \mathrm{~N}$, 83.2W at $00 \mathrm{Z}$ (COADS). $35 \mathrm{kt} \mathrm{SE}$ and $1010 \mathrm{mb}$ at $29.6 \mathrm{~N}, 77.1 \mathrm{~W}$ at $18 \mathrm{Z}$ (micro). Land highlights: $10 \mathrm{kt} \mathrm{NW}$ and $1003 \mathrm{mb}$ at Alligator Reef Light, FL at 00Z (micro). $15 \mathrm{kt} \mathrm{SE}$ and $1005 \mathrm{mb}$ at High Rock, Bahamas at 06Z (micro). $15 \mathrm{kt} \mathrm{ENE}$ and $1005 \mathrm{mb}$ at Vero Beach, FL at $1830 Z$ (SWO).

May 26:

HWM analyzes a closed low pressure of at most 1010 near $27.0 \mathrm{~N}, 50.5 \mathrm{~W}$ with a weakening cold front to the west at 12Z. Microfilm shows a closed low pressure of at most 1005 at $31.0 \mathrm{~N}, 77.0 \mathrm{~W}$ at 12Z. Ship highlights: $35 \mathrm{kt} \mathrm{ESE}$ and $1006 \mathrm{mb}$ at $29.5 \mathrm{~N}$, $77.4 \mathrm{~W}$ at $00 \mathrm{Z}$ (COADS). $35 \mathrm{kt} \mathrm{SE}$ and $1001 \mathrm{mb}$ at $30.2 \mathrm{~N}, 77.4 \mathrm{~W}$ at $06 \mathrm{Z}$ (COADS). $45 \mathrm{kt}$ $\mathrm{E}$ and $1004 \mathrm{mb}$ at $31.5 \mathrm{~N}, 76.5 \mathrm{~W}$ at $06 \mathrm{Z}$ (COADS). $15 \mathrm{kt} \mathrm{SE}$ and $1003 \mathrm{mb}$ at $30.5 \mathrm{~N}$, $77.3 \mathrm{~W}$ at $12 \mathrm{Z}$ (COADS). $10 \mathrm{kt} \mathrm{SW}$ and $1004 \mathrm{mb}$ at $30.7 \mathrm{~N}, 75.8 \mathrm{~W}$ at $18 \mathrm{Z}$ (COADS).

May 27:

HWM analyzes a tropical storm of at most 1000 near $35.5 \mathrm{~N}, 70.7 \mathrm{~W}$ with a weakening cold front to the west and a warm front to the north at 12Z. Microfilm shows a closed low pressure of at most 1002 at $36.0 \mathrm{~N}, 70.0 \mathrm{~W}$ at 12Z. Ship highlights: $10 \mathrm{kt} \mathrm{W}$ and $1003 \mathrm{mb}$ at $32.3 \mathrm{~N}, 74.1 \mathrm{~W}$ at $00 \mathrm{Z}$ (COADS). $40 \mathrm{kt} \mathrm{NW}$ and $999 \mathrm{mb}$ at $34.2 \mathrm{~N}, 71.8 \mathrm{~W}$ at $03 \mathrm{Z}$ (COADS). $15 \mathrm{kt} \mathrm{S}$ and $1003 \mathrm{mb}$ at $33.4 \mathrm{~N}, 70.6 \mathrm{~W}$ at $06 \mathrm{Z}$ (COADS). $40 \mathrm{kt} \mathrm{SSE}$ and $1004 \mathrm{mb}$ at $35.5 \mathrm{~N}, 67.9 \mathrm{~W}$ at $12 \mathrm{Z}$ (COADS). $50 \mathrm{kt} \mathrm{SSE}$ and $1004 \mathrm{mb}$ at $36.1 \mathrm{~N}, 68.7 \mathrm{~W}$ at $15 \mathrm{Z}$ (COADS). $35 \mathrm{kt} \mathrm{NNE}$ and $999 \mathrm{mb}$ at $37.4 \mathrm{~N}, 70.1 \mathrm{~W}$ at 18Z (COADS). $50 \mathrm{kt} \mathrm{NE}$ and $1000 \mathrm{mb}$ at $38.3 \mathrm{~N}, 70.2 \mathrm{~W}$ at $21 \mathrm{Z}$ (COADS).

May 28:

HWM analyzes a tropical storm of at most 1000 near $39.5 \mathrm{~N}, 67.2 \mathrm{~W}$ with a warm front to the north at 12Z. Microfilm shows a closed low pressure of at most 996 at $39.0 \mathrm{~N}$, 67.5W at 12Z. Ship highlights: $40 \mathrm{kt} \mathrm{NW}$ and $996 \mathrm{mb}$ at $37.8 \mathrm{~N}, 70.4 \mathrm{~W}$ at $00 \mathrm{Z}$ (COADS). $55 \mathrm{kt} \mathrm{N}$ and $999 \mathrm{mb}$ at $38.0 \mathrm{~N}, 70.5 \mathrm{~W}$ at $03 \mathrm{Z}$ (COADS). $45 \mathrm{kt} \mathrm{NNW}$ and $1005 \mathrm{mb}$ at $38.5 \mathrm{~N}, 71.0 \mathrm{~W}$ at $06 \mathrm{Z}$ (COADS). $35 \mathrm{kt} \mathrm{NE}$ and $1001 \mathrm{mb}$ at $40.2 \mathrm{~N}, 68.3 \mathrm{~W}$ at $12 \mathrm{Z}$ (COADS). $20 \mathrm{kt} \mathrm{N}$ and $996 \mathrm{mb}$ at $41.0 \mathrm{~N}, 66.5 \mathrm{~W}$ at 18Z (COADS). Land highlights: $42 \mathrm{kt}$ $\mathrm{NE}$ and $1008 \mathrm{mb}$ at Nantucket Shoals, MA at 0855Z (SWO). $36 \mathrm{kt} \mathrm{ENE} \mathrm{(gusts} \mathrm{to} 40 \mathrm{kt}$ ) and $1008 \mathrm{mb}$ at Georges Shoal, MA at 12Z (SWO). $23 \mathrm{kt} \mathrm{NNE} \mathrm{(gusts} \mathrm{to} 31 \mathrm{kt}$ ) and 1001 $\mathrm{mb}$ at Georges Shoal, MA at $20 \mathrm{Z}$ (SWO).

May 29:

HWM analyzes a tropical storm of at most 1000 near $48.0 \mathrm{~N}, 63.7 \mathrm{~W}$ with a warm front to the northeast and a stationary front to the west at $12 \mathrm{Z}$. Microfilm shows a closed 
low pressure of at most 999 near $49.0 \mathrm{~N}, 68.0 \mathrm{~W}$ with a frontal boundary to the south at 12Z. Ship highlights: $35 \mathrm{kt} \mathrm{S}$ and $1014 \mathrm{mb}$ at $40.3 \mathrm{~N}, 58.8 \mathrm{~W}$ at $00 \mathrm{Z}$ (COADS). $15 \mathrm{kt} \mathrm{W}$ and $1000 \mathrm{mb}$ at $42.9 \mathrm{~N}, 65.4 \mathrm{~W}$ at 06Z (COADS). Land highlights: $25 \mathrm{kt} \mathrm{S}$ and $998 \mathrm{mb}$ at Halifax, Canada at 06Z (micro).

May 30:

HWM analyzes an extratropical cyclone of at most 990 near $57.0 \mathrm{~N}, 63.0 \mathrm{~W}$ with a stationary front to the southeast at $12 \mathrm{Z}$. Microfilm indicates that the low pressure is off the map at 12Z. Ship highlights: No gale force winds or equivalent low pressures.

A broad area of low pressure developed over the southwestern Caribbean Sea around May $21^{\text {st }}$ and slowly moved northwestward. The large disturbance intensified and became a $25 \mathrm{kt}$ tropical depression at $00 \mathrm{Z}$ on May $24^{\text {th }}$, south of the Guanahacabibes peninsula of western Cuba. Cabo San Antonio, Cuba reported $10 \mathrm{kt} \mathrm{NE}$ and $1005 \mathrm{mb}$ at $00 \mathrm{Z}$ on the $24^{\text {th }}$, suggesting a central pressure of $1004 \mathrm{mb}$, which has been added. Moving to the northeast, it crossed the province of Pinar del Río, Cuba as a tropical depression shortly after forming and passed close to the Florida Keys late on the $24^{\text {th }}$ and early on the May $25^{\text {th }}$. It should be noted that the evidence for a closed low level circulation on May $24^{\text {th }}$ and early on the $25^{\text {th }}$ is modest as the tropical cyclone was on its formative stage. Alligator Reef, FL reported $10 \mathrm{kt} \mathrm{NW}$ and $1003 \mathrm{mb}$ at $00 \mathrm{Z}$ on the $25^{\text {th }}$, suggesting a central pressure of $1002 \mathrm{mb}$, which has been added to HURDAT. Early on the $25^{\text {th }}$, the tropical depression reached the Bahamas where its forward speed decreased. High Rock, Bahamas reported $15 \mathrm{kt} \mathrm{SE}$ and $1005 \mathrm{mb}$ at $06 \mathrm{Z}$ on the $25^{\text {th }}$, suggesting a central pressure of $1003 \mathrm{mb}$, which has been added. It is noted that despite the relatively low central pressures on the $24^{\text {th }}$ and early on the $25^{\text {th }}$, these did not support tropical storm intensity because of the system's large size and low environmental pressure. Freeport, Bahamas reported $5 \mathrm{kt} \mathrm{SW}$ and $1005 \mathrm{mb}$ at $12 \mathrm{Z}$ on the $25^{\text {th }}$, suggesting a central pressure of 1004 $\mathrm{mb}$, which has been added. Intensification to a tropical storm is analyzed at $18 \mathrm{Z}$ on the $25^{\text {th }}$ on the basis of a ship report of $35 \mathrm{kt}$ northeast of the center. A ship near the center of the tropical storm reported $25 \mathrm{kt} \mathrm{E}$ and $1005 \mathrm{mb}$ at $18 \mathrm{Z}$ on the $25^{\text {th }}$, suggesting a central pressure of $1002 \mathrm{mb}$, which has been added.

On May $26^{\text {th }}$, the tropical cyclone increased in forward speed to the northeast. Although the system was broad in nature, it was embedded within a moist environment with dew points in the low to mid 70s around its periphery. A ship reported $45 \mathrm{kt}$ on the $26^{\text {th }}$ but the report was over $200 \mathrm{~nm}$ from the center and near another ship that reported $20 \mathrm{kt}$. It is likely that the $45 \mathrm{kt}$ ship has a high wind bias. However, two other ships closer to the center reported $35 \mathrm{kt}$ winds on the $26^{\text {th }}$, confirming minimal tropical storm intensity on that date. A ship reported $15 \mathrm{kt} \mathrm{SE}$ and $1003 \mathrm{mb}$ at $12 \mathrm{Z}$ on the $26^{\text {th }}$, suggesting a central pressure of $1001 \mathrm{mb}$, which has been added. A frontal system approached the tropical 
storm from the west on May $27^{\text {th }}$ causing further acceleration to the northeast. A couple of ships reported $40 \mathrm{kt}$ early on the $27^{\text {th }}$ and even $50 \mathrm{kt}$ at $15 \mathrm{Z}$ on this date. The peak intensity is analyzed at $50 \mathrm{kt}$ at $12 \mathrm{Z}$ on the $27^{\text {th }}$, likely partially influenced by baroclinic processes as the tropical cyclone began to acquire extratropical characteristics. Ship observations at $18 \mathrm{Z}$ on the $27^{\text {th }}$ show a distinct temperature gradient $\mathrm{E}-\mathrm{W}$ across the cyclone and the development of frontal features, especially a warm front to the northeast. It is analyzed that the tropical storm became an extratropical cyclone at $18 \mathrm{Z}$ on the $27^{\text {th }}$. The extratropical cyclone produced gale force winds on Nantucket Shoals, MA and Georges Shoal, MA on May $28^{\text {th }}$. Early on May $29^{\text {th }}$, the extratropical cyclone moved over the Atlantic provinces of Canada where it merged with another extratropical cyclone. Dissipation is analyzed after $06 \mathrm{Z}$ on the $29^{\text {th }}$.

Tropical Storm Alma [June 14-16, 1958]

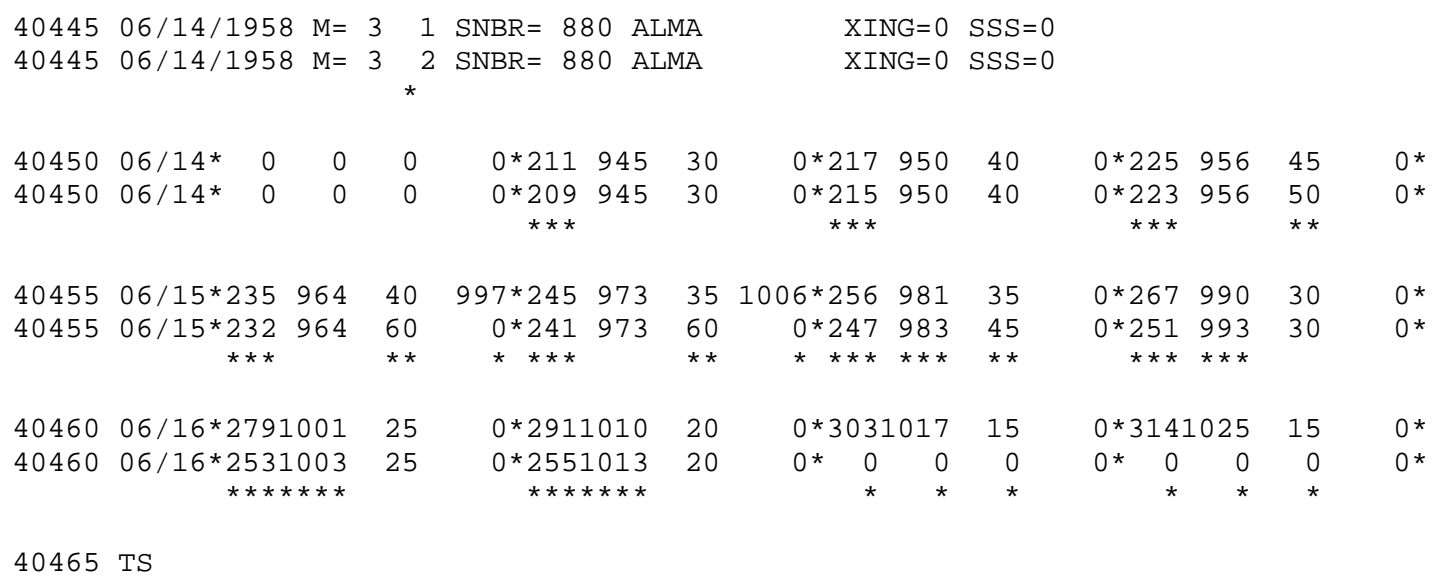

Tropical Storm Landfall

\section{6/15 09Z 24.4N 97.7W 60 kt Mexico}

Major changes to the track and intensity shown in McAdie et al. (2009). Evidence for these alterations comes from the NHC microfilm maps, the Historical Weather Maps series, the COADS ship database, Monthly Weather Review, Surface Weather Observations, Local Climatological Data, Mexican surface maps, Navy reconnaissance book and the NHC Storm Wallets.

June 12:

HWM analyzes a spot low pressure at $20.5 \mathrm{~N}, 94.0 \mathrm{~W}$ at $12 \mathrm{Z}$. HURDAT does not list an organized storm on this date. Microfilm shows a trough or tropical wave over 
the Yucatan peninsula at 12Z. Ship highlights: No gales or low pressures. Land highlights: $5 \mathrm{kt}$ ENE and $1005 \mathrm{mb}$ at Campeche, Mexico at 18Z (micro).

MWR: "Tropical storm Alma developed in an easterly wave that was first detected in the central Caribbean on June 9 and 10. Abnormally heavy shower activity was occurring on these dates over the western and central Caribbean Sea and northward across Cuba into the Bahamas. There was some evidence of a closed circulation at 1800 GMT on the $10^{\text {th }}$ near latitude $15 \mathrm{~N}$, longitude $78 \mathrm{~W}$."

June 13:

HWM analyzes a closed low pressure of at most $1005 \mathrm{mb}$ at $20.5 \mathrm{~N}, 94.5 \mathrm{~W}$ at 12Z. HURDAT does not list an organized storm on this date. Microfilm shows a trough or tropical wave over the Bay of Campeche at 12Z. Ship highlights: No gales or low pressures. Land highlights: $15 \mathrm{kt} \mathrm{E}$ and $1003 \mathrm{mb}$ at Campeche, Mexico at 00Z (micro). 5 kt SE and $1003 \mathrm{mb}$ at Ciudad del Carmen, Mexico at 12Z (micro).

MWR: "On succeeding maps, a weak circulation was observed and heavy rains continued over the northwestern Caribbean and eventually spread into Centra1 America. The weak circulation moved westward into the Yucatan Peninsula-Guatemala area on the $12^{\text {th }}$ and into the Gulf of Campeche on the $13^{\text {th }}$." ATSR: "A low cell on the ITC was located over northern Guatemala causing intensive rainfall on June $13^{\text {th }}$."

June 14:

HWM analyzes a tropical storm of at most $1005 \mathrm{mb}$ at $21.6 \mathrm{~N}, 94.9 \mathrm{~W}$ at $12 \mathrm{Z}$. HURDAT lists a $40 \mathrm{kt}$ tropical storm at $21.7 \mathrm{~N}, 95.0 \mathrm{~W}$ at $12 \mathrm{Z}$. Microfilm shows a closed low pressure of at most $1005 \mathrm{mb}$ at $23.0 \mathrm{~N}, 96.8 \mathrm{~W}$ at $12 \mathrm{Z}$. Ship highlights: $40 \mathrm{kt} \mathrm{SSE}$ and $997 \mathrm{mb}$ at $22.8 \mathrm{~N}, 95.6 \mathrm{~W}$ at $21 \mathrm{Z}$ (MWR). Land highlights: $1005 \mathrm{mb}$ at Campeche, Mexico at $00 \mathrm{Z}$ (micro). $15 \mathrm{kt} \mathrm{WNW}$ and $1004 \mathrm{mb}$ at Tampico, Mexico at $18 \mathrm{Z}$ (micro).

MWR: "The disturbance continued northwestward along and off the Mexican coast and developed into tropical storm Alma about midday, on the 14th some 150 miles east of Tampico. At 2100 GMT on the $14^{\text {th }}$, the Motor Vessel Mada, at latitude $22.8 \mathrm{~N}$, longitude 95.6W, reported a south-southeast wind of $45 \mathrm{mph}$, pressure of $997 \mathrm{mb}$, and mountainous seas. A Navy reconnaissance aircraft was dispatched to the storm on the $14^{\text {th }}$. However, the center had apparently moved inland and broken up before the aircraft reached the area. The plane reported maximum winds of 22 knots and minimum pressure of $1008 \mathrm{mb}$, and observed no radar echoes. ... Highest winds reported were 45 to $50 \mathrm{mph}$ from the MV Mada on the $14^{\text {th }}$." ATSR: "This low apparently was separated from the ITC by June 14 and gradually developed into a small tropical storm over the Gulf of Campeche. The first report (DTG 142100Z) of the storm was by a ship at $22.8 \mathrm{~N} 95.7 \mathrm{~W}$. This message was not received until 150715Z. The ship reported winds of 45 miles per hour, pressure $997 \mathrm{mb}$, and mountainous seas." 
June 15:

HWM analyzes a tropical storm of at most $1005 \mathrm{mb}$ at $25.5 \mathrm{~N}, 99.1 \mathrm{~W}$ at $12 \mathrm{Z}$. HURDAT lists a $35 \mathrm{kt}$ tropical storm at $25.6 \mathrm{~N}, 98.1 \mathrm{~W}$ at $12 \mathrm{Z}$. Microfilm shows a spot low pressure at $26.0 \mathrm{~N}, 102.0 \mathrm{~W}$ at 12Z. Ship highlights: $35 \mathrm{kt} \mathrm{SW}$ and $1006 \mathrm{mb}$ at $20.2 \mathrm{~N}$, 93.0W at 05Z (MWR/micro). Land highlights: $15 \mathrm{kt} \mathrm{W}$ and $1004 \mathrm{mb}$ at Tampico, Mexico at $00 \mathrm{Z}$ (micro). $1005 \mathrm{mb}$ at Monterrey, Mexico at $12 \mathrm{Z}$ (micro). $35 \mathrm{kt}$, gusts to $40 \mathrm{kt}$ at South Padre Island, TX at 16Z (WALLETS). $20 \mathrm{kt} \mathrm{NNE}$ and $1005 \mathrm{mb}$ at Monterrey, Mexico at $18 Z$ (micro). Aircraft highlights: Coast Guard aircraft measured $50 \mathrm{kt}$ near 25.3N, 97.2W at $14 \mathrm{Z}$ (MWR).

MWR: "At 0500 GMT on the 15th, this ship, located about 100 miles northwest of Carmen, Mexico, was encountering south-southwest winds of 35 to $40 \mathrm{mph}$, pressure of $1006 \mathrm{mb}$ and very rough seas." ATSR: "Warning Number One, Tropical Storm Alma, was issued at 150830Z. ALMA entered the coast of Mexico about sixty miles south of Brownsville, Texas, at approximately 151000Z. Except for heavy rains and flooding in the Rio Grande Valley, ALMA caused no damages. Highest wind from a coastal station was 45 miles per hour at Port Isabel, Texas. One reconnaissance flight was flown but ALMA had entered land prior to the aircraft arrival. ... Highest reported winds were 50 knots from a Coast Guard aircraft 50 miles south of Port Isabel, Tex., at 0800 CST and 40 to $45 \mathrm{mph}$ at south Padre Island, Tex., at $1000 \mathrm{CST}$ on the $15^{\text {th }}$. Heavy rains fell over the hill country to the west of San Antonio, generally averaging 7 to 10 inches with some amounts reported as high as 20 inches a little to the west of Medina, Tex. Very little damage was caused by wind and tides associated with this storm and major damage to crops and property was associated with floods caused by the attendant rains. One death by drowning occurred in the Galveston area during passage of the storm."

June 16:

HWM analyzes a tropical storm of at most $1005 \mathrm{mb}$ at $31.2 \mathrm{~N}, 101.5 \mathrm{~W}$ at $12 \mathrm{Z}$. HURDAT lists a $15 \mathrm{kt}$ tropical depression at $30.3 \mathrm{~N}, 101.7 \mathrm{~W}$ at $12 \mathrm{Z}$. Microfilm shows a frontal boundary over the central United States and a closed low pressure of at most 1002 mb over northern Mexico at 12Z. Ship highlights: No gales or low pressures. Land highlights: $25 \mathrm{kt} \mathrm{E}$ and $1002 \mathrm{mb}$ at Monterrey, Mexico at 00Z (micro).

June 17:

HWM analyzes a cold front across Texas at 12Z. HURDAT does not list an organized storm on this date. Microfilm at 12Z. Ship highlights: No gales or low pressures.

WALLETS: "Tropical Storm Alma developed in a low pressure area over the west Gulf of Mexico some 150 miles east of Tampico, Mexico about noon June 14, 1958. This low pressure area had been over the Bay of Campeche on June 13 probably having been 
associated with low pressures of several days earlier over extreme eastern Pacific near Guatemala and an easterly wave from the Caribbean. The storm moved towards the northwest and reached the coast about 75 miles south of Brownsville, Texas early on the $15^{\text {th }}$ and became disorganized as it moved up the Rio Grande Valley that day and lost its identity at all levels near Del Rio the following day, June 16, 1958."

Tropical Storm Alma developed from a tropical wave over the Bay of Campeche. Genesis is analyzed at $06 \mathrm{Z}$ on June $14^{\text {th }}$ as a $30 \mathrm{kt}$ tropical depression, no change from the original HURDAT. Coastal stations along the Bay of Campeche reported very low pressures on June $13^{\text {th }}$, possibly an indication that the tropical cyclone may have formed around $20 \mathrm{~N}$ and $92 \mathrm{~W}$ on that day. However, the data are not sufficient to start the system earlier. Intensification to a tropical storm is analyzed at $12 \mathrm{Z}$ on June $14^{\text {th }}$, same as the original HURDAT. Minor track changes are analyzed on the $14^{\text {th }}$. At $21 \mathrm{Z}$ on the $14^{\text {th }}$, a ship over the western Gulf of Mexico reported a pressure of $997 \mathrm{mb}$, winds of $40 \mathrm{kt} \mathrm{SSE}$ and mountainous seas. A peripheral pressure of $997 \mathrm{mb}$ suggests maximum sustained winds greater than $53 \mathrm{kt}$ south of $25 \mathrm{~N}$ from the Brown et al. pressure-wind relationship. Intensities of $50 \mathrm{kt}$ and $60 \mathrm{kt}$ are selected at $18 \mathrm{Z}$ on June $14^{\text {th }}$ and $00 \mathrm{Z}$ on June $15^{\text {th }}$, up from $45 \mathrm{kt}$ and $40 \mathrm{kt}$ originally in HURDAT, a major intensity change. A central pressure of $997 \mathrm{mb}$ was present in HURDAT at $00 \mathrm{Z}$ on the $15^{\text {th }}$ and since the pressure reported by the ship was not a central pressure, it has been removed. $60 \mathrm{kt}$ is also the peak intensity for this tropical cyclone, up from $45 \mathrm{kt}$ originally in HURDAT, a minor intensity change for $00 \mathrm{Z}$. The intensity is kept at $60 \mathrm{kt}$ for $06 \mathrm{Z}$ on the $16^{\text {th }}$, up from $35 \mathrm{kt}$ originally in HURDAT, a major intensity change. A central pressure of $1006 \mathrm{mb}$ is present in HURDAT at $06 \mathrm{Z}$ on the $15^{\text {th }}$ but it was not a central pressure since it was reported by a ship over the Bay of Campeche, hundreds of miles from the center of Alma. Thus, it has been removed. It is possible that Alma continued to intensify until landfall, potentially achieving hurricane status. The tropical cyclone continued moving toward the northwest early on the $15^{\text {th }}$ making landfall over a sparsely populated area in the northeast coast of Mexico around 09Z. Alma crossed the coast near 24.4N, 97.7W, about $35 \mathrm{~nm}$ southeast of San Fernando, Tamaulipas, Mexico or about $90 \mathrm{~nm}$ south-southwest of Brownsville, TX. The northern squalls of Alma impacted southern Texas producing $35 \mathrm{kt}$ winds in South Padre Island, TX. Thus, this cyclone is considered a tropical storm impact for the United States. A reconnaissance aircraft investigated the western Gulf of Mexico on the $15^{\text {th }}$ around $15 \mathrm{Z}$ and found that Alma had already moved inland. Minor track changes are analyzed on the $15^{\text {th }}$. Late on the $15^{\text {th }}$, the track of the tropical cyclone began to turn to the west-northwest. Weakening to a tropical depression is analyzed at $18 \mathrm{Z}$ on the $15^{\text {th }}$, no change from the original HURDAT. Observations from Monterrey, Mexico on June $16^{\text {th }}$ indicate that Alma did not continue on a northwestward course into the Rio Grande Valley as shown by HURDAT but instead turned to the west passing south of the city. Major changes to the track are analyzed at $00 \mathrm{Z}$ and $06 \mathrm{Z}$ on the $16^{\text {th }}$. Dissipation is 
analyzed at $06 \mathrm{Z}$ on the $16^{\text {th }}$ over the mountainous terrain over northeast Mexico, twelve hours earlier than the original HURDAT.

Tropical Storm Becky [August 8-17, 1958]

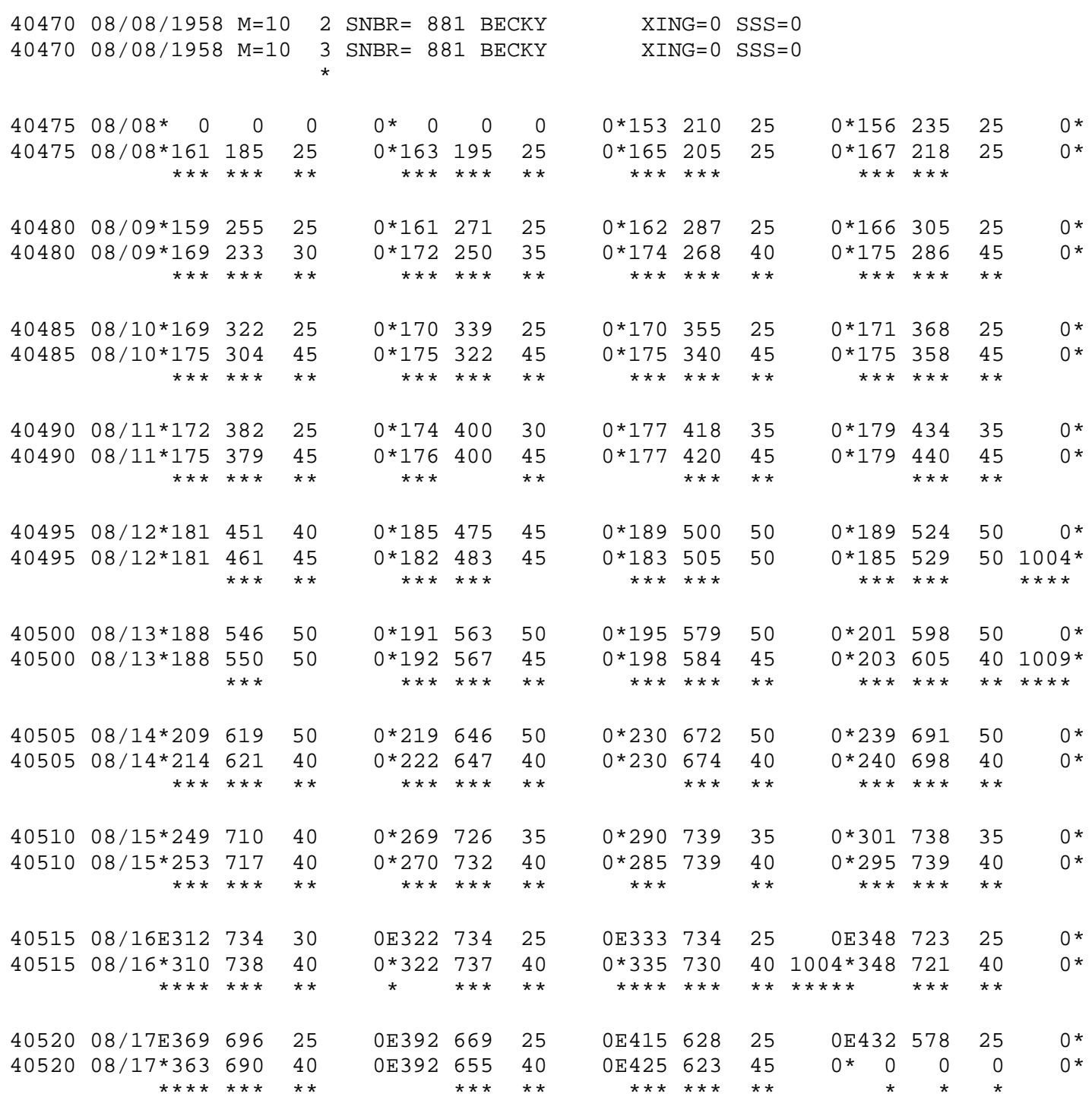

40525 TS

Major changes to the track and intensity shown in McAdie et al. (2009). Another major change is to indicate extratropical transition over a day later than originally shown. Evidence for these alterations comes from the NHC microfilm maps, the Historical Weather Maps series, the COADS ship database, Monthly Weather Review, Navy reconnaissance book, Mariners Weather Log and NHC Storm Wallets. 
August 7:

HWM is not available on this date (system south of $20^{\circ} \mathrm{N}$ ). HURDAT does not list an organized storm on this date. Microfilm does not show an organized system at 12Z. Ship highlights: No gales or low pressures.

ATSR: "On 4 August this facility received a message from the Fleet Weather Central, Port Lyautey, which indicated that an easterly wave, labeled 3AW, was near 14 degrees west longitude. This wave was confirmed on 7 August near 25W. From 7 August to 11 August this wave continued westerly at about 5 degrees per day through an area of sparse or no reports."

August 8:

HWM is not available on this date (system south of $20^{\circ} \mathrm{N}$ ). HURDAT lists a 25 knot tropical depression at $15.3 \mathrm{~N}, 21.0 \mathrm{~W}$ at $12 \mathrm{Z}$ (first position). Microfilm does not show an organized system at 12Z. Ship highlights: No gales or low pressures.

MWR: "Reports on August 7 and 8 from the Cape Verde Islands had indicated a westward-moving tropical depression."

August 9:

HWM is not available on this date (system south of $20^{\circ} \mathrm{N}$ ). HURDAT lists a 25 knot tropical depression at $16.2 \mathrm{~N}, 28.7 \mathrm{~W}$ at $12 \mathrm{Z}$. Microfilm shows a closed low pressure of at most $1011 \mathrm{mb}$ at $15.0 \mathrm{~N}, 31.0 \mathrm{~W}$ at 12Z. Ship highlights: $45 \mathrm{kt} \mathrm{ENE}$ and $1004 \mathrm{mb}$ at $18.1 \mathrm{~N}, 28.1 \mathrm{~W}$ at $18 \mathrm{Z}$ (MWL). $40 \mathrm{kt} \mathrm{E}$ and $1008 \mathrm{mb}$ at $17.7 \mathrm{~N}, 27.8 \mathrm{~W}$ at $21 \mathrm{Z}$ (COADS/micro).

MWR: "A continued westward movement with some intensification was confirmed on August 9 by reports from the ship Tatra."

August 10:

HWM is not available on this date (system south of $20^{\circ} \mathrm{N}$ ). HURDAT lists a 25 knot tropical depression at $17.0 \mathrm{~N}, 35.5 \mathrm{~W}$ at $12 \mathrm{Z}$. Microfilm does not show an organized system at 12Z. Ship highlights: No gales or low pressures.

August 11:

HWM is not available on this date (system south of $20^{\circ} \mathrm{N}$ ). HURDAT lists a 35 knot tropical storm at $17.7 \mathrm{~N}, 41.8 \mathrm{~W}$ at $12 \mathrm{Z}$. Microfilm shows a closed low pressure of at most $1011 \mathrm{mb}$ at $17.0 \mathrm{~N}, 43.0 \mathrm{~W}$ at 12Z. Ship highlights: $30 \mathrm{kt} \mathrm{NE}$ and $1009 \mathrm{mb}$ at $18.8 \mathrm{~N}$, $44.7 \mathrm{~W}$ at $15 \mathrm{Z}$ (micro). 
MWR: "Becky, the second tropical storm of the season, was first positively identified on August 11. A series of reports from the ship Industrious indicated the storm's existence near latitude $18 \mathrm{~N}$, longitude $45 \mathrm{~W}$, halfway between Puerto Rico and the Cape Verde Islands." ATSR: "From $111200 Z$ to $112100 Z$ the SS INDUSTRIOUS reported each three hours indicating increasing seas and winds with a falling barometer near $18 \mathrm{~N} 46 \mathrm{~W}$. This was the approximate position of the easterly wave..."

August 12:

HWM is not available on this date (system south of $20^{\circ} \mathrm{N}$ ). HURDAT lists a 50 knot tropical storm at $18.9 \mathrm{~N}, 50.0 \mathrm{~W}$ at $12 \mathrm{Z}$. Microfilm shows a closed low pressure of at most $1014 \mathrm{mb}$ at $18.0 \mathrm{~N}, 51.0 \mathrm{~W}$ at 12Z. Ship highlights: $45 \mathrm{kt}$ ESE and $1013 \mathrm{mb}$ at $19.6 \mathrm{~N}, 45.8 \mathrm{~W}$ at $00 \mathrm{Z}$ (micro). $40 \mathrm{kt} \mathrm{E}$ and $1014 \mathrm{mb}$ at $19.9 \mathrm{~N}, 49.3 \mathrm{~W}$ at $12 \mathrm{Z}$ (micro). 45 $\mathrm{kt} \mathrm{E}$ and $1011 \mathrm{mb}$ at $20.4 \mathrm{~N}, 50.0 \mathrm{~W}$ at $15 \mathrm{Z}$ (micro). $40 \mathrm{kt} \mathrm{ENE}$ at $21.3 \mathrm{~N}, 51.3 \mathrm{~W}$ at $18 \mathrm{Z}$ (micro). Aircraft highlights: Penetration center fix measured a central pressure of 1004 $\mathrm{mb}$ and flight level winds ( $700 \mathrm{mb}$ ) of $60 \mathrm{kt}$ at $18.4 \mathrm{~N}, 52.6 \mathrm{~W}$ at $16 \mathrm{Z}$ (WALLET/ATSR).

MWR: "The Weather Bureau Office at San Juan issued the first advisory at 0400 GMT, August 12. On August 12, reconnaissance aircraft flying at $700 \mathrm{mb}$ reported a complete cyclonic circulation, a maximum wind speed at flight level of $60 \mathrm{kt}$, and minimum sea level pressure by dropsonde of $1006 \mathrm{mb}$. There after Becky continued on a westward to west-northwestward course passing about 290 miles northeast of Puerto Rico at the nearest point.” ATSR: “... at 120400Z, the first coordinated warning was issued on Tropical Storm Becky. On 12 August the USAF $59^{\text {th }}$ Weather Reconnaissance Squadron located BECKY at $18.4 \mathrm{~N} 52.6 \mathrm{~W}$ with maximum winds of 40 knots and minimum pressure of $1006 \mathrm{mb} . "$

August 13:

HWM is not available on this date (system south of $20^{\circ} \mathrm{N}$ ). HURDAT lists a 50 knot tropical storm at $19.5 \mathrm{~N}, 57.9 \mathrm{~W}$ at $12 \mathrm{Z}$. Microfilm shows a trough at $15 \mathrm{~N}-23 \mathrm{~N}, 59 \mathrm{~W}$ at 12Z. Ship highlights: $40 \mathrm{kt} \mathrm{NE}$ and $1013 \mathrm{mb}$ at $20.5 \mathrm{~N}, 55.8 \mathrm{~W}$ at $00 \mathrm{Z}$ (micro). $35 \mathrm{kt} \mathrm{E}$ and $1014 \mathrm{mb}$ at $21.4 \mathrm{~N}, 58.2 \mathrm{~W}$ at $12 \mathrm{Z}$ (COADS). $40 \mathrm{kt} \mathrm{SE}$ and $1011 \mathrm{mb}$ at $22.3 \mathrm{~N}, 60.2 \mathrm{~W}$ at $18 \mathrm{Z}$ (COADS). Aircraft highlights: Penetration center fix measured a central pressure of $1013 \mathrm{mb}$, estimated maximum surface winds of $45 \mathrm{kt}$ and an eye diameter of $70 \mathrm{~nm}$ at $22.0 \mathrm{~N}, 60.1 \mathrm{~W}$ at $20 \mathrm{Z}$ (ATSR) (possible latitude error, maybe $21.0 \mathrm{~N}$ ). Radar center fix at $21.6 \mathrm{~N}, 61.2 \mathrm{~W}$ at $2148 \mathrm{Z}$ (ATSR). Penetration center fix at $21.4 \mathrm{~N}, 61.5 \mathrm{~W}$ at $2317 \mathrm{Z}$ (ATSR).

August 14:

HWM analyzes a closed low pressure of at most $1010 \mathrm{mb}$ at $23.0 \mathrm{~N}, 66.8 \mathrm{~W}$ at 12Z. HURDAT lists a 50 knot tropical storm at 23.0N, $67.2 \mathrm{~W}$ at 12Z. Microfilm shows a 
trough at $18 \mathrm{~N}-25 \mathrm{~N}, 63 \mathrm{~W}$ at $12 \mathrm{Z}$. Ship highlights: $40 \mathrm{kt} \mathrm{SE}$ and $1016 \mathrm{mb}$ at $22.5 \mathrm{~N}, 59.4 \mathrm{~W}$ at $00 \mathrm{Z}$ (COADS). $40 \mathrm{kt} \mathrm{ESE}$ and $1017 \mathrm{mb}$ at $25.6 \mathrm{~N}, 67.7 \mathrm{~W}$ at $18 \mathrm{Z}$ (micro). Aircraft highlights: Radar center fix at $21.6 \mathrm{~N}, 68.8 \mathrm{~W}$ at $1151 \mathrm{Z}$ (ATSR).

August 15:

HWM analyzes a closed low pressure of at most $1010 \mathrm{mb}$ at $29.2 \mathrm{~N}, 72.9 \mathrm{~W}$ at 12Z. HURDAT lists a $35 \mathrm{knot}$ tropical storm at $29.0 \mathrm{~N}, 72.9 \mathrm{~W}$ at $12 \mathrm{Z}$. Microfilm shows a closed low pressure of at most $1014 \mathrm{mb}$ at $28.5 \mathrm{~N}, 70.5 \mathrm{~W}$ at $12 \mathrm{Z}$. Ship highlights: $35 \mathrm{kt}$ $\mathrm{SE}$ and $1013 \mathrm{mb}$ at $25.2 \mathrm{~N}, 67.2 \mathrm{~W}$ at $00 \mathrm{Z}$ (micro). $40 \mathrm{kt} \mathrm{SE}$ at $28.1 \mathrm{~N}, 72.1 \mathrm{~W}$ at $17 \mathrm{Z}$ (micro). $45 \mathrm{kt} \mathrm{SSE}$ and $1011 \mathrm{mb}$ at $31.4 \mathrm{~N}, 71.8 \mathrm{~W}$ at $18 \mathrm{Z}$ (COADS).

ATSR: "The subtropical high over the Atlantic north of BECKY was very strong throughout most of her life span; therefore, she moved very rapidly (over 20 knots average) until she recurved into a trough in the westerlies on 15 August. By 15 August she had reached a cold trough which had moved off the east coast of the United States and quickly became more diffuse in a large area of squalls."

August 16:

HWM analyzes a closed low pressure of at most $1005 \mathrm{mb}$ at $34.5 \mathrm{~N}, 73.3 \mathrm{~W}$ with a cold front to the north at 12Z. HURDAT lists a 25 knot extratropical depression at $33.3 \mathrm{~N}, 73.4 \mathrm{~W}$ at $12 \mathrm{Z}$. Microfilm shows a closed low pressure of at most $1008 \mathrm{mb}$ at $33.5 \mathrm{~N}, 74.0 \mathrm{~W}$ and a cold front to the north at 12Z. Ship highlights: $40 \mathrm{kt} \mathrm{SW}$ and 1012 $\mathrm{mb}$ at $30.8 \mathrm{~N}, 71.7 \mathrm{~W}$ at $00 \mathrm{Z}$ (COADS). $35 \mathrm{kt} \mathrm{SSW}$ and $1013 \mathrm{mb}$ at $31.0 \mathrm{~N}, 72.1 \mathrm{~W}$ at $12 \mathrm{Z}$ (COADS). $35 \mathrm{kt} \mathrm{S}$ and $1009 \mathrm{mb}$ at $33.6 \mathrm{~N}, 71.0 \mathrm{~W}$ at $18 \mathrm{Z}$ (COADS).

MWR: "Then the storm began to recurve broadly to the northwest and north and on the $16^{\text {th }}$ toward the northeast around the western periphery of the subtropical high pressure area."

August 17:

HWM analyzes a closed low pressure of at most $1010 \mathrm{mb}$ at $43.4 \mathrm{~N}, 61.8 \mathrm{~W}$ with a warm front to the north and a cold front to the west at 12Z. HURDAT lists a 25 knot extratropical depression at $41.5 \mathrm{~N}, 62.8 \mathrm{~W}$ at $12 \mathrm{Z}$. Microfilm shows an extratropical cyclone of at most $999 \mathrm{mb}$ at $43.5 \mathrm{~N}, 64.5 \mathrm{~W}$ at 12Z. Ship highlights: $50 \mathrm{kt} \mathrm{S}$ and $1000 \mathrm{mb}$ at $38.5 \mathrm{~N}, 68.3 \mathrm{~W}$ at $00 \mathrm{Z}$ (micro). $40 \mathrm{kt} \mathrm{SW}$ and $1012 \mathrm{mb}$ at $30.8 \mathrm{~N}, 71.7 \mathrm{~W}$ at $00 \mathrm{Z}$ (COADS). $40 \mathrm{kt} \mathrm{WNW}$ and $995 \mathrm{mb}$ at 40.4N, 64.4W at 09Z (micro). $45 \mathrm{kt} \mathrm{W}$ and 982 $\mathrm{mb}$ at $43.0 \mathrm{~N}, 62.5 \mathrm{~W}$ at $12 \mathrm{Z}$ (micro). $50 \mathrm{kt} \mathrm{W}$ and $992 \mathrm{mb}$ at $45.6 \mathrm{~N}, 58.2 \mathrm{~W}$ at $18 \mathrm{Z}$ (COADS). 
August 18:

HWM analyzes an extratropical cyclone of at most $995 \mathrm{mb}$ at $52.5 \mathrm{~N}, 48.5 \mathrm{~W}$, likely the system that absorbed Becky, at 12Z. HURDAT does not list an organized storm on this date. Microfilm shows a closed low pressure of at most $1011 \mathrm{mb}$ at $52.0 \mathrm{~N}, 50.0 \mathrm{~W}$ with a frontal boundary to the north at $12 \mathrm{Z}$.

MWR: "The minimum pressure of $1006 \mathrm{mb}$ reported by the first reconnaissance into Becky was as low as any succeeding central pressure report while the storm was under close surveillance by aircraft. The area of gale winds gradually increased in size but remained mostly north and east of the center. Maximum reported winds increased very slowly from about 35 knots up to an estimated 55 or 60 knots during the first two and one-half days. Up to 75 -knot winds were reported in squalls about 210 miles eastnortheast of the center on August 14. Reconnaissance aircraft made frequent reference to lightning, heavy thunderstorms, and turbulence on the east and north sides of the storm. From the time of Becky's first confirmed existence until it began a northward course, the subtropical high pressure cell to the north of it remained well established with highest pressures generally above $1023 \mathrm{mb}$, which is about normal for the month of August. The average speed of the storm during the time it was under close surveillance by aircraft was about 20 knots. The reason for lack of intensification is not known, but an old empirical forecasting rule states that movement of $20 \mathrm{mph}$ or more is unfavorable for intensification. Reconnaissance aircraft and ship reports in the region early on August 15 indicated that Becky had degenerated into an area of squalls with little if any cyclonic pattern. However, late on the 16th, after Becky moved into an old frontal zone and became extratropical, rapid intensification took place, with one ship for a short time reporting hurricane-force winds."

The first Cape Verde cyclone of the season formed between the Cape Verde Islands and the African coast on August $8^{\text {th }}$. Observations from ships and coastal stations indicate that a $25 \mathrm{kt}$ tropical depression developed at $00 \mathrm{Z}$ on the $8^{\text {th }}$, making genesis twelve earlier than originally shown in HURDAT. Minor track alterations are analyzed during the lifetime of this tropical cyclone, except for major track changes on August $9^{\text {th }}$ at $00 \mathrm{Z}$ and 06Z, east-northeast of that originally shown. The tropical depression moved westward passing just north of the Cape Verde Islands early on the $9^{\text {th }}$. Intensification to a tropical storm is analyzed at $06 \mathrm{Z}$ on the $9^{\text {th }}$, based on a ship measurement of $45 \mathrm{kt}$ at $18 \mathrm{Z}$ on this day. This is 54 hours earlier than originally shown in HURDAT. Major intensity changes are analyzed between $18 \mathrm{Z}$ on the $9^{\text {th }}$ to $00 \mathrm{Z}$ on the $11^{\text {th }}$ as HURDAT originally showed $25 \mathrm{kt}$ and the selected intensity is $45 \mathrm{kt}$. Becky continued to move westward on August $10^{\text {th }}$ and $11^{\text {th }}$ with a forward speed of about 21 knots. The intensity during these days is kept at $45 \mathrm{kt}$ but ship observations were sparse. On August $12^{\text {th }}$, Becky crossed $50^{\circ} \mathrm{W}$ and the ship observations became more numerous with a few reports of winds up to $45 \mathrm{kt}$. The first reconnaissance aircraft reached Becky at $16 \mathrm{Z}$ on the $12^{\text {th }}$ measuring a central pressure of $1004 \mathrm{mb}$ and flight level winds $(700 \mathrm{mb}$ ) of $60 \mathrm{kt}$. Both MWR and the Navy reconnaissance book show that the central pressure measured during this mission was $1006 \mathrm{mb}$ but the report of Becky in the Storm Wallets indicates that it was $1004 \mathrm{mb}$ and this is the accepted value for the reanalysis. A central pressure of $1004 \mathrm{mb}$ is added to 
$18 \mathrm{Z}$ on the $12^{\text {th }}$. A central pressure of $1004 \mathrm{mb}$ suggests maximum sustained winds of 39 kt south of $25 \mathrm{~N}$ from the Brown et al. pressure-wind relationship. Since Becky was moving at about 22 knots and a couple of ships reported $40-45 \mathrm{kt}$, an intensity of $50 \mathrm{kt}$ is selected for $18 \mathrm{Z}$ on the $12^{\text {th }}$, same as the original HURDAT. $50 \mathrm{kt}$ is also the peak intensity for this tropical cyclone, same as the original HURDAT.

Observations from ships, coastal stations in the Lesser and Greater Antilles, and reconnaissance aircrafts during August $13^{\text {th }}, 14^{\text {th }}$ and early on the $15^{\text {th }}$ indicate that Becky was a very disorganized tropical cyclone and it may have weakened to a tropical wave during these days. The forward speed of about 20-25 kt during these days likely contributed to the disorganization. Nonetheless, the data available is not sufficient to justify downgrading Becky to a tropical wave. A reconnaissance aircraft reached Becky at $20 \mathrm{Z}$ on the $13^{\text {th }}$ measuring a central pressure of $1013 \mathrm{mb}$, estimating surface winds of $45 \mathrm{kt}$ and an eye diameter of $70 \mathrm{~nm}$. Although the center fix is shown to have been made at $22.0 \mathrm{~N}$, data from the microfilm map at $18 \mathrm{Z}$ on the $13^{\text {th }}$, Storm Wallets and Navy reconnaissance book suggests that it was likely at $21.0 \mathrm{~N}$ and that the central pressure was $1009 \mathrm{mb}$. A central pressure of $1009 \mathrm{mb}$ is added to $18 \mathrm{Z}$ on the $13^{\text {th }}$. The intensity of Becky is gradually decreased to $40 \mathrm{kt}$ on the $13^{\text {th }}$ as a reflection of the system losing organization but a few ships still reported gale-force winds on that date, mainly in the northeast quadrant. On August $15^{\text {th }}$, the track of Becky turned to the north ahead of a frontal boundary. Ship observations late on the day indicated that it had a closed lowlevel circulation. Gale-force winds were reported on the $15^{\text {th }}$ in the eastern quadrant of the tropical cyclone. HURDAT indicates that Becky becomes an extratropical cyclone at $00 \mathrm{Z}$ on August $16^{\text {th }}$ but ship and coastal observations indicate that there were no frontal boundaries associated with the system and the actual cold front was still over the eastern United States. Transition to an extratropical cyclone is delayed until $06 \mathrm{Z}$ on the $17^{\text {th }}, 30$ hours later than originally shown in HURDAT. A ship passed close to the center of Becky at $12 \mathrm{Z}$ on the $16^{\text {th }}$ reporting $20 \mathrm{kt} \mathrm{NW}$ and $1006 \mathrm{mb}$, suggesting a central pressure of $1004 \mathrm{mb}$. A central pressure of $1004 \mathrm{mb}$ has been added to $12 \mathrm{Z}$ on the $16^{\text {th }}$. A central pressure of $1004 \mathrm{mb}$ suggests $39 \mathrm{kt}$ maximum winds south of $25 \mathrm{~N}$ and $36 \mathrm{kt}$ north of $25 \mathrm{~N}$, according to the pressure-wind relationships. Due to the now slower forward motion of Becky of about 14 knots, an intensity of 40 kt is selected at $12 Z$ on the $16^{\text {th }}$, up from 25 kt originally in HURDAT, a minor intensity change. Late on the $16^{\text {th }}$, while located about $170 \mathrm{~nm}$ east of the Outer Banks, Becky began to interact with a frontal system to the northwest. At this time, the tropical cyclone began to increase in forward speed as it recurved to the northeast. Cold, dry continental air entered the circulation of Becky early on August $17^{\text {th }}$ and it is analyzed that it became extratropical at 06Z. Ship observations suggest that although extratropical and along a frontal boundary, the circulation of Becky remained strong and distinct until after $12 \mathrm{Z}$ on the $17^{\text {th }}$. Slight intensification is noticed at $12 \mathrm{Z}$ on the $17^{\text {th }}$ as a ship close to the center reported $45 \mathrm{kt}$ and the intensity is increased to $45 \mathrm{kt}$ at this time, up from $25 \mathrm{kt}$ originally in HURDAT, a major intensity change. At $18 \mathrm{Z}$ on the $17^{\text {th }}$, the data does indicate that Becky has been absorbed by a larger extratropical cyclone to the northwest. Therefore, $12 \mathrm{Z}$ on the $17^{\text {th }}$ is the last position analyzed before it was absorbed, six hours earlier than the original HURDAT. 
Hurricane Cleo [August 11-22, 1958]

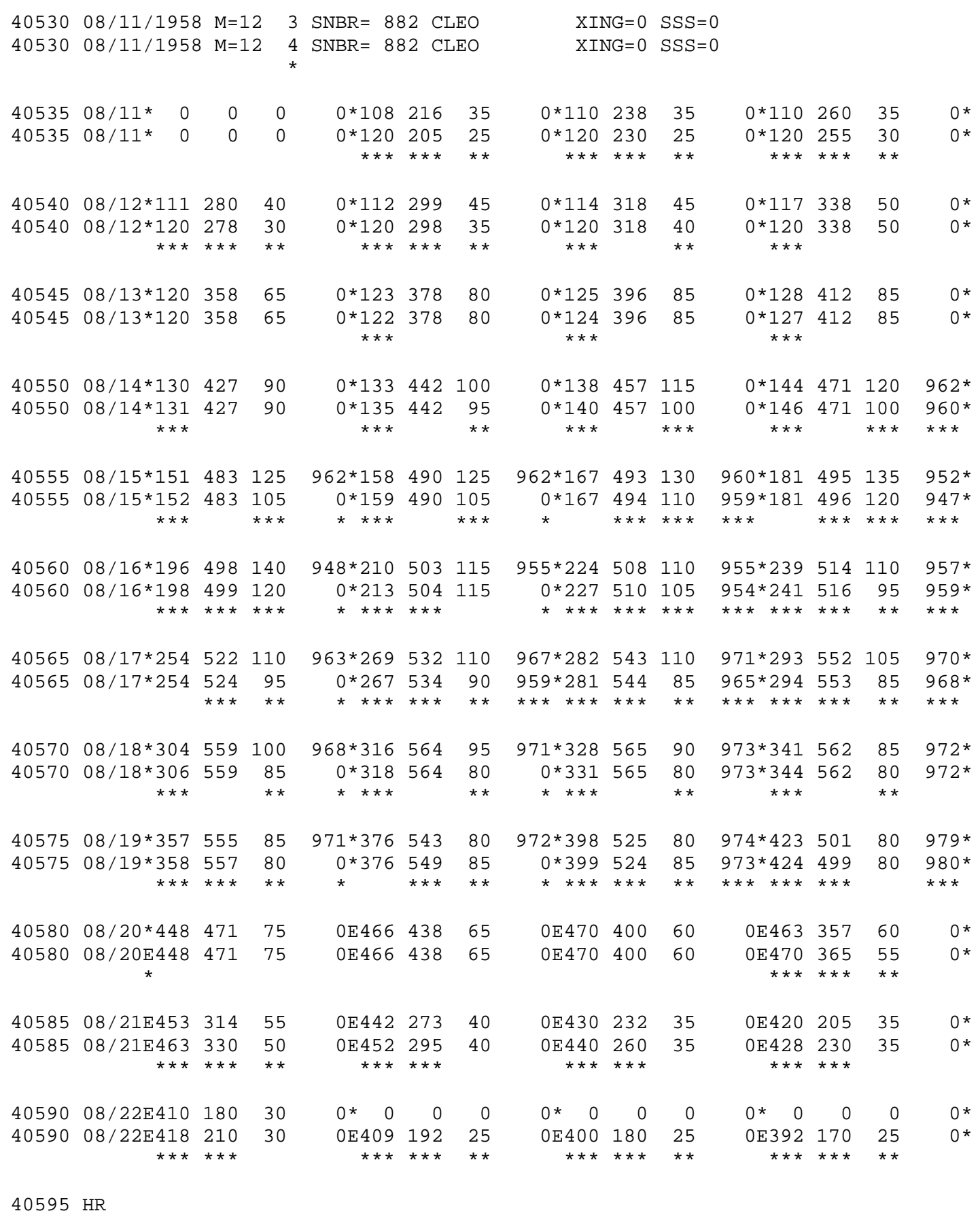

40595 HR

Major changes to the track and intensity shown in McAdie et al. (2009). Evidence for these alterations comes from the NHC microfilm maps, the Historical Weather Maps series, the COADS ship database, Monthly Weather Review, Navy reconnaissance book, Mariners Weather Log, the National Hurricane Research Project (NHRP)(Shea and Gray, 1973) and NHC Storm Wallets. 
August 10:

HWM is not available on this date (system south of $20^{\circ} \mathrm{N}$ ). HURDAT does not list an organized system on this date. Microfilm does not show an organized system at 12Z. Ship highlights: No gales or low pressures.

ATSR: "Earlier, about 8 August, there were indications that a disturbance passed to the south of the Cape Verde Islands and it is now believed that the TATRO covered as CLEO. Apparently CLEO formed from a vortex off the International Convergence Zone. ... On 9 August the SS TATRO reported near 17N 28W with winds of 45 knots, pressure $1003.9 \mathrm{mb}$ and heavy seas."

August 11:

HWM is not available on this date (system south of $20^{\circ} \mathrm{N}$ ). HURDAT lists a 35 knot tropical storm at $11.0 \mathrm{~N}, 23.8 \mathrm{~W}$ at $12 \mathrm{Z}$. Microfilm does not show an organized system at 12Z. Ship highlights: No gales or low pressures.

MWR: "The existence of hurricane Cleo was first suspected on August 11 based on reports from the Cape Verde Islands. Weather conditions and 24-hour surface pressure changes indicated that a fairly well developed easterly wave was passing through the area. Judging from surface and low-level wind reports, any possible circulation associated with the wave must have passed well to the south of the Cape Verdes." ATSR: "Later, on 11 August, a storm formed near 18N 46W which was named BECKY. Some forecasters believe this storm was the same disturbance that was reported by the TATRO, however, this would mean that the disturbance had moved westward at about 25 knots. This speed is considered to be unlikely, based on climatological indications since normal speeds of a fully developed storm are nearer to 12 knots in that area."

August 12:

HWM is not available on this date (system south of $20^{\circ} \mathrm{N}$ ). HURDAT lists a 45 knot tropical storm at $11.4 \mathrm{~N}, 31.8 \mathrm{~W}$ at $12 \mathrm{Z}$. Microfilm shows a closed low pressure of at most $1011 \mathrm{mb}$ at $14.5 \mathrm{~N}, 31.5 \mathrm{~W}$ at 12Z. Ship highlights: No gales or low pressures.

MWR: "On August 12 and 13, reports from several ships on the outer periphery of the suspected storm indicated that a large cyclonic circulation was developing; however, none was close enough to even estimate the location or intensity of Cleo."

August 13:

HWM is not available on this date (system south of $20^{\circ} \mathrm{N}$ ). HURDAT lists an 85 knot hurricane at $12.5 \mathrm{~N}, 39.6 \mathrm{~W}$ at $12 \mathrm{Z}$. Microfilm shows a closed low pressure of at most $1005 \mathrm{mb}$ at $12.0 \mathrm{~N}, 39.0 \mathrm{~W}$ at 12Z. Ship highlights: No gales or low pressures. 
August 14:

HWM is not available on this date (system south of $20^{\circ} \mathrm{N}$ ). HURDAT lists an 115 knot hurricane at $13.8 \mathrm{~N}, 45.7 \mathrm{~W}$ at $12 \mathrm{Z}$. Microfilm shows a closed low pressure of at most $1011 \mathrm{mb}$ at $13.0 \mathrm{~N}, 47.0 \mathrm{~W}$ at 12Z. Ship highlights: $35 \mathrm{kt} \mathrm{SE}$ and $1010 \mathrm{mb}$ at $16.2 \mathrm{~N}$, $45.9 \mathrm{~W}$ at $09 \mathrm{Z}$ (micro). $15 \mathrm{kt} \mathrm{NW}$ and $1001 \mathrm{mb}$ at $12.6 \mathrm{~N}, 47.6 \mathrm{~W}$ at $12 \mathrm{Z}$ (micro). Aircraft highlights: Penetration center fix estimated maximum surface winds of $80 \mathrm{kt}$, measured a central pressure of $960 \mathrm{mb}$ and an eye diameter of $15 \mathrm{~nm}$ at $14.7 \mathrm{~N}, 47.2 \mathrm{~W}$ at $1811 \mathrm{Z}$ (micro).

MWR: "On August 14, an Air Force reconnaissance aircraft located hurricane Cleo at 1820 GMT near latitude $14.7 \mathrm{~N}$, longitude $47.1 \mathrm{~W}$. By this time, Cleo had developed into a very intense storm with lowest pressure of $962 \mathrm{mb}$ and winds estimated at $146 \mathrm{mph}$ on the basis of fringe data, it is believed the storm was moving at about $21 \mathrm{mph}$ from August 11 to 13; however, on August 14, the time of first aircraft penetration, the storm undoubtedly was decelerating as it began turning northward under the influence of a weak upper trough near longitude 50W." ATSR: "The first positive report on CLEO was on 14 August when the $59^{\text {th }}$ Weather Reconnaissance Squadron positioned the eye at $14.7 \mathrm{~N} 47.2 \mathrm{~W}$ with flight level winds of 127 knots, surface winds estimated at 80 knots, center pressure $960 \mathrm{mb}$ and well defined wall clouds."

August 15:

HWM is not available on this date (system south of $20^{\circ} \mathrm{N}$ ). HURDAT lists a 130 knot hurricane at $16.7 \mathrm{~N}, 49.3 \mathrm{~W}$ at $12 \mathrm{Z}$. Microfilm shows a closed low pressure of at most $1005 \mathrm{mb}$ at $17.0 \mathrm{~N}, 49.5 \mathrm{~W}$ at 12Z. Ship highlights: $25 \mathrm{kt} \mathrm{SW}$ and $1005 \mathrm{mb}$ at $12.8 \mathrm{~N}$, $49.1 \mathrm{~W}$ at $06 \mathrm{Z}$ (COADS). $40 \mathrm{kt} \mathrm{SE}$ and $1002 \mathrm{mb}$ at $19.1 \mathrm{~N}, 48.9 \mathrm{~W}$ at $12 \mathrm{Z}$ (micro). $50 \mathrm{kt}$ $\mathrm{SE}$ and $999 \mathrm{mb}$ at $18.4 \mathrm{~N}, 48.3 \mathrm{~W}$ at $18 \mathrm{Z}$ (micro). $110 \mathrm{kt} \mathrm{E}$ and $994 \mathrm{mb}$ at $19.4 \mathrm{~N}, 48.6 \mathrm{~W}$ (position likely erroneous) at $18 \mathrm{Z}$ (micro). $10 \mathrm{kt}$ and $954 \mathrm{mb}$ near $19.3 \mathrm{~N}, 49.3 \mathrm{~W}$ at $2320 \mathrm{Z}$ (WALLET). Aircraft highlights: Penetration center fix estimated maximum surface winds of $90 \mathrm{kt}$, measured a central pressure of $959 \mathrm{mb}$ and an eye diameter of $10 \mathrm{~nm}$ at $17.0 \mathrm{~N}$, 49.6W at $14 \mathrm{Z}$ (micro). Penetration center fix estimated flight level winds (700 mb) of 110 kt and measured a central pressure of $947 \mathrm{mb}$ at $19.0 \mathrm{~N}, 49.7 \mathrm{~W}$ at $2030 \mathrm{Z}$ (micro/MWR).

MWR: "Although the highest winds were reported by reconnaissance aircraft on first penetration, the hurricane did not reach maximum intensity (based on pressure and radar pattern) until the $15^{\text {th }}$ when a dropsonde in the eye at 2030 GMT indicated a sea level pressure of $947 \mathrm{mb}$. It is probable that the aircraft did not find the area of maximum winds on this day so it still may be assumed that this was the date of maximum intensity." ATSR: "After the first fix at $141822 \mathrm{Z}$ no further fixes were received until 151400Z. This latter fix indicated that CLEO was moving northwest (305). A further fix at $152030 \mathrm{Z}$ indicated that CLEO was now moving on a course of 355 at 18 knots. These two latter fixes further indicated that the center pressure was about the same $(960 \mathrm{mb})$ but that the storm was concentrated in a very small area. The following is quoted from the post-flight 
summary from GULL ONE CLEO on 15 August: "CLEO IS A SMALL BUT INTENSE STORM. DIAMTER OF EYE IS TEN MILES ... MAX SURFACE WIND ESTIMATED AT 90 KNOTS. THIS STORM IS SO SMALL THAT IT WOULD HAVE BEEN VERY DIFFICULT IF NOT IMPOSSIBLE TO LOCATE WITHOUT APN $82 \ldots$ MARSH" This was indicative of CLEO's character throughout most of her life span, a small-cored vicious hurricane with strong winds extending out a very short distance from her center."

August 16:

HWM analyzes a hurricane with a central pressure of $953 \mathrm{mb}$ at $22.5 \mathrm{~N}, 51.0 \mathrm{~W}$ at $12 \mathrm{Z}$. HURDAT lists an 110 knot hurricane at $22.4 \mathrm{~N}, 50.8 \mathrm{~W}$ at $12 \mathrm{Z}$. Microfilm shows a closed low pressure of at most $1011 \mathrm{mb}$ at $20.0 \mathrm{~N}, 51.0 \mathrm{~W}$ at $12 \mathrm{Z}$. Ship highlights: $55 \mathrm{kt} \mathrm{E}$ and $1000 \mathrm{mb}$ at $18.5 \mathrm{~N}, 48.1 \mathrm{~W}$ at $00 \mathrm{Z}$ (micro). $110 \mathrm{kt} \mathrm{ENE}$ and $996 \mathrm{mb}$ at $20.3 \mathrm{~N}, 47.8 \mathrm{~W}$ (position likely erroneous) at $03 \mathrm{Z}$ (micro). $65 \mathrm{kt} \mathrm{SE}$ and $1002 \mathrm{mb}$ at $22.3 \mathrm{~N}, 51.6 \mathrm{~W}$ at $06 \mathrm{Z}$ (micro). $95 \mathrm{kt} \mathrm{SSE}$ and $998 \mathrm{mb}$ at $20.7 \mathrm{~N}, 47.2 \mathrm{~W}$ (position likely erroneous) at $09 \mathrm{Z}$ (micro). $45 \mathrm{kt} \mathrm{WNW}$ and $999 \mathrm{mb}$ at $22.0 \mathrm{~N}, 51.1 \mathrm{~W}$ at $12 \mathrm{Z}$ (micro). $70 \mathrm{kt} \mathrm{SE}$ and $1005 \mathrm{mb}$ at $20.5 \mathrm{~N}, 46.9 \mathrm{~W}$ (position likely erroneous) at $12 \mathrm{Z}$ (micro). $60 \mathrm{kt}$ ESE and $1006 \mathrm{mb}$ at $26.5 \mathrm{~N}, 49.2 \mathrm{~W}$ at $21 \mathrm{Z}$ (MWL). Aircraft highlights: Radar center fix estimated maximum surface winds of $75 \mathrm{kt}$ and an eye diameter of $28 \mathrm{~nm}$ at $21.5 \mathrm{~N}, 50.4 \mathrm{~W}$ at $08 \mathrm{Z}$ (ATSR). Penetration center fix estimated flight level winds $(700 \mathrm{mb})$ of $102 \mathrm{kt}$, measured a central pressure of $954 \mathrm{mb}$ and an eye diameter of $15 \mathrm{~nm}$ at $23.0 \mathrm{~N}, 51.2 \mathrm{~W}$ at $14 \mathrm{Z}$ (micro). Penetration center fix estimated flight level winds $(500 \mathrm{mb})$ of $90 \mathrm{kt}$, measured a central pressure of $959 \mathrm{mb}$ and an eye diameter of $30 \mathrm{~nm}$ at $25.0 \mathrm{~N}, 51.9 \mathrm{~W}$ at $2052 \mathrm{Z}$ (micro).

MWR: "On the 16th, the storm turned toward the north-northwest and gradually increased its forward speed. Recurvature south of latitude $20^{\circ} \mathrm{N}$ during August is very unusual and in this case was never completed. An active short wave which passed through the Northeastern States on the 16th and 17th began to affect Cleo by the 18th as the storm slowed to about $14 \mathrm{mph}$ and gradually turned to a northward course."

August 17:

HWM analyzes a hurricane with a central pressure of $972 \mathrm{mb}$ at $28.3 \mathrm{~N}, 54.3 \mathrm{~W}$ at $12 \mathrm{Z}$. HURDAT lists a 110 knot hurricane at $28.2 \mathrm{~N}, 54.3 \mathrm{~W}$ at $12 \mathrm{Z}$. Microfilm shows an open low pressure at $28.7 \mathrm{~N}, 54.5 \mathrm{~W}$ at $12 \mathrm{Z}$. Ship highlights: $55 \mathrm{kt} \mathrm{SE}$ and $1010 \mathrm{mb}$ at $26.2 \mathrm{~N}, 48.9 \mathrm{~W}$ at $00 \mathrm{Z}$ (micro). $40 \mathrm{kt} \mathrm{SE}$ and $1011 \mathrm{mb}$ at $28.7 \mathrm{~N}, 50.0 \mathrm{~W}$ at $06 \mathrm{Z}$ (micro). 45 kt SW and $1000 \mathrm{mb}$ at $26.8 \mathrm{~N}, 53.2 \mathrm{~W}$ at $12 \mathrm{Z}$ (micro). $40 \mathrm{kt} \mathrm{S}$ and $1007 \mathrm{mb}$ at $27.9 \mathrm{~N}$, $52.7 \mathrm{~W}$ at $18 \mathrm{Z}$ (micro). Aircraft highlights: Penetration center fix measured a central pressure of $959 \mathrm{mb}$ at $27.9 \mathrm{~N}, 53.8 \mathrm{~W}$ at $0930 \mathrm{Z}$ (ATSR/micro). Penetration center fix measured a central pressure of $965 \mathrm{mb}$ at $28.8 \mathrm{~N}, 54.9 \mathrm{~W}$ at $1330 \mathrm{Z}$ (ATSR/micro). Penetration center fix estimated surface winds of $88 \mathrm{kt}$, measured a central pressure of $968 \mathrm{mb}$ and an eye diameter of $20 \mathrm{~nm}$ at $29.8 \mathrm{~N}, 55.4 \mathrm{~W}$ at $1930 \mathrm{Z}$ (micro). 
August 18:

HWM analyzes a hurricane with a central pressure of $973 \mathrm{mb}$ at $32.9 \mathrm{~N}, 56.5 \mathrm{~W}$ at $12 \mathrm{Z}$. HURDAT lists a $110 \mathrm{knot}$ hurricane at $32.8 \mathrm{~N}, 56.5 \mathrm{~W}$ at $12 \mathrm{Z}$. Microfilm shows a closed low pressure of at most $1002 \mathrm{mb}$ at $33.0 \mathrm{~N}, 57.0 \mathrm{~W}$ with a frontal boundary to the north at 12Z. Ship highlights: $35 \mathrm{kt} \mathrm{E}$ and $1005 \mathrm{mb}$ at $32.9 \mathrm{~N}, 56.0 \mathrm{~W}$ at $00 \mathrm{Z}$ (micro). $40 \mathrm{kt}$ $\mathrm{SE}$ and $1004 \mathrm{mb}$ at $33.0 \mathrm{~N}, 54.5 \mathrm{~W}$ at $06 \mathrm{Z}$ (micro). $35 \mathrm{kt} \mathrm{SSE}$ and $1013 \mathrm{mb}$ at $32.0 \mathrm{~N}$, $52.1 \mathrm{~W}$ at $12 \mathrm{Z}$ (micro). $35 \mathrm{kt} \mathrm{S}$ and $1019 \mathrm{mb}$ at $35.5 \mathrm{~N}, 49.7 \mathrm{~W}$ at $18 \mathrm{Z}$ (micro). Aircraft highlights: Penetration center fix estimated surface winds of $80 \mathrm{kt}$ and measured a central pressure of $973 \mathrm{mb}$ at $33.5 \mathrm{~N}, 56.3 \mathrm{~W}$ at $14 \mathrm{Z}$ (ATSR/micro). Penetration center fix estimated surface winds of $84 \mathrm{kt}$, measured a central pressure of $972 \mathrm{mb}$, and a RMW of $22 \mathrm{~nm}$ at $33.0 \mathrm{~N}, 56.0 \mathrm{~W}$ around $1630 \mathrm{Z}$ (NHRP). Penetration center fix measured a central pressure of $971 \mathrm{mb}$ at $34.8 \mathrm{~N}, 56.1 \mathrm{~W}$ at $1935 \mathrm{Z}$ (ATSR/micro).

ATSR: "After CLEO's turn toward the north, following the first positive location on 14 August, she continued on a course between north-northwest and north for four days and finally recurved through north at about $1000 \mathrm{Z}$ on 18 August."

August 19:

HWM analyzes a hurricane with a central pressure of $976 \mathrm{mb}$ at $40.0 \mathrm{~N}, 52.9 \mathrm{~W}$ with a warm front to the north and a dissipating front to the west at 12Z. HURDAT lists a 110 knot hurricane at $39.8 \mathrm{~N}, 52.5 \mathrm{~W}$ at $12 \mathrm{Z}$. Microfilm shows a closed low pressure of at most $999 \mathrm{mb}$ at $40.0 \mathrm{~N}, 53.0 \mathrm{~W}$ with a frontal boundary to the west at 12Z. Ship highlights: $40 \mathrm{kt} \mathrm{SSW}$ and $1019 \mathrm{mb}$ at $34.6 \mathrm{~N}, 50.5 \mathrm{~W}$ at $00 \mathrm{Z}$ (COADS). $40 \mathrm{kt} \mathrm{S}$ and 1019 $\mathrm{mb}$ at $36.5 \mathrm{~N}, 49.7 \mathrm{~W}$ at $06 \mathrm{Z}$ (micro). $45 \mathrm{kt} \mathrm{S}$ and $1020 \mathrm{mb}$ at $36.3 \mathrm{~N}, 50.3 \mathrm{~W}$ at $12 \mathrm{Z}$ (COADS). $55 \mathrm{kt} \mathrm{SSW}$ and $998 \mathrm{mb}$ at 42.0N, 47.3W at $18 \mathrm{Z}$ (micro). $65 \mathrm{kt} \mathrm{SW}$ and 982 $\mathrm{mb}$ at $42.2 \mathrm{~N}, 48.7 \mathrm{~W}$ at $20 \mathrm{Z}$ (micro). Aircraft highlights: Penetration center fix estimated surface winds of $79 \mathrm{kt}$, measured a central pressure of $973 \mathrm{mb}$ and an eye diameter of 30 $\mathrm{nm}$ at $39.4 \mathrm{~N}, 52.9 \mathrm{~W}$ at $1055 \mathrm{Z}$ (ATSR/micro). Penetration center fix estimated surface winds of $70-75 \mathrm{kt}$ and measured a central pressure of $973 \mathrm{mb}$ at $39.8 \mathrm{~N}, 52.8 \mathrm{~W}$ at $1112 \mathrm{Z}$ (micro). Penetration center fix measured a central pressure of $976 \mathrm{mb}$ at $40.4 \mathrm{~N}, 51.8 \mathrm{~W}$ at $1336 Z$ (ATSR/micro). Penetration center fix estimated surface winds of $88 \mathrm{kt}$, measured a central pressure of $980 \mathrm{mb}$ and an eye diameter of $40 \mathrm{~nm}$ at $43.3 \mathrm{~N}, 48.5 \mathrm{~W}$ at $1930 \mathrm{Z}$ (micro).

MWR: "On the $19^{\text {th }}$ Cleo accelerated to around $29 \mathrm{mph}$ on a northeastward and later a more eastward course until becoming extratropical on the $20^{\text {th }}$." 
August 20:

HWM analyzes a tropical storm of at most $995 \mathrm{mb}$ at $47.1 \mathrm{~N}, 40.1 \mathrm{~W}$ with a warm front just to the north at $12 \mathrm{Z}$. HURDAT lists a 60 knot extratropical storm at $47.0 \mathrm{~N}, 40.0 \mathrm{~W}$ at $12 \mathrm{Z}$. Microfilm shows an extratropical cyclone of at most $1011 \mathrm{mb}$ at $46.0 \mathrm{~N}, 38.0 \mathrm{~W}$ at $12 \mathrm{Z}$. Ship highlights: $45 \mathrm{kt} \mathrm{S}$ and $1012 \mathrm{mb}$ at $43.9 \mathrm{~N}, 44.2 \mathrm{~W}$ at $00 \mathrm{Z}$ (COADS). $60 \mathrm{kt} \mathrm{S}$ and $1003 \mathrm{mb}$ at 45.4N, 41.0W at 06Z (COADS). $50 \mathrm{kt} \mathrm{SSW}$ and 1007 $\mathrm{mb}$ at $44.0 \mathrm{~N}, 41.0 \mathrm{~W}$ at $09 \mathrm{Z}$ (COADS). $50 \mathrm{kt} \mathrm{SW}$ and $1004 \mathrm{mb}$ at $44.8 \mathrm{~N}, 39.5 \mathrm{~W}$ at $12 \mathrm{Z}$ (COADS). $45 \mathrm{kt} \mathrm{NNE}$ and $1004 \mathrm{mb}$ at $46.5 \mathrm{~N}, 39.8 \mathrm{~W}$ at $18 \mathrm{Z}$ (micro).

August 21:

HWM analyzes an extratropical cyclone of at most $1005 \mathrm{mb}$ at $44.0 \mathrm{~N}, 28.0 \mathrm{~W}$ at 12Z. HURDAT lists a 35 knot extratropical storm at $43.0 \mathrm{~N}, 23.2 \mathrm{~W}$ at $12 \mathrm{Z}$. Microfilm shows that the extratropical cyclone has moved off the northeast edge of the synoptic map at 12Z. Ship highlights: $45 \mathrm{kt} \mathrm{S}$ at $45.4 \mathrm{~N}, 28.6 \mathrm{~W}$ at $00 \mathrm{Z}$ (COADS). $35 \mathrm{kt} \mathrm{WNW}$ and $1009 \mathrm{mb}$ at $42.4 \mathrm{~N}, 33.2 \mathrm{~W}$ at $06 \mathrm{Z}$ (COADS). $35 \mathrm{kt} \mathrm{NW}$ and $1014 \mathrm{mb}$ at $42.2 \mathrm{~N}, 33.1 \mathrm{~W}$ at $12 \mathrm{Z}$ (COADS).

August 22:

HWM analyzes an extratropical cyclone of at most $1010 \mathrm{mb}$ at $40.5 \mathrm{~N}, 18.0 \mathrm{~W}$ at 12Z. HURDAT lists a 30 knot extratropical depression at $41.0 \mathrm{~N}, 18.0 \mathrm{~W}$ at $00 \mathrm{Z}$ (last position). Microfilm is not available on this date. Ship highlights: No gales or low pressures.

August 23:

HWM analyzes an extratropical cyclone of at most $1015 \mathrm{mb}$ at $38.0 \mathrm{~N}, 17.5 \mathrm{~W}$ at 12Z. HURDAT does not list an organized storm on this date. Microfilm is not available on this date. Ship highlights: No gales or low pressures.

August 24:

HWM analyzes an extratropical cyclone of at most $1015 \mathrm{mb}$ at $40.0 \mathrm{~N}, 3.5 \mathrm{~W}$ at 12Z. HURDAT does not list an organized storm on this date. Microfilm is not available on this date. Ship highlights: No gales or low pressures.

August 25:

HWM analyzes a cold front over western Europe at 12Z. HURDAT does not list an organized storm on this date. Microfilm is not available on this date. Ship highlights: No gales or low pressures. 
MWR: "Fortunately hurricane Cleo remained at sea throughout its history and no reports were received of any severe damage to shipping or loss of life despite the storm's traversal of the principal transatlantic shipping lanes. An interesting account of a vessel passing through the eye of Cleo can be found in the November Mariners Weather Log."

The first hurricane of the season developed from a tropical wave that left the African coast around August $9^{\text {th }}$. Genesis is analyzed at $06 \mathrm{Z}$ on August $11^{\text {th }}$, same as the original HURDAT. Ship and coastal observations indicate that the system was a tropical depression at formation, and an intensity of $25 \mathrm{kt}$ is selected for $06 \mathrm{Z}$ on the $11^{\text {th }}$, down from the original $35 \mathrm{kt}$ in HURDAT, a minor intensity change. Intensification to a tropical storm is delayed 24 hours until $06 \mathrm{Z}$ on August $12^{\text {th }}$, indicating a gradual strengthening of the tropical cyclone. Minor track alterations are introduced during the lifetime of Cleo, except for August $21^{\text {st }}$ at $06 \mathrm{Z}$ through August $22^{\text {nd }}$ at $00 \mathrm{Z}$ when it was an extratropical cyclone. The Navy reconnaissance book indicates that originally there was confusion on the reports of ship observations from the eastern Atlantic concerning Becky and Cleo. Becky had formed a few days earlier in the same general area. The ship SS TATRO located near $17 \mathrm{~N} 28 \mathrm{~W}$ on August $9^{\text {th }}$ reported $45 \mathrm{kt}$ and $1004 \mathrm{mb}$ and originally it was not clear to which storm it corresponded. It is now clear that the SS TATRO was reporting on Becky and not Cleo. The observations became sparse as the tropical storm moved generally westward toward the central Atlantic. Intensification to a hurricane is analyzed at $00 \mathrm{Z}$ on August $13^{\text {th }}$, same as the original HURDAT. The first gale-force winds were observed on August $14^{\text {th }}$ and at $1811 \mathrm{Z}$ on this day, a reconnaissance aircraft reached the hurricane measuring a central pressure of $960 \mathrm{mb}$, estimating surface winds of $80 \mathrm{kt}$ and an eye diameter of $15 \mathrm{~nm}$. A central pressure of $960 \mathrm{mb}$ suggests maximum sustained winds of $102 \mathrm{kt}$ south of $25 \mathrm{~N}$ intensifying from the Brown et al. pressure-wind relationship. An eye diameter of $15 \mathrm{~nm}$ suggests an RMW of about $12 \mathrm{~nm}$ and climatology suggests about the same. An intensity of $100 \mathrm{kt}$ is selected for $18 \mathrm{Z}$ on the $14^{\text {th }}$, down from $120 \mathrm{kt}$ originally shown in HURDAT, a major intensity change. A central pressure of $962 \mathrm{mb}$ was present in HURDAT at $18 \mathrm{Z}$ on the $14^{\text {th }}$ and has been replaced with $960 \mathrm{mb}$. Intensification to a major hurricane is now analyzed at $12 \mathrm{Z}$ on the $14^{\text {th }}$, six hours later than originally shown in HURDAT. Cleo gradually intensified on August $15^{\text {th }}$ as the track turned to the north-northwest while located over $650 \mathrm{~nm}$ east of the Leeward Islands. A central pressure of $962 \mathrm{mb}$ was present in HURDAT at $00 \mathrm{Z}$ and $06 \mathrm{Z}$ on the $15^{\text {th }}$ and they have been removed since there was no reconnaissance aircraft investigating the hurricane at these times and no central pressure measurements was received from ships in the area. (The original HURDAT for this hurricane had central pressure values for each 6 hour period from $18 \mathrm{Z}$ on the $14^{\text {th }}$ to $18 \mathrm{Z}$ on the $19^{\text {th }}$. These were obviously analyses that were added in, not based upon actual observations. These have now been removed from HURDAT.) A reconnaissance mission reached Cleo at $14 \mathrm{Z}$ on the $15^{\text {th }}$ measuring a central pressure of $959 \mathrm{mb}$ and estimating surface winds of $90 \mathrm{kt}$ and an eye diameter of $10 \mathrm{~nm}$. A central pressure of $959 \mathrm{mb}$ suggests maximum sustained winds of $104 \mathrm{kt}$ south of $25 \mathrm{~N}$ intensifying from the pressure-wind relationship. An eye diameter of $10 \mathrm{~nm}$ suggests an RMW of about $7 \mathrm{~nm}$ and climatology suggests about 12 $\mathrm{nm}$. Since the hurricane has a smaller RMW, an intensity of $110 \mathrm{kt}$ is selected at $12 \mathrm{Z}$ on 
the $15^{\text {th }}$, down from $130 \mathrm{kt}$ originally in HURDAT, a major intensity change. Another reconnaissance aircraft reached Cleo at $2030 \mathrm{Z}$ on the $15^{\text {th }}$ measuring a central pressure of $947 \mathrm{mb}$. A central pressure of $947 \mathrm{mb}$ suggests maximum sustained winds of $116 \mathrm{kt}$ south of $25 \mathrm{~N}$ intensifying from the pressure-wind relationship. An intensity of $120 \mathrm{kt}$ is selected for $18 \mathrm{Z}$ on the $15^{\text {th }}$, down from $135 \mathrm{kt}$ originally in HURDAT, a minor intensity change. Major intensity changes are also analyzed at $00 \mathrm{Z}$ and $06 \mathrm{Z}$ on the $15^{\text {th }}$. The original HURDAT shows $125 \mathrm{kt}$ for the mentioned times and the selected intensity is 105 $\mathrm{kt}$ for both times. A central pressure of $960 \mathrm{mb}$ is present in HURDAT at $12 \mathrm{Z}$ on the $15^{\text {th }}$ and based on the reconnaissance report at 14Z, it has been replaced with $959 \mathrm{mb}$. Similarly, HURDAT originally had a central pressure of $952 \mathrm{mb}$ at $18 \mathrm{Z}$ on the $15^{\text {th }}$ and has been replaced with $947 \mathrm{mb}$ reported by the reconnaissance aircraft at 2030Z. A few ships reported gale-force winds on August $15^{\text {th }}$, and although the position seems to be erroneous, a few even reported hurricane-force winds. The ship TAHITIEN entered the eye of Cleo late on the $15^{\text {th }}$ measuring a minimum pressure of $954 \mathrm{mb}$ and estimating surface winds around $105 \mathrm{kt}$, consistent with aircraft reconnaissance. A major intensity change is analyzed at $00 \mathrm{Z}$ on the $16^{\text {th }}$ as HURDAT originally had $140 \mathrm{kt}$ and the selected intensity for this time is $120 \mathrm{kt} .120 \mathrm{kt}$ is also the peak intensity of Cleo, down from 140 kt originally in HURDAT, a major intensity change. There is no evidence to support Cleo attaining category 5 throughout its lifetime.

On August $16^{\text {th }}$, Cleo turned to the northwest. A reconnaissance aircraft reached the hurricane at $14 \mathrm{Z}$ on the $16^{\text {th }}$ measuring a central pressure of $954 \mathrm{mb}$ and estimating flight level winds of $102 \mathrm{kt}$ and an eye diameter of $15 \mathrm{~nm}$. A central pressure of $954 \mathrm{mb}$ suggests maximum sustained winds of $107 \mathrm{kt}$ south of $25 \mathrm{~N}$ and $104 \mathrm{kt}$ south of $25 \mathrm{~N}$ weakening from the pressure-wind relationships. An eye diameter of $15 \mathrm{~nm}$ suggests an RMW of about $12 \mathrm{~nm}$ and climatology suggests about $18 \mathrm{~nm}$. An intensity of $105 \mathrm{kt}$ is selected for $12 Z$ on the $16^{\text {th }}$, down from $110 \mathrm{kt}$ originally in HURDAT, a minor intensity change. A central pressure of $955 \mathrm{mb}$ is present in HURDAT at $12 \mathrm{Z}$ on the $16^{\text {th }}$ and has been replaced with the $954 \mathrm{mb}$ reported by the reconnaissance aircraft at $14 \mathrm{Z}$ on this day. Central pressures of $948 \mathrm{mb}$ and $955 \mathrm{mb}$ are present in HURDAT at 00Z and 06Z, respectively, on the $16^{\text {th }}$, but there is no evidence that these were measured central pressures as there were no reports of central pressures by aircraft or ships around these times, and thus, they have been removed. Cleo may have undergone an eyewall replacement cycle late on the day as the central pressure increased and the eye expanded. Another reconnaissance aircraft reached Cleo at $20 \mathrm{Z}$ on the $16^{\text {th }}$ measuring a central pressure of $959 \mathrm{mb}$ and estimating flight level winds of $90 \mathrm{kt}$ and an eye diameter of 30 $\mathrm{nm}$. A central pressure of $959 \mathrm{mb}$ suggests maximum sustained winds of $99 \mathrm{kt}$ south of $25 \mathrm{~N}$ weakening and $92 \mathrm{kt}$ north of $25 \mathrm{~N}$ weakening, from the pressure-wind relationships. An eye diameter of $30 \mathrm{~nm}$ suggests an RMW of about $23 \mathrm{~nm}$ and climatology suggests about $12 \mathrm{~nm}$. An intensity of $95 \mathrm{kt}$ is selected for $18 \mathrm{Z}$ on the $16^{\text {th }}$, down from $110 \mathrm{kt}$ originally shown in HURDAT, a minor intensity change. Weakening below major hurricane status is now analyzed 36 hours earlier than originally shown in HURDAT. A central pressure of $957 \mathrm{mb}$ is present in HURDAT at $18 \mathrm{Z}$ on the $16^{\text {th }}$ and has been replaced with $959 \mathrm{mb}$ reported by the reconnaissance aircraft at $20 \mathrm{Z}$ on this day. On August $17^{\text {th }}$, Cleo continued to the northwest and three center penetrations occurred on this day. The first aircraft reached Cleo at $0930 \mathrm{Z}$ measuring a central pressure of $959 \mathrm{mb}$. 
The second aircraft measured a central pressure of $965 \mathrm{mb}$ at 1330Z. A central pressure of $965 \mathrm{mb}$ suggests maximum sustained winds of $90 \mathrm{kt}$ north of $25 \mathrm{~N}$ and $86 \mathrm{kt}$ north of $25 \mathrm{~N}$ weakening from the pressure-wind relationships. An intensity of $85 \mathrm{kt}$ is selected for $12 \mathrm{Z}$ on the $17^{\text {th }}$, down from $110 \mathrm{kt}$ originally in HURDAT, a major intensity change. A central pressure of $959 \mathrm{mb}$ is added to HURDAT at $06 \mathrm{Z}$ and $965 \mathrm{mb}$ is added to $12 \mathrm{Z}$ on the $17^{\text {th }}$, replacing the existing $967 \mathrm{mb}$ and $971 \mathrm{mb}$, respectively. These central pressures in HURDAT do not correspond with the central pressures reported by the reconnaissance aircraft. A central pressure of $963 \mathrm{mb}$ is present in HURDAT at $00 \mathrm{Z}$ on the $17^{\text {th }}$ and has been removed since there was no reconnaissance aircraft in the area around this time and no central pressure was reported by ships. The last center penetration of August $17^{\text {th }}$ occurred at 1930Z measuring a central pressure of $968 \mathrm{mb}$, an eye diameter of $20 \mathrm{~nm}$ and estimated surface winds of $88 \mathrm{kt}$. A central pressure of $968 \mathrm{mb}$ suggests maximum sustained winds of $87 \mathrm{kt}$ north of $25 \mathrm{~N}$ and $83 \mathrm{kt}$ north of $25 \mathrm{~N}$ weakening from the pressure-wind relationships. An eye diameter of $20 \mathrm{~nm}$ suggests an RMW of about $15 \mathrm{~nm}$ and climatology suggests about $23 \mathrm{~nm}$. Although the eye had contracted from the previous day, the central pressure continued to rise and an intensity of $85 \mathrm{kt}$ is selected for $18 \mathrm{Z}$ on the $17^{\text {th }}$, down from $105 \mathrm{kt}$ originally in HURDAT, a major intensity change. A central pressure of $968 \mathrm{mb}$ has been added to $18 \mathrm{Z}$ on the $17^{\text {th }}$, replacing the existing $970 \mathrm{mb}$.

Early on August $18^{\text {th }}$, Cleo passed about $430 \mathrm{~nm}$ northeast of Bermuda while making a turn to the north. A reconnaissance aircraft reached the hurricane at $14 \mathrm{Z}$ on the $18^{\text {th }}$ measuring a central pressure of $973 \mathrm{mb}$ and estimating surface winds of $80 \mathrm{kt}$. A central pressure of $973 \mathrm{mb}$ suggests maximum sustained winds of $81 \mathrm{kt}$ north of $25 \mathrm{~N}$ and $77 \mathrm{kt}$ north of $25 \mathrm{~N}$ weakening from the pressure-wind relationships. An intensity of $80 \mathrm{kt}$ is selected for $12 \mathrm{Z}$ on the $18^{\text {th }}$, down from $90 \mathrm{kt}$ originally in HURDAT, a minor intensity change. The central pressure of Cleo remained almost constant during the next 24 hours. The National Hurricane Research Project reported a central pressure of $972 \mathrm{mb}$ around $1630 \mathrm{Z}$ on the $18^{\text {th }}$ and $971 \mathrm{mb}$ was reported at $1930 \mathrm{Z}$ by a reconnaissance aircraft on this day. A central pressure of $972 \mathrm{mb}$ is present in HURDAT at $18 \mathrm{Z}$ on the $18^{\text {th }}$ and has been retained. Central pressures of $968 \mathrm{mb}$ and $971 \mathrm{mb}$ are present in the original HURDAT at $00 \mathrm{Z}$ and $06 \mathrm{Z}$, respectively, on the $18^{\text {th }}$ and although they appear reasonable, they have been removed because there were no reconnaissance missions around $00 \mathrm{Z}$ and $06 \mathrm{Z}$, and no ships reported central pressures. On August $19^{\text {th }}$, Cleo turned to the northeast and started to increase in forward speed ahead of a frontal boundary. A reconnaissance aircraft measured a central pressure of $973 \mathrm{mb}$ and estimated surface winds of $79 \mathrm{kt}$ and an eye diameter of $30 \mathrm{~nm}$ at 1055Z. A central pressure of $973 \mathrm{mb}$ suggests maximum sustained winds of $80 \mathrm{kt}$ north of $35 \mathrm{~N}$ from the Landsea et al. pressure-wind relationship. An eye diameter of $30 \mathrm{~nm}$ suggests an RMW of about $23 \mathrm{~nm}$ and climatology suggests about $28 \mathrm{~nm}$. Due to the relatively small size of the hurricane and forward speed of about $27 \mathrm{kt}$, an intensity of $85 \mathrm{kt}$ is selected at $12 \mathrm{Z}$ on the $19^{\text {th }}$, up from $80 \mathrm{kt}$ originally in HURDAT. A central pressure of $973 \mathrm{mb}$ is added to HURDAT at $12 \mathrm{Z}$ on the $19^{\text {th }}$ replacing the existing $974 \mathrm{mb}$. Later on the $19^{\text {th }}$, a final reconnaissance mission reported a central pressure of $980 \mathrm{mb}$, estimated surface winds of $88 \mathrm{kt}$ and an eye diameter of 40 $\mathrm{nm}$ at 1930Z. A central pressure of $980 \mathrm{mb}$ suggests maximum sustained winds of $73 \mathrm{kt}$ north of $35 \mathrm{~N}$ from the pressure-wind relationship. An eye diameter of $40 \mathrm{~nm}$ suggests an 
RMW of about $30 \mathrm{~nm}$ and climatology suggests about $40 \mathrm{~nm}$. Same as earlier on the day, due to the relatively small size of Cleo and rapid forward speed of about $30 \mathrm{kt}$, an intensity of $80 \mathrm{kt}$ is selected for $18 \mathrm{Z}$ on the $19^{\text {th }}$, same as the original HURDAT. A central pressure of $980 \mathrm{mb}$ is added to HURDAT at $18 \mathrm{Z}$ on the $19^{\text {th }}$ replacing the existing $979 \mathrm{mb}$.

Ship observations late on August $19^{\text {th }}$ indicate that Cleo had begun to take on extratropical characteristics with a warm front developing in the northeast quadrant. It is analyzed that Cleo became an extratropical cyclone at $00 \mathrm{Z}$ on August $20^{\text {th }}$, six hours earlier than originally shown in HURDAT. At this time, ship reports show a clear temperature gradient E-W across the circulation, indicating cold, dry air entraining into the center of the hurricane. Furthermore, the observations also show that the warm front over the northeast quadrant was closer to the center of Cleo at $00 \mathrm{Z}$ on the $20^{\text {th }}$ than late on the $19^{\text {th }}$. On the $20^{\text {th }}$, the track of Cleo turned to the east and later to the east-southeast. Weakening below hurricane force occurred at $12 \mathrm{Z}$ on the $20^{\text {th }}$, same as the original HURDAT. On August $21^{\text {st }}$, Cleo continued to move east-southeast passing about $330 \mathrm{~nm}$ northeast of the Azores. The intensity of the extratropical cyclone decreased steadily on the $21^{\text {st }}$ and dissipation is analyzed to have occurred after $18 \mathrm{Z}$ on the $22^{\text {nd }}, 18$ hours later than originally shown in HURDAT.

Hurricane Daisy [August 24-31, 1958]

\begin{tabular}{|c|c|c|c|c|c|c|c|c|c|c|c|c|c|}
\hline \multirow{3}{*}{$\begin{array}{l}40600 \\
40600 \\
40605\end{array}$} & \multirow{2}{*}{$\begin{array}{l}08 / 24 / 1958 \\
08 / 24 / 1958\end{array}$} & \multirow{2}{*}{$\begin{array}{l}M= \\
M=\end{array}$} & \multirow{2}{*}{$\begin{array}{ll}8 & 4 \\
8 & 5 \\
& *\end{array}$} & SNBR= & \multicolumn{2}{|c|}{883 DAISY } & \multicolumn{3}{|c|}{$X I N G=\odot \quad S S S=\odot$} & & & \multirow{3}{*}{ ๑* } \\
\hline & & & & SNBR $=8$ & $83 \mathrm{D}$ & AISY & $X I$ & $N G=\odot$ & SSS $=$ & & & & \\
\hline & $08 / 24$ * & $\odot$ & $\odot$ & $\Theta^{*}$ & $\odot$ & $\odot$ & $\odot * 252$ & 736 & 35 & $\odot * 259$ & 746 & 40 & \\
\hline 40605 & $08 / 24$ * & $\odot$ & $\odot$ & $0^{*}$ & $\odot$ & $\odot$ & $\begin{array}{r}\Theta^{*} 258 \\
* * *\end{array}$ & $\begin{array}{l}740 \\
* * *\end{array}$ & 35 & $0^{0 *} 261$ & $\begin{array}{l}745 \\
* * *\end{array}$ & 40 & ○* \\
\hline 40610 & $08 / 25^{*} 264$ & 753 & $5 \odot$ & $10 \odot 2 * 267$ & 757 & 55 & $1000^{*} 270$ & 760 & 65 & $997 * 272$ & 763 & 65 & $994^{*}$ \\
\hline 40610 & $08 / 25_{* \star *}^{263}$ & $\begin{array}{l}749 \\
* * *\end{array}$ & 50 & $\begin{array}{r}1002 * 265 \\
* * *\end{array}$ & $\begin{array}{l}753 \\
\star * *\end{array}$ & $\begin{array}{l}50 \\
* *\end{array}$ & $\begin{array}{r}1000 * 268 \\
* * *\end{array}$ & $\begin{array}{l}756 \\
* * *\end{array}$ & $\begin{array}{l}55 \\
* *\end{array}$ & $\begin{array}{l}996 * 271 \\
* * * * * *\end{array}$ & $\begin{array}{l}759 \\
\star * *\end{array}$ & $\begin{array}{l}6 \odot \\
* *\end{array}$ & $\begin{array}{l}990^{*} \\
* * *\end{array}$ \\
\hline 40615 & $08 / 26 * 274$ & 765 & 65 & $989 * 278$ & 768 & 65 & $985 * 281$ & 770 & 70 & $979 * 285$ & 771 & 75 & $974^{*}$ \\
\hline 40615 & $\odot 8 / 26$ * 274 & $\begin{array}{l}764 \\
* * *\end{array}$ & 65 & $989 * 278$ & 768 & $\begin{array}{l}75 \\
* *\end{array}$ & $985 * 281$ & 770 & $\begin{array}{l}85 \\
* *\end{array}$ & $979 * 285$ & 771 & $\begin{array}{l}95 \\
* *\end{array}$ & $974^{*}$ \\
\hline 40620 & $08 / 27 * 288$ & 769 & 80 & $968 * 291$ & 766 & 85 & $963 * 294$ & 762 & 90 & $956 * 298$ & 757 & 95 & $944^{*}$ \\
\hline 40620 & $\odot 8 / 27 * 288$ & 769 & $\begin{array}{l}10 \odot \\
* * *\end{array}$ & $\begin{array}{r}968 * 290 \\
* * *\end{array}$ & $\begin{array}{l}765 \\
* * *\end{array}$ & $\begin{array}{l}105 \\
* * *\end{array}$ & $\begin{array}{r}963 * 292 \\
* * *\end{array}$ & $\begin{array}{l}760 \\
* * *\end{array}$ & $\begin{array}{l}110 \\
* * *\end{array}$ & $\begin{array}{l}952 * 296 \\
* * * * * *\end{array}$ & $\begin{array}{l}756 \\
\star * *\end{array}$ & $\begin{array}{l}120 \\
* * *\end{array}$ & $\begin{array}{l}942^{*} \\
* * *\end{array}$ \\
\hline 40625 & $08 / 28 * 304$ & 751 & 105 & $935 * 315$ & 746 & 110 & $938 * 330$ & 742 & 110 & $946 * 346$ & 741 & 110 & $955^{*}$ \\
\hline 40625 & $\begin{array}{r}\odot 8 / 28 * 3 \odot 3 \\
* * *\end{array}$ & $\begin{array}{l}750 \\
* * *\end{array}$ & $\begin{array}{l}120 \\
\star * *\end{array}$ & $\Theta_{*}^{*} 315$ & 746 & $\begin{array}{l}115 \\
\star * *\end{array}$ & $\begin{array}{l}\odot * 331 \\
* \quad * * *\end{array}$ & 742 & $\begin{array}{l}115 \\
* * *\end{array}$ & $\begin{array}{l}947 * 347 \\
* * * * * *\end{array}$ & 741 & 110 & $\begin{array}{l}949^{*} \\
* * *\end{array}$ \\
\hline 40630 & $08 / 29 * 362$ & 740 & 110 & $963 * 380$ & 729 & 110 & $970 * 398$ & 708 & 105 & $977 * 412$ & 683 & 90 & $982^{*}$ \\
\hline 40630 & $\begin{array}{r}08 / 29 * 363 \\
* * *\end{array}$ & $\begin{array}{l}739 \\
* * *\end{array}$ & $\begin{array}{l}100 \\
\star * *\end{array}$ & $963 * 380$ & $\begin{array}{l}726 \\
\star * *\end{array}$ & $\begin{array}{l}90 \\
* *\end{array}$ & $\begin{array}{r}970 \mathrm{E} 400 \\
* * * *\end{array}$ & $\begin{array}{l}704 \\
* * *\end{array}$ & $\begin{array}{l}80 \\
* *\end{array}$ & $\begin{array}{r}977 \mathrm{E} 415 \\
* * * *\end{array}$ & $\begin{array}{l}679 \\
* * *\end{array}$ & $\begin{array}{l}70 \\
* *\end{array}$ & $982^{*}$ \\
\hline 40635 & $08 / 30 \mathrm{E} 420$ & 650 & 85 & $987 \mathrm{E} 430$ & 605 & 55 & OE422 & 561 & 50 & OE415 & 529 & 50 & $0^{*}$ \\
\hline 40635 & ๑8/3०Е42० & 650 & $\begin{array}{l}65 \\
* *\end{array}$ & $\begin{array}{c}987 \mathrm{E} 425 \\
\star \star \star\end{array}$ & $\begin{array}{l}610 \\
* * *\end{array}$ & $\begin{array}{l}60 \\
* *\end{array}$ & OE422 & $\begin{array}{l}570 \\
* * *\end{array}$ & 50 & $\begin{array}{c}\text { OE422 } \\
\star \star \star\end{array}$ & $\begin{array}{l}530 \\
* * *\end{array}$ & 50 & ○* \\
\hline 40640 & $08 / 31 E 410$ & 496 & 45 & OE410 & 459 & 40 & OE410 & 422 & 35 & OE417 & 389 & 30 & $\Theta^{*}$ \\
\hline
\end{tabular}




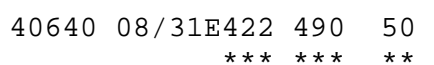

$\begin{array}{rrrrrrrrrrrrrr}0 * & 0 & 0 & 0 & 0 * & 0 & 0 & 0 & 0 * & 0 & 0 & 0 & 0 * \\ * & * & * & * & * & * & * & * & * & * & * & * & \end{array}$

$40645 \mathrm{HR}$

Minor changes to the track and major changes to the intensity shown in McAdie et al. (2009). Evidence for these alterations comes from the NHC microfilm maps, the Historical Weather Maps series, the COADS ship database, Monthly Weather Review, Jack D. Tracy (MWR, 1966), the Local Climatological Data, Surface Weather Observations, Mariners Weather Log, Navy reconnaissance book and NHC Storm Wallets.

August 22:

HWM analyzes a trough or tropical wave along $20 \mathrm{~N}-27 \mathrm{~W}, 71 \mathrm{~W}$ at $12 \mathrm{Z}$. HURDAT does not list an organized storm on this date. Microfilm shows a frontal boundary north of the Leeward Islands at 12Z. Ship highlights: No gales or low pressures.

MWR: "Hurricane Daisy formed in a strong easterly wave which passed through the Lesser Antilles during August 20-21.”

August 23:

HWM analyzes a spot low pressure at $22.5 \mathrm{~N}, 72.9 \mathrm{~W}$ at $12 \mathrm{Z}$. HURDAT does not list an organized storm on this date. Microfilm shows a closed low pressure of at most $1014 \mathrm{mb}$ at $21.0 \mathrm{~N}, 72.5 \mathrm{~W}$ at 12Z. Ship highlights: No gales or low pressures.

MWR: "There was little indication of intensification, however, until the $23 \mathrm{~d}$, when the wave passed through the Windward Passage and a definite increase in its amplitude was evident." ATSR: "An easterly wave was noted at approximately 50 degrees west longitude on 19 August. This wave moved generally westward at 17 knots until 23 August. On the 231200Z synoptic chart, a weak circulation (maximum winds of 10 knots) had developed in the vicinity of Great Inagua, Bahama Islands. Although there was no indicated deepening of this system at that time, the easterly wave became almost stationary at this longitude."

August 24:

HWM analyzes a tropical storm of at most $1010 \mathrm{mb}$ at $25.4 \mathrm{~N}, 73.7 \mathrm{~W}$ at $12 \mathrm{Z}$. HURDAT lists a 35 knot tropical storm at $25.2 \mathrm{~N}, 73.6 \mathrm{~W}$ at $12 \mathrm{Z}$ (first position). Microfilm shows a closed low pressure of at most $1011 \mathrm{mb}$ at $26.5 \mathrm{~N}, 74.0 \mathrm{~W}$ at $12 \mathrm{Z}$. Ship highlights: $35 \mathrm{kt} \mathrm{SW}$ and $1005 \mathrm{mb}$ at 26.0N, 74.3W at 16Z (micro). $40 \mathrm{kt} \mathrm{SE}$ and 1009 $\mathrm{mb}$ at $27.1 \mathrm{~N}, 74.6 \mathrm{~W}$ at $21 \mathrm{Z}$ (micro). Aircraft highlights: Penetration center fix measured a central pressure of $1002 \mathrm{mb}$ and estimated surface winds of $45 \mathrm{kt}$ at $2311 \mathrm{Z}$ (ATSR/MWR). 
MWR: "A vortex developed on the 24th and reconnaissance aircraft located an eye just north of the central Bahamas with maximum winds of about $55 \mathrm{mph}$ and a central pressure of 1002 mb." ATSR: "The circulation made a "break off" from the wave and moved slowly northward. At 240600Z, a definite circulation was in evidence at $26 \mathrm{~N}$ 73 W. Maximum winds of 20 knots were reported by ships in the area. A Navy reconnaissance WV3 from Jacksonville was ordered into the area on the $24^{\text {th }}$. The eye was located by this flight at $242311 \mathrm{Z}$ and the first warning was issued at 250100Z."

August 25:

HWM analyzes a tropical storm of at most $1005 \mathrm{mb}$ at $27.3 \mathrm{~N}, 76.0 \mathrm{~W}$ at $12 \mathrm{Z}$. HURDAT lists a 65 knot hurricane at 27.0N, 76.0W at 12Z. Microfilm shows a closed low pressure of at most $1008 \mathrm{mb}$ at $26.5 \mathrm{~N}, 75.5 \mathrm{~W}$ at $12 \mathrm{Z}$. Ship highlights: $50 \mathrm{kt} \mathrm{SE}$ and $1009 \mathrm{mb}$ at $27.2 \mathrm{~N}, 74.2 \mathrm{~W}$ at $00 \mathrm{Z}$ (micro). $35 \mathrm{kt} \mathrm{SW}$ and $1005 \mathrm{mb}$ at $26.0 \mathrm{~N}, 74.3 \mathrm{~W}$ at $00 \mathrm{Z}$ (micro). $45 \mathrm{kt} \mathrm{SSE}$ and $1010 \mathrm{mb}$ at 27.1N, 74.6W at 06Z (COADS). $40 \mathrm{kt}$ ESE and 1009 $\mathrm{mb}$ at $26.9 \mathrm{~N}, 75.2 \mathrm{~W}$ at $12 \mathrm{Z}$ (COADS). $55 \mathrm{kt} \mathrm{SE}$ and $1016 \mathrm{mb}$ at $26.4 \mathrm{~N}, 74.4 \mathrm{~W}$ at $18 \mathrm{Z}$ (COADS). Aircraft highlights: Penetration center fix measured a central pressure of 996 $\mathrm{mb}$ and estimated winds of $70 \mathrm{kt}$ at $5000 \mathrm{ft}$ at $26.7 \mathrm{~N}, 75.5 \mathrm{~W} 1310 \mathrm{Z}$ (micro). Radar center fix at $27.0 \mathrm{~N}, 75.6 \mathrm{~W}$ at $1603 \mathrm{Z}$ (micro). Penetration center fix measured a central pressure of $990 \mathrm{mb}$ and estimated winds of $50 \mathrm{kt}$ at $5000 \mathrm{ft}$ at $2030 \mathrm{Z}$ (micro).

MWR: "The first advisory was issued at 0100 GMT August 25. Hurricane Daisy moved very slowly north-northwestward during the 25th and the morning of the 26th." ATSR: "During the morning of 25 August, a ridge at the $200 \mathrm{mb}$ level pushed across the southeast coast of the United States and brought high-level divergence to the area. DAISY commenced rapid intensification and hurricane force winds were first observed the same day."

August 26:

HWM analyzes a hurricane with a central pressure of $975 \mathrm{mb}$ at $28.2 \mathrm{~N}, 77.0 \mathrm{~W}$ and a frontal boundary over the Southeast of the United States at 12Z. HURDAT lists a 70 knot hurricane at $28.1 \mathrm{~N}, 77.0 \mathrm{~W}$ at $12 \mathrm{Z}$. Microfilm shows a closed low pressure of at most $999 \mathrm{mb}$ at $28.5 \mathrm{~N}, 77.0 \mathrm{~W}$ with a frontal boundary over the Southeast of the United States at 12Z. Ship highlights: $35 \mathrm{kt} \mathrm{N}$ and $1006 \mathrm{mb}$ at $27.0 \mathrm{~N}, 77.1 \mathrm{~W}$ at $00 \mathrm{Z}$ (micro). 75 kt NNE and $996 \mathrm{mb}$ at $28.2 \mathrm{~N}, 76.7 \mathrm{~W}$ at $13 \mathrm{Z}$ (micro). $55 \mathrm{kt} \mathrm{S}$ and $1007 \mathrm{mb}$ at $28.9 \mathrm{~N}$, $75.7 \mathrm{~W}$ at $18 \mathrm{Z}$ (micro). Aircraft highlights: Radar center fix estimated surface winds of 50 $\mathrm{kt}$ and an eye diameter of $20 \mathrm{~nm}$ at $27.8 \mathrm{~N}, 76.3 \mathrm{~W}$ at $0115 \mathrm{Z}$ (micro). Radar center fix at $27.9 \mathrm{~N}, 76.9 \mathrm{~W}$ at $06 \mathrm{Z}$ (ATSR). Radar center fix estimated an eye diameter of $12 \mathrm{~nm}$ at $28.1 \mathrm{~N}, 77.0 \mathrm{~W}$ at $0944 \mathrm{Z}$ (ATSR).

MWR: "The hurricane recurved initially near latitude $28 \mathrm{~N}$ on the 26th, and its forward speed accelerated." 
August 27:

HWM analyzes a hurricane of at most $990 \mathrm{mb}$ at $29.5 \mathrm{~N}, 76.0 \mathrm{~W}$ with cold front to the northwest at 12Z. HURDAT lists a 90 knot hurricane at $29.4 \mathrm{~N}, 76.2 \mathrm{~W}$ at $12 \mathrm{Z}$. Microfilm shows a closed low pressure of at most $1002 \mathrm{mb}$ at $30.0 \mathrm{~N}, 76.0 \mathrm{~W}$ with a frontal boundary to the northwest at $12 \mathrm{Z}$. Ship highlights: $50 \mathrm{kt} \mathrm{S}$ at $28.0 \mathrm{~N}, 75.5 \mathrm{~W}$ at $06 \mathrm{Z}$ (micro). $25 \mathrm{kt} \mathrm{ESE}$ and $1001 \mathrm{mb}$ at $31.0 \mathrm{~N}, 74.8 \mathrm{~W}$ at 12Z (COADS). $40 \mathrm{kt} \mathrm{SSE}$ and 1004 $\mathrm{mb}$ at $29.6 \mathrm{~N}, 74.0 \mathrm{~W}$ at $18 \mathrm{Z}$ (micro). $50 \mathrm{kt} \mathrm{SW}$ and $1005 \mathrm{mb}$ at $28.5 \mathrm{~N}, 75.1 \mathrm{~W}$ at $21 \mathrm{Z}$ (MWL). Aircraft highlights: Radar center fix estimated an eye diameter of $14 \mathrm{~nm}$ at $29.2 \mathrm{~N}, 76.8 \mathrm{~W}$ at $01 \mathrm{Z}$ (ATSR). Radar center fix estimated an eye diameter of $10 \mathrm{~nm}$ at $29.0 \mathrm{~N}, 76.2 \mathrm{~W}$ at $0630 \mathrm{Z}$ (ATSR). Penetration center fix estimated surface winds of $90 \mathrm{kt}$, an eye diameter of $10 \mathrm{~nm}$ and measured a central pressure of $952 \mathrm{mb}$ at $14 \mathrm{Z}$ (ATSR). Penetration center fix estimated surface winds of $109 \mathrm{kt}$, an RMW of $10 \mathrm{~nm}$ and measured a central pressure of $944 \mathrm{mb}$ around 1630Z (NHRP). Penetration center fix estimated surface winds of $104 \mathrm{kt}$, an RMW of $12 \mathrm{~nm}$ and measured a central pressure of $940 \mathrm{mb}$ around 19Z (NHRP). Penetration center fix estimated surface winds of $100 \mathrm{kt}$, an eye diameter of $12 \mathrm{~nm}$ and measured a central pressure of $935 \mathrm{mb}$ (erroneous, $948 \mathrm{mb}$ according to MWR) at $1945 Z$ (ATSR).

August 28:

HWM analyzes a hurricane of at most $990 \mathrm{mb}$ at $33.1 \mathrm{~N}, 74.5 \mathrm{~W}$ with cold front to the west at 12Z. HURDAT lists an 110 knot hurricane at $33.0 \mathrm{~N}, 74.2 \mathrm{~W}$ at $12 \mathrm{Z}$. Microfilm shows a closed low pressure of at most $1002 \mathrm{mb}$ at $33.5 \mathrm{~N}, 74.0 \mathrm{~W}$ with a frontal boundary to the northwest at 12Z. Ship highlights: $40 \mathrm{kt} \mathrm{WSW}$ and $1006 \mathrm{mb}$ at $28.5 \mathrm{~N}, 75.2 \mathrm{~W}$ at $00 \mathrm{Z}$ (COADS). $35 \mathrm{kt} \mathrm{NE}$ and $1008 \mathrm{mb}$ at $32.3 \mathrm{~N}, 77.9 \mathrm{~W}$ at $06 \mathrm{Z}$ (micro). $40 \mathrm{kt} \mathrm{S}$ and $1010 \mathrm{mb}$ at $31.0 \mathrm{~N}, 71.9 \mathrm{~W}$ at $09 \mathrm{Z}$ (micro). $40 \mathrm{kt} \mathrm{SE}$ and $1011 \mathrm{mb}$ at $35.6 \mathrm{~N}$, $73.8 \mathrm{~W}$ at $12 \mathrm{Z}$ (micro). $50 \mathrm{kt} \mathrm{SE}$ and $1001 \mathrm{mb}$ at $36.8 \mathrm{~N}, 72.7 \mathrm{~W}$ at $18 \mathrm{Z}$ (COADS). $100 \mathrm{kt}$ WNW and $999 \mathrm{mb}$ at $35.0 \mathrm{~N}, 74.8 \mathrm{~W}$ at $21 \mathrm{Z}$ (micro). Land highlights: $25 \mathrm{NNW}$ and 1000 $\mathrm{mb}$ at Cape Hatteras, NC at $21 \mathrm{Z}$ (micro). Aircraft highlights: Radar center fix at $30.5 \mathrm{~N}$, $75.1 \mathrm{~W}$ at $0001 \mathrm{Z}$ (ATSR). Radar center fix at $31.6 \mathrm{~N}, 74.5 \mathrm{~W}$ at $06 \mathrm{Z}$ (ATSR). Radar center fix estimated flight level winds of $105 \mathrm{kt}$ and an eye diameter of $15 \mathrm{~nm}$ at 0930Z (ATSR). Penetration center fix estimated surface winds of $100 \mathrm{kt}$, an eye diameter of $15 \mathrm{~nm}$ and measured a central pressure of $947 \mathrm{mb}$ at 14Z (ATSR/micro). Penetration center fix estimated surface winds of $101 \mathrm{kt}$, an RMW of $20 \mathrm{~nm}$ and measured a central pressure of $950 \mathrm{mb}$ around $17 \mathrm{Z}$ (NHRP). Penetration center fix estimated surface winds of $110 \mathrm{kt}$ and measured a central pressure of $949 \mathrm{mb}$ at $1933 \mathrm{Z}$ (ATSR).

MWR: "The center passed about 75 miles east of Hatteras on the 28th moving about 20 mph. It then passed about 70 miles southeast of Nantucket, moving east-northeastward about $25 \mathrm{mph}$ on a second recurve. Neither the North Carolina nor the New England 
coasts, however, felt much effect of this severe hurricane. The strongest wind at Hatteras was NNW $27 \mathrm{mph}$, with gusts to 36." ATSR: "DAISY developed further and winds increased to values in excess of 100 knots."

August 29:

HWM analyzes a hurricane of at most $995 \mathrm{mb}$ at $39.5 \mathrm{~N}, 70.5 \mathrm{~W}$ with a frontal just north and west at 12Z. HURDAT lists a 105 knot hurricane at $39.8 \mathrm{~N}, 70.8 \mathrm{~W}$ at $12 \mathrm{Z}$. Microfilm shows a closed low pressure of at most $999 \mathrm{mb}$ at $40.0 \mathrm{~N}, 71.0 \mathrm{~W}$ with a frontal boundary going through the center at 12Z. Ship highlights: $55 \mathrm{kt} \mathrm{SSW}$ and $994 \mathrm{mb}$ at $36.0 \mathrm{~N}, 74.0 \mathrm{~W}$ at $00 \mathrm{Z}$ (micro/MWL). $45 \mathrm{kt} \mathrm{WSW}$ and $1001 \mathrm{mb}$ at $36.5 \mathrm{~N}, 71.9 \mathrm{~W}$ at $06 \mathrm{Z}$ (micro). $55 \mathrm{kt} \mathrm{SSW}$ and $1005 \mathrm{mb}$ at $38.5 \mathrm{~N}, 70.0 \mathrm{~W}$ at $12 \mathrm{Z}$ (micro). $40 \mathrm{kt} \mathrm{S}$ and $1008 \mathrm{mb}$ at $39.1 \mathrm{~N}, 64.8 \mathrm{~W}$ at $18 \mathrm{Z}$ (micro). Land highlights: $35 \mathrm{kt}$ (gusts to $40 \mathrm{kt}$ ) at Block Island, RI (no time given) (MWR). $60 \mathrm{kt}$ (gusts to $76 \mathrm{kt}$ ) at Texas Tower (Georges Shoal), 120 miles east of Cape Cod, MA (no time given) (MWR). (37 kt ENE and $1005 \mathrm{mb}$ at Nantucket Shoals, MA at 12Z (SWO). $45 \mathrm{kt} \mathrm{NE}$ (gusts to $52 \mathrm{kt}$ ) and $997 \mathrm{mb}$ at Nantucket Shoals, MA at 15Z (SWO). $55 \mathrm{kt} \mathrm{N}$ (gusts to $66 \mathrm{kt}$ ) at Nantucket Shoals, MA at 17Z (SWO). $54 \mathrm{kt} \mathrm{NE}$ (gusts to $68 \mathrm{kt}$ ) at Georges Shoal, MA at 18Z (SWO). Aircraft highlights: Penetration center fix at $36.8 \mathrm{~N}, 73.8 \mathrm{~W}$ at $02 \mathrm{Z}$ (ATSR). Penetration center fix measured a central pressure of $967 \mathrm{mb}$ at $37.7 \mathrm{~N}, 72.9 \mathrm{~W}$ at $0428 \mathrm{Z}$ (ATSR/micro). Penetration center fix estimated an eye diameter of $20 \mathrm{~nm}$ and measured a central pressure of $973 \mathrm{mb}$ at $0812 \mathrm{Z}$ (micro). Radar center fix estimated surface winds of $75 \mathrm{kt}$ at $39.2 \mathrm{~N}, 71.4 \mathrm{~W}$ at $1446 \mathrm{Z}$ (ATSR/micro). Penetration center fix at $41.8 \mathrm{~N}, 67.2 \mathrm{~W}$ at $1930 \mathrm{Z}$ (ATSR).

MWR: "Block Island reported $40 \mathrm{mph}$, with gusts to 45. A Texas Tower, 120 miles east of Cape Cod, experienced a sustained wind of $69 \mathrm{mph}$ with gusts to 87 . There was no loss of life or appreciable property damage in the United States from Daisy."

August 30:

HWM analyzes a tropical storm of at most $1000 \mathrm{mb}$ at $42.2 \mathrm{~N}, 56.0 \mathrm{~W}$ with a weakening cold front just north at 12Z. HURDAT lists a 50 knot extratropical storm at $42.2 \mathrm{~N}, 56.1 \mathrm{~W}$ at $12 \mathrm{Z}$. Microfilm shows a closed low pressure of at most $999 \mathrm{mb}$ at $43.5 \mathrm{~N}, 55.0 \mathrm{~W}$ with a frontal boundary to the west at 12Z. Ship highlights: $60 \mathrm{kt} \mathrm{SW}$ and $1005 \mathrm{mb}$ at $39.7 \mathrm{~N}, 64.2 \mathrm{~W}$ at $00 \mathrm{Z}$ (COADS). $50 \mathrm{kt} \mathrm{S}$ and $1001 \mathrm{mb}$ at $41.2 \mathrm{~N}, 59.8 \mathrm{~W}$ at 06Z (COADS). $55 \mathrm{kt} \mathrm{WSW}$ and $999 \mathrm{mb}$ at $41.4 \mathrm{~N}, 56.5 \mathrm{~W}$ at $12 \mathrm{Z}$ (MWL). $55 \mathrm{kt} \mathrm{W}$ and $999 \mathrm{mb}$ at $40.9 \mathrm{~N}, 56.4 \mathrm{~W}$ at $15 \mathrm{Z}$ (COADS). $50 \mathrm{kt} \mathrm{N}$ and $1008 \mathrm{mb}$ at $40.9 \mathrm{~N}, 57.1 \mathrm{~W}$ at $18 \mathrm{Z}$ (COADS). 
August 31:

HWM analyzes a tropical storm of at most $1000 \mathrm{mb}$ at $41.0 \mathrm{~N}, 42.0 \mathrm{~W}$ with a cold front to the south and northeast at 12Z. HURDAT lists a 35 knot extratropical storm at $41.0 \mathrm{~N}, 42.2 \mathrm{~W}$ at $12 \mathrm{Z}$. Microfilm shows that the extratropical cyclone has moved off the northeast edge of the synoptic map at 12Z. Ship highlights: $50 \mathrm{kt} \mathrm{NNE}$ and $1006 \mathrm{mb}$ at $41.8 \mathrm{~N}, 51.6 \mathrm{~W}$ at $00 \mathrm{Z}$ (COADS). $50 \mathrm{kt} \mathrm{NNE}$ and $1009 \mathrm{mb}$ at $42.3 \mathrm{~N}, 49.1 \mathrm{~W}$ at $06 \mathrm{Z}$ (COADS). $40 \mathrm{kt} \mathrm{N}$ and $1011 \mathrm{mb}$ at $43.0 \mathrm{~N}, 47.0 \mathrm{~W}$ at $12 \mathrm{Z}$ (COADS). $40 \mathrm{kt} \mathrm{NE}$ and 1012 $\mathrm{mb}$ at $43.8 \mathrm{~N}, 44.8 \mathrm{~W}$ at $18 \mathrm{Z}$ (COADS).

September 1:

HWM analyzes an extratropical cyclone of at most $985 \mathrm{mb}$ at $50.5 \mathrm{~N}, 23.0 \mathrm{~W}$, likely indicating that Daisy has been absorbed, at 12Z. HURDAT does not list an organized storm on this date. Microfilm is not available on this date. Ship highlights: 40 kt SW and $1005 \mathrm{mb}$ at $39.3 \mathrm{~N}, 35.8 \mathrm{~W}$ at $00 \mathrm{Z}$ (COADS). $35 \mathrm{kt} \mathrm{WSW}$ and $1013 \mathrm{kt}$ at $36.4 \mathrm{~N}, 34.5 \mathrm{~W}$ at $06 \mathrm{Z}(\mathrm{COADS})$.

Hurricane Daisy developed from a tropical wave just north of the central Bahamas. A strong tropical wave was noticeable in the ship and coastal observations over the northern Caribbean during the $22^{\text {nd }}$ and $23^{\text {rd }}$ of August. A well-defined surface center formed on August $24^{\text {th }}$ at $12 \mathrm{Z}$ and a $35 \mathrm{kt}$ tropical storm is analyzed to have developed at this time, same as the original HURDAT. It is possible that Daisy may have formed about twelve to eighteen hours earlier but the data is not sufficient to make a conclusive assessment. The track alterations were minor during the lifetime of this tropical cyclone. The forward speed of Daisy was slow during its first days and it gradually intensified. The first reconnaissance aircraft to reach Daisy occurred at $2311 \mathrm{Z}$ on the $24^{\text {th }}$ measuring a central pressure of $1002 \mathrm{mb}$ and estimating surface winds of $45 \mathrm{kt}$. A central pressure of 1002 mb suggests maximum sustained winds of $42 \mathrm{kt}$ south of $25 \mathrm{~N}$ intensifying from the Brown et al. pressure-wind relationship. Due in part to a ship report of $50 \mathrm{kt}$ northeast of the center, an intensity of $50 \mathrm{kt}$ analyzed at $00 \mathrm{Z}$ on September $25^{\text {th }}$, same as originally shown in HURDAT. A central pressure of $1002 \mathrm{mb}$ was in HURDAT at $00 \mathrm{Z}$ on the $25^{\text {th }}$ and has been retained. (The original HURDAT for this tropical cyclone had central pressure values for each 6 hour period from $00 \mathrm{Z}$ on the $25^{\text {th }}$ to $00 \mathrm{Z}$ on the $31^{\text {th }}$. These were obviously analyses that were added in, not based upon actual observations. Most of the analyzed central pressures appear reasonable and have been retained.) The next aircraft reached Daisy at $1310 \mathrm{Z}$ on the $25^{\text {th }}$ measuring a central pressure of $996 \mathrm{mb}$ and estimating flight level winds of $70 \mathrm{kt}$. A central pressure of $996 \mathrm{mb}$ suggests maximum sustained winds of $52 \mathrm{kt}$ north of $25 \mathrm{~N}$ intensifying from the pressure-wind relationship. Daisy was moving at about $4 \mathrm{kt}$ but it was also synoptically a small tropical cyclone, thus an intensity of $55 \mathrm{kt}$ has been selected for $12 \mathrm{Z}$ on the $25^{\text {th }}, 10 \mathrm{kt}$ less than the original 
HURDAT. A central pressure of $996 \mathrm{mb}$ has been added to HURDAT at $12 \mathrm{Z}$ on the $25^{\text {th }}$, replacing the existing $997 \mathrm{mb}$. Another reconnaissance aircraft visited Daisy late on the $25^{\text {th }}$ measuring a central pressure of $990 \mathrm{mb}$ and estimated $50 \mathrm{kt}$ at 5000 feet of altitude at 2030Z. A central pressure of $990 \mathrm{mb}$ suggests maximum sustained winds of $62 \mathrm{kt}$ north of $25 \mathrm{~N}$ intensifying from the pressure-wind relationship. Due to the slow forward speed of about $5 \mathrm{kt}$ but small size of the tropical cyclone, an intensity of $60 \mathrm{kt}$ has been selected for $18 \mathrm{Z}$ on the $25^{\text {th }}$, down from $65 \mathrm{kt}$ originally in HURDAT, a minor intensity change. A central pressure of $990 \mathrm{mb}$ has been added to $18 \mathrm{Z}$ on the $25^{\text {th }}$, replacing the existing 994 $\mathrm{mb}$ in the original HURDAT. No central pressures were reported on August $26^{\text {th }}$ but it is likely that Daisy experienced a period of rapid intensification based from the estimates of the eye diameter reported by the reconnaissance aircraft radar, ship observations and subsequent central pressure measurements on the $27^{\text {th }}$. The eye diameter of Daisy decreased from $20 \mathrm{~nm}$ to $12 \mathrm{~nm}$ between $1930 \mathrm{Z}$ on the $25^{\text {th }}$ and $0944 \mathrm{Z}$ on the $26^{\text {th }}$ according to reports from the reconnaissance aircrafts. A few ships reported tropical storm force winds and there was even a ship at $12 \mathrm{Z}$ near the center of the hurricane that registered $75 \mathrm{kt}$. Intensification to a hurricane is analyzed at $00 \mathrm{Z}$ on the $26^{\text {th }}$, six hours later than the original HURDAT. A major intensity change is analyzed at $18 \mathrm{Z}$ on the $26^{\text {th }}$. An intensity of $95 \mathrm{kt}$ is selected for this time and $75 \mathrm{kt}$ is originally shown in HURDAT. Late on the $26^{\text {th }}$, the track of Daisy turned to the north and then northeast.

A reconnaissance aircraft reached the hurricane at $14 \mathrm{Z}$ on September $27^{\text {th }}$ measuring a central pressure of $952 \mathrm{mb}$ and estimating surface winds of $90 \mathrm{kt}$ and an eye diameter of $10 \mathrm{~nm}$. A central pressure of $952 \mathrm{mb}$ suggests maximum sustained winds of $108 \mathrm{kt}$ north of $25 \mathrm{~N}$ intensifying from the pressure-wind relationship. An eye diameter of $10 \mathrm{~nm}$ suggests an RMW of about $8 \mathrm{~nm}$ and climatology suggest about $19 \mathrm{~nm}$. Due to the slow forward speed of about $6 \mathrm{kt}$ but relatively small size, an intensity of $110 \mathrm{kt}$ is selected for $12 \mathrm{Z}$ on the $27^{\text {th }}$, up from $90 \mathrm{kt}$ originally in HURDAT, a major intensity change. Based on this information, intensification to a major hurricane is analyzed at $00 \mathrm{Z}$ on the $27^{\mathrm{th}}, 24$ hours earlier than originally in HURDAT. Major intensity changes are also analyzed at $00 \mathrm{Z}$ and $06 \mathrm{Z}$ on the $27^{\text {th }}$. HURDAT originally had $80 \mathrm{kt}$ and $85 \mathrm{kt}$, respectively, and the analyzed intensities for these times are $100 \mathrm{kt}$ and $105 \mathrm{kt}$, respectively. A central pressure of $952 \mathrm{mb}$ has been added to HURDAT at $12 \mathrm{Z}$ on the $27^{\text {th }}$, replacing the existing $956 \mathrm{mb}$. Daisy continued to gain strength on the $27^{\text {th }}$ according to reports from the aircraft reconnaissance. The central pressure decreased to $944 \mathrm{mb}$ around 1630Z, $942 \mathrm{mb}$ around $18 \mathrm{Z}$ and $940 \mathrm{mb}$ around 19Z, according to the National Hurricane Research Project. A central pressure of $942 \mathrm{mb}$ suggests maximum sustained winds of $118 \mathrm{kt}$ north of $25 \mathrm{~N}$ intensifying from the pressure-wind relationship. The NHRP reconnaissance aircraft also reported an RMW of $12 \mathrm{~nm}$ and climatology suggest about $14 \mathrm{~nm}$. Due to a forward speed of about $8 \mathrm{kt}$ and an RMW close to climatology, an intensity of $120 \mathrm{kt}$ is selected for $18 \mathrm{Z}$ on the $27^{\text {th }}$, up from $95 \mathrm{kt}$ originally in HURDAT, a major intensity change. 120 
kt is also the peak intensity of Daisy, up from 110 kt originally in HURDAT between $06 \mathrm{Z}$ on September $28^{\text {th }}$ to $06 \mathrm{Z}$ on the $29^{\text {th }}$. A central pressure of $944 \mathrm{mb}$ is present in HURDAT at $18 Z$ on the $27^{\text {th }}$ and has been replaced with $942 \mathrm{mb}$ measured by the NHRP reconnaissance aircraft. A central pressure of $935 \mathrm{mb}$ is present in HURDAT at $00 \mathrm{Z}$ on the $28^{\text {th }}$, but an article on the Monthly Weather Review (Tracy, 1966) indicates that there was an error made during the measurement of this central pressure and that the actual value was $948 \mathrm{mb}$. Thus, the central pressure of $935 \mathrm{mb}$ has been removed from HURDAT. A central pressure of $938 \mathrm{mb}$ is in HURDAT at $06 \mathrm{Z}$ on the $28^{\text {th }}$ and has also been removed since there is no evidence that the central pressure decreased below 940 $\mathrm{mb}$.

The next aircraft to reach the hurricane occurred at $14 \mathrm{Z}$ on the $28^{\text {th }}$ measuring a central pressure of $947 \mathrm{mb}$, and estimating surface winds of $100 \mathrm{kt}$ and an eye diameter of 15 $\mathrm{nm}$. A central pressure of $947 \mathrm{mb}$ suggests maximum sustained winds of $108 \mathrm{kt}$ north of $25 \mathrm{~N}$ from the pressure-wind relationship. An eye diameter of $15 \mathrm{~nm}$ suggests an RMW of about $12 \mathrm{~nm}$ and climatology suggests $23 \mathrm{~nm}$. Since Daisy was moving at about $16 \mathrm{kt}$ and the RMW was smaller than the climatological value, an intensity of $115 \mathrm{kt}$ is selected at $12 \mathrm{Z}$ on the $28^{\text {th }}$, up from $110 \mathrm{kt}$ originally in HURDAT, a minor intensity change. A central pressure of $947 \mathrm{mb}$ is added to $12 \mathrm{Z}$ on the $28^{\text {th }}$, replacing the exiting $946 \mathrm{mb}$. Another reconnaissance aircraft measured a central pressure of $949 \mathrm{mb}$ at 1933Z, suggesting maximum sustained winds of $106 \mathrm{kt}$ north of $25 \mathrm{~N}$ from the Brown et al. pressure-wind relationship and $98 \mathrm{kt}$ north of $35 \mathrm{~N}$ from the Landsea et al. pressure-wind relationship. Around 17Z, the NHRP reconnaissance aircraft reported an RMW of $20 \mathrm{~nm}$ and climatology suggest about $25 \mathrm{~nm}$. Daisy was moving at about $16 \mathrm{kt}$ and remained a small hurricane, thus an intensity of $110 \mathrm{kt}$ is selected for $18 \mathrm{Z}$ on the $28^{\text {th }}$, same as the original HURDAT. A central pressure of $955 \mathrm{mb}$ was present in HURDAT at $18 \mathrm{Z}$ on the $28^{\text {th }}$ and has been replaced with $949 \mathrm{mb}$. Late on the $28^{\text {th }}$, Daisy passed about $90 \mathrm{~nm}$ east of Cape Hatteras. No tropical storm force winds were reported, indicative of the small size of the hurricane. Early on the $29^{\text {th }}$, Daisy made a sharp turn to the northeast increasing in forward speed ahead of a frontal boundary. Central pressures of $967 \mathrm{mb}$ and $973 \mathrm{mb}$ were reported at $0428 \mathrm{Z}$ and $0812 \mathrm{Z}$, respectively, by the reconnaissance aircraft. A central pressure of $970 \mathrm{mb}$ was in HURDAT at $06 \mathrm{Z}$ on the $29^{\text {th }}$ and has been retained based on a blend of these two measurements. A central pressure of $970 \mathrm{mb}$ suggests maximum sustained winds of $82 \mathrm{kt}$ north of $35 \mathrm{~N}$ from the pressure-wind relationship. Due to the fast forward speed of about $25 \mathrm{kt}$ and small size of the hurricane, an intensity of $90 \mathrm{kt}$ is selected at $06 \mathrm{Z}$ on the $29^{\text {th }}$, down from $110 \mathrm{kt}$ originally in HURDAT, a major intensity change. A major intensity change is also analyzed at $12 \mathrm{Z}$ and $18 \mathrm{Z}$ on the $29^{\text {th }}$. HURDAT originally had $105 \mathrm{kt}$ and $90 \mathrm{kt}$, respectively, and the selected intensities are 80 $\mathrm{kt}$ and $70 \mathrm{kt}$, respectively. Ship and coastal observations indicate that Daisy began to acquire extratropical characteristics early on the $29^{\text {th }}$. The surface analysis early on the 
$29^{\text {th }}$ suggests that the circulation was becoming more elongated N-S with frontal features developing as the hurricane became embedded within the frontal boundary. It is analyzed that Daisy became an extratropical cyclone at $12 \mathrm{Z}$ on the $29^{\text {th }}$, twelve hours earlier than originally shown in HURDAT. Late on the $29^{\text {th }}$, the extratropical cyclone passed about 50 $\mathrm{nm}$ southeast of Cape Cod. Gale force winds were reported at Block Island and Nantucket. Georges Shoals located about $120 \mathrm{~nm}$ east of Cape Cod, experienced hurricane-force gusts. The extratropical cyclone continued to weaken on the $30^{\text {th }}$ while its track turned to the east. Daisy passed about $90 \mathrm{~nm}$ south of Nova Scotia early on the $30^{\text {th }}$. Weakening below hurricane force is analyzed at $06 \mathrm{Z}$ on the $30^{\text {th }}$, same as the original HURDAT. Ship observations on August $31^{\text {st }}$ indicate that a larger extratropical cyclone over the north Atlantic gradually absorbed the much smaller Daisy. Dissipation is analyzed after $00 \mathrm{Z}$ on the $31^{\text {st }}$, eighteen hours earlier than originally shown in HURDAT.

\begin{tabular}{|c|c|c|c|}
\hline Date & $\begin{array}{l}\text { Original } \\
\text { HURDAT } \\
\text { Central } \\
\text { Pressure } \\
\end{array}$ & Evidence & Changes \\
\hline Aug $2500 \mathrm{Z}$ & $1002 \mathrm{mb}$ & $\begin{array}{l}\text { Penetration center fix: } 1002 \mathrm{mb} \text { at } 2311 \mathrm{Z} \\
\text { on Aug } 24^{\text {th }}\end{array}$ & Retained \\
\hline Aug $2506 \mathrm{Z}$ & $1000 \mathrm{mb}$ & $\begin{array}{l}\text { Ship: } 20 \mathrm{kt} \mathrm{SW} \text { and } 1001 \mathrm{mb} \text { at } 09 \mathrm{Z} \text { on } \\
\text { Aug } 25^{\text {th }}\end{array}$ & Retained \\
\hline Aug $2512 Z$ & $997 \mathrm{mb}$ & $\begin{array}{l}\text { Penetration center fix: } 996 \mathrm{mb} \text { at } 1310 \mathrm{Z} \\
\text { on Aug } 25^{\text {th }}\end{array}$ & $996 \mathrm{mb}$ \\
\hline Aug $2518 \mathrm{Z}$ & $994 \mathrm{mb}$ & $\begin{array}{l}\text { Penetration center fix: } 990 \mathrm{mb} \text { at } 2030 \mathrm{Z} \\
\text { on Aug } 25^{\text {th }}\end{array}$ & $990 \mathrm{mb}$ \\
\hline Aug $2600 \mathrm{Z}$ & $989 \mathrm{mb}$ & \multirow{6}{*}{$\begin{array}{l}\text { No central pressure reports but appear } \\
\text { reasonable based on the central pressure } \\
\text { reports from late Aug } 25^{\text {th }} \text { and } 14 \mathrm{Z} \text { on } \\
\operatorname{Aug} 27^{\text {th }}\end{array}$} & \multirow{6}{*}{ Retained } \\
\hline Aug $2606 Z$ & $985 \mathrm{mb}$ & & \\
\hline Aug $2612 Z$ & $979 \mathrm{mb}$ & & \\
\hline Aug $2618 \mathrm{Z}$ & $974 \mathrm{mb}$ & & \\
\hline Aug $2700 \mathrm{Z}$ & $968 \mathrm{mb}$ & & \\
\hline Aug $2706 Z$ & $963 \mathrm{mb}$ & & \\
\hline Aug $2712 Z$ & $956 \mathrm{mb}$ & $\begin{array}{l}\text { Penetration center fix: } 952 \mathrm{mb} \text { at } 14 \mathrm{Z} \text { on } \\
\text { Aug } 27^{\text {th }}\end{array}$ & $952 \mathrm{mb}$ \\
\hline Aug $2718 \mathrm{Z}$ & $944 \mathrm{mb}$ & $\begin{array}{l}\text { Penetration center fix: } 942 \mathrm{mb} \text { at } 18 \mathrm{Z} \text { on } \\
\text { Aug } 25^{\text {th }}\end{array}$ & $942 \mathrm{mb}$ \\
\hline
\end{tabular}




\begin{tabular}{|c|c|c|c|}
\hline Aug 28 00Z & $935 \mathrm{mb}$ & $\begin{array}{l}\text { Tracy, } 1966 \text { indicates that } 935 \mathrm{mb} \\
\text { measured at } 1945 \mathrm{Z} \text { on Aug } 27^{\text {th }} \text { was } 948 \\
\text { mb }\end{array}$ & Removed \\
\hline Aug 28 06Z & $938 \mathrm{mb}$ & $\begin{array}{l}\text { No evidence the central pressure dropped } \\
\text { below } 940 \mathrm{mb} \text { measured by the NHRP } \\
\text { around } 19 \mathrm{Z} \text { on Aug } 27^{\text {th }}\end{array}$ & Removed \\
\hline Aug $2812 Z$ & $946 \mathrm{mb}$ & $\begin{array}{l}\text { Penetration center fix: } 947 \mathrm{mb} \text { at } 14 \mathrm{Z} \text { on } \\
\text { Aug } 28^{\text {th }}\end{array}$ & $947 \mathrm{mb}$ \\
\hline Aug $2818 \mathrm{Z}$ & $955 \mathrm{mb}$ & $\begin{array}{l}\text { Penetration center fix: } 949 \mathrm{mb} \text { at } 1933 \mathrm{Z} \\
\text { on Aug } 28^{\text {th }}\end{array}$ & $949 \mathrm{mb}$ \\
\hline Aug 29 00Z & $963 \mathrm{mb}$ & \multirow{5}{*}{$\begin{array}{l}\text { No central pressure reports but appear } \\
\text { reasonable }\end{array}$} & \multirow{5}{*}{ Retained } \\
\hline Aug $2906 Z$ & $970 \mathrm{mb}$ & & \\
\hline Aug $2912 Z$ & $977 \mathrm{mb}$ & & \\
\hline Aug $2918 Z$ & $982 \mathrm{mb}$ & & \\
\hline Aug $3000 Z$ & $987 \mathrm{mb}$ & & \\
\hline
\end{tabular}

Hurricane Ella [August 30 - September 7, 1958]

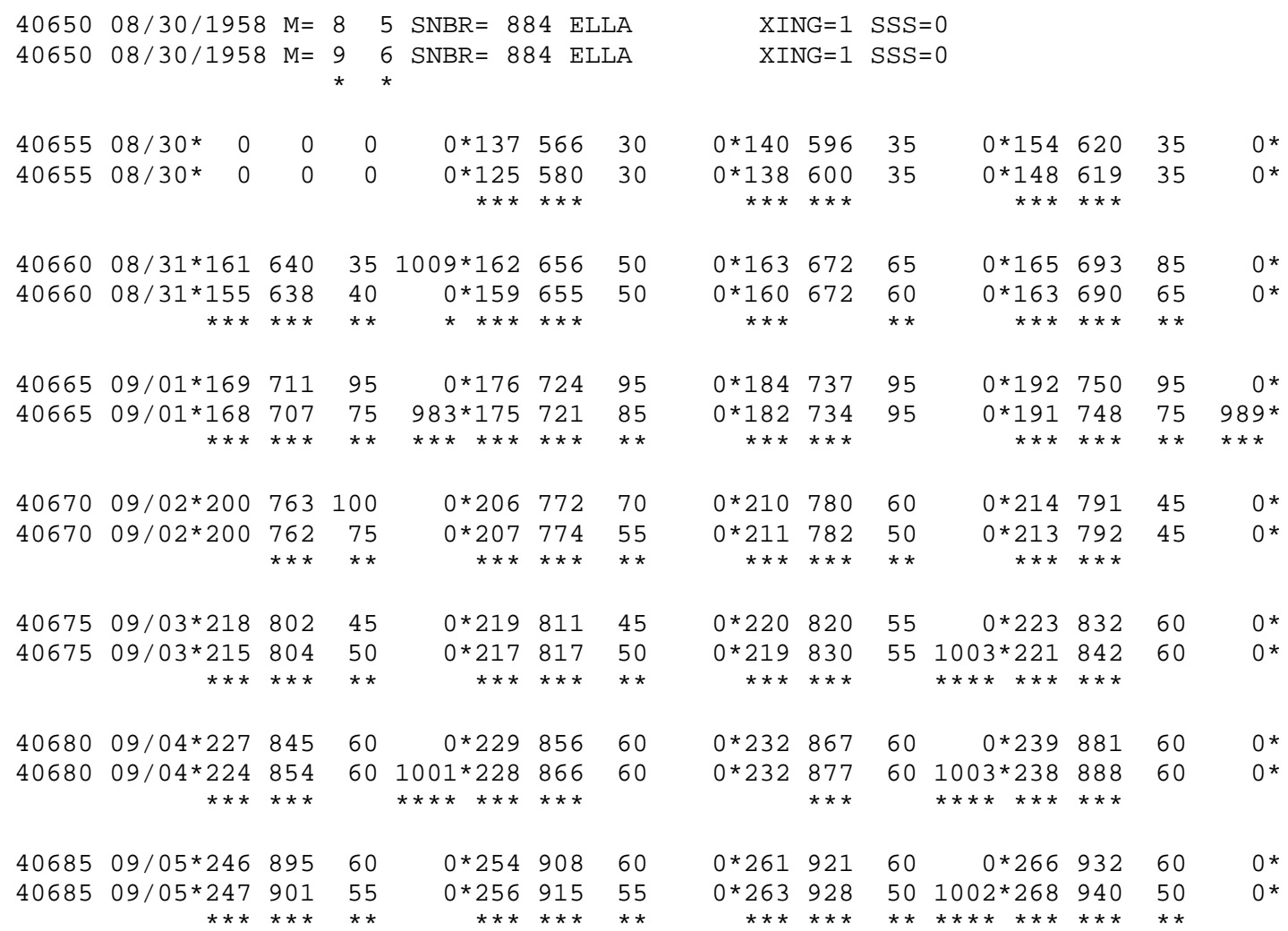




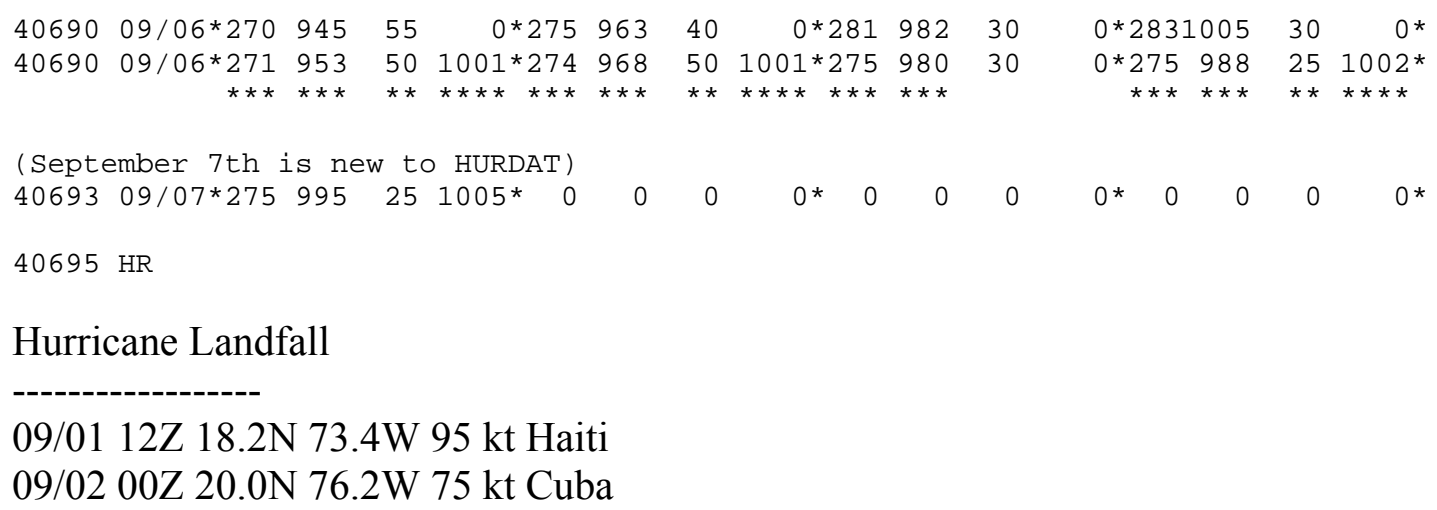

Tropical Storm Landfall

09/03 11Z 21.8N 82.7W 55 kt Cuba

09/03 17Z 22.1N 84.0W 60 kt Cuba

U.S. Tropical Storm Impact

09/03 12Z 21.9N 83.0W 50 kt FL

09/05 18Z 26.8N 94.0W 40 kt LA

\section{U.S. Tropical Storm Landfall}

09/06 08Z 27.5N 97.2W 50 kt TX

Major changes to the intensity and minor changes to the track shown in McAdie et al. (2009). Evidence for these alterations comes from the NHC microfilm maps, the Historical Weather Maps series, the COADS ship database, Monthly Weather Review, the Local Climatological Data, Surface Weather Observations, Navy reconnaissance book, Mariners Weather Log, Perez et al. (2000), and NHC Storm Wallets.

\section{August 29:}

HWM is not available on this date (system south of $20^{\circ} \mathrm{N}$ ). HURDAT does not list an organized storm on this date. Microfilm shows a tropical wave extending along $10 \mathrm{~N}-16 \mathrm{~N}$, 50-52W at 12Z. Ship highlights: No gales or low pressures.

MWR: "First indication of Ella was a fairly active easterly wave in the vicinity of longitude 50W on August 29. Reconnaissance aircraft on a routine flight east of the Windward and Leeward Islands reported a wind shift and above average shower activity, but no indication of a cyclonic circulation."

August 30: 
HWM is not available on this date (system south of $20^{\circ} \mathrm{N}$ ). HURDAT lists a 35 knot tropical storm at $14.0 \mathrm{~N}, 59.6 \mathrm{~W}$ at $12 \mathrm{Z}$. Microfilm shows a tropical wave along longitude $60 \mathrm{~W}$, from $10 \mathrm{~N}-16 \mathrm{~N}$ at $12 \mathrm{Z}$. Ship highlights: No gales or low pressures.

MWR: "The wave moved through the islands during the $30^{\text {th }}$ causing heavy rains and winds of 35 to $40 \mathrm{mph}$ and lowest pressure around $1010 \mathrm{mb}$." ATSR: "ELLA formed in the Leeward Islands, under circumstances, that were definitely unfavorable for hurricane development. ELLA was first detected with a closed vortex late on the $30^{\text {th }}$ of August very near Guadaloupe Island."

August 31:

HWM is not available on this date (system south of $20^{\circ} \mathrm{N}$ ). HURDAT lists a 65 knot hurricane at $16.3 \mathrm{~N}, 67.2 \mathrm{~W}$ at $12 \mathrm{Z}$. Microfilm shows closed low pressure of at most $1002 \mathrm{mb}$ at $15.5 \mathrm{~N}, 67.0 \mathrm{~W}$ at 12Z. Ship highlights: $35 \mathrm{kt} \mathrm{E}$ and $1009 \mathrm{mb}$ at $16.5 \mathrm{~N}, 66.7 \mathrm{~W}$ at $06 \mathrm{Z}$ (micro). $56 \mathrm{kt} \mathrm{E}$ and $1000 \mathrm{mb}$ at $16.2 \mathrm{~N}, 67.0 \mathrm{~W}$ at $12 \mathrm{Z}$ (COADS/MWL). $50 \mathrm{kt} \mathrm{SE}$ and $1007 \mathrm{mb}$ at $15.6 \mathrm{~N}, 66.4 \mathrm{~W}$ at $12 \mathrm{Z}$ (micro). $40 \mathrm{kt} \mathrm{S}$ and $1006 \mathrm{mb}$ at $16.3 \mathrm{~N}, 69.5 \mathrm{~W}$ at $21 \mathrm{Z}$ (micro). Aircraft highlights: Radar center fix estimated surface winds of $50 \mathrm{kt}$ and measured a minimum pressure (not a central pressure) of $1009 \mathrm{mb}$ at $16.5 \mathrm{~N}, 64.7 \mathrm{~W}$ at $0330 \mathrm{Z}$ (micro). Radar center fix estimated surface winds of $35 \mathrm{kt}$ at $16.1 \mathrm{~N}, 66.7 \mathrm{~W}$ at $10 \mathrm{Z}$ (ATSR). Radar center fix estimated an eye diameter of $40 \mathrm{~nm}$ at $16.1 \mathrm{~N}, 67.2 \mathrm{~W}$ at $12 \mathrm{Z}$ (ATSR). Radar center fix estimated surface winds of $75 \mathrm{kt}$ and an eye diameter of $28 \mathrm{~nm}$ at $16.1 \mathrm{~N}, 67.7 \mathrm{~W}$ at $14 \mathrm{Z}$ (ATSR). Radar center fix estimated surface winds of $80 \mathrm{kt}$ and an eye diameter of $14 \mathrm{~nm}$ at $16.6 \mathrm{~N}, 69.4 \mathrm{~W}$ at $20 \mathrm{Z}$ (ATSR). Penetration center fix estimated surface winds of $80 \mathrm{kt}$, measured a central pressure of $983 \mathrm{mb}$ and an eye diameter of 30 $\mathrm{nm}$ at $16.8 \mathrm{~N}, 70.5 \mathrm{~W}$ at $23 \mathrm{Z}$ (ATSR).

MWR: "Reconnaissance aircraft located a center by radar at latitude $16.3 \mathrm{~N}$., longitude 64.7W., during the evening of the $30^{\text {th }}$ (local time) and the first advisory was issued on tropical storm Ella. Highest winds were estimated at 55 to $60 \mathrm{mph}$ near the center and the minimum pressure had dropped to about $1009 \mathrm{mb}$. Advice to small craft and residents of the islands from Puerto Rico eastward and southward had previously by bulletins had been given previously from the San Juan Bureau Weather Bureau Office. The storm intensified rapidly as it moved westward at about $18 \mathrm{mph}$ in the eastern Caribbean and by 1600 GMT of the $31^{\text {st }}$ winds were estimated by aircraft at $85 \mathrm{mph}$..." ATSR: "A Navy reconnaissance aircraft investigated the area just to the west of the Leeward Islands early on the morning of the $31^{\text {st }}$, and the eye was centered by radar at $310330 \mathrm{Z}, 80$ miles south of Saint Croix Island. ELLA rapidly developed into a full hurricane and, by midafternoon on the $31^{\text {st }}$, hurricane force winds were reported by reconnaissance aircraft. ... Later on the $31^{\text {st }}$ (312130Z) the reconnaissance aircraft tracking ELLA reported that the eye was becoming diffuse and as the center passed over south-western Haiti, it became 
very diffuse."

September 1:

HWM is not available on this date (system south of $20^{\circ} \mathrm{N}$ ). HURDAT lists a 95 knot hurricane at $18.4 \mathrm{~N}, 73.7 \mathrm{~W}$ at $12 \mathrm{Z}$. Microfilm shows a tropical wave or trough along longitude $75 \mathrm{~W}$, from $14 \mathrm{~N}-21 \mathrm{~N}$ at $12 \mathrm{Z}$. Ship highlights: No gales or low pressures. Land highlights: $40 \mathrm{kt}$ ENE and $1006 \mathrm{mb}$ at Guantanamo Bay, Cuba at 21Z (micro). Aircraft highlights: Radar center fix estimated an eye diameter of $30 \mathrm{~nm}$ at $17.0 \mathrm{~N}, 70.9 \mathrm{~W}$ at $0035 \mathrm{Z}$ (ATSR). Radar center fix measured a minimum pressure (not a central pressure) of $996 \mathrm{mb}$ and estimated an eye diameter of $20 \mathrm{~nm}$ at $16.8 \mathrm{~N}, 71.4 \mathrm{~W}$ at $02 \mathrm{Z}$ (ATSR). Radar center fix at $18.1 \mathrm{~N}, 73.2 \mathrm{~W}$ at $11 \mathrm{Z}$ (ATSR). Penetration center fix measured a minimum pressure (not a central pressure) north of the center of $999 \mathrm{mb}$ at $18.3 \mathrm{~N}, 73.5 \mathrm{~W}$ at $1242 \mathrm{Z}$ (ATSR). Penetration center fix measured a central pressure of $989 \mathrm{mb}$, estimated surface winds of $110 \mathrm{kt}$ and an eye diameter of $16 \mathrm{~nm}$ at $19.7 \mathrm{~N}, 75.5 \mathrm{~W}$ at 2042Z (ATSR/MWR/WALLET).

MWR: “... increasing to $110 \mathrm{mph}$ by 0400 GMT of September 1. The course had changed to the west-northwest during the day, as the center skirted along and just south of the Dominican Republic and Haitian coasts, causing torrential rains and considerable damage on the southern slopes of the mountains. It was thought that the hurricane passed over the southwestern peninsula of Haiti, however, since the original intensity was maintained until it encountered the Sierra Maestra in eastern Cuba, the center of the hurricane may have skirted along the immediate south coast of Haiti. In fact, reports from the Haitian Meteorological Service indicate the hurricane followed a path parallel to the peninsula. Reconnaissance aircraft on September 1 reported winds of $115 \mathrm{mph}$ and lowest pressure of $989 \mathrm{mb}$ while the center was over the Caribbean Sea between Jamaica, Haiti, and eastern Cuba. The center passed inland over the Sierra Maestra in Oriente Province in eastern Cuba a short distance west of Santiago and the storm weakened below hurricane strength. It never regained hurricane force in its long path along the southern coast of Cuba, across the Gulf of Mexico, to the lower Texas coast." ATSR: "ELLA continued intensification and late on the first of September wind velocity of 110 knots was reported by the Navy aircraft. On passing over water between Haiti and Cuba, ELLA reorganized and winds of 110 knots were estimated near the center until the $2^{\text {nd }}$."

September 2:

HWM analyzes a hurricane of at most $1005 \mathrm{mb}$ at $21.0 \mathrm{~N}, 78.2 \mathrm{~W}$ at $12 \mathrm{Z}$. HURDAT lists a 60 knot tropical storm at 21.0N, $78.0 \mathrm{~W}$ at 12Z. Microfilm shows closed low pressure of at most $1008 \mathrm{mb}$ at $20.0 \mathrm{~N}, 80.0 \mathrm{~W}$ at 12Z. Ship highlights: $40 \mathrm{kt}$ ESE and $1011 \mathrm{mb}$ at $21.5 \mathrm{~N}, 76.6 \mathrm{~W}$ at $00 \mathrm{Z}$ (micro). $35 \mathrm{kt} \mathrm{SE}$ and $1010 \mathrm{mb}$ at $17.8 \mathrm{~N}, 74.9 \mathrm{~W}$ at $06 \mathrm{Z}$ 
(COADS). $35 \mathrm{kt} \mathrm{ESE}$ and $1009 \mathrm{mb}$ at $18.2 \mathrm{~N}, 75.0 \mathrm{~W}$ at 12Z (COADS). $40 \mathrm{kt} \mathrm{SE}$ and 1011 $\mathrm{mb}$ at $18.9 \mathrm{~N}, 75.3 \mathrm{~W}$ at $18 \mathrm{Z}$ (COADS). Land highlights: $50 \mathrm{kt} \mathrm{SSE}$, gusts to $60 \mathrm{kt}$ and $1008 \mathrm{mb}$ at Santiago de Cuba, Cuba at 03Z (micro). $35 \mathrm{kt}$ and $1018 \mathrm{mb}$ at Carysfort Reef Light, FL at 1230Z (SWO). $41 \mathrm{kt}$ and $1010 \mathrm{mb}$ at Alligator Reef Light, FL at $1530 \mathrm{Z}$ (SWO). $35 \mathrm{kt} \mathrm{E}$, gusts to $45 \mathrm{kt}$, and $1012 \mathrm{mb}$ at Key West, FL at 2335Z (SWO). Aircraft highlights: Radar center fix estimated an eye diameter of $25 \mathrm{~nm}$ at $20.0 \mathrm{~N}, 76.2 \mathrm{~W}$ at 0030Z (ATSR). Radar center fix estimated flight level winds (500 mb) of $74 \mathrm{kt}$ and an eye diameter of $12 \mathrm{~nm}$ at $21.6 \mathrm{~N}, 78.1 \mathrm{~W}$ at $0853 \mathrm{Z}$ (ATSR). Radar center fix estimated surface winds of $50 \mathrm{kt}$ and measured a minimum pressure (not a central pressure) of 1010 $\mathrm{mb}$ at $21.7 \mathrm{~N}, 78.3 \mathrm{~W}$ at $1645 \mathrm{Z}$ (MICRO/ATSR).

MWR: "As the storm moved west-northwestward along the southern coast of Cuba, a building high pressure system was moving into the Atlantic States, and consequently gale warnings were hoisted on the lower east coast of Florida and in the Florida Keys, because of the anticipated increase of pressure gradient caused by interaction between the two systems. Highest winds had dropped to 40 to $50 \mathrm{mph}$ in squalls but the area of squalls and rather heavy rain extended across Cuba into the southern Bahamas and the Florida Straits and Keys." ATSR: "ELLA moved inland into Cuba and lost much of her "punch" during her journey over land for almost the entire length of Cuba."

September 3:

HWM analyzes a tropical storm of at most $1005 \mathrm{mb}$ at $22.2 \mathrm{~N}, 82.3 \mathrm{~W}$ at $12 \mathrm{Z}$. HURDAT lists a 55 knot tropical storm at $22.0 \mathrm{~N}, 82.0 \mathrm{~W}$ at $12 \mathrm{Z}$. Microfilm shows closed low pressure of at most $1005 \mathrm{mb}$ at $21.5 \mathrm{~N}, 83.5 \mathrm{~W}$ at $12 \mathrm{Z}$. Ship highlights: $35 \mathrm{kt} \mathrm{ENE}$ and $1010 \mathrm{mb}$ at $23.8 \mathrm{~N}, 81.4 \mathrm{~W}$ at $03 \mathrm{Z}$ (micro). $45 \mathrm{kt} \mathrm{SE}$ and $1009 \mathrm{mb}$ at $20.5 \mathrm{~N}, 80.5 \mathrm{~W}$ at $12 \mathrm{Z}$ (COADS). $50 \mathrm{kt}$ ESE and $1012 \mathrm{mb}$ at $24.8 \mathrm{~N}, 83.8 \mathrm{~W}$ at $15 \mathrm{Z}$ (COADS). $50 \mathrm{kt} \mathrm{SE}$ and 1012 $\mathrm{mb}$ at $24.3 \mathrm{~N}, 83.0 \mathrm{~W}$ at $18 \mathrm{Z}$ (COADS). $50 \mathrm{kt} \mathrm{E}$ and $1013 \mathrm{mb}$ at $24.4 \mathrm{~N}, 85.4 \mathrm{~W}$ at $21 \mathrm{Z}$ (micro). Land highlights: $50 \mathrm{kt} \mathrm{SSE}$ and $1006 \mathrm{mb}$ at Cabo Cruz, Cuba at 00Z (micro). 40 kt ESE, gusts to $45 \mathrm{kt}$ and $1012 \mathrm{mb}$ at Key West, FL at 06Z (micro). $15 \mathrm{kt} \mathrm{SW}$ and 1005 $\mathrm{mb}$ at Isla de la Juventud, Cuba at $12 \mathrm{Z}$ (micro). $37 \mathrm{kt}$ and $1014 \mathrm{mb}$ at Dry Tortugas Light, FL at $1230 Z$ (SWO). $36 \mathrm{kt}$ ESE, gusts to $44 \mathrm{kt}$ and $1015 \mathrm{mb}$ at Key West, FL at $1550 \mathrm{Z}$ (SWO). $50 \mathrm{kt}$ ENE and $1013 \mathrm{mb}$ at Dry Tortugas Light, FL at $21 \mathrm{Z}$ (micro). Aircraft highlights: Radar center fix estimated surface winds of $40 \mathrm{kt}$ and measured a minimum pressure (not a central pressure) $1006 \mathrm{mb}$ at $22.8 \mathrm{~N}, 82.9 \mathrm{~W}$ at $0330 \mathrm{Z}$ (ATSR). Radar center fix measured a minimum pressure (not a central pressure) $1006 \mathrm{mb}$ at $22.6 \mathrm{~N}$, 84.9W at $2110 \mathrm{Z}$ (ATSR).

MWR: "The center crossed extreme western Cuba on the 3rd, moving toward the westnorthwest at $12 \mathrm{mph}$. A west-northwestward course was continued at 12 to $15 \mathrm{mph}$ across the Gulf of Mexico, with highest winds generally about $50 \mathrm{mph."}$ 
September 4:

HWM analyzes a tropical storm with a central pressure of $1004 \mathrm{mb}$ at $23.4 \mathrm{~N}$, $86.7 \mathrm{~W}$ at $12 \mathrm{Z}$. HURDAT lists a 60 knot tropical storm at $23.2 \mathrm{~N}, 86.7 \mathrm{~W}$ at $12 \mathrm{Z}$.

Microfilm shows a tropical wave or trough along longitude $90 \mathrm{~W}$, from $22 \mathrm{~N}-28 \mathrm{~N}$ at $12 \mathrm{Z}$. Ship highlights: $55 \mathrm{kt} \mathrm{E}$ and $1011 \mathrm{mb}$ at $24.4 \mathrm{~N}, 85.4 \mathrm{~W}$ at $00 \mathrm{Z}$ (COADS/MWR). $55 \mathrm{kt} \mathrm{E}$ and $1012 \mathrm{mb}$ at $24.4 \mathrm{~N}, 85.4 \mathrm{~W}$ at $06 \mathrm{Z}$ (COADS). $50 \mathrm{kt} \mathrm{E}$ and $1009 \mathrm{mb}$ at $21.5 \mathrm{~N}, 84.8 \mathrm{~W}$ at $12 \mathrm{Z}$ (COADS). $40 \mathrm{kt}$ ESE and $1015 \mathrm{mb}$ at $28.5 \mathrm{~N}, 88.7 \mathrm{~W}$ at $18 \mathrm{Z}$ (COADS). $50 \mathrm{kt} \mathrm{E}$ and $1012 \mathrm{mb}$ at $26.2 \mathrm{~N}, 89.3 \mathrm{~W}$ at $21 \mathrm{Z}$ (micro). Land highlights: $43 \mathrm{kt} \mathrm{E}$ and $1016 \mathrm{mb}$ at Dry Tortugas Light, FL at 0030Z (SWO). $57 \mathrm{kt} \mathrm{E}$ at Dry Tortugas, FL at 04Z (MWR). Aircraft highlights: Penetration center fix estimated surface winds of $60 \mathrm{kt}$ and measured a central pressure of $1003 \mathrm{mb}$ at $23.5 \mathrm{~N}, 87.6 \mathrm{~W}$ at $1440 \mathrm{Z}$ (ATSR).

ATSR: "It was believed that ELLA would regain much of her lost strength when she passed over water into the Gulf of Mexico, but she never regained hurricane force winds. The maximum recorded winds after 040000Z (Dry Tortugas wind 040000Z was 090/57 knots) gradually decreased. the SS Jean Lykes reported a wind of 55 knots near latitude $24.5 \mathrm{~N}$, longitude $85.5 \mathrm{~W}$ late on the 3rd."

September 5:

HWM analyzes a tropical storm of at most $1005 \mathrm{mb}$ at $26.2 \mathrm{~N}, 92.0 \mathrm{~W}$ at $12 \mathrm{Z}$. HURDAT lists a 60 knot tropical storm at $26.1 \mathrm{~N}, 92.1 \mathrm{~W}$ at $12 \mathrm{Z}$. Microfilm shows closed low pressure of at most $1002 \mathrm{mb}$ at $27.0 \mathrm{~N}, 94.0 \mathrm{~W}$ at $12 \mathrm{Z}$. Ship highlights: $40 \mathrm{kt}$ ESE and $1007 \mathrm{mb}$ at $26.2 \mathrm{~N}, 90.0 \mathrm{~W}$ at $00 \mathrm{Z}$ (COADS). $40 \mathrm{kt} \mathrm{ENE}$ and $1010 \mathrm{mb}$ at $28.8 \mathrm{~N}, 92.2 \mathrm{~W}$ at 06Z (COADS). $25 \mathrm{kt} \mathrm{SSE}$ and $1005 \mathrm{mb}$ at $26.6 \mathrm{~N}, 92.0 \mathrm{~W}$ at $09 \mathrm{Z}$ (micro). $35 \mathrm{kt} \mathrm{ESE}$ and $1010 \mathrm{mb}$ at $28.2 \mathrm{~N}, 91.1 \mathrm{~W}$ at $12 \mathrm{Z}$ (COADS). $40 \mathrm{kt} \mathrm{ESE}$ and $1011 \mathrm{mb}$ at $28.8 \mathrm{~N}, 90.8 \mathrm{~W}$ at $18 Z$ (micro). Land highlights $40 \mathrm{kt}$ ESE and $1015 \mathrm{mb}$ at Grande Isle, LA at 18Z (micro). Aircraft highlights: Radar center fix estimated an eye diameter of $30 \mathrm{~nm}$ at $24.1 \mathrm{~N}, 88.2 \mathrm{~W}$ at $0230 \mathrm{Z}$ (ATSR). Radar center fix at $24.6 \mathrm{~N}, 88.9 \mathrm{~W}$ at $0630 \mathrm{Z}$ (ATSR). Radar center fix estimated surface winds of $50 \mathrm{kt}$ and measured a minimum pressure (not a central pressure) $1006 \mathrm{mb}$ at $27.6 \mathrm{~N}, 93.8 \mathrm{~W}$ at $19 \mathrm{Z}$ (ATSR).

MWR: "Grand Isle, La., reported gusts to $75 \mathrm{mph}$ during a squall on the morning of the $5^{\text {th }} \ldots$ Highest winds on the Texas and Louisiana coasts were generally around $40 \mathrm{mph}$ with tides 2 to 4 feet above normal.” ATSR: “... and when ELLA went ashore near Corpus Christi, the maximum winds recorded were at Sabine Pass Coast Guard Station "Highest gusts ENE 50 mph several times 051900C to 052100C." 
September 6:

HWM analyzes a closed low pressure of at most $1005 \mathrm{mb}$ at $27.0 \mathrm{~N}, 98.0 \mathrm{~W}$ at 12Z. HURDAT lists a 30 knot tropical depression at $28.1 \mathrm{~N}, 98.2 \mathrm{~W}$ at $12 \mathrm{Z}$. Microfilm shows closed low pressure of at most $1005 \mathrm{mb}$ at $27.5 \mathrm{~N}, 98.0 \mathrm{~W}$ at $12 \mathrm{Z}$. Ship highlights: $15 \mathrm{kt}$ ENE and $1003 \mathrm{mb}$ at 26.9N, 96.5W at 00Z (COADS). Land highlights $47 \mathrm{kt}$, gusts to $55 \mathrm{kt}$ at Port Lavaca, TX (no time given but likely early on the $6^{\text {th }}$ ) (WALLET). $4 \mathrm{kt}$ NNW and $1002 \mathrm{mb}$ at Kingsville, Texas at 0756Z (SWO). $5 \mathrm{kt} \mathrm{SSE}$ and $1005 \mathrm{mb}$ at Corpus Christi, TX at 12Z (micro). $14 \mathrm{kt} \mathrm{SSW}$ and $1005 \mathrm{mb}$ at Harlinger, TX at $2056 \mathrm{Z}$ (SWO). Aircraft highlights: Radar center fix at 27.8N, 96.8W at 0624Z (ATSR).

September 7:

HWM does not analyze an organized storm at 12Z. HURDAT does not list an organized storm on this date. Microfilm shows closed low pressure of at most $1008 \mathrm{mb}$ at $28.2 \mathrm{~N}, 101.2 \mathrm{~W}$ at 12Z. Ship highlights: No gales or low pressures. Land highlights: $5 \mathrm{kt}$ E and $1006 \mathrm{mb}$ at Laredo, TX at 00Z (micro).

Hurricane Ella developed from a tropical wave just east of the Lesser Antilles during late August. Genesis is analyzed at $06 \mathrm{Z}$ on August $30^{\text {th }}$ as a $30 \mathrm{kt}$ tropical depression, same as the original HURDAT. Minor track alterations are introduced during the lifetime of Ella. Intensification to a tropical storm is analyzed at $12 \mathrm{Z}$ on the $30^{\text {th }}$, same as the original HURDAT. Late on August $30^{\text {th }}$, Ella entered the eastern Caribbean Sea passing between Martinique and St. Lucia. The tropical cyclone turned westward on the $31^{\text {st }}$ and steadily intensified as the eye diameter contracted based on the reports from the reconnaissance aircrafts. The first reconnaissance aircraft reached the tropical cyclone early on August $31^{\text {st }}$ making a couple of radar center fixes and estimating surface winds of $50 \mathrm{kt}$. A central pressure of $1009 \mathrm{mb}$ was present in HURDAT at $00 \mathrm{Z}$ on the $31^{\text {st }}$ but it has been removed since the reconnaissance aircraft did not make a penetration fix and the $1009 \mathrm{mb}$ was a peripheral pressure. A ship passed close to the center of Ella at $12 \mathrm{Z}$ on the $31^{\text {st }}$ reporting $56 \mathrm{kt} \mathrm{E}$ and $1000 \mathrm{mb}$. A reconnaissance aircraft made a penetration center fix at $23 \mathrm{Z}$ on the $31^{\text {st }}$ measuring a central pressure of $983 \mathrm{mb}$, estimating surface winds of $80 \mathrm{kt}$ and an eye diameter of $30 \mathrm{~nm}$. A central pressure of $983 \mathrm{mb}$ suggests maximum sustained winds of $74 \mathrm{kt}$ south of $25 \mathrm{~N}$ intensifying from the Brown et al. pressure-wind relationship. An eye diameter of $30 \mathrm{~nm}$ suggests an RMW of about $22 \mathrm{~nm}$ and climatology suggests about $14 \mathrm{~nm}$. The forward speed of Ella was around $14 \mathrm{kt}$ and an intensity of $75 \mathrm{kt}$ is analyzed at $00 \mathrm{Z}$ on September $1^{\text {st }}$, down from $95 \mathrm{kt}$ originally in HURDAT, a major intensity change. A central pressure of $983 \mathrm{mb}$ is added to HURDAT at $00 \mathrm{Z}$ on the $1^{\text {st }}$. Based upon this information early on the $1^{\text {st }}$, intensification to a 
hurricane is analyzed at $18 \mathrm{Z}$ on the $31^{\text {st }}$, six hours later than originally shown in HURDAT. A major intensity change is analyzed at $18 \mathrm{Z}$ on the $31^{\text {st }}$, as HURDAT originally had $85 \mathrm{kt}$ and the analyzed intensity is $65 \mathrm{kt}$. On September $1^{\text {st }}$, the track of Ella turned to the northwest passing south of the Dominican Republic early on the day. It is analyzed that Ella continued to intensify until making landfall in the mountainous Tiburon peninsula in southwest Haiti. Landfall occurred around $12 \mathrm{Z}$ on the $1^{\text {st }}$ near $18.2 \mathrm{~N}, 73.4 \mathrm{~W}$ or about $65 \mathrm{~nm}$ southwest of Port-Au-Prince, Haiti with winds of $95 \mathrm{kt}$. Data from the reconnaissance aircraft at $20 \mathrm{Z}$ on the $1^{\text {st }}$ indicates that the central pressure had increased to $989 \mathrm{mb}$ (the Navy reconnaissance book indicates that the central pressure was $995 \mathrm{mb}$ at this time but MWR and advisories suggest it was $989 \mathrm{mb}$ ), estimated surface winds of $110 \mathrm{kt}$ and an eye diameter of $16 \mathrm{~nm}$. HURDAT originally indicated that Ella did not weaken while crossing the mountainous terrain, which appears unlikely. A central pressure of $989 \mathrm{mb}$ suggests maximum sustained winds of $65 \mathrm{kt}$ south of $25 \mathrm{~N}$ according to the pressure-wind relationship. An eye diameter of $16 \mathrm{~nm}$ suggests an RMW of about $12 \mathrm{~nm}$ and climatology suggests about $16 \mathrm{~nm}$. Based on the RMW being slightly smaller than average, a forward speed of about $15 \mathrm{kt}$ and putting some weight on the estimated surface winds, an intensity of $75 \mathrm{kt}$ is selected for $18 \mathrm{Z}$ on the $1^{\text {st }}$, down from $95 \mathrm{kt}$ originally in HURDAT, a major intensity change. A central pressure of $989 \mathrm{mb}$ has been added to $18 \mathrm{Z}$ on the $1^{\text {st }}$. Ella continued to move northwestward making landfall in southeastern Cuba around $00 \mathrm{Z}$ on September $2^{\text {nd }}$. Landfall occurred near 20.0N, 76.2W or about $20 \mathrm{~nm}$ west of Santiago de Cuba with winds of $75 \mathrm{kt}$. HURDAT originally had $100 \mathrm{kt}$ at $00 \mathrm{Z}$ on the $2^{\text {nd }}$, a major intensity change. Perez et al. indicates that Ella is recognized in Cuba as a category 1 hurricane impact, same as this reanalysis. Thus, Ella is analyzed to have never reached major hurricane status and the peak intensity is $95 \mathrm{kt}$, down from $100 \mathrm{kt}$ originally in HURDAT. It is possible that Ella may have reached major hurricane status before impacting Haiti, but it is unlikely that it was a major hurricane when it struck Cuba as the very high terrain of the Tiburon peninsula should have disrupted the small circulation of the cyclone.

Weakening occurred over the mountainous terrain of eastern Cuba. Ella is analyzed to have weakened to a tropical storm at $06 \mathrm{Z}$ on the $2^{\text {nd }}$, six hours earlier than originally in HURDAT. Late on the $2^{\text {nd }}$, the track of the tropical cyclone turned to the west and Ella moved back into the Caribbean Sea. Reconnaissance aircraft investigated Ella during the $2^{\text {nd }}$ making a few radar center fixes but it appears that the disorganized state of the tropical storm caused the center fixes to be erroneous showing the system farther northward compared to the ship and coastal observations. These center fixes were generally disregarded for the reanalysis and more weight was put on the ship and coastal observations. Also around September $2^{\text {nd }}$, a significant pressure gradient was developing between Ella and a strong high pressure to the north. From this point on to the demise of the tropical cyclone, the strongest winds were found on the northern quadrant and 
generally about 100-200 nm away from the center. While over the Caribbean Sea and likely in part due to the pressure gradient to the north, Ella started to slowly intensify. On a general west-northwest track, the tropical storm made landfall in La Isla de la Juventud, Cuba near $21.8 \mathrm{~N}, 82.7 \mathrm{~W}$ or about $5 \mathrm{~nm}$ east of Nueva Gerona, around $11 \mathrm{Z}$ with winds of $55 \mathrm{kt}$. A reporting station (or a stationary ship) in the southern portion of Isla de la Juventud reported $15 \mathrm{kt} \mathrm{SW}$ and $1005 \mathrm{mb}$, suggesting a central pressure of $1003 \mathrm{mb}$, which has been added to HURDAT at $12 \mathrm{Z}$ on the $3^{\text {rd }}$. A central pressure of $1003 \mathrm{mb}$ suggests maximum sustained winds of $41 \mathrm{kt}$ south of $25 \mathrm{~N}$ according to the pressure-wind relationship. Due ships north of the center reporting winds up to $50 \mathrm{kt}$, an intensity of 55 $\mathrm{kt}$ is selected at $12 \mathrm{Z}$ on the $3^{\text {rd }}$, same as the original HURDAT. The system continued west-northwest making another landfall around $17 \mathrm{Z}$ near $22.1 \mathrm{~N}, 84.0 \mathrm{~W}$ or about $15 \mathrm{~nm}$ east of Sandino, Cuba as a $60 \mathrm{kt}$ tropical storm. Late on the $3^{\text {rd }}$, Ella entered the Gulf of Mexico turning northwestward early on September $4^{\text {th }}$. A ship reported $15 \mathrm{kt} \mathrm{NE}$ and $1003 \mathrm{mb}$ at $00 \mathrm{Z}$ on the $4^{\text {th }}$, suggesting a central pressure of $1001 \mathrm{mb}$, which has been added to HURDAT. No change in intensity is analyzed on the $4^{\text {th }}$. The highest winds reported in Florida were $57 \mathrm{kt}$ at $04 \mathrm{Z}$ on the $4^{\text {th }}$ at Dry Tortugas, but since the measurement was at an elevation of about $158 \mathrm{ft}$ above ground, the reduction formula suggests winds of around $50 \mathrm{kt}$ at the surface. On the $4^{\text {th }}$, ships north of Ella reported winds up to $55 \mathrm{kt}$. A reconnaissance aircraft measured a central pressure of $1003 \mathrm{mb}$ and estimated surface winds of $60 \mathrm{kt}$ at $1440 \mathrm{Z}$ on the $4^{\text {th }}$. A central pressure of $1003 \mathrm{mb}$ has been added to HURDAT at $12 \mathrm{Z}$ on the $4^{\text {th }}$. The radar and penetration fixes from the reconnaissance aircrafts on the $4^{\text {th }}$ do not agree with the surface observations from ships and coastal stations on the position of the center of Ella, likely due to the somewhat disorganized center of the cyclone. Thus, for the reanalysis of the track, more weight has been put on the observations from ships and coastal stations. Ella began to slowly weaken on September $5^{\text {th }}$ as it moved farther away from the strong high pressure to the northeast. A ship reported $25 \mathrm{kt} \mathrm{SE}$ and $1005 \mathrm{mb}$ at $09 \mathrm{Z}$ on the $5^{\text {th }}$, suggesting a central pressure of about $1002 \mathrm{mb}$, which has been added to HURDAT at $12 \mathrm{Z}$ on the $5^{\text {th }}$. Late on the $5^{\text {th }}$, the tropical storm made its closest approach to Louisiana producing winds of $40 \mathrm{kt}$ at Grand Isle. On September $6^{\text {th }}$, the track of Ella changed to the west. A ship reported $15 \mathrm{kt}$ ENE and $1003 \mathrm{mb}$ at $00 \mathrm{Z}$ on the $6^{\text {th }}$ suggesting a central pressure of $1001 \mathrm{mb}$, which has been added to HURDAT. Landfall occurred around $09 \mathrm{Z}$ on the $6^{\text {th }}$ near $27.4 \mathrm{~N}, 97.3 \mathrm{~W}$ or about $20 \mathrm{~nm}$ south of Corpus Christi, TX, with winds of $50 \mathrm{kt}$. Kingsville, TX, reported $4 \mathrm{kt}$ NNW and $1002 \mathrm{mb}$ around $08 \mathrm{Z}$ on the $6^{\text {th }}$, suggesting a central pressure of about 1001 $\mathrm{mb}$, which has been added to HURDAT at $06 \mathrm{Z}$ on the $7^{\text {th }}$. Highest winds reported in Texas were $47 \mathrm{kt}$ at Port Lavaca at an unknown time but likely early on the $6^{\text {th }}$. Weakening to a tropical depression is analyzed at $12 \mathrm{Z}$ on the $6^{\text {th }}$, same as the original HURDAT. Surface observations from southern Texas and northeastern Mexico indicate that the forward speed of Ella slowed significantly after moving inland and a moderate 
track change had to be made for $18 Z$ on the $6^{\text {th }}$. Furthermore, HURDAT shows dissipation to have occurred after $18 \mathrm{Z}$ on the $6^{\text {th }}$ but observations in the mentioned area indicate that a closed circulation was still present at $00 \mathrm{Z}$ on September $7^{\text {th }}$. Dissipation is now shown to have occurred after $00 \mathrm{Z}$ on the $7^{\text {th }}$, six hours later than the original HURDAT. Laredo, TX, reported $5 \mathrm{kt} \mathrm{E}$ and $1006 \mathrm{mb}$ at $00 \mathrm{Z}$ on the $7^{\text {th }}$, suggesting a central pressure of $1005 \mathrm{mb}$, which has been added to HURDAT.

Tropical Storm Fifi [September 4-11, 1958]

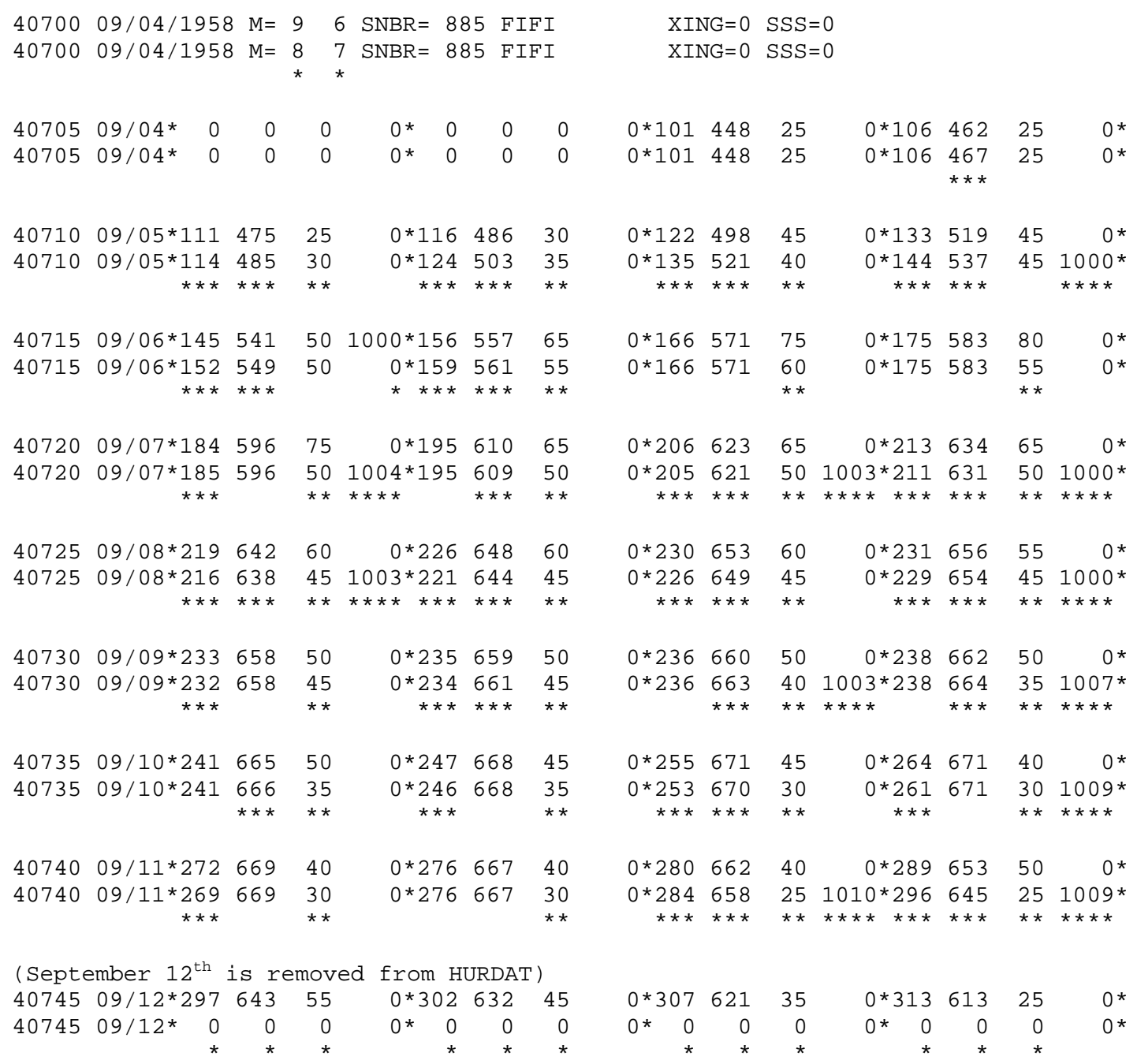

$40750 \mathrm{HR}$

40750 TS

Major changes to the track and intensity shown in McAdie et al. (2009). Evidence for these alterations comes from the NHC microfilm maps, the Historical Weather Maps 
series, the COADS ship database, Monthly Weather Review, Navy reconnaissance book and the NHC Storm Wallets.

September 3:

HWM is not available on this date (system south of $20^{\circ} \mathrm{N}$ ). HURDAT does not list an organized storm on this date. Microfilm does not show an organized system at 12Z. Ship highlights: No gales or low pressures.

MWR: "Possibly the increase in winds at $700 \mathrm{mb}$ shown by the regular Gull Papa reconnaissance flight on September 3 was the first bit of evidence of the existence of the easterly wave which later developed into Fifi."

September 4:

HWM is not available on this date (system south of $20^{\circ} \mathrm{N}$ ). HURDAT lists a 25 knot tropical depression at $10.1 \mathrm{~N}, 44.8 \mathrm{~W}$ at $12 \mathrm{Z}$ (first position). Microfilm does not show an organized system at 12Z. Ship highlights: No gales or low pressures.

MWR: "On the 4th, the suspicious area was coordinated by the SS Robin Hood, located near latitude $12 \mathrm{~N}$, longitude $48 \mathrm{~W}$, which reported squalls and pressure of $1008.8 \mathrm{mb}$, falling. Later that day the Robin Hood's wind veered from east to south but the development was so weak and slow that no cyclonic circulation could be found by the aircraft. The flight did observe cumulonimbus tops being blown toward the northeast and this was in agreement with a high-level vortex over the extreme eastern part of the Caribbean Sea."

September 5:

HWM is not available on this date (system south of $20^{\circ} \mathrm{N}$ ). HURDAT lists a 45 knot tropical storm at $12.2 \mathrm{~N}, 49.8 \mathrm{~W}$ at $12 \mathrm{Z}$. Microfilm shows a closed low pressure of at most $1005 \mathrm{mb}$ at $16.0 \mathrm{~N}, 52.0 \mathrm{~W}$ at 12Z. Ship highlights: No gales or low pressures. Aircraft highlights: No gales or low pressures. Penetration center fix estimated surface winds of $55 \mathrm{kt}$ and measured a central pressure of $1000 \mathrm{mb}$ at $14.9 \mathrm{~N}, 54.3 \mathrm{~W}$ at $2045 \mathrm{Z}$ (ATSR/WALLET).

MWR: "Early on the $5^{\text {th }}$, reconnaissance indicated possibly two centers of action, but by afternoon a single center was firmly established. The first advisory, at 2200 GMT September 5, located tropical storm Fifi at latitude $15.1 \mathrm{~N}$, longitude $55.0 \mathrm{~W}$ with highest winds of 50 to $55 \mathrm{mph}$. A solid wall cloud was observed and the sea level pressure was $1000 \mathrm{mb}$. This was the lowest central pressure observed during the history of the storm although it was equaled at a later date." ATSR: "The easterly wave, from which FIFI developed, was first reported to be approximately 300 miles off to the coast of northwest 
Africa, or at 22 degrees west longitude. This wave was designated 7AW in a regular easterly wave message from Fleet Weather Central, Port Lyautey, six days before FIFI was discovered. This wave was tracked along at 12 knots. Until 5 September, there was never any reason to suspect that 7AW was anything more than a weak wave. On 5 September, there were two routine flights into the area - an Air Force GULL PAPA and Navy Delta. The winds and weather of these two flights indicated that 7AW had intensified and was now a strong easterly, with the possibility of a circulation. It was decided to divert GULL PAPA to the area of a possible center and at $052045 \mathrm{Z}$ the eye was centered by visual means at $14.9 \mathrm{~N} 54.3 \mathrm{~W}$. At this early stage, FIFI could only be located by surface pressure and winds - the eye was not discernible at $700 \mathrm{mb}$. The minimum pressure was $1000 \mathrm{mb}$, and the maximum winds were to be 55 knots in the northwest quadrant a short distance from the center."

September 6:

HWM is not available on this date (system south of $20^{\circ} \mathrm{N}$ ). HURDAT lists a 75 knot hurricane at $16.6 \mathrm{~N}, 57.1 \mathrm{~W}$ at $12 \mathrm{Z}$. Microfilm shows a closed low pressure of at most $1005 \mathrm{mb}$ at $16.8 \mathrm{~N}, 57.0 \mathrm{~W}$ at $12 \mathrm{Z}$. Ship highlights: No gales or low pressures. Aircraft highlights: $25 \mathrm{kt} \mathrm{ESE}$ and $1005 \mathrm{mb}$ at $15.9 \mathrm{~N}, 55.3 \mathrm{~W}$ at $00 \mathrm{Z}$ (micro). Penetration center fix estimated surface winds of 75-80 kt and measured a central pressure of $1010 \mathrm{mb}$ at $17.0 \mathrm{~N}, 57.5 \mathrm{~W}$ at $1330 \mathrm{Z}$ (ATSR/WALLET/MWR). Penetration center fix at $18.0 \mathrm{~N}$, $59.5 \mathrm{~W}$ at $20 \mathrm{Z}$ (ATSR).

MWR: "Fifi had been moving rapidly northwestward about $23 \mathrm{mph}$, but by early afternoon of the $6^{\text {th }}$ the forward speed had decreased to $16 \mathrm{mph}$ and the storm had increased to hurricane intensity. It was located near latitude $17.0 \mathrm{~N}$, longitude $57.5 \mathrm{~W}$ at 1330 GMT on the $6^{\text {th }}$, attended by surface winds up to $92 \mathrm{mph}$ north of the center. This was the maximum intensity of hurricane Fifi." ATSR: "Although the winds increased in intensity on the $6^{\text {th }}$ of September, to hurricane force ( 75 knots), the surface pressure rose to $1010 \mathrm{mb}$. From all reports the pressure fluctuated between 1000 and $1010 \mathrm{mb}$ throughout FIFI's life."

September 7:

HWM analyzes a hurricane of at most $1005 \mathrm{mb}$ at $20.8 \mathrm{~N}, 62.5 \mathrm{~W}$ at $12 \mathrm{Z}$. HURDAT lists a 65 knot hurricane at $20.6 \mathrm{~N}, 62.3 \mathrm{~W}$ at $12 \mathrm{Z}$. Microfilm shows a closed low pressure of at most $1005 \mathrm{mb}$ at $20.5 \mathrm{~N}, 62.5 \mathrm{~W}$ at 12Z. Ship highlights: No gales or low pressures. Aircraft highlights: No gales or low pressures. Penetration center fix estimated flight level winds $(700 \mathrm{mb})$ of $70 \mathrm{kt}$ and measured a central pressure of 1004 $\mathrm{mb}$ at $19.0 \mathrm{~N}, 60.4 \mathrm{~W}$ at $02 \mathrm{Z}$ (ATSR). Penetration center fix at $20.0 \mathrm{~N}, 61.1 \mathrm{~W}$ at $0750 \mathrm{Z}$ (ATSR). Penetration center fix measured a central pressure of $1003 \mathrm{mb}$ at $20.7 \mathrm{~N}, 62.5 \mathrm{~W}$ 
at $14 \mathrm{Z}$ (ATSR/WALLET). Penetration center fix measured a central pressure of $1000 \mathrm{mb}$ at $21.1 \mathrm{~N}, 63.6 \mathrm{~W}$ at $20 \mathrm{Z}$ (ATSR/WALLET).

MWR: "The storm slowed to around $12 \mathrm{mph}$ and highest winds decreased to $75 \mathrm{mph}$ on the $7^{\text {th }}$."

September 8:

HWM analyzes a tropical storm of at most $1005 \mathrm{mb}$ at $23.0 \mathrm{~N}, 65.5 \mathrm{~W}$ at $12 \mathrm{Z}$. HURDAT lists a 60 knot tropical storm at $23.0 \mathrm{~N}, 65.3 \mathrm{~W}$ at $12 \mathrm{Z}$. Microfilm shows a closed low pressure of at most $1008 \mathrm{mb}$ at $23.0 \mathrm{~N}, 65.0 \mathrm{~W}$ at 12Z. Ship highlights: No gales or low pressures. Aircraft highlights: Penetration center fix measured a central pressure of $1003 \mathrm{mb}$ and estimated an eye diameter of $15 \mathrm{~nm}$ at $21.5 \mathrm{~N}, 63.8 \mathrm{~W}$ at $02 \mathrm{Z}$ (ATSR). Penetration center fix estimated surface winds of $50 \mathrm{kt}$, measured a central pressure of $1009 \mathrm{mb}$ and an eye diameter of $20 \mathrm{~nm}$ at $22.8 \mathrm{~N}, 65.1 \mathrm{~W}$ at $1537 \mathrm{Z}$ (micro). Penetration center fix measured a central pressure of $1000 \mathrm{mb}$ at $22.8 \mathrm{~N}, 65.7 \mathrm{~W}$ at $1930 \mathrm{Z}$ (ATSR/WALLET). Penetration center fix at 23.1N, 65.8W at 2309Z (ATSR/WALLET).

MWR: "During the $8^{\text {th }}$, Fifi continued on a northwestward course at $7 \mathrm{mph}$ and maximum winds dropped to $60 \mathrm{mph}$. Prior to this time, a jet maximum at high levels had worked around peninsular Florida."

September 9:

HWM analyzes a tropical storm of at most $1005 \mathrm{mb}$ at $23.5 \mathrm{~N}, 66.1 \mathrm{~W}$ at $12 \mathrm{Z}$. HURDAT lists a 50 knot tropical storm at $23.6 \mathrm{~N}, 66.0 \mathrm{~W}$ at $12 \mathrm{Z}$. Microfilm shows a closed low pressure of at most $1005 \mathrm{mb}$ at 23.6N, 66.1W at 12Z. Ship highlights: No gales or low pressures. Aircraft highlights: No gales or low pressures. Penetration center fix measured a central pressure of $1003 \mathrm{mb}$ at $23.5 \mathrm{~N}, 67.1 \mathrm{~W}$ at $1135 \mathrm{Z}$ (ATSR/WALLET). Penetration center fix estimated flight level winds $(700 \mathrm{mb})$ of $50 \mathrm{kt}$, measured a central pressure of $1005 \mathrm{mb}$ and an eye diameter of $40 \mathrm{~nm}$ at $24.0 \mathrm{~N}, 67.1 \mathrm{~W}$ at $1430 \mathrm{Z}$ (micro). Penetration center fix measured a central pressure of $1007 \mathrm{mb}$ at $24.0 \mathrm{~N}$, 66.4W at $1949 Z$ (ATSR/WALLET).

MWR: “. .. by evening of the $8^{\text {th }}$ it was located from the central Bahamas to Bermuda. It was this wind field which influenced the storm to make a turn to the north during the $9^{\text {th }}$ and $10^{\text {th }} . "$

September 10:

HWM analyzes a tropical storm of at most $1010 \mathrm{mb}$ at $25.6 \mathrm{~N}, 66.8 \mathrm{~W}$ at $12 \mathrm{Z}$. HURDAT lists a 45 knot tropical storm at $25.5 \mathrm{~N}, 67.1 \mathrm{~W}$ at $12 \mathrm{Z}$. Microfilm shows a closed low pressure of at most $1014 \mathrm{mb}$ at $24.0 \mathrm{~N}, 67.0 \mathrm{~W}$ at 12Z. Ship highlights: $20 \mathrm{kt}$ 
NNW and $1005 \mathrm{mb}$ at 25.9N, 69.2W at 18Z (micro). Aircraft highlights: Penetration center fix estimated surface winds of $35 \mathrm{kt}$ at $25.9 \mathrm{~N}, 67.0 \mathrm{~W}$ at 1430Z (ATSR/WALLET). Penetration center fix estimated surface winds of $20 \mathrm{kt}$ and measured a central pressure of $1009 \mathrm{mb}$ at $26.2 \mathrm{~N}, 66.8 \mathrm{~W}$ at $1930 \mathrm{Z}$ (ATSR/WALLET).

September 11:

HWM analyzes a tropical storm of at most $1010 \mathrm{mb}$ at $28.5 \mathrm{~N}, 66.2 \mathrm{~W}$ and a cold front to the northwest at 12Z. HURDAT lists a $45 \mathrm{knot}$ tropical storm at $28.0 \mathrm{~N}, 66.2 \mathrm{~W}$ at 12Z. Microfilm shows a trough along longitude $65 \mathrm{~N}$, from $25 \mathrm{~N}-35 \mathrm{~N}$ at $12 \mathrm{Z}$. Ship highlights: Aircraft highlights: No gales or low pressures. Penetration center fix estimated surface winds of $45 \mathrm{kt}$ and measured a central pressure of $1010 \mathrm{mb}$ at $28.6 \mathrm{~N}, 65.4 \mathrm{~W}$ at $1330 \mathrm{Z}$ (ATSR/WALLET). Penetration center fix estimated surface winds of $55 \mathrm{kt}$ and measured a central pressure of $1009 \mathrm{mb}$ at $29.9 \mathrm{~N}, 64.1 \mathrm{~W}$ at $1930 \mathrm{Z}$ (ATSR/WALLET).

MWR: "Fifi turned northeastward and accelerated during the $11^{\text {th }}$. The storm passed within 150 miles of the Leeward Islands and approximately the same distance southeast of Bermuda. No loss of life or property damage was reported."

Storm Wallet Preliminary Report: "On the $11^{\text {th }}$ its movement accelerated to the northeast and winds began to increase again as it moved into the westerlies near Bermuda."

September 12:

HWM analyzes a tropical storm of at most $1015 \mathrm{mb}$ at $30.7 \mathrm{~N}, 62.2 \mathrm{~W}$ and a cold front just to the north at $12 \mathrm{Z}$. HURDAT lists a 35 knot tropical storm at $30.7 \mathrm{~N}, 62.1 \mathrm{~W}$ at 12Z. Microfilm shows a frontal boundary over the western Atlantic, likely indicating that Fifi has been absorbed, at 12Z. Ship highlights: No gales or low pressures.

September 13:

HWM analyzes a frontal boundary over the North Atlantic, likely indicating that Fifi has been absorbed, at 12Z. HURDAT does not list an organized storm on this date. Microfilm shows a frontal boundary over the western Atlantic at 12Z. Ship highlights: No gales or low pressures.

Tropical Storm Fifi developed east of the Lesser Antilles during the first days of September. Data over the central Atlantic is sparse and it is possible that Fifi may have developed earlier than indicated. The first position is at $12 \mathrm{Z}$ on September $4^{\text {th }}$ as a $25 \mathrm{kt}$ tropical depression, same as the original HURDAT. Track alterations are generally minor for the lifetime of Fifi, except for September $5^{\text {th }}$ at $12 \mathrm{Z}$ were a major track change was implemented. The tropical cyclone moved generally west-northwest at a fast forward speed on the $4^{\text {th }}$. The first reconnaissance aircraft to reach the system occurred at $2045 \mathrm{Z}$ 
on September $5^{\text {th }}$ measuring a central pressure of $1000 \mathrm{mb}$ and estimating surface winds of $55 \mathrm{kt}$. A central pressure of $1000 \mathrm{mb}$ suggests maximum sustained winds of $47 \mathrm{kt}$ south of $25 \mathrm{~N}$ from the Brown et al. pressure-wind relationship. An intensity of $45 \mathrm{kt}$ is selected for $18 Z$ on the $5^{\text {th }}$, same as the original HURDAT. A central pressure of 1000 mb was present in HURDAT at $00 \mathrm{Z}$ on September $6^{\text {th }}$ and has been moved to $18 \mathrm{Z}$ on the $5^{\text {th }}$. Based upon this information, intensification to a tropical storm is analyzed at $06 \mathrm{Z}$ on the $5^{\text {th }}$, six hours earlier than originally shown in HURDAT. Fifi continued to intensify on the $6^{\text {th }}$. A reconnaissance aircraft reached the tropical storm at $1330 \mathrm{Z}$ on the $6^{\text {th }}$ estimating surface winds of 75-80 kt and measuring a central pressure of $1010 \mathrm{mb}$. It is likely that the measured minimum pressure of $1010 \mathrm{mb}$ was not a central pressure and therefore, it is not added to HURDAT. The true central pressure around $12 \mathrm{Z}$ on the $6^{\text {th }}$ likely did not drop appreciably, as reliable values of $1000 \mathrm{mb}$ and $1004 \mathrm{mb}$ were observed at $2045 \mathrm{Z}$ on the $5^{\text {th }}$ and $02 \mathrm{Z}$ on the $7^{\text {th }}$, respectively. Due to the discrepancy between the observed pressure and estimated surface winds, as well as the preceding and subsequent aircraft reconnaissance, the intensity at $12 \mathrm{Z}$ is analyzed at $60 \mathrm{kt}$, down from the original $75 \mathrm{kt}$ in HURDAT, a minor intensity change. $60 \mathrm{kt}$ is also the peak intensity for Fifi, down from $80 \mathrm{kt}$ originally in HURDAT, a major intensity change. Thus, it is analyzed that Fifi never attained hurricane intensity during its lifetime. Another major intensity change is analyzed at $18 \mathrm{Z}$ on the $6^{\text {th }}$. HURDAT originally had $80 \mathrm{kt}$ and $55 \mathrm{kt}$ is now analyzed.

Early on September $7^{\text {th }}$, Fifi made its closest approach on the Leeward Islands, passing about $100 \mathrm{~nm}$ northeast of Barbuda while on a northwest track. A reconnaissance aircraft measured a central pressure of $1004 \mathrm{mb}$ and estimated flight level winds of $70 \mathrm{kt}$ at $02 \mathrm{Z}$ on the $7^{\text {th }}$. A central pressure of $1004 \mathrm{mb}$ suggests maximum sustained winds of $41 \mathrm{kt}$ south of $25 \mathrm{~N}$ weakening from the pressure-wind relationship. Due to the forward speed of about $16 \mathrm{kt}$ and small synoptic scale of the tropical cyclone, an intensity of $50 \mathrm{kt}$ is analyzed at $00 \mathrm{Z}$ on the $7^{\text {th }}$, down from $75 \mathrm{kt}$ originally in HURDAT, a major intensity change. A central pressure of $1004 \mathrm{mb}$ is added to HURDAT at $00 \mathrm{Z}$ on the $7^{\text {th }}$. Another reconnaissance mission measured a central pressure of $1003 \mathrm{mb}$ at $14 \mathrm{Z}$ on the $7^{\text {th }}$, suggesting maximum sustained winds of $41 \mathrm{kt}$ south of $25 \mathrm{~N}$ from the pressure-wind relationship. Once again, due to the forward speed of about $15 \mathrm{kt}$ and small size of the tropical cyclone, an intensity of $50 \mathrm{kt}$ is selected for $12 \mathrm{Z}$ on the $7^{\text {th }}$, down from $65 \mathrm{kt}$ originally in HURDAT, a minor intensity change. A central pressure of $1003 \mathrm{mb}$ is added to HURDAT at $12 \mathrm{Z}$ on the $7^{\text {th }}$. The last measured central pressure on the $7^{\text {th }}$ by a reconnaissance aircraft was $1000 \mathrm{mb}$ at 20Z. A central pressure of $1000 \mathrm{mb}$ suggests maximum sustained winds of $47 \mathrm{kt}$ south of $25 \mathrm{~N}$ from the pressure-wind relationship. At this time, the forward speed of Fifi had decreased to about $10 \mathrm{kt}$ but still remained small synoptically, thus an intensity of $50 \mathrm{kt}$ is analyzed at $00 \mathrm{Z}$ on the $7^{\text {th }}$, down from $65 \mathrm{kt}$ originally in HURDAT, a minor intensity change. A central pressure of $1000 \mathrm{mb}$ is added 
to HURDAT at $18 \mathrm{Z}$ on the $7^{\text {th }}$. The forward speed of the tropical cyclone decreased significantly on September $8^{\text {th }}$ and $9^{\text {th }}$. A reconnaissance aircraft measured a central pressure of $1003 \mathrm{mb}$ and an eye diameter of $15 \mathrm{~nm}$ at $02 \mathrm{Z}$ on the $8^{\text {th }}$. A central pressure of $1003 \mathrm{mb}$ suggests maximum sustained winds of $41 \mathrm{kt}$ south of $25 \mathrm{~N}$ from the pressurewind relationship. An eye diameter of $15 \mathrm{~nm}$ suggests an RMW of about $11 \mathrm{~nm}$ and climatology suggests about $17 \mathrm{~nm}$. The forward speed had decreased to $8 \mathrm{kt}$ but Fifi remained a small tropical storm, thus an intensity of $45 \mathrm{kt}$ is selected for $00 \mathrm{Z}$ on the $8^{\text {th }}$. A central pressure of $1003 \mathrm{mb}$ is added to HURDAT at $00 \mathrm{Z}$ on the $8^{\text {th }}$. Another penetration center fix at $1537 \mathrm{Z}$ estimated surface winds of $50 \mathrm{kt}$, an eye diameter of $20 \mathrm{~nm}$ and measured a central pressure of $1009 \mathrm{mb}$. It is likely that the aircraft did not measure the central pressure based on a central pressure measurement of $1000 \mathrm{mb}$ at $20 \mathrm{Z}$ by another reconnaissance mission. Therefore, the $1009 \mathrm{mb}$ is likely not a central pressure and not added to HURDAT. A central pressure of $1000 \mathrm{mb}$ suggests maximum sustained winds of $47 \mathrm{kt}$ south of $25 \mathrm{~N}$ from the pressure-wind relationship. Since Fifi was moving at about $5 \mathrm{kt}$ but remained a small cyclone, an intensity of $45 \mathrm{kt}$ is selected at $18 \mathrm{Z}$ on the $8^{\text {th }}$, down from the original $55 \mathrm{kt}$ in HURDAT, a minor intensity change. A central pressure of $1000 \mathrm{mb}$ is added to HURDAT at $18 \mathrm{Z}$ on the $8^{\text {th }}$.

Observations from the reconnaissance aircraft on September $9^{\text {th }}$ indicated that Fifi became less organized, especially late in the day. A central pressure of $1003 \mathrm{mb}$ was measured at $1135 \mathrm{Z}$, suggesting maximum sustained winds of $41 \mathrm{kt}$ south of $25 \mathrm{~N}$ from the pressure-wind relationship. An intensity of $40 \mathrm{kt}$ is selected at $12 \mathrm{Z}$ on the $9^{\text {th }}$, down from 50 kt originally in HURDAT, a minor intensity of change. A central pressure of $1003 \mathrm{mb}$ is added to HURDAT at $12 \mathrm{Z}$ on the $9^{\text {th }}$. A penetration center fix measured a central pressure of $1007 \mathrm{mb}$ at 1949Z. A central pressure of $1007 \mathrm{mb}$ suggests maximum sustained winds of $35 \mathrm{kt}$ south of $25 \mathrm{~N}$ weakening and $29 \mathrm{kt}$ north of $25 \mathrm{~N}$ weakening, from the pressure-wind relationships. An intensity of $35 \mathrm{kt}$ is selected for $18 \mathrm{Z}$ on the $9^{\text {th }}$, down from $50 \mathrm{kt}$ originally in HURDAT, a minor intensity change. On September $10^{\text {th }}$, Fifi started to increase in forward speed as it moved northward and later northeastward ahead of a frontal boundary. Weakening to a tropical depression is analyzed at $12 \mathrm{Z}$ on the $10^{\text {th }}, 30$ hours earlier than originally shown in HURDAT. Central pressures of 1009,1010 and $1009 \mathrm{mb}$ were measured on the by the reconnaissance aircrafts at $1949 \mathrm{Z}$ on the $9^{\text {th }}$, and $1430 \mathrm{Z}$ and $1930 \mathrm{Z}$ on the $10^{\text {th }}$, respectively, and have been added to HURDAT at $18 \mathrm{Z}$ on the $9^{\text {th }}$, and $12 \mathrm{Z}$ and $18 \mathrm{Z}$ on the $10^{\text {th }}$, respectively. Ship and aircraft observations suggest that Fifi became increasingly less organized on September $11^{\text {th }}$ and dissipation is analyzed to have occurred after $18 \mathrm{Z}$ on the $10^{\text {th }}$ about $150 \mathrm{~nm}$ south of Bermuda, 24 hours earlier than originally shown in HURDAT. HURDAT suggests that the system reintensified late on the $10^{\text {th }}$ and early on the $11^{\text {th }}$, but the observations clearly indicate that these winds were associated with the frontal boundary and not likely to be associated 
with tiny Fifi. Observations suggest that Fifi weakened into a surface trough on September $11^{\text {th }}$ and was absorbed shortly thereafter.

Tropical Storm Gerda [September 14-22, 1958]

\begin{tabular}{|c|c|c|c|c|c|c|c|c|c|c|c|c|c|}
\hline 40755 & $09 / 13 / 1958$ & $3 M=$ & 3 & $7 \mathrm{SNBR}=8$ & $386 \mathrm{G}$ & RDA & XII & $J G=\odot$ & SSS $=$ & & & & \\
\hline 40755 & $\underset{* \star}{09 / 14 / 1958}$ & $M=$ & $\begin{array}{l}9 \\
*\end{array}$ & $3 \mathrm{SNBR}=8$ & $386 \mathrm{G}$ & RDA & XII & $J G=\odot$ & SSS $=$ & & & & \\
\hline 40760 & $09 / 13$ * & $\odot$ & $\odot$ & $0^{*}$ & $\odot$ & $\odot$ & $\odot * 151$ & 620 & 25 & $\odot * 159$ & 642 & 35 & $\Theta^{*}$ \\
\hline 40760 & $09 / 13^{*}$ & $\odot$ & $\odot$ & $0^{*}$ & $\odot$ & $\odot$ & 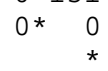 & $\begin{array}{l}0 \\
*\end{array}$ & $\begin{array}{l}0 \\
*\end{array}$ & $\Theta^{*}{ }^{*}$ & $\begin{array}{l}0 \\
*\end{array}$ & $\begin{array}{l}\odot \\
*\end{array}$ & ๑* \\
\hline $\begin{array}{l}4 \odot 765 \\
4 \odot 765\end{array}$ & $\begin{array}{l}09 / 14 * 166 \\
09 / 14 *{ }^{*} \\
\\
*\end{array}$ & $\begin{array}{r}661 \\
0 \\
*\end{array}$ & $\begin{array}{r}35 \\
\odot \\
*\end{array}$ & $\begin{array}{l}\Theta^{*} 172 \\
\Theta^{*} \quad \odot \\
\\
*\end{array}$ & 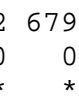 & $\begin{array}{r}45 \\
0 \\
*\end{array}$ & $\begin{array}{r}\Theta^{*} 176 \\
\Theta^{*} 175 \\
* * *\end{array}$ & $\begin{array}{l}694 \\
694\end{array}$ & $\begin{array}{l}50 \\
4 \odot \\
* *\end{array}$ & $\begin{array}{r}\odot * 179 \\
0 * 178 \\
* * *\end{array}$ & $\begin{array}{l}706 \\
706\end{array}$ & $\begin{array}{l}60 \\
5 \odot \\
* *\end{array}$ & $\begin{array}{l}1004^{*} \\
1004^{*}\end{array}$ \\
\hline $\begin{array}{l}40770 \\
40770\end{array}$ & $\begin{array}{r}09 / 15^{*} 182 \\
09 / 15^{*} 181 \\
* \star *\end{array}$ & $\begin{array}{l}719 \\
719\end{array}$ & $\begin{array}{l}45 \\
4 \odot \\
* *\end{array}$ & $\begin{array}{r}0^{*} 186 \\
0^{*} 183 \\
* * *\end{array}$ & $\begin{array}{r}733 \\
3734 \\
* * *\end{array}$ & $\begin{array}{l}40 \\
40\end{array}$ & $\begin{array}{r}\Theta^{*} 190 \\
\text { OW185 } \\
* * * *\end{array}$ & $\begin{array}{l}748 \\
759 \\
* * *\end{array}$ & $\begin{array}{l}35 \\
35\end{array}$ & $\begin{array}{r}\odot * 195 \\
\text { OW187 } \\
* * * *\end{array}$ & $\begin{array}{l}768 \\
786 \\
\star * *\end{array}$ & $\begin{array}{l}25 \\
35\end{array}$ & $\begin{array}{l}\Theta^{*} \\
\Theta^{*}\end{array}$ \\
\hline (Sep & ember 16th & th & ugh & u & new & L & & & & & & & \\
\hline 40771 & 09/16W188 & 815 & 30 & OW185 & 5845 & 30 & OW181 & 870 & 25 & OW176 & 892 & 25 & ०* \\
\hline 40772 & 09/17W176 & 905 & 25 & OW180 & 914 & 25 & OW186 & 920 & 25 & OW193 & 925 & 25 & ०* \\
\hline 40773 & 09/18W199 & 930 & 25 & OW204 & 4935 & 25 & OW208 & 940 & 25 & OW212 & 944 & 25 & 0 * \\
\hline 40774 & 09/19W216 & 948 & 25 & OW218 & 3952 & 25 & $0 * 221$ & 958 & 30 & $0 * 225$ & 965 & 35 & 1004 * \\
\hline 40775 & $09 / 20 * 233$ & 972 & 40 & $1001 * 241$ & L 976 & 40 & $\odot * 255$ & 978 & 35 & $1003 * 270$ & 978 & 30 & 1003 * \\
\hline 40776 & $09 / 21 * 284$ & 975 & 30 & ○*296 & 970 & 25 & $0 * 305$ & 960 & 25 & $0 * 311$ & 946 & 25 & ०* \\
\hline 40777 & $09 / 22 * 313$ & 930 & 25 & $0^{*}$ & $\odot$ & $\odot$ & ๑* & $\odot$ & $\odot$ & ○* 0 & $\odot$ & $\odot$ & ०* \\
\hline
\end{tabular}

40780 TS

Tropical Storm Landfall

09/14 21Z 18.0N 71.2W 50 kt Dominican Republic 09/20 08Z 24.5N 97.7W 40 kt Mexico

Minor changes to the track and intensity shown in McAdie et al. (2009). One day is removed from this system at the beginning of the track. Six additional days are added to the end of this cyclone. Evidence for these alterations comes from the NHC microfilm maps, the Historical Weather Maps series, the COADS ship database, Monthly Weather Review, Local Climatological Data, Surface Weather Observations, Mexican Observations, Navy reconnaissance book and the NHC Storm Wallets.

September 12:

HWM is not available on this date (system south of $20^{\circ} \mathrm{N}$ ). HURDAT does not list an organized storm on this date. Microfilm shows a tropical wave east of the Lesser Antilles near Longitude 56W at 12Z. Ship highlights: No gales or low pressures. 
MWR: "The seventh tropical cyclone of the season, Gerda, developed in an easterly wave which was first identified about 400 statute miles east of the Lesser Antilles on September 11. Reconnaissance aircraft found no evidence of cyclonic flow or unusual weather in the wave on September 12." ATSR: "The 12 September surface analysis, as derived from Navy reconnaissance aircraft and land station reports, indicated a weak, low pressure about 200 miles east of Barbados."

September 13:

HWM is not available on this date (system south of $20^{\circ} \mathrm{N}$ ). HURDAT lists a 25 knot tropical depression at $15.1 \mathrm{~N}, 62.0 \mathrm{~W}$ at $12 \mathrm{Z}$ (first position). Microfilm shows a tropical wave over the eastern Caribbean Sea near Longitude 61W at 12Z. Ship highlights: No gales or low pressures.

MWR: “ ... but on the following day, September 13, surface reports from the Windward Islands indicated that the wave had intensified. The same reports indicated some evidence of cyclonic circulation in the Caribbean Sea, a short distance west of Martinique." ATSR: "This low moved over the Antilles early on 13 September with very light winds but with heavy rainfall at most of the reporting stations. A Navy reconnaissance flight investigated the eastern Caribbean late on 13 September. This flight reported heavy rain but the pressure pattern indicated the low had degenerated into an easterly wave without a circulation center."

September 14:

HWM is not available on this date (system south of $20^{\circ} \mathrm{N}$ ). HURDAT lists a 50 kt tropical storm at $17.6 \mathrm{~N}, 69.4 \mathrm{~W}$ at $12 \mathrm{Z}$. Microfilm shows a tropical wave over the central Caribbean Sea near Longitude 70W at 12Z. Ship highlights: $40 \mathrm{kt}$ SE and 1011 $\mathrm{mb}$ at $17.6 \mathrm{~N}, 64.1 \mathrm{~W}$ at $00 \mathrm{Z}$ (COADS). $45 \mathrm{kt} \mathrm{SE}$ and $1012 \mathrm{mb}$ at $16.4 \mathrm{~N}, 65.1 \mathrm{~W}$ at $06 \mathrm{Z}$ (COADS). $35 \mathrm{kt} \mathrm{ESE}$ and $1013 \mathrm{mb}$ at $17.0 \mathrm{~N}, 68.0 \mathrm{~W}$ at $12 \mathrm{Z}$ (COADS). $35 \mathrm{kt} \mathrm{ESE}$ and $1013 \mathrm{mb}$ at $19.8 \mathrm{~N}, 70.0 \mathrm{~W}$ at 18Z (COADS). Land highlights: $40 \mathrm{kt}$ at Roosevelt Roads NAS, PR at 03Z (WALLET). $35 \mathrm{kt}$ at Ponce, PR at 09Z (WALLET). $37 \mathrm{kt}$ at Cabo Rojo, PR at $15 Z$ (WALLET). Aircraft highlights: Penetration center fix measured a central pressure of $1004 \mathrm{mb}$ at $17.8 \mathrm{~N}, 70.8 \mathrm{~W}$ at $1910 \mathrm{Z}$ (ATSR). Penetration center fix estimated maximum surface winds of $60 \mathrm{kt}$ and an eye diameter of $20 \mathrm{~nm}$ at $17.9 \mathrm{~N}, 71.1 \mathrm{~W}$ at $2118 Z$ (ATSR). Radar center fix at $18.0 \mathrm{~N}, 71.4 \mathrm{~W}$ at $2230 \mathrm{Z}$ (ATSR).

MWR: "...but apparently it was not well defined because aircraft reconnaissance did not confirm its existence until about noon (EST) of September 14. At that time the cyclonic circulation was centered 75 miles southwest of Ciudad Trujillo [Santo Domingo], Dominican Republic, with highest winds $60 \mathrm{kt}$. in the southeastern quadrant and a minimum central pressure of $1004 \mathrm{mb}$. The center of Gerda, moving west-northwestward 
about $18 \mathrm{mph}$, passed over the southern peninsula of the Dominican Republic and evidently the mountainous terrain of that island disrupted the cyclonic flow around its center." ATSR: "At 0700Z, 14 September, the ship PANDORA reported a "storm center" with winds of 65 knots at $17.6 \mathrm{~N}, 67.6 \mathrm{~W}$, or about 65 miles southwest of Ramey AFB, Puerto Rico. Another Navy reconnaissance flight was dispatched to the area and, after thorough investigation found a very weak circulation at $17.8 \mathrm{~N} 70.8 \mathrm{~W}$, surface pressure of $1004 \mathrm{mb}$. The circulation at that time was entering land along the mountainous southern coast of Hispaniola. During the next ten hours GERDA remained over the mountainous terrain and lost all characteristics of a circulation." Tropical Cyclone Report: "By 0600Z on the $14^{\text {th }}$ a ship observation (presumably Navy) about 30 miles SSW of Cabo Rojo reported "gusts to $65 \mathrm{kts}$, storm center located by radar at $17.6 \mathrm{~N}, 67.6 \mathrm{~W}$."

September 15:

HWM is not available on this date (system south of $20^{\circ} \mathrm{N}$ ). HURDAT lists a 35 kt tropical storm at $19.0 \mathrm{~N}, 74.8 \mathrm{~W}$ at $12 \mathrm{Z}$. Microfilm shows a tropical wave over the central Caribbean Sea near Longitude 76W at 12Z. Ship highlights: $35 \mathrm{kt} \mathrm{NE}$ and 1011 $\mathrm{mb}$ at $16.3 \mathrm{~N}, 70.5 \mathrm{~W}$ at $00 \mathrm{Z}$ (COADS). $35 \mathrm{kt}$ ESE and $1015 \mathrm{mb}$ at $20.7 \mathrm{~N}, 73.1 \mathrm{~W}$ at $12 \mathrm{Z}$ (COADS). $35 \mathrm{kt} \mathrm{E}$ and $1011 \mathrm{mb}$ at 18.8N, 78.6W at 18Z (COADS). Land highlights: 40 kt at Port-au-Prince, Haiti at 06Z (WALLET).

MWR: “On September 15, reconnaissance planes could not locate evidence of a circulation and reports thereafter indicated that tropical storm Gerda had again degenerated into an easterly wave. Gale warnings were issued for the southern coasts of Puerto Rico and Dominican Republic in connection with Gerda. Three deaths in Puerto Rico, two of which were drownings, were attributed to the storm." ATSR: "By 1000Z, 15 September, the only remains of GERDA was a strong rapidly moving easterly wave oriented southwest from the southern coast of Cuba and the final warning was issued at that time."

September 16:

HWM is not available on this date (system south of $20^{\circ} \mathrm{N}$ ). HURDAT does not list an organized storm on this date. Microfilm shows a closed low pressure of at most $1011 \mathrm{mb}$ at $17.5 \mathrm{~N}, 86.0 \mathrm{~W}$ at 12Z. Ship highlights: $35 \mathrm{kt} \mathrm{E}$ and $1017 \mathrm{mb}$ at $23.1 \mathrm{~N}, 74.4 \mathrm{~W}$ at $00 \mathrm{Z}$ (COADS).

ATSR: "Reconnaissance flights were continued for the next two days along the easterly wave but no further indications of tropical storm formation were observed." 
September 17:

HWM is not available on this date (system south of $20^{\circ} \mathrm{N}$ ). HURDAT does not list an organized storm on this date. Microfilm shows a tropical wave along $18-23 \mathrm{~N}, 92 \mathrm{~W}$ at 12Z. Ship highlights: No gales or low pressures.

September 18:

HWM is not available on this date (system south of $20^{\circ} \mathrm{N}$ ). HURDAT does not list an organized storm on this date. Microfilm shows a closed low pressure of at most $1008 \mathrm{mb}$ at $19.5 \mathrm{~N}, 92.8 \mathrm{~W}$ at $12 \mathrm{Z}$. Ship highlights: No gales or low pressures.

September 19:

HWM shows a warm front over the northern coast of the Gulf of Mexico at 12Z. HURDAT does not list an organized storm on this date. Microfilm shows a tropical wave along 20-25N, 92W at 12Z. Ship highlights: $1004 \mathrm{mb}$ near 21.0N, 94.5W (report says "early on the $19^{\text {th" }}$ (WALLET).

New Orleans Weather Bureau Bulletin 1930Z: “A few squalls developed in the southwest Gulf of Mexico last night and aircraft reconnaissance this morning indicated that a weak low pressure area has developed. At 130 PM CST the low was centered about 90 statue miles northeast off of the upper Mexican coast. The low is expected to continue northnorthwest at about the same rate moving inland a little south of Brownsville Texas tonight. A few squalls with winds up to $35 \mathrm{mph}$ may occur along the lower Texas coast tonight and small craft Port Aransas southward should remain in port. An increase in the heavy rain in south and central Texas is likely during the next 24 hours causing additional flooding in that area and all interests should watch for flood bulletins from local weather bureau offices."

September 20:

HWM shows a closed low pressure of at most $1005 \mathrm{mb}$ at $25.5 \mathrm{~N}, 97.5 \mathrm{~W}$ with a stationary front to the north at $12 \mathrm{Z}$. HURDAT does not list an organized storm on this date. Microfilm shows a closed low pressure of at most $1005 \mathrm{mb}$ at $25.5 \mathrm{~N}, 97.7 \mathrm{~W}$ at $12 \mathrm{Z}$. Ship highlights: $15 \mathrm{kt} \mathrm{SE}$ and $1005 \mathrm{mb}$ at 22.4N, 96.4W at 00Z (COADS). $35 \mathrm{kt} \mathrm{SSE}$ and $1009 \mathrm{mb}$ at 27.7N, 94.9W at 18Z (COADS). Land highlights: $5 \mathrm{kt} \mathrm{NE}$ and $1002 \mathrm{mb}$ at Soto La Marina, Mexico at $00 \mathrm{Z}$ (micro). $5 \mathrm{kt} \mathrm{SE}$ and $1004 \mathrm{mb}$ at Brownsville, Texas at $12 \mathrm{Z}$ (micro). $6 \mathrm{kt} \mathrm{SE}$ and $1004 \mathrm{mb}$ at Port Isabel, Texas at 18Z (SWO).

New Orleans Weather Bureau Bulletin 13Z: "The small low moved inland from the western Gulf of Mexico and at 7 AM CST it was centered near Brownsville Texas moving northward about $15 \mathrm{mph}$. A few squalls with winds up to $35 \mathrm{mph}$ are occurring 
off the Texas coast. The low is expected to move northward at about the same rate today and turn northeastward moving through east Texas tonight. A few squalls and rough seas are expected along the Texas and western Louisiana coasts through tonight and small craft in that area

September 21:

HWM shows a stationary front over Texas and a second warm-front over northern Texas and Oklahoma at 12Z. HURDAT does not list an organized storm on this date. Microfilm shows a closed low pressure of at most $1011 \mathrm{mb}$ at $31.5 \mathrm{~N}, 91.0 \mathrm{~W}$ with a frontal boundary to the northeast and southwest, and a second warm-front over northern Texas and Oklahoma at 12Z. Ship highlights: No gales or low pressures.

September 22:

HWM shows a warm front over the northwest coast of the Gulf of Mexico at 12Z. HURDAT does not list an organized storm on this date. Microfilm shows a frontal boundary north of the Gulf of Mexico at 12Z. Ship highlights: No gales or low pressures.

Local Climatological Data Corpus Christi, Texas: "A small tropical low developed in the southwest Gulf of Mexico from a weak easterly wave on the $18^{\text {th }}$ of Sep. This small low pressure area did not develop as it moved northward and only caused some locally heavy rains in the area. It moved over Brownsville and then north to our area, passing from the south to the north over Corpus Christi during the afternoon of the $20^{\text {th }}$. Winds remained light most of the time during the day. The very unstable air caused the formation of two funnel clouds near Freer the evening of the $20^{\text {th }}$. Our lowest pressure during the passage of the low center was 29.67."

A strong tropical wave entered the eastern Caribbean Sea on September $13^{\text {th }}$ moving rapidly to the west-northwest. HURDAT indicates that genesis occurred on September $13^{\text {th }}$ at $12 \mathrm{Z}$ as a $25 \mathrm{kt}$ tropical depression, but observations from ships and reconnaissance aircrafts indicate that the tropical wave did not have a closed circulation on the $13^{\text {th }}$ and early on the $14^{\text {th }}$. Genesis is delayed 24 hours until September $14^{\text {th }}$ at $12 \mathrm{Z}$ as a $40 \mathrm{kt}$ tropical storm based on reports from the reconnaissance aircraft later on the day and a couple of ships reporting tropical storm force winds. It is interesting to note that advisories on Gerda were originally started at $21 \mathrm{Z}$ on the $14^{\text {th }}$ and the MWR Tracks of Centers of Cyclones at Sea Level for the month of September has Gerda starting at 06Z on the $14^{\text {th }}$. The northern portion of the tropical wave was quite active on September $14^{\text {th }}$ causing tropical storm force winds in Puerto Rico and nearby islands. A couple of ships also reported gale force winds on the $14^{\text {th }}$, similar to this reanalysis. A reconnaissance mission reached the tropical cyclone at $1904 \mathrm{Z}$ measuring a central pressure of $1004 \mathrm{mb}$ and at $2118 \mathrm{Z}$ estimated surface winds of $60 \mathrm{kt}$ and an eye diameter of $20 \mathrm{~nm}$. A central 
pressure of $1004 \mathrm{mb}$ suggests maximum sustained winds of $39 \mathrm{kt}$ from the south of $25 \mathrm{~N}$ Brown et al. pressure-wind relationship. An eye diameter of $20 \mathrm{~nm}$ suggests an RMW of about $15 \mathrm{~nm}$ and climatology suggests about the same. An intensity of $50 \mathrm{kt}$ is analyzed at $18 \mathrm{Z}$ on the $14^{\text {th }}$, down from $60 \mathrm{kt}$ originally in HURDAT, a minor intensity change. The analyzed intensity is a combination between the obtained value from the pressurewind relationship and the estimated surface winds reported by the reconnaissance aircraft. $50 \mathrm{kt}$ is also the peak intensity during the lifetime of this tropical cyclone, down from 60 kt originally in HURDAT. A central pressure of $1004 \mathrm{mb}$ was already in HURDAT at $18 \mathrm{Z}$ on the $14^{\text {th }}$ and has been retained. Landfall occurred at $21 \mathrm{Z}$ on the $14^{\text {th }}$ on the Barahona Peninsula in the southern Dominican Republic near $18.0 \mathrm{~N}, 71.2 \mathrm{~W}$ as a $50 \mathrm{kt}$ tropical storm. The mountainous terrain of Hispaniola took its toll on Gerda and weakening to a tropical wave is analyzed at $12 \mathrm{Z}$ on September $15^{\text {th }}$. HURDAT maintained Gerda as a tropical cyclone until $18 \mathrm{Z}$ on the $15^{\text {th }}$ but reports from ships, coastal stations and a reconnaissance aircraft indicate that it did not have a closed circulation after $06 \mathrm{Z}$ on the $15^{\text {th }}$. Ships still reported gale-force winds late on September $15^{\text {th }}$ and on that basis, the intensity of the tropical wave is retained at gale-force at $12 \mathrm{Z}$ and $18 \mathrm{Z}$ on this day. HURDAT originally indicated that Gerda had weakened to a tropical depression at $18 \mathrm{Z}$ on the $15^{\text {th }}$ and dissipated afterwards.

The tropical wave moved rapidly across the western Caribbean Sea on September $16^{\text {th }}$. Weakening below gale-force is analyzed at $00 \mathrm{Z}$ on the $16^{\text {th }}$. Around $12 \mathrm{Z}$ on September $17^{\text {th }}$, the tropical wave entered the Bay of Campeche and the forward speed of the disturbance decreased. Over the next couple of days, the disturbance moved northwestward gaining in organization. A $30 \mathrm{kt}$ tropical depression is analyzed to have developed at $12 \mathrm{Z}$ on September $19^{\text {th }}$ based on observations later in the day. It is possible that development may have occurred a day earlier due to the scarcity of ships in the Bay of Campeche. At $18 \mathrm{Z}$ on the $19^{\text {th }}$, a ship reported $20 \mathrm{kt} \mathrm{N}$ and $1006 \mathrm{mb}$ near the center of the cyclone, suggesting a central pressure of about $1004 \mathrm{mb}$, which has been added to HURDAT. A central pressure of $1004 \mathrm{mb}$ suggests maximum sustained winds of $39 \mathrm{kt}$ south of $25 \mathrm{~N}$ according to the pressure-wind relationship. Based on generally low environmental pressures and slow forward speed of about $8 \mathrm{kt}$, an intensity of $35 \mathrm{kt}$ is selected at $18 \mathrm{Z}$ on the $19^{\text {th }}$. A reconnaissance aircraft visited the tropical cyclone on the $19^{\text {th }}$ estimating surface winds of $35 \mathrm{kt}$ and a minimum pressure of $1005 \mathrm{mb}$, but did not make a center fix. At $00 \mathrm{Z}$ on September $20^{\text {th }}$, the north-northwestward motion of Gerda brought the center closer to the coast of northeast Mexico. At this time, Soto la Marina, Mexico reported $5 \mathrm{kt} \mathrm{NE}$ and $1002 \mathrm{mb}$, suggesting a central pressure of $1001 \mathrm{mb}$, which has been added to HURDAT. A central pressure of $1001 \mathrm{mb}$ suggests maximum sustained winds of $45 \mathrm{kt}$ according to the south of $25 \mathrm{~N}$ pressure-wind relationship. An intensity of $40 \mathrm{kt}$ is selected at $00 \mathrm{Z}$ on the $20^{\text {th }}$ due to the slow forward speed of Gerda and low environmental pressures. Landfall is analyzed at $08 \mathrm{Z}$ on the $20^{\text {th }}$ over 
northeastern Tamaulipas, Mexico at $24.5 \mathrm{~N}, 97.7 \mathrm{~W}$ as a $40 \mathrm{kt}$ tropical storm. At $12 \mathrm{Z}$ on the $20^{\text {th }}$, Brownsville, Texas reported $5 \mathrm{kt} \mathrm{SE}$ and $1004 \mathrm{mb}$, suggesting a central pressure of $1003 \mathrm{mb}$, which has been added to HURDAT. Late on the $20^{\text {th }}$, Gerda turned to the north and increased in forward speed. Weakening to a tropical depression occurred at $18 \mathrm{Z}$ on the $20^{\text {th }}$. Gerda was a tropical depression when it reached Texas and was not a tropical storm impact for the state. At $18 \mathrm{Z}$ on the $20^{\text {th }}$, Port Isabel, Texas reported $6 \mathrm{kt} \mathrm{NE}$ and $1004 \mathrm{mb}$, suggesting a central pressure of $1003 \mathrm{mb}$, which has been added to HURDAT. A ship reported $35 \mathrm{kt}$ at $18 \mathrm{Z}$ on the $20^{\text {th }}$ but appears to have a slight high bias. On September $21^{\text {st }}$, Gerda turned to the northeast ahead of a frontal boundary. Microfilm analyzes a frontal system across the tropical cyclone and another frontal system to the north at $12 \mathrm{Z}$ on the $21^{\text {st }}$. Observations around the tropical depression show dew points in the low 70s northwest of the center, indicating that the analyzed frontal boundary in microfilm is likely non-existent. The depression is not analyzed to have become extratropical at any point during its lifetime. Dissipation is analyzed after $00 \mathrm{Z}$ on September $22^{\text {nd }}$ over western Louisiana. The re-development of Gerda in the Gulf of Mexico is mentioned as a suspect in Jack Beven's List of Suspects. An analog to this tropical cyclone is Tropical Storm Helene in 2012.

Hurricane Helene [September 21 - October 4, 1958]

\begin{tabular}{|c|c|c|c|c|c|c|c|c|c|c|c|c|c|}
\hline 40780 & $09 / 21 / 1958$ & $3 \quad M=1$ & 4 & SNBR $=88$ & $37 \mathrm{HE}$ & ELENE & XIN & $V G=\odot$ & $\mathrm{SSS}=$ & & & & \\
\hline 40780 & $09 / 21 / 1958$ & $3 \quad M=1$ & 4 & SNBR= 88 & & ELENE & XIN & $V G=\odot$ & SSS $=$ & & & & \\
\hline 40785 & $09 / 21$ * & $\odot$ & $\odot$ & $0 * 185$ & 515 & 25 & ๑*190 & 542 & 25 & 0*195 & 563 & 25 & ○* \\
\hline 40785 & $09 / 21$ * & $\odot$ & 0 & $\begin{array}{c}0 * 170 \\
\star \star *\end{array}$ & $\begin{array}{l}520 \\
* * *\end{array}$ & 25 & $\begin{array}{c}0 * 176 \\
* * *\end{array}$ & 542 & 25 & $\begin{array}{r}0 * 183 \\
* * *\end{array}$ & $\begin{array}{l}563 \\
* * *\end{array}$ & 25 & ○* \\
\hline 40790 & $09 / 22 * 201$ & 583 & 25 & $\odot * 207$ & 602 & 25 & $0 * 213$ & 619 & 25 & $1015 * 219$ & 635 & 30 & 1014 * \\
\hline $4079 \odot$ & $09 / 22 * 191$ & $\begin{array}{l}584 \\
\star * *\end{array}$ & 25 & $\begin{array}{r}0 * 201 \\
\star \star \star\end{array}$ & $\begin{array}{l}604 \\
* * *\end{array}$ & 25 & $\begin{array}{l}0 * 211 \\
* \star \star\end{array}$ & $\begin{array}{l}624 \\
\star * *\end{array}$ & 25 & $\begin{array}{l}0 * 219 \\
\star \star \star * *\end{array}$ & $\begin{array}{r}641 \\
* * * *\end{array}$ & 30 & $\begin{array}{l}1013^{*} \\
\star * * *\end{array}$ \\
\hline 40795 & $09 / 23 * 225$ & 648 & 35 & $1013 * 230$ & 658 & 40 & $1011 * 234$ & 669 & 45 & $10 \odot 9 * 24 \odot$ & 682 & 45 & $1007^{*}$ \\
\hline 40795 & $\begin{array}{r}09 / 23 * 224 \\
* * *\end{array}$ & $\begin{array}{l}652 \\
* * *\end{array}$ & 35 & $\begin{array}{l}\odot * 230 \\
\star \quad * *\end{array}$ & $\begin{array}{l}662 \\
* * *\end{array}$ & 40 & $\begin{array}{l}0 * 235 \\
* \quad * * *\end{array}$ & $\begin{array}{l}672 \\
* * *\end{array}$ & $\begin{array}{l}40 \\
* *\end{array}$ & $\begin{array}{r}1003 * 240 \\
* * *\end{array}$ & $\begin{array}{l}684 \\
* * *\end{array}$ & 45 & $\begin{array}{l}1000^{*} \\
\star * * *\end{array}$ \\
\hline 40800 & $09 / 24 * 247$ & 696 & 45 & 1005 *257 & 709 & 50 & $1004 * 267$ & 720 & 65 & $1002 * 272$ & 729 & 65 & 998 * \\
\hline 40800 & $\begin{array}{r}09 / 24 * 246 \\
* * *\end{array}$ & 696 & $\begin{array}{l}50 \\
* *\end{array}$ & $\begin{array}{l}\odot * 256 \\
* * * *\end{array}$ & $\begin{array}{l}707 \\
* * *\end{array}$ & $\begin{array}{l}55 \\
* *\end{array}$ & $\begin{array}{l}\Theta * 265 \\
* * * *\end{array}$ & $\begin{array}{l}717 \\
\star * *\end{array}$ & $\begin{array}{l}60 \\
* *\end{array}$ & $\begin{array}{l}997 * 272 \\
\star * * \star \star * *\end{array}$ & $\begin{array}{l}724 \\
* * *\end{array}$ & 65 & $\begin{array}{l}\Theta^{*} \\
*\end{array}$ \\
\hline 40805 & $09 / 25 * 277$ & 734 & 65 & $993 * 283$ & 736 & 70 & $987^{*} 288$ & 739 & 75 & 984 *292 & 743 & 80 & $983^{*}$ \\
\hline 40805 & $\begin{array}{r}09 / 25 * 277 \\
\star \star * *\end{array}$ & $\begin{array}{l}730 \\
* * *\end{array}$ & 65 & $993 * 283$ & $\begin{array}{l}735 \\
* * *\end{array}$ & 70 & $987 * 288$ & 739 & $\begin{array}{l}70 \\
* *\end{array}$ & $\begin{array}{r}984 * 292 \\
* \star *\end{array}$ & $\begin{array}{l}742 \\
* * *\end{array}$ & $\begin{array}{l}70 \\
* *\end{array}$ & $\begin{array}{l}982^{*} \\
* * \star\end{array}$ \\
\hline 40810 & $09 / 26$ *296 & 748 & 85 & $980 * 299$ & 754 & 85 & $977 * 303$ & 761 & $9 \odot$ & $967 * 310$ & 771 & 105 & $955 *$ \\
\hline 40810 & $\begin{array}{r}09 / 26 * 295 \\
* \star *\end{array}$ & $\begin{array}{l}747 \\
\star * *\end{array}$ & $\begin{array}{l}65 \\
\star *\end{array}$ & $\begin{array}{l}986 * 297 \\
\star \star \star * \star *\end{array}$ & 754 & $\begin{array}{l}80 \\
\star *\end{array}$ & $\begin{array}{l}974 * 302 \\
\star \star \star * \star * \star\end{array}$ & $\begin{array}{l}762 \\
\star * *\end{array}$ & $\begin{array}{l}95 \\
* *\end{array}$ & $\begin{array}{l}963 * 309 \\
* * \star * * *\end{array}$ & $\begin{array}{l}773 \\
\star * *\end{array}$ & $\begin{array}{l}110 \\
\star * *\end{array}$ & $\begin{array}{l}948 * \\
\star \star \star\end{array}$ \\
\hline 8 & $09 / 27 * 317$ & 781 & 110 & $943 * 324$ & 785 & 110 & $934 * 331$ & 782 & 115 & $938 * 339$ & 775 & 115 & 943 * \\
\hline 0815 & $09 / 27 * 316$ & 783 & 115 & $943 * 323$ & 786 & 125 & $933 * 331$ & 785 & 120 & $938 * 339$ & 776 & 120 & $0^{*}$ \\
\hline
\end{tabular}




\begin{tabular}{|c|c|c|c|c|c|c|c|c|c|c|c|c|c|}
\hline & $\star * *$ & $\star \star *$ & $\star * *$ & $\star \star *$ & $\star * *$ & $\star \star *$ & $* * *$ & $\star * *$ & $\star * *$ & & $\star * *$ & $\star * *$ & * \\
\hline $\begin{array}{l}40820 \\
40820\end{array}$ & $\begin{array}{r}09 / 28 * 348 \\
09 / 28 * 347 \\
* * *\end{array}$ & $\begin{array}{l}758 \\
759 \\
* * *\end{array}$ & $\begin{array}{l}110 \\
115 \\
\star \star *\end{array}$ & $\begin{array}{l}946 * 358 \\
938 * 355 \\
\star * \star * \star *\end{array}$ & $\begin{array}{l}732 \\
738 \\
\star * *\end{array}$ & $\begin{array}{l}110 \\
110\end{array}$ & $\begin{array}{r}950 * 369 \\
950^{*} 366 \\
* * *\end{array}$ & $\begin{array}{l}705 \\
713 \\
\star * *\end{array}$ & $\begin{array}{l}105 \\
105\end{array}$ & $\begin{array}{l}954 * 380 \\
954 * 380\end{array}$ & $\begin{array}{l}683 \\
683\end{array}$ & $\begin{array}{r}90 \\
100 \\
* * *\end{array}$ & $\begin{array}{l}957^{*} \\
943^{*} \\
* * *\end{array}$ \\
\hline $\begin{array}{l}40825 \\
40825\end{array}$ & $\begin{array}{r}\odot 9 / 29 * 39 \odot \\
09 / 29 \mathrm{E} 4 \odot \odot \\
* * * *\end{array}$ & $\begin{array}{l}659 \\
650 \\
\star * *\end{array}$ & $\begin{array}{l}85 \\
90 \\
* *\end{array}$ & $\begin{array}{l}959 * 417 \\
951 \mathrm{E} 430 \\
\star * \star \star * \star *\end{array}$ & $\begin{array}{l}619 \\
625 \\
\star * *\end{array}$ & $\begin{array}{l}70 \\
80 \\
\star *\end{array}$ & $\begin{array}{r}963 * 457 \\
963 \mathrm{E} 465 \\
\star \star \star *\end{array}$ & $\begin{array}{l}590 \\
602 \\
* * *\end{array}$ & $\begin{array}{l}65 \\
75 \\
* *\end{array}$ & $\begin{array}{r}966 \mathrm{E} 490 \\
966 \mathrm{E} 495 \\
* \star *\end{array}$ & $\begin{array}{l}566 \\
560 \\
* * *\end{array}$ & $\begin{array}{l}65 \\
70 \\
* *\end{array}$ & $\begin{array}{l}968 * \\
968 *\end{array}$ \\
\hline $\begin{array}{l}40830 \\
40830\end{array}$ & $\begin{array}{r}09 / 30 E 520 \\
09 / 30 E 515 \\
* * *\end{array}$ & $\begin{array}{l}524 \\
515 \\
* * *\end{array}$ & $\begin{array}{l}60 \\
65 \\
* *\end{array}$ & $\begin{array}{r}972 \mathrm{E} 539 \\
972 \mathrm{E} 535 \\
* \star *\end{array}$ & $\begin{array}{l}488 \\
488\end{array}$ & $\begin{array}{l}60 \\
60\end{array}$ & $\begin{array}{l}\text { OE55० } \\
\text { OE55० }\end{array}$ & $\begin{array}{l}450 \\
460 \\
\star \star *\end{array}$ & $\begin{array}{l}60 \\
6 \odot\end{array}$ & $\begin{array}{l}\text { ๑E562 } \\
\text { ๑E562 }\end{array}$ & $\begin{array}{l}411 \\
415 \\
\star * *\end{array}$ & $\begin{array}{l}55 \\
60 \\
* *\end{array}$ & $\begin{array}{l}\Theta^{*} \\
\Theta^{*}\end{array}$ \\
\hline $\begin{array}{l}40835 \\
40835\end{array}$ & $\begin{array}{l}10 / 01 \mathrm{E} 570 \\
10 / 01 \mathrm{E} 57 \odot\end{array}$ & $\begin{array}{l}373 \\
373\end{array}$ & $\begin{array}{l}55 \\
60 \\
* *\end{array}$ & $\begin{array}{l}\text { OE573 } \\
\text { OE570 }\end{array}$ & $\begin{array}{l}345 \\
345\end{array}$ & $\begin{array}{l}55 \\
60 \\
* *\end{array}$ & $\begin{array}{r}\text { OE575 } \\
\text { OE565 } \\
\star * *\end{array}$ & $\begin{array}{l}320 \\
320\end{array}$ & $\begin{array}{l}50 \\
65 \\
* *\end{array}$ & $\begin{array}{r}\text { @E577 } \\
\text { OE558 } \\
* * *\end{array}$ & $\begin{array}{l}289 \\
300 \\
* * *\end{array}$ & $\begin{array}{l}50 \\
70 \\
* *\end{array}$ & $\begin{array}{l}\Theta^{*} \\
\Theta^{*}\end{array}$ \\
\hline $\begin{array}{l}40840 \\
4084 \odot\end{array}$ & $\begin{array}{r}10 / 02 \mathrm{E} 575 \\
10 / 02 \mathrm{E} 550 \\
* * *\end{array}$ & $\begin{array}{l}255 \\
270 \\
\star * *\end{array}$ & $\begin{array}{l}50 \\
70 \\
\star *\end{array}$ & $\begin{array}{l}\text { OE561 } \\
\text { OE540 } \\
* * *\end{array}$ & $\begin{array}{l}212 \\
230 \\
\star * *\end{array}$ & $\begin{array}{l}45 \\
65 \\
\star *\end{array}$ & $\begin{array}{r}\text { OE543 } \\
\text { OE523 } \\
\star * *\end{array}$ & $\begin{array}{l}173 \\
205 \\
\star \star \star\end{array}$ & $\begin{array}{l}45 \\
55 \\
\star *\end{array}$ & $\begin{array}{r}\text { OE531 } \\
\text { @E5๑7 } \\
* * *\end{array}$ & $\begin{array}{l}154 \\
190 \\
\star * *\end{array}$ & $\begin{array}{l}45 \\
50 \\
\star *\end{array}$ & $\begin{array}{l}\Theta^{*} \\
\Theta^{*}\end{array}$ \\
\hline $\begin{array}{l}40845 \\
40845\end{array}$ & $\begin{array}{r}10 / \text { O3E522 } \\
10 / 03 E 510 \\
* * *\end{array}$ & $\begin{array}{l}142 \\
160 \\
* * *\end{array}$ & $\begin{array}{l}40 \\
50 \\
* *\end{array}$ & $\begin{array}{l}\text { OE518 } \\
\text { OE512 } \\
* * *\end{array}$ & $\begin{array}{l}134 \\
138 \\
\star * *\end{array}$ & $\begin{array}{l}35 \\
45 \\
\star *\end{array}$ & $\begin{array}{l}\text { OE514 } \\
\text { OE512 } \\
* * *\end{array}$ & $\begin{array}{l}125 \\
128 \\
* * *\end{array}$ & $\begin{array}{l}35 \\
4 \odot \\
* *\end{array}$ & $\begin{array}{l}\text { OE510 } \\
\text { OE512 } \\
* * *\end{array}$ & $\begin{array}{l}104 \\
115 \\
* * *\end{array}$ & $\begin{array}{l}35 \\
40 \\
* *\end{array}$ & $\begin{array}{l}\Theta^{*} \\
\Theta^{*}\end{array}$ \\
\hline $\begin{array}{l}40850 \\
40850\end{array}$ & $\begin{array}{r}10 / 04 \mathrm{E} 505 \\
10 / 04 \mathrm{E} 512 \\
* * *\end{array}$ & $\begin{array}{l}73 \\
85 \\
* *\end{array}$ & $\begin{array}{l}35 \\
35\end{array}$ & $\begin{array}{r}\text { OE516 } \\
\text { OE512 } \\
* * *\end{array}$ & $\begin{array}{l}49 \\
55 \\
* *\end{array}$ & $\begin{array}{l}35 \\
35\end{array}$ & $\begin{array}{ll}\Theta^{*} & \odot \\
\Theta^{*} & \odot\end{array}$ & $\begin{array}{l}\odot \\
\odot\end{array}$ & $\begin{array}{l}\odot \\
\odot\end{array}$ & $\begin{array}{ll}\Theta^{*} & \odot \\
\Theta^{*} & \odot\end{array}$ & $\begin{array}{l}\odot \\
\odot\end{array}$ & $\begin{array}{l}\odot \\
\odot\end{array}$ & $\begin{array}{l}\Theta^{*} \\
\Theta^{*}\end{array}$ \\
\hline $\begin{array}{l}40855 \\
40855\end{array}$ & $\begin{array}{l}\text { HR NC3 } \\
\text { HR SC1NC3 }\end{array}$ & & & & & & & & & & & & \\
\hline
\end{tabular}

09/27 15Z 33.4N 78.2W 80 kt South Carolina

09/27 18Z 33.9N 77.6W 110 kt North Carolina

\section{U.S. Tropical Storm Impact}

\section{9/28 03Z 35.1N 74.9W $40 \mathrm{kt}$ Virginia}

Major changes to the track and intensity shown in McAdie et al. (2009). Evidence for these alterations comes from the NHC microfilm maps, the Historical Weather Maps series, the COADS ship database, Monthly Weather Review, Surface Weather Observations, Navy reconnaissance book, Mariners Weather Log and NHC Storm Wallets.

September 20:

HWM is not available on this date (system south of $20^{\circ} \mathrm{N}$ ). HURDAT does not list an organized system on this date. Microfilm shows a tropical wave along longitude 47W, extending from $12 \mathrm{~N}-20 \mathrm{~N}$ at $12 \mathrm{Z}$. Ship highlights: No gales or low pressures. 
MWR: "Hurricane Helene, one of the most intense storms of the 1958 season as well as the most destructive, developed from an easterly wave which can be traced back to the Cape Verde Islands on September 16. Slow intensification of the wave began near longitude $50 \mathrm{~W}$ on September 20 with pressure falls and above normal shower activity reported by shipping in the area." ATSR: "Hurricane Helene, the eight storm of the 1958 season, started from an easterly wave which was tracked across the Atlantic commencing 17 September. The wave message, designated 7SM, as received from Fleet Weather Central, Port Lyautey, on 16 September indicated that it was of moderate strength; however, from 16 to 20 September, it appeared to be very weak. On 20 September, ship reports of heavy showers and rain activity in the vicinity of the wave warranted a Navy reconnaissance flight on 21 September. The flight reported only a weak circulation with less than 20 knots surface wind."

September 21:

HWM is not available on this date (system south of $20^{\circ} \mathrm{N}$ ). HURDAT lists a 25 knot tropical depression at $19.0 \mathrm{~N}, 54.2 \mathrm{~W}$ at $12 \mathrm{Z}$. Microfilm shows a tropical wave along longitude $54 \mathrm{~W}$, extending from $12 \mathrm{~N}-20 \mathrm{~N}$ at $12 \mathrm{Z}$. Ship highlights: $40 \mathrm{kt} \mathrm{SE}$ and $1012 \mathrm{mb}$ at $18.5 \mathrm{~N}, 52.0 \mathrm{~W}$ at $18 \mathrm{Z}$ (micro).

MWR: "On the 21st, aircraft located evidence of a weak circulation near 19N, 54W with maximum winds of 35 to $40 \mathrm{mph}$ in scattered squalls."

September 22:

HWM analyzes a tropical storm of at most $1010 \mathrm{mb}$ at $21.3 \mathrm{~N}, 62.5 \mathrm{~W}$ at $12 \mathrm{Z}$. HURDAT lists a 25 knot tropical depression at $21.3 \mathrm{~N}, 61.9 \mathrm{~W}$ at $12 \mathrm{Z}$. Microfilm shows a tropical wave along longitude $61 \mathrm{~W}$, extending from $18 \mathrm{~N}-25 \mathrm{~N}$ at $12 \mathrm{Z}$. Ship highlights: No gales or low pressures. Aircraft highlights: Penetration center fix measured a central pressure of $1013 \mathrm{mb}$ and estimated surface winds of $20 \mathrm{kt}$ at $22.1 \mathrm{~N}, 64.9 \mathrm{~W}$ at $1930 \mathrm{Z}$ (ATSR/MWR).

MWR: "The incipient storm moved on a west-northwestward course at approximately 20 mph on the $22^{\text {nd }}$ with little change in intensity. However, an extensive anticyclone in the upper troposphere was developing off the South Atlantic coast during this period so that the disturbance was moving into a much more favorable environment for the deepening process to begin." ATSR: "The USAF GULL PAPA was diverted to the area on 22 September and reported a well-defined circulation, strong radar definition but with less than 20 knots surface wind and sea-level pressure of $1013 \mathrm{mb} . "$ 
September 23:

HWM analyzes a tropical storm of at most $1010 \mathrm{mb}$ at $23.5 \mathrm{~N}, 68.0 \mathrm{~W}$ at $12 \mathrm{Z}$. HURDAT lists a 45 knot tropical storm at $23.4 \mathrm{~N}, 66.9 \mathrm{~W}$ at $12 \mathrm{Z}$. Microfilm shows a closed low pressure of at most $1011 \mathrm{mb}$ at $23.5 \mathrm{~N}, 68.0 \mathrm{~W}$ at $12 \mathrm{Z}$. Ship highlights: $15 \mathrm{kt} \mathrm{W}$ and $1002 \mathrm{mb}$ at $23.5 \mathrm{~N}, 68.5 \mathrm{~W}$ at $15 \mathrm{Z}$ (COADS). $40 \mathrm{kt} \mathrm{NW}$ and $1009 \mathrm{mb}$ at $24.0 \mathrm{~N}$, $69.0 \mathrm{~W}$ at $18 \mathrm{Z}$ (micro). $40 \mathrm{kt} \mathrm{SW}$ and $1001 \mathrm{mb}$ at $24.5 \mathrm{~N}, 69.3 \mathrm{~W}$ at $21 \mathrm{Z}$ (micro). Aircraft highlights: Penetration center fix at $23.6 \mathrm{~N}, 67.7 \mathrm{~W}$ at $10 \mathrm{Z}$ (ATSR). Penetration center fix measured a central pressure of $1003 \mathrm{mb}$ and estimated surface winds of $45 \mathrm{kt}$ at $23.7 \mathrm{~N}$, 68.3W at $1330 \mathrm{Z}$ (ATSR). Penetration center fix at 24.1N, 69.1W at $1930 \mathrm{Z}$ (ATSR).

MWR: "On the morning (EST) of the 23rd, reconnaissance aircraft located a center near $23 \mathrm{~N}, 68 \mathrm{~W}$, indicating a slowing of forward speed to $12 \mathrm{mph}$ and an increase of winds to $50 \mathrm{mph}$ in squalls." ATSR: "Again on 23 September, the routine GULL PAPA was cancelled in favor of further reconnaissance of this circulation. This flight reported the storm center at $23.7 \mathrm{~N} 68.3 \mathrm{~W}$ with maximum surface winds of 45 knots, sea-level pressure of $1003 \mathrm{mb}$ but with a poor radar presentation. Shortly after this report, the first warning on Tropical Storm HELENE was issued."

September 24:

HWM analyzes a hurricane with a central pressure of $997 \mathrm{mb}$ at $26.5 \mathrm{~N}, 72.0 \mathrm{~W}$ and a warm front to the north at 12Z. HURDAT lists a 65 knot hurricane at $26.7 \mathrm{~N}, 72.0 \mathrm{~W}$ at $12 \mathrm{Z}$. Microfilm shows a closed low pressure of at most $1005 \mathrm{mb}$ at $26.5 \mathrm{~N}, 72.0 \mathrm{~W}$ at 12Z. Ship highlights: $40 \mathrm{kt} \mathrm{SSW}$ and $1001 \mathrm{mb}$ at $24.8 \mathrm{~N}, 69.4 \mathrm{~W}$ at $00 \mathrm{Z}$ (micro). $30 \mathrm{kt} \mathrm{SSE}$ and $1001 \mathrm{mb}$ at $25.0 \mathrm{~N}, 69.6 \mathrm{~W}$ at $03 \mathrm{Z}$ (micro). $40 \mathrm{kt} \mathrm{SE}$ and $1012 \mathrm{mb}$ at $26.1 \mathrm{~N}, 69.4 \mathrm{~W}$ at $06 \mathrm{Z}$ (micro). $65 \mathrm{kt} \mathrm{S}$ and $1013 \mathrm{mb}$ at $26.0 \mathrm{~N}, 69.1 \mathrm{~W}$ at $09 \mathrm{Z}$ (micro). $65 \mathrm{kt} \mathrm{SSE} 27.6 \mathrm{~N}$, $70.9 \mathrm{~W}$ at $18 \mathrm{Z}$ (micro). $50 \mathrm{kt} \mathrm{S}$ at $27.5 \mathrm{~N}, 70.9 \mathrm{~W}$ at $21 \mathrm{Z}$ (micro). Aircraft highlights: Radar center fix estimated an eye diameter of $15 \mathrm{~nm}$ at $24.7 \mathrm{~N}, 69.8 \mathrm{~W}$ at $02 \mathrm{Z}$ (ATSR).

Penetration center fix measured a central pressure of $997 \mathrm{mb}$, and estimated surface winds of $55 \mathrm{kt}$ and an eye diameter of $9 \mathrm{~nm}$ at 26.7N, $71.6 \mathrm{~W}$ at $1330 \mathrm{Z}$ (ATSR). Radar center fix estimated an eye diameter of $10 \mathrm{~nm}$ at $27.2 \mathrm{~N}, 72.9 \mathrm{~W}$ at $19 \mathrm{Z}$ (ATSR).

MWR: "Helene continued on a west-northwestward course at 12 to $15 \mathrm{mph}$ through the 24th with slow intensification."

September 25:

HWM analyzes a hurricane with a central pressure of $980 \mathrm{mb}$ at $28.9 \mathrm{~N}, 74.0 \mathrm{~W}$ and a dissipating front to the north at $12 \mathrm{Z}$. HURDAT lists a 75 knot hurricane at $28.8 \mathrm{~N}$, $73.9 \mathrm{~W}$ at $12 \mathrm{Z}$. Microfilm shows a closed low pressure of at most $1005 \mathrm{mb}$ at $29.0 \mathrm{~N}$, 74.0W at 12Z. Ship highlights: $40 \mathrm{kt} \mathrm{E}$ and $1013 \mathrm{mb}$ at $29.2 \mathrm{~N}, 72.4 \mathrm{~W}$ at $00 \mathrm{Z}$ (COADS). 
$40 \mathrm{kt} \mathrm{S}$ and $1010 \mathrm{mb}$ at $27.0 \mathrm{~N}, 70.0 \mathrm{~W}$ at $03 \mathrm{Z}$ (micro). $40 \mathrm{kt} \mathrm{SE}$ and $1010 \mathrm{mb}$ at $26.5 \mathrm{~N}$, $70.8 \mathrm{~W}$ at $06 \mathrm{Z}$ (COADS). $65 \mathrm{kt} \mathrm{ESE}$ and $1009 \mathrm{mb}$ at $30.0 \mathrm{~N}, 72.7 \mathrm{~W}$ at $12 \mathrm{Z}$ (micro). $35 \mathrm{kt}$ $\mathrm{SE}$ and $1006 \mathrm{mb}$ at $30.0 \mathrm{~N}, 71.5 \mathrm{~W}$ at $15 \mathrm{Z}$ (micro). $40 \mathrm{kt} \mathrm{SSE}$ and $1011 \mathrm{mb}$ at $27.7 \mathrm{~N}$, $71.1 \mathrm{~W}$ at $18 \mathrm{Z}$ (COADS). $35 \mathrm{kt} \mathrm{N}$ and $1010 \mathrm{mb}$ at $28.6 \mathrm{~N}, 77.1 \mathrm{~W}$ at $21 \mathrm{Z}$ (micro). Aircraft highlights: Radar center fix estimated surface winds of $60 \mathrm{kt}$ and an eye diameter of 20 $\mathrm{nm}$ at $29.2 \mathrm{~N}, 73.7 \mathrm{~W}$ at $1737 \mathrm{Z}$ (ATSR). Penetration center fix measured a central pressure of $982 \mathrm{mb}$, and estimated surface winds of $75 \mathrm{kt}$ and an eye diameter of $30 \mathrm{~nm}$ at $29.2 \mathrm{~N}$, $74.2 \mathrm{~W}$ at $1826 \mathrm{Z}$ (ATSR). Penetration center fix measured a central pressure of $982 \mathrm{mb}$, estimated surface winds of $76 \mathrm{kt}$ and a $28 \mathrm{~nm}$ RMW at $29.0 \mathrm{~N}, 74.0 \mathrm{~W}$ around $1820 \mathrm{Z}$ (NHRP).

September 26:

HWM analyzes a hurricane of at most $1000 \mathrm{mb}$ at $30.0 \mathrm{~N}, 76.0 \mathrm{~W}$ at $12 \mathrm{Z}$. HURDAT lists a 90 knot hurricane at $30.3 \mathrm{~N}, 76.1 \mathrm{~W}$ at $12 \mathrm{Z}$. Microfilm shows a closed low pressure of at most $996 \mathrm{mb}$ at $30.5 \mathrm{~N}, 76.0 \mathrm{~W}$ at 12Z. Ship highlights: $40 \mathrm{kt} \mathrm{W}$ and $1006 \mathrm{mb}$ at $29.8 \mathrm{~N}, 78.0 \mathrm{~W}$ at $00 \mathrm{Z}$ (COADS). $45 \mathrm{kt} \mathrm{SW}$ and $1002 \mathrm{mb}$ at $28.7 \mathrm{~N}, 75.2 \mathrm{~W}$ at $0230 \mathrm{Z}$ (micro). $40 \mathrm{kt}$ ESE and $1015 \mathrm{mb}$ at $33.7 \mathrm{~N}, 75.9 \mathrm{~W}$ at $06 \mathrm{Z}$ (micro). $35 \mathrm{kt} \mathrm{S}$ and $1007 \mathrm{mb}$ at $28.6 \mathrm{~N}, 74.2 \mathrm{~W}$ at $09 \mathrm{Z}$ (micro). $35 \mathrm{kt} \mathrm{S}$ and $1007 \mathrm{mb}$ at $28.9 \mathrm{~N}, 74.8 \mathrm{~W}$ at $12 \mathrm{Z}$ (micro). $50 \mathrm{kt} \mathrm{NE}$ and $1002 \mathrm{mb}$ at 31.3N, $77.4 \mathrm{~W}$ at 15Z (COADS). $65 \mathrm{kt} \mathrm{NW}$ and 981 $\mathrm{mb}$ at $29.0 \mathrm{~N}, 74.7 \mathrm{~W}$ at $18 \mathrm{Z}$ (micro). $65 \mathrm{kt} \mathrm{W}$ and $998 \mathrm{mb}$ at $30.0 \mathrm{~N}, 78.3 \mathrm{~W}$ at $21 \mathrm{Z}$ (MWL). Aircraft highlights: Radar center fix estimated an eye diameter of $20 \mathrm{~nm}$ at $29.5 \mathrm{~N}, 74.9 \mathrm{~W}$ at $0055 \mathrm{Z}$ (ATSR). Penetration center fix measured a central pressure of $986 \mathrm{mb}$ at $29.5 \mathrm{~N}, 74.8 \mathrm{~W}$ at $0230 \mathrm{Z}$ (ATSR). Penetration center fix at $29.5 \mathrm{~N}, 75.5 \mathrm{~W}$ at 06Z (ATSR). Penetration center fix measured a central pressure of $974 \mathrm{mb}$, estimated surface winds of $50 \mathrm{kt}$ and an eye diameter of $20 \mathrm{~nm}$ at $29.8 \mathrm{~N}, 75.7 \mathrm{~W}$ at $08 \mathrm{Z}$ (ATSR). Penetration center fix measured a central pressure of $963 \mathrm{mb}$, estimated surface winds of $55 \mathrm{kt}$ and an eye diameter of $32 \mathrm{~nm}$ at $30.5 \mathrm{~N}, 76.8 \mathrm{~W}$ at $14 \mathrm{Z}$ (ATSR). Penetration center fix measured a central pressure of $948 \mathrm{mb}$, estimated surface winds of $99 \mathrm{kt}$ and a $25 \mathrm{~nm}$ RMW at $30.0 \mathrm{~N}, 76.0 \mathrm{~W}$ around 1830Z (NHRP). Penetration center fix measured a central pressure of $948 \mathrm{mb}$, estimated surface winds of $110 \mathrm{kt}$ and an eye diameter of $32 \mathrm{~nm}$ at $31.1 \mathrm{~N}, 77.8 \mathrm{~W}$ at $20 \mathrm{Z}$ (ATSR). Penetration center fix measured a central pressure of 948 mb, estimated surface winds of $119 \mathrm{kt}$ and a $15 \mathrm{~nm}$ RMW at $30.0 \mathrm{~N}, 76.0 \mathrm{~W}$ around $2030 \mathrm{Z}$ (NHRP). Radar center fix at $31.1 \mathrm{~N}, 77.9 \mathrm{~W}$ at $2307 \mathrm{Z}$ (ATSR).

MWR: "On the 26th, reconnaissance aircraft found that the hurricane's central pressure had dropped to $948 \mathrm{mb}$ with winds near the center in excess of $100 \mathrm{mph}$ compared to 988 $\mathrm{mb}$ and 75 to $90 \mathrm{mph}$ winds the day before. On September 26, at $1100 \mathrm{EST}$, hurricane emergency warnings were issued for the coastal areas from Savannah, Ga., to Cape Fear, N.C. At this time the center of Helene was located about 260 miles east of Brunswick, 
Ga., moving northwestward toward the coast at $14 \mathrm{mph}$, and the hurricane center was forecast to reach the coast in the vicinity of Charleston. During the evening it became apparent that Helene was gradually acquiring a more northward component of motion and hurricane warnings were extended northward along the North Carolina coast to Cape Hatteras. The western edge of the hurricane eye came within approximately 10 miles of the coast at Cape Fear and a portion of the intense convective wall cloud passed over land in this area." ATSR: "HELENE was probably the best covered storm in history by reconnaissance aircraft and land-based radar. From $261100 \mathrm{Z}$ to $280430 \mathrm{Z}$, the storm was under constant surveillance by both. During the period when HELENE threatened the Carolina coast, AEWRON FOUR WV-3 "Super Connies" made dropsondes and storm penetrations "at will," further proving the ability of the aircraft to penetrate a severe hurricane."

September 27:

HWM analyzes a hurricane of at most $990 \mathrm{mb}$ at $33.4 \mathrm{~N}, 78.0 \mathrm{~W}$ and a frontal boundary to the northwest at 12Z. HURDAT lists an 115 knot hurricane at $33.1 \mathrm{~N}, 78.2 \mathrm{~W}$ at 12Z. Microfilm shows a closed low pressure of at most $993 \mathrm{mb}$ at $33.5 \mathrm{~N}, 78.5 \mathrm{~W}$ with a frontal boundary to the northwest at 12Z. Ship highlights: $50 \mathrm{kt} \mathrm{W}$ and $1006 \mathrm{mb}$ at $29.3 \mathrm{~N}$, $78.6 \mathrm{~W}$ at $00 \mathrm{Z}$ (COADS). $40 \mathrm{kt} \mathrm{SE}$ and $1011 \mathrm{mb}$ at $33.7 \mathrm{~N}, 74.7 \mathrm{~W}$ at $03 \mathrm{Z}$ (micro). $35 \mathrm{kt}$ $\mathrm{SW}$ and $1006 \mathrm{mb}$ at $30.8 \mathrm{~N}, 77.3 \mathrm{~W}$ at $06 \mathrm{Z}$ (COADS). $40 \mathrm{kt} \mathrm{SE}$ and $1006 \mathrm{mb}$ at 32.0N, $75.5 \mathrm{~W}$ at $12 \mathrm{Z}$ (micro). $55 \mathrm{kt} \mathrm{S}$ at $32.1 \mathrm{~N}, 75.6 \mathrm{~W}$ at $15 \mathrm{Z}$ (micro). $55 \mathrm{kt} \mathrm{SSW}$ and $996 \mathrm{mb}$ at $36.6 \mathrm{~N}, 76.5 \mathrm{~W}$ at $18 \mathrm{Z}$ (COADS). $65 \mathrm{kt} \mathrm{S}$ and $994 \mathrm{mb}$ at $34.1 \mathrm{~N}, 74.9 \mathrm{~W}$ at $20 \mathrm{Z}$ (MWL). 70 $\mathrm{kt} \mathrm{SSW}$ and $1000 \mathrm{mb}$ at 32.4N, 75.7W at 21Z (MWL). Land highlights: $40 \mathrm{kt} \mathrm{E}$ and 1004 $\mathrm{mb}$ at Frying Pan, NC at 06Z (micro). $994 \mathrm{mb}$ at Sullivan's Islands, SC at 0920Z

(WALLET). $60 \mathrm{kt} \mathrm{E}$ and $992 \mathrm{mb}$ at Frying Pan, NC at 12Z (micro). $90 \mathrm{kt} \mathrm{S}$ (gusts to 105 kt) and $973 \mathrm{mb}$ at Frying Pan, NC at 1430Z (micro). $50 \mathrm{kt} \mathrm{NNE} \mathrm{(gusts} \mathrm{to} 90 \mathrm{kt}$ ) and 987 $\mathrm{mb}$ at Wilmington, $\mathrm{NC}$ at $15 \mathrm{Z}$ (micro). $74 \mathrm{kt} \mathrm{N}$ (gusts to $117 \mathrm{kt}$ ) and $977 \mathrm{mb}$ at Wilmington, $\mathrm{NC}$ at $18 \mathrm{Z}$ (micro). $60 \mathrm{kt} \mathrm{NW}$ (gusts to $108 \mathrm{kt}$ ) and $983 \mathrm{mb}$ at Wilmington, $\mathrm{NC}$ at $20 \mathrm{Z}$ (SWO). Gusts estimated to $125 \mathrm{kt}, 948 \mathrm{mb}$ at Cape Lookout, NC at $2230 \mathrm{Z}$ (WALLET). $971 \mathrm{mb}$ at Oriental, NC at 2330Z (WALLET). $56 \mathrm{kt} \mathrm{NNW} \mathrm{(gusts} \mathrm{to} 84 \mathrm{kt}$ ) and $983 \mathrm{mb}$ at Cherry Point, NC at 2359Z (SWO). Aircraft highlights: Penetration center fix estimated surface winds of $100 \mathrm{kt}$ and an eye diameter of $25 \mathrm{~nm}$ at $31.5 \mathrm{~N}, 78.3 \mathrm{~W}$ at $0130 \mathrm{Z}$ (ATSR). Penetration center fix measured a central pressure of $943 \mathrm{mb}$ at $31.7 \mathrm{~N}$, $78.5 \mathrm{~W}$ at $0230 \mathrm{Z}$ (ATSR). Penetration center fix measured a central pressure of $933 \mathrm{mb}$ and an eye diameter of $25 \mathrm{~nm}$ at $32.4 \mathrm{~N}, 78.6 \mathrm{~W}$ at $0630 \mathrm{Z}$ (ATSR). Penetration center fix measured a central pressure of $932 \mathrm{mb}$, estimated surface winds of $100 \mathrm{kt}$ and an eye diameter of $25 \mathrm{~nm}$ at $32.7 \mathrm{~N}, 78.7 \mathrm{~W}$ at $08 \mathrm{Z}$ (ATSR). Penetration center fix measured a central pressure of $938 \mathrm{mb}$, estimated surface winds of $75 \mathrm{kt}$ and an eye diameter of 25 $\mathrm{nm}$ at $33.1 \mathrm{~N}, 78.5 \mathrm{~W}$ at $11 \mathrm{Z}$ (ATSR). Radar center fix measured a peripheral pressure of 
$940 \mathrm{mb}$ at $1730 \mathrm{Z}$ (ATSR). Penetration center fix measured a central pressure of $938 \mathrm{mb}$ and estimated surface winds of $75 \mathrm{kt}$ at $34.4 \mathrm{~N}, 76.3 \mathrm{~W}$ at $2230 \mathrm{Z}$ (ATSR).

MWR: "Helene moved on a northwestward course at 8 to $10 \mathrm{mph}$ during the 26th as it continued to deepen, finally attaining a minimum pressure of $933 \mathrm{mb}$ around midnight (local time) at a position some 80 miles east of Charleston, S.C. Hurricane-force winds, accompanied by high tides and torrential rains, pounded the coastal areas from Cape Fear to Cape Lookout. The Weather Bureau at Wilmington, N.C. recorded a maximum wind (one mile) of $88 \mathrm{mph}$ and a peak gust of $135 \mathrm{mph}$. Both of these speeds greatly exceeded all previous records there. Total rainfall at Wilmington during the hurricane was 8.29 inches. At Cape Fear, winds were estimated at $125 \mathrm{mph}$ with gusts to 150 to $160 \mathrm{mph}$. According to Sumner, the wind speeds and wind damage associated with Helene indicate a more intense hurricane than Hazel of 1954, but the fact that the center of Helene passed about 20 miles off the coast prevented the extremely high tides and wave damage associated with the 1954 hurricane. Reconnaissance and other types of observational data from hurricane Helene provided a wealth of material for research and some interesting experimental work was accomplished. Two balloon-borne radio tracking beacons were dropped into the eye of Helene by aircraft of the National Hurricane Research Project and remained in the eye for a significant period. A Navy plane also dropped a metallicized inflated plastic ball on the ocean surface in the eye for radar tracking. It was observed on radar for 12 hours or more."

September 28:

HWM analyzes a hurricane of at most $985 \mathrm{mb}$ at $36.9 \mathrm{~N}, 70.2 \mathrm{~W}$ and a dissipating front just to the northwest at 12Z. HURDAT lists a 105 knot hurricane at $36.9 \mathrm{~N}, 70.5 \mathrm{~W}$ at $12 \mathrm{Z}$. Microfilm shows a closed low pressure of at most $990 \mathrm{mb}$ at $36.5 \mathrm{~N}, 70.5 \mathrm{~W}$ with a frontal boundary to the north and west at 12Z. Ship highlights: $65 \mathrm{kt}$ SSE and $990 \mathrm{mb}$ at $34.8 \mathrm{~N}, 74.1 \mathrm{~W}$ at $00 \mathrm{Z}$ (COADS). $55 \mathrm{kt} \mathrm{SSW}$ and $997 \mathrm{mb}$ at $33.3 \mathrm{~N}$, $74.5 \mathrm{~W}$ at $03 \mathrm{Z}$ (micro). $60 \mathrm{kt} \mathrm{W}$ and $1000 \mathrm{mb}$ at $33.5 \mathrm{~N}, 74.8 \mathrm{~W}$ at $06 \mathrm{Z}$ (COADS). $70 \mathrm{kt} \mathrm{S}$ and $988 \mathrm{mb}$ at $35.9 \mathrm{~N}, 70.8 \mathrm{~W}$ at $12 \mathrm{Z}$ (COADS). $100 \mathrm{kt} \mathrm{N}$ and $996 \mathrm{mb}$ at $37.9 \mathrm{~N}, 70.5 \mathrm{~W}$ at $12 \mathrm{Z}$ (micro). $75 \mathrm{kt} \mathrm{SE}$ and $988 \mathrm{mb}$ at $38.1 \mathrm{~N}, 66.4 \mathrm{~W}$ at $18 \mathrm{Z}$ (micro). $110 \mathrm{kt} \mathrm{NW}$ and 958 $\mathrm{mb}$ at $37.5 \mathrm{~N}, 67.4 \mathrm{~W}$ at $20 \mathrm{Z}$ (micro). Land highlights: $50 \mathrm{kt} \mathrm{E}$ (gusts to $75 \mathrm{kt}$ ) and $978 \mathrm{mb}$ at Cape Hatteras, NC at 0055Z (SWO). $40 \mathrm{kt} \mathrm{NNE} \mathrm{and} 1003 \mathrm{mb}$ at Langley, VA at 0156Z (SWO). $60 \mathrm{kt} \mathrm{NNE} \mathrm{(gusts} \mathrm{to} 90 \mathrm{kt}$ ) and $975 \mathrm{mb}$ at Cape Hatteras, NC at 0255Z (SWO). $50 \mathrm{kt} \mathrm{NNE}$ and $1002 \mathrm{mb}$ at Chesapeake Light, VA at 06Z (micro). Aircraft highlights: Radar center fix at $34.6 \mathrm{~N}, 75.9 \mathrm{~W}$ at $00 \mathrm{Z}$ (ATSR). Penetration center fix measured a central pressure of $945 \mathrm{mb}$ at $34.9 \mathrm{~N}, 75.1 \mathrm{~W}$ at $03 \mathrm{Z}$ (ATSR). Penetration center fix measured a central pressure of $955 \mathrm{mb}$ and estimated an eye diameter of $24 \mathrm{~nm}$ at $35.6 \mathrm{~N}, 73.0 \mathrm{~W}$ at $08 \mathrm{Z}$ (ATSR). Penetration center fix measured a central pressure of 
$966 \mathrm{mb}$, estimated surface winds of $90 \mathrm{kt}$ and estimated an eye diameter of $24 \mathrm{~nm}$ at $36.9 \mathrm{~N}, 70.0 \mathrm{~W}$ at $14 \mathrm{Z}$ (ATSR). Penetration center fix measured a central pressure of 943 $\mathrm{mb}$ and estimated surface winds of $105 \mathrm{kt}$ at $38.7 \mathrm{~N}, 66.9 \mathrm{~W}$ at $2130 \mathrm{Z}$ (ATSR). Penetration center fix measured a central pressure of $951 \mathrm{mb}$ at $39.0 \mathrm{~N}, 65.0 \mathrm{~W}$ at $2230 \mathrm{Z}$ (ATSR).

September 29:

HWM analyzes a hurricane of at most $970 \mathrm{mb}$ at $46.9 \mathrm{~N}, 59.0 \mathrm{~W}$ and a warm front to the northeast and a cold front to the south at 12Z. HURDAT lists a 65 knot hurricane at $45.7 \mathrm{~N}, 59.0 \mathrm{~W}$ at $12 \mathrm{Z}$. Microfilm shows an extratropical cyclone of at most $978 \mathrm{mb}$ at $42.0 \mathrm{~N}, 62.0 \mathrm{~W}$ at $12 \mathrm{Z}$. Ship highlights: $975 \mathrm{mb}$ at $40.5 \mathrm{~N}, 65.7 \mathrm{~W}$ at $00 \mathrm{Z}$ (COADS). $65 \mathrm{kt} \mathrm{N}$ and $1003 \mathrm{mb}$ at 39.9N, 69.4W at 00Z (COADS). $65 \mathrm{kt} \mathrm{NNW}$ and 990 $\mathrm{mb}$ at $42.5 \mathrm{~N}, 64.0 \mathrm{~W}$ at $06 \mathrm{Z}$ (COADS). $80 \mathrm{kt} \mathrm{SSW}$ and $975 \mathrm{mb}$ at $40.9 \mathrm{~N}, 62.2 \mathrm{~W}$ at $06 \mathrm{Z}$ (micro). $55 \mathrm{kt} \mathrm{NW}$ and $983 \mathrm{mb}$ at $43.3 \mathrm{~N}, 61.2 \mathrm{~W}$ at $09 \mathrm{Z}$ (micro). $55 \mathrm{kt} \mathrm{NW}$ and $993 \mathrm{mb}$ at $43.4 \mathrm{~N}, 60.4 \mathrm{~W}$ at $12 \mathrm{Z}$ (micro). $70 \mathrm{kt} \mathrm{SW}$ and $979 \mathrm{mb}$ at $45.7 \mathrm{~N}, 56.2 \mathrm{~W}$ at $15 \mathrm{Z}$ (COADS). $60 \mathrm{kt} \mathrm{W}$ and $989 \mathrm{mb}$ at $45.7 \mathrm{~N}, 56.4 \mathrm{~W}$ at 18Z (COADS). Land highlights: $50 \mathrm{kt} \mathrm{N}$ and 990 $\mathrm{mb}$ at Halifax, Canada at $06 \mathrm{Z}$ (micro). $30 \mathrm{kt}$ ESE and $978 \mathrm{mb}$ at St. Paul Island, Canada at $12 \mathrm{Z}$ (micro). $30 \mathrm{kt} \mathrm{SE}$ and $973 \mathrm{mb}$ at Benton, Canada at $18 \mathrm{Z}$ (micro). $45 \mathrm{kt} \mathrm{WSW}$ and $982 \mathrm{mb}$ at St. Paul Island, Canada at $18 \mathrm{Z}$ (micro).

MWR: "After recurvature, Helene moved northeastward at an accelerated rate and crossed Newfoundland on the $29^{\text {th }}$. The storm continued across the Atlantic as a large and vicious extratropical Low that dominated the weather over a large area for several more days."

September 30:

HWM analyzes an extratropical cyclone of at most $970 \mathrm{mb}$ at $55.5 \mathrm{~N}, 45.0 \mathrm{~W}$ at 12Z. HURDAT lists a 60 knot extratropical storm at $55.0 \mathrm{~N}, 45.0 \mathrm{~W}$ at $12 \mathrm{Z}$. Microfilm shows an extratropical cyclone of at most $993 \mathrm{mb}$ at $55.5 \mathrm{~N}, 42.5 \mathrm{~W}$ at 12Z. Ship highlights: $60 \mathrm{kt} \mathrm{SW}$ and $988 \mathrm{mb}$ at $48.2 \mathrm{~N}, 50.1 \mathrm{~W}$ at $00 \mathrm{Z}$ (COADS). $50 \mathrm{kt} \mathrm{N}$ and $976 \mathrm{mb}$ at $53.6 \mathrm{~N}, 50.7 \mathrm{~W}$ at $06 \mathrm{Z}$ (COADS). $50 \mathrm{kt} \mathrm{SW}$ and $981 \mathrm{mb}$ at $52.2 \mathrm{~N}, 44.0 \mathrm{~W}$ at $12 \mathrm{Z}$ (COADS). $60 \mathrm{kt} \mathrm{NW}$ and $986 \mathrm{mb}$ at 54.0N, $47.0 \mathrm{~W}$ at $18 \mathrm{Z}$ (COADS).

October 1:

HWM analyzes an extratropical cyclone of at most $970 \mathrm{mb}$ at $57.0 \mathrm{~N}, 33.0 \mathrm{~W}$ at 12Z. HURDAT lists a 50 knot extratropical storm at $57.5 \mathrm{~N}, 32.0 \mathrm{~W}$ at $12 \mathrm{Z}$. Microfilm shows that the extratropical cyclone has moved off the northeast edge of the synoptic map at 12Z. Ship highlights: $60 \mathrm{kt} \mathrm{WSW}$ and $987 \mathrm{mb}$ at 53.6N, 35.3W at 00Z (COADS). $55 \mathrm{kt} \mathrm{WSW}$ and $989 \mathrm{mb}$ at $52.9 \mathrm{~N}, 33.0 \mathrm{~W}$ at $06 \mathrm{Z}$ (COADS). $60 \mathrm{kt} \mathrm{W}$ and $996 \mathrm{mb}$ at 
$52.8 \mathrm{~N}, 35.5 \mathrm{~W}$ at $09 \mathrm{Z}$ (COADS). $55 \mathrm{kt} \mathrm{WNW}$ and $999 \mathrm{mb}$ at $52.8 \mathrm{~N}, 35.5 \mathrm{~W}$ at $12 \mathrm{Z}$ (COADS). $70 \mathrm{kt} \mathrm{W}$ and $996 \mathrm{mb}$ at $53.4 \mathrm{~N}, 35.5 \mathrm{~W}$ at $18 \mathrm{Z}$ (COADS).

October 2:

HWM analyzes an extratropical cyclone of at most $985 \mathrm{mb}$ at $55.7 \mathrm{~N}, 14.9 \mathrm{~W}$ at 12Z. HURDAT lists a 45 knot extratropical storm at $54.3 \mathrm{~N}, 17.3 \mathrm{~W}$ at $12 \mathrm{Z}$. Microfilm is not available on this date. Ship highlights: $40 \mathrm{kt} \mathrm{W}$ and $985 \mathrm{mb}$ at $53.2 \mathrm{~N}, 20.8 \mathrm{~W}$ at $00 \mathrm{Z}$ (COADS). $45 \mathrm{kt} \mathrm{W}$ and $1004 \mathrm{mb}$ at $46.5 \mathrm{~N}, 28.8 \mathrm{~W}$ at $06 \mathrm{Z}$ (COADS). $45 \mathrm{kt} \mathrm{NW}$ and 988 $\mathrm{mb}$ at $49.1 \mathrm{~N}, 26.9 \mathrm{~W}$ at $12 \mathrm{Z}$ (COADS). $50 \mathrm{kt} \mathrm{NW}$ and $1000 \mathrm{mb}$ at $47.3 \mathrm{~N}, 29.2 \mathrm{~W}$ at $14 \mathrm{Z}$ (COADS). $45 \mathrm{kt} \mathrm{W}$ and $1002 \mathrm{mb}$ at $43.2 \mathrm{~N}, 23.6 \mathrm{~W}$ at $18 \mathrm{Z}$ (COADS). $50 \mathrm{kt} \mathrm{NW}$ and 998 $\mathrm{mb}$ at $47.4 \mathrm{~N}, 26.9 \mathrm{~W}$ at $20 \mathrm{Z}$ (COADS).

October 3:

HWM analyzes an extratropical cyclone of at most $980 \mathrm{mb}$ at $56.5 \mathrm{~N}, 14.0 \mathrm{~W}$ at 12Z. HURDAT lists a $35 \mathrm{knot}$ extratropical storm at $51.4 \mathrm{~N}, 12.5 \mathrm{~W}$ at $12 \mathrm{Z}$. Microfilm is not available on this date. Ship highlights: $45 \mathrm{kt} \mathrm{W}$ and $999 \mathrm{mb}$ at $43.5 \mathrm{~N}, 23.7 \mathrm{~W}$ at $00 \mathrm{Z}$ (COADS). $45 \mathrm{kt} \mathrm{NNW}$ and $999 \mathrm{mb}$ at $44.2 \mathrm{~N}, 23.0 \mathrm{~W}$ at 06Z (COADS). $35 \mathrm{kt} \mathrm{NW}$ and $1000 \mathrm{mb}$ at $45.4 \mathrm{~N}, 20.7 \mathrm{~W}$ at $12 \mathrm{Z}$ (COADS). $40 \mathrm{kt} \mathrm{S}$ and $991 \mathrm{mb}$ at $48.8 \mathrm{~N}, 6.3 \mathrm{~W}$ at $18 \mathrm{Z}$ (COADS). Land highlights: $10 \mathrm{kt} \mathrm{S}$ and $988 \mathrm{mb}$ at Kerry, Ireland at 12Z (HWM).

October 4:

HWM analyzes a frontal boundary over western Europe at 12Z. HURDAT lists a 35 knot extratropical storm at $51.6 \mathrm{~N}, 4.9 \mathrm{~W}$ at $06 \mathrm{Z}$ (last position). Microfilm is not available on this date. Ship highlights: $25 \mathrm{kt} \mathrm{SW}$ and $987 \mathrm{mb}$ at $50.1 \mathrm{~N}, 7.5 \mathrm{~W}$ at $00 \mathrm{Z}$ (COADS). $30 \mathrm{kt} \mathrm{SSW}$ and $992 \mathrm{mb}$ at 50.3N, 2.7W at 06Z (COADS).

October 5:

HWM analyzes a frontal boundary over western Europe at 12Z. HURDAT does not list an organized storm on this date. Microfilm is not available on this date. Ship highlights: No gales or low pressures.

Hurricane Helene developed from a tropical wave that left the African coast around midSeptember. Microfilm indicates that the wave showed little signs of development as it tracked westward across the eastern and central Atlantic, although the ship data over this area of the basin is sparse. Minor track changes are analyzed during the lifetime of Helene as a tropical cyclone; major track changes were analyzed at $12 \mathrm{Z}$ and $18 \mathrm{Z}$ on October $2^{\text {nd }}$ when the system was an extratropical cyclone. The first position is at $06 \mathrm{Z}$ on September $21^{\text {st }}$ as a $25 \mathrm{kt}$ tropical depression, same as the original HURDAT. The actual genesis of this tropical cyclone is highly uncertain due to the low ship traffic east of the 
Lesser Antilles, but the data available suggests that the center was about $90 \mathrm{~nm}$ south than originally shown in HURDAT. It is also possible that the tropical cyclone did not develop a well-defined low-level circulation until September $22^{\text {nd }}$ based on aircraft reconnaissance reports and ship observations. A ship reported $40 \mathrm{kt}$ SE on September $21^{\text {st }}$ at $18 \mathrm{Z}$ but this was about $300 \mathrm{~nm}$ east of the center and appears to have a high wind bias. The first reconnaissance aircraft penetration center fix measured a central pressure of $1013 \mathrm{mb}$ and estimated surface winds of $20 \mathrm{kt}$ at $1930 \mathrm{Z}$ on September $22^{\text {nd }}$. (Central pressures values for each 6 hour period were present in the original HURDAT between September $22^{\text {nd }}$ at $12 \mathrm{Z}$ and September $30^{\text {th }}$ at $00 \mathrm{Z}$. Some of these were obviously analyses that were added in, not based upon actual observations. Thus, based on actual observations, some were retained and others removed. Detailed information on these changes can be found in the table at the end.) Intensification to a tropical storm is analyzed at $00 Z$ on September $23^{\text {rd }}$, same as the original HURDAT. The next reconnaissance aircraft reached Helene at $1330 \mathrm{Z}$ and measured a central pressure of 1003 $\mathrm{mb}$ and estimated surface winds of $45 \mathrm{kt}$. A central pressure of $1003 \mathrm{mb}$ suggests maximum sustained winds of $41 \mathrm{kt}$ intensifying south of $25 \mathrm{~N}$ from the Brown et al. pressure-wind relationship. An intensity of $40 \mathrm{kt}$ is selected for $12 \mathrm{Z}$ on the $23^{\text {rd }}, 5 \mathrm{kt}$ less than originally shown in HURDAT, a minor intensity change. A few ships late on September $23^{\text {rd }}$ reported low-end tropical storm force winds near the tropical cyclone.

On September $24^{\text {th }}$, Helene continued to intensify while moving to the northwest. A reconnaissance aircraft reached the tropical cyclone at $1330 \mathrm{Z}$ and measured a central pressure of $997 \mathrm{mb}$, estimated surface winds of $55 \mathrm{kt}$ and an eye diameter of $9 \mathrm{~nm}$. A central pressure of $997 \mathrm{mb}$ suggests maximum surface winds of $51 \mathrm{kt}$ north of $25 \mathrm{~N}$ from the pressure-wind relationship. An eye diameter of $9 \mathrm{~nm}$ suggests an RMW of about $7 \mathrm{~nm}$ and the climatological value is $20 \mathrm{~nm}$. Based on an RMW smaller than the climatology value and a forward speed of about $14 \mathrm{kt}$, an intensity of $60 \mathrm{kt}$ is selected at $12 \mathrm{Z}$ on the $24^{\text {th }}$, down from $65 \mathrm{kt}$ originally in HURDAT, a minor intensity change. Intensification to a hurricane is analyzed at $18 \mathrm{Z}$ on the $24^{\text {th }}$, six hours later than originally shown in HURDAT. A ship reported $65 \mathrm{kt} \mathrm{S}$ at $09 \mathrm{Z}$ on the $24^{\text {th }}$, but it was located about $150 \mathrm{~nm}$ southeast of the center and it is likely to have a high wind bias, compared to other ships nearby. Late on September $25^{\text {th }}$, the Navy and NHRP were investigating Helene and measured a central pressure of $982 \mathrm{mb}$ around 18Z. The Navy aircraft also estimated surface winds of $75 \mathrm{kt}$ and an eye diameter of $30 \mathrm{~nm}$, while the NHRP aircraft estimated surface winds of $76 \mathrm{kt}$ and an RMW of $28 \mathrm{~nm}$. A central pressure of $982 \mathrm{mb}$ suggests maximum sustained winds of $73 \mathrm{kt}$ north of $25 \mathrm{~N}$ intensifying. Since the forward speed of the hurricane had decreased to about $5 \mathrm{kt}$ and the RMW is somewhat larger than climatology ( $28 \mathrm{~nm}$ vs $22 \mathrm{~nm}$ ), an intensity of $70 \mathrm{kt}$ is selected for $18 \mathrm{Z}$ on the $25^{\text {th }}$, down from $80 \mathrm{kt}$ originally in HURDAT, a minor intensity change. Another penetration center fix at $0230 \mathrm{Z}$ on September $26^{\text {th }}$ measured a central pressure of $986 \mathrm{mb}$, indicating that 
Helene may have temporarily weakened. A central pressure of $986 \mathrm{mb}$ suggests maximum sustained winds of $65 \mathrm{kt}$ north of $25 \mathrm{~N}$ from the pressure-wind relationship. An intensity of $65 \mathrm{kt}$ is selected for $00 \mathrm{Z}$ on the $26^{\text {th }}$, down from $85 \mathrm{kt}$ originally in HURDAT, a major intensity change. It is possible that Helene may have weakened to a high-end tropical storm early on the $26^{\text {th }}$. Soon thereafter, Helene started to rapidly intensify. A reconnaissance aircraft measured a central pressure of $974 \mathrm{mb}$, estimated surface winds of $50 \mathrm{kt}$ and an eye diameter of $20 \mathrm{~nm}$ at $08 \mathrm{Z}$ on the $26^{\text {th }}$. A central pressure of $974 \mathrm{mb}$ suggests maximum surface winds of $83 \mathrm{kt}$ north of $25 \mathrm{~N}$ intensifying from the pressure wind-relationship. An eye diameter of $20 \mathrm{~nm}$ suggests an RMW of about $15 \mathrm{~nm}$ and the climatological value is $23 \mathrm{~nm}$. Based on the RMW being smaller than the climatological value and a forward speed of about $8 \mathrm{kt}$, an intensity of $80 \mathrm{kt}$ is selected for $06 \mathrm{Z}$ on the $26^{\text {th }}$, down from $85 \mathrm{kt}$ originally in HURDAT, a minor intensity change. Another reconnaissance aircraft measured a central pressure of $963 \mathrm{mb}$, estimated surface winds of $55 \mathrm{kt}$ and an eye diameter of $32 \mathrm{~nm}$ at $14 \mathrm{Z}$ on the $26^{\text {th }}$. A central pressure of $963 \mathrm{mb}$ suggests maximum surface winds of $96 \mathrm{kt}$ north of $25 \mathrm{~N}$ intensifying from the pressure wind-relationship. An eye diameter of $32 \mathrm{~nm}$ suggests an RMW of about $24 \mathrm{~nm}$ and the climatological value is $22 \mathrm{~nm}$. Because the RMW is similar to climatology and the forward speed was about $10 \mathrm{kt}$, an intensity of $95 \mathrm{kt}$ is selected for $12 \mathrm{Z}$ on the $26^{\text {th }}$, up from 90 kt originally in HURDAT, a minor intensity change. Finally, a NHRP reconnaissance aircraft measured a central pressure of $948 \mathrm{mb}$, estimated surface winds of $99 \mathrm{kt}$ and an RMW of $25 \mathrm{~nm}$ around $1830 \mathrm{Z}$ on the $26^{\text {th }}$. Later at 20Z, a Navy aircraft measured a central pressure of $948 \mathrm{mb}$, estimated surface winds of $110 \mathrm{kt}$ and an eye diameter of $32 \mathrm{~nm}$. A central pressure of $948 \mathrm{mb}$ suggests maximum surface winds of $112 \mathrm{kt}$ north of $25 \mathrm{~N}$ intensifying from the pressure wind-relationship. Based on an RMW slightly larger than climatology ( $25 \mathrm{~nm}$ versus $20 \mathrm{~nm}$ ) and a forward speed of about 13 $\mathrm{kt}$, an intensity of $110 \mathrm{kt}$ is selected for $18 \mathrm{Z}$ on the $26^{\text {th }}$, up from $105 \mathrm{kt}$ originally in HURDAT, a minor intensity change. Intensification to a major hurricane is analyzed at $18 \mathrm{Z}$ on the $26^{\text {th }}$, same as shown in the original HURDAT.

On September $27^{\text {th }}$, Helene continued to intensify as it approached the United States and started to turn to the north and later to the northeast. A reconnaissance aircraft measured a central pressure of $943 \mathrm{mb}$ at $0230 \mathrm{Z}$ on the $27^{\text {th }}$. A central pressure of $943 \mathrm{mb}$ suggests maximum surface winds of $117 \mathrm{kt}$ north of $25 \mathrm{~N}$ intensifying from the pressure windrelationship. An eye diameter of $25 \mathrm{~nm}$ measured at $0630 \mathrm{Z}$ at the $27^{\text {th }}$ suggests an RMW of about $19 \mathrm{~nm}$ and the climatological value is $21 \mathrm{~nm}$. Since the RMW is close to the climatological value and the forward speed was about $10 \mathrm{kt}$, an intensity of $115 \mathrm{kt}$ is selected for $00 \mathrm{Z}$ on the $27^{\text {th }}$, up from 110 kt originally in HURDAT, a minor intensity change. Another reconnaissance aircraft measured a central pressure of $933 \mathrm{mb}$ at $06 \mathrm{Z}$ on the $27^{\text {th }}$. The aircraft also estimated surface winds of $100 \mathrm{kt}$ and an eye diameter of $25 \mathrm{~nm}$ at $08 \mathrm{Z}$. A central pressure of $933 \mathrm{mb}$ suggests maximum surface winds of $127 \mathrm{kt}$ north of 
$25 \mathrm{~N}$ intensifying from the pressure wind-relationship. An eye diameter of $25 \mathrm{~nm}$ suggests an RMW of about $19 \mathrm{~nm}$ and the climatological value is $21 \mathrm{~nm}$. An intensity of $125 \mathrm{kt}$ is selected for $06 \mathrm{Z}$ on the $27^{\text {th }}$, up from 110 kt originally in HURDAT, a minor intensity change. The next reconnaissance aircraft measured a central pressure of $938 \mathrm{mb}$, estimated surface winds of $75 \mathrm{kt}$ and an eye diameter of $25 \mathrm{~nm}$ at $11 \mathrm{Z}$ on the $27^{\text {th }}$. A central pressure of $938 \mathrm{mb}$ suggests maximum surface winds of $116 \mathrm{kt}$ north of $25 \mathrm{~N}$ and $111 \mathrm{kt}$ north of $25 \mathrm{~N}$ weakening from the pressure wind-relationship. An eye diameter of $25 \mathrm{~nm}$ suggests an RMW of about $19 \mathrm{~nm}$ and the climatological value is $23 \mathrm{~nm}$. An intensity of $120 \mathrm{kt}$ is selected for $12 \mathrm{Z}$ on the $27^{\text {th }}$, up from $115 \mathrm{kt}$ originally in HURDAT, a minor intensity change. Late on the $27^{\text {th }}$, the eye of Helene passed very close to North Carolina, about $10 \mathrm{~nm}$ south of Cape Fear and Cape Lookout. The strongest winds likely affected southeast North Carolina. The strongest winds reported in North Carolina were $74 \mathrm{kt}$ at Wilmington and $110 \mathrm{kt}$ estimated at Cape Fear. The Schwerdt et al. parametric hurricane wind model suggests that the highest sustained winds that impacted North Carolina reached $110 \mathrm{kt}$. The same wind model suggests that South Carolina was impacted by $92 \mathrm{kt}$ winds, but since the winds that affected the state were coming from the north and northeast moving over land, a 15\% wind reduction was implemented, suggesting maximum winds of $80 \mathrm{kt}$. Therefore, Helene is analyzed as a category 3 hurricane impact for North Carolina and category 1 hurricane impact for South Carolina. The strongest winds likely affected eastern South Carolina. The strongest winds reported in South Carolina were $35 \mathrm{kt}$ at Myrtle Beach on the $27^{\text {th }}$ at $15 \mathrm{Z}$. Moreover, tropical storm force winds impacted southern Virginia and both, the hurricane wind model and surface observations at Norfolk and Langley, indicate that the highest winds were around $40 \mathrm{kt}$. Early on September $28^{\text {th }}$, Helene started to move away from the United States ahead of a frontal boundary. A reconnaissance aircraft measured a central pressure of 938 $\mathrm{mb}$ and estimated surface winds of $75 \mathrm{kt}$ at $2230 \mathrm{Z}$ on the $27^{\text {th }}$. A central pressure of 938 $\mathrm{mb}$ suggests maximum surface winds of $116 \mathrm{kt}$ north of $25 \mathrm{~N}$ from the Brown et al. pressure wind-relationship and $104 \mathrm{kt}$ north of $35 \mathrm{~N}$ from the Landsea et al. pressure-wind relationship. Based on a forward speed of about $10 \mathrm{kt}$, an intensity of $115 \mathrm{kt}$ is selected for $00 \mathrm{Z}$ on the $28^{\text {th }}$, up from $110 \mathrm{kt}$ originally in HURDAT, a minor intensity change. Two more penetration center fixes reported a central pressure of $945 \mathrm{mb}$ at $03 \mathrm{Z}$ and 955 $\mathrm{mb}$ at $08 \mathrm{Z}$ on the $28^{\text {th }}$. A blend of these two measurements suggests a central pressure of about $950 \mathrm{mb}$ around $06 \mathrm{Z}$ on the $27^{\text {th }}$, same as the original HURDAT. The aircraft also reported an eye diameter of $24 \mathrm{~nm}$ at $08 \mathrm{Z}$ on the $28^{\text {th }}$. A central pressure of $950 \mathrm{mb}$ suggests sustained maximum winds of $101 \mathrm{kt}$ north of $25 \mathrm{~N}$ weakening and $97 \mathrm{kt}$ north of $35 \mathrm{kt}$, according to the corresponding pressure-wind relationships. An eye diameter of 24 $\mathrm{nm}$ suggests an RMW of about $18 \mathrm{~nm}$ and the climatological value is $25 \mathrm{~nm}$. At this time, Helene was increasing in forward speed as it moved northeastward. Based on a forward 
speed of about $25 \mathrm{kt}$ and an RMW smaller than climatology, an intensity of $110 \mathrm{kt}$ is selected at $06 \mathrm{Z}$ on the $28^{\text {th }}$, same as originally shown in HURDAT.

On the $28^{\text {th }}$, Helene started to interact with a frontal boundary off the Mid-Atlantic of the United States and began to acquire extratropical characteristics. A reconnaissance aircraft at $14 \mathrm{Z}$ estimated surface winds of $90 \mathrm{kt}$ and measured a pressure of $966 \mathrm{mb}$. Based on central pressure reports earlier and later on the day, it is likely that this pressure report was not a central pressure and has not been added to HURDAT. The last reconnaissance aircraft to reach Helene measured a central pressure of $943 \mathrm{mb}$ and estimated surface winds of $105 \mathrm{kt}$ at $2130 \mathrm{Z}$ and $951 \mathrm{mb}$ at $2230 \mathrm{Z}$ on the $28^{\text {th }}$. A central pressure of $943 \mathrm{mb}$ suggests maximum surface winds of $101 \mathrm{kt}$ north of $35 \mathrm{~N}$ from the pressure-wind relationship. Since the hurricane was becoming extratropical and also moving very rapidly ( $\sim 39 \mathrm{kt}$ ) towards the east-northeast, an intensity of $100 \mathrm{kt}$ is selected at $18 \mathrm{Z}$ on the $28^{\text {th }}$, up from $90 \mathrm{kt}$ originally in HURDAT, a minor intensity change. Early on September $29^{\text {th }}$, coastal and ship observations indicate that Helene had become an extratropical cyclone. A temperature gradient had developed E-W across the circulation, along with frontal features. Extratropical transition is analyzed eighteen hours earlier than originally shown in HURDAT. Later on the $29^{\text {th }}$, Helene moved over the Atlantic provinces of Canada before moving northeast into the North Atlantic. It is analyzed that Helene reached Canada as a powerful extratropical cyclone and not as a hurricane as originally shown in HURDAT. Weakening below hurricane force occurred at 06Z on September $30^{\text {th }}$, six hours later than originally shown in HURDAT. Late on October $1^{\text {st }}$, ship observations indicate that the extratropical cyclone regained winds of hurricane force, but the strengthening was short-lived as the system started to weaken again on October $2^{\text {nd }}$. Major intensity changes are analyzed at $18 \mathrm{Z}$ on the $1^{\text {st }}$, and $00 \mathrm{Z}$ and $06 \mathrm{Z}$ on the $2^{\text {nd }}$. The analyzed intensity for these times is $70 \mathrm{kt}, 70 \mathrm{kt}$ and $65 \mathrm{kt}$, and HURDAT originally showed $50 \mathrm{kt}, 50 \mathrm{kt}$ and $45 \mathrm{kt}$, respectively. Late on the $2^{\text {nd }}$, the extratropical cyclone weakened again below hurricane force and kept a general eastward track. Early on October $4^{\text {th }}$, the weakened extratropical cyclone merged with another extratropical cyclone to the north. The last position is analyzed at $00 \mathrm{Z}$ on the $4^{\text {th }}$, same as originally shown in HURDAT.

\begin{tabular}{|c|c|l|c|}
\hline Date & $\begin{array}{c}\text { Original } \\
\text { HURDAT } \\
\text { Central } \\
\text { Pressure }\end{array}$ & \multicolumn{1}{|c|}{ Evidence } & Changes \\
\hline Sep 22 12Z & $1015 \mathrm{mb}$ & $\begin{array}{l}\text { Ship: } 20 \mathrm{kt} \mathrm{E} \text { and } 1012 \mathrm{mb} \text { at } 12 \mathrm{Z} \text { on Sep } \\
22^{\text {nd }}\end{array}$ & Removed \\
\hline Sep 22 18Z & $1014 \mathrm{mb}$ & $\begin{array}{l}\text { Penetration center fix: } 1013 \mathrm{mb} \text { at } 1930 \mathrm{Z} \text { on } \\
\text { Sep 22 }\end{array}$ & $1013 \mathrm{mb}$ \\
\hline
\end{tabular}




\begin{tabular}{|c|c|c|c|}
\hline Sep $2300 Z$ & $1013 \mathrm{mb}$ & \multirow{2}{*}{$\begin{array}{l}\text { Based on penetration center fix at } 18 \mathrm{Z} \text { on } \\
\text { Sep } 23^{\text {rd }}\end{array}$} & \multirow{2}{*}{ Removed } \\
\hline Sep $2306 Z$ & $1011 \mathrm{mb}$ & & \\
\hline Sep $2312 Z$ & $1009 \mathrm{mb}$ & $\begin{array}{l}\text { Penetration center fix: } 1003 \mathrm{mb} \text { at } 1330 \mathrm{Z} \text { on } \\
\text { Sep } 23^{\text {rd }}\end{array}$ & $1003 \mathrm{mb}$ \\
\hline Sep $2318 Z$ & $1007 \mathrm{mb}$ & $\begin{array}{l}\text { Ship: } 15 \mathrm{kt} \mathrm{W} \text { and } 1002 \mathrm{mb} \text { at } 15 \mathrm{Z} \text { on Sep } \\
23^{\text {rd }}\end{array}$ & $1000 \mathrm{mb}$ \\
\hline Sep $2400 Z$ & $1005 \mathrm{mb}$ & \multirow{2}{*}{$\begin{array}{l}\text { Lower central pressures at } 18 \mathrm{Z} \text { on Sep } 23^{\text {rd }} \\
\text { and } 122 \mathrm{Z} \text { on Sep } 24^{\text {th }}\end{array}$} & \multirow{2}{*}{ Removed } \\
\hline Sep $2406 Z$ & $1004 \mathrm{mb}$ & & \\
\hline Sep $2412 Z$ & $1002 \mathrm{mb}$ & $\begin{array}{l}\text { Penetration center fix: } 997 \mathrm{mb} \text { at } 1330 \mathrm{Z} \text { on } \\
\text { Sep } 24^{\text {th }}\end{array}$ & $997 \mathrm{mb}$ \\
\hline Sep $2418 Z$ & $998 \mathrm{mb}$ & Lower central pressure at $12 \mathrm{Z}$ on Sep $24^{\text {th }}$ & Removed \\
\hline Sep $2500 Z$ & $993 \mathrm{mb}$ & \multirow{3}{*}{$\begin{array}{l}\text { No central pressure reports but appear } \\
\text { reasonable }\end{array}$} & \multirow{3}{*}{ Retained } \\
\hline Sep $2506 Z$ & $987 \mathrm{mb}$ & & \\
\hline Sep $2512 Z$ & $984 \mathrm{mb}$ & & \\
\hline Sep $2518 Z$ & $983 \mathrm{mb}$ & $\begin{array}{l}\text { Penetration center fix: } 982 \mathrm{mb} \text { at } 1826 \mathrm{Z} \text { on } \\
\text { Sep } 25^{\text {th }}\end{array}$ & $982 \mathrm{mb}$ \\
\hline Sep $2600 Z$ & $980 \mathrm{mb}$ & $\begin{array}{l}\text { Penetration center fix: } 986 \mathrm{mb} \text { at } 0230 \mathrm{Z} \text { on } \\
\text { Sep } 26^{\text {th }}\end{array}$ & $986 \mathrm{mb}$ \\
\hline Sep $2606 Z$ & $977 \mathrm{mb}$ & $\begin{array}{l}\text { Penetration center fix: } 974 \mathrm{mb} \text { at } 08 \mathrm{Z} \text { on } \\
\text { Sep } 26^{\text {th }}\end{array}$ & $974 \mathrm{mb}$ \\
\hline Sep $2612 Z$ & $967 \mathrm{mb}$ & $\begin{array}{l}\text { Penetration center fix: } 963 \mathrm{mb} \text { at } 14 \mathrm{Z} \text { on } \\
\text { Sep } 26^{\text {th }}\end{array}$ & $963 \mathrm{mb}$ \\
\hline Sep $2618 Z$ & $955 \mathrm{mb}$ & $\begin{array}{l}\text { Penetration center fix: } 948 \mathrm{mb} \text { around } \\
1830 \mathrm{Z} \text { on Sep } 26^{\text {th }}\end{array}$ & $948 \mathrm{mb}$ \\
\hline Sep $2700 Z$ & $943 \mathrm{mb}$ & $\begin{array}{l}\text { Penetration center fix: } 943 \mathrm{mb} \text { at } 0230 \mathrm{Z} \text { on } \\
\text { Sep } 27^{\text {th }}\end{array}$ & Retained \\
\hline Sep $2706 Z$ & $934 \mathrm{mb}$ & $\begin{array}{l}\text { Penetration center fix: } 933 \mathrm{mb} \text { at } 06 \mathrm{Z} \text { on } \\
\text { Sep } 27^{\text {th }}\end{array}$ & $933 \mathrm{mb}$ \\
\hline Sep $2712 Z$ & $938 \mathrm{mb}$ & $\begin{array}{l}\text { Penetration center fix: } 938 \mathrm{mb} \text { at } 11 \mathrm{Z} \text { on } \\
\text { Sep } 27^{\text {th }}\end{array}$ & Retained \\
\hline Sep $2718 Z$ & $943 \mathrm{mb}$ & $\begin{array}{l}\text { Lower central pressures measured at } 12 \mathrm{Z} \text { on } \\
\text { Sep } 27^{\text {th }} \text { and } 00 \mathrm{Z} \text { on Sep } 28^{\text {th }}\end{array}$ & Removed \\
\hline Sep $2800 Z$ & $946 \mathrm{mb}$ & $\begin{array}{l}\text { Penetration center fix: } 938 \mathrm{mb} \text { at } 2230 \mathrm{Z} \text { on } \\
\text { Sep } 27^{\text {th }}\end{array}$ & $938 \mathrm{mb}$ \\
\hline Sep $2806 Z$ & $950 \mathrm{mb}$ & Penetration center fixes: $945 \mathrm{mb}$ at $03 \mathrm{Z}$ on & Retained \\
\hline
\end{tabular}




\begin{tabular}{|c|c|c|c|}
\hline & & Sep $28^{\text {th }}$ and $955 \mathrm{mb}$ at $08 \mathrm{Z}$ on Sep $28^{\text {th }}$ & \\
\hline Sep $2812 Z$ & $954 \mathrm{mb}$ & $\begin{array}{l}\text { No central pressure reports but appears } \\
\text { reasonable }\end{array}$ & \\
\hline Sep $2818 Z$ & $957 \mathrm{mb}$ & $\begin{array}{l}\text { Penetration center fix: } 943 \mathrm{mb} \text { at } 2130 \mathrm{Z} \text { on } \\
\text { Sep } 28^{\text {th }}\end{array}$ & $943 \mathrm{mb}$ \\
\hline Sep $2900 Z$ & $959 \mathrm{mb}$ & $\begin{array}{l}\text { Penetration center fix: } 951 \mathrm{mb} \text { at } 2230 \mathrm{Z} \text { on } \\
\text { Sep } 28^{\text {th }}\end{array}$ & $951 \mathrm{mb}$ \\
\hline Sep 29 06Z & $963 \mathrm{mb}$ & \multirow{4}{*}{$\begin{array}{l}\text { No central pressure reports but appear } \\
\text { reasonable }\end{array}$} & \multirow{4}{*}{ Retained } \\
\hline Sep $2912 Z$ & $966 \mathrm{mb}$ & & \\
\hline Sep $2918 Z$ & $968 \mathrm{mb}$ & & \\
\hline Sep $3000 Z$ & $972 \mathrm{mb}$ & & \\
\hline
\end{tabular}

Hurricane Ilsa [September 24-30, 1958]

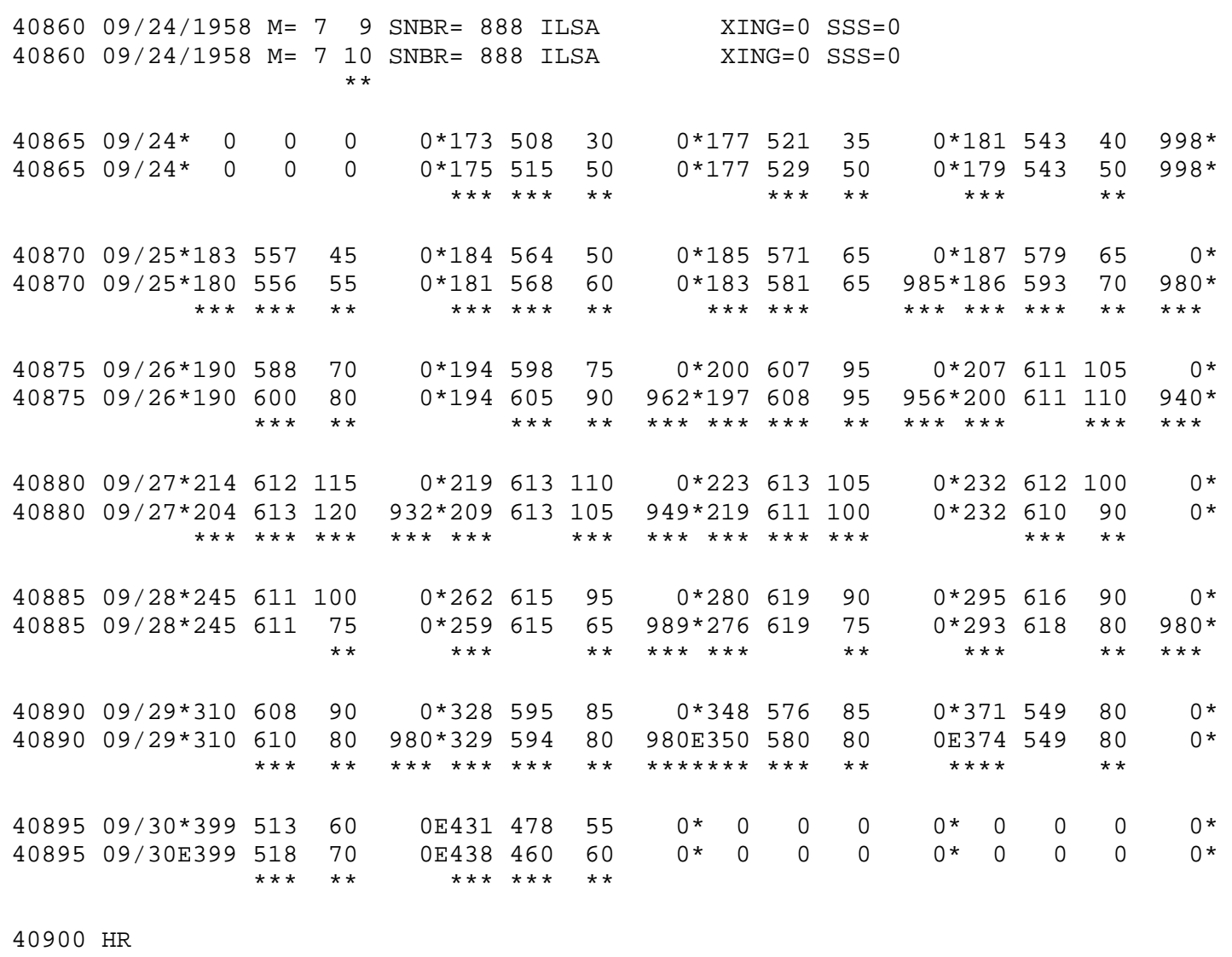

Minor changes to the track and major changes to the intensity shown in McAdie et al. (2009). Evidence for these alterations comes from the NHC microfilm maps, the 
Historical Weather Maps series, the COADS ship database, Monthly Weather Review, and Navy reconnaissance book and NHC Storm Wallets.

September 23:

HWM is not available on this date (system south of $20^{\circ} \mathrm{N}$ ). HURDAT does not list an organized system on this date. Microfilm does not show an organized system at 12Z. Ship highlights: No gales or low pressures.

MWR: "Ship reports on September 23 indicated that special aircraft reconnaissance into the area east of the Antilles was necessary."

September 24:

HWM is not available on this date (system south of $20^{\circ} \mathrm{N}$ ). HURDAT lists a 35 knot tropical storm at $17.7 \mathrm{~N}, 52.1 \mathrm{~W}$ at $12 \mathrm{Z}$. Microfilm shows a closed low pressure of at most $999 \mathrm{mb}$ at $17.5 \mathrm{~N}, 54.0 \mathrm{~W}$ at 12Z. Ship highlights: $40 \mathrm{kt} \mathrm{ENE}$ and $1002 \mathrm{mb}$ at $18.5 \mathrm{~N}$, $54.7 \mathrm{~W}$ at $18 \mathrm{Z}$ (micro). $50 \mathrm{kt} \mathrm{E}$ and $1007 \mathrm{mb}$ at $18.5 \mathrm{~N}, 54.7 \mathrm{~W}$ at $2030 \mathrm{Z}$ (micro). Aircraft highlights: Penetration center fix estimated surface winds at $35 \mathrm{kt}$ and measured a central pressure of $998 \mathrm{mb}$ at $17.7 \mathrm{~N}, 54.0 \mathrm{~W}$ at $1606 \mathrm{Z}$ (MWR).

MWR: "Tropical storm Ilsa was located at 1606 GMT on the 24th at latitude $17.7 \mathrm{~N}$, longitude 54.0W, about 800 statute miles east of San Juan, P.R., and 1,300 miles eastsoutheast of the position of tropical storm Helene. At this time, highest winds were 40 mph and central pressure 997.6 mb.” ATSR: “On 24 September a vortex was definitely confirmed by an Air Force reconnaissance aircraft at $241728 \mathrm{Z}$ in position 17.7N 54.0W."

September 25:

HWM is not available on this date (system south of $20^{\circ} \mathrm{N}$ ). HURDAT lists a 65 knot hurricane at $18.5 \mathrm{~N}, 57.1 \mathrm{~W}$ at $12 \mathrm{Z}$. Microfilm shows a closed low pressure of at most $1005 \mathrm{mb}$ at $18.0 \mathrm{~N}, 57.0 \mathrm{~W}$ at $12 \mathrm{Z}$. Ship highlights: $35 \mathrm{kt} \mathrm{N}$ and $1009 \mathrm{mb}$ at $18.1 \mathrm{~N}, 57.6 \mathrm{~W}$ at $12 \mathrm{Z}$ (micro). $60 \mathrm{kt} \mathrm{E}$ and $1005 \mathrm{mb}$ at $19.5 \mathrm{~N}, 59.9 \mathrm{~W}$ at $18 \mathrm{Z}$ (micro). Aircraft highlights: Radar center fix at $18.7 \mathrm{~N}, 57.5 \mathrm{~W}$ at $1120 \mathrm{Z}$ (ATSR). Penetration center fix estimated surface winds at $65 \mathrm{kt}$, measured a central pressure of $985 \mathrm{mb}$ and an eye diameter of 30 $\mathrm{nm}$ at $17.7 \mathrm{~N}, 54.0 \mathrm{~W}$ at $14 \mathrm{Z}$ (ATSR). Penetration center fix estimated surface winds at 70 $\mathrm{kt}$, measured a central pressure of $980 \mathrm{mb}$ and an eye diameter of $30 \mathrm{~nm}$ at $18.8 \mathrm{~N}, 59.8 \mathrm{~W}$ at $20 Z$ (ATSR).

MWR: "By the 25th, Ilsa and Helene, both of hurricane intensity, were located some 1,100 miles apart." 
September 26:

HWM analyzes a hurricane with a central pressure of $957 \mathrm{mb}$ at $20.0 \mathrm{~N}, 60.8 \mathrm{~W}$ at $12 \mathrm{Z}$. HURDAT lists a $95 \mathrm{knot}$ hurricane at $20.0 \mathrm{~N}, 60.7 \mathrm{~W}$ at $12 \mathrm{Z}$. Microfilm shows a closed low pressure of at most $993 \mathrm{mb}$ at $20.0 \mathrm{~N}, 60.5 \mathrm{~W}$ at 12Z. Ship highlights: $35 \mathrm{kt} \mathrm{SE}$ and $1013 \mathrm{mb}$ at $17.6 \mathrm{~N}, 55.7 \mathrm{~W}$ at $00 \mathrm{Z}$ (micro). $40 \mathrm{kt} \mathrm{ENE}$ and $1015 \mathrm{mb}$ at $22.0 \mathrm{~N}, 61.5 \mathrm{~W}$ at $03 \mathrm{Z}$ (micro). $70 \mathrm{kt} \mathrm{SSE}$ at $18.9 \mathrm{~N}, 59.4 \mathrm{~W}$ at $06 \mathrm{Z}$ (COADS). $70 \mathrm{kt} \mathrm{SSE}$ at $19.3 \mathrm{~N}, 59.1 \mathrm{~W}$ at $09 \mathrm{Z}$ (COADS). $85 \mathrm{kt} \mathrm{SE}$ at $19.5 \mathrm{~N}, 58.9 \mathrm{~W}$ at $12 \mathrm{Z}$ (COADS). $70 \mathrm{kt} \mathrm{SE}$ at $19.5 \mathrm{~N}, 58.8 \mathrm{~W}$ at $15 \mathrm{Z}$ (COADS). $70 \mathrm{kt} \mathrm{SE}$ at $19.3 \mathrm{~N}, 58.3 \mathrm{~W}$ at $18 \mathrm{Z}$ (COADS). $60 \mathrm{kt} \mathrm{SE}$ at $19.1 \mathrm{~N}, 58.1 \mathrm{~W}$ at $21 \mathrm{Z}$ (COADS). Aircraft highlights: Radar fix estimated an eye diameter of $35 \mathrm{~nm}$ at $19.3 \mathrm{~N}, 59.8 \mathrm{~W}$ at $0110 \mathrm{Z}$ (ATSR). Penetration center fix measured a central pressure of $962 \mathrm{mb}$ at $19.5 \mathrm{~N}, 60.4 \mathrm{~W}$ at $0730 \mathrm{Z}$ (ATSR/micro). Penetration center fix measured a central pressure of $956 \mathrm{mb}$ at $19.8 \mathrm{~N}, 60.6 \mathrm{~W}$ at $1330 \mathrm{Z}$ (ATSR/micro). Penetration center fix estimated surface winds at $80 \mathrm{kt}$, measured a central pressure of $940 \mathrm{mb}$ and an eye diameter of $30 \mathrm{~nm}$ at $20.1 \mathrm{~N}, 61.3 \mathrm{~W}$ at $20 \mathrm{Z}$ (ATSR/micro).

MWR: "Ilsa deepened rapidly on the 26th, reaching $932 \mathrm{mb}$ (dropsonde), a fall of $48 \mathrm{mb}$ in about $24 \mathrm{hr}$. The eye was well defined, and spiral bands were described as a typical textbook picture. Winds were estimated to exceed $125 \mathrm{mph}$."

September 27:

HWM analyzes a hurricane with a central pressure of $984 \mathrm{mb}$ at $22.5 \mathrm{~N}, 61.2 \mathrm{~W}$ at $12 \mathrm{Z}$. HURDAT lists a $105 \mathrm{knot}$ hurricane at $22.3 \mathrm{~N}, 61.3 \mathrm{~W}$ at $12 \mathrm{Z}$. Microfilm shows a closed low pressure of at most $1008 \mathrm{mb}$ at $21.5 \mathrm{~N}, 62.0 \mathrm{~W}$ at 12Z. Ship highlights: $40 \mathrm{kt}$ $\mathrm{SE}$ and $1008 \mathrm{mb}$ at $20.4 \mathrm{~N}, 58.9 \mathrm{~W}$ at $12 \mathrm{Z}$ (micro). $65 \mathrm{kt} \mathrm{SE}$ and $1008 \mathrm{mb}$ at $22.9 \mathrm{~N}, 59.8 \mathrm{~W}$ at $15 \mathrm{Z}$ (micro). $60 \mathrm{kt} \mathrm{SE}$ and $1005 \mathrm{mb}$ at $22.4 \mathrm{~N}, 59.7 \mathrm{~W}$ at $18 \mathrm{Z}$ (micro). $50 \mathrm{kt} \mathrm{SE}$ and $1009 \mathrm{mb}$ at $23.7 \mathrm{~N}, 58.7 \mathrm{~W}$ at $21 \mathrm{Z}$ (micro). Aircraft highlight: Penetration center fix measured a central pressure of $932 \mathrm{mb}$ at $20.7 \mathrm{~N}, 61.2 \mathrm{~W}$ at $02 \mathrm{Z}$ (ATSR/micro). Penetration center fix measured a central pressure of $949 \mathrm{mb}$ and an eye diameter of 40 $\mathrm{nm}$ at $20.9 \mathrm{~N}, 61.1 \mathrm{~W}$ at $08 \mathrm{Z}$ (ATSR). Penetration center fix at $22.4 \mathrm{~N}, 61.0 \mathrm{~W}$ at $14 \mathrm{Z}$ (ATSR). Penetration center fix at 23.5N, 60.8W at 1930Z (ATSR).

MWR: "The storm began to fill on the $27^{\text {th }}$ and regular advisories were discontinued on the $30^{\text {th }}$. No loss of life or property damage was reported."

September 28:

HWM analyzes a hurricane with a central pressure of $967 \mathrm{mb}$ at $28.1 \mathrm{~N}, 61.9 \mathrm{~W}$ at $12 \mathrm{Z}$. HURDAT lists a 90 knot hurricane at $28.1 \mathrm{~N}, 61.9 \mathrm{~W}$ at $12 \mathrm{Z}$. Microfilm shows a closed low pressure of at most $993 \mathrm{mb}$ at $29.0 \mathrm{~N}, 62.5 \mathrm{~W}$ at $12 \mathrm{Z}$. Ship highlights: $35 \mathrm{kt} \mathrm{S}$ at $22.4 \mathrm{~N}, 57.0 \mathrm{~W}$ at $00 \mathrm{Z}(\mathrm{COADS}) .50 \mathrm{kt} \mathrm{SE}$ and $1005 \mathrm{mb}$ at $26.5 \mathrm{~N}, 59.9 \mathrm{~W}$ at $03 \mathrm{Z}$ 
(micro). $45 \mathrm{kt} \mathrm{NE}$ and $1006 \mathrm{mb}$ at $28.3 \mathrm{~N}, 62.1 \mathrm{~W}$ at $06 \mathrm{Z}$ (micro). $90 \mathrm{kt} \mathrm{S}$ and $1001 \mathrm{mb}$ at $28.5 \mathrm{~N}, 61.0 \mathrm{~W}$ at $12 \mathrm{Z}$ (micro). $45 \mathrm{kt} \mathrm{NW}$ and $1003 \mathrm{mb}$ at $28.3 \mathrm{~N}, 64.4 \mathrm{~W}$ at $15 \mathrm{Z}$ (COADS). $95 \mathrm{kt} \mathrm{SSW}$ and $998 \mathrm{mb}$ at $28.1 \mathrm{~N}, 61.4 \mathrm{~W}$ at $18 \mathrm{Z}$ (micro). Aircraft hilights: Radar center fix at $26.3 \mathrm{~N}, 60.8 \mathrm{~W}$ and an eye diameter of $45 \mathrm{~nm}$ at $02 \mathrm{Z}$ (ATSR). Penetration center fix estimated surface winds at $60 \mathrm{kt}$, measured a central pressure of $989 \mathrm{mb}$ and an eye diameter of $50 \mathrm{~nm}$ at $27.8 \mathrm{~N}, 61.8 \mathrm{~W}$ at $0728 \mathrm{Z}$ (ATSR). Penetration center fix at $27.7 \mathrm{~N}$, $62.2 \mathrm{~W}$ at $1348 \mathrm{Z}$ (ATSR). Penetration center fix measured a central pressure of $980 \mathrm{mb}$ at $29.1 \mathrm{~N}, 61.9 \mathrm{~W}$ at $17 \mathrm{Z}$ (ATSR/micro). Penetration center fix measured a central pressure of $975 \mathrm{mb}$ at $30.6 \mathrm{~N}, 61.3 \mathrm{~W}$ at $2140 \mathrm{Z}$ (ATSR/micro).

September 29:

HWM analyzes a hurricane with a central pressure of $975 \mathrm{mb}$ at $34.8 \mathrm{~N}, 57.5 \mathrm{~W}$ and a cold front just to the northwest at 12Z. HURDAT lists an 85 knot hurricane at $34.8 \mathrm{~N}, 57.6 \mathrm{~W}$ at $12 \mathrm{Z}$. Microfilm shows a closed low pressure of at most $1002 \mathrm{mb}$ with a frontal boundary going through the center at $35.0 \mathrm{~N}, 59.0 \mathrm{~W}$ at $12 \mathrm{Z}$. Ship highlights: $45 \mathrm{kt}$ SSE and $1001 \mathrm{mb}$ at $33.1 \mathrm{~N}, 58.0 \mathrm{~W}$ at $06 \mathrm{Z}$ (COADS). $40 \mathrm{kt} \mathrm{NW}$ and $1003 \mathrm{mb}$ at $38.8 \mathrm{~N}$, $58.5 \mathrm{~W}$ at $12 \mathrm{Z}$ (COADS). $75 \mathrm{kt} \mathrm{WNW}$ at $35.2 \mathrm{~N}, 54.5 \mathrm{~W}$ at $18 \mathrm{Z}$ (micro). Aircraft highlights: Penetration center fix measured a central pressure of $980 \mathrm{mb}$ at $30.8 \mathrm{~N}, 60.7 \mathrm{~W}$ at $0130 \mathrm{Z}$ (ATSR/micro). Penetration center fix measured a central pressure of $980 \mathrm{mb}$ at $32.9 \mathrm{~N}, 58.9 \mathrm{~W}$ at $0744 \mathrm{Z}$ (ATSR/micro). Penetration center fix at $35.3 \mathrm{~N}, 56.7 \mathrm{~W}$ at $1415 \mathrm{Z}$ (ATSR). Radar center fix at 37.7N, $54.3 \mathrm{~W}$ at $1936 \mathrm{Z}$ (ATSR).

September 30:

HWM analyzes an extratropical cyclone of at most $995 \mathrm{mb}$ at $46.0 \mathrm{~N}, 41.5 \mathrm{~W}$ embedded within a frontal boundary at 12Z. HURDAT lists a 55 knot extratropical storm at $43.1 \mathrm{~N}, 47.8 \mathrm{~W}$ at $06 \mathrm{Z}$ (last position). Microfilm shows that Ilsa has been absorbed by a much larger extratropical cyclone (Helene) to the north at 12Z. Ship highlights: $50 \mathrm{kt} \mathrm{S}$ and $1007 \mathrm{mb}$ at $38.9 \mathrm{~N}, 49.5 \mathrm{~W}$ at $00 \mathrm{Z}$ (micro). $35 \mathrm{kt} \mathrm{S}$ and $997 \mathrm{mb}$ at $43.7 \mathrm{~N}, 45.4 \mathrm{~W}$ at 06Z (COADS). $40 \mathrm{kt} \mathrm{SSW}$ and $992 \mathrm{mb}$ at $46.0 \mathrm{~N}, 41.2 \mathrm{~W}$ at $12 \mathrm{Z}$ (micro).

Hurricane Ilsa developed from a tropical wave over the central Atlantic late on September. The first position, not genesis, is analyzed at $06 \mathrm{Z}$ on September $24^{\text {th }}$ as a 50 $\mathrm{kt}$ tropical storm based on observations later on the day, up from $30 \mathrm{kt}$ originally in HURDAT, a major intensity change. Data over the central Atlantic is sparse and the genesis of Ilsa could have occurred substantially earlier than originally shown in HURDAT. Minor track changes are introduced for the duration of this system. At $1606 \mathrm{Z}$ on the $24^{\text {th }}$, a reconnaissance aircraft reached Ilsa measuring a central pressure of $998 \mathrm{mb}$ and estimating surface winds of $35 \mathrm{kt}$. A central pressure of $998 \mathrm{mb}$ suggests maximum winds of $51 \mathrm{kt}$ south of $25 \mathrm{~N}$ from the Brown et al. pressure-wind relationship. An 
intensity of $50 \mathrm{kt}$ is selected for $18 \mathrm{Z}$ on the $24^{\text {th }}$, up from $40 \mathrm{kt}$ originally in HURDAT, a minor intensity change. A central pressure of $998 \mathrm{mb}$ is present in HURDAT at $18 \mathrm{Z}$ on the $24^{\text {th }}$ and has been retained. Gale-force winds up to $50 \mathrm{kt}$ were reported by ships late on the $24^{\text {th }}$. Ilsa moved west-northwest on September $25^{\text {th }}$ and continued to strengthen. A reconnaissance aircraft reached the tropical cyclone at $14 \mathrm{Z}$ on the $25^{\text {th }}$ measuring a central pressure of $985 \mathrm{mb}$ and estimated surface winds of $65 \mathrm{kt}$ and an eye diameter of $30 \mathrm{~nm}$. A central pressure of $985 \mathrm{mb}$ suggests maximum winds of $71 \mathrm{kt}$ south of $25 \mathrm{~N}$ intensifying from the pressure-wind relationship. An eye diameter of $30 \mathrm{~nm}$ suggests an RMW of about $22 \mathrm{~nm}$ and climatology suggests about $15 \mathrm{~nm}$. Due to the RMW being larger than climatology, an intensity of $65 \mathrm{kt}$ is selected at $12 \mathrm{Z}$ on the $25^{\text {th }}$, same as the original HURDAT. Intensification to a hurricane is analyzed at $12 \mathrm{Z}$ on the $25^{\text {th }}$, same as the original HURDAT. A central pressure of $985 \mathrm{mb}$ is added to HURDAT at $12 \mathrm{Z}$ on the $25^{\text {th }}$. Another reconnaissance aircraft reached Ilsa at $20 \mathrm{Z}$ on the $25^{\text {th }}$ measuring a central pressure of $980 \mathrm{mb}$ and estimated surface winds of $70 \mathrm{kt}$ and an eye diameter of $30 \mathrm{~nm}$. A central pressure of $980 \mathrm{mb}$ suggests maximum winds of $78 \mathrm{kt}$ south of $25 \mathrm{~N}$ intensifying from the pressure-wind relationship. An eye diameter of $30 \mathrm{~nm}$ suggests an RMW of about $22 \mathrm{~nm}$ and climatology suggests about $16 \mathrm{~nm}$. Since the RMW remained slightly larger than average, an intensity of $70 \mathrm{kt}$ is selected at $18 \mathrm{Z}$ on the $25^{\text {th }}$, up from $65 \mathrm{kt}$ in the original HURDAT, a minor intensity change. A central pressure of $980 \mathrm{mb}$ is added to HURDAT at $18 \mathrm{Z}$ on the $25^{\text {th }}$.

Early on September $26^{\text {th }}$, Ilsa made its closest approach to the Leeward Islands passing about $130 \mathrm{~nm}$ northeast of Barbuda. On this day, the forward speed of the hurricane decreased to about $4 \mathrm{kt}$ and the track turned to the northwest while rapidly gaining strength. A reconnaissance aircraft reached the hurricane at $0730 \mathrm{Z}$ on the $26^{\text {th }}$ measuring a central pressure of $962 \mathrm{mb}$. A central pressure of $962 \mathrm{mb}$ suggests maximum winds of $100 \mathrm{kt}$ south of $25 \mathrm{~N}$ intensifying according to the pressure-wind relationship. Due to the slow forward speed of about $4 \mathrm{kt}$ and large RMW from the previous day and confirmed on a reconnaissance mission later on the $26^{\text {th }}$, an intensity of $90 \mathrm{kt}$ is selected for $06 \mathrm{Z}$, up from $75 \mathrm{kt}$ originally in HURDAT, a minor intensity change. A central pressure of 962 $\mathrm{mb}$ is added to $06 \mathrm{Z}$ on the $26^{\text {th }}$. Another reconnaissance aircraft measured a central pressure of $956 \mathrm{mb}$ at $1330 \mathrm{Z}$ on the $26^{\text {th }}$. A central pressure of $956 \mathrm{mb}$ suggests maximum winds of $107 \mathrm{kt}$ south of $25 \mathrm{~N}$ intensifying according to the pressure-wind relationship. Due to the slow forward speed of about $4 \mathrm{kt}$ and relatively large RMW, an intensity of $95 \mathrm{kt}$ is selected for 06Z, same as the original HURDAT. A central pressure of $956 \mathrm{mb}$ is added to $12 \mathrm{Z}$ on the $26^{\text {th }}$. The last center penetration on the $26^{\text {th }}$ by the reconnaissance aircraft occurred at $20 \mathrm{Z}$ measuring a central pressure of $940 \mathrm{mb}$ and estimating surface winds of $80 \mathrm{kt}$ and an eye diameter of $30 \mathrm{~nm}$. A central pressure of $940 \mathrm{mb}$ suggests maximum winds of $123 \mathrm{kt}$ south of $25 \mathrm{~N}$ intensifying according to the pressure-wind relationships. An eye diameter of $30 \mathrm{~nm}$ suggests an RMW of about $22 \mathrm{~nm}$ 
and climatology suggests about $12 \mathrm{~nm}$. Due to the RMW being larger than climatology and slow forward speed of about $4 \mathrm{kt}$, an intensity of $110 \mathrm{kt}$ is selected at $18 \mathrm{Z}$ on the $26^{\text {th }}$, up from $105 \mathrm{kt}$ in the original HURDAT, a minor intensity change. A central pressure of $940 \mathrm{mb}$ is added to $18 \mathrm{Z}$ on the $26^{\text {th }}$. Intensification to a major hurricane is analyzed at $18 \mathrm{Z}$ on the $26^{\text {th }}$, same as the original HURDAT. On September $27^{\text {th }}$, the track of Ilsa turned to the north slowly gaining in forward speed. The period of rapid intensification continued into the morning of the $27^{\text {th }}$ when a reconnaissance aircraft measured a central pressure of $932 \mathrm{mb}$ at $02 \mathrm{Z}$. A central pressure of $932 \mathrm{mb}$ suggests maximum winds of $130 \mathrm{kt}$ south of $25 \mathrm{~N}$ intensifying according to the pressure-wind relationship. Since the hurricane was still moving at around $5 \mathrm{kt}$ and the RMW was larger than climatology, an intensity of $120 \mathrm{kt}$ is selected at $00 \mathrm{Z}$ on the $27^{\text {th }}$, up from $115 \mathrm{kt}$ originally in HURDAT, a minor intensity change. $120 \mathrm{kt}$ is also the peak intensity for this hurricane, up from 115 kt originally in HURDAT, a minor intensity change. A central pressure of $932 \mathrm{mb}$ is added to $00 \mathrm{Z}$ on the $27^{\text {th }}$. The next reconnaissance aircraft found that Ilsa had begun to weaken, measuring a central pressure of $949 \mathrm{mb}$ and an eye diameter of $40 \mathrm{~nm}$ at $08 \mathrm{Z}$. A central pressure of $949 \mathrm{mb}$ suggests maximum winds of $108 \mathrm{kt}$ south of $25 \mathrm{~N}$ weakening according to the pressure-wind relationships. An eye diameter of $40 \mathrm{~nm}$ suggests an RMW of about $30 \mathrm{~nm}$ and climatology suggests about $14 \mathrm{~nm}$. Because the hurricane was moving around $8 \mathrm{kt}$ and the RMW was larger than average, an intensity of $105 \mathrm{kt}$ is selected for $06 Z$ on the $27^{\text {th }}$, down from $110 \mathrm{kt}$ originally in HURDAT, a minor intensity change. A central pressure of $949 \mathrm{mb}$ is added to $06 \mathrm{Z}$ on the $27^{\text {th }}$. Weakening below major hurricane status is analyzed at $12 \mathrm{Z}$ on the $27^{\text {th }}, 18$ hours earlier than originally shown in HURDAT. Most ships remained away from the circulation of Ilsa on the $27^{\text {th }}$ but a few reported tropical storm force winds.

Ilsa continued to weaken on September $28^{\text {th }}$. A reconnaissance aircraft reached the hurricane at $0728 \mathrm{Z}$ measuring a central pressure of $989 \mathrm{mb}$ and estimating surface winds of $60 \mathrm{kt}$ and an eye diameter of $50 \mathrm{~nm}$. A central pressure of $989 \mathrm{mb}$ suggests maximum winds of $58 \mathrm{kt}$ north of $25 \mathrm{~N}$ weakening according to the pressure-wind relationships. An eye diameter of $50 \mathrm{~nm}$ suggests an RMW of about $38 \mathrm{~nm}$ and climatology suggests about $24 \mathrm{~nm}$. Although the RMW is larger than average, the forward speed had increased to about $17 \mathrm{kt}$ and a few ships reported hurricane-force winds, thus an intensity of $65 \mathrm{kt}$ is selected for $06 Z$ on the $28^{\text {th }}$, down from $95 \mathrm{kt}$ originally in HURDAT, a major intensity change. A central pressure of $989 \mathrm{mb}$ is added to $06 \mathrm{Z}$ on the $28^{\text {th }}$. Another major intensity change is at $00 \mathrm{Z}$ on the $28^{\text {th }}$ as $75 \mathrm{kt}$ is the selected and HURDAT originally had $100 \mathrm{kt}$. A ship reported $90 \mathrm{kt}$ at $12 \mathrm{Z}$ and $95 \mathrm{kt}$ at $18 \mathrm{Z}$ but it appears likely that the wind reports were elevated and/or biased high based on the reports from the reconnaissance aircrafts. Another aircraft reached Ilsa at $17 \mathrm{Z}$ on the $28^{\text {th }}$ measuring a central pressure of $980 \mathrm{mb}$. A central pressure of $980 \mathrm{mb}$ suggests maximum winds of $73 \mathrm{kt}$ north of $25 \mathrm{~N}$ and $77 \mathrm{kt}$ north of $25 \mathrm{~N}$ intensifying according to the pressure-wind relationships. Since the 
hurricane was moving at about $18 \mathrm{kt}$ ahead of a frontal boundary, an intensity of $80 \mathrm{kt}$ is selected at $18 \mathrm{Z}$ on the $28^{\text {th }}$, down from $90 \mathrm{kt}$ originally in HURDAT, a minor intensity change. A central pressure of $980 \mathrm{mb}$ is added to HURDAT at $18 \mathrm{Z}$ on the $28^{\text {th }}$. Ilsa passed about $200 \mathrm{~nm}$ east of Bermuda early on September $29^{\text {th }}$ while accelerating to the northeast. A reconnaissance aircraft penetrated the center of the hurricane at $0130 \mathrm{Z}$ and $0744 \mathrm{Z}$ measuring a central pressure of $980 \mathrm{mb}$ in both occasions. A central pressure of $980 \mathrm{mb}$ suggests maximum winds of $73 \mathrm{kt}$ north of $25 \mathrm{~N}$ according to the pressure-wind relationship. An intensity of $80 \mathrm{kt}$ is selected for $00 \mathrm{Z}$ and $06 \mathrm{Z}$ on the $29^{\text {th }}$, down from 90 kt and $85 \mathrm{kt}$, respectively; both are minor intensity changes to the original HURDAT. Ship observations at $12 \mathrm{Z}$ on the $29^{\text {th }}$ indicate that the center of Ilsa had become embedded within the frontal boundary associated with a larger extratropical cyclone (Helene) to the north. Thus, it is analyzed that Ilsa became an extratropical cyclone at $12 \mathrm{Z}$ on the $29^{\text {th }}, 18$ hours earlier than originally shown in HURDAT. Weakening below hurricane force is analyzed at $06 \mathrm{Z}$ on the $30^{\text {th }}$, six hours later than originally shown in HURDAT. Ship observations indicate that Ilsa was absorbed by the larger extratropical cyclone after $06 Z$ on September $30^{\text {th }}$. The last position is analyzed at $06 \mathrm{Z}$ on the $30^{\text {th }}$, same as the original HURDAT.

Hurricane Janice [October 4-13, 1958]

\begin{tabular}{|c|c|c|c|c|c|c|c|c|c|c|c|c|c|}
\hline 40905 & $10 / 05 / 1958$ & $M=$ & 10 & SNBR $=88$ & $39 \mathrm{JA}$ & JICE & XII & $V G=\odot$ & SSS $=$ & & & & $\mathrm{L}$ \\
\hline 40905 & $\begin{array}{c}10 / 04 / 1958 \\
* \star\end{array}$ & $M=1$ & $\begin{array}{l}11 \\
* * *\end{array}$ & SNBR $=88$ & $39 \mathrm{JA}$ & JICE & XII & $V G=\odot$ & SSS $=$ & & & & L \\
\hline (Octob & ber 4 th is & new & $\mathrm{H}$ & (URDAT) & & & & & & & & & \\
\hline $4 \odot 9 \odot 7$ & $10 / \odot 4^{*} \odot$ & $\odot$ & $\odot$ & $\Theta^{*} \odot$ & $\odot$ & $\odot$ & $0 * 185$ & 811 & 30 & 0*190 & 812 & 30 & ○* \\
\hline 40910 & $10 / 05^{*}$ & $\odot$ & $\odot$ & ๑*192 & 813 & 30 & $0 * 200$ & 816 & 30 & ๑*209 & 815 & 35 & 999* \\
\hline 40910 & $10 / 05^{*} 194$ & $\begin{array}{l}813 \\
* * *\end{array}$ & $\begin{array}{l}30 \\
* *\end{array}$ & $\begin{array}{l}1005^{*} 198 \\
* * * * * * *\end{array}$ & $\begin{array}{l}814 \\
* * *\end{array}$ & 30 & $\begin{array}{r}0 * 203 \\
* * *\end{array}$ & $\begin{array}{l}814 \\
* * *\end{array}$ & $\begin{array}{l}35 \\
* *\end{array}$ & ๑*209 & $\begin{array}{l}812 \\
* * *\end{array}$ & $\begin{array}{l}40 \\
* *\end{array}$ & $\begin{array}{l}1002 * \\
* * * *\end{array}$ \\
\hline 40915 & $10 / 06 * 218$ & 810 & 40 & $999 * 225$ & 801 & 45 & $999 * 233$ & 791 & 50 & $998 * 246$ & 778 & 55 & 997 * \\
\hline 40915 & $\begin{array}{r}10 / 06 * 216 \\
\star \star \star *\end{array}$ & $\begin{array}{l}806 \\
* * *\end{array}$ & $\begin{array}{l}45 \\
* *\end{array}$ & $\begin{array}{l}0 * 224 \\
* \quad * * *\end{array}$ & $\begin{array}{l}799 \\
* * *\end{array}$ & 45 & $999 * 233$ & $\begin{array}{l}788 \\
* * *\end{array}$ & $\begin{array}{l}50 \\
\star *\end{array}$ & $\begin{array}{r}998 * 245 \\
* \star *\end{array}$ & $\begin{array}{l}776 \\
* * *\end{array}$ & $\begin{array}{l}55 \\
* *\end{array}$ & $\begin{array}{l}991^{*} \\
* \star \star\end{array}$ \\
\hline 40920 & $10 / 07 * 260$ & 766 & 60 & $996 * 272$ & 756 & 65 & $988 * 282$ & 750 & 75 & $987 * 287$ & 747 & 80 & $990 *$ \\
\hline 40920 & $\begin{array}{r}10 / 07 * 258 \\
* \star \star\end{array}$ & 766 & $\begin{array}{l}65 \\
* *\end{array}$ & $\begin{array}{l}985 * 272 \\
\star \star \star *\end{array}$ & 756 & 65 & $\begin{array}{l}0 * 283 \\
* * * *\end{array}$ & $\begin{array}{l}751 \\
* * *\end{array}$ & $\begin{array}{l}65 \\
* *\end{array}$ & $\begin{array}{l}0^{*} 289 \\
* \quad \star * *\end{array}$ & $\begin{array}{l}748 \\
* * *\end{array}$ & $\begin{array}{l}65 \\
* *\end{array}$ & $\begin{array}{l}983^{*} \\
* * *\end{array}$ \\
\hline 40925 & $10 / 08 * 292$ & 745 & 80 & 995 * 300 & 742 & 80 & $995 * 308$ & 738 & 80 & $992 * 315$ & 733 & 70 & $990 *$ \\
\hline 40925 & $\begin{array}{r}10 / 08 * 294 \\
* * *\end{array}$ & 745 & $\begin{array}{l}65 \\
* *\end{array}$ & $\begin{array}{l}0 * 300 \\
*\end{array}$ & 742 & $\begin{array}{l}65 \\
* *\end{array}$ & $\begin{array}{l}986 * 307 \\
* * * * * *\end{array}$ & 738 & $\begin{array}{l}65 \\
* *\end{array}$ & $\begin{array}{l}0 * 314 \\
* \quad * * *\end{array}$ & 733 & $\begin{array}{l}65 \\
* *\end{array}$ & $\begin{array}{l}\odot^{*} \\
*\end{array}$ \\
\hline 40930 & $10 / 09 * 320$ & 726 & 70 & 987 *321 & 719 & 65 & $985 * 322$ & 710 & 65 & $983 * 327$ & 697 & 65 & $977^{*}$ \\
\hline 40930 & $\begin{array}{r}10 / 09 * 318 \\
\star \star \star *\end{array}$ & $\begin{array}{l}728 \\
* * *\end{array}$ & $\begin{array}{l}65 \\
* *\end{array}$ & $\begin{array}{l}984 * 320 \\
\star \star \star * \star * *\end{array}$ & $\begin{array}{l}721 \\
\star * *\end{array}$ & 65 & $985 * 322$ & $\begin{array}{l}709 \\
* * *\end{array}$ & $\begin{array}{l}70 \\
* *\end{array}$ & $983 * 327$ & $\begin{array}{l}696 \\
\star * *\end{array}$ & $\begin{array}{l}75 \\
* *\end{array}$ & $977^{*}$ \\
\hline 409 & $10 / 10 * 333$ & 682 & 65 & $970 * 341$ & 670 & 75 & $968 * 350$ & 658 & 80 & $970 * 360$ & 639 & 80 & $970 *$ \\
\hline 409 & $10 / 10 * 333$ & $\begin{array}{l}684 \\
* * *\end{array}$ & $\begin{array}{l}80 \\
\star *\end{array}$ & $\begin{array}{r}970 * 340 \\
* \star \star\end{array}$ & $\begin{array}{l}671 \\
* * *\end{array}$ & $\begin{array}{l}80 \\
* *\end{array}$ & $\begin{array}{r}968 * 348 \\
* * *\end{array}$ & $\begin{array}{l}657 \\
* * *\end{array}$ & 80 & $970 * 360$ & 639 & 80 & 970 * \\
\hline
\end{tabular}




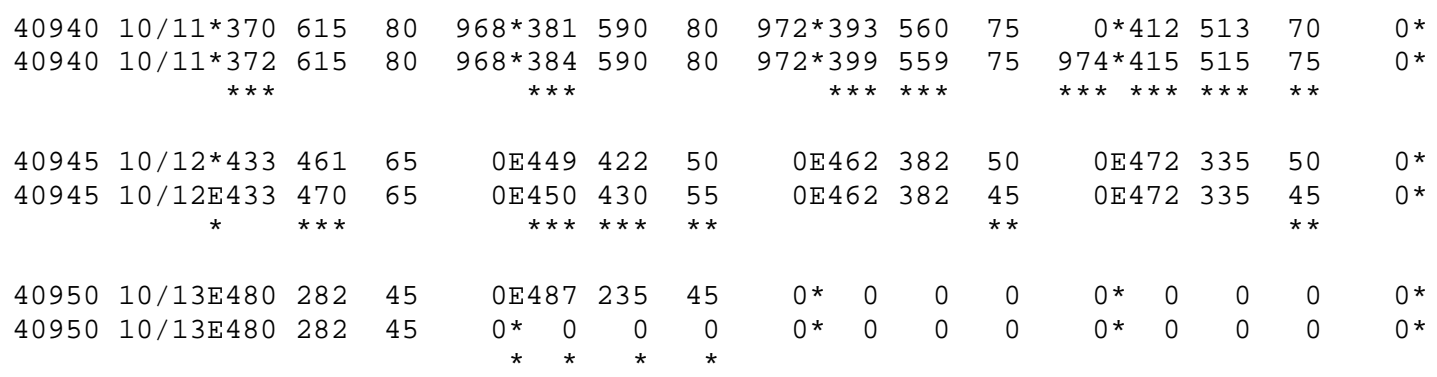

40955 HR

Tropical Storm Landfall

10/06 03Z 22.0N 80.3W $50 \mathrm{kt}$ Cuba

10/06 16Z 24.2N 78.0W 55 kt Bahamas

10/06 21Z 25.1N 77.1W 60 kt Bahamas

Hurricane Landfall

10/06 23Z 25.5N 76.8W 65 kt Bahamas

Minor changes to the track and intensity shown in McAdie et al. (2009). Evidence for these alterations comes from the NHC microfilm maps, the Historical Weather Maps series, the COADS ship database, Monthly Weather Review, Surface Weather Observations, Navy reconnaissance book, Mariners Weather Log, Perez et al. (2000) and NHC Storm Wallets.

October 1:

HWM is not available on this date (system south of $20^{\circ} \mathrm{N}$ ). HURDAT does not list an organized system on this date. Microfilm shows a tropical wave along 12N-20N, 66W$69 \mathrm{~W}$ at 12Z. Ship highlights: No gales or low pressures.

MWR: "A fairly active easterly wave passed through the Lesser Antilles on September 30 and into the Virgin Islands on October 1."

October 2:

HWM is not available on this date (system south of $20^{\circ} \mathrm{N}$ ). HURDAT does not list an organized system on this date. Microfilm shows a tropical wave along $13 \mathrm{~N}-25 \mathrm{~N}, 70 \mathrm{~W}-$ $72 \mathrm{~W}$ at $12 \mathrm{Z}$. Ship highlights: $35 \mathrm{kt} \mathrm{ESE}$ and $1009 \mathrm{mb}$ at $16.6 \mathrm{~N}, 69.3 \mathrm{~W}$ at $18 \mathrm{Z}$ (micro). 
October 3:

HWM is not available on this date (system south of $20^{\circ} \mathrm{N}$ ). HURDAT does not list an organized system on this date. Microfilm shows a tropical wave along $15 \mathrm{~N}-23 \mathrm{~N}, 74 \mathrm{~W}-$ $77 \mathrm{~W}$ at $12 \mathrm{Z}$. Ship highlights: $40 \mathrm{kt} \mathrm{E}$ and $1013 \mathrm{mb}$ at $20.9 \mathrm{~N}, 74.2 \mathrm{~W}$ at $06 \mathrm{Z}$

(COADS/MWL). $35 \mathrm{kt} \mathrm{ESE}$ and $1012 \mathrm{mb}$ at $17.5 \mathrm{~N}, 75.7 \mathrm{~W}$ at $12 \mathrm{Z}$ (micro). $35 \mathrm{kt} \mathrm{E}$ and $1011 \mathrm{mb}$ at $16.1 \mathrm{~N}, 73.7 \mathrm{~W}$ at $1630 \mathrm{Z}$ (micro).

MWR: "By midday of the 2d, the wave had reached central Hispaniola, and 24 hours later extended from extreme eastern Cuba southward near Jamaica. A broad flat quasicirculation was evident southwest of Jamaica on the $3^{\text {rd }}$, however, reconnaissance aircraft on this date found no closed circulation. Squalls in the northern semicircle were attended by maximum winds of $40 \mathrm{mph}$ and the lowest sea level pressure observed was $1010 \mathrm{mb}$."

October 4:

HWM is not available on this date (system south of $20^{\circ} \mathrm{N}$ ). HURDAT does not list an organized system on this date. Microfilm shows a closed low pressure of at most 1008 $\mathrm{mb}$ at $17.7 \mathrm{~N}, 81.7 \mathrm{~W}$ at $12 \mathrm{Z}$. Ship highlights: $35 \mathrm{kt} \mathrm{SE}$ and $1014 \mathrm{mb}$ at $17.1 \mathrm{~N}, 75.6 \mathrm{~W}$ at 00Z (COADS). Land highlights: $40 \mathrm{kt} \mathrm{E}$ and $1011 \mathrm{mb}$ at Kingston, Jamaica at 06Z (micro).

MWR: "By the $4^{\text {th }}$ the wave had moved to the central Cuba-Grand Cayman Island area. This wave had been attended by heavy shower and thunderstorm activity from the central Caribbean northward across Puerto Rico, Hispaniola, Cuba, and into the Bahamas as it progressed westward. By the $4^{\text {th }}$ this circulation was located a short distance southwest of Grand Cayman Island. The aircraft found a large but very weak circulation with minimum pressure of $1008 \mathrm{mb}$ and maximum winds of $25 \mathrm{mph} . "$

October 5:

HWM analyzes a tropical storm of at most $1005 \mathrm{mb}$ at $20.1 \mathrm{~N}, 81.4 \mathrm{~W}$ at $12 \mathrm{Z}$. HURDAT lists a 30 knot tropical depression at $20.0 \mathrm{~N}, 81.6 \mathrm{~W}$ at $12 \mathrm{Z}$. Microfilm shows a closed low pressure of at most $1005 \mathrm{mb}$ at $20.5 \mathrm{~N}, 82.0 \mathrm{~W}$ at $12 \mathrm{Z}$. Ship highlights: $30 \mathrm{kt}$ NW and $1005 \mathrm{mb}$ at $20.6 \mathrm{~N}, 83.3 \mathrm{~W}$ at $12 \mathrm{Z}$ (micro). $35 \mathrm{kt} \mathrm{S}$ and $1008 \mathrm{mb}$ at $20.5 \mathrm{~N}, 80.0 \mathrm{~W}$ at $15 \mathrm{Z}$ (micro). $35 \mathrm{kt} \mathrm{ENE}$ and $1003 \mathrm{mb}$ at $21.6 \mathrm{~N}, 80.6 \mathrm{~W}$ at $18 \mathrm{Z}$ (micro). $45 \mathrm{kt} \mathrm{NE}$ and $999 \mathrm{mb}$ at $21.5 \mathrm{~N}, 81.2 \mathrm{~W}$ at $21 \mathrm{Z}$ (micro). Land highlights: $5 \mathrm{kt} \mathrm{WNW}$ and $1006 \mathrm{mb}$ at Grand Cayman at 00Z (micro). Aircraft highlights: Penetration center fix estimated surface winds of $35 \mathrm{kt}$ and measured a central pressure of $1002 \mathrm{mb}$ at $1756 \mathrm{Z}$ (ATSR). 
MWR: "The weak circulation drifted slowly north-northwestward during the night, gradually becoming better organized, and by afternoon of the 5 th had developed into a tropical storm with the center just south of the central Cuban coast, Winds had increased to 40 to $45 \mathrm{mph}$ in squalls within 60 miles north and east of the center." ATSR: "Although the first warning on JANICE was issued 051600Z, an area of squalls and gusty winds, associated with a series of easterly waves, had been watched closely since the first of October when a Navy reconnaissance aircraft was dispatched from Roosevelt Roads to investigate the area to the south of Puerto Rico. No circulation was found and the winds were light except for a band of easterlies just south of Puerto Rico where the maximum wind was 30 knots. Again on 3 October, a Navy aircraft investigated the easterly in the central Caribbean and found no vortex, but the winds had increased to 35 knots and the band of higher winds had now spread over the north central Caribbean. On the fourth, a "Track Bravo" was flown out of Jacksonville. This flight reported a weak pressure and wind circulation approximately 50 miles southeast of Grand Cayman at approximately 1300Z; however, the maximum surface winds observed were 20 knots and the minimum pressure was $1008 \mathrm{mb}$. There was an apparent "break off" of the ITC on the fourth just to the south of the most active area on the easterly wave, lending further cause for intensification. The first warning was issued on JANICE at 051600Z. A diverted "Navy Track Alfa" located the tropical depression center at $051735 \mathrm{Z}$ in position $20.9 \mathrm{~N}$ 81.9W. Maximum observed winds were 35 knots."

October 6:

HWM analyzes a tropical storm of at most $1000 \mathrm{mb}$ at $23.5 \mathrm{~N}, 79.0 \mathrm{~W}$ at $12 \mathrm{Z}$. HURDAT lists a 50 knot tropical storm at $23.3 \mathrm{~N}, 79.1 \mathrm{~W}$ at $12 \mathrm{Z}$. Microfilm shows a closed low pressure of at most $999 \mathrm{mb}$ at $23.5 \mathrm{~N}, 78.0 \mathrm{~W}$ at 12Z. Ship highlights: $35 \mathrm{kt}$ $\mathrm{NNE}$ and $1000 \mathrm{mb}$ at $21.5 \mathrm{~N}, 80.5 \mathrm{~W}$ at $00 \mathrm{Z}$ (micro). $35 \mathrm{kt} \mathrm{S}$ and $1009 \mathrm{mb}$ at $19.6 \mathrm{~N}$, $79.0 \mathrm{~W}$ at $03 \mathrm{Z}$ (micro). $35 \mathrm{kt} \mathrm{S}$ and $1006 \mathrm{mb}$ at $20.0 \mathrm{~N}, 78.4 \mathrm{~W}$ at $06 \mathrm{Z}$ (COADS). $30 \mathrm{kt} \mathrm{S}$ and $1002 \mathrm{mb}$ at $22.3 \mathrm{~N}, 77.6 \mathrm{~W}$ at $12 \mathrm{Z}$ (COADS). $40 \mathrm{kt}$ SSE and $1004 \mathrm{mb}$ at $24.7 \mathrm{~N}$, $74.7 \mathrm{~W}$ at $18 \mathrm{Z}$ (micro). $45 \mathrm{kt} \mathrm{SSE}$ and $1006 \mathrm{mb}$ at $24.2 \mathrm{~N}, 74.3 \mathrm{~W}$ at $21 \mathrm{Z}$ (COADS). Land highlights: $35 \mathrm{kt} \mathrm{NE}$ and $1002 \mathrm{mb}$ at Cienfuegos, Cuba at 00Z (micro). $35 \mathrm{kt} \mathrm{SSE}$ and $1008 \mathrm{mb}$ at Cabo Cruz, Cuba at 03Z (micro). $1001 \mathrm{mb}$ at Cienfuegos, Cuba at 06Z (micro). $55 \mathrm{kt} \mathrm{SW}$ and $1001 \mathrm{mb}$ at Cayo Coco, Cuba at $12 \mathrm{Z}$ (micro). $30 \mathrm{kt} \mathrm{SW}$ and 997 $\mathrm{mb}$ at Mangrove Cay, Bahamas at 15Z (micro). $45 \mathrm{kt} \mathrm{SSE}$ and $1004 \mathrm{mb}$ at $24.3 \mathrm{~N}, 75.5 \mathrm{~W}$ at $18 \mathrm{Z}$ (micro). $30 \mathrm{kt} \mathrm{SSE}$ and $988 \mathrm{mb}$ at Eleuthera, Bahamas at $21 \mathrm{Z}$ (micro). $30 \mathrm{kt} \mathrm{NE}$ and $991 \mathrm{mb}$ at Mangrove Cay, Bahamas (no time given) (WALLET). Aircraft highlights: Radar center fix at $23.2 \mathrm{~N}, 78.6 \mathrm{~W}$ at $12 \mathrm{Z}$ (ATSR). Radar center fix estimated an eye diameter of $80 \mathrm{~nm}$ at $23.6 \mathrm{~N}, 78.3 \mathrm{~W}$ at $14 \mathrm{Z}$ (ATSR). Penetration center fix at $24.8 \mathrm{~N}$, $77.3 \mathrm{~W}$ at $1830 \mathrm{Z}$ (ATSR). Penetration center fix estimated surface winds of $65 \mathrm{kt}$ and 
measured a central pressure of $996 \mathrm{mb}$ at $25.1 \mathrm{~N}, 77.6 \mathrm{~W}$ at $20 \mathrm{Z}$ (ATSR). Penetration center fix at $25.9 \mathrm{~N}, 76.1 \mathrm{~W}$ at $2330 \mathrm{Z}$ (ATSR).

MWR: "The storm turned northeastward and crossed Cuba during the night and by midday of the $6^{\text {th }}$ was centered between New Providence and Andros Island in the central Bahamas. Minimum pressure in the Bahamas was $988 \mathrm{mb}$. at Harbour Island, Eleuthera. Highest wind was $63 \mathrm{mph}$ at San Salvador, although Nassau reported $61 \mathrm{mph}$. The storm, gradually increased in force and size and accelerating in forward speed during this period, reached hurricane intensity during the evening of the $6^{\text {th }}$. Minimum sea level pressure at this time by dropsonde was around 996 mb." ATSR: "Hurricane force winds were first observed at $061800 \mathrm{Z}$ after the center had crossed Andros Island and was again out over water."

October 7:

HWM analyzes a hurricane with a central pressure of $983 \mathrm{mb}$ at $28.6 \mathrm{~N}, 75.0 \mathrm{~W}$ with a dissipating front to the north at $12 \mathrm{Z}$. HURDAT lists a 75 knot hurricane at $28.2 \mathrm{~N}$, $75.0 \mathrm{~W}$ at $12 \mathrm{Z}$. Microfilm shows a closed low pressure of at most $990 \mathrm{mb}$ at $28.5 \mathrm{~N}$, $75.2 \mathrm{~W}$ with a frontal boundary to the north at 12Z. Ship highlights: $65 \mathrm{kt} \mathrm{E}$ and $993 \mathrm{mb}$ at $26.2 \mathrm{~N}, 76.3 \mathrm{~W}$ at $00 \mathrm{Z}$ (COADS). $50 \mathrm{kt} \mathrm{ENE}$ and $999 \mathrm{mb}$ at $27.6 \mathrm{~N}, 75.8 \mathrm{~W}$ at $03 \mathrm{Z}$ (MWL). $55 \mathrm{kt} \mathrm{SSW}$ and $994 \mathrm{mb}$ at 26.6N, 75.2W at 06Z (COADS). $65 \mathrm{kt} \mathrm{SSW}$ and $999 \mathrm{mb}$ at $27.4 \mathrm{~N}, 74.4 \mathrm{~W}$ at $12 \mathrm{Z}$ (COADS). $55 \mathrm{kt} \mathrm{S}$ and $994 \mathrm{mb}$ at $29.2 \mathrm{~N}, 74.2 \mathrm{~W}$ at $18 \mathrm{Z}$ (COADS). Land highlights: $15 \mathrm{kt} \mathrm{W}$ and $993 \mathrm{mb}$ at Eleuthera, Bahamas at 00Z (micro). $40 \mathrm{kt} \mathrm{SW}$ and $1005 \mathrm{mb}$ at Cat Island, Bahamas at 06Z (micro). $20 \mathrm{kt} \mathrm{NNW}$ and $1003 \mathrm{mb}$ at Abaco Island, Bahamas at $12 \mathrm{Z}$ (micro). Aircraft highlights: Penetration center fix at $25.8 \mathrm{~N}$, 77.0W at $0045 Z$ (ATSR). Radar center fix estimated an eye diameter of $30 \mathrm{~nm}$ at $26.2 \mathrm{~N}$, $76.4 \mathrm{~W}$ at $02 \mathrm{Z}$ (ATSR). Radar center fix estimated flight level winds of $55 \mathrm{kt}$ and measured a minimum pressure (not a central pressure) of $987 \mathrm{mb}$ at $28.3 \mathrm{~N}, 75.2 \mathrm{~W}$ at $08 \mathrm{Z}$ (ATSR). Penetration center fix at 28.7N, $75.2 \mathrm{~W}$ at $1330 \mathrm{Z}$ (micro). Penetration center fix estimated surface winds of $80 \mathrm{kt}$, measured a central pressure of $983 \mathrm{mb}$ and an eye diameter of $30 \mathrm{~nm}$ at $29.3 \mathrm{~N}, 75.1 \mathrm{~W}$ at $1930 \mathrm{Z}$ (micro).

MWR: "The hurricane decelerated in forward speed from 15-20 mph to $7 \mathrm{mph}$ by afternoon of the $7^{\text {th }}$."

October 8:

HWM analyzes a hurricane with a central pressure of $985 \mathrm{mb}$ at $30.8 \mathrm{~N}, 73.8 \mathrm{~W}$ at $12 \mathrm{Z}$. HURDAT lists an $80 \mathrm{knot}$ hurricane at $30.8 \mathrm{~N}, 73.8 \mathrm{~W}$ at $12 \mathrm{Z}$. Microfilm shows a closed low pressure of at most $999 \mathrm{mb}$ at $31.2 \mathrm{~N}, 73.5 \mathrm{~W}$ at $12 \mathrm{Z}$. Ship highlights: $65 \mathrm{kt} \mathrm{S}$ and $992 \mathrm{mb}$ at $30.0 \mathrm{~N}, 74.2 \mathrm{~W}$ at $00 \mathrm{Z}$ (COADS). $50 \mathrm{kt} \mathrm{NW}$ and $994 \mathrm{mb}$ at $31.2 \mathrm{~N}, 74.9 \mathrm{~W}$ at $06 \mathrm{Z}$ (COADS). $40 \mathrm{kt} \mathrm{N}$ and $1004 \mathrm{mb}$ at $33.4 \mathrm{~N}, 76.0 \mathrm{~W}$ at $12 \mathrm{Z}$ (micro). $40 \mathrm{kt} \mathrm{S}$ and 
$1011 \mathrm{mb}$ at $31.2 \mathrm{~N}, 70.4 \mathrm{~W}$ at $18 \mathrm{Z}$ (COADS). $45 \mathrm{kt} \mathrm{N}$ and $1010 \mathrm{mb}$ at $31.8 \mathrm{~N}, 77.1 \mathrm{~W}$ at $21 \mathrm{Z}$ (micro). Aircraft highlights: Penetration center fix estimated surface winds of $40 \mathrm{kt}$, measured a central pressure of $993 \mathrm{mb}$ and an eye diameter of $50 \mathrm{~nm}$ at $29.5 \mathrm{~N}, 74.4 \mathrm{~W}$ at $02 \mathrm{Z}$ (ATSR). Penetration center fix measured a central pressure of $986 \mathrm{mb}$ at $30.1 \mathrm{~N}$, $74.0 \mathrm{~W}$ at $0745 \mathrm{Z}$ (ATSR). Penetration center fix at $30.9 \mathrm{~N}, 73.7 \mathrm{~W}$ at $1330 \mathrm{Z}$ (ATSR). Penetration center fix at $31.2 \mathrm{~N}, 73.0 \mathrm{~W}$ at $2007 \mathrm{Z}$ (ATSR).

October 9:

HWM analyzes a hurricane with a central pressure of $988 \mathrm{mb}$ at $32.5 \mathrm{~N}, 71.5 \mathrm{~W}$ at $12 \mathrm{Z}$. HURDAT lists a 65 knot hurricane at $32.2 \mathrm{~N}, 71.0 \mathrm{~W}$ at $12 \mathrm{Z}$. Microfilm shows a closed low pressure of at most $990 \mathrm{mb}$ at $32.2 \mathrm{~N}, 70.8 \mathrm{~W}$ at $12 \mathrm{Z}$. Ship highlights: $40 \mathrm{kt}$ $\mathrm{NNE}$ and $1010 \mathrm{mb}$ at $33.7 \mathrm{~N}, 76.8 \mathrm{~W}$ at $00 \mathrm{Z}$ (COADS). $45 \mathrm{kt} \mathrm{S}$ and $998 \mathrm{mb}$ at $31.0 \mathrm{~N}$, $71.7 \mathrm{~W}$ at $03 \mathrm{Z}$ (micro). $50 \mathrm{kt} \mathrm{SW}$ and $1001 \mathrm{mb}$ at $30.6 \mathrm{~N}, 71.7 \mathrm{~W}$ at $06 \mathrm{Z}$ (micro). $55 \mathrm{kt} \mathrm{W}$ and $998 \mathrm{mb}$ at $31.4 \mathrm{~N}, 71.0 \mathrm{~W}$ at $12 \mathrm{Z}$ (COADS). $50 \mathrm{kt} \mathrm{SW}$ and $1006 \mathrm{mb}$ at $30.7 \mathrm{~N}, 70.7 \mathrm{~W}$ at $18 \mathrm{Z}$ (COADS). Aircraft highlights: Penetration center fix estimated flight level (500 $\mathrm{mb}$ ) winds of $55 \mathrm{kt}$, measured a central pressure of $984 \mathrm{mb}$ and an eye diameter of $50 \mathrm{~nm}$ at $31.8 \mathrm{~N}, 72.7 \mathrm{~W}$ at $0144 \mathrm{Z}$ (micro). Penetration center fix at $32.0 \mathrm{~N}, 72.5 \mathrm{~W}$ at $0430 \mathrm{Z}$ (ATSR). Penetration center fix at $32.0 \mathrm{~N}, 70.2 \mathrm{~W}$ at $1345 \mathrm{Z}$ (ATSR). Radar center fix at $32.9 \mathrm{~N}, 69.3 \mathrm{~W}$ at $1908 \mathrm{Z}$ (ATSR). Penetration center fix at $33.1 \mathrm{~N}, 68.5 \mathrm{~W}$ at $2340 \mathrm{Z}$ (ATSR).

MWR: "The hurricane drifted slowly north-northeastward to northeastward then began accelerating northeastward to east-northeastward on the $9^{\text {th }}$."

October 10:

HWM analyzes a hurricane with a central pressure of $972 \mathrm{mb}$ at $35.0 \mathrm{~N}, 65.7 \mathrm{~W}$ at $12 \mathrm{Z}$. HURDAT lists an 80 knot hurricane at $35.0 \mathrm{~N}, 65.8 \mathrm{~W}$ at $12 \mathrm{Z}$. Microfilm shows a closed low pressure of at most $996 \mathrm{mb}$ at $34.8 \mathrm{~N}, 66.2 \mathrm{~W}$ at $12 \mathrm{Z}$. Ship highlights: $35 \mathrm{kt}$ WNW and $1014 \mathrm{mb}$ at $32.1 \mathrm{~N}, 71.8 \mathrm{~W}$ at $00 \mathrm{Z}$ (COADS). $10 \mathrm{kt} \mathrm{E}$ and $1005 \mathrm{mb}$ at $40.7 \mathrm{~N}$, $68.0 \mathrm{~W}$ at $18 \mathrm{Z}$ (COADS). Aircraft highlights: Penetration center fix at $33.6 \mathrm{~N}, 68.0 \mathrm{~W}$ at $02 Z$ (ATSR). Penetration center fix measured a central pressure of $968 \mathrm{mb}$ at $34.1 \mathrm{~N}$, $67.0 \mathrm{~W}$ at $0735 \mathrm{Z}$ (ATSR/micro). Penetration center fix at $34.9 \mathrm{~N}, 65.5 \mathrm{~W}$ at $13 \mathrm{Z}$ (ATSR). Penetration center fix at $36.1 \mathrm{~N}, 63.3 \mathrm{~W}$ at $1930 \mathrm{Z}$ (ATSR).

MWR: "Minimum sea level pressure by dropsonde was $968 \mathrm{mb}$. on the $10^{\text {th }}$. Highest winds were estimated at $90 \mathrm{mph}$ over a small area near the center of the hurricane on the $7^{\text {th }}$ and again on the $10^{\text {th }}$, with slightly lower wind speeds on intervening days." 
October 11:

HWM analyzes a hurricane with a central pressure of $974 \mathrm{mb}$ at $39.1 \mathrm{~N}, 55.8 \mathrm{~W}$ and a cold front to the northwest at 12Z. HURDAT lists a 75 knot hurricane at $39.3 \mathrm{~N}$, $56.0 \mathrm{~W}$ at $12 \mathrm{Z}$. Microfilm shows a closed low pressure of at most $981 \mathrm{mb}$ at $40.3 \mathrm{~N}$, $56.3 \mathrm{~W}$ with a frontal boundary to the west at 12Z. Ship highlights: $40 \mathrm{kt} \mathrm{SW}$ and 1013 $\mathrm{mb}$ at $33.8 \mathrm{~N}, 65.0 \mathrm{~W}$ at $00 \mathrm{Z}$ (COADS). $65 \mathrm{kt} \mathrm{SSW}$ and $1002 \mathrm{mb}$ at $36.7 \mathrm{~N}, 57.6 \mathrm{~W}$ at $06 \mathrm{Z}$ (micro). $75 \mathrm{kt} \mathrm{WSW}$ and $976 \mathrm{mb}$ at $40.0 \mathrm{~N}, 54.7 \mathrm{~W}$ at $12 \mathrm{Z}$ (MWL). $75 \mathrm{kt} \mathrm{S}$ and $992 \mathrm{mb}$ at $40.6 \mathrm{~N}, 50.1 \mathrm{~W}$ at $18 \mathrm{Z}$ (micro). Aircraft highlights: Penetration center fix measured a central pressure of $974 \mathrm{mb}$ at $39.4 \mathrm{~N}, 56.7 \mathrm{~W}$ at $1035 \mathrm{Z}$ (ATSR/micro). Penetration center fix measured a central pressure of $974 \mathrm{mb}$ at $40.5 \mathrm{~N}, 54.4 \mathrm{~W}$ at $1351 \mathrm{Z}$ (ATSR/micro).

MWR: “... continued until the $11^{\text {th }}$ when it began losing tropical characteristics and later merged with a deep low pressure system that moved from the Canadian Maritime Provinces into the North Atlantic."

October 12:

HWM analyzes a tropical storm of at most $1000 \mathrm{mb}$ at $46.4 \mathrm{~N}, 37.2 \mathrm{~W}$ and a cold front to the west at 12Z. HURDAT lists a 50 knot extratropical storm at $46.2 \mathrm{~N}, 38.2 \mathrm{~W}$ at 12Z. Microfilm shows that Janice has been absorbed by a larger extratropical cyclone to the northwest at 12Z. Ship highlights: $25 \mathrm{kt} \mathrm{S}$ and $981 \mathrm{mb}$ at $44.5 \mathrm{~N}, 45.1 \mathrm{~W}$ at $03 \mathrm{Z}$ (COADS). $55 \mathrm{kt} \mathrm{SSW}$ and $995 \mathrm{mb}$ at $44.0 \mathrm{~N}, 41.0 \mathrm{~W}$ at 06Z (COADS). $40 \mathrm{kt} \mathrm{WSW}$ and $1004 \mathrm{mb}$ at $45.5 \mathrm{~N}, 38.6 \mathrm{~W}$ at $12 \mathrm{Z}$ (COADS).

October 13:

HWM analyzes a spot low pressure at $50.5 \mathrm{~N}, 20.0 \mathrm{~W}$ at $12 \mathrm{Z}$. HURDAT lists a 45 knot extratropical storm at $48.7 \mathrm{~N}, 23.5 \mathrm{~W}$ at $06 \mathrm{Z}$ (last position). Microfilm indicates that Janice has been absorbed at 12Z. Ship highlights: $35 \mathrm{kt} \mathrm{SW}$ and $1009 \mathrm{mb}$ at $46.3 \mathrm{~N}$, $27.2 \mathrm{~W}$ at $00 \mathrm{Z}$ (COADS). $40 \mathrm{kt} \mathrm{WSW}$ and $1015 \mathrm{mb}$ at $45.5 \mathrm{~N}, 29.0 \mathrm{~W}$ at $06 \mathrm{Z}$ (COADS).

The last tropical cyclone of the 1958 Hurricane Season developed from a strong tropical wave that entered the Caribbean Sea on early October. The vigorous disturbance produced tropical storm force winds on October $2^{\text {nd }}, 3^{\text {rd }}$ and early on the $4^{\text {th }}$. Ship and coastal observations, however, along with reconnaissance aircraft investigative missions, indicate that a well-defined low-level circulation did not form until around $12 \mathrm{Z}$ on the $4^{\text {th }}$ while the system was over the western Caribbean, just south of the Cayman Islands. By this time, the forward speed of the disturbance had decreased to about $5 \mathrm{kt}$. Genesis is analyzed at $12 \mathrm{Z}$ on the $4^{\text {th }}$ as a $30 \mathrm{kt}$ tropical depression, eighteen hours earlier than 
originally shown in HURDAT. Minor track alterations are analyzed for the lifetime of this tropical cyclone. The tropical depression moved generally northward making landfall in Grand Cayman around $00 \mathrm{Z}$ on October $5^{\text {th }}$. Grand Cayman reported $5 \mathrm{kt} \mathrm{WNW}$ and $1006 \mathrm{mb}$ at $00 \mathrm{Z}$ on the $5^{\text {th }}$, suggesting a central pressure of $1005 \mathrm{mb}$, which has been added to HURDAT. A central pressure of $1005 \mathrm{mb}$ suggests maximum sustained winds $37 \mathrm{kt}$ south of $25 \mathrm{~N}$ according to the Brown et al. pressure-wind relationship. Due to the slow forward speed of about $5 \mathrm{kt}$ and low environmental pressures (outer closed isobar of $1009 \mathrm{mb}$ ), an intensity of $30 \mathrm{kt}$ has been selected for $00 \mathrm{Z}$ on the $5^{\text {th }}$. Intensification to a tropical storm is analyzed at $12 \mathrm{Z}$ on the $5^{\text {th }}$, six hours earlier than the original HURDAT, based upon information later on the day. A reconnaissance aircraft investigated Janice at $1756 \mathrm{Z}$ on the $5^{\text {th }}$ measuring a central pressure of $1002 \mathrm{mb}$ and estimating surface winds of $35 \mathrm{kt}$. A central pressure of $1002 \mathrm{mb}$ suggests maximum sustained winds of $43 \mathrm{kt}$ south of $25 \mathrm{~N}$ from the pressure-wind relationship. Based on the slow forward speed, low environmental pressures and a ship report of $45 \mathrm{kt}$ at $21 \mathrm{Z}$, an intensity of $40 \mathrm{kt}$ is selected for $18 \mathrm{Z}$ on the $5^{\text {th }}$, up from $35 \mathrm{kt}$ originally in HURDAT. A central pressure of $999 \mathrm{mb}$ was present in HURDAT at $18 \mathrm{Z}$ on the $5^{\text {th }}$, it has been removed and replaced with the $1002 \mathrm{mb}$ measured by the reconnaissance aircraft because $999 \mathrm{mb}$ and $45 \mathrm{kt}$ were reported by a ship at 21Z, thus $999 \mathrm{mb}$ is not a central pressure. For the same reason, the central pressure of $999 \mathrm{mb}$ at $00 \mathrm{Z}$ on October $6^{\text {th }}$ has been removed. Late on the $5^{\text {th }}$, the track of Janice turned to the northeast as it approached the southern coast of Cuba.

Landfall in Cuba is analyzed at $03 \mathrm{Z}$ on the $6^{\text {th }}$ near $22.0 \mathrm{~N}, 80.3 \mathrm{~W}$ or about $10 \mathrm{~nm}$ southeast of Cienfuegos, as a $50 \mathrm{kt}$ tropical storm. Perez et al. (2000) also indicates that Janice was a tropical storm at landfall in Cuba. Slight weakening occurred over Cuba and Janice emerged into the Atlantic as a $45 \mathrm{kt}$ tropical storm. Over the warm waters of the Bahamas, the tropical storm began to strengthen as it increased in forward speed to the northeast on the $6^{\text {th }}$. At $12 \mathrm{Z}$, Cayo Coco, Cuba reported $55 \mathrm{kt} \mathrm{SW}$ and $1001 \mathrm{mb}$. The wind report appears to have a high bias based on nearby wind reports and that it blowing from the land to the sea. The intensity at $12 \mathrm{Z}$ on the $6^{\text {th }}$ is analyzed at $50 \mathrm{kt}$, same as the original HURDAT. Around $16 \mathrm{Z}$ on the $6^{\text {th }}$, Janice made landfall on Andros Island as a 55 kt tropical storm. Mangrove Cay, on the southern end of Andros Island, reported a minimum pressure of $991 \mathrm{mb}$ and it is likely, based on the track of the tropical cyclone, that this was a central pressure, which has been added to HURDAT at $18 \mathrm{Z}$ on the $6^{\text {th }}$. Furthermore, at $18 \mathrm{Z}$ on the $6^{\text {th }}$, Mangrove Cay was reporting $30 \mathrm{kt} \mathrm{NW}$ and $994 \mathrm{mb}$, which also suggests a central pressure of around $991 \mathrm{mb}$. A central pressure of $991 \mathrm{mb}$ suggests maximum sustained winds of $61 \mathrm{kt}$ south of $25 \mathrm{~N}$ intensifying and $60 \mathrm{kt}$ north of $25 \mathrm{~N}$ intensifying, according to the pressure-wind relationship. Due to the low environmental pressures and forward speed of about $15 \mathrm{kt}$, an intensity of $55 \mathrm{kt}$ is selected for $18 \mathrm{Z}$ on the $6^{\text {th }}$, same as the original HURDAT. A central pressure of $991 \mathrm{mb}$ was added to HURDAT at 18Z, replacing the existing $997 \mathrm{mb}$. Central pressures of 999 
$\mathrm{mb}$ and $998 \mathrm{mb}$ were present in HURDAT at $06 \mathrm{Z}$ and 12Z, respectively, on the $6^{\text {th }}$ and have been retained as they appear reasonable. A second Bahamian landfall occurred around $21 \mathrm{Z}$ on Rose Island near New Providence as a $60 \mathrm{kt}$ tropical storm and a third landfall occurred around $23 \mathrm{Z}$ on North Eleuthera as a $65 \mathrm{kt}$ hurricane. A reconnaissance aircraft reported $996 \mathrm{mb}$ at $20 \mathrm{Z}$ on the $6^{\text {th }}$ but based on the observations in the Bahamas, it has been determined that it was not a central pressure. At $21 \mathrm{Z}$ on the $7^{\text {th }}$, North Eleuthera reported $30 \mathrm{kt} \mathrm{SSE}$ and $988 \mathrm{mb}$, suggesting a central pressure of $985 \mathrm{mb}$, which has been added to HURDAT at $00 \mathrm{Z}$ on October $7^{\text {th }}$. A central pressure of $985 \mathrm{mb}$ suggests maximum sustained winds of $69 \mathrm{kt}$ north of $25 \mathrm{~N}$ intensifying from the pressurewind relationship. Data from a reconnaissance aircraft at $00 \mathrm{Z}$ on the $7^{\text {th }}$ indicated that the RMW was about $22 \mathrm{~nm}$ and climatology is $20 \mathrm{~nm}$. Based on low environmental pressures (outer closed isobar about $1007 \mathrm{mb}$ ), an intensity of $65 \mathrm{kt}$ is selected for $00 \mathrm{Z}$ on the $7^{\text {th }}$, up from $60 \mathrm{kt}$ originally in HURDAT, a minor intensity change. Intensification to a hurricane is analyzed at $00 \mathrm{Z}$ on the $7^{\text {th }}$, six hours earlier than originally shown in HURDAT. The next reconnaissance aircraft reached Janice at $1930 Z$ on the $7^{\text {th }}$ and measured a central pressure of $983 \mathrm{mb}$, estimated surface winds of $80 \mathrm{kt}$ and an eye diameter of $30 \mathrm{~nm}$. A central pressure of $983 \mathrm{mb}$ suggests maximum sustained winds of $69 \mathrm{kt}$ north of $25 \mathrm{~N}$ from the pressure-wind relationship. An eye diameter of $30 \mathrm{~nm}$ suggests an RMW of about $22 \mathrm{~nm}$ and climatology is $20 \mathrm{~nm}$. Based on the slow forward speed of the hurricane of about $6 \mathrm{kt}$, an intensity of $65 \mathrm{kt}$ is selected at $18 \mathrm{Z}$ on the $7^{\text {th }}, 15$ kt less than originally shown in HURDAT, a minor intensity change. A couple of ships reported gale-force winds on the $7^{\text {th }}$ and even a report of $65 \mathrm{kt}$ at $12 \mathrm{Z}$. Between October $7^{\text {th }}$ and the $9^{\text {th }}$, Janice entered an area of weak steering currents between the United States and Bermuda, resulting in a slow motion toward the northeast. The next penetration center fix measured a pressure of $993 \mathrm{mb}$ at $02 \mathrm{Z}$ on October $8^{\text {th }}$ but based on the central pressure reports from late on the $7^{\text {th }}$ and later on the $8^{\text {th }}$, it is determined that it was not a central pressure. A central pressure of $986 \mathrm{mb}$ was measured by a reconnaissance aircraft at $0745 \mathrm{Z}$. A central pressure of $986 \mathrm{mb}$ suggests maximum sustained winds of $65 \mathrm{kt}$ north of $25 \mathrm{~N}$ according to the pressure-wind relationship. An intensity of $65 \mathrm{kt}$ is selected at $06 \mathrm{Z}$ on the $8^{\text {th }}$ based on a ship report $65 \mathrm{kt} \mathrm{S}$ and $992 \mathrm{mb}$ at $00 \mathrm{Z}$ on this day. HURDAT originally had $80 \mathrm{kt}$ at $06 \mathrm{Z}$ on the $8^{\text {th }}$, a minor intensity change. A central pressure of 986 $\mathrm{mb}$ is added to HURDAT, replacing the existing $995 \mathrm{mb}$ at $06 \mathrm{Z}$ on the $8^{\text {th }}$.

A reconnaissance aircraft reached Janice on October $9^{\text {th }}$ at $0144 Z$ and measured a central pressure of $984 \mathrm{mb}$ and an eye diameter of $50 \mathrm{~nm}$. A central pressure of $984 \mathrm{mb}$ suggests maximum sustained winds of $68 \mathrm{kt}$ north of $25 \mathrm{~N}$ according to the pressure-wind relationship. An eye diameter of $50 \mathrm{~nm}$ suggests an RMW of about $38 \mathrm{~nm}$ and climatology is $25 \mathrm{~nm}$. Based on the RMW being larger than climatology and the slow forward speed of the hurricane of about $5 \mathrm{kt}$, an intensity of $65 \mathrm{kt}$ is selected for $00 \mathrm{Z}$ on the $9^{\text {th }}$, down from $70 \mathrm{kt}$ originally in HURDAT, a minor intensity change. A central 
pressure of $984 \mathrm{mb}$ is added to HURDAT at $00 \mathrm{Z}$ on the $9^{\text {th }}$, replacing the existing 987 $\mathrm{mb}$. The forward speed of Janice started to increase late on the $9^{\text {th }}$ and the hurricane began to intensify. A couple of ships near the center of the hurricane reported gale-force winds on the $9^{\text {th }}$. On October $10^{\text {th }}$, a reconnaissance aircraft measured a central pressure of $968 \mathrm{mb}$ at $0735 \mathrm{Z}$, suggesting maximum surface winds of $91 \mathrm{kt}$ north of $25 \mathrm{~N}$ intensifying from the Brown et al. pressure-wind relationship and $84 \mathrm{kt}$ north of $35 \mathrm{~N}$ from the Landsea et al. pressure-wind relationship. Due to a large RMW, an intensity of $80 \mathrm{kt}$ is selected for $06 \mathrm{Z}$ on the $10^{\text {th }}$, up from $75 \mathrm{kt}$ originally in HURDAT, a minor intensity change. $80 \mathrm{kt}$ is also the peak intensity for this hurricane, same as originally shown in HURDAT. A central pressure of $968 \mathrm{mb}$ was present in HURDAT at 06Z on the $10^{\text {th }}$ and has been retained. Janice began to interact with a frontal boundary on the $11^{\text {th }}$ and the hurricane started to acquire extratropical characteristics. At $1035 \mathrm{Z}$ on the $11^{\text {th }}$, the last reconnaissance aircraft to investigate Janice measured a central pressure of $974 \mathrm{mb}$, suggesting maximum surface winds of $79 \mathrm{kt}$ north of $35 \mathrm{~N}$ from the pressure-wind relationship. Because Janice was starting to become extratropical, an intensity of $75 \mathrm{kt}$ is selected at $12 \mathrm{Z}$ on the $11^{\text {th }}$, same as originally shown in HURDAT. A central pressure of $974 \mathrm{mb}$ is added to HURDAT at $06 \mathrm{Z}$ on the $11^{\text {th }}$. A couple of ships observed hurricaneforce winds on the $11^{\text {th }}$, especially a ship at $12 \mathrm{Z}$ that reported $75 \mathrm{kt} \mathrm{WSW}$ and $976 \mathrm{mb}$. Ship observations early on October $12^{\text {th }}$ indicate that Janice had become an extratropical cyclone, with a significant the temperature gradient $\mathrm{E}-\mathrm{W}$ across the cyclone. Transition to an extratropical cyclone is analyzed at $00 \mathrm{Z}$ on the $12^{\text {th }}$, six hours earlier than originally shown in HURDAT. Weakening below hurricane intensity occurred at $06 \mathrm{Z}$ on the $12^{\text {th }}$, same as the original HURDAT. Janice continued to move rapidly to the northeast on the $12^{\text {th }}$ and early on October $13^{\text {th }}$, and was absorbed by a stronger extratropical cyclone to the north. The last position is analyzed at $00 \mathrm{Z}$ on the $13^{\text {th }}$, six hours earlier than originally shown in HURDAT.

\begin{tabular}{|c|c|l|c|}
\hline Date & $\begin{array}{c}\text { Original } \\
\text { HURDAT } \\
\text { Central } \\
\text { Pressure }\end{array}$ & \multicolumn{1}{|c|}{ Evidence } & Changes \\
\hline Oct $500 \mathrm{Z}$ & & $\begin{array}{l}\text { Grand Cayman: } 5 \mathrm{kt} \mathrm{WNW} \text { and } 1006 \mathrm{mb} \text { at } \\
00 \mathrm{Z} \text { on Oct } 5^{\text {th }}\end{array}$ & $1005 \mathrm{mb}$ \\
\hline Oct $518 \mathrm{Z}$ & $999 \mathrm{mb}$ & $\begin{array}{l}\text { Penetration center fix: } 1002 \mathrm{mb} \text { at } 1756 \mathrm{Z} \text { on } \\
\text { Oct } 5^{\text {th }}\end{array}$ & $1002 \mathrm{mb}$ \\
\hline Oct $600 \mathrm{Z}$ & $999 \mathrm{mb}$ & Ship: $45 \mathrm{kt} \mathrm{NE}$ and $999 \mathrm{mb}$ at $21 \mathrm{Z}$ on Oct $5^{\text {th }}$ & Removed \\
\hline Oct $606 \mathrm{Z}$ & $999 \mathrm{mb}$ & $\begin{array}{l}\text { No central pressures but appear reasonable } \\
\text { with an intensifying storm }\end{array}$ & Retained \\
\hline Oct $612 \mathrm{Z}$ & $998 \mathrm{mb}$ & \\
\hline
\end{tabular}




\begin{tabular}{|c|c|c|c|}
\hline Oct $618 \mathrm{Z}$ & $997 \mathrm{mb}$ & $\begin{array}{l}\text { Mangrove Cay: } 30 \mathrm{kt} \mathrm{NW} \text { and } 994 \mathrm{mb} \text { at } 18 \mathrm{Z} \\
\text { on Oct } 6^{\text {th }}\end{array}$ & $991 \mathrm{mb}$ \\
\hline Oct 7 00Z & $996 \mathrm{mb}$ & $\begin{array}{l}\text { North Eleuthera: } 30 \mathrm{kt} \mathrm{SSE} \text { and } 988 \mathrm{mb} \text { at } \\
21 \mathrm{Z} \text { on Oct } 6^{\text {th }}\end{array}$ & $985 \mathrm{mb}$ \\
\hline Oct $706 Z$ & $988 \mathrm{mb}$ & \multirow{2}{*}{$\begin{array}{l}\text { Lower central pressures at } 00 \mathrm{Z} \text { and } 18 \mathrm{Z} \text { on } \\
\text { Oct } 7^{\text {th }}\end{array}$} & \multirow{2}{*}{ Removed } \\
\hline Oct $712 \mathrm{Z}$ & $987 \mathrm{mb}$ & & \\
\hline Oct $718 Z$ & $990 \mathrm{mb}$ & $\begin{array}{l}\text { Penetration center fix: } 983 \mathrm{mb} \text { at } 1930 \mathrm{Z} \text { on } \\
\text { Oct } 7^{\text {th }}\end{array}$ & $983 \mathrm{mb}$ \\
\hline Oct $800 \mathrm{Z}$ & $995 \mathrm{mb}$ & $\begin{array}{l}\text { Lower central pressures at } 18 \mathrm{Z} \text { on Oct } 7^{\text {th }} \text { and } \\
06 \mathrm{Z} \text { on Oct } 8^{\text {th }}\end{array}$ & Removed \\
\hline Oct $806 Z$ & $995 \mathrm{mb}$ & $\begin{array}{l}\text { Penetration center fix: } 986 \mathrm{mb} \text { at } 0745 \mathrm{Z} \text { on } \\
\text { Oct } 8^{\text {th }}\end{array}$ & $986 \mathrm{mb}$ \\
\hline Oct $812 Z$ & $992 \mathrm{mb}$ & \multirow{2}{*}{$\begin{array}{l}\text { Lower central pressures at } 06 \mathrm{Z} \text { on Oct } 8^{\text {th }} \text { and } \\
00 \mathrm{Z} \text { on Oct } 9^{\text {th }}\end{array}$} & \multirow[t]{2}{*}{ Removec } \\
\hline Oct $818 \mathrm{Z}$ & $990 \mathrm{mb}$ & & \\
\hline Oct $900 Z$ & $987 \mathrm{mb}$ & $\begin{array}{l}\text { Penetration center fix: } 984 \mathrm{mb} \text { at } 0144 \mathrm{Z} \text { on } \\
\text { Oct } 9^{\text {th }}\end{array}$ & $984 \mathrm{mb}$ \\
\hline Oct $906 \mathrm{Z}$ & $985 \mathrm{mb}$ & \multirow{4}{*}{$\begin{array}{l}\text { No central pressure reports but appear } \\
\text { reasonable }\end{array}$} & \multirow{9}{*}{ Retained } \\
\hline Oct $912 Z$ & $983 \mathrm{mb}$ & & \\
\hline Oct $918 \mathrm{Z}$ & $977 \mathrm{mb}$ & & \\
\hline Oct $1000 \mathrm{Z}$ & $970 \mathrm{mb}$ & & \\
\hline Oct $1006 Z$ & $968 \mathrm{mb}$ & $\begin{array}{l}\text { Penetration center fix: } 968 \mathrm{mb} \text { at } 0735 \mathrm{Z} \text { on } \\
\text { Oct } 10^{\text {th }}\end{array}$ & \\
\hline Oct $1012 Z$ & $970 \mathrm{mb}$ & \multirow{4}{*}{$\begin{array}{l}\text { No central pressure reports but appear } \\
\text { reasonable }\end{array}$} & \\
\hline Oct $1018 \mathrm{Z}$ & $970 \mathrm{mb}$ & & \\
\hline Oct $1100 \mathrm{Z}$ & $968 \mathrm{mb}$ & & \\
\hline Oct $1106 Z$ & $972 \mathrm{mb}$ & & \\
\hline Oct $1112 Z$ & & $\begin{array}{l}\text { Penetration center fix: } 974 \mathrm{mb} \text { at } 1035 \mathrm{Z} \text { on } \\
\text { Oct } 11^{\text {th }}\end{array}$ & $974 \mathrm{mb}$ \\
\hline
\end{tabular}




\section{8 - Additional Notes}

1) January 14-17: Historical Weather Maps show an extratropical cyclone over the north Atlantic on January $14^{\text {th }}$. The system slowly moves southward on the $15^{\text {th }}$ as it detaches from its parent frontal boundary and becomes an occluded low. The occluded low slowly weakens during the next couple of days before being absorbed by a frontal boundary on January $18^{\text {th }}$. Gale-force winds were only observed on the $14^{\text {th }}$. Therefore, because the system was likely not tropical or subtropical, it is not added to HURDAT. This disturbance was in Jack Beven's and David Roth's List of Suspects.

$\begin{array}{cccc}\text { Day } & \text { Latitude } & \text { Longitude } & \text { Status } \\ \text { January 14 } & 38 \mathrm{~N} & 44 \mathrm{~W} & \text { Extratropical } \\ \text { January 15 } & 32 \mathrm{~N} & 48 \mathrm{~W} & \text { Occluded } \\ \text { January 16 } & 33 \mathrm{~N} & 44 \mathrm{~W} & \text { Occluded } \\ \text { January 17 } & 35 \mathrm{~N} & 45 \mathrm{~W} & \text { Occluded } \\ \text { January 18 } & & & \text { Absorbed }\end{array}$

2) May 20 - June 1: Historical Weather Maps indicate that a frontal boundary over the central Atlantic weakened into a trough of low pressure on May $22^{\text {nd }}$. The disturbance drifted slowly to the west over the next couple of days. Ship observations show that a closed low-level circulation developed on May $27^{\text {th }}$ as the disturbance was located about $700 \mathrm{~nm}$ northeast of the Leeward Islands. A strong pressure gradient developed on May $28^{\text {th }}$ and gale-force winds were being reported about $350 \mathrm{~nm}$ northeast of the center. On May $30^{\text {th }}$, as the disturbance started to move northward ahead of a frontal boundary, the gale-force winds were closer to the center but still located about $200 \mathrm{~nm}$ to the northeast. Ship observations on May $31^{\text {st }}$ indicate that the system began to weaken and was absorbed by a frontal boundary on June $1^{\text {st }}$. Therefore, because the gale-force winds were far removed from the center and likely associated with the synoptic pressure gradient, it is not added to HURDAT. This disturbance was in Jack Beven's and David Roth's List of Suspects.

\begin{tabular}{|c|c|c|c|}
\hline Day & Latitude & Longitude & Status \\
\hline May 20 & \multicolumn{2}{|c|}{ Central Atlantic } & Dissipating cold front \\
\hline May 21 & \multicolumn{2}{|c|}{ Central Atlantic } & Trough \\
\hline May 22 & \multicolumn{2}{|c|}{ Central Atlantic } & Trough \\
\hline May 23 & \multicolumn{2}{|c|}{ Central Atlantic } & Trough \\
\hline May 24 & \multicolumn{2}{|c|}{ Central Atlantic } & Trough \\
\hline May 25 & \multirow{2}{*}{\multicolumn{2}{|c|}{$\begin{array}{l}\text { Central Atlantic } \\
\text { Central Atlantic }\end{array}$}} & Trough \\
\hline May 26 & & & Trough \\
\hline May 27 & $26 \mathrm{~N}$ & $52 \mathrm{~W}$ & $\begin{array}{c}\text { Tropical } \\
\text { Depression? }\end{array}$ \\
\hline May 28 & $26 \mathrm{~N}$ & $50 \mathrm{~W}$ & Tropical Storm? \\
\hline May 29 & $26 \mathrm{~N}$ & $49 \mathrm{~W}$ & Tropical Storm? \\
\hline May 30 & $30 \mathrm{~N}$ & $48 \mathrm{~W}$ & Tropical Storm? \\
\hline May 31 & $34 \mathrm{~N}$ & $50 \mathrm{~W}$ & $\begin{array}{c}\text { Tropical } \\
\text { Depression? }\end{array}$ \\
\hline
\end{tabular}


3) August 22-27: A strong tropical wave left the African coast around August $21^{\text {st }}$. Microfilm shows a tropical cyclone symbol on August $22^{\text {nd }}$ southwest of the Cape Verde Islands. A closed low pressure was intermittently tracked for the next couple of days as the disturbance moved west-northwest. Ship and coastal observations indicate that a closed low-level circulation was present but no tropical storm force winds were found on the microfilm, COADS or Mariners Weather Log. Microfilm indicates that the disturbance likely weakened into a tropical wave on August $27^{\text {th }}$ over the central Atlantic. Therefore, because no gale-force winds were found associated to this disturbance, it is not added to HURDAT.

$\begin{array}{cccc}\text { Day } & \text { Latitude } & \text { Longitude } & \text { Status } \\ \text { August 22 } & 10-16 \mathrm{~N} & 19 \mathrm{~W} & \text { Tropical Wave } \\ \text { August } 23 & 14 \mathrm{~N} & 24 \mathrm{~W} & \text { Tropical Storm? } \\ \text { August } 24 & 14 \mathrm{~N} & 29 \mathrm{~W} & \text { Tropical Storm? } \\ \text { August } 25 & 15 \mathrm{~N} & 33 \mathrm{~W} & \text { Tropical Storm? } \\ \text { August } 26 & 18 \mathrm{~N} & 37 \mathrm{~W} & \text { Tropical } \\ \text { August } 27 & 13-21 \mathrm{~N} & 41 \mathrm{~W} & \text { Depression? } \\ & & & \text { Tropical Wave }\end{array}$

4) September 8-10: Mariners Weather Log's Track of Centers of Cyclones at Sea Level indicate that a low pressure developed about $400 \mathrm{~nm}$ east of the Lesser Antilles on September $8^{\text {th }}$ and remained generally stationary for about a day. On the $10^{\text {th }}$, the disturbance moved northwest before dissipating east of the Lesser Antilles. This disturbance was in Jack Beven's List of Suspects.

$\begin{array}{cccc}\text { Day } & \text { Latitude } & \text { Longitude } & \begin{array}{c}\text { Status } \\ \text { Tropical }\end{array} \\ \text { September } 8 & 8 \mathrm{~N} & 52 \mathrm{~W} & \begin{array}{c}\text { Depression? } \\ \text { Tropical }\end{array} \\ \text { September } 9 & 8 \mathrm{~N} & 52 \mathrm{~W} & \begin{array}{c}\text { Depression? } \\ \text { Tropical }\end{array} \\ \text { September } 10 & 12 \mathrm{~N} & 55 \mathrm{~W} & \text { Depression? }\end{array}$

5) October 4-7: Historical Weather Maps indicate that a low pressure formed about 800 $\mathrm{nm}$ northeast of the Leeward Islands on October $4^{\text {th }}$. The disturbance moved generally to the northwest before dissipating on October $7^{\text {th }}$ ahead of a frontal boundary over the northwest Atlantic. COADS were obtained but produced no tropical storm force winds. Therefore, because no gale-force winds were found associated with this disturbance, it is not added to HURDAT. This disturbance was in Ryan Truchelut's List of Suspects.

\begin{tabular}{|c|c|c|c|}
\hline Day & Latitude & Longitude & Status \\
\hline October 4 & $23 N$ & $49 W$ & $\begin{array}{c}\text { Tropical } \\
\text { Depression? }\end{array}$ \\
\hline
\end{tabular}




$\begin{array}{cccc}\text { October } 5 & 25 \mathrm{~N} & 58 \mathrm{~W} & \begin{array}{c}\text { Tropical } \\ \text { Depression? } \\ \text { Tropical }\end{array} \\ \text { October } 6 & 28 \mathrm{~N} & 56 \mathrm{~W} & \begin{array}{c}\text { Depression? } \\ \text { October } 7\end{array} \\ & 35 \mathrm{~N} & 45 \mathrm{~W} & \text { Absorbed }\end{array}$

6) October 15-19: Historical Weather Maps and microfilm show a frontal boundary over the Bahamas and north of the Greater Antilles around mid-October. A low pressure system forms in the tail-end of the frontal boundary late on October $15^{\text {th }}$ and starts moving northeastward increasing in forward speed. Gale-force winds developed to the north and northeast of the center on October $16^{\text {th }}$. On October $17^{\text {th }}$, ship observations indicate that the disturbance has become an extratropical cyclone with gales as it raced to the northeast. It continued quickly to the northeast for the next two days before dissipating. Therefore, because the disturbance maintains a baroclinic appearance on the HWM and microfilm maps based on the ship observations, it is not added to HURDAT. This disturbance was in Ryan Truchelut's List of Suspects.

\begin{tabular}{|c|c|c|c|}
\hline Day & Latitude & Longitude & Status \\
\hline October 14 & \multicolumn{2}{|c|}{ North of the Greater Antilles } & Cold front \\
\hline October 15 & $21 N$ & $70 W$ & $\begin{array}{c}\text { Subtropical } \\
\text { Depression? }\end{array}$ \\
\hline October 16 & $25 N$ & $68 \mathrm{~W}$ & $\begin{array}{c}\text { Subtropical } \\
\text { Depression? }\end{array}$ \\
\hline October 17 & $30 N$ & $65 W$ & Extratropical \\
\hline $\begin{array}{l}\text { October } 18 \\
\text { October } 19\end{array}$ & $\begin{array}{l}37 \mathrm{~N} \\
55 \mathrm{~N}\end{array}$ & $\begin{array}{l}56 W \\
50 W\end{array}$ & $\begin{array}{l}\text { Extratropical } \\
\text { Extratropical }\end{array}$ \\
\hline
\end{tabular}

7) October 17-24: Historical Weather Maps show a frontal boundary over the eastern Gulf of Mexico around mid-October. A low pressure forms on the tail-end of the frontal boundary on October $18^{\text {th }}$ and starts moving to the northeast crossing Florida between the $18^{\text {th }}$ and $19^{\text {th }}$. On October $19^{\text {th }}$, a high pressure system over the Northeast blocks the extratropical cyclone off the Southeast of the United States. On October $21^{\text {st }}$, the disturbance becomes an occluded low and begins to weaken. Another frontal boundary arrives from the west on October $23^{\text {rd }}$ and on the next day, the disturbance is moving away from the United States as an extratropical cyclone. Therefore, because the system was likely not tropical or subtropical, it is not added to HURDAT. This disturbance was in Ryan Truchelut's List of Suspects.

Day

October 17

October 18

October 19

October 20

$\begin{array}{lc}\text { Latitude } & \text { Longitude } \\ \text { Northern Gulf of Mexico } \\ 25 \mathrm{~N} & 88 \mathrm{~W} \\ 31 \mathrm{~N} & 78 \mathrm{~W} \\ 35 \mathrm{~N} & 72 \mathrm{~W}\end{array}$

Status

Warm front

Extratropical

Extratropical

Extratropical 
October 21

October 22

October 23

October 24
$33 N$

$31 \mathrm{~N}$

$36 \mathrm{~N}$

$39 N$
$78 \mathrm{~W}$

$78 \mathrm{~W}$

$74 \mathrm{~W}$

$68 \mathrm{~W}$
Occluded

Occluded

Occluded

Extratropical 


\section{9 hurricane season}

Tropical Storm Arlene [May 28 - June 1, 1959]

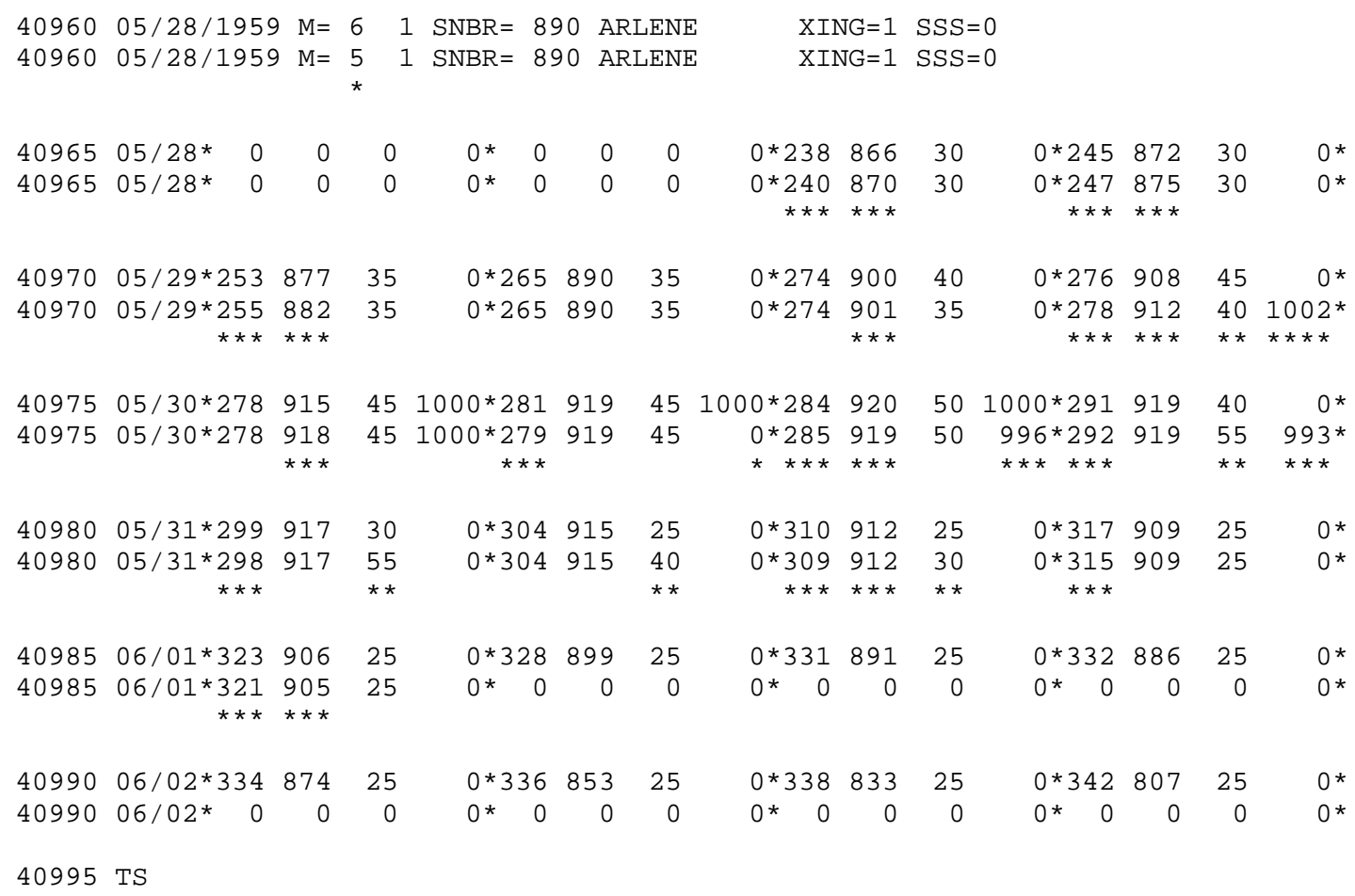

U.S. Tropical Storm Landfall

05/30 21Z 29.5N 91.9W $55 \mathrm{kt}$ LA

05/30 23Z 29.7N 91.8W $55 \mathrm{kt} \mathrm{LA}$

Minor changes to the track and major changes to the intensity shown in McAdie et al. (2009). Another major change is to indicate that the tropical cyclone dissipated 42 hours earlier than originally shown in HURDAT. Evidence for these alterations comes from the NHC microfilm maps, the Historical Weather Maps series, the COADS ship database, Monthly Weather Review, Navy reconnaissance book, Surface Weather Observations, State Climatological Data, Mariners Weather Log and NHC Storm Wallets.

May 25:

HWM analyzes a trough or tropical wave along $14-23 \mathrm{~N}, 77-79 \mathrm{~W}$ at $12 \mathrm{Z}$. HURDAT does not list an organized system on this date. Microfilm shows a trough or tropical wave along $12-25 \mathrm{~N}, 81 \mathrm{~W}$ at $12 \mathrm{Z}$. Ship highlights: No gales or low pressures.

MWR: "Tropical storm Arlene originated in an easterly wave which was fairly well defined with a northeast-southwest orientation over the Dominican Republic as early as 
May 23. Shower activity indicating low stability was evident over a wide area including most of the Caribbean Sea and the Bahamas. At 0700 EST on the 25th, a weak cyclonic flow appeared at $500 \mathrm{mb}$ over the northwestern Caribbean, but there was no evidence of any concentrated bad weather. About this time a slow but definite increase in pressure gradient began north of western Cuba, leaving an extensive area of relatively slight gradient over the western Caribbean Sea." ATSR: "Tropical Storm Arlene formed on an easterly wave which progressed through the western Caribbean producing copious precipitation. A closed low formed first at the $500 \mathrm{mb}$ level (250000Z) and then developed towards the lower layers."

May 26:

HWM analyzes a trough or tropical wave along $17-25 \mathrm{~N}, 79-81 \mathrm{~W}$ at $12 \mathrm{Z}$. HURDAT does not list an organized system on this date. Microfilm shows a trough or tropical wave along $15-25 \mathrm{~N}, 83 \mathrm{~W}$ at $12 \mathrm{Z}$. Ship highlights: No gales or low pressures. Land highlights: $35 \mathrm{kt} \mathrm{ESE} \mathrm{and} 1017 \mathrm{mb}$ at Dry Tortugas, FL at 12Z (micro). May 27:

HWM analyzes a trough or tropical wave along $17-27 \mathrm{~N}, 79-84 \mathrm{~W}$ at $12 \mathrm{Z}$. HURDAT does not list an organized system on this date. Microfilm shows a trough or tropical wave along $19-25 \mathrm{~N}, 78-82 \mathrm{~W}$ at $12 \mathrm{Z}$. Ship highlights: No gales or low pressures. Land highlights: $36 \mathrm{kt} \mathrm{NNE}$ and $1018 \mathrm{mb}$ at Carysfort Reef, FL at 06Z (SWO). $35 \mathrm{kt} \mathrm{E}$ and $1018 \mathrm{mb}$ at Alligator Lighthouse, FL at 18Z (micro).

MWR: "This trend in the pressure pattern continued until wind warnings were required for small craft on both coasts of Florida on May 27. The 500-mb Low had moved into the southeastern Gulf of Mexico on May 27."

May 28:

HWM analyzes a tropical storm of at most $1010 \mathrm{mb}$ at $24.8 \mathrm{~N}, 87.0 \mathrm{~W}$ at $12 \mathrm{Z}$. HURDAT lists a 30 knot tropical depression at $23.8 \mathrm{~N}, 86.6 \mathrm{~W}$ at $12 \mathrm{Z}$ (first position). Microfilm shows a closed low pressure of at most $1011 \mathrm{mb}$ at $24.0 \mathrm{~N}, 87.0 \mathrm{~W}$ at 12Z. Ship highlights: $35 \mathrm{kt} \mathrm{E}$ and $1012 \mathrm{mb}$ at $25.2 \mathrm{~N}, 84.6 \mathrm{~W}$ at $00 \mathrm{Z}$ (COADS).

MWR: "On the 0700 EST surface chart of May 28 a ship reported a light southwest wind at $22.5 \mathrm{~N}, 88.5 \mathrm{~W}$, providing the first indication that the closed circulation had extended down to the surface." ATSR: "Ship reports indicated that this low became closed on the surface at 281800Z." 
May 29:

HWM analyzes a tropical storm of at most $1005 \mathrm{mb}$ at $27.0 \mathrm{~N}, 90.2 \mathrm{~W}$ at $12 \mathrm{Z}$. HURDAT lists a 40 knot tropical storm at $27.4 \mathrm{~N}, 90.0 \mathrm{~W}$ at $12 \mathrm{Z}$. Microfilm shows a closed low pressure of at most $1011 \mathrm{mb}$ at $27.0 \mathrm{~N}, 90.0 \mathrm{~W}$ at $12 \mathrm{Z}$. Ship highlights: $35 \mathrm{kt}$ $\mathrm{SE}$ and $1008 \mathrm{mb}$ at $27.1 \mathrm{~N}, 88.0 \mathrm{~W}$ at $00 \mathrm{Z}$ (COADS). $35 \mathrm{kt} \mathrm{NE}$ at $26.2 \mathrm{~N}, 89.7 \mathrm{~W}$ at $02 \mathrm{Z}$ (micro). $35 \mathrm{kt} \mathrm{ESE}$ and $1012 \mathrm{mb}$ at $25.7 \mathrm{~N}, 86.5 \mathrm{~W}$ at $06 \mathrm{Z}$ (COADS). $35 \mathrm{kt} \mathrm{SSE}$ and 1006 $\mathrm{mb}$ at $26.9 \mathrm{~N}, 88.9 \mathrm{~W}$ at $12 \mathrm{Z}$ (COADS). $35 \mathrm{kt} \mathrm{SSE}$ and $1008 \mathrm{mb}$ at $26.5 \mathrm{~N}, 88.0 \mathrm{~W}$ at $15 \mathrm{Z}$ (micro). $35 \mathrm{kt} \mathrm{SSE}$ and $1013 \mathrm{mb}$ at $26.6 \mathrm{~N}, 88.2 \mathrm{~W}$ at $18 \mathrm{Z}$ (COADS). $35 \mathrm{kt} \mathrm{SSE}$ at $27.6 \mathrm{~N}$, $90.3 \mathrm{~W}$ at $21 \mathrm{Z}$ (micro). Aircraft highlights: Penetration center fix measured a central pressure of $1008 \mathrm{mb}$, estimated maximum surface winds of $45 \mathrm{kt}$ and an eye diameter of $40 \mathrm{~nm}$ at $12 \mathrm{Z}$ (ATSR). Penetration center fix measured a central pressure of $1002 \mathrm{mb}$ and estimated maximum surface winds of $45 \mathrm{kt}$ at $1854 \mathrm{Z}$ (ATSR).

MWR: "Ship reports during the evening of May 28 confirmed the development of tropical storm Arlene and the New Orleans Weather Bureau office at 2100 CST issued the first tropical storm advisory of the 1959 season. The storm center moved northwestward for about 12 hours from its initial position near 26N, 88W." ATSR: "Increased to storm intensity by $290000 \mathrm{Z}$. On the basis of these reports, the first warning was issued at $290300 \mathrm{Z}$ and aircraft reconnaissance ordered. The Navy reconnaissance aircraft reported 45-knot winds at 291200Z. ARLENE reached maximum intensity of 50 knots at 291800Z. At the time of most rapid intensification (291200Z), a strong outflow mechanism was evidenced at $200 \mathrm{mb}$."

May 30:

HWM analyzes a tropical storm of at most $1005 \mathrm{mb}$ at $27.5 \mathrm{~N}, 92.0 \mathrm{~W}$ at $12 \mathrm{Z}$. HURDAT lists a 50 knot tropical storm at $28.4 \mathrm{~N}, 92.0 \mathrm{~W}$ at $12 \mathrm{Z}$. Microfilm shows a closed low pressure of at most $999 \mathrm{mb}$ at $28.5 \mathrm{~N}, 92.3 \mathrm{~W}$ at $12 \mathrm{Z}$. Ship highlights: $45 \mathrm{kt} \mathrm{N}$ at $28.0 \mathrm{~N}, 92.0 \mathrm{~W}$ at $00 \mathrm{Z}$ (micro). $20 \mathrm{kt} \mathrm{W}$ and $998 \mathrm{mb}$ at $28.6 \mathrm{~N}, 92.4 \mathrm{~W}$ at $12 \mathrm{Z}$ (micro). 40 kt SSE and $999 \mathrm{mb}$ at $28.3 \mathrm{~N}, 91.9 \mathrm{~W}$ at $12 \mathrm{Z}$ (micro). $35 \mathrm{kt} \mathrm{N}$ and $1008 \mathrm{mb}$ at $29.6 \mathrm{~N}$, 92.5W at $18 \mathrm{Z}$ (micro). Land highlights: $35 \mathrm{kt} \mathrm{SE}$ and $1003 \mathrm{mb}$ at Point Au Fer Reef Light, LA at $18 \mathrm{Z}$ (micro). $20 \mathrm{kt} \mathrm{NNE}$ and $1001 \mathrm{mb}$ at Weeks Island, LA at $22 \mathrm{Z}$ (WALLET). $48 \mathrm{kt}$ (gusts to $65 \mathrm{kt}$ ) and $1000 \mathrm{mb}$ at Patterson, LA at 2330Z (MWR/CLIMO). Aircraft highlights: Penetration center fix measured a central pressure of $1000 \mathrm{mb}$, estimated maximum surface winds of $50 \mathrm{kt}$ and an eye diameter of $8 \mathrm{~nm}$ at 01Z. Penetration center fix measured a central pressure of $1004 \mathrm{mb}$ and estimated maximum surface winds of $40 \mathrm{kt}$ at $1540 \mathrm{Z}$. Penetration center fix measured a central pressure of $993 \mathrm{mb}$ and estimated maximum surface winds of $40 \mathrm{kt}$ at $1917 \mathrm{Z}$. 
MWR: "Thereafter it moved westward for 12 hours, became stationary at $28 \mathrm{~N}, 92 \mathrm{~W}$ during the night of May 29-30. Then moved northward across the Louisiana coast between Weeks Island and Pt. Au Fer, La., during the late afternoon of May 30. Winds diminished gradually after the center crossed the coast. Highest winds reported in the storm were $48 \mathrm{kt}$ with gusts to $65 \mathrm{kt}$ on the Louisiana coast. Lowest central pressure reported was $999.7 \mathrm{mb}$. at Patterson, La. Several ships and Navy reconnaissance aircraft also reported a central pressure of around $1000 \mathrm{mb}$ while the storm was over the Gulf of Mexico. Highest tides were 3 feet above normal at Weeks Island and Pt. Au Fer, La. One man was drowned in the surf at Galveston."

May 31:

HWM analyzes a closed low pressure of at most $1010 \mathrm{mb}$ at $31.0 \mathrm{~N}, 91.5 \mathrm{~W}$ with a cold front to the northwest and a warm front to the northeast at 12Z. HURDAT lists a 25 knot tropical depression at $31.0 \mathrm{~N}, 91.2 \mathrm{~W}$ at $12 \mathrm{Z}$. Microfilm shows a closed low pressure of at most $1008 \mathrm{mb}$ at $31.0 \mathrm{~N}, 91.5 \mathrm{~W}$ at $12 \mathrm{Z}$. Ship highlights: No gales or low pressures. Land highlights: $10 \mathrm{kt} \mathrm{N}$ and $1005 \mathrm{mb}$ at Lafayette, LA at $00 \mathrm{Z}$ (micro). $20 \mathrm{kt}$ SSE and $1003 \mathrm{mb}$ at Baton Rouge, LA at 0658Z (SWO).

June 1:

HWM analyzes a closed low pressure of at most $1010 \mathrm{mb}$ at $33.5 \mathrm{~N}, 89.0 \mathrm{~W}$ with a cold front to the northwest at 12Z. HURDAT lists a 25 knot tropical depression at $33.1 \mathrm{~N}, 89.1 \mathrm{~W}$ at $12 \mathrm{Z}$. Microfilm shows a closed low pressure of at most $1011 \mathrm{mb}$ at $33.0 \mathrm{~N}, 89.0 \mathrm{~W}$ with a frontal boundary to the northwest at 12Z. Ship highlights: No gales or low pressures.

June 2:

HWM analyzes a closed low pressure of at most $1015 \mathrm{mb}$ at $35.0 \mathrm{~N}, 82.0 \mathrm{~W}$ with a frontal boundary to the northwest at 12Z. HURDAT lists a 25 knot tropical depression at $33.8 \mathrm{~N}, 83.3 \mathrm{~W}$ at $12 \mathrm{Z}$. Microfilm shows a closed low pressure of at most $1011 \mathrm{mb}$ at $34.0 \mathrm{~N}, 82.5 \mathrm{~W}$ with a frontal boundary extended to the south and another to the northwest at 12Z. Ship highlights: No gales or low pressures.

June 3:

HWM analyzes an extratropical cyclone of at most $1005 \mathrm{mb}$ at $42.0 \mathrm{~N}, 68.0 \mathrm{~W}$ at 12Z. HURDAT does not list an organized system on this day. Microfilm shows an extratropical cyclone of at most $1002 \mathrm{mb}$ at $39.5 \mathrm{~N}, 71.5 \mathrm{~W}$ at $12 \mathrm{Z}$. Ship highlights: $35 \mathrm{kt}$ $\mathrm{S}$ and $1015 \mathrm{mb}$ at $32.9 \mathrm{~N}, 71.6 \mathrm{~W}$ at $00 \mathrm{Z}$ (COADS). $35 \mathrm{kt} \mathrm{WSW}$ and $1004 \mathrm{mb}$ at $38.4 \mathrm{~N}$, $70.9 \mathrm{~W}$ at $12 \mathrm{Z}$ (COADS). $40 \mathrm{kt} \mathrm{SSW}$ and $1010 \mathrm{mb}$ at $40.2 \mathrm{~N}, 64.6 \mathrm{~W}$ at $18 \mathrm{Z}$ (COADS). 
June 4:

HWM analyzes an extratropical cyclone of at most $1005 \mathrm{mb}$ at $42.0 \mathrm{~N}, 68.0 \mathrm{~W}$ at 12Z. HURDAT does not list an organized system on this day. Microfilm shows a large extratropical cyclone over the Labrador Sea at 12Z. Ship highlights: No gales or low pressures.

A strong tropical wave moved across the Caribbean Sea during the last week of May. The disturbance became better organized over the southeast Gulf of Mexico and a welldefined low level circulation developed at $12 \mathrm{Z}$ on May $28^{\text {th }}$. Genesis is analyzed at $12 \mathrm{Z}$ on May $28^{\text {th }}$ as a $30 \mathrm{kt}$ tropical depression, same as the original HURDAT. Minor alterations were made to the track of this tropical cyclone between May $28^{\text {th }}$ at $12 \mathrm{Z}$ and June $1^{\text {st }}$ at $00 \mathrm{Z}$. The tropical depression moved northwestward and intensified into a tropical storm at $00 \mathrm{Z}$ on May $29^{\text {th }}$, same as the original HURDAT. The first reconnaissance aircraft to reach Arlene occurred at $12 \mathrm{Z}$ on the $29^{\text {th }}$ estimating surface winds of $45 \mathrm{kt}$ and a central pressure of $1008 \mathrm{mb}$. Around this time, a couple of ships near the center reported pressures of $1006 \mathrm{mb}$ with $35 \mathrm{kt} \mathrm{SE}$ and $1007 \mathrm{mb}$ with $20 \mathrm{kt} \mathrm{W}$, indicating that the pressure measured by the aircraft was not a central pressure. Thus, it is not added to HURDAT. Another aircraft measured a central pressure of $1002 \mathrm{mb}$ and estimated surface winds of $45 \mathrm{kt}$ at $1854 \mathrm{Z}$ on the $29^{\text {th }}$. A central pressure of $1002 \mathrm{mb}$ suggests maximum sustained winds of $40 \mathrm{kt}$ north of $25 \mathrm{~N}$ from the Brown et al. pressurewind relationship. At this time, Arlene was starting to slow its forward speed and was moving around $7 \mathrm{kt}$ to the west. An intensity of $40 \mathrm{kt}$ is selected at $18 \mathrm{Z}$ on the $29^{\text {th }}, 5 \mathrm{kt}$ less than the original HURDAT, a minor intensity change. A central pressure of $1002 \mathrm{mb}$ is added to HURDAT at $18 \mathrm{Z}$ on the $29^{\text {th }}$. The next reconnaissance aircraft reached Arlene at $01 \mathrm{Z}$ on May $30^{\text {th }}$ measured a central pressure of $1000 \mathrm{mb}$, estimated surface winds of $50 \mathrm{kt}$ and an eye diameter $8 \mathrm{~nm}$. A central pressure of $1000 \mathrm{mb}$ suggests maximum sustained winds of $44 \mathrm{kt}$ north of $25 \mathrm{~N}$ from the pressure-wind relationship. At $00 \mathrm{Z}$ on the $30^{\text {th }}$, a ship just west of the center reported $45 \mathrm{kt} \mathrm{N}$. Based on the data from the aircraft center fix and ship observation, an intensity of $45 \mathrm{kt}$ is selected at $00 \mathrm{Z}$ on the $30^{\text {th }}$, same as the original HURDAT. A central pressure of $1000 \mathrm{mb}$ was present in HURDAT at 00Z on the $30^{\text {th }}$ and has been retained.

Arlene became almost stationary early on the $30^{\text {th }}$ before starting to move northward later on the day. A ship at $12 \mathrm{Z}$ on the $30^{\text {th }}$ reported $20 \mathrm{kt} \mathrm{W}$ and $998 \mathrm{mb}$, suggesting a central pressure of $996 \mathrm{mb}$, which has been added to HURDAT replacing the existing $1000 \mathrm{mb}$. A central pressure of $1000 \mathrm{mb}$ was present in HURDAT at $06 \mathrm{Z}$ on the $30^{\text {th }}$, but based on ship observations and reconnaissance data later on the day, it has been removed. A central pressure of $996 \mathrm{mb}$ suggests maximum sustained winds of $50 \mathrm{kt}$ north of $25 \mathrm{~N}$ from the pressure-wind relationship. An intensity of $50 \mathrm{kt}$ is analyzed at $12 \mathrm{Z}$ on the $30^{\text {th }}$ 
based on the reconnaissance data and land observations later on the day. This intensity agrees with the original shown in HURDAT. At 1917Z, a penetration center fix measured a central pressure of $993 \mathrm{mb}$ and estimated surface winds of $40 \mathrm{kt}$. A central pressure of $993 \mathrm{mb}$ suggests maximum sustained winds of $55 \mathrm{kt}$ north of $25 \mathrm{~N}$ from the pressure-wind relationship. An intensity of $55 \mathrm{kt}$ is analyzed at $18 \mathrm{Z}$ on the $30^{\text {th }}$ based on the reconnaissance data and land observations later on the day. This intensity is $15 \mathrm{kt}$ more than originally shown in HURDAT, a minor intensity change. A central pressure of 993 $\mathrm{mb}$ is added to HURDAT at $18 \mathrm{Z}$ on the $30^{\text {th }}$. Landfall occurred around $21 \mathrm{Z}$ near $29.5 \mathrm{~N}$, 91.9W on Marsh Island located on south-central Louisiana as a $55 \mathrm{kt}$ tropical storm. Shortly after, the center of Arlene moved into the West Cote Blanche Bay and made a second landfall around $23 \mathrm{Z}$ near $29.7 \mathrm{~N}, 91.8 \mathrm{~W}$ or about 15 miles south of New Iberia as a $55 \mathrm{kt}$ tropical storm. A report on Tropical Storm Arlene in the Louisiana State Climatological Data indicates that Patterson, LA reported $48 \mathrm{kt}$ sustained with gusts at 65 $\mathrm{kt}$ and a pressure of $1000 \mathrm{mb}$ at $2330 \mathrm{Z}$ on the $30^{\text {th }}$. MWR indicates that a central pressure was measured at Patterson, LA, but the data suggests that landfall occurred west of Patterson, LA, thus it is not a central pressure. An intensity of $55 \mathrm{kt}$ is analyzed at $00 \mathrm{Z}$ on May $31^{\text {st }}$, up from $30 \mathrm{kt}$ originally in HURDAT, a major intensity change. $55 \mathrm{kt}$ is also the peak intensity for this tropical cyclone, up from $50 \mathrm{kt}$ originally in HURDAT at $12 \mathrm{Z}$ on the $30^{\text {th }}$, a minor intensity change. After landfall, the track turned to the northeast and the tropical storm started to weaken. Weakening to a tropical depression is analyzed at $12 \mathrm{Z}$ on the $31^{\text {st }}$, twelve hours later than originally shown in HURDAT. Surface observations indicate that Arlene continued to weaken late on the $31^{\text {st }}$ and early on June $1^{\text {st }}$. Dissipation is analyzed after $00 \mathrm{Z}$ on the $1^{\text {st }}, 42$ hours earlier than originally shown in HURDAT. The remnants of Arlene continued moving northeastward ahead of a frontal boundary before becoming absorbed a few days later over the southeastern United States.

Tropical Storm Beulah [June 15-19, 1959]

\begin{tabular}{|c|c|c|c|c|c|c|c|c|c|c|c|c|c|}
\hline 41000 & $06 / 15 / 1959$ & 9 $M=$ & 4 & SNBR $=89$ & $1 \mathrm{~B}$ & JLAH & XII & $V G=\odot$ & $\mathrm{SSS}=$ & & & & \\
\hline 41000 & $06 / 15 / 1959$ & $9=$ & 5 & SNBR $=89$ & $1 \mathrm{BE}$ & JLAH & XII & $V G=0$ & SSS $=$ & & & & \\
\hline 41005 & $06 / 15^{*}$ & $\odot$ & $\odot$ & ०* & $\odot$ & $\odot$ & ○* & $\odot$ & $\odot$ & $\odot * 211$ & 947 & 25 & ○* \\
\hline 41010 & $06 / 16 * 217$ & 952 & 25 & $0 * 220$ & 956 & 45 & $\odot * 223$ & 960 & 50 & $\odot * 226$ & 962 & 50 & 0 * \\
\hline 41010 & $06 / 16 * 216$ & 952 & $\begin{array}{l}30 \\
\star \star\end{array}$ & $0^{*} \underset{* \star}{221}$ & $\begin{array}{l}957 \\
* * *\end{array}$ & $\begin{array}{l}40 \\
* *\end{array}$ & $\begin{array}{r}0 * 225 \\
* \star \star\end{array}$ & $\begin{array}{l}961 \\
\star \star \star\end{array}$ & 50 & $\begin{array}{r}0 * 228 \\
* \star \star\end{array}$ & $\begin{array}{l}963 \\
\star \star \star\end{array}$ & $\begin{array}{l}60 \\
\star *\end{array}$ & $\begin{array}{l}987^{*} \\
\star \star *\end{array}$ \\
\hline 41015 & $06 / 17$ * 228 & 963 & 55 & $0 * 230$ & 965 & 55 & $0 * 231$ & 967 & 55 & $0 * 232$ & 971 & 60 & $987^{*}$ \\
\hline 41015 & $\begin{array}{r}06 / 17^{*} 229 \\
* \star *\end{array}$ & $\begin{array}{l}964 \\
* * *\end{array}$ & $\begin{array}{l}60 \\
\star *\end{array}$ & $0 * 230$ & 965 & $\begin{array}{l}60 \\
* *\end{array}$ & $\begin{array}{l}987^{*} 230 \\
\star \star * * * *\end{array}$ & 967 & 55 & $\begin{array}{l}992 * 229 \\
* \star \star * * *\end{array}$ & $\begin{array}{l}969 \\
\star * *\end{array}$ & $\begin{array}{l}55 \\
\star *\end{array}$ & $\begin{array}{l}992^{*} \\
\star * \star\end{array}$ \\
\hline 41020 & $06 / 18$ * 230 & 973 & 55 & $\odot * 224$ & 973 & 45 & $\odot * 218$ & 972 & 35 & ๑*212 & 972 & 30 & ๑* \\
\hline 41020 & $06 / 18 * 226$ & $\begin{array}{l}970 \\
\star * *\end{array}$ & $\begin{array}{l}50 \\
\star *\end{array}$ & $\begin{array}{l}997 * 223 \\
\star \star \star * * *\end{array}$ & $\begin{array}{l}971 \\
* * *\end{array}$ & 45 & $\begin{array}{r}0 * 221 \\
* * *\end{array}$ & 972 & $\begin{array}{l}40 \\
* *\end{array}$ & $\begin{array}{l}1001 * 210 \\
* * * * * * *\end{array}$ & $\begin{array}{l}973 \\
\star * *\end{array}$ & $\begin{array}{l}40 \\
* *\end{array}$ & $\begin{array}{l}1001^{*} \\
\star * * *\end{array}$ \\
\hline
\end{tabular}


(June $19^{\text {th }}$ is new to HURDAT)

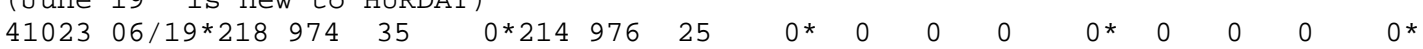

41025 TS

Tropical Storm Landfall

06/19 02Z 21.7N 97.5W 35 kt Mexico

Minor changes to the track and intensity shown in McAdie et al. (2009). A major change is to indicate that Beulah made landfall as a tropical storm in Mexico. Evidence for these alterations comes from the NHC microfilm maps, the Historical Weather Maps series, the COADS ship database, Monthly Weather Review, Navy reconnaissance book, Surface Weather Observations, Mariners Weather Log and NHC Storm Wallets.

June 13:

HWM analyzes a closed low pressure of at most $1010 \mathrm{mb}$ at $21.0 \mathrm{~N}, 95.5 \mathrm{~W}$ at 12Z. HURDAT does not list an organized system on this date. Microfilm shows a trough or tropical wave along 18-26N, 93W at 12Z. Ship highlights: No gales or low pressures.

MWR: "The synoptic situation contributing to the formation and dissipation of Beulah was rather complex. Pressure first began to fall over the western Gulf on June 13 with the movement of a weak cold front into the northern Gulf. A rather strong anticyclone centered over the Great Lakes contributed to a marked increase in the easterly flow over the northern Gulf." ATSR: "For several days prior to the formation of Tropical Storm BEULAH, widespread cloudiness and precipitation prevailed over the Gulf of Mexico as a series of easterly waves entered from the Caribbean, a weakening cold front entered from the north, and the Equatorial Front surged northward toward the Gulf of Campeche."

June 14:

HWM analyzes a spot low at 21.0N, 96.0W at 12Z. HURDAT does not list an organized system on this date. Microfilm shows a closed low pressure of at most 1008 $\mathrm{mb}$ at $24.0 \mathrm{~N}, 95.0 \mathrm{~W}$ with a frontal boundary to the northeast at 12Z. Ship highlights: No gales or low pressures.

June 15:

HWM analyzes a closed low pressure of at most $1005 \mathrm{mb}$ at $21.5 \mathrm{~N}, 96.0 \mathrm{~W}$ at 12Z. HURDAT lists a 25 knot tropical depression at $21.1 \mathrm{~N}, 94.7 \mathrm{~W}$ at $18 \mathrm{Z}$ (first position). 
Microfilm shows a closed low pressure of at most $1005 \mathrm{mb}$ at $21.5 \mathrm{~N}, 93.0 \mathrm{~W}$ at 12Z. Ship highlights: No gales or low pressures.

MWR: "This High broke down rapidly on the $15^{\text {th }}$ and $16^{\text {th }}$ with the approach of an active short wave from the Plains States, probably one of the factors that prevented Beulah from becoming a well developed storm." ATSR: "By 150000Z, A well developed low at 500 $\mathrm{mb}$ formed over the western Gulf of Mexico and surface reports revealed increased precipitation and a possible low in the southwestern Gulf."

June 16:

HWM analyzes a tropical storm of at most $1005 \mathrm{mb}$ at $23.0 \mathrm{~N}, 96.0 \mathrm{~W}$ at $12 \mathrm{Z}$. HURDAT lists a 50 knot tropical storm at $23.3 \mathrm{~N}, 96.0 \mathrm{~W}$ at $12 \mathrm{Z}$. Microfilm shows a closed low pressure of at most $1005 \mathrm{mb}$ at $22.7 \mathrm{~N}, 95.8 \mathrm{~W}$ at $12 \mathrm{Z}$. Ship highlights: $50 \mathrm{kt}$ $\mathrm{NE}$ and $997 \mathrm{mb}$ near 23.0N, 96.0W at 09Z (MWR/micro). $10 \mathrm{kt} \mathrm{SSE}$ and $1004 \mathrm{mb}$ at $22.9 \mathrm{~N}, 94.3 \mathrm{~W}$ at $12 \mathrm{Z}$ (COADS). $40 \mathrm{kt} \mathrm{S}$ and $996 \mathrm{mb}$ at $22.7 \mathrm{~N}, 95.8 \mathrm{~W}$ at $18 \mathrm{Z}$ (COADS/MWL). Land highlights: $20 \mathrm{kt} \mathrm{W}$ and $1004 \mathrm{mb}$ at Tampico, Mexico at $12 \mathrm{Z}$ (HWM). Aircraft highlights: Penetration center fix measured a central pressure of 988 $\mathrm{mb}$, estimated maximum surface winds of $45 \mathrm{kt}$ and an eye diameter of $25 \mathrm{~nm}$ at $22.7 \mathrm{~N}$, 96.3W at 1630Z (ATSR). Penetration center fix measured a central pressure of $987 \mathrm{mb}$, estimated maximum surface winds of $45 \mathrm{kt}$ and an eye diameter of $25 \mathrm{~nm}$ at $22.9 \mathrm{~N}$, 96.3W at $1832 \mathrm{Z}$ (ATSR).

MWR: "Tropical Storm Beulah was first detected during the night of June 15-16 when the SS Hondo reported a 50-kt. northeasterly wind with heavy rain and high seas near $23 \mathrm{~N}, 96 \mathrm{~W}$. The storm was short lived as it drifted northwestward on the $16^{\text {th }}$, westward during the $17^{\text {th }}$." ATSR: "Navy aircraft reconnaissance was ordered on the afternoon of June $15^{\text {th }}$ for takeoff early on the $16^{\text {th }}$. This aircraft reported a wind, cloud, and pressure eye located at $22.5 \mathrm{~N}, 96.4 \mathrm{~W}$ at $161541 \mathrm{Z}$ (at about the same time this report was received, a late report from the SS HONDO was received stating that an intense tropical depression had been encountered with winds of force 10 at $0900 \mathrm{Z}$ in the same approximate location). On the basis of this information, the first warning was issued at 1900Z."

June 17:

HWM analyzes a tropical storm of at most $1000 \mathrm{mb}$ at $23.5 \mathrm{~N}, 96.2 \mathrm{~W}$ at $12 \mathrm{Z}$. HURDAT lists a 55 knot tropical storm at $23.1 \mathrm{~N}, 96.7 \mathrm{~W}$ at $12 \mathrm{Z}$. Microfilm shows a closed low pressure of at most $993 \mathrm{mb}$ at $23.0 \mathrm{~N}, 96.8 \mathrm{~W}$ at 12Z. Ship highlights: $40 \mathrm{kt} \mathrm{S}$ at $22.2 \mathrm{~N}, 96.2 \mathrm{~W}$ at $00 \mathrm{Z}$ (COADS). $35 \mathrm{kt} \mathrm{W}$ and $1000 \mathrm{mb}$ at $22.1 \mathrm{~N}, 96.4 \mathrm{~W}$ at $06 \mathrm{Z}$ (COADS). Land highlights: $15 \mathrm{kt} \mathrm{W}$ and $1004 \mathrm{mb}$ at Tuxpan, Mexico at $00 \mathrm{Z}$ (micro). 10 kt NW and $1005 \mathrm{mb}$ at Tampico, Mexico at 06Z (micro). $15 \mathrm{kt} \mathrm{W}$ and $1003 \mathrm{mb}$ at Tampico, Mexico at $12 \mathrm{Z}$ (micro). $25 \mathrm{kt} \mathrm{W}$ and $1005 \mathrm{mb}$ at Tampico, Mexico at $18 \mathrm{Z}$ 
(micro). Aircraft highlights: Radar center fix estimated an eye diameter of $15 \mathrm{~nm}$ at $22.9 \mathrm{~N}, 96.3 \mathrm{~W}$ at $0255 \mathrm{Z}$ (ATSR). Penetration center fix measured a central pressure of $987 \mathrm{mb}$, estimated maximum surface winds of $50 \mathrm{kt}$ and an eye diameter of $18 \mathrm{~nm}$ at $22.9 \mathrm{~N}, 96.4 \mathrm{~W}$ at $06 \mathrm{Z}$ (ATSR). Penetration center fix measured a central pressure of 992 $\mathrm{mb}$, estimated maximum surface winds of $60 \mathrm{kt}$ and an eye diameter of $28 \mathrm{~nm}$ at $23.0 \mathrm{~N}$, $96.8 \mathrm{~W}$ at $13 \mathrm{Z}$ (ATSR). Penetration center fix measured a central pressure of $992 \mathrm{mb}$, estimated maximum surface winds of $50 \mathrm{kt}$ and an eye diameter of $25 \mathrm{~nm}$ at $22.8 \mathrm{~N}$, 97.0W at 19Z (ATSR).

MWR: "Highest winds were estimated by reconnaissance aircraft at $61 \mathrm{kt}$ with lowest pressure $987 \mathrm{mb} . "$

June 18:

HWM analyzes a tropical storm of at most $1005 \mathrm{mb}$ at $22.2 \mathrm{~N}, 97.5 \mathrm{~W}$ at $12 \mathrm{Z}$. HURDAT lists a 35 knot tropical storm at $21.8 \mathrm{~N}, 97.2 \mathrm{~W}$ at $12 \mathrm{Z}$. Microfilm shows a closed low pressure of at most $1005 \mathrm{mb}$ at $22.0 \mathrm{~N}, 97.0 \mathrm{~W}$ at 12Z. Ship highlights: No gales or low pressures. Land highlights: $15 \mathrm{kt} \mathrm{NNW}$ and $1005 \mathrm{mb}$ at Tampico, Mexico at $00 \mathrm{Z}$ (micro). $15 \mathrm{kt} \mathrm{NW}$ and $1005 \mathrm{mb}$ at Tampico, Mexico at 06Z (micro). $10 \mathrm{kt} \mathrm{NNW}$ and $1004 \mathrm{mb}$ at Tampico, Mexico at $12 \mathrm{Z}$ (micro). Aircraft highlights: Penetration center fix measured a central pressure of $997 \mathrm{mb}$, estimated maximum surface winds of $40 \mathrm{kt}$ and an eye diameter of $15 \mathrm{~nm}$ at $22.5 \mathrm{~N}, 96.9 \mathrm{~W}$ at $01 \mathrm{Z}$ (ATSR). Radar center fix at $22.3 \mathrm{~N}$, $97.1 \mathrm{~W}$ at $06 \mathrm{Z}$ (ATSR). Penetration center fix measured a central pressure of $1001 \mathrm{mb}$, estimated maximum surface winds of $30 \mathrm{kt}$ and an eye diameter of $12 \mathrm{~nm}$ at $22.1 \mathrm{~N}$, $97.3 \mathrm{~W}$ at $1330 \mathrm{Z}$ (ATSR). Penetration center fix measured a central pressure of $1001 \mathrm{mb}$, estimated maximum surface winds of $30 \mathrm{kt}$ and an eye diameter of $12 \mathrm{~nm}$ at $21.9 \mathrm{~N}$, 97.3W at 19Z (ATSR).

MWR: "Turned southward moving inland over Mexico south of Tampico on the $18^{\text {th }}$. The storm weakened rapidly on turning southward late on the $17^{\text {th }}$, and winds were generally less than $30 \mathrm{kt}$. as it moved inland. No reports of damage have been received from Mexico; it was probably minor."

June 19:

HWM analyzes a spot low at $21.0 \mathrm{~N}, 99.5 \mathrm{~W}$ at $12 \mathrm{Z}$. HURDAT does not list an organized system on this date. Microfilm shows a tropical wave along $17-25 \mathrm{~N}, 94 \mathrm{~W}$ at 12Z. Ship highlights: No gales or low pressures.

The origin of Tropical Storm Beulah is uncertain. A frontal boundary entered the northwestern Gulf of Mexico on June $13^{\text {th }}$ and likely interacted with a trough or tropical wave over the southwestern Gulf. A decrease of about 2-3 millibars was noticed on June 
$14^{\text {th }}$ on the coastal stations of the western Gulf of Mexico compared to a day earlier. The first position is analyzed at $18 \mathrm{Z}$ on June $15^{\text {th }}$ as a $25 \mathrm{kt}$ tropical depression, same as the original HURDAT. The actual genesis timing is uncertain because of the lack of observations on the Bay of Campeche and it is possible that the tropical cyclone may have developed earlier. Minor track changes were analyzed during the lifetime of this system. Intensification to a tropical storm is analyzed at $06 \mathrm{Z}$ on the $16^{\text {th }}$, same as originally shown in HURDAT. The ship SS HONDO reported $50 \mathrm{kt} \mathrm{NE}$ and $997 \mathrm{mb}$ at $09 \mathrm{Z}$ on June $16^{\text {th }}$. A reconnaissance aircraft measured a central pressure of $987 \mathrm{mb}$, estimated surface winds of $45 \mathrm{kt}$ and an eye diameter of $25 \mathrm{~nm}$ at $1832 \mathrm{Z}$ on the $16^{\text {th }}$. A central pressure of $987 \mathrm{mb}$ suggests maximum surface winds of $68 \mathrm{kt}$ south of $25 \mathrm{~N}$ from the Brown et al. pressure-wind relationship. An eye diameter of $25 \mathrm{~nm}$ suggests an RMW of about $19 \mathrm{~nm}$ and climatology is $18 \mathrm{~nm}$. Due to a forward speed of about $3 \mathrm{kt}$ and low environmental pressures (outer closed isobar of $1007 \mathrm{mb}$ ), an intensity of $60 \mathrm{kt}$ is selected at $18 \mathrm{Z}$ on the $16^{\text {th }}$, up from $50 \mathrm{kt}$ originally in HURDAT, a minor intensity change. A central pressure of $987 \mathrm{mb}$ is added to HURDAT at $18 \mathrm{Z}$ on the $16^{\text {th }}$. It is possible that Beulah may have reached hurricane intensity late on the $16^{\text {th }}$ or early on June 17th, but the data available is not sufficient to justify hurricane intensity. The next aircraft to reach Beulah occurred at $06 \mathrm{Z}$ on the $17^{\text {th }}$ and measured a central pressure of $987 \mathrm{mb}$, estimated surface winds of $50 \mathrm{kt}$ and an eye diameter of $18 \mathrm{~nm}$. A central pressure of $987 \mathrm{mb}$ suggests maximum surface winds of $68 \mathrm{kt}$ south of $25 \mathrm{~N}$ from pressure-wind relationship. An eye diameter of $18 \mathrm{~nm}$ suggests an RMW of about $14 \mathrm{~nm}$ and climatology suggests about $18 \mathrm{~nm}$. Since Beulah was almost stationary and the environmental pressures remained low, an intensity of $60 \mathrm{kt}$ is again analyzed at $06 \mathrm{Z}$ on the $17^{\text {th }}$, up from $55 \mathrm{kt}$ originally shown in HURDAT. A central pressure of $987 \mathrm{mb}$ is added to HURDAT at $06 \mathrm{Z}$ on the $17^{\text {th }} .60 \mathrm{kt}$ is also the peak intensity for this tropical cyclone, same as the original HURDAT, but 12-24 hours later.

The next penetration center fix measured a central pressure of $992 \mathrm{mb}$, estimated surface winds of $60 \mathrm{kt}$ and an eye diameter of $28 \mathrm{~nm}$ at 13Z. A central pressure of $992 \mathrm{mb}$ suggests maximum sustained winds of $61 \mathrm{kt}$ south of $25 \mathrm{~N}$ from the pressure-wind relationship. An eye diameter of $28 \mathrm{~nm}$ suggests an RMW of about $21 \mathrm{~nm}$ and climatology is $18 \mathrm{~nm}$. Due to the slow forward speed of about $2 \mathrm{kt}$, an intensity of $55 \mathrm{kt}$ is selected at $12 \mathrm{Z}$ on the $17^{\text {th }}$, same as originally shown in HURDAT. A central pressure of $992 \mathrm{mb}$ is added to HURDAT at $12 \mathrm{Z}$ on the $17^{\text {th }}$. At $19 \mathrm{Z}$, another penetration center fix measured a central pressure of $992 \mathrm{mb}$, estimated surface winds of $50 \mathrm{kt}$ and an eye diameter of about $25 \mathrm{~nm}$. An intensity of $55 \mathrm{kt}$ is selected for $18 \mathrm{Z}$ on the $17^{\text {th }}, 5 \mathrm{kt}$ less than originally shown in HURDAT. A central pressure of $987 \mathrm{mb}$ was present in HURDAT at $18 \mathrm{Z}$ on the $17^{\text {th }}$ and has been replaced with $992 \mathrm{mb}$. Beulah continued to weaken on June $18^{\text {th }}$ as it moved generally southward. A reconnaissance aircraft measured a central pressure of $997 \mathrm{mb}$ and estimated surface winds of $40 \mathrm{kt}$ at $01 \mathrm{Z}$ on the 
$18^{\text {th }}$. A central pressure of $997 \mathrm{mb}$ suggests maximum sustained winds of $54 \mathrm{kt}$ south of $25 \mathrm{~N}$ weakening from the pressure-wind relationship. Due to the slow forward speed of about $3 \mathrm{kt}$, an intensity of $50 \mathrm{kt}$ is selected at $00 \mathrm{Z}$ on the $18^{\text {th }}, 5 \mathrm{kt}$ less than originally shown in HURDAT, a minor intensity change. A central pressure of $997 \mathrm{mb}$ is added to HURDAT at $00 \mathrm{Z}$ on the $18^{\text {th }}$. Another two penetration center fixes measured $1001 \mathrm{mb}$, estimated surface winds of $30 \mathrm{kt}$ at $1330 \mathrm{Z}$ and $19 \mathrm{Z}$ on the $18^{\text {th }}$. A central pressure of 1001 mb suggests maximum sustained winds of $45 \mathrm{kt}$ south of $25 \mathrm{~N}$ from the pressure-wind relationship. Due to the slow forward speed of about $2 \mathrm{kt}$ and low environmental pressures, an intensity of $40 \mathrm{kt}$ is selected at $12 \mathrm{Z}$ and $18 \mathrm{Z}$ on the $17^{\text {th }}$, up from $35 \mathrm{kt}$ and $30 \mathrm{kt}$, respectively, in HURDAT, minor intensity changes. A central pressure of $1001 \mathrm{mb}$ is added to HURDAT at $12 \mathrm{Z}$ and $18 \mathrm{Z}$ on the $18^{\text {th }}$. The last position in HURDAT is at $18 \mathrm{Z}$ on the $18^{\text {th }}$ over the Gulf of Mexico but surface observations, especially Tampico and Tuxpan, indicate that Beulah remained a closed low pressure system for at least twelve more hours. The small tropical cyclone moved southwestward early on June $19^{\text {th }}$ making landfall about $02 \mathrm{Z}$ around $21.7 \mathrm{~N}, 97.5 \mathrm{~W}$ near Cabo Rojo, Mexico or about halfway between Tuxpan and Tampico, as a $35 \mathrm{kt}$ tropical storm. Having the system make landfall before dissipating is consistent with the assessment in the MWR. Weakening to a tropical depression is analyzed at $06 \mathrm{Z}$ on the $19^{\text {th }}$, twelve hours later than originally shown in HURDAT. Dissipation occurred shortly after $06 Z$ on the $19^{\text {th }}$.

\section{Unnamed Tropical Storm \#3 [June 18-22, 1959]}

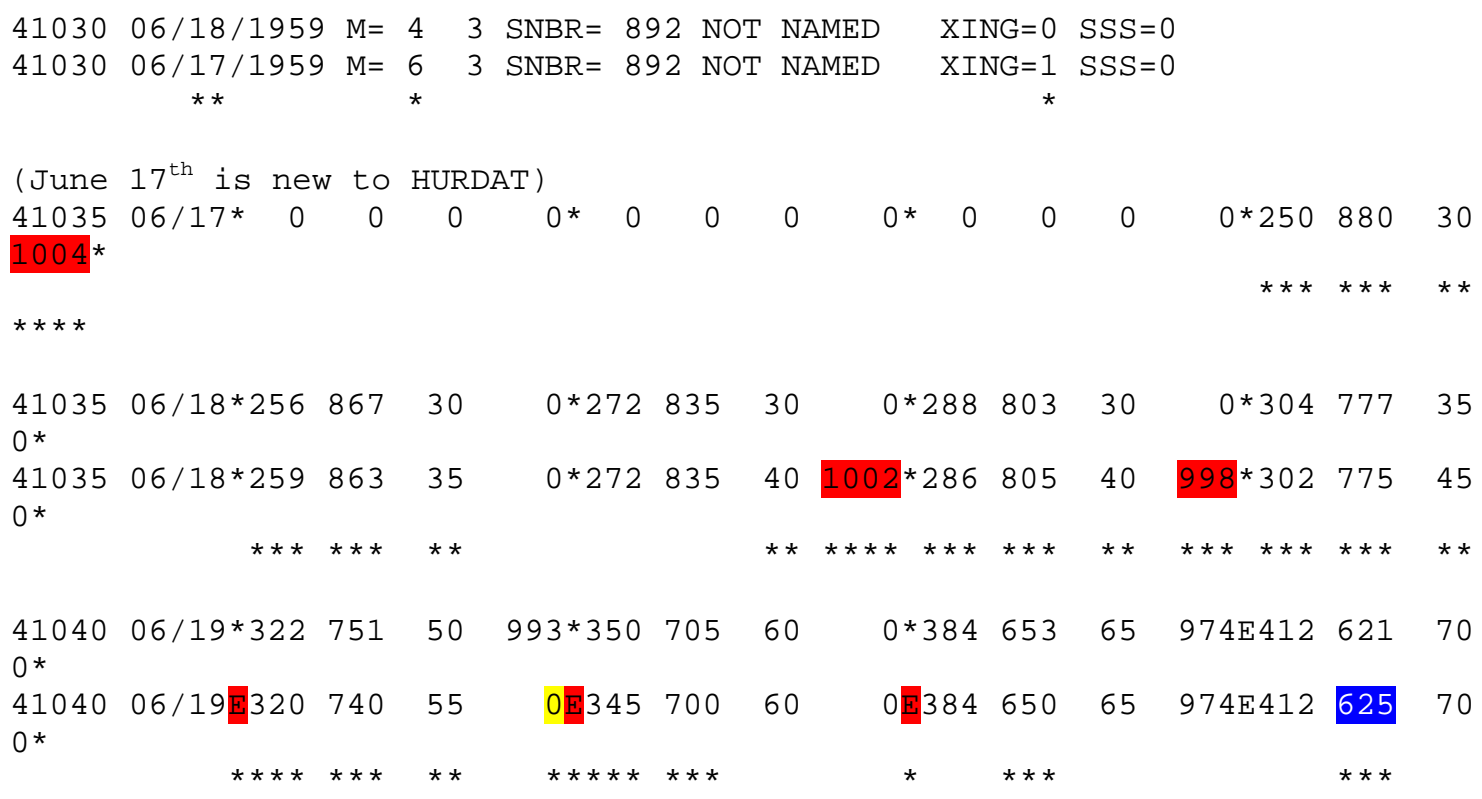




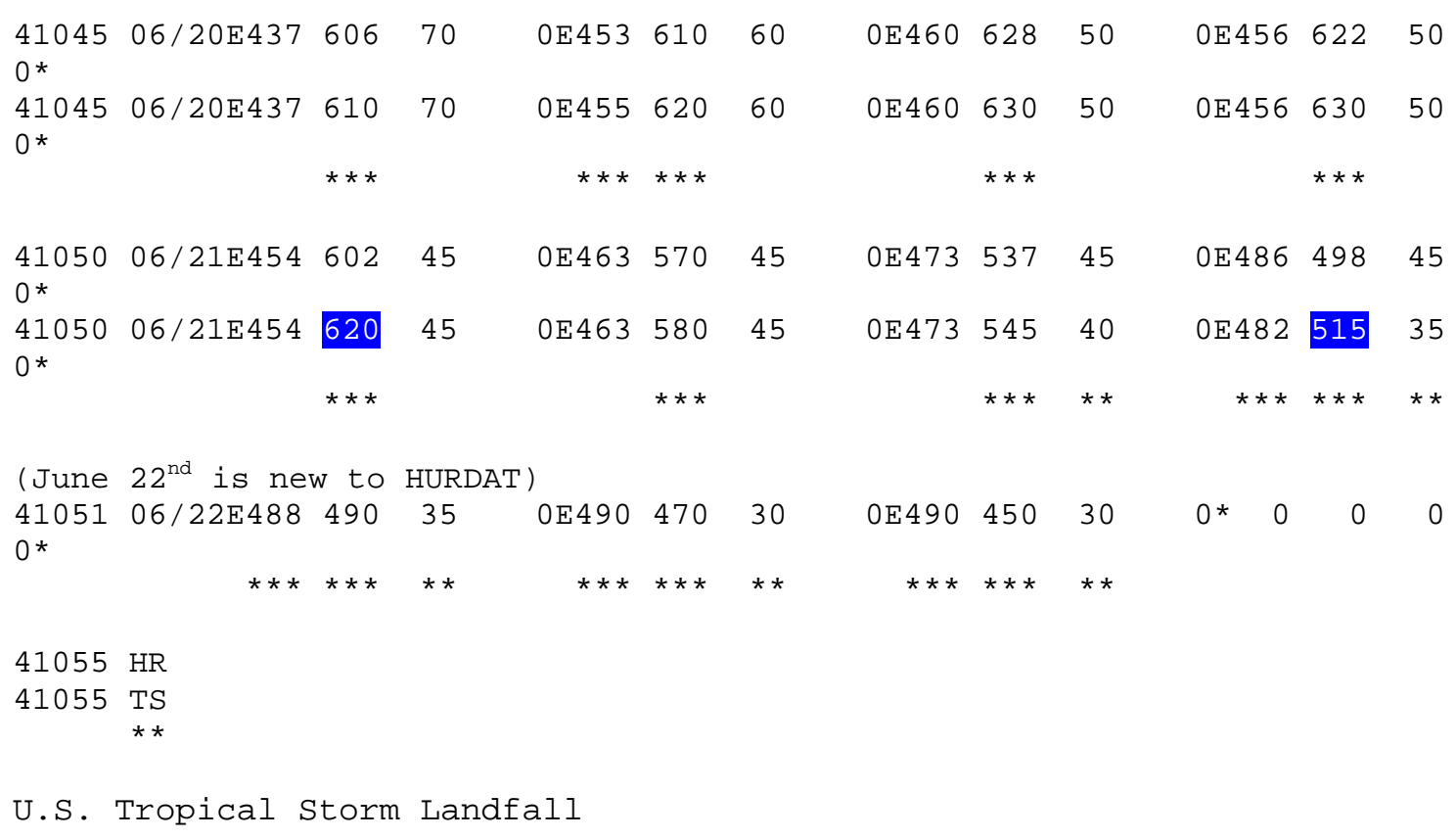

06/18 $08 \mathrm{Z} 27.6 \mathrm{~N} 82.7 \mathrm{~W} 40 \mathrm{kt} \mathrm{FL}$

Minor changes to the track and intensity shown in McAdie et al. (2009). Additionally, extratropical transition is shown 18 hours earlier than originally in HURDAT. Evidence for these alterations comes from the NHC microfilm maps, the Historical Weather Maps series, the COADS ship database, Monthly Weather Review, Surface Weather Observations, and Mariners weather Log.

June 15:

HWM analyzes a stationary cold front over the northern Gulf of Mexico at $12 Z$. HURDAT does not list an organized system on this date. Microfilm Ship highlights: No gales or low pressures.

MWR: "While Beulah was developing in the southwestern Gulf of Mexico, an unstable easterly wave was noted in the northwestern Caribbean on June 15."

June 16:

HWM analyzes a spot low at 24. ON, 89. OW with a stationary front to the northwest and Beulah to the west at $12 Z$. HURDAT does not list an organized system on this date. Microfilm shows a trough over the central Gulf of Mexico at 12Z. Ship highlights: $35 \mathrm{kt}$ SE and $1008 \mathrm{mb}$ at $25.3 \mathrm{~N}, 87.1 \mathrm{~W}$ at $12 \mathrm{Z}$ (COADS). $35 \mathrm{kt} \mathrm{S}$ and $1012 \mathrm{mb}$ at $26.3 \mathrm{~N}, 86.8 \mathrm{~W}$ at $18 \mathrm{Z}$ (COADS) .

MWR: "This wave moved northwestward into the central Gulf on the $16^{\text {th }} . "$ 
June 17:

HWM analyzes a tropical storm of at most $1005 \mathrm{mb}$ at $24.0 \mathrm{~N}, 89 . \mathrm{OW}$ with a weakening front to the northeast and Beulah to the west at $12 Z$. HURDAT does not list an organized system on this date. Microfilm shows a closed low pressure of at most $1005 \mathrm{mb}$ at $28.5 \mathrm{~N}, 87.0 \mathrm{~W}$ at $12 \mathrm{Z}$. Ship highlights: $5 \mathrm{kt} \mathrm{SE}$ and $1004 \mathrm{mb}$ at $25.0 \mathrm{~N}, 89.3 \mathrm{~W}$ at $12 \mathrm{Z}$ (HWM). $5 \mathrm{kt} \mathrm{S}$ and $1005 \mathrm{mb}$ at $25.0 \mathrm{~N}, 87.4 \mathrm{~W}$ at $18 \mathrm{Z}$ (COADS).

MWR: "A weak closed circulation appeared in the east-central Gulf on the 17th. It began moving northeastward."

June 18:

HWM analyzes a tropical storm of at most $1000 \mathrm{mb}$ at $28.2 \mathrm{~N}, 80.4 \mathrm{~W}$ with a stationary front to the northeast at $12 \mathrm{Z}$. HURDAT lists a 30 knot tropical depression at $28.8 \mathrm{~N}, 80.3 \mathrm{~W}$ at $12 \mathrm{Z}$. Microfilm shows a closed low pressure of at most $1005 \mathrm{mb}$ at 29. $\mathrm{ON}$, 80. OW with a frontal boundary to the north at $12 \mathrm{Z}$. Ship highlights: $35 \mathrm{kt} \mathrm{S}$ and $1006 \mathrm{mb}$ at $25.7 \mathrm{~N}$, $85.3 \mathrm{~W}$ at $00 \mathrm{Z}$ (COADS). $35 \mathrm{kt} \mathrm{SSW}$ and $1016 \mathrm{mb}$ at $27.2 \mathrm{~N}, 79.3 \mathrm{~W}$ at $12 \mathrm{Z}$ (COADS). $45 \mathrm{kt} \mathrm{NE}$ and $1003 \mathrm{mb}$ at $30.7 \mathrm{~N}, 76.6 \mathrm{~W}$ at $18 \mathrm{Z}$ (COADS). $40 \mathrm{kt} \mathrm{SW}$ and $997 \mathrm{mb}$ at $30.7 \mathrm{~N}, 75.9 \mathrm{~W}$ at $20 \mathrm{Z}$ (MWL). $55 \mathrm{kt}$ SE and $982 \mathrm{mb}$ (possible low pressure bias) at $30.7 \mathrm{~N}, 74.7 \mathrm{~W}$ at $20 \mathrm{Z}$ (micro). Land highlights: 40 kt $\mathrm{S}$ and $1008 \mathrm{mb}$ at Dry Tortugas Light, $\mathrm{FL}$ at $\odot \odot \mathrm{Z}$ (micro). $40 \mathrm{kt}$ at West Palm Beach, FL (no time given) (CLIMO). $18 \mathrm{kt} \mathrm{SW}$ and $1004 \mathrm{mb}$ at Tampa, FL at $08 Z$ (SWO). $12 \mathrm{kt} \mathrm{SW}$ and $1003 \mathrm{mb}$ at MacDill AFB, FL at $09 \mathrm{Z}$ (SWO). $35 \mathrm{kt} \mathrm{W}$ at Sarasota, FL at $12 Z$ (SWO). $20 \mathrm{kt}$ SSW and $1002 \mathrm{mb}$ at Cape Canaveral, FL at $12 Z$ (SWO). $35 \mathrm{kt}$ WNW at Sarasota, FL at $13 Z$ (SWO). $35 \mathrm{kt} \mathrm{NW}$ at Sarasota, FL at $14 Z$ (SWO).

MWR: "When the tropical depression was still about 350 miles west of Miami, a tornado moved across the city of Miami at about $10 \mathrm{pm}$ EST on the $17^{\text {th }}$, lasting 20-30 minutes and causing approximately $\$ 1,500,000$ damage, many injuries, but no deaths. At the same time another tornado formed north of West Palm Beach and lasted about 20 minutes but fortunately traversed a sparsely inhabited area. The tropical cyclone moved across central Florida during the night of June 17-18 attended by heavy rains and gusty winds, fluctuating rapidly in the SarasotaBradenton area from 9-13 kt to $43 \mathrm{kt}$. Tides 2 to 3 feet above normal were reported along the beaches from St. Petersburg to Naples causing damage estimated at $\$ 156,000$. The torrential rains following previous heavy rainfall caused considerable additional damage to crops, particularly in the Fort Myers area. Several bulletins on this storm were issued by the Miami Hurricane Center. The last, on the afternoon of June 18, indicated winds of 43 to $56 \mathrm{kt}$, and the likelihood of additional development, and contained cautionary advices to shipping."

June 19:

HWM analyzes a hurricane of at most $990 \mathrm{mb}$ at $37.2 \mathrm{~N}, 66.5 \mathrm{~W}$ with a cold front to the southwest and a weakening front to the west and north at $12 \mathrm{Z}$. HURDAT lists a 65 knot hurricane at $38.4 \mathrm{~N}, 65.3 \mathrm{~W}$ at $12 \mathrm{Z}$. Microfilm shows a closed low pressure of at most $999 \mathrm{mb}$ at $38.5 \mathrm{~N}, 65 . \mathrm{W}$ at 12Z. Ship highlights: $50 \mathrm{kt} W$ and $1008 \mathrm{mb}$ at $26.6 \mathrm{~N}, 74.4 \mathrm{~W}$ at $00 \mathrm{Z}$ 
(COADS). $60 \mathrm{kt} \mathrm{WSW} \mathrm{(gusts} \mathrm{to} 80 \mathrm{kt}$ ) and $993 \mathrm{mb}$ at $0250 \mathrm{Z}$ (micro). $35 \mathrm{kt}$ SSW and $1013 \mathrm{mb}$ at $29.1 \mathrm{~N}, 71.2 \mathrm{~W}$ at $06 \mathrm{Z}$ (COADS). $65 \mathrm{kt} \mathrm{NW}$ and $999 \mathrm{mb}$ at $38.7 \mathrm{~N}, 65.3 \mathrm{~W}$ at $12 \mathrm{Z}$ (micro). $35 \mathrm{kt} \mathrm{SSW}$ and $1013 \mathrm{mb}$ at $29.1 \mathrm{~N}, 71.2 \mathrm{~W}$ at 06Z (COADS). $974 \mathrm{mb}$ (no position or time given, but likely around 12Z) (MWR). $40 \mathrm{kt}$ SSE and $985 \mathrm{mb}$ at $40.5 \mathrm{~N}, 61.5 \mathrm{~W}$ at $18 \mathrm{Z}$ (COADS).

MWR: "After passing off the Florida east coast the storm deepened steadily and at 0250 GMT on the 19th, the Atlantic Union reported a barometer reading of $993 \mathrm{mb}$, falling, and west-southwesterly winds occasionally $80 \mathrm{kt}$. Although the hurricane was in a diffused frontal zone, it now appears to have remained warm-core and essentially tropical for some time. The lowest reported pressure was $974 \mathrm{mb}$. The hurricane struck the Canadian Maritime Provinces in the vicinity of Northumberland Straits. Associated wind and barometric data as the storm moved inland are lacking, but the press reported 33 deaths, mostly lobster fishermen, and considerable property damage. Notices of this severe storm had been carried in the NSS bulletins."

June 20 :

HWM analyzes a tropical storm of at most $985 \mathrm{mb}$ at $46 . \mathrm{ON}, 64 . \mathrm{W}$ with a weakening cold front to the west and a cold front to the east at 12Z. HURDAT lists a 50 knot extratropical cyclone at $46.0 \mathrm{~N}, 62.8 \mathrm{~W}$ at 12Z. Microfilm shows a closed low pressure of at most $984 \mathrm{mb}$ at $45.5 \mathrm{~N}$, $63.7 \mathrm{~W}$ with a frontal boundary to the west at 12Z. Ship highlights: 50 $\mathrm{kt} \mathrm{NW}$ and $997 \mathrm{mb}$ at $42.6 \mathrm{~N}, 62.4 \mathrm{~W}$ at $00 \mathrm{Z}$ (COADS). $35 \mathrm{kt}$ ESE and $998 \mathrm{mb}$ at $46.0 \mathrm{~N}, 58.0 \mathrm{~W}$ at $06 \mathrm{Z}$ (COADS). $45 \mathrm{kt} \mathrm{SW}$ and $989 \mathrm{mb}$ at $44.4 \mathrm{~N}, 63.4 \mathrm{~W}$ at $12 Z$ (COADS). $35 \mathrm{kt} \mathrm{S}$ and $989 \mathrm{mb}$ at $44.8 \mathrm{~N}, 61.8 \mathrm{~W}$ at $18 \mathrm{Z}$ (COADS). Land highlights: $50 \mathrm{kt} \mathrm{E}$ and $993 \mathrm{mb}$ at Iles de la Madelaine, Canada at $06 \mathrm{Z}$ (micro). $35 \mathrm{kt} \mathrm{ESE}$ and $995 \mathrm{mb}$ at Iles de la Madelaine, Canada at $12 \mathrm{Z}$ (micro).

MWR: "The hurricane struck the Canadian Maritime Provinces in the vicinity of Northumberland Straits. Associated wind and barometric data as the storm moved inland are lacking, but the press reported 33 deaths, mostly lobster fishermen, and considerable property damage. Notices of this severe storm had been carried in the NSS bulletins."

June 21:

HWM analyzes a closed low pressure of at most $1000 \mathrm{mb}$ at $47.0 \mathrm{~N}$, 55. OW with a weakening front to the east at $12 Z$. HURDAT lists a 45 knot extratropical cyclone at $47.3 \mathrm{~N}, 53.7 \mathrm{~W}$ at $12 \mathrm{Z}$. Microfilm shows a closed low pressure of at most $999 \mathrm{mb}$ at $47.0 \mathrm{~N}, 54.0 \mathrm{~W}$ at 12Z. Ship highlights: $45 \mathrm{kt} \mathrm{SW}$ and $1001 \mathrm{mb}$ at $41.2 \mathrm{~N}, 60.7 \mathrm{~W}$ at $00 \mathrm{Z}$ (COADS). $45 \mathrm{kt} \mathrm{W}$ at $37.7 \mathrm{~N}$, $59.7 \mathrm{~W}$ at $06 \mathrm{Z}$ (COADS). $35 \mathrm{kt}$ WSW and $1008 \mathrm{mb}$ at $41.1 \mathrm{~N}, 52.9 \mathrm{~W}$ at $12 \mathrm{Z}$ (COADS). $35 \mathrm{kt} \mathrm{SW}$ and $1006 \mathrm{mb}$ at $42.4 \mathrm{~N}, 49.6 \mathrm{~W}$ at $18 \mathrm{Z}$ (COADS).

June 22:

HWM analyzes a closed low pressure of at most $1000 \mathrm{mb}$ at $49.0 \mathrm{~N}$, 43. OW with a cold front to the northwest at $12 \mathrm{Z}$. HURDAT does not list 
an organized storm on this date. Microfilm shows a closed low pressure of at most $1002 \mathrm{mb}$ at $58.0 \mathrm{~N}, 32 . \mathrm{W}$ at 12Z. Ship highlights: $35 \mathrm{kt} \mathrm{W}$ and $1011 \mathrm{mb}$ at $42.2 \mathrm{~N}, 50.5 \mathrm{~W}$ at $00 \mathrm{Z}$ (COADS).

June 23:

HWM analyzes an extratropical cyclone of at most $1000 \mathrm{mb}$ at $52.0 \mathrm{~N}, 27 . \mathrm{OW}$ at $12 \mathrm{Z}$. HURDAT does not list an organized storm on this date. Microfilm shows a closed low pressure of at most $1005 \mathrm{mb}$ at $55.0 \mathrm{~N}, 30 . \mathrm{W}$ with a frontal boundary to the north at $12 \mathrm{Z}$. Ship highlights: No gales or low pressures.

A tropical wave reached the western Caribbean Sea around mid-June and soon after entered the southeastern Gulf of Mexico. At the same time, Tropical Storm Bertha was brewing over the southwest Gulf. The disturbance remained largely disorganized on June $16^{\text {th }}$ and early on the $17^{\text {th }}$ while moving very slowly westward, almost stationary. The system began to move northeastward late on the $17^{\text {th }}$ and became better organized. Genesis is analyzed at $18 \mathrm{z}$ on the $17^{\text {th }}$ as a $30 \mathrm{kt}$ tropical depression, six hours earlier than originally shown in HURDAT. A ship near the center reported $5 \mathrm{kt} \mathrm{S}$ and $1005 \mathrm{mb}$ at $18 \mathrm{Z}$ on the $17^{\text {th }}$ indicating a central pressure of $1004 \mathrm{mb}$, which has been added to HURDAT. Minor track alterations are indicated during the lifetime of this tropical cyclone. The tropical cyclone exhibited some subtropical characteristics from the beginning, including the large size of the circulation and the strongest winds being present about $200 \mathrm{~nm}$ away from the center in the eastern quadrant. Intensification to a tropical storm occurred at $\odot \odot Z$ on June $18^{\text {th }}$, eighteen hours earlier than originally shown in HURDAT. The first report of gale-force winds occurred at $\odot \odot z$ on the $18^{\text {th }}$ as a ship reported $35 \mathrm{kt}$ in the southeast quadrant. The tropical storm moved rapidly to the northeast reaching the Florida Gulf coast early on the $18^{\text {th }}$. MacDill Air Force Base near Tampa, FL reported $12 \mathrm{kt} \mathrm{SW}$ and $1003 \mathrm{mb}$ at $09 \mathrm{Z}$ on the $18^{\text {th }}$ indicating a central pressure of $1002 \mathrm{mb}$, which has been added to HURDAT at $06 \mathrm{Z}$. A central pressure of $1002 \mathrm{mb}$ suggests maximum sustained winds of $40 \mathrm{kt}$ north of $25 \mathrm{~N}$ from the Brown et al. pressure-wind relationship. Since the tropical storm was moving at about $33 \mathrm{kt}$ but had a large circulation, an intensity of $4 \odot \mathrm{kt}$ is selected at $\odot 6 \mathrm{Z}$ on the $18^{\text {th }}$, up from $30 \mathrm{kt}$ originally in HURDAT, a minor intensity change. Landfall occurred around $\odot 8 \mathrm{Z}$ as a $40 \mathrm{kt}$ tropical storm near $27.6 \mathrm{~N}, 82.7 \mathrm{~W}$ or about $10 \mathrm{~nm}$ southwest of St. Petersburg. This intensity is consistent with $35 \mathrm{kt}$ sustained wind reports from Sarasota, FL. The landfall intensity is $10 \mathrm{kt}$ higher than originally shown in HURDAT, a minor intensity change. The synoptic map at $06 \mathrm{Z}$ on the $18^{\text {th }}$ indicates that the tropical storm was elongated NE-SW and a moderate temperature gradient was starting to develop between the northeastern and southeastern quadrants. Still, the tropical storm was embedded within a tropical airmass and the approaching cold front was located over central Georgia. Cape Canaveral reported $20 \mathrm{kt} \mathrm{SSW}$ (land exposure wind) and 
$1002 \mathrm{mb}$ at $12 \mathrm{Z}$ on the $18^{\mathrm{th}}$, suggesting a central pressure of about 998 $\mathrm{mb}$, which has been added to HURDAT. The tropical storm rapidly crossed Florida, entering the Atlantic at about $11 z$ on the $18^{\text {th }}$. The tropical cyclone rapidly began to intensify over the Atlantic ocean late on the $18^{\text {th }}$ as it began to acquire extratropical characteristics. Transition to an extratropical cyclone is analyzed at $\odot \odot z$ on June $19^{\text {th }}$, eighteen hours earlier than originally shown in HURDAT. The synoptic map at $\odot \odot z$ on the $19^{\text {th }}$ clearly shows that the cyclone had developed a warm and cold front, along with a significant temperature gradient. The peak intensity of this system as a tropical cyclone is analyzed at $45 \mathrm{kt}$ at $12 \mathrm{Z}$ on the $19^{\text {th }}$, likely partially influenced by baroclinic processes. This is $20 \mathrm{kt}$ lower than originally shown in HURDAT, which indicated that the peak intensity was $65 \mathrm{kt}$ at $18 \mathrm{Z}$ on the $18^{\text {th }}$, a major intensity change.

A central pressure of $993 \mathrm{mb}$ was present in HURDAT at $\odot \odot Z$ on the $19^{\text {th }}$ and has been removed since this was reported by a ship at $0230 \mathrm{z}$ along with winds of $60 \mathrm{kt}$ and gusts to $80 \mathrm{kt}$. Two ships reported $65 \mathrm{kt}$ at $12 \mathrm{Z}$ on the $19^{\text {th }}$ and it is analyzed that the extratropical cyclone reached hurricane-force intensity at this time, same as the original HURDAT. A central pressure of $974 \mathrm{mb}$ was present in HURDAT at $12 \mathrm{Z}$ on the $19^{\text {th }}$ and has been retained as it seems reasonable, although it is only mentioned in the Monthly weather Review and does not appear in any of the other available sources. It is also interesting to mention that while extratropical, the synoptic map at $12 \mathrm{Z}$ on the $19^{\text {th }}$ shows that the system retained a tight core of strong winds. The extratropical cyclone interacted with another extratropical cyclone over the Northeast of the United States on the $19^{\text {th }}$ causing the motion of the system to change to the north and later northwest. Weakening below hurricane force occurred at $06 z$ on June $20^{\text {th }}$, same as originally shown in HURDAT. Early on the $20^{\text {th }}$, the strong extratropical cyclone made landfall over Nova Scotia and remained over the area for the next eighteen hours. The extratropical cyclone began to move eastward early on the $21^{\text {st }}$ and continued to weaken. The center crossed eastern Newfounland around $12 \mathrm{Z}$ on the $21^{\text {st }}$ and weakening below gale-force winds occurred at $06 z$ on June $22^{\text {nd }}$. The weak extratropical cyclone was absorbed by a large extratropical cyclone located southeast of Greenland after $12 \mathrm{Z}$ on the $22^{\text {nd }}$, eighteen hours later than originally shown in HURDAT.

Tropical Storm Cindy [July 4-12, 1959]

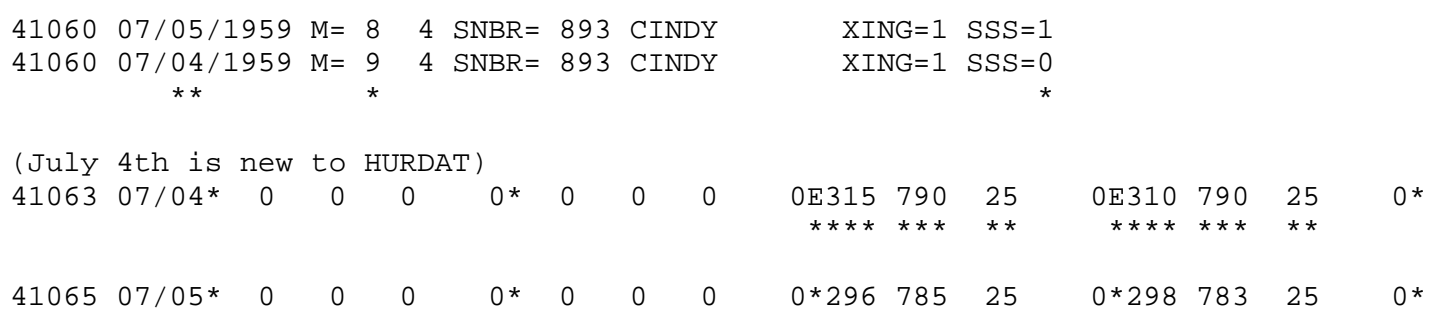




\begin{tabular}{|c|c|c|c|c|c|c|c|c|c|c|c|c|c|}
\hline 41065 & $\begin{array}{r}07 / 05 \mathrm{E} 305 \\
* * * *\end{array}$ & $\begin{array}{l}789 \\
\star * *\end{array}$ & $\begin{array}{l}25 \\
* *\end{array}$ & $\begin{array}{r}\odot \mathrm{E} 30 \odot \\
\star \star \star *\end{array}$ & $\begin{array}{l}787 \\
\star * *\end{array}$ & $\begin{array}{l}25 \\
\star *\end{array}$ & $\begin{array}{r}\odot * 298 \\
* \star *\end{array}$ & 785 & 25 & ๑*298 & 783 & 25 & ○* \\
\hline $\begin{array}{l}41070 \\
41070\end{array}$ & $\begin{array}{l}07 / 06 * 30 \odot \\
07 / 06 * 30 \odot\end{array}$ & $\begin{array}{l}782 \\
782\end{array}$ & $\begin{array}{l}25 \\
25\end{array}$ & $\begin{array}{l}0 * 303 \\
0 * 303\end{array}$ & $\begin{array}{l}780 \\
780\end{array}$ & $\begin{array}{l}25 \\
25\end{array}$ & $\begin{array}{l}0 * 306 \\
0 * 305 \\
* * *\end{array}$ & $\begin{array}{l}779 \\
779\end{array}$ & $\begin{array}{l}25 \\
30 \\
* *\end{array}$ & $\begin{array}{r}\Theta * 309 \\
\Theta * 308 \\
* * *\end{array}$ & $\begin{array}{l}776 \\
777 \\
* * *\end{array}$ & $\begin{array}{l}25 \\
35 \\
* *\end{array}$ & $\begin{array}{l}\Theta^{*} \\
\Theta^{*}\end{array}$ \\
\hline $\begin{array}{l}41075 \\
41075\end{array}$ & $\begin{array}{r}07 / 07 * 312 \\
07 / 07 * 313 \\
* * *\end{array}$ & $\begin{array}{l}773 \\
774 \\
\star * *\end{array}$ & $\begin{array}{l}30 \\
4 \odot \\
\star *\end{array}$ & $\begin{array}{r}0 * 315 \\
0 * 318 \\
* * *\end{array}$ & $\begin{array}{l}771 \\
772 \\
\star * *\end{array}$ & $\begin{array}{l}35 \\
4 \odot \\
\star *\end{array}$ & $\begin{array}{c}0 * 317 \\
0 * 320 \\
* \star *\end{array}$ & $\begin{array}{l}770 \\
770 \\
* * *\end{array}$ & $\begin{array}{l}45 \\
45\end{array}$ & $\begin{array}{l}\odot * 321 \\
\odot * 321\end{array}$ & $\begin{array}{l}768 \\
769 \\
* * *\end{array}$ & $\begin{array}{l}50 \\
50\end{array}$ & $\begin{array}{l}\Theta^{*} \\
\Theta^{*}\end{array}$ \\
\hline $\begin{array}{l}41080 \\
41080\end{array}$ & $\begin{array}{r}07 / 08 * 324 \\
07 / 08 * 322 \\
* * *\end{array}$ & $\begin{array}{l}769 \\
770 \\
* * *\end{array}$ & $\begin{array}{l}55 \\
55\end{array}$ & $\begin{array}{r}0 * 324 \\
997 * 323 \\
* * * * * *\end{array}$ & $\begin{array}{l}775 \\
775 \\
* * *\end{array}$ & $\begin{array}{l}60 \\
60\end{array}$ & $\begin{array}{c}0 * 323 \\
0 * 324 \\
* * *\end{array}$ & $\begin{array}{l}782 \\
781 \\
\star \star *\end{array}$ & $\begin{array}{l}65 \\
60 \\
* *\end{array}$ & $\begin{array}{r}0 * 323 \\
995 * 324 \\
* * * * * *\end{array}$ & $\begin{array}{l}788 \\
787 \\
* * *\end{array}$ & $\begin{array}{l}65 \\
60 \\
\star *\end{array}$ & $\begin{array}{l}\Theta^{*} \\
\Theta^{*}\end{array}$ \\
\hline $\begin{array}{l}41085 \\
41085\end{array}$ & $\begin{array}{r}07 / 09 * 324 \\
07 / 09 * 325 \\
* * *\end{array}$ & $\begin{array}{l}793 \\
794 \\
* * *\end{array}$ & $\begin{array}{l}65 \\
60 \\
\star *\end{array}$ & $\begin{array}{r}0 * 330 \\
995 * 332 \\
* * * * * *\end{array}$ & $\begin{array}{l}798 \\
80 \odot \\
* * *\end{array}$ & $\begin{array}{l}50 \\
50\end{array}$ & $\begin{array}{l}0 * 337 \\
0 * 337\end{array}$ & $\begin{array}{l}802 \\
802\end{array}$ & $\begin{array}{l}35 \\
35\end{array}$ & $\begin{array}{l}\odot * 341 \\
0 * 341\end{array}$ & $\begin{array}{l}803 \\
803\end{array}$ & $\begin{array}{l}30 \\
30\end{array}$ & $\begin{array}{l}\Theta^{*} \\
\Theta^{*}\end{array}$ \\
\hline $\begin{array}{l}41090 \\
41090\end{array}$ & $\begin{array}{l}07 / 10 * 345 \\
07 / 10 * 345\end{array}$ & $\begin{array}{l}799 \\
799\end{array}$ & $\begin{array}{l}30 \\
30\end{array}$ & $\begin{array}{l}\Theta * 351 \\
\odot * 351\end{array}$ & $\begin{array}{l}792 \\
792\end{array}$ & $\begin{array}{l}30 \\
35 \\
\star *\end{array}$ & $\begin{array}{l}0 * 359 \\
0 * 359\end{array}$ & $\begin{array}{l}779 \\
779\end{array}$ & $\begin{array}{l}30 \\
35 \\
* *\end{array}$ & $\begin{array}{r}\odot * 370 \\
\odot * 369 \\
\star * *\end{array}$ & $\begin{array}{l}762 \\
764 \\
* * *\end{array}$ & $\begin{array}{l}35 \\
4 \odot \\
\star *\end{array}$ & $\begin{array}{l}\Theta^{*} \\
\Theta^{*}\end{array}$ \\
\hline $\begin{array}{l}41095 \\
41095\end{array}$ & $\begin{array}{r}07 / 11 * 382 \\
07 / 11 * 380 \\
* * *\end{array}$ & $\begin{array}{l}743 \\
746 \\
\star * *\end{array}$ & $\begin{array}{l}40 \\
45 \\
\star *\end{array}$ & $\begin{array}{l}0 * 395 \\
0 * 395\end{array}$ & $\begin{array}{l}724 \\
723 \\
\star * *\end{array}$ & $\begin{array}{l}45 \\
50 \\
\star *\end{array}$ & $\begin{array}{l}0 * 412 \\
0^{*} 412\end{array}$ & $\begin{array}{l}703 \\
703\end{array}$ & $\begin{array}{l}50 \\
50\end{array}$ & $\begin{array}{r}0 \mathrm{E} 435 \\
998 \mathrm{E} 443 \\
\star * * * * *\end{array}$ & $\begin{array}{l}677 \\
673 \\
* * *\end{array}$ & $\begin{array}{l}50 \\
45 \\
\star *\end{array}$ & $\begin{array}{l}\theta^{*} \\
100 \odot^{*} \\
* * * *\end{array}$ \\
\hline $\begin{array}{l}41100 \\
41100\end{array}$ & $\begin{array}{r}07 / 12 \mathrm{E} 458 \\
07 / 12 \mathrm{E} 463 \\
* * *\end{array}$ & $\begin{array}{l}649 \\
650 \\
* * *\end{array}$ & $\begin{array}{l}45 \\
4 \odot \\
\star *\end{array}$ & $\begin{array}{r}0 \mathrm{E} 480 \\
\text { OE483 } \\
* * *\end{array}$ & $\begin{array}{l}620 \\
620\end{array}$ & $\begin{array}{l}35 \\
35\end{array}$ & $\begin{array}{r}\text { OE5०2 } \\
\text { OE5०5 } \\
* * *\end{array}$ & $\begin{array}{l}591 \\
591\end{array}$ & $\begin{array}{l}35 \\
30 \\
* *\end{array}$ & $\begin{array}{c}\text { OE524 } \\
\text { OE530 } \\
* * *\end{array}$ & $\begin{array}{l}562 \\
562\end{array}$ & $\begin{array}{l}35 \\
25 \\
* *\end{array}$ & $\begin{array}{l}0^{*} \\
0^{*}\end{array}$ \\
\hline
\end{tabular}

41105 HR SC1

41105 TS

U.S. Tropical Storm Landfall

07/09 03Z 32.8N 79.7W 60 kt SC

07/11 12Z 41.2N 70.3W $50 \mathrm{kt} \mathrm{MA}$

07/11 13Z 41.7N 70.0W $50 \mathrm{kt} \mathrm{MA}$

Minor changes to the track and intensity shown in McAdie et al. (2009). Evidence for these alterations comes from the NHC microfilm maps, the Historical Weather Maps series, the COADS ship database, Monthly Weather Review, Navy reconnaissance book, Surface Weather Observations, Mariners Weather Log, Jarrell et al. (1992) and NHC Storm Wallets.

July 3:

HWM and microfilm analyze a frontal system over the southeast United States and northwestern Atlantic at 12Z. HURDAT does not list an organized system on this date. Ship highlights: No gales or low pressures. 
July 4:

HWM analyzes a spot low at $29.0 \mathrm{~N}, 80.0 \mathrm{~W}$ with a weakening cold front to the north at 12Z. HURDAT does not list an organized system on this date. Microfilm shows a closed low pressure of at most $1014 \mathrm{mb}$ at $32.0 \mathrm{~N}, 79.5 \mathrm{~W}$ with a frontal boundary to the north at 12Z. Ship highlights: No gales or low pressures.

ATSR: "Hurricane Cindy developed from a stagnant low on a trailing cold front off the northern Florida coast. As this low drifted eastward and then northward during the period of 4 to 7 July, it slowly warmed and intensified."

July 5:

HWM analyzes a closed low pressure of at most $1010 \mathrm{mb}$ with a warm front to the northeast at $29.8 \mathrm{~N}, 78.8 \mathrm{~W}$ at $12 \mathrm{Z}$. HURDAT lists a $25 \mathrm{knot}$ tropical depression at $29.6 \mathrm{~N}, 78.5 \mathrm{~W}$ at $12 \mathrm{Z}$ (first position). Microfilm shows a closed low pressure of at most $1011 \mathrm{mb}$ at $29.8 \mathrm{~N}, 78.7 \mathrm{~W}$ with a frontal boundary to the northeast at $12 \mathrm{Z}$. Ship highlights: No gales or low pressures.

MWR: "The circulation which produced the storm had been noticed first some three days earlier (July $5^{\text {th }}$ ) off the Florida upper east coast. A deepening low pressure system had moved from the Great Lakes to the Canadian Maritime Provinces while the associated cold front moved southeastward and became stationary from near Bermuda to extreme northern Florida. With the fracture of the short-wave trough, a cut-off Low developed off the south Atlantic coast-most pronounced at the $500-\mathrm{mb}$ level. Usually tropical storms forming in this type of situation develop slowly, remain small, and seldom intensify too much more than minimal hurricane strength. Cindy conformed to this pattern."

July 6:

HWM analyzes a tropical storm of at most $1010 \mathrm{mb}$ at $31.2 \mathrm{~N}, 77.8 \mathrm{~W}$ at $12 \mathrm{Z}$. HURDAT lists a 25 knot tropical depression at $30.6 \mathrm{~N}, 77.9 \mathrm{~W}$ at $12 \mathrm{Z}$. Microfilm shows a closed low pressure of at most $1011 \mathrm{mb}$ at $31.0 \mathrm{~N}, 78.1 \mathrm{~W}$ at 12Z. Ship highlights: No gales or low pressures.

MWR: "On July 6, winds just east of the center increased to 26-35 kt as convective activity, evidenced by numerous showers extending outward some 200 miles to the north, contributed to the conversion from a cold to a warm-core system. An intensifying anticyclone increased the easterly gradient north of the center and Cindy developed and intensified"

July 7:

HWM analyzes a tropical storm of at most $1010 \mathrm{mb}$ at $32.0 \mathrm{~N}, 76.4 \mathrm{~W}$ with a cold front to the north at 12Z. HURDAT lists a 45 knot tropical storm at $31.7 \mathrm{~N}, 77.0 \mathrm{~W}$ at 12Z. Microfilm shows a closed low pressure of at most $1014 \mathrm{mb}$ at $32.0 \mathrm{~N}, 77.5 \mathrm{~W}$ at $12 \mathrm{Z}$. 
Ship highlights: $40 \mathrm{kt} \mathrm{S}$ at $31.4 \mathrm{~N}, 76.0 \mathrm{~W}$ at $00 \mathrm{Z}$ (COADS). $40 \mathrm{kt} \mathrm{SW}$ and $1015 \mathrm{mb}$ at $30.2 \mathrm{~N}, 77.0 \mathrm{~W}$ at $06 \mathrm{Z}$ (COADS). $50 \mathrm{kt} \mathrm{S}$ and $1013 \mathrm{mb}$ at $32.0 \mathrm{~N}, 76.2 \mathrm{~W}$ at $12 \mathrm{Z}$ (COADS). $50 \mathrm{kt} \mathrm{SSE}$ and $1008 \mathrm{mb}$ at $32.4 \mathrm{~N}, 76.5 \mathrm{~W}$ at $18 \mathrm{Z}$ (COADS). $50 \mathrm{kt} \mathrm{S}$ and $1013 \mathrm{mb}$ at $31.8 \mathrm{~N}, 76.4 \mathrm{~W}$ at $23 \mathrm{Z}$ (MWL). Aircraft highlights: Penetration center fix measured a central pressure of $997 \mathrm{mb}$, estimated maximum surface winds of $60 \mathrm{kt}$ and an eye diameter of $15 \mathrm{~nm}$ at $32.2 \mathrm{~N}, 76.9 \mathrm{~W}$ at $2145 \mathrm{Z}$ (ATSR).

MWR: "A reconnaissance plane located the eye late on the afternoon of the 7th some 190 miles east of Charleston with maximum winds 52 to $56 \mathrm{kt}$ and minimum pressure 997 mb." ATSR: "At 072145Z, a Navy reconnaissance aircraft reported a wind, cloud, and pressure eye which indicated that this circulation had attained tropical characteristics. First warning on CINDY was issued at 072330Z."

July 8:

HWM analyzes a hurricane of at most $1005 \mathrm{mb}$ at $32.9 \mathrm{~N}, 76.7 \mathrm{~W}$ with a weakening cold front to the north at $12 \mathrm{Z}$. HURDAT lists a 65 knot hurricane at $32.3 \mathrm{~N}$, $78.2 \mathrm{~W}$ at $12 \mathrm{Z}$. Microfilm shows a closed low pressure of at most $1011 \mathrm{mb}$ at $32.2 \mathrm{~N}$, $78.1 \mathrm{~W}$ with a frontal boundary to the north at $12 \mathrm{Z}$. Ship highlights: $50 \mathrm{kt} \mathrm{S}$ and $1005 \mathrm{mb}$ at $32.1 \mathrm{~N}, 76.6 \mathrm{~W}$ at $00 \mathrm{Z}(\mathrm{COADS}) .50 \mathrm{kt} \mathrm{S}$ and $1012 \mathrm{mb}$ at $31.7 \mathrm{~N}, 77.0 \mathrm{~W}$ at $06 \mathrm{Z}$ (COADS). $50 \mathrm{kt} \mathrm{NNW}$ and $1012 \mathrm{mb}$ at $32.0 \mathrm{~N}, 79.0 \mathrm{~W}$ at $09 \mathrm{Z}$ (micro). $25 \mathrm{kt} \mathrm{ENE}$ and 998 $\mathrm{mb}$ at $32.2 \mathrm{~N}, 78.7 \mathrm{~W}$ at $11 \mathrm{Z}$ (micro). $35 \mathrm{kt} \mathrm{SE}$ and $1021 \mathrm{mb}$ at $32.9 \mathrm{~N}, 75.9 \mathrm{~W}$ at $12 \mathrm{Z}$ (COADS). $55 \mathrm{kt} \mathrm{ESE}$ and $1014 \mathrm{mb}$ at 32.8N, 77.3W at 15Z (MWL). $45 \mathrm{kt} \mathrm{NW}$ and 1011 $\mathrm{mb}$ at $32.3 \mathrm{~N}, 79.2 \mathrm{~W}$ at $18 \mathrm{Z}$ (COADS). Land highlights: $41 \mathrm{kt} \mathrm{N}$ (fastest mile) at Charleston, SC (no time given, but likely late on the $8^{\text {th }}$ ) (CLIMO). $1005 \mathrm{mb}$ at Charleston, SC (no time given, but likely late on the $8^{\text {th }}$ or early on the $9^{\text {th }}$ ) (CLIMO). Aircraft highlights: Radar center fix at $32.5 \mathrm{~N}, 76.9 \mathrm{~W}$ at $00 \mathrm{Z}$ (ATSR). Radar center fix estimated an eye diameter of $17 \mathrm{~nm}$ at $32.3 \mathrm{~N}, 77.6 \mathrm{~W}$ at $0542 \mathrm{Z}$ (ATSR). Penetration center fix measured a central pressure of $995 \mathrm{mb}$, estimated maximum surface winds of $35 \mathrm{kt}$ and an eye diameter of $12 \mathrm{~nm}$ at $32.3 \mathrm{~N}, 78.2 \mathrm{~W}$ at $13 \mathrm{Z}$ (ATSR). Penetration center fix measured a central pressure of $1000 \mathrm{mb}$, estimated maximum surface winds of $60 \mathrm{kt}$ and an eye diameter of $15 \mathrm{~nm}$ at $32.4 \mathrm{~N}, 78.8 \mathrm{~W}$ at $1727 \mathrm{Z}$ (ATSR). Penetration center fix measured a central pressure of $995 \mathrm{mb}$ at $32.5 \mathrm{~N}, 79.2 \mathrm{~W}$ at $23 \mathrm{Z}$ (ATSR).

ATSR: "Under the influence of a $200 \mathrm{mb}$ high cell, CINDY continued to intensify attaining a maximum wind speed of 65 knots just before passing inland near Charleston, South Carolina, on the afternoon of 8 July." Preliminary Report: "During the night of July 7-8 it began moving slowly westward toward the South Carolina coast, under close surveillance by Navy reconnaissance aircraft operating from Jacksonville and Air Defense Command land based radar located near Charleston, SC and Wilmington, NC. It barely reached hurricane force July 8 , with highest winds in squalls near the center of 70 to 75 miles per hour." 
July 9:

HWM analyzes a tropical storm of at most $1015 \mathrm{mb}$ at $34.2 \mathrm{~N}, 79.8 \mathrm{~W}$ with a cold front to the northwest and a warm front to the northeast at 12Z. HURDAT lists a 35 knot tropical storm at $33.7 \mathrm{~N}, 80.2 \mathrm{~W}$ at $12 \mathrm{Z}$. Microfilm shows a closed low pressure of at most $1011 \mathrm{mb}$ at $33.9 \mathrm{~N}, 80.7 \mathrm{~W}$ with a frontal system to the northwest and northeast at 12Z. Ship highlights: $40 \mathrm{kt} \mathrm{S}$ and $1016 \mathrm{mb}$ at $32.0 \mathrm{~N}, 78.0 \mathrm{~W}$ at $00 \mathrm{Z}$ (COADS). $35 \mathrm{kt} \mathrm{W}$ and $1014 \mathrm{mb}$ at $31.7 \mathrm{~N}, 79.2 \mathrm{~W}$ at $06 \mathrm{Z}$ (micro). Land highlights: $56 \mathrm{kt}$ at McClellanville, $\mathrm{SC}$ (no time given but likely early on the ${ }^{\text {th }}$ ) (MWR). $35 \mathrm{kt} \mathrm{N}$ (gusts to $50 \mathrm{kt}$ ) and 1012 $\mathrm{mb}$ at Congaree $\mathrm{AB}, \mathrm{SC}$ at $0955 \mathrm{Z}$ (SWO). Aircraft highlights: Radar center fix estimated flight level winds of $56 \mathrm{kt}$ and an eye diameter of $24 \mathrm{~nm}$ at $32.9 \mathrm{~N}, 79.3 \mathrm{~W}$ at $0130 \mathrm{Z}$ (ATSR). "Jul - SC1 - Cat 1 - 993 mb" (Jarrell et al. (1992).

MWR: "The small storm moved northwestward, reaching hurricane intensity a short distance offshore, and the center made landfall about 0245 GMT on the $9^{\text {th }}$ between Charleston and Georgetown, S.C. Winds of $56 \mathrm{kt}$ were recorded at McClellanville, a short distance inland, with squalls estimated at just about hurricane force in the sparsely settled coastal area. The storm tide was about 4 feet above normal near the center. The storm curved northward through South Carolina on the $9^{\text {th }}$." ATSR: "Recurvature took place on 9 July in advance of a cold front." Preliminary Report: "The center moved inland near McClellanville, SC (between Georgetown and Charleston) about 9:30 pm EST July 8 [0230Z on the $9^{\text {th }}$ ] attended by winds of whole gale force, tides up to about 4 feet above normal, and heavy rain."

July 10:

HWM analyzes a tropical storm of at most $1010 \mathrm{mb}$ at $36.0 \mathrm{~N}, 77.7 \mathrm{~W}$ with a cold front to the northwest at 12Z. HURDAT lists a 30 knot tropical depression at $35.9 \mathrm{~N}$, $77.9 \mathrm{~W}$ at $12 \mathrm{Z}$. Microfilm shows a closed low pressure of at most $1008 \mathrm{mb}$ at $36.0 \mathrm{~N}$, $77.9 \mathrm{~W}$ with a frontal boundary to the northwest at $12 \mathrm{Z}$. Ship highlights: $35 \mathrm{kt} \mathrm{SSW}$ and $1018 \mathrm{mb}$ at $34.4 \mathrm{~N}, 76.1 \mathrm{~W}$ at $06 \mathrm{Z}$ (COADS). $40 \mathrm{kt} \mathrm{S}$ and $1013 \mathrm{mb}$ at $36.4 \mathrm{~N}, 75.1 \mathrm{~W}$ at $18 \mathrm{Z}$ (COADS). $45 \mathrm{kt} \mathrm{S}$ and $1013 \mathrm{mb}$ at $36.1 \mathrm{~N}, 75.1 \mathrm{~W}$ at $21 \mathrm{Z}$ (COADS). Land highlights: $42 \mathrm{kt} \mathrm{NW}$ (gusts to $52 \mathrm{kt}$ ) at Charlotte, NC at $2105 \mathrm{Z}$ (SWO).

July 11:

HWM analyzes a tropical storm of at most $1010 \mathrm{mb}$ at $42.0 \mathrm{~N}, 70.6 \mathrm{~W}$ with a weakening front close to the west at 12Z. HURDAT lists a 50 knot tropical storm at $41.2 \mathrm{~N}, 70.3 \mathrm{~W}$ at $12 \mathrm{Z}$. Microfilm shows a closed low pressure of at most $1002 \mathrm{mb}$ at $41.5 \mathrm{~N}, 70.0 \mathrm{~W}$ with a frontal boundary to the north at $12 \mathrm{Z}$. Ship highlights: $30 \mathrm{kt} \mathrm{S}$ and $1002 \mathrm{mb}$ at $37.9 \mathrm{~N}, 74.5 \mathrm{~W}$ at $00 \mathrm{Z}$ (COADS). $65 \mathrm{kt} \mathrm{S}$ (45 kt MWL) and $1003 \mathrm{mb}$ at $38.9 \mathrm{~N}$, $72.1 \mathrm{~W}$ at $06 \mathrm{Z}$ (COADS). $35 \mathrm{kt} \mathrm{S}$ and $1012 \mathrm{mb}$ at $40.9 \mathrm{~N}, 68.4 \mathrm{~W}$ at $15 \mathrm{Z}$ (COADS). Land highlights: $40 \mathrm{kt} \mathrm{SSE}$ (gusts to $47 \mathrm{kt}$ ) at Nantucket Shoals, MA at 1056Z (SWO). $25 \mathrm{kt}$ 
SSW and $1001 \mathrm{mb}$ at Nantucket, MA at 1159Z (SWO). $47 \mathrm{kt} \mathrm{SE} \mathrm{(gusts} \mathrm{to} 51 \mathrm{kt}$ ) at Georges Shoal, MA at 13Z (SWO). $36 \mathrm{kt} \mathrm{SSW} \mathrm{at} \mathrm{Georges} \mathrm{Shoal,} \mathrm{MA} \mathrm{at} \mathrm{18Z} \mathrm{(SWO).} 10$ kt NE and $1001 \mathrm{mb}$ at Eastport, ME at 18Z (micro).

MWR: "Then turned northeastward at a little faster rate to the southern tip of Chesapeake Bay by late afternoon on July 10 . The sustained winds had dropped rapidly after the center moved inland but gusts up to $39 \mathrm{kt}$ were still occurring at this time. As the remains of the circulation moved back into the Atlantic, marked re-intensification took place. At 0600 GMT, with the center some 75-100 miles off the New Jersey coast, the ship Ocean Monarch reported winds of $65 \mathrm{kt}$ just southeast of the center, and other ships reported 45 to $50 \mathrm{kt}$. Accelerating northeastward, Cindy had passed across Cape Cod by 1200 GMT July 11 . Winds were generally 22 to $35 \mathrm{kt}$. along the coast but ranged up to 35 to $52 \mathrm{kt}$ over the open waters just east of the center with a gust of 59 kt. at Block Island, R.I." July 12 :

HWM analyzes a tropical storm of at most $1015 \mathrm{mb}$ at $49.1 \mathrm{~N}, 59.8 \mathrm{~W}$ with a warm front to the northeast and a cold front to the south at 12Z. HURDAT lists a 35 knot extratropical cyclone at $50.2 \mathrm{~N}, 59.1 \mathrm{~W}$ at $12 \mathrm{Z}$. Microfilm shows a closed low pressure of at most $1011 \mathrm{mb}$ at $52.0 \mathrm{~N}, 59.5 \mathrm{~W}$ with a frontal boundary to the south at 12Z. Ship highlights: $40 \mathrm{kt} \mathrm{SW}$ and $1014 \mathrm{mb}$ at $44.4 \mathrm{~N}, 63.4 \mathrm{~W}$ at $00 \mathrm{Z}$ (COADS).

July 13:

HWM analyzes an extratropical cyclone of at most $1010 \mathrm{mb}$ at $56.0 \mathrm{~N}, 44.0 \mathrm{~W}$ at 12Z. HURDAT does not list an organized system on this date. Microfilm does not show an organized system at 12Z. Ship highlights: No gales or low pressures.

July 14:

HWM analyzes an extratropical cyclone of at most $1005 \mathrm{mb}$ at $62.0 \mathrm{~N}, 27.0 \mathrm{~W}$ at 12Z. HURDAT does not list an organized system on this date. Microfilm is not available on this date. Ship highlights: No gales or low pressures.

July 15:

HWM analyzes an extratropical cyclone of at most $995 \mathrm{mb}$ at $60.0 \mathrm{~N}, 22.0 \mathrm{~W}$ at 12Z. HURDAT does not list an organized system on this date. Microfilm is not available on this date. Ship highlights: No gales or low pressures.

July 16 :

HWM analyzes an extratropical cyclone of at most $990 \mathrm{mb}$ at $62.0 \mathrm{~N}, 22.0 \mathrm{~W}$ at 12Z. HURDAT does not list an organized system on this date. Microfilm is not available on this date. Ship highlights: No gales or low pressures. 
July 17:

HWM analyzes an extratropical cyclone of at most $995 \mathrm{mb}$ at $64.0 \mathrm{~N}, 18.0 \mathrm{~W}$ at 12Z. HURDAT does not list an organized system on this date. Microfilm is not available on this date. Ship highlights: No gales or low pressures.

July 18:

HWM analyzes an extratropical cyclone of at most $995 \mathrm{mb}$ at $69.0 \mathrm{~N}, 14.0 \mathrm{~W}$ at 12Z. HURDAT does not list an organized system on this date. Microfilm is not available on this date. Ship highlights: No gales or low pressures.

July 19:

HWM analyzes an extratropical cyclone of at most $1005 \mathrm{mb}$ at $70.0 \mathrm{~N}, 22.0 \mathrm{~W}$ at 12Z. HURDAT does not list an organized system on this date. Microfilm is not available on this date. Ship highlights: No gales or low pressures.

A slow-moving frontal boundary entered the western Atlantic Ocean on July $3^{\text {rd }}$ allowing for the development of a frontal low just off the southeast coast of the United States. Genesis is analyzed at $12 \mathrm{Z}$ on July $4^{\text {th }}$ as a $25 \mathrm{kt}$ extratropical depression. The system initially moved slowly to the south, later turning to the east on July $5^{\text {th }}$. Transition to a tropical depression is analyzed at $12 \mathrm{Z}$ on the $5^{\text {th }}$, same as the original HURDAT, based on surface observations indicating the dissipation of the frontal features and a more uniform and tropical airmass around the system. Minor alterations were made to the track of this tropical cyclone for all days of its existence. The tropical depression turned to the northeast on July $6^{\text {th }}$ and intensification to a tropical storm is indicated at $18 \mathrm{Z}$ on the $6^{\text {th }}$, six hours earlier than originally shown in HURDAT, based on a ship report of $40 \mathrm{kt} \mathrm{SW}$ and $1014 \mathrm{mb}$ at $00 \mathrm{Z}$ on July $7^{\text {th }}$. Cindy continued to intensify on the $7^{\text {th }}$ according to a couple of ships reports of gale-force winds, reaching up to $50 \mathrm{kt}$ later on the day. The first reconnaissance aircraft reached Cindy at $2145 \mathrm{Z}$ on the $7^{\text {th }}$ measuring a central pressure of $997 \mathrm{mb}$, estimating surface winds of $60 \mathrm{kt}$ and an eye diameter of $15 \mathrm{~nm}$. A central pressure of $997 \mathrm{mb}$ suggests maximum sustained winds of $49 \mathrm{kt}$ north of $25 \mathrm{~N}$ from the Brown et al. pressure-wind relationship. An eye diameter of $15 \mathrm{~nm}$ suggests an RMW of about $12 \mathrm{~nm}$ and the climatological value is $26 \mathrm{~nm}$. Due to an RMW smaller than average and environmental pressures higher than average, but Cindy being almost stationary, an intensity of $55 \mathrm{kt}$ is selected for $00 \mathrm{Z}$ on July $8^{\text {th }}$, same as the original HURDAT. A central pressure of $997 \mathrm{mb}$ is added to HURDAT at $00 \mathrm{Z}$ on the $8^{\text {th }}$. Cindy turned to the west on the $8^{\text {th }}$ and gained in forward speed. A couple of ships reported gale-force winds, up to 55 kt. The next aircraft reached Cindy at $13 Z$ on the $8^{\text {th }}$ measuring a central pressure of 995 $\mathrm{mb}$, estimating surface winds of $35 \mathrm{kt}$ and an eye diameter of $12 \mathrm{~nm}$. A central pressure of $995 \mathrm{mb}$ suggests maximum sustained winds of $52 \mathrm{kt}$ north of $25 \mathrm{~N}$ from the pressure- 
wind relationship. An eye diameter of $12 \mathrm{~nm}$ suggests an RMW of about $9 \mathrm{~nm}$ and the climatological value is $27 \mathrm{~nm}$. Since the RMW is smaller than average and the environmental pressures higher than average, but the forward speed was about $7 \mathrm{kt}$, an intensity of $60 \mathrm{kt}$ is selected for $12 \mathrm{Z}$ on the $8^{\text {th }}, 5 \mathrm{kt}$ lower than originally shown in HURDAT, a minor intensity change. A central pressure of $995 \mathrm{mb}$ is added to HURDAT at $12 \mathrm{Z}$ on the $8^{\text {th }}$. The next penetration fixes occurred at $1645 \mathrm{Z}$ and $1727 \mathrm{Z}$ on the $8^{\text {th }}$, reporting central pressures of $1002 \mathrm{mb}$ and $1000 \mathrm{mb}$, respectively, along with estimated surface winds of $60 \mathrm{kt}$ and an eye diameter of $15 \mathrm{~nm}$. Later at 23Z, a penetration fix reported a central pressure of $995 \mathrm{mb}$, which makes the reports of central pressures at $1645 \mathrm{Z}$ and $1727 \mathrm{Z}$ a bit suspicious, although the system could have slightly weakened at those times. The intensity at $00 \mathrm{Z}$ on July $9^{\text {th }}$ is analyzed at $60 \mathrm{kt}$, down from $65 \mathrm{kt}$ originally in HURDAT, a minor intensity change. A central pressure of $995 \mathrm{mb}$ is added to HURDAT at $00 \mathrm{Z}$ on the $9^{\text {th }} .60 \mathrm{kt}$ is also the peak intensity of Cindy, down from $65 \mathrm{kt}$ originally in HURDAT, a minor intensity change. Thus, it is analyzed that Cindy did not reach hurricane intensity during its lifetime.

Landfall occurred around $03 \mathrm{Z}$ on the $9^{\text {th }}$ as a $60 \mathrm{kt}$ tropical storm near $32.8 \mathrm{~N}, 79.7 \mathrm{~W}$ or about $15 \mathrm{~nm}$ northeast of Charleston, SC. All surface observations available (reconnaissance aircraft, ships and coastal stations) indicate that Cindy was a high-end tropical storm when it made landfall in South Carolina. No hurricane-force winds or equivalent low pressures were reported by ships, coastal stations or estimated by reconnaissance aircraft either at the surface or flight level. This intensity is based primarily upon the aircraft reconnaissance fix that occurred about four hours before landfall. This is consistent with the $56 \mathrm{kt}$ sustained winds observed in McClellanville, SC. An approaching frontal boundary caused Cindy to turn to the northeast late on the $9^{\text {th }}$ and increase in forward speed. Weakening to a tropical depression occurred at $18 \mathrm{Z}$ on the $9^{\text {th }}$, same as the original HURDAT. A ship near the North Carolina coast reported $35 \mathrm{kt} \mathrm{SE}$ at $06 \mathrm{Z}$ on the $10^{\text {th }}$ and it is analyzed that Cindy regained tropical storm status at this time, twelve hours earlier than originally in HURDAT. Cindy moved back over the Atlantic Ocean late on the $10^{\text {th }}$ and continued to gain strength. A ship at $06 \mathrm{Z}$ on the $11^{\text {th }}$ reported $65 \mathrm{kt} \mathrm{S}$ and $1003 \mathrm{mb}$ according to the microfilm, COADS and MWR, but the Mariners Weather Log indicates that the intensity of the wind from that ship was $45 \mathrm{kt}$, which appears more reasonable with the reports of ships nearby. Moving northeastward at about $26 \mathrm{kt}$, the tropical storm made landfall in Nantucket, MA with winds of $50 \mathrm{kt}$ at $12 \mathrm{Z}$ on the $11^{\text {th }}$ and an hour later the center reached Cape Cod, MA with the same intensity. Nantucket Shoals, MA reported $25 \mathrm{kt} \mathrm{SSW}$ and $1001 \mathrm{mb}$ at 1155Z, suggesting a central pressure of 998, which has been added to HURDAT at $12 \mathrm{Z}$ on the $11^{\text {th }}$. Georges Shoals, MA had a peak sustained wind of $47 \mathrm{kt}$ at $13 Z$. The platform is elevated at 200 feet above sea level, which means that the $10-\mathrm{m}$ winds were around $41 \mathrm{kt}$. Transition to an extratropical cyclone is analyzed at $18 \mathrm{Z}$ on the $11^{\text {th }}$, same as the original HURDAT. The 
synoptic map at $18 \mathrm{Z}$ on the $11^{\text {th }}$ clearly shows that cold, dry continental air had entrained into the circulation of Cindy. Eastport, ME reported a $10 \mathrm{kt} \mathrm{NE}$ and $1001 \mathrm{mb}$ at $18 \mathrm{Z}$ on the $11^{\text {th }}$, suggesting a central pressure of $1000 \mathrm{mb}$, which has been added to HURDAT. Late on the $11^{\text {th }}$, Cindy made landfall as a weakening extratropical cyclone on New Brunswick, Canada. Weakening to an extratropical depression is analyzed at $12 \mathrm{Z}$ on July $12^{\text {th }}$. HURDAT did not show the system weakening below gale-force as an extratropical cyclone. Late on the $12^{\text {th }}$, the extratropical cyclone became disorganized, becoming difficult to assess if a closed circulation was still present after 18Z. The last position is analyzed at $18 \mathrm{Z}$ on the $12^{\text {th }}$, same as the original HURDAT.

Hurricane Debra [July 22-27, 1959]

\begin{tabular}{|c|c|c|c|c|c|c|c|c|c|c|c|c|c|c|}
\hline 41110 & $07 / 23 / 1959$ & $9 M=$ & 6 & SNBR $=89$ & $94 \mathrm{DE}$ & BRA & & XIN & $\mathrm{JG}=1$ & SSS $=$ & & & & \\
\hline 41110 & $07 / 22 / 1959$ & $M=$ & 6 & SNBR $=89$ & $94 \mathrm{DE}$ & BRA & & XIN & $\mathrm{JG}=1$ & $\mathrm{SSS}=$ & & & & \\
\hline (July & $22 \mathrm{nd}$ is ne & ew to & HUR & DAT ) & & & & & & & & & & \\
\hline 41113 & $07 / 22 *$ & 0 & $\odot$ & $0^{*}$ & $\odot$ & $\odot$ & $\Theta^{*}$ & $\odot$ & $\odot$ & $\odot$ & $\odot * 275$ & 912 & 25 & $\Theta^{*}$ \\
\hline 41115 & $07 / 23^{*} 269$ & 921 & 25 & $\odot * 272$ & 926 & 30 & $\odot * 27$ & & 931 & 35 & $\odot * 276$ & 937 & 35 & $\Theta^{*}$ \\
\hline 41115 & $07 / 23 * 276$ & 917 & 25 & $\odot * 279$ & 923 & 25 & $0 * 28$ & & 929 & 30 & $0 * 285$ & 935 & 30 & ○* \\
\hline & *** & $\star \star \star ~$ & & *** & $* * *$ & ** & * * & ** & $\star \star *$ & ** & $\star \star \star *$ & $\star * *$ & ** & \\
\hline 41120 & $07 / 24 * 276$ & 944 & 35 & $\odot * 279$ & 950 & 40 & $\odot * 28$ & & 954 & 65 & 1007 *285 & 953 & 65 & $\Theta^{*}$ \\
\hline 41120 & $07 / 24 * 285$ & 941 & 35 & $0 * 283$ & 946 & 45 & $0 * 28$ & & 950 & 55 & $0 * 284$ & 952 & 65 & $985 *$ \\
\hline & $* * *$ & $* * *$ & & $\star * *$ & $\star * *$ & * * & & ** & $* * *$ & ** & $\star \star \star * *$ & $* * *$ & & $* * *$ \\
\hline 41125 & $07 / 25 * 288$ & 951 & 70 & $984 * 292$ & 951 & 75 & $\odot * 29$ & & 951 & 65 & $0 * 301$ & 951 & 60 & $0^{*}$ \\
\hline 41125 & $\begin{array}{r}07 / 25^{\star} 287 \\
\star * *\end{array}$ & $\begin{array}{l}952 \\
\star * *\end{array}$ & 70 & $\begin{array}{r}984 * 291 \\
* * *\end{array}$ & 951 & 75 & $\begin{array}{l}980 * 29 \\
* * * * *\end{array}$ & & 951 & $\begin{array}{l}55 \\
* *\end{array}$ & $\begin{array}{l}986 * 300 \\
* * * * * *\end{array}$ & 951 & $\begin{array}{l}50 \\
* *\end{array}$ & ○* \\
\hline 41130 & $07 / 26 * 306$ & 951 & 45 & $0 * 313$ & 952 & 30 & $\odot * 32$ & & 954 & 30 & $0 * 331$ & 956 & 30 & ०* \\
\hline 41130 & $07 / 26$ *306 & 951 & $\begin{array}{l}40 \\
* *\end{array}$ & ๑*313 & 952 & 30 & $0 * 32$ & & 954 & 30 & $0 * 331$ & 956 & $\begin{array}{l}25 \\
* *\end{array}$ & ๑* \\
\hline 41135 & $07 / 27 * 341$ & 960 & 30 & $0 * 350$ & 968 & 25 & $0 * 35$ & & 977 & 25 & $0 * 362$ & 984 & 25 & ०* \\
\hline 41135 & $07 / 27 * 341$ & $\begin{array}{l}962 \\
* * *\end{array}$ & $\begin{array}{l}25 \\
* *\end{array}$ & $0 * 350$ & $\begin{array}{l}971 \\
* * *\end{array}$ & 25 & $0 * 35$ & & $\begin{array}{l}980 \\
* * *\end{array}$ & 25 & $0 * 362$ & $\begin{array}{l}988 \\
\star * *\end{array}$ & 25 & ०* \\
\hline ( July & 28 th has $b$ & been & remo & ved from & HURD & AT) & & & & & & & & \\
\hline 41140 & $07 / 28 * 363$ & 995 & 25 & $0 * 3641$ & 1003 & 25 & $\Theta^{*}$ & $\odot$ & $\odot$ & $\odot$ & ○* $\odot$ & $\odot$ & $\odot$ & ०* \\
\hline 41140 & $07 / 28$ * $\odot$ & $\odot$ & $\odot$ & $0^{*} \quad \odot$ & $\odot$ & $\odot$ & $\Theta^{*}$ & $\odot$ & $\odot$ & $\odot$ & $\odot * \quad \odot$ & $\odot$ & $\odot$ & $\odot$ * \\
\hline
\end{tabular}

\section{U.S. Hurricane Landfall}

July $25^{\text {th }}-06 \mathrm{Z}-29.1 \mathrm{~N} 95.1 \mathrm{~W}-75 \mathrm{kt}-$ Category $1-980 \mathrm{mb}-1012 \mathrm{mb}-150 \mathrm{~nm}$ ROCI - 25 nm RMW

Minor changes to the track and intensity shown in McAdie et al. (2009). Evidence for these alterations comes from the NHC microfilm maps, the Historical Weather Maps 
series, the COADS ship database, Monthly Weather Review, Navy reconnaissance book, Surface Weather Observations, Mariners Weather Log, Jarrell et al. (1992) and NHC Storm Wallets.

July 20:

HWM and microfilm do not analyze an organized system at 12Z. HURDAT does not list an organized system on this date. Ship highlights: No gales or low pressures.

MWR: "The beginning of hurricane Debra can probably be traced back to July 15 . Considerable shower and thundershower activity began about this time in the western Bahamas and over Florida, under the influence of a cold-core vortex which developed in the high troposphere and at $500 \mathrm{mb}$ drifted slowly southwestward through the western Bahamas, over western Cuba, and into the east Gulf of Mexico by the $20^{\text {th }}$. The activity spread into the Gulf as the upper circulation flattened into an inverted trough and continued westward."

July 21:

HWM analyzes a spot low at $26.5 \mathrm{~N}, 92.0 \mathrm{~W}$ at $12 \mathrm{Z}$. HURDAT does not list an organized system on this date. Microfilm shows a spot low at $28.5 \mathrm{~N}, 87.0 \mathrm{~W}$ at $12 \mathrm{Z}$. Ship highlights: No gales or low pressures.

MWR: "The first weak surface circulation, detected as early as 1900 EST on the $20^{\text {th }}$, later developed into hurricane Debra over the northwestern Gulf of Mexico."

July 22:

HWM analyzes a spot low at $26.5 \mathrm{~N}, 92.0 \mathrm{~W}$ at $12 \mathrm{Z}$. HURDAT does not list an organized system on this date. Microfilm shows a trough over the northwestern Gulf of Mexico at 12Z. Ship highlights: No gales or low pressures.

July 23:

HWM analyzes a tropical storm of at most $1005 \mathrm{mb}$ at $28.2 \mathrm{~N}, 92.9 \mathrm{~W}$ at $12 \mathrm{Z}$. HURDAT lists a 35 knot tropical storm at $27.5 \mathrm{~N}, 93.1 \mathrm{~W}$ at $12 \mathrm{Z}$. Microfilm shows a closed low pressure of at most $1011 \mathrm{mb}$ at $28.2 \mathrm{~N}, 93.2 \mathrm{~W}$ at 12Z. Ship highlights: No gales or low pressures.

MWR: "The circulation continued weak until the $23 \mathrm{~d}$, when winds up to 22-30 kt. accompanied showers and squalls in the northwestern Gulf and along the Louisiana and upper Texas coasts."

July 24:

HWM analyzes a tropical storm of at most $1005 \mathrm{mb}$ at $28.3 \mathrm{~N}, 95.2 \mathrm{~W}$ at $12 \mathrm{Z}$. HURDAT lists a 65 knot hurricane at $28.3 \mathrm{~N}, 95.4 \mathrm{~W}$ at $12 \mathrm{Z}$. Microfilm shows a closed low pressure of at most $1011 \mathrm{mb}$ at $28.5 \mathrm{~N}, 95.8 \mathrm{~W}$ at 12Z. Ship highlights: $40 \mathrm{kt} \mathrm{SW}$ and 
$1008 \mathrm{mb}$ at $28.0 \mathrm{~N}, 94.2 \mathrm{~W}$ at $08 \mathrm{Z}$ (MWR/micro). $50 \mathrm{kt} \mathrm{SW}$ and $1009 \mathrm{mb}$ at $28.0 \mathrm{~N}, 95.2 \mathrm{~W}$ at $12 \mathrm{Z}$ (MWR/micro). $45 \mathrm{kt} \mathrm{S}$ and $1008 \mathrm{mb}$ at $27.2 \mathrm{~N}, 94.3 \mathrm{~W}$ at $18 \mathrm{Z}$ (MWL). Aicraft highlights: Penetration center fix measured a central pressure of $987 \mathrm{mb}$, estimated surface winds of $55 \mathrm{kt}$ and an eye diameter of $15 \mathrm{~nm}$ at $28.3 \mathrm{~N}, 95.4 \mathrm{~W}$ at $1521 \mathrm{Z}$ (ATSR). Penetration center fix measured a central pressure of $985 \mathrm{mb}$ and estimated surface winds of $60 \mathrm{kt}$ at $28.4 \mathrm{~N}, 95.2 \mathrm{~W}$ at $19 \mathrm{Z}$ (ATSR).

MWR: "An indication that some intense weather was in the making in the western Gulf of Mexico came from the SS Atlantic Navigator (at 0000 GMT on the 24th at 23.7" N., 94.5 " W.) which reported a northwest wind of $32 \mathrm{kt}$. with rough seas from the southwest. This was later corrected to southwest wind of $23 \mathrm{kt}$. The report indicated that a vortex was developing, which was later verified by reports from that area and to the north toward the Texas coast during the next 12 to 18 hours. A delayed observation, received at 1130 GMT on the $24^{\text {th }}$ from the ship Mexican Trader (located at 28.0" N., 94.2 OW.) reporting a surface wind from the southwest at $40 \mathrm{kt}$. and pressure of $1007.5 \mathrm{mb}$, indicated additional intensification. At 1200 GMT this ship had moved about 60 miles west and the surface winds had increased to southwest $50 \mathrm{kt}$. That Debra was already a fully developed hurricane is evidenced by the radar photograph (fig. 2) taken at the Dow Chemical Plant in Freeport at 0733 CST July 24 when the set was turned on. No spiral organization had been noted on the radar scope the previous afternoon. Reconnaissance aircraft located the center of tropical storm Debra during the early forenoon of July 24 . It seems likely the plane did not pass through the most severe squalls prevailing at the time." ATSR: "DEBRA formed close to the Texas coastline and intensified rapidly within a large area of squally weather which covered almost the entire Gulf of Mexico. The $0000 Z$ surface chart on 24 July indicated a trough oriented NNW - SSE through Galveston, Texas, which a very weak cyclonic circulation centered over the coastline and a much stronger circulation centered 300 miles southward. Accordingly, the Navy "Alfa" flight for the $24^{\text {th }}$ of July was modified in order to permit early investigation of this system. At 241130Z, while the aircraft was enroute to the southernmost of the two circulations, an observation made at $240800 \mathrm{Z}$ was received from the ship MEXICAN TRADER located about 75 miles south of Galveston reporting as follows: "Wind southwest force 8, very rough seas and high swell, barometer 29.75 inches, heavy rain squalls with gusty winds, visibility poor obscured by sea spray." At 241328Z, The Navy aircraft reported a radar eye located 28 degrees 07 minutes north latitude and 95 degrees 27 minutes west longitude and immediately diverted towards this point where winds up to $55 \mathrm{kt}$ were reported. A Freeport, Teas, radar report bearing a date time group of $241400 \mathrm{Z}$ reported a closed eye at $28.3 \mathrm{~N} 95.3 \mathrm{~W}$. The first warning was issued by this activity at $241500 \mathrm{Z}$."

July 25:

HWM analyzes a hurricane of at most $1000 \mathrm{mb}$ at $29.8 \mathrm{~N}, 95.5 \mathrm{~W}$ at $12 \mathrm{Z}$. HURDAT lists a 65 knot hurricane at 29.6N, 95.1W at 12Z. Microfilm shows a closed low pressure of at most $1002 \mathrm{mb}$ at $29.5 \mathrm{~N}, 93.7 \mathrm{~W}$ with a frontal boundary to the west at 12Z. Ship highlights: $50 \mathrm{kt} \mathrm{ESE}$ and $1011 \mathrm{mb}$ at 28.9N, 93.7W at 06Z (MWL). $984 \mathrm{mb}$ at 
Coast Guard Cutter Cahoone, Texas (no time given) (MWR). Land highlights: $35 \mathrm{kt} \mathrm{N}$ (gusts to $59 \mathrm{kt}$ ) and $999 \mathrm{mb}$ at Brazos River Floodgate, Texas at 00Z (SWO). $987 \mathrm{mb}$ at Freeport, Texas at $0430 \mathrm{Z}$ (WALLET). $70 \mathrm{kt} \mathrm{W}$ (might be an estimate)(gusts to $90 \mathrm{kt}$ ) at Brazos River Floodgate, Texas at 05Z (SWO). $73 \mathrm{kt} \mathrm{WSW} \mathrm{(fastest} \mathrm{mile)} \mathrm{(gusts} \mathrm{to} 77 \mathrm{kt}$ ) at Freeport, Texas at 0630Z (WALLET). $986 \mathrm{mb}$ at Dickinson, Texas at $1145 \mathrm{Z}$ (WALLET). $989 \mathrm{mb}$ at Ellington AFB, Texas at 1458Z (SWO). $35 \mathrm{kt} \mathrm{WSW}$ (gusts to 51 kt) and $1002 \mathrm{mb}$ at Houston, Texas at 1858Z (SWO). Aicraft highlights: Penetration center fix measured a central pressure of $988 \mathrm{mb}$ at $28.8 \mathrm{~N}, 95.1 \mathrm{~W}$ at $01 \mathrm{Z}$ (ATSR). Radar center fix at $29.1 \mathrm{~N}, 95.2 \mathrm{~W}$ at $06 \mathrm{Z}$ (ATSR). "Jul - TX1 - Cat 1N - $984 \mathrm{mb}$ " (Jarrell et al. (1992).

MWR: "Hurricane Debra increased further in intensity during the afternoon and evening of July 24 and passed inland on the Texas coast between Freeport and Galveston near midnight on the $24^{\text {th }}$. The lowest reported central pressure in hurricane Debra was 984.4 $\mathrm{mb}$ from the Coast Guard Cutter Cahoone late on July 24. Dickinson, Tex. reported 986.5 $\mathrm{mb}$, the lowest reading from a land station. Highest reported wind was 70 to $78 \mathrm{kt}$ with gusts to $91 \mathrm{kt}$. from Brazos Floodgates near Freeport, Tex. Tides were generally 3 to 5 feet above normal over Galveston Bay. Morgan Point, at the head, or north, end of Galveston Bay, reported the highest tide of 7.9 feet m.s.1. Rainfall was heavy throughout eastern Texas and extreme western Louisiana; Orange, Tex., reported the greatest amount, 14.42 inches. No casualties occurred in connection with Debra, but ten persons suffered minor injuries in Brazoria County, Tex. Damage in Brazoria, Galveston, and the eastern portion of Harris County, Tex., was estimated at $\$ 6,685,000$ with some additional in other areas. Development so close to the coastline is rather unusual and the forecast problem was complicated by lack of ship reports, and delays and transmission errors in the few that were received. It continued slowly northward across extreme eastern Texas and rapidly lost intensity on the $25^{\text {th }}$ and $26^{\text {th }}$, and finally lost its identity in central Oklahoma on the $27^{\text {th }}$." ATSR: "DEBRA moved inland near Freeport, Texas, at about $250600 \mathrm{Z}$ with maximum wind gusts near $90 \mathrm{kt}$. Maximum rainfall of about 15 inches was reported at Orange, Texas. No deaths or injuries were noted even though $\$ 7,000,000$ damage was reported."

July 26:

HWM analyzes a tropical storm of at most $1005 \mathrm{mb}$ at $32.5 \mathrm{~N}, 95.5 \mathrm{~W}$ at $12 \mathrm{Z}$. HURDAT lists a 30 knot tropical depression at $32.1 \mathrm{~N}, 95.4 \mathrm{~W}$ at $12 \mathrm{Z}$. Microfilm shows a closed low pressure of at most $1008 \mathrm{mb}$ at $32.4 \mathrm{~N}, 95.5 \mathrm{~W}$ at 12Z. Ship highlights: No gales or low pressures.

July 27:

HWM analyzes a closed low pressure of at most $1010 \mathrm{mb}$ at $35.5 \mathrm{~N}, 97.5 \mathrm{~W}$ with a weakening front to the north at 12Z. HURDAT lists a $25 \mathrm{knot}$ tropical depression at $35.8 \mathrm{~N}, 97.7 \mathrm{~W}$ at $12 \mathrm{Z}$. Microfilm shows a closed low pressure of at most $1008 \mathrm{mb}$ at 
$35.5 \mathrm{~N}, 98.5 \mathrm{~W}$ with a frontal boundary to the northwest at 12Z. Ship highlights: No gales or low pressures.

July 28:

HWM and microfilm do not analyze an organized system on this date. HURDAT lists a 25 knot tropical depression at $36.4 \mathrm{~N}, 100.3 \mathrm{~W}$ at $06 \mathrm{Z}$ (last position). Ship highlights: No gales or low pressures.

A disturbance developed over the northeastern Gulf of Mexico around July $20^{\text {th }}$. The area of disturbed weather moved generally westward and slowly became better organized. Genesis is analyzed at $18 \mathrm{Z}$ on July $22^{\text {nd }}$ as a $25 \mathrm{kt}$ tropical depression, six hours earlier than originally shown in HURDAT. Minor track changes are made for the lifetime of this tropical cyclone. The tropical depression moved slowly to the west-northwest and became a tropical storm twelve hours later than originally shown in HURDAT. No gale force winds or equivalent low pressures on July $23^{\text {rd }}$ were observed, despite substantial ship observations being available. Debra rapidly intensified on July $24^{\text {th }}$ while slowly moving to the west near the northeast Texas coast. Various ships reported gale force winds, up to $50 \mathrm{kt}$, on this day. The first reconnaissance aircraft that investigated Debra measured a central pressure of $985 \mathrm{mb}$ and estimated surface winds of $60 \mathrm{kt}$ at $19 \mathrm{Z}$ on the $24^{\text {th }}$. A central pressure of $985 \mathrm{mb}$ suggests maximum sustained winds of $66 \mathrm{kt}$ north of $25 \mathrm{~N}$ from the Brown et al. pressure-wind relationship. At 1521Z, the reconnaissance aircraft estimated an eye diameter of $15 \mathrm{~nm}$, suggesting an RMW of about $11 \mathrm{~nm}$ and climatology is $22 \mathrm{~nm}$. Due to slow forward speed of about $2 \mathrm{kt}$ but an RMW smaller than climatology, an intensity of $65 \mathrm{kt}$ is selected for $18 \mathrm{Z}$ on the $24^{\text {th }}$, same as the original HURDAT. A central pressure of $985 \mathrm{mb}$ is added to HURDAT at $18 \mathrm{Z}$ on the $24^{\text {th }}$. Intensification to a hurricane is analyzed at $18 \mathrm{Z}$ on the $24^{\text {th }}$, six hours later than originally shown in HURDAT, which had an unrealistic $25 \mathrm{kt}$ gain between $06 \mathrm{Z}$ and $12 \mathrm{Z}$ (40 to 65 $\mathrm{kt}$ ) with no supporting observations. A central pressure of $1007 \mathrm{mb}$ was present in HURDAT at $12 \mathrm{Z}$ on the $24^{\text {th }}$, but has been removed based on a ship report of $50 \mathrm{kt} \mathrm{SW}$ and $1009 \mathrm{mb}$ at this time, and the reconnaissance aircraft measurement of a central pressure of $987 \mathrm{mb}$ at $1521 \mathrm{Z}$. A central pressure of $984 \mathrm{mb}$ was present in HURDAT at $00 \mathrm{Z}$ on July $25^{\text {th }}$ and it is mentioned in the MWR that it was measured by the Coast Guard Cutter Cahoone late on the $24^{\text {th }}$. Although the location of the ship was not found, the central pressure report appears reasonable and has been retained. Early on the $25^{\text {th }}$, Debra started moving to the north at a forward speed of about $5 \mathrm{kt}$. Landfall occurred at $06 \mathrm{Z}$ on the $25^{\text {th }}$ near $29.1 \mathrm{~N} 95.1 \mathrm{~W}$ or about 20 miles northeast of Freeport, Texas, as a 75 $\mathrm{kt}$ hurricane. A central pressure of $986 \mathrm{mb}$ was measured at Dickinson, Texas, at $1145 \mathrm{Z}$ on the $26^{\text {th }}$. The Ho et al. Inland Pressure Decay Model suggests a central pressure at landfall of $972 \mathrm{mb}$ since the central pressure is suggested by the model to have filled 
about $14 \mathrm{mb}$ between landfall and the measurement at Dickinson, Texas. Nevertheless, a great portion of the eastern quadrant of the circulation was located over Galveston Bay during these six hours and it is assumed that the weakening was not as fast as indicated by Ho et al. Thus, a central pressure of $980 \mathrm{mb}$ is analyzed at landfall and added to HURDAT at $06 \mathrm{Z}$ on the $25^{\text {th }}$. A central pressure of $980 \mathrm{mb}$ suggests maximum sustained winds of $76 \mathrm{kt}$ from the intensifying pressure-wind relationship. Based on both the pressure-wind relationship and surface winds of $73 \mathrm{kt}$ measured at Freeport, Texas, at $0630 \mathrm{Z}$, the intensity is kept at $75 \mathrm{kt}$, same as the original HURDAT. A central pressure of $986 \mathrm{mb}$ is added to HURDAT at $12 \mathrm{Z}$ on the $25^{\text {th }}$.

Hurricane Debra continued moving northward on the $25^{\text {th }}$ after landfall. The Kaplan and DeMaria inland decay model was run for $12 \mathrm{Z}$ and $18 \mathrm{Z}$ on the $25^{\text {th }}$ and $00 \mathrm{Z}$ on July $26^{\text {th }}$. The model suggested $54 \mathrm{kt}$ at $12 \mathrm{Z}, 45 \mathrm{kt}$ at $18 \mathrm{Z}$ and $34 \mathrm{kt}$ at $00 \mathrm{Z}$. The highest winds observed within two hours of these times were $48 \mathrm{kt}, 47 \mathrm{kt}$ and less than $34 \mathrm{kt}$, respectively. $55 \mathrm{kt}$ was selected at $12 \mathrm{Z}, 50 \mathrm{kt}$ at $18 \mathrm{Z}$ and $40 \mathrm{kt}$ at $00 \mathrm{Z}$, while HURDAT originally had $65 \mathrm{kt}, 60 \mathrm{kt}$, and $45 \mathrm{kt}$, respectively. Minor intensity changes to HURDAT. Thus, weakening to a tropical storm is analyzed at $12 \mathrm{Z}$ on the $25^{\text {th }}$, six hours earlier than originally shown in HURDAT. Weakening to a tropical depression occurred at $06 \mathrm{Z}$ on the $26^{\text {th }}$ over eastern Texas, same as the original HURDAT. The track of the tropical depression veered to the northwest on July $27^{\text {th }}$ while over Oklahoma. Dissipation is analyzed after $18 \mathrm{Z}$ on the $27^{\text {th }}$, twelve hours earlier than originally shown in HURDAT. Surface observations on July $28^{\text {th }}$ indicate that the tropical cyclone had lost its closed circulation.

\begin{tabular}{|c|c|c|c|c|c|c|c|c|c|c|c|c|c|}
\hline \multirow{3}{*}{$\begin{array}{l}37265 \\
37265\end{array}$} & \multicolumn{13}{|c|}{ New Tropical Storm [August 2-6, 1959] } \\
\hline & $\bullet 8 / 02 / 1959$ & $M=$ & 5 & $6 \mathrm{SNBR}=82$ & $20 \mathrm{UN}$ & NAMED & & XING & a $\mathrm{S}$ & & & & \\
\hline & $08 / 02 * \quad \odot$ & 0 & $\odot$ & $0 * 348$ & 758 & 40 & $0 * 345$ & 746 & 60 & $0 * 352$ & 730 & 60 & $0^{*}$ \\
\hline 37265 & $08 / 03 * 363$ & 707 & 60 & $\Theta * 372$ & 683 & 55 & $0 * 379$ & 662 & 55 & OE387 & 642 & 50 & 0* \\
\hline 37265 & ๑8/๑4Е394 & 625 & 50 & ๑E4०2 & 615 & 45 & ๑E4०9 & 612 & 45 & OE415 & 612 & 45 & 0 * \\
\hline 37265 & ๑8/๑5E420 & 612 & 45 & OE425 & 611 & 40 & OE430 & 608 & 40 & OE437 & 605 & 40 & ○* \\
\hline 37265 & ๑8/०6E444 & $6 \odot 2$ & 35 & OE452 & 599 & 30 & OE462 & 595 & 25 & ๑E475 & 585 & 25 & $\Theta^{*}$ \\
\hline
\end{tabular}

A new tropical storm has been added to HURDAT, not previously shown in McAdie et al. (2009). Evidence for its existence comes from the Historical Weather Map series, Microfilm, COADS ship database, Mariners Weather Log and Jack Beven's and David Roth's suspect list. 
August 1:

HWM analyzes a weakening cold front over the southeast of the United States at 12Z. Microfilm shows a closed low pressure of at most $1014 \mathrm{mb}$ at $33.0 \mathrm{~N}, 81.0 \mathrm{~W}$ with a frontal boundary to the north at 12Z. Ship highlights: No gale force winds or equivalent low pressures.

August 2:

HWM analyzes a tropical storm of at most $1005 \mathrm{mb}$ at $33.0 \mathrm{~N}, 75.5 \mathrm{~W}$ with weakening cold front to the north at $12 \mathrm{Z}$. Microfilm shows a closed low pressure of at most $1011 \mathrm{mb}$ at $34.2 \mathrm{~N}, 74.5 \mathrm{~W}$ with a frontal boundary to the north at $12 \mathrm{Z}$. Ship highlights: $40 \mathrm{kt} \mathrm{SW}$ and $1012 \mathrm{mb}$ at $33.1 \mathrm{~N}, 75.2 \mathrm{~W}$ at $06 \mathrm{Z}$ (COADS). $60 \mathrm{kt} \mathrm{SW}$ and $1007 \mathrm{mb}$ at $33.8 \mathrm{~N}, 74.3 \mathrm{~W}$ at $12 \mathrm{Z}$ (COADS). $35 \mathrm{kt} \mathrm{S}$ and $1005 \mathrm{mb}$ at $35.5 \mathrm{~N}, 72.3 \mathrm{~W}$ at $18 \mathrm{Z}$ (COADS).

MWL: "A weak disturbance on August 2, off the Carolinas, moved slowly northeastward and dissipated late on the $6^{\text {th }}$ in the Gulf of St. Lawrence. Several ships near this storm's center during the period August 2-4 reported 35 to $60 \mathrm{kt}$ winds. The highest wind for the month [in the entire Atlantic], $60 \mathrm{kt}$ from the southwest, was reported by the SS MOBILOIL on the $2^{\text {nd }}$ while off the South Carolina coast near $34^{\circ} \mathrm{N}, 74^{\circ} \mathrm{W} . "$

August 3:

HWM analyzes a tropical storm of at most $1000 \mathrm{mb}$ at $37.7 \mathrm{~N}, 71.2 \mathrm{~W}$ with a cold front to the southeast and stationary front to the northeast at 12Z. Microfilm shows a closed low pressure of at most $1005 \mathrm{mb}$ at $37.5 \mathrm{~N}, 72.3 \mathrm{~W}$ with a frontal boundary going through the system at 12Z. Ship highlights: $45 \mathrm{kt} \mathrm{SW}$ and $1009 \mathrm{mb}$ at $34.1 \mathrm{~N}, 71.0 \mathrm{~W}$ at 00Z (COADS). $55 \mathrm{kt} \mathrm{SE}$ and $999 \mathrm{mb}$ at $37.5 \mathrm{~N}, 68.0 \mathrm{~W}$ at $06 \mathrm{Z}$ (COADS). $45 \mathrm{kt} \mathrm{N}$ and $1004 \mathrm{mb}$ at $37.5 \mathrm{~N}, 68.0 \mathrm{~W}$ at $12 \mathrm{Z}$ (micro). $45 \mathrm{kt} \mathrm{NW}$ at $37.8 \mathrm{~N}, 66.9 \mathrm{~W}$ at $18 \mathrm{Z}$ (micro). 35 kt $\mathrm{NE}$ and $1010 \mathrm{mb}$ at $41.5 \mathrm{~N}, 62.8 \mathrm{~W}$ at $21 \mathrm{Z}$ (COADS).

August 4:

HWM analyzes a tropical storm of at most $995 \mathrm{mb}$ at $40.5 \mathrm{~N}, 60.5 \mathrm{~W}$ with a cold front to the south and warm front to the northeast at 12Z. Microfilm shows a closed low pressure of at most $999 \mathrm{mb}$ at $41.0 \mathrm{~N}, 61.5 \mathrm{~W}$ with a frontal boundary going through the system at 12Z. Ship highlights: $50 \mathrm{kt} \mathrm{NW}$ and $1008 \mathrm{mb}$ at $38.7 \mathrm{~N}, 64.7 \mathrm{~W}$ at $03 \mathrm{Z}$ (micro). $40 \mathrm{kt} \mathrm{N}$ and $1005 \mathrm{mb}$ at $40.8 \mathrm{~N}, 64.7 \mathrm{~W}$ at $06 \mathrm{Z}$ (COADS). $45 \mathrm{kt} \mathrm{E}$ and $997 \mathrm{mb}$ at $41.1 \mathrm{~N}$, $61.2 \mathrm{~W}$ at $12 \mathrm{Z}$ (COADS). $35 \mathrm{kt} \mathrm{N}$ and $1004 \mathrm{mb}$ at $41.5 \mathrm{~N}, 62.8 \mathrm{~W}$ at $15 \mathrm{Z}$ (COADS). $40 \mathrm{kt}$ $\mathrm{SE}$ and $1005 \mathrm{mb}$ at $41.3 \mathrm{~N}, 58.6 \mathrm{~W}$ at $18 \mathrm{Z}$ (COADS). $35 \mathrm{kt} \mathrm{NE}$ and $1014 \mathrm{mb}$ at $44.7 \mathrm{~N}$, $61.2 \mathrm{~W}$ at $21 \mathrm{Z}$ (COADS). 
August 5:

HWM analyzes a tropical storm of at most $1000 \mathrm{mb}$ at $42.3 \mathrm{~N}, 60.0 \mathrm{~W}$ at $12 \mathrm{Z}$. Microfilm shows a closed low pressure of at most $1002 \mathrm{mb}$ at $42.5 \mathrm{~N}, 60.7 \mathrm{~W}$ with a frontal boundary going through the system at 12Z. Ship highlights: $45 \mathrm{kt} \mathrm{SW}$ and $995 \mathrm{mb}$ at $41.0 \mathrm{~N}, 61.5 \mathrm{~W}$ at $00 \mathrm{Z}$ (micro). $40 \mathrm{kt} \mathrm{NE}$ and $1002 \mathrm{mb}$ at $42.6 \mathrm{~N}, 62.8 \mathrm{~W}$ at $06 \mathrm{Z}$ (COADS). $40 \mathrm{kt} \mathrm{SW}$ and $1005 \mathrm{mb}$ at $40.8 \mathrm{~N}, 60.2 \mathrm{~W}$ at $12 \mathrm{Z}$ (COADS/micro). $40 \mathrm{kt} \mathrm{SE}$ at $47.4 \mathrm{~N}, 59.3 \mathrm{~W}$ at $17 \mathrm{Z}$ (COADS). $30 \mathrm{kt} \mathrm{S}$ and $998 \mathrm{mb}$ at $43.9 \mathrm{~N}, 60.0 \mathrm{~W}$ at $18 \mathrm{Z}$ (micro).

August 6:

HWM analyzes a closed low pressure of at most $1010 \mathrm{mb}$ at $46.4 \mathrm{~N}, 59.5 \mathrm{~W}$ with a cold front to the north at 12Z. Microfilm shows a closed low pressure of at most $1008 \mathrm{mb}$ at $46.8 \mathrm{~N}, 59.0 \mathrm{~W}$ with a frontal boundary going through the system at 12Z. Ship highlights: $15 \mathrm{kt} \mathrm{NE}$ and $1001 \mathrm{mb}$ at 44.6N, 60.3W at 00Z (COADS). $15 \mathrm{kt} \mathrm{W}$ and 1002 $\mathrm{mb}$ at $43.9 \mathrm{~N}, 60.0 \mathrm{~W}$ at $06 \mathrm{Z}$ (micro).

A non-frontal disturbance developed off the southeast coast of the United States and rapidly intensified as it moved to the northeast. Coastal and ship observations at $06 \mathrm{Z}$ on August $2^{\text {nd }}$ indicated that a well-defined low pressure system had formed just off North Carolina and a ship about $120 \mathrm{~nm}$ south of the center was reporting $40 \mathrm{kt}$ winds. Possibly the same ship also reported $40 \mathrm{kt}$ at $08 \mathrm{Z}$ on the $2^{\text {nd }}$. Genesis is analyzed at $06 \mathrm{Z}$ on the $2^{\text {nd }}$ as a $40 \mathrm{kt}$ tropical storm. The structure of the tropical cyclone indicates that it may have been more subtropical in nature with the strongest winds over the southern and eastern quadrant, especially early during its lifetime. However, the frontal features analyzed in HWM and the microfilm maps through the cyclone in the $2^{\text {nd }}$ and $3^{\text {rd }}$ (through 12Z) do not appears to be valid. At $12 \mathrm{Z}$ on the $2^{\text {nd }}$, a ship about $60 \mathrm{~nm}$ south of the center reported $60 \mathrm{kt}$ and another ship nearby reported $45 \mathrm{kt}$. The intensity at $12 \mathrm{Z}$ on the $2^{\text {nd }}$ is increased to $60 \mathrm{kt}$. $60 \mathrm{kt}$ is also the peak intensity for this tropical storm, although it is possible that briefly it may have reached hurricane intensity. An approaching frontal boundary caused the tropical storm to accelerate to the northeast late on the $2^{\text {nd }}$. The tropical storm began to weaken on August $3^{\text {rd }}$ as it began to interact with the frontal boundary. The circulation remained small with winds up to $55 \mathrm{kt}$ being reported near the center on the $3^{\text {rd }}$. At $18 \mathrm{Z}$ on the $3^{\text {rd }}$, the tropical storm is analyzed to have transitioned into an extratropical cyclone. Synoptic data showed drier air being entrained into the center of the cyclone, with a strong dew point gradient between the eastern and western quadrant. The circulation of the extratropical storm expanded on August $4^{\text {th }}$ as the forward speed decreased. Gradual weakening continued during the $4^{\text {th }}$ and $5^{\text {th }}$ as the extratropical cyclone was approaching eastern Nova Scotia. Weakening to an extratropical depression is analyzed at $06 \mathrm{Z}$ on August $6^{\text {th }}$. The extratropical depression continued to lose strength 
and dissipated after $18 \mathrm{Z}$ on the $6^{\text {th }}$. Final position is analyzed at $18 \mathrm{Z}$ on the $6^{\text {th }}$. Analogs for this tropical storm are Tropical Storms Alberto, 1988 and Arthur, 2002.

Tropical Storm Edith [August 18-19, 1959]

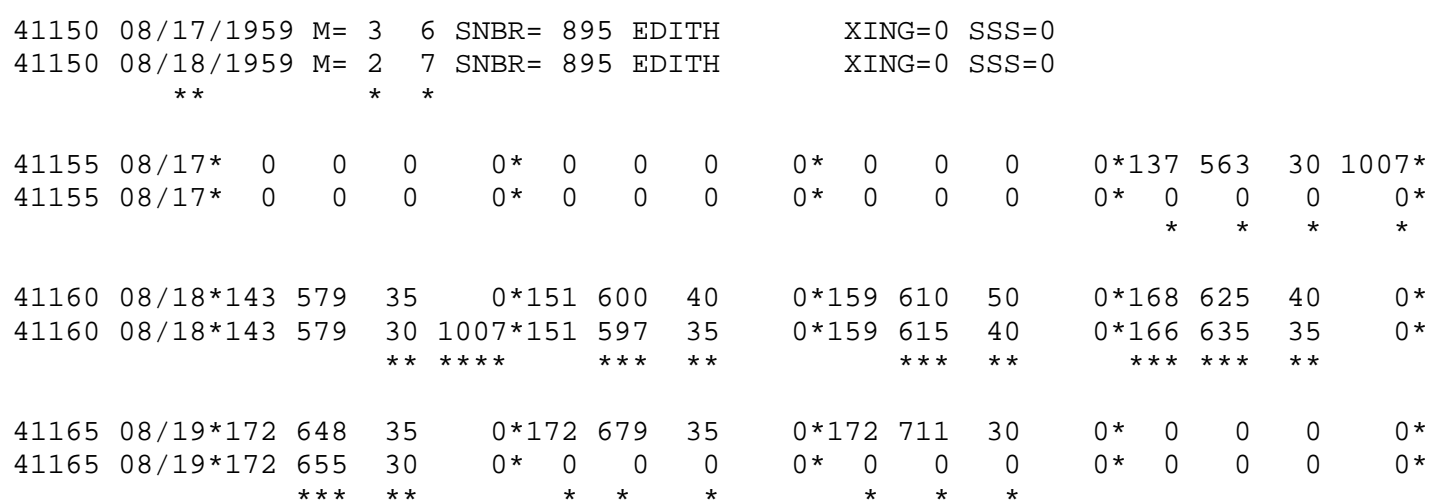

41170 TS

Tropical Storm Landfall

08/18 12Z 15.9N 61.5W 40 kt Guadeloupe

Minor changes to the track and intensity shown in McAdie et al. (2009). Evidence for these alterations comes from the NHC microfilm maps, the Historical Weather Maps series, the COADS ship database, Monthly Weather Review, Navy reconnaissance book, Surface Weather Observations, Mariners Weather Log, and NHC Storm Wallets.

August 15:

HWM and microfilm do not show an organized system at 12Z. HURDAT does not list an organized system on this date. Ship highlights: No gales or low pressures.

ATSR: "Tropical Storm Edith formed on an easterly wave which was located 23 degrees west longitude at 081200Z, by the Fleet Weather Central, Port Lyautey."

August 16:

HWM analyzes a spot low at 9.5N, 54.5W at 12Z. HURDAT does not list an organized system on this date. Microfilm does not show an organized system at 12Z. Ship highlights: No gales or low pressures. 
August 17:

HWM analyzes a tropical storm of at most $1010 \mathrm{mb}$ at $11.6 \mathrm{~N}, 56.7 \mathrm{~W}$ at $12 \mathrm{Z}$. HURDAT lists a 30 knot tropical depression at $13.7 \mathrm{~N}, 56.3 \mathrm{~W}$ at $18 \mathrm{Z}$ (first position). Microfilm shows a tropical wave near the Lesser Antilles at 12Z. Ship highlights: No gales or low pressures. Aircraft highlights: Penetration center fix estimated surface winds of $30 \mathrm{kt}$ and measured a central pressure of $1007 \mathrm{mb}$ at $14.1 \mathrm{~N}, 57.7 \mathrm{~W}$ at $2230 \mathrm{Z}$ (ATSR).

MWR: "Tropical storm Edith formed in an easterly wave in the Atlantic Ocean east of the Windward Islands. At 1530 EST, August 17, reconnaissance aircraft found a weak center near 13.8" N, 57.2" W. The minimum surface pressure was $1007 \mathrm{mb}$, while highest winds were $30 \mathrm{kt}$ in squalls north of the center." ATSR: "This wave was carried by extrapolation and peripheral ship reports until $170000 \mathrm{Z}$ when a ship report indicated its location at 57 degrees west longitude. On the basis of this ship report and observations from the Windward Islands which were characteristic of an approaching easterly wave, a Navy reconnaissance flight was ordered. The flight revealed a diffuse circulation center at $1720 \mathrm{Z}$ with maximum winds of 30 knots in squalls to the north."

August 18:

HWM analyzes a tropical storm of at most $1010 \mathrm{mb}$ at $15.9 \mathrm{~N}, 61.8 \mathrm{~W}$ at $12 \mathrm{Z}$. HURDAT lists a 50 knot tropical storm at $15.9 \mathrm{~N}, 61.0 \mathrm{~W}$ at $12 \mathrm{Z}$. Microfilm shows a closed low pressure of at most $1011 \mathrm{mb}$ at $16.5 \mathrm{~N}, 61.3 \mathrm{~W}$ at $12 \mathrm{Z}$. Ship highlights: $35 \mathrm{kt}$ ENE and $1010 \mathrm{mb}$ at $16.7 \mathrm{~N}, 61.5 \mathrm{~W}$ at $12 \mathrm{Z}$ (micro). $35 \mathrm{kt}$ ENE and $1016 \mathrm{mb}$ at $17.3 \mathrm{~N}$, 61.0W at 12Z (micro). Land highlights: $34 \mathrm{kt} \mathrm{S}$ at Raizet Airport, Guadeloupe at $1310 \mathrm{Z}$ (WALLET). Aircraft: Estimated surface winds of $50 \mathrm{kt}$ near $16.7 \mathrm{~N}, 61.2 \mathrm{~W}$ at $13 \mathrm{Z}$ (ATSR).

MWR: "The storm was never well defined as it moved on a westnorthwestward course with an average speed of $20 \mathrm{kt}$, passing through the Leeward Islands in the vicinity of Guadeloupe early on the $18^{\text {th }}$. Highest winds never exceeded 48 kt." ATSR: "On 18 August, the Navy reconnaissance flight was unable to find any definite circulation; however, southeast winds of 50 knots were observed with numerous strong weather bands about 40 miles east of Guadaloupe. The first warning of EDITH was issued at 180100Z. Between 1000Z and 1100Z on 18 August, observations from the Lesser Antilles evidenced the passage of a weak cyclonic circulation between the islands of Dominica and Martinique. Subsequent to this time, warning positions were carried further to the north of this position because of the stronger winds through the Guadaloupe-Antigua area."

August 19:

HWM analyzes a spot low at $16.0 \mathrm{~N}, 71.4 \mathrm{~W}$ at $12 \mathrm{Z}$. HURDAT lists a 30 knot tropical depression at $17.2 \mathrm{~N}, 71.1 \mathrm{~W}$ at $12 \mathrm{Z}$. Microfilm shows a tropical wave south of Hispaniola along longitude $71 \mathrm{~W}$ at $12 \mathrm{Z}$. Ship highlights: No gales or low pressures. 
MWR: "Highest winds never exceeded $48 \mathrm{kt}$ and the storm dissipated just to the south of Mona Passage during the night of August 18-19. Indeed, there is considerable doubt if a complete circulation ever existed and whether this disturbance meets the specifications for a tropical storm. There were two important synoptic features associated with this storm. Very warm air was observed in the middle troposphere just prior to formation, and the wind field in the high troposphere never became favorable for high-level evacuation. There were no reports of loss of life or of damage attributable to Edith." ATSR: "No further evidence of a cyclonic circulation in EDITH was found. The last warning was issued at 190000Z. The circulation damped out in the eastern Circulation and EDITH was followed across the Caribbean and Gulf of Mexico as an easterly wave."

August 20:

HWM does not analyze an organized system at 12Z. HURDAT does not list an organized system on this date. Microfilm shows a tropical wave extending along $15-23 \mathrm{~N}$, 75-83W at 12Z. Ship highlights: $35 \mathrm{kt} \mathrm{E}$ and $1010 \mathrm{mb}$ at 21.6N, 72.9W at 06Z (COADS).

August 21:

HWM and microfilm do not analyze an organized system at 12Z. Ship highlights: No gales or low pressures.

August 22:

HWM analyzes a closed low pressure of at most $1010 \mathrm{mb}$ at $21.5 \mathrm{~N}, 96.5 \mathrm{~W}$ at 12Z. Microfilm does not show an organized system at 12Z. Ship highlights: No gales or low pressures.

August 23:

HWM and microfilm do not analyze an organized system at 12Z. Ship highlights: No gales or low pressures.

A tropical wave became better organized as it approached the Lesser Antilles on August $17^{\text {th }}$. Ship observations east of the Lesser Antilles are sparse, which makes it difficult to assess the organization of the disturbance between Africa and the islands. The first reconnaissance aircraft to investigate the disturbance encountered a weak but closed lowlevel circulation near $14.1 \mathrm{~N}$ and $57.7 \mathrm{~W}$, and estimated surface winds of $30 \mathrm{kt}$ and measured a central pressure of $1007 \mathrm{mb}$ at $2230 \mathrm{Z}$ on the $17^{\text {th }}$. Surface observations at $18 \mathrm{Z}$ on the $17^{\text {th }}$ indicate that the disturbance did not have a closed circulation and was a sharp tropical wave at this time. Thus, genesis is analyzed at $00 \mathrm{Z}$ on August $18^{\text {th }}$ as a $30 \mathrm{kt}$ tropical depression, six hours later than originally shown in HURDAT. A central pressure of $1007 \mathrm{mb}$ appears in HURDAT at $18 \mathrm{Z}$ on the $17^{\text {th }}$ and has been moved to $00 \mathrm{Z}$ on the $18^{\text {th }}$ based on the reconnaissance data. Minor alterations were made to the track of this tropical cyclone. Intensification to a tropical storm is analyzed at $06 \mathrm{Z}$ on the $18^{\text {th }}$, six 
hours later than originally shown in HURDAT. The next reconnaissance aircraft to investigate Edith arrived at midday on the $18^{\text {th }}$ and did not formally report a low-level circulation. Nonetheless, the reconnaissance mission did find southwest and southsouthwest winds at 1030Z, 12Z and $1230 \mathrm{Z}$ on the southern and southeastern quadrant, indicating that a weak circulation was still present. Two ships at $12 \mathrm{Z}$ reported $35 \mathrm{kt}$ on the northern quadrant and around the same time and location, the reconnaissance aircraft estimated surface winds of $50 \mathrm{kt}$. A blend of these observations is used for an analyzed intensity of $40 \mathrm{kt}$ at $12 \mathrm{Z}$ on the $18^{\text {th }}$, down from $50 \mathrm{kt}$ originally in HURDAT, a minor intensity change. $40 \mathrm{kt}$ is also the peak intensity of Edith, down from $50 \mathrm{kt}$ originally in HURDAT, a minor intensity change. Landfall on the island of Guadeloupe occurred near $12 \mathrm{Z}$ as a $40 \mathrm{kt}$ tropical storm. Two more reconnaissance missions late on the $18^{\text {th }}$ were not able to find a closed low-level circulation but these may not have been in the best location for determining whether a closed circulation existed. Weakening to a tropical depression is analyzed at $00 \mathrm{Z}$ on August $19^{\text {th }}$, twelve hours earlier than originally shown in HURDAT. Observations over the eastern Caribbean indicate that Edith weakened to a tropical wave soon after $00 \mathrm{Z}$ on the $19^{\text {th }}$. The last position is analyzed at $00 \mathrm{Z}$ on the $19^{\text {th }}$, twelve hours earlier than the original HURDAT. The tropical wave continued westward over the Caribbean Sea passing south of the Greater Antilles and did not show any signs of redevelopment. A recent analog to this tropical storm is Tropical Storm Erika in 2009.

New Tropical Storm [August 28 - September 4, 1959]

$\begin{array}{llll}37265 & 08 / 28 / 1959 & M= & 8 \\ 37265 & 08 / 28 * 330 & 54 \odot & 35 \\ 37265 & 08 / 29 * 354 & 557 & 4 \odot \\ 37265 & 08 / 30 * 367 & 547 & 45 \\ 37265 & 08 / 31 * 380 & 473 & 45 \\ 37265 & 09 / 01 * 388 & 454 & 5 \odot \\ 37265 & 09 / 02 * 399 & 449 & 55 \\ 37265 & 09 / 03 * 420 & 398 & 55 \\ 37265 & 09 / 04 * 495 & 290 & 60 \\ 37285 & \text { TS }\end{array}$

\begin{tabular}{|c|c|c|}
\hline $0 * 337$ & 544 & 40 \\
\hline $0 * 362$ & 563 & $4 \odot$ \\
\hline $0 * 370$ & 523 & 45 \\
\hline $0 * 380$ & 470 & 50 \\
\hline $0 * 395$ & 450 & 50 \\
\hline$\odot * 401$ & 439 & 55 \\
\hline ๑E432 & 378 & 55 \\
\hline ๑E532 & 250 & 60 \\
\hline
\end{tabular}

\begin{tabular}{|c|c|c|c|c|c|c|}
\hline \multicolumn{7}{|c|}{$X I N G=\odot \quad S S S=0$} \\
\hline$\odot * 342$ & 548 & 40 & $0 * 347$ & 552 & 40 & 0 * \\
\hline$\odot * 366$ & 565 & 40 & $0 * 366$ & 560 & 45 & ○* \\
\hline$\odot * 375$ & 501 & 45 & $0 * 378$ & 485 & 45 & 0 * \\
\hline $0 * 380$ & 466 & 50 & $0 * 382$ & 461 & 50 & ○* \\
\hline ๑*396 & 448 & 50 & ๑*397 & 448 & 55 & 0 * \\
\hline$\odot * 4 \odot 4$ & 426 & 55 & $0 * 410$ & 413 & 55 & 0 * \\
\hline OE445 & 352 & 55 & OE470 & 325 & 55 & ○* \\
\hline OE585 & 215 & 60 & $\Theta^{*}$ & $\odot$ & $\odot$ & 0 * \\
\hline
\end{tabular}

A new tropical storm has been added to HURDAT, not previously shown in McAdie et al. (2009). Evidence for its existence comes from the Historical Weather Map series, Microfilm, COADS ship database, Mariners Weather Log and David Roth's suspect list.

August 26:

HWM analyzes a frontal boundary over the central Atlantic at 12Z. Microfilm shows a closed low pressure of at most $1014 \mathrm{mb}$ at 29.0N, 53.0W at 12Z. Ship highlights: No gale force winds or equivalent low pressures. 
August 27:

HWM analyzes a closed low pressure of at most $1010 \mathrm{mb}$ at $30.0 \mathrm{~N}, 56.0 \mathrm{~W}$ with a warm front extending to the northeast and a cold front extending to the southwest at $12 \mathrm{Z}$. Microfilm shows an elongated closed low pressure of at most $1011 \mathrm{mb}$ at $30.0 \mathrm{~N}, 55.0 \mathrm{~W}$ at 12Z. Ship highlights: $35 \mathrm{kt} \mathrm{NE}$ and $1009 \mathrm{mb}$ at $32.8 \mathrm{~N}, 51.3 \mathrm{~W}$ at $12 \mathrm{Z}$ (COADS). $35 \mathrm{kt}$ $\mathrm{E}$ and $1015 \mathrm{mb}$ at $37.5 \mathrm{~N}, 50.3 \mathrm{~W}$ at $18 \mathrm{Z}$ (COADS).

August 28:

HWM analyzes a closed low pressure of at most $1005 \mathrm{mb}$ at $35.0 \mathrm{~N}, 54.0 \mathrm{~W}$ with a warm front to the northeast and a cold front extending to the southwest at $12 \mathrm{Z}$. Microfilm shows a closed low pressure of at most $1008 \mathrm{mb}$ at $33.5 \mathrm{~N}, 53.0 \mathrm{~W}$ at $12 \mathrm{Z}$. Ship highlights: $35 \mathrm{kt}$ ESE and $1016 \mathrm{mb}$ at $37.4 \mathrm{~N}, 48.7 \mathrm{~W}$ at $00 \mathrm{Z}$ (COADS). $40 \mathrm{kt} \mathrm{S}$ and $1002 \mathrm{mb}$ at $33.5 \mathrm{~N}, 52.5 \mathrm{~W}$ at $06 \mathrm{Z}$ (COADS). $25 \mathrm{kt} \mathrm{W}$ and $1002 \mathrm{mb}$ at $32.9 \mathrm{~N}, 54.4 \mathrm{~W}$ at $12 \mathrm{Z}$ (COADS). $25 \mathrm{kt} \mathrm{SW}$ and $1002 \mathrm{mb}$ at $33.7 \mathrm{~N}, 54.5 \mathrm{~W}$ at $18 \mathrm{Z}$ (COADS).

August 29:

HWM analyzes a closed low pressure of at most $1005 \mathrm{mb}$ at $37.5 \mathrm{~N}, 56.0 \mathrm{~W}$ with a cold front to the northeast at $12 \mathrm{Z}$. Microfilm shows a closed low pressure of at most 999 $\mathrm{mb}$ at $37.2 \mathrm{~N}, 56.0 \mathrm{~W}$ at $12 \mathrm{Z}$. Ship highlights: $30 \mathrm{kt} \mathrm{SW}$ and $1002 \mathrm{mb}$ at $33.3 \mathrm{~N}, 55.8 \mathrm{~W}$ at 00Z (COADS). $20 \mathrm{kt} \mathrm{W}$ and $1002 \mathrm{mb}$ at 35.7N, 56.4W at 06Z (COADS). $30 \mathrm{kt} \mathrm{N}$ and $1000 \mathrm{mb}$ at $37.1 \mathrm{~N}, 57.0 \mathrm{~W}$ at $12 \mathrm{Z}$ (COADS). $35 \mathrm{kt} \mathrm{W}$ and $1000 \mathrm{mb}$ at $35.9 \mathrm{~N}, 56.0 \mathrm{~W}$ at $18 \mathrm{Z}$ (COADS).

August 30:

HWM analyzes a closed low pressure of at most $1010 \mathrm{mb}$ at $37.5 \mathrm{~N}, 50.0 \mathrm{~W}$ with a cold front extending to the east at $12 \mathrm{Z}$. Microfilm shows a closed low pressure of at most $999 \mathrm{mb}$ at $37.5 \mathrm{~N}, 50.0 \mathrm{~W}$ with frontal boundary well north of cyclone at $12 \mathrm{Z}$. Ship highlights: $35 \mathrm{kt} \mathrm{E}$ and $1003 \mathrm{mb}$ at $37.3 \mathrm{~N}, 51.5 \mathrm{~W}$ at $06 \mathrm{Z}$ (COADS). $35 \mathrm{kt} \mathrm{SSW}$ and 999 $\mathrm{mb}$ at $37.2 \mathrm{~N}, 49.5 \mathrm{~W}$ at $12 \mathrm{Z}$ (COADS). $30 \mathrm{kt} \mathrm{WSW}$ and $1004 \mathrm{mb}$ at $36.8 \mathrm{~N}, 49.3 \mathrm{~W}$ at $18 \mathrm{Z}$ (COADS).

August 31:

HWM analyzes a closed low pressure of at most $1005 \mathrm{mb}$ at $39.0 \mathrm{~N}, 48.0 \mathrm{~W}$ with a cold front to the east and another approaching from the northwest at 12Z. Microfilm shows a closed low pressure of at most $1008 \mathrm{mb}$ at $39.5 \mathrm{~N}, 44.0 \mathrm{~W}$ with a frontal boundary to the west at 12Z. Ship highlights: $30 \mathrm{kt} \mathrm{SSW}$ and $1005 \mathrm{mb}$ at $37.8 \mathrm{~N}, 46.4 \mathrm{~W}$ at $00 \mathrm{Z}$ (COADS). $40 \mathrm{kt} \mathrm{NW}$ and $996 \mathrm{mb}$ at 37.5N, 48.0W at 06Z (COADS).

September 1:

HWM analyzes a closed low pressure of at most $1005 \mathrm{mb}$ at $39.0 \mathrm{~N}, 45.5 \mathrm{~W}$ with a weakening frontal boundary to the north at $12 \mathrm{Z}$. Microfilm shows a closed low pressure of at most $1011 \mathrm{mb}$ at $41.0 \mathrm{~N}, 42.5 \mathrm{~W}$ with a frontal boundary going through the cyclone 
at 12Z. Ship highlights: $40 \mathrm{kt} \mathrm{SE}$ and $1017 \mathrm{mb}$ at $42.4 \mathrm{~N}, 38.0 \mathrm{~W}$ at $12 \mathrm{Z}$ (COADS/micro). $30 \mathrm{kt} \mathrm{S}$ and $1003 \mathrm{mb}$ at $39.2 \mathrm{~N}, 43.8 \mathrm{~W}$ at $18 \mathrm{Z}$ (COADS).

September 2:

HWM analyzes a closed low pressure of at most $1005 \mathrm{mb}$ at $40.0 \mathrm{~N}, 42.5 \mathrm{~W}$ with a weakening warm front to the northwest at 12Z. Microfilm shows a closed low pressure of at most $1008 \mathrm{mb}$ at $39.5 \mathrm{~N}, 44.5 \mathrm{~W}$ with a frontal boundary going through the cyclone at 12Z. Ship highlights: $55 \mathrm{kt} \mathrm{W}$ and $999 \mathrm{mb}$ at $39.0 \mathrm{~N}, 45.5 \mathrm{~W}$ at $00 \mathrm{Z}$ (micro). $35 \mathrm{kt} \mathrm{SE}$ and $1000 \mathrm{mb}$ at $40.1 \mathrm{~N}, 44.2 \mathrm{~W}$ at $06 \mathrm{Z}$ (COADS). $35 \mathrm{kt} \mathrm{W}$ and $1004 \mathrm{mb}$ at $39.5 \mathrm{~N}, 43.0 \mathrm{~W}$ at $12 \mathrm{Z}$ (COADS). $45 \mathrm{kt} \mathrm{SW}$ and $998 \mathrm{mb}$ at $40.1 \mathrm{~N}, 41.7 \mathrm{~W}$ at 18Z (COADS).

September 3:

HWM analyzes a closed low pressure of at most $1000 \mathrm{mb}$ at $44.5 \mathrm{~N}, 35.0 \mathrm{~W}$ with a cold front to the northwest at $12 \mathrm{Z}$. Microfilm shows a closed low pressure of at most $1002 \mathrm{mb}$ at $45.0 \mathrm{~N}, 35.0 \mathrm{~W}$ with a frontal boundary to the west at 12Z. Ship highlights: 40 kt SW and $1011 \mathrm{mb}$ at $39.9 \mathrm{~N}, 41.6 \mathrm{~W}$ at $00 \mathrm{Z}$ (COADS). $40 \mathrm{kt} \mathrm{S}$ and $1010 \mathrm{mb}$ at $41.3 \mathrm{~N}$, $35.3 \mathrm{~W}$ at $06 \mathrm{Z}$ (COADS/micro). $35 \mathrm{kt} \mathrm{WSW}$ and $1012 \mathrm{mb}$ at $41.6 \mathrm{~N}, 35.5 \mathrm{~W}$ at $12 \mathrm{Z}$ (COADS). $50 \mathrm{kt} \mathrm{N}$ and $1011 \mathrm{mb}$ at $49.1 \mathrm{~N}, 38.4 \mathrm{~W}$ at $18 \mathrm{Z}$ (micro).

September 4:

HWM analyzes a closed low pressure of at most $1000 \mathrm{mb}$ at $58.0 \mathrm{~N}, 22.0 \mathrm{~W}$ with a cold front to the south and another extratropical cyclone of at most $990 \mathrm{mb}$ at $61.5 \mathrm{~N}$, 32.0W at 12Z. Microfilm shows a closed low pressure of at most $1002 \mathrm{mb}$ at $45.0 \mathrm{~N}$, $35.0 \mathrm{~W}$ with a frontal boundary to the west at 12Z. Ship highlights: $60 \mathrm{kt} \mathrm{S}$ and $999 \mathrm{mb}$ at $48.7 \mathrm{~N}, 25.8 \mathrm{~W}$ at $00 \mathrm{Z}$ (COADS). $60 \mathrm{kt} \mathrm{W}$ and $1005 \mathrm{mb}$ at $48.5 \mathrm{~N}, 30.5 \mathrm{~W}$ at $06 \mathrm{Z}$ (COADS). $45 \mathrm{kt} \mathrm{WNW}$ and $1006 \mathrm{mb}$ at $57.0 \mathrm{~N}, 37.0 \mathrm{~W}$ at $12 \mathrm{Z}$ (COADS). $55 \mathrm{kt} \mathrm{S}$ and $1010 \mathrm{mb}$ at $58.7 \mathrm{~N}, 14.6 \mathrm{~W}$ at $18 \mathrm{Z}(\mathrm{COADS})$.

A low pressure developed along the tail-end of a frontal boundary over the central Atlantic on August $26^{\text {th }}$. The disturbance moved slowly northward during the next couple of days becoming better organized. A strong high pressure system to the north blocked its northward movement and the microfilm maps indicate that the frontal boundary dissipated by August $27^{\text {th }}$. Genesis is analyzed at $00 \mathrm{Z}$ on August $28^{\text {th }}$ as a $35 \mathrm{kt}$ tropical storm. It is likely that the system may have developed earlier but the data is inconclusive to suggest that a well-defined center was present during that time. The strong pressure gradient caused gale-force winds to be present well northeast of the center, but at $06 \mathrm{Z}$ on the $28^{\text {th }}$, a ship reported $40 \mathrm{kt} \mathrm{S}$ and $1002 \mathrm{mb}$ about $60 \mathrm{~nm}$ east of the center and the intensity is increased to $40 \mathrm{kt}$. The tropical cyclone moved slowly to the northwest maintaining its intensity. The HWM on the $28^{\text {th }}$ depicts the tropical cyclone as a closed low pressure with a warm front extended to the northeast and a cold front extended to the south. Synoptic data suggest instead that the environment around the cyclone was uniform with temperatures in the mid 70 s, the circulation was symmetric and strongest winds were near the center - all indications that the system was tropical in nature. On August $29^{\text {th }}$, the cyclone stopped moving to the northwest and began to accelerate to the 
east-northeast ahead of an approaching frontal boundary. On this day, the HWM depicts an occluding low pressure while microfilm shows no frontal features associated with the tropical cyclone. At $18 \mathrm{Z}$ on the $29^{\text {th }}$, a ship near the center reported $35 \mathrm{kt} \mathrm{W}$ and 1000 $\mathrm{mb}$. A peripheral pressure of $1000 \mathrm{mb}$ suggest sustained maximum winds over $49 \mathrm{kt}$ north of $35 \mathrm{~N}$ from the Landsea et al. (2004a) pressure-wind relationship. Due to the slow forward speed of about $5 \mathrm{kt}$, an intensity of $45 \mathrm{kt}$ is selected at $18 \mathrm{Z}$ on the $29^{\text {th }}$. On August $30^{\text {th }}$, the tropical storm moved rapidly to the east-northeast with no change in the intensity. On this day, the HWM depicts a closed low pressure with a cold front extended to the east and southeast of the center, while microfilm shows no frontal features associated with the tropical cyclone and a cold front well to the north. Based on the synoptic data, the depiction by microfilm appears to be correct. Late on the $30^{\text {th }}$, microfilm suggests that the tropical cyclone interacted with the approaching frontal boundary and by $00 \mathrm{Z}$ on August $31^{\text {st }}$, a frontal boundary is drown across the center of the tropical storm. Synoptic data suggests that the environment around the system remained uniform with temperatures in the mid to high 70 s, the strongest winds were near the center and the circulation was symmetric, characteristics of a tropical cyclone. A ship reported $40 \mathrm{kt} \mathrm{NW}$ and $996 \mathrm{mb}$ at $06 \mathrm{Z}$ on the $31^{\text {st }}$. A peripheral pressure of $996 \mathrm{mb}$ suggest sustained maximum winds over $55 \mathrm{kt}$ north of $35 \mathrm{~N}$ from the pressure-wind relationship. At this time, the forward speed of the cyclone had decreased to about $3 \mathrm{kt}$, thus an intensity of $50 \mathrm{kt}$ is selected at $06 \mathrm{Z}$ on the $31^{\text {st }}$. On August $31^{\text {st }}$ and September $1^{\text {st }}$, the tropical storm moved very slowly while located about halfway between Newfoundland and the Azores. Early on September $2^{\text {nd }}$, an approaching frontal boundary caused the tropical cyclone to start moving northeastward with an increase in forward speed. A ship at $00 Z$ on the $2^{\text {nd }}$ reported $55 \mathrm{kt} \mathrm{W}$ and $999 \mathrm{mb}$, and another ship at $18 \mathrm{Z}$ on this day reported $45 \mathrm{kt} \mathrm{SW}$ and $998 \mathrm{mb}$. An intensity of $55 \mathrm{kt}$ is analyzed at $18 \mathrm{Z}$ on the $1^{\text {st }} .55 \mathrm{kt}$ is the peak intensity of this storm as a tropical cyclone. Microfilm depicts a frontal boundary going through the system on the $1^{\text {st }}$ and $2^{\text {nd }}$ (except at 18Z), but synoptic data clearly shows that the temperatures near the center remained in the mid 70s, with colder temperatures staying well to the north and northwest of the cyclone. Furthermore, the strongest winds were located very close to the center and the circulation remained symmetrical. Early on September $3^{\text {rd }}$, a stronger frontal boundary approaching from the northwest caught up to the tropical cyclone and synoptic data suggest that transition to an extratropical cyclone occurred at $06 \mathrm{Z}$ on the $3^{\text {rd }}$. At this time, a temperature gradient developed across the circulation and the windfield expanded, with the strongest winds being reported away from the center. The system was an intense extratropical cyclone with winds up to $60 \mathrm{kt}$ being reported by ships at $00 \mathrm{Z}$ and $06 \mathrm{Z}$ on September $4^{\text {th }}$. At $18 \mathrm{Z}$ on the $4^{\text {th }}$, synoptic data suggests that the extropical cyclone merged with a larger extratropical cyclone located southwest of Iceland. The final position is analyzed at $12 \mathrm{Z}$ on the $4^{\text {th }}$. An analog for this tropical storm is Tropical Storm Josephine, 2002.

New Tropical Storm [September 7-14, 1959]

\begin{tabular}{|c|c|c|c|c|c|c|c|c|c|c|c|c|c|}
\hline 726 & 9 & $M=$ & 8 & SNBR= & $820 \mathrm{~L}$ & UNNAMED & & XING & $\mathrm{S}$ & & & & \\
\hline 3726 & $\odot 9 / 07$ * & $\odot$ & $\odot$ & $\theta^{*}$ & $\odot$ & $\odot$ & $0 * 315$ & 670 & 25 & $0 * 320$ & 670 & 25 & \\
\hline 726 & $09 / 08 * 323$ & 670 & 25 & $0 * 325$ & 5670 & 25 & $0 * 325$ & 670 & 25 & $0 * 324$ & 672 & 25 & ๑* \\
\hline
\end{tabular}


$3726509 / 09 * 32367525$

$3726509 / 10 * 341670 \quad 30$

$3726509 / 11 * 373703 \quad 35$

$3726509 / 12 E 410650 \quad 45$

37265 09/13E439 57850

$3726509 / 14 E 505465 \quad 45$

37285 TS

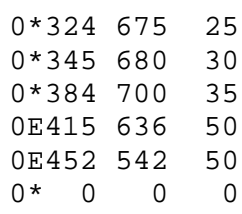

\begin{tabular}{|c|c|c|c|c|c|}
\hline $0 * 330$ & 672 & 30 & $0 * 336$ & 670 & 30 \\
\hline $0 * 350$ & 700 & 35 & $0 * 360$ & 700 & 35 \\
\hline ๑ *395 & 685 & 40 & $1002 \mathrm{E} 404$ & 668 & 40 \\
\hline OE420 & 622 & 55 & OE428 & 608 & 55 \\
\hline OE46 & 509 & 45 & OE485 & 485 & 45 \\
\hline ○* & 0 & 0 & ○* & 0 & \\
\hline
\end{tabular}

A new tropical storm has been added to HURDAT, not previously shown in McAdie et al. (2009). Evidence for its existence comes from the Historical Weather Map series, Microfilm, COADS ship database, Surface Weather Observations, Mariners Weather Log and Jack Beven's and David Roth's suspect list.

September 6:

HWM analyzes a closed low pressure of at most $1015 \mathrm{mb}$ at $26.0 \mathrm{~N}, 73.5 \mathrm{~W}$ at 12Z. Microfilm shows a closed low pressure of at most $1014 \mathrm{mb}$ at $26.5 \mathrm{~N}, 73.0 \mathrm{~W}$ at $12 \mathrm{Z}$. Ship highlights: No gale force winds or equivalent low pressures.

September 7:

HWM analyzes a stationary front over the Western Atlantic at 12Z. Microfilm shows a closed low pressure of at most $1017 \mathrm{mb}$ at $31.0 \mathrm{~N}, 66.0 \mathrm{~W}$ at $12 \mathrm{Z}$. Ship highlights: No gale force winds or equivalent low pressures.

September 8:

HWM analyzes a closed low pressure of at most $1015 \mathrm{mb}$ at $33.0 \mathrm{~N}, 65.0 \mathrm{~W}$ with a stationary front extended from the low pressure to the northeast at 12Z. Microfilm shows a closed low pressure of at most $1011 \mathrm{mb}$ at $35.5 \mathrm{~N}, 66.0 \mathrm{~W}$ at 12Z. Ship highlights: No gale force winds or equivalent low pressures.

September 9:

HWM analyzes a closed low pressure of at most $1010 \mathrm{mb}$ at $32.5 \mathrm{~N}, 66.5 \mathrm{~W}$ with a weakening stationary front to the northeast at $12 \mathrm{Z}$. Microfilm shows a closed low pressure of at most $1011 \mathrm{mb}$ at $34.0 \mathrm{~N}, 65.0 \mathrm{~W}$ at 12Z. Ship highlights: No gale force winds or equivalent low pressures.

September 10:

HWM analyzes a closed low pressure of at most $1010 \mathrm{mb}$ at $33.0 \mathrm{~N}, 70.0 \mathrm{~W}$ with a warm front to the north at $12 \mathrm{Z}$. Microfilm shows a closed low pressure of at most 1011 $\mathrm{mb}$ at $35.0 \mathrm{~N}, 69.0 \mathrm{~W}$ at $12 \mathrm{Z}$. Ship highlights: $35 \mathrm{kt} \mathrm{NE}$ and $1015 \mathrm{mb}$ at $36.9 \mathrm{~N}, 71.1 \mathrm{~W}$ at $12 \mathrm{Z}$ (COADS). $35 \mathrm{kt} \mathrm{E}$ and $1009 \mathrm{mb}$ at $37.1 \mathrm{~N}, 68.0 \mathrm{~W}$ at $18 \mathrm{Z}$ (COADS). 
September 11:

HWM analyzes a closed low pressure of at most $1005 \mathrm{mb}$ at $38.0 \mathrm{~N}, 66.0 \mathrm{~W}$ with a cold front to the west at 12Z. Microfilm shows a closed low pressure of at most $1005 \mathrm{mb}$ at $40.0 \mathrm{~N}, 67.0 \mathrm{~W}$ with a frontal boundary to the west at 12Z. Ship highlights: $20 \mathrm{kt} \mathrm{NE}$ and $1003 \mathrm{mb}$ at $40.3 \mathrm{~N}, 69.2 \mathrm{~W}$ at $12 \mathrm{Z}$ (COADS). $25 \mathrm{kt} \mathrm{NW}$ and $998 \mathrm{mb}$ at $40.2 \mathrm{~N}, 67.5 \mathrm{~W}$ at 18Z (COADS). Land highlights: $34 \mathrm{kt} \mathrm{NNE} \mathrm{(max} \mathrm{winds)} \mathrm{and} 1007 \mathrm{mb}$ at Nantucket Shoals, MA at $1158 \mathrm{Z}$ (SWO). $40 \mathrm{kt} \mathrm{N}$ (gusts to $45 \mathrm{kt}$, max winds) and $1005 \mathrm{mb}$ at Georges Shoals, MA at 18Z (SWO).

September 12:

HWM analyzes a closed low pressure of at most $1000 \mathrm{mb}$ at $42.0 \mathrm{~N}, 62.0 \mathrm{~W}$ with a frontal system going through the cyclone at 12Z. Microfilm shows a closed low pressure of at most $1002 \mathrm{mb}$ at $43.0 \mathrm{~N}, 62.0 \mathrm{~W}$ with a frontal boundary going through the cyclone at 12Z. Ship highlights: $15 \mathrm{kt} \mathrm{NE}$ and $1001 \mathrm{mb}$ at $44.6 \mathrm{~N}, 60.3 \mathrm{~W}$ at $00 \mathrm{Z}$ (COADS). $40 \mathrm{kt}$ ESE and $1010 \mathrm{mb}$ at $41.5 \mathrm{~N}, 60.4 \mathrm{~W}$ at $00 \mathrm{Z}$ (COADS/micro). $40 \mathrm{kt} \mathrm{SE}$ and $1000 \mathrm{mb}$ at $42.6 \mathrm{~N}, 63.4 \mathrm{~W}$ at $06 \mathrm{Z}$ (COADS). $50 \mathrm{kt} \mathrm{N}$ and $1007 \mathrm{mb}$ at $41.7 \mathrm{~N}, 64.5 \mathrm{~W}$ at $08 \mathrm{Z}$ (COADS). $55 \mathrm{kt} \mathrm{SSW}$ and $1005 \mathrm{mb}$ at $40.8 \mathrm{~W}, 62.1 \mathrm{~W}$ at $12 \mathrm{Z}$ (COADS). $40 \mathrm{kt} \mathrm{N}$ and $1000 \mathrm{mb}$ at $42.7 \mathrm{~N}, 61.5 \mathrm{~W}$ at $18 \mathrm{Z}$ (COADS).

September 13:

HWM analyzes a closed low pressure of at most $995 \mathrm{mb}$ at $46.0 \mathrm{~N}, 51.0 \mathrm{~W}$ with a frontal system going through the cyclone at 12Z. Microfilm shows a closed low pressure of at most $996 \mathrm{mb}$ at $46.0 \mathrm{~N}, 50.5 \mathrm{~W}$ with a frontal boundary going through the cyclone at 12Z. Ship highlights: $40 \mathrm{kt} \mathrm{SW}$ and $1006 \mathrm{mb}$ at 41.3N, 55.2W at 00Z (COADS). $25 \mathrm{kt}$ NNW and $998 \mathrm{mb}$ at $45.1 \mathrm{~N}, 56.0 \mathrm{~W}$ at $06 \mathrm{Z}$ (micro). $45 \mathrm{kt} \mathrm{NNW}$ and $1001 \mathrm{mb}$ at $42.4 \mathrm{~N}$, $55.0 \mathrm{~W}$ at $12 \mathrm{Z}$ (COADS). $35 \mathrm{kt} \mathrm{N}$ and $995 \mathrm{mb}$ at $46.9 \mathrm{~N}, 51.2 \mathrm{~W}$ at $18 \mathrm{Z}$ (COADS). $35 \mathrm{kt}$ $\mathrm{W}$ and $992 \mathrm{mb}$ at $47.7 \mathrm{~N}, 47.5 \mathrm{~W}$ at $23 \mathrm{Z}$ (COADS).

September 14:

HWM analyzes an extratropical cyclone of at most $985 \mathrm{mb}$ at $54.0 \mathrm{~N}, 51.0 \mathrm{~W}$ with a frontal system going through the cyclone at 12Z. Microfilm shows an extratropical cyclone of at most $987 \mathrm{mb}$ at $56.5 \mathrm{~N}, 52.0 \mathrm{~W}$ at 12Z. Ship highlights: $35 \mathrm{kt} \mathrm{W}$ and $997 \mathrm{mb}$ at $45.0 \mathrm{~N}, 47.0 \mathrm{~W}$ at $00 \mathrm{Z}$ (COADS). $35 \mathrm{kt} \mathrm{SE}$ and $992 \mathrm{mb}$ at $57.4 \mathrm{~N}, 42.7 \mathrm{~W}$ at $12 \mathrm{Z}$ (COADS). $35 \mathrm{kt} \mathrm{SW}$ and $987 \mathrm{mb}$ at $54.2 \mathrm{~N}, 49.4 \mathrm{~W}$ at $18 \mathrm{Z}$ (COADS).

A broad area of low pressure developed between the Bahamas and Bermuda on September $6^{\text {th }}$. The disturbance moved lowly northward becoming a $25 \mathrm{kt}$ tropical depression on September $7^{\text {th }}$ at $12 Z$. Historical Weather Maps show a stationary front just 
north of the depression on the $7^{\text {th }}$ but microfilm indicates that the boundary was not present, which appears correct based on the synoptic data. The tropical depression remained nearly stationary during the next two days with little change in intensity. A ship reported $35 \mathrm{kt}$ far north of the center on September $9^{\text {th }}$ at $18 \mathrm{Z}$ but nearby ships suggests that the wind report likely has a high bias. The tropical depression increased in forward speed on September $10^{\text {th }}$ while moving northwestward. Intensification to a tropical storm is analyzed at $12 \mathrm{Z}$ on the $10^{\text {th }}$ based on a ship report of $35 \mathrm{kt}$ about $125 \mathrm{~nm}$ northwest of the center. Another ship at about the same distance northeast of the center reported $35 \mathrm{kt}$ at $18 \mathrm{Z}$ on the $10^{\text {th }}$. The tropical storm retained a large circulation embedded within a moist environment. It is likely that it was a subtropical cyclone during its lifetime, but this cannot be confirmed without satellite imagery. An approaching frontal boundary caused the tropical cyclone to turn to the northeast on September $11^{\text {th }}$. A ship reported 5 $\mathrm{kt} \mathrm{SW}$ and $1003 \mathrm{mb}$ on the $11^{\text {th }}$ at $12 \mathrm{Z}$ and another reported $20 \mathrm{kt} \mathrm{NE}$ and $1003 \mathrm{mb}$ at the same time, suggesting a central pressure near $1002 \mathrm{mb}$, which has been added to HURDAT. A central pressure of $1002 \mathrm{mb}$ suggests maximum sustained winds of $45 \mathrm{kt}$ north of $35 \mathrm{~N}$ from the Landsea et al. pressure-wind relationship. Due to the large circulation of the tropical storm, an intensity of $40 \mathrm{kt}$ is selected at $12 \mathrm{Z}$ on the $11^{\text {th }} .40 \mathrm{kt}$ is also the peak intensity of the system while it was a tropical cyclone. The elevated weather stations of Nantucket Shoals and Georges Shoals reported maximum sustained winds of $34 \mathrm{kt}$ and $40 \mathrm{kt}$ at $1158 \mathrm{Z}$ and $18 \mathrm{Z}$ on the $11^{\text {th }}$, respectively. Transition to an extratropical cyclone is analyzed at $18 \mathrm{Z}$ on the $11^{\text {th }}$ based on the synoptic data, which shows that the cold front had already reached the center of the cyclone. The extratropical cyclone continued to gain in forward speed on September $12^{\text {th }}$ as it passed south of Nova Scotia, Canada. Ships reported gale-force winds up to $55 \mathrm{kt}$ on the $12^{\text {th }}$. Ship and coastal observations on September $13^{\text {th }}$ indicate that the circulation of the extratropical cyclone expanded and the winds began to decrease. At the same time, another extratropical cyclone began to organize over northern Canada. Early on September $14^{\text {th }}$, synoptic data suggests that the two extratropical cyclones merged. This solution is consistent with the track of lows of September, 1959 in the Mariners Weather Log. The last position is analyzed at $00 \mathrm{Z}$ on the $14^{\text {th }}$.

\section{Hurricane Flora [September 9-12, 1959]}

\begin{tabular}{|c|c|c|c|c|c|c|c|c|c|c|c|c|c|c|}
\hline 41175 & $09 / 09 / 1$ & 959 & $M=$ & 6 & SNBR $=8$ & $96 \mathrm{FL}$ & ORA & $X I$ & $\mathrm{JG}=0$ & $S S S=0$ & & & & \\
\hline 41175 & $09 / 09 / 1$ & 959 & $M=$ & $\begin{array}{l}410 \\
* \quad *\end{array}$ & $\mathrm{SNBR}=8 \mathrm{~S}$ & $96 \mathrm{FL}$ & ORA & $X I$ & $\mathrm{JG}=0$ & $S S S=0$ & & & & \\
\hline 41180 & ๑9/09* & $\odot$ & $\odot$ & $\odot$ & $0 * 168$ & 458 & 25 & $0 * 180$ & 465 & 25 & $0 * 195$ & 467 & 25 & 0 * \\
\hline 41180 & $09 / 09 *$ & $\Theta$ & 0 & $\Theta$ & $0 * 168$ & 458 & 25 & $\begin{array}{r}0 * 182 \\
* * *\end{array}$ & 465 & 25 & $0 * 195$ & 467 & 25 & $0^{*}$ \\
\hline 1185 & $09 / 10 * 2$ & 8 & 465 & 30 & $1008 * 220$ & 460 & 35 & $0 * 231$ & 454 & 40 & $0 * 243$ & 447 & 45 & $0^{*}$ \\
\hline
\end{tabular}




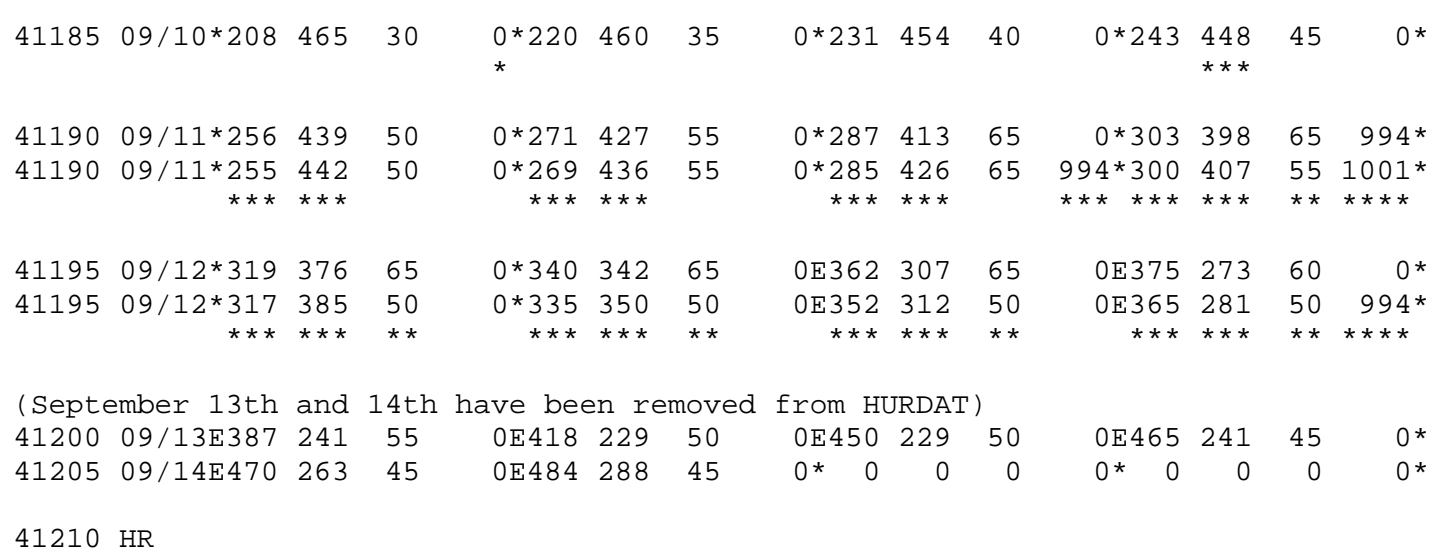

Minor changes to the track and intensity shown in McAdie et al. (2009). Evidence for these alterations comes from the NHC microfilm maps, the Historical Weather Maps series, the COADS ship database, Monthly Weather Review, Navy reconnaissance book, Surface Weather Observations, Mariners Weather Log and NHC Storm Wallets.

September 8:

HWM analyzes a closed low of at most $1010 \mathrm{mb}$ at $14.0 \mathrm{~N}, 46.0 \mathrm{~W}$ at $12 \mathrm{Z}$. HURDAT does not list an organized system on this date. Microfilm shows a broad area of low pressure near $11.0 \mathrm{~N}, 45.0 \mathrm{~W}$ at 12Z. Ship highlights: No gales or low pressures.

ATSR: "Hurricane FLORA had a long and nebulous period of development. Reports from the Cape Verde Islands evidenced the passage of an easterly wave or depression on the Intertropical Convergence Zone on the $6^{\text {th }}$ of September with a marked wind shift and heavy precipitation."

September 9:

HWM analyzes a closed low of at most $1010 \mathrm{mb}$ at $17.0 \mathrm{~N}, 48.0 \mathrm{~W}$ at $12 \mathrm{Z}$. HURDAT lists a $25 \mathrm{kt}$ tropical depression at $18.0 \mathrm{~N}, 46.5 \mathrm{~W}$ at 12Z. Microfilm does not show an organized system at 12Z. Ship highlights: No gales or low pressures.

ATSR: "At 090000Z, a ship at $12.7 \mathrm{~N}, 41.3 \mathrm{~W}$ reported a westerly wind of 15 knots and rain, the first concrete evidence of a cyclonic circulation. On the $9^{\text {th }}$ and $10^{\text {th }}$, FLORA moved northwest and then north around the periphery of the Azores high."

September 10:

HWM analyzes a closed low of at most $1010 \mathrm{mb}$ at $23.0 \mathrm{~N}, 46.4 \mathrm{~W}$ at $12 \mathrm{Z}$. HURDAT lists a $40 \mathrm{kt}$ tropical storm at $23.1 \mathrm{~N}, 45.4 \mathrm{~W}$ at $12 \mathrm{Z}$. Microfilm shows a closed low pressure of at most $1008 \mathrm{mb}$ at $22.0 \mathrm{~N}, 46.5 \mathrm{~W}$ at 12Z. Ship highlights: $35 \mathrm{kt} \mathrm{ESE}$ and $1008 \mathrm{mb}$ at $22.8 \mathrm{~N}, 45.0 \mathrm{~W}$ at $09 \mathrm{Z}$ (micro). $35 \mathrm{kt} \mathrm{S}$ and $1011 \mathrm{mb}$ at $22.8 \mathrm{~N}, 45.0 \mathrm{~W}$ at $12 \mathrm{Z}$ 
(COADS). $35 \mathrm{kt} \mathrm{SE}$ and $1013 \mathrm{mb}$ at 24.5N, 43.7W at 15Z (micro). Aircraft highlights: Penetration center fix measured a central pressure of $1008 \mathrm{mb}$ and estimated surface winds of $25 \mathrm{kt}$ at $22.1 \mathrm{~N}, 46.3 \mathrm{~W}$ at $16 \mathrm{Z}$ (ATSR).

MWR: "The history of the formation of Flora is rather uncertain beyond about 24 hours prior to the first advisory issued at noon EST, September 10. However, four days earlier, on the afternoon of September 6, pressure and wind in the Cape Verde Islands indicated a trough passage. This trough could not be followed from day to day through the ocean area due to a lack of reports, but if it moved at an average speed of $13 \mathrm{kt}$ it would have reached the position where Flora was found on September 10 near latitude 22.1N, longitude $46.3 \mathrm{~W}$. Ship and aircraft reports indicated highest winds of $39 \mathrm{kt}$ and minimum central pressure of $1008.1 \mathrm{mb}$." ATSR: "Peripheral ship reports at $10000 \mathrm{Z}$ permitted drawing a weak circulation centered at about $21 \mathrm{~N} 44 \mathrm{~W}$ with the ITC well to the south. A Navy reconnaissance aircraft was sent out from Roosevelt Roads, Puerto Rico on the $10^{\text {th }}$ of September, and near the extreme limits of endurance, encountered a closed circulation located near $22 \mathrm{~N} 46 \mathrm{~W}$ at $101600 \mathrm{Z}$ with maximum winds of 25 knots. First warning was issued at $101700 \mathrm{Z}$ with intensification expected."

September 11:

HWM analyzes a hurricane of at most $1000 \mathrm{mb}$ at $28.9 \mathrm{~N}, 41.5 \mathrm{~W}$ at $12 \mathrm{Z}$. HURDAT lists a $65 \mathrm{kt}$ hurricane at $28.7 \mathrm{~N}, 41.3 \mathrm{~W}$ at $12 \mathrm{Z}$. Microfilm shows a closed low pressure of at most $999 \mathrm{mb}$ at $29.2 \mathrm{~N}, 40.9 \mathrm{~W}$ at 12Z. Ship highlights: $35 \mathrm{kt}$ SE and 1011 mb near $30.7 \mathrm{~N}, 38.4 \mathrm{~W}$ at $12 \mathrm{Z}$ (micro). $50 \mathrm{kt} \mathrm{NNE}$ and $1008 \mathrm{mb}$ at $30.0 \mathrm{~N}, 41.1 \mathrm{~W}$ at $18 \mathrm{Z}$ (micro). Aircraft highlights: Penetration center fix measured a central pressure of $994 \mathrm{mb}$ and estimated surface winds of $65 \mathrm{kt}$ at $29.1 \mathrm{~N}, 41.1 \mathrm{~W}$ at $1445 \mathrm{Z}$ (MWR/ATSR).

Penetration center fix measured a central pressure of $1001 \mathrm{mb}$ and estimated surface winds of $60 \mathrm{kt}$ at $29.4 \mathrm{~N}, 40.2 \mathrm{~W}$ at $17 \mathrm{Z}$ (MWR/ATSR).

MWR: "By mid-morning of September 11, aircraft found that Flora's winds had increased to barely hurricane force, $65 \mathrm{kt}$, and the minimum pressure was $994 \mathrm{mb}$. The next highest wind speed reported was $60 \mathrm{kt}$ on the afternoon of the same day when central pressure had risen to $1001.0 \mathrm{mb}$." ATSR: "Reports indicated that FLORA reached maximum intensity of 65 knots at about $111500 \mathrm{Z}$ close to the center of a $200 \mathrm{mb}$ low (in the southeastern quadrant of that low) then weakened slowly. Then recurved sharply and accelerated about $110400 \mathrm{Z}$ about 600 miles in advance of the surface cold front."

September 12:

HWM analyzes a tropical storm of at most $1000 \mathrm{mb}$ at $36.5 \mathrm{~N}, 30.5 \mathrm{~W}$ with a cold front just to the northwest at $12 \mathrm{Z}$. HURDAT lists a 65 knot extratropical cyclone at $36.2 \mathrm{~N}, 30.7 \mathrm{~W}$ at $12 \mathrm{Z}$. Microfilm shows an extratropical cyclone at $36.0 \mathrm{~N}, 31.0 \mathrm{~W}$ with a frontal boundary extending south at $12 \mathrm{Z}$. Ship highlights: $35 \mathrm{kt} \mathrm{S}$ and $1008 \mathrm{mb}$ at $31.6 \mathrm{~N}$, $36.7 \mathrm{~W}$ at $00 \mathrm{Z}$ (COADS). $35 \mathrm{kt} \mathrm{S}$ and $1005 \mathrm{mb}$ at $32.6 \mathrm{~N}, 34.2 \mathrm{~W}$ at $06 \mathrm{Z}$ (COADS). Aircraft highlights: Penetration center fix measured a minimum pressure of $994 \mathrm{mb}$, 
estimated surface winds of $40-50 \mathrm{kt}$ and an eye diameter of $40 \mathrm{~nm}$ at $36.4 \mathrm{~N}, 27.8 \mathrm{~W}$ at $1935 Z$ (ATSR/micro).

MWR: “On September 12, although a lower pressure of $994.2 \mathrm{mb}$ was measured as the storm became extratropical, highest surface winds were about $45 \mathrm{kt}$. Flora recurved quickly to the north and northeastward before she became a threat to any land areas except the Azores islands, due to a major trough in the westerlies extending southward into the Tropics. No loss of life or property damage has been attributed to Flora." ATSR: "An Air Force reconnaissance aircraft reported the eye of FLORA closely associated with the cold front 150 miles to the southwest of the Azores at 121935Z. FLORA then appeared to merge rapidly with the cold front, and finally dissipated off the coast of Spain."

September 13:

HWM analyzes a tropical storm of at most $995 \mathrm{mb}$ at $45.3 \mathrm{~N}, 22.0 \mathrm{~W}$ with a cold front to the south at $12 \mathrm{Z}$. HURDAT lists a 50 knot extratropical cyclone at $45.0 \mathrm{~N}, 22.9 \mathrm{~W}$ at $12 \mathrm{Z}$. Microfilm shows a closed low pressure of at most $996 \mathrm{mb}$ at $45.5 \mathrm{~N}, 22.5 \mathrm{~W}$ at 12Z. Ship highlights: No gales or low pressures.

September 14:

HWM analyzes a closed low pressure of at most $1000 \mathrm{mb}$ with a cold front to the east at $43.0 \mathrm{~N}, 17.0 \mathrm{~W}$ at $12 \mathrm{Z}$. HURDAT lists a 45 knot extratropical cyclone at $48.4 \mathrm{~N}$, $28.8 \mathrm{~W}$ at $06 \mathrm{Z}$ (last position). Microfilm shows that the low pressure had moved off the map at 12Z. Ship highlights: No gales or low pressures.

September 15:

HWM analyzes a closed low pressure of at most $1005 \mathrm{mb}$ at $43.5 \mathrm{~N}, 15.0 \mathrm{~W}$ at 12Z. HURDAT does not list an organized storm on this date. Microfilm is not available on this date. Ship highlights: No gales or low pressures.

September 16:

HWM analyzes a closed low pressure of at most $1005 \mathrm{mb}$ at $44.0 \mathrm{~N}, 12.0 \mathrm{~W}$ at 12Z. HURDAT does not list an organized storm on this date. Microfilm is not available on this date. Ship highlights: No gales or low pressures.

September 17:

HWM does not analyze an organized storm on this date. HURDAT does not list an organized storm on this date. Microfilm is not available on this date. Ship highlights: No gales or low pressures. 
Hurricane Flora developed from a tropical wave that left the African coast early in September. Data over the eastern and central Atlantic is sparse, which makes the genesis time highly uncertain. The first position is analyzed at $06 \mathrm{Z}$ on September $9^{\text {th }}$ as a $25 \mathrm{kt}$ tropical depression, same as originally in HURDAT. It is possible that this tropical cyclone developed significantly earlier. Minor alterations were made to the track of this tropical cyclone. The most significant change occurred at $12 \mathrm{Z}$ on the $11^{\text {th }}$ due to a couple of ship reports which indicated a more westward position. A break in the subtropical ridge allowed the tropical depression to turn northward over the central Atlantic. A central pressure of $1008 \mathrm{mb}$ was present in HURDAT at $00 \mathrm{Z}$ on September $10^{\text {th }}$ and has been removed because the reconnaissance mission that measured $1008 \mathrm{mb}$ arrived at $16 \mathrm{Z}$ on the $10^{\text {th }}$. Intensification to a tropical storm is retained from the original HURDAT at $06 \mathrm{Z}$ on the $10^{\text {th }}$. It is at this time that the first gale is reported near this tropical cyclone. As mentioned earlier, the first reconnaissance aircraft reached Flora at $16 \mathrm{Z}$ on the $10^{\text {th }}$ measuring a central pressure of $1008 \mathrm{mb}$ and estimating surface winds of $25 \mathrm{kt}$. This position is over 1000 miles from the closest landmass and based on the synoptic data, it appears that the aircraft did not reach the center of the tropical cyclone. Therefore, this center fix was not used to adjust the track or intensity of the tropical cyclone. It is also interesting to note that the synoptic data shows an elongated and disorganized system, and may have not had a closed low-level circulation at this time.

On September $11^{\text {th }}$, Flora accelerated to the northeast as a frontal boundary approached from the northwest. Another reconnaissance aircraft reached the tropical cyclone at $1445 \mathrm{Z}$ measuring a central pressure of $994 \mathrm{mb}$ and estimating surface winds of $65 \mathrm{kt}$. A central pressure of $994 \mathrm{mb}$ suggests maximum surface winds of $53 \mathrm{kt}$ north of $25 \mathrm{~N}$ according to the Brown et al. pressure-wind relationship. Due to Flora's forward speed of about $20 \mathrm{kt}$ and high environmental pressures, an intensity of $65 \mathrm{kt}$ is selected for $12 \mathrm{Z}$ on the $11^{\text {th }}$, same as the original HURDAT. This is also the peak intensity of this tropical cyclone, same as the original HURDAT. It is also possible that Flora peaked as a highend tropical storm. The reanalyzed HURDAT keeps Flora as a hurricane for only one sixhour period, compared to the original HURDAT which kept Flora at hurricane intensity between $12 \mathrm{Z}$ on the $11^{\text {th }}$ and $12 \mathrm{Z}$ on the $12^{\text {th }}$. A central pressure of $994 \mathrm{mb}$ was added to HURDAT at $12 \mathrm{Z}$ on the $11^{\text {th }}$. Synoptic data at $12 \mathrm{Z}$ on the $11^{\text {th }}$ also indicates that the reconnaissance center fix was about a degree or so too far to the east. Another penetration center fix measured a central pressure of $1001 \mathrm{mb}$ and estimated surface winds of $60 \mathrm{kt}$ at $17 \mathrm{Z}$ on the $11^{\text {th }}$. A central pressure of $1001 \mathrm{mb}$ suggests maximum surface winds of $41 \mathrm{kt}$ from the north of $25 \mathrm{~N}$ weakening subset of the pressure-wind relationship. Due to a forward speed of about $20 \mathrm{kt}$ and a ship report of $50 \mathrm{kt}$ at $18 \mathrm{Z}$ on the $11^{\text {th }}$ on the weak side of Flora, an intensity of $55 \mathrm{kt}$ is selected at $18 \mathrm{Z}$ on the $11^{\text {th }}, 10 \mathrm{kt}$ lower than originally shown in HURDAT, a minor intensity change. A central pressure of $1001 \mathrm{mb}$ was added to HURDAT at $18 \mathrm{Z}$ on the $11^{\text {th }}$, replacing the existing $994 \mathrm{mb}$, which belongs 
at the $12 \mathrm{Z}$ slot. It is analyzed that Flora weakened to tropical storm intensity at $18 \mathrm{Z}$ on the $11^{\text {th }}, 24$ hours earlier than originally shown in HURDAT. Flora continued to increase in forward speed on September $12^{\text {th }}$ as it became increasingly embedded within the frontal boundary associated with a large extratropical cyclone to the north. Transition to an extratropical cyclone is analyzed at $12 \mathrm{Z}$ on the $12^{\text {th }}$, same as the original HURDAT. This is consistent with the synoptic data showing the development of frontal features and a temperature gradient across the cyclone. A final reconnaissance mission reached Flora at $1945 \mathrm{Z}$ on the $12 \mathrm{Z}$ measuring a central pressure of $994 \mathrm{mb}$ and estimating surface winds of 40-50 kt. A central pressure of $994 \mathrm{mb}$ has been added to HURDAT at 18Z on the $12^{\text {th }}$. An intensity of $50 \mathrm{kt}$ is selected at $18 \mathrm{Z}$ on the $12^{\text {th }}$, down from $60 \mathrm{kt}$ originally in HURDAT, a minor intensity change. Ship and surface observations from the Azores Islands indicate that Flora had already been absorbed by $00 \mathrm{Z}$ on September $13^{\text {th }}$ by the larger extratropical cyclone to the north. A vort max was likely still present early on the $13^{\text {th }}$ but observations indicate that the circulation was not closed. Thus, the last position is analyzed at $18 \mathrm{Z}$ on the $12^{\text {th }}, 36$ hours earlier than originally shown in HURDAT. Mariners Weather Log's Track of Lows for the month of September indicate that the extratropical cyclone associated with Flora absorbed the extratropical cyclone to the north but this solution appears incorrect based on the synoptic data on the $12^{\text {th }}$ and $13^{\text {th }}$.

Hurricane Gracie [September 20 - October 2, 1959]

\begin{tabular}{|c|c|c|c|c|c|c|c|c|c|c|c|c|c|}
\hline 41215 & $09 / 20 / 1950$ & $M=13$ & 8 & SNBR $=8$ & $97 \mathrm{GR}$ & CIE & XII & $\mathrm{G}=1$ & SSS= & & & & \\
\hline 41215 & $09 / 20 / 1959$ & $M=13$ & $3 \begin{array}{l}11 \\
* *\end{array}$ & SNBR $=8$ & $97 \mathrm{GR}$ & ACIE & XII & $\mathrm{G}=\overline{1}$ & SSS & $\begin{array}{l}=4 \\
*\end{array}$ & & & \\
\hline 41220 & $09 / 20$ * & $\odot$ & $\odot$ & $0 *$ & $\odot$ & $\odot$ & ๑*197 & 686 & 25 & ๑*199 & 699 & 25 & ๑* \\
\hline 41220 & $09 / 20$ * & $\odot$ & $\odot$ & $0^{*}$ & $\odot$ & $\odot$ & $\begin{array}{r}0 * 198 \\
* * *\end{array}$ & $\begin{array}{l}683 \\
* * *\end{array}$ & 25 & $\underset{* * * *}{1009 * 199}$ & $\begin{array}{l}696 \\
* * *\end{array}$ & 25 & $\begin{array}{l}1008 * \\
\star \star \star \star\end{array}$ \\
\hline 41225 & $09 / 21 * 201$ & 713 & 25 & $0 * 203$ & 727 & 30 & $0 * 206$ & 740 & 30 & $0 * 212$ & 745 & 30 & ○* \\
\hline 41225 & $09 / 21 * 201$ & $\begin{array}{l}710 \\
* * *\end{array}$ & 25 & $\Theta * 203$ & $\begin{array}{l}724 \\
\star * *\end{array}$ & 30 & $0 * 206$ & $\begin{array}{l}737 \\
* * *\end{array}$ & 30 & $\begin{array}{l}1011 * 212 \\
\star \star \star \star *\end{array}$ & $\begin{array}{l}741 \\
* * *\end{array}$ & 30 & $\begin{array}{l}1009 * \\
\star * * *\end{array}$ \\
\hline 41230 & $09 / 22 * 218$ & 741 & 35 & $0 * 222$ & 736 & 45 & $0 * 226$ & 732 & 50 & $\odot * 233$ & 730 & 65 & $997^{*}$ \\
\hline 41230 & $09 / 22 * 218$ & 741 & 35 & $0 * 222$ & 736 & 45 & $0 * 226$ & 732 & 50 & $0 * 232$ & 730 & $\begin{array}{l}60 \\
\star *\end{array}$ & $997^{*}$ \\
\hline 41235 & $09 / 23 * 239$ & $\begin{array}{l}729 \\
730\end{array}$ & $\begin{array}{l}85 \\
55\end{array}$ & $\begin{array}{r}0 * 244 \\
10 * 244\end{array}$ & $\begin{array}{l}730 \\
732\end{array}$ & $\begin{array}{l}85 \\
55\end{array}$ & $0 * 248$ & $\begin{array}{l}733 \\
735\end{array}$ & $\begin{array}{l}85 \\
55\end{array}$ & $\begin{array}{l}0 * 253 \\
0 * 254\end{array}$ & $\begin{array}{l}739 \\
749\end{array}$ & $\begin{array}{l}80 \\
55\end{array}$ & $\Theta^{*}$ \\
\hline 41235 & $09 / 23 * 239$ & $\begin{array}{l}730 \\
* * *\end{array}$ & $\begin{array}{l}55 \\
* *\end{array}$ & $\begin{array}{l}1000 * 244 \\
\star * * *\end{array}$ & $\begin{array}{l}732 \\
* * *\end{array}$ & $\begin{array}{l}55 \\
* *\end{array}$ & $\begin{array}{r}0 * 249 \\
* \star *\end{array}$ & $\begin{array}{l}735 \\
* * *\end{array}$ & $\begin{array}{l}55 \\
* *\end{array}$ & $\begin{array}{r}0 * 254 \\
\star \star \star *\end{array}$ & $\begin{array}{l}740 \\
* * *\end{array}$ & $\begin{array}{l}55 \\
* *\end{array}$ & 0 * \\
\hline 41240 & $09 / 24 * 258$ & 746 & 75 & $\odot * 261$ & 750 & 70 & $0 * 263$ & 753 & 65 & $1000 * 268$ & 754 & 65 & $\Theta^{*}$ \\
\hline 41240 & $\odot 9 / 24 * 258$ & 746 & $\begin{array}{l}55 \\
* *\end{array}$ & $\begin{array}{l}1001 * 262 \\
\star * * * * * *\end{array}$ & $\begin{array}{l}751 \\
\star \star \star\end{array}$ & $\begin{array}{l}55 \\
* *\end{array}$ & $\begin{array}{c}\odot * 265 \\
\star * *\end{array}$ & $\begin{array}{l}754 \\
* * *\end{array}$ & $\begin{array}{l}55 \\
* *\end{array}$ & $\begin{array}{r}1000 * 269 \\
* * *\end{array}$ & $\begin{array}{l}755 \\
* * *\end{array}$ & $\begin{array}{l}50 \\
\star *\end{array}$ & ○* \\
\hline 41245 & $09 / 25 * 273$ & 754 & 65 & $\Theta * 278$ & 752 & 65 & $0 * 281$ & 750 & 65 & $\odot * 280$ & 747 & 65 & $997^{*}$ \\
\hline 41245 & $\begin{array}{r}09 / 25 * 274 \\
\star \star *\end{array}$ & 754 & $\begin{array}{l}45 \\
* *\end{array}$ & $\begin{array}{l}1004 * 277 \\
\star \star \star * * \star * *\end{array}$ & 752 & $\begin{array}{l}45 \\
* *\end{array}$ & $\begin{array}{l}0^{*} 279 \\
* * *\end{array}$ & 750 & $\begin{array}{l}50 \\
* *\end{array}$ & $0 * 280$ & 748 & $\begin{array}{l}50 \\
\star *\end{array}$ & $997^{*}$ \\
\hline $4125 c$ & $09 / 26 * 277$ & 744 & 65 & $\odot * 277$ & 740 & 65 & $\odot * 277$ & 736 & 65 & $\odot * 277$ & 732 & 65 & ๑* \\
\hline
\end{tabular}




\begin{tabular}{|c|c|c|c|c|c|c|c|c|c|c|c|c|c|}
\hline 41250 & $\begin{array}{r}09 / 26 * 278 \\
* \star *\end{array}$ & $\begin{array}{l}745 \\
\star \star \star\end{array}$ & $\begin{array}{l}45 \\
* *\end{array}$ & $\begin{array}{l}1000 * 278 \\
\star \star \star \star * * *\end{array}$ & $\begin{array}{l}741 \\
\star \star \star\end{array}$ & $\begin{array}{l}50 \\
* *\end{array}$ & $\begin{array}{r}0 * 278 \\
\star \star \star\end{array}$ & $\begin{array}{l}735 \\
\star \star \star\end{array}$ & $\begin{array}{l}55 \\
\star *\end{array}$ & $\begin{array}{r}0 * 279 \\
\star \star \star\end{array}$ & $\begin{array}{l}730 \\
\star \star *\end{array}$ & $\begin{array}{l}60 \\
* *\end{array}$ & ○* \\
\hline 41255 & $09 / 27 * 278$ & 731 & 65 & $0 * 280$ & 735 & 70 & $0 * 282$ & 740 & 75 & $0 * 285$ & 745 & 75 & ○* \\
\hline 41255 & $\begin{array}{r}09 / 27^{*} 280 \\
* \star *\end{array}$ & $\begin{array}{l}730 \\
* * *\end{array}$ & 65 & $\begin{array}{r}992 * 282 \\
* * \star * * * *\end{array}$ & 735 & $\begin{array}{l}65 \\
* *\end{array}$ & $\begin{array}{r}0 * 284 \\
\star \star \star\end{array}$ & 740 & $\begin{array}{l}65 \\
* *\end{array}$ & $0 * 285$ & 745 & $\begin{array}{l}70 \\
* *\end{array}$ & ०* \\
\hline 41260 & $09 / 28 * 287$ & 750 & 80 & $979 * 289$ & 756 & 85 & $0 * 290$ & 763 & 90 & $0 * 294$ & 771 & 100 & 0 * \\
\hline 41260 & $\begin{array}{r}09 / 28 * 285 \\
* \star *\end{array}$ & 750 & $\begin{array}{l}75 \\
* *\end{array}$ & $\begin{array}{l}0 * 287 \\
\star \quad \star * *\end{array}$ & $\begin{array}{l}755 \\
\star \star *\end{array}$ & $\begin{array}{l}80 \\
\star *\end{array}$ & $\begin{array}{l}979 * 289 \\
\star \star \star * * *\end{array}$ & 763 & 90 & $0 * 294$ & 771 & $\begin{array}{l}105 \\
\star \star \star\end{array}$ & $\begin{array}{l}964 * \\
\star \star *\end{array}$ \\
\hline 41265 & $09 / 29 * 299$ & 779 & 110 & $0 * 305$ & 787 & 120 & $0 * 313$ & 796 & 120 & $950 * 324$ & 804 & 105 & ०* \\
\hline 41265 & $\begin{array}{r}09 / 29 * 300 \\
* * *\end{array}$ & $\begin{array}{l}781 \\
\star \star \star\end{array}$ & 110 & $\begin{array}{l}957 * 306 \\
\star \star \star \star * *\end{array}$ & $\begin{array}{l}791 \\
\star \star \star\end{array}$ & $\begin{array}{r}110 \\
* *\end{array}$ & $\begin{array}{l}958 * 316 \\
\star \star \star * \star *\end{array}$ & $\begin{array}{l}798 \\
\star \star *\end{array}$ & 115 & $\begin{array}{l}0 * 325 \\
\star \quad \star \star *\end{array}$ & $\begin{array}{l}806 \\
\star \star \star\end{array}$ & $\begin{array}{l}115 \\
\star \star \star\end{array}$ & $\begin{array}{l}951^{*} \\
\star \star *\end{array}$ \\
\hline 41270 & $09 / 30 * 336$ & 811 & 60 & $0 * 349$ & 815 & 60 & OE362 & 817 & 45 & OE377 & 817 & 40 & 0 * \\
\hline 41270 & $\begin{array}{r}09 / 30 * 337 \\
* * *\end{array}$ & $\begin{array}{l}809 \\
\star \star \star\end{array}$ & $\begin{array}{l}65 \\
* *\end{array}$ & $0 * 348$ & $\begin{array}{l}813 \\
\star \star *\end{array}$ & $\begin{array}{l}45 \\
\star *\end{array}$ & $\begin{array}{r}0 * 360 \\
* \star \star *\end{array}$ & $\begin{array}{l}816 \\
\star * *\end{array}$ & $\begin{array}{l}35 \\
* *\end{array}$ & OE377 & 817 & $\begin{array}{l}30 \\
* *\end{array}$ & 0* \\
\hline 41275 & 10/01E393 & 810 & 35 & ○E4०6 & 791 & 30 & OE417 & 767 & 30 & OE425 & 743 & 30 & ○* \\
\hline 41275 & $10 / 01 E 393$ & 810 & $\begin{array}{l}25 \\
* *\end{array}$ & OE406 & 791 & $\begin{array}{l}25 \\
* *\end{array}$ & OE417 & $\begin{array}{l}770 \\
\star \star *\end{array}$ & $\begin{array}{l}25 \\
* *\end{array}$ & OE425 & $\begin{array}{l}748 \\
\star \star *\end{array}$ & $\begin{array}{l}25 \\
* *\end{array}$ & ०* \\
\hline 41280 & $10 / 02 E 429$ & 716 & 25 & OE43० & 680 & 25 & OE428 & 634 & 25 & OE428 & 592 & 25 & ०* \\
\hline 41280 & $10 / 02 \mathrm{E} 429$ & $\begin{array}{l}720 \\
\star \star \star\end{array}$ & 25 & OE430 & 680 & 25 & $\begin{array}{r}\text { OE430 } \\
* \star \star\end{array}$ & 634 & 25 & ○* $\begin{array}{l}0 \\
*\end{array}$ & $\begin{array}{l}\odot \\
\text { * }\end{array}$ & $\begin{array}{l}0 \\
\star\end{array}$ & ०* \\
\hline $\begin{array}{l}41285 \\
41285\end{array}$ & $\begin{array}{ll}\mathrm{HR} & \mathrm{SC} 3 \\
\mathrm{HR} & \mathrm{SC} 4 \mathrm{GA} 1 \\
& \star \star \star \star * \star *\end{array}$ & & & & & & & & & & & & \\
\hline
\end{tabular}

U.S. Hurricane Landfall

Sep $29^{\text {th }}-17 \mathrm{Z}-32.5 \mathrm{~N} 80.4 \mathrm{~W}-115 \mathrm{kt}-$ Category $4-951 \mathrm{mb}-1013 \mathrm{mb}$ OCI $-300 \mathrm{~nm}$ ROCI

Minor changes to the track and major intensity to the intensity shown in McAdie et al. (2009). Evidence for these alterations comes from the NHC microfilm maps, the Historical Weather Maps series, the COADS ship database, Monthly Weather Review, Navy reconnaissance book, Surface Weather Observations, Mariners Weather Log, Schwerdt et al. (1979), Ho et al. (1987) Jarrell et al. (1992) and NHC Storm Wallets.

September 18:

HWM does not analyze an organized system at 12Z. Microfilm shows a closed low pressure of at most 1011 at $16.8 \mathrm{~N}, 54.2 \mathrm{~W}$ at $12 \mathrm{Z}$. HURDAT does not list an organized system on this date. Ship highlights: No gales or low pressures.

ATSR: "Hurricane GRACIE was the most intense storm to hit the United States coastline in the 1959 season and also one of the most interesting to study because of its almost "explosive" intensification and erratic movement in its early stages. Because of the large amount of aircraft reconnaissance and other data available, a more detailed analysis of this storm is included in this section. GRACIE formed on a moderate easterly wave that 
was first detected and reported near the African coastline by the Fleet Weather Central, Port Lyautey, on 11 September 1959. It was observed passing the Cape Verde Islands on the $13^{\text {th }}$ and was followed westward at a speed of about 15 knots across the South Atlantic by extrapolation and peripheral ship reports. Reports indicated that this wave was attended by heavy shower activity during its entire life. At 171200Z, ship reports indicated that the wave was increasing in intensity 750 miles to the east of Antigua. Aircraft reconnaissance was planned for the following day. The Navy reconnaissance aircraft observed a partial circulation, closed except in the south quadrant, about 420 miles due east of Antigua on the $18^{\text {th }}$ with surface conditions considered favorable for development. Daily reconnaissance into the suspicious area during the period 18 to 21 September showed little change in the low pressure of near $1008 \mathrm{mb}$ and a small area of calm surface winds. Winds to the north of the area continued easterly 20 to 30 knots, with very little westerly winds to the south of the calm area." MWR: "The easterly wave in which Gracie developed was first noted on September 16 about midway between the Lesser Antilles and Africa. It moved westward at about $17 \mathrm{kt}$ during the next 5 days eventually moving into the southeastern Bahamas. The wave was investigated daily by reconnaissance aircraft beginning on the 18th and no closed circulation was found until the $22^{\text {nd }}$. Indeed, the wave remained remarkably constant in all details and as attended by heavy shower activity from the time first noted."

September 19:

HWM analyzes a spot low at 19.0N, 64.0W at 12Z. HURDAT does not list an organized system on this date. Microfilm shows a tropical wave over the northeast Caribbean Sea at 12Z. Ship highlights: No gales or low pressures.

September 20:

HWM analyzes a closed low pressure of at most $1010 \mathrm{mb}$ at $20.0 \mathrm{~N}, 68.5 \mathrm{~W}$ at 12Z. HURDAT lists a 25 knot tropical depression at $19.7 \mathrm{~N}, 68.6 \mathrm{~W}$ at $12 \mathrm{Z}$ (first position). Microfilm shows a sharp tropical wave over eastern Hispaniola at 12Z. Ship highlights: No gales or low pressures. Aircraft highlights: Penetration center fix measured a central pressure of $1009 \mathrm{mb}$ and estimated surface winds of $28 \mathrm{kt}$ at $19.8 \mathrm{~N}, 68.3 \mathrm{~W}$ at $1145 \mathrm{Z}$ (ATSR). Penetration center fix measured a central pressure of $1008 \mathrm{mb}$ and estimated surface winds of $28 \mathrm{kt}$ at $19.8 \mathrm{~N}, 69.1 \mathrm{~W}$ at $19 \mathrm{Z}$ (ATSR). Penetration center fix measured a central pressure of $1009 \mathrm{mb}$ and estimated surface winds of $26 \mathrm{kt}$ at $19.9 \mathrm{~N}, 69.3 \mathrm{~W}$ at $2045 Z$ (ATSR).

MICRO: "NAVY THIRTEEN ... Completed low level investigation involving well defined easterly wave near Lesser Antilles, no evidence of closed circulation, broken line, moderate echoes 50 mile wide oriented $1630 \mathrm{~N} 6335 \mathrm{~W}, 1730 \mathrm{~N} 6310 \mathrm{~W}, 1810 \mathrm{~N} 6235 \mathrm{~W}$, 
$1640 \mathrm{~N} 6147 \mathrm{~W}, 1922 \mathrm{~N} 6040 \mathrm{~W}$ at 1330Z, line moving westward at $22 \mathrm{kt}$, maximum observed surface wind $35 \mathrm{kt}$, minimum observed surface pressure $1013 \mathrm{mb} . "$

September 21:

HWM analyzes a closed low pressure of at most $1010 \mathrm{mb}$ at $20.5 \mathrm{~N}, 74.0 \mathrm{~W}$ at 12Z. HURDAT lists a 30 knot tropical depression at $20.6 \mathrm{~N}, 74.0 \mathrm{~W}$ at $12 \mathrm{Z}$. Microfilm shows a closed low pressure of at most $1011 \mathrm{mb}$ at $20.5 \mathrm{~N}, 74.5 \mathrm{~W}$ at $12 \mathrm{Z}$. Ship highlights: No gales or low pressures. Aircraft highlights: Penetration center fix measured a central pressure of $1011 \mathrm{mb}$ and estimated surface winds of $25 \mathrm{kt}$ at $20.6 \mathrm{~N}, 74.0 \mathrm{~W}$ at $1320 \mathrm{Z}$ (ATSR). Penetration center fix measured a central pressure of $1009 \mathrm{mb}$ at $21.3 \mathrm{~N}, 74.1 \mathrm{~W}$ at $19 \mathrm{Z}$ (ATSR).

ATSR: "Reconnaissance reports during the afternoon and evening of the 21 st definitely indicated that the direction of movement of the weak circulation was changing to northerly and development taking place."

September 22:

HWM analyzes a tropical storm of at most $1010 \mathrm{mb}$ at $22.9 \mathrm{~N}, 72.9 \mathrm{~W}$ with a stationary front to the north at $12 \mathrm{Z}$. HURDAT lists a 50 knot tropical storm at $22.6 \mathrm{~N}$, $73.2 \mathrm{~W}$ at $12 \mathrm{Z}$. Microfilm shows a closed low pressure of at most $1002 \mathrm{mb}$ at $23.0 \mathrm{~N}$, $73.5 \mathrm{~W}$ at 12Z. Ship highlights: $40 \mathrm{kt}$ ENE and $1017 \mathrm{mb}$ at $22.6 \mathrm{~N}, 73.2 \mathrm{~W}$ at $00 \mathrm{Z}$ (COADS). Aircraft highlights: Penetration center fix measured a central pressure of 1003 $\mathrm{mb}$, estimated surface winds of $50 \mathrm{kt}$ and an eye diameter of $15 \mathrm{~nm}$ at $23.0 \mathrm{~N}, 72.8 \mathrm{~W}$ at $1645 Z$ (ATSR). Penetration center fix measured a central pressure of $997 \mathrm{mb}$ and estimated surface winds of $75 \mathrm{kt}$ at $23.3 \mathrm{~N}, 73.0 \mathrm{~W}$ at $1945 \mathrm{Z}$ (ATSR). Radar center fix estimated an eye diameter of $15 \mathrm{~nm}$ at $23.3 \mathrm{~N}, 73.0 \mathrm{~W}$ at $21 \mathrm{Z}$ (ATSR).

MWR: "The intensity of hurricane Gracie was as erratic as its movement. On September 22 the storm deepened rather rapidly to $997 \mathrm{mb}$. with winds 78 to $87 \mathrm{kt}$." ATSR: "At $0000 \mathrm{Z}$, the $22^{\text {nd }}$, westerly winds of 20 to 25 knots were reported immediately to the south of the center. Surface pressures in the area were falling slowly, accompanied the southeastern Bahamas reported 8.40 inches of rain during the period $0000 \mathrm{Z}$ to $1200 \mathrm{Z}$ on the $22^{\text {nd }}$. The first warning of GRACIE was issued at 221600Z. Reconnaissance aircraft reported a radar eye at $1645 Z$. During the period from $1645 Z$ to $2100 Z$, while under surveillance, winds increased from 45 knots to 75 knots, the center pressure dropped to $997 \mathrm{mb}$, and the radar eye became well developed and clearly defined. The unusually rapid intensification which took place immediately after the issuance of the first warning on GRACIE is of particular interest."

September 23:

HWM analyzes a hurricane of at most $1005 \mathrm{mb}$ at $25.1 \mathrm{~N}, 73.8 \mathrm{~W}$ with a weakening front to the north at $12 \mathrm{Z}$. HURDAT lists a 85 knot hurricane at $24.8 \mathrm{~N}, 73.3 \mathrm{~W}$ 
at $12 \mathrm{Z}$. Microfilm shows a closed low pressure of at most $1002 \mathrm{mb}$ at $25.0 \mathrm{~N}, 73.5 \mathrm{~W}$ at 12Z. Ship highlights: $35 \mathrm{kt} \mathrm{SE}$ and $1011 \mathrm{mb}$ at $25.2 \mathrm{~N}, 74.3 \mathrm{~W}$ at $00 \mathrm{Z}$ (micro). $35 \mathrm{kt}$ ENE and $1015 \mathrm{mb}$ at $26.1 \mathrm{~N}, 74.7 \mathrm{~W}$ at $06 \mathrm{Z}$ (COADS). $40 \mathrm{kt} \mathrm{SE}$ and $1013 \mathrm{mb}$ at $25.5 \mathrm{~N}, 72.0 \mathrm{~W}$ at $12 \mathrm{Z}$ (COADS). $70 \mathrm{kt} \mathrm{ESE}$ and $1012 \mathrm{mb}$ at $25.3 \mathrm{~N}, 73.4 \mathrm{~W}$ at $15 \mathrm{Z}$ (MWL). $65 \mathrm{kt} \mathrm{SE}$ and $1014 \mathrm{mb}$ at $25.5 \mathrm{~N}, 73.1 \mathrm{~W}$ at $18 \mathrm{Z}$ (micro). $40 \mathrm{kt} \mathrm{ESE}$ and $1015 \mathrm{mb}$ at $26.6 \mathrm{~N}, 73.4 \mathrm{~W}$ at $21 Z$ (micro). Aircraft highlights: Penetration center fix measured a central pressure of $1000 \mathrm{mb}$ and estimated an eye diameter of $18 \mathrm{~nm}$ at $24.1 \mathrm{~N}, 73.1 \mathrm{~W}$ at $01 \mathrm{Z}$ (ATSR). Radar center fix at $24.4 \mathrm{~N}, 73.4 \mathrm{~W}$ at $06 \mathrm{Z}$ (ATSR). Penetration center fix at $25.0 \mathrm{~N}, 73.5 \mathrm{~W}$ at $13 \mathrm{Z}$ (ATSR). Penetration center fix at $25.5 \mathrm{~N}, 74.1 \mathrm{~W}$ at $1830 \mathrm{Z}$ (ATSR). Penetration center fix measured a central pressure of $1001 \mathrm{mb}$, estimated maximum surface winds of $45 \mathrm{kt}$ and an eye diameter of $12 \mathrm{~nm}$ at $25.8 \mathrm{~N}, 74.1 \mathrm{~W}$ at $2307 \mathrm{Z}$ (ATSR).

MWR: "On the $23^{\text {rd }}$ and $24^{\text {th }}$, central pressure varied from 1000 to $1006 \mathrm{mb}$ with winds from 45 to 65 kt." ATSR: "After intensifying rapidly to hurricane force, a peak appeared to have been reached and on the $23^{\text {rd }}$ a slight decrease in the intensity of the circulation was apparent. The wind velocity dropped to approximately 65 knots and maintained this velocity for the next 48 hours."

September 24:

HWM analyzes a hurricane of at most $1000 \mathrm{mb}$ at $26.5 \mathrm{~N}, 75.4 \mathrm{~W}$ at $12 \mathrm{Z}$. HURDAT lists a 65 knot hurricane at $26.3 \mathrm{~N}, 75.3 \mathrm{~W}$ at $12 \mathrm{Z}$. Microfilm shows a closed low pressure of at most $1008 \mathrm{mb}$ at $26.5 \mathrm{~N}, 75.5 \mathrm{~W}$ at 12Z. Ship highlights: $40 \mathrm{kt} \mathrm{E}$ and $1017 \mathrm{mb}$ at $26.8 \mathrm{~N}, 72.8 \mathrm{~W}$ at $00 \mathrm{Z}$ (COADS). $35 \mathrm{kt} \mathrm{SE}$ and $1018 \mathrm{mb}$ at $26.8 \mathrm{~N}, 73.1 \mathrm{~W}$ at $15 \mathrm{Z}$ (micro). $35 \mathrm{kt} \mathrm{S}$ and $1011 \mathrm{mb}$ at $26.7 \mathrm{~N}, 74.6 \mathrm{~W}$ at $21 \mathrm{Z}$ (micro). Aircraft highlights: Radar center fix at $25.7 \mathrm{~N}, 74.3 \mathrm{~W}$ at $01 \mathrm{Z}$ (ATSR). Penetration center fix at $26.3 \mathrm{~N}, 75.3 \mathrm{~W}$ at $0650 \mathrm{Z}$ (ATSR). Radar center fix at $26.6 \mathrm{~N}, 75.5 \mathrm{~W}$ at $16 \mathrm{Z}$ (ATSR). Penetration center fix at $26.9 \mathrm{~N}, 75.5 \mathrm{~W}$ at $1845 \mathrm{Z}$ (ATSR). Penetration center fix measured a central pressure of $1004 \mathrm{mb}$, estimated surface winds of $40 \mathrm{kt}$ and an eye diameter of $15 \mathrm{~nm}$ at $27.3 \mathrm{~N}$, $75.4 \mathrm{~W}$ at $2309 \mathrm{Z}$ (ATSR).

ATSR: "GRACIE followed a generally northwesterly track until $241000 \mathrm{Z}$ then moved on erratic courses at varying speeds for the next 96 hours."

September 25:

HWM analyzes a hurricane of at most $995 \mathrm{mb}$ at $26.9 \mathrm{~N}, 74.5 \mathrm{~W}$ at $12 \mathrm{Z}$. HURDAT lists a 65 knot hurricane at $28.1 \mathrm{~N}, 75.0 \mathrm{~W}$ at $12 \mathrm{Z}$. Microfilm shows a closed low pressure of at most $1002 \mathrm{mb}$ at $28.2 \mathrm{~N}, 74.9 \mathrm{~W}$ at $12 \mathrm{Z}$. Ship highlights: $40 \mathrm{kt} \mathrm{S}$ and $1011 \mathrm{mb}$ at $26.7 \mathrm{~N}, 73.5 \mathrm{~W}$ at $00 \mathrm{Z}$ (COADS). $35 \mathrm{kt} \mathrm{S}$ and $1009 \mathrm{mb}$ at $26.9 \mathrm{~N}, 73.2 \mathrm{~W}$ at 06Z (COADS). $40 \mathrm{kt} \mathrm{SE}$ and $1006 \mathrm{mb}$ at 28.3N, $73.0 \mathrm{~W}$ at $09 \mathrm{Z}$ (micro). $40 \mathrm{kt} \mathrm{S}$ and 1009 $\mathrm{mb}$ at $27.7 \mathrm{~N}, 72.6 \mathrm{~W}$ at $15 \mathrm{Z}$ (micro). $35 \mathrm{kt} \mathrm{SW}$ and $1008 \mathrm{mb}$ at $28.6 \mathrm{~N}, 73.3 \mathrm{~W}$ at $21 \mathrm{Z}$ (micro). Aircraft highlights: Radar center fix at $27.5 \mathrm{~N}, 75.1 \mathrm{~W}$ at $04 \mathrm{Z}$ (ATSR). Radar 
center fix at 27.3N, 75.1W at $06 \mathrm{Z}$ (ATSR). Penetration center fix at 28.0N, 75.0W at $1245 Z$ (ATSR). Penetration center fix at $28.0 \mathrm{~N}, 74.6 \mathrm{~W}$ at $1835 \mathrm{Z}$ (ATSR). Penetration center fix measured a central pressure of $1000 \mathrm{mb}$ and estimated surface winds of $55 \mathrm{kt}$ at $2230 Z$ (ATSR).

MWR: "On the $25^{\text {th }}$ the minimum barometer again dropped to $997 \mathrm{mb}$ and reconnaissance aircraft reported an increase in maximum winds, the size of the storm area, and the intensity of weather around the eye." ATSR: "It made a sharp, hairpin like turn through east onto a south-southeasterly course during the day of the $25^{\text {th }}$."

September 26:

HWM analyzes a hurricane of at most $995 \mathrm{mb}$ at $27.9 \mathrm{~N}, 73.3 \mathrm{~W}$ at $12 \mathrm{Z}$. HURDAT lists a 65 knot hurricane at 27.7N, 73.6W at 12Z. Microfilm shows a closed low pressure of at most $1002 \mathrm{mb}$ at $27.9 \mathrm{~N}, 73.5 \mathrm{~W}$ at 12Z. Ship highlights: $35 \mathrm{kt} \mathrm{E}$ and $1009 \mathrm{mb}$ at $29.1 \mathrm{~N}, 73.0 \mathrm{~W}$ at $00 \mathrm{Z}$ (COADS). $30 \mathrm{kt} \mathrm{W}$ and $1004 \mathrm{mb}$ at $26.4 \mathrm{~N}, 74.5 \mathrm{~W}$ at $06 Z$ (micro). $40 \mathrm{kt} \mathrm{S}$ and $1011 \mathrm{mb}$ at $25.6 \mathrm{~N}, 72.5 \mathrm{~W}$ at $15 \mathrm{Z}$ (micro). $40 \mathrm{kt}$ ESE at $28.3 \mathrm{~N}$, $71.5 \mathrm{~W}$ at $18 \mathrm{Z}$ (micro). Aircraft highlights: Radar center fix estimated an eye diameter of $40 \mathrm{~nm}$ at $27.8 \mathrm{~N}, 73.9 \mathrm{~W}$ at $01 \mathrm{Z}$ (ATSR). Penetration center fix at $27.8 \mathrm{~N}, 73.4 \mathrm{~W}$ at $13 \mathrm{Z}$ (ATSR). Penetration center fix at $28.1 \mathrm{~N}, 72.8 \mathrm{~W}$ at $1830 \mathrm{Z}$ (ATSR). Penetration center fix measured a central pressure of $992 \mathrm{mb}$, estimated surface winds of $85 \mathrm{kt}$ and an eye diameter of $15 \mathrm{~nm}$ at $28.0 \mathrm{~N}, 73.0 \mathrm{~W}$ at $2330 \mathrm{Z}$ (ATSR).

ATSR: "The night of the $25^{\text {th }}$ saw Gracie again intensifying and slowly turning to a northeast heading. The storm continued to intensify steadily until it crossed the east coast of the United States. On the $26^{\text {th }}$, GRACIE made an apparent 270 degree right turn to a northerly course."

September 27:

HWM analyzes a hurricane of at most $995 \mathrm{mb}$ at $28.5 \mathrm{~N}, 73.3 \mathrm{~W}$ at $12 \mathrm{Z}$. HURDAT lists a 75 knot hurricane at $28.2 \mathrm{~N}, 74.0 \mathrm{~W}$ at $12 \mathrm{Z}$. Microfilm shows a closed low pressure of at most $996 \mathrm{mb}$ at $28.5 \mathrm{~N}, 74.1 \mathrm{~W}$ at 12Z. Ship highlights: $45 \mathrm{kt} \mathrm{NE}$ and $1010 \mathrm{mb}$ at $29.0 \mathrm{~N}, 71.5 \mathrm{~W}$ at $00 \mathrm{Z}$ (micro). $40 \mathrm{kt} \mathrm{NW}$ and $1008 \mathrm{mb}$ at $27.9 \mathrm{~N}, 73.8 \mathrm{~W}$ at $03 \mathrm{Z}$ (micro). $35 \mathrm{kt} \mathrm{SE}$ and $1010 \mathrm{mb}$ at $29.5 \mathrm{~N}, 69.5 \mathrm{~W}$ at $06 \mathrm{Z}$ (micro). $45 \mathrm{kt} \mathrm{N}$ and 1005 $\mathrm{mb}$ at $28.3 \mathrm{~N}, 75.2 \mathrm{~W}$ at $12 \mathrm{Z}$ (micro). $50 \mathrm{kt} \mathrm{NE}$ and $1009 \mathrm{mb}$ at $30.0 \mathrm{~N}, 74.6 \mathrm{~W}$ at $15 \mathrm{Z}$ (MWL). $45 \mathrm{kt} \mathrm{SW}$ and $1003 \mathrm{mb}$ at $27.0 \mathrm{~N}, 74.0 \mathrm{~W}$ at $18 \mathrm{Z}$ (micro). $45 \mathrm{kt} \mathrm{W}$ and $1003 \mathrm{mb}$ at $27.0 \mathrm{~N}, 74.1 \mathrm{~W}$ at $21 \mathrm{Z}$ (micro). Aircraft highlights: Radar center fix at $28.2 \mathrm{~N}, 72.8 \mathrm{~W}$ at $01 Z$ (ATSR). Radar center fix estimated an eye diameter of $9 \mathrm{~nm}$ at $28.3 \mathrm{~N}, 73.8 \mathrm{~W}$ at $0550 Z$ (ATSR). Penetration center fix at $28.6 \mathrm{~N}, 74.1 \mathrm{~W}$ at $1240 \mathrm{Z}$ (ATSR). Penetration center fix at $28.6 \mathrm{~N}, 74.4 \mathrm{~W}$ at $1539 \mathrm{Z}$ (ATSR). Radar center fix at $28.4 \mathrm{~N}, 74.7 \mathrm{~W}$ at $2335 \mathrm{Z}$ (ATSR). 
MWR: "On the $27^{\text {th }}$ the central pressure decreased further to $979 \mathrm{mb}$ with an almost complete wall cloud. The hurricane continued to intensify further during the next 2 days to 950 mb." ATSR: "A left turn early on the $27^{\text {th }}$ brought the storm to the northwesterly course it was to maintain most of its remaining overwater trajectory."

September 28:

HWM analyzes a hurricane of at most $995 \mathrm{mb}$ at $29.0 \mathrm{~N}, 76.2 \mathrm{~W}$ at $12 \mathrm{Z}$. HURDAT lists a 90 knot hurricane at $29.0 \mathrm{~N}, 76.3 \mathrm{~W}$ at $12 \mathrm{Z}$. Microfilm shows a closed low pressure of at most $996 \mathrm{mb}$ at $29.0 \mathrm{~N}, 76.0 \mathrm{~W}$ at 12Z. Ship highlights: $40 \mathrm{kt} \mathrm{ESE}$ and $1007 \mathrm{mb}$ at $29.5 \mathrm{~N}, 73.7 \mathrm{~W}$ at $00 \mathrm{Z}$ (MWL). $50 \mathrm{kt} \mathrm{E}$ and $1005 \mathrm{mb}$ at $29.0 \mathrm{~N}, 74.3 \mathrm{~W}$ at $03 \mathrm{Z}$ (micro). $40 \mathrm{kt} \mathrm{NW}$ and $1008 \mathrm{mb}$ at $27.8 \mathrm{~N}, 77.3 \mathrm{~W}$ at $06 \mathrm{Z}$ (micro). $35 \mathrm{kt} \mathrm{NW}$ and $1006 \mathrm{mb}$ at $27.8 \mathrm{~N}, 77.5 \mathrm{~W}$ at $12 \mathrm{Z}$ (COADS). $60 \mathrm{kt} \mathrm{SW}$ and $1004 \mathrm{mb}$ at $28.1 \mathrm{~N}, 75.5 \mathrm{~W}$ at $15 \mathrm{Z}$ (micro). $40 \mathrm{kt} \mathrm{NNW}$ and $1010 \mathrm{mb}$ at $28.5 \mathrm{~N}, 79.6 \mathrm{~W}$ at $18 \mathrm{Z}$ (COADS). $40 \mathrm{kt} \mathrm{NW}$ and $1000 \mathrm{mb}$ at $29.1 \mathrm{~N}, 78.5 \mathrm{~W}$ at $21 \mathrm{Z}$ (micro). Aircraft highlights: Penetration center fix at $28.5 \mathrm{~N}, 75.1 \mathrm{~W}$ at $0030 \mathrm{Z}$ (ATSR). Penetration center fix measured a central pressure of $979 \mathrm{mb}$ at $28.5 \mathrm{~N}, 75.2 \mathrm{~W}$ at $04 \mathrm{Z}$ (ATSR). Penetration center fix at $29.0 \mathrm{~N}, 76.2 \mathrm{~W}$ at $1255 \mathrm{Z}$ (ATSR). Penetration center fix measured a central pressure of $971 \mathrm{mb}$, estimated surface winds of $80 \mathrm{kt}$ and eye diameter of $15 \mathrm{~nm}$ at $29.3 \mathrm{~N}, 76.8 \mathrm{~W}$ at $1620 \mathrm{Z}$ (ATSR). Penetration center fix measured a central pressure of $964 \mathrm{mb}$, estimated surface winds of $90 \mathrm{kt}$ and eye diameter of $7 \mathrm{~nm}$ at $29.7 \mathrm{~N}, 77.4 \mathrm{~W}$ at $1906 \mathrm{Z}$ (ATSR).

September 29:

HWM analyzes a hurricane of at most $995 \mathrm{mb}$ at $31.5 \mathrm{~N}, 79.4 \mathrm{~W}$ with a weakening front to the northwest at 12Z. HURDAT lists a 120 knot hurricane at $31.3 \mathrm{~N}$, $79.6 \mathrm{~W}$ at $12 \mathrm{Z}$. Microfilm shows a closed low pressure of at most $1002 \mathrm{mb}$ at $32.0 \mathrm{~N}$, $80.0 \mathrm{~W}$ with a frontal boundary to the northwest at 12Z. Ship highlights: $35 \mathrm{kt} \mathrm{NW}$ and $1005 \mathrm{mb}$ at $28.9 \mathrm{~N}, 79.8 \mathrm{~W}$ at $00 \mathrm{Z}$ (COADS). $40 \mathrm{kt} \mathrm{NE}$ and $1009 \mathrm{mb}$ at $31.7 \mathrm{~N}, 80.5 \mathrm{~W}$ at $03 \mathrm{Z}$ (micro). $40 \mathrm{kt} \mathrm{NW}$ and $1009 \mathrm{mb}$ at $28.3 \mathrm{~N}, 79.8 \mathrm{~W}$ at $06 \mathrm{Z}$ (COADS). $40 \mathrm{kt} \mathrm{NE}$ and $1000 \mathrm{mb}$ at $31.7 \mathrm{~N}, 80.4 \mathrm{~W}$ at $09 \mathrm{Z}$ (micro). $50 \mathrm{kt} \mathrm{N}$ and $993 \mathrm{mb}$ at $31.9 \mathrm{~N}, 80.1 \mathrm{~W}$ at $12 \mathrm{Z}$ (micro). $40 \mathrm{kt} \mathrm{SE}$ and $1012 \mathrm{mb}$ at $31.5 \mathrm{~N}, 76.8 \mathrm{~W}$ at $15 \mathrm{Z}$ (micro). $35 \mathrm{kt} \mathrm{SE}$ and $1016 \mathrm{mb}$ at $33.5 \mathrm{~N}, 76.6 \mathrm{~W}$ at $18 \mathrm{Z}$ (COADS). $50 \mathrm{kt} \mathrm{SW}$ and $993 \mathrm{mb}$ at $31.9 \mathrm{~N}, 80.4 \mathrm{~W}$ at $21 \mathrm{Z}$ (micro). Land highlights: $45 \mathrm{kt}$ at Hunter AFB, GA at 1316Z (SWO). $35 \mathrm{kt} \mathrm{NE}$ at Charleston, SC at $15 \mathrm{Z}$ (micro). $130 \mathrm{kt}$ (estimated) and $965 \mathrm{mb}$ (min pressure) at Edisto Beach, SC at 1635Z-1640Z (WALLET). $49 \mathrm{kt} \mathrm{NW} \mathrm{(gusts} \mathrm{to} 65 \mathrm{kt}$ ) at Savannah, GA at 17Z (SWO). 84 kt 5-min WSW (max wind)(gusts to $120 \mathrm{kt}$ ) and $960 \mathrm{mb}$ at MCAAS Beaufort, SC (WALLET/MWR) at 1745Z. $42 \mathrm{kt}$ (gusts to $62 \mathrm{kt}$ ) and $987 \mathrm{mb}$ at Charleston, SC at $1816 \mathrm{Z}$ (WALLET). $38 \mathrm{kt} \mathrm{ESE} \mathrm{(gusts} \mathrm{to} 58 \mathrm{kt}$ ) and $1010 \mathrm{mb}$ at Wilmington, NC at $1859 \mathrm{Z}$ (SWO). 50-60 kt estimated (gusts estimated to 70-80 kt) (max wind) and $973 \mathrm{mb}$ (min pressure) at Orangeburg, SC at $2240 \mathrm{Z}$ (WALLET). $80 \mathrm{kt}$ (no time given)(max wind) at 
Folly Island, SC (WALLET). Aircraft highlights: Penetration center fix measured a central pressure of $957 \mathrm{mb}$, estimated surface winds of $74 \mathrm{kt}$ and eye diameter of $18 \mathrm{~nm}$ at $30.1 \mathrm{~N}, 78.3 \mathrm{~W}$ at $0142 \mathrm{Z}$ (ATSR). Penetration center fix measured a central pressure of $958 \mathrm{mb}$ and estimated eye diameter of $15 \mathrm{~nm}$ at $30.8 \mathrm{~N}, 79.1 \mathrm{~W}$ at $07 \mathrm{Z}$ (ATSR). Penetration center fix measured a central pressure of $951 \mathrm{mb}$ at $32.5 \mathrm{~N}, 80.2 \mathrm{~W}$ at $1530 \mathrm{Z}$ (ATSR/WALLET). "28.08” (950.9 mb) central pressure measured by RECON - RMW $26 \mathrm{nmi}-12 \mathrm{kt}$ forward speed - landfall pt 32.5N, 80.4W" (Ho et al. (1987). "Sep - SC3 - Cat 3 - 950 mb" (Jarrell et al. (1992). "32.6N, 80.4W - $962 \mathrm{mb}$ at 32.2N, 80.2W - 951 mb Penv - RMW $10 \mathrm{nmi}$ - speed $12 \mathrm{kt}-91 \mathrm{kt}$ est max sustained 10m, 10-min wind" (Schwardt et al. (1979)).

MWR: "The center of the hurricane crossed the coast near Beaufort, S.C., near noon on September 29. The Marine Corps Auxiliary Air Station at Beaufort reported a minimum barometer reading of $950 \mathrm{mb}$, a sustained 5-minute wind of $84 \mathrm{kt}$, and gusts estimated to $120 \mathrm{kt}$. Wind was estimated as high as $152 \mathrm{kt}$. closer to the exact center of the storm and gusts as high as $130 \mathrm{kt}$. seem quite credible. After moving inland the hurricane weakened gradually as it turned northward along the Appalachians." ATSR: "GRACIE past inland near Beaufort, South Carolina, at 291615Z. Twenty-two deaths and damage estimated at 14 million dollars were caused. Fortunately, the Charleston area escaped major flood damage because GRACIE struck at low tide. The intensity of Hurricane GRACIE on passing inland may be evaluated from the following report submitted by the Marine Corps Auxiliary Air Station, Beaufort, compiled by Marine Weather Service:

a. Lowest observed surface pressure and time: 28.05 inches $(950 \mathrm{mb}$.) at approximately $1230 \mathrm{E}$.

b. Highest observed average hourly wind velocity and direction: 64 knots from the West-southwest (1200E - 1300E).

c. Highest observed 5 minute velocity and direction: 84 knots from the West-southwest at $1245 \mathrm{E}$.

d. Highest observed gust and direction: 120 knots from the West-southwest.

e. Maximum rainfall for a six-hour period: 4.90 inches (0650E to $1250 \mathrm{E})$.

f. From the hourly sea level pressures plotted from stations along the Eastern seaboard directly preceding Hurricane GRACIE, it was determined by the Marine Weather Service that the eye of the storm passed very close to the Beaufort area itself.

g. The following is an eye-witness report by Beaufort County Sheriff J.E. McTeer: 
"The eye of Hurricane GRACIE passed over my home located on Coffin Point located near the town of Frogmore, South Carolina. A dead calm lasted 35 minutes. During this time, there was absolutely no wind. It quit as suddenly as it began and the sun appeared and it was extremely hot. There was a thin veil of cirro-stratus covering the entire sky. As the rear of the eye approached, you would see a very dark cloud touching the ground. The cloud appeared as fog filled with dust and flying debris. To those people not observing the dark cloud, there was no warning, whatsoever as the rear of the eye passed over us.

In seconds, the wind rose to approximately 175 miles per hour. I based this estimation on the fact that I saw a water tower containing some 10,000 gallons of water lifted twice by the force of the wind. Also, a roll of tin, weighting approximately one ton was moved over 200 feet. The heaviest winds were definitely experienced after passage of the eye. In advance of the eye, I estimated them to be from 140 - 150 miles per hour. A Mrs. Van de Linde, living at Coffin Point also, has a barometer trace recorded during the storm which could be obtained if necessary."

h. Sheriff McTeer also stated that residents of Frogmore, South Carolina (approximately 5 miles southwest of Coffin Point, South Carolina) observed the passage of the eye and that it was about five minutes in duration."

September 30:

HWM analyzes a tropical storm of at most $1000 \mathrm{mb}$ at $36.5 \mathrm{~N}, 82.5 \mathrm{~W}$ with a cold front about $120 \mathrm{~nm}$ to the northwest at 12Z. HURDAT lists a 45 knot extratropical cyclone at $36.2 \mathrm{~N}, 81.5 \mathrm{~W}$ at $12 \mathrm{Z}$. Microfilm shows a closed low pressure of at most 1002 $\mathrm{mb}$ at $35.5 \mathrm{~N}, 82.0 \mathrm{~W}$ along a frontal boundary at 12Z. Ship highlights: $50 \mathrm{kt}$ SSW (likely too high) and $999 \mathrm{mb}$ at $31.8 \mathrm{~N}, 80.5 \mathrm{~W}$ at $00 \mathrm{Z}$ (micro). Land highlights: $979 \mathrm{mb}$ at Orangeburg, SC at 0005Z (WALLET). $45 \mathrm{kt} \mathrm{NE}$ at Congaree, SC at 0045Z (SWO). $33 \mathrm{kt}$ ESE (gusts to $48 \mathrm{kt}$ ) and $986 \mathrm{mb}$ at Columbia, SC at 03Z (SWO). $20 \mathrm{kt} \mathrm{SSW}$ and $996 \mathrm{mb}$ at Columbia, SC at 06Z (SWO). $35 \mathrm{kt} \mathrm{S}$ and $1012 \mathrm{mb}$ at Frying Pan, NC at 06Z (micro). $15 \mathrm{kt}$ ESE and $998 \mathrm{mb}$ at Hickory, SC at 1158Z (SWO).

October 1:

HWM analyzes an extratropical cyclone at $41.0 \mathrm{~N}, 77.5 \mathrm{~W}$ at $12 \mathrm{Z}$. HURDAT lists a 30 knot extratropical depression at $41.7 \mathrm{~N}, 76.7 \mathrm{~W}$ at $12 \mathrm{Z}$. Microfilm shows an extratropical cyclone at $41.5 \mathrm{~N}, 77.5 \mathrm{~W}$ at $12 \mathrm{Z}$. Ship highlights: No gales or low pressures. 
October 2:

HWM analyzes does not analyze an organized system at 12Z. HURDAT lists a 25 knot extratropical depression at $42.8 \mathrm{~N}, 63.4 \mathrm{~W}$ at $12 \mathrm{Z}$. Microfilm shows a weak extratropical cyclone at $43.5 \mathrm{~N}, 60.0 \mathrm{~W}$ at $12 \mathrm{Z}$. Ship highlights: No gales or low pressures.

A sharp tropical wave was located east of the Leeward Islands on September $18^{\text {th }}$. Ships in the area indicated that a closed-level circulation was not present at this time. The disturbance moved westward and a reconnaissance aircraft investigated in the afternoon of September $19^{\text {th }}$ but did not find a closed-low level circulation. The tropical wave continued moving westward and while located just north of the eastern tip of Hispaniola, a reconnaissance aircraft found a closed low-level center with a central pressure of 1009 $\mathrm{mb}$ and estimated surface winds of $28 \mathrm{kt}$. Genesis is analyzed as a $25 \mathrm{kt}$ tropical depression at $12 \mathrm{Z}$ on September $20^{\text {th }}$, same as originally shown in HURDAT. A central pressure of $1009 \mathrm{mb}$ is added to HURDAT at $12 \mathrm{Z}$ on the $20^{\text {th }}$. Yet, synoptic data does not show a well-defined circulation associated with this system on the $20^{\text {th }}$ and early on the $21^{\text {st }}$, and it is possible that it may have not been a tropical cyclone during that time. Minor track alterations are introduced during the lifetime of this tropical cyclone. Another reconnaissance aircraft measured a central pressure of $1008 \mathrm{mb}$ and estimated surface winds $28 \mathrm{kt}$ at $19 \mathrm{Z}$ on the $20^{\text {th }}$. A central pressure of $1008 \mathrm{mb}$ has been added to HURDAT at $18 \mathrm{Z}$ on the $20^{\text {th }}$. The tropical depression skirted the northern coast of Hispaniola late on the $20^{\text {th }}$ and early on the $21^{\text {st }}$ while moving west-northwest before the steering currents started to break down late on the $21^{\text {st }}$. Aircraft reconnaissance on the $21^{\text {st }}$ indicated that the disturbance remained a tropical depression with little or no intensification. An aircraft measured a central pressure of $1011 \mathrm{mb}$ and estimated surface winds of $25 \mathrm{kt}$ at $1320 \mathrm{Z}$. A central pressure of $1011 \mathrm{mb}$ has been added to HURDAT at $12 \mathrm{Z}$ on the $21^{\mathrm{st}}$. Another aircraft measured a central pressure of $1009 \mathrm{mb}$ and estimated surface winds of $26 \mathrm{kt}$ at $19 \mathrm{Z}$. A central pressure of $1009 \mathrm{mb}$ has been added to HURDAT at $18 \mathrm{Z}$ on the $21^{\text {st }}$. Intensification to a tropical storm is analyzed at $00 \mathrm{Z}$ on September $22^{\text {nd }}$, same originally shown in HURDAT. A ship reported $40 \mathrm{kt}$ at $00 \mathrm{Z}$ on the $22^{\text {nd }}$ but nearby observations indicate that it likely has a high bias. Gracie intensified steadily on the $22^{\text {nd }}$ while located over the eastern Bahamas. A reconnaissance aircraft reached the tropical storm at $1645 \mathrm{Z}$ on the $22^{\text {nd }}$ measuring a central pressure of $1003 \mathrm{mb}$ and estimated surface winds of $50 \mathrm{kt}$. At 1945Z, another penetration center fix measured a central pressure of $997 \mathrm{mb}$ and estimated surface winds of $75 \mathrm{kt}$. An eye diameter of 15 $\mathrm{nm}$ was estimated at $21 \mathrm{Z}$ by a radar fix. A central pressure of $997 \mathrm{mb}$ suggests maximum surface winds of $53 \mathrm{kt}$ from the south of $25 \mathrm{~N}$ Brown et al. pressure-wind relationship. An eye diameter of $15 \mathrm{~nm}$ suggests an RMW of about $11 \mathrm{~nm}$ and the climatological value is $18 \mathrm{~nm}$. Due to an RMW smaller than climatology, estimated surface winds of $75 \mathrm{kt}$ but a forward speed of about $8 \mathrm{kt}$, an intensity of $60 \mathrm{kt}$ is selected for $18 \mathrm{Z}$ on the $22^{\text {nd }}$, down 
from 65 kt originally in HURDAT, a minor intensity change. A central pressure of 997 mb was present in the original HURDAT at $18 \mathrm{Z}$ on the $22^{\text {nd }}$ and has been retained.

On October $23^{\text {rd }}$, a reconnaissance aircraft measured a central pressure of $1000 \mathrm{mb}$ and an eye diameter of $18 \mathrm{~nm}$ at $01 \mathrm{Z}$. A central pressure of $1000 \mathrm{mb}$ suggests maximum surface winds of $47 \mathrm{kt}$ from the south of $25 \mathrm{~N}$ pressure-wind relationship. An eye diameter of 18 $\mathrm{nm}$ suggests an RMW of about $14 \mathrm{~nm}$ and the climatological value is $19 \mathrm{~nm}$. Since the RMW was smaller than average, an intensity of $55 \mathrm{kt}$ is selected at $00 \mathrm{Z}$ on the $23^{\text {rd }}$, down from $85 \mathrm{kt}$ originally shown in HURDAT, a major intensity change. A central pressure of $1000 \mathrm{mb}$ was added to HURDAT at $00 \mathrm{Z}$ on the $23^{\text {rd }}$. Gracie moved slowly northwestward on the $23^{\text {rd }}$ with little change in intensity. Major changes in intensity are analyzed at $06 \mathrm{Z}, 12 \mathrm{Z}$ and $18 \mathrm{Z}$ on the $23^{\text {rd }}$. HURDAT had $85 \mathrm{kt}$ at $06 \mathrm{Z}$ and $12 \mathrm{Z}$ and $80 \mathrm{kt}$ at $18 \mathrm{Z}$, and the selected intensity at these times was $55 \mathrm{kt}$. A ship reported hurricaneforce winds at $15 \mathrm{Z}$ and $18 \mathrm{Z}$, but a reconnaissance aircraft at $2307 \mathrm{Z}$ estimated surface winds of $45 \mathrm{kt}$. It is likely that the ship had a high bias. The same reconnaissance aircraft also measured a central pressure of $1001 \mathrm{mb}$ and an eye diameter of $12 \mathrm{~nm}$. A central pressure of $1001 \mathrm{mb}$ suggests maximum surface winds of $45 \mathrm{kt}$ south of $25 \mathrm{~N}$ and $42 \mathrm{kt}$ north of the $25 \mathrm{~N}$ from the pressure-wind relationship. An eye diameter of $12 \mathrm{~nm}$ suggests an RMW of about $9 \mathrm{~nm}$ and the climatological value is $20 \mathrm{~nm}$. Since the RMW was smaller than average and the storm was moving at about $9 \mathrm{kt}$, an intensity of $55 \mathrm{kt}$ is selected at $00 \mathrm{Z}$ on the $24^{\text {th }}$, down from $75 \mathrm{kt}$ originally shown in HURDAT, a major intensity change. A central pressure of $1001 \mathrm{mb}$ was added to HURDAT at $00 \mathrm{Z}$ on the $24^{\text {th }}$. The tropical cyclone continued moving northwestward on the $24^{\text {th }}$, turning to the north late on the day. A central pressure of $1000 \mathrm{mb}$ was present in HURDAT at $12 \mathrm{Z}$ on the $24^{\text {th }}$ and although there is no observation to indicate that it was a central pressure, it appears reasonable and has been retained. A central pressure of $1004 \mathrm{mb}$, estimated surface winds of $40 \mathrm{kt}$ and an eye diameter of $15 \mathrm{~nm}$ was measured by a reconnaissance aircraft at $2309 \mathrm{Z}$ on the $24^{\text {th }}$. A central pressure of $1004 \mathrm{mb}$ suggests maximum surface winds of $36 \mathrm{kt}$ north of $25 \mathrm{~N}$ from the pressure-wind relationship. An eye diameter of 15 $\mathrm{nm}$ suggests an RMW of about $12 \mathrm{~nm}$ and the climatological value is $20 \mathrm{~nm}$. Due to an RMW smaller than climatology and ship reports of winds up to $40 \mathrm{kt}$, an intensity of 45 $\mathrm{kt}$ is selected at $00 \mathrm{Z}$ on the $25^{\text {th }}$, down from $65 \mathrm{kt}$ originally shown in HURDAT, a major intensity change. A central pressure of $1004 \mathrm{mb}$ was added to HURDAT at $00 \mathrm{Z}$ on the $25^{\text {th }}$. On the $25^{\text {th }}$, Gracie moved very slowly to the northeast and east. A central pressure of $997 \mathrm{mb}$ was present in HURDAT at $18 \mathrm{Z}$ on the $25^{\text {th }}$ and since it is in the MWR summary, it is likely to have been a measurement [but it was not found] and has been retained. A central pressure of $997 \mathrm{mb}$ suggests maximum surface winds of $49 \mathrm{kt}$ north of $25 \mathrm{~N}$ from the pressure-wind relationship. An intensity of $50 \mathrm{kt}$ is selected for $18 \mathrm{Z}$ on the $25^{\text {th }}$, down from $65 \mathrm{kt}$ originally in HURDAT, a minor change. 
Another reconnaissance aircraft measured a central pressure of $1000 \mathrm{mb}$ and estimated surface winds of $55 \mathrm{kt}$ at $2230 \mathrm{Z}$ on the $25^{\text {th }}$. A central pressure of $1000 \mathrm{mb}$ suggests maximum surface winds of $44 \mathrm{kt}$ north of $25 \mathrm{~N}$ from the pressure-wind relationship. Since the RMW was smaller than average, an intensity of $55 \mathrm{kt}$ is selected at $00 \mathrm{Z}$ on the $23^{\text {rd }}$, down from $85 \mathrm{kt}$ originally shown in HURDAT, a major intensity change. A central pressure of $1000 \mathrm{mb}$ was added to HURDAT at $00 \mathrm{Z}$ on the $26^{\text {th }}$. Gracie intensified on the $26^{\text {th }}$ as indicated by a reconnaissance aircraft measuring a central pressure of $992 \mathrm{mb}$, estimating surface winds of $85 \mathrm{kt}$ and an eye diameter of $15 \mathrm{~nm}$ at 2330Z. A central pressure of $992 \mathrm{mb}$ suggests maximum surface winds of $56 \mathrm{kt}$ north of $25 \mathrm{~N}$ and $59 \mathrm{kt}$ north of $25 \mathrm{~N}$ intensifying from the pressure-wind relationship. An eye diameter of $15 \mathrm{~nm}$ suggests an RMW of about $12 \mathrm{~nm}$ and the climatological value is $22 \mathrm{~nm}$. Since the RMW was smaller than average, an intensity of $65 \mathrm{kt}$ is selected at $00 \mathrm{Z}$ on the $27^{\text {th }}$, same as originally shown in HURDAT. A central pressure of $992 \mathrm{mb}$ was added to HURDAT at $00 \mathrm{Z}$ on the $27^{\text {th }}$. Intensification to a hurricane is analyzed at $00 \mathrm{Z}$ on the $27^{\text {th }}, 102$ hours (4.25 days) later than originally shown in HURDAT. On October $27^{\text {th }}$, Gracie started to move to the west-northwest and continued to gain in strength. A reconnaissance aircraft reached the hurricane at $04 \mathrm{Z}$ on October $28^{\text {th }}$ measuring a central pressure of $979 \mathrm{mb}$. A central pressure of $979 \mathrm{mb}$ suggests maximum surface winds of $74 \mathrm{kt}$ north of $25 \mathrm{~N}$ and $77 \mathrm{kt}$ north of $25 \mathrm{~N}$ intensifying from the pressure-wind relationship. An intensity of $80 \mathrm{kt}$ is selected at $06 \mathrm{Z}$ on the $28^{\text {th }}$, down from $85 \mathrm{kt}$ originally shown in HURDAT, a minor intensity change. A central pressure of $979 \mathrm{mb}$ was present in HURDAT at $00 \mathrm{Z}$ on the $28^{\text {th }}$ and based on the aircraft report, it was moved to $06 \mathrm{Z}$. A penetration center fix at $1906 \mathrm{Z}$ on the $28^{\text {th }}$ measured a central pressure of $964 \mathrm{mb}$, an eye diameter of $7 \mathrm{~nm}$ and estimated surface winds of $90 \mathrm{kt}$. A central pressure of $964 \mathrm{mb}$ suggests maximum surface winds of $91 \mathrm{kt}$ north of $25 \mathrm{~N}$ and $95 \mathrm{kt}$ north of $25 \mathrm{~N}$ intensifying from the pressure-wind relationship. An eye diameter of $7 \mathrm{~nm}$ suggests an RMW of about $5 \mathrm{~nm}$ and the climatological value is $23 \mathrm{~nm}$. Due to a small RMW and forward speed of about $11 \mathrm{kt}$, an intensity of $105 \mathrm{kt}$ is selected at $18 \mathrm{Z}$ on the $28^{\text {th }}$, up from $100 \mathrm{kt}$ originally shown in HURDAT, a minor intensity change. A central pressure of $964 \mathrm{mb}$ was added to HURDAT at $18 \mathrm{Z}$ on the $28^{\text {th }}$. Intensification to a major hurricane is analyzed at $18 \mathrm{Z}$ on the $28^{\text {th }}$, same as originally shown in HURDAT.

The next penetration center fix measured a central pressure of $957 \mathrm{mb}$ and estimated surface winds of $74 \mathrm{kt}$ and an eye diameter of $18 \mathrm{~nm}$ at $0142 \mathrm{Z}$ on October $29^{\text {th }}$. A central pressure of $957 \mathrm{mb}$ suggests maximum surface winds of $98 \mathrm{kt}$ north of $25 \mathrm{~N}$ and $103 \mathrm{kt}$ north of $25 \mathrm{~N}$ intensifying from the pressure-wind relationship. An eye diameter of $18 \mathrm{~nm}$ suggests an RMW of about $14 \mathrm{~nm}$ and the climatological value is $21 \mathrm{~nm}$. Due to a small RMW and forward speed of about $10 \mathrm{kt}$, an intensity of $110 \mathrm{kt}$ is selected at $18 \mathrm{Z}$ on the $28^{\text {th }}$, same as originally shown in HURDAT. A central pressure of $957 \mathrm{mb}$ was added to HURDAT at $00 \mathrm{Z}$ on the $29^{\text {th }}$. At $07 \mathrm{Z}$ on the $29^{\text {th }}$, the reconnaissance aircraft measured a 
central pressure of $958 \mathrm{mb}$, which have been added to HURDAT at 06Z. The final center penetration occurred at $1530 \mathrm{Z}$ on the $29^{\text {th }}$ and the reconnaissance aircraft reported a central pressure of $951 \mathrm{mb}$. A central pressure of $951 \mathrm{mb}$ suggests maximum surface winds of $104 \mathrm{kt}$ north of $25 \mathrm{~N}$ and $109 \mathrm{kt}$ north of $25 \mathrm{~N}$ intensifying from the pressurewind relationship. Since the circulation remained small and the forward speed was about $13 \mathrm{kt}$, an intensity of $115 \mathrm{kt}$ is selected at $12 \mathrm{Z}$ and $18 \mathrm{Z}$ on the $29^{\text {th }}$. HURDAT originally had $120 \mathrm{kt}$ and $105 \mathrm{kt}$, respectively, a minor intensity change. The peak intensity is analyzed at $115 \mathrm{kt}$, down from $120 \mathrm{kt}$ originally in HURDAT. A central pressure of 951 $\mathrm{mb}$ was added to HURDAT at $18 \mathrm{Z}$ on the $29^{\text {th }}$. A central pressure of $950 \mathrm{mb}$ was present in HURDAT at $12 \mathrm{Z}$ on the $29^{\text {th }}$ and has been removed. Landfall is analyzed at $17 \mathrm{Z}$ as a $115 \mathrm{kt}$ hurricane near $32.5 \mathrm{~N}, 80.4 \mathrm{~W}$, or very close to Beaufort, SC. MWR and ATSR indicate that a pressure of $950 \mathrm{mb}$ was measured at the Marine Corps Air Station in Beaufort, SC. But the Storm Wallet of Gracie has data that indicates that the report was later corrected to $960 \mathrm{mb}$, which fits the observation from the Surface Weather Observation (SWO). It appears that the minimum pressure at MCAS Beaufort was originally reported at 28.05 inches $(950 \mathrm{mb})$, but it was later corrected to 28.35 inches (960 mb). Furthermore, surface observations suggest that the center of Gracie passed just east of Beaufort. The central pressure of $951 \mathrm{mb}$ measured by reconnaissance aircraft about an hour and a half before landfall is now shown as the landfall pressure. The highest sustained wind measured over land was $84 \mathrm{kt} 5$-min at Beaufort and $80 \mathrm{kt}$ at Folly Island, SC. It is analyzed that Gracie made landfall in South Carolina as a category 4 hurricane, up from category 3 originally shown in HURDAT. The radar fixes from Charleston, SC and Fort Fisher, NC were helpful in determining the time of landfall. The Schwerdt et al. parametric hurricane wind model suggests that the highest sustained winds that impacted Georgia were $78 \mathrm{kt}$ winds, but since the winds that affected the state were coming from the north and northeast moving over land, a 15\% wind reduction was implemented, suggesting maximum winds of $66 \mathrm{kt}$. Therefore, Gracie is analyzed as a category 1 hurricane impact for Georgia. Hurricane Gracie weakened quickly as it progressed inland. The Kaplan and DeMaria model was run for 00Z, 06Z and 12Z on the $30^{\text {th }}$ yielding $66 \mathrm{kt}, 47 \mathrm{kt}$ and $33 \mathrm{kt}$, respectively. The highest winds recorded within 2 hours of these times at these times were $50 \mathrm{kt}, 47 \mathrm{kt}$ and $33 \mathrm{kt}$, respectively. An intensity of $65 \mathrm{kt}$ is selected for $00 \mathrm{Z}, 45 \mathrm{kt}$ at $06 \mathrm{Z}$ and $35 \mathrm{kt}$ at $12 \mathrm{Z}$ on the $30^{\text {th }}$ (up from $60 \mathrm{kt}$ at $00 \mathrm{Z}$, down from $60 \mathrm{kt}$ at $06 \mathrm{Z}$, and down from $45 \mathrm{kt}$ at $12 \mathrm{Z}$ on the $30^{\text {th }}$, originally in HURDAT. Weakening to a tropical storm is analyzed at $06 \mathrm{Z}$ on the $30^{\text {th }}$, six hours later than originally shown in HURDAT. An approaching cold front caused Gracie to turn to the north and later northeast on the $30^{\text {th }}$. At $18 \mathrm{Z}$ on the $30^{\text {th }}$, the synoptic data indicates that Gracie merged with the frontal boundary and became an extratropical cyclone. Transition to an extratropical cyclone is analyzed six hours later than originally shown in HURDAT. Weakening below tropical storm force is analyzed also at $18 \mathrm{Z}$ on the $30^{\text {th }}$, 
twelve hours earlier than originally shown in HURDAT. The extratropical depression increased in forward speed on October $1^{\text {st }}$ over the Northeast of the United States and turned to the east. Early on October $2^{\text {nd }}$, the extratropical cyclone became less organized and weakened into a trough after $12 \mathrm{Z}$. Final position is at $12 \mathrm{Z}$ on the $2^{\text {nd }}$, six hours earlier than originally shown.

Hurricane Hannah [September 27 - October 8, 1959]

\begin{tabular}{|c|c|c|c|c|c|c|c|c|c|c|c|c|c|}
\hline \multirow{3}{*}{$\begin{array}{r}41290 \\
41290 \\
41295\end{array}$} & \multirow{2}{*}{$\begin{array}{l}09 / 27 / 1959 \\
09 / 27 / 1959\end{array}$} & $M=12$ & \multirow{2}{*}{$\begin{array}{rr}2 & 9 \\
2 & 12 \\
* *\end{array}$} & SNBR $=$ & \multicolumn{2}{|c|}{898 HANNAH } & \multicolumn{3}{|c|}{$X I N G=0 \quad S S S=0$} & & & \\
\hline & & $M=1$ & & SNBR $=89$ & $98 \mathrm{H}$ & ANNAH & XII & $N G=\odot$ & $\mathrm{SSS}=\mathrm{C}$ & & & & \\
\hline & $09 / 27^{*}$ & $\odot$ & $\odot$ & $\Theta^{*}$ & $\odot$ & $\odot$ & $0 * 268$ & 499 & 30 & ๑*269 & 505 & 30 & $\Theta^{*}$ \\
\hline 41300 & $09 / 28 * 269$ & 512 & 35 & $0 * 270$ & 519 & 50 & $\Theta * 270$ & 528 & 60 & $0 * 270$ & 549 & 65 & $\Theta^{*}$ \\
\hline 41300 & $\begin{array}{r}09 / 28 * 270 \\
* \star *\end{array}$ & 512 & 35 & $\begin{array}{r}\Theta * 272 \\
\star \star *\end{array}$ & 519 & $\begin{array}{l}4 \odot \\
* *\end{array}$ & $\begin{array}{r}\theta^{*} 275 \\
* \star *\end{array}$ & 528 & $\begin{array}{l}45 \\
* *\end{array}$ & $\begin{array}{r}0 * 276 \\
\star * \star\end{array}$ & $\begin{array}{l}540 \\
* * *\end{array}$ & $\begin{array}{l}55 \\
* *\end{array}$ & $0^{*}$ \\
\hline $\begin{array}{l}41305 \\
41305\end{array}$ & $\begin{array}{r}09 / 29 * 27 \odot \\
09 / 29 * 274 \\
* * \text { * }\end{array}$ & $\begin{array}{l}573 \\
554 \\
* * *\end{array}$ & $\begin{array}{l}70 \\
60 \\
* *\end{array}$ & $\begin{array}{l}\Theta^{*} 267 \\
996^{*} 267 \\
* * *\end{array}$ & $\begin{array}{l}583 \\
572 \\
* * *\end{array}$ & $\begin{array}{l}75 \\
65 \\
* *\end{array}$ & $\begin{array}{l}\odot^{*} 263 \\
\Theta^{*} 263\end{array}$ & $\begin{array}{l}593 \\
590 \\
\star * *\end{array}$ & $\begin{array}{l}75 \\
70 \\
\star *\end{array}$ & $\begin{array}{l}\Theta^{*} 262 \\
0^{*} 262\end{array}$ & $\begin{array}{l}611 \\
610 \\
* * *\end{array}$ & $\begin{array}{l}80 \\
75 \\
* *\end{array}$ & $\begin{array}{l}\Theta^{*} \\
\Theta^{*}\end{array}$ \\
\hline $\begin{array}{l}41310 \\
41310\end{array}$ & $\begin{array}{l}\odot 9 / 30 * 262 \\
09 / 30 * 262\end{array}$ & $\begin{array}{l}628 \\
626 \\
\star * *\end{array}$ & $\begin{array}{l}85 \\
80 \\
\star *\end{array}$ & $\begin{array}{r}\Theta * 263 \\
\Theta * 264 \\
\star * *\end{array}$ & $\begin{array}{l}638 \\
638\end{array}$ & $\begin{array}{l}90 \\
85 \\
* *\end{array}$ & $\begin{array}{r}\Theta^{*} 267 \\
\Theta^{*} 269 \\
* * *\end{array}$ & $\begin{array}{l}647 \\
647\end{array}$ & $\begin{array}{l}9 \odot \\
9 \odot\end{array}$ & $\begin{array}{r}0^{*} 277 \\
975^{*} 279 \\
* * \quad * * *\end{array}$ & $\begin{array}{l}654 \\
656 \\
\star * *\end{array}$ & $\begin{array}{r}95 \\
105 \\
* * *\end{array}$ & $\begin{array}{l}0^{*} \\
959^{*} \\
* * *\end{array}$ \\
\hline $\begin{array}{l}41315 \\
41315\end{array}$ & $\begin{array}{l}10 / 01 * 288 \\
10 / 01 * 288\end{array}$ & $\begin{array}{l}661 \\
664 \\
\star * *\end{array}$ & $\begin{array}{l}105 \\
105\end{array}$ & $\begin{array}{l}\odot * 296 \\
\odot * 296\end{array}$ & $\begin{array}{l}671 \\
672 \\
\star * *\end{array}$ & $\begin{array}{l}110 \\
100\end{array}$ & $\begin{array}{r}959 * 304 \\
0 * 305 \\
* * * *\end{array}$ & $\begin{array}{l}681 \\
681\end{array}$ & $\begin{array}{r}110 \\
95 \\
* *\end{array}$ & $\begin{array}{l}959 * 315 \\
967 * 316 \\
* * * * * *\end{array}$ & $\begin{array}{l}689 \\
690 \\
* * *\end{array}$ & $\begin{array}{l}110 \\
100 \\
* * *\end{array}$ & $\begin{array}{l}959^{*} \\
963^{*} \\
\star * *\end{array}$ \\
\hline $\begin{array}{l}41320 \\
41320\end{array}$ & $\begin{array}{l}10 / 02 * 326 \\
10 / 02 * 326\end{array}$ & $\begin{array}{l}693 \\
692 \\
\star * *\end{array}$ & $\begin{array}{l}110 \\
100 \\
\star * *\end{array}$ & $\begin{array}{c}959 * 335 \\
0 * 335 \\
*\end{array}$ & $\begin{array}{l}689 \\
689\end{array}$ & $\begin{array}{l}110 \\
100 \\
\star * *\end{array}$ & $\begin{array}{c}959 * 341 \\
0 * 341 \\
*\end{array}$ & $\begin{array}{l}681 \\
680 \\
* * *\end{array}$ & $\begin{array}{l}110 \\
100 \\
\star * *\end{array}$ & $\begin{array}{l}959 * 345 \\
0 * 345 \\
*\end{array}$ & $\begin{array}{l}671 \\
672 \\
* * *\end{array}$ & $\begin{array}{r}110 \\
95 \\
* *\end{array}$ & $\begin{array}{l}959^{*} \\
961^{*} \\
\star * *\end{array}$ \\
\hline $\begin{array}{l}41325 \\
41325\end{array}$ & $\begin{array}{r}10 / 03 * 349 \\
10 / 03 * 350 \\
* * *\end{array}$ & $\begin{array}{l}662 \\
665 \\
\star * *\end{array}$ & $\begin{array}{r}110 \\
95 \\
* *\end{array}$ & $\begin{array}{r}959 * 351 \\
0 * 353 \\
* \quad * * *\end{array}$ & $\begin{array}{l}654 \\
657 \\
* * *\end{array}$ & $\begin{array}{r}110 \\
90 \\
\star *\end{array}$ & $\begin{array}{r}959 * 354 \\
0 * 357 \\
* * * *\end{array}$ & $\begin{array}{l}646 \\
647 \\
* * *\end{array}$ & $\begin{array}{r}105 \\
85 \\
* *\end{array}$ & $\begin{array}{l}959 * 359 \\
966 * 361 \\
\star * \star * \star *\end{array}$ & $\begin{array}{l}638 \\
634 \\
\star * *\end{array}$ & $\begin{array}{r}100 \\
85 \\
* *\end{array}$ & $\begin{array}{l}\Theta^{*} \\
\Theta^{*}\end{array}$ \\
\hline $\begin{array}{l}41330 \\
41330\end{array}$ & $\begin{array}{l}10 / 04 * 364 \\
10 / 04 * 364\end{array}$ & $\begin{array}{l}630 \\
623 \\
* * *\end{array}$ & $\begin{array}{l}95 \\
85 \\
\star *\end{array}$ & $\begin{array}{l}\odot * 367 \\
\odot * 367\end{array}$ & $\begin{array}{l}620 \\
615 \\
* * *\end{array}$ & $\begin{array}{l}90 \\
9 \odot\end{array}$ & $\begin{array}{r}\odot * 370 \\
0 * 369 \\
* * *\end{array}$ & $\begin{array}{l}607 \\
601 \\
\star \star \star *\end{array}$ & $\begin{array}{l}85 \\
85\end{array}$ & $\begin{array}{l}\odot * 371 \\
0 * 371\end{array}$ & $\begin{array}{l}590 \\
584 \\
* * *\end{array}$ & $\begin{array}{l}90 \\
85 \\
\star *\end{array}$ & $\begin{array}{l}0^{*} \\
970^{*} \\
* * *\end{array}$ \\
\hline $\begin{array}{l}41335 \\
41335\end{array}$ & $\begin{array}{l}10 / 05 * 371 \\
10 / 05 * 371\end{array}$ & $\begin{array}{l}570 \\
565 \\
* * *\end{array}$ & $\begin{array}{l}95 \\
85 \\
* *\end{array}$ & $\begin{array}{l}\odot * 369 \\
\odot * 369\end{array}$ & $\begin{array}{l}546 \\
541 \\
* * *\end{array}$ & $\begin{array}{l}95 \\
85 \\
* *\end{array}$ & $\begin{array}{r}0 * 365 \\
0 * 366 \\
* * *\end{array}$ & $\begin{array}{l}517 \\
515 \\
\star * *\end{array}$ & $\begin{array}{l}95 \\
90 \\
* *\end{array}$ & $\begin{array}{r}\odot * 360 \\
\odot * 364 \\
* * *\end{array}$ & $\begin{array}{l}478 \\
481 \\
\star * \star\end{array}$ & $\begin{array}{l}95 \\
9 \odot \\
* *\end{array}$ & $\begin{array}{r}0^{*} \\
\Theta^{*} \\
* * *\end{array}$ \\
\hline $\begin{array}{l}41340 \\
41340\end{array}$ & $\begin{array}{r}10 / 06 * 356 \\
10 / 06 * 361 \\
* * *\end{array}$ & $\begin{array}{l}440 \\
445 \\
* * *\end{array}$ & $\begin{array}{l}9 \odot \\
9 \odot\end{array}$ & $\begin{array}{r}\odot * 352 \\
\odot * 355 \\
* * *\end{array}$ & $\begin{array}{l}411 \\
411 \\
\star * *\end{array}$ & $\begin{array}{l}9 \odot \\
9 \odot\end{array}$ & $\begin{array}{r}0 * 349 \\
0 * 350 \\
* * *\end{array}$ & $\begin{array}{l}381 \\
381 \\
\star * *\end{array}$ & $\begin{array}{l}9 \odot \\
9 \odot\end{array}$ & $\begin{array}{r}0 * 344 \\
971 * 355 \\
* * * \quad * * *\end{array}$ & $\begin{array}{l}347 \\
347\end{array}$ & $\begin{array}{l}9 \odot \\
9 \odot\end{array}$ & $\begin{array}{l}\Theta^{*} \\
\Theta^{*}\end{array}$ \\
\hline $\begin{array}{l}41345 \\
41345\end{array}$ & $\begin{array}{r}10 / 07 * 349 \\
10 / 07 * 366 \\
* * *\end{array}$ & $\begin{array}{l}308 \\
308\end{array}$ & $\begin{array}{l}85 \\
85\end{array}$ & $\begin{array}{r}\odot * 362 \\
\text { OE378 } \\
* * * *\end{array}$ & $\begin{array}{l}281 \\
278 \\
* * *\end{array}$ & $\begin{array}{l}85 \\
85\end{array}$ & $\begin{array}{r}\odot * 383 \\
\text { OE392 } \\
* * * *\end{array}$ & $\begin{array}{l}249 \\
249\end{array}$ & $\begin{array}{l}85 \\
85\end{array}$ & $\begin{array}{c}\odot * 405 \\
\text { OE410 } \\
\star * * *\end{array}$ & $\begin{array}{l}206 \\
215 \\
\star \star *\end{array}$ & $\begin{array}{l}85 \\
85\end{array}$ & $\begin{array}{l}\Theta^{*} \\
\Theta^{*}\end{array}$ \\
\hline $\begin{array}{l}41350 \\
41350\end{array}$ & $\begin{array}{r}10 / 08 * 437 \\
10 / 08 E 450 \\
* * *\end{array}$ & $\begin{array}{l}172 \\
180 \\
\star * *\end{array}$ & $\begin{array}{l}80 \\
80\end{array}$ & $\begin{array}{r}\odot * 483 \\
\text { OE490 } \\
* * *\end{array}$ & $\begin{array}{l}176 \\
195 \\
\star * *\end{array}$ & $\begin{array}{l}65 \\
80 \\
\star *\end{array}$ & $\begin{array}{r}\text { OE530 } \\
967 \mathrm{E} 530 \\
* * *\end{array}$ & $\begin{array}{l}209 \\
209\end{array}$ & $\begin{array}{l}50 \\
70 \\
\star *\end{array}$ & $\begin{array}{r}\text { OE573 } \\
\text { OE56 } \\
* * *\end{array}$ & $\begin{array}{l}265 \\
250 \\
* * *\end{array}$ & $\begin{array}{l}40 \\
65 \\
\star *\end{array}$ & $\begin{array}{l}0^{*} \\
0^{*}\end{array}$ \\
\hline
\end{tabular}


41355 HR

Minor changes to the track and major changes to the intensity shown in McAdie et al. (2009). Evidence for these alterations comes from the NHC microfilm maps, the Historical Weather Maps series, the COADS ship database, Monthly Weather Review, Navy reconnaissance book, Mariners Weather Log, and NHC Storm Wallets.

September 25:

HWM and microfilm do not analyze an organized system at 12Z. HURDAT does not list an organized system on this date. Ship highlights: No gales or low pressures.

September 26:

HWM analyzes a spot low at 26.0N, $50.5 \mathrm{~W}$ at $12 \mathrm{Z}$. HURDAT does not list an organized system on this date. Microfilm does not show an organized system at 12Z. Ship highlights: No gales or low pressures.

September 27:

HWM analyzes a closed low pressure of at most $1015 \mathrm{mb}$ at $26.5 \mathrm{~N}, 50.0 \mathrm{~W}$ at 12Z. HURDAT lists a 30 knot tropical depression at $26.8 \mathrm{~N}, 49.9 \mathrm{~W}$ at $12 \mathrm{Z}$ (first position). Microfilm does not show an organized system at 12Z. Ship highlights: No gales or low pressures.

MWR: "On September 27, when hurricane Gracie was some 300 miles off the Florida east coast, ship reports indicated the development of a broad cyclonic circulation centered in the Atlantic near latitude 27" N, longitude 50" W." ATSR: "An easterly wave reported 300 miles west of the Cape Verde Islands by the Fleet Weather Central, Port Lyautey, on the $22^{\text {nd }}$ of September gave birth to HANNAH. With only a few distant ship reports available, this wave extrapolated westward across the Atlantic, until, on the $27^{\text {th }}$, a number of ships near the northern tip of the wave reported intensification. Ship reports at $271200 \mathrm{Z}$ indicated a possible closed circulation at 25N 52.5W. Successive ship reports indicated slow intensification and the apparent merging of the circulation with a wave on the remnants of a trailing cold front."

September 28:

HWM analyzes a tropical storm of at most $1005 \mathrm{mb}$ at $27.1 \mathrm{~N}, 52.3 \mathrm{~W}$ at $12 \mathrm{Z}$. HURDAT lists a 60 knot tropical storm at $27.0 \mathrm{~N}, 52.8 \mathrm{~W}$ at $12 \mathrm{Z}$. Microfilm shows a closed low pressure of at most $1002 \mathrm{mb}$ at $27.3 \mathrm{~N}, 52.4 \mathrm{~W}$ at $12 \mathrm{Z}$. Ship highlights: $35 \mathrm{kt} \mathrm{E}$ and $1008 \mathrm{mb}$ at $28.5 \mathrm{~N}, 53.5 \mathrm{~W}$ at $18 \mathrm{Z}$ (micro). Aircraft highlight: Penetration center fix measured a central pressure of $996 \mathrm{mb}$, estimated surface winds of $75 \mathrm{kt}$ and an eye diameter of $10 \mathrm{~nm}$ at $2120 \mathrm{Z}$ (ATSR).

MWR: "Aircraft reconnaissance the next day found a fully developed hurricane circulation and the first advisory on Hannah was issued at 2300 GMT, September 28. The 
hurricane at this time was located near 27" N, 57" W and was moving toward the west at about $14 \mathrm{kt}$ with highest winds around $74 \mathrm{kt}$. Hannah increased in intensity during the next 48 hours with central pressure dropping to $959 \mathrm{mb}$ and maximum winds reaching 108 kt." ATSR: “A Navy reconnaissance aircraft from Roosevelt Roads reported a radar eye at $282045 \mathrm{Z}$ and, less than an hour later, made a penetration reporting winds of hurricane force. The first warning was issued at 283000Z."

September 29:

HWM analyzes a hurricane of at most $995 \mathrm{mb}$ at $26.2 \mathrm{~N}, 59.6 \mathrm{~W}$ at $12 \mathrm{Z}$. HURDAT lists a 75 knot hurricane at $26.3 \mathrm{~N}, 59.3 \mathrm{~W}$ at $12 \mathrm{Z}$. Microfilm shows a closed low pressure of at most $1008 \mathrm{mb}$ at $26.0 \mathrm{~N}, 58.0 \mathrm{~W}$ at $12 \mathrm{Z}$. Ship highlights: $35 \mathrm{kt} \mathrm{SE}$ and $1009 \mathrm{mb}$ at $27.8 \mathrm{~N}, 54.5 \mathrm{~W}$ at $00 \mathrm{Z}$ (micro). $45 \mathrm{kt} \mathrm{SE}$ at $26.8 \mathrm{~N}, 56.8 \mathrm{~W}$ at $03 \mathrm{Z}$ (micro). $40 \mathrm{kt}$ ENE and $1010 \mathrm{mb}$ at $28.4 \mathrm{~N}, 59.1 \mathrm{~W}$ at $06 \mathrm{Z}$ (micro). $40 \mathrm{kt} \mathrm{NE}$ and $1017 \mathrm{mb}$ at $29.5 \mathrm{~N}$, $62.9 \mathrm{~W}$ at $12 \mathrm{Z}$ (COADS). $60 \mathrm{kt} \mathrm{NE}$ and $1001 \mathrm{mb}$ at $26.8 \mathrm{~N}, 61.5 \mathrm{~W}$ at $18 \mathrm{Z}$ (micro). Aircraft highlights: Penetration center fix at $26.2 \mathrm{~N}, 59.7 \mathrm{~W}$ and estimated maximum surface winds of $80 \mathrm{kt}$ at $1316 \mathrm{Z}$ (ATSR/micro). Penetration center fix at $26.2 \mathrm{~N}, 61.3 \mathrm{~W}$ at $1853 Z$ (ATSR).

September 30:

HWM analyzes a hurricane of at most $995 \mathrm{mb}$ at $26.4 \mathrm{~N}, 64.6 \mathrm{~W}$ at $12 \mathrm{Z}$. HURDAT lists a 90 knot hurricane at $26.7 \mathrm{~N}, 64.7 \mathrm{~W}$ at $12 \mathrm{Z}$. Microfilm shows a closed low pressure of at most $1005 \mathrm{mb}$ at $27.0 \mathrm{~N}, 64.0 \mathrm{~W}$ at $12 \mathrm{Z}$. Ship highlights: $70 \mathrm{kt} \mathrm{SE}$ and $1000 \mathrm{mb}$ at $28.0 \mathrm{~N}, 61.5 \mathrm{~W}$ at $00 \mathrm{Z}$ (micro) (likely wrong location). $50 \mathrm{kt} \mathrm{NE}$ and $997 \mathrm{mb}$ at $26.9 \mathrm{~N}, 63.1 \mathrm{~W}$ at $04 \mathrm{Z}$ (COADS). $50 \mathrm{kt} \mathrm{SE}$ and $996 \mathrm{mb}$ at $26.9 \mathrm{~N}, 63.1 \mathrm{~W}$ at $08 \mathrm{Z}$ (COADS). $50 \mathrm{kt} \mathrm{SE}$ and $1005 \mathrm{mb}$ at 26.9N, 63.2W at 12Z (COADS). $40 \mathrm{kt} \mathrm{SE}$ and 1010 $\mathrm{mb}$ at $27.6 \mathrm{~N}, 63.0 \mathrm{~W}$ at $15 \mathrm{Z}$ (micro). $45 \mathrm{kt} \mathrm{E}$ and $1010 \mathrm{mb}$ at $29.8 \mathrm{~N}, 63.9 \mathrm{~W}$ at $18 \mathrm{Z}$ (COADS). $45 \mathrm{SE}$ and $1010 \mathrm{mb}$ at 29.5N, 63.5W at 21Z (MWL). Aircraft highlights: Penetration center fix measured a central pressure of $975 \mathrm{mb}$ at $27.3 \mathrm{~N}, 64.5 \mathrm{~W}$ at $1241 \mathrm{Z}$ (ATSR/ ADVISORIES). Penetration center fix measured a central pressure of $959 \mathrm{mb}$ at 28.0N, 65.6W at 1838Z (ATSR/ADVISORIES). Radar center fix estimated surface winds of $40 \mathrm{kt}$ and an eye diameter of $9 \mathrm{~nm}$ at $1925 \mathrm{Z}$ (ATSR).

October 1:

HWM analyzes a hurricane of at most $995 \mathrm{mb}$ at $30.7 \mathrm{~N}, 68.5 \mathrm{~W}$ at $12 \mathrm{Z}$. HURDAT lists a 110 knot hurricane at $30.4 \mathrm{~N}, 68.1 \mathrm{~W}$ at $12 \mathrm{Z}$. Microfilm shows a closed low pressure of at most $1008 \mathrm{mb}$ at $30.5 \mathrm{~N}, 68.5 \mathrm{~W}$ at $12 \mathrm{Z}$. Ship highlights: $35 \mathrm{kt} \mathrm{SE}$ and $1012 \mathrm{mb}$ at $29.0 \mathrm{~N}, 63.1 \mathrm{~W}$ at $00 \mathrm{Z}$ (COADS). $35 \mathrm{kt} \mathrm{W}$ and $1014 \mathrm{mb}$ at $31.7 \mathrm{~N}, 79.2 \mathrm{~W}$ at 06Z (micro). Aircraft highlights: Radar center fix at 29.1N, 67.2W at 0243Z (ATSR). Penetration center fix measured a central pressure of $967 \mathrm{mb}$ at $30.5 \mathrm{~N}, 68.2 \mathrm{~W}$ at $1132 \mathrm{Z}$ (ATSR/micro). Penetration center fix estimated surface winds of $95 \mathrm{kt}$ and a $20 \mathrm{~nm}$ 
RMW near $31 \mathrm{~N}, 68 \mathrm{~W}$ at $\sim 1740 \mathrm{Z}$ (NHRP). Penetration center fix measured a central pressure of $963 \mathrm{mb}$ at $31.7 \mathrm{~N}, 69.0 \mathrm{~W}$ at $1750 \mathrm{Z}$ (ATSR).

MWR: "Hurricane Hannah never became a serious threat to the United States coast, or to Bermuda, and it presented no particularly difficult forecast problems. The most unusual feature of the storm was its long life and sustained intensity, somewhat similar to hurricane Carrie of 1957, A hurricane beacon developed cooperatively by the Air Force Geophysics Research Directorate and the Weather Bureau was tested in the hurricane on October 14. Some highly encouraging results were obtained since the beacon balloon remained in and transmitted signals from the eye for 24 hours on one occasion."

October 2:

HWM analyzes a hurricane of at most $995 \mathrm{mb}$ at $33.8 \mathrm{~N}, 68.2 \mathrm{~W}$ with a weakening front to the west at 12Z. HURDAT lists a 110 knot hurricane at $34.1 \mathrm{~N}, 68.1 \mathrm{~W}$ at $12 \mathrm{Z}$. Microfilm shows a closed low pressure of at most $1005 \mathrm{mb}$ at $34.2 \mathrm{~N}, 68.1 \mathrm{~W}$ with a frontal boundary to the west at 12Z. Ship highlights: $45 \mathrm{kt} \mathrm{SE}$ and $1009 \mathrm{mb}$ at $33.5 \mathrm{~N}$, $66.2 \mathrm{~W}$ at $03 \mathrm{Z}$ (MWL). $40 \mathrm{kt} \mathrm{E}$ and $1007 \mathrm{mb}$ at $35.0 \mathrm{~N}, 67.5 \mathrm{~W}$ at $12 \mathrm{Z}$ (COADS). $40 \mathrm{kt} \mathrm{SE}$ and $1007 \mathrm{mb}$ at $34.4 \mathrm{~N}, 65.5 \mathrm{~W}$ at $18 \mathrm{Z}$ (micro). $75 \mathrm{kt} \mathrm{SSE}$ at $34.8 \mathrm{~N}, 65.9 \mathrm{~W}$ at $23 \mathrm{Z}$ (MWL). Aircraft highlights: Radar center fix at $32.8 \mathrm{~N}, 69.0 \mathrm{~W}$ at $0035 \mathrm{Z}$ (ATSR). Penetration center fix estimated surface winds of $96 \mathrm{kt}$ and a $23 \mathrm{~nm}$ RMW near $34 \mathrm{~N}$, $68 \mathrm{~W}$ at $\sim 1110 \mathrm{Z}$ (NHRP). Penetration center fix at $34.2 \mathrm{~N}, 68.2 \mathrm{~W}$ at $1130 \mathrm{Z}$ (ATSR). Penetration center fix measured a central pressure of $961 \mathrm{mb}$, estimated surface winds of $120 \mathrm{kt}$ and an eye diameter of $25-35 \mathrm{~nm}$ at $34.3 \mathrm{~N}, 67.7 \mathrm{~W}$ at $1603 \mathrm{Z}$ (ATSR). Penetration center fix at $34.4 \mathrm{~N}, 67.5 \mathrm{~W}$ at $18 \mathrm{Z}$ (ATSR). Penetration center fix at $34.7 \mathrm{~N}, 67.0 \mathrm{~W}$ at $21 \mathrm{Z}$ (ATSR).

ATSR: "After detection, HANNAH increased steadily in intensity reaching a maximum wind speed of 120 knots on 2 October. The track of HANNAH was fairly regular, recurving at about $0000 \mathrm{Z}$ on the $2^{\text {nd }}$ of October around the periphery of a $500 \mathrm{mb}$ high located to the southeast of Bermuda and in advance of a cold front on the eastern United States seaboard. The storm then traveled rapidly eastward, imbedded in a strong westerly current ..."

October 3:

HWM analyzes a hurricane of at most $1000 \mathrm{mb}$ at $35.7 \mathrm{~N}, 64.5 \mathrm{~W}$ with a warm front to the northeast at $12 \mathrm{Z}$. HURDAT lists a 105 knot hurricane at $35.4 \mathrm{~N}, 64.6 \mathrm{~W}$ at 12Z. Microfilm shows a closed low pressure of at most $1008 \mathrm{mb}$ at $36.0 \mathrm{~N}, 64.0 \mathrm{~W}$ with a frontal boundary going through the system at 12Z. Ship highlights: $65 \mathrm{kt} \mathrm{S}$ and $1001 \mathrm{mb}$ at $34.0 \mathrm{~N}, 65.9 \mathrm{~W}$ at $00 \mathrm{Z}$ (MWL). $50 \mathrm{kt} \mathrm{SW}$ and $1005 \mathrm{mb}$ at $34.0 \mathrm{~N}, 66.0 \mathrm{~W}$ at $06 \mathrm{Z}$ (micro). $95 \mathrm{kt} \mathrm{SSE}$ at $34.2 \mathrm{~N}, 65.4 \mathrm{~W}$ at $09 \mathrm{Z}$ (MWL). $45 \mathrm{kt} \mathrm{SW}$ and $1009 \mathrm{mb}$ at $33.4 \mathrm{~N}, 64.4 \mathrm{~W}$ at $12 \mathrm{Z}$ (COADS). $40 \mathrm{kt} \mathrm{NE}$ and $1008 \mathrm{mb}$ at $36.7 \mathrm{~N}, 66.0 \mathrm{~W}$ at $18 \mathrm{Z}$ (COADS). Aircraft 
highlights: Penetration center fix measured a central pressure of $966 \mathrm{mb}$ at $35.7 \mathrm{~N}, 64.7 \mathrm{~W}$ at $1245 \mathrm{Z}$ (ATSR). Penetration center fix at $36.2 \mathrm{~N}, 63.0 \mathrm{~W}$ at $1830 \mathrm{Z}$ (ATSR).

October 4:

HWM analyzes a hurricane of at most $1000 \mathrm{mb}$ at $37.2 \mathrm{~N}, 60.2 \mathrm{~W}$ with a warm front to the northeast at 12Z. HURDAT lists a 85 knot hurricane at $37.0 \mathrm{~N}, 60.7 \mathrm{~W}$ at $12 \mathrm{Z}$. Microfilm shows a closed low pressure of at most $999 \mathrm{mb}$ at $37.5 \mathrm{~N}, 59.5 \mathrm{~W}$ with a frontal boundary going through the system at 12Z. Ship highlights: $45 \mathrm{kt} \mathrm{NNW}$ and $1012 \mathrm{mb}$ at $35.4 \mathrm{~N}, 66.0 \mathrm{~W}$ at $00 \mathrm{Z}$ (COADS). $40 \mathrm{kt} \mathrm{SW}$ and $1010 \mathrm{mb}$ at $35.5 \mathrm{~N}, 59.8 \mathrm{~W}$ at $12 \mathrm{Z}$ (COADS). $40 \mathrm{kt} \mathrm{SW}$ at $36.0 \mathrm{~N}, 57.2 \mathrm{~W}$ at $1750 \mathrm{Z}$ (micro). Aircraft highlights: Penetration center fix estimated surface winds of $108 \mathrm{kt}$ and a $30 \mathrm{~nm}$ RMW near $37 \mathrm{~N}, 61 \mathrm{~W}$ at $\sim 1220 \mathrm{Z}$ (NHRP). Penetration center fix at $37.2 \mathrm{~N}, 60.2 \mathrm{~W}$ at $1250 \mathrm{Z}$ (ATSR). Penetration center fix measured a central pressure of $970 \mathrm{mb}$ and estimated surface winds of $100 \mathrm{kt}$ at $37.1 \mathrm{~N}, 58.0 \mathrm{~W}$ at $1845 \mathrm{Z}$ (ATSR/WALLET).

MWR: "The last advisory was issued when the hurricane was 200 miles south-southwest of the Azores on " ATSR: "...decreasing to about 70 knots on 4 October."

October 5:

HWM analyzes a hurricane of at most $995 \mathrm{mb}$ at $36.6 \mathrm{~N}, 51.8 \mathrm{~W}$ with a cold front to the north at 12Z. HURDAT lists a 95 knot hurricane at $36.6 \mathrm{~N}, 51.7 \mathrm{~W}$ at $12 \mathrm{Z}$. Microfilm shows a closed low pressure of at most $990 \mathrm{mb}$ at $36.5 \mathrm{~N}, 51.2 \mathrm{~W}$ at $12 \mathrm{Z}$. Ship highlights: $25 \mathrm{kt} \mathrm{SSW}$ and $999 \mathrm{mb}$ at $36.8 \mathrm{~N}, 54.8 \mathrm{~W}$ at $00 \mathrm{Z}$ (micro). $65 \mathrm{kt} \mathrm{SW}$ and 995 $\mathrm{mb}$ at $34.4 \mathrm{~N}, 50.8 \mathrm{~W}$ at $06 \mathrm{Z}$ (COADS). $65 \mathrm{kt} \mathrm{SW}$ and $999 \mathrm{mb}$ at $33.6 \mathrm{~N}, 51.0 \mathrm{~W}$ at $12 \mathrm{Z}$ (COADS). $50 \mathrm{kt} \mathrm{W}$ and $998 \mathrm{mb}$ at $35.1 \mathrm{~N}, 50.5 \mathrm{~W}$ at $15 \mathrm{Z}$ (micro). $45 \mathrm{kt} \mathrm{NW}$ and $1005 \mathrm{mb}$ at $34.6 \mathrm{~N}, 50.4 \mathrm{~W}$ at $18 \mathrm{Z}$ (micro). Aircraft highlights: Penetration center fix at $36.6 \mathrm{~N}$, $51.2 \mathrm{~W}$ at $1258 \mathrm{Z}$ (ATSR). Radar center fix at $36.1 \mathrm{~N}, 48.2 \mathrm{~W}$ at $1745 \mathrm{Z}$ (ATSR).

October 6:

HWM analyzes a hurricane of at most $990 \mathrm{mb}$ at $34.7 \mathrm{~N}, 38.3 \mathrm{~W}$ with a weakening cold front to the north at 12Z. HURDAT lists a 90 knot hurricane at $34.9 \mathrm{~N}$, $38.1 \mathrm{~W}$ at $12 \mathrm{Z}$. Microfilm shows a closed low pressure of at most $999 \mathrm{mb}$ at $34.5 \mathrm{~N}$, $38.5 \mathrm{~W}$ at 12Z. Ship highlights: $55 \mathrm{kt} \mathrm{SSE}$ and $1002 \mathrm{mb}$ at $33.3 \mathrm{~N}, 47.3 \mathrm{~W}$ at $00 \mathrm{Z}$ (micro). $45 \mathrm{kt} \mathrm{SW}$ and $1007 \mathrm{mb}$ at $31.7 \mathrm{~N}, 40.9 \mathrm{~W}$ at $06 \mathrm{Z}$ (micro). $45 \mathrm{kt} \mathrm{SW}$ and $1007 \mathrm{mb}$ at $31.7 \mathrm{~N}$, $36.9 \mathrm{~W}$ at $12 \mathrm{Z}$ (micro). $35 \mathrm{kt} \mathrm{NE}$ and $1001 \mathrm{mb}$ at $36.3 \mathrm{~N}, 36.6 \mathrm{~W}$ at $18 \mathrm{Z}$ (COADS). Aircraft highlights: Penetration center fix measured a central pressure at $971 \mathrm{mb}$ and estimated maximum surface winds of $45 \mathrm{kt}$ at $34.9 \mathrm{~N}, 38.0 \mathrm{~W}$ at $1230 \mathrm{Z}$ (ATSR/ADVISORIES/MICRO). Radar center fix at $37.4 \mathrm{~N}, 30.5 \mathrm{~W}$ at $2345 \mathrm{Z}$ (ATSR). 
ATSR: “...then increasing again to 120 knots on 6 October. Reports received from aircraft of Barrier Force, Atlantic Fleet while operating in the vicinity of the Azores on the $6^{\text {th }}$ of October were of particular value in relocating HANNAH after a long period with little or no data."

October 7:

HWM analyzes a hurricane of at most $990 \mathrm{mb}$ at $39.0 \mathrm{~N}, 24.9 \mathrm{~W}$ with a cold front to the north at $12 \mathrm{Z}$. HURDAT lists a 85 knot hurricane at $38.3 \mathrm{~N}, 24.9 \mathrm{~W}$ at $12 \mathrm{Z}$.

Microfilm shows a closed low pressure of at most $987 \mathrm{mb}$ at $39.5 \mathrm{~N}, 24.9 \mathrm{~W}$ with a trough extending southwest of the low pressure at 12Z. Ship highlights: $45 \mathrm{kt} \mathrm{NNW}$ and $990 \mathrm{mb}$ at $36.9 \mathrm{~N}, 31.5 \mathrm{~W}$ at $00 \mathrm{Z}$ (micro). $60 \mathrm{kt} \mathrm{SW}$ and $1000 \mathrm{mb}$ at $35.9 \mathrm{~N}, 26.4 \mathrm{~W}$ at $06 \mathrm{Z}$ (COADS). $986 \mathrm{mb}$ at $39.1 \mathrm{~N}, 25.4 \mathrm{~W}$ at $12 \mathrm{Z}$ (COADS). $45 \mathrm{kt} \mathrm{WSW}$ and $1005 \mathrm{mb}$ at $36.1 \mathrm{~N}, 24.6 \mathrm{~W}$ at $12 \mathrm{Z}$ (COADS). $45 \mathrm{kt} \mathrm{N}$ and $985 \mathrm{mb}$ at $41.2 \mathrm{~N}, 22.6 \mathrm{~W}$ at $18 \mathrm{Z}$ (COADS). Land highlights: $35 \mathrm{kt} \mathrm{S}$ and $1000 \mathrm{mb}$ at Santa Maria, Azores at 06Z (micro). $15 \mathrm{kt} \mathrm{SSE}$ and $991 \mathrm{mb}$ at Terceira, Azores at 06Z (micro). Aircraft highlights: Radar center fix at $38.0 \mathrm{~N}, 28.9 \mathrm{~W}$ at $0330 \mathrm{Z}$ (ATSR).

ATSR: "... and finally appeared to merge with a second cold front in the vicinity of the Azores."

October 8:

HWM analyzes a hurricane of at most $975 \mathrm{mb}$ at $53.5 \mathrm{~N}, 20.5 \mathrm{~W}$ with a cold front extending to the southeast and a weakening stationary front to the northwest connected to an extratropical cyclone at $60.0 \mathrm{~N}, 32.0 \mathrm{~W}$ at $12 \mathrm{Z}$. HURDAT lists a $50 \mathrm{knot}$ extratropical cyclone at $53.0 \mathrm{~N}, 20.9 \mathrm{~W}$ at $12 \mathrm{Z}$. Microfilm shows an extratropical cyclone at $61.0 \mathrm{~N}, 32.0 \mathrm{~W}$, possibly indicating that Hannah has been absorbed, at 18Z. Ship highlights: $80 \mathrm{kt} \mathrm{S}$ and $980 \mathrm{mb}$ at 45.3N, 16.4W at 00Z (COADS). $55 \mathrm{kt} \mathrm{NW}$ and $979 \mathrm{mb}$ at $48.2 \mathrm{~N}, 19.5 \mathrm{~W}$ at $06 \mathrm{Z}$ (COADS). $80 \mathrm{kt} \mathrm{S}$ and $981 \mathrm{mb}$ at $53.0 \mathrm{~N}, 18.0 \mathrm{~W}$ at $12 \mathrm{Z}$ (COADS). $70 \mathrm{kt} \mathrm{WSW}$ and $974 \mathrm{mb}$ at $54.0 \mathrm{~N}, 22.5 \mathrm{~W}$ at 14Z (COADS). $45 \mathrm{kt} \mathrm{SE}$ and 956 $\mathrm{mb}$ at $56.3 \mathrm{~N}, 23.7 \mathrm{~W}$ at $18 \mathrm{Z}$ (COADS).

October 9:

HWM analyzes an extratropical cyclone at $60.5 \mathrm{~N}, 42.5 \mathrm{~W}$ at $12 \mathrm{Z}$. HURDAT does not list an organized system on this date. Microfilm shows an extratropical cyclone at $61.0 \mathrm{~N}, 32.0 \mathrm{~W}$ at 12Z. Ship highlights: $60 \mathrm{kt} \mathrm{WNW}$ and $983 \mathrm{mb}$ at $53.8 \mathrm{~N}, 32.7 \mathrm{~W}$ at 00Z (COADS). 


\begin{tabular}{|c|c|c|c|}
\hline Date & $\begin{array}{l}\text { Original } \\
\text { HURDAT } \\
\text { Central } \\
\text { Pressure } \\
\end{array}$ & Evidence & Changes \\
\hline Sep 29 00Z & & $\begin{array}{l}\text { Penetration center fix: } 996 \mathrm{mb} \text { at } 2120 \mathrm{Z} \\
\text { on Sep } 28^{\text {th }}\end{array}$ & $996 \mathrm{mb}$ \\
\hline Sep 30 12Z & & $\begin{array}{l}\text { Penetration center fix: } 975 \mathrm{mb} \text { at } 1241 \mathrm{Z} \\
\text { on Sep } 30^{\text {th }}\end{array}$ & $975 \mathrm{mb}$ \\
\hline Sep 30 18Z & & $\begin{array}{l}\text { Penetration center fix: } 959 \mathrm{mb} \text { at } 1838 \mathrm{Z} \\
\text { on Sep } 30^{\text {th }}\end{array}$ & $959 \mathrm{mb}$ \\
\hline Oct $106 Z$ & $959 \mathrm{mb}$ & $\begin{array}{l}\text { No penetration center fix occurred around } \\
\text { this time, nor a ship reported a central } \\
\text { pressure }\end{array}$ & Removed \\
\hline Oct $112 \mathrm{Z}$ & $959 \mathrm{mb}$ & $\begin{array}{l}\text { Penetration center fix: } 967 \mathrm{mb} \text { at } 1137 \mathrm{Z} \\
\text { on Oct } 1^{\text {st }}\end{array}$ & $967 \mathrm{mb}$ \\
\hline Oct $118 \mathrm{Z}$ & $959 \mathrm{mb}$ & $\begin{array}{l}\text { Penetration center fix: } 963 \mathrm{mb} \text { at } 1750 \mathrm{Z} \\
\text { on Oct } 1^{\text {st }}\end{array}$ & $963 \mathrm{mb}$ \\
\hline Oct $200 Z$ & \multirow{3}{*}{$959 \mathrm{mb}$} & \multirow{3}{*}{$\begin{array}{l}\text { No central pressure were reported around } \\
\text { these times by penetration center fixes or } \\
\text { ships }\end{array}$} & \multirow{3}{*}{ Removed } \\
\hline Oct $206 Z$ & & & \\
\hline Oct $212 Z$ & & & \\
\hline Oct $218 \mathrm{Z}$ & $959 \mathrm{mb}$ & $\begin{array}{l}\text { Penetration center fix: } 961 \mathrm{mb} \text { at } 1603 \mathrm{Z} \\
\text { on Oct } 2^{\text {nd }}\end{array}$ & $961 \mathrm{mb}$ \\
\hline Oct $300 Z$ & \multirow[b]{2}{*}{$959 \mathrm{mb}$} & \multirow{2}{*}{$\begin{array}{l}\text { No central pressure were reported around } \\
\text { these times by penetration center fixes or } \\
\text { ships }\end{array}$} & \multirow[b]{2}{*}{ Removed } \\
\hline Oct $306 Z$ & & & \\
\hline Oct $312 Z$ & $959 \mathrm{mb}$ & $\begin{array}{l}\text { Penetration center fix: } 966 \mathrm{mb} \text { at } 1245 \mathrm{Z} \\
\text { on Oct } 3^{\text {rd }}\end{array}$ & $966 \mathrm{mb}$ \\
\hline Oct $418 Z$ & & $\begin{array}{l}\text { Penetration center fix: } 970 \mathrm{mb} \text { at } 1845 \mathrm{Z} \\
\text { on Oct } 4^{\text {th }}\end{array}$ & $970 \mathrm{mb}$ \\
\hline Oct $612 Z$ & & $\begin{array}{l}\text { Penetration center fix: } 971 \mathrm{mb} \text { at } 1230 \mathrm{Z} \\
\text { on Oct } 6^{\text {th }}\end{array}$ & $971 \mathrm{mb}$ \\
\hline Oct $806 \mathrm{Z}$ & & Ship report: $15 \mathrm{kt} E$ and $969 \mathrm{mb}$ & $967 \mathrm{mb}$ \\
\hline
\end{tabular}

The development of Hannah appears to be associated with the northern portion of a tropical wave that left the African coast around September $22^{\text {nd }}$. Data over the eastern and central Atlantic is sparse and the precise time of genesis is uncertain. Late on September 
$26^{\text {th }}$ and early on the $27^{\text {th }}$, ship observations in the periphery of the circulation indicate that the disturbance had become better organized. The first position in HURDAT is at $12 \mathrm{Z}$ on the $27^{\text {th }}$ as a $30 \mathrm{kt}$ tropical depression and it has been retained, but the genesis of the tropical cyclone may have occurred 12-24 hours earlier. Minor track alterations are introduced during the lifetime of this tropical cyclone. The most significant changes are presented on October $7^{\text {th }}$. The tropical depression moved generally westward and intensification to a tropical storm is analyzed at $00 \mathrm{Z}$ on September $28^{\text {th }}$, same as the original HURDAT. Hannah continued to intensify on the $28^{\text {th }}$ with the first gales appearing northeast of the center at 18Z. A reconnaissance aircraft investigated the tropical storm at $2120 \mathrm{Z}$ on the $28^{\text {th }}$ measuring a central pressure of $996 \mathrm{mb}$, estimating surface winds of $75 \mathrm{kt}$ and an eye diameter of $10 \mathrm{~nm}$. A central pressure of $996 \mathrm{mb}$ suggests maximum surface winds of $50 \mathrm{kt}$ north of $25 \mathrm{~N}$ according to the Brown et al. pressure-wind relationship. An eye diameter of $10 \mathrm{~nm}$ suggests an RMW of about $8 \mathrm{~nm}$ and climatology is $22 \mathrm{~nm}$. Due to a small RMW, forward speed of about $14 \mathrm{kt}$ and estimated surface winds of $75 \mathrm{kt}$, an intensity of $55 \mathrm{kt}$ is selected for $18 \mathrm{Z}$ on the $28^{\text {th }}$ and $60 \mathrm{kt}$ for $00 \mathrm{Z}$ on the $29^{\text {th }}$, down from $60 \mathrm{kt}$ and $65 \mathrm{kt}$, respectively, originally in HURDAT, minor intensity changes. Intensification to a hurricane is analyzed at $06 \mathrm{Z}$ on the $29^{\text {th }}$, twelve hours later than originally shown in HURDAT. Hannah continued to intensify on the $29^{\text {th }}$ and $30^{\text {th }}$ as the track turned to the northwest. A reconnaissance aircraft reached the hurricane measuring a central pressure of $975 \mathrm{mb}$ at $1241 \mathrm{Z}$ on the $30^{\text {th }}$. A central pressure of $975 \mathrm{mb}$ suggests maximum surface winds of $79 \mathrm{kt}$ north of $25 \mathrm{~N}$ from the pressure-wind relationship. An intensity of $90 \mathrm{kt}$ is selected for $12 \mathrm{Z}$ on the $30^{\text {th }}$, same as the original HURDAT. Another penetration center fix measured a central pressure of $959 \mathrm{mb}$ at $1838 \mathrm{Z}$ on the $30^{\text {th }}$ and a radar fix at $1925 \mathrm{Z}$ estimated an eye diameter of $9 \mathrm{~nm}$. A central pressure of $959 \mathrm{mb}$ suggests maximum surface winds of 96 $\mathrm{kt}$ north of $25 \mathrm{~N}$ and $101 \mathrm{kt}$ intensifying from the pressure-wind relationship. An eye diameter of $9 \mathrm{~nm}$ suggests an RMW of about $7 \mathrm{~nm}$ and the climatological value is $20 \mathrm{~nm}$. Due to the small size of the hurricane and a forward speed of about $14 \mathrm{~nm}$, an intensity of $105 \mathrm{kt}$ is selected for $18 \mathrm{Z}$ on the $30^{\text {th }}$, up from $95 \mathrm{kt}$ originally in HURDAT, a minor intensity change. Intensification to a major hurricane is analyzed at $18 \mathrm{Z}$ on the $30^{\text {th }}$, six hours earlier than originally in HURDAT. $105 \mathrm{kt}$ is the peak intensity of this hurricane, down from 110 kt originally in HURDAT, a minor intensity change. HURDAT originally had $110 \mathrm{kt}$ from October $1^{\text {st }}$ at $06 \mathrm{Z}$ to October $3^{\text {rd }}$ at $06 \mathrm{Z}$.

On October $1^{\text {st }}$, the major hurricane passed about $200 \mathrm{~nm}$ southwest of Bermuda and started to make a turn to the north. Most of the ships stayed away from the hurricane on the $1^{\text {st }}$ but a reconnaissance aircraft reached Hannah at $1132 \mathrm{Z}$ measuring a central pressure of $967 \mathrm{mb}$. A central pressure of $967 \mathrm{mb}$ suggests maximum surface winds of 88 kt north of $25 \mathrm{~N}$ from the pressure-wind relationship. Due to a forward speed of about 14 $\mathrm{kt}$, an intensity of $95 \mathrm{kt}$ is selected for $12 \mathrm{Z}$ on the $1^{\text {st }}$, down from $110 \mathrm{kt}$ originally in 
HURDAT, a minor intensity change. For some unknown reason, HURDAT had a central pressure of $959 \mathrm{mb}$ from $06 \mathrm{Z}$ on October $1^{\text {st }}$ to $12 \mathrm{Z}$ on October $3^{\text {rd }}$. Central pressure reports from the reconnaissance aircrafts indicated that the central pressure of Hannah fluctuated during that period, not that it remained constant, which would be very rare for a hurricane. A reconnaissance aircraft at $1750 \mathrm{Z}$ on the $1^{\text {st }}$ reported a central pressure of $963 \mathrm{mb}$, indicating a slight deepening. A NHRP aircraft estimated surface winds of $95 \mathrm{kt}$ and an RMW of $20 \mathrm{~nm}$ around 1740Z. A central pressure of $963 \mathrm{mb}$ suggests maximum surface winds of $92 \mathrm{kt}$ north of $25 \mathrm{~N}$ and $96 \mathrm{kt}$ intensifying from the pressure-wind relationship. The climatological value for the RMW is $25 \mathrm{~nm}$. Due to the hurricane being smaller than climatology and a forward speed of about $14 \mathrm{kt}$, an intensity of $100 \mathrm{kt}$ is selected for $18 \mathrm{Z}$ on the $1^{\text {st }}$, down from $110 \mathrm{kt}$ originally in HURDAT, a minor intensity change. On October $2^{\text {nd }}$, Hannah turned to the northeast and slowed its forward speed. A reconnaissance aircraft measured a central pressure of $961 \mathrm{mb}$, estimated surface winds of $120 \mathrm{kt}$ and an eye diameter of 25-35 nm at 1603Z. A central pressure of $961 \mathrm{mb}$ suggests maximum surface winds of $94 \mathrm{kt}$ north of $25 \mathrm{~N}$ and $89 \mathrm{kt}$ north of $35 \mathrm{~N}$ from the pressure-wind relationship. An eye diameter of 25-35 nm suggests an RMW of about 19$26 \mathrm{~nm}$ and the climatological value is $27 \mathrm{~nm}$. Due to a forward speed of about $10 \mathrm{kt}$ and an RMW slightly below average, an intensity of $95 \mathrm{kt}$ is selected for $18 \mathrm{Z}$ on the $2^{\text {nd }}$, down from $110 \mathrm{kt}$ originally in HURDAT, a minor intensity change.

The structure of Hannah became less symmetric on the $3^{\text {rd }}$ and $4^{\text {th }}$ of October as it interacted with a frontal boundary. The circulation became stretched E-W but the synoptic observations indicate that the hurricane remained a tropical system. Early on the $3^{\text {rd }}$, Hannah made its closest approach to Bermuda passing about $170 \mathrm{~nm}$ northwest of the island. A couple of ships passed close to the center of Hannah on the $3^{\text {rd }}$ experiencing hurricane-force winds. The next reconnaissance aircraft reached the hurricane at $1245 \mathrm{Z}$ measuring a central pressure of $966 \mathrm{mb}$. A central pressure of $966 \mathrm{mb}$ suggests maximum surface winds of $89 \mathrm{kt}$ north of $25 \mathrm{~N}, 85 \mathrm{kt}$ north of $25 \mathrm{~N}$ weakening and also north of $35 \mathrm{~N}$ from the pressure-wind relationship. Due to the slow movement of hurricane near $10 \mathrm{kt}$, the intensity is analyzed at $85 \mathrm{kt}$, down from $105 \mathrm{kt}$ originally in HURDAT, a major intensity change. On October $4^{\text {th }}$, Hannah turned to the east and began to increase in forward speed. Around 1220Z, NHRP estimated surface winds of $108 \mathrm{kt}$ and an RMW of $22 \mathrm{~nm}$. A reconnaissance aircraft measured a central pressure of $970 \mathrm{kt}$ and estimated surface winds of $100 \mathrm{kt}$ at $1845 \mathrm{Z}$ on the $4^{\text {th }}$. A central pressure of $970 \mathrm{mb}$ suggests maximum surface winds of $82 \mathrm{kt}$ north of $35 \mathrm{~N}$ from the pressure-wind relationship. Climatology suggests an RMW of $30 \mathrm{~nm}$. Since the RMW was smaller than average and the forward speed was about $15 \mathrm{kt}$, an intensity of $85 \mathrm{kt}$ is selected at $18 \mathrm{Z}$ on the $4^{\text {th }}$, down from $90 \mathrm{kt}$ originally in HURDAT, a minor intensity change. On October $5^{\text {th }}$ and $6^{\text {th }}$, Hannah gained in forward speed over the north Atlantic as it tracked eastward with minor intensity fluctuations. A reconnaissance aircraft reached the hurricane at $1230 \mathrm{Z}$ on 
the $6^{\text {th }}$ measuring a central pressure of $971 \mathrm{mb}$. A central pressure of $971 \mathrm{mb}$ suggests maximum surface winds of $83 \mathrm{kt}$ north of $25 \mathrm{~N}$ and $81 \mathrm{kt}$ north of $35 \mathrm{~N}$ from the pressurewind relationship. Due to a forward speed of about $25 \mathrm{kt}$, an intensity of $90 \mathrm{kt}$ is selected at $18 \mathrm{Z}$ on the $6^{\text {th }}$, same as originally shown in HURDAT. Late on the $6^{\text {th }}$, the track of Hannah turned to the northeast around the periphery of a large extratropical cyclone north of the Azores. Transition to an extratropical cyclone occurred at $06 \mathrm{Z}$ on October $7^{\text {th }}$ as Hannah approached the Azores. Synoptic data indicates that a significant temperature gradient had developed by this time between the eastern and western quadrants, although the structure of the cyclone remained symmetric. Transition to an extratropical cyclone is analyzed 30 hours earlier than originally shown in HURDAT. Hannah remained an intense extratropical cyclone on October $8^{\text {th }}$ with a few reports of hurricane-force winds from ships near the storm. A couple of ships reported $80 \mathrm{kt}$ at $00 \mathrm{Z}$ and $12 \mathrm{Z}$ on the $8^{\text {th }}$, and although the $00 \mathrm{Z}$ report may be suspect compared to nearby ships, the other report looks reasonable. Thus, Hannah is kept at hurricane intensity on the $8^{\text {th }}$. HURDAT originally indicated that Hannah weakened to tropical storm intensity at $12 \mathrm{Z}$ on the $8^{\text {th }}$. A ship near the center of Hannah reported $15 \mathrm{kt} \mathrm{E}$ and $969 \mathrm{mb}$ at $06 \mathrm{Z}$ on the $8^{\text {th }}$, suggesting a central pressure of $967 \mathrm{mb}$. Surface observations late on October $8^{\text {th }}$ and early on the $9^{\text {th }}$ indicate that Hannah and the large extratropical cyclone southeast of Greenland had merged, making $18 \mathrm{Z}$ on the $8^{\text {th }}$ the last position of Hannah, which is consistent with the original HURDAT and the map of the Track of Lows of October of the MWL. A recent analog to Hurricane Hannah is Hurricane Gordon, 2012.

Tropical Storm Irene [October 6-9, 1959]

\begin{tabular}{|c|c|c|c|c|c|c|c|c|c|c|c|c|c|}
\hline 41360 & $10 / 06 / 195$ & $9 M=$ & 410 & SNBR $=8 \mathrm{~S}$ & 99 IR & ENE & XII & $N G=1$ & SSS= & & & & \\
\hline 41360 & $10 / 06 / 195$ & $9 M=$ & $4 \underset{* *}{13}$ & $3 \mathrm{SNBR}=8 \mathrm{~S}$ & 99 IR & ENE & XIN & $N G=1$ & SSS= & & & & \\
\hline 41365 & $10 / 06$ * & $\odot$ & $\odot$ & $0^{*}$ & $\odot$ & $\odot$ & $0^{*}$ & $\odot$ & $\odot$ & $0 * 231$ & 923 & 25 & ○* \\
\hline 41365 & $10 / 06$ * & $\odot$ & $\odot$ & $0^{*}$ & $\odot$ & $\odot$ & $\odot *$ & $\odot$ & $\odot$ & $\begin{array}{r}\Theta * 232 \\
* * *\end{array}$ & $\begin{array}{l}925 \\
* * *\end{array}$ & $\begin{array}{l}30 \\
\star *\end{array}$ & $0^{*}$ \\
\hline 41370 & $10 / 07 * 240$ & 916 & 25 & $0 * 249$ & 907 & 30 & $0 * 258$ & 897 & 30 & $\Theta * 271$ & 889 & 35 & $\odot *$ \\
\hline 41370 & $\begin{array}{r}10 / 07^{*} 242 \\
* \star \star\end{array}$ & $\begin{array}{l}918 \\
* * *\end{array}$ & $\begin{array}{l}30 \\
* *\end{array}$ & $\begin{array}{r}0 * 252 \\
* * *\end{array}$ & $\begin{array}{l}910 \\
\star * *\end{array}$ & 30 & $0 * 262$ & 900 & 30 & $\begin{array}{l}1003 * 273 \\
* * * * * * *\end{array}$ & $\begin{array}{l}89 \odot \\
* * *\end{array}$ & 35 & $\begin{array}{l}10 \odot 1^{*} \\
* * * *\end{array}$ \\
\hline 41375 & $10 / 08 * 284$ & 882 & 40 & $0 * 293$ & 879 & 45 & $0 * 302$ & 876 & 50 & $1001 * 311$ & 870 & 30 & $0^{*}$ \\
\hline 41375 & $10 / 08 * 284$ & 882 & $\begin{array}{l}35 \\
* *\end{array}$ & $\begin{array}{l}1002 * 294 \\
\star * * * * * *\end{array}$ & $\begin{array}{l}878 \\
\star * *\end{array}$ & $\begin{array}{l}40 \\
* *\end{array}$ & $\begin{array}{r}0 * 306 \\
* * *\end{array}$ & 876 & $\begin{array}{l}40 \\
* *\end{array}$ & $\begin{array}{l}1000 * 317 \\
* * * * * * *\end{array}$ & 870 & 30 & $\begin{array}{l}1003^{*} \\
* * * *\end{array}$ \\
\hline 41380 & $10 / 09 * 323$ & 861 & 25 & $0 * 331$ & 849 & 25 & $\Theta^{*}$ & $\odot$ & $\odot$ & $0^{*}$ & $\odot$ & $\odot$ & $\Theta^{*}$ \\
\hline 41380 & $\begin{array}{r}10 / 09 * 328 \\
* * *\end{array}$ & $\begin{array}{l}863 \\
* * *\end{array}$ & 25 & $\begin{array}{r}0 * 337 \\
* * *\end{array}$ & $\begin{array}{l}853 \\
\star * *\end{array}$ & $\begin{array}{l}20 \\
* *\end{array}$ & $\begin{array}{r}0 * 345 \\
* * *\end{array}$ & $\begin{array}{l}835 \\
\star * *\end{array}$ & $\begin{array}{l}20 \\
* *\end{array}$ & $\Theta^{*} \quad \odot$ & $\odot$ & $\odot$ & $\Theta^{*}$ \\
\hline & & & & & & & & & & & & & \\
\hline
\end{tabular}




\section{U.S. Tropical Storm Landfall}

10/08 10Z 30.3N 87.6W $40 \mathrm{kt} \mathrm{AL}$

Minor changes to the track and intensity shown in McAdie et al. (2009). Evidence for these alterations comes from the NHC microfilm maps, the Historical Weather Maps series, the COADS ship database, Monthly Weather Review, Navy reconnaissance book, Surface Weather Observations, Mariners Weather Log, and NHC Storm Wallets.

October 4:

HWM does not analyze an organized system at 12Z. HURDAT does not list an organized system on this date. Ship highlights: No gales or low pressures.

MWR: "Prior to the development of Irene, a short wave with surface cyclogenesis moved through the southern Plains and Texas on October 4."

October 5:

HWM analyzes a closed low pressure of at most $1010 \mathrm{mb}$ at $20.5 \mathrm{~N}, 92.0 \mathrm{~W}$ at 12Z. HURDAT does not list an organized system on this date. Microfilm shows a closed low pressure of at most $1008 \mathrm{mb}$ at $17.5 \mathrm{~N}, 92.5 \mathrm{~W}$ with a frontal boundary to the north at 12Z. Ship highlights: No gales or low pressures.

MWR: "This permitted the trailing cold front to move into the western Gulf of Mexico on the $5^{\text {th }}$; the front then dissipated leaving a rather sharp trough. At $500 \mathrm{mb}$, temperatures over the western Gulf were relatively warm. At, $200 \mathrm{mb}$, a weak anticyclone persisted over the surface development." ATSR: "Tropical Storm IRENE formed from a flat low pressure area in the Central Gulf of Mexico induced by a cold front which entered the Western Gulf about $1800 Z$ on 5 October."

October 6:

HWM analyzes a spot low at $23.2 \mathrm{~N}, 91.8 \mathrm{~W}$ with a cold front to the north at 12Z. HURDAT lists a 25 knot tropical depression at $23.1 \mathrm{~N}, 92.3 \mathrm{~W}$ at $18 \mathrm{Z}$ (first position). Microfilm shows a spot low pressure near $22.0 \mathrm{~N}, 95.0 \mathrm{~W}$ with a frontal boundary to the north at 12Z. Ship highlights: No gales or low pressures.

MWR: "Tropical storm Irene formed on October 6 in the central portion of the Gulf of Mexico and moved north-northeastward during the next two days." ATSR: "A closed low was drawn on the $1800 Z$ surface chart on 6 October with the ship CARL SCHMEDAN located at $22.2 \mathrm{~N}$ and $89.3 \mathrm{~W}$ reporting a southerly wind of 30 knots and squalls." 
October 7:

HWM analyzes a closed low pressure of at most $1005 \mathrm{mb}$ at $26.0 \mathrm{~N}, 89.5 \mathrm{~W}$ with a weakening cold front to the north at 12Z. HURDAT lists a 30 knot tropical depression at $25.8 \mathrm{~N}, 89.7 \mathrm{~W}$ at $12 \mathrm{Z}$. Microfilm shows a closed low pressure of at most $1005 \mathrm{mb}$ at $26.5 \mathrm{~N}, 90.0 \mathrm{~W}$ at $12 \mathrm{Z}$. Ship highlights: $40 \mathrm{kt} \mathrm{S}$ and $1009 \mathrm{mb}$ at $26.3 \mathrm{~N}, 87.6 \mathrm{~W}$ at $12 \mathrm{Z}$ (COADS). $35 \mathrm{kt} \mathrm{SSE}$ and $1005 \mathrm{mb}$ at $26.4 \mathrm{~N}, 88.8 \mathrm{~W}$ at $15 \mathrm{Z}$ (micro). $35 \mathrm{kt} \mathrm{SW}$ and 1006 $\mathrm{mb}$ at $26.3 \mathrm{~N}, 87.9 \mathrm{~W}$ at $18 \mathrm{Z}$ (micro). Land highlights: $10 \mathrm{kt} \mathrm{SE}$ and $1004 \mathrm{mb}$ at Burrwood, LA at 2055Z (SWO). Aircraft highlights: Penetration center fix measured a central pressure of $1003 \mathrm{mb}$ and estimated maximum surface winds of $35 \mathrm{kt}$ at $26.4 \mathrm{~N}$, $89.1 \mathrm{~W}$ at $14 \mathrm{Z}$ (ATSR). Penetration center fix measured a central pressure of $1001 \mathrm{mb}$ and estimated maximum surface winds of $45 \mathrm{kt}$ at $27.8 \mathrm{~N}, 88.5 \mathrm{~W}$ at $19 \mathrm{Z}$ (ATSR). Penetration center fix measured a central pressure of $1002 \mathrm{mb}$ and estimated maximum surface winds of $40 \mathrm{kt}$ at $28.0 \mathrm{~N}, 88.5 \mathrm{~W}$ at $2230 \mathrm{Z}$ (ATSR).

ATSR: “A Navy reconnaissance aircraft flight was sent out on 7 October to investigate this apparent circulation and found a definite closed low pressure center with winds gusting to 45 knots in squalls to the north and east. On the basis of this information, the first tropical storm warning was issued at 071600Z. The lowest sea level pressure reported by reconnaissance aircraft was $1001 \mathrm{mb}$. The highest winds were gusts of $48 \mathrm{kt}$ in squalls at the Pensacola Airport."

October 8:

HWM analyzes a tropical storm of at most $1005 \mathrm{mb}$ at $30.1 \mathrm{~N}, 87.2 \mathrm{~W}$ at $12 \mathrm{Z}$. HURDAT lists a 50 knot tropical storm at $30.2 \mathrm{~N}, 87.6 \mathrm{~W}$ at $12 \mathrm{Z}$. Microfilm shows a closed low pressure of at most $1002 \mathrm{mb}$ at $30.5 \mathrm{~N}, 87.7 \mathrm{~W}$ at $12 \mathrm{Z}$. Ship highlights: $25 \mathrm{kt}$ SSW and $1004 \mathrm{mb}$ at $27.3 \mathrm{~N}, 87.0 \mathrm{~W}$ at $00 \mathrm{Z}$ (COADS). $25 \mathrm{kt} \mathrm{SW}$ and $1004 \mathrm{mb}$ at $29.2 \mathrm{~N}$, $87.5 \mathrm{~W}$ at $06 \mathrm{Z}$ (micro). $30 \mathrm{kt} \mathrm{SSW}$ and $1008 \mathrm{mb}$ at $28.0 \mathrm{~N}, 86.4 \mathrm{~W}$ at $12 \mathrm{Z}$ (COADS). Land highlights: $5 \mathrm{kt} \mathrm{NE}$ and $1004 \mathrm{mb}$ at Burrwood, LA at 03Z (micro). $20 \mathrm{kt} \mathrm{SE}$ and $1003 \mathrm{mb}$ at Pensacola, FL at 06Z (micro). $20 \mathrm{kt} \mathrm{SSE}$ and $1002 \mathrm{mb}$ at Pensacola, FL at $0858 \mathrm{Z}$ (SWO). $20 \mathrm{kt} \mathrm{S}$ and $1003 \mathrm{mb}$ at Pensacola, FL at 12Z (micro). $13 \mathrm{kt} \mathrm{ENE} \mathrm{and} 1005 \mathrm{mb}$ at Montgomery, AL at 1958Z (SWO). Aircraft highlights: Penetration center fix measured a central pressure of $1007 \mathrm{mb}$ and estimated an eye diameter of $17 \mathrm{~nm}$ at $28.3 \mathrm{~N}, 87.3 \mathrm{~W}$ at $01 Z$ (ATSR).

MWR: "Irene was never a well organized storm and although the center moved inland near Pensacola early on the $8^{\text {th }}$, highest tides were 4.4 feet above normal at Cedar Keys, Fla., a considerable distance east of the track and landfall." ATSR: "The reconnaissance aircraft tracking IRENE on the night of 7-8 October was unable to find a definite eye; however, Burrwood, Louisiana, reported a triangular hole in a radar weather band at 080428Z, and Apalachicola, Florida, radar reported a center based on spiral overlay at 080800Z. IRENE passed inland just west of the city of Pensacola at $081110 \mathrm{Z}$ with 
maximum wind gusts to 48 knots at Naval Air Station, Pensacola. The storm dissipated rapidly on moving northward. No deaths, injuries, or significant damage were reported." October 9:

HWM analyzes a cold front over the eastern United States at 12Z. HURDAT lists a 25 knot tropical depression at $33.1 \mathrm{~N}, 84.9 \mathrm{~W}$ at $06 \mathrm{Z}$ (last position). Microfilm shows a frontal boundary over the eastern United States at 12Z. Ship highlights: No gales or low pressures.

Tropical Storm Irene developed from a tropical wave that reached the Gulf of Mexico on October $5^{\text {th }}$. The disturbance slowly became better organized as a frontal system entered the gulf from the northwest. A 30-kt tropical depression is analyzed to have formed at $18 \mathrm{Z}$ on October $6^{\text {th }}$, same as the original HURDAT. Data over the southern Gulf of Mexico is sparse and this tropical cyclone may have formed earlier than indicated. Minor track alterations are introduced for the lifetime of this tropical cyclone. The first reconnaissance aircraft to reach the system measured a central pressure of $1003 \mathrm{mb}$ and estimated surface winds of $35 \mathrm{kt}$ at 14Z. A central pressure of $1003 \mathrm{mb}$ suggests maximum sustained surface winds of $38 \mathrm{kt}$ north of $25 \mathrm{~N}$ from the Brown et al. pressurewind relationship. Due to low environmental pressures, an intensity of $30 \mathrm{kt}$ is selected at $12 \mathrm{Z}$ on October $7^{\text {th }}$, same as originally shown in HURDAT. A central pressure of 1003 $\mathrm{mb}$ has been added to HURDAT at $12 \mathrm{Z}$ on the $7^{\text {th }}$. A ship reported $40 \mathrm{kt}$ at $12 \mathrm{Z}$ on the $7^{\text {th }}$, but reports from surrounding ships indicate that it has a high wind bias. The first reliable gales were reported later in the day. Another reconnaissance aircraft measured a central pressure of $1001 \mathrm{mb}$ and estimated surface winds at $45 \mathrm{kt}$ at 19Z. A central pressure of $1001 \mathrm{mb}$ suggests maximum surface winds of $42 \mathrm{kt}$ north of $25 \mathrm{~N}$ from the pressure-wind relationship. Due to low environmental pressures and ship reports of $35 \mathrm{kt}$ winds, an intensity of $35 \mathrm{kt}$ is selected at $18 \mathrm{Z}$ on the $7^{\text {th }}$, same as originally shown in HURDAT. A central pressure of $1001 \mathrm{mb}$ has been added to HURDAT at $18 \mathrm{Z}$ on the $7^{\text {th }}$. Intensification to a tropical storm is analyzed at $18 \mathrm{Z}$ on the $7^{\text {th }}$, same as the original HURDAT. A penetration center fix at $2230 \mathrm{Z}$ on the $7^{\text {th }}$ measured a central pressure of $1002 \mathrm{mb}$ and estimated surface winds of $40 \mathrm{kt}$. A central pressure of $1002 \mathrm{mb}$ suggests maximum surface winds of $40 \mathrm{kt}$ north of $25 \mathrm{~N}$ from the pressure-wind relationship. An intensity of $35 \mathrm{kt}$ is selected at $00 \mathrm{Z}$ on October $8^{\text {th }}$, down from $40 \mathrm{kt}$ originally in HURDAT, a minor intensity change. Center fixes early on the $8^{\text {th }}$ were about $60 \mathrm{~nm}$ east of the center of Irene based on the synoptic data. The poorly-organized state of the cyclone likely contributed to the difficulty of fixing the center. Thus, these fixes have been disregarded. A minimum pressure of $1002 \mathrm{mb}$ and $20 \mathrm{kt} \mathrm{SSE}$ was reported in Pensacola, FL around 09Z, indicating a central pressure of $1000 \mathrm{mb}$, which has been added to HURDAT at $12 \mathrm{Z}$ on the $8^{\text {th }}$, replacing the existing $1001 \mathrm{mb}$. A central pressure of $1000 \mathrm{mb}$ suggests maximum surface winds of $44 \mathrm{kt}$ north of $25 \mathrm{~N}$ from the pressure- 
wind relationship. An intensity of $40 \mathrm{kt}$ is analyzed at $06 \mathrm{Z}$ and $12 \mathrm{Z}$, down from $45 \mathrm{kt}$ and $50 \mathrm{kt}$ originally in HURDAT, minor intensity changes. $40 \mathrm{kt}$ is also the peak intensity for this tropical cyclone, down from $50 \mathrm{kt}$ originally in HURDAT, a minor intensity change. Irene continued north-northeast early on the $8^{\text {th }}$ making landfall in Alabama with $40 \mathrm{kt}$ winds near $30.3 \mathrm{~N}, 87.6 \mathrm{~W}$ or about 25 miles southwest of Pensacola, FL at 10Z. No tropical storm force winds were reported by coastal stations. The tropical storm quickly weakened to a tropical depression at $18 \mathrm{Z}$ on the $8^{\text {th }}$, same as the original HURDAT. Montgomery, AL reported $13 \mathrm{kt} \mathrm{ENE}$ and $1005 \mathrm{mb}$ at 1958Z, which suggests a central pressure of $1003 \mathrm{mb}$, which has been added to HURDAT at $18 \mathrm{Z}$ on the $8^{\text {th }}$. A cold front was approaching from the northwest and caused Irene to accelerate to the northeast before being absorbed after $12 \mathrm{Z}$ on October $9^{\text {th }}$. The last position is analyzed at $12 \mathrm{Z}$ on the $9^{\text {th }}$, six hours later than originally shown in HURDAT.

Hurricane Judith [October 17-22, 1959]

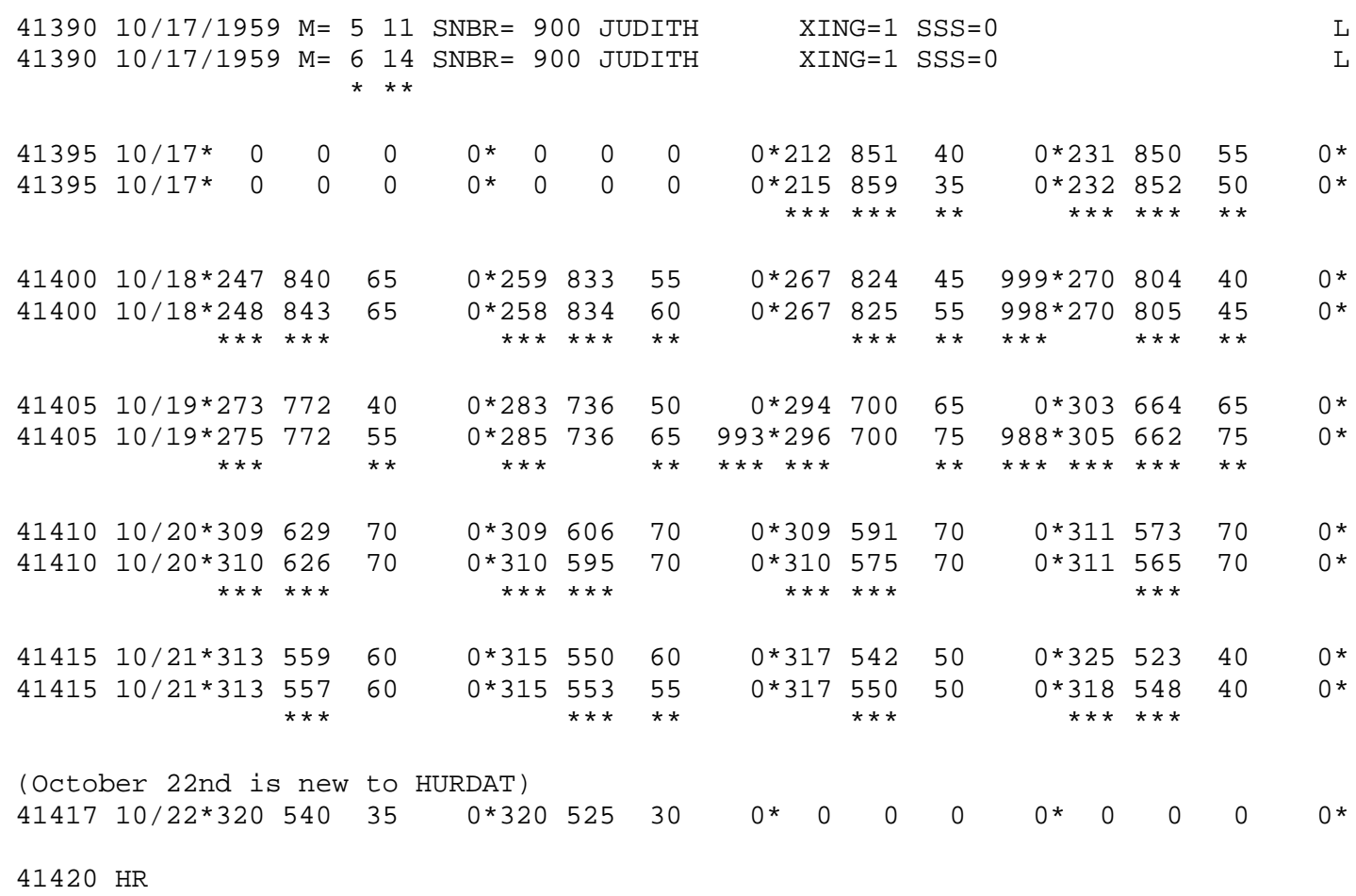

U.S. Tropical Storm Landfall

10/18 14Z 26.7N 82.3W 55 kt FL

Major changes to the track and minor alterations to the intensity shown in McAdie et al. (2009). Evidence for these alterations comes from the NHC microfilm maps, the 
Historical Weather Maps series, the COADS ship database, Monthly Weather Review, Navy reconnaissance book, Surface Weather Observations, Mariners Weather Log and NHC Storm Wallets.

October 12:

HWM does not analyze an organized system at 12Z. HURDAT does not list an organized system on this date. Microfilm shows a tropical wave over the eastern Caribbean Sea at 12Z. Ship highlights: No gales or low pressures.

MWR: "Activity along the intertropical convergence zone continued strong throughout mid-October in the Caribbean and Central America area. Pilots reported 52-kt. squalls in the vicinity of $15 \mathrm{~N}, 73 \mathrm{~W}$ late on the $10^{\text {th }}$ and early on the $11^{\text {th }}$, but the perturbation continued along the ITC with no development. During the afternoon of the $11^{\text {th }}$ a new unstable easterly wave approached the Leeward Islands, and Barbados experienced heavy squalls." ATSR: "Hurricane JUDITH had its origin from an easterly wave which appeared between Barbados Island and the other Windward Islands on 11 October. As this wave moved westward into the Caribbean the "Bermuda" high bulged southward producing a strong southeasterly wind field in the area. As the wave was followed through the Caribbean, ship reports, investigative flights, and land station reports indicated considerable squally weather and winds as high as 40 knots."

October 13:

HWM does not analyze an organized system at 12Z. HURDAT does not list an organized system on this date. Microfilm shows a tropical wave over the central Caribbean Sea at 12Z. Ship highlights: No gales or low pressures.

October 14:

HWM does not analyze an organized system at 12Z. HURDAT does not list an organized system on this date. Microfilm shows a tropical wave extending from $9 \mathrm{~N}-22 \mathrm{~N}$ and $72 \mathrm{~W}-77 \mathrm{~W}$ at $12 \mathrm{Z}$. Ship highlights: $40 \mathrm{kt} \mathrm{E}$ and $1010 \mathrm{mb}$ at $15.2 \mathrm{~N}, 72.1 \mathrm{~W}$ at $03 \mathrm{Z}$ (micro). $40 \mathrm{kt} \mathrm{SE}$ and $1009 \mathrm{mb}$ at 16.0N, 72.0W at 06Z (micro). $35 \mathrm{kt} \mathrm{SE}$ and $1012 \mathrm{mb}$ at $17.1 \mathrm{~N}, 71.3 \mathrm{~W}$ at $18 \mathrm{Z}$ (COADS). Aircraft highlights: Possible penetration center fix measured a central pressure of $1004 \mathrm{mb}$ and estimated surface winds of $50 \mathrm{kt}$ at $14.5 \mathrm{~N}$, 77.5W around $20 \mathrm{Z}$ (micro).

October 15:

HWM does not analyze an organized system at 12Z. HURDAT does not list an organized system on this date. Microfilm shows a closed low pressure of at most 1005 $\mathrm{mb}$ at $15.0 \mathrm{~N}, 79.3 \mathrm{~W}$ at $12 \mathrm{Z}$. Ship highlights: $35 \mathrm{kt}$ ESE and $1012 \mathrm{mb}$ at $16.4 \mathrm{~N}, 73.0 \mathrm{~W}$ at $00 \mathrm{Z}$ (COADS). $40 \mathrm{kt}$ ESE and $1012 \mathrm{mb}$ at $18.0 \mathrm{~N}, 75.9 \mathrm{~W}$ at $12 \mathrm{Z}$ (COADS). 
MWR: "This wave moved steadily across the Caribbean at $15 \mathrm{kt}$ and on October 15 developed a weak circulation south of Jamaica. During this same period, a tropical low pressure pattern gradually developed in the Bay of Campeche, remaining essentially stationary, while a cold front moved slowly southeastward from Texas into the western Gulf of Mexico."

October 16:

HWM does not analyze an organized system but it depicts a stationary front over the western Gulf of Mexico at 12Z. HURDAT does not list an organized system on this date. Microfilm shows a tropical wave over the western Caribbean Sea with a spot low near $18.0 \mathrm{~N}, 87.0 \mathrm{~W}$ at $12 \mathrm{Z}$. Ship highlights: No gales or low pressures.

MWR: "On the morning of October 16, the Caribbean wave had drifted into the Gulf of Honduras, the Campeche depression had weakened, and the west Gulf front had become diffused. Squalliness had decreased although moderates squalls were still occurring as far east as Jamaica. The Caribbean wave had been investigated daily by aircraft reconnaissance and, since development was thought possible when the, two disturbances eventually merged in the south-central Gulf, arrangements were made for aircraft reconnaissance in the area the following day. At both 1300 EST and 1900 EST on the $16^{\text {th }}$, all reporting stations within 500 miles of the disturbed area reported 24-hour rises in surface pressure."

October 17:

HWM analyzes a spot low at $21.3 \mathrm{~N}, 87.0 \mathrm{~W}$ at $12 \mathrm{Z}$. HURDAT lists a 40 knot tropical storm at $21.2 \mathrm{~N}, 85.1 \mathrm{~W}$ at $12 \mathrm{Z}$ (first position). Microfilm shows a closed low pressure of at most $1008 \mathrm{mb}$ at $21.0 \mathrm{~N}, 86.8 \mathrm{~W}$ at $12 \mathrm{Z}$. Ship highlights: $35 \mathrm{kt} \mathrm{SE}$ at $24.5 \mathrm{~N}$, $81.5 \mathrm{~W}$ at $21 \mathrm{Z}$ (micro). $45 \mathrm{kt} \mathrm{ESE}$ and $999 \mathrm{mb}$ at $24.4 \mathrm{~N}, 83.7 \mathrm{~W}$ at $22 \mathrm{Z}$ (micro). $45 \mathrm{kt} \mathrm{SW}$ and $1004 \mathrm{mb}$ at $24.4 \mathrm{~N}, 83.7 \mathrm{~W}$ at $2220 \mathrm{Z}$ (micro). $65 \mathrm{kt} \mathrm{SW}$ and $1004 \mathrm{mb}$ at $24.8 \mathrm{~N}, 83.5 \mathrm{~W}$ at $23 \mathrm{Z}$ (micro/MWL). Land highlights: $40 \mathrm{kt} \mathrm{SE}$ and $1018 \mathrm{mb}$ at Dry Tortugas Light, FL at $21 \mathrm{Z}$ (micro). Aircraft highlights: Penetration center fix measured a central pressure of $1007 \mathrm{mb}$ and estimated surface winds of $35 \mathrm{kt}$ at $21.7 \mathrm{~N}, 85.9 \mathrm{~W}$ at $1345 \mathrm{Z}$ (ATSR). Penetration center fix measured a central pressure of $1006 \mathrm{mb}$ and estimated surface winds of $43 \mathrm{kt}$ at $22.4 \mathrm{~N}, 85.9 \mathrm{~W}$ at $1745 \mathrm{Z}$ (ATSR). Penetration center fix measured a central pressure of $1005 \mathrm{mb}$ and estimated surface winds of $45 \mathrm{kt}$ at $23.6 \mathrm{~N}, 84.0 \mathrm{~W}$ (possible new center) at $1840 \mathrm{Z}$ (ATSR).

MWR: "However, surface reports at $0700 \mathrm{EST}$ on the 17th, as well as aircraft reconnaissance during the forenoon, indicated a complete circulation. Gale warnings were issued for the Florida Gulf coast south of Cedar Keys at 1600 EST as gradual intensification occurred during the day. In the afternoon, shortly before departing for 
home base, the aircraft reported a new center apparently developing some 150 miles northeast of the old center, with 45-kt surface winds. At 1700 EST, the MV Italsole encountered a small vortex at $24.5 \mathrm{~N}, 83.7 \mathrm{~W}$ with the barometer falling rapidly from 1008.5 to $999.3 \mathrm{mb}$, and the wind increasing to $43 \mathrm{kt}$. The wind shifted gradually from east-southeast to southwest in 30 minutes. The barometer then began rising steadily. An hour or two later another ship in the same area reported winds of hurricane force. With fairly rapid intensification indicated by these ships and by aircraft and with direction of movement in doubt, hurricane warnings were issued at 2030 EST for the Florida Gulf coast from Punta Gorda to Cedar Keys."

October 18:

HWM analyzes a tropical storm of at most $1005 \mathrm{mb}$ at $26.9 \mathrm{~N}, 82.8 \mathrm{~W}$ with a cold front to the northwest and another cold front to the northeast at 12Z. HURDAT lists a 45 knot tropical storm at $26.7 \mathrm{~N}, 82.4 \mathrm{~W}$ at $12 \mathrm{Z}$. Microfilm shows a closed low pressure of at most $999 \mathrm{mb}$ at $26.8 \mathrm{~N}, 82.4 \mathrm{~W}$ with a frontal boundary to the north at 12Z. Ship highlights: $20 \mathrm{kt} \mathrm{SE}$ and $1005 \mathrm{mb}$ at 24.6N, 83.6W at 00Z (COADS). $35 \mathrm{kt} \mathrm{S}$ and 1008 $\mathrm{mb}$ at $24.9 \mathrm{~N}, 80.3 \mathrm{~W}$ at $12 \mathrm{Z}$ (COADS). Land highlights: $40 \mathrm{kt} \mathrm{SSW}$ and $1009 \mathrm{mb}$ at Dry Tortugas Light, FL at 00Z (micro). $55 \mathrm{kt} \mathrm{S}$ and $1008 \mathrm{mb}$ at Carysfort Reef Light, FL at $25.2 \mathrm{~N}, 80.2 \mathrm{~W}$ at $12 \mathrm{Z}$ (micro). $35 \mathrm{kt} \mathrm{SSW}$ (gusts to $46 \mathrm{kt}$ ) at Fort Myers, FL at $1317 \mathrm{Z}$ (WALLET). $999 \mathrm{mb}$ at Boca Grande, FL at 14Z (WALLET). $39 \mathrm{kt} \mathrm{SW}$ and $1008 \mathrm{mb}$ at Key West, FL at 1450Z (SWO). $45 \mathrm{kt} \mathrm{SW}$ and $1006 \mathrm{mb}$ at Carysfort Reef Light, FL at $25.2 \mathrm{~N}, 80.2 \mathrm{~W}$ at $18 \mathrm{Z}$ (micro). Aircraft highlights: Penetration center fix measured a central pressure of $1005 \mathrm{mb}$ and estimated an eye diameter of $9 \mathrm{~nm}$ at $25.2 \mathrm{~N}, 83.7 \mathrm{~W}$ at $00 \mathrm{Z}$ (ATSR). Penetration center fix measured a central pressure of $1004 \mathrm{mb}$ at $25.3 \mathrm{~N}$, $83.5 \mathrm{~W}$ at $02 \mathrm{Z}$ (ATSR). Penetration center fix measured a central pressure of $998 \mathrm{mb}$ and estimated surface winds of $40 \mathrm{kt}$ at $26.7 \mathrm{~N}, 82.5 \mathrm{~W}$ at $12 \mathrm{Z}$ (ATSR).

MWR: "The observer at Dry Tortugas, some 70 miles west of Key West, reports as follows: Late in the afternoon, Cuban fishing boats in the area came to Dry Tortugas harbor area to avoid rough water. Just before dark the wind began to pick up, and in about 5 minutes the wild increased from about $10 \mathrm{mph}$ to about $50 \mathrm{mph}$ and the ocean became extremely rough. The high winds (about, $50-55 \mathrm{mph}$ ) continued, developing waves of nearly 10 feet. The wind shifted from east to south and blew all night at about 50-55 mph, although the rain did not get above a heavy drizzle. Neither the Miami WBO radar (the new WSR-57) nor the reconnaissance aircraft radar could pick up any wall cloud around the eye during the night and thus it was difficult to track the storm center. With time, the weather bands observed on radar appeared to lose intensity as well as much of their spiral character. These radar observations and weather trends along the Florida Gulf coast indicated definite loss of intensity and hurricane warnings were changed to gale warnings at 0500 EST. The storm center reached the coast near Boca 
Grande Island between 0800 and 0900 EST on the $18^{\text {th }}$, with lowest pressure $999.0 \mathrm{mb}$, and very little wind north of the center. South of the center the maximum sustained velocity at Fort Myers was south-southwest $35 \mathrm{kt}$, and gusts to $46 \mathrm{kt}$. Total rainfall was 7.57 inches and highest tides 2 feet above normal. There were no deaths but one injury. The storm crossed the Florida peninsula during the $18^{\text {th }}$, passing into the Atlantic near Fort Pierce. Gales were reported over extreme southern Florida with gusts of $48 \mathrm{kt}$ at Miami. Within a few hours after the storm passed out to sea, a new center apparently developed just northeast of Great Abaco Island in the Bahamas and began to intensify, reaching hurricane force by the next morning. Again the strongest winds first appeared on the south side of the center but gradually extended completely around the storm. No explanation is available for Judith's loss of intensity in the 6- to 8-hour period prior to landfall on the Florida west coast. Re-intensification over the Atlantic took place under west-southwesterly winds of around $45 \mathrm{kt}$ at $200 \mathrm{mb}$."

October 19:

HWM analyzes a hurricane of at most $1000 \mathrm{mb}$ at $29.8 \mathrm{~N}, 70.2 \mathrm{~W}$ with a frontal boundary about $60 \mathrm{~nm}$ to the northwest at $12 \mathrm{Z}$. HURDAT lists a 65 knot hurricane at $29.4 \mathrm{~N}, 70.0 \mathrm{~W}$ at $12 \mathrm{Z}$. Microfilm shows a frontal boundary between the East Coast of the United States and Bermuda at 12Z. Ship highlights: $40 \mathrm{kt} \mathrm{SSW}$ and $1005 \mathrm{mb}$ at 26.8N, $75.5 \mathrm{~W}$ at $00 \mathrm{Z}$ (COADS). $40 \mathrm{kt} \mathrm{SW}$ and $1006 \mathrm{mb}$ at $26.1 \mathrm{~N}, 75.8 \mathrm{~W}$ at $06 \mathrm{Z}$ (micro). $65 \mathrm{kt}$ $\mathrm{N}$ and $996 \mathrm{mb}$ at $30.2 \mathrm{~N}, 71.2 \mathrm{~W}$ at $11 \mathrm{Z}$ (MWL). $50 \mathrm{kt} \mathrm{SW}$ and $1011 \mathrm{mb}$ at $27.8 \mathrm{~N}, 68.5 \mathrm{~W}$ at $16 \mathrm{Z}$ (micro). $60 \mathrm{kt} \mathrm{WNW}$ and $1013 \mathrm{mb}$ at $26.6 \mathrm{~N}, 68.8 \mathrm{~W}$ at $18 \mathrm{Z}$ (COADS). Aircraft highlights: Penetration center fix at $27.7 \mathrm{~N}, 75.3 \mathrm{~W}$ at $03 \mathrm{Z}$ (ATSR). Penetration center fix measured a central pressure of $993 \mathrm{mb}$, estimated an eye diameter of $15 \mathrm{~nm}$ and maximum surface winds of $45 \mathrm{kt}$ at $28.8 \mathrm{~N}, 73.4 \mathrm{~W}$ at $0630 \mathrm{Z}$ (ATSR/micro). Penetration center fix measured a central pressure of $988 \mathrm{mb}$, estimated surface winds of $70 \mathrm{kt}$ and eye diameter of $12 \mathrm{~nm}$ at $29.6 \mathrm{~N}, 70.4 \mathrm{~W}$ at $1139 \mathrm{Z}$ (ATSR). Penetration center fix at $30.5 \mathrm{~N}, 66.0 \mathrm{~W}$ at $1830 \mathrm{Z}$ (ATSR).

ATSR: “...developed to hurricane intensity on the $19^{\text {th }}$ of October."

October 20:

HWM analyzes a hurricane of at most $1000 \mathrm{mb}$ at $31.5 \mathrm{~N}, 58.8 \mathrm{~W}$ with a frontal boundary about $60 \mathrm{~nm}$ to the northwest at 12Z. HURDAT lists a 70 knot hurricane at $30.9 \mathrm{~N}, 59.1 \mathrm{~W}$ at $12 \mathrm{Z}$. Microfilm shows a closed low pressure of at most $1002 \mathrm{mb}$ at $31.2 \mathrm{~N}, 57.2 \mathrm{~W}$ at $12 \mathrm{Z}$. Ship highlights: No gales or low pressures. Aircraft highlights: Radar center fix at $31.0 \mathrm{~N}, 62.5 \mathrm{~W}$ at $0030 \mathrm{Z}$ (ATSR). Penetration center fix at $31.3 \mathrm{~N}$, $56.2 \mathrm{~W}$ at $1903 \mathrm{Z}$ (ATSR). 
October 21:

HWM analyzes a tropical storm of at most $1010 \mathrm{mb}$ at $32.1 \mathrm{~N}, 53.8 \mathrm{~W}$ with a frontal boundary just to the northwest at $12 \mathrm{Z}$. HURDAT lists a 50 knot tropical storm at $31.7 \mathrm{~N}, 54.2 \mathrm{~W}$ at $12 \mathrm{Z}$. Microfilm shows a closed low pressure of at most $1017 \mathrm{mb}$ at $32.0 \mathrm{~N}, 54.0 \mathrm{~W}$ at $12 \mathrm{Z}$. Ship highlights: $35 \mathrm{kt} \mathrm{S}$ and $1001 \mathrm{mb}$ at $31.7 \mathrm{~N}, 54.7 \mathrm{~W}$ at $12 \mathrm{Z}$ (COADS). Aircraft highlights: Penetration center fix at $32.0 \mathrm{~N}, 54.5 \mathrm{~W}$ at $1245 \mathrm{Z}$ (ATSR). Penetration center fix at $32.0 \mathrm{~N}, 55.1 \mathrm{~W}$ at $1832 \mathrm{Z}$ (ATSR/micro).

October 22:

HWM analyzes a NE-SW elongated, closed low pressure of at most $1005 \mathrm{mb}$ at $31.0 \mathrm{~N}, 51.0 \mathrm{~W}$ embedded within a frontal boundary at 12Z. HURDAT does not list an organized system on this date. Microfilm shows a closed low pressure of at most 1017 $\mathrm{mb}$ at $31.0 \mathrm{~N}, 51.0 \mathrm{~W}$ embedded within a frontal boundary at 12Z. Ship highlights: No gales or low pressures.

ATSR: "JUDITH was forecast to move approximately parallel to the wind flow at 500 $\mathrm{mb}$ on a continuing east-northeasterly heading while in the Atlantic. Verification of this direction proved highly satisfactory; however, the speed was somewhat erratic. JUDITH became extra-tropical and weakened on the $28^{\text {th }}$ of October after becoming involved with a cold front."

October 23:

HWM analyzes a frontal boundary over the north Atlantic at 12Z. HURDAT does not list an organized system on this date. Microfilm shows a trough of low pressure extending $27 \mathrm{~N}-35 \mathrm{~N}, 44 \mathrm{~W}-50 \mathrm{~W}$ at 12Z. Ship highlights: No gales or low pressures.

A strong tropical wave entered the Caribbean Sea on October $12^{\text {th }}$. As the disturbance moved westward, it became better organized and tropical storm force winds were reported over the central Caribbean Sea early on October $14^{\text {th }}$. Synoptic data is scarce over this area but it did not appear that a closed low-level circulation had developed at that time. Late on the $14^{\text {th }}$, a reconnaissance aircraft investigated the disturbance finding a central pressure of $1004 \mathrm{mb}$ and maximum surface winds of $50 \mathrm{kt}$, as shown on microfilm. Although it is possible that a tropical cyclone may have formed on the $14^{\text {th }}$, synoptic data late on the $14^{\text {th }}$ and $15^{\text {th }}$ does not support that a well-define low level circulation was present. A few ships over the southern Caribbean Sea were reporting southwest winds on these days, but this wind pattern continued into October $16^{\text {th }}$ when the disturbance had already left the area. This likely was an indication that these southwest winds were responding to the Pacific monsoon trough impinging into the 
Caribbean Sea and were not associated with the disturbance. Late on the $16^{\text {th }}$, the strong tropical wave reached the Gulf of Honduras and turned to the north becoming better organized. At the same time, a stationary cold front was present over the central Gulf of Mexico. A reconnaissance aircraft reached the disturbance at $1345 \mathrm{Z}$ on October $17^{\text {th }}$ estimating surface winds of $35 \mathrm{kt}$ and measuring a central pressure of $1007 \mathrm{mb}$. This central pressure value was not added to HURDAT because ship and coastal observations indicate that the pressures were slightly lower than the reported value. The first position is analyzed at $12 \mathrm{Z}$ on the $17^{\text {th }}$ as a $35 \mathrm{kt}$ tropical storm named Judith, slightly weaker than originally shown in HURDAT. Minor track alterations are indicated during most of the lifetime of this tropical cyclone, with the only major alteration to the track occurring at $18 \mathrm{Z}$ on October $21^{\text {st }}$. Subsequent reconnaissance center fixes on the $17^{\text {th }}$ indicate that the aircraft had trouble locating the center, which would normally suggest that the tropical cyclone was poorly organized. Nonetheless, as the tropical storm moved northeastward late on the $17^{\text {th }}$, a ship measured $45 \mathrm{kt} \mathrm{SE}$ and the pressure dropped to $999 \mathrm{mb}$ around 22Z. About an hour later, around $23 \mathrm{Z}$ on October $17^{\text {th }}$, another ship near the center measured $65 \mathrm{kt} \mathrm{SW}$ and $1004 \mathrm{mb}$. Intensification to a hurricane is analyzed at $00 \mathrm{Z}$ on the $18^{\text {th }}$, same as originally shown in HURDAT. Early on the $18^{\text {th }}$, reconnaissance data suggested that Judith had a small eye of about $9 \mathrm{~nm}$ in diameter. The tropical cyclone continued moving northeastward on the $18^{\text {th }}$ but data suggests that it started weakening soon after reaching hurricane intensity. Weakening to a tropical storm is analyzed at $06 \mathrm{Z}$ on the $18^{\text {th }}$, same as originally shown in HURDAT. A reconnaissance aircraft measured a central pressure of $998 \mathrm{mb}$ and estimated surface winds of $40 \mathrm{kt}$ at $12 \mathrm{Z}$ on the $18^{\text {th }}$. A central pressure of $998 \mathrm{mb}$ suggests maximum surface winds of $49 \mathrm{kt}$ from the north $25 \mathrm{~N}$ Brown et al. pressure-wind relationship. Since Judith was moving at about $16 \mathrm{kt}$, an intensity of $55 \mathrm{kt}$ is selected at $12 \mathrm{Z}$ on the $18^{\text {th }}$, up from $45 \mathrm{kt}$ originally in HURDAT, a minor intensity change. A central pressure of $998 \mathrm{mb}$ is added to HURDAT at $12 \mathrm{Z}$ on the $18^{\text {th }}$, replacing the existing $999 \mathrm{mb}$, which was measured a couple of hours later.

Around $14 \mathrm{Z}$ on the $18^{\text {th }}$, Judith made landfall near Boca Grande, FL with an intensity of $55 \mathrm{kt}$. This is based primarily upon the reconnaissance data a few hours before landfall. Surface observations include $55 \mathrm{kt}$ at Carysfort Reef Light at 12Z, $35 \mathrm{kt}$ at Fort Myers at $1317 \mathrm{Z}$ and $39 \mathrm{kt}$ at Key West at 1450Z, consistent with an intensity of $55 \mathrm{kt}$ at landfall. After landfall, the track of Judith turned east-northeast and the forward speed rapidly increased. The center of the storm made oceanfall in the Atlantic Ocean around 19Z on the $18^{\text {th }}$ after just five hours overland. Judith re-intensified over the Atlantic waters while located on the warm side of a weak frontal boundary. A reconnaissance aircraft measured a central pressure of $993 \mathrm{mb}$ and estimated an eye diameter of $15 \mathrm{~nm}$ at $0630 \mathrm{Z}$ on October $19^{\text {th }}$. A central pressure of $993 \mathrm{mb}$ suggests maximum surface winds of $57 \mathrm{kt}$ from the north of $25 \mathrm{~N}$ intensifying pressure-wind relationship. An eye diameter of $15 \mathrm{~nm}$ suggests an RMW of about $11 \mathrm{~nm}$ and the climatological value is $23 \mathrm{~nm}$. Due to a 
forward speed of about $35 \mathrm{kt}$ and an RMW smaller than normal, an intensity of $65 \mathrm{kt}$ is selected at $06 \mathrm{Z}$ on the $19^{\text {th }}$, up from $50 \mathrm{kt}$ originally in HURDAT, a minor intensity change. A central pressure of $993 \mathrm{mb}$ is added to HURDAT at $06 \mathrm{Z}$ on the $19^{\text {th }}$. Reintensification to a hurricane is analyzed six hours earlier than originally shown in HURDAT. A penetration center fix measured a central pressure of $988 \mathrm{mb}$, estimated surface winds of $70 \mathrm{kt}$ and an eye diameter of $12 \mathrm{~nm}$ at 1139Z. A central pressure of 988 $\mathrm{mb}$ suggests maximum surface winds of $65 \mathrm{kt}$ from the north of $25 \mathrm{~N}$ intensifying pressure-wind relationship. An eye diameter of $12 \mathrm{~nm}$ suggests an RMW of about $9 \mathrm{~nm}$ and the climatological value is $24 \mathrm{~nm}$. Due to a forward speed of about $35 \mathrm{kt}$ and an RMW smaller than normal, an intensity of $75 \mathrm{kt}$ is selected at $12 \mathrm{Z}$ on the $19^{\text {th }}$, up from 65 kt originally in HURDAT, a minor intensity change. A central pressure of $988 \mathrm{mb}$ is added to HURDAT at $12 \mathrm{Z}$ on the $19^{\text {th }} .75 \mathrm{kt}$ is the peak intensity of this tropical cyclone, up from 70 kt originally in HURDAT, a minor intensity change. On October $20^{\text {th }}$, Judith moved generally eastward and began to slow its forward speed. Intensity is retained at 70 $\mathrm{kt}$ on the $20^{\text {th }}$, as originally shown in HURDAT, based in part on a surface wind estimate of $70 \mathrm{kt}$ from a reconnaissance aircraft at 20Z. Synoptic observations in the $20^{\text {th }}$ were scarce with no ship reports of gale-force winds. The frontal boundary helping to cause the eastward movement of the storm remained north of the storm's circulation. Judith weakened rapidly on October $21^{\text {st }}$. Weakening below hurricane force is analyzed at $00 \mathrm{Z}$ on the $21^{\text {st }}$, same as originally shown in HURDAT. Weakening continued and Judith became a tropical depression around $06 \mathrm{Z}$ on October $22^{\text {nd }}$, becoming absorbed by a stronger frontal system after $06 \mathrm{Z}$. Final position is analyzed at $06 \mathrm{Z}$ on the $22^{\text {nd }}$, twelve hours later than originally shown in HURDAT.

\section{9 - Additional Notes}

1) May 29 - June 2: Historical Weather Maps show an area of low pressure developing over the central Atlantic during the last days of May. The disturbance moved slowly northward ahead of an approaching frontal boundary. A well-defined low was present but the data suggests that it was producing winds below gale force. The disturbance weakened on June $1^{\text {st }}$ and became absorbed by the frontal boundary on the $2^{\text {nd }}$. Therefore, because the system did not produce gale force winds, it is not added to HURDAT. This disturbance was in Jack Beven's List of Suspects.

$\begin{array}{cccc}\text { Day } & \text { Latitude } & \text { Longitude } & \text { Status } \\ \text { May } 29 & 30 \mathrm{~N} & 55 \mathrm{~W} & \text { Trough } \\ \text { May } 30 & 30 \mathrm{~N} & 55 \mathrm{~W} & \text { Tropical } \\ & & & \text { Depression? }\end{array}$


May 31

June 1

June 2
$31 \mathrm{~N}$

$34 \mathrm{~N}$

$55 \mathrm{~W}$
Tropical

Depression?

Tropical

Depression?

Absorbed

2) August 24-27: A tropical wave entered the Gulf of Mexico around August $23^{\text {rd }}$ and slowly became better organized. The disturbance was investigated by reconnaissance aircrafts on a couple of occasions between August $24^{\text {th }}$ and $26^{\text {th }}$. The reconnaissance aircrafts reported a diffuse center on the $25^{\text {th }}$ and estimated winds of $30 \mathrm{kt}$. Before landfall on the $26^{\text {th }}$, the aircraft reported estimated winds of $38 \mathrm{kt}$ and a central pressure of $1004 \mathrm{mb}$. No gales were reported by ships or coastal stations. It is interesting to note that the Historical Weather Maps do not show any disturbance over the western Gulf of Mexico on these days. Therefore, because no sustained tropical storm force winds were measured, it is not added to HURDAT. This disturbance was in Jack Beven's List of Suspects.

NAVY RECON book: "From the $241200 Z$ synoptic chart, it became apparent that one of a series of weak early waves which had been moving through the Gulf of Mexico was intensifying. Reports from the Coast Guard patrol vessel NUZY off Tampico and the Navy reconnaissance "Alfa" flight indicated a possible cyclonic circulation about 120 miles east of Tampico. A special flight was ordered to investigate this area and at $252030 \mathrm{Z}$ the aircraft reported an eye within a diffuse storm area with maximum observed winds of 30 knots in the south quadrant. A Navy reconnaissance aircraft made the last fix of the storm at $261300 \mathrm{Z}$ reporting maximum winds 38 knots in thunderstorms offshore. The storm passed inland about 10 miles south of Corpus Christi at $261500 \mathrm{Z}$ dissipating shortly. No winds over 20 knots were experienced by land stations at this time. The name FLORA was used by this activity to designate this storm, but not by the Weather Bureau. The Weather Bureau at New Orleans issued bulletins calling this a "weak circulation" further stating in the initial bulletin that conditions were favorable for further development. In order to avoid confusing the public and in compliance with the desires of the Chief of the Weather Bureau, the next storm of the season was also named FLORA."

$\begin{array}{cccc}\text { Day } & \text { Latitude } & \text { Longitude } & \begin{array}{c}\text { Status } \\ \text { Tropical }\end{array} \\ \text { August } 24 & 21 \mathrm{~N} & 94 \mathrm{~W} & \text { Depression? } \\ \text { August } 25 & 23 \mathrm{~N} & 96 \mathrm{~W} & \text { Tropical Storm? } \\ \text { August } 26 & 26 \mathrm{~N} & 97 \mathrm{~W} & \text { Tropical Storm? } \\ \text { August } 27 & & & \text { Dissipated }\end{array}$


3) October 21-24: Historical Weather Maps show a stationary front stretching from the eastern Gulf of Mexico into the north Atlantic on October $21^{\text {st }}$. A low pressure developed off the southeast coast of the United States on October $22^{\text {nd }}$ and remained almost stationary during the next 24 hours. A ship reported $60 \mathrm{kt}$ at $14 \mathrm{Z}$ on the $22^{\text {nd }}$. Synoptic data suggests that the low pressure retained its extratropical characteristics and the system dissipated on October $24^{\text {th }}$. Therefore, because the disturbance did not acquire tropical characteristics, it is not added to HURDAT. This disturbance was in Jack Beven's List of Suspects.

$\begin{array}{cccc}\text { Day } & \text { Latitude } & \text { Longitude } & \text { Status } \\ \text { October } 21 & \text { Off southeast of the United States } & \text { Stationary front } \\ \text { October } 22 & 30 \mathrm{~N} & 79 \mathrm{~W} & \text { Extratropical } \\ \text { October } 23 & 31 \mathrm{~N} & 77 \mathrm{~W} & \text { Extratropical } \\ \text { October } 24 & & & \text { Dissipated }\end{array}$

4) October 24-27: Historical Weather Maps show a cold front over the northeast Atlantic on October $24^{\text {th }}$ and an extratropical cyclone developing on October $25^{\text {th }}$. Gale-force winds were observed on the $24^{\text {th }}$ well away from the system's center. The disturbance moved westward on October $26^{\text {th }}$ and became an occluded low. An approaching cold front caused the occluded cyclone to turn to the northeast and weaken on October $27^{\text {th }}$. The disturbance was absorbed on October $28^{\text {th }}$. Therefore, because it did not acquire tropical characteristics, it is not added to HURDAT. This disturbance was in Jack Beven's List of Suspects.

$\begin{array}{cccc}\text { Day } & \text { Latitude } & \text { Longitude } & \text { Status } \\ \text { October } 24 & 35 \mathrm{~N} & 38 \mathrm{~W} & \text { Cold front } \\ \text { October } 25 & 37 \mathrm{~N} & 38 \mathrm{~W} & \text { Extratropical } \\ \text { October } 26 & 38 \mathrm{~N} & 47 \mathrm{~W} & \text { Occluded } \\ \text { October } 27 & 39 \mathrm{~N} & 41 \mathrm{~W} & \text { Occluded } \\ \text { October } 28 & & & \text { Absorbed }\end{array}$

5) October 28 - November 1: Historical Weather Maps indicate that a low pressure formed over the north-central Atlantic on October $28^{\text {th }}$. The disturbance moved generally to the northwest before merging on October $30^{\text {th }}$ with a frontal boundary over the north Atlantic. COADS were obtained but produced no tropical storm force winds. Therefore, because no gale-force winds were found associated with this disturbance, it is not added to HURDAT. This disturbance was in Jack Beven and Ryan Truchelut's List of Suspects. 


$\begin{array}{cccc}\text { Day } & \text { Latitude } & \text { Longitude } & \begin{array}{c}\text { Status } \\ \text { October } 28\end{array} \\ \text { October } 29 & 27 \mathrm{~N} & 45 \mathrm{~W} & \begin{array}{c}\text { Tropical Depression? } \\ \text { Tropical Depression? } \\ \text { October } 30\end{array} \\ 30 \mathrm{~N} & 49 \mathrm{~W} & \text { Merging with cold } \\ \text { October } 31 & 30 \mathrm{~N} & 49 \mathrm{~W} & \text { front } \\ \text { November } 1 & 39 \mathrm{~N} & 40 \mathrm{~W} & \text { Extratropical } \\ & 52 \mathrm{~N} & 28 \mathrm{~W} & \text { Extratropical }\end{array}$

6) November 8-12: Historical Weather Maps show a trough over the eastern Atlantic on November $8^{\text {th }}$ and $9^{\text {th }}$. The disturbance moved generally westward becoming better organized and a low pressure developed on November $10^{\text {th }}$. An approaching frontal system caused the disturbance to turn northwestward on November $11^{\text {th }}$ becoming absorbed a day later. The COADS were obtained for this disturbance but no gale-force winds were found. Therefore, because the disturbance did not produce any observed tropical storm force winds, it is not added to HURDAT. This disturbance was in Jack Beven and David Roth's List of Suspects.

$\begin{array}{cccc}\text { Day } & \text { Latitude } & \text { Longitude } & \text { Status } \\ \text { November } 8 & 23 \mathrm{~N} & 35 \mathrm{~W} & \text { Trough } \\ \text { November } 9 & 25 \mathrm{~N} & 39 \mathrm{~W} & \text { Trough } \\ \text { November } 10 & 25 \mathrm{~N} & 44 \mathrm{~W} & \text { Tropical Depression? } \\ \text { November } 11 & 30 \mathrm{~N} & 49 \mathrm{~W} & \text { Tropical Depression? } \\ \text { November } 12 & & & \text { Absorbed }\end{array}$

7) December 24-27: Historical Weather Maps show a frontal boundary over the western Atlantic. An extratropical cyclone developed on December $25^{\text {th }}$ near the Bahamas producing gale-force winds and rapidly moved to the northeast maintaining its baroclinic characteristics. Therefore, because the system was likely not tropical or subtropical, it is not added to HURDAT. This disturbance was in Jack Beven's List of Suspects.

Day

December 24

December 25

December 26

December 27
Latitude

Western Atlantic $25 \mathrm{~N}$

$31 \mathrm{~N}$

$39 \mathrm{~N}$
Longitude

$75 \mathrm{~W}$

$55 \mathrm{~W}$

$45 \mathrm{~W}$
Status

Cold front

Extratropical

Extratropical

Extratropical 


\section{0 hurricane season}

Unnamed Tropical Storm One [June 22-28, 1960]

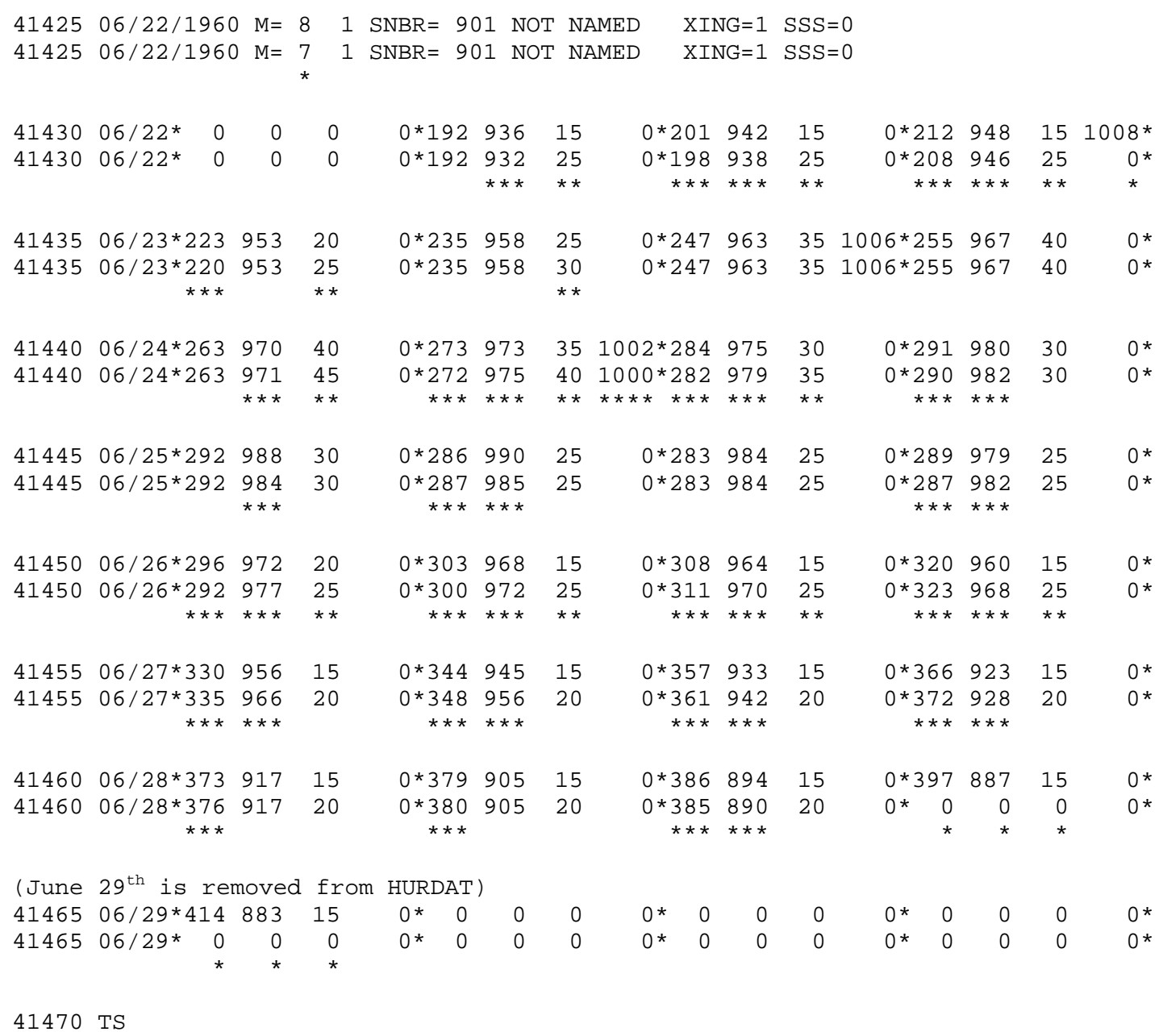

\section{U.S. Tropical Storm Landfall}

\section{6/24 04Z 26.9N 97.4W 45 kt TX}

Minor changes to the track and intensity shown in McAdie et al. (2009). Evidence for these alterations comes from the NHC microfilm maps, the Historical Weather Maps series, the COADS ship database, Monthly Weather Review, Surface Weather Observations, Mariners Weather Log, Mexican surface maps, and NHC Storm Wallets.

June 21:

HWM analyzes a closed low pressure of at most $1010 \mathrm{mb}$ at $20.0 \mathrm{~N}, 94.5 \mathrm{~W}$ at 12Z. HURDAT does not list an organized system on this date. Microfilm shows a closed 
low pressure of at most $1008 \mathrm{mb}$ at $18.5 \mathrm{~N}, 93.5 \mathrm{~W}$ at $12 \mathrm{Z}$. Ship highlights: No gales or low pressures.

June 22:

HWM analyzes a spot low at $19.5 \mathrm{~N}, 94.5 \mathrm{~W}$ at $12 \mathrm{Z}$. HURDAT lists a $15 \mathrm{knot}$ tropical depression at $20.1 \mathrm{~N}, 94.2 \mathrm{~W}$ at $12 \mathrm{Z}$. Microfilm shows a closed low pressure of at most $1008 \mathrm{mb}$ at $19.0 \mathrm{~N}, 94.2 \mathrm{~W}$ at 12Z. Ship highlights: No gales or low pressures.

MWR: "A routine reconnaissance flight into the extreme southwestern Gulf of Mexico on June 22 found a large mass of weather including heavy thunderstorms and squally winds up to $35 \mathrm{kt}$. The lowest observed pressure along the reconnaissance track was $1008 \mathrm{mb}$ with no circulation reported, although the Mexican coastal stations did indicate a slight circulation."

June 23:

HWM analyzes a closed low of at most $1005 \mathrm{mb}$ at $24.0 \mathrm{~N}, 96.0 \mathrm{~W}$ at $12 \mathrm{Z}$. HURDAT lists a 35 knot tropical storm at $24.7 \mathrm{~N}, 96.3 \mathrm{~W}$ at $12 \mathrm{Z}$. Microfilm shows an elongated and closed low pressure of at most $1008 \mathrm{mb}$ at 20.0N, 95.0W at 12Z. Ship highlights: Ship highlights: No gales or low pressures.

MWR: "On the morning of June 23 the 200-mb level had become more favorable for intensification and the barometer had fallen significantly along the Mexican coast from Tampico to Brownsville indicating a northerly drift of the disturbed condition. A Navy reconnaissance plane was dispatched to the area and found maximum winds of only $15 \mathrm{kt}$ but sea level pressure of $1006 \mathrm{mb}$. However, it is believed the plane did not fly under the most severe weather."

June 24:

HWM analyzes a closed low of at most $1005 \mathrm{mb}$ at $27.5 \mathrm{~N}, 98.0 \mathrm{~W}$ at $12 \mathrm{Z}$. HURDAT lists a 30 knot tropical depression at $28.4 \mathrm{~N}, 97.5 \mathrm{~W}$ at $12 \mathrm{Z}$. Microfilm shows a closed low pressure of at most $1008 \mathrm{mb}$ at $28.5 \mathrm{~N}, 97.8 \mathrm{~W}$ at 12Z. Ship highlights: No gales or low pressures. Land highlights: $45 \mathrm{kt}$ (gusts to $50 \mathrm{kt}$, max winds) at Padre Island Park, TX (no time given, likely early on the $24^{\text {th }}$ ) (WALLET). $35 \mathrm{kt}$ (gusts to $50 \mathrm{kt}$, max winds) at Rockport, TX (no time given, likely early on the $24^{\text {th }}$ ) (WALLET). $34 \mathrm{kt}$ (gusts to $45 \mathrm{kt}$, max winds) at Naval Base, TX (no time given) (WALLET). $27 \mathrm{kt} \mathrm{SSE} \mathrm{(gusts} \mathrm{to}$ $41 \mathrm{kt}$, max winds) and $1004 \mathrm{mb}$ at Corpus Christi, TX at 0658Z (SWO). $12 \mathrm{kt} \mathrm{SSW} \mathrm{and}$ $1002 \mathrm{mb}$ (min pressure) at Kingsville, TX at 0758Z (SWO). $3 \mathrm{kt} \mathrm{W}$ and $1002 \mathrm{mb}$ (min pressure) at Alice, TX at $0858 \mathrm{Z}$ (SWO). $15 \mathrm{kt} \mathrm{SSE}$ and $1004 \mathrm{kt}$ (min pressure) at Beeville, TX at 1158Z (SWO). $15 \mathrm{kt} \mathrm{N}$ and $1004 \mathrm{mb}$ (min pressure) at Cotulla, TX at 2258Z (SWO). 
MWR: "During the night of June 23-24 the tropical storm moved inland, south and about 30 miles west of Corpus Christi, Texas. Rockport reported sustained winds of $40 \mathrm{mph}$ with gusts to 60 and Padre Island Park $50 \mathrm{mph}$ with gusts to 60 . The lowest reported pressure was $1002.4 \mathrm{mb}$ at Alice at $0300 \mathrm{CST}$ on the $24^{\text {th }}$. Corpus Christi reported a tide of $3.5 \mathrm{ft}$ above mean low water. It appears that there was no wall cloud. There was some mild curvature on the rain bands seen on airborne radar on the $23^{\text {rd }}$ and the Dow Chemical Co. radar at Freeport near noon on the $23^{\text {rd }}$ reported a characteristically curved rain band. Apparent cloud centers were reported by radars at Victoria and Kelly Air Force Base on several occasions. Three fishing piers were wrecked on Copano Bay; one shrimp boat sank with three lives lost, and another was beached."

June 25:

HWM analyzes a weakening cold front over Texas at 12Z. Microfilm shows a closed low pressure of at most $1005 \mathrm{mb}$ at 28.6N, 98.0W at 12Z. Ship highlights: Ship highlights: No gales or low pressures. Land highlights: $15 \mathrm{kt} \mathrm{S}$ and $1004 \mathrm{kt}$ (min pressure) at Beeville, TX at 2058Z (SWO).

MWR: "The storm moved very slowly on June 24-25 attended by heavy rains of 5 to 15 inches or more from Corpus Christi to San Antonio and northeastward with considerable flooding. Port Lavaca reported 29.76 inches of rain for the period of 23-26."

June 26:

HWM analyzes a closed low of at most $1010 \mathrm{mb}$ at $30.5 \mathrm{~N}, 96.5 \mathrm{~W}$ at $12 \mathrm{Z}$. HURDAT lists a 15 knot tropical depression at $30.8 \mathrm{~N}, 96.4 \mathrm{~W}$ at $12 \mathrm{Z}$. Microfilm shows a closed low pressure of at most $1008 \mathrm{mb}$ at $31.4 \mathrm{~N}, 96.5 \mathrm{~W}$ at $12 \mathrm{Z}$. Ship highlights: No gales or low pressures.

MWR: "Tornadoes were reported on the $26^{\text {th }}$ as the dying storms moved northnortheastward. Unusually heavy rains extended into Arkansas and southern Illinois. Fifteen persons apparently were drowned either in the high seas or subsequent floods. Damage, mostly from the floods, is estimated at $\$ 3,600,000$."

June 27:

HWM analyzes a closed low pressure of at most $1010 \mathrm{mb}$ near $36.0 \mathrm{~N}, 94.0 \mathrm{~W}$ at 12Z. HURDAT lists a 15 knot tropical depression at $35.7 \mathrm{~N}, 93.3 \mathrm{~W}$ at $12 \mathrm{Z}$. Microfilm shows a closed low pressure of at most $1011 \mathrm{mb}$ at $36.0 \mathrm{~N}, 93.5 \mathrm{~W}$ at $12 \mathrm{Z}$. Ship highlights: No gales or low pressures.

June 28:

HWM analyzes a weakening cold front across the central United States at $12 \mathrm{Z}$. HURDAT lists a 15 knot tropical depression at $38.6 \mathrm{~N}, 89.4 \mathrm{~W}$ at $12 \mathrm{Z}$. Microfilm shows a 
closed low pressure of at most $1014 \mathrm{mb}$ at $38.5 \mathrm{~N}, 88.0 \mathrm{~W}$ at 12Z. Ship highlights: No gales or low pressures.

June 29:

HWM and microfilm analyzes a cold front moving across the Midwest at $12 \mathrm{Z}$. HURDAT does not list an organized system on this date. Ship highlights: No gales or low pressures.

A tropical wave reached the Bay of Campeche on June $20^{\text {th }}$ and gradually became better organized. Although the data is scarce, coastal and ship observations indicate that the disturbance did not have a well-defined low level circulation on June $21^{\text {st }}$. Genesis is analyzed at $06 \mathrm{Z}$ on June $22^{\text {nd }}$ as a tropical depression, same as originally shown in HURDAT. It is possible that genesis could have taken place six or twelve hours earlier. The tropical depression is initialized with an intensity of $25 \mathrm{kt}$, up from $15 \mathrm{kt}$ originally in HURDAT, a minor intensity change. Minor alterations were made to the track of this tropical cyclone. The daily routine reconnaissance flight, pattern "ALPHA," into the southern Gulf of Mexico on the $22^{\text {nd }}$ appears to have missed the tropical cyclone staying northeast of the center as indicated by the track of the reconnaissance aircraft. Since the aircraft did not make a center penetration, the $1008 \mathrm{mb}$ in HURDAT at $18 \mathrm{Z}$ on the $22^{\text {nd }}$ has been removed. The tropical depression moved generally to the northwest and no gales were observed by ships during its lifetime. Intensification to a tropical storm is analyzed at $12 \mathrm{Z}$ on June $23^{\text {rd }}$, same as originally shown in HURDAT. A central pressure of 1006 $\mathrm{mb}$ is present in HURDAT at $12 \mathrm{Z}$ on the $23^{\text {rd }}$ and since it was measured by a Navy reconnaissance aircraft, it has been retained. The small tropical storm approached the coast of southern Texas late on the $23^{\text {rd }}$ and early on the $24^{\text {th }}$. Sustained tropical storm force winds were recorded over portions of the coast and the highest was $45 \mathrm{kt}$ at Padre Island Park, TX. An intensity of $45 \mathrm{kt}$ is analyzed at $00 \mathrm{Z}$ on August $24^{\text {th }}$, up from $40 \mathrm{kt}$ originally in HURDAT, a minor intensity change. $45 \mathrm{kt}$ is the peak intensity of this tropical cyclone, up from $40 \mathrm{kt}$ originally in HURDAT, a minor intensity change. Landfall occurred around $04 \mathrm{Z}$ on the $24^{\text {th }}$ near $26.9 \mathrm{~N}, 97.4 \mathrm{~W}$ or about halfway between Brownsville and Corpus Christi as a $45 \mathrm{kt}$ tropical storm. Kingsville, TX reported $12 \mathrm{kt}$ SSW and $1002 \mathrm{mb}$ at $0858 \mathrm{Z}$ on the $24^{\text {th }}$, suggesting a central pressure of $1000 \mathrm{mb}$, which has been added to HURDAT at $06 \mathrm{Z}$ on the $24^{\text {th }}$, replacing the existing $1002 \mathrm{mb}$. After landfall, the forward speed decreased rapidly and the tropical storm weakened to a tropical depression at $18 \mathrm{Z}$ on the $24^{\text {th }}$, six hours later than originally shown in HURDAT. Late on the $24^{\text {th }}$ and on the $25^{\text {th }}$, the tropical depression performed a small counterclockwise loop over south-central Texas resulting in very heavy rainfall for the area. Late on the $25^{\text {th }}$, the tropical depression turned to the northeast and increased in forward speed. 
On August $26^{\text {th }}$, the tropical depression turned to the north-northeast over northeast Texas. A couple of ships were reporting winds up to $30 \mathrm{kt}$ over the northwest Gulf of Mexico on the $26^{\text {th }}$ but it seems that these winds were not associated with the circulation of this tropical cyclone. The intensities are boosted systematically on the $27^{\text {th }}$ and $28^{\text {th }}$ from 15 to $20^{\text {th }}$, as a system moving 10-15 kt and maintaining a closed circulation would have to have at least $20 \mathrm{kt}$ max wind in the right front quadrant. Dissipation is analyzed after $12 Z$ on June $28^{\text {th }}$ over southern Illinois based on synoptic observations. The last position is analyzed at $12 \mathrm{Z}$ on the $28^{\text {th }}$, twelve hours earlier than originally shown in HURDAT.

Hurricane Abby [July 9-17, 1960]

\begin{tabular}{|c|c|c|c|c|c|c|c|c|c|c|c|c|c|}
\hline 41475 & $07 / 10 / 1960$ & $M=$ & 7 & SNBR $=9 \odot$ & $2 \mathrm{AB}$ & & XII & $N G=\odot$ & $\mathrm{SSS}=\mathrm{C}$ & & & & \\
\hline 41475 & $\underset{* *}{07 / 09 / 1960}$ & $M=$ & $\begin{array}{l}9 \\
*\end{array}$ & SNBR $=9 \odot$ & $2 A B$ & & XII & $N G=\odot$ & $S S S=C$ & & & & \\
\hline (July & 9 th is new & $v$ to & HURD & AT) & & & & & & & & & \\
\hline 41480 & $\odot 7 / \odot 9 * \quad \odot$ & $\odot$ & $\odot$ & $0^{*}$ & $\odot$ & $\odot$ & $\begin{array}{r}0 * 120 \\
* * *\end{array}$ & $\begin{array}{l}558 \\
\star * *\end{array}$ & $\begin{array}{l}40 \\
* *\end{array}$ & $\begin{array}{r}0 * 125 \\
* * *\end{array}$ & $\begin{array}{l}570 \\
* * *\end{array}$ & $\begin{array}{l}40 \\
* *\end{array}$ & ०* \\
\hline 41480 & $07 / 10 * 130$ & 562 & 30 & $0 * 130$ & 580 & 30 & $0 * 138$ & 610 & 65 & $0 * 142$ & 623 & 70 & ०* \\
\hline 41480 & $07 / 10 * 130$ & $\begin{array}{l}582 \\
\star * *\end{array}$ & $\begin{array}{l}45 \\
* *\end{array}$ & $\begin{array}{r}0 * 135 \\
* * *\end{array}$ & $\begin{array}{l}596 \\
* * *\end{array}$ & $\begin{array}{l}50 \\
* *\end{array}$ & $\begin{array}{r}0 * 139 \\
* * *\end{array}$ & 610 & $\begin{array}{l}55 \\
* *\end{array}$ & $\begin{array}{l}1003 * 141 \\
* * * * * * *\end{array}$ & 623 & $\begin{array}{l}55 \\
* *\end{array}$ & $\begin{array}{l}10 \odot 2^{*} \\
* * * *\end{array}$ \\
\hline 41485 & $07 / 11 * 145$ & 635 & 80 & $0 * 144$ & 648 & 80 & $0 * 148$ & 660 & 85 & $0 * 152$ & 675 & 80 & ०* \\
\hline 41485 & $07 / 11^{*} 143$ & 635 & $\begin{array}{l}55 \\
* *\end{array}$ & $\begin{array}{c}0 * 145 \\
* * *\end{array}$ & $\begin{array}{l}647 \\
* * *\end{array}$ & $\begin{array}{l}60 \\
* *\end{array}$ & $\begin{array}{r}0 * 147 \\
* * *\end{array}$ & $\begin{array}{l}658 \\
* * *\end{array}$ & $\begin{array}{l}60 \\
* *\end{array}$ & $\begin{array}{l}999 * 149 \\
* * * * * *\end{array}$ & $\begin{array}{l}673 \\
* * *\end{array}$ & $\begin{array}{l}55 \\
* *\end{array}$ & $\begin{array}{l}1004 \text { * } \\
* * * *\end{array}$ \\
\hline 41490 & $07 / 12 * 149$ & 690 & 70 & $0 * 147$ & 705 & 70 & $0 * 147$ & 720 & 75 & $0 * 150$ & 732 & 75 & ○* \\
\hline 41490 & $07 / 12 * 149$ & $\begin{array}{l}689 \\
* * *\end{array}$ & $\begin{array}{l}50 \\
* *\end{array}$ & $\begin{array}{l}1005 * 147 \\
* * * *\end{array}$ & $\begin{array}{l}704 \\
* * *\end{array}$ & $\begin{array}{l}50 \\
\star *\end{array}$ & $\begin{array}{l}1005 * 147 \\
* * * *\end{array}$ & $\begin{array}{l}719 \\
\star * *\end{array}$ & $\begin{array}{l}50 \\
* *\end{array}$ & $\begin{array}{l}10 \odot 7 * 150 \\
* * * *\end{array}$ & 732 & $\begin{array}{l}50 \\
* *\end{array}$ & 0 * \\
\hline 41495 & $07 / 13 * 152$ & 743 & 75 & ○*151 & 755 & 65 & $0 * 148$ & 768 & 50 & $0 * 147$ & 781 & 40 & ०* \\
\hline 41495 & $07 / 13 * 152$ & 743 & $\begin{array}{l}50 \\
* *\end{array}$ & $\begin{array}{l}10 \odot 4 * 152 \\
* * * * * * *\end{array}$ & $\begin{array}{l}754 \\
* * *\end{array}$ & $\begin{array}{l}50 \\
\star *\end{array}$ & $\begin{array}{r}0 * 149 \\
* * *\end{array}$ & $\begin{array}{l}767 \\
\star * *\end{array}$ & $\begin{array}{l}45 \\
* *\end{array}$ & $\begin{array}{l}1008 * 147 \\
* * * *\end{array}$ & 781 & $\begin{array}{l}45 \\
* *\end{array}$ & 0 * \\
\hline 41500 & $07 / 14 * 147$ & 795 & 40 & ๑*151 & 811 & 45 & $0 * 156$ & 827 & 55 & ๑*159 & 840 & 60 & $0^{*}$ \\
\hline 41500 & $07 / 14 * 147$ & 795 & $\begin{array}{l}45 \\
* *\end{array}$ & $\begin{array}{l}10 \odot 4 * 151 \\
* * * *\end{array}$ & $\begin{array}{l}810 \\
* * *\end{array}$ & $\begin{array}{l}50 \\
* *\end{array}$ & $0 * 156$ & $\begin{array}{l}825 \\
* * *\end{array}$ & 55 & $\begin{array}{l}999 * 159 \\
* * *\end{array}$ & $\begin{array}{l}839 \\
* * *\end{array}$ & $\begin{array}{l}55 \\
* *\end{array}$ & ०* \\
\hline 41505 & $07 / 15^{*} 162$ & 852 & 65 & $0 * 164$ & 865 & 70 & $0 * 165$ & 878 & 65 & ๑*163 & 893 & 45 & 0 * \\
\hline 41505 & $07 / 15^{*} 161$ & 852 & $\begin{array}{l}60 \\
* *\end{array}$ & $\begin{array}{l}995 * 163 \\
* * * * * *\end{array}$ & $\begin{array}{l}866 \\
\star * *\end{array}$ & 70 & $0 * 165$ & $\begin{array}{l}880 \\
* * *\end{array}$ & $\begin{array}{l}70 \\
\star *\end{array}$ & $0 * 166$ & $\begin{array}{l}894 \\
* * *\end{array}$ & 45 & $0^{*}$ \\
\hline 41510 & $07 / 16 * 165$ & 906 & 30 & $0 * 173$ & 916 & 25 & $0 * 180$ & 925 & 25 & $0 * 180$ & 937 & 25 & $0^{*}$ \\
\hline 41510 & $07 / 16^{*} \underset{* \star *}{168}$ & 906 & 30 & $\begin{array}{c}0 * 171 \\
\star * \star\end{array}$ & $\begin{array}{l}916 \\
\star * *\end{array}$ & $\begin{array}{l}30 \\
* *\end{array}$ & $\begin{array}{r}0 * 175 \\
* * *\end{array}$ & $\begin{array}{l}927 \\
* * *\end{array}$ & $\begin{array}{l}30 \\
* *\end{array}$ & $0 * 180$ & $\begin{array}{l}940 \\
* * *\end{array}$ & $\begin{array}{l}30 \\
* *\end{array}$ & ○* \\
\hline ( July & 17 th is ne & ew to & $\mathrm{HU}$ & DAT ) & & & & & & & & & \\
\hline 41513 & $07 / 17^{*} 185$ & $\begin{array}{l}955 \\
* * *\end{array}$ & $\begin{array}{l}30 \\
* *\end{array}$ & $\begin{array}{r}0 * 192 \\
* * *\end{array}$ & $\begin{array}{l}970 \\
* * *\end{array}$ & $\begin{array}{l}30 \\
* *\end{array}$ & $\begin{array}{l}0 * 20 \odot \\
* * *\end{array}$ & $\begin{array}{l}985 \\
* * *\end{array}$ & $\begin{array}{l}30 \\
* *\end{array}$ & $0^{*} \quad 0$ & $\odot$ & 0 & ○* \\
\hline
\end{tabular}

41515 HR 
Tropical Storm Landfall

07/10 11Z 13.9N 60.9W 55 kt St. Lucia

Hurricane Landfall

07/15 06Z 16.3N 86.6W 70 kt Roatan, Honduras

07/15 14Z 16.5N 88.4W 70 kt Belize

Major changes to the track and intensity shown in McAdie et al. (2009). Evidence for these alterations comes from the NHC microfilm maps, the Historical Weather Maps series, the COADS ship database, Monthly Weather Review, Navy reconnaissance book, Mariners Weather Log, Mexican synoptic maps and NHC Storm Wallets.

July 7 :

HWM and microfilm do not show an organized system at 12Z. HURDAT does not list an organized system on this date. Ship highlights: No gales or low pressures.

ATSR: "Hurricane ABBY formed from an easterly wave, first located in the vicinity of $15 \mathrm{~N} 45 \mathrm{~W}$ at $1200 \mathrm{Z}$ on the 7 th of July by ship reports and reconnaissance flight Delta."

July 8:

HWM and microfilm do not show an organized system at 12Z. HURDAT does not list an organized system on this date. Ship highlights: No gales or low pressures.

July 9:

HWM analyzes a spot low at $12.0 \mathrm{~N}, 56.5 \mathrm{~W}$ at $12 \mathrm{Z}$. Microfilm does not show an organized system at 12Z. HURDAT does not list an organized system on this date. Navy reconnaissance book lists the best track position at $13.1 \mathrm{~N}, 56.7 \mathrm{~W}$ at $12 \mathrm{Z}$ (first position). Ship highlights: $40 \mathrm{kt}$ ESE and $1013 \mathrm{mb}$ at $13.2 \mathrm{~N}, 56.2 \mathrm{~W}$ at $10 \mathrm{Z}$ (micro).

MWR: "The first indication of the disturbance which finally grew into hurricane Abby was received from a ship about $3.5^{\circ}$ east of the island of Barbados, at 0500 EST on July 9. Showery weather was reported with east-southeast winds of near $40 \mathrm{kt}$. Some shower activity had been occurring in the Lesser Antilles, and 24-hour pressure changes were small but negative." ATSR: "No further reports indicating the presence of this wave were received until 091000Z when the ship ADOLF LEONHARDT reported an east-southeast wind of Beaufort Force 8 to 9 and showers at 13.2N 56.2W. The initial intensification on the 9th and 10th was associated with the surface center moving under a southerly current 
at $200 \mathrm{MB}$. The $200 \mathrm{MB}$ charts for the 9th and 10th depicted a weak ridge east of the Lesser Antilles and a low just north of Puerto Rico."

July 10:

HWM analyzes a tropical storm of at most $1010 \mathrm{mb}$ at $13.6 \mathrm{~N}, 60.8 \mathrm{~W}$ at $12 \mathrm{Z}$. HURDAT lists a 65 knot hurricane at $13.8 \mathrm{~N}, 61.0 \mathrm{~W}$ at $12 \mathrm{Z}$. Microfilm shows a closed low pressure of at most $1005 \mathrm{mb}$ at $13.5 \mathrm{~N}, 60.8 \mathrm{~W}$ at $12 \mathrm{Z}$. Navy reconnaissance book lists the best track position at $14.0 \mathrm{~N}, 60.9 \mathrm{~W}$ at 12Z. Ship highlights: $40 \mathrm{kt}$ ENE and $1007 \mathrm{mb}$ at $13.8 \mathrm{~N}$, $59.8 \mathrm{~W}$ at $06 \mathrm{Z}$ (micro). Land highlights: $36 \mathrm{kt}$ (gusts to $66 \mathrm{kt}$, max winds) at Martinique at $1115 \mathrm{Z}$ (WALLET). $48 \mathrm{kt}$ ENE (gusts to $55 \mathrm{kt}$, max winds) at St. Lucia at $12 \mathrm{Z}$ (WALLET). Aircraft highlights: Penetration center fix estimated surface winds of $70 \mathrm{kt}$, an eye diameter of $6 \mathrm{~nm}$ and measured a central pressure of $1003 \mathrm{mb}$ at $14.1 \mathrm{~N}, 61.4 \mathrm{~W}$ at $14 Z$ (ATSR). Penetration center fix estimated surface winds of $70 \mathrm{kt}$, an eye diameter of $7 \mathrm{~nm}$ and measured a central pressure of $1003 \mathrm{mb}$ at $13.9 \mathrm{~N}, 62.2 \mathrm{~W}$ at $1630 \mathrm{Z}$ (ATSR). Penetration center fix estimated surface winds of $50 \mathrm{kt}$ and measured a central pressure of $1002 \mathrm{mb}$ at $14.4 \mathrm{~N}, 62.5 \mathrm{~W}$ at $19 \mathrm{Z}$ (ATSR). Penetration center fix estimated surface winds of $75 \mathrm{kt}$ and measured a central pressure of $1006 \mathrm{mb}$ at $14.4 \mathrm{~N}, 63.3 \mathrm{~W}$ at $2258 \mathrm{Z}$ (ATSR).

MWR: "At 0100 est on the 10th, a report received from the SS Del Oro, located at $13.8^{\circ} \mathrm{N}$., $59.7^{\circ} \mathrm{W}$., with sea level pressure of $1007.6 \mathrm{mb}$ and wind ENE $45 \mathrm{kt}$, indicated a strong easterly wave or a small vortex. A small center passed just to the north of Barbados during the next few hours. At 0800 EST July 10, an advisory was issued on tropical storm Abby, based on reports from the Leeward Islands and a few ships. The storm was moving toward the west-northwest and was forecast to reach hurricane intensity during the day. Reconnaissance aircraft were dispatched to the area and confirmed the existence of hurricane Abby by 1100 EST. Highest winds were estimated at 90-100 mph over a small area near the center. Gale warnings and a hurricane watch were ordered for the Virgin Islands and Puerto Rico and for the island of Hispaniola as the hurricane moved westward." ATSR: "On the 10th of July, the SS DEL ORO located $13.8 \mathrm{~N} 59.7 \mathrm{~W}$ reported a wind from 070 degrees of 40 knots and a pressure of $1007.6 \mathrm{MB}$ at 0600Z. The island of Martinique reported gale force winds at 0830Z. A Navy reconnaissance flight, diverted from track Delta, reported spiral bands in the vicinity of St. Lucia Island at $1140 Z$ and a radar eye over that island at 1300Z. The first official warning was issued at 101330Z. ABBY passed over St. Lucia Island with gale force winds and continued development to hurricane force as she moved into the Caribbean on a west-northwesterly heading. Deepening of the low, evident on the 10th, appeared to produce a speed divergence factor conducive to further intensification of the surface low. Later fluctuations in the strength of ABBY over the Caribbean appeared to be related to a 200 MB trough which extended into the northwestern Caribbean." 
July 11:

HWM analyzes a hurricane of at most $1005 \mathrm{mb}$ at $14.5 \mathrm{~N}, 66.0 \mathrm{~W}$ at $12 \mathrm{Z}$. HURDAT lists a 85 knot hurricane at $14.8 \mathrm{~N}, 66.0 \mathrm{~W}$ at $12 \mathrm{Z}$. Microfilm shows a closed low pressure of at most $1002 \mathrm{mb}$ at $14.5 \mathrm{~N}, 65.6 \mathrm{~W}$ at $12 \mathrm{Z}$. Navy reconnaissance book lists the best track position at $14.8 \mathrm{~N}, 66.0 \mathrm{~W}$ at $12 \mathrm{Z}$. Ship highlights: $50 \mathrm{kt} \mathrm{NE}$ and $1005 \mathrm{mb}$ at $14.4 \mathrm{~N}$, 64.9W at $06 \mathrm{Z}$ (COADS). $35 \mathrm{kt} \mathrm{E}$ and $1008 \mathrm{mb}$ at $14.0 \mathrm{~N}, 64.5 \mathrm{~W}$ at $12 \mathrm{Z}$ (COADS). $40 \mathrm{kt}$ $\mathrm{E}$ and $1014 \mathrm{mb}$ at $15.7 \mathrm{~N}, 68.3 \mathrm{~W}$ at $18 \mathrm{Z}$ (COADS). $45 \mathrm{kt} \mathrm{E}$ and $1013 \mathrm{mb}$ at $16.1 \mathrm{~N}, 68.1 \mathrm{~W}$ at $21 \mathrm{Z}$ (MWL). Aircraft highlights: Penetration center fix at $14.5 \mathrm{~N}, 64.4 \mathrm{~W}$ at $0345 \mathrm{Z}$ (ATSR). Radar center fix estimated an eye diameter of $9 \mathrm{~nm}$ at $14.6 \mathrm{~N}, 64.8 \mathrm{~W}$ at $0510 \mathrm{Z}$ (ATSR). Penetration center fix estimated surface winds of $85 \mathrm{kt}$, an eye diameter of 15 $\mathrm{nm}$ and measured a central pressure of $999 \mathrm{mb}$ at $14.6 \mathrm{~N}, 65.7 \mathrm{~W}$ at $1223 \mathrm{Z}$ (ATSR). Penetration center fix estimated surface winds of $85 \mathrm{kt}$ and measured a central pressure of $1004 \mathrm{mb}$ at $14.9 \mathrm{~N}, 67.3 \mathrm{~W}$ at $18 \mathrm{Z}$ (ATSR).

MWR: "On July 11 and 12, the hurricane continued on a westerly course, with doubt concerning its intensity. From reconnaissance aircraft and surface ship reports, it appeared to be rather poorly organized and much of the time was barely discernible on aircraft radar. ... Abby appeared to be fairly well organized when it first formed and moved into the extreme eastern Caribbean. Reconnaissance and surface reports, particularly on the 11th, 12th and 13th, indicated a very small circulation and a minimum of convective activity. This is possibly one reason for the loss of intensity. The area was covered with considerable stratified cloudiness, and radar coverage was difficult." ATSR: "After reaching a maximum intensity of 86 knots at $1400 \mathrm{Z}$ on the 11th, ABBY fluctuated several times in intensity while passing through the Caribbean."

July 12:

HWM analyzes a hurricane of at most $1005 \mathrm{mb}$ at $14.5 \mathrm{~N}, 72.0 \mathrm{~W}$ at $12 \mathrm{Z}$. HURDAT lists a 75 knot hurricane at $14.7 \mathrm{~N}, 72.0 \mathrm{~W}$ at $12 \mathrm{Z}$. Microfilm shows a closed low pressure of at most $1011 \mathrm{mb}$ at $14.3 \mathrm{~N}, 72.2 \mathrm{~W}$ at $12 \mathrm{Z}$. Navy reconnaissance book lists the best track position at $14.7 \mathrm{~N}, 72.0 \mathrm{~W}$ at $12 \mathrm{Z}$. Ship highlights: $47 \mathrm{kt} \mathrm{E}$ and $1014 \mathrm{mb}$ at $16.5 \mathrm{~N}, 67.7 \mathrm{~W}$ at $00 \mathrm{Z}$ (MWL). Aircraft highlights: Penetration center fix estimated surface winds of 65 $\mathrm{kt}$ and measured a central pressure of $1005 \mathrm{mb}$ at $14.9 \mathrm{~N}, 69.0 \mathrm{~W}$ at $01 \mathrm{Z}$ (ATSR). Penetration center fix measured a central pressure of $1005 \mathrm{mb}$ at $15.0 \mathrm{~N}, 69.9 \mathrm{~W}$ at $0330 \mathrm{Z}$ (ATSR). Penetration center fix estimated surface winds of $65 \mathrm{kt}$, an eye diameter of $7 \mathrm{~nm}$ and measured a central pressure of $1005 \mathrm{mb}$ at $14.8 \mathrm{~N}, 69.6 \mathrm{~W}$ at $05 \mathrm{Z}$ (ATSR). Penetration center fix estimated surface winds of $65 \mathrm{kt}$, an eye diameter of $7 \mathrm{~nm}$ and measured a central pressure of $1007 \mathrm{mb}$ at $14.4 \mathrm{~N}, 72.1 \mathrm{~W}$ at $1256 \mathrm{Z}$ (ATSR). Penetration center fix at $14.9 \mathrm{~N}, 73.0 \mathrm{~W}$ at $1748 \mathrm{Z}$ (ATSR). Penetration center fix estimated surface winds of $70 \mathrm{kt}$, 
an eye diameter of $10 \mathrm{~nm}$ and measured a central pressure of $1004 \mathrm{mb}$ at $15.4 \mathrm{~N}, 74.3 \mathrm{~W}$ at $2350 Z$ (ATSR).

ATSR: "At 120100Z, the maximum wind speed diminished to 65 knots then increased to 75 knots at $121600 Z . "$

July 13:

HWM analyzes a tropical storm of at most $1005 \mathrm{mb}$ at $14.7 \mathrm{~N}, 76.8 \mathrm{~W}$ at $12 \mathrm{Z}$. HURDAT lists a 50 knot tropical storm at $14.8 \mathrm{~N}, 76.8 \mathrm{~W}$ at $12 \mathrm{Z}$. Microfilm shows a tropical wave or trough over the central Caribbean Sea at 12Z. Navy reconnaissance book lists the best track position at $14.9 \mathrm{~N}, 76.8 \mathrm{~W}$ at $12 \mathrm{Z}$. Ship highlights: $35 \mathrm{kt} \mathrm{E}$ and $1011 \mathrm{mb}$ at $14.6 \mathrm{~N}$, $72.8 \mathrm{~W}$ at $00 \mathrm{Z}$ (COADS). $35 \mathrm{kt} \mathrm{E}$ at $16.2 \mathrm{~N}, 75.2 \mathrm{~W}$ at $06 \mathrm{Z}$ (micro). $40 \mathrm{kt} \mathrm{SE}$ at $16.5 \mathrm{~N}$, $76.1 \mathrm{~W}$ at $12 \mathrm{Z}$ (micro). Aircraft highlights: Radar center fix at $15.3 \mathrm{~N}, 74.4 \mathrm{~W}$ at $01 \mathrm{Z}$ (ATSR). Radar center fix at 15.4N, 75.2W at 06Z (ATSR). Penetration center fix measured a central pressure of $1008 \mathrm{mb}$ and estimated surface winds of $45 \mathrm{kt}$ at $14.1 \mathrm{~N}$, $77.4 \mathrm{~W}$ at $13 \mathrm{Z}$ (ATSR). Penetration center fix at $14.8 \mathrm{~N}, 78.3 \mathrm{~W}$ at $19 \mathrm{Z}$ (ATSR).

Penetration center fix measured a central pressure of $1004 \mathrm{mb}$ and estimated surface winds of $35 \mathrm{kt}$ at $14.7 \mathrm{~N}, 79.3 \mathrm{~W}$ at $2346 \mathrm{Z}$ (ATSR).

MWR: "By the morning of the 13th, the hurricane had diminished in intensity with maximum winds estimated at $60 \mathrm{mph}$ in a few squalls near the center in the northern semicircle."

July 14:

HWM analyzes a tropical storm of at most $1005 \mathrm{mb}$ at $15.4 \mathrm{~N}, 82.5 \mathrm{~W}$ at $12 \mathrm{Z}$. HURDAT lists a 55 knot tropical storm at $15.6 \mathrm{~N}, 82.7 \mathrm{~W}$ at $12 \mathrm{Z}$. Microfilm shows a closed low pressure of at most $1008 \mathrm{mb}$ at $15.5 \mathrm{~N}, 83.3 \mathrm{~W}$ at $12 \mathrm{Z}$. Navy reconnaissance book lists the best track position at $15.6 \mathrm{~N}, 82.7 \mathrm{~W}$ at $12 \mathrm{Z}$. Ship highlights: $35 \mathrm{kt} \mathrm{NE}$ and $1005 \mathrm{mb}$ at $15.3 \mathrm{~N}, 79.5 \mathrm{~W}$ at $00 \mathrm{Z}$ (micro). $35 \mathrm{kt} \mathrm{ESE}$ and $1013 \mathrm{mb}$ at $17.0 \mathrm{~N}, 77.1 \mathrm{~W}$ at $03 \mathrm{Z}$ (MWL). Aircraft highlights: Penetration center fix measured a central pressure of $1008 \mathrm{mb}$ and estimated an eye diameter of $20 \mathrm{~nm}$ at $15.2 \mathrm{~N}, 81.5 \mathrm{~W}$ at $07 \mathrm{Z}$ (ATSR). Penetration center fix measured a central pressure of $999 \mathrm{mb}$, estimated surface winds of $75 \mathrm{kt}$ and an eye diameter of $7 \mathrm{~nm}$ at $15.6 \mathrm{~N}, 82.6 \mathrm{~W}$ at $1315 \mathrm{Z}$ (ATSR). Penetration center fix at $15.9 \mathrm{~N}$, $83.9 \mathrm{~W}$ at $18 \mathrm{Z}$ (ATSR). Penetration center fix measured a central pressure of $1002 \mathrm{mb}$ and estimated an eye diameter of $20 \mathrm{~nm}$ at $15.9 \mathrm{~N}, 84.2 \mathrm{~W}$ at $19 \mathrm{Z}$ (ATSR).

MWR: "By early morning of the 14th, the storm had intensified to hurricane strength with highest winds of $80 \mathrm{mph}$ estimated by reconnaissance aircraft." ATSR: "After diminishing to a low of 36 knots at 140000Z, the wind speed again increased to 76 knots at $142000 \mathrm{Z}$ while the storm center was passing just a few miles north of the Honduran 
coast. This trough appeared to be fractured on the $140000 \mathrm{Z}$ chart as a portion of the trough moved eastward into Haiti. Rising $200 \mathrm{MB}$ heights over the western Caribbean following this fracture were coincident with the reintensification of ABBY."

July 15:

HWM analyzes a hurricane of at most $1000 \mathrm{mb}$ at $16.3 \mathrm{~N}, 87.8 \mathrm{~W}$ at $12 \mathrm{Z}$. HURDAT lists a 65 knot hurricane at $16.5 \mathrm{~N}, 87.8 \mathrm{~W}$ at $12 \mathrm{Z}$. Microfilm shows a closed low pressure of at most $1008 \mathrm{mb}$ at $16.5 \mathrm{~N}, 87.8 \mathrm{~W}$ at $12 \mathrm{Z}$. Navy reconnaissance book lists the best track position at $16.5 \mathrm{~N}, 88.0 \mathrm{~W}$ at $12 \mathrm{Z}$. Ship highlights: $35 \mathrm{kt} \mathrm{SE}$ and $1008 \mathrm{mb}$ at $16.4 \mathrm{~N}, 87.4 \mathrm{~W}$ at $12 \mathrm{Z}$ (COADS). Land highlights: $45 \mathrm{kt} \mathrm{NE}$ at Guanaja Island, Honduras at $02 \mathrm{Z}$ (WALLET). Aircraft highlights: Penetration center fix measured a central pressure of 995 $\mathrm{mb}$, estimated surface winds of $55 \mathrm{kt}$, and an eye diameter of $15 \mathrm{~nm}$ at $16.1 \mathrm{~N}, 85.4 \mathrm{~W}$ at $01 \mathrm{Z}$ (ATSR). Radar center fix at 16.5N, 88.3W at $1324 \mathrm{Z}$ (ATSR). Radar center fix estimated surface winds of $55 \mathrm{kt}$ and an eye diameter of $20 \mathrm{~nm}$ at $16.5 \mathrm{~N}, 88.8 \mathrm{~W}$ at $15 \mathrm{Z}$ (ATSR).

MWR: "The hurricane retained this strength but remained quite small in size as it skirted along the northern coast of Honduras, passing inland in extreme southern British Honduras early on the morning of the 15th. Advisories were discontinued after the cyclone moved inland. No loss of life has been reported in Central America. Property damage in British Honduras was light but damage to crops was quite heavy." ATSR: "ABBY passed inland over British Honduras on the 15th of July at near hurricane intensity and finally dissipated over southern Mexico."

July 16 :

HWM analyzes a tropical storm at $16.5 \mathrm{~N}, 92.5 \mathrm{~W}$ at $12 \mathrm{Z}$. HURDAT lists a $25 \mathrm{knot}$ tropical depression at $18.0 \mathrm{~N}, 92.5 \mathrm{~W}$ at $12 \mathrm{Z}$. Microfilm shows a closed low pressure of at most $1005 \mathrm{mb}$ at $18.0 \mathrm{~N}, 93.0 \mathrm{~W}$ at $12 \mathrm{Z}$. Navy reconnaissance book lists the best track position at $17.6 \mathrm{~N}, 92.5 \mathrm{~W}$ at $12 \mathrm{Z}$ (last position). Ship highlights: $40 \mathrm{kt}$ and $1004 \mathrm{mb}$ at $16.3 \mathrm{~N}, 87.5 \mathrm{~W}$ at $00 \mathrm{Z}$ (WALLET). Land highlights: $10 \mathrm{kt} \mathrm{NE}$ and $1005 \mathrm{mb}$ at Villahermosa, Mexico at $12 \mathrm{Z}$ (micro).

MWR: "Considerable rain occurred in Central America from Honduras northnorthwestward into most of southern Mexico and the Gulf of Campeche as the remnants of Abby continued west-northwestward over the land area. Reconnaissance aircraft in the southwestern Gulf of Mexico on the 16th confirmed that the radar center of circulation did not emerge over the Gulf of Campeche but remained over the rugged terrain of the Isthmus of Tehuantepec." 
July 17:

HWM analyzes a spot low south of the Gulf of Tehuantepec in the eastern Pacific at 12Z. HURDAT does not list an organized system on this date. Microfilm shows a trough of low pressure of at most $1008 \mathrm{mb}$ from central Mexico to western Guatemala at 12Z. Ship highlights: No gales or low pressures.

MWR: "Some remnants of Abby apparently continued across southern Mexico and developed into hurricane Celeste off the west coast." ATSR: "It was noted that the movement of the trough remnant from ABBY into the Pacific appeared to influence the propagation of a hurricane off the west coast of Mexico. The interesting succession of storms from the Caribbean into the Pacific has been observed over several occasions."

\begin{tabular}{|c|c|c|c|}
\hline Date & $\begin{array}{c}\text { Original } \\
\text { HURDAT } \\
\text { Central } \\
\text { Pressure } \\
\end{array}$ & Evidence & Changes \\
\hline $\begin{array}{l}\text { July } 10 \\
12 Z\end{array}$ & & $\begin{array}{l}\text { Penetration center fix: } 1003 \mathrm{mb} \text { at } \\
14 \mathrm{Z} \text { on July } 10^{\text {th }}\end{array}$ & $1003 \mathrm{mb}$ \\
\hline $\begin{array}{c}\text { July } 10 \\
18 z\end{array}$ & & $\begin{array}{l}\text { Penetration center fix: } 1002 \mathrm{mb} \text { at } \\
19 \mathrm{Z} \text { on July } 10^{\text {th }}\end{array}$ & $1002 \mathrm{mb}$ \\
\hline $\begin{array}{l}\text { July } 11 \\
122\end{array}$ & & $\begin{array}{l}\text { Penetration center fix: } 999 \mathrm{mb} \text { at } \\
1223 Z \text { on July } 11^{\text {th }}\end{array}$ & $999 \mathrm{mb}$ \\
\hline $\begin{array}{c}\text { July } 11 \\
18 z\end{array}$ & & $\begin{array}{l}\text { Penetration center fix: } 1004 \mathrm{mb} \text { at } \\
18 \mathrm{Z} \text { on July } 11^{\text {th }}\end{array}$ & $1004 \mathrm{mb}$ \\
\hline $\begin{array}{c}\text { July } 12 \\
\text { o๑z }\end{array}$ & & $\begin{array}{l}\text { Penetration center fix: } 1005 \mathrm{mb} \text { at } \\
01 \mathrm{Z} \text { on July } 12^{\text {th }}\end{array}$ & $1005 \mathrm{mb}$ \\
\hline $\begin{array}{c}\text { July } 12 \\
\text { O6z }\end{array}$ & & $\begin{array}{l}\text { Penetration center fix: } 1005 \mathrm{mb} \text { at } \\
05 \mathrm{Z} \text { on July } 12^{\text {th }}\end{array}$ & $1005 \mathrm{mb}$ \\
\hline $\begin{array}{l}\text { July } 12 \\
122\end{array}$ & & $\begin{array}{l}\text { Penetration center fix: } 1007 \mathrm{mb} \text { at } \\
12 \mathrm{Z} \text { on July } 12^{\text {th }}\end{array}$ & $1007 \mathrm{mb}$ \\
\hline $\begin{array}{l}\text { July } 13 \\
\text { ๑๑z }\end{array}$ & & $\begin{array}{l}\text { Penetration center fix: } 1004 \mathrm{mb} \text { at } \\
2350 \mathrm{z} \text { on July } 12^{\text {th }}\end{array}$ & $10 \odot 4 \mathrm{mb}$ \\
\hline $\begin{array}{l}\text { July } 14 \\
\text { OOz }\end{array}$ & & $\begin{array}{l}\text { Penetration center fix: } 1004 \mathrm{mb} \text { at } \\
2346 \mathrm{Z} \text { on July } 13^{\text {th }}\end{array}$ & $1004 \mathrm{mb}$ \\
\hline $\begin{array}{l}\text { July } 14 \\
122\end{array}$ & & $\begin{array}{l}\text { Penetration center fix: } 999 \mathrm{mb} \text { at } \\
1315 \mathrm{Z} \text { on July } 14^{\text {th }}\end{array}$ & $999 \mathrm{mb}$ \\
\hline $\begin{array}{l}\text { July } 15 \\
\text { ๑๑z }\end{array}$ & & $\begin{array}{l}\text { Penetration center fix: } 995 \mathrm{mb} \text { at } \\
01 \mathrm{Z} \text { on July } 15^{\text {th }}\end{array}$ & $995 \mathrm{mb}$ \\
\hline
\end{tabular}

A tropical wave left the African coast early in July and moved generally westward approaching the Lesser Antilles about a week later. Data over the central Atlantic is 
scarce, which makes the exact time of genesis uncertain. Peripheral data early on July 9th indicate that a well-defined circulation may have already been present and the first position is analyzed at $12 \mathrm{Z}$ on the 9 th as a $40 \mathrm{kt}$ tropical storm based on a ship report of $40 \mathrm{kt}$ ESE at $10 \mathrm{Z}$ about $60 \mathrm{~nm}$ north of the center. The first position is analyzed twelve hours earlier than originally shown in HURDAT. Intensification to a tropical storm is analyzed 24 hours earlier than originally shown in HURDAT, although HURDAT never showed a tropical storm stage as the intensity was increased from $30 \mathrm{kt}$ at $06 \mathrm{Z}$ on July 10 th to $65 \mathrm{kt}$ at $12 \mathrm{Z}$ on the 10 th. Minor alterations are made to the track of this tropical cyclone, except for a major change on July 10th at 00Z, two degrees to the west. The first reconnaissance aircraft to reach the center of Abby occurred at $14 \mathrm{Z}$ on the 10 th measuring a central pressure of $1003 \mathrm{mb}$, estimating surface winds of $70 \mathrm{kt}$ and an eye diameter of $7 \mathrm{~nm}$. A central pressure of $1003 \mathrm{mb}$ suggests maximum sustained winds of $41 \mathrm{kt}$ south of $25 \mathrm{~N}$ from the Brown et al. pressure-wind relationship. An eye diameter of $7 \mathrm{~nm}$ suggests an RMW of about $5 \mathrm{~nm}$ and the climatological value is $12 \mathrm{~nm}$. Based on a forward speed of about $13 \mathrm{kt}$, an RMW smaller than normal and a visual estimate of 70 $\mathrm{kt}$, an intensity of $55 \mathrm{kt}$ is selected at $12 \mathrm{Z}$ on the $10 \mathrm{th}$, down from $65 \mathrm{kt}$ originally in HURDAT, a minor intensity change. A major intensity change is analyzed at $06 \mathrm{Z}$ on the 10th. HURDAT originally had $30 \mathrm{kt}$ and the analyzed intensity is $50 \mathrm{kt}$. Around $11 \mathrm{Z}$ on the 10th, the center of Abby made landfall in the island of St. Lucia where sustained winds of $48 \mathrm{kt}$ were measured with gusts to $55 \mathrm{kt}$. In the nearby island of Martinique, the maximum sustained winds were $36 \mathrm{kt}$ with gusts to $66 \mathrm{kt}$. Late on the 10th, Abby entered the eastern Caribbean Sea and continued to move generally westward. A reconnaissance aircraft measured a central pressure of $999 \mathrm{mb}$, estimated surface winds of $85 \mathrm{kt}$ and an eye diameter of $15 \mathrm{~nm}$ at $1223 \mathrm{Z}$ on July $11 \mathrm{th}$. A central pressure of $999 \mathrm{mb}$ suggests maximum sustained winds of $49 \mathrm{kt}$ south of $25 \mathrm{~N}$ from the pressure-wind relationship. An eye diameter of $15 \mathrm{~nm}$ suggests an RMW of about $12 \mathrm{~nm}$ and the climatological value is $13 \mathrm{~nm}$. Based on a forward speed of about $12 \mathrm{kt}$, an RMW close to climatology and a visual estimate of $85 \mathrm{kt}$, an intensity of $60 \mathrm{kt}$ is selected at $12 \mathrm{Z}$ on the $11 \mathrm{th}$, down from 85 kt originally in HURDAT, a major intensity change. Later at $18 \mathrm{Z}$ on the 11 th, a penetration center fix measured a central pressure of $1004 \mathrm{mb}$ and estimated surface winds of $85 \mathrm{kt}$. A central pressure of $1004 \mathrm{mb}$ suggests maximum sustained winds of 39 kt south of $25 \mathrm{~N}$ from the pressure-wind relationship. Based on a forward speed of about $12 \mathrm{kt}$ and a visual estimate of $85 \mathrm{kt}$, an intensity of $55 \mathrm{kt}$ is selected at $18 \mathrm{Z}$ on the $11 \mathrm{th}$, down from $80 \mathrm{kt}$ originally in HURDAT, a major intensity change. Major intensity changes are also analyzed at $00 \mathrm{Z}$ and $06 \mathrm{Z}$ on the $11 \mathrm{th}$. HURDAT originally showed $80 \mathrm{kt}$ at these times and the analyzed intensities are $55 \mathrm{kt}$ and $60 \mathrm{kt}$, respectively. The tropical storm continued westward on July 12 th passing well south of Hispaniola. A reconnaissance aircraft reported a central pressure of $1005 \mathrm{mb}$ and estimated surface winds of $65 \mathrm{kt}$ at $01 \mathrm{Z}$ on the $12 \mathrm{th}$. A central pressure of $1005 \mathrm{mb}$ suggests maximum 
sustained winds of $37 \mathrm{kt}$ south of $25 \mathrm{~N}$ from the pressure-wind relationship. Based on a forward speed of about $15 \mathrm{kt}$ and a visual estimate of $65 \mathrm{kt}$, an intensity of $50 \mathrm{kt}$ is selected at $00 \mathrm{Z}$ on the $12 \mathrm{th}$, down from $70 \mathrm{kt}$ originally in HURDAT, a major intensity change. Major changes in intensity are also analyzed at 06Z, 12Z and 18Z on the 12th. HURDAT originally showed $70 \mathrm{kt}$ at $06 \mathrm{Z}$, and $75 \mathrm{kt}$ at $12 \mathrm{Z}$ and $18 \mathrm{Z}$, and the analyzed intensity is $50 \mathrm{kt}$ for these times. A reconnaissance aircraft reported a central pressure of $1004 \mathrm{mb}$, estimated surface winds of $70 \mathrm{kt}$ and an eye diameter of $10 \mathrm{~nm}$ at $2350 \mathrm{Z}$ on the 12th. A central pressure of $1004 \mathrm{mb}$ suggests maximum sustained winds of $39 \mathrm{kt}$ south of $25 \mathrm{~N}$ from the pressure-wind relationship. An eye diameter of $10 \mathrm{~nm}$ suggests an RMW of about $8 \mathrm{~nm}$ and the climatological value is $14 \mathrm{~nm}$. Based on a forward speed of about 12 $\mathrm{kt}$, small size of the tropical cyclone, and visual estimate of $70 \mathrm{kt}$, an intensity of $50 \mathrm{kt}$ is selected at $00 \mathrm{Z}$ on the $12 \mathrm{th}$, down from $75 \mathrm{kt}$ originally in HURDAT, a major intensity change. A ship reported $80 \mathrm{kt}$ at $03 \mathrm{Z}$ on July 13 th but this appears to have a high bias based on the central pressure measured by the reconnaissance aircraft a couple of hours earlier and location of the ship. A penetration center fix reported a central pressure of $1008 \mathrm{mb}$ at $13 \mathrm{Z}$ on the 13th but based on the center fix location, likely it was not a central pressure and therefore, not added to HURDAT. Obviously there is a significant spread in the pressure-wind derived intensity and that visually estimate by the aircraft reconnaissance crew. The revised intensities from the 10th to the 13 th represent a blend of these topping out at $60 \mathrm{kt}$ at $06 \mathrm{Z}$ and $12 \mathrm{Z}$ on the $11 \mathrm{th}$. However, it is quite possible that the system was a minimal hurricane during part of the dates.

On July 14th, Abby began to gain in latitude as it approached Central America. A reconnaissance aircraft reported a central pressure of $1004 \mathrm{mb}$ and estimated surface winds of $35 \mathrm{kt}$ at $2346 \mathrm{Z}$ on the $13 \mathrm{th}$. A central pressure of $1004 \mathrm{mb}$ suggests maximum sustained winds of $39 \mathrm{kt}$ south of $25 \mathrm{~N}$ from the pressure-wind relationship. Based on a forward speed of about $14 \mathrm{kt}$ and a visual estimate of $35 \mathrm{kt}$, an intensity of $45 \mathrm{kt}$ is selected at $00 \mathrm{Z}$ on the 14 th, up from $40 \mathrm{kt}$ originally in HURDAT, a minor intensity change. Another reconnaissance aircraft reached Abby at $1315 \mathrm{Z}$ on the 14th measuring a central pressure of $999 \mathrm{mb}$, estimating surface winds of $75 \mathrm{kt}$ and an eye diameter of 7 $\mathrm{nm}$. A central pressure of $999 \mathrm{mb}$ suggests maximum sustained winds of $49 \mathrm{kt}$ south of $25 \mathrm{~N}$ from the pressure-wind relationship. An eye diameter of $7 \mathrm{~nm}$ suggests an RMW of about $5 \mathrm{~nm}$ and the climatological value of $13 \mathrm{~nm}$. Based on a forward speed of about 15 $\mathrm{kt}$, an RMW smaller than normal and a visual estimate of $75 \mathrm{kt}$, an intensity of $55 \mathrm{kt}$ is selected at $12 \mathrm{Z}$ on the 14 th, same as originally shown in HURDAT. Late on the 14th and early on the 15th, the center of Abby passed very close to the northeast coast of Honduras. A penetration center fix at $01 \mathrm{Z}$ on the 15 th measured a central pressure of 995 $\mathrm{mb}$, estimated surface winds of $55 \mathrm{kt}$ and an eye diameter of $15 \mathrm{~nm}$. A central pressure of $995 \mathrm{mb}$ suggests maximum sustained winds of $56 \mathrm{kt}$ south of $25 \mathrm{~N}$ from the pressure-wind relationship. An eye diameter of $15 \mathrm{~nm}$ suggests an RMW of about $12 \mathrm{~nm}$ and the 
climatological value is $12 \mathrm{~nm}$. Since Abby was moving at about $14 \mathrm{kt}$, the RMW was near the climatological value and the visual estimate was $55 \mathrm{kt}$, an intensity of $60 \mathrm{kt}$ is selected at $00 \mathrm{Z}$ on the $15 \mathrm{th}$, down from $65 \mathrm{kt}$ originally in HURDAT, a minor intensity change. Intensification to a hurricane is analyzed at $06 \mathrm{Z}$ on the 15 th, nearly five days later than originally shown in HURDAT.

Abby made landfall in the island of Roatan, Honduras as a $70 \mathrm{kt}$ hurricane at $06 \mathrm{Z}$ and later at $14 \mathrm{Z}$ made another landfall as a $70 \mathrm{kt}$ hurricane in southern British Honduras (today the country of Belize). MWR provides a radar image of the hurricane making landfall in British Honduras showing a small but well-formed cyclone with a closed eye. Abby weakened rapidly over mountains of Guatemala and southern Mexico. Weakening to a tropical storm is analyzed at $18 \mathrm{Z}$ on the 15 th and to a tropical depression at $00 \mathrm{Z}$ on the 16th, same as originally shown in HURDAT. Surface observations over southern Mexico and Bay of Campeche indicate that the circulation of Abby remained inland on the 16th and this was corroborated by a reconnaissance aircraft mission. Nevertheless, the system was still producing $30 \mathrm{kt}$ winds and it is retained as a tropical depression until $12 \mathrm{Z}$ on the 17th, eighteen hours later than originally shown in HURDAT. Abby is analyzed to have dissipated after $12 \mathrm{Z}$ on the 17 th over the mountains of central Mexico. A recent analog to Abby over the eastern Caribbean Sea is Hurricane Lili, 2002, which reached 60 kt with a central pressure of $1004 \mathrm{mb}$.

Tropical Storm Brenda [July 27-31, 1960]

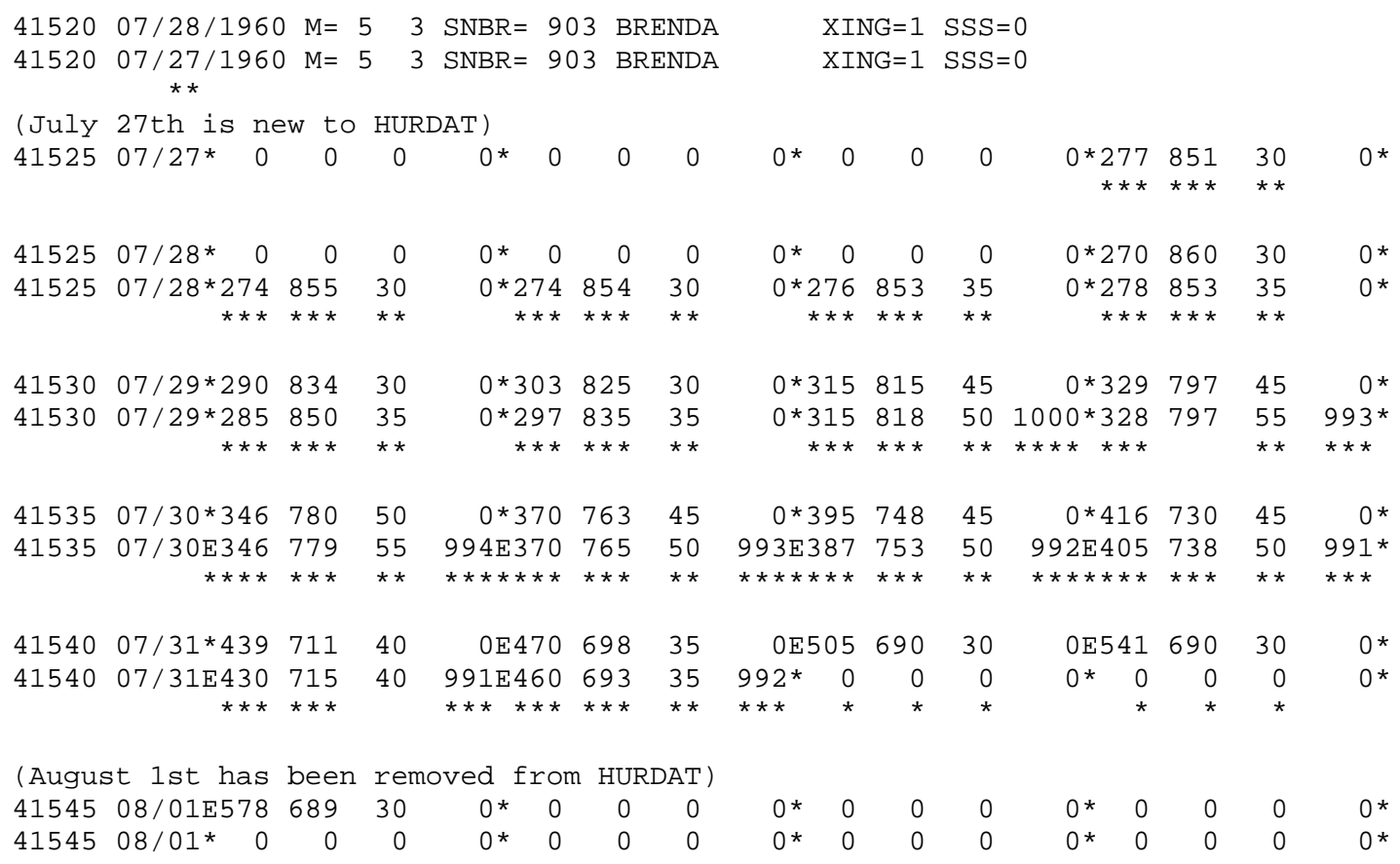


41550 TS

\section{U.S. Tropical Storm Landfall}

07/29 06Z 29.7N 83.5W $35 \mathrm{kt} \mathrm{FL}$

$07 / 2921 \mathrm{Z} 33.9 \mathrm{~N} 78.2 \mathrm{~W} 55 \mathrm{kt} \mathrm{NC}$

Minor changes to the track and intensity shown in McAdie et al. (2009). Evidence for these alterations comes from the NHC microfilm maps, the Historical Weather Maps series, the COADS ship database, Monthly Weather Review, Navy reconnaissance book, Surface Weather Observations, Local Climatological Data, Mariners Weather Log, and NHC Storm Wallets. Major changes are to indicate genesis 24 hours earlier and extratropical transition 30 hours earlier than originally shown in HURDAT.

July 26:

HWM analyzes a spot low at 27.0N, 85.0W at 12Z. HURDAT does not list an organized system on this date. Microfilm does not show an organized system at 12Z. Ship highlights: No gales or low pressures.

ATSR: "Tropical Storm BRENDA developed slowly in the Gulf of Mexico from a somewhat complex synoptic situation. The formation of a weak, diffuse surface low was noted about 180 miles west of Fort Myers on the 26th of July. At the $500 \mathrm{MB}$ level on the same date, a well-defined, easterly trough was approaching a weaker, quasi-stationary trough oriented from east to west and crossing southern Florida. From the 26th through the 30th of July, the surface low deepened very slowly while under the southeastern quadrant of a $200 \mathrm{MB}$ high cell."

July 27:

HWM analyzes a spot low at 27.0N, $86.0 \mathrm{~W}$ at 12Z. HURDAT does not list an organized system on this date. Microfilm shows a closed low pressure of at most 1011 $\mathrm{mb}$ at $27.0 \mathrm{~N}, 85.0 \mathrm{~W}$ at $12 \mathrm{Z}$. Ship highlights: No gales or low pressures.

MWR: "A weak cyclonic circulation that can be traced back to a position just off the southwestern Florida coast on July 27 began to deepen some 150 miles west of Tampa Bay area the next day."

July 28:

HWM analyzes a closed low pressure of at most $1010 \mathrm{mb}$ at $27.0 \mathrm{~N}, 85.5 \mathrm{~W}$ at 12Z. HURDAT lists a $30 \mathrm{knot}$ tropical depression at $27.0 \mathrm{~N}, 86.0 \mathrm{~W}$ at $18 \mathrm{Z}$ (first position). 
Microfilm shows a closed low pressure of at most $1008 \mathrm{mb}$ at $28.5 \mathrm{~N}, 85.0 \mathrm{~W}$ at $12 \mathrm{Z}$. Navy reconnaissance book lists the best track position at $27.3 \mathrm{~N}, 85.5 \mathrm{~W}$ at $12 \mathrm{Z}$ (first position). Ship highlights: $35 \mathrm{kt} \mathrm{SW}$ at $26.5 \mathrm{~N}, 83.2 \mathrm{~W}$ at $18 \mathrm{Z}$ (micro). Aircraft highlight: Radar center fix estimated surface winds of $40 \mathrm{kt}$ at $27.5 \mathrm{~N}, 85.5 \mathrm{~W}$ at $14 \mathrm{Z}$ (ATSR/micro). Penetration center fix measured a minimum pressure of $1007 \mathrm{mb}$ and estimated surface winds of $35 \mathrm{kt}$ at $27.8 \mathrm{~N}, 85.3 \mathrm{~W}$ at $19 \mathrm{Z}$ (ATSR).

July 29:

HWM analyzes a tropical storm of at most $1005 \mathrm{mb}$ at $31.2 \mathrm{~N}, 81.2 \mathrm{~W}$ at $12 \mathrm{Z}$. HURDAT lists a 45 knot tropical storm at $31.5 \mathrm{~N}, 81.5 \mathrm{~W}$ at $12 \mathrm{Z}$. Microfilm shows a closed low pressure of at most $999 \mathrm{mb}$ at $31.3 \mathrm{~N}, 81.8 \mathrm{~W}$ at $12 \mathrm{Z}$. Navy reconnaissance book lists the best track position at $31.5 \mathrm{~N}, 81.5 \mathrm{~W}$ at $12 \mathrm{Z}$. Ship highlights: $35 \mathrm{kt} \mathrm{SW}$ and $1006 \mathrm{mb}$ at $26.9 \mathrm{~N}, 83.3 \mathrm{~W}$ at $00 \mathrm{Z}$ (micro). $45 \mathrm{kt} \mathrm{SW}$ and $1007 \mathrm{mb}$ at $31.5 \mathrm{~N}, 80.0 \mathrm{~W}$ at $12 \mathrm{Z}$ (COADS). $55 \mathrm{kt} \mathrm{SW}$ and $1007 \mathrm{mb}$ at $30.1 \mathrm{~N}, 79.3 \mathrm{~W}$ at $13 \mathrm{Z}$ (COADS). $55 \mathrm{kt} \mathrm{SW}$ and $1002 \mathrm{mb}$ at $31.7 \mathrm{~N}, 78.5 \mathrm{~W}$ at $18 \mathrm{Z}$ (COADS). Land highlights: $35 \mathrm{kt}$ (max wind) $\mathrm{W}$ and $1011 \mathrm{mb}$ at Dry Tortugas Light, FL at 00Z (micro). $8 \mathrm{kt} \mathrm{SSE}$ and $1003 \mathrm{mb}$ (min pressure) at Gainesville, FL at 0558Z (SWO). $18 \mathrm{kt} \mathrm{S}$ and $1002 \mathrm{mb}$ (min pressure) at Brunswick, GA at $1058 \mathrm{Z}$ (SWO). $12 \mathrm{kt} \mathrm{NNE}$ and $1001 \mathrm{mb}$ (min pressure) at Hunter AFB, GA at 1459Z (SWO). $10 \mathrm{kt} \mathrm{SSW}$ and $997 \mathrm{mb}$ (min pressure) at Myrtle Beach, FL at 2057Z (SWO). $15 \mathrm{kt} \mathrm{S}$ and $996 \mathrm{mb}$ (min pressure) at Wilmington, NC at 2359Z (SWO). Aircraft highlights: Penetration center fix estimated surface winds of $45 \mathrm{kt}$ at $32.6 \mathrm{~N}, 80.0 \mathrm{~W}$ at $17 Z$ (ATSR). Penetration center fix measured a central pressure of $993 \mathrm{mb}$ at $33.1 \mathrm{~N}$, $79.1 \mathrm{~W}$ at $20 \mathrm{Z}$ (ATSR).

MWR: "By the night of July 28, pressure had dropped to near $1000 \mathrm{mb}$ as the Low began accelerating and moving northeastward onto the Florida coast southwest of Cross City. Thereafter the storm continued with gradually accelerating speed along the Carolina coasts on July 29th, through the mid-Atlantic States on the 30th, finally passing through the New England States on the 31st and dissipating over southeastern Canada. The storm was not officially named until the 29th when reconnaissance aircraft indicated tropical storm structure. Earlier aircraft and surface reports indicated rather light winds over an area within 50 to 100 miles of the lowest pressure. A tropical storm is usually associated with a zone of concentrated winds near the center, but not until the Low began accelerating northeastward and had reached the coastal area of the Carolinas was this type of pattern apparent. Wind gusts in squalls to $60 \mathrm{mph}$ were reported from many locations along the Atlantic coast and the central portion of the Florida Gulf coast. A gust of $65 \mathrm{mph}$ was reported at Cape Cod Canal, however, the highest sustained wind at an official Weather Bureau station was $58 \mathrm{mph}$ at Cape Hatteras. The storm had no opportunity to reach hurricane force as the track was mostly over land after making 
landfall on the Florida coast." ATSR: "On the morning of the 29th of July, this low accelerated rapidly while moving northeastward along the Georgia and South Carolina coast. Under the influence of southwesterly flow at the $200 \mathrm{MB}$ level, further intensification on the day of the 29th and continued through the morning of the 30th. The first warning on BRENDA was issued at $292000 Z$ shortly after a Navy reconnaissance aircraft reported evidence of a tropical storm structure."

July 30 :

HWM analyzes a tropical storm of at most $995 \mathrm{mb}$ at $38.9 \mathrm{~N}, 75.5 \mathrm{~W}$ at $12 \mathrm{Z}$. HURDAT lists a 45 knot tropical storm at $39.5 \mathrm{~N}, 74.8 \mathrm{~W}$ at $12 \mathrm{Z}$. Microfilm shows a closed low pressure of at most $993 \mathrm{mb}$ at $38.5 \mathrm{~N}, 75.0 \mathrm{~W}$ at 12Z. Navy reconnaissance book lists the best track position at $39.5 \mathrm{~N}, 74.8 \mathrm{~W}$ at $12 \mathrm{Z}$. Ship highlights: $45 \mathrm{kt} \mathrm{S}$ and $1008 \mathrm{mb}$ at $30.3 \mathrm{~N}, 77.4 \mathrm{~W}$ at $00 \mathrm{Z}$ (COADS). $50 \mathrm{kt} \mathrm{SE}$ and $1001 \mathrm{mb}$ at $35.6 \mathrm{~N}, 74.7 \mathrm{~W}$ at $06 \mathrm{Z}$ (COADS). $45 \mathrm{kt} \mathrm{S}$ and $997 \mathrm{mb}$ at 37.6N, 75.4W at 09Z (COADS). $50 \mathrm{kt} \mathrm{SE}$ and $1000 \mathrm{mb}$ at $39.3 \mathrm{~N}, 74.2 \mathrm{~W}$ at $12 \mathrm{Z}$ (COADS). $50 \mathrm{kt} \mathrm{W}$ and $1002 \mathrm{mb}$ at $38.6 \mathrm{~N}, 74.1 \mathrm{~W}$ at $18 \mathrm{Z}$ (COADS). Land highlight: $50 \mathrm{kt}$ (max winds) and $1000 \mathrm{mb}$ (min pressure) at Hatteras, NC (time unknown, likely early on the 30th) (CLIMO/MWR). $20 \mathrm{kt} \mathrm{S} \mathrm{and} 996$ $\mathrm{mb}$ at Cherry Point, NC at 01Z (SWO). $15 \mathrm{kt} \mathrm{SE}$ and $995 \mathrm{mb}$ at Langley AFB, VA at 0555Z (SWO). $11 \mathrm{kt} \mathrm{SSW} \mathrm{and} 994 \mathrm{mb}$ at Salisbury, MD at 1159Z (SWO). $46 \mathrm{kt} \mathrm{SE}$ (gusts to $55 \mathrm{kt}$, max winds) at New York Shoals, NY at 1559Z (SWO). $10 \mathrm{kt} \mathrm{NW}$ and $993 \mathrm{mb}$ at Belmar, NJ at 1758Z (SWO). $35 \mathrm{kt} \mathrm{SSE} \mathrm{(gusts} \mathrm{to} 42 \mathrm{kt}$, max winds) and 998 $\mathrm{mb}$ (min winds) at Block Island, RI at $18 \mathrm{Z}$ (SWO). $5 \mathrm{kt} \mathrm{SW}$ and $993 \mathrm{mb}$ (min pressure) at Worcester, MA at 2358Z (SWO). $36 \mathrm{kt}$ (max winds) and $993 \mathrm{mb}$ (min pressure) at Middletown, CT (time unknown, likely late on the 30th) (CLIMO). Aircraft highlights: Penetration center fix at $34.6 \mathrm{~N}, 77.7 \mathrm{~W}$ at $00 \mathrm{Z}$ (ATSR).

ATSR: "BRENDA continued to move on a northeasterly heading and passed inland near Cape Fear, North Carolina with maximum winds of near 50 knots. On moving rapidly northward, under the steering influence of an approaching westerly trough, BRENDA became extra-tropical. The last warning was issued at 302200Z." CLIMO Hatteras: "Tropical Storm Brenda occurring on the 29th and 30th produced a total rainfall of 2.30 inches. Peak gust during this storm was $60 \mathrm{mph}$. No reported damage to boats or buildings."

July 31 :

HWM analyzes a large extratropical cyclone over eastern Canada at $12 \mathrm{Z}$. HURDAT lists a 30 knot extratropical depression at $50.5 \mathrm{~N}, 69.0 \mathrm{~W}$ at $12 \mathrm{Z}$. Microfilm shows an extratropical cyclone at $50.5 \mathrm{~N}, 69.0 \mathrm{~W}$ at $12 \mathrm{Z}$. Navy reconnaissance book lists the best track position at $45.8 \mathrm{~N}, 70.8 \mathrm{~W}$ at $04 \mathrm{Z}$ (last position). Ship highlights: $40 \mathrm{kt} \mathrm{NE}$ 
and $1004 \mathrm{mb}$ at $48.4 \mathrm{~N}, 69.6 \mathrm{~W}$ at $00 \mathrm{Z}$ (COADS). $35 \mathrm{kt} \mathrm{WSW}$ and $1006 \mathrm{mb}$ at $43.0 \mathrm{~N}$, $68.3 \mathrm{~W}$ at $12 \mathrm{Z}$ (COADS). Land highlights: $35 \mathrm{kt} \mathrm{SW}$ (gusts to $45 \mathrm{kt}$, max winds) at Martha's Vineyard, MA at 00Z (SWO). 38 kt SW (max winds) at Nantucket Shoals, MA at $0258 \mathrm{Z}$ (SWO). $10 \mathrm{kt} \mathrm{S}$ and $994 \mathrm{mb}$ (min pressure) at Houlton, ME at 0558Z (SWO).

August 1:

HWM analyzes an extratropical cyclone at $62.0 \mathrm{~N}, 71.0 \mathrm{~W}$ at $12 \mathrm{Z}$. HURDAT lists a 30 knot extratropical depression at $57.8 \mathrm{~N}, 68.9 \mathrm{~W}$ at $00 \mathrm{Z}$ (last position). Microfilm shows an extratropical cyclone at $62.5 \mathrm{~N}, 75.0 \mathrm{~W}$ at $12 \mathrm{Z}$. Ship highlights: No gales or low pressures.

\begin{tabular}{|c|c|c|c|}
\hline Date & $\begin{array}{c}\text { Original } \\
\text { HURDAT } \\
\text { Central } \\
\text { Pressure }\end{array}$ & Evidence & Changes \\
\hline $\begin{array}{c}\text { July } 29 \\
12 Z\end{array}$ & & $\begin{array}{l}\text { Land: } 12 \mathrm{kt} \text { SSW and } 1002 \mathrm{mb} \text { at } \\
\text { Brunswick, GA at } 1158 \mathrm{Z} \text { on July } 29^{\text {th }}\end{array}$ & $1000 \mathrm{mb}$ \\
\hline $\begin{array}{c}\text { July } 29 \\
18 z\end{array}$ & & $\begin{array}{l}\text { Penetration center fix: } 993 \mathrm{mb} \text { at } 20 \mathrm{Z} \\
\text { on July } 30^{\text {th }}\end{array}$ & $993 \mathrm{mb}$ \\
\hline $\begin{array}{l}\text { July } 3 \odot \\
\text { ๑๑z }\end{array}$ & & $\begin{array}{l}\text { Land: } 15 \mathrm{kt} \mathrm{S} \text { and } 996 \mathrm{mb} \text { at } \\
\text { Wilmington, } \mathrm{NC} \text { at } 2359 \mathrm{Z} \text { on July } 29^{\text {th }}\end{array}$ & $994 \mathrm{mb}$ \\
\hline $\begin{array}{l}\text { July } 30 \\
\text { 06z }\end{array}$ & & $\begin{array}{l}\text { Land: } 15 \mathrm{kt} \text { SE and } 995 \mathrm{mb} \text { at Landley } \\
\text { AFB, VA at } 0555 \mathrm{Z} \text { on July } 30^{\text {th }}\end{array}$ & $993 \mathrm{mb}$ \\
\hline $\begin{array}{c}\text { July } 30 \\
12 Z\end{array}$ & & $\begin{array}{l}\text { Land: } 11 \mathrm{kt} \text { SSW and } 994 \mathrm{mb} \text { at } \\
\text { Salisbury, MD at } 1159 \mathrm{Z} \text { on July } 30^{\text {th }}\end{array}$ & $992 \mathrm{mb}$ \\
\hline $\begin{array}{c}\text { July } 30 \\
18 z\end{array}$ & & $\begin{array}{l}\text { Land: } 10 \mathrm{kt} \mathrm{NW} \text { and } 993 \mathrm{mb} \text { at Belmar, } \\
\mathrm{NJ} \text { at } 1758 \mathrm{Z} \text { on July } 30^{\mathrm{th}}\end{array}$ & $991 \mathrm{mb}$ \\
\hline $\begin{array}{l}\text { July } 31 \\
\text { ๑๑Z }\end{array}$ & & $\begin{array}{l}\text { Land: } 5 \mathrm{kt} \mathrm{SW} \text { and } 993 \mathrm{mb} \text { at } \\
\text { Worcester, MA at } 2358 \mathrm{Z} \text { on July } 30^{\text {th }}\end{array}$ & $991 \mathrm{mb}$ \\
\hline $\begin{array}{l}\text { July } 31 \\
\text { O6z }\end{array}$ & & $\begin{array}{l}\text { Land: } 10 \mathrm{kt} \mathrm{S} \text { and } 994 \mathrm{mb} \text { at Houlton, } \\
\text { ME at } 0558 \mathrm{Z} \text { on July } 31^{\mathrm{st}}\end{array}$ & $992 \mathrm{mb}$ \\
\hline
\end{tabular}

A broad area of low pressure developed over the eastern Gulf of Mexico around July 26th. The disturbance remained almost stationary over the next 48 hours as it slowly became better organized. Synoptic data late on the 27 th indicates that a well-defined circulation was present and genesis is analyzed at $18 \mathrm{Z}$ on the 27 th, 24 hours earlier than originally shown in HURDAT. The tropical depression retained a large circulation embedded within a moist environment. The strongest winds were generally located in the southeast quadrant, about 100-200 nm from the center. This suggests that the cyclone 
likely had subtropical characteristics, but without satellite images, it is not possible to assess. On July 28 th at $12 Z$, the microfilm map indicates that a reconnaissance aircraft estimated surface winds of $40 \mathrm{kt}$ about $120 \mathrm{~nm}$ south of the center. Nearby surface observations show a ship report of $30 \mathrm{kt}$. A blend of these data is used to select an intensity of $35 \mathrm{kt}$ at $12 \mathrm{Z}$ on the 28th. Intensification to a tropical storm is analyzed 24 hours earlier than originally shown in HURDAT. A couple of ships reported $35 \mathrm{kt}$ at $18 \mathrm{Z}$ on the 28th. A reconnaissance aircraft made a center fix at $19 \mathrm{Z}$ on the 28th estimating surface winds of $35 \mathrm{kt}$ and a minimum pressure of $1007 \mathrm{mb}$. The aircraft did not make a penetration fix, thus the minimum pressure is not a central pressure and not added to HURDAT. On July 29th, Brenda began to accelerate to the northeast making landfall in the Big Bend of Florida as a $35 \mathrm{kt}$ tropical storm around 06Z. No tropical storm force winds were reported along the Gulf coast of Florida on the 29th, as the strongest winds were $30 \mathrm{kt}$ at Tampa and $32 \mathrm{kt}$ at Fort Myers. The tropical storm quickly crossed the Florida peninsula and straddled the Georgia to North Carolina coast during the remainder of the 29th. Despite the center of tropical cyclone remaining near the coast, the system gained in strength according to multiple ship observations of gale-force winds up to 55 kt. A reconnaissance aircraft measured a central pressure of $993 \mathrm{mb}$ at $20 \mathrm{Z}$ on the 29th with the center just offshore. A central pressure of $993 \mathrm{mb}$ suggests maximum surface winds of $55 \mathrm{kt}$ north of $25 \mathrm{~N}$ from the Brown et al. pressure-wind relationship. An intensity of $55 \mathrm{kt}$ is selected at $18 \mathrm{Z}$ on the 29th, up from $45 \mathrm{kt}$ originally in HURDAT, a minor intensity change. $55 \mathrm{kt}$ is also the peak intensity of Brenda, up from $50 \mathrm{kt}$ originally in HURDAT, a minor intensity change. There was a discrepancy between the reconnaissance center fixes around $23 \mathrm{Z}$ and the surface observations at $21 \mathrm{Z}$ on the 29th, possibly indicating that the circulation was tilted to the south with height.

Synoptic data late on the 29th indicates that Brenda was beginning to acquire extratropical characteristics with an elongated circulation on the northeast side, but the dew points around the cyclone showed little or no gradient. The center of Brenda moved briefly over the Atlantic Ocean around $18 \mathrm{Z}$ on the 29th and the storm made another landfall in southern North Carolina, near 33.9N, $78.2 \mathrm{~W}$ around 21Z, as a $55 \mathrm{kt}$ tropical storm. Transition to an extratropical cyclone is analyzed at $00 \mathrm{Z}$ on July 30 th, 30 hours earlier than originally shown in HURDAT. Synoptic data clearly shows the development of frontal features and a significant gradient in the dew points between the western and eastern quadrant at that time. Early on the 30th, Cape Hatteras, NC experienced sustained winds of about $50 \mathrm{kt}$ according to the Local Climatological Data and Monthly Weather Review. These were the strongest winds measured on land due to Brenda. The extratropical cyclone moved rapidly along the eastern coast of the United States affecting the Mid-Atlantic around midday on the 30th and reaching New England late in the day. Early on July 31 st, the extratropical cyclone began to interact with another extratropical cyclone over eastern Canada and synoptic data suggests that both had merged by $12 Z$. 
The merged cyclone then prescribed a slow loop over the next few days over Canada. The last position is analyzed at $06 \mathrm{Z}$ on the 31 st, eighteen hours earlier than originally shown in HURDAT.

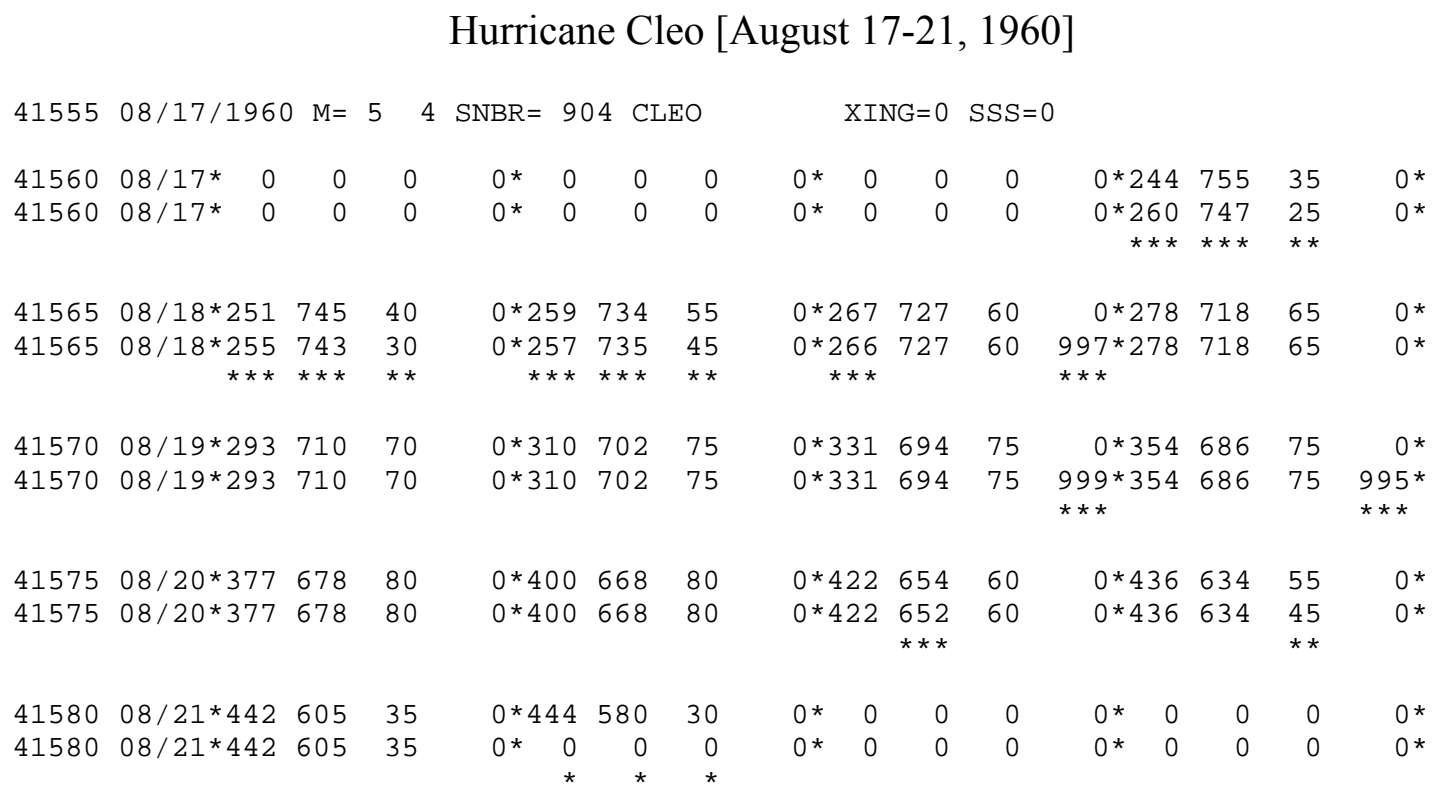

41585 HR

Minor changes to the track and intensity shown in McAdie et al. (2009). Evidence for these alterations comes from the NHC microfilm maps, the Historical Weather Maps series, the COADS ship database, Monthly Weather Review, Navy reconnaissance book, Mariners Weather Log, and NHC Storm Wallets.

August 16:

HWM analyzes a spot low at 24.0N, 73.0W at 12Z. HURDAT does not list an organized system on this date. Microfilm does not show an organized system at 12Z. Ship highlights: No gales or low pressures.

ATSR: "Developing later into a small, but relatively intense hurricane, CLEO originated in the southeastern Bahama Islands within a broad trough resulting from the juncture of an easterly wave and a trailing polar trough. As early as $1200 \mathrm{Z}$ on the 16th of August, considerable precipitation was noted throughout western Cuba and the Bahamas associated with an easterly wave located over eastern Cuba. This easterly wave was well defined at both the 700 and $500 \mathrm{MB}$ levels. At the same time, a long wave was noted aloft extending from northern Florida off the southeastern United States seaboard." 
August 17:

HWM analyzes a spot low at $27.5 \mathrm{~N}, 74.0 \mathrm{~W}$ with a weakening front to the north at $12 \mathrm{Z}$. HURDAT lists a $35 \mathrm{knot}$ tropical storm at $24.4 \mathrm{~N}, 75.5 \mathrm{~W}$ at $18 \mathrm{Z}$ (first position). Microfilm shows a trough over the central Bahamas at 12Z. Ship highlights: No gales or low pressures.

ATSR: "By 170000Z, a closed low at both the 700 and $500 \mathrm{MB}$ levels was centered in vicinity of central Cuba. At $171800 Z$, this low was located at the surface over the central Bahamas with another small low in the same trough about 240 miles to the northnortheast. CLEO developed from the southernmost of these two lows."

August 18:

HWM analyzes a tropical storm of at most $1010 \mathrm{mb}$ at $26.7 \mathrm{~N}, 72.5 \mathrm{~W}$ and a closed low pressure of at most $1010 \mathrm{mb}$ at $29.0 \mathrm{~N}, 74.5 \mathrm{~W}$ at $12 \mathrm{Z}$. HURDAT lists a 60 knot tropical storm at $26.7 \mathrm{~N}, 72.7 \mathrm{~W}$ at $12 \mathrm{Z}$. Microfilm shows a closed low pressure of at most $1011 \mathrm{mb}$ at $26.8 \mathrm{~N}, 72.5 \mathrm{~W}$ at $12 \mathrm{Z}$. Navy reconnaissance book lists the best track position at $26.7 \mathrm{~N}, 72.7 \mathrm{~W}$ at 12Z. Ship highlights: $40 \mathrm{kt}$ ENE and $1002 \mathrm{mb}$ at $27.0 \mathrm{~N}$, $72.6 \mathrm{~W}$ at $13 \mathrm{Z}$ (COADS). $45 \mathrm{kt} \mathrm{NW}$ and $1009 \mathrm{mb}$ at $27.1 \mathrm{~N}, 72.5 \mathrm{~W}$ at $14 \mathrm{Z}$ (COADS). 40 kt SSW and $1006 \mathrm{mb}$ at 26.0N, 69.9W at 16Z (micro). Aircraft highlights: Penetration center fix estimated surface winds of $75 \mathrm{kt}$ and an eye diameter of $7 \mathrm{~nm}$, and measured a central pressure of $997 \mathrm{mb}$ at 27.2N, 72.4W at 1430Z (ATSR). Penetration center fix at $28.8 \mathrm{~N}, 71.2 \mathrm{~W}$ at $2245 \mathrm{Z}$ (ATSR).

MWR: "Hurricane Cleo formed in a broad area of squally weather some 350 miles northeast of Nassau, Bahamas, on August 18. From surface considerations, the formation was unique in that a marked trough with at least one circulation center present to the north of the area of formation. Thus, Cleo's development did not conform to the normal increasing easterlies and cyclonic vorticity in the north portion of the trough which usually accompany tropical cyclone development." ATSR: "The first report indicated that CLEO had intensified to tropical storm intensity was in $181300 \mathrm{Z}$ observation received from the SS CHICAGO at 27.0N 72.6W: "wind from 070 degrees 40 knots, pressure 1002.0 MB, rough sea, confused swell, barometer falling straight." At almost the same time (181300Z), a Navy reconnaissance aircraft which was enroute to investigate reported a radar eye located at $26.5 \mathrm{~N} 71.4 \mathrm{~W}$. The first warning on CLEO was released at 181600Z."

August 19:

HWM analyzes a hurricane of at most $1005 \mathrm{mb}$ at $32.9 \mathrm{~N}, 69.0 \mathrm{~W}$ at $12 \mathrm{Z}$. HURDAT lists a 75 knot hurricane at $33.1 \mathrm{~N}, 69.4 \mathrm{~W}$ at $12 \mathrm{Z}$. Microfilm shows a separate 
closed low pressure of at most $1008 \mathrm{mb}$ at $39.5 \mathrm{~N}, 72.5 \mathrm{~W}$ with a trough extending south at 12Z. Navy reconnaissance book lists the best track position at $33.1 \mathrm{~N}, 69.4 \mathrm{~W}$ at $12 \mathrm{Z}$. Ship highlights: $40 \mathrm{kt} \mathrm{S}$ and $1004 \mathrm{mb}$ at $29.7 \mathrm{~N}, 70.6 \mathrm{~W}$ at $00 \mathrm{Z}$ (micro). $45 \mathrm{kt} \mathrm{S}$ and $1004 \mathrm{mb}$ at $29.5 \mathrm{~N}, 70.6 \mathrm{~W}$ at $03 \mathrm{Z}$ (micro). Aircraft highlights: Penetration center fix estimated an eye diameter of $14 \mathrm{~nm}$ at $29.3 \mathrm{~N}, 71.1 \mathrm{~W}$ at $00 \mathrm{Z}$ (ATSR). Radar center fix at $31.0 \mathrm{~N}, 70.2 \mathrm{~W}$ at $06 Z$ (ATSR). Penetration center fix measured a central pressure of $999 \mathrm{mb}$ at $33.3 \mathrm{~N}$, $69.2 \mathrm{~W}$ at $13 \mathrm{Z}$ (ATSR/WALLET). Reconnaissance aircraft estimated surface winds of 96 $\mathrm{kt}$ at 16Z (WALLET). Penetration center fix measured a central pressure of $995 \mathrm{mb}$ at $35.7 \mathrm{~N}, 68.5 \mathrm{~W}$ at 19Z (ATSR/WALLET). Penetration center fix estimated winds of 122 kt (likely flight level) at $37.6 \mathrm{~N}, 67.8 \mathrm{~W}$ at $2319 \mathrm{Z}$ (WALLET).

MWR: "Hurricane Cleo remained small and moved about parallel to the Atlantic coast at an initial forward speed of $12 \mathrm{kt}$, later accelerating to 20 to $30 \mathrm{kt}$. It appears to have attained its greatest intensity as it approached southeastern New England when winds near the center were estimated at $80 \mathrm{kt}$. Except during the early and late stages of the storm, there was never a good correlation between reported winds and central pressures. Wind reports from aircraft were consistently high compared with winds calculated from sea level pressures obtained by aircraft penetrations. Some compromise has been made and this accounts for the estimate sea level pressure noted on the storm track." ATSR: "Intensifying, CLEO accelerated and moved rapidly north-northeastward following the steering current at 500 and $200 \mathrm{MB}$ quite closely. Maximum surface wind speed, estimated at 96 knots, occurred at about 191600Z when CLEO was 300 miles east of Cape Hatteras. It is interesting to note that the closed circulation with the storm at this time was only 150 miles in diameter. On moving northward from this point off Cape Hatteras, the extra tropical low to the north of CLEO was in a position just south of Massachusetts. The advection of cool, drier air from the New England area into the tropical circulation in addition to the cooling effect from water, caused CLEO to weaken."

August 20:

HWM analyzes a tropical storm of at most $1015 \mathrm{mb}$ at $42.0 \mathrm{~N}, 65.0 \mathrm{~W}$ with a cold front to the north at 12Z. HURDAT lists a 60 knot tropical storm at $42.2 \mathrm{~N}, 65.4 \mathrm{~W}$ at 12Z. Microfilm shows a closed low pressure of at most $1011 \mathrm{mb}$ at $41.8 \mathrm{~N}, 65.2 \mathrm{~W}$ at $12 \mathrm{Z}$. Navy reconnaissance book lists the best track position at $42.2 \mathrm{~N}, 65.3 \mathrm{~W}$ at 12Z. Ship highlights: $35 \mathrm{kt}$ ESE and $1011 \mathrm{mb}$ at 42.2N, 64.3W at 12Z (COADS). USS Edisto radar center fix at $41.8 \mathrm{~N}, 65.0 \mathrm{~W}$ at $12 \mathrm{Z}$ (WALLET). USS Lookout radar center fix at $42.2 \mathrm{~N}$, $65.2 \mathrm{~W}$ at $12 \mathrm{Z}$ (WALLET). $40 \mathrm{kt} \mathrm{SW}$ and $1011 \mathrm{mb}$ at $41.9 \mathrm{~N}, 64.2 \mathrm{~W}$ at $15 \mathrm{Z}$ (COADS). Navy ship radar center fix at $42.5 \mathrm{~N}, 64.7 \mathrm{~W}$ at $1330 \mathrm{Z}$ (WALLET). Navy ship radar center fix at $43.5 \mathrm{~N}, 63.7 \mathrm{~W}$ at $17 \mathrm{Z}$ (reported "appears to be dissipating") (WALLET). Aircraft 
highlights: Penetration center fix estimated flight level winds of $100 \mathrm{kt}$ at $700 \mathrm{mb}$ at $38.4 \mathrm{~N}, 67.5 \mathrm{~W}$ at $0132 \mathrm{Z}$ (ATSR). Radar center fix at $40.0 \mathrm{~N}, 66.6 \mathrm{~W}$ at $06 \mathrm{Z}$ (ATSR).

ATSR: "At about 201800Z, CLEO curved rapidly to an easterly course following the steering current associated with the $500 \mathrm{MB}$ ridge in the Atlantic, and passed a few miles north of Sable Island."

August 21:

HWM analyzes a frontal boundary over eastern Canada and North Atlantic (no organized system) at $12 \mathrm{Z}$. HURDAT lists a 30 knot tropical depression at $44.4 \mathrm{~N}, 58.0 \mathrm{~W}$ at $06 \mathrm{Z}$ (last position). Microfilm shows a closed low pressure of at most $1008 \mathrm{mb}$ at $48.0 \mathrm{~N}, 51.5 \mathrm{~W}$ at $12 \mathrm{Z}$. Ship highlights: No gales or low pressures.

ATSR: "It finally dissipated south of Newfoundland. The final warning on CLEO was issued at 210400Z."

The interaction of a tropical wave and a trough over the Bahamas caused the development of a low pressure on August 17th. The disturbance rapidly gained strength and a $25 \mathrm{kt}$ tropical depression is analyzed to have developed at $18 \mathrm{Z}$ on the 17 th (originally begun as a $35 \mathrm{kt}$ tropical storm). The time of genesis is the same as originally shown in HURDAT, but synoptic observations suggest that the center of the tropical cyclone was located substantially northeast of the position originally shown in HURDAT at $18 \mathrm{Z}$ on the 17 th. It is also possible that genesis may have taken place six hours later as more than one low pressure system developed along the trough that caused the formation of this tropical cyclone. Minor track alterations are introduced during the lifetime of this tropical cyclone. The tropical depression quickly intensified on August 18th as it began to accelerate to the north-northeast. The first gale-force winds were reported at $13 \mathrm{Z}$ on the 18th, ship CHICAGO observed $40 \mathrm{kt}$ ENE and $1002 \mathrm{mb}$. Intensification to a tropical storm is analyzed at $06 \mathrm{Z}$ on the 18 th based on data later in the day. Intensification to a tropical storm is twelve hours later than originally shown in HURDAT. At 1430Z, a reconnaissance aircraft reported a central pressure of $997 \mathrm{mb}$, estimated surface winds of $75 \mathrm{kt}$ and an eye diameter of $7 \mathrm{~nm}$. A central pressure of $997 \mathrm{mb}$ suggests maximum sustained winds of $49 \mathrm{kt}$ from the north of $25 \mathrm{~N}$ Brown et al. pressure-wind relationship. An eye diameter of $7 \mathrm{~nm}$ suggests an RMW of $5 \mathrm{~nm}$ and the climatological value is 22 $\mathrm{nm}$. Due to an RMW smaller than average, a forward speed of about $14 \mathrm{kt}$ and taking into consideration the surface wind estimate of $75 \mathrm{kt}$, an intensity of $60 \mathrm{kt}$ is selected at $12 \mathrm{Z}$, same as originally shown in HURDAT. A central pressure of $997 \mathrm{mb}$ is added to HURDAT at $12 \mathrm{Z}$ on the 18 th. Cleo is analyzed to have become a hurricane at $18 \mathrm{Z}$ on the 18th, same as originally shown in HURDAT. 
On August 19th, the forward speed of Cleo continued to increase to the north-northeast as a strong low pressure system developed off the Mid-Atlantic states. The hurricane remained small and it was difficult to almost impossible to spot synoptically, but the reconnaissance aircraft had no trouble locating it. A reconnaissance aircraft measured a central pressure of $999 \mathrm{mb}$ at $13 \mathrm{Z}$ on the 19th. A central pressure of $999 \mathrm{mb}$ suggests maximum sustained winds of $45 \mathrm{kt}$ from the north of $25 \mathrm{~N}$ pressure-wind relationship. A central pressure of $999 \mathrm{mb}$ is added to HURDAT at $12 \mathrm{Z}$ on the 19 th. At $19 \mathrm{Z}$ on the 19 th, a reconnaissance aircraft measured a central pressure of $995 \mathrm{mb}$. A central pressure of $995 \mathrm{mb}$ suggests maximum sustained winds of $52 \mathrm{kt}$ north of $25 \mathrm{~N}$ and $56 \mathrm{kt}$ from the north of $35 \mathrm{~N}$ Landsea et al. pressure-wind relationship. The highest estimated surface winds were $96 \mathrm{kt}$ at $16 \mathrm{Z}$ on the 19th according to the Navy reconnaissance book. At $12 \mathrm{Z}$ and $18 \mathrm{Z}$, due to the extremely small size of the hurricane, fast forward speed and some weighting of the visual surface wind estimate, the intensity of $75 \mathrm{kt}$ in HURDAT is retained. A central pressure of $995 \mathrm{mb}$ is added to HURDAT at $18 \mathrm{Z}$ on the 19th. It is interesting to note that the 1960 MWR North Atlantic Hurricane Tracking chart shows central pressures values at $00 \mathrm{Z}$ and $12 \mathrm{Z}$ on the 19 th and $00 \mathrm{Z}$ on the 20th that were obtained based on the estimated surface winds. [1960 was the first year, that we can best determine, that a rudimentary understanding of the pressure-wind relationship became available. In particular, the Kraft (1961) pressure-wind relationship was being used. Kraft (1961) uses 14 cases of tropical cyclones that reached the coast with different maximum winds (not gusts) and central pressures. These measurements were deemed to be reliable by Kraft. Based on these measurements, Kraft created a curve of maximum wind versus central pressure, and a formula is provided, $\mathrm{Vmax}=14 \sqrt{ } 1013$-Pcenter]. These values were not measured but because the actual central pressure values that were reported by the reconnaissance aircrafts did not match the winds reported, a compromise was made in 1960 between the estimated surface winds and observed surface values. These values were not included in the original HURDAT. Today we know that it is possible for a small, fast-moving tropical cyclone to produce hurricane-force winds with relatively high central pressure values. Recent examples include Hurricanes Frances, 1986 and Debby, 2000. The strong low pressure system off the Mid-Atlantic coast moved inland into southern New England late on the 19th. A reconnaissance aircraft reported winds of 122 $\mathrm{kt}$ at $2319 \mathrm{Z}$ on the 19th but it is uncertain whether these winds are surface or flight-level estimates. At $0132 Z$ on September 20th, a reconnaissance aircraft estimated flight-level winds of $100 \mathrm{kt}$. HURDAT shows a peak intensity of $80 \mathrm{kt}$ at $00 \mathrm{Z}$ and $06 \mathrm{Z}$ on the 20 th as Cleo passed east of New England. Due to the lack of reliable data from the center of the hurricane, the peak intensity is retained. Later on the 20th, the track of Cleo turned to the northeast and the hurricane rapidly began to weaken. Weakening to a tropical storm is analyzed at $12 \mathrm{Z}$ on the 20th, same as originally shown in HURDAT. Synoptic observations early on September 21 st indicate that Cleo degenerated into a trough of low 
pressure just south of Newfoundland and the remnants were likely absorbed by an intense extratropical cyclone over the north Atlantic. The last position is analyzed at $00 \mathrm{Z}$ on the 21 st, six hours earlier than originally shown in HURDAT.

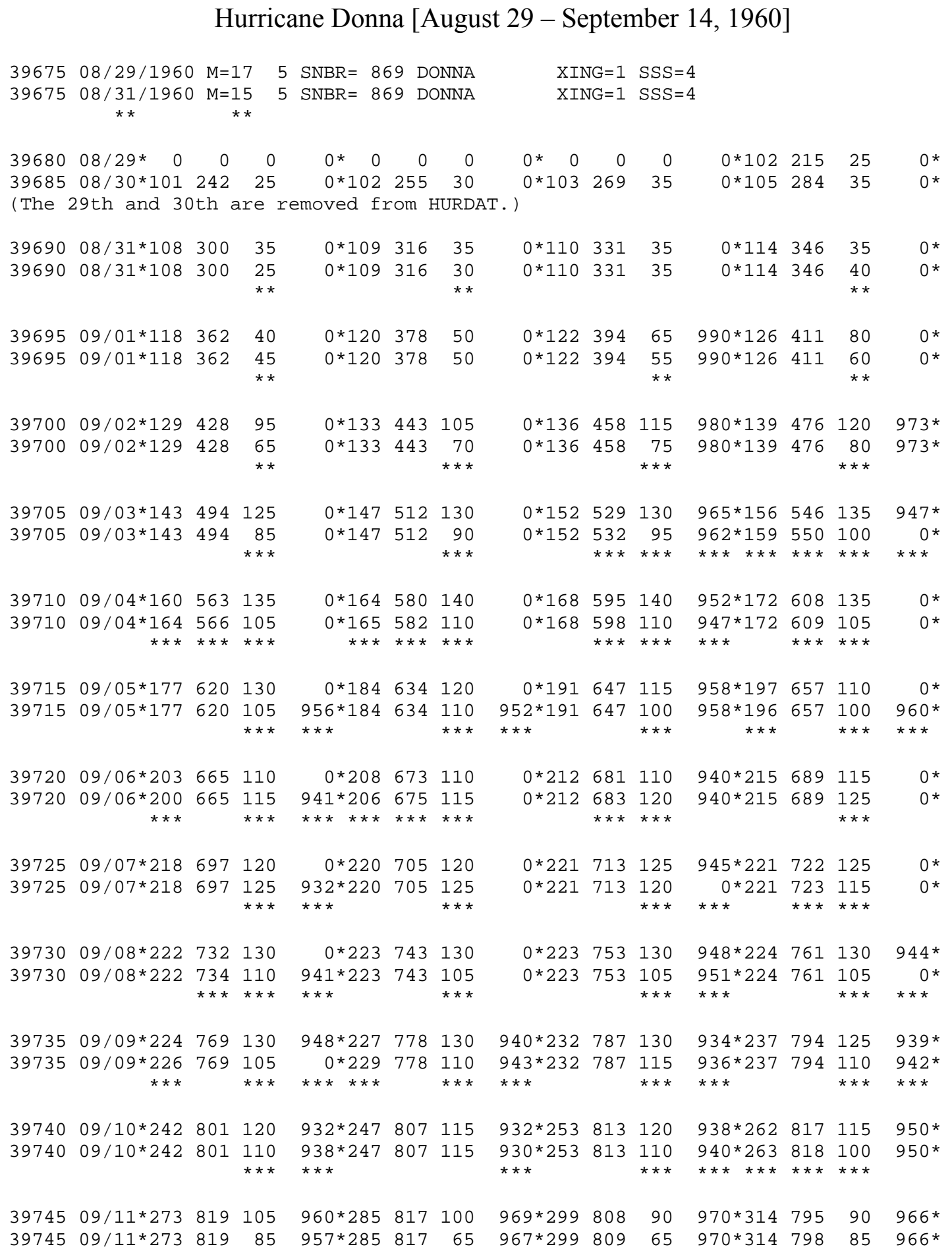




\begin{tabular}{|c|c|c|c|c|c|c|c|c|c|c|c|c|c|}
\hline & & & $\star \star \star *$ & $\star \star \star *$ & & $\star * *$ & $\star * \star$ & $\star * *$ & $* *$ & & $* * *$ & $\star *$ & \\
\hline $\begin{array}{l}39750 \\
39750\end{array}$ & $\begin{array}{r}09 / 12 * 331 \\
09 / 12 * 332 \\
* * *\end{array}$ & $\begin{array}{l}780 \\
781 \\
\star * \star\end{array}$ & $\begin{array}{l}95 \\
95\end{array}$ & $\begin{array}{l}958 * 350 \\
955 * 351 \\
* * * * * *\end{array}$ & $\begin{array}{l}769 \\
768 \\
\star * *\end{array}$ & $\begin{array}{l}9 \odot \\
9 \odot\end{array}$ & $\begin{array}{r}0 * 373 \\
958 * 373 \\
* * *\end{array}$ & $\begin{array}{l}748 \\
748\end{array}$ & $\begin{array}{l}95 \\
90 \\
\star *\end{array}$ & $\begin{array}{l}965 * 400 \\
958^{*} 401 \\
* * * * *\end{array}$ & $\begin{array}{l}731 \\
733 \\
\star * *\end{array}$ & $\begin{array}{l}90 \\
85 \\
* *\end{array}$ & $\begin{array}{r}0^{*} \\
959^{*} \\
* * *\end{array}$ \\
\hline $\begin{array}{l}39755 \\
39755\end{array}$ & $\begin{array}{r}09 / 13 * 431 \\
09 / 13 * 430 \\
* * *\end{array}$ & $\begin{array}{l}712 \\
712\end{array}$ & $\begin{array}{l}75 \\
65 \\
\star *\end{array}$ & $\begin{array}{r}\text { OE466 } \\
975 \mathrm{E} 470 \\
* * * * * *\end{array}$ & $\begin{array}{l}689 \\
686 \\
\star * *\end{array}$ & $\begin{array}{l}60 \\
60\end{array}$ & $\begin{array}{l}\text { } \mathrm{E} 50 \odot \\
975 \mathrm{E} 50 \odot \\
* * *\end{array}$ & $\begin{array}{l}660 \\
660\end{array}$ & $\begin{array}{l}55 \\
60 \\
\star *\end{array}$ & $\begin{array}{r}\text { OE531 } \\
975 \mathrm{E} 531 \\
* * *\end{array}$ & $\begin{array}{l}625 \\
625\end{array}$ & $\begin{array}{l}45 \\
6 \odot \\
\star *\end{array}$ & $\begin{array}{r}\theta^{*} \\
980^{*} \\
* * *\end{array}$ \\
\hline $\begin{array}{l}39760 \\
39760\end{array}$ & $\begin{array}{l}09 / 14 E 56 \odot \\
09 / 14 E 56 \odot\end{array}$ & $\begin{array}{l}582 \\
582\end{array}$ & $\begin{array}{l}35 \\
45 \\
\star *\end{array}$ & $\begin{array}{rr}0^{*} & 0 \\
985 \mathrm{E} 585 \\
* * * * * *\end{array}$ & $\begin{array}{r}0 \\
540 \\
* * *\end{array}$ & $\begin{array}{r}\odot \\
4 \odot \\
* *\end{array}$ & $\begin{array}{c}0^{*} \odot \\
990 \mathrm{E} 610 \\
* * * * * *\end{array}$ & $\begin{array}{r}\odot \\
50 \odot \\
* * *\end{array}$ & $\begin{array}{r}\odot \\
4 \odot \\
* *\end{array}$ & $\begin{array}{rr}0^{*} & \odot \\
995^{*} & \odot \\
* * * & \end{array}$ & $\begin{array}{l}\odot \\
\odot\end{array}$ & $\begin{array}{l}\odot \\
\odot\end{array}$ & $\begin{array}{l}0^{*} \\
0^{*}\end{array}$ \\
\hline
\end{tabular}

39765 HRBFL4 DFL2 NC3 NY3 CT2 RI1 MA1 NH1 ME1 39765 HRBFL4CFL2DFL1 NC2 VA1 NY2 CT1 RI1 MA1

$* * * * * * * * * * * * * * * * * * *$

Major changes to the track and to the intensity shown in Neumann et al. (1999). Evidence for these alterations comes from the Historical Weather Map series,_Monthly Weather Review_, daily Surface Weather Observations from NCDC, U.S. Weather Bureau six hourly maps available via microfilm at $\mathrm{NHC}$, aircraft observations available from the Storm Wallets at NHC, the COADS ship database, Cry (1960), Harris (1963), Miller (1964), Schwerdt et al. (1979), Ho et al. (1987), Jarrell et al. (1992), Boose et al. (2001), and Dunion et al. (2003).

1st Landfall:

10/07Z: 24.8N 80.9W - $930 \mathrm{mb}-115 \mathrm{kt}-18 \mathrm{nmi}$ RMW - BFL4,CFL2

2nd Landfall:

10/19Z: $26.5 \mathrm{~N} 81.9 \mathrm{~W}-951 \mathrm{mb}-100 \mathrm{kt}$-(winds low at landfall as right front quadrant overland well before landfall of center) - $11 \mathrm{nmi}$ RMW - DFL1 (as the hurricane moved across the state)

3rd Landfall:

12/04Z: 34.6N 77.4W - 955 mb - 95 kt - 26 nmi RMW - NC2,VA1

4th Landfall:

12/19Z: 40.7N 72.9W - $959 \mathrm{mb}-85 \mathrm{kt}$ - 48 nmi RMW - NY2

5th Landfall:

12/20Z: 41.3N 72.4W - 962 mb - 80 kt - 48 nmi RMW - CT1, RI1, MA1

Aug 29- HWM indicates a low near 10.5N, 19.5W. Station highlight: No gales or low pressures. Ship highlight: No gales or low pressures. Aircraft highlight: No gales or low pressures. "The passage of an active easterly wave through the area was suggested by unusually heavy rain at Dakar, with which the crash of an airliner there on August 29 was associated and by heavy rain in the Cape Verde Islands on the $30^{\text {th }}$ " (MWR). 
Aug 30- HWM indicates a closed low of at most 1010mb near 9.0N, 27.0W. HURDAT lists this as a Tropical Storm with $35 \mathrm{kt}$ winds at $10.3 \mathrm{~N}, 26.9 \mathrm{~W}$ at $12 \mathrm{UTC}$. Station highlight: No gales or low pressures. Ship highlight: No gales or low pressures. Aircraft highlight: No gales or low pressures. "An aircraft reported indication of a tropical disturbance near 10.0N, 24.0W" (MWR).

Aug 31- HWM indicates a storm with at most 1010mb near 11.0N, 32.8W. HURDAT lists this as a Tropical Storm with $35 \mathrm{kt}$ winds at $11.0 \mathrm{~N}, 33.1 \mathrm{~W}$ at $12 \mathrm{UTC}$. Station highlight: No gales or low pressures. Ship highlight: No gales or low pressures. Aircraft highlight: No gales or low pressures.

Sept 1- HWM indicates a storm with at most $1005 \mathrm{mb}$ near $11.5 \mathrm{~N}, 39.1 \mathrm{~W}$. HURDAT lists this as a Category 1 hurricane with $65 \mathrm{kt}$ winds and a pressure of $990 \mathrm{mb}$ at $12.2 \mathrm{~N}, 39.4 \mathrm{~W}$ at 12 UTC. The revised HURDAT lists this as a Tropical Storm with 55kt winds and a pressure of $990 \mathrm{mb}$ at $12.2 \mathrm{~N}, 39.4 \mathrm{~W}$ at 12 UTC. Station highlight: No gales or low pressures. Ship highlight: No gales or low pressures. Aircraft highlight: No gales or low pressures.

Sept 2- HWM indicates a storm with at most $1000 \mathrm{mb}$ near $13.4 \mathrm{~N}, 46.1 \mathrm{~W}$. HURDAT lists this as a Category 4 hurricane with $115 \mathrm{kt}$ winds and a pressure of $980 \mathrm{mb}$ at $13.6 \mathrm{~N}$, $45.8 \mathrm{~W}$ at 12 UTC. The revised HURDAT lists this as a Category 1 hurricane with $75 \mathrm{kt}$ winds and a pressure of $980 \mathrm{mb}$ at $13.6 \mathrm{~N}, 45.8 \mathrm{~W}$ at 12 UTC. Station highlight: No gales or low pressures. Ship highlight: $45 \mathrm{kt}$ with pressure of $1004 \mathrm{mb}$ at $14.2 \mathrm{~N}, 48.6 \mathrm{~W}$ at 1600UTC. Aircraft highlight: Pressure of $973 \mathrm{mb}$ at $14.2 \mathrm{~N}, 48.4 \mathrm{~W}$ at $2001 \mathrm{UTC}$. "Donna, the one major hurricane of the season and the most destructive ever to strike Florida, was detected by aerial reconnaissance on the afternoon of September 2 near 14.0N, 49.0W. Max observed surface winds at that time were $120 \mathrm{kt}$ and there was a well-developed eye with a central pressure of $973 \mathrm{mb}$ " (MWR).

Sept 3- HWM indicates a storm with at most $1000 \mathrm{mb}$ near $14.9 \mathrm{~N}, 53.2 \mathrm{~W}$. HURDAT lists this as a Category 4 hurricane with $130 \mathrm{kt}$ winds and a pressure of $965 \mathrm{mb}$ at $15.2 \mathrm{~N}$, $52.9 \mathrm{~W}$ at 12 UTC. The revised HURDAT lists this as a Category 2 hurricane with $95 \mathrm{kt}$ winds and a pressure of $962 \mathrm{mb}$ at $15.2 \mathrm{~N}, 53.2 \mathrm{~W}$ at 12 UTC. Station highlight: No gales or low pressures. Ship highlight: No gales or low pressures. Aircraft highlight: Pressure of $962 \mathrm{mb}$ at $15.3 \mathrm{~N}, 53.2 \mathrm{~W}$ at $1255 \mathrm{UTC} ; 43 \mathrm{kt}$ winds at $17.0 \mathrm{~N}, 53.0 \mathrm{~W}$ at $1450 \mathrm{UTC}$.

Sept 4- HWM indicates a storm with at most $995 \mathrm{mb}$ near $16.4 \mathrm{~N}, 59.6 \mathrm{~W}$. HURDAT lists this as a Category 5 hurricane with 140kt winds and a pressure of $952 \mathrm{mb}$ at $16.8 \mathrm{~N}$, $59.5 \mathrm{~W}$ at 12 UTC. The revised HURDAT lists this as a Category 3 hurricane with $110 \mathrm{kt}$ winds and a pressure of $947 \mathrm{mb}$ at $16.8 \mathrm{~N}, 59.8 \mathrm{~W}$ at 12 UTC. Station highlight: No gales or low pressures. Ship highlight: No gales or low pressures. Aircraft highlight: Pressure of $942 \mathrm{mb}$ at $17.0 \mathrm{~N}, 60.0 \mathrm{~W}$ at $1317 \mathrm{UTC} ; 35 \mathrm{kt}$ winds at $19.5 \mathrm{~N}, 60.7 \mathrm{~W}$ at $1620 \mathrm{UTC}$. "Donna continued toward the west-northwest on approximately the climatological track, but at a slightly faster-than-average rate of about $17 \mathrm{kt}$. This course took the hurricane 
through the northern Leeward islands during the evening of September 4 with the eye passing over Barbuda, St. Barthelemy, Sint Maarten, Anguila, and about 10 miles to the south of Anegada" (MWR). "The maximum sustained wind observed at Sint Maarten was $110 \mathrm{kt}$ and the lowest barometer reading $952 \mathrm{mb}$, compared to earlier reports from reconnaissance of 140kt winds and dropsonde measurements of $947 \mathrm{mb}$ " (MWR). "Wind and tide damage was heavy in the Leeward Islands. A large percentage of the houses on Sint Maarten, Barbuda, and Anguilla were destroyed or severely damaged, with about $\$ 3.25$ million in property losses, and five fatalities on Anguilla. Major damage occurred on St. Berthelemy, and on Sombrero and Virgin Gordo damage was characterized as heavy to severe to property, crops, and livestock" (CLIMDAT).

Sept 5- HWM indicates a storm with at most $995 \mathrm{mb}$ near $18.3 \mathrm{~N}, 64.9 \mathrm{~W}$. HURDAT lists this as a Category 4 hurricane with $115 \mathrm{kt}$ winds and a pressure of $958 \mathrm{mb}$ at $19.1 \mathrm{~N}$, $64.7 \mathrm{~W}$ at 12 UTC. The revised HURDAT lists this as a Category 3 hurricane with $100 \mathrm{kt}$ winds and a pressure of $958 \mathrm{mb}$ at $19.1 \mathrm{~N}, 64.7 \mathrm{~W}$ at 12 UTC. Station highlight: $110 \mathrm{kts}$ with pressure of $952 \mathrm{mb}$ at St. Martin (18.0N, 63.0W) (no time given). Ship highlight: $10 \mathrm{kts}$ with pressure of $992 \mathrm{mb}$ at $20.5 \mathrm{~N}, 72.8 \mathrm{~W}$ at 2300 UTC. Aircraft highlight: Pressure of $956 \mathrm{mb}$ at $18.1 \mathrm{~N}, 62.3 \mathrm{~W}$ at $0100 \mathrm{UTC} ; 130 \mathrm{kts}$ with pressure of $965 \mathrm{mb}$ at $19.6 \mathrm{~N}$, $65.3 \mathrm{~W}$ at 1555 UTC. "Only minor damage was reported at St. Thomas, Virgin Islands, with the wind reaching a gust speed of $52 \mathrm{kt}$ as the storm center passed about 35 miles to the northeast on September 5. Movement continued toward the west-northwest on the $5^{\text {th }}$ and highest sustained winds were $33 \mathrm{kt}$ at San Juan, P.R. as the hurricane passed some 85 miles north" (MWR).

Sept 6- HWM indicates a storm with at most $995 \mathrm{mb}$ near $21.0 \mathrm{~N}, 68.2 \mathrm{~W}$. HURDAT lists this as a Category 3 hurricane with $110 \mathrm{kt}$ winds and a pressure of $940 \mathrm{mb}$ at $21.2 \mathrm{~N}$, $68.1 \mathrm{~W}$ at 12 UTC. The revised HURDAT lists this as a Category 4 hurricane with $120 \mathrm{kt}$ winds and a pressure of $940 \mathrm{mb}$ at $21.2 \mathrm{~N}, 68.3 \mathrm{~W}$ at $12 \mathrm{UTC}$. Station highlight: No gales or low pressures. Ship highlight: $35 \mathrm{kt}$ SE with pressure of $1016 \mathrm{mb}$ at $23.2 \mathrm{~N}, 64.87 \mathrm{~W}$ at 0600 UTC. Aircraft highlight: $120 \mathrm{kt}$ with pressure of $932 \mathrm{mb}$ at $21.7 \mathrm{~N}, 69.1 \mathrm{~W}$ at 2230 UTC. "Serious floods developed over the northern and eastern portions of [Puerto Rico] on the morning of September 6. Despite the warnings, 107 persons were drowned. The greatest loss of life was at Humacao where 84 deaths occurred" (MWR). "A change in the movement of the storm occurred on the $6^{\text {th }}$ with a shift of direction to the west toward the north coast of Cuba. The forward motion also slowed to $12 \mathrm{kt}$ and later to $7-9 \mathrm{kt}$ with a concurrent drop of central pressure to near $941 \mathrm{mb}$ and an increase in maximum surface winds to around 122kt and later to 130kt" (CLIMDAT).

Sept 7- HWM indicates a storm with at most 990mb near 21.3N, 71.4W. HURDAT lists this as a Category 4 hurricane with $125 \mathrm{kt}$ winds and a pressure of $945 \mathrm{mb}$ at $22.1 \mathrm{~N}$, $71.3 \mathrm{~W}$ at 12 UTC. The revised HURDAT lists this as a Category 4 hurricane with $120 \mathrm{kt}$ winds at $22.1 \mathrm{~N}, 71.3 \mathrm{~W}$ at $12 \mathrm{UTC}$. Station highlight: $45-50 \mathrm{kt}$ at Turks Island $(21.5 \mathrm{~N}$, $71.2 \mathrm{~W}$ ) no time given. Ship highlight: $43 \mathrm{kt} \mathrm{W}$ with pressure of $985 \mathrm{mb}$ at $21.4 \mathrm{~N}, 71.0 \mathrm{~W}$ at 0900 UTC; $48 \mathrm{kt} \mathrm{W}$ at $21.5 \mathrm{~N}, 71.0 \mathrm{~W}$ at 0600 UTC. Aircraft highlight: Pressure of $941 \mathrm{mb}$ at $22.1 \mathrm{~N}, 73.0 \mathrm{~W}$ at $2150 \mathrm{UTC} ; 43 \mathrm{kt} \mathrm{SE}$ at $23.2 \mathrm{~N}, 70.8 \mathrm{~W}$ at $1530 \mathrm{UTC}$. "The 
central pressure given by dropsonde was $940 \mathrm{mb}$ on the $6^{\text {th }}$ and $944 \mathrm{mb}$ on the $7^{\text {th, }}$ (MWR). "Donna moved into the southeastern Bahamas on the afternoon of the $7^{\text {th }}$, with the eye passing slightly north of Turks and Grand Caicos Islands, thence westward to the vicinity of Grand Ragged Island by the morning of the $8^{\text {th" }}$ (CLIMDAT). "As Donna approached the southeastern Bahamas, maximum winds were estimated up to 150 m.p.h. Mayaguana was buffeted for 13 hours $b$ y winds of hurricane force which reached over 100 m.p.h., at times. Heavy rain continued to accompany the storm in the Bahamas" (CLIMDAT).

Sept 8- HWM indicates a storm with at most $995 \mathrm{mb}$ near $22 \mathrm{~N}, 75.2 \mathrm{~W}$. HURDAT lists this as a Category 4 hurricane with $130 \mathrm{kt}$ winds and a pressure of $948 \mathrm{mb}$ at $22.3 \mathrm{~N}$, $75.3 \mathrm{~W}$ at $12 \mathrm{UTC}$. The revised HURDAT lists this as Category 3 hurricane with $105 \mathrm{kt}$ winds and a pressure of $951 \mathrm{mb}$ at $22.3 \mathrm{~N}, 75.3 \mathrm{~W}$ at 12 UTC. Station highlight: $61 \mathrm{kt} \mathrm{ENE}$ at The Exumas $(23.4 \mathrm{~N}, 75.6 \mathrm{~W})$ at 1200 UTC. Ship highlight: $35 \mathrm{kt} \mathrm{S}$ with pressure of $1007 \mathrm{mb}$ at $19.5 \mathrm{~N}, 75.1 \mathrm{~W}$ at 1200 UTC. Aircraft highlight: Pressure of $951 \mathrm{mb}$ at $22.2 \mathrm{~N}$, $75.5 \mathrm{~W}$ at $1300 \mathrm{UTC} ; 35 \mathrm{kt} \mathrm{E}$ at $23.3 \mathrm{~N}, 77.0 \mathrm{~W}$ at $2030 \mathrm{UTC}$. "The eye passed over or very near Mayaguana, Acklins Island, Fortune Island, and Ragged Island. Mayaguana ...was battered by hurricane force winds for 13 hours" (MWR). "At 0700 EST on September 8, when the hurricane was located only 380 miles southeast of Miami and moving westward at about10kt the Miami wind at 500mb was still blowing from the west" (MWR).

"Damage on Turks and Caicos was estimated at \$288,000. Heavy rains on the southern fringes of the storm lashed at Hispaniola and Jamaica" (CLIMDAT).

Sept 9- HWM indicates a storm near 23N, 78.6W. HURDAT lists this as a Category 4 hurricane with $130 \mathrm{kt}$ winds and a pressure of $934 \mathrm{mb}$ at $23.2 \mathrm{~N}, 78.7 \mathrm{~W}$ at $12 \mathrm{UTC}$. The revised HURDAT lists this as a Category 4 hurricane with $115 \mathrm{kt}$ winds and a pressure of $936 \mathrm{mb}$ at $23.2 \mathrm{~N}, 78.7 \mathrm{~W}$ at $12 \mathrm{UTC}$. Station highlight: $65 \mathrm{kt} \mathrm{S}$ at with pressure of $1004 \mathrm{mb}$ at Andros (24.1N, 77.5W) at 1200 UTC. Ship highlight: $87 \mathrm{kt} \mathrm{NNW}$ at $24.0 \mathrm{~N}, 80.0 \mathrm{~W}$ at 1800 UTC. Aircraft highlight: $130 \mathrm{kt}$ with a pressure of $933 \mathrm{mb}$ at $23.1 \mathrm{~N}, 78.3 \mathrm{~W}$ at 0920 UTC. "On September 9, Donna skirted the northeastern coast of Cuba, bringing gales and heavy rains to much of the island, then took a west-northwest course, toward the Florida Keys" (MWR). "A progressively increasing turn to the west-northwest began during the afternoon and brought the storm center across Grand Bahama Bank well south of Andros Island to a position near $24.0 \mathrm{~N}, 80.0 \mathrm{~W}$ by $1900 \mathrm{EST}$ on the $9^{\text {th }}$, thence over the middle Florida Keys between 0200 and 0300 EST on the $10^{\text {th }}$ " (CLIMDAT). "Gales winds and high tides lashed the north coast of Cuba from Havana eastward. High tides also pounded portions of the south coast, and floods destroyed about 80 houses at Gibard in Oriente Province" (CLIMDAT).

Sept 10- HWN indicates a storm with at most $990 \mathrm{mb}$ near $25 \mathrm{~N}, 81 \mathrm{~W}$. HURDAT lists this as a Category 4 hurricane with $120 \mathrm{kt}$ winds and a pressure of $938 \mathrm{mb}$ at $25.3 \mathrm{~N}, 81.3 \mathrm{~W}$ at 12 UTC. The revised HURDAT lists this as a Category 3 hurricane with $110 \mathrm{kt}$ winds and a pressure of $940 \mathrm{mb}$ at $25.3 \mathrm{~N}, 81.3 \mathrm{~W}$ at 12 UTC. Station highlight: Pressure of $933 \mathrm{mb}$ at Conch Key (24.8N, 80.9W) no time given; $111 \mathrm{kt}$ NW at Sombrero Key (24.6N, 81.1W) at 0630 UTC. Ship highlight: No gales or low pressures. Aircraft highlight: Pressure of 
$937 \mathrm{mb}$ at $24.7 \mathrm{~N}, 80.4 \mathrm{~W}$ at $0400 \mathrm{UTC} ; 39 \mathrm{kt} \mathrm{NNW}$ at $25.8 \mathrm{~N}, 83.7 \mathrm{~W}$ at $1830 \mathrm{UTC}$. "The center crossed over the middle Keys just northeast of Marathon between 0200 and 0300 EST on September 10. The central pressure had continued to drop as the hurricane moved across the warm waters of the Florida Straits and was approximately $930 \mathrm{mb}$ when the center reached the Keys" (MWR). "On the Keys, the central eye extended from just north and east of Marathon shores to Lignumvitae Key" (CLIMDAT). "At Sombrero Light, west of the area of strongest winds, the fastest recorded mile was at a rate of 128 m.p.h., at 1:30 am, est., on the $10^{\text {th }}$ with gusts to $150 \mathrm{mph}$. At Tavernier, to the east of the area of strongest winds, the fastest measured mile was $120 \mathrm{mph}$, the limit of the anemometer. The indicator needle held sold against this maximum for at least 45 minutes. Anemometers were blown away or stations evacuated at Flamingo, Everglades, and Naples" (CLIMDAT). "The lowest atmospheric pressure measured by a calibrated aneroid barometer was 27.55 inches in Conch Key as the eye passed" (CLIMDAT). "Tides in the Everglades - Naples - Ft. Myers Beach area were estimated 4 to 7 feet above normal (slightly higher at places) and pushed into the towns, damaging streets, buildings, and docks. Beach erosion and deposition were extensive. North of Bradenton on the west coast and Palm Beach on the east coast maximum tides were mostly 1 to 3 feet above normal and in the Miami area were generally 2 to 4 feet above normal" (CLIMDAT).

Sept 11- HWM indicates a storm near 30.0N, 80.2W. HURDAT lists this as a Category 2 hurricane with $90 \mathrm{kt}$ winds and a pressure of $970 \mathrm{mb}$ at $29.9 \mathrm{~N}, 80.8 \mathrm{~W}$ at $12 \mathrm{UTC}$. The revised HURDAT lists this as a Category 1 hurricane with $65 \mathrm{kt}$ winds and a pressure of $970 \mathrm{mb}$ at $29.9 \mathrm{~N}, 80.8 \mathrm{~W}$ at 12 UTC. Station highlight: Pressure of $950 \mathrm{mb}$ at Fort Myers $(26.2 \mathrm{~N}, 81.9 \mathrm{~W})$ no time given; 59kt NE at Lakeland $(28.0 \mathrm{~N}, 81.9 \mathrm{~W})$ at $0235 \mathrm{UTC}$. Ship highlight: $25 \mathrm{kt} \mathrm{S}$ with pressure of $976 \mathrm{mb}$ at $27.5 \mathrm{~N}, 77.6 \mathrm{~W}$ at $0600 \mathrm{UTC}$; $65 \mathrm{kt} \mathrm{WNW}$ with pressure of $985 \mathrm{mb}$ at $30.5 \mathrm{~N}, 79.5 \mathrm{~W}$ at 2100 UTC. Aircraft highlight: $85 \mathrm{kt}$ with pressure of $968 \mathrm{mb}$ at $30.7 \mathrm{~N}, 80.6 \mathrm{~W}$ at 1545 UTC. "The eye passed over Naples and Fort Myers as the hurricane turned northward, moved inland, and then continued northeastward to reenter the Atlantic just north of Daytona Beach about 0400 EST, September 11" (MWR). "Despite the trajectory over land and a filling of central pressure from $950 \mathrm{mb}$ at Fort Myers to $970 \mathrm{mb}$ on the east coast, the storm was still intense and well organized when it moved into the Atlantic again" (MWR). "Rapid intensification occurred over the ocean and when the center was about 80miles southeast of Charleston, S.C., on the afternoon of September 11, the SS Mae reported winds of 105kt and 20 to 30-foot seas" (MWR). "Damage from wind and tide was extremely heavy on the Keys and the southwest coast, varying from almost complete destruction of all but the most substantial buildings in the area from marathon to Tavernier to battered boats, dock, broken windows and water damage, and lost roofs in all but the western Keys. Extensive destruction of small houses and buildings and roof damage occurred northward to Punta Gorda. Outside these main damage areas, the wind blew over thousands of trees, shattered windows, blew off or damaged roofs and demolished many weak buildings. Wind-driven rain also added to the damage. Power and communications facilities were disrupted throughout central and south Florida" (CLIMDAT). "Some tornadoes, embedded in the forward quadrant of the storm, occurred during the afternoon of the $11^{\text {th }}$. These caused some local damage near 
Clinton, North Carolina, around 5pm est., and near Elizabethtown, North Carolina, around $2 \mathrm{pm}$. Several persons were injured in the storm near Clinton. Preliminary damage reports indicate property damage in N. Carolina to beaches and cities along the immediate coast and sounds affected by tides and wind near \$20 million; to crops and farm property also near $\$ 20$ million; to forests near \$5million; to inland communities near \$1million, and to bridges and highways, near \$500,000” (CLIMDAT).

Sept 12- HWM indicates a storm of at most $975 \mathrm{mb}$ near $37.7 \mathrm{~N}, 74.5 \mathrm{~W}$. HURDAT lists this as a Category 2 hurricane with $95 \mathrm{kt}$ and a pressure of $965 \mathrm{mb}$ at $37.3 \mathrm{~N}, 74.8 \mathrm{~W}$ at 12 UTC. The revised HURDAT lists this as a Category 2 hurricane with pressure of $958 \mathrm{mb}$ at $37.3 \mathrm{~N}, 74.8 \mathrm{~W}$ at $12 \mathrm{UTC}$. Station highlight: Pressure of $958 \mathrm{mb}$ at Belhaven $(35.5 \mathrm{~N}$, $76.6 \mathrm{~W})$ at $0700-0745 \mathrm{UTC} ; 90 \mathrm{kt}$ at Long Island $(40.8 \mathrm{~N}, 73.0 \mathrm{~W})$ no time given. Ship highlight: $61 \mathrm{kt} \mathrm{SSE}$ with pressure of $974 \mathrm{mb}$ at $39.7 \mathrm{~N}, 72.0 \mathrm{~W}$ at $1800 \mathrm{UTC} ; 75 \mathrm{kt} \mathrm{E}$ with pressure of $991 \mathrm{mb}$ at $32.3 \mathrm{~N}, 79.2 \mathrm{~W}$ at $0000 \mathrm{UTC}$. Aircraft highlight: $110 \mathrm{kt}$ at $37.5 \mathrm{~N}$, $74.5 \mathrm{~W}$ at 1320 UTC. "During its passage over North Carolina, Donna's eye was usually large with the area of calm or light variable winds ranging from 50 to 80 miles in diameter. Minimum pressures reported along this section of the track ranged from 958 to $967 \mathrm{mb}$ and highest winds were in the 70-90kt bracket" (MWR). "When Donna again reached the ocean, it resumed its rapid movement with a forward speed of 30-35kt, moving northeastward a short distance off the coast and crossing Long Island shortly after noon on September 12. Sustained winds reached about 90kt at several points on Long Island and 50-60kt on western Long Island and in New York City" (MWR). "During the period the hurricane was moving from North Carolina to southern New England this was as much as 50 to over 100 miles in diameter, an extreme and probably unprecedented size for a hurricane eye" (MWR). "The large eye (possibly the largest of record) was a continuing feature as Donna moved rapidly northeastward, paralleling the Middle Atlantic coast, at some 30-35kt during the morning hours of the $12^{\text {th }}$, (CLIMDAT). "Losses to property were great along the immediate shore, where wind and tide damage to boats, docks, boardwalks, cottages, and buildings were severe in some areas. Hardest hit was Ocean City, Md., where the storm was described by some old residents as the most severe in the City's history. Extensive minor property damage from wind, rain, and small stream overflow throughout inland sections was considerable in the aggregate. Trees falling on lines disrupted power and communications. Additional wind damage was chiefly to small structures, windows and roofs, and signs" (CLIMDAT). "Damages in the heavily populated Northeastern States were heavy. Unprecedented flood damage occurred in the Catskill area. The loss at Windham alone was estimated at more than $\$ 1$ million. Damage to all types of boats, docks, highways, and bridges on Long Island was very heavy from flooding, high tides, and heavy seas. Many thousands of tress and limbs were blown down by high winds in the Long Island- lower Hudson Valley area, disrupting power, communications, and travel. Tide damage from coastal erosion and flooding was extensive" (CLIMDAT).

Sept 13- HWM indicates a closed low near 49.5N, 66.5W. HURDAT lists this as an Extratropical storm with $55 \mathrm{kt}$ winds at $50.0 \mathrm{~N}, 66.0 \mathrm{~W}$ at $12 \mathrm{UTC}$. The revised HURDAT lists this as an Extratropical storm with $60 \mathrm{kt}$ winds at $50.0 \mathrm{~N}, 66.0 \mathrm{~W}$ at $12 \mathrm{UTC}$. Station 
highlight: Pressure of $969 \mathrm{mb}$ at Haverhill (42.8N, 71.1W) at $0030 \mathrm{UTC} ; 54 \mathrm{kt} \mathrm{SE}$ at Portland $(43.7 \mathrm{~N}, 70.3 \mathrm{~W})$ at 0013 UTC. Ship highlight: $20 \mathrm{kt} \mathrm{S}$ with pressure of $979 \mathrm{mb}$ at $49.6 \mathrm{~N}, 65.2 \mathrm{~W}$ at $1200 \mathrm{UTC} ; 60 \mathrm{kt} \mathrm{W}$ at $47.7 \mathrm{~N}, 59.3 \mathrm{~W}$ at $1700 \mathrm{UTC}$. Aircraft highlight: No gales or low pressures. "Gradual filling and weakening occurred farther north as the center continued rapidly northeastward, moving through Maine just west of Caribou and into Canada late on September 13. Winds of hurricane force still persisted in squalls near the center until about the time it reached the Canadian border" (MWR).

Genesis for Donna is delayed 36 hours due to observations showing that the closed circulation did not exist until around 00 UTC on the 31 st. Other that this major change of the track at genesis (and another discussed later for dissipation), only minor alterations of the track were introduced for all days except for the 31 st through the 2nd. Unlike most tropical cyclones of the late 1950s and 1960s, central pressure values were provided in HURDAT for the 12 UTC times from the 1st until the 12th. Many of these are not based upon any observation, but were estimated. Those values that were reasonable were retained, but a few were either replaced by actual measurements of the central pressure or removed. As is clear from the Monthly Weather Review writeup, no gale force winds or low pressures were observed until the $2 \mathrm{nd}$. The $990 \mathrm{mb}$ central pressure listed at 12 UTC was likely not actually observed, but does suggest winds of $64 \mathrm{kt}$ from the southern pressure-wind relationship. $65 \mathrm{kt}$ retained, as this is consistent with what was observed on the 2 nd. The Navy aircraft reached Donna on the 2nd and found $120 \mathrm{kt}$ estimated surface winds, $973 \mathrm{mb}$ central pressure, and a $22 \mathrm{nmi}$ diameter eye at 2001 UTC. Estimated surface winds, especially in this era, are notoriously unreliable and even Navy/Air Force flight-level winds are suspect. The $973 \mathrm{mb}$ pressure suggests winds of $86 \mathrm{kt}$ from the southern-pressure wind relationship. $80 \mathrm{kt}$ (down from $120 \mathrm{kt}$ ) are chosen given the larger than typical (for this central pressure and latitude - Vickery et al. 2000). The $980 \mathrm{mb}$ value in HURDAT for 12 UTC on the 2nd is not based on any observations, but appears to be reasonable and is retained. The next aircraft found that the central pressure dropped to $962 \mathrm{mb}$ with an $18 \mathrm{nmi}$ eye at $1255 \mathrm{UTC}$ on the $3 \mathrm{rd}$. This pressure gives $98 \mathrm{mb}$ from the southern pressure-wind relationship and the eye size is slightly larger than typical - $95 \mathrm{kt}$ chosen for 12 UTC on the 3rd down from 130 kt originally. A central pressure of $947 \mathrm{mb}$ late on the $3 \mathrm{rd}$ suggests winds of $114 \mathrm{kt}$ from the southern pressure-wind relationship. $110 \mathrm{kt}$ chosen for $18 \mathrm{UTC}$ on the 3rd, down from $135 \mathrm{kt}$, due to slightly larger size than climatology.

The hurricane filled some as it reached the Lesser Antilles. A $952 \mathrm{mb}$ central pressure at 1317 UTC on the 4th with an eye diameter of $20 \mathrm{nmi}$ suggests winds of $108 \mathrm{kt}$ from the southern pressure-wind relationship. $105 \mathrm{kt}$ is chosen for $1200 \mathrm{UTC}$ on the 4th due to slightly larger eye than climatology. The pressure oscillated some $(956 \mathrm{mb}$ from aircraft at 
$01 \mathrm{UTC}$ on the 5th, $952 \mathrm{mb}$ from Sint Maarten around $06 \mathrm{UTC}, 956 \mathrm{mb}$ from aircraft at $07 \mathrm{UTC}, 958 \mathrm{mb}$ from aircraft at $1245 \mathrm{UTC}, 960 \mathrm{mb}$ from aircraft at $1345 \mathrm{UTC}, 965 \mathrm{mb}$ from aircraft at $1555 \mathrm{UTC}$, and $956 \mathrm{mb}$ from aircraft at 1943 UTC) during the 5th. Observed sustained winds of $110 \mathrm{kt}$ from Sint Maarten early on the 5th along with a central pressure of $952 \mathrm{mb}$ from the island justify a $110 \mathrm{kt}$ estimate in HURDAT (down from $120 \mathrm{kt}$ originally). Winds during the remainder of the 5 th with pressures slightly $h$ igher are analyzed to be $105 \mathrm{kt}$. The drop in pressure late on the 5th continued into the 6th as $941 \mathrm{mb}$ was observed by aircraft at $0130 \mathrm{UTC}$, $940 \mathrm{mb}$ at $1306 \mathrm{UTC}$, and $932 \mathrm{mb}$ at 1835 and 2230 UTC. The $941 \mathrm{mb}$ pressure suggests winds of $118 \mathrm{kt}$ from the southern-pressure wind relationship. As the $21 \mathrm{nmi}$ eye was larger than climatology, the reanalyzed winds were set to $115 \mathrm{kt}$, up from $110 \mathrm{kt}$ originally at $00 \mathrm{UTC}$ on the $6 \mathrm{th}$. However, the eye contracted down to 10-14 nmi during the remainder of the 6th. The $940 \mathrm{mb}$ pressure suggested winds of $119 \mathrm{kt}, 120 \mathrm{kt}$ used in HURDAT at 12 UTC up from $110 \mathrm{kt}$ originally. The $932 \mathrm{mb}$ readings suggest winds of $125 \mathrm{kt}$, which is used in HURDAT for 18 UTC on the 5th and 00 UTC on the 6th, up from 115 and $120 \mathrm{kt}$ originally. The next available aircraft indicated some weakening with $941 \mathrm{mb}$ central pressure at 2150 UTC on the 7th, which suggested $118 \mathrm{kt}$ from the southern-pressure wind relationship. As the eye had expanded again to $27 \mathrm{nmi}, 115 \mathrm{kt}$ is chosen for HURDAT at $18 \mathrm{UTC} / 7 \mathrm{th}$ and $110 \mathrm{kt}$ at $00 \mathrm{UTC} / 8$ th (down from 125 and $130 \mathrm{kt}$, originally). By $13 \mathrm{UTC}$ on the 8th, aircraft reported that the central pressure had risen to $951 \mathrm{mb}$ with an eliptical eye with axes of 30 and $20 \mathrm{nmi}$. $951 \mathrm{mb}$ suggests winds of $109 \mathrm{kt}$ from the southern-pressure wind relationship. Winds are chosen at 12 UTC on the 8 th to be $105 \mathrm{kt}$ due to the larger than climatologically expected eye, down from $130 \mathrm{kt}$ originally. No reliable surface observations of central pressure and/or maximum winds were available from the Bahamas, during Donna's trek across the islands on the 8th and 9th. During the 9th, another intensification of Donna occurred, as $943 \mathrm{mb}$ at 07 UTC, $933 \mathrm{mb}$ at $0920 \mathrm{UTC}, 936 \mathrm{mb}$ at $13 \mathrm{UTC}, 942 \mathrm{mb}$ at $16 \mathrm{UTC}$, and $943 \mathrm{mb}$ at $22 \mathrm{UTC}$ were measured by aircraft reconnaissance. The $936 \mathrm{mb}$ suggests winds of $122 \mathrm{kt}$ from the southern pressure-wind relationship and $113 \mathrm{kt}$ from the subtropical pressure-wind relationship. With the eye diameter being larger than climatological, winds are set at $115 \mathrm{kt}$ at 12 UTC on the 9th which is reduced from $130 \mathrm{kt}$ originally in HURDAT.

The hurricane intensified again on the 10th as it made landfall in the Florida Keys. Aircraft central pressure was $938 \mathrm{mb}$ at 0050 UTC and $937 \mathrm{mb}$ at 04 UTC. $938 \mathrm{mb}$ pressures suggests winds of $120 \mathrm{kt}$ from the southern and $112 \mathrm{kt}$ from the subtropical pressure-wind relationships. As Donna retained a 20-25 nmi diameter eye, winds were chosen to be $110 \mathrm{kt}$ at $00 \mathrm{UTC}$, down from $120 \mathrm{kt}$ originally. Donna made landfall over the middle Florida Keys at $24.8 \mathrm{~N} 80.9 \mathrm{~W}$ around $07 \mathrm{UTC}$ on the 10th wind central pressure of $930 \mathrm{mb}$, based primarily upon a $933 \mathrm{mb}$ observation from Conch Key. $930 \mathrm{mb}$ suggests 
winds of $127 \mathrm{kt}$ from the southern and $117 \mathrm{kt}$ from the subtropical pressure-wind relationships. The RMW of $18 \mathrm{nmi}$ is near the average $(15 \mathrm{nmi})$ for this pressure and latitude. Other factors include the slow forward speed of Donna (around $9 \mathrm{kt}$ ) and low environmental pressure $(1009 \mathrm{mb}$ ). These suggest a slighly lower value than the average of the two pressure 108 wind relationships, so $115 \mathrm{kt}$ is estimated to be the maximum sustained winds at landfall, retaining Donna as a Category 4 for the Florida Keys (southwest Florida - "BFL"). This is in agreement with the Schwerdt et al. and Dunion et al. estimates. It is noted that the highest sustained wind was $111 \mathrm{kt}$ from Sombrero Key. The close pass of Donna to the boundary between southwest and southeast Florida (at $80.85 \mathrm{~W}$ ) indicates that southeast Florida also received hurricane impacts, which are estimated to be Category 2 based upon the size and landfall location of Donna. After passing the Keys, Donna briefly entered the Gulf of Mexico and then made landfall just north of Naples around 19 UTC on the 10th at $26.5 \mathrm{~N} 81.9 \mathrm{~W}$ with a central pressure of $949 \mathrm{mb}$ observed at Naples. This pressure would suggest winds of $111 \mathrm{kt}$ from the southern and $103 \mathrm{kt}$ from the subtropical pressure-wind relationship, but the front right quadrant of the hurricane had already been overland for a couple of hours. Thus maximum sustained winds at second landfall are estimated to be $100 \mathrm{kt}$. The inland decay of Donna over Florida was considered by Dunion et al. with a combination of all available observations along with the Kaplan and DeMaria model. Dunion et al. analyzed 78, 54, and $61 \mathrm{kt}$ for 00,06 , and 12 (just offshore) UTC on the 11th, respectfully. Given that data not observed may cause a small low-bias in the $\mathrm{H}^{*}$ Wind analysis scheme, winds in HURDAT are reanalyzed to be 85,60 , and $65 \mathrm{kt}$, down from 105, 100 , and $90 \mathrm{kt}$ originally. This change is consistent with the relative lack of significant structural damage over Lakeland and Orlando, that one would have had if Donna were still a Category 3 hurricane over central Florida. However, it is likely that by the time Donna reached into Northeast Florida (north of $28.2 \mathrm{~N}$ along its track), it caused sustained Category 1 conditions. Thus it is analyzed as Category 1 for Northeast Florida ("DFL1"), down from Category 2 hurricane status for the region originally. The central pressure for 00 and 06 UTC on the 11th were adjusted downward slightly to 957 and $967 \mathrm{mb}$ (from 960 and $969 \mathrm{mb}$ originally) due to $962 \mathrm{mb}$ measured (at time of peak estimate winds) in Wauchula at 02 UTC. After passing back into the Atlantic, Donna began reintensifying. A Navy reconnaissance measured $968 \mathrm{mb}$ and a $50 \mathrm{nmi}$ diameter eye at $1545 \mathrm{UTC}$ on the 11th, which was the last aircraft to penetrate the hurricane.

HURDAT originally had $966 \mathrm{mb}$ at 18 UTC on the 11th and while this was not from an observation, it appears reasonable given the reintensification of the hurricane. $966 \mathrm{mb}$ suggests winds of $85 \mathrm{kt}$ from the subtropical pressure-wind relationship. Winds are chosen to be $85 \mathrm{kt}$ (down from $90 \mathrm{kt}$ ) originally due to the large reported eye. 
Donna made a third landfall in the United States around 05 UTC on the 12th at $34.6 \mathrm{~N} 77.4 \mathrm{~W}$. Lowest observed pressure was $958 \mathrm{mb}$ in the eye at Bellhaven in eastern North Carolina a couple hours after landfall. Thus it is estimated that the central pressure at landfall in North Carolina was about $955 \mathrm{mb}$. This pressure suggests winds of $99 \mathrm{kt}$ from the subtropical pressure-wind relationship. Because of the large eye size and relatively low ( 1009 mb) environmental pressure, $95 \mathrm{kt}$ is analyzed as the maximum sustained winds at North Carolina landfall. This agrees with the Schwerdt et al. assessment, but is a downgrade from Category 3 originally analyzed in HURDAT to a Category 2 (though the winds in HURDAT at 06 UTC on the 12th remain $95 \mathrm{kt})$. Highest observed winds in Virginia were $70 \mathrm{kt}$ in Cape Henry, indicating that the state should be listed as having Category 1 hurricane impacts (none were indicated originally).

Donna went back out to sea for about nine more hours before making a fourth U.S. landfall in New York, at 40.7N 72.9W at 19 UTC on the 12th. Observed lowest pressure was at Brookhaven, New York with $961 \mathrm{mb}$. As the center of Donna appears to have passed just east of Brookhaven, the analyzed central pressure at landfall is $959 \mathrm{mb}$, in agreement with Ho et al. $959 \mathrm{mb}$ suggests winds of $90 \mathrm{kt}$ from the northern pressure-wind relationship, However, given the large size (48 nmi RMW), maximum sustained surface winds are estimated to be $85 \mathrm{kt}$ at landfall. (Highest observed sustained winds were $83 \mathrm{kt}$ from Block Island, RI.) Around 20 UTC on the 11th, Donna made its fifth (and final) landfall in the United States at $41.3 \mathrm{~N} 72.4 \mathrm{~W}$ along the Connecticut coastline. Winds are estimated to have dropped to $80 \mathrm{kt}$ by this point. New York is analyzed to have been impacted by Category 2 winds (along the southeastern end of Long Island), which is a downgrade from Category 3 originally. Connecticut, Rhode Island, and Massachusetts are all analyzed to have been impacted by Category 1 winds, which is a downgrade from Category 2 originally for Connecticut and Rhode Island. While winds in Donna are still indicated as $65 \mathrm{kt}$ at 00 UTC on the 13th, these were likely occurring offshore so that New Hampshire and Maine did not receive sustained hurricane force winds. Thus these two states are removed from listing as being impacted by Category 1 conditions. Donna transitioned to extratropical around 06 UTC on the 13th as it approached the Maine-Canada border. Ship observations late on the 13th and on the 14th allowed for analysis of a stronger extratropical storm than originally indicated. An additional 12 hours (06 and 12 UTC on the 14th) were added to HURDAT for Donna as the system was still a distinct entity until that time.

Hurricane Ethel [September 12-17, 1960]

$4168509 / 14 / 1960 M=4 \quad 6 \quad \mathrm{SNBR}=906 \quad \mathrm{ETHEL} \quad \mathrm{XING=1} \mathrm{SSS}=1$ $4168509 / 12 / 1960 M=4 \quad 8$ SNBR= 906 ETHEL $\quad X I N G=1$ SSS=1 


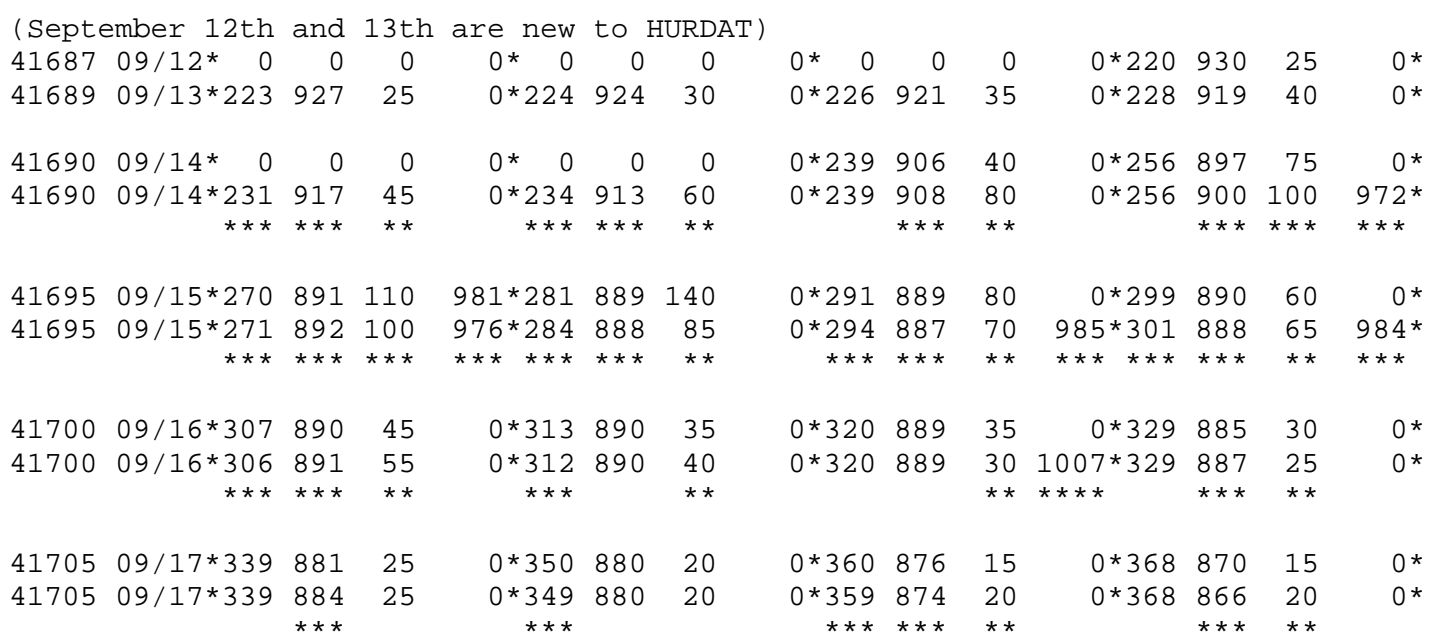

41710 HR MS1

41710 HR LA1MS1

U.S. Hurricane Landfall

Sep 15th $-21 \mathrm{Z}-30.4 \mathrm{~N} 89.0 \mathrm{~W}-70 \mathrm{kt}-$ Category $1-980 \mathrm{mb}-1013 \mathrm{mb}$ OCI $-150 \mathrm{~nm}$ ROCI

Minor changes to the track and major changes to the intensity shown in McAdie et al. (2009). Evidence for these alterations comes from the NHC microfilm maps, the Historical Weather Maps series, the COADS ship database, Monthly Weather Review, Navy reconnaissance book, Surface Weather Observations, Mariners Weather Log, Schwardt et al. (1979), Ho et al. (1987), and Jarrell et al. (1992) and NHC Storm Wallets.

September 12:

HWM analyzes a spot low at $22.0 \mathrm{~N}, 95.0 \mathrm{~W}$ with a weakening front just north at 12Z. HURDAT does not list an organized system on this date. Microfilm shows two areas of low pressure along a frontal boundary stretching NE-SW over the Gulf of Mexico at 12Z. Ship highlights: No gales or low pressures.

ATSR: "The incipient stage of Hurricane ETHEL was noticed as early as 8 September, when a weak trough appeared in the Gulf of Campeche. By 10 September, this trough dominated the entire western portion of the Gulf of Mexico. Two weak vortices formed, one located approximately 150 miles due east of Tampico, and the other south of the Louisiana coastline. During the following three days, the surface trough and its diffuse vortices persisted." 
September 13:

HWM analyzes a closed low pressure of at most $1010 \mathrm{mb}$ at $21.0 \mathrm{~N}, 94.0 \mathrm{~W}$ with a stationary front to the northeast at 12Z. HURDAT does not list an organized system on this date. Microfilm shows a closed low pressure of at most $1009 \mathrm{mb}$ at $22.0 \mathrm{~N}, 91.0 \mathrm{~W}$ with a frontal boundary to the northeast at 12Z. Ship highlights: No gales or low pressures.

ATSR: "As Hurricane DONNA progressed northward along the Eastern seaboard, a weak frontal system moved as far as the central Gulf of Mexico and dissipated by 13 September. This left a surface trough oriented northeast to southwest across the entire Gulf. Now, only the "Tampico" vortex remained, and it had drifted slowly eastward."

September 14:

HWM analyzes a tropical storm of at most $1005 \mathrm{mb}$ at $24.1 \mathrm{~N}, 90.2 \mathrm{~W}$ with a warm front to the north and northeast at $12 \mathrm{Z}$. HURDAT lists a 40 knot tropical storm at $23.9 \mathrm{~N}, 90.6 \mathrm{~W}$ at $12 \mathrm{Z}$ (first position). Microfilm shows a large closed low pressure of at most $1008 \mathrm{mb}$ at $23.5 \mathrm{~N}, 91.5 \mathrm{~W}$ at $12 \mathrm{Z}$. Navy reconnaissance book lists the best track position at $24.0 \mathrm{~N}, 90.5 \mathrm{~W}$ at $12 \mathrm{Z}$. Ship highlights: $35 \mathrm{kt} \mathrm{NE}$ and $1007 \mathrm{mb}$ at $25.6 \mathrm{~N}$, $90.5 \mathrm{~W}$ at $12 \mathrm{Z}$ (micro). $55 \mathrm{kt} \mathrm{ENE}$ and $987 \mathrm{mb}$ at $25.1 \mathrm{~N}, 90.0 \mathrm{~W}$ at $15 \mathrm{Z}$ (ATSR). $35 \mathrm{kt} \mathrm{S}$ and $1002 \mathrm{mb}$ at $24.9 \mathrm{~N}, 89.9 \mathrm{~W}$ at $17 \mathrm{Z}$ (micro). $40 \mathrm{kt} \mathrm{NNE}$ and $1002 \mathrm{mb}$ at $25.7 \mathrm{~N}, 90.3 \mathrm{~W}$ at $18 \mathrm{Z}$ (COADS). $50 \mathrm{kt} \mathrm{SSW}$ and $1009 \mathrm{mb}$ at $25.0 \mathrm{~N}, 87.8 \mathrm{~W}$ at $21 \mathrm{Z}$ (MWL). Aircraft highlights: Radar fix at 24.0N, 90.0W at $1435 \mathrm{Z}$ (MWR). Penetration center fix estimated surface winds of $130 \mathrm{kt}$, an eye diameter of $10 \mathrm{~nm}$ and measured a central pressure of 972 $\mathrm{mb}$ at $25.9 \mathrm{~N}, 90.0 \mathrm{~W}$ at $19 \mathrm{Z}$ (ATSR). Penetration center fix estimated surface winds of $140 \mathrm{kt}$, an eye diameter of $10 \mathrm{~nm}$ and measured a central pressure of $976 \mathrm{mb}$ at $26.6 \mathrm{~N}$, 89.3W at 2212Z (ATSR).

MWR: "Hurricane Ethel developed quickly in the central Gulf of Mexico early on September 14. Its position and intensity were established by the 0930 CST report from MAMOS (Marine Automatic Meteorological Observing Station) in the central Gulf of Mexico. The hurricane moved northward and continued to intensify rapidly during the day with a central pressure of $972 \mathrm{mb}$ and winds of $140 \mathrm{kt}$ reported by reconnaissance aircraft that afternoon." ATSR: "Retrogression of the $200 \mathrm{MB}$ from the central to the extreme western Gulf by $140000 \mathrm{Z}$ placed the cyclone under a strong, divergent southwesterly current. This triggered the extremely rapid development of the low pressure center. The gradient to the northeast of the surface low began increasing slowly early on the 14th of September, and at $1200 \mathrm{Z}$ there were a number of ships reporting easterly to southeasterly winds of 20 to 25 knots. Reported pressures led to the conclusion that the cyclone's central pressure at this time must have been approximately 
$1004 \mathrm{MB}$. This represented a drop of four MB in six hours. At 141435Z, a Braniff flight enroute from Balboa, Canal Zone to Brownsville, Texas reported a "small hurricane, well developed eye at 24N 90W." At 1500Z, the MAMOS located at 25.1N 90.0W reported winds of 55 knots from 070 degrees, and a pressure of $987 \mathrm{MB}$. The first warning on Hurricane ETHEL was issued at $141800 Z$ on the basis of this timely report from the ocean based weather buoy. At 1745Z, a Navy reconnaissance flight reported a fix on ETHEL, located at $25.6 \mathrm{~N} 90.1 \mathrm{~W}$. Subsequently, at $1900 \mathrm{Z}$ the aircraft reached the eye of the hurricane and reported maximum surface winds of 140 knots and a minimum surface pressure of 972 MB."

September 15:

HWM analyzes a tropical storm of at most $995 \mathrm{mb}$ at $29.0 \mathrm{~N}, 88.5 \mathrm{~W}$ at $12 \mathrm{Z}$. HURDAT lists an 80 knot hurricane at $29.1 \mathrm{~N}, 88.9 \mathrm{~W}$ at $12 \mathrm{Z}$. Microfilm shows a closed low pressure of at most $987 \mathrm{mb}$ at $28.8 \mathrm{~N}, 88.9 \mathrm{~W}$ at $09 \mathrm{Z}$ (the $12 \mathrm{Z}$ map is not available). Navy reconnaissance book lists the best track position at $29.3 \mathrm{~N}, 88.6 \mathrm{~W}$ at $12 \mathrm{Z}$. Ship highlights: $65 \mathrm{kt} \mathrm{ESE}$ and $999 \mathrm{mb}$ at 27.4N, 88.1W at $00 \mathrm{Z}$ (micro). $70 \mathrm{kt} \mathrm{SE}$ and $996 \mathrm{mb}$ at $27.6 \mathrm{~N}, 88.9 \mathrm{~W}$ at $03 \mathrm{Z}$ (micro). $65 \mathrm{kt} \mathrm{S}$ and $1000 \mathrm{mb}$ at $27.6 \mathrm{~N}, 88.7 \mathrm{~W}$ at $06 \mathrm{Z}$ (micro). 55 kt SSW and $1003 \mathrm{mb}$ at $27.4 \mathrm{~N}, 88.8 \mathrm{~W}$ at $09 \mathrm{Z}$ (micro). $78 \mathrm{kt}$ (max wind) at Venice, LA at 1015Z (WALLET). $45 \mathrm{kt} \mathrm{W}$ and $1008 \mathrm{mb}$ at 27.4N, 89.1 W at 12Z (COADS). $45 \mathrm{kt} \mathrm{SW}$ and $1006 \mathrm{mb}$ at $28.2 \mathrm{~N}, 88.0 \mathrm{~W}$ at $15 \mathrm{Z}$ (micro). Land highlights: $40 \mathrm{kt} \mathrm{NE}$ and $1001 \mathrm{mb}$ at Burrwood, LA at 0650Z (SWO). $35 \mathrm{kt} \mathrm{NNE}$ at Burrwood, LA at 09Z (micro). $49 \mathrm{kt} \mathrm{NE}$ (max wind) at Keesler AFB, MS at 1953Z (WALLET). $52 \mathrm{kt} \mathrm{N}$ estimated and $979 \mathrm{mb}$ (min pressure) at Gulfport, MS at 21Z (WALLET). $10 \mathrm{kt} \mathrm{S}$ and $981 \mathrm{mb}$ (min pressure) at Keesler AFB, MS at 2208Z (WALLET). Aircraft highlights: Penetration center fix at $27.1 \mathrm{~N}, 89.2 \mathrm{~W}$ at $00 \mathrm{Z}$ (ATSR). Penetration center fix at $29.3 \mathrm{~N}, 88.0 \mathrm{~W}$ at $0740 \mathrm{Z}$ (ATSR). Penetration center fix estimated surface winds of $60 \mathrm{kt}$, an eye diameter of $40 \mathrm{~nm}$ and measured a central pressure of $985 \mathrm{mb}$ at $29.4 \mathrm{~N}, 88.6 \mathrm{~W}$ at $1312 \mathrm{Z}$ (ATSR). Penetration center fix measured a central pressure of $984 \mathrm{mb}$ at $30.2 \mathrm{~N}, 88.7 \mathrm{~W}$ at $17 \mathrm{Z}$ (ATSR). (979 $\mathrm{mb}$ ) measured at Gulfport, MS - RMW $22 \mathrm{nmi}-10 \mathrm{kt}$ forward speed - landfall pt $30.3 \mathrm{~N}$, 89.3W” (Ho et al. (1987). "Sep - MS1 - Cat 1 - 981 mb” (Jarrell et al. (1992). “30.4N, 86.1W - $972 \mathrm{mb}-1015 \mathrm{mb}$ Penv - RMW $18 \mathrm{nmi}$ - speed $10 \mathrm{kt}-74 \mathrm{kt}$ est max sustained 10m, 10-min wind" (Schwardt et al. (1979)).

MWR: "During the night of September 14-15, cool dry air entered the circulation and the hurricane's intensity diminished quickly. The hurricane center reached the coast near Biloxi, Miss, with the lowest pressure $981.4 \mathrm{mb}$ during the afternoon of September 15 at Keesler Air Force Base. It continued to weaken as it moved northward through eastern Mississippi that night. The highest sustained wind reported by a land station was $78 \mathrm{kt}$ with gusts to 90 at Venice, LA, at 0415 CST, September 15. Burrwood, LA, reported 
winds of $45 \mathrm{kt}$ with gusts to 60 . The highest tide reported was 7 feet above mean sea level on Quarantine Bay on the east side of the Mississippi River about 0400 CST on the 15th." ATSR: "With the advent of darkness on the evening 14 September, ETHEL apparently began dissipating at a rate nearly as great as that with which she had intensified. A Navy reconnaissance flight during the night reported the radar eyes as being "open northeast through south" at $150400 \mathrm{Z}$. Radar coverage became increasingly difficult during the remainder of the mission. As best as can be determined, ETHEL maintained hurricane force winds for 24 hours ( $141600 \mathrm{Z}$ to $151600 \mathrm{Z}$ ), during which time she moved on a north-northeasterly course at a speed of approximately 15 knots. She decelerated to ten knots and assumed a more northerly course near the end of the period. Daylight reconnaissance on the morning of 15 September located ETHEL a short distance east of the Mississippi River Delta, 60 miles south of Biloxi, Mississippi. Maximum observed surface winds were reported to be 60 knots and the radar eye a "poorly defined 40 mile diameter" at this time. ETHEL passed inland just to the east of Biloxi at 152100Z. Five hours later there were no reports of winds in excess of 24 knots." September 16:

HWM analyzes a closed low pressure of at most $1010 \mathrm{mb}$ at $32.0 \mathrm{~N}, 88.5 \mathrm{~W}$ at 12Z. HURDAT lists a $35 \mathrm{knot}$ tropical storm at $32.0 \mathrm{~N}, 88.9 \mathrm{~W}$ at $12 \mathrm{Z}$. Microfilm shows a closed low pressure of $1008 \mathrm{mb}$ at $32.0 \mathrm{~N}, 88.5 \mathrm{~W}$ at $12 \mathrm{Z}$. Navy reconnaissance book lists the best track position at $32.1 \mathrm{~N}, 88.8 \mathrm{~W}$ at $12 \mathrm{Z}$. Ship highlights: No gales or low pressures. Land highlights: $8 \mathrm{kt} \mathrm{NE}$ and $1008 \mathrm{mb}$ at Meridian, MS at 12Z (SWO).

September 17:

HWM analyzes a closed low pressure of at most $1015 \mathrm{mb}$ at $36.0 \mathrm{~N}, 87.3 \mathrm{~W}$ at 12Z. HURDAT lists a $15 \mathrm{knot}$ tropical depression at $36.0 \mathrm{~N}, 87.6 \mathrm{~W}$ at $12 \mathrm{Z}$. Microfilm shows a closed low pressure of at most $1014 \mathrm{mb}$ at $35.7 \mathrm{~N}, 87.5 \mathrm{~W}$ at 12Z. Ship and land highlights: No gales or low pressures.

MWR: "The remnants of the storm were located in central Tennessee on the morning of September 17."

September 18:

HWM analyzes a frontal boundary over the Midwest at 12Z. Microfilm does not analyze an organized system at 12Z. HURDAT does not list an organized system on this date. Ship and land highlights: No gales or low pressures. 
Hurricane Ethel had a complex development over the southern Gulf of Mexico. Monthly Weather Review indicates that the interaction between a weak trough over the Bay of Campeche and a weakening frontal boundary led to the development of a low pressure on September 10th. The disturbance slowly became better organized and ships observations indicate that a $25 \mathrm{kt}$ tropical depression developed around 18Z on September 12th, 42 hours earlier than originally shown in HURDAT. Minor track alterations are introduced from the 14th through 17th for this tropical cyclone. The tropical depression initially moved slowly to the northeast and intensification to a tropical storm is analyzed at $12 \mathrm{Z}$ on September 13th based on ship and aircraft reconnaissance on September 14th. This is a day earlier than originally shown in HURDAT. At 1445Z on the 14th, Monthly Weather Review indicates that an aircraft (non-reconnaissance) flying from Panama to Brownville, Texas reported a hurricane with a well-defined eye. At 15Z, a buoy named "MAMOS" reported $55 \mathrm{kt} \mathrm{NE}$ and $987 \mathrm{mb}$. Intensification to a hurricane is analyzed at $12 \mathrm{Z}$ on the 14th, six hours earlier than originally shown in HURDAT. The intensity analyzed at $12 \mathrm{Z}$ on the 14 th is $80 \mathrm{kt}$, up from $40 \mathrm{kt}$ originally in HURDAT, a major intensity change. The first reconnaissance aircraft reached the hurricane at $19 \mathrm{Z}$ on the 14th measuring a central pressure of $972 \mathrm{mb}$, estimating surface winds of $130 \mathrm{kt}$ and an eye diameter of $10 \mathrm{~nm}$. A central pressure of $972 \mathrm{mb}$ suggests maximum surface winds of $89 \mathrm{kt}$ intensifying south of $25 \mathrm{~N}$ and $86 \mathrm{kt}$ intensifying north of $25 \mathrm{~N}$ from the Brown et al. pressure-wind relationship. An eye diameter of $10 \mathrm{~nm}$ suggests an RMW of about $8 \mathrm{~nm}$ and climatology indicates $19 \mathrm{~nm}$. Due to a forward speed of about $18 \mathrm{kt}$, an RMW smaller than climatology, and some weighting of the visual surface estimate, an intensity of $100 \mathrm{kt}$ is selected at $18 \mathrm{Z}$ on the 14th, up from $75 \mathrm{kt}$ originally in HURDAT, a major intensity change. A central pressure of $972 \mathrm{mb}$ is added to HURDAT at 18Z on the 14th. Intensification to a major hurricane is analyzed six hours earlier than originally shown in HURDAT. Another reconnaissance aircraft reached Ethel at $2212 \mathrm{Z}$ measuring a central pressure of $976 \mathrm{mb}$, estimating surface winds of $140 \mathrm{kt}$ and an eye diameter of $10 \mathrm{~nm}$. A central pressure of $976 \mathrm{mb}$ suggests maximum surface winds of $77 \mathrm{kt}$ north of $25 \mathrm{~N}$ from the pressure-wind relationship. An eye diameter of $10 \mathrm{~nm}$ suggests an RMW of about 8 $\mathrm{nm}$ and climatology indicates $20 \mathrm{~nm}$. Due to a forward speed of about $18 \mathrm{kt}, \mathrm{RMW}$ smaller than climatology, and some weighting of the visual estimate, an intensity of 100 $\mathrm{kt}$ is selected at $00 \mathrm{Z}$ on September $15 \mathrm{th}$, down from $110 \mathrm{kt}$ originally in HURDAT, a minor intensity change. $100 \mathrm{kt}$ is also the peak intensity of this tropical cyclone, down from $140 \mathrm{kt}$ originally in HURDAT, a major intensity change. The $140 \mathrm{kt}$ intensity originally in HURDAT at $06 \mathrm{Z}$ on the 15th very likely came from the $140 \mathrm{kt}$ visual estimate via the aircraft reconnaissance late on the 14th. Thus, it is indicated that Hurricane Ethel did not reach category 5 as previously shown in HURDAT. A few ships reported hurricane-force winds early on the 15th as Ethel moved toward the northern Gulf coast. Gale-force winds reached the mouth of the Mississippi River early on the 
15th. Burrwood, LA reported $40 \mathrm{kt} \mathrm{NE}$ and $1001 \mathrm{mb}$ at $0650 \mathrm{Z}$ on the 15 th. A reconnaissance aircraft investigated Ethel at $1312 \mathrm{Z}$ on the 15 th and found that the hurricane had weakened significantly from late on the 14th. The aircraft reported a central pressure of $985 \mathrm{mb}$, estimated surface winds of $60 \mathrm{kt}$ and an eye diameter of 40 $\mathrm{nm}$. A central pressure of $985 \mathrm{mb}$ suggests maximum surface winds of $63 \mathrm{kt}$ weakening north of $25 \mathrm{~N}$ from the pressure-wind relationship. An eye diameter of $40 \mathrm{~nm}$ suggests an RMW of about $30 \mathrm{~nm}$ and climatology indicates $24 \mathrm{~nm}$. At 1015Z, Venice, LA reported a peak sustained wind of $78 \mathrm{kt}$. Due to a slower forward speed of about $7 \mathrm{kt}$, an RMW larger than climatology but hurricane-force winds reported a couple of hours earlier, an intensity of $70 \mathrm{kt}$ is selected at $12 \mathrm{Z}$ on the 15 th, down from $80 \mathrm{kt}$ originally in HURDAT, a minor intensity change. A central pressure of $985 \mathrm{mb}$ is added to HURDAT at $12 \mathrm{Z}$ on the 15 th. A major intensity change is shown at $06 \mathrm{Z}$ on the 15 th as HURDAT originally had $140 \mathrm{kt}$ and the analyzed intensity is $85 \mathrm{kt}$.

A reconnaissance aircraft investigated Ethel at $17 \mathrm{Z}$ on the 15 th measuring a central pressure of $984 \mathrm{mb}$. Earlier at $1525 \mathrm{Z}$ on this date, another reconnaissance aircraft estimated an eye diameter at $40 \mathrm{~nm}$. An eye diameter of $40 \mathrm{~nm}$ suggests an RMW of about $30 \mathrm{~nm}$ and climatology indicates $24 \mathrm{~nm}$. A central pressure of $984 \mathrm{mb}$ suggests maximum surface winds of $68 \mathrm{kt}$ north of $25 \mathrm{~N}$ from the pressure-wind relationship. Due to the slow forward speed of about $7 \mathrm{kt}$ and RMW larger than climatology, an intensity of $65 \mathrm{kt}$ is selected at $18 \mathrm{Z}$ on the 15th, up from $60 \mathrm{kt}$ originally in HURDAT, a minor intensity change. The tropical cyclone continued northward making landfall around $22 \mathrm{Z}$ near 30.4N, 89.0W or about halfway between Biloxi, MS and Gulfport, MS. Surface observations at Biloxi, MS clearly show that the hurricane passed just west of the city. The surface observations in the preliminary report in the storm wallets show that the pressure dropped to $979 \mathrm{mb}$ at Gulfport, MS at $21 \mathrm{Z}$ on the 15th and $981 \mathrm{mb}$ at Biloxi, MS at $23 \mathrm{Z}$ on the same date. Nevertheless, the observation at Gulfport, MS was not mentioned in the reports of the Monthly Weather Review or Navy reconnaissance book, leading us to believe that it was not a valid observation as it was consequently discarded. Moreover, the surface weather observations at Biloxi, MS indicate that the lowest pressure was $982.9 \mathrm{mb}$ occurring at $2208 \mathrm{Z}$ on the 15 th. But both the preliminary report of Ethel and Monthly Weather Report indicate that the lowest pressure at Biloxi, MS was $981 \mathrm{mb}$. So this value appears to have corrected downward slightly from $982.9 \mathrm{mb}$. Thus, $981 \mathrm{mb}$ with a south wind of $10 \mathrm{kt}$ indicates that the central pressure at landfall was 980 $\mathrm{mb}$. A central pressure of $980 \mathrm{mb}$ suggests maximum surface winds of $73 \mathrm{kt}$ north of $25 \mathrm{~N}$ from the pressure-wind relationship. Due to the slow forward speed of about $6 \mathrm{kt}$, an intensity of $70 \mathrm{kt}$ at landfall at $22 \mathrm{Z}$ on the 15th. HURDAT originally indicated that Ethel made landfall as a category 1 hurricane but the intensity at $18 \mathrm{Z}$ on the 15 th prior to landfall was $60 \mathrm{kt}$. Observations at Alabama indicate that hurricane-force winds did not affect the area and based on the surface observations, it is likely that the strongest winds 
associated with Ethel were unusually present on the western quadrant, which affected Louisiana and Mississippi. Ethel rapidly weakened over Mississippi and weakening to a tropical storm is analyzed at $00 \mathrm{Z}$ on September 16th, six hours later than originally shown in HURDAT. The Kaplan and DeMaria model was run for 00Z, 06Z and 12Z on the 16th yielding $55 \mathrm{kt}, 41 \mathrm{kt}$ and $31 \mathrm{kt}$, respectively. The highest winds recorded at these times were below gale-force, though observations at these time were quite sparse. An intensity of $55 \mathrm{kt}$ is selected at $00 \mathrm{Z}, 40 \mathrm{kt}$ at $06 \mathrm{Z}$, and $30 \mathrm{kt}$ at $12 \mathrm{Z}$ on the 16 th (up from $45 \mathrm{kt}$ at $00 \mathrm{Z}, 35 \mathrm{kt}$ at $06 \mathrm{Z}$ and down from $35 \mathrm{kt}$ at 12Z, originally in HURDAT), all minor changes. Weakening below tropical storm force is indicated at $12 \mathrm{Z}$ on the 16 th, six hours earlier than originally shown in HURDAT. At $12 \mathrm{Z}$ on the 16 th, Meridian, MS reported 8 $\mathrm{kt} \mathrm{NE}$ and $1008 \mathrm{mb}$ suggesting a central pressure of $1007 \mathrm{mb}$, which has been added to HURDAT. The tropical depression continued weakening on the 16th and 17th ahead of an approaching frontal boundary. Dissipation is analyzed after $18 \mathrm{Z}$ on the 17 th, same as originally shown in HURDAT.

Tropical Storm Florence [September 17-27, 1960]

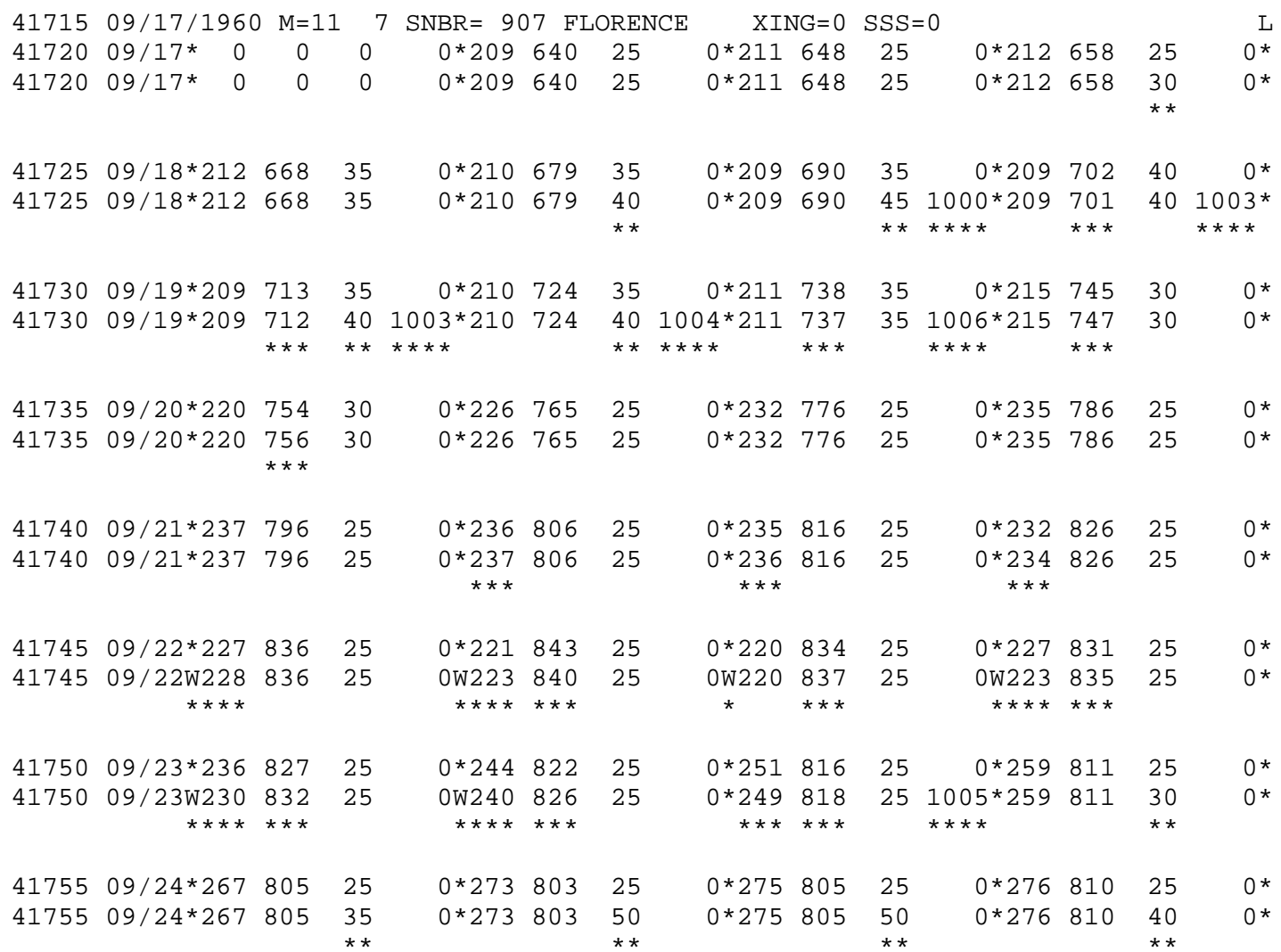


$41760 \quad 09 / 25 * 277 \quad 818 \quad 25$

$\begin{array}{lll}41760 & 09 / 25 * 277818 \quad 30 \\ \text { ** }\end{array}$

$0 * 278 \quad 829 \quad 20$

$\odot * 278829 \quad 25$

๑*279 $839 \quad 15$

๑*279 83925

○*283 $848 \quad 15 \quad 0$ *

$4176509 / 26 * 289856 \quad 15$

$4176509 / 26 * 289856 \quad 25$

○*295864 15

$0 * 29586420$

๑*301 $871 \quad 15$

$0 * 30187120$

๑*308 $877 \quad 15 \quad$ ๑*

0 *325 $890 \quad 15$

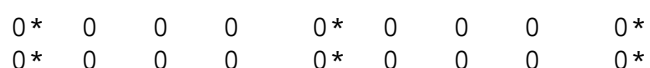

$\begin{array}{llll}41770 & 09 / 27 * 318 & 885 & 15 \\ 41770 & 09 / 27^{*} 318 & 885 & 15\end{array}$

$\odot * \begin{array}{rrr}0 & 0 & 0 \\ * & * & *\end{array}$

41775 TS

Tropical Storm Landfall

09/19 09Z 21.1N 73.1W 35 kt Great Inagua, Bahamas

Minor changes to the track and major changes to the intensity shown in McAdie et al. (2009). Evidence for these alterations comes from the NHC microfilm maps, the Historical Weather Maps series, the COADS ship database, Monthly Weather Review, Navy reconnaissance book, Surface Weather Observations, Mariners Weather Log, and NHC Storm Wallets. A major alteration is to indicate that Florence weakened to a tropical wave for 36 hours.

September 16:

HWM analyzes a spot low at $18.7 \mathrm{~N}, 61.4 \mathrm{~W}$ at $12 \mathrm{Z}$. HURDAT does not list an organized system on this date. Microfilm does not show an organized system at 12Z. Ship highlights: No gales or low pressures.

MWR: "An extensive shower area was noted well to the northeast of the Leeward Islands September 16 although there were no indications of a definite circulation." ATSR:

"Tropical Storm Florence developed from an easterly wave which first was detected by ship reports about 500 miles east of the Leeward Islands on the 15 of September. This wave was extrapolated westward with the aid of a few peripheral ship reports."

September 17:

HWM analyzes a closed low pressure of at most $1010 \mathrm{mb}$ at $20.9 \mathrm{~N}, 65.0 \mathrm{~W}$ at 12Z. HURDAT lists a $25 \mathrm{kt}$ tropical depression at $21.1 \mathrm{~N}, 64.8 \mathrm{~W}$ at $12 \mathrm{Z}$. Microfilm shows a closed low pressure of at most $1011 \mathrm{mb}$ at $21.5 \mathrm{~N}, 63.0 \mathrm{~W}$ at $12 \mathrm{Z}$. Navy reconnaissance book lists the best track position at $21.2 \mathrm{~N}, 64.7 \mathrm{~W}$ at $12 \mathrm{Z}$ (first position). Ship highlights: No gales or low pressures.

MWR: "By the morning of the 17th, pressures through the eastern Antilles had fallen 3 to $5 \mathrm{mb}$ with light south and southwest winds indicating the possibility that a circulation had developed. On the evening of the 17th, reports from shipping to the north of Puerto Rico 
placed a closed circulation near $21^{\circ} \mathrm{N}, 66^{\circ} \mathrm{W}$ with winds up to $35 \mathrm{mph}$." ATSR:

"Subsequently, at $171800 \mathrm{Z}$, three ship reports indicated a closed cyclonic circulation located at $21.4 \mathrm{~N} 65.7 \mathrm{~W}$ with rain squalls and winds of 25 knots."

September 18:

HWM analyzes a tropical storm of at most $1005 \mathrm{mb}$ at $20.5 \mathrm{~N}, 69.0 \mathrm{~W}$ at $12 \mathrm{Z}$. HURDAT lists a 35 knot tropical storm at 20.9N, 69.0W at 12Z. Microfilm shows a closed low pressure of at most $1005 \mathrm{mb}$ at $21.0 \mathrm{~N}, 69.2 \mathrm{~W}$ at $12 \mathrm{Z}$. Navy reconnaissance book lists the best track position at $20.9 \mathrm{~N}, 69.0 \mathrm{~W}$ at $12 \mathrm{Z} .35 \mathrm{kt} \mathrm{N}$ and $1012 \mathrm{mb}$ at $23.7 \mathrm{~N}$, $66.1 \mathrm{~W}$ at $00 \mathrm{Z}$ (COADS). $35 \mathrm{kt} \mathrm{SSE}$ and $1000 \mathrm{mb}$ (dubious) at $20.4 \mathrm{~N}, 68.1 \mathrm{~W}$ at $12 \mathrm{Z}$ (micro). $35 \mathrm{kt} \mathrm{SE}$ and $1007 \mathrm{mb}$ at $21.7 \mathrm{~N}, 69.1 \mathrm{~W}$ at 18Z (COADS). Land highlights: $20 \mathrm{kt}$ $\mathrm{NE}$ and $1005 \mathrm{mb}$ at Cockburn Town, Grand Turk at 18Z (micro). $15 \mathrm{kt} \mathrm{NE}$ and $1004 \mathrm{mb}$ at Cockburn Town, Grand Turk at $21 \mathrm{Z}$ (micro). Aircraft highlights: Penetration center fix measured a central pressure of $1000 \mathrm{mb}$ and estimated surface winds of $45 \mathrm{kt}$ at $20.8 \mathrm{~N}$, $69.7 \mathrm{~W}$ at $1352 \mathrm{Z}$ (ATSR). Penetration center fix measured a central pressure of $1003 \mathrm{mb}$ and estimated surface winds of $45 \mathrm{kt}$ at $20.9 \mathrm{~N}, 70.1 \mathrm{~W}$ at $18 \mathrm{Z}$ (ATSR).

MWR: "The Low continued westward about $10 \mathrm{mph}$ and reconnaissance aircraft located a broad, ill-defined center with maximum winds around $40 \mathrm{mph}$ on the morning of the 18th near $21^{\circ} \mathrm{N}, 69^{\circ} \mathrm{W}$." ATSR: “At 181352Z, a Navy reconnaissance flight located a wind and pressure center at $20.8 \mathrm{~N} 69.7 \mathrm{~W}$ with maximum surface winds of 45 knots. The first warning on FLORENCE was issued at 181600Z. FLORENCE reached her maximum intensity on the 18 th of September."

September 19:

HWM analyzes a tropical storm of at most $1010 \mathrm{mb}$ at $20.7 \mathrm{~N}, 73.7 \mathrm{~W}$ at $12 \mathrm{Z}$. HURDAT lists a 35 knot tropical storm at $21.1 \mathrm{~N}, 73.8 \mathrm{~W}$ at $12 \mathrm{Z}$. Microfilm shows a closed low pressure of at most $1008 \mathrm{mb}$ at $21.5 \mathrm{~N}, 73.5 \mathrm{~W}$ at $12 \mathrm{Z}$. Navy reconnaissance book lists the best track position at $21.2 \mathrm{~N}, 73.5 \mathrm{~W}$ at $12 \mathrm{Z}$. Ship highlights: $35 \mathrm{kt} \mathrm{E}$ and $1005 \mathrm{mb}$ at $22.1 \mathrm{~N}, 70.9 \mathrm{~W}$ at $00 \mathrm{Z}$ (micro). $40 \mathrm{kt} \mathrm{SE}$ and $1001 \mathrm{mb}$ at $21.8 \mathrm{~N}, 70.2 \mathrm{~W}$ at $03 \mathrm{Z}$ (COADS). Land highlights: $10 \mathrm{kt}$ ESE and $1004 \mathrm{mb}$ at Cockburn Town, Grand Turk at 00Z (micro). $15 \mathrm{kt} \mathrm{W}$ and $1005 \mathrm{mb}$ at Matthew Town, Bahamas at 09Z (micro). Aircraft highlights: Penetration center fix measured a central pressure of $1006 \mathrm{mb}$ and estimated surface winds of $35 \mathrm{kt}$ at $21.3 \mathrm{~N}, 73.8 \mathrm{~W}$ at $1330 \mathrm{Z}$ (ATSR). Penetration center fix estimated an eye diameter of $15 \mathrm{~nm}$ at $21.9 \mathrm{~N}, 74.3 \mathrm{~W}$ at $1553 \mathrm{Z}$ (ATSR).

ATSR: "Then dissipated on the 19th of September. The final warning was issued at 191600Z." 
September 20:

HWM analyses a closed low pressure of at most $1010 \mathrm{mb}$ at $22.9 \mathrm{~N}, 77.5 \mathrm{~W}$ at 12Z. HURDAT lists a 25 knot tropical depression at $23.2 \mathrm{~N}, 77.6 \mathrm{~W}$ at $12 \mathrm{Z}$. Microfilm shows a spot low pressure at $23.5 \mathrm{~N}, 77.6 \mathrm{~W}$ at $12 \mathrm{Z}$. Navy reconnaissance book lists the best track position at $23.4 \mathrm{~N}, 77.5 \mathrm{~W}$ at $12 \mathrm{Z}$. Ship highlights: No gales or low pressures. MWR: "Tropical Storm Florence moved on a west to westnorthwest track near $12 \mathrm{mph}$, gradually weakening until the 20th when reconnaissance aircraft found only a weak Low south of Andros Island in the Bahamas with no significant weather or strong winds." ATSR: "The remaining weak, poorly defined low pressure cell followed an erratic track which passed between the Bahamas and Cuba."

September 21:

HWM analyzes a spot low at $23.7 \mathrm{~N}, 81.4 \mathrm{~W}$ at $12 \mathrm{Z}$. HURDAT lists a $25 \mathrm{knot}$ tropical depression at $23.5 \mathrm{~N}, 81.6 \mathrm{~W}$ at $12 \mathrm{Z}$. Microfilm shows a closed low pressure of at most $1011 \mathrm{mb}$ at $23.8 \mathrm{~N}, 80.2 \mathrm{~W}$ at $12 \mathrm{Z}$. Navy reconnaissance book lists the best track position at $23.8 \mathrm{~N}, 81.6 \mathrm{~W}$ at $12 \mathrm{Z}$. Ship highlights: No gales or low pressures.

September 22:

HWM analyzes a spot low at $21.7 \mathrm{~N}, 83.6 \mathrm{~W}$ at $12 \mathrm{Z}$. HURDAT lists a $25 \mathrm{knot}$ tropical depression at $22.0 \mathrm{~N}, 83.4 \mathrm{~W}$ at $12 \mathrm{Z}$. Microfilm shows a closed low pressure of at most $1009 \mathrm{mb}$ near $21.0 \mathrm{~N}, 84.0 \mathrm{~W}$ at $12 \mathrm{Z}$. Navy reconnaissance book lists the best track position at $22.1 \mathrm{~N}, 83.2 \mathrm{~W}$ at $12 \mathrm{Z}$. Ship highlights: No gales or low pressures.

MWR: "The remains of Florence moved into the western end of Cuba and became nearly stationary until the evening of the 22 nd when conditions became more favorable for redevelopment." ATSR: "It made a loop over western Cuba and headed northeastward over southern Florida."

September 23:

HWM analyzes a spot low at $23.8 \mathrm{~N}, 82.8 \mathrm{~W}$ at $12 \mathrm{Z}$. HURDAT lists a $25 \mathrm{knot}$ tropical depression at $25.1 \mathrm{~N}, 81.6 \mathrm{~W}$ at $12 \mathrm{Z}$. Microfilm shows an elongated, closed low pressure of at most $1008 \mathrm{mb}$ near $24.0 \mathrm{~N}, 84$.W at 12Z. Navy reconnaissance book lists the best track position at $25.3 \mathrm{~N}, 81.5 \mathrm{~W}$ at $12 \mathrm{Z}$. Ship highlights: No gales or low pressures. Land highlights: $35 \mathrm{kt}$ ENE (gusts to $52 \mathrm{kt}$, max wind) and $1009 \mathrm{mb}$ at Vero Beach, FL at 2359Z (SWO). Aircraft highlights: Penetration center fix measured a central 
pressure of $1005 \mathrm{mb}$ and estimated surface winds of $22 \mathrm{kt}$ at $25.5 \mathrm{~N}, 81.4 \mathrm{~W}$ at $1330 \mathrm{Z}$ (ATSR).

MWR: "The Low began moving northeastward and was located just off the southwestern Florida coast by the morning of the 23rd with winds up to $30 \mathrm{mph}$ and widespread rain over southeastern Florida. It then became blocked by a large high pressure system along the mid-Atlantic coast after reaching the vicinity of Lake Okeechobee the evening of the 23rd and changed to a west-northwest track..." ATSR: "During its entire course, FLORENCE never developed a well defined wall cloud or eye. Redevelopment appeared imminent late on the 23rd of September. In the late afternoon of this date, a heavy spiral band of showers moved across southern Florida. Peak wind gusts to 50 knots were reported in the vicinity of Vero Beach as the depression approached the east coast of Florida. Rapid weakening took place, however, after the low pressure center doubled back across Florida and headed into the Gulf of Mexico."

September 24:

HWM analyzes a spot low at $27.4 \mathrm{~N}, 80.3 \mathrm{~W}$ at $12 \mathrm{Z}$. HURDAT lists a 25 knot tropical depression at $27.5 \mathrm{~N}, 80.5 \mathrm{~W}$ at $12 \mathrm{Z}$. Microfilm shows a closed low pressure of at most $1008 \mathrm{mb}$ at $27.8 \mathrm{~N}, 80.5 \mathrm{~W}$ at $12 \mathrm{Z}$. Navy reconnaissance book lists the best track position at $27.7 \mathrm{~N}, 80.7 \mathrm{~W}$ at $12 \mathrm{Z}$. Ship highlights: $50 \mathrm{kt} \mathrm{E}$ and $1009 \mathrm{mb}$ at $27.4 \mathrm{~N}, 79.9 \mathrm{~W}$ at $06 \mathrm{Z}$ (COADS). $40 \mathrm{kt} \mathrm{E}$ and $1012 \mathrm{mb}$ at $29.0 \mathrm{~N}, 79.8 \mathrm{~W}$ at $12 \mathrm{Z}$ (COADS). $40 \mathrm{kt} \mathrm{SE}$ and $1010 \mathrm{mb}$ at $28.2 \mathrm{~N}, 79.3 \mathrm{~W}$ at $18 \mathrm{Z}$ (COADS).

September 25:

HWM analyzes a closed low pressure of at most $1010 \mathrm{mb}$ at $27.4 \mathrm{~N}, 84.0 \mathrm{~W}$ at 12Z. HURDAT lists a $15 \mathrm{knot}$ tropical depression at $27.9 \mathrm{~N}, 83.9 \mathrm{~W}$ at $12 \mathrm{Z}$. Microfilm shows a closed low pressure of at most $1008 \mathrm{mb}$ at $27.8 \mathrm{~N}, 85.0 \mathrm{~W}$ at $12 \mathrm{Z}$. Navy reconnaissance book lists the best track position at $28.0 \mathrm{~N}, 83.7 \mathrm{~W}$ at $12 \mathrm{Z}$. Ship highlights: No gales or low pressures.

MWR: "...drifting into the eastern Gulf of Mexico near Tampa early on the 25th." ATSR: "Then, turning westward and northwestward across the Gulf of Mexico, it finally moved into southern Alabama where complete dissipation occurred."

September 26:

HWM analyzes a spot low at $29.5 \mathrm{~N}, 87.1 \mathrm{~W}$ with a front to the west at $12 \mathrm{Z}$. HURDAT lists a 15 knot tropical depression at $30.1 \mathrm{~N}, 87.1 \mathrm{~W}$ at $12 \mathrm{Z}$. Microfilm shows a closed low pressure of at most $1011 \mathrm{mb}$ at $29.4 \mathrm{~N}, 87.1 \mathrm{~W}$ at $12 \mathrm{Z}$. Navy reconnaissance 
book lists the best track position at $30.1 \mathrm{~N}, 87.0 \mathrm{~W}$ at 12Z. Ship highlights: No gales or low pressures.

MWR: "The Low continued quite weak over the Gulf and moved into the Pensacola area on the morning of the 26th with winds less than $25 \mathrm{mph}$ but with a rather large rain area that covered the southern portions of Alabama and Georgia and northwestern Florida. Florence was never a well-defined tropical storm and maximum winds were just barely of tropical storm intensity (for only a short period) although gusts to $52 \mathrm{mph}$ were reported in the Vero Beach area in a squall when the Low was nearest that station. The only significant damage in this storm was from local flooding in Florida. Rainfall totals of 3 to 6 inches or more were reported during passage of the Low on ground that was already saturated from the previous heavy rains of Donna."

September 27:

HWM analyzes a cold front over the southeast of the United States stretching into the Gulf as Florence appears to have dissipated at 12Z. HURDAT lists a $15 \mathrm{knot}$ tropical depression at $32.5 \mathrm{~N}, 89.0 \mathrm{~W}$ at $06 \mathrm{Z}$ (last position). Microfilm does not show an organized system at $12 \mathrm{Z}$. Navy reconnaissance book lists the best track position at $31.5 \mathrm{~N}$, $88.2 \mathrm{~W}$ at $12 \mathrm{Z}$ (last position). Ship highlights: No gales or low pressures.

A tropical wave left the African coast on the second week of September and slowly became better organized as it approached the Leeward Islands. Observations of the reconnaissance routine surveillance on the microfilm at $12 \mathrm{Z}$ on September 16th indicate that the tropical wave did not have a well-defined center. The tropical wave became better defined early on September 17th. The first position in HURDAT is at 06Z on the 17 th as a $25 \mathrm{kt}$ tropical depression located northeast of Puerto Rico. The data is scarce around the tropical depression, which makes it difficult to determine the exact time of genesis. Thus, the first position in HURDAT is retained. Minor track alterations are introduced during the lifetime of this tropical cyclone. The tropical cyclone moved westward becoming a tropical storm at $00 \mathrm{Z}$ on September 18th, same as originally shown in HURDAT. The first gale was reported at $00 \mathrm{Z}$ on the 18th on the northern quadrant of Florence. The first reconnaissance aircraft reached the tropical storm at $1352 \mathrm{Z}$ on the 18th measuring a central pressure of $1000 \mathrm{mb}$ and estimating surface winds of $45 \mathrm{kt}$. A central pressure of $1000 \mathrm{mb}$ suggests maximum surface winds of $47 \mathrm{kt}$ south of $25 \mathrm{~N}$ from the Brown et al. pressure-wind relationship. Based on an average forward speed of $11 \mathrm{kt}$, an intensity of $45 \mathrm{kt}$ is selected at $12 \mathrm{Z}$ on the $18 \mathrm{th}$, up from $35 \mathrm{kt}$ originally in HURDAT, a minor intensity change. A central pressure of $1000 \mathrm{mb}$ is added to HURDAT at $12 \mathrm{Z}$ on the 18th. Another center penetration measured a central pressure of $1003 \mathrm{mb}$ and estimated surface winds of $45 \mathrm{kt}$ at $18 \mathrm{Z}$ on the 18th. A central pressure of $1003 \mathrm{mb}$ suggests maximum surface winds of $41 \mathrm{kt}$ south of $25 \mathrm{~N}$ from the pressure-wind 
relationship. Based on an average forward speed of $11 \mathrm{kt}$, an intensity of $40 \mathrm{kt}$ is selected at $18 \mathrm{Z}$ on the 18th, same as originally shown in HURDAT. A central pressure of 1003 $\mathrm{mb}$ is added to HURDAT at $18 \mathrm{Z}$ on the $18 \mathrm{th}$. Early on the 19th, the tropical storm passed south of the Turks and Caicos. At 00Z, Cockburn Town, Grand Turk reported $10 \mathrm{kt} \mathrm{NE}$ and $1004 \mathrm{mb}$, suggesting a central pressure of $1003 \mathrm{mb}$, which has been added to HURDAT. Florence gradually weakened on the 19th as it continued moving westward. At $09 \mathrm{Z}$ on the 19th, Great Inagua, Bahamas reported $15 \mathrm{kt} \mathrm{W}$ and $1005 \mathrm{mb}$, suggesting a central pressure of $1004 \mathrm{mb}$, which has been added to HURDAT at 06Z. Around 10Z on the 19th, the center of Florence made landfall in Great Inagua, Bahamas with winds of 35 kt. A reconnaissance aircraft reached the tropical storm at $1330 \mathrm{Z}$ on the 19 th measuring a central pressure of $1006 \mathrm{mb}$ and estimating surface winds of $35 \mathrm{kt}$. A central pressure of $1006 \mathrm{mb}$ suggests maximum surface winds of $35 \mathrm{kt}$ south of $25 \mathrm{~N}$ from the pressure-wind relationship. An intensity of $35 \mathrm{kt}$ is selected at $12 \mathrm{Z}$ on the 19 th, same as originally shown in HURDAT. A central pressure of $1006 \mathrm{mb}$ has been added to HURDAT at $12 \mathrm{Z}$ on the 19 th. Weakening to a tropical depression occurred at $18 \mathrm{Z}$ on the 19 th, same as originally shown in HURDAT.

Florence continued westward to west-northwest on the 20th and 21st passing between Florida and Cuba with little change in intensity, but the tropical cyclone gradually became less organized. Synoptic observations early on September 22nd indicate that Florence degenerated into a sharp trough stretching from southern Florida into the northwest Caribbean Sea. The disturbance stayed generally over the same area for the next 24 hours. Early on September 23rd, the remnants of Florence began to become better organized as the disturbance started to move northeastward toward Florida. It is analyzed that Florence regained tropical depression status at $12 \mathrm{Z}$ on the $23 \mathrm{rd}$ while located just north of the Florida Keys. A reconnaissance aircraft investigated the system at $1330 \mathrm{Z}$ on the 23rd measuring a central pressure of $1005 \mathrm{mb}$ and estimating surface winds of $22 \mathrm{kt}$. An intensity of $25 \mathrm{kt}$ is selected at $12 \mathrm{Z}$ on the $23 \mathrm{rd}$, same as originally shown in HURDAT. A central pressure of $1005 \mathrm{mb}$ has been added to HURDAT at $12 \mathrm{Z}$ on the 23rd. Late on the 23rd, the tropical depression made landfall in southwest Florida and the forward speed began to decrease. At $00 \mathrm{Z}$ on September 24th, Vero Beach, FL reported sustained winds of $35 \mathrm{kt}$ and gusts to $52 \mathrm{kt}$. Intensification to a tropical storm is indicated at $00 \mathrm{Z}$ on the 24 th while the center was over the Florida peninsula, up from $35 \mathrm{kt}$ originally in HURDAT, a minor intensity change. HURDAT originally kept Florence as a tropical depression after it weakened from a tropical storm on the 19th. At 06Z on the 24th, a couple of ships within $120 \mathrm{~nm}$ of the center reported gale-force winds, including $50 \mathrm{kt}$ E. This last ship "77902" was located about $30 \mathrm{~nm}$ from the center over the eastern quadrant. Observations from "77902" before and after $06 Z$ on the 24 th are consistent with nearby ships. An intensity of $50 \mathrm{kt}$ is selected at $06 \mathrm{Z}$ and $12 \mathrm{Z}$ on the $24 \mathrm{th}$, up from $25 \mathrm{kt}$ originally in HURDAT, a major intensity change. $50 \mathrm{kt}$ is also the peak intensity of 
this tropical cyclone, up from $40 \mathrm{kt}$ originally in HURDAT, a minor intensity change. Florence approached the east coast of Florida around $06 \mathrm{Z}$ on the 24th but did not reach the Atlantic. The intensification of Florence over land is similar to Tropical Storm Fay in 2008. Late on the 24th, Florence turned to the northwest and began to weaken.

Weakening to a tropical depression is analyzed at $00 \mathrm{Z}$ on September 25 th. The center of the tropical cyclone moved back into the Gulf of Mexico around 06Z on the 25th. The tropical depression continued northwestward on the 25th and 26th, making landfall as a $20 \mathrm{kt}$ tropical depression in the western Panhandle of Florida. Dissipation is analyzed after 00Z on September 27th, six hours earlier than originally shown in HURDAT.

\section{0 - Additional Notes}

1) May 3-9: Historical Weather Maps and Microfilm show a frontal boundary over the western Atlantic on May $3^{\text {rd }}$. A low pressure developed between Bermuda and the Bahamas on May $4^{\text {th }}$ but remained embedded within the frontal boundary. The disturbance drifted to the southeast and COADS showed that it began producing gales in the northern quadrant on the $4^{\text {th }}$. The extratropical cyclone started to occlude on May $5^{\text {th }}$ while producing gales up to $55 \mathrm{kt}$ about $250 \mathrm{~nm}$ north of the center. Late on May $6^{\text {th }}$, microfilm maps show that the extratropical cyclone lost its frontal boundaries and there was little temperature gradient around the system. Nonetheless, the strongest winds remained well north of the center. On May $7^{\text {th }}$, the disturbance began to weaken and dissipation occurred on May $9^{\text {th }}$ as another frontal boundary approached the area. Therefore, because synoptic data suggests that the disturbance did not become a tropical cyclone or subtropical, it is not added to HURDAT. This disturbance was in Jack Beven's and David Roth's List of Suspects.

$\begin{array}{ccc}\text { Day } & \text { Latitude } & \text { Longitude } \\ \text { May 3 } & 30 \mathrm{~N} & 78 \mathrm{~W} \\ \text { May 4 } & 30 \mathrm{~N} & 74 \mathrm{~W} \\ \text { May 5 } & 29 \mathrm{~N} & 68 \mathrm{~W} \\ \text { May 6 } & 29 \mathrm{~N} & 67 \mathrm{~W} \\ \text { May 7 } & 28 \mathrm{~N} & 68 \mathrm{~W} \\ \text { May 8 } & 28 \mathrm{~N} & 68 \mathrm{~W}\end{array}$

May 9

2) May 26-31: Historical Weather Maps indicate that a frontal boundary moved off the east coast of the United States on May $26^{\text {th }}$. An extratropical cyclone developed along the 
frontal boundary on May $27^{\text {th }}$ and began to move to the northeast. Gale-force winds were observed on May $29^{\text {th }}$ but Historical Weather Maps clearly show that the disturbance remained extratropical with a significant temperature gradient across the circulation. On May $30^{\text {th }}$, the extratropical cyclone weakened and dissipated the next day. The remnants were absorbed by a larger extratropical cyclone over the north Atlantic. Therefore, because the disturbance did not acquire tropical characteristics, it is not added to HURDAT. This disturbance was in Jack Beven's List of Suspects.

\begin{tabular}{cccc} 
Day & Latitude & Longitude & Status \\
May 26 & \multicolumn{2}{c}{ Northwest Atlantic } & Frontal boundary \\
May 27 & $33 \mathrm{~N}$ & $66 \mathrm{~W}$ & Extratropical \\
May 28 & $37 \mathrm{~N}$ & $61 \mathrm{~W}$ & Extratropical \\
May 29 & $39 \mathrm{~N}$ & $56 \mathrm{~W}$ & Extratropical \\
May 30 & $43 \mathrm{~N}$ & $51 \mathrm{~W}$ & Extratropical \\
May 31 & & & Dissipated
\end{tabular}

3) June 2-10: Historical Weather Maps show a low pressure system that meandered over the central Atlantic for about a week early in June. Synoptic data suggests that the disturbance was non-frontal and closed, likely a tropical depression, but COADS indicate that the winds remained below tropical storm force. By June $10^{\text {th }}$, the disturbance dissipated as a frontal system approached the area. Therefore, because the disturbance did not produce tropical storm force winds, it is not added to HURDAT. This disturbance was in Jack Beven's List of Suspects.

\begin{tabular}{|c|c|c|c|}
\hline Day & Latitude & Longitude & Status \\
\hline June 2 & $29 \mathrm{~N}$ & $59 \mathrm{~W}$ & $\begin{array}{c}\text { Tropical } \\
\text { Depression? }\end{array}$ \\
\hline June 3 & $30 \mathrm{~N}$ & $57 \mathrm{~W}$ & $\begin{array}{c}\text { Tropical } \\
\text { Depression? }\end{array}$ \\
\hline June 4 & $30 \mathrm{~N}$ & $53 \mathrm{~W}$ & $\begin{array}{c}\text { Tropical } \\
\text { Depression? }\end{array}$ \\
\hline June 5 & $28 \mathrm{~N}$ & $48 \mathrm{~W}$ & $\begin{array}{c}\text { Tropical } \\
\text { Depression? }\end{array}$ \\
\hline June 6 & $29 \mathrm{~N}$ & $44 \mathrm{~W}$ & $\begin{array}{c}\text { Tropical } \\
\text { Depression? }\end{array}$ \\
\hline June 7 & $29 \mathrm{~N}$ & $43 \mathrm{~W}$ & $\begin{array}{c}\text { Tropical } \\
\text { Depression? }\end{array}$ \\
\hline June 8 & $35 \mathrm{~N}$ & $45 \mathrm{~W}$ & $\begin{array}{c}\text { Tropical } \\
\text { Depression? }\end{array}$ \\
\hline
\end{tabular}


4) June 7-12: Historical Weather Maps indicate that a low pressure developed over the western Caribbean Sea on June $7^{\text {th }}$, likely associated with a tropical wave or an eastward incursion of the eastern Pacific monsoon trough. The disturbance was embedded within an environment of low pressure and moved very little after formation. COADS were obtained but no gale-force winds were reported, it was likely a tropical depression. Therefore, because it did not produce tropical storm force winds, it is not added to HURDAT. This disturbance was in Jack Beven's List of Suspects.

$\begin{array}{cccc}\text { Day } & \text { Latitude } & \text { Longitude } & \begin{array}{c}\text { Status } \\ \text { Tropical }\end{array} \\ \text { June } 7 & 18 \mathrm{~N} & 86 \mathrm{~W} & \begin{array}{c}\text { Depression? } \\ \text { Tropical } \\ \text { Depression? } \\ \text { June } 8\end{array} \\ \text { June } 9 & 18 \mathrm{~N} & 86 \mathrm{~W} & \begin{array}{c}\text { Tropical } \\ \text { Depression? } \\ \text { Tropical }\end{array} \\ \text { June } 10 & 17 \mathrm{~N} & 82 \mathrm{~W} & \begin{array}{c}\text { Depression? } \\ \text { Tropical }\end{array} \\ \text { June } 11 & 18 \mathrm{~N} & 81 \mathrm{~W} & \begin{array}{c}\text { Depression? } \\ \text { Tropical }\end{array} \\ \text { June } 12 & 18 \mathrm{~N} & 85 \mathrm{~W} & \begin{array}{c}\text { Depression? } \\ \text { Dissipated }\end{array} \\ \text { June } 13 & 18 \mathrm{~N} & 85 \mathrm{~W} & \end{array}$

5) June 9-12: Historical Weather Maps indicate that a frontal system entered the western Atlantic on June $6^{\text {th }}$. The frontal boundary moved little over the next couple of days and an extratropical cyclone developed on June $9^{\text {th }}$. The disturbance moved generally northeastward and produced gale-force winds on June $11^{\text {th }}$ when it began to occlude, but a significant temperature gradient remained present across the cyclone. On June $13^{\text {th }}$, it became embedded again within a frontal boundary as it moved into the north Atlantic. Therefore, because the disturbance did not acquire tropical characteristics, it is not added to HURDAT. This disturbance was in Jack Beven's List of Suspects.

$\begin{array}{cccc}\text { Day } & \text { Latitude } & \text { Longitude } & \text { Status } \\ \text { June } 9 & 32 \mathrm{~N} & 74 \mathrm{~W} & \text { Extratropical } \\ \text { June } 10 & 36 \mathrm{~N} & 64 \mathrm{~W} & \text { Extratropical }\end{array}$




$\begin{array}{cccc}\text { June } 11 & 38 \mathrm{~N} & 70 \mathrm{~W} & \text { Occluded } \\ \text { June } 12 & 44 \mathrm{~N} & 60 \mathrm{~W} & \text { Occluded } \\ \text { June } 13 & 49 \mathrm{~N} & 49 \mathrm{~W} & \text { Extratropical }\end{array}$

6) August 26 - September 2: Historical Weather Maps show that a tropical wave left the African coast on August $26^{\text {th }}$. The disturbance moved generally westward over the next couple of days over an area of sparse ship traffic. The strong tropical wave was located about $800 \mathrm{~nm}$ east of the Leeward Islands on August $31^{\text {st }}$ and the synoptic data in the microfilm maps shows winds up to $30 \mathrm{kt}$ on the northern portion of the circulation. Data remained sparse but it appears likely that it did not have a closed circulation at this time. On September $1^{\text {st }}$, the disturbance turned northward, and COADS and microfilm indicate that it was producing gale-force winds over the northeast quadrant. Ship and routine surveillance reconnaissance data suggests that a closed circulation may have developed at $18 \mathrm{Z}$ on the $1^{\text {st }}$, but observations before and after this time indicate that only a sharp trough was present. The disturbance continued northward on September $2^{\text {nd }}$ and a closed circulation appears to have formed late in the day but no gale-force winds were reported at this time. An approaching frontal boundary caused the disturbance to weaken on September $3^{\text {rd }}$ leading to its dissipation. Therefore, although it is possible that this system may have been a tropical storm, the data available does not suggest that a well-defined circulation was present at the time the disturbance was producing gale-force winds and it is not added to HURDAT. This disturbance was in Jack Beven's List of Suspects.

$\begin{array}{cccc}\text { Day } & \text { Latitude } & \text { Longitude } & \text { Status } \\ \text { August } 26 & 14 \mathrm{~N} & 23 \mathrm{~W} & \text { Tropical Wave? } \\ \text { August } 27 & 12 \mathrm{~N} & 24 \mathrm{~W} & \text { Tropical Wave? } \\ \text { August } 28 & 13 \mathrm{~N} & 30 \mathrm{~W} & \text { Tropical Wave? } \\ \text { August } 29 & 14 \mathrm{~N} & 40 \mathrm{~W} & \text { Tropical Wave? } \\ \text { August } 30 & 17 \mathrm{~N} & 47 \mathrm{~W} & \text { Tropical Wave? } \\ \text { August } 31 & 20 \mathrm{~N} & 49 \mathrm{~W} & \text { Tropical Depression? } \\ \text { September } 1 & 26 \mathrm{~N} & 52 \mathrm{~W} & \text { Tropical Storm? } \\ \text { September } 2 & 30 \mathrm{~N} & 51 \mathrm{~W} & \text { Tropical Storm? } \\ \text { September } 3 & & & \text { Dissipated }\end{array}$

7) September 16-19: Historical Weather Maps show a disturbance over the far eastern Atlantic on September $16^{\text {th }}$. The disturbance moved slowly westward over the next couple of days and dissipated on September $19^{\text {th }}$. COADS were obtained but no galeforce winds were reported. Therefore, because no gale-force winds were observed, it is not added to HURDAT. 


$\begin{array}{cccc}\text { Day } & \text { Latitude } & \text { Longitude } & \text { Status } \\ \text { September } 16 & 24 \mathrm{~N} & 34 \mathrm{~W} & \text { Tropical Depression? } \\ \text { September } 17 & 24 \mathrm{~N} & 38 \mathrm{~W} & \text { Tropical Depression? } \\ \text { September } 18 & 24 \mathrm{~N} & 41 \mathrm{~W} & \text { Tropical Depression? } \\ \text { September } 19 & & & \text { Dissipated }\end{array}$

8) September 22-30: Historical Weather Maps and microfilm maps show a frontal boundary over the western Atlantic on September $22^{\text {nd }}$. An extratropical cyclone developed on September $23^{\text {rd }}$ and COADS were obtained showing gale-force winds about $250 \mathrm{~nm}$ north of the center. On September $24^{\text {th }}$ and early on the $25^{\text {th }}$, the circulation became elongated NE-SW and the gales remained well north of the center. Late on the $25^{\text {th }}$, synoptic data indicate that the disturbance may have become a tropical or subtropical cyclone as the circulation became more symmetric and gale-force winds were reported about $60 \mathrm{~nm}$ from the center. Yet, observations early on September $26^{\text {th }}$ indicate that the disturbance became less organized and the gale-force winds were observed far to the northwest of the center. On September $27^{\text {th }}$ and $28^{\text {th }}$, the disturbance moved slowly northward with little change in organization. On September $29^{\text {th }}$, the disturbance developed frontal features as it began to accelerate northeastward into the north Atlantic. Late on September $30^{\text {th }}$, the disturbance dissipated south of Newfoundland. Therefore, because observations indicate that the system likely remained non-tropical, it is not added to HURDAT. This disturbance was in Jack Beven and David Roth's List of Suspects.

Day Latitude Longitude Status

September 22

September 23

September 24

September 25

September 26

September 27

September 28

September 29

September 30
Western Atlantic

$34 \mathrm{~N} \quad 62 \mathrm{~W}$

$34 \mathrm{~N} \quad 63 \mathrm{~W}$

$33 \mathrm{~N} \quad 64 \mathrm{~W}$

$34 \mathrm{~N} \quad 67 \mathrm{~W}$

$34 \mathrm{~N} \quad 71 \mathrm{~W}$

$37 \mathrm{~N} \quad 71 \mathrm{~W}$

$41 \mathrm{~N}$

$45 \mathrm{~N}$
Frontal boundary

Extratropical

Occluded

Subtropical Storm?

Subtropical Storm?

Subtropical Storm?

Subtropical Storm?

67W Extratropical

$51 \mathrm{~W} \quad$ Extratropical

9) September 22-29: Historical Weather Maps show a tropical wave that left the African coast on September $22^{\text {nd }}$. Observations over the eastern Atlantic are scarce and the tropical wave moved generally westward over the next couple of days. Microfilm maps 
show a $35 \mathrm{kt}$ ship at $12 \mathrm{Z}$ on September $27^{\text {th }}$ but observations from ships nearby indicate that it likely has a high bias. At $00 \mathrm{Z}$ on September $28^{\text {th }}$, HWM synoptic data indicates that a closed circulation may have developed and a couple of ships reported gale-force winds. Yet, COADS indicates that one of the gales was just $20 \mathrm{kt}$ and the other ship was the same one with the high bias observed on the $27^{\text {th }}$. Observations late on the $28^{\text {th }}$ show that the disturbance had degraded into a tropical wave and dissipation occurred on September $29^{\text {th }}$. Therefore, because the disturbance never had a well-defined circulation and the reported gale-force winds likely have a high bias, it is not added to HURDAT. This disturbance was in Ryan Truchelut's List of Suspects.

$\begin{array}{cccc}\text { Day } & \text { Latitude } & \text { Longitude } & \text { Status } \\ \text { September 22 } & 13 \mathrm{~N} & 16 \mathrm{~W} & \text { Tropical Wave? } \\ \text { September 23 } & 13 \mathrm{~N} & 23 \mathrm{~W} & \text { Tropical Wave? } \\ \text { September 24 } & 14 \mathrm{~N} & 25 \mathrm{~W} & \text { Tropical Wave? } \\ \text { September 25 } & 14 \mathrm{~N} & 30 \mathrm{~W} & \text { Tropical Wave? } \\ \text { September 26 } & 14 \mathrm{~N} & 40 \mathrm{~W} & \text { Tropical Wave? } \\ \text { September 27 } & 15 \mathrm{~N} & 50 \mathrm{~W} & \text { Tropical Depression? } \\ \text { September 28 } & 20 \mathrm{~N} & 56 \mathrm{~W} & \text { Tropical Storm? } \\ \text { September 29 } & & & \text { Dissipated }\end{array}$

10) October 27 - November 3: Historical Weather Maps indicate that a frontal boundary over the western Atlantic caused the development of an extratropical cyclone on October $28^{\text {th }}$. The extratropical cyclone moved generally eastward and the HWM shows that it may have become detached from the frontal boundary on November $1^{\text {st }}$. The next day, the disturbance became embedded within a frontal boundary again and later dissipated over the north Atlantic on November $3^{\text {rd }}$. Therefore, because the disturbance did not acquire tropical characteristics, it is not added to HURDAT. This disturbance was in Jack Beven's List of Suspects.

\begin{tabular}{cccc} 
Day & Latitude & Longitude & Status \\
October 27 & \multicolumn{2}{c}{ Western Atlantic } & Frontal boundary \\
October 28 & $35 \mathrm{~N}$ & $72 \mathrm{~W}$ & Extratropical \\
October 29 & $36 \mathrm{~N}$ & $72 \mathrm{~W}$ & Extratropical \\
October 30 & $37 \mathrm{~N}$ & $67 \mathrm{~W}$ & Extratropical \\
October 31 & $35 \mathrm{~N}$ & $60 \mathrm{~W}$ & Extratropical \\
November 1 & $33 \mathrm{~N}$ & $57 \mathrm{~W}$ & Subtropical Storm? \\
November 2 & $35 \mathrm{~N}$ & $46 \mathrm{~W}$ & Extratropical \\
November 3 & & & Dissipation
\end{tabular}


11) December 19-24: Historical Weather Maps show an extratropical cyclone near the eastern Azores on December $19^{\text {th }}$. COADS were obtained showing gale-force winds over the north and western quadrants but far from the center. The extratropical cyclone detached from the frontal boundary on December $20^{\text {th }}$. The disturbance moved southwestward over the next couple of days and winds weakened below gale-force.

Dissipation occurred over the central Atlantic on December $24^{\text {th }}$. Therefore, because the disturbance did not acquire tropical characteristics when it was producing gale-force winds, it is not added to HURDAT. This disturbance was in David Roth's List of Suspects.

$\begin{array}{cccc}\text { Day } & \text { Latitude } & \text { Longitude } & \begin{array}{c}\text { Status } \\ \text { Extratropical } \\ \text { Occluded }\end{array} \\ \text { December 19 } & 35 \mathrm{~N} & 22 \mathrm{~W} & \begin{array}{c}\text { Subtropical } \\ \text { Depression? } \\ \text { December } 20\end{array} \\ \text { December 21 } & 31 \mathrm{~N} & 28 \mathrm{~W} & \begin{array}{c}\text { Subtropical } \\ \text { Depression? }\end{array} \\ \text { December 22 } & 28 \mathrm{~N} & 31 \mathrm{~W} & \begin{array}{c}\text { Subtropical } \\ \text { Depression? } \\ \text { Dissipation }\end{array} \\ \text { December 23 } & 26 \mathrm{~N} & 33 \mathrm{~W} & \end{array}$




\section{1 hurricane season}

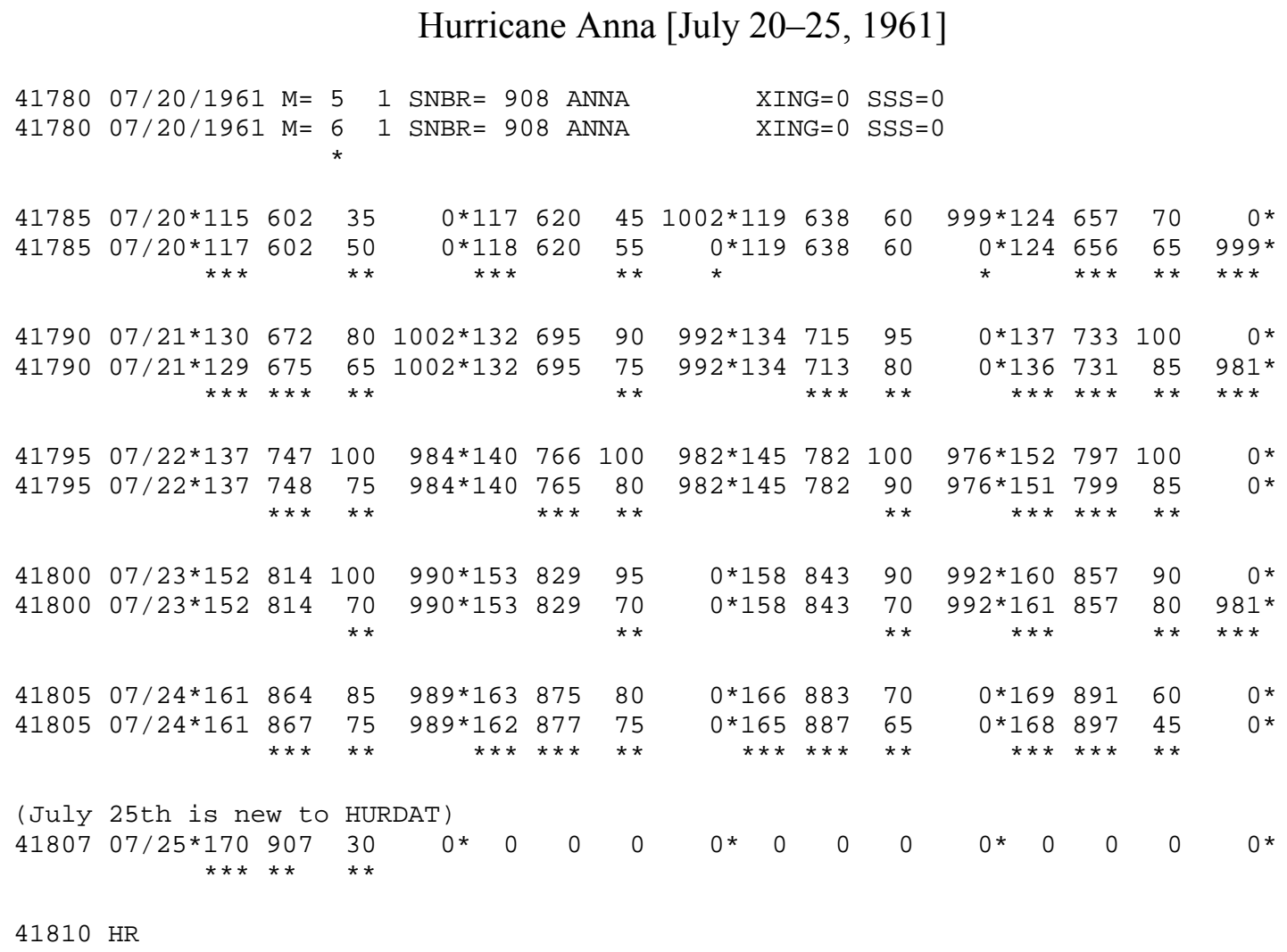

Hurricane Landfall

07/23 12Z 15.8N 84.3W $70 \mathrm{kt}$ Honduras

07/24 01Z 16.1N 86.9W 75 kt Utila Island, Honduras

07/24 10Z 16.4N 88.5W 75 kt Belize

Minor changes to the track and major changes to the intensity shown in McAdie et al. (2009). Evidence for these alterations comes from the NHC microfilm maps, the Historical Weather Maps series, the COADS ship database, Monthly Weather Review, Navy reconnaissance book, National Hurricane Research Project, Mexican synoptic maps, Mariners Weather Log, Fritz (1962) and NHC Storm Wallets.

July 17:

HWM and microfilm do not show an organized system at 12Z. HURDAT does not list an organized system on this date. Ship highlights: No gales or low pressures. 
ATSR: "An area of suspicion was noted well to the east of this position on July 17 when Navy reconnaissance aircraft reported a mass of strong radar echoes associated with an easterly wave between 14-16N and 50-54W."

July 18:

HWM and microfilm do not show an organized system at 12Z. HURDAT does not list an organized system on this date. Ship highlights: No gales or low pressures.

July 19:

HWM and microfilm do not show an organized system at 12Z. HURDAT does not list an organized system on this date. Ship highlights: No gales or low pressures.

ATSR: "ANNA, the first tropical storm of the 1961 hurricane season, developed just east of Windward Islands on the evening of July 19. During the 18th and 19th the Intertroical Convergence Zone shifted well north of its normal position and it appears that cyclogenesis began at its intersection with the easterly wave first noted by the Navy aircraft on the 17 th. At $191200 \mathrm{Z}$ the vessel BENNEKON reported easterly winds of 20 knots and 7 -foot seas near $15 \mathrm{~N} 55 \mathrm{~W}$. About this time the Windward Islands began to show abnormal falls in pressure."

July 20:

HWM analyzes a tropical storm of at most $1010 \mathrm{mb}$ at $11.7 \mathrm{~N}, 63.9 \mathrm{~W}$ at $12 \mathrm{Z}$. HURDAT lists a 60 knot tropical storm at $11.9 \mathrm{~N}, 63.8 \mathrm{~W}$ at $12 \mathrm{Z}$. Microfilm shows a closed low pressure of at most $1011 \mathrm{mb}$ at $12.0 \mathrm{~N}, 63.8 \mathrm{~W}$ at $12 \mathrm{Z}$. Navy reconnaissance book lists the best track position at $11.9 \mathrm{~N}, 63.8 \mathrm{~W}$ at 12Z. Ship highlights: $40 \mathrm{kt} \mathrm{SE}$ and $1010 \mathrm{mb}$ at $13.1 \mathrm{~N}, 62.8 \mathrm{~W}$ at $12 \mathrm{Z}$ (COADS). $50 \mathrm{kt} \mathrm{SE}$ and $1003 \mathrm{mb}$ at $12.5 \mathrm{~N}, 64.5 \mathrm{~W}$ at $1550 \mathrm{Z}$ (micro). $40 \mathrm{kt}$ ESE at 12.6N, 64.0W at 18Z (micro). Land highlights: $1002 \mathrm{mb}$ (min pressure) at Grenada at 05Z (WALLET/MWR/ATSR). Aircraft highlights: Penetration center fix estimated maximum surface winds of $55 \mathrm{kt}$ at $11.8 \mathrm{~N}, 63.8 \mathrm{~W}$ at $1130 Z$ (ATSR). Penetration center fix measured a central pressure of $999 \mathrm{mb}$ and estimated maximum surface winds of $85 \mathrm{kt}$ at $12.2 \mathrm{~N}, 65.5 \mathrm{~W}$ at $1834 \mathrm{Z}$ (ATSR).

MWR: "Anna, the first tropical cyclone of the 1961 Atlantic hurricane season, developed a short distance east of the Windward Islands on the evening of July 19. An area of suspicion was first noted well to the east on July 17 as Navy reconnaissance reported an extensive area of strong radar echoes between 14-16N and 50-55W. Shipping in the area also reported numerous showers with winds generally light and variable. TIROS showed the principal concentration of weather near $12 \mathrm{~N}, 43 \mathrm{~W}$. During the 18th and 19th the ITCs shifted well north of its normal position and cyclogenesis probably occurred at, its 
intersection with the easterly wave first noted by Navy aircraft on the 17th. Following reports from the island of Grenada, indicating heavy squalls with gusts to $50 \mathrm{mph}$ and pressure of $1002 \mathrm{mb}$ around midnight local time on the 19th, reconnaissance aircraft located Anna in the extreme southeastern Caribbean some 75 miles north of the Venezuelan coast on the morning of July 20. By afternoon winds had increased to slightly over hurricane force. From its inception, Anna maintained a course slightly north of due west on its entire track through the Caribbean Sea with forward speed between 15 and 23 mph." ATSR: "At 200000Z the wind at Barbados had increased to 25 knots from 110 degrees, while St. Lucia reported 25 knots at 050 degrees. Coupled with considerable shower activity in the area, indications were that the easterly wave had passed Barbados and intensified. Intensification was confirmed when Granada at $200500 \mathrm{Z}$ reported heavy squalls with gusts to 45 knots and a $1002 \mathrm{mb}$ pressure. At $201025 \mathrm{Z}$ a Navy reconnaissance aircraft reported a weak, diffuse eye near $12.7 \mathrm{~N} 64.0 \mathrm{~W}$. The first official warning was issued at 201330Z. By afternoon, winds had increased to slightly over hurricane force. ANNA continued to intensify while moving through the Caribbean on a heading just north of west. Anna caused minor damage at Trinidad and Grenada but there were no casualties."

July 21:

HWM analyzes a tropical storm of at most $1000 \mathrm{mb}$ at $13.1 \mathrm{~N}, 71.2 \mathrm{~W}$ at $12 \mathrm{Z}$. HURDAT lists a 95 knot hurricane at $13.4 \mathrm{~N}, 71.5 \mathrm{~W}$ at $12 \mathrm{Z}$. Microfilm shows a closed low pressure of at most $1005 \mathrm{mb}$ at $13.5 \mathrm{~N}, 71.5 \mathrm{~W}$ at $12 \mathrm{Z}$. Navy reconnaissance book lists the best track position at $13.4 \mathrm{~N}, 71.5 \mathrm{~W}$ at $12 \mathrm{Z}$. Ship highlights: $50 \mathrm{kt} \mathrm{NNE}$ and $1000 \mathrm{mb}$ at $13.4 \mathrm{~N}, 68.2 \mathrm{~W}$ (likely wrong location) at $06 \mathrm{Z}$ (micro). $35 \mathrm{kt} \mathrm{E}$ at $15.3 \mathrm{~N}, 68.4 \mathrm{~W}$ at $10 \mathrm{Z}$ (micro). $50 \mathrm{kt} \mathrm{ENE}$ and $1009 \mathrm{mb}$ at $14.5 \mathrm{~N}, 72.3 \mathrm{~W}$ at $18 \mathrm{Z}$ (COADS). $40 \mathrm{kt} \mathrm{E}$ and 1011 $\mathrm{mb}$ at $13.9 \mathrm{~N}, 70.9 \mathrm{~W}$ at $21 \mathrm{Z}$ (micro). Land highlights: $40 \mathrm{kt}$ (max wind) at Aruba (time unknown)(WALLET). Aircraft highlights: Penetration center fix measured a central pressure of $1002 \mathrm{mb}$ and estimated an eye diameter of $13 \mathrm{~nm}$ at $13.1 \mathrm{~N}, 67.7 \mathrm{~W}$ at $01 \mathrm{Z}$ (ATSR). Penetration center fix measured a central pressure of $992 \mathrm{mb}$, estimated maximum flight level winds of $90 \mathrm{kt}$ and an eye diameter of $8 \mathrm{~nm}$ at $13.3 \mathrm{~N}, 69.8 \mathrm{~W}$ at $07 Z$ (ATSR). Penetration center fix measured a central pressure of $983 \mathrm{mb}$, estimated maximum surface winds of $98 \mathrm{kt}$ and an RMW of $12 \mathrm{~nm}$ at $13.0 \mathrm{~N}, 71.0 \mathrm{~W}$ around $1730 \mathrm{Z}$ (NHRP). Radar center fix at 13.4N, $71.7 \mathrm{~W}$ at $1355 \mathrm{Z}$ (ATSR). Penetration center fix measured a central pressure of $981 \mathrm{mb}$, estimated maximum surface winds of $110 \mathrm{kt}$ and an eye diameter of $18 \mathrm{~nm}$ at $13.8 \mathrm{~N}, 73.8 \mathrm{~W}$ at $1910 \mathrm{Z}$ (ATSR).

July 22:

HWM analyzes a tropical storm of at most $1000 \mathrm{mb}$ at $14.3 \mathrm{~N}, 78.1 \mathrm{~W}$ at $12 \mathrm{Z}$. HURDAT lists a 100 knot hurricane at $14.5 \mathrm{~N}, 78.2 \mathrm{~W}$ at $12 \mathrm{Z}$. Microfilm shows a sharp 
trough or tropical wave over the southern Caribbean Sea along longitude $78 \mathrm{~W}$ at $12 \mathrm{Z}$. Navy reconnaissance book lists the best track position at $14.5 \mathrm{~N}, 78.2 \mathrm{~W}$ at $12 \mathrm{Z}$. Ship highlights: $35 \mathrm{kt} \mathrm{E}$ and $1012 \mathrm{mb}$ at 16.3N, 76.0W at 06Z (micro). $40 \mathrm{kt} \mathrm{ENE}$ and 1016 $\mathrm{mb}$ at $19.3 \mathrm{~N}, 80.0 \mathrm{~W}$ at $18 \mathrm{Z}$ (COADS). $40 \mathrm{kt} \mathrm{NE}$ and $1007 \mathrm{mb}$ at $15.6 \mathrm{~N}, 81.6 \mathrm{~W}$ at $21 \mathrm{Z}$ (micro). Aircraft highlights: Penetration center fix measured a central pressure of $984 \mathrm{mb}$ and estimated an eye diameter of $25 \mathrm{~nm}$ at $13.6 \mathrm{~N}, 74.9 \mathrm{~W}$ at $01 \mathrm{Z}$ (ATSR). Penetration center fix estimated maximum surface winds of $88 \mathrm{kt}$ and an eye diameter of $21 \mathrm{~nm}$ at $14.1 \mathrm{~N}, 76.6 \mathrm{~W}$ at $07 \mathrm{Z}$ (ATSR). Penetration center fix measured a central pressure of 976 $\mathrm{mb}$ and estimated an eye diameter of $18 \mathrm{~nm}$ at $14.5 \mathrm{~N}, 77.8 \mathrm{~W}$ at $1030 \mathrm{Z}$ (ATSR). Penetration center fix at $15.1 \mathrm{~N}, 80.0 \mathrm{~W}$ at $1823 \mathrm{Z}$ (ATSR).

MWR: "lowest pressure $976 \mathrm{mb}$ (28.62 inches) on the 22nd." ATSR: "After maximum winds increased to 110 knots early on the 22 nd."

July 23:

HWM analyzes a tropical storm of at most $995 \mathrm{mb}$ at $15.8 \mathrm{~N}, 84.1 \mathrm{~W}$ at $12 \mathrm{Z}$. HURDAT lists a 90 knot hurricane at $15.8 \mathrm{~N}, 84.3 \mathrm{~W}$ at $12 \mathrm{Z}$. Microfilm shows a large closed low pressure of at most $1008 \mathrm{mb}$ at $14.5 \mathrm{~N}, 84.5 \mathrm{~W}$ at $12 \mathrm{Z}$. Navy reconnaissance book lists the best track position at $15.8 \mathrm{~N}, 84.3 \mathrm{~W}$ at 12Z. Ship highlights: No gales or low pressures. Aircraft highlights: Penetration center fix measured a central pressure of $990 \mathrm{mb}$, estimated maximum surface winds of $55 \mathrm{kt}$ (limited by darkness) and an eye diameter of $25 \mathrm{~nm}$ at $15.2 \mathrm{~N}, 81.7 \mathrm{~W}$ at $01 \mathrm{Z}$ (ATSR). Radar center fix at $15.3 \mathrm{~N}, 82.7 \mathrm{~W}$ at 06Z (ATSR). Penetration center fix measured a central pressure of $992 \mathrm{mb}$, estimated maximum surface winds of $90 \mathrm{kt}$ and an eye diameter of $18 \mathrm{~nm}$ at $15.7 \mathrm{~N}, 84.4 \mathrm{~W}$ at $1230 Z$ (ATSR). Penetration center fix measured a central pressure of $981 \mathrm{mb}$, estimated maximum flight level winds of $50 \mathrm{kt}$ and an eye diameter of $12 \mathrm{~nm}$ at $16.1 \mathrm{~N}, 85.2 \mathrm{~W}$ at $16 Z$ (ATSR). Penetration center fix estimated maximum surface winds of $85 \mathrm{kt}$ and an eye diameter of $14 \mathrm{~nm}$ at $16.1 \mathrm{~N}, 86.3 \mathrm{~W}$ at $2122 \mathrm{Z}$ (ATSR). Penetration center fix measured a central pressure of $989 \mathrm{mb}$ at $16.1 \mathrm{~N}, 86.6 \mathrm{~W}$ at $2352 \mathrm{Z}$ (ATSR).

MWR: "On the 23rd the center skirted the extreme northeastern coast of Honduras." ATSR: “...she grazed the northern coast of Honduras....Considerable damage was reported along the extreme northern Honduras coast with several hundred buildings damaged or destroyed and many plantations suffering heavy damage to fruit trees. One death and a dozen casualties were reported from Trujillo, Honduras, and the Bay Islands, just north of Honduras. More than 5,000 coconut trees were blown down on Utila, a small island off the Honduras coast directly in the path of Anna."

July 24: 
HWM analyzes a tropical storm of at most $1000 \mathrm{mb}$ at $16.0 \mathrm{~N}, 88.6 \mathrm{~W}$ at $12 \mathrm{Z}$. HURDAT lists a 70 knot hurricane at $16.6 \mathrm{~N}, 88.3 \mathrm{~W}$ at $12 \mathrm{Z}$. Microfilm shows a closed low pressure of at most $1002 \mathrm{mb}$ at $16.8 \mathrm{~N}, 88.3 \mathrm{~W}$ at $12 \mathrm{Z}$. Navy reconnaissance book lists the best track position at $16.6 \mathrm{~N}, 88.3 \mathrm{~W}$ at 12Z. Ship highlights: $45 \mathrm{kt} \mathrm{NW}$ and $1004 \mathrm{mb}$ at $16.1 \mathrm{~N}, 86.4 \mathrm{~W}$ at $00 \mathrm{Z}$ (micro). Land highlights: $35 \mathrm{kt} \mathrm{ESE}$ and $1008 \mathrm{mb}$ at Guanaja Island, Honduras at 03Z (micro). $10 \mathrm{kt} \mathrm{S}$ and $1005 \mathrm{mb}$ at Tela, Honduras at 06Z (WALLET/micro). $40 \mathrm{kt} \mathrm{NE}$ and $1009 \mathrm{mb}$ at Belize City, British Honduras at 12Z (micro).

MWR: "then passed westward into the mountains of southern British Honduras the next morning." ATSR: “...before passing inland on the 24th over British Honduras and dissipating. A total of 61 fixes on Anna was made by VW-4 in a maximum reconnaissance effort....Unofficial reports from British Honduras indicated that damage was rather extensive at Punta Gorda $[16.1 \mathrm{~N}, 88.6 \mathrm{~W}]$ in extreme southeastern British Honduras. The center of Anna moved inland over the British Honduras coast, a sparsely populated area, at approximately the same point that Abby entered in July 1960. The often observed succession of storms from the Caribbean into the Pacific did not occur on this occasion."

July 25:

HMW analyzes a sport low pressure at $16.5 \mathrm{~N}, 94.0 \mathrm{~W}$ at $12 \mathrm{Z}$. HURDAT does not list an organized storm on this day. Microfilm shows a closed low pressure of at most $1008 \mathrm{mb}$ at $16.5 \mathrm{~N}, 93.5 \mathrm{~W}$ at $12 \mathrm{Z}$. Ship highlights: No gales or low pressures.

A tropical wave left the African coast around mid-July. The disturbance moved westward and on July 17th at 1440Z, a TIROS III satellite image (MWR 1962, pg. 109) indicated that the tropical wave was organizing with some banding features in the northern and southern quadrants. This satellite image appears to be a milestone in hurricane history as for the first time a satellite image is referenced in the Monthly Weather Review. The report of a west wind at $9.7 \mathrm{~N}, 46.3 \mathrm{~W}$ at $18 \mathrm{Z}$ on the 17 th may indicate that the low-level circulation was closed, but the data is sparse and determined to be inconclusive. A paper by Fritz (1962) indicates that the tropical wave continued to become better organized on July 18th as shown by a TIROS III satellite image at 1557Z (MWR 1962, pg. 511). Data over the central Atlantic was sparse and the time of genesis is uncertain but likely occurred earlier than July 20th at $00 \mathrm{Z}$ as originally shown in HURDAT. The first position, not genesis, is analyzed at $00 \mathrm{Z}$ on July 20 th as a $50 \mathrm{kt}$ tropical storm. This intensity is based on a minimum pressure of $1002 \mathrm{mb}$ measured at $05 \mathrm{Z}$ on the 20th on the island of Grenada as the center of Anna passed to the south. The barograph in the storm wallets indicates that the pressure dropped about $12 \mathrm{mb}$ in 24 hours. A peripheral pressure of $1002 \mathrm{mb}$ suggests maximum surface winds greater than $43 \mathrm{kt}$ from the south 
of $25 \mathrm{~N}$ Brown et al. pressure-wind relationship. Due to a forward speed of about $18 \mathrm{kt}$, an intensity of $50 \mathrm{kt}$ is selected at $00 \mathrm{Z}$ and $55 \mathrm{kt}$ at $06 \mathrm{Z}$ on the $20 \mathrm{th}$, up from $35 \mathrm{kt}$ and $45 \mathrm{kt}$, respectively, originally in HURDAT, minor intensity changes. A central pressure of 1002 $\mathrm{mb}$ originally in HURDAT at $06 \mathrm{Z}$ on the 20th has been removed since it was a not a central pressure. Minor track alterations are introduced during the lifetime of this tropical cyclone. After entering the Caribbean Sea, Anna continued slightly north of due west at a fast forward speed. The first reconnaissance aircraft to reach the tropical storm measured a central pressure of $999 \mathrm{mb}$ and estimated maximum surface winds of $85 \mathrm{kt}$ at $1834 \mathrm{Z}$ on the 20th. A central pressure of $999 \mathrm{mb}$ suggests maximum surface winds of $49 \mathrm{kt}$ from the south of $25 \mathrm{~N}$ pressure-wind relationship. Due to the forward speed of about $20 \mathrm{kt}$ and slightly weighting the surface estimate, an intensity of $65 \mathrm{kt}$ is selected at $18 \mathrm{Z}$ on the 20th, down from $70 \mathrm{kt}$ originally in HURDAT, a minor intensity change. A central pressure of $999 \mathrm{mb}$ was present in HURDAT at $12 \mathrm{Z}$ on the 20th and has been moved to $18 \mathrm{Z}$. Intensification to a hurricane is analyzed at $18 \mathrm{Z}$ on the 20 th, same as originally shown in HURDAT.

Another penetration center fix occurred at $01 \mathrm{Z}$ on July 21 st measuring a central pressure of $1002 \mathrm{mb}$ and estimating an eye diameter of $13 \mathrm{~nm}$. A central pressure of 1002 $\mathrm{mb}$ suggests maximum surface winds of $43 \mathrm{kt}$ from the south of $25 \mathrm{~N}$ pressure-wind relationship. An eye diameter of $13 \mathrm{~nm}$ suggests an RMW of about $10 \mathrm{~nm}$ and the climatological value is $12 \mathrm{~nm}$. Due to the fast forward speed of about $21 \mathrm{kt}$, RMW slightly below the climatological value and data later in the day, an intensity of $65 \mathrm{kt}$ is analyzed for $00 Z$ on the $21 \mathrm{st}$, down from $80 \mathrm{kt}$ originally in HURDAT, a minor change. At $07 \mathrm{Z}$ on the $21 \mathrm{st}$, the reconnaissance aircraft measured a central pressure of $992 \mathrm{mb}$, estimated flight level winds of $90 \mathrm{kt}$ and an eye diameter of $8 \mathrm{~nm}$. A central pressure of $992 \mathrm{mb}$ suggests maximum surface winds of $61 \mathrm{kt}$ from the south of $25 \mathrm{~N}$ pressure-wind relationship. An eye diameter of $8 \mathrm{~nm}$ suggests an RMW of about $6 \mathrm{~nm}$ and the climatological value is $12 \mathrm{~nm}$. Due to the fast forward speed of about $20 \mathrm{kt}$ and RMW below the climatological value, an intensity of $75 \mathrm{kt}$ is analyzed for $06 \mathrm{Z}$ on the $21 \mathrm{st}$, down from $90 \mathrm{kt}$ originally in HURDAT, a minor change. Early on the 21st, Anna passed north of the ABC Islands where the strongest winds reported reached $40 \mathrm{kt}$. At $1548 \mathrm{Z}$ on the 21 st, a TIROS III satellite image (MWR 1962, pg. 109) depicts a small, wellorganized tropical cyclone with an organized CDO near or over the center, located just northwest of the Guajira Peninsula in Colombia. No eye is apparent in the satellite image. This was also a milestone as the first hurricane to appear in a satellite image. Another penetration fix occurred at $1910 \mathrm{Z}$ on the $21 \mathrm{st}$ measuring a central pressure of $981 \mathrm{mb}$, estimating surface winds of $110 \mathrm{kt}$ and an eye diameter of $18 \mathrm{~nm}$. A central pressure of $981 \mathrm{mb}$ suggests maximum surface winds of $76 \mathrm{kt}$ from the south of $25 \mathrm{~N}$ pressure-wind relationship. An eye diameter of $18 \mathrm{~nm}$ suggests an RMW of about $14 \mathrm{~nm}$ and the climatological value is $13 \mathrm{~nm}$. Due to a forward speed of $18 \mathrm{kt}$, RMW close to the 
climatological value and slightly weighting the surface estimate, an intensity of $85 \mathrm{kt}$ is analyzed for $18 \mathrm{Z}$ on the 21 st, down from 100 kt originally in HURDAT, a minor intensity change. A central pressure of $981 \mathrm{mb}$ has been added to HURDAT at $18 \mathrm{Z}$ on the 21 st.

On July 22nd, Anna moved away from South America and entered the central Caribbean on its way to Central America. The first aircraft to investigate the hurricane on the 22nd occurred at $01 \mathrm{Z}$ and measured a central pressure of $984 \mathrm{mb}$ and an eye diameter of $25 \mathrm{~nm}$. A central pressure of $984 \mathrm{mb}$ suggests maximum surface winds of $72 \mathrm{kt}$ from the south of $25 \mathrm{~N}$ pressure-wind relationship. An eye diameter of $25 \mathrm{~nm}$ suggests an RMW of about $19 \mathrm{~nm}$ and the climatological value is $13 \mathrm{~nm}$. Due to a forward speed of $18 \mathrm{kt}$ and RMW larger than the climatological value, an intensity of $75 \mathrm{kt}$ is analyzed for $00 \mathrm{Z}$ on the $22 \mathrm{nd}$, down from $100 \mathrm{kt}$ originally in HURDAT, a major intensity change. A central pressure of $982 \mathrm{mb}$ was present in HURDAT at $06 \mathrm{Z}$ and has been retained as it appears reasonable (but could not be confirmed) with the data available. At 07Z, an aircraft reconnaissance estimated surface winds of $88 \mathrm{kt}$ and an eye diameter of $21 \mathrm{~nm}$. This flight might have measured the $982 \mathrm{mb}$ central pressure present in HURDAT at 06Z on the 22nd. A central pressure of $982 \mathrm{mb}$ suggests maximum surface winds of $75 \mathrm{kt}$ from the south of $25 \mathrm{~N}$ pressure-wind relationship. An eye diameter of $21 \mathrm{~nm}$ suggests an RMW of about $16 \mathrm{~nm}$ and the climatological value is $14 \mathrm{~nm}$. Due to a forward speed of $18 \mathrm{kt}$ and RMW close to the climatological value, an intensity of $80 \mathrm{kt}$ is analyzed for $06 \mathrm{Z}$ on the 22nd, down from $100 \mathrm{kt}$ originally in HURDAT, a major intensity change. Another penetration fix measured a central pressure of $976 \mathrm{mb}$ and an eye diameter of 18 $\mathrm{nm}$ at $1030 \mathrm{Z}$ on the $22 \mathrm{nd}$. A central pressure of $976 \mathrm{mb}$ suggests maximum surface winds of $83 \mathrm{kt}$ from the south of $25 \mathrm{~N}$ pressure-wind relationship. An eye diameter of $18 \mathrm{~nm}$ suggests an RMW of about $14 \mathrm{~nm}$ and the climatological value is $14 \mathrm{~nm}$. Due to a forward speed of $18 \mathrm{kt}$ and RMW same as the climatological value, an intensity of $90 \mathrm{kt}$ is analyzed for $12 \mathrm{Z}$ on the $22 \mathrm{nd}$, down from $100 \mathrm{kt}$ originally in HURDAT, a minor intensity change. $90 \mathrm{kt}$ is also the peak intensity of hurricane Anna, down from $100 \mathrm{kt}$ originally in HURDAT from $18 \mathrm{Z}$ on the 21 st to $00 \mathrm{Z}$ on the $23 \mathrm{rd}$. Hence, Anna is analyzed to have remained below major hurricane intensity during its lifetime. On July $23 \mathrm{rd}$ at 01Z, a reconnaissance aircraft measured a central pressure of $990 \mathrm{mb}$, estimated surface winds of $55 \mathrm{kt}$ (wind estimate limited by darkness) and an eye diameter of $25 \mathrm{~nm}$. A central pressure of $990 \mathrm{mb}$ suggests maximum surface winds of $64 \mathrm{kt}$ from the south of $25 \mathrm{~N}$ pressure-wind relationship. An eye diameter of $25 \mathrm{~nm}$ suggests an RMW of about 19 $\mathrm{nm}$ and the climatological value is $14 \mathrm{~nm}$. Due to a forward speed of $15 \mathrm{kt}$ and RMW larger than the climatological value, an intensity of $70 \mathrm{kt}$ is analyzed for $00 \mathrm{Z}$ on the $23 \mathrm{rd}$, down from 100 kt originally in HURDAT, a major intensity change. Anna continued west-northwest and made landfall around $12 \mathrm{Z}$ in northeastern Honduras as a $70 \mathrm{kt}$ hurricane. At 1230Z, a penetration fix measured a central pressure of $992 \mathrm{mb}$, estimated 
surface winds of $90 \mathrm{kt}$ and an eye diameter of $18 \mathrm{~nm}$. A central pressure of $992 \mathrm{mb}$ suggests maximum surface winds of $61 \mathrm{kt}$ from the south of $25 \mathrm{~N}$ pressure-wind relationship. An eye diameter of $18 \mathrm{~nm}$ suggests an RMW of about $14 \mathrm{~nm}$ and the climatological value is $14 \mathrm{~nm}$. Due to a forward speed of $15 \mathrm{kt}$, RMW close to the climatological value and some weighting of the visual estimate, an intensity of $70 \mathrm{kt}$ is analyzed for $12 \mathrm{Z}$ on the $22 \mathrm{nd}$, down from 90 kt originally in HURDAT, a major intensity change. The center of Anna skirted the coast of Honduras for about four hours.

Interaction with land apparently did not weaken Anna as a reconnaissance aircraft at $16 \mathrm{Z}$ measured a central pressure of $981 \mathrm{mb}$ and an eye diameter of $12 \mathrm{~nm}$. A central pressure of $981 \mathrm{mb}$ suggests maximum surface winds of $76 \mathrm{kt}$ from the south of $25 \mathrm{~N}$ pressurewind relationship. An eye diameter of $12 \mathrm{~nm}$ suggests an RMW of about $9 \mathrm{~nm}$ and the climatological value is $14 \mathrm{~nm}$. Due to a forward speed of $14 \mathrm{kt}$ and RMW smaller than the climatological value, an intensity of $80 \mathrm{kt}$ is analyzed for $06 \mathrm{Z}$ on the $22 \mathrm{nd}$, down from 90 kt originally in HURDAT, a minor intensity change. A central pressure of $981 \mathrm{mb}$ has been added to HURDAT at $18 \mathrm{Z}$ on the $23 \mathrm{rd}$. The last penetration fix occurred at $2352 \mathrm{Z}$ on the 23rd measuring a central pressure of $989 \mathrm{mb}$. At 2122Z, another pass estimated surface winds of $85 \mathrm{kt}$ and an eye diameter of $14 \mathrm{~nm}$. A central pressure of $989 \mathrm{mb}$ suggests maximum surface winds of $65 \mathrm{kt}$ from the south of $25 \mathrm{~N}$ pressure-wind relationship. An eye diameter of $14 \mathrm{~nm}$ suggests an RMW of about $11 \mathrm{~nm}$ and the climatological value is $14 \mathrm{~nm}$. Due to a forward speed of $10 \mathrm{kt}$ and RMW smaller than the climatological value, an intensity of $75 \mathrm{kt}$ is analyzed for $00 \mathrm{Z}$ on the 24th, down from 85 kt originally in HURDAT, a minor intensity change. The hurricane continued westnorthwest affecting the Bay Islands along its path. Landfall in the island of Utila, Honduras is analyzed at $01 \mathrm{Z}$ on the 24 th as a $75 \mathrm{kt}$ hurricane. The island was reported to have sustained heavy damages. Anna maintained a west-northwest course early on the 24th and impacted Belize near $16.4 \mathrm{~N}, 88.5 \mathrm{~W}$ or about $70 \mathrm{~nm}$ south of Belize City, at $10 \mathrm{Z}$ as a $75 \mathrm{kt}$ hurricane. The landfall intensity in Belize is uncertain as there were no observations near the center of Anna during the last 10 hours before landfall or after landfall. The observations in Belize available in the Storm Wallets contradict the data available as the pressure values and time observed do not match the synoptic data in microfilm and HWM, nor are mentioned in the MWR. Thus, these observations have been disregarded. Anna is analyzed to have weakened to a tropical storm over Guatemala at $18 \mathrm{Z}$, same as originally shown in HURDAT. The weakening tropical cyclone kept moving west-northwest and dissipated over eastern Mexico early on July 25th. The last position is analyzed at $00 \mathrm{Z}$ on the 25 th, six hours later than originally shown in HURDAT. The last position in the original HURDAT had Anna as a $60 \mathrm{kt}$ tropical storm and the last official advisory had Anna as a hurricane over Belize. Anna was a typical fast-moving hurricane in the Caribbean Sea during the month of July. The central pressures reported over the eastern Caribbean when the tropical cyclone was moving at 
its fastest were higher than typical from that expected of the Brown et al. pressure-wind relationship but this is not abnormal for the area. In 2002, Lili had a central pressure of $1004 \mathrm{mb}$ and sustained winds of $60 \mathrm{kt}$ over the eastern Caribbean Sea and Debby in 2000, reached hurricane intensity with only $1005 \mathrm{mb}$ just north of the Leeward Islands. Both of these cyclones were also fast-moving storms.

Hurricane Betsy [September 2-15, 1961]

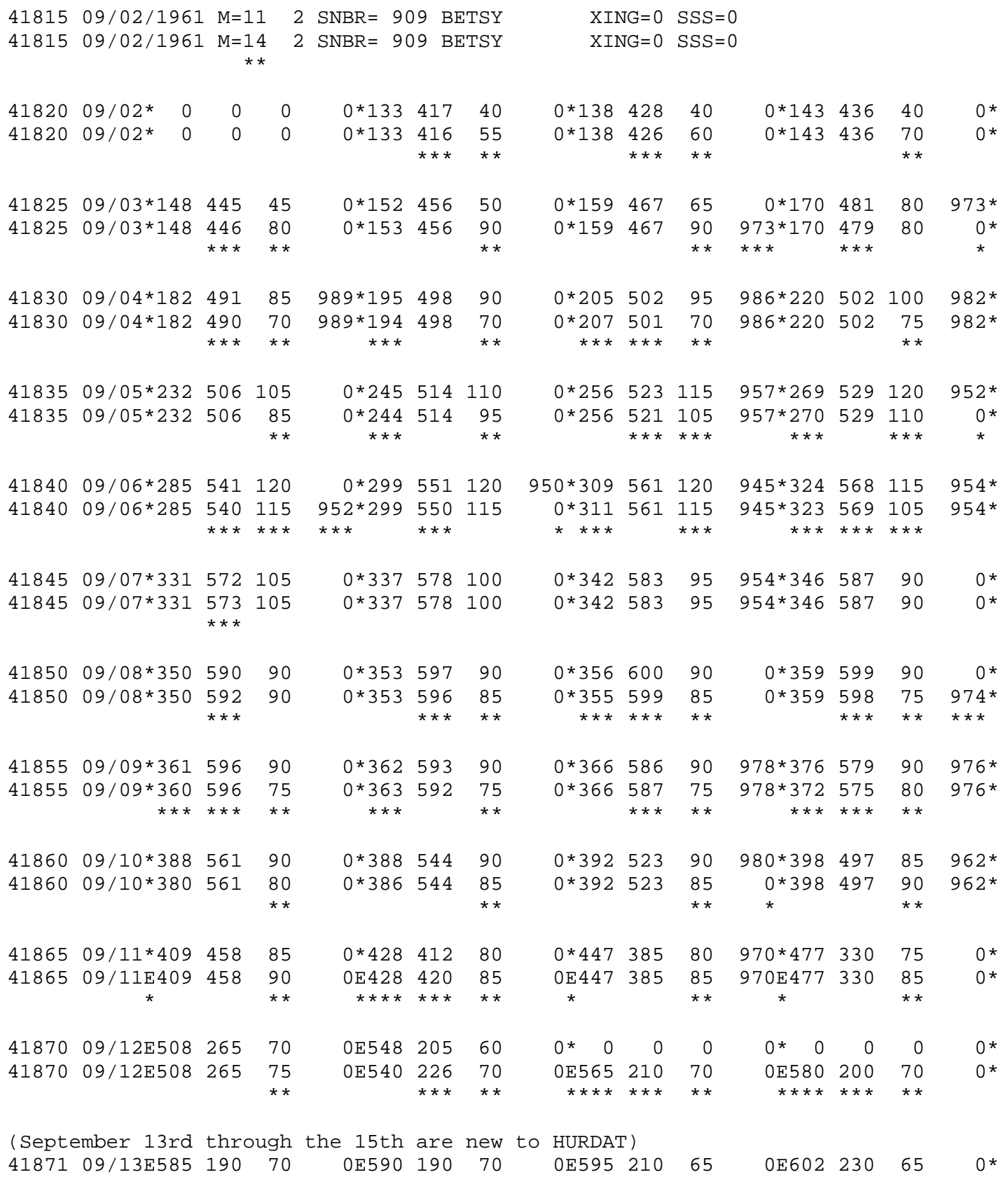


$4187209 / 14 \mathrm{E} 610240 \quad 60$

$4187309 / 15 E 610260 \quad 50$

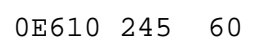

OE610 $250 \quad 60$

OE610 $255 \quad 55$

$0^{*}$

41875 HR

Minor changes to the track and major changes to the intensity shown in McAdie et al. (2009). Major alterations to this tropical cyclone are to show transition to extratropical 24 hours earlier than originally shown in HURDAT and to add three days to its lifetime. Evidence for these alterations comes from the NHC microfilm maps, the Historical Weather Maps series, the COADS ship database, Monthly Weather Review, Navy reconnaissance book, Mariners Weather Log, and NHC Storm Wallets.

August 30:

HWM analyzes a spot low pressure at $10.0 \mathrm{~N}, 36.0 \mathrm{~W}$ at $12 \mathrm{Z}$. HURDAT does not list an organized storm on this day. Ship highlights: No gales or low pressures. August 31:

HWM analyzes a spot low pressure at $11.5 \mathrm{~N}, 36.5 \mathrm{~W}$ at $12 \mathrm{Z}$. HURDAT does not list an organized storm on this day. Ship highlights: No gales or low pressures.

September 1:

HWM analyzes a closed low pressure of at most $1010 \mathrm{mb}$ at $11.0 \mathrm{~N}, 39.4 \mathrm{~W}$ at $12 \mathrm{Z}$. HURDAT does not list an organized storm on this day. Microfilm shows a closed low pressure of at most $1011 \mathrm{mb}$ along the ITCZ near $12.5 \mathrm{~N}, 44.4 \mathrm{~W}$ at $12 \mathrm{Z}$. Ship highlights: No gales or low pressures.

September 2:

HWM analyzes a tropical storm of at most $1010 \mathrm{mb}$ at $13.3 \mathrm{~N}, 43.0 \mathrm{~W}$ at $12 \mathrm{Z}$. HURDAT lists a $40 \mathrm{kt}$ tropical storm at $13.8 \mathrm{~N}, 42.8 \mathrm{~W}$ at $12 \mathrm{Z}$. Microfilm does not show an organized storm at 12Z. Ship highlights: $998 \mathrm{mb}$ at 13.6N, 42.2W at 08Z (MWR). $40 \mathrm{kt}$ $\mathrm{N}$ and $1004 \mathrm{mb}$ at $15.6 \mathrm{~N}, 45.2 \mathrm{~W}$ at 15Z (MWR). $40 \mathrm{kt} \mathrm{NNE}$ and $1002 \mathrm{mb}$ at $15.4 \mathrm{~N}$, $44.7 \mathrm{~W}$ at $23 \mathrm{Z}$ (micro).

MWR: "The formation of hurricane Betsy inaugurated one of the most active tropical cyclone periods in the history of the North Atlantic Ocean. No less than three other hurricanes made their appearance before Betsy dissipated. Betsy formed in the eastern tropical Atlantic apparently from a perturbation moving along the ITCZ. An observation from the SS Granheim at 0300 EST, September 2, located at 13.6N, 42.2W, with a barometer reading of " 980 " which is interpreted as $998.0 \mathrm{mb}$, was the first indication of Betsy. At 1000 EST the SS Charlotte Maersk at 15.6N, $45.2 \mathrm{~W}$, reported winds of $40 \mathrm{kt}$, and pressure of $1004 \mathrm{mb}$, steadily falling." ATSR: "The second storm of the season, 
Hurricane Betsy, interrupted a lull of more than a month in tropical storm activity. This storm apparently formed at the intersection of an easterly wave and the Intertropical Convergence Zone. The easterly wave had been reported earlier by Fleet Weather Central, Port Lyautey, and subsequently tracked across the eastern Atlantic on weather charts by Fleet Weather Facility, Miami. An observation from the SS GRANHEIM, position near $13.5 \mathrm{~N} 42.0 \mathrm{~W}$ at $020800 \mathrm{Z}$, gave a surface pressure of $1009 \mathrm{mb}$ - the first unusual activity in the area. A Tiros satellite at $021137 \mathrm{Z}$ indicated possible cyclonic activity near $15 \mathrm{~N} 45 \mathrm{~W}$. Shortly thereafter, a second vessel, the SS CHAROLETTE MAERSK, reporting from a position $15.5 \mathrm{~N} 46 \mathrm{~W}$, gave a surface pressure of $1004.5 \mathrm{mb}$, steadily falling, and ENE to $\mathrm{N}$ winds up to 40 knots in squalls."

September 3:

HWM analyzes a hurricane of at most $1000 \mathrm{mb}$ at $15.5 \mathrm{~N}, 46.8 \mathrm{~W}$ at $12 \mathrm{Z}$. HURDAT lists a $65 \mathrm{kt}$ hurricane at $15.9 \mathrm{~N}, 46.7 \mathrm{~W}$ at $12 \mathrm{Z}$. Microfilm shows a closed low pressure of at most $999 \mathrm{mb}$ at $16.1 \mathrm{~N}, 46.5 \mathrm{~W}$ at 12Z. Ship highlights: $45 \mathrm{kt} \mathrm{NE}$ and $1001 \mathrm{mb}$ at $15.6 \mathrm{~N}$, $44.3 \mathrm{~W}$ at $01 \mathrm{Z}$ (micro). $50 \mathrm{kt} \mathrm{ESE}$ and $1001 \mathrm{mb}$ at $15.6 \mathrm{~N}, 44.6 \mathrm{~W}$ at $03 \mathrm{Z}$ (micro). $50 \mathrm{kt}$ SSE and $1003 \mathrm{mb}$ at $15.9 \mathrm{~N}, 44.3 \mathrm{~W}$ at $06 \mathrm{Z}$ (micro). $45 \mathrm{kt} \mathrm{NNW}$ and $1010 \mathrm{mb}$ at $14.8 \mathrm{~N}$, $48.7 \mathrm{~W}$ at $12 \mathrm{Z}$ (micro). $40 \mathrm{kt} \mathrm{E}$ and $1009 \mathrm{mb}$ at $19.0 \mathrm{~N}, 46.3 \mathrm{~W}$ at $18 \mathrm{Z}$ (COADS). Aircraft highlights: Penetration center fix measured a central pressure of $973 \mathrm{mb}$, estimated surface winds of $90 \mathrm{kt}$ and an eye diameter of $15 \mathrm{~nm}$ at $16.2 \mathrm{~N}, 47.1 \mathrm{~W}$ at $14 \mathrm{Z}$ (ATSR).

MWR: "The first advisory was issued by the San Juan Weather Bureau at 2300 EST, September 2, for a tropical storm. A reconnaissance aircraft was dispatched to the storm area September 3 and found surface winds of $90 \mathrm{kt}$, and a central pressure of $973 \mathrm{mb}$. The track and changes of intensity of Betsy can be associated nicely with fluctuations in the westerlies. Ridges near the east coast of the United States and in the eastern Atlantic Ocean with a trough near $50 \mathrm{~W}$ were the main features of the upper-level flow pattern during the period of the storm. This trough not only steered Betsy into higher latitudes, but also later picked up Debbie and even temporarily pulled Esther northward before the trough finally filled." ATSR: "The first warning was issued 030400Z for Tropical Storm Betsy. The disturbance came within reconnaissance range early on the 3rd and was investigated by a Navy aircraft. Maximum winds of 90 knots and a central surface pressure of $973 \mathrm{mb}$ were found. Accordingly, Betsy was termed a hurricane on the 031600Z warning."

September 4:

HWM analyzes a hurricane of at most $995 \mathrm{mb}$ at $20.1 \mathrm{~N}, 50.1 \mathrm{~W}$ at $12 \mathrm{Z}$. HURDAT lists a $95 \mathrm{kt}$ hurricane at $20.5 \mathrm{~N}, 50.2 \mathrm{~W}$ at $12 \mathrm{Z}$. Microfilm shows a closed low pressure of at most $1005 \mathrm{mb}$ at $20.0 \mathrm{~N}, 51.0 \mathrm{~W}$ at 12Z. Ship highlights: $35 \mathrm{kt}$ ESE and $1012 \mathrm{mb}$ at 
$19.0 \mathrm{~N}, 45.9 \mathrm{~W}$ at $00 \mathrm{Z}$ (COADS). $45 \mathrm{kt} \mathrm{E}$ and $1009 \mathrm{mb}$ at $20.0 \mathrm{~N}, 48.0 \mathrm{~W}$ at $06 \mathrm{Z}$ (micro). $45 \mathrm{kt}$ ENE and $1009 \mathrm{mb}$ at $19.7 \mathrm{~N}, 48.2 \mathrm{~W}$ at $1230 \mathrm{Z}$ (micro). $45 \mathrm{kt} \mathrm{SSW}$ and $1004 \mathrm{mb}$ at $19.6 \mathrm{~N}, 49.8 \mathrm{~W}$ at $15 \mathrm{Z}$ (micro). $50 \mathrm{kt} \mathrm{SE}$ and $1011 \mathrm{mb}$ at $22.0 \mathrm{~N}, 48.0 \mathrm{~W}$ at $18 \mathrm{Z}$ (micro). Aircraft highlights: Penetration center fix measured a central pressure of $989 \mathrm{mb}$ and estimated an eye diameter of $15 \mathrm{~nm}$ at $18.5 \mathrm{~N}, 49.2 \mathrm{~W}$ at $01 \mathrm{Z}$ (ATSR). Radar center fix at $21.8 \mathrm{~N}, 50.0 \mathrm{~W}$ at $13 \mathrm{Z}$ (ATSR). Penetration center fix measured a central pressure of 982 $\mathrm{mb}$, estimated surface winds of $85 \mathrm{kt}$ and an eye diameter of $20 \mathrm{~nm}$ at $22.3 \mathrm{~N}, 50.3 \mathrm{~W}$ at 2016Z (ATSR).

MWR: "A closed Low developed and intensified in the trough on September 4, weakening the ridge to the north of the storm and accordingly Betsy filled, with a central pressure rising to near $990 \mathrm{mb}$."

September 5:

HWM analyzes a hurricane of at most $995 \mathrm{mb}$ at $25.1 \mathrm{~N}, 52.3 \mathrm{~W}$ at $12 \mathrm{Z}$. HURDAT lists an $115 \mathrm{kt}$ hurricane at $25.6 \mathrm{~N}, 52.3 \mathrm{~W}$ at $12 \mathrm{Z}$. Microfilm shows a closed low pressure of at most $1005 \mathrm{mb}$ at $25.5 \mathrm{~N}, 52.3 \mathrm{~W}$ at 12Z. Ship highlights: $40 \mathrm{kt}$ ESE and $1004 \mathrm{mb}$ at $24.8 \mathrm{~N}, 52.4 \mathrm{~W}$ at $00 \mathrm{Z}$ (micro). $50 \mathrm{kt} \mathrm{E}$ and $1008 \mathrm{mb}$ at $25.9 \mathrm{~N}, 51.6 \mathrm{~W}$ at $11 \mathrm{Z}$ (micro). 50 $\mathrm{kt} \mathrm{S}$ and $1008 \mathrm{mb}$ at $25.0 \mathrm{~N}, 51.6 \mathrm{~W}$ at $12 \mathrm{Z}$ (COADS). $45 \mathrm{kt} \mathrm{SE}$ and $1011 \mathrm{mb}$ at $25.4 \mathrm{~N}$, $51.1 \mathrm{~W}$ at $15 \mathrm{Z}$ (COADS). $50 \mathrm{kt}$ ESE and $1002 \mathrm{mb}$ at $27.1 \mathrm{~N}, 52.2 \mathrm{~W}$ at $18 \mathrm{Z}$ (micro). $50 \mathrm{kt}$ SE and $1000 \mathrm{mb}$ at $27.9 \mathrm{~N}, 51.6 \mathrm{~W}$ at $21 \mathrm{Z}$ (micro). Aircraft highlights: Penetration center fix measured a central pressure of $970 \mathrm{mb}$ at $26.3 \mathrm{~N}, 52.6 \mathrm{~W}$ at $15 \mathrm{Z}$ (ATSR/WALLET). Penetration center fix measured a central pressure of $952 \mathrm{mb}$ at $27.8 \mathrm{~N}, 53.4 \mathrm{~W}$ at $2138 \mathrm{Z}$ (ATSR/WALLET).

MWR: "On September 5, a short wave approached the trough and begun forcing the closed Low northeastward, resulting in height rises of the storm."

September 6:

HWM analyzes a hurricane of at most $995 \mathrm{mb}$ at $30.6 \mathrm{~N}, 56.4 \mathrm{~W}$ with a weakening stationary front far to the northwest at 12Z. HURDAT lists a $120 \mathrm{kt}$ hurricane at $30.9 \mathrm{~N}$, $56.1 \mathrm{~W}$ at $12 \mathrm{Z}$. Microfilm shows a closed low pressure of at most $1002 \mathrm{mb}$ at $31.1 \mathrm{~N}$, $56.2 \mathrm{~W}$ at 12Z. Ship highlights: $40 \mathrm{kt} \mathrm{SE}$ and $1006 \mathrm{mb}$ at 28.0N, 50.3W at 00Z (COADS). Aircraft highlights: Penetration center fix measured a central pressure of $950 \mathrm{mb}$ at $30.5 \mathrm{~N}, 55.6 \mathrm{~W}$ at $0912 \mathrm{Z}$ (ATSR/WALLET). Penetration center fix measured a central pressure of $945 \mathrm{mb}$ at $31.0 \mathrm{~N}, 56.4 \mathrm{~W}$ at $13 \mathrm{Z}$ (ATSR/WALLET). Penetration center fix measured a central pressure of $954 \mathrm{mb}$ at $32.9 \mathrm{~N}, 56.9 \mathrm{~W}$ at $19 \mathrm{Z}$ (ATSR/WALLET).

MWR: "In response, Betsy again intensified until September 6, when the central pressure reached its lowest value, $945 \mathrm{mb}$. Surface winds at this time were estimated near $120 \mathrm{kt}$. 
Betsy missed connection with the short wave on September 6, slowed almost to a standstill."

September 7:

HWM analyzes a hurricane of at most $995 \mathrm{mb}$ at $33.9 \mathrm{~N}, 58.3 \mathrm{~W}$ with a weakening front to the north at $12 \mathrm{Z}$. HURDAT lists a $95 \mathrm{kt}$ hurricane at $34.2 \mathrm{~N}, 58.3 \mathrm{~W}$ at $12 \mathrm{Z}$. Microfilm shows a closed low pressure of at most $1005 \mathrm{mb}$ at $34.5 \mathrm{~N}, 58.6 \mathrm{~W}$ with a frontal boundary to the north at 12Z. Ship highlights: $40 \mathrm{kt} \mathrm{NNW}$ and $1007 \mathrm{mb}$ at $34.0 \mathrm{~N}, 60.6 \mathrm{~W}$ at $12 \mathrm{Z}$ (micro). $40 \mathrm{kt} \mathrm{NNW}$ and $1007 \mathrm{mb}$ at $34.0 \mathrm{~N}, 60.8 \mathrm{~W}$ at $15 \mathrm{Z}$ (micro). $35 \mathrm{kt} \mathrm{NW}$ and 1011 $\mathrm{mb}$ at $33.2 \mathrm{~N}, 60.4 \mathrm{~W}$ at $18 \mathrm{Z}$ (micro). $50 \mathrm{kt} \mathrm{SSE}$ and $1007 \mathrm{mb}$ at $34.7 \mathrm{~N}, 56.5 \mathrm{~W}$ at $21 \mathrm{Z}$ (micro). Aircraft highlights: Penetration center fix estimated surface winds of at least 65 $\mathrm{kt}$ at $34.5 \mathrm{~N}, 59.0 \mathrm{~W}$ at $1245 \mathrm{Z}$ (ATSR/micro). Penetration center fix at $34.4 \mathrm{~N}, 58.5 \mathrm{~W}$ at $1845 Z$ (ATSR).

September 8:

HWM analyzes a hurricane of at most $1000 \mathrm{mb}$ at $35.1 \mathrm{~N}, 60.0 \mathrm{~W}$ with a warm front far to the northeast at $12 \mathrm{Z}$. HURDAT lists a $90 \mathrm{kt}$ hurricane at $35.6 \mathrm{~N}, 60.0 \mathrm{~W}$ at $12 \mathrm{Z}$. Microfilm shows a closed low pressure of at most $1011 \mathrm{mb}$ at $35.5 \mathrm{~N}, 60.2 \mathrm{~W}$ with a frontal boundary to the northeast at 12Z. Ship highlights: $55 \mathrm{kt} \mathrm{S}$ and $1012 \mathrm{mb}$ at $34.3 \mathrm{~N}, 56.0 \mathrm{~W}$ at $00 \mathrm{Z}$ (COADS). $45 \mathrm{kt} \mathrm{S}$ and $1012 \mathrm{mb}$ at 34.0N, 56.2W at 03Z (COADS). $35 \mathrm{kt} \mathrm{S}$ and $1012 \mathrm{mb}$ at $33.8 \mathrm{~N}, 56.5 \mathrm{~W}$ at $06 \mathrm{Z}$ (COADS). $35 \mathrm{kt} \mathrm{S}$ and $1013 \mathrm{mb}$ at $33.4 \mathrm{~N}, 58.0 \mathrm{~W}$ at $12 \mathrm{Z}$ (COADS). Aircraft highlights: Penetration center fix estimated surface winds of at least $60 \mathrm{kt}$ at $35.5 \mathrm{~N}, 60.1 \mathrm{~W}$ at $12 \mathrm{Z}$ (ATSR/micro). Penetration center fix measured a central pressure of $974 \mathrm{mb}$ at $35.5 \mathrm{~N}, 59.7 \mathrm{~W}$ at $1845 \mathrm{Z}$ (ATSR/micro).

ATSR: "Due to a long wave trough near $55 \mathrm{~W}$ in the upper air flow, Betsy recurved into northerly latitudes quite early in her life cycle. She came almost to a standstill near $36 \mathrm{~N}$ $60 \mathrm{~W}$ on 8 September, before finally being caught in westerly flow on the same day."

September 9:

HWM analyzes a hurricane of at most $1000 \mathrm{mb}$ at $36.1 \mathrm{~N}, 58.7 \mathrm{~W}$ with a warm front far to the northeast at $12 \mathrm{Z}$. HURDAT lists a $90 \mathrm{kt}$ hurricane at $36.6 \mathrm{~N}, 58.6 \mathrm{~W}$ at $12 \mathrm{Z}$. Microfilm shows a closed low pressure of at most $1014 \mathrm{mb}$ at $36.5 \mathrm{~N}, 58.5 \mathrm{~W}$ at $12 \mathrm{Z}$. Ship highlights: $40 \mathrm{kt} \mathrm{W}$ and $1010 \mathrm{mb}$ at $33.7 \mathrm{~N}, 60.5 \mathrm{~W}$ at $00 \mathrm{Z}$ (COADS). $35 \mathrm{kt} \mathrm{W}$ and $1011 \mathrm{mb}$ at $33.9 \mathrm{~N}$, $61.0 \mathrm{~W}$ at $03 \mathrm{Z}$ (micro). $35 \mathrm{kt} \mathrm{S}$ and $1008 \mathrm{mb}$ at $34.4 \mathrm{~N}, 58.2 \mathrm{~W}$ at $12 \mathrm{Z}$ (COADS). $40 \mathrm{kt} \mathrm{SW}$ and $1011 \mathrm{mb}$ at $35.5 \mathrm{~N}, 55.5 \mathrm{~W}$ at $18 \mathrm{Z}$ (micro). Aircraft highlights: Penetration center fix estimated maximum surface winds of at least $70 \mathrm{kt}$ at $36.7 \mathrm{~N}, 58.9 \mathrm{~W}$ at $13 \mathrm{Z}$ (ATSR/micro). Penetration center fix at $37.6 \mathrm{~N}, 57.2 \mathrm{~W}$ at $19 \mathrm{Z}$ (ATSR). 
MWR: “...then was picked up by another minor trough on September 9.”

September 10:

HWM analyzes a hurricane of at most $995 \mathrm{mb}$ at $39.0 \mathrm{~N}, 52.5 \mathrm{~W}$ with a warm front far to the northeast at 12Z. HURDAT lists a $90 \mathrm{kt}$ hurricane at $39.2 \mathrm{~N}, 52.3 \mathrm{~W}$ at $12 \mathrm{Z}$. Microfilm shows a closed low pressure of at most $1008 \mathrm{mb}$ at $39.5 \mathrm{~N}, 51.5 \mathrm{~W}$ at $12 \mathrm{Z}$. Ship highlights: $40 \mathrm{kt} \mathrm{SSW}$ and $1009 \mathrm{mb}$ at $35.0 \mathrm{~N}, 55.4 \mathrm{~W}$ at $00 \mathrm{Z}$ (COADS). $35 \mathrm{kt} \mathrm{SW}$ and $1013 \mathrm{mb}$ at $35.2 \mathrm{~N}, 53.5 \mathrm{~W}$ at $06 \mathrm{Z}$ (COADS). $45 \mathrm{kt} \mathrm{SSE}$ and $1007 \mathrm{mb}$ at $37.4 \mathrm{~N}, 50.0 \mathrm{~W}$ at $10 \mathrm{Z}$ (COADS). $50 \mathrm{kt} \mathrm{S}$ and $1006 \mathrm{mb}$ at 37.4N, 51.1W at $12 \mathrm{Z}$ (COADS). $45 \mathrm{kt} \mathrm{S}$ and $1004 \mathrm{mb}$ at $37.9 \mathrm{~N}, 48.1 \mathrm{~W}$ at $18 \mathrm{Z}$ (COADS). Aircraft highlights: Penetration center fix at $39.3 \mathrm{~N}$, $51.5 \mathrm{~W}$ at $1438 \mathrm{Z}$ (ATSR). Radar center fix estimated maximum surface winds of at least $60 \mathrm{kt}$ at $40.0 \mathrm{~N}, 49.4 \mathrm{~W}$ at $1850 \mathrm{Z}$ (ATSR/micro).

September 11:

HWM analyzes a hurricane of at most $980 \mathrm{mb}$ at $44.5 \mathrm{~N}, 38.8 \mathrm{~W}$ with a weakening warm front to the northeast and cold front to the southwest at 12Z. HURDAT lists an $80 \mathrm{kt}$ hurricane at $44.7 \mathrm{~N}, 38.5 \mathrm{~W}$ at $12 \mathrm{Z}$. Microfilm shows a closed low pressure of at most 990 $\mathrm{mb}$ at $46.0 \mathrm{~N}, 36.0 \mathrm{~W}$ with a frontal boundary extending to the south at 12Z. Ship highlights: $40 \mathrm{kt} \mathrm{NE}$ and $998 \mathrm{mb}$ at $43.5 \mathrm{~N}, 46.8 \mathrm{~W}$ at $00 \mathrm{Z}$ (COADS). $30 \mathrm{kt} \mathrm{NE}$ and 994 $\mathrm{mb}$ at $45.7 \mathrm{~N}, 42.9 \mathrm{~W}$ at $06 \mathrm{Z}$ (COADS). $85 \mathrm{kt} \mathrm{SW}$ and $996 \mathrm{mb}$ at $43.9 \mathrm{~N}, 34.3 \mathrm{~W}$ at $15 \mathrm{Z}$ (MWL). $75 \mathrm{kt} \mathrm{SW}$ and $1006 \mathrm{mb}$ at 43.8N, 34.4W at 18Z (COADS). Aircraft highlights: Penetration center fix estimated maximum surface winds of at least $55 \mathrm{kt}$ at $45.5 \mathrm{~N}$, $36.9 \mathrm{~W}$ at $1440 \mathrm{Z}$ (ATSR/micro). Penetration center fix at $47.1 \mathrm{~N}, 34.1 \mathrm{~W}$ at $1720 \mathrm{Z}$ (ATSR).

MWR: "Thirty-five advisories were issued on this hurricane, the last by the Washington Weather Bureau at 1100 EST, September 11. Betsy remained over the ocean and apparently no damage was sustained by vessels along her path." ATSR: "She then moved rapidly northeastward and became extratropical. The 35th and final warning was issued at 111600Z. Betsy remained entirely at sea and resulted in no known damage."

September 12:

HWM analyzes a large extratropical cyclone of at most $950 \mathrm{mb}$ at $56.5 \mathrm{~N}, 21.2 \mathrm{~W}$ at $12 \mathrm{Z}$. HURDAT lists a $60 \mathrm{kt}$ extratropical cyclone at $54.8 \mathrm{~N}, 20.5 \mathrm{~W}$ at $06 \mathrm{Z}$ (last position). Microfilm shows an extratropical cyclone of at most $969 \mathrm{mb}$ at $56.7 \mathrm{~N}, 25.0 \mathrm{~W}$ at $12 \mathrm{Z}$. Ship highlights: $70 \mathrm{kt} \mathrm{NW}$ and $963 \mathrm{mb}$ at $50.5 \mathrm{~N}, 27.8 \mathrm{~W}$ at $00 \mathrm{Z}$ (COADS). $70 \mathrm{kt} \mathrm{SSW}$ and $962 \mathrm{mb}$ at $52.5 \mathrm{~N}, 20.0 \mathrm{~W}$ at $06 \mathrm{Z}$ (COADS). $70 \mathrm{kt} \mathrm{NW}$ and $967 \mathrm{mb}$ at $55.8 \mathrm{~N}, 26.7 \mathrm{~W}$ at $12 \mathrm{Z}$ (COADS). $60 \mathrm{kt} \mathrm{NNW}$ and $978 \mathrm{mb}$ at $56.7 \mathrm{~N}, 28.4 \mathrm{~W}$ at $18 \mathrm{Z}$ (COADS). 
September 13:

HWM analyzes a large extratropical cyclone of at most $955 \mathrm{mb}$ at $59.5 \mathrm{~N}, 20.2 \mathrm{~W}$ at $12 \mathrm{Z}$. HURDAT does not list an organized storm on this day. Microfilm does not show an organized storm on this day (cyclone moving off the NE corner of the map). Ship highlights: $60 \mathrm{kt} \mathrm{NNW}$ and $981 \mathrm{mb}$ at $56.9 \mathrm{~N}, 29.9 \mathrm{~W}$ at $00 \mathrm{Z}$ (COADS). $60 \mathrm{kt} \mathrm{NNW}$ and $981 \mathrm{mb}$ at $57.1 \mathrm{~N}, 31.5 \mathrm{~W}$ at $06 \mathrm{Z}$ (COADS). $55 \mathrm{kt} \mathrm{N}$ and $986 \mathrm{mb}$ at $57.4 \mathrm{~N}, 33.5 \mathrm{~W}$ at $12 \mathrm{Z}$ (COADS). $60 \mathrm{kt} \mathrm{E}$ and $973 \mathrm{mb}$ at 65.3N, 20.3W at 18Z (COADS).

September 14:

HWM analyzes a large extratropical cyclone of at most $960 \mathrm{mb}$ at $61.5 \mathrm{~N}, 24.8 \mathrm{~W}$ at $12 \mathrm{Z}$. Ship highlights: $45 \mathrm{kt} \mathrm{SE}$ and $969 \mathrm{mb}$ at $61.6 \mathrm{~N}, 17.9 \mathrm{~W}$ at $00 \mathrm{Z}$ (COADS). $50 \mathrm{kt} \mathrm{NE}$ and $985 \mathrm{mb}$ at $66.6 \mathrm{~N}, 24.6 \mathrm{~W}$ at $06 \mathrm{Z}$ (COADS). $50 \mathrm{kt} \mathrm{NE}$ and $988 \mathrm{mb}$ at $66.6 \mathrm{~N}, 24.4 \mathrm{~W}$ at $12 \mathrm{Z}$ (COADS). $60 \mathrm{kt} \mathrm{NNE}$ and $988 \mathrm{mb}$ at $62.4 \mathrm{~N}, 40.5 \mathrm{~W}$ at $18 \mathrm{Z}$ (COADS).

September 15:

HWM analyzes two extratropical cyclones of at most $970 \mathrm{mb}$ and $965 \mathrm{mb}$ at $58.5 \mathrm{~N}$, $28.8 \mathrm{~W}$ and $60.9 \mathrm{~N}, 15.0 \mathrm{~W}$, respectively, at 12Z. Ship highlights: $60 \mathrm{kt} \mathrm{SW}$ and $967 \mathrm{mb}$ at $55.2 \mathrm{~N}, 15.0 \mathrm{~W}$ at $00 \mathrm{Z}$ (COADS). $45 \mathrm{kt} \mathrm{NE}$ and $990 \mathrm{mb}$ at $66.3 \mathrm{~N}, 24.0 \mathrm{~W}$ at $06 \mathrm{Z}$ (COADS). $50 \mathrm{kt} \mathrm{NE}$ and $992 \mathrm{mb}$ at 66.3N, 24.0W at 09Z (COADS).

September 16:

HWM analyzes an extratropical cyclone of at most $980 \mathrm{mb}$ at $60.9 \mathrm{~N}, 15.4 \mathrm{~W}$ at $12 \mathrm{Z}$.

A strong tropical wave left the African coast during the last days of August. Ship observations over the eastern and central Atlantic are sparse, thus the time of genesis of Betsy is uncertain but may have occurred on August 31st or September 1st. The first ship to encounter the tropical cyclone reported a pressure of $998 \mathrm{mb}$ at $08 \mathrm{Z}$ on September 2nd. Although no winds were reported with the pressure measurement, MWR does not indicate that it was a central pressure and it is analyzed as a peripheral pressure. A peripheral pressure of $998 \mathrm{mb}$ suggests maximum sustained winds greater than $51 \mathrm{kt}$ south of $25 \mathrm{~N}$ from the Brown et al. pressure-wind relationship. The first position, not genesis, is analyzed at $06 \mathrm{Z}$ on the $2 \mathrm{nd}$, same as the original HURDAT, as a $55 \mathrm{kt}$ tropical storm, up from $40 \mathrm{kt}$ originally in HURDAT, a minor intensity change. Minor track alterations are analyzed during the lifetime of this tropical cyclone. The first aircraft to investigate Betsy arrived at $14 \mathrm{Z}$ on September 13th. A penetration fix measured a central pressure of $973 \mathrm{mb}$, estimated surface winds of $90 \mathrm{kt}$ and an eye diameter of $15 \mathrm{~nm}$. A central pressure of $973 \mathrm{mb}$ suggests maximum sustained winds of $86 \mathrm{kt}$ south of $25 \mathrm{~N}$ 
from the pressure-wind relationship. An eye diameter of $15 \mathrm{~nm}$ suggests an RMW of 11 $\mathrm{nm}$ and the climatological value is $14 \mathrm{~nm}$. Due to a forward speed of $18 \mathrm{kt}$ and an RMW smaller than climatology, an intensity of $90 \mathrm{kt}$ is selected at $12 \mathrm{Z}$ on the $3 \mathrm{rd}$, up from $65 \mathrm{kt}$ originally in HURDAT, a major intensity change. A central pressure of $973 \mathrm{mb}$ was present in HURDAT at $18 \mathrm{Z}$ on the 3rd and based on the penetration fix at 14Z, it has been moved to $12 \mathrm{Z}$ on the $3 \mathrm{rd}$. Intensification to a hurricane is analyzed at $18 \mathrm{Z}$ on the 2nd, 18 hours earlier than originally shown in HURDAT. Various ships reported tropical storm force winds on the $3 \mathrm{rd}$, up to $50 \mathrm{kt}$. Reconnaissance aircraft observations on September 4th indicate that Betsy weakened as the central pressure rose and the eye diameter expanded. A penetration fix at $01 \mathrm{Z}$ on the 4th measured a central pressure of $989 \mathrm{mb}$ and an eye diameter of $15 \mathrm{~nm}$. A central pressure of $989 \mathrm{mb}$ suggests maximum sustained winds of $65 \mathrm{kt}$ south of $25 \mathrm{~N}$ weakening from the pressure-wind relationship. An eye diameter of $15 \mathrm{~nm}$ suggests an RMW of $11 \mathrm{~nm}$ and the climatological value is 15 $\mathrm{nm}$. Due to a forward speed of $15 \mathrm{kt}$ and an RMW smaller than climatology, an intensity of $70 \mathrm{kt}$ is selected at $00 \mathrm{Z}$ on the $4 \mathrm{th}$, down from $85 \mathrm{kt}$ originally in HURDAT, a minor intensity change. A central pressure of $989 \mathrm{mb}$ is added to HURDAT at $00 \mathrm{Z}$ on the 4th. A central pressure of $986 \mathrm{mb}$ was present in HURDAT at $12 \mathrm{Z}$ on the 4th and although it appears to have been added in without observations of the central pressure of the hurricane around that time, it seems reasonable and has been retained. A central pressure of $986 \mathrm{mb}$ suggests maximum sustained winds of $70 \mathrm{kt}$ south of $25 \mathrm{~N}$ from the pressurewind relationship. Due to a forward speed of $13 \mathrm{kt}$, an intensity of $70 \mathrm{kt}$ is selected at $12 \mathrm{Z}$ on the 4th, down from 95 kt originally in HURDAT, a major intensity change. A penetration fix occurred at $2016 \mathrm{Z}$ on the 4th measuring a central pressure of $982 \mathrm{mb}$, estimating surface winds of $85 \mathrm{kt}$ and an eye diameter of $20 \mathrm{~nm}$. A central pressure of $982 \mathrm{mb}$ suggests maximum sustained winds of $75 \mathrm{kt}$ south of $25 \mathrm{~N}$ from the pressure-wind relationship. An eye diameter of $20 \mathrm{~nm}$ suggests an RMW of $15 \mathrm{~nm}$ and the climatological value is $16 \mathrm{~nm}$. Due to a forward speed of $13 \mathrm{kt}$ and an RMW close to climatology, an intensity of $75 \mathrm{kt}$ is selected at $18 \mathrm{Z}$ on the 4 th, down from $100 \mathrm{kt}$ originally in HURDAT, a major intensity change. A central pressure of $982 \mathrm{mb}$ was present in HURDAT at $18 \mathrm{Z}$ on the 4 th and has been retained.

On September 5th, Betsy continued on a northwest track over the central Atlantic and intensified. A central pressure of $957 \mathrm{mb}$ was present in HURDAT at 12Z on the 5th and although it appears to have been added in without actual observations, it seems reasonable based on reconnaissance data later on the day and has been retained. A central pressure of $957 \mathrm{mb}$ suggests maximum surface winds of $106 \mathrm{kt}$ south of $25 \mathrm{~N}$ intensifying and $103 \mathrm{kt}$ north of $25 \mathrm{~N}$ intensifying from the pressure wind-relationship. Due to a forward speed of $15 \mathrm{kt}$, an intensity of $105 \mathrm{kt}$ is selected at $12 \mathrm{Z}$ on the $5 \mathrm{th}$, down from $115 \mathrm{kt}$ originally in HURDAT, a minor intensity change. Intensification to a major hurricane is analyzed at $12 \mathrm{Z}$ on the 5 th, 18 hours later than originally shown in 
HURDAT. Another penetration fix occurred at $2138 \mathrm{Z}$ on the 5 th measuring a central pressure of $952 \mathrm{mb}$. A central pressure of $952 \mathrm{mb}$ suggests maximum sustained winds of $108 \mathrm{kt}$ south of $25 \mathrm{~N}$ intensifying from the pressure-wind relationship. Due to a forward speed of $19 \mathrm{kt}$, an intensity of $115 \mathrm{kt}$ is selected at $18 \mathrm{Z}$ on the $5 \mathrm{th}$, down from $120 \mathrm{kt}$ originally in HURDAT, a minor intensity change. A central pressure of $952 \mathrm{mb}$ was present in HURDAT at $18 \mathrm{Z}$ on the 5 th but it was measured closer to $00 \mathrm{Z}$ on September 6 th, thus it has been moved to that time slot. A penetration fix at $15 \mathrm{Z}$ on the 5 th in the Storm Wallets show a central pressure of $970 \mathrm{mb}$ but this measurement has been discounted as it appears erroneous based on the central pressure already in HURDAT at $12 \mathrm{Z}$ on the 5 th and the reconnaissance aircraft report at $2138 \mathrm{Z}$ on the 5 th. Various ships recorded gale-force winds on the 5 th, including a couple of reports of $50 \mathrm{kt}$. On September 6th, Betsy remained on a northwestward course but began to slow its forward speed. A reconnaissance aircraft reached the hurricane at $0912 \mathrm{Z}$ on the 6 th measuring a central pressure of $950 \mathrm{mb}$. The next penetration fix occurred at $13 \mathrm{Z}$ on the 6 th measuring a central pressure of $945 \mathrm{mb}$. A central pressure of $945 \mathrm{mb}$ suggests maximum surface winds of $115 \mathrm{kt}$ north of $25 \mathrm{~N}$ intensifying from the pressure wind-relationship. Based on a forward speed of $15 \mathrm{kt}$, an intensity of $115 \mathrm{kt}$ is analyzed at $12 \mathrm{Z}$ on the $6 \mathrm{th}$, down from $120 \mathrm{kt}$ originally in HURDAT, a minor intensity change. $115 \mathrm{kt}$ is also the peak intensity of Betsy, down from $120 \mathrm{kt}$ originally in HURDAT from $18 \mathrm{Z}$ on the 5 th to $12 \mathrm{Z}$ on the 6th. A central pressure of $950 \mathrm{mb}$ was present in HURDAT at $06 \mathrm{Z}$ on the 6th and has been removed as it was measured at $0912 \mathrm{Z}$ on the 6 th, closer to the $12 \mathrm{Z}$ time slot than 06Z. A central pressure of $945 \mathrm{mb}$ was present in HURDAT at $12 \mathrm{Z}$ on the 6 th and has been retained. The last penetration fix on the 6th occurred at $19 \mathrm{Z}$ measuring a central pressure of $954 \mathrm{mb}$. A central pressure of $954 \mathrm{mb}$ suggests maximum surface winds of $101 \mathrm{kt}$ north of $25 \mathrm{~N}$ and $97 \mathrm{kt}$ weakening from the pressure wind-relationship. Based on a forward speed of $13 \mathrm{kt}$, an intensity of $105 \mathrm{kt}$ is analyzed at $18 \mathrm{Z}$ on the $6 \mathrm{th}$, down from $115 \mathrm{kt}$ originally in HURDAT, a minor intensity change. A central pressure of $954 \mathrm{mb}$ was present in HURDAT at $18 \mathrm{Z}$ on the 6 th and has been retained.

On September 7th, Betsy continued to slow its forward speed as a dissipating frontal boundary approached from the north. A central pressure of $954 \mathrm{mb}$ was present in HURDAT at $12 \mathrm{Z}$ on the 7 th and there was reconnaissance investigating the hurricane around that time, thus it has been retained. A central pressure of $954 \mathrm{mb}$ suggests maximum surface winds of $101 \mathrm{kt}$ north of $25 \mathrm{~N}$ from the Brown et al. pressure windrelationship and $94 \mathrm{kt}$ north of $35 \mathrm{~N}$ from the Landsea et al. pressure wind-relationship. Based on a forward speed of $6 \mathrm{kt}$, an intensity of $95 \mathrm{kt}$ is analyzed at $12 \mathrm{Z}$ on the $7 \mathrm{th}$, same as originally shown in HURDAT. Weakening below major hurricane is analyzed at $12 \mathrm{Z}$ on the 7 th, same as originally shown in HURDAT. Various ships reported gale-force winds on the 7 th, including $50 \mathrm{kt}$ at $21 \mathrm{Z}$. On September 8 th, the westward progression of Betsy ended and the hurricane slowly turned to the northeast late in the day. A 
reconnaissance aircraft investigated Betsy at $19 \mathrm{Z}$ on the 8 th measuring a central pressure of $974 \mathrm{mb}$. A central pressure of $974 \mathrm{mb}$ suggests maximum surface winds of $79 \mathrm{kt}$ north of $35 \mathrm{~N}$ and $80 \mathrm{kt}$ north of $25 \mathrm{~N}$ from the pressure wind-relationships. Based on a forward speed of $3 \mathrm{kt}$, an intensity of $75 \mathrm{kt}$ is analyzed at $18 \mathrm{Z}$ on the 8 th, down from $90 \mathrm{kt}$ originally in HURDAT, a minor intensity change. A central pressure of $974 \mathrm{mb}$ is added to HURDAT at $18 \mathrm{Z}$ on the 8th. A TIROS III satellite image available on MWR 1962, pg. 110 , shows hurricane Betsy at $2015 \mathrm{Z}$ on the 8 th. The satellite image shows a wellorganized cyclone with distinct banding to the north and south, $\mathrm{CDO}$ and cirrus clouds over the eastern and southern quadrants. On September 9th, Betsy continued moving to the northeast and slowly gained in forward speed. Central pressures of $978 \mathrm{mb}$ and 976 mb were present in HURDAT at $12 \mathrm{Z}$ and $18 \mathrm{Z}$, respectively, on the 9th. Reconnaissance aircrafts investigated the hurricane around those times, thus the central pressures appear reasonable (but could not be confirmed) and have been retained. A central pressure of $978 \mathrm{mb}$ suggests maximum surface winds of $75 \mathrm{kt}$ north of $35 \mathrm{~N}$ from the pressure-wind relationship. Due to a forward speed of $10 \mathrm{kt}$, an intensity of $75 \mathrm{kt}$ is selected at $12 \mathrm{Z}$ on the 9th, down from 90 kt originally in HURDAT, a minor intensity change. Also, a central pressure of $976 \mathrm{mb}$ suggests maximum surface winds of $77 \mathrm{kt}$ north of $35 \mathrm{~N}$ from the pressure-wind relationship. Due to a forward speed of $17 \mathrm{kt}$, an intensity of $80 \mathrm{kt}$ is selected at $18 \mathrm{Z}$ on the 9th, down from 80 kt originally in HURDAT, a minor intensity change.

On September 10th, Betsy was moving quite rapidly to the northeast crossing $40^{\circ} \mathrm{N}$ late in the day. The environment around the system became less tropical with cool, dry air to the north and west and warm, moist air to the east and south. Reconnaissance aircrafts continued to investigate the tropical cyclone. Central pressures of $980 \mathrm{mb}$ and $962 \mathrm{mb}$ were present in HURDAT at $12 \mathrm{Z}$ and $18 \mathrm{Z}$ on the 10th, respectively. The central pressure of $980 \mathrm{mb}$ has been removed as it appears erroneous based on the data available on the previous and subsequent days. The central pressure of $962 \mathrm{mb}$ appears reasonable and has been retained. A central pressure of $962 \mathrm{mb}$ suggests maximum surface winds of $88 \mathrm{kt}$ north of $35 \mathrm{~N}$ from the pressure-wind relationship. Due to a forward speed of $34 \mathrm{kt}$, an intensity of $90 \mathrm{kt}$ is selected at $18 \mathrm{Z}$ on the 10th, up from $85 \mathrm{kt}$ originally in HURDAT, a minor intensity change. Synoptic observations on September 11th at $00 \mathrm{Z}$ indicate that Betsy had become an extratropical cyclone 24 hours earlier than originally shown in HURDAT. The data shows a temperature gradient across the circulation as frontogenesis had occurred. Betsy passed halfway between the Azores and Newfoundland on the 11th. A central pressure of $970 \mathrm{mb}$ was present in HURDAT at $12 \mathrm{Z}$ on the 11th, appears reasonable (but not confirmed) and has been retained. Ship observations indicate that Betsy was still a very powerful extratropical cyclone on the 11th. A ship reported $85 \mathrm{kt}$ $\mathrm{SW}$ and $996 \mathrm{mb}$ at $15 \mathrm{Z}$ and another reported $70 \mathrm{kt} \mathrm{SW}$ and $965 \mathrm{mb}$ at 18Z. On September 12th, Betsy began to slow its forward speed south of Iceland and on September 13th, 
turned to the west. Weakening below hurricane intensity is analyzed at $00 \mathrm{Z}$ on September 14th, 42 hours later than originally shown in HURDAT. On the 14th, an extratropical cyclone developed along Betsy's cold front and the two extratropical systems began to rotate around each other. By September 15th at 06Z, it was clear that both centers had merged, thus the final position of Betsy is analyzed at $00 \mathrm{Z}$ on the 15 th, 60 hours later than originally shown in HURDAT.

Hurricane Carla [September 3-16, 1961]

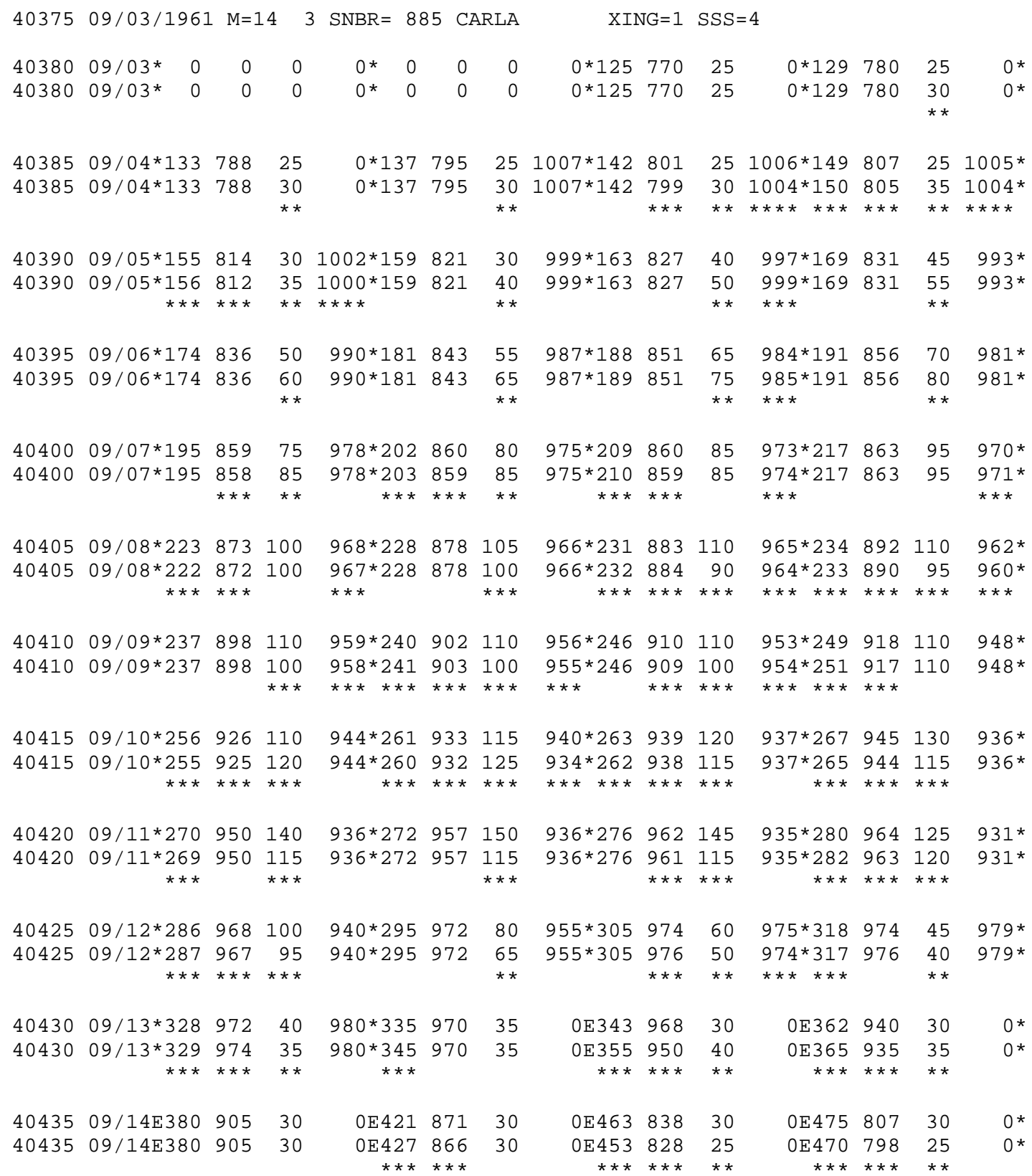




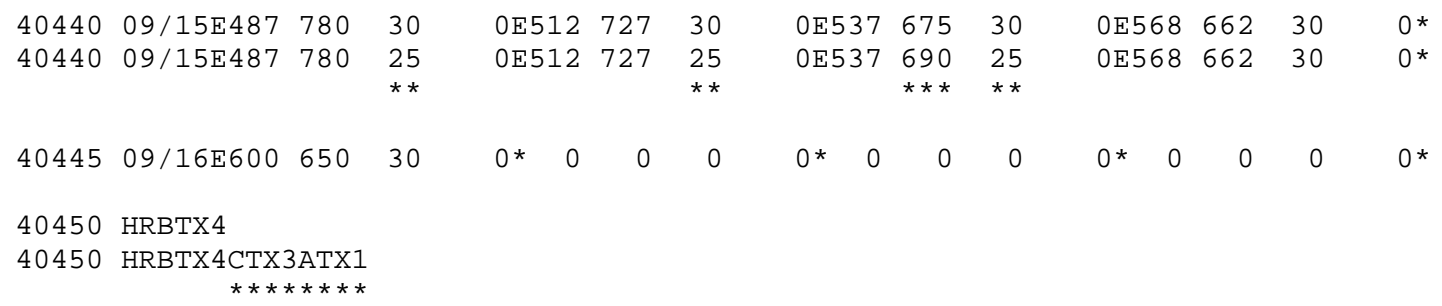

Major alterations to the intensity but minor track changes were made to Carla. Evidence for these alterations comes from the Historical Weather Map series, the COADS ships database, the Monthly Weather Review, NHC Microfilm of synoptic weather maps, Annual Tropical Storm Reports, Storm Wallets, North Atlantic Tropical Cyclones Report, and Tropical Cyclone Data. Evidence for these alterations also comes from Jarrell et al. (1992), Shcwerdt et al. (1979), Francis; Ho (1987), and Wiggert; Jarvinen (1986).

September 1-2: "Somewhat above normal shower activity was evident in the eastern Caribbean as early as September 1, apparently associated with a weak perturbation in the Intertropical Convergence Zone" (MWR). Ship highlights: 35kt ENE with a pressure of $1014 \mathrm{mb}$ at $18 \mathrm{Z}$ on Sept. $2^{\text {nd }}$ at $18.7 \mathrm{~N}, 68 \mathrm{~W}$ (COA). Station highlights: No gales or low pressures. Aircraft highlights: No gales or low pressures.

September 3: HWM indicates a closed low near 12N, 76W. HURDAT lists this as a Tropical Depression with $25 \mathrm{kt}$ winds at $12.5 \mathrm{~N}, 77 \mathrm{~W}$ at $12 \mathrm{Z}$. The MWR North Atlantic Tropical Cyclones chart showed a center at $12.5 \mathrm{~N}, 77 \mathrm{~W}(\mathrm{am})$ and at $14.5 \mathrm{~N}, 78.9 \mathrm{~W}(\mathrm{pm})$. Ship highlights: No gales or low pressures. Station highlights: No gales or low pressures. Aircraft highlights: No gales or low pressures. "The first indication of intensification and a closed circulation was noted on the 0700 EST September 3 surface chart and abnormal pressure and shower activity were mentioned in the tropical weather summary on that date" (MWR).

September 4: HWM indicates a closed low of at most $1005 \mathrm{mb}$ near $14 \mathrm{~N}, 80 \mathrm{~W}$. The MWR North Atlantic Tropical Cyclones chart showed a center at 14N, 80W (am) and at $15.5 \mathrm{~N}, 81 \mathrm{~W}(\mathrm{pm})$. Station highlights: No gales or low pressures. Ship highlights: $15 \mathrm{kt}$ NNW with a pressure of $1004 \mathrm{mb}$ at $14.8 \mathrm{~N}, 81.7 \mathrm{~W}$ at $22 \mathrm{Z}$ (COA). Aircraft highlights: a central pressure of $1004 \mathrm{mb}$ at $15.4 \mathrm{~N}, 80.8 \mathrm{~W}$ at $2125 \mathrm{Z}$ (storm wallets); $35 \mathrm{kt} \mathrm{SE}$ at $16 \mathrm{~N}$, $76 \mathrm{~W}$ at $1930 \mathrm{Z}$ (microfilm). "At $0700 \mathrm{EST}$ on September 4 the circulation had increased to depression intensity (winds 32 to $38 \mathrm{mph}$ ) and the light north-northeast wind at San Andres Island the evening before had shifted to westerly $12 \mathrm{mph}$ and the barometer, while still below normal, had risen slightly" (MWR).

September 5: HWM indicates a tropical storm with a pressure of at most $1000 \mathrm{mb}$ near $15 \mathrm{~N}, 83 \mathrm{~W}$. The MWR North Atlantic Tropical Cyclones chart showed a center at 16.2N, $82.5 \mathrm{~W}$ (am) and at $17.5 \mathrm{~N}, 84 \mathrm{~W}(\mathrm{pm})$. Station highlights: No gales or low pressures. Ship highlights: $30 \mathrm{kt} \mathrm{E}$ with a pressure of $1002 \mathrm{mb}$ at $15.7 \mathrm{~N}, 81.4 \mathrm{~W}$ at $00 \mathrm{Z}$ (COA); $35 \mathrm{kt} \mathrm{E}$ with a pressure of $1009 \mathrm{mb}$ at $18.5 \mathrm{~N}, 79.2 \mathrm{~W}$ at $06 \mathrm{Z}$ (COA). Aircraft highlights: a central 
pressure of $998 \mathrm{mb}$ at $16.4 \mathrm{~N}, 82.8 \mathrm{~W}$ at $1312 \mathrm{Z}$ (storm wallets); $45 \mathrm{kt}$ at $1320 \mathrm{Z}$ (no location given) (Annual TS report).

September 6: HWM indicates a hurricane with a pressure of at most $990 \mathrm{mb}$ near $18.5 \mathrm{~N}$, $85 \mathrm{~W}$. The MWR North Atlantic Tropical Cyclones chart showed a center at $18.9 \mathrm{~N}$, $85.1 \mathrm{~W}(\mathrm{am})$ and at $20 \mathrm{~N}, 85.9 \mathrm{~W}(\mathrm{pm})$. Station highlights: No gales or low pressures. Ship highlights: $35 \mathrm{kt} \mathrm{SSE}$ with a pressure of $994 \mathrm{mb}$ at $20.5 \mathrm{~N}, 84.2 \mathrm{~W}$ at $18 \mathrm{Z}$ (microfilm); $45 \mathrm{kt}$ NNW with a pressure of $996 \mathrm{mb}$ at $17.5 \mathrm{~N}, 86.5 \mathrm{~W}$ at $21 \mathrm{Z}$ (storm wallets). Aircraft highlights: a central pressure of $978 \mathrm{mb}$ at $19.2 \mathrm{~N}, 85.8 \mathrm{~W}$ at $2030 \mathrm{Z}$ (storm wallets); $70 \mathrm{kt}$ SW with a pressure of $999 \mathrm{mb}$ at $18.2 \mathrm{~N}, 85 \mathrm{~W}$ at $2130 \mathrm{Z}$ (microfilm). "During the next several days Carla continued a slow but remarkably steady intensification (fig. 9) reaching hurricane forced on the morning of the $6^{\text {th }} \ldots$ " (MWR).

September 7: HWM indicates a hurricane with a pressure of at most $985 \mathrm{mb}$ near $20.1 \mathrm{~N}$, 86W. The MWR North Atlantic Tropical Cyclones chart showed a center at 21N, 85.5W (am) and at $22.5 \mathrm{~N}, 87 \mathrm{~W}$ (pm). Station highlights: No gales or low pressures. Ship highlights: $60 \mathrm{kt} \mathrm{SSW}$ with a pressure of $993 \mathrm{mb}$ at $19.7 \mathrm{~N}, 84.9 \mathrm{~W}$ at $09 \mathrm{Z}$ (COA). Aircraft highlights: a pressure of $967 \mathrm{mb}$ at $22.2 \mathrm{~N}, 87.2 \mathrm{~W}$ at $2230 \mathrm{Z}$ (storm wallets); $95 \mathrm{kt} \mathrm{NE}$ at $22 \mathrm{~N}, 87 \mathrm{~W}$ at $1830 \mathrm{Z}$ (Annual TS report).

September 8: HWM indicates a hurricane with a pressure of at most $975 \mathrm{mb}$ near $22.5 \mathrm{~N}$, 88W. The MWR North Atlantic Tropical Cyclones chart showed a center at 23.1N, 88.1W (am) and at 23.9N, 89.5W. Station highlights: No gales or low pressures. Ship highlights: $50 \mathrm{kt} \mathrm{NW}$ with a pressure of $977 \mathrm{mb}$ at $22.9 \mathrm{~N}, 88.8 \mathrm{~W}$ at $12 \mathrm{Z}$ (COA). Aircraft highlights: a central pressure of $961 \mathrm{mb}$ at $23.3 \mathrm{~N}, 88.5 \mathrm{~W}$ at $13 \mathrm{Z}$ (storm wallets); $50 \mathrm{kt}$ $\mathrm{NNE}$ at $23 \mathrm{~N}, 90.5 \mathrm{~W}$ at $1130 \mathrm{Z}$ (Annual TS report). "High tides began affecting the upper Texas coast on September 8 and waves and tides continued to batter the Texas coast with ever increasing fury until the center moved inland three days later" (MWR).

September 9: HWM indicates a hurricane with a pressure of at most $980 \mathrm{mb}$ near $24 \mathrm{~N}$, 91W. The MWR North Atlantic Tropical Cyclones chart showed a center at 24.5N, 91W (am) and at $25.5 \mathrm{~N}, 92.5 \mathrm{~W}(\mathrm{pm})$. Station highlights: No gales or low pressures. Ship highlights: $45 \mathrm{kt} \mathrm{SW}$ with a pressure of $987 \mathrm{mb}$ at $23 \mathrm{~N}, 90.9 \mathrm{~W}$ at $12 \mathrm{Z}$ (COA); 60kt E with a pressure of $996 \mathrm{mb}$ at $26.9 \mathrm{~N}, 91.1 \mathrm{~W}$ at $18 \mathrm{Z}(\mathrm{COA})$. Aircraft highlights: a central pressure of $954 \mathrm{mb}$ at $24.6 \mathrm{~N}, 90.8 \mathrm{~W}$ at $1130 \mathrm{Z}$ (storm wallets); $70 \mathrm{kt} \mathrm{E}$ with a central pressure of $993 \mathrm{mb}$ at $27 \mathrm{~N}, 92 \mathrm{~W}$ at $2330 \mathrm{Z}$ (microfilm).

September 10: HWM indicates a hurricane with a pressure of at most $980 \mathrm{mb}$ near $26 \mathrm{~N}$, 94W. The MWR North Atlantic Tropical Cyclones chart showed a center at 26.5N, 93.9W (am) and at 27.1N, 95W (pm). Station highlights: Ship highlights: 50kt W with a pressure of $984 \mathrm{mb}$ at $25.1 \mathrm{~N}, 95.1 \mathrm{~W}$ at $18 \mathrm{Z}$ (COA); 70kt ESE with a pressure of $990 \mathrm{mb}$ at $28.4 \mathrm{~N}, 93.3 \mathrm{~W}$ at $18 \mathrm{Z}(\mathrm{COA})$. Aircraft highlights: $934 \mathrm{mb}$ at $26.2 \mathrm{~N}, 93.4 \mathrm{~W}$ at $06 \mathrm{Z}$ (Annual TS Report); flight level winds of $130 \mathrm{kt}$ and a pressure of $936 \mathrm{mb}$ at $27 \mathrm{~N}, 94.1 \mathrm{~W}$ at $19 \mathrm{Z}$ (storm wallets); 110kt with a central pressure of $938 \mathrm{mb}$ at $25.6 \mathrm{~N}, 92.3 \mathrm{~W}$ at $03 \mathrm{Z}$ (Annual TS report). 
September 11: HWM indicates a hurricane with a pressure of at most $980 \mathrm{mb}$ near $27.5 \mathrm{~N}$, 96.2W. The MWR North Atlantic Tropical Cyclones chart showed a center at 27.8N, 96W (am) and at 29.9N, 96.8W (pm). Station highlights: $\leq 935 \mathrm{mb}$ at Port Lavaca $(28.6 \mathrm{~N}$, 96.6W) at 2145Z (TC Data); 126kt NE at Port Lavaca (no time given) (North Atlantic TC). Ship highlights: $75 \mathrm{kt}$ ESE with a pressure of $987 \mathrm{mb}$ at $28.4 \mathrm{~N}, 93.5 \mathrm{~W}$ at $00 \mathrm{Z}$ (COA); 95kt SE with a pressure of $991 \mathrm{mb}$ at $28.5 \mathrm{~N}, 93.6 \mathrm{~W}$ at $06 \mathrm{Z}$ (COA). Aircraft highlights: $120 \mathrm{kt}$ at $28.2 \mathrm{~N}, 96.4 \mathrm{~W}$ at $1810 \mathrm{Z}$ (Annual TS report). "The center of Carla was under surveillance for some 48 hours by three land-based radars located at Brownsville, Galveston, and Lake Charles. All radars showed a strong cycloidal track during the period preceding landfall. The New Orleans hurricane center described Carla as one of the largest, most intense and destructive hurricanes ever to strike the United States Gulf coast. Carla's center moved inland over the Port O'Conner-Port Lavaca area on the central Texas coast during the afternoon of September 11 (fig.11). Sustained hurricane force winds were reported from Corpus Christi to Galveston and hurricane gusts were felt along almost the entire length of Texas coast" (MWR). "Highest tides were 16.6ft MSL at Port Lavaca, 14.5ft MSL at Port O'Connor, 15.2ft MSL at Matagorda, and 14.8ft MSL on the upper Houston ship channel" (MWR). "Peak gusts of $175 \mathrm{mph}$ were estimated at Port Lavaca. A gust of $153 \mathrm{mph}$ was observed on the anemometer of the Bauer Dredging Co. before the instrument failed. The lowest reported pressure at Port Lavaca was 27.62 in $(935 \mathrm{mb})$ and it remained at that value from 1545 to $1735 \mathrm{CST}$. Available information indicates the needle was below the scale during that period" (MWR). "Early in the afternoon of the $11^{\text {th }}$ the center moved over the northeastern tip of Matagorda Island and inland over the Port Lavaca - Port O'Conner area. Reconnaissance aircraft indicated a central pressure of 27.50 in $[931 \mathrm{mb}]$ just prior to its crossing the coast. The eye of the hurricane, approximately 30miles in diameter, (fig 1) moved into the Port O'Conner area about 1400 CST of the $11^{\text {th }}$. The leading edge of the eye reached Port Lavaca at 1545 CST. Carla moved slowly, and was almost stationary at times as she approached the middle Texas Coast. From Port Lavaca, the storm followed a northwesterly course, that carried the center over Inez, Yoakum, and Waelder, No well defined "eye" was apparent after the storm moved out the Waelder area about 0100 CST on the $12^{\text {th }}$, and it began to weaken rapidly as it followed a more northerly course, passing near Austin, Waco, and Fort Worth" (N. Atlantic TC). "Gusts of hurricane force were reported for the Texas coast from Port Arthur to north of Brownsville, a distance of over 300 miles. The highest wind was reported at Port Lavaca with a peak gust estimated at $175 \mathrm{mph}$ at Bauer Dredging Company on bay front. At 1414 CST at this location a wind gust of $153 \mathrm{mph}$ was observed on the anemometer before the instrument failed. Matagorda reported a gust of 160mph and gusts of 150mph were estimated at Aransas Pass, Austwell, Edna, Port Aransas, and Victoria. Sustained winds (fasted mile) were reported as 145 at Matagorda and Port Lavaca. Aransas Pass and Victoria estimated fastest miles of 135 and 110, respectively. In Louisiana sustained winds were generally less than $50 \mathrm{mph}$. Peak gusts of 75, 60, and 58mph were reported at Chauvin, Cameron, and Lake Charles, respectively" (N. Atlantic TC). "A low pressure of 27.62 in was reported by the Bauer Dredging Company at Port Lavaca from a recently calibrated barometer before the needle went below the scale. Other low pressures were 27.91 in at Victoria and 28.60 in at Matagorda. 
Austin, Fort Worth, and Waco reported their lowest pressures of record: 28.76, 28.94, and 28.91 in, respectively" (N. Atlantic TC). “...Its lowest central pressure $(931 \mathrm{mb})$ on the afternoon of the $11^{\text {th }}$ (MWR).

September 12: HWM indicates a tropical storm with a pressure of at most $985 \mathrm{mb}$ near $30 \mathrm{~N}, 97 \mathrm{~W}$. The MWR North Atlantic Tropical Cyclones chart showed a center at 31N, 97W (am) and at 33N, 97W (pm). Station highlights: a pressure of $945 \mathrm{mb}$ at Victoria (28.8N, 96.6W at 23Z (TC Data); 45kt ESE at Houston AP (30N, 95.4W) at 0258Z (TC Data). Ship highlights: $65 \mathrm{kt} \mathrm{S}$ with a pressure of $994 \mathrm{mb}$ at $28.2 \mathrm{~N}, 94.2 \mathrm{~W}$ at $00 \mathrm{Z}$ (COA). Aircraft highlights: No gales or low pressures.

September 13: HWM indicates a tropical storm with a pressure of at most $995 \mathrm{mb}$ near 34.9N, 95.1W. The MWR North Atlantic Tropical Cyclones chart showed a center at $35 \mathrm{~N}, 97 \mathrm{~W}$ (am). "Total damage in Texas was estimated at \$300million, two-thirds to property and one-third to crops. Fatalities were 34 in Texas, 6 in Louisiana, 5 in Kansas, and 1 in Missouri. Of the 34 dead in Texas 8 were killed in a tornado which swept across Galveston from the Gulf as the hurricane there was subsiding. Eight tornadoes in all were associated with Carla in Texas and 10 in Louisiana. Persons injured in Texas totaled 465; 1,915 homes, 568 farm buildings, and 415 other buildings were destroyed; 7,398 homes, 1,382 farm buildings, and 1,219 other buildings received major damage; and 43,325 homes, 4,238 farm buildings, and 9,268 other buildings received minor damage" (MWR). "Increasing its forward movement it began a recurve northeastward and by the morning of the $13^{\text {th }}$, it became extratropical and was located over east-central Oklahoma. Continuing to pick up speed it moved northeastward toward the Great Lakes at about $35 \mathrm{mph}$, reaching Lake Huron on the $14^{\text {th }}$. Extensive flooding from heavy rains was reported from areas along the storm's path" (N. Atlantic TC).

No changes were made to the timing of genesis of this system. Minor changes to the track were made throughout the existence of Carla. However, major alterations were made to the intensity of Carla, especially on the days HURDAT had the storm at its peak. From September 3 at $18 \mathrm{Z}$ to September 7 at 06Z, the intensity was raised about 10kts from what was documented in HURDAT at each six hour period. These 10kt changes were based upon nearby ship and aircraft observations that recorded higher winds than what was being mentioned in HURDAT. Intensification to a tropical storm is now indicated to be around $18 \mathrm{Z}$ on the $4^{\text {th }}$, eighteen hours earlier than genesis as a $40 \mathrm{kt}$ tropical storm originally. Basis for this comes from an aircraft ob showing $35 \mathrm{kt}$ at $18 \mathrm{Z}$ on the $4^{\text {th }}$ and an aircraft ob at $2125 \mathrm{Z}$ on the 5 th having a pressure of $1004 \mathrm{mb}$ which translates to $39 \mathrm{kt}$ from the Brown et al. south of $25 \mathrm{~N}$ pressure-wind relationship. On the $8^{\text {th }}$ at $12 \mathrm{Z}$, the intensity was lowered significantly from $110 \mathrm{kt}$ to $90 \mathrm{kt}$. Two Navy aircrafts recording central pressures of $966 \mathrm{mb}$ and $961 \mathrm{mb}$ at $10 \mathrm{Z}$ and 13Z, respectively, suggest the pressure at $12 \mathrm{Z}$ was about $964 \mathrm{mb}$. According to the Brown et al. south of $25 \mathrm{~N}$ pressure-wind relationship, $964 \mathrm{mb}$ gives $96 \mathrm{kt}$ and $97 \mathrm{kt}$ from the intensifying subset. However, Carla had a very large eye (an RMW of $35 \mathrm{~nm}$ ) hence the intensity was lowered to $90 \mathrm{kt}$. The intensities continued to be lowered by about $10 \mathrm{kts}$ from the original throughout the $8^{\text {th }}$ 
and $9^{\text {th }}$ because Carla remained slow and steady state and the eye continued to be very large. A central pressure of $934 \mathrm{mb}$ recorded by a Navy aircraft on the $10^{\text {th }}$ at $06 \mathrm{Z}$ gives $129 \mathrm{kt}$ from the Brown et al. south of $25 \mathrm{~N}$ (intensifying) and $126 \mathrm{kt}$ north of $25 \mathrm{~N}$ pressurewind relationship (intensifying). This suggested a peak intensity of $125 \mathrm{kt}, 24$ hours before the original peak intensity of 150kt was mentioned in HURDAT.

Carla made landfall around on September 11 around $20 \mathrm{Z}$ near $28.3 \mathrm{~N}, 96.4 \mathrm{~W}$ on the northeastern tip of Matagorda Island and inland over Port Lavaca - Port O'Conner area. Peak 30 second winds were 120kt at Matagorda and Port Lavaca. Jarrell et al. (1992), Francis; Ho (1987), and Wiggert; Jarvinen (1986) all mention a central pressure at landfall of $931 \mathrm{mb}$. The lowest pressure found on the $11^{\text {th }}$ was $941 \mathrm{mb}$ recorded by a Navy aircraft at around 1810Z. However, a pressure of $935 \mathrm{mb}$ was recorded at Port Lavaca, which would suggest it was deeper at the coast and would be consistent with a pressure of $931 \mathrm{mb}$. Carla still had a large eye, with a 30nm RMW (as suggested by Francis; Ho (1987) and Wiggert; Jarvinen (1986)) hence 115kt was chosen as the landfall intensity which keeps it a Category 4 hurricane at landfall in central Texas. The landfall characterization - "BTX4" - of a Category 4 for the central Texas coast remains unchanged. A landfall characterization - "ATX1" - of a Category 1 for the southern Texas coast was added (winds of about 72kt) and a landfall characterization - "CTX3"of a Category 3 hurricane for the northern Texas coast was also added (winds of about $112 \mathrm{kt}$ ). Runs of the Kaplan and DeMaria inland decay wind model (1995) suggests winds of $85 \mathrm{kt}$ at $00 \mathrm{Z}$ on the $12^{\text {th }}, 56 \mathrm{kt}$ at $06 \mathrm{Z}, 39 \mathrm{kt}$ at $12 \mathrm{Z}$, and $29 \mathrm{kt}$ at $18 \mathrm{Z}$. Winds were selected to be slightly higher than the model for HURDAT because Carla was a very large storm and large storms tend to weaken at a slower pace. Even though the winds were selected to be higher than the model, they were still lower than what was previously mentioned in HURDAT: $95 \mathrm{kt}$ at $00 \mathrm{Z}$ (originally $100 \mathrm{kt}$ ), 65kt at $06 \mathrm{Z}$ (originally $80 \mathrm{kt}$ ), $50 \mathrm{kt}$ at $12 \mathrm{Z}$ (originally $60 \mathrm{kt}$ ), and $40 \mathrm{kt}$ at $18 \mathrm{Z}$ (originally $45 \mathrm{kt}$ ). Transition into Extratropical storm and dissipation remained unchanged.

Hurricane Debbie [September 5-18, 1961]

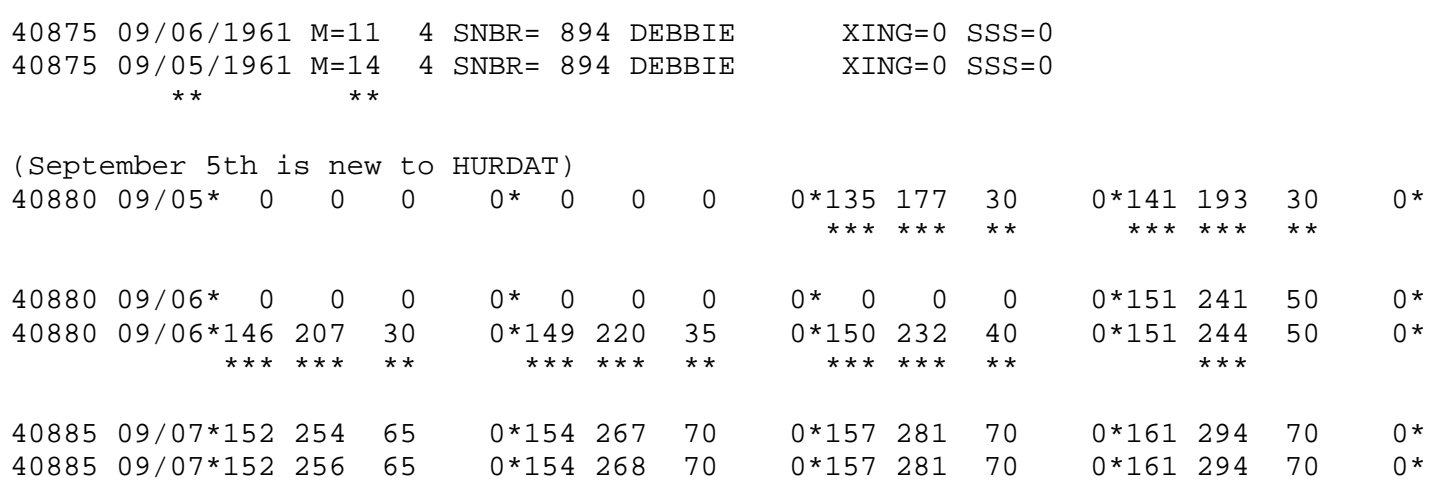




\begin{tabular}{|c|c|c|c|c|c|c|c|c|c|c|c|c|c|}
\hline 40890 & $09 / 08 * 165$ & 307 & $7 \odot$ & $0 * 170$ & 320 & 70 & $0 * 175$ & 332 & 70 & $0 * 180$ & 345 & 70 & $\Theta^{*}$ \\
\hline 40895 & $09 / 09 * 185$ & 357 & 70 & ๑*191 & 370 & 70 & ๑*197 & 382 & 70 & $0 * 204$ & 394 & 70 & $0^{*}$ \\
\hline 40900 & $09 / 10 * 212$ & 406 & 70 & $\Theta * 220$ & 418 & 70 & ๑*228 & 430 & 75 & $0 * 238$ & 441 & 75 & ०* \\
\hline 40905 & $09 / 11$ * 250 & 450 & 80 & $0 * 266$ & 457 & 90 & ๑*279 & 459 & 100 & $976 * 293$ & 459 & 105 & ०* \\
\hline 40905 & $09 / 11 * 250$ & 450 & $\begin{array}{l}75 \\
* *\end{array}$ & $0^{*} \underset{* \star *}{265}$ & 457 & $\begin{array}{l}75 \\
* *\end{array}$ & $\odot * 279$ & 460 & $\begin{array}{l}80 \\
* *\end{array}$ & $\begin{array}{l}0 * 292 \\
\star * * *\end{array}$ & $\begin{array}{l}461 \\
* * *\end{array}$ & $\begin{array}{l}80 \\
* *\end{array}$ & $\begin{array}{l}976 * \\
* * *\end{array}$ \\
\hline 40910 & $09 / 12 * 305$ & 459 & 105 & $0 * 315$ & 459 & 105 & $0 * 322$ & 458 & 105 & $975 * 330$ & 456 & 105 & 0 * \\
\hline 40910 & $\begin{array}{r}09 / 12 * 304 \\
* \star *\end{array}$ & $\begin{array}{l}461 \\
\star * *\end{array}$ & $\begin{array}{l}80 \\
\star *\end{array}$ & $0 * 315$ & $\begin{array}{l}460 \\
* * *\end{array}$ & $\begin{array}{l}75 \\
* *\end{array}$ & $0 * 323$ & 458 & $\begin{array}{l}75 \\
* *\end{array}$ & $\begin{array}{l}975 * 331 \\
\star \star \star * \star *\end{array}$ & 456 & $\begin{array}{l}75 \\
* *\end{array}$ & ०* \\
\hline 40915 & $09 / 13 * 339$ & 453 & 100 & $0 * 347$ & 451 & 85 & $980 * 352$ & 442 & 75 & $0 * 355$ & 431 & 70 & ○* \\
\hline 40915 & $09 / 13 * 339$ & $\begin{array}{l}454 \\
* * *\end{array}$ & $\begin{array}{l}70 \\
* *\end{array}$ & $\begin{array}{r}0 * 346 \\
* * *\end{array}$ & $\begin{array}{l}450 \\
* * *\end{array}$ & $\begin{array}{l}70 \\
* *\end{array}$ & $\begin{array}{r}980 * 351 \\
* * *\end{array}$ & 442 & $\begin{array}{l}70 \\
* *\end{array}$ & $0 * 355$ & $\begin{array}{l}430 \\
* * *\end{array}$ & $\begin{array}{l}70 \\
* *\end{array}$ & ○* \\
\hline 40920 & $09 / 14$ *359 & 411 & 70 & $0 * 362$ & 389 & 70 & $0 * 366$ & 365 & 70 & $0 * 370$ & 341 & 70 & ○* \\
\hline 40920 & $09 / 14$ * 359 & $\begin{array}{l}413 \\
* * *\end{array}$ & 70 & $0 * 362$ & $\begin{array}{l}394 \\
* * *\end{array}$ & 70 & $\begin{array}{r}0 * 365 \\
* * *\end{array}$ & $\begin{array}{l}370 \\
\star * *\end{array}$ & 70 & $0 * 370$ & $\begin{array}{l}344 \\
\star * *\end{array}$ & 70 & 0 * \\
\hline 40925 & $09 / 15 * 378$ & 310 & 70 & $0 * 395$ & 264 & 70 & $0 * 417$ & 222 & 70 & $0 * 446$ & 182 & 70 & ○* \\
\hline 40925 & $\underset{*}{09 / 15 E 378}$ & 310 & $7 \odot$ & $\underset{*}{\text { OE395 }}$ & 264 & 70 & $\underset{\star}{\text { OE417 }}$ & 222 & $7 \odot$ & $\begin{array}{c}\text { OE446 } \\
*\end{array}$ & 182 & 70 & $0^{*}$ \\
\hline 40930 & $09 / 16 * 480$ & 148 & 70 & ๑*519 & 116 & 70 & $970 * 557$ & 85 & $7 \odot$ & $\odot * \quad \odot$ & $\odot$ & $\odot$ & $\odot^{*}$ \\
\hline 40930 & $\underset{*}{09 / 16 E 480}$ & 148 & 70 & $\underset{*}{\text { OE517 }}$ & 116 & $\begin{array}{l}75 \\
* *\end{array}$ & $\begin{array}{r}\odot \mathrm{E} 56 \odot \\
\star * * *\end{array}$ & 85 & 75 & $\begin{array}{l}961 \mathrm{E} 605 \\
* * * * * * *\end{array}$ & $\begin{array}{l}58 \\
* *\end{array}$ & $\begin{array}{l}75 \\
* *\end{array}$ & 0 * \\
\hline (Septe & ember $17 \mathrm{tr}$ & and & $18 \mathrm{tr}$ & are new & to $r$ & HURDA & \multirow{3}{*}{\multicolumn{2}{|c|}{$\begin{array}{l}\text { OE6703580 } \\
\text { OE6903350 }\end{array}$}} & & \multirow{3}{*}{\multicolumn{2}{|c|}{$\begin{array}{l}\text { OE6753540 } \\
\text { OE6953270 }\end{array}$}} & & \\
\hline 40931 & 09/17E640 & 30 & 70 & ๑E6603 & $36 \odot \odot$ & 65 & & & 55 & & & 45 & $0^{*}$ \\
\hline 40933 & 09/18E6803 & 3480 & 40 & OE6853 & 3420 & 35 & & & 35 & & & 30 & 0 * \\
\hline & & & & & & & & & & & & & \\
\hline
\end{tabular}

Tropical Storm Landfall

09/05 13Z 15.0N 23.4W 40 kt Santiago Island, Cape Verde Islands

Minor changes to the track and major changes to the intensity shown in McAdie et al. (2009). A major alteration is to show that the system was an extratropical cyclone for four days and to add two additional days to the track of the cyclone. Evidence for these alterations comes from the NHC microfilm maps, the Historical Weather Maps series, the COADS ship database, Monthly Weather Review, Navy reconnaissance book, Mariners Weather Log, Met Éireann (Irish National Meteorological Service), Erickson (1963), Hickey and Connolly-Johnson (2012), and NHC Storm Wallets.

September 5:

HWM analyzes a closed low pressure of at most $1010 \mathrm{mb}$ at $13.0 \mathrm{~N}, 17.5 \mathrm{~W}$ at $12 \mathrm{Z}$. HURDAT does not list an organized storm on this day. Microfilm shows a tropical wave near the Cape Verde Islands along longitude 24W at 12Z. Ship highlights: No gales or low pressures. 
MWR: "Hurricane Debbie probably developed between the Cape Verde Islands and Africa. Pressures in that area fell to well below their normal values with evidence of cyclonic circulation during the first few days of September."

September 6:

HWM analyzes a closed low pressure of at most $1010 \mathrm{mb}$ at $14.2 \mathrm{~N}, 23.2 \mathrm{~W}$ at $12 \mathrm{Z}$. HURDAT lists a $50 \mathrm{kt}$ tropical storm at $15.1 \mathrm{~N}, 24.1 \mathrm{~W}$ at $18 \mathrm{Z}$ (first position). Microfilm shows a closed low pressure of at most $1011 \mathrm{mb}$ at $14.5 \mathrm{~N}, 22.5 \mathrm{~W}$ at $12 \mathrm{Z}$. Ship highlights: $50 \mathrm{kt} \mathrm{ENE}$ and $994 \mathrm{mb}$ (observation or location possibly erroneous) at $14.5 \mathrm{~N}, 20.7 \mathrm{~W}$ at $06 \mathrm{Z}$ (COADS). $30 \mathrm{kt} \mathrm{N}$ and $1004 \mathrm{mb}$ at 14.8N, 27.2W at 19Z (WALLET/ERICKSON).

ATSR: "Although below-normal surface pressures has been observed near the Cape Verde Islands since the beginning of September, it was not until the 6th that ship and land station reports indicated that Debbie had formed. A Pan-American Airways report revealed an "active" tropical depression at 13N 23W at 061300Z."

September 7:

HWM analyzes a hurricane of at most $1000 \mathrm{mb}$ at $15.3 \mathrm{~N}, 28.4 \mathrm{~W}$ at $12 \mathrm{Z}$. HURDAT lists a $70 \mathrm{kt}$ hurricane at $15.7 \mathrm{~N}, 28.1 \mathrm{~W}$ at $12 \mathrm{Z}$. Microfilm shows a closed low pressure of at most $1011 \mathrm{mb}$ at $15.5 \mathrm{~N}, 28.0 \mathrm{~W}$ at 12Z. Ship highlights: $50 \mathrm{kt} \mathrm{WNW}$ and $995 \mathrm{mb}$ at $14.8 \mathrm{~N}, 26.3 \mathrm{~W}$ at $01 \mathrm{Z}$ (micro/ERICKSON). $45 \mathrm{kt} \mathrm{WSW}$ and $1001 \mathrm{mb}$ at $14.8 \mathrm{~N}, 25.6 \mathrm{~W}$ at $03 \mathrm{Z}$ (micro/ERICKSON). $45 \mathrm{kt} \mathrm{S}$ and $1004 \mathrm{mb}$ at $14.8 \mathrm{~N}, 25.0 \mathrm{~W}$ at $06 \mathrm{Z}$ (micro/ERICKSON). $35 \mathrm{kt} \mathrm{S}$ and $1008 \mathrm{mb}$ at $14.2 \mathrm{~N}, 23.5 \mathrm{~W}$ at $09 \mathrm{Z}$ (micro/ERICKSON).

MWR: "Late on the 6th and early on the 7th, several reports from the SS C. Maersk indicated that a storm, probably already of hurricane intensity, existed near $15^{\circ} \mathrm{N}, 25^{\circ} \mathrm{W}$. The storm moved west-northwestward for the next several days but there were no observations in the area and it was not possible to locate the center accurately." ATSR: "....and at $070000 \mathrm{Z}$ the first warning on the disturbance was issued by Fleet Weather Central, Port Lyautey. On the initial warning, it was termed a tropical depression but unnamed. Early on the 7th the SS CHARLOTTE MAERSK, which had done yeoman service in sending initial reports on Betsy, radioed an observation from $15 \mathrm{~N} 26 \mathrm{~W}$ giving a west wind of 40 knots, 15 to 20 foot seas, and a surface pressure of $996 \mathrm{mb}$. Fleet Weather Facility, Miami assumed the forecast responsibility on the depression at $071600 \mathrm{Z}$ and at $072200 \mathrm{Z}$ the first regularly numbered, named warning was issued." 
September 8:

HWM analyzes a hurricane of at most $995 \mathrm{mb}$ at $18.3 \mathrm{~N}, 33.3 \mathrm{~W}$ at $12 \mathrm{Z}$. HURDAT lists a $70 \mathrm{kt}$ hurricane at $18.0 \mathrm{~N}, 34.5 \mathrm{~W}$ at $12 \mathrm{Z}$. Microfilm shows a weather bulletin over the location of the tropical cyclone at 12Z. Ship highlights: No gales or low pressures.

ATSR: "Late on the 7th Debbie was determined to be of tropical storm intensity. Beyond range of reconnaissance aircraft and with a lack of ship reports from the 7 th to the 10th, no amplifying data on Debbie was available for three days. The positions and forecasts were based largely on climatology. The storm was positioned on a more westerly track then proved to be the case."

September 9:

HWM analyzes a hurricane of at most $995 \mathrm{mb}$ at $19.4 \mathrm{~N}, 38.2 \mathrm{~W}$ at $12 \mathrm{Z}$. HURDAT lists a $70 \mathrm{kt}$ hurricane at $19.7 \mathrm{~N}, 38.2 \mathrm{~W}$ at $12 \mathrm{Z}$. Microfilm shows a weather bulletin over the location of the tropical cyclone at 12Z. Ship highlights: No gales or low pressures.

September 10:

HWM analyzes a hurricane of at most $995 \mathrm{mb}$ at $22.3 \mathrm{~N}, 43.3 \mathrm{~W}$ at $12 \mathrm{Z}$. HURDAT lists a $75 \mathrm{kt}$ hurricane at $22.8 \mathrm{~N}, 43.0 \mathrm{~W}$ at $12 \mathrm{Z}$. Microfilm shows a closed low pressure of at most $1011 \mathrm{mb}$ at $26.5 \mathrm{~N}, 40.9 \mathrm{~W}$ at 12Z. Ship highlights: No gales or low pressures.

MWR: "However, on September 10 TIROS photographs indicated that the center was near $25^{\circ} \mathrm{N}, 45^{\circ} \mathrm{W}$. This estimate was less than 200 miles from the actual center." ATSR: "The first indication that Debbie had taken a more northerly course than anticipated was at $101904 Z$ when the Tiros satellite photographs placed the center much farther north."

September 11:

HWM analyzes a hurricane of at most $995 \mathrm{mb}$ at $27.3 \mathrm{~N}, 45.9 \mathrm{~W}$ with a weakening front to the north at $12 \mathrm{Z}$. HURDAT lists a $100 \mathrm{kt}$ hurricane at $27.9 \mathrm{~N}, 45.9 \mathrm{~W}$ at $12 \mathrm{Z}$. Microfilm shows a closed low pressure of at most $1002 \mathrm{mb}$ at $28.5 \mathrm{~N}, 47.0 \mathrm{~W}$ at $12 \mathrm{Z}$. Ship highlights: $50 \mathrm{kt} \mathrm{NE}$ and $1000 \mathrm{mb}$ at $25.5 \mathrm{~N}, 45.9 \mathrm{~W}$ at $00 \mathrm{Z}$ (micro). $55 \mathrm{kt} \mathrm{NE}$ and $1001 \mathrm{mb}$ at $28.4 \mathrm{~N}$, $47.1 \mathrm{~W}$ at $10 \mathrm{Z}$ (COADS). $50 \mathrm{kt} \mathrm{NE}$ at $30.1 \mathrm{~N}, 47.0 \mathrm{~W}$ at $13 \mathrm{Z}$ (micro). $60 \mathrm{kt} \mathrm{NNW}$ and 987 $\mathrm{mb}$ at $28.3 \mathrm{~N}, 46.7 \mathrm{~W}$ at $15 \mathrm{Z}$ (micro). $60 \mathrm{kt} \mathrm{WNW}$ and $999 \mathrm{mb}$ at $27.9 \mathrm{~N}, 46.2 \mathrm{~W}$ at $18 \mathrm{Z}$ (COADS). Aircraft highlights: Penetration center fix measured a central pressure of 976 $\mathrm{mb}$, estimated surface winds of $100 \mathrm{kt}$ and an eye diameter of $45 \mathrm{~nm}$ at $28.8 \mathrm{~N}, 46.2 \mathrm{~W}$ at $1615 Z$ (ATSR) [values not consistent with storm summary].

MWR: "From September 11 through 14 the center was within range of hurricane reconnaissance planes and during this time it moved northward." ATSR: "Shortly 
thereafter, at $110000 \mathrm{Z}$, a ship report from $25.5 \mathrm{~N} 45.7 \mathrm{~W}$ revealed for certain that Debbie's true position was further north and that she was proceeding on a northerly course. Early on the 11th a Navy reconnaissance aircraft discovered Debbie to be a full blown hurricane with maximum winds of $120 \mathrm{kt}$ and a central pressure of $975 \mathrm{mb}$. The storm moved steadily northward under the influence of the same long wave trough that had steered Betsy."

September 12:

HWM analyzes a hurricane of at most $995 \mathrm{mb}$ at $32.2 \mathrm{~N}, 46.0 \mathrm{~W}$ with a warm front far to the northeast at 12Z. HURDAT lists a $105 \mathrm{kt}$ hurricane at $32.2 \mathrm{~N}, 45.8 \mathrm{~W}$ at $12 \mathrm{Z}$.

Microfilm shows a closed low pressure of at most $996 \mathrm{mb}$ at 32.5N, $46.0 \mathrm{~W}$ at 12Z. Ship highlights: $60 \mathrm{kt} \mathrm{E}$ and $1005 \mathrm{mb}$ at $31.4 \mathrm{~N}, 45.0 \mathrm{~W}$ at $00 \mathrm{Z}$ (micro). $45 \mathrm{kt} \mathrm{N}$ and $1002 \mathrm{mb}$ at $32.4 \mathrm{~N}, 47.4 \mathrm{~W}$ at $06 \mathrm{Z}$ (COADS). $75 \mathrm{kt} \mathrm{E}$ and $995 \mathrm{mb}$ at $33.0 \mathrm{~N}, 46.2 \mathrm{~W}$ at $12 \mathrm{Z}$ (micro). 45 kt WNW and $1000 \mathrm{mb}$ at $32.4 \mathrm{~N}, 46.3 \mathrm{~W}$ at $18 \mathrm{Z}$ (micro). Aircraft highlights: Penetration center fix measured a central pressure of $975 \mathrm{mb}$ and estimated an eye diameter of $80 \mathrm{~nm}$ at $32.5 \mathrm{~N}, 45.7 \mathrm{~W}$ at $1315 \mathrm{Z}$ (ATSR).

MWR: “... This agrees well with earlier reconnaissance reports of $975 \mathrm{mb}$ while the hurricane was in the central Atlantic."

September 13:

HWM analyzes a hurricane of at most $1000 \mathrm{mb}$ at $35.1 \mathrm{~N}, 44.2 \mathrm{~W}$ with a cold front far to the north at 12Z. HURDAT lists a $75 \mathrm{kt}$ hurricane at $35.2 \mathrm{~N}, 44.2 \mathrm{~W}$ at $12 \mathrm{Z}$. Microfilm shows a closed low pressure of at most $1002 \mathrm{mb}$ at $35.8 \mathrm{~N}, 43.8 \mathrm{~W}$ at $12 \mathrm{Z}$. Ship highlights: $50 \mathrm{kt} \mathrm{NNW}$ and $1003 \mathrm{mb}$ at $33.6 \mathrm{~N}, 47.3 \mathrm{~W}$ at $00 \mathrm{Z}$ (COADS). $50 \mathrm{kt} \mathrm{NW}$ and $1004 \mathrm{mb}$ at $33.9 \mathrm{~N}, 47.1 \mathrm{~W}$ at $06 \mathrm{Z}$ (COADS). $50 \mathrm{kt} \mathrm{NW}$ and $1009 \mathrm{mb}$ at $34.1 \mathrm{~N}, 46.8 \mathrm{~W}$ at $12 \mathrm{Z}$ (COADS). $50 \mathrm{kt} \mathrm{SSW}$ and $1009 \mathrm{mb}$ at 33.7N, $41.1 \mathrm{~W}$ at $18 \mathrm{Z}$ (micro). $60 \mathrm{kt} \mathrm{SE}$ and 1012 $\mathrm{mb}$ at $37.5 \mathrm{~N}, 41.1 \mathrm{~W}$ at $21 \mathrm{Z}$ (micro). Aircraft highlights: Penetration center fix at $34.9 \mathrm{~N}$, $44.9 \mathrm{~W}$ at $0901 \mathrm{Z}$ (ATSR). Penetration center fix at $35.2 \mathrm{~N}, 44.0 \mathrm{~W}$ at $13 \mathrm{Z}$ (ATSR).

MWR: “... and turned sharply east-northeastward on the 13th." ATSR: "On the 13th she turned sharply east-northeast."

September 14:

HWM analyzes a hurricane of at most $990 \mathrm{mb}$ at $36.5 \mathrm{~N}, 36.8 \mathrm{~W}$ with a weakening cold front to the northwest at $12 \mathrm{Z}$. HURDAT lists a $70 \mathrm{kt}$ hurricane at $36.6 \mathrm{~N}, 36.5 \mathrm{~W}$ at $12 \mathrm{Z}$. Microfilm shows a closed low pressure of at most $996 \mathrm{mb}$ at 37.0N, 37.0W at 12Z. Ship highlights: $50 \mathrm{kt} \mathrm{SW}$ and $1002 \mathrm{mb}$ at $34.3 \mathrm{~N}, 40.3 \mathrm{~W}$ at $00 \mathrm{Z}$ (COADS). $60 \mathrm{kt}$ SSE and $1012 \mathrm{mb}$ at $38.2 \mathrm{~N}, 35.8 \mathrm{~W}$ at $02 \mathrm{Z}$ (micro). $50 \mathrm{kt} \mathrm{SW}$ and $1009 \mathrm{mb}$ at $33.7 \mathrm{~N}, 42.8 \mathrm{~W}$ at $06 \mathrm{Z}$ 
(micro). $45 \mathrm{kt} \mathrm{SSW}$ and $1010 \mathrm{mb}$ at $34.0 \mathrm{~N}, 35.9 \mathrm{~W}$ at $09 \mathrm{Z}$ (micro). $70 \mathrm{kt} \mathrm{S}$ and $1000 \mathrm{mb}$ at $35.8 \mathrm{~N}, 35.3 \mathrm{~W}$ at $12 \mathrm{Z}$ (COADS). $95 \mathrm{kt} \mathrm{SW}$ and $992 \mathrm{mb}$ at $35.7 \mathrm{~N}, 35.6 \mathrm{~W}$ at $15 \mathrm{Z}$ (COADS). $70 \mathrm{kt} \mathrm{W}$ and $1002 \mathrm{mb}$ at $35.7 \mathrm{~N}, 35.5 \mathrm{~W}$ at $18 \mathrm{Z}$ (COADS). Aircraft highlights: Penetration center fix at $37.0 \mathrm{~N}, 35.0 \mathrm{~W}$ at $1653 \mathrm{Z}$ (ATSR).

September 15:

HWM analyzes a hurricane of at most $985 \mathrm{mb}$ at $41.5 \mathrm{~N}, 22.5 \mathrm{~W}$ with a warm front to the northeast and cold front to the south at 12Z. HURDAT lists a $70 \mathrm{kt}$ hurricane at $41.7 \mathrm{~N}$, $22.2 \mathrm{~W}$ at $12 \mathrm{Z}$. Microfilm shows a trough along longitude $22 \mathrm{~W}$ extending from a large extratropical cyclone of at most $981 \mathrm{mb}$ at $57.5 \mathrm{~N}, 27.0 \mathrm{~W}$ to $33 \mathrm{~N}$ at 12Z. Ship highlights: $45 \mathrm{kt} \mathrm{SSW}$ and $1010 \mathrm{mb}$ at $35.4 \mathrm{~N}, 29.9 \mathrm{~W}$ at $00 \mathrm{Z}$ (COADS). $55 \mathrm{kt} \mathrm{SW}$ and $1007 \mathrm{mb}$ at $38.6 \mathrm{~N}, 29.0 \mathrm{~W}$ at $06 \mathrm{Z}$ (micro). $35 \mathrm{kt} \mathrm{SSW}$ and $999 \mathrm{mb}$ at $41.1 \mathrm{~N}, 22.0 \mathrm{~W}$ at $12 \mathrm{Z}$ (HWM). $45 \mathrm{kt} \mathrm{S}$ and $985 \mathrm{mb}$ at $45.3 \mathrm{~N}, 16.3 \mathrm{~W}$ at $18 \mathrm{Z}$ (COADS).

MWR: “... passing through the Azores during the night of September 14-15." ATSR: "...raced through the Azores on the night of the 14th-15th."

September 16:

HWM analyzes a hurricane of at most $960 \mathrm{mb}$ at $55.5 \mathrm{~N}, 10.0 \mathrm{~W}$ with a warm front to the northeast and cold front to the east and southeast at 12Z. HURDAT lists a $70 \mathrm{kt}$ hurricane at $55.7 \mathrm{~N}, 8.5 \mathrm{~W}$ at $12 \mathrm{Z}$ (last position). Microfilm shows a closed low pressure of at most $990 \mathrm{mb}$ at $54.5 \mathrm{~N}, 13.0 \mathrm{~W}$ at $12 \mathrm{Z}$. Ship highlights: $50 \mathrm{kt} \mathrm{S}$ and $990 \mathrm{mb}$ at $45.5 \mathrm{~N}, 11.5 \mathrm{~W}$ at $00 \mathrm{Z}$ (COADS). $60 \mathrm{kt} \mathrm{W}$ and $976 \mathrm{mb}$ at 50.6N, 13.7W at 05Z (MWL). $45 \mathrm{kt} \mathrm{NW}$ and 983 $\mathrm{mb}$ at $50.2 \mathrm{~N}, 13.2 \mathrm{~W}$ at $06 \mathrm{Z}$ (COADS). Land highlights: $961 \mathrm{mb}$ at Belmullet, Ireland around 11Z-12Z (Met Eirean). $66 \mathrm{kt}$ (10-min max wind) and gusts to $98 \mathrm{kt} 10-\mathrm{min}$ at Malin Head, Ireland at 13Z (Met Eirean/Hickey/Connolly-Johnson).

MWR: "It then accelerated and turned northward, passing along the western coasts of Ireland and Scotland on the 16th. The lowest available pressure was $970 \mathrm{mb}$ reported by a ship a short distance from the center and offshore from Ireland. Gusts reached $106 \mathrm{mph}$ at Ballykelly and $104 \mathrm{mph}$ at Tiree and Snaefill. An Associated Press account of the hurricane from Longon follows: "The edge of Hurricane Debbie battered the British Isles Saturday night and left 11 or more dead and at least 50 injured. Flooding caused heavy damage in Ireland, Scotland, and Wales. Coastal areas of western Scotland were inundated by pounding surf whipped up by winds of $106 \mathrm{mph}$. Shipping and airplane traffic was disrupted. Coastal radio stations reported the airwaves were jammed with calls for help from small ships and fishing craft. Weathermen reported strong winds from northern Norway to the Bay of Biscay." ATSR: “.... and finally grazed the coasts of Ireland and Scotland on the 16th. In Ireland and Scotland, Debbie caused heavy damage to shipping and the coastal sections and claimed 11 lives." 


\section{September 17:}

HWM analyzes a large extratropical cyclone of at most $975 \mathrm{mb}$ at $67.5 \mathrm{~N}, 3.0 \mathrm{E}$ at $12 \mathrm{Z}$. HURDAT does not list an organized storm on this day. Microfilm does not show an organized storm on this day (cyclone moving off the NE corner of the map). Ship highlights: $55 \mathrm{kt} \mathrm{SW}$ and $979 \mathrm{mb}$ at 58.8N, 3.7W at 00Z (COADS). Land highlights: 45 kt SW and $991 \mathrm{mb}$ at Rorvik, Norway at 12Z (HWM).

September 18:

HWM analyzes a broad extratropical cyclone of at most $985 \mathrm{mb}$ at $68.0 \mathrm{~N}, 30.0 \mathrm{E}$ at $12 \mathrm{Z}$. HURDAT does not list an organized storm on this day. Microfilm is not available on this date. No gales or low pressures.

A vigorous tropical wave developed over central Africa around September 1st. The disturbance moved westward and became better organized still over western Africa. A paper by Erickson (MWR 1963, pg. 61) details the early history of this tropical system and provides excellent data on its formation and development. Surface observations over western Africa indicate that the tropical wave developed a well-defined, low-level circulation while still over land. Genesis is analyzed at $12 \mathrm{Z}$ on September 5 th as a $30 \mathrm{kt}$ tropical depression, just off the African coast, 30 hours earlier than originally shown in HURDAT. Minor track alterations are introduced during the lifetime of this tropical cyclone. The tropical depression moved westward on September 6th and gained strength. A ship reported $50 \mathrm{kt} \mathrm{NE}$ and $994 \mathrm{mb}$ at $06 \mathrm{Z}$ on the 6th and although it is possible that the observation is correct, the position reported contradicts the other ship and coastal observations, thus it has been disregarded. Intensification to a tropical storm is analyzed at $06 \mathrm{Z}$ on the 6th based on data from the ship Charlotte Maersk later in the day and on September 7 th. Originally HURDAT showed an initial intensity as a $50 \mathrm{kt}$ tropical storm at $18 \mathrm{Z}$ on the 6th, also the original first position. Debbie made landfall in the island of Santiago, Cape Verde Islands, at $13 \mathrm{Z}$ on the 6th as a $40 \mathrm{kt}$ tropical storm. Late on the 6th, the ship Charlotte Maersk was moving eastward near $15 \mathrm{~N}, 27 \mathrm{~W}$ and began to report lowering pressures and an increase in the winds. At $01 \mathrm{Z}$ on the 7 th, the ship reported 50 kt WNW and $995 \mathrm{mb}$; the strongest winds experienced by the ship and also the lowest pressure. A peripheral pressure of $995 \mathrm{mb}$ suggest maximum sustained winds greater than $56 \mathrm{kt}$ from the Brown et al. pressure-wind relationship. Intensification to a hurricane is analyzed at $00 \mathrm{Z}$ on the 7th, same as originally shown in HURDAT. A TIROS III satellite image (MWR 1963, pg. 64) at $1913 \mathrm{Z}$ on the 7th shows hurricane Debbie in the southwest corner and an eye is apparent. It is possible that Debbie may have been stronger than analyzed $(70 \mathrm{kt})$, but there is no other data to suggest increasing the winds from the values already in HURDAT, nor can an intensity assessment be made from the satellite image. Observations over the eastern Atlantic were very sparse as the hurricane moved 
away from the Cape Verde Islands. No ships passed near Debbie from September 8th through the 10th. No changes to the intensity or track were made from the 8 th through the 10th. A TIROS III satellite image (MWR 1962, pg. 111) at $1907 \mathrm{Z}$ on the 10th shows hurricane Debbie in a better angle to judge its organization. The hurricane has a wellorganized CDO but convection is restricted on the western and southern quadrants, it appears that southwesterly shear is affecting the storm. At $18 \mathrm{Z}$ on the 10th, HURDAT originally showed an intensity of $75 \mathrm{kt}$ and this is retained.

On September 11th, Debbie entered an area of heavier shipping traffic in the central Atlantic and gale-force winds were reported, including $60 \mathrm{kt}$ at $15 \mathrm{Z}$ and 18Z. Also on the 11 th, the hurricane turned to the north feeling the weakness left behind by the trough that picked up Betsy a couple of days before. The first reconnaissance aircraft reached the hurricane at $1615 \mathrm{Z}$ on the 11 th measured a central pressure of $976 \mathrm{mb}$, estimated surface winds of $100 \mathrm{kt}$ and an eye diameter of $45 \mathrm{~nm}$. It is worth mentioning that these values differ slightly from those mentioned in the storm summary of the Navy book (ATSR). A central pressure of $976 \mathrm{mb}$ suggests maximum sustained winds of $77 \mathrm{kt}$ from the north of $25 \mathrm{~N}$ pressure-wind relationship. An eye diameter of $45 \mathrm{~nm}$ suggests an RMW of $34 \mathrm{~nm}$ and the climatological value is $23 \mathrm{~nm}$. Due to a forward speed of $14 \mathrm{kt}$, an RMW greater than the climatological value, and slightly weighting in the surface estimate, an intensity of $80 \mathrm{kt}$ is selected at $18 \mathrm{Z}$ on the $11 \mathrm{th}$, down from $105 \mathrm{kt}$ originally in HURDAT, a major intensity change. A central pressure of $976 \mathrm{mb}$ was present in HURDAT at $12 \mathrm{Z}$ on the 11 th and based on the time of the penetration fix, it has been moved to the $18 \mathrm{Z}$ time slot on the 11 th. $80 \mathrm{kt}$ is also the peak intensity of this tropical cyclone, down from $105 \mathrm{kt}$ originally in HURDAT, a major intensity change. It is analyzed that Debbie did not reach major hurricane intensity during its lifetime. Yet, it is possible that Debbie may have peaked in intensity earlier in its life and by the time the reconnaissance aircraft reached the hurricane, it had already weakened. An analog could be hurricane Julia in 2010 that peaked in intensity east of $35 \mathrm{~W}$ and was a category 1 hurricane when it reached $45 \mathrm{~W}$. The next aircraft to investigate Debbie arrived at $1315 \mathrm{Z}$ on September 12th estimating a central pressure of $975 \mathrm{mb}$ and an eye diameter of $80 \mathrm{~nm}$. A central pressure of $975 \mathrm{mb}$ suggests maximum sustained winds of $79 \mathrm{kt}$ from the north of $25 \mathrm{~N}$ pressure-wind relationship. An eye diameter of $80 \mathrm{~nm}$ suggests an RMW of $60 \mathrm{~nm}$ and the climatological value is $27 \mathrm{~nm}$. Due to a forward speed of $8 \mathrm{kt}$ and an RMW greater than the climatological value, an intensity of $75 \mathrm{kt}$ is selected at $12 \mathrm{Z}$ on the $12 \mathrm{th}$, down from $105 \mathrm{kt}$ originally in HURDAT, a major intensity change. A central pressure of $975 \mathrm{mb}$ was present in HURDAT at $12 \mathrm{Z}$ on the 12 th and it has been retained. Various ships reported gale-force winds on the 12 th and a ship even reported hurricane-force winds, 75 $\mathrm{kt} \mathrm{E}$ and $995 \mathrm{mb}$ at $12 \mathrm{Z}$. 
On September 13th, Debbie turned to the east-northeast. A central pressure of $980 \mathrm{mb}$ is present in HURDAT at $06 \mathrm{Z}$ on the 13th and reconnaissance data shows that aircrafts were present around this time, thus the central pressure has been retained even though it could not be confirmed. A central pressure of $980 \mathrm{mb}$ suggests maximum sustained winds of $73 \mathrm{kt}$ from the Brown et al. north of $35 \mathrm{~N}$ south of $25 \mathrm{~N}$ pressure-wind relationship and also $73 \mathrm{kt}$ north of $25 \mathrm{~N}$ from the Landsea et al. pressure-wind relationship. Due to a forward speed of $10 \mathrm{kt}$ and a large RMW, an intensity of $70 \mathrm{kt}$ is selected at $06 \mathrm{Z}$ on the 13th, down from $85 \mathrm{kt}$ originally in HURDAT, a minor intensity change. Various ships reported tropical storm force winds, up to $60 \mathrm{kt}$. A great satellite image of hurricane Debbie made the cover of Mariners Weather Log, Volume 5, Number 6, November 1961. The satellite image was taken at $1416 \mathrm{Z}$ on the 13th by the Mercury spacecraft 12 minutes after launch at an altitude of 90 miles. In the satellite image, Debbie appears as a wellorganized hurricane with what seems to be a large eye surrounded by a symmetric CDO. On September 14th, the hurricane continued east-northeast gaining in forward speed with no appreciable changes in intensity. Many ships reported gale-force winds and a couple even recorded hurricane-force winds. A ship reported $95 \mathrm{kt}$ at $15 \mathrm{Z}$ but this observation appears dubious and was disregarded. Late on the 14th, Debbie began to become extratropical as dry, cool air entered the circulation. Synoptic data at 00Z on September 15th indicate that Debbie became an extratropical cyclone as a temperature gradient was present between the eastern and western quadrants and frontogenesis had taken place. HURDAT did not show Debbie becoming an extratropical cyclone despite reaching $55^{\circ} \mathrm{N}$. The strong extratropical cyclone crossed the Azores around $04 \mathrm{Z}$ as it raced to the northeast. Early on September 16th, Debbie approached Ireland and the United Kingdom producing hurricane-force winds and damaging storm surge. A central pressure of 970 mb was present in HURDAT at $06 \mathrm{Z}$ on the 16th and has been removed as a ship near the center reported $25 \mathrm{kt} \mathrm{SE}$ and $963 \mathrm{mb}$ at this time. Debbie made landfall in Ireland around $11 \mathrm{Z}$ and the lowest pressure recorded was $961 \mathrm{mb}$ at Belmullet. This was likely a central pressure based on the track of the extratropical cyclone; thus, it has been added to HURDAT at $12 \mathrm{Z}$ on the $16 \mathrm{th}$. The strongest winds recorded in Ireland were $66 \mathrm{kt} 10$-min (74 kt 1-min). An intensity of $75 \mathrm{kt}$ is analyzed at $06 \mathrm{Z}$ and $12 \mathrm{Z}$ on the $16 \mathrm{th}$, up from $70 \mathrm{kt}$ originally in HURDAT, a minor intensity change. On September 17th, the extratropical cyclone turned to the northeast and east as it approached Norway. Weakening below hurricane intensity is analyzed at $12 \mathrm{Z}$ on the 17 th. HWM indicates that gale-force winds affected Norway. On September 18th, the system moved over northern Norway and northwestern Russia. Surface observations indicate that the extratropical cyclone weakened into an elongated trough and the last position is analyzed at $18 \mathrm{Z}$ on the 18 th, 54 hours later than originally shown in HURDAT. 
Hurricane Esther [September 10-27, 1961]

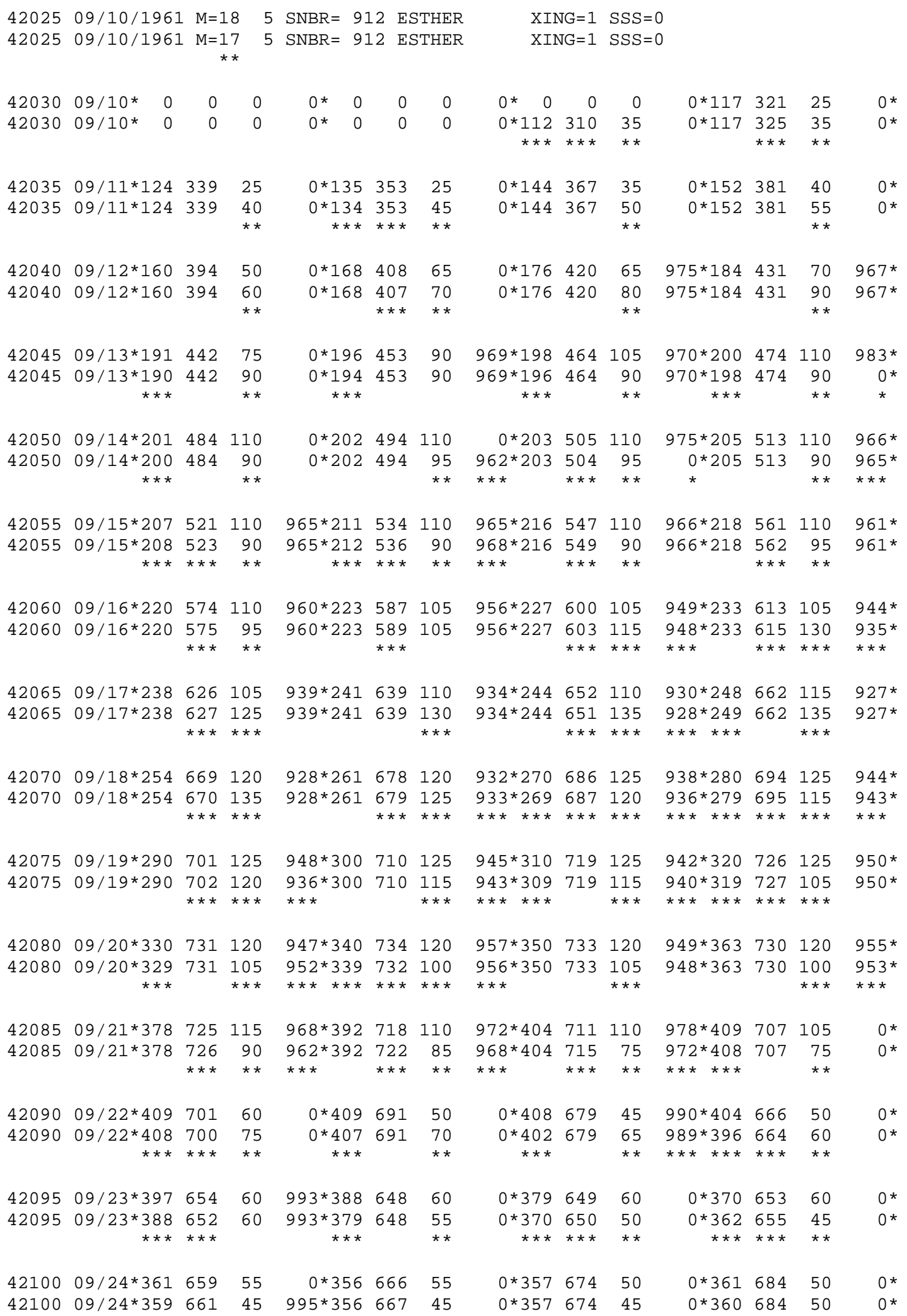




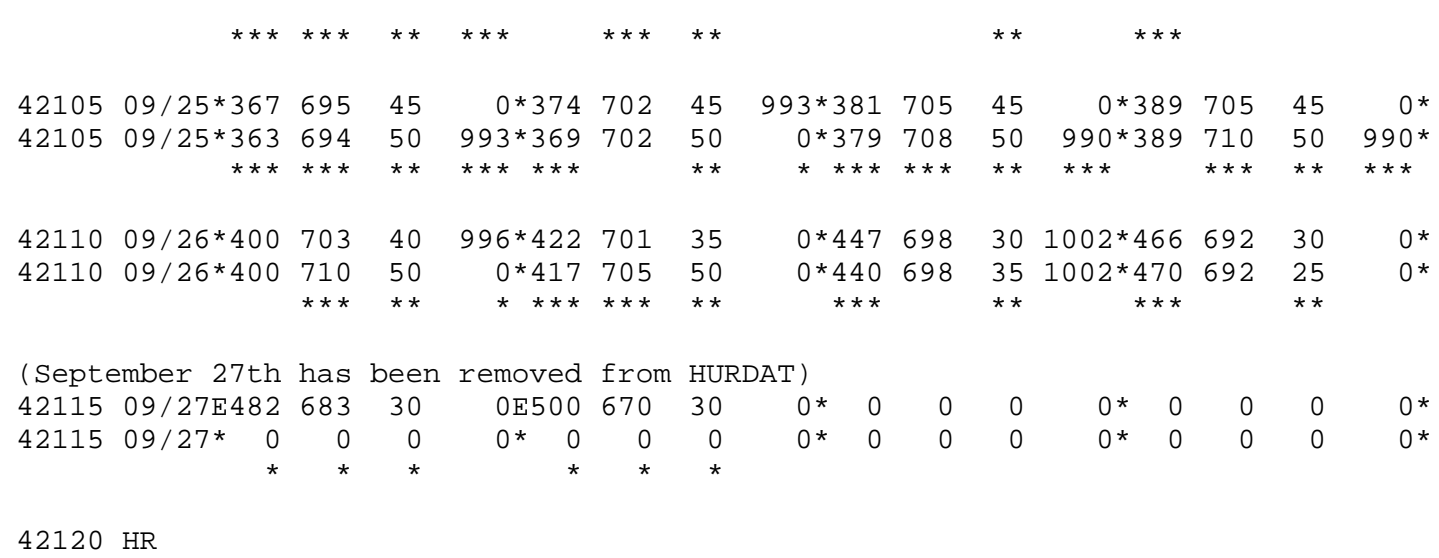

U.S. Tropical Storm Landfall

09/26 05Z 41.4N 70.6W 50 kt MA

09/26 06Z 41.6N 70.5W 50 kt MA

09/26 11Z 43.8N 69.9W $35 \mathrm{kt} \mathrm{ME}$

U.S. Tropical Storm Impact

09/21 08Z 39.6N 72.0W $40 \mathrm{kt}$ New Jersey

09/21 12Z 40.4N 71.5W $60 \mathrm{kt}$ New York

09/21 15Z 40.6N 71.1W 60 kt Rhode Island

09/21 15Z 40.6N 71.1W 50 kt Connecticut

Minor changes to the track and major changes to the intensity shown in McAdie et al. (2009). Evidence for these alterations comes from the NHC microfilm maps, the Historical Weather Maps series, the COADS ship database, Monthly Weather Review, Navy reconnaissance book, Mariners Weather Log, National Hurricane Research Project, Local Climatological Data and NHC Storm Wallets.

September 9:

HWM analyzes a spot low pressure at $10.0 \mathrm{~N}, 21.2 \mathrm{~W}$ at $12 \mathrm{Z}$. HURDAT does not list an organized storm on this day. Microfilm is not available on this date. Ship highlights: No gales or low pressures.

September 10:

HWM analyzes a closed low pressure of at most $1010 \mathrm{mb}$ at $9.4 \mathrm{~N}, 30.2 \mathrm{~W}$ at $12 \mathrm{Z}$. HURDAT lists a $25 \mathrm{kt}$ tropical depression at $11.7 \mathrm{~N}, 32.1 \mathrm{~W}$ at $18 \mathrm{Z}$ (first position). Microfilm is not available on this date. Ship highlights: No gales or low pressures.

ATSR: "Hurricane Esther formed in the eastern Atlantic and probably developed from a perturbation along the Intertropical Convergence Zone. Early indication of the existence 
of the tropical disturbance was provided by the weather satellite Tiros III at 1904Z on 10 September."

September 11:

HWM analyzes a tropical storm of at most $1005 \mathrm{mb}$ at $13.3 \mathrm{~N}, 37.8 \mathrm{~W}$ at $12 \mathrm{Z}$. HURDAT lists a $35 \mathrm{kt}$ tropical storm at $14.4 \mathrm{~N}, 36.7 \mathrm{~W}$ at $12 \mathrm{Z}$. Microfilm is not available on this date. Ship highlights: No gales or low pressures.

MWR: "On September 11, with Carla moving inland in Texas and Betsy and Debbie still threatening shipping in the Atlantic, evidence of a new disturbance began to appear. At 1330 EST on that date, pictures from the TIROS III satellite showed a vortex near $15^{\circ} \mathrm{N}$, $38^{\circ} \mathrm{W}$." ATSR: "The following day, the Tiros III nephanalysis (111820Z) indicated a possible vortex."

September 12:

HWM analyzes a hurricane of at most $995 \mathrm{mb}$ at $17.3 \mathrm{~N}, 42.1 \mathrm{~W}$ at $12 \mathrm{Z}$. HURDAT lists a $65 \mathrm{kt}$ hurricane at $17.6 \mathrm{~N}, 42.0 \mathrm{~W}$ at $12 \mathrm{Z}$. Microfilm shows a spot low at $14.3 \mathrm{~N}, 44.0 \mathrm{~W}$ at 12Z. Ship highlights: $30 \mathrm{kt} \mathrm{NW}$ and $1000 \mathrm{mb}$ at $18.2 \mathrm{~N}, 45.2 \mathrm{~W}$ at $21 \mathrm{Z}$ (micro). Aircraft highlights: Penetration center fix measured a central pressure of $967 \mathrm{mb}$, estimated surface winds of $110 \mathrm{kt}$ and an eye diameter of $40 \mathrm{~nm}$ at $18.8 \mathrm{~N}, 43.6 \mathrm{~W}$ at $2010 \mathrm{Z}$ (ATSR).

MWR: "A reconnaissance flight was therefore dispatched to the area on September 12. It revealed that Esther had formed and was of full hurricane intensity with a central pressure of $967 \mathrm{mb}$. The first advisory at $1730 \mathrm{EST}$ placed the center at $19^{\circ} \mathrm{N}, 44^{\circ} \mathrm{W}$ moving toward the northwest at $15 \mathrm{kt}$, accompanied by 110 -kt winds. The intensity at this time suggests that Esther undoubtedly reached hurricane strength by September 11. In fact, a "possible" vortex near $11^{\circ} \mathrm{N} 30^{\circ} \mathrm{W}$ in the TIROS III nephanalysis for $1412 \mathrm{EST}$, September 10 may have represented near hurricane intensity." ATSR: "A reconnaissance aircraft was dispatched on the morning of the 12th after estimating the position of the vortex to be within range of Roosevelt Roads, Puerto Rico. The aircraft located the eye near $18-45 \mathrm{~N} 43-32 \mathrm{~W}$ at $2010 \mathrm{Z}$ on 12 September and reported winds of 110 knots and a central pressure of $967 \mathrm{mb}$. The initial warning on Hurricane Esther was issued at 2230Z on 12 September. During the period of 12-17 September an anticyclone was building to the north, causing Esther to move in a fairly steady course to the west-northwest." September 13:

HWM analyzes a hurricane of at most $995 \mathrm{mb}$ at $19.2 \mathrm{~N}, 46.4 \mathrm{~W}$ at $12 \mathrm{Z}$. HURDAT lists a $105 \mathrm{kt}$ hurricane at $19.8 \mathrm{~N}, 46.4 \mathrm{~W}$ at $12 \mathrm{Z}$. Microfilm shows a closed low pressure of at most $1002 \mathrm{mb}$ at $19.7 \mathrm{~N}, 46.5 \mathrm{~W}$ at 12Z. Ship highlights: $80 \mathrm{kt} \mathrm{WNW}$ and $978 \mathrm{mb}$ at 
$18.4 \mathrm{~N}, 44.9 \mathrm{~W}$ at $00 \mathrm{Z}$ (micro). $60 \mathrm{kt} \mathrm{NE}$ and $1003 \mathrm{mb}$ at $20.1 \mathrm{~N}, 45.1 \mathrm{~W}$ at $06 \mathrm{Z}$ (COADS). $45 \mathrm{kt} \mathrm{E}$ and $1009 \mathrm{mb}$ at $20.7 \mathrm{~N}, 44.6 \mathrm{~W}$ at $12 \mathrm{Z}$ (COADS). $40 \mathrm{kt}$ ESE and $1013 \mathrm{mb}$ at $21.5 \mathrm{~N}, 43.5 \mathrm{~W}$ at $18 \mathrm{Z}$ (COADS). Aircraft highlights: Penetration center fix measured a central pressure of $969 \mathrm{mb}$, estimated surface winds of $100 \mathrm{kt}$ and an eye diameter of 40 $\mathrm{nm}$ at $18.8 \mathrm{~N}, 43.6 \mathrm{~W}$ at $09 \mathrm{Z}$ (ATSR). Radar center fix at $19.6 \mathrm{~N}, 47.1 \mathrm{~W}$ at $1810 \mathrm{Z}$ (ATSR).

MWR: "On the 13th and 14th surface pressure to the north of Esther began to rise as Debbie headed toward the Azores and a building anticyclone moved eastward from the vicinity of Bermuda. As a result, Esther was deflected to a west-northwestward course for the next few days. Also, as often happens under the influence of the increased gradient accompanying the passage of a High to the north of a hurricane, a gradual intensification began."

September 14:

HWM analyzes a hurricane of at most $995 \mathrm{mb}$ at $20.2 \mathrm{~N}, 50.6 \mathrm{~W}$ at $12 \mathrm{Z}$. HURDAT lists a $110 \mathrm{kt}$ hurricane at $20.3 \mathrm{~N}, 50.5 \mathrm{~W}$ at $12 \mathrm{Z}$. Microfilm shows a closed low pressure of at most $1008 \mathrm{mb}$ at $20.5 \mathrm{~N}, 50.6 \mathrm{~W}$ at $12 \mathrm{Z}$. Ship highlights: $35 \mathrm{kt} \mathrm{W}$ and $1008 \mathrm{mb}$ at $18.7 \mathrm{~N}$, $52.2 \mathrm{~W}$ at $19 \mathrm{Z}$ (micro). Aircraft highlights: Penetration center fix measured a central pressure of $962 \mathrm{mb}$ and estimated an eye diameter of $40 \mathrm{~nm}$ at $20.3 \mathrm{~N}, 49.8 \mathrm{~W}$ at $07 \mathrm{Z}$ (ATSR). Penetration center fix measured a central pressure of $965 \mathrm{mb}$ at $20.4 \mathrm{~N}, 51.1 \mathrm{~W}$ at 2017Z (ATSR/micro).

September 15:

HWM analyzes a hurricane of at most $995 \mathrm{mb}$ at $21.4 \mathrm{~N}, 54.5 \mathrm{~W}$ at $12 \mathrm{Z}$. HURDAT lists a $110 \mathrm{kt}$ hurricane at $21.6 \mathrm{~N}, 54.7 \mathrm{~W}$ at $12 \mathrm{Z}$. Microfilm does not provide an analysis in the area at 12Z. Ship highlights: $35 \mathrm{kt} \mathrm{E}$ and $1018 \mathrm{mb}$ at $24.8 \mathrm{~N}, 52.8 \mathrm{~W}$ at $12 \mathrm{Z}$ (COADS). 45 $\mathrm{kt} \mathrm{E}$ and $1016 \mathrm{mb}$ at $24.0 \mathrm{~N}, 52.8 \mathrm{~W}$ at $18 \mathrm{Z}$ (COADS). Aircraft highlights: Penetration center fix measured a central pressure of $968 \mathrm{mb}$ at $21.3 \mathrm{~N}, 54.0 \mathrm{~W}$ at $07 \mathrm{Z}$ (ATSR). Penetration center fix measured a central pressure of $966 \mathrm{mb}$, estimated maximum surface winds of $100 \mathrm{kt}$ and an eye diameter of $30 \mathrm{~nm}$ at $21.6 \mathrm{~N}, 55.0 \mathrm{~W}$ at $13 \mathrm{Z}$ (ATSR). Penetration center fix at $21.8 \mathrm{~N}, 56.2 \mathrm{~W}$ at $19 \mathrm{Z}$ (ATSR).

September 16:

HWM analyzes a hurricane of at most $990 \mathrm{mb}$ at $23.3 \mathrm{~N}, 60.0 \mathrm{~W}$ with a stationary front far to the northwest at $12 \mathrm{Z}$. HURDAT lists a $105 \mathrm{kt}$ hurricane at $22.7 \mathrm{~N}, 60.0 \mathrm{~W}$ at $12 \mathrm{Z}$. Microfilm does not provide an analysis in the area at 12Z. Ship highlights: No gales or low pressures. Aircraft highlights: Penetration center fix measured a central pressure of $960 \mathrm{mb}$ and estimated an eye diameter of $30 \mathrm{~nm}$ at $22.0 \mathrm{~N}, 57.8 \mathrm{~W}$ at $01 \mathrm{Z}$ (ATSR).

Penetration center fix at $22.5 \mathrm{~N}, 59.5 \mathrm{~W}$ at $07 \mathrm{Z}$ (ATSR). Penetration center fix measured a 
central pressure of $948 \mathrm{mb}$, estimated surface winds of $120 \mathrm{kt}$ and an eye diameter of 20 $\mathrm{nm}$ at $22.8 \mathrm{~N}, 60.5 \mathrm{~W}$ at $1255 \mathrm{Z}$ (ATSR). Penetration center fix measured a central pressure of $935 \mathrm{mb}$, estimated surface winds of $128 \mathrm{kt}$ and an RMW of $13 \mathrm{~nm}$ near $\sim 23.0 \mathrm{~N}$, $\sim 60.0 \mathrm{~W}$ around 18Z (NHRP). Penetration center fix measured a central pressure of 936 $\mathrm{mb}$, estimated surface winds of $100 \mathrm{kt}$ and an eye diameter of $20 \mathrm{~nm}$ at $23.3 \mathrm{~N}, 61.5 \mathrm{~W}$ at $1830 \mathrm{Z}$ (ATSR). Penetration center fix at 23.6N, 62.6W at 2330Z (ATSR).

September 17:

HWM analyzes a hurricane of at most $990 \mathrm{mb}$ at $24.2 \mathrm{~N}, 65.3 \mathrm{~W}$ with a frontal boundary far to the northwest at $12 \mathrm{Z}$. HURDAT lists a $110 \mathrm{kt}$ hurricane at $24.4 \mathrm{~N}, 65.2 \mathrm{~W}$ at $12 \mathrm{Z}$. Microfilm shows a closed low pressure of at most $1002 \mathrm{mb}$ at $24.5 \mathrm{~N}, 66.0 \mathrm{~W}$ at $12 \mathrm{Z}$. Ship highlights: $40 \mathrm{kt}$ SE and $1013 \mathrm{mb}$ at $27.4 \mathrm{~N}, 62.8 \mathrm{~W}$ at $12 \mathrm{Z}$ (COADS). $40 \mathrm{kt} \mathrm{W}$ and 1008 $\mathrm{mb}$ at $22.5 \mathrm{~N}, 68.9 \mathrm{~W}$ at $15 \mathrm{Z}$ (micro). $45 \mathrm{kt} \mathrm{W}$ and $1004 \mathrm{mb}$ at $22.8 \mathrm{~N}, 68.1 \mathrm{~W}$ at $18 \mathrm{Z}$ (COADS). $45 \mathrm{kt} \mathrm{W}$ and $1001 \mathrm{mb}$ at $23.0 \mathrm{~N}, 68.1 \mathrm{~W}$ at $21 \mathrm{Z}$ (MWL). Aircraft highlights: Penetration center fix measured an eye diameter of $17 \mathrm{~nm}$ at $24.1 \mathrm{~N}, 64.1 \mathrm{~W}$ at $07 \mathrm{Z}$ (ATSR). Penetration center fix measured a central pressure of $928 \mathrm{mb}$, estimated surface winds of $80 \mathrm{kt}$ and an eye diameter of $18 \mathrm{~nm}$ at $24.5 \mathrm{~N}, 65.5 \mathrm{~W}$ at $1313 \mathrm{Z}$ (ATSR/micro). Penetration center fix measured a central pressure of $940 \mathrm{mb}$, estimated surface winds of $112 \mathrm{kt}$ and an RMW of $10 \mathrm{~nm}$ at 24.0N, 65.0W around 1420Z (NHRP). Penetration center fix measured a central pressure of $927 \mathrm{mb}$, estimated surface winds of $120 \mathrm{kt}$ and an eye diameter of $15 \mathrm{~nm}$ at $25.0 \mathrm{~N}, 66.4 \mathrm{~W}$ at $19 \mathrm{Z}$ (ATSR). Radar center fix estimated an eye diameter of $17 \mathrm{~nm}$ at $25.4 \mathrm{~N}, 66.9 \mathrm{~W}$ at $2346 \mathrm{Z}$ (ATSR).

MWR: "By the 17th, the central pressure had dropped to $927 \mathrm{mb}$. According to the various formulae relating central pressure and maximum wind, this would support 150- to 175-kt squalls. Since the storm path was well to the north of the Virgin Islands, Puerto Rico, and the Bahamas, effects in these areas consisted mostly of increased surf and large swells." ATSR: "Gradual intensification was indicated when, on the 17th, a reconnaissance aircraft reported a central pressure of $927 \mathrm{mb}$."

September 18:

HWM analyzes a hurricane of at most $990 \mathrm{mb}$ at $26.5 \mathrm{~N}, 68.6 \mathrm{~W}$ with a weakening stationary front to the northwest at 12Z. HURDAT lists a $125 \mathrm{kt}$ hurricane at $27.0 \mathrm{~N}$, $68.6 \mathrm{~W}$ at 12Z. Microfilm shows a closed low pressure of at most $1002 \mathrm{mb}$ at $27.0 \mathrm{~N}$, $68.8 \mathrm{~W}$ at 12Z. Ship highlights: $50 \mathrm{kt} \mathrm{SE}$ and $1012 \mathrm{mb}$ at $27.2 \mathrm{~N}, 64.1 \mathrm{~W}$ at $00 \mathrm{Z}$ (COADS). $55 \mathrm{kt} \mathrm{SE}$ and $1010 \mathrm{mb}$ at $27.2 \mathrm{~N}, 64.7 \mathrm{~W}$ at $06 \mathrm{Z}$ (COADS). $40 \mathrm{kt} \mathrm{SSW}$ and $1006 \mathrm{mb}$ at $23.9 \mathrm{~N}, 66.3 \mathrm{~W}$ at $09 \mathrm{Z}$ (MWL). $55 \mathrm{kt} \mathrm{SE}$ and $1010 \mathrm{mb}$ at $27.1 \mathrm{~N}, 65.5 \mathrm{~W}$ at $12 \mathrm{Z}$ (COADS). $55 \mathrm{kt} \mathrm{E}$ and $1014 \mathrm{mb}$ at $30.3 \mathrm{~N}, 66.2 \mathrm{~W}$ at $15 \mathrm{Z}$ (COADS). $55 \mathrm{kt} \mathrm{E}$ and $1006 \mathrm{mb}$ at $30.0 \mathrm{~N}$, $69.3 \mathrm{~W}$ at $18 \mathrm{Z}$ (COADS). $45 \mathrm{kt} \mathrm{SSE}$ and $1013 \mathrm{mb}$ at $29.6 \mathrm{~N}, 65.0 \mathrm{~W}$ at $21 \mathrm{Z}$ (micro). 
Aircraft highlights: Penetration center fix measured a central pressure of $928 \mathrm{mb}$, estimated flight level winds of $80 \mathrm{kt}$ and an eye diameter of $16 \mathrm{~nm}$ at $25.6 \mathrm{~N}, 67.5 \mathrm{~W}$ at 0130Z (ATSR). Penetration center fix measured a central pressure of $933 \mathrm{mb}$, estimated an eye diameter of $16 \mathrm{~nm}$ at $26.0 \mathrm{~N}, 68.3 \mathrm{~W}$ at $07 \mathrm{Z}$ (ATSR). Penetration center fix measured a central pressure of $936 \mathrm{mb}$ and estimated surface winds of $140 \mathrm{kt}$ at $27.0 \mathrm{~N}$, $68.8 \mathrm{~W}$ at $13 \mathrm{Z}$ (ATSR/WALLET). Penetration center fix measured a central pressure of $946 \mathrm{mb}$ and estimated an eye diameter of $40 \mathrm{~nm}$ at $27.6 \mathrm{~N}, 69.4 \mathrm{~W}$ at $16 \mathrm{Z}$ (ATSR/WALLET). Penetration center fix measured a central pressure of $943 \mathrm{mb}$ at $28.2 \mathrm{~N}, 69.8 \mathrm{~W}$ at $19 \mathrm{Z}$ (ATSR/WALLET). Penetration center fix measured a central pressure of $936 \mathrm{mb}$ at $28.7 \mathrm{~N}, 69.9 \mathrm{~W}$ at $22 \mathrm{Z}$ (ATSR).

ATSR: "The track changed to a more northwesterly direction on the morning of the 18th as Esther headed toward Cape Hatteras."

September 19:

HWM analyzes a hurricane of at most $990 \mathrm{mb}$ at $30.6 \mathrm{~N}, 71.5 \mathrm{~W}$ with a warm front far to the north at $12 \mathrm{Z}$. HURDAT lists a $125 \mathrm{kt}$ hurricane at $31.0 \mathrm{~N}, 71.9 \mathrm{~W}$ at $12 \mathrm{Z}$. Microfilm shows a closed low pressure of at most $1002 \mathrm{mb}$ at $31.0 \mathrm{~N}, 72.0 \mathrm{~W}$ at $12 \mathrm{Z}$. Ship highlights: $55 \mathrm{kt} \mathrm{E}$ and $1003 \mathrm{mb}$ at $30.0 \mathrm{~N}, 68.7 \mathrm{~W}$ at $00 \mathrm{Z}$ (COADS). $55 \mathrm{kt} \mathrm{SSE}$ and $1008 \mathrm{mb}$ at $31.4 \mathrm{~N}, 68.1 \mathrm{~W}$ at $06 \mathrm{Z}$ (COADS). $50 \mathrm{kt} \mathrm{SE}$ and $1010 \mathrm{mb}$ at $31.3 \mathrm{~N}, 67.6 \mathrm{~W}$ at $12 \mathrm{Z}$ (COADS). $40 \mathrm{kt} \mathrm{NNE}$ and $1008 \mathrm{mb}$ at $33.2 \mathrm{~N}, 74.7 \mathrm{~W}$ at $15 \mathrm{Z}$ (micro). $55 \mathrm{kt} \mathrm{NW}$ at $30.9 \mathrm{~N}$, $74.7 \mathrm{~W}$ at $18 \mathrm{Z}$ (micro). Aircraft highlights: Penetration center fix measured a central pressure of $950 \mathrm{mb}$ and estimated an eye diameter of $25 \mathrm{~nm}$ at $29.4 \mathrm{~N}, 70.4 \mathrm{~W}$ at $01 \mathrm{Z}$ (ATSR). Penetration center fix measured a central pressure of $943 \mathrm{mb}$ at $29.8 \mathrm{~N}, 71.1 \mathrm{~W}$ at 0430Z (ATSR). Penetration center fix measured a central pressure of $948 \mathrm{mb}$ at $30.0 \mathrm{~N}$, $71.4 \mathrm{~W}$ at $07 \mathrm{Z}$ (ATSR). Penetration center fix measured a central pressure of $940 \mathrm{mb}$ and estimated an eye diameter of $35 \mathrm{~nm}$ at $30.4 \mathrm{~N}, 71.8 \mathrm{~W}$ at $1030 \mathrm{Z}$ (WALLET). Penetration center fix measured a central pressure of $943 \mathrm{mb}$, estimated flight level winds of $105 \mathrm{kt}$ and an eye diameter of $35 \mathrm{~nm}$ at $30.8 \mathrm{~N}, 71.9 \mathrm{~W}$ at $13 \mathrm{Z}$ (WALLET). Penetration center fix measured a central pressure of $949 \mathrm{mb}$ and estimated surface winds of $100 \mathrm{kt}$ at $31.4 \mathrm{~N}$, $72.3 \mathrm{~W}$ at $1545 \mathrm{Z}$ (ATSR). Penetration center fix measured a central pressure of 951 at $32.0 \mathrm{~N}, 72.7 \mathrm{~W}$ at $19 \mathrm{Z}$ (WALLET). Penetration center fix measured a central pressure of $945 \mathrm{mb}$, estimated flight level winds of $95 \mathrm{kt}$ and an eye diameter of $35 \mathrm{~nm}$ at $32.5 \mathrm{~N}$, $72.9 \mathrm{~W}$ at $2155 \mathrm{Z}$ (WALLET).

September 20:

HWM analyzes a hurricane of at most $990 \mathrm{mb}$ at $35.0 \mathrm{~N}, 73.2 \mathrm{~W}$ with a weakening warm front to the north at $12 \mathrm{Z}$. HURDAT lists a $120 \mathrm{kt}$ hurricane at $35.0 \mathrm{~N}, 73.3 \mathrm{~W}$ at $12 \mathrm{Z}$. Microfilm shows a closed low pressure of at most $999 \mathrm{mb}$ at $35.0 \mathrm{~N}, 73.2 \mathrm{~W}$ at $12 \mathrm{Z}$. Ship 
highlights: $55 \mathrm{kt} \mathrm{NNE}$ and $1004 \mathrm{mb}$ at $34.0 \mathrm{~N}, 75.4 \mathrm{~W}$ at $00 \mathrm{Z}$ (COADS). $55 \mathrm{kt} \mathrm{NW}$ and $1004 \mathrm{mb}$ at $31.5 \mathrm{~N}, 74.5 \mathrm{~W}$ at $03 \mathrm{Z}$ (micro). $45 \mathrm{kt} \mathrm{SE}$ and $1007 \mathrm{mb}$ at $35.0 \mathrm{~N}, 70.0 \mathrm{~W}$ at $06 \mathrm{Z}$ (COADS). $45 \mathrm{kt} \mathrm{WNW}$ and $1005 \mathrm{mb}$ at $31.8 \mathrm{~N}, 74.3 \mathrm{~W}$ at $09 \mathrm{Z}$ (micro). $70 \mathrm{kt} \mathrm{SE}$ at $36.4 \mathrm{~N}$, $70.1 \mathrm{~W}$ at $12 \mathrm{Z}$ (micro). $45 \mathrm{kt} \mathrm{S}$ and $1003 \mathrm{mb}$ at $33.9 \mathrm{~N}, 70.2 \mathrm{~W}$ at $15 \mathrm{Z}$ (micro). $70 \mathrm{kt} \mathrm{ESE}$ and $1006 \mathrm{mb}$ at $36.5 \mathrm{~N}, 69.1 \mathrm{~W}$ at $18 \mathrm{Z}$ (micro). $40 \mathrm{kt} \mathrm{NNW}$ and $1006 \mathrm{mb}$ at $37.5 \mathrm{~N}, 76.1 \mathrm{~W}$ at 21Z (COADS). Land highlights: $37 \mathrm{kt} \mathrm{NNE}$ and $1011 \mathrm{mb}$ at Frying Pan Shoals, NC at 00Z (SWO). $28 \mathrm{kt} \mathrm{N}$ (31 kt peak) and $999 \mathrm{mb}$ at Cape Hatteras, NC at 0955Z (SWO/CLIMO). $40 \mathrm{kt} \mathrm{N}$ and $1001 \mathrm{mb}$ at Diamond Shoals, NC at 06Z (micro). $25 \mathrm{kt} \mathrm{NW}$ and $1003 \mathrm{mb}$ at $35.2 \mathrm{~N}, 75.3 \mathrm{~W}$ at Diamond Shoals, NC at $18 \mathrm{Z}$ (micro). Aircraft highlights: Penetration center fix measured a central pressure of $952 \mathrm{mb}$, estimated flight level winds of $95 \mathrm{kt}$ and an eye diameter of $25-35 \mathrm{~nm}$ at $33.2 \mathrm{~N}, 73.1 \mathrm{~W}$ at $01 \mathrm{Z}$ (ATSR). Penetration center fix measured a central pressure of $957 \mathrm{mb}$ at $33.7 \mathrm{~N}, 73.2 \mathrm{~W}$ at $04 \mathrm{Z}$ (ATSR). Penetration center fix measured a central pressure of $956 \mathrm{mb}$ at $33.9 \mathrm{~N}, 73.2 \mathrm{~W}$ at $07 Z$ (ATSR). Penetration center fix measured a central pressure of $948 \mathrm{mb}$, estimated flight level winds of $115 \mathrm{kt}$ and an eye diameter of $32 \mathrm{~nm}$ at $35.1 \mathrm{~N}, 73.3 \mathrm{~W}$ at $1215 \mathrm{Z}$ (ATSR). Penetration center fix measured a central pressure of $953 \mathrm{mb}$ and estimated an eye diameter of $25-40 \mathrm{~nm}$ at $35.9 \mathrm{~N}, 72.9 \mathrm{~W}$ at $1544 \mathrm{Z}$ (WALLET). Radar center fix at $36.8 \mathrm{~N}, 72.8 \mathrm{~W}$ at $1845 \mathrm{Z}$ (ATSR). Penetration center fix estimated surface winds of at least $65 \mathrm{kt}$ at $37.7 \mathrm{~N}, 72.3 \mathrm{~W}$ at $23 \mathrm{Z}$ (ATSR).

MWR: "A gradual curving to the north and subsequently to the north-northeast took the center about 120 miles to the east of Cape Hatteras on the morning of the 20th." ATSR: "After $1000 \mathrm{Z}$ on the 20th, when the center was approximately 130 miles east-southeast of Cape Hatteras, the hurricane began to recurve to the north-northeast. The track was nearly parallel to the east coast of the United States for the next 24 hours."

September 21:

HWM analyzes a hurricane of at most $990 \mathrm{mb}$ at $40.0 \mathrm{~N}, 71.2 \mathrm{~W}$ at 12Z. HURDAT lists a $110 \mathrm{kt}$ hurricane at $40.4 \mathrm{~N}, 71.1 \mathrm{~W}$ at $12 \mathrm{Z}$. Microfilm shows a closed low pressure of at most $996 \mathrm{mb}$ at $40.5 \mathrm{~N}, 71.2 \mathrm{~W}$ at 12Z. Ship highlights: $65 \mathrm{kt} \mathrm{NE}$ and $991 \mathrm{mb}$ at $38.9 \mathrm{~N}$, $73.2 \mathrm{~W}$ at $00 \mathrm{Z}$ (COADS). $45 \mathrm{kt} \mathrm{SW}$ and $1004 \mathrm{mb}$ at $36.0 \mathrm{~N}, 70.1 \mathrm{~W}$ at $03 \mathrm{Z}$ (micro). $70 \mathrm{kt}$ $\mathrm{NW}$ and $998 \mathrm{mb}$ at $38.0 \mathrm{~N}, 73.8 \mathrm{~W}$ at $06 \mathrm{Z}$ (COADS). $55 \mathrm{kt} \mathrm{W}$ and $1003 \mathrm{mb}$ at $38.1 \mathrm{~N}$, $72.4 \mathrm{~W}$ at $12 \mathrm{Z}$ (COADS). $60 \mathrm{kt} \mathrm{NW}$ and $992 \mathrm{mb}$ at $40.5 \mathrm{~N}, 72.1 \mathrm{~W}$ at $18 \mathrm{Z}$ (COADS). Land highlights: $988 \mathrm{mb}$ at Block Island, RI (time unknown) (CLIMO). $40 \mathrm{kt} \mathrm{NW}$ (gusts to 51 $\mathrm{kt}$ ) and $1001 \mathrm{mb}$ at Atlantic City, NJ at 0756Z (SWO). $41 \mathrm{kt} \mathrm{NNE} \mathrm{(gusts} \mathrm{to} 55 \mathrm{kt}$ ) and $998 \mathrm{mb}$ at $0958 \mathrm{Z}$ (SWO). $41 \mathrm{kt} \mathrm{NNE} \mathrm{(gusts} \mathrm{to} 72 \mathrm{kt}$ ) at Block Island, RI at 10Z (SWO). $42 \mathrm{kt} \mathrm{NE}$ and $991 \mathrm{mb}$ at Block Island, RI at 12Z (SWO). $48 \mathrm{kt} \mathrm{N}$ (gusts to $60 \mathrm{kt}$ ) at Calverton, NY at 13Z (SWO). $50 \mathrm{kt} \mathrm{N}$ (gusts to $63 \mathrm{kt}$ ) at Calverton, NY at 15Z (SWO). $33 \mathrm{kt} \mathrm{NNE}$ and $989 \mathrm{mb}$ at Block Island, RI at 18Z (SWO). Aircraft highlights: 
Penetration center fix measured a central pressure of $962 \mathrm{mb}$ at 37.9N, $72.4 \mathrm{~W}$ at $01 \mathrm{Z}$ (ATSR). Penetration center fix measured a central pressure of $968 \mathrm{mb}$ at $38.4 \mathrm{~N}, 72.2 \mathrm{~W}$ at $0355 Z$ (ATSR). Penetration center fix measured a central pressure of $970 \mathrm{mb}$ at $40.0 \mathrm{~N}$, $71.9 \mathrm{~W}$ at $1030 \mathrm{Z}$ (ATSR). Penetration center fix measured a central pressure of $974 \mathrm{mb}$ at $40.2 \mathrm{~N}, 71.6 \mathrm{~W}$ at $13 \mathrm{Z}$ (ATSR). Radar center fix at $40.8 \mathrm{~N}, 71.3 \mathrm{~W}$ at $19 \mathrm{Z}$ (ATSR).

MWR: “. ...and to about 35 miles south-southeast of Block Island, RI, 24 hours later. Gales swept the coastal strip from the Outer Banks of North Carolina to New Jersey and, early on September 21, winds reached hurricane force from eastern Long Island to Block Island. Gusts hit $40 \mathrm{kt}$ at Ocean City, MD, and $60 \mathrm{kt}$ at Atlantic City, NJ. Montauk Point, $\mathrm{RI}$, and Block Island, which were nearer the storm center, reported peak gusts of $94 \mathrm{kt}$ and $72 \mathrm{kt}$, respectively, at 0500 EST on the 21st Cape Cod also experienced hurricane force gusts. Fortunately for New England, Esther weakened markedly in passing over colder waters north of $35^{\circ} \mathrm{N}$, and also took a sharp eastward turn on the afternoon of September 21. This turn was the beginning of a large clockwise loop which carried the center southward almost to the latitude of Cape Hatteras then back to intersect the original path near Nantucket Island four days later." ATSR: "As Esther deceased in intensity the track changed to the east on the morning of the 21 st and eventually completed a large clockwise loop."

September 22:

HWM analyzes a tropical storm of at most $995 \mathrm{mb}$ at $40.2 \mathrm{~N}, 67.2 \mathrm{~W}$ with a weakening stationary front far to the northwest and a warm front far to the east at 12Z. HURDAT lists a $45 \mathrm{kt}$ tropical storm at $40.8 \mathrm{~N}, 67.9 \mathrm{~W}$ at $12 \mathrm{Z}$. Microfilm shows a closed low pressure of at most $996 \mathrm{mb}$ at 39.8.N, 67.0W at 12Z. Ship highlights: $50 \mathrm{kt} \mathrm{W}$ and 991 $\mathrm{mb}$ at $39.6 \mathrm{~N}, 71.1 \mathrm{~W}$ at $00 \mathrm{Z}$ (COADS). $70 \mathrm{kt} \mathrm{WSW}$ and $993 \mathrm{mb}$ at $39.5 \mathrm{~N}, 69.0 \mathrm{~W}$ at $06 \mathrm{Z}$ (COADS). $40 \mathrm{kt} \mathrm{W}$ and $1002 \mathrm{mb}$ at $38.8 \mathrm{~N}, 68.2 \mathrm{~W}$ at $12 \mathrm{Z}$ (COADS). $20 \mathrm{kt}$ SE and 991 $\mathrm{mb}$ at $39.6 \mathrm{~N}, 67.3 \mathrm{~W}$ at $12 \mathrm{Z}$ (COADS). $50 \mathrm{kt} \mathrm{NNW}$ and $1001 \mathrm{mb}$ at $39.2 \mathrm{~N}, 68.5 \mathrm{~W}$ at $18 \mathrm{Z}$ (COADS). Land highlights: $8 \mathrm{kt} \mathrm{N}$ and $995 \mathrm{mb}$ at Nantucket Light, MA at 00Z (SWO). 8 kt $\mathrm{N}$ and $997 \mathrm{mb}$ at Nantucket Light, MA at 06Z (SWO).

MWR: "The storm was producing only 35- to 45-kt squalls on the 22nd, but showed some regeneration over the warmer waters at the southernmost part of the loop and when it moved northward again passed Cape Cod maximum winds where 50 to 60 knots."

September 23:

HWM analyzes a tropical storm of at most $1000 \mathrm{mb}$ at $38.4 \mathrm{~N}, 64.7 \mathrm{~W}$ with a cold front far to the northwest and weakening warm front to the northeast at 12Z. HURDAT lists a 60 $\mathrm{kt}$ tropical storm at $37.9 \mathrm{~N}, 64.9 \mathrm{~W}$ at $12 \mathrm{Z}$. Microfilm shows a closed low pressure of at most $993 \mathrm{mb}$ at $37.0 \mathrm{~N}, 65.5 \mathrm{~W}$ at 12Z. Ship highlights: $993 \mathrm{mb}$ at $38.3 \mathrm{~N}, 65.1 \mathrm{~W}$ at $00 \mathrm{Z}$ 
(COADS). $35 \mathrm{kt} \mathrm{W}$ and $998 \mathrm{mb}$ at $36.1 \mathrm{~N}, 66.3 \mathrm{~W}$ at $00 \mathrm{Z}$ (COADS). $45 \mathrm{kt} \mathrm{N}$ and $1005 \mathrm{mb}$ at $39.5 \mathrm{~N}, 67.3 \mathrm{~W}$ at $06 \mathrm{Z}$ (COADS). $45 \mathrm{kt} \mathrm{NW}$ and $1014 \mathrm{mb}$ at $30.6 \mathrm{~N}, 70.0 \mathrm{~W}$ at $12 \mathrm{Z}$ (COADS). $40 \mathrm{kt} \mathrm{NNW}$ and $1005 \mathrm{mb}$ at $36.0 \mathrm{~N}, 69.6 \mathrm{~W}$ at $18 \mathrm{Z}$ (micro).

September 24:

HWM analyzes a tropical storm of at most $1005 \mathrm{mb}$ at $35.3 \mathrm{~N}, 67.7 \mathrm{~W}$ with a cold front to the north at $12 \mathrm{Z}$. HURDAT lists a $50 \mathrm{kt}$ tropical storm at $35.7 \mathrm{~N}, 67.4 \mathrm{~W}$ at $12 \mathrm{Z}$. Microfilm shows a closed low pressure of at most $1008 \mathrm{mb}$ at $35.0 \mathrm{~N}, 68.0 \mathrm{~W}$ with a frontal boundary to the northwest at 12Z. Ship highlights: $20 \mathrm{kt} \mathrm{NNE}$ and $997 \mathrm{mb}$ at $36.2 \mathrm{~N}, 66.8 \mathrm{~W}$ at $00 \mathrm{Z}$ (COADS). $35 \mathrm{kt} \mathrm{NW}$ and $1005 \mathrm{mb}$ at $35.6 \mathrm{~N}, 68.7 \mathrm{~W}$ at $00 \mathrm{Z}$ (COADS). $40 \mathrm{kt} \mathrm{NE}$ and $1013 \mathrm{mb}$ at 39.0N, 69.0W at 06Z (COADS). $40 \mathrm{kt} \mathrm{E}$ and 1013 $\mathrm{mb}$ at $39.1 \mathrm{~N}, 67.7 \mathrm{~W}$ at $12 \mathrm{Z}$ (COADS). $50 \mathrm{kt} \mathrm{W}$ and $1009 \mathrm{mb}$ at $35.3 \mathrm{~N}, 65.8 \mathrm{~W}$ at $18 \mathrm{Z}$ (COADS).

September 25:

HWM analyzes a tropical storm of at most $1000 \mathrm{mb}$ at $37.7 \mathrm{~N}, 70.3 \mathrm{~W}$ with a frontal boundary to the north at $12 \mathrm{Z}$. HURDAT lists a $45 \mathrm{kt}$ tropical storm at $38.1 \mathrm{~N}, 70.5 \mathrm{~W}$ at 12Z. Microfilm shows a closed low pressure of at most $999 \mathrm{mb}$ at $38.0 \mathrm{~N}, 70.5 \mathrm{~W}$ at $12 \mathrm{Z}$. Ship highlights: $20 \mathrm{kt} \mathrm{S}$ and $995 \mathrm{mb}$ at 36.1N, 68.6W at 00Z (COADS). $40 \mathrm{kt} \mathrm{NE}$ and 998 $\mathrm{mb}$ at $37.3 \mathrm{~N}, 70.2 \mathrm{~W}$ at $00 \mathrm{Z}$ (COADS). $50 \mathrm{kt} \mathrm{SE}$ and $994 \mathrm{mb}$ at $37.2 \mathrm{~N}, 69.9 \mathrm{~W}$ at $06 \mathrm{Z}$ (COADS). $30 \mathrm{kt} \mathrm{NW}$ and $990 \mathrm{mb}$ at 37.9N, 71.3W at 12Z (COADS). $50 \mathrm{kt} \mathrm{SSE}$ and 1000 $\mathrm{mb}$ at $37.9 \mathrm{~N}, 70.0 \mathrm{~W}$ at $12 \mathrm{Z}$ (micro). $45 \mathrm{kt} \mathrm{E}$ and $999 \mathrm{mb}$ at $39.5 \mathrm{~N}, 71.2 \mathrm{~W}$ at $18 \mathrm{Z}$ (COADS). $25 \mathrm{kt} \mathrm{WSW}$ and $993 \mathrm{mb}$ at $38.0 \mathrm{~N}, 71.1 \mathrm{~W}$ at $18 \mathrm{Z}$ (micro).

September 26:

HWM analyzes a closed low pressure of at most $1005 \mathrm{mb}$ at $44.2 \mathrm{~N}, 70.5 \mathrm{~W}$ in the warm sector of an extratropical cyclone of at most $1005 \mathrm{mb}$ at $45.0 \mathrm{~N}, 79.5 \mathrm{~W}$ at $12 \mathrm{Z}$. HURDAT lists a $30 \mathrm{kt}$ tropical storm at $44.7 \mathrm{~N}, 69.8 \mathrm{~W}$ at $12 \mathrm{Z}$. Microfilm shows a closed low pressure of at most $1002 \mathrm{mb}$ at $44.7 \mathrm{~N}, 70.3 \mathrm{~W}$ with an extratropical cyclone to the west at 12Z. Ship highlights: $40 \mathrm{kt} \mathrm{S}$ and $997 \mathrm{mb}$ at 39.2N, 70.0W at 00Z (COADS). $20 \mathrm{kt} \mathrm{SW}$ and $997 \mathrm{mb}$ at $39.0 \mathrm{~N}, 70.0 \mathrm{~W}$ at $00 \mathrm{Z}$ (COADS). $40 \mathrm{kt} \mathrm{SW}$ and $1008 \mathrm{mb}$ at $39.5 \mathrm{~N}, 68.5 \mathrm{~W}$ at $06 \mathrm{Z}$ (COADS). $55 \mathrm{kt} \mathrm{SW}$ and $1013 \mathrm{mb}$ at $41.0 \mathrm{~N}, 66.5 \mathrm{~W}$ at $12 \mathrm{Z}$ (COADS). $35 \mathrm{kt} \mathrm{SW}$ and $1018 \mathrm{mb}$ at $40.9 \mathrm{~N}, 65.4 \mathrm{~W}$ at 18Z (COADS). Land highlights: $40 \mathrm{kt} \mathrm{SSE}$ and 1002 $\mathrm{mb}$ at Nantucket Light, MA at 00Z (SWO). $55 \mathrm{kt} \mathrm{SSW}$ and $999 \mathrm{mb}$ at Nantucket Light, MA at 06Z (SWO). $4 \mathrm{kt} \mathrm{NE}$ and $1004 \mathrm{mb}$ at Augusta, ME at 1158Z (SWO). $8 \mathrm{kt} \mathrm{SSW}$ and $1002 \mathrm{mb}$ at Loring AFB, ME at $2055 \mathrm{Z}$ (SWO).

MWR: "The storm accelerated northward through Maine on the 26th, gradually weakened, and turned northeastward toward Labrador as a frontal disturbance. No deaths 
have been attributed to Esther. Property damage totaled 5,000,000 to 10,000,000 dollars." ATSR: "The storm became extratropical over Maine on the 26th. The Joint Hurricane Warning Center promulgated a total of 40 warnings on Esther during the period 12-21 September. In addition to aircraft reconnaissance, land-based radars located at Hatteras, Wilmington, Norfolk, Wallops Island, New York City, and Nantucket participated in the tracking of the hurricane from a position approximately 200 miles to the southeast of Cape Hatteras until the start of the loop. Gale force winds, rain and storm surge caused considerable damage along the eastern seaboard from the Virginia Capes to Nantucket Island. Storm surges ranged up to 5 feet above normal in some areas. Esther was the subject of a large scale cloud seeding experiment which was conducted jointly by the Navy, Weather Bureau and Air Force."

September 27:

HWM analyzes an extratropical cyclone of at most $1000 \mathrm{mb}$ at $53.0 \mathrm{~N}, 57.0 \mathrm{~W}$ at $12 \mathrm{Z}$. HURDAT lists a $30 \mathrm{kt}$ extratropical depression at $50.0 \mathrm{~N}, 67.0 \mathrm{~W}$ at $12 \mathrm{Z}$. Microfilm shows an extratropical cyclone of at most $1005 \mathrm{mb}$ at $52.0 \mathrm{~N}, 57.0 \mathrm{~W}$ at 12Z. Ship highlights: No gales or low pressures. Land highlights: $5 \mathrm{kt} \mathrm{SSE}$ and $1004 \mathrm{mb}$ at Sainte Angele de Merici, Canada at $00 \mathrm{Z}$ (micro).

Hurricane Esther developed from a tropical wave that left the African coast around September 8th. The strong disturbance rapidly became better organized and based on a TIROS III satellite image on September 10th at 1912Z (MWR 1962, pg. 111), the system is upgraded to a tropical storm at $12 \mathrm{Z}$ on the 10th, 24 hours earlier than originally shown in HURDAT. Genesis likely occurred on September 9th or early on the 10th, but the synoptic data is sparse over the eastern Atlantic. Minor track changes are analyzed during the lifetime of Esther. The first position in HURDAT was at $18 \mathrm{Z}$ on the 10th as a $25 \mathrm{kt}$ tropical depression. The satellite image clearly indicates that the tropical cyclone had attained tropical storm intensity at this time and even our analysis of $35 \mathrm{kt}$ may be conservative. The tropical storm initially moved northwestward under the influence of a mid-upper level trough which had steered Debbie to the north over the central Atlantic. By September 13th, an anticyclone was strengthening north of Esther causing the tropical cyclone to turn to the west-northwest while moving at a steady pace of about $12 \mathrm{kt}$. Conducive environmental conditions allowed the tropical storm to intensify and Esther is analyzed to have become a hurricane at $06 \mathrm{Z}$ on September 12th, same as originally shown in HURDAT. A central pressure of $975 \mathrm{mb}$ was present in HURDAT at $12 \mathrm{Z}$ on the 12th and has been retained as it appears reasonable, although it seems to have been added in and not based on actual observations. The first reconnaissance hurricane reached the hurricane at $2010 \mathrm{Z}$ on the 12 th measuring a central pressure of $967 \mathrm{mb}$, estimating surface winds of $110 \mathrm{kt}$ and an eye diameter of $40 \mathrm{~nm}$. A central pressure of $967 \mathrm{mb}$ 
suggests maximum sustained winds of $93 \mathrm{kt}$ south of $25 \mathrm{~N}$ Brown et al. pressure-wind relationship and $95 \mathrm{kt}$ intensifying from the pressure-wind relationship. An eye diameter of $40 \mathrm{~nm}$ suggests an RMW of $30 \mathrm{~nm}$ and climatology indicates $14 \mathrm{~nm}$. Based on a forward speed of $13 \mathrm{kt}$ and an RMW larger than climatology, an intensity of $90 \mathrm{kt}$ is selected for $18 \mathrm{Z}$ on the 12 th, up from $70 \mathrm{kt}$ originally shown in HURDAT, a major intensity change. (Central pressures values for almost every 6 hour period were present in the original HURDAT between September 12th at 12Z and September 26th at 12Z. Some of these were obviously analyses that were added in, not based upon actual observations. Thus, based on proceeding and subsequent actual observations, some were retained, others removed and new central pressure values added. Detailed information on these changes can be found in the table at the end.)

A ship at $00 \mathrm{Z}$ on September 13th reported $80 \mathrm{kt} \mathrm{WNW}$ and $978 \mathrm{mb}$. Reconnaissance aircraft on the 13th indicated that Esther had stopped intensifying as the central pressure remained steady near $970 \mathrm{mb}$. A penetration fix at $09 \mathrm{Z}$ on the 12 th measured a central pressure of $969 \mathrm{mb}$, estimated surface winds of $100 \mathrm{kt}$ and an eye diameter of $40 \mathrm{~nm}$. A central pressure of $969 \mathrm{mb}$ suggests maximum sustained winds of $91 \mathrm{kt}$ south of $25 \mathrm{~N}$ from the pressure-wind relationship. An eye diameter of $40 \mathrm{~nm}$ suggests an RMW of 30 $\mathrm{nm}$ and climatology indicates $15 \mathrm{~nm}$. Based on a forward speed of $12 \mathrm{kt}$, an RMW larger than climatology but lightly weighing in the surface wind estimate, an intensity of $90 \mathrm{kt}$ is selected for $06 Z$ on the 13th, same as originally shown in HURDAT. On September 14th, the synoptic observations become sparse as ships avoided the hurricane. A reconnaissance aircraft measured a central pressure of $962 \mathrm{mb}$ at $07 \mathrm{Z}$. A central pressure of $962 \mathrm{mb}$ suggests maximum sustained winds of $99 \mathrm{kt}$ south of $25 \mathrm{~N}$ and $100 \mathrm{kt}$ intensifying from the pressure-wind relationship. An eye diameter of $40 \mathrm{~nm}$ suggests an RMW of $30 \mathrm{~nm}$ and climatology indicates $15 \mathrm{~nm}$. Based on a forward speed of $10 \mathrm{kt}$ and an RMW larger than climatology, an intensity of $95 \mathrm{kt}$ is selected for $06 \mathrm{Z}$ on the 14th, down from $110 \mathrm{kt}$ originally shown in HURDAT, a minor intensity change. Another penetration fix at $2017 \mathrm{Z}$ on the 14th measured a central pressure of $965 \mathrm{mb}$ suggesting maximum sustained winds of $96 \mathrm{kt}$ south of $25 \mathrm{~N}$ from the pressure-wind estimate. An intensity of $90 \mathrm{kt}$ is selected for $18 \mathrm{Z}$ on the $14 \mathrm{th}$, down from $110 \mathrm{kt}$ originally in HURDAT, a major intensity change. On September 15th, the intensity of Esther remained generally steady according to the reports from the reconnaissance aircrafts. Ships continued to avoid getting too close to the hurricane and remained in the periphery. A penetration fix measured a central pressure of $966 \mathrm{mb}$, estimated surface winds of 100 $\mathrm{kt}$ and an eye diameter of $30 \mathrm{~nm}$ at $13 \mathrm{Z}$ on the $15 \mathrm{th}$. A central pressure of $966 \mathrm{mb}$ suggests maximum sustained winds of $94 \mathrm{kt}$ south of $25 \mathrm{~N}$ from the pressure-wind relationship. An eye diameter of $30 \mathrm{~nm}$ suggests an RMW of $23 \mathrm{~nm}$ and climatology indicates $15 \mathrm{~nm}$. Based on a forward speed of $13 \mathrm{kt}$ and an RMW larger than climatology, an intensity of $90 \mathrm{kt}$ is selected for $12 \mathrm{Z}$ on the $15 \mathrm{th}$, down from $110 \mathrm{kt}$ originally in 
HURDAT, a major intensity change. A central pressure of $961 \mathrm{mb}$ was in HURDAT at $18 \mathrm{Z}$ on the 15 th. This value appears reasonable with aircraft reconnaissance reports and has been retained. A central pressure of $961 \mathrm{mb}$ suggests maximum sustained winds of $101 \mathrm{kt}$ intensifying south of $25 \mathrm{~N}$ from the pressure-wind relationship. Based on a forward speed of $14 \mathrm{kt}$, an intensity of $95 \mathrm{kt}$ is selected for $18 \mathrm{Z}$ on the $15 \mathrm{th}$, down from $110 \mathrm{kt}$ originally in HURDAT, a minor intensity change.

On September 16th, Esther began to intensify rapidly as the central pressure decreased and eye diameter contracted. A reconnaissance aircraft measured a central pressure of $960 \mathrm{mb}$ and an eye diameter of $30 \mathrm{~nm}$ at $01 \mathrm{Z}$ on the 16th. A central pressure of $960 \mathrm{mb}$ suggests maximum sustained winds of $101 \mathrm{kt}$ south of $25 \mathrm{~N}$ from the pressure-wind relationship. An eye diameter of $30 \mathrm{~nm}$ suggests an RMW of $23 \mathrm{~nm}$ and climatology indicates $15 \mathrm{~nm}$. Based on a forward speed of $15 \mathrm{kt}$ and an RMW larger than climatology, an intensity of $95 \mathrm{kt}$ is selected for $00 \mathrm{Z}$ on the 16th, down from $110 \mathrm{kt}$ originally in HURDAT, a minor intensity change. A central pressure of $956 \mathrm{mb}$ was present in HURDAT at $06 Z$ on the 16 th and appears reasonable, thus it has been retained. A central pressure of $956 \mathrm{mb}$ suggests maximum sustained winds of $105 \mathrm{kt}$ south of $25 \mathrm{~N}$ from the pressure-wind relationship. An intensity of $105 \mathrm{kt}$ is selected at $06 \mathrm{Z}$ on the $16 \mathrm{th}$, same as originally shown in HURDAT. Intensification to a major hurricane is analyzed at $06 \mathrm{Z}$ on the 16th, 66 hours later than originally shown in HURDAT. Another penetration fix measured a central pressure of $948 \mathrm{mb}$, estimated surface winds of $120 \mathrm{kt}$ and an eye diameter of $20 \mathrm{~nm}$ at $1255 \mathrm{Z}$ on the 16th. A central pressure of $948 \mathrm{mb}$ suggests maximum sustained winds of $115 \mathrm{kt}$ intensifying south of $25 \mathrm{~N}$ from the pressure-wind relationship. An eye diameter of $20 \mathrm{~nm}$ suggests an RMW of $15 \mathrm{~nm}$, same as climatology. Based on a forward speed of $14 \mathrm{kt}$ and an RMW same as climatology, an intensity of $115 \mathrm{kt}$ is selected for $12 \mathrm{Z}$ on the $16 \mathrm{th}$, up from $105 \mathrm{kt}$ originally in HURDAT, a minor intensity change. A penetration fix around $18 \mathrm{Z}$ on the 16 th measured a central pressure of $935 \mathrm{mb}$, estimated surface winds of $128 \mathrm{kt}$ and an RMW of $13 \mathrm{~nm}$. A central pressure of $935 \mathrm{mb}$ suggests maximum sustained winds of $128 \mathrm{kt}$ intensifying south of $25 \mathrm{~N}$ from the pressure-wind relationship. Climatology indicates an RMW of 14 $\mathrm{nm}$. Based on a forward speed of $13 \mathrm{kt}$ and an RMW close to climatology, an intensity of $130 \mathrm{kt}$ is selected for $18 \mathrm{Z}$ on the 16th, up from $105 \mathrm{kt}$ originally in HURDAT, a major intensity change.

On September 17th, Esther was a powerful hurricane between Puerto Rico and Bermuda. An approaching trough caused the ridge to the north to weaken allowing the hurricane to take more northwestward track. Central pressures of $939 \mathrm{mb}$ and $934 \mathrm{mb}$ were present in HURDAT at $00 Z$ and $06 Z$ on the 17 th. Both values appear reasonable and have been retained. A penetration fix at $1313 \mathrm{Z}$ on the 17 th measured a central pressure of $928 \mathrm{mb}$, estimated surface winds of $80 \mathrm{kt}$ and an eye diameter of $18 \mathrm{~nm}$. An eye diameter of 18 
$\mathrm{nm}$ suggests an RMW of $14 \mathrm{~nm}$ and climatology indicates $15 \mathrm{~nm}$. A central pressure of $928 \mathrm{mb}$ suggests maximum sustained winds of $134 \mathrm{kt}$ intensifying south of $25 \mathrm{~N}$ and 131 $\mathrm{kt}$ intensifying north of $25 \mathrm{~N}$ from the pressure-wind relationship. Based on a forward speed of $11 \mathrm{kt}$ and an RMW close to climatology, an intensity of $135 \mathrm{kt}$ is selected for $12 \mathrm{Z}$ on the $17 \mathrm{th}$, up from $110 \mathrm{kt}$ originally in HURDAT, a major intensity change. $135 \mathrm{kt}$ is the peak intensity of Hurricane Esther, up from $125 \mathrm{kt}$ originally in HURDAT from $12 \mathrm{Z}$ on the 18 th to $18 \mathrm{Z}$ on the 19th. A relative minimum of $125 \mathrm{kt}$ is assessed at $00 \mathrm{Z}$ on the 17 th consistent with the likely estimated central pressure. Another penetration fix at $19 \mathrm{Z}$ on the 17th measured a central pressure of $927 \mathrm{mb}$, estimated surface winds of 120 $\mathrm{kt}$ and an eye diameter of $15 \mathrm{~nm}$. An eye diameter of $15 \mathrm{~nm}$ suggests an RMW of $11 \mathrm{~nm}$ and climatology indicates $15 \mathrm{~nm}$. A central pressure of $927 \mathrm{mb}$ suggests maximum sustained winds of $133 \mathrm{kt}$ south of $25 \mathrm{~N}$ and $126 \mathrm{kt}$ north of $25 \mathrm{~N}$ from the pressure-wind relationship. Based on a forward speed of $10 \mathrm{kt}$ and an RMW smaller than climatology, an intensity of $135 \mathrm{kt}$ is selected for $18 \mathrm{Z}$ on the $17 \mathrm{th}$, up from $115 \mathrm{kt}$ originally in HURDAT, a major intensity change. On September 18th, Esther continued on a northwestward track passing between Bermuda and the Bahamas. Ships on the 18th remained in the periphery of the hurricane and the highest winds reported were $55 \mathrm{kt}$. Reconnaissance aircraft continued to routinely penetrate the center of Esther. The first penetration fix on the 18th occurred at $0130 \mathrm{Z}$ measuring a central pressure of $928 \mathrm{mb}$, estimating flight level winds of $80 \mathrm{kt}$ and an eye diameter of $16 \mathrm{~nm}$. An eye diameter of $16 \mathrm{~nm}$ suggests an RMW of $12 \mathrm{~nm}$ and climatology indicates $15 \mathrm{~nm}$. A central pressure of $928 \mathrm{mb}$ suggests maximum sustained winds of $132 \mathrm{kt}$ south of $25 \mathrm{~N}$ and $125 \mathrm{kt}$ north of $25 \mathrm{~N}$ from the pressure-wind relationship. Based on a forward speed of $10 \mathrm{kt}$ and an RMW smaller than climatology, an intensity of $135 \mathrm{kt}$ is selected for $00 \mathrm{Z}$ on the 18th, up from $120 \mathrm{kt}$ originally in HURDAT, a minor intensity change. A penetration fix at $07 \mathrm{Z}$ on the 18th measured a central pressure of $933 \mathrm{mb}$ and an eye diameter of $16 \mathrm{~nm}$. An eye diameter of $16 \mathrm{~nm}$ suggests an RMW of $12 \mathrm{~nm}$ and climatology indicates $15 \mathrm{~nm}$. A central pressure of $933 \mathrm{mb}$ suggests maximum sustained winds of $116 \mathrm{kt}$ weakening north of $25 \mathrm{~N}$ and $122 \mathrm{kt}$ weakening south of $25 \mathrm{~N}$ from the pressure-wind relationship. Based on a forward speed of $11 \mathrm{kt}$ and an RMW smaller than climatology, an intensity of $125 \mathrm{kt}$ is selected for $06 \mathrm{Z}$ on the 18th, up from $120 \mathrm{kt}$ originally in HURDAT, a minor intensity change. Another penetration fix at $13 \mathrm{Z}$ on the 18 th measured a central pressure of $936 \mathrm{mb}$ and estimated surface winds of $140 \mathrm{kt}$. A central pressure of $936 \mathrm{mb}$ suggests maximum sustained winds of $118 \mathrm{kt}$ north of $25 \mathrm{~N}$ from the pressure-wind relationship. Based on a forward speed of $14 \mathrm{kt}$, an intensity of $120 \mathrm{kt}$ is selected for $12 \mathrm{Z}$ on the 18th, down from $125 \mathrm{kt}$ originally in HURDAT, a minor intensity change. Another penetration fix at $19 \mathrm{Z}$ on the 18th measured a central pressure of $943 \mathrm{mb}$. At 16Z, a reconnaissance aircraft estimated an eye diameter of $40 \mathrm{~nm}$. A central pressure of $943 \mathrm{mb}$ suggests maximum sustained winds of $112 \mathrm{kt}$ north of $25 \mathrm{~N}$ and $107 \mathrm{kt}$ weakening from the 
pressure-wind relationship. An eye diameter of $40 \mathrm{~nm}$ suggests an RMW of $30 \mathrm{~nm}$ and climatology indicates $17 \mathrm{~nm}$. Based on a forward speed of $13 \mathrm{kt}$ and an RMW larger than climatology, an intensity of $115 \mathrm{kt}$ is selected for $18 \mathrm{Z}$ on the $18 \mathrm{th}$, down from $125 \mathrm{kt}$ originally in HURDAT, a minor intensity change. Given the rather sudden increase in size and moderate filling of the central pressure, Esther may have undergone through a concentric eyewall cycle.

On September 19th, Esther was still a major hurricane on a northwestward track toward the East Coast of the United States. A penetration fix at $22 \mathrm{Z}$ on the 18th measured a central pressure of $936 \mathrm{mb}$. A central pressure of $936 \mathrm{mb}$ suggests maximum sustained winds of $118 \mathrm{kt}$ north of $25 \mathrm{~N}$ and $124 \mathrm{kt}$ intensifying from the pressure-wind relationship. Based on a forward speed of $13 \mathrm{kt}$, an intensity of $120 \mathrm{kt}$ is selected for $00 \mathrm{Z}$ on the 19th, down from $125 \mathrm{kt}$ originally in HURDAT, a minor intensity change. Another reconnaissance aircraft at $0430 \mathrm{Z}$ on the 19th measured a central pressure of $943 \mathrm{mb}$. A central pressure of $943 \mathrm{mb}$ suggests maximum sustained winds of $112 \mathrm{kt}$ north of $25 \mathrm{~N}$ from the pressure-wind relationship. An intensity of $115 \mathrm{kt}$ is selected for $06 \mathrm{Z}$ on the 19th, down from $125 \mathrm{kt}$ originally in HURDAT, a minor intensity change. At 1030Z on the 19th, a reconnaissance aircraft measured a central pressure of $940 \mathrm{mb}$ and estimated an eye diameter of $35 \mathrm{~nm}$. A central pressure of $940 \mathrm{mb}$ suggests maximum sustained winds of $115 \mathrm{kt}$ north of $25 \mathrm{~N}$ from the pressure-wind relationship. An eye diameter of 35 $\mathrm{nm}$ suggests an RMW of $26 \mathrm{~nm}$ and climatology indicates $19 \mathrm{~nm}$. Due to a forward speed of $13 \mathrm{kt}$ and an RMW larger than climatology, an intensity of $115 \mathrm{kt}$ is selected for $12 \mathrm{Z}$ on the 19th, down from 125 kt originally in HURDAT, a minor intensity change. A penetration fix at $1545 \mathrm{Z}$ on the 19th measured a central pressure of $949 \mathrm{kt}$ and estimated surface winds of $100 \mathrm{kt}$. At $19 \mathrm{Z}$ on the 19th, a central pressure of $951 \mathrm{mb}$ was measured. A blend of these measurements gives $950 \mathrm{mb}$, which was already in HURDAT at $18 \mathrm{Z}$ and has been retained. A central pressure of $950 \mathrm{mb}$ suggests maximum sustained winds of $105 \mathrm{kt}$ north of $25 \mathrm{~N}$ from the pressure-wind relationship. An intensity of $105 \mathrm{kt}$ is selected for $18 \mathrm{Z}$ on the 19th, down from $125 \mathrm{kt}$ originally in HURDAT, a major intensity change. Early on September 20th, Esther turned to the north passing about $110 \mathrm{~nm}$ east of Cape Hatteras, North Carolina. The Schwerdt et al. parametric hurricane wind model suggests that the highest sustained winds that impacted North Carolina were $40 \mathrm{kt}$ in the Outer Banks. Surface observations show tropical force winds near the coast, especially at elevated sites, but the highest sustained winds measured at Cape Hatteras were $31 \mathrm{kt}$. Thus, North Carolina is not added to the list of states impacted by tropical storm force winds, although it is possible that somewhere along the Outer Banks winds may have reached gale-force on the 20th. Esther entered an area of heavier shipping traffic on the 21 st along the East Coast of the United States and various ships reported tropical storm force winds, there was even a ship that experienced hurricane-force winds $(70 \mathrm{kt})$ at $12 \mathrm{Z}$ and $18 \mathrm{Z}$. At $01 \mathrm{Z}$ on the $21 \mathrm{th}$, a reconnaissance aircraft measured a central pressure of 952 
$\mathrm{mb}$, estimated flight level winds of $95 \mathrm{kt}$ and an elongated eye diameter of $25-35 \mathrm{~nm}$. A central pressure of $952 \mathrm{mb}$ suggests maximum sustained winds of $103 \mathrm{kt}$ north of $25 \mathrm{~N}$ from the pressure-wind relationship. An eye diameter of 25-35 nm suggests an RMW of 19-26 nm and climatology indicates $24 \mathrm{~nm}$. Due to a forward speed of $10 \mathrm{kt}$ and an RMW close to climatology, an intensity of $105 \mathrm{kt}$ is selected for $00 \mathrm{Z}$ on the 20th, down from 120 kt originally in HURDAT, a minor intensity change. At $07 \mathrm{Z}$ on the 21 th, a reconnaissance aircraft measured a central pressure of $956 \mathrm{mb}$. A central pressure of 956 $\mathrm{mb}$ suggests maximum sustained winds of $99 \mathrm{kt}$ north of $25 \mathrm{~N}$ from the Brown et al. pressure-wind relationship and $93 \mathrm{kt}$ north of $35 \mathrm{~N}$ from the Landsea et al. pressure-wind relationship. Due to a forward speed of $11 \mathrm{kt}$, an intensity of $100 \mathrm{kt}$ is selected for $06 \mathrm{Z}$ on the 20th, down from $120 \mathrm{kt}$ originally in HURDAT, a major intensity change. A reconnaissance aircraft measured a central pressure of $948 \mathrm{mb}$, estimated flight level winds of $115 \mathrm{kt}$ and an eye diameter of $32 \mathrm{~nm}$ at $1215 \mathrm{Z}$ on the 20th. A central pressure of $948 \mathrm{mb}$ suggests maximum sustained winds of $107 \mathrm{kt}$ north of $25 \mathrm{~N}$ and $112 \mathrm{kt}$ intensifying from the Brown et al. pressure-wind relationship and $98 \mathrm{kt}$ north of $35 \mathrm{~N}$ from the Landsea et al. pressure-wind relationship. An eye diameter of $32 \mathrm{~nm}$ suggests an RMW of $24 \mathrm{~nm}$ and climatology indicates $25 \mathrm{~nm}$. Due to a forward speed of $13 \mathrm{kt}$ and an RMW close to climatology, an intensity of $105 \mathrm{kt}$ is selected for $12 \mathrm{Z}$ on the 20th, down from 120 kt originally in HURDAT, a minor intensity change. Another penetration fix measured a central pressure of $953 \mathrm{mb}$ at $1544 \mathrm{Z}$ on the 20th. A central pressure of 953 $\mathrm{mb}$ suggests maximum sustained winds of $95 \mathrm{kt}$ north of $35 \mathrm{~N}$ from the Landsea et al. pressure-wind relationship. Due to a forward speed of $16 \mathrm{kt}$, an intensity of $100 \mathrm{kt}$ is selected for $18 Z$ on the 20th, down from 120 kt originally in HURDAT, a major intensity change.

On September 21st, Esther approached the Northeast of the United States before slowing its forward speed and turning to the east. The Schwerdt et al. parametric hurricane wind model suggests that the highest sustained winds that impacted New Jersey on the 21st were $39 \mathrm{kt}$. The model also suggests that New York experienced $59 \mathrm{kt}$ winds, also $59 \mathrm{kt}$ in Rhode Island and $52 \mathrm{kt}$ in Connecticut. It is possible that higher winds could have affected the coast as the RMW used in the formula was the last available, reported at $1544 \mathrm{Z}$ on the 20 th, and by the 21 st, the RMW was likely larger. The highest sustained winds reported in New Jersey were $40 \mathrm{kt}$ measured at Atlantic City at 0756Z and Newark at $1039 \mathrm{Z}$ on the $21 \mathrm{st}$. The highest sustained winds in New York were $50 \mathrm{kt}$ at Calverton at $15 \mathrm{Z}$ on the 21 st. The highest sustained winds in Connecticut were $41 \mathrm{kt}$ at Bridgeport at $0958 \mathrm{Z}$ on the $21 \mathrm{st}$. And the highest sustained winds in Rhode Island were $42 \mathrm{kt}$ at Block Island at $12 \mathrm{Z}$ on the 21 st. Thus, New Jersey is added as a tropical storm impact with $40 \mathrm{kt}$ winds, New York and Rhode Island with $60 \mathrm{kt}$ winds, and Connecticut with 50 kt winds. The center of the hurricane passed about $30 \mathrm{~nm}$ south of Martha's Vineyard around $18 \mathrm{Z}$ on the $21 \mathrm{st}$. A reconnaissance aircraft measured a central pressure of $962 \mathrm{mb}$ 
at $01 \mathrm{Z}$ on the $21 \mathrm{th}$. A central pressure of $962 \mathrm{mb}$ suggests maximum sustained winds of $88 \mathrm{kt}$ north of $35 \mathrm{~N}$ from the pressure-wind relationship. Due to a forward speed of $15 \mathrm{kt}$, an intensity of $90 \mathrm{kt}$ is selected for $00 \mathrm{Z}$ on the $21 \mathrm{st}$, down from $115 \mathrm{kt}$ originally in HURDAT, a major intensity change. Weakening below major hurricane status is analyzed at $06 Z$ on the $21 \mathrm{st}, 24$ hours earlier than originally shown in HURDAT. Another penetration fix measured a central pressure of $968 \mathrm{mb}$ at $0355 \mathrm{Z}$ on the $21 \mathrm{th}$. A central pressure of $968 \mathrm{mb}$ suggests maximum sustained winds of $84 \mathrm{kt}$ north of $35 \mathrm{~N}$ from the pressure-wind relationship. Due to a forward speed of $15 \mathrm{kt}$, an intensity of $85 \mathrm{kt}$ is selected for $06 Z$ on the $21 \mathrm{st}$, down from $110 \mathrm{kt}$ originally in HURDAT, a major intensity change. A penetration fix at $1030 \mathrm{Z}$ on the $21 \mathrm{st}$ measured a central pressure of $970 \mathrm{kt}$. At $13 \mathrm{Z}$ on the $21 \mathrm{st}$, a central pressure of $974 \mathrm{mb}$ was measured. A blend of these measured gives $972 \mathrm{mb}$. A central pressure of $972 \mathrm{mb}$ suggests maximum sustained winds of $80 \mathrm{kt}$ north of $35 \mathrm{~N}$ from the pressure-wind relationship. Due to a forward speed of $9 \mathrm{kt}$, an intensity of $75 \mathrm{kt}$ is selected for $12 \mathrm{Z}$ on the $21 \mathrm{st}$, down from $110 \mathrm{kt}$ originally in HURDAT, a major intensity change. The last aircraft reconnaissance occurred late on the 21 st. HURDAT originally showed an unrealistic drop in intensity from $105 \mathrm{kt}$ at $18 \mathrm{Z}$ on the $21 \mathrm{st}$ to $60 \mathrm{kt}$ at $00 \mathrm{Z}$ on September $22 \mathrm{nd}$. Synoptic observations on the $22 \mathrm{nd}$ indicate that Esther moved southeastward, away from the Northeast of the United States. The hurricane continued to slowly lose strength and is analyzed to have weakened to a tropical storm at $18 \mathrm{Z}$ on the $22 \mathrm{nd}, 18$ hours later than originally shown in HURDAT. Official advisories were ended at $16 \mathrm{Z}$ on the $22 \mathrm{nd}$ by the Boston Weather Bureau citing that the cyclone was no longer tropical. Ship and coastal observations do show a slight temperature gradient across Esther but the cyclone remained symmetric and no frontal boundaries developed, indicating that the system retained its tropical characteristics. Major intensity changes are analyzed at $06 \mathrm{Z}$ and $12 \mathrm{Z}$ on the $22 \mathrm{nd}$. Intensities of $70 \mathrm{kt}$ and $65 \mathrm{kt}$ are selected, respectively, based upon a ship report of $70 \mathrm{kt}$ at 06Z, and HURDAT originally showed $50 \mathrm{kt}$ and $45 \mathrm{kt}$, respectively.

On September 23rd, Esther moved southward and southwestward toward warmer waters and the temperature gradient gradually disappeared. The intensity of the cyclone continued to decrease reaching $45 \mathrm{kt}$ at $18 \mathrm{Z}$ on the $23 \mathrm{rd}$, down from $60 \mathrm{kt}$ originally in HURDAT, a minor intensity change. Various ships reported gale-force winds, including $45 \mathrm{kt}$ at $06 \mathrm{Z}$ and 12Z. On September 24th, Esther turned to the west and northwest and began to regain strength late on the day. A ship reported $50 \mathrm{kt}$ at $18 \mathrm{Z}$ on the $24 \mathrm{th}$. On September 25th, Esther turned to the north and once again took aim at the New England coast, although much weaker than a couple of days ago. Advisories were reinitiated by the Boston Weather Bureau at $14 \mathrm{Z}$ on the 25 th announcing the approaching storm. Various ships reported tropical storm force winds, including $50 \mathrm{kt}$ at $06 \mathrm{Z}$ and $12 \mathrm{Z}$. The intensity of Esther remained at $50 \mathrm{kt}$ on the $25 \mathrm{th}, 5 \mathrm{kt}$ higher than originally shown in HURDAT, minor intensity changes. On September 26th, Esther finished a long, 
clockwise loop that began late on the 21st. The tropical storm made landfall in Martha's Vineyard at $05 \mathrm{Z}$ on the 26th with $50 \mathrm{kt}$ winds. An hour later, the center reached Cape Cod with the same intensity. Surface observations indicate that the strongest winds were located on the eastern quadrant. Cities in Massachusetts on the western quadrant did not experience tropical storm force winds based on the surface reports. The strongest winds were $55 \mathrm{kt}$, measured at Nantucket Light, MA, an elevated site of about $60 \mathrm{ft}$, at $06 \mathrm{Z}$ on the 26th. The winds reduced to $10 \mathrm{~m}$ are about $53 \mathrm{kt}$. An approaching extratropical cyclone from the west caused Esther to accelerate to the north and landfall in Maine is analyzed at $11 \mathrm{Z}$ on the $26 \mathrm{th}$ as a $35 \mathrm{kt}$ tropical storm. Over land, Esther weakened to a tropical depression at $18 \mathrm{Z}$ on the 26th, six hours later than originally shown in HURDAT. Surface observations at $00 \mathrm{Z}$ on September 27th indicate that the strong extratropical cyclone had absorbed Esther and the last position is analyzed at $18 \mathrm{Z}$ on the 26th. Thus, dissipation is analyzed 12 hours earlier than originally shown in HURDAT. Moreover, it is analyzed that Esther did not become extratropical before being absorbed, as previously shown in HURDAT.

\begin{tabular}{|c|c|c|c|}
\hline Date & $\begin{array}{l}\text { Original } \\
\text { HURDAT } \\
\text { Central } \\
\text { Pressure }\end{array}$ & Evidence & Changes \\
\hline Sep $1212 Z$ & $975 \mathrm{mb}$ & $\begin{array}{l}\text { First central pressure report was } \\
\text { later in the day but appears } \\
\text { reasonable }\end{array}$ & \multirow[t]{2}{*}{ Retained } \\
\hline Sep $1218 Z$ & $967 \mathrm{mb}$ & $\begin{array}{l}\text { Penetration center fix: } 967 \mathrm{mb} \text { at } \\
2010 \mathrm{Z} \text { on Sep } 12^{\text {th }}\end{array}$ & \\
\hline Sep $1306 Z$ & & $\begin{array}{l}\text { Penetration center fix: } 969 \mathrm{mb} \text { at } \\
\odot 9 Z \text { on Sep } 13^{\text {th }}\end{array}$ & $969 \mathrm{mb}$ \\
\hline Sep $1312 Z$ & $970 \mathrm{mb}$ & $\begin{array}{l}\text { No central pressure report but } \\
\text { appears reasonable }\end{array}$ & Retained \\
\hline Sep $1318 Z$ & $983 \mathrm{mb}$ & $\begin{array}{l}\text { No central pressure reports around } \\
18 z \text {, but central pressure reports } \\
\text { at } 09 \mathrm{z} \text { on the } 13^{\text {th }} \text { and } 07 z \text { on the } \\
14^{\text {th }} \text { suggest that it is likely } \\
\text { erroneous }\end{array}$ & Removed \\
\hline Sep $1406 Z$ & & $\begin{array}{l}\text { Penetration center fix: } 962 \mathrm{mb} \text { at } \\
07 \mathrm{Z} \text { on Sep } 14^{\text {th }}\end{array}$ & $962 \mathrm{mb}$ \\
\hline Sep $1412 Z$ & $975 \mathrm{mb}$ & $\begin{array}{l}\text { No central pressure reports around } \\
18 Z \text {, but central pressure reports } \\
\text { at } 07 Z \text { and } 2017 z \text { on the } 14^{\text {th }} \\
\text { suggest that it is likely } \\
\text { erroneous }\end{array}$ & Removed \\
\hline Sep $1418 Z$ & $966 \mathrm{mb}$ & $\begin{array}{l}\text { Penetration center fix: } 965 \mathrm{mb} \text { at } \\
2017 \mathrm{Z} \text { on Sep } 14^{\text {th }}\end{array}$ & $965 \mathrm{mb}$ \\
\hline
\end{tabular}




\begin{tabular}{|c|c|c|c|c|}
\hline Sep & $1500 z$ & $965 \mathrm{mb}$ & $\begin{array}{l}\text { No central pressure report but } \\
\text { appears reasonable }\end{array}$ & Retained \\
\hline Sep & 15062 & $965 \mathrm{mb}$ & $\begin{array}{l}\text { Penetration center fix: } 968 \mathrm{mb} \text { at } \\
07 \mathrm{Z} \text { on Sep } 15^{\text {th }}\end{array}$ & $968 \mathrm{mb}$ \\
\hline Sep & 15122 & $966 \mathrm{mb}$ & $\begin{array}{l}\text { Penetration center fix: } 966 \mathrm{mb} \text { at } \\
13 \mathrm{Z} \text { on Sep } 15^{\text {th }}\end{array}$ & \multirow{4}{*}{ Retaineo } \\
\hline Sep & 15182 & $961 \mathrm{mb}$ & $\begin{array}{l}\text { No central pressure report but } \\
\text { appears reasonable }\end{array}$ & \\
\hline Sep & $16 \odot \odot z$ & $960 \mathrm{mb}$ & $\begin{array}{l}\text { Penetration center fix: } 960 \mathrm{mb} \text { at } \\
01 \mathrm{Z} \text { on Sep } 16^{\text {th }}\end{array}$ & \\
\hline Sep & $1606 z$ & $956 \mathrm{mb}$ & $\begin{array}{l}\text { No central pressure report but } \\
\text { appears reasonable }\end{array}$ & \\
\hline Sep & 16122 & $949 \mathrm{mb}$ & $\begin{array}{l}\text { Penetration center fix: } 948 \mathrm{mb} \text { at } \\
1255 \mathrm{Z} \text { on Sep } 16^{\text {th }}\end{array}$ & $948 \mathrm{mb}$ \\
\hline Sep & 16182 & $944 \mathrm{mb}$ & $\begin{array}{l}\text { Penetration center fix: } 935 \mathrm{mb} \text { at } \\
\sim 18 \mathrm{Z} \text { on Sep } 16^{\text {th }}\end{array}$ & $935 \mathrm{mb}$ \\
\hline Sep : & $17 \odot \odot z$ & $939 \mathrm{mb}$ & \multirow{2}{*}{$\begin{array}{l}\text { No central pressure report but } \\
\text { appears reasonable }\end{array}$} & \multirow[t]{2}{*}{ Retained } \\
\hline Sep & $1706 z$ & $934 \mathrm{mb}$ & & \\
\hline Sep & $17 \quad 122$ & $930 \mathrm{mb}$ & $\begin{array}{l}\text { Penetration center fix: } 928 \mathrm{mb} \text { at } \\
1333 \mathrm{z} \text { on Sep } 17^{\text {th }}\end{array}$ & $928 \mathrm{mb}$ \\
\hline Sep & 17182 & $927 \mathrm{mb}$ & $\begin{array}{l}\text { Penetration center fixes: } 927 \mathrm{mb} \\
\text { at } 19 \mathrm{Z} \text { on Sep } 17^{\text {th }}\end{array}$ & \multirow{3}{*}{ Retaine } \\
\hline Sep & $1800 z$ & $928 \mathrm{mb}$ & $\begin{array}{l}\text { Penetration center fixes: } 928 \mathrm{mb} \\
\text { at } 0130 \mathrm{Z} \text { on Sep } 18^{\text {th }}\end{array}$ & \\
\hline Sep & $1806 z$ & $933 \mathrm{mb}$ & $\begin{array}{l}\text { Penetration center fix: } 933 \mathrm{mb} \text { at } \\
07 \mathrm{Z} \text { on Sep } 18^{\text {th }}\end{array}$ & \\
\hline Sep & 18122 & $938 \mathrm{mb}$ & $\begin{array}{l}\text { Penetration center fix: } 936 \mathrm{mb} \text { at } \\
13 Z \text { on Sep } 18^{\text {th }}\end{array}$ & $936 \mathrm{mb}$ \\
\hline Sep & 18182 & $944 \mathrm{mb}$ & $\begin{array}{l}\text { Penetration center fix: } 943 \mathrm{mb} \text { at } \\
19 \mathrm{Z} \text { on Sep } 18^{\text {th }}\end{array}$ & $943 \mathrm{mb}$ \\
\hline Sep & $19 \odot \odot z$ & $948 \mathrm{mb}$ & $\begin{array}{l}\text { Penetration center fix: } 936 \mathrm{mb} \text { at } \\
22 \mathrm{Z} \text { on Sep } 19^{\text {th }}\end{array}$ & $936 \mathrm{mb}$ \\
\hline Sep & $1906 z$ & $945 \mathrm{mb}$ & $\begin{array}{l}\text { Penetration center fix: } 943 \mathrm{mb} \text { at } \\
\odot 430 \mathrm{Z} \text { on Sep } 19^{\text {th }}\end{array}$ & $943 \mathrm{mb}$ \\
\hline Sep & 19122 & $942 \mathrm{mb}$ & $\begin{array}{l}\text { Penetration center fix: } 940 \mathrm{mb} \text { at } \\
1030 \mathrm{Z} \text { on Sep } 19^{\text {th }}\end{array}$ & $940 \mathrm{mb}$ \\
\hline Sep & 19182 & $950 \mathrm{mb}$ & $\begin{array}{l}\text { Penetration center fix: } 949 \mathrm{mb} \text { at } \\
1545 \mathrm{Z} \text { and } 951 \mathrm{mb} \text { at } 19 \mathrm{Z} \text { on Sep } 19^{\text {th }}\end{array}$ & Retained \\
\hline Sep & $2 \odot \odot \odot z$ & $947 \mathrm{mb}$ & $\begin{array}{l}\text { Penetration center fix: } 952 \mathrm{mb} \text { at } \\
01 \mathrm{Z} \text { on Sep } 20^{\text {th }}\end{array}$ & $952 \mathrm{mb}$ \\
\hline Sep & $2006 z$ & $957 \mathrm{mb}$ & $\begin{array}{l}\text { Penetration center fix: } 956 \mathrm{mb} \text { at } \\
07 \mathrm{Z} \text { on Sep } 20^{\text {th }}\end{array}$ & $956 \mathrm{mb}$ \\
\hline
\end{tabular}




\begin{tabular}{|c|c|c|c|c|c|}
\hline Sep & 20 & $12 Z$ & $949 \mathrm{mb}$ & $\begin{array}{l}\text { Penetration center fix: } 948 \mathrm{mb} \text { at } \\
1215 \mathrm{Z} \text { on Sep } 20^{\text {th }}\end{array}$ & $948 \mathrm{mb}$ \\
\hline Sep & 20 & $18 Z$ & $955 \mathrm{mb}$ & $\begin{array}{l}\text { Penetration center fix: } 953 \mathrm{mb} \text { at } \\
1544 \mathrm{Z} \text { on Sep } 20^{\text {th }}\end{array}$ & $953 \mathrm{mb}$ \\
\hline Sep & 21 & $\odot \odot Z$ & $968 \mathrm{mb}$ & $\begin{array}{l}\text { Penetration center fix: } 962 \mathrm{mb} \text { at } \\
01 \mathrm{z} \text { on Sep } 21^{\mathrm{st}}\end{array}$ & $962 \mathrm{mb}$ \\
\hline Sep & 21 & $06 Z$ & $972 \mathrm{mb}$ & $\begin{array}{l}\text { Penetration center fix: } 968 \mathrm{mb} \text { at } \\
0355 \mathrm{Z} \text { on Sep } 21^{\mathrm{st}}\end{array}$ & $968 \mathrm{mb}$ \\
\hline Sep & 21 & $12 Z$ & $978 \mathrm{mb}$ & $\begin{array}{l}\text { Penetration center fix: } 970 \mathrm{mb} \text { at } \\
1030 \mathrm{Z} \text { and } 974 \mathrm{mb} \text { at } 13 \mathrm{Z} \text { on Sep } 21^{\text {st }}\end{array}$ & $972 \mathrm{mb}$ \\
\hline Sep & 22 & $12 Z$ & $990 \mathrm{mb}$ & $\begin{array}{l}\text { Ship: } 20 \mathrm{kt} \text { SE and } 991 \mathrm{mb} \text { at } 12 Z \\
\text { on Sep } 22^{\text {nd }}\end{array}$ & $989 \mathrm{mb}$ \\
\hline Sep & 23 & $\odot \odot Z$ & $993 \mathrm{mb}$ & $\begin{array}{l}\text { No central pressure report but } \\
\text { looks reasonable }\end{array}$ & Retained \\
\hline Sep & 24 & $\odot \odot Z$ & & $\begin{array}{l}\text { Ship: } 2 \odot \mathrm{kt} \text { NNE and } 997 \mathrm{mb} \text { at } \odot \odot Z \\
\text { on Sep } 24^{\text {th }}\end{array}$ & $995 \mathrm{mb}$ \\
\hline Sep & 25 & $\odot \odot Z$ & & $\begin{array}{l}\text { Ship: } 30 \mathrm{kt} \mathrm{N} \text { and } 996 \mathrm{mb} \text { at } 12 \mathrm{Z} \text { on } \\
\text { Sep } 25^{\text {th }}\end{array}$ & $993 \mathrm{mb}$ \\
\hline Sep & 25 & $06 z$ & $993 \mathrm{mb}$ & $\begin{array}{l}\text { A ship report near the center of } \\
5 \odot \mathrm{kt} \text { SE and } 994 \mathrm{mb} \text { at } \odot 6 Z \text { on Sep } \\
25 \text { suggest a lower central } \\
\text { pressure }\end{array}$ & Removed \\
\hline Sep 2 & 25 & $12 Z$ & & $\begin{array}{l}\text { Ship: } 30 \mathrm{kt} \mathrm{NW} \text { and } 993 \mathrm{mb} \text { at } 12 \mathrm{Z} \\
\text { on Sep } 25^{\text {th }}\end{array}$ & $990 \mathrm{mb}$ \\
\hline Sep 2 & 25 & $18 Z$ & & $\begin{array}{l}\text { Ship: } 25 \mathrm{kt} \text { WSW and } 993 \mathrm{mb} \text { at } 18 \mathrm{Z} \\
\text { on Sep } 25^{\text {th }}\end{array}$ & $990 \mathrm{mb}$ \\
\hline Sep 2 & 26 & $\odot \odot Z$ & $996 \mathrm{mb}$ & $\begin{array}{l}\text { A ship report near the center of } \\
40 \mathrm{kt} \mathrm{S} \text { and } 997 \mathrm{mb} \text { at } \odot \odot \mathrm{Z} \text { on Sep } \\
26^{\text {th }} \text { suggest a lower central } \\
\text { pressure }\end{array}$ & Removed \\
\hline Sep 2 & 26 & $12 Z$ & $1002 \mathrm{mb}$ & $\begin{array}{l}\text { Portland, ME: } 10 \mathrm{kt} \text { WSW and } 1004 \\
\text { mb at } 12 Z \text { on Sep } 26^{\text {th }}\end{array}$ & Retained \\
\hline
\end{tabular}

Unnamed Tropical Storm [September 12-15, 1961]

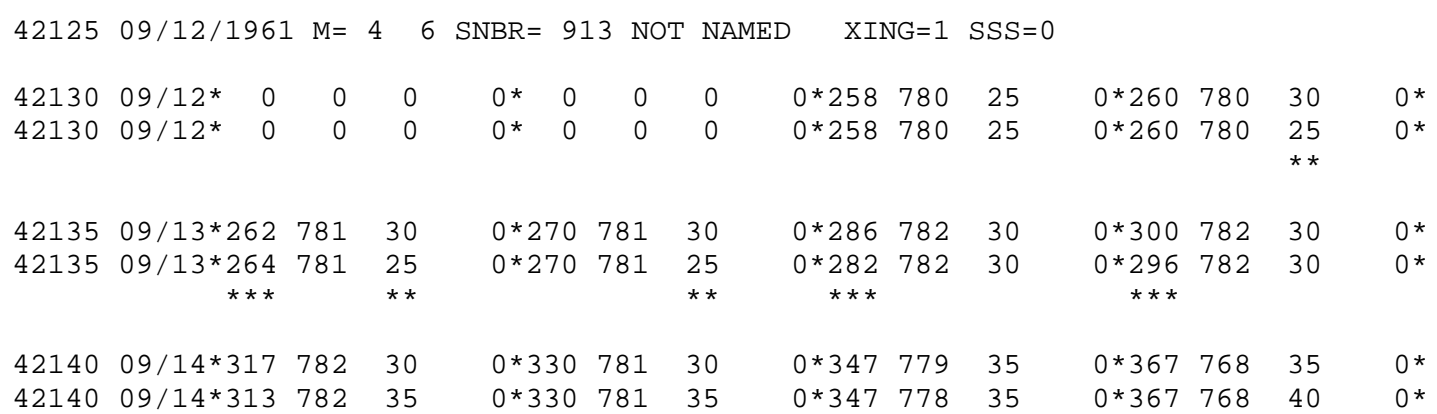


U.S. Tropical Storm Landfall

09/14 09Z 33.8N 78.0W 35 kt NC

Minor changes to the track and major changes to the intensity shown in McAdie et al. (2009). Another major change is to introduce a short extratropical phase. Evidence for these alterations comes from the NHC microfilm maps, the Historical Weather Maps series, the COADS ship database, Monthly Weather Review, Mariners Weather Log, Surface Weather Observations, Local Climatological Data, National Hurricane Research Project Storm Data, Fay (1962) and NHC Storm Wallets.

September 10:

HWM analyzes a trough or tropical wave over the Windward Passage along longitude $74 \mathrm{~W}$ at $12 \mathrm{Z}$. HURDAT does not list an organized storm on this day. Microfilm shows a trough or tropical wave north of Hispaniola along longitude $71 \mathrm{~W}$ at $12 \mathrm{Z}$. Ship highlights: No gales or low pressures.

FAY: "During the period from September 9 to 12, 1961, T1ROS III was well oriented for photographing the area south and east of Florida. On each of these days, nephanalyses from the photographs indicated a vortex present just east of the Bahamas. It is not possible to determine in what portion of the atmosphere these vortices were located, nor even if they were one and the same."

September 11:

HWM analyzes a spot low pressure at $23.0 \mathrm{~N}, 72.2 \mathrm{~W}$ at $12 \mathrm{Z}$. HURDAT does not list an organized storm on this day. Microfilm shows a trough or tropical wave over the central Bahamas at 12Z. Ship highlights: No gales or low pressures.

September 12:

HWM analyzes a spot low pressure at $25.8 \mathrm{~N}, 77.1 \mathrm{~W}$ at $12 \mathrm{Z}$. HURDAT lists a $25 \mathrm{kt}$ tropical depression at $25.8 \mathrm{~N}, 78.0 \mathrm{~W}$ at $12 \mathrm{Z}$ (first position). Microfilm shows an elongated, closed low pressure of at most $1013 \mathrm{mb}$ near 25.0N, 78.0W at 12Z. Fay (1962) estimates the position of the center from a TIROS III satellite image at $23.5 \mathrm{~N}, 73.0 \mathrm{~W}$ at 1935Z. Ship highlights: No gales or low pressures. 
September 13:

HWM analyzes a spot low pressure at $27.5 \mathrm{~N}, 78.3 \mathrm{~W}$ at $12 \mathrm{Z}$. HURDAT lists a $30 \mathrm{kt}$ tropical depression at $28.6 \mathrm{~N}, 78.2 \mathrm{~W}$ at $12 \mathrm{Z}$. Microfilm shows an elongated, closed low pressure of at most $1013 \mathrm{mb}$ near 28.0N, 78.6W at 12Z. Ship highlights: No gales or low pressures.

FAY: "By September 13 surface reports clearly indicated a cyclonic circulation east of Florida, and the edge of the circulation was again photographed by TIROS III (fig. 4), but wide the clouds appear quite dense, the cyclonic circulation is not clearly defined in the reproduction."

September 14:

HWM analyzes a closed low pressure of at most $1010 \mathrm{mb}$ at $34.0 \mathrm{~N}, 77.8 \mathrm{~W}$ with a cold front well to the west at 12Z. HURDAT lists a $35 \mathrm{kt}$ tropical storm at $34.7 \mathrm{~N}$, $77.9 \mathrm{~W}$ at $12 \mathrm{Z}$. Microfilm shows a closed low pressure of at most $1008 \mathrm{mb}$ at $33.5 \mathrm{~N}$, 77.0W at 12Z. Ship highlights: $35 \mathrm{kt} \mathrm{ESE}$ and $1015 \mathrm{mb}$ at $31.0 \mathrm{~N}, 77.0 \mathrm{~W}$ at $00 \mathrm{Z}$ (COADS). $5 \mathrm{kt} \mathrm{NE}$ and $1003 \mathrm{mb}$ at $37.1 \mathrm{~N}, 76.3 \mathrm{~W}$ at $37.1 \mathrm{~N}, 76.3 \mathrm{~W}$ at $21 \mathrm{Z}$ (COADS). Land highlights: $35 \mathrm{kt} \mathrm{SE}$ and $1012 \mathrm{mb}$ at Frying Pan, NC at 06Z (micro). $18 \mathrm{kt} \mathrm{SSW}$ (gusts to $32 \mathrm{kt}$ ) and $1002 \mathrm{mb}$ at Elizabeth City, NC at 19Z (SWO)

FAY: "The photographs from subsequent orbital passes over the storm on September 14 and 15 failed to show any circulation in the general cloudiness in which it was imbedded. The tropical cyclone crossed the coast of North Carolina just east of Wilmington at about 0600 EST, September 14. At this time it was traveling toward the north-northeast at about $18 \mathrm{kt}$. The cyclone never moved far from the coastline and perhaps in this way maintained its tropical characteristics."

September 15:

HWM analyzes a closed low pressure of at most $995 \mathrm{mb}$ at $44.5 \mathrm{~N}, 69.5 \mathrm{~W}$ with a cold front just to the west at 12Z. HURDAT lists a $35 \mathrm{kt}$ tropical storm at $44.1 \mathrm{~N}, 70.1 \mathrm{~W}$ at $12 \mathrm{Z}$. Microfilm shows a closed low pressure of at most $987 \mathrm{mb}$ at $54.0 \mathrm{~N}, 69.0 \mathrm{~W}$ with a frontal boundary to the south (appears that the tropical cyclone has been absorbed) at 12Z. Ship highlights: $50 \mathrm{kt} \mathrm{S}$ and $1008 \mathrm{mb}$ at $38.1 \mathrm{~N}, 73.5 \mathrm{~W}$ at $00 \mathrm{Z}$ (COADS). $35 \mathrm{kt} \mathrm{SW}$ and $1009 \mathrm{mb}$ at $37.5 \mathrm{~N}, 74.6 \mathrm{~W}$ at $06 \mathrm{Z}$ (COADS). Land highlights: Gusts to $60 \mathrm{kt}$ at Point Judith, RI (no time given) (SD). $70 \mathrm{kt}$ (1-min) at Eastport, ME (no time given) (FAY, 1962). $8 \mathrm{kt} \mathrm{NW}$ and $1003 \mathrm{mb}$ at Atlantic City, NJ at 0258Z (SWO). $34 \mathrm{kt} \mathrm{SSE}$ and 1010 $\mathrm{mb}$ at Nantucket Shoals, MA at 0555Z (SWO). $4 \mathrm{kt} \mathrm{SE}$ and $1000 \mathrm{mb}$ at Worcester, MA at 0758Z (SWO). $36 \mathrm{kt} \mathrm{S} \mathrm{(gusts} \mathrm{to} 45 \mathrm{kt}$ ) at Providence, RI at 0810Z (SWO/CLIMO). $6 \mathrm{kt} \mathrm{S}$ 
and $996 \mathrm{mb}$ at Brunswick, ME at $1158 \mathrm{Z}$ (SWO). Gusts to $70 \mathrm{kt}$ at Saint John, Canada at $16 Z$ (FAY, 1962).

FAY: "From the forecast point of view, one of the problems was the acceleration which was continuous for the 27 hours when it was within the continental limits of the United States. During the find 2 hours it was moving at $60 \mathrm{kt}$. While the central pressure continued to decrease as the cyclone moved northward, the reported winds dropped off alter it pressed Cape Hatteras. Highest gusts there were $38 \mathrm{kt}$, while Atlantic City recorded no winds of over $15 \mathrm{kt}$. By the time it reached Long Island, winds had again increased to $38 \mathrm{kt}$, which was recorded at Suffolk County Air Force Base as the center passed by. At about this time the Research Vessel Eugenie VIII, of the Woods Hole Oceanographic Institution was about $80 \mathrm{mi}$ south-southeast of Block Island, R.I., and some $110 \mathrm{mi}$ from the storm center. The captain, a man with long experience in small boats at sea, estimated winds of $50 \mathrm{kt}$ and reported the sea condition as "very rough" and had some difficulty in bringing the vessel about to run before the wind. Point Judith, R.I., recorded gusts to $61 \mathrm{kt}$. and at Quonset Point, R.I., the carrier Lake Champlain parted her lines and drifted away from the dock. An airplane at the Groton (Conn.) Airport tore loose from three 1550-lb test nylon lines. At 0500 EST wave heights of $16 \mathrm{ft}$. were measured at a tower off the south coast of Martha's Vineyard. For a minimum duration of 3 hours, which is probably a maximum in this case, a sustained wind of $55 \mathrm{kt}$ is required to produce this wave height; for a 2-hour minimum duration, winds over $70 \mathrm{kt}$ are required. The winds caused a storm surge of $4.1 \mathrm{ft}$. in Narragansett' Bay. Fortunately the surge arrived at time of low tide, so no serious damage resulted. Highest winds and most damage to power lines occurred as the storm sped across eastern Maine. At Beals, Maine, a waterspout was reported, and apparently moved onshore where a new $26 \mathrm{ft}$ by $52 \mathrm{ft}$ boatshop was lifted from its foundation and moved $15 \mathrm{ft}$. Winds at' the top of an 800-ft. radio tower at Cutler, Maine, were recorded at $100 \mathrm{mph}$, while the surface winds were up to $70 \mathrm{mph}$. There was some evidence of a tornado in the Machias area; most trees were blown down from south to north, while a few were noted to have fallen from west to east and east to west. The triple register at Eastport, Maine, showed a 2-minute wind speed of close to $60 \mathrm{mph}(52 \mathrm{kt})$ and 1 -minute speed of about $80 \mathrm{mph}(70 \mathrm{kt})$. There seems little doubt that the winds reached hurricane force at least occasionally during the time the storm moved across New England. Saint John, New Brunswick, reported gusts to $62 \mathrm{kt}$ at $1000 \mathrm{EST}$, and to $70 \mathrm{kt}$ at 1100 . All the highest winds reported were from the south to southwest." 
The unnamed tropical storm developed from a tropical wave that left the African coast early in September. The disturbance did not show signs of organization while crossing the eastern and central Atlantic. A paper by Richard Fay (MWR 1962, pg. 351) titled "Northbound Tropical Cyclone" shows a nephanalysis (fig. 1) of a TIROS III satellite image of September 9th while the system was north of Hispaniola. The nephanalysis suggests that the convection was located over the developed northern and eastern quadrant of the circulation. However, surface observations indicated that no closed circulation at the surface existed on that day. Surface observations show that a tropical wave reached the Bahamas on September 11th and slowly a well-defined lowlevel center. Genesis is analyzed at $12 \mathrm{Z}$ on September 12th as a $25 \mathrm{kt}$ tropical depression, same as originally shown in HURDAT. Minor track alterations are introduced during the lifetime of this tropical cyclone. Fig. 3 (Fay 1962) shows a TIROS III satellite image from September 12th at 1935Z. The weak tropical depression moved northward slowly gaining in forward speed on the 13th. Synoptic data on the 13th indicated that the winds remained below gale-force and the highest reported were $30 \mathrm{kt}$ at $18 \mathrm{Z}$. At $00 \mathrm{Z}$ on September 14th, a ship close to the tropical cyclone reported $35 \mathrm{kt}$. Thus, the tropical depression is upgraded to a tropical storm, twelve hours earlier than originally shown in HURDAT. Frying Pan Shoals, NC, an elevated station, reported $35 \mathrm{kt}$ at 06Z. The tropical storm continued northward early on the 14th, later turning to the northeast after crossing the coast. Landfall is analyzed near Wilmington, $\mathrm{NC}$ as a $35 \mathrm{kt}$ tropical storm at $09 \mathrm{Z}$ on the 14th. The radar image from Hatteras, NC, on the 14th at $1630 \mathrm{Z}$ in the Fay report (MWR 1962, pg. 355) shows a weak low pressure with convection around the center. At the same time, a strong extratropical cyclone, remnants of Hurricane Carla, was located over the Great Lakes and moving northeastward. The small tropical storm, under the influence of the extratropical cyclone, accelerated over the East Coast of the United States and intensified. The radar image from Atlantic City, NJ, on September 15th at $0330 \mathrm{Z}$ shows a well-organized tropical cyclone with convection around the center. A ship reported $50 \mathrm{kt}$ at $00 \mathrm{Z}$ on the 15 th and the intensity is increased to $50 \mathrm{kt}$ at this time, up from $35 \mathrm{kt}$ originally in HURDAT, a minor intensity change. $8 \mathrm{kt} \mathrm{NW}$ and $1003 \mathrm{mb}$ were reported at Atlantic City, NJ, at 0258Z, suggesting a central pressure of $1001 \mathrm{mb}$, which has been added to HURDAT at $00 \mathrm{Z}$ on the 15 th. Early on the 15 th, the cold front associated with the extratropical cyclone was approaching the center of the small tropical cyclone. Despite its fast forward speed, surface observations indicate that the center remained closed early on the 15 th. By $06 Z$ on the 15 th, the center of the tropical storm was just north of New York City, NY, based on the synoptic data. It is unclear from the surface observations if the circulation was still closed at this time. Fay (1962) mentions a research vessel located near $40.3 \mathrm{~N}, 70.8 \mathrm{~W}$ and the captain estimated sustained winds of $50 \mathrm{kt}$ and rough conditions, and although it does not mention a time, based on the track of the tropical cyclone, it appears that the estimate was around $06 \mathrm{Z}$ on the 15 th. An intensity 
of $55 \mathrm{kt}$ is selected at $06 \mathrm{Z}$ on the $15 \mathrm{th}$, up from $35 \mathrm{kt}$ originally in HURDAT, a major intensity change. $55 \mathrm{kt}$ is also the peak intensity of this system as a tropical cyclone, up from $35 \mathrm{kt}$ originally in HURDAT, a major intensity change. $4 \mathrm{kt} \mathrm{SE}$ and $1000 \mathrm{mb}$ were reported at Worcester, MA, at 0555Z, suggesting a central pressure of $999 \mathrm{mb}$, which has been added to HURDAT at $06 \mathrm{Z}$ on the 15 th. By $12 \mathrm{Z}$ on the 15 th, the surface observations suggest that the cold front had caught up to the tropical cyclone and the system was embedded within the frontal boundary, thus losing its tropical characteristics. Transition to an extratropical cyclone is analyzed at $12 \mathrm{Z}$ on the $15 \mathrm{th}$. An intensity of $60 \mathrm{kt}$ is selected at $12 \mathrm{Z}$ on the 15th, up from $35 \mathrm{kt}$ originally in HURDAT. $6 \mathrm{kt} \mathrm{S}$ and $996 \mathrm{mb}$ were reported at Brunswick, ME, at 1158Z, suggesting a central pressure of $995 \mathrm{mb}$, which has been added to HURDAT at $12 \mathrm{Z}$ on the 15 th. Surface observations at $18 \mathrm{Z}$ on the 15th indicate that the weaker extratropical cyclone had been absorbed by the larger extratropical cyclone to the north. At about the same time, Eastport, ME experienced 1min winds of $70 \mathrm{kt}$ indicating that even though the system was absorbed, the larger extratropical cyclone contained quite vigorous winds. Thus, the last position is analyzed at $12 \mathrm{Z}$ on the 15 th, six hours earlier than originally shown in HURDAT.

Hurricane Frances [September 30 - October 10, 1961]

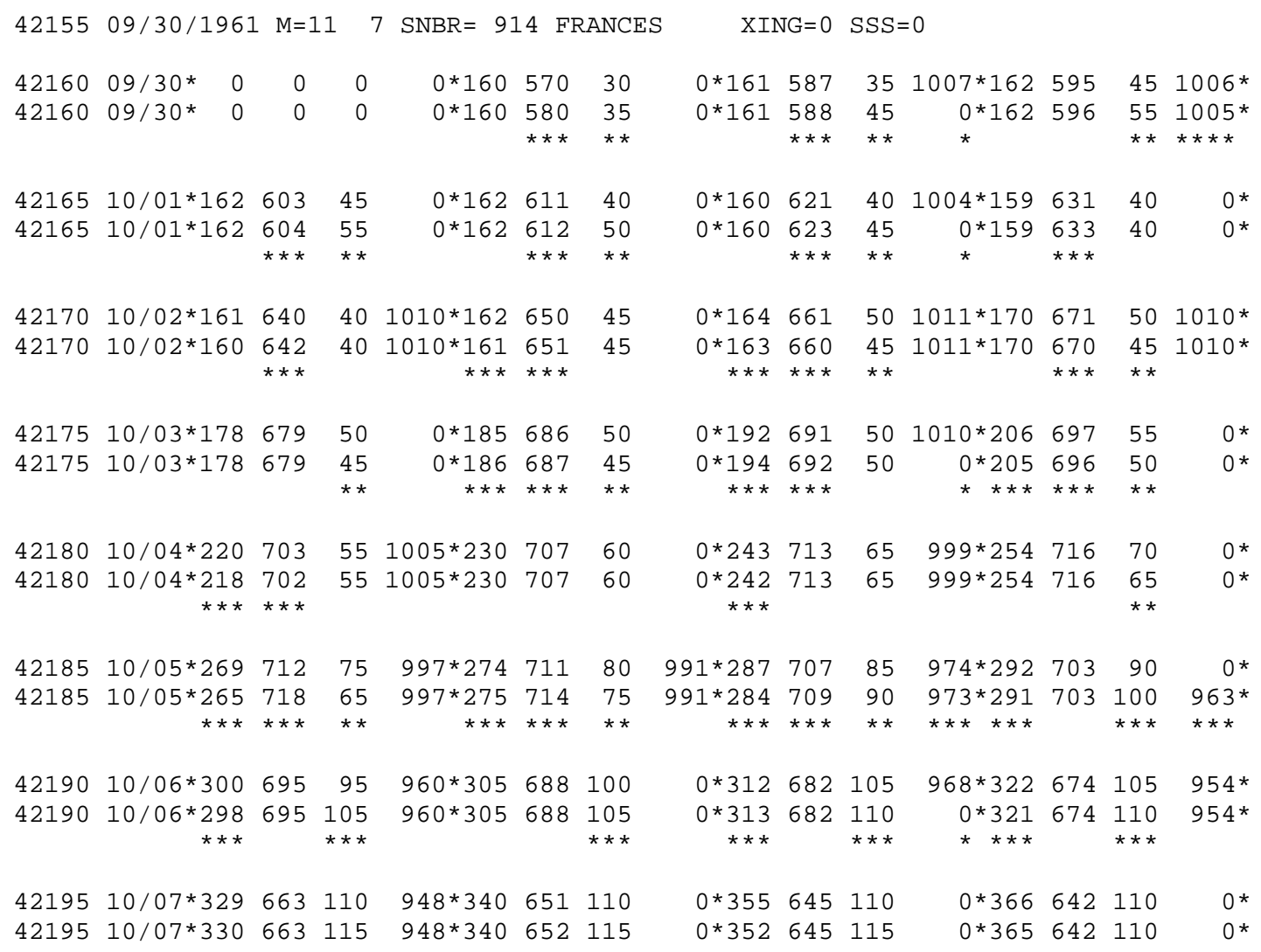




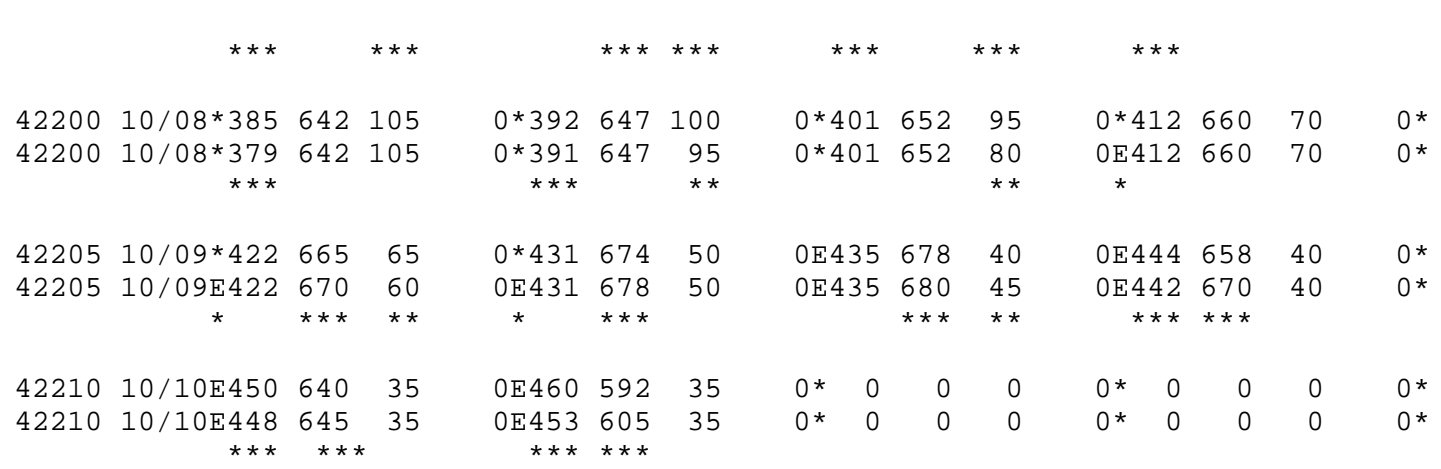

42215 HR

Tropical Storm Landfall:

10/01 08Z 16.1N 61.6W 50 kt Guadeloupe 10/03 05Z 18.3N 68.5W 45 kt Dominican Republic

Minor changes to the track and intensity shown in McAdie et al. (2009). Evidence for these alterations comes from the NHC microfilm maps, the Historical Weather Maps series, the COADS ship database, Monthly Weather Review, Navy reconnaissance book, Mariners Weather Log, Advisories and NHC Storm Wallets.

September 28:

HWM analyzes a spot low pressure at $14.0 \mathrm{~N}, 52.5 \mathrm{~W}$ at $12 \mathrm{Z}$. HURDAT does not list an organized system on this date. Microfilm does not show an organized system at 12Z. Ship highlights: No gales or low pressures.

September 29:

HWM analyzes a spot low pressure at $15.0 \mathrm{~N}, 55.5 \mathrm{~W}$ at $12 \mathrm{Z}$. HURDAT does not list an organized system on this date. Microfilm does not show an organized system at 12Z. Ship highlights: No gales or low pressures.

ATSR: "On the 29th of September, considerable shower activity and shifting winds indicated the possibility of a disturbed area just east of the Lesser Antilles."

September 30:

HWM analyzes a tropical storm at $16.0 \mathrm{~N}, 58.5 \mathrm{~W}$ at $12 \mathrm{Z}$. HURDAT lists a $35 \mathrm{kt}$ tropical storm at $16.1 \mathrm{~N}, 58.7 \mathrm{~W}$ at $12 \mathrm{Z}$. Microfilm shows a tropical wave extended between 12$22 \mathrm{~N}, 59 \mathrm{~W}$ at $12 \mathrm{Z}$. Ship highlights: No gales or low pressures. Aircraft highlights: Penetration center fix measured a central pressure of $1007 \mathrm{mb}$ and estimated surface winds of $70 \mathrm{kt}$ at $16.2 \mathrm{~N}, 59.9 \mathrm{~W}$ at $17 \mathrm{Z}$ (WALLET). Penetration center fix measured a 
central pressure of $1005 \mathrm{mb}$ and estimated surface winds of $70 \mathrm{kt}$ at $16.1 \mathrm{~N}, 59.9 \mathrm{~W}$ at $19 \mathrm{Z}$ (WALLET).

MWR: "Although there were slight indications of a disturbed area east of the Antilles as early as September 28, it was not until the morning of the 30th that aircraft reconnaissance confirmed the development of tropical storm Frances. On this date the storm was very poorly organized with a sea level pressure no lower than $1005 \mathrm{mb}$ (29.68 inches)." ATSR: "Early on the 30th, a Navy reconnaissance plane investigated the area and found a poorly defined storm with very little radar presentation. It did find up to 70 knots of wind in a few squalls. Consequently, warning number one on Tropical Storm Frances was issued at 301930Z."

October 1:

HWM analyzes a tropical storm of at most $1010 \mathrm{mb}$ at $15.2 \mathrm{~N}, 61.9 \mathrm{~W}$ at $12 \mathrm{Z}$. HURDAT lists a $40 \mathrm{kt}$ tropical storm at $16.0 \mathrm{~N}, 62.1 \mathrm{~W}$ at $12 \mathrm{Z}$. Microfilm shows a closed low pressure of at most $1014 \mathrm{mb}$ at $16.0 \mathrm{~N}, 62.0 \mathrm{~W}$ at 12Z. Ship highlights: $60 \mathrm{kt}$ ESE and $1012 \mathrm{mb}$ at 16.4N, 60.8W at 04Z (micro/WALLET/MWR). $45 \mathrm{kt} \mathrm{SSE}$ and $1002 \mathrm{mb}$ (low pressure bias) at $15.6 \mathrm{~N}, 61.7 \mathrm{~W}$ at $12 \mathrm{Z}$ (micro). Aircraft highlights: Radar center fix at $16.2 \mathrm{~N}, 60.9 \mathrm{~W}$ at $0445 \mathrm{Z}$ (ATSR). Penetration center fix measured a central pressure of $1012 \mathrm{mb}$ and estimated surface winds of $35 \mathrm{kt}$ at $15.9 \mathrm{~N}, 62.8 \mathrm{~W}$ at $1455 \mathrm{Z}$ (ATSR). Penetration center fix measured a central pressure of $1010 \mathrm{mb}$, estimated surface winds of $35 \mathrm{kt}$ and an eye diameter of $25 \mathrm{~nm}$ at $16.2 \mathrm{~N}, 63.8 \mathrm{~W}$ at $2130 \mathrm{Z}$ (WALLET).

MWR: "Tropical storm Frances passed between the islands of Marie Galante and Guadaloupe, French Antilles between 0000 and 0100 EST on October 1. At 0100 EST, the Netherlands steamship Viajero near 16.4 north, 60.8 west just off the island of La Desirade, French Antilles, reported 60 knots winds from $120^{\circ}$ during a heavy squall. At 0230 EST an amateur radio operator at Guadeloupe reported wind gusting to 50 to 60 miles per hour from the south. In the passage from Guadeloupe, French Antilles, to Dominica, West Indies Federation, the appears that the wind field was completely distorted by the 6000 foot mountains on Dominica and the 5000 foot range on Guadeloupe. The occasionally happens to tropical storms passing between or over these two islands while in the developmental stage. Frances never recovered its earlier intensity while in the Caribbean. Indeed, it was here the forecasters were confronted with a most difficult problem. Reconnaissance planes were able to follow and an area of weather and relative calm moving westward, while other planes were tracking a very weak circulation moving northwestward toward the extreme eastern portion of Hispaniola. That latter turn out to be the most important and the one that eventually intensified. The absence of a good divergence field at high levels was noted during this period and perhaps this was the paramount reason for the slow development and the 
disorganized state of the storm. ATSR: "Already diffuse, the storm became completely disorganized as it headed westward and passed between the mountainous islands of Guadeloupe and Dominica early on 1 October. This lack of organization presented a serious forecasting and reconnaissance problem as the storm entered the Caribbean. Seemingly, Frances split into two separate areas of weather or circulations. One circulation moved westward and did not develop, another moved northwestward, passed over eastern Hispaniola and finally intensified. Lack of a good outflow mechanism in the upper air flow in the area of the storm is thought to have contributed to Frances' slow development."

October 2:

HWM analyzes a tropical storm of at most $1010 \mathrm{mb}$ at $16.1 \mathrm{~N}, 65.9 \mathrm{~W}$ at $12 \mathrm{Z}$. HURDAT lists a $50 \mathrm{kt}$ tropical storm at $16.4 \mathrm{~N}, 66.1 \mathrm{~W}$ at $12 \mathrm{Z}$. Microfilm shows a closed low pressure of at most $1011 \mathrm{mb}$ at $16.6 \mathrm{~N}, 66.3 \mathrm{~W}$ at 12Z. Ship highlights: $40 \mathrm{kt} \mathrm{ESE}$ and $1010 \mathrm{mb}$ at $16.7 \mathrm{~N}, 64.7 \mathrm{~W}$ at $03 \mathrm{Z}$ (micro). $35 \mathrm{kt} \mathrm{SE}$ and $1010 \mathrm{mb}$ at $15.9 \mathrm{~N}, 65.8 \mathrm{~W}$ at $18 \mathrm{Z}$ (COADS). $35 \mathrm{kt} \mathrm{SSE}$ and $1010 \mathrm{mb}$ at $16.7 \mathrm{~N}, 66.2 \mathrm{~W}$ at $21 \mathrm{Z}$ (micro/MWL). Aircraft highlights: Penetration center fix measured a central pressure of $1003 \mathrm{mb}$ and flight level winds of $50 \mathrm{kt}$ at $16.1 \mathrm{~N}, 64.4 \mathrm{~W}$ at $0050 \mathrm{Z}$ (WALLET). Penetration center fix measured a central pressure of $1011 \mathrm{mb}$ and estimated surface winds of $50 \mathrm{kt}$ at $16.2 \mathrm{~N}, 65.7 \mathrm{~W}$ at $1140 \mathrm{Z}$ (WALLET). Penetration center fix measured a central pressure of $1010 \mathrm{mb}$ and estimated surface winds of $50 \mathrm{kt}$ at $16.2 \mathrm{~N}, 67.6 \mathrm{~W}$ at $1845 \mathrm{Z}$ (WALLET).

October 3:

HWM analyzes a tropical storm of at most $1010 \mathrm{mb}$ at $19.5 \mathrm{~N}, 69.5 \mathrm{~W}$ at $12 \mathrm{Z}$. HURDAT lists a $50 \mathrm{kt}$ tropical storm at $19.2 \mathrm{~N}, 69.1 \mathrm{~W}$ at $12 \mathrm{Z}$. Microfilm shows a closed low pressure of at most $1011 \mathrm{mb}$ at $19.5 \mathrm{~N}, 69.3 \mathrm{~W}$ at $12 \mathrm{Z}$. Ship highlights: $35 \mathrm{kt}$ SE and 1010 $\mathrm{mb}$ at $17.1 \mathrm{~N}, 66.8 \mathrm{~W}$ at $00 \mathrm{Z}$ (COADS). $40 \mathrm{kt} \mathrm{SE}$ and $1010 \mathrm{mb}$ at $18.3 \mathrm{~N}, 67.7 \mathrm{~W}$ at $06 \mathrm{Z}$ (COADS). $40 \mathrm{kt} \mathrm{SE}$ and $1008 \mathrm{mb}$ at 19.0N, 68.3W at 09Z (micro/MWL). $40 \mathrm{kt} \mathrm{SE}$ and $1010 \mathrm{mb}$ at $19.9 \mathrm{~N}, 68.3 \mathrm{~W}$ at $12 \mathrm{Z}$ (COADS). $45 \mathrm{kt} \mathrm{SSE}$ and $1008 \mathrm{mb}$ at $21.6 \mathrm{~N}, 69.7 \mathrm{~W}$ at $21 \mathrm{Z}$ (micro). Aircraft highlights: Radar center fix at $16.7 \mathrm{~N}, 69.5 \mathrm{~W}$ at $03 \mathrm{Z}$ (WALLET). Radar center fix at $18.7 \mathrm{~N}, 68.7 \mathrm{~W}$ at $06 \mathrm{Z}$ (WALLET). Radar center fix at $19.4 \mathrm{~N}, 69.3 \mathrm{~W}$ at $13 Z$ (WALLET). Penetration center fix measured a central pressure of $1006 \mathrm{mb}$ and estimated surface winds of $50 \mathrm{kt}$ at $21.3 \mathrm{~N}, 70.0 \mathrm{~W}$ at $2150 \mathrm{Z}$ (WALLET).

October 4:

HWM analyzes a hurricane of at most $1000 \mathrm{mb}$ at $23.7 \mathrm{~N}, 71.5 \mathrm{~W}$ at $12 \mathrm{Z}$. HURDAT lists a $65 \mathrm{kt}$ hurricane at $24.3 \mathrm{~N}, 71.3 \mathrm{~W}$ at $12 \mathrm{Z}$. Microfilm shows a closed low pressure of at most $1005 \mathrm{mb}$ at $24.2 \mathrm{~N}, 71.2 \mathrm{~W}$ at 12Z. Ship highlights: $35 \mathrm{kt} \mathrm{ESE}$ and $1013 \mathrm{mb}$ at $22.8 \mathrm{~N}, 68.0 \mathrm{~W}$ at $03 \mathrm{Z}$ (micro). $35 \mathrm{kt} \mathrm{SE}$ and $1012 \mathrm{mb}$ at $22.3 \mathrm{~N}, 67.9 \mathrm{~W}$ at $06 \mathrm{Z}$ (micro). 40 
kt ESE and $1011 \mathrm{mb}$ at 26.1N, 70.4W at 12Z (COADS). $35 \mathrm{kt} \mathrm{SE}$ and $1012 \mathrm{mb}$ at 27.6N, $69.8 \mathrm{~W}$ at $21 \mathrm{Z}$ (micro). Aircraft highlights: Penetration center fix measured a central pressure of $1005 \mathrm{mb}$ at $22.3 \mathrm{~N}, 70.0 \mathrm{~W}$ at $01 \mathrm{Z}$ (WALLET). Radar center fix at 23.6N, $70.8 \mathrm{~W}$ at $07 \mathrm{Z}$ (WALLET). Penetration center fix measured a central pressure of $999 \mathrm{mb}$ and estimated surface winds of $100 \mathrm{kt}$ at $24.2 \mathrm{~N}, 71.2 \mathrm{~W}$ at $12 \mathrm{Z}$ (WALLET/ATSR). Penetration center fix estimated surface winds of $70 \mathrm{kt}$ at $25.0 \mathrm{~N}, 71.6 \mathrm{~W}$ at $1615 \mathrm{Z}$ (WALLET). Penetration center fix measured a central pressure of $994 \mathrm{mb}$ and estimated surface winds of $60 \mathrm{kt}$ at $26.0 \mathrm{~N}, 71.5 \mathrm{~W}$ at $2145 \mathrm{Z}$ (WALLET).

ATSR: "Steadily intensifying as she moved north-northwestward, Frances reached hurricane force on the 4 th."

October 5:

HWM analyzes a hurricane of at most $1000 \mathrm{mb}$ at $27.8 \mathrm{~N}, 70.8 \mathrm{~W}$ at $12 \mathrm{Z}$. HURDAT lists an $85 \mathrm{kt}$ hurricane at $28.7 \mathrm{~N}, 70.7 \mathrm{~W}$ at $12 \mathrm{Z}$. Microfilm shows a closed low pressure of at most $1014 \mathrm{mb}$ at $28.5 \mathrm{~N}, 70.5 \mathrm{~W}$ at $12 \mathrm{Z}$. Ship highlights: $35 \mathrm{kt} \mathrm{SE}$ and $1011 \mathrm{mb}$ at $27.2 \mathrm{~N}$, $70.3 \mathrm{~W}$ at $00 \mathrm{Z}$ (COADS). $45 \mathrm{kt} \mathrm{S}$ and $1007 \mathrm{mb}$ at $26.6 \mathrm{~N}, 70.8 \mathrm{~W}$ at $03 \mathrm{Z}$ (micro). $40 \mathrm{kt} \mathrm{SW}$ and $1009 \mathrm{mb}$ at $26.5 \mathrm{~N}, 71.0 \mathrm{~W}$ at $06 \mathrm{Z}$ (COADS). $35 \mathrm{kt} \mathrm{NNE}$ and $1016 \mathrm{mb}$ at $29.4 \mathrm{~N}$, $75.6 \mathrm{~W}$ at $15 \mathrm{Z}$ (MWL). $55 \mathrm{kt} \mathrm{W}$ and $963 \mathrm{mb}$ at $29.5 \mathrm{~N}, 70.0 \mathrm{~W}$ at $21 \mathrm{Z}$ (micro). Aircraft highlights: Penetration center fix measured a central pressure of $997 \mathrm{mb}$ and an eye diameter of $12 \mathrm{~nm}$ at $26.7 \mathrm{~N}, 71.9 \mathrm{~W}$ at $01 \mathrm{Z}$ (WALLET). Penetration center fix measured a central pressure of $991 \mathrm{mb}$ and an eye diameter of $11-13 \mathrm{~nm}$ at $27.5 \mathrm{~N}, 71.1 \mathrm{~W}$ at $07 \mathrm{Z}$ (WALLET). Penetration center fix measured a central pressure of $973 \mathrm{mb}$ at $28.6 \mathrm{~N}$, 70.6W at 1410Z (ATSR/micro). Penetration center fix measured a central pressure of 963 $\mathrm{mb}$ at $29.3 \mathrm{~N}, 70.2 \mathrm{~W}$ at $1840 \mathrm{Z}$ (ATSR/advisories). Penetration center fix at $29.7 \mathrm{~N}, 69.7 \mathrm{~W}$ at $2140 \mathrm{Z}$ (ATSR).

October 6:

HWM analyzes a hurricane of at most $995 \mathrm{mb}$ at $31.0 \mathrm{~N}, 68.2 \mathrm{~W}$ at $12 \mathrm{Z}$. HURDAT lists a $105 \mathrm{kt}$ hurricane at $31.2 \mathrm{~N}, 68.2 \mathrm{~W}$ at $12 \mathrm{Z}$. Microfilm shows a closed low pressure of at most $1002 \mathrm{mb}$ at $31.5 \mathrm{~N}, 67.6 \mathrm{~W}$ with a frontal boundary to the northwest at $12 \mathrm{Z}$. Ship highlights: $45 \mathrm{kt} \mathrm{WSW}$ and $984 \mathrm{mb}$ at $29.0 \mathrm{~N}, 69.5 \mathrm{~W}$ at $00 \mathrm{Z}$ (micro). $35 \mathrm{kt} \mathrm{SE}$ and 1013 $\mathrm{mb}$ at $29.9 \mathrm{~N}, 64.3 \mathrm{~W}$ at $12 \mathrm{Z}$ (micro). $35 \mathrm{kt} \mathrm{NE}$ and $1011 \mathrm{mb}$ at $31.5 \mathrm{~N}, 69.5 \mathrm{~W}$ at $18 \mathrm{Z}$ (COADS). $35 \mathrm{kt} \mathrm{NNE}$ and $1011 \mathrm{mb}$ at $34.0 \mathrm{~N}, 67.3 \mathrm{~W}$ at $21 \mathrm{Z}$ (micro). Aircraft highlights: Penetration center fix measured a central pressure of $965 \mathrm{mb}$ at $31.1 \mathrm{~N}, 69.1 \mathrm{~W}$ at $1115 \mathrm{Z}$ (ATSR/micro). Penetration center fix measured a central pressure of $954 \mathrm{mb}$ at $32.6 \mathrm{~N}$, 67.2W at 19Z (ATSR/advisories). Penetration center fix measured a central pressure of $948 \mathrm{mb}$, estimated surface winds of $125 \mathrm{kt}$ and an eye diameter of $20 \mathrm{~nm}$ at $32.7 \mathrm{~N}$, 66.6W at 22Z (WALLET). 
MWR: "Frances moved just to the west of Bermuda on October 6. The lowest sea level pressure reported was $948 \mathrm{mb}$ (27.99 inches) which is in good agreement with the maximum winds estimated at $110 \mathrm{kt}(127 \mathrm{mph})$. The maximum intensity occurred when the hurricane was west and northwest of Bermuda and gales were reported throughout the islands at this time. As it turned out, flooding along the south coastal plain of Puerto Rico caused more damage than at any place along the entire path, mainly to roads and bridges. There has been no loss of life reported in connection with Frances." ATSR: "After turning northeastward in advance of an approaching cold front and buffeting Bermuda with gale force winds on the 6th, Frances pointed for the coast of Maine."

October 7:

HWM analyzes a hurricane of at most $995 \mathrm{mb}$ at $35.1 \mathrm{~N}, 64.5 \mathrm{~W}$ with a stationary boundary to the northeast at $12 \mathrm{Z}$. HURDAT lists a $110 \mathrm{kt}$ hurricane at $35.5 \mathrm{~N}, 64.5 \mathrm{~W}$ at 12Z. Microfilm shows a closed low pressure of at most $1011 \mathrm{mb}$ at $35.0 \mathrm{~N}, 65.0 \mathrm{~W}$ at $12 \mathrm{Z}$. Ship highlights: $35 \mathrm{kt} \mathrm{NE}$ and $1015 \mathrm{mb}$ at 28.4N, 69.0W at 06Z (COADS). $35 \mathrm{kt} \mathrm{ENE}$ and $1014 \mathrm{mb}$ at $37.7 \mathrm{~N}, 65.9 \mathrm{~W}$ at $12 \mathrm{Z}$ (micro). $35 \mathrm{kt} \mathrm{ENE}$ and $1017 \mathrm{mb}$ at $39.3 \mathrm{~N}, 61.6 \mathrm{~W}$ at $18 \mathrm{Z}$ (COADS). Land highlights: $35 \mathrm{kt} \mathrm{SSE}$ and $1008 \mathrm{mb}$ at Bermuda at $00 \mathrm{Z}$ (micro). Aircraft highlights: Penetration center fix at $35.8 \mathrm{~N}, 64.5 \mathrm{~W}$ at $1330 \mathrm{Z}$ (ATSR). Penetration center fix at $36.7 \mathrm{~N}, 64.0 \mathrm{~W}$ at $19 \mathrm{Z}$ (ATSR).

October 8:

HWM analyzes a hurricane of at most $1000 \mathrm{mb}$ at $39.7 \mathrm{~N}, 65.5 \mathrm{~W}$ at $12 \mathrm{Z}$. HURDAT lists a $95 \mathrm{kt}$ hurricane at $40.1 \mathrm{~N}, 65.2 \mathrm{~W}$ at $12 \mathrm{Z}$. Microfilm shows a closed low pressure of at most $1002 \mathrm{mb}$ at $40.0 \mathrm{~N}, 65.0 \mathrm{~W}$ at 12Z. Ship highlights: $35 \mathrm{kt} \mathrm{E}$ and $1018 \mathrm{mb}$ at $40.2 \mathrm{~N}$, $60.3 \mathrm{~W}$ at $00 \mathrm{Z}$ (COADS). $40 \mathrm{kt} \mathrm{N}$ and $1017 \mathrm{mb}$ at $39.5 \mathrm{~N}, 67.7 \mathrm{~W}$ at $06 \mathrm{Z}$ (COADS). $55 \mathrm{kt}$ $\mathrm{NE}$ and $1002 \mathrm{mb}$ at $40.7 \mathrm{~N}, 65.1 \mathrm{~W}$ at $12 \mathrm{Z}$ (COADS). $60 \mathrm{kt} \mathrm{ESE}$ and $1006 \mathrm{mb}$ at $41.0 \mathrm{~N}$, $62.8 \mathrm{~W}$ at $16 \mathrm{Z}$ (MWL). $40 \mathrm{kt} \mathrm{SE}$ and $1006 \mathrm{mb}$ at $41.2 \mathrm{~N}, 65.3 \mathrm{~W}$ at $18 \mathrm{Z}$ (COADS). $40 \mathrm{kt}$ $\mathrm{SE}$ and $1006 \mathrm{mb}$ at $41.2 \mathrm{~N}, 65.3 \mathrm{~W}$ at $18 \mathrm{Z}$ (COADS). $60 \mathrm{kt} \mathrm{W}$ and $1006 \mathrm{mb}$ at $40.9 \mathrm{~N}$, $66.8 \mathrm{~W}$ at $21 \mathrm{Z}$ (MWL). Aircraft highlights: Penetration center fix at $40.3 \mathrm{~N}, 65.2 \mathrm{~W}$ at $14 \mathrm{Z}$ (ATSR). Penetration center fix at 41.7N, 66.5W at 19Z (ATSR).

MWR: “...then threatened Maine on October 8th. It later made an abrupt turn to the right and dissipated over Nova Scotia."

October 9:

HWM analyzes a tropical storm of at most $1010 \mathrm{mb}$ at $43.1 \mathrm{~N}, 67.8 \mathrm{~W}$ with a stationary front to the north at $12 \mathrm{Z}$. HURDAT lists a $40 \mathrm{kt}$ extratropical cyclone at $43.5 \mathrm{~N}, 67.8 \mathrm{~W}$ at 12Z. Microfilm shows a closed low pressure of at most $1011 \mathrm{mb}$ at $43.5 \mathrm{~N}, 67.8 \mathrm{~W}$ with a frontal boundary to the north at 12Z. Ship highlights: $45 \mathrm{kt} \mathrm{W}$ and $1008 \mathrm{mb}$ at $41.8 \mathrm{~N}$, 
67.9W at $00 \mathrm{Z}$ (micro). $40 \mathrm{kt} \mathrm{W}$ and $1008 \mathrm{mb}$ at $42.0 \mathrm{~N}, 68.1 \mathrm{~W}$ at $06 \mathrm{Z}$ (COADS). $45 \mathrm{kt}$ WSW and $1011 \mathrm{mb}$ at $41.9 \mathrm{~N}, 68.0 \mathrm{~W}$ at $12 \mathrm{Z}$ (COADS).

ATSR: "Coming to within 50 miles of the mainland on the 9th, the decaying storm was caught in a westerly current, sharply turned to the northeast and dissipated over Nova Scotia. Only minor damage, mostly due to flooding in Puerto Rico, was attributed to Frances. No loss of life was reported."

October 10:

HWM analyzes a tropical storm of at most $1010 \mathrm{mb}$ at $44.0 \mathrm{~N}, 56.5 \mathrm{~W}$ with an extratropical cyclone to the north at 12Z. HURDAT lists a $35 \mathrm{kt}$ extratropical cyclone at $46.0 \mathrm{~N}, 59.2 \mathrm{~W}$ at $06 \mathrm{Z}$ (last position). Microfilm shows an extratropical cyclone of at most $1008 \mathrm{mb}$ at $50.0 \mathrm{~N}, 62.0 \mathrm{~W}$ at 12Z. Ship highlights: No gales or low pressures.

A tropical wave left the African coast late in September and traveled westward showing little signs of development. Data over the eastern and central Atlantic is sparse and the first signs that the disturbance was becoming better organized occurred on September 28th when it was located about $500 \mathrm{~nm}$ east of the Lesser Antilles. Ship observations on the 28th and 29th show that a sharp trough was present but the disturbance lacked a closed low-level circulation. Genesis is analyzed at 06Z on September 30th as a $35 \mathrm{kt}$ tropical storm based on data later in the day, up from $30 \mathrm{kt}$ originally in HURDAT, a minor intensity change. Time of genesis is the same as originally shown in HURDAT. Very minor track alterations are introduced during the lifetime of this tropical cyclone. Frances moved westward and steadily intensified. The first reconnaissance aircraft reached the storm at $17 \mathrm{Z}$ on the 30th measuring a central pressure of $1007 \mathrm{mb}$ and estimating surface winds of $70 \mathrm{kt}$. At $19 \mathrm{Z}$ on the $30 \mathrm{th}$, another penetration fix measured a central pressure of $1005 \mathrm{mb}$, estimated surface winds of $70 \mathrm{kt}$ and an eye diameter of 8 $\mathrm{nm}$. A central pressure of $1005 \mathrm{mb}$ suggests maximum sustained winds of $37 \mathrm{kt}$ south of $25 \mathrm{~N}$ from the Brown et al. pressure-wind relationship. An eye diameter of $8 \mathrm{~nm}$ suggests an RMW of $6 \mathrm{~nm}$ and the climatological value is $14 \mathrm{~nm}$. Due to the small size of the circulation, forward speed of about $8 \mathrm{kt}$ and using a blend between the pressure-wind value and the visual surface estimate, an intensity of $55 \mathrm{kt}$ is analyzed at $18 \mathrm{Z}$ on the $30 \mathrm{th}$, up from $45 \mathrm{kt}$ originally in HURDAT, a minor intensity change. (Central pressures values for almost every 6 hour period were present in the original HURDAT between September 30 th at $12 \mathrm{Z}$ and October 7 th at $00 \mathrm{Z}$. Some of these were obviously analyses that were added in, not based upon actual observations. Thus, based on actual observations, some were retained, others removed and new central pressure values added. Detailed information on these changes can be found in the table at the end.) 
Frances continued westward on October 1st as it crossed into the eastern Caribbean Sea. A ship at $04 \mathrm{Z}$ on the 1st reported $60 \mathrm{kt} \mathrm{SE}$ and $1012 \mathrm{mb}$ in a heavy squall. Observations from nearby ships and island stations seem to indicate that this measurement had a high bias but it cannot be disregarded due to the small size of the tropical cyclone and earlier visual estimates from the reconnaissance aircraft. The tropical storm made landfall in Guadeloupe around $08 \mathrm{Z}$ with an intensity of $50 \mathrm{kt}$. Frances weakened over the eastern Caribbean Sea during the 1st based on observations from reconnaissance aircrafts and synoptic data. Penetration center fixes at $1455 \mathrm{Z}$ and $1558 \mathrm{Z}$ on the 1 st measured central pressures of $1012 \mathrm{mb}$ and $1011 \mathrm{mb}$, respectively, and the surface wind estimates were only $35 \mathrm{kt}$. Observations from nearby ships and island stations show that these pressure values likely do not represent the central pressure as the synoptic data indicates slightly lower pressure values, thus they were not added to HURDAT as central pressures. Nonetheless, it shows that the tropical cyclone was less organized on the 1st than 24 hours earlier. On the 2nd, the weakened tropical storm passed south of Puerto Rico. Ships observations and reconnaissance aircraft indicate that the low-level circulation of Frances became much disorganized on the 2 nd and the tropical cyclone may have weakened to a strong tropical wave. Late on the 2nd, reconnaissance aircraft data indicate that they were following two centers, one moving westward into the central Caribbean and the other moving northwestward toward Hispaniola. The system is retained as a tropical storm on the 2 nd and early on the 3rd due to the small size of the circulation, which may have persisted but was difficult to locate, and because ship observations indicate that it was producing gale-force winds.

Ships, coastal and reconnaissance aircraft observations indicate that the northwestwardbound center of Frances became the dominant center. Landfall in southeast Dominican Republic is analyzed at $05 \mathrm{Z}$ on the $3 \mathrm{rd}$ as a $45 \mathrm{kt}$ tropical storm. Observations over the northeastern coast of the Dominican Republic late on the 3rd indicate that a closed lowlevel circulation was present. The tropical cyclone began to intensify later on the $3 \mathrm{rd}$ as it passed about $60 \mathrm{~nm}$ east of the Turks and Caicos. A reconnaissance aircraft measured a central pressure of $1005 \mathrm{mb}$ at $01 \mathrm{Z}$ on October 4th. A central pressure of $1005 \mathrm{mb}$ suggests maximum sustained winds of $37 \mathrm{kt}$ from the south of $25 \mathrm{~N}$ pressure-wind relationship. Due to the small circulation of Frances, forward speed of about $13 \mathrm{kt}$ and a ship report of $45 \mathrm{kt}$ at $21 \mathrm{Z}$ on the $3 \mathrm{rd}$, an intensity of $55 \mathrm{kt}$ is analyzed at $0 \mathrm{Z}$ on the $4 \mathrm{th}$, same as originally shown in HURDAT. The next reconnaissance aircraft measured a central pressure of $999 \mathrm{mb}$ and estimated surface winds of $100 \mathrm{kt}$ at $12 \mathrm{Z}$ on the 4 th. A central pressure of $999 \mathrm{mb}$ suggests maximum sustained winds of $49 \mathrm{kt}$ from the south of $25 \mathrm{~N}$ pressure-wind relationship. Based on a forward speed of $14 \mathrm{kt}$, small size of the circulation and weighting in the visual estimate, an intensity of $65 \mathrm{kt}$ is analyzed at $12 \mathrm{Z}$ on the 4th, same as originally shown in HURDAT. Intensification to a hurricane is analyzed at $12 \mathrm{Z}$ on the 4 th, same as originally shown in HURDAT. Late on the 4th, the 
track of Frances turned to the north while located east of the northwestern Bahamas. On October 5th, the small hurricane continued to gain strength while turning to the northeast ahead of an approaching frontal boundary. A reconnaissance aircraft measured a central pressure of $997 \mathrm{mb}$ and estimated an eye diameter of $12 \mathrm{~nm}$. A central pressure of 997 mb suggests maximum sustained winds of $49 \mathrm{kt}$ from the north of $25 \mathrm{~N}$ pressure-wind relationship. An eye diameter of $12 \mathrm{~nm}$ suggests an RMW of $9 \mathrm{~nm}$ and the climatological value is $20 \mathrm{~nm}$. Due to a forward speed of $11 \mathrm{kt}$ and an RMW smaller than the climatological value, an intensity of $65 \mathrm{kt}$ is analyzed at $00 \mathrm{Z}$ on the $5 \mathrm{th}$, down from $75 \mathrm{kt}$ originally in HURDAT, a minor intensity change. The next penetration center fix occurred at $07 \mathrm{Z}$ on the 5 th measuring a central pressure of $991 \mathrm{mb}$ and an eye diameter of 11-13 nm. A central pressure of $991 \mathrm{mb}$ suggests maximum sustained winds of $60 \mathrm{kt}$ from the north of $25 \mathrm{~N}$ intensifying pressure-wind relationship. An eye diameter of 11-13 $\mathrm{nm}$ suggests an RMW of about $9 \mathrm{~nm}$ and the climatological value is $22 \mathrm{~nm}$. Due to a forward speed of $10 \mathrm{kt}$ and an RMW smaller than the climatological value, an intensity of $75 \mathrm{kt}$ is analyzed at $06 \mathrm{Z}$ on the $5 \mathrm{th}$, down from $80 \mathrm{kt}$ originally in HURDAT, a minor intensity change. Another penetration center fix occurred at $1410 \mathrm{Z}$ on the 5 th measuring a central pressure of $973 \mathrm{mb}$. A central pressure of $973 \mathrm{mb}$ suggests maximum sustained winds of $85 \mathrm{kt}$ from the intensifying north of $25 \mathrm{~N}$ pressure-wind relationship. Due to a forward speed of $9 \mathrm{kt}$ and the small size of the circulation, an intensity of $90 \mathrm{kt}$ is analyzed at $12 \mathrm{Z}$ on the 5 th, up from $85 \mathrm{kt}$ originally in HURDAT, a minor intensity change. Advisory \#22 of Hurricane Frances issued on the 5 th at $22 \mathrm{Z}$ shows that a central pressure of $963 \mathrm{mb}$ was measured by the reconnaissance aircraft. The Navy book indicates that penetration center fixes occurred at $1840 \mathrm{Z}$ and $1950 \mathrm{Z}$ on the 5 th corresponding to the advisory data. For the purpose of this reanalysis, the central pressure measurement has been assigned to the $1840 \mathrm{Z}$ penetration center fix, which is closer to the $18 \mathrm{Z}$ time slot on the $5 \mathrm{th}$. A central pressure of $963 \mathrm{mb}$ suggests maximum sustained winds of $96 \mathrm{kt}$ from the intensifying north of $25 \mathrm{~N}$ pressure-wind relationship. Due to the small size of the circulation and forward speed of $9 \mathrm{kt}$, an intensity of $100 \mathrm{kt}$ is analyzed at $18 \mathrm{Z}$ on the 5 th, up from $90 \mathrm{kt}$ originally in HURDAT. Intensification to a major hurricane is analyzed twelve hours earlier than originally shown in HURDAT. At 21Z on the 5th, a ship passed near the center of Frances and reported $55 \mathrm{kt} \mathrm{W}$ and $963 \mathrm{mb}$.

On October 6th, Frances continued to the northeast and kept intensifying. A central pressure of $960 \mathrm{mb}$ was in HURDAT at $00 \mathrm{Z}$ on the 6th and was retained as it appears to be reasonable. A central pressure of $960 \mathrm{mb}$ suggests maximum sustained winds of $95 \mathrm{kt}$ north of $25 \mathrm{~N}$ and $100 \mathrm{kt}$ intensifying from the pressure-wind relationship. Due to the small size of circulation and forward speed of about $11 \mathrm{kt}$, an intensity of $105 \mathrm{kt}$ is analyzed at $00 \mathrm{Z}$ on the $6 \mathrm{th}$, up from $95 \mathrm{kt}$ originally in HURDAT, a minor intensity change. Microfilm shows a central pressure of $965 \mathrm{mb}$ measured by a dropsonde at $11 \mathrm{Z}$ on the 6th. It appears that the dropsonde missed the small center of Frances based on data 
later in the day. A central pressure of $954 \mathrm{mb}$ was in HURDAT at $18 \mathrm{Z}$ on the 6 th and has been retained. A penetration center fix occurred at 19Z, which may have measured that central pressure, and advisory \#26 at $22 \mathrm{Z}$ on the 6 th also mentions a central pressure of $954 \mathrm{mb}$. A central pressure of $991 \mathrm{mb}$ suggests maximum sustained winds of $106 \mathrm{kt}$ from the north of $25 \mathrm{~N}$ intensifying pressure-wind relationship. Based on the small size of the circulation and a forward speed of $14 \mathrm{kt}$, an intensity of $110 \mathrm{kt}$ is analyzed at $18 \mathrm{Z}$ on the 6th, up from $105 \mathrm{kt}$ originally shown in HURDAT. A reconnaissance aircraft measured a central pressure of $948 \mathrm{mb}$, estimated surface winds of $125 \mathrm{kt}$ and an eye diameter of 20 $\mathrm{nm}$ at $22 \mathrm{Z}$ on the $6 \mathrm{th}$. A central pressure of $948 \mathrm{mb}$ suggests maximum sustained winds of $112 \mathrm{kt}$ north of $25 \mathrm{~N}$ intensifying from the pressure-wind relationship. An eye diameter of $20 \mathrm{~nm}$ suggests an RMW of $15 \mathrm{~nm}$ and the climatological value is $22 \mathrm{~nm}$. Due to a forward speed of $14 \mathrm{kt}$ and an RMW smaller than climatology, an intensity of $115 \mathrm{kt}$ is analyzed at $00 \mathrm{Z}$ on the 7th, up from 110 originally shown in HURDAT. $115 \mathrm{kt}$ is also the peak intensity of this tropical cyclone, up from $110 \mathrm{kt}$ originally shown in HURDAT, a minor intensity change. Early on the 7th, Frances passed about $120 \mathrm{~nm}$ northwest of Bermuda where it produced gale-force winds. Late on the 7 th, the hurricane turned to the north. Penetration center fixes occurred late on the 7 th but no central pressures were reported. On October 8th, Frances turned to the northwest posing a threat to the Northeast of the United States. Cooler sea-surface temperatures caused the hurricane to rapidly weaken on the 8th and weakening below major hurricane intensity is analyzed at $06 \mathrm{Z}$ on the 8th, six hours earlier than originally shown in HURDAT. As the hurricane crossed $40 \mathrm{~N}$, cold, dry air started to enter the circulation and the system began to acquire extratropical characteristics. Transition to an extratropical cyclone is analyzed at $18 \mathrm{Z}$ on the 8th, eighteen hours earlier than originally shown in HURDAT. The small cyclone likely transitioned to a post-tropical cyclone as no frontal features are discernable in the ship observations. However, such a stage is uncertain without satellite and will not be formally shown here. An approaching frontal boundary caused the extratropical cyclone to stop its westward advancement and turn to the northeast toward Nova Scotia on October 9 th. Weakening below hurricane intensity is analyzed at $00 \mathrm{Z}$ on the 9 th, six hours earlier than originally shown in HURDAT. The small extratropical cyclone continued to weaken on the 9th and 10th, and it finally merged with another extratropical cyclone to the north around $12 \mathrm{Z}$ on the 10 th. The last position is analyzed at $06 \mathrm{Z}$ on the 10th, same as originally shown in HURDAT.

\begin{tabular}{|c|c|c|c|}
\hline Date & $\begin{array}{c}\text { Original } \\
\text { HURDAT } \\
\text { Central } \\
\text { Pressure }\end{array}$ & \multicolumn{1}{|c|}{ Evidence } & Changes \\
\hline Sep 30 12Z & $1007 \mathrm{mb}$ & $\begin{array}{l}\text { Penetration center fix occurred } \\
\text { at 17Z, closer to the 18Z time } \\
\text { slot }\end{array}$ & Removed \\
\hline
\end{tabular}




\begin{tabular}{|c|c|c|c|}
\hline Sep $3018 Z$ & $1006 \mathrm{mb}$ & $\begin{array}{l}\text { Penetration center fix: } 1005 \mathrm{mb} \\
\text { at } 19 \mathrm{z} \text { on Sep } 30^{\text {th }}\end{array}$ & $1005 \mathrm{mb}$ \\
\hline Oct $112 \mathrm{Z}$ & $10 \odot 4 \mathrm{mb}$ & $\begin{array}{l}\text { Ship reported } 45 \mathrm{kt} \text { SSE and } 1002 \\
\text { mb, and penetration center fixes } \\
\text { reported } 1012 \mathrm{mb} \text { at } 1455 \mathrm{Z} \text { and } \\
1011 \mathrm{mb} \text { at } 1558 \mathrm{Z} \text { on } 0 \mathrm{ct} 1^{\text {st }}\end{array}$ & Removed \\
\hline Oct $2 \odot \odot Z$ & $1010 \mathrm{mb}$ & $\begin{array}{l}\text { Penetration center fix: } 1010 \mathrm{mb} \\
\text { at } 2130 \mathrm{Z} \text { on } 0 \text { ct } 1^{\text {st }}\end{array}$ & \multirow{3}{*}{ Retained } \\
\hline oct $212 Z$ & $1011 \mathrm{mb}$ & $\begin{array}{l}\text { Penetration center fix: } 1011 \mathrm{mb} \\
\text { at } 1140 \mathrm{Z} \text { on } 0 \text { ct } 2^{\text {nd }}\end{array}$ & \\
\hline oct $218 Z$ & $1010 \mathrm{mb}$ & $\begin{array}{l}\text { Penetration center fix: } 1010 \mathrm{mb} \\
\text { at } 1845 \mathrm{Z} \text { on } 0 \mathrm{ct} 2^{\text {nd }}\end{array}$ & \\
\hline Oct $312 Z$ & $1010 \mathrm{mb}$ & $\begin{array}{l}\text { Synoptic data indicate a central } \\
\text { pressure lower than } 1010 \mathrm{mb}\end{array}$ & Removed \\
\hline Oct $4 \odot \odot Z$ & $1005 \mathrm{mb}$ & $\begin{array}{l}\text { Penetration center fix: } 1005 \mathrm{mb} \\
\text { at } 01 \mathrm{z} \text { on } 0 \text { ct } 4^{\text {th }}\end{array}$ & \multirow{4}{*}{ Retained } \\
\hline Oct $412 Z$ & $999 \mathrm{mb}$ & $\begin{array}{l}\text { Penetration center fix: } 999 \mathrm{mb} \text { at } \\
12 Z \text { on } 0 \mathrm{ct} 4^{\text {th }}\end{array}$ & \\
\hline Oct $5 \odot \odot Z$ & 997 mb & $\begin{array}{l}\text { Penetration center fix: } 997 \mathrm{mb} \text { at } \\
\odot \odot \mathrm{z} \text { on Oct } 5^{\text {th }}\end{array}$ & \\
\hline Oct $5 \odot 6 Z$ & 991 mb & $\begin{array}{l}\text { Penetration center fix: } 991 \mathrm{mb} \text { at } \\
12 Z \text { on 0ct } 5^{\text {th }}\end{array}$ & \\
\hline Oct $512 Z$ & $974 \mathrm{mb}$ & $\begin{array}{l}\text { Penetration center fix: } 973 \mathrm{mb} \text { at } \\
1410 \mathrm{z} \text { on } 0 \mathrm{ct} 5^{\text {th }}\end{array}$ & $973 \mathrm{mb}$ \\
\hline Oct $518 Z$ & & $\begin{array}{l}\text { Penetration center fix: } 963 \mathrm{mb} \text { at } \\
1840 \mathrm{Z} \text { on } 0 \mathrm{ct} 5^{\text {th }}\end{array}$ & $963 \mathrm{mb}$ \\
\hline Oct $6 \odot \odot z$ & $960 \mathrm{mb}$ & $\begin{array}{l}\text { No ship or aircraft observation } \\
\text { and appears reasonable }\end{array}$ & Retained \\
\hline Oct $612 \mathrm{Z}$ & $968 \mathrm{mb}$ & $\begin{array}{l}\text { No ship or aircraft observation } \\
\text { and does not appear reasonable } \\
\text { with other available data }\end{array}$ & Removed \\
\hline Oct $618 Z$ & $954 \mathrm{mb}$ & $\begin{array}{l}\text { Penetration center fix: } 954 \mathrm{mb} \text { at } \\
19 \mathrm{Z} \text { on } 0 \mathrm{ct} 6^{\text {th }}\end{array}$ & \multirow{2}{*}{ Retained } \\
\hline Oct $7 \odot \odot Z$ & $948 \mathrm{mb}$ & $\begin{array}{l}\text { Penetration center fix: } 948 \mathrm{mb} \text { at } \\
22 \mathrm{Z} \text { on } 0 \mathrm{ct} 6^{\text {th }}\end{array}$ & \\
\hline
\end{tabular}

Tropical Storm Gerda [October 16-22, 1961]

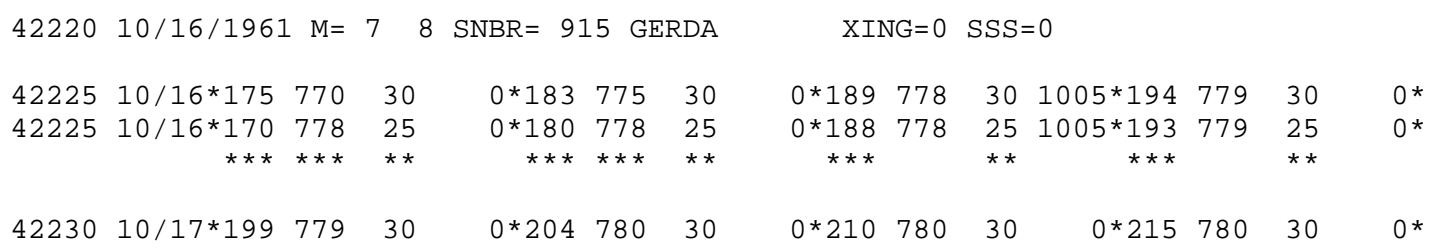




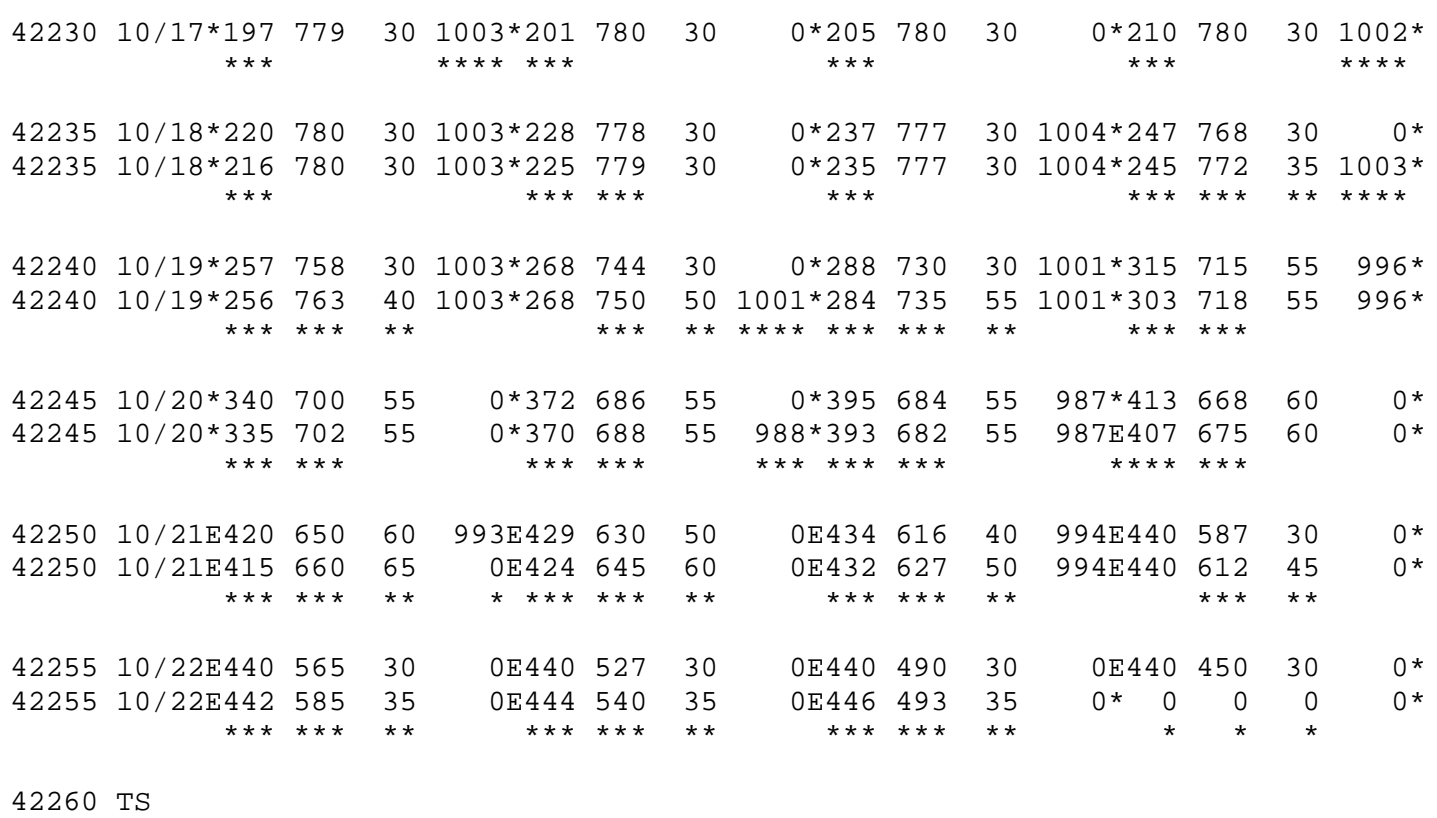

Major changes to the track (only during the extratropical phase) and intensity shown in McAdie et al. (2009). Evidence for these alterations comes from the NHC microfilm maps, the Historical Weather Maps series, the COADS ship database, Monthly Weather Review, Navy reconnaissance book, Mariners Weather Log, Surface Weather Observations, State Climatological Data, Perez et al. (2000) and NHC Storm Wallets.

October 14:

HWM does not analyze an organized system at 12Z. HURDAT does not list an organized system on this date. Microfilm shows a closed low pressure of at most $1008 \mathrm{mb}$ at $15.5 \mathrm{~N}$, $80.5 \mathrm{~W}$ at 12Z. Ship highlights: No gales or low pressures.

October 15:

HWM analyzes a spot low pressure at $15.2 \mathrm{~N}, 78.1 \mathrm{~W}$ with a cold front far to the northwest at 12Z. HURDAT does not list an organized system on this date. Microfilm shows a tropical wave or trough over the central Bahamas and eastern Cuba, with a frontal boundary to the northwest at 12Z. Ship highlights: No gales or low pressures.

ATSR: "On the 15th of October, conditions began to appear very unsettled in the Central Caribbean."

October 16:

HWM analyzes a closed low pressure at $18.0 \mathrm{~N}, 78.0 \mathrm{~W}$ at $12 \mathrm{Z}$. HURDAT lists a $30 \mathrm{kt}$ tropical depression at $18.9 \mathrm{~N}, 77.8 \mathrm{~W}$ at $12 \mathrm{Z}$. Microfilm shows a closed low pressure of at 
most $1008 \mathrm{mb}$ at $18.0 \mathrm{~N}, 79.0 \mathrm{~W}$ at 12Z. Ship highlights: No gales or low pressures. Land highlights: $20 \mathrm{kt} \mathrm{SE}$ and $1004 \mathrm{mb}$ at Cabo Cruz, Cuba at 18Z (micro).

MWR: "Several days before tropical storm Gerda developed, a Navy reconnaissance aircraft investigated an easterly wave in the eastern Caribbean, finding widespread shower activity and some evidence of a weak circulation. However, winds were not strong, generally less than $25 \mathrm{mph}$. The wave continued slowly westward and began to show evidence of intensification the night of the 15th with pressures dropping in the central Caribbean and heavy rain beginning over Jamaica and eastern Cuba. By the morning of the 16th, pressure at Kingston had dropped to $1005 \mathrm{mb}$ with winds both at the surface and aloft indicating a circulation with the center a short distance north of Jamaica." ATSR: "By the 15th of October, widespread shower activity and evidence of a circulation appeared, although wind velocities in general were light. The lowest pressure observed at this time was $1005.9 \mathrm{mb}$ at Jamaica. The circulation remained weak and poorly organized as it began moving northward across Cuba."

October 17:

HWM analyzes a closed low pressure of at most $1005 \mathrm{mb}$ at $20.0 \mathrm{~N}, 78.0 \mathrm{~W}$ at $12 \mathrm{Z}$. HURDAT lists a $30 \mathrm{kt}$ tropical depression at $21.0 \mathrm{~N}, 78.0 \mathrm{~W}$ at $12 \mathrm{Z}$. Microfilm shows an elongated area of low pressure of at most $1004 \mathrm{mb}$ with two centers located at $18.5 \mathrm{~N}$, $82.0 \mathrm{~W}$ and $20.8 \mathrm{~N}, 77.5 \mathrm{~W}$ with a frontal boundary to the north at 12Z. Ship highlights: 15 $\mathrm{kt}$ and $1005 \mathrm{mb}$ at $18.8 \mathrm{~N}, 77.6 \mathrm{~W}$ at $00 \mathrm{Z}$ (COADS). Land highlights: $40 \mathrm{kt} \mathrm{S}$ and $1005 \mathrm{mb}$ at Santiago de Cuba, Cuba at 00Z (micro). $10 \mathrm{kt} \mathrm{NE}$ and $1004 \mathrm{mb}$ at Cabo Cruz, Cuba at 00Z (micro). $1004 \mathrm{mb}$ at Cabo Cruz, Cuba at 12Z (micro). $15 \mathrm{kt} \mathrm{SW}$ and $1004 \mathrm{mb}$ at Cabo Cruz, Cuba at $18 \mathrm{Z}$ (micro).

October 18:

HWM analyzes a closed low pressure of at most $1005 \mathrm{mb}$ at $23.0 \mathrm{~N}, 78.0 \mathrm{~W}$ with a warm front far to the north at 12Z. HURDAT lists a $30 \mathrm{kt}$ tropical depression at $23.7 \mathrm{~N}, 77.7 \mathrm{~W}$ at $12 \mathrm{Z}$. Microfilm shows a closed low pressure of at most $1005 \mathrm{mb}$ at $23.5 \mathrm{~N}, 77.3 \mathrm{~W}$ with a frontal boundary to the north at 12Z. Ship highlights: $25 \mathrm{kt} \mathrm{NNE}$ and $1005 \mathrm{mb}$ at $23.2 \mathrm{~N}$, 80.2W at $06 \mathrm{Z}$ (COADS). Land highlights: $30 \mathrm{kt} \mathrm{S}$ and $1005 \mathrm{mb}$ at Santiago de Cuba, Cuba at $00 \mathrm{Z}$ (micro). $10 \mathrm{kt} \mathrm{SW}$ and $1004 \mathrm{mb}$ at Cabo Cruz, Cuba at 00Z (micro). $15 \mathrm{kt}$ $\mathrm{NE}$ and $1005 \mathrm{mb}$ at Andros Island, Bahamas at 12Z (micro). $10 \mathrm{kt} \mathrm{NNE}$ and $1004 \mathrm{mb}$ at Andros Island, Bahamas at $18 \mathrm{Z}$ (micro).

MWR: "The poorly organized disturbance moved slowly northward across central Cuba, thence northeastward through the western Bahamas on the 18th with slow deepening but winds still only 25 to $40 \mathrm{mph}$ in scattered squalls." ATSR: "Reconnaissance was hampered by air space restrictions, but on the 18th two separate Navy flights investigated 
areas north and south of Cuba, with one flight finding a low pressure area of $1005 \mathrm{mb}$ just east of Andros Island in the Bahamas. No sign of development was encountered."

October 19:

HWM analyzes a closed low pressure of at most $1000 \mathrm{mb}$ at $28.0 \mathrm{~N}, 73.5 \mathrm{~W}$ with a warm front to the north at $12 \mathrm{Z}$. HURDAT lists a $30 \mathrm{kt}$ tropical depression at $28.8 \mathrm{~N}, 73.0 \mathrm{~W}$ at 12Z. Microfilm shows a closed low pressure of at most $1002 \mathrm{mb}$ at $28.5 \mathrm{~N}, 73.0 \mathrm{~W}$ with a frontal boundary to the north at 12Z. Ship highlights: $40 \mathrm{kt} \mathrm{SE}$ and $1007 \mathrm{mb}$ at $25.3 \mathrm{~N}$, $73.6 \mathrm{~W}$ at $00 \mathrm{Z}$ (COADS). $50 \mathrm{kt} \mathrm{SSE}$ and $1007 \mathrm{mb}$ at $24.9 \mathrm{~N}, 73.0 \mathrm{~W}$ at $03 \mathrm{Z}$ (micro/MWL). $45 \mathrm{kt} \mathrm{SE}$ and $1007 \mathrm{mb}$ at $24.5 \mathrm{~N}, 72.4 \mathrm{~W}$ at $06 \mathrm{Z}$ (COADS). $20 \mathrm{kt} \mathrm{SW}$ and $1003 \mathrm{mb}$ at $26.6 \mathrm{~N}, 74.8 \mathrm{~W}$ at $06 \mathrm{Z}$ (COADS). $35 \mathrm{kt} \mathrm{S}$ and $1004 \mathrm{mb}$ at $27.7 \mathrm{~N}, 71.4 \mathrm{~W}$ at $12 \mathrm{Z}$ (COADS). $55 \mathrm{kt} \mathrm{SW}$ (47 kt in MWL) and $1003 \mathrm{mb}$ at $27.8 \mathrm{~N}, 72.0 \mathrm{~W}$ at $14 \mathrm{Z}$ (micro/MWL). $55 \mathrm{kt} \mathrm{S}$ and $1000 \mathrm{mb}$ at $29.2 \mathrm{~N}, 70.9 \mathrm{~W}$ at $18 \mathrm{Z}$ (COADS). $40 \mathrm{kt} \mathrm{SE}$ and $993 \mathrm{mb}$ at $34.0 \mathrm{~N}, 67.1 \mathrm{~W}$ at $21 \mathrm{Z}$ (micro).

MWR: "North of the Bahamas, reconnaissance aircraft found winds up to $60 \mathrm{mph}$ on the morning of the 19th, although the storm still remained poorly organized with a large center and no evidence of a wall cloud." ATSR: "However, on the 19th, ship reports indicated deepening had occurred overnight since 45-knot winds were reported in the eastern quadrant of the low. The first warning on Gerda was issued at 192200Z."

October 20:

HWM analyzes a closed low pressure of at most $990 \mathrm{mb}$ at $39.5 \mathrm{~N}, 67.8 \mathrm{~W}$ with weakening frontal boundaries to the north at $12 \mathrm{Z}$. HURDAT lists a $55 \mathrm{kt}$ tropical storm at $39.5 \mathrm{~N}, 68.4 \mathrm{~W}$ at $12 \mathrm{Z}$. Microfilm shows a closed low pressure of at most $990 \mathrm{mb}$ at $40.0 \mathrm{~N}, 68.0 \mathrm{~W}$ with a frontal boundary to the north at 12Z. Ship highlights: $50 \mathrm{kt} \mathrm{SSW}$ and $993 \mathrm{mb}$ at $33.4 \mathrm{~N}, 67.5 \mathrm{~W}$ at $00 \mathrm{Z}$ (micro). $55 \mathrm{kt} \mathrm{SW}$ and $995 \mathrm{mb}$ at $33.9 \mathrm{~N}, 68.5 \mathrm{~W}$ at 03Z (micro). $40 \mathrm{kt} \mathrm{S}$ and $994 \mathrm{mb}$ at 36.2N, 67.1W at 06Z (COADS). $25 \mathrm{kt} \mathrm{SSE}$ and 991 $\mathrm{mb}$ at $37.2 \mathrm{~N}, 68.6 \mathrm{~W}$ at $06 \mathrm{Z}$ (COADS). $50 \mathrm{kt} \mathrm{SSW}$ and $1004 \mathrm{mb}$ at $39.7 \mathrm{~N}, 63.6 \mathrm{~W}$ at $12 \mathrm{Z}$ (COADS). $55 \mathrm{kt} \mathrm{S}$ and $999 \mathrm{mb}$ at 39.9N, 61.8W at 18Z (COADS). $63 \mathrm{kt} \mathrm{S}$ and $1000 \mathrm{mb}$ at $39.7 \mathrm{~N}, 61.0 \mathrm{~W}$ at $21 \mathrm{Z}$ (MWL). Land highlights: $45 \mathrm{kt} \mathrm{NE}$ (gusts to $57 \mathrm{kt}$ ) and $999 \mathrm{mb}$ at Nantucket Shoals, MA at 0855Z (SWO). $68 \mathrm{kt} \mathrm{NE} \mathrm{(gusts} \mathrm{to} 74 \mathrm{kt}$ ) and $993 \mathrm{mb}$ at Georges Shoals, MA at 1455Z (SWO). $42 \mathrm{kt} \mathrm{N}$ (peak winds, gusts to $54 \mathrm{kt}$ ) at Nantucket, MA at 1630Z (SWO). $65 \mathrm{kt} \mathrm{NE} \mathrm{(gusts} \mathrm{to} 78 \mathrm{kt}$ ) and $989 \mathrm{mb}$ at Georges Shoals, MA at $2055 Z$ (SWO). $68 \mathrm{kt} \mathrm{NNE} \mathrm{(peak} \mathrm{winds,} \mathrm{gusts} \mathrm{to} 80 \mathrm{kt}$ ) at Georges Shoals, MA at 2255Z (SWO).

MWR: "Gerda moved north-northeastward to a position just off Nantucket on the 20th reaching its maximum intensity at that time. Texas Towers off the Massachusetts coast reported whole gale winds, occasionally of hurricane force for short periods." ATSR: 
"Under the influence of a long wave positioned over the eastern seaboard of the United States, Gerda moved in a north-northeasterly direction to a point approximately 120 miles east of Nantucket on the 20th where reports showed it reached its maximum intensity. Texas towers Bravo and Charlie received wind gusts of hurricane force for a short period at this time. The storm then turned east-northeastward, accelerated."

October 21:

HWM analyzes a closed low pressure of at most $1000 \mathrm{mb}$ at $43.0 \mathrm{~N}, 60.0 \mathrm{~W}$ with a frontal boundary going through the center at $12 \mathrm{Z}$. HURDAT lists a $40 \mathrm{kt}$ extratropical cyclone at $43.4 \mathrm{~N}, 61.6 \mathrm{~W}$ at 12Z. Microfilm shows an extratropical cyclone of at most $996 \mathrm{mb}$ at $43.2 \mathrm{~N}, 61.5 \mathrm{~W}$ at $12 \mathrm{Z}$. Ship highlights: $63 \mathrm{kt} \mathrm{S}$ and $1000 \mathrm{mb}$ at $39.8 \mathrm{~N}, 61.4 \mathrm{~W}$ at $00 \mathrm{Z}$ (MWL). $35 \mathrm{kt} \mathrm{S}$ and $984 \mathrm{mb}$ at $41.0 \mathrm{~N}, 65.6 \mathrm{~W}$ at $00 \mathrm{Z}$ (COADS). $25 \mathrm{kt} \mathrm{NW}$ and $991 \mathrm{mb}$ at $41.6 \mathrm{~N}, 65.2 \mathrm{~W}$ at $06 \mathrm{Z}$ (COADS). $60 \mathrm{kt} \mathrm{N}$ and $1000 \mathrm{mb}$ at $41.6 \mathrm{~N}, 67.9 \mathrm{~W}$ at $06 \mathrm{Z}$ (micro). $50 \mathrm{kt} \mathrm{SW}$ and $999 \mathrm{mb}$ at $42.0 \mathrm{~N}, 62.0 \mathrm{~W}$ at $12 \mathrm{Z}$ (COADS). $15 \mathrm{kt} \mathrm{SSW}$ and $996 \mathrm{mb}$ at $43.5 \mathrm{~N}, 62.2 \mathrm{~W}$ at $12 \mathrm{Z}$ (COADS). $45 \mathrm{kt} \mathrm{ENE}$ and $1008 \mathrm{mb}$ at $46.5 \mathrm{~N}, 57.0 \mathrm{~W}$ at $18 \mathrm{Z}$ (COADS). $15 \mathrm{kt} \mathrm{SW}$ and $999 \mathrm{mb}$ at 43.4N, 61.1W at 18Z (COADS). Land highlights: Estimated $50 \mathrm{kt} \mathrm{N}$ (gusts to $60 \mathrm{kt}$ ) at Georges Shoals, MA at 0055Z (SWO). Estimated 60 kt N (gusts to $75 \mathrm{kt}$ ) at Georges Shoals, MA at 0458Z (SWO). $42 \mathrm{kt} \mathrm{NNW} \mathrm{(gusts} \mathrm{to} 49$ kt) and $1006 \mathrm{mb}$ at Georges Shoals, MA at 1158Z (SWO). $34 \mathrm{kt} \mathrm{NE} \mathrm{(gusts} \mathrm{to} 42 \mathrm{kt}$ ) and $1009 \mathrm{mb}$ at Georges Shoals, MA at 1456Z (SWO).

MWR: "From this position Gerda turned to an east-northeastward course gradually accelerating and becoming extratropical on the 21st. Although Gerda had most of the characteristics of a tropical storm at low levels, conditions in the upper troposphere were not favorable for strong deepening.” ATSR: “...became extratropical on the 21st.”

October 22:

HWM analyzes a spot low pressure at $43.2 \mathrm{~N}, 49.5 \mathrm{~W}$ with a frontal boundary close to the north at 12Z. HURDAT lists a $30 \mathrm{kt}$ extratropical depression at $44.0 \mathrm{~N}, 49.0 \mathrm{~W}$ at $12 \mathrm{Z}$. Microfilm shows an extratropical cyclone of at most $1008 \mathrm{mb}$ at $44.0 \mathrm{~N}, 48.0 \mathrm{~W}$ at $12 \mathrm{Z}$. Ship highlights: $35 \mathrm{kt} \mathrm{NE}$ and $1009 \mathrm{mb}$ at $46.5 \mathrm{~N}, 55.6 \mathrm{~W}$ at $00 \mathrm{Z}$ (COADS). $35 \mathrm{kt} \mathrm{SW}$ and $1012 \mathrm{mb}$ at $41.1 \mathrm{~N}, 48.0 \mathrm{~W}$ at $06 \mathrm{Z}$ (COADS). $35 \mathrm{kt} \mathrm{WSW}$ and $1019 \mathrm{mb}$ at $40.6 \mathrm{~N}, 46.3 \mathrm{~W}$ at $18 \mathrm{Z}(\mathrm{COADS})$.

October 23:

HWM analyzes an extratropical cyclone of at most $995 \mathrm{mb}$ at $49.0 \mathrm{~N}, 27.0 \mathrm{~W}$ at $12 \mathrm{Z}$. HURDAT does not list an organized system on this date. Microfilm shows an extratropical cyclone at $49.5 \mathrm{~N}, 25.8 \mathrm{~W}$ at $12 \mathrm{Z}$. Ship highlights: $40 \mathrm{kt} \mathrm{SW}$ and $998 \mathrm{mb}$ at $46.4 \mathrm{~N}, 26.6 \mathrm{~W}$ at $12 \mathrm{Z}$ (COADS). 
MWR: "Reconnaissance aircraft did not report any indication of wall cloud formation or spiral bands at any time of the strong winds at the course of the storm. Even at the time of the strong winds at the Texas towers, an Air Force reconnaissance aircraft very near their location reported winds of only $10 \mathrm{kt}$ at $700 \mathrm{mb}$. A low-level injection of polar air into Gerda was occurring at this time and the circulation apparently was quite shallow. Damage from Gerda was not heavy although according to press reports information was received from eastern Cuba of extensive flooding resulting in seven deaths. Five deaths were reported from Jamaica due to drowning. Heavy rains occurred for several days over Jamaica and extreme eastern Cuba. Orographic effects probably caused excessive amounts with flash flooding quite common over the more mountainous sections of these areas. Damage through the New England area was about the same as that from a typical wintertime northeaster. The strong winds reported by the Texas Towers did not occur on the coast where 30 to $50 \mathrm{mph}$ were the strongest winds reported." ATSR: "Except for its nascent stage, Gerda seemed to exhibit both tropical and extratropical characteristics. There was never any reports signifying the existence of either a wall cloud or spiral bands throughout the life of the storm. At the same time that the Texas towers were being buffeted with hurricane force gusts, an Air Force reconnaissance plane at $700 \mathrm{mn}$, near the same location, found only light winds, indicating a shallow system. Throughout Gerda's cycle a cold low was located over the eastern United States in the upper levels and her existence appeared to begin and end in the warm tongue to the east of the cold low. Gerda left only moderate damage in her path. Extensive flooding resulting from heavy rains was reported by the press to have caused a total of 12 deaths in eastern Cuba and Jamaica. The New England area received only moderate gale winds along the coastal sections."

A broad disturbance developed in the central Caribbean Sea around October 14th. Under weak steering currents, the disturbance slowly drifted northward becoming better organized. Genesis is analyzed at $00 \mathrm{Z}$ on October 16th as a $25 \mathrm{kt}$ tropical depression, down from 30 kt originally shown in HURDAT. Minor track alterations are introduced during the lifetime of this system as a tropical cyclone. Major track alterations are introduced on October $21 \mathrm{st}$ at $18 \mathrm{Z}$ and October $22 \mathrm{nd}$ at $00 \mathrm{Z}$ when it was an extratropical cyclone based on synoptic data. The tropical depression remained embedded in a large area of low pressure and was elongated southwest-northeast. A central pressure of $1005 \mathrm{mb}$ was present in HURDAT at $12 \mathrm{Z}$ on the 16th and has been retained as it appears reasonable (but could not be verified, which occurred several times during the lifetime of this system). Late on the 16th, the center of the depression was located between eastern Cuba and Jamaica and a frontal boundary stretched across the Florida Straits. Cabo Cruz, Cuba reported $10 \mathrm{kt} \mathrm{NE}$ and $1004 \mathrm{mb}$ at $00 \mathrm{Z}$ on October 17th, suggesting a central pressure of $1003 \mathrm{mb}$, which has been added to HURDAT. Santiago de Cuba reported $40 \mathrm{kt} \mathrm{S}$ at $00 \mathrm{Z}$ on the 17th but it was determined that this station 
continuously reported winds higher than nearby observations, which is suspect. Thus the tropical cyclone was retained at tropical depression intensity. On the 17th, surface observations indicate that the center of the tropical depression was ill-defined and the system resembled a trough of low pressure extended from eastern Cuba to the eastern coast of Nicaragua. The ill-defined center of the tropical depression made landfall in Cuba around $15 Z$ on the 17 th. Perez et al. (2000) does not show this system as a tropical storm impacting Cuba, same as our reanalysis. Camaguey, Cuba reported $5 \mathrm{kt} \mathrm{NE}$ and $1004 \mathrm{mb}$ at $18 \mathrm{Z}$ on the $17 \mathrm{th}$, suggesting a central pressure of $1003 \mathrm{mb}$, which has been added to HURDAT. Central pressures of $1003 \mathrm{mb}$ and $1004 \mathrm{mb}$ were present in HURDAT at $00 \mathrm{Z}$ and 12Z, respectively, on October 18th and both have been retained as they seem reasonable with the available data. On the 18th, the low-level circulation became better organized as the tropical depression moved into the western Bahamas. A strong pressure gradient to the northwest of the cyclone caused gale-force winds, about $300 \mathrm{~nm}$ from the center. These winds were not considered to be part of the circulation. Andros Island reported $10 \mathrm{kt} \mathrm{NNE}$ and $1004 \mathrm{mb}$ at $18 \mathrm{Z}$ on the 18th, suggesting a central pressure of $1003 \mathrm{mb}$, which has been added to HURDAT. Intensification to a tropical storm is analyzed at $18 \mathrm{Z}$ on the 18 th based on data early on the 19th. This transition is eighteen hours earlier than originally shown in HURDAT.

Gerda intensified on the 19th as it moved away from the Bahamas. Central pressures of $1003 \mathrm{mb}, 1001 \mathrm{mb}$ and $996 \mathrm{mb}$ were present in HURDAT at 00Z, 12Z and $18 Z$, respectively, on October 19th and all three have been retained as they seem reasonable with the available data. A ship reported $20 \mathrm{kt} \mathrm{SW}$ and $1003 \mathrm{mb}$ at $06 \mathrm{Z}$ on the 19th, suggesting a central pressure of $1001 \mathrm{mb}$, which has been added to HURDAT. Based on surface observations of $50 \mathrm{kt}$ at $03 \mathrm{Z}$ and $55 \mathrm{kt}$ at $14 \mathrm{Z}$, an intensity of $50 \mathrm{kt}$ is analyzed at $06 \mathrm{Z}$ and $55 \mathrm{kt}$ at $12 \mathrm{Z}$ on the 19 th, up from $30 \mathrm{kt}$ originally in HURDAT at both times, major intensity changes. $55 \mathrm{kt}$ is also the peak intensity of this system as a tropical cyclone, down from $60 \mathrm{kt}$ originally in HURDAT, a minor intensity change. Gerda increased in forward speed on October 20th traveling between Bermuda and East Coast of the United States. A ship reported $25 \mathrm{kt} \mathrm{SSE}$ and $991 \mathrm{mb}$ at $06 Z$ on the 20th, suggesting a central pressure of $988 \mathrm{mb}$, which has been added to HURDAT. A central pressure of $987 \mathrm{mb}$ was present in HURDAT at 12Z on October 20th and has been retained as it seems reasonable with the available data. Synoptic observations indicate that Gerda began to transition into an extratropical cyclone around midday on the 20th with a distinct temperature gradient across the circulation and the beginning of frontogenesis. Transition to an extratropical cyclone is analyzed at $18 \mathrm{Z}$ on the 20 th, six hours earlier than originally shown in HURDAT. Gerda remained a powerful extratropical cyclone and the offshore platforms off Massachusetts recorded hurricaneforce winds. Georges Shoals, MA reported $68 \mathrm{kt}$ at $1455 \mathrm{Z}$ and 2255Z. At an elevation of 200 feet, this suggests sustained winds of about $60 \mathrm{kt}$ at the surface. A ship reported $63 \mathrm{kt}$ 
at $21 \mathrm{Z}$ on the 20 th and $00 \mathrm{Z}$ on the $21 \mathrm{st}$. An intensity of $65 \mathrm{kt}$ is analyzed at $00 \mathrm{Z}$ on the $21 \mathrm{st}$, up from $60 \mathrm{kt}$ originally in HURDAT, a minor intensity change. A central pressure of $993 \mathrm{mb}$ was present in HURDAT at $00 \mathrm{Z}$ on the $21 \mathrm{st}$ and has been removed due to a ship close to the center that reported $35 \mathrm{kt} \mathrm{SSW}$ and $984 \mathrm{mb}$. On the $21 \mathrm{st}$, the extratropical cyclone turned to the northeast and moved away from the United States while gradually losing strength. Weakening below hurricane intensity is analyzed at $06 \mathrm{Z}$ on the $21 \mathrm{st}$. A central pressure of $994 \mathrm{mb}$ is analyzed at $12 \mathrm{Z}$ on the $21 \mathrm{st}$ and has been retained as it seems reasonable with the available data. HURDAT originally showed the extratropical cyclone weakening below gale-force at $18 \mathrm{Z}$ on the 21 st but ship observations suggest that it retained minimal gale-force winds until dissipation. On October 22nd, the extratropical cyclone continued to weaken and degenerated into trough of low pressure over the north Atlantic after $12 \mathrm{Z}$ on the $22 \mathrm{nd}$. The last position is analyzed at $12 \mathrm{Z}$ on the 22nd, six hours earlier than originally shown in HURDAT. While in the Caribbean Sea, Gerda resembled Tropical Storm Nicole in 2010 by not having a well-defined low level circulation.

\section{Hurricane Hattie [October 27 - November 1, 1961]}

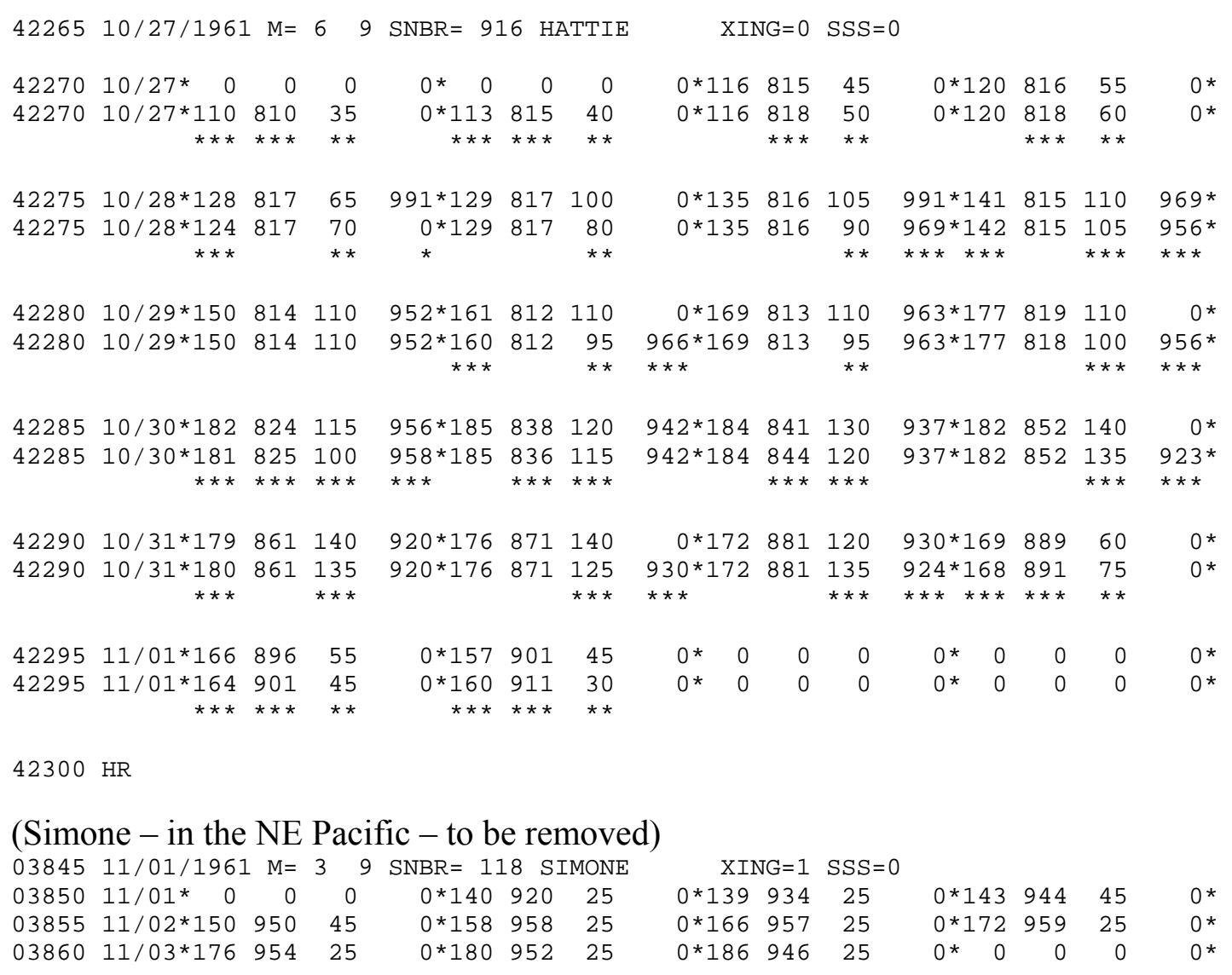


03865 TS

Hurricane Landfall

10/31 13Z 17.1N 88.3W 135 kt Belize

Minor changes to the track and major changes to the intensity shown in McAdie et al. (2009). Evidence for these alterations comes from the NHC microfilm maps, the Historical Weather Maps series, the COADS ship database, Monthly Weather Review, Navy reconnaissance book, Mariners Weather Log, Mexican synoptic maps and NHC Storm Wallets.

October 25:

HWM and HURDAT do not analyze an organized system on this date. Microfilm shows a closed low pressure of at most $1008 \mathrm{mb}$ at $11.0 \mathrm{~N}, 79.2 \mathrm{~W}$ at 12Z. Ship highlights: No gales or low pressures.

October 26:

HWM analyzes a spot low pressure at $10.2 \mathrm{~N}, 82.0 \mathrm{~W}$ at $12 \mathrm{Z}$. HURDAT does not list an organized system on this date. Microfilm shows a closed low pressure of at most 1008 $\mathrm{mb}$ at $10.0 \mathrm{~N}, 80.2 \mathrm{~W}$ at $12 \mathrm{Z}$. Ship highlights: $35 \mathrm{kt} \mathrm{E}$ and $1009 \mathrm{mb}$ at $13.5 \mathrm{~N}, 77.6 \mathrm{~W}$ at $12 \mathrm{Z}(\mathrm{COADS})$.

ATSR: "Not since Hurricane Charlie of 1951 and Hurricane Janet of 1955 has a tropical storm in the western Caribbean taken a great toll of human life as the "killer" storm of the 1961 season, Hurricane Hattie, which claimed at least 300 victims with many more missing and presumed dead. Considerable rainfall, widespread altostratus, and slighly higher than normal winds were observed in the extreme southwestern Caribbean early on the 26th of October."

October 27:

HWM analyzes a tropical storm of at most $1005 \mathrm{mb}$ at $11.2 \mathrm{~N}, 81.5 \mathrm{~W}$ at $12 \mathrm{Z}$. HURDAT lists a $45 \mathrm{kt}$ tropical storm at $11.6 \mathrm{~N}, 81.5 \mathrm{~W}$ at $12 \mathrm{Z}$ (first position). Microfilm shows a closed low pressure of at most $1008 \mathrm{mb}$ at $11.8 \mathrm{~N}, 81.4 \mathrm{~W}$ at $12 \mathrm{Z}$. Ship highlights: $30 \mathrm{kt} \mathrm{S}$ and $1007 \mathrm{mb}$ at $10.9 \mathrm{~N}, 80.1 \mathrm{~W}$ at $00 \mathrm{Z}$ (COADS). $20 \mathrm{kt} \mathrm{NE}$ and $1004 \mathrm{mb}$ at $11.4 \mathrm{~N}, 82.0 \mathrm{~W}$ at $06 Z$ (COADS). Land highlights: $40 \mathrm{kt} \mathrm{ESE}$ and $1004 \mathrm{mb}$ at San Andres, Colombia at $18 Z$ (micro).

MWR: "Hurricane Hattie was the killer storm of the 1961 hurricane season, although property damage mas much greater in Carla. Approximately 275 people perished in Hattie. Not since hurricane Janet, 1955, has a storm inflicted so much damage in the 
Yucatan Peninsula region. The first indication of a tropical storm came from a ship, located about 120 rides south-southeast of San Andres Island at 1900 EST, October 26, reporting the 40-kt southerly wind. By 1000 EST, October 27, the airport at San Andres Island reported that it was closed because of 40- to 50-kt. easterly winds and, based on this report, the first tropical storm advisory for Hattie was issued by the Miami Weather Bureau at 1700 EST." ATSR: "A ship about 120 miles south-southeast of San Andres Island reported a southerly wind of 30 knots at $270000 \mathrm{Z}$ with 8 -foot seas from the south. At $271500 \mathrm{Z}$ the airport at San Andres radioed that it was closed due to 30 to 40 knot easterly winds and foul weather. The first warning for Hattie was issued at 272200Z. After passing over San Andres Island on the afternoon of the 27th, the storm moved northward and intensified."

October 28:

HWM analyzes a hurricane of at most $1000 \mathrm{mb}$ at $13.3 \mathrm{~N}, 81.6 \mathrm{~W}$ at $12 \mathrm{Z}$. HURDAT lists a $105 \mathrm{kt}$ hurricane at $13.5 \mathrm{~N}, 81.6 \mathrm{~W}$ at $12 \mathrm{Z}$. Microfilm shows a closed low pressure of at most $1002 \mathrm{mb}$ at $13.9 \mathrm{~N}, 81.6 \mathrm{~W}$ at 12Z. Ship highlights: $25 \mathrm{kt}$ ENE and $1005 \mathrm{mb}$ at $13.5 \mathrm{~N}, 81.5 \mathrm{~W}$ at $00 \mathrm{Z}$ (COADS). $30 \mathrm{kt} \mathrm{NW}$ and $1005 \mathrm{mb}$ at $12.8 \mathrm{~N}, 83.0 \mathrm{~W}$ at $18 \mathrm{Z}$ (COADS). Land highlights: $70 \mathrm{kt}$ (gusts to $90 \mathrm{kt}$ ) at San Andres, Colombia (time not given, likely early on the 28th) (MWR). $50 \mathrm{kt} \mathrm{ESE} \mathrm{and} 993 \mathrm{mb}$ at San Andres, Colombia at 00Z (micro). $991 \mathrm{mb}$ at San Andres, Colombia at 01Z (MWR). $15 \mathrm{kt} \mathrm{SW}$ and $1004 \mathrm{mb}$ at San Andres, Colombia at $12 \mathrm{Z}$ (micro). $35 \mathrm{kt} \mathrm{W}$ and $1005 \mathrm{mb}$ at San Andres, Colombia at $18 \mathrm{Z}$ (micro). $15 \mathrm{kt} \mathrm{NW}$ and $1001 \mathrm{mb}$ at Puerto Cabezas, Nicaragua at $21 \mathrm{Z}$ (micro). Aircraft highlights: Radar center fix at $12.4 \mathrm{~N}, 81.5 \mathrm{~W}$ at $0322 \mathrm{Z}$ (ATSR). Penetration center fix measured a central pressure of $998 \mathrm{mb}$ and an eye diameter of $20 \mathrm{~nm}$ at $13.0 \mathrm{~N}$, $81.7 \mathrm{~W}$ at $07 \mathrm{Z}$ (ATSR). Penetration center fix measured a central pressure of $969 \mathrm{mb}$, estimated surface winds of $110 \mathrm{kt}$ and an eye diameter of $20 \mathrm{~nm}$ at $13.6 \mathrm{~N}, 81.6 \mathrm{~W}$ at $1247 \mathrm{Z}$ (ATSR). Penetration center fix measured a central pressure of $963 \mathrm{mb}$ at $13.8 \mathrm{~N}$, $81.6 \mathrm{~W}$ at $15 \mathrm{Z}$ (ATSR). Penetration center fix measured a central pressure of $964 \mathrm{mb}$, estimated surface winds of $110 \mathrm{kt}$ and an eye diameter of $10 \mathrm{~nm}$ at $14.4 \mathrm{~N}, 81.6 \mathrm{~W}$ at 1935Z (ATSR). Penetration center fix measured a central pressure of $956 \mathrm{mb}$ and estimated surface winds of $100 \mathrm{kt}$ at $14.3 \mathrm{~N}, 81.6 \mathrm{~W}$ at $20 \mathrm{Z}$ (ATSR).

MWR: "Hattie passed over or just to the west of San Andres in the late afternoon of the 27th. A minimum pressure of $991 \mathrm{mb}$ was observed at $2100 \mathrm{EST}$, October 27, and highest steady winds were $70 \mathrm{kt}$ with 90 -kt gusts. One person was killed on the island and 15 were injured, with property damage estimated at $\$ 300,000$.” ATSR: “A Navy reconnaissance plane obtained a nighttime fix on Hattie early on the 28th and reported a poorly defined eye and a surface pressure by dropsonde of $998 \mathrm{mb}$.

October 29: 
HWM analyzes a hurricane of at most $990 \mathrm{mb}$ at $16.5 \mathrm{~N}, 81.2 \mathrm{~W}$ at $12 \mathrm{Z}$. HURDAT lists a $110 \mathrm{kt}$ hurricane at $16.9 \mathrm{~N}, 81.3 \mathrm{~W}$ at $12 \mathrm{Z}$. Microfilm shows a closed low pressure of at most $1002 \mathrm{mb}$ at $16.5 \mathrm{~N}, 81.2 \mathrm{~W}$ at 12Z. Ship highlights: Ship highlights: $30 \mathrm{kt} \mathrm{NW}$ and $1004 \mathrm{mb}$ at $14.4 \mathrm{~N}, 83.1 \mathrm{~W}$ at $00 \mathrm{Z}$ (COADS). $35 \mathrm{kt} \mathrm{E}$ and $1009 \mathrm{mb}$ at $19.5 \mathrm{~N}, 79.0 \mathrm{~W}$ at $06 \mathrm{Z}$ (micro). $35 \mathrm{kt} \mathrm{SSW}$ and $1004 \mathrm{mb}$ at $15.2 \mathrm{~N}, 80.7 \mathrm{~W}$ at $09 \mathrm{Z}$ (micro). $35 \mathrm{kt} \mathrm{ESE}$ and $1010 \mathrm{mb}$ at $19.9 \mathrm{~N}, 79.9 \mathrm{~W}$ at $12 \mathrm{Z}$ (COADS). $35 \mathrm{kt} \mathrm{SSW}$ and $1007 \mathrm{mb}$ at $15.7 \mathrm{~N}, 81.0 \mathrm{~W}$ at $15 \mathrm{Z}$ (micro). $40 \mathrm{kt} \mathrm{NE}$ and $1006 \mathrm{mb}$ at $19.2 \mathrm{~N}, 83.3 \mathrm{~W}$ at $18 \mathrm{Z}$ (COADS). $50 \mathrm{kt} \mathrm{NE}$ at $19.5 \mathrm{~N}, 84.0 \mathrm{~W}$ at $21 \mathrm{Z}$ (micro). Land highlights: $10 \mathrm{kt} \mathrm{N}$ and $1003 \mathrm{mb}$ at Cabo Gracias a Dios, Honduras at 00Z (micro). $15 \mathrm{kt} \mathrm{NE}$ and $1005 \mathrm{mb}$ at Swan Islands, Honduras at 09Z (micro). $25 \mathrm{kt} \mathrm{NE}$ and $1004 \mathrm{mb}$ at Grand Cayman at 18Z (micro). $30 \mathrm{kt} \mathrm{E}$ and $1002 \mathrm{mb}$ at Grand Cayman at $21 \mathrm{Z}$ (micro). Aircraft highlights: Penetration center fix measured a central pressure of $952 \mathrm{mb}$ at $15.1 \mathrm{~N}, 81.4 \mathrm{~W}$ at $0030 \mathrm{Z}$ (WALLET). Penetration center fix measured a central pressure of $966 \mathrm{mb}$ and estimated an eye diameter of $12 \mathrm{~nm}$ at $16.3 \mathrm{~N}$, $81.2 \mathrm{~W}$ at $07 \mathrm{Z}$ (ATSR). Penetration center fix measured a central pressure of $963 \mathrm{mb}$, estimated surface winds of $110 \mathrm{kt}$ and an eye diameter of $40 \mathrm{~nm}$ at $17.0 \mathrm{~N}, 81.4 \mathrm{~W}$ at $13 \mathrm{Z}$ (ATSR). Penetration center fix measured a central pressure of $956 \mathrm{mb}$, estimated surface winds of $110 \mathrm{kt}$ and an eye diameter of $40 \mathrm{~nm}$ at $18.0 \mathrm{~N}, 82.2 \mathrm{~W}$ at $1915 \mathrm{Z}$ (ATSR).

ATSR: "Twenty-four hours later another Navy aircraft reported a $963 \mathrm{mb}$ surface pressure, showing rapidly development had occurred. Hattie continued her northerly course until approximately 291000Z, then began a wide cyclonic curve before eventually ending up on a west-southwest course. This turn is probably accounted for by marked height rises to the north and north-west of the storm in conjection with a cut-off low over the southwestern United States in the upper levels. Hattie's continuing increase in intensity, coinciding with the $500 \mathrm{mb}$ height rises, supports the thumb rule that one can expect intensification when height rises occur north of the storm."

October 30:

HWM analyzes a hurricane of at most $990 \mathrm{mb}$ at $18.0 \mathrm{~N}, 84.3 \mathrm{~W}$ at $12 \mathrm{Z}$. HURDAT lists a $130 \mathrm{kt}$ hurricane at $18.4 \mathrm{~N}, 84.1 \mathrm{~W}$ at $12 \mathrm{Z}$. Microfilm shows a closed low pressure of at most $993 \mathrm{mb}$ at $18.5 \mathrm{~N}, 84.5 \mathrm{~W}$ at $12 \mathrm{Z}$. Ship highlights: $40 \mathrm{kt} \mathrm{N}$ at $18.2 \mathrm{~N}, 83.6 \mathrm{~W}$ at $00 \mathrm{Z}$ (COADS). $35 \mathrm{kt} \mathrm{SW}$ and $1005 \mathrm{mb}$ at $16.3 \mathrm{~N}, 82.5 \mathrm{~W}$ at $06 \mathrm{Z}$ (COADS). $50 \mathrm{kt} \mathrm{N}$ and 1004 $\mathrm{mb}$ at $18.0 \mathrm{~N}, 85.3 \mathrm{~W}$ at $12 \mathrm{Z}$ (COADS). $45 \mathrm{kt} \mathrm{NW}$ and $999 \mathrm{mb}$ at $17.4 \mathrm{~N}, 85.2 \mathrm{~W}$ at $15 \mathrm{Z}$ (micro). $70 \mathrm{kt} \mathrm{W}$ and $1000 \mathrm{mb}$ at $17.4 \mathrm{~N}, 85.2 \mathrm{~W}$ at $18 \mathrm{Z}$ (micro). $75 \mathrm{kt} \mathrm{SSW}$ and $991 \mathrm{mb}$ at $17.1 \mathrm{~N}, 85.0 \mathrm{~W}$ at $21 \mathrm{Z}$ (micro). Land highlights: $15 \mathrm{kt} \mathrm{NNW}$ and $1002 \mathrm{mb}$ at Swan Islands, Honduras at 00Z (micro). $20 \mathrm{kt} \mathrm{W}$ and $1000 \mathrm{mb}$ at Swan Islands, Honduras at 06Z (micro). $30 \mathrm{kt} \mathrm{WSW}$ and $997 \mathrm{mb}$ at Swan Islands, Honduras at 09Z (micro). $35 \mathrm{kt} \mathrm{SW}$ and $996 \mathrm{mb}$ at Swan Islands, Honduras at 12Z (micro). $50 \mathrm{kt} \mathrm{SW}$ and $999 \mathrm{mb}$ at Swan Islands, Honduras at 15Z (micro). $45 \mathrm{kt} \mathrm{SSW}$ and $1002 \mathrm{mb}$ at Swan Islands, Honduras at 
18Z (micro). $40 \mathrm{kt} \mathrm{S}$ and $1002 \mathrm{mb}$ at Swan Islands, Honduras at $21 \mathrm{Z}$ (micro). Aircraft highlights: Penetration center fix measured a central pressure of $958 \mathrm{mb}$ and estimated an eye diameter of $30 \mathrm{~nm}$ at $18.1 \mathrm{~N}, 82.6 \mathrm{~W}$ at $01 \mathrm{Z}$ (ATSR). Penetration center fix measured a central pressure of $942 \mathrm{mb}$ and estimated an eye diameter of $28 \mathrm{~nm}$ at $18.5 \mathrm{~N}, 83.9 \mathrm{~W}$ at 07Z (ATSR). Penetration center fix measured a central pressure of $937 \mathrm{mb}$, estimated surface winds of $115 \mathrm{kt}$ and an eye diameter of $25 \mathrm{~nm}$ at $18.5 \mathrm{~N}, 84.2 \mathrm{~W}$ at $10 \mathrm{Z}$ (ATSR). Penetration center fix measured a central pressure of $924 \mathrm{mb}$, estimated surface winds of $130 \mathrm{kt}$ and an eye diameter of $20 \mathrm{~nm}$ at $18.4 \mathrm{~N}, 84.5 \mathrm{~W}$ at $15 \mathrm{Z}$ (ATSR). Penetration center fix measured a central pressure of $923 \mathrm{mb}$ and estimated an eye diameter of $20 \mathrm{~nm}$ at $18.3 \mathrm{~N}, 85.0 \mathrm{~W}$ at $17 \mathrm{Z}$ (ATSR). Penetration center fix measured a central pressure of 920 $\mathrm{mb}$ and estimated an eye diameter of $22 \mathrm{~nm}$ at $18.0 \mathrm{~N}, 86.0 \mathrm{~W}$ at $22 \mathrm{Z}$ (ATSR).

MWR: "From this point Hattie continued on a generally northerly course for the next 36 hours and intensified with the central pressure reaching $952 \mathrm{mb}$ near $15^{\circ} \mathrm{N}$. By $1900 \mathrm{EST}$, October 29, a change to a more westerly course became clearly evident. The storm continued on a cyclonic turn passing between Swan and Cayman Islands with maximum winds on these two islands remaining under hurricane force. Hattie finally settled on a west-southwestward course and intensified markedly during the morning of October 30 when the central pressure probably reached its lowest value, $924 \mathrm{mb}$ at $0800 \mathrm{EST}$. A lower pressure of $920 \mathrm{mb}$ was computed at $1700 \mathrm{EST}$; however, this was based upon the $700 \mathrm{mb}$ height and not determined by dropsonde." ATSR: "On the 30th a central pressure of $923 \mathrm{mb}$ was reported by dropsonde."

October 31:

HWM analyzes a hurricane of at most $985 \mathrm{mb}$ at $17.1 \mathrm{~N}, 88.0 \mathrm{~W}$ at $12 \mathrm{Z}$. HURDAT lists a $120 \mathrm{kt}$ hurricane at $17.2 \mathrm{~N}, 88.1 \mathrm{~W}$ at $12 \mathrm{Z}$. Microfilm shows a closed low pressure of at most $1002 \mathrm{mb}$ at $17.2 \mathrm{~N}, 88.2 \mathrm{~W}$ at 12Z. Ship highlights: $65 \mathrm{kt} \mathrm{SW}$ and $980 \mathrm{mb}$ at $17.3 \mathrm{~N}$, 85.0W at $00 \mathrm{Z}$ (micro). $40 \mathrm{kt} \mathrm{SE}$ and $1009 \mathrm{mb}$ at $19.8 \mathrm{~N}, 84.7 \mathrm{~W}$ at $03 \mathrm{Z}$ (micro). $60 \mathrm{kt} \mathrm{SE}$ and $996 \mathrm{mb}$ at $17.8 \mathrm{~N}, 85.4 \mathrm{~W}$ at $06 \mathrm{Z}$ (COADS). $30 \mathrm{kt} \mathrm{E}$ and $1003 \mathrm{mb}$ at $18.1 \mathrm{~N}, 85.5 \mathrm{~W}$ at $12 \mathrm{Z}$ (COADS). $35 \mathrm{kt} \mathrm{NW}$ and $1005 \mathrm{mb}$ at $13.4 \mathrm{~N}, 94.0 \mathrm{~W}$ at $18 \mathrm{Z}$ (micro). Land highlights: $25 \mathrm{kt} \mathrm{SE}$ and $1005 \mathrm{mb}$ at Swan Islands, Honduras at 00Z (micro). $25 \mathrm{kt} \mathrm{NW}$ and $999 \mathrm{mb}$ at Belize City, Belize at 06Z (micro). $966 \mathrm{mb}$ at Belize City, Belize at 11Z (WALLET). $924 \mathrm{mb}$ at $11 \mathrm{Z}$ (ship located between Belize City and Stann Creek) (WALLET). $40 \mathrm{kt} \mathrm{W}$ and $1001 \mathrm{mb}$ at San Pedro Sula, Honduras at 12Z (micro). $10 \mathrm{kt} \mathrm{S}$ and $999 \mathrm{mb}$ at Santa Barbara, Honduras at $18 \mathrm{Z}$ (micro). Aircraft highlights: Radar center fix at $18.1 \mathrm{~N}, 86.1 \mathrm{~W}$ at $00 Z$ (ATSR). Penetration center fix measured a central pressure of $930 \mathrm{mb}$ and estimated an eye diameter of $22 \mathrm{~nm}$ at $17.5 \mathrm{~N}, 87.3 \mathrm{~W}$ at $07 \mathrm{Z}$ (ATSR). Penetration center fix measured a central pressure of $933 \mathrm{mb}$ at $17.5 \mathrm{~N}, 87.3 \mathrm{~W}$ at $08 \mathrm{Z}$ (ATSR). Radar center fix estimated an eye diameter of $25 \mathrm{~nm}$ at $17.2 \mathrm{~N}, 88.1 \mathrm{~W}$ at $1130 \mathrm{Z}$ (ATSR). 
MWR: "Hattie moved inland on the British Honduras coast about sunrise on October 31. The center of the radar eye, which measured approximately 25 miles in diameter, passed 20 miles southeast of Belize. The lowest pressure on the barograph at Stanley Field, Belize, was $972 \mathrm{mb}$ indicating a gradient of some 45 to $50 \mathrm{mb}$ in the 20 miles between that point and the center of the eye. A trained observer estimated winds from 150 to 160 $\mathrm{mph}$ at Belize with unofficial estimates to $200 \mathrm{mph}$ or more. A copy of the Dines anemometer record is shown in figure 14. The pen remained at the top of the graph for a while. Storm tides of 10 to 11 feet along the Belize waterfront were general and waves deposited mud on the third floor of some buildings. Other locations near Belize reported storm tides up to 14 feet. Seventy-five percent of Belize, the capital of British Honduras, was either destroyed or severely damaged. Some communities such as Stann Creek were almost completely erased. Damage was so great in Belize that plans are under consideration for its relocation farther inland. Latest fatality figures show 262 dead in British Honduras. The ready-to-harvest citrus crop scheduled for export and worth $\$ 2,000,000$ was destroyed and unknown million were lost in timber, cocoa, and bananas. Damage is estimated near $\$ 60$ million. Guatemala reported 11 deaths and Honduras 1 , most of these apparently occurring in flash flooding. The Governor of British Honduras stated that hurricane Hattie was much worse than the 1931 hurricane in which 2,000 persons died and the fact that the death toll was not higher at this time was due to the excellent warnings. A large percentage of the people in Belize either evacuated or moved to supposedly safer buildings. In Stan Creek, 3,500 of the 4,500 residents were evacuated. Hattie continued west-southwestward and southwestward through British Honduras and Guatemala, dissipating in the mountains of Guatemala. Tropical Storm Simone was already in existence in the Pacific Ocean as Hattie passed near Belize, and the remnants of Hattie developed into neither Simone nor Inga. There are a number of interesting points connected with hurricane Hattie which are worthy of mention. This is the fourth hurricane of record to affect San Andres Island, and its most unusual to have one form south of the island. Residents could recall only one other hurricane with passed over the island since the turn of the century; this one occurred in October 1908. This development of hurricane Hattie appears to have been triggered by events near the outflow level. Riehl pointed out the importance of this level suggesting that superposition of high-level divergence over a low-level disturbance could lead to intensification. More recently, Alaka proposed that anomalous winds in the upper troposphere may be the dynamic mechanism for triggering hurricane formation." ATSR: "The storm entered the coast of British Honduras about 20 miles south of Belize at approximately $311300 \mathrm{Z}$ and wreaked such destruction that this capitol city has since been relocated further inland. Hattie then dissipated in the mountains of Guatemala. The final warning was issued at 311600Z." 
November 1:

HWM analyzes a tropical storm of at most $995 \mathrm{mb}$ at $14.0 \mathrm{~N}, 91.5 \mathrm{~W}$ and a spot low pressure at $13.5 \mathrm{~N}, 93.5 \mathrm{~W}$ at $12 \mathrm{Z}$. HURDAT lists a $45 \mathrm{kt}$ tropical storm at $15.7 \mathrm{~N}, 90.1 \mathrm{~W}$ at $06 \mathrm{Z}$ (last position). Microfilm shows a closed low pressure of at most $1002 \mathrm{mb}$ at $14.0 \mathrm{~N}, 93.5 \mathrm{~W}$ at $12 \mathrm{Z}$. Ship highlights: $25 \mathrm{kt} \mathrm{NNW}$ and $1004 \mathrm{mb}$ at $12.7 \mathrm{~N}, 92.3 \mathrm{~W}$ at $00 \mathrm{Z}$ (micro). $35 \mathrm{kt} \mathrm{W}$ and $1000 \mathrm{mb}$ at $13.5 \mathrm{~N}, 93.1 \mathrm{~W}$ at $12 \mathrm{Z}$ (COADS). $40 \mathrm{kt} \mathrm{W}$ and $1002 \mathrm{mb}$ at $14.0 \mathrm{~N}, 94.4 \mathrm{~W}$ at $18 \mathrm{Z}(\mathrm{COADS})$.

November 2:

HWM analyzes a closed low pressure of at most $1000 \mathrm{mb}$ at $16.5 \mathrm{~N}, 97.8 \mathrm{~W}$ at $12 \mathrm{Z}$. HURDAT does not list an organized system in the Atlantic Ocean on this date. Microfilm shows a closed low pressure of at most $1002 \mathrm{mb}$ at $16.0 \mathrm{~N}, 97.7 \mathrm{~W}$ at $12 \mathrm{Z}$. Ship highlights: $20 \mathrm{kt} \mathrm{W}$ and $1001 \mathrm{mb}$ at $15.8 \mathrm{~N}, 98.9 \mathrm{~W}$ at $00 \mathrm{Z}$ (micro). $30 \mathrm{kt} \mathrm{SW}$ and $1005 \mathrm{mb}$ at $14.8 \mathrm{~N}$, $96.0 \mathrm{~W}$ at $12 \mathrm{Z}$ (micro).

November 3:

HWM analyzes a closed low pressure of at most $1000 \mathrm{mb}$ at $19.2 \mathrm{~N}, 94.2 \mathrm{~W}$ with a weakening cold front to the north at $12 \mathrm{Z}$. HURDAT does not list an organized system in the Atlantic Ocean on this date. Microfilm shows a closed low pressure of at most 1002 $\mathrm{mb}$ at $21.5 \mathrm{~N}, 95.3 \mathrm{~W}$ with a frontal boundary to the north at $12 \mathrm{Z}$. Ship highlights: No gales or low pressures.

Synoptic observations over the southern Caribbean Sea indicate that a tropical disturbance developed north of Panama around October 25th, likely associated with the Eastern Pacific monsoon trough extending into the Caribbean. Ship data shows that the system steadily became better organized and the first position is analyzed as a $35 \mathrm{kt}$ tropical storm at $00 \mathrm{Z}$ on October $27 \mathrm{th}$, twelve hours earlier than originally shown in HURDAT. Genesis may have occurred late on October 26th but observations over the extreme southern Caribbean Sea, especially over Panama, are sparse. Minor track alterations were introduced during the lifetime of this tropical cyclone. Intensification to a tropical storm is analyzed 12 hours earlier than originally shown in HURDAT. Hattie slowly moved northward in the general direction of the Colombian island of San Andres. Late on the 27th, San Andres began to report gale-force winds and winds reached hurricane-force very late on the 27 th and early on October 28 th. Thus, intensification to a hurricane is analyzed at $00 \mathrm{Z}$ on the 28th, same as originally shown in HURDAT. A central pressure of $991 \mathrm{mb}$ was present in HURDAT at $00 \mathrm{Z}$ on the 28th and has been removed since MWR does not indicate that this was a central pressure (MWR says 
minimum pressure) and at $00 \mathrm{Z}$ on the 28th San Andres was reporting $50 \mathrm{kt}$ ESE and 993 $\mathrm{mb}$, indicating a central pressure lower than $991 \mathrm{mb}$. At $07 \mathrm{Z}$ on the 28th, the first reconnaissance aircraft reported a central pressure of $998 \mathrm{mb}$ and an eye diameter of 20 $\mathrm{nm}$. Based on the observations from San Andres and also because this was a nighttime fix, it was determined that the dropsonde did not fall at the center of Hattie. Thus, $998 \mathrm{mb}$ is not a central pressure and was not used to determine the intensity of Hattie, nor added to HURDAT. Hurricane Hattie steadily intensified on the 28th as it moved away from San Andres. The next reconnaissance aircraft measured a central pressure of $969 \mathrm{mb}$, estimated surface winds of $110 \mathrm{kt}$ and an eye diameter of $20 \mathrm{~nm}$ at $1247 \mathrm{Z}$ on the $28 \mathrm{th}$. A central pressure of $969 \mathrm{mb}$ suggests maximum sustained winds of $92 \mathrm{kt}$ south of $25 \mathrm{~N}$ intensifying from the south of $25 \mathrm{~N}$ Brown et al. pressure-wind relationship. An eye diameter of $20 \mathrm{~nm}$ suggests an RMW of $15 \mathrm{~nm}$ and the climatological value is $12 \mathrm{~nm}$. An intensity of $90 \mathrm{kt}$ is selected at $12 \mathrm{Z}$ on the $28 \mathrm{th}$, down from $105 \mathrm{kt}$ originally shown in HURDAT, a minor intensity change. A central pressure of $991 \mathrm{mb}$ was present in HURDAT at $12 \mathrm{Z}$ on the 28th and has been replaced with $969 \mathrm{mb}$. Another reconnaissance aircraft measured a central pressure of $956 \mathrm{mb}$ and estimated surface winds of $100 \mathrm{kt}$ at $20 \mathrm{Z}$ on the $28 \mathrm{th}$. An eye diameter of $10 \mathrm{~nm}$ was estimated at $1935 \mathrm{Z}$. A central pressure of $956 \mathrm{mb}$ suggests maximum sustained winds of $107 \mathrm{kt}$ south of $25 \mathrm{~N}$ intensifying from the south of $25 \mathrm{~N}$ pressure-wind relationship. An eye diameter of $10 \mathrm{~nm}$ suggests an RMW of about $8 \mathrm{~nm}$ and the climatological value is $12 \mathrm{~nm}$. Due to an RMW close or slightly smaller than climatology and a forward speed of $8 \mathrm{kt}$, an intensity of 105 $\mathrm{kt}$ is selected at $18 \mathrm{Z}$ on the $28 \mathrm{th}$, down from $110 \mathrm{kt}$ originally shown in HURDAT, a minor intensity change. A central pressure of $969 \mathrm{mb}$ was present in HURDAT at $18 \mathrm{Z}$ on the 28th and has been replaced with $956 \mathrm{mb}$. Intensification to a major hurricane is analyzed at $18 \mathrm{Z}$ on the $28 \mathrm{th}, 36$ hours later than originally shown in HURDAT. Hattie likely produced gale-force winds over northeastern Nicaragua and Honduras late on the 28th and early the next day.

Early on October 29th, the tropical cyclone moved northward fluctuating in intensity. Late on the 29th, Hattie turned to the northwest. The first reconnaissance aircraft on the 29th arrived at $0030 \mathrm{Z}$ measuring a central pressure of $952 \mathrm{mb}$. A central pressure of 952 $\mathrm{mb}$ suggests maximum sustained winds of $111 \mathrm{kt}$ south of $25 \mathrm{~N}$ intensifying from the pressure-wind relationship. An intensity of $110 \mathrm{kt}$ is selected at $00 \mathrm{Z}$ on the 29th, same as originally shown in HURDAT. A central pressure of $952 \mathrm{mb}$ was present in HURDAT at $00 \mathrm{Z}$ on the 29th and has been retained. It is apparent that Hattie began a concentric eyewall replacement cycle early on the 29th based on reconnaissance aircraft data and radar images available in the 1961 Navy book (pg. 229 and 233). At 07Z on the 29th, a penetration center fix measured a central pressure of $966 \mathrm{mb}$ and an eye diameter (of the inner eye) of $12 \mathrm{~nm}$. A central pressure of $966 \mathrm{mb}$ suggests maximum sustained winds of $92 \mathrm{kt}$ south of $25 \mathrm{~N}$ weakening from the pressure-wind relationship. An eye diameter of 
$12 \mathrm{~nm}$ suggests an RMW of about $9 \mathrm{~nm}$ and the climatological value is $13 \mathrm{~nm}$. An intensity of $95 \mathrm{kt}$ is selected at $06 \mathrm{Z}$ on the $29 \mathrm{th}$, down from $110 \mathrm{kt}$ originally in HURDAT, a minor intensity change. A central pressure of $966 \mathrm{mb}$ has been added to HURDAT at $06 \mathrm{Z}$ on the 29 th. The next reconnaissance aircraft measured a central pressure of $963 \mathrm{mb}$ and estimated surface winds of $110 \mathrm{kt}$ and an eye diameter of $40 \mathrm{~nm}$ at $13 \mathrm{Z}$ on the $29 \mathrm{th}$. A central pressure of $963 \mathrm{mb}$ suggests maximum sustained winds of $98 \mathrm{kt}$ south of $25 \mathrm{~N}$ from the pressure-wind relationship. An eye diameter of $40 \mathrm{~nm}$ suggests an RMW of about $30 \mathrm{~nm}$ and the climatological value is $13 \mathrm{~nm}$. Due to an RMW larger than the climatological value and forward speed of $8 \mathrm{kt}$, an intensity of $95 \mathrm{kt}$ is selected at $12 \mathrm{Z}$ on the 29 th, down from $110 \mathrm{kt}$ originally shown in HURDAT, a minor intensity change. A central pressure of $963 \mathrm{mb}$ was present in HURDAT at $12 \mathrm{Z}$ and has been retained. Another reconnaissance aircraft measured a central pressure of $956 \mathrm{mb}$ and estimated surface winds of $110 \mathrm{kt}$ and an eye diameter of $40 \mathrm{~nm}$ at $1915 \mathrm{Z}$ on the 29th. A central pressure of $956 \mathrm{mb}$ suggests maximum sustained winds of $105 \mathrm{kt}$ south of $25 \mathrm{~N}$ intensifying from the pressure-wind relationship. An eye diameter of $40 \mathrm{~nm}$ suggests an RMW of about $30 \mathrm{~nm}$ and the climatological value is $12 \mathrm{~nm}$. Due to an RMW larger than the climatological value and forward speed of $6 \mathrm{kt}$, an intensity of $100 \mathrm{kt}$ is selected at $18 Z$ on the 29th, down from $100 \mathrm{kt}$ originally shown in HURDAT, a minor intensity change. A central pressure of $956 \mathrm{mb}$ was added to HURDAT at $12 \mathrm{Z}$ on the 29th.

On October 30th, Hattie experienced a period of rapid intensification as the system turned to the west and west-southwest. Early on the 30th, the hurricane passed between Swan Island and the Cayman Islands, producing gale-force winds. The first reconnaissance aircraft on the 30th measured a central pressure of $958 \mathrm{mb}$ and an eye diameter of $30 \mathrm{~nm}$ at $01 \mathrm{Z}$. A central pressure of $958 \mathrm{mb}$ suggests maximum sustained winds of $103 \mathrm{kt}$ south of $25 \mathrm{~N}$ from the pressure-wind relationship. An eye diameter of $30 \mathrm{~nm}$ suggests an RMW of about $23 \mathrm{~nm}$ and the climatological value is $12 \mathrm{~nm}$. Due to the large circulation and forward speed of about $10 \mathrm{kt}$, an intensity of $100 \mathrm{kt}$ is selected at $00 \mathrm{Z}$ on the $30 \mathrm{th}$, down from $115 \mathrm{kt}$ originally shown in HURDAT, a minor intensity change. A central pressure of $956 \mathrm{mb}$ was present in HURDAT at $00 \mathrm{Z}$ on the 30th and has been replaced with 958 $\mathrm{mb}$. The next reconnaissance aircraft measured a central pressure of $942 \mathrm{mb}$ and estimated an eye diameter of $28 \mathrm{~nm}$ at $07 \mathrm{Z}$ on the 30th. A central pressure of $942 \mathrm{mb}$ suggests maximum sustained winds of $121 \mathrm{kt}$ south of $25 \mathrm{~N}$ intensifying from the pressure-wind relationship. An eye diameter of $28 \mathrm{~nm}$ suggests an RMW of about $21 \mathrm{~nm}$ and the climatological value is $11 \mathrm{~nm}$. Based on an RMW larger than climatology and forward speed of about $11 \mathrm{kt}$, an intensity of $115 \mathrm{kt}$ is selected at $06 \mathrm{Z}$ on the $30 \mathrm{th}$, down from $120 \mathrm{kt}$ originally shown in HURDAT, a minor intensity change. A central pressure of $942 \mathrm{mb}$ was present in HURDAT at $06 \mathrm{Z}$ on the 30th and has been retained. At $10 \mathrm{Z}$ on the 30th, a penetration center fix measured a central pressure of $937 \mathrm{mb}$, estimated surface winds of $115 \mathrm{kt}$ and an eye diameter of $25 \mathrm{~nm}$. A central pressure of $937 \mathrm{mb}$ 
suggests maximum sustained winds of $126 \mathrm{kt}$ south of $25 \mathrm{~N}$ intensifying from the pressure-wind relationship. An eye diameter of $25 \mathrm{~nm}$ suggests an RMW of about $19 \mathrm{~nm}$ and the climatological value is $11 \mathrm{~nm}$. Based on an RMW larger than climatology and forward speed of about $6 \mathrm{kt}$, an intensity of $120 \mathrm{kt}$ is selected at $12 \mathrm{Z}$ on the 30th, down from $130 \mathrm{kt}$ originally shown in HURDAT, a minor intensity change. A central pressure of $937 \mathrm{mb}$ was present in HURDAT at 12Z on the 30th and has been retained. Another penetration center fix measured a central pressure of $923 \mathrm{mb}$ and an eye diameter of 20 $\mathrm{nm}$ at $17 \mathrm{Z}$ on the 30th. A central pressure of $923 \mathrm{mb}$ suggests maximum sustained winds of $139 \mathrm{kt}$ south of $25 \mathrm{~N}$ intensifying from the pressure-wind relationship. An eye diameter of $20 \mathrm{~nm}$ suggests an RMW of about $15 \mathrm{~nm}$ and the climatological value is $10 \mathrm{~nm}$. Based on an RMW larger than climatology and forward speed of about $10 \mathrm{kt}$, an intensity of 135 $\mathrm{kt}$ is selected at $18 \mathrm{Z}$ on the 30 th, down from 140 kt originally shown in HURDAT, a minor intensity change. $135 \mathrm{kt}$ is also the peak intensity of this tropical cyclone, down from 140 kt originally in HURDAT, a minor intensity change. A central pressure of 923 mb was added to HURDAT at $18 \mathrm{Z}$ on the 30th. Late on the 30th, ships near the tropical cyclone reported hurricane-force winds.

On October 31st, powerful hurricane Hattie moved southwestward toward central Belize. At $22 \mathrm{Z}$ on the 30th, a reconnaissance aircraft measured a central pressure of $920 \mathrm{mb}$ and estimated an eye diameter of $22 \mathrm{~nm}$. A central pressure of $920 \mathrm{mb}$ suggests maximum sustained winds of $141 \mathrm{kt}$ south of $25 \mathrm{~N}$ intensifying from the pressure-wind relationship. An eye diameter of $22 \mathrm{~nm}$ suggests an RMW of about $17 \mathrm{~nm}$ and the climatological value is $10 \mathrm{~nm}$. Based on an RMW larger than climatology and forward speed of $9 \mathrm{kt}$, an intensity of $135 \mathrm{kt}$ is selected at $00 \mathrm{Z}$ on the 31 th, down from $140 \mathrm{kt}$ originally shown in HURDAT, a minor intensity change. A central pressure of $920 \mathrm{mb}$ was present in HURDAT at $00 \mathrm{Z}$ on the 31 st and has been retained. The next penetration center fix measured a central pressure of $930 \mathrm{mb}$ and estimated an eye diameter of $22 \mathrm{~nm}$ at $07 \mathrm{Z}$ on the $31 \mathrm{st}$. A central pressure of $930 \mathrm{mb}$ suggests maximum sustained winds of $124 \mathrm{kt}$ south of $25 \mathrm{~N}$ weakening from the pressure-wind relationship. An eye diameter of $22 \mathrm{~nm}$ suggests an RMW of about $17 \mathrm{~nm}$ and the climatological value is $11 \mathrm{~nm}$. Due to the large RMW and forward speed of $10 \mathrm{kt}$, an intensity of $125 \mathrm{kt}$ is selected at $06 \mathrm{Z}$ on the 31th, down from 140 kt originally shown in HURDAT, a minor intensity change. A central pressure of $930 \mathrm{mb}$ was added to HURDAT at $06 \mathrm{Z}$ on the 31st. Thus, it is analyzed that Hattie did not reach category 5 in the Saffir-Simpson scale as originally shown in HURDAT. It is interesting to note that the highest winds estimated by the reconnaissance aircrafts were $130 \mathrm{kt}$ and the advisories of Hattie also show a peak intensity of $130 \mathrm{kt}$. As the hurricane approached the coastline of Belize, a British ship named "M.V. Tactician" was caught between Belize City and Stann Creek. The captain of the ship wrote a detailed account about the experience and the letter reached the US Weather Bureau on June 1st, 1962, about three months after the 1961 Hurricane Season summary had been published 
in the Monthly Weather Review. A comparison between the reported central pressures by the ship and Belize City indicates that the barometer was well calibrated. According to the captain, a central pressure of $924 \mathrm{mb}$ was recorded at $11 \mathrm{Z}$ on the $31 \mathrm{st}$. The captain also recounts a lull that lasted about 45 minutes, providing enough time to reposition the ship ahead of the second half of the hurricane. Hence, a central pressure of $924 \mathrm{mb}$ was added to HURDAT at 12Z. In this time slot HURDAT originally had $930 \mathrm{mb}$. A central pressure of $924 \mathrm{mb}$ suggests maximum sustained winds of $135 \mathrm{kt}$ south of $25 \mathrm{~N}$ and 138 kt intensifying from the pressure-wind relationship. At 1135Z, a reconnaissance aircraft made a radar center fix and estimated an eye diameter of $25 \mathrm{~nm}$. An eye diameter of 25 $\mathrm{nm}$ suggests an RMW of about $19 \mathrm{~nm}$ and the climatological value is 9 . Based on an RMW larger than the climatological value and a forward speed of about $11 \mathrm{kt}$, an intensity of $135 \mathrm{kt}$ is selected at $12 \mathrm{Z}$ on the $31 \mathrm{st}$, up from $120 \mathrm{kt}$ originally in HURDAT, a minor intensity change. Landfall in analyzed at $13 \mathrm{Z}$ on the 31 st near $17.1 \mathrm{~N}$ and $88.3 \mathrm{~W}$, or about $24 \mathrm{~nm}$ south of Belize City, Belize. The impact of the northern eyewall of Hattie on Belize City was devastating, causing the rebuilding of the city to take place farther inland. After landfall, the large hurricane continued inland on a southwest course and rapidly weakened. The Kaplan and DeMaria model was run for $18 \mathrm{Z}$ on the $31 \mathrm{st}$, and $00 \mathrm{Z}$, and $06 \mathrm{Z}$ on November 1st yielding $87 \mathrm{kt}, 60 \mathrm{kt}$ and $43 \mathrm{kt}$, respectively. Data over western Central America and southeastern Mexico was sparse and no winds of tropical storm intensity were reported on land during those three time periods. An intensity of $75 \mathrm{kt}$ is selected for $18 \mathrm{Z}$ on the $31 \mathrm{st}, 45 \mathrm{kt}$ at $00 \mathrm{Z}$ and $30 \mathrm{kt}$ at $06 \mathrm{Z}$ on the $1 \mathrm{st}$ (up from $60 \mathrm{kt}$ at $18 \mathrm{Z}$ on the $31 \mathrm{st}$, down from $55 \mathrm{kt}$ and $45 \mathrm{kt}$ at $00 \mathrm{Z}$ and $06 \mathrm{Z}$, respectively, on the $1 \mathrm{st}$, originally in HURDAT), minor intensity changes. The analyzed intensity is below that suggested by Kaplan-DeMaria due to the mountainous terrain in Central America. Weakening to a tropical storm is analyzed at $00 \mathrm{Z}$ on the 1st, six hours later than originally shown in HURDAT. The last position of Hattie is analyzed at $06 \mathrm{Z}$ on the $1 \mathrm{st}$, same as originally shown in HURDAT. Over the Eastern Pacific, synoptic data indicates that the circulation of Hattie remained the dominant feature as the hurricane made landfall in Belize and moved southwestward toward that ocean basin. There is no evidence to support the statement in the Monthly Weather Review that Tropical Storm Simone was already in existence as Hattie made landfall in Belize. Furthermore, the first advisory issued on Simone clearly indicates the opinion at the time was that this tropical cyclone was the former Atlantic hurricane. Nonetheless, data over the Eastern Pacific shows that the location in which Simone was supposedly located was in a large area of low environmental pressures with strong westerly flow associated with the monsoon trough. Based on the ship and coastal observations, it appears that Simone never had a closed low-level circulation and therefore, was not been a tropical cyclone. Thus, in addition to alterations for Hattie, it is recommended that Simone be removed from the Northeast Pacific HURDAT. 
Hurricane Jenny [November 2-11, 1961]

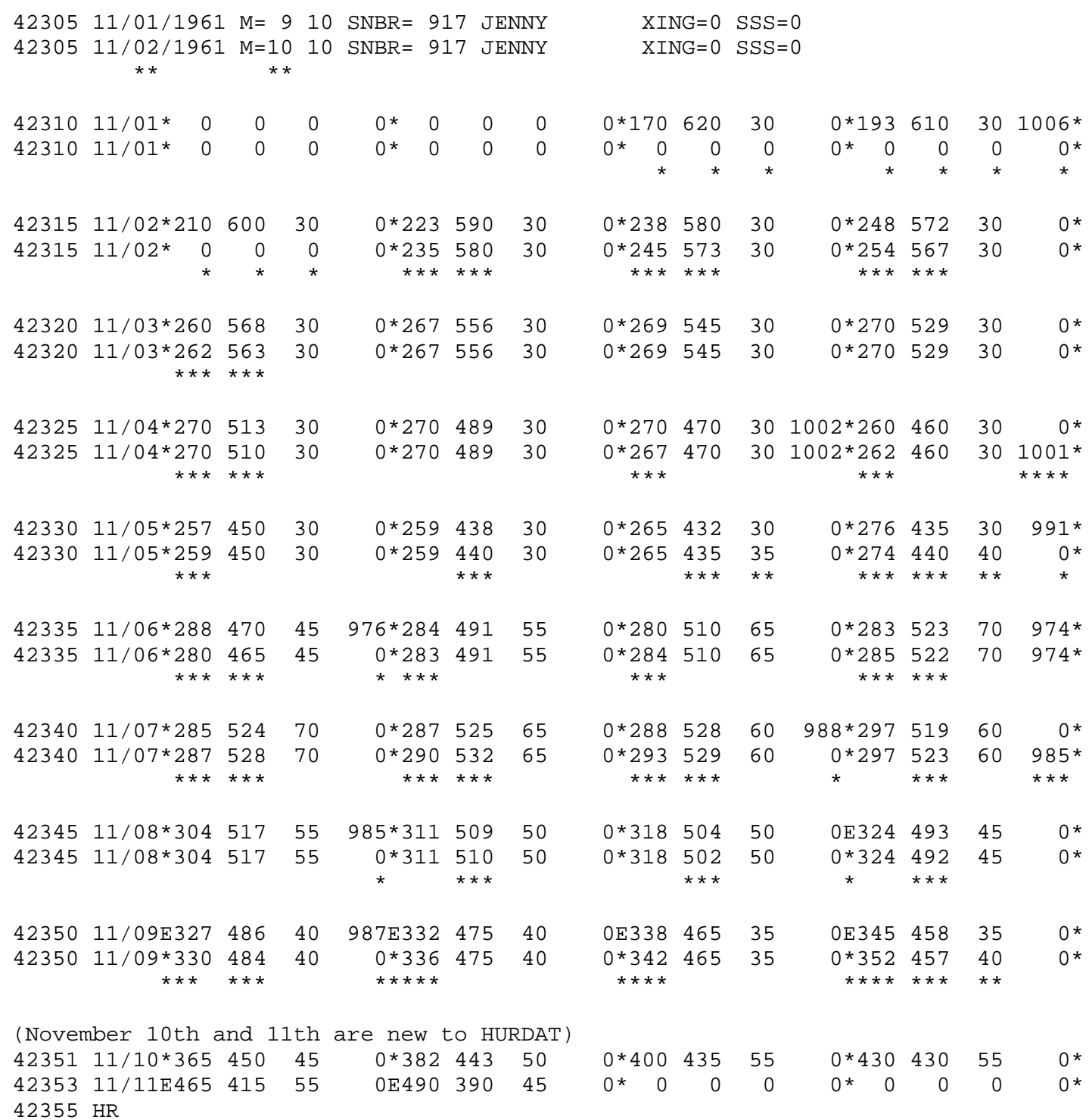

Minor changes to the track and intensity shown in McAdie et al. (2009). Major alterations are also introduced to show that the tropical cyclone did not become extratropical until two days after that originally shown in HURDAT and to add 36 hours to its lifetime. Evidence for these alterations comes from the NHC microfilm maps, the Historical Weather Maps series, the COADS ship database, Monthly Weather Review, Navy reconnaissance book, Mariners Weather Log, and NHC Storm Wallets. 


\section{October 31:}

HWM does not analyze an organized system at 12Z. HURDAT does not list an organized system on this date. Microfilm shows a tropical wave or trough over the eastern Caribbean at 12Z. Ship highlights: No gales or low pressures. Land highlights: $10 \mathrm{kt} \mathrm{S}$ and $1005 \mathrm{mb}$ at Dominique at $18 \mathrm{Z}$ (micro).

\section{November 1:}

HWM does not analyze an organized system at 12Z. HURDAT lists a $30 \mathrm{kt}$ tropical depression at $17.0 \mathrm{~N}, 62.0 \mathrm{~W}$ at $12 \mathrm{Z}$. Microfilm shows a tropical wave or trough over the eastern Caribbean at 12Z. Ship highlights: $15 \mathrm{kt} \mathrm{S}$ and $1005 \mathrm{mb}$ at $16.4 \mathrm{~N}, 62.0 \mathrm{~W}$ at $18 \mathrm{Z}$ (COADS).

MWR: "Jenny, the tenth and last cyclone for which advisories were issued in the 1961 hurricane season, was only quasi-tropical, resembling the Kona Low of the Pacific or what has been called the "subtropical" storm in the Atlantic. These develop in connection with cold-core cyclones and are more likely to occur outside the usual hurricane season. Some other examples were hurricane Greta of 1956 and the unusual May hurricane in 1951. The disturbance which eventually became Jenny was first noted in the vicinity of the Windward Islands on November 1, at which time it was only a broad area of unsettled weather with lowest pressure around $1005 \mathrm{mb}$. The formation of the disturbance coincided with the development of a cut-off Low in the middle and upper troposphere just to the north of Puerto Rico. The depression moved northeastward during the next two days then turned abruptly eastward in advance of a deepening upper-level trough in the westerlies." ATSR: "The disturbance which became the tenth and last tropical storm of the season originated near Antigua in the Windward Islands on 1 November. Navy reconnaissance aircraft investigating the area on the 1st reported what appeared to be "the joining of the Intertropical Convergence Zone and a polar trough east of Puerto Rico." The low began to move rapidly to the northeast while filling slightly."

November 2:

HWM analyzes a closed low pressure of at most $1010 \mathrm{mb}$ at $23.0 \mathrm{~N}, 59.0 \mathrm{~W}$ at $12 \mathrm{Z}$. HURDAT lists a $30 \mathrm{kt}$ tropical depression at $23.8 \mathrm{~N}, 58.0 \mathrm{~W}$ at $12 \mathrm{Z}$. Microfilm shows a closed low pressure of at most $1008 \mathrm{mb}$ at $22.5 \mathrm{~N}, 57.5 \mathrm{~W}$ at $12 \mathrm{Z}$. Ship highlights: No gales or low pressures.

November 3:

HWM analyzes a closed low pressure of at most $1005 \mathrm{mb}$ at $26.0 \mathrm{~N}, 54.5 \mathrm{~W}$ with a weakening cold front to the north at $12 \mathrm{Z}$. HURDAT lists a $30 \mathrm{kt}$ tropical depression at 
$26.9 \mathrm{~N}, 54.5 \mathrm{~W}$ at $12 \mathrm{Z}$. Microfilm shows a closed low pressure of at most $1014 \mathrm{mb}$ at $29.0 \mathrm{~N}, 52.5 \mathrm{~W}$ at $12 \mathrm{Z}$. Ship highlights: $35 \mathrm{kt} \mathrm{NE}$ and $1018 \mathrm{mb}$ at $31.0 \mathrm{~N}, 53.8 \mathrm{~W}$ at $23 \mathrm{Z}$ (COADS).

ATSR: "It continued on this course until the third when reports from Ocean Station Echo indicated considerable deepening of an upper level trough to the northwest of the surface disturbance. The low on the surface appeared to react by turning eastward abruptly."

November 4:

HWM analyzes a closed low pressure of at most $1005 \mathrm{mb}$ at $26.5 \mathrm{~N}, 48.0 \mathrm{~W}$ with a warm front to the north at 12Z. HURDAT lists a $30 \mathrm{kt}$ tropical depression at $27.0 \mathrm{~N}, 47.0 \mathrm{~W}$ at 12Z. Microfilm shows a closed low pressure of at most $1008 \mathrm{mb}$ at $26.0 \mathrm{~N}, 45.0 \mathrm{~W}$ with a frontal boundary to the north at 12Z. Ship highlights: $35 \mathrm{kt} \mathrm{NE}$ and $1007 \mathrm{mb}$ at $31.7 \mathrm{~N}$, $52.2 \mathrm{~W}$ at $06 \mathrm{Z}$ (COADS). $25 \mathrm{kt} \mathrm{NW}$ and $1003 \mathrm{mb}$ at $24.7 \mathrm{~N}, 46.3 \mathrm{~W}$ at $18 \mathrm{Z}$ (micro).

November 5:

HWM analyzes a closed low pressure of at most $1000 \mathrm{mb}$ at $26.0 \mathrm{~N}, 44.0 \mathrm{~W}$ with warm front to the north at $12 \mathrm{Z}$. HURDAT lists a $30 \mathrm{kt}$ tropical depression at $26.5 \mathrm{~N}, 43.2 \mathrm{~W}$ at 12Z. Microfilm shows a closed low pressure of at most $996 \mathrm{mb}$ at $25.7 \mathrm{~N}, 43.0 \mathrm{~W}$ with a frontal boundary to the north at 12Z. Ship highlights: $40 \mathrm{kt}$ (50 kt in micro) NE and 1010 $\mathrm{mb}$ at $30.3 \mathrm{~N}, 47.2 \mathrm{~W}$ at $00 \mathrm{Z}$ (COADS). $15 \mathrm{kt} \mathrm{NE}$ and $1002 \mathrm{mb}$ at $25.8 \mathrm{~N}, 47.7 \mathrm{~W}$ at $06 \mathrm{Z}$ (micro). $20 \mathrm{kt} \mathrm{NE}$ and $999 \mathrm{mb}$ at 27.5N, $43.7 \mathrm{~W}$ at $12 \mathrm{Z}$ (COADS). $35 \mathrm{kt} \mathrm{SE}$ and $991 \mathrm{mb}$ at $27.9 \mathrm{~N}, 43.1 \mathrm{~W}$ at $18 \mathrm{Z}$ (COADS).

MWR: "On November 5, the $500 \mathrm{mb}$ charts showed that the trough had sheared, cutting off an intense cold Low some 300 miles northwest of the position of the surface disturbance. ATSR: "On the 5th the upper level trough sheared, cutting off a cold upper low approximately 300 miles to the north of the surface system. This cold low moved southwestward as a warm high pressure cell moved eastward across its northern boundary. The surface system came under the upper low and radically altered its course to the west while deepening rapidly to hurricane intensity."

November 6:

HWM analyzes a hurricane of at most $985 \mathrm{mb}$ at $28.0 \mathrm{~N}, 51.1 \mathrm{~W}$ with warm front to the north at $12 \mathrm{Z}$. HURDAT lists a $65 \mathrm{kt}$ hurricane at $28.0 \mathrm{~N}, 51.0 \mathrm{~W}$ at $12 \mathrm{Z}$. Microfilm shows a closed low pressure of at most $987 \mathrm{mb}$ at $28.5 \mathrm{~N}, 51.5 \mathrm{~W}$ at $12 \mathrm{Z}$. Ship highlights: $40 \mathrm{kt}$ $\mathrm{SE}$ and $1008 \mathrm{mb}$ at $32.5 \mathrm{~N}, 44.0 \mathrm{~W}$ at $00 \mathrm{Z}$ (COADS). $55 \mathrm{kt}$ SE and $1007 \mathrm{mb}$ at $32.1 \mathrm{~N}$, $45.3 \mathrm{~W}$ at $06 \mathrm{Z}$ (COADS). $60 \mathrm{kt} \mathrm{NW}$ and $992 \mathrm{mb}$ at $28.1 \mathrm{~N}, 52.6 \mathrm{~W}$ at $12 \mathrm{Z}$ (COADS). $65 \mathrm{kt}$ $\mathrm{E}$ and $989 \mathrm{mb}$ at $29.7 \mathrm{~N}, 51.9 \mathrm{~W}$ at $18 \mathrm{Z}$ (micro). $70 \mathrm{kt} \mathrm{SE}$ and $986 \mathrm{mb}$ at $28.8 \mathrm{~N}, 51.7 \mathrm{~W}$ at 
$21 Z$ (MWL). Aircraft highlights: Penetration center fix measured a central pressure of $974 \mathrm{mb}$ and estimated surface winds of $70 \mathrm{kt}$ at $28.4 \mathrm{~N}, 52.4 \mathrm{~W}$ at 1910Z (WALLET).

MWR: "This Low moved southwestward during the next 24 hours and the surface Low, apparently steered by the upper system, reversed its course and moved rapidly westward. As the surface Low began to move under the upper cyclone, it deepened rapidly and the central pressure on November 6 was $974 \mathrm{mb}$. Maximum winds were barely of hurricane force near the center but gales extended outward as much as 600 miles to the north and 300 miles to the south. This was evidently due to reflection in the surface pressure gradients of the upper Low and not to a true tropical development. However, the latitude of the storm and the concentration of winds of hurricane force about the center made it advisable to treat the storm as tropical for purposes of marine advisories. It has been observed in "subtropical" storms that a warm core may exist within the circulation of the larger cold Low. The possibility that this was true in the case of Jenny cannot be ruled out but it could have been for only a matter of hours and was not observed by the reconnaissance flight on November 6, which reported "no eye, no temperature rise, no spiral bands." It was never a threat to land and the only known damage was to the ship Venore, an 8000-ton ore carrier, which required assistance after becoming disabled in the storm on the afternoon of November 6." ATSR: "Warning number one went out on hurricane Jenny at 062200Z."

November 7:

HWM analyzes a hurricane of at most $985 \mathrm{mb}$ at $28.4 \mathrm{~N}, 52.3 \mathrm{~W}$ with a weakening stationary front to the north at $12 \mathrm{Z}$. HURDAT lists a $40 \mathrm{kt}$ tropical storm at $28.8 \mathrm{~N}$, $52.8 \mathrm{~W}$ at $12 \mathrm{Z}$. Microfilm shows a closed low pressure of at most $990 \mathrm{mb}$ at $29.2 \mathrm{~N}$, $52.5 \mathrm{~W}$ at $12 \mathrm{Z}$. Ship highlights: $50 \mathrm{kt} \mathrm{ENE}$ and $983 \mathrm{mb}$ at $29.3 \mathrm{~N}, 52.7 \mathrm{~W}$ at $00 \mathrm{Z}$ (micro). $30 \mathrm{kt} \mathrm{NNW}$ and $985 \mathrm{mb}$ at $28.7 \mathrm{~N}, 53.4 \mathrm{~W}$ at $03 \mathrm{Z}$ (micro). $60 \mathrm{kt} \mathrm{NNW}$ and $990 \mathrm{mb}$ at $29.0 \mathrm{~N}, 53.7 \mathrm{~W}$ at $06 \mathrm{Z}$ (COADS). $45 \mathrm{kt} \mathrm{NNW}$ and $990 \mathrm{mb}$ at $28.8 \mathrm{~N}, 53.8 \mathrm{~W}$ at $09 \mathrm{Z}$ (micro). $50 \mathrm{kt} \mathrm{N}$ and $994 \mathrm{mb}$ at $28.0 \mathrm{~N}, 54.5 \mathrm{~W}$ at $12 \mathrm{Z}$ (COADS). $40 \mathrm{kt} \mathrm{SSE}$ and $994 \mathrm{mb}$ at $30.3 \mathrm{~N}, 50.8 \mathrm{~W}$ at $18 \mathrm{Z}$ (micro). Aircraft highlights: Penetration center fix at $29.0 \mathrm{~N}, 52.6 \mathrm{~W}$ at $1155 \mathrm{Z}$ (ATSR). Penetration center fix measured a central pressure of $988 \mathrm{mb}$ at $28.8 \mathrm{~N}$, $52.5 \mathrm{~W}$ at $1554 \mathrm{Z}$ (WALLET). Penetration center fix estimated surface winds of $55 \mathrm{kt}$ at $29.5 \mathrm{~N}, 52.0 \mathrm{~W}$ at $1610 \mathrm{Z}$ (WALLET). Penetration center fix measured a central pressure of $985 \mathrm{mb}$ and estimated surface winds of $60 \mathrm{kt}$ at $29.8 \mathrm{~N}, 51.8 \mathrm{~W}$ at $19 \mathrm{Z}$ (WALLET).

MWR: "Jenny became essentially stationary on November 7, then began to move to the northeast and weaken, becoming clearly extratropical during the next two days." ATSR: "By the 7th, the upper level pressure rises had moved northeast of the storm, enabling it to turn once again to a northeastward course." 
November 8:

HWM analyzes a tropical storm of at most $995 \mathrm{mb}$ at $31.4 \mathrm{~N}, 50.4 \mathrm{~W}$ with a frontal boundary close to the north at $12 \mathrm{Z}$. HURDAT lists a $50 \mathrm{kt}$ tropical storm at $31.8 \mathrm{~N}, 50.4 \mathrm{~W}$ at $12 \mathrm{Z}$. Microfilm shows a closed low pressure of at most $993 \mathrm{mb}$ at $31.7 \mathrm{~N}, 49.0 \mathrm{~W}$ at 12Z. Ship highlights: $40 \mathrm{kt} \mathrm{SW}$ and $1004 \mathrm{mb}$ at 26.2N, 51.2W at 00Z (COADS). $35 \mathrm{kt}$ $\mathrm{SSE}$ and $1007 \mathrm{mb}$ at $32.3 \mathrm{~N}, 45.1 \mathrm{~W}$ at $06 \mathrm{Z}$ (COADS). $40 \mathrm{kt} \mathrm{S}$ and $994 \mathrm{mb}$ at $29.8 \mathrm{~N}$, $48.1 \mathrm{~W}$ at $09 \mathrm{Z}$ (micro). $40 \mathrm{kt} \mathrm{WSW}$ and $999 \mathrm{mb}$ at $30.0 \mathrm{~N}, 50.2 \mathrm{~W}$ at $12 \mathrm{Z}$ (COADS). $35 \mathrm{kt}$ $\mathrm{S}$ and $998 \mathrm{mb}$ at $31.3 \mathrm{~N}, 46.6 \mathrm{~W}$ at $18 \mathrm{Z}$ (COADS).

ATSR: "The final warning was issued at 081600Z."

November 9:

HWM analyzes a closed low pressure of at most $995 \mathrm{mb}$ at $33.2 \mathrm{~N}, 47.0 \mathrm{~W}$ with an extratropical cyclone to the west at $12 \mathrm{Z}$. HURDAT lists a $35 \mathrm{kt}$ extratropical cyclone at $33.8 \mathrm{~N}, 46.5 \mathrm{~W}$ at $12 \mathrm{Z}$. Microfilm shows a closed low pressure of at most $993 \mathrm{mb}$ at $34.0 \mathrm{~N}, 46.0 \mathrm{~W}$ at 12Z. Ship highlights: $40 \mathrm{kt} \mathrm{SSW}$ and $997 \mathrm{mb}$ at $30.8 \mathrm{~N}, 47.3 \mathrm{~W}$ at $00 \mathrm{Z}$ (COADS). $35 \mathrm{kt} \mathrm{WSW}$ and $999 \mathrm{mb}$ at 31.0N, 47.3W at 06Z (COADS). $30 \mathrm{kt} \mathrm{NE}$ and 993 $\mathrm{mb}$ at $34.5 \mathrm{~N}, 46.7 \mathrm{~W}$ at $12 \mathrm{Z}$ (micro). $30 \mathrm{kt} \mathrm{ESE}$ and $1001 \mathrm{mb}$ at $36.9 \mathrm{~N}, 44.5 \mathrm{~W}$ at $18 \mathrm{Z}$ (micro).

ATSR: "Jenny was clearly extratropical by the 9th."

November 10:

HWM analyzes a closed low pressure of at most $990 \mathrm{mb}$ at $40.0 \mathrm{~N}, 43.0 \mathrm{~W}$ with a cold front to the west at 12Z. HURDAT does not list an organized system on this date. Microfilm shows a closed low pressure of at most $996 \mathrm{mb}$ at $39.2 \mathrm{~N}, 43.0 \mathrm{~W}$ at $12 \mathrm{Z}$. Ship highlights: $35 \mathrm{kt} \mathrm{E}$ and $997 \mathrm{mb}$ at $37.5 \mathrm{~N}, 45.0 \mathrm{~W}$ at 00Z (COADS). $35 \mathrm{kt} \mathrm{S}$ and $999 \mathrm{mb}$ at $38.3 \mathrm{~N}, 43.6 \mathrm{~W}$ at $06 \mathrm{Z}$ (COADS). $35 \mathrm{kt} \mathrm{SE}$ and $988 \mathrm{mb}$ at $40.2 \mathrm{~N}, 42.7 \mathrm{~W}$ at $12 \mathrm{Z}$ (COADS). $56 \mathrm{kt} \mathrm{SSE}$ and $1001 \mathrm{mb}$ at $39.8 \mathrm{~N}, 42.8 \mathrm{~W}$ at $12 \mathrm{Z}$ (MWL). $30 \mathrm{kt} \mathrm{WNW}$ and $999 \mathrm{mb}$ at $42.7 \mathrm{~N}, 44.0 \mathrm{~W}$ at $18 \mathrm{Z}$ (COADS).

November 11:

HWM analyzes a spot low pressure at $50.2 \mathrm{~N}, 35.0 \mathrm{~W}$ with a frontal boundary close to the west at 12Z. HURDAT does not list an organized system on this date. Microfilm is not available on this date. Ship highlights: $45 \mathrm{kt} \mathrm{SW}$ and $1009 \mathrm{mb}$ at $47.4 \mathrm{~N}, 34.1 \mathrm{~W}$ at $06 \mathrm{Z}$ (COADS).

ATSR: "From her inception, Jenny appeared to be only quasitropical in nature. Although scarce data in the area of the storm precluded accurate temperature and pressure analyses, 
all available reports from Ocean Station Echo and reconnaissance aircraft indicated that the upper level structure around the storm was extratropical. The deepening of Jenny, which coincided with its movement underneath an upper level low, indicated that jenny had extratropical characteristics. After the central pressure dropped to $974 \mathrm{mb}$, maximum winds did not exceed an average of 65 knots, although some gusts to as 600 miles, and, as depicted on surface charts at the time that Jenny was most intense, she resembled a wintertime "Nor'easter." It is conjectured that a small warm core could have existed within the circulation of the larger low."

A tropical wave entered the eastern Caribbean Sea late in October generating an area of disturbed weather. In an environment of weak steering currents, the disturbance slowly moved northeastward and became better organized. On November 1st, the sharp trough stretched from the southeast Caribbean Sea, across the Leeward Islands, and into the Atlantic Ocean. HURDAT originally indicated that genesis occurred at $12 \mathrm{Z}$ on November 1 st but synoptic observations show that the disturbance did not have a closed low-level circulation at this time. Genesis is analyzed at $06 \mathrm{Z}$ on November $2 \mathrm{nd}$ as a $30 \mathrm{kt}$ tropical depression, 18 hours later than originally shown in HURDAT. Very minor track alterations were introduced during the lifetime of this tropical cyclone. The broad tropical depression moved northeastward during the 2 nd and turned to the east on November 3rd. During this time, the synoptic-scale pressure gradient increased to the northwest of the cyclone and gale-force winds began to be reported about $300 \mathrm{~nm}$ from the center. During most of the lifetime of the tropical cyclone (with the exception of the 6th and 7th), the system exhibited characteristics of a subtropical cyclone. The Monthly Weather Review mentions the similarities of this cyclone with previous cyclones that have exhibited subtropical characteristics like Hurricane Greta in 1956. Furthermore, they mention the term "subtropical" to describe this tropical cyclone, a milestone. Previously the term used to describe these cyclones was quasi-tropical.

On November 4th, the tropical depression moved east-southeast maintaining a large circulation with gale-force winds about $300 \mathrm{~nm}$ and further from the center, but these were not judged to have been directly associated with this system. A central pressure of $1002 \mathrm{mb}$ is present in HURDAT at $12 \mathrm{Z}$ on November 4th and although there is no evidence to suggest that it was an actual measurement, it appears reasonable and has been retained. A central pressure of $1002 \mathrm{mb}$ suggests maximum sustained winds of $40 \mathrm{kt}$ north of $25 \mathrm{~N}$ and $43 \mathrm{kt}$ south of $25 \mathrm{~N}$ from the Brown et al. pressure-wind relationship. While the tropical cyclone had a forward speed of $19 \mathrm{kt}$, the analyzed intensity is $30 \mathrm{kt}$ due to its large circulation and ship observations near the center showing winds below gale-force, same as originally shown in HURDAT. A ship reported $20 \mathrm{kt} \mathrm{NE}$ and 1003 $\mathrm{mb}$ at $18 \mathrm{Z}$ on the 4th, suggesting a central pressure of $1001 \mathrm{mb}$, which has been added to HURDAT. On November 5th, synoptic observations indicate that the tropical cyclone 
became better organized and the gale-force winds were being reported closer to the center. Intensification to a tropical storm is analyzed at $12 \mathrm{Z}$ on the 5 th, twelve hours earlier than originally shown in HURDAT. A central pressure of $991 \mathrm{mb}$ was present in HURDAT at $18 \mathrm{Z}$ on the 5 th but it has been removed since it was likely originally added due to a ship that reported $35 \mathrm{kt} \mathrm{SE}$ and $991 \mathrm{mb}$. A peripheral pressure of $991 \mathrm{mb}$ suggests maximum sustained winds greater than $58 \mathrm{kt}$ from the north of $25 \mathrm{~N}$ pressurewind relationship. Due to the large size of the circulation, an intensity of $40 \mathrm{kt}$ is analyzed at $18 \mathrm{Z}$ on the 5 th, up from $30 \mathrm{kt}$ originally in HURDAT, a minor intensity change. A central pressure of $976 \mathrm{mb}$ was present in HURDAT at $00 \mathrm{Z}$ on November 6th and it has been removed since there is no evidence that it was an actual observation, nor does it appear reasonable. A reconnaissance aircraft reached Jenny at $1910 \mathrm{Z}$ on the 6th measuring a central pressure of $974 \mathrm{mb}$ and estimated surface winds of $70 \mathrm{kt}$. A central pressure of $974 \mathrm{mb}$ suggests maximum sustained winds of $80 \mathrm{kt}$ and $83 \mathrm{kt}$ intensifying from the north of $25 \mathrm{~N}$ pressure-wind relationship. Due to the very large size of the circulation and forward speed of about $12 \mathrm{kt}$, an intensity of $70 \mathrm{kt}$ is analyzed at $18 \mathrm{Z}$ on the 6th, same as originally shown in HURDAT. $70 \mathrm{kt}$ is also the peak intensity of this hurricane, same as originally shown in HURDAT. Intensification to a hurricane is analyzed at $12 \mathrm{Z}$ on the 6th, same as originally shown in HURDAT. A central pressure of $974 \mathrm{mb}$ was present in HURDAT at $18 \mathrm{Z}$ on the 6th and has been retained. Late on the 6th, ships observations near the center indicated that Jenny had developed a strong, tighter core. A couple of ships reported hurricane-force winds, up to $70 \mathrm{kt}$.

On November 7th, Jenny turned to the northeast ahead of a frontal boundary. The period of intensification observed on the 5th and 6th came to a stop early on the 7th and Jenny began to weaken. The next reconnaissance aircraft measured a central pressure of $988 \mathrm{mb}$ at $1554 \mathrm{Z}$ and $985 \mathrm{mb}$ at $19 \mathrm{Z}$. A central pressure of $988 \mathrm{mb}$ was present in HURDAT at $12 \mathrm{Z}$ on the 7 th and has been removed since the observation was closer to the $18 \mathrm{Z}$ time slot. A central pressure of $985 \mathrm{mb}$ was present at $00 \mathrm{Z}$ on November 8 th and has been moved to $18 \mathrm{Z}$ on the $7 \mathrm{th}$. A central pressure of $985 \mathrm{mb}$ suggests maximum sustained winds of $66 \mathrm{kt}$ from the north of $25 \mathrm{~N}$ pressure-wind relationship. Due to the very large size of the circulation, forward speed of about $10 \mathrm{kt}$ and visual estimate from the aircraft of $60 \mathrm{kt}$, an intensity of $60 \mathrm{kt}$ is analyzed at $18 \mathrm{Z}$ on the 7th, same as originally shown in HURDAT. Weakening below hurricane intensity is analyzed at $12 \mathrm{Z}$ on the 7 th, same as originally shown in HURDAT. Jenny increased in forward speed to the northeast on the 8th and continued to lose strength. HURDAT shows transition to an extratropical cyclone at $18 \mathrm{Z}$ on the 8 th but synoptic observations indicate that Jenny remained a tropical storm in the warm sector of an approaching frontal boundary. The circulation remained symmetric and the data shows no signs of frontal boundaries associated with Jenny on that date. As the frontal boundary got closer to Jenny, the storm continued to gain in forward speed and began to re-intensify over the North Atlantic. A ship reported $55 \mathrm{kt} \mathrm{SE}$ 
at $12 \mathrm{Z}$ on the 10th near the center of Jenny. Transition to an extratropical cyclone is analyzed at $00 \mathrm{Z}$ on the 11 th, 54 hours later than originally shown in HURDAT. The last position in HURDAT was at $18 Z$ on the 9th but surface observations show that Jenny retained a well-defined center into November 10th and early on the 11 th. Ship observations at $12 \mathrm{Z}$ on the 11th indicate that Jenny had been absorbed by a larger extratropical cyclone, thus the last position is analyzed at $06 \mathrm{Z}$ on the $11 \mathrm{th}, 36$ hours later than originally shown in HURDAT. Furthermore, it is probable that Jenny was a posttropical cyclone on the 9 th and 10th but without satellite images it is not possible to use this classification.

Tropical Storm Inga [November 4-8, 1961]

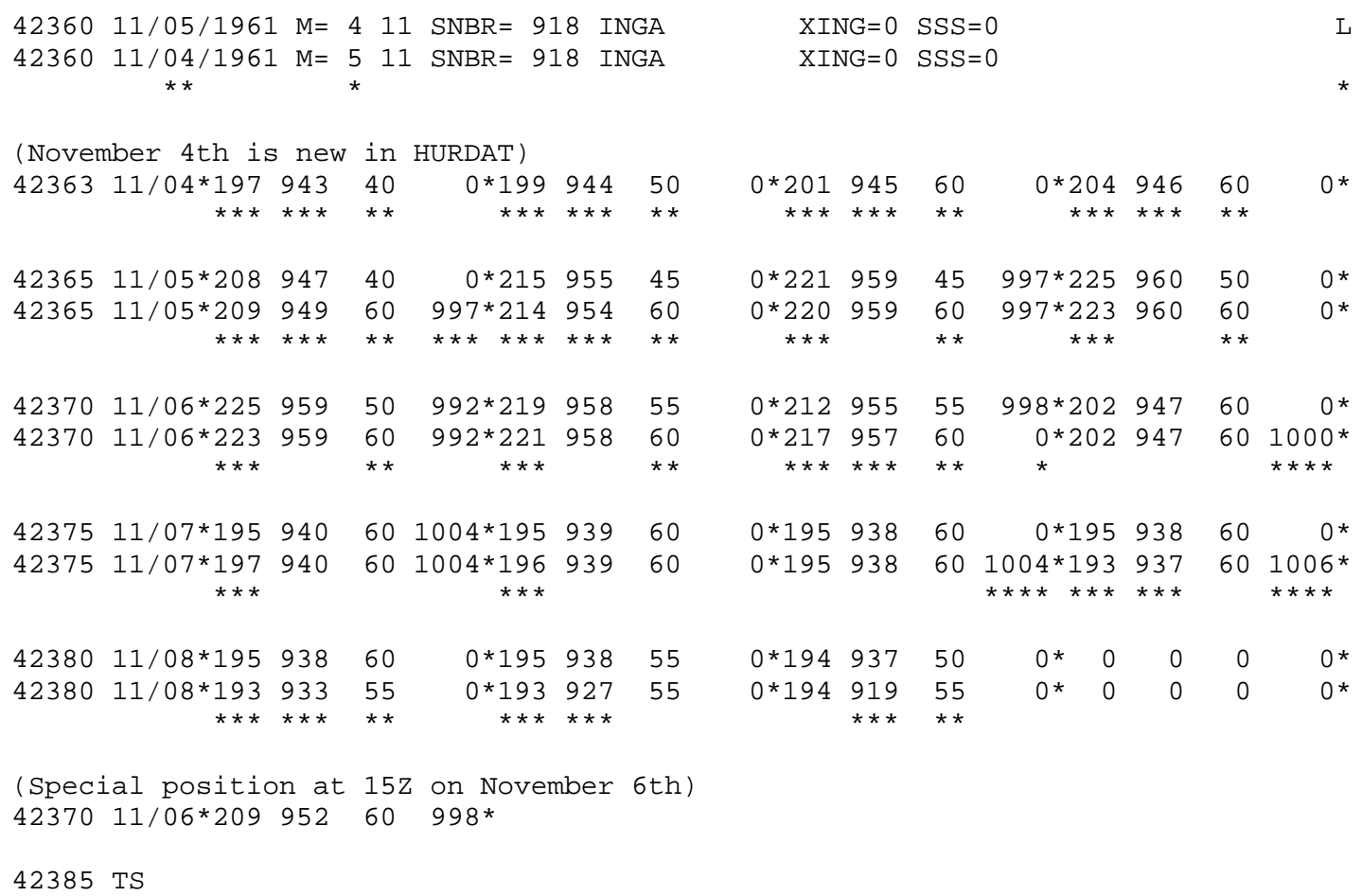

Minor changes to the track and major changes to the intensity shown in McAdie et al. (2009). Another major change is to indicate genesis 24 hours earlier than originally in HURDAT. Evidence for these alterations comes from the NHC microfilm maps, the Historical Weather Maps series, the COADS ship database, Monthly Weather Review, Navy reconnaissance book, Mariners Weather Log, and NHC Storm Wallets. 
November 3:

HWM analyzes a closed low pressure of at most $1000 \mathrm{mb}$ at $19.2 \mathrm{~N}, 94.2 \mathrm{~W}$ with a weakening cold front to the north at $12 \mathrm{Z}$. HURDAT lists a $25 \mathrm{kt}$ tropical depression at $18.6 \mathrm{~N}, 94.6 \mathrm{~W}$ at $12 \mathrm{Z}$ (last position of Eastern Pacific's Simone). Microfilm shows a closed low pressure of at most $1002 \mathrm{mb}$ at $21.5 \mathrm{~N}, 95.3 \mathrm{~W}$ with a frontal boundary to the north at 12Z. Ship highlights: No gales or low pressures.

November 4:

HWM analyzes a closed low pressure of at most $1000 \mathrm{mb}$ at $19.9 \mathrm{~N}, 94.8 \mathrm{~W}$ with a weakening cold front to the north at 12Z. HURDAT does not list an organized system on this date. Microfilm shows a closed low pressure of at most $999 \mathrm{mb}$ at $20.5 \mathrm{~N}, 95.4 \mathrm{~W}$ with a frontal boundary to the north at 12Z. Ship highlights: $40 \mathrm{kt} \mathrm{NW}$ and $1006 \mathrm{mb}$ at $19.5 \mathrm{~N}$, $94.5 \mathrm{~W}$ at $00 \mathrm{Z}$ (COADS). $70 \mathrm{kt} \mathrm{NNW}$ and $1001 \mathrm{mb}$ at $20.0 \mathrm{~N}, 95.0 \mathrm{~W}$ at $11 \mathrm{Z}$ (micro). $40 \mathrm{kt}$ $\mathrm{NW}$ and $1008 \mathrm{mb}$ at $19.9 \mathrm{~N}, 95.5 \mathrm{~W}$ at $18 \mathrm{Z}$ (COADS). Land highlights: $40 \mathrm{kt} \mathrm{NW}$ and $1007 \mathrm{mb}$ at Veracruz, Mexico at 00Z (micro). Aircraft highlights: Penetration center fix measured a central pressure of $997 \mathrm{mb}$, estimated an eye diameter of $15 \mathrm{~nm}$ and surface winds of $40 \mathrm{kt}$ at $20.6 \mathrm{~N}, 94.6 \mathrm{~W}$ at $2215 \mathrm{Z}$ (ATSR).

MWR: "Inga, a very late-season tropical cyclone in the Gulf of Mexico, moved and behaved quite erratically. It was of true tropical nature during only part of its life, and the first of record to form in November in the Gulf. Early on November 4, the SS Navigator reported northwesterly winds estimated at 70 to $80 \mathrm{kt}$ with pressure dropping rapidly to $1001 \mathrm{mb}$ at a position about 100 miles northeast of Vera Cruz, Mexico. That afternoon the Navy reconnaissance plane located the center of the storm circulation about 150 miles northeast of Vera Cruz with a central pressure of $998 \mathrm{mb}$ and the highest winds $50 \mathrm{kt}$." ATSR: "Early on the 4th of November, reports from Vera Cruz, Mexico, and the SS MAASLLOYD indicated an area of gale force winds in the extreme southwestern Gulf of Campeche. This phenomenon was thought at the time to be associated with a cold front which had moved into the area. At $041200 Z$ the SS NAVIGATOR, at a position about 90 miles northeast of Vera Cruz reported northwesterly winds of 70 to 80 knots and a pressure of $1001 \mathrm{mb}$ falling rapidly. A short time later Navy reconnaissance verified the existence of a short circulation about 100 miles north-northeast of Vera Cruz. This flight reported a central pressure of $997 \mathrm{mb}$ and a maximum wind of only 40 knot. Direction of movement appeared to be northwest."

November 5:

HWM analyzes a closed low pressure of at most $1000 \mathrm{mb}$ at $22.0 \mathrm{~N}, 95.7 \mathrm{~W}$ with a cold front far to the north at 12Z. HURDAT lists a $45 \mathrm{kt}$ tropical storm at $22.1 \mathrm{~N}, 95.9 \mathrm{~W}$ at 12Z. Microfilm shows a closed low pressure of at most $1002 \mathrm{mb}$ at $22.1 \mathrm{~N}, 95.9 \mathrm{~W}$ with a 
frontal boundary far to the north at 12Z. Ship highlights: $35 \mathrm{kt} \mathrm{NW}$ and $1004 \mathrm{mb}$ at $20.3 \mathrm{~N}, 95.6 \mathrm{~W}$ at $00 \mathrm{Z}$ (COADS). $35 \mathrm{kt} \mathrm{W}$ and $1005 \mathrm{mb}$ at $20.5 \mathrm{~N}, 95.7 \mathrm{~W}$ at $06 \mathrm{Z}$ (COADS). $30 \mathrm{kt} \mathrm{W}$ and $1003 \mathrm{mb}$ at $21.3 \mathrm{~N}, 95.0 \mathrm{~W}$ at $12 \mathrm{Z}$ (COADS). $35 \mathrm{kt} \mathrm{E}$ and 1003 $\mathrm{mb}$ at $23.6 \mathrm{~N}, 93.6 \mathrm{~W}$ at $22 \mathrm{Z}$ (micro). Aircraft highlights: Penetration center fix measured a central pressure of $997 \mathrm{mb}$, estimated an eye diameter of $5 \mathrm{~nm}$ and surface winds of 50 $\mathrm{kt}$ at $22.1 \mathrm{~N}, 95.9 \mathrm{~W}$ at $1223 \mathrm{Z}$ (ATSR). Penetration center fix estimated surface winds of $50 \mathrm{kt}$ at $22.2 \mathrm{~N}, 95.9 \mathrm{~W}$ at $16 \mathrm{Z}$ (ATSR). Penetration center fix measured a central pressure of $992 \mathrm{mb}$, estimated an eye diameter of $25 \mathrm{~nm}$ and surface winds of $50 \mathrm{kt}$ at $22.3 \mathrm{~N}$, 95.7W at 2155Z (ATSR).

ATSR: "Warning number one on tropical storm Inga was issued at 050000Z. By noon of the 5th, a cold front had pushed southward off the Texas coast in advance of a strong surface high pressure ridge."

November 6:

HWM analyzes a closed low pressure of at most $1005 \mathrm{mb}$ at $21.3 \mathrm{~N}, 95.8 \mathrm{~W}$ with a cold front close to the northwest at 12Z. HURDAT lists a $55 \mathrm{kt}$ tropical storm at $21.2 \mathrm{~N}, 95.5 \mathrm{~W}$ at $12 \mathrm{Z}$. Microfilm shows a closed low pressure of at most $1002 \mathrm{mb}$ at $21.5 \mathrm{~N}, 95.4 \mathrm{~W}$ with a frontal boundary to the northwest at 12Z. Ship highlights: $35 \mathrm{kt} \mathrm{NNW}$ at $20.9 \mathrm{~N}, 96.7 \mathrm{~W}$ at (micro). $45 \mathrm{kt} \mathrm{NW}$ and $1009 \mathrm{mb}$ at $21.2 \mathrm{~N}, 96.8 \mathrm{~W}$ at $12 \mathrm{Z}$ (COADS). $60 \mathrm{kt} \mathrm{WNW}$ and $1003 \mathrm{mb}$ at $19.5 \mathrm{~N}, 94.9 \mathrm{~W}$ at $18 \mathrm{Z}$ (COADS). Aircraft highlights: Penetration center fix measured a central pressure of $998 \mathrm{mb}$ at $22.3 \mathrm{~N}, 95.7 \mathrm{~W}$ at $00 \mathrm{Z}$ (ATSR). Penetration center fix measured a central pressure of $998 \mathrm{mb}$, estimated an eye diameter of $3 \mathrm{~nm}$ and surface winds of $60 \mathrm{kt}$ at $20.6 \mathrm{~N}, 95.0 \mathrm{~W}$ at $1425 \mathrm{Z}$ (ATSR). Penetration center fix measured a central pressure of $1000 \mathrm{mb}$, estimated an eye diameter of $3 \mathrm{~nm}$ and surface winds of $60 \mathrm{kt}$ at $20.0 \mathrm{~N}, 94.5 \mathrm{~W}$ at $19 \mathrm{Z}$ (ATSR). Penetration center fix measured a central pressure of $1004 \mathrm{mb}$ and estimated surface winds of $40 \mathrm{kt}$ at $19.6 \mathrm{~N}, 93.8 \mathrm{~W}$ at $2326 \mathrm{Z}$ (ATSR).

MWR: "The storm moved north-northwest to a position about 100 miles east of Tampico by the night of the 5th. A strong pressure rise and cold front pushed southward out of Texas into the northwestern Gulf and southward along the Mexican coast during the night of the 5th. The strong pressure rises to the northwest of the storm caused it to turn southward, and at 0800 EST on the 6th a Navy plane located the center about 100 miles east-northeast of Tuxpan. The plane flew on southward and located a second eye at 0900 EST about 80 miles southeast of the first eye. The cold air apparently moved into the first eye and it dissipated rapidly, leaving the southern eye as the main center. This center moved slowly southeastward and became stationary in the Gulf of Campeche about 160 miles east-northeast of Vera Cruz on the afternoon of the 6th. It continued essentially stationary in this area and gradually became extratropical as the cold air moved into it." 
ATSR: "The combination of high pressure and cold air seemed to have a marked effect on the storm for it made a sharp turn early on the 6th and, almost retracing its previous track, moved slowly toward the southeast. An oddity occurred later on the 6th. A Navy reconnaissance plane staging out of Corpus Christi located the storm as it was moving on its southeasterly heading; then, about 80 miles further to the southeast, the plane found a separate eye. Subsequent reports led forecasters to believe that the first eye filled and the second eye became the storm circulation."

November 7:

HWM analyzes a closed low pressure of at most $1005 \mathrm{mb}$ at $19.4 \mathrm{~N}, 93.5 \mathrm{~W}$ with a cold front close to the northwest at 12Z. HURDAT lists a $60 \mathrm{kt}$ tropical storm at $19.5 \mathrm{~N}, 93.8 \mathrm{~W}$ at $12 \mathrm{Z}$. Microfilm does not show a closed low pressure but a tropical cyclone symbol at $19.6 \mathrm{~N}, 93.5 \mathrm{~W}$ with a frontal boundary to the north at $12 \mathrm{Z}$. Ship highlights: $55 \mathrm{kt} \mathrm{NW}$ and $1007 \mathrm{mb}$ at $19.0 \mathrm{~N}, 94.6 \mathrm{~W}$ at $00 \mathrm{Z}$ (COADS). $50 \mathrm{kt} \mathrm{NW}$ and $1011 \mathrm{mb}$ at $19.4 \mathrm{~N}, 95.3 \mathrm{~W}$ at $06 \mathrm{Z}$ (COADS). $65 \mathrm{kt} \mathrm{NW}$ and $1010 \mathrm{mb}$ at $19.4 \mathrm{~N}, 95.4 \mathrm{~W}$ at $12 \mathrm{Z}$ (COADS). $45 \mathrm{kt} \mathrm{NW}$ and $1013 \mathrm{mb}$ at $19.6 \mathrm{~N}, 96.1 \mathrm{~W}$ at $18 \mathrm{Z}$ (micro). $45 \mathrm{kt} \mathrm{NW}$ and $1008 \mathrm{mb}$ at $19.8 \mathrm{~N}, 94.8 \mathrm{~W}$ at $21 \mathrm{Z}$ (micro). Land highlights: $40 \mathrm{kt} \mathrm{NNW}$ at Veracruz, Mexico at 00Z (micro). Aircraft highlights: Penetration center fix measured a central pressure of $1004 \mathrm{mb}$, estimated an eye diameter of $20 \mathrm{~nm}$ and surface winds of $60 \mathrm{kt}$ at $19.5 \mathrm{~N}, 93.8 \mathrm{~W}$ at $13 \mathrm{Z}$ (ATSR). Penetration center fix measured a central pressure of $1003 \mathrm{mb}$ and estimated surface winds of $60 \mathrm{kt}$ at $19.3 \mathrm{~N}, 93.9 \mathrm{~W}$ at $16 \mathrm{Z}$ (ATSR/WALLET). Penetration center fix measured a central pressure of $1006 \mathrm{mb}$ and estimated surface winds of $65 \mathrm{kt}$ at $19.3 \mathrm{~N}$, 93.7W at $19 \mathrm{Z}$ (ATSR).

ATSR: "Inga became stationary by the 7th in the south central Gulf of Campeche."

November 8:

HWM analyzes a stationary front over the southern Gulf of Mexico at 12Z. HURDAT lists a $50 \mathrm{kt}$ tropical storm at $19.4 \mathrm{~N}, 93.7 \mathrm{~W}$ at $12 \mathrm{Z}$ (last position). Microfilm shows a frontal boundary over the southern Gulf of Mexico at 12Z. Ship highlights: $55 \mathrm{kt} \mathrm{NW}$ and $1011 \mathrm{mb}$ at $19.7 \mathrm{~N}, 95.2 \mathrm{~W}$ at $00 \mathrm{Z}$ (COADS). $45 \mathrm{kt} \mathrm{NW}$ and $1014 \mathrm{mb}$ at $19.7 \mathrm{~N}, 95.2 \mathrm{~W}$ at $06 \mathrm{Z}$ (COADS). $40 \mathrm{kt} \mathrm{NW}$ and $1016 \mathrm{mb}$ at $20.3 \mathrm{~N}, 95.1 \mathrm{~W}$ at $12 \mathrm{Z}$ (COADS). $55 \mathrm{kt} \mathrm{NW}$ and $1017 \mathrm{mb}$ at $19.5 \mathrm{~N}, 95.4 \mathrm{~W}$ at $18 \mathrm{Z}$ (micro). Aircraft highlights: Penetration center fix found no closed circulation, lowest pressure was $1012 \mathrm{mb}$ and estimated surface winds of $45 \mathrm{kt}$ at $19.4 \mathrm{~N}, 91.7 \mathrm{~W}$ at $13 \mathrm{Z}$ (ATSR).

MWR: "On the morning of the 8th, the flight into the area encountered no closed circulation but ships a short distance northeast of Vera Cruz continued to report winds of gale force until that night." ATSR: "Navy reconnaissance on the 8th found no wind circulation and a low pressure of $1012 \mathrm{mb}$. The final warning on Inga was issued at 
081600Z. It is interesting to note that the same flight on the 8th which could find no evidence of a circulation did find an area of 45-knot northwesterly winds near Inga's original birthplace. This couples with the even more interesting fact that no ship ever reported strong winds in the eastern quadrant of the storm, yet a number of ships reported gale to hurricane force northwesterly winds between the circulation center and the Mexican coast, a distance of approximately 180 miles. It is believed that the Sierra Madre Orion mountain range, which juts outward to the coast near Vera Cruz, had some effect on Inga's abnormal windfield, or conceivably, triggered the disturbance initially."

November 9:

HWM analyzes a stationary front over the southern Gulf of Mexico at 12Z. HURDAT does not list an organized system on this date. Microfilm shows a closed low pressure of at most $1012 \mathrm{mb}$ at $19.4 \mathrm{~N}, 92.8 \mathrm{~W}$ at 12Z. Ship highlights: $40 \mathrm{kt} \mathrm{NW}$ and $1016 \mathrm{mb}$ at $19.4 \mathrm{~N}, 95.6 \mathrm{~W}$ at $00 \mathrm{Z}$ (COADS). $40 \mathrm{kt} \mathrm{NW}$ and $1016 \mathrm{mb}$ at $19.5 \mathrm{~N}, 95.5 \mathrm{~W}$ at $06 \mathrm{Z}$ (COADS).

\section{November 10:}

HWM and microfilm do not show an organized system at 12Z. HURDAT does not list an organized system on this date. Ship highlights: No gales or low pressures.

MWR: "The storm was apparently a shallow system, because its movement was determined mainly by the forces at low levels. On the 6th, the strong pressure rises moving southward along the Mexican coast ahead of the cold front apparently caused the new eye or center to develop in the same area where the original circulation was found. This first circulation developed as a strong pressure rise pushed southward along the Mexican coast ahead of a weak cold front of the night of the $3 \mathrm{rd}$. This area of development is about 100 miles east of the position where a high mountain range in Mexico protrudes eastward to near the coast in the vicinity of Nautla. The New Orleans hurricane center hypothesized that the funneling effect set up by these mountains may be a factor in the development of the circulations in that particular area. The lowest pressure reported by dropsondes from reconnaissance was $997 \mathrm{mb}(992 \mathrm{mb}$ from the low-level extrapolation), and the highest wind was $65 \mathrm{kt}$ in the cold air to the west and south of the circulation on the afternoon of the 7th, after the storm had been stationary for about 24 hours in the Gulf of Campeche and was becoming extratropical. During the period when the storm was predominantly tropical in nature, the highest winds were about $50 \mathrm{kt}$."

Tropical Storm Inga had a unique time and place of formation. The remnants of Tropical Storm Simone in the Eastern Pacific reached the Gulf of Mexico early on the 
November 3rd and interacted with an approaching cold front. Genesis likely occurred in the Bay of Campeche late on the 3rd but the first position is analyzed at $00 \mathrm{Z}$ on November 4th, 24 hours earlier than originally shown in HURDAT, based on synoptic data. The initial intensity is assessed at $40 \mathrm{kt}$ based on a ship near the center that reported $40 \mathrm{kt} \mathrm{NW}$ and $1006 \mathrm{mb}$ at $00 \mathrm{Z}$ on the 4 th. Minor track alterations are introduced during the lifetime of this tropical cyclone. The tropical storm steadily intensified and reached a peak intensity of $60 \mathrm{kt}$ at $12 \mathrm{Z}$ on the 4 th. $60 \mathrm{kt}$ is also the original peak intensity in HURDAT. At this time, a ship named "SS Navigator" near the center reported $70 \mathrm{kt}$ and $1001 \mathrm{mb}$. A significant pressure gradient had developed over the western and northwestern quadrants as a strong ridge moved into the central United States behind the frontal boundary just northwest of the tropical cyclone. At $2215 \mathrm{Z}$ on the 4 th, the first reconnaissance aircraft reached Inga measuring a central pressure of $997 \mathrm{mb}$, estimating surface winds of $40 \mathrm{kt}$ and an eye diameter of $15 \mathrm{~nm}$. A central pressure of $997 \mathrm{mb}$ suggests maximum sustained winds of $53 \mathrm{kt}$ south of $25 \mathrm{~N}$ from the Brown et al. pressurewind relationship. An eye diameter of $15 \mathrm{~nm}$ suggests an RMW of about $11 \mathrm{~nm}$ and the climatological value is $17 \mathrm{~nm}$. Due to an RMW smaller than the climatological value, forward speed of $6 \mathrm{kt}$ and strong pressure gradient, an intensity of $60 \mathrm{kt}$ is analyzed at $00 Z$ on November 5th, up from 40 kt originally in HURDAT, a major intensity change. A central pressure of $997 \mathrm{mb}$ was added to HURDAT at 00Z on the 5th. Even though the first reconnaissance aircraft visually estimated weaker winds than those reported by the SS Navigator, it is possible that the ship's measurement was high biased slightly and/or was a transient event. When the aircraft reached the storm, it was diurnal minimum and the strong convection could have weakened. The ESRL Daily Mean Wind Shear for the 4th indicates that Inga was being affected by moderate southwest vertical wind shear. It is possible that Inga may have reached hurricane intensity for a brief period early on the 4th. An analog is Tropical Storm Alberto in 2006, which while in the northern Gulf of Mexico under strong vertical wind shear, a significant convective burst caused the winds to increase to $60 \mathrm{kt}$. On the 5th, Inga moved northwestward before stalling late in the day as another frontal boundary moved into the Gulf of Mexico. At $1223 \mathrm{Z}$ on the 5th, a reconnaissance aircraft reported a central pressure of $997 \mathrm{mb}$, estimated surface winds of $50 \mathrm{kt}$ and an eye diameter of $5 \mathrm{~nm}$. A central pressure of $997 \mathrm{mb}$ suggests maximum sustained winds of $53 \mathrm{kt}$ south of $25 \mathrm{~N}$ from the pressure-wind relationship. An eye diameter of $5 \mathrm{~nm}$ suggests an RMW of about $4 \mathrm{~nm}$ and the climatological value is $17 \mathrm{~nm}$. Due to an RMW much smaller than the climatological value but a forward speed of only $3 \mathrm{kt}$, an intensity of $60 \mathrm{kt}$ is analyzed at $12 \mathrm{Z}$ on the 5 th, up from $45 \mathrm{kt}$ originally in HURDAT, a minor intensity change. A central pressure of $997 \mathrm{mb}$ was present in HURDAT at $12 \mathrm{Z}$ on the 5 th and has been retained. At $2155 \mathrm{Z}$ on the 5 th, another penetration fix measured a central pressure of $992 \mathrm{mb}$, estimated surface winds of $50 \mathrm{kt}$ and an eye diameter of $25 \mathrm{~nm}$. A central pressure of $992 \mathrm{mb}$ suggests maximum sustained 
winds of $61 \mathrm{kt}$ south of $25 \mathrm{~N}$ from the pressure-wind relationship. An eye diameter of 25 $\mathrm{nm}$ suggests an RMW of about $19 \mathrm{~nm}$ and the climatological value is $17 \mathrm{~nm}$. Due to an RMW close to the climatological value and being almost stationary, an intensity of $60 \mathrm{kt}$ is analyzed at $00 \mathrm{Z}$ on November 6th, up from $50 \mathrm{kt}$ originally in HURDAT, a minor intensity change. A central pressure of $992 \mathrm{mb}$ was present in HURDAT and has been retained.

After a period when the movement of the storm was almost stationary, Inga started to move to the southeast later on the 6th. Observations from the reconnaissance aircraft investigating the tropical cyclone around midday on the 6th indicate that the original low-level center dissipated after $13 \mathrm{Z}$ and another low-level center was fixed about an hour later about $80 \mathrm{~nm}$ to the southeast. An analog of a system in the Gulf that had a center dissipate and a new one form elsewhere is Tropical Storm Arlene in 1993. At $1425 \mathrm{Z}$ on the 6th, a penetration fix measured a central pressure of $998 \mathrm{mb}$, estimated surface winds of $60 \mathrm{kt}$ and an eye diameter of $3 \mathrm{~nm}$. A central pressure of $998 \mathrm{mb}$ suggests maximum sustained winds of $51 \mathrm{kt}$ south of $25 \mathrm{~N}$ from the pressure-wind relationship. An eye diameter of $3 \mathrm{~nm}$ suggests an RMW of about $2 \mathrm{~nm}$ and the climatological value is $16 \mathrm{~nm}$. Based on a tiny RMW and ship data later on the day, an intensity of $60 \mathrm{kt}$ is analyzed at $12 \mathrm{Z}$ on the 6th, up from $55 \mathrm{kt}$ originally in HURDAT, a minor intensity change. A central pressure of $998 \mathrm{mb}$ was present in HURDAT at $12 \mathrm{Z}$ on the 6 th and has been moved to a special $15 \mathrm{Z}$ best track position due to the reformation of the center farther to the southeast as it did not represent the central pressure of the old center at 12Z. At 19Z, another penetration center fix measured a central pressure of 1000 $\mathrm{mb}$, estimated surface winds of $60 \mathrm{kt}$ and an eye diameter of $3 \mathrm{~nm}$. A central pressure of $1000 \mathrm{mb}$ suggests maximum sustained winds of $47 \mathrm{kt}$ south of $25 \mathrm{~N}$ weakening from the pressure-wind relationship. An eye diameter of $3 \mathrm{~nm}$ suggests an RMW of about $2 \mathrm{~nm}$ and the climatological value is $16 \mathrm{~nm}$. Based on a tiny RMW, forward speed of about $5 \mathrm{kt}$ and a ship at $16 \mathrm{Z}$ that measured $60 \mathrm{kt}$, an intensity of $60 \mathrm{kt}$ is analyzed at $18 \mathrm{Z}$ on the $6 \mathrm{th}$, same as originally shown in HURDAT. A central pressure of $1000 \mathrm{mb}$ has been added to HURDAT at $18 \mathrm{Z}$ on the 6 th. A final penetration fix on the 6 th occurred at $2326 \mathrm{Z}$ and measured a central pressure of $1004 \mathrm{mb}$ and estimated surface winds of $40 \mathrm{kt}$. A central pressure of $1004 \mathrm{mb}$ suggests maximum sustained winds of $41 \mathrm{kt}$ south of $25 \mathrm{~N}$ weakening from the pressure-wind relationship. Based on ship data early on November $7 \mathrm{th}$, an intensity of $60 \mathrm{kt}$ is analyzed at $00 \mathrm{Z}$ on the $7 \mathrm{th}$, same as originally shown in HURDAT. On the 7th, Inga stalled again in the Bay of Campeche. Ships observations indicate that the strong pressure gradient continued over the western quadrant of Inga, generating winds up to hurricane force. These winds were in part caused by Inga but it is difficult to determine if they were part of the circulation and what portion of the winds were due to funneling induced by interaction of the cold front with the orography, thus the intensity is retained at $60 \mathrm{kt}$, as originally shown in HURDAT, just below hurricane 
intensity. Dry, cold air behind the cold front was present as far south as Tampico but ship observations near the center of Inga show that the tropical storm retained its tropical characteristics. Penetration center fixes occurred at $13 \mathrm{Z}$ and $19 \mathrm{Z}$ on the 7 th measuring central pressures of $1004 \mathrm{mb}$ and $1006 \mathrm{mb}$, respectively, which have been added to HURDAT. Early on November 8th, Inga began to move to the east and slightly weakened before dissipating and being absorbed by the cold front after 12Z. The last position is analyzed at $12 Z$ on the 8th, same as originally shown in HURDAT. Inga is the only tropical cyclone since 1851 to have formed in the Bay of Campeche in the month of November.

New Tropical Storm [November 17-21, 1961]

\begin{tabular}{|c|c|c|c|c|c|c|c|c|c|c|c|c|c|c|c|}
\hline 265 & $11 / 17 / 1961$ & $1 M=$ & 512 & SNBR= & 820 & & VAME & & & $N G=$ & פ & & & & \\
\hline 12 & $11 / 17$ & $\odot$ & $\odot$ & $0^{*}$ & $\odot$ & $\odot$ & 0 & ०* & $\odot$ & $\odot$ & 0 & $0 * 2$ & 550 & 25 & \\
\hline & $11 / 18 * 240$ & 543 & 25 & $0 * 2$ & & 536 & 25 & $1004 * 26$ & & 30 & 30 & $0 * 273$ & 523 & 30 & ○* \\
\hline & $11 / 19 * 278$ & 510 & 30 & $\Theta * 2$ & & 495 & 35 & $0 * 29$ & & 175 & 40 & $0 * 314$ & 460 & 40 & ○* \\
\hline & $11 / 20 * 330$ & 445 & 40 & $0 * 3$ & & 425 & 40 & $0 * 35$ & & 10 & 45 & $0 * 362$ & 395 & 50 & \\
\hline 2 & 11/21E370 & 382 & 50 & ๑EЗ & & 370 & 50 & $0^{*}$ & $\odot$ & $\odot$ & $\odot$ & $\Theta^{*} \quad \odot$ & $\odot$ & 0 & $\theta^{x}$ \\
\hline
\end{tabular}
37275 TS

A new tropical storm has been added to HURDAT, not previously shown in McAdie et al. (2009). Evidence for its existence comes from the Historical Weather Map series, Microfilm, COADS ship database, Mariners Weather Log and Jack Beven's and David Roth's suspect list.

November 16:

HWM analyzes a closed low pressure of at most $1010 \mathrm{mb}$ at $19.0 \mathrm{~N}, 51.0 \mathrm{~W}$ at $12 \mathrm{Z}$. Microfilm shows a closed low pressure of at most $1011 \mathrm{mb}$ over the northeastern Caribbean Sea near 17.0N, 64.0W at 12Z. Ship highlights: No gale force winds or equivalent low pressures.

November 17:

HWM analyzes an elongated area of low pressure with a center at $21.2 \mathrm{~N}, 60.0 \mathrm{~W}$ and another center at $22.2 \mathrm{~N}, 48.2 \mathrm{~W}$ and a stationary front to the north at $12 \mathrm{Z}$. Microfilm shows a closed low pressure of at most $1008 \mathrm{mb}$ at $21.0 \mathrm{~N}, 60.0 \mathrm{~W}$ at $12 \mathrm{Z}$. Ship highlights: No gale force winds or equivalent low pressures.

November 18:

HWM analyzes a closed low pressure of at most $1000 \mathrm{mb}$ at $27.2 \mathrm{~N}, 53.2 \mathrm{~W}$ with a frontal boundary going through the center at $12 \mathrm{Z}$. Microfilm shows a closed low pressure of at 
most $1008 \mathrm{mb}$ at $25.0 \mathrm{~N}, 53.5 \mathrm{~W}$ at 12Z. Ship highlights: $10 \mathrm{kt} \mathrm{WNW}$ and $1005 \mathrm{mb}$ at $23.9 \mathrm{~N}, 53.9 \mathrm{~W}$ at $06 \mathrm{Z}$ (COADS). $25 \mathrm{kt} \mathrm{S}$ and $1001 \mathrm{mb}$ at $26.9 \mathrm{~N}, 52.8 \mathrm{~W}$ at $12 \mathrm{Z}$ (COADS). $30 \mathrm{kt} \mathrm{WSW}$ and $1001 \mathrm{mb}$ at $25.2 \mathrm{~N}, 52.6 \mathrm{~W}$ at $18 \mathrm{Z}$ (COADS).

November 19:

HWM analyzes a closed low pressure of at most $1005 \mathrm{mb}$ at $29.0 \mathrm{~N}, 48.0 \mathrm{~W}$ with a cold front to the east and a cold front to the south at 12Z. Microfilm shows a closed low pressure of at most $999 \mathrm{mb}$ at $30.5 \mathrm{~N}, 47.0 \mathrm{~W}$ with a frontal boundary going through the center at 12Z. Ship highlights: $20 \mathrm{kt} \mathrm{SE}$ and $1002 \mathrm{mb}$ at $28.1 \mathrm{~N}, 51.0 \mathrm{~W}$ at $00 \mathrm{Z}$ (COADS). $15 \mathrm{kt} \mathrm{WNW}$ and $1000 \mathrm{mb}$ at $27.2 \mathrm{~N}, 50.0 \mathrm{~W}$ at $06 \mathrm{Z}$ (COADS). $40 \mathrm{kt} \mathrm{SW}$ and $1005 \mathrm{mb}$ at $28.6 \mathrm{~N}, 46.7 \mathrm{~W}$ at $12 \mathrm{Z}$ (COADS). $35 \mathrm{kt} \mathrm{S}$ and $1006 \mathrm{mb}$ at $28.6 \mathrm{~N}, 45.7 \mathrm{~W}$ at $12 \mathrm{Z}$ (COADS). $40 \mathrm{kt} \mathrm{SW}$ and $1005 \mathrm{mb}$ at $29.0 \mathrm{~N}, 45.2 \mathrm{~W}$ at $18 \mathrm{Z}$ (COADS). $25 \mathrm{kt} \mathrm{S}$ and $1000 \mathrm{mb}$ at $31.5 \mathrm{~N}, 45.8 \mathrm{~W}$ at $18 \mathrm{Z}$ (COADS).

November 20:

HWM analyzes a closed low pressure of at most $1010 \mathrm{mb}$ at $35.0 \mathrm{~N}, 41.0 \mathrm{~W}$ with a warm front to the northeast and weakening cold front to the south and an approaching weakening front to the west at $12 \mathrm{Z}$. Microfilm shows a closed low pressure of at most $1005 \mathrm{mb}$ at $33.0 \mathrm{~N}, 46.5 \mathrm{~W}$ with a frontal boundary to the west at 12Z. Ship highlights: 30 $\mathrm{kt} \mathrm{NE}$ and $1002 \mathrm{mb}$ at $33.5 \mathrm{~N}, 46.0 \mathrm{~W}$ at $00 \mathrm{Z}$ (COADS). $40 \mathrm{kt} \mathrm{SE}$ and $1014 \mathrm{mb}$ at $34.3 \mathrm{~N}$, $39.6 \mathrm{~W}$ at $00 \mathrm{Z}$ (COADS). $30 \mathrm{kt} \mathrm{NE}$ and $998 \mathrm{mb}$ at $33.6 \mathrm{~N}, 45.1 \mathrm{~W}$ at $06 \mathrm{Z}$ (COADS). $35 \mathrm{kt}$ $\mathrm{S}$ and $995 \mathrm{mb}$ at $35.3 \mathrm{~N}, 40.1 \mathrm{~W}$ at $12 \mathrm{Z}$ (COADS). $40 \mathrm{kt} \mathrm{SE}$ and $1013 \mathrm{mb}$ at $34.5 \mathrm{~N}, 36.1 \mathrm{~W}$ at $12 \mathrm{Z}$ (COADS). $30 \mathrm{kt} \mathrm{W}$ and $992 \mathrm{mb}$ at $35.6 \mathrm{~N}, 40.8 \mathrm{~W}$ at $18 \mathrm{Z}$ (COADS). $40 \mathrm{kt} \mathrm{W}$ and $1003 \mathrm{mb}$ at $32.6 \mathrm{~N}, 40.8 \mathrm{~W}$ at $18 \mathrm{Z}$ (COADS).

November 21:

HWM analyzes a closed low pressure of at most $990 \mathrm{mb}$ at $40.0 \mathrm{~N}, 33.5 \mathrm{~W}$ with a warm front to the southeast and cold front to the south at 12Z. Microfilm is not available on this date, storm has moved off the map. Ship highlights: $35 \mathrm{kt} \mathrm{SW}$ and $998 \mathrm{mb}$ at $34.3 \mathrm{~N}$, $36.6 \mathrm{~W}$ at $00 \mathrm{Z}$ (COADS). $40 \mathrm{kt} \mathrm{SE}$ and $1007 \mathrm{mb}$ at $34.7 \mathrm{~N}, 32.0 \mathrm{~W}$ at $00 \mathrm{Z}$ (COADS). $15 \mathrm{kt}$ $\mathrm{SW}$ and $987 \mathrm{mb}$ at $38.0 \mathrm{~N}, 36.8 \mathrm{~W}$ at $06 \mathrm{Z}$ (COADS). $40 \mathrm{kt} \mathrm{E}$ and $997 \mathrm{mb}$ at $40.7 \mathrm{~N}, 37.4 \mathrm{~W}$ at $06 \mathrm{Z}$ (COADS). $45 \mathrm{kt} \mathrm{W}$ and $991 \mathrm{mb}$ at $37.7 \mathrm{~N}, 38.2 \mathrm{~W}$ at $12 \mathrm{Z}$ (COADS). $55 \mathrm{kt} \mathrm{NNE}$ and $987 \mathrm{mb}$ at $41.1 \mathrm{~N}, 41.7 \mathrm{~W}$ at $18 \mathrm{Z}$ (COADS).

The origin of this unnamed tropical storm is uncertain but the Historical Weather Maps indicate that a trough of low pressure led to the development of a surface circulation around mid-November over the central Atlantic. The broad and elongated low pressure moved northward and slowly became better organized on the 16th and 17th. A 25-kt tropical depression is analyzed to have developed on November 17th at 18Z. A ship 
reported $10 \mathrm{kt} \mathrm{WNW} \mathrm{and} 1005 \mathrm{mb}$ at $06 \mathrm{Z}$ on November 18th, which suggests a central pressure of $1004 \mathrm{mb}$, which has been added to this time slot. A central pressure of 1004 $\mathrm{mb}$ suggests maximum sustained winds of $39 \mathrm{kt}$ from the south of $25 \mathrm{~N}$ Brown et al. and $36 \mathrm{kt}$ from the north of $35 \mathrm{~N}$ from the Landsea et al. pressure-wind relationships. Due to the large circulation of the tropical cyclone and synoptic observations, an intensity of 25 $\mathrm{kt}$ is selected at $06 \mathrm{Z}$ on the $18 \mathrm{th}$. At $12 \mathrm{Z}$ on the $18 \mathrm{th}$, a ship reported $25 \mathrm{kt} \mathrm{S}$ and 1001 $\mathrm{mb}$, indicating that the tropical cyclone was intensifying. The intensity is increased to 30 $\mathrm{kt}$ at $12 \mathrm{Z}$ on the $18 \mathrm{th}$. The HWM at $12 \mathrm{Z}$ on the 18 th shows frontal features associated with this system. This depiction appears erroneous as there is no temperature gradient across the circulation. At the same time, microfilm shows a low pressure without frontal features. Ship observations late on the 18th showed that the circulation was more symmetrical, but it retained its large size. It is probable that the system had some subtropical characteristics. Intensification to a tropical storm is analyzed at $06 \mathrm{Z}$ on November 19th. The first gales were recorded at $12 \mathrm{Z}$ on November 19th. Two ships in the southern quadrant reported $40 \mathrm{kt} \mathrm{SW}$ and $35 \mathrm{kt} \mathrm{S}$, about 60-90 nm from the center. HWM and microfilm depict the system with frontal features at $12 \mathrm{Z}$ on the 19th, but surface observations indicate that the environment was warm and moist around the center and no temperature gradient was present across the circulation. Two more ships reported gale-force winds at $18 \mathrm{Z}$ on the 19 th.

On November 20th, a frontal boundary began to approach the tropical cyclone. A ship at $12 \mathrm{Z}$ on the 20th reported $35 \mathrm{kt} \mathrm{S}$ and $995 \mathrm{mb}$. A peripheral pressure of $995 \mathrm{mb}$ suggests maximum surface winds greater than $52 \mathrm{kt}$ from the north of $25 \mathrm{~N}$ Brown et al. and $56 \mathrm{kt}$ from the north of $35 \mathrm{~N}$ Landsea et al. pressure-wind relationships. Due to the large size of the circulation, an intensity of $45 \mathrm{kt}$ is selected at $12 \mathrm{Z}$ on the 20 th. At $18 \mathrm{Z}$ on the $20 \mathrm{th}$, a ship reported $30 \mathrm{kt} \mathrm{W}$ and $992 \mathrm{mb}$. A peripheral pressure of $992 \mathrm{mb}$ suggests maximum surface winds greater than $60 \mathrm{kt}$ from the north of $35 \mathrm{~N}$ pressure-wind relationship. An intensity of $50 \mathrm{kt}$ is selected at $18 \mathrm{Z}$ on the $20 \mathrm{th} .50 \mathrm{kt}$ is the peak intensity of this tropical storm. Synoptic data late on the 20th indicate that the tropical cyclone was beginning to acquire extratropical characteristics as it interacted with the approaching frontal boundary. Transition to an extratropical cyclone is analyzed at $00 \mathrm{Z}$ on November 21 st. Ship observations at $12 \mathrm{Z}$ on the 21 st indicate that the system had merged with an extratropical cyclone associated with the frontal boundary. The last position is analyzed at $06 \mathrm{Z}$ on the $21 \mathrm{st}$. 


\section{1 - Additional Notes}

1) May 16-20: Historical Weather Maps show a trough of low pressure over the eastern Bahamas on May $16^{\text {th }}$. The disturbance moved northward ahead of a frontal boundary and surface observations indicate that a tropical depression may have developed by May $18^{\text {th }}$. COADS indicate that the peak winds associated with this system stayed below gale-

force. The disturbance began to interact with the frontal boundary on May $19^{\text {th }}$ and became absorbed the next day. Therefore, because the system did not produce winds of tropical storm intensity, it is not added to HURDAT. This disturbance was in Jack Beven's and David Roth's List of Suspects.

$\begin{array}{cccc}\text { Day } & \text { Latitude } & \text { Longitude } & \text { Status } \\ \text { May } 16 & 22 \mathrm{~N} & 72 \mathrm{~W} & \text { Trough } \\ \text { May } 17 & 26 \mathrm{~N} & 71 \mathrm{~W} & \text { Trough } \\ \text { May } 18 & 29 \mathrm{~N} & 68 \mathrm{~W} & \text { Tropical Depression? } \\ \text { May } 19 & 32 \mathrm{~N} & 68 \mathrm{~W} & \text { Tropical Depression? } \\ \text { May } 20 & & & \text { Absorbed }\end{array}$

2) June 8-14: Historical Weather Maps and Microfilm indicate that a tropical wave reached the western Caribbean Sea on June $8^{\text {th }}$. The disturbance slowly became better organized as it moved toward the southeastern Gulf of Mexico and a closed surface circulation developed early on the $10^{\text {th }}$ as it moved across South Florida toward the Atlantic Ocean. The disturbance moved generally northeastward along the east coast of the United States producing winds up to $30 \mathrm{kt}$ based on synoptic observations. At $15 \mathrm{Z}$ on the $12^{\text {th }}$, one ship reported $35 \mathrm{kt}$, the only definite piece of evidence to indicate that this disturbance may have been a small tropical storm. An approaching frontal boundary caused the small system to accelerate northeastward and on the $13^{\text {th }}$ it appears that it weakened to a trough of low pressure east of New England. By the $14^{\text {th }}$, it was absorbed by an extratropical cyclone over eastern Canada. Therefore, because there is not enough evidence to support upgrading this system to a tropical storm, it is not added to HURDAT. This disturbance was in Jack Beven, David Roth and Ryan Truchelut's List of Suspects.

$\begin{array}{cccc}\text { Day } & \text { Latitude } & \text { Longitude } & \text { Status } \\ \text { June } 8 & 11 \mathrm{~N}-26 \mathrm{~N} & 81 \mathrm{~W} & \text { Tropical Wave } \\ \text { June } 9 & 15 \mathrm{~N}-30 & 83 \mathrm{~W} & \text { Tropical Wave } \\ \text { June } 10 & 28 \mathrm{~N} & 80 \mathrm{~W} & \text { Tropical Depression } \\ \text { June } 11 & 31 \mathrm{~N} & 78 \mathrm{~W} & \text { Tropical Depression }\end{array}$




$\begin{array}{cccc}\text { June } 12 & 36 \mathrm{~N} & 74 \mathrm{~W} & \text { Tropical Storm? } \\ \text { June } 13 & 41 \mathrm{~N} & 63 \mathrm{~W} & \text { Trough } \\ \text { June } 14 & & & \text { Absorbed }\end{array}$

3) July 28-31: Historical Weather Maps show a low pressure over the eastern Atlantic during the last few days of July. Synoptic data over the eastern Atlantic is sparse and no winds of gale-force were observed. Therefore, because the disturbance did not produce tropical storm force winds and that it may not have been a closed low, it is not added to HURDAT. This disturbance was in Ryan Truchelut's List of Suspects.

$\begin{array}{cccc}\text { Day } & \text { Latitude } & \text { Longitude } & \text { Status } \\ \text { July } 28 & 14 \mathrm{~N} & 21 \mathrm{~W} & \text { Tropical Wave? } \\ \text { July } 29 & 14 \mathrm{~N} & 23 \mathrm{~W} & \text { Tropical Depression? } \\ \text { July } 30 & 14 \mathrm{~N} & 26 \mathrm{~W} & \text { Tropical Depression? } \\ \text { July } 31 & & & \text { Dissipated }\end{array}$

4) August 2-5: Historical Weather Maps indicate that a tropical wave left the African coast early on August. Synoptic data over the eastern Atlantic show that the disturbance steadily moved westward. COADS indicate that winds stayed below tropical storm force. Therefore, because the disturbance did not produce tropical storm force winds and that it may not have been a closed low, it is not added to HURDAT. This disturbance was in Ryan Truchelut's List of Suspects.

$\begin{array}{cccc}\text { Day } & \text { Latitude } & \text { Longitude } & \text { Status } \\ \text { August } 2 & 13 \mathrm{~N} & 22 \mathrm{~W} & \text { Tropical Depression? } \\ \text { August 3 } & 13 \mathrm{~N} & 25 \mathrm{~W} & \text { Tropical Depression? } \\ \text { August } 4 & 13 \mathrm{~N} & 28 \mathrm{~W} & \text { Tropical Wave? } \\ \text { August } 5 & & & \text { Dissipated }\end{array}$

5) October 10-15: Historical Weather Maps show a trough over the northwest Bahamas on October $10^{\text {th }}$. The disturbance moved initially northward and slowly became better organized. On the $12^{\text {th }}$, the system turned to the northeast and intensified to a tropical depression while on a high-pressure environment. Over the next two days, the circulation of the system became much better organized and synoptic data show a discernible decrease in pressure. Yet, COADS indicate that winds remained below gale-force and lowest pressure was only $1009 \mathrm{mb}$. On the $15^{\text {th }}$, the system merged with an approaching 
frontal boundary. Therefore, because the disturbance did not produce tropical storm force winds, it is not added to HURDAT. This disturbance was in Jack Beven and David Roth's List of Suspects.

$\begin{array}{cccc}\text { Day } & \text { Latitude } & \text { Longitude } & \text { Status } \\ \text { October 10 } & 28 \mathrm{~N} & 74 \mathrm{~W} & \text { Trough } \\ \text { October 11 } & 29 \mathrm{~N} & 76 \mathrm{~W} & \text { Trough } \\ \text { October 12 } & 34 \mathrm{~N} & 71 \mathrm{~W} & \text { Tropical Depression } \\ \text { October 13 } & 36 \mathrm{~N} & 66 \mathrm{~W} & \text { Tropical Depression } \\ \text { October 14 } & 37 \mathrm{~N} & 61 \mathrm{~W} & \text { Tropical Depression } \\ \text { October 15 } & & & \text { Merged }\end{array}$

6) October 20-30: Historical Weather Maps indicate that a weakening frontal boundary entered the Atlantic Ocean from the United States on October $20^{\text {th }}$. A low pressure system quickly developed in the tail-end of front and moved to the northeast. The extratropical cyclone occluded on the $22^{\text {nd }}$ but became entangled with another frontal boundary on the $23^{\text {rd }}$. Over the next couple of days, the disturbance moved northeastward into the North Atlantic and was absorbed on the $30^{\text {th }}$. COADS indicate that the system was producing gale-force winds on the $22^{\text {nd }}$, when it was occluded, but it also shows that it maintained a cold core. Therefore, because the system remained non-tropical, it is not added to HURDAT. This disturbance was in Jack Beven's List of Suspects.

\begin{tabular}{|c|c|c|c|}
\hline Day & Latitude & Longitude & Status \\
\hline October 20 & \multicolumn{2}{|c|}{ East Coast } & Weakening cold front \\
\hline October 21 & $33 \mathrm{~N}$ & $74 \mathrm{~W}$ & Extratropical \\
\hline October 22 & $37 \mathrm{~N}$ & $72 \mathrm{~W}$ & Occluded \\
\hline October 23 & $37 \mathrm{~N}$ & $67 \mathrm{~W}$ & Extratropical \\
\hline October 24 & $40 \mathrm{~N}$ & $65 \mathrm{~W}$ & Extratropical \\
\hline October 25 & $42 \mathrm{~N}$ & $60 \mathrm{~W}$ & Extratropical \\
\hline October 26 & $46 \mathrm{~N}$ & $60 \mathrm{~W}$ & Extratropical \\
\hline October 27 & $50 \mathrm{~N}$ & $50 \mathrm{~W}$ & Extratropical \\
\hline October 28 & $50 \mathrm{~N}$ & $36 \mathrm{~W}$ & Extratropical \\
\hline October 29 & $50 \mathrm{~N}$ & $35 \mathrm{~W}$ & Extratropical \\
\hline October 30 & & & Absorbed \\
\hline
\end{tabular}

7) November 19-27: Historical Weather Maps show a frontal boundary entering the Atlantic Ocean from the United States on November $18^{\text {th }}$. An extratropical low pressure 
developed on November $20^{\text {th }}$ off the southeast coast of the United States and initially traveled northeastward. Beginning on the $21^{\text {st }}$, the extratropical cyclone began to move southeastward and occluded. The disturbance reached its southernmost latitude on the $24^{\text {th }}$ and $25^{\text {th }}$. Surface analyses indicate that the frontal boundaries had dissipated and the environment around the system was warmer and the temperature gradient had decreased across the circulation, but at this time it was large low pressure producing winds below gale force. On the $26^{\text {th }}$, an approaching cold front caused the disturbance to move northward and gales were registered about $300 \mathrm{~nm}$ northeast of the center due to the strong pressure-gradient. On the $27^{\text {th }}$, it had been absorbed by a stronger extratropical cyclone over the north Atlantic. Therefore, because observations indicate that the system did not acquire tropical characteristics, it is not added to HURDAT. This disturbance was in Jack Beven and David Roth's List of Suspects.

$\begin{array}{cccc}\text { Day } & \text { Latitude } & \text { Longitude } & \text { Status } \\ \text { November } 19 & 30 \mathrm{~N} & 78 \mathrm{~W} & \text { Cold front } \\ \text { November } 20 & 36 \mathrm{~N} & 73 \mathrm{~W} & \text { Extratropical } \\ \text { November } 21 & 41 \mathrm{~N} & 67 \mathrm{~W} & \text { Extratropical } \\ \text { November } 22 & 40 \mathrm{~N} & 63 \mathrm{~W} & \text { Extratropical } \\ \text { November } 23 & 37 \mathrm{~N} & 57 \mathrm{~W} & \text { Occluded } \\ \text { November } 24 & 33 \mathrm{~N} & 54 \mathrm{~W} & \text { Occluded } \\ \text { November } 25 & 33 \mathrm{~N} & 50 \mathrm{~W} & \text { Occluded } \\ \text { November } 26 & 38 \mathrm{~N} & 49 \mathrm{~W} & \text { Occluded } \\ \text { November } 27 & & & \text { Absorbed }\end{array}$




\section{2 hurricane season}

New Tropical Storm [June 29 - July 6, 1962]

\begin{tabular}{|c|c|c|c|c|c|c|c|c|c|c|c|c|c|}
\hline 42130 & ๑6/29E322 & 777 & 40 & OE324 & 770 & 40 & ОE327 & 762 & 40 & OE332 & 756 & 45 & 0 \\
\hline 42135 & ๑6/30Е338 & 754 & 50 & OE344 & 757 & 50 & 1000E350 & 761 & 55 & 1000 * 354 & 760 & 55 & 998* \\
\hline 42140 & 350 & 757 & 55 & $0 * 348$ & 751 & 55 & $0 * 350$ & 741 & 50 & ๑*352 & 730 & 45 & $\odot$ \\
\hline 42145 & $2 * 354$ & 710 & 45 & $0 * 356$ & 685 & 40 & ๑*359 & 660 & $4 \odot$ & OE362 & 630 & 40 & $\odot$ \\
\hline 2150 & 3E368 & 610 & 45 & OE380 & 585 & 45 & $\odot \mathrm{E} 4 \odot \odot$ & 545 & 45 & 37 & 523 & 45 & $\odot$ \\
\hline 2 & $07 /$ & 550 & 40 & OE485 & 590 & 35 & OE477 & 625 & 35 & OE470 & 640 & 35 & $\odot$ \\
\hline & 450 & 650 & 30 & OE432 & 650 & 25 & ๑E425 & 644 & 25 & OE430 & 637 & 25 & $\odot$ \\
\hline 2165 & 07/06E435 & 630 & 25 & OE442 & 625 & 25 & ○* & 0 & 0 & OE & 0 & 0 & \\
\hline
\end{tabular}

\section{U.S. Tropical Storm Landfall}

\section{6/30 21Z 35.2N 75.8W $55 \mathrm{kt} \mathrm{NC}$}

A new tropical storm has been added to HURDAT, not previously shown in McAdie et al. (2009). Evidence for these alterations comes from the NHC microfilm maps, the Historical Weather Maps series, the COADS ship database, Mariners Weather Log, Surface Weather Observations, and Local Climatological Data. This disturbance was in Jack Beven's List of Suspects

June 28:

HWM and microfilm analyze a stationary front over the western Atlantic at 12Z. Ship highlights: No gales or low pressures.

June 29:

HWM analyzes an extratropical cyclone of at most $1015 \mathrm{mb}$ at $32.0 \mathrm{~N}, 77.0 \mathrm{~W}$ at $12 \mathrm{Z}$. Microfilm shows an extratropical cyclone of at most $1014 \mathrm{mb}$ at $33.3 \mathrm{~N}, 75.0 \mathrm{~W}$ at $12 \mathrm{Z}$. Ship highlights: $40 \mathrm{kt} \mathrm{NE}$ and $1023 \mathrm{mb}$ at $33.5 \mathrm{~N}, 77.6 \mathrm{~W}$ at $00 \mathrm{Z}$ (micro). $35 \mathrm{kt} \mathrm{E}$ and 1015 $\mathrm{mb}$ at $35.0 \mathrm{~N}, 75.1 \mathrm{~W}$ at $12 \mathrm{Z}$ (COADS). $40 \mathrm{kt} \mathrm{ENE}$ and $1021 \mathrm{mb}$ at $33.6 \mathrm{~N}, 77.5 \mathrm{~W}$ at $18 \mathrm{Z}$ (micro). $35 \mathrm{kt} \mathrm{E}$ and $1016 \mathrm{mb}$ at $35.4 \mathrm{~N}, 74.1 \mathrm{~W}$ at $23 \mathrm{Z}$ (COADS).

CLIMO: "On June 29 an offshore storm caused torrential rains over the central section of the coast, with very heavy rains extending inland fifty to sixty miles. Cedar Island reported 17 inches in about 18 hours, the second greatest one-day rain in North Carolina weather history. Several stations in that section of the State had their greatest 24-hour rainfall of record and their greatest June total of record. Agricultural losses from the storm rainfall were very high."

June 30:

HWM analyzes an extratropical cyclone of at most $1005 \mathrm{mb}$ at $35.0 \mathrm{~N}, 75.0 \mathrm{~W}$ at $12 \mathrm{Z}$. Microfilm shows an extratropical cyclone of at most $1002 \mathrm{mb}$ at $35.5 \mathrm{~N}, 76.2 \mathrm{~W}$ at $12 \mathrm{Z}$. 
Ship highlights: $50 \mathrm{kt} \mathrm{NW}$ and $1003 \mathrm{mb}$ at $33.7 \mathrm{~N}, 76.7 \mathrm{~W}$ at $00 \mathrm{Z}$ (COADS). $10 \mathrm{kt} \mathrm{NW}$ and $1001 \mathrm{mb}$ at $34.3 \mathrm{~N}, 75.9 \mathrm{~W}$ at $06 \mathrm{Z}$ (COADS). $55 \mathrm{kt} \mathrm{W}$ and $1008 \mathrm{mb}$ at $34.0 \mathrm{~N}, 76.5 \mathrm{~W}$ at $12 \mathrm{Z}$ (COADS). $40 \mathrm{kt} \mathrm{W}$ and $1009 \mathrm{mb}$ at $33.9 \mathrm{~N}, 74.9 \mathrm{~W}$ at $18 \mathrm{Z}$ (COADS). $35 \mathrm{kt} \mathrm{SSW}$ and $1006 \mathrm{mb}$ at 35.8N, 74.0W at 23Z (MWL). Land highlights: $21 \mathrm{kt} \mathrm{NNW}$ and $1003 \mathrm{mb}$ at Cherry Point, NC at $1058 \mathrm{Z}$ (SWO). $20 \mathrm{kt} \mathrm{SE}$ and $1002 \mathrm{mb}$ at Cape Hatteras, NC at $12 \mathrm{Z}$ (micro). $20 \mathrm{kt} \mathrm{W}$ and $1000 \mathrm{mb}$ at Cape Hatteras, NC at 1558Z (SWO).

July 1 :

HWM analyzes an extratropical cyclone of at most $1010 \mathrm{mb}$ at $36.0 \mathrm{~N}, 71.0 \mathrm{~W}$ at $12 \mathrm{Z}$. Microfilm shows a closed low pressure of at most $1002 \mathrm{mb}$ at $36.0 \mathrm{~N}, 73.5 \mathrm{~W}$ at 12Z. Ship highlights: $50 \mathrm{kt} \mathrm{SW}$ and $1006 \mathrm{mb}$ at $34.5 \mathrm{~N}, 74.3 \mathrm{~W}$ at $00 \mathrm{Z}$ (COADS). $35 \mathrm{kt} \mathrm{W}$ and 1010 $\mathrm{mb}$ at $33.0 \mathrm{~N}, 75.5 \mathrm{~W}$ at $06 \mathrm{Z}$ (COADS). $35 \mathrm{kt} \mathrm{NE}$ and $1013 \mathrm{mb}$ at $40.5 \mathrm{~N}, 68.9 \mathrm{~W}$ at $12 \mathrm{Z}$ (micro). $35 \mathrm{kt} \mathrm{WSW}$ at $34.7 \mathrm{~N}, 73.0 \mathrm{~W}$ at $18 \mathrm{Z}$ (COADS). Land highlights: $50 \mathrm{kt} \mathrm{NE}$ and $1001 \mathrm{mb}$ at Diamond Shoals, NC at 06Z (micro).

July 2 :

HWM analyzes an extratropical cyclone of at most $1010 \mathrm{mb}$ at $39.0 \mathrm{~N}, 67.0 \mathrm{~W}$ at $12 \mathrm{Z}$. Microfilm shows a closed low pressure of at most $1005 \mathrm{mb}$ at $36.7 \mathrm{~N}, 64.3 \mathrm{~W}$ with a frontal boundary just to the northwest at 12Z. Ship highlights: $35 \mathrm{kt} \mathrm{SW}$ and $1008 \mathrm{mb}$ at $34.0 \mathrm{~N}, 66.3 \mathrm{~W}$ at $12 \mathrm{Z}$ (COADS). $35 \mathrm{kt} \mathrm{SW}$ and $1009 \mathrm{mb}$ at $34.6 \mathrm{~N}, 62.8 \mathrm{~W}$ at $18 \mathrm{Z}$ (COADS).

July 3 :

HWM analyzes an extratropical cyclone of at most $995 \mathrm{mb}$ at $41.0 \mathrm{~N}, 54.0 \mathrm{~W}$ at $12 \mathrm{Z}$. Microfilm shows an extratropical cyclone of at most $999 \mathrm{mb}$ at $40.0 \mathrm{~N}, 54.0 \mathrm{~W}$ at $12 \mathrm{Z}$. Ship highlights: $45 \mathrm{kt} \mathrm{NNE}$ and $999 \mathrm{mb}$ at $36.6 \mathrm{~N}, 66.5 \mathrm{~W}$ at $00 \mathrm{Z}$ (COADS). $55 \mathrm{kt}$ (or 25 kt) SE and $1002 \mathrm{mb}$ at $37.5 \mathrm{~N}, 58.5 \mathrm{~W}$ at $06 \mathrm{Z}$ (micro). $45 \mathrm{kt} \mathrm{SSE}$ and $996 \mathrm{mb}$ at $40.1 \mathrm{~N}$, $53.5 \mathrm{~W}$ at $12 \mathrm{Z}$ (COADS/micro). $35 \mathrm{kt} \mathrm{NW}$ and $1003 \mathrm{mb}$ at $42.0 \mathrm{~N}, 53.0 \mathrm{~W}$ at $18 \mathrm{Z}$ (COADS).

July 4:

HWM analyzes an occluded extratropical cyclone of at most $1000 \mathrm{mb}$ at $48.0 \mathrm{~N}, 63.0 \mathrm{~W}$ at 12Z. Microfilm shows a closed low pressure of at most $1005 \mathrm{mb}$ at $47.0 \mathrm{~N}, 63.5 \mathrm{~W}$ at $12 \mathrm{Z}$. Ship highlights: $40 \mathrm{kt} \mathrm{SW}$ and $1005 \mathrm{mb}$ at $46.0 \mathrm{~N}, 51.5 \mathrm{~W}$ at $00 \mathrm{Z}$ (COADS). $40 \mathrm{kt} \mathrm{E}$ and $1009 \mathrm{mb}$ at $50.4 \mathrm{~N}, 52.0 \mathrm{~W}$ at $03 \mathrm{Z}$ (COADS). Land highlights: $35 \mathrm{kt} \mathrm{NE}$ and $1013 \mathrm{mb}$ at Anticosti Island, Canada at $18 \mathrm{Z}$ (micro).

July 5 :

HWM does not analyze an organized system at 12Z. Microfilm shows a closed low pressure of at most $1008 \mathrm{mb}$ at $47.0 \mathrm{~N}, 64.5 \mathrm{~W}$ at $12 \mathrm{Z}$. Ship highlights: No gales or low pressures.

July 6:

HWM analyzes an extratropical cyclone of at most $1005 \mathrm{mb}$ at $40.5 \mathrm{~N}, 61.5 \mathrm{~W}$ (original cyclone appears to have been absorbed) at $12 \mathrm{Z}$. Microfilm shows a closed low pressure 
of at most $1008 \mathrm{mb}$ at $43.0 \mathrm{~N}, 62.0 \mathrm{~W}$ at 12Z. Land highlights: $40 \mathrm{kt} \mathrm{ESE}$ and $1015 \mathrm{mb}$ at Fatima, Canada at $06 \mathrm{Z}$ (micro).

A weakening frontal boundary over the western Atlantic led to the formation of an extratropical cyclone early on June 29th off the southeast of the United States. The first position is analyzed at $00 \mathrm{Z}$ on June 29 th as a $40 \mathrm{kt}$ extratropical cyclone based on synoptic data. The extratropical cyclone moved northeastward, turning to the north and northwest on June 30th. The system gradually intensified and a couple of ships reported winds of $40 \mathrm{kt}$ on the $29 \mathrm{th}, 50 \mathrm{kt}$ at $00 \mathrm{Z}$ on the 30 th and $55 \mathrm{kt}$ at $06 \mathrm{Z}$ on the $30 \mathrm{th}$. A ship reported $10 \mathrm{kt} \mathrm{NW}$ and $1001 \mathrm{mb}$ at $06 \mathrm{Z}$ on the 30th, suggesting a central pressure of 1000 $\mathrm{mb}$, which has been added to the corresponding time slot. Cape Hatteras, NC, reported 20 $\mathrm{kt} \mathrm{SE}$ and $1002 \mathrm{mb}$ at $12 \mathrm{Z}$ on the 30th, suggesting a central pressure of $1000 \mathrm{mb}$, which was also added to the appropriate time slot. Transition to a tropical storm was gradual and based on the synoptic data, is analyzed to have occurred at $18 \mathrm{Z}$ on the 30 th. At this time, there was no temperature gradient across the circulation and the strongest winds were about $60 \mathrm{~nm}$ from the center. The system may have been a subtropical storm but at the moment, without the availability of satellite images, it is going to be analyzed as a tropical storm. $55 \mathrm{kt}$ is analyzed as the peak intensity. Cape Hatteras, NC, measured $20 \mathrm{kt}$ $\mathrm{W}$ and $1000 \mathrm{mb}$ at $1558 \mathrm{Z}$ on the 30th suggesting a central pressure of $998 \mathrm{mb}$, which has been added at $18 \mathrm{Z}$ on this day. A central pressure of $998 \mathrm{mb}$ suggests maximum surface winds of $47 \mathrm{kt}$ north of $25 \mathrm{~N}$ from the Brown et al. and $52 \mathrm{kt}$ north of $35 \mathrm{~N}$ from the Landsea et al. pressure-wind relationships. The analyzed intensity at $18 \mathrm{Z}$ on the 30 th is $55 \mathrm{kt}$ based on the pressure-wind relationship and synoptic data. The tropical storm moved to the southeast late on the 30th making landfall in the Outer Banks of North Carolina. An approaching frontal boundary caused the tropical cyclone to move eastward increasing in forward speed on July 1st. Gales were also reported on the 1st, up to $50 \mathrm{kt}$. At $06 Z$ on the 1st, Diamond Shoals reported $50 \mathrm{kt} \mathrm{NE}$ and $1001 \mathrm{mb}$. The reporting station located at an elevation of 65 feet, suggesting surface winds of about $48 \mathrm{kt}$. The tropical storm weakened on July 1st and 2nd as it moved away from the United States. Late on the $2 \mathrm{nd}$, the tropical cyclone interacted with the approaching frontal boundary and transition back to an extratropical cyclone is analyzed at $18 \mathrm{Z}$ on the $2 \mathrm{nd}$. A ship at $06 \mathrm{Z}$ on July 3rd appears in microfilm suggesting $55 \mathrm{kt} \mathrm{SE}$ and $1002 \mathrm{mb}$. It is possible that the reading was $25 \mathrm{kt}$ since the triangle is unfilled and $55 \mathrm{kt}$ appears substantially too high compared to the surrounding ships. The reported pressure also appears inconsistent with the surrounding synoptic data. Because of all the inconsistencies, it is not used in this reanalysis. The extratropical cyclone moved across Newfoundland on July 4th and across New Brunswick and Nova Scotia on July 5th while performing a large counter-clockwise loop. Weakening below gale-force is analyzed at $00 \mathrm{Z}$ on the 5th. A rapidly developing extratropical cyclone approached the weakening system early on July 6th and synoptic 
data suggests that both merged after $06 \mathrm{Z}$ on this day. The last position is analyzed at $06 \mathrm{Z}$ on the 6 th.

Hurricane Alma [August 26 - September 2, 1962]

\begin{tabular}{|c|c|c|c|c|c|c|c|c|c|c|c|c|c|}
\hline 42390 & $08 / 26 / 1962$ & $2 M=$ & 8 & $1 \mathrm{SNBR}=91$ & $19 \mathrm{Al}$ & & $X I$ & $N G=1$ & SSS $=$ & & & & \\
\hline 42390 & $08 / 26 / 1962$ & $2 M=$ & 8 & ${ }^{2} \mathrm{SNBR}=9$ & $19 \mathrm{Al}$ & & $X I$ & $N G=1$ & SSS $=$ & & & & \\
\hline 42395 & $08 / 26$ * & 0 & $\odot$ & $\Theta^{*}$ & 0 & $\odot$ & $\odot * 253$ & 797 & 25 & $\Theta * 264$ & 801 & 25 & $0^{*}$ \\
\hline 42395 & $08 / 26$ * & $\odot$ & $\odot$ & $\theta^{*}$ & $\odot$ & $\odot$ & $\underbrace{*}_{* \star *} 261$ & 797 & 25 & $\begin{array}{r}\Theta * 270 \\
* \star *\end{array}$ & 801 & $\begin{array}{l}30 \\
* *\end{array}$ & ०* \\
\hline 42400 & $08 / 27$ * 277 & 803 & 25 & ๑*292 & 802 & 30 & 1007 * 306 & 797 & 40 & $0 * 318$ & 788 & 45 & ○* \\
\hline 42400 & $08 / 27^{*} \underset{* \star *}{279}$ & 803 & $\begin{array}{l}30 \\
* *\end{array}$ & ๑*292 & 802 & $\begin{array}{l}35 \\
* *\end{array}$ & $\begin{array}{l}\odot * 304 \\
* \quad * * *\end{array}$ & . 797 & 40 & $\begin{array}{r}0 * 315 \\
* * *\end{array}$ & 788 & 45 & $\begin{array}{l}1002 * \\
* * * *\end{array}$ \\
\hline 42405 & $08 / 28 * 329$ & 777 & 45 & $1002 * 341$ & 766 & 50 & $\odot * 352$ & 753 & 65 & $986 * 369$ & 735 & 75 & $991^{*}$ \\
\hline 42405 & $\begin{array}{r}08 / 28 * 326 \\
* * *\end{array}$ & 777 & 45 & $\begin{array}{r}1002 * 338 \\
* * *\end{array}$ & 766 & $\begin{array}{l}55 \\
* *\end{array}$ & $\begin{array}{l}1000 * 352 \\
* * * *\end{array}$ & 753 & 65 & $\underset{*}{\ominus * 369}$ & 735 & 75 & $\begin{array}{l}990^{*} \\
* * *\end{array}$ \\
\hline 42410 & $08 / 29 * 387$ & 717 & 80 & $988 * 401$ & 704 & 85 & $\odot * 410$ & 694 & 80 & $990 * 415$ & 687 & 75 & $\odot^{*}$ \\
\hline 42410 & $08 / 29 * 387$ & 717 & $\begin{array}{l}75 \\
* *\end{array}$ & $988 * 401$ & $\begin{array}{l}702 \\
* * *\end{array}$ & $\begin{array}{l}75 \\
* *\end{array}$ & $0 * 410$ & 694 & $\begin{array}{l}70 \\
* *\end{array}$ & $990 * 415$ & 687 & $\begin{array}{l}70 \\
* *\end{array}$ & $\begin{array}{l}984^{*} \\
* * *\end{array}$ \\
\hline 42415 & $08 / 30 * 415$ & 679 & 60 & $994 * 413$ & 670 & 55 & $\odot * 410$ & 665 & 45 & OE4०8 & 651 & 40 & ○* \\
\hline 42415 & $08 / 30 * 415$ & $\begin{array}{l}678 \\
* * *\end{array}$ & 60 & $\begin{array}{l}\text { OE413 } \\
\star *\end{array}$ & $\begin{array}{l}669 \\
* * *\end{array}$ & 55 & $\underset{*}{0 \mathrm{E} 410}$ & $\begin{array}{l}660 \\
* * *\end{array}$ & 45 & OE408 & 651 & 40 & ○* \\
\hline 42420 & ๑8/31E405 & 643 & 40 & OE399 & 635 & $4 \odot$ & ๑E391 & 633 & 40 & ๑E386 & 638 & 35 & $\odot^{*}$ \\
\hline 42420 & $\begin{array}{r}\odot 8 / 31 \mathrm{E} 4 \odot 4 \\
* \star *\end{array}$ & 643 & 40 & OE399 & $\begin{array}{l}640 \\
\star * *\end{array}$ & 40 & OE391 & $\begin{array}{l}638 \\
\star * *\end{array}$ & 40 & $\begin{array}{r}\text { OE386 } \\
* \star *\end{array}$ & $\begin{array}{l}641 \\
\star \star *\end{array}$ & 35 & ○* \\
\hline 42425 & 09/01E383 & 644 & 35 & OE384 & 651 & 35 & OE388 & 656 & 35 & OE393 & 652 & 35 & ०* \\
\hline 42425 & 09/01E383 & $\begin{array}{l}645 \\
* * *\end{array}$ & 35 & ОE384 & $\begin{array}{l}650 \\
\star * *\end{array}$ & 35 & $\begin{array}{r}\text { OE386 } \\
* * *\end{array}$ & $\begin{array}{l}655 \\
* * *\end{array}$ & 35 & $\begin{array}{r}\text { OE39๑ } \\
* * *\end{array}$ & $\begin{array}{l}654 \\
* * *\end{array}$ & 35 & 0 * \\
\hline 42430 & 09/02Е397 & 650 & 35 & ○E4०9 & 636 & 25 & $1002 \mathrm{E} 422$ & 610 & 15 & OE453 & 555 & 15 & 0 * \\
\hline 42430 & $\begin{array}{r}09 / 02 \mathrm{E} 395 \\
* * *\end{array}$ & 650 & 35 & $\begin{array}{r}\mathrm{OE} 404 \\
* * *\end{array}$ & 636 & 35 & $\begin{array}{ll}\odot^{*} & \odot \\
* & \end{array}$ & $\odot$ & $\odot$ & $0^{*} \quad 0$ & $\odot$ & 0 & ๑* \\
\hline
\end{tabular}

\section{U.S. Tropical Storm Impact}

08/28 11Z 35.0N 75.1W 40 kt North Carolina

Minor changes to the track and intensity shown in McAdie et al. (2009). Evidence for these alterations comes from the NHC microfilm maps, the Historical Weather Maps series, the COADS ship database, Monthly Weather Review, Navy reconnaissance book, Mariners Weather Log, State Climatological Data, Atlas of Cloud Vortex Patterns, and NHC Storm Wallets.

August 13:

HWM and microfilm do not show an organized system at 12Z. HURDAT does not list an organized storm on this date. Ship highlights: No gales or low pressures. 
August 14:

HWM does not analyze an organized system at 12Z. HURDAT does not list an organized storm on this date. Microfilm shows a tropical wave near longitude $40 \mathrm{~W}$ at $12 \mathrm{Z}$. Ship highlights: No gales or low pressures.

MWR: "A possible weak circulation center was first noted in the eastern Atlantic by TIROS V on August 14." MICRO: "Special TIROS Bulletin. TIROS V Photographs at $14 / 1606 Z$ show a well defined circulation in 14 degrees north 38 degrees west with the main band spiraling from the center to 15 degrees north 40 degrees west to 15 degrees north 35 degrees west then south east. A second band is evident from 15 degrees west to 15 degrees north 32 degrees west. Major cloudiness is in the east and north east quadrants with little cloudiness south west thru north west."

August 15:

HWM does not analyze an organized system at 12Z. HURDAT does not list an organized storm on this date. Microfilm shows a closed low pressure of at most $1014 \mathrm{mb}$ at $18.5 \mathrm{~N}$, $42.2 \mathrm{~W}$ at 12Z. Ship highlights: No gales or low pressures.

MICRO: "Flight summary. No significant radar weather encountered entire track area invof $1510 \mathrm{~N} 4418 \mathrm{~W}$ overcast with cs. Max obsd sfc wnd $15 \mathrm{kts}$ min obsd slp $1012 \mathrm{mb}$ by drop min 700 mb hgt."

\section{August 16:}

HWM analyzes a spot low pressure at $12.2 \mathrm{~N}, 41.6 \mathrm{~W}$ at 12Z. HURDAT does not list an organized storm on this date. Microfilm shows a tropical wave near longitude $42 \mathrm{~W}$ at 12Z. Ship highlights: No gales or low pressures.

August 17:

HWM analyzes a spot low pressure at $12.2 \mathrm{~N}, 46.9 \mathrm{~W}$ at $12 \mathrm{Z}$. HURDAT does not list an organized storm on this date. Microfilm shows a tropical wave near longitude $45 \mathrm{~W}$ at 12Z. Ship highlights: No gales or low pressures.

August 18:

HWM analyzes a spot low pressure at $12.3 \mathrm{~N}, 51.7 \mathrm{~W}$ at $12 \mathrm{Z}$. HURDAT does not list an organized storm on this date. Microfilm shows a tropical wave near longitude $50 \mathrm{~W}$ at 12Z. Ship highlights: No gales or low pressures. 
MWR: "Subsequent westward movement at about $10 \mathrm{kt}$. brought the perturbation to the vicinity of $12.5 \mathrm{~N}, 51 \mathrm{~W}$ on August 18 where Weather Bureau research aircraft, on a routine flight to the Cape Verdes, located a weak center."

August 19:

HWM analyzes a spot low pressure at $11.1 \mathrm{~N}, 56.1 \mathrm{~W}$ at $12 \mathrm{Z}$. HURDAT does not list an organized storm on this date. Microfilm does not show an organized system at 12Z. Ship highlights: No gales or low pressures.

August 20:

HWM and microfilm do not show an organized system at 12Z. HURDAT does not list an organized storm on this date. Ship highlights: No gales or low pressures.

MWR: "Crossing the Windward Islands during August 20, the circulation moved west northwestward at $10 \mathrm{kt} \ldots$...

August 21:

HWM does not analyze an organized system at 12Z. HURDAT does not list an organized storm on this date. Microfilm shows a tropical wave near longitude $65 \mathrm{~W}$ at $12 \mathrm{Z}$. Ship highlights: No gales or low pressures.

August 22:

HWM does not analyze an organized system at 12Z. HURDAT does not list an organized storm on this date. Microfilm shows a tropical wave near longitude $67 \mathrm{~W}$ at $12 \mathrm{Z}$. Ship highlights: No gales or low pressures.

MWR: "and was again located by Weather Bureau reconnaissance aircraft near $21 \mathrm{~N}$, 69W on August 22."

August 23:

HWM analyzes a tropical wave along longitude $76 \mathrm{~W}$ at $12 \mathrm{Z}$. HURDAT does not list an organized storm on this date. Microfilm shows a tropical wave near longitude $72 \mathrm{~W}$ at 12Z. Ship highlights: No gales or low pressures.

August 24:

HWM analyzes a broad low pressure of at most $1010 \mathrm{mb}$ at $19.0 \mathrm{~N}, 81.0 \mathrm{~W}$ at $12 \mathrm{Z}$. HURDAT does not list an organized system on this date. Microfilm shows a tropical wave over the Windward Passage at 12Z. Ship highlights: No gales or low pressures. 
MWR: "Gradually recurving, the Low moved across eastern Cuba on August 24 remaining weak and unorganized." ATSR: "The first significant tropical disturbance of the 1962 Hurricane Season appeared in the form of an easterly wave moving across the Caribbean during the period of 24 to 26 August attended by considerable shower activity, below normal pressures and gusty winds."

\section{August 25:}

HWM analyzes a low pressure of at most $1010 \mathrm{mb}$ at $22.3 \mathrm{~N}, 79.8 \mathrm{~W}$ at $12 \mathrm{Z}$. HURDAT does not list an organized system on this date. Microfilm shows a tropical wave over central Cuba and western Bahamas at 12Z. Ship highlights: $35 \mathrm{kt} \mathrm{SE}$ and $1013 \mathrm{mb}$ at 22.0N, 74.4W at $00 \mathrm{Z}$ (COADS).

August 26:

HWM analyzes a low pressure of at most $1010 \mathrm{mb}$ at $25.5 \mathrm{~N}, 79.6 \mathrm{~W}$ at $12 \mathrm{Z}$. HURDAT lists a $25 \mathrm{kt}$ tropical depression at $25.3 \mathrm{~N}, 79.7 \mathrm{~W}$ at $12 \mathrm{Z}$ (first position). Microfilm shows a closed low pressure of at most $1011 \mathrm{mb}$ at $26.0 \mathrm{~N}, 79.5 \mathrm{~W}$ at $12 \mathrm{Z}$. Ship highlights: No gales or low pressures.

MWR: "On the morning of August 26, slow development began between the Florida east coast and the western Bahamas, with the depression moving on a course which kept it a short distance off the United States east coast until August 29." ATSR: "Imposing an immediate threat to the U.S. Coastline, a weak vortex formed off ships reporting winds of 30 knots."

\section{August 27:}

HWM analyzes a tropical storm of at most $1010 \mathrm{mb}$ at $30.2 \mathrm{~N}, 80.1 \mathrm{~W}$ at $12 \mathrm{Z}$. HURDAT lists a $40 \mathrm{kt}$ tropical storm at $30.6 \mathrm{~N}, 79.7 \mathrm{~W}$ at $12 \mathrm{Z}$. Microfilm shows a closed low pressure of at most $1011 \mathrm{mb}$ at $29.5 \mathrm{~N}, 79.0 \mathrm{~W}$ at 12Z. Ship highlights: $35 \mathrm{kt} \mathrm{SSW}$ and $1011 \mathrm{mb}$ at $28.9 \mathrm{~N}, 77.7 \mathrm{~W}$ at $12 \mathrm{Z}$ (COADS). $45 \mathrm{kt} \mathrm{SSE}$ and $1005 \mathrm{mb}$ at $30.8 \mathrm{~N}, 78.2 \mathrm{~W}$ at $15 \mathrm{Z}$ (COADS). $40 \mathrm{kt} \mathrm{SE}$ and $1011 \mathrm{mb}$ at $31.8 \mathrm{~N}, 77.1 \mathrm{~W}$ at $18 \mathrm{Z}$ (COADS). $20 \mathrm{kt} \mathrm{S}$ and $1004 \mathrm{mb}$ at $31.6 \mathrm{~N}, 77.9 \mathrm{~W}$ at $18 \mathrm{Z}$ (COADS). $45 \mathrm{kt} \mathrm{S}$ and $1005 \mathrm{mb}$ at $32.3 \mathrm{~N}, 78.0 \mathrm{~W}$ at $21 \mathrm{Z}$ (micro).

MWR: "As deepening continued, the first advisory was issued on August 27 when Alma was about $150 \mathrm{mi}$. east of the Georgia coast." ATSR: "While moving northward in the circulation pattern of the Bermuda High, slow intensification occurred and a Tropical Disturbance Warning was issued at $271500 \mathrm{Z}$ followed by the first numbered warning on Tropical Storm Alma at 271830Z." 
August 28:

HWM analyzes a closed low pressure of at most $995 \mathrm{mb}$ at $35.5 \mathrm{~N}, 74.6 \mathrm{~W}$ with a warm front to the north at $12 \mathrm{Z}$. HURDAT lists a $65 \mathrm{kt}$ hurricane at $35.2 \mathrm{~N}, 75.3 \mathrm{~W}$ at $12 \mathrm{Z}$. Microfilm shows a closed low pressure of at most $1005 \mathrm{mb}$ at $34.5 \mathrm{~N}, 75.5 \mathrm{~W}$ at $12 \mathrm{Z}$. Ship highlights: $45 \mathrm{kt} \mathrm{S}$ and $1006 \mathrm{mb}$ at 32.8N, 77.2W at 00Z (COADS). $20 \mathrm{kt} \mathrm{NE}$ and 1002 $\mathrm{mb}$ at $33.0 \mathrm{~N}, 78.2 \mathrm{~W}$ at $03 \mathrm{Z}$ (micro). $50 \mathrm{kt} \mathrm{S}$ and $1007 \mathrm{mb}$ at $34.0 \mathrm{~N}, 76.0 \mathrm{~W}$ at $06 \mathrm{Z}$ (COADS). $55 \mathrm{kt} \mathrm{SSE}$ and $1006 \mathrm{mb}$ at $34.4 \mathrm{~N}, 74.2 \mathrm{~W}$ at $10 \mathrm{Z}$ (COADS). $55 \mathrm{kt} \mathrm{S}$ and 1005 $\mathrm{mb}$ at $34.3 \mathrm{~N}, 74.2 \mathrm{~W}$ at $12 \mathrm{Z}$ (COADS). $60 \mathrm{kt} \mathrm{SSW}$ and $1006 \mathrm{mb}$ at $35.0 \mathrm{~N}, 74.2 \mathrm{~W}$ at $15 \mathrm{Z}$ (micro). $50 \mathrm{kt} \mathrm{W}$ and $990 \mathrm{mb}$ at 36.7N, 73.8W at 18Z (COADS). $50 \mathrm{kt} \mathrm{NNW}$ and 1002 $\mathrm{mb}$ at $36.6 \mathrm{~N}, 73.7 \mathrm{~W}$ at $21 \mathrm{Z}$ (micro). Land highlights: $10 \mathrm{kt}$ and $1001 \mathrm{mb}$ at Frying Pan Shoals, NC at 05Z (SWO). $997 \mathrm{mb}$ (min pressure) at Cape Hatteras WB, NC at $1105 Z$ (WALLET). $35 \mathrm{kt} \mathrm{NNE} \mathrm{(peak} \mathrm{winds,} \mathrm{gusts} \mathrm{to} 42 \mathrm{kt}$ ) at Cape Hatteras WB, NC at $1110 \mathrm{Z}$ (CLIMO/WALLET). Aircraft highlights: Penetration center fix measured a central pressure of $990 \mathrm{mb}$ and estimated surface winds of $80 \mathrm{kt}$ at $37.9 \mathrm{~N}, 72.7 \mathrm{~W}$ at $2054 \mathrm{Z}$ (ATSR). Penetration center fix at 38.0N, 72.2W at 2215Z (ATSR).

MWR: "Hurricane Alma reached maximum intensity August 28 north of the Virginia Capes but was classified as a hurricane for only 12 hours. No well defined eye with wall cloud development was ever observed and radar tracking was difficult. On the North Carolina Capes, Nags Head reported gusts to $53 \mathrm{mph}$ and Hatteras $48 \mathrm{mph}$. Tides in general were about $2 \mathrm{ft}$. above normal in the Hatteras-Norfolk area but up to $3 \mathrm{ft}$. at Nags Head. Beach erosion was slight. Over 8 in. of rain fell at Cape Hatteras on August 27-28. After moving northeastward from the Capes, the storm increased in intensity and during the afternoon of the 28th) aircraft reconnaissance reported a sustained wind speed of 92 mph." ATSR: "By 281200Z, while moving northeastward from a point about 120 miles off the Virginia coast, ALMA began rapid intensification under the influence of a strong, divergent, high level flow immediately in advance of a $200 \mathrm{MB}$ trough approaching from the west. Hurricane force winds were reported by 281800Z."

August 29:

HWM analyzes a closed low pressure of at most $990 \mathrm{mb}$ at $41.2 \mathrm{~N}, 69.0 \mathrm{~W}$ with a weakening warm front to the northeast at 12Z. HURDAT lists an $80 \mathrm{kt}$ hurricane at $41.0 \mathrm{~N}, 69.4 \mathrm{~W}$ at $12 \mathrm{Z}$. Microfilm shows a closed low pressure of at most $993 \mathrm{mb}$ at $40.9 \mathrm{~N}, 69.4 \mathrm{~W}$ with a frontal boundary to the northeast at 12Z. Ship highlights: $55 \mathrm{kt} \mathrm{SE}$ and $992 \mathrm{mb}$ at $38.8 \mathrm{~N}, 71.0 \mathrm{~W}$ at $00 \mathrm{Z}$ (COADS). $45 \mathrm{kt} \mathrm{NE}$ and $1002 \mathrm{mb}$ at $40.7 \mathrm{~N}, 69.5 \mathrm{~W}$ at $03 \mathrm{Z}$ (micro). $45 \mathrm{kt} \mathrm{NE}$ and $1002 \mathrm{mb}$ at $40.5 \mathrm{~N}, 69.4 \mathrm{~W}$ at $06 \mathrm{Z}$ (micro). $25 \mathrm{kt} \mathrm{ESE}$ and $992 \mathrm{mb}$ at $41.0 \mathrm{~N}, 69.0 \mathrm{~W}$ at $09 \mathrm{Z}$ (micro). $35 \mathrm{kt}$ ENE and $992 \mathrm{mb}$ at $41.5 \mathrm{~N}, 68.9 \mathrm{~W}$ at $12 \mathrm{Z}$ (COADS). $50 \mathrm{kt} \mathrm{NE}$ and $990 \mathrm{mb}$ at 41.8N, 68.8W at 15Z (micro). $45 \mathrm{kt} \mathrm{ENE}$ and $992 \mathrm{mb}$ at $42.0 \mathrm{~N}, 68.8 \mathrm{~W}$ at $18 \mathrm{Z}$ (COADS). $45 \mathrm{kt} \mathrm{NE}$ and $1002 \mathrm{mb}$ at $43.3 \mathrm{~N}, 68.5 \mathrm{~W}$ at $21 \mathrm{Z}$ 
(COADS). Land highlights: $28 \mathrm{kt} \mathrm{N}$ (gusts to $42 \mathrm{kt}$ ) and $994 \mathrm{mb}$ at Nantucket, MA at 0957Z (SWO). $19 \mathrm{kt}$ and $990 \mathrm{mb}$ at Nantucket Light, MA at 11Z (SWO). $35 \mathrm{kt}$ and 993 mb at Pollock Rip Lightship, MA at 12Z (SWO). 36 kt and 994 mb at Pollock Rip Lightship, MA at 18Z (SWO). Aircraft highlights: Penetration center fix measured a central pressure of $992 \mathrm{mb}$ at $41.5 \mathrm{~N}, 68.9 \mathrm{~W}$ at $1447 \mathrm{Z}$ (WALLET). Penetration center fix measured a central pressure of $984 \mathrm{mb}$ at $41.8 \mathrm{~N}, 68.6 \mathrm{~W}$ at $1850 \mathrm{Z}$ (WALLET).

MWR: "Alma began to weaken to tropical storm strength at about the time the center passed some $60 \mathrm{mi}$ to the east of Nantucket. Coastal areas of Massachusetts and Rhode Island were buffeted by northerly gales gusting to $60 \mathrm{mph}$."

August 30:

HWM analyzes a closed low pressure of at most $1000 \mathrm{mb}$ at $41.2 \mathrm{~N}, 65.8 \mathrm{~W}$ with a weakening warm front to the north at $12 \mathrm{Z}$. HURDAT lists a $45 \mathrm{kt}$ tropical storm at $41.0 \mathrm{~N}, 66.5 \mathrm{~W}$ at $12 \mathrm{Z}$. Microfilm shows a closed low pressure of at most $1005 \mathrm{mb}$ at $40.5 \mathrm{~N}, 65.5 \mathrm{~W}$ at $12 \mathrm{Z}$. Ship highlights: $40 \mathrm{kt} \mathrm{SW}$ and $994 \mathrm{mb}$ at $40.8 \mathrm{~N}, 68.0 \mathrm{~W}$ at $00 \mathrm{Z}$ (COADS). $50 \mathrm{kt} \mathrm{NE}$ and $1010 \mathrm{mb}$ at $40.5 \mathrm{~N}, 71.0 \mathrm{~W}$ at 06Z (COADS). $25 \mathrm{kt} \mathrm{NW}$ and $1001 \mathrm{mb}$ at $40.2 \mathrm{~N}, 67.7 \mathrm{~W}$ at $12 \mathrm{Z}$ (COADS). $25 \mathrm{kt} \mathrm{NE}$ and $1002 \mathrm{mb}$ at $41.5 \mathrm{~N}, 66.7 \mathrm{~W}$ at $18 \mathrm{Z}$ (micro). $35 \mathrm{kt} \mathrm{E}$ and $1013 \mathrm{mb}$ at $42.1 \mathrm{~N}, 67.1 \mathrm{~W}$ at $23 \mathrm{Z}$ (COADS).

MWR: "Blocking over eastern Canada prevented complete recurvature into the westerlies. During the period August 30 through September 1, Alma drifted on a clockwise loop 200-300 mi. east-southeast of Cape Cod and slowly filled." ATSR: "After coming under the influence of a cold low at the $500 \mathrm{MB}$ level, ALMA dissipated and her course was radically defected to the eastward. The last advisory was transmitted at 301000Z, making a total of twelve. Storm damage was widespread, but minor, along the eastern seaboard, mostly confined to small craft and moorings with some erosion along the mid-eastern states. Rainfall in excess of 10 inches was reported in some areas north of Cape Hatteras."

August 31:

HWM analyzes a closed low pressure of at most $1005 \mathrm{mb}$ at $39.1 \mathrm{~N}, 63.8 \mathrm{~W}$ with a warm front to the north at $12 \mathrm{Z}$. HURDAT lists a $40 \mathrm{kt}$ extratropical storm at $39.1 \mathrm{~N}, 63.3 \mathrm{~W}$ at 12Z. Microfilm shows a closed low pressure of at most $1008 \mathrm{mb}$ at $38.5 \mathrm{~N}, 63.3 \mathrm{~W}$ at $12 \mathrm{Z}$. Ship highlights: $35 \mathrm{kt} \mathrm{NE}$ and $1013 \mathrm{mb}$ at 43.3N, 64.5W at 00Z (COADS). $15 \mathrm{kt} \mathrm{WSW}$ and $1004 \mathrm{mb}$ at $40.0 \mathrm{~N}, 64.3 \mathrm{~W}$ at $00 \mathrm{Z}$ (COADS). $40 \mathrm{kt} \mathrm{NE}$ and $1014 \mathrm{mb}$ at $43.5 \mathrm{~N}, 64.0 \mathrm{~W}$ at $06 \mathrm{Z}$ (COADS). $35 \mathrm{kt} \mathrm{SSW}$ and $1015 \mathrm{mb}$ at $41.6 \mathrm{~N}, 58.2 \mathrm{~W}$ at $12 \mathrm{Z}$ (COADS). 
September 1:

HWM analyzes a closed low pressure of at most $1010 \mathrm{mb}$ at $38.5 \mathrm{~N}, 65.9 \mathrm{~W}$ with a warm front to the north at $12 \mathrm{Z}$. HURDAT lists a $35 \mathrm{kt}$ extratropical storm at $38.8 \mathrm{~N}, 65.6 \mathrm{~W}$ at 12Z. Microfilm shows a closed low pressure of at most $1011 \mathrm{mb}$ at $38.0 \mathrm{~N}, 65.0 \mathrm{~W}$ at $12 \mathrm{Z}$. Ship highlights: $35 \mathrm{kt} \mathrm{N}$ and $1013 \mathrm{mb}$ at $38.4 \mathrm{~N}, 68.1 \mathrm{~W}$ at $00 \mathrm{Z}$ (COADS). $35 \mathrm{kt} \mathrm{N}$ and $1010 \mathrm{mb}$ at $38.7 \mathrm{~N}, 66.3 \mathrm{~W}$ at $06 \mathrm{Z}$ (COADS).

September 2:

HWM analyzes an extratropical cyclone of at most $995 \mathrm{mb}$ at 54.0N, 63.0W (Alma appears to have been absorbed) at 12Z. HURDAT lists a $25 \mathrm{kt}$ extratropical depression at $42.2 \mathrm{~N}, 61.0 \mathrm{~W}$ at $12 \mathrm{Z}$. Microfilm shows an extratropical cyclone of at most $995 \mathrm{mb}$ at $54.0 \mathrm{~N}, 62.0 \mathrm{~W}$ (Alma appears to have been absorbed) at 12Z. Ship highlights: $35 \mathrm{kt} \mathrm{SW}$ and $1013 \mathrm{mb}$ at $39.9 \mathrm{~N}, 63.0 \mathrm{~W}$ at $06 \mathrm{Z}$ (COADS).

MWR: "On September 2 Alma accelerated northeastward and was absorbed by an active trough in the westerlies."

September 3:

HWM analyzes an extratropical cyclone of at most $995 \mathrm{mb}$ at 54.0N, 50.0W (Alma appears to have been absorbed) at 12Z. HURDAT does not list an organized storm on this date. Microfilm shows an extratropical cyclone of at most $1002 \mathrm{mb}$ at $48.0 \mathrm{~N}, 62.0 \mathrm{~W}$ (Alma appears to have been absorbed) at 12Z. Ship highlights: No gales or low pressures.

MWR: "Damage along the east coast was comparatively minor with no fatalities and only one injury. Tides were generally less than $2 \mathrm{ft}$. above normal and there was little flooding of low-lands and shore roads. However, huge waves pounded exposed coastal installations inflicting widespread but mostly minor damage. Damage also resulted from wind and wave action. More than 100 small pleasure craft were sunk along the Massachusetts coast. Total damage was estimated at less than $\$ 1,000,000$ along the New England coast and $\$ 35,000$ to crops and property in North Carolina. Benefits to agriculture and water supplies in the drought areas of New England more than offset property damage inflicted by the storm."

Hurricane Alma developed from a strong tropical wave that left the African coast around August 11th. The tropical wave traveled westward becoming better organized. The TIROS V satellite captured an image of the disturbance on August 14th at 1606Z located near $14 \mathrm{~N}, 38 \mathrm{~W}$ depicted in the microfilm nephanalysis at $18 \mathrm{Z}$ on the 14 th showing an area of convection over the center with banding features over the northern and eastern quadrant. The surface data over the eastern Atlantic is sparse and it is not possible to 
determine if a closed, low-level circulation was present. The system continued westward and was investigated by a reconnaissance aircraft on August 15th, which did not find a closed circulation and the lowest sea level pressure measured by a drop was $1012 \mathrm{mb}$. Late on August 20th and early on the 21st, the disturbance crossed the Windward Islands and surface observations suggest that a closed surface circulation may have been present, but the circulation was likely transient based on subsequent synoptic data late on the 21 st. The sharp tropical wave continued across the Caribbean Sea, turning to the north on August 24th. While approaching the Florida peninsula, the disturbance became better organized and intensified into a $25 \mathrm{kt}$ tropical depression at $12 \mathrm{Z}$ on August 26th, same as originally shown in HURDAT, just off Miami. Minor track alterations are introduced during the lifetime of this tropical cyclone.

The tropical depression moved northward on the 26th paralleling the east coast of Florida and turned to the northeast on August 27th. Intensification to a tropical storm is analyzed at $06 \mathrm{Z}$ on the 27 th, six hours earlier than originally shown in HURDAT based upon gales observed later in the day. A central pressure of $1007 \mathrm{mb}$ was present in HURDAT at 06Z on the 27 th and has been removed based on surface observations indicating lower pressure values. The first gales were reported at $12 \mathrm{Z}$ on the 27 th on the eastern quadrant of the tropical cyclone. At $15 \mathrm{Z}$ and $21 \mathrm{Z}$ on the $27 \mathrm{th}$, two ships reported $45 \mathrm{kt}$ near the center of Alma. A ship reported $20 \mathrm{kt} \mathrm{SE}$ and $1004 \mathrm{mb}$ at $18 \mathrm{Z}$ on the 27th, suggesting a central pressure of $1002 \mathrm{mb}$, which has been added to HURDAT. A central pressure of $1002 \mathrm{mb}$ suggests maximum sustained winds of $40 \mathrm{kt}$ north of $25 \mathrm{~N}$ from the Brown et al. pressure-wind relationship. Based on a forward speed of about $15 \mathrm{kt}$ and synoptic data, an intensity of $45 \mathrm{kt}$ is selected at $18 \mathrm{Z}$ on the $27 \mathrm{th}$, same as originally shown in HURDAT.

A central pressure of $1002 \mathrm{mb}$ was present in HURDAT at 00Z on August 28th and although there was no central pressure measured by a reconnaissance aircraft or ship, it appears reasonable and it is retained. At $03 \mathrm{Z}$ on the 28th, a ship reported $20 \mathrm{kt} \mathrm{NE}$ and $1002 \mathrm{mb}$ near the center and Frying Pan Shoals, NC, had $10 \mathrm{kt}$ with $1001 \mathrm{mb}$ at 05Z, both suggesting a central pressure of $1000 \mathrm{mb}$, which has been added to HURDAT at 06Z on the 28 th. At $06 \mathrm{Z}$ on the $28 \mathrm{th}$, two ships reported $50 \mathrm{kt}$ on the eastern quadrant. A central pressure of $1000 \mathrm{mb}$ suggests maximum surface winds of $47 \mathrm{kt}$ from the north of $25 \mathrm{~N}$ pressure-wind relationship. Based on a forward speed of about $17 \mathrm{kt}$ and synoptic data, an intensity of $55 \mathrm{kt}$ is selected at $06 \mathrm{Z}$ on the 28th, same as originally shown in HURDAT. Alma made its closest approach to the Outer Banks of North Carolina, passing about 10 $\mathrm{nm}$ east of Hatteras Island, around $11 \mathrm{Z}$ on the $28 \mathrm{th}$. At $1110 \mathrm{Z}$ on the $28 \mathrm{th}$, WB Cape Hatteras, NC reported sustained winds of $35 \mathrm{kt}$ and gusts to $42 \mathrm{kt}$, and five minutes earlier, the station reported its minimum pressure for the day of $997 \mathrm{mb}$. The Schwerdt et al. parametric hurricane wind model suggests that the highest sustained winds that impacted North Carolina reached $40 \mathrm{kt}$. Therefore, Alma is analyzed as a tropical storm 
impact for North Carolina. Intensification to a hurricane is analyzed at $12 \mathrm{Z}$ on the 28th, same as originally shown in HURDAT. A central pressure of $986 \mathrm{mb}$ was present in HURDAT at $12 \mathrm{Z}$ on the 28 th and has been removed since there was no central pressure measured by a ship or reconnaissance aircraft around $12 \mathrm{Z}$ on the 28th. Observations from Cape Hatteras, NC, and subsequent reconnaissance data indicate that the central pressure was likely higher than $986 \mathrm{mb}$ at $12 \mathrm{Z}$ on the 28th. At $15 \mathrm{Z}$ on the 28th, a ship reported 60 kt SW and $1006 \mathrm{mb}$. The reconnaissance aircraft to investigating Alma on the 28th at $2054 \mathrm{Z}$ measured a central pressure of $990 \mathrm{mb}$ and estimated surface winds of $80 \mathrm{kt}$. A central pressure of $990 \mathrm{mb}$ suggests maximum surface winds of $63 \mathrm{kt}$ north of $35 \mathrm{~N}$ from the pressure-wind relationship. Based on a forward speed of about $25 \mathrm{kt}$, an intensity of $75 \mathrm{kt}$ is analyzed at $18 \mathrm{Z}$ on the $28 \mathrm{th}$, same as originally shown in HURDAT. $75 \mathrm{kt}$ is also the peak intensity of this tropical cyclone, down from $85 \mathrm{kt}$ originally in HURDAT, a minor intensity change. A central pressure of $988 \mathrm{mb}$ was present in HURDAT at $00 \mathrm{Z}$ on August 29th and although there was no central pressure measured by a reconnaissance aircraft or ship, it appears reasonable and has been retained. The existing central pressure of $990 \mathrm{mb}$ in HURDAT at $12 \mathrm{Z}$ on the 29th has been retained based on surface observations near the center. A reconnaissance aircraft investigated the hurricane at $1850 \mathrm{Z}$ on the 29th measuring a central pressure of $984 \mathrm{mb}$. A central pressure of $984 \mathrm{mb}$ suggests maximum surface winds of $69 \mathrm{kt}$ north of $35 \mathrm{~N}$ from the pressure-wind relationship. Based on a forward speed of about $8 \mathrm{kt}$ and an increase in the size of the circulation of the hurricane, an intensity of $70 \mathrm{kt}$ is selected at $18 \mathrm{Z}$ on the $29 \mathrm{th}$, down from 75 kt originally in HURDAT, a minor intensity change.

Early on August 30th, Alma turned to the southeast and continued to lose strength. Weakening to a tropical storm is analyzed at $00 \mathrm{Z}$ on the 30 th, same as originally shown in HURDAT. A central pressure of $994 \mathrm{mb}$ was present in HURDAT at 00Z on the 30th and has been removed based on surface observations indicating a lower central pressure. Synoptic data late on the 29th and early on the 30th indicates that Alma began to acquire extratropical characteristics over the cool waters south of Nova Scotia, Canada.

Transition to an extratropical cyclone is analyzed at $06 \mathrm{Z}$ on the 30th, twelve hours earlier than originally shown in HURDAT. This is based on the development of frontal features and a temperature-gradient between the eastern and western quadrant. The extratropical cyclone continued to weaken on August 31st and September 1st while performing a small clock-wise loop south of Nova Scotia. An approaching frontal boundary caused the weak cyclone to turn to the northeast late on the 1 st and surface observations indicate that it was absorbed after $06 \mathrm{Z}$ on the $2 \mathrm{nd}$. Thus, the last position is analyzed at $06 \mathrm{Z}$ on the $2 \mathrm{nd}$, twelve hours earlier than originally shown in HURDAT. A central pressure of $1002 \mathrm{mb}$ was present in HURDAT at $06 \mathrm{Z}$ on the $2 \mathrm{nd}$ and has been removed based on surface observations indicating a higher central pressure. 
Tropical Storm Becky [August 27 - September 1, 1962]

\begin{tabular}{|c|c|c|c|c|c|c|c|c|c|c|c|c|c|}
\hline 42440 & $\odot 8 / 27 / 1962$ & $M=$ & 6 & SNBR $=9$ & $20 \mathrm{BE}$ & CKY & $X I$ & $\mathrm{JG}=0$ & $S S S=0$ & & & & \\
\hline 42440 & $08 / 27 / 1962$ & $M=$ & 6 & SNBR $=9$ & $20 \mathrm{BE}$ & CKY & $X I$ & $\mathrm{JG}=0$ & $S S S=0$ & & & & \\
\hline 42445 & $08 / 27$ * & $\odot$ & $\odot$ & $0 * 160$ & 188 & 15 & $0 * 160$ & 198 & 15 & $\odot * 161$ & 207 & 15 & $0^{*}$ \\
\hline 42445 & $08 / 27^{*}$ & $\odot$ & $\odot$ & $0 * 160$ & $\begin{array}{l}180 \\
\star \star *\end{array}$ & $\begin{array}{l}40 \\
* *\end{array}$ & $\begin{array}{r}0 * 161 \\
* * *\end{array}$ & $\begin{array}{l}190 \\
* * *\end{array}$ & $\begin{array}{l}4 \odot \\
* *\end{array}$ & $\begin{array}{r}0 * 163 \\
* * *\end{array}$ & $\begin{array}{l}199 \\
\star * *\end{array}$ & $\begin{array}{l}40 \\
* *\end{array}$ & ๑* \\
\hline 42450 & $08 / 28 * 164$ & 217 & 15 & $0 * 171$ & 223 & 25 & $0 * 182$ & 233 & 30 & ๑*195 & 233 & 35 & 0 * \\
\hline 42450 & $08 / 28 * 167$ & $\begin{array}{l}207 \\
\star * *\end{array}$ & $\begin{array}{l}40 \\
* *\end{array}$ & $0 * 176$ & 215 & $\begin{array}{l}40 \\
\star *\end{array}$ & $0 * 187$ & $\begin{array}{l}220 \\
* * *\end{array}$ & $\begin{array}{l}40 \\
* *\end{array}$ & $0^{*} 201$ & 225 & $\begin{array}{l}40 \\
* *\end{array}$ & $\Theta^{*}$ \\
\hline 42455 & $08 / 29 * 211$ & 235 & 35 & $0 * 229$ & 239 & 35 & $0 * 246$ & 248 & 35 & $\odot * 26 \odot$ & 260 & 35 & $\Theta^{*}$ \\
\hline 42455 & $08 / 29 * 219$ & $\begin{array}{l}230 \\
* * *\end{array}$ & $\begin{array}{l}40 \\
* *\end{array}$ & $\begin{array}{r}0 * 239 \\
* * *\end{array}$ & $\begin{array}{l}235 \\
* * *\end{array}$ & $\begin{array}{l}45 \\
* *\end{array}$ & $0^{*} 255$ & $\begin{array}{l}242 \\
* * *\end{array}$ & $\begin{array}{l}50 \\
* *\end{array}$ & $\begin{array}{r}0^{*} 269 \\
* * *\end{array}$ & $\begin{array}{l}254 \\
* * *\end{array}$ & $\begin{array}{l}50 \\
* *\end{array}$ & 0 * \\
\hline 42460 & $\odot 8 / 30 * 274$ & 271 & 35 & $\odot * 29 \odot$ & 282 & 35 & $\odot * 307$ & 288 & 35 & $\odot * 326$ & 279 & 35 & $\Theta^{*}$ \\
\hline 42460 & $08 / 30 * 281$ & $\begin{array}{l}270 \\
* * *\end{array}$ & $\begin{array}{l}50 \\
* *\end{array}$ & $\begin{array}{r}0 * 293 \\
* * *\end{array}$ & 282 & $\begin{array}{l}50 \\
\star *\end{array}$ & $0 * 307$ & 288 & $\begin{array}{l}50 \\
* *\end{array}$ & $\begin{array}{r}0 * 322 \\
* * *\end{array}$ & $\begin{array}{l}281 \\
\star \star \star\end{array}$ & $\begin{array}{l}50 \\
* *\end{array}$ & $0^{*}$ \\
\hline 42465 & $08 / 31 * 343$ & 268 & 35 & OE360 & 252 & 30 & OE374 & 236 & 25 & OE39० & 219 & 25 & 0* \\
\hline 42465 & $\begin{array}{r}08 / 31^{*} 338 \\
* * *\end{array}$ & $\begin{array}{l}270 \\
\star * *\end{array}$ & $\begin{array}{l}50 \\
* *\end{array}$ & $\begin{array}{r}0 * 354 \\
* * * *\end{array}$ & $\begin{array}{l}254 \\
\star * *\end{array}$ & $\begin{array}{l}45 \\
\star *\end{array}$ & $\begin{array}{r}0 * 370 \\
* * * *\end{array}$ & $\begin{array}{l}238 \\
* * *\end{array}$ & $\begin{array}{l}4 \odot \\
* *\end{array}$ & $\begin{array}{r}\text { OE388 } \\
* * *\end{array}$ & $\begin{array}{l}221 \\
\star * *\end{array}$ & $\begin{array}{l}35 \\
* *\end{array}$ & 0 * \\
\hline 42470 & $09 / 01 E 407$ & 195 & 25 & OE421 & 170 & 20 & OE433 & 154 & 15 & OE449 & 140 & 15 & 0 * \\
\hline 42470 & 09/01E407 & 195 & 25 & $\begin{array}{r}\Theta^{*} \\
* \\
*\end{array}$ & $\odot$ & ๑ & $\begin{array}{r}\Theta^{*} \\
* \\
*\end{array}$ & $\begin{array}{l}\odot \\
*\end{array}$ & $\begin{array}{l}\odot \\
*\end{array}$ & $\begin{array}{r}\Theta^{*} \\
* \\
*\end{array}$ & $\begin{array}{l}\odot \\
*\end{array}$ & $\begin{array}{l}\odot \\
*\end{array}$ & 0 * \\
\hline
\end{tabular}

42475 TS

Minor changes to the track and major changes to the intensity shown in McAdie et al. (2009). Evidence for these alterations comes from the NHC microfilm maps, the Historical Weather Maps series, the COADS ship database, Monthly Weather Review, Navy reconnaissance book, Mariners Weather Log, Atlas of Cloud Vortex Patterns, and NHC Storm Wallets.

\section{August 25:}

HWM and microfilm do not analyze an organized system at 12Z. HURDAT does not list an organized system on this date. Ship highlights: No gales or low pressures.

August 26:

HWM analyzes a spot low pressure at 15.8N, 19.9W at 12Z. HURDAT does not list an organized system on this date. Microfilm does not show an organized system on this date. Ship highlights: No gales or low pressures. 
August 27:

HWM analyzes a closed low pressure of at most $1010 \mathrm{mb}$ at $15.5 \mathrm{~N}, 20.0 \mathrm{~W}$ at $12 \mathrm{Z}$. HURDAT lists a $15 \mathrm{kt}$ tropical depression at $16.0 \mathrm{~N}, 19.8 \mathrm{~W}$ at $12 \mathrm{Z}$. Microfilm does not show an organized system at 12Z. Ship highlights: $40 \mathrm{kt} \mathrm{SSW}$ and $1005 \mathrm{mb}$ at $14.8 \mathrm{~N}$, $17.7 \mathrm{~W}$ at $06 \mathrm{Z}$ (COADS). $25 \mathrm{kt} \mathrm{S}$ and $1005 \mathrm{mb}$ at $16.7 \mathrm{~N}, 17.7 \mathrm{~W}$ at $18 \mathrm{Z}$ (COADS).

MWR: "The first indication of Becky in the eastern Atlantic Ocean was an increase in cloudiness and showers in the Cape Verde Islands beginning at 1200 GMT, August 27. The bad weather lasted about $30 \mathrm{hr}$ and was accompanied by a surface pressure drop to about 1008 mb." ATSR: "The first indication of a tropical disturbance in the eastern Atlantic ocean was an increase in cloudiness and showers in the vicinity of the Cape Verdes Islands on 27 August."

August 28:

HWM analyzes a closed low pressure of at most $1010 \mathrm{mb}$ at $18.0 \mathrm{~N}, 23.0 \mathrm{~W}$ at $12 \mathrm{Z}$. HURDAT lists a $30 \mathrm{kt}$ tropical depression at $18.2 \mathrm{~N}, 23.3 \mathrm{~W}$ at $12 \mathrm{Z}$. Microfilm does not show an organized system at 12Z. Ship highlights: No gales or low pressures.

MWR: "The wind backed gradually from east and northeast to west and southwest by 1800 GMT, August 28, which suggested that a Low had moved northward east of the Islands."

August 29:

HWM analyzes a tropical storm of at most $1005 \mathrm{mb}$ at $24.5 \mathrm{~N}, 25.1 \mathrm{~W}$ at $12 \mathrm{Z}$. HURDAT lists a $35 \mathrm{kt}$ tropical storm at $24.6 \mathrm{~N}, 24.8 \mathrm{~W}$ at $12 \mathrm{Z}$. Microfilm does not show an organized system at $12 Z$. Ship highlights: No gales or low pressures.

MWR: "Cloud pictures from the TIROS satellite on August 29, 1106 GMT, confirmed an area of weather with a possible vortex near $25 \mathrm{~N}, 25 \mathrm{~W}$. Even though it is difficult to infer flow patterns from the TIROS data in the early stages of tropical cyclone development, once a well developed tropical cyclone appears, past experience suggests cloud patterns take on definite characteristics. The TIROS picture on the 29th had all the characteristics of a tropical storm." ATSR: "Two days later, at 291106Z, the TIROS satellite revealed a cloud area with a possible vortex near $25^{\circ} \mathrm{N}-25^{\circ} \mathrm{W}$."

August 30:

HWM analyzes a tropical storm of at most $1005 \mathrm{mb}$ at $30.5 \mathrm{~N}, 28.8 \mathrm{~W}$ at $12 \mathrm{Z}$. HURDAT lists a $35 \mathrm{kt}$ tropical storm at $30.7 \mathrm{~N}, 28.8 \mathrm{~W}$ at $12 \mathrm{Z}$. Microfilm shows a closed low 
pressure of at most $1005 \mathrm{mb}$ at $30.0 \mathrm{~N}, 27.5 \mathrm{~W}$ at 12Z. Ship highlights: $50 \mathrm{kt} \mathrm{NE}$ and 1006 $\mathrm{mb}$ at $30.7 \mathrm{~N}, 29.2 \mathrm{~W}$ at $1130 \mathrm{Z}$ (micro/MWR/WALLET).

MWR: "Further verification was received $24 \mathrm{hr}$ later from a ship reporting NE winds force 9 ( $45 \mathrm{kt}$.) and rough seas near $30.7 \mathrm{~N}, 29.2 \mathrm{~W}$. On the basis of this information, the US Fleet Weather Central at Port Lyautey issued an advisory at 1730 GMT. The Weather Bureau does not normally issue advisories for Atlantic storms east of longitude $35 \mathrm{~W}$, but arrangements have been made with military forecasting offices having responsibility in this area to use names from the official list of tropical cyclone names." ATSR: "Twentyfour hours later a ship reported $45 \mathrm{knots}$ winds and rough seas near $31^{\circ} \mathrm{N}-29^{\circ} \mathrm{W}$. On the basis of this information, the U.S. Fleet Weather Central, Port Lyautey issued the first of nine warnings on Tropical Storm Becky at 291730Z."

August 31:

HWM analyzes a closed low pressure of at most $1010 \mathrm{mb}$ at $37.8 \mathrm{~N}, 23.2 \mathrm{~W}$ with a cold front just to the west at 12Z. HURDAT lists a $25 \mathrm{kt}$ extratropical depression at $37.4 \mathrm{~N}$, 23.6W at 12Z. Microfilm shows a closed low pressure of at most $1011 \mathrm{mb}$ at $38.2 \mathrm{~N}$, $21.8 \mathrm{~W}$ at $12 \mathrm{Z}$. Ship highlights: $40 \mathrm{kt} \mathrm{SE}$ at $38.6 \mathrm{~N}, 20.4 \mathrm{~W}$ at $12 \mathrm{Z}$ (micro). Aircraft highlights: Penetration center fix at 39.1N, 22.0W at 1845Z (WALLET).

MWR: "The first of two reconnaissance flights was made on the 31st when an eye fix at 1845 GMT located the storm at $39.1 \mathrm{~N}, 21.8 \mathrm{~W}$. At this time there was no evidence of a warm center since the $500-\mathrm{mb}$ temperature was $-10^{\circ} \mathrm{C}$. The normal increase in temperature within the eye also was not indicated and the pilot added the remark that the storm showed no tropical characteristics. There is little doubt that the storm was extratropical at this time." ATSR: "On the 31st of September the first of two Air Force reconnaissance flights fixed the storm's eye position approximately 175 miles soth of the Azores. Shortly thereafter, as BECKY moved over colder waters, she became extratropical while continuing on a northeasterly track toward the British Isles."

September 1:

HWM analyzes a spot low at $43.3 \mathrm{~N}, 15.9 \mathrm{~W}$ with a cold front just to the west at $12 \mathrm{Z}$. HURDAT lists a $15 \mathrm{kt}$ extratropical depression at $43.3 \mathrm{~N}, 15.4 \mathrm{~W}$ at $12 \mathrm{Z}$. Microfilm shows a closed low pressure of at most $1011 \mathrm{mb}$ at $44.0 \mathrm{~N}, 16.0 \mathrm{~W}$ at 12Z. Ship highlights: No gales or low pressures.

MWR: "A second flight on the next day did not even find a circulation at $500 \mathrm{mb}$." 


\section{September 2:}

HWM analyzes an extratropical cyclone of at most $990 \mathrm{mb}$ at 57.0N, 28.0W (Becky appears to have been absorbed) at 12Z. HURDAT does not analyze an organized storm on this date. Microfilm does not show an organized storm at 12Z. Ship highlights: No gales or low pressures.

Tropical Storm Becky developed from a strong tropical wave that left the African coast late on August 26th based on surface observations from ships and coastal stations. The first position is analyzed at $06 \mathrm{Z}$ on August 27th off the African coast, same as originally shown in HURDAT. The initial intensity is analyzed at $40 \mathrm{kt}$ based on a ship report of 40 kt SW and $1005 \mathrm{mb}$ at $06 \mathrm{Z}$ on the 27th, up from $15 \mathrm{kt}$ originally shown in HURDAT, a major intensity change. Intensification to a tropical storm is analyzed at $06 \mathrm{Z}$ on the 27 th, 36 hours earlier than originally shown in HURDAT. Minor track alterations are introduced during the lifetime of this tropical cyclone with the most significant changes made to the east-northeast on the 28th based on ship observations. Becky moved to the northwest passing about $90 \mathrm{~nm}$ northeast of the Cape Verde Islands early on August 28th. Surface observations over the far eastern Atlantic are generally sparse due to the low tripping traffic. On August 29th, the TIROS V satellite captured an image of the tropical storm at 1106Z, showing a large circulation with organized convection and banding features. The satellite image also indicates that wind shear from the south was affecting Becky and the center of circulation was tucked in the southern portion of the area of convection. The next day, a ship reported $50 \mathrm{kt} \mathrm{NE}$ in the northwest quadrant at $1130 \mathrm{Z}$. Based on the satellite image and ship observation, an intensity of $50 \mathrm{kt}$ is selected between $12 Z$ on the 29th and $12 Z$ on the 30th, up from 35 kt originally in HURDAT, a minor intensity change. $50 \mathrm{kt}$ is also the peak intensity of this tropical cyclone, up from 35 kt originally in HURDAT, a minor intensity change. The peak intensity of Becky is uncertain due to the lack of data and it is possible the system may have been significantly stronger than shown. An approaching frontal boundary caused Becky to turn to the northeast on the 30th and the system began to weaken. Due to the potential threat the tropical storm posed to the Azores, a reconnaissance aircraft from the Air Force investigated Becky late on August 31st and found that it had lost its tropical characteristics. Transition to an extratropical cyclone is analyzed at $18 \mathrm{Z}$ on the 31 st, twelve hours later than originally shown in HURDAT. Surface observation after $00 Z$ on September 1st indicate that Becky had been absorbed by the frontal boundary, thus the last position is analyzed at $00 \mathrm{Z}$ on the 1st, eighteen hours earlier than originally shown in HURDAT.

Tropical Storm Celia [September 12-21, 1962] 


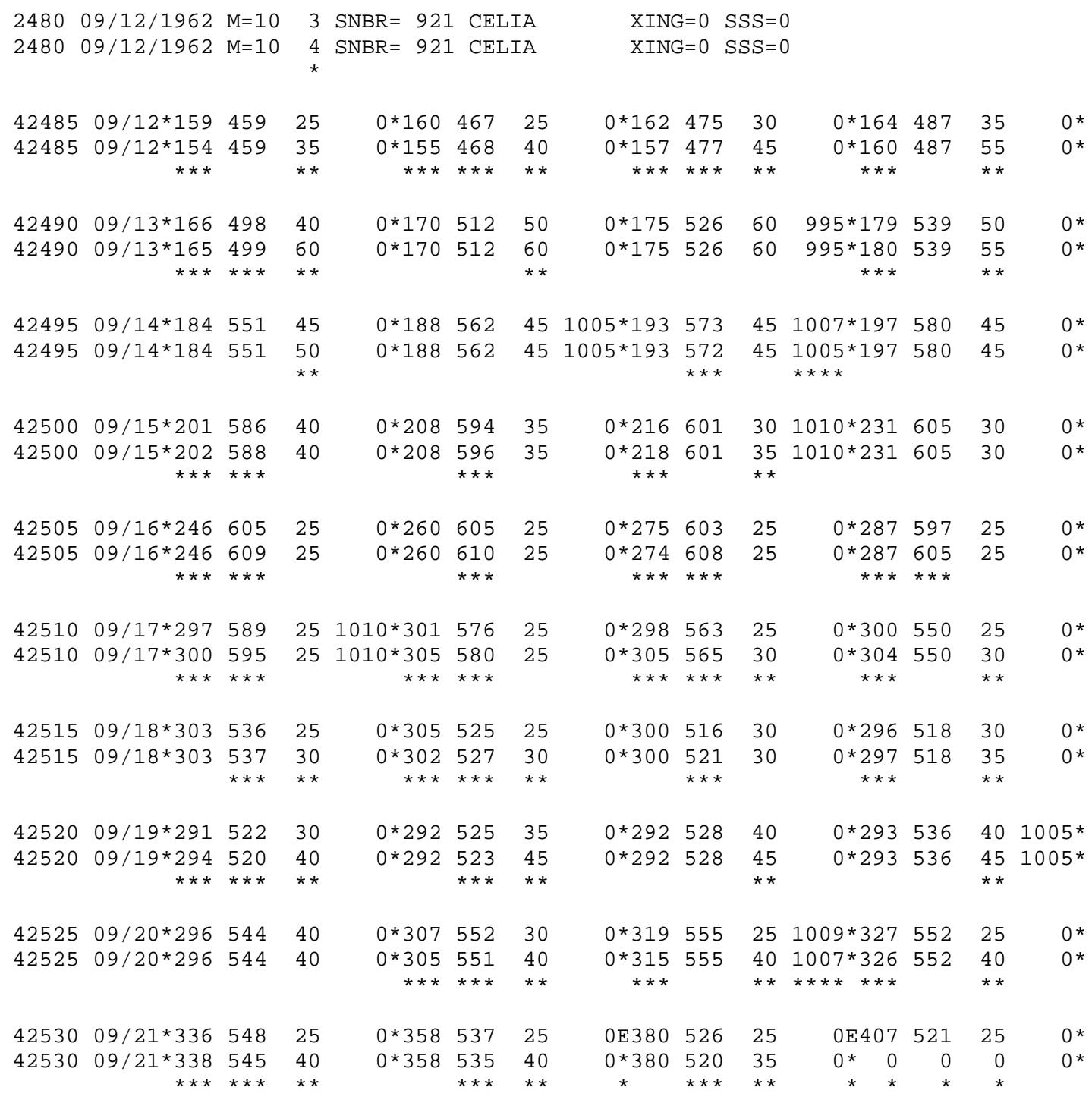

42535 TS

Minor changes to the track and major changes to the intensity shown in McAdie et al. (2009). Evidence for these alterations comes from the NHC microfilm maps, the Historical Weather Maps series, the COADS ship database, Monthly Weather Review, Navy reconnaissance book, Mariners Weather Log, Atlas of Cloud Vortex Patterns, and NHC Storm Wallets.

September 9:

HWM analyzes a spot low pressure at $8.5 \mathrm{~N}, 34.8 \mathrm{~W}$ at $12 \mathrm{Z}$. HURDAT does not list an organized system on this date. Microfilm does not show an organized system on this date. Ship highlights: No gales or low pressures. 
September 10:

HWM analyzes a closed low pressure of at most $1010 \mathrm{mb}$ at $10.5 \mathrm{~N}, 38.7 \mathrm{~W}$ at $12 \mathrm{Z}$. HURDAT does not list an organized system on this date. Microfilm does not show an organized system on this date. Ship highlights: No gales or low pressures.

September 11:

HWM analyzes a closed low pressure of at most $1010 \mathrm{mb}$ at $13.3 \mathrm{~N}, 45.0 \mathrm{~W}$ at $12 \mathrm{Z}$. HURDAT does not list an organized system on this date. Microfilm does not show an organized system at 12Z. Ship highlights: No gales or low pressures.

MWR: "A photograph from the weather satellite TIROS V showed an unorganized cloud mass near $12 \mathrm{~N}, 40 \mathrm{~W}$ at $0000 \mathrm{GMT}$, September 11, which was probably the storm in an early depression stage."

September 12:

HWM analyzes a closed low pressure of at most $1010 \mathrm{mb}$ at $16.2 \mathrm{~N}, 47.7 \mathrm{~W}$ at $12 \mathrm{Z}$. HURDAT lists a $30 \mathrm{kt}$ tropical depression at $16.2 \mathrm{~N}, 47.5 \mathrm{~W}$ at $12 \mathrm{Z}$. Microfilm shows a tropical wave along longitude $49 \mathrm{~W}$ at $12 \mathrm{Z}$. Ship highlights: $35 \mathrm{kt} \mathrm{E}$ and $1015 \mathrm{mb}$ at $18.4 \mathrm{~N}, 50.7 \mathrm{~W}$ at $12 \mathrm{Z}$ (COADS). $40 \mathrm{kt} \mathrm{E}$ and $1008 \mathrm{mb}$ at $17.1 \mathrm{~N}, 49.6 \mathrm{~W}$ at $18 \mathrm{Z}$ (micro). $60 \mathrm{kt} \mathrm{E}$ and $1008 \mathrm{mb}$ at $17.0 \mathrm{~N}, 49.6 \mathrm{~W}$ at $21 \mathrm{Z}$ (micro). TIROS highlights: Center fix at $16.8 \mathrm{~N}, 47.7 \mathrm{~W}$ around $12 \mathrm{Z}$ (ATSR). Aircraft highlights: Penetration center fix measured a central pressure of $1011 \mathrm{mb}$ and estimated surface winds of $35 \mathrm{kt}$ at $16.9 \mathrm{~N}, 48.0 \mathrm{~W}$ at 2237Z (ATSR).

MWR: "Tropical storm Celia formed in an easterly wave in the tropical atlantic on September 12, 1962. The first indication of development was an observation from the ship Mormacbay at $18.4 \mathrm{~N}, 50.7 \mathrm{~W}$ which reported an east wind of $35 \mathrm{kt}$, pressure 1014.9 $\mathrm{mb}$ and an easterly swell of $13 \mathrm{ft}$. at $1200 \mathrm{GMT}$, September 12 . As the Mormacbay continued southeastward, its pressure fell rapidly and at 2100 GMT on the 12th it reported a pressure of $1007.8 \mathrm{mb}$ with an east wind of $60 \mathrm{kt}$. A TIROS V photograph on September 12 showed a definite circulatory pattern with spiral bands centered near $17.0 \mathrm{~N}, 47.5 \mathrm{~W}$. Navy reconnaissance aircraft reached the storm area the evening of September 12, but did not obtain a good eye fix due to darkness and because radar coverage was not feasible." ATSR: "On the morning of 12 September, a ship in the vicinity of $16 \mathrm{~N} 47 \mathrm{~W}$ reported winds to 35 knots with increasing seas. The unsetted area appeared to be associated with a moderate easterly wave which had been under observation during the previous 24 to 36 hours. A Navy reconnaissance aircraft was immediately dispatched from Puerto Rico. Shortly thereafter, a TIROS V satellite photograph indicated a possible vortex at $16.8 \mathrm{~N}$ and $47.7 \mathrm{~W}$. The circulation indicated by 
TIROS V was partially verified by reconnaissance at $122137 \mathrm{Z}$ when the aircraft reported an apparent eye with a wide area of considerable shower and thunderstorm activity and maximum winds of 35 knots. Coincidently, at 2100Z, the same ship which had initially been affected by the disturbance reported winds reaching 50 knots approximately 60 miles to the east-northeast of the area."

September 13:

HWM analyzes a tropical storm of at most $1005 \mathrm{mb}$ at $17.2 \mathrm{~N}, 51.9 \mathrm{~W}$ at $12 \mathrm{Z}$. HURDAT lists a $60 \mathrm{kt}$ tropical storm at $17.5 \mathrm{~N}, 52.6 \mathrm{~W}$ at $12 \mathrm{Z}$. Microfilm shows a closed low pressure of at most $1005 \mathrm{mb}$ at $17.5 \mathrm{~N}, 52.9 \mathrm{~W}$ at 12Z. Ship highlights: $35 \mathrm{kt}$ ENE and $1011 \mathrm{mb}$ at $17.9 \mathrm{~N}, 50.5 \mathrm{~W}$ at $00 \mathrm{Z}$ (micro). $60 \mathrm{kt} \mathrm{E}$ and $1011 \mathrm{mb}$ at $17.1 \mathrm{~N}, 49.1 \mathrm{~W}$ at $03 \mathrm{Z}$ (micro). $35 \mathrm{kt} \mathrm{ESE}$ and $1014 \mathrm{mb}$ at $19.0 \mathrm{~N}, 50.9 \mathrm{~W}$ at $12 \mathrm{Z}$ (micro). $35 \mathrm{kt} \mathrm{SE}$ and $1013 \mathrm{mb}$ at $18.7 \mathrm{~N}, 50.9 \mathrm{~W}$ at $15 \mathrm{Z}$ (micro). $35 \mathrm{kt} \mathrm{SE}$ and $1012 \mathrm{mb}$ at $18.2 \mathrm{~N}, 50.9 \mathrm{~W}$ at $18 \mathrm{Z}$ (micro). Aircraft highlights: Penetration center fix measured a central pressure of $995 \mathrm{mb}$ and an eye diameter of $16 \mathrm{~nm}$ at $17.8 \mathrm{~N}, 53.4 \mathrm{~W}$ at $1340 \mathrm{Z}$ (ATSR/WALLET). Penetration center fix measured a central pressure of $1007 \mathrm{mb}$, estimated surface winds of $45 \mathrm{kt}$ and an eye diameter of $6 \mathrm{~nm}$ at $18.5 \mathrm{~N}, 54.6 \mathrm{~W}$ at $1922 \mathrm{Z}$ (ATSR).

MWR: "The first advisory on Tropical Storm Celia, issued by the San Juan Weather Bureau Office at $0000 \mathrm{Gm}$, September 13, located the storm near 16.4N, 48.6W. with winds near the center estimated to be 55 to $60 \mathrm{mph}$. A hurricane watch was issued for the northern Leeward Islands at 1600 GMT September 13. Navy reconnaissance located the eye of Celia at 1000 GMT, September 13, near 17.4N, 52.5W. The eye was poorly defined, maximum winds were $45 \mathrm{kt}$, and minimum sea level pressure was $995 \mathrm{mb}$ by dropsonde. This was the lowest pressure ever measured during the life cycle of Celia." ATSR: "The first warning on Tropical Storm CELIA was issued at 130000Z. As CELIA moved toward the northwest, a cyclonic circulation was observed northeast of the Leeward Islands at the $200 \mathrm{MB}$ level. CELIA reached an intensity slightly under 1000 MBS with winds to 60 knots during a brief period on 13 September."

September 14:

HWM analyzes a tropical storm of at most $1005 \mathrm{mb}$ at $19.3 \mathrm{~N}, 57.1 \mathrm{~W}$ at $12 \mathrm{Z}$. HURDAT lists a $45 \mathrm{kt}$ tropical storm at 19.3N, 57.3W at 12Z. Microfilm shows a closed low pressure of at most $1005 \mathrm{mb}$ at $19.2 \mathrm{~N}, 57.5 \mathrm{~W}$ at 12Z. Ship highlights: No gales or low pressures. Aircraft highlights: Penetration center fix measured a central pressure of 1012 $\mathrm{mb}$ and estimated an eye diameter of $20 \mathrm{~nm}$ at $18.2 \mathrm{~N}, 54.2 \mathrm{~W}$ at $0053 \mathrm{Z}$ (ATSR). Penetration center fix measured a central pressure of $1005 \mathrm{mb}$ at $18.8 \mathrm{~N}, 56.6 \mathrm{~W}$ at $0940 \mathrm{Z}$ (ATSR). Penetration center fix measured a central pressure of $1005 \mathrm{mb}$ and estimated surface winds of $55 \mathrm{kt}$ at $19.3 \mathrm{~N}, 57.6 \mathrm{~W}$ at $1245 \mathrm{Z}$ (ATSR). 
MWR: "On the 14th the storm began to take a more northwestward course and appeared to be very poorly organized. In fact, Navy reconnaissance late on the 14th reported that the associated weather no longer resembled a tropical cyclone. The hurricane watch for the northern Leewards was discontinued at 1600 GMT, September 14."

September 15:

HWM analyzes a closed low pressure of at most $1010 \mathrm{mb}$ at $21.2 \mathrm{~N}, 60.8 \mathrm{~W}$ with a weakening stationary front far to the north at 12Z. HURDAT lists a $30 \mathrm{kt}$ tropical depression at $21.6 \mathrm{~N}, 60.1 \mathrm{~W}$ at $12 \mathrm{Z}$. Microfilm shows a trough northeast of the Leeward Islands at 12Z. Ship highlights: $35 \mathrm{kt} \mathrm{SE}$ and $1013 \mathrm{mb}$ at 22.6N, 58.0W at $12 \mathrm{Z}$ (COADS). Aircraft highlights: Penetration center fix measured a central pressure of $1014 \mathrm{mb}$ at $22.5 \mathrm{~N}, 57.2 \mathrm{~W}$ at $01 \mathrm{Z}$ (ATSR).

MWR: "Reconnaissance early on the 15 th confirmed that the storm was no longer in evidence and the last advisory on Celia was issued by the Miami Weather Bureau Office at 1600 GMT, September 15. The storm had moved underneath the eastern side of a trough in the westerlies at middle and upper tropospheric levels. At the surface there was a marked absence of any significant easterly gradient winds over a large area to the north and northwest of the storm. These factors no doubt contributed to the degeneration of Celia in an area climatologically favorable for development." ATSR: "As CELIA approached the trough, she veered to the north and by the 15th had lost tropical storm intensity. The final warning was issued at 151600Z."

September 16:

HWM analyzes a closed low pressure of at most $1015 \mathrm{mb}$ at $27.2 \mathrm{~N}, 60.8 \mathrm{~W}$ with a frontal boundary far to the northwest at $12 \mathrm{Z}$. HURDAT lists a $25 \mathrm{kt}$ tropical depression at $27.5 \mathrm{~N}$, $60.3 \mathrm{~W}$ at $12 \mathrm{Z}$. Microfilm shows a spot low pressure at $28.3 \mathrm{~N}, 57.8 \mathrm{~W}$ at $12 \mathrm{Z}$. Ship highlights: No gales or low pressures. TIROS highlights: Center fix near $29.5 \mathrm{~N}, 59.0 \mathrm{~W}$ at $1813 Z$ (micro).

ATSR: "In a weakened stage, the cyclone continued north-northeast and on the 16th TIROS photographed the circulation near 30N 58W."

September 17:

HWM analyzes a closed low pressure of at most $1015 \mathrm{mb}$ at $29.5 \mathrm{~N}, 57.0 \mathrm{~W}$ with a stationary front to the north at $12 \mathrm{Z}$. HURDAT lists a $25 \mathrm{kt}$ tropical depression at $29.8 \mathrm{~N}$, $56.3 \mathrm{~W}$ at $12 \mathrm{Z}$. Microfilm shows a closed low pressure of at most $1014 \mathrm{mb}$ at $32.5 \mathrm{~N}$, $54.0 \mathrm{~W}$ with a frontal boundary just to the northwest at 12Z. Ship highlights: No gales or low pressures. 
MWR: "Celia was not in evidence from data on surface weather charts from the time of the last advisory until late on September 17 when it became apparent that there was a weak surface circulation well to the southeast of Bermuda. This no doubt was the remains of Celia and it apparently was reintensifying slightly.” ATSR: “...completed a small clockwise loop near $30 \mathrm{~N} 55 \mathrm{~W}$ during the period 17 thru the 20th."

September 18:

HWM analyzes a closed low pressure of at most $1015 \mathrm{mb}$ at $30.0 \mathrm{~N}, 52.0 \mathrm{~W}$ with a warm front to the north at 12Z. HURDAT lists a $30 \mathrm{kt}$ tropical depression at $30.0 \mathrm{~N}, 51.6 \mathrm{~W}$ at 12Z. Microfilm shows a closed low pressure of at most $1017 \mathrm{mb}$ at $30.0 \mathrm{~N}, 51.0 \mathrm{~W}$ with a frontal boundary just to the north at 12Z. Ship highlights: No gales or low pressures.

September 19:

HWM analyzes a tropical storm of at most $1010 \mathrm{mb}$ at $29.2 \mathrm{~N}, 52.9 \mathrm{~W}$ at $12 \mathrm{Z}$. HURDAT lists a $40 \mathrm{kt}$ tropical storm at $29.2 \mathrm{~N}, 52.8 \mathrm{~W}$ at $12 \mathrm{Z}$. Microfilm shows a closed low pressure of at most $1008 \mathrm{mb}$ at $29.2 \mathrm{~N}, 52.8 \mathrm{~W}$ at 12Z. Ship highlights: $45 \mathrm{kt} \mathrm{SSW}$ and $1009 \mathrm{mb}$ at $29.1 \mathrm{~N}, 50.9 \mathrm{~W}$ at $06 \mathrm{Z}$ (COADS). $35 \mathrm{kt} \mathrm{SSE}$ and $1009 \mathrm{mb}$ at $29.5 \mathrm{~N}, 52.0 \mathrm{~W}$ at $12 \mathrm{Z}$ (COADS). $35 \mathrm{kt} \mathrm{SE}$ and $1016 \mathrm{mb}$ at $30.7 \mathrm{~N}, 50.7 \mathrm{~W}$ at $18 \mathrm{Z}$ (COADS).

MWR: "Surface ship reports in the area indicate that Celia probably regained tropical storm intensity for about $24 \mathrm{hr}$ around September 19 before turning northward and becoming extratropical. During this period of regeneration it apparently made a loop in the area some 600 mi. east-southeast of Bermuda."

September 20:

HWM analyzes a closed low pressure of at most $1015 \mathrm{mb}$ at $31.7 \mathrm{~N}, 55.8 \mathrm{~W}$ with a weakening stationary front to the northwest at $12 \mathrm{Z}$. HURDAT lists a $25 \mathrm{kt}$ tropical depression at $31.9 \mathrm{~N}, 55.5 \mathrm{~W}$ at $12 \mathrm{Z}$. Microfilm shows a closed low pressure of at most $1011 \mathrm{mb}$ at $32.3 \mathrm{~N}, 55.5 \mathrm{~W}$ at 12Z. Ship highlights: No gales or low pressures.

MWR: "A reconnaissance flight from Bermuda investigated the area early on the 20th and reported lowest pressure $1009.0 \mathrm{mb}$ with maximum winds $28 \mathrm{kt}$." ATSR: "After completing the loop the cyclone resumed its northward movement and appeared to regenerate as reconnaissance aircraft reported a wind eye together with a dispersed area of squally weather at $201300 \mathrm{Z}$ at a position 500 miles east-southeast of Bermuda." September 21:

HWM analyzes a closed low pressure of at most $1010 \mathrm{mb}$ at $38.0 \mathrm{~N}, 53.0 \mathrm{~W}$ with a cold front just to the west at 12Z. HURDAT lists a $25 \mathrm{kt}$ extratropical depression at $38.0 \mathrm{~N}$, 
$52.6 \mathrm{~W}$ at $12 \mathrm{Z}$. Microfilm shows a closed low pressure of at most $1011 \mathrm{mb}$ at $38.0 \mathrm{~N}$, $51.5 \mathrm{~W}$ with an extratropical cyclone just to the northwest at 12Z. Ship highlights: $35 \mathrm{kt}$ $\mathrm{SE}$ and $1018 \mathrm{mb}$ at $31.7 \mathrm{~N}, 53.2 \mathrm{~W}$ at $00 \mathrm{Z}$ (micro). $40 \mathrm{kt} \mathrm{SE}$ and $1012 \mathrm{mb}$ at $36.0 \mathrm{~N}, 52.4 \mathrm{~W}$ at $06 \mathrm{Z}$ (COADS). $35 \mathrm{kt} \mathrm{SW}$ and $1014 \mathrm{mb}$ at $36.1 \mathrm{~N}, 52.5 \mathrm{~W}$ at $12 \mathrm{Z}$ (COADS).

ATSR: "On the 21st the circulation again decreased in intensity and finally merged with a developing extratropical low off the Grand Banks of Newfoundland."

September 22:

HWM analyzes an extratropical cyclone of at most $985 \mathrm{mb}$ at 55.5N, 40.0W (Celia appears to have been absorbed) at 12Z. HURDAT does not list an organized storm on this date. Microfilm shows an extratropical cyclone of at most $996 \mathrm{mb}$ at $54.5 \mathrm{~N}, 38.0 \mathrm{~W}$ (Celia appears to have been absorbed) at 12Z. Ship highlights: No gales or low pressures.

Tropical Storm Celia developed from a tropical wave that left the African coast around September 6th. The tropical wave moved westward and the first indications that it was becoming better organized came from a satellite image from the TIROS V on September 11 th mentioned in the hurricane season summary of the Monthly Weather Review describing an unorganized cloud mass near $12 \mathrm{~N}, 40 \mathrm{~W}$ at $00 \mathrm{Z}$. Ship data over the eastern and central Atlantic, especially between Africa and the Lesser Antilles, is sparse and it is difficult to assess the time of genesis. The disturbance continued westward and the first position, not genesis, is analyzed at $00 \mathrm{Z}$ on September 12th, same as HURDAT, as a 35 kt tropical storm, up from 25 kt originally shown in HURDAT. Minor track alterations are analyzed during the lifetime of this tropical cyclone. Intensification to a tropical storm is analyzed 18 hours earlier than originally shown in HURDAT. The first gale was reported at $12 \mathrm{Z}$ on the $12 \mathrm{th}$, a ship northwest of the center reported $45 \mathrm{kt} \mathrm{E}$ and $1015 \mathrm{mb}$. It is this report that is the basis for indicating $35 \mathrm{kt}$ at the initial point at $00 \mathrm{Z}$ on the 12th. Later at $21 \mathrm{Z}$ on the 12th, a ship reported $60 \mathrm{kt} \mathrm{E}$ and $1008 \mathrm{mb}$. Based on the ship reports and reconnaissance aircraft data later on September 13th, the intensity is analyzed at 55 $\mathrm{kt}$ on the 12th and $60 \mathrm{kt}$ at $00 \mathrm{Z}$ on the 13th, up from $35 \mathrm{kt}$ and $40 \mathrm{kt}$, respectively, major intensity changes to the original HURDAT. $60 \mathrm{kt}$ is also the peak intensity of this tropical cyclone, same as originally analyzed in HURDAT. The TIROS V satellite captured an image of Celia at $1850 \mathrm{Z}$ on the 12th showing a large, organized area of convection centered near $16 \mathrm{~N}, 48 \mathrm{~W}$ with banding features over the northern and eastern quadrant. The center appears to be displaced, just under the convection in the southwest corner. The first reconnaissance aircraft reached the tropical cyclone late on the 12th estimating surface winds of $35 \mathrm{kt}$ and measuring a central pressure of $1011 \mathrm{mb}$. Based on synoptic data, it is likely that the dropsonde missed the center of the tropical cyclone, thus it is not added to HURDAT. Another ship reported $60 \mathrm{kt} \mathrm{E}$ at $03 \mathrm{Z}$ on the 13th. The next reconnaissance aircraft investigated Celia at $10 \mathrm{Z}$ on the 13 th measuring a central pressure 
of $995 \mathrm{mb}$, estimating surface winds of $45 \mathrm{kt}$ and an eye diameter of $16 \mathrm{~nm}$. A central pressure of $995 \mathrm{mb}$ suggests maximum surface winds of $56 \mathrm{kt}$ south of $25 \mathrm{~N}$ from the Brown et al. pressure-wind relationship. An eye diameter of $16 \mathrm{~nm}$ suggests an RMW of about $12 \mathrm{~nm}$ and the climatological value is 14. Based on a forward speed of about $15 \mathrm{kt}$, an RMW close to climatology and surface observations, an intensity of $60 \mathrm{kt}$ is selected at $12 \mathrm{Z}$ on the 13 th, same as originally shown in HURDAT.

As the tropical storm moved closer to the Lesser Antilles, it likely encountered a less favorable environment and began to gradually weaken. A reconnaissance aircraft reached Celia at $1922 \mathrm{Z}$ on the 13th estimating surface winds of $45 \mathrm{kt}$ and a central pressure of $1007 \mathrm{mb}$. It appears likely that the dropsonde missed the center of the tropical cyclone due to the irregularities observed in the measurements on the 13th and 14th, possibly due to the poor organization of the tropical cyclone, thus the value measured was not a central pressure and it is not added to HURDAT. The next penetration fix occurred at $0053 \mathrm{Z}$ on September 14th measuring a central pressure of $1012 \mathrm{mb}$, which also missed the center. Another penetration fix occurred at $0940 \mathrm{Z}$ on the 14 th measuring a central pressure of $1005 \mathrm{mb}$. A central pressure of $1005 \mathrm{mb}$ was present in HURDAT at 06Z and has been retained. A central pressure of $1005 \mathrm{mb}$ suggests maximum surface winds of $39 \mathrm{kt}$ weakening from the south of $25 \mathrm{~N}$ pressure-wind relationship. Based on a forward speed of about $13 \mathrm{kt}$, an intensity of $45 \mathrm{kt}$ is analyzed at $06 \mathrm{Z}$ on the $14 \mathrm{th}$, same as originally shown in HURDAT. Ship data indicates that no gales or low pressures were reported on the 14th. A reconnaissance aircraft investigated Celia at $1245 \mathrm{Z}$ on the 14 th measuring a central pressure of $1005 \mathrm{mb}$ and estimating surface winds of $55 \mathrm{kt}$. A central pressure of $1007 \mathrm{mb}$ was present in HURDAT at $12 \mathrm{Z}$ on the 14th and has been replaced with 1005 $\mathrm{mb}$. An intensity of $45 \mathrm{kt}$ is analyzed at $12 \mathrm{Z}$ on the $14 \mathrm{th}$, same as originally shown in HURDAT.

On September 15th, Celia turned to the north, passing about $225 \mathrm{~nm}$ to the northeast of the Leeward Islands early on the day. A reconnaissance aircraft investigated the tropical cyclone at $01 \mathrm{Z}$ on the 15 th reporting a central pressure of $1014 \mathrm{mb}$ and a center fix about $200 \mathrm{~nm}$ east of the analyzed position, an indication of the poorly organized state of the system. The aircraft likely missed the center, thus the central pressure value is not added to HURDAT. A central pressure of $1010 \mathrm{mb}$ is present in HURDAT at $12 \mathrm{Z}$ on the 15 th and although it was not measured by the reconnaissance aircraft or ship, it appears reasonable and has been retained. A ship reported $35 \mathrm{kt} \mathrm{SE}$ and $1013 \mathrm{mb}$ at $12 \mathrm{Z}$ on the 15 th. Weakening to a tropical depression is analyzed at $18 \mathrm{Z}$ on the 15 th, six hours later than originally shown in HURDAT. Synoptic observations late on the 15th and on September 16th indicate that Celia was very poorly organized and may have weakened to a tropical wave. The data is inconclusive, thus Celia is retained as a tropical depression during that time. At $1821 \mathrm{Z}$ on the 16th, the TIROS V satellite captured another image of 
Celia, showing a sheared system with a poorly organized center and all the convection over the northeast quadrant. Late on the 16th, an approaching frontal boundary caused the tropical cyclone to turn to the northeast and to the east on September 17th. A central pressure of $1010 \mathrm{mb}$ is present in HURDAT at 00Z on the 17th and although it was not measured by the reconnaissance aircraft or ship, it appears reasonable and has been retained. On September 18th, the forward motion of Celia slowed down and on September 19th, the tropical cyclone turned to the west while performing a clock-wise loop. In the meantime, Celia became better organized and it is analyzed to have regained tropical storm status at $18 \mathrm{Z}$ on the 18th based upon susbsequent ship data, twelve hours earlier than originally shown in HURDAT. At 06Z on the 19th, a ship reported $45 \mathrm{kt}$ SSW and $1009 \mathrm{mb}$. An intensity of $45 \mathrm{kt}$ is analyzed at $06 \mathrm{Z}$ on the 19th, up from $35 \mathrm{kt}$ originally in HURDAT. A central pressure of $1005 \mathrm{mb}$ is present in HURDAT at $18 \mathrm{Z}$ on the 19th and appears reasonable based on a ship report of $30 \mathrm{kt} \mathrm{S}$ and $1008 \mathrm{mb}$ near the center, thus it is retained. A central pressure of $1005 \mathrm{mb}$ suggests maximum surface winds of $34 \mathrm{kt}$ north of $25 \mathrm{~N}$ from the pressure-wind relationship. Based on synoptic data, an intensity of $45 \mathrm{kt}$ is analyzed at $18 \mathrm{Z}$ on the 19 th, up from $40 \mathrm{kt}$ originally in HURDAT, a minor intensity change. On September 20th, Celia turned to the northeast ahead of a frontal boundary. A central pressure of $1009 \mathrm{mb}$ at $12 \mathrm{Z}$ on the 20 th is present in HURDAT and has been replaced with $1007 \mathrm{mb}$ based on a reconnaissance aircraft investigation which reported $1009 \mathrm{mb}$ and $15 \mathrm{kt} \mathrm{SW}$ at $1230 \mathrm{Z}$ on the 20th. HURDAT originally had Celia weakening to a tropical depression at $06 \mathrm{Z}$ on September 21 st but ship observations indicate that the tropical cyclone continued to produce gale-force winds until it was absorbed. HURDAT also originally indicated that Celia became extratropical at $12 \mathrm{Z}$ on the $21 \mathrm{st}$ but synoptic data show that the system retained its tropical characteristics until becoming absorbed after $12 \mathrm{Z}$ on the 21 st. The last position is analyzed at $12 \mathrm{Z}$ on the $21 \mathrm{st}$, six hours earlier than originally shown in HURDAT.

New Tropical Storm [September 20-24, 1962]

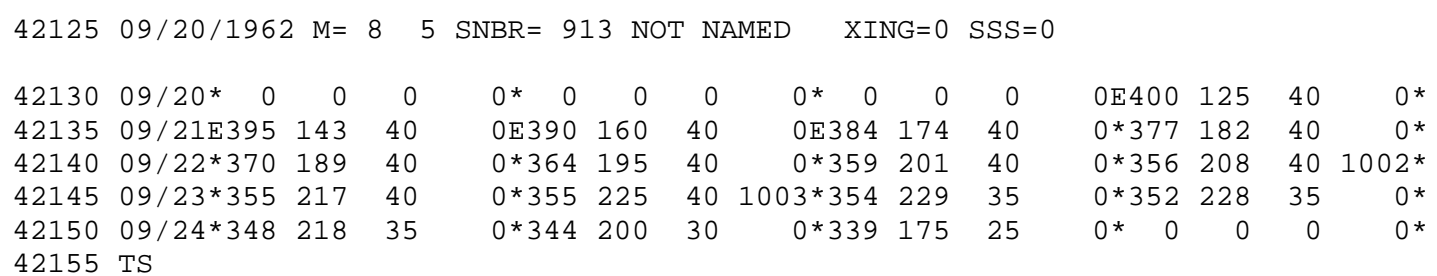

A new tropical storm has been added to HURDAT, not previously shown in McAdie et al. (2009). Evidence for these alterations comes from the NHC microfilm maps, the Historical Weather Maps series, the COADS ship database, and Mariners Weather Log. This disturbance was in Jack Beven's List of Suspects. 
September 19:

HWM and microfilm analyze a stationary front over the western Atlantic at 12Z. Ship highlights: No gales or low pressures.

September 20:

HWM analyzes an extratropical cyclone of at most $1010 \mathrm{mb}$ at $40.0 \mathrm{~N}, 12.0 \mathrm{~W}$ at $12 \mathrm{Z}$. Microfilm shows a closed low pressure of at most $1011 \mathrm{mb}$ at $41.0 \mathrm{~N}, 13.5 \mathrm{~W}$ at $12 \mathrm{Z}$. Ship highlights: $40 \mathrm{kt} \mathrm{E}$ and $1021 \mathrm{mb}$ at 47.0N, 10.5W at 18Z (COADS). $40 \mathrm{kt}$ ENE and 1016 $\mathrm{mb}$ at $45.1 \mathrm{~N}, 16.3 \mathrm{~W}$ at $21 \mathrm{Z}$ (COADS).

September 21:

HWM analyzes an extratropical cyclone of at most $1005 \mathrm{mb}$ at $35.5 \mathrm{~N}, 18.0 \mathrm{~W}$ at $12 \mathrm{Z}$. Microfilm shows a closed low pressure of at most $1005 \mathrm{mb}$ at $35.5 \mathrm{~N}, 16.5 \mathrm{~W}$ at $12 \mathrm{Z}$. Ship highlights: $35 \mathrm{kt} \mathrm{ENE}$ and $1018 \mathrm{mb}$ at $45.1 \mathrm{~N}, 16.3 \mathrm{~W}$ at $00 \mathrm{Z}$ (COADS). $40 \mathrm{kt} \mathrm{N}$ and 1014 $\mathrm{mb}$ at $40.2 \mathrm{~N}, 23.5 \mathrm{~W}$ at $06 \mathrm{Z}$ (COADS). $40 \mathrm{kt} \mathrm{N}$ and $1010 \mathrm{mb}$ at $39.3 \mathrm{~N}, 20.9 \mathrm{~W}$ at $12 \mathrm{Z}$ (COADS). $40 \mathrm{kt} \mathrm{ENE}$ and $1008 \mathrm{mb}$ at 39.2N, 18.6W at $18 \mathrm{Z}$ (COADS). $30 \mathrm{kt} \mathrm{N}$ and 1002 $\mathrm{mb}$ at $37.5 \mathrm{~N}, 19.1 \mathrm{~W}$ at $18 \mathrm{Z}$ (COADS/micro).

September 22:

HWM analyzes a closed low pressure of at most $1005 \mathrm{mb}$ at $36.0 \mathrm{~N}, 20.0 \mathrm{~W}$ at $12 \mathrm{Z}$. Microfilm shows a closed low pressure of at most $1005 \mathrm{mb}$ at $36.0 \mathrm{~N}, 20.0 \mathrm{~W}$ at 12Z. Ship highlights: $40 \mathrm{kt} \mathrm{NE}$ and $1006 \mathrm{mb}$ at $38.6 \mathrm{~N}, 18.6 \mathrm{~W}$ at $00 \mathrm{Z}$ (COADS). $35 \mathrm{kt} \mathrm{SE}$ and 1010 $\mathrm{mb}$ at $39.2 \mathrm{~N}, 14.5 \mathrm{~W}$ at $06 \mathrm{Z}$ (COADS). $35 \mathrm{kt} \mathrm{NNW}$ and $1017 \mathrm{mb}$ at $34.2 \mathrm{~N}, 27.6 \mathrm{~W}$ at $12 \mathrm{Z}$ (COADS). $35 \mathrm{kt} \mathrm{NE}$ and $1017 \mathrm{mb}$ at $39.1 \mathrm{~N}, 26.9 \mathrm{~W}$ at $18 \mathrm{Z}$ (COADS). $25 \mathrm{kt} \mathrm{W}$ and 1005 $\mathrm{mb}$ at $34.4 \mathrm{~N}, 20.6 \mathrm{~W}$ at $18 \mathrm{Z}$ (COADS).

September 23:

HWM analyzes a closed low pressure of at most $1010 \mathrm{mb}$ at $35.5 \mathrm{~N}, 23.2 \mathrm{~W}$ with a cold front to the northwest at 12Z. Microfilm shows a closed low pressure of at most $1008 \mathrm{mb}$ at $37.0 \mathrm{~N}, 22.0 \mathrm{~W}$ at $12 \mathrm{Z}$. Ship highlights: $35 \mathrm{kt} \mathrm{SW}$ and $1014 \mathrm{mb}$ at $33.9 \mathrm{~N}, 20.1 \mathrm{~W}$ at $06 \mathrm{Z}$ (COADS). $15 \mathrm{kt} \mathrm{W}$ and $1014 \mathrm{mb}$ at 34.6N, 23.3W at 06Z (COADS).

September 24:

HWM analyzes a closed low pressure of at most $1015 \mathrm{mb}$ at $34.0 \mathrm{~N}, 18.8 \mathrm{~W}$ with a cold front to the northwest at 12Z. Microfilm shows a closed low pressure of at most $1011 \mathrm{mb}$ at $35.0 \mathrm{~N}, 19.0 \mathrm{~W}$ with a frontal boundary to the northwest at 12Z. Ship highlights: No gales or low pressures. 


\section{September 25:}

HWM analyzes a cold front over the northeast Atlantic, just off Western Europe at 12Z. Microfilm shows a closed low pressure of at most $1008 \mathrm{mb}$ at $47.0 \mathrm{~N}, 5.0 \mathrm{~W}$ (original system appears to have dissipated) at 12Z. Ship highlights: No gales or low pressures.

A frontal boundary extended from the northeast Atlantic into the Iberian Peninsula on September 19th. Synoptic data indicate that an extratropical low pressure gradually organized on September 20th off the Portugal coast and moved southwestward. Surface observations show that a closed low-level circulation had developed by $18 \mathrm{Z}$ on the 20th and the first position is analyzed at this time as a $40 \mathrm{kt}$ extratropical cyclone. Gales were reported on the 20th about $300 \mathrm{~nm}$ north of the center. The system gradually acquired tropical characteristics and ship observations indicate that it transitioned to a tropical storm at $18 \mathrm{Z}$ on September 21 st. At this time, ships near the center show that the temperature gradient is uniform and the strongest winds are about $100 \mathrm{~nm}$ north of the center. Based on its origin and size of the circulation, it is possible that this system may have been a subtropical cyclone. A ship reported $40 \mathrm{kt}$ ENE and $1008 \mathrm{mb}$ at $18 \mathrm{Z}$ on the $21 \mathrm{st} .40 \mathrm{kt}$ is the peak intensity of this tropical cyclone. On September 22nd, the tropical cyclone continued on a southwest course maintaining its intensity. At $1318 \mathrm{Z}$ on the 22nd, a TIROS V captured an image of the system showing an area of convection around the center. On September 23rd, the westward movement of the tropical cyclone came to a halt as a frontal boundary approached from the west. Gales and low pressures were also reported on the 23rd by ships near the center. On September 24th, the small tropical storm turned to the southeast and is analyzed to have weakened to a tropical depression at 06Z. At $12 \mathrm{Z}$ on the 24 th, TIROS VI captured another image of the tropical cyclone showing a sheared circulation with most of the convection northeast of the center. Surface observations at $18 \mathrm{Z}$ on the 24th indicate that the tropical cyclone had weakened into a trough over the northeast Atlantic. The last position is analyzed at $12 \mathrm{Z}$ on the 24th. Analogs to this tropical cyclone include Hurricane Vince, 2005, and Tropical Storm Grace, 2009.

\begin{tabular}{|c|c|c|c|c|c|c|c|c|c|c|c|c|c|}
\hline \multicolumn{14}{|c|}{ Hurricane Daisy [September 29 - October 9, 1962] } \\
\hline & $09 / 29 / 1962$ & $M=11$ & 4 & SNBR $=922$ & $2 \mathrm{DA}$ & & XINC & $\mathrm{G}=\odot$ & $S S=c$ & & & & \\
\hline 2540 & $09 / 29 / 1962$ & $M=11$ & 5 & SNBR $=922$ & $2 \mathrm{DA}$ & & XINC & $G=\odot$ & $S S=0$ & & & & \\
\hline 42545 & $509 / 29 * \odot$ & $\odot$ & $\odot$ & $0 * 145$ & 489 & 25 & $0 * 148$ & 505 & 25 & $0 * 150$ & 523 & 30 & ०* \\
\hline 42550 & $09 / 30 * 152$ & 540 & 30 & $0 * 155$ & 556 & 30 & $0 * 158$ & 572 & 30 & $0 * 163$ & 588 & 30 & ○* \\
\hline 42550 & $09 / 30 * 152$ & 540 & 30 & ๑*155 & $\begin{array}{l}557 \\
* * *\end{array}$ & $\begin{array}{l}35 \\
* *\end{array}$ & $0 * 158$ & $\begin{array}{l}574 \\
\star * *\end{array}$ & $\begin{array}{l}40 \\
* *\end{array}$ & $\begin{array}{l}1005 * 163 \\
\star * * *\end{array}$ & $\begin{array}{l}590 \\
* * *\end{array}$ & $\begin{array}{l}40 \\
* *\end{array}$ & $\begin{array}{l}1006 * \\
* * * *\end{array}$ \\
\hline 42555 & $510 / 01 * 169$ & 599 & 30 & $0 * 174$ & 607 & 30 & $0 * 178$ & 612 & 30 & $0 * 190$ & 620 & 30 & ०* \\
\hline
\end{tabular}




\begin{tabular}{|c|c|c|c|c|c|c|c|c|c|c|c|c|c|}
\hline 42555 & $10 / 01_{* \star *}^{*}$ & $\begin{array}{l}601 \\
* * *\end{array}$ & $\begin{array}{l}35 \\
* *\end{array}$ & $\odot * 174$ & $\begin{array}{l}608 \\
* * *\end{array}$ & $\begin{array}{l}35 \\
* *\end{array}$ & $0^{*} \underset{* *}{180}$ & $\begin{array}{l}614 \\
\star \star *\end{array}$ & $\begin{array}{l}35 \\
* *\end{array}$ & $\begin{array}{l}1004 * 190 \\
\star * * *\end{array}$ & $\begin{array}{l}619 \\
* * *\end{array}$ & $\begin{array}{l}35 \\
* *\end{array}$ & ๑* \\
\hline $\begin{array}{l}42560 \\
42560\end{array}$ & $\begin{array}{r}10 / 02 * 203 \\
10 / 02 * 201 \\
* \star *\end{array}$ & $\begin{array}{l}626 \\
623 \\
\star \star *\end{array}$ & $\begin{array}{l}30 \\
35 \\
\star *\end{array}$ & $\begin{array}{l}\Theta^{*} 213 \\
\Theta^{*} 211 \\
* * *\end{array}$ & $\begin{array}{l}628 \\
626 \\
\star \star *\end{array}$ & $\begin{array}{l}30 \\
35 \\
* *\end{array}$ & $\begin{array}{r}1003 * 218 \\
0 * 220 \\
* \quad * *\end{array}$ & $\begin{array}{l}632 \\
630 \\
\star * *\end{array}$ & $\begin{array}{l}40 \\
35 \\
* *\end{array}$ & $\begin{array}{r}0^{*} 225 \\
1005^{*} 225 \\
* * * *\end{array}$ & $\begin{array}{l}638 \\
638\end{array}$ & $\begin{array}{l}45 \\
4 \odot \\
\star \star\end{array}$ & $\begin{array}{l}\Theta^{*} \\
\Theta^{*}\end{array}$ \\
\hline $\begin{array}{l}42565 \\
42565\end{array}$ & $\begin{array}{l}10 / 03 * 228 \\
10 / 03 * 228\end{array}$ & $\begin{array}{l}644 \\
645 \\
\star * *\end{array}$ & $\begin{array}{l}50 \\
45 \\
\star *\end{array}$ & $\begin{array}{r}0^{*} 231 \\
1003^{*} 231 \\
* * * *\end{array}$ & $\begin{array}{l}651 \\
651\end{array}$ & $\begin{array}{l}55 \\
50 \\
\star *\end{array}$ & $\begin{array}{l}\odot * 233 \\
\odot * 233\end{array}$ & $\begin{array}{l}656 \\
656\end{array}$ & $\begin{array}{l}60 \\
50 \\
\star *\end{array}$ & $\begin{array}{r}\theta^{*} 236 \\
100 \odot^{*} 236 \\
* * * *\end{array}$ & $\begin{array}{l}663 \\
662 \\
\star * *\end{array}$ & $\begin{array}{l}65 \\
55 \\
\star *\end{array}$ & $\begin{array}{r}0^{*} \\
995^{*} \\
* * *\end{array}$ \\
\hline $\begin{array}{l}42570 \\
42570\end{array}$ & $\begin{array}{l}10 / 04 * 239 \\
10 / 04 * 239\end{array}$ & $\begin{array}{l}670 \\
668 \\
\star * *\end{array}$ & $\begin{array}{l}65 \\
55 \\
* *\end{array}$ & $\begin{array}{l}994^{*} 241 \\
994^{*} 241\end{array}$ & $\begin{array}{l}673 \\
674 \\
\star * *\end{array}$ & $\begin{array}{l}65 \\
6 \odot \\
* *\end{array}$ & $\begin{array}{l}\odot * 243 \\
\odot * 243\end{array}$ & $\begin{array}{l}681 \\
681\end{array}$ & $\begin{array}{l}65 \\
65\end{array}$ & $\begin{array}{r}0^{*} 248 \\
992 * 247 \\
* * * * * *\end{array}$ & $\begin{array}{l}689 \\
688 \\
\star * *\end{array}$ & $\begin{array}{l}70 \\
70\end{array}$ & $\begin{array}{l}986^{*} \\
986^{*}\end{array}$ \\
\hline $\begin{array}{l}42575 \\
42575\end{array}$ & $\begin{array}{r}10 / 05^{*} 255 \\
10 / 05^{*} 252 \\
* * *\end{array}$ & $\begin{array}{l}694 \\
693 \\
* * *\end{array}$ & $\begin{array}{l}80 \\
70 \\
* *\end{array}$ & $\begin{array}{r}\odot^{*} 264 \\
985^{*} 260 \\
\star * * * * *\end{array}$ & $\begin{array}{l}698 \\
696 \\
\star * *\end{array}$ & $\begin{array}{l}85 \\
70 \\
* *\end{array}$ & $\begin{array}{r}\Theta^{*} 272 \\
984^{*} 270 \\
* * * * * *\end{array}$ & $\begin{array}{l}698 \\
696 \\
* * *\end{array}$ & $\begin{array}{l}85 \\
80 \\
\star *\end{array}$ & $\begin{array}{r}\Theta^{*} 280 \\
973 * 280 \\
* * *\end{array}$ & $\begin{array}{l}696 \\
696\end{array}$ & $\begin{array}{l}95 \\
85 \\
* *\end{array}$ & $\begin{array}{l}969 * \\
969 *\end{array}$ \\
\hline $\begin{array}{l}42580 \\
42580\end{array}$ & $\begin{array}{l}10 / 06 * 292 \\
10 / 06 * 292\end{array}$ & $\begin{array}{l}696 \\
693 \\
* * *\end{array}$ & $\begin{array}{l}9 \odot \\
9 \odot\end{array}$ & $\begin{array}{r}\odot * 310 \\
967 * 308 \\
* * * * * *\end{array}$ & $\begin{array}{l}686 \\
686\end{array}$ & $\begin{array}{l}80 \\
9 \odot \\
* *\end{array}$ & $\begin{array}{r}\odot * 328 \\
\odot * 326 \\
* \star \star\end{array}$ & $\begin{array}{l}681 \\
679 \\
* * *\end{array}$ & $\begin{array}{l}85 \\
9 \odot \\
* *\end{array}$ & $\begin{array}{r}965 * 345 \\
965 * 348 \\
* * *\end{array}$ & $\begin{array}{l}675 \\
672 \\
* * *\end{array}$ & $\begin{array}{l}95 \\
85 \\
* *\end{array}$ & $\begin{array}{l}968 * \\
968^{*}\end{array}$ \\
\hline $\begin{array}{l}42585 \\
42585\end{array}$ & $\begin{array}{r}10 / 07 * 371 \\
10 / 07 * 375 \\
* * *\end{array}$ & $\begin{array}{l}663 \\
665 \\
* * *\end{array}$ & $\begin{array}{l}95 \\
85 \\
\star *\end{array}$ & $\begin{array}{l}\odot * 391 \\
\odot E 4 \odot \odot \\
* * * *\end{array}$ & $\begin{array}{l}654 \\
660 \\
* * *\end{array}$ & $\begin{array}{l}70 \\
80 \\
* *\end{array}$ & $\begin{array}{r}975 * 422 \\
\text { OE } 417 \\
\star * * * *\end{array}$ & $\begin{array}{l}666 \\
665 \\
* * *\end{array}$ & $\begin{array}{l}65 \\
8 \odot \\
* *\end{array}$ & $\begin{array}{r}\odot^{*} 427 \\
96 \odot \mathrm{E} 427 \\
* * * *\end{array}$ & $\begin{array}{l}669 \\
669\end{array}$ & $\begin{array}{l}65 \\
75 \\
\star *\end{array}$ & $\begin{array}{l}\Theta^{*} \\
\Theta^{*}\end{array}$ \\
\hline $\begin{array}{l}42590 \\
42590\end{array}$ & $\begin{array}{c}10 / 08 * 435 \\
10 / 08 E 435 \\
*\end{array}$ & $\begin{array}{l}665 \\
665\end{array}$ & $\begin{array}{l}65 \\
70 \\
\star *\end{array}$ & $\begin{array}{l}\odot * 441 \\
\Theta \mathrm{E} 441 \\
*\end{array}$ & $\begin{array}{l}648 \\
648\end{array}$ & $\begin{array}{l}65 \\
65\end{array}$ & $\begin{array}{l}\text { ๑E447 } \\
\text { ๑E447 }\end{array}$ & $\begin{array}{l}628 \\
633 \\
* \star *\end{array}$ & $\begin{array}{l}55 \\
55\end{array}$ & $\begin{array}{r}\text { OE451 } \\
\text { OE453 } \\
* * *\end{array}$ & $\begin{array}{l}603 \\
615 \\
* * *\end{array}$ & $\begin{array}{l}50 \\
50\end{array}$ & $\begin{array}{l}\Theta^{*} \\
0^{*}\end{array}$ \\
\hline $\begin{array}{l}42595 \\
42595\end{array}$ & $\begin{array}{l}10 / 09 E 455 \\
10 / 09 E 455\end{array}$ & $\begin{array}{l}577 \\
595 \\
* * *\end{array}$ & $\begin{array}{l}50 \\
50\end{array}$ & 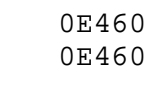 & $\begin{array}{l}549 \\
549\end{array}$ & $\begin{array}{l}50 \\
50\end{array}$ & $\begin{array}{ll}\Theta^{*} & \odot \\
\Theta^{*} & \odot\end{array}$ & $\begin{array}{l}\odot \\
\odot\end{array}$ & $\begin{array}{l}\odot \\
\odot\end{array}$ & $\begin{array}{ll}\Theta^{*} & \odot \\
\Theta^{*} & \odot\end{array}$ & $\begin{array}{l}\odot \\
\odot\end{array}$ & $\begin{array}{l}\odot \\
\odot\end{array}$ & $\begin{array}{l}\Theta^{*} \\
\Theta^{*}\end{array}$ \\
\hline
\end{tabular}

$42600 \mathrm{HR}$

Minor changes to the track and intensity shown in McAdie et al. (2009). A major alteration is to show extratropical transition 30 hours earlier than originally shown in HURDAT. Evidence for these alterations comes from the NHC microfilm maps, the Historical Weather Maps series, the COADS ship database, Monthly Weather Review, Navy reconnaissance book, Mariners Weather Log, Surface Weather Observations, Environment Canada and NHC Storm Wallets.

September 24:

HWM analyzes a closed low pressure of at most $1015 \mathrm{mb}$ at $8.6 \mathrm{~N}, 26.8 \mathrm{~W}$ at $12 \mathrm{Z}$. HURDAT does not list an organized system on this date. Microfilm does not show an organized system on this date. Ship highlights: No gales or low pressures.

September 25:

HWM analyzes a spot low pressure at $10.3 \mathrm{~N}, 31.3 \mathrm{~W}$ at $12 \mathrm{Z}$. HURDAT does not list an organized system on this date. Microfilm does not show an organized system on this date. Ship highlights: No gales or low pressures. 
September 26:

HWM analyzes a spot low pressure at $11.6 \mathrm{~N}, 36.3 \mathrm{~W}$ at $12 \mathrm{Z}$. HURDAT does not list an organized system on this date. Microfilm shows a tropical wave along longitude $45 \mathrm{~W}$ at 12Z. Ship highlights: No gales or low pressures.

ATSR: "The origin of the fourth tropical cyclone can be synoptically traced to 26 September when the TIROS satellite nephanalysis revealed a cloud mass at $12^{\circ} \mathrm{N}$ and $36^{\circ} \mathrm{W}$. In approximately the same area, surface analysis indicated a moderate easterly wave."

September 27:

HWM analyzes a spot low pressure at 13.0N, $41.5 \mathrm{~W}$ at $12 \mathrm{Z}$. HURDAT does not list an organized system on this date. Microfilm shows a tropical wave along longitude $47 \mathrm{~W}$ at 12Z. Ship highlights: No gales or low pressures.

September 28:

HWM analyzes a spot low pressure at $14.5 \mathrm{~N}, 46.2 \mathrm{~W}$ at 12Z. HURDAT does not list an organized system on this date. Microfilm shows a closed low pressure of at most 1005 $\mathrm{mb}$ at $17.5 \mathrm{~N}, 52.9 \mathrm{~W}$ at $12 \mathrm{Z}$. Ship highlights: No gales or low pressures. TIROS: Satellite center fix at $13.5 \mathrm{~N}, 47 \mathrm{~W}$ at $1303 \mathrm{Z}$ (micro).

MWR: "It was nearly a week after the discovery of a weak circulation that Daisy reached hurricane intensity. On September 28 ship reports and a TIROS satellite picture indicated a circulation well to the east of the Antilles." ATSR: "On the 28th, analysis and extrapolation placed the wave at a position where TIROS again photographed a possible vortex near $28.5^{\circ} \mathrm{N}$ and $47^{\circ} \mathrm{W}$."

September 29:

HWM analyzes a spot low pressure at $14.5 \mathrm{~N}, 51.0 \mathrm{~W}$ at $12 \mathrm{Z}$. HURDAT lists a $25 \mathrm{kt}$ tropical depression at $14.8 \mathrm{~N}, 50.5 \mathrm{~W}$ at $12 \mathrm{Z}$. Microfilm shows a closed low pressure of at most $1011 \mathrm{mb}$ at $14.0 \mathrm{~N}, 52.0 \mathrm{~W}$ at 12Z. Ship highlights: No gales or low pressures. Aircraft highlights: Radar center fix near 15.0N, 52.0W at 1710Z (micro).

MWR: "The next day [29] reconnaissance aircraft located a tropical depression near 15N, $52 \mathrm{~W}$. The core of this circulation was cold and remained so for several days." ATSR:

"Subsequently, three NAVY reconnaissance flights were dispatched into the area on 29 and 30 September." 
September 30:

HWM analyzes a closed low pressure of at most $1010 \mathrm{mb}$ at $15.5 \mathrm{~N}, 57.5 \mathrm{~W}$ at $12 \mathrm{Z}$. HURDAT lists a $30 \mathrm{kt}$ tropical depression at $15.8 \mathrm{~N}, 57.2 \mathrm{~W}$ at $12 \mathrm{Z}$. Microfilm shows a closed low pressure of at most $1011 \mathrm{mb}$ at $15.5 \mathrm{~N}, 56.5 \mathrm{~W}$ at 12Z. Ship highlights: No gales or low pressures. Aircraft highlights: Penetration center fix measured a central pressure of $1005 \mathrm{mb}$ at $14.8 \mathrm{~N}, 57.6 \mathrm{~W}$ at $13 \mathrm{Z}$ (ATSR). Penetration center fix measured a central pressure of $1006 \mathrm{mb}$ and estimated surface winds of $35 \mathrm{kt}$ at $16.3 \mathrm{~N}, 58.8 \mathrm{~W}$ at $1726 \mathrm{Z}$ (ATSR). TIROS: Center fix at 15.0N, 56.3W at 1356Z (micro).

ATSR: "The last flight prompted the first of 31 advisories on DAISY at 301930Z."

October 1:

HWM analyzes a closed low pressure of at most $1010 \mathrm{mb}$ at $18.0 \mathrm{~N}, 61.0 \mathrm{~W}$ at $12 \mathrm{Z}$. HURDAT lists a $30 \mathrm{kt}$ tropical depression at $17.8 \mathrm{~N}, 61.2 \mathrm{~W}$ at $12 \mathrm{Z}$. Microfilm shows a closed low pressure of at most $1008 \mathrm{mb}$ at $18.0 \mathrm{~N}, 61.0 \mathrm{~W}$ at 12Z. Ship highlights: No gales or low pressures. Aircraft highlights: Penetration center fix measured a central pressure of $1006 \mathrm{mb}$ and estimated surface winds of $28 \mathrm{kt}$ at $17.8 \mathrm{~N}, 60.9 \mathrm{~W}$ at $1137 \mathrm{Z}$ (ATSR). Penetration center fix measured a central pressure of $1009 \mathrm{mb}$ and estimated surface winds of $30 \mathrm{kt}$ at $18.6 \mathrm{~N}, 62.1 \mathrm{~W}$ at $1615 \mathrm{Z}$ (ATSR).

MWR: "The depression moved toward the west-northwest, turned northward on October $1 . "$

October 2:

HWM analyzes a tropical storm of at most $1005 \mathrm{mb}$ at $22.1 \mathrm{~N}, 63.5 \mathrm{~W}$ at 12Z. HURDAT lists a $40 \mathrm{kt}$ tropical storm at $21.8 \mathrm{~N}, 63.2 \mathrm{~W}$ at $12 \mathrm{Z}$. Microfilm shows a closed low pressure of at most $1008 \mathrm{mb}$ at $22.0 \mathrm{~N}, 63.0 \mathrm{~W}$ at $12 \mathrm{Z}$. Ship highlights: $35 \mathrm{kt} \mathrm{E}$ and 1011 $\mathrm{mb}$ at $23.0 \mathrm{~N}, 60.9 \mathrm{~W}$ at $06 \mathrm{Z}$ (COADS). $35 \mathrm{kt} \mathrm{E}$ at $24.2 \mathrm{~N}, 62.5 \mathrm{~W}$ at $12 \mathrm{Z}$ (micro). $35 \mathrm{kt}$ ESE and $1012 \mathrm{mb}$ at $24.8 \mathrm{~N}, 61.1 \mathrm{~W}$ at $17 \mathrm{Z}$ (micro). Aircraft highlights: Penetration center fix measured a central pressure of $1005 \mathrm{mb}$, estimated surface winds of $35 \mathrm{kt}$ and an eye diameter of $4 \mathrm{~nm}$ at $22.2 \mathrm{~N}, 63.0 \mathrm{~W}$ at $1140 \mathrm{Z}$ (ATSR). Penetration center fix measured a central pressure of $1003 \mathrm{mb}$ and estimated surface winds of $40 \mathrm{kt}$ at $22.5 \mathrm{~N}, 64.4 \mathrm{~W}$ at $23 \mathrm{Z}$ (WALLET).

MWR: “...reached storm intensity on the 2nd." ATSR: "The track of DAISY shows several marked changes in direction of movement following a northwesterly course to a position north of the Leeward Islands, then a dogleg to the west followed by a northerly track for approximately 60 hours."

October 3: 
HWM analyzes a tropical storm of at most $1005 \mathrm{mb}$ at $23.1 \mathrm{~N}, 65.5 \mathrm{~W}$ with a warm front far to the north at $12 \mathrm{Z}$. HURDAT lists a $40 \mathrm{kt}$ tropical storm at $23.3 \mathrm{~N}, 65.6 \mathrm{~W}$ at $12 \mathrm{Z}$. Microfilm shows a closed low pressure of at most $1008 \mathrm{mb}$ at $22.2 \mathrm{~N}, 65.8 \mathrm{~W}$ with a frontal boundary far to the north at 12Z. Ship highlights: $50 \mathrm{kt} \mathrm{SSE} \mathrm{(gusts} \mathrm{to} 58 \mathrm{kt}$ ) and $1003 \mathrm{mb}$ at $22.8 \mathrm{~N}, 64.4 \mathrm{~W}$ at $09 \mathrm{Z}$ (micro). $45 \mathrm{kt} \mathrm{SSW}$ and $1011 \mathrm{mb}$ at $20.9 \mathrm{~N}, 64.2 \mathrm{~W}$ at $15 \mathrm{Z}$ (micro). $45 \mathrm{kt} \mathrm{SW}$ and $1008 \mathrm{mb}$ at $22.0 \mathrm{~N}, 65.0 \mathrm{~W}$ at $18 \mathrm{Z}$ (COADS). $15 \mathrm{kt}$ and 999 $\mathrm{mb}$ at $22.8 \mathrm{~N}, 66.2 \mathrm{~W}$ at $21 \mathrm{Z}$ (micro). Aircraft highlights: Penetration center fix measured a central pressure of $1000 \mathrm{mb}$ and estimated surface winds of $40 \mathrm{kt}$ at $23.5 \mathrm{~N}, 64.8 \mathrm{~W}$ at $1051 \mathrm{Z}$ (WALLET). Penetration center fix measured a central pressure of $995 \mathrm{mb}$ and estimated surface winds of $57 \mathrm{kt}$ at 23.6N, 66.5W at 1830Z (WALLET). Penetration center fix measured a central pressure of $994 \mathrm{mb}$ and estimated surface winds of $55 \mathrm{kt}$ at $23.7 \mathrm{~N}, 66.5 \mathrm{~W}$ at $2152 \mathrm{Z}$ (WALLET).

MWR: “... and hurricane force on the 3rd. The main intensification occurred from October 3 to October 5."

October 4:

HWM analyzes a hurricane of at most $995 \mathrm{mb}$ at $24.3 \mathrm{~N}, 68.8 \mathrm{~W}$ with a stationary front to the north at $12 \mathrm{Z}$. HURDAT lists a $65 \mathrm{kt}$ hurricane at $24.3 \mathrm{~N}, 68.1 \mathrm{~W}$ at $12 \mathrm{Z}$. Microfilm shows a closed low pressure of at most $1002 \mathrm{mb}$ at $24.5 \mathrm{~N}, 68.5 \mathrm{~W}$ with a frontal boundary to the north at 12Z. Ship highlights: $15 \mathrm{kt} \mathrm{SSE}$ and $998 \mathrm{mb}$ at $23.6 \mathrm{~N}, 66.1 \mathrm{~W}$ at $00 \mathrm{Z}$ (micro). $35 \mathrm{kt} \mathrm{S}$ and $1001 \mathrm{mb}$ at $23.3 \mathrm{~N}, 66.2 \mathrm{~W}$ at $06 \mathrm{Z}$ (micro). $40 \mathrm{kt} \mathrm{SE}$ and $1003 \mathrm{mb}$ at $24.3 \mathrm{~N}, 66.4 \mathrm{~W}$ at $09 \mathrm{Z}$ (COADS). $40 \mathrm{kt} \mathrm{SE}$ and $1007 \mathrm{mb}$ at $24.9 \mathrm{~N}, 66.4 \mathrm{~W}$ at $12 \mathrm{Z}$ (COADS). $35 \mathrm{kt} \mathrm{SW}$ and $1006 \mathrm{mb}$ at $22.7 \mathrm{~N}, 68.2 \mathrm{~W}$ at $15 \mathrm{Z}$ (micro). $45 \mathrm{kt} \mathrm{ESE}$ and 1005 $\mathrm{mb}$ at $26.1 \mathrm{~N}, 67.2 \mathrm{~W}$ at $18 \mathrm{Z}$ (micro). $45 \mathrm{kt} \mathrm{SE}$ and $1007 \mathrm{mb}$ at $25.7 \mathrm{~N}, 66.5 \mathrm{~W}$ at $21 \mathrm{Z}$ (micro). Aircraft highlights: Ship radar fix at $24.2 \mathrm{~N}, 67.3 \mathrm{~W}$ at $02 \mathrm{Z}$ (WALLET). Penetration center fix at $24.5 \mathrm{~N}, 67.4 \mathrm{~W}$ at $0630 \mathrm{Z}$ (WALLET). Penetration center fix measured a central pressure of $992 \mathrm{mb}$, estimated surface winds of $50 \mathrm{kt}$ and an eye diameter of $10 \mathrm{~nm}$ at $24.2 \mathrm{~N}, 68.1 \mathrm{~W}$ at $1105 \mathrm{Z}$ (WALLET/ATSR). Penetration center fix measured a central pressure of $986 \mathrm{mb}$, estimated surface winds of $65 \mathrm{kt}$ and an eye diameter of $12 \mathrm{~nm}$ at $24.8 \mathrm{~N}, 68.9 \mathrm{~W}$ at $19 \mathrm{Z}$ (ATSR). Penetration center fix measured a central pressure of $985 \mathrm{mb}$ at $25.1 \mathrm{~N}, 69.1 \mathrm{~W}$ at $2135 \mathrm{Z}$ (ATSR).

October 5:

HWM analyzes a hurricane of at most $995 \mathrm{mb}$ at $26.6 \mathrm{~N}, 69.8 \mathrm{~W}$ with a weakening stationary front to the northeast and a cold front to the northwest at 12Z. HURDAT lists an $85 \mathrm{kt}$ hurricane at $27.2 \mathrm{~N}, 69.8 \mathrm{~W}$ at $12 \mathrm{Z}$. Microfilm shows a closed low pressure of at most $993 \mathrm{mb}$ at $26.8 \mathrm{~N}, 69.5 \mathrm{~W}$ with a frontal boundary to the northwest at $12 \mathrm{Z}$. Ship highlights: $45 \mathrm{kt} \mathrm{SE}$ and $1008 \mathrm{mb}$ at 25.1N, 66.6W at 00Z (micro). $45 \mathrm{kt} \mathrm{SE}$ and $1008 \mathrm{mb}$ 
at $24.0 \mathrm{~N}, 66.5 \mathrm{~W}$ at $03 \mathrm{Z}$ (micro). $50 \mathrm{kt} \mathrm{SSE}$ and $1008 \mathrm{mb}$ at $24.0 \mathrm{~N}, 66.4 \mathrm{~W}$ at $06 \mathrm{Z}$ (micro). $40 \mathrm{kt} \mathrm{SSW}$ and $1003 \mathrm{mb}$ at $25.0 \mathrm{~N}, 68.5 \mathrm{~W}$ at $09 \mathrm{Z}$ (micro). $45 \mathrm{kt} \mathrm{SE}$ and $1010 \mathrm{mb}$ at $26.6 \mathrm{~N}, 67.2 \mathrm{~W}$ at $12 \mathrm{Z}$ (micro). $50 \mathrm{kt} \mathrm{E}$ and $1010 \mathrm{mb}$ at $28.2 \mathrm{~N}, 69.0 \mathrm{~W}$ at $15 \mathrm{Z}$ (micro). 60 kt SE and $1006 \mathrm{mb}$ at $29.0 \mathrm{~N}, 67.0 \mathrm{~W}$ at $18 \mathrm{Z}$ (micro). $60 \mathrm{kt} \mathrm{NW}$ and $1000 \mathrm{mb}$ at $27.0 \mathrm{~N}$, 68.0W at $21 \mathrm{Z}$ (micro). Aircraft highlights: Penetration center fix measured a central pressure of $984 \mathrm{mb}$ at $25.5 \mathrm{~N}, 69.1 \mathrm{~W}$ at $0345 \mathrm{Z}$ (WALLET). Penetration center fix measured a central pressure of $973 \mathrm{mb}$ at $26.6 \mathrm{~N}, 69.7 \mathrm{~W}$ at $1025 \mathrm{Z}$ (WALLET). Penetration center fix at 27.1N, 69.4W at 13Z (WALLET). Penetration center fix measured a central pressure of $969 \mathrm{mb}$, estimated surface winds of $85 \mathrm{kt}$ and an eye diameter of $35 \mathrm{~nm}$ at $27.8 \mathrm{~N}, 69.7 \mathrm{~W}$ at $1801 \mathrm{Z}$ (ATSR).

October 6:

HWM analyzes a hurricane of at most $995 \mathrm{mb}$ at $32.5 \mathrm{~N}, 68.5 \mathrm{~W}$ with a weakening front to the northwest and a warm front to the northeast at 12Z. HURDAT lists an $85 \mathrm{kt}$ hurricane at $32.8 \mathrm{~N}, 68.1 \mathrm{~W}$ at $12 \mathrm{Z}$. Microfilm shows a closed low pressure of at most $1005 \mathrm{mb}$ at $32.6 \mathrm{~N}, 68.5 \mathrm{~W}$ with an extratropical cyclone to the northwest at 12Z. Ship highlights: 55 $\mathrm{kt} \mathrm{N}$ and $1002 \mathrm{mb}$ at $29.9 \mathrm{~N}, 70.6 \mathrm{~W}$ at $00 \mathrm{Z}$ (micro). $45 \mathrm{kt} \mathrm{SE}$ and $1011 \mathrm{mb}$ at $30.0 \mathrm{~N}$, $65.5 \mathrm{~W}$ at $03 \mathrm{Z}$ (micro). $35 \mathrm{kt} \mathrm{SSE}$ and $1011 \mathrm{mb}$ at $27.2 \mathrm{~N}, 65.4 \mathrm{~W}$ at $06 \mathrm{Z}$ (micro). $35 \mathrm{kt}$ ESE and $1009 \mathrm{mb}$ at $35.1 \mathrm{~N}, 67.1 \mathrm{~W}$ at $09 \mathrm{Z}$ (COADS). $45 \mathrm{kt} \mathrm{WNW}$ and $1011 \mathrm{mb}$ at $30.7 \mathrm{~N}, 69.3 \mathrm{~W}$ at $12 \mathrm{Z}$ (micro). $35 \mathrm{kt} \mathrm{NNE}$ and $1001 \mathrm{mb}$ at $36.2 \mathrm{~N}, 69.2 \mathrm{~W}$ at $18 \mathrm{Z}$ (COADS). Land highlights: $35 \mathrm{kt} \mathrm{SSE} \mathrm{(gusts} \mathrm{to} 43 \mathrm{kt}$ ) and $1004 \mathrm{mb}$ at Bermuda at $12 \mathrm{Z}$ (micro). $30 \mathrm{kt} \mathrm{SSW}$ (gusts to $46 \mathrm{kt}$ ) and $1003 \mathrm{mb}$ at Bermuda at 18Z (micro). Aircraft highlights: Radar center fix estimated an eye diameter of $45 \mathrm{~nm}$ at $29.4 \mathrm{~N}, 69.2 \mathrm{~W}$ at 0130Z (ATSR). Penetration center fix measured a central pressure of $967 \mathrm{mb}$ at $29.3 \mathrm{~N}$, $69.2 \mathrm{~W}$ at $02 \mathrm{Z}$ (ATSR). Penetration center fix measured a central pressure of $965 \mathrm{mb}$ and estimated surface winds of $90 \mathrm{kt}$ at $32.3 \mathrm{~N}, 68.3 \mathrm{~W}$ at 1010Z (WALLET). Penetration center fix measured a central pressure of $968 \mathrm{mb}$, estimated surface winds of $100 \mathrm{kt}$ and an eye diameter of $50 \mathrm{~nm}$ at $35.1 \mathrm{~N}, 66.8 \mathrm{~W}$ at $1924 \mathrm{Z}$ (ATSR).

MWR: "The hurricane passed well west of Bermuda on the 6th and the lowest central pressure, $965 \mathrm{mb}$, was reported at that time with winds of about $100 \mathrm{mph}$. The combined impact in New England of a "northeaster" on the 5th and 6th and tropical storm Daisy on the 6 th and 7th produced widespread and heavy damage. Casualties included two fatalities and five injuries. Heaviest rainfall yields were produced by the coastal storm while Daisy's contribution intensified and prolonged the floods. Rain fell almost continuously for 65 hours. Areas that received more than 4 in. with flood damage included the eastern half of southern New England, eastern Vermont, New Hampshire except for the extreme northern parts, and southwestern Maine. Within the limits of these areas, amounts gradually increased to a record or near fall of 10 to 12 inches in 
Middlesex and Essex Counties, Mass. Highest winds were experienced over the coastal areas of Maine, especially the central sections where speeds of 60 to more than $70 \mathrm{mph}$. were reported. Coastal installations were hammered by giant waves. Lobster fishermen suffered heavy losses and hundreds of small boats were ripped from their moorings and sunk or damaged. Acre-size Mt. Desert Rock, 22 mi offshore from Southwest Harbor, Maine, was pounded and washed by mountainous waves, some of which reportedly reached elevations $50 \mathrm{ft}$. above sea level. Damage was said to be the heaviest in the 115yr history of the Coast Guard Base there. Estimates indicate damage from the combined storms (coastal storm immediately preceding Daisy and Daisy) may have reached $\$ 10,000,000$. Estimates of damage attributed directly to Daisy were $\$ 600,000$ from surf and waves, mostly in Maine, and about $\$ 500,000$ from wind for all of New England. Damage was also considerable in Nova Scotia." ATSR: "DAISY passed 200 miles to the west of Bermuda early on the 6th."

\section{October 7:}

HWM analyzes a hurricane of at most $975 \mathrm{mb}$ at $42.0 \mathrm{~N}, 66.9 \mathrm{~W}$ with a cold front to the southeast and a warm front to the northeast at 12Z. HURDAT lists a $65 \mathrm{kt}$ hurricane at $42.2 \mathrm{~N}, 66.6 \mathrm{~W}$ at $12 \mathrm{Z}$. Microfilm shows an extratropical cyclone of at most $990 \mathrm{mb}$ at $42.0 \mathrm{~N}, 67.0 \mathrm{~W}$ at 12Z. Ship highlights: $65 \mathrm{kt} \mathrm{NNW}$ and $995 \mathrm{mb}$ at $38.1 \mathrm{~N}, 68.4 \mathrm{~W}$ at $00 \mathrm{Z}$ (COADS). $70 \mathrm{kt} \mathrm{ENE}$ at $39.9 \mathrm{~N}, 68.0 \mathrm{~W}$ at $03 \mathrm{Z}$ (micro). $50 \mathrm{kt} \mathrm{W}$ and $992 \mathrm{mb}$ at $38.0 \mathrm{~N}$, $68.0 \mathrm{~W}$ at $06 \mathrm{Z}$ (COADS). $60 \mathrm{kt} \mathrm{N}$ and $963 \mathrm{mb}$ at $42.0 \mathrm{~N}, 68.0 \mathrm{~W}$ at $12 \mathrm{Z}$ (COADS). $5 \mathrm{kt}$ $\mathrm{SW}$ (70 kt in micro) and $990 \mathrm{mb}$ at $39.7 \mathrm{~N}, 65.3 \mathrm{~W}$ at $12 \mathrm{Z}$ (COADS). $70 \mathrm{kt} \mathrm{WSW}$ and 996 $\mathrm{mb}$ at $40.0 \mathrm{~N}, 64.4 \mathrm{~W}$ at $15 \mathrm{Z}$ (COADS). $60 \mathrm{kt} \mathrm{SW}$ and $997 \mathrm{mb}$ at $40.3 \mathrm{~N}, 63.0 \mathrm{~W}$ at $18 \mathrm{Z}$ (COADS). Land highlights: $18 \mathrm{kt} \mathrm{N}$ and $997 \mathrm{mb}$ at Nantucket, MA at 0555Z (SWO). 18 kt NW and $992 \mathrm{mb}$ at Nantucket, MA at 1158Z (SWO). $50 \mathrm{kt} \mathrm{ESE}$ and $975 \mathrm{mb}$ at Yarmouth, Canada at 15Z (micro). $40 \mathrm{kt} \mathrm{ENE} \mathrm{and} 983 \mathrm{mb}$ at Eastport, ME at 18Z (micro). Aircraft highlights: Penetration center fix measured a central pressure of $975 \mathrm{mb}$ and estimated an eye diameter of $8 \mathrm{~nm}$ at $40.7 \mathrm{~N}, 64.9 \mathrm{~W}$ at $0733 \mathrm{Z}$ (ATSR). Penetration center fix measured a central pressure of $960 \mathrm{mb}$ at $42.0 \mathrm{~N}, 66.7 \mathrm{~W}$ at $13 \mathrm{Z}$ (WALLET).

MWR: "Cold air began feeding into the circulation October 7. It reached land near Yarmouth, Nova Scotia, late that day and turned sharply eastward. Yarmouth reported $977 \mathrm{mb}$ as the weakening center passed there." ATSR: "On 7 October the circulation associated with a mid-tropospheric low approaching from the west briefly turned the storm to the northwest so that it skirted the New England coast with high winds and excessive precipitation. Late on the 7th the storm's circulation merged with the upper level circulation and thereafter, DAISY rapidly lost tropical characteristics. The last warning was issued at $072200 \mathrm{Z}$ calling for the storm to become extratropical during the forecast period." 
October 8:

HWM analyzes a hurricane of at most $985 \mathrm{mb}$ at $44.5 \mathrm{~N}, 63.1 \mathrm{~W}$ with a cold front to the north at $12 \mathrm{Z}$. HURDAT lists a $55 \mathrm{kt}$ extratropical storm at $44.7 \mathrm{~N}, 62.8 \mathrm{~W}$ at $12 \mathrm{Z}$. Microfilm shows a closed low pressure of at most $981 \mathrm{mb}$ at $45.0 \mathrm{~N}, 63.0 \mathrm{~W}$ at $12 \mathrm{Z}$. Ship highlights: $60 \mathrm{kt} \mathrm{SW}$ and $1001 \mathrm{mb}$ at $40.7 \mathrm{~N}, 61.5 \mathrm{~W}$ at $00 \mathrm{Z}$ (COADS). $45 \mathrm{kt} \mathrm{SW}$ and 996 $\mathrm{mb}$ at $40.1 \mathrm{~N}, 62.8 \mathrm{~W}$ at $06 \mathrm{Z}$ (micro). $40 \mathrm{kt} \mathrm{SW}$ and $989 \mathrm{mb}$ at $42.3 \mathrm{~N}, 62.8 \mathrm{~W}$ at $12 \mathrm{Z}$ (COADS). $45 \mathrm{kt} \mathrm{WSW}$ and $996 \mathrm{mb}$ at $41.6 \mathrm{~N}, 61.2 \mathrm{~W}$ at $18 \mathrm{Z}$ (COADS). $15 \mathrm{kt} \mathrm{NE}$ and 984 $\mathrm{mb}$ at $46.0 \mathrm{~N}, 62.0 \mathrm{~W}$ at $18 \mathrm{Z}$ (micro). Land highlights: $20 \mathrm{kt} \mathrm{SE}$ and $978 \mathrm{mb}$ at Yarmouth, Canada at 00Z (micro). $20 \mathrm{kt} \mathrm{SE}$ and $985 \mathrm{mb}$ at Halifax, Canada at 06Z (micro). $15 \mathrm{kt} \mathrm{N}$ and $982 \mathrm{mb}$ at Halifax, Canada at $12 \mathrm{Z}$ (micro).

October 9:

HWM analyzes a closed low pressure of at most $995 \mathrm{mb}$ at $45.0 \mathrm{~N}, 50.0 \mathrm{~W}$ with a cold front going through the center at 12Z. HURDAT lists a $50 \mathrm{kt}$ extratropical storm at $46.0 \mathrm{~N}, 54.9 \mathrm{~W}$ at $06 \mathrm{Z}$ (last position). Microfilm shows a closed low pressure of at most $990 \mathrm{mb}$ at $48.5 \mathrm{~N}, 47.0 \mathrm{~W}$ at 12Z. Ship highlights: $50 \mathrm{kt} \mathrm{NW}$ and $1000 \mathrm{mb}$ at $41.5 \mathrm{~N}$, $63.1 \mathrm{~W}$ at $00 \mathrm{Z}$ (COADS). $40 \mathrm{kt} \mathrm{NE}$ and $1005 \mathrm{mb}$ at $48.2 \mathrm{~N}, 61.2 \mathrm{~W}$ at $06 \mathrm{Z}$ (COADS). $40 \mathrm{kt}$ $\mathrm{S}$ and $1003 \mathrm{mb}$ at $46.2 \mathrm{~N}, 40.5 \mathrm{~W}$ at $12 \mathrm{Z}$ (COADS).

October 10:

HWM analyzes an extratropical cyclone of at most $985 \mathrm{mb}$ at $57.0 \mathrm{~N}, 40.0 \mathrm{~W}$ at $12 \mathrm{Z}$. HURDAT does not list an organized storm on this date. Microfilm shows a closed low pressure of at most $990 \mathrm{mb}$ at $48.5 \mathrm{~N}, 47.0 \mathrm{~W}$ at 12Z. Ship highlights: No gales or low pressures.

Hurricane Daisy developed from a tropical wave that left the African coast late in September. The system moved westward and slowly became better organized. Data over the eastern and central Atlantic is sparse, thus the time of genesis is uncertain. The first indication that the tropical wave was developing was a TIROS VI satellite image on September 28th at $1303 \mathrm{Z}$ showing a large area of convection with some banding features on the northern quadrant, as depicted in the nephanalysis at $12 \mathrm{Z}$ on the 28 th. The first position is analyzed at $06 \mathrm{Z}$ on September 29th as a $25 \mathrm{kt}$ tropical depression, same as originally shown in HURDAT. The tropical cyclone moved westward at a rapid forward speed of about $17 \mathrm{kt}$ on the 29th and 30th. A reconnaissance aircraft reached the tropical depression at $13 \mathrm{Z}$ on September 30th measuring a central pressure of $1005 \mathrm{mb}$. A central pressure of $1005 \mathrm{mb}$ suggests maximum surface winds of $37 \mathrm{kt}$ south of $25 \mathrm{~N}$ from the Brown et al. pressure-wind relationship. Based on a forward speed of about $17 \mathrm{kt}$, an intensity of $40 \mathrm{kt}$ is selected at $12 \mathrm{Z}$ on the $30 \mathrm{th}$, up from $30 \mathrm{kt}$ originally in HURDAT, a minor intensity change. (Central pressures values for almost every 6 hour period were 
present in the original HURDAT between October 2nd at $06 \mathrm{Z}$ and October 7th at 06Z. Some of these were obviously analyses that were added in, not based upon actual observations. Thus, based on actual observations, some were retained, others removed and new central pressure values added. Detailed information on these changes can be found in the table at the end.) Intensification to a tropical storm is analyzed at $06 \mathrm{Z}$ on the 30th, 54 hours earlier than originally shown in HURDAT. Minor track changes are analyzed during the lifetime of this tropical cyclone. On October 1st, Daisy turned to the northwest and decreased in forward speed, passing about $30 \mathrm{~nm}$ northeast of Barbuda, closest approach to the Leeward Islands. Surface observations and data from the reconnaissance aircrafts on October 1st and 2nd indicate that the system remained a weak tropical storm with only minor fluctuations in intensity. The first gale-force wind was reported on the 2 nd at $06 \mathrm{Z}$ by a ship in the northeast quadrant of Daisy.

The tropical cyclone began to deepen on October 3rd while located north of Puerto Rico. A reconnaissance aircraft at $23 \mathrm{Z}$ on the $2 \mathrm{nd}$ reported a central pressure of $1003 \mathrm{mb}$ and estimated surface winds of $40 \mathrm{kt}$. A central pressure of $1003 \mathrm{mb}$ suggests maximum surface winds of $41 \mathrm{kt}$ south of $25 \mathrm{~N}$ from the pressure-wind relationship. Based on a forward speed of about $7 \mathrm{kt}$ and synoptic observations, an intensity of $45 \mathrm{kt}$ is analyzed at $00 \mathrm{Z}$ on the $3 \mathrm{rd}$, down from $50 \mathrm{kt}$ originally in HURDAT, a minor intensity change. A ship at $09 \mathrm{Z}$ on the $3 \mathrm{rd}$ reported $50 \mathrm{kt} \mathrm{SSE}$ and $1003 \mathrm{mb}$. Another penetration fix occurred at $1051 \mathrm{Z}$ on the $3 \mathrm{rd}$ measuring a central pressure of $1000 \mathrm{mb}$ and estimated surface winds of $40 \mathrm{kt}$. A central pressure of $1000 \mathrm{mb}$ suggests maximum surface winds of $47 \mathrm{kt}$ south of $25 \mathrm{~N}$ from the pressure-wind relationship. Based on a forward speed of about $9 \mathrm{kt}$ and ship data, an intensity of $50 \mathrm{kt}$ is analyzed at $12 \mathrm{Z}$ on the $3 \mathrm{rd}$, down from $60 \mathrm{kt}$ originally in HURDAT, a minor intensity change. A penetration fix occurred at $1830 \mathrm{Z}$ on the $3 \mathrm{rd}$ measuring a central pressure of $995 \mathrm{mb}$ and estimated surface winds of $57 \mathrm{kt}$. A central pressure of $995 \mathrm{mb}$ suggests maximum surface winds of $56 \mathrm{kt}$ south of $25 \mathrm{~N}$ from the pressure-wind relationship. Based on a forward speed of about $8 \mathrm{kt}$, an intensity of $55 \mathrm{kt}$ is analyzed at $18 \mathrm{Z}$ on the $3 \mathrm{rd}$, down from $65 \mathrm{kt}$ originally in HURDAT, a minor intensity change. At $2152 \mathrm{Z}$ on the $3 \mathrm{rd}$, another reconnaissance aircraft investigated Daisy measuring a central pressure of $994 \mathrm{mb}$ and estimating surface winds of $55 \mathrm{kt}$. A central pressure of 994 was already present in HURDAT at $00 \mathrm{Z}$ on October 4th and it is retained. An intensity of $55 \mathrm{kt}$ is selected at $00 \mathrm{Z}$ on the 4 th, down from $65 \mathrm{kt}$ originally in HURDAT, a minor intensity change. The next reconnaissance aircraft measured a central pressure of $992 \mathrm{mb}$, estimated surface winds of $50 \mathrm{kt}$ and an eye diameter of $10 \mathrm{~nm}$. A central pressure of $992 \mathrm{mb}$ suggests maximum surface winds of $61 \mathrm{kt}$ south of $25 \mathrm{~N}$ and $56 \mathrm{kt}$ north of $25 \mathrm{~N}$ from the pressure-wind relationship. An eye diameter of $10 \mathrm{~nm}$ suggests an RMW of about $8 \mathrm{~nm}$ and the climatological value is 20. Based on an RMW smaller than the climatological value and a forward speed of about $8 \mathrm{kt}$, an intensity of 65 $\mathrm{kt}$ is selected at $12 \mathrm{Z}$ on the 4 th, same as originally shown in HURDAT. Intensification to 
a hurricane is analyzed at $12 \mathrm{Z}$ on the 4 th, 18 hours later than originally shown in HURDAT. The TIROS V satellite captured an image of Daisy at $1312 \mathrm{Z}$ on the 4th showing a well-organized tropical cyclone with a central dense overcast and an eye. A penetration center fix measured a central pressure of $986 \mathrm{mb}$, estimated surface winds of $65 \mathrm{kt}$ and an eye diameter of $12 \mathrm{~nm}$ at $19 \mathrm{Z}$ on the 4th. A central pressure of $986 \mathrm{mb}$ suggests maximum surface winds of $70 \mathrm{kt}$ south of $25 \mathrm{~N}, 65 \mathrm{kt}$ north of $25 \mathrm{~N}$, and $68 \mathrm{kt}$ intensifying from the pressure-wind relationship. An eye diameter of $12 \mathrm{~nm}$ suggests an RMW of about $9 \mathrm{~nm}$ and the climatological value is 20 . Based on an RMW smaller than the climatological value and a forward speed of about $8 \mathrm{kt}$, an intensity of $70 \mathrm{kt}$ is selected at $18 \mathrm{Z}$ on the 4 th, same as originally shown in HURDAT. Another center fix measured a central pressure of $985 \mathrm{mb}$ at $2135 \mathrm{Z}$ on the 4th. An intensity of $70 \mathrm{kt}$ is analyzed at $00 \mathrm{Z}$ on the 5 th, down from 80 kt originally shown in HURDAT.

On October 5th, Daisy turned to the north gradually intensifying. At $0345 \mathrm{Z}$ on the 5 th, the reconnaissance aircraft measured a central pressure of $984 \mathrm{mb}$. A central pressure of $984 \mathrm{mb}$ suggests maximum surface winds of $68 \mathrm{kt}$ north of $25 \mathrm{~N}$ from the pressure-wind relationship. Based on a forward speed of about $10 \mathrm{kt}$, an intensity of $70 \mathrm{kt}$ is selected at $06 \mathrm{Z}$ on the 5 th, down from $85 \mathrm{kt}$ originally shown in HURDAT. Another penetration fix measured a central pressure of $973 \mathrm{mb}$ at $1025 \mathrm{Z}$ on the 5th. A central pressure of $973 \mathrm{mb}$ suggests maximum surface winds of $81 \mathrm{kt}$ north of $25 \mathrm{~N}$ from the pressure-wind relationship. Based on a forward speed of about $10 \mathrm{kt}$, an intensity of $80 \mathrm{kt}$ is selected at $12 \mathrm{Z}$ on the 5 th, down from $85 \mathrm{kt}$ originally shown in HURDAT. The TIROS V satellite captured an image of $1245 \mathrm{Z}$ on the 5 th showing a well-organized tropical cyclone. The next reconnaissance aircraft measured a central pressure of $969 \mathrm{mb}$, estimated surface winds of $85 \mathrm{kt}$ and an eye diameter of $35 \mathrm{~nm}$ at $1801 \mathrm{Z}$ on the 5 th. A central pressure of $969 \mathrm{mb}$ suggests maximum surface winds of $86 \mathrm{kt}$ north of $25 \mathrm{~N}$ from the pressure-wind relationship. An eye diameter of $35 \mathrm{~nm}$ suggests an RMW of about $26 \mathrm{~nm}$ and the climatological value is 22 . Based on an RMW close or slightly larger than climatology and a forward speed of about $10 \mathrm{kt}$, an intensity of $85 \mathrm{kt}$ is selected at $18 \mathrm{Z}$ on the $5 \mathrm{th}$, down from 95 kt originally shown in HURDAT. On October 6th, Daisy turned to the northeast and passed about $150 \mathrm{~nm}$ west of Bermuda. The first reconnaissance aircraft on the 6th reached the hurricane at $02 \mathrm{Z}$ measuring a central pressure of $967 \mathrm{mb}$. A central pressure of $967 \mathrm{mb}$ suggests maximum surface winds of $88 \mathrm{kt}$ north of $25 \mathrm{~N}$ from the pressure-wind relationship. Based on a forward speed of about $17 \mathrm{kt}$, an intensity of $90 \mathrm{kt}$ is selected at $00 \mathrm{Z}$ on the 6th, same as originally shown in HURDAT. $90 \mathrm{kt}$ is also the peak intensity of this tropical cyclone, down from $95 \mathrm{kt}$ originally in HURDAT. A penetration center fix at $1010 \mathrm{Z}$ on the 6th measured a central pressure of $965 \mathrm{mb}$ and estimated surface winds of $90 \mathrm{kt}$. A central pressure of $965 \mathrm{mb}$ suggests maximum surface winds of $90 \mathrm{kt}$ north of 25 north from the pressure-wind relationship. Based on a forward speed of $23 \mathrm{kt}$ and large circulation, an intensity of $90 \mathrm{kt}$ is analyzed at $12 \mathrm{Z}$ on 
the 6th, down from the $85 \mathrm{kt}$ originally shown in HURDAT, a minor intensity change. Another penetration center fix at $1924 \mathrm{Z}$ on the 6th measured a central pressure of 968 $\mathrm{mb}$, estimated surface winds of $100 \mathrm{kt}$ and an eye diameter of $50 \mathrm{~nm}$. A central pressure of $968 \mathrm{mb}$ suggests maximum surface winds of $87 \mathrm{kt}$ north of $25 \mathrm{~N}$ from the Brown et al. and $84 \mathrm{kt}$ north of $35 \mathrm{~N}$ from the Landsea et al. pressure-wind relationships. An eye diameter of $50 \mathrm{~nm}$ suggests an RMW of about $38 \mathrm{~nm}$ and the climatological value is 28 . Based on a forward speed of $28 \mathrm{kt}$ and large circulation, an intensity of $85 \mathrm{kt}$ is analyzed at $18 \mathrm{Z}$ on the 6 th, down from the $95 \mathrm{kt}$ originally shown in HURDAT, a minor intensity change. Late on the 6th and early on October 7th, Daisy began to acquire extratropical characteristics. Synoptic observations indicate that it became an extratropical cyclone at $06 \mathrm{Z}$ on the 7 th while located south of Nova Scotia. Transition to an extratropical cyclone is analyzed 30 hours earlier than originally shown in HURDAT. On October 7th, Daisy turned to the northwest and slowed its forward speed. The windfield expanded producing strong winds across the coastal areas of the Northeast of the United States and the southeastern Canada. The strong winds produced large waves that battered the coastline and heavy rains led to flooding. The last reconnaissance aircraft to investigate Ella measured a central pressure of $960 \mathrm{mb}$ at $13 \mathrm{Z}$ on the 7 th. On October 8 th, the extratropical cyclone turned to the east-northeast increasing in forward speed while crossing Nova Scotia. Weakening below hurricane intensity is analyzed at $12 \mathrm{Z}$ on the 8th, same as originally shown in HURDAT. Ella continued to weaken on the 9 th and synoptic observations indicate that it was absorbed by a larger extratropical cyclone after 06Z. The last position is analyzed at $06 \mathrm{Z}$ on the 9 th, same as originally shown in HURDAT.

\begin{tabular}{|c|c|c|c|}
\hline Date & $\begin{array}{l}\text { Original } \\
\text { HURDAT } \\
\text { Central } \\
\text { Pressure }\end{array}$ & Evidence & Changes \\
\hline Sep $3012 Z$ & & $\begin{array}{l}\text { Penetration center fix: } 1005 \mathrm{mb} \\
\text { at } 13 Z \text { on Sep } 30^{\text {th }}\end{array}$ & $1005 \mathrm{mb}$ \\
\hline Sep $3018 Z$ & & $\begin{array}{l}\text { Penetration center fix: } 1006 \mathrm{mb} \\
\text { at } 1726 \mathrm{Z} \text { on Sep } 30^{\text {th }}\end{array}$ & $1006 \mathrm{mb}$ \\
\hline Oct $0112 Z$ & & $\begin{array}{l}\text { Dropsonde measured } 1006 \mathrm{mb} \text { and } \\
20 \mathrm{kt} \mathrm{SSW} \text { at } 1045 \mathrm{Z} \text { on } 0 \mathrm{ct} 01^{\text {th }}\end{array}$ & $1004 \mathrm{mb}$ \\
\hline Oct $\odot 206 Z$ & $1003 \mathrm{mb}$ & $\begin{array}{l}\text { No central pressure report } \\
\text { around this time from } \\
\text { reconnaissance aircraft or } \\
\text { ships }\end{array}$ & Removed \\
\hline Oct $0212 Z$ & & $\begin{array}{l}\text { Penetration center fix: } 1005 \mathrm{mb} \\
\text { at } 1140 \mathrm{Z} \text { on } 0 \mathrm{ct} \odot 2^{\text {nd }}\end{array}$ & $1005 \mathrm{mb}$ \\
\hline Oct $\odot 3 \odot \odot z$ & & $\begin{array}{l}\text { Penetration center fix: } 1003 \mathrm{mb} \\
\text { at } 23 \mathrm{Z} \text { on } 0 \mathrm{ct} 02^{\text {nd }}\end{array}$ & $1003 \mathrm{mb}$ \\
\hline
\end{tabular}




\begin{tabular}{|c|c|c|c|c|}
\hline Oct 0312 & $12 Z$ & & $\begin{array}{l}\text { Penetration center fix: } 1000 \mathrm{mb} \\
\text { at } 1051 \mathrm{Z} \text { on } 0 \mathrm{ct} 03^{\text {rd }}\end{array}$ & $1000 \mathrm{mb}$ \\
\hline Oct 0318 & $18 Z$ & & $\begin{array}{l}\text { Penetration center fix: } 995 \mathrm{mb} \\
\text { at } 1830 \mathrm{Z} \text { on } 0 \mathrm{ct} 03^{\text {rd }}\end{array}$ & $995 \mathrm{mb}$ \\
\hline Oct $04 \odot$ & $\ominus$ & $994 \mathrm{mb}$ & $\begin{array}{l}\text { Penetration center fix: } 994 \mathrm{mb} \\
\text { at } 2152 Z \text { on } 0 \text { ct } 03^{\text {rd }}\end{array}$ & Retained \\
\hline Oct $04 \quad 12$ & $12 Z$ & & $\begin{array}{l}\text { Penetration center fix: } 992 \mathrm{mb} \\
\text { at } 1105 \mathrm{Z} \text { on } 0 \mathrm{ct} 04^{\text {th }}\end{array}$ & $992 \mathrm{mb}$ \\
\hline Oct 0418 & $18 Z$ & $986 \mathrm{mb}$ & $\begin{array}{l}\text { Penetration center fix: } 986 \mathrm{mb} \\
\text { at } 19 \mathrm{z} \text { on } 0 \mathrm{ct} 04^{\text {th }}\end{array}$ & Retained \\
\hline Oct $05 \odot$ & $\ominus$ & & $\begin{array}{l}\text { Penetration center fix: } 985 \mathrm{mb} \\
\text { at } 2135 \mathrm{Z} \text { on } 0 \mathrm{ct} 04^{\text {th }}\end{array}$ & $985 \mathrm{mb}$ \\
\hline Oct $05 \odot$ & $6 z$ & & $\begin{array}{l}\text { Penetration center fix: } 984 \mathrm{mb} \\
\text { at } 0345 \mathrm{Z} \text { on } 0 \text { ct } 05^{\text {th }}\end{array}$ & $984 \mathrm{mb}$ \\
\hline Oct 0512 & $2 Z$ & & $\begin{array}{l}\text { Penetration center fix: } 973 \mathrm{mb} \\
\text { at } 1025 \mathrm{Z} \text { on } 0 \mathrm{ct} 05^{\mathrm{th}}\end{array}$ & $973 \mathrm{mb}$ \\
\hline Oct 0518 & $8 Z$ & $969 \mathrm{mb}$ & $\begin{array}{l}\text { Penetration center fix: } 969 \mathrm{mb} \\
\text { at } 1801 \mathrm{Z} \text { on } 0 \mathrm{ct} 05^{\mathrm{th}}\end{array}$ & Retained \\
\hline Oct $06 \odot$ & $\bullet Z$ & & $\begin{array}{l}\text { Penetration center fix: } 967 \mathrm{mb} \\
\text { at } 02 Z \text { on } 0 \mathrm{ct} 06^{\text {th }}\end{array}$ & $967 \mathrm{mb}$ \\
\hline Oct 0612 & $2 Z$ & $965 \mathrm{mb}$ & $\begin{array}{l}\text { Penetration center fix: } 965 \mathrm{mb} \\
\text { at } 1010 \mathrm{Z} \text { on } 0 \mathrm{ct} 06^{\text {th }}\end{array}$ & \multirow{2}{*}{ Retained } \\
\hline Oct 0618 & $8 Z$ & $968 \mathrm{mb}$ & $\begin{array}{l}\text { Penetration center fix: } 968 \mathrm{mb} \\
\text { at } 1924 Z \text { on } 0 \text { ct } 06^{\text {th }}\end{array}$ & \\
\hline Oct $07 \odot$ & $6 Z$ & $975 \mathrm{mb}$ & $\begin{array}{l}\text { Ship observations suggests that } \\
\text { the central pressure was lower }\end{array}$ & Removed \\
\hline Oct 07 & $2 Z$ & & $\begin{array}{l}\text { Penetration center fix: } 960 \mathrm{mb} \\
\text { at } 13 Z \text { on } 0 \mathrm{ct} 07^{\text {th }}\end{array}$ & $960 \mathrm{mb}$ \\
\hline
\end{tabular}

Hurricane Ella [October 14-23, 1962]

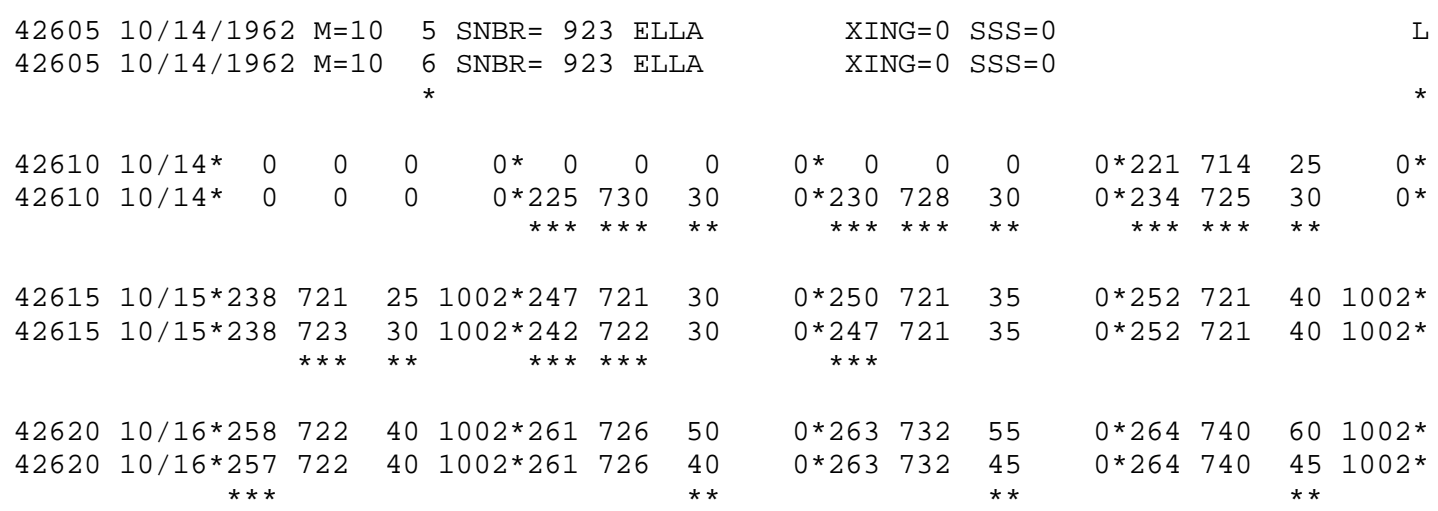




\begin{tabular}{|c|c|c|c|c|c|c|c|c|c|c|c|c|c|}
\hline 42625 & $10 / 17^{*} 267$ & 748 & 60 & $994 * 270$ & 751 & 60 & $997 * 274$ & 752 & 60 & $992 * 281$ & 754 & 70 & 987 * \\
\hline 42625 & $10 / 17^{*} 266$ & 748 & $\begin{array}{l}50 \\
* *\end{array}$ & $994 * 270$ & 751 & $\begin{array}{l}50 \\
* *\end{array}$ & $\begin{array}{r}997 * 275 \\
\star \star \star\end{array}$ & 752 & $\begin{array}{l}55 \\
* *\end{array}$ & $\begin{array}{r}992 * 282 \\
* \star *\end{array}$ & 754 & $\begin{array}{l}60 \\
* *\end{array}$ & $\begin{array}{l}989 * \\
* * *\end{array}$ \\
\hline 42630 & $10 / 18 * 287$ & 756 & 75 & ๑*292 & 757 & 70 & $981 * 297$ & 758 & 70 & $978 * 302$ & 758 & 70 & 976 * \\
\hline 42630 & $10 / 18 * 290$ & $\begin{array}{l}755 \\
\star * *\end{array}$ & $\begin{array}{l}65 \\
* *\end{array}$ & $\begin{array}{r}0 * 295 \\
* * *\end{array}$ & $\begin{array}{l}756 \\
\star * *\end{array}$ & $\begin{array}{l}65 \\
* *\end{array}$ & $\begin{array}{r}981 * 298 \\
* * *\end{array}$ & 758 & 70 & $978 * 302$ & $\begin{array}{l}760 \\
* * *\end{array}$ & $\begin{array}{l}75 \\
* *\end{array}$ & $\begin{array}{l}973^{*} \\
* * *\end{array}$ \\
\hline $\begin{array}{l}42635 \\
42635\end{array}$ & $\begin{array}{r}10 / 19 * 307 \\
10 / 19 * 306 \\
* * *\end{array}$ & $\begin{array}{l}758 \\
760 \\
* * *\end{array}$ & $\begin{array}{l}75 \\
75\end{array}$ & $\begin{array}{l}\odot * 307 \\
\odot * 307\end{array}$ & $\begin{array}{l}751 \\
756 \\
* * *\end{array}$ & $\begin{array}{l}80 \\
75 \\
\star *\end{array}$ & $\begin{array}{l}973 * 307 \\
973 * 307\end{array}$ & $\begin{array}{l}746 \\
746\end{array}$ & $\begin{array}{l}90 \\
80 \\
* *\end{array}$ & $\begin{array}{r}969 * 313 \\
969 * 311 \\
* * *\end{array}$ & $\begin{array}{l}736 \\
736\end{array}$ & $\begin{array}{r}100 \\
90 \\
* *\end{array}$ & $\begin{array}{l}962 * \\
962^{*}\end{array}$ \\
\hline $\begin{array}{l}42640 \\
42640\end{array}$ & $\begin{array}{l}10 / 20 * 319 \\
10 / 20 * 319\end{array}$ & $\begin{array}{l}728 \\
727 \\
\star * *\end{array}$ & $\begin{array}{r}100 \\
90 \\
* *\end{array}$ & $\begin{array}{l}\theta^{*} 330 \\
960^{*} 330 \\
* * *\end{array}$ & $\begin{array}{l}718 \\
718\end{array}$ & $\begin{array}{l}85 \\
9 \odot \\
\star *\end{array}$ & $\begin{array}{l}960 * 339 \\
963 * 339 \\
* * *\end{array}$ & $\begin{array}{l}708 \\
708\end{array}$ & $\begin{array}{l}85 \\
90 \\
* *\end{array}$ & $\begin{array}{l}960 * 346 \\
960^{*} 345\end{array}$ & $\begin{array}{l}696 \\
697 \\
* * *\end{array}$ & $\begin{array}{l}85 \\
85\end{array}$ & $\begin{array}{l}964^{*} \\
964^{*}\end{array}$ \\
\hline $\begin{array}{l}42645 \\
42645\end{array}$ & $\begin{array}{l}10 / 21 * 352 \\
10 / 21 * 352\end{array}$ & $\begin{array}{l}681 \\
681\end{array}$ & $\begin{array}{l}80 \\
85 \\
\star *\end{array}$ & $\begin{array}{l}\Theta * 360 \\
\Theta * 360\end{array}$ & $\begin{array}{l}663 \\
663\end{array}$ & $\begin{array}{l}75 \\
80 \\
\star *\end{array}$ & $\begin{array}{l}\odot * 367 \\
\odot * 367\end{array}$ & $\begin{array}{l}646 \\
645 \\
* * *\end{array}$ & $\begin{array}{l}70 \\
80 \\
* *\end{array}$ & $\begin{array}{l}972 * 375 \\
961 * 375 \\
\star * *\end{array}$ & $\begin{array}{l}626 \\
626\end{array}$ & $\begin{array}{l}65 \\
80 \\
* *\end{array}$ & $\begin{array}{l}950^{*} \\
958^{*} \\
* * *\end{array}$ \\
\hline $\begin{array}{l}42650 \\
42650\end{array}$ & $\begin{array}{l}10 / 22 * 395 \\
10 / 22 * 395\end{array}$ & $\begin{array}{l}597 \\
599 \\
* * *\end{array}$ & $\begin{array}{l}65 \\
75 \\
* *\end{array}$ & $\begin{array}{l}\text { OE429 } \\
\text { OE429 }\end{array}$ & $\begin{array}{l}563 \\
572 \\
* * *\end{array}$ & $\begin{array}{l}60 \\
65 \\
\star *\end{array}$ & $\begin{array}{r}\text { OE467 } \\
\text { OE46९ } \\
* \star *\end{array}$ & $\begin{array}{l}534 \\
540 \\
* * *\end{array}$ & $\begin{array}{l}60 \\
60\end{array}$ & $\begin{array}{r}\text { OE490 } \\
\text { OE48० } \\
* * *\end{array}$ & $\begin{array}{l}500 \\
490 \\
\star * *\end{array}$ & $\begin{array}{l}60 \\
60\end{array}$ & $\begin{array}{l}\Theta * \\
\Theta *\end{array}$ \\
\hline $\begin{array}{l}42655 \\
42655\end{array}$ & $\begin{array}{r}10 / 23 E 520 \\
10 / 23 E 510 \\
\star \star *\end{array}$ & $\begin{array}{l}451 \\
451\end{array}$ & $\begin{array}{l}60 \\
60\end{array}$ & $\begin{array}{l}\text { OE541 } \\
\text { OE541 }\end{array}$ & $\begin{array}{l}414 \\
421 \\
\star * *\end{array}$ & $\begin{array}{l}60 \\
60\end{array}$ & $\begin{array}{r}\text { OE562 } \\
\text { OE555 } \\
* * *\end{array}$ & $\begin{array}{l}370 \\
390 \\
\star * *\end{array}$ & $\begin{array}{l}60 \\
60\end{array}$ & 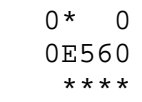 & $\begin{array}{r}0 \\
350 \\
* * *\end{array}$ & $\begin{array}{r}0 \\
55 \\
* *\end{array}$ & $\begin{array}{l}\odot^{*} \\
\odot^{*}\end{array}$ \\
\hline $\begin{array}{l}\text { (Octob } \\
42657\end{array}$ & $\begin{array}{l}\text { ber 24th a } \\
10 / 24 \text { E570 }\end{array}$ & $\begin{array}{l}\text { nd } 25 \\
310\end{array}$ & 50 & $\begin{array}{l}\text { new tc } \\
\text { @E58\% }\end{array}$ & $\begin{array}{l}\text { HUR } \\
270\end{array}$ & $\begin{array}{l}\text { OAT ) } \\
50\end{array}$ & OE59๑ & 230 & 50 & ○Е6०९ & 175 & 50 & ○* \\
\hline 42659 & $10 / 25 E 605$ & 105 & 50 & OE610 & 055 & 50 & $0^{*} \quad \odot$ & $\odot$ & $\odot$ & $\Theta^{*} \quad \odot$ & $\odot$ & $\odot$ & ○* \\
\hline
\end{tabular}

Minor changes to the track and major changes to the intensity shown in McAdie et al. (2009). Evidence for these alterations comes from the NHC microfilm maps, the Historical Weather Maps series, the COADS ship database, Monthly Weather Review, Navy reconnaissance book, Mariners Weather Log, Local Climatological Data, National Hurricane Research Project and NHC Storm Wallets.

October 11:

HWM does not analyze an organized system at 12Z. HURDAT does not list an organized system on this date. Microfilm shows a tropical wave near the Lesser Antilles along longitude 59W. Ship highlights: No gales or low pressures.

October 12:

HWM does not analyze an organized system at 12Z. HURDAT does not list an organized system on this date. Microfilm shows a tropical wave over the Lesser Antilles. Ship highlights: No gales or low pressures. Aircraft highlights: Flight level winds of $35 \mathrm{kt}$ and a pressure of $1010 \mathrm{mb}$ at $14.8 \mathrm{~N}, 63.8 \mathrm{~W}$ at $1130 \mathrm{Z}$ (micro). 
October 13:

HWM analyzes a closed low pressure of at most $1010 \mathrm{mb}$ at $16.8 \mathrm{~N}, 75.8 \mathrm{~W}$ at $12 \mathrm{Z}$. HURDAT does not list an organized system on this date. Microfilm shows a tropical wave over Hispaniola and attached is a closed low pressure of at most $1011 \mathrm{mb}$ at $17.7 \mathrm{~N}$, $72.7 \mathrm{~W}$ at $12 \mathrm{Z}$. Ship highlights: No gales or low pressures.

MWR: "The only prior indication of a disturbance was an area of increasing cloudiness and shower activity centered about 200 mi northeast of Turks Island on the 13th. This area coincided with the northern portion of a weak $500-\mathrm{mb}$ Low which had become cut off at the base of a polar trough and was drifting slowly west-northwestward. The surface charts on the 13th showed a rather weak gradient with general easterly flow and a minor inverted trough with cyclonic curvature and shear in the vicinity of the unsettled weather." ATSR: "First evidence of a surface disturbance was a weak inverted trough located north of Hispaniola coast on 13 October. This was attended by squally weather and stratus type clouds while peripheral ships to the north of the center were reporting winds of 20-25 knots."

October 14:

HWM analyzes a closed low pressure of at most $1010 \mathrm{mb}$ at $23.0 \mathrm{~N}, 72.0 \mathrm{~W}$ at $12 \mathrm{Z}$. HURDAT lists a $25 \mathrm{kt}$ tropical depression at $22.1 \mathrm{~N}, 71.4 \mathrm{~W}$ at $18 \mathrm{Z}$ (first position). Microfilm shows a closed low pressure of at most $1011 \mathrm{mb}$ at 23.0N, $72.0 \mathrm{~W}$ at 12Z. Ship highlights: $35 \mathrm{kt}$ ENE and $1011 \mathrm{mb}$ at $24.3 \mathrm{~N}, 72.2 \mathrm{~W}$ at $00 \mathrm{Z}$ (COADS). Aircraft highlights: Penetration center fix measured a central pressure of $1012 \mathrm{mb}$, estimated surface winds of $18 \mathrm{kt}$ and an eye diameter of $20 \mathrm{~nm}$ at $23.8 \mathrm{~N}, 73.0 \mathrm{~W}$ at $20 \mathrm{Z}$ (ATSR).

MWR: "The depression which was to grow into hurricane Ella developed in the southeastern Bahamas on October 14. Ships and islands near and to the north of the circulation center reported winds of 20 to 30 knots on that date." ATSR: "The unsettled area drifted north and then west-northwest so that the 14th it was located in the extreme southeastern Bahamas area. Early on the 14th aircraft reconnaissance reported that a depression had formed and this prompted the first of four tropical depression warnings issued at $141805 \mathrm{Z}$. The depression remained to the east of the Bahamas while gradually intensifying."

October 15:

HWM analyzes a closed low pressure of at most $1010 \mathrm{mb}$ at $24.2 \mathrm{~N}, 72.9 \mathrm{~W}$ with a weakening cold front to the north at 12Z. HURDAT lists a $35 \mathrm{kt}$ tropical storm at $25.0 \mathrm{~N}$, $72.1 \mathrm{~W}$ at $12 \mathrm{Z}$. Microfilm shows a closed low pressure of at most $1008 \mathrm{mb}$ at $24.8 \mathrm{~N}$, $71.2 \mathrm{~W}$ with a frontal boundary to the north at $12 \mathrm{Z}$. Ship highlights: $35 \mathrm{kt} \mathrm{NE}$ and 1011 
$\mathrm{mb}$ at $26.2 \mathrm{~N}, 74.1 \mathrm{~W}$ at $15 \mathrm{Z}$ (micro). $40 \mathrm{kt} \mathrm{NE}$ and $1011 \mathrm{mb}$ at $28.5 \mathrm{~N}, 69.6 \mathrm{~W}$ at $18 \mathrm{Z}$ (COADS). $35 \mathrm{kt}$ ENE and $1012 \mathrm{mb}$ at $28.1 \mathrm{~N}, 71.7 \mathrm{~W}$ at $21 \mathrm{Z}$ (micro). Aircraft highlights: Penetration center fix measured a central pressure of $1002 \mathrm{mb}$, estimated surface winds of $40 \mathrm{kt}$ and an eye diameter of $20 \mathrm{~nm}$ at $25.5 \mathrm{~N}, 72.4 \mathrm{~W}$ at $1850 \mathrm{Z}$ (WALLET). Penetration center fix measured a central pressure of $1003 \mathrm{mb}$ and estimated surface winds of $40 \mathrm{kt}$ at 25.3N, 71.8W at 2125Z (WALLET).

MWR: "The depression drifted toward the north, then west-northwestward, and gradually intensified. It attained tropical storm force on the 15th, but remained poorly organized." ATSR: "Tropical storm force was reached by late afternoon on the 15 th. The first numbered advisory on Tropical Storm ELLA was issued at 152200Z."

October 16:

HWM analyzes a tropical storm of at most $1005 \mathrm{mb}$ at $26.4 \mathrm{~N}, 73.3 \mathrm{~W}$ with a warm front to the northeast at $12 \mathrm{Z}$. HURDAT lists a $55 \mathrm{kt}$ tropical storm at $26.3 \mathrm{~N}, 73.2 \mathrm{~W}$ at $12 \mathrm{Z}$. Microfilm shows a closed low pressure of at most $1008 \mathrm{mb}$ at $25.5 \mathrm{~N}, 74.0 \mathrm{~W}$ at $12 \mathrm{Z}$. Ship highlights: $40 \mathrm{kt} \mathrm{NE}$ and $1014 \mathrm{mb}$ at $29.8 \mathrm{~N}, 70.3 \mathrm{~W}$ at $00 \mathrm{Z}$ (COADS). $45 \mathrm{kt} \mathrm{NE}$ and 1011 $\mathrm{mb}$ at $29.0 \mathrm{~N}, 74.0 \mathrm{~W}$ at $03 \mathrm{Z}$ (micro). $35 \mathrm{kt} \mathrm{ENE}$ and $1009 \mathrm{mb}$ at $27.6 \mathrm{~N}, 74.0 \mathrm{~W}$ at $06 \mathrm{Z}$ (COADS). $35 \mathrm{kt} \mathrm{NE}$ and $1012 \mathrm{mb}$ at $28.7 \mathrm{~N}, 74.0 \mathrm{~W}$ at 12Z (COADS). $40 \mathrm{kt} \mathrm{NE}$ and 1012 $\mathrm{mb}$ at $30.0 \mathrm{~N}, 73.9 \mathrm{~W}$ at $18 \mathrm{Z}$ (COADS). Land highlights: $35 \mathrm{kt} \mathrm{N}$ and $1009 \mathrm{mb}$ at North Eleuthera, Bahamas at $12 \mathrm{Z}$ (micro). Aircraft highlights: Penetration center fix measured a central pressure of $1006 \mathrm{mb}$ (1002 mb from $700 \mathrm{mb})$, estimated surface winds of $70 \mathrm{kt}$ in the northeast quadrant and an eye diameter of $20 \mathrm{~nm}$ at $26.4 \mathrm{~N}, 73.7 \mathrm{~W}$ at $1353 \mathrm{Z}$ (WALLET/ATSR). Penetration center fix measured a central pressure of $1002 \mathrm{mb}$ and estimated surface winds of $70 \mathrm{kt}$ at $26.4 \mathrm{~N}, 73.8 \mathrm{~W}$ at $16 \mathrm{Z}$ (WALLET). Penetration center fix measured a central pressure of $994 \mathrm{mb}$, estimated flight level winds of $60 \mathrm{kt}$ and an eye diameter of $25 \mathrm{~nm}$ at $26.6 \mathrm{~N}, 74.9 \mathrm{~W}$ at $2242 \mathrm{Z}$ (WALLET).

October 17:

HWM analyzes a tropical storm of at most $1000 \mathrm{mb}$ at $27.5 \mathrm{~N}, 75.4 \mathrm{~W}$ with a warm front to the northeast at $12 \mathrm{Z}$. HURDAT lists a $60 \mathrm{kt}$ tropical storm at $27.4 \mathrm{~N}, 75.2 \mathrm{~W}$ at $12 \mathrm{Z}$. Microfilm shows a closed low pressure of at most $993 \mathrm{mb}$ at 28.1N, 75.2W at 12Z. Ship highlights: $35 \mathrm{kt} \mathrm{E}$ and $1010 \mathrm{mb}$ at 29.2N, 71.6W at 00Z (COADS). $35 \mathrm{kt} \mathrm{NE}$ and 1010 $\mathrm{mb}$ at $30.6 \mathrm{~N}, 74.9 \mathrm{~W}$ at $06 \mathrm{Z}$ (COADS). $25 \mathrm{kt} \mathrm{WSW}$ and $999 \mathrm{mb}$ at $26.1 \mathrm{~N}, 74.2 \mathrm{~W}$ at $09 \mathrm{Z}$ (micro). $35 \mathrm{kt} \mathrm{SW}$ and $1000 \mathrm{mb}$ at $26.9 \mathrm{~N}, 73.9 \mathrm{~W}$ at $12 \mathrm{Z}$ (COADS). $45 \mathrm{kt} \mathrm{SE}$ and 1000 $\mathrm{mb}$ at $29.4 \mathrm{~N}, 73.5 \mathrm{~W}$ at $15 \mathrm{Z}$ (micro). $60 \mathrm{kt} \mathrm{NE}$ and $994 \mathrm{mb}$ at $28.9 \mathrm{~N}, 76.6 \mathrm{~W}$ at $18 \mathrm{Z}$ (micro). $40 \mathrm{kt} \mathrm{SSE}$ and $997 \mathrm{mb}$ at 28.6N, 73.7W at 21Z (micro). Land highlights: $20 \mathrm{kt} \mathrm{W}$ and $1005 \mathrm{mb}$ at San Salvador, Bahamas at 00Z (micro). $30 \mathrm{kt} \mathrm{NW}$ and $1005 \mathrm{mb}$ at Central Abaco, Bahamas at 12Z (micro). $30 \mathrm{kt} \mathrm{NW}$ and $1004 \mathrm{mb}$ at Central Abaco, 
Bahamas at $18 \mathrm{Z}$ (micro). Aircraft highlights: Penetration center fix measured a central pressure of $997 \mathrm{mb}$ at $27.1 \mathrm{~N}, 75.0 \mathrm{~W}$ at $04 \mathrm{Z}$ (WALLET). Penetration center fix measured a central pressure of $992 \mathrm{mb}$ and estimated surface winds of $60 \mathrm{kt}$ at $27.5 \mathrm{~N}, 75.1 \mathrm{~W}$ at $1215 Z$ (WALLET). Penetration center fix measured a central pressure of $989 \mathrm{mb}$, estimated surface winds of $75 \mathrm{kt}$ and an eye diameter of $80 \mathrm{~nm}$ at $28.5 \mathrm{~N}, 75.4 \mathrm{~W}$ at $1735 \mathrm{Z}$ (WALLET).

MWR: "A turn to the north-northwest occurred on the 17th and Ella reached hurricane intensity about noon on that date. Intermittent gales and heavy seas affected the central and northern Bahamas but the hurricane-force winds were well to the north of the islands." ATSR: "After attaining hurricane force, aircraft reconnaissance reported eyes from 60 to 100 miles in diameter as she progressed in a northeasterly direction off the Atlantic coastline."

October 18:

HWM analyzes a tropical storm of at most $990 \mathrm{mb}$ at $29.7 \mathrm{~N}, 75.7 \mathrm{~W}$ with a cold front to the northwest at 12Z. HURDAT lists a $70 \mathrm{kt}$ hurricane at $29.7 \mathrm{~N}, 75.8 \mathrm{~W}$ at $12 \mathrm{Z}$.

Microfilm shows a closed low pressure of at most $986 \mathrm{mb}$ at $30.1 \mathrm{~N}, 75.5 \mathrm{~W}$ with a frontal boundary to the northwest at $12 \mathrm{Z}$. Ship highlights: $35 \mathrm{kt} \mathrm{S}$ and $1000 \mathrm{mb}$ at $28.3 \mathrm{~N}, 73.4 \mathrm{~W}$ at $00 \mathrm{Z}$ (COADS). $50 \mathrm{kt} \mathrm{NE}$ and $1009 \mathrm{mb}$ at $32.2 \mathrm{~N}, 78.6 \mathrm{~W}$ at $00 \mathrm{Z}$ (COADS). $40 \mathrm{kt} \mathrm{NE}$ and $1016 \mathrm{mb}$ at $33.7 \mathrm{~N}, 74.3 \mathrm{~W}$ at $06 \mathrm{Z}$ (COADS). $40 \mathrm{kt} \mathrm{SSE}$ and $999 \mathrm{mb}$ at $30.7 \mathrm{~N}, 73.0 \mathrm{~W}$ at $09 \mathrm{Z}$ (micro). $35 \mathrm{kt} \mathrm{S}$ and $999 \mathrm{mb}$ at $28.3 \mathrm{~N}, 73.6 \mathrm{~W}$ at $12 \mathrm{Z}$ (micro). $90 \mathrm{kt} \mathrm{SSE}$ (gusts to $100 \mathrm{kt}$ ) and $987 \mathrm{mb}$ at $30.6 \mathrm{~N}, 74.5 \mathrm{~W}$ at $15 \mathrm{Z}$ (micro). $85 \mathrm{kt} \mathrm{SSE}$ and $983 \mathrm{mb}$ at $30.6 \mathrm{~N}$, $74.6 \mathrm{~W}$ at $18 \mathrm{Z}$ (micro). $60 \mathrm{kt} \mathrm{S}$ and $995 \mathrm{mb}$ at $30.9 \mathrm{~N}, 73.9 \mathrm{~W}$ at $21 \mathrm{Z}$ (micro). Land highlights: $35 \mathrm{kt} \mathrm{NE}$ and $1008 \mathrm{mb}$ at Diamond Shoals, NC at 15Z (micro). Aircraft highlights: Aircraft highlights: Penetration center fix measured a central pressure of 981 $\mathrm{mb}$ at $29.5 \mathrm{~N}, 75.4 \mathrm{~W}$ at $0726 \mathrm{Z}$ (WALLET). Penetration center fix measured a central pressure of $978 \mathrm{mb}$ and estimated surface winds of $60 \mathrm{kt}$ at $29.8 \mathrm{~N}, 76.0 \mathrm{~W}$ at $1247 \mathrm{Z}$ (WALLET). Penetration center fix measured a central pressure of $973 \mathrm{mb}$, estimated surface winds of $75 \mathrm{kt}$ and an eye diameter of $61-84 \mathrm{~nm}$ at $30.5 \mathrm{~N}, 76.3 \mathrm{~W}$ at $1910 \mathrm{Z}$ (ATSR).

MWR: "On October 18, Ella continued toward the north-northwest with gradual deepening. Central pressure dropped to $976 \mathrm{mb}$ and maximum winds were reported as 80 kt. A ship 90 mi southeast of the center reported heavy confused seas ranging up to 40 to $45 \mathrm{ft.}$.

October 19:

HWM analyzes a hurricane of at most $985 \mathrm{mb}$ at $30.7 \mathrm{~N}, 74.7 \mathrm{~W}$ with a weakening stationary front just to the northwest at 12Z. HURDAT lists a $90 \mathrm{kt}$ hurricane at $30.7 \mathrm{~N}$, 
74.6W at 12Z. Microfilm shows a closed low pressure of at most $1005 \mathrm{mb}$ at $30.5 \mathrm{~N}$, $74.5 \mathrm{~W}$ at 12Z. Ship highlights: $50 \mathrm{kt} \mathrm{N}$ and $1006 \mathrm{mb}$ at $32.2 \mathrm{~N}, 79.0 \mathrm{~W}$ at $00 \mathrm{Z}$ (COADS). $40 \mathrm{kt} \mathrm{S}$ and $992 \mathrm{mb}$ at $29.7 \mathrm{~N}, 73.7 \mathrm{~W}$ at $06 \mathrm{Z}$ (COADS). $55 \mathrm{kt} \mathrm{WNW}$ and $1004 \mathrm{mb}$ at $27.9 \mathrm{~N}, 76.5 \mathrm{~W}$ at $12 \mathrm{Z}$ (COADS). $105 \mathrm{kt} \mathrm{SW}$ and $999 \mathrm{mb}$ at $30.3 \mathrm{~N}, 74.4 \mathrm{~W}$ at $15 \mathrm{Z}$ (micro). $80 \mathrm{kt} \mathrm{W}$ and $982 \mathrm{mb}$ at $30.2 \mathrm{~N}, 74.3 \mathrm{~W}$ at $18 \mathrm{Z}$ (micro). $75 \mathrm{kt} \mathrm{W}$ and $993 \mathrm{mb}$ at $29.5 \mathrm{~N}$, $73.8 \mathrm{~W}$ at $21 \mathrm{Z}$ (MWL). Aircraft highlights: Penetration center fix at $30.6 \mathrm{~N}, 75.9 \mathrm{~W}$ at $01 \mathrm{Z}$ (WALLET). Penetration center fix measured a central pressure of $976 \mathrm{mb}$ and an eye diameter of $40-60 \mathrm{~nm}$ at $30.7 \mathrm{~N}, 75.9 \mathrm{~W}$ at $04 \mathrm{Z}$ (WALLET). Penetration center fix measured a central pressure of $973 \mathrm{mb}$ and estimated surface winds of $95 \mathrm{kt}$ at $30.3 \mathrm{~N}$, $75.5 \mathrm{~W}$ at $07 \mathrm{Z}$ (WALLET). Penetration center fix measured a central pressure of $969 \mathrm{mb}$, estimated surface winds of $90 \mathrm{kt}$ and an eye diameter of $55 \mathrm{~nm}$ at $30.7 \mathrm{~N}, 74.5 \mathrm{~W}$ at $1205 \mathrm{Z}$ (WALLET). Penetration center fix measured a central pressure of $962 \mathrm{mb}$, estimated flight level winds of $105 \mathrm{kt}$ and an eye diameter of $50 \mathrm{~nm}$ at $31.2 \mathrm{~N}, 73.6 \mathrm{~W}$ at $19 \mathrm{Z}$ (WALLET).

MWR: "The hurricane came under the influence of a short-wave trough passing to the north on the 19th and changed course first to the east, then to the northeast, accelerating from about $5 \mathrm{kt}$ to 12 to $15 \mathrm{kt}$." ATSR: "The passage of a short wave late on the 19th veered ELLA to the east then northeast."

October 20:

HWM analyzes a hurricane of at most $985 \mathrm{mb}$ at $33.6 \mathrm{~N}, 70.9 \mathrm{~W}$ with a weakening stationary front just to the south and a warm front to the north at 12Z. HURDAT lists an $85 \mathrm{kt}$ hurricane at $33.9 \mathrm{~N}, 70.8 \mathrm{~W}$ at $12 \mathrm{Z}$. Microfilm shows a closed low pressure of at most $1005 \mathrm{mb}$ at $33.5 \mathrm{~N}, 70.5 \mathrm{~W}$ at 12Z. Ship highlights: $80 \mathrm{kt} \mathrm{S}$ and $968 \mathrm{mb}$ at $32.0 \mathrm{~N}$, $72.3 \mathrm{~W}$ at $00 \mathrm{Z}$ (COADS). $85 \mathrm{kt} \mathrm{E}$ and $969 \mathrm{mb}$ at $32.7 \mathrm{~N}, 72.3 \mathrm{~W}$ at $03 \mathrm{Z}$ (COADS). $55 \mathrm{kt}$ SSE and $972 \mathrm{mb}$ at $33.6 \mathrm{~N}, 70.5 \mathrm{~W}$ at $06 \mathrm{Z}$ (micro). $50 \mathrm{kt} \mathrm{SW}$ and $979 \mathrm{mb}$ at $32.4 \mathrm{~N}, 70.5 \mathrm{~W}$ at $12 \mathrm{Z}$ (COADS). $45 \mathrm{kt} \mathrm{SW}$ and $988 \mathrm{mb}$ at $32.5 \mathrm{~N}, 75.5 \mathrm{~W}$ at $15 \mathrm{Z}$ (micro). $50 \mathrm{kt} \mathrm{SW}$ and $994 \mathrm{mb}$ at $31.8 \mathrm{~N}, 69.4 \mathrm{~W}$ at $18 \mathrm{Z}$ (COADS). Aircraft highlights: Penetration center fix measured a central pressure of $960 \mathrm{mb}$, estimated flight level winds of $78 \mathrm{kt}$ and an eye diameter of $50 \mathrm{~nm}$ at $32.2 \mathrm{~N}, 72.7 \mathrm{~W}$ at $0204 \mathrm{Z}$ (WALLET/ATSR). Penetration center fix measured a central pressure of $963 \mathrm{mb}$ at $33.3 \mathrm{~N}, 71.7 \mathrm{~W}$ at $0705 \mathrm{Z}$ (WALLET/ATSR). Penetration center fix measured a central pressure of $960 \mathrm{mb}$, estimated surface winds of $85 \mathrm{kt}$ and an eye diameter of $100 \mathrm{~nm}$ at 33.9N, 70.4W at 13Z (WALLET). Penetration center fix measured a central pressure of $964 \mathrm{mb}$, estimated surface winds of $85 \mathrm{kt}$ and an eye diameter of $100 \mathrm{~nm}$ at $34.5 \mathrm{~N}, 69.7 \mathrm{~W}$ at $19 \mathrm{Z}$ (WALLET).

MWR: "Some further intensification occurred with a minimum pressure of $960 \mathrm{mb}$ and maximum winds of about $90 \mathrm{kt}$ on the 20th." 


\section{October 21:}

HWM analyzes a hurricane of at most $975 \mathrm{mb}$ at $36.3 \mathrm{~N}, 64.9 \mathrm{~W}$ with a weakening warm front to the north at $12 \mathrm{Z}$. HURDAT lists a $70 \mathrm{kt}$ hurricane at $36.7 \mathrm{~N}, 64.6 \mathrm{~W}$ at $12 \mathrm{Z}$. Microfilm shows a closed low pressure of at most $990 \mathrm{mb}$ at $36.7 \mathrm{~N}, 64.6 \mathrm{~W}$ with a frontal boundary to the north at 12Z. Ship highlights: $60 \mathrm{kt} \mathrm{SE}$ and $1011 \mathrm{mb}$ at $32.1 \mathrm{~N}, 65.9 \mathrm{~W}$ at 00Z (COADS). $40 \mathrm{kt} \mathrm{WNW}$ and $977 \mathrm{mb}$ at 35.8N, 62.5W (longitude likely 5 degrees off to the east) at $06 \mathrm{Z}$ (COADS). $65 \mathrm{kt} \mathrm{SW}$ and $992 \mathrm{mb}$ at $34.3 \mathrm{~N}, 64.8 \mathrm{~W}$ at $12 \mathrm{Z}$ (COADS). $50 \mathrm{kt} \mathrm{W}$ and $1001 \mathrm{mb}$ at $34.1 \mathrm{~N}, 64.9 \mathrm{~W}$ at $18 \mathrm{Z}$ (COADS). $55 \mathrm{kt} \mathrm{S}$ and $997 \mathrm{mb}$ at $37.3 \mathrm{~N}$, $57.3 \mathrm{~W}$ at $21 \mathrm{Z}$ (MWL). Aircraft highlights: Penetration center fix measured a central pressure of $961 \mathrm{mb}$, estimated surface winds of $60 \mathrm{kt}$ and an eye diameter of $100 \mathrm{~nm}$ at $36.8 \mathrm{~N}, 64.2 \mathrm{~W}$ at $13 \mathrm{Z}$ (WALLET). Penetration center fix measured a central pressure of $958 \mathrm{mb}$, estimated surface winds of $70 \mathrm{kt}$ and an eye diameter of $100 \mathrm{~nm}$ at $37.9 \mathrm{~N}$, $62.3 \mathrm{~W}$ at $19 \mathrm{Z}$ (WALLET).

MWR: "A gradual rise in central pressure followed, accompanied by a slow decrease in maximum winds and a spread of the gale area as Ella moved northeastward more rapidly on the 21 st and 22nd of October. An interesting feature of Ella was an unusually large eye. The diameter was reported as $25 \mathrm{mi}$. on the 16th, 40 to $60 \mathrm{mi}$ on the $19 \mathrm{th}$, and $100 \mathrm{mi}$ on the 21 st." ATSR: "This course was maintained until the hurricane merged with a frontal system south of Newfoundland and became extratropical on the 21st."

October 22:

HWM analyzes a closed low pressure of at most $975 \mathrm{mb}$ at $44.5 \mathrm{~N}, 51.5 \mathrm{~W}$ with a warm front to the east at 12Z. HURDAT lists a $60 \mathrm{kt}$ extratropical storm at $46.7 \mathrm{~N}, 53.4 \mathrm{~W}$ at 12Z. Microfilm shows an extratropical cyclone of at most $984 \mathrm{mb}$ at $47.3 \mathrm{~N}, 54.7 \mathrm{~W}$ at 12Z. Ship highlights: $75 \mathrm{kt} \mathrm{SE}$ and $994 \mathrm{mb}$ at 37.2N, 57.5W at 00Z (COADS/MWL). 65 kt SE and $999 \mathrm{mb}$ at 39.1N, 52.9W at 06Z (COADS). $55 \mathrm{kt} \mathrm{S}$ and $1002 \mathrm{mb}$ at $41.2 \mathrm{~N}$, $48.4 \mathrm{~W}$ at $12 \mathrm{Z}$ (COADS). $50 \mathrm{kt} \mathrm{SW}$ and $994 \mathrm{mb}$ at $44.2 \mathrm{~N}, 46.8 \mathrm{~W}$ at $18 \mathrm{Z}$ (micro).

MWR: "However, by the evening of the $21 \mathrm{st}$, her broad circulation pattern had begun to merge with that of a developing frontal wave moving through Nova Scotia with a resultant gradual loss of tropical characteristics." ATSR: "However advisories were continued with the final warning being issued at 221600Z."

October 23:

HWM analyzes an extratropical cyclone of at most $970 \mathrm{mb}$ at $56.0 \mathrm{~N}, 38.0 \mathrm{~W}$ at $12 \mathrm{Z}$. HURDAT lists a $60 \mathrm{kt}$ extratropical storm at $56.2 \mathrm{~N}, 37.0 \mathrm{~W}$ at $12 \mathrm{Z}$ (last position). Microfilm shows an extratropical cyclone of at most $1002 \mathrm{mb}$ at $54.7 \mathrm{~N}, 42.7 \mathrm{~W}$ at $12 \mathrm{Z}$. Ship highlights: $50 \mathrm{kt} \mathrm{W}$ and $1007 \mathrm{mb}$ at $43.5 \mathrm{~N}, 49.0 \mathrm{~W}$ at $00 \mathrm{Z}$ (COADS). $50 \mathrm{kt} \mathrm{SW}$ and 
$994 \mathrm{mb}$ at $50.7 \mathrm{~N}, 37.6 \mathrm{~W}$ at $06 \mathrm{Z}$ (COADS). $50 \mathrm{kt} \mathrm{SSW}$ and $987 \mathrm{mb}$ at $53.0 \mathrm{~N}, 36.2 \mathrm{~W}$ at $12 \mathrm{Z}$ (COADS). $50 \mathrm{kt} \mathrm{SW}$ and $993 \mathrm{mb}$ at $52.8 \mathrm{~N}, 35.5 \mathrm{~W}$ at $15 \mathrm{Z}$ (COADS). $30 \mathrm{kt} \mathrm{SW}$ and $973 \mathrm{mb}$ at $56.1 \mathrm{~N}, 34.1 \mathrm{~W}$ at $18 \mathrm{Z}$ (micro).

October 24:

HWM analyzes an extratropical cyclone of at most $985 \mathrm{mb}$ at $61.0 \mathrm{~N}, 19.0 \mathrm{~W}$ at $12 \mathrm{Z}$. HURDAT does not list an organized storm on this date. Microfilm shows a closed low pressure of at most $999 \mathrm{mb}$ at 58.5N, 20.0W at 12Z. Ship highlights: $45 \mathrm{kt} \mathrm{NE}$ and 998 $\mathrm{mb}$ at $62.1 \mathrm{~N}, 32.7 \mathrm{~W}$ at $00 \mathrm{Z}$ (COADS). $50 \mathrm{kt} \mathrm{N}$ and $997 \mathrm{mb}$ at $58.6 \mathrm{~N}, 35.0 \mathrm{~W}$ at $06 \mathrm{Z}$ (COADS). $45 \mathrm{kt} \mathrm{SW}$ and $990 \mathrm{mb}$ at 55.0N, 21.8W at 12Z (COADS). $45 \mathrm{kt} \mathrm{NE}$ and 993 $\mathrm{mb}$ at $62.2 \mathrm{~N}, 18.3 \mathrm{~W}$ at $18 \mathrm{Z}$ (COADS).

October 25:

HWM analyzes an extratropical cyclone of at most $985 \mathrm{mb}$ at $72.0 \mathrm{~N}, 11.0 \mathrm{E}$ at $12 \mathrm{Z}$. HURDAT does not list an organized storm on this date. Microfilm is not available on this date (cyclone outside the map). Ship highlights: $35 \mathrm{kt} \mathrm{N}$ and $997 \mathrm{mb}$ at 58.9N, 19.1 W at $00 \mathrm{Z}$ (COADS). $50 \mathrm{kt} \mathrm{NE}$ and $999 \mathrm{mb}$ at $61.3 \mathrm{~N}, 10.7 \mathrm{~W}$ at $06 \mathrm{Z}$ (COADS). $45 \mathrm{kt} \mathrm{N}$ and $1001 \mathrm{mb}$ at $58.8 \mathrm{~N}, 9.2 \mathrm{~W}$ at $12 \mathrm{Z}$ (COADS).

MWR: "Property damage associated with Ella was minor, consisting mostly of beach erosion along the middle Atlantic coast. Two fishermen apparently lost their lives in the fringes of the hurricane during its closest approach to the coast. The men set out from near Charleston, S.C., on October 18 in a 14-ft outboard motor boat. They were never found despite an intensive air and sea search."

Hurricane Ella developed from a tropical wave that was first dtected as it approached the Lesser Antilles on October 11th. The disturbance moved northwestward across the Greater Antilles and reached the southeastern Bahamas on October 13th. Surface observations early on October 14th indicate that a closed, low-level circulation was forming and intensification to a $30 \mathrm{kt}$ tropical depression is analyzed at $06 \mathrm{Z}$ on the 14 th, twelve hours earlier than originally shown in HURDAT. Minor track alterations are introduced during the lifetime of this tropical cyclone. In an area of weak steering currents, the tropical depression slowly moved northward while becoming better organized. The first reconnaissance aircraft to investigate the tropical cyclone arrived at $20 \mathrm{Z}$ on the 14th measuring a central pressure of $1012 \mathrm{mb}$. Synoptic observations indicate that the dropsonde missed the center, thus the value reported is not a central pressure and was not added to HURDAT. A ship reported $40 \mathrm{kt} \mathrm{E}$ at $00 \mathrm{Z}$ on October 15 th and appears to have a high bias compared to ships nearby. Intensification to a tropical storm is analyzed at $12 \mathrm{Z}$ on the $15 \mathrm{th}$, same as originally shown in HURDAT. The first gale-force winds were reported at $18 \mathrm{Z}$ on the 15 th. This tropical cyclone presented a large 
circulation and the gale-force winds were reported about $200 \mathrm{~nm}$ north of the center but within the envelope of the outermost closed isobar. It is possible that Ella had some subtropical characteristics. (Central pressures values for almost every 6 hour period were present in the original HURDAT between October 15th at $00 \mathrm{Z}$ and October $21 \mathrm{st}$ at $18 \mathrm{Z}$. Some of these were obviously analyses that were added in, not based upon actual observations. Thus, based on actual observations, some were retained and new central pressure values added. Detailed information on these changes can be found in the table at the end.) The next reconnaissance aircraft reached Ella at $1850 \mathrm{Z}$ measuring a central pressure of $1002 \mathrm{mb}$, estimating surface winds of $40 \mathrm{kt}$ and an eye diameter of $20 \mathrm{~nm}$. A central pressure of $1002 \mathrm{mb}$ suggests maximum surface winds of $43 \mathrm{kt}$ south of $25 \mathrm{~N}$ from the Brown et al. pressure-wind relationship. Due to the large circulation of the tropical cyclone and forward speed of about $4 \mathrm{kt}$, an intensity of $40 \mathrm{kt}$ is selected at $18 \mathrm{Z}$ on the 15th, same as originally shown in HURDAT. Another reconnaissance aircraft investigated the tropical storm late on the 15th suggesting that the system was generally stationary between $1745 \mathrm{Z}$ and $2315 \mathrm{Z}$, measuring a central pressure of $1002 \mathrm{mb}$ and estimating surface winds of $40 \mathrm{kt}$.

On October 16th, Ella turned to the northwest and began to deepen later in the day. The first reconnaissance aircraft on the 16th reached the tropical cyclone at $16 \mathrm{Z}$ measuring a central pressure of $1002 \mathrm{mb}$ and estimating surface winds of $70 \mathrm{kt}$. An intensity of $45 \mathrm{kt}$ is selected at $18 \mathrm{Z}$ on the 16 th based on a blend between the reconnaissance aircraft data and synoptic observations, down from 60 kt originally in HURDAT, a minor intensity change. Another penetration fix at $2242 \mathrm{Z}$ on the 16th measured a central pressure of 994 $\mathrm{mb}$, estimated flight level winds of $60 \mathrm{kt}$ and an eye diameter of $25 \mathrm{~nm}$. A central pressure of $994 \mathrm{mb}$ suggests maximum surface winds of $53 \mathrm{kt}$ north of $25 \mathrm{~N}$ and $56 \mathrm{kt}$ intensifying from the pressure-wind relationship. An eye diameter of $25 \mathrm{~nm}$ suggests an RMW of about $19 \mathrm{~nm}$ and the climatological value is $20 \mathrm{~nm}$. Based on a forward speed of about $8 \mathrm{kt}$, an RMW close to climatology and the large circulation of the tropical cyclone, an intensity of $50 \mathrm{kt}$ is selected at $00 \mathrm{Z}$ on the $17 \mathrm{th}$, down from $60 \mathrm{kt}$ originally in HURDAT, a minor intensity change. At $04 Z$ on the 17 th, another penetration fix measured a central pressure of $997 \mathrm{mb}$. An intensity of $50 \mathrm{kt}$ is analyzed at $06 \mathrm{Z}$ on the 17th, down from 60 kt originally in HURDAT, a minor intensity change. The next penetration fix measured a central pressure of $992 \mathrm{mb}$ and estimated surface winds of 60 kt. A central pressure of $992 \mathrm{mb}$ suggests maximum surface winds of $56 \mathrm{kt}$ north of $25 \mathrm{~N}$ from the pressure-wind relationship. An intensity of $55 \mathrm{kt}$ is analyzed at $12 \mathrm{Z}$ on the $17 \mathrm{th}$, down from 60 kt originally shown in HURDAT, a minor intensity change. Numerous ships reported gale-force winds on the 17th, not just in the periphery like in the previous days, but also close to the center. The highest wind reported on the 17th was $60 \mathrm{kt} \mathrm{NE}$ and $994 \mathrm{mb}$ at 18Z. A reconnaissance aircraft measured a central pressure of $989 \mathrm{mb}$, estimated surface winds of $75 \mathrm{kt}$ and an eye diameter of $80 \mathrm{~nm}$ at $1735 \mathrm{Z}$ on the $17 \mathrm{th}$. A 
central pressure of $989 \mathrm{mb}$ suggests maximum surface winds of $61 \mathrm{kt}$ north of $25 \mathrm{~N}$ from the pressure-wind relationship. An eye diameter of $80 \mathrm{~nm}$ suggests an RMW of about 60 $\mathrm{nm}$ and the climatological value is $23 \mathrm{~nm}$. Based on the forward speed of about $6 \mathrm{kt}$, large circulation and synoptic data, an intensity of $60 \mathrm{kt}$ is selected at $18 \mathrm{Z}$ on the $17 \mathrm{th}$, down from $70 \mathrm{kt}$ originally in HURDAT, a minor intensity change. A central pressure of 987 mb was present in HURDAT at $18 \mathrm{Z}$ on the 17 th and has been replaced by $989 \mathrm{mb}$.

On October 18th, Ella moved very slowly to the north-northwest while intensifying. A reconnaissance aircraft measured a central pressure of $981 \mathrm{mb}$ at $0726 \mathrm{Z}$ on the $18 \mathrm{th}$. A central pressure of $981 \mathrm{mb}$ suggests maximum surface winds of $71 \mathrm{kt}$ north of $25 \mathrm{~N}$ from the pressure-wind relationship. Due to the large circulation of Ella and forward speed of about $6 \mathrm{kt}$, an intensity of $65 \mathrm{kt}$ is analyzed at $06 \mathrm{Z}$ on the 18th, down from $70 \mathrm{kt}$ originally in HURDAT, a minor intensity change. Intensification to a hurricane is analyzed at $00 \mathrm{Z}$ on October 18th, six hours later than originally shown in HURDAT. The next penetration fix measured a central pressure of $978 \mathrm{mb}$ and estimated surface winds of $60 \mathrm{kt}$ at $1247 \mathrm{Z}$ on the $18 \mathrm{th}$. A central pressure of $978 \mathrm{mb}$ suggests maximum surface winds of $75 \mathrm{kt}$ north of $25 \mathrm{~N}$ from the pressure-wind relationship. Due to the large circulation of Ella and forward speed of about $6 \mathrm{kt}$, an intensity of $70 \mathrm{kt}$ is analyzed at $12 \mathrm{Z}$ on the $18 \mathrm{th}$, down from $70 \mathrm{kt}$ originally in HURDAT, a minor intensity change. The final penetration fix on the 18th occurred at $1910 \mathrm{Z}$ measuring a central pressure of 973 $\mathrm{mb}$, estimating surface winds of $75 \mathrm{kt}$ and an eye diameter of 61-84 nm. A central pressure of $973 \mathrm{mb}$ suggests maximum surface winds of $81 \mathrm{kt}$ north of $25 \mathrm{~N}$ from the pressure-wind relationship. An eye diameter of 61-84 nm suggests an RMW of about 46$63 \mathrm{~nm}$ and the climatological value is $23 \mathrm{~nm}$. Due to the large circulation of Ella and forward speed of about $5 \mathrm{kt}$, an intensity of $75 \mathrm{kt}$ is analyzed at $18 \mathrm{Z}$ on the $18 \mathrm{th}$, up from 70 kt originally in HURDAT, a minor intensity change. Many ships reported gale-force winds on the 18th. The ship "CHRV" appears to have a high bias reporting $90 \mathrm{kt}$ at $15 \mathrm{Z}$ and $95 \mathrm{kt}$ at $18 \mathrm{Z}$. It is interesting to note that Monthly Weather Review mentions the waves reported by the ship "CHRV" but does not mention the winds, possibly an indication that Gordon Dunn did not have confidence in the measurements. On October 19th, Ella turned to the east and later northeast, as it continued to strengthen. A reconnaissance aircraft reached the hurricane at $1205 \mathrm{Z}$ on the 19 th measuring a central pressure of $969 \mathrm{mb}$, estimated surface winds of $90 \mathrm{kt}$ and an eye diameter of $55 \mathrm{~nm}$. A central pressure of $969 \mathrm{mb}$ suggests maximum surface winds of $86 \mathrm{kt}$ north of $25 \mathrm{~N}$ from the pressure-wind relationship. An eye diameter of $55 \mathrm{~nm}$ suggests an RMW of about 41 $\mathrm{nm}$ and the climatological value is $23 \mathrm{~nm}$. Due to the large circulation of Ella and a forward speed of about $10 \mathrm{kt}$, an intensity of $80 \mathrm{kt}$ is selected at $12 \mathrm{Z}$ on the $19 \mathrm{th}$, down from $90 \mathrm{kt}$ originally shown in HURDAT, a minor intensity change. The next reconnaissance aircraft investigated the hurricane at $19 \mathrm{Z}$ on the 19th measuring a central pressure of $962 \mathrm{mb}$, estimated flight level winds of $105 \mathrm{kt}$ and an eye diameter of $50 \mathrm{~nm}$. 
A central pressure of $962 \mathrm{mb}$ suggests maximum surface winds of $93 \mathrm{kt}$ north of $25 \mathrm{~N}$ and $97 \mathrm{kt}$ intensifying from the pressure-wind relationship. An eye diameter of $50 \mathrm{~nm}$ suggests an RMW of about $38 \mathrm{~nm}$ and the climatological value is $22 \mathrm{~nm}$. Due to the large circulation of Ella and a forward speed of about $10 \mathrm{kt}$, an intensity of $90 \mathrm{kt}$ is selected at $18 \mathrm{Z}$ on the 19 th, down from $100 \mathrm{kt}$ originally shown in HURDAT, a minor intensity change. $90 \mathrm{kt}$ is also the peak intensity of this tropical cyclone, down from $100 \mathrm{kt}$ originally shown in HURDAT, a minor intensity change. Thus, it is analyzed that Ella did not reach major hurricane intensity.

On October 20th, hurricane Ella began to move to the northeast, away from the United States while holding its strength. A penetration center fix at $0204 \mathrm{Z}$ on the 20th measured a central pressure of $960 \mathrm{mb}$, estimating flight level winds of $78 \mathrm{kt}$ and an eye diameter of $50 \mathrm{~nm}$. A central pressure of $960 \mathrm{mb}$ suggests maximum surface winds of $95 \mathrm{kt}$ north of $25 \mathrm{~N}$ from the pressure-wind relationship. An eye diameter of $50 \mathrm{~nm}$ suggests an RMW of about $38 \mathrm{~nm}$ and the climatological value is $24 \mathrm{~nm}$. Due to the large circulation of Ella and a forward speed of about $12 \mathrm{kt}$, an intensity of $90 \mathrm{kt}$ is selected at $00 \mathrm{Z}$ on the $20 \mathrm{th}$, down from $100 \mathrm{kt}$ originally shown in HURDAT, a minor intensity change. Another penetration center fix occurred at $13 \mathrm{Z}$ on the 20th and measured a central pressure of 960 $\mathrm{mb}$, estimated surface winds of $85 \mathrm{kt}$ and an eye diameter of $100 \mathrm{~nm}$. A central pressure of $960 \mathrm{mb}$ suggests maximum surface winds of $95 \mathrm{kt}$ north of $25 \mathrm{~N}$ from the Brown et al. pressure-wind relationship and $90 \mathrm{kt}$ north of $35 \mathrm{~N}$ from the Landsea et al. pressure-wind relationship. An eye diameter of $100 \mathrm{~nm}$ suggests an RMW of about $75 \mathrm{~nm}$ and the climatological value is $26 \mathrm{~nm}$. Due to the large circulation of Ella and a forward speed of about $11 \mathrm{kt}$, an intensity of $90 \mathrm{kt}$ is selected at $12 \mathrm{Z}$ on the $20 \mathrm{th}$, up from $85 \mathrm{kt}$ originally shown in HURDAT, a minor intensity change. The final penetration center fix on the 20th occurred at 19Z and measured a central pressure of $964 \mathrm{mb}$ and an eye diameter of $100 \mathrm{~nm}$. A central pressure of $964 \mathrm{mb}$ suggests maximum surface winds of $91 \mathrm{kt}$ north of $25 \mathrm{~N}$ and $87 \mathrm{kt}$ north of $35 \mathrm{~N}$ from the pressure-wind relationships. An eye diameter of 100 $\mathrm{nm}$ suggests an RMW of about $75 \mathrm{~nm}$ and the climatological value is $26 \mathrm{~nm}$. Due to the large circulation of Ella and a forward speed of about $17 \mathrm{kt}$, an intensity of $85 \mathrm{kt}$ is selected at $18 \mathrm{Z}$ on the 20th, same as originally shown in HURDAT. Numerous ships experienced gale-force winds on the 20th, including a few up to hurricane intensity. On October 21 st, Ella continued moving to the northeast while gradually acquiring extratropical characteristics. A central pressure of $972 \mathrm{mb}$ appears in HURDAT at $12 \mathrm{Z}$ on the 21 st, likely a dropsonde measurement. The list of aircraft reconnaissance fixes available in the Storm Wallets of Ella indicates that the central pressure adjusted to the surface from $700 \mathrm{mb}$ is $961 \mathrm{mb}$. This appears more reasonable and has been used to replace the existing $972 \mathrm{mb}$ at $12 \mathrm{Z}$ on the $21 \mathrm{st}$. Similarly, at $18 \mathrm{Z}$ on the $21 \mathrm{st}$, HURDAT has a central pressure of $950 \mathrm{mb}$ and the list of aircraft reconnaissance fixes indicates that the central pressure adjusted from $700 \mathrm{mb}$ is $958 \mathrm{mb}$. This also appears more reasonable 
and has been used to replace the existing $950 \mathrm{mb}$ at $18 \mathrm{Z}$ on the $21 \mathrm{st}$. Transition to an extratropical cyclone is analyzed at $06 \mathrm{Z}$ on October $22 \mathrm{nd}$, same as originally shown in HURDAT. Synoptic observations at $06 \mathrm{Z}$ on the $22 \mathrm{nd}$ indicate that a temperature-gradient had developed across the tropical cyclone, along with frontal features. Weakening below hurricane intensity is analyzed at $12 \mathrm{Z}$ on the $22 \mathrm{nd}$, six hours later than originally shown in HURDAT. Numerous ships reported gale-force winds on the 22nd and hurricane-force winds were registered at $00 \mathrm{Z}$ and $06 \mathrm{Z}$ on this date. Over the next couple of days, the extratropical cyclone moved northeastward across the North Atlantic passing south of Greenland on October 23rd and between Iceland and the United Kingdom on October 24 th and 25 th. The system gradually weakened and began to interact with a larger extratropical cyclone on the 24th. Synoptic data early on the 25th indicate that Ella was absorbed after 06Z. Thus, the last position is analyzed at $06 \mathrm{Z}$ on the $25 \mathrm{th}, 42$ hours later than originally shown in HURDAT.

\begin{tabular}{|c|c|c|c|}
\hline Date & $\begin{array}{l}\text { Original } \\
\text { HURDAT } \\
\text { Central } \\
\text { Pressure } \\
\end{array}$ & Evidence & Changes \\
\hline Oct $15 \odot \odot Z$ & $10 \odot 2 \mathrm{mb}$ & $\begin{array}{l}\text { No central pressure report but } \\
\text { appears reasonable based on } \\
\text { synoptic observations }\end{array}$ & \multirow{7}{*}{ Retained } \\
\hline Oct $1518 Z$ & $10 \odot 2 \mathrm{mb}$ & $\begin{array}{l}\text { Penetration center fix: } 1002 \mathrm{mb} \\
\text { at } 1850 \mathrm{z} \text { on } 0 \mathrm{ct} 15^{\text {th }}\end{array}$ & \\
\hline Oct $16 \odot \odot z$ & $10 \odot 2 \mathrm{mb}$ & $\begin{array}{l}\text { Penetration center fix: } 1002 \mathrm{mb} \\
\text { at } 1745 \mathrm{Z}-2315 \mathrm{Z} \text { on } 0 \mathrm{ct} 01^{\text {th }}\end{array}$ & \\
\hline Oct $1618 \mathrm{Z}$ & $10 \odot 2 \mathrm{mb}$ & $\begin{array}{l}\text { Penetration center fix: } 1002 \mathrm{mb} \\
\text { at } 16 \mathrm{z} \text { on } 0 \mathrm{ct} 15^{\mathrm{th}}\end{array}$ & \\
\hline Oct $17 \odot \odot Z$ & $994 \mathrm{mb}$ & $\begin{array}{l}\text { Penetration center fix: } 994 \mathrm{mb} \\
\text { at } 2242 Z \text { on } 0 \text { ct } 15^{\text {th }}\end{array}$ & \\
\hline Oct $17 \odot 6 z$ & $997 \mathrm{mb}$ & $\begin{array}{l}\text { Penetration center fix: } 997 \mathrm{mb} \\
\text { at } 04 Z \text { on Oct } 17^{\text {th }}\end{array}$ & \\
\hline Oct $17 \quad 12 Z$ & $992 \mathrm{mb}$ & $\begin{array}{l}\text { Penetration center fix: } 992 \mathrm{mb} \\
\text { at } 1215 Z \text { on oct } 17^{\text {th }}\end{array}$ & \\
\hline Oct $1718 \mathrm{Z}$ & $987 \mathrm{mb}$ & $\begin{array}{l}\text { Penetration center fix: } 989 \mathrm{mb} \\
\text { at } 1735 \mathrm{z} \text { on } 0 \mathrm{ct} 17^{\text {th }}\end{array}$ & 989 mb \\
\hline Oct $18 \odot 6 z$ & $981 \mathrm{mb}$ & $\begin{array}{l}\text { Penetration center fix: } 981 \mathrm{mb} \\
\text { at } 0726 \mathrm{z} \text { on } 0 \mathrm{ct} 18^{\text {th }}\end{array}$ & \multirow{2}{*}{ Retained } \\
\hline Oct $1812 Z$ & $978 \mathrm{mb}$ & $\begin{array}{l}\text { Penetration center fix: } 978 \mathrm{mb} \\
\text { at } 1247 Z \text { on } 0 \text { ct } 18^{\text {th }}\end{array}$ & \\
\hline Oct $1818 Z$ & $976 \mathrm{mb}$ & $\begin{array}{l}\text { Penetration center fix: } 973 \mathrm{mb} \\
\text { at } 1910 \mathrm{z} \text { on oct } 18^{\text {th }}\end{array}$ & $973 \mathrm{mb}$ \\
\hline Oct $19 \odot 6 z$ & $973 \mathrm{mb}$ & $\begin{array}{l}\text { Penetration center fix: } 973 \mathrm{mb} \\
\text { at } 07 z \text { on } 0 \mathrm{ct} 19^{\text {th }}\end{array}$ & Retained \\
\hline
\end{tabular}




\begin{tabular}{|c|c|c|c|}
\hline Oct $1912 Z$ & $969 \mathrm{mb}$ & $\begin{array}{l}\text { Penetration center fix: } 969 \mathrm{mb} \\
\text { at } 1205 \mathrm{Z} \text { on } 0 \mathrm{ct} 19^{\text {th }}\end{array}$ & \\
\hline Oct $1918 Z$ & $962 \mathrm{mb}$ & $\begin{array}{l}\text { Penetration center fix: } 962 \mathrm{mb} \\
\text { at } 19 \mathrm{z} \text { on oct } 19^{\text {th }}\end{array}$ & \\
\hline Oct $2 \odot \odot \odot Z$ & & $\begin{array}{l}\text { Penetration center fix: } 960 \mathrm{mb} \\
\text { at } 0204 \mathrm{Z} \text { on } 0 \text { ct } 20^{\text {th }}\end{array}$ & $960 \mathrm{mb}$ \\
\hline Oct $2 \odot \odot 6 Z$ & $960 \mathrm{mb}$ & $\begin{array}{l}\text { Penetration center fix: } 963 \mathrm{mb} \\
\text { at } 0705 \mathrm{Z} \text { on } 0 \text { ct } 20^{\text {th }}\end{array}$ & $963 \mathrm{mb}$ \\
\hline Oct $2012 \mathrm{Z}$ & $960 \mathrm{mb}$ & $\begin{array}{l}\text { Penetration center fix: } 960 \mathrm{mb} \\
\text { at } 13 Z \text { on } 0 \mathrm{ct} 20^{\text {th }}\end{array}$ & \multirow{2}{*}{ Retained } \\
\hline Oct $2018 \mathrm{Z}$ & $964 \mathrm{mb}$ & $\begin{array}{l}\text { Penetration center fix: } 964 \mathrm{mb} \\
\text { at } 19 \mathrm{Z} \text { on } 0 \mathrm{ct} 20^{\text {th }}\end{array}$ & \\
\hline Oct $2112 \mathrm{Z}$ & $972 \mathrm{mb}$ & $\begin{array}{l}\text { Penetration center fix: } 961 \mathrm{mb} \\
\text { at } 13 Z \text { on } 0 \mathrm{ct} 21^{\text {th }}\end{array}$ & $961 \mathrm{mb}$ \\
\hline Oct $2118 \mathrm{Z}$ & $950 \mathrm{mb}$ & $\begin{array}{l}\text { Penetration center fix: } 958 \mathrm{mb} \\
\text { at } 19 \mathrm{Z} \text { on oct } 21^{\text {th }}\end{array}$ & $958 \mathrm{mb}$ \\
\hline
\end{tabular}

New Hurricane [November 26 - December 6, 1962]

\begin{tabular}{|c|c|c|c|c|c|c|c|c|c|c|c|c|c|}
\hline 42125 & $11 / 26 / 1962$ & $M=11$ & 7 & SNBR= & $13 \mathrm{NO}^{-}$ & NAMED & XIN & $G=\odot$ & $S S S=\odot$ & & & & $\mathrm{L}$ \\
\hline 42130 & $11 / 26$ * & $\odot$ & $\odot$ & $\Theta^{*}$ & $\odot$ & $\odot$ & ๑E33० & 730 & $7 \odot$ & ОЕ33० & 745 & 70 & $0^{*}$ \\
\hline 42135 & $11 / 27$ E327 & 757 & 70 & ๑E320 & 764 & 70 & ๑E313 & 766 & 65 & OE3०2 & 762 & 65 & $0^{*}$ \\
\hline 42140 & $11 / 28 * 291$ & 756 & 65 & $\Theta^{*} 288$ & 745 & 65 & $\odot * 288$ & 732 & $6 \odot$ & $0 * 295$ & 722 & 60 & $0^{*}$ \\
\hline 42145 & $11 / 29 * 303$ & 716 & 55 & $\odot * 308$ & 714 & 55 & $\odot * 310$ & 717 & 50 & $0 * 310$ & 722 & 50 & $0^{*}$ \\
\hline 42150 & $11 / 30 * 308$ & 728 & 50 & $\odot * 305$ & 736 & 55 & $\odot * 305$ & 742 & 55 & $0 * 310$ & 744 & 60 & $\Theta^{*}$ \\
\hline 42155 & $12 / 01 * 317$ & 744 & 65 & $\odot * 324$ & 740 & 70 & $\odot * 33 \odot$ & 737 & 75 & $0 * 337$ & 743 & 80 & $\Theta^{*}$ \\
\hline 42160 & $12 / 02 * 343$ & 749 & 80 & $0 * 341$ & 753 & 75 & $\odot * 337$ & 755 & 70 & $0 * 331$ & 758 & 65 & $0^{*}$ \\
\hline 42165 & $12 / 03 * 326$ & 760 & 60 & $\odot * 321$ & 755 & 55 & $\odot * 32 \odot$ & 749 & 50 & $0 * 325$ & 744 & 50 & $\Theta^{*}$ \\
\hline 42170 & $12 / 04 * 330$ & 742 & 50 & $0 * 333$ & 740 & 50 & $\odot * 338$ & 737 & 50 & $0 * 346$ & 730 & 55 & $0^{*}$ \\
\hline 42175 & 12/05E356 & 720 & 60 & ๑E364 & 710 & 65 & ๑Е37๑ & 699 & 70 & ๑E376 & 687 & 70 & $0^{*}$ \\
\hline 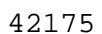 & 12/06Е380 & 670 & 60 & ๑E385 & 652 & 50 & ○* & & $\odot$ & $0^{*}$ & $\odot$ & $\odot$ & * \\
\hline
\end{tabular}
42180 TS

\section{U.S. Tropical Storm Impact}

12/01 18Z 33.7N 74.3W 40 kt North Carolina

A new hurricane has been added to HURDAT, not previously shown in McAdie et al. (2009). Evidence for these alterations comes from the NHC microfilm maps, the Historical Weather Maps series, the COADS ship database, Surface Weather Observations, Local and State Climatological Data, Atlas of Cloud Vortex Patterns, Weather Bureau Bulletins and Mariners Weather Log. This disturbance was in Jack Beven and David Roth's List of Suspects.

\# = synoptic observations outside of OCI 
November 25:

HWM analyzes a stationary front over the western Atlantic at 12Z. Microfilm shows a frontal boundary over the western Atlantic at 12Z. Ship highlights: No gales or low pressures.

November 26:

HWM analyzes an extratropical cyclone of at most $1005 \mathrm{mb}$ at $33.5 \mathrm{~N}, 73.0 \mathrm{~W}$ at $12 \mathrm{Z}$. Microfilm shows a closed low pressure of at most $1008 \mathrm{mb}$ at $33.0 \mathrm{~N}, 72.5 \mathrm{~W}$ at $12 \mathrm{Z}$. Ship highlights: $40 \mathrm{kt} \mathrm{NE}$ and $1023 \mathrm{mb}$ at 37.2N, $74.0 \mathrm{~W}$ at $06 \mathrm{Z}$ (COADS). $70 \mathrm{kt} \mathrm{NE}$ and 1009 $\mathrm{mb}$ at $35.0 \mathrm{~N}, 74.0 \mathrm{~W}$ at $12 \mathrm{Z}$ (COADS). $70 \mathrm{kt} \mathrm{NE}$ and $1006 \mathrm{mb}$ at $34.8 \mathrm{~N}, 74.2 \mathrm{~W}$ at $15 \mathrm{Z}$ (COADS). $70 \mathrm{kt} \mathrm{NE}$ and $1003 \mathrm{mb}$ at $34.6 \mathrm{~N}, 74.4 \mathrm{~W}$ at $18 \mathrm{Z}$ (COADS). $60 \mathrm{kt} \mathrm{ENE}$ and $1005 \mathrm{mb}$ at $34.5 \mathrm{~N}, 74.6 \mathrm{~W}$ at $21 \mathrm{Z}$ (COADS). Land highlights: $40 \mathrm{kt} \mathrm{NNE}$ (peak winds) at WB Cape Hatteras, NC (time unknown) (CLIMO). $35 \mathrm{kt} \mathrm{NNE} \mathrm{and} 1021 \mathrm{mb}$ at Flying Pan, NC at 11Z (SWO). $50 \mathrm{kt} \mathrm{NNE} \mathrm{and} 1017 \mathrm{mb}$ at Flying Pan, NC at 17Z (SWO). $43 \mathrm{kt}$ $\mathrm{H}$ (peak winds) at Cape Henry WB, VA at $2151 \mathrm{Z}$ (MWL). Gusts to $77 \mathrm{kt}$ NNE at Oak Island, $\mathrm{NC}$ at 22Z (MWL). $64 \mathrm{kt} \mathrm{NNE} \mathrm{(peak} \mathrm{winds)} \mathrm{and} 1011 \mathrm{mb}$ at Flying Pan, $\mathrm{NC}$ at $23 \mathrm{Z}$ (SWO). $51 \mathrm{kt} \mathrm{N}$ (peak winds) (gusts to $57 \mathrm{kt} \mathrm{N}$ ) at Wilmington, $\mathrm{NC}$ at $2311 \mathrm{Z}$ (MWL).

BULLETIN: "The pressure center of this storm is located about 200 miles east-southeast of Cape Hatteras, North Carolina with very little movement expected during the next 12 to 24 hours. Highest winds along the coast have been $56 \mathrm{mph}$ in gusts at Cape Hatteras but winds over $60 \mathrm{mph}$ have been reported by vessels."

November 27:

HWM analyzes an occluded extratropical cyclone of at most $1000 \mathrm{mb}$ at $29.5 \mathrm{~N}, 75.5 \mathrm{~W}$ at 12Z. Microfilm shows a closed low pressure of at most $1005 \mathrm{mb}$ at $31.5 \mathrm{~N}, 76.5 \mathrm{~W}$ at $12 \mathrm{Z}$. Ship highlights: $70 \mathrm{kt}$ ENE and $1000 \mathrm{mb}$ at 33.9N, $75.9 \mathrm{~W}$ at $00 \mathrm{Z}$ (COADS). $60 \mathrm{kt} \mathrm{NE}$ and $1020 \mathrm{mb}$ at $37.2 \mathrm{~N}, 74.5 \mathrm{~W}$ at $06 \mathrm{Z}$ (COADS). $50 \mathrm{kt} \mathrm{NNE}$ and $1011 \mathrm{mb}$ at $32.3 \mathrm{~N}$, $78.2 \mathrm{~W}$ at $12 \mathrm{Z}$ (COADS). $65 \# \mathrm{kt} \mathrm{NE}$ and $1014 \mathrm{mb}$ at $35.1 \mathrm{~N}, 74.8 \mathrm{~W}$ at $18 \mathrm{Z}$ (COADS). 50 kt SW and $1002 \mathrm{mb}$ at $27.8 \mathrm{~N}, 74.7 \mathrm{~W}$ at $18 \mathrm{Z}$ (COADS). Land highlights: $38 \mathrm{kt} \mathrm{NNE}$ (peak winds) at WB Cape Hatteras, NC (time unknown) (CLIMO). $61 \mathrm{kt} \mathrm{NNE} \mathrm{and} 1011$ $\mathrm{mb}$ at Flying Pan, NC at 05Z (SWO). $55 \mathrm{kt} \mathrm{NNE}$ and $1013 \mathrm{mb}$ at Flying Pan, NC at $11 \mathrm{Z}$ (SWO). $36 \mathrm{kt} \mathrm{NNE}$ and $1016 \mathrm{mb}$ at Flying Pan, NC at 17Z (SWO). $36 \mathrm{kt} \mathrm{NNE}$ and 1016 $\mathrm{mb}$ at Flying Pan, NC at 23Z (SWO).

BULLETIN: "The severe winter type storm has drifted a few miles southward and is now centered about 300 miles east of Jacksonville, Florida. It is expected to remain essentially stationary for the next 24 hours. No reports have been received from the immediate 
vicinity of the storm center but winds of as much as 60 to $70 \mathrm{mph}$ are being reported by ships some 300 miles north of the center."

November 28:

HWM analyzes an occluded extratropical cyclone of at most $1005 \mathrm{mb}$ at $29.0 \mathrm{~N}, 74.0 \mathrm{~W}$ at 12Z. Microfilm shows a closed low pressure of at most $999 \mathrm{mb}$ at $28.8 \mathrm{~N}, 73.0 \mathrm{~W}$ at $12 \mathrm{Z}$. Ship highlights: 60\# kt ENE and $101 \mathrm{mb}$ at $34.9 \mathrm{~N}, 73.9 \mathrm{~W}$ at $00 \mathrm{Z}$ (COADS). $40 \mathrm{kt} \mathrm{E}$ and $1008 \mathrm{mb}$ at $30.8 \mathrm{~N}, 74.5 \mathrm{~W}$ at $00 \mathrm{Z}$ (COADS). $60 \mathrm{kt} \mathrm{E}$ and $1005 \mathrm{mb}$ at $29.9 \mathrm{~N}, 74.0 \mathrm{~W}$ at $06 \mathrm{Z}$ (COADS). $50 \mathrm{kt}$ ENE and $1013 \mathrm{mb}$ at $31.4 \mathrm{~N}, 68.5 \mathrm{~W}$ at $12 \mathrm{Z}$ (COADS). $60 \# \mathrm{kt} \mathrm{E}$ and $1019 \mathrm{mb}$ at $36.0 \mathrm{~N}, 71.5 \mathrm{~W}$ at $18 \mathrm{Z}$ (COADS). $45 \mathrm{kt} \mathrm{NE}$ and $1013 \mathrm{mb}$ at $33.1 \mathrm{~N}, 71.8 \mathrm{~W}$ at 18Z (COADS). Land highlights: $35 \mathrm{kt} \mathrm{NE}$ and $1017 \mathrm{mb}$ at Flying Pan, $\mathrm{NC}$ at 05Z (SWO). $36 \mathrm{kt} \mathrm{NE}$ and $1017 \mathrm{mb}$ at Flying Pan, NC at 11Z (SWO). $35 \mathrm{kt} \mathrm{SE}$ and $1015 \mathrm{mb}$ at Bermuda at $18 \mathrm{Z}$ (micro).

BULLETIN: "At 5 pm EST the large intense Atlantic storm was located some 600 miles east of Daytona Beach moving eastward $15 \mathrm{mph}$. Continued eastward movement of 15 mph is forecast for the next 24 hours. Gales from 35 to 55 knots extend outward some 300 miles from the center except to near 600 miles in the northeast quadrant. No worsening of the flooding and erosion problem along the southeast coast is expected, however, it will be late Thursday before any important decrease in the seas take place. Seas of near 30 feet have been reported some 100 miles east of St. Augustine, Florida while winds of 59 knots were recorded at Bermuda."

November 29:

HWM analyzes an occluded extratropical cyclone of at most $1000 \mathrm{mb}$ at $30.0 \mathrm{~N}, 73.0 \mathrm{~W}$ at 12Z. Microfilm shows a closed low pressure of at most $1008 \mathrm{mb}$ at $31.0 \mathrm{~N}, 72.0 \mathrm{~W}$ at $12 \mathrm{Z}$. Ship highlights: $50 \# \mathrm{kt} \mathrm{E}$ and $1020 \mathrm{mb}$ at $36.7 \mathrm{~N}, 71.3 \mathrm{~W}$ at $00 \mathrm{Z}$ (COADS). $45 \mathrm{kt} \mathrm{ENE}$ and $1008 \mathrm{mb}$ at $32.2 \mathrm{~N}, 71.4 \mathrm{~W}$ at $00 \mathrm{Z}$ (COADS). $50 \mathrm{kt} \mathrm{E}$ and $1017 \mathrm{mb}$ at $34.5 \mathrm{~N}, 75.1 \mathrm{~W}$ at $06 \mathrm{Z}$ (COADS). 50\# kt ENE and $1022 \mathrm{mb}$ at $37.2 \mathrm{~N}, 68.6 \mathrm{~W}$ at $12 \mathrm{Z}$ (COADS). $40 \mathrm{kt} \mathrm{SW}$ and $1003 \mathrm{mb}$ at $30.0 \mathrm{~N}, 71.3 \mathrm{~W}$ at $12 \mathrm{Z}$ (COADS). $50 \mathrm{kt}$ ENE and $1015 \mathrm{mb}$ at $33.2 \mathrm{~N}$, $76.5 \mathrm{~W}$ at $18 \mathrm{Z}$ (COADS). Land highlights: $35 \mathrm{kt} \mathrm{NE}$ and $1017 \mathrm{mb}$ at Flying Pan, NC at $17 \mathrm{Z}$ (SWO). $38 \mathrm{kt} \mathrm{NE}$ and $1016 \mathrm{mb}$ at Flying Pan, NC at 23Z (SWO).

BULLETIN: "The large and intense Atlantic storm remains stationary some 600 miles east of Jacksonville, Florida. Gales with very rough seas are occurring over most of the area from off the middle Atlantic coast to the north and east to the north and east of Bermuda and southward in the area east of the northern Bahamas." 
November 30:

HWM analyzes a closed low pressure of at most $1005 \mathrm{mb}$ at $31.0 \mathrm{~N}, 73.0 \mathrm{~W}$ with a warm front to the north at 12Z. Microfilm shows a closed low pressure of at most 996 $\mathrm{mb}$ at $30.5 \mathrm{~N}, 74.5 \mathrm{~W}$ at $12 \mathrm{Z}$. Ship highlights: $55 \mathrm{kt} \mathrm{NE}$ and $1015 \mathrm{mb}$ at $33.8 \mathrm{~N}, 75.8 \mathrm{~W}$ at 00Z (COADS). $55 \mathrm{kt} \mathrm{NE}$ and $1013 \mathrm{mb}$ at 32.6N, 77.6W at 06Z (COADS). $55 \mathrm{kt} \mathrm{NE}$ and $1006 \mathrm{mb}$ at $32.9 \mathrm{~N}, 73.9 \mathrm{~W}$ at $12 \mathrm{Z}$ (COADS). $55 \mathrm{kt} \mathrm{NE}$ and $1014 \mathrm{mb}$ at $33.5 \mathrm{~N}, 77.0 \mathrm{~W}$ at $18 Z$ (COADS). Land highlights: $34 \mathrm{kt} \mathrm{NE}$ and $1016 \mathrm{mb}$ at Frying Pan, NC at 05Z (SWO). $40 \mathrm{kt} \mathrm{NE}$ and $1015 \mathrm{mb}$ at Flying Pan, NC at 11Z (SWO). $42 \mathrm{kt} \mathrm{NE}$ and $1016 \mathrm{mb}$ at Flying Pan, NC at 17Z (SWO). $38 \mathrm{kt} \mathrm{NE}$ and $1014 \mathrm{mb}$ at Flying Pan, NC at 23Z (SWO).

BULLETIN: "The intense Atlantic storm was located about 550 statute miles east of Jacksonville at noon and has moved southward between 5 and 10 mph during the past 12 hours. Gales with very rough seas cover an area approximately 400 miles wide from the middle Atlantic coast to Bermuda. Ships near the storm center have reported 45 to 60 mph winds and 25 foot seas. A ship about 100 miles southeast of Wilmington, North Carolina is currently reporting $65 \mathrm{mph."}$

December 1:

HWM analyzes a closed low pressure of at most $1005 \mathrm{mb}$ at $32.5 \mathrm{~N}, 75.0 \mathrm{~W}$ with a warm front to the north at 12Z. Microfilm shows a closed low pressure of at most $1002 \mathrm{mb}$ at 33.0N, 74.0W at 12Z. Ship highlights: $45 \mathrm{kt} \mathrm{NNE}$ and $1014 \mathrm{mb}$ at $34.3 \mathrm{~N}, 76.1 \mathrm{~W}$ at $00 \mathrm{Z}$ (COADS). $45 \mathrm{kt} \mathrm{N}$ and $1002 \mathrm{mb}$ at 32.7N, 75.4W at 06Z (COADS). $50 \mathrm{kt} \mathrm{N}$ and 1003 $\mathrm{mb}$ at $34.3 \mathrm{~N}, 75.6 \mathrm{~W}$ at $12 \mathrm{Z}$ (COADS). $75 \mathrm{kt} \mathrm{NE}$ and $1004 \mathrm{mb}$ at $35.2 \mathrm{~N}, 75.0 \mathrm{~W}$ at $18 \mathrm{Z}$ (COADS/MWL). $55 \mathrm{kt} \mathrm{NNE}$ and $988 \mathrm{mb}$ at 34.1N, 75.0W at 20Z (MWL). Land highlights: $35 \mathrm{kt} \mathrm{NE}$ and $1013 \mathrm{mb}$ at Frying Pan, NC at 05Z (SWO). $39 \mathrm{kt} \mathrm{NNE} \mathrm{(peak}$ winds) at WB Cape Hatteras, NC (time unknown) (CLIMO). $33 \mathrm{kt} \mathrm{NNE} \mathrm{(gusts} \mathrm{to} 48 \mathrm{kt}$ ) and $1006 \mathrm{mb}$ at Cape Hatteras, NC at $1949 \mathrm{Z}$ (SWO).

BULLETIN: "At 5 pm EST the severe Atlantic storm was moving northward abreast of the North Carolina coast some 100 miles offshore. Gale winds extend over an area 250 statute miles north and west of the center and 150 miles to the east and south. Ships have reported winds up to 50 to $60 \mathrm{mph}$ in heavier squalls near the center and during the afternoon winds gusts up to $50 \mathrm{mph}$ where recorded in the vicinity of Hatteras, North Carolina."

December 2:

HWM analyzes an extratropical cyclone of at most $1005 \mathrm{mb}$ at $34.0 \mathrm{~N}, 74.0 \mathrm{~W}$ at $12 \mathrm{Z}$. Microfilm shows a closed low pressure of at most $999 \mathrm{mb}$ at $33.5 \mathrm{~N}, 75.0 \mathrm{~W}$ at $12 \mathrm{Z}$. Ship 
highlights: $55 \mathrm{kt} \mathrm{N}$ and $1002 \mathrm{mb}$ at $35.0 \mathrm{~N}, 75.3 \mathrm{~W}$ at $00 \mathrm{Z}$ (COADS). $50 \mathrm{kt} \mathrm{N}$ and $1006 \mathrm{mb}$ at $34.0 \mathrm{~N}, 76.4 \mathrm{~W}$ at $06 \mathrm{Z}$ (COADS). $60 \mathrm{kt} \mathrm{E}$ and $1004 \mathrm{mb}$ at $34.6 \mathrm{~N}, 74.5 \mathrm{~W}$ at $12 \mathrm{Z}$ (COADS). $50 \mathrm{kt} \mathrm{N}$ and $1000 \mathrm{mb}$ at 33.3N, 76.5W at 18Z (COADS). Land highlights: 38 kt NNE and $1011 \mathrm{mb}$ at Frying Pan, NC at 17Z (SWO). $40 \mathrm{kt} \mathrm{NNE}$ and $1010 \mathrm{mb}$ at Frying Pan, NC at 23Z (SWO).

BULLETIN: At 5 pm today the center of the Atlantic storm was located about 125 miles south of Cape Hatteras. The movement of the storm continued to be erratic and since early this morning it has moved slowly toward the southwest. During the next 12 hours it is expected to drift slowly southward with a tendency to move toward the east thereafter.

December 3:

HWM analyzes a closed low pressure of at most $1005 \mathrm{mb}$ at $33.0 \mathrm{~N}, 75.0 \mathrm{~W}$ with a stationary front to the north at $12 \mathrm{Z}$. Microfilm shows a closed low pressure of at most $1008 \mathrm{mb}$ at $32.0 \mathrm{~N}, 75.0 \mathrm{~W}$ at 12Z. Ship highlights: $45 \mathrm{kt} \mathrm{NNE}$ and $1009 \mathrm{mb}$ at $33.1 \mathrm{~N}$, $77.1 \mathrm{~W}$ at $00 \mathrm{Z}$ (COADS). $35 \mathrm{kt} \mathrm{N}$ and $1006 \mathrm{mb}$ at $33.3 \mathrm{~N}, 76.9 \mathrm{~W}$ at $06 \mathrm{Z}$ (COADS). $45 \mathrm{kt}$ $\mathrm{N}$ and $1010 \mathrm{mb}$ at $33.1 \mathrm{~N}, 77.1 \mathrm{~W}$ at $12 \mathrm{Z}$ (COADS). $35 \mathrm{kt} \mathrm{E}$ and $1010 \mathrm{mb}$ at $34.3 \mathrm{~N}, 75.0 \mathrm{~W}$ at $18 \mathrm{Z}$ (micro). Land highlights: $36 \mathrm{kt} \mathrm{NNE}$ and $1011 \mathrm{mb}$ at Frying Pan, NC at 05Z (SWO).

BULLETIN: "The storm is forecast to remain nearly stationary during the day with little change in size or intensity. Gale winds up to $65 \mathrm{mph}$ in the heavier squalls are occurring near the center while winds from 25 to $45 \mathrm{mph}$ extend outward some 300 miles from the center. The storm is seven days old and during this time has moved in every possible direction with the center remaining within an area which could roughly be called a circle with radius of less than 250 miles. The circulation of the storm has been cutoff from the general circulation of the atmosphere from its position. While cutoff lows are not new certainly one as strong as this is indeed unusual for this area and since it has remained so long in such a relatively small area."

December 4:

HWM analyzes a closed low pressure of at most $995 \mathrm{mb}$ at $34.5 \mathrm{~N}, 73.0 \mathrm{~W}$ with a stationary front to the north at $12 \mathrm{Z}$. Microfilm shows a closed low pressure of at most $993 \mathrm{mb}$ at $34.0 \mathrm{~N}, 73.5 \mathrm{~W}$ at 12Z. Ship highlights: $35 \mathrm{kt} \mathrm{WSW}$ and $1002 \mathrm{mb}$ at $32.6 \mathrm{~N}$, $74.2 \mathrm{~W}$ at $00 \mathrm{Z}$ (COADS). $35 \mathrm{kt} \mathrm{NE}$ and $997 \mathrm{mb}$ at $33.4 \mathrm{~N}, 74.5 \mathrm{~W}$ at $06 \mathrm{Z}$ (COADS). $45 \mathrm{kt}$ $\mathrm{NE}$ and $994 \mathrm{mb}$ at $34.7 \mathrm{~N}, 73.6 \mathrm{~W}$ at $12 \mathrm{Z}$ (COADS). $50 \mathrm{kt} \mathrm{NW}$ and $998 \mathrm{mb}$ at $34.8 \mathrm{~N}$, $74.8 \mathrm{~W}$ at $18 \mathrm{Z}$ (COADS).

BULLETIN: "The Atlantic storm continues to move slowly toward the north-northeast and at 5 pm was centered about 150 miles east of Cape Hatteras. Highest winds are 
estimated $55 \mathrm{mph}$ near the center and winds of $30 \mathrm{mph}$ or higher extend out 200 miles from the center with rough seas and squalls. Seas as high as 30 feet have been reported near the center today."

December 5:

HWM analyzes a closed low pressure of at most $995 \mathrm{mb}$ at $36.2 \mathrm{~N}, 71.2 \mathrm{~W}$ with a stationary front to the northeast at $12 \mathrm{Z}$. Microfilm shows a closed low pressure of at most $990 \mathrm{mb}$ at $34.0 \mathrm{~N}, 73.5 \mathrm{~W}$ at $12 \mathrm{Z}$. Ship highlights: $45 \mathrm{kt} \mathrm{NE}$ and $992 \mathrm{mb}$ at $36.9 \mathrm{~N}, 72.5 \mathrm{~W}$ at $00 \mathrm{Z}$ (COADS). $70 \mathrm{kt} \mathrm{SW}$ and $987 \mathrm{mb}$ at $34.9 \mathrm{~N}, 71.1 \mathrm{~W}$ at $00 \mathrm{Z}$ (COADS). $45 \mathrm{kt} \mathrm{N}$ and $1010 \mathrm{mb}$ at $33.1 \mathrm{~N}, 77.1 \mathrm{~W}$ at $12 \mathrm{Z}$ (COADS). $80 \mathrm{kt} \mathrm{SW}$ and $990 \mathrm{mb}$ at $34.9 \mathrm{~N}, 71.2 \mathrm{~W}$ at $12 \mathrm{Z}$ (COADS). $70 \mathrm{kt} \mathrm{WNW}$ and $1000 \mathrm{mb}$ at $34.7 \mathrm{~N}, 71.9 \mathrm{~W}$ at $18 \mathrm{Z}$ (COADS). $50 \mathrm{kt}$ $\mathrm{WSW}$ and $978 \mathrm{mb}$ at $36.5 \mathrm{~N}, 68.7 \mathrm{~W}$ at $18 \mathrm{Z}$ (COADS).

BULLETIN: "At 5 pm EST the Atlantic storm was centered about 240 miles southsoutheast of Cape Cod moving north-northeast about $15 \mathrm{mph}$. This storm is forecast to continue moving north-northeast at about $15 \mathrm{mph}$ tonight and pass close to the east of Cape Cod after midnight. Strongest winds are 45 to $65 \mathrm{mph}$ near the storm center and winds 25 to $45 \mathrm{mph}$ extend about 300 miles to the north and 200 miles in other quadrants. The storm is expected to maintain about the same intensity and spread out over a larger area during the next 24 hours."

December 6:

HWM analyzes an extratropical cyclone over the Mid-Atlantic (system appears to be dissipated) at 12Z. Microfilm shows a closed low pressure of at most $993 \mathrm{mb}$ at $39.0 \mathrm{~N}$, $65.0 \mathrm{~W}$ with a frontal boundary to the east at $12 \mathrm{Z}$. Ship highlights: $40 \mathrm{kt} \mathrm{SW}$ and $1005 \mathrm{mb}$ at $33.8 \mathrm{~N}, 64.2 \mathrm{~W}$ at $00 \mathrm{Z}$ (COADS). $35 \mathrm{kt} \mathrm{SSE}$ and $979 \mathrm{mb}$ at $38.8 \mathrm{~N}, 64.7 \mathrm{~W}$ at $06 \mathrm{Z}$ (micro). $40 \mathrm{kt} \mathrm{E}$ and $1000 \mathrm{mb}$ at $40.6 \mathrm{~N}, 68.8 \mathrm{~W}$ at $12 \mathrm{Z}$ (COADS). $45 \mathrm{kt} \mathrm{E}$ and $1014 \mathrm{mb}$ at $44.5 \mathrm{~N}, 62.5 \mathrm{~W}$ at $18 \mathrm{Z}$ (COADS).

December 7:

HWM and microfilm analyze an extratropical cyclone over the Great Lakes (system appears to be dissipated) at 12Z. Ship highlights: No gales or low pressures.

CLIMO: "An unusually persistent low pressure storm whose center remained off the North Carolina coast from the night of November 25th until December 5th caused very heavy beach erosion and widespread minor wind damage. Sections of protective sand dunes several hundred feet in length were washed flat and beaches were cut back as much as 50 feet in width in some areas. Several buildings were destroyed and many damaged when undermined by the pounding seas; sand thus carried away was deposited in other 
areas, burying streets and highways in several feet of sand. Small boats tied up in port were badly battered by the long siege of onshore winds and waves, and one ship sank."

MWL (Volume 7, Number 2, March 1963, Page 50): “A well-developed low pressure system of extratropical origin lay off the coast of the southeastern states from November26toDecember5, its center meandering between latitudes $28^{\circ} \mathrm{N}$ and $35^{\circ} \mathrm{N}$ and between longitudes $70^{\circ} \mathrm{W}$ and $75^{\circ} \mathrm{W}$ during the entire period. The intensity of the storm varied considerably from day to day, but at weakest it was an active closed low pressure circulation and at strongest it was the equal of a minor hurricane. The center of the storm remained offshore at all times, but the prolonged pounding of the coast with winds between north and east and high seas and tides caused severe erosion along the coast from Virginia southward to central Florida. Rainfall amounts were generally light except for locally heavy amounts along the immediate coast of North Carolina and Georgia. Whole gale winds off Hampton Roads blew the Chesapeake Lightship off station early in the storm, and a huge dredge used on the Chesapeake Bridge-Tunnel Project broke loose and was driven aground off Little Creek. Farther south along the Virginia coast much of the sand which had been replaced at great expense in resort areas since the March 1962 storm was washed away again. Very extensive erosion also occurred along the Outer Banks of North Carolina. The 700-ft. wide inlet cut through Hatteras Island north of Buxton by the March storm was widened by an additional estimated 1,000 ft. , and the bridge which had been built across it was destroyed. A state-owned ferry sank in Pamlico Sound, a loaded tanker was severely damaged, and small boats along the coast were battered. Some minor shallow flooding occurred at high tides. At Carolina Beach south of Wilmington about a 1,000-ft. length of beach was cut back as much as $50 \mathrm{ft}$. in width, and sections of dunes $500 \mathrm{ft}$. or more in length were reported washed flat in a number of areas. Numerous beach cottages were undermined, and several of them fell into the ocean and were washed up as debris. Shoreline erosion of a less severe nature extended southward along the South Carolina and Georgia coast. A fishing trawler based at Charleston was lost during the storm but the crew was subsequently rescued. A schooner valued at $\$ 35,000$ was also lost off the South Carolina coast. Sections along the Florida coast also experienced severe erosion mostly from Cape Canaveral northward with many seawalls, docks, and piers sustaining damage. No lives were reported lost and damage estimates are rather incomplete though probably not exceeding $\$ 10,000,000$."

MWL (Volume 7, Number 2, March 1963, Page 63): “An unusual storm developed southeast of Cape Hatteras on the 26th. A warm HIGH had rapidly been developing over New England and a dynamically sympathetic LOW formed about $200 \mathrm{mi}$. southeast of Cape Hatteras at about the same time. This LOW at first moved southwestward to about $250 \mathrm{mi}$. east of the central Florida coast on the 28th accompanied by whole gale winds. The storm then drifted northward describing a couple of minor loops to the southeast of 
Hatteras before moving northeastward out of the area on December 3. This storm, though considered an extratropical LOW cut off from the westerlies aloft, exhibited many characteristics of a tropical cyclone while meandering over the warm Gulf Stream south of Hatteras. Even when finally moving northward off the coast on December 4 and 5 it was imbedded in a mid-tropospheric ridge with no associated fronts and with core temperatures being quite warm. Extensive beach erosion and minor flooding at high tides were experienced mainly from the central Florida coast northward to Hampton Roads. Highest winds along the coast were recorded at cooperative hurricane reporting stations along the North Carolina coast south of Cape Lookout on the 26th. Oak Island reported a gust from the north-northeast of $77 \mathrm{kt}$. and Sneads Ferry $70 \mathrm{kt}$. Precipitation generally was not excessive over land and confined to the immediate coast. Fog and haze, associated with the persistent high pressure cell centered over New England during the end of November and into the first week of December, was bothersome to shipping in the Great Lakes and in the ports along the upper Atlantic coast. The 6,471-ton freighter SARAH BOWATER and the 10,730-ton tanker CHEMICAL TRANSPORTER collided in fog in New York harbor on December 4. No injuries were reported, and damage to both vessels was about $12 \mathrm{ft}$."

A frontal boundary is observed in the Historical Weather Maps over the southeast of the United States and extended into the western Atlantic on November 25th. Synoptic observations late on the 25th and early on November 26th indicate that an extratropical cyclone gradually organized and is analyzed to have developed around $12 \mathrm{Z}$ on the 26th. A strong ridge over the northeast of the United States and the intensifying cyclone combined to produce a strong pressure gradient and gale-force winds quickly developed. At $12 \mathrm{Z}$ on the 26th, two ships reported hurricane-force winds about $200 \mathrm{~nm}$ north of the center and the intensity at the first position is analyzed at $70 \mathrm{kt}$. Gale-force winds affected the coastal areas of Virginia and North Carolina late on the 26th with recorded gusts up to $77 \mathrm{kt}$. The intense extratropical cyclone initially moved westward but turned to the south and southeast on November 27 th. On the $27 \mathrm{th}$, the pressure gradient remained strong and gale-force winds were being reported over $300 \mathrm{~nm}$ northeast of the center. Late on the 27 th, synoptic data indicates that the system became more symmetric with a decrease in the temperature gradient. Transition to a tropical cyclone is analyzed at $00 \mathrm{Z}$ on November 28th with an intensity of $65 \mathrm{kt}$ based upon a ship report near the center at $06 \mathrm{Z}$ on the 28th of $60 \mathrm{kt} \mathrm{E}$ and $1005 \mathrm{mb}$. Synoptic data on the 28th shows that even though gale-force winds were being measured near the center of the hurricane, the strong pressure gradient continued to produce gale-force winds over $500 \mathrm{~nm}$ northeast of center. The winds outside of the outermost closed isobar are not considered part of the circulation of the hurricane. The tropical cyclone is analyzed to have weakened to a tropical storm at $12 \mathrm{Z}$ on the 28 th based on ship data. TIROS VI captured an image of the tropical storm at $1951 \mathrm{Z}$ on the 28th showing a sheared cyclone with most of the 
convection over the north and eastern quadrants. After moving eastward early on the 28th, the tropical storm moved northeast late on this date and early on November 29th. Synoptic observations on the 29th continued to show gale-force winds near the center of the tropical storm, up to $45 \mathrm{kt}$. Late on the 29th, the tropical cyclone moved to the southwest and turned to the west on November 30th. Late on the 30th, the erratic tropical storm turned to the north and began to intensify. Winds near the center reported by ships reached up to $55 \mathrm{kt}$ on the 30th. Another TIROS VI image of the tropical storm was captured at $1933 \mathrm{Z}$ on the 30th showing a large area of convection, especially in the northeast quadrant, and an eye-like feature.

On December 1st, the strong ridge over the Northeast of the United States weakened and the gale-force winds decreased to about $150 \mathrm{~nm}$ away from the center. Synoptic observations late on the 1st show that the tropical cyclone had strengthened and it is analyzed to have regained hurricane intensity at $00 \mathrm{Z}$ on the 1 st. Two ships reported hurricane intensity at $18 \mathrm{Z}$ on the $1 \mathrm{st}, 75 \mathrm{kt} \mathrm{NE}$ and $95 \mathrm{kt} \mathrm{N}$. The ship report of $95 \mathrm{kt}$ appears to have a high bias compared to the neighboring observations, thus a blend of the two observations have been used to come up with an intensity of $80 \mathrm{kt}$ at $18 \mathrm{Z}$ on the 1st. $80 \mathrm{kt}$ is also the peak intensity of this hurricane. Climatological Data indicates that 45 mph (fastest mile) was measured on the 1st in Cape Hatteras, NC, time unknown. This measurement likely occurred late on the 1st or early on the 2nd (zulu time). Thus, North Carolina is added as a tropical storm impact. The hurricane turned to the southwest on December 2nd and gradually weakened. Gale-force winds up to $60 \mathrm{kt}$ were reported by ships near the center. TIROS VI captured an image of the hurricane at $1919 \mathrm{Z}$ on the $2 \mathrm{nd}$ showing a large area of convection all-around the center and no signs of strong wind shear. On December 3rd, the tropical cyclone turned to the east and later to the northeast. Synoptic observations indicate that the hurricane weakened to a tropical storm at $00 \mathrm{Z}$ on the 3rd. At $1817 \mathrm{Z}$ on the 3rd, TIROS VI captured another image of the tropical cyclone showing a sheared system with most of the convection over the northern and eastern quadrants. An approaching frontal boundary on December 4th caused the tropical storm to increase in forward speed to the northeast as it began to lose its tropical characteristics late in the day. Ship data at $18 \mathrm{Z}$ on the 4th showed an increase in the temperature gradient between the eastern and western quadrants as the system moved away from the Gulf Stream and into cooler waters of the northwest Atlantic. Transition to an extratropical cyclone is analyzed at $00 \mathrm{Z}$ on December 5 th based upon synoptic observations showing a strong temperature gradient. A ship at $06 \mathrm{Z}$ on the 5 th showed 70 $\mathrm{kt} \mathrm{SW}, 80 \mathrm{kt} \mathrm{SW}$ at 12Z, and $70 \mathrm{kt} \mathrm{WNW}$ at 18Z, and based upon nearby ship observations is analyzed that this ship has a high wind bias. Thus, the extratropical cyclone is analyzed to have regained hurricane intensity at $06 \mathrm{Z}$ on the 5 th, reaching a tertiary peak in intensity at $12 \mathrm{Z}$ on this day of $70 \mathrm{kt}$. TIROS V captured an image of the extratropical cyclone at $1832 \mathrm{Z}$ on the 5 th showing a large system over the northwest 
Atlantic. The extratropical cyclone weakened on December 6th. Synoptic observations indicate that it became elongated and weakened into a trough before being absorbed by a larger extratropical cyclone over the Northeast of the United States. The last position is analyzed at $06 \mathrm{Z}$ on the 6 th. There is no proper analog to compare to this system, but the Yankee Hurricane of 1935 had a similar development and unusual southward track that enabled it to attain tropical cyclone status.

\section{2 - Additional Notes}

1) February 24 - March 3: Historical Weather Maps show an extratropical cyclone exiting the United States on February $24^{\text {th }}$. The disturbance moved eastward and became occluded on February $27^{\text {th }}$ producing gales. After meandering over the north Atlantic for a couple of days, an approaching frontal boundary absorbed the non-tropical cyclone on March $4^{\text {th }}$. Therefore, because the system did not acquire tropical characteristics, it is not added to HURDAT. This disturbance was in Jack Beven's List of Suspects.

$\begin{array}{cccc}\text { Day } & \text { Latitude } & \text { Longitude } & \text { Status } \\ \text { February 24 } & 40 \mathrm{~N} & 75 \mathrm{~W} & \text { Extratropical } \\ \text { February 25 } & 41 \mathrm{~N} & 51 \mathrm{~W} & \text { Extratropical } \\ \text { February 26 } & 46 \mathrm{~N} & 44 \mathrm{~W} & \text { Extratropical } \\ \text { February 27 } & 40 \mathrm{~N} & 47 \mathrm{~W} & \text { Occluded } \\ \text { February 28 } & 38 \mathrm{~N} & 39 \mathrm{~W} & \text { Occluded } \\ \text { March 1 } & 41 \mathrm{~N} & 42 \mathrm{~W} & \text { Occluded } \\ \text { March 2 } & 43 \mathrm{~N} & 48 \mathrm{~W} & \text { Occluded } \\ \text { March 3 } & 42 \mathrm{~N} & 41 \mathrm{~W} & \text { Occluded } \\ \text { March 4 } & & & \text { Absorbed }\end{array}$

2) April 28 - May 3: Historical Weather Maps and Microfilm indicate that a trough of low pressure developed north of Puerto Rico late on the April $28^{\text {th }}$ or early on the $29^{\text {th }}$. The disturbance moved northward developing a closed low-level circulation on April $30^{\text {th }}$. The system turned to the northeast on May $1^{\text {st }}$ becoming better defined at the surface. A gale of $35 \mathrm{kt}$ was reported at $12 \mathrm{Z}$ and $18 \mathrm{Z}$ on the $1^{\text {st }}$ in the southwest quadrant, about $200 \mathrm{~nm}$ from the center, but both likely have a high bias compared to the surrounding ship data. On May $2^{\text {nd }}$, the disturbance continued moving eastward and weakened due to an approaching frontal system, becoming absorbed the next day. Therefore, because there is not enough evidence to support upgrading this system to a 
tropical storm, it is not added to HURDAT. This disturbance was in Jack Beven and David Roth's List of Suspects.

$\begin{array}{cccc}\text { Day } & \text { Latitude } & \text { Longitude } & \text { Status } \\ \text { April } 28 & 15 \mathrm{~N}-25 \mathrm{~N} & 68 \mathrm{~W} & \text { Trough } \\ \text { April } 29 & 15 \mathrm{~N}-25 \mathrm{~N} & 65 \mathrm{~W} & \text { Trough } \\ \text { April 30 } & 25 \mathrm{~N} & 65 \mathrm{~W} & \text { Tropical Depression } \\ \text { May 1 } & 29 \mathrm{~N} & 65 \mathrm{~W} & \text { Tropical Storm? } \\ \text { May 2 } & 29 \mathrm{~N} & 61 \mathrm{~W} & \text { Tropical Storm? } \\ \text { May 3 } & & & \end{array}$

3) May 11-22: Historical Weather Maps shows an extratropical cyclone exiting the United States on May $11^{\text {th }}$ and moving to the southeast. On May $15^{\text {th }}$, the disturbance became an occluded cyclone while producing gale-force winds over $300 \mathrm{~nm}$ away from the center. The system moved little over the next couple of days while filling as a nontropical cyclone. On May $19^{\text {th }}$, the disturbance began to move eastward and synoptic observations indicate that it dissipated around May $22^{\text {nd }}$. Therefore, because the system did not acquire tropical characteristics, it is not added to HURDAT. This disturbance was in Jack Beven and David Roth's List of Suspects.

$\begin{array}{cccc}\text { Day } & \text { Latitude } & \text { Longitude } & \text { Status } \\ \text { May } 11 & 37 \mathrm{~N} & 82 \mathrm{~W} & \text { Extratropical } \\ \text { May 12 } & 34 \mathrm{~N} & 70 \mathrm{~W} & \text { Extratropical } \\ \text { May 13 } & 33 \mathrm{~N} & 60 \mathrm{~W} & \text { Extratropical } \\ \text { May 14 } & 36 \mathrm{~N} & 56 \mathrm{~W} & \text { Extratropical } \\ \text { May 15 } & 36 \mathrm{~N} & 57 \mathrm{~W} & \text { Occluded } \\ \text { May 16 } & 32 \mathrm{~N} & 62 \mathrm{~W} & \text { Occluded } \\ \text { May 17 } & 32 \mathrm{~N} & 60 \mathrm{~W} & \text { Occluded } \\ \text { May 18 } & 33 \mathrm{~N} & 63 \mathrm{~W} & \text { Occluded } \\ \text { May 19 } & 34 \mathrm{~N} & 59 \mathrm{~W} & \text { Occluded } \\ \text { May 20 } & 35 \mathrm{~N} & 53 \mathrm{~W} & \text { Occluded } \\ \text { May 21 } & 34 \mathrm{~N} & 47 \mathrm{~W} & \text { Occluded } \\ \text { May 22 } & 37 \mathrm{~N} & 44 \mathrm{~W} & \text { Dissipated }\end{array}$

4) June 5-7: Historical Weather Maps indicate that a small, non-frontal low pressure system developed between the Bahamas and Bermuda on June $5^{\text {th }}$. The disturbance moved northeastward and dissipated on June $7^{\text {th }}$. No gale-force winds were associated 
with this disturbance based on the synoptic data in Microfilm, COADS and MWL. Therefore, because the system did not produce tropical storm force winds, it is not added to HURDAT. This disturbance was in Jack Beven's List of Suspects.

$\begin{array}{cccc}\text { Day } & \text { Latitude } & \text { Longitude } & \text { Status } \\ \text { June } 5 & 29 \mathrm{~N} & 71 \mathrm{~W} & \text { Tropical Depression? } \\ \text { June } 6 & 31 \mathrm{~N} & 68 \mathrm{~W} & \text { Tropical Depression? } \\ \text { June } 7 & & & \text { Dissipated }\end{array}$

5) July 14-20: Microfilm shows a tropical wave east of the Lesser Antilles on July $14^{\text {th }}$ moving westward. Synoptic observations indicate that the disturbance became better organized as it crossed the Windward Islands but no gales were reported. The disturbance continued westward entering the Gulf of Mexico on July $19^{\text {th }}$ and dissipated two days later. Therefore, because the system did not produce tropical storm force winds and did not have a closed circulation, it is not added to HURDAT. This disturbance was in Jack Beven's List of Suspects.

$\begin{array}{cccc}\text { Day } & \text { Latitude } & \text { Longitude } & \begin{array}{c}\text { Status } \\ \text { Tuly } 14\end{array} \\ 8 \mathrm{~N}-15 \mathrm{~N} & 47 \mathrm{~W} & \text { Tropical Wave } \\ \text { July } 15 & 9 \mathrm{~N}-17 \mathrm{~N} & 54 \mathrm{~W} & \text { Tropical Wave } \\ \text { July } 16 & 12 \mathrm{~N}-20 \mathrm{~N} & 62 \mathrm{~W} & \text { Tropical Wave } \\ \text { July } 17 & 12 \mathrm{~N}-20 \mathrm{~N} & 71 \mathrm{~W} & \text { Tropical Wave } \\ \text { July } 18 & 15 \mathrm{~N}-25 \mathrm{~N} & 80 \mathrm{~W} & \text { Tropical Wave } \\ \text { July } 19 & 16 \mathrm{~N}-25 \mathrm{~N} & 87 \mathrm{~W} & \text { Tropical Wave } \\ \text { July } 20 & 20 \mathrm{~N}-30 \mathrm{~N} & 95 \mathrm{~W} & \text { Dissipated } \\ \text { July } 21 & & & \end{array}$

6) August 23-25: Microfilm indicates that a trough of low pressure developed northeast of the Leeward Island around August $23^{\text {rd }}$. A non-frontal, low pressure formed on August $24^{\text {th }}$ and a ship reported $40 \mathrm{kt}$ in the southeast quadrant, close to the center. An approaching frontal boundary caused the system to move to the northeast, absorbing it on August $25^{\text {th }}$. Therefore, because there is not enough evidence to support upgrading this system to a tropical storm, it is not added to HURDAT. This disturbance was in Jack Beven's List of Suspects.

$\begin{array}{cccc}\text { Day } & \text { Latitude } & \text { Longitude } & \text { Status } \\ \text { August } 23 & 23 \mathrm{~N}-32 \mathrm{~N} & 56 \mathrm{~W} & \text { Trough }\end{array}$


7) August 25-30: Historical Weather Maps and Microfilm show that the southern portion of the tropical wave that produced Hurricane Alma continued westward into the Gulf of Mexico. The disturbance became better organized on the Bay of Campeche and a tropical depression likely formed on August $27^{\text {th }}$. The system moved northward and a ship reported $55 \mathrm{kt}$, but it appears to have a very high bias, so it's disregarded. Late on the $28^{\text {th }}$ and on the $29^{\text {th }}$, an oil rig over the northwestern Gulf of Mexico reported $35 \mathrm{kt}$, but this is an elevated site, thus the winds at the surface are likely below gale-force. TIROS V captured an image of the system at $16 \mathrm{Z}$ on the $29^{\text {th }}$. In the picture, the system is inland over eastern Texas and looks very well-organized with a large area of convection. At the same time, surface observations show a weak reflection with winds below tropical storm force. The depression produced severe weather across eastern Texas and western Louisiana, including very heavy rains and tornadoes. However, no land based station reported tropical storm force winds. The system dissipated on the $30^{\text {th }}$. Therefore, because there is not enough evidence to support upgrading this system to a tropical storm, it is not added to HURDAT. This disturbance was in Jack Beven's List of Suspects.

$\begin{array}{cccc}\text { Day } & \text { Latitude } & \text { Longitude } & \text { Status } \\ \text { August } 25 & 20 \mathrm{~N}-27 \mathrm{~N} & 89 \mathrm{~W}-92 \mathrm{~W} & \text { Tropical Wave } \\ \text { August } 26 & 20 \mathrm{~N}-28 \mathrm{~N} & 89 \mathrm{~W}-95 \mathrm{~W} & \text { Tropical Wave } \\ \text { August } 27 & 22 \mathrm{~N} & 94 \mathrm{~W} & \text { Tropical Depression } \\ \text { August } 28 & 26 \mathrm{~N} & 95 \mathrm{~W} & \text { Tropical Depression } \\ \text { August } 29 & 30 \mathrm{~N} & 95 \mathrm{~W} & \text { Tropical Depression } \\ \text { August } 30 & & & \text { - Inland } \\ & & & \text { Dissipated }\end{array}$

8) September 19-24: Historical Weather Maps and Microfilm indicates that a tropical wave and frontal boundary interacted in the eastern Gulf of Mexico. A trough of low pressure developed on September $19^{\text {th }}$ and intensified into a tropical depression on the $20^{\text {th }}$. The system continued to interact with the stationary frontal boundary to the north producing very heavy rains over the Florida peninsula. The depression moved erratically over the next couple of days before dissipating on the $24^{\text {th }}$ over the water. No gales or low pressures were associated with this system based on the ship data in the Microfilm, COADS and MWL. Therefore, because the system did not produce tropical storm force 
winds, it is not added to HURDAT. This disturbance was in Ryan Truchelut's List of Suspects.

$\begin{array}{cccc}\text { Day } & \text { Latitude } & \text { Longitude } & \text { Status } \\ \text { September 19 } & 20 \mathrm{~N}-27 \mathrm{~N} & 85 \mathrm{~W}-90 \mathrm{~W} & \text { Trough } \\ \text { September 20 } & 27 \mathrm{~N} & 86 \mathrm{~W} & \text { Tropical Depression } \\ \text { September 21 } & 25 \mathrm{~N} & 85 \mathrm{~W} & \text { Tropical Depression } \\ \text { September 22 } & 28 \mathrm{~N} & 85 \mathrm{~W} & \text { Tropical Depression } \\ \text { September 23 } & 28 \mathrm{~N} & 85 \mathrm{~W} & \text { Tropical Depression } \\ \text { September 24 } & & & \text { Dissipated }\end{array}$

9) September 28 - October 5: Historical Weather Maps and Microfilm show that a tropical wave entered the Caribbean Sea on September $28^{\text {th }}$. The disturbance moved westward and became better organized over the central Caribbean. TIROS V captured an image of the disturbance on October $1^{\text {st }}$ at $12 \mathrm{Z}$ showing a large area of convection with some signs of organization. Another satellite image was captured at 1410Z on October $2^{\text {nd }}$, showing some banding in the northern quadrant of the circulation. The system moved westward, making landfall over northern Nicaragua on October $3^{\text {rd }}$. Another satellite image captured at $1348 \mathrm{Z}$ on the $4^{\text {th }}$ indicates that although the system was interacting with land, it remained organized with a large area of convection. The system moved into southern Mexico on October $5^{\text {th }}$ and weakened into a tropical wave. No gales or low pressures were associated with this system based on the synoptic data in Microfilm, COADS and MWL. Therefore, because the system did not produce tropical storm force winds, it is not added to HURDAT.

$\begin{array}{cccc}\text { Day } & \text { Latitude } & \text { Longitude } & \text { Status } \\ \text { September 28 } & 13 \mathrm{~N}-16 \mathrm{~N} & 58 \mathrm{~W}-66 \mathrm{~W} & \text { Tropical Wave } \\ \text { September } 29 & 12 \mathrm{~N}-17 \mathrm{~N} & 67-69 \mathrm{~W} & \text { Tropical Wave } \\ \text { September 30 } & 12 \mathrm{~N}-17 \mathrm{~N} & 72 \mathrm{~W} & \text { Tropical Wave } \\ \text { October } 1 & 14 \mathrm{~N} & 75 \mathrm{~W} & \text { Tropical Depression? } \\ \text { October 2 } & 14 \mathrm{~N} & 80 \mathrm{~W} & \text { Tropical Depression? } \\ \text { October 3 } & 15 \mathrm{~N} & 84 \mathrm{~W} & \text { Tropical Depression? } \\ \text { October 4 } & 16 \mathrm{~N} & 89 \mathrm{~W} & \text { Tropical Depression? } \\ \text { October 5 } & 16 \mathrm{~N} & 94 \mathrm{~W} & \text { Tropical Wave }\end{array}$

10) October 14-15: Microfilm indicates that a tropical wave was located southwest of the Cape Verde Islands on October $14^{\text {th }}$. Bulletins were issued on this system as a tropical 
depression, mistakenly available in the Storm Wallets of 1963 as TD8. The system moved westward, and gradually weakening and later dissipating over the central Atlantic. No gales or low pressures were associated with this system according to Microfilm, COADS and MWL. Therefore, because the system did not produce tropical storm force winds, it is not added to HURDAT. This disturbance was in Jack Beven's List of Suspects.

$\begin{array}{cccc}\text { Day } & \text { Latitude } & \text { Longitude } & \text { Status } \\ \text { October } 14 & 13 \mathrm{~N} & 29 \mathrm{~W} & \text { Tropical Depression? } \\ \text { October } 15 & 13 \mathrm{~N} & 34 \mathrm{~W} & \text { Tropical Depression? } \\ \text { October 16 } & & & \text { Absorbed }\end{array}$

11) November 12-15: Historical Weather Maps shows that an extratropical cyclone developed along the tail-end of a frontal boundary on November $12^{\text {th }}$. The disturbance moved slowly northward becoming an occluded cyclone on the $13^{\text {th }}$ while producing gales far north of the center. On the $14^{\text {th }}$, TIROS VI captured an image at $1308 \mathrm{Z}$ showing a large non-tropical cyclone. The disturbance was absorbed a day later. Therefore, because the system did not acquire tropical characteristics, it is not added to HURDAT.

$\begin{array}{cccc}\text { Day } & \text { Latitude } & \text { Longitude } & \text { Status } \\ \text { November 12 } & 30 \mathrm{~N} & 40 \mathrm{~W} & \text { Extratropical } \\ \text { November 13 } & 33 \mathrm{~N} & 40 \mathrm{~W} & \text { Occluded } \\ \text { November 14 } & 34 \mathrm{~N} & 37 \mathrm{~W} & \text { Occluded } \\ \text { November 15 } & & & \text { Absorbed }\end{array}$

12) November 25-30: Historical Weather Maps indicates that an extratropical cyclone developed on November $25^{\text {th }}$. The disturbance moved westward becoming an occluded cyclone the next day and gale-force winds were reported on the $27^{\text {th }}$ about $200 \mathrm{~nm}$ north of the center. The disturbance was absorbed by a larger extratropical cyclone on the $30^{\text {th }}$. Therefore, because the system did not acquire tropical characteristics, it is not added to HURDAT. This disturbance was in Jack Beven's List of Suspects.

$\begin{array}{cccc}\text { Day } & \text { Latitude } & \text { Longitude } & \text { Status } \\ \text { November } 25 & 40 \mathrm{~N} & 15 \mathrm{~W} & \text { Extratropical } \\ \text { November } 26 & 38 \mathrm{~N} & 15 \mathrm{~W} & \text { Occluded } \\ \text { November } 27 & 38 \mathrm{~N} & 20 \mathrm{~W} & \text { Occluded } \\ \text { November } 28 & 40 \mathrm{~N} & 22 \mathrm{~W} & \text { Occluded }\end{array}$


Occluded

13) December 9-14: Historical Weather Maps shows an extratropical cyclone developing on December $9^{\text {th }}$ along the tail-end of a frontal boundary. The disturbance moved southwestward becoming an occluded cyclone the next day with gales reported over 200 $\mathrm{nm}$ north of the elongated center. The system became better organized on December $11^{\text {th }}$ with gales and a prominent decrease in the pressure near the center. Nevertheless, the ship coverage south of $30 \mathrm{~N}$ is sparse over the eastern Atlantic and it cannot be established if the disturbance had a closed low-level circulation. The system continued to the southwest over the next couple of days gradually losing strength and dissipating on December $14^{\text {th }}$. Therefore, because it cannot be shown that a closed low-level circulation was present, it is not added to HURDAT. This disturbance was in David Roth's List of Suspects.

$\begin{array}{cccc}\text { Day } & \text { Latitude } & \text { Longitude } & \text { Status } \\ \text { December } 9 & 33 \mathrm{~N} & 28 \mathrm{~W} & \text { Extratropical } \\ \text { December } 10 & 31 \mathrm{~N} & 36 \mathrm{~W} & \text { Occluded } \\ \text { December } 11 & 30 \mathrm{~N} & 40 \mathrm{~W} & \text { Tropical Storm? } \\ \text { December } 12 & 24 \mathrm{~N} & 45 \mathrm{~W} & \text { Tropical Storm? } \\ \text { December } 13 & 18 \mathrm{~N} & 50 \mathrm{~W} & \text { Tropical Depression? } \\ \text { December } 14 & & & \text { Dissipated }\end{array}$




\section{3 hurricane season}

Unnamed Tropical Storm [June 2-4, 1963]

$4212506 / 02 / 1963 \mathrm{M}=31 \mathrm{SNBR}=913$ NOT NAMED $\quad \mathrm{XING}=0 \quad \mathrm{SSS}=0$

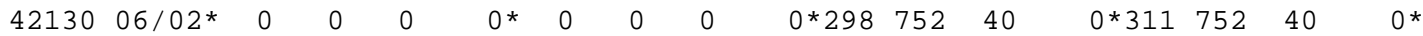

$4213506 / 03^{*} 325754 \quad 451008^{*} 344756 \quad 50 \quad 1002 * 364760 \quad 501002 * 382765 \quad 40 \quad 1002 *$

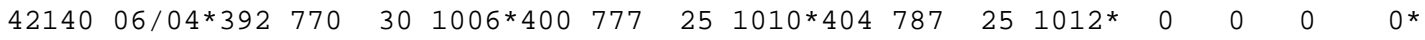

42145 TS

\section{U.S. Tropical Storm Landfall}

06/03 08Z 35.2N 75.8W $50 \mathrm{kt} \mathrm{NC} \mathrm{(40} \mathrm{kt} \mathrm{peak} \mathrm{winds} \mathrm{along} \mathrm{the} \mathrm{coast)}$

A new tropical storm has been added to HURDAT, not previously shown in McAdie et al. (2009). Evidence for these alterations comes from the NHC microfilm maps, the Historical Weather Maps series, the COADS ship database, Mariners Weather Log, Surface Weather Observations, and State Climatological Data. This disturbance was in Jack Beven and David Roth's List of Suspects.

May 29:

HWM analyzes a closed low pressure of $1010 \mathrm{mb}$ at $11.5 \mathrm{~N}, 76.5 \mathrm{~W}$ at $12 \mathrm{Z}$. Microfilm does not show an organized system at 12Z. Ship highlights: No gales or low pressures.

MWL: "A tropical disturbance, which had been tracked north-northeastward from just north of Panama on May 29."

May 30:

HWM analyzes a closed low pressure of $1010 \mathrm{mb}$ at $11.0 \mathrm{~N}, 78.0 \mathrm{~W}$ at $12 \mathrm{Z}$.

Microfilm shows a spot low pressure near $13 \mathrm{~N}, 78 \mathrm{~W}$ at $12 \mathrm{Z}$. Ship highlights: No gales or low pressures.

May 31:

HWM analyzes a spot low pressure of $1010 \mathrm{mb}$ at $16.8 \mathrm{~N}, 79.8 \mathrm{~W}$ at $12 \mathrm{Z}$.

Microfilm shows a closed low pressure at $18.0 \mathrm{~N}, 79.5 \mathrm{~W}$ at $12 \mathrm{Z}$. Ship highlights: No gales or low pressures.

MWL: "Heavy rainfall was reported along the track of the disturbance with Santiago de Cuba receiving about 7.50 in. during a 2-day period in the incipient stage."

June 1:

HWM analyzes a closed low pressure of $1010 \mathrm{mb}$ at $26.0 \mathrm{~N}, 77.0 \mathrm{~W}$ with a weakening frontal boundary to the north at $12 \mathrm{Z}$. Microfilm shows a closed low pressure of at most $1008 \mathrm{mb}$ at $26.0 \mathrm{~N}, 78.0 \mathrm{~W}$ at 12Z. Ship highlights: $35 \mathrm{kt} \mathrm{SE}$ and $1009 \mathrm{mb}$ at $26.0 \mathrm{~N}, 74.0 \mathrm{~W}$ at $12 \mathrm{Z}$ (micro). $35 \mathrm{kt} \mathrm{SE}$ and $1012 \mathrm{mb}$ at $27.2 \mathrm{~N}, 74.7 \mathrm{~W}$ at $15 \mathrm{Z}$ (micro). 
MWL: "Developed a closed sea level circulation over the northwestern Bahamas during the afternoon hours of June 1."

June 2:

HWM analyzes a closed low pressure of $1010 \mathrm{mb}$ at $30.0 \mathrm{~N}, 76.0 \mathrm{~W}$ with a warm frontal boundary to the north at $12 \mathrm{Z}$. Microfilm shows a closed low pressure of at most $1011 \mathrm{mb}$ at $30.5 \mathrm{~N}, 75.0 \mathrm{~W}$ at $12 \mathrm{Z}$. Ship highlights: $35 \mathrm{kt} \mathrm{SE}$ and $1011 \mathrm{mb}$ at $28.2 \mathrm{~N}$, $74.5 \mathrm{~W}$ at $00 \mathrm{Z}$ (COADS). $35 \mathrm{kt} \mathrm{SE}$ and $1010 \mathrm{mb}$ at $30.7 \mathrm{~N}, 73.3 \mathrm{~W}$ at $12 \mathrm{Z}$ (COADS). $55 \mathrm{kt}$ [likely high bias] ESE and $1015 \mathrm{mb}$ at $31.3 \mathrm{~N}, 72.7 \mathrm{~W}$ at $12 \mathrm{Z}$ (COADS). $40 \mathrm{kt}$ ESE and $1003 \mathrm{mb}$ at 33.6B, 74.6W at 18Z (COADS). Aircraft highlights: Central pressure of 1008 $\mathrm{mb}$ near $32.5 \mathrm{~N}, 75.5 \mathrm{~W}$ at $2130 \mathrm{Z}$ (micro).

MWL: "The tropical depression continued toward Hatteras, reaching tropical storm Intensity late the following day when information received from a Navy reconnaissance aircraft and from ship reports near the center of the cyclone indicated winds in excess of $34 \mathrm{kt}$. This unnamed tropical storm was the first of the season in the North Atlantic region. The highest sustained wind measured in the storm was recorded aboard the ALCOA POLARIS at noon on the $2 \mathrm{~d}$ near $31^{\circ} \mathrm{N}, 73^{\circ} \mathrm{W}$ when $55-\mathrm{kt}$ east-southeasterly winds were encountered."

June 3:

HWM analyzes a closed low pressure of $1005 \mathrm{mb}$ at $36.5 \mathrm{~N}, 76.2 \mathrm{~W}$ with a warm frontal boundary extending to the northeast at 12Z. Microfilm shows a closed low pressure of at most $1005 \mathrm{mb}$ at $36.5 \mathrm{~N}, 76.0 \mathrm{~W}$ at 12Z. Ship highlights: $40 \mathrm{kt}$ SE and 1009 $\mathrm{mb}$ at $33.4 \mathrm{~N}, 73.4 \mathrm{~W}$ at $00 \mathrm{Z}$ (COADS). $40 \mathrm{kt} \mathrm{S}$ and $1001 \mathrm{mb}$ at $33.4 \mathrm{~N}, 74.2 \mathrm{~W}$ at $03 \mathrm{Z}$ (MWL). $40 \mathrm{kt} \mathrm{SSE}$ and $1015 \mathrm{mb}$ at 33.2N, 71.7W at 05Z (MWL). $40 \mathrm{kt} \mathrm{S}$ and $1016 \mathrm{mb}$ at $36.8 \mathrm{~N}, 72.5 \mathrm{~W}$ at $12 \mathrm{Z}$ (COADS). Land highlights: $40 \mathrm{kt}$ ESE and $1006 \mathrm{mb}$ at Diamond Shoals, NC at 06Z (micro). $11 \mathrm{kt} \mathrm{SE}$ and $1003 \mathrm{mb}$ at Cape Hatteras, NC at 0659Z (SWO). $20 \mathrm{kt} \mathrm{ENE} \mathrm{and} 1004 \mathrm{mb}$ at NAS Oceana, VA at 1058Z (SWO). $40 \mathrm{kt} \mathrm{ENE} \mathrm{and}$ $1006 \mathrm{mb}$ at Chesapeake Lightship, VA at 11Z (SWO). $35 \mathrm{kt} \mathrm{SSE}$ and $1011 \mathrm{mb}$ at Ocean City, MD at 18Z (micro/SWO). $14 \mathrm{kt} \mathrm{ENE} \mathrm{and} 1005 \mathrm{mb}$ at NAS Patuxent River, MD at 19Z (SWO). $12 \mathrm{kt}$ ENE and $1008 \mathrm{mb}$ at Baltimore, MD at 2156Z (SWO). $34 \mathrm{kt} \mathrm{NE}$ at Norfolk, VA (no time given) (CLIMO).

MWL: "The cyclone crossed over the Carolina Outer Banks before noon on the $3 \mathrm{~d}$ with a central pressure of $1004 \mathrm{mb}$ and continued in a generally northwesterly direction up the Chesapeake Bay while losing intensity. At Norfolk, Virginia a new all time 24-hourly precipitation record was set with $6.87 \mathrm{in}$. collected after 0650 EST on the $2 \mathrm{~d}$. The fastest mile recorded at Norfolk during the storm was $39 \mathrm{mph}$ registered on the $3 \mathrm{~d}$. Vessels encountering gale force winds off the southeastern United States coast in this tropical cyclone were mainly concentrated in the northeastern quadrant of the storm in the 5degree square between latitudes $30^{\circ}$ and $35^{\circ} \mathrm{N}$., longitudes $70^{\circ}$ and $75^{\circ} \mathrm{W}$ on the $2 \mathrm{~d}$ and $3 \mathrm{~d}$. They include the ALCOA POLARIS, ASTID ONSTAD, CHARIS, COMAYAGUA, CROWN TRADER, KENDALL FISH, RIVIERA PRIMA, and WORLD CHARITY." September Unnamed Storm MWR: "Each year several storms occur which are not entirely tropical in character. Tropical cyclones derive their energy from latent heat of condensation while extratropical cyclones depend upon proper positioning of cold and 
warm air masses; i.e., cold air sinks and spreads under warm air causing air motion. At times "half-breed" cyclones develop over tropical oceans and tap both energy sources. In these cases it is difficult to decide whether a tropical cyclone name should be assigned to the Low. The Unnamed Storm in September was of this type, as was the late May-early June storm."

June 4:

HWM analyzes a closed low pressure of $1015 \mathrm{mb}$ at $40.0 \mathrm{~N}, 78.0 \mathrm{~W}$ with a weakening warm frontal boundary extending to the northeast at $12 \mathrm{Z}$. Microfilm shows a closed low pressure of at most $1014 \mathrm{mb}$ at $40.0 \mathrm{~N}, 78.5 \mathrm{~W}$ at 12Z. Ship highlights: $9 \mathrm{kt}$ ESE and $1012 \mathrm{mb}$ at Harrisburg, PA at 0559Z (SWO). $10 \mathrm{kt} \mathrm{ESE} \mathrm{and} 1014 \mathrm{mb}$ at Philipsburg, PA at 1151Z (SWO).

MWL: "Late on the $4^{\text {th }}$ it dissipated over eastern Ohio."

A tropical disturbance developed over the southern Caribbean Sea late ion May and slowly moved northward. The system began to become better organized just south of Cuba late on May 31st, crossing the island early on June 1st as a trough over into the western Bahamas. A few ships reported gales over the eastern and northeastern quadrants on the 1st in its periphery due to the strong synoptic scale pressure gradient. Synoptic observations indicate that a well-defined center developed around $12 \mathrm{Z}$ on the June 2 nd. The first position is analyzed at $12 \mathrm{Z}$ on the $2 \mathrm{nd}$ as a 40 knot tropical storm based on a few ship reports of gale-force winds. COADS shows two ships at $12 \mathrm{Z}$ on the $2 \mathrm{nd}$ reporting $55 \mathrm{kt}$ in the northeast quadrant but MWL and microfilm indicate that it was only one ship. Furthermore, comparison with nearby ship data at $12 \mathrm{Z}$ on the 2 nd show that the $55 \mathrm{kt}$ reported is likely to have a $10-15 \mathrm{kt}$ high bias. At $2130 \mathrm{Z}$ on the $2 \mathrm{nd}$, a reconnaissance aircraft investigated the tropical storm measuring a central pressure of $1008 \mathrm{mb}$, which has been added to the $00 \mathrm{Z}$ time slot of June 3rd. On the 3rd, the tropical storm continued northward and a couple of ships reported gale-force winds, mainly over the northern and eastern quadrant where the pressure-gradient was the strongest. The tropical storm made landfall around $08 \mathrm{Z}$ on the 3rd, just west of Cape Hatteras, NC. Cape Hatteras, NC, reported $11 \mathrm{kt} \mathrm{SE}$ and $1003 \mathrm{mb}$ at $0659 \mathrm{Z}$ on the 3rd, suggesting a central pressure of $1002 \mathrm{mb}$, which has been added to the $06 \mathrm{Z}$ time slot. A central pressure of $1002 \mathrm{mb}$ suggests maximum surface winds of $40 \mathrm{kt}$ and $45 \mathrm{kt}$, from the north of $25 \mathrm{~N}$ Brown et al. and north of $35 \mathrm{~N}$ Landsea et al. pressure-wind relationships, respectively. Based on a forward speed of about $20 \mathrm{kt}$, an intensity of $50 \mathrm{kt}$ is analyzed at $06 \mathrm{Z}$ on the $3 \mathrm{rd}$ and at landfall. $50 \mathrm{kt}$ is also the peak intensity of this tropical cyclone. Diamond Shoals, NC, reported $40 \mathrm{kt} \mathrm{E}$ at $06 \mathrm{Z}$ on the $3 \mathrm{rd}$. The fast-moving tropical storm reached the coast of North Carolina around $08 \mathrm{Z}$ on the $3 \mathrm{rd}$ as a $50 \mathrm{kt}$ tropical storm. No gale-force winds were reported in the Outer Banks of North Carolina likely because the radius of maximum winds stayed offshore. However, some tropical storm force winds did occur farther north along the coast (see below) and it is analyzed that the strongest winds along the coast were about $40 \mathrm{kt}$. At $1058 \mathrm{Z}$ on the $3 \mathrm{rd}$, Oceana, VA, a coastal station, reported $20 \mathrm{kt}$ ENE and $1004 \mathrm{mb}$, suggesting a central pressure of $1002 \mathrm{mb}$, which has been added to the $12 \mathrm{Z}$ time slot. Late on the $3 \mathrm{rd}$, the tropical storm moved farther inland 
and began to weaken. Ocean City, MD, reported $35 \mathrm{kt} \mathrm{SSE}$ and $1011 \mathrm{mb}$ at $18 \mathrm{Z}$ on the 3rd. Norfolk, VA, reported $34 \mathrm{kt} \mathrm{NE}$ but the time is unknown. At 19Z on the 3rd, Patuxent River, MD, an inland station, reported $14 \mathrm{kt} \mathrm{ENE}$ and $1005 \mathrm{mb}$, suggesting a central pressure of $1002 \mathrm{mb}$, which has been added to the $18 \mathrm{Z}$ time slot. At $2156 \mathrm{Z}$ on the 3rd, Baltimore, MD, reported $12 \mathrm{kt} \mathrm{ENE}$ and $1008 \mathrm{mb}$, suggesting a central pressure of $1006 \mathrm{mb}$, which has been added to the $00 \mathrm{Z}$ time slot on June 4th. On the 4th, the tropical cyclone turned to the northwest and west and gradually lost strength. Weakening to a tropical depression is analyzed at $00 \mathrm{Z}$ on the 4th. At $0559 \mathrm{Z}$ on the 4th, Harrisburg, PA, reported $9 \mathrm{kt}$ ESE and $1012 \mathrm{mb}$, suggesting a central pressure of $1010 \mathrm{mb}$, which has been added to the $06 \mathrm{Z}$ time slot. At $1151 \mathrm{Z}$ on the 4th, Philipsburg, PA, reported $10 \mathrm{kt}$ ESE and $1014 \mathrm{mb}$, suggesting a central pressure of $1012 \mathrm{mb}$, which has been added to the $12 \mathrm{Z}$ time slot. Synoptic observations over the Ohio Valley after $12 \mathrm{Z}$ on the 4th indicate that the tropical cyclone had weakened to a trough of low pressure. The last position is analyzed at $12 \mathrm{Z}$ on the 4 th.

Hurricane Arlene [July 31 - August 12, 1963]

\begin{tabular}{|c|c|c|c|c|c|c|c|c|c|c|c|c|c|}
\hline $\begin{array}{l}42665 \\
42665\end{array}$ & $\begin{array}{l}07 / 31 / 196 \\
07 / 31 / 196\end{array}$ & $\begin{array}{l}3 M=1 \\
3 \quad M=1\end{array}$ & 1 & $\begin{array}{l}\text { SNBR }=9 \\
\text { SNBR }=9\end{array}$ & $\begin{array}{ll}24 & \mathrm{AP} \\
24 \mathrm{AP}\end{array}$ & $\begin{array}{l}\text { LENE } \\
\text { LENE }\end{array}$ & $\begin{array}{l}\text { XIN } \\
\text { XIN }\end{array}$ & $\begin{array}{l}J G=\odot \\
J G=\odot\end{array}$ & $\begin{array}{l}\text { SSS }= \\
\text { SSS }=\end{array}$ & & & & \\
\hline 42670 & $07 / 31$ * $\odot$ & $\odot$ & $\odot$ & $\Theta^{*}$ & $\odot$ & $\odot$ & $\odot^{*}$ & $\odot$ & $\odot$ & $\odot * 110$ & 394 & 25 & ०* \\
\hline 42675 & $08 / 01 * 110$ & 409 & 25 & $0 * 111$ & 422 & 25 & $0 * 112$ & 435 & 25 & $0 * 113$ & 448 & 30 & ०* \\
\hline 42675 & $08 / 01 * 110$ & 409 & 25 & $0 * 111$ & 422 & $\begin{array}{l}30 \\
* *\end{array}$ & ๑*112 & 435 & $\begin{array}{l}35 \\
* *\end{array}$ & $\begin{array}{r}\odot * 114 \\
* * *\end{array}$ & 448 & $\begin{array}{l}45 \\
* *\end{array}$ & $0^{*}$ \\
\hline $\begin{array}{l}42680 \\
42680\end{array}$ & $\begin{array}{r}08 / 02 * 115 \\
08 / 02 * 118 \\
* * *\end{array}$ & $\begin{array}{l}460 \\
461 \\
\star * *\end{array}$ & $\begin{array}{l}40 \\
55 \\
\star *\end{array}$ & $\begin{array}{l}0 * 124 \\
0 * 124\end{array}$ & $\begin{array}{l}474 \\
474\end{array}$ & $\begin{array}{l}50 \\
65 \\
* *\end{array}$ & $\begin{array}{l}0 * 133 \\
0 * 133\end{array}$ & $\begin{array}{l}487 \\
487\end{array}$ & $\begin{array}{l}70 \\
75 \\
* *\end{array}$ & $\begin{array}{l}\Theta * 143 \\
0 * 143\end{array}$ & $\begin{array}{l}499 \\
499\end{array}$ & $\begin{array}{l}90 \\
75 \\
* *\end{array}$ & $\begin{array}{l}987^{*} \\
987^{*}\end{array}$ \\
\hline $\begin{array}{l}42685 \\
42685\end{array}$ & $\begin{array}{l}\odot 8 / 03 * 149 \\
08 / 03 * 149\end{array}$ & $\begin{array}{l}508 \\
511 \\
\star * *\end{array}$ & $\begin{array}{l}80 \\
65 \\
\star *\end{array}$ & $\begin{array}{l}996 * 152 \\
996 * 152\end{array}$ & $\begin{array}{l}523 \\
524 \\
* * *\end{array}$ & $\begin{array}{l}65 \\
65\end{array}$ & $\begin{array}{l}\odot * 155 \\
\odot * 155\end{array}$ & $\begin{array}{l}539 \\
539\end{array}$ & $\begin{array}{l}65 \\
70 \\
* *\end{array}$ & $\begin{array}{l}1000 * 159 \\
0^{*} 159 \\
*\end{array}$ & $\begin{array}{l}553 \\
553\end{array}$ & $\begin{array}{l}65 \\
75 \\
* *\end{array}$ & $\begin{array}{l}988^{*} \\
988^{*}\end{array}$ \\
\hline $\begin{array}{l}42690 \\
42690\end{array}$ & $\begin{array}{l}08 / 04 * 163 \\
08 / 04 * 163\end{array}$ & $\begin{array}{l}567 \\
567\end{array}$ & $\begin{array}{l}50 \\
65 \\
* *\end{array}$ & $\begin{array}{r}\odot * 167 \\
\odot * 17 \odot \\
* * *\end{array}$ & $\begin{array}{l}580 \\
580\end{array}$ & $\begin{array}{l}45 \\
50 \\
* *\end{array}$ & $\begin{array}{r}\odot * 174 \\
\odot * 179 \\
* \star *\end{array}$ & $\begin{array}{l}592 \\
594 \\
\star * *\end{array}$ & $\begin{array}{l}30 \\
35 \\
* *\end{array}$ & $\begin{array}{r}1007 * 182 \\
0 * 190 \\
* \quad * * *\end{array}$ & $\begin{array}{l}603 \\
607 \\
* * *\end{array}$ & $\begin{array}{l}30 \\
30\end{array}$ & $\begin{array}{l}0^{*} \\
0^{*}\end{array}$ \\
\hline $\begin{array}{l}42695 \\
42695\end{array}$ & $\begin{array}{r}08 / 05 * 191 \\
08 / 05 * 20 \odot \\
* * *\end{array}$ & $\begin{array}{l}614 \\
620 \\
* * *\end{array}$ & $\begin{array}{l}30 \\
30\end{array}$ & $\begin{array}{r}\odot * 2 \odot \odot \\
\odot * 2 \odot 7 \\
* * *\end{array}$ & $\begin{array}{l}625 \\
632 \\
* * *\end{array}$ & $\begin{array}{l}25 \\
25\end{array}$ & $\begin{array}{l}0 * 210 \\
0 * 214 \\
* \star *\end{array}$ & $\begin{array}{l}636 \\
642 \\
* * *\end{array}$ & $\begin{array}{l}25 \\
25\end{array}$ & $\begin{array}{c}1011 * 220 \\
0^{*} 220 \\
*\end{array}$ & $\begin{array}{l}646 \\
652 \\
\star * *\end{array}$ & $\begin{array}{l}25 \\
25\end{array}$ & $\begin{array}{l}0^{*} \\
0^{*}\end{array}$ \\
\hline $\begin{array}{l}42700 \\
4270 \odot\end{array}$ & $\begin{array}{c}08 / 06 * 228 \\
08 / 06 \mathrm{~W} 228 \\
\star\end{array}$ & $\begin{array}{l}656 \\
662 \\
\star \star \star\end{array}$ & $\begin{array}{l}25 \\
25\end{array}$ & $\begin{array}{l}\text { ๑*235 } \\
\text { OW235 } \\
\star\end{array}$ & $\begin{array}{l}667 \\
671 \\
\star * *\end{array}$ & $\begin{array}{l}25 \\
25\end{array}$ & $\begin{array}{l}\odot * 240 \\
\text { OW240 } \\
\star\end{array}$ & $\begin{array}{l}680 \\
680\end{array}$ & $\begin{array}{l}25 \\
25\end{array}$ & $\begin{array}{r}1012 * 244 \\
1012 W 245 \\
* * * *\end{array}$ & $\begin{array}{l}688 \\
688\end{array}$ & $\begin{array}{l}30 \\
30\end{array}$ & $\begin{array}{l}0^{*} \\
0^{*}\end{array}$ \\
\hline $\begin{array}{l}42705 \\
42705\end{array}$ & $\begin{array}{l}\odot 8 / 07 * 25 \odot \\
\odot 8 / 07 * 25 \odot\end{array}$ & $\begin{array}{l}695 \\
695\end{array}$ & $\begin{array}{l}30 \\
30\end{array}$ & $\begin{array}{r}\Theta^{*} 254 \\
\Theta^{*} 257 \\
* * *\end{array}$ & $\begin{array}{l}701 \\
701\end{array}$ & $\begin{array}{l}30 \\
30\end{array}$ & $\begin{array}{r}\Theta * 260 \\
\Theta * 264 \\
\star \star \star\end{array}$ & $\begin{array}{l}703 \\
703\end{array}$ & $\begin{array}{l}30 \\
30\end{array}$ & $\begin{array}{r}\Theta * 265 \\
\Theta * 27 \odot \\
\star * \star *\end{array}$ & $\begin{array}{l}7 \odot 4 \\
7 \odot 4\end{array}$ & $\begin{array}{l}30 \\
35 \\
* *\end{array}$ & $\begin{array}{l}\Theta^{*} \\
\Theta^{*}\end{array}$ \\
\hline $\begin{array}{l}42710 \\
42710\end{array}$ & $\begin{array}{r}08 / 08 * 273 \\
08 / 08 * 275 \\
* * *\end{array}$ & $\begin{array}{l}705 \\
704 \\
\star * *\end{array}$ & $\begin{array}{l}55 \\
45 \\
\star *\end{array}$ & $\begin{array}{r}\Theta * 280 \\
\Theta^{*} 279 \\
* * *\end{array}$ & $\begin{array}{l}701 \\
703 \\
\star * *\end{array}$ & $\begin{array}{l}60 \\
55 \\
\star *\end{array}$ & $\begin{array}{c}\Theta * 285 \\
\Theta * 283 \\
* \star *\end{array}$ & $\begin{array}{l}697 \\
699 \\
\star \star *\end{array}$ & $\begin{array}{l}65 \\
65\end{array}$ & $\begin{array}{l}981 * 288 \\
992 * 287 \\
\star * * * * *\end{array}$ & $\begin{array}{l}691 \\
693 \\
\star * *\end{array}$ & $\begin{array}{l}65 \\
75 \\
* *\end{array}$ & $\begin{array}{l}981^{*} \\
981^{*}\end{array}$ \\
\hline $\begin{array}{l}42715 \\
42715\end{array}$ & $\begin{array}{l}\odot 8 / 09 * 293 \\
\odot 8 / 09 * 293\end{array}$ & $\begin{array}{l}685 \\
685\end{array}$ & $\begin{array}{l}65 \\
75\end{array}$ & $\begin{array}{l}\odot * 300 \\
\odot * 30 \odot\end{array}$ & $\begin{array}{l}676 \\
676\end{array}$ & $\begin{array}{l}70 \\
80\end{array}$ & $\begin{array}{l}0 * 313 \\
0 * 313\end{array}$ & $\begin{array}{l}662 \\
662\end{array}$ & $\begin{array}{l}75 \\
9 \odot\end{array}$ & $\begin{array}{l}979 * 328 \\
979 * 328\end{array}$ & $\begin{array}{l}640 \\
640\end{array}$ & $\begin{array}{r}90 \\
100\end{array}$ & $\begin{array}{l}974^{*} \\
970^{*}\end{array}$ \\
\hline
\end{tabular}




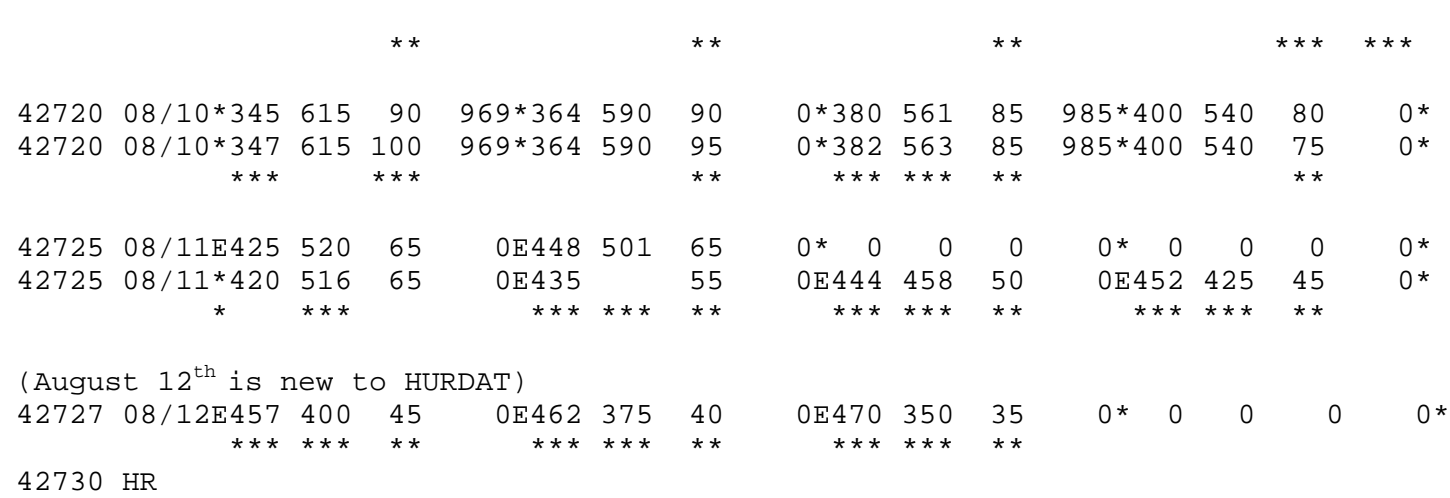

Hurricane Landfall

08/09 1530Z 32.3N 64.8W 95 kt Bermuda - 975 mb

Minor changes to the track and intensity shown in McAdie et al. (2009). Major alterations are to show a tropical wave stage on August $6^{\text {th }}$ and to add 30 hours to the track as an extratropical cyclone. Evidence for these alterations comes from the NHC microfilm maps, the Historical Weather Maps series, the COADS ship database, Monthly Weather Review, Navy reconnaissance book, Mariners Weather Log, Tucker (1996), Allison \& Thompson (1966) and NHC Storm Wallets.

July 30:

HWM and microfilm do not analyze an organized system at 12Z. HURDAT does not list an organized system on this date. Ship highlights: No gales or low pressures.

July 31 :

HWM analyzes a spot low pressure at $10.8 \mathrm{~N}, 38.8 \mathrm{~W}$ at $12 \mathrm{Z}$. HURDAT lists a 25 kt tropical depression at $11.0 \mathrm{~N}, 39.4 \mathrm{~W}$ at $18 \mathrm{Z}$ (first position). Microfilm does not show an organized system on this date. Ship highlights: No gales or low pressures.

MWR: "A cloud mass first detected in the mid-Atlantic by the TIROS VI satellite at 1505 GMT July 31, was undoubtedly Arlene in her embryonic tropical depression stage." ATSR: "Hurricane ARLENE began formation in the tropical Atlantic near $11 \mathrm{~N} 39 \mathrm{~W}$. An area of unusual cloudiness detected by TIROS VI at $1505 \mathrm{Z}$ on 31 July was beyond the range of reconnaissance aircraft."

August 1:

HWM analyzes a closed low pressure of at most $1005 \mathrm{mb}$ at $11.1 \mathrm{~N}, 43.8 \mathrm{~W}$ at 12Z. HURDAT lists a $25 \mathrm{kt}$ tropical depression at $11.2 \mathrm{~N}, 43.5 \mathrm{~W}$ at $12 \mathrm{Z}$. Microfilm shows a tropical wave at $45 \mathrm{~W}$ at $12 \mathrm{Z}$. Ship highlights: No gales or low pressures.

August 2:

HWM analyzes a hurricane of at most $1000 \mathrm{mb}$ at $13.5 \mathrm{~N}, 48.5 \mathrm{~W}$ at $12 \mathrm{Z}$. HURDAT lists a $70 \mathrm{kt}$ hurricane at $13.3 \mathrm{~N}, 48.7 \mathrm{~W}$ at $12 \mathrm{Z}$. Microfilm shows a closed low pressure of at most $1008 \mathrm{mb}$ at $12.5 \mathrm{~N}, 49.5 \mathrm{~W}$ at $12 \mathrm{Z}$. Ship highlights: No gales or low 
pressures. Aircraft highlights: Penetration center fix measured a central pressure of 987 $\mathrm{mb}$, estimated surface winds of $85 \mathrm{kt}$ and an eye diameter of $18 \mathrm{~nm}$ at $14.2 \mathrm{~N}, 49.8 \mathrm{~W}$ at $1642 \mathrm{Z}$ (ATSR). Penetration center fix estimated flight level winds of $54 \mathrm{kt}$ at $14.8 \mathrm{~N}$, $50.7 \mathrm{~W}$ at $2338 \mathrm{Z}$ (ATSR).

MWR: "Too far away then for immediate air reconnaissance, the Navy as a fully developed hurricane at 1642 GMT located it August 2 at $14.2^{\circ}$ N., $49.8^{\circ} \mathrm{W}$. During the preceding night the Mormactrader passed very close to Arlene. Although a complete ship's log is not available, an examination of her excellent 6-hourly reports indicates that the cyclone had just reached tropical storm intensity. It is estimated that Arlene intensified from storm to Hurricane force within $12 \mathrm{hr}$., a rather rapid development." ATSR: "It was determined that a normal westerly movement would bring the cloud mass within striking distance of the reconnaissance aircraft on 2 August. Departing Roosevelt Roads at first light, a Navy reconnaissance aircraft investigated the area and by $1642 \mathrm{Z}$ had located fully developed Hurricane ARLENE at 14.2N 49.8W. The first warning on Hurricane ARLENE was issued at 021800Z. Maximum winds were 85 knots."

August 3:

HWM analyzes a hurricane of at most $1000 \mathrm{mb}$ at $15.8 \mathrm{~N}, 53.8 \mathrm{~W}$ at $12 \mathrm{Z}$. HURDAT lists a $65 \mathrm{kt}$ hurricane at $15.5 \mathrm{~N}, 53.9 \mathrm{~W}$ at $12 \mathrm{Z}$. Microfilm shows a closed low pressure of at most $1011 \mathrm{mb}$ at $15.0 \mathrm{~N}, 52.5 \mathrm{~W}$ at 12Z. Ship highlights: No gales or low pressures. Aircraft highlights: Penetration center fix measured a central pressure of 996 $\mathrm{mb}$, estimated flight level winds of $82 \mathrm{kt}$ and an eye diameter of $12 \mathrm{~nm}$ at $14.9 \mathrm{~N}, 50.9 \mathrm{~W}$ at $01 Z$ (ATSR). Penetration center fix measured a central pressure of $1000 \mathrm{mb}$ and estimated surface winds of $55 \mathrm{kt}$ at $15.6 \mathrm{~N}, 54.7 \mathrm{~W}$ at $14 \mathrm{Z}$ (WALLET). Penetration center fix measured a central pressure of $988 \mathrm{mb}$, estimated surface winds of $110 \mathrm{kt}$ and an eye diameter of $25 \mathrm{~nm}$ at $16.1 \mathrm{~N}, 55.4 \mathrm{~W}$ at $1803 \mathrm{Z}$ (ATSR).

MWR: "Three different flights, which penetrated the cyclone during the next 26-hr period, reported hurricane-force winds. Based upon the surface pressures taken from the dropsondes, various pressure-wind graphs would support most of the Hurricane-force winds reported by the aircraft. There is no doubt it was a well-developed hurricane, and was so described by the plane's meteorologist, yet rapid deterioration of the eye structure as well as a reduction of winds took place during the night of August 3-4 in an area where this rarely occurs..." ATSR: "Subsequent reconnaissance flights throughout 2 and 3 august indicated that ARLENE was maintaining hurricane intensity and moving northwestward."

August 4:

HWM analyzes a tropical storm of at most $1010 \mathrm{mb}$ at $17.6 \mathrm{~N}, 59.0 \mathrm{~W}$ at $12 \mathrm{Z}$. HURDAT lists a $30 \mathrm{kt}$ tropical depression at $17.4 \mathrm{~N}, 59.2 \mathrm{~W}$ at $12 \mathrm{Z}$. Microfilm shows a closed low pressure of at most $1005 \mathrm{mb}$ at $18.6 \mathrm{~N}, 60.4 \mathrm{~W}$ at 12Z. Ship highlights: No gales or low pressures. Aircraft highlights: Radar center fix estimated an eye diameter of $23 \mathrm{~nm}$ at $15.6 \mathrm{~N}, 55.8 \mathrm{~W}$ at $0248 \mathrm{Z}$ (WALLET). Radar center fix measured a peripheral pressure of $1004 \mathrm{mb}$ and estimated surface winds of $60 \mathrm{kt}$ at $15.6 \mathrm{~N}, 57.9 \mathrm{~W}$ at $0630 \mathrm{Z}$ (WALLET). 
MWR: "and by midday of the $4^{\text {th }}$ Arlene was, at most, a tropical depression." ATSR: "However, during the night of 3 August, ARLENE rapidly weakened and by $041600 Z$ was a moderate tropical depression."

August 5:

HWM analyzes a closed low pressure of at most $1010 \mathrm{mb}$ at $20.8 \mathrm{~N}, 63.7 \mathrm{~W}$ at $12 \mathrm{Z}$. HURDAT lists a $25 \mathrm{kt}$ tropical depression at $21.0 \mathrm{~N}, 63.6 \mathrm{~W}$ at $12 \mathrm{Z}$. Microfilm shows a closed low pressure of at most $1011 \mathrm{mb}$ at $21.5 \mathrm{~N}, 64.8 \mathrm{~W}$ at $12 \mathrm{Z}$. Ship highlights: $40 \mathrm{kt} \mathrm{SW}$ at $22.5 \mathrm{~N}, 64.0 \mathrm{~W}$ at $18 \mathrm{Z}$ (micro).

ATSR: "Further weakening occurred and by 050400Z ARLENE's winds were less than 25 knots. The reason for this weakening was not fully understood at the time, but postanalyses indicate that troughing at $200 \mathrm{mbs}$ in the storm area had a "damping" effect on the storm's outflow. During the period 5-7 August, ARLENE remained a weak tropical depression, moving northwestward to a point approximately 550 miles east of the southern tip of Florida."

August 6:

HWM analyzes a closed low pressure of at most $1015 \mathrm{mb}$ at $23.8 \mathrm{~N}, 68.8 \mathrm{~W}$ at 12Z. HURDAT lists a $25 \mathrm{kt}$ tropical depression at $24.0 \mathrm{~N}, 68.0 \mathrm{~W}$ at $12 \mathrm{Z}$. Microfilm shows a closed low pressure of at most $1014 \mathrm{mb}$ at $23.8 \mathrm{~N}, 68.3 \mathrm{~W}$ at $12 \mathrm{Z}$. Ship highlights: No gales or low pressures.

August 7:

HWM analyzes a closed low pressure of at most $1015 \mathrm{mb}$ at $26.5 \mathrm{~N}, 70.0 \mathrm{~W}$ with a warm front to the north at 12Z. HURDAT lists a $30 \mathrm{kt}$ tropical depression at $26.0 \mathrm{~N}$, $70.3 \mathrm{~W}$ at $12 \mathrm{Z}$. Microfilm shows a closed low pressure of at most $1014 \mathrm{mb}$ at $28.0 \mathrm{~N}$, $69.0 \mathrm{~W}$ with a frontal boundary to the north at 12Z. Ship highlights: $15 \mathrm{kt} \mathrm{SSE}$ and 1005 $\mathrm{mb}$ at $28.9 \mathrm{~N}, 69.4 \mathrm{~W}$ at $12 \mathrm{Z}$ (COADS). $35 \mathrm{kt} \mathrm{S}$ and $1012 \mathrm{mb}$ at $27.0 \mathrm{~N}, 70.0 \mathrm{~W}$ at $18 \mathrm{Z}$ (COADS).

MWR: "Tropical depression intensity was maintained through August 7, mainly, it is believed, as it reflection of a circulation aloft which seemed to persist throughout this degenerate stage, although at times the surface perturbation appeared to be nothing more than a disturbed area."

August 8:

HWM analyzes a tropical storm of at most $1005 \mathrm{mb}$ at $28.5 \mathrm{~N}, 69.5 \mathrm{~W}$ with a cold front far to the northwest and a warm front to the north at 12Z. HURDAT lists a $65 \mathrm{kt}$ hurricane at $28.5 \mathrm{~N}, 69.7 \mathrm{~W}$ at $12 \mathrm{Z}$. Microfilm shows a closed low pressure of at most $1011 \mathrm{mb}$ at $28.5 \mathrm{~N}, 69.7 \mathrm{~W}$ at $12 \mathrm{Z}$. Ship highlights: $45 \mathrm{kt} \mathrm{SSW}$ and $1009 \mathrm{mb}$ at $27.4 \mathrm{~N}$, $70.0 \mathrm{~W}$ at $00 \mathrm{Z}$ (COADS). $15 \mathrm{kt} \mathrm{NW}$ and $1002 \mathrm{mb}$ at $27.5 \mathrm{~N}, 72.8 \mathrm{~W}$ at $06 \mathrm{Z}$ (COADS). 55 $\mathrm{kt} \mathrm{S}$ and $1000 \mathrm{mb}$ at $28.5 \mathrm{~N}, 69.2 \mathrm{~W}$ at $18 \mathrm{Z}$ (COADS). Aircraft highlights: Penetration center fix measured a central pressure of $992 \mathrm{mb}$ and estimated an eye diameter of $20 \mathrm{~nm}$ at $28.6 \mathrm{~N}, 69.6 \mathrm{~W}$ at $1357 \mathrm{Z}$ (WALLET). Penetration center fix measured a central pressure of $981 \mathrm{mb}$, estimated surface winds of $65 \mathrm{kt}$ and an eye diameter of $22 \mathrm{~nm}$ at $28.8 \mathrm{~N}$, 
69.3W at 19Z (ATSR). Penetration center fix estimated surface winds of $65 \mathrm{kt}$ at $29.1 \mathrm{~N}$, $68.8 \mathrm{~W}$ at $2230 \mathrm{Z}$ (WALLET).

MWR: "Ship reports during the late evening of the 7th indicated that Arlene was once again a tropical storm and by 1357 GMT August 8, an Air Force plane penetrated the center. The eye was well defined and maximum surface winds were estimated at $75 \mathrm{mph}$. A rather unusual type of fix and a very excellent one was obtained by radar from the USS Lawrence just prior to the Air Force plane penetration. Except for an increase in forward speed, Arlene changed little during the night and early morning hours of August 8-9." ATSR: "By 080400Z, however, ship reports indicated that ARLENE was reintensifying, and a tropical storm warning was issued at 080500Z. Reintensification continued and by 081600Z ARLENE was again a hurricane. By this time, she had commenced recurvature and the eye subsequently passed over Bermuda at 091600Z. Maximum winds recorded in Bermuda were gust to 84 knots."

August 9:

HWM analyzes a hurricane of at most $1000 \mathrm{mb}$ at $31.5 \mathrm{~N}, 66.4 \mathrm{~W}$ with a cold front just to the northwest at 12Z. HURDAT lists a $75 \mathrm{kt}$ hurricane at $31.3 \mathrm{~N}, 66.2 \mathrm{~W}$ at $12 \mathrm{Z}$. Microfilm shows a closed low pressure of at most $1008 \mathrm{mb}$ at $31.3 \mathrm{~N}, 66.1 \mathrm{~W}$ with a frontal boundary to the north at 12Z. Ship highlights: $70 \mathrm{kt} \mathrm{SW}$ and $991 \mathrm{mb}$ at $28.9 \mathrm{~N}$, 68.7W at $00 \mathrm{Z}$ (micro). $45 \mathrm{kt} \mathrm{WSW}$ and $1007 \mathrm{mb}$ at $29.2 \mathrm{~N}, 67.6 \mathrm{~W}$ at $09 \mathrm{Z}$ (COADS). 35 kt SW and $1011 \mathrm{mb}$ at $29.3 \mathrm{~N}, 67.0 \mathrm{~W}$ at $12 \mathrm{Z}$ (COADS). $35 \mathrm{kt} \mathrm{S}$ and $1011 \mathrm{mb}$ at $31.4 \mathrm{~N}$, $62.7 \mathrm{~W}$ at $18 \mathrm{Z}$ (COADS). $40 \mathrm{kt} \mathrm{SW}$ and $1006 \mathrm{mb}$ at $32.6 \mathrm{~N}, 61.9 \mathrm{~W}$ at $21 \mathrm{Z}$ (micro). Land highlights: $975 \mathrm{mb}$ at Kindley Air Force Base, Bermuda near 16Z (WALLET). $60 \mathrm{kt}$ (gusts to $85 \mathrm{kt}$ ) at Kindley Air Force Base, Bermuda near 16Z (WALLET). Aircraft highlights: Radar center fix at 30.1N, 67.4W at 0611Z (WALLET). Penetration center fix measured a central pressure of $979 \mathrm{mb}$, estimated surface winds of $65 \mathrm{kt}$ and an eye diameter of $20 \mathrm{~nm}$ at $30.9 \mathrm{~N}, 66.8 \mathrm{~W}$ at $1005 \mathrm{Z}$ (WALLET). Penetration center fix measured a central pressure of $982 \mathrm{mb}$, estimated surface winds of $65 \mathrm{kt}$ and an eye diameter of $8 \mathrm{~nm}$ at $31.4 \mathrm{~N}, 66.0 \mathrm{~W}$ at $1220 \mathrm{Z}$ (WALLET). Penetration center fix measured a central pressure of $970 \mathrm{mb}$ and estimated surface winds of $100 \mathrm{kt}$ at $33.0 \mathrm{~N}, 63.6 \mathrm{~W}$ at $19 Z$ (WALLET). Penetration center fix measured a central pressure of $969 \mathrm{mb}$, estimated surface winds of $115 \mathrm{kt}$ and an eye diameter of $20-30 \mathrm{~nm}$ at $34.1 \mathrm{~N}, 62.5 \mathrm{~W}$ at $22 \mathrm{Z}$ (WALLET).

MWR: "The eye passed over Bermuda at 1600 GMT and observers there were able to obtain an eye sounding. Temperatures in the eye, at least in the lower and middle troposphere, were quite similar to those obtained in the eye of an October hurricane at Tampa in 1944. Temperatures at higher levels in the Bermuda sounding were considerably lower than in the Tampa sounding. As observed winds aloft indicate, the radiosonde did not remain within the eye throughout its flight. There were no lives lost at Bermuda although there was $\$ 300,000$ property damage. The lowest pressure was 28.78 in. or $974.5 \mathrm{mb}$, while rainfall was 2.69 in. Highest winds at Bermuda were from the eastsoutheast, $69 \mathrm{mph}$, with gusts to $98 \mathrm{mph}$, and tides were estimated at $4 \mathrm{ft}$. above normal."

August 10: 
HWM analyzes a hurricane of at most $990 \mathrm{mb}$ at 38.8N, 56.2W with a weakening cold front just to the west and a warm front to the north at 12Z. HURDAT lists an $85 \mathrm{kt}$ hurricane at $38.0 \mathrm{~N}, 56.1 \mathrm{~W}$ at $12 \mathrm{Z}$. Microfilm shows a closed low pressure of at most $1005 \mathrm{mb}$ at $38.3 \mathrm{~N}, 55.7 \mathrm{~W}$ with an extratropical cyclone just to the northwest at 12Z. Ship highlights: $45 \mathrm{kt} \mathrm{SSW}$ and $1010 \mathrm{mb}$ at $32.7 \mathrm{~N}, 60.4 \mathrm{~W}$ at $00 \mathrm{Z}$ (COADS). $40 \mathrm{kt} \mathrm{S}$ and 1015 $\mathrm{mb}$ at $38.0 \mathrm{~N}, 49.2 \mathrm{~W}$ at $18 \mathrm{Z}$ (COADS). $45 \mathrm{kt} \mathrm{E}$ and $1005 \mathrm{mb}$ at $45.9 \mathrm{~N}, 40.6 \mathrm{~W}$ at $21 \mathrm{Z}$ (COADS/micro). Aircraft highlights: Penetration center fix at $34.8 \mathrm{~N}, 61.3 \mathrm{~W}$ at $01 \mathrm{Z}$ (WALLET). Penetration center fix measured a central pressure of $985 \mathrm{mb}$, estimated surface winds of $75 \mathrm{kt}$ and an eye diameter of $15 \mathrm{~nm}$ at $38.6 \mathrm{~N}, 55.3 \mathrm{~W}$ at $1340 \mathrm{Z}$ (WALLET). Penetration center fix at 40.4N, 53.7W at 19Z (WALLET).

MWR: "After leaving Bermuda, Arlene moved on a northward course and probably increased slightly in intensity for a short while, only to weaken a bit on the $10^{\text {th }}$."

August 11:

HWM analyzes an extratropical cyclone of at most $1005 \mathrm{mb}$ at $50.0 \mathrm{~N}, 50.0 \mathrm{~W}$ with frontal boundaries extending to the southeast and southwest at 12Z. HURDAT lists a $65 \mathrm{kt}$ extratropical cyclone at $44.8 \mathrm{~N}, 50.1 \mathrm{~W}$ at $06 \mathrm{Z}$ (last position). Microfilm shows a closed low pressure of at most $1002 \mathrm{mb}$ at $39.0 \mathrm{~N}, 45.4 \mathrm{~W}$ with an extratropical cyclone to the northwest at 12Z. Ship highlights: $40 \mathrm{kt} \mathrm{SW}$ and $1018 \mathrm{mb}$ at $36.2 \mathrm{~N}, 47.0 \mathrm{~W}$ at $00 \mathrm{Z}$ (COADS). $5 \mathrm{kt} \mathrm{SE}$ and $1003 \mathrm{mb}$ at $44.2 \mathrm{~N}, 48.3 \mathrm{~W}$ at $06 \mathrm{Z}$ (COADS). $35 \mathrm{kt} \mathrm{SW}$ and 1010 $\mathrm{mb}$ at $43.0 \mathrm{~N}, 43.9 \mathrm{~W}$ at $12 \mathrm{Z}$ (COADS). $35 \mathrm{kt} \mathrm{WNW}$ and $1008 \mathrm{mb}$ at $44.5 \mathrm{~N}, 45.0 \mathrm{~W}$ at $15 \mathrm{Z}$ (COADS). $35 \mathrm{kt} \mathrm{WNW}$ and $1001 \mathrm{mb}$ at $45.1 \mathrm{~N}, 43.0 \mathrm{~W}$ at $18 \mathrm{Z}$ (COADS).

MWR: "During the night of August 10-11, it quickly lost tropical characteristics and merged with a polar front some 200 mi. southeast of Cape Race, Newfoundland." ATSR: "After passing Bermuda, ARLENE continued on a northeasterly course and finally lost all tropical characteristics during the night of 10 August as the storm came under the influence of a cool air mass and low sea temperatures."

August 12:

HWM analyzes an extratropical cyclone of at most $1015 \mathrm{mb}$ at $42.0 \mathrm{~N}, 23.0 \mathrm{~W}$ at 12Z. HURDAT does not list an organized storm on this date. Microfilm shows an extratropical cyclone of at most $1017 \mathrm{mb}$ at $43.0 \mathrm{~N}, 35.0 \mathrm{~W}$ at $12 \mathrm{Z}$. Ship highlights: $40 \mathrm{kt}$ $\mathrm{E}$ and $1013 \mathrm{mb}$ at $46.4 \mathrm{~N}, 38.9 \mathrm{~W}$ at $00 \mathrm{Z}$ (COADS). $35 \mathrm{kt} \mathrm{W}$ and $1017 \mathrm{mb}$ at $41.7 \mathrm{~N}$, $38.2 \mathrm{~W}$ at $12 \mathrm{Z}$ (COADS).

Hurricane Arlene developed from a tropical wave that left the African coast around July $27^{\text {th }}$. The disturbance moved westward across the far eastern Atlantic where the ship data is sparse. Time of genesis is uncertain and it is retained from the original HURDAT at $18 \mathrm{Z}$ on July $31^{\text {st }}$ as a $25 \mathrm{kt}$ tropical depression. Minor track alterations are shown during the lifetime of this tropical cyclone. At $18 \mathrm{Z}$ on the $31^{\text {st }}$, microfilm shows a nephanalysis of a TIROS satellite image that captured the system, indicating a large area of convection around the estimated position. The tropical depression continued moving westward on the August $1^{\text {st }}$ and another satellite image appears as a nephanalysis at $18 \mathrm{Z}$ on this date but only captured the eastern half of the system. Intensification to a tropical storm is analyzed 
at $12 \mathrm{Z}$ on the $1^{\text {st }}$, twelve hours earlier than originally shown in HURDAT, based on aircraft reconnaissance data on August $2^{\text {nd }}$. A ship moved across the tropical cyclone early on the $2^{\text {nd }}$, showing a distinctive shift in the winds, and it is the first confirmation that a closed low-level circulation was present. The first reconnaissance aircraft to investigate Arlene on the $2^{\text {nd }}$ measured a central pressure of $987 \mathrm{mb}$, estimated surface winds of $85 \mathrm{kt}$ and an eye diameter of $18 \mathrm{~nm}$ at 1642Z. A central pressure of $987 \mathrm{mb}$ suggests maximum surface winds of $68 \mathrm{kt}$ from the Brown et al. south of $25 \mathrm{~N}$ pressurewind relationship. An eye diameter of $18 \mathrm{~nm}$ suggests an RMW of about $14 \mathrm{~nm}$ and the climatological value is 13 . Based on a blend of the pressure-wind relationship and the estimated surface wind, an intensity of $75 \mathrm{kt}$ is selected at $18 \mathrm{Z}$ on the $2^{\text {nd }}$, down from 90 kt originally in HURDAT, a minor intensity change. Intensification to a hurricane is analyzed at $06 \mathrm{Z}$ on the $2^{\text {nd }}$, six hours earlier than originally shown in HURDAT, as HURDAT showed - without justification - a very rapid intensification which is now smoothed out. (Some central pressures values were present in the original HURDAT between August $2^{\text {nd }}$ at $18 \mathrm{Z}$ and August $10^{\text {th }}$ at $12 \mathrm{Z}$. Some of these were in the wrong time slots or not accurate. Thus, based on actual observations, some were retained, others removed and new central pressure values added. Detailed information on these changes can be found in the table at the end.) The next penetration center fix measured a central pressure of $996 \mathrm{mb}$, estimated surface winds of $82 \mathrm{kt}$ and an eye diameter of $12 \mathrm{~nm}$ at $01 \mathrm{Z}$ on August $3^{\text {rd }}$. A central pressure of $996 \mathrm{mb}$ suggests maximum surface winds of 55 kt from the weakening subset south of $25 \mathrm{~N}$ pressure-wind relationship. An eye diameter of $12 \mathrm{~nm}$ suggests an RMW of about $9 \mathrm{~nm}$ and the climatological value is 14 . Based on a fast forward speed of about $15 \mathrm{kt}$ and a blend of the other values, an intensity of $65 \mathrm{kt}$ is selected at $00 \mathrm{Z}$ on the $3^{\text {rd }}$, down from $80 \mathrm{kt}$ originally in HURDAT, a minor intensity change. The next reconnaissance aircraft reached Arlene late on the $3^{\text {rd }}$ and the measurements obtained show some irregularities. At $14 \mathrm{Z}$ on the $3^{\text {rd }}$, a center penetration fix measured a central pressure of $1000 \mathrm{mb}$ and estimated surface winds of $55 \mathrm{kt}$. Four hours later, at $1803 \mathrm{Z}$ on the $3^{\text {rd }}$, a center penetration fix measured a central pressure of $988 \mathrm{mb}$, estimated surface winds of $110 \mathrm{kt}$ and an eye diameter of $25 \mathrm{~nm}$. Based upon the data available, it is difficult to determine which measurement is incorrect, but based on the estimated surface winds, the measurement at $1803 \mathrm{Z}$ on the $3^{\text {rd }}$ appears to be correct and has been retained. A central pressure of $988 \mathrm{mb}$ suggests maximum surface winds of $67 \mathrm{kt}$ from the south of $25 \mathrm{~N}$ pressure-wind relationship. An eye diameter of $25 \mathrm{~nm}$ suggests an RMW of about $19 \mathrm{~nm}$ and the climatological value is 14 . Based on a quick forward speed of about $14 \mathrm{kt}$ and putting some weight on the estimated surface winds, an intensity of $75 \mathrm{kt}$ is selected at $18 \mathrm{Z}$ on the $3^{\text {rd }}$, up from $65 \mathrm{kt}$ originally in HURDAT, a minor intensity change.

On August $4^{\text {th }}$, Arlene likely entered an area of unfavorable environmental conditions and rapidly weakened. Weakening to a tropical storm is analyzed at $06 \mathrm{Z}$ on the $4^{\text {th }}$, six hours later than originally shown in HURDAT. Weakening to a tropical depression is analyzed at $18 \mathrm{Z}$ on the $4^{\text {th }}$, also six hours later than originally shown in HURDAT. A recent analog showing a similar rapid weakening due to strong vertical wind shear is Hurricane Carlos, 2009 , in the eastern Pacific. Reconnaissance aircraft investigating Arlene on the $4^{\text {th }}$ were not able to locate a center. Synoptic observations late on the $4^{\text {th }}$ and on August $5^{\text {th }}$ indicate that Arlene may have weakened to a sharp tropical wave. But a reconnaissance 
mission around noon (12Z) on the $5^{\text {th }}$ shows that Arlene still had a closed circulation, thus it is retained as a tropical depression late on the $4^{\text {th }}$ through late on the $5^{\text {th }}$. A ship reported $40 \mathrm{kt} \mathrm{SW}$ at $18 \mathrm{Z}$ on the $5^{\text {th }}$ but appears to have a high bias compared to the nearby ship observations. Ship data on August $6^{\text {th }}$ at $00 \mathrm{Z}$ show that Arlene had weakened to a tropical wave as the wind flow was easterly in the southwest quadrant. The sharp tropical wave continued moving west-northwest and slowed its forward speed. At $00 \mathrm{Z}$ on August $7^{\text {th }}$, ship observations indicate that Arlene had regained a closed circulation, thus becoming a tropical depression once again. On the $7^{\text {th }}$, Arlene reached the westernmost extent of its track and began to slowly move to the north while becoming better organized. Intensification to a tropical storm is analyzed at $18 \mathrm{Z}$ on the $7^{\text {th }}$, six hours earlier than HURDAT, based on a ship report of $35 \mathrm{kt} \mathrm{S}$ in the eastern quadrant. HURDAT originally showed an unrealistic jump in intensity from $30 \mathrm{kt}$ at $18 \mathrm{Z}$ on the $7^{\text {th }}$ to $55 \mathrm{kt}$ at $00 \mathrm{Z}$ on August $8^{\text {th }}$. A few ships reported gale-force winds and even stormforce winds, up to $55 \mathrm{kt}$ on the $8^{\text {th }}$. A reconnaissance aircraft measured a central pressure of $992 \mathrm{mb}$ and estimated an eye diameter of $20 \mathrm{~nm}$ at $1357 \mathrm{Z}$ on the $8^{\text {th }}$. A central pressure of $992 \mathrm{mb}$ suggests maximum surface winds of $64 \mathrm{kt}$ from the south of $25 \mathrm{~N}$ pressurewind relationship. An eye diameter of $20 \mathrm{~nm}$ suggests an RMW of about $15 \mathrm{~nm}$ and the climatological value is 20 . Based on a forward speed of about $7 \mathrm{kt}$, an intensity of $65 \mathrm{kt}$ is selected at $12 Z$ on the $8^{\text {th }}$, same as originally shown in HURDAT. Regaining hurricane intensity is analyzed at $12 Z$ on the $8^{\text {th }}$, same as originally shown in HURDAT. TIROS VII captured a partial satellite image of Arlene at $1749 \mathrm{Z}$ on the $8^{\text {th }}$ showing a wellorganized area of convection with banding features. The next penetration center fix measured a central pressure of $981 \mathrm{mb}$, estimated surface winds of $65 \mathrm{kt}$ and an eye diameter of $22 \mathrm{~nm}$ at $19 \mathrm{Z}$ on the $8^{\text {th }}$. A central pressure of $981 \mathrm{mb}$ suggests maximum surface winds of $71 \mathrm{kt}$ and $74 \mathrm{kt}$ from the north of $25 \mathrm{~N}$ and intensifying subset of the pressure-wind relationship, respectively. An eye diameter of $22 \mathrm{~nm}$ suggests an RMW of about $17 \mathrm{~nm}$ and the climatological value is 22 . Based on a slow forward speed of about 6 $\mathrm{kt}$, but a small RMW, an intensity of $75 \mathrm{kt}$ is selected at $18 \mathrm{Z}$ on the $8^{\text {th }}$, up from $65 \mathrm{kt}$ originally in HURDAT, a minor intensity change. On August $9^{\text {th }}$, Arlene increased its forward speed to the northeast and impacted the island of Bermuda. A ship reported $70 \mathrm{kt}$ $\mathrm{SW}$ and $991 \mathrm{mb}$ at $00 \mathrm{Z}$ on the $9^{\text {th }}$ in the southern quadrant of the hurricane. At $1005 \mathrm{Z}$ on the $9^{\text {th }}$, a penetration center fix measured a central pressure of $979 \mathrm{mb}$, estimated surface winds of $65 \mathrm{kt}$ and an eye diameter of $20 \mathrm{~nm}$. A central pressure of $979 \mathrm{mb}$ suggests maximum surface winds of $74 \mathrm{kt}$ from the north of $25 \mathrm{~N}$ pressure-wind relationship. An eye diameter of $20 \mathrm{~nm}$ suggests an RMW of about $15 \mathrm{~nm}$ and the climatological value is 24. Based on a fast forward speed of about $22 \mathrm{kt}$ and an RMW smaller than the climatological value, an intensity of $90 \mathrm{kt}$ is selected at $12 \mathrm{Z}$ on the $9^{\text {th }}$, up from $75 \mathrm{kt}$ originally shown in HURDAT, a minor intensity change. Arlene made landfall in Bermuda around $1530 \mathrm{Z}$ on the $9^{\text {th }}$ as a small, rapidly-moving and intensifying hurricane. The Kindley Air Force Base, located in the northeastern part of the island, measured maximum sustained winds of $66 \mathrm{kt}$ and with gusts to $85 \mathrm{kt}$ around 16Z. A central pressure measured in Bermuda was $975 \mathrm{mb}$, which suggests maximum surface winds of $79 \mathrm{kt}$ from the north of $25 \mathrm{~N}$ pressure-wind relationship. Based on a forward speed of about $31 \mathrm{kt}$ and small RMW, an intensity of $95 \mathrm{kt}$ is selected at the time of landfall. After leaving Bermuda, a reconnaissance aircraft investigated Arlene measuring a central 
pressure of $970 \mathrm{mb}$ and estimated surface winds of $100 \mathrm{kt}$ at $19 \mathrm{Z}$ on the $9^{\text {th }}$. A central pressure of $970 \mathrm{mb}$ suggests maximum surface winds of $84 \mathrm{kt}$ and $88 \mathrm{kt}$ from the north of $25 \mathrm{~N}$ and intensifying subset of the pressure-wind relationship, respectively. Based upon a forward speed of $31 \mathrm{kt}$ and small RMW, an intensity of $100 \mathrm{kt}$ is selected at $18 \mathrm{Z}$ on the $9^{\text {th }}$, up from $90 \mathrm{kt}$ originally in HURDAT, a minor intensity change. An intensity of 100 $\mathrm{kt}$ is also the peak intensity of this tropical cyclone, up from $90 \mathrm{kt}$ originally in HURDAT. This reanalysis indicates that Arlene was a major hurricane. At $22 \mathrm{Z}$ on the $9^{\text {th }}$, another penetration center fix measured a central pressure of $969 \mathrm{mb}$, estimated surface winds of $115 \mathrm{kt}$ and an eye diameter of 20-30 nm. A central pressure of $969 \mathrm{mb}$ suggests maximum surface winds of $86 \mathrm{kt}$ from the north of $25 \mathrm{~N}$ Brown et al. and $83 \mathrm{kt}$ from the north of $35 \mathrm{~N}$ Landsea et al. pressure-wind relationships. An eye diameter of 20-30 nm suggests an RMW of about 15-23 nm and the climatological value is 28 . Based on a forward speed of $31 \mathrm{kt}$, small circulation and putting some weight on the estimated surface winds, an intensity of $100 \mathrm{kt}$ is analyzed at $00 \mathrm{Z}$ on August $10^{\text {th }}$, up from the $90 \mathrm{kt}$ originally shown in HURDAT, a minor intensity change.

On the $10^{\text {th }}$, Arlene was moving northeastward ahead of a frontal boundary. The hurricane was so small synoptically, that in the microfilm the ship observations available do not even suggest that a closed circulation was present. Later on the $10^{\text {th }}$, the hurricane began to weaken. The last reconnaissance aircraft to investigate Arlene reached the tropical cyclone at $1340 \mathrm{Z}$ on the $10^{\text {th }}$ measuring a central pressure of $985 \mathrm{mb}$, estimating surface winds of $75 \mathrm{kt}$ and an eye diameter of $15 \mathrm{~nm}$. A central pressure of $985 \mathrm{mb}$ suggests maximum surface winds of $68 \mathrm{kt}$ from the Landsea et al. north of $35 \mathrm{~N}$ pressurewind relationship. An eye diameter of $15 \mathrm{~nm}$ suggests an RMW of about $11 \mathrm{~nm}$ and the climatological value is 34 . Based on a forward speed of about $31 \mathrm{kt}$ and small circulation, an intensity of $85 \mathrm{kt}$ is analyzed at $12 \mathrm{Z}$ on the $10^{\text {th }}$, same as originally shown in HURDAT. Early on August $11^{\text {th }}$, Arlene passed a couple of hundred miles southeast of Newfoundland and turned to the east-northeast. Transition to an extratropical cyclone is analyzed in HURDAT at $00 \mathrm{Z}$ on the $11^{\text {th }}$ but synoptic observations indicate that Arlene remained in the warm sector of an extratropical cyclone located to the northwest. Transition to an extratropical cyclone is analyzed at $06 \mathrm{Z}$ on the $11^{\text {th }}$, six hours later than originally shown in HURDAT. Weakening below hurricane intensity is analyzed at $06 Z$ on the $11^{\text {th }}$, six hours earlier than originally shown in HURDAT. Arlene continued to weaken on the $11^{\text {th }}$ and synoptic observations show that it weakened into a trough after $12 \mathrm{Z}$ on the $12^{\text {th }}$ while located northwest of the Azores. The last position is analyzed at $12 \mathrm{Z}$ on the $12^{\text {th }}, 30$ hours later than originally shown in HURDAT.

\begin{tabular}{|c|c|c|c|}
\hline Date & $\begin{array}{c}\text { Original } \\
\text { HURDAT } \\
\text { Central } \\
\text { Pressure }\end{array}$ & Evidence & Changes \\
\hline Aug $0218 \mathrm{Z}$ & $987 \mathrm{mb}$ & $\begin{array}{l}\text { Penetration center fix: } 987 \mathrm{mb} \text { at } 1642 \mathrm{Z} \text { on } \\
\text { Aug } 02^{\text {nd }}\end{array}$ & Retained \\
\hline
\end{tabular}




\begin{tabular}{|c|c|c|c|}
\hline Aug $0300 Z$ & $996 \mathrm{mb}$ & $\begin{array}{l}\text { Penetration center fix: } 996 \mathrm{mb} \text { at } 01 \mathrm{Z} \text { on } \\
\text { Aug } 03^{\text {rd }}\end{array}$ & \\
\hline Aug $0312 Z$ & $1000 \mathrm{mb}$ & $\begin{array}{l}\text { Penetration center fix: } 1000 \mathrm{mb} \text { at } 14 \mathrm{Z} \text { on } \\
\text { Aug } 03^{\text {rd }}-\text { Likely incorrect based on } \\
\text { subsequent central pressure measurement }\end{array}$ & Removed \\
\hline Aug 03 18Z & $988 \mathrm{mb}$ & $\begin{array}{l}\text { Penetration center fix: } 988 \mathrm{mb} \text { at } 1803 \mathrm{Z} \text { on } \\
\text { Aug } 03^{\text {rd }}\end{array}$ & Retained \\
\hline Aug $0412 Z$ & $1007 \mathrm{mb}$ & $\begin{array}{l}\text { Ship reported } 1007 \mathrm{mb} \text { and } 20 \mathrm{kt} \\
\text { suggesting a central pressure of a lower } \\
\text { value }\end{array}$ & \multirow[t]{2}{*}{ Removed } \\
\hline Aug $0512 Z$ & $1011 \mathrm{mb}$ & $\begin{array}{l}\text { Dropsonde measured } 1011 \mathrm{mb} \text { and } 15 \mathrm{kt} \\
\text { SW at } 1 \mathrm{Z} \text { on Aug } 05^{\text {th }}\end{array}$ & \\
\hline Aug $0612 Z$ & $1012 \mathrm{mb}$ & $\begin{array}{l}\text { Aircraft reconnaissance measured a } \\
\text { minimum pressure of } 1012 \mathrm{mb}\end{array}$ & Retained \\
\hline Aug $0812 Z$ & $981 \mathrm{mb}$ & $\begin{array}{l}\text { Penetration center fix: } 992 \mathrm{mb} \text { at } 1357 \mathrm{Z} \text { on } \\
\text { Aug } 08^{\text {th }}\end{array}$ & $992 \mathrm{mb}$ \\
\hline Aug 08 18Z & $981 \mathrm{mb}$ & $\begin{array}{l}\text { Penetration center fix: } 981 \mathrm{mb} \text { at } 19 \mathrm{Z} \text { on } \\
\text { Aug } 08^{\text {th }}\end{array}$ & \multirow{2}{*}{ Retained } \\
\hline Aug $0912 \mathrm{Z}$ & $979 \mathrm{mb}$ & $\begin{array}{l}\text { Penetration center fix: } 979 \mathrm{mb} \text { at } 1005 \mathrm{Z} \text { on } \\
\text { Aug } 09^{\text {th }}\end{array}$ & \\
\hline Aug 09 18Z & $974 \mathrm{mb}$ & $\begin{array}{l}\text { Penetration center fix: } 970 \mathrm{mb} \text { at } 19 \mathrm{Z} \text { on } \\
\text { Aug } 09^{\text {th }}\end{array}$ & $970 \mathrm{mb}$ \\
\hline Aug $1012 Z$ & $985 \mathrm{mb}$ & $\begin{array}{l}\text { Penetration center fix: } 985 \mathrm{mb} \text { at } 1340 \mathrm{Z} \text { on } \\
\text { Aug } 10^{\text {th }}\end{array}$ & $985 \mathrm{mb}$ \\
\hline
\end{tabular}

Hurricane Beulah [August 20 - September 6, 1963]

\begin{tabular}{|c|c|c|c|c|c|c|c|c|c|c|c|c|c|}
\hline 42735 & $08 / 2 \odot / 1963$ & $3 M=$ & 2 & SNBR $=92$ & $25 \mathrm{BE}$ & ULAH & XII & $N G=0$ & SSS $=$ & & & & \\
\hline 42735 & $08 / 20 / 1963$ & $\begin{array}{r}M=1 \\
*\end{array}$ & 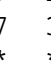 & SNBR $=92$ & $25 \mathrm{BE}$ & ULAH & XII & $N G=0$ & SSS $=$ & & & & \\
\hline 42740 & $08 / 20$ * & $\odot$ & $\odot$ & $\Theta^{*}$ & $\odot$ & $\odot$ & $0 * 137$ & 495 & 30 & $0 * 143$ & 509 & 30 & 1006 * \\
\hline 42740 & $\begin{array}{r}08 / 20 * 112 \\
* * *\end{array}$ & $\begin{array}{l}474 \\
* * *\end{array}$ & $\begin{array}{l}25 \\
* *\end{array}$ & $\begin{array}{r}0 * 121 \\
* * *\end{array}$ & $\begin{array}{l}485 \\
* * *\end{array}$ & $\begin{array}{l}25 \\
* *\end{array}$ & $\begin{array}{r}0 * 130 \\
* * *\end{array}$ & $\begin{array}{l}496 \\
\star * *\end{array}$ & 30 & $\begin{array}{r}\odot * 139 \\
* * *\end{array}$ & $\begin{array}{l}507 \\
\star * *\end{array}$ & 30 & 1006 * \\
\hline 42745 & $08 / 21 * 150$ & 517 & 30 & ๑*155 & 528 & 35 & $0 * 160$ & 535 & 35 & $0 * 165$ & 546 & 45 & 1005 * \\
\hline 42745 & $08 / 21 * 147$ & $\begin{array}{l}518 \\
* * *\end{array}$ & 30 & $\begin{array}{r}\odot * 154 \\
* * *\end{array}$ & 528 & 35 & $0 * 160$ & $\begin{array}{l}537 \\
* * *\end{array}$ & 35 & $0 * 165$ & 546 & 45 & 1005 * \\
\hline 42750 & $08 / 22 * 168$ & 554 & 45 & $0 * 173$ & 560 & 55 & $0 * 179$ & 569 & 70 & $994 * 187$ & 578 & 75 & $0^{*}$ \\
\hline 42750 & $08 / 22 * 169$ & 554 & $\begin{array}{l}50 \\
* *\end{array}$ & $0 * 173$ & 560 & 55 & $0 * 179$ & 569 & $\begin{array}{l}60 \\
* *\end{array}$ & $994 * 187$ & 578 & $\begin{array}{l}70 \\
* *\end{array}$ & 0* \\
\hline $\begin{array}{l}42755 \\
42755\end{array}$ & $\begin{array}{l}08 / 23 * 196 \\
08 / 23 * 196\end{array}$ & $\begin{array}{l}583 \\
583\end{array}$ & $\begin{array}{l}80 \\
75\end{array}$ & $\begin{array}{l}\Theta * 205 \\
\Theta * 205\end{array}$ & $\begin{array}{l}588 \\
588\end{array}$ & $\begin{array}{l}85 \\
80\end{array}$ & $\begin{array}{r}0^{*} 213 \\
977 * 213\end{array}$ & $\begin{array}{l}591 \\
591\end{array}$ & $\begin{array}{l}85 \\
90\end{array}$ & $\begin{array}{l}\odot * 221 \\
\odot * 22 \odot\end{array}$ & $\begin{array}{l}592 \\
592\end{array}$ & $\begin{array}{l}90 \\
95\end{array}$ & $\begin{array}{l}962 * \\
963^{*}\end{array}$ \\
\hline
\end{tabular}




\begin{tabular}{|c|c|c|c|c|c|c|c|c|c|c|c|c|c|}
\hline $\begin{array}{l}42760 \\
42760\end{array}$ & $\begin{array}{l}08 / 24 * 226 \\
08 / 24 * 226\end{array}$ & $\begin{array}{l}594 \\
594\end{array}$ & $\begin{array}{l}95 \\
95\end{array}$ & $\begin{array}{r}\odot^{*} 231 \\
962 * 231 \\
* * *\end{array}$ & $\begin{array}{l}596 \\
596\end{array}$ & $\begin{array}{l}105 \\
100 \\
\star * *\end{array}$ & $\begin{array}{l}958 * 237 \\
958 * 237\end{array}$ & $\begin{array}{l}597 \\
597\end{array}$ & $\begin{array}{l}105 \\
100 \\
* * *\end{array}$ & $\begin{array}{r}0 * 241 \\
961^{*} 243 \\
* * \star * * *\end{array}$ & $\begin{array}{l}598 \\
598\end{array}$ & $\begin{array}{r}100 \\
95 \\
* *\end{array}$ & $\begin{array}{l}961^{*} \\
961^{*}\end{array}$ \\
\hline $\begin{array}{l}42765 \\
42765\end{array}$ & $\begin{array}{l}\odot 8 / 25^{*} 248 \\
08 / 25 * 248\end{array}$ & $\begin{array}{l}600 \\
60 \odot\end{array}$ & $\begin{array}{l}85 \\
90 \\
* *\end{array}$ & $\begin{array}{l}\odot * 256 \\
\odot * 256\end{array}$ & $\begin{array}{l}6 \odot 2 \\
6 \odot 2\end{array}$ & $\begin{array}{l}80 \\
80\end{array}$ & $\begin{array}{l}\odot * 266 \\
\odot * 266\end{array}$ & $\begin{array}{l}603 \\
603\end{array}$ & $\begin{array}{l}75 \\
65 \\
* *\end{array}$ & $\begin{array}{l}985^{*} 278 \\
985^{*} 278\end{array}$ & $\begin{array}{l}604 \\
604\end{array}$ & $\begin{array}{l}80 \\
75 \\
* *\end{array}$ & $\begin{array}{l}976^{*} \\
976^{*}\end{array}$ \\
\hline $\begin{array}{l}42770 \\
42770\end{array}$ & $\begin{array}{l}\odot 8 / 26 * 29 \odot \\
\odot 8 / 26 * 29 \odot\end{array}$ & $\begin{array}{l}602 \\
601 \\
* * *\end{array}$ & $\begin{array}{l}80 \\
75 \\
* *\end{array}$ & $\begin{array}{l}978 * 304 \\
978 * 304\end{array}$ & $\begin{array}{l}592 \\
593 \\
* * *\end{array}$ & $\begin{array}{l}85 \\
7 \odot \\
\star *\end{array}$ & $\begin{array}{l}* 316 \\
* 316\end{array}$ & $\begin{array}{l}583 \\
583\end{array}$ & $\begin{array}{l}85 \\
70 \\
* *\end{array}$ & $\begin{array}{l}983 * 329 \\
983 * 329\end{array}$ & $\begin{array}{l}570 \\
570\end{array}$ & $\begin{array}{l}85 \\
75 \\
* *\end{array}$ & $\begin{array}{l}979 * \\
979 *\end{array}$ \\
\hline $\begin{array}{l}42775 \\
42775\end{array}$ & $\begin{array}{l}08 / 27 * 345 \\
08 / 27 * 345\end{array}$ & $\begin{array}{l}553 \\
553\end{array}$ & $\begin{array}{l}80 \\
75 \\
* *\end{array}$ & $\begin{array}{l}\odot * 363 \\
\odot * 363\end{array}$ & $\begin{array}{l}536 \\
536\end{array}$ & $\begin{array}{l}75 \\
75\end{array}$ & $\begin{array}{l}\odot * 384 \\
\odot * 384\end{array}$ & $\begin{array}{l}523 \\
523\end{array}$ & $\begin{array}{l}70 \\
70\end{array}$ & $\begin{array}{l}\Theta * 416 \\
\text { OE416 } \\
\star\end{array}$ & $\begin{array}{l}510 \\
510\end{array}$ & $\begin{array}{l}70 \\
70\end{array}$ & $\begin{array}{l}\Theta^{*} \\
\Theta^{*}\end{array}$ \\
\hline $\begin{array}{l}42780 \\
42780\end{array}$ & $\begin{array}{c}08 / 28 * 458 \\
08 / 28 E 458 \\
*\end{array}$ & $\begin{array}{l}483 \\
483\end{array}$ & $\begin{array}{l}70 \\
70\end{array}$ & $\begin{array}{l}\text { OE494 } \\
\text { OE494 }\end{array}$ & $\begin{array}{l}449 \\
449\end{array}$ & $\begin{array}{l}65 \\
65\end{array}$ & $\begin{array}{r}\text { OE516 } \\
\text { OE518 } \\
* * *\end{array}$ & $\begin{array}{l}410 \\
410\end{array}$ & $\begin{array}{l}60 \\
6 \odot\end{array}$ & $\begin{array}{r}\text { OE542 } \\
\text { OE540 } \\
* * *\end{array}$ & $\begin{array}{l}355 \\
370 \\
* * *\end{array}$ & $\begin{array}{l}60 \\
60\end{array}$ & $\begin{array}{l}\Theta^{*} \\
\Theta^{*}\end{array}$ \\
\hline $\begin{array}{l}\text { (Augu } \\
42781\end{array}$ & $\begin{array}{l}\text { st } 29^{\text {th }} \text { thr } \\
08 / 29 \mathrm{E} 550\end{array}$ & $\begin{array}{l}\text { ough } \\
340\end{array}$ & $\begin{array}{c}31^{\text {st }}, \\
55\end{array}$ & $\begin{array}{c}\text { and Sep } \\
\text { OE560 }\end{array}$ & $\begin{array}{l}\text { temb } \\
300\end{array}$ & $\begin{array}{l}r 1^{s} \\
55\end{array}$ & $\begin{array}{c}\text { througl } \\
\text { OE564 }\end{array}$ & $\begin{array}{r}6^{\text {th }} \\
250\end{array}$ & $\begin{array}{r}\operatorname{are} \\
55\end{array}$ & $\begin{array}{r}\text { new to } H \\
\text { oE567 }\end{array}$ & $\begin{array}{l}\text { URDAT } \\
210\end{array}$ & 55 & $0^{*}$ \\
\hline 42783 & ๑8/30E57๑ & 170 & 55 & OE572 & 140 & 55 & OE572 & 110 & 55 & OE560 & 085 & 55 & O* \\
\hline 42785 & ๑8/31E545 & 070 & 60 & OE525 & 060 & 60 & OE510 & 050 & 60 & OE5०० & $\odot 4 \odot$ & 60 & ○* \\
\hline 42787 & ๑9/01E49๑ & 030 & 55 & OE485 & 020 & 50 & OE485 & 010 & 45 & OE49० & $\odot \odot 5$ & 40 & ○* \\
\hline 42789 & ๑9/०2E5०९ & $\odot \odot \odot$ & 35 & OE515 & 005 & 30 & OE530 & 010 & 30 & OE540 & 005 & 30 & $\Theta^{*}$ \\
\hline 42791 & ०9/०3E55० & $\odot \odot \odot$ & 30 & OE5553 & 3590 & 30 & OE560 & 3580 & 30 & OE565 & 3575 & 30 & ๑* \\
\hline 42793 & ๑9/०4E57०3 & 3572 & 30 & OE5803 & 3575 & 30 & OE595 & 3580 & 30 & OE610 & 3570 & 30 & $\odot^{*}$ \\
\hline 42795 & $09 / 0$ & 3560 & 30 & OE6503 & 3545 & 30 & OE665 & 3530 & 25 & OE680 & 3520 & 25 & $\Theta^{*}$ \\
\hline 42797 & 9/०6E6903 & 3510 & 25 & OE7003 & 3505 & 25 & OE710 & 3500 & 25 & OE720 & 3495 & 25 & $\Theta^{*}$ \\
\hline
\end{tabular}

$42800 \mathrm{HR}$

Minor changes to the track and intensity shown in McAdie et al. (2009). A major alteration is to add eight days to the lifetime of this tropical cyclone. Evidence for these alterations comes from the NHC microfilm maps, the Historical Weather Maps series, the COADS ship database, Monthly Weather Review, Navy reconnaissance book, Mariners Weather Log, National Hurricane Research Project (NHRP), Allison \& Thompson (1966) and NHC Storm Wallets.

August 16:

HWM analyzes a spot low pressure at $15.6 \mathrm{~N}, 44.2 \mathrm{~W}$ at $12 \mathrm{Z}$. HURDAT does not list an organized system on this date. Microfilm does not show an organized system on this date. Ship highlights: No gales or low pressures.

\section{August 17:}

HWM analyzes a spot low pressure at $14.7 \mathrm{~N}, 46.0 \mathrm{~W}$ at $12 \mathrm{Z}$. HURDAT does not list an organized system on this date. Microfilm shows a tropical wave at $49 \mathrm{~W}$ at $12 \mathrm{Z}$. Ship highlights: No gales or low pressures.

MIAMI WEATHER BUREAU BULLETIN: "Special statement from the Miami Weather Bureau. A Navy reconnaissance aircraft today investigated an area of suspicion photographed by TIROS satellite yesterday some 1000 miles east of the Lesser Antilles in the central Atlantic. The flight found no evidence of a tropical disturbance or a developing circulation and reported no unusual weather in the area." 
August 18:

HWM analyzes a spot low pressure at $14.0 \mathrm{~N}, 47.5 \mathrm{~W}$ at $12 \mathrm{Z}$. HURDAT does not list an organized system on this date. Microfilm does not show an organized system on this date. Ship highlights: No gales or low pressures.

August 19:

HWM analyzes a spot low pressure at $14.4 \mathrm{~N}, 48.5 \mathrm{~W}$ at $12 \mathrm{Z}$. HURDAT does not list an organized system on this date. Microfilm does not show an organized system on this date. Ship highlights: No gales or low pressures.

August 20:

HWM analyzes a closed low pressure of at most $1010 \mathrm{mb}$ at $13.5 \mathrm{~N}, 48.5 \mathrm{~W}$ at 12Z. HURDAT lists a $30 \mathrm{kt}$ tropical depression at $13.7 \mathrm{~N}, 49.5 \mathrm{~W}$ at $12 \mathrm{Z}$ (first position). Microfilm shows a closed low pressure of at most $1011 \mathrm{mb}$ at $13.0 \mathrm{~N}, 49.0 \mathrm{~W}$ at 12Z. Ship highlights: No gales or low pressures.

MWR: "The circulation that developed into hurricane Beulah was located by aerial reconnaissance near $14^{\circ} \mathrm{N}, 51^{\circ} \mathrm{W}$ about midday on August 20. Maximum winds were 35 mph in squalls and the lowest observed surface pressure was $1006 \mathrm{mb}$ or $29.71 \mathrm{in}$. Cloudiness and shower activity covered a large area. Surface ship reports during the preceding several days had indicated disturbed conditions over much of the area from the Cape Verdes westward to the longitude of the incipient storm. Data limitations preclude specification of the exact position of the Inter-tropical Convergence Zone during this period, but south and southwest winds of 23 to 30 m.p.h. were prevalent its much as 300 mi. to the north of the normal ITC position. Sparsity of data also makes the earlier history of the vortex obscure. Westward movement of about $11 \mathrm{mph}$ would have brought a cloud mass photographed by TIROS VI near $13^{\circ} \mathrm{N}, 25^{\circ} \mathrm{W}$ on August 14 to the vicinity of the developing circulation. However, it is not possible to say whether this represented the nascent stages of Beulah." ATSR: "The circulation that developed into Hurricane BEULAH apparently formed on the Intertropical Convergence Zone during a period of abnormal northward displacement of this zone. Surface ship reports for several days had indicated disturbed weather conditions in an area east of the Antilles but no closed circulation could be found. Location of the first well-defined closed circulation was observed by reconnaissance aircraft on the $20^{\text {th }}$, about 660 miles east of the Lesser Antilles. Maximum winds were 30 knots in squalls and the lowest observed surface pressure was 1006 millibars."

August 21:

HWM analyzes a tropical storm of at most $1005 \mathrm{mb}$ at $16.3 \mathrm{~N}, 53.5 \mathrm{~W}$ at $12 \mathrm{Z}$. HURDAT lists a $35 \mathrm{kt}$ tropical storm at $16.0 \mathrm{~N}, 53.5 \mathrm{~W}$ at $12 \mathrm{Z}$. Microfilm shows a closed low pressure of at most $1011 \mathrm{mb}$ at $16.5 \mathrm{~N}, 54.0 \mathrm{~W}$ at 12Z. Ship highlights: $35 \mathrm{kt} \mathrm{SE}$ and $1005 \mathrm{mb}$ at $16.9 \mathrm{~N}, 54.3 \mathrm{~W}$ at $12 \mathrm{Z}$ (micro). $45 \mathrm{kt} \mathrm{NW}$ and $1011 \mathrm{mb}$ at $16.5 \mathrm{~N}, 51.0 \mathrm{~W}$ (may 
be $56.0 \mathrm{~W}$ ) at $18 \mathrm{Z}$ (micro). Aircraft highlights: Penetration center fix measured a central pressure of $1005 \mathrm{mb}$ and estimated surface winds of $45 \mathrm{kt}$ at $16.5 \mathrm{~N}, 54.5 \mathrm{~W}$ at $1645 \mathrm{Z}$ (WALLET).

MWR: “At 1200 GMT August 21, surface ships reported winds of 35 to $40 \mathrm{mph}$ and when reconnaissance aircraft reached the area around noon, maximum winds were 52 mph with a minimum pressure of $1005 \mathrm{mb}\left(29.68 \mathrm{in}\right.$.) at the center near $16.5^{\circ} \mathrm{N}, 54.5^{\circ} \mathrm{W}$. The storm moved toward the west-northwest at about $10 \mathrm{mph}$ and slowly intensified during the next $24 \mathrm{hr}$." ATSR: "The wind reached tropical storm velocity at $1000 \mathrm{Z}$ on the $21^{\text {st }}$, and the first warning was issued at $211830 \mathrm{Z}$. Anti-cyclonic flow at $200 \mathrm{mbs}$ was well established at this time and steady intensification had begun."

August 22:

HWM analyzes a tropical storm of at most $1000 \mathrm{mb}$ at $18.0 \mathrm{~N}, 56.7 \mathrm{~W}$ at $12 \mathrm{Z}$. HURDAT lists a $70 \mathrm{kt}$ hurricane at $17.9 \mathrm{~N}, 56.9 \mathrm{~W}$ at $12 \mathrm{Z}$. Microfilm shows a closed low pressure of at most $1002 \mathrm{mb}$ at $18.3 \mathrm{~N}, 57.2 \mathrm{~W}$ at 12Z. Ship highlights: $30 \mathrm{kt} \mathrm{W}$ and 1003 $\mathrm{mb}$ at $16.6 \mathrm{~N}, 55.1 \mathrm{~W}$ at $00 \mathrm{Z}$ (micro). Aircraft highlights: Penetration center fix measured a central pressure of $994 \mathrm{mb}$, estimated surface winds of $68 \mathrm{kt}$ and an eye diameter of 25 $\mathrm{nm}$ at $18.1 \mathrm{~N}, 57.4 \mathrm{~W}$ at $1255 \mathrm{Z}$ (WALLET). Penetration center fix estimated surface winds of $55 \mathrm{kt}$ and an eye diameter of $15 \mathrm{~nm}$ at $18.6 \mathrm{~N}, 57.3 \mathrm{~W}$ at $1635 \mathrm{Z}$ (WALLET/ATSR). Penetration center fix at $19.5 \mathrm{~N}, 58.6 \mathrm{~W}$ at $2330 \mathrm{Z}$ (WALLET).

MWR: "On August 22, Navy reconnaissance reported that Beulah had increased to hurricane intensity with a well-formed eye and central pressure $994 \mathrm{mb}$ or $29.35 \mathrm{in}$. Winds of $78 \mathrm{mph}$ were observed just east of the center. A change to a more northwestward course, which began during the afternoon, removed my threat to the Leeward Islands. The highest swells that hit Saint Maarten, Netherlands West Indies, were $4 \mathrm{ft}$. over the open waters." ATSR: "Hurricane intensity was reached 26 hours later as BEULAH progressed northwestward at 10 knots, apparently carrying her own stratospheric anti-cyclone with her. Aircraft reconnaissance on the $22^{\text {nd }}$ showed a welldefined eye 15 miles in diameter with six-degree Centigrade temperature rise from outside the wall cloud to the center. A change to a more northerly direction also occurred on the $22^{\text {nd }}$."

August 23:

HWM analyzes a hurricane of at most $995 \mathrm{mb}$ at $21.7 \mathrm{~N}, 59.2 \mathrm{~W}$ at $12 \mathrm{Z}$. HURDAT lists an $85 \mathrm{kt}$ hurricane at $21.3 \mathrm{~N}, 59.1 \mathrm{~W}$ at $12 \mathrm{Z}$. Microfilm shows a closed low pressure of at most $1011 \mathrm{mb}$ at $21.0 \mathrm{~N}, 59.5 \mathrm{~W}$ at 12Z. Ship highlights: $40 \mathrm{kt} \mathrm{SE}$ and $1011 \mathrm{mb}$ at $21.1 \mathrm{~N}, 56.5 \mathrm{~W}$ at $00 \mathrm{Z}$ (micro). $40 \mathrm{kt} \mathrm{ESE}$ and $1004 \mathrm{mb}$ at $22.1 \mathrm{~N}, 57.5 \mathrm{~W}$ at $06 \mathrm{Z}$ (micro). $35 \mathrm{kt} \mathrm{ESE}$ and $1008 \mathrm{mb}$ at $22.6 \mathrm{~N}, 56.1 \mathrm{~W}$ at $12 \mathrm{Z}$ (micro). $40 \mathrm{kt} \mathrm{SSE}$ and $1009 \mathrm{mb}$ at $21.5 \mathrm{~N}, 58.5 \mathrm{~W}$ at $18 \mathrm{Z}$ (micro). $40 \mathrm{kt} \mathrm{SSW}$ and $1002 \mathrm{mb}$ at $21.1 \mathrm{~N}, 58.4 \mathrm{~W}$ at $21 \mathrm{Z}$ (micro). Aircraft highlights: Penetration center fix measured a central pressure of $978 \mathrm{mb}$, estimated surface winds of $90 \mathrm{kt}$ and an eye diameter of $25 \mathrm{~nm}$ at $20.6 \mathrm{~N}, 58.7 \mathrm{~W}$ at $07 \mathrm{Z}$ (WALLET). Penetration center fix measured a central pressure of $979 \mathrm{mb}$ at $21.8 \mathrm{~N}$, 59.6W at 15Z (WALLET). Penetration center fix measured a central pressure of $963 \mathrm{mb}$ and estimated surface winds of $85 \mathrm{kt}$ at $22.1 \mathrm{~N}, 59.1 \mathrm{~W}$ at $1740 \mathrm{Z}$ (WALLET). Penetration center fix measured a central pressure of $962 \mathrm{mb}$, estimated surface winds of $84 \mathrm{kt}$ and an 
RMW of $19 \mathrm{~nm}$ near 21.0N, 59.0W at 2030Z (NHRP). Penetration center fix measured a central pressure of $962 \mathrm{mb}$, estimated surface winds of $90 \mathrm{kt}$ and an eye diameter of 29 $\mathrm{nm}$ at $22.1 \mathrm{~N}, 59.3 \mathrm{~W}$ at $22 \mathrm{Z}$ (WALLET/ATSR).

MWR: "The hurricane began to deepen more rapidly late on the $22^{\text {nd }}$ and continued to intensify through the $23^{\text {rd }}$."

August 24:

HWM analyzes a hurricane of at most $990 \mathrm{mb}$ at 23.7N, 59.6W at 12Z. HURDAT lists a $105 \mathrm{kt}$ hurricane at $23.7 \mathrm{~N}, 59.7 \mathrm{~W}$ at $12 \mathrm{Z}$. Microfilm shows a closed low pressure of at most $1008 \mathrm{mb}$ at $23.0 \mathrm{~N}, 60.0 \mathrm{~W}$ at 12Z. Ship highlights: $40 \mathrm{kt} \mathrm{SE}$ and $1008 \mathrm{mb}$ at $22.8 \mathrm{~N}, 56.5 \mathrm{~W}$ at $00 \mathrm{Z}$ (micro). $45 \mathrm{kt} \mathrm{SE}$ and $1006 \mathrm{mb}$ at $22.0 \mathrm{~N}, 57.2 \mathrm{~W}$ at $03 \mathrm{Z}$ (micro). 60 kt E and $998 \mathrm{mb}$ at $24.2 \mathrm{~N}, 58.1 \mathrm{~W}$ at $06 \mathrm{Z}$ (micro). $50 \mathrm{kt} \mathrm{NW}$ and $993 \mathrm{mb}$ at $23.1 \mathrm{~N}, 60.6 \mathrm{~W}$ at $10 \mathrm{Z}$ (micro). $60 \mathrm{kt} \mathrm{SE}$ and $996 \mathrm{mb}$ at $16.9 \mathrm{~N}, 58.3 \mathrm{~W}$ at $12 \mathrm{Z}$ (micro). $45 \mathrm{kt} \mathrm{SE}$ and 989 $\mathrm{mb}$ at $23.7 \mathrm{~N}, 59.7 \mathrm{~W}$ at $13 \mathrm{Z}$ (micro). $40 \mathrm{kt} \mathrm{SSE}$ and $1002 \mathrm{mb}$ at $23.5 \mathrm{~N}, 57.2 \mathrm{~W}$ at $19 \mathrm{Z}$ (micro). Aircraft highlights: Radar center fix estimated an eye diameter of $29 \mathrm{~nm}$ at $22.6 \mathrm{~N}, 58.1 \mathrm{~W}$ at $0037 \mathrm{Z}$ (WALLET). Penetration center fix measured a central pressure of $958 \mathrm{mb}$ and estimated an eye diameter of $20 \mathrm{~nm}$ at $23.0 \mathrm{~N}, 59.6 \mathrm{~W}$ at $0630 \mathrm{Z}$

(WALLET). Penetration center fix measured a central pressure of $961 \mathrm{mb}$, estimated surface winds of $96 \mathrm{kt}$ and an RMW of $25 \mathrm{~nm}$ near $21.0 \mathrm{~N}, 59.0 \mathrm{~W}$ at $14 \mathrm{Z}$ (NHRP). Penetration center fix measured a central pressure of $961 \mathrm{mb}$, estimated surface winds of $102 \mathrm{kt}$ and an eye diameter of $20 \mathrm{~nm}$ at $24.1 \mathrm{~N}, 59.7 \mathrm{~W}$ at $1450 \mathrm{Z}$ (WALLET). Penetration center fix measured a central pressure of $961 \mathrm{mb}$, estimated surface winds of $108 \mathrm{kt}$ and an RMW of $20 \mathrm{~nm}$ near $21.0 \mathrm{~N}, 59.0 \mathrm{~W}$ at $1630 \mathrm{Z}$ (NHRP).

MWR: "The lowest central pressure observed during the life of the storm was $958 \mathrm{mb}$. (28.29 in.) at 0630 GMT August 24. Radar showed an elliptical eye with a 20- to 30-mi. diameter. It is estimated that maximum winds at this time were about 120 m.p.h. During the late forenoon, aircraft penetrating the center indicated the beginning of a filling trend with an observed central pressure of $961 \mathrm{mb}$ or 28.38 in., and maximum winds of 115 mph." ATSR: "Maximum intensity of 105 knots was reached on the $24^{\text {th }}$, coinciding with a minimum central pressure of 958 millibars. Rapid de-intensification began very soon after this peak, as BEULAH began to move away from the $200 \mathrm{mb}$ anticyclone and weakening continued for 24 hours."

August 25:

HWM analyzes a hurricane of at most $1000 \mathrm{mb}$ at $26.5 \mathrm{~N}, 61.0 \mathrm{~W}$ at $12 \mathrm{Z}$. HURDAT lists a $75 \mathrm{kt}$ hurricane at $26.6 \mathrm{~N}, 60.3 \mathrm{~W}$ at $12 \mathrm{Z}$. Microfilm shows a closed low pressure of at most $1011 \mathrm{mb}$ at 27.0N, 60.0W at 12Z. Ship highlights: $45 \mathrm{kt}$ SE and 1013 $\mathrm{mb}$ at $23.5 \mathrm{~N}, 56.5 \mathrm{~W}$ at $00 \mathrm{Z}$ (micro). $35 \mathrm{kt} \mathrm{S}$ and $1011 \mathrm{mb}$ at $22.8 \mathrm{~N}, 56.7 \mathrm{~W}$ at $06 \mathrm{Z}$ (COADS). Aircraft highlights: Penetration center fix estimated flight level winds of 77 $\mathrm{kt}$ and an eye diameter of $30 \mathrm{~nm}$ at $25.6 \mathrm{~N}, 60.5 \mathrm{~W}$ at $0647 \mathrm{Z}$ (WALLET/ATSR). Penetration center fix measured a central pressure of $985 \mathrm{mb}$, estimated flight level winds of $60 \mathrm{kt}$ and an eye diameter of $40 \mathrm{~nm}$ at $27.0 \mathrm{~N}, 60.1 \mathrm{~W}$ at $1310 \mathrm{Z}$ (WALLET). Penetration center fix measured a central pressure of $976 \mathrm{mb}$, estimated surface winds of $80 \mathrm{kt}$ and an eye diameter of $60 \mathrm{~nm}$ at $28.0 \mathrm{~N}, 60.4 \mathrm{~W}$ at $19 \mathrm{Z}$ (WALLET). Penetration center fix measured a central pressure of $978 \mathrm{mb}$ at $28.5 \mathrm{~N}, 60.6 \mathrm{~W}$ at $22 \mathrm{Z}$ (WALLET). 
MWR: "The weakening stage, which persisted for the next $24 \mathrm{hr}$., was accompanied by an increase in the eye diameter to $60 \mathrm{mi}$. Maximum winds dropped to about $105 \mathrm{mph}$ on the $25^{\text {th }}$. Beulah moved at 5 to $10 \mathrm{mph}$ toward the north-northwest during the 2-day period covering the marked deepening and subsequent filling, then turned to the north mid began to accelerate."

August 26:

HWM analyzes a hurricane of at most $995 \mathrm{mb}$ at $31.8 \mathrm{~N}, 58.2 \mathrm{~W}$ with a stationary front to the northwest at 12Z. HURDAT lists an $85 \mathrm{kt}$ hurricane at $31.6 \mathrm{~N}, 58.3 \mathrm{~W}$ at $12 \mathrm{Z}$. Microfilm shows a closed low pressure of at most $1002 \mathrm{mb}$ at $31.8 \mathrm{~N}, 58.2 \mathrm{~W}$ with a frontal boundary to the northwest at 12Z. Ship highlights: $45 \mathrm{kt} \mathrm{NNW}$ and $1004 \mathrm{mb}$ at $31.9 \mathrm{~N}, 60.4 \mathrm{~W}$ at $1245 \mathrm{Z}$ (micro). $35 \mathrm{kt} \mathrm{SW}$ and $1015 \mathrm{mb}$ at $26.2 \mathrm{~N}, 57.5 \mathrm{~W}$ at $18 \mathrm{Z}$ (micro). Aircraft highlights: Radar center fix at 28.9N, 60.4W at 0010Z (WALLET). Radar center fix at $29.8 \mathrm{~N}, 59.6 \mathrm{~W}$ at $05 \mathrm{Z}$ (WALLET). Penetration center fix measured a central pressure of $983 \mathrm{mb}$, estimated surface winds of $70 \mathrm{kt}$ and an eye diameter of $50 \mathrm{~nm}$ at $32.1 \mathrm{~N}, 57.8 \mathrm{~W}$ at $1345 \mathrm{Z}$ (WALLET). Penetration center fix measured a central pressure of $979 \mathrm{mb}$, estimated surface winds of $90 \mathrm{kt}$ and an eye diameter of $80 \mathrm{~nm}$ at $33.1 \mathrm{~N}$, $56.8 \mathrm{~W}$ at $19 \mathrm{Z}$ (WALLET).

MWR: "By the $26^{\text {th }}$, forward speed had increased to $23 \mathrm{mph}$ or more toward the northeast." ATSR: "By the $26^{\text {th }}$, BEULAH came under the influence of a trough in the westerlies and began to accelerate toward the northeast."

August 27:

HWM analyzes a hurricane of at most $990 \mathrm{mb}$ at $38.8 \mathrm{~N}, 52.2 \mathrm{~W}$ with a weakening front just to the northwest at 12Z. HURDAT lists a $70 \mathrm{kt}$ hurricane at $38.4 \mathrm{~N}, 52.3 \mathrm{~W}$ at 12Z. Microfilm shows a closed low pressure of at most $993 \mathrm{mb}$ at $39.2 \mathrm{~N}, 53.2 \mathrm{~W}$ with a frontal boundary very close to the west at 12Z. Ship highlights: $35 \mathrm{kt} \mathrm{NE}$ and $1017 \mathrm{mb}$ at $27.2 \mathrm{~N}, 58.0 \mathrm{~W}$ at $00 \mathrm{Z}$ (COADS). $40 \mathrm{kt} \mathrm{SE}$ and $1001 \mathrm{mb}$ at $33.9 \mathrm{~N}, 52.3 \mathrm{~W}$ at $06 \mathrm{Z}$ (micro). $55 \mathrm{E}$ and $985 \mathrm{mb}$ at $40.3 \mathrm{~N}, 53.0 \mathrm{~W}$ at $12 \mathrm{Z}$ (COADS). $60 \mathrm{kt} \mathrm{SSW}$ and $988 \mathrm{mb}$ at $40.5 \mathrm{~N}$, $50.4 \mathrm{~W}$ at $15 \mathrm{Z}$ (micro). $65 \mathrm{kt} \mathrm{S}$ and $1002 \mathrm{mb}$ at $42.0 \mathrm{~N}, 46.5 \mathrm{~W}$ at $18 \mathrm{Z}$ (COADS). $45 \mathrm{kt}$ WSW and $1001 \mathrm{mb}$ at $41.7 \mathrm{~N}, 49.7 \mathrm{~W}$ at $21 \mathrm{Z}$ (COADS). $50 \mathrm{kt} \mathrm{NNW}$ and $989 \mathrm{mb}$ at $44.2 \mathrm{~N}, 49.7 \mathrm{~W}$ at $23 \mathrm{Z}(\mathrm{COADS})$.

MWR: "Under the influence of an upper trough off the United States east coast, the hurricane continued to accelerate and late on the $27^{\text {th }}$ passed some $250 \mathrm{mi}$. east of Newfoundland, moving on a north-northeastward course at about 40 mph." ATSR: "On the $27^{\text {th }}$, she passed some 250 miles east of Newfoundland, moving north-northeasterly at about 35 knots."

August 28:

HWM analyzes a tropical storm of at most $980 \mathrm{mb}$ at $51.7 \mathrm{~N}, 40.3 \mathrm{~W}$ with a warm front just to the north and a cold front to the south at 12Z. HURDAT lists a $60 \mathrm{kt}$ extratropical cyclone at $51.6 \mathrm{~N}, 41.0 \mathrm{~W}$ at $12 \mathrm{Z}$. Microfilm shows an extratropical cyclone of at most $996 \mathrm{mb}$ at $51.7 \mathrm{~N}, 39.8 \mathrm{~W}$ at $12 \mathrm{Z}$. Ship highlights: $70 \mathrm{kt} \mathrm{E}$ and $975 \mathrm{mb}$ at $46.5 \mathrm{~N}$, 48.0W at $00 \mathrm{Z}$ (micro). $65 \mathrm{kt} \mathrm{SW}$ and $987 \mathrm{mb}$ at $47.5 \mathrm{~N}, 43.5 \mathrm{~W}$ at $06 \mathrm{Z}$ (COADS). $60 \mathrm{kt}$ 
SSW and $1009 \mathrm{mb}$ at $47.7 \mathrm{~N}, 39.2 \mathrm{~W}$ at $12 \mathrm{Z}$ (COADS). $55 \mathrm{kt} \mathrm{SW}$ at $50.0 \mathrm{~N}, 40.9 \mathrm{~W}$ at $18 \mathrm{Z}$ (COADS).

MWR: "By 0400 GMT August 28, it was considered extratropical, a cold front having entered the circulation." ATSR: "By $0400 \mathrm{Z}$ on the $28^{\text {th }}$, she was considered extratropical, a cool air mass having entered the circulation."

August 29:

HWM analyzes an extratropical cyclone of at most $990 \mathrm{mb}$ at $52.5 \mathrm{~N}, 23.0 \mathrm{~W}$ at 12Z. HURDAT does not list an organized storm on this date. Microfilm shows that the system has moved off the map. Ship highlights: $50 \mathrm{kt} \mathrm{W}$ and $1004 \mathrm{mb}$ at $52.7 \mathrm{~N}, 35.5 \mathrm{~W}$ at $00 \mathrm{Z}$ (COADS). $45 \mathrm{kt} \mathrm{W}$ and $1002 \mathrm{mb}$ at $52.6 \mathrm{~N}, 26.5 \mathrm{~W}$ at $06 \mathrm{Z}$ (COADS). $50 \mathrm{kt} \mathrm{W}$ and $1008 \mathrm{mb}$ at $52.6 \mathrm{~N}, 27.8 \mathrm{~W}$ at $12 \mathrm{Z}$ (COADS). $5 \mathrm{kt} 0 \mathrm{~W}$ and $1003 \mathrm{mb}$ at $53.1 \mathrm{~N}, 21.0 \mathrm{~W}$ at $18 \mathrm{Z}$ (COADS).

August 30:

HWM analyzes an extratropical cyclone of at most $985 \mathrm{mb}$ at $51.0 \mathrm{~N}, 11.0 \mathrm{~W}$ at 12Z. Ship highlights: $50 \mathrm{kt} \mathrm{W}$ and $1006 \mathrm{mb}$ at $53.2 \mathrm{~N}, 21.5 \mathrm{~W}$ at $00 \mathrm{Z}$ (COADS). $50 \mathrm{kt} \mathrm{W}$ and $991 \mathrm{mb}$ at $54.4 \mathrm{~N}, 17.6 \mathrm{~W}$ at $06 \mathrm{Z}$ (COADS). $50 \mathrm{kt} \mathrm{W}$ and $997 \mathrm{mb}$ at $54.3 \mathrm{~N}, 18.0 \mathrm{~W}$ at $12 \mathrm{Z}$ (COADS). $50 \mathrm{kt} \mathrm{NW}$ and $1005 \mathrm{mb}$ at $54.2 \mathrm{~N}, 19.0 \mathrm{~W}$ at $18 \mathrm{Z}$ (COADS).

MWR: "However, maximum winds remained $70 \mathrm{mph}$ or higher and when the low center reached the British Isles, on August 30, it was still accompanied by gales. There was no loss of life or property damage attributable to hurricane Beulah."

August 31:

HWM analyzes an extratropical cyclone of at most $995 \mathrm{mb}$ at $51.5 \mathrm{~N}, 5.0 \mathrm{~W}$ at 12Z. Ship highlights: $50 \mathrm{kt} \mathrm{W}$ at 50.7N, 10.2W at 00Z (COADS). $60 \mathrm{kt} \mathrm{NW}$ and $1010 \mathrm{mb}$ at $49.9 \mathrm{~N}, 14.5 \mathrm{~W}$ at $06 \mathrm{Z}$ (COADS). $60 \mathrm{kt} \mathrm{NW}$ and $1016 \mathrm{mb}$ at $50.0 \mathrm{~N}, 15.3 \mathrm{~W}$ at $12 \mathrm{Z}$ (COADS). $45 \mathrm{kt} \mathrm{WNW}$ and $1009 \mathrm{mb}$ at $46.7 \mathrm{~N}, 10.3 \mathrm{~W}$ at $18 \mathrm{Z}$ (COADS).

September 1:

HWM analyzes an extratropical cyclone of at most $1000 \mathrm{mb}$ at $49.0 \mathrm{~N}, 0.5 \mathrm{~W}$ at 12Z. Ship highlights: $40 \mathrm{kt} \mathrm{NNW}$ at $51.0 \mathrm{~N}, 12.5 \mathrm{~W}$ at $00 \mathrm{Z}$ (COADS). $35 \mathrm{kt} \mathrm{NW}$ and 1003 $\mathrm{mb}$ at $46.8 \mathrm{~N}, 6.2 \mathrm{~W}$ at $06 \mathrm{Z}$ (COADS).

September 2:

HWM analyzes an extratropical cyclone of at most $1010 \mathrm{mb}$ at $53.0 \mathrm{~N}, 0.0 \mathrm{~W}$ at 12Z. Ship highlights: No gales or low pressures.

September 3:

HWM analyzes an extratropical cyclone of at most $1005 \mathrm{mb}$ at $58.0 \mathrm{~N}, 2.0 \mathrm{E}$ at 12Z. Ship highlights: $10 \mathrm{kt} \mathrm{SE}$ and $1004 \mathrm{mb}$ at $56.5 \mathrm{~N}, 3.0 \mathrm{E}$ at $12 \mathrm{Z}$ (COADS).

September 4:

HWM analyzes an extratropical cyclone of at most $1005 \mathrm{mb}$ at $58.0 \mathrm{~N}, 2.0 \mathrm{E}$ at 12Z. Ship highlights: $15 \mathrm{kt} \mathrm{NNE}$ and $1000 \mathrm{mb}$ at 59.3N, $0.1 \mathrm{~W}$ at $12 \mathrm{Z}$ (COADS). 
September 5:

HWM analyzes an extratropical cyclone of at most $1005 \mathrm{mb}$ at $66.0 \mathrm{~N}, 5.0 \mathrm{E}$ at 12Z. Ship highlights: $10 \mathrm{kt} \mathrm{NE}$ and $1000 \mathrm{mb}$ at $67.9 \mathrm{~N}, 8.8 \mathrm{E}$ at $12 \mathrm{Z}$ (COADS).

September 6:

HWM analyzes an extratropical cyclone of at most $1005 \mathrm{mb}$ at $71.0 \mathrm{~N}, 8.0 \mathrm{E}$ at 12Z. Ship highlights: $25 \mathrm{kt} \mathrm{NE}$ and $1000 \mathrm{mb}$ at $70.3 \mathrm{~N}, 1.5 \mathrm{~W}$ at $12 \mathrm{Z}$ (COADS).

September 7:

HWM analyzes an extratropical cyclone of at most $980 \mathrm{mb}$ at $62.0 \mathrm{~N}, 26.0 \mathrm{E}$ (Beulah appears to have been absorbed) at 12Z. Ship highlights: No gales or low pressures.

Hurricane Beulah developed from a tropical wave that left the African coast around August $11^{\text {th }}$ based upon the Microfilm and Historical Weather Maps. The disturbance moved westward into an area of scarce ship data over the eastern and central Atlantic, thus the time of genesis is uncertain. A reconnaissance aircraft investigated the tropical disturbance late on August $19^{\text {th }}$ while it was located about $900 \mathrm{~nm}$ east of the Lesser Antilles. The aircraft did not found a closed circulation but its observations and the synoptic data at $18 \mathrm{Z}$ on the $19^{\text {th }}$ showed that a very sharp tropical wave was present. The first position is analyzed at $00 \mathrm{Z}$ on August $20^{\text {th }}$ as a $25 \mathrm{kt}$ tropical depression, twelve hours earlier than originally shown in HURDAT, based upon ship data showing a weak west wind and $20 \mathrm{kt} \mathrm{SW}$. Minor track alterations are shown during the lifetime of this tropical cyclone. The tropical depression moved northwestward on the $20^{\text {th }}$ while slowly organizing. A reconnaissance aircraft investigated the tropical cyclone at $1830 \mathrm{Z}$ on the $20^{\text {th }}$ measuring a central pressure of $1006 \mathrm{mb}$ and estimated surface winds of $30 \mathrm{kt}$. A central pressure of $1006 \mathrm{mb}$ suggests maximum sustained winds of $35 \mathrm{kt}$ from the south of $25 \mathrm{~N}$ Brown et al. pressure-wind relationship. Based ship data showing winds belowgale force, an intensity of $30 \mathrm{kt}$ is selected at $18 \mathrm{Z}$ on the $20^{\text {th }}$, same as originally shown in HURDAT. The first gales associated with this tropical cyclone were reported on August $21^{\text {st }}$, although it seems that some of the ships in the microfilm maps were either not plotted correctly or the ships reported the wrong position. Intensification to a tropical storm is analyzed at $06 \mathrm{Z}$ on the $21^{\text {st }}$, same as originally shown in HURDAT, based upon ship and reconnaissance data later in the day. A reconnaissance aircraft investigated Beulah at $1645 \mathrm{Z}$ on the $21^{\text {st }}$ measuring a central pressure of $1005 \mathrm{mb}$ and estimated surface winds of $45 \mathrm{kt}$. A central pressure of $1005 \mathrm{mb}$ suggests maximum sustained winds of $37 \mathrm{kt}$ from the south of $25 \mathrm{~N}$ pressure-wind relationship. Based on a forward speed of about $10 \mathrm{kt}$ and ship data also showing winds up to $45 \mathrm{kt}$, an intensity of $45 \mathrm{kt}$ is selected at $18 \mathrm{Z}$ on the $21^{\text {st }}$, same as originally shown in HURDAT.

At $00 \mathrm{Z}$ on August $22^{\text {nd }}$, a ship passed close to the center of Beulah reporting $30 \mathrm{kt} \mathrm{W}$ and $1003 \mathrm{mb}$, suggesting that the system had continued to deepen. Thus, an intensity of $50 \mathrm{kt}$ is selected at $00 \mathrm{Z}$ on the $22^{\text {nd }}$, up from $45 \mathrm{kt}$ originally in HURDAT. A penetration center fix occurred at $1255 \mathrm{Z}$ on the $22^{\text {nd }}$ measuring a central pressure of $994 \mathrm{mb}$, estimated surface winds of $68 \mathrm{kt}$ and an eye diameter of $25 \mathrm{~nm}$. A central pressure of $994 \mathrm{mb}$ 
suggests maximum sustained winds of $58 \mathrm{kt}$ from the south of $25 \mathrm{~N}$ and also intensifying subset of the pressure-wind relationship. An eye diameter of $25 \mathrm{~nm}$ suggests an RMW of about $19 \mathrm{~nm}$ and the climatological value is 15 . An intensity of $60 \mathrm{kt}$ is selected at $12 \mathrm{Z}$ on the $22^{\text {nd }}$, down from $70 \mathrm{kt}$ originally shown in HURDAT, a minor intensity change. TIROS VII captured an image of the tropical cyclone around noon (Zulu time) on the $22^{\text {nd }}$, available in the MWL on page 10 in Volume 8, Number 1, January 1964. The satellite image shows a well-organized tropical cyclone with spiral bands and little to no signs of shear. Intensification to a hurricane is analyzed at $18 \mathrm{Z}$ on the $22^{\text {nd }}$, six hours later than originally shown in HURDAT. On August $23^{\text {rd }}$, Beulah made its closest approach to the Leeward Islands, passing a couple of hundred miles to the northeast. Also on this date, the track of the hurricane turned to the north-northwest and the system continued to intensify. A couple of ships reported gale-force winds on the $23^{\text {rd }}$ but all remained in the periphery of Beulah. The next reconnaissance aircraft to make a penetration center fix arrived at $07 \mathrm{Z}$ on the $23^{\text {rd }}$ measuring a central pressure of $977 \mathrm{mb}$, estimating surface winds of $90 \mathrm{kt}$ and an eye diameter of $25 \mathrm{~nm}$. A central pressure of $977 \mathrm{mb}$ suggests maximum sustained winds of $82 \mathrm{kt}$ from the south of $25 \mathrm{~N}$ intensifying subset of the pressure-wind relationship. An eye diameter of $25 \mathrm{~nm}$ suggests an RMW of about $19 \mathrm{~nm}$ and the climatological value is 16 . An intensity of $80 \mathrm{kt}$ is selected at $06 \mathrm{Z}$ on the $23^{\text {rd }}$, down from 85 kt originally shown in HURDAT, a minor intensity change. The next reconnaissance aircraft found that Beulah had continued to strengthen, measuring a central pressure of $963 \mathrm{mb}$ and estimating surface winds of $85 \mathrm{kt}$ at $1740 \mathrm{Z}$ on the $23^{\text {rd }}$. A few hours later, at $2030 \mathrm{Z}$ on the $23^{\text {rd }}$, another penetration fix estimated an eye diameter of $25 \mathrm{~nm}$. A central pressure of $963 \mathrm{mb}$ suggests maximum sustained winds of $99 \mathrm{kt}$ from the south of $25 \mathrm{~N}$ intensifying subset of the pressure-wind relationship. An eye diameter of $25 \mathrm{~nm}$ suggests an RMW of about $19 \mathrm{~nm}$ and the climatological value is 18. Based on a slow forward speed of about $8 \mathrm{kt}$, an intensity of $95 \mathrm{kt}$ is analyzed at $18 \mathrm{Z}$ on the $23^{\text {rd }}$, down from 100 kt originally shown in HURDAT, a minor intensity change. A penetration center fix at $22 \mathrm{Z}$ on the $23^{\text {rd }}$ measured a central pressure of $962 \mathrm{mb}$, estimated surface winds of $90 \mathrm{kt}$ and an eye diameter of $29 \mathrm{~nm}$. An intensity of $95 \mathrm{kt}$ is selected on August $24^{\text {th }}$ at $00 \mathrm{Z}$, down from $100 \mathrm{kt}$ originally in HURDAT, a minor intensity change.

On the $24^{\text {th }}$, the tropical cyclone continued to slowly move away from the Leeward Islands into the central Atlantic. Various ships reported gale-force winds and even stormforce winds, up to $60 \mathrm{kt}$. A penetration center fix measured a central pressure of $958 \mathrm{mb}$ and estimated an eye diameter of $20 \mathrm{~nm}$ at $0630 \mathrm{Z}$ on the $24^{\text {th }}$. A central pressure of 958 $\mathrm{mb}$ suggests maximum sustained winds of $102 \mathrm{kt}$ from the south of $25 \mathrm{~N}$ intensifying subset of the pressure-wind relationship. An eye diameter of $20 \mathrm{~nm}$ suggests an RMW of about $15 \mathrm{~nm}$ and the climatological value is 18 . Based on a slow forward speed of about 6 $\mathrm{kt}$, an intensity of $100 \mathrm{kt}$ is analyzed at $06 \mathrm{Z}$ on the $24^{\text {th }}$, down from $105 \mathrm{kt}$ originally shown in HURDAT, a minor intensity change. $100 \mathrm{kt}$ is also the peak intensity of this tropical cyclone, down from 105 kt originally in HURDAT, a minor intensity change. The next penetration center fix occurred after $12 \mathrm{Z}$ on the $24^{\text {th }}$, measuring a central pressure of $961 \mathrm{mb}$ at $1450 \mathrm{Z}$ and $1630 \mathrm{Z}$. The peak intensity of $100 \mathrm{kt}$ is analyzed for two consecutive time slots, $06 \mathrm{Z}$ and $12 \mathrm{Z}$ on the $24^{\text {th }}$, and based on the slight increase in central pressure, decreased to $95 \mathrm{kt}$ at $18 \mathrm{Z}$ on the $24^{\text {th }}$, down from $100 \mathrm{kt}$ originally in HURDAT, a minor intensity change. On August $25^{\text {th }}$, Beulah increased in forward speed 
to the north and continued to weaken. A reconnaissance aircraft investigated the hurricane at $1310 \mathrm{Z}$ on the $25^{\text {th }}$ measuring a central pressure of $985 \mathrm{mb}$, estimating flight level winds of $60 \mathrm{kt}$ and an eye diameter of $40 \mathrm{~nm}$. A central pressure of $985 \mathrm{mb}$ suggests maximum sustained winds of $66 \mathrm{kt}$ and $63 \mathrm{kt}$ from the north of $25 \mathrm{~N}$ and weakening subset of the pressure-wind relationship, respectively. An eye diameter of $40 \mathrm{~nm}$ suggests an RMW of about $30 \mathrm{~nm}$ and the climatological value is 20 . An intensity of $65 \mathrm{kt}$ is analyzed at $12 \mathrm{Z}$ on the $25^{\text {th }}$, down from $75 \mathrm{kt}$ originally shown in HURDAT, a minor intensity change. Another penetration fix occurred at $19 \mathrm{Z}$ on the $25^{\text {th }}$ measuring a central pressure of $976 \mathrm{mb}$, estimating surface winds of $80 \mathrm{kt}$ and an eye diameter of $60 \mathrm{~nm}$. A central pressure of $976 \mathrm{mb}$ suggests maximum sustained winds of $77 \mathrm{kt}$ and $81 \mathrm{kt}$ from the north of $25 \mathrm{~N}$ and intensifying subset of the pressure-wind relationship, respectively. An eye diameter of $60 \mathrm{~nm}$ suggests an RMW of about $45 \mathrm{~nm}$ and the climatological value is 20 . An intensity of $75 \mathrm{kt}$ is analyzed at $18 \mathrm{Z}$ on the $25^{\text {th }}$, down from $80 \mathrm{kt}$ originally shown in HURDAT, a minor intensity change. Another reconnaissance aircraft penetration center fix occurred at $22 \mathrm{Z}$ on the $25^{\text {th }}$ and measured a central pressure of 978 $\mathrm{mb}$. An intensity of $75 \mathrm{kt}$ is analyzed at $00 \mathrm{Z}$ on August $24^{\text {th }}$, down from $80 \mathrm{kt}$ in HURDAT, a minor intensity change. The ships remained in the periphery of the hurricane and the highest winds reported on the $25^{\text {th }}$ were $45 \mathrm{kt}$.

On the $26^{\text {th }}$, Beulah turned to the northeast ahead of a frontal boundary. A penetration center fix occurred at $1345 \mathrm{Z}$ on the $26^{\text {th }}$ measuring a central pressure of $983 \mathrm{mb}$, estimated surface winds of $70 \mathrm{kt}$ and an eye diameter of $50 \mathrm{~nm}$. A central pressure of 983 $\mathrm{mb}$ suggests maximum sustained winds of $69 \mathrm{kt}$ and $66 \mathrm{kt}$ from the north of $25 \mathrm{~N}$ and weakening subset of the pressure-wind relationship, respectively. An eye diameter of 50 $\mathrm{nm}$ suggests an RMW of about $38 \mathrm{~nm}$ and the climatological value is 21 . Based on a fast forward speed of about $18 \mathrm{kt}$ but large circulation, an intensity of $70 \mathrm{kt}$ is analyzed at $12 \mathrm{Z}$ on the $26^{\text {th }}$, down from $85 \mathrm{kt}$ originally shown in HURDAT, a minor intensity change. The final penetration fix measured a central pressure of $979 \mathrm{mb}$, estimated surface winds of $90 \mathrm{kt}$ and an eye diameter of $80 \mathrm{~nm}$ at $19 \mathrm{Z}$ on the $26^{\text {th }}$. A central pressure of $979 \mathrm{mb}$ suggests maximum sustained winds of $74 \mathrm{kt}$ from the north of $25 \mathrm{~N}$ pressure-wind relationship. An eye diameter of $80 \mathrm{~nm}$ suggests an RMW of about $60 \mathrm{~nm}$ and the climatological value is 22 . Based on a fast forward speed of about $18 \mathrm{kt}$ and large circulation, an intensity of $75 \mathrm{kt}$ is analyzed at $18 \mathrm{Z}$ on the $26^{\text {th }}$, down from $85 \mathrm{kt}$ originally shown in HURDAT, a minor intensity change. Synoptic observations late on the $27^{\text {th }}$ indicated that Beulah was becoming embedded within the approaching frontal boundary. Transition to an extratropical cyclone is analyzed at $18 \mathrm{Z}$ on the $27^{\text {th }}$ based upon ship data showing a substantial temperature gradient across the circulation. On August $28^{\text {th }}$, Beulah passed a couple of hundred miles east of Newfoundland and ships near the center reported winds up to $70 \mathrm{kt}$. On this date, the system turned to the eastnortheast passing south of Greenland. Weakening below hurricane intensity is analyzed at $12 \mathrm{Z}$ on the $28^{\text {th }}$, same as originally shown in HURDAT. Late on August $29^{\text {th }}$ and early on August $30^{\text {th }}$, Beulah passed south of Iceland. Late on the $30^{\text {th }}$, the extratropical cyclone approached northern Ireland and turned to the southeast. On August $31^{\text {st }}$, Beulah crossed northern Ireland and southwest Wales en route to France. Ship data indicates that it was still producing winds up to $60 \mathrm{kt}$. On September $1^{\text {st }}$, the extratropical cyclone moved over northwest France, later turning to the north and crossing into England on September $2^{\text {nd }}$. 
Synoptic observations indicate that Beulah weakened below gale-force at $06 \mathrm{Z}$ on the $2^{\text {nd }}$. Early on September $3^{\text {rd }}$, ship data show that the weak cyclone moved into the North Sea and traveled northeastward passing west of Norway on September $4^{\text {th }}$ and finally dissipating after $18 \mathrm{Z}$ on September $6^{\text {th }}$. The last position is analyzed at $18 \mathrm{Z}$ on the $6^{\text {th }}, 8$ days later than originally shown in HURDAT. A major change is to add eight days to the track as an extratropical cyclone.

\begin{tabular}{|c|c|c|c|}
\hline Date & $\begin{array}{c}\text { Original } \\
\text { HURDAT } \\
\text { Central } \\
\text { Pressure } \\
\end{array}$ & Evidence & Changes \\
\hline Aug $2018 Z$ & $1006 \mathrm{mb}$ & $\begin{array}{l}\text { Penetration center fix: } 1006 \\
\mathrm{mb} \text { at } 1830 \mathrm{z} \text { on Aug } 20^{\mathrm{th}}\end{array}$ & \multirow{3}{*}{ Retained } \\
\hline Aug $2118 Z$ & $1005 \mathrm{mb}$ & $\begin{array}{l}\text { Penetration center fix: } 1005 \\
\text { mb at } 1645 Z \text { on Aug } 21^{\text {st }}\end{array}$ & \\
\hline Aug $2212 Z$ & $994 \mathrm{mb}$ & $\begin{array}{l}\text { Penetration center fix: } 994 \\
\mathrm{mb} \text { at } 1255 \mathrm{Z} \text { on Aug } 22^{\text {nd }}\end{array}$ & \\
\hline Aug $23 \odot 6 z$ & & $\begin{array}{l}\text { Penetration center fix: } 977 \\
\mathrm{mb} \text { at } 07 \mathrm{z} \text { on Aug } 23^{\text {rd }}\end{array}$ & $977 \mathrm{mb}$ \\
\hline Aug $2318 z$ & $962 \mathrm{mb}$ & $\begin{array}{l}\text { Penetration center fix: } 963 \\
\mathrm{mb} \text { at } 1740 \mathrm{z} \text { on Aug } 23^{\text {rd }}\end{array}$ & $963 \mathrm{mb}$ \\
\hline Aug $24 \odot \odot Z$ & & $\begin{array}{l}\text { Penetration center fix: } 962 \\
\mathrm{mb} \text { at } 22 Z \text { on Aug } 23^{\text {rd }}\end{array}$ & $962 \mathrm{mb}$ \\
\hline Aug $24 \odot 6 Z$ & $958 \mathrm{mb}$ & $\begin{array}{l}\text { Penetration center fix: } 958 \\
\mathrm{mb} \text { at } 0630 \mathrm{z} \text { on Aug } 24^{\text {th }}\end{array}$ & Retained \\
\hline Aug $2412 Z$ & & $\begin{array}{l}\text { Penetration center fix: } 961 \\
\mathrm{mb} \text { at } 14 Z \text { on Aug } 24^{\text {th }}\end{array}$ & $961 \mathrm{mb}$ \\
\hline Aug $2418 Z$ & $961 \mathrm{mb}$ & $\begin{array}{l}\text { Penetration center fix: } 961 \\
\mathrm{mb} \text { at } 1630 \mathrm{z} \text { on Aug } 24^{\text {th }}\end{array}$ & \multirow{6}{*}{ Retained } \\
\hline Aug $2512 Z$ & $985 \mathrm{mb}$ & $\begin{array}{l}\text { Penetration center fix: } 985 \\
\mathrm{mb} \text { at } 1310 \mathrm{z} \text { on Aug } 25^{\text {th }}\end{array}$ & \\
\hline Aug $2518 Z$ & $976 \mathrm{mb}$ & $\begin{array}{l}\text { Penetration center fix: } 976 \\
\mathrm{mb} \text { at } 19 \mathrm{Z} \text { on Aug } 25^{\mathrm{th}}\end{array}$ & \\
\hline Aug $26 \odot \odot Z$ & $978 \mathrm{mb}$ & $\begin{array}{l}\text { Penetration center fix: } 978 \\
\mathrm{mb} \text { at } 22 Z \text { on Aug } 25^{\text {th }}\end{array}$ & \\
\hline Aug $2612 Z$ & $983 \mathrm{mb}$ & $\begin{array}{l}\text { Penetration center fix: } 983 \\
\mathrm{mb} \text { at } 1345 \mathrm{Z} \text { on Aug } 26^{\text {th }}\end{array}$ & \\
\hline Aug $2618 Z$ & $979 \mathrm{mb}$ & $\begin{array}{l}\text { Penetration center fix: } 979 \\
\mathrm{mb} \text { at } 19 \mathrm{Z} \text { on Aug } 26^{\text {th }}\end{array}$ & \\
\hline
\end{tabular}




\section{Unnamed Hurricane [September 9-14, 1963]}

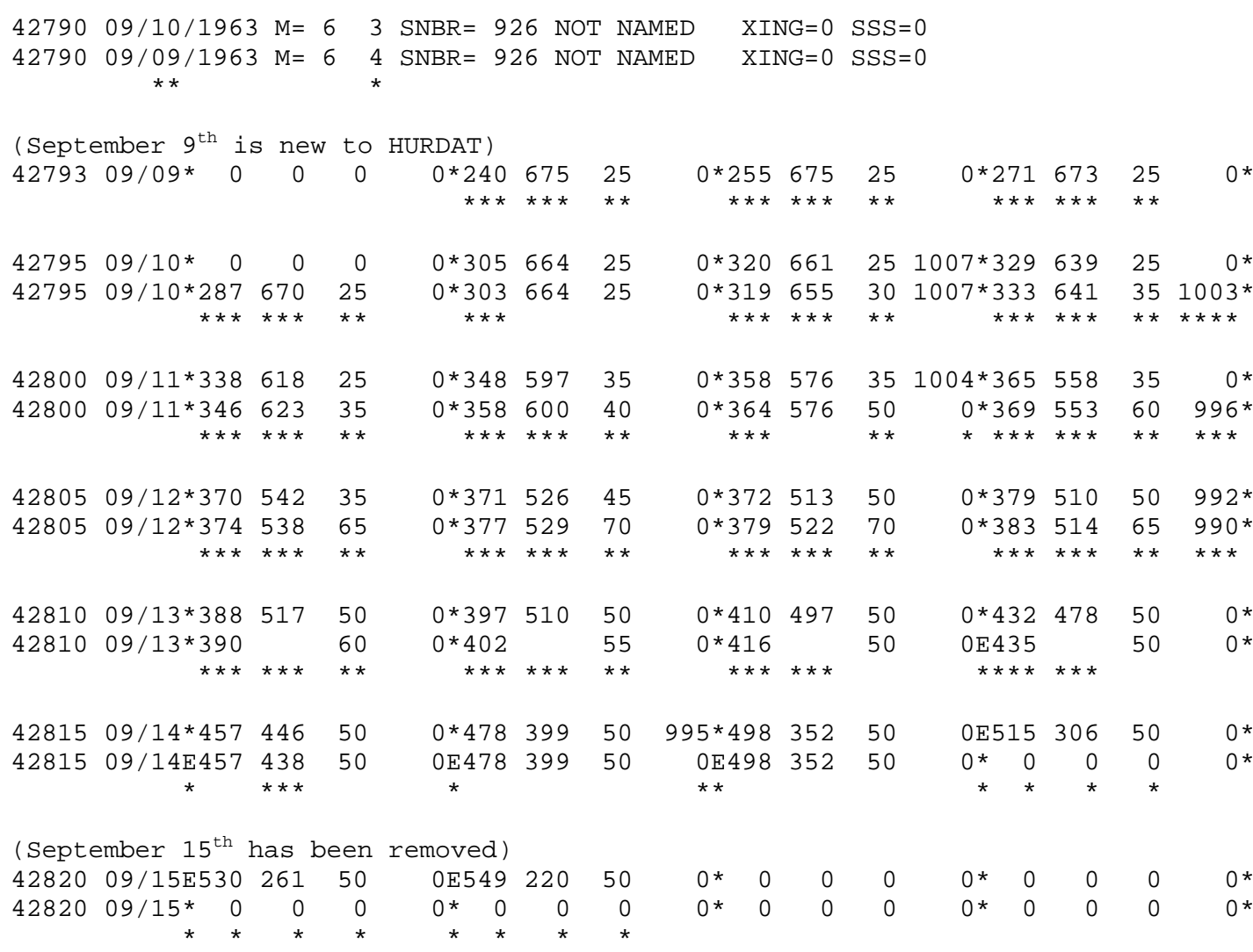

42825 TS

$42825 \mathrm{H}$

Minor changes to the track and major changes to the intensity shown in McAdie et al. (2009). A major alteration is to indicate that the tropical cyclone reached hurricane intensity. Evidence for these alterations comes from the NHC microfilm maps, the Historical Weather Maps series, the COADS ship database, Monthly Weather Review, Mariners Weather Log, and NHC Storm Wallets.

September 8:

HWM analyzes a trough of low pressure extended from $20 \mathrm{~N}-30 \mathrm{~N}, 66 \mathrm{~W}$ with a stationary front far to the northwest at 12Z. HURDAT does not list an organized system on this date. Microfilm shows a tropical wave or trough extended from $19 \mathrm{~N}-28 \mathrm{~N}, 66 \mathrm{~W}$ at 12Z. Ship highlights: No gales or low pressures.

MWR: "Each year several storms occur which are not entirely tropical in character.

Tropical cyclones derive their energy from latent heat of condensation while extratropical cyclones depend upon proper positioning of cold and warm air masses; i.e., cold air sinks and spreads under warm air causing air motion. At times "half-breed" cyclones develop over tropical oceans and tap both energy sources. In these cases it is difficult to decide whether a tropical cyclone name should be assigned to the Low. The Unnamed Storm in 
September was of this type, as was the late May-early June storm. It was not until a critical ship log was received after the hurricane season that the decision could be made to include the September storm in the official list. Ship reports indicated a weak circulation north of Puerto Rico on September 8."

September 9:

HWM analyzes a spot low pressure at $28.0 \mathrm{~N}, 67.0 \mathrm{~W}$ and another spot low at $25.7 \mathrm{~N}, 74.2 \mathrm{~W}$ with a cold front to the northwest at 12Z. HURDAT does not list an organized system on this date. Microfilm shows a closed low pressure of at most 1011 $\mathrm{mb}$ at $25.7 \mathrm{~N}, 67.3 \mathrm{~W}$ at $12 \mathrm{Z}$. Ship highlights: No gales or low pressures.

September 10:

HWM analyzes a closed low pressure of at most $1010 \mathrm{mb}$ at $32.0 \mathrm{~N}, 66.0 \mathrm{~W}$ with a weakening cold front to the west at 12Z. HURDAT lists a $25 \mathrm{kt}$ tropical depression at $32.0 \mathrm{~N}, 66.1 \mathrm{~W}$ at $12 \mathrm{Z}$. Microfilm shows a closed low pressure of at most $1011 \mathrm{mb}$ at $32.0 \mathrm{~N}, 66.7 \mathrm{~W}$ with another low pressure to the west and a frontal boundary to the north at 12Z. Ship highlights: $15 \mathrm{kt} \mathrm{N}$ and $1005 \mathrm{mb}$ at $33.4 \mathrm{~N}, 64.3 \mathrm{~W}$ at $18 \mathrm{Z}$ (COADS).

MWR: "The depression drifted slowly northward passing over Bermuda during the afternoon of the 10th. The pressure on Bermuda dropped to $1007 \mathrm{mb}$, or $29.74 \mathrm{in}$, and winds increased to $25 \mathrm{mph."}$

September 11:

HWM analyzes a closed low pressure of at most $1005 \mathrm{mb}$ at $36.5 \mathrm{~N}, 57.5 \mathrm{~W}$ with a cold front just to the west at 12Z. HURDAT lists a $35 \mathrm{kt}$ tropical storm at $35.8 \mathrm{~N}, 57.6 \mathrm{~W}$ at $12 \mathrm{Z}$. Microfilm shows a closed low pressure of at most $1011 \mathrm{mb}$ at $37.5 \mathrm{~N}, 58.0 \mathrm{~W}$ with a frontal boundary extending to the southwest at 12Z. Ship highlights: $35 \mathrm{kt} \mathrm{SSE}$ and $1001 \mathrm{mb}$ at $36.6 \mathrm{~N}, 57.4 \mathrm{~W}$ at $12 \mathrm{Z}$ (COADS). $40 \mathrm{kt} \mathrm{N}$ and $1011 \mathrm{mb}$ at $36.4 \mathrm{~N}, 60.7 \mathrm{~W}$ at $12 \mathrm{Z}$ (COADS). $50 \mathrm{kt} \mathrm{SSE}$ and $1001 \mathrm{mb}$ at $37.0 \mathrm{~N}, 55.0 \mathrm{~W}$ at $18 \mathrm{Z}$ (COADS). $25 \mathrm{kt} \mathrm{WNW}$ and $999 \mathrm{mb}$ at $37.0 \mathrm{~N}, 55.5 \mathrm{~W}$ at $18 \mathrm{Z}$ (COADS). $5 \mathrm{kt} \mathrm{SW}$ and $1000 \mathrm{mb}$ at $37.0 \mathrm{~N}, 54.6 \mathrm{~W}$ at 212 (COADS).

MWR: "Tropical storm intensity was reached shortly before sunrise on the $11^{\text {th }}$."

September 12:

HWM analyzes a tropical storm of at most $1010 \mathrm{mb}$ at $37.5 \mathrm{~N}, 51.5 \mathrm{~W}$ with a weakening stationary front just to the west and a warm front to the northeast at $12 \mathrm{Z}$. HURDAT lists a $50 \mathrm{kt}$ tropical storm at $37.2 \mathrm{~N}, 51.3 \mathrm{~W}$ at $12 \mathrm{Z}$. Microfilm shows a closed low pressure of at most $1008 \mathrm{mb}$ at $37.0 \mathrm{~N}, 52.5 \mathrm{~W}$ with a frontal boundary extending through the center at 12Z. Ship highlights: $45 \mathrm{kt} \mathrm{N}$ and $1012 \mathrm{mb}$ at $36.8 \mathrm{~N}, 54.8 \mathrm{~W}$ at $00 \mathrm{Z}$ (COADS). $10 \mathrm{kt} \mathrm{W}$ and $998 \mathrm{mb}$ at 37.4N, 52.5W at 06Z (COADS). $70 \mathrm{kt} \mathrm{S}$ and $996 \mathrm{mb}$ at $37.4 \mathrm{~N}, 52.2 \mathrm{~W}$ at $09 \mathrm{Z}$ (COADS). $50 \mathrm{kt} \mathrm{S}$ and $1008 \mathrm{mb}$ at $37.0 \mathrm{~N}, 52.0 \mathrm{~W}$ at $12 \mathrm{Z}$ (COADS). $15 \mathrm{kt} \mathrm{SE}$ and $992 \mathrm{mb}$ at 38.5N, 50.9W at 18Z (micro). $45 \mathrm{kt} \mathrm{SSE}$ and $1000 \mathrm{mb}$ at $38.0 \mathrm{~N}, 51.6 \mathrm{~W}$ at $15 \mathrm{Z}$ (COADS). $45 \mathrm{kt} \mathrm{NW}$ and $1005 \mathrm{mb}$ at $37.9 \mathrm{~N}, 52.3 \mathrm{~W}$ at $18 \mathrm{Z}$ (COADS). 
MWR: "Maximum intensity occurred on the $12^{\text {th }}$ when the Freiburg experienced $78 \mathrm{mph}$ winds, 27-ft. seas, and a pressure of $995 \mathrm{mb}$, or $29.39 \mathrm{in}$. The center remained small and tightly knit as the storm accelerated rapidly northeastward ahead of a cold front."

September 13:

HWM analyzes a tropical storm of at most $1005 \mathrm{mb}$ at $41.4 \mathrm{~N}, 49.4 \mathrm{~W}$ with a warm front just to the northeast at 12Z. HURDAT lists a $50 \mathrm{kt}$ tropical storm at $41.0 \mathrm{~N}, 49.7 \mathrm{~W}$ at $12 \mathrm{Z}$. Microfilm shows a closed low pressure of at most $1011 \mathrm{mb}$ at $40.8 \mathrm{~N}, 48.3 \mathrm{~W}$ with a frontal boundary extending through the center at 12Z. Ship highlights: $35 \mathrm{kt} \mathrm{N}$ and 1014 $\mathrm{mb}$ at $43.1 \mathrm{~N}, 45.7 \mathrm{~W}$ at $12 \mathrm{Z}$ (COADS). $35 \mathrm{kt} \mathrm{W}$ and $1013 \mathrm{mb}$ at $42.1 \mathrm{~N}, 48.4 \mathrm{~W}$ at $18 \mathrm{Z}$ (COADS).

September 14:

HWM analyzes a tropical storm of at most $1005 \mathrm{mb}$ at $50.3 \mathrm{~N}, 35.2 \mathrm{~W}$ with a cold front just to the west at 12Z. HURDAT lists a $50 \mathrm{kt}$ tropical storm at $49.8 \mathrm{~N}, 35.2 \mathrm{~W}$ at 12Z. Microfilm shows an extratropical cyclone of at most $1005 \mathrm{mb}$ at $53.0 \mathrm{~N}, 38.0 \mathrm{~W}$ at 12Z. Ship highlights: $40 \mathrm{kt} \mathrm{SSW}$ and $1016 \mathrm{mb}$ at $44.0 \mathrm{~N}, 41.0 \mathrm{~W}$ at $00 \mathrm{Z}$ (COADS). $45 \mathrm{kt}$ SW and $1017 \mathrm{mb}$ at $44.0 \mathrm{~N}, 41.0 \mathrm{~W}$ at $03 \mathrm{Z}$ (COADS). $35 \mathrm{kt} \mathrm{SSW}$ and $1016 \mathrm{mb}$ at $44.5 \mathrm{~N}$, $39.6 \mathrm{~W}$ at $06 \mathrm{Z}$ (COADS). $40 \mathrm{kt} \mathrm{SW}$ and $997 \mathrm{mb}$ at $48.6 \mathrm{~N}, 35.3 \mathrm{~W}$ at $12 \mathrm{Z}$ (COADS).

MWR: "Tropical characteristics were lost on September 14."

September 15:

HWM analyzes an extratropical cyclone of at most $1015 \mathrm{mb}$ at $52.0 \mathrm{~N}, 27.0 \mathrm{~W}$ at 12Z. HURDAT lists a $50 \mathrm{kt}$ extratropical cyclone at $54.9 \mathrm{~N}, 22.0 \mathrm{~W}$ at $06 \mathrm{Z}$ (last position). Microfilm shows a closed low pressure at $54.5 \mathrm{~N}, 18.0 \mathrm{~W}$ at $12 \mathrm{Z}$ (system exiting the map boundaries). Ship highlights: No gales or low pressures.

A tropical wave or trough of low pressure was located north of Puerto Rico on September $8^{\text {th }}$ based upon Microfilm and Historical Weather Maps. The disturbance moved northward and became better organized. A $25 \mathrm{kt}$ tropical depression is analyzed to have developed at $06 \mathrm{Z}$ on September $9^{\text {th }}$ based on synoptic data in the microfilm maps, 24 hours earlier than originally shown in HURDAT. Minor track alterations are introduced during the lifetime of this tropical cyclone. The tropical depression turned to the northeast on September $10^{\text {th }}$ ahead of an approaching frontal boundary. A central pressure of $1007 \mathrm{mb}$ is present in HURDAT at $12 \mathrm{Z}$ on the $10^{\text {th }}$ and has been retained based on the report of $15 \mathrm{kt} \mathrm{SE}$ and $1009 \mathrm{mb}$ by Bermuda at $12 \mathrm{Z}$ on the $10^{\text {th }}$. Around $14 \mathrm{Z}$ on the $10^{\text {th }}$, the tropical depression passed about $10 \mathrm{~nm}$ west of Bermuda. At $18 \mathrm{Z}$ on the $10^{\text {th }}$, a ship reported $15 \mathrm{kt} \mathrm{N}$ and $1005 \mathrm{mb}$, suggesting a central pressure of $1003 \mathrm{mb}$, which has been added to HURDAT. A central pressure of $1003 \mathrm{mb}$ suggests maximum sustained winds of $38 \mathrm{kt}$ from the north of $25 \mathrm{~N}$ Brown et al. pressure-wind relationship. Based upon a forward speed of about $21 \mathrm{kt}$ but relatively low environmental pressures $(1010 \mathrm{mb}$ OCI $)$ at this latitude, an intensity of $35 \mathrm{kt}$ is selected at $18 \mathrm{Z}$ on the $10^{\text {th }}$, up from 25 kt originally in HURDAT, a minor intensity change. Intensification to a tropical storm is analyzed at $18 \mathrm{Z}$ on the $10^{\text {th }}$, twelve hours earlier than originally shown in HURDAT. 
The tropical storm continued to the northeast on September $11^{\text {th }}$ and rapidly intensified. The first gales were reported at $12 \mathrm{Z}$ on the $11^{\text {th }}$. At this time, microfilm shows a frontal boundary extended from the center to the southwest and another frontal boundary to the north, but HWM indicates that the small tropical cyclone was still ahead of the frontal boundary and in the warm sector. Synoptic observations are in better agreement with HWM and show that there is no temperature gradient across the circulation, thus it was still a tropical cyclone. A central pressure of $1004 \mathrm{mb}$ is present in HURDAT at 12Z on the $11^{\text {th }}$ and has been removed due to a ship report of $35 \mathrm{kt} \mathrm{SSE}$ and $1001 \mathrm{mb}$, suggesting a central pressure lower than what appears in HURDAT. A ship reported $50 \mathrm{kt} \mathrm{SE}$ and 1001 and another registered $25 \mathrm{kt} \mathrm{NW}$ and $999 \mathrm{mb}$. The latter ship observation indicates a central pressure of $996 \mathrm{mb}$, which has been added to HURDAT at $18 \mathrm{Z}$ on the $11^{\text {th }}$. A central pressure of $996 \mathrm{mb}$ suggests maximum sustained winds of $55 \mathrm{kt}$ from the north of $35 \mathrm{~N}$ Landsea et al. pressure-wind relationship. Due to a forward speed of about $26 \mathrm{kt}$ and normal environmental pressures (1014 mb OCI), an intensity of $60 \mathrm{kt}$ is selected at $18 \mathrm{Z}$ on the $11^{\text {th }}$, up from $35 \mathrm{kt}$ originally in HURDAT, a major intensity change.

On September $12^{\text {th }}$, the tropical cyclone decreased in forward speed and kept intensifying. Intensification to a hurricane is analyzed at $00 \mathrm{Z}$ on the $12^{\text {th }}$, a major change to HURDAT, which originally indicated that the tropical cyclone had peaked as a tropical storm. An intensity of $65 \mathrm{kt}$ is selected at $00 \mathrm{Z}$ on the $12^{\text {th }}$ based upon ship data later in the day, up from $35 \mathrm{kt}$ originally in HURDAT, a major intensity change. A ship named "Freiburg" reported $70 \mathrm{kt} \mathrm{S}$ and $996 \mathrm{mb}$ at $09 \mathrm{Z}$ on the $12^{\text {th }}$. Based on this data, a peak intensity of $70 \mathrm{kt}$ is analyzed at $06 \mathrm{Z}$ and $12 \mathrm{Z}$ on the $12^{\text {th }}$, up from $45 \mathrm{kt}$ and $50 \mathrm{kt}$, respectively, originally in HURDAT, major intensity changes. Originally HURDAT showed a peak intensity of $50 \mathrm{kt}$ from September $12^{\text {th }}$ at $12 \mathrm{Z}$ to September $14^{\text {th }}$ at $12 \mathrm{Z}$. At $18 \mathrm{Z}$ on the $12^{\text {th }}$, a ship reported $15 \mathrm{kt} \mathrm{SE}$ and $992 \mathrm{mb}$, suggesting a central pressure of $990 \mathrm{mb}$, which has been added to HURDAT replacing the existing $992 \mathrm{mb}$. A central pressure of $990 \mathrm{mb}$ suggests maximum sustained winds of $63 \mathrm{kt}$ from the north of $35 \mathrm{~N}$ pressure-wind relationship. Based on a slow forward speed of $7 \mathrm{kt}$ and also the earlier 70 kt ship report, an intensity of $65 \mathrm{kt}$ is selected at $18 \mathrm{Z}$ on the $12^{\text {th }}$, up from $50 \mathrm{kt}$ originally in HURDAT, a minor intensity change. On September $13^{\text {th }}$, the hurricane weakened and began to acquire extratropical characteristics. Weakening to a tropical storm is analyzed at $00 \mathrm{Z}$ on the $13^{\text {th }}$. An approaching frontal boundary and intensifying extratropical cyclone caused the small tropical storm to gain in forward speed. Synoptic observations at $18 \mathrm{Z}$ on the $13^{\text {th }}$ indicate that a temperature gradient had developed across the circulation and frontogenesis had taken place. Thus, transition to an extratropical cyclone is analyzed at $18 \mathrm{Z}$ on the $13^{\text {th }}, 30$ earlier than originally shown. Late on the $13^{\text {th }}$, the extratropical cyclone passed a couple hundred miles southeast of Newfoundland, Canada. A central pressure of $995 \mathrm{mb}$ appears in HURDAT at $12 \mathrm{Z}$ on the $14^{\text {th }}$, and has been removed due to a ship reporting $40 \mathrm{kt} \mathrm{SW}$ and $997 \mathrm{mb}$, indicating a lower central pressure. Ship data on September $14^{\text {th }}$ indicate that the small extratropical cyclone was absorbed by the larger extratropical cyclone to the north. The last position is analyzed at $12 \mathrm{Z}$ on the $14^{\text {th }}, 18$ hours earlier than originally shown in HURDAT. 
Tropical Storm Cindy [September 16-20, 1963]

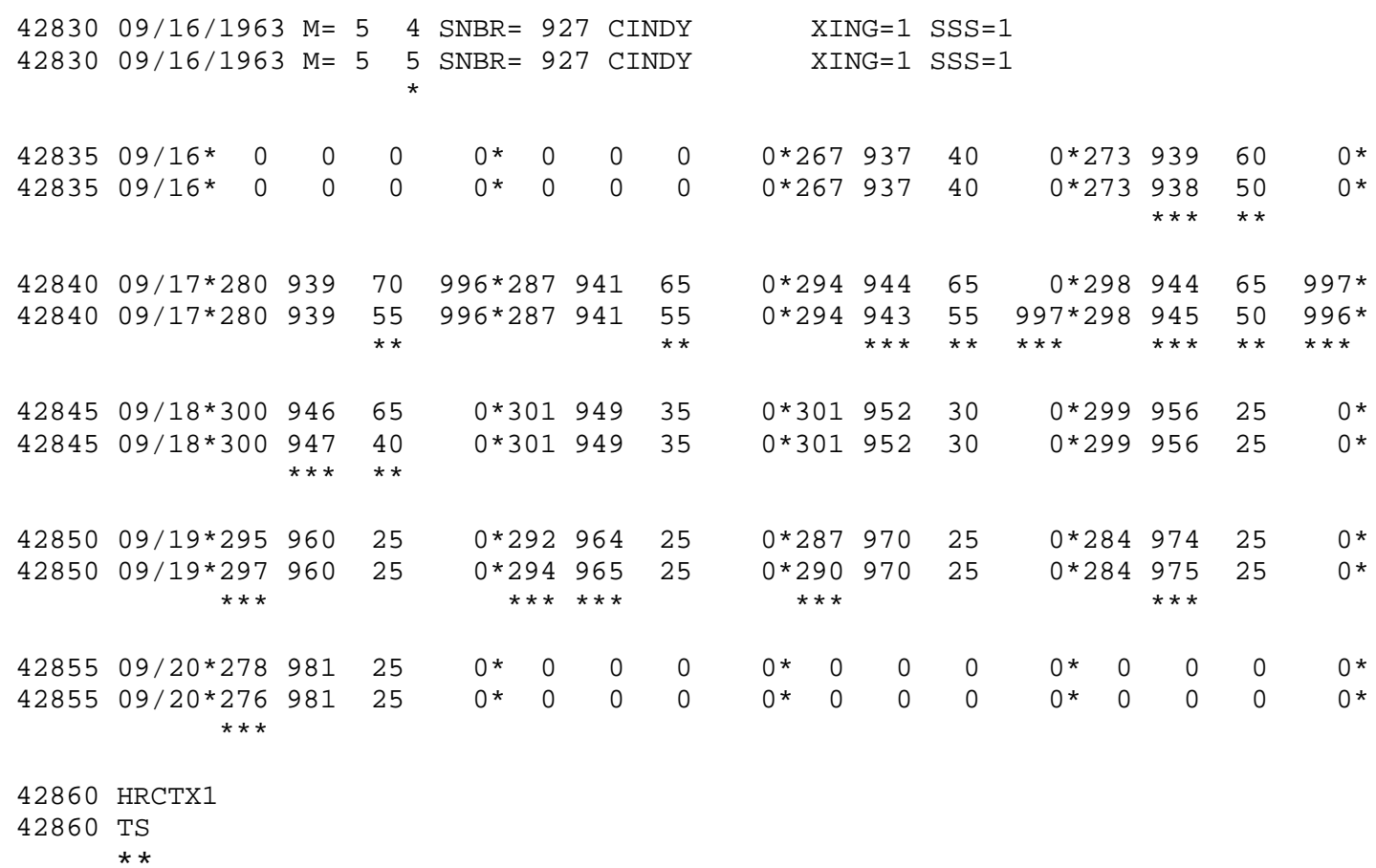

\section{U.S. Tropical Storm Landfall}

09/17 14Z 29.6N 94.3W 55 kt TX - 997 mb

Minor changes to the track and major changes to the intensity, including a downgrade for the system from a hurricane to a tropical storm, shown in McAdie et al. (2009). Evidence for these alterations comes from the NHC microfilm maps, the Historical Weather Maps series, the COADS ship database, Monthly Weather Review, Navy reconnaissance book, Mariners Weather Log, Surface Weather Observations, Mexican Surface Observations and NHC Storm Wallets.

September 13:

HWM and microfilm do not analyze an organized system at 12Z. HURDAT does not list an organized system on this date. Ship highlights: No gales or low pressures.

September 14:

HWM analyzes does not analyze an organized system at 12Z. HURDAT does not list an organized system on this date. Microfilm shows a spot low at 20.1N, 94.6W at 12Z. Ship highlights: No gales or low pressures.

MWR: "Weather conditions had been highly disturbed in the southwestern Gulf on the $14^{\text {th }}$ and $15^{\text {th }} . "$ 
September 15:

HWM analyzes a spot low pressure at $24.2 \mathrm{~N}, 92.8 \mathrm{~W}$ at $12 \mathrm{Z}$. HURDAT does not list an organized system on this date. Microfilm shows a spot low at $21.5 \mathrm{~N}, 97.0 \mathrm{~W}$ at 12Z. Ship highlights: $25 \mathrm{kt} \mathrm{SE}$ and $1004 \mathrm{mb}$ at $21.0 \mathrm{~N}, 92.4 \mathrm{~W}$ at $12 \mathrm{Z}$ (micro).

September 16:

HWM analyzes a tropical storm of at most $1005 \mathrm{mb}$ at $26.8 \mathrm{~N}, 93.8 \mathrm{~W}$ at $12 \mathrm{Z}$. HURDAT lists a $40 \mathrm{kt}$ tropical storm at $26.7 \mathrm{~N}, 93.7 \mathrm{~W}$ at $12 \mathrm{Z}$ (first position). Microfilm shows a trough of low pressure over the western Gulf of Mexico at 12Z. Ship highlights: $45 \mathrm{kt} \mathrm{SE}$ and $1009 \mathrm{mb}$ at 27.1N, 93.2W at $15 \mathrm{Z}$ (micro). $50 \mathrm{kt} \mathrm{W}$ and $1008 \mathrm{mb}$ (999 mb in MWL) at 27.2N, 94.0W at 18Z (COADS). $65 \mathrm{kt}$ at 20Z (SS Sabine) (MWR). $45 \mathrm{kt} \mathrm{E}$ and $1005 \mathrm{mb}$ at $28.2 \mathrm{~N}, 93.5 \mathrm{~W}$ at $21 \mathrm{Z}$ (micro). Aircraft highlights: Penetration center fix measured a central pressure of $996 \mathrm{mb}$, estimated surface winds of $55 \mathrm{kt}$ and an eye diameter of $30 \mathrm{~nm}$ at $27.9 \mathrm{~N}, 93.9 \mathrm{~W}$ at $2325 \mathrm{Z}$ (ATSR). Radar highlights: Galveston radar center fix at $27.8 \mathrm{~N}, 94.0 \mathrm{~W}$ at $2047 \mathrm{Z}$ (WALLET). Galveston radar center fix at $28.1 \mathrm{~N}$, 93.7W at $2345 \mathrm{Z}$ (WALLET).

MWR: "Cindy, the first hurricane in the Gulf of Mexico in two years, formed in a trough of low pressure located about 200 mi. east-northeast of Brownsville, Tex., in the morning of September 16. Ship reports received around noon CST, indicated that the circulation was of tropical storm strength and was intensifying rapidly. By 2:00 p.m. the central eye was developed sufficiently to be located about 200 mi. east of Corpus Christi by the WSR-57 radar at Galveston. At the same hour, a report from the SS Sabine near the storm center indicated hurricane force winds, although there is some question whether the wind velocity recorder was read carefully, Cindy moved northward at an average speed of 8 mph during the afternoon and night of the $16^{\text {th }}$, remaining relatively small in area and with no further increase in intensity, although most of the circulation was still over the warm Gulf waters." ATSR: "CINDY apparently formed on the trailing edge of a surface quasi-stationary front elongated east-west through the Northern Gulf of Mexico. A trough of low pressure at the upper levels was located in the Western Gulf. Hurricane CINDY, the third and most short-lived storm of the 1963 season, formed over the western Gulf of Mexico approximately 225 miles east of Brownsville, Texas. On the morning of 16 September, several ships reported winds and pressure which indicated the possible development of a tropical storm. Later ship reports indicated that a circulation had formed and was rapidly intensifying. Based on this information, the first of five numbered warnings was issued at $1900 \mathrm{Z}$ on the $16^{\text {th }}$. Warnings two, three, and four placed her in the category of a hurricane." MWL: "Hurricane Cindy, the first in the Gulf of Mexico in two years, formed about 200 mi. east-northeast of Brownsville, Tex., on the morning of September 16. Ship reports received around 1800 GMT, indicated that the circulation was of tropical storm force and intensifying rapidly. Two hours later a report from the SABINE near the storm center indicated hurricane force winds. Cindy moved slowly northward toward the Texas coast, remaining relatively small in area and with no further increase in intensity." 
September 17:

HWM analyzes a closed low pressure of at most $1000 \mathrm{mb}$ at $29.5 \mathrm{~N}, 94.5 \mathrm{~W}$ at 12Z. HURDAT lists a $65 \mathrm{kt}$ hurricane at $29.4 \mathrm{~N}, 94.4 \mathrm{~W}$ at $12 \mathrm{Z}$. Microfilm shows a closed low pressure of at most $1008 \mathrm{mb}$ at $29.5 \mathrm{~N}, 94.5 \mathrm{~W}$ at $12 \mathrm{Z}$. Ship highlights: $50 \mathrm{kt} \mathrm{NE}$ and $1009 \mathrm{mb}$ at $27.4 \mathrm{~N}, 95.1 \mathrm{~W}$ at $00 \mathrm{Z}$ (COADS). $50 \mathrm{kt} \mathrm{SE}$ at $28.9 \mathrm{~N}, 92.8 \mathrm{~W}$ at $06 \mathrm{Z}$ (COADS). Land highlights: $45 \mathrm{kt}$ (fastest mile, gusts to $65 \mathrm{kt}$ ) at Galveston, TX at $0815 \mathrm{Z}$ (WALLET). $1000 \mathrm{mb}$ (min pressure) at Galveston, TX at 1129Z (WALLET). $997 \mathrm{mb}$ (min pressure) at High Island, TX at 16Z (WALLET). $996 \mathrm{mb}$ (min pressure) at Anahuac, TX at 2027-2045Z (WALLET). Radar highlights: Lake Charles radar center fix estimated an eye diameter of $30 \mathrm{~nm}$ at $28.4 \mathrm{~N}, 93.6 \mathrm{~W}$ at $0119 \mathrm{Z}$ (WALLET). Galveston radar center fix at $28.8 \mathrm{~N}, 94.0 \mathrm{~W}$ at $0645 \mathrm{Z}$ (WALLET). Galveston radar center fix at $29.6 \mathrm{~N}, 94.4 \mathrm{~W}$ at $1245 \mathrm{Z}$ (WALLET).

MWR: "Winds and tides along the coast from the Galveston area eastward increased during the evening, with winds reaching maximum values during the early morning hours of the $17^{\text {th }}$. Over the Gulf, highest sustained winds were estimated at $80 \mathrm{mph}$ and highest gusts on the coast were $80 \mathrm{mph}$, measured near the eastern tip of Galveston Island. The Weather Bureau Office at Galveston recorded a fastest mile at the rate of $50 \mathrm{mph}$, and a peak gust of $74 \mathrm{mph}$ on the $17^{\text {th }}$. In the Port Arthur area, the highest gusts were from 40 to $50 \mathrm{mph}$, while in Louisiana gusts were estimated as high as $60 \mathrm{mph}$ at Grand Chenier and $45 \mathrm{mph}$ at Cameron, but were generally in the 25 to $35 \mathrm{mph}$ range. The central eye of Cindy, some $20 \mathrm{mi}$ in diameter, moved on shore around High Island, about midway between Galveston and Port Arthur. The Corps of Engineers there reported "light winds and near calm" between 7:30 and 11:00 a.m., CST, on the $17^{\text {th }}$ and a low barometer reading of $29.44 \mathrm{in.} \mathrm{(997} \mathrm{mb.)} \mathrm{at} \mathrm{10:00} \mathrm{am.} \mathrm{A} \mathrm{slightly} \mathrm{lower} \mathrm{pressure,} \mathrm{29.41} \mathrm{in.} \mathrm{(996}$ mb.), was recorded inland at Anahuac between 2:27 and 2:45 pm." ATSR: "From her source area, CINDY moved on a northward course, reaching the shoreline on the $17^{\text {th }}$ between Galveston and Port Arthur, Texas. Upon reaching shore, CINDY slowed considerably and began drifting westward, then finally southwestward until dissipation occurred just southwest of Houston, Texas. The highest winds accompanying CINDY were estimated to be near 80 knots while she was still over open waters, and 55-65 knots [likely gusts] while over land. Minimum pressure recorded was 996 millibars. CINDY, although a relatively small, short-lived storm, had captured several distinctions for the 1963 season. She was the only storm to originate in the Gulf of Mexico, and she was the only storm to hit the United States mainland. Winds accounted for little damage, but excessive precipitation and the slow movement caused damaged by heavy flooding. Since CINDY developed near land, the abnormal high tide which is generally associated with hurricanes was absent." 
September 18:

HWM analyzes a closed low pressure of at most $1005 \mathrm{mb}$ at $30.5 \mathrm{~N}, 95.3 \mathrm{~W}$ at 12Z. HURDAT lists a $30 \mathrm{kt}$ tropical depression at 30.1N, 95.2W at 12Z. Microfilm shows a closed low pressure of at most $1011 \mathrm{mb}$ at $29.8 \mathrm{~N}, 95.5 \mathrm{~W}$ at $12 \mathrm{Z}$. Ship highlights: No gales or low pressures. Radar highlights: Lake Charles radar center fix at $29.8 \mathrm{~N}$, 94.5W at $0115 \mathrm{Z}$ (WALLET). Lake Charles radar center fix at $30.1 \mathrm{~N}, 94.9 \mathrm{~W}$ at $0545 \mathrm{Z}$ (WALLET).

MWR: "The storm center became almost stationary for about $18 \mathrm{hr}$. shortly after moving inland, then drifted very slowly westward and southwestward with slowly decreasing intensity through the Texas Coastal Plain on September 18 and 19. This unusually slow movement during the decay of the storm resulted in an extended period of heavy rainfall in its northeastern sector over extreme southeastern Texas and southwestern Louisiana. Storm rainfall totals were 15 to 20 in. in portions of Jefferson, Newton, and Orange Counties, Texas and Calcasieu and Vermilion Parishes, Louisiana. The heaviest rain occurred at Deweyville, in southern Newton County: a 3-day total of 23.50 in., including 20.60 in. in $24 \mathrm{hr}$. between 7 am CST, observations on September 17 and 18."

September 19:

HWM analyzes a closed low pressure of at most $1010 \mathrm{mb}$ at $29.5 \mathrm{~N}, 97.0 \mathrm{~W}$ at 12Z. HURDAT lists a $25 \mathrm{kt}$ tropical depression at $28.7 \mathrm{~N}, 97.0 \mathrm{~W}$ at $12 \mathrm{Z}$. Microfilm shows a closed low pressure of at most $1011 \mathrm{mb}$ at $29.0 \mathrm{~N}, 96.5 \mathrm{~W}$ at $12 \mathrm{Z}$. Ship highlights: No gales or low pressures.

September 20:

HWM and microfilm do not analyze an organized system at 12Z. HURDAT lists a $25 \mathrm{kt}$ tropical depression at $27.8 \mathrm{~N}, 98.1 \mathrm{~W}$ at $00 \mathrm{Z}$ (last position). Ship highlights: No gales or low pressures.

September 21:

HWM and microfilm do not analyze an organized system at 12Z. HURDAT does not list an organized system on this date. Ship highlights: No gales or low pressures.

MWR: "Property damage from wind was minor, consisting of roof damage to beach homes. Only minor flooding and some slight damage occurred from tides, but several roads were impassable for short periods, and waves destroyed several piers and caused some damage to boats. Considerable damage was produced by the flooding of streams arid drainage canals and ponding of water in the areas of extremely heavy rainfall over the lower Sabine Basin in both Texas and Louisiana. The flood waters areas most severe in the Port Arthur-Port Acres area of Jefferson County. Water entered about 4000 homes in Jefferson, Orange, and Newton Counties, remaining in some areas for extended periods. Overall property damage-mainly from the flooding-was estimated at $\$ 11.7$ million. Principal crop damage, estimated near $\$ 500,000$ in Testis and $\$ 360,000$ in Louisiana, was to unharvested rice. Fortunately most of the crop had already been combined, and rainfall in most areas was considered more beneficial than damaging to crops and ranges." 
A tropical wave or trough of low pressure was located over the western Gulf of Mexico on September $14^{\text {th }}$ based upon the microfilm maps. An area of low pressure developed in the Bay of Campeche on September $15^{\text {th }}$ and moved northward becoming better organized. Two ships reported low pressures $(1004 \mathrm{mb}$ and $1002 \mathrm{mb})$ at $12 \mathrm{Z}$ on the $15^{\text {th }}$ but subsequent observations from the ships indicate that there likely was a low bias of a few millibars in the measurements. The first position is analyzed at $12 \mathrm{Z}$ on September $16^{\text {th }}$ as a $40 \mathrm{kt}$ tropical storm, same as originally shown in HURDAT. The time of genesis is uncertain because surface observations over the southwest Gulf of Mexico were sparse, but observations from South Texas and ships early on the $16^{\text {th }}$ suggests that genesis may have occurred as early as late on the $15^{\text {th }}$ or early on the $16^{\text {th }}$. Minor track alterations are made during the lifetime of this tropical cyclone. The first gale was reported by the ship SS SABINE at $15 Z$ on the $16^{\text {th }}$, indicating $45 \mathrm{kt} \mathrm{SE}$ and $1009 \mathrm{mb}$. At $18 \mathrm{Z}$ on the $16^{\text {th }}$, SS SABINE reported $50 \mathrm{kt} \mathrm{W}$ and $999 \mathrm{mb}$. The MWR says that two hours after this report, 20Z, the SS SABINE reported hurricane-force winds but MWR questions the accuracy of the report. Nonetheless, this report was originally used by the forecasters to operationally upgrade the tropical cyclone to a hurricane. The hurricane-force wind report was not found on COADS, microfilm or MWL, even though other observations from this ship were present in all three sources. A few hours later, at $2325 \mathrm{Z}$ on the $16^{\text {th }}$, a reconnaissance aircraft made a center penetration measuring a central pressure of 996 $\mathrm{mb}$, estimating surface winds of $55 \mathrm{kt}$ and an eye diameter of $30 \mathrm{~nm}$. A central pressure of $996 \mathrm{mb}$ suggests maximum sustained winds of $50 \mathrm{kt}$ from the north of $25 \mathrm{~N}$ Brown et al. pressure-wind relationship. An eye diameter of $30 \mathrm{~nm}$ suggests an RMW of $23 \mathrm{~nm}$ and the climatological value is also $23 \mathrm{~nm}$. Based upon the reliable ship data showing winds up to $50 \mathrm{kt}$, an intensity of $55 \mathrm{kt}$ is analyzed at $00 \mathrm{Z}$ on September $17^{\text {th }}$, down from $70 \mathrm{kt}$ originally in HURDAT, a minor intensity change. $55 \mathrm{kt}$ is also the peak intensity of this tropical cyclone, down from 70 kt originally in HURDAT, a minor intensity change. It is analyzed that Cindy did not reach hurricane intensity as previously shown in HURDAT. A central pressure of $996 \mathrm{mb}$ was present in HURDAT at $00 \mathrm{Z}$ on the $17^{\text {th }}$ and has been retained.

Cindy moved slowly northward on the $17^{\text {th }}$ making landfall around $14 \mathrm{Z}$ near High Island, Texas, as a $55 \mathrm{kt}$ tropical storm. High Island, TX, reported near calm conditions and a minimum pressure of $997 \mathrm{mb}$, which has been added as a central pressure at landfall and to the $12 \mathrm{Z}$ time slot on the $17^{\text {th }}$. A radar image captured by the Galveston radar at $0950 \mathrm{Z}$ on the $17^{\text {th }}$ shows a well-organized tropical cyclone with spiral bands over the eastern and northern quadrants. The highest sustained winds on land were $45 \mathrm{kt}$ and gusts to $65 \mathrm{kt}$ at Galveston, Texas, at $0815 \mathrm{Z}$ on the $17^{\text {th }}$. The slow-moving tropical storm remained close to the large Galveston Bay and a few hours after landfall, Anahuac, Texas, reported a minimum pressure of $996 \mathrm{mb}$. The minimum pressure was registered around 2030Z, thus it is used to replace the existing central pressure of $997 \mathrm{mb}$ in HURDAT at $18 \mathrm{Z}$ on the $17^{\text {th }}$. On September $18^{\text {th }}$, Cindy turned to the west and southwest and weakened over southeast Texas. At $00 \mathrm{Z}$ on the $18^{\text {th }}$, an intensity of $40 \mathrm{kt}$ is analyzed, down from $65 \mathrm{kt}$ originally shown in HURDAT, a major intensity change. HURDAT originally unrealistically maintained Cindy as a hurricane for 10 hours after the small tropical 
cyclone made landfall at barely hurricane intensity. Weakening to a tropical depression is analyzed at $12 \mathrm{Z}$ on the $18^{\text {th }}$, same as originally shown in HURDAT. Synoptic

observations indicate that Cindy retained a closed low-level circulation on September $19^{\text {th }}$ while moving southwest over South Texas and finally dissipated after 00Z on September $20^{\text {th }}$. The last position is analyzed at $00 \mathrm{Z}$ on the $20^{\text {th }}$, same as originally shown in HURDAT.

Tropical Storm Debra [September 19-24, 1963]

\begin{tabular}{|c|c|c|c|c|c|c|c|c|c|c|c|c|c|}
\hline 42865 & $09 / 19 / 10$ & 963 & $M=6$ & $5 \mathrm{SNBI}$ & $3 R=$ & 928 & DEBRA & & & $N G=\odot \quad S S S$ & & & \\
\hline 42865 & $09 / 19 / 19$ & 963 & $M=6$ & $\begin{array}{l}6 \mathrm{SNB} \\
\star\end{array}$ & $B R=$ & 928 & DEBRA & & & $N G=0 \quad S S S$ & $S=0$ & & \\
\hline 42870 & $09 / 19$ * & $\odot$ & $\odot$ & $0 * 144$ & 383 & 25 & $\odot * 150$ & 398 & 25 & $1011 * 157$ & 412 & 30 & $\odot$ * \\
\hline 42870 & $09 / 19 *$ & $\odot$ & $\odot$ & $0 * 140$ & 383 & $\begin{array}{l}35 \\
* *\end{array}$ & $0 * 148$ & 398 & $\begin{array}{l}35 \\
* *\end{array}$ & $0 * 156$ & 412 & $\begin{array}{l}40 \\
* *\end{array}$ & ○* \\
\hline 42875 & $09 / 20 * 164$ & 426 & 30 & $0 * 172$ & 440 & 25 & $\odot * 179$ & 453 & 25 & $0 * 188$ & 467 & 30 & 1008 * \\
\hline 42875 & $09 / 20 * 164$ & 426 & $\begin{array}{l}40 \\
* *\end{array}$ & $0 * 172$ & 440 & $\begin{array}{l}45 \\
* *\end{array}$ & $0 * 180$ & 453 & $\begin{array}{l}50 \\
* *\end{array}$ & $0 * 189$ & 467 & $\begin{array}{l}50 \\
* *\end{array}$ & $\begin{array}{l}0 * \\
*\end{array}$ \\
\hline 42880 & $09 / 21 * 199$ & 479 & 35 & $0 * 209$ & 485 & 40 & $\odot * 219$ & 488 & 50 & $0 * 230$ & 489 & 65 & 1000 * \\
\hline 42880 & $09 / 21 * 199$ & 479 & $\begin{array}{l}50 \\
* *\end{array}$ & $\begin{array}{c}0 * 210 \\
\star * *\end{array}$ & 485 & $\begin{array}{l}50 \\
* *\end{array}$ & $\Theta_{* * *}^{*} 221$ & 488 & $\begin{array}{l}55 \\
* *\end{array}$ & $\begin{array}{r}0 * 231 \\
* * *\end{array}$ & 489 & $\begin{array}{l}55 \\
* *\end{array}$ & 1000 * \\
\hline $\begin{array}{l}42885 \\
42885\end{array}$ & $\begin{array}{l}09 / 22 * 238 \\
09 / 22 * 238\end{array}$ & $\begin{array}{l}489 \\
489\end{array}$ & $\begin{array}{l}65 \\
55 \\
* *\end{array}$ & $\begin{array}{l}\Theta^{*} 246 \\
\Theta^{*} 246\end{array}$ & $\begin{array}{l}488 \\
488\end{array}$ & $\begin{array}{l}65 \\
55 \\
* *\end{array}$ & $\begin{array}{l}\odot * 253 \\
\oplus^{*} 253\end{array}$ & $\begin{array}{l}487 \\
487\end{array}$ & $\begin{array}{l}65 \\
55 \\
* *\end{array}$ & $\begin{array}{r}1002 * 260 \\
1002 * 258 \\
* * *\end{array}$ & $\begin{array}{l}485 \\
485\end{array}$ & $\begin{array}{l}65 \\
55 \\
* *\end{array}$ & $\begin{array}{l}999^{*} \\
999^{*}\end{array}$ \\
\hline $\begin{array}{l}42890 \\
42890\end{array}$ & $\begin{array}{r}09 / 23 * 266 \\
09 / 23^{*} 265 \\
* * *\end{array}$ & $\begin{array}{l}482 \\
482\end{array}$ & $\begin{array}{l}65 \\
50 \\
* *\end{array}$ & $\begin{array}{l}\theta^{*} 273 \\
\Theta^{*} 272 \\
\star \star \star\end{array}$ & $\begin{array}{l}479 \\
479\end{array}$ & $\begin{array}{l}55 \\
5 \odot \\
* *\end{array}$ & $\begin{array}{l}\Theta^{*} 280 \\
\odot^{*} 280\end{array}$ & $\begin{array}{l}477 \\
477\end{array}$ & $\begin{array}{l}50 \\
50 \\
* *\end{array}$ & $\begin{array}{l}\Theta * 288 \\
\Theta * 288\end{array}$ & $\begin{array}{l}475 \\
475\end{array}$ & $\begin{array}{l}45 \\
50 \\
* *\end{array}$ & $\begin{array}{l}999^{*} \\
999^{*}\end{array}$ \\
\hline 42895 & $09 / 24 * 302$ & 475 & $4 \odot$ & $0 * 317$ & 479 & 35 & $\odot * 334$ & 484 & 35 & 1011E354 & 480 & 30 & ๑* \\
\hline 42895 & $09 / 24$ *302 & $\begin{array}{l}478 \\
\star * *\end{array}$ & 40 & $0 * 317$ & $\begin{array}{l}481 \\
\star * *\end{array}$ & 35 & $\begin{array}{rl}0^{*} & 0 \\
* & *\end{array}$ & $\stackrel{\odot}{*}$ & $\begin{array}{l}0 \\
*\end{array}$ & $\begin{array}{ll}\Theta^{*} & \ominus \\
* & *\end{array}$ & $\begin{array}{l}\odot \\
*\end{array}$ & $\begin{array}{l}\odot \\
*\end{array}$ & ○* \\
\hline $\begin{array}{l}42900 \\
42900\end{array}$ & $\begin{array}{l}\text { HR } \\
\text { TS }\end{array}$ & & & & & & & & & & & & \\
\hline
\end{tabular}

Minor changes to the track and major changes to the intensity shown in McAdie et al. (2009). A major alteration is to indicate that the tropical cyclone did not reach hurricane intensity. Another major revision is to indicate that no extratropical transition took place in this cyclone. Evidence for these alterations comes from the NHC microfilm maps, the Historical Weather Maps series, the COADS ship database, Monthly Weather Review, Navy reconnaissance book, Mariners Weather Log, Allison \& Thompson (1966) and NHC Storm Wallets.

September 17:

HWM analyzes a spot low pressure at $12.0 \mathrm{~N}, 27.0 \mathrm{~W}$ at $12 \mathrm{Z}$. HURDAT does not list an organized system on this date. Microfilm does not show an organized system on this date. Ship highlights: No gales or low pressures. 
September 18:

HWM analyzes a closed low pressure of at most $1010 \mathrm{mb}$ at $13.8 \mathrm{~N}, 33.8 \mathrm{~W}$ at 12Z. HURDAT does not list an organized system on this date. Microfilm does not show an organized system on this date. Ship highlights: No gales or low pressures.

September 19:

HWM analyzes a closed low pressure of at most $1010 \mathrm{mb}$ at $15.0 \mathrm{~N}, 39.7 \mathrm{~W}$ at 12Z. HURDAT lists a $25 \mathrm{kt}$ tropical depression at $15.0 \mathrm{~N}, 39.8 \mathrm{~W}$ at $12 \mathrm{Z}$. Microfilm does not show an organized system at 12Z. Ship highlights: No gales or low pressures. Satellite highlights: TIROS fix center at $17.5 \mathrm{~N}, 41.5 \mathrm{~W}$ at $1205 \mathrm{Z}$ (WALLET).

MWR: "Hurricane Debra formed in the mid-tropical Atlantic and moved on a course well removed from any land areas. The first evidence of the circulation which later developed into Debra came from a ship report and a TIROS picture early on September 19." ATSR: "The first appearance of the disturbed area which was to develop into Hurricane DEBRA was reported at $190600 \mathrm{Z}$ by a ship near $14 \mathrm{~N} 38 \mathrm{~W}$ that encountered a overcast sky, light winds and a surface pressure several millibars below normal. A TIROS photograph at $191200 \mathrm{Z}$ indicated a possible vortex in the disturbed area, and a ship near $16 \mathrm{~N} 40 \mathrm{~W}$ reported winds easterly 25 knots and increasing, overcast skies and steady rain. DEBRA's course, from early development on the $19^{\text {th }}$ until the storm was absorbed by a large extratropical low on the $24^{\text {th }}$, was predominately northerly. While at storm intensity, DEBRA was never well organized. The eye was poorly defined, and the wall cloud contained large open areas."

September 20:

HWM analyzes a closed low pressure of at most $1010 \mathrm{mb}$ at $17.5 \mathrm{~N}, 45.5 \mathrm{~W}$ at 12Z. HURDAT lists a $25 \mathrm{kt}$ tropical depression at $17.9 \mathrm{~N}, 45.3 \mathrm{~W}$ at $12 \mathrm{Z}$. Microfilm does not show an organized system at 12Z. Ship highlights: $40 \mathrm{kt} \mathrm{E}$ and $1011 \mathrm{mb}$ at $18.6 \mathrm{~N}$, $39.1 \mathrm{~W}$ at $00 \mathrm{Z}$ (micro). $50 \mathrm{kt} \mathrm{E}$ and $1013 \mathrm{mb}$ at $19.6 \mathrm{~N}, 47.3 \mathrm{~W}$ at $12 \mathrm{Z}$ (micro). Satellite highlights: TIROS fix center at $17.0 \mathrm{~N}, 44.0 \mathrm{~W}$ at $1225 \mathrm{Z}$ (WALLET). Aircraft highlights: Radar center fix at $19.3 \mathrm{~N}, 47.2 \mathrm{~W}$ and $25 \mathrm{kt} \mathrm{W}$ at $1654 \mathrm{Z}$ (ATSR).

MWR: "A reconnaissance aircraft was dispatched to investigate on the $20^{\text {th }}$ and reached the southeast quadrant of the storm before being forced to return because of fuel limitation. The plane reported a radar eye and observed $30 \mathrm{mph}$ west winds at the surface 20 mi. south of the center." ATSR: "A Navy weather reconnaissance aircraft departed Roosevelt Roads, Puerto Rico, at 201420Z, and, upon reaching the area at 202030Z, reported a developing eye near $19.3 \mathrm{~N} 47.2 \mathrm{~W}$ with westerly winds of 25 knots."

September 21:

HWM analyzes a tropical storm of at most $1005 \mathrm{mb}$ at $21.8 \mathrm{~N}, 48.8 \mathrm{~W}$ at $12 \mathrm{Z}$. HURDAT lists a $50 \mathrm{kt}$ tropical storm at $21.9 \mathrm{~N}, 48.8 \mathrm{~W}$ at $12 \mathrm{Z}$. Microfilm shows a closed low pressure of at most $1005 \mathrm{mb}$ at $22.7 \mathrm{~N}, 48.6 \mathrm{~W}$ at $12 \mathrm{Z}$. Ship highlights: $35 \mathrm{kt} \mathrm{E}$ and $1007 \mathrm{mb}$ at $24.0 \mathrm{~N}, 47.0 \mathrm{~W}$ at $12 \mathrm{Z}$ (micro). $35 \mathrm{kt} \mathrm{E}$ and $1014 \mathrm{mb}$ at $24.5 \mathrm{~N}, 47.7 \mathrm{~W}$ at $18 \mathrm{Z}$ 
(COADS). $55 \mathrm{kt} \mathrm{ENE}$ and $1007 \mathrm{mb}$ at 24.0N, $48.3 \mathrm{~W}$ at 21Z (COADS). Aircraft highlights: Penetration center fix measured a central pressure of $1001 \mathrm{mb}$, estimated surface winds of $65 \mathrm{kt}$ and an eye diameter of $5 \mathrm{~nm}$ at $23.0 \mathrm{~N}, 49.0 \mathrm{~W}$ at $1654 \mathrm{Z}$ (WALLET/ATSR). Satellite highlights: TIROS fix center at $21.5 \mathrm{~N}, 46.3 \mathrm{~W}$ at $1332 \mathrm{Z}$ (WALLET).

MWR: "The next day, September 21, a second reconnaissance aircraft found $75 \mathrm{mph}$ winds and a central pressure of about $1000 \mathrm{mb}$ or $29.53 \mathrm{in}$. Debra was at best barely a minimal hurricane for no more than $24 \mathrm{hr}$." ATSR: "DEBRA continued to intensity and by $211654 \mathrm{Z}$ the second reconnaissance aircraft found winds of 65 knots. A hurricane warning was issued at $211830 \mathrm{Z}$, naming the storm."

September 22:

HWM analyzes a hurricane of at most $1000 \mathrm{mb}$ at $25.5 \mathrm{~N}, 48.5 \mathrm{~W}$ at $12 \mathrm{Z}$. HURDAT lists a $65 \mathrm{kt}$ hurricane at $25.3 \mathrm{~N}, 48.7 \mathrm{~W}$ at $12 \mathrm{Z}$. Microfilm shows a closed low pressure of at most $1002 \mathrm{mb}$ at $25.5 \mathrm{~N}, 48.5 \mathrm{~W}$ at $12 \mathrm{Z}$. Ship highlights: $45 \mathrm{kt} \mathrm{NE}$ at $26.0 \mathrm{~N}$, $49.0 \mathrm{~W}$ at $06 \mathrm{Z}$ (micro). $35 \mathrm{kt} \mathrm{SE}$ and $1007 \mathrm{mb}$ at $27.0 \mathrm{~N}, 45.8 \mathrm{~W}$ at $12 \mathrm{Z}$ (micro). $50 \mathrm{kt} \mathrm{SE}$ at $26.0 \mathrm{~N}, 45.8 \mathrm{~W}$ at $18 \mathrm{Z}$ (micro). Aircraft highlights: Penetration center fix measured a central pressure of $1002 \mathrm{mb}$, estimated surface winds of $45 \mathrm{kt}$ and an eye diameter of 5 $\mathrm{nm}$ at $25.5 \mathrm{~N}, 48.8 \mathrm{~W}$ at $1350 \mathrm{Z}$ (WALLET/ATSR). Penetration center fix measured a central pressure of $999 \mathrm{mb}$, estimated surface winds of $65 \mathrm{kt}$ and an eye diameter of 50 $\mathrm{nm}$ at $25.8 \mathrm{~N}, 48.2 \mathrm{~W}$ at $1830 \mathrm{Z}$ (WALLET).

MWR: "The storm continued northward slowly on the $22^{\text {nd }}$ with little change in intensity." ATSR: "During the 18-hour period of hurricane intensity, DEBRA became better organized; however, the subsequent decrease in intensity after $221200 \mathrm{Z}$ brought rapid deterioration in organization."

September 23:

HWM analyzes a tropical storm of at most $1010 \mathrm{mb}$ at $28.0 \mathrm{~N}, 47.6 \mathrm{~W}$ with a cold front to the northwest at $12 \mathrm{Z}$. HURDAT lists a $50 \mathrm{kt}$ tropical storm at $28.0 \mathrm{~N}, 47.7 \mathrm{~W}$ at 12Z. Microfilm shows a closed low pressure of at most $1011 \mathrm{mb}$ at $28.8 \mathrm{~N}, 47.4 \mathrm{~W}$ at $12 \mathrm{Z}$. Ship highlights: $40 \mathrm{kt} \mathrm{SE}$ and $1015 \mathrm{mb}$ at $25.2 \mathrm{~N}, 45.8 \mathrm{~W}$ at $00 \mathrm{Z}$ (micro). Aircraft highlights: Penetration center fix at $28.5 \mathrm{~N}, 47.6 \mathrm{~W}$ at $1355 \mathrm{Z}$ (WALLET). Penetration center fix measured a central pressure of $999 \mathrm{mb}$, estimated surface winds of $50 \mathrm{kt}$ and an eye diameter of $30 \mathrm{~nm}$ at $28.9 \mathrm{~N}, 47.5 \mathrm{~W}$ at $19 \mathrm{Z}$ (WALLET). Satellite highlights: TIROS fix center at $28.4 \mathrm{~N}, 47.6 \mathrm{~W}$ at $1316 \mathrm{Z}$ (WALLET).

MWR: "...then weakened and began accelerating on the $23^{\text {rd }}$."

September 24:

HWM analyzes a tropical storm of at most $1010 \mathrm{mb}$ at $33.5 \mathrm{~N}, 48.0 \mathrm{~W}$ with a cold front just to the west at 12Z. HURDAT lists a $35 \mathrm{kt}$ tropical storm at $33.4 \mathrm{~N}, 48.4 \mathrm{~W}$ at 12Z. Microfilm shows a closed low pressure of at most $1008 \mathrm{mb}$ at $33.0 \mathrm{~N}, 48.5 \mathrm{~W}$ with a frontal boundary to the west at 12Z. Ship highlights: $35 \mathrm{kt} \mathrm{S}$ and $1009 \mathrm{mb}$ at $38.7 \mathrm{~N}$, $46.9 \mathrm{~W}$ at $12 \mathrm{Z}$ (COADS). 
MWR: "It was finally absorbed by an extratropical Low on the $24^{\text {th }}$. There was no loss of life or property damage associated with Debra."

September 25:

HWM analyzes a stationary front over the North Atlantic at 12Z. HURDAT does not list an organized system on this date. Microfilm shows a spot low at $34.0 \mathrm{~N}, 53.0 \mathrm{~W}$ at 12Z. Ship highlights: No gales or low pressures.

Tropical Storm Debra developed from a tropical wave that entered the eastern Atlantic Ocean around September $15^{\text {th }}$. Data over this part of the basin is sparse, thus the time of genesis is uncertain. The HWM show a spot low pressure near $13 \mathrm{~N}, 17 \mathrm{~W}$ on September $17^{\text {th }}$ while the disturbance was located southwest of the Cape Verde Islands. TIROS VII captured an image of the tropical system at $13 \mathrm{Z}$ on the $17^{\text {th }}$ showing a large area of organized cloudiness with a center near $13 \mathrm{~N}, 43 \mathrm{~W}$. This position is about 10-15 degrees too far to the west based on ship and reconnaissance data over the next couple of days and may either reflect bad navigation of the satellite picture or there was a second wave in the vecinity. The disturbance moved westward and became better organized. Another satellite image was captured on September $19^{\text {th }}$ at $1205 \mathrm{Z}$ near $18 \mathrm{~N}, 42 \mathrm{~W}$ showing a wellorganized system. Once again, the position appears to be misplaced, but this time, by about $150 \mathrm{~nm}$ too far to the northwest based on ship data at the time the satellite image was taken. Due to the rudimentary technology of the day, it has been noticed with other satellite images of tropical cyclones over the open Atlantic Ocean that their estimated position has also been off by a few degrees. The first position is analyzed at $12 \mathrm{Z}$ on the $19^{\text {th }}$, same as originally shown in HURDAT, as a $35 \mathrm{kt}$ tropical storm based upon the appearance of tropical cyclone in the satellite image, up from $25 \mathrm{kt}$ originally shown in HURDAT, a minor intensity change. Intensification to a tropical storm is analyzed 42 hours earlier than originally shown in HURDAT. Minor track alterations are introduced during the lifetime of this tropical cyclone. (A few central pressure values were present in the original HURDAT between September $19^{\text {th }}$ at $12 \mathrm{Z}$ and September $24^{\text {th }}$ at $12 \mathrm{Z}$. Some of these were obviously based upon observations of peripheral pressures and not central pressures. Thus, based on actual observations, some were retained and some were removed. Detailed information on these changes can be found in the table at the end.) Debra moved to the northwest on the $19^{\text {th }}$ and slowly intensified. The first gale associated with Debra was reported on September $20^{\text {th }}$ at $00 \mathrm{Z}$ by a ship, $40 \mathrm{kt} \mathrm{E}$ and $1011 \mathrm{mb}$. At $12 \mathrm{Z}$ on the $20^{\text {th }}$, another ship reported $50 \mathrm{kt} \mathrm{E}$ and $1013 \mathrm{mb}$. The first reconnaissance aircraft to investigate Debra reached the system at $1420 \mathrm{Z}$ on the $20^{\text {th }}$ making a radar fix and estimating $25 \mathrm{kt}$ westerly winds in the southern quadrant before departing due to fuel limitations. Based upon the $50 \mathrm{kt}$ reported by the ship at $12 \mathrm{Z}$ on the $20^{\text {th }}$, the report of an eye visible in radar images by the reconnaissance aircraft, westerly winds of $25 \mathrm{kt}$ in the southern quadrant and the satellite image on the $19^{\text {th }}$, an intensity of $50 \mathrm{kt}$ is selected at $12 \mathrm{Z}$ on the $20^{\text {th }}$, up from $25 \mathrm{kt}$ originally in HURDAT, a major intensity change. $50 \mathrm{kt}$ is also analyzed at $18 \mathrm{Z}$ on the $20^{\text {th }}$, up from $30 \mathrm{kt}$ originally in HURDAT, a major intensity change. 
On September $21^{\text {st }}$, Debra turned to the north over the central Atlantic. At $12 \mathrm{Z}$ on the $21^{\text {st }}$, a ship reported $35 \mathrm{kt} \mathrm{E}$ and $1007 \mathrm{mb}$ in the northeast quadrant of the tropical cyclone. At $1654 \mathrm{Z}$ on the $21^{\text {st }}$, a reconnaissance aircraft measured a central pressure of $1001 \mathrm{mb}$, estimated surface winds of $65 \mathrm{kt}$ and an eye diameter of $5 \mathrm{~nm}$. MWR indicates that the central pressure measured in this mission was $1000 \mathrm{mb}$, which was already in HURDAT and it has been retained. A central pressure of $1000 \mathrm{mb}$ suggests maximum surface winds of $47 \mathrm{kt}$ from the south of $25 \mathrm{~N}$ Brown et al. pressure-wind relationship. An eye diameter of $5 \mathrm{~nm}$ suggests an RMW of about $4 \mathrm{~nm}$ and the climatological value is 19 $\mathrm{nm}$. Based upon a forward speed of $10 \mathrm{kt}$, an RMW smaller than climatology and a ship report of $55 \mathrm{kt}$ at $21 \mathrm{Z}$ on the $21^{\mathrm{st}}$, an intensity of $55 \mathrm{kt}$ is analyzed at $18 \mathrm{Z}$ on the $21^{\mathrm{st}}$, down from $65 \mathrm{kt}$ originally in HURDAT, a minor intensity change. $55 \mathrm{kt}$ is also the peak intensity of this tropical cyclone, down from $65 \mathrm{kt}$ originally in HURDAT, a minor intensity change. It is analyzed that Debra did not reach hurricane intensity as previously shown in HURDAT. On September $22^{\text {nd }}$, Debra continued to move northward at a slower forward speed. A couple of ships reported winds of tropical storm force on this day. The next reconnaissance aircraft to make a penetration fix occurred at $1350 \mathrm{Z}$ on the $22^{\text {nd }}$ measuring a central pressure of $1002 \mathrm{mb}$, estimating surface winds of $45 \mathrm{kt}$ and an eye diameter of $5 \mathrm{~nm}$. A central pressure of $1002 \mathrm{mb}$ suggests maximum surface winds of 40 $\mathrm{kt}$ and $43 \mathrm{kt}$ from the north of $25 \mathrm{~N}$ and south of $25 \mathrm{~N}$ pressure-wind relationships, respectively. An eye diameter of $5 \mathrm{~nm}$ suggests an RMW of about $4 \mathrm{~nm}$ and the climatological value is $20 \mathrm{~nm}$. Based upon an RMW smaller than the climatological value and a ship report of $50 \mathrm{kt}$ at $18 \mathrm{Z}$ on the $22^{\text {nd }}$, an intensity of $55 \mathrm{kt}$ is analyzed at $12 \mathrm{Z}$ on the $22^{\text {nd }}$, down from $65 \mathrm{kt}$ originally shown in HURDAT, a minor intensity change. Another penetration fix occurred at $1830 \mathrm{Z}$ on the $22^{\text {nd }}$ measuring a central pressure of $999 \mathrm{mb}$, estimating surface winds of $50 \mathrm{kt}$ and an eye diameter of $50 \mathrm{~nm}$. An eye diameter of $50 \mathrm{~nm}$ suggests an RMW of about $43 \mathrm{~nm}$ and the climatological value is 20 $\mathrm{nm}$. A central pressure of $999 \mathrm{mb}$ suggests maximum surface winds of $45 \mathrm{kt}$ and $49 \mathrm{kt}$ from the north of $25 \mathrm{~N}$ and the south of $25 \mathrm{~N}$ pressure-wind relationships, respectively. Based upon the ship report of $50 \mathrm{kt}$ and a couple other ship reports of $40 \mathrm{kt}$ at $18 \mathrm{Z}$ on the $22^{\text {nd }}$, an intensity of $55 \mathrm{kt}$ is analyzed at $18 \mathrm{Z}$ on the $22^{\text {nd }}$, down from $65 \mathrm{kt}$ originally in HURDAT, a minor intensity change. On September $23^{\text {rd }}$, Debra continued northward over the open Atlantic. A reconnaissance aircraft investigated the tropical storm at $19 \mathrm{Z}$ on the $23^{\text {rd }}$ measuring a central pressure of $999 \mathrm{mb}$, estimating surface winds of $50 \mathrm{kt}$ and an eye diameter of $30 \mathrm{~nm}$. An eye diameter of $30 \mathrm{~nm}$ suggests an RMW of about $23 \mathrm{~nm}$ and the climatological value is also $23 \mathrm{~nm}$. A central pressure of $999 \mathrm{mb}$ suggests maximum surface winds of $45 \mathrm{kt}$ from the north of $25 \mathrm{~N}$ pressure-wind relationship. Based upon an eye diameter close to climatology and a forward speed of about $8 \mathrm{kt}$, an intensity of $50 \mathrm{kt}$ is analyzed at $18 \mathrm{Z}$ on the $23^{\mathrm{rd}}$, up from $45 \mathrm{kt}$ originally in HURDAT, a minor intensity change. On September $24^{\text {th }}$, a frontal boundary approached Debra from the west. Synoptic observations after $06 \mathrm{Z}$ on the $24^{\text {th }}$ indicate that Debra lost its closed circulation and was later absorbed by the frontal boundary. Last position is analyzed at $06 Z$ on the $24^{\text {th }}$, twelve hours earlier than originally shown in HURDAT. It is also analyzed that Debra was absorbed before transitioning into an extratropical cyclone as previously shown in HURDAT. 


\begin{tabular}{|c|c|c|c|}
\hline Date & $\begin{array}{c}\text { Original } \\
\text { HURDAT } \\
\text { Central } \\
\text { Pressure } \\
\end{array}$ & Evidence & Changes \\
\hline Sep $1912 Z$ & $1011 \mathrm{mb}$ & $\begin{array}{l}25 \mathrm{kt} \mathrm{E} \text { and } 1010 \mathrm{mb} \text { reported by a ship } \\
\text { near } 16 \mathrm{~N}, 40 \mathrm{~W}\end{array}$ & \multirow{2}{*}{ Removed } \\
\hline Sep $2018 Z$ & $1008 \mathrm{mb}$ & $\begin{array}{l}\text { Peripheral pressure from an aircraft } \\
\text { making a radar fix }\end{array}$ & \\
\hline Sep $2118 Z$ & $1000 \mathrm{mb}$ & $\begin{array}{l}\text { Penetration center fix: } 1001 \mathrm{mb} \text { at } 1654 \mathrm{Z} \\
\text { on Sep } 21^{\text {st }}\end{array}$ & \multirow{4}{*}{ Retained } \\
\hline Sep $2212 Z$ & $1002 \mathrm{mb}$ & $\begin{array}{l}\text { Penetration center fix: } 1002 \mathrm{mb} \text { at } 1350 \mathrm{Z} \\
\text { on Sep } 22^{\text {nd }}\end{array}$ & \\
\hline Sep $2218 Z$ & $999 \mathrm{mb}$ & $\begin{array}{l}\text { Penetration center fix: } 999 \mathrm{mb} \text { at } 1830 \mathrm{Z} \\
\text { on Sep } 22^{\text {nd }}\end{array}$ & \\
\hline Sep $2318 Z$ & $999 \mathrm{mb}$ & $\begin{array}{l}\text { Penetration center fix: } 999 \mathrm{mb} \text { at } 19 \mathrm{Z} \text { on } \\
\text { Sep } 23^{\text {rd }}\end{array}$ & \\
\hline Sep $2412 Z$ & $1011 \mathrm{mb}$ & $\begin{array}{l}\text { Circulation not closed, thus it has been } \\
\text { removed }\end{array}$ & Removed \\
\hline
\end{tabular}

Hurricane Edith [September 23-29, 1963]

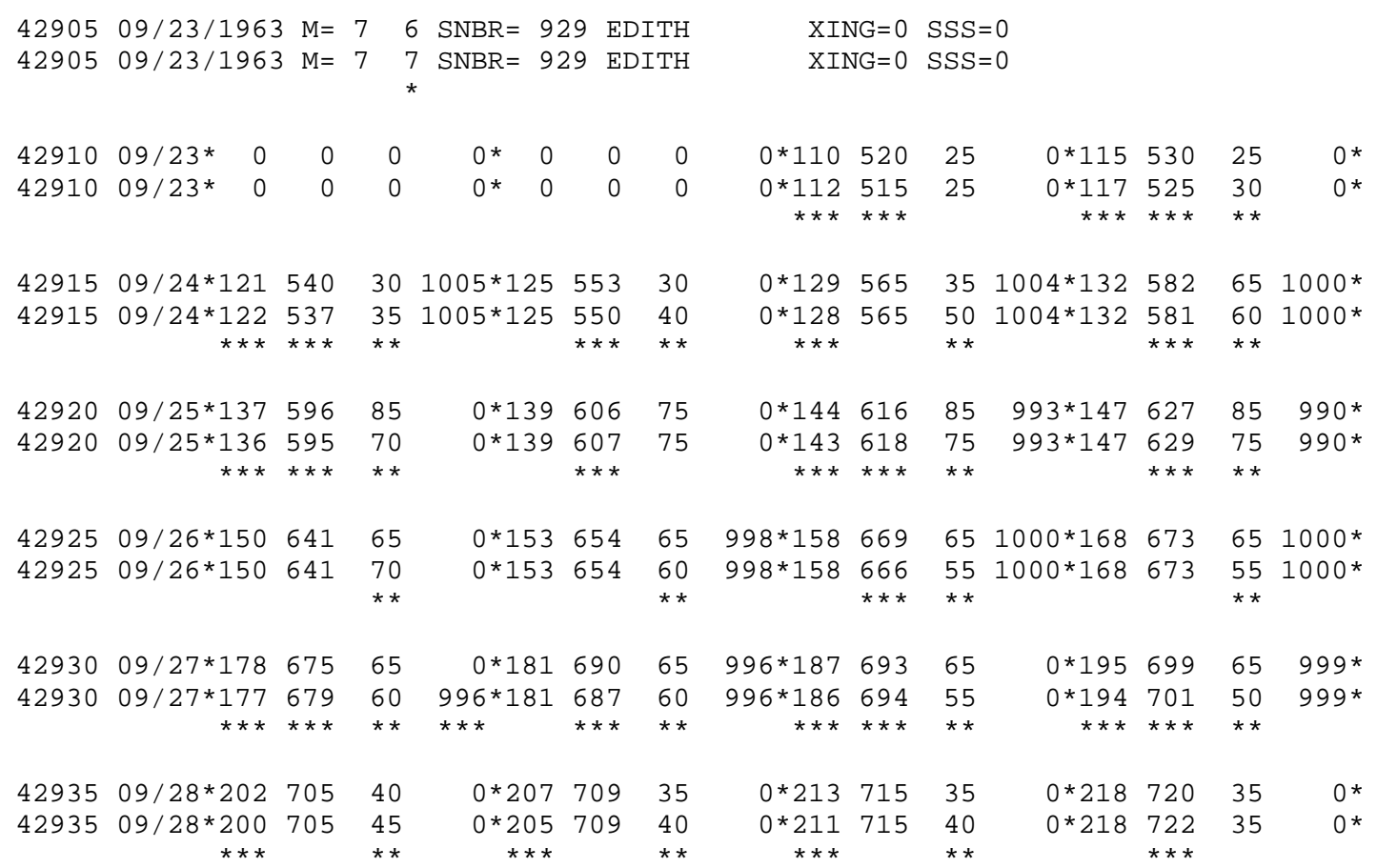


$42940 \quad 09 / 29 * 226723 \quad 30$

$42940 \quad 09 / 29 * 226728 \quad 30$
$0 * 231720 \quad 30$

$\odot * 23472530$
0 * $0 \quad 0 \quad 0$

$0 * 24271530$ $\begin{array}{lrrrr}{ }^{*} & 0 & 0 & 0 & 0 * \\ 0 * 250 & 705 & 30 & 0 *\end{array}$

42945 HR

Hurricane Landfall

09/25 07Z 14.0N 60.9W 75 kt St. Lucia

Tropical Storm Landfall

09/27 10Z 18.4N 69.1W 60 kt Dominican Republic

09/28 18Z 21.8N 72.2W $35 \mathrm{kt}$ Turks and Caicos Islands

Minor changes to the track and intensity shown in McAdie et al. (2009). Evidence for these alterations comes from the NHC microfilm maps, the Historical Weather Maps series, the COADS ship database, Monthly Weather Review, Navy reconnaissance book, Mariners Weather Log, Allison \& Thompson (1966) and NHC Storm Wallets.

September 22:

HWM and microfilm do not show an organized system at 12Z. HURDAT does not list an organized system on this date. Ship highlights: No gales or low pressures.

MWR: "Existence of a disturbance was first suspected when the Dutch tanker Acteon reported a south wind of $28 \mathrm{mph}$. and surface pressure of $1010.1 \mathrm{mb}$. (29.83 in.) as it moved southward through the inter-tropical Convergence Zone on September 22."

September 23:

HWM analyzes a closed low pressure of at most $1010 \mathrm{mb}$ at $11.0 \mathrm{~N}, 52.0 \mathrm{~W}$ at 12Z. HURDAT lists a $25 \mathrm{kt}$ tropical depression at $11.0 \mathrm{~N}, 52.0 \mathrm{~W}$ at $12 \mathrm{Z}$. Microfilm shows a closed low pressure of at most $1008 \mathrm{mb}$ at $11.0 \mathrm{~N}, 51.8 \mathrm{~W}$ at $12 \mathrm{Z}$. Ship highlights: No gales or low pressures. Aircraft highlights: Penetration center fix measured a central pressure of $1005 \mathrm{mb}$ and estimated surface winds of $25 \mathrm{kt}$ at $12.3 \mathrm{~N}, 52.8 \mathrm{~W}$ at $22 \mathrm{Z}$ (micro). TIROS highlights: Satellite center fix at $11.0 \mathrm{~N}, 52.5 \mathrm{~W}$ at $1156 \mathrm{Z}$ (WALLET).

MWR: "Photographs taken by TIROS VII at 1156 GMT September 23, showed a vortex and extensive circulation area centered near $11^{\prime}$ N., $52^{\prime}$ W. A reconnaissance aircraft reached the area late that afternoon and found winds of $29 \mathrm{mph}$ and a surface pressure of $1005 \mathrm{mb}$ (29.68 in.), but could see no definite spiral band pattern on radar." ATSR: "EDITH's discovery can be attributed primarily to photographs taken by TIROS VII on the $23^{\text {rd }}$ of September at 1156Z. These photographs showed an abnormal mass of cloudiness with a possible vortex near $11 \mathrm{~N} 52 \mathrm{~W}$. On the afternoon of the $23^{\text {rd }}$, a Navy reconnaissance plane was dispatched to the area and found winds of 25 knots and a surface pressure of 1005 millibars. This data prompted the issuance of a tropical depression warning by the Fleet Weather Facility, Miami." 
September 24:

HWM analyzes a tropical storm of at most $1005 \mathrm{mb}$ at $13.0 \mathrm{~N}, 56.0 \mathrm{~W}$ at $12 \mathrm{Z}$. HURDAT lists a $35 \mathrm{kt}$ tropical storm at $12.9 \mathrm{~N}, 56.5 \mathrm{~W}$ at $12 \mathrm{Z}$. Microfilm shows a closed low pressure of at most $1011 \mathrm{mb}$ at $12.0 \mathrm{~N}, 58.0 \mathrm{~W}$ at $12 \mathrm{Z}$. Ship highlights: $15 \mathrm{kt} \mathrm{S}$ and $1004 \mathrm{mb}$ at $12.7 \mathrm{~N}, 57.2 \mathrm{~W}$ at $12 \mathrm{Z}$ (micro). $60 \mathrm{kt} \mathrm{E}$ and $1004 \mathrm{mb}$ at $13.7 \mathrm{~N}, 57.6 \mathrm{~W}$ at $18 \mathrm{Z}$ (WALLET). Aircraft highlights: Penetration center fix measured a central pressure of $1004 \mathrm{mb}$, estimated surface winds of $60 \mathrm{kt}$ and an eye diameter of $50 \mathrm{~nm}$ at $12.8 \mathrm{~N}$, $56.6 \mathrm{~W}$ at $1315 \mathrm{Z}$ (WALLET). Penetration center fix measured a central pressure of 1000 $\mathrm{mb}$, estimated surface winds of $70 \mathrm{kt}$ and an eye diameter of $30 \mathrm{~nm}$ at $13.4 \mathrm{~N}, 58.4 \mathrm{~W}$ at $18 \mathrm{Z}$ (WALLET). TIROS highlights: Satellite center fix at $12.0 \mathrm{~N}, 55.5 \mathrm{~W}$ at $1217 \mathrm{Z}$ (WALLET).

MWR: "Hurricane Edith formed in the Atlantic east of the Lesser Antilles on September 24. Early morning reconnaissance on the $24^{\text {th }}$ found winds of $70 \mathrm{mph}$, and a short time later Edith was reported to be of hurricane intensity with $80 \mathrm{mph}$ winds. This location was some 120 mi. east of Barbados. Lowest pressure computed in Edith was $978 \mathrm{mb}$, or 28.88 in., on September 24." ATSR: "Subsequent reconnaissance flights indicated a gradual intensification to tropical storm status and the first of 20 numbered warnings was issued at $1600 \mathrm{Z}$ on the $24^{\text {th }}$. Warning number two indicated that EDITH bad rapidly intensified to hurricane strength."

September 25:

HWM analyzes a hurricane of at most $1000 \mathrm{mb}$ at $14.4 \mathrm{~N}, 61.3 \mathrm{~W}$ at $12 \mathrm{Z}$. HURDAT lists an $85 \mathrm{kt}$ hurricane at $14.4 \mathrm{~N}, 61.6 \mathrm{~W}$ at $12 \mathrm{Z}$. Microfilm shows a closed low pressure of at most $1008 \mathrm{mb}$ at $14.0 \mathrm{~N}, 61.5 \mathrm{~W}$ at $12 \mathrm{Z}$. Ship highlights: $20 \mathrm{kt} \mathrm{NNW}$ and $1004 \mathrm{mb}$ at $14.0 \mathrm{~N}, 62.0 \mathrm{~W}$ at $06 \mathrm{Z}$ (micro). $40 \mathrm{kt} \mathrm{NE}$ and $1004 \mathrm{mb}$ at $14.1 \mathrm{~N}, 62.0 \mathrm{~W}$ at $12 \mathrm{Z}$ (micro). Land highlights: $15 \mathrm{kt} \mathrm{WSW}$ and $1004 \mathrm{mb}$ at Barbados at 00Z (micro). $60 \mathrm{kt} \mathrm{N}$ at St. Lucia at 06Z (micro). Calm at Port Castries, St. Lucia between 07-0815Z (WALLET). $995 \mathrm{mb}$ (min pressure) at Fort-de-France, Martinique at 08Z (WALLET). 85 kt (direct reading) [likely gusts] at Caravelle, Martinique at 0750Z (WALLET). $55 \mathrm{kt}$ at Le Lamentin, Martinique at 08Z (WALLET). Greater than $100 \mathrm{kt}$ (115 kt registered before anemometer was blocked) [likely gusts] at Fort-de-France, Martinique between 0810Z and 10Z (WALLET). $35 \mathrm{kt} \mathrm{SE}$ and $1008 \mathrm{mb}$ at Guadeloupe at $12 \mathrm{Z}$ (micro). Aircraft highlights: Radar center fix at $14.2 \mathrm{~N}, 59.8 \mathrm{~W}$ at 02Z (WALLET). Penetration center fix measured a central pressure of $993 \mathrm{mb}$, estimated surface winds of $90 \mathrm{kt}$ and an eye diameter of $14-18 \mathrm{~nm}$ eye diameter at $14.3 \mathrm{~N}, 61.7 \mathrm{~W}$ at $1318 \mathrm{Z}$ (WALLET).

Penetration center fix measured a central pressure of $990 \mathrm{mb}$ and estimated surface winds of $90 \mathrm{kt}$ at $14.7 \mathrm{~N}, 62.8 \mathrm{~W}$ at $1848 \mathrm{Z}$ (WALLET). Penetration center fix estimated an eye diameter of $40 \mathrm{~nm}$ at $14.9 \mathrm{~N}, 63.9 \mathrm{~W}$ at $2330 \mathrm{Z}$ (ATSR).

MWR: "Edith passed over the north portion of St. Lucia between midnight and daybreak on the $25^{\text {th }}$ and was at her maximum intensity at about this time. Edith was weakened considerably by the mountains of the Lesser Antilles and was barely of hurricane intensity thereafter as it moved across the northeastern Caribbean and the Dominican 
Republic. Martinique was heavily damaged, to the extent of $\$ 40$ million, with 10 persons killed and 50 injured. Storm tides of $8 \mathrm{ft}$. above normal were noted. Fort de France reported a minimum pressure of $995 \mathrm{mb}$, or $29.33 \mathrm{in}$., with maximum winds of $127 \mathrm{mph}$. Damage on Dominica was $\$ 2,611,600$ and winds reached $80 \mathrm{mph}$ in gusts. There was no loss of life there. On St. Lucia, 40 to 50 percent of the bananas were destroyed and the cocoa crop was a total loss. Tides there were 8 to $10 \mathrm{ft}$. above normal and Port Castries reported a dead calm beginning at 2 a.m. (EST) which lasted 75 min. Maximum winds were $90 \mathrm{mph}$. There was no loss of life, but damage totaled $\$ 3,465,000$. On Barbados, winds reached 60 to $65 \mathrm{mph}$ in squalls on the northern tip of the island and damage was estimated at $\$ 145,000$."

September 26:

HWM analyzes a hurricane of at most $1000 \mathrm{mb}$ at $16.0 \mathrm{~N}, 66.8 \mathrm{~W}$ at $12 \mathrm{Z}$. HURDAT lists a $65 \mathrm{kt}$ hurricane at $15.8 \mathrm{~N}, 66.9 \mathrm{~W}$ at $12 \mathrm{Z}$. Microfilm shows a closed low pressure of at most $1011 \mathrm{mb}$ at $15.5 \mathrm{~N}, 67.0 \mathrm{~W}$ at 12Z. Ship highlights: $35 \mathrm{kt} \mathrm{NE}$ and 1008 $\mathrm{mb}$ at $15.0 \mathrm{~N}, 65.2 \mathrm{~W}$ at $00 \mathrm{Z}$ (COADS). Aircraft highlights: Penetration center fix estimated an eye diameter of $40 \mathrm{~nm}$ at $15.1 \mathrm{~N}, 64.2 \mathrm{~W}$ at $0105 \mathrm{Z}$ (ATSR). Penetration center fix measured a central pressure of $998 \mathrm{mb}$, estimated flight level winds of $60 \mathrm{kt}$ and an eye diameter of $25 \mathrm{~nm}$ eye diameter at $15.3 \mathrm{~N}, 65.5 \mathrm{~W}$ at $0704 \mathrm{Z}$ (WALLET). Penetration center fix measured a central pressure of $1000 \mathrm{mb}$, estimated surface winds of $45 \mathrm{kt}$ and an eye diameter of $80 \mathrm{~nm}$ at $15.8 \mathrm{~N}, 67.1 \mathrm{~W}$ at $13 \mathrm{Z}$ (WALLET). Penetration center fix measured a central pressure of $1000 \mathrm{mb}$ and estimated an eye diameter of 12 $\mathrm{nm}$ eye diameter at $17.2 \mathrm{~N}, 67.5 \mathrm{~W}$ at $1945 \mathrm{Z}$ (WALLET).

MWR: "The hurricane then moved on a general west-northwest-ward course to a point some $120 \mathrm{mi}$. south of Puerto Rico...50 to $60 \mathrm{mph}$ winds along the south and southwestern coasts of Puerto Rico, together with heavy rains, caused \$400,000 damage there." ATSR: "Hurricane EDITH moved on a general west-northwest course to a point some 120 miles south of Puerto Rico."

September 27:

HWM analyzes a tropical storm of at most $1010 \mathrm{mb}$ at $19.0 \mathrm{~N}, 69.0 \mathrm{~W}$ at $12 \mathrm{Z}$. HURDAT lists a $65 \mathrm{kt}$ hurricane at $18.7 \mathrm{~N}, 69.3 \mathrm{~W}$ at $12 \mathrm{Z}$. Microfilm shows a closed low pressure of at most $1008 \mathrm{mb}$ at $19.0 \mathrm{~N}, 69.5 \mathrm{~W}$ at 12Z. Ship highlights: $35 \mathrm{kt} \mathrm{E}$ and 1010 $\mathrm{mb}$ at $17.9 \mathrm{~N}, 68.2 \mathrm{~W}$ at $00 \mathrm{Z}$ (COADS). $60 \mathrm{kt} \mathrm{E}$ and $1009 \mathrm{mb}$ at $18.7 \mathrm{~N}, 67.6 \mathrm{~W}$ at $06 \mathrm{Z}$ (COADS). $40 \mathrm{kt} \mathrm{SSE}$ at $19.5 \mathrm{~N}, 68.9 \mathrm{~W}$ at $12 \mathrm{Z}$ (micro). $35 \mathrm{kt} \mathrm{SSE}$ and $1012 \mathrm{mb}$ at $19.4 \mathrm{~N}$, $67.6 \mathrm{~W}$ at $15 \mathrm{Z}$ (micro). $35 \mathrm{kt} \mathrm{S}$ and $1009 \mathrm{mb}$ at $19.6 \mathrm{~N}, 68.5 \mathrm{~W}$ at $18 \mathrm{Z}$ (COADS). Aircraft highlights: Penetration center fix measured a central pressure of $996 \mathrm{mb}$ and estimated an eye diameter of $20 \mathrm{~nm}$ at $17.9 \mathrm{~N}, 68.0 \mathrm{~W}$ at $01 \mathrm{Z}$ (ATSR). Penetration center fix measured a central pressure of $996 \mathrm{mb}$ at $17.8 \mathrm{~N}, 68.7 \mathrm{~W}$ at $0829 \mathrm{Z}$ (WALLET). Radar center fix at $18.9 \mathrm{NM}, 69.3 \mathrm{~W}$ at $1236 \mathrm{Z}$ (WALLET). Radar center fix calculated a central pressure of $999 \mathrm{mb}$ and estimated surface winds of $40 \mathrm{kt}$ at $19.5 \mathrm{~N}, 70.3 \mathrm{~W}$ at $1850 \mathrm{Z}$ (WALLET). Land highlights: $20 \mathrm{kt} \mathrm{NW}$ and $1005 \mathrm{mb}$ at Puerto Plata, Dominican Republic at 18Z (micro). TIROS highlights: Satellite center fix at $18.5 \mathrm{~N}, 69.5 \mathrm{~W}$ at $1243 \mathrm{Z}$ (WALLET).

MWR: "and then turned to a more northwestward course passing over the eastern portion of the Dominican Republic before dissipating as it moved out north of Hispaniola. In the 
Dominican Republic damage was minor...” ATSR: “...then turned to a more northwesterly course, passing over the eastern portion of Hispaniola."

September 28:

HWM analyzes a tropical storm of at most $1005 \mathrm{mb}$ at $21.5 \mathrm{~N}, 71.8 \mathrm{~W}$ with a warm front to the north at $12 \mathrm{Z}$. HURDAT lists a $35 \mathrm{kt}$ tropical storm at $18.7 \mathrm{~N}, 69.3 \mathrm{~W}$ at $12 \mathrm{Z}$. Microfilm shows a closed low pressure of at most $1008 \mathrm{mb}$ at $19.0 \mathrm{~N}, 69.5 \mathrm{~W}$ with a frontal boundary to the north at 12Z. Ship highlights: $35 \mathrm{kt} \mathrm{S}$ and $1006 \mathrm{mb}$ at $20.0 \mathrm{~N}$, $69.8 \mathrm{~W}$ at $00 \mathrm{Z}$ (COADS). $35 \mathrm{kt} \mathrm{S}$ and $1006 \mathrm{mb}$ at $20.2 \mathrm{~N}, 70.8 \mathrm{~W}$ at $03 \mathrm{Z}$ (micro). $20 \mathrm{kt} \mathrm{NE}$ and $1005 \mathrm{mb}$ at $20.3 \mathrm{~N}, 71.4 \mathrm{~W}$ at $06 \mathrm{Z}$ (COADS). $40 \mathrm{kt} \mathrm{NE}$ and $1005 \mathrm{mb}$ at $21.5 \mathrm{~N}, 72.4 \mathrm{~W}$ at $12 \mathrm{Z}$ (micro). Land highlights: $15 \mathrm{kt} \mathrm{NW}$ and $1005 \mathrm{mb}$ at Puerto Plata, Dominican Republic at 00Z (micro). $20 \mathrm{kt} \mathrm{ESE}$ and $1005 \mathrm{mb}$ at Grand Turk at $09 \mathrm{Z}$ (micro). $20 \mathrm{kt} \mathrm{E}$ and $1004 \mathrm{mb}$ at South Caicos at 18Z (micro).

MWR: "On the $28^{\text {th }}$ as Edith was dissipating north of Hispaniola, the upper trough had flattened out into general easterly flow with no particularly well marked divergent or convergent pattern. The frontal wave development moving across to the north of Edith weakened the pressure gradient markedly over and east of the Bahamas, thus lessening greatly the easterly low-level flow north of Edith and probably was a major factor in the storm's dissipation. As it moved out into an area of very flat pressure gradient and poor low-level inflow underneath a non-divergent pattern in the upper atmosphere, Edith was unable to recover from the distortion effects of the mountains of eastern Hispaniola." ATSR: "Gradual dissipation occurred after EDITH passed over Hispaniola and the final numbered warning was issued at $2200 \mathrm{Z}$ on the $28^{\text {th }}$."

\section{September 29:}

HWM analyzes a spot low at $23.0 \mathrm{~N}, 71.8 \mathrm{~W}$ with a dissipating warm front to the northeast at 12Z. HURDAT lists a $30 \mathrm{kt}$ tropical depression at $23.1 \mathrm{~N}, 72.0 \mathrm{~W}$ at $06 \mathrm{Z}$ (final position). Microfilm shows a closed low pressure of at most $1008 \mathrm{mb}$ at $24.5 \mathrm{~N}, 71.5 \mathrm{~W}$ with a frontal boundary to the northeast at 12Z. Ship highlights: $35 \mathrm{kt} \mathrm{S}$ and $1012 \mathrm{mb}$ at 25.1N, 68.3W at $18 \mathrm{Z}$ (COADS). TIROS highlights: Satellite center fix at 23.0N, 71.5W at $1229 \mathrm{Z}$ (WALLET).

September 30:

HWM analyzes frontal boundaries over the western Atlantic at 12Z. HURDAT does not list an organized system on this date. Microfilm shows an extratropical cyclone of at most $1002 \mathrm{mb}$ at $37.0 \mathrm{~N}, 69.0 \mathrm{~W}$ at $12 \mathrm{Z}$ (Edith appears to have been absorbed). Ship highlights: No gales or low pressures.

The disturbance that spawned Edith was a tropical wave that left the African coast around September $16^{\text {th }}$. The system moved westward and slowly became better organized. On September $22^{\text {nd }}$, surface observations between the Lesser Antilles and Africa indicated that a circulation was developing. The first position, not genesis, is analyzed at $12 \mathrm{Z}$ on September $23^{\text {rd }}$ as a $25 \mathrm{kt}$ tropical depression, as originally shown in HURDAT. Time of genesis is uncertain due to the sparse observations over the central Atlantic. A TIROS 
satellite center fix, image not available, at $1156 \mathrm{Z}$ on the $23^{\text {rd }}$ was available in the Storm Wallets and appears to have been the basis for starting the tropical cyclone in HURDAT. Operationally, the first advisory was issued at $01 \mathrm{Z}$ on September $24^{\text {th }}$. Minor alterations to the track were introduced during the lifetime of this tropical cyclone. The first reconnaissance aircraft to investigate the tropical depression arrived at late on the $23^{\text {rd }}$ making a center penetration at $22 \mathrm{Z}$ and measuring a central pressure of $1005 \mathrm{mb}$ and estimating surface winds of $25 \mathrm{kt}$. A central pressure of $1005 \mathrm{mb}$ suggests maximum surface winds of $37 \mathrm{kt}$ from the south of $25 \mathrm{~N}$ Brown et al. pressure-wind relationship. Based on a forward speed of $13 \mathrm{kt}$, an intensity of $35 \mathrm{kt}$ is analyzed at $00 \mathrm{Z}$ on September $24^{\text {th }}$, up from $30 \mathrm{kt}$ originally in HURDAT, a minor intensity change. Intensification to a tropical storm is analyzed at $00 \mathrm{Z}$ on the $24^{\text {th }}$, twelve hours earlier than originally shown in HURDAT. (Central pressures values were present for many of the times in the original HURDAT between September $24^{\text {nd }}$ at $18 \mathrm{Z}$ and September $27^{\text {th }}$ at $18 \mathrm{Z}$. All the original central pressure values were retained and one added. Detailed information on these changes can be found in the table at the end.) Edith rapidly intensified on the $24^{\text {th }}$ based on ship and reconnaissance data. The next reconnaissance aircraft made a center penetration at $1315 \mathrm{Z}$ on the $24^{\text {th }}$ measuring a central pressure of $1004 \mathrm{mb}$, estimating surface winds of $60 \mathrm{kt}$ and an eye diameter of $50 \mathrm{~nm}$. A central pressure of $1004 \mathrm{mb}$ suggests maximum surface winds of $39 \mathrm{kt}$ from the south of $25 \mathrm{~N}$ pressure-wind relationship. An eye diameter of $50 \mathrm{~nm}$ suggests an RMW of about $38 \mathrm{~nm}$ and the climatological value is $13 \mathrm{~nm}$. Based on a forward speed of $17 \mathrm{kt}$, a ship report of $60 \mathrm{kt}$ at $18 \mathrm{Z}$ on the $24^{\text {th }}$ and putting some weight on the visual estimate, an intensity of $50 \mathrm{kt}$ is selected at $12 \mathrm{Z}$ on the $24^{\text {th }}$, up from $35 \mathrm{kt}$ originally in HURDAT, a minor intensity change. At $18 \mathrm{Z}$ on the $24^{\text {th }}$, another reconnaissance aircraft measured a central pressure of $1000 \mathrm{mb}$, estimated surface winds of $70 \mathrm{kt}$ and an eye diameter of $30 \mathrm{~nm}$. A central pressure of $1000 \mathrm{mb}$ suggests maximum surface winds of $47 \mathrm{kt}$ from the south of $25 \mathrm{~N}$ pressure-wind relationship. An eye diameter of $30 \mathrm{~nm}$ suggests an RMW of about $23 \mathrm{~nm}$ and the climatological value is $13 \mathrm{~nm}$. Based upon the ship report of $60 \mathrm{kt} E$ and $1004 \mathrm{mb}$ at $18 \mathrm{Z}$ on the $24^{\text {th }}$ and a forward speed of about $15 \mathrm{kt}$, an intensity of $60 \mathrm{kt}$ is analyzed at $18 \mathrm{Z}$ on the $24^{\text {th }}$, down from $65 \mathrm{kt}$ originally in HURDAT, a minor intensity change. MWR and the Storm Wallets have the measurement of $1000 \mathrm{mb}$ as $978 \mathrm{mb}$ but the ATSR book clearly indicates that the measurement was $1000 \mathrm{mb}$, which makes more sense with the data available before and after this measurement. The original HURDAT showed a dramatic $30 \mathrm{kt} 6 \mathrm{hr}$ increase in intensity from $35 \mathrm{kt}$ at $12 \mathrm{Z}$ on the $24^{\text {th }}$ to $65 \mathrm{kt}$ at $18 \mathrm{Z}$ on the $24^{\text {th }}$ but based on the data available, this rapid increase in intensity does not appear to have occurred.

On September $25^{\text {th }}$, Edith crossed the Lesser Antilles into the eastern Caribbean Sea. Intensification to a hurricane is analyzed at $00 \mathrm{Z}$ on the $25^{\text {th }}$ based on synoptic and reconnaissance observations later in the day. Intensification to a hurricane is analyzed six hours later than originally shown in HURDAT. Edith made landfall in northern Saint Lucia around $07 \mathrm{Z}$ on the $25^{\text {th }}$ as a $75 \mathrm{kt}$ hurricane. Calm conditions were reported between $07 Z$ and $0815 Z$ at Port Castries, the capital of Saint Lucia, indicating the passage of the eye of the hurricane. In Saint Lucia, the strongest sustained winds appear to have been $60 \mathrm{kt}$ reported in the microfilm at $06 \mathrm{Z}$ on the $25^{\text {th }}$. The island of Martinique, about $20 \mathrm{~nm}$ north of Saint Lucia, reported gusts up to $115 \mathrm{kt}$ and a minimum pressure of 995 
$\mathrm{mb}$. At $1318 \mathrm{Z}$ on the $25^{\text {th }}$, a reconnaissance aircraft measured a central pressure of 993 $\mathrm{mb}$, estimated surface winds of $90 \mathrm{kt}$ and an eye diameter $14-18 \mathrm{~nm}$. A central pressure of $993 \mathrm{mb}$ suggests maximum surface winds of $59 \mathrm{kt}$ from the south of $25 \mathrm{~N}$ pressure-wind relationship. An eye diameter of 14-18 nm suggests an RMW of about 11-14 nm and the climatological value is $13 \mathrm{~nm}$. Based upon a forward speed of $12 \mathrm{kt}$, observations in the Lesser Antilles and putting some weight on the visual estimate, an intensity of $75 \mathrm{kt}$ is selected at $12 \mathrm{Z}$ on the $25^{\text {th }}$, down from 85 kt originally in HURDAT, a minor intensity change. $75 \mathrm{kt}$ is also the peak intensity of this tropical cyclone, down from $85 \mathrm{kt}$ originally shown in HURDAT, a minor intensity change. At $1848 \mathrm{Z}$ on the $25^{\text {th }}$, another penetration center fix measured a central pressure of $990 \mathrm{mb}$ and estimated surface winds of $90 \mathrm{kt}$. A central pressure of $990 \mathrm{mb}$ suggests maximum surface winds of $64 \mathrm{kt}$ from the south of $25 \mathrm{~N}$ pressure-wind relationship. Based on a forward speed of $12 \mathrm{kt}$ and putting some weight on the visual estimate, an intensity of $75 \mathrm{kt}$ is analyzed at $18 \mathrm{Z}$ on the $25^{\text {th }}$, down from 85 kt originally in HURDAT, a minor intensity change. On September $26^{\text {th }}$, Edith moved generally northwestward and weakened. A ship reported $35 \mathrm{kt}$ at $00 \mathrm{Z}$ on the $26^{\text {th }}$, the only synoptic gale-force winds associated with Edith on this date. A reconnaissance aircraft investigated the tropical cyclone early on the $26^{\text {th }}$ making a penetration center fix at $0704 \mathrm{Z}$ and measuring a central pressure of $998 \mathrm{mb}$ and estimating an eye diameter of $25 \mathrm{~nm}$. A central pressure of $998 \mathrm{mb}$ suggests maximum surface winds of $51 \mathrm{kt}$ from the south of $25 \mathrm{~N}$ pressure-wind relationship. An eye diameter of $25 \mathrm{~nm}$ suggests an RMW of about $19 \mathrm{~nm}$ and the climatological value is 13 $\mathrm{nm}$. Based upon a forward speed of $14 \mathrm{kt}$, an intensity of $60 \mathrm{kt}$ is analyzed at $06 \mathrm{Z}$ on the $26^{\text {th }}$, down from $65 \mathrm{kt}$ originally shown in HURDAT, a minor intensity change. Another penetration center fix occurred at $13 \mathrm{Z}$ on the $26^{\text {th }}$ measuring a central pressure of 1000 $\mathrm{mb}$, estimating surface winds of $45 \mathrm{kt}$ and an eye diameter of $80 \mathrm{~nm}$. A central pressure of $1000 \mathrm{mb}$ suggests maximum surface winds of $47 \mathrm{kt}$ from the south of $25 \mathrm{~N}$ pressurewind relationship. An eye diameter of $80 \mathrm{~nm}$ suggests an RMW of about $60 \mathrm{~nm}$ and the climatological value is $14 \mathrm{~nm}$. Based upon a forward speed of $12 \mathrm{kt}$, an intensity of $55 \mathrm{kt}$ is selected at $12 \mathrm{Z}$ on the $26^{\text {th }}$, down from $65 \mathrm{kt}$ originally in HURDAT, a minor intensity change. The next penetration center fix occurred at $1945 \mathrm{Z}$ on the $26^{\text {th }}$ also measuring a central pressure of $1000 \mathrm{mb}$. An intensity of $55 \mathrm{kt}$ is selected at $18 \mathrm{Z}$ on the $26^{\text {th }}$, down from 65 kt originally in HURDAT, a minor intensity change.

On September $27^{\text {th }}$, Edith maintained a northwestward course impacting Hispaniola. The first reconnaissance aircraft to investigate the tropical cyclone on the $27^{\text {th }}$ made a penetration center fix at $01 \mathrm{Z}$ measuring a central pressure of $996 \mathrm{mb}$ and an eye diameter of $20 \mathrm{~nm}$. A central pressure of $996 \mathrm{mb}$ suggests maximum surface winds of $54 \mathrm{kt}$ from the south of $25 \mathrm{~N}$ pressure-wind relationship. An eye diameter of $20 \mathrm{~nm}$ suggests an RMW of about $15 \mathrm{~nm}$ and the climatological value is also $15 \mathrm{~nm}$. Based upon a forward speed of about $11 \mathrm{kt}$ and a ship report of $60 \mathrm{kt}$ at $06 \mathrm{Z}$ on the $27^{\text {th }}$, an intensity of $60 \mathrm{kt}$ is selected at $00 \mathrm{Z}$ on the $27^{\text {th }}$, down from $65 \mathrm{kt}$ originally in HURDAT, a minor intensity change. Another penetration center fix measured a central pressure of $996 \mathrm{mb}$ at $0829 \mathrm{Z}$ on the $27^{\text {th }}$ and an intensity of $60 \mathrm{kt}$ is selected at $06 \mathrm{Z}$ on the $27^{\text {th }}$, down from $65 \mathrm{kt}$ originally in HURDAT, a minor intensity change. Landfall in southeastern Dominican Republic is analyzed around $10 \mathrm{Z}$ on the $27^{\text {th }}$ as a $60 \mathrm{kt}$ tropical storm. TIROS captured an image of the tropical storm at $1243 \mathrm{Z}$ on the $27^{\text {th }}$ showing a large area of convection over 
the Dominican Republic with no hints of an eye. Around $19 \mathrm{Z}$ on the $27^{\text {th }}$, Edith reached the Atlantic Ocean after emerging north of Hispaniola. A reconnaissance aircraft measured a central pressure of $999 \mathrm{mb}$ and estimated surface winds of $40 \mathrm{kt}$ at $1850 \mathrm{Z}$ on the $27^{\text {th }}$. A central pressure of $999 \mathrm{mb}$ suggests maximum surface winds of $49 \mathrm{kt}$ from the south of $25 \mathrm{~N}$ pressure-wind relationship. Based upon a forward speed of about $12 \mathrm{kt}$, an intensity of $50 \mathrm{kt}$ is analyzed at $18 \mathrm{Z}$ on the $27^{\text {th }}$, down from $65 \mathrm{kt}$ originally in HURDAT, a minor intensity change. On September $28^{\text {th }}$, Edith continued northwestward and further weakened. Gale-force winds were reported by ships at $00 \mathrm{Z}$ and $12 \mathrm{Z}$ on the $28^{\text {th }}$. The center of Edith crossed the Turks and Caicos at $18 \mathrm{Z}$ on the $28^{\text {th }}$ as a $35 \mathrm{kt}$ tropical storm. On September $29^{\text {th }}$, a frontal boundary north of the Bahamas caused Edith to turn to the northeast. Weakening to a tropical depression is analyzed at $00 \mathrm{Z}$ on the $29^{\text {th }}$, same as originally shown in HURDAT. The last position originally in HURDAT was at 06Z on the $29^{\text {th }}$ but synoptic observations and a TIROS image at $1229 \mathrm{Z}$ indicate that the system was still a tropical cyclone. The satellite image shows a large area of convection with some banding. Synoptic observations after $18 \mathrm{Z}$ on the $29^{\text {th }}$ indicate that Edith weakened into a trough of low pressure and was likely absorbed by a developing extratropical cyclone off the East Coast of the United States on September $30^{\text {th }}$. Thus, the last position is analyzed at $18 \mathrm{Z}$ on the $29^{\text {th }}$, twelve hours later than originally shown in HURDAT.

\begin{tabular}{|c|c|c|c|}
\hline Date & $\begin{array}{c}\text { Original } \\
\text { HURDAT } \\
\text { Central } \\
\text { Pressure }\end{array}$ & Evidence & Changes \\
\hline Sep $2400 Z$ & $1005 \mathrm{mb}$ & $\begin{array}{l}\text { Penetration center fix: } 987 \mathrm{mb} \text { at } 1642 \mathrm{Z} \\
\text { on Aug } 02^{\text {nd }}\end{array}$ & \multirow{8}{*}{ Retained } \\
\hline Sep $2412 Z$ & $1004 \mathrm{mb}$ & $\begin{array}{l}\text { Penetration center fix: } 1004 \mathrm{mb} \text { at } 1315 \mathrm{Z} \\
\text { on Sep } 24^{\text {th }}\end{array}$ & \\
\hline Sep $2418 Z$ & $1000 \mathrm{mb}$ & $\begin{array}{l}\text { Penetration center fix: } 1000 \mathrm{mb} \text { at } 18 \mathrm{Z} \text { on } \\
\text { Sep } 24^{\text {th }}\end{array}$ & \\
\hline Sep $2512 Z$ & $993 \mathrm{mb}$ & $\begin{array}{l}\text { Penetration center fix: } 993 \mathrm{mb} \text { at } 1318 \mathrm{Z} \\
\text { on Sep } 25^{\text {th }}\end{array}$ & \\
\hline Sep $2518 Z$ & $990 \mathrm{mb}$ & $\begin{array}{l}\text { Penetration center fix: } 990 \mathrm{mb} \text { at } 1848 \mathrm{Z} \\
\text { on Sep } 25^{\text {th }}\end{array}$ & \\
\hline Sep $2606 Z$ & $998 \mathrm{mb}$ & $\begin{array}{l}\text { Penetration center fix: } 998 \mathrm{mb} \text { at } 0704 \mathrm{Z} \\
\text { on Sep } 26^{\text {th }}\end{array}$ & \\
\hline Sep $2612 Z$ & $1000 \mathrm{mb}$ & $\begin{array}{l}\text { Penetration center fix: } 1000 \mathrm{mb} \text { at } 13 \mathrm{Z} \text { on } \\
\text { Sep } 26^{\text {th }}\end{array}$ & \\
\hline Sep $2618 Z$ & $1000 \mathrm{mb}$ & $\begin{array}{l}\text { Penetration center fix: } 1000 \mathrm{mb} \text { at } 1945 \mathrm{Z} \\
\text { on Sep } 26^{\text {th }}\end{array}$ & \\
\hline Sep $2700 Z$ & & Penetration center fix: $996 \mathrm{mb}$ at $01 \mathrm{Z}$ on & $996 \mathrm{mb}$ \\
\hline
\end{tabular}




\begin{tabular}{|c|c|l|l|}
\hline Sep 27 06Z & $996 \mathrm{mb}$ & $\begin{array}{l}\text { Pep 27 } \\
\text { Pentration center fix: } 996 \mathrm{mb} \text { at } 0829 \mathrm{Z} \\
\text { on Sep } 7^{\text {th }}\end{array}$ & \multirow{2}{*}{ Retained } \\
\cline { 1 - 3 } Sep 27 18Z & $999 \mathrm{mb}$ & $\begin{array}{l}\text { Penetration center fix: } 999 \mathrm{mb} \text { at } 1850 \mathrm{Z} \\
\text { on Sep } 27^{\text {th }}\end{array}$ & \\
\hline
\end{tabular}

Hurricane Flora [September 26 - October 13, 1963]

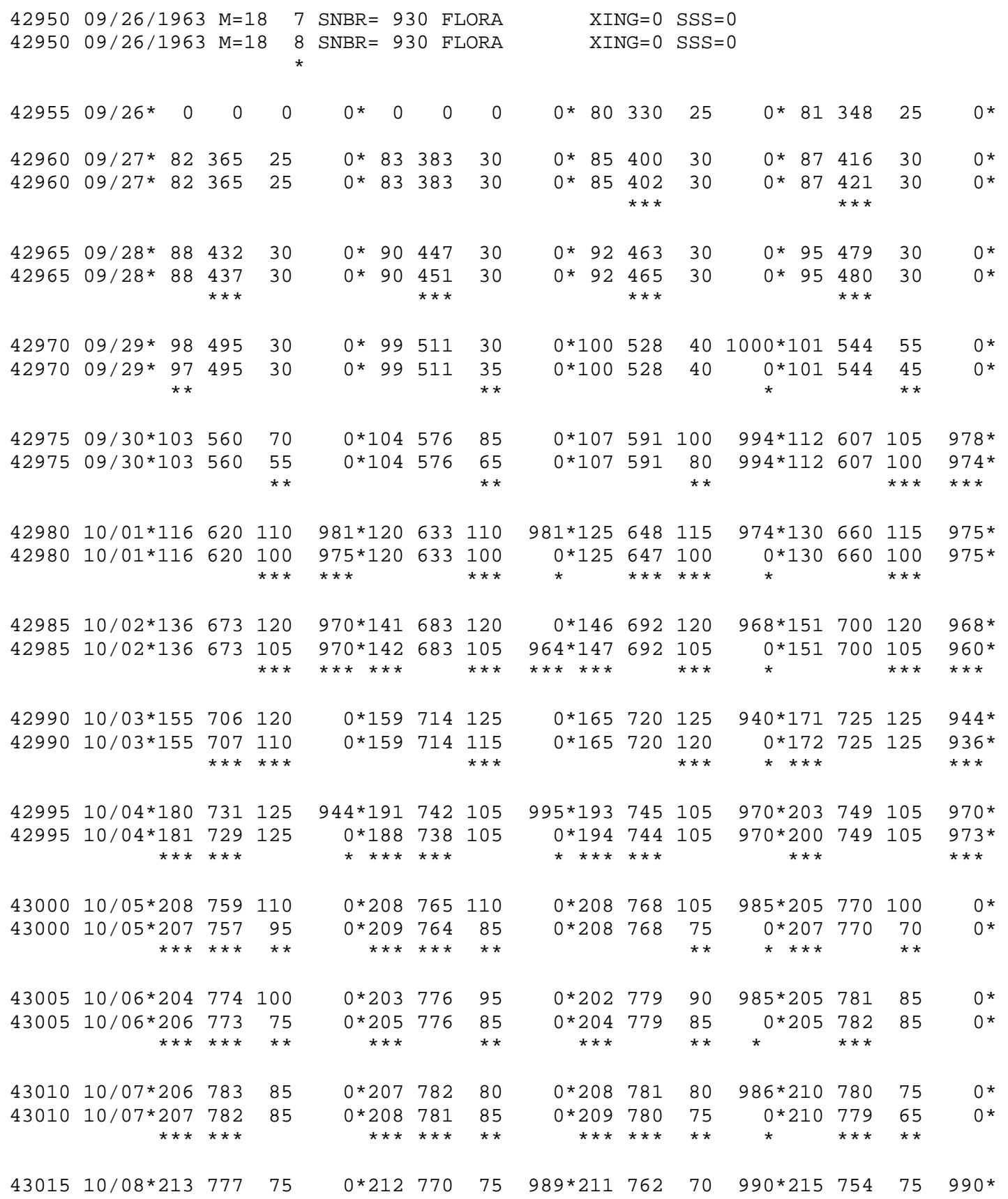




\begin{tabular}{|c|c|c|c|c|c|c|c|c|c|c|c|c|c|}
\hline 43015 & $10 / 08 * 211$ & $\begin{array}{l}776 \\
\star * *\end{array}$ & $\begin{array}{l}60 \\
* *\end{array}$ & $0 * \underset{* \star *}{211}$ & 770 & $\begin{array}{l}55 \\
* *\end{array}$ & $\begin{array}{l}0^{*} \\
*\end{array}$ & 762 & $\begin{array}{l}55 \\
* *\end{array}$ & $\begin{array}{l}0^{*} 213 \\
* * * *\end{array}$ & 754 & $\begin{array}{l}65 \\
* *\end{array}$ & $\begin{array}{l}\Theta_{*}^{*} \\
*\end{array}$ \\
\hline $\begin{array}{l}43020 \\
43020\end{array}$ & $\begin{array}{l}10 / 09 * 217 \\
10 / 09 * 217\end{array}$ & $\begin{array}{l}744 \\
743 \\
\star * *\end{array}$ & $\begin{array}{l}75 \\
75\end{array}$ & $\begin{array}{l}983^{*} 223 \\
983^{*} 223\end{array}$ & $\begin{array}{l}728 \\
729 \\
\star * *\end{array}$ & $\begin{array}{l}75 \\
85 \\
* *\end{array}$ & $\begin{array}{r}0^{*} 235 \\
977^{*} 233 \\
* * * * * *\end{array}$ & $\begin{array}{l}716 \\
716\end{array}$ & $\begin{array}{l}80 \\
9 \odot \\
* *\end{array}$ & $\begin{array}{l}975^{*} 250 \\
976^{*} 246 \\
\star * * * *\end{array}$ & $\begin{array}{l}70 \odot \\
70 \odot\end{array}$ & $\begin{array}{r}85 \\
100 \\
\star * *\end{array}$ & $\begin{array}{l}965^{*} \\
965^{*}\end{array}$ \\
\hline $\begin{array}{l}43025 \\
43025\end{array}$ & $\begin{array}{r}10 / 10 * 260 \\
10 / 10 * 258 \\
* \star *\end{array}$ & $\begin{array}{l}683 \\
683\end{array}$ & $\begin{array}{r}95 \\
100 \\
\star \star *\end{array}$ & $\begin{array}{r}965 * 271 \\
965 * 269 \\
\star \star *\end{array}$ & $\begin{array}{l}665 \\
665\end{array}$ & $\begin{array}{r}95 \\
100 \\
\star * *\end{array}$ & $\begin{array}{r}969 * 281 \\
0 * 280 \\
* \quad * * *\end{array}$ & $\begin{array}{l}649 \\
648 \\
\star * *\end{array}$ & $\begin{array}{r}100 \\
95 \\
* *\end{array}$ & $\begin{array}{l}969 * 299 \\
969 * 299\end{array}$ & $\begin{array}{l}622 \\
624 \\
\star \star *\end{array}$ & $\begin{array}{r}100 \\
95 \\
* *\end{array}$ & $\begin{array}{l}972 * \\
972 *\end{array}$ \\
\hline $\begin{array}{l}43030 \\
43030\end{array}$ & $\begin{array}{l}10 / 11 * 322 \\
10 / 11 * 322\end{array}$ & $\begin{array}{l}598 \\
598\end{array}$ & $\begin{array}{l}95 \\
95\end{array}$ & $\begin{array}{r}0 * 343 \\
968 * 342 \\
* * *\end{array}$ & $\begin{array}{l}583 \\
583\end{array}$ & $\begin{array}{l}90 \\
95 \\
* *\end{array}$ & $\begin{array}{l}970 * 362 \\
970 * 362\end{array}$ & $\begin{array}{l}570 \\
570\end{array}$ & $\begin{array}{l}85 \\
90 \\
\star *\end{array}$ & $\begin{array}{r}963 * 383 \\
963 \mathrm{E} 381 \\
* * * *\end{array}$ & $\begin{array}{l}560 \\
56 \odot\end{array}$ & $\begin{array}{l}80 \\
9 \odot \\
* *\end{array}$ & $\begin{array}{c}963^{*} \\
0^{*} \\
*\end{array}$ \\
\hline $\begin{array}{l}43035 \\
43035\end{array}$ & $\begin{array}{r}10 / 12 * 401 \\
10 / 12 E 398 \\
* * * *\end{array}$ & $\begin{array}{l}540 \\
550 \\
* * *\end{array}$ & $\begin{array}{l}80 \\
90 \\
* *\end{array}$ & $\begin{array}{c}\odot * 420 \\
0 \mathrm{E} 415 \\
\star * \star *\end{array}$ & 520 & $\begin{array}{l}75 \\
85 \\
\star *\end{array}$ & $\begin{array}{r}\Theta * 435 \\
\Theta \mathrm{E} 430 \\
* * * *\end{array}$ & 498 & $\begin{array}{l}75 \\
80 \\
* *\end{array}$ & $\begin{array}{r}985 \mathrm{E} 452 \\
\text { OE445 } \\
\star * \star *\end{array}$ & $\begin{array}{l}475 \\
475\end{array}$ & $\begin{array}{l}75 \\
75\end{array}$ & $\begin{array}{l}\Theta^{*} \\
\Theta^{*}\end{array}$ \\
\hline $\begin{array}{l}43040 \\
43040\end{array}$ & $\begin{array}{r}10 / 13 \mathrm{E} 470 \\
10 / 13 \mathrm{E} 460 \\
* * *\end{array}$ & $\begin{array}{l}450 \\
440 \\
* * *\end{array}$ & $\begin{array}{l}70 \\
70\end{array}$ & $\begin{array}{c}\text { OE492 } \\
\Theta^{*} \quad \odot \\
* \quad *\end{array}$ & $\begin{array}{r}428 \\
0 \\
*\end{array}$ & $\begin{array}{r}70 \\
\odot \\
*\end{array}$ & $\begin{array}{l}0 \mathrm{OE} 515 \\
0^{*} \quad 0 \\
* \quad *\end{array}$ & $\begin{array}{r}410 \\
0 \\
*\end{array}$ & $\begin{array}{r}70 \\
0 \\
*\end{array}$ & $\begin{array}{ll}\Theta^{*} & \odot \\
\Theta^{*} & \odot\end{array}$ & $\begin{array}{l}\odot \\
\odot\end{array}$ & $\begin{array}{l}\odot \\
\odot\end{array}$ & $\begin{array}{l}\Theta^{*} \\
\Theta^{*}\end{array}$ \\
\hline
\end{tabular}

43045 HR

Hurricane Landfall

09/30 18Z 11.2N 60.7W $100 \mathrm{kt}$ Tobago

10/04 01Z 18.2N 73.0W 125 kt Haiti

10/04 18Z 20.0N 74.9W $105 \mathrm{kt}$ Cuba

$10 / 0706 Z 20.8 \mathrm{~N} 78.1 \mathrm{~W} 85 \mathrm{kt}$ Cuba

10/09 06Z 22.3N 72.8W 85 kt Mayaguana, Bahamas

Minor changes to the track and major changes to the intensity shown in McAdie et al. (2009). A major alteration is to show transition to an extratropical cyclone 24 hours earlier than originally shown in HURDAT. Evidence for these alterations comes from the NHC microfilm maps, the Historical Weather Maps series, the COADS ship database, Monthly Weather Review, Navy reconnaissance book, Mariners Weather Log, Cuban surface maps (CUBA), National Hurricane Research Project (NHRP), Advisories Perez et al., correspondence with Maritza Ballester from the Cuban Meteorological Institute and NHC Storm Wallets.

September 25:

HWM and microfilm do not show an organized system at 12Z. HURDAT does not list an organized system on this date. Ship highlights: No gales or low pressures. September 26:

HWM and microfilm do not show an organized system at 12Z. HURDAT lists a $25 \mathrm{kt}$ tropical depression at 8.0N, 33.0W at 12Z. Ship highlights: No gales or low pressures.

MWR: "At 8:50 am, EST, on September 26, the National Hurricane Center in Miami received an advisory from the Weather Bureau's National Weather Satellite Center stating 
that TIROS VII at 4:40 am., EST, had sighted a poorly organized vortex at approximately $11.5 "$ N., 35.0" W., with a central overcast area about 4" in diameter with some banding to the north and east. Actually the TIROS satellite had sighted a complex cloud system with two principal areas of cloud concentration. The northern center mentioned in the advisory was probably associated with an upper-level vortex, and Flora eventually developed from the second cloud mass located at about 8.0" N., 32.5" W., which was associated with a very weak depression in the Intertropical Convergence Zone (ITC)." ATSR: "The incipient stage of Hurricane FLORA is believed to have been observed by satellite as early as 26 September when photographs showed a cloud mass in the midAtlantic near 38W."

September 27:

HWM analyzes a closed low pressure of at most $1010 \mathrm{mb}$ at $8.0 \mathrm{~N}, 40.2 \mathrm{~W}$ at $12 \mathrm{Z}$. HURDAT lists a $30 \mathrm{kt}$ tropical depression at $8.5 \mathrm{~N}, 40.0 \mathrm{~W}$ at $12 \mathrm{Z}$. Microfilm shows a tropical wave along longitude 40W at 12Z. Ship highlights: No gales or low pressures.

MWR: "On the next day, September 27, TIROS VII photographed the same complex cloud system, which retained rather remarkable resemblance to that of the day before. The center of the southern cloud mass had moved to 8.0" N., 40.0" W. The cloud mass had grown somewhat in size but there were still no indications of spiral bands and apparently it was still associated with an ordinary depression in the ITC." ATSR: "On the following day a photograph from the satellite, again, indicated an area of unsettled conditions near 8N 40W."

September 28:

HWM analyzes a closed low pressure of at most $1010 \mathrm{mb}$ at $9.0 \mathrm{~N}, 46.5 \mathrm{~W}$ at $12 \mathrm{Z}$. HURDAT lists a $30 \mathrm{kt}$ tropical depression at $9.2 \mathrm{~N}, 46.3 \mathrm{~W}$ at $12 \mathrm{Z}$. Microfilm shows a tropical wave along longitude 46W at 12Z. Ship highlights: No gales or low pressures.

September 29:

HWM analyzes a tropical storm of at most $1005 \mathrm{mb}$ at $9.8 \mathrm{~N}, 52.6 \mathrm{~W}$ at $12 \mathrm{Z}$. HURDAT lists a $40 \mathrm{kt}$ tropical storm at $10.0 \mathrm{~N}, 52.8 \mathrm{~W}$ at $12 \mathrm{Z}$. Microfilm does not show an organized storm at 12Z. Ship highlights: $1000 \mathrm{mb}$ at 2230Z (MWR).

MWR: "TIROS was not in a position to photograph the cloud system on September 28 and 29 and there were not sufficient ship reports to indicate the existence of a circulation. However, on the $29^{\text {th }}$, the San Juan Hurricane Center requested surface observations from all ships in the area, and a Navy hurricane reconnaissance flight was arranged for daybreak on September 30. A series of ship reports began to arrive early in the morning, September 30. A much delayed weather observation from the Sinon arrived around 3:30 am EST. The report stated that the barometer at 5:30 pm the afternoon before had dipped to $1000 \mathrm{mb}$ (29.54 in.) with a wind shift from northwest to southwest, but nothing was said about the strength of the winds."

September 30:

HWM analyzes a hurricane of at most $1000 \mathrm{mb}$ at $10.8 \mathrm{~N}, 59.1 \mathrm{~W}$ at $12 \mathrm{Z}$. HURDAT lists a $100 \mathrm{kt}$ hurricane at $10.7 \mathrm{~N}, 59.1 \mathrm{~W}$ at $12 \mathrm{Z}$. Microfilm shows a closed low 
pressure of at most $1005 \mathrm{mb}$ at $10.7 \mathrm{~N}, 59.2 \mathrm{~W}$ at 12Z. Ship highlights: $35 \mathrm{kt} \mathrm{NE}$ and 1007 $\mathrm{mb}$ at $10.9 \mathrm{~N}, 58.3 \mathrm{~W}$ at $06 \mathrm{Z}$ (COADS). $45 \mathrm{kt} \mathrm{SSE}$ at $10.4 \mathrm{~N}, 59.1 \mathrm{~W}$ at $10 \mathrm{Z}$ (micro). $35 \mathrm{kt}$ $\mathrm{NE}$ at $12.0 \mathrm{~N}, 62.0 \mathrm{~W}$ at $18 \mathrm{Z}$ (micro). Land highlights: $2 \mathrm{kt} \mathrm{W}$ and $974 \mathrm{mb}$ (uncorrected) at Crown Point, Tobago at 1840Z (WALLET). Aircraft highlights: Penetration center fix measured a central pressure of $994 \mathrm{mb}$, estimated surface winds of $110 \mathrm{kt}$ and an eye diameter of $25 \mathrm{~nm}$ at $10.8 \mathrm{~N}, 59.8 \mathrm{~W}$ at $1407 \mathrm{Z}$ (WALLET). Radar center fix with peripheral pressure of $986 \mathrm{mb}$ at $11.1 \mathrm{~N}, 60.2 \mathrm{~W}$ at $1630 \mathrm{Z}$ (WALLET). Penetration center fix measured a central pressure of $975 \mathrm{mb}$, estimated surface winds of $130 \mathrm{kt}$ and an eye diameter of $10 \mathrm{~nm}$ at $11.4 \mathrm{~N}, 61.5 \mathrm{~W}$ at $2110 \mathrm{Z}$ (WALLET).

MWR: "The SS Del Alba forwarded all observation made at 1:00 a.m., EST, which arrived around 4:30 am., indicating winds from the northeast of $35 \mathrm{kt}$., and a barometer reading of $1006.8 \mathrm{mb}$ with a fall of $5 \mathrm{mb}$ in the past $3 \mathrm{hr}$. At 10:00 am, EST, much too late for adequate warning to Tobago, the Del Alba sent in a complete report as follows: "PASSED THROUGH STORM AREA COMMENCING 4 PM ON THE 29THPASSED NORTH OF CENTER 2 AM ON THE 30TH- ESTIMATED POSITION AT 6 AM 11.0 57.5- WINDS FROM THE NORTHWEST AT 4 PM TO NORTHEAST 28 MPH AT 10 PM TO EAST 40 MPH AT 2 AM-PRESENT POSITION AT 10 AM 10.9N 56.3W WIND EASTSOUTHEAST TO SOUTHEAST 16 MPH BAROMETER 29.94 INCHES RISING SOUTHEAST SEAS ROUGH WITH MODERATE HEAVY SWELL-HAVE PASSED STORM." At 9:07 am, EST, the hurricane hunter plane reached the center of the storm, found a circular eye well defined, central pressure 994 $\mathrm{mb}$, surface winds in excess of hurricane force, and the wall cloud around the eye $8 \mathrm{mi}$. wide. This observation indicated that hurricane Flora was the most concentrated and best organized tropical cyclone of the past two years. The San Juan Weather Bureau office issued a bulletin at $9 \mathrm{am}$, and the first formal hurricane advisory on Flora at $11 \mathrm{am}$, EST. The eye of hurricane Flora passed over Tobago at 1:40 pm, EST, with lowest pressure $28.77 \mathrm{in}, 974 \mathrm{mb}$ (uncorrected) and maximum sustained winds 90 to $100 \mathrm{mph}$. Seventeen people were killed and crop and property damage was around \$30 million. On Trinidad, maximum winds were estimated at about $55 \mathrm{mph}$ in extreme gusts from the southwest. There was only minor damage over most of Trinidad due to the protection afforded by the mountain range along the north coast. However, when the wind shifted to the southwest, many small boats in the harbor, which is an open roadstead to the west, were sunk. The large vessels had put out to sea. At Northwest Point on the northern slope of the mountains, the marine reporting station estimated winds up to $70 \mathrm{mph}$ with torrential rains. An amateur radio operator about 10 mi. east of Northwest Point and on the slope about $1 / 2 \mathrm{mi}$. from the shore, estimated the winds at $65 \mathrm{mph}$ in gusts and zero visibility due to the heavy driving rain." ATSR: "However, it wasn't until the night of 29 September that ships began reporting heavy seas, falling pressures and westerly winds, which prompted a disturbance warning to be issued by Fleet Weather Facility, Miami the following morning at 301100Z. A navy reconnaissance aircraft from Roosevelt Roads 
was dispatched into the area the morning of the $30^{\text {th }}$. The aircraft found the circulation approximately 120 miles to the easy of Trinidad. The disturbance had intensified into a well-developed hurricane with a well-defined wall cloud and central pressure of $994 \mathrm{mbs}$. Warning number one on Hurricane FLORA was issued at 301600Z."

October 1:

HWM analyzes a hurricane of at most $1000 \mathrm{mb}$ at $12.8 \mathrm{~N}, 64.8 \mathrm{~W}$ at $12 \mathrm{Z}$. HURDAT lists a $115 \mathrm{kt}$ hurricane at $12.5 \mathrm{~N}, 64.8 \mathrm{~W}$ at $12 \mathrm{Z}$. Microfilm shows a closed low pressure of at most $1008 \mathrm{mb}$ at $13.0 \mathrm{~N}, 65.5 \mathrm{~W}$ at 12Z. Ship highlights: $35 \mathrm{kt} \mathrm{E}$ and 1013 $\mathrm{mb}$ at $14.2 \mathrm{~N}, 66.4 \mathrm{~W}$ at $18 \mathrm{Z}$ (micro). Aircraft highlights: Radar center fix at $11.6 \mathrm{~N}$, $62.3 \mathrm{~W}$ at $01 \mathrm{Z}$ (WALLET). Radar center fix measured a peripheral pressure of $981 \mathrm{mb}$ and estimated an eye diameter of $13-20 \mathrm{~nm}$ at $12.2 \mathrm{~N}, 63.8 \mathrm{~W}$ at $07 \mathrm{Z}$ (WALLET). Penetration center fix measured a central pressure of $974 \mathrm{mb}$, estimated surface winds of $120 \mathrm{kt}$ and an eye diameter of $13 \mathrm{~nm}$ at $13.1 \mathrm{~N}, 65.9 \mathrm{~W}$ at $16 \mathrm{Z}$ (WALLET/ATSR).

Penetration center fix measured a central pressure of $975 \mathrm{mb}$, estimated surface winds of $120 \mathrm{kt}$ and an eye diameter of $13 \mathrm{~nm}$ at $13.2 \mathrm{~N}, 66.2 \mathrm{~W}$ at $19 \mathrm{Z}$ (WALLET). Penetration center fix measured a central pressure of $970 \mathrm{mb}$ and estimated eye diameter of $11 \mathrm{~nm}$ at $13.5 \mathrm{~N}, 66.7 \mathrm{~W}$ at $2110 \mathrm{Z}$ (WALLET).

MWR: "On Grenada damage was minor but six people lost their lives by drowning. After leaving the southern Windwards, hurricane Flora moved on a fairly smooth and regular track toward the southwestern Haitian peninsula gradually acquiring a more northward component."

October 2:

HWM analyzes a hurricane of at most $1000 \mathrm{mb}$ at $14.8 \mathrm{~N}, 69.2 \mathrm{~W}$ at $12 \mathrm{Z}$. HURDAT lists a $120 \mathrm{kt}$ hurricane at $14.6 \mathrm{~N}, 69.2 \mathrm{~W}$ at $12 \mathrm{Z}$. Microfilm shows a closed low pressure of at most $1008 \mathrm{mb}$ at $14.5 \mathrm{~N}, 69.0 \mathrm{~W}$ at 12Z. Ship highlights: $40 \mathrm{kt} \mathrm{NE}$ and 1012 $\mathrm{mb}$ at $17.4 \mathrm{~N}, 69.8 \mathrm{~W}$ at $12 \mathrm{Z}$ (COADS). $50 \mathrm{kt} \mathrm{ESE}$ and $1008 \mathrm{mb}$ at $15.2 \mathrm{~N}, 68.6 \mathrm{~W}$ (COADS/MWL). Aircraft highlights: Penetration center fix at $13.5 \mathrm{~N}, 67.1 \mathrm{~W}$ at $02 \mathrm{Z}$ (ATSR). Penetration center fix measured a central pressure of $964 \mathrm{mb}$, estimated flight level winds of $145 \mathrm{kt}$ and an eye diameter of $11 \mathrm{~nm}$ at $14.4 \mathrm{~N}, 68.3 \mathrm{~W}$ at $0710 \mathrm{Z}$ (WALLET). Radar center fix measured a peripheral pressure of $968 \mathrm{mb}$, estimated surface winds of $130 \mathrm{kt}$ and an eye diameter of $11 \mathrm{~nm}$ at $14.8 \mathrm{~N}, 69.6 \mathrm{~W}$ at $1342 \mathrm{Z}$ (WALLET). Penetration center fix measured a central pressure of $960 \mathrm{mb}$, estimated surface winds of $120 \mathrm{kt}$ and an eye diameter of $16 \mathrm{~nm}$ at $15.1 \mathrm{~N}, 70.1 \mathrm{~W}$ at $1946 \mathrm{Z}$ (WALLET).

October 3:

HWM analyzes a hurricane of at most $1000 \mathrm{mb}$ at $16.8 \mathrm{~N}, 72.0 \mathrm{~W}$ at $12 \mathrm{Z}$. HURDAT lists a $125 \mathrm{kt}$ hurricane at $16.5 \mathrm{~N}, 72.0 \mathrm{~W}$ at $12 \mathrm{Z}$. Microfilm shows a closed low pressure of at most $1008 \mathrm{mb}$ at $15.0 \mathrm{~N}, 72.0 \mathrm{~W}$ at 12Z. Ship highlights: $35 \mathrm{kt} \mathrm{E}$ and 1011 $\mathrm{mb}$ at $16.7 \mathrm{~N}, 68.5 \mathrm{~W}$ at $00 \mathrm{Z}$ (COADS). $45 \mathrm{kt}$ ESE and $1004 \mathrm{mb}$ at $16.1 \mathrm{~N}, 68.9 \mathrm{~W}$ at $06 \mathrm{Z}$ (COADS). $35 \mathrm{kt} \mathrm{SE}$ and $1005 \mathrm{mb}$ at $15.2 \mathrm{~N}, 69.4 \mathrm{~W}$ at $12 \mathrm{Z}$ (COADS). Land highlights: $1001 \mathrm{mb}$ at Barahona, Dominican Republic at 21Z (WALLET). $42 \mathrm{kt}$ (gusts to $55 \mathrm{kt}$ ) at 
Port-au-Prince, Haiti at 23Z (WALLET). Aircraft highlights: Radar center fix measured a peripheral pressure of $963 \mathrm{mb}$, estimated surface winds of $140 \mathrm{kt}$ and an eye diameter of $16 \mathrm{~nm}$ at $15.5 \mathrm{~N}, 70.8 \mathrm{~W}$ at $0046 \mathrm{Z}$ (WALLET). Radar center fix measured a peripheral pressure of $954 \mathrm{mb}$, estimated flight level winds of $140 \mathrm{kt}$ and an eye diameter of $15 \mathrm{~nm}$ at $15.9 \mathrm{~N}, 71.6 \mathrm{~W}$ at $0617 \mathrm{Z}$ (WALLET). Penetration center fix estimated surface winds of $110 \mathrm{kt}$ and an eye diameter of $18 \mathrm{~nm}$ at $16.6 \mathrm{~N}, 72.2 \mathrm{~W}$ at $1342 \mathrm{Z}$ (WALLET). Penetration center fix measured a central pressure of $936 \mathrm{mb}$, estimated surface winds of $130 \mathrm{kt}$ and an eye diameter of $15 \mathrm{~nm}$ at $16.8 \mathrm{~N}, 72.4 \mathrm{~W}$ at $1620 \mathrm{Z}$ (WALLET). Penetration center fix estimated surface winds of $143 \mathrm{kt}$ and an eye diameter of $12 \mathrm{~nm}$ at $17.2 \mathrm{~N}, 72.6 \mathrm{~W}$ at $1838 Z$ (WALLET).

MWR: "Flora intensified slowly until it began to deepen rapidly on October 3. At 11:2O am. EST, the Navy reconnaissance plane reported a central pressure of $936 \mathrm{mb}$, or 27.64 in. Flight level winds of $167 \mathrm{mph}$ were measured on the $2^{\text {nd }}$ and about the same on the $3^{\text {rd }}$. Probably some further intensification continued on the $3^{\text {rd }}$ until the center reached the coastline around $8 \mathrm{pm}, \mathrm{EST}$. At this time it was estimated sustained winds on the surface were around $140 \mathrm{mph}$ with gusts 180-200 mph. Thus at this time, Flora was comparable to hurricane Donna when it crossed the Florida Keys in 1960 and Carla when it reached the Texas coast in 1961."

October 4:

HWM analyzes a hurricane of at most $995 \mathrm{mb}$ at $19.7 \mathrm{~N}, 74.3 \mathrm{~W}$ at $12 \mathrm{Z}$. HURDAT lists a $105 \mathrm{kt}$ hurricane at $19.3 \mathrm{~N}, 74.5 \mathrm{~W}$ at $12 \mathrm{Z}$. Microfilm shows a closed low pressure of at most $1005 \mathrm{mb}$ at $19.0 \mathrm{~N}, 75.0 \mathrm{~W}$ at 12Z. Ship highlights: $20 \mathrm{kt} \mathrm{NW}$ and $1004 \mathrm{mb}$ at $17.2 \mathrm{~N}, 74.5 \mathrm{~W}$ at $06 \mathrm{Z}$ (COADS). $65 \mathrm{kt} \mathrm{NW}$ and $988 \mathrm{mb}$ at $18 \mathrm{Z}$ (micro). Land highlights: calm for 15 minutes at Fonds des Negres, Haiti starting at 0245Z (WALLET). calm for an 1 hour, 10 minutes at Ause a Veau, Haiti starting at 04Z (WALLET). $978 \mathrm{mb}$ (min pressure) at Port-au-Prince, Haiti at 0430Z (WALLET). $55 \mathrm{kt} \mathrm{NE}$ and $1006 \mathrm{mb}$ at Punta de Maisi, Cuba at 06Z (CUBA). $50 \mathrm{kt} \mathrm{E}$ and $1005 \mathrm{mb}$ at Punta de Maisi, Cuba at $12 \mathrm{Z}$ (CUBA). $83 \mathrm{kt} \mathrm{ESE}$ at Punta de Maisi, Cuba at 16Z-18Z (WALLET). $70 \mathrm{kt}$ E and 1000 $\mathrm{mb}$ at Punta de Maisi, Cuba at $18 \mathrm{Z}$ (micro). $30 \mathrm{kt} \mathrm{NW}$ and $995 \mathrm{mb}$ at Guantanamo Bay, Cuba at $18 Z$ (micro). Aircraft highlights: Radar center fix estimated an eye diameter of $12 \mathrm{~nm}$ at $18.4 \mathrm{~N}, 73.3 \mathrm{~W}$ at $01 \mathrm{Z}$ (WALLET). Radar center fix measured a peripheral pressure of $995 \mathrm{mb}$, estimated surface winds of $80 \mathrm{kt}$ and an eye diameter of 8-12 $\mathrm{nm}$ at 19.1N, 74.0W at 05Z (WALLET). Penetration center fix measured a central pressure of $970 \mathrm{mb}$, estimated surface winds of $110 \mathrm{kt}$ and an eye diameter of $17 \mathrm{~nm}$ at $19.3 \mathrm{~N}$, $74.6 \mathrm{~W}$ at $1231 \mathrm{Z}$ (WALLET). Penetration center fix measured a central pressure of 973 $\mathrm{mb}$, estimated surface winds of $100 \mathrm{kt}$ and an eye diameter of $20 \mathrm{~nm}$ at $19.5 \mathrm{~N}, 74.8 \mathrm{~W}$ at $1540 Z$ (WALLET).

MWR: "The vortex entered the Haitian south coast at Cotes de Fer and calms were noted at Fond des Negres and Anse a Veau. Winds of $102 \mathrm{mph}$ were noted at Cotes de Fer at 7 pm, EST October 3 and $120 \mathrm{mph}$ at the Army base near Durez. The total rainfall at Miragoane during the period when western Haiti was under the influence of Flora probably exceeded 75 in. On October 6-8 when Miragoane was under the principal rain band feeding into Flora, the rain gage at the Reynolds Haitian Mines, Inc., which holds 
$19 \mathrm{in}$., was observed overflowing three times and was emptied. Thus at least 57 in. fell during this 3-day period. This does not include rainfall during the passage of the center nearby on October 3 and 4 , or some rain which fell on the $5^{\text {th }}$. Destruction over the mountainous terrain of the Haitian peninsula ranged from severe to complete. Flash floods washed away sections of many towns and landslides buried others. The height of the storm surge on the south shore is unknown but could easily have been $12 \mathrm{ft}$. or more. Crops were totally destroyed. About 3,500 bodies were counted and several thousand persons are missing. Of the missing, normally about half are eventually found to be casualties and half turn up sooner or later in some other locality. Therefore, an estimate of 5,000 deaths appears reasonable. Property and crop damage is estimated at $\$ 125$ million with some reliable figures as high as $\$ 180$ million. In the Dominican Republic, preliminary information indicates that damage, mostly from floods but to some extent from wind, to agriculture, livestock, communication lines, etc., is estimated at $\$ 60$ million. There was also considerable damage to bridges and roads. In the western section of the Republic $10,000 \mathrm{~km}^{2}$ were inundated. The known loss of life is 29 but is estimated in excess of 400. Floods were the most extensive of record, and several months after the storm roads were still impassable and communication channels in many western sections unrestored. As Flora entered Cuba about 30 mi. east of Guantanamo Bay late on the forenoon of October 4, a warm High at sea level was located over Lake Huron." ATSR: "The hurricane reached maximum intensity on 4 October just prior to passing over the southwestern peninsula of Haiti. Later information from Haiti indicated that winds of 135 knots with gusts to 175 knots occurred as FLORA passed over the peninsula. Minimum pressure of $936 \mathrm{mbs}$ was reported by aircraft. Reconnaissance aircraft from Airborne Early Warning Squadron FOUR maintained almost constant surveillance during FLORA's passage through the Caribbean. The meteorological information provided to the hurricane forecasters resulted in accurate tracking of the storm's path and assisted in the prediction of the expansive wind fields which eventually devastated portions of Haiti."

\section{October 5:}

HWM analyzes a hurricane of at most $1000 \mathrm{mb}$ at $21.8 \mathrm{~N}, 76.7 \mathrm{~W}$ with a weakening front far to the north at 12Z. HURDAT lists a $105 \mathrm{kt}$ hurricane at $20.8 \mathrm{~N}$, $76.8 \mathrm{~W}$ at $12 \mathrm{Z}$. Microfilm shows a closed low pressure of at most $999 \mathrm{mb}$ at $20.4 \mathrm{~N}$, $76.5 \mathrm{~W}$ at $12 \mathrm{Z}$. Ship highlights: $45 \mathrm{kt} \mathrm{SE}$ and $1008 \mathrm{mb}$ at $21.9 \mathrm{~N}, 73.0 \mathrm{~W}$ at $00 \mathrm{Z}$ (micro). $25 \mathrm{kt} \mathrm{SW}$ and $1004 \mathrm{mb}$ at $18.9 \mathrm{~N}, 76.0 \mathrm{~W}$ at $06 \mathrm{Z}$ (COADS). $35 \mathrm{kt} \mathrm{SE}$ and $1008 \mathrm{mb}$ at $19.8 \mathrm{~N}, 75.1 \mathrm{~W}$ at $12 \mathrm{Z}$ (COADS). $45 \mathrm{kt} \mathrm{SE}$ and $1003 \mathrm{mb}$ at $19.2 \mathrm{~N}, 75.2 \mathrm{~W}$ at $15 \mathrm{Z}$ (COADS). $40 \mathrm{kt} \mathrm{SE}$ and $1008 \mathrm{mb}$ at $19.3 \mathrm{~N}, 75.2 \mathrm{~W}$ at $18 \mathrm{Z}$ (COADS). Land highlights: 95 $\mathrm{kt} \mathrm{E}$ (max winds) and $995 \mathrm{mb}$ at Punta Lucrecia, Cuba at 00Z (CUBA). $60 \mathrm{kt} \mathrm{ESE}$ and $1003 \mathrm{mb}$ at Punta Lucrecia, Cuba at 06Z (micro). $60 \mathrm{kt} \mathrm{SE}$ and $1001 \mathrm{mb}$ at Santiago de Cuba, Cuba at $12 \mathrm{Z}$ (micro). $60 \mathrm{kt} \mathrm{SSE}$ and $1003 \mathrm{mb}$ at Santiago de Cuba, Cuba at 18Z (CUBA). $75 \mathrm{kt}$ at Camagüey, Cuba at 21Z-22Z (WALLET). 
October 6:

HWM analyzes a hurricane of at most $995 \mathrm{mb}$ at $20.5 \mathrm{~N}, 78.2 \mathrm{~W}$ with a warm front far to the northeast at 12Z. HURDAT lists a $90 \mathrm{kt}$ hurricane at $20.2 \mathrm{~N}, 77.9 \mathrm{~W}$ at $12 \mathrm{Z}$. Microfilm shows a closed low pressure of at most $990 \mathrm{mb}$ at $20.5 \mathrm{~N}, 77.7 \mathrm{~W}$ at $12 \mathrm{Z}$. Ship highlights: $40 \mathrm{kt} \mathrm{SSW}$ and $1008 \mathrm{mb}$ at $18.5 \mathrm{~N}, 75.6 \mathrm{~W}$ at $00 \mathrm{Z}$ (micro). $35 \mathrm{kt} \mathrm{E}$ and 1012 $\mathrm{mb}$ at $23.8 \mathrm{~N}, 74.6 \mathrm{~W}$ at $06 \mathrm{Z}$ (COADS). $40 \mathrm{kt}$ ENE and $1013 \mathrm{mb}$ at $25.0 \mathrm{~N}, 75.2 \mathrm{~W}$ at $12 \mathrm{Z}$ (COADS). $45 \mathrm{kt} \mathrm{ENE}$ and $1014 \mathrm{mb}$ at $26.1 \mathrm{~N}, 75.6 \mathrm{~W}$ at 18Z (COADS). Land highlights: $75 \mathrm{kt} \mathrm{SE}$ and $1003 \mathrm{mb}$ at Santiago de Cuba, Cuba at 00Z (CUBA). $80 \mathrm{kt} \mathrm{NE}$ (gusts to 100 $\mathrm{kt}$ ) and $1002 \mathrm{mb}$ at Camagüey, Cuba at 06Z (micro). $50 \mathrm{kt} \mathrm{NE}$ and $1000 \mathrm{mb}$ at Camagüey, Cuba at 12Z (micro). $60 \mathrm{kt} \mathrm{SE}$ and $1003 \mathrm{mb}$ at Santiago de Cuba, Cuba at $18 Z$ (CUBA). Aircraft highlights: Radar center fix at 20.3N, 78.0W at 11Z (WALLET). Radar center fix at $20.5 \mathrm{~N}, 78.3 \mathrm{~W}$ at $1835 \mathrm{Z}$ (WALLET).

ATSR: "The initial track of Hurricane FLORA was predominately influenced by the easterlies as FLORA passed over the island of Tobago in the Southern Windwards, across the Caribbean and into Eastern Cuba. At this point, lacking sufficient tropospheric steering, FLORA stalled for more than four days over Cuba."

October 7:

HWM analyzes a hurricane of at most $985 \mathrm{mb}$ at $21.0 \mathrm{~N}, 78.5 \mathrm{~W}$ with a stationary front far to the northeast at 12Z. HURDAT lists an $80 \mathrm{kt}$ hurricane at $20.8 \mathrm{~N}, 78.1 \mathrm{~W}$ at 12Z. Microfilm shows a closed low pressure of at most $990 \mathrm{mb}$ at $20.8 \mathrm{~N}, 78.2 \mathrm{~W}$ at $12 \mathrm{Z}$. Ship highlights: $40 \mathrm{kt} \mathrm{S}$ and $1003 \mathrm{mb}$ at $17.3 \mathrm{~N}, 74.9 \mathrm{~W}$ at $00 \mathrm{Z}$ (COADS). $35 \mathrm{kt} \mathrm{S}$ and $1003 \mathrm{mb}$ at $18.2 \mathrm{~N}, 76.3 \mathrm{~W}$ at $06 \mathrm{Z}$ (COADS). $35 \mathrm{kt} \mathrm{SE}$ and $1001 \mathrm{mb}$ at $18.4 \mathrm{~N}, 75.3 \mathrm{~W}$ at $12 \mathrm{Z}$ (COADS). $45 \mathrm{kt} \mathrm{ENE}$ and $1014 \mathrm{mb}$ at 26.1N, 75.6W at 18Z (MWL). Land highlights: $55 \mathrm{kt} \mathrm{SE}$ and $1003 \mathrm{mb}$ at Santiago de Cuba, Cuba at 00Z (CUBA). $55 \mathrm{kt} \mathrm{SE}$ and $1004 \mathrm{mb}$ at Santiago de Cuba, Cuba at 06Z (CUBA). $70 \mathrm{kt} \mathrm{SE}$ and $1002 \mathrm{mb}$ at Santiago de Cuba, Cuba at 12Z (CUBA). $35 \mathrm{kt} \mathrm{SW}$ and $996 \mathrm{mb}$ at Cabo Cruz, Cuba at $18 Z$ (CUBA). $35 \mathrm{kt} \mathrm{NE}$ at Caibarien, Cuba at 21Z-22Z (WALLET). Aircraft highlights: Radar center fix near 21.0N, 78.0W at $1115 \mathrm{Z}$ (WALLET). Radar center fix estimated a peripheral pressure of $986 \mathrm{mb}$ and surface winds of $55 \mathrm{kt}$ at $21.1 \mathrm{~N}, 78.1 \mathrm{~W}$ at $1315 \mathrm{Z}$ (WALLET/ATSR).

MWR: "During October 7 and 8 Flora moved slowly eastward to east-northeastward almost directly over the same portion of eastern Cuba it had traversed two days before."

October 8:

HWM analyzes a hurricane of at most $985 \mathrm{mb}$ at $21.5 \mathrm{~N}, 76.2 \mathrm{~W}$ at $12 \mathrm{Z}$. HURDAT lists a $70 \mathrm{kt}$ hurricane at $21.1 \mathrm{~N}, 76.2 \mathrm{~W}$ at $12 \mathrm{Z}$. Microfilm shows a closed low pressure of at most $993 \mathrm{mb}$ at $21.1 \mathrm{~N}, 76.2 \mathrm{~W}$ at 12Z. Ship highlights: $35 \mathrm{kt} \mathrm{NE}$ and $1005 \mathrm{mb}$ at $22.2 \mathrm{~N}, 73.4 \mathrm{~W}$ at $00 \mathrm{Z}$ (COADS). $35 \mathrm{kt} \mathrm{S}$ and $1000 \mathrm{mb}$ at $18.9 \mathrm{~N}, 74.9 \mathrm{~W}$ at $06 \mathrm{Z}$ (COADS). $35 \mathrm{kt} \mathrm{SE}$ and $1000 \mathrm{mb}$ at 20.6N, 73.9W at 12Z (COADS/micro). $60 \mathrm{kt} \mathrm{E}$ and $994 \mathrm{mb}$ at $22.4 \mathrm{~N}, 74.4 \mathrm{~W}$ at $18 \mathrm{Z}$ (COADS/MWL). $55 \mathrm{kt} \mathrm{NNE}$ and $991 \mathrm{mb}$ at $21.5 \mathrm{~N}, 76.1 \mathrm{~W}$ at $20 \mathrm{Z}$ (MWL). Land highlights: $35 \mathrm{kt} \mathrm{NE}$ and $1009 \mathrm{mb}$ at North Eleuthera, Bahamas at 00Z (micro). $60 \mathrm{kt} \mathrm{S}$ (possible high bias) and $999 \mathrm{mb}$ at Santiago de Cuba, Cuba at 06Z (micro). $35 \mathrm{kt} \mathrm{SE}$ and $1000 \mathrm{mb}$ at Punta de Maisi, Cuba at 12Z (micro). $80 \mathrm{kt} \mathrm{S}$ at Punta 
de Maisi, Cuba at 17Z (WALLET). Aircraft highlights: Penetration center fix measured a central pressure of $983 \mathrm{mb}$ and estimated surface winds of $100 \mathrm{kt}$ at $21.5 \mathrm{~N}, 75.0 \mathrm{~W}$ at $2215 Z$ (WALLET).

MWR: "By October 8, another active short wave was morning into the long-wave trough position off the east coast and accelerating the southwesterly flow in the area of the hurricane. Thus Flora began to follow a more normal northeastward course at a gradually increasing forward speed into higher latitudes." ATSR: "Recurvature to the northeast and acceleration occurred on 8 October as FLORA left the North Cuban coast and emerged into the Atlantic after passing Mayaguana Island in the Southeastern Bahamas."

October 9:

HWM analyzes a hurricane of at most $985 \mathrm{mb}$ at $23.5 \mathrm{~N}, 71.2 \mathrm{~W}$ with a weakening warm front to the northeast at 12Z. HURDAT lists an $80 \mathrm{kt}$ hurricane at $23.5 \mathrm{~N}, 71.6 \mathrm{~W}$ at 12Z. Microfilm shows a closed low pressure of at most $996 \mathrm{mb}$ at $23.8 \mathrm{~N}, 71.3 \mathrm{~W}$ at $12 \mathrm{Z}$. Ship highlights: $45 \mathrm{kt} \mathrm{S}$ and $998 \mathrm{mb}$ at 19.7N, 73.7W at 00Z (micro). $40 \mathrm{kt}$ ESE and 998 $\mathrm{mb}$ at $24.0 \mathrm{~N}, 72.1 \mathrm{~W}$ at $06 \mathrm{Z}$ (micro). $50 \mathrm{kt} \mathrm{S}$ and $998 \mathrm{mb}$ at $21.7 \mathrm{~N}, 68.7 \mathrm{~W}$ at $12 \mathrm{Z}$ (micro). $35 \mathrm{kt} \mathrm{SSE}$ and $1006 \mathrm{mb}$ at 24.6N, 66.5W at 15Z (COADS). $55 \mathrm{kt} \mathrm{NNE}$ and $1003 \mathrm{mb}$ at 26.8N, 67.3W at 18Z (MWL). Land highlights: $40 \mathrm{kt} \mathrm{SSW}$ and $989 \mathrm{mb}$ at Matthew Town, Bahamas at 00Z (micro). $977 \mathrm{mb}$ at Mayaguana, Bahamas at 0545Z (WALLET). $35 \mathrm{kt} \mathrm{SE}$ and $998 \mathrm{mb}$ at Grand Turk at 06Z (micro). $40 \mathrm{kt} \mathrm{SW}$ and $999 \mathrm{mb}$ at Grand Turk at $12 \mathrm{Z}$ (micro). Aircraft highlights: Penetration center fix measured a central pressure of $976 \mathrm{mb}$, estimated surface winds of $70 \mathrm{kt}$ and an eye diameter of $30 \mathrm{~nm}$ at $23.2 \mathrm{~N}, 72.0 \mathrm{~W}$ at $11 \mathrm{Z}$ (WALLET). Penetration center fix measured a central pressure of $975 \mathrm{mb}$, estimated surface winds of $120 \mathrm{kt}$ and an eye diameter of $35 \mathrm{~nm}$ at $23.9 \mathrm{~N}, 71.1 \mathrm{~W}$ at $14 \mathrm{Z}$ (WALLET). Penetration center fix measured a central pressure of $965 \mathrm{mb}$, estimated surface winds of $130 \mathrm{kt}$ and an eye diameter of $70 \mathrm{~nm}$ at $25.0 \mathrm{~N}, 69.5 \mathrm{~W}$ at $19 \mathrm{Z}$ (WALLET). Radar center fix measured a central pressure of $965 \mathrm{mb}$, doppler estimated surface winds of $105 \mathrm{kt}$ and an eye diameter of $40 \mathrm{~nm}$ at $25.7 \mathrm{~N}, 68.4 \mathrm{~W}$ at $2321 \mathrm{Z}$ (WALLET).

MWR: "Hurricane Flora passed through the southeastern Bahamas on the night of October 8. On Inagua, Flora was described as the "worst hurricane ever experienced there within living memory." Winds were estimated at 75 to 80 m.p.h. Two wharves were destroyed, the sea wall was damaged, and there was extensive damage to crops, roofs, and roads. The eye passed over Mayaguana shortly after midnight with maximum winds at 1:30 a.m. EST of 83 m.p.h. The sea wall was washed away and crop destruction was total. There was extensive damage to roofs and communication lines. One person was drowned. Exuma, Long, Acklins, Crooked Islands, and Long Cay reported some damage to roads and property and crop damage ranged from moderate to total."

October 10:

HWM analyzes a hurricane of at most $985 \mathrm{mb}$ at $28.4 \mathrm{~N}, 64.9 \mathrm{~W}$ with a weakening stationary front to the northeast at $12 \mathrm{Z}$. HURDAT lists a $100 \mathrm{kt}$ hurricane at $28.1 \mathrm{~N}$, $64.9 \mathrm{~W}$ at $12 \mathrm{Z}$. Microfilm shows a closed low pressure of at most $999 \mathrm{mb}$ at $27.5 \mathrm{~N}$, $64.8 \mathrm{~W}$ with a frontal boundary to the northwest at 12Z. Ship highlights: $75 \mathrm{kt} \mathrm{SE}$ and 990 $\mathrm{mb}$ at $25.5 \mathrm{~N}, 68.0 \mathrm{~W}$ at $00 \mathrm{Z}$ (micro). $60 \mathrm{kt} \mathrm{WNW}$ and $1003 \mathrm{mb}$ at $25.3 \mathrm{~N}, 67.7 \mathrm{~W}$ at $06 \mathrm{Z}$ 
(micro). $75 \mathrm{kt} \mathrm{S}$ and $983 \mathrm{mb}$ at $27.0 \mathrm{~N}, 64.3 \mathrm{~W}$ at $12 \mathrm{Z}$ (COADS). $50 \mathrm{kt} \mathrm{S}$ and $1002 \mathrm{mb}$ at $27.6 \mathrm{~N}, 60.0 \mathrm{~W}$ at $18 \mathrm{Z}$ (COADS). $35 \mathrm{kt} \mathrm{N}$ and $1022 \mathrm{mb}$ at $35.8 \mathrm{~N}, 74.4 \mathrm{~W}$ at $21 \mathrm{Z}$ (COADS). $50 \mathrm{kt} \mathrm{E}$ and $998 \mathrm{mb}$ at 33.9N, 61.0W at 23Z (COADS). Aircraft highlights: Radar center fix estimated a peripheral pressure of $968 \mathrm{mb}$ at $26.3 \mathrm{~N}, 67.2 \mathrm{~W}$ at $0109 \mathrm{Z}$ (WALLET). Penetration center fix measured a central pressure of $969 \mathrm{mb}$, estimated surface winds of $120 \mathrm{kt}$ and an eye diameter of $70 \mathrm{~nm}$ at $27.8 \mathrm{~N}, 64.4 \mathrm{~W}$ at $1307 \mathrm{Z}$ (WALLET). Penetration center fix measured a central pressure of $972 \mathrm{mb}$ and estimated flight level winds of 85 at 30.3N, 61.8W at 19Z (WALLET). Penetration center fix measured a central pressure of $968 \mathrm{mb}$, estimated surface winds of $122 \mathrm{kt}$ and an eye diameter of $50 \mathrm{~nm}$ at $31.4 \mathrm{~N}, 60.5 \mathrm{~W}$ at $2220 \mathrm{Z}$ (WALLET).

October 11:

HWM analyzes a hurricane of at most $985 \mathrm{mb}$ at $36.7 \mathrm{~N}, 56.9 \mathrm{~W}$ with a frontal boundary just to the west at 12Z. HURDAT lists an $85 \mathrm{kt}$ hurricane at $36.2 \mathrm{~N}, 57.0 \mathrm{~W}$ at 12Z. Microfilm shows a closed low pressure of at most $999 \mathrm{mb}$ at $36.5 \mathrm{~N}, 57.0 \mathrm{~W}$ with a frontal boundary to the west and another to the southwest at 12Z. Ship highlights: $40 \mathrm{kt}$ WSW and $1006 \mathrm{mb}$ at $27.0 \mathrm{~N}, 60.0 \mathrm{~W}$ at $00 \mathrm{Z}$ (COADS). $40 \mathrm{kt} \mathrm{N}$ and $999 \mathrm{mb}$ at $33.7 \mathrm{~N}$, $62.3 \mathrm{~W}$ at $06 \mathrm{Z}$ (MWL). $60 \mathrm{kt}$ ESE and $1001 \mathrm{mb}$ at $40.1 \mathrm{~N}, 56.3 \mathrm{~W}$ at $12 \mathrm{Z}$ (COADS). $70 \mathrm{kt}$ $\mathrm{NE}$ and $990 \mathrm{mb}$ at $40.1 \mathrm{~N}, 57.2 \mathrm{~W}$ at $15 \mathrm{Z}$ (COADS). $70 \mathrm{kt} \mathrm{SE}$ and $961 \mathrm{mb}$ at $38.3 \mathrm{~N}$, $55.6 \mathrm{~W}$ at $18 \mathrm{Z}$ (COADS/micro). $100 \mathrm{kt} \mathrm{NE}$ at $40.2 \mathrm{~N}, 55.3 \mathrm{~W}$ at $18 \mathrm{Z}$ (micro). $70 \mathrm{kt} \mathrm{N}$ and $978 \mathrm{mb}$ at $40.1 \mathrm{~N}, 57.2 \mathrm{~W}$ at $21 \mathrm{Z}$ (COADS). Aircraft highlights: Radar center fix at $32.6 \mathrm{~N}$, $59.7 \mathrm{~W}$ at $0106 \mathrm{Z}$ (WALLET). Penetration center fix measured a central pressure of 963 $\mathrm{mb}$, estimated flight level winds of $80 \mathrm{kt}$ and an eye diameter of $80 \mathrm{~nm}$ at $36.9 \mathrm{~N}, 56.8 \mathrm{~W}$ at $1315 Z$ (WALLET). Penetration center fix estimated flight level winds of $75 \mathrm{kt}$ at $38.6 \mathrm{~N}, 56.0 \mathrm{~W}$ at $1915 \mathrm{Z}$ (WALLET).

October 12:

HWM analyzes a hurricane of at most $980 \mathrm{mb}$ at $43.7 \mathrm{~N}, 50.0 \mathrm{~W}$ with a warm front to the northeast and a cold front to the south and an extratropical cyclone at $50.0 \mathrm{~N}$, $66.0 \mathrm{~W}$ at $12 \mathrm{Z}$. HURDAT lists a $75 \mathrm{kt}$ hurricane at $43.5 \mathrm{~N}, 49.8 \mathrm{~W}$ at $12 \mathrm{Z}$. Microfilm shows an extratropical cyclone of at most $993 \mathrm{mb}$ at $43.0 \mathrm{~N}, 51.0 \mathrm{~W}$ at 12Z. Ship highlights: $75 \mathrm{kt} \mathrm{NE}$ and $988 \mathrm{mb}$ at 42.4N, 54.3W at 00Z (COADS/MWL). $100 \mathrm{kt} \mathrm{NW}$ and $983 \mathrm{mb}$ at $39.6 \mathrm{~N}, 56.3 \mathrm{~W}$ at $00 \mathrm{Z}$ (micro). $80 \mathrm{kt} \mathrm{E}$ at $43.2 \mathrm{~N}, 52.0 \mathrm{~W}$ at $03 \mathrm{Z}$ (micro). 70 kt NW and $983 \mathrm{mb}$ at $41.1 \mathrm{~N}, 56.3 \mathrm{~W}$ at 06Z (COADS). $60 \mathrm{kt} \mathrm{N}$ and $982 \mathrm{mb}$ at $42.5 \mathrm{~N}$, $52.8 \mathrm{~W}$ at $12 \mathrm{Z}$ (COADS/micro). $60 \mathrm{kt} \mathrm{WSW}$ and $999 \mathrm{mb}$ at $40.4 \mathrm{~N}, 49.1 \mathrm{~W}$ at $18 \mathrm{Z}$ (COADS). $50 \mathrm{kt} \mathrm{SW}$ and $1001 \mathrm{mb}$ at $41.5 \mathrm{~N}, 45.3 \mathrm{~W}$ at $21 \mathrm{Z}$ (COADS).

ATSR: "FLORA passed southeast of Newfoundland on the $12^{\text {th }}$, and soon became extratropical after coming under the influence of a cool air mass. The last of 49 warnings was transmitted at 121600Z."

October 13:

HWM analyzes a hurricane of at most $970 \mathrm{mb}$ at $51.5 \mathrm{~N}, 41.8 \mathrm{~W}$ at $12 \mathrm{Z}$. HURDAT lists a $70 \mathrm{kt}$ extratropical cyclone at $51.5 \mathrm{~N}, 41.0 \mathrm{~W}$ at $12 \mathrm{Z}$ (last position). Microfilm shows an extratropical cyclone of at most $969 \mathrm{mb}$ at $53.5 \mathrm{~N}, 43.5 \mathrm{~W}$ at 12Z. Ship highlights: $70 \mathrm{kt} \mathrm{SW}$ and $995 \mathrm{mb}$ at $44.1 \mathrm{~N}, 44.5 \mathrm{~W}$ at 00Z (COADS). $50 \mathrm{kt} \mathrm{WSW}$ and 
$1009 \mathrm{mb}$ at $44.1 \mathrm{~N}, 41.0 \mathrm{~W}$ at $06 \mathrm{Z}$ (COADS). $50 \mathrm{kt} \mathrm{ENE}$ and $987 \mathrm{mb}$ at $55.2 \mathrm{~N}, 41.2 \mathrm{~W}$ at $12 \mathrm{Z}$ (COADS). $35 \mathrm{kt} \mathrm{NNE}$ and $969 \mathrm{mb}$ at $53.4 \mathrm{~N}, 44.1 \mathrm{~W}$ at $12 \mathrm{Z}$ (COADS). $65 \mathrm{kt} \mathrm{N}$ and $971 \mathrm{mb}$ at $55.1 \mathrm{~N}, 43.2 \mathrm{~W}$ at $18 \mathrm{Z}$ (COADS).

MWR: "However, for portions of five days, completely boxed in by the high-pressure areas to the west, the north, and the east, the hurricane meandered back and forth over eastern Cuba with winds of hurricane or near hurricane force and torrential rain.

Members of the staff of the National Observatory at Havana jointly with personnel of the National Academy of Sciences (Cuba) carefully surveyed the hurricane area and on the basis of the survey and hourly observations during the storm, determined the track as shown in figure 2. Although Flora had not completely regained its former intensity by the time it entered Cuba, nevertheless winds of 70 to $100 \mathrm{mph}$ lashed eastern Cuba for 100 hr. or more. Cuba's productive valleys and lowlands remained flooded for many days and crop damage was tremendous. Rainfall amounts were enormous. Radio broadcasts from Cuba mentioned a total of 90 in. near Velasco. At Guantanamo Bay, the rainfall from hurricane Flora greatly exceeded the recorded amount for the entire year of 1962. Dr. Luis Larragoiti Alonso, Director of the National Observatory, has forwarded rainfall accumulations in Cuba during the storm period as shown in table 2. The last official announcement listed 1159 people dead with more than 1000 people missing. Applying the same estimating procedure as in Haiti, gives a death toll of at least 1750. No official estimate of crop and property damage is available so far. Based on reports emanating from Cuba, estimates of damage to the sugar crop range from 15 to 60 percent; to tobacco 15 to 50 percent; to coffee and cocoa 25 to 100 percent; and to rice 50 to 75 percent. There were heavy losses in cattle, poultry, vegetables, bananas, pineapples, and cotton, and extensive damage to factories, roads, and bridges. Estimates of total damage have ranged upward to $\$ 500$ million, but at the present time it is believed $\$ 300$ million is reasonably realistic. Dr. Mario E. Rodriguez Ramirez, Chief of the Meteorological Division of the Civil Aviation Department of Cuba, lists three other prolonged Cuban hurricanes: 1851, August 19-21. Crossed the island from Oriente to Pinar del Rio. 1886, August 16-18. Took three days to travel from Oriente to Havana. 1910, October 13-17. Famous "huracan de cinco dias" which lashed the provinces of Pinar del Rio and La Havana. Dr. Jose Carlos Millas has recently discovered a prolonged hurricane, which occurred during the last days of September 1616 and resulted in a great disaster around Bayamo similar to that caused by Flora. While only peripheral effects were felt in Jamaica, there was considerable damage including: waterworks $\$ 420,000$; bananas $\$ 5,600,000$; other crops $\$ 1,400,000$; roads and bridges $\$ 4,200,000$; houses, etc. $\$ 280,000$, or a total of $\$ 11,900,000$. There were 11 fatalities mostly from flash floods. Some rainfall amounts are as follows: Palisadoes Airport 16.70 in.; Hope Gardens 14.11; Constant Spring 15.66; St. Georges College 18.38; Hermitage Dam 44.32; Hope Filter Plant 21.99; Seaview 31.94; Caraliers 19.72; Jack’s Hill 22.36. Gordon Town 35.00; Castleton 
Gardens 47.00; Cedar Valley 51.7; and Spring Hill 60.00 in. Flora is an historic hurricane-the second most deadly tropical cyclone ever to occur in the Atlantic area. The currently estimated total of 7,186 deaths considerably exceeds the death toll of the Galveston hurricane in 1900. Also, there are many small boats missing in the Caribbean with two to seven or more crewmen and passengers aboard each. These missing persons have not been included but may total 100 or more. In the great hurricane which devastated the Windward and Leeward Islands from October 10-12, 1780, apparently over 20,000 persons perished; 4,326 on Barbados; 9,000 on Martinique; 4,500 on St. Eustatius; several thousand sailors in the Spanish, Dutch, British, and French Fleets; mid a smaller number on other islands. The estimate of some $\$ 528,550,000$ damage to crops and property from Flora is conservative. There are, of course, indirect additional losses, which will be incurred from loss of work, and long-period effects on crops which, in some cases, will materially lessen crop production for the next five to eight years. Since the time Columbus discovered the New World, no hurricane has dealt such a devastating blow to the countries of Haiti and Cuba."

The tropical wave that developed into Hurricane Flora entered the eastern Atlantic late on September $23^{\text {th }}$ or early on September $24^{\text {th }}$ according to the Historical Weather Maps, and moved westward slowly becoming better organized. The disturbance was first detected in a TIROS VII satellite image (not available) on September $26^{\text {th }}$ over the central Atlantic. MWR indicates that the disturbance was a large area of convection with possibly multiple centers. The time of genesis is uncertain due to the sparse ship traffic over the central Atlantic. Thus, the first position is analyzed at $12 \mathrm{Z}$ on September $26^{\text {th }}$ as a $25 \mathrm{kt}$ tropical depression, same as originally shown in HURDAT. Minor track alterations are introduced during the lifetime of this tropical cyclone. (Central pressures values for many of the six hour periods were present in the original HURDAT between September $29^{\text {th }}$ at $12 \mathrm{Z}$ and October $12^{\text {th }}$ at $12 \mathrm{Z}$. Some of these were obviously analyses that were added in, not based upon actual observations. Thus, based on actual observations, some were retained and new central pressure values added. Detailed information on these changes can be found in the table at the end.) The tropical depression moved just north of due west on September $27^{\text {th }}$ and $28^{\text {th }}$ with little change in intensity. On September $29^{\text {th }}$ around 2230Z, a ship passed near the center of the tropical cyclone measuring a peripheral pressure of $1000 \mathrm{mb}$. A peripheral pressure of $1000 \mathrm{mb}$ suggests maximum surface winds greater than $47 \mathrm{kt}$ from the south of $25 \mathrm{~N}$ Brown et al. pressure-wind relationship. Intensities of $45 \mathrm{kt}$ at $18 \mathrm{Z}$ on the $29^{\text {th }}$ and $55 \mathrm{kt}$ at $00 \mathrm{Z}$ on the $30^{\text {th }}$ are assessed (down from $55 \mathrm{kt}$ an $70 \mathrm{kt}$ originally). Intensification to a tropical storm is analyzed at $06 \mathrm{Z}$ on October $29^{\text {th }}$, six hours earlier than originally shown in HURDAT, a minor intensity change. On September $30^{\text {th }}$, Flora rapidly intensified while approaching and later 
impacting the Windward Islands. At $1407 \mathrm{Z}$ on the $30^{\text {th }}$, a reconnaissance aircraft reached Flora measuring a central pressure of $994 \mathrm{mb}$, estimated surface winds of $110 \mathrm{kt}$, and an eye diameter of $25 \mathrm{~nm}$. A central pressure of $994 \mathrm{mb}$ suggests maximum surface winds of $58 \mathrm{kt}$ from the south of $25 \mathrm{~N}$ pressure-wind relationship. An eye diameter of $25 \mathrm{~nm}$ suggests an RMW of $19 \mathrm{~nm}$ and the climatological value is $11 \mathrm{~nm}$. Based upon a forward speed of about $17 \mathrm{kt}$, small size of the circulation (ROCI about $120 \mathrm{~nm}$ ) and putting some weight on the visual estimate, an intensity of $80 \mathrm{kt}$ is analyzed at $12 \mathrm{Z}$ on the $30^{\text {th }}$, down from $100 \mathrm{kt}$ originally in HURDAT, a major intensity change. Intensification to a hurricane is analyzed at $06 \mathrm{Z}$ on the $30^{\text {th }}$, six hours later than originally shown in HURDAT. The analyzed intensity at $06 \mathrm{Z}$ on the $30^{\text {th }}$ is $65 \mathrm{kt}$, down from $85 \mathrm{kt}$ originally shown in HURDAT, a major intensity change. Around $18 \mathrm{Z}$ on the $30^{\text {th }}$, the center of Flora made landfall in Tobago and a central pressure of $974 \mathrm{mb}$ was measured. A central pressure of $974 \mathrm{mb}$ suggests maximum surface winds of $85 \mathrm{kt}$ and $86 \mathrm{kt}$ from the south of $25 \mathrm{~N}$ and the intensifying subset pressure-wind relationship, respectively. Due to the forward speed of about $15 \mathrm{kt}$ and small circulation, an intensity of $100 \mathrm{kt}$ is analyzed at $18 \mathrm{Z}$ on the $30^{\text {th }}$, down from $105 \mathrm{kt}$ originally in HURDAT, a minor intensity change. Intensification to a major hurricane is analyzed at $18 \mathrm{Z}$ on the $30^{\text {th }}$, six hours later than originally shown in HURDAT.

On October $1^{\text {st }}$, Flora was located over the eastern Caribbean Sea moving west-northwest with no appreciable changes in intensity. Reconnaissance aircrafts made made penetration center fixes at 16Z, 19Z and $2110 \mathrm{Z}$ measuring a central pressure of $974 \mathrm{mb}$, $975 \mathrm{mb}$ and $970 \mathrm{mb}$, respectively. An intensity of $100 \mathrm{kt}$ is analyzed at all time slot on the $1^{\text {st }}$, down from $110 \mathrm{kt}$ at $00 \mathrm{Z}$ and $06 \mathrm{Z}$ and down from $115 \mathrm{kt}$ at $12 \mathrm{Z}$ and $18 \mathrm{Z}$ as originally shown in HURDAT, all minor intensity changes. Ship data over the southeastern Caribbean Sea is sparse and only one ship reported gale-force winds on the $1^{\text {st }}$. The penetration center fix at $2110 \mathrm{Z}$ also estimated surface winds of $120 \mathrm{kt}$ and an eye diameter of $13 \mathrm{~nm}$. A central pressure of $970 \mathrm{mb}$ suggests maximum surface winds of 90 $\mathrm{kt}$ from the south of $25 \mathrm{~N}$ pressure-wind relationship. An eye diameter of $13 \mathrm{~nm}$ suggests an RMW of $10 \mathrm{~nm}$ and the climatological value is $11 \mathrm{~nm}$. Based upon a forward speed of about $14 \mathrm{kt}$, small circulation and putting some weight on the visual estimate, an intensity of $105 \mathrm{kt}$ is analyzed at $00 \mathrm{Z}$ on October $2^{\text {nd }}$, down from $120 \mathrm{kt}$ originally in HURDAT, a minor intensity change. On the $2^{\text {nd }}$, Flora continued west-northwestward passing north of the $\mathrm{ABC}$ Islands. At $0710 \mathrm{Z}$ on the $2^{\text {nd }}$, a penetration center fix measured a central pressure of $964 \mathrm{mb}$ and an eye diameter of $11 \mathrm{~nm}$. A central pressure of $964 \mathrm{mb}$ suggests maximum surface winds of $97 \mathrm{kt}$ from the south of $25 \mathrm{~N}$ pressure-wind relationship. An eye diameter of $11 \mathrm{~nm}$ suggests an RMW of about $8 \mathrm{~nm}$ and the climatological value is $12 \mathrm{~nm}$. Based upon a forward speed of about $11 \mathrm{kt}$ and an RMW smaller than the climatological value, an intensity of $105 \mathrm{kt}$ is analyzed at $06 \mathrm{Z}$ on the $2^{\text {nd }}$, down from 120 kt originally in HURDAT, a minor intensity change. The next penetration center fix at 
$1946 Z$ on the $2^{\text {nd }}$, measured a central pressure of $960 \mathrm{mb}$, estimated surface winds of 120 $\mathrm{kt}$ and an eye diameter of $16 \mathrm{~nm}$. A central pressure of $960 \mathrm{mb}$ suggests maximum surface winds of $100 \mathrm{kt}$ from the south of $25 \mathrm{~N}$ pressure-wind relationship. An eye diameter of $16 \mathrm{~nm}$ suggests an RMW of about $12 \mathrm{~nm}$ and the climatological value is also $12 \mathrm{~nm}$. Based upon a forward speed of about $7 \mathrm{kt}$ and an RMW close to the climatological value, an intensity of $105 \mathrm{kt}$ is analyzed at $18 \mathrm{Z}$ on the $2^{\text {nd }}$, down from 120 kt originally in HURDAT, a minor intensity change. A few ships reported gale-force winds on the $2^{\text {nd }}$, and also a storm-force wind report of $50 \mathrm{kt}$ at $18 \mathrm{Z}$. On October $3^{\text {rd }}$, Flora continued to slow its forward speed and turned to the northwest while gaining in strength. At $0617 \mathrm{Z}$ on the $3^{\text {rd }}$, a reconnaissance aircraft measured a peripheral pressure of $954 \mathrm{mb}$ and an eye diameter of $15 \mathrm{~nm}$. A peripheral pressure of $954 \mathrm{mb}$ suggests maximum surface winds greater than $107 \mathrm{kt}$ from the south of $25 \mathrm{~N}$ pressure-wind relationship. An eye diameter of $15 \mathrm{~nm}$ suggests an RMW of about $11 \mathrm{~nm}$ and the climatological value is also $11 \mathrm{~nm}$. Based upon a forward speed of about $8 \mathrm{kt}$ and an RMW close to the climatological value, an intensity of $115 \mathrm{kt}$ is analyzed at $06 \mathrm{Z}$ on the $3^{\text {rd }}$, down from $125 \mathrm{kt}$ originally in HURDAT, a minor intensity change. At $1620 \mathrm{Z}$ on the $3^{\text {rd }}$, a penetration center fix measured a central pressure of $936 \mathrm{mb}$, estimated surface winds of $130 \mathrm{kt}$ and an eye diameter of $15 \mathrm{~nm}$. A central pressure of $936 \mathrm{mb}$ suggests maximum surface winds of $127 \mathrm{kt}$ from the south of $25 \mathrm{~N}$ intensifying subset pressurewind relationship. An eye diameter of $15 \mathrm{~nm}$ suggests an RMW of about $11 \mathrm{~nm}$ and the climatological value is also $11 \mathrm{~nm}$. Based upon a forward speed of about $8 \mathrm{kt}$, an intensity of $125 \mathrm{kt}$ is analyzed at $18 \mathrm{Z}$ on the $3^{\text {rd }}$, same as originally shown in HURDAT. $125 \mathrm{kt}$ is also the peak intensity of Hurricane Flora, same as originally shown in HURDAT.

Hurricane Flora made landfall in southwestern Haiti around $01 \mathrm{Z}$ on October $4^{\text {th }}$ as a 125 kt hurricane. The intensity at landfall may have been substantially higher than analyzed since the hurricane was intensifying as it was moving toward Hispaniola and the last center penetration occurred about nine hours before landfall. Calm conditions were experienced at Fonds des Negres, Haiti, for about 15 minutes and at Aude a Veau, Haiti, for over one hour. The hurricane crossed the Tiburon Peninsula of Haiti in about two hours and continued northwestward toward eastern Cuba. A reconnaissance aircraft made a center penetration fix at $1231 \mathrm{Z}$ on the 4th and measured a central pressure of $970 \mathrm{mb}$, estimated surface winds of $110 \mathrm{kt}$ and an eye diameter of $17 \mathrm{~nm}$. A central pressure of $970 \mathrm{mb}$ suggests maximum surface winds of $90 \mathrm{kt}$ from the south of $25 \mathrm{~N}$ pressure-wind relationship. An eye diameter of $17 \mathrm{~nm}$ suggests an RMW of about $13 \mathrm{~nm}$ and the climatological value is $14 \mathrm{~nm}$. Due to some weighting of the visual surface winds and the synoptic observations over eastern Cuba later in the day and at $00 \mathrm{Z}$ on October $5^{\text {th }}$, an intensity of $105 \mathrm{kt}$ is analyzed at $12 \mathrm{Z}$ on the $4^{\text {th }}$, same as originally shown in HURDAT. Flora made landfall in Cuba around $18 \mathrm{Z}$ on the $4^{\text {th }}$ as a $105 \mathrm{kt}$ hurricane, category 3 impact. The Storm Wallets indicate that Punta de Maisi, Cuba's easternmost point, 
experienced sustained winds of $83 \mathrm{kt}$ between $16 \mathrm{Z}$ and $18 \mathrm{Z}$ on the $4^{\text {th }}$. Over eastern Cuba, Flora changed course and began to move slowly westward on the $5^{\text {th }}$. At $00 \mathrm{Z}$ on the $5^{\text {th }}$, Punta Lucrecia, Cuba, reported $95 \mathrm{kt} \mathrm{E}$ and $995 \mathrm{mb}$. In an email communication with Maritza Ballester, it was confirmed that this was indeed a sustained wind measurement and not a gust. Maritza also mentions that the station is very close to the coast at a height of 4 meters. This $95 \mathrm{kt}$ measurement six hours after landfall in Cuba is consistent with an $105 \mathrm{kt}$ intensity at landfall. Note that category 3 at landfall in Cuba is higher than the assessment of Perez et al. of the intensity of Flora at landfall in Cuba as category 2 in the Saffir-Simpson scale. Maritza comments that a landfall intensity of $90 \mathrm{kt}$ was estimated from a gust measurement of $110 \mathrm{kt}$ and data from the last aircraft reconnaissance investigation before landfall. After approaching the northern coast of Cuba near Punta Lucrecia around $00 \mathrm{Z}$ on the $5^{\text {th }}$, Flora turned to the west and moved toward the Gulf of Guacanayabo, emerging over the Caribbean around 22Z. The Kaplan and DeMaria model was run starting with $95 \mathrm{kt}$ at $00 \mathrm{Z}$ for $06 \mathrm{Z}, 12 \mathrm{Z}$ and $18 \mathrm{Z}$ on the $5^{\text {th }}$, yielding $69 \mathrm{kt}, 52 \mathrm{kt}$ and $50 \mathrm{kt}$, respectively. On the $5^{\text {th }}, 60 \mathrm{kt}$ were registered at $06 \mathrm{Z}$ at Punta Lucrecia, $55 \mathrm{kt}$ at Punta Lucrecia and $60 \mathrm{kt}$ at Santiago de Cuba at $12 \mathrm{Z}$ and $50 \mathrm{kt}$ at Punta Lucrecia and $55 \mathrm{kt}$ at Santiago de Cuba at $18 \mathrm{Z}$. An intensity of $85 \mathrm{kt}$ is selected for $06 \mathrm{Z}, 75 \mathrm{kt}$ at $12 \mathrm{Z}$ and $70 \mathrm{kt}$ at $18 \mathrm{Z}$ on the $5^{\text {th }}$ (down from $110 \mathrm{kt}$ at $06 \mathrm{Z}, 105 \mathrm{kt}$ at $12 \mathrm{Z}$ and $100 \mathrm{kt}$ at $18 \mathrm{Z}$ on the $5^{\text {th }}$, respectively, originally in HURDAT), major intensity changes. The observations from Santiago de Cuba appear to have a high bias and this is not the first time we notice this problem, similar situation occurred during the reanalysis of Tropical Storm Gerda, 1961. Maritza mentioned in the email that currently the station is at a height of 45 meters but she was not sure if in 1963 it was at the same elevation. At $00 \mathrm{Z}$ on October $6^{\text {th }}$, Santiago de Cuba reported $75 \mathrm{kt}$ and at this time the hurricane was about $100 \mathrm{~nm}$ to the northwest. The analyzed intensities at $06 \mathrm{Z}, 12 \mathrm{Z}$ and $18 \mathrm{Z}$ on the $5^{\text {th }}$ were above that suggested by Kaplan-DeMaria due to a report of $80 \mathrm{kt}$ by Camagüey, Cuba, at $06 \mathrm{Z}$ on October $6^{\text {th }}$. Maritza commented that Camagüey is currently at a height of 119 meters but was not sure about the station's altitude in 1963. Nevertheless, it does appear suspicious. On the $6^{\text {th }}$, Flora came to almost a halt over the Gulf of Guacanayabo and some gradual intensification is shown. Observations near the center were sparse on this day but the system likely regained some of its strength over the warm waters of the gulf.

Reconnaissance aircrafts investigated the hurricane around $12 \mathrm{Z}$ and $18 \mathrm{Z}$ but only radar center fixes were obtained. Synoptic observations indicate that the circulation of Flora expanded after crossing eastern Cuba. The ROCI had expanded to about $330 \mathrm{~nm}$ by $18 \mathrm{Z}$ on the $6^{\text {th }}$, compared to about $120 \mathrm{~nm}$ on the $1^{\text {st }}$. A couple of ships reported gale-force winds on the $6^{\text {th }}$. On October $7^{\text {th }}$, Flora moved slowly northward making landfall in Camagüey at $06 \mathrm{Z}$ as an $85 \mathrm{kt}$ hurricane, just a few miles to the west of Santa Cruz del Sur. A few ships reported gale-force winds on the $7^{\text {th }}$. After making landfall, Flora moved generally eastward over eastern Cuba and weakened. The Kaplan and DeMaria model 
was run for $12 \mathrm{Z}$ and $18 \mathrm{Z}$ on the $7^{\text {th }}$ and $00 \mathrm{Z}$ and $06 \mathrm{Z}$ on the $8^{\text {th }}$, yielding $60 \mathrm{kt}$ at $12 \mathrm{Z}$ and $49 \mathrm{kt}$ at $18 \mathrm{Z}$ on the $7^{\text {th }}$ and $40 \mathrm{kt}$ at $00 \mathrm{Z}$ and $43 \mathrm{kt}$ on the $8^{\text {th }}$. The highest recorded winds were $70 \mathrm{kt}$ and $60 \mathrm{kt}$ at Santiago de Cuba at $12 \mathrm{Z}$ and $18 \mathrm{Z}$ on the $7^{\text {th }}$, respectively, and 55 $\mathrm{kt}$ and $60 \mathrm{kt}$ at Santiago de Cuba at $00 \mathrm{Z}$ and $06 \mathrm{Z}$ on the $8^{\text {th }}$, respectively. An intensity of $75 \mathrm{kt}$ is selected at $12 \mathrm{Z}$, and $65 \mathrm{kt}$ at $18 \mathrm{Z}$ on the $7^{\mathrm{th}}, 60 \mathrm{kt}$ at $00 \mathrm{Z}$ and $55 \mathrm{kt}$ at $06 \mathrm{Z}$ on the $8^{\text {th }}$, down from $80 \mathrm{kt}$ originally in HURDAT at $12 \mathrm{Z}$, and $75 \mathrm{kt}$ at $18 \mathrm{Z}$ on the $7^{\text {th }}, 00 \mathrm{Z}$ and $06 Z$ on the $8^{\text {th }}$. Minor intensity changes to HURDAT at $12 \mathrm{Z}$ and $18 \mathrm{Z}$ on the $7^{\text {th }}$ and $00 \mathrm{Z}$ on the $8^{\text {th }}$, and major intensity change at $06 Z$ on the $8^{\text {th }}$. The original HURDAT did not show Flora weakening to a tropical storm.

Flora entered the Atlantic Ocean after $12 Z$ on the $8^{\text {th }}$ near the city of Gibara, Holguín, Cuba. The tropical cyclone immediately began to intensify and it is analyzed to have regained hurricane intensity at $18 \mathrm{Z}$ on the $8^{\text {th }}$. A ship reported $60 \mathrm{kt} \mathrm{E}$ and $994 \mathrm{mb}$ at $18 \mathrm{Z}$ and another registered $55 \mathrm{kt} \mathrm{NNE}$ and $991 \mathrm{mb}$ at $20 \mathrm{Z}$. At $2215 \mathrm{Z}$ on the $8^{\text {th }}$, a reconnaissance aircraft made a penetration center fix measuring a central pressure of 983 $\mathrm{mb}$ and estimated surface winds of $100 \mathrm{kt}$. A central pressure of $983 \mathrm{mb}$ suggests maximum surface winds of $74 \mathrm{kt}$ from the south of $25 \mathrm{~N}$ pressure-wind relationship. Based on a forward speed of about $11 \mathrm{kt}$, an intensity of $75 \mathrm{kt}$ is analyzed at $00 \mathrm{Z}$ on October $9^{\text {th }}$, same as originally shown in HURDAT. On the $9^{\text {th }}$, Flora continued to move away from Cuba impacting the eastern Bahamas as it gained in forward speed to the northeast. The hurricane made landfall in Mayaguana, Bahamas, around 06Z on the $9^{\text {th }}$. The eye went over the location and a central pressure of $977 \mathrm{mb}$ was measured. A central pressure of $977 \mathrm{mb}$ suggests maximum surface winds of $81 \mathrm{kt}$ from the south of $25 \mathrm{~N}$ pressure-wind relationship. Due to a forward speed of about $17 \mathrm{kt}$, an intensity of $85 \mathrm{kt}$ is analyzed at $06 \mathrm{Z}$ on the $9^{\text {th }}$, up from $75 \mathrm{kt}$ originally in HURDAT, a minor intensity change. At $11 \mathrm{Z}$ on the $9^{\text {th }}$, a penetration center fix measured a central pressure of $976 \mathrm{mb}$, estimated surface winds of $70 \mathrm{kt}$ and an eye diameter of $30 \mathrm{~nm}$. A central pressure of 976 $\mathrm{mb}$ suggests maximum surface winds of $83 \mathrm{kt}$ from the south of $25 \mathrm{~N}$ pressure-wind relationship. An eye diameter of $30 \mathrm{~nm}$ suggests an RMW of about $23 \mathrm{~nm}$ and the climatological value is $19 \mathrm{~nm}$. Due to a forward speed of about $17 \mathrm{kt}$, an intensity of $90 \mathrm{kt}$ is selected at $12 \mathrm{Z}$ on the $9^{\text {th }}$, up from $80 \mathrm{kt}$ originally in HURDAT, a minor intensity change. At $19 \mathrm{Z}$ on the $9^{\text {th }}$, another penetration center fix measured a central pressure of $965 \mathrm{mb}$, estimated surface winds of $130 \mathrm{kt}$ and an eye diameter of $70 \mathrm{~nm}$. A central pressure of $965 \mathrm{mb}$ suggests maximum surface winds of $86 \mathrm{kt}$ from the south of $25 \mathrm{~N}$ and $90 \mathrm{kt}$ from the north of $25 \mathrm{~N}$ pressure-wind relationship. An eye diameter of $70 \mathrm{~nm}$ suggests an RMW of about $53 \mathrm{~nm}$ and the climatological value is $19 \mathrm{~nm}$. Due to a forward speed of about $23 \mathrm{kt}$, an intensity of $100 \mathrm{kt}$ is selected at $18 \mathrm{Z}$ on the $9^{\text {th }}$, up from $85 \mathrm{kt}$ originally in HURDAT, a minor intensity change. It is analyzed that Flora regained major hurricane intensity at $18 \mathrm{Z}$ on the $9^{\text {th }}, 18$ hours earlier than originally shown in HURDAT. A final penetration fix on the $9^{\text {th }}$ measured a central pressure of $965 \mathrm{mb}$ at 
$2321 \mathrm{Z}$, thus an intensity of $100 \mathrm{kt}$ is also analyzed at $00 \mathrm{Z}$ on October $10^{\text {th }}$, up from $95 \mathrm{kt}$ originally in HURDAT, a minor intensity change. A couple of ships recorded tropical storm force winds on the $9^{\text {th }}$, up to $55 \mathrm{kt}$. On the $10^{\text {th }}$, Flora continued to move rapidly to the northeast over the western Atlantic. A few ships reported hurricane-force winds on the $10^{\text {th }}$, including $75 \mathrm{kt} \mathrm{SE}$ and $990 \mathrm{mb}$ at $00 \mathrm{Z}$. At $1307 \mathrm{Z}$ on the $10^{\text {th }}$, a penetration center fix measured a central pressure of $969 \mathrm{mb}$, estimated surface winds of $120 \mathrm{kt}$ and an eye diameter of $70 \mathrm{~nm}$. A central pressure of $969 \mathrm{mb}$ suggests maximum surface winds of $86 \mathrm{kt}$ from the north of $25 \mathrm{~N}$ pressure-wind relationship. An eye diameter of 70 $\mathrm{nm}$ suggests an RMW of about $53 \mathrm{~nm}$ and the climatological value is $24 \mathrm{~nm}$. Due to a forward speed of about $31 \mathrm{kt}$, an intensity of $95 \mathrm{kt}$ is selected at $12 \mathrm{Z}$ on the $10^{\text {th }}$, down from $100 \mathrm{kt}$ originally in HURDAT, a minor intensity change. Weakening below major hurricane intensity is analyzed at $12 \mathrm{Z}$ on the $10^{\text {th }}$, twelve hours earlier than originally shown in HURDAT. Another penetration center fix measured a central pressure of 972 $\mathrm{mb}$ at $19 \mathrm{Z}$ on the $10^{\text {th }}$. A central pressure of $972 \mathrm{mb}$ suggests maximum surface winds of $82 \mathrm{kt}$ from the north of $25 \mathrm{~N}$ pressure-wind relationship. Due to a forward speed of about $35 \mathrm{kt}$, an intensity of $95 \mathrm{kt}$ is selected at $18 \mathrm{Z}$ on the $10^{\text {th }}$, down from $100 \mathrm{kt}$ originally in HURDAT, a minor intensity change. Finally, at $2220 \mathrm{Z}$ on the $10^{\text {th }}$, a penetration center fix measured a central pressure of $968 \mathrm{mb}$, estimated surface winds of $122 \mathrm{kt}$ and an eye diameter of $50 \mathrm{~nm}$. A central pressure of $968 \mathrm{mb}$ suggests maximum surface winds of 87 $\mathrm{kt}$ from the north of $25 \mathrm{~N}$ pressure-wind relationship. An eye diameter of $50 \mathrm{~nm}$ suggests an RMW of about $38 \mathrm{~nm}$ and the climatological value is $24 \mathrm{~nm}$. Due to a forward speed of about $35 \mathrm{kt}$, an intensity of $95 \mathrm{kt}$ is selected at $00 \mathrm{Z}$ on October $11^{\text {th }}$, same as originally shown in HURDAT.

At $1315 \mathrm{Z}$ on the $11^{\text {th }}$, a penetration center fix measured a central pressure of $963 \mathrm{mb}$ and an eye diameter of $80 \mathrm{~nm}$. A central pressure of $963 \mathrm{mb}$ suggests maximum surface winds of $88 \mathrm{kt}$ from the Landsea et al. north of $35 \mathrm{~N}$ pressure-wind relationship. An eye diameter of $80 \mathrm{~nm}$ suggests an RMW of about $60 \mathrm{~nm}$ and the climatological value is 29 $\mathrm{nm}$. Due to a forward speed of about $21 \mathrm{kt}$ but large RMW, an intensity of $90 \mathrm{kt}$ is selected at $12 \mathrm{Z}$ on the $11^{\text {th }}$, up from $85 \mathrm{kt}$ originally in HURDAT, a minor intensity change. Hurricane Flora began to lose its tropical characteristics on the $11^{\text {th }}$ as a frontal boundary approached from the west and the tropical cyclone moved into the midlatitudes. Synoptic observations indicate that the transition into an extratropical cyclone occurred around $18 \mathrm{Z}$ on the $11^{\text {th }}$ as the temperature gradient became more pronounced between the eastern and western quadrants and frontogenesis occurred. Transition into an extratropical cyclone is analyzed at $18 \mathrm{Z}$ on the $11^{\text {th }}, 24$ hours earlier than originally shown in HURDAT. A couple of ships reported tropical storm force winds on the $11^{\text {th }}$ and even a few experienced hurricane-force winds, including $100 \mathrm{kt}$ at $18 \mathrm{Z}$, although the two ships that reported $100 \mathrm{kt}$ appears to have a high wind bias in comparison with nearby ships. On October $12^{\text {th }}$, Flora began to interact with an extratropical cyclone to the 
northwest as both cyclones moved to the northeast. Flora remained a very powerful extratropical cyclone on the $12^{\text {th }}$ as ships continued to report hurricane-force winds up to $75 \mathrm{kt}$, but the system was gradually weakening. Synoptic observations around $06 \mathrm{Z}$ on the $13^{\text {th }}$ indicate that Flora had merged with the other extratropical cyclone, thus the last position is analyzed at $00 \mathrm{Z}$ on the $13^{\text {th }}$, twelve hours earlier than originally shown in HURDAT.

\begin{tabular}{|c|c|c|c|}
\hline Date & $\begin{array}{l}\text { Original } \\
\text { HURDAT } \\
\text { Central } \\
\text { Pressure }\end{array}$ & Evidence & Changes \\
\hline Sep $2912 Z$ & $1000 \mathrm{mb}$ & $\begin{array}{l}\text { Ship report around } 2230 \mathrm{Z} \text { on the } 29^{\text {th }} \text { and } \\
\text { does not suggest it was a central pressure } \\
\text { measurement }\end{array}$ & Removed \\
\hline Sep $3012 Z$ & $994 \mathrm{mb}$ & $\begin{array}{l}\text { Penetration center fix: } 994 \mathrm{mb} \text { at } 1407 \mathrm{Z} \text { on } \\
\text { Sep } 30^{\text {th }}\end{array}$ & Retained \\
\hline Sep $3018 Z$ & $978 \mathrm{mb}$ & $\begin{array}{l}\text { Tobago: } 2 \mathrm{kt} \mathrm{W} \text { and } 974 \mathrm{mb} \text { at } 1840 \mathrm{Z} \text { on Sep } \\
30^{\text {th }}\end{array}$ & $974 \mathrm{mb}$ \\
\hline Oct $0100 Z$ & $981 \mathrm{mb}$ & $\begin{array}{l}\text { Penetration center fix: } 975 \mathrm{mb} \text { at } 2110 \mathrm{Z} \text { on } \\
\text { Sep } 30^{\text {th }}\end{array}$ & $975 \mathrm{mb}$ \\
\hline Oct $0106 Z$ & $981 \mathrm{mb}$ & Peripheral pressure at $07 \mathrm{Z}$ on Oct $1^{\text {st }}$ & \multirow[b]{2}{*}{ Removed } \\
\hline Oct $0112 Z$ & $974 \mathrm{mb}$ & $\begin{array}{l}\text { Penetration center fix at } 16 \mathrm{Z} \text { on Oct } 1^{\text {st }} \\
\text { closer to the } 18 \mathrm{Z} \text { time slot than } 12 \mathrm{Z}\end{array}$ & \\
\hline Oct $0118 Z$ & $975 \mathrm{mb}$ & $\begin{array}{l}\text { Penetration center fix: } 975 \mathrm{mb} \text { at } 19 \mathrm{Z} \text { on Oct } \\
1^{\text {st }}\end{array}$ & \multirow{2}{*}{ Retained } \\
\hline Oct $0200 Z$ & $970 \mathrm{mb}$ & $\begin{array}{l}\text { Penetration center fix: } 970 \mathrm{mb} \text { at } 22 \mathrm{Z} \text { on Oct } \\
1^{\text {st }}\end{array}$ & \\
\hline Oct $0206 Z$ & & $\begin{array}{l}\text { Penetration center fix: } 964 \mathrm{mb} \text { at } 0710 \mathrm{Z} \text { on } \\
\text { Oct } 2^{\text {nd }}\end{array}$ & $964 \mathrm{mb}$ \\
\hline Oct $0212 Z$ & $968 \mathrm{mb}$ & Peripheral pressure at $13427 \mathrm{Z}$ on Oct $2^{\text {nd }}$ & Removed \\
\hline Oct $0218 Z$ & $968 \mathrm{mb}$ & $\begin{array}{l}\text { Penetration center fix: } 960 \mathrm{mb} \text { at } 1946 \mathrm{Z} \text { on } \\
\text { Oct } 2^{\text {nd }}\end{array}$ & $960 \mathrm{mb}$ \\
\hline Oct $0312 \mathrm{Z}$ & $940 \mathrm{mb}$ & $\begin{array}{l}\text { No central pressure was reported by the } \\
\text { reconnaissance aircraft around } 12 \mathrm{Z} \text { on Oct } \\
3^{\text {rd }}\end{array}$ & Removed \\
\hline Oct $0318 Z$ & $944 \mathrm{mb}$ & Penetration center fix: $936 \mathrm{mb}$ at $1620 \mathrm{Z}$ on & $936 \mathrm{mb}$ \\
\hline
\end{tabular}




\begin{tabular}{|c|c|c|c|}
\hline & & Oct $3^{\text {rd }}$ & \\
\hline Oct $0400 Z$ & $944 \mathrm{mb}$ & $\begin{array}{l}\text { Only radar center fixes were made around } \\
00 \mathrm{Z} \text { on Oct } 4^{\text {th }} \text { near the time of landfall }\end{array}$ & \multirow{2}{*}{ Removed } \\
\hline Oct $0406 Z$ & $995 \mathrm{mb}$ & Peripheral pressure at $05 \mathrm{Z}$ on Oct $4^{\text {th }}$ & \\
\hline Oct 04 12Z & $970 \mathrm{mb}$ & $\begin{array}{l}\text { Penetration center fix: } 970 \mathrm{mb} \text { at } 1231 \mathrm{Z} \text { on } \\
\text { Oct } 4^{\text {th }}\end{array}$ & Retained \\
\hline Oct 04 18Z & $970 \mathrm{mb}$ & $\begin{array}{l}\text { Penetration center fix: } 973 \mathrm{mb} \text { at } 1540 \mathrm{Z} \text { on } \\
\text { Oct } 4^{\text {th }}\end{array}$ & $973 \mathrm{mb}$ \\
\hline Oct $0512 Z$ & $985 \mathrm{mb}$ & \multirow{5}{*}{$\begin{array}{l}\text { Between October } 5^{\text {th }} \text { and October } 8^{\text {th }} \text {, the } \\
\text { center of Flora meandered over eastern Cuba } \\
\text { and the nearby waters of the Caribbean Sea. } \\
\text { The reconnaissance aircraft observations } \\
\text { were radar center fixes and the synoptic data } \\
\text { available is not sufficient to estimate the } \\
\text { central pressure during these time slots }\end{array}$} & \multirow{6}{*}{ Removed } \\
\hline Oct $0612 Z$ & $985 \mathrm{mb}$ & & \\
\hline Oct $0712 Z$ & $986 \mathrm{mb}$ & & \\
\hline Oct $0806 \mathrm{Z}$ & $989 \mathrm{mb}$ & & \\
\hline Oct $0812 Z$ & $990 \mathrm{mb}$ & & \\
\hline Oct $0818 \mathrm{Z}$ & $990 \mathrm{mb}$ & $\begin{array}{l}\text { Ship: } 55 \mathrm{kt} \mathrm{NE} \text { and } 991 \mathrm{mb} \text { at } 20 \mathrm{Z} \text { on Oct } \\
18^{\text {th }}\end{array}$ & \\
\hline Oct $0900 \mathrm{Z}$ & $983 \mathrm{mb}$ & $\begin{array}{l}\text { Penetration center fix: } 983 \mathrm{mb} \text { at } 2215 \mathrm{Z} \text { on } \\
\text { Oct } 8^{\text {th }}\end{array}$ & Retained \\
\hline Oct $0906 Z$ & & $\begin{array}{l}\text { Penetration center fix: } 977 \mathrm{mb} \text { at } 0545 \mathrm{Z} \text { on } \\
\text { Oct } 9^{\text {th }}\end{array}$ & $977 \mathrm{mb}$ \\
\hline Oct $0912 Z$ & $975 \mathrm{mb}$ & $\begin{array}{l}\text { Penetration center fix: } 976 \mathrm{mb} \text { at } 11 \mathrm{Z} \text { on Oct } \\
9^{\text {th }}\end{array}$ & $976 \mathrm{mb}$ \\
\hline Oct $0918 \mathrm{Z}$ & $965 \mathrm{mb}$ & $\begin{array}{l}\text { Penetration center fix: } 965 \mathrm{mb} \text { at } 19 \mathrm{Z} \text { on Oct } \\
9^{\text {th }}\end{array}$ & \multirow{2}{*}{ Retained } \\
\hline Oct $1000 \mathrm{Z}$ & $965 \mathrm{mb}$ & $\begin{array}{l}\text { Penetration center fix: } 965 \mathrm{mb} \text { at } 2321 \mathrm{Z} \text { on } \\
\text { Oct } 9^{\text {th }}\end{array}$ & \\
\hline Oct $1006 Z$ & $969 \mathrm{mb}$ & $\begin{array}{l}\text { No reconnaissance aircraft was present } \\
\text { around } 06 Z \text { on Oct } 10^{\text {th }} \text {, nor there was a ship } \\
\text { observation near the center }\end{array}$ & Removed \\
\hline Oct $1012 Z$ & $969 \mathrm{mb}$ & $\begin{array}{l}\text { Penetration center fix: } 969 \mathrm{mb} \text { at } 1307 \mathrm{Z} \text { on } \\
\text { Oct } 10^{\text {th }}\end{array}$ & \multirow{2}{*}{ Retained } \\
\hline Oct $1018 \mathrm{Z}$ & $972 \mathrm{mb}$ & $\begin{array}{l}\text { Penetration center fix: } 972 \mathrm{mb} \text { at } 19 \mathrm{Z} \text { on Oct } \\
10^{\text {th }}\end{array}$ & \\
\hline Oct $1100 Z$ & & $\begin{array}{l}\text { Penetration center fix: } 968 \mathrm{mb} \text { at } 2220 \mathrm{Z} \text { on } \\
\text { Oct } 10^{\text {th }}\end{array}$ & $968 \mathrm{mb}$ \\
\hline Oct $1106 Z$ & $970 \mathrm{mb}$ & $\begin{array}{l}\text { No reconnaissance aircraft was present } \\
\text { around } 06 \mathrm{Z} \text { on Oct } 11^{\text {th }} \text { but appears }\end{array}$ & Retained \\
\hline
\end{tabular}




\begin{tabular}{|c|c|c|c|}
\hline & & reasonable & \\
\hline Oct $1112 Z$ & $963 \mathrm{mb}$ & $\begin{array}{l}\text { Penetration center fix: } 963 \mathrm{mb} \text { at } 1315 \mathrm{Z} \text { on } \\
\text { Oct } 11^{\text {th }}\end{array}$ & \\
\hline Oct $1118 \mathrm{Z}$ & $963 \mathrm{mb}$ & \multirow{2}{*}{$\begin{array}{l}\text { Synoptic data suggests a lower central } \\
\text { pressure }\end{array}$} & \multirow{2}{*}{ Removed } \\
\hline Oct $1212 Z$ & $985 \mathrm{mb}$ & & \\
\hline
\end{tabular}

Hurricane Ginny [October 17-30, 1963]

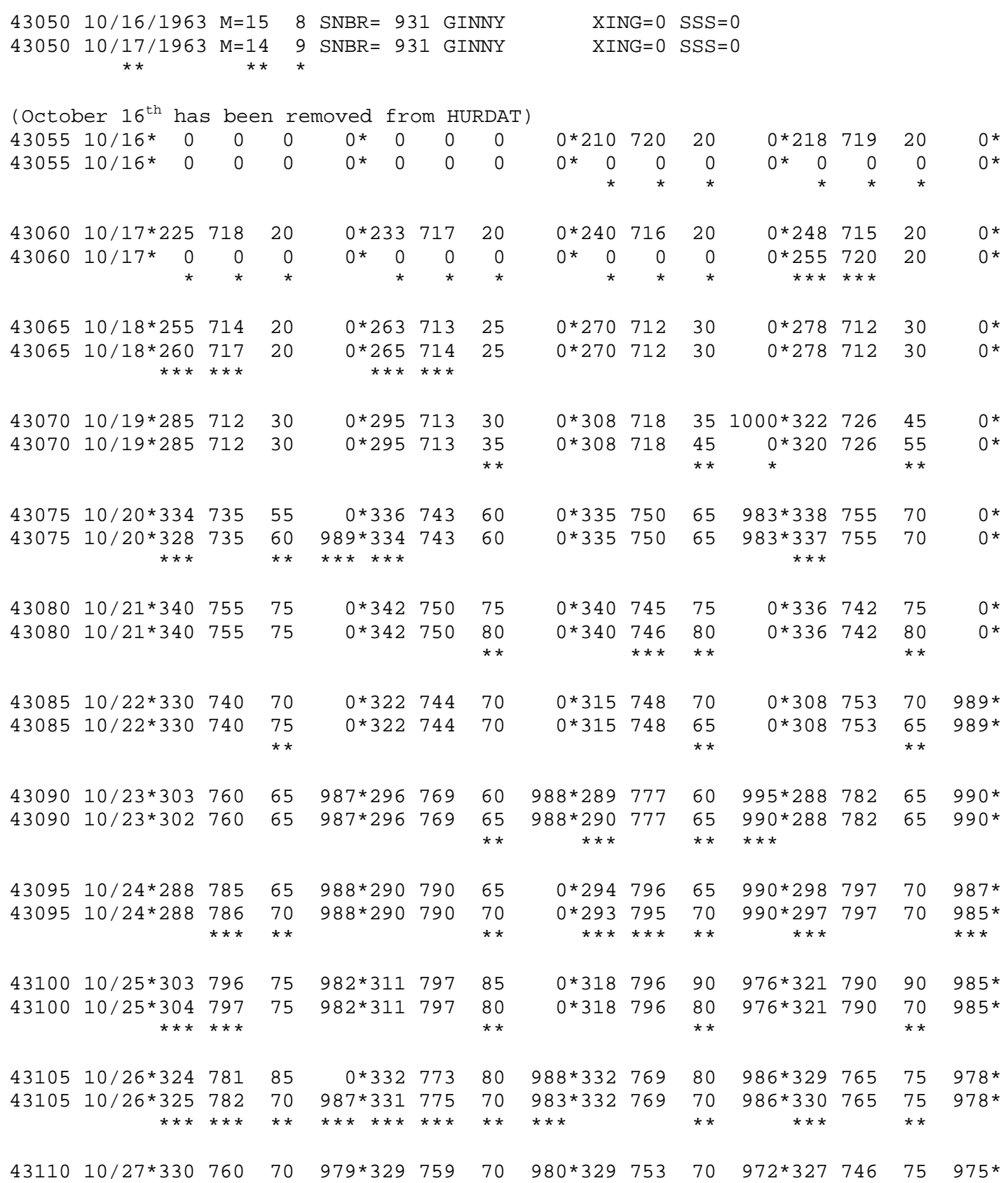




\begin{tabular}{|c|c|c|c|c|c|c|c|c|c|c|c|c|c|}
\hline 43110 & $\begin{array}{r}10 / 27^{*} 329 \\
* * *\end{array}$ & $\begin{array}{l}762 \\
\star * *\end{array}$ & $\begin{array}{l}75 \\
* *\end{array}$ & $979 * 329$ & 759 & $\begin{array}{l}75 \\
* *\end{array}$ & $980 * 329$ & $\begin{array}{l}754 \\
* * *\end{array}$ & $\begin{array}{l}80 \\
\star *\end{array}$ & $972 * 327$ & 746 & $\begin{array}{l}80 \\
\star *\end{array}$ & $975^{*}$ \\
\hline $\begin{array}{l}43115 \\
43115\end{array}$ & $\begin{array}{r}10 / 28 * 326 \\
10 / 28 * 327 \\
* * *\end{array}$ & $\begin{array}{l}734 \\
737 \\
* * *\end{array}$ & $\begin{array}{l}75 \\
85 \\
\star *\end{array}$ & $\begin{array}{l}\Theta^{*} 332 \\
970^{*} 332 \\
* * *\end{array}$ & $\begin{array}{l}729 \\
730 \\
* * *\end{array}$ & $\begin{array}{l}80 \\
85 \\
* *\end{array}$ & $\begin{array}{l}\odot * 339 \\
0 * 339\end{array}$ & $\begin{array}{l}723 \\
723\end{array}$ & $\begin{array}{l}80 \\
90 \\
* *\end{array}$ & $\begin{array}{l}968 * 351 \\
968 * 351\end{array}$ & $\begin{array}{l}715 \\
715\end{array}$ & $\begin{array}{l}85 \\
95 \\
\star *\end{array}$ & $\begin{array}{l}963^{*} \\
963^{*}\end{array}$ \\
\hline $\begin{array}{l}43120 \\
43120\end{array}$ & $\begin{array}{l}10 / 29 * 363 \\
10 / 29 * 363\end{array}$ & $\begin{array}{l}703 \\
703\end{array}$ & $\begin{array}{l}95 \\
95\end{array}$ & $\begin{array}{l}0 * 378 \\
0 * 381 \\
* * *\end{array}$ & $\begin{array}{l}688 \\
688\end{array}$ & $\begin{array}{l}95 \\
95\end{array}$ & $\begin{array}{l}\odot * 4 \odot 8 \\
\text { OE4๑8 } \\
\star\end{array}$ & $\begin{array}{l}672 \\
672\end{array}$ & $\begin{array}{l}95 \\
95\end{array}$ & $\begin{array}{l}958 \mathrm{E} 440 \\
958 \mathrm{E} 440\end{array}$ & $\begin{array}{l}660 \\
657 \\
\star * *\end{array}$ & $\begin{array}{l}90 \\
9 \odot\end{array}$ & $\begin{array}{l}\Theta^{*} \\
948^{*} \\
* * *\end{array}$ \\
\hline $\begin{array}{l}43125 \\
43125\end{array}$ & $\begin{array}{l}10 / 30 E 470 \\
10 / 30 E 470\end{array}$ & $\begin{array}{l}640 \\
640\end{array}$ & $\begin{array}{l}80 \\
70 \\
\star *\end{array}$ & 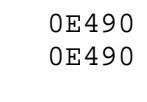 & $\begin{array}{l}630 \\
630\end{array}$ & $\begin{array}{l}80 \\
50 \\
* *\end{array}$ & $\begin{array}{ll}\odot^{*} & \odot \\
\odot^{*} & \odot\end{array}$ & $\begin{array}{l}\odot \\
\odot\end{array}$ & $\begin{array}{l}\odot \\
\odot\end{array}$ & $\begin{array}{ll}\Theta^{*} & \odot \\
\Theta^{*} & \odot\end{array}$ & $\begin{array}{l}\odot \\
\odot\end{array}$ & $\begin{array}{l}\odot \\
\odot\end{array}$ & $\begin{array}{l}\Theta^{*} \\
\Theta^{*}\end{array}$ \\
\hline
\end{tabular}

\section{U.S. Tropical Storm Impact}

09/26 06Z 33.1N 76.9W 55 kt North Carolina 09/29 06Z 38.1N 68.8W 35 kt Massachusetts

Minor changes to the track and intensity shown in McAdie et al. (2009). Evidence for these alterations comes from the NHC microfilm maps, the Historical Weather Maps series, the COADS ship database, Monthly Weather Review, Navy reconnaissance book, Mariners Weather Log, Allison \& Thompson (1966) and NHC Storm Wallets.

October 15:

HWM and microfilm do not show an organized system at 12Z. HURDAT does not list an organized system on this date. Ship highlights: $45 \mathrm{kt}$ ESE at $28.7 \mathrm{~N}, 71.1 \mathrm{~W}$ at $18 \mathrm{Z}$ (micro).

October 16:

HWM analyzes a closed low pressure of at most $1010 \mathrm{mb}$ at $21.0 \mathrm{~N}, 72.0 \mathrm{~W}$ at 12Z. HURDAT lists a $20 \mathrm{kt}$ tropical depression at $21.0 \mathrm{~N}, 72.0 \mathrm{~W}$ at $12 \mathrm{Z}$ (first position). Microfilm shows a closed low pressure of at most $1011 \mathrm{mb}$ at $22.0 \mathrm{~N}, 72.0 \mathrm{~W}$ at $12 \mathrm{Z}$. Ship highlights: No gales or low pressures.

MWR: "The depression which grew into hurricane Ginny developed in the southeastern Bahamas during October 16. Although there was a weak surface circulation at this time, there was a marked trough, surface and aloft, extending northeastward toward Bermuda, which represented a fracture from a polar trough. Consequently the trough was cold and the air mass baroclinic."

October 17:

HWM analyzes a closed low pressure of at most $1010 \mathrm{mb}$ at $24.0 \mathrm{~N}, 72.0 \mathrm{~W}$ at 12Z. HURDAT lists a $20 \mathrm{kt}$ tropical depression at $24.0 \mathrm{~N}, 71.6 \mathrm{~W}$ at $12 \mathrm{Z}$. Microfilm shows a closed low pressure of at most $1011 \mathrm{mb}$ at $27.0 \mathrm{~N}, 69.0 \mathrm{~W}$ at 12Z. Ship highlights: No gales or low pressures. 
October 18:

HWM analyzes a closed low pressure of at most $1010 \mathrm{mb}$ at $27.0 \mathrm{~N}, 72.0 \mathrm{~W}$ with a stationary front to the north at $12 \mathrm{Z}$. HURDAT lists a $30 \mathrm{kt}$ tropical depression at $27.0 \mathrm{~N}$, $71.2 \mathrm{~W}$ at $12 \mathrm{Z}$. Microfilm shows a trough of low pressure north of the eastern Bahamas at 12Z. Ship highlights: No gales or low pressures.

ATSR: "The first sustained closed circulation appeared on the $18^{\text {th }}$, after the center of lowest pressure had moved north-northeast for the two days remaining under the trough line aloft. Lowest surface pressure at this time was estimated to be $1008 \mathrm{mbs}$. Slow intensification began and the system had all indications of remaining a cold core extratropical circulation."

October 19:

HWM analyzes a tropical storm of at most $1000 \mathrm{mb}$ at $30.9 \mathrm{~N}, 71.4 \mathrm{~W}$ with a warm front to the northeast at $12 \mathrm{Z}$. HURDAT lists a $35 \mathrm{kt}$ tropical storm at $30.8 \mathrm{~N}, 71.8 \mathrm{~W}$ at 12Z. Microfilm shows a closed low pressure of at most $1011 \mathrm{mb}$ at $29.0 \mathrm{~N}, 73.0 \mathrm{~W}$ with a frontal boundary extended to the northeast at 12Z. Ship highlights: $35 \mathrm{kt} \mathrm{NE}$ and $1015 \mathrm{mb}$ at $32.6 \mathrm{~N}, 74.3 \mathrm{~W}$ at $00 \mathrm{Z}$ (COADS). $35 \mathrm{kt} \mathrm{NE}$ and $1011 \mathrm{mb}$ at $31.1 \mathrm{~N}, 74.7 \mathrm{~W}$ at $03 \mathrm{Z}$ (COADS). $35 \mathrm{kt} \mathrm{NE}$ and $1015 \mathrm{mb}$ at $34.5 \mathrm{~N}, 71.8 \mathrm{~W}$ at $09 \mathrm{Z}$ (COADS). $40 \mathrm{kt} \mathrm{NE}$ and 1009 $\mathrm{mb}$ at $33.0 \mathrm{~N}, 73.0 \mathrm{~W}$ at $12 \mathrm{Z}$ (COADS). $993 \mathrm{mb}$ at $32.0 \mathrm{~N}, 72.5 \mathrm{~W}$ at $18 \mathrm{Z}$ (micro). $50 \mathrm{kt}$ $\mathrm{NNE}$ and $1007 \mathrm{mb}$ at $32.6 \mathrm{~N}, 73.8 \mathrm{~W}$ at $18 \mathrm{Z}$ (COADS). $40 \mathrm{kt} \mathrm{E}$ and $1007 \mathrm{mb}$ at $34.0 \mathrm{~N}$, $71.0 \mathrm{~W}$ at $21 \mathrm{Z}$ (COADS). Aircraft highlights: Estimated surface winds of $60 \mathrm{kt}$ and an eye diameter of $80 \mathrm{~nm}$ near $31.0 \mathrm{~N}, 73.0 \mathrm{~W}$ around $20 \mathrm{Z}$ (ATSR).

MWR: "In reality, the depression was not tropical and neither was the storm, which developed later on the $19^{\text {th }}$. There was no warm core." ATSR: "Intensification accelerated on the $19^{\text {th }}$ as the circulation became closed through the $200 \mathrm{mb}$ level and cold advection had increased in the upper tropospheric levels. Storm velocity of 48 knots was attained this day. The first reconnaissance flight was dispatched this date from Naval Air Station, Jacksonville to investigate an area in the vicinity of $31 \mathrm{~N} 73 \mathrm{~W}$. A cyclonic circulation 80 miles in diameter was observed; however, no radar eye or warm core was discernible."

October 20:

HWM analyzes a hurricane of at most $985 \mathrm{mb}$ at $33.8 \mathrm{~N}, 75.0 \mathrm{~W}$ with a warm front to the northeast at $12 \mathrm{Z}$. HURDAT lists a $65 \mathrm{kt}$ hurricane at $33.5 \mathrm{~N}, 75.0 \mathrm{~W}$ at $12 \mathrm{Z}$. Microfilm shows a closed low pressure of at most $996 \mathrm{mb}$ at $33.5 \mathrm{~N}, 75.2 \mathrm{~W}$ at $12 \mathrm{Z}$. Ship highlights: $55 \mathrm{kt} \mathrm{NE}$ and $1011 \mathrm{mb}$ at 33.8N, 75.6W at 00Z (COADS). $30 \mathrm{kt} \mathrm{SE}$ and 992 $\mathrm{mb}$ at $32.6 \mathrm{~N}, 72.8 \mathrm{~W}$ at $00 \mathrm{Z}$ (COADS/micro). $55 \mathrm{kt} \mathrm{SSW}$ and $994 \mathrm{mb}$ at $31.7 \mathrm{~N}, 72.6 \mathrm{~W}$ at 03Z (micro). $45 \mathrm{kt} \mathrm{ENE}$ and $996 \mathrm{mb}$ at 32.6N, 75.5W at 06Z (COADS). $55 \mathrm{kt} \mathrm{NNW}$ and $994 \mathrm{mb}$ at $32.8 \mathrm{~N}, 75.8 \mathrm{~W}$ at $09 \mathrm{Z}$ (micro). $55 \mathrm{kt} \mathrm{NNE}$ and $1005 \mathrm{mb}$ at $33.9 \mathrm{~N}, 75.9 \mathrm{~W}$ at $12 \mathrm{Z}$ (COADS). $35 \mathrm{kt} \mathrm{E}$ and $988 \mathrm{mb}$ at $33.9 \mathrm{~N}, 75.2 \mathrm{~W}$ at $12 \mathrm{Z}$ (COADS). $60 \mathrm{kt} \mathrm{NE}$ and 999 $\mathrm{mb}$ at $34.1 \mathrm{~N}, 75.6 \mathrm{~W}$ at $15 \mathrm{Z}$ (micro). $70 \mathrm{kt} \mathrm{NE}$ and $990 \mathrm{mb}$ at $34.0 \mathrm{~N}, 75.1 \mathrm{~W}$ at $18 \mathrm{Z}$ (micro). $75 \mathrm{kt} \mathrm{S}$ and $999 \mathrm{mb}$ at 33.8N, $74.0 \mathrm{~W}$ at 21Z (micro). $60 \mathrm{kt} \mathrm{SE}$ and $983 \mathrm{mb}$ at $34.0 \mathrm{~N}, 75.2 \mathrm{~W}$ at $21 \mathrm{Z}$ (micro). $65 \mathrm{kt} \mathrm{NNE}$ and $991 \mathrm{mb}$ at $34.2 \mathrm{~N}, 75.8 \mathrm{~W}$ at $21 \mathrm{Z}$ (MWL). 
ATSR: "A high pressure area had become well established over the middle Atlantic states through the lower half of the troposphere as GINNY progressed along her northerly track. This caused a tightening of the gradient in the northern semi-circle with accompanying winds of hurricane velocity, on the $20^{\text {th }}$. At this time, GINNY was 120 miles southsoutheast of Cape Hatteras and in all respects appeared to be a well-developed "Hatteras Low," which is well known along the Atlantic seaboard for its extensive precipitation, high winds and angry seas."

October 21:

HWM analyzes a hurricane of at most $995 \mathrm{mb}$ at $34.5 \mathrm{~N}, 74.5 \mathrm{~W}$ with a cold front to the north at 12Z. HURDAT lists a $75 \mathrm{kt}$ hurricane at $34.0 \mathrm{~N}, 74.5 \mathrm{~W}$ at $12 \mathrm{Z}$. Microfilm shows a closed low pressure of at most $1002 \mathrm{mb}$ at $34.0 \mathrm{~N}, 74.5 \mathrm{~W}$ at $12 \mathrm{Z}$. Ship highlights: $75 \mathrm{kt} \mathrm{S}$ and $999 \mathrm{mb}$ at $33.8 \mathrm{~N}, 74.2 \mathrm{~W}$ at $00 \mathrm{Z}$ (COADS). $60 \mathrm{kt}$ ESE and $1000 \mathrm{mb}$ at $35.0 \mathrm{~N}$, $74.8 \mathrm{~W}$ at $03 \mathrm{Z}$ (micro). $80 \mathrm{kt} \mathrm{N}$ and $1000 \mathrm{mb}$ at $34.3 \mathrm{~N}, 76.1 \mathrm{~W}$ at $06 \mathrm{Z}$ (COADS/MWL). 55 $\mathrm{kt} \mathrm{NE}$ and $1003 \mathrm{mb}$ at $33.4 \mathrm{~N}, 77.4 \mathrm{~W}$ at $09 \mathrm{Z}$ (micro). $60 \mathrm{kt} \mathrm{N}$ and $1002 \mathrm{mb}$ at $34.5 \mathrm{~N}$, $75.8 \mathrm{~W}$ at $12 \mathrm{Z}$ (COADS). $50 \mathrm{kt} \mathrm{N}$ and $1003 \mathrm{mb}$ at $34.8 \mathrm{~N}, 75.5 \mathrm{~W}$ at $15 \mathrm{Z}$ (MWL). $55 \mathrm{kt}$ $\mathrm{NNW}$ and $1007 \mathrm{mb}$ at $34.3 \mathrm{~N}, 76.1 \mathrm{~W}$ at $18 \mathrm{Z}$ (COADS). $80 \mathrm{kt} \mathrm{SW}$ and $999 \mathrm{mb}$ at $33.6 \mathrm{~N}$, $76.4 \mathrm{~W}$ at $21 \mathrm{Z}$ (MWL). Aircraft highlights: Radar center fix measured a peripheral pressure of $1005 \mathrm{mb}$ and estimated surface winds of $60 \mathrm{kt}$ at $33.5 \mathrm{~N}, 76.2 \mathrm{~W}$ at $1125 \mathrm{Z}$ (ATSR). Radar highlights: Cape Hatteras radar center fix at 34.2N, 75.1W at 0644Z (WALLET). Cape Hatteras radar center fix at 33.8N, 74.1W at 1742Z (WALLET). Cape Hatteras radar center fix at $33.6 \mathrm{~N}, 74.2 \mathrm{~W}$ at $2343 \mathrm{Z}$ (WALLET).

ATSR: "On the $21^{\text {st }}$, Hurricane GINNY had come to a virtual stand-still over the warmer waters of the Gulf Stream off the coast of Hatteras. This temporary respite in such a favored location was undoubtedly the beginning of its transition from cold to warm core. Additionally, anticyclonic flow at the $200 \mathrm{mb}$ level was observed moving in from the west. On the $21^{\text {st }}$, reconnaissance flights out of NAS Jacksonville were diverted to search for and later maintain overhead contact with a disabled naval vessel which had become adrift near the center of GINNY. This limited the reconnaissance during the transition from extratropical to tropical."

October 22:

HWM analyzes a hurricane of at most $1000 \mathrm{mb}$ at $31.5 \mathrm{~N}, 74.8 \mathrm{~W}$ with a weakening front to the north at $12 \mathrm{Z}$. HURDAT lists a $70 \mathrm{kt}$ hurricane at $31.5 \mathrm{~N}, 74.8 \mathrm{~W}$ at 12Z. Microfilm shows a closed low pressure of at most $1008 \mathrm{mb}$ at $32.0 \mathrm{~N}, 75.0 \mathrm{~W}$ with a frontal boundary to the north at 12Z. Ship highlights: $60 \mathrm{kt} \mathrm{W}$ and $1003 \mathrm{mb}$ at $32.3 \mathrm{~N}$, $74.4 \mathrm{~W}$ at $00 \mathrm{Z}$ (COADS). $65 \mathrm{kt} \mathrm{NNW}$ and $1005 \mathrm{mb}$ at $33.4 \mathrm{~N}, 76.4 \mathrm{~W}$ at $03 \mathrm{Z}$ (micro). $60 \mathrm{kt}$ $\mathrm{W}$ and $990 \mathrm{mb}$ at $32.4 \mathrm{~N}, 74.8 \mathrm{~W}$ at $06 \mathrm{Z}$ (COADS). $55 \mathrm{kt} \mathrm{NNW}$ and $999 \mathrm{mb}$ at $31.9 \mathrm{~N}$, $75.6 \mathrm{~W}$ at $09 \mathrm{Z}$ (micro). $60 \mathrm{kt} \mathrm{ENE}$ and $1007 \mathrm{mb}$ at $32.6 \mathrm{~N}, 75.5 \mathrm{~W}$ at $12 \mathrm{Z}$ (COADS). $60 \mathrm{kt}$ $\mathrm{S}$ and $1007 \mathrm{mb}$ at $30.6 \mathrm{~N}, 73.6 \mathrm{~W}$ at $15 \mathrm{Z}$ (COADS). $50 \mathrm{kt} \mathrm{W}$ and $1000 \mathrm{mb}$ at $30.6 \mathrm{~N}$, $75.1 \mathrm{~W}$ at $18 \mathrm{Z}$ (micro). $55 \mathrm{kt} \mathrm{SE}$ and $1000 \mathrm{mb}$ at $31.0 \mathrm{~N}, 74.5 \mathrm{~W}$ at $21 \mathrm{Z}$ (micro). Aircraft highlights: Penetration center fix measured a central pressure of $989 \mathrm{mb}$, estimated surface winds of $55 \mathrm{kt}$ and an eye diameter of $80 \mathrm{~nm}$ at $30.8 \mathrm{~N}, 75.2 \mathrm{~W}$ at $1620 \mathrm{Z}$ (WALLET). Penetration center fix measured a central pressure of $992 \mathrm{mb}$, estimated surface winds of $50 \mathrm{kt}$ and an eye diameter of $60 \mathrm{~nm}$ at $30.1 \mathrm{~N}, 76.2 \mathrm{~W}$ at $2252 \mathrm{Z}$ 
(WALLET). Radar highlights: Cape Hatteras radar center fix at 33.1N, $74.6 \mathrm{~W}$ at $0345 \mathrm{Z}$ (WALLET).

MWR: "Even though hurricane-force winds were observed on the $20^{\text {th }}$, it was not until the morning of the $22^{\text {nd }}$ that aircraft reconnaissance found a thermal structure that was more like a hurricane, rather than the late-season, hybrid type of the previous days. An eye of 20-mi. diameter had formed on the morning of the $22^{\text {nd }}$; however, definition was reported poor." ATSR: "By the $22^{\text {nd }}$, GINNY had completed a clockwise loop off Hatteras and had begun to accelerate toward the southwest. At the same time, she was moving away from the Gulf Stream."

October 23:

HWM analyzes a tropical storm of at most $1005 \mathrm{mb}$ at $29.0 \mathrm{~N}, 77.7 \mathrm{~W}$ at $12 \mathrm{Z}$. HURDAT lists a $60 \mathrm{kt}$ tropical storm at 28.9N, 77.7W at 12Z. Microfilm shows a closed low pressure of at most $1005 \mathrm{mb}$ at $29.0 \mathrm{~N}, 77.0 \mathrm{~W}$ at 12Z. Ship highlights: $50 \mathrm{kt} \mathrm{SE}$ and $1011 \mathrm{mb}$ at $29.7 \mathrm{~N}, 73.3 \mathrm{~W}$ at $00 \mathrm{Z}$ (micro). $50 \mathrm{kt} \mathrm{NNE}$ and $1017 \mathrm{mb}$ at $33.2 \mathrm{~N}, 77.7 \mathrm{~W}$ at $03 \mathrm{Z}$ (MWL). $45 \mathrm{kt} \mathrm{NE}$ and $1013 \mathrm{mb}$ at $31.6 \mathrm{~N}, 77.4 \mathrm{~W}$ at $06 \mathrm{Z}$ (COADS). $45 \mathrm{kt} \mathrm{S}$ and 1010 $\mathrm{mb}$ at $27.8 \mathrm{~N}, 74.6 \mathrm{~W}$ at $09 \mathrm{Z}$ (micro). $40 \mathrm{kt} \mathrm{N}$ and $1008 \mathrm{mb}$ at $29.0 \mathrm{~N}, 79.2 \mathrm{~W}$ at $12 \mathrm{Z}$ (COADS). $45 \mathrm{kt} \mathrm{N}$ and $1018 \mathrm{mb}$ at $30.7 \mathrm{~N}, 80.7 \mathrm{~W}$ at $15 \mathrm{Z}$ (micro). $45 \mathrm{kt} \mathrm{NE}$ and $1020 \mathrm{mb}$ at $33.7 \mathrm{~N}, 74.1 \mathrm{~W}$ at $18 \mathrm{Z}$ (COADS). $55 \mathrm{kt} \mathrm{NNE}$ and $1008 \mathrm{mb}$ at $29.5 \mathrm{~N}, 79.5 \mathrm{~W}$ at $21 \mathrm{Z}$ (micro). Aircraft highlights: Radar center fix measured a central pressure of $987 \mathrm{mb}$ and an eye diameter of $45 \mathrm{~nm}$ at $30.1 \mathrm{~N}, 76.0 \mathrm{~W}$ at $0055 \mathrm{Z}$ (WALLET). Penetration center fix measured a central pressure of $988 \mathrm{mb}$ and estimated an eye diameter of $45 \mathrm{~nm}$ at $29.7 \mathrm{~N}$, $76.8 \mathrm{~W}$ at $04 \mathrm{Z}$ (WALLET). Penetration center fix measured a central pressure of $995 \mathrm{mb}$, estimated surface winds of $55 \mathrm{kt}$ and an eye diameter of $40 \mathrm{~nm}$ at $28.9 \mathrm{~N}, 77.8 \mathrm{~W}$ at $13 \mathrm{Z}$ (WALLET). Penetration center fix measured a central pressure of $990 \mathrm{mb}$ and estimated an eye diameter of $40 \mathrm{~nm}$ at $28.8 \mathrm{~N}, 77.8 \mathrm{~W}$ at $1445 \mathrm{Z}$ (WALLET). Penetration center fix measured a central pressure of $990 \mathrm{mb}$, estimated surface winds of $45 \mathrm{kt}$ and an eye diameter of $40 \mathrm{~nm}$ at $28.8 \mathrm{~N}, 78.3 \mathrm{~W}$ at $18 \mathrm{Z}$ (WALLET). Penetration center fix measured a central pressure of $988 \mathrm{mb}$, estimated surface winds of $60 \mathrm{kt}$ and an eye diameter of 38 $\mathrm{nm}$ at $28.8 \mathrm{~N}, 78.4 \mathrm{~W}$ at $2145 \mathrm{Z}$ (WALLET). Radar highlights: Patrick AFB radar center fix at $28.7 \mathrm{~N}, 77.9 \mathrm{~W}$ at $1320 \mathrm{Z}$ (WALLET). Patrick AFB radar center fix at $28.8 \mathrm{~N}, 77.7 \mathrm{~W}$ at $18 \mathrm{Z}$ (WALLET).

MWR: "During the $23^{\text {rd }}$, some weakening of the hurricane occurred and there was probably a period of $10 \mathrm{hr}$. when the tropical cyclone was only of storm intensity. Ginny quickly returned to hurricane force and there were only minor variations in intensity during the remainder of its life history although very slow intensification took place from this time until landfall was made on Nova Scotia on the $29^{\text {th }}$."

October 24:

HWM analyzes a hurricane of at most $1000 \mathrm{mb}$ at $29.6 \mathrm{~N}, 79.6 \mathrm{~W}$ with a cold front to the northeast at $12 \mathrm{Z}$. HURDAT lists a $65 \mathrm{kt}$ hurricane at $29.4 \mathrm{~N}, 79.6 \mathrm{~W}$ at $12 \mathrm{Z}$. Microfilm shows a closed low pressure of at most $999 \mathrm{mb}$ at $29.5 \mathrm{~N}, 79.5 \mathrm{~W}$ at $12 \mathrm{Z}$. Ship highlights: $75 \mathrm{kt} \mathrm{ENE}$ and $999 \mathrm{mb}$ at 29.4N, 78.0W at 00Z (micro). $65 \mathrm{kt} \mathrm{NE}$ and 1007 $\mathrm{mb}$ at $29.3 \mathrm{~N}, 79.1 \mathrm{~W}$ at $03 \mathrm{Z}$ (micro). $50 \mathrm{kt} \mathrm{ENE}$ and $1010 \mathrm{mb}$ at $30.5 \mathrm{~N}, 79.9 \mathrm{~W}$ at $06 \mathrm{Z}$ (COADS). $65 \mathrm{kt} \mathrm{NE}$ and $1000 \mathrm{mb}$ at 29.6N, 78.8W at 09Z (micro). $65 \mathrm{kt}$ ESE and 999 
$\mathrm{mb}$ at $29.6 \mathrm{~N}, 78.6 \mathrm{~W}$ at $12 \mathrm{Z}$ (micro). $65 \mathrm{kt} \mathrm{E}$ and $1002 \mathrm{mb}$ at $29.5 \mathrm{~N}, 78.4 \mathrm{~W}$ at $15 \mathrm{Z}$ (micro). $15 \mathrm{kt} \mathrm{E}$ and $987 \mathrm{mb}$ at 29.8N, 79.7W at $18 \mathrm{Z}$ (micro). $65 \mathrm{kt} \mathrm{SE}$ and $1002 \mathrm{mb}$ at $29.8 \mathrm{~N}, 79.7 \mathrm{~W}$ at $18 \mathrm{Z}$ (micro). $55 \mathrm{kt} \mathrm{SSW}$ and $1001 \mathrm{mb}$ at $29.4 \mathrm{~N}, 79.2 \mathrm{~W}$ at $20 \mathrm{Z}$ (COADS). Aircraft highlights: Penetration center fix estimated an eye diameter of $35 \mathrm{~nm}$ at $28.8 \mathrm{~N}, 78.5 \mathrm{~W}$ at $0130 \mathrm{Z}$ (WALLET). Penetration center fix estimated flight level winds of $50 \mathrm{kt}$ and an eye diameter of $35 \mathrm{~nm}$ at 29.1N, 79.0W at 07Z (ATSR). Penetration center fix measured a central pressure of $990 \mathrm{mb}$, estimated surface winds of $75 \mathrm{kt}$ and an eye diameter of $30 \mathrm{~nm}$ at $29.5 \mathrm{~N}, 79.7 \mathrm{~W}$ at $14 \mathrm{Z}$ (WALLET). Penetration center fix measured a central pressure of $987 \mathrm{mb}$, estimated surface winds of $85 \mathrm{kt}$ and an eye diameter of $44 \mathrm{~nm}$ at $29.7 \mathrm{~N}, 79.8 \mathrm{~W}$ at $17 \mathrm{Z}$ (WALLET). Penetration center fix measured a central pressure of $982 \mathrm{mb}$, estimated surface winds of $75 \mathrm{kt}$ and an eye diameter of 40 $\mathrm{nm}$ at $30.0 \mathrm{~N}, 79.7 \mathrm{~W}$ at $2215 \mathrm{Z}$ (WALLET). Radar highlights: Daytona Beach radar center fix at $29.0 \mathrm{~N}, 78.4 \mathrm{~W}$ at $0020 \mathrm{Z}$ (WALLET). Daytona Beach radar center fix at $29.3 \mathrm{~N}$, $79.0 \mathrm{~W}$ and an eye diameter of $40 \mathrm{~nm}$ at $0615 \mathrm{Z}$ (WALLET). Daytona Beach radar center fix at 29.6N, 79.5W and an eye diameter of $42 \mathrm{~nm}$ at 1215Z (WALLET). Daytona Beach radar center fix at $29.8 \mathrm{~N}, 79.7 \mathrm{~W}$ and an eye diameter of $44 \mathrm{~nm}$ at $1745 \mathrm{Z}$ (WALLET).

October 25:

HWM analyzes a hurricane of at most $1005 \mathrm{mb}$ at $32.0 \mathrm{~N}, 79.5 \mathrm{~W}$ with a warm front to the east at $12 \mathrm{Z}$. HURDAT lists a $90 \mathrm{kt}$ hurricane at $31.8 \mathrm{~N}, 79.6 \mathrm{~W}$ at $12 \mathrm{Z}$. Microfilm shows a closed low pressure of at most $1002 \mathrm{mb}$ at $31.5 \mathrm{~N}, 79.0 \mathrm{~W}$ at $12 \mathrm{Z}$. Ship highlights: $65 \mathrm{kt} \mathrm{S}$ and $1007 \mathrm{mb}$ at $30.3 \mathrm{~N}, 78.5 \mathrm{~W}$ at $00 \mathrm{Z}$ (COADS). $50 \mathrm{kt}$ SE and 1012 $\mathrm{mb}$ at $31.8 \mathrm{~N}, 78.2 \mathrm{~W}$ at $06 \mathrm{Z}$ (micro). $45 \mathrm{kt} \mathrm{E}$ and $1007 \mathrm{mb}$ at $32.4 \mathrm{~N}, 78.4 \mathrm{~W}$ at $12 \mathrm{Z}$ (COADS). $35 \mathrm{kt} \mathrm{SE}$ and $1009 \mathrm{mb}$ at $31.1 \mathrm{~N}, 77.8 \mathrm{~W}$ at $15 \mathrm{Z}$ (micro). $40 \mathrm{kt} \mathrm{SSW}$ and 1004 $\mathrm{mb}$ at $31.0 \mathrm{~N}, 78.4 \mathrm{~W}$ at $18 \mathrm{Z}$ (micro). Aircraft highlight: Radar center fix at $30.1 \mathrm{~N}, 79.6 \mathrm{~W}$ at $00 \mathrm{Z}$ (WALLET). Penetration center fix measured a central pressure of $976 \mathrm{mb}$, estimated surface winds of $80 \mathrm{kt}$ and an eye diameter of $30 \mathrm{~nm}$ at $31.8 \mathrm{~N}, 79.6 \mathrm{~W}$ at $12 \mathrm{Z}$ (WALLET). Penetration center fix measured a central pressure of $985 \mathrm{mb}$ and an eye diameter of $30 \mathrm{~nm}$ at $32.1 \mathrm{~N}, 79.0 \mathrm{~W}$ at $1859 \mathrm{Z}$ (WALLET). Penetration center fix measured a central pressure of $987 \mathrm{mb}$, estimated surface winds of $95 \mathrm{kt}$ and an eye diameter of $30 \mathrm{~nm}$ at $32.2 \mathrm{~N}, 78.5 \mathrm{~W}$ at $22 \mathrm{Z}$ (WALLET/ATSR). Radar highlights: Charleston radar center fix at $30.3 \mathrm{~N}, 79.5 \mathrm{~W}$ and an eye diameter of $23 \mathrm{~nm}$ at $0015 \mathrm{Z}$ (WALLET). Daytona Beach center fix at $31.1 \mathrm{~N}, 79.8 \mathrm{~W}$ and an eye diameter of $30 \mathrm{~nm}$ at $0545 Z$ (WALLET). Charleston radar center fix at $31.8 \mathrm{~N}, 79.4 \mathrm{~W}$ and an eye diameter of $32 \mathrm{~nm}$ at $1222 \mathrm{Z}$ (WALLET). Charleston radar center fix at $32.1 \mathrm{~N}, 79.1 \mathrm{~W}$ and an eye diameter of $18 \mathrm{~nm}$ at $1818 \mathrm{Z}$ (WALLET).

October 26:

HWM analyzes a hurricane of at most $1000 \mathrm{mb}$ at $33.5 \mathrm{~N}, 76.5 \mathrm{~W}$ with a warm front to the east at $12 \mathrm{Z}$. HURDAT lists an $80 \mathrm{kt}$ hurricane at $33.2 \mathrm{~N}, 76.9 \mathrm{~W}$ at $12 \mathrm{Z}$. Microfilm shows a closed low pressure of at most $1005 \mathrm{mb}$ at $33.0 \mathrm{~N}, 77.0 \mathrm{~W}$ at $12 \mathrm{Z}$. Ship highlights: $35 \mathrm{kt} \mathrm{W}$ and $1000 \mathrm{mb}$ at $32.0 \mathrm{~N}, 78.8 \mathrm{~W}$ at $00 \mathrm{Z}$ (COADS). $45 \mathrm{kt} \mathrm{SW}$ and 1012 $\mathrm{mb}$ at $31.2 \mathrm{~N}, 75.7 \mathrm{~W}$ at $06 \mathrm{Z}$ (COADS). $60 \mathrm{kt} \mathrm{S}$ and $990 \mathrm{mb}$ at $31.4 \mathrm{~N}, 76.7 \mathrm{~W}$ at $12 \mathrm{Z}$ (COADS). $60 \mathrm{kt} \mathrm{NW}$ and $1002 \mathrm{mb}$ at $32.5 \mathrm{~N}, 77.5 \mathrm{~W}$ at $18 \mathrm{Z}$ (COADS). Aircraft highlights: Penetration center fix estimated flight level winds of $53 \mathrm{kt}$ and an eye 
diameter of $20 \mathrm{~nm}$ at $32.4 \mathrm{~N}, 78.0 \mathrm{~W}$ at $01 \mathrm{Z}$ (WALLET). Penetration center fix measured a central pressure of $988 \mathrm{mb}$ and estimated flight level winds of $53 \mathrm{kt}$ at $32.8 \mathrm{~N}, 77.6 \mathrm{~W}$ at 0359Z (WALLET). Penetration center fix measured a central pressure of $983 \mathrm{mb}$, estimated flight level winds of $55 \mathrm{kt}$ and an eye diameter of $21 \mathrm{~nm}$ at $33.1 \mathrm{~N}, 77.4 \mathrm{~W}$ at 0559Z (WALLET/ATSR). Penetration center fix measured a central pressure of $986 \mathrm{mb}$, estimated surface winds of $90 \mathrm{kt}$ and an eye diameter of $25 \mathrm{~nm}$ at $33.2 \mathrm{~N}, 76.9 \mathrm{~W}$ at $12 \mathrm{Z}$ (WALLET). Penetration center fix measured a central pressure of $978 \mathrm{mb}$, estimated surface winds of $80 \mathrm{kt}$ and an eye diameter of $16 \mathrm{~nm}$ at $32.9 \mathrm{~N}, 76.4 \mathrm{~W}$ at $19 \mathrm{Z}$ (WALLET). Radar highlights: Charleston radar center fix at 32.5N, $77.9 \mathrm{~W}$ and an eye diameter of $24 \mathrm{~nm}$ at $0015 \mathrm{Z}$ (WALLET). Charleston radar center fix at $33.1 \mathrm{~N}, 77.3 \mathrm{~W}$ at $0540 \mathrm{Z}$ (WALLET). Charleston radar center fix at 33.3N, $77.0 \mathrm{~W}$ and an eye diameter of $30-50 \mathrm{~nm}$ at $1244 \mathrm{Z}$ (WALLET). Hatteras radar center fix at $33.2 \mathrm{~N}, 76.1 \mathrm{~W}$ at $1745 \mathrm{Z}$ (WALLET).

MWR: "Highest wind at any land station was $70 \mathrm{mph}$, with gusts to 100 , reported at Cape Fear at the Oak Island, NC, observation point when the center took a temporary odd turn toward the North Carolina coast." NC State Climatologist: "Reports from other than First-Order stations were received erratically, but most reports gave winds at less than 50 miles per hour at all times. The exception was Oak Island Life Boat Station, which gave consistently higher winds than any other point. These reports indicated sustained winds as high as 70 miles per hour, with one gusts to $100 \mathrm{mph}$ reported on the $260255 \mathrm{E}$ report. On some of the Oak Island reports winds were marked "estimated" and it is believed that many of the speeds were overestimated. Lowest pressure at Oak Island, the lowest reported other than that at Hatteras, was given as 29.62 inches from about 260400260600E."

October 27:

HWM analyzes a hurricane of at most $995 \mathrm{mb}$ at $33.1 \mathrm{~N}, 75.0 \mathrm{~W}$ with a warm front to the northeast at $12 \mathrm{Z}$. HURDAT lists a $70 \mathrm{kt}$ hurricane at $32.9 \mathrm{~N}, 75.3 \mathrm{~W}$ at $12 \mathrm{Z}$. Microfilm shows a closed low pressure of at most $1002 \mathrm{mb}$ at 33.0N, 75.0W at 12Z. Ship highlights: $60 \mathrm{kt} \mathrm{E}$ and $999 \mathrm{mb}$ at 33.6N, 75.3W at 00Z (COADS). $50 \mathrm{kt} \mathrm{W}$ and $1004 \mathrm{mb}$ at $31.5 \mathrm{~N}, 75.9 \mathrm{~W}$ at $06 \mathrm{Z}$ (COADS). $45 \mathrm{kt} \mathrm{WNW}$ and $1006 \mathrm{mb}$ at $31.4 \mathrm{~N}, 76.1 \mathrm{~W}$ at $12 \mathrm{Z}$ (COADS). $45 \mathrm{kt} \mathrm{NNE}$ and $1009 \mathrm{mb}$ at 33.7N, $77.0 \mathrm{~W}$ at $15 \mathrm{Z}$ (micro). $50 \mathrm{kt} \mathrm{NW}$ and 1006 $\mathrm{mb}$ at $32.0 \mathrm{~N}, 76.7 \mathrm{~W}$ at $18 \mathrm{Z}$ (COADS). $55 \mathrm{kt}$ SSE and $989 \mathrm{mb}$ at $32.3 \mathrm{~N}, 73.5 \mathrm{~W}$ at $20 \mathrm{Z}$ (MWL). Aircraft highlights: Penetration center fix measured a central pressure of 979 $\mathrm{mb}$, estimated surface winds of $75 \mathrm{kt}$ and an eye diameter of $28 \mathrm{~nm}$ at $32.9 \mathrm{~N}, 76.3 \mathrm{~W}$ at $0157 Z$ (WALLET). Penetration center fix measured a central pressure of $980 \mathrm{mb}$, estimated surface winds of $85 \mathrm{kt}$ and an eye diameter of $22 \mathrm{~nm}$ at $33.0 \mathrm{~N}, 75.8 \mathrm{~W}$ at $0645 \mathrm{Z}$ (WALLET/ATSR). Penetration center fix measured a central pressure of $972 \mathrm{mb}$ and estimated surface winds of $85 \mathrm{kt}$ at $32.9 \mathrm{~N}, 75.4 \mathrm{~W}$ at $0945 \mathrm{Z}$ (WALLET). Penetration center fix at $32.9 \mathrm{~N}, 75.3 \mathrm{~W}$ at $13 \mathrm{Z}$ (WALLET). Penetration center fix measured a central pressure of $975 \mathrm{mb}$, estimated surface winds of $90 \mathrm{kt}$ and an eye diameter of $30 \mathrm{~nm}$ at $32.6 \mathrm{~N}, 74.5 \mathrm{~W}$ at $19 \mathrm{Z}$ (WALLET). Radar highlights: Hatteras radar center fix at $33.1 \mathrm{~N}$, $76.0 \mathrm{~W}$ at $0045 \mathrm{Z}$ (WALLET). Hatteras radar center fix at $32.9 \mathrm{~N}, 75.5 \mathrm{~W}$ at $0545 \mathrm{Z}$ (WALLET). Hatteras radar center fix at $32.8 \mathrm{~N}, 74.8 \mathrm{~W}$ at $1215 \mathrm{Z}$ (WALLET). Hatteras 
radar center fix at $32.8 \mathrm{~N}, 74.4 \mathrm{~W}$ at $1744 \mathrm{Z}$ (WALLET). Hatteras radar center fix at $32.8 \mathrm{~N}$, $73.4 \mathrm{~W}$ at $2345 \mathrm{Z}$ (WALLET).

October 28:

HWM analyzes a hurricane of at most $990 \mathrm{mb}$ at $34.1 \mathrm{~N}, 72.5 \mathrm{~W}$ with a cold front to the north at $12 \mathrm{Z}$. HURDAT lists an $80 \mathrm{kt}$ hurricane at $33.9 \mathrm{~N}, 72.3 \mathrm{~W}$ at $12 \mathrm{Z}$. Microfilm shows a closed low pressure of at most $1008 \mathrm{mb}$ at $33.9 \mathrm{~N}, 72.3 \mathrm{~W}$ with a frontal boundary to the northwest at 12Z. Ship highlights: $55 \mathrm{kt} \mathrm{SSE}$ and $989 \mathrm{mb}$ at $32.3 \mathrm{~N}, 73.5 \mathrm{~W}$ at $00 \mathrm{Z}$ (COADS). $50 \mathrm{kt} \mathrm{WNW} \mathrm{and} 997 \mathrm{mb}$ at $31.9 \mathrm{~N}, 74.0 \mathrm{~W}$ at $03 \mathrm{Z}$ (micro). $40 \mathrm{kt} \mathrm{WNW}$ and $1001 \mathrm{mb}$ at $31.6 \mathrm{~N}, 74.4 \mathrm{~W}$ at $06 \mathrm{Z}$ (COADS). $40 \mathrm{kt} \mathrm{SE}$ and $999 \mathrm{mb}$ at $34.1 \mathrm{~N}, 70.0 \mathrm{~W}$ at $12 \mathrm{Z}$ (micro). $50 \mathrm{kt} \mathrm{E}$ and $988 \mathrm{mb}$ at $34.0 \mathrm{~N}, 71.0 \mathrm{~W}$ at $18 \mathrm{Z}$ (COADS). $50 \mathrm{kt} \mathrm{S}$ and $999 \mathrm{mb}$ at $35.5 \mathrm{~N}, 68.0 \mathrm{~W}$ at $21 \mathrm{Z}$ (micro). Aircraft highlights: Penetration center fix measured a central pressure of $970 \mathrm{mb}$ and estimated an eye diameter of $40 \mathrm{~nm}$ at $32.8 \mathrm{~N}, 73.3 \mathrm{~W}$ at $0130 Z$ (WALLET). Penetration center fix estimated an eye diameter of $32 \mathrm{~nm}$ at $33.3 \mathrm{~N}$, $73.1 \mathrm{~W}$ at $0722 \mathrm{Z}$ (WALLET). Penetration center fix measured a central pressure of 968 $\mathrm{mb}$, estimated surface winds of $75 \mathrm{kt}$ and an eye diameter of $25 \mathrm{~nm}$ at $34.1 \mathrm{~N}, 72.1 \mathrm{~W}$ at $13 Z$ (WALLET). Penetration center fix measured a central pressure of $963 \mathrm{mb}$, estimated surface winds of $100 \mathrm{kt}$ and an eye diameter of $25 \mathrm{~nm}$ at $35.3 \mathrm{~N}, 71.4 \mathrm{~W}$ at $19 \mathrm{Z}$ (WALLET).

October 29:

HWM analyzes a hurricane of at most $980 \mathrm{mb}$ at $41.0 \mathrm{~N}, 67.0 \mathrm{~W}$ with a cold front just to the west and a warm front just to the north at 12Z. HURDAT lists a $95 \mathrm{kt}$ hurricane at $40.8 \mathrm{~N}, 67.2 \mathrm{~W}$ at 12Z. Microfilm shows a closed low pressure of at most 993 $\mathrm{mb}$ at $41.0 \mathrm{~N}, 67.0 \mathrm{~W}$ with a frontal boundary going through the center at $12 \mathrm{Z}$. Ship highlights: $75 \mathrm{kt} \mathrm{NNW}$ and $996 \mathrm{mb}$ at 36.4N, 71.5W at 00Z (micro). $65 \mathrm{kt} \mathrm{E}$ and $977 \mathrm{mb}$ at $37.0 \mathrm{~N}, 70.3 \mathrm{~W}$ at $00 \mathrm{Z}$ (COADS). $60 \mathrm{kt} \mathrm{N}$ and $996 \mathrm{mb}$ at $38.3 \mathrm{~N}, 72.1 \mathrm{~W}$ at $03 \mathrm{Z}$ (micro). $65 \mathrm{kt} \mathrm{NW}$ and $981 \mathrm{mb}$ at $35.0 \mathrm{~N}, 71.5 \mathrm{~W}$ at $06 \mathrm{Z}$ (COADS). $55 \mathrm{kt} \mathrm{S}$ and $995 \mathrm{mb}$ at $39.3 \mathrm{~N}$, $64.2 \mathrm{~W}$ at $09 \mathrm{Z}$ (COADS). $85 \mathrm{kt} \mathrm{NW}$ and $975 \mathrm{mb}$ at $39.5 \mathrm{~N}, 68.0 \mathrm{~W}$ at $12 \mathrm{Z}$ (MWL). $70 \mathrm{kt} \mathrm{S}$ and $964 \mathrm{mb}$ at $41.3 \mathrm{~N}, 65.8 \mathrm{~W}$ at $15 \mathrm{Z}$ (micro). $65 \mathrm{kt} \mathrm{NW}$ and $987 \mathrm{mb}$ at $43.0 \mathrm{~N}, 68.5 \mathrm{~W}$ at $18 \mathrm{Z}$ (micro). Land highlights: $35 \mathrm{kt} \mathrm{NNE}$ and $997 \mathrm{mb}$ at Nantucket, MA at 06Z (micro). $48 \mathrm{kt} \mathrm{N}$ (gusts to $66 \mathrm{kt}$ ) and $988 \mathrm{mb}$ at Nantucket, MA at 1259Z (SWO). $55 \mathrm{kt} \mathrm{NE}$ and $994 \mathrm{mb}$ at Nantucket Lightship, MA at 23Z (SWO/MWR). Aircraft highlights: Radar center fix at $36.9 \mathrm{~N}, 71.0 \mathrm{~W}$ at $0215 \mathrm{Z}$ (WALLET). Radar center fix at $37.9 \mathrm{~N}, 68.7 \mathrm{~W}$ at 06Z (WALLET). Penetration center fix measured a central pressure of $958 \mathrm{mb}$, estimated surface winds of $120 \mathrm{kt}$ and an eye diameter of $25 \mathrm{~nm}$ at $41.4 \mathrm{~N}, 66.9 \mathrm{~W}$ at $1315 \mathrm{Z}$

(WALLET). Penetration center fix measured a central pressure of $948 \mathrm{mb}$ and estimated surface winds of $120 \mathrm{kt}$ at $43.1 \mathrm{~N}, 66.2 \mathrm{~W}$ at $1630 \mathrm{Z}$ (WALLET).

MWR: "Later the hurricane threatened New England but gale warnings, which were in effect were ample. The fastest mile on the New England coast was $65 \mathrm{mph}$ reported at Nantucket. The Coast Guard vessel Cowslip, off Portland, Maine, reported seas 30 to 40 $\mathrm{ft}$. high and the anemometer broke at about $105 \mathrm{mph}$. The lowest barometer reading was 28.98 in." 
October 30:

HWM analyzes an extratropical cyclone of at most $985 \mathrm{mb}$ at $43.0 \mathrm{~N}, 65.5 \mathrm{~W}$ at 12Z. HURDAT lists an $80 \mathrm{kt}$ extratropical cyclone at $49.0 \mathrm{~N}, 63.0 \mathrm{~W}$ at $06 \mathrm{Z}$ (last position). Microfilm shows a closed low pressure of at most $996 \mathrm{mb}$ at $45.0 \mathrm{~N}, 62.0 \mathrm{~W}$ with a large extratropical cyclone to the south at 12Z. Ship highlights: $45 \mathrm{kt} \mathrm{NW}$ and 997 $\mathrm{mb}$ at $43.1 \mathrm{~N}, 68.5 \mathrm{~W}$ at $00 \mathrm{Z}$ (COADS). Land highlights: $75 \mathrm{kt}$ (likely gusts) (time unknown) at Saint John, Canada (Canada). $35 \mathrm{kt} \mathrm{SW}$ and $977 \mathrm{mb}$ at Moncton, Canada at 00Z (micro). $40 \mathrm{kt} \mathrm{WSW} \mathrm{and} 994 \mathrm{mb}$ at Ile du Havre, Canada at 06Z (micro). $30 \mathrm{kt} \mathrm{N}$ and $991 \mathrm{mb}$ at 50.1N, 64.2W at 06Z (COADS).

MWR: "The track of Ginny was most unusual although not unique. Many hurricanes have looped and a few others have had rather long trajectories toward the southwest. The reader is referred to the "Yankee Storm" of October 30-November 8, 1935, and to hurricane Able of May 15-24, 1951. It would seem that these two storms and Ginny certainly had an affinity for the warm Gulf Stream. Operationally, aside from the erratic track, Ginny was a most difficult hurricane in that a large part of its life history was uncomfortably close to land. For eight consecutive days while Ginny was meandering off the southeastern coast, the center was within $250 \mathrm{n}$. mi. of the United States mainland and during one day the wall cloud was less than $50 \mathrm{mi}$. from the Cape Canaveral-Daytona Beach, Fla. area. Two persons apparently perished in the snow storm and there was one other fatality. Possibly four others were lost on the Tug Otho. Damage resulted from minor beach erosion and relatively small structural loss to boats, houses, autos, etc., mainly in Maine and on Cape Cod. Total damage in the United States probably did not exceed $\$ 400,000$. According to reports, damage in the Canadian Maritime Provinces was confined to small boats and from minor flooding with no known deaths."

Ginny originated from a tropical wave that entered the Caribbean Sea on October $14^{\text {th }}$. The disturbance moved westward over the Greater Antilles becoming better organized north of Hispaniola on October $16^{\text {th }}$. Based upon synoptic observations, the low-level circulation became better defined on October $17^{\text {th }}$ while drifting northward and a $20 \mathrm{kt}$ tropical depression is analyzed to have developed at $18 \mathrm{Z}$ on the $17^{\text {th }}, 30$ hours later than originally shown in HURDAT. Observations on the $16^{\text {th }}$ and early on the $17^{\text {th }}$ indicate that the disturbance was a sharp tropical wave or trough over the eastern Bahamas, thus genesis was delayed from the original HURDAT. Minor track alterations are introduced during the lifetime of this tropical cyclone. (Central pressures values for many six hour period were present in the original HURDAT between October $19^{\text {th }}$ at $12 Z$ and October $29^{\text {st }}$ at $18 \mathrm{Z}$. Some of these were obviously analyses that were added in, not based upon actual observations. Thus, based on actual observations, some were retained and new central pressure values added. Detailed information on these changes can be found in the table at the end.) On October $18^{\text {th }}$, the tropical depression moved northward and slowly intensified. Synoptic observations indicate that the tropical cyclone had a large circulation, radius of OCI about $240 \mathrm{~nm}$, and it was interacting with a stationary boundary over the western Atlantic, and thus this system had some subtropical characteristics during the first few days of its existence. At $00 \mathrm{Z}$ on October $19^{\text {th }}$, gales 
were reported about $300 \mathrm{~nm}$ northwest of the center but the observations were outside the outermost closed isobar and therefore, not considered part of the circulation and were instead due to the large scale synoptic pressure gradients. Ginny turned to the northwest on the $19^{\text {th }}$ and quickly strengthened. Intensification to a tropical storm is analyzed at $06 \mathrm{Z}$ on the $19^{\text {th }}$, six hours earlier than originally shown in HURDAT. A couple of ships reported gale-force winds on the $19^{\text {th }}$, including storm-force winds of $50 \mathrm{kt} \mathrm{N}$ at $18 \mathrm{Z}$. An intensity of $55 \mathrm{kt}$ is analyzed at $18 \mathrm{Z}$ on the $19^{\text {th }}$ based on the synoptic data, up from $45 \mathrm{kt}$ originally in HURDAT, a minor intensity change. On October $20^{\text {th }}$, Ginny turned to the west and slowed its forward speed. A ship reported $30 \mathrm{kt} \mathrm{SE}$ and $992 \mathrm{mb}$ at $00 \mathrm{Z}$ on the $20^{\text {th }}$, suggesting a central pressure of $989 \mathrm{mb}$. A central pressure of $989 \mathrm{mb}$ suggests maximum surface winds of $61 \mathrm{kt}$ from the north of $25 \mathrm{~N}$ Brown et al. pressure-wind relationship. Based on a forward speed of $16 \mathrm{kt}$, an intensity of $60 \mathrm{kt}$ is analyzed at $00 \mathrm{Z}$ on the $20^{\text {th }}$, up from 55 knots originally shown in HURDAT, a minor intensity change. Also on the $20^{\text {th }}$, numerous ships reported tropical storm force winds and even hurricaneforce winds at 18Z. Based on the synoptic data available, intensification to a hurricane is analyzed at $12 \mathrm{Z}$ on the $20^{\text {th }}$, same as originally shown in HURDAT. On October $21^{\text {st }}$, Ginny made a clock-wise loop off the North Carolina coast. The hurricane continued to intensify on the $21^{\text {st }}$ and reached a first peak of $80 \mathrm{kt}$ at $06 \mathrm{Z}$, up from $75 \mathrm{kt}$ originally in HURDAT, a minor intensity change. A ship at $06 \mathrm{Z}$ on the $21^{\mathrm{st}}$ reported $80 \mathrm{kt} \mathrm{N}$ and 1000 $\mathrm{mb}$. On October $22^{\text {nd }}$, the hurricane turned to the south and later southwest while gradually weakening. A reconnaissance aircraft made a penetration center fix at $1620 \mathrm{Z}$ on the $22^{\text {nd }}$ measuring a central pressure of $989 \mathrm{mb}$, estimating surface winds of $55 \mathrm{kt}$ and an eye diameter of $80 \mathrm{~nm}$. A central pressure of $989 \mathrm{mb}$ suggests maximum surface winds of $61 \mathrm{kt}$ from the north of $25 \mathrm{~N}$ pressure-wind relationship. An eye diameter of 80 $\mathrm{nm}$ suggests an RMW of $60 \mathrm{~nm}$ and the climatological value is $25 \mathrm{~nm}$. At $1815 \mathrm{Z}$ on the $22^{\text {nd }}$, TIROS VII captured an image of Ginny showing a large area of convection with a poorly-defined eye and banding features. Based upon a forward speed of about $9 \mathrm{kt}$ and the TIROS satellite image, an intensity of $65 \mathrm{kt}$ is analyzed at $18 \mathrm{Z}$ on the $22^{\text {nd }}$, down from 70 kt originally in HURDAT, a minor intensity change. On October $23^{\text {rd }}$, Ginny continued on a southwestward track with no appreciable changes in intensity. A few reconnaissance aircrafts made penetration center fixes throughout the day and the central pressure of the tropical cyclone fluctuated between $988 \mathrm{mb}$ and $995 \mathrm{mb}$. The intensity is analyzed at $65 \mathrm{kt}$ at every time slot on the $23^{\text {rd }}$, same as originally shown in HURDAT at $00 \mathrm{Z}$ and 18Z, and up from $60 \mathrm{kt}$ at $06 \mathrm{Z}$ and 12Z, which are minor changes in intensity. Numerous ships reported gale and storm-force winds on the $23^{\text {rd }}$.

On October $24^{\text {th }}$, Ginny made its closest approach to Florida, passing about $75 \mathrm{~nm}$ east of Daytona Beach, before turning to the north. The radar images from Daytona Beach showed a well-defined eyewall about $40 \mathrm{~nm}$ in diameter. The hurricane slightly intensified on the $24^{\text {th }}$ based upon data from the reconnaissance aircraft and ship observations. Various ships reported tropical storm force winds and a couple even experienced hurricane-force winds. At $18 \mathrm{Z}$ on the $24^{\text {th }}$, a ship reported $15 \mathrm{kt} \mathrm{E}$ and 987 $\mathrm{mb}$, suggesting a central pressure of $985 \mathrm{mb}$. A central pressure of $985 \mathrm{mb}$ suggests maximum surface winds of $69 \mathrm{kt}$ from the north of $25 \mathrm{~N}$ intensifying subset pressure-wind relationship. A reconnaissance aircraft investigating Ginny estimated surface winds of 85 $\mathrm{kt}$ and an eye diameter of $44 \mathrm{~nm}$ at 17Z. An eye diameter of $44 \mathrm{~nm}$ suggests an RMW of 
about $33 \mathrm{~nm}$ and the climatological value is 24 . An intensity of $70 \mathrm{kt}$ is selected at $18 \mathrm{Z}$ on the $24^{\text {th }}$, same as originally shown in HURDAT. On October $25^{\text {th }}$, Ginny moved slowly to the north and late on the day turned to the northeast passing about $60 \mathrm{~nm}$ southeast of South Carolina. A penetration center fix occurred at $2215 \mathrm{Z}$ on the $24^{\text {th }}$ measuring a central pressure of $982 \mathrm{mb}$, estimating surface winds of $75 \mathrm{kt}$ and an eye diameter of 40 $\mathrm{nm}$. A central pressure of $982 \mathrm{mb}$ suggests maximum surface winds of $73 \mathrm{kt}$ from the north of $25 \mathrm{~N}$ intensifying subset pressure-wind relationship. An eye diameter of $40 \mathrm{~nm}$ suggests an RMW of about $30 \mathrm{~nm}$ and the climatological value is $23 \mathrm{~nm}$. An intensity of $75 \mathrm{kt}$ is selected at $00 \mathrm{Z}$ on the $25^{\text {th }}$, same as originally shown in HURDAT. The next penetration center fix measured a central pressure of $976 \mathrm{mb}$, estimated surface winds of $80 \mathrm{kt}$ and an eye diameter of $30 \mathrm{~nm}$. A central pressure of $976 \mathrm{mb}$ suggests maximum surface winds of $81 \mathrm{kt}$ from the north of $25 \mathrm{~N}$ intensifying subset pressure-wind relationship. An eye diameter of $30 \mathrm{~nm}$ suggests an RMW of about $23 \mathrm{~nm}$ and the climatological value is $24 \mathrm{~nm}$. An intensity of $80 \mathrm{kt}$ is selected at $12 \mathrm{Z}$ on the $25^{\text {th }}$, down from $90 \mathrm{kt}$ originally in HURDAT, a minor intensity change. $80 \mathrm{kt}$ is a second peak in intensity as reconnaissance data indicated that Ginny began to weaken late on the $25^{\text {th }}$. TIROS VII captured an image of the hurricane at $1741 \mathrm{Z}$ on the $25^{\text {th }}$ showing a large area of convection with some banding features. A penetration center fix measured a central pressure of $985 \mathrm{mb}$ and an eye diameter of $30 \mathrm{~nm}$ at $1859 \mathrm{Z}$ on the $25^{\text {th }}$. A central pressure of $985 \mathrm{mb}$ suggests maximum surface winds of $66 \mathrm{kt}$ and $63 \mathrm{kt}$ from the north of $25 \mathrm{~N}$ and the weakening subset pressure-wind relationship, respectively. An eye diameter of $30 \mathrm{~nm}$ suggests an RMW of about $23 \mathrm{~nm}$ and the climatological value is $24 \mathrm{~nm}$. Based upon a forward speed of about $5 \mathrm{kt}$ and satellite image, an intensity of $70 \mathrm{kt}$ is analyzed at $18 \mathrm{Z}$ on the $25^{\text {th }}$, down from $90 \mathrm{kt}$ originally in HURDAT, a major intensity change.

On October $26^{\text {th }}$, Ginny moved generally northeastward at a slow forward speed and made its closest approach to North Carolina, passing about $50 \mathrm{~nm}$ southeast of Cape Fear. Around $06 \mathrm{Z}$ on the $26^{\text {th }}$, Oak Island, North Carolina, experienced tropical storm force winds up to $60 \mathrm{kt}$ according to the NC State Climatologist. The report also states that some of the wind reports were estimates and some may have been overestimated. The Schwerdt et al. parametric hurricane wind model suggests that the highest sustained winds that impacted North Carolina, especially in the Cape Fear area, reached $55 \mathrm{kt}$. Thus, Ginny is analyzed as a tropical storm impact for North Carolina. A penetration center fix at $0559 \mathrm{Z}$ on the $26^{\text {th }}$ measuring a central pressure of $983 \mathrm{mb}$ and estimating an eye diameter of $21 \mathrm{~nm}$. A central pressure of $983 \mathrm{mb}$ suggests maximum surface winds of $69 \mathrm{kt}$ from the north of $25 \mathrm{~N}$ pressure-wind relationship. An eye diameter of $21 \mathrm{~nm}$ suggests an RMW of about $16 \mathrm{~nm}$ and the climatological value is $26 \mathrm{~nm}$. Based upon an RMW smaller than the climatological value but slow forward speed of about $6 \mathrm{kt}$, an intensity of $70 \mathrm{kt}$ is analyzed at $06 \mathrm{Z}$ on the $26^{\text {th }}$, down from $80 \mathrm{kt}$ originally shown in HURDAT, a minor intensity change. A couple of ships reported gale and storm-force winds on the $26^{\text {th }}$, up to $60 \mathrm{kt}$ at $12 \mathrm{Z}$ and $18 \mathrm{Z}$. Another penetration center fix occurred at $19 \mathrm{Z}$ on the $26^{\text {th }}$ measuring a central pressure of $978 \mathrm{mb}$, estimated surface winds of $80 \mathrm{kt}$ and an eye diameter of $16 \mathrm{~nm}$. A central pressure of $978 \mathrm{mb}$ suggests maximum surface winds of $75 \mathrm{kt}$ and $78 \mathrm{kt}$ from the north of $25 \mathrm{~N}$ and the intensifying subset pressure-wind relationship, respectively. An eye diameter of $16 \mathrm{~nm}$ suggests an RMW of about $12 \mathrm{~nm}$ and the climatological value is $26 \mathrm{~nm}$. Based upon an RMW smaller than the 
climatological value but slow forward speed of about $6 \mathrm{kt}$, an intensity of $75 \mathrm{kt}$ is analyzed at $18 \mathrm{Z}$ on the $26^{\text {th }}$, same as originally shown in HURDAT. On October $27^{\text {th }}$, Ginny continued slowly moving to the east and finished a large clockwise loop off the southeast coast of the United States. At $0157 \mathrm{Z}$ on the $27^{\text {th }}$, a penetration center fix measured a central pressure of $979 \mathrm{mb}$ and $980 \mathrm{mb}$ was measured at $0645 \mathrm{Z}$, thus the intensity at $00 \mathrm{Z}$ and $06 \mathrm{Z}$ on the $27^{\text {th }}$ is analyzed at $75 \mathrm{kt}$, up from $70 \mathrm{kt}$ originally in HURDAT, respectively, minor intensity changes. At $0945 \mathrm{Z}$ on the $27^{\text {th }}$, a reconnaissance aircraft measured a central pressure of $972 \mathrm{mb}$ and estimated surface winds of $85 \mathrm{kt}$. A central pressure of $972 \mathrm{mb}$ suggests maximum surface winds of $82 \mathrm{kt}$ from the north of $25 \mathrm{~N}$ pressure-wind relationship. An intensity of $80 \mathrm{kt}$ is analyzed at $12 \mathrm{Z}$ on the $27^{\text {th }}$, up from $70 \mathrm{kt}$ originally in HURDAT, a minor intensity change. At $1646 \mathrm{Z}$ on the $27^{\text {th }}$, TIROS VII captured an image of Ginny showing a well-organized eye surrounded by a large area of convection and banding features. At $19 \mathrm{Z}$ on the $27^{\text {th }}$, a penetration center fix measured a central pressure of $975 \mathrm{mb}$, estimated surface winds of $90 \mathrm{kt}$ and an eye diameter of $30 \mathrm{~nm}$. A central pressure of $975 \mathrm{mb}$ suggests maximum surface winds of 79 $\mathrm{kt}$ from the north of $25 \mathrm{~N}$ pressure-wind relationship. An eye diameter of $30 \mathrm{~nm}$ suggests an RMW of about $23 \mathrm{~nm}$ and the climatological value is $26 \mathrm{~nm}$. Based on a forward speed of about $10 \mathrm{kt}$ and the satellite image, an intensity of $80 \mathrm{kt}$ is analyzed at $18 \mathrm{Z}$ on the $27^{\text {th }}$, up from $75 \mathrm{kt}$ originally in HURDAT, a minor intensity change. On October $28^{\text {th }}$, Ginny turned to the northeast and began to accelerate ahead of an approaching frontal boundary. The first reconnaissance aircraft to investigate the hurricane on the $28^{\text {th }}$ measured a central pressure of $970 \mathrm{mb}$ and estimated an eye diameter of $40 \mathrm{~nm}$ at $0130 \mathrm{Z}$. A central pressure of $970 \mathrm{mb}$ suggests maximum surface winds of $84 \mathrm{kt}$ from the north of $25 \mathrm{~N}$ pressure-wind relationship. An eye diameter of $40 \mathrm{~nm}$ suggests an RMW of about 30 $\mathrm{nm}$ and the climatological value is $26 \mathrm{~nm}$. Based upon a forward speed of $8 \mathrm{kt}$, an intensity of $85 \mathrm{kt}$ is analyzed at $00 \mathrm{Z}$ on the $28^{\text {th }}$. At $13 \mathrm{Z}$ on the $28^{\text {th }}$, another penetration center fix measured a central pressure of $968 \mathrm{mb}$, estimated surface winds of $75 \mathrm{kt}$ and an eye diameter of $25 \mathrm{~nm}$. A central pressure of $968 \mathrm{mb}$ suggests maximum surface winds of $87 \mathrm{kt}$ from the north of $25 \mathrm{~N}$ Brown et al. pressure-wind relationship and $84 \mathrm{kt}$ from the north of $35 \mathrm{~N}$ Landsea et al. pressure-wind relationship. An eye diameter of $25 \mathrm{~nm}$ suggests an RMW of about $19 \mathrm{~nm}$ and the climatological value is $28 \mathrm{~nm}$. Based on a forward speed of about $14 \mathrm{kt}$ and an RMW smaller than climatology, an intensity of $90 \mathrm{kt}$ is analyzed at $12 \mathrm{Z}$ on the $28^{\text {th }}$, up from 80 kt originally in HURDAT, a minor intensity change. At $1709 \mathrm{Z}$ on the $28^{\text {th }}$, TIROS VII captured an image of Ginny showing a large area of convection with a well-defined eye ahead of a frontal boundary. At $19 \mathrm{Z}$ on the $28^{\text {th }}$, another penetration center fix measured a central pressure of 963 , estimated surface winds of $100 \mathrm{kt}$ and an eye diameter of $25 \mathrm{~nm}$. A central pressure of $963 \mathrm{mb}$ suggests maximum surface winds of $96 \mathrm{kt}$ from the north of $25 \mathrm{~N}$ pressure-wind relationship intensifying subset and $88 \mathrm{kt}$ from the north of $35 \mathrm{~N}$ pressure-wind relationship. An eye diameter of $25 \mathrm{~nm}$ suggests an RMW of about $19 \mathrm{~nm}$ and the climatological value is 27 $\mathrm{nm}$. Based on a forward speed of about $14 \mathrm{kt}$ and an RMW smaller than climatology, an intensity of $95 \mathrm{kt}$ is analyzed at $18 \mathrm{Z}$ on the $28^{\text {th }}$, up from $85 \mathrm{kt}$ originally in HURDAT, a minor intensity change. $95 \mathrm{kt}$ is also the peak intensity of this hurricane, same as originally shown in HURDAT. 
On October $29^{\text {th }}$, Ginny continued to increase in forward speed to the northeast impacting parts of New England and Atlantic Canada. At $06 Z$ on the $29^{\text {th }}$, Nantucket, MA, registered sustained winds of $35 \mathrm{kt}$, thus Massachusetts is added as a tropical storm impact. Ginny produced sustained winds up to $48 \mathrm{kt}$ in Nantucket later on as a nontropical cyclone. The Nantucket Lightship measured $55 \mathrm{kt}$ at $23 \mathrm{Z}$ on the $29^{\text {th }}$; the anemometer was 60 feet in height. Synoptic observations early on the $29^{\text {th }}$ showed that Ginny had begun to acquire extratropical characteristics with an increase in the temperature gradient across the circulation. Transition to an extratropical cyclone is analyzed at $12 Z$ on the $29^{\text {th }}$, six hours earlier than originally shown in HURDAT. Ginny was a very strong extratropical cyclone as penetration center fixes at $1315 \mathrm{Z}$ and $1630 \mathrm{Z}$ on the $29^{\text {th }}$ measured central pressures of $958 \mathrm{mb}$ and $948 \mathrm{mb}$, respectively. The strongest winds remained offshore but heavy rain and high waves impacted coastal New England as Ginny moved to eastern Canada. In Canada, hurricane-force winds, especially in gusts, affected the provinces of Nova Scotia and New Brunswick. A developing extratropical cyclone off the East Coast of the United States began to interact with Ginny late on the $29^{\text {th }}$ and Ginny appears to have been absorbed after $06 \mathrm{Z}$ on October $30^{\text {th }}$. The last position is analyzed at $06 \mathrm{Z}$ on the $30^{\text {th }}$, same as originally shown in HURDAT.

\begin{tabular}{|c|c|c|c|}
\hline Date & $\begin{array}{c}\text { Original } \\
\text { HURDAT } \\
\text { Central } \\
\text { Pressure }\end{array}$ & Evidence & Changes \\
\hline Oct $1912 \mathrm{Z}$ & $1000 \mathrm{mb}$ & $\begin{array}{l}\text { No central pressure reports around } 12 \mathrm{Z} \text { and } \\
\text { it does not appear reasonable based on the } \\
\text { synoptic data available }\end{array}$ & Removed \\
\hline Oct $2000 \mathrm{Z}$ & & $\begin{array}{l}\text { Ship: } 30 \mathrm{kt} \mathrm{NE} \text { and } 992 \mathrm{mb} \text { at } 00 \mathrm{Z} \text { on Oct } \\
20^{\text {th }}\end{array}$ & $989 \mathrm{mb}$ \\
\hline Oct $2012 \mathrm{Z}$ & $983 \mathrm{mb}$ & $\begin{array}{l}\text { No central pressure report but looks } \\
\text { reasonable, ship report of } 35 \mathrm{kt} \mathrm{E} \text { and } 988 \\
\text { mb at } 12 \mathrm{Z} \text { on Oct } 20^{\text {th }}\end{array}$ & \multirow{4}{*}{ Retained } \\
\hline Oct $2218 \mathrm{Z}$ & $989 \mathrm{mb}$ & $\begin{array}{l}\text { Penetration center fix: } 989 \mathrm{mb} \text { at } 1620 \mathrm{Z} \text { on } \\
\text { Sep } 22^{\text {nd }}\end{array}$ & \\
\hline Oct $2300 \mathrm{Z}$ & $987 \mathrm{mb}$ & $\begin{array}{l}\text { Penetration center fix: } 987 \mathrm{mb} \text { at } 0055 \mathrm{Z} \text { on } \\
\text { Oct } 23^{\text {rd }}\end{array}$ & \\
\hline Oct $2306 \mathrm{Z}$ & $988 \mathrm{mb}$ & $\begin{array}{l}\text { Penetration center fix: } 988 \mathrm{mb} \text { at } 04 \mathrm{Z} \text { on } \\
\text { Oct } 23^{\text {rd }}\end{array}$ & \\
\hline Oct $2312 \mathrm{Z}$ & $995 \mathrm{mb}$ & $\begin{array}{l}\text { Penetration center fix: } 990 \mathrm{mb} \text { at } 1445 \mathrm{Z} \text { on } \\
\text { Oct } 23^{\text {rd }}\end{array}$ & $990 \mathrm{mb}$ \\
\hline Oct $2318 Z$ & $990 \mathrm{mb}$ & $\begin{array}{l}\text { Penetration center fix: } 990 \mathrm{mb} \text { at } 18 \mathrm{Z} \text { on } \\
\text { Oct } 23^{\text {rd }}\end{array}$ & Retained \\
\hline
\end{tabular}




\begin{tabular}{|c|c|c|c|}
\hline Oct $2400 \mathrm{Z}$ & $988 \mathrm{mb}$ & $\begin{array}{l}\text { Penetration center fix: } 988 \mathrm{mb} \text { at } 2145 \mathrm{Z} \text { on } \\
\text { Oct } 23^{\text {rd }}\end{array}$ & \\
\hline Oct $2412 Z$ & $990 \mathrm{mb}$ & $\begin{array}{l}\text { Penetration center fix: } 990 \mathrm{mb} \text { at } 14 \mathrm{Z} \text { on } \\
\text { Oct } 24^{\text {th }}\end{array}$ & \\
\hline Oct $2418 Z$ & $987 \mathrm{mb}$ & $\begin{array}{l}\text { Ship: } 15 \mathrm{kt} \mathrm{E} \text { and } 987 \mathrm{mb} \text { at } 18 \mathrm{Z} \text { on Oct } \\
24^{\text {th }}\end{array}$ & $985 \mathrm{mb}$ \\
\hline Oct $2500 \mathrm{Z}$ & $982 \mathrm{mb}$ & $\begin{array}{l}\text { Penetration center fix: } 982 \mathrm{mb} \text { at } 2215 \mathrm{Z} \text { on } \\
\text { Oct } 24^{\text {th }}\end{array}$ & \multirow{3}{*}{ Retained } \\
\hline Oct $2512 \mathrm{Z}$ & $976 \mathrm{mb}$ & $\begin{array}{l}\text { Penetration center fix: } 976 \mathrm{mb} \text { at } 12 \mathrm{Z} \text { on } \\
\text { Oct } 25^{\text {th }}\end{array}$ & \\
\hline Oct $2518 \mathrm{Z}$ & $985 \mathrm{mb}$ & $\begin{array}{l}\text { Penetration center fix: } 985 \mathrm{mb} \text { at } 1859 \mathrm{Z} \text { on } \\
\text { Oct } 25^{\text {th }}\end{array}$ & \\
\hline Oct $2600 \mathrm{Z}$ & & $\begin{array}{l}\text { Penetration center fix: } 987 \mathrm{mb} \text { at } 22 \mathrm{Z} \text { on } \\
\text { Oct } 25^{\text {th }}\end{array}$ & $987 \mathrm{mb}$ \\
\hline Oct $2606 \mathrm{Z}$ & $988 \mathrm{mb}$ & $\begin{array}{l}\text { Penetration center fix: } 983 \mathrm{mb} \text { at } 0559 \mathrm{Z} \text { on } \\
\text { Oct } 26^{\text {th }}\end{array}$ & $983 \mathrm{mb}$ \\
\hline Oct $2612 \mathrm{Z}$ & $986 \mathrm{mb}$ & $\begin{array}{l}\text { Penetration center fix: } 986 \mathrm{mb} \text { at } 12 \mathrm{Z} \text { on } \\
\text { Oct } 26^{\text {th }}\end{array}$ & \multirow{6}{*}{ Retainec } \\
\hline Oct $2618 \mathrm{Z}$ & $978 \mathrm{mb}$ & $\begin{array}{l}\text { Penetration center fix: } 978 \mathrm{mb} \text { at } 19 \mathrm{Z} \text { on } \\
\text { Oct } 26^{\text {th }}\end{array}$ & \\
\hline Oct $2700 \mathrm{Z}$ & $979 \mathrm{mb}$ & $\begin{array}{l}\text { Penetration center fix: } 979 \mathrm{mb} \text { at } 0157 \mathrm{Z} \text { on } \\
\text { Oct } 27^{\text {th }}\end{array}$ & \\
\hline Oct $2706 \mathrm{Z}$ & $980 \mathrm{mb}$ & $\begin{array}{l}\text { Penetration center fix: } 980 \mathrm{mb} \text { at } 0645 \mathrm{Z} \text { on } \\
\text { Oct } 27^{\text {th }}\end{array}$ & \\
\hline Oct $2712 \mathrm{Z}$ & $972 \mathrm{mb}$ & $\begin{array}{l}\text { Penetration center fix: } 972 \mathrm{mb} \text { at } 0945 \mathrm{Z} \text { on } \\
\text { Oct } 27^{\text {th }}\end{array}$ & \\
\hline Oct $2718 \mathrm{Z}$ & $975 \mathrm{mb}$ & $\begin{array}{l}\text { Penetration center fix: } 975 \mathrm{mb} \text { at } 19 \mathrm{Z} \text { on } \\
\text { Oct } 27^{\text {th }}\end{array}$ & \\
\hline Oct $2800 \mathrm{Z}$ & & $\begin{array}{l}\text { Penetration center fix: } 970 \mathrm{mb} \text { at } 0130 \mathrm{Z} \text { on } \\
\text { Oct } 28^{\text {th }}\end{array}$ & $970 \mathrm{mb}$ \\
\hline Oct $2812 \mathrm{Z}$ & $968 \mathrm{mb}$ & $\begin{array}{l}\text { Penetration center fix: } 968 \mathrm{mb} \text { at } 13 \mathrm{Z} \text { on } \\
\text { Oct } 28^{\text {th }}\end{array}$ & \multirow{3}{*}{ Retained } \\
\hline Oct $2818 \mathrm{Z}$ & $963 \mathrm{mb}$ & $\begin{array}{l}\text { Penetration center fix: } 963 \mathrm{mb} \text { at } 19 \mathrm{Z} \text { on } \\
\text { Oct } 28^{\text {th }}\end{array}$ & \\
\hline Oct $2912 Z$ & $958 \mathrm{mb}$ & $\begin{array}{l}\text { Penetration center fix: } 958 \mathrm{mb} \text { at } 1315 \mathrm{Z} \text { on } \\
\text { Oct } 29^{\text {th }}\end{array}$ & \\
\hline
\end{tabular}




\begin{tabular}{|l|l|l|}
\hline Oct $2918 \mathrm{Z}$ & $\begin{array}{l}\text { Penetration center fix: } 948 \mathrm{mb} \text { at } 1630 \mathrm{Z} \text { on } \\
\text { Oct } 29^{\text {th }}\end{array}$ & $948 \mathrm{mb}$ \\
\hline
\end{tabular}

Tropical Storm Helena [October 25-30, 1963]

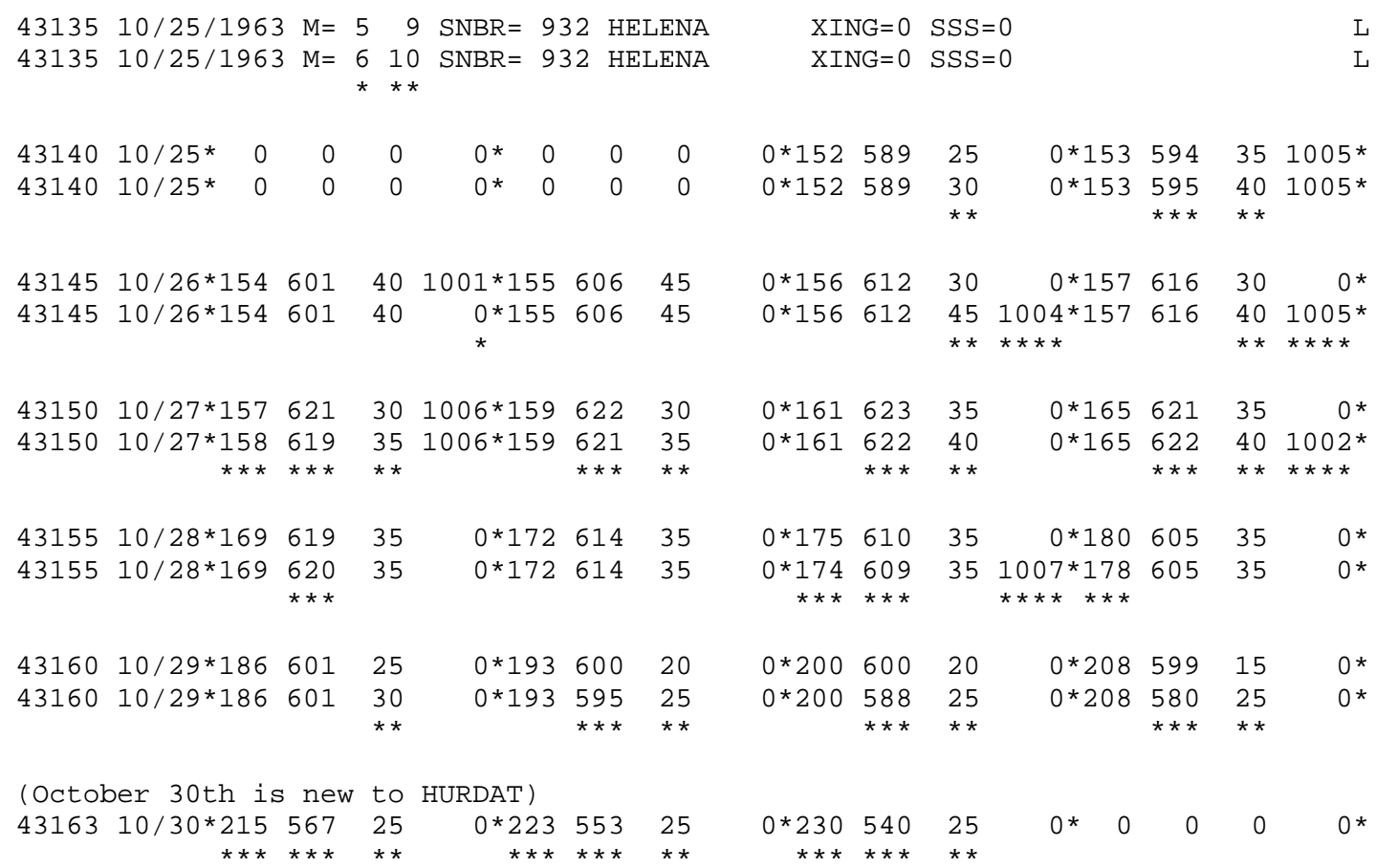

43165 TS

Tropical Storm Landfall

10/28 02Z 17.0N 61.8W 35 kt Antigua

Minor changes to the track and intensity shown in McAdie et al.(2009). Evidence for these alterations comes from the NHC microfilm maps, the Historical Weather Maps series, the COADS ship database, Monthly Weather Review, Navy reconnaissance book, Mariners Weather Log, Allison \& Thompson (1966) and NHC Storm Wallets.

October 24:

HWM and microfilm do not analyze an organized system at 12Z. HURDAT does not list an organized system on this date. Ship highlights: No gales or low pressures.

October 25:

HWM analyzes a closed low pressure of at most $1010 \mathrm{mb}$ at $15.2 \mathrm{~N}, 59.0 \mathrm{~W}$ at 12Z. HURDAT lists a $25 \mathrm{kt}$ tropical depression at $15.2 \mathrm{~N}, 58.9 \mathrm{~W}$ at $12 \mathrm{Z}$ (first position). 
Microfilm shows a closed low pressure of at most $1011 \mathrm{mb}$ at $16.3 \mathrm{~N}, 59.3 \mathrm{~W}$ at 12Z. Ship highlights: $40 \mathrm{kt} \mathrm{S}$ and $1011 \mathrm{mb}$ at $13.4 \mathrm{~N}, 58.8 \mathrm{~W}$ at $18 \mathrm{Z}$ (micro). Aircraft highlights: Penetration center fix measured a central pressure of $1005 \mathrm{mb}$ and estimated surface winds of $65 \mathrm{kt}$ at $15.4 \mathrm{~N}, 59.6 \mathrm{~W}$ at $2005 \mathrm{Z}$ (WALLET/ATSR).

MWR: "Tropical Storm Helena developed in an easterly wave a short distance east of the Lesser Antilles on October 25. An extensive cloud mass, apparently associated with the easterly wave, was observed by the TIROS satellite near $15^{\circ} \mathrm{N}, 55^{\circ} \mathrm{W}$, on the previous day. Two ships in the disturbed area during the early afternoon of October 25 reported southerly winds of 32 and $40 \mathrm{kt}$. with continuous rain. A reconnaissance aircraft later in the day found similar conditions and a central pressure of $1005 \mathrm{mb}$, or $29.68 \mathrm{in}$. The system was described as ill-defined with no wall cloud but with squall bands in the eastern semicircle. The storm intensified slightly as it moved west-northwestward but later weakened to below storm force after passing between Dominica and Guadeloupe. The 5000-ft. mountains of the islands evidently disrupted the poorly organized circulation." ATSR: "Tropical Storm HELENA developed on an easterly wave approximately 110 miles east of the island of Dominica, in the Lesser Antilles, during the morning of 25 October. A Navy reconnaissance aircraft was dispatched on the $25^{\text {th }}$ as a result of several ship reports and a TIROS photograph which had indicated a disturbed area near $15 \mathrm{~N} 55 \mathrm{~W}$ on the previous day. At 2000Z, the aircraft encountered a cyclonic circulation near $15.4 \mathrm{~N} 61.3 \mathrm{~W}$ and reported a poorly defined eye with maximum observed surface winds of 35 knots. At $252135 \mathrm{Z}$, the aircraft reported a "second eye" approximately 25 miles southeast of the original eye. There were no later sightings of the second eye, and it is assumed to have dissipated."

October 26:

HWM analyzes a closed low pressure of at most $1010 \mathrm{mb}$ at $15.0 \mathrm{~N}, 62.0 \mathrm{~W}$ at 12Z. HURDAT lists a $30 \mathrm{kt}$ tropical depression at $15.6 \mathrm{~N}, 61.2 \mathrm{~W}$ at $12 \mathrm{Z}$. Microfilm shows a closed low pressure of at most $1005 \mathrm{mb}$ at $15.7 \mathrm{~N}, 61.5 \mathrm{~W}$ at $12 \mathrm{Z}$. Ship highlights: No gales or low pressures. Land highlights: $35 \mathrm{kt}$ (gusts to $40 \mathrm{kt}$ ) at St. Lucia at $12 \mathrm{Z}$ (micro). Aircraft highlights: Penetration center fix measured a central pressure of 1005 $\mathrm{mb}$ at $15.3 \mathrm{~N}, 61.1 \mathrm{~W}$ at $1045 \mathrm{Z}$ (ATSR). Penetration center fix measured a central pressure of $1004 \mathrm{mb}$, estimated surface winds of $40 \mathrm{kt}$ and an eye diameter of $30 \mathrm{~nm}$ at $15.7 \mathrm{~N}$, $61.3 \mathrm{~W}$ at $1330 \mathrm{Z}$ (WALLET/ATSR). Penetration center fix measured a central pressure of $1005 \mathrm{mb}$ and estimated surface winds of $30 \mathrm{kt}$ at $15.7 \mathrm{~N}, 61.5 \mathrm{~W}$ at $16 \mathrm{Z}$ (WALLET). Penetration center fix measured a central pressure of $1006 \mathrm{mb}$, estimated surface winds of $31 \mathrm{kt}$ and an eye diameter of $24-93 \mathrm{~nm}$ at $15.8 \mathrm{~N}, 62.6 \mathrm{~W}$ at $2155 \mathrm{Z}$ (WALLET).

ATSR: "The storm intensified slightly as it moved west-northwest until it passed between the islands of Dominica and Guadeloupe during the early hours of the $26^{\text {th }}$ when the wind reached 45 knots for brief periods. The close proximity to the two mountainous islands disrupted the circulation and weakened the storm, which had never become well organized since the formation." 
October 27:

HWM analyzes a tropical storm of at most $1005 \mathrm{mb}$ at $16.5 \mathrm{~N}, 62.5 \mathrm{~W}$ at $12 \mathrm{Z}$. HURDAT lists a $35 \mathrm{kt}$ tropical storm at $16.1 \mathrm{~N}, 62.3 \mathrm{~W}$ at $12 \mathrm{Z}$. Microfilm shows a closed low pressure of at most $1008 \mathrm{mb}$ at $16.2 \mathrm{~N}, 62.0 \mathrm{~W}$ at 12Z. Ship highlights: $40 \mathrm{kt} \mathrm{SSW}$ and $1008 \mathrm{mb}$ at $15.4 \mathrm{~N}, 62.5 \mathrm{~W}$ at $18 \mathrm{Z}$ (micro). Aircraft highlights: Penetration center fix measured a central pressure of $1008 \mathrm{mb}$, estimated surface winds of $55 \mathrm{kt}$ and an eye diameter of $35 \mathrm{~nm}$ at $15.9 \mathrm{~N}, 62.3 \mathrm{~W}$ at $1247 \mathrm{Z}$ (WALLET/ATSR). Penetration center fix measured a central pressure of $1002 \mathrm{mb}$ and estimated surface winds of 30-35 kt at $16.6 \mathrm{~N}, 62.3 \mathrm{~W}$ at $19 \mathrm{Z}$ (WALLET).

MWR: "During the night of the $26^{\text {th }}$, Helena became almost stationary then turned northward and intensified slightly the next day. Central pressure dropped to $1002 \mathrm{mb}$ (29.59 in.) and reconnaissance aircraft reported winds of $58 \mathrm{mph}$ in squalls between Guadeloupe and Dominica." ATSR: "During the late hours of the $26^{\text {th }}$, HELENA became nearly stationary, and then began drifting north-northeastward on the $27^{\text {th }}$, which slight reintensification. Since upper level conditions were not favorable for further development, and the absence of a high pressure ridge to the north did not provide a strong surface pressure gradient, HELENA's reintensification was very slight..."

October 28:

HWM analyzes a tropical storm of at most $1010 \mathrm{mb}$ at $18.0 \mathrm{~N}, 61.0 \mathrm{~W}$ at $12 \mathrm{Z}$. HURDAT lists a $35 \mathrm{kt}$ tropical storm at $17.5 \mathrm{~N}, 61.0 \mathrm{~W}$ at $12 \mathrm{Z}$. Microfilm shows a closed low pressure of at most $1011 \mathrm{mb}$ at $17.5 \mathrm{~N}, 60.8 \mathrm{~W}$ at 12Z. Ship highlights: $35 \mathrm{kt} \mathrm{SSW}$ and $1009 \mathrm{mb}$ at $16.2 \mathrm{~N}, 60.0 \mathrm{~W}$ at $00 \mathrm{Z}$ (COADS).

MWR: "Most of the squalliness was confined to a small area in the eastern quadrant of the storm as the center moved northeastward from the vicinity of Antigua on the night of the $27^{\text {th }}$." ATSR: “... by $280000 Z$, the storm was weakening again. Aircraft reconnaissance at $281300 \mathrm{Z}$ reported that the circulation was very weak and, by $281800 \mathrm{Z}$, the circulation could no longer be located."

October 29:

HWM analyzes a closed low pressure of at most $1010 \mathrm{mb}$ at $20.0 \mathrm{~N}, 60.0 \mathrm{~W}$ at 12Z. HURDAT lists a $20 \mathrm{kt}$ tropical depression at $20.0 \mathrm{~N}, 20.0 \mathrm{~W}$ at $12 \mathrm{Z}$. Microfilm shows a closed low pressure of at most $1011 \mathrm{mb}$ at $18.5 \mathrm{~N}, 60.0 \mathrm{~W}$ at $12 \mathrm{Z}$. Ship highlights: No gales or low pressures.

MWR: "During the next 24 hours the storm assumed a more northward course and gradually weakened. Reconnaissance aircraft on the $29^{\text {th }}$ found only an area of squally weather with highest winds about $23 \mathrm{mph}$. Although Helena was never a well-defined storm, it caused considerable damage to small craft and roads in the Windward Islands. On Guadeloupe, five persons were reported dead, 500 homeless, and 14 seriously injured. A number of barges and fishing craft were sunk or seriously damaged. Total damage is estimated at no more than $\$ 500,000$." ATSR: "Aircraft reconnaissance on the $29^{\text {th }}$ reported scattered squalls and maximum surface winds of less than 15 knots." 
October 30:

HWM analyzes a closed low pressure of at most $1010 \mathrm{mb}$ at $24.0 \mathrm{~N}, 56.5 \mathrm{~W}$ with a cold front far to the west at 12Z. HURDAT does not list an organized system on this date. Microfilm shows a closed low pressure of at most $1011 \mathrm{mb}$ at $23.5 \mathrm{~N}, 54.5 \mathrm{~W}$ at $12 \mathrm{Z}$. Ship highlights: No gales or low pressures.

October 31:

HWM analyzes a closed low pressure of at most $1010 \mathrm{mb}$ at $27.5 \mathrm{~N}, 50.2 \mathrm{~W}$ with a cold front just to the west at 12Z. HURDAT does not list an organized system on this date. Microfilm shows a closed low pressure of at most $1011 \mathrm{mb}$ at $24.0 \mathrm{~N}, 54.0 \mathrm{~W}$ with a frontal boundary just to the west at 12Z. Ship highlights: No gales or low pressures.

November 1:

HWM analyzes a cold front over the central Atlantic at 12Z. HURDAT does not list an organized system on this date. Microfilm shows a closed low pressure of at most $1011 \mathrm{mb}$ at $24.0 \mathrm{~N}, 54.0 \mathrm{~W}$ with a frontal boundary just to the west at $12 \mathrm{Z}$. Ship highlights: No gales or low pressures.

Tropical Storm Helena developed late in October from a westward-moving easterly wave. Synoptic data east of the Lesser Antilles is scarce and the time of genesis is uncertain. There were very few signs for the islands that a tropical cyclone was developing to the east. Pressure reports indicate only a slight decrease (about $1 \mathrm{mb}$ ) in the values between October $24^{\text {th }}$ at $12 \mathrm{Z}$ and October $25^{\text {th }}$ at $12 \mathrm{Z}$. The winds did change from easterly at about $10 \mathrm{kt}$ to variable at about $5 \mathrm{kt}$. The first position is analyzed at $12 \mathrm{Z}$ on the $25^{\text {th }}$, same as originally shown in HURDAT, as a $30 \mathrm{kt}$ tropical depression, $5 \mathrm{kt}$ higher than originally shown in HURDAT. Minor track alterations are introduced during the lifetime of this tropical cyclone. The TIROS VII satellite captured an image of the tropical cyclone at $1607 \mathrm{Z}$ on the $25^{\text {th }}$ showing a large area of convection, circular in shape, with some indications of a westerly shear pattern. Intensification to a tropical storm is analyzed at $18 \mathrm{Z}$ on the $25^{\text {th }}$ based on a ship report of $40 \mathrm{kt} \mathrm{S}$ and $1010 \mathrm{mb}$ and data from a reconnaissance aircraft. At $2005 \mathrm{Z}$ on the $25^{\text {th }}$, a reconnaissance aircraft made a center penetration measuring a central pressure of $1005 \mathrm{mb}$ and estimated surface winds of $65 \mathrm{kt}$. A central pressure of $1005 \mathrm{mb}$ suggests maximum surface winds of $37 \mathrm{kt}$ from the south of $25 \mathrm{~N}$ Brown et al. pressure-wind relationship. Based on the ship report, an intensity of $40 \mathrm{kt}$ is analyzed at $18 \mathrm{Z}$ on the $25^{\text {th }}$, up from $35 \mathrm{kt}$ originally shown in HURDAT, a minor intensity change. A central pressure of $1005 \mathrm{mb}$ was present in HURDAT at $18 Z$ on the $25^{\text {th }}$ and has been retained. On October $26^{\text {th }}$, Helena continued moving westward at a slow forward speed. A central pressure of $1001 \mathrm{mb}$ was present in HURDAT at $00 \mathrm{Z}$ on the $26^{\text {th }}$ and has been removed since no reconnaissance aircraft was investigating the tropical cyclone at this time, nor a ship reported a central pressure. A reconnaissance aircraft investigated Helena at $1330 \mathrm{Z}$ on the $26^{\text {th }}$ measuring a central pressure of $1004 \mathrm{mb}$ and estimating surface winds of $40 \mathrm{kt}$. A central pressure of 1004 mb suggests maximum surface winds of $39 \mathrm{kt}$ from the south of $25 \mathrm{~N}$ pressure-wind relationship. Based on the pressure-wind relationship and synoptic data, an intensity of 45 
$\mathrm{kt}$ is selected at $12 \mathrm{Z}$ on the $26^{\text {th }}$, up from $30 \mathrm{kt}$ originally shown in HURDAT, a minor intensity change. $45 \mathrm{kt}$ is also the peak intensity of this tropical storm, same as originally shown in HURDAT. A central pressure of $1004 \mathrm{mb}$ is added to HURDAT at $12 \mathrm{Z}$ on the $26^{\text {th }}$. HURDAT originally showed Helena weakening to a tropical depression at $12 \mathrm{Z}$ on the $26^{\text {th }}$ as it passed between the islands of Guadeloupe and Dominica but data from the reconnaissance aircraft and surface observations indicate that the tropical cyclone likely maintained gale-force winds. Around $12 \mathrm{Z}$ on the $26^{\text {th }}$, St. Lucia reported sustained winds of $35 \mathrm{kt}$. At $16 \mathrm{Z}$ on the $26^{\text {th }}$, another reconnaissance aircraft made a penetration fix measuring a central pressure of $1005 \mathrm{mb}$ and estimated surface winds of $30 \mathrm{kt}$. A central pressure of $1005 \mathrm{mb}$ suggests maximum surface winds of $37 \mathrm{kt}$ from the south of $25 \mathrm{~N}$ pressure-wind relationship. Due to the slow forward speed of about 3 knots, an intensity of $40 \mathrm{kt}$ is selected at $18 \mathrm{Z}$ on the $26^{\text {th }}$, up from $30 \mathrm{kt}$ originally shown in HURDAT, a minor intensity change. A central pressure of $1005 \mathrm{mb}$ is added to HURDAT at $18 \mathrm{Z}$ on the $26^{\text {th }}$. The next penetration center fix measured a central pressure of $1006 \mathrm{mb}$ at $2155 \mathrm{Z}$ on the $26^{\text {th }}$ and estimated surface winds of $31 \mathrm{kt}$. An intensity of $35 \mathrm{kt}$ is selected at $00 \mathrm{Z}$ on September $27^{\text {th }}$, up from $30 \mathrm{kt}$ originally in HURDAT, a minor intensity change. A central pressure of $1006 \mathrm{mb}$ was present in HURDAT at $00 \mathrm{Z}$ on the $27^{\text {th }}$ and has been retained.

On the $27^{\text {th }}$, Helena turned to the north over the extreme northeastern Caribbean Sea. Early on this day, the weak tropical storm was almost stationary about $50 \mathrm{~nm}$ west of Guadeloupe. A reconnaissance aircraft investigated Helena at $1247 \mathrm{Z}$ on the $27^{\text {th }}$ and indicated a central pressure of $1008 \mathrm{mb}$ and estimated surface winds of $55 \mathrm{kt}$. The central pressure value is considered to be inaccurate based on another penetration fix later in the day, thus it is not added to HURDAT as a central pressure. TIROS VII captured an image of Helena showing a large area of cloudiness between $15 \mathrm{~N}$ and $25 \mathrm{~N}$ and $65 \mathrm{~W}$ and $50 \mathrm{~W}$. The satellite image indicates that westerly shear was impacting the tropical cyclone. A ship reported $40 \mathrm{kt} \mathrm{SSW}$ at $18 \mathrm{Z}$ on the $27^{\text {th }}$. Another penetration center fix measured a central pressure of $1002 \mathrm{mb}$ and estimated surface winds of $30-35 \mathrm{kt}$ at $19 \mathrm{Z}$ on the $27^{\text {th }}$. A central pressure of $1002 \mathrm{mb}$ suggests maximum surface winds of $43 \mathrm{kt}$ from the south of $25 \mathrm{~N}$ pressure-wind relationship. Based upon the ship report of $40 \mathrm{kt}$ and a slow forward speed of about $5 \mathrm{kt}$, an intensity of $40 \mathrm{kt}$ is analyzed at $18 \mathrm{Z}$ on the $27^{\text {th }}$, up from $35 \mathrm{kt}$ originally in HURDAT, a minor intensity change. A central pressure of $1002 \mathrm{mb}$ is added to HURDAT at $18 \mathrm{Z}$ on the $27^{\text {th }}$. Early on the $28^{\text {th }}$, the center of Helena crossed Antigua as a $35 \mathrm{kt}$ tropical storm and the system was once again over the open Atlantic Ocean. The last gale-force wind report associated with Helena occurred at $00 \mathrm{Z}$ on the $28^{\text {th }}, 35 \mathrm{kt}$ $\mathrm{SW}$ and $1008 \mathrm{mb}$. A reconnaissance aircraft investigated the tropical cyclone at $1450 \mathrm{Z}$ on the $28^{\text {th }}$ measuring a central pressure of $1007 \mathrm{mb}$ and estimated surface winds of $30 \mathrm{kt}$. A central pressure of $1007 \mathrm{mb}$ suggests maximum surface winds of $32 \mathrm{kt}$ from the south of $25 \mathrm{~N}$ pressure-wind relationship. An intensity of $35 \mathrm{kt}$ is selected at $12 \mathrm{Z}$ on the $28^{\text {th }}$, same as originally shown in HURDAT, a minor intensity change. Helena continued northeastward, moving away from the Leeward Islands, and it is analyzed to have weakened to a tropical depression at $00 \mathrm{Z}$ on October $29^{\text {th }}$, same as originally shown in HURDAT. The last position in HURDAT originally was at $18 \mathrm{Z}$ on the $29^{\text {th }}$, but synoptic observations indicate that the tropical cyclone continued moving northeastward into the central Atlantic ahead of a frontal boundary. The last position is analyzed at $12 \mathrm{Z}$ on 
October $30^{\text {th }}, 18$ hours later than originally shown in HURDAT. The last position is uncertain as it is possible that Helena could have lasted about 24-30 more hours longer than analyzed as a weak tropical depression based on synoptic observations but the data are inconclusive.

\section{3 - Additional Notes}

1. September 23-30: Microfilm shows a tropical wave or trough of low pressure over the eastern Gulf of Mexico on September $22^{\text {nd }}$ and a tropical disturbance develops over the Bay of Campeche on September $23^{\text {rd }}$ and appears to have become a tropical depression later that day based upon synoptic data and an aircraft reconnaissance flight. A frontal boundary reached the northern Gulf of Mexico on the $23^{\text {rd }}$ and remained stationary over the area for the next couple of days. On September $24^{\text {th }}$, the frontal boundary reached the central Gulf of Mexico generating gales over the northern gulf while the tropical depression remained almost stationary over the eastern Bay of Campeche. On September $25^{\text {th }}$, synoptic observations indicate that the tropical depression had a well-defined low-level circulation in an environment of low environmental pressures (OCI $1007 \mathrm{mb}$ ). The tropical cyclone moved slowly eastward on the $25^{\text {th }}$ and made landfall in western Yucatan late on the day. Late on September $26^{\text {th }}$, the tropical depression moved back over the eastern Bay of Campeche. On September $27^{\text {th }}$, the tropical depression remained almost stationary. The ships near the system reported pressures below $1005 \mathrm{mb}$ but no gales. On September $28^{\text {th }}$, the tropical system begins to move northeastward and the Microfilm surface analysis depicts the cyclone attached to the frontal boundary and shows a north-south elongation of the circulation. Very low environmental pressures, below $1010 \mathrm{mb}$, encompass the Gulf of Mexico. Ships reported gales in the southern quadrant of the circulation starting at $12 \mathrm{Z}$ on the $28^{\text {th }}$ but they were about $180 \mathrm{~nm}$ away from the center. It is possible that the tropical depression may have become a subtropical cyclone at that point but the data is inconclusive, especially since we do not have satellite images to observe the structure of the system. On September $29^{\text {th }}$, the system continues to gain in forward speed to the northeast and became embedded within the frontal boundary. The non-tropical system continued northeastward dissipating over the western Atlantic on October $1^{\text {st }}$. Therefore, because the data available does not suggest that it was a tropical cyclone when it produced gales, it is not added to HURDAT. This disturbance was in Jack Beven's List of Suspects.

$\begin{array}{cccc}\text { Day } & \text { Latitude } & \text { Longitude } & \text { Status } \\ \text { September 22 } & 20 \mathrm{~N} & 89 \mathrm{~W} & \text { Tropical Wave } \\ \text { September 23 } & 20 \mathrm{~N} & 93 \mathrm{~W} & \text { Tropical Depression }\end{array}$


September 24

September 25

September 26

September 27

September 28

September 29

September 30

October 1
$20 \mathrm{~N}$

$20 \mathrm{~N}$

$19 \mathrm{~N}$

$19 \mathrm{~N}$

$23 \mathrm{~N}$

$27 \mathrm{~N}$

$36 \mathrm{~N}$
$91 \mathrm{~W}$

$91 \mathrm{~W}$

$91 \mathrm{~W}$

$92 \mathrm{~W}$

$91 \mathrm{~W}$

$85 \mathrm{~W}$

$74 \mathrm{~W}$
Tropical Depression

Tropical Depression

Tropical Depression

Tropical Depression

Subtropical Storm?

Extratropical

Extratropical

Dissipated

2. September 25 - October 3: Historical Weather Maps indicate that a extratropical cyclone developed along a stationary front on September $26^{\text {th }}$ east of Florida. The system moved eastward producing gales and on September $29^{\text {th }}$ it became an occluded cyclone over the central Atlantic. As the cyclone began to lose its nontropical characteristics, the winds dropped below gale-force and the system slowly weakened until it dissipated on October $3^{\text {rd }}$ over the eastern Atlantic. Therefore, because the system did not acquire tropical characteristics, it is not added to HURDAT. This disturbance was in Jack Beven's List of Suspects.

Day

September 25

September 26

September 27

September 28

September 29

September 30

October 1

October 2

October 3
Latitude

Longitude

Eastern Gulf of Mexico to Western

Atlantic

$29 \mathrm{~N}$

$30 \mathrm{~N}$

$33 \mathrm{~N}$

$33 \mathrm{~N}$

$30 \mathrm{~N}$

$29 \mathrm{~N}$

$28 \mathrm{~N}$
$77 \mathrm{~W}$

$70 \mathrm{~W}$

$57 \mathrm{~W}$

$51 \mathrm{~W}$

49W

$45 \mathrm{~W}$

$41 \mathrm{~W}$
Status

Stationary front

Extratropical

Extratropical

Extratropical

Occluded

Occluded

Occluded

Occluded

Dissipated

3. October 7-11: A tropical wave left the African coast on October $6^{\text {th }}$ and synoptic data indicates that it may have reached tropical storm intensity on October $8^{\text {th }}$ while it was passing south of the Cape Verde Islands. A ship reported peripheral pressure of 1005 $\mathrm{mb}$ on October $8^{\text {th }}$ at $12 \mathrm{Z}$ and $45 \mathrm{kt} \mathrm{E}$ and $1006 \mathrm{mb}$ at $18 \mathrm{Z}$. Other ship data suggests that the gale-force winds have a high wind bias. Therefore, because there is not enough evidence to suggest that it attained tropical storm intensity, it is not added to HURDAT. This disturbance was in Ryan Truchelut's List of Suspects. 


$\begin{array}{cccc}\text { Day } & \text { Latitude } & \text { Longitude } & \begin{array}{c}\text { Status } \\ \text { Tropical }\end{array} \\ \text { October } 7 & 14 \mathrm{~N} & 21 \mathrm{~W} & \begin{array}{c}\text { Depression? } \\ \text { October } 8\end{array} \\ \text { October } 9 & 14 \mathrm{~N} & 23 \mathrm{~W} & \begin{array}{c}\text { Tropical Storm? } \\ \text { Tropical }\end{array} \\ \text { October } 10 & 14 \mathrm{~N} & 25 \mathrm{~W} & \begin{array}{c}\text { Depression? } \\ \text { Tropical }\end{array} \\ \text { October } 11 & 14 \mathrm{~N} & 29 \mathrm{~W} & \begin{array}{c}\text { Depression? } \\ \text { Dissipation }\end{array}\end{array}$

4. October 12-16: The Historical Weather Maps suggests that a tropical wave left the African coast on October $11^{\text {th }}$. A ship reported gale-force winds on October $12^{\text {th }}$ but the data over the eastern Atlantic is sparse. Therefore, because there is only one key piece of evidence, it is not added to HURDAT. This disturbance was in Ryan Truchelut's List of Suspects.

\begin{tabular}{|c|c|c|c|}
\hline Day & Latitude & Longitude & Status \\
\hline October 12 & $11 \mathrm{~N}$ & $22 \mathrm{~W}$ & Tropical Storm? \\
\hline October 13 & $13 \mathrm{~N}$ & $22 \mathrm{~W}$ & $\begin{array}{c}\text { Tropical } \\
\text { Depression? }\end{array}$ \\
\hline October 14 & $14 \mathrm{~N}$ & $22 \mathrm{~W}$ & $\begin{array}{c}\text { Tropical } \\
\text { Depression? }\end{array}$ \\
\hline October 15 & $16 \mathrm{~N}$ & $19 \mathrm{~W}$ & $\begin{array}{c}\text { Tropical } \\
\text { Depression? }\end{array}$ \\
\hline October 16 & & & Dissipation \\
\hline
\end{tabular}

5. October 23-30: The Historical Weather Maps shows a trough of low pressure between Bermuda and Bahamas. The disturbance moved to the northeast and became embedded within a frontal boundary on the $25^{\text {th }}$. Gale-force winds were reported on October $26^{\text {th }}$. On October $30^{\text {th }}$, the disturbance was absorbed by another frontal boundary. Therefore, because it did not acquire tropical characteristics, it is not added to HURDAT.

$\begin{array}{cccc}\text { Day } & \text { Latitude } & \text { Longitude } & \text { Status } \\ \text { October 23 } & 28 \mathrm{~N} & 65 \mathrm{~W} & \text { Trough } \\ \text { October } 24 & 32 \mathrm{~N} & 64 \mathrm{~W} & \text { Trough } \\ \text { October 25 } & 32 \mathrm{~N} & 64 \mathrm{~W} & \text { Extratropical } \\ \text { October 26 } & 34 \mathrm{~N} & 54 \mathrm{~W} & \text { Extratropical }\end{array}$


October 27

October 28

October 29

October 30
$36 \mathrm{~N}$

$38 \mathrm{~N}$

$42 \mathrm{~N}$
$43 \mathrm{~W}$

$33 \mathrm{~W}$

$14 \mathrm{~W}$
Extratropical

Extratropical

Extratropical

Absorbed

6. November 3-8: The Historical Weather Maps indicates that an extratropical cyclone formed in the tail-end of a frontal boundary on November $5^{\text {th }}$. The extratropical cyclone moved eastward over the next couple of days before turning to the northeast on November $8^{\text {th }}$ and becoming absorbed on November $9^{\text {th }}$. Therefore, because it did not acquire tropical characteristics, it is not added to HURDAT. This disturbance was in Jack Beven's List of Suspects.

\begin{tabular}{cccc} 
Day & Latitude & Longitude & Status \\
November 3 & \multicolumn{2}{c}{ Eastern Atlantic } & Cold front \\
November 4 & $30 \mathrm{~N}$ & $40 \mathrm{~W}$ & Trough \\
November 5 & $30 \mathrm{~N}$ & $35 \mathrm{~W}$ & Extratropical \\
November 6 & $30 \mathrm{~N}$ & $31 \mathrm{~W}$ & Extratropical \\
November 7 & $33 \mathrm{~N}$ & $25 \mathrm{~W}$ & Extratropical \\
November 8 & $40 \mathrm{~N}$ & $15 \mathrm{~W}$ & Extratropical \\
November 9 & & & Absorbed
\end{tabular}

